\title{
FLORA
}

OF THE

Qt.176.5

\section{ROCKY MOUNTAINS}

AND

\section{ADJACENT PLAINS}

COLORADO, UTAH, WYOMING, IDAHO, MONTANA, SASKATCHEWAN,

ALBERTA,

AND NEIGHBORING PARTS OF

NEBRASKA, SOUTH DAKOTA, NORTH DAKOTA, AND BRITISH COLUMBIA

BY

P. A. RYDBERG, Рн.D.

Curator, New York Botanical Garden

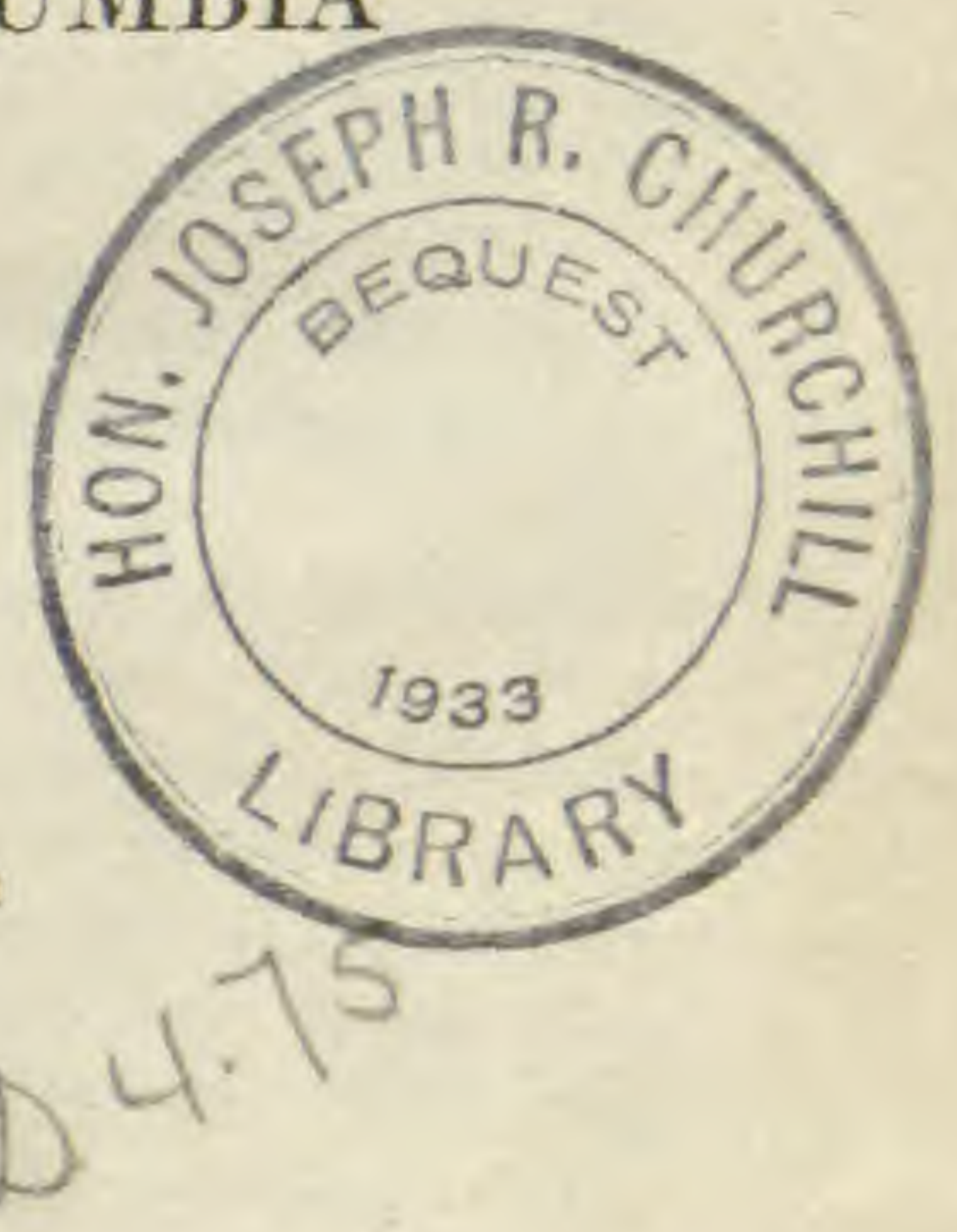

Valued dy Feder K.4.C. at $\$ 50.00=3-15-49$

NEW YORK

Published by the Author

1917

Se - Phodora 38:329 for correct dates of forlelication

SSOURI BOT AUG 161933

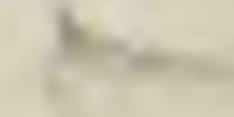


Copyright, 1917

Per Axel Rydberg

Press of

Steinman \& Foltz,

Lancaster, Pa. 


\section{PREFACE}

After more than twenty-five years of study of the flora of the Rocky Mountain region, and seventeen years after the first description was drawn for the book, this manual is now presented to the public. Its history, purpose and scope are given in the introduction, with certain necessary explanations regarding the general features of the book.

Thanks are due to the custodians of many herbaria for the privilege of studying collections and types, and for the loan of specimens; these herbaria are enumerated in my introduction. The author wishes to thank all his associates at the New York Botanical Garden, especially Dr. N. L. Britton, Director-in-Chief, for encouragement and help in his work; Dr. J. K. Small, for help in critical cases and in certain groups, as for instance PoLYGONACEAE and SAXIFragaceat, and in the original draft of the key to the families; and Dr. J. H. Barnhart, for help in questions of nomenclature and literature. In drawing the generic descriptions, the author has frequently consulted Dr. Small's Flora of the Southeastern United States. Dr. Barnhart has contributed also the list of authors, including their full names and years of births and deaths wherever it has been possible.

Thanks are also due to Mr. K. K. Mackenzie, who contributed the manuscript of Carex; to Professor E. Brainerd, who prepared that of Viola; and to Mr. W. W. Eggleston, who revised that of Crataegus.

As most manuals of phaenerogamic botany also contain the ferns and their allies, an account of the fern-worts by Miss Margaret Slosson has been appended. The families Isoetaceae, Equisetaceae and Selaginellaceae were left by her until the last. She did some preliminary work on Selaginella, but before the work was finished she left the New York Botanical Garden temporarily, and the completion of the fernworts fell upon the author, who feels that the treatment of the three families is not adequate, as the manuscript was prepared hurriedly while the book was going through the press.

The author is indebted especially to the following botanists, who have kindly corrected the statements of the ranges of all of the species and furnished, additions to the list of species known to occur in their respective states and provinces: Mr. J. M. Macoun, western Canadian provinces; Professor J. E. Kirkwood, Montana; Mr. J Francis Macbride, Idaho; Professor A. O. Garrett, Utah; and Mr. George E. Osterhout, Colorado. Thanks are also due to the following persons who have gratuitously helped in reading the proofs: Professor A. O. Garrett, Mr. G. E. Osterhout, Miss K. D. Kimball, and Mr. A. E. Urban, now manager of The Hershey Press, who kindly continued proofreading even after he left his old concern. The help of Mr. Urban, who is an amateur botanist as well, has been especially valuable.

The New York Botanical Garden, November, 1917.

\section{P. A. RYDBERG.}




\section{TABLE OF CONTENTS}

INTRODUCTION $\ldots \ldots \ldots \ldots \ldots \ldots \ldots \ldots \ldots \ldots \ldots \ldots \ldots \ldots \ldots \ldots \ldots$

TABLEs: Abbreviations, Signs and Measurements ........... xii

Descriptive Flora

Spermatophyta: Key to the Families .............. 1

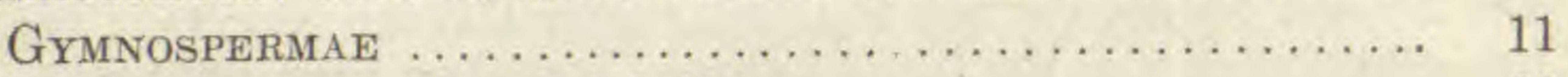

Angiospermae: Monocotyledones ................. 20

Dicotyledones.................. 185

Pteridophyta . . . . . . . . . . . . . . . . . . . . . 1038

APPENDIX

Summart . . . . . . . . . . . . . . . . . . . . . . 1057

New Genera and Species and New Combinations. . . . . . . . . . 1060

Abbreviations of the Names of Authors. . . . . . . . . . . . 1070

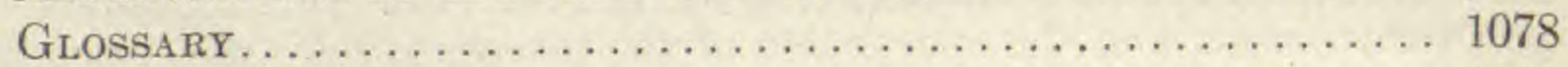

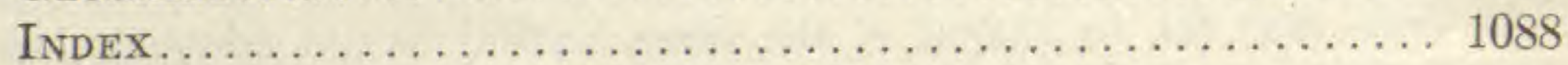




\section{INTRODUCTION}

\section{Preliminary Work}

In 1890 , the author spent a month in western Nebraska. In the following summer he was commissioned to collect in the same region for the United States Department of Agriculture, and in 1892 in the Black Hills of South Dakota. A report on the last was published in 1896 , in the CoNTRIBUTIONS FROM THE NATIONAL HeRBaRIUM, volume 3. These trips first introduced him to the flora of a part of the region covered by this manual. Since then he has done field work, partly for the United States Department of Agriculture and partly for the New York Botanical Garden, in Montana, Yellowstone National Park, Colorado and Utah, and has made shorter stops in eastern Idaho and southern Wyoming. In all, he has spent eleven summers in the Rocky Mountain region. In this field work he was associated with or assisted by the following men: C. L. Shear, Ernst A. Bessey, A. O. Garrett, J. H. Flodman, F. K. Vreeland, and E. C. Carlton, to whom thanks are due.

After collecting for two summers and a half in Montana and the Yellowstone National Park, the author published in 1900, a Catalogue of the Flora of Montana and the Yellowstone National Park. ${ }^{*}$ In preparing this, he studied the extensive collections made by Frank Tweedy of the United States Geological Survey, as well as that of W. M. Canby, and one made for the World's Fair in Chicago, 1893.

In 1901 the author was requested to determine the collection accumulated at the Agricultural College at Fort Collins, Colorado, made by James Cassidy, C. S. Crandall, J. H. Cowan, and their assistants and students, and finally to prepare the results for publication. THE FLORA OF CoLoradot appeared in 1906. At this time the author had spent a summer and a half collecting in Colorado and the New York Botanical Garden had secured an almost complete set of C. F. Baker's, and Baker, Earle and Tracy's collections in that state. Together with the older collections preserved in the herbarium of Columbia University the material mentioned above made possible an almost complete catalogue of the Colorado flora.

The preparation of the manual has taken a longer time than expected, as only a small part of the author's time could be used for the work. During the time (1900-1916) the work has been progressing, the author has published a series of 29 papers under the title "Studies on the Rocky Mountain Flora," in which numerous new species have been published. The publication of a second edition of Coulter's Manual in the form of "A New Manual of Botany of the Central Rocky Mountains," by J. M. Coulter and Aven Nelson, in 1909, made the appearance of the contemplated flora less urgent, as the need was partly supplied, and the issuing of the manual was delayed.

\section{Material Used in the Work}

The main part of the work has been done in the herbarium of the New York Botanical Garden, where also the collections of Columbia University (including the Torrey and Morong herbaria) are deposited. These herbaria contain numerous types or duplicates of types of species described by Torrey, Torrey and Gray, Nuttall, Hooker, and Richardson, as well as the first sets of several collections and duplicate sets of many others.

The author has visited the United States National Herbarium five times, for weeks at a time, and has often had specimens as loans for study. He has gone through it quite thoroughly, except the family CichoriaceaE. The studies

* Mem. N. Y. Bot. Gard. vol. 1.

$\dagger$ Agr. Exp. Sta. Colo. Agr. Coll. Bull. no. 100. 
there included investigations of the types of species described by Vasey, Coville, Rose, Hitchcock, Scribner, Standley, and others; Dr. E. L. Greene's herbarium was deposited there at that time. The author has also made four similar visits to the Gray Herbarium, mainly to study types, especially those of plants described by Gray, Watson, Robinson, Fernald, Greenman, and others; three short visits to the Philadelphia Academy to study the types of Pursh and Nuttall; one to the Field Museum, Chicago; one to the Missouri Botanical Garden; one to the Geological Survey of Canada; and a day's stop at the Rocky Mountain Herbarium at Laramie. In 1901 he spent more than a week at the Royal Gardens, Kew, where he studied all the types of the plants deseribed in Hooker's Flora Boreali-Americana, and made a visit to the British Museum, which contains many of Nuttall's types. The herbarium of the College of Pharmacy of New York City has often been consulted and specimens borrowed therefrom. In addition, the following herbaria have passed through his hands for study and determination: Herbarium of the Agricultural College of Colorado; Herbarium of the Agricultural College of Montana (before 1900); Frank Tweedy's herbarium, now at Yale University; and the herbaria of F. D. Kelsey and F. E. Leonard, now at Oberlin College. The only important collections from the Rocky Mountains not studied are that of M. E. Jones and that of the University of Wyoming; many duplicates from these have been available, however. The author has also corresponded for years with Mr. Osterhout, Prof. Garrett, Prof. Cockerell, Mr. Macoun, and many others.

\section{Area Covered by the Manual}

When the manual was first contemplated the author estimated that it would comprise the description of about 4000 species; this estimate might have proved correct if the work had been limited to the Rocky Mountains themselves. His knowledge of the vegetation of the plains east of them, a flora not adequately treated in any manual, induced the author to include that also. As he has been interested in the flora of the northern Rockies, perhaps more than any one else in the United States, the Geological Survey of Canada has for years sent the first. set of its exchanges from the Rocky Mountain region to the New York Botanical Garden; it was desirable, therefore, to include the flora of this part of Canada in the manual, and perhaps 200 northern species have been added. The parts of Utah west and south of Wahsatch Mountains, as well as western Idaho, have not been included in any of the floras of the Rocky Mountain region. As many collections have been made in the part of Utah mentioned, by Edward Palmer, C. C. Parry, A. L. Siler, Mrs. Almon H. Thompson, L. F. Ward, and others, and especially by M. E. Jones, the whole of the states of Utah and Idaho was included and at least 500 or 600 species thus added. The total number of species, in the meantime, has grown to nearly 5900 .

The area covered by this flora thus includes the entire states of Colorado, Utah, Wyoming, Idaho, and Montana, and extends eastward to long. $102^{\circ} \mathrm{W}$. in Nebraska, South Dakota and North Dakota; it also includes the Canadian provinces of Saskatchewan and Alberta, south of lat. $55^{\circ} \mathrm{N}$. (the old boundary of the territories of the same name*), and the Kootenay Districts of British Columbia. The Rockies extend for some distance south into New Mexico, but no attempt has been made to cover any part of that state; as far as the truly mountain flora is concerned, however, it is practically covered.

As the number of known species within the area has increased, the author has been obliged to shorten the descriptions in order to make the book of a convenient size; cutting down original descriptions one-fourth or more, and usually avoiding repetition of characters given in the keys. The resulting brevity will naturally detract from the value of the work, but otherwise the book would have become too bulky to be convenient, especially in the field. The descriptions are nearly all redrawn from actual specimens. The original types or duplicates of the types have been consulted wherever possible, and rarely have the original descriptions been merely copied or condensed.

* The present boundary is lat. $60^{\circ}$, but the region between lat. $55^{\circ}$ and $60^{\circ}$, is botanically practically unknown. 


\section{Nomenclature and Limitation of Genera and Species}

The nomenclature used agrees, as far as possible, with the so-called American Code, used at the United States National Herbarium and Department of Agriculture, the New York Botanical Garden, and many of the universities and botanical institutions of this country. It differs from the International Code, followed by many institutions, principally in the following two features: itallows few exceptions from the rule that the oldest generic and specific name (after Linnaeus' Species Plantarum of 1753) should be used, and provides that, if a Latin name has been used for one plant, it can never be used for another. The nomenclature used in this manual differs somewhat on this'account from that used by other writers on the flora of the region or a part thereof. Another important difference is due to the fact that the author believes that in many cases unnatural groups of species of diverse habit and structure should not be retained as genera just because our predecessors have regarded them as such. In other words, a genus should be divided into several, if it can be split up into smaller and more natural ones. Such divided genera are, for instance, the old large genera Astragalus, Oenothera, and Aster. On the other hand, the fully as large genera Carex, Eriogonum, and Senecio have been kept intact, as no natural division could be found.

For those who disagree with the author in the matters of nomenclature and limitation of genera and species, there will be very little difficulty in finding the scientific name to which they are accustomed, as synonyms have been freely cited, in fact as far as deemed necessary. The synonymy, of course, is by no means complete; only such is included as has been in use for the plant recently, or is necessary for the explanation of the accepted name, or represents supposed new species, which the author regards as indistinguishable from the one deseribed. In the cases where a synonym is preceded by a "(?)" this means that the author has not seen the type of the synonym, but from the description supposes that it represents the same species as the one accepted.

A few of my friends have suggested that the place of publication of each name should also be given; while this would have increased the utility of the book, it would have added perhaps 150 pages. This manual will be useful to three classes: the amateur botanists, the students in high schools and colleges, and the professional botanists. The first two classes, as a rule, do not care for the full citation, and most of the professional botanists have access to the "Kew Index" and the "Card Catalogue," or other reference books. The omission of the place of publication will work hardships, therefore, to only a few.

\section{Pronunciation and Accentuation}

In most of the schools of this country the so-called Roman pronunciation is used in reading Latin, but exceedingly few botanists pronounce the Latin names in accordance with it. They are supposed to pronounce it according to the socalled English method, but the author has not found two persons who do it alike. He frankly admits that he does not know how to pronounce the names according to the latter method. According to the Roman method, as he was taught it, the vowels are pronounced nearly as follows:

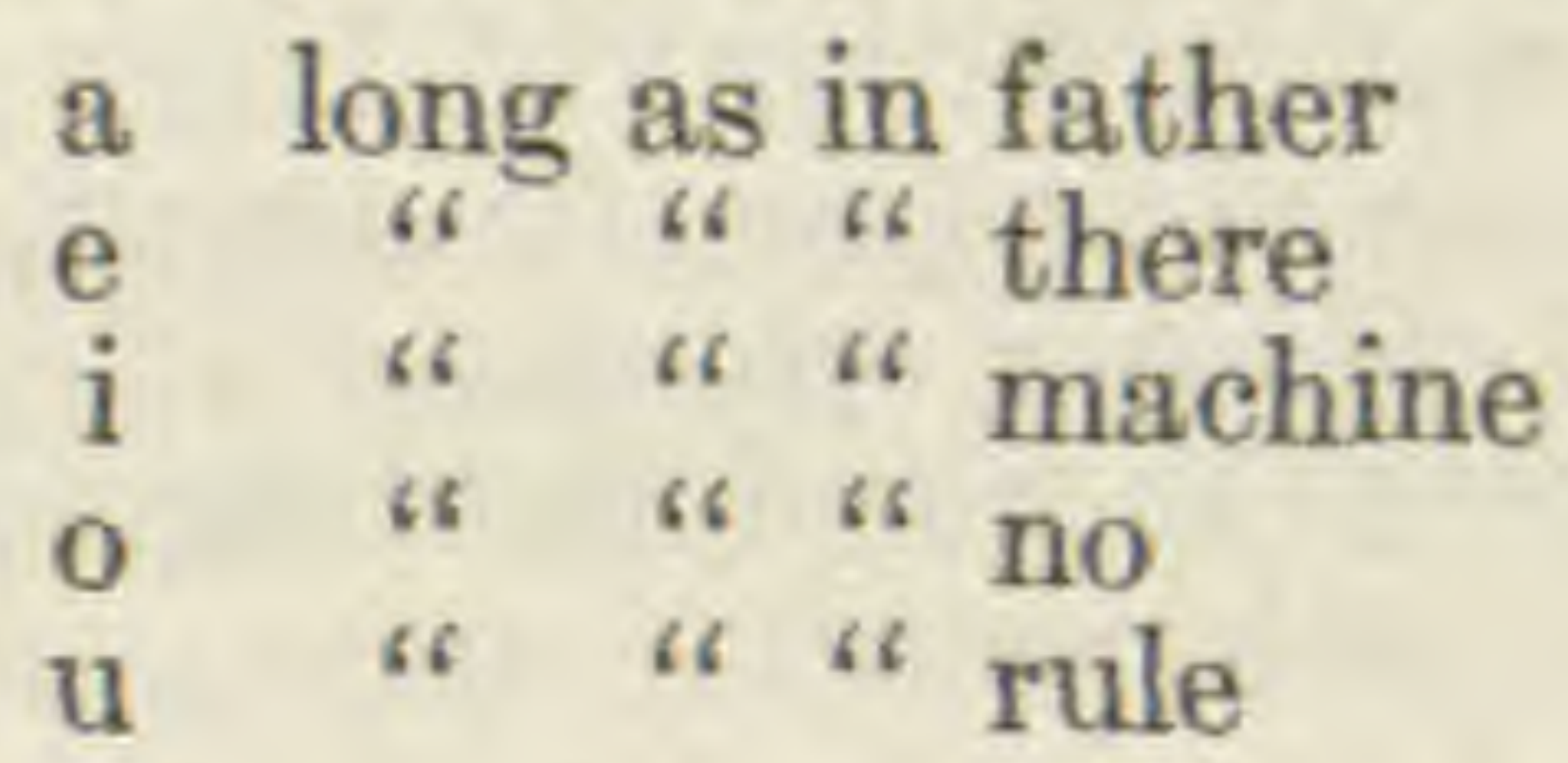

$\begin{array}{ccc}\text { short as in hat } \\ \text { " } \\ \text { " } & \text { " } & \text { met } \\ \text { " } & \text { " } \\ \text { " } & \text { not } \\ \text { put }\end{array}$

The consonants he learned to pronounce as they are in English, except that $c$ and $g$ are hard as in cat or go, even before $e, i$, and $y ; j$ as consonant $y, z$ as $t s$, and $c h$ and $p h$ in Greek words as. $k$ and $f$.

Most of the mispronunciations, whether the English, Continental, or Roman pronunciation is used, are due to ignorance of the accent. On the proper accentuation the author wishes to say more, ${ }^{*}$ as the specific names in this volume

* The explanations given in this discussion may not agree with most Latin grammars in English, but the author thinks that this is because the English grammarians consciously or unconsciously interpret constructions in Latin according to the models of the highly individualized English language. 
do not have the accent indicated. Clements gives the following rule for accents: "In words of two syllables or more the accent is on the penult [next to the last syllable], when it is long; when the penult is short, the antepenult [third syllable from the end] is accented." This is correct if rightly understood. Long syllables are of two kinds, however; one with vowel length, the other with consonant length, that is, when it ends in one or more consonant sounds. Unfortunately, in a syllable with consonant length the vowel is usually called short, not only in English, but in most modern languages. In many Latin lexicons the vowel in such a syllable is marked as long (wrong according to modern notions), in a few as short; others are noncommittal. In fact, the syllable is long (as shown in verse) although the vowel is short. There are three kinds of syllables, two ending in vowels, and one in a consonant. If there are one or more consonants between two vowels, one of these is always counted to the second syllable and the rest to the first, except that $c h, p h$, and $t h$ are regarded as one letter and a mute followed by $r$ is carried to the second syllable (hy-dra, as-tra).

The grave accent (a) is here used to denote a long vowel* and the acute (á) a short vowel syllable or a syllable with consonant length. The penult has the accent when it ends in a consonant, but if it ends in a vowel it has the accent only if this vowel is long. In hy-dro-phyl-lum (water-leaf) the penult ends in a consonant and hence has the accent, and the vowel is marked short, as the syllable has consonant length; in hy-dró-phi-la (water-lover) the penult ends in a vowel and this is short; the accent is removed to the antepenult and, as the connecting vowels $i$ (in Latin) or $o$ (in Greek) in compound words are short, the antepenult has a short accent. Greek words follow practically the same rules, but unfortunately they do not always have the same quantity as the corresponding Latin words. For instance, in Latin the $y$ in stylus (in classical Latin better stilus) is short, while in $\sigma \tau v \lambda$ os the $v$ is long. In brevistylis (Latin) the accent is on the antepenult, while in brachystỳlis (Greek) it is on the penult. A person must not be influenced by the English pronunciation of words similar to or derived from the Latin or Greek scientific terms, as it is very often corrupted. The words Spermatóphyta, Pteridóphyta, etc., have the accent on the antepenult and short $o$ and $y$, while the English Spermatophyte and Pteridophyte have the accent on the antepenult with a long $y$ in the last syllable. Just the reverse we find in the Greek and Latin Anemòne and the English Anémone.

As stated before, when the penult ends in a consonant, $i$. $e$., when the vowel is followed by two consonants or more, or a double consonant, it always has the accent and this is short. If, however, the vowel is followed by one or no consonant, one has to find out whether it is long or short. To determine this one has very often to go to the lexicon. Most of the specific names are Latin or Greek adjective, some are nouns in the genitive case, and a few are old generic names or nouns of barbaric origin. For the last two categories no rules can be given, but the following hints may help in pronouncing the adjectives and genitives:

The penult is long, as a rule, in the following adjective endings and hence takes the long accent: -àliss, $\dagger$-ànus, -àris, -àtus, -ènus, -ètus, -inus, $\ddagger$-ìtus, -ivus, ò̀des, -òvus, -̀̀sus, -ùnus, -ùnes, ùrus, -ùsus, -ùtus. In classical Latin there were very few compound adjectives, but in botanical Latin they are used freely. A few in which the last term has a long vowel in the penult and hence accented, may be mentioned: -fùsus, -glùmis, -phỳsus, -flòrus.

The penult has usually a short vowel in the following adjective endings, and hence the accent is removed to the antepenult: -acus, -eus, -eris, -erus, -eger

* This must not be confused with the so-called long English $a$, for in English nearly all the sounds of $a$ (except the short $a$ as in "hat") are long. The $a$ in "hall" is long in English, though not the so-called long sound. In Latin, a word with such a spelling Would have consonant length and be denoted with the short accent. In English the $a$ in the names Hall and Haller are pronounced differently, as it is in mall and mallet, but in Latin the $a$ is pronounced the same in Hallii and Halleri.

$\dagger$ Only the masculine form is given here, the feminine and neuter forms follow the same rule; -alis and -anus stand for -alis, -alis, -ale, and -anus, -ana, -anum, etc.

$\ddagger$ Short in serotinus, gossipinus, cannabinus, and others. On the other hand salicinus and cyperinus are usually indicated as long. The classical form of these words were, however, salignus and cyprinus. 
(-egra, -egrum), -icus, -ichus, -idis, -idus, -ilis, -ilus, -imus, -ior, -ius, -uus, -yus. The compound words ending in the following syllables have also a short vowel in the penult: -cladus, -cola, -color, -fera, -ferum, -gera, -gerum, -gynus, -fidus, -filus, -philus, -lepis, -olens, -pilis, -podus, -stomus, -tomus, -virens, -phytum. If the short connecting vowels $i$ (in Latin) and $o$ (in Greek) appear in the penult, they are not accented; when they appear in the antepenult in words with short penult they receive the short accent: ármiger, armígera, spinifer, spinifera. Of course, in adjective endings in which the penult has consonant length, this is accented and the vowel is short: -énsis, -éllus, -illus, -formis, -éstus, -úster, -éster, -éssus. The same rule applies to compound words enging in -cárpus, -róstris, -phýllus.

By following the hints given above, any one can accent correctly eighty per cent. of the specific names in this flora. A few words may be said concerning the genitives of personal names and the same remarks apply to generic names dedicated to persons. The usual method of Latinizing a personal name is to add ius (genitive -ii) or, in case of a generic name dedicated to a person, $-i a$, to it if it ends in a consonant (except $r$ ), and $-u s(-i)$ and $-a$ if the name ends in a vowel or $r$. If the noun ends in -er, as Palmer, it is better to regard this as the proper Latin form with Palmer- $i$ in the genitive. As the $i$ in the penult of $-i i$ and $-i a$ always is short, the accent in such words will always be on the antepenult. Harder to determine is the place of accent if the genitive ends in a single $-i$ or the generic name in merely $-a$, as it depends upon whether the penult is long or short. Many botanists pronounce the names derived from persons as they would the family name itself, with the Latin ending added, as $J d m e s-i-a$ and $J$ àmes- $i-i$, named for James; while the Latin usage would require $J a-m e ̀-s i-a$ and $J a-m e ̀-s i-i$. In Latin all syllables are pronounced and the accent can never be further from the end than in the antepenult. It has been a custom to regard the vowel in the antepenult of the endings -esii, -onii, -inii, -unii,-elii, etc., and in the penult of -onis, -oni as long. Many include the ending -eri. This would be perhaps defendable in the case of Berlandièri, Plumieri, where the ending er has the accent in French and in plant names dedicated to some German and Scandinavian persons who write their name with an accent on the last syllable, but the author does not think it correct in Palmeri, Bòreri, Brèweri, Wárneri, where the English name has a short er and the words in er following the second declension in Latin as a rule had short $e$ in the genitive or dropped it altogether. The author thinks that the four names just mentioned should have the accent on the first syllable.

The generie names are much harder to treat. They are old Latin or Greek nouns, or vernacular names, with or without Latin endings, or modified personal names, or compound words (mostly Greek) manufactured according to the whims of the authors. The author saw no other way but to indicate their proper accent in each case as far as they could be ascertained.

\section{NaMes OF AUTHORS}

The generic and specific names are followed by the names of their authors, usually abbreviated; the abbreviations are explained on pages 1070-8. If an author's name is placed in parenthesis after a generic name, it means that he published it before 1753 and that it was accepted after that date by the author following the parenthesis (usually Linnaeus). After the specific name, an author's name in parenthesis signifies that he originally proposed it, either in another genus or else only as a subspecies, variety, or form, and the author following the parenthesis was the first one to make the accepted combination.

\section{Common Names}

The common names are given in most cases after the Latin generic name. A common name has been inserted after the description of a species only where it seems to apply exclusively or principally to that species. In the Rocky Mountain region the common names apply usually to all species of the genus rather than to a particular one. No attempt has been made to manufacture a "common name" where there is none in existence. 


\section{Measurements}

The measurements have been given in metric system, now used by most of the scientific bureaus of the United States and universities and colleges of the country. In the old English system, formerly used in descriptive botany, the inch was divided into twelve lines. A ruler with this division is hard to find now-a-days, while metric rulers can be had nearly everywhere. For those who are more accustomed to the English measurements a table is given on page xii, with equivalents near enough for all practical purposes.

\section{Habitat and Distribution}

Near the end of each specific description is given the usual habitat of the plant and its geographic distribution. In order to save space the latter is given in abbreviation. Usually four states or provinces, or less, are mentioned; if the distribution is irregular, sometimes more than four. The expression: Man.Kans.-Utah-Alta. would mean that the area in which the plant grows naturally extends from Manitoba to Kansas, Utah, and Alberta. If a state or province is placed within parenthesis with a question mark preceding, as for instance (? Colo.), it means that the plant has been reported from said state, but that the author has not verified the assertion and doubts its correctness. Isolated or exotic distribution is set off from the general endemic one by a semicolon; and immigrants are distinguished as adventive (adv.), i. e., not fully established, or fully naturalized (nat.), or escaped from cultivation. The abbreviations used are included in the table on page xii.

\section{Altitudes AND Life Zones}

In the original draft, altitudinal distribution was stated. In an area which extends in latitude 18 degrees, or approximately 1250 miles, however, a statement of the altitudes does not mean very much, as a plant which has its best development in Colorado at 3000 meters (10,000 feet) does not reach half that altitude in the Canadian Rockies. Instead of the altitude in meters or feet, the zonal distribution is therefore given. The following life zones have been accepted in this work:

Alpine Zone (Alp.), the region above timberline.

Subalpine Zone (Subalp.), or Spruce Belt.

Montane Zone (Mont.), or Pine Belt.

Submontane Zone (Submont.), or Foothills, or in the south the Chaparral Belt.

Sonoran, or rather Upper Sonoran, Zone (Son.), or Piñon-Cedar Belt and the Upper Desert.

Lower Sonoran Zone (L. Son.) or Lower Desert, limited with the manual area to the Colorado River Cañon and Virgin River Valley in Utah.

As the first four of these zonal names apply only to a mountain region, they could not be used for the part of the area occupied by the plains, especially east thereof. The same life zone that occupies the high mountains in temperate latitudes will occupy the lowlands nearer the poles, and these zones there become Arctic, Subarctic, Boreal, and Subboreal. The Montane and Subalpine Zone reach the lowlands or plains in Alberta and hence also meet the western extension of the Boreal and Subarctic Zones of the east. This merging takes place, however, mostly north of latitude $55^{\circ}$, as the grass-covered plains push across the northern branch of Saskatchewan River; it is practically only along the lower part of said river that the Boreal and Subaretic flora enters the area of this work. The hardwood forests of the subboreal zone does not reach the Rockies; only a small element represents it in the foothills of the Black Hills, South Dakota, and exceedingly few of its plants reach eastern Saskatchewan. The zone is represented on the plains by grasslands and as these are so different from both the foothills of the Rockies and the eastern subboreal hardwood forest, it has seemed better to designate them with a different name, and the word Plain represents the grass-covered portion of the Subboreal Zone. The plains south of the divide between the Arkansas and Platte rivers belong in reality to the Sonoran Zone, but as the transition is so gradual and the general characters of the two divisions 
are much alike, in many cases the word Plain also includes the Sonoran portion of the plains, the so-called Staked Plains. Tables showing the approximate altitudes occupied by the different zones in southern Colorado and southern Montana, and in Alberta at the crossing of the Canadian Pacific Railroad, and also the approximate latitudes at which they meet the plains, lowlands, or level basins are shown below.

The western side of the mountains is warmer than the eastern. It is also dryer, except in the northern part, where the moisture conditions are reversed. The lower zones, therefore, extend further north on the west side.

\section{Colorado}

Alpine (Alp.) Montane (Mont.) ....... $3000-3500 \mathrm{~m}$. Submontane (Submont.) ... 1800-2500 m. Upper Sonoran (Son.) ..... 1350-1800 m.

This table may be given also in the English measures: Alpine............. 11,500-14,400 ft. Subalpine........... 10,000-11,500 ft. Montane........... 8,000-10,000 ft. Submontane.......... 6,000-8,000 ft. Upper Sonoran. ...... 4, 4,500-6,000 ft.

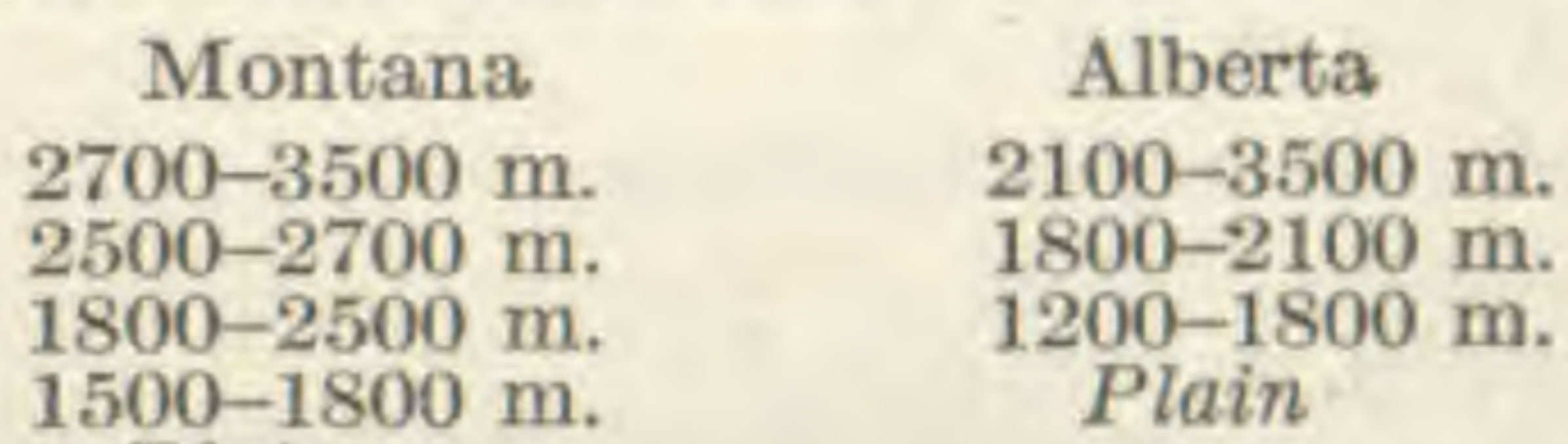

Montana

$2700-3500 \mathrm{~m}$.

$2500-2700 \mathrm{~m}$.

$1800-2500 \mathrm{~m}$.

$1500-1800 \mathrm{~m}$

Alberta

2100-3500 m. $1800-2100 \mathrm{~m}$. 1200-1800 m.

Plain Plain

9,000-12,000 ft.

$8,000-9,000 \mathrm{ft}$.

$6,000-8,000 \mathrm{ft}$.

$5,000-6,000 \mathrm{ft}$. Plain

$7,000-12,000 \mathrm{ft}$. $6,000-7,000 \mathrm{ft}$. $4,000-6,000 \mathrm{ft}$. Plain

The different zones meet the lowlands, plains or level basins at approximately the following latitudes:

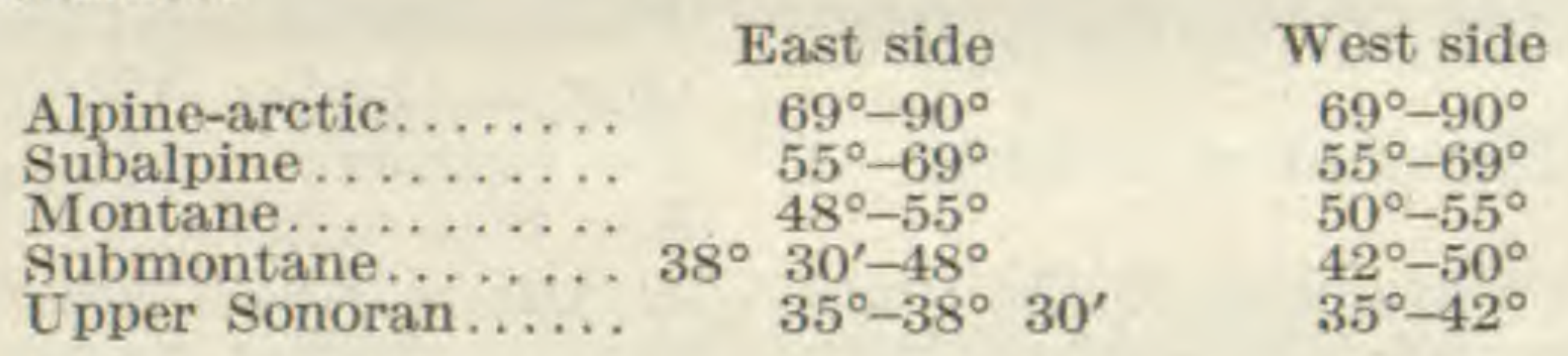

Time of Flowering

At the end of the specific description is given the month of flowering. The symbols used are: Ja, F, Mr, Ap, My, Je, Ji, Au, S, O, N, D. 


\section{TABLES}

\section{AbBreviations}

The well known abbreviations of the states of the United States are here omitted.

Adv. = adventive

$A l p .=$ Alpine Zone

Alta. $=$ Alberta $*$

Am. $=$ America or American

Ap $=$ April

Arctic $=$ Aretic Zone

$\mathrm{Au}=$ August

Auth. $=$ Authors $\dagger$

B. C. = British Columbia

Boreal $=$ Boreal Zone

$\mathrm{c}=$ central

C. Am. $=$ Central America

$\mathrm{cm} .=$ centimeter

$\mathrm{D}=$ December

$\mathrm{dm} .=$ decimeter

$\mathrm{e}=$ eastern

Eu. = Europe

Eurasia $=$ Europe and northern Asia

$\mathrm{F}=$ February

(Fl. Colo. $)=$ The Author's Flora of Colorado

(Fl. Mont.) $=$ Catalogue of the Flora of Montana and Yellowstone Park

Greenl. = Greenland

$\mathrm{Ja}=$ January

$\mathrm{Je}=$ June

$\mathrm{Jl}=\mathrm{July}$

Labr. = Labrador

L. Calif. = Lower California

L. Son. = Lower Sonoran Zone

$\mathrm{m} .=$ meter

Mack. = Mackenzie Territory

Man, = Manitoba

Mex. $=$ Mexico $\ddagger$

$\mathrm{mm} .=$ millimeter

Mont.$=$ Montane Zone

Mont. = Montana

$\mathrm{Mr}=\mathrm{March}$

$\mathrm{My}=$ May

$\mathrm{n}=$ northern

$\mathrm{N}=$ November

N. Am. $=$ North America

Nat. = Naturalized

N. B. = New Brunswick

$\mathrm{ne}=$ northeastern

Newf. = Newfoundland

N. S. = Nova Seotia

$\mathrm{nw}=$ northwestern

$\mathrm{O}=$ October

Ont. = Ontario

P. E. I. = Prince Edward's Island

Plain $=$ Subboreal Plains

Que. = Quebec

$\mathrm{s}=$ southern

$\mathrm{S}=$ September

S. Am. = South America

Sask. $=$ Saskatehewan

$\mathrm{se}=$ southeastern

Son.$=$ Sonoran Zone

Subalp, $=$ Subalpine Zone

Subarctic $=$ Subarctic Zone

Subboreal $=$ Subboreal Zone

Submont $=$ Submontane Zone

$\mathrm{sW}=$ southwestern

Trop. $=$ tropical

$\mathrm{w}=$ western

W. Ind. $=$ West Indies

\section{SIGNS}

- (short dash) between figures or words means that the two figures or two words denote the extreme of variation.

§ Subgenus or section of a genus.

- (long dash) between the names of two or more states denotes the extent of distribution.

$X$ denotes a hybrid between the two species mentioned.

\section{Measurements}

$1 \mathrm{~mm} .=1 / 25$ inch

$3 \mathrm{~mm} .=1 / 8$ inch

$1 \mathrm{~cm} .=2 \%$ inches

$5 \mathrm{~cm} .=2$ inches

$1 \mathrm{dm} .=4$ inches

$1 \mathrm{~m}$. $=40$ inches or $31 / 3$ feet
1 line $=2 \mathrm{~mm}$.

$1 / 8$ inch $=3 \mathrm{~mm}$.

1 inch $=2.5 \mathrm{~cm}$.

$1 \operatorname{span}=1 \mathrm{dm}$.

1 foot $=3 \mathrm{dm}$.

1 yard $=9 \mathrm{dm}$.

$300 \mathrm{~m} .=1000$ feet

* Many people use the abbreviation "Alb.", but as far as the author has been able to ascertain, the official one is "Alta."

† Used in cases of misapplications of names where the author flrst using it in such a sense has not been ascertained.

$\ddagger$ Observe the difference between N. M. (New Mexico) and n Mex. (northern Mexico). 


\section{SPERMATOPHYTA}

\section{Seed-Bearing or Flowering Plants.}

Plants with flowers containing stamens, or pistils, or both, and producing seeds containing an embryonic plant. Alternation of generations not apparent, the gametophyte being exceedingly reduced. The pollen-grains (microspores) contained in the anthersacs of the stamens, after liberation and reaching the stigma of the pistil or the naked ovules, germinate and produce a tube, by means of which the egg-cell (macrospore) of the ovules (macrosporange) is fertilized.

Orules and seeds borne on the surface of an open bract or scale; stigmas wanting. Class I. GYMNOSPERMAE

Ovules and seeds in a closed cavity (ovary), formed by one or more united modified leaves, with one or more stigmas at the end.

Class II. ANGIOSPERMAE

Cotyledons usually single; earlier leaves alternate; leaves mostly parallel-veined;

Subclass 1 . MONOCOTYLEDONES
stem endogenous.

Subclass 1. MONOCOTYLEDONES stem exogenous.

Subclass 2, DiCotyledones

PAGE

\section{KEY TO THE FAMILIES.}

\section{Class 1. GYMNOSPERMaE. NAKed-Seeded Plants.}

Perianth none; trees or shrubs with needle- or scale-like leaves not sheathing.

Pistillate flowers in aments; fruit a cone, either dry or berry-like.

Carpellary scales subtended by bracts, never peltate; ovules inverted; buds scaly; wings of the seeds formed from a portion of the carpellary scales.

Carpellary scales not subtended by bracts, mostly peitate or fleshy; ovules erect; buds naked; wings of the seeds, if present, a part of the seedcoat. 2 . JUNIPERACEA

Pistillate flowers single or in pairs, without carpellary scales; fruit drupaceous or baccate.

3. TAXACEAE

Perianth present, urn-shaped; pistillate flowers single or in pairs; horsetail
shrubs with jointed branches and the leaves reduced to sheathing scales.

shrubs with jointed branches and the leaves reduced to sheathing scales.
4 . EPHEDRAcEAE

\section{Class 2. ANGiospermae Seed-venseled Plants.}

\section{Subclass 1. MONOCOTYLEDONES.}

Small lens-shaped, ellipsoid, or flask-shaped floating aquatics without leaves. 15. LEMNACEAE

Plants with true stems and leaves, the latter however, sometimes scale-like.

Perianth rudimentary or degenerate, its members often bristles or mere scales, not corolla-like, or wanting.

Flowers not in the axils of dry or chaffy bracts (glumes).

Perianth of bristles or chaffy scales.

Flowers in elongate terminal spikes; fruit hidden among bristles.

5. TYPHACEAE.

Flowers in globose lateral spikes: fruit not hidden among bristles.

6. SPARGANIACEAE

Perianth fleshy or herbaceous, or wanting.

Flowers in dense spikes subtended by an enlarged bract (spathe): fruit baccate; endosperm present; emersed water or bog plants.

14. ARACEAE

Flowers, if spicate, not subtended by a spathe; fruit drupaceous: endosperm wanting; submerged water plants. 
Gynoecium of distinct carpels; stigma disk-like or cup-like.

7. ZANICHELLIACEAE

Gynoecium of united carpels; stigmas 2-4, slender.

8. NAJADACEAE

Flowers in the axils of dry or chaffy, usually imbricate bracts (glumes). Leaves 2-ranked, their sheaths with their margins not united; stem mostly hollow; fruit a grain. 12. POACEAE

Leaves 3-ranked, their sheaths with united margins; stems solid; fruit an achene.

13. CYPERACEAE

Perianth of 2 distinct series, the inner series usually corolloid.

Gynoecium of distinct carpels.

Petals similar to the sepals; anthers long and narrow; carpels coherent.

Petals different from the sepals, in ours white; anthers short and thick; carpels not coherent.
Gynoecium of united carpels.

10. AlISMACEAE

Stamens numerous; water plants with broad netted-veined floating leafblades.

47. NYMPHAEACEAE

Stamens 3-6.

Ovary and fruit superior.

Stamens dissimilar, or only 3 with fertile anthers; endosperm mealy.

Calyx and corolla of free, very different members; stamens free. 16. COMMELINACEAE

Calyx and corolla of quite similar members and partly united; stamens partly adnate to the perianth.

17. Pontedertacean

Stamens alike and fertile; endosperm fleshy, horny, or cartilaginous.

Styles present, distinct or united; stigmas terminal.

Styles distinct; capsule septicidal. 18. MELANTHACEAE Styles united, often very short or obsolete during anthesis. Petals and sepals very unlike; capsules septicidal. 24. OALOCHORTACEAE

Petals and sepals nearly alike; capsules loculicidal. Sepals and petals chaffy. 19. JUNCAEAE Sepals and petals not chaffy.

Herbs with bulbs, corms or rootstocks.

Plants with bulbs, or corms, or short erect rootstocks.

Flowers in umbels, at first included in and later subtended by a scarious involuere. 20. AlLLACEAE

Flowers solitary or racemose, or in Leucocrinum by shortening of the stem the inflorescence umbel-like, without involucre. 21. LILIACEAE.

Plants with elongate horizontal rootstocks.

22. Convallariaceae

Shrubby plants with woody caudices, or trees. 23. DRACaEnaceae

Styles wanting.

Flowers perfect; plants not climbing.

Leaves and bracts alternate; plants with bulbs; fruit a capsule. 24 . CALOCHORTACEAE

Leaves or leaf-like bracts whorled; plants with rootstock; fruit a berry. 25. TRILLIACEAE

Flowers dioecious; plants climbing or trailing.

26. SMILACACEAE

Ovary and fruit wholly or partly inferior .

Flowers regular; androecium not reduced; stamens 3 or more.

Aquatic plants, dioecious or polygamous.

Land-plants with perfect flowers.

Stamens 6; leaves not equitant.

Stamens 3; leaves equitant.

11. Elodiaceae

Flowers irregular, perfect; terrestrial or epiphytic plants; stamens 1 or 2.

29. ORCHIDACEAE

\section{Subclass 2. DICOTYLEDONES.}

A. Corolla wanting.

I. Calyx wanting, at least in the staminate flowers.

Herbs.

Land plants; styles distinct, cleft or foliaceous; ovaries 3-celled.

Aquatic plants; styles simple, united into pairs; ovaries 4-celled. 75 . CALLITRICHACEAE

Trees or shrubs.

Fruit 1-seeded; seeds without tufts of hairs, 
Fruit a nut or an achene.

Fruit a drupe or a samara.

33. CORYlaceaE

101. OLEACEAF

205

Fruit many-seeded; seeds each with a tuft of hairs.

30. SAlicaceae

II. Calyx present at least in the staminate or in the perfect flowers.

655

185

1. Flowers, at least the staminate, in aments or ament-like spikes.

Plant not parasitic; fruit a nut or an achene.

Staminate and pistillate flowers both in aments; fruit not with a bur or cup.

Staminate flowers 2 or 3 together in the axils of the bracts, each with a calyx; pistillate flowers without a calyx.

32. Betulaceae

Staminate flowers solitary in the axils of each bract, without a calyx; pistillate flowers with a calyx.

33. Coryllaceae

Staminate flowers in aments; pistillate ones often solitary.

Fruit a nut, at least partly enclosed in a cup or bur.

Fruit drupaceous, not enclosed in a cup or bur. 31. FAGaceae

(Garrya in) 95. CoRnACEAE. 125. LORANTHACEAE

Plant parasitic; fruit berry-like. 125.

2. Flowers, at least the staminate, not in aments.

a. Ovary superior.

Gynoecium of 1, or several and distinct carpels; stigma and style of each solitary.

Carpel solitary.

Ovary neither enclosed nor seated in a hypanthium or a calyxtube.

Flowers not solitary in the axils of the leaves; land plants. Plants with scarious stipules; flowers cymose.

Plants not with scarious stipuigiol CORACEA.

es; flowers clustered.

36. URTICACEAE

Flowers solitary in the axils of the leaves; aquatic plants. 46. CERATOPHYLLACEAE

Ovary enclosed in or seated in a hypanthium or a calyx-tube.

Stamens borne under the gynoecium; calyx corolla-like; herbs. 40. NYCTAGINIACEAE

Stamens borne on the hypanthium or adnate to the calyxtube; calyx not corolla-like; shrubs.

Hypanthium becoming fleshy in fruit, enclosing the tail-less achenes; calyx 4-merous; stamens 4 or 8 ; leaves silvery-scurfy, 89. ELAEAGNACEAE

Hypanthium not becoming fleshy; achenes tailed; calyx 5-merous; leaves not scurfy. (Coleogyne and

Carpels several. Cercocarpus in) 60. ROSACEAE

Stamens inserted below the ovary.

(Genera in) 48. RANUNCULACEAE

Stamens inserted on the edge of a cup-shaped hypanthium. (Genera in) 60. ROSACEAE

Gynoecium of 2 or several united carpels; stigmas or styles 2 or several.

Ovary, by abortion, 1-celled and 1-ovuled.

Leaves with sheathing stipules (ocreae).

37. Polygonaceae

Leaves estipulate, or stipules, if present, not sheathing.

Trees or shrubs; ovary not seated in a hypanthium.

Herbs or vines.

34. ULMACEAE

Stipules herbaceous; inflorescence spicate or racemose; leaf-blades palmately veined.

35. Cannabinaceae

Stipules scarious, or hyaline, or none: inflorescence cymose: leaf-blades pinnately veined.

Fruit a utricle, or achene, circumscissile or bursting irregularly.

Stipules wanting.

Flowers subtended by an involucre formed by more or less united bracts.

37. POLYGONACEAE

Flowers not involucrate. Bracts not scarious.

38. Chenopodiaceae

Bracts scarious. 39. AMARANTHACEAE 
Fruit a capsule, dehiscent by apical or longitudinal valves.

Ovary several-celled, or with several placentae, several-ovuled.

Stamens hypogynous, inserted under the gynoecium in the perfect flowers, not on a disk in the staminate flowers.

Flowers perfect.

Stamens not tetradynamous.

Stamens 2; inflorescence spicate.

(Besseya in) 117. ScrophULARIACEA E

Stamens 3-10; inflorescence cymose or axillary. Ovary 1-celled.

Placentae parietal; pistils 2-carpillary.

57. SAXIFRAGACEAE

Placentae central or basal; pistils of $3-5$ carpels.

Calyx not petaloid, of 4 or 5 distinct sepals. 44. ALSINACEAE

Calyx more or less petaloid, campanulate, merely 5-lobed.

(Glaux in) 100. PRIMULACEAE

Ovary 3-5-celled; leaves verticillate.

41. TETRAGONLACEAE

Stamens tetradynamous.

(Apetalous species in) 52. BRASSICACEAE Flowers monoecious or dioecious.

74. EUPHORBIACEAE

Stamens perigynous or epigynous, inserted on the margin of a hypanthium or a disk.

Fruit a samara.

78. ACERACEAE

Fruit drupe-like or berry-like.

b. Ovary inferior.

(Apetalous species in) 79. RHAMNACEAE

Flowers not in involucrate heads.

Fruit a berry, or a drupe, or nut-like.

Shrubs, with scurfy and usually silvery leaves.

Herbs, not with scurfy leaves.

89. ElaAEAgNACEAE

Stamens as many as the perianth-members and alternate with them, or fewer. 41. TETRAGONIACEAE

Stamens as many as the perianth-members and opposite them, or twice as many; water plants.

Water plants, with whorled leaves.

Land plants, parasitic or saprophytic, with alternate

Fruit a capsule. leaves.

126. SANTALACEAE

Sepals as many as the ovary-cavities, or one-half as many.

Hypanthium merely enclosing the ovary.

90. LYTHRACEAE

Hypanthium adnate to the ovary. 91. ONAGRACEAE

Sepals not of the same number as the ovary-cavities.

Styles 2; leaves alternate.

57. SAXIFRAGACEAE

Styles 6 ; leaves 2 , basal.

128. ARISTOLCCHIACEAE

Flowers, at least the staminate, in involucrate heads,

$\begin{array}{lll}\text { Calyx corolla-like. } & \text { 40. NYCTAGINACEAE } & 255\end{array}$

Calyx not corolla-like.

B. Corolla present.

605

582

583

376

821

825

\section{Petals distinct, at least at the base.}

1. Carpels solitary, or several and distinct, or united only at the base.

Stamens at the base of the receptacle, $i$. e., hypogynous.

Plants with relatively firm stems and leaves, not succulent.

Stamens numerous; anther-sacs opening by slits.

Submerged water plants with minute axillary sessile monoecious flowers; anthers with horn-like appendages.

46. Ceratophyllaceae

Land plants or rarely water plants with perfect or rarely dioecious flowers; anthers not with horn-like appendages.

48 . RANUNCULACEAE
Stamens definite (in ours 6 ) ; anther-sacs opening by hinged-valves.

Plants with succulent stems and leaves. 55 . BERBERIDACEAE

Stamens on the margin of a hypanthium (the hypanthium very small in some Saxifragaceae).

Flowers regular or nearly so (actinomorphic).

Endorsperm present, usually copious and fleshy.

Herbs; stipules mostly wanting.

Carpels as many as the sepals; succulent plants. 
Carpels fewer than the sepals, 2 or rarely 3 , distinct or only partly united; plant scarcely succulent.

57. SAXIFRAGACEAE

Shrubs or trees; fruit thin-walled follicles; stipules present.

(Opulaster in) 60 . ROSACEAE
Endosperm wanting or scant; stipules mostly present.

Carpels several or numerous, or, if solitary, becoming an achene.

Carpel solitary, not becoming an achene.

60. ROSACEAE

Ovary 2-ovuled; fruit a drupe; leaves simple.

62. AMYGDALACEAE

Ovary several-ovuled; fruit a legume; leaves pinnately compound.

63. MrmosaceaE

Flowers irregular (mostly zygomorphic).

Upper petal enclosed by the lateral ones in the bud; corolla not papilionaceous. 64. OAESALPINIACEAE

Upper petal enclosing the lateral ones in bud; corolla papilionaceous. 65. FABACEAE

2. Carpels several and united.

\section{a. Ovary superior. \\ * Stamens inserted at the base of the ovary or receptacle. \\ $\dagger$ Stamens numerous.}

Sepals imbricate.

Filaments united in 3 or more sets; leaves pellucid-punctate.

Filaments distinct; leaves not punctate. Calyx deciduous.

Calyx persistent.

50. Papaveraceat

Stigmas distinct or united, but not discoid; land plants; petals and sepals 4.

53. CAPPARIDACEAE

Stigmas united into a disk; aquatic plants; petals and sepals numerous. 47. NYMPHAEACEAE

Sepals valvate; stamens with united filaments.

81. Malvaceae

$\dagger \dagger$ Stamens few, not over twice as many as the petals.

Stamens as many as the petals and opposite them.

Anther-sacs opening by hinged valves.

Anther-sacs opening by slits.

Flowers monoecious.

49. BERBERIDACEAE

74. EUPHORBIACEAE Flowers perfect.

42. PORTULACACEAE

Stamens as many as the petals and alternate with them, or more, sometimes twice as many.

Stamens 6 or less; petals 4 : sepals 2 or 4 .

Sepals 2; endosperm present; flowers irregular; stamens diadelphous. 51. FUMARIACEAE

Sepals 4, rarely more; endosperm wanting; flowers regular.

Capsule 2-celled; stamens tetradynamous, rarely 2 or 4 52. BRASSICACEAE

Capsule 1-celled; stamens not tetradynamous.

53. CAPPARIDACEAE

Stamens, petals, and sepals of the same number, or stamens more, usually twice as many as the sepals or petals.

Ovary 1-celled.

Ovules, or seeds, on basal or central placentae.

Sepals 2; or, if more (in Lewisia), plant scapose, with fleshy basal leaves and the flowers solitary on a jointed scape.

Sepals 4-5; plants leafy-stemmed.

42. Portulacaceae

Sepals distinct; petals not clawed; ovary sessile.

44. A LSINACEAE

Sepals united; petals clawed; ovary more or less distinctly stipitate.

45. CARYophyllaceae

Ovules, or seeds, on parietal placentae.

Stamens with united flaments and no staminodia.

81. Malvaceae

Stamens with distinct filaments. Staminodia present.

56. Parnassiaceae 
Staminodia wanting.

Stigmas 2-cleft; plants insectivorous, with glandular-hispid leaves.

54. Droseraceae

Stigmas entire; land plants, not insectivorous; leaves not glandular-hispid. Styles in ours distinct.

Sepals persistent, united into a tube; leaves not pellucid-dotted. 84. FRANKENIACEAE

Sepals distinct; leaves pelluciddotted.

82. HYPERICACEAE

Styles wholly united.

Corolla regular or nearly so; stamens 8 or more.

Sepals and petals 4 ; the latter not fugaceous.

53. CAPPARIDACEAE

Sepals and petals 3 or 5 ; the latter fugaceous.

85. Cistaceie

Corolla irregular; one petal spurred stamens 5.

86. VIOLACEAE

Ovary several-celled.

Stamens adnate to the gynoecium.

106. AsCLEPIADACEAE

Stamens not adnate to the gynoecium.

Stamens with wholly or partly united filaments.

Anthers opening lengthwise; corolla regular.

Leaves punctate; filaments polyadelphous,

$i$, e., united in three or more bundles.

82. HYPERICACEAE

Leaves not punctate; flaments monadelphous, $i, \ell_{\text {, }}$ united in a single bundle

Styles united around a central column

from which they break at matur-

ity. 66. GERANIACEAE

Styles distinct or permanently and partly united; the tips and the stigmas free.

Leaves simple; stamens 5.

68. LINACEAE

Leaves compound; stamens 10-15.

67. OXALIDACEAF

Anthers opening by pores; corolla irregular.

73. PolygalaceaE

Stamens with distinct filaments.

Anthers united; flowers irregular.

69. BAISAMINACEAF

Anthers distinet; flowers regular or nearly so.

Anthers opening by pores.

Gynoecium superior; fruit usually capsular.

Herbaceous saprophytes without green leaves.

97. MONOTROPACEAE

Herbs with green leaves and rootstocks. 96. Pyrolaceat

Gynoecium inferior; fruit baccate or drupaceous.

99. VACCTNIACEAE

Anthers opening by slits.

Stigmas or styles distinct and cleft, or foliaceous.

74. EUPHORBIACEAE

Stigmas or styles distinet or united, neither cleft nor foliaceous.

Style wanting; dwarf water plants. 83. Eiatinaceae

Styles present; not water herbs. Stamens 2, rarely 3 . 101. Olficeate

Stamens more than 3.

Leaves punctate with translucent dots.

Leaves without translucent dots. 
Calyx irregular, one of the sepals spurred or saccate; anthers united around the stigma.

69. BAISAMINACEAE

Calyx regular; none of the sepals saccate; anthers distinct.

Style basal, arising between the nearly distinct lobes of the ovary; leaves oddpinnate.

70. LIMNANTHACEAE

Styles not basal; leaves in ours abruptly pinnate, or digitate.

71. ZYGOPHYLLACEAE

** Stamens inserted on the margin of a disk or hypanthium (perigynous or hypogynous).

Styles and upper part of the ovaries distinet.

Styles united.

\section{SAXIFRAGACEAE}

Stamens as many as the petals and opposite them.

Fruit a samara. 78 . ACERACEAE

Fruit a berry, drupe, or capsule.

Sepals manifest; petals involute; fruit capsular or drupaceous; ours shrubs or trees.

79. Rhamnaceae

Sepals minute or obsolete; petals valvate; fruit a berry; ours vines with tendrils. 80 . VITACEAE

tamens as many as the petals and alternate with them, or more.

Hypanthium flat or obsolete; disk fleshy.

Styles united, arising in the center, between the nearly distinct lobes of the ovary; small hydrophytic plants.

70. LIMNANTHACEAE

Styles not arising between the ovaries; trees or shrubs. Plants without secreting glands in the bark.

Plants with resiniferous tissue; fruit drupaceous: seeds without aril; leaves in ours compound. 77. ANACARDIACEAE

Plants without resiniferous tissue; fruit a loculicidal capsule; seed with a fleshy aril; leaves simple. 76. CElastracen

Plants with secreting glands in the bark.

72. RUTACEAE

Hypanthium cup-shaped or campanulate; disk obsolete or inconspicuous,

90. LYTHRACEAE

2. Ovary at least partly inferior.

a. Stamens numerous.

Ovary partly inferior.

Fruit a capsule.

58. Hydrangeaceae

392

Fruit a pome.

61. MaLACEAF

Ovary wholly inferior.

Sepals and petals 4 or 5 , very unlike each other; leaves ample.

Trees or shrubs; fruit fleshy. 61. MALACEAE

Herbs with rigid hairs; fruit capsular.

87. LOASACEAE

Sepals and petals nearly alike, at least the latter numerous: leaves typically and in all ours mere scales or wanting; succulent plants armed with spines. 88 . CACTACEAE

b. Stamens not more than twice as many as the petals.

Styles wanting; stigmas sessile.

92. HALORIGIDACEAE

605

Styles present.
Plants without tendrils.

Styles distinct.

Ovules several in each cavity of the ovary; fruit a capsule or a fleshy many-seeded berry.

Fruit, if dehiscent, valvate.

Leaves opposite; fruit a leathery capsule.

58. HYDRANGEACEAE

392

Leaves alternate; fruit a berry.

59. Grossullariaceae

Fruit circumscissile.

42. Portullacaceat

Ovules solitary in each cavity of the ovary: fruit a drupe or 2-5 more or less united achenes.

Fruit drupaceous or baccate; gynoecium 1-severalcarpellary, if 2-carpellary the stigmas introrse. 
Ovule with a ventral raphe; leaves mostly alternate; blades lobed or compound.

94. ArallaceAe

Ovule with a dorsal raphe; leaves mostly opposite; blades entire or merely toothed.

95. CORNACEAE

Fruit dry, a cremocarp; gynoecium 2-carpellary;

stigmas terminal. 93. AMMIACEAE Styles united, or single.

Ovary enclosed in or surpassed by the hypanthium or adnate to it.

Anthers opening by pores; fruit a berry.

99. VACCINIACEAE

Anthers opening by slits; fruit a capsule.

Ovary with parietal placentae.

87. Loasaceat

Ovary with central or basal placentae.

Hypanthium merely enclosing the ovary. 90. LYTHRACEAE

Hypanthium adnate to the ovary.

91. ONAGRACEAE

Ovary exceeding the hypanthium, the top free.

58. HYDRANGIACEAE

Plants with tendrils; fruit a pepo; leaf-blades palmately veined.

II. Petals more or less united.

\section{A. Ovary superior.}

1. Stamens free from the corolla.

Gynoecium of a single carpel; corolla papilionaceous.

Gynoecium of several united carpels.

65. FABACEAE

Filaments united.

Stamens diadelphous.

Stamens monadelphous.

\section{FUMARIACEAE}

Anther-sacs opening by slits; calyx and corolla regular.

Anther-sacs opening by pores; calyx and corolla very

irregular. 73. POLYgalaceate

Filaments distinct.

Corolla regular; anthers distinct.

Herbaceous saprophytes, without green leaves.

Herbs or shrubs with green leaves.

$$
\text { 97. MONOTROPACEAE }
$$

Corolla of essentially distinct petals, $i$. $e_{\text {., }}$ united only at the base; herbs with rootstocks.

Corolla of distinctly united petals; shrubs.

98. Shrubs.

Corolla irregular; one of the petals free; anthers united.

69. BAISAMINACEAF

635

2. Stamens partially adnate to the corolla.

a. Stamens as many as the lobes of the corolla and opposite them, or twice as many or more; ovary 1-celled; placentae central or basal.

100. Primulacean

b. Stamens as many as the lobes of the corolla and alternate with them, or fewer

* Corolla not scarious, veiny; fruit various, but not a pyxis.

$\dagger$ Carpels distinct, except sometimes at the apex.

Styles united; stamens distinct or gynandrous.

Styles distinct; stamens monadelphous.

105. APOCYNACEAE

$\dagger+$ Carpels united.

106. AsCLEPIADACEAE

Ovary 1-celled, with central placentae.

Corolla-lobes convolute or imbricated in the bud; leaves typically opposite and simple.

103. GENTLANACEAE

Corolla-lobes induplicate-valvate in the bud; leaves alternate, in ours mostly basal and trifoliolate.

104. MFNYANTHACEAE
Ovary 2-3-celled, or falsely 4-celled, or if 1-celled with parietal placentae.

Stamens 2, opposite to each other; corolla regular.

101. OLEACEAE

Stamens usually more than 2 , if only 2 not opposite to each other and the corolla irregular.

Leaves with stipules or stipular lines. 
Leaves without traces of stipules.

Stamens 5, if only 3-4, not didynamous.

Fruit a capsule or berry; ovary not 4-lobed.

Styles or stigmas usually distinct.

Parasitic twining plants, with scalelike leaves.

108 . CUSCUTACEAE
Plants not parasitic; leaves normal.

Inflorescence not scorpioid; flowers cymose or solitary; ovary $2-3$ celled.

Corolla plaited and the plaits convolute in the bud; flowers axillary, solitary or cymose-conglomerate; plants usually twining.

107. ConvolvulaceaE

Corolla merely convolute in the bud, not plaited; flowers cymose; plants never twining.

109. Polemoniachae

Inflorescence more or less distinctly scorpioid; ovary in ours i-celled or imperfectly 2-celled.

Fruit a capsule.

110. HYDROPHYLLACEAE

Fruit more or less drupaceous. 111. EHRETIACEAE

Styles and stigmas wholly united.

Ovules few. 109. ConvolvUlaceae

Ovules numerous.

Median axis of the gynoecium in the same plane as the axis of the stem; seeds mostly pitted. 116. SOLANACEAE

Median axis of the gynoecium not in the same plane as the axis of the stem; seed tuberculate.

(Verbascum in) 117. SCROPHULARLACEAE Fruit of 1-4 nutlets; ovary more or less distinctly 4-lobed.

Style or stigma furnished with a glandular ring. 112. HELIOTROPACEAE Style or stigma not furnished with a glandular ring.

Fruit 4 dry nutlets.

$$
\text { 113. BORAGINACEAE }
$$

Fruit more or less drupaceous.

$$
\text { 111. EHRETIACEAE }
$$

Stamens 4 and didynamous, or 2 or 1.

Stamens 2 and opposite to each other; corolla regular. 101. OLEACEAE

Stamens, if 2, not opposite to each other, nor the corolla regular.

Carpels ripening into 2 or 4 nutlets, an achene, or a drupe.

Style apical on the lobeless ovary. 114. VERBENACEAE:

Style arising between the 4 lobes of the ovary.

\section{LAMIACEAE}

Carpels ripening into a capsule.

Ovary 2-celled, rarely 3-5-celled land-plants. 117. SCROPHULARIACEAF

Ovary 1-celled; ours submerged water plants or bog plants. 118. LENTIBULARIACEAE

Placentae of the ovary parietal.

Herbs parasitic on the roots of other plants; leaves scale-like, not green.

119. OROBANCHACEAE

Herbs with green leaves, not parasitic. 120. MARTYNIACEAE 
** Corolla scarious, veinless; fruit a pyxis.

B. Ovary inferior.

Stamens with the fllaments free from the corolla.

Stamens 10; anther-sacs opening by terminal pores or chinks.

Stamens 5 or fewer; anther-sacs opening by longitudinal slits.

Corolla regular; anthers distinct. 130. CAMPANULACEAE

Corolla irregular; anthers united. 131. LOBELIACEAE

Stamens adnate to the corolla.

Ovary with 2-many fertile cavities and 2-many ovules; calyx unmodified, at least not a pappus.

Plants tendril-bearing.

129. CUCURbitaceae

Ovules mostly on basal placentae; plants parasitic or saprophytic.

Leaves opposite; fruit a berry; tree-parasites.

125. LORANTHACEAE

Leaves alternate; fruit a drupe or nut; root-parasites or saprophytes.

126. SANTALACEAE

Ovules variously borne, but not on a basal placenta; plants not parasitic.

Stamens as many as the corolla-lobes.

Leaves with stipules (often leaf-like and usually regarded as leaves) adnate to the stem between the leaf-bases.

122. RUBIACEAE

Leaves without stipules or if present these adnate to the petioles. 123 . CAPRIFOLIACEAE

Stamens twice as many as the corolla-lobes; low herbs with ternately dissected leaves. 124. ADOXACEAE

Ovary with one fertile cavity; calyx often modified into a pappus.

Flowers not in heads, often in head-like spikes or racemes.

Flowers in involucrate heads.

127. VALERIANACEAE

Flowers all with tubular corollas or none, or only the rayflowers with ligulate corollas.

Stamens distinct.

Flowers hermaphrodite, surrounded by a cup-like involucel; anthers versatile. 132. DIPSACEAE

Flowers unisexual, not involucellate; anthers basifixed. 133. AMBrostacene

Stamens united by the anthers, or if distinct (in $K u h n i a$ ) the flowers hermaphrodite and anthers basifixed.

Flowers all with ligulate corollas. 135 . CICHORIACEAE 


\section{Class 1. GYMNOSPERMae. Naked-Seeded Plants.}

Ovules naked, inserted on the upper side of an open, mostly flat, more or less developed scale, not enclosed in an ovary. Pollengrains divide into two or more cells, of which one produces a pollentube; this fertilizes the ovule directly. All trees or shrubs, most of them evergreen.

\section{Family 1. Pinaceae. Pine Family.}

Resinous trees or shrubs, mostly with evergreen, needle-shaped or linear leaves. Stamens several together, subtended by a scale, forming elongated aments; filaments more or less united; anthers usually 2-celled; pollen-grains globose, ellipsoid, or lobed. Pistillate aments consisting of usually numerous spirally disposed scales subtended by bracts. Ovules inverted, usually 2 at the base of each scale. Fruit a dry cone. Seeds usually 2 at the base of each scale, often samara-like; wing formed by a part of the scale.

Leaves several together (in one species solitary), surrounded by a sheath at the base; cones maturing the second year.

Cone-scales with dorsal, usually spine-armed appendages.

Seeds with elongated wings attached to the seeds when they fall; leaves mostly
with two flbro-vascular bundles. with two fibro-vascular bundles.

Seeds with narrow or rudimentary wings, which remain attached to the scales when the seeds fall; leaves with a single fibro-vascular bundle.

Cone-scales with inconspicuous terminal unarmed appendages, 2 . CARYoPITYs.

Seeds with rudimentary wings attached to the scales; cones subsessile, spreading.

Seeds with well-developed wings, which remain attached to the seeds; co

tinctly stalked

Leaves not surrounded by sheaths; cones maturing the first year.

Leaves in fascicles at the ends of short branches, deciduous.

Leaves scattered along the branches, persistent.

Branches smooth, not roughened by persistent leaf-bases.

Cones erect, their scales and bracts deciduous from the persistent axis; leavos sessile with circular leaf-scars. 6. ABIEs.

Cones pendulous, their scales and bracts persistent; leaves petioled with trans-

versal oval leaf-scars.
Branches roughened by persistent leaf-bases (sterigmata).

4. STROBUS.

5. LARIX.

Leaf-blades petioled with a single dorsal duct; anthers opening transversely; seeds with resin-vesicles.

Leaves flat, with stomata only on the lower side, 2-ranked by twisting of

the petioles; cones small, drooping.
Leaves not much flattened, keeled on the lower side, with stomata on both

8. TSUGA. sides, spreading in all directions; cones elongated, erect at least at first.

Leaf-blades sessile, with two lateral ducts, in ours 4-angled and spreading in all directions; anthers opening longitudinally; seeds without resin-vesicles.

10. Picea.

\section{Pìnus (Tourn.) L. Hard Pines, Pitch Pines.}

Monoecious evergreen trees or rarely shrubs, with two kinds of leaves, the primary leaves chaff-like, deciduous, the secondary ones green, needle-shaped, usually with two fibro-vascular bundles (in all ours except in $P$. aristata), in fascicles of $2-5$, surrounded by a sheath, which is usually persistent. Staminate aments elongated, at the ends of branches of the preceding year; anthers 2celled, opening longitudinally; pollen-grains 3-celled, the two lateral cells empty. Pistillate aments globose or oblong, sessile or nearly so, below the terminal bud or on the young twigs. Cones in ours subsessile, maturing the second autumn; scales thick, spreading at maturity, with a dorsal appendage or thickening, usually armed with a spine or at least a tubercle. Seeds samara-like, with the wing remaining attached to the seed. 
Leaves in 4's or 5's, with solitary fibro-vascular bundles and more or less deciduous sheaths; spines of the cone-scales long and slender.

1. P, aristata.

Leaves in 2's or 3's, with usually two fibro-vascular bundles and persistent sheaths; spines of the cone-scales short or none.

Cones 6-15 cm. long and 5-6 cm. in diameter; leaves $8-25 \mathrm{~cm}$. long. Leaves $12-25 \mathrm{~cm}$. long; cones $8-15 \mathrm{~cm}$. long, elongated-ovoid. $\quad 2$. $P$. ponderosa. Leaves $8-15 \mathrm{~cm}$. long; cones $6-9 \mathrm{~cm}$. long, rounded-ovoid. $3 . P$. scopulorum.

Cones 3-5 cm. long and about $3 \mathrm{~cm}$. in diameter.

Cones spreading, or somewhat reflexed; scales with evident dorsal spines.

4. P. Murrayana.

Cones erect, more or less incurved; scales unarmed or nearly so, at least at maturity.

5. P. Banksiana.

1. P. aristata Engelm. A low stunted tree, $3-15 \mathrm{~m}$. high; bark of the trunks dull reddish brown, shallowly furrowed; that of the smaller trunks and limbs smooth, milky-white; leaves dark green above, glaucous beneath, 3-4 cm. long, in fascicles of 5 , crowded toward the ends of the branches; staminate flowers orange-red; pistillate ones dark purple; cones sessile, 7-10 cm. long, ellipsoid, obtuse; scales with a thickened purple-brown back. BRIsTLE-CONE Pine. High mountains: Colo,-N.M.-Calif.-Nev. Mont.-Subalp.

2. P. ponderosa Dougl. A tree $35-60 \mathrm{~m}$. high, with a trunk $1-2 \mathrm{~m}$. in diameter; bark in older trees 5-10 $\mathrm{cm}$. thick, dark brown, separating into cinnamon-red scales; leaves in fascicles of 3, yellowish green, $12-25 \mathrm{~cm}$. long; staminate flowers yellow; pistillate ones dark red; cones broadly ellipsoid, horizontal, subsessile, 1-1.5 dm. long. Bull Pine. Slopes and valleys: B.C.Mont.-Ida.-Calif. Submont.

3. P. scopulorum (Engelm.) Lemmon. A tree 25-30 m. high; bark thick, deeply divided into plates; leaves in 2's or 3's, yellowish green, 8-15 cm. long; staminate flowers yellow; pistillate ones purple; cones conic-ovoid, horizontal. P. ponderosa scopulorum Engelm. Rock Pine, Bull Pine. Hills and mountains: S.D.-Neb.-N. M.-Ariz.-Mont. Submont.-Mont.

4. P. Murrayana Balf. A tree 20-30 m., sometimes $45 \mathrm{~m}$. high; bark of the trunk about $5 \mathrm{~mm}$. thick, close and firm, covered with appressed scales, orangebrown; branches light orange; leaves yellowish green, 3-7 $\mathrm{cm}$, usually about 5 $\mathrm{cm}$. long; flowers orange-red; cones spreading, 3-4 cm. long, short-ovoid. $P$. contorta Murrayana Engelm. LODge-POLE PINE. Hills and mountains: Sask. (Cypress Hills) -Colo.-Calif,-Alaska. Mont.

5. P. Banksiana Lamb. A tree $10-20 \mathrm{~m}$., rarely $30 \mathrm{~m}$. high; bark dark brown, tinged with red, irregularly furrowed; leaves in rather remote clusters of 2, dark green, 2-3 cm. long; staminate flowers yellow; pistillate ones dark purple; cones conic-ovoid, erect and incurved, 3-5 cm. long, dull purple or green, turning yellow and shining. P. divaricata (Ait.) Gordon. Gray or Northern Scrub Pine, Banrsian Pine. Sandy soil: N.S.-n N.Y.-Minn.-Alta.-Mack. Boreal.

\section{CARYÓPITYS Small. Nut-Pines, Piñons.}

Monoecious evergreen trees or shrubs, with 2 kinds of leaves as in Pinus; secondary leaves with solitary fibro-vascular bundles, in fascicles of $2-4$, or in one species usually solitary, surrounded by a deciduous sheath. Staminate aments as in the preceding. Pistillate cones subsessile just below the terminal bud; scales in rather few series. Cones maturing the second season; scales becoming leathery, thick, with a dorsal thickening, usually with a small spinetip. Seeds large and edible, with a very narrow wing or mere margin, remaining attached to the scale when the seed falls.

Cones about $3 \mathrm{~cm}$. long; leaves usually in pairs, seldom in threes. Cones 4-5 cm. long; leaves singly or sometimes in pairs.

1. C. edulis.

2. C. monophylla.

1. C. edulis (Engelm.) Small. A tree 6-12 m. high; bark of the trunk divided into ridges and brown scales; that of the young branches orange or yellow; foliage-leaves in clusters of 2's, rarely in 3's, semi-terete or triangular, 2-4 $\mathrm{cm}$. long; staminate flowers dark red; cones very short-peduncled, spreading, short-ovoid, $2-4 \mathrm{~cm}$. long, almost as wide. Pinus edulis Engelm. PrÑon, NuTPINE. Foot-hills: Wyo.-w Tex.-Ariz.-Utah; Mex. Son.-Submont. 
2. C. monophylla (Torr. \& Frem.) Rydb. A tree usually 4-6 m., rarely up to $15 \mathrm{~m}$. high; bark irregularly furrowed, brown, tinged with red or orange; branches smooth, light gray or yellowish; leaves single or in pairs, yellowish green, incurved, $3-5 \mathrm{~cm}$. long, when single terete, when in pairs flat and glaucous on the inside; staminate flowers reddish; cones depressed-ovoid, $3-6 \mathrm{~cm}$. long. P. monophylla Torr. \& Frem. One-Leaved Piñon. Dry hillsides and slopes: Utah-Ariz.-L. Calif.-Nev. Son.-Submont.

\section{APİNuS Necker. Cembra Pines.}

Monoecious trees or shrubs, with two kinds of leaves as in Pinus; secondary leaves with single fibro-vascular bundles, in fascicles of 5 . Staminate aments as in Pinus. Pistillate cones subsessile below the terminal bud; scales in several series. Cones maturing the second season, spreading; scales more or less thickened, but without dorsal thickening or spine. Seeds large, edible, with a very short wing or mere margin remaining attached to the scale when the seeds fall.

Cones 8-15 cm. long; scales neither much thickened nor impressed around the scar, spreading at maturity.

Cones 5-8 cm. long; scales much thickened and impressed around the terminal scar, remaining closed.

2. A. albicaulis.

1. A. flexilis (James) Rydb. A tree 10-15 m. high; bark of the old trunks blackish or dark brown, deeply furrowed between rectangular blocks; that of the branches light gray, shining, smooth; leaves dark green, crowded at the ends of the branches, $3.5-7 \mathrm{~cm}$. long; staminate flowers reddish; pistillate flowers redpurple; cones 8-25 cm. Iong, ovoid, short-stalked; scales somewhat thickened, opening at maturity, exposed portion greenish or yellowish brown, unexposed portion pale red. Pinus flexilis James. Limber Pine. High mountains: Alta. - w Tex. - se Calif. Submont. $\rightarrow$ Subalp.

2. A. albicaulis (Engelm.) Rydb. A tree $1-10 \mathrm{~m}$. high, rarely $15 \mathrm{~m}$. high, sometimes in exposed situations a mere sprawling shrub; bark of the trunks thin, slightly if at all fissured, ashy; that of the branches yellowish, downy; leaves crowded near the ends of the branches, dark green, 4-6 cm. long; flowers scarlet; cones ovoid, horizontal, sessile, dark purple; scales much thickened, remaining closed. P. albicaulis Engelm. WHITE BARK or NUT PINe. High exposed mountains: Alta. $-\mathrm{n}$ Wyo.-Calif.-B.C. Mont.-Subalp.

\section{Stròbus Opiz. White Pines.}

Monoecious evergreen trees, with two kinds of leaves as in Pinus; secondary leaves mostly with a single fibro-vascular bundle, in fascicles of 5 , surrounded at the base by deciduous sheathing bud-scales. Staminate aments as in Pinus. Pistillate cones stalked, borne behind the terminal bud; scales in many series. Cones maturing the second season, drooping; scales becoming leathery, without dorsal thickening or spine. Seeds with a well-developed wing remaining attached to the seed.

1. S, monticola (Dougl.) Rydb. A tree often $30 \mathrm{~m}$., rarely $45 \mathrm{~m}$. high, with a trunk 7-12 dm. in diameter; bark of the trunk 2-3 $\mathrm{cm}$. thick, grayish purple to cinnamon-colored; leaves bluish green, whitened by 2-6 rows of stomata, 5-10 cm. long; staminate flowers yellow; pistillate cones purple, $1.5-2.5 \mathrm{dm}$. long; tips of scales reddish- or yellowish-brown, lower and inside portions bright red. $P$. monticola Dougl. Western White Pine. Mountains: B.C. - nw Mont.Ida. - s Calif. Submont.-Mont.

\section{LÀrIX (Tourn.) Adans. Larch, Tamarack.}

Slender deciduous monoecious trees. Leaves needle-shaped, soft, very many in each fascicle, developed in early spring from lateral scaly buds. Staminate aments terminating short lateral branches of the preceding year, from naked buds. Anthers 2-celled, opening transversely; pollen-grains 1-celled, globular. Pistillate aments crimson, usually subtended by leaves; cone-scales persistent. Seeds samara-like; wings attached to the seeds. 
Oones 1-2 cm. long, subglobose; their scales few, longer than the bracts; leaves 3-angled.

Cones 2-4 cm. long, ovoid; their scales numerous, shorter than the bracts.

Leaves triangular; branches soon becoming glabrate.

Leaves quadrangular; branchlets tomentose.

. L. laricina.

1. L. laricina (Du Roi) Koch. A tree $15-25 \mathrm{~m}$. high, with a trunk 3-6 dm. in diameter; bark of the trunk separating into reddish brown or ashy scales; twigs smooth, at first whitish, turning yellowish brown; leaves in clusters of 1220 , somewhat 3-angled, ridged beneath, 2-3 cm. long, bright green; cones russetbrown, 1.5-2 cm. long; scales about 20, obovate, erose, twice as long as the bracts. L. americana Michx. Tamarack, American Larch. Swamps: Lab.Mass,-Pa.-Ill.-Sask.-Alaska. Boreal-Subarct.

2. L. occidentalis Nutt. A tree with a narrow crown, usually $30-50 \mathrm{~m}$. high, rarely $60-70 \mathrm{~m}$. high, with a trunk $10-15 \mathrm{dm}$. thick; bark of the trunk very thick, deeply furrowed, cinnamon-brown; twigs dark or grayish brown; leaves $15-30$ in each cluster, pale greenish yellow, 3-5 cm. long, triangular, ridged on their inner face; cones 3-4 cm. long, short-peduncled; scales villous below the middle outside, obovate, with reflexed margins, shorter than the bracts; the latter lanceolate, 3-toothed at the apex. WESTERN LARCH. Wet or gravelly soil, on mountain sides and valleys: B.C.-nw Mont.-Ore. Submont.-Mont.

3. L. Lyallii Parl. A tree 10-15 m. high, with a trunk $2.5-6 \mathrm{dm}$. in diameter, rarely $20 \mathrm{~m}$. high; bark of the trunk slightly furrowed, purplish or reddish brown; twigs pale gray, shining, smooth, white-villous for about two seasons; leaves 4-angled, pale blue-green, 3-4 cm. long, 30-40 in each cluster; cones ellipsoid, 4-5 cm. long, subsessile or short-stalked, tomentose; seales obovate, erose, reddish purple, rarely green; bracts much longer, 3-lobed. LYALL's LARCH. High mountain slopes, near timberline: B.C.-Alta.-Mont.-n Ore. Subalp.

\section{6. ÀBIES (Tourn.) Hill, Fir, BaLsaM.}

Monoecious evergreen trees with spreading branches. Leaves flattened, leaving rounded scars on the smooth branches (without sterigmata), with 2 longitudinal resin-ducts and solitary fibro-vascular bundles, those of the lateral branches appearing 2-ranked by the twisting of the base, those of the cone-bearing branches usually curved upward and shorter. Staminate aments in theaxils of the leaves of the preceding year, subtended by imbricate bracts; pollensacs opening transversely or nearly so. Pistillate aments lateral, erect; cones maturing the first year, erect; scales and bracts deciduous at maturity. Seeds samara-like; wings remaining attached to the seeds.

Resin-ducts of the leaves within the soft tissues, remote from the epidermis.

Bracts longer than the cone-scales; leaves dark green above, pale beneath.

Bracts much shorter than the cone-scales; leaves blue-green and glaucous. Bark of the trunk hard, not corky; cone-scales longer than broad. 2. A. lasiocarpa. Bark of the trunk elastic, corky; cone-scales broader than long. 3. A. arizonica. Resin-ducts of the leaves close to the epidermis on the lower side. Bracts obcordate with a short acumination; leaves (except those of the cone-bearing
branches) emarginate, dark green above, white beneath.

Bracts truncate with a short acumination; leaves acute or acuminate, seldom obtuse at the apex, pale blue-green and glaucous

5. A. concolor.

1. A. balsamea (L.) Mill. A tree $15-20 \mathrm{~m}$., rarely $27 \mathrm{~m}$. high, with broadly conic crown; bark on old trunks scaly, of young trunks and branches smooth, warty with resin-blisters; leaves dark green and shining above, silvery white beneath; those of the sterile branches $2-3 \mathrm{~cm}$. long, obtuse; staminate flowers yellow, tinged with purplish; pistillate deeply purple; cones oblong, puberulent, 5-10 cm. long; seales obovate, longer than broad, usually twice as long as the bracts, serrulate. BALSAM FIr. Low ground: Lab.-Mass.-Va. -Iowa-Man.-Alta.-Mack. Boreal-Subarct.

2. A. lasiocarpa (Hook.) Nutt. A tree usually $25-30 \mathrm{~m}$., rarely $45 \mathrm{~m}$. high, with a trunk 3-10 dm. in diameter, at the timberline a shrub 1-2 m. high; bark of the trunks smooth with resin-blisters, only in old trees somewhat cracked and scaly; twigs usually puberulent; leaves of the lower branches $2.5-4 \mathrm{~cm}$. long, rounded at the apex; staminate flowers dark blue, turning violet; pistillate 
violet-purple, rarely yellow; cones oblong, 5-10 cm. long; scales obovate, narrowed at the base, more than twice as long as the bracts. A. subalpina Engelm. SubalpINE Fir, Balsam. Subalpine mountains: Alta.-N.M.-Ariz.-Ore.-Alaska. Subalp.

3. A. arizonica Merriam. A tree about $15 \mathrm{~m}$. high; trunk 2-4 dm. in diameter; bark of the stem whitish, corky, elastic, irregularly ridged; that of the branches smooth and with resin-blisters; leaves of the lower branches $2.5-3 \mathrm{~cm}$. long, usually notched at the apex; those of the cone-bearing branches $2 \mathrm{~cm}$. long, sharp-pointed; pistillate flowers purple; cones oblong, about $5 \mathrm{~cm}$. long; scales transversely rounded-oval, nearly twice as long as the bracts. Arizona Balsam. High mountains: Ariz. $\rightarrow$ C Colo.-N.M. Subalp.

4. A. grandis Lindl. A tree 75-100 m. high, with a trunk often $12 \mathrm{dm}$. thick; bark of old trees $5 \mathrm{~cm}$. thick, shallowly fissured and scaly; twigs yellowish green, puberulous, becoming glabrate; leaves dark green and shining above, silvery white beneath; those of the sterile branches $3-5 \mathrm{~cm}$. long, spreading, 2ranked, usually conspicuously emarginate; staminate flowers pale yellow; pistillate yellowish green; cones cylindric, puberulent, 5-10 cm. long; scales obovate, broader than long, 3-4 times as long as the bracts. Grand Fir. Valleys and lower slopes: Mont.-Wyo.-Calif,-B.C. Mont.-Submont.

5. A. concolor Lindl. \& Gord. A tree $25-30 \mathrm{~m}$., rarely $45 \mathrm{~m}$. high, on the Pacific Coast much higher; bark on the old trees deeply furrowed and scaly; that of the upper part and of young trees smooth and grayish, with resin-blisters; leaves pale blue or glaucous; those of the lower branches $5-7 \mathrm{~cm}$. long, straight, acute or acuminate; staminate flowers dark red to rose-colored; pistillate ones purplish or yellowish green; cones oblong-cylindric, rounded, 7-12 $\mathrm{cm}$. long, puberulent; scales obovate, broader than long, twice as long as the bracts; seeds 4-5 mm. long. White Frr. Mountain slopes; Colo.-N.M.-L. Calif,-Ore. Mont.

\section{7. pSeUdotsùga Carr. Red Fir, False Spruce.}

Monoecious evergreen trees, with spreading branches. Leaves flattened, petioled, on the lateral branches appearing 2-ranked by the twisting of the petioles, leaving transversely oval, slightly raised scars, with 2 resin-ducts close to the epidermis on the lower side. Staminate aments axillary to the leaves of the preceding season, cylindric; anther-sacs 2 , obliquely splitting. Pistillate aments subterminal, drooping; seales persistent, much shorter than the 3-lobed caudateacuminate bracts; cones maturing the first season. Seeds winged.

1. P. mucronata (Raf.) Sudw. A tree 25-60 m. high, sometimes taller, with a trunk 6-25 dm. thick; leaves dark yellowish green, 2-3 cm. long, flat, obtuse, short-stalked; staminate flowers orange-red; pistillate ones greenish or purplish, the bracts deep purple; cones 5-10 cm. long; scales obovate-rounded, puberulent, shorter than the bracts. P. taxifolia (Poir.) Britt. P. Douglasii Carr. Red Fir, Douglas Spruce, or Douglas Frr. Hills and mountains: Alta.-w Tex.-Calif.-B.C.; n Mex. Submont.-Subalp.

\section{TSÜGA (Endl.) Carr. Hemlock.}

Monoecious evergreens with spreading or somewhat reflexed branches. Leaves flattened, with stomata only on the lower side, on the lateral branches, appearing 2-ranked by the twisting of the petioles, articulate to short persistent bases (sterigmata). Staminate aments axillary to leaves of the preceding year; pollen-sacs confluent, opening by a transverse slit. Pistillate aments solitary, terminal on branches of the preceding year; bracts membranous, inconspicuous; scales in few series. Cones drooping, maturing the first year; scale at last loose and spreading, persistent. Seeds samara-like; wings attached to the seeds.

1. T. heterophylla (Raf.) Sarg. A tree $40-50 \mathrm{~m}$., rarely $60 \mathrm{~m}$. high, with a trunk 6-20 dm. thick; leaves flat, rounded at the apex, deeply grooved and dark green above, with two broad white or glaucous bands beneath, $1-2 \mathrm{~cm}$. long, petioled; staminate flowers yellow; pistillate ones purple; cones ovoid, 1.5$2.5 \mathrm{~cm}$. long, pendulous; scales obovate, strongly striate, persistent. WESTERN Hemlock. Moist places: B.C.-w Mont.-Ida.-n Calif. Mont.-Submont. 


\section{HeSperopeùce Lemmon. Black Hemlock, Mountain Hemlock.}

Monoecious evergreen trees with spreading branches. Leaves rather plump, keeled beneath, spreading in all directions, articulated to persistent bases (sterigmata), with stomata on both sides. Staminate aments axillary to leaves of preceding year; anther-sacs opening transversely. Pistillate aments terminal, at first erect; scales in rather many series. Cones maturing the first year; scales persistent. Seeds samara-like.

1. H. Mertensiana (Bong.) Rydb. A tree usually $10-20 \mathrm{~m}$. high, but sometimes up to $35 \mathrm{~m}$. high, with a trunk $2.5-10 \mathrm{dm}$. in diameter; leaves bluish green, rather thick, blunt-pointed, 1-2.5 cm. long; staminate flowers purple; pistillate flowers erect, dark-purple or yellowish green; cones cylindric, $3-7 \mathrm{~cm}$. long; scales persistent, obovate, striate. Tsuga Pattoniana Sen. T. Mertensiana (Bong.) Sargent. H. Pattoniana Lemmon. Exposed ridges and slopes: Alaska $\longrightarrow$ w Mont.-Ida.-Calif. Subalp.

\section{PİCEA Link. SPRUCES.}

Evergreen monoecious trees. Leaves needle-shaped, in ours quadrangular or nearly terete, leaving persistent bases (sterigmata) when falling, scattered, pointing in all directions. Staminate aments from the axils of the leaves of the preceding year, or rarely terminal; anther-sacs opening longitudinally. Pistillate aments terminal. Cones maturing the first season, drooping; scales closely imbricate, leathery, thin, without dorsal thickening, persistent. Seeds samaralike, with hyaline wings, remaining attached to the seeds.

Cone-scales rounded at the apex.

Branchlets pubescent; cones $1.5-3 \mathrm{~cm}$. long, persistent for several years; scales rigld, erose or dentate.

Branchlets glabrous; cones 3-5 cm. long, deciduous in the first winter; scales rather thin.

Cone-scales entire or minutely denticulate on the margins; cones cylindricoblong, $3.5-5 \mathrm{~cm}$. long.

2. P. canadensis.

Cone-scales erose on the margins; cones ellipsoid, $3-3.5 \mathrm{~cm}$. long. 3 . P. albertiana.

Cone-scales more or less rhomboid in outline.

Branchlets pubescent; cones $3-5 \mathrm{~cm}$. long.

Branchlets glabrous; cones $5-9 \mathrm{~cm}$. long.

4. P. Engelmannt.

5. P. pungens.

1. P. Mariana (Mill.) B.S.P. A tree usually 6-10 m. high, occasionally 25 $\mathrm{m}$. high, with a trunk 1-3 dm. in diameter; bark grayish brown, scaly; twigs russet-brown, short-pilose; leaves pale blue-green and glaucous, 1-2 cm. long, callous-tipped at the apex; staminate flowers dark red; pistillate ones purple; cones short, ovoid, 1-3 cm. long, ashy brown, persistent; scales rounded, erosedentate. P. nigra Link. Black Spruce. Swamps: Lab.-Newf.-N.C.Wisc.-Sask.-Alta.-Mack. Boreal-Subartic.

2. P. canadensis (Mill.) B.S.P. A tree $10-20 \mathrm{~m}$, rarely $30 \mathrm{~m}$. high, with a trunk 3-9 dm. in diameter; bark ashy brown, sealy; branches and sterigmata glabrous; leaves incurved, acute or acuminate, blue-green; staminate flowers pale red, becoming yellow from shedding the pollen; pistillate flowers pale red or yellowish green; cones cylindric or oblong, 3-6 cm. long; scales orbicular, slightly emarginate. $P$. alba Link. WhIte Spruce. River banks and hillsides: Lab.-Newf.-Me.-n N.Y.-Wisc.-S.D. (Black Hills)-Alta.-Alaska. Boreal-Subarctic.

3. P. albertiana S. Brown, A slender tree $10-20 \mathrm{~m}$. high; twigs and sterigmata smooth and shining, yellowish brown, becoming darker in age; leaves pale blue-green, $1.5-2.5 \mathrm{~cm}$. long, incurved, acute or acuminate; pistillate flowers bright crimson; cones ovate, $2.5-3.5 \mathrm{~cm}$. long; scales stiff, rounded, cinnamonbrown. Alberta Spruce. Mountains: Alta.-n Wyo.-B.C. Mont.

4. P. Engelmanni (Parry) Engelm. A tree $25-30 \mathrm{~m}$., rarely $45 \mathrm{~m}$. high, with a trunk 4.5-10 dm. thick; bark light cinnamon-red, loosely scaly; leaves soft, with acute tips, $2.5-3 \mathrm{~cm}$. long, bluish green; staminate flowers dark purple; pistillate ones scarlet, turning chestnut-brown; cones oblong-ellipsoid, subsessile, 3-6 cm. long; scales thin, erose-dentate. Engelmann's Spruce. Cold mountains and ravines, especially on the north sides: Alta.-N.M.-Ariz.-B.C.Yukon. Subalp.-Mont. 
5. P. pungens Engelm. A tree usually $25-30 \mathrm{~m}$. high, occasionally $45 \mathrm{~m}$. high, and a trunk 6-9 dm. thick; bark furrowed and scaly, cinnamon-red; leaves strongly incurved, rigid, acuminate, $2-3 \mathrm{~cm}$. long on the sterile branches, $1-2$ $\mathrm{em}$. long on the cone-bearing ones, dull bluish green, of ten with a silvery bloom; staminate flowers yellow, tinged with red; pistillate ones pale green or purplish; cones usually $7-8 \mathrm{~cm}$. long, oblong. P. Parryana (André) Sargent. Colorado Blue Spruce. Mountains, especially along streams: Wyo.-N.M.-Utah. Mont.

\section{Family 2. JUNIPERACEAE. JUNIPER FAMily.}

Evergreen dioecious or monoecious trees or shrubs. Buds naked. Leaves opposite or whorled, mostly reduced and scale-like, appressed or sometimes subulate and spreading. Perianth wanting. Aments solitary, the pistillate ones with few carpellary scales. Ovules erect, 1-several under each scale. Cones often with peltate scales, in some genera fleshy. Seeds wingless or, if winged, the wings formed by a portion of the seed-coat.

Plants monoecious; cones dry; scales merely imbricate.

Plants mostly dioecious;

Aments axillary; cones with spreading.

subulate and

Aments terminal; pistillate cones with larger scales at the top; leaves 2. JUNIPERUs. mature plants scale-like and appressed. 3 . SABINA.

\section{1. thùja L. Arbor Vitae, White Cedar.}

Evergreen monoecious shrubs or trees. Leaves scale-like, 4-ranked, alternately opposite, usually with a gland on the back. Staminate aments terminal, solitary, nearly sessile between the leaves; anthers in 2 or 3 series, stalked; anther-sacs 4; pistillate aments solitary, terminal, ovoid or oblong; scales 2ranked in several series. Cones oblong or ovoid, persistent; scales dry and flat. Seeds flat, winged on both sides.

1. T. plicata D. Don. A tree $45-50 \mathrm{~m}$., sometimes $60 \mathrm{~m}$. high, with a trunk 1-3 m. in diameter; bark bright cinnamon; leaves of the leading shoots ovate, long-pointed, glandular on the back, $6 \mathrm{~mm}$. long, on the lateral branches acute, $3 \mathrm{~mm}$. long, with no or obscure glands; staminate flowers dark brown, $3 \mathrm{~mm}$. long; cones reflexed, about $12 \mathrm{~mm}$. long; scales elliptic, 3-4 pairs. $T$. gigantea Nutt. Bottom lands: Alaska-Mont.-Ida.-n Calif. Submont.-Mont.

\section{JUNÍPERUS (Tourn.) L. JUNIPER.}

Dioecious or monoecious shrubs or trees. Leaves in whorls of 3 , subulate, ascending or spreading, without glands on their back. Staminate aments axillary, solitary; pollen-sacs several under each scale. Pistillate ament of 2-3 series of fleshy scales; ovules solitary. Cone berry-like. Seeds wingless.

Low shrub with depressed branches; leaves abruptly bent at the base, deeply channeled, abruptly acute. Tree or erect shrub; leaves straight or nearly so, shallowly channeled, gradually
acuminate.

2. J. communis.

1. J. sibirica Burgsd. Shrub seldom $5 \mathrm{dm}$. high, usually with decumbent branches; bark dark red, scaly; leaves 5-12 $\mathrm{cm}$. long, keeled, dark green below, white above, ascending; fruit dark blue, with a bloom, 7-9 $\mathrm{mm}$. in diameter; seeds $1-3$, ovate, acute, angled, about $3 \mathrm{~mm}$. long. $J$. nana Willd. High mountains or dry open rocky places. Lab. -N. Y.-Mich.-N.M.-Calif.Alaska. Subalp.-Mont.

2. J. communis L. An erect shrub or low tree sometimes $7-8 \mathrm{~m}$. high; bark dark red, scaly; leaves spreading, mostly straight, prickly-pointed, keeled, 1-2 cm. long, dark green on the lower side, white on the upper; fruit 6-7 mm. in diameter, dark blue, 1-3-seeded; seeds ovate, acute, about $3 \mathrm{~mm}$. long. Dry hills: N.S.-N.J.-Pa.-w Neb.-N.M.-B.C.; Eurasia, Submont.-Plain.

\section{SABINA Haller. Red Cedar.}

Evergreen monoecious or dioecious shrubs. Leaves alternately opposite or in 3's, scale-like and appressed, or in young plants subulate and more spreading, 
often with a gland on the back. Staminate aments small, solitary or 3-6 together, terminal on the branchlets; pollen-sacs 3-6 under each ovate or shield-like scale. Pistillate aments subglobose, of $2-3$ series of fleshy seales. Ovules erect, solitary or sometimes 2 under each scale. Cones berry-like. Seeds 1-4, wingless.

Fruit reddish-brown or bluish by a bloom, with dry fibrous sweet flesh.

Fruit blue or blue-black, rarely copper-colored, with juicy resinous flesh.

1. S. utahensis.

Trees or erect shrubs; fruit on straight peduncles.

Leaves minutely dentate at the apex; fruit $5-8 \mathrm{~mm}$. in diameter

Leaves not glandular or obscurely so; seeds usually 1.

Leaves very glandular; seeds 2 or 3 .
Leaves entire; fruit $4-5 \mathrm{~mm}$. in diameter, usually with more than one seed.

2. S. monosperma.

Prostrate shrub; fruit on recurved peduncles.

4. S. scopulorum.

5. S. horizontalis.

1. S. utahensis (Engelm.) Rydb. A bushy tree, rarely $6 \mathrm{~m}$. high, irregularly branched near the base; bark ashy gray or almost white, scaly; leaves in whorls of 3 , or opposite on the mature branches, rhombic in outline, subacute, $2 \mathrm{~mm}$. long, $1 \mathrm{~mm}$. wide, neither glandular nor pitted on the back; fruit copper-colored when ripe, 7-10 $\mathrm{mm}$. thick; seeds ovate, acute or obtusish, grooved. Juniperus utahensis (Engelm.) Lemmon. J. Knightii A. Nels. Dry hills: Wyo.-N.M.Ariz.- - Se Calif.-Nev. Submont.-Son.

2. S. monosperma (Engelm.) Rydb. A shrub or much branched tree, up to $15 \mathrm{~m}$. high; bark ashy, ridged and scaly; leaves usually in pairs, rarely in 3's, ovate, 1-2 mm. long, thick, with obscure glands or glandless; fruit globose, 5-6 mm. thick, dark blue, with a bloom; seeds broadly ovate, obtuse, angled. $J$. occidentalis monosperma Engelm. Foot-hills: s Colo.-N.M.-Ariz,-Utah; n Mex. Son.-Submont.

3. S. occidentalis (Hook.) Heller. A tree 5-10 m., rarely $15-18 \mathrm{~m}$. high, with a trunk 6-10 dm. thick; bark cinnamon-red, fissured and scaly; leaves in 3's, appressed, ovate, acute, rounded and conspicuously glandular on the back, $2 \mathrm{~mm}$. long; berries globose or elliptic, $6-8 \mathrm{~mm}$. long, with thick skin, blueblack, with a bloom; seeds ovate, acute, deeply grooved on the back. $J$. occidentalis Hook. Arid hills and plains: B.C.-W Ida.-s Calif. Submont.-Mont.

4. S. scopulorum (Sarg.) Rydb. A tree sometimes 10-12 m. high, with rounded crown; bark dark reddish brown or grayish red, fissured and scaly; leaves opposite, appressed, acute or acuminate, with obscure glands on the back, dark green, 1-1.5 mm. long; berry globose, dark blue, with a bloom; seeds $4 \mathrm{~mm}$. long, acute, angled, grooved. Juniperus scopulorum Sargent. Foot-hills and river bluffs: Alta.-Tex.-Ariz.-B.C. Submont.

5. S. horizontalis (Moench) Rydb. A prostrate shrub, spreading on the ground; horizontal branches sometimes $5 \mathrm{~m}$. long; leaves of the mature branches ovate, opposite, acute, distinctly glandular on the back, 1-1.5 mm. long; berrylike cones on recurved peduncles, globose, 5-7 mm. long, dark blue, with a bloom, 1-3-seeded. J. Sabina procumbens Pursh. On banks and hillsides: N.S.-Me.-n N.Y.-Minn.-Wyo.-B.C. Mont.-Submont.

\section{Family 3. TAXACEAE. YeW Family.}

Evergreen monoecious or dioecious trees or shrubs. Buds scaly. Leaves spirally arranged, but usually 2-ranked, spreading, in ours simple and linear. Staminate flowers usually in crowded aments, in ours axillary; pollen-sacs opening longitudinally. Pistillate flowers solitary. Ovules solitary, orthotropous, sessile, without carpellary scale. Fruit berry-like; seed nearly enclosed by the pulpy aril or naked; seed-coats woody or bony. Endosperm fleshy or mealy. Cotyledons 2.

\section{TÁXUS (Tourn.) L. YEW.}

Usually dioecious evergreen trees or shrubs. Leaves linear, 2-ranked and spreading. Staminate aments, short-stalked, subtended by several imbricate 
bracts, axillary. Pollen-sacs 6-8 under each shield-like scale. Pistillate aments consisting of a single sessile ovule subtended by imbricate bracts. Aril accrescent into a fleshy cup. Seeds nut-like.

1. T. brevifolia Nutt. A tree usually $5-10 \mathrm{~m}$. high, occasionally as high as $20 \mathrm{~m}$., with a trunk $3-10 \mathrm{dm}$. thick; bark scaly; leaves $1-2 \mathrm{~cm}$. long, yellowish green, paler beneath, slender-petioled, linear, flat, with strong midrib, spinulosetipped; staminate flowers yellow; seed ovoid, fully $5 \mathrm{~mm}$. long, 2-4-angled; aril a translucent red cup, 4-5 mm. broad. Banks of streams: Alaska-Alta.Mont.-Calif. Submont.-Mont.

\section{Family 4. EPHEDRACEAE. Joint Fir Family.}

Shrubs or trees, with jointed opposite or fascicled branches, and scale-like opposite or whorled leaves. Plants mostly dioecious; aments with persistent bracts. Stamens monadelphous, within a bifid, membranous, calyxlike perianth; anthers dehiscent by terminal pores. Pistillate flowers of a single naked ovule, enclosed in a perianth, which becomes hardened in fruit.

\section{EPHÉdRA L. Joint Fir, Brigham Tea.}

Characters of the family.

Scales and branches opposite; bracts opposite and connate, only the margins scarious.

Scales distinct, subpersistent; filaments free above. 1 1. E. antisyphylitica.

Scales connate, sheathing, scarious, deciduous; filaments adnate to the top of the bracts.

Branches stout, more or less spreading; plant light brownish green.

$\begin{array}{ll}\text { Branches slender, erect; plant bright yellowish green. } & \text { 2. E. nevadensis. Eiridis. }\end{array}$

Scales, branches, and bracts in 3's; bracts scarcely connate, those of the pistillate aments nearly wholly scarious and more or less unguiculate.

Scales 2-3 mm. long, not becoming shreddy; fruit scabrous, 4. E. Torreyana.

Scales 6-12 mm. long, becoming shreddy; fruit smooth. $\quad 5$. E. trifurca.

1. E. antisyphylitica C. A. Mey. A shrub 2-3 m. high; stems slender, lax, prostrate or reclining; bark neither shreddy nor fibrous; scales triangular-ovate, 2-4 mm. long, setaceously tipped when young; aments on short bracteate peduncles; pistillate aments with 3-4 pairs of bracts, which are rounded-ovate; fruit 5-6 mm. long, smooth. Arid regions: w Tex. $\rightarrow$ Colo. (?) $-\mathrm{n}$ Mex. Son.

2. E. nevadensis S. Wats. A shrub 6-10 dm. high, with diffusely spreading branches; bark becoming white and shreddy or fibrous; scales with somewhat foliaceous tips, $2-6 \mathrm{~mm}$. long; staminate aments sessile or nearly so; filaments long-exserted; anthers 4-8; pistillate aments on short scaly peduncles; bracts 4 or 5 pairs, round-ovate, connate; fruit solitary or in pairs, 6-7 $\mathrm{mm}$. long, exserted, smooth, acute. Arid regions: N.M.-Utah-Nev.-Calif.; n Mex. Son.

3. E. viridis Coville. An erect shrub 5-10 dm. high, with erect branches, bright yellowish green; bark becoming ash-colored; scales with slender foliaceous tips; staminate aments sessile; anthers 4-6; pistillate aments on short scaly peduncles; bracts 5 pairs, ovate; fruits in pairs, $6 \mathrm{~mm}$. long, exserted. Arid regions: N.M.-Wyo.-Calif. Son.-Submont. Mr-Je.

4. E. Torreyana S. Wats. An erect shrub 3-10 dm. high, with of ten flexuose branches, not spinose; scales short, 2-4 mm. long, subpersistent; staminate aments sessile, of $6-8$ whorls of broad bracts; anthers $5-8$, stipitate; pistillate aments $6-10 \mathrm{~mm}$. long, short-peduncled, of 5 or 6 whorls of bracts; bracts thin, broadly dilated, more or less crenate; fruit solitary, or in 3 's, 7-8 mm. long. Arid regions: N.M. - s Colo.-Nev,-Ariz. Son.

5. E. trifurca Torr. An erect shrub 6-20 dm. high, with rigid branches, often spinescent; scales acuminate, persistent; staminate aments on very short peduncles, with 5 whorls of ovate bracts; anthers 4 or 5 , stipitate; pistillate aments nearly sessile, $10-12 \mathrm{~mm}$. long, of 8-10 whorls of very thin, scarious, entire, rounded-cordate bracts; fruit solitary, $12 \mathrm{~mm}$. long, 4-sided. Arid regions: w Tex.-sw Colo.-Ariz. Son. 


\section{Class 2. ANGIOSPermae. Seed-vesseled Plants.}

Ovules enclosed in a cavity (ovary), formed either by one modified infolded leaf (carpel) with united margins, or by several united leaves. The apex of the carpel (stigma) is formed of and kept moist by secretive cells; when a pollen grain falls on the stigma, it germinates and sends out a tube which penetrates the tissues of the pistil till it reaches an ovule, which it fertilizes.

\section{Subclass I. MONOCOTYLEDONES.}

Embryo with a single seed-leaf; the first leaves alternate. Stem endogenous, $i . e$. , the fibro-vascular bundles irregularly arranged in the soft tissues, without differentiation of pith, wood, and bark. Leaves usually parallel-veined, or the secondary veins running from the midrib to the margins without ramifications. Parts of the flowers mostly in 3's or multiples of 3's.

\section{Family 5. TYPhaceae. Cat-tail Family.}

Tall water or marsh plants, with simple glabrous terete stems and creeping rootstocks. Leaves alternate, long, linear, striate, sheathing at the base. Flowers monoecious, crowded in dense terminal spike-like racemes, which are subtended by spathaceous, usually deciduous bracts; staminate spike uppermost. Perianth consisting of bristles. Stamens 2-7; filaments connate or free. Ovary 1, stipitate, 1-2-celled; styles 1-2. Fruit nut-like. Endosperm copious, mealy.

\section{TỲPha (Tourn.) L. Cat-tail, Cat-tail Flag.}

Characters of the family.

Racemes with the staminate and pistillate portions usually separate; pollen of simple grains; fruiting pedicels short, $1 \mathrm{~mm}$. long or less. $\quad$ 1. T. angustifolia. Racemes with the staminate and pistillate portions usually contiguous; pollen-grains in 4 's; fruiting pedicels bristle-like, $2-3 \mathrm{~mm}$. long.

2. T. latifolia.

1. T. angustifolia L. A slender perennial; stem 1-3 m. high; leaves narrowly linear, 3-15 mm. wide, striate, usually plano-convex; racemes light brown; pistillate portion 5-15 mm. in diameter, with bractlets; stigmas linear or linearoblong; nutlets terete, not bursting in water. Marshes, mostly along the coast: N.S.-Fla.-Mex.-Calif.; Ida.; W. Ind., C. and S. Am., Eurasia. Plains.

2. T. latifolia L. A stout perennial, 1-2.5 m. high; leaves flat, 5-25 mm. wide; staminate racemes light brown, with intermixed bractlets, the pistillate ones dark brown or black, without bractlets, each 1-2 dm. long; stigmas rhomboid or spatulate; fruit furrowed, bursting in water. Marshes and shallow lakes: Newf.-Fla.-Mex.-Calif.-B.C.-Mack.; Eurasia. Plain-Submont. Je-Au.

\section{Family 6. SPARganiaCeae. Bur-Reed Family.}

Marsh or water plants, with creeping rootstocks, fibrous roots, and linear alternate leaves sheathing at the base. Flowers monoecious, in dense globular heads, the staminate heads uppermost, generally sessile, the pistillate ones below, sessile or the lowest peduncled, often subtended by leafy 
bracts. Perianth reduced to a few (3-6) irregular chaffy scales. Stamens usually 5 , distinet. Ovary 1 - (seldom 2-) celled; style 1 ; stigma 1, seldom 2. Fruit nut-like, 1- or 2-celled, 1- or 2-seeded. Ovules anatropous. Endosperm copious.

\section{SPARGĀNIUM (Tourn.) L. BUUR-REED.}

Characters of the family.

Achenes broadly obovoid or cuneate-obpyramidal, sessile, long-beaked; stigmas usually 2 ; leaves somewhat keeled.

1. S. eurycarpum.

Achenes fusiform (in S. minimum somewhat obovoid, but then short-beaked and shortstipitate); stigmas solitary.

Stipe and beak of the fruit each $2 \mathrm{~mm}$. long or more; fruiting heads $1.5 \mathrm{~cm}$. in diameter or more; anthers 3-4 times as long as broad.

Leaves, at least the middle ones, strongly triangular-keeled; fruiting heads about $3 \mathrm{~cm}$. in diameter; achenes brown, gradually tapering into the beak, which is fully as long as the body.

Leaves not keeled or only slightly so, narrow and slender: stem often floating; beak of the achenes decidedly shorter than the body.

Leaves usually $5-10 \mathrm{~mm}$. wide, as well as the bracts conspicuously scariousmargined; heads $1.7-2 \mathrm{~cm}$. in diameter; achenes gradually beaked.

3. S. multipedunculatum.

Leaves 3-4 mm. wide, not conspicuously scarious-margined; heads about 1.5 $\mathrm{cm}$. in diameter; achenes abruptly beaked. 4. S. angustifolium.

Stipe and beak of the fruit short, less than $1 \mathrm{~mm}$, long; fruiting heads about $1 \mathrm{~cm}$. in diameter; stigmas oblong; anthers 1.5-2 times as long as broad.

5. S. minimum.

1. S. eurycarpum Engelm. A stout glabrous perennial marsh plant, 5-25 $\mathrm{dm}$. high; leaves linear, 5-10 dm. long, 7-10 mm. wide; inflorescence more or less compound, the branches usually with one or two pistillate heads and several staminate heads; the former compact, in fruit $2-2.5 \mathrm{~cm}$. in diameter; achenes bluntly 4 - or 5-angled, the top rounded, flat or even a little depressed, abruptly contracted into the style. In swamps and along streams: Newf.-Fla.-UtahCalif.-B.C. Plain-Submont. Je-Au.

2. S. simplex Huds. A slender marsh plant, 3-7 dm. high; leaves linear, 5-9 dm. long, 8-15 mm. wide; inflorescence simple; pistillate heads $2-5$, generally sessile or the lower ones peduncled, usually supra-axillary; achenes fusiform, often contracted in the middle, and gradually acuminate at the apex. In marshes and shallow water: Que.-Ont.-Wash.-B.C.; Eu. Submont. Je-Au.

3. S. multipedunculatum (Morong) Rydb. A rather slender marsh plant, 3-5 dm. high; leaves linear, $2-5 \mathrm{dm}$. long, slightly keeled; inflorescence simple or a little branched; staminate heads $3-5$, of ten close together, but distant from the pistillate ones; these $2-6$, the upper ones sessile, the lower peduncled, and most often axillary; achenes fusiform, gradually acuminate above. S. simplex multipedunculatum Morong. S. subvaginatum Meinsh, in part. In shallow water: Mack.-w Ont.-Mont.-Colo.-Calif.-B.C. Plain-Subm. Je-Au.

4. S. angustifolium Michx. A slender, more or less floating water plant; leaves narrowly linear, 3-6 dm. long, flat, not keeled, often dilated at the base, floating; inflorescence mostly simple; staminate heads $2-5$; pistillate ones $2-4$, sessile, or the lowest one peduncled and supra-axillary; achenes fusiform, abruptly acuminate at the apex. S. simplex angustifolium Engelm. In deep water: Newf.-Conn.-Pa.-Colo.-Calif.-B.C. Plain-Subalp. Je-Au.

5. S. minimum Fries. A slender and floating water plant; stem 1-3 dm. long, or in shallow water shorter and erect; leaves 1-4 dm. long, 1-7 mm. wide, thin and flat, usually floating; inflorescence simple; staminate heads 1 or 2 , close together; pistillate heads 1-3, sessile or the lowest peduncled and axillary; body of the achenes obovoid, abruptly contracted into a short beak. Ponds and streams: Lab.-N.J.-Mich.-Utah-Ore.-Alaska; Eurasia. Mont.-Subalp. $\mathrm{Je}-\mathrm{Au}$.

\section{Family 7. ZANNICHELLIACEAE. Pondweed Famil.}

Immersed water plants, with slender jointed, often branching stems, flat leaves, and perfect or monoecious flowers, in axillary spikes or clusters. 
Perianth none, but flowers sometimes in hyaline envelopes. Stamens 1-4, seldom more, distinct and hypogynous in the perfect flowers, or solitary in the staminate ones. Ovaries 1-4, distinct, 1-celled and 1-ovuled. Fruit mostly drupelets or achenes.

Stamens 4, the connectives with dilated appendages; drupelets sessile. 1. Potamogeton.

Stamens 1-2, the connectives without appendages; drupelets manifestly stipitate.

Stigmas sessile; anthers 2; flowers perfect, on long peduncles. 2. RUPPIA.

Stigma terminating a long style; anther 1; flowers monoecious, the two kinds together in the same axils.

3. ZANNICHELLIA.

\section{Potamogèton (Tourn.) L. Pondweed, Fishweed.}

Immersed water plants, with flat, 2-ranked leaves, alternate or the upper opposite, often of two kinds, floating and submerged, the former more or less coriaceous and broad, the latter pellucid, thin, and narrower. Stipules present, free or adnate to the lower part of the petiole or blade, enclosing the young flower-buds. Inflorescence spicate, axillary, mostly emersed. Stamens 4 ; appendages short-clawed, valvate in the bud. Ovaries 4, sessile, distinct, with a short style or sessile stigma. Fruit of 4 drupelets. Seeds crustaceous.

Species with both floating and submerged leaves.

Submerged leaves bladeless.

Submerged leaves with proper blades.

1. P. natans.

Submerged leaves of two kinds, oval or oblong ones and lanceolate and strongly curved ones; floating leaves with 30 or more nerves. $\quad 2 . P$. amplifolius.

Submerged leaves of only one kind; floating leaves with less numerous nerves. Stipules free from the petioles and blades.

Submerged leaves lanceolate.

Submerged leaves all petioled, more than 7 -nerved. 3. P. americanus.

Submerged leaves all sessile or the uppermost short-petioled.

Peduncles of the same thickness as the stem; leaves not serrulate at the apex.

Plant green; submerged leaves narrower than the floating ones.

7. P. heterophyllus.

Plant red; submerged leaves as wide as the floating ones or wider.

4. P. alpinus.

Peduncles thicker than the stem; leaves serrulate at the apex.

Submerged leaves linear.

5. P. augustifolius.

Submerged leaves of nearly the same width throughout, coarsely reticulate in the middle.

6. P. epihydrus.

Submerged leaves broader below the middle, without reticulation.

Stipules adnate to the base of the linear-setaceous submerged leaves.

7. P. heterophyllus.

Species with submerged leaves only.

Leaves with broad blades, lanceolate or oval, many-nerved.

Leaves short-petioled or sessile, not amplexicaul.

8. $P$. diversifolius.

Leaves more or less amplexicaul.

Leaves elongate-lanceolate, semi-amplexicaul, cucullate; the straight apex of the embryo pointing to the base of the fruit. 10. $P$. praelongus.

Leaves rounded-ovate to short-lanceolate, amplexicaul, not cucullate; the curved embryo pointing inside the base of the fruit. 11. P. Richardsonii. Leaves narrowly linear to capillary.

Stipules free from the petioles and the leaf-blades.

Leaves $1.5-4 \mathrm{~mm}$. wide.

Species without glands at the base of the leaves; leaves with 3 principal nerves and several fine ones.

Species with glands at the base of the leaves.

Glands large and translucent; nerves mostly 3 ; the curved end of the

embryo pointing inside the base of the fruit. $13 . P$. obtusifolius.
Glands small, dull; nerves of the leaves $5-7$; the straight end of the embryo pointing to the base of the fruit.

Leaves seldom more than $1.5 \mathrm{~mm}$. wide, often less.

Glands absent; nutlets keeled.

Glands present; nutlets not keeled.

Stipules adnate to the base of the leaves.

Leaves $1.5 \mathrm{~mm}$. wide or less, with entire margins.

Stigma broad, sessile; nutlets indistinctly 1-keeled or keel-less.

Leaves filiform, less than $0.5 \mathrm{~mm}$. wide; stipular sheaths $3-8 \mathrm{~mm}$. long.

Leaves about $1 \mathrm{~mm}$. wide; stipular sheaths $1-2 \mathrm{~cm}$. long.

14. P. Friesii.

15. $P$. foliosus.

16. P. pusillus.

18. $P$. interior.

Stigma capitate, on an evident style; nutlets with 2 lateral but no median keel.

19. P. pectinatus.

Leaves several-nerved, 3-6 mm. wide, finely serrulate seen under a lens. 20. P. Robbinsii. 
1. P. natans L. Stem 6-15 dm. long, mostly simple; floating leaf-blades oval or ovate, abruptly short-pointed, rounded or cordate at the base, thick, 21-29-nerved, 5-10 cm. long, 2.5-5.5 $\mathrm{cm}$. wide; submerged leaves bladeless and early perishing; peduncles $5-10 \mathrm{~cm}$. long; spike cylindric, $3-5 \mathrm{~cm}$. long, very dense; fruit 4-4.5 mm. long, 2-5 mm. thick; stone 2-grooved on the back. Ponds and streams: N.S.-N.J.-Calif.-Alaska; Eurasia. Plain-Mont. J1-S.

2. P. amplifolius Tuckerm. Stem occasionally branched; floating leafblades (occasionally wanting) ovate or oval, acute at the apex, rounded or subcordate at the base; submerged leaves mostly short-petioled; the blades of the upper ovate or elliptic, 7-15 $\mathrm{cm}$. long, 3-6 cm. wide, thin and shining; those of the lower lanceolate, of ten $1 \mathrm{dm}$. long, about 25-nerved, generally conduplicate and falcate; peduncles thickened upwards, 5-20 cm. long; spike cylindric, 2.5 $\mathrm{cm}$. long; fruit 4-5 mm. long, $2.5 \mathrm{~mm}$. thick, 3-keeled. Lakes: N.B.-Ga.Neb.-B.C. Plain. Jl-S.

3. P. americanus Cham. \& Sehlecht. Stem much branched, 1-2 m. long; floating leaf-blades rather thick, elliptic, pointed at each end, $5-15 \mathrm{~cm}$. long, 1.5-3 cm. wide, 11-23-nerved; submerged leaf-blades pellucid, thin, 1-3 dm. long, $0.5-2.5 \mathrm{~cm}$. wide, 7-15-nerved, lanceolate to linear-lanceolate, with distinct petioles; peduncles thickened upwards, $5-7 \mathrm{~cm}$. long; spike cylindric, $3-5 \mathrm{~cm}$. long; fruit about $4 \mathrm{~mm}$. long, obliquely obovoid, 3-keeled on the back. $P$. lonchites Tuckerm. P. fluitans Am. auth. Ponds and slow streams: N.B.-Fla. - Calif.-B.C. Plain. Je-O.

4. P. alpinus Balbis. Stem slender, simple or branched; floating leafblades rather thin, oblanceolate or spatulate, or sometimes oblong, 11-17nerved, 5-12 cm. long, sometimes wanting; submerged leaves thin, semi-pellucid, oblong to linear-lanceolate, $7-30 \mathrm{~cm}$. long, 5-20 mm. wide, 7-17-nerved, sessile or the upper short-petioled; spike cylindrie, $2-4 \mathrm{~cm}$. long; fruit obovoid-lenticular, reddish, 2-5 mm. long, 3-keeled. P. rufescens Schrader. Ponds and streams: N.S.-N.J.-Colo.-Calif.-Alaska; Eu. Plain-Mont. Jl.-Au.

5. P. angustifolius Berch. \& Presl. Stem slender, branching; floating leafblades somewhat coriaceous, elliptic, 4-10 cm. long, 12-35 mm. wide, manynerved; submerged leaves lanceolate or oblanceolate, thin, acute or cuspidate, 5-15 cm. long, 5-30 mm. wide, 7-17-nerved; peduncles thicker than the stem, 6-15 $\mathrm{cm}$. long; spike cylindric, $2.5-5 \mathrm{~cm}$. long; fruit obliquely ovoid, $2.5-4 \mathrm{~mm}$. long, $2 \mathrm{~mm}$. thick, 3-ribbed; style short, blunt. P. Zizii Roth. Lakes and streams: Me.-Fla.-Tex.-Calif.-B.C.; Mex., C. Am., and Eu. Plain -Submont. J1-Au.

6. P. epihydrus Raf. Stem slender, simple, compressed, 3-18 dm. long; floating leaves opposite; blades elliptic or obovate, 4-9 cm. long, 6-17 $\mathrm{mm}$. wide, many-nerved, obtuse, short-petioled; submerged leaf-blades linear or linear-lanceolate, $5-15 \mathrm{~cm}$. long, 2-4 mm. wide, coarsely reticulate along the midrib, 5-nerved; spike cylindric, 1-6 m. long; fruit rounded-obovoid, $2.5-4$ $\mathrm{mm}$. long, 2-3 mm. thick, 3-keeled; style short, terminal. P. Nuttallii Cham. \& Schlecht. Ponds and streams: Newf.-S.C.-Iowa-B.C. Plain. Je-Au.

7. P. heterophyllus Sehreb. Stem slender, much branched, sometimes $3 \mathrm{~m}$. long; floating leaf-blades oval, pointed at the apex, narrowed, rounded, or subcordate at the base, $1.5-6 \mathrm{~cm}$. long, 8-28 mm. wide, 9-19-nerved; submerged leaves linear or linear-lanceolate, pellucid, 1-5 cm. long, 2-18 mm. wide, 3-9(mostly 7-) nerved, acuminate or cuspidate; peduncles often thickened upwards; spike cylindric, $1-2 \mathrm{~cm}$. long; fruit rounded or obliquely obovoid, $2-3 \mathrm{~mm}$. long, 1-2 mm, thick, indistinctly 3-keeled; style short, apical. A form with the submerged leaves linear, flaccid, $5-12 \mathrm{~cm}$. long, 2-6 mm. wide, is $P$. heterophyllus graminifolius. Ponds or lakes, and slow streams: Lab.-Fla.-Utah-Calif.B.C.; Eu. Plain-Submont. J1-S.

8. P. diversifolius Raf. Stem very slender, much branched; floating leafblades coriaceous, oval or elliptic and obtuse, or lanceolate-oblong and acute, 1-2.5 cm. long, 4.5-12 mm. wide; submerged leaves linear-setaceous, $2-4 \mathrm{~cm}$. long, $1 \mathrm{~mm}$. wide or less; stipules of the floating leaves free, those of the submerged 
leaves mostly adnate; emersed peduncles $6-15 \mathrm{~mm}$. long; submerged ones 4-6 $\mathrm{mm}$. long, clavate, as long as the spikes; emersed spikes $3.5-7 \mathrm{~mm}$. long, of ten interrupted; fruit cochleate, about $1 \mathrm{~mm}$. long, 3-keeled, the middle keel narrowly winged. Still water: Me.-Fla.-Tex.-Calif.-Mont.; Mex. Je-S.

9. P. lucens L. Stem thick, branched, leafy; leaves submerged, lliptiec or lanceolate, or the uppermost oval, thin, shining, acute or acuminate, or rarely rounded at both ends and merely mucronate, 6-20 cm. long, $15-40 \mathrm{~mm}$. wide, the ends often serrulate; peduncles $7-15 \mathrm{~cm}$. long; spike cylindric, $3-6 \mathrm{~cm}$. long, thick; fruit roundish, $3 \mathrm{~mm}$. long, $2.5 \mathrm{~mm}$. thick. Ponds: N.S.-Fla.-Mex.Calif.; Eu., C. Am., and W. Ind. Plain-Mont. Au-O.

10. P. praelongus Wulf. Stem flexuose, white, often $25 \mathrm{dm}$. long, flattened, much branched; leaves submerged, oblong-lanceolate, thin, bright green, semiamplexicaul, 0.5-3 dm. long, 1-4 cm. wide, with 3-5 principal nerves; peduncles 7-50 cm. long, straight, as thick as the stem; spike cylindric or globose, 1-3 $\mathrm{cm}$. long; fruit obliquely obovoid, 4-5 $\mathrm{mm}$. long, 3-4 $\mathrm{mm}$. thick; middle keel sharp; style short. Ponds and streams: N.S.-N.J.-Minn.-Calif.-B.C.; Eu. $\mathrm{Je}-\mathrm{Au}$.

11. P. Richardsonii (A. Bennett) Rydb. Stem very leafy and much branched; leaves submerged, thin, lanceolate, $5-10 \mathrm{~cm}$. long, $8-15 \mathrm{~mm}$. wide at the broadened amplexicaul base, 13-23-nerved, acute or acuminate and incurved at the apex; peduncles $3-4 \mathrm{~cm}$. long, thickened upwards; spike cylindric, $2-2.5$ $\mathrm{cm}$. long; fruit about $4 \mathrm{~mm}$. long, $2.5 \mathrm{~mm}$. thick, obscurely 3-keeled. $P$. perfoliatus lanceolatus Robbins. P. perfoliatus Richardsonii A. Bennett. Ponds and lakes: N.Y.-Del.-Wyo.-Calif.-Alaska. Plain-Submont. Je-S.

12. P. compressus L. Stem branching, much flattened, often winged; leaves submerged, linear, obtuse or mucronate, 5-30 $\mathrm{cm}$. long, 2-4 $\mathrm{mm}$. wide, with 3 principal veins and many fine ones; peduncles 4-10 $\mathrm{cm}$. long; spike cylindric, 12-15-flowered, about $1 \mathrm{~cm}$. long; fruit obovoid, with a broad base, about $4 \mathrm{~mm}$. long, 2.5-3 mm. thick, 3-keeled on the back; style short, recurved. The plant often propagates by means of terminal leaf-buds. $P$. zosteraefolius Schum. Ponds and slow streams: N.B.-N.J.-Sask.-Ore.-B.C.; Eu. Plain. Jl-S.

13. P. obtusifolius Mert. \& Koch. Stem slender, branched above, more or less compressed; leaves linear, obtuse or mucronate, 5-8 cm. long, 1-4 mm. wide, usually 3-nerved, with a broad midrib, and 2 translucent glands at the base; peduncles $2-3 \mathrm{~cm}$. long, slender, erect; spike ovoid, 5-8-flowered, 6-8 $\mathrm{mm}$. long; fruit obliquely obovoid, $3 \mathrm{~mm}$. long, $2 \mathrm{~mm}$. thick, 3-keeled; style short. Still water: Que.-Kans.-Wyo.-Pa.; Eu. Jl-O.

14. P. Friesii Rupr. Stem compressed, branching, 5-12 dm. long; leaves linear, 4-7 cm. long, about $2 \mathrm{~mm}$. wide, obtuse or mucronate at the apex, 5(rarely 7-) nerved; peduncles 2-4 cm. long, often thickened upwards and thicker than the stem; spike interrupted; fruit obliquely ellipsoid, about $2 \mathrm{~mm}$. long, 2-grooved on the back, usually with a shallow pit on the sides; style recurved. $P$. compressus Oeder, not L. Still water: N.B.-N.Y.-Minn.-B.C.; Eu. $\mathrm{Jl}-\mathrm{Au}$.

15. P. foliosus Raf. Stem very slender, branched, flattened, $3-10 \mathrm{dm}$. long; leaves very narrowly linear, almost filiform, $3-5 \mathrm{~cm}$. long, $0.5-1 \mathrm{~mm}$. wide, $3-$ nerved; peduncles clavate, about $1 \mathrm{~cm}$. long; spike short, about 4-flowered; fruit lenticular, almost orbicular, $2 \mathrm{~mm}$. long, 3-keeled on the back; middle keel winged, sinuate-dentate. $P$. pauciflorus Pursh. Ponds and streams: N.B.Fla.-N.M.-Calif.-B.C.; W. Ind. Plain-Mont. Jl-Au.

16. P. pusillus L. Stem very slender, filiform, much branched, $1.5-6 \mathrm{dm}$. long; leaves filiform, 3-12 cm. long, 0.5-1.5 mm. wide, 1-3-nerved; peduncles 5-30 mm. long, rarely 3-6 cm. long; spike 3-10-flowered; fruit obliquely ellipsoid, about $2 \mathrm{~mm}$. long, $1 \mathrm{~mm}$. thick, 2 -grooved on the back, not keeled. It propagates often by buds. Ponds and slow streams: N.S.-Va.-Tex.-Mex.-Calif. -B.C.-Yukon; Eu. Plain-Submont. Je-Au.

17. P. filiformis Pers. Stem slender, filiform above, branching, leafy, 1-4 $\mathrm{dm}$. long; leaves linear-filiform, $5-30 \mathrm{~cm}$. long; free portion of the stipules $3-5 \mathrm{~cm}$. 
long; peduncles 4-7 cm. long; spike interrupted, with 2-12 flowers in each whorl; fruit ovoid, $2-3 \mathrm{~mm}$. long, nearly $2 \mathrm{~mm}$. thick, not keeled; stigma sessile. Ponds and lakes: Que.-N.Y.-Mich.-Wyo.-Alta. Je-Au.

18. P. interior Rydb. Stem slender, branched, 3-6 dm. long; leaves linear, $3-15 \mathrm{~cm}$. long, about $1 \mathrm{~mm}$. wide, obtuse, with a strong midrib and raised or revolute margins; peduncles $3-7 \mathrm{~cm}$. long; spike interrupted; fruit obliquely ovoid, 2-grooved on the back; stigma subsessile; free portion of the stipules 2-4 $\mathrm{mm}$. long. P. marinus occidentalis Robbins. Ponds and lakes, especially in alkali water: Ont.-N.M.-Utah-Nev. Plain-Submont. Jl-Au.

19. P. pectinatus L. Stem slender, much branched, very leafy, 3-10 dm. long; leaves setaceous, attenuate at the apex, $3-15 \mathrm{~cm}$. long, $0.1-0.5 \mathrm{~mm}$. wide, sometimes nerveless; stipular sheath 1-2 $\mathrm{cm}$. long; free portion 3-8 $\mathrm{mm}$. long; peduncles filiform, 5-20 cm. long; spike interrupted, with several whorls of flowers; fruit obliquely ovoid, $3-4 \mathrm{~mm}$. long. Fresh, salt, or alkali waters: N.B.Fla.-L. Calif.-Alaska; Eu. Plain-Submont. Jl-S.

20. P. Robbinsii Oakes. Stem stout, widely branching, sometimes rooting at the nodes, 5-10 dm. long; leaves linear, acute, crowded in 2 ranks, 7-12 $\mathrm{cm}$. long, $2-6 \mathrm{~mm}$. wide, auricled at the point of union with the stipules; stipular sheath about $1 \mathrm{~cm}$. long; free portion of the stipules $1-2 \mathrm{~cm}$. long, mostly lacerate; peduncles 3-10 cm. long; spike interrupted, flowering under water; fruit obovoid, about $4 \mathrm{~mm}$. long, $3 \mathrm{~mm}$. thick, 3 -keeled, the middle keel sharp. Ponds and lakes: N.B.-N.J.-Mich.-Ida.-Ore.-B.C. Plain. Jl-S.

\section{RÚPPIA L.}

Slender water plants, widely branched and with capillary stems, filiform alternate 1-nerved leaves, with membranous sheaths. Peduncles spadix-like, filiform, at first very short, at last generally much elongated and spirally coiled. Flowers consisting of 2 sessile anthers, and 4 pistils, sessile at first, in fruit longstipitate. Fruit small, more or less obliquely ovoid drupes.

Sheaths 6-10 mm. long; drupe about $2 \mathrm{~mm}$. long or less.

Drupe very oblique; beak $0.5-1 \mathrm{~mm}$. long.

Drupe scarcely oblique, almost beakless.

Sheaths 20-40 $\mathrm{mm}$. long; drupe 3-4 $\mathrm{mm}$. long.

1. R. maritima.

2. R. pectinata.

3. $R$. occidentalis.

1. R. maritima L. Stem slender, filiform, whitish; leaves $2-10 \mathrm{~cm}$. long, $0.5 \mathrm{~mm}$. or less wide; sheaths $6-8 \mathrm{~mm}$. long, with a short free tip; peduncles in fruit sometimes $3 \mathrm{dm}$. long; drupes about $2 \mathrm{~mm}$. long; beak almost straight or curved. R. curvicarpa A. Nels. In brackish or salt water, along the coasts: Newf.-Tex.-Alaska-L. Calif.; occasionally in the interior, Sask.-Mex.; Eurasia and S. Am. Plain Je-Au.

2. R. pectinata Rydb. Stem intricately branched and very leafy, with very short internodes; leaves filiform, 3-6 cm. long, $0.5 \mathrm{~mm}$. or less wide; sheaths 7-10 mm. long, seldom with a small rounded tip; peduncles $3-5 \mathrm{~cm}$. long, in fruit recurved, but apparently not in a spiral; drupe about $1.2 \mathrm{~mm}$. long, with an almost sessile stigma. In brackish ponds: Yellowstone National Park, Wyo. -Utah-Wash.-Calif. Submont.-Mont.

3. R. occidentalis S. Wats. Stem comparatively stout, $3-6 \mathrm{dm}$. long, with very short internodes and fan-like clustered branches; leaves $7-20 \mathrm{~cm}$. long, and $0.3 \mathrm{~mm}$. wide or less; sheaths with distinct free tips, often overlapping each other; peduncles sometimes $5 \mathrm{dm}$. long; stipes about $25 \mathrm{~mm}$. long; drupes ovoid or pyriform, scarcely oblique; beak short, straight. In saline ponds: Neb.B.C.-Alaska. Plain-Submont. J1-Au.

\section{ZANNICHÉLLIA (Mich.) L.}

Slender branching aquatics, with opposite filiform leaves and sheathing membranous stipules. Flowers monoecious, sessile, naked, usually both kinds in the same axil; the staminate ones consisting of a single 2-celled anther, borne on a pedicel-like filament, the pistillate ones of 2-6 sessile pistils in a cup-shaped involucre. Fruit nut-like, obliquely oblong, flattened, with a short slender beak, ribbed or toothed on the back. Seed orthotropous. 
1. Z. palustris L. Stem capillary from a creeping rhizome; leaves $3-7 \mathrm{~cm}$. long, $0.5 \mathrm{~mm}$. or less wide, acute, thin, 1-nerved; fruit 2-6 together, $2-4 \mathrm{~mm}$. long, sessile or short-pedicelled; style persistent, 1-2 $\mathrm{mm}$. long. In fresh and brackish ponds and ditches: Ont.-Fla.-Tex.-Calif.-B.C.; also in the Old World. Plain-Submont. Jl-O.

\section{Family 8. NAJADACEAE. NaJAS Family.}

Slender submerged aquatic plants, with linear spinulose-toothed whorled or opposite leaves, sheathing at the base. Flowers monoecious or dioecious, solitary and axillary. Staminate flowers with a double perianth, the inner hyaline; stamen 1. Pistillate flowers of a single pistil, with 2-4 subulate stigmas. Fruit a small drupe.

Characters of the family.

\section{NĀJAS L.}

Leaves 1-3 mm. wide, coarsely toothed; back of the leaves and internodes spiny; plant dioecious.

1. N. marina.

Leaves $0.5-1 \mathrm{~mm}$. wide, finely, almost microscopically serrulate; back of the leaves and internodes unarmed; plant monoecious.

Drupe shining, with $30-50$ rows of indistinct reticulations.

Drupe dull, with 16-20 rows of strongly marked reticulations. 3. N. guadalupensis,

1. N. marina L. Stem stout, compressed, generally armed with teeth twice as long as broad; leaves broadly linear, $12-45 \mathrm{~mm}$. long, with $6-10$ spinepointed teeth on each margin; sheaths broadly rounded; their margins entire or with a few teeth; fruit 4-5 $\mathrm{mm}$. long; epicarp as well as the dull nutlet rugosereticulate. In lakes and ponds with fresh or brackish water: N.Y.-Fla.-L. Calif.-Calif. (in the range reported only from Utah); Eurasia and Austr. Plain. Jl-Au.

2. N. flexilis (Willd.) Rost. \& Schmidt. Stem slender, forking, unarmed; leaves narrowly linear, 1-2 cm. long, numerous and crowded, pellucid, with 2030 minute teeth on each margin; sheaths rounded, with 5-10 teeth on each side; fruit ellipsoid, 2-3 mm. long. In ponds and slow streams: Que.-Fla.-La.Calif.-Ore.; Eu. Plain. My-Au.

3. N. guadalupensis (Spreng.) Morong. Stem very slender, filiform, 3-6 $\mathrm{dm}$. long, branched and leafy; leaves numerous, crowded, 12-25 $\mathrm{mm}$. long, $0.5-1.5$ $\mathrm{mm}$. wide, with 40-50 teeth on the margins; sheaths as in $N$. flexilis; fruit about $2 \mathrm{~mm}$. long. $N$. microdon R. Br. In ponds and lakes: Neb.-Fla.-La.-Tex. -Ore.; Mex. and Trop. Am. Plain. J-S.

\section{Family 9. SCHEUCHZERIACEAE. ARRow-GRAss FAMILy.}

Marsh plants, with terete rush-like leaves and small perfect, spicate or racemose flowers. Perianth-segments 4 or 6 , in two series. Stamens 3-6; anthers 2-celled. Carpels 3-6, 1-2-ovuled, more or less united, separating at maturity, either dehiscent or indehiscent. Seeds anatropous. Embryo straight; endosperm none.

Stem scapose; leaves all basal; flowers spicate or racemose.

Stem leafy; flowers few, in loose racemes.

1. TRIGLOCHIN.

2. SCHEUCHZERTA.

\section{TRIGLÒCHIN L. ARROW-GRASS,}

Marsh herbs, with half-round elongated linear leaves, sheathing at the base, and terminal racemes or spikes on long naked scapes. Perianth-segments in ours 6, the inner 3 inserted higher up. Stamens 6; anthers 2-celled, sessile or nearly so. Ovaries 3-6, 1-celled and 1-ovuled; style short or none; stigmas 3-6, plumose. Fruit of 3-6, cylindraceous, oblong, obovoid, or clavate carpels, united at first, at maturity separating from the base upwards. Seeds cylindraceous or ovoid-oblong, compressed or angular.

Carpels 3; fruit linear-clavate, tapering at the base. Carpels 6; fruit oblong or ovoid, obtuse at the base. 
1. T. palustris L. A slender plant, with short rootstock and slender stolons, 2-4 dm. high; leaves shorter than the scape, 1-3 dm. long, sharp-pointed; racemes 1-3 dm. long; pedicels slender, capillary, in fruit erect, 5-7 $\mathrm{mm}$. long; stigmas sessile; fruit 6-7 mm. long. In bogs: Greenl.-N.Y.-Ind.-N.M.-Alaska; Eurasia and S. Am. Plain-Mont. Jl-S.

2. T. maritima L. A stout plant, with subligneous rootstock, without stolons; leaves half-cylindric, $2 \mathrm{~mm}$. wide; racemes often $4 \mathrm{dm}$. long or more; pedicels decurrent, $2-3 \mathrm{~mm}$. long, in fruit ascending; fruit 5-6 mm. long, 3-4 $\mathrm{mm}$. in diameter; carpels triangular, grooved on the back. In salt marshes: Lab.-N.J.-Calif.-Alaska; Eurasia. Plain-Submont. Je-S.

\section{SCHEUCHZÈRIA L.}

Rush-like bog plants, with perennial, creeping rootstock. Leaves half-round below, flat above, striate, and with membranous sheaths at the base. Perianth with 6 segments in two series. Stamens 6; filaments elongated; anthers linear, basifixed. Ovaries 3, rarely 4-6, distinct or connate at the base, 1-celled, each cell with 1-2 ovules. Fruit of 3-6 divergent follicles, opening on the inside.

1. S. palustris L. A leafy bog plant, 1-2.5 dm. high; leaves $1-4 \mathrm{dm}$. long, the upper reduced to bracts; basal leaves with sheaths often $1 \mathrm{dm}$. long and ligules $1 \mathrm{~cm}$. long; pedicels $6-20 \mathrm{~mm}$. long, in fruit spreading; flowers white; segments 1 -nerved, $3 \mathrm{~mm}$. long; follicles $5-6 \mathrm{~mm}$. long. In bogs: Lab.-N.J.Wisc.-Calif.-Alaska; Eurasia. Boreal-Submont. Je-Jl.

\section{Family 10. AlismaCeae. Water-Plantain Family.}

Marsh or aquatic plants, with scapose stems, basal long-petioled sheathing, mostly cross-veined, leaves, and fibrous roots. Flowers mostly verticillate, in elongated racemes or panicles, regular, pedicelled. Sepals 3, persistent. Petals 3 , deciduous. Stamens 6 or more, included. Pistils many, distinct; ovaries 1-celled and generally 1-ovuled, becoming achenes in fruit.

Carpels in a ring on a small flat receptacle; flowers perfect.

1. Alisma.

Carpels in several series on a convex receptacle; flowers monoecious or dioecious.

\section{ALÍSma L. Water-PLantain.}

2. SAgitTARia.

Annual or mostly perennial scapose herbs. Leaves erect or floating; blades several-veined, petioled. Flowers perfect in compound panicles. Sepals 3, usually ribbed, persistent. Petals 3 , white or pinkish, spreading, deciduous. Stamens 6 , two opposite each petal. Carpels few or many, in one whorl. Achenes ribbed or grooved on the back.

Achenes longer than wide, grooved on the back, their inner edges not meeting; pedicels straight, ascending.
Achenes as wide as long, ribbed on the back, their inner edges meeting; pedicels recurved.

1. A. brevipes Greene. Perennial; leaf-blades oblong to ovate, 5-19 $\mathrm{cm}$. long, acute at the apex, rounded, truncate or subcordate at the base; scape $1 \mathrm{~m}$. high or less; sepals orbicular or rounded-ovate, $3 \mathrm{~mm}$. long or more; petals 5-6 $\mathrm{mm}$. long; fruiting heads $5-6.5 \mathrm{~mm}$. broad; achenes broadly obovate, $2.5-3 \mathrm{~mm}$. long; beak ascending. A. superba Lunell. In water and wet places: N.S.-N.D. N.M.-Calif.-B.C. Plain-Mont.

2. A. Geyeri Torr. Perennial; leaf-blades oblong to ovate-lanceolate, rarely lance-linear, 5-9 cm. long, acute at both ends; scapes mostly 1-5 dm. long, diffusely spreading; sepals rounded-ovate, about $2-5 \mathrm{~mm}$. long; petals 2-4 mm. long; fruiting heads 4.5-5.5 mm: broad; achenes suborbicular; beaks erect. Wet places: w N.Y.-N.D.-Nev.-Ore. Plain-Submont.

\section{SAgittària L. Arrow-head, Swan or Swamp Potato.}

Perennial water or bog plants, with tuber-bearing or nodose rootstocks. Leaves long-petioled, with a sagittate or lanceolate blade or, especially the earlier ones, reduced to bladeless phylloids. Flowers monoecious or dioecious, borne 
in verticils of 3's near the top of the scapes, pedicelled, the staminate uppermost. Sepals and petals 3 ; the latter large, white. Stamens numerous, inserted on the convex receptacle; anthers 2-celled, dehiscent by lateral slits. Pistillate flowers with numerous pistils. Achenes densely aggregated in globular heads, flat and often wing-margined.

Leaf-blades usually without basal lobes; beak borne below the top of the achenes.

Leaf-blades or some of them sagittate or hastate, with basal lobes; beak borne at the top of the achenes.

Beak short, erect; bracts lanceolate or linear-lanceolate. Basal lobes of the leaves acute or acuminate. Basal lobes of the leaves rounded or obtuse.

Beak of the achenes horizontal.

Beak short; basal lobes of the leaves at least twice as long as the terminal one; bracts lanceolate.

Beak long; basal lobes of the leaves usually shorter than the terminal one; bracts ovate.

5. S. latifolia.

1. S. graminea Michx. Plant emersed or submerged, 1-6 dm. high; phylloids if present, flattened, linear-lanceolate, acute, 8-30 cm. long, 1-2 cm. wide; leaf-blades lanceolate to ovate-elliptical, acute at both ends, or very rarely truncate, with short divaricate lobes at the base, $5-15 \mathrm{~cm}$. long, 3-5-ribbed; bracts ovate, acute, $3-5 \mathrm{~mm}$. long, connate to the middle; fruiting heads $5-10 \mathrm{~mm}$. in diameter; achenes $1.5 \mathrm{~mm}$. long, dorsally crested and obliquely one-ribbed on the sides. In shallow ponds and marshes: Newf.-Fla.-Tex.-Sask. Plain.

2. S. cuneata Sheld. A rather weak plant growing in mud or water, glabrous, 2-4 dm. high; leaves when emersed sagittate; petiole rather stout, usually curving outwards; blade $6-18 \mathrm{~cm}$. long; basal lobes narrow, lanceolate, somewhat divergent; blades in deep water less developed, sometimes not lobed, floating; bracts lanceolate or linear-lanceolate, acute, 8-20 mm. long, scarious-margined; fruiting heads $10-15 \mathrm{~mm}$. in diameter; achenes $2 \mathrm{~mm}$. long, winged on both margins. S. arifolia Nutt. In mud and shallow water: Me.-N.D.-Conn. -Kans.-N.M.-Calif.-B.C. Plain-Submont.

3. S. hebetiloba A. Nels. A rather stout plant, 2-5 dm. high, monoecious; leaf-blades sagittate, 8-14 cm. long, subacute; bracts linear-lanceolate, 15-20 $\mathrm{mm}$. long, subscarious; corolla about $2 \mathrm{~cm}$. in diameter; fruiting heads $10-15$ $\mathrm{mm}$. in diameter; achenes about $2 \mathrm{~mm}$. long, winged on both margins and the summit. In a bog, formed from warm-spring: Laramie Co., Wyo. Submont.

4. S. longiloba Engelm. A monoecious, slender, erect perennial, 3-5 dm. high; leaf-blades sagittate; basal lobes linear-lanceolate, acuminate; fruiting heads $10-12 \mathrm{~mm}$. in diameter; achenes $2 \mathrm{~mm}$. long, narrowly winged on both margins; beak lateral. In shallow ponds: Neb.-Colo.-Tex.-Sonora. Plain-Son.

5. S. latifolia Willd. A rather stout plant, monoecious, 3-6 dm. high; with the lower verticils fertile, or rarely dioecious, 3-6 dm. high; leaf-blades sagittate, $15-40 \mathrm{~cm}$. long, very variable, glabrous; lobes from broadly ovate to linear-lanceolate [v. angustifolia], acute or acuminate; bracts ovate, acute, 1-3 cm. long; flowers 3-4 cm. wide; fruiting heads 15-30 $\mathrm{mm}$. in diameter; achenes about $3 \mathrm{~mm}$. long, winged on both margins; beak triangular-lanceolate, acuminate, making almost a right angle to the achenes. Shallow water: N.B.-Fla.-Calif.-B.C. Mex. and C. Am. Son.-Plain-Mont. Je-S.

\section{Family 11 . ELODEACEAE. Water-Weed Family.}

Submersed or floating water plants. Leaves in ours opposite or whorled. Plants monoecious, dioecious or polygamous. Flowers enclosed in a spathe of 1-3, usually united bracts. Hypanthium in the pistillate flowers well developed, tubular, in the staminate flowers often shorter or obsolete. Perianth regular or nearly so. Sepals 3. Petals 3, or wanting. Stamens 3-9; filaments short, often monadelphous. Pistil single, compound. Ovary 1celled with 2-6, usually 3 , parietal placentae. Ovules numerous. Fruit indehiscent, maturing under water. 


\section{PHilòtria Raf. Water-Weed.}

Submerged water plants with elongated branched stems, often rooting at the nodes, dioecious or polygamo-dioecious. Leaves opposite or whorled, sessile, pellucid, 1-nerved. Spathe 2-cleft at the apex, that of the staminate plant oval or obovate, sessile, stipitate, in the pistillate plant lanceolate and sessile. Sepals and petals 3 or the latter lacking. Stamens in the staminate flowers usually 9 , in two series, in the inner series 3 ; in the hermaphrodite usually only 3. Fruit linear or lanee-linear. [Elodea Michx.]

Staminate flowers sessile, breaking off within the spathe; petals wanting.

1. P. Planchonii.

Staminate flowers on elongating pedicels, carrying them to the water surface; petals present.

1. P. Planchonii (Casp.) Rydb. Dioecious water plant; stem slender, 1-10 dm. long; leaves in 3's or the lower opposite, oblong to linear, 7-15 $\mathrm{mm}$. long, 1-2 $\mathrm{mm}$. wide, acutish; spathe of the staminate plant obovoid-clavate, nearly $1 \mathrm{~cm}$. long, on a stipe $5-10 \mathrm{~mm}$. long; sepals elliptic, $5 \mathrm{~mm}$. long; petals lacking; spathe of the pistillate plant lance-linear, sessile; tube of the hypanthium 3-5 $\mathrm{cm}$. long; sepals and petals linear, about $3 \mathrm{~mm}$. long. Lakes and ponds: Sask.-Colo.-Nev. Plain-Submont.

2. P. iowensis Wylie. Dioecious water plant; leaves lanceolate to oblonglinear, 8-14 mm. long, 2-3.5 $\mathrm{mm}$. wide; spathe of the staminate flowers obovate, contracted to a narrow base; sepals oval, $4 \mathrm{~mm}$. long; petals linear-lanceolate, acuminate; spathe of the pistillate flowers linear-cylindric, $1-1.5 \mathrm{~cm}$. long; hypanthium $3-15 \mathrm{~cm}$. long; sepals oval, $2 \mathrm{~mm}$. long; petals obovate; staminodia 3. Lakes: Iowa-Colo. Plain.

\section{Family 12. POACEae. Grass Family.}

Annual or perennial herbs, or in warmer climates sometimes trees or vines. Stems (culms) usually hollow except at the nodes. Leaves sheathing at the base; the sheaths usually split on the side opposite the blades. Inflorescence spicate, racemose or paniculate, consisting of spikelets composed of usually 2-ranked bracts called glumes, the lower 1-4, usually 2, empty, the remaining (lemma) enclosing a bract-like organ (the palet), and inside this a flower, usually consisting of 3 stamens and 1 pistil. Ovary 1celled, 1-seeded. Styles 1-3, usually 2. Fruit a seed-like grain (caryopsis), in some exotic species nut-like or berry-like.

Spikelets falling from the pedicels entire, naked or enclosed in bristles or bur-like involucres, 1-flowered, or if 2-flowered the lower flower staminate; no upper empty

glumes; rachilla not extending above the upper glume.
Spikelets round or somewhat compressed dorsally; empty glumes manifest; hilum

punctiform.
Lemma and palet hyaline, thin, much more delicate in texture than the empty

glumes.
Spikelets in pairs, one sessile and the other pedicellate.

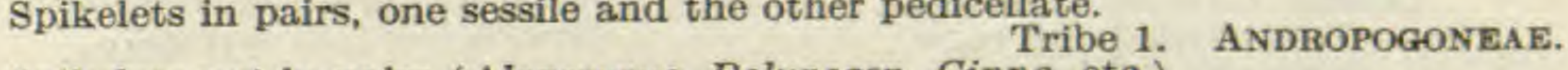
Spikelets not in pairs (Alopecurus, Polypogon, Cinna, etc.)

Tribe 6. AgRostideaE.

Lemma, at least that of the perfect flower, similar in texture to the empty glumes, or thicker and firmer, never hyaline and thin.

Lemma and palet membranous; the first glume usually larger than the rest. Lemma and palet Tribe 2. ZOYSIEAE.

Lemma and palet chartaceous to coriaceous, very different in color and appearance from the remaining glumes. Tribe 3. PANICEAE.

Spikelets much compressed laterally; empty glumes none or rudimentary; hilum linear.

Tribe 4. ORYZEAE.

Spikelets with the empty glumes persistent, the rachilla articulated above them, 1-manyflowered; upper lemmas frequently empty; rachilla often produced beyond the

upper lemma.
Spikelets borne in an open or spike-like panicle or raceme, usually upon distinct pedicels.

Spikelets 1-flowered.

Empty glumes 4 ; palet 1 -nerved.

Empty glumes 2, rarely 1; palet 2-nerved (except in Cinna.)

Tribe 5. Phalarideae.

Tribe 6. AgrostideaE. 
Spikelets 2-many-flowered.

Lemma usually shorter than the empty glumes; the awn dorsal and usually bent.

Tribe 7. AVENEAE.

Lemma usually longer than the empty glumes; the awn terminal and straight (rarely dorsal in Bromus) or none.

Spikelets in two rows, sessile or nearly so.

Tribe 9. FEsTuCEAE.

Spikelets on one side of the continuous axis, forming one-sided spikes.

Tribe 8. CHLORIDEAE.

Spikelets alternately on opposite sides of the axis, which is often articulated. Tribe 10. HORDEAE.

TRIBE 1. ANDROPOGONEAE.

Racemes singly disposed; apex of the rachis-internodes with a translucent cup-shaped appendage.

1. SCHIZACHYRIUM.

Racemes disposed in pairs or more; apex of the rachis-internodes not appendaged.

Rachis-internodes and pedicels sulcate, the median portion translucent, the margins thickened.

Rachis-internodes not sulcate.

Some or all of the racemes sessile.

All of the racemes more or less peduncled.

Pedicellate spikelets wanting.

2. AMPHILOPHIS.

Pedicellate spikelets present and usually staminate.

3. ANDROPOGON.

4. SORGHASTRUM.

5. HoLCUS.

Only one genus represented.

TRIBE 2. ZOYSIEAE.

Spikelets naked, not involucrate.

TRIBE 3. PANICEAE.

6. Pleuraphis.

Empty glumes 2.

Rachis produced beyond the upper spikelet; spikelets narrow.

Rachis not so produced; spikelets globose or obovoid. Spikelets obovoid, turgid. Spikelets plano-convex.

39. SPARTINA.

40. BECKMANNIA.

7. Paspailum.

Empty glumes 3.

Empty glumes not awned.

Spikelets in very slender 1-sided racemes, which are usually whorled or approximate.

Spikelets in panicles or panicled racemes.

Spikelets lanceolate, acuminate, long-hairy.

8. SYNTHERISMA.

Spikelets involucrate.

Involucre of bristles.

Involucre of two spine-bearing valves.

glabrous.

11. ECHINOCHLOA.

12. Chamtochloa.

13. CENCHRUS.

TRIBE 4. ORYZEAE.

Spikelets perfect; empty glumes wanting or rarely rudimentary. 14. HOMALOCENCHRUS.

TRIBE 5. PHALARIDEAE.

Third and fourth glumes empty, awnless.

Third and fourth glumes enclosing staminate flowers.

15. Phalaris.

16. TORRESIA.

TRIBE 6. AGROSTIDEAE.

Lemma indurate when mature and very closely embracing the grain, or at least firmer than the empty glumes.

Spikelets all perfect, not in pairs.

Lemma 3-awned.

Lemma 1-awned or awnless.

Awn twisted and bent.

Awn not twisted.

Lemma broad; awn deciduous.

Inflorescence paniculate or racemiform. 19. ORYZOPSIS.

Intiorescence dichotomous.

20. ERIOCOMA.

Lemma narrow, glabrous or with short, appressed hairs; awn, if any, persistent.

17. ARISTIDA.

18. STIPA.

1. MUHLENBERGIA.

Spikelets in pairs, one perfect and the other staminate or sterile, in a spike-like panicle.

22. LYCURUS.

Lemma usually hyaline or membranaceous at maturity, at least more delicate than the empty glumes.

Stigma sub-plumose ( $i$. e., with short hairs all around), projecting from the apex of the nearly closed glumes.

Inflorescence spike-like.

Rachilla of the spikelets articulated above the empty glumes, which are therefore persistent.

23. PHLEuM

Rachilla of the spikelets articulated below the empty glumes, hence the

spikelets falling off entire.
Inflorescence an open small panicle; dwarf arctic-alpine plant.

25. Phippsia. 
Stigma plumose, projecting from the sides of the spikelets; inflorescence an open or spike-like panicle.

Grain not permanently enclosed in the lemma and palet; pericarp opening readily at maturity.

Flowering glumes long-hairy on the veins.

Flowering glumes not long-hairy on the veins.

26. BLEPHARONEURON.

27. SPOROBOLUS.

Grain permanently enclosed in the lemma and the palet; pericarp adherent. Spikelets readily falling off when mature.

Spikelets with the empty scales at least persistent.

Palet 1-nerved and 1-keeled; stamen 1.

28. POLYPOGON.

Palet 2-nerved and 2-keeled or sometimes wanting; stamens 3.

Lemma naked at the base.
Lemma with long hairs at the base.

Flowering glume and palet thin-membranous. 31. CALAMagrosts. Flowering glume and palet chartaceous.

32. Calamovilfa.

TRIBE 7. AVENEAE.

Awn of the lemma inserted dorsally below the teeth.

Flowers all perfect or the upper staminate.

Grain free, unfurrowed; spikelets less than $1 \mathrm{~cm}$. long.

Lemma erose-toothed or shortly 2-lobed at the apex. 33. Deschampsia.

Lemma 2-cleft or deeply 2-toothed at the apex; teeth awn-pointed.

Awn twisted and bent.

Awn if present not twisted, straight. 35. GrAPHEPHORL
Grain furrowed, adherent to the glumes; spikelets exceeding $1 \mathrm{~cm}$. in length.

34. TRISETUM.

Ovary not erowned by a villous appendage. 36 AvENA.

Ovary crowned by a villous appendage (awned species of)

Upper flowers perfect, the lower staminate.

70. BROMUS,

Awn of the lemma inserted between the teeth.

37. ARRHENATHERUM.

38. Danthonia.

\section{TRIBE 8. CHLORIDEAE.}

Plants with perfect flowers.

Spikelets with 1 (rarely 2) perfect flowers.

Spikelets deciduous as a whole; rachis articulated below the empty glumes.

Rachis produced above the upper spikelet; spikelets narrow.

39. SPARTINA.

Rachis not produced above the upper spikelet; spikelets globose.

Spikelets with at least the empty glumes persistent.

40. BECKMANNLA.

Glumes above the perfect flower none; spikes digitate, very slender.

41. SCHEDONNARDUS.

Glumes above the perfect flower 1-several; spikes scattered.

Spikes closely approximate, subverticillate.

Spikes scattered.

Spikelets with $2-3$ perfect flowers; spikelets alternate.

Plants dioecious; spikelets of the two sexes very unlike,

42. CHIORIS.

43. BOUTELOUA.

44. LEPTOCHLOA.

45. Bulbilis.

TRIBE 9. FESTUCEAE.

Lemmas, at least of the pistillate spikelets, 3-lobed and 3-awned; plant dioecious.

Lemmas entire or at most 3-lobed.

46. SCLFROPOGON.

Hairs on the rachilla or the lemma very long and enclosing the latter.

47. Phragmites.

Hairs, if any, on the rachilla and the lemma shorter than the latter.

Stigmas barbellate on elongated styles; spikelets in threes in the axils of spinescent leaves.

Stigmas plumose, sessile or on short styles.

48. MUNROA.

Lemma 1-3-nerved.

Lateral nerves of the lemmas hairy. Lemma deeply 3-lobed.

Internodes of the rachilla long, often half as long as the lemma; plants without stolons.

50. TRIPLASIS.

Internodes of the rachilla short, many times shorter than the lemmas. Fertile flower one, with 2 empty lemmas below and one above.

49. BLEPHARIDACHNE.
Fertile flowers 3 or more, with no empty lemmas below.

51. DASYOCHLOA.

Lemma entire or slightly 2-lobed; internodes of the rachilla short.

Inflorescence a short congested raceme; leaf-blades with thick cartilaginous margins. 52 . ERIONEURON.

Inflorescence a panicle; leaf-blades not with cartilaginous margins. Panicle simple or compound, the spikelets on pedicels of varying length. 52. TRIDENS.

Panicle composed of long branches, along which the appressed spikelets are arranged on short pedicels.

54. DiplachNe.

Lateral nerves of the lemmas glabrous.

Callus of the lemma copiously pubescent with long hairs; panicle open. 55. REDFIELDIA. 
Callus of the lemma glabrous.

Second empty glume similar to the first one or nearly so.

Panicle narrow, dense and spike-like, shining; its branches erect.

Panicle open; its branches spreading.

56. KoElERIA.

Rachilla continuous (except in $E$. megastachya); lemma deciduous; palet persistent; plants of dry soil.

57. ERAgrostis.

Rachilla articulated; lemma and palet both deciduous with the rachilla-internodes; water plants with 2 -flowered spikelets. 58. Catabrosa.

Second empty glume very unlike the first one, broad at the summit.

Lemma 5-many-nerved.

Spikelets with two or more of the upper glumes empty, broad and enfolding each other.

59. SPHENOPHOIIS.

Spikelets with upper glumes flower-bearing or narrow and abortive.

Stigmas arising at or near the apex of the ovary.

Spikelets borne in one-sided fascicles which are arranged in a glomerate or interrupted panicle; lemma herbaceous.

Spikelets borne in panicles or racemes.

61. DACTYLIS.

Glumes more or less compressed and keeled.

Spikelets cordate, large. 62 . BRIZA.

Spikelets not cordate.

Plants dioecious; lemma of the pistillate spikelets coriaceous; palet strongly 2 -keeled and serrate on the margin.

63. Distichlis.

Plants with perfect flowers or in some species of Poa dioecious; spikelets all alike; lemma thin; palet ciliate or smooth on the margin.

Lemma scarious-margined; rachis glabrous or with webby hairs.

64. POA.

Lemma membranous, not scarious-margined; rachis with stiff hairs, extending into a hairy appendage. 35. GRAPHEPHORUM.

Glumes rounded on the back, at least below.

Lemma with a basal ring of hairs, prominently 7-nerved, toothed at the apex.

65. SCOLOCHLOA.

Lemma naked at the base.

Lemma obtuse or acutish and scarious at apex, usually toothed.

Lemma distinctly 5-7-nerved; style present.

Lemma obscurely 5-nerved; style none.

66. PANICULARIA.

67. Puccinelita.

Lemma acute, pointed or more commonly awned at apex. Stigmas bilaterally plumose; flowers hermaphrodite. 68. FesTuCA.

Stigmas subplumose, the branches arising on all sides; plant dioecious.

69. HESPEROCHLOA.

Stigmas plainly arising below the apex of the ovary which is tipped by a hairy cushion.

70. BROMUS.

TRIBE 10. HORDEAE.

Spikelets usually single at the nodes of the rachis.

Empty glumes broad, with their sides turned to the rachis.

Glumes broad, several-toothed or several-awned.

Glumes not toothed, 1-awned or awnless.

Perennials; spikelets several-flowered.

Annuals or biennials; spikelets 2-flowered.

Empty glumes with their back turned to the rachis.

73. TRITICUM,

72. AgROPYRON.

74. SECALE.

71. LoLIUM.

Spikelets 2-6 at each node of the rachis, or if solitary the empty glumes arranged obliquely to the rachis.

Spikelets 1-flowered or with a rudimentary second flower.

Spikelets 2-many-flowered.

Rachis of spikes articulated, readily breaking up into joints. 76. SITANION.

Rachis of spikes continuous, not breaking up into joints.

Empty glumes well developed.

Empty glumes wanting or reduced to short bristles.

77. ELYMUS.

78. HYSTRIX.

\section{SCHIZACHÝRIUM Nees. BEARD-GRASS, BUNCH-GRASs.}

Annual or perennial grasses, with spike-like racemes, singly disposed, terminating the stem or its branches. Spikelets in pairs at the nodes of the articulate and frequently hairy rachis, one sessile, the other stalked. Sessile spikelet of 4 glumes, the outer 2 empty glumes indurate, the third and the lemma hyaline; the latter bearing a straight, contorted, or twisted awn; palet small, hyaline. Pedicellate spikelet sterile, with 1 or 2 glumes, or rarely wanting. Stigmas plumose. 
1. S. scoparium (Michx.) Nash. Perennial with a strong rootstock; stems tufted, 4-15 dm. high, glabrous, scabrous, and in the western form usually glaucous; leaf-blades 4-6 $\mathrm{cm}$. long, $8 \mathrm{~mm}$. wide or less, seabrous and sometimes hirsute at the base; racemes 3-6 $\mathrm{cm}$. long, with white-hairy internodes and pedicels; sessile spikelet 5-7 mm. long; awn of the lemma geniculate, 8-15 mm. long, twisted at the base; pedicellate spikelet $2-4.5 \mathrm{~mm}$. long, tipped with an awn 1 $\mathrm{mm}$. long or less. Andropogon scoparius Michx. Dry sandy soil: N.B.-Fla.Tex.-N.M.-Alta. Plain-Submont. Jl-S.

\section{AMPHILÒPHIS Nash. Beard-Grass.}

Perennial grasses, resembling Andropogon, with showy, often silvery panicles. Racemes numerous, the internodes with manifestly thickened margins; the median portion thin and translucent. Sessile spikelet of 4 glumes, the outer 2 indurate, the first 2-keeled, the second 1-keeled, the third and the lemma hyaline, the latter very narrow, gradually merging into the awn; the pedicellate spikelet staminate and similar, or sterile and reduced. Stigmas plumose.

1. A. saccharoides (Sw.) Nash. Tufted perennial, smooth and glaucous; stems 5-10 dm. high, simple or somewhat branched; leaf-blades 1-5 dm. long, $3-7 \mathrm{~mm}$. wide, rough above; racemes $1-4 \mathrm{~cm}$. long, the terminal hairs $1 \frac{1}{2}-2$ times as long as the internodes; sessile spikelet $4 \mathrm{~mm}$. long, half longer than the internodes; awn geniculate, more or less twisted, $1-1.5 \mathrm{~cm}$. long; pedicellate spikelet consisting of a single glume $2-3 \mathrm{~mm}$. long. Andropogon glaucum Torr. A. Torreyanum Steud. Dry soil: Tex.-Mo.-Colo,-Ariz.; Mex. Son. JeAu.

\section{ANDROPÒGON (Royen) L. Bluestem, BEARD-Grass.}

Perennial grasses, tufted or from elongated rootstocks, with spike-like racemes, disposed in pairs or sometimes in 3's or more, terminating the stem or its branches. Spikelets sometimes with a ring of short hairs at the base, in pairs at each node of the articulated and frequently hairy rachis, one sessile, the other pedicellate. Sessile spikelet of 4 scales, the outer 2 indurated, of ten pubescent, the third usually hyaline, the lemma entire or 2-toothed at the apex, bearing a straight contorted or spiral awn, or sometimes awnless; palet small, hyaline. Pedicellate spikelet usually sterile, of 1 or 2 glumes, sometimes of four glumes and enclosing a staminate or more rarely a perfect flower, or frequently entirely wanting, the first glume rarely short-awned. Stamens 1-3. Styles distinct; stigmas plumose.

Lemma of the sessile spikelets with a long geniculate awn, more or less spiral at the base. Outer two glumes of the sessile spikelets more or less hispidulous all over; hairs of the rachis-internodes usually $2 \mathrm{~mm}$. long or less, mostly white. 1. A. provincialis.

Outer two glumes of the sessile spikelets smooth or nearly so, except on the nerves; hairs of the rachis-internodes $3-4 \mathrm{~mm}$. long, usually yellow. 2. A. chrysocomus. Lemma of the sessile spikelets awnless or with a short straight untwisted awn.

Marginal hairs of the pedicels and rachis-internodes copious, stiff. 3 . A. Hallii.

Marginal hairs of the pedicels and rachis-internodes seant, lax, crisp, or almost wanting.

1. A. provincialis Lam. Stem 1-2 m. high; shesths glabrous, or sometimes slightly hairy; leaf-blades $1.5-6 \mathrm{dm}$. long, $5-12 \mathrm{~mm}$. wide, usually glabrous and smooth beneath, slightly scabrous above and somewhat hairy at the base; racemes in 2's-6's, 5-10 $\mathrm{cm}$. long; sessile spikelet 7-10 $\mathrm{mm}$. long; awn $7-15 \mathrm{~mm}$. long; pedicellate spikelet nearly as large, staminate, awnless. A. furcatus Muhl. Meadows: Me.-Fla.-Tex.-N.M.-Mont.-Sask. Plain-Submont. Jl-S.

2. A. chrysocomus Nash. Stem 7-15 dm. high; sheaths smooth and glabrous; leaf-blades $2-3 \mathrm{dm}$. long, $7 \mathrm{~mm}$. wide or less, smooth beneath, slightly scabrous above; racemes in 2's-4's, 5-9 cm. long, long-exserted; sessile spikelet about $1 \mathrm{~cm}$. long; outer two glumes hispid on the nerves; awn $10-12 \mathrm{~mm}$. long; pedicellate spikelet awnless. Prairies and plains: Neb.-Tex.-Colo. PlainSubmont. Ji-S.

3. A. Hallii Hack. Stem robust, 1-2 m. high, more or less glaucous, glabrous; sheaths glabrous and glaucous; leaf-blades 2-3 dm. long, 5-8 mm. wide; spikes in 2's-5's, 5-10 cm. long; hairs of the internodes about $2 \mathrm{~mm}$. long, yellowish or whitish; sessile spikelet about $8 \mathrm{~mm}$. long; outer glumes glabrous at the 
base, pubescent towards the apex; awn straight, 4-10 $\mathrm{mm}$. long or sometimes wanting; pedicellate spikelet awnless, usually larger than the sessile one, staminate. Sandy soil: N.D.-Miss.-Mex.-Mont. Plain-Son. Jl-S.

4. A. paucipilus Nash. Stem 1-1.5 m. tall, stout; sheaths smooth and glabrous; leaf-blades $3 \mathrm{dm}$. long or less; racemes in 2's-3's, 5-7 cm. long, exserted; sessile spikelets $9-10 \mathrm{~mm}$. long; outer 2 glumes hispid on the nerves toward the apex, pubescent towards the summit; awn almost none; pedicellate spikelet similar to the sessile one, staminate. Dry soil: Mont,-Neb. Plain. Jl.

\section{SORGHÁSTRUM Nash. Indian Grass.}

Perennials with rootstocks. Panicles large, with the principal branches solitary but branching near the base and hence appearing verticillate. Sessile spikelet dorsally compressed; empty glumes 3 , the outer two indurate, often hairy, the third hyaline. Lemma hyaline, with a long awn, which is spiral at the base. Pedicellate spikelet wanting or rudimentary, usually represented merely by a hairy pedicel at one side of the sessile spikelet, or at the ends of the branches by two pedicels, one on each side. Styles distinct; stigmas plumose.

1. S. nutans (L.) Nash. Perennial, with a scaly rootstock; stems $1-2.5 \mathrm{~m}$. high; leaf-sheaths usually smooth and glabrous; blades 3-6 dm. long, 5-13. mm. wide, very rough; panicles $2-5 \mathrm{dm}$. long, loose, the apex usually nodding; spikelets 6-8 mm. long, lanceolate, the 2 outer glumes golden-brown, the first one densely pubescent with long erect hairs; awn geniculate, 1-1.5 $\mathrm{cm}$. long, closely spiral up to the bend, then loosely twisted. Andropogon nutans L. Chrysopogon nutans A. Gray. Meadows: Ont,-Fla.-Tex.-Ariz.-Sask.; n Mex. Plain -Submont-Son. II-S.

\section{5. hólcus L Johnson Grass, Broom Corn, Sugar Corn.}

Perennials with rootstocks, or annuals. Branches of the large panicle verticillate. Spikelets in pairs or at the ends of the branches in 3's, 1 sessile and pistillate, 1 or 2 pedicelled and staminate or neutral. Empty glumes 3, the outer two indurate, the third hyaline. Lemma hyaline, awned, or awnless. Styles distinct; stigmas plumose. [Sorghum Pers.]

1. H. halapense L. Perennial; stem 5-15 dm. tall; leaf-blades 2-5 dm. long, $0.5-3 \mathrm{~cm}$. wide; panicle $1.5-5 \mathrm{dm}$. long, oblong to oval; sessile spikelet $4.5-$ $5.5 \mathrm{~mm}$. long, ovoid, the two outer glumes densely appressed-pubescent; awn readily deciduous, $1-1.5 \mathrm{~cm}$. long; pedicellate spikelets $5-7 \mathrm{~mm}$. long, lanceolate, the 2 outer glumes sparingly pubescent. Sorghum halapense Pers. JoHnson Grass. In fields and waste places: Pa.-Fla.-Tex.-Colo.; Calif.; Mex., C. Am. and S. Am.; escaped from cultivation. Je-D.

\section{Pleuràphis Torr. Black Bunch-grass, Galleta Grass,
Tobosa Grass.}

Tufted perennials with scaly rootstocks. Spikelets in sessile clusters of three, forming a spike-like inflorescence; central spikelet 1-flowered, the lateral ones of 2 staminate flowers. Glumes 3 in the central flower, the outer two-ridged, the first larger, 2-toothed at the apex, awnless or with an awn between the teeth, the second narrower and keeled, the third thin-membranous and like the lemma. Glumes of the lateral flowers only two. Styles a little united at the base; stigmas short-plumose.

Stem and leaf-sheath, at least the lower ones, densely woolly. stem and leaf-sheath not woolly.

1. P. rigida.

Outer glumes of the spikelets cuneate, awnless; nerves strongly divergent.

Outer glumes linear or oblong, awned; nerves parallel.

2. P. mutica.

3. P. Jamesii.

1. P. rigida Thurb. Stem $3-8 \mathrm{dm}$. high, branching, eovered with a dense tomentum; leaf-blades $3-12 \mathrm{~cm}$. long, rigid, 3-5 mm. wide, often involute; spike 3-10 cm. long; glumes of the central perfect spikelet cuneate at base, bifid above, fringed with wool; awn divergent, a little exceeding the glume; glumes of the lateral spikelets irregularly toothed above; awns short, straight or recurved. Hilaria rigida Benth. Desert regions: s Utah-Ariz - s Calif - L. Calif. L. Son. Ap-Je. 
2. P. mutica Buckl. Stems $2-6 \mathrm{~cm}$. high, smooth and glabrous; blades 3-10 cm. long, involute, scabrous; spikes dense, 3-6 $\mathrm{cm}$. long, 5-12 mm. thick; spikelets usually overlapping; lower glumes of the middle spikelet narrow, keeled, bearing $5-6$ bristles; those of the lateral spikelets 4-5 mm. long, cuneate, the outer one 6-9-nerved with a rounded scarious margin, the inner 4-nerved with a short awn. H. mutica Benth. ToBosa Grass. Dry plains: Tex.Colo.-Ariz.; Mex. Son. Ap-S.

3. P. Jamesii Torr. Stem slightly hairy at the nodes, otherwise scabrous or smooth, $1.5-4 \mathrm{dm}$. high; blades $1-15 \mathrm{~cm}$. long, glaucous and scabrous, usually revolute; spikes $5-8 \mathrm{~cm}$. long, often purple-tinged; glumes of the middle spikelet keeled, eiliate, 2-cleft, with 3-7 bristles on the back; lower glume of the lateral spikelets 6-7 mm. long, awned above the middle; upper glume emarginate, cuspidate. H. Jamesii Benth. Galleta Grass. Hills and plains: Tex.-Wyo.Nev.-N.M. Plain-Submont.-Son. My-Au.

\section{PÁSPALUM L. PAspalum.}

Usually perennials with rootstocks. Inflorescence of one or more unilateral racemes; spikelets 1-flowered, arranged singly or in pairs alternately in two rows on one side of a flattened and more or less winged rachis. Glumes 2, rarely 3, membranous. Lemma glabrous and shining, convex, with its back turned towards the rachis, at last indurate. Styles distinct, long; stigmas plumose.

1. P. stramineum Nash. Stem $2-8 \mathrm{dm}$. high; sheaths all but the lowest ones glabrous, except the ciliate margins; blades yellowish-green, long-ciliate on the margins, 5-25 cm. long, 5-10 $\mathrm{mm}$. wide; racemes 4-10 $\mathrm{cm}$. long, usually in pairs; spikelets in pairs, orbicular, $2 \mathrm{~mm}$. broad; first glume 3-nerved, pubescent; second glume 2-nerved, glabrous or nearly so. P. setaceum A. Nels., not Michx. Sandy places: Neb.-Okla.-Colo. Plain. JI-S.

\section{SYNTHERÍSMA Walt. CRAB-GRASS.}

Annual grasses. Inflorescence composed of spike-like racemes, which are disposed in whorls, or approximate at the summit of the stems. Spikelets narrow, acute, in 2's or 3's on one side of the flat and winged or triangular rachis, one of the spikelets generally longer-pedicelled than the rest. Glumes membranous, the first small or wanting, the lemma chartaceous, glabrous and shining, at length indurated, enclosing a palet. Styles distinct; stigmas plumose. [Digitaria Scop., not Heist.]

Pedicels terete or nearly so, sparingly if at all hispidulous; lower sheaths glabrous; lemma brown in fruit.

Spikelets more than $2 \mathrm{~mm}$. long.

Spikelets $1.25-1.5 \mathrm{~mm}$. long.

Pedicels sharply 3 -angled, the angles strongly hispidulous, as alceum. white in fruit.

Spikelets about $2.5 \mathrm{~mm}$. long; third glume with the nerves strongly hispid above the middle.

Spikelets $3 \mathrm{~mm}$. long or more; third glume with the nerves smooth or nearly so.

4. S. marginatum.

1. S. Ischaemum (Schreb.) Nash. Stems $2-5 \mathrm{dm}$. long, at last prostrate and rooting; leaf-blades $1.5-13 \mathrm{~cm}$. long, $2.5-6 \mathrm{~mm}$. wide, smooth and glabrous on both sides; racemes $2-5,2-8 \mathrm{~cm}$. long; spikelets fully $2 \mathrm{~mm}$. long, elliptic, acute; first glume rudimentary or wanting. Panicum lineare Krock., not L. P. glabrum Gaud. Syntherisma humifusum (Pers.) Rydb. Waste places, fields, and roadsides: N.S.-Fla.-Colo.-Mont.; introduced from Eu. Plain-Mont. JI-S.

2. S. paniceum (Sw.) Nash. Stem tufted, 1-4.5 dm. high, glabrous; sheaths glabrous; blades glabrous, up to $1 \mathrm{dm}$. long, $6 \mathrm{~mm}$. wide; racemes $3-5$, digitate, up to $1 \mathrm{dm}$. long; rachis winged; spikelets about $1.3 \mathrm{~mm}$. long, white, acute, elliptic; first glume wanting, second and third subequal, nearly equalling the lemma, appressed-pubescent, 3-5-nerved. Waste places: n Mex.-Colo.W. Ind.; also in the Old World. Son.

3. S. sanguinale (L.) Dulac. Stem 3-10 dm. high, prostrate at the base and rooting; leaf-blades 4-20 $\mathrm{cm}$. long, 4-10 $\mathrm{mm}$. wide, more or less papillose-hirsute 
on both sides; racemes 3-10, linear, 5-18 cm. long; spikelets elliptic-lanceolate, acute; first glume minute, triangular; lemma apiculate, elliptic-lanceolate. $P$. sanguinale L. CraB-Grass. Cultivated ground and waste places: Mass.Fla.-Calif.-Wash.; Mex.; naturalized from the Old World. Je-S.

4. S. marginatum (Link) Nash. Stem 5-8 dm. long, prostrate at the base and rooting at the nodes; sheaths densely papillose-hirsute; blades $5-8 \mathrm{~cm}$. long, 3-10 $\mathrm{mm}$. wide, flat, glabrous or pubescent; racemes 2-9, variously disposed, 2-12 cm. long; spikelets 3-4 mm. long, lance-oblong; first glume minute, triangular, glabrous; second and third glumes long-pubescent; lemma elliptic. Waste places: Md.-Fla.-Mex.-Utah; W. Ind., C. Am., and S. Am.

\section{VALLÒTA Chase.}

Perennial grasses, with usually tufted stems, panicles usually densely hairy, narrow or contracted. Spikelets numerous, articulated below the empty glumes, 1-flowered, lanceolate, acute or acuminate. Glumes 3, membranous, the second and usually also the much shorter first densely silky-pilose or long ciliate on the margins, often acuminate, and sometimes with a short bristle at the apex; the lemma shorter, chartaceous, glabrous and shining, finally indurated, enclosing a shorter palet. Styles distinet; stigmas plumose.

1. V. saccharata (Buckl.) Chase. Erect perennial; stem 3-9 dm. high, usually much-branched below; sheaths mostly exceeding the internodes, glabrous or papillose-hirsute; leaf-blades $5-15 \mathrm{~cm}$. long, flat, $5 \mathrm{~mm}$. wide or less, more or less pubescent; panicle 1-2 dm. long; spikelets $3-3.5 \mathrm{~mm}$. long, acute; first glume minute, second and third glumes densely silvery-villous. Panicum saccharatum Buckl. P. lachnanthum Torr. Trichacne saccaratum Nash. Dry hillsides: Tex. -Colo.-Ariz.; Mex. Son.-Submont. My-S.

\section{PÁNICUM L. PaniC-GRass, Wrtch-Grass.}

Annuals or perennials. Spikelets in open or contraced panicles, 1-2-flowered, lanceolate, oblong, ovate to obovate or globose, obtuse to acute or acuminate. Glumes 3, membranous, the first and second empty, the first usually much shorter than the spikelet, sometimes minute, the third one empty or enclosing a shorter hyaline palet and of ten also a staminate flower; lemma shorter and usually more obtuse than the glumes, chartaceous, glabrous and shining, at length indurated, enclosing a palet. Styles distinct; stigmas plumose.

Inflorescence truly paniculate.

Basal leaf-blades long and narrow; spikelets lanceolate or ovate, acute or acuminate. Annuals.

Branches of the panicle widely spreading, the well developed pulvinus in their axils long-hairy; spikelets lanceolate, acuminate. 1. P. barbipulvinatum.

Branches of the panicle ascending, rarely spreading, the pulvinus glabrous or sparingly hairy; spikelets ovate to ellipsoid, acute. 2. P. capillare.

Perennials, with long scaly rootstocks and stolons.

Basal leaf-blades ovate to lanceolate, obtuse.

Spikelets less than $2 \mathrm{~mm}$. long.

Stem and sheaths sparingly pubescent, with spreading papillate hairs.

Vernal leaves glabrous or nearly so on the upper side.

A utumnal stems branching from the lower nodes, forming a spreading bunch, $1-1.5 \mathrm{dm}$. high. 4 4. P. occidentale.

Autumnal stems branching from the middle nodes, forming widely spreading mats.

Vernal leaves pubescent on the upper side, especially towards the base.

Spikelets $1.8-2 \mathrm{~mm}$. long; autumnal form decumbent-spreading.

Spikelets $1.6-1.8 \mathrm{~mm}$. long; autumnal form not decumbent-spread

decumbent-spreading.

Stem and sheaths densely soft-pubescent: hairs scarcely papillate.

Spikelets more than 2 mm. long.
Blades of stem-leaves elongated, narrowly linear
Spikelets glabrous or with a few scattered

at the base.
at or with a few scattered hairs: stem branching only Spikelets densely pubescent; stem branching above.

Blades of stem-leaves lanceolate.

Inflorescence with racemiform branches.

10. $P$. Wilcoxianum.

11. P. Scribnerianum.

12. $P$, obtusum. 
1. P. barbipulvinatum Nash. Annual; stem at length branched and rooting at the nodes; sheaths densely pubescent with spreading hairs, papillate at the base; blades hairy on both sides, 4-13 $\mathrm{cm}$. long, 5-10 $\mathrm{mm}$. wide; panicles ovate, 1-2 dm. long; spikelets 3-3.5 mm. long; first glume less than one-half as long as the spikelet, broadly ovate, 3-nerved; second and third glumes pubescent at the apex. Western Witch-grass. Wet sandy soil: Minn.-Kans.-Wyo.-Ore. -B.C. Plain-Submont. Jl-S.

2. P. capillare L. Erect or decumbent annual; stem 2-8 dm. high, simple or sparingly branched; sheaths papillose-hirsute; leaf-blades $1.5-3 \mathrm{dm}$. long, 5$15 \mathrm{~mm}$. wide, pubescent; terminal panicle 2-3.5 dm. long; lateral ones when present smaller; spikelets $2-2.5 \mathrm{~mm}$. long, somewhat acuminate or acute; first glume $1 / 4^{-1 / 2}$ as long as the spikelet, 5-7-nerved; second and third glabrous. Witch-GRASs. Dry or sandy soil and waste places: N.S.-Fla.-Tex.-Nev.Wash.-B.C. Plain. Je-S.

3. P. virgatum L. Perennial with a creeping, scaly rootstock; stem 1-2 m. high, glabrous; sheaths smooth; leaf-blades elongated, $3 \mathrm{dm}$. long or more, 6-12 $\mathrm{mm}$. wide, flat, rough on the margins; panicle $1.5-5 \mathrm{dm}$. long; spikelets ovate, acuminate, $4-4.5 \mathrm{~mm}$. long; first glume acuminate, about half as long as the spikelet, 3-5-nerved; second glume usually longer than the rest. Meadows and plains. Me.-Fla.-Tex.-Ariz.-Sask.; W. Ind. and C. Am. Plain-Son. $\mathrm{Au}-\mathrm{S}$.

4. P. occidentale Scribn. Tufted perennial, yellowish green; stem 1.5-4 $\mathrm{dm}$. high, with short lower internodes; blades 4-8 $\mathrm{cm}$. long, 5-7 $\mathrm{mm}$. wide, glabrous or with a few hairs towards the base above, appressed-pubescent beneath; panicle long-exserted, 4-7 cm. long, lax, with flexuose spreading branches; spikelets about $1.8 \mathrm{~mm}$. long, obovate, acute, pubescent; first glume one-fourth as long as the spikelet or less; second and third glumes subequal, as long as the fruit. Bogs and sandy ground: B.C.-Ida.-Calif. Submont.

5. P. tennesseense Ashe. Perennial, at first spreading; stem 2.5-6 dm. high; sheaths spreading-pubescent; leaf-blades 6-9 $\mathrm{cm}$. long, often ciliate at the base, glabrous or nearly so above, appressed-pubescent beneath; panicle 4-7 cm. long, rather dense; spikelets 1.6-1.7 mm. long, obovate, obtuse, pubescent; first glume about one-fourth as long as the spikelet; second glume shorter than the third. Open moist ground: Me.-Ga.-Miss,-Utah. Plain-Submont.

6. P. pacificum Hitchc. \& Chase. Tufted perennial; stem $2.5-5 \mathrm{dm}$. high; leaf-blades 5-10 $\mathrm{cm}$. long, 5-8 mm. wide, acuminate, papillose-pilose, with shorter hairs intermixed, appressed-pubescent beneath; panicle short-exserted, 5-10 cm. long, with flexuose ascending branches; spikelets obovate, obtuse, papillose-pubescent; first glume one-fourth to one-third as long as the spikelet, truncate; second and third glumes equalling the fruit. Sandy shores: B.C.-Ida.Ariz.-Calif. Plain-Submont.

7. P. Huachucae Ashe. Erect or ascending perennial, at length much branched; stems 2-6 dm. high; leaf-blades lanceolate or lance-linear, acuminate, pubescent beneath with short hairs, 4-10 $\mathrm{cm}$. long, 5-12 mm. wide; paniele 5-10 $\mathrm{cm}$. long, usually purplish; branches spreading, few-flowered; spikelets obovate, obtuse, $1.5-1.8 \mathrm{~mm}$. long; first glume small, about one-third as long as the spikelet; second and third glumes equal, pubescent with spreading hairs. $P$. pubescens A. Gray, not Lam. Meadows: Me.-N.C.-Calif.-Mont. Plain-Mont. $\mathrm{Je}-\mathrm{S}$.

8. P. thermale Bolander. Tufted perennial; stem 1-3 dm. high; leafblades lanceolate, $2-10 \mathrm{~cm}$. long, $5-10 \mathrm{~mm}$. wide, thick, finely and densely pubescent on both sides, or glabrate above; terminal panicle exserted, $2-4 \mathrm{~cm}$. long; branches spreading, few-flowered; lateral panicles often included; spikelets obovoid; first glume rounded-ovate, about one-fourth as long as the spikelet; the second and third glumes pubescent. Around hot springs: Calif.-Nev,-Wyo. Mont. Mont.-Submont. Au.

9. P. perlongum Nash. Tufted pubescent perennial; stems $2-4 \mathrm{dm}$. high, simple; sheaths hirsute with long ascending hairs; leaf-blades papillose-hispid 
beneath, 2-3 $\mathrm{mm}$. wide, the upper usually $8-14 \mathrm{~cm}$. long; panicle much exserted, 4-6 $\mathrm{cm}$. long, its branches nearly erect; spikelets about $3.25 \mathrm{~mm}$. long and 1.5$1.75 \mathrm{~mm}$. wide; first empty glume ovate, one-third as long as the spikelet. Prairies and hills: Ind.-Okla.-(Black Hills) S.D. Plain-Submont. My-Jl.

10. P. Wilcoxianum Vasey. Cespitose perennial, tufted; stems $1-2.5 \mathrm{dm}$. high, sparingly pilose with long white hairs; sheaths papillose-pilose; leaf-blades $3.5-7.5 \mathrm{~cm}$. long, less than $4 \mathrm{~mm}$. wide, pubescent with long hairs; panicle $3-4$ $\mathrm{cm}$. long, ovoid, flexuose; spikelets about $2.5 \mathrm{~mm}$. long, ellipsoid; first glume ovate, about one-fourth as long as the spikelet; second and third glumes pubescent. Prairies: S.D.-Kans.-Ore. Plains. Je-Jl.

11. P. Scribnerianum Nash. Somewhat cespitose perennial; stem erect, 1.5-6 dm. high, simple or later dichotomously branched, sparingly hairy; sheaths strongly papillose-hirsute; leaf-blades 5-10 $\mathrm{cm}$. long, 6-12 $\mathrm{mm}$. wide, glabrous and smooth above, scabrous and sparingly hairy beneath; primary panicle ovoid, $3.5-7.5 \mathrm{~cm}$. long, the secondary ones much smaller and more or less included; spikelets obovoid, $3 \mathrm{~mm}$. long; first glume ovate, one-fourth as long as the spikelet; second and third glumes glabrous or finely pubescent. Panicum scoparium S. Wats., not Lam. Meadows: Me.-Va.-Ariz.-Ore--B.C. Plain -Submont. My-Jl.

12. P. obtusum H.B.K. Perennial, with a more or less tufted rootstock, producing creeping stolons; stem compressed, $2-8 \mathrm{dm}$. high, decumbent at the base, glabrous; leaf-blades $3-20 \mathrm{~cm}$. long, 2-7 $\mathrm{mm}$. wide, involute towards the tip, glabrous or nearly so; panicle short-exserted, $3-12 \mathrm{~cm}$. long; spikelets shortpedicelled, 3-4 mm. long, obovoid, glabrous; first glume nearly as long as the spikelet; second and third glumes subequal; third glume often enclosing a staminate flower. Brachiaria obtusa (H.B.K.) Nash. Sandy and gravelly soil: Mo.-Tex.-Ariz.-Colo; Mex. Son.

\section{1. echinóchloa Beauv. Barnyard Grass, Jungle Rice.}

Coarse and often tall annuals. Inflorescence of several unilateral spikes or racemes. Spikelets 1- or 2-flowered, crowded in small clusters or racemes, in two rows on one side of the flat rachis. Empty glumes 3, membranous, hispid, the first much shorter than the spikelet; all awned or*awn-pointed. Lemma chartaceous, glabrous and shining, indurate, acute or acuminate, enclosing a shorter palet. Styles distinct; stigmas plumose.

1. E. Crus-galli (L.) Beauv. Stem 4-12 dm. high, branched at the base; leaf-sheaths keeled; blades 1.5-4 dm. long, 6-10 mm. wide, glabrous, smooth; panicle of 5-15 secund branches; spikelets ovate, crowded in 2-4 rows, about 4 $\mathrm{mm}$. long, hispidulous, hispid on the nerves; first glume broadly ovate, nearly half as long as the rest; the third glume in the typical form usually with an awn 4-10 $\mathrm{mm}$. long, but in the native form of the Rocky Mountain region (var. mutica) usually all merely cuspidate. Panicum Crus-galli L. Wet places, cultivated ground and waste places: N.S.-Fla.-Calif.-Wash.; Mex., W. Ind., Eurasia. Plain-Submont. Je-O.

\section{Chaetóchloa Seribn. Foxtail Grass.}

Annuals or perennials. Inflorescence of dense terminal cylindric spike-like or narrowly thyrsoid panicles. Spikelets in a cluster of 1-several sterile barbed bristle-like persistent branches. Empty glumes 3, membranous, the first often very short and together with the larger second one empty, the third glume frequently longer than the second, empty, or rarely enclosing a palet and also sometimes a staminate flower, the lemma usually shorter than the spikelet, chartaceous, glabrous, shining, often transversely rugose, finally indurated, obtuse, enclosing a shorter palet. Styles distinet, elongated; stigmas plumose. [Setaria Beauv.]

Inflorescence with the spikelets racemosely arranged; bristles $5-16$ at the base of each spikelet, involucrate, tawny-orange.

Inflorescence with the spikelets in clusters on the branches; bristles 1-3 at the base of each spikelet, not involucrate,

Second glume of the spikelet as long as the lemma, or very nearly so; annuals.

Panicle usually $1 \mathrm{~cm}$. thick or less; bristles commonly green; spikelets about 2 $\mathrm{mm}$. long.

2. C. viridis. 
Panicle usually 1-3 cm. thick; bristles usually purple; spikelets $2.5-3 \mathrm{~mm}$. long.

Second glume manifestly shorter than the lemma; perennials.

3. C. italica.

4. C. composita.

1. C. glauca (L.) Scribn. Erect or ascending, glaucous annual; stem 3-12 $\mathrm{dm}$. high, branching at the base, glabrous, compressed; leaf-blades $5-15 \mathrm{~cm}$. long, 4-8 mm. wide, glabrous or with scattered long hairs at the base; spikelet broadly ovate, $3 \mathrm{~mm}$. long; second glume one-half to two-thirds as long as the spikelet, ovate, acute; third glume equalling the lemma, which is broadly ovate, striate, transversely rugose. Setaria glauca Beauv. Waste places and cultivated ground: N.S.-Fla.-Tex.-Colo.-Sask.; naturalized from Eurasia. PlainSubmont. Je-S.

2. C. viridis (L.) Seribn. Erect glabrous annual; stem $2-9 \mathrm{dm}$. high, branched at the base, compressed; leaf-blades 5-25 cm. long, 4-10 mm. wide, long-acuminate, slightly scabrous on both sides; bristles slender, seabrous, $1-1.5 \mathrm{~cm}$. long, green or rarely purplish; lemma elliptic; finely and faintly wrinkled below or only striate. S. viridis Beauv. Waste places and cultivated ground: Newf.Fla.-Calif.-B.C.; Mex.; naturalized from Eu. Plain-Submont. JI-S.

3. C. italica (L.) Scribn. Stout, erect, somewhat glaucous annual; stem simple or branched at the base, $5-20 \mathrm{dm}$. high, glabrous; nodes bearded; leafblades lanceolate, $2-4 \mathrm{dm}$. long, $1.5-3 \mathrm{~cm}$. wide, scabrous on both sides; bristles green or purplish, 3-10 cm. long, scabrous; lemma smooth or faintly transversely rugose, striate. S. italica Beauv. Waste places and fields; escaped from cultivation: Que.-Fla.-Tex.-Colo.-S.D.; native of Eurasia. J1-S.

4. C. composita (H.B.K.) Scribn. Pale, glaucous perennial; stem geniculate and branched at the base, subcompressed, scabrous or pubescent especially below the nodes; blades linear, plane, 1-2.5 dm. long, 2-5 mm. wide, glaucous, seabrous on both sides; panicle pale-green, loose, interrupted below; bristles usually single below each spikelet, flexuose, $5-15 \mathrm{~mm}$. long, scabrous; spikelets narrowly ovate, 2-3 mm. long; lemma striate, smooth, obseurely transversely wrinkled below. S. composita H.B.K. Hills, plains, and cañons: Tex,-Colo.-Ariz.; Mex., and S. Am. Son. Je-O.

13. CÉnChrus L. Bur-grass, Sandbur, Sandspur.

Annuals or perennials. Spikes terminal. Spikelets $2-6$, in an ovate or globose involuere, consisting of two thick hard valves, which are exteriorly armed with stout spines at the base, the involucres articulated to the rachis and readily deciduous, earrying the persistent spikelets with them. The first and second glumes empty, the first small or minute, the third equalling or longer than the second, enclosing a palet and also sometimes a staminate flower, the lemma chartaceous, firmer, enclosing a palet of similar texture and a perfect flower. Stamens 3. Styles often connate at the very base; stigmas plumose.

1. C. carolinianus Walt. Erect or decumbent annual; stem $2-9 \mathrm{dm}$. long, branching; leaf-sheaths usually loose, compressed, smooth; blades 6-12 cm. long, 4-8 mm. wide, smooth or rough; spikes $3-6 \mathrm{~cm}$. long, sometimes partly included; involucres 6-20, enclosing each 2 spikelets, $3-5 \mathrm{~mm}$. broad, pubescent; spines 3-4 mm. long; spikelets 6-7 $\mathrm{mm}$. long, usually exserted beyond the involucre. C. tribuloides Auth., not L. Sandy banks and waste places, sometimes becoming a noxious weed: Me.-Fla.-Tex.-Colo.-S.D.; Mex., C. Am., and W. Ind. Plain-Son. Mr-N.

\section{4. homalocénchruS Mieg. Rice Cut-grass.}

Perennials. Panicles usually open, rarely contracted, terminal, the branches slender. Spikelets often with a cartilaginous ring at the base, articulated below the scales, compressed, 1-flowered. Glumes 2, compressed-keeled, somewhat rigid, awnless, the first one usually ciliate on the keel, broader than the second, which encloses a perfect flower but no palet. Stamens 1-6. Styles short or slender, distinct; stigmas plumose with branched hairs. [Leersia Sw., not Hedw.]

1. H. oryzoides (L.) Poll. Stem $3-15 \mathrm{dm}$. high, often rooting at the nodes; leaf-blades 6-25 cm. long, 4-13 mm. wide, very rough; terminal panicle 1-2 dm. 
long, at last exserted; lateral ones often included at the base; spikelets 4-5 $\mathrm{mm}$. long, about $1.5 \mathrm{~mm}$. wide, elliptic; outer glumes hispid on the keel and margins, hispidulous on the sides; stamens 3. Leersia oryzoides (L.) Sw. In swamps: N.S.-Fla.-Tex.-Colo.-Sask.; also Eu. Plain-Submont. Au-O.

\section{PHÂLARIS L. CANARY-GRASS.}

Annuals or perennials. Panicles terminal, cylindric and spike-like, capitate, or densely thyrsoidal and somewhat interrupted. Spikelets articulated above the empty glumes, compressed, 1-flowered, crowded. Empty glumes 4, the lower 2 persistent, larger than the rest, thin-paleaceous, compressed-keeled, the keel usually more or less winged, sometimes wingless, awnless; third and fourth glumes shorter, very thin and narrowly lanceolate, sometimes reduced to bristles, or rarely one of them wanting; lemma chartaceous, at length indurated, awnless, sometimes pointed, obscurely 3-5-nerved, the midnerve sometimes obsolete, enclosing a faintly 2-nerved palet. Styles distinct; stigmas plumose.

Outer glumes not winged; inflorescence a narrow panicle.

Outer glumes winged; inflorescence a spike or spike-like panicle.

Spikelets narrow; third and fourth glumes much reduced; blades subulate-linear, hairy.

Spikelets broad; third and fourth glumes thin, membranous; glabrous, rarely sparingly hairy.

1. P. arundinacea.

1. P. arundinacea L. Glabrous perennial, with a horizontal rootstock; stem erect, 6-15 dm. high; leaf-blades $1-2.5 \mathrm{dm}$. long, 6-16 $\mathrm{mm}$. wide; panicle 7-20 cm. long, dense, 1-2 cm. thick; spikelets 5-6 mm. long; outer glumes 3nerved; third and fourths glumes less than half as long as the lemma, which is pubescent with long appressed hairs. Wet places: N.S.-N.J.-Nev.-B.C.; Eurasia. Plain-Mont. Je-Au.

2. P. caroliniana Walt. Glabrous annual; stem $3-10 \mathrm{dm}$. high; leafblades 5-15 cm. long, 4-10 mm. wide; panicle oblong, 2.5-10 $\mathrm{cm}$. long, 1-1.5 $\mathrm{cm}$. thick; spikelets $5 \mathrm{~mm}$. long; outer glumes 3-nerved; third and fourth glumes less than half as long as the lemma, which is acuminate and with long appressed hairs. Wet ground: Fla.-S.C.-Mo.-Colo.-Calif.; Mex. Son-Aust. MyAu.

3. P. canariensis L. Glabrous annual; stem $3-9 \mathrm{dm}$. high, branched at the base; leaf-blades $5-30 \mathrm{~cm}$. long, 4-12 $\mathrm{mm}$. wide, strongly scabrous; panicles oblong or ovoid, $1-4 \mathrm{~cm}$. long; spikelets $6-8 \mathrm{~mm}$. long; outer glumes whitish with green nerves; third and fourth glumes broadly lanceolate, about half as long as the pubescent lemma. Waste places: N.S.-Va.-Colo.-S.D.; also Calif.Ore.; naturalized from Europe and Africa. Plain-Submont. Je-Jl.

\section{TORrèsia R. \& P. Sweet Grass, Holy Grass.}

Sweet-scented perennials with rootstocks. Panicles open or contracted. Spikelets 3-flowered, the terminal flower perfect, the others staminate. Empty glumes nearly equal, acute, glabrous. Lemma 2-toothed or 2-lobed, with or without an awn. Stamens in the staminate flowers 3, in the perfect flowers 2. Styles distinet; stigmas plumose. [Hierochloa Gmel, Savastana Schrank.]

1. T. odorata (L.) Hitchc. Perennial with a creeping rootstock; stem 3-6 $\mathrm{dm}$. high, smooth; lower leaf-blades elongated, 1-2 dm. long, 2-6 mm. wide, the upper ones 1-5 cm. long; panicle $5-10 \mathrm{~cm}$. long, its branehes spreading or reflexed; spikelets yellowish brown or purplish, 4-6 mm. long: first and second gllumes acute; third and fourth glumes villous and strongly ciliate, awn-pointed. H. odorata (L.) Wahl. H.borealis R. \& S. Salastana odorata Seribn. Moist paces and among bushes: Lab.-N.J.-Neb.-Colo.-Ariz.-Alaska; Eurasia. Submont.-Alp. Je-Jl.

\section{ARÍstida L. Poverty Grass, Wire-grass.}

Tufted perennials, with narrow leaves. Inflorescence paniculate or racemose. Spikelets 1-flowered, narrow. Empty glumes 2, membranous, persistent, keeled, awnless, usually longer than the lemma. The latter firm, narrow, 
rigid, strongly convolute, with a prominent callus at the base, 3-awned at the apex; the central awn often bent and twisted, the lateral ones shorter and spreading or ascending. Styles distinct; stigmas plumose.

Awns neither twisted nor bent.

Panicle narrow; branches erect or ascending.

First glume much shorter than the second.

Spikelets not crowded, usually $1-3$, on branches naked at the base; awn over $2 \mathrm{~cm}$. Iong; perennials.

Second glume of the spikelets $2 \mathrm{~cm}$. Iong or more, 1.5-2 times as long as the lemma, 1. A. longiseta.

Second glume of the spikelets $1.5 \mathrm{~cm}$. long or less, scarcely exceeding the lemma. 2. A. Fendleriana.

Spikelets crowded, 4-6 on the short branches, spikelet-bearing to near the base; awn less than $2 \mathrm{~cm}$. long; annuals.

Stem 3-6 dm. high; first glume 7-8 mm. long; middle awn 10-16 mm. long; leaf-blades usually flat. 3. A. fasciculata.

Stem 1-3 dm. high; first glume 4-6 mm. long; middle awn 6-8 mm. Jong :

leaf -blades strongly involute,
First glume nearly equalling the second; perennials with a dense panicle.

Panicle open; branches 3-forked, divergent.

Middle awn twisted and divaricately bent near the base.

7. A. arizonica.

5. A. Humboldtiana.

6. A. Curtissii.

1. A. longiseta Steud. Densely tufted glaucous glabrous perennial; stem 1-4 dm. high; sheaths shorter than the internodes; leaf-blades strongly involute, 2-11 cm. long; spikelets purplish; first empty glume shorter than the lemma; lemma 12-16 mm. long; awns 6-11 cm. long. Sandy soil: Ill.-Tex.-Ariz.Wash.; Mex. Plain-Submont. My-Au.

2. A. Fendleriana Steud. Densely tufted glabrous perennial; stem 1.5-3 $\mathrm{dm}$. high, erect; sheaths smooth, confined to the base of the stem; leaf-blades involute, often curved; panicle 7-10 $\mathrm{cm}$. long, strict; spikelets $12-15 \mathrm{~mm}$. long; lemma 9-12 mm. long; central awn 2-3.5 cm. long; lateral awns a little shorter. A. purpurea Coult., not Nutt. A. longiseta Fendleriana Merrill. Dry soil: Tex.-Mont.-Calif. Son.-Plain-Submont. Je-S.

3. A. fasciculata Torr. A tufted annual; stems $3-6 \mathrm{dm}$. high, branched; leaf-blades $5-15 \mathrm{~cm}$. long, $2 \mathrm{~mm}$. wide; panicle $5-17 \mathrm{~cm}$. long, loose; branches at first strict, later more or less spreading; first glume 1-nerved, shorter than the second; lemma equalling or longer than the second; awns ascending, the lateral ones shorter than the middle one. (Mistaken for A. oligantha Michx.) Dry soil: Tex.-Kans.-s Utah-Ariz.-Mex. Son. My-S.

4. A. bromoides H.B.K. Low tufted annual; stem 1-3 dm. high; leafblades 2-7 $\mathrm{cm}$. long, involute; panicle purple, $2-5 \mathrm{~cm}$. long, dense; first glume one-nerved, shorter than the second, slightly longer than the lemma; awns ascending, the lateral ones $6-8 \mathrm{~mm}$. Iong. Arid regions: Tex.-Colo.-UtahCalif.; Mex. Son. Ap $-\mathrm{N}$.

5. A. Humboldtiana Trin. \& Rup. Tufted perennial; stem 3-9 dm. high, branched; sheaths rough; blades of the stem-leaves $1.5-3 \mathrm{dm}$. long, $2-4 \mathrm{~mm}$. wide; those of the sterile shoots longer and narrower; panicles $3-5 \mathrm{dm}$. long, open; empty glumes acuminate, awn-pointed, 9-13 mm. long; central awn 1.2-2 $\mathrm{cm}$. long, erect; lateral ones somewhat shorter, ascending. A. divaricata H.B.K. Dry soil: Kans.-Colo.-Ariz.; Mex. Son. Jl-S.

6. A. Curtissii (A. Gray) Nash. Tufted; stem 2-5 dm. high, branching; leaf-blades 4-16 cm. Jong, 1-2 mm. wide; panicle spike-like, 5-9 $\mathrm{cm}$. long, branches short, erect; first glume shorter than the second, which usually equals the lemma, 7-11 mm. long; middle awn 10-15 mm. long; lateral awns 1-2 mm. long, straight. Dry soil: Va. - w Neb.-Okla. Aust. S-O.

7. A. arizonica Vasey. Tufted perennial; stem 3-6 dm. high, rigid, glabrous; leaf-blades 1-2 dm. long, becoming involute; panicle $1-2.5 \mathrm{dm}$. long; branches 2 at each node, appressed, one longer, peduncled, the other shorter and sessile; glumes 12-14 mm. long, bidentate at the apex; awns of the lemma nearly equal, $1.5-2 \mathrm{~cm}$. long, divergent when mature. Plains and hills: Tex.s Colo.-Utah-Ariz. Son.-Submont. 


\section{Stìta L. Spear Grass, Porcupine Grass, Devil's Darning- Needles, Feather Grass.}

Usually tufted perennials. Inflorescence paniculate. Spikelets narrow, 1flowered; flowers perfect. Empty glumes 2, narrow, persistent, keeled, acute, rarely awned. Lemma narrow, strongly convolute, rigid, with a strong, usually acute callus at the base and ending in a bent awn, which is spirally twisted below the knee. Styles distinct, short; stigmas plumose.

Outer glume of the spikelet $2 \mathrm{~cm}$. long or more.

Awn plumose.

1. S. neo-mexicana.

Awn not plumose.

Base of the panicle exserted; lemma more than $12 \mathrm{~mm}$. Iong; awn straight above the bend.

Lemma 20-25 mm. long.

Lemma 12-15 $\mathrm{mm}$. long.

2. S. spartea.

3. S. Tweedyi.

Base of the panicle usually included in the upper sheath; lemma 8-12 mm. long; awn slender and curled above the bend.

4. S. comata.

Outer glume of the spikelet $1.5 \mathrm{~cm}$. long or less.

Panicle loose and open; branches spreading or reflexed.

Awn plumose.

Awn not plumose.

Callus acute; lemma $7-8 \mathrm{~mm}$. long.

Callus short, blunt; lemma about $4 \mathrm{~mm}$. long.

Panicle dense and spike-like.

Awn glabrous, scabrous, or strigose, not plumose.

Lemma long-hairy towards the apex.

Lemma about $5 \mathrm{~mm}$. long.

Glumes green, rarely slightly tinged with purple; lemma nearly glabrous below.

8. S. Lettermanii.

Glumes purplish with paler margins; lemma pubescent throughout, though more densely so above. $\quad 9 . \mathrm{S}$. pinetorum.

Lemma about $8 \mathrm{~mm}$. long.

10. S. Scribneri.

Lemma equally hairy throughout.

Sheaths glabrous.

Empty glumes scarious or hyaline; their nerves hence prominent.

Lemma 4-6 mm. long, spindle-shaped when mature; callus short. Stem-leaves broader than the basal leaves, often flat: sheaths with a ring of hairs at the throat.

11. S, viridula.

Stem-leaves as well as the basal leaves very narrow, involute; sheaths glabrous.

Plant green; sheaths close; inflorescence distinctly exserted.

12. S. columbiana.

Plant pale and glaucous; sheaths loose; inflorescence included or barely exserted; awn glabrous. 13. S. arida.

Lemma 6-7 mm. long, almost cylindric; callus long and pointed.

14. S. Nelsonii.

Empty glumes firm, thickish, herbaceous; the nerves not prominent. Lemma about $5 \mathrm{~mm}$. long; leaf-blades narrow and involute.

Lemma 8-10 mm. long; leaf-blades broad.

Panicle slender; stem low and slender.

Sheaths and lower leaf-blade pubescent.

15. S. minor

9. S. Scribneri.

16. S. Vaseyi. Awns plumose or subplumose at least below.

Hairs of the awns less than $1 \mathrm{~mm}$. long; empty glumes 10-12 mm. long.

Ligules $1 \mathrm{~mm}$. long or less.

Sheaths, at least the lower ones, hairy.

Sheaths glabrous.

Ligules 2-4 mm. long.

Hairs of the awns 3-6 mm. Iong; empty glumes $15-18 \mathrm{~mm}$. Iong.

18. S. Elmeri.

19. S. oregonensis.

20. S. Thurberiana.

1. S. neo-mexicana (Thurb.) Vasey. Tufted perennial; stem erect, smooth, 3-10 dm. high; basal leaf-blades 2-3 dm. long, strongly involute, those of the stem-leaves shorter; panicle narrow, 1-1.5 dm. long; branches ereet, with 1-3 spikelets; empty glumes lanceolate, $3-4.5 \mathrm{~cm}$. long; lemma strigose, $10-15 \mathrm{~mm}$. long; awn 1-1.5 dm. long, plumose, twisted for one-third its length, twice bent; callus long and sharp. S. pennata neo-mexicana Thurb. Dry hills: Tex.Colo.-Utah-Calif. Son.-Submont. My-Au.

2. S. spartea Trin. Tufted perennial; stem 6-15 dm. high, erect, simple; basal leaf-blades 2-5 dm. long, usually involute, scabrous above; stem-leaves $1.5-3 \mathrm{dm}$. long, usually flat; panicle 1-2.5 dm. long; outer glumes of spikelets 2.5-3.7 cm. long, acuminate, awn-pointed, glabrous; callus long, sharp; awn 12$20 \mathrm{~cm}$. long. Prairies: Man.-Ill.-N.M.-B.C. Plain-Submont. Je-Au. 
3. S. Tweedyi Scribn. Tufted perennial; stem 6-9 dm. high, smooth; blades of the stem-leaves 1-1.5 dm. long, scabrous above; those of the shoots usually longer; first glumes $2-2.5 \mathrm{~cm}$. long, 3-nerved; the second slightly longer, 5-nerved, long-attenuate; awn about 7-10 $\mathrm{cm}$. long, twice bent, scabrous. $S$. comata intermedia Scribn. \& Tweedy. Plains and mountains: Sask.-Colo. -Ariz.-Ida. Plain-Submont. Je-Au.

4. S. comata Trin. \& Rup. Tufted perennial; stem 3-6 dm, high, glabrous; sheaths usually longer than the internodes, the uppermost inflated, enclosing the base of the panicle; leaf-blades somewhat scabrous, involute; those of the basal innovations filiform, 1-3 dm. long, those of the stem 6-15 cm. long, broader; panicles 15-20 $\mathrm{cm}$. long, loose; outer glumes $18-25 \mathrm{~mm}$. long, glabrous; awn 1-2 $\mathrm{dm}$. long, twice bent below. Prairies and sandy places: Alta.-Neb.-N.M.Calif.-Alaska. Plain-Submont. Je-Au.

5. S. Porteri Rydb. Tufted perennial; stems lender, $3-4 \mathrm{dm}$. high; leafblades 4-10 $\mathrm{cm}$. long, involute, filiform; branches of the panicle with 1-2 spikelets; empty glumes membranous, $5 \mathrm{~mm}$. long, purplish; lemma hairy below, slightly shorter; callus short, acute; awn $12-15 \mathrm{~mm}$. long, plumose, with a single bend. S. mongolica Porter \& Coulter, not Turcz. Mountains: Colo.-Tex. Mont.

6. S. Richardsonii Link. Tufted perennial; stem slender, 5-10 dm. high; leaf-blades involute, filiform, 5-15 cm. long, smooth; panicle open, 7-12 cm. long; branches slender, with 1-3 spikelets; empty glumes purplish, $8-9 \mathrm{~mm}$. long, broadly lanceolate, acute; lemma thinly pubescent; awn $12-20 \mathrm{~mm}$. long, strigulose. Hillsides and open woods: Sask.-S.D.-Colo.-Alta. Mont. Jl-S.

7. S. canadensis Poir. Tufted perennial; stem 3-6 dm. high, smooth or somewhat scabrous; blades 5-12 $\mathrm{cm}$. long, 1-2 mm. wide, scabrous; panicle 5-12 $\mathrm{cm}$. long; outer glumes 4-5 mm. long, obtuse or acutish, glabrous, membranous; lemma silky-strigose; awn $8-10 \mathrm{~mm}$. long, twisted but only slightly bent. $S$. Macounii Seribn. Sand hills and open woods: N.B.-Me.-Mich.-Sask. Boreal. Jl.

8. S. Lettermani Vasey. Tufted perennial; stem $3-5 \mathrm{dm}$. high, slender; basal leaf-blades filiform, 1-1.5 dm. long, involute, glabrous; panicle 1-1.5 dm. long; branches mostly single, spikelet-bearing to near the base; empty glumes 6-7 mm. long, acuminate, awn-pointed, 3-nerved; awn 12-16 mm. long, once bent. Hills and plains: Ida.-Wyo.-Colo. Submont. Jl-Au.

9. S. pinetorum M. E. Jones. Tufted perennial; stem 2-3 dm. high, slender, glabrous; basal leaves with thick brown sheaths; blades filiform, involute, 5-10 cm. long, glabrous; panicle narrow, 1-1.5 dm. long, barely exserted; branches appressed; empty glumes purple-tinged, $7-8 \mathrm{~mm}$. long, the first 3-nerved, the second 1-nerved; lemma about $5 \mathrm{~mm}$. long, hairy throughout but more densely so at the apex; awn 12-20 mm. long, glabrous, twice bent. Open pinelands: Utah. Mont. Au-S.

10. S. Scribneri Vasey. Tufted perennial; stem erect, strict, 4-7 dm. high, glabrous; sheaths close, smooth or slightly scabrous; leaf-blades 1-3 dm. long, usually flat, scabrous above; inflorescence 1-2 dm. long; first glume 12-14 mm. long, linear-lanceolate, acuminate, 3-nerved, the second about $10 \mathrm{~mm}$. long; awn 1.5-2 cm. long. Dry hills: N.M.-Colo.-Utah-Ariz. Son.-Mont. $\mathrm{Jl}-\mathrm{Au}$.

11. S. viridula Trin. Tufted perennial; stem smooth, $3-6 \mathrm{dm}$. high; leafblades involute, smooth or scabrous above, the lower 1-2 dm. long; stem-leaves 6-15 cm. long; outer glumes 7-9 $\mathrm{mm}$. long, prominently 3-nerved, awn-pointed; lemma 5-6 mm. long, strigose; awn 2-2.5 cm. long, twice bent, glabrous or somewhat scabrous. Plains and prairies: Sask.-Kans.-Utah-Mont. PlainSubmont. Jl-Au.

12. S. columbiana Macoun. Tufted perennial; stem very slender, $3-5 \mathrm{dm}$. high; basal leaf-blades 1-2 dm. long; stem-leaves much shorter; empty glumes 7-9 $\mathrm{mm}$. long, awn-pointed; lemma silky-strigose, about $6 \mathrm{~mm}$. long; awn about $3 \mathrm{~cm}$. long, twice bent, minutely strigulose. Hills and mountains: B.C.-Wyo. Submont.-Mont. Jl-Au. 
13. S. arida M. E. Jones. Densely tufted perennial; stem erect, about 3 $\mathrm{dm}$. high, smooth; blades $3-10 \mathrm{~cm}$. long, filiform, involute, smooth; panicle narrow, 1-1.5 dm. long; lower branches in 5's, short; empty glumes lanceolate, acuminate, 8-10 $\mathrm{mm}$. long; lemma $4 \mathrm{~mm}$. long, glabrous above, short-pubescent below; awn 3-5 cm. long, slender, glabrous, only slightly bent. Dry hillsides: Utah-Colo. Son.-Submont. My-Je.

14. S. Nelsonii Scribn. Tufted perennial; stem stout, $7-9 \mathrm{dm}$. high, smooth; leaf-blades 1-3 dm. long, those of the innovations narrow and involute; stemleaves 2-4 mm. wide and of ten flat; panicle $1.5-3 \mathrm{~cm}$. long; first glume 9-10 $\mathrm{mm}$. long, 3-nerved; second glume slightly longer, 5-nerved; lemma $7 \mathrm{~mm}$. long, almost cylindric, silky-strigose; awn about $3.5 \mathrm{~cm}$. long, minutely scabrous. Plains, hills, and cañons: Sask.-Colo.-Utah-Ida.-Alta. Submont.-Mont. $\mathrm{Jl}-\mathrm{Au}$.

15. S. minor (Vasey) Scribn. Densely tufted perennial; stem smooth, 3-6 $\mathrm{dm}$. high; leaf-blades 1-3 dm. long, $2-3 \mathrm{~mm}$. wide, usually strongly involute, scabrous on the margin; panicle purplish, 5-12 cm. long; empty glumes faintly 3 -nerved near the base; lemma thinly strigose; awn minutely scabrous, about $2 \mathrm{~cm}$. long. Mountain sides: Mont.-N.M.-Utah. Submont.-Subalp.

16. S. Vaseyi Scribn. Densely tufted perennial; stem 1-2 m. high, stout, often $1 \mathrm{~cm}$. thick below; sheaths usually broad and loose, hairy at the junction of the blades; blades of stem-leaves usually flat, 3-6 dm. long, scabrous, those of the innovations narrower, involute; panicle $2.5-4 \mathrm{dm}$. long, dense; empty glumes nearly equal, lanceolate, about $1 \mathrm{~cm}$. long, acuminate; lemma about $8 \mathrm{~mm}$. long, silky-strigose; awn $2.5-3 \mathrm{~cm}$. long, minutely seabrous. Hills and mountain sides: Tex.-Colo.-Ida.; Mex. Son.-Mont. My-Au.

17. S. Williamsii Scribn. Tufted perennial; stem 7-9 dm. high; leafblades 1.5-3 dm. long, pubescent on the back, scabrous above; empty glumes lanceolate, long-acuminate, $6-8 \mathrm{~mm}$. long; lemma about $6 \mathrm{~mm}$. long, finely strigose; awn about $2.5 \mathrm{~cm}$. long, minutely scabrous. Dry soil: Wyo.-Mont. Submont.-Mont. Jl-Au.

18. S. Elmeri Piper \& Brodie. Tufted perennial; stem 3-6 dm. high, glabrous or somewhat pubescent; lower leaf-blades slender and involute, those of the stem broader, often flat, 5-15 $\mathrm{cm}$. long; inflorescence 1-2 dm. long; empty glumes 10-12 mm. long, acuminate, hyaline, 3-nerved; lemma about $7 \mathrm{~mm}$. long, finely strigose; awn $3-3.5 \mathrm{~cm}$. long, sub-plumose up to the second bend. Meadows and fields: Wash.-Wyo.-s Calif. Submont. Je-Au.

19. S. oregonensis Scribn. Tufted perennial; stem $3-5 \mathrm{dm}$. high, glabrous; uppermost sheath loose, enclosing the base of the panicle; basal leaf-blades involute-filiform, 1-2 dm. long; upper stem-leaves 4-6 cm. long; panicle 8-16 cm. long, narrow; outer glumes narrowly lanceolate, acuminate, 3-nerved, $10 \mathrm{~mm}$. long; lemma 7-8 mm. long, thinly pubescent; awn $2.5-3.5 \mathrm{~cm}$. long, sub-plumose on the lower half. S. stricta Vasey, not Lam. S. occidentalis Piper, not Thurb. Ridges and bench-lands: Wash.-Wyo.-Calif. Submont. JI-S.

20. S. Thurberiana Piper. Tufted perennial; stem 3-10 dm. high, sometimes tinged with purple, scabrous or puberulent, of ten pubescent at the nodes; sheaths close, usually puberulent; blades 1-2 dm. Iong, or the upper shorter, involute; panicle $7-15 \mathrm{~cm}$. long, with the base often included; first glume $1 \mathrm{~cm}$. long, 5-nerved, the second shorter, 3 -nerved; lemma $6-7 \mathrm{~mm}$. long, strigose; awn Submont.-Son. Je-Jl.

21. S. speciosa Trin. \& Rup. Tufted perennial; stem 3-6 dm. high; lower sheaths more or less pubescent, the upper glabrous and loose; lower leaf-blades 1-3 dm. long, usually involute; panicle $1.5-2 \mathrm{dm}$. long, included below; empty glumes hyaline, long-acuminate; lemma 10-12 mm. long, pubescent; awn 4-5 $\mathrm{cm}$. long, long-plumose below, glabrous above, with a single bend. Hills: Calif.-Utah-Ariz.; Mex. Son. My-Jl. 


\section{ORYZÓPSIS Michx. Mountain Rice.}

Tufted perennials. Inflorescence paniculate with racemose branches. Spikelets 1-flowered, broad; flowers perfect. Empty glumes subequal, acute. Lemma broad, indurate, convolute, with a short and obtuse callus at the base, ending in a terminal, early deciduous, mostly straight awn. Styles distinct: stigmas plumose. Grain oblong, free.

Lemma glabrous, or pubescent with short appressed hairs.

Spikelets, exclusive of the awn, $2.5-5 \mathrm{~mm}$. long; leaves slender and involute.

Awn less than $2 \mathrm{~mm}$. long, much shorter than the glume; outer glumes $3-4 \mathrm{~mm}$.

long.
Awn 4-8 $\mathrm{mm}$. long, much longer than the glume.

Inflorescence very narrow, with short erect branches;outer glumes $3-5 \mathrm{~mm}$. long. 2. O. exigua.

Inflorescence at length open, with long spreading or reflexed branches; outer

Spikelets, exclusive of the awn, long.

4. O. asperifolia.

Lemma with long loose hairs.

Inflorescence open; plant $3-6 \mathrm{dm}$. high.

Inflorescence narrow and spike-like; plant 1-3 dm. high.

5. O. Bloomeri.

6. O. Webberi.

1. O. pungens (Torr.) Hitche. Tufted perennial; stem glabrous, $1.5-3 \mathrm{dm}$. tall, simple; sheaths shorter than the internodes, smooth; leaf-blades smooth or scabrous, the lower 1-2 dm. long, the upper 3-10 $\mathrm{cm}$. long; panicle 3-6 cm. long; branches ereet or ascending; spikelets 3-4 $\mathrm{mm}$. long; empty glumes glabrous, whitish, faintly nerved, acute; lemma strigose, ellipsoid. $\tilde{O}$. canadensis Torr. O. juncea B.S.P. Dry rocky places: Que.-Pa.-S.D.-B.C. Boreal-Mont. $\mathrm{My}-\mathrm{Je}$.

2. O. exigua Thurb. Densely tufted perennial; stem $1.5-4 \mathrm{dm}$. high; panicle 2-6 cm. long; empty glumes $4-5 \mathrm{~mm}$. long, acute or abruptly acuminate, the first 1-nerved, the second 3-nerved; lemma sparingly strigose; awn slightly twisted below, 4-6 mm. long. Hills and mountain sides: Mont.-Colo.-Ore. -Wash. Mont.-Subalp. Je-Au.

3. O. micrantha (Trin, \& Rup.) Thurb. Somewhat tufted perennial; stem glabrous, 3-7 dm. tall, slender; leaf-blades erect, scabrous, less than $1 \mathrm{~mm}$. wide, usually involute, the lower $2-3 \mathrm{dm}$. long; panicle $8-15 \mathrm{~cm}$. long; empty glumes 2-2.5 mm. long, glabrous, acute; lemma a little shorter, glabrous, shining; awn 6-8 mm. long. Hillsides and among bushes: Sask.-Neb.-N.M.-Ariz.Mont. Plain-Mont. Je-Au.

4. O. asperifolia Michx. Tufted perennial; stem $3-5 \mathrm{dm}$. high, simple, usually scabrous; leaf-blades erect, scabrous, 1-4 dm. long, 4-10 mm. wide; panicle 5-8 $\mathrm{cm}$. long, narrow, spike-like; empty glumes glabrous, 6-8 $\mathrm{mm}$. long, many-nerved, apiculate; lemma whitish, sparingly hairy, except a ring of dense hairs at the base; awn 7-10 mm. long. Woods: N.S.-Pa.-Minn.-N.M.B.C. Mont. My-Je.

5. O. Bloomeri (Bolander) Ricker. Tufted perennial; stem $3-6 \mathrm{dm}$. high, glabrous; leaf-blades involute, 1-2 dm. long; panicle 1-2 dm. long, open but rather narrow; empty glumes dull green, tinged with purple, 6-7 $\mathrm{mm}$. long, acuminate; lemma $5 \mathrm{~mm}$. long, clothed with spreading or ascending long white hairs; awn twisted and bent, about $2 \mathrm{~cm}$. long. O. caduca (Scribn.) Beal. Eriocoma caduca Rydb. Hills: Mont.-Colo.-Calif. Submont. Jl.

6. O. Webberi (Thurb.) Benth. Densely tufted perennial; stem 1-3 dm. high, wiry; lower sheaths crowded, glabrous; leaf-blades very narrow, stiff, involute, the lower $5-10 \mathrm{~cm}$. long, glaucous; panicle dense and spike-like, 2-10 $\mathrm{cm}$. long; branches short and erect; empty glumes $8 \mathrm{~mm}$. long, acuminate, often purple-tinged; lemma $6 \mathrm{~mm}$. long, copiously long-hairy; awn $4 \mathrm{~mm}$. long, very slender, soon caducous. Arid regions: Calif.-Colo. Son. My-Jl.

\section{ERIOCÒMA Nutt. Indian Millet, Wild Rice.}

Densely tufted perennials with involute leaves. Inflorescence cymosely and divaricately branched. Spikelets 1-flowered; flower perfect. Empty glumes 2 , membranous, somewhat scarious, acuminate. Lemma rather broad, indurate 
and convolute, densely pubescent with silky hairs, with an obtuse callus at the base, and a deciduous straight awn at the apex. Styles distinet; stigmas plumose. Grain oblong, free, enclosed in the lemma.

1. E. hymenoides (R. \& S.) Rydb. Stem 3-6 dm. high, erect, rigid, smooth; leaf-blades $1.5-3 \mathrm{dm}$. long, involute, less than $2 \mathrm{~mm}$. wide; panicle $1.5-3 \mathrm{dm}$. long; branches spreading, flexuose; lower glumes $6-8 \mathrm{~mm}$. long, long-acuminate, with somewhat spreading tips; lemma $4 \mathrm{~mm}$. long, broadly ellipsoid, densely pubescent with white hairs. Eriocoma cuspidata Nutt. Bad lands and sandy places: Sask.-Kans.-Tex.-Calif.-Wash.; Mex. Plain-Mont. My-J1.

\section{MUHLENBÉRGIA Schreb.}

Perennials or annuals. Inflorescence a narrow contracted or open diffuse panicle. Spikelets 1-flowered; flower perfect. Empty glumes 2, membranous or hyaline, persistent, keeled, acute to short-awned, the second sometimes 3toothed. Lemma somewhat rigid, enclosing the palet, entire or 2-toothed at the apex, obtuse, acute, or awned. Stamens usually 3. Styles distinct; stigmas plumose.

Panicle contracted, narrow, spike-like, the short branches rarely spreading.

Empty glumes awl-shaped; leafy and branched plants, with long rootstocks covered by imbricated scales,

Lemma not awned; basal hairs not equalling the lemma.

Empty glumes about equalling the lemma in length, sharp-pointed, about 3 $\mathrm{mm}$. long.

Empty glumes exceeding the lemma, generally twice as 1. M. mexicana.

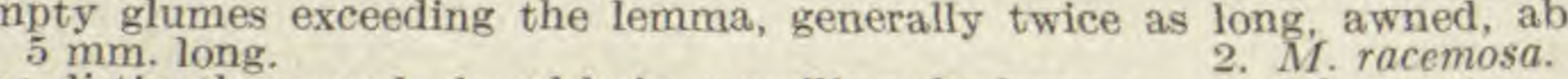

Lemma distinctly awned; basal hairs equalling the lemma. 3. M. comata.

Empty glumes lanceolate to ovate.

Second glume not toothed or slightly so.

Lemma awnless or rarely very short-awned.

Empty glumes more than half as long as the lemma.

Plant 1.5-7 dm. high; sheaths close; empty glumes acuminate, lanceolate.

Lemma scabrous, green or dark.

Panicle dense, obtuse, 5-10 mm. wide. 4. M. Wrightii.

Panicle slender and lax, attenuate at the apex, less than $5 \mathrm{~mm}$. Lemma more or less purplish, sparingly long-hairy.

5. M. cuspidata.

Plant less than $1.2 \mathrm{dm}$. high; sheaths loose; lower leaves lanceolate,
. Thurberi. short, squarrose; empty glumes ovate, acute. 7 . M. squarrosa.

Empty glumes less than half as long as the lemma, obtuse or abruptly acute.

Spikelets (excluding the awn if present) $1.5 \mathrm{~mm}$. or more long.

Plant with a strong perennial, scaly rootstock.

Empty glumes less than one-fourth as long as the lemma; stem diffuse, decumbent or creeping; plant not tufted.

8. M. Schreberi.

Empty glumes one-third as long as the lemma or longer; stem erect or decumbent at the base only; plant tufted.

Plant annual; rootstock, if any, very slender.

9. M. Richardsonis.

Lemma merely awn-pointed, decidedly purplish; plant 1-2 dm. high.

Spikelets $2 \mathrm{~mm}$. long or more; inflorescence short and rather dense; stem $0.5-1 \mathrm{~mm}$. thick. 10. M. simplex.

Spikelets about $1.5 \mathrm{~mm}$, long; inflorescence slender and lax; stem very slender, fliform. $11 . M$. filiformis.

Lemma with a distinct awn 0.5-1 mm. long, greenish; plant

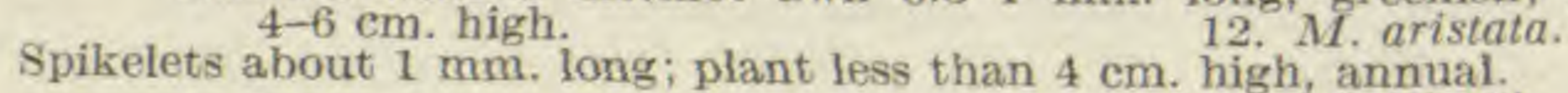

Lemma long-awned.

13. M. Wolfii.

Leaf-blades erect, glabrous or minutely scabrous; stem and sheaths glabrous.

Lemma glabrous; rootstock short and woody. 14. M. pauciflora.
Lemma pubescent on the lower half; rootstock slender, creeping, branched.

Leaf-blades spreading, as well at the stem below the nodes and the sheath scabrous-puberulent; lemma pubescent on the lower half; rootstock

16. M. curtifolia.
Second glume sharply 3-5-toothed; flowering glume long-awned; awn at least one-half as long as the glume.

Stem 3-6 dm. high, leafy; panicle $7-12 \mathrm{~cm}$. long; awn $8-15 \mathrm{~mm}$. long.

17. M. gracilis. 
Stem 1-3 dm. high, almost naked above; panicle $3-7 \mathrm{~cm}$. long; awn $1-4 \mathrm{~mm}$. long. Spikelets 3-4 mm. long; awn 2-4 mm.; leaf-blades usually stiff. Spikelets about $2 \mathrm{~mm}$, long; awn 1-2 mm.; leaf-blades filiform . Subalpina.

Panicle open, its branches long and spreading.

19. M. filiculmis.

Plants densely cespitose, branched only at the base.

Secondary branches of the panicle single; basal leaves short, strongly recurved.

Secondary branches of the panicle fascicled; basal leaves not recurved. 20. M. gracillima.

Plants diffusely branched, prostrate. 21. M. pungens. 22. M. Porteri.

1. M. mexicana (L.) Trin. Perennial; stem decumbent, prostrate, or erect, smooth, branched and very leafy; leaf-blades scabrous, 4-15 cm. long, 2-6 $\mathrm{mm}$. wide; panicle $5-15 \mathrm{~cm}$. long; spikelets $2.5-3 \mathrm{~mm}$. long; empty glumes somewhat unequal, seabrous on the keel. Wet meadows and swamps: N.B.-N.C.Tex.-Colo.-Wyo.-N.D. Plain-Submont. Je-S.

2. M. racemosa (Michx.) B.S.P. Perennial; stem erect, $3-10 \mathrm{dm}$. high, branched, smooth; leaf-blades 5-12 cm. long, 2-6 mm. wide, scabrous; paniele 5-10 cm. long, dense, usually interrupted; branches $1-2.5 \mathrm{~cm}$. long, ereet; spikelets much crowded; lemma one-half to two-thirds as long as the empty glumes, acuminate to awn-pointed. $M$. glomerata Torr. Wet places: Newf.-N.J.Mo.-N.M.-Utah-B.C. Plain-Mont. Jl-S.

3. M. comata (Thurb.) Benth. Perennial; stem 3-7 dm. high, erect, smooth; leaf-blades 5-12 cm. long, erect, flat, scabrous; panicle of ten tinged with purple, 5-10 $\mathrm{cm}$. long, dense, 1-1.5 cm. thick; empty glumes equal or the second a little longer, 2.5-3 mm. long; lemma a little shorter; awn 6-10 $\mathrm{mm}$. long. Prairies and river valleys: Mont.-Colo.-Calif.-Wash. Submont.-Mont. JI-S.

4. M. Wrightii Vasey. Somewhat tufted perennial, with short rootstock; stem erect or decumbent at the base, $3-7 \mathrm{dm}$. high, somewhat compressed; leafblades $6-15 \mathrm{~cm}$. long, scabrous above, about $2 \mathrm{~mm}$. wide; panicle cylindric, more or less interrupted; outer glumes nearly equal, $2 \mathrm{~mm}$. long, thin, ovate or lanceolate, awn-pointed; lemma a little longer, tipped with a short awn. Mountains: N.M.-Colo.-Ariz,; Mex. Submont. Jl-S.

5. M. cuspidata (Torr.) Rydb. Somewhat tufted perennial, occasionally with elongated scaly rootstocks; stem slender, 3-6 dm. high, glabrous; leafblades $2.5-10 \mathrm{~cm}$. long, less than $2 \mathrm{~mm}$. wide, involute-setaceous at least when dry; panicle 4-12 $\mathrm{cm}$. long; empty glumes about $2 \mathrm{~mm}$. long, scabrous on the keel; flowering glume long-acuminate, about $3 \mathrm{~mm}$. long. Sporobolus brevifolius (Nutt.) Scribn. Dry soil: Man.-Mo.-Colo--Alta. Plain-Submont. Jl-S.

6. M. Thurberi (Scribn.) Rydb. Tufted perennial with a scaly rootstock; stems $1.5-3 \mathrm{dm}$. high; leaf-blades 1-3 cm. long, strongly involute, the lower more or less spreading; panicle $2-5 \mathrm{~cm}$. long, $2-3 \mathrm{~mm}$. thick; empty glumes equal, 1-nerved, lanceolate, $3 \mathrm{~mm}$. long, usually purplish; lemma lanceolate, cuspidate, 3-nerved, 4-4.5 mm. long. Sporobolus filiculmis Vasey, not Dewey. S. Thurberi Seribn. Dry places and cañons: Tex.-Colo.-N.M. Son.-Submont. Jl-S.

7. M. squarrosa (Trin.) Rydb. Tufted perennial; stems less than $1 \mathrm{dm}$. high, decumbent at the base, glabrous and almost smooth; leaf-blades scarcely $1 \mathrm{~cm}$. long; panicle 1-2 $\mathrm{cm}$. long, narrow and rather few-flowered; empty glumes 1-1.5 mm. long, 1-nerved, straw-colored; lemma lanceolate, acute, 1.5-2 mm. long. Sporobolus depauperatus (Torr.) Seribn. Dry, sandy or alkali soil: Wash. -Mont.-Wyo.-Calif. Son.-Submont. Jl-Au.

8. M. Schreberi Gmel. Perennial, with a creeping, scaly rootstock; stem 3-9 dm. long; leaf-blades $3-9 \mathrm{~cm}$. long, scabrous; panicle $5-20 \mathrm{~cm}$. long, 2-5 $\mathrm{mm}$. thick, lax; empty glumes small, the first often wanting; lemma without the awn about $2 \mathrm{~mm}$. long, strongly seabrous; awn 1-4 mm. long. $M$. diffusa Willd. Dry hills and woods: Me.-Fla.-Tex.-w Neb.-Minn. Boreal-Plain. Au-S.

9. M. Richardsonis (Trin.) Rydb. More or less tufted perennial, with a strong rootstock; stem 1-4.5 dm. high, erect or decumbent at the base, slender, smooth; leaves $1-5 \mathrm{~cm}$. long, usually involute; panicle $1-7 \mathrm{~cm}$. long, 2-4 mm. 
thick; empty glumes ovate, obtuse, or abruptly acute, about $1 \mathrm{~mm}$. long; lemma 2.5-3 mm, long, long-acuminate. Vilfa Richardsonis Trin. Prairies and meadows: Que.-Me.-N.M.-Calif.-B.C. Plain-Mont. Je-S.

10. M. simplex (Scribn.) Rydb. Cespitose leafy annual; stem $5-15 \mathrm{~cm}$. high, smooth, with short lower internodes; leaf-blades $1-4 \mathrm{~cm}$. long, 1-2 mm. broad, scabrous on the margins and nerves above; panicle $2-5 \mathrm{~cm}$. long, 2-4 mm. thick; empty glumes less than $1 \mathrm{~mm}$. long, ovate, obtuse or truncate; lemma 3 -nerved, mucronate, scabrous above, $2-2.3 \mathrm{~mm}$. long. Sporobolus simplex Scribn. Wet places: Neb.-N.M.-Mont. Plain-Mont. Au-S.

11. M. filiformis (Thurb.) Rydb. Cespitose annual; stem 7-30 cm. high, slender, filiform, glabrous; leaf-blades $1-2 \mathrm{~cm}$. long, $0.5 \mathrm{~mm}$. wide or less, usually flat, scabrous above; panicle long-exserted, narrow, lax, 2-10 $\mathrm{cm}$. long, more than $2 \mathrm{~mm}$. thick; empty glumes less than $1 \mathrm{~mm}$. long, ovate, obtuse, 1-nerved, mucronate; lemma $2 \mathrm{~mm}$. long, lanceolate, acuminate. Vilfa depauperata filiformis Thurb. V. gracillima Thurb. Wet places: Mont.-Colo.-Calif.-B.C. Submont.-Subalp. My-Au.

12. M. aristata Rydb. Cespitose annual; stems usually only $4-6 \mathrm{~cm}$. high; leaf-blades 8-14 $\mathrm{mm}$. long, and about $1 \mathrm{~mm}$. wide; panicle few-flowered, very narrow, with short erect branches; empty glumes 1-1.25 mm. long, ovate, acutish or obtuse and somewhat erose at the apex; lemma about $2.5 \mathrm{~mm}$. long, strongly veined. Sporobolus aristatus Rydb. Wet places: Utah-Wyo.-Colo. Submont. Jl-Au.

13. M. Wolfii (Vssey) Rydb. Cespitose annual; stem $2-5 \mathrm{~cm}$. high; lower sheaths inflated, glabrous; leaf-blades rarely over $1 \mathrm{~cm}$. long, strongly nerved; panicle spike-like, about $1 \mathrm{~cm}$. long, scarcely $2 \mathrm{~mm}$. thick, lax; empty glumes ovate, about $0.5 \mathrm{~mm}$. long; lemma ovate, acute, about $1 \mathrm{~mm}$. long. Sporobolus Wolfii Vasey. Wet places: Colo.-Ariz. Mont.-Subalp.

14. M. pauciflora Buckl. Perennial; stems tufted, wiry, ereet, 3-5 dm. high, scabrous, leafy; leaf-blades narrow, involute, $5-15 \mathrm{~cm}$. long, minutely scabrous; panicle $10-15 \mathrm{~cm}$. long; spikelets nearly sessile; empty glumes subequal, lanceolate, usually awn-pointed, $2 \mathrm{~mm}$. long; lemma 3-nerved, lanceolate, acuminate, 3-4 mm. long, scabrous on the keel; awn 8-12 $\mathrm{mm}$. long. Rocky hills: Tex.-Colo.-Utah-Mex. Son. My-S.

15. M. polycaulis Scribn. Perennial, fasciculate-branched at the base; stems ascending or erect, leafy, glabrous or minutely scabrous; leaf-blades erect, 2-6 $\mathrm{cm}$. long, 1-2 $\mathrm{mm}$. wide, often involute; panicle $5-10 \mathrm{~cm}$. long, narrow; rachis scabrous, triangular; pedicels scabrous, short; empty glumes subequal, broadly lanceolate, acute or awn-pointed; lemma broadly lanceolate; awn 1-2.5 $\mathrm{cm}$. long. Dry ledges and in cañons: Tex.-se Utah-Mex. Son. Au-S.

16. M. curtifolia Scribn. Perennial, fasciculate-branched at the base; leaf-blades 1-2.5 cm. long, $2 \mathrm{~mm}$. wide or less, pungent at the end; panicle narrow, 4-8 cm. long; branches erect; rachis triangular or compressed, scabrous; empty glumes lanceolate, acute, subequal, $2.5 \mathrm{~mm}$. long, seabrous along the keel; lemma broadly lanceolate; awn scabrous, 1-3 $\mathrm{mm}$. long. Cañons: s Utah. Son. Au.

17. M. gracilis (H.B.K.) Trin. Tufted perennial; stems $3-6 \mathrm{dm}$. high, erect; leaf-blades of ten convolute, $5-20 \mathrm{~cm}$. long; panicle narrow but rather loose; branches ereet, flowering to the base; empty glumes unequal, the first 2 $\mathrm{mm}$. long, 1-nerved, acute; lemma without the awn about $4 \mathrm{~mm}$. long, scabrous on the back, ciliate on the margins. M. trifida Woot. \& Standl., not Hack. Mountains: Tex.-Colo.-Calif.; Mex. Son.-Mont. Je-S.

18. M. subalpina Vasey. Tufted perennial; stem erect, 1-3 dm. high; leaf-blades usually involute, $2-7 \mathrm{~cm}$. long; panicle narrow, dense; branches erect, less than $1 \mathrm{~cm}$. long; first empty glume about $2 \mathrm{~mm}$. long, acute, 1-nerved, awnpointed; lemma 3-3.5 mm. long. M. gracilis breviaristata Vasey. Dry ridges: Wyo.-N.M. Mont.-Submont. Jl-Au.

19. M. filiculmis Vasey. Tufted perennial; stem erect, filiform, 1-2.5 dm. high, leafy at the base; leaf-blades filiform, $2-4 \mathrm{~cm}$. long, involute; panicle spike- 
like, 2-5 cm. long; branches short, erect; first empty glume thin, ovate, acute, 1.5 $\mathrm{mm}$. long, the second slightly longer; lemma lanceolate, sparsely pubescent below, $2 \mathrm{~mm}$. long. Mountains: Colo. Mont. Jl-Au.

20. M. gracillima Torr Cespitose perennial; stems 1-4 dm. high, erect, or decumbent at the base; leaves mostly basal; leaf-blades involute-setaceous, somewhat scabrous; panicle $5-20 \mathrm{~cm}$. long, open; empty glumes unequal, the first about $1.5 \mathrm{~mm}$., the second $2 \mathrm{~mm}$. long, awn-pointed; lemma $2.5-3 \mathrm{~mm}$. long, scabrous; awn 2-4 mm. long. Ring GRAss. Plains and foot-hills: Tex.Kans.-Colo.-N.M. Plain-Mont. Jl-O.

21. M. pungens Thurb. Perennisl, with a cespitose, creeping rootstock; stems decumbent at the base, $1.5-4 \mathrm{dm}$. high; leaf-blades $2.5-5 \mathrm{~cm}$. long, involute, rigid, scabrous; panicle $7-15 \mathrm{~cm}$. long, open, its branches $5-7 \mathrm{~cm}$. long; outer glumes 2-2.5 mm. long, purplish, scabrous; lemma $3-4 \mathrm{~mm}$. long, seabrous; awn short. Purple Hair-grass, Blow-out Grass. Sand hills and bad-lands: Tex. -Neb.-Utah-Ariz. Plain-Mont. Jl-Au.

22. M. Porteri Scribn. Cespitose perennial; stems geniculste, decumbent, branching; leaf-blades usually flat, $3-5 \mathrm{~cm}$. long, about $6 \mathrm{~mm}$. wide, acuminate, scabrous above; panicle $7-10 \mathrm{~cm}$. long, about $5 \mathrm{~cm}$. wide; empty glumes narrowly lanceolate, 2-2.5 mm. long, purplish; lemma without the awn $3.5-4 \mathrm{~mm}$. long, purple, pilose; awn 5-10 mm. long. M. texana Thurb., not Buckley. MesQUite Grass. Hills and plains: Tex.-Colo.-Calif,; Mex. Son. Au-O.

\section{LYCÙRUS H.B.K. Texas Timothy.}

Cespitose perennials. Panicle dense, spike-like. Spikelets 1-flowered, usually in pairs. Empty glumes 2, often awned, 3-nerved. Lemma 3-nerved, awned. Palet smaller, 2-nerved and 2-keeled. Stamens 3. Styles distinct, short; stigmas plumose. Grain free, included in the lemma.

1. L. phleoides H.B.K. Tufted perennial; stems decumbent at the base, 2-5 dm. high, compressed; leaf-blades scabrous above, 4-7 cm. long, $3 \mathrm{~mm}$. wide; spike cylindric, dense, 4-10 $\mathrm{cm}$. long, $5-8 \mathrm{~mm}$. thick; first glume $1.5 \mathrm{~mm}$. long, with 2 awns, $2-3 \mathrm{~mm}$. long; second glume with an awn $4 \mathrm{~mm}$. long; lemma lanceelliptic, $3 \mathrm{~mm}$. long, pubescent on the back; awn 2-3 mm. long. 'Hills: Tex.Colo.-Ariz.; Mex. Son.-Submont. Au-O.

\section{PHLÈUM L. Trmothy.}

Annuals or perennials. Inflorescence a dense spike-like panicle. Spikelets 1-flowered, compressed; flower perfect. Empty glumes 2, persistent, compressed, keeled, oblique at the summit, awned. Lemma shorter, membranous, truncate, denticulate. Styles distinct, long; stigmas sub-plumose. Grain free.

Spikes usually elongated-cylindric; awns less than one-half the length of the outer glumes. Spikes short, ovoid or oblong; awns about one-half the length of the outer glumes. pratense.

2. P. alpinum.

P. pratense L. Short-lived perennial, with a bulbiform thickened base; stem erect, glabrous and smooth, 3-15 dm. high; sheaths often exceeding the internodes, the upper long and close; leaf-blades 7-20 $\mathrm{cm}$. long, 4-6 mm. wide, usually somewhat scabrous; spike $3-20 \mathrm{~cm}$. long, 5-8 mm. thick; outer glumes 3-4 mm. long, ciliate on the keel; awns about $1 \mathrm{~mm}$. long. Meadows; native but also of ten escaped from cultivation: N.S.-Fla.-Calif.-B.C.; Eurasia. Plain -Subalp. Je-O.

2. P. alpinum L. Short-lived perennial; stem 1-5 dm. high, erect or sometimes decumbent at the base, smooth; sheaths often shorter than the internodes, the upper usually inflated; leaf-blades scabrous above, $2-7 \mathrm{~cm}$. long, 3-8 $\mathrm{mm}$. wide; spike $1-5 \mathrm{~cm}$. long, 6-12 $\mathrm{mm}$. thick; outer glumes $3 \mathrm{~mm}$. long, strongly ciliate on the keel; awns 1.5-2 mm. long. Wet places: Lab.-N.H.-S.D.N.M.-Calif.-Alaska; Eurasia. Mont.-Alp. Je-S. 


\section{ALOPECÙRUS L. FoxtaIL.}

Annuals or perennials. Inflorescence a cylindric dense spike-like panicle. Spikelets articulate under the empty glumes, 1-flowered, compressed; flower perfect. Empty glumes 2, acute, sometimes short-awned, more or less united at the base, compressed-keeled. Lemma hyaline, obtuse, with a dorsal awn or point, their margins usually more or less united at the base. Styles distinct or nearly so; stigmas long, sub-plumose.

Awn about twice as long as the lemma.

Spikes 8-12 mm. thick; empty glumes $3.5-4.5 \mathrm{~mm}$. long, abruptly acuminate.

Spike about $5 \mathrm{~mm}$. thick; empty glumes about $3 \mathrm{~mm}$. long, obtuse. Stem erect, 3-5 dm. high, slightly if at all geniculate at the base, pale; ligules 4-5 $\mathrm{mm}$. long, acutish.

2. A. pallescens.

Stem decumbent, and geniculate at the base, 1-1.5 dm. high; ligules $2 \mathrm{~mm}$. long, obtuse.

A wn scarcely exceeding the lemma.

Stem erect, 1.5-5 dm. high; spike cylindric, obtuse

Stem geniculate at the base, $1-5 \mathrm{~cm}$. high; spike oblong, acute.

3. A. Macounii.

1. A. occidentalis Scribn. \& Tweedy. Perennial, with a rootstock; stem erect, 2-10 dm. high; leaf-blades 5-15 cm. long, 4-7 mm. wide, flat, scabrous on the veins above; spike $2-3 \mathrm{~cm}$. long; empty glumes equalling or slightly exceeding the obtuse lemma, which is scabrous and ciliate near the tips; awn $6 \mathrm{~mm}$. long, twisted below, bent at the middle, attached near the base of the glume. Wet meadows: Alta.-Colo.-Utah-Ida. Mont.-Subalp. Je-Au.

2. A. pallescens Piper. Somewhat tufted perennial, pale green; blades flat, 6-12 cm. long, 2-6 mm. wide, strongly scabrous above; spike exserted, pale, 2-7 cm. long; empty glumes strongly ciliate on the keel, obtuse; lemma as long as the empty glumes, obtuse; awn nearly basal, about $5 \mathrm{~mm}$. long. Wet meadows: Wash.-Mont.-Ida. Submont. My-Je.

3. A. Macounii Vasey. Somewhat cespitose perennial; blades $1-5 \mathrm{~cm}$. long; spike 1-3 cm. long, $5 \mathrm{~mm}$. thick; empty glumes ciliate on the keel, smooth on the sides, obtuse; lemma slightly shorter, glabrous, ovate-oblong, obtuse; awn nearly basal, bent at the middle, $6-8 \mathrm{~mm}$. long. A. geniculatus caespitosus Scribn. Rocky places: Sask.-B.C. Boreal-Mont. My-Je.

4. A. aristulatus Michx. Somewhat tufted perennial; leaf-blades 5-15 $\mathrm{cm}$. long, 3-4 mm. wide, scabrous, especially above; spike $3-8 \mathrm{~cm}$. long, 4-6 $\mathrm{mm}$. thick; outer glumes $2-2.5 \mathrm{~mm}$. long, acutish; lemma somewhat shorter, obtuse, glabrous; awn inserted at or near the middle. A. geniculatus Am. auth., not L. A. fulvus Am. auth., not Smith. Wet meadows: Me.-Pa.-Calif.-Alaska. Plain-Subalp. Je-S.

5. A. caespitosus Trin. Cespitose perennial; leaf-blades flat, less than 2 $\mathrm{cm}$. long, $1 \mathrm{~mm}$. wide; spike $0.5-1.5 \mathrm{~cm}$. long, 3-4 mm. thick, acute; outer glumes $2 \mathrm{~mm}$. long, acutish; lemma nearly as long, obtuse; awn inserted near the base. [Perhaps a depauperate form of the preceding.] Wet places: Canadian Rockies -N. W. Coast.

\section{PHÍPPSIA R. Br.}

Tufted annuals. Inflorescence a narrow panicle. Spikelets 1-flowered; flowers perfect. Empty glumes 2, minute, or the first one wanting. Lemma thin-membranous, keeled. Palet shorter, 2-keeled. Stamens 1, rarely more. Styles short, distinct; stigmas short-plumose. Grain enclosed in the lemma and the palet, which splits and lets it drop.

1. P. algida (Solander) R. Br. Stems 2-10 cm. high, erect or ascending; sheaths short, loose; leaf-blades 1-2 $\mathrm{cm}$. long, $0.5-2 \mathrm{~mm}$. wide, obtuse; panicle $0.5-3.5 \mathrm{~cm}$. long, narrow; spikelets $1-1.5 \mathrm{~mm}$. long; empty glumes minute or the first one wanting; lemma thin, 1-nerved, obtuse or truncate and somewhat erose. Aretic-alpine situations: Greenl.-Alaska; Colo.; aretic Eurasia. Alp. $\mathrm{Jl}-\mathrm{Au}$.

\section{BLEPHARONEÜRON Nash.}

Tufted perennials. Panicles open, loosely flowered. Spikelets 1-flowered. Empty glumes membranous, 1-nerved, smooth, the first shorter and narrower 
than the second. Lemma 3-nerved, the nerves densely pilose with long silky hairs; midnerve usually excurrent into a short awn. Palet as long as the lemma, 2-nerved, densely pilose between the nerves. Stamens 3. Styles distinct; stigmas plumose.

1. B. tricholepis (Torr.) Nash. Stem often purplish, glabrous, $3-10 \mathrm{dm}$. high; leaf-blades involute, 5-15 cm. long; panicle oblong, open, 1-1.5 dm. long; spikelets $2.5-3 \mathrm{~mm}$. long; empty glumes oblong, obtuse, nearly equal. Sporobolus tricholepis Torr. Mountain valleys: Tex.-Colo.-Utah-Ariz.; Mex. Submont.-Subalp. Jl-N.

\section{SPORÓBOLUS R. Br. Drop-SEed, Rush-Grass.}

Perennials or rarely annuals. Inflorescence a panicle, either open or narrow and spike-like. Spikelets usually 1-flowered; flowers perfect. Empty glumes 2, the first shorter than the second. Lemma usually longer than the second glume. Palet 2-nerved, of ten deeply 2-cleft, about equalling the lemma. Stamens 2 or 3. Styles short, distinet; stigmas plumose. Grain free from the lemma and readily dropping off.

Perennials.

First glume one-half as long as the second or less; plants not with long, scaly rootstocks.

Branches of the panicle verticillate.

Branches of the panicle scattered.

Spikelets about $2 \mathrm{~mm}$. long; first glume lanceolate.

Sheath naked or sparingly ciliate at the throat; empty glumes glabrous.

Plant $3 \mathrm{dm}$. high or less; spikelets long-pedicelled; sheaths sparingly villous.

9. S. texanus.

Plant 5-10 dm. high; spikelets short-pedicelled; sheaths glabrous.

2. $S$. airoides.

Sheath with a conspicuous tuft of hairs at the throat; empty glumes scabrous on the keel.

Leaf-blades widely spreading, involute; sheath pubescent with long hairs, at least towards the base.

3. S. Nealleyi.

Leaf-blades not widely spreading; sheaths glabrous, except the apex, and slightly on the margins.

Panicle narrow and spike-like.

Panicle not spike-like.

Panicle always exserted, oblong, comparatively narrow; its lower branches but little, if any, exceeding the upper ones.

5. S. flexuosus.

Panicle usually more or less included in the sheath; its lower branches much exceeding the upper ones. 6. S. cryptandrus.

Spikelets 4.5-5 mm. long; first glume subulate, usually awned.

7. S. heterolepis.

First glume almost equalling the second; plants with long, scaly rootstocks.

Annuals; empty glumes almost equal, ovate.

8. S. asperifolius. 10. S. confusus.

1 S. argutus (Nees) Kunth. Tufted perennial; stem 1-4 dm. high, erect or decumbent at the base; leaf-blades $2.5-5 \mathrm{~cm}$. long, 2-4 mm. wide, often sparingly hairy at the base; panicle-branches 1-2.5 $\mathrm{cm}$. long; spikelets $1.5 \mathrm{~mm}$. long. Plains: Tex.-Kans.-Colo.-Mex.; W. Ind., C. Am. and S. Am. Son. Ap.-O.; in the tropics the year around.

2. S. airoides Torr. Densely tufted perennial; stem 5-10 dm. high, erect; leaf-blades sometimes sparingly hairy at the base, 1-3 $\mathrm{mm}$. wide, involute, 5-35 cm. long; panicle 1-4 dm. long, its branches at length widely spreading; spikelets $1.5-2 \mathrm{~mm}$. long; glumes acute, glabrous. Dry plains and river valleys: Tex.-Mo.-Mont.-Calif. Plain-Submont. Au-S.

3. S. Nealleyi Vasey. Tufted perennial; stems $3-4 \mathrm{dm}$. high, rigid; leaf-blades $2.5-3.5 \mathrm{~cm}$. long, rigid, light-green, spreading, involute; panicle open, branches ascending; spikelets $1.5 \mathrm{~mm}$. long; lower empty glume lance-subulate; second glume and the lemma lanceolate and acute. Dry ground: Tex.-Colo. Son. J1-S.

4. S. strictus (Scribn.) Merr. Tufted perennial; stem strict, 5-10 dm. high, glabrous; blades $5-20 \mathrm{~cm}$. long, 3-5 mm. broad, mostly flat, glabrous; panicle 1-2 dm. long, the base included in the upper sheaths; flowers pale or green, shining; empty glumes lanceolate, $2-2.5 \mathrm{~mm}$. long, acute, smooth. River bottoms: Tex.-Utah-Ariz. Son. Je-O. 
5. S. flexuosus (Thurb.) Rydb. Tufted perennial; stem $3-8 \mathrm{dm}$. high; leaf-blades $5-20 \mathrm{~cm}$. long, 2-4 mm. wide, usually flat, somewhat scabrous above; inflorescence 2-4 dm. long; branches 3-6 cm. long, spreading or reflexed; spikelets about $2 \mathrm{~mm}$. long, usually lead-colored; empty glumes lanceolate, somewhat scabrous. Sandy soil: Tex.-Nev.-Ariz.; Mex. Son. Jl-S.

6. S. cryptandrus (Torr.) A. Gray. More or less tufted perennial; stem 4$10 \mathrm{dm}$. long, erect, glabrous; leaf-blades $7-15 \mathrm{~cm}$. long, $2-4 \mathrm{~mm}$. wide, flat, glabrous beneath, scabrous above; panicle 1.5-2.5 dm. long; spikelets lead-colored, 2-2.5 mm. long; glumes scabrous on the keel. Sandy soil: Mass.-Pa.-Ariz. -Wash.; Mex. Plain-Submont. Au-O.

7. S. heterolepis A. Gray. Tufted perennial; stem $3-10 \mathrm{dm}$. high, erect; leaf-blades involute, glabrous, with rough margins and midribs, $2-5 \mathrm{dm}$. long; panicle 7-25 $\mathrm{cm}$. long, open, exserted; branches ascending; glumes smooth and glabrous, the first one subulate, $2-3 \mathrm{~mm}$. long, the second lanceolate, 4-5 $\mathrm{mm}$. long, awn-pointed; lemma obtuse or acute. Dry soil: Que.-Pa.-Tex.-S.D. -Sask. Plain-Submont. Au-S.

8. S. asperifolius (Nees \& Meyen) Thurb. Perennial with a cespitose creeping rootstock; stem 1-5 dm. high, erect from a decumbent base; leaf-blades $2.5-10 \mathrm{~cm}$. long, $2-3 \mathrm{~mm}$. wide, flat, very scabrous above; panicles $7-20 \mathrm{~cm}$. long, usually included at the base; branches usually spreading in age; spikelets 1.5 $\mathrm{mm}$. long; glumes acute, glabrous, somewhat scabrous; lemma slightly exceeding them. Sandy or dry soil: Sask.-Mo.-Tex.-Calif.-B.C.; Mex. Plain-Submont. Je-S.

9. S. texanus Vasey. Tufted perennial, otherwise resembling S. asperifolius; stems rigid; leaf-blades $2.5-7.5 \mathrm{~cm}$. long, scabrous above; panicle half the length of the plant, included in the sheath below; lower glume half as long as the second one, which is fully as long as the lemma. Plains: Tex.-Okla. - s Colo.-N.M. Son.

10. S. confusus (Fourn.) Vasey. Tufted annual; stem 1-3 dm. high, slender, branched below; sheaths short, loose, glabrous; leaf-blades 1-4 cm. long, 0.5-1.5 $\mathrm{mm}$. wide; panicle open, $3-20 \mathrm{~cm}$. long; branches spreading; spikelets $1-1.5$ $\mathrm{mm}$. long; empty glumes shorter than the lemma, glabrous or pubescent; lemma pubescent. Meadows especially in sandy soil: Neb.-Tex.-Ariz.-Ida.; Mex. Son.-Submont. JI-S.

\section{POLYPÒGON Desf. BEARD-GRAsS.}

Annuals or rarely perennials. Inflorescence a dense, contracted, spike-like panicle. Spikelets articulate below the empty glumes, crowded, 1-flowered. Flowers perfect. Empty glumes about equal, each terminating in a slender awn. Lemma thin, emarginate or 2-toothed at the apex, awned or awn-pointed on the back. Stamens 1-3. Styles short, distinet; stigmas plumose.

1. P. monspeliensis (L.) Desf. Simple annual; stem 1-6 dm. high, erect or decumbent at the base; leaf-blades $4-15 \mathrm{~cm}$. long, 3-6 $\mathrm{mm}$. wide, scabrous; panicle $2-10 \mathrm{~cm}$. long; empty glumes about $2 \mathrm{~mm}$. long, bearing a more or less bent awn 4-6 mm. long; lemma shorter, erose-truncate, hyaline; awn $0.5 \mathrm{~mm}$. long. Waste places: S.C.-N.H.-B.C.-Calif.; Mex.; naturalized from Eurasia. Plain-Submont. Ap-Au.

\section{Cínna L. Reed-grass.}

Tall perennials with broad flat leaves. Inflorescence a large often nodding panicle. Spikelets numerous, 1-flowered, articulate under the empty glumes. Flowers perfect. Empty glumes 2, persistent, keeled, acute. Lemma similar, short-awned or awn-pointed just below the apex. Palet 1-nerved, keeled, the keel minutely ciliate. Stamen 1. Styles short, distinct; stigmas plumose.

1. C. latifolia (Trev.) Griseb. Stem 6-15 dm. high, erect; leaf-blades 1-2.5 $\mathrm{dm}$. long, 4-12 mm. wide, scabrous; panicle 1-2.5 dm. long; spikelets $3 \mathrm{~mm}$. long; empty glumes equal, acute, hispidulous on the keel; lemma somewhat shorter, 2-toothed at the apex; awn 1-2 mm. long. Cinna pendula Trin. Damp woods: Newf.-N.C.-Utah-B.C. Submont.-Mont. Jl-S. 


\section{AgRóstis L. Red-top, Bent-grass, Tickle-grass.}

Annuals or perennial, mostly tufted, Inflorescence paniculate. Spikelets numerous, small, 1-flowered, articulate above the empty glumes. Empty glumes 2 , persistent, membranous, keeled, acute, awnless. Lemma shorter, or barely equalling the empty glumes, thin-hyaline, awnless or awned. Palet small, thinhyaline, or often wanting. Stamens usually 3. Styles short, distinet; stigmas plumose.

Rachilla prolonged above the palet, naked or minutely pubescent: lemma equalling the empty glumes; palet nearly as long.

Spikelets about $3 \mathrm{~mm}$. long, purple; rachilla one-third to one-half as long as the flower.

Spikelets about $2 \mathrm{~mm}$. long; rachilla less than one-third as long as the aequivalvis.

(ack purple, broadly lanceolate, abruptly acute or acuminate; inflorescence short and open; stem few-leaved. 2 . A. atrata.

Empty glumes green, only tinged with purple towards the tip, narrowly lanceolate, gradually acute; inflorescence long and narrow; stem leafy. 3. A. Thurberiana.

Rachilla not prolonged above the palet; lemma shorter than the empty glumes.

Palet evident, 2-nerved, at least one-fourth as long as the lemma.

Empty glumes obtuse, scabrous on the back; panicle dense; branches flowerbearing from the base, verticillate.

Empty glumes acute or acuminate, glabrous or scabrous on the keel only.

Plant erect or decumbent at the base, but not extensively stoloniferous.

Plant tall, usually over $3 \mathrm{dm}$. high; panicle large, open; spikelets over 2 $\mathrm{mm}$. long.

5. A. alba.

Plant low, slender, 1-3 dm. high; panicle narrow; spikelets about $2 \mathrm{~mm}$. long or less.

Lemma nearly as long as the empty glumes; palet about two-thirds as long as the lemma; plant erect.

Lemma one-third shorter than the empty glumes; palet about one-half as long as the lemma; plant decumbent at the base.

7. A. depressa.

Plant extensively stoloniferous; stolons with short leaves; palet one-fourth to one-half as long as the lemma.

Palet lacking or minute.

Plant with creeping rootstock.

Plant tufted, without creeping rootstock.

8. A. reptans.

Panicle dense and narrow; branches ascending or erect, flower-bearing to near the base.

Plant over $3 \mathrm{dm}$. high; empty glumes $2.5-3 \mathrm{~mm}$. long.

Panicle lobed or interrupted; branches densely verticillate and flowerbearing to the base; empty glumes narrowly lanceolate, gradually attenuate; ligules 4-5 mm. long, lacerate; leaf-blades 6-10 $\mathrm{mm}$. wide.

10. A. grandis.

Panicle usually contiguous; branches few and soms naked at the base; empty glumes lanceolate, abruptly pointed; ligules 2-4 mm. long, entire or toothed; leaf-blades $2-5 \mathrm{~mm}$. wide. 11. A. asperifolia,

Plant 1-2 dm. high; empty glumes $2 \mathrm{~mm}$. long or less.

Basal leaf-blades flat, $2 \mathrm{~mm}$. wide; lemma two-thirds as long as the empty glumes, obtuse.

12. A. Rossae.

Basal leaf-blades $1 \mathrm{~mm}$. wide or less, conduplicate; lemma three-fourths as long as the empty glumes, acute. 13. A. variabilis.

Panicle open; branches more or less spreading, or sometimes reflexed.

Lemma awnless or with a very short awn.

Panicle oblong-ovoid, its branches ascending.

Plant 1-4 dm. high; empty glumes unequal, 1.5-2 mm. long.

14. A. idahoensis.

Plant 3-6 dm. high; empty glumes equal or nearly so, $3 \mathrm{~mm}$. Iong.

15. A. oregonensis.

Panicle triangular-ovoid or broadly conic; branches at least in age divaricate or even reflexed.

Leaf-blades filiform, $1 \mathrm{~mm}$. wide or less, usually involute; the basal ones numerous; upper sheaths close.

16. A. oreophila.

Leaf-blades usually flat, 1-3 mm. wide; upper sheaths loose.

Lemma awned; awn equalling or exceeding the glume.

17. A. hyemalis.

Panicle open, diffuse; branches spreading or ascending.

Leaf-blades about $0.5 \mathrm{~mm}$. wide; panicle broadly conic; branches very scabrous, in age spreading or reflexed. 18. A. geminata. Leaf-blades 1-2 mm. wide; panicle ovoid; branches ascending.

Panicle narrow; branches nearly erect. $\quad 20$. A. melaleuca.

1. A. aequivalvis Trin. Tufted perennial; stems $2-6 \mathrm{dm}$. high; leaf-blades erect, 4-6 $\mathrm{cm}$. long, 1-2 $\mathrm{mm}$. wide, somewhat scabrous; panicle open, 5-15 $\mathrm{cm}$. long; empty glumes equal, acuminate, scabrous on the keel towards the end; lemma obtuse. Meadows: Alaska-B.C.-Ore.; Lab. Subalp. Je-Au. 
2. A. atrata Rydb. A somewhat tufted perennial; stems $1.5-3 \mathrm{dm}$. high, few-leaved, more or less bulbous at the base; leaf-blades $5-10 \mathrm{~cm}$. long, about 2 $\mathrm{mm}$. wide, flat, smooth; panicle $5-8 \mathrm{~cm}$. long; empty glumes nearly equal; lemma nearly as long, obtusish. Mountains: B.C. Mont.-Subalp.

3. A. Thurberiana Hitchc. Tufted perennial; stem $2-4 \mathrm{dm}$. high, leafy; leaf-blades 5-10 $\mathrm{cm}$. long, $2 \mathrm{~mm}$. wide, lax, light green; panicle more or less drooping, 5-20 cm. long; empty glumes about $2 \mathrm{~mm}$. long, narrow, gradually acute; lemma nearly as long, obtuse, faintly 5-nerved. Meadows: B.C.-Mont. -Utah-Calif. Submont.-Subalp. Jl-Au.

4. A. stolonifera L. Perennial, with a long creeping rootstock and stolons; stem 2-8 dm. high; leaf-blades 5-10 cm. long, 3-4 mm. wide, light- or glaucousgreen, scabrous; panicle interrupted, 3-10 cm. long; empty glumes obtuse, scabrous on the keel and back, $2 \mathrm{~mm}$. long; lemma about half as long, awnless, truncate and toothed at the apex. A. verticillata Vill. Wet meadows: Tex.Utah-Calif.; Mex., C. Am., S. Am., Eu., Africa and Asia. Son.-Submont. F-O.

5. A. alba L. Tufted perennial; stems $2-15 \mathrm{dm}$. high, erect or decumbent at the base; leaf-blades 4-15 cm. long, 3-8 mm. wide; panicle upright, $5-30 \mathrm{~cm}$. long, with spreading branches, the lower usually verticillate; empty glumes $2-3$ $\mathrm{mm}$. long, pale or purplish, nearly equal, acute; lemma two-thirds to threefourths as long, obtuse, seldom awned. Wet meadows: Newf.-Fla.-Calif.B.C.; Eurasia. Plain-Submont. Je-O.

6. A. humilis Vasey. Tufted perennial; stems 1-4 dm. high, slender, 1-3leaved; leaves mostly basal; leaf-blades $2-10 \mathrm{~cm}$. long, $1 \mathrm{~mm}$. wide or less, usually conduplicate; panicles 2-5 cm. long; branches ascending; empty glumes equal, abruptly pointed, $1.5-2 \mathrm{~mm}$. long, purple; lemma nearly as long, awnless. High mountains: B.C.-Ore.-Colo.-Wyo. Mont.-Alp. Au-O.

7. A. depressa Vasey. Tufted perennial; stems decumbent and geniculate at the base, $1.5-2.5 \mathrm{dm}$. high, slender, leafy below; leaf-blades $3-5 \mathrm{~cm}$. long, 1 $\mathrm{mm}$. wide, flat; panicle narrow, 3-5 cm. long, in age open; empty glumes $2 \mathrm{~mm}$. long, acute; lemma obtuse or minutely dentate at the apex. Mountains: Colo. Mont.-Subalp. JI.

8. A. reptans Rydb. Cespitose and stoloniferous perennial; stems $2-3 \mathrm{dm}$. long; leaves $2-6 \mathrm{~cm}$. long, 1-2 mm. wide, flat; panicle $3-5 \mathrm{~cm}$. long; branches ascending, flower-bearing to near the base; empty glumes purplish, nearly equal, acute; lemma one-third shorter, toothed at the apex, often with a minute awn. A. exarata stolonifera Vasey. Bottom lands: B.C.-Calif. Submont. Jl-Au,

9. A. foliosa Vasey. Perennial, with a creeping rootstock; stem 5-10 dm. high; leaf-blades $8-15 \mathrm{~cm}$. long, $3-4 \mathrm{~mm}$. wide; panicles open, but often narrow' 1-1.5 dm. long; branches ascending, naked below; empty glumes pale, nearly equal, $2-3 \mathrm{~mm}$. long, abruptly acute; lemma nearly as long, obtuse and minutely toothed at the apex, awnless or short-awned. Wet meadows: B.C.-Ida.-
Calif. Submont. Je-Au.

10. A. grandis Trin. Tufted perennial; stem 5-15 dm. high; leaf-blades 1-2 dm. long, 6-10 mm. wide, very seabrous, abruptly contracted at the ligules; panicle 1-2 dm. long, dense, contracted; empty glumes about $3 \mathrm{~mm}$. long, gradually tapering at the apex, light green, scarious-margined; lemma one-half to two-thirds as long, obtuse. Wet meadows: B.C.-Mont.-Neb.-N.M.-

11. A. asperifolia Trin. Tufted perennial; stem 3-6 dm. high; blades 5-15 $\mathrm{cm}$. long, 2-5 mm. wide, scabrous; panicle $5-10 \mathrm{~cm}$. long, narrow and dense; empty glumes broadly lanceolate, $2.5-3 \mathrm{~mm}$. long, usually abruptly pointed, of ten tinged with purple; lemma two-thirds to three-fourths as long, awnless; A. exarata minor Hook. A. Drummondii Torr. Wet meadows: Man.-Neb.N.M.-Calif.-B.C. Plain-Mont. Je-Au.

12. A. Rossae Vasey. Cespitose perennial; stem about $1.5 \mathrm{dm}$. high, smooth, ereet; leaf-blades $2-4 \mathrm{~cm}$. long, flat, $2 \mathrm{~mm}$. wide; panicle oblong, $2-4 \mathrm{~cm}$. long, dense; branches nearly erect, $1-2 \mathrm{~cm}$. long, very scabrous; empty glumes $2 \mathrm{~mm}$. 
long, broadly lanceolate, acute; lemma minutely toothed at the apex. Mountains: Wyo.-Colo.-N.M. Mont.-Subalp. Au.

13. A. variabilis Rydb. Tufted, dwarf perennial; stem 1-2-leaved, 1-2 $\mathrm{dm}$. high; basal leaves numerous, their blades $2-5 \mathrm{em}$. long; stem-leaves somewhat broader and often flat; panicle contracted, $3-6 \mathrm{~cm}$. long, about $5 \mathrm{~mm}$. wide; branches erect or nearly so, usually short; empty glumes $2 \mathrm{~mm}$. long, usually more or less purplish, nearly equal, acute; lemma $1.5 \mathrm{~mm}$. long, awnless. Mountains: B.C.-Alta.-Colo.-Calif. Mont.-Subalp. J1-S.

14. A. idahoensis Nash. Tufted perennial; stem slender, 1-4 dm. high; leaf-blades narrow, 4-9 $\mathrm{cm}$. long, '1-2 mm. wide, flaccid, somewhat seabrous; panicle oblong-ovoid, $5-12 \mathrm{~cm}$. long, $2.5-4.5 \mathrm{~cm}$. wide; empty glumes unequal, $1.5-2 \mathrm{~mm}$. long, acuminate, purple; lemma two-thirds to three-fifths as long as the first glume. A. tenuiculmis recta Nash. Mountain meadows: Wash.Mont.-Colo. Submont.-Subalp.

15. A. oregonensis Vasey. Tufted perennial; stem 3-6 dm. high; leafblades 5-10 $\mathrm{cm}$. long, 1-2 mm. wide, often involute; panicle $8-15 \mathrm{~cm}$. long, often nodding, flexuose; empty glumes purple, narrowly lanceolate, gradually acute; lemma slightly shorter than the empty glumes, obtuse. Meadows: Wash.Ore.-Wyo. Submont. Jl-Au.

16. A. oreophila Trin, Densely cespitose perennial; stems slender, 2-4 $\mathrm{dm}$. high; leaf-blades filiform-setaceous, involute; those of the stem slightly broader, about $1 \mathrm{~mm}$. wide, scabrous; panicle 1-2 dm. long; lower branches 5-10 $\mathrm{cm}$. long; empty glumes slightly unequal, about $2 \mathrm{~mm}$. long, pale or purple, aeute. A. hiemalis geminata Hitche., in part. Mountains: Que.-Me.-N.Y.Pa.-Sask.-Colo.-Utah-B.C. Boreal-Mont.-Subalp. Jl-S.

17. A. hyemalis (Walt.) B.S.P. Tufted perennial; stem 2-8 dm. high; leaf-blades $2-3 \mathrm{~mm}$. wide, flat, $5-10 \mathrm{~cm}$. long; panicle large and diffuse, 2-6 dm. long; spikelets crowded at the ends of the branches; empty glumes nearly equal, purplish or pale, about $2 \mathrm{~mm}$. long, acute or acuminate; lemma obtuse, two-thirds to three-fourths as long. A. scabra Willd. Open places: Lab.Fla.-Calif.-Alaska; Mex. Plain-Subalp.

18. A. geminata Trin. Cespitose perennial; stem $2-3 \mathrm{dm}$. high, glabrous, slender; leaf-blades about $0.5 \mathrm{~mm}$. wide, $5-10 \mathrm{~cm}$. long, the basal ones usually involute; those of the stem-leaves usually flat; inflorescence 5-15 $\mathrm{cm}$. long, 4-8 $\mathrm{em}$. wide; empty glumes about $3 \mathrm{~mm}$. long, acute; lemma two-thirds to threefourths as long, obtuse, bearing at the middle of the back a straight awn. Wet places: Alaska-B.C. Subalp.-Alp. Jl-Au.

19. A. Bakeri Rydb. Cespitose perennial; stem about $3 \mathrm{dm}$. high, erect, slightly geniculate below, glabrous; basal leaves numerous; leaf-blades flat, 1-2 mm. wide, 5-10 $\mathrm{cm}$. long; panicle ovoid, 8-10 $\mathrm{cm}$. long, open; empty glumes nearly equal, purple, $2-2.5 \mathrm{~mm}$. long, acuminate; lemma three-fourths as long, obtuse, bearing above the middle a dorsal straight awn. Mountains: Colo. Mont.

20. A. melaleuca (Trin.) Hitchc. Cespitose perennial; stem erect, $2-5 \mathrm{dm}$. high; leaf-blades flat, 1-2 mm. wide, 5-10 $\mathrm{cm}$. long; branches of the panicle flower-bearing to near the base; empty glumes copper-colored or purplish, lanceolate, gradually acute or acuminate, $2.5-3 \mathrm{~mm}$. long; lemma slightly shorter, bearing above the middle a straight awn. A. canina Rydb. (Fl. Colo.) Wet places: Alaska-B.C.-Colo. Mont.-Subalp. J1-Au.

\section{CALAMAgRÓSTis Adans. Reed-grass.}

Erect perennials. Inflorescence panieulate. Spikelets numerous, 1-flowered; flowers perfect; the rachilla usually produced beyond the flower; the prolongation with a hair-pencil. Empty glumes 2, persistent, narrow, keeled, acute or acuminate. Lemma much shorter, thickly hyaline, with a basal ring of long hairs, and a dorsal awn, Palet small, narrow, thin, hyaline. Styles short, distinet; stigmas plumose. 
Awn of the lemma geniculate, exserted; callus-hairs usually much shorter than the glume. Awns of the lemma greatly exceeding the empty glumes; plant tufted; leaf-blades involute.

Empty glumes very scabrous throughout; marcescent basal leaf-sheaths very long, loose and numerous.

Empty glumes nearly glabrous, except on the keels; marcescent basal leaf-sheaths short and few.

Awns of the lemma about equalling the empty glumes.

2. C. Vaseyi.

Empty glumes sharply keeled; spikelets strongly compressed; plant stoloniferous. 3. C. montanensis.

Empty glumes not strongly keeled; spikelets not strongly conpressed; plants tufted.

Leaves usually involute; panicle very dense.

Panicle very narrow, spike-like, usually red-purplish. 4. C. rubescens.

Panicle lance-oblong, usually pale green.

Leaves usually flat; panicle ovoid, open.

5. C. Suksdorfi

6. C. luxurians.

Awn of the lemma straight or nearly so, included; callus-hairs usually equalling the lemma (except in C. scopulorum and C. Cusickii).

Panicle open, the lower branches spreading; leaf-blades usually flat; callus-hairs nearly or quite equalling the lemma.

Empty glumes 4-6 mm. long, narrow, sharp-acuminate: awn of the lemma attached below the middle, exceeding the lemma. 7 , C. Langsdorfit.

Empty glumes 2-4 mm. long; awn of the lemma autached at or above the middle, shorter than the lemma.

Awn attached near the middle of the lemma; spikelets usually purple. Spikelets 3-4 mm. long; panicle loosely flowered. $\quad 8$. C. canadensis. Spikelets 2-2.5 mm. long; panicle densely flowered. 9. C. Macouniana.

Awn attached near the apex of the lemma; spikelets pale or white.

Panicle more or less contracted.

10. C. blanda.

Leaf-bladas flat or nearly so.

Empty glumes smooth or nearly so, except on the veins.

Callus-hairs copious, at least two-thirds as long as the lemma; plant with a rootstock.

Callus-hairs sparse, much shorter than the lemma.

Plant tall, 9-12 dm. high; sheaths bearded at the summit; plant with a rootstock.

Plant lower, 3-8 dm. high; sheaths not bearded; plant tufted.

Empty glumes very scabrous; plant tufted.

13. C. scopulorum.

eaf-blades strongly involute.

Panicle open.

Panicle dense, narrow, spike-like.

14. C. elongata.

15. C. lucida.

Spikelets $2 \mathrm{~mm}$. long; empty glumes thickish, barely acute or obtusish.

Spikelets 3-4.5 mm. long.

16. C. micrantha.

Plant scarcely cespitose; empty glumes long-acuminate.

Leaves filiform, soft; plant 4-6 dm. high, slender; empty glumes minutely scabrous on the veins.

17. C. neglecta.

Leaves stiff and hard; plant 8-12 dm. high; empty glumes scrongly scabrous.

Plant densely cespitose; empty glumes abruptly acute ot short-acuminate, very scabrous.

19. C. americana.

1. C. purpurascens $\mathrm{R}$. Br. Tufted perennial; stem $3-6 \mathrm{dm}$. high; leaves numerous and erowded at the base; blades of the basal leaves $2-4 \mathrm{dm}$. long, 4-5 mm. wide, scabrous, rigid, more or less involute; those of the stem 7-15 $\mathrm{cm}$. long; panicle spike-like, strict, 7-10 $\mathrm{cm}$. long, purplish; spikelets $6-7 \mathrm{~mm}$. long; lemma slightly shorter than the glumes, acute or acuminate; awn near the base, twisted below and bent at the middle. Mountains: Greenl.-S.D.-Colo.Calif.-Alaska. Mont.-Alp. Jl-S.

2. C. Vaseyi Beal. Tufted perennial; stem 3-7 dm. high, leafy; leaf-blades $1.5-2 \mathrm{dm}$. long, 3-7 mm. wide, the lower involute, the upper often flat; panicle spike-like, 7-10 cm. long, usually more or less purple; empty glumes $4-5 \mathrm{~mm}$. long, equal, lanceolate; lemma one-fourth shorter, obtuse; awn inserted one-third from the base and extending little beyond the empty glumes. Mountains: Ore. -Wash.-Mont. Alp.-Subalp. Ji-Au.

3. C. montanensis Scribn. Stoloniferous perennial; stem 2-4 dm. high, stiff, erect; leaf-blades $5-15 \mathrm{~cm}$. long, strongly involute, scabrous; panicle spikelike, 5-8 cm. long, dense; empty glumes narrowly lanceolate, acute, 4-6 mm. long, scabrous, pale or purple; lemma one-fourth shorter, thin, finely scabrous, awn borne one-third from the base. Dry plains: Sask.-S.D.-Ida.-Alta. Plain-Submont. J1-Au. 
4. C. rubescens Buckley. Cespitose perennial; stem 4-10 dm. high; leafblades 5-15 cm. long, involute, scabrous, stiff; panicle striet, spike-like, purplish, 5-15 $\mathrm{cm}$. long; empty glumes 4-5 $\mathrm{mm}$. long, acute, minutely scabrous; lemma about as long, awned below the middle. Grassy banks: B.C.-Alta.-Wyo.Calif. Submont.-Mont. Jl-Au.

5. C. Suksdorfii Scribn. Tufted perennial; stem 6-10 dm. high; leafblades 1-3 dm. long, mostly involute; panicles 7-12 $\mathrm{cm}$. long, narrow, but not spike-like, often lobed and interrupted; empty glumes 3-4 $\mathrm{mm}$. long, acute, pale, and somewhat translucent, nearly smooth; lemma one-fourth shorter, oblong, obtuse, 4-toothed, awned near the base. Open woods and banks: Sask.-Wyo.Calif.-B.C. Submont.-Mont. Je-Au.

6. C. luxurians (Kearney) Rydb. Tufted perennial; stem 1-1.5 m. high; leaf-blades flat, $1.5-3 \mathrm{dm}$. long, 4-5 mm. wide, scabrous; panicle $1-2 \mathrm{dm}$. long, ovoid, pale, open; empty glumes narrowly lanceolate, acute; lemma one-fourth or one-fifth shorter, nearly glabrous, awn-bearing near the base. C. Suksdorfii luxurians Kearney. Open woods: B.C.-Mont.-Colo.-Ida. Submont. JeJl.

7. C. Langsdorfii (Link) Trin. Perennial, with a rootstock; stem 3-6 $\mathrm{dm}$. high, erect, simple; leaf-blades 1-3 dm. long, 4-8 mm. wide, seabrous, usually flat and spreading; panicle 5-15 cm. long; empty glumes 4-6 mm. long, long-acuminate, strongly scabrous, lead-colored, brown or purplish; lemma onefourth shorter, scabrous, awned below the middle. Alpine-arctic situations: Greenl.-N.C.-Sask.-N.M.-Calif.-Alaska. Mont.-Alp. Jl-S.

8. C. canadensis (Michx.) Beauv. Perennial, with a rootstock; stems $5-15$ $\mathrm{dm}$. high, erect, simple; blades $1.5-3 \mathrm{dm}$. long, $2-8 \mathrm{~mm}$. wide, scabrous, usually flat; panicle 1-2 dm. long, open, usually purple; branches spreading; empty glumes 3-3.5 mm. long, acute, or (in var.. acuminata) $3.5-4 \mathrm{~mm}$. long and acuminate, scabrous; lemma slightly shorter, scabrous, awn-bearing near the middle; awn slender, nearly equalling the glumes. Banks and swamps: Newf.-N.C.N.M.-Calif.-Alaska. Plain-Subalp. JI-S.

9. C. Macouniana Vasey. Perennial; stem 6-10 dm. high, erect, somewhat branched below, leafy; leaf-blades flat, $1.5-2.5 \mathrm{dm}$. long; panicle $7-10 \mathrm{~cm}$. long, lanceolate or conic, open; spikelets crowded on the upper part of the branchlets; empty glumes about $4 \mathrm{~mm}$. long, purplish, acute, finely scabrous on the back; lemma equalling the empty glumes. Wet places: Man.-S.D.-Wash. PlainSubmont.

10. C. blanda Beal. Perennial, with a rootstock; stem 6-12 dm. high; leafe-blades $1.5-2 \mathrm{dm}$. long, 4-8 mm. wide, flat, scabrous; panicle $1.5-2 \mathrm{dm}$. long, loose, spreading; empty glumes about $3 \mathrm{~mm}$. long, long-acuminate, scabrous on the veins; lemma one-fourth shorter, thin, acutely toothed. C. pallida Vasey \& Scribn. Wet places: Colo.-Mont.-Wash. Submont. JI.

11. C. Scribneri Beal. Perennial, with a rootstock; leaf-blades flat, 1-2 dm. long, 4-5 mm. wide, scabrous; panicle contracted, lanceolate, 1-1.5 dm. long; branches flower-bearing to near the base; empty glumes brown or purple, about $4 \mathrm{~mm}$. long, lanceolate, acute or acuminate, lemma one-fourth shorter; awn attached below the middle, exceeding the lemma. C. dubia Scribn. Wet places: Alta.-Colo.-Wash.-B.C.; Que. Mont.-Subalp. Jl-Au.

12. C. Cusickii Vasey. Perennial, with a ereeping rootstock; stem 10-12 $\mathrm{dm}$. high; leaf-blades flat, 1-3 dm. long, 5-8 mm. wide; panicles about $1.5 \mathrm{dm}$. long, acute, narrow; branches flower-bearing to the base; glumes about $4 \mathrm{~mm}$. long, acute or acuminate, smooth, thin; lemma nearly as long as the empty glumes, acuminate; awn erect, inserted a little below the middle, slightly exceeding the lemma. Wet places: Ore.-Ida.-Calif. Jl.

13. C. scopulorum M. E. Jones. Tufted perennial; stem 3-8 dm. high; leaf-blades 1-3 dm. long, $6 \mathrm{~mm}$. wide, flat, pale; panicle narrow, 1-1.5 dm. long; empty glumes about $4 \mathrm{~mm}$. long, white or pale, acute, smooth except on the nerves; lemma nearly as long; awn attached below the middle, shorter than the lemma. Mountains and hills: Utah-Colo. Son.-Mont. Au-S. 
14. C. elongata (Kearney) Rydb. Tufted perennial; stem 7-12 dm. high; leaf-blades 1-3 dm. long, usually flat, 3-8 mm. wide, scabrous; panicle 1-2 dm. long, narrow but scarcely spike-like; empty glumes $3-4 \mathrm{~mm}$. long, acute, very scabrous; lemma somewhat shorter, scabrous; awn attached below the middle. C. hyperborea elongata Kearney. Wet meadows: Ont.-Pa.-Colo.-Calif.B.C. Plain-Mont. Jl-Au.

15. C. lucida Seribn. Perennial, with a slender rootstock; stem 2.5-4 dm. high, slender with few marcescent sheaths at the base; leaf-blades $5-13 \mathrm{~cm}$. long, 2-3 mm. wide, strongly involute, slightly scabrous on the margins and nerves; panicle 4.5-7 cm. long, ovoid to lanceolate, strongly flexuose; empty glumes about $3 \mathrm{~mm}$. long, short-acuminate, strongly keeled, minutely hispidulous on the keel; lemma slightly shorter; awn attached near the middle. C. laxiflora Kearney. Meadows: Wyo. Au.

16. C. micrantha Kearney. Perennial, with a slender, creeping rootstock; stems 4-6 dm. high, slender; leaf-blades 5-20 cm. long, 1-1.5 mm. wide, more or less involute, filiform; panicle $5-8 \mathrm{dm}$. long, densely-flowered, purple or pale; empty glumes $2 \mathrm{~mm}$. long, scabrous; lemma slightly shorter; awn attached at or below the middle. Wet places: Sask.-Colo. Plain-Mont. J-Au.

17. C. neglecta (Ehrh.) Gaertn. Perennial, with a rootstock; stem 4-6 dm. high, slender; leaves narrow, involute, soft, $5-15 \mathrm{~cm}$. long; panicle contracted, 6-10 $\mathrm{cm}$. long; branches mostly erect; empty glumes about $4 \mathrm{~mm}$. long, gradually acute; lemma about one-fourth shorter, obtuse; awn attached near the middle. C. stricta Trin. Wet places: Greenl--Me.-Wis.-Colo-Ore.-Alaska; Eu. Plain-Subalp. JI-S.

18. C. inexpansa A. Gray. Perennial, with a rootstock; stem usually simple, 8-12 dm. high; leaf-blades 2-3 dm. long, $4 \mathrm{~mm}$. wide or less, scabrous; panicle $1.5-2 \mathrm{dm}$. long, usually nodding at the summit; empty glumes $4-4.5 \mathrm{~mm}$. long, very scabrous throughout, gradually aeute; lemma scabrous, about as long, acutish; awn inserted below the middle, about equalling the lemma. Wet places: N.Y.-N.J.-S.D.-Colo.-Ida.-Wash.-B.C. Plain-Submont. JI$\mathrm{Au}$.

19. C. americana Scribn. Cespitose perennial, with numerous marcescent sheaths at the base; stem 3-6 dm. high, scabrous above; leaf-blades 1-3 dm. long, 4-5 mm. wide, usually more or less involute, scabrous, stiff; panicle contracted, 7-15 cm. long, spike-like; empty glumes 3-4 mm. long, very scabrous; lemma nearly as long, acute, scabrous; awn attached below the middle. $C$. hyperborea Kearney, not Lange. Wet meadows: Lab.-Vt.-Neb.-Colo.-Calif.-Alaska. Plain-Submont. J-Au.

\section{CALAMOVÍlfa Hack. Reed-grass, Sand-grass.}

Tall perennials with horizontal rootstocks and elongated narrow leaf-blades. Inflorescence a panicle. Spikelets flattened, 1-flowered, crowded, the rachilla articulated above the empty glumes and not prolonged beyond the flower. Empty glumes 2 , unequal, persistent, rigid, chartaceous, awnless, keeled, 1-nerved; lemma with a ring of long hairs at the base, enclosing a 2 -keeled palet and a perfect flower. Stamens 3. Styles distinct; stigmas plumose.

1. C. longifolia (Hook.) Hack. Perennial, with a long, scaly rootstock; stem 6-20 dm. high, stout, smooth, and glabrous; leaf-blades $2-3 \mathrm{dm}$. long, stiff, more or less involute; panicle $1-4 \mathrm{dm}$. long, pale, narrow; empty glumes $6-8 \mathrm{~mm}$. long, the first shorter than the second; lemma about as long as the second glume, glabrous; callus-hairs copious, half as long as the lemma. Calamagrostis longifolia Hook. Sandy soil: Ont.-Ind.-Colo.-Ida.-Sask. Plain-Submont.

\section{DESCHÁMPSIA Beauv. HAIR-GRAss.} Perennials or annuals. Inflorescence a terminal contracted or open paniele.
Spikelets 2-flowered, the rachilla articulated above the empty glumes and prolonged beyond the flowers. Empty glumes 2, persistent, keeled, acute, mem- 
branous, usually somewhat shining. Lemma thin-membranous, almost hyaline, entire or toothed, acute, obtuse, or truncate and denticulate at the apex, each bearing a slender dorsal straight or geniculate awn, which is twisted at the base. Palet narrow, 2-nerved. Stamens 3. Styles distinct; stigmas plumose.

Empty glumes not extending beyond the apex of the upper lemma; lower empty glume 1-nerved; densely cespitose tufted perennials.

Leaves neither stiff nor pungent.

Awn inserted one-third to one-fifth from the base of the lemma; branches of the inflorescence at last spreading or reflexed.

Awns long-exserted, at least half longer than the lemma.

Empty glumes 3-4 mm. long; leaves filiform, revolute, scarcely $1 \mathrm{~mm}$. wide; plant $2-3 \mathrm{dm}$. high.

1. D. curtifolia.

Empty glumes $4-5 \mathrm{~mm}$. long; leaves broader and often flat, $1.5-2.5 \mathrm{~mm}$. wide; plant $3-5 \mathrm{dm}$. high. $\quad 2$. D. alpicola.

Awns scarcely exserted beyond the lemma.

3. D. caespitosa.

Awn inserted near the base of the lemma, slightly if at all exceeding it; branches of the inflorescence ascending.

Leaves arcuate, strongly involute, very stiff and pungent.

Empty glumes extending beyond the apex of the upper lemma.

Spikelets usually dark purple; empty glumes lanceolate, purple, about $5 \mathrm{~mm}$. long. the lower 1-nerved.

Spikelets light green; empty glumes linear-lanceolate, both 3-nerved.

Spikelets 3-5 mm. long; tufted perennials.

Leaves filiform-involute; sheaths close; spikelets $3-4 \mathrm{~mm}$. long.

Leaves involute but not filiform, or the stem-leaves flat; upper sheaths loose; spikelets $4-5 \mathrm{~mm}$. long.

Spikelets $5-8 \mathrm{~mm}$. long; annuals.

8. D. ciliata,

9. D. calycina.

1. D. curtifolia Scribn. Basal leaf-blades $1-10 \mathrm{~cm}$. long, the cauline ones 1-2 cm. long; panicle small, 3-10 cm. long, its branches in 2's or 3's, or single, at last spreading; empty glume $3-4 \mathrm{~mm}$. long, lanceolate, acute; lemma nearly as long. D. brevifolia R. Br. D. brachyphylla Nash. Alpine ridges: Colo.Utah-Mont. Subalp.-Alp.

2. D. alpicola Rydb. Basal leaf-blades 1-2 dm. long; stem-leaves $1-4 \mathrm{~cm}$. long; panicle short, open, 8-15 cm. long, its branches in 2's to 5's, 3-6 cm. long, soon spreading; spikelets about $5 \mathrm{~mm}$. long; empty glumes lanceolate, acute; lemma nearly as long, hirsute at the base. Deschampsia caespitosa alpina Vasey. Alpine meadows: N.M.-Wyo.-Utah. Mont.-Alp. Jl-S.

3. D. caespitosa (L.) Beauv. Stem 3-10 dm. high; basal leaf-blades $2-5$ $\mathrm{cm}$. long, $1.5-3 \mathrm{~mm}$. wide, flat or in drier situations involute, rather firm; stemleaves 3-10 cm. long; panicles 1-3 dm. long, 5-15 cm. wide; empty glumes $3.5-5$ $\mathrm{mm}$. long, lanceolate, acute or acuminate; lemma 3-4 $\mathrm{mm}$. long, purple or leadcolored. Wet meadows and swamps. Newf.-N.J.-N.M.-Calif.-Alaska. Submont.-Subalp. Je-S.

4. D. confinis (Vasey) Rydb. Stem 3-9 dm. high, glabrous; leaf-blades 1-3 dm. long, more or less involute when dry; panicle narrow, 1-3 dm. long, the base often included in the upper sheath; empty glume unequal, 4-5 mm. long, lead-colored or purplish with straw-colored margins, lanceolate, acute; lemma nearly as long, lanceolate, acute. Wet places: s Calif. $-\mathrm{s}$ Utah-Ariz. Son. Je-Au.

5. D. pungens Rydb. Stem 3-4 dm. high, glabrous and shining, the base covered with subchartaceous sheaths from preceding season; leaf-blades bluish green or in age straw-colored, scabrous-pruinose; panicle open, with spreading branches; empty glumes subequal, $3.5-4.5 \mathrm{~mm}$. long, purplish, lanceolate, acute; lemma 3-3.5 mm. long, similar; awn attached at the base, about equalling the lemma. Near hot springs: Alta.-Wyo. Mont. Jl-Au.

6. D. atropurpurea (Wahl.) Seheele. Perennial, with a cespitose rootstock; stem glabrous, $1.5-5 \mathrm{dm}$. high; leaf-blades 2-5 mm. wide, $5-12 \mathrm{~cm}$. long, flat and flaceid; panicle narrow, 2-10 cm. long, with short ereet branches; lemma about $3 \mathrm{~mm}$. long, erose-truncate at the apex; awn attached about the middle, bent. D. latifolia (Hook.) Vasey. D. Hookeriana Scribn. Wet places: Greenl. -N.H.-Colo.-Calif.-Alaska;n Eu. Subalp.-Alp. Jl-S.

7. D. elongata (Hook.) Munro. Stem 3-10 dm. high, slender; leaf-blades 5-10 cm. long, $1 \mathrm{~mm}$. wide; panicle very narrow, 1-2 dm. long, with erect 
branches; empty glumes 3-4 mm. long, 3-nerved, green; lemma about $2 \mathrm{~mm}$. long, irregularly 5-toothed at the apex; awn inserted near the base, almost twice as long as the lemma. Wet places: B.C.-Calif.-Ariz.-Wyo.-Mont.; Mex. Submont. Je-Au.

8. D. ciliata (Vasey) Rydb. Stem 4-7 dm. high, comparatively stiff; leafblades 1-2 dm. long, about $2 \mathrm{~mm}$. wide; panicle elongated, with nearly erect branches; empty glumes minutely scabrous; lemma $3 \mathrm{~mm}$. long, erose-dentate at the apex; awn attached a little below the middle, $2-3$ times as long as the lemma. D. elongaia ciliata Vasey. Wet places: B.C.-Calif.-Ida. Submont. Мy-J.

9. D. calycina Presl. Annual, simple or branched at the base; stems 1-4 dm. high; leaf-blades $1-10 \mathrm{~cm}$. long, filiform; inflorescence ovoid, $3-20 \mathrm{~cm}$. long, with ascending branches; spikelets usually purplish; empty glumes linear-lanceolate, acuminate, 3-nerved; lemma $3 \mathrm{~mm}$. long, 3-toothed at the apex; awn attached near the middle, about 3 times as long as the lemma. Wet places: Yukon-B.C.-Ida.-Ariz.-Calif. Submont. My-Jl.

\section{TRISÈTUM Pers. FALSE $\mathrm{O}_{\mathrm{AT}}$.}

Annual or perennial tufted grasses, with flat leaf-blades. Inflorescence a spike-like contracted or open panicle. Spikelets usually 2-flowered, rarely 3-6flowered, the flowers perfect, or the upper one staminate. Empty glumes membranous, unequal, acute, entire at the apex, awnless, persistent. Lemma 2toothed at the apex, the teeth acuminate and often terminating in a bristle or slender awn; awn often twisted, inserted below the apex and arising between the teeth. Palet hyaline, 2-toothed. Styles distinct; stigmas plumose.

Inflorescence lanceolate, open; lower empty glume shorter than and scarcely more than half as broad as the upper; leaf-blades broader than the sheaths and therefore with auricles at the base.

Lemma about $7 \mathrm{~mm}$. long; sheaths hairy.

Lemma about $5 \mathrm{~mm}$. long; sheaths glabrous.

1. $T$, canescens.

Ovary pubescent at the apex; panicle loose; its branches spikelet-bearing above the middle. $\quad 2 . T$. cernuum.

Ovary glabrous; panicle denser; its branches spikelet-bearing to the base.

3. T. montanum.

Inflorescence dense, oblong or oblong-lanceolate; lower empty glume nearly as broad as the upper; leaf-blades not broader than the sheaths, not auricled.

Leaf-sheaths and blades long-hairy; upper part of the stem densely pubescent.

Leaf-sheaths and blades glabrous or the lowest sheath short-pubes. 4 . subspicatum. hajrs; stem glabrous or sed

h. 1 . majus.

1. T. canescens Buckl. Perennial, with a rootstock, more or less cespitose; stem 5-10 dm. high; leaf-blades $1-1.5 \mathrm{~cm}$. long, about $5 \mathrm{~mm}$. wide; panicle $1.5-3$ $\mathrm{dm}$. long, narrow; branches spikelet-bearing to near the base; spikelets 2-3flowered; awn about twice as long as the lemma. Open woods and hillsides: B.C.-Mont.-Calif. Submont. Je-Au.

2. T. cernuum (Kuntb) Trin. Perennial, with a rootstock; stem 6-10 dm. high; leaves glabrous; blades 1-2 dm. long, 5-7 mm. wide; panicle 1-2.5 dm. long, open and nodding; spikelets 2-3-flowered; lemma about $6 \mathrm{~mm}$. long, slightly seabrous above; awn twice as long as the lemma. Stream-banks: Alaska-Ida.Calif. Submont. Je-S.

3. T. montanum Vasey. Perennial, with a rootstock; stem 4-10 dm. high, glabrous; leaf-blades glabrous, $1.5-2.5 \mathrm{dm}$. long, $3-5 \mathrm{~mm}$. broad; panicle $1-2 \mathrm{dm}$. long, with ascending branches; spikelets about $5 \mathrm{~mm}$. long; upper glume $4 \mathrm{~mm}$. long, broadly lanceolate; lemma about $4 \mathrm{~mm}$. long; awn about twice as long as the lemma. Moist places among bushes: Wyo.-N.M.-Utah. Submont.Mont. J1-S.

4. T. subspicatum (L.) Beauv. Cespitose perennial; stems 2-4 dm. high; leaf-blades 3-15 cm. long, 2-3 mm. wide, flat or in age involute; paniele oblong, often obtuse, usually more or less purple, $2-8 \mathrm{~cm}$. long; empty glumes lanceolate, acuminate or acute, slightly shorter than the lemma; awn bent and twisted, 7-8 mm. long. T. subspicatum molle A. Gray. T. spicatum (L.) Richter. Mead- 
ows and hillsides: Greenl.-N.H.-N.M.-Calif.-Alaska; Eurasia. Subalp.Alp. Jl-Au.

5. T. majus (Vasey) Rydb. Cespitose perennial; stems $2-5 \mathrm{dm}$. high, glabrous; leaf-blades $5-15 \mathrm{~cm}$. long, 1-4 mm. wide, usually flat; panicle of ten interrupted, acute, green, rarely purple, 6-15 $\mathrm{cm}$. long; empty glume lanceolate, acuminate, about $6 \mathrm{~mm}$. long, usually a little longer than the lemma; awn bent and twisted, 7-8 mm. long. T. subspicatum Am. auth., not Beauv. Meadows: Mont.-Colo.-Utah-B.C. Submont.-Subalp

\section{GRAPHÉPHORUM Desv.}

Erect perennials, with short rootstocks. Inflorescence paniculate. Spikelets 2-4-flowered, flattened, the rachilla hirsute and extending beyond the flowers. Empty glumes 2, somewhat shorter than the lemma, thin-membranous, acute, keeled, shining. Lemma membranous, obseurely nerved, entire, sometimes short-awned just below the apex, shining; awn straight. Styles distinct; stigmas plumose.

Empty glumes nearly equal; inflorescence narrow.

Sheaths and upper surface of the leaves pubescent; spikelets 3 -flowered.

Sheaths and leaves scabrous.

Empty glumes barely equalling the lemma; spikelets 2-flowered; rudiment longhaìry.

2. G. Wolfii.

Empty glumes longer than the lemma; spikelets 3-4-flowered; rudiment shorthairy.

Empty glumes unequal; inflorescence open.

3. G. Brandegei.

4. G. Shearii.

1. G. muticum (Bolander) Greene. Stem 4-8 dm. high; leaf-blades 1-4 $\mathrm{dm}$. long, 3-6 mm. wide; inflorescence 1-2 dm. long; empty glumes 6-7 mm. long, acute, scabrous on the back; lemma $5-6 \mathrm{~mm}$. long, minutely scabrous; awn very short, or almost none. Trisetum muticum Seribn. Meadows: Calif. -Wash.-Mont. Submont.-Subalp. Je-Jl.

2. G. Wolfii Vasey. Stem erect from a decumbent base; leaf-blades 5-15 $\mathrm{cm}$. long, $1.5-3 \mathrm{~mm}$. wide; panicle $5-10 \mathrm{~cm}$. long, with few branches; empty glumes 4-5 mm. long, slightly shorter than the lemma, acuminate; lemma 2-toothed at the apex; awn about $1 \mathrm{~mm}$. long. Mountain meadows: Colo. Subalp.

3. G. Brandegei (Scribn.) Rydb. Stem 3-6 dm. high, smooth; leaf-blades 1-2 dm. long, 4-8 mm. wide, scabrous on both sides; panicle 1-2 dm. long, more or less interrupted; empty glumes scabrous on the keel, 6-7 $\mathrm{mm}$. long; lemma 5-6 mm. long, obtusely 2-lobed; awn borne below the apex, often obsolete. Wet meadows: Mont.-Colo.-Calif.-Wash. Submont.-Mont. Je-Au.

4. G. Shearii (Scribn.) Rydb. Stem 5-7 dm. high, minutely pubescent at the nodes; leaf-blades 1-1.5 dm. long, $3-4 \mathrm{~mm}$. wide, minutely scabrous below, smooth above; panicle $1-2 \mathrm{dm}$. long; spikelets usually 2-flowered; empty glumes acute; the first $3 \mathrm{~mm}$. long, 1-nerved, lance-subulate, the second $4 \mathrm{~mm}$. long; lemma about $4 \mathrm{~mm}$. long, slightly 2 -cleft at the apex; awn straight, $1-3 \mathrm{~mm}$. long. Trisetum argenteum Seribn. T. Shearii Scribn. Among rocks: Colo. Mont. Au.

\section{AVÈNA (Tourn.) L. OATs.}

Annuals or perennials. Inflorescence a contracted or open panicle. Spikelets usually large, erect or pendulous, usually 2 -several-flowered, rarely 1 -flowered, the rachilla articulated between the flowers, the lower flowers perfect, the upper ones often staminate or wanting. Empty glumes 2, membranous, exceeding or shorter than the lemma, persistent. Lemma 5-9-nerved, rounded on the back, the apex frequently shortly 2-toothed, bearing a dorsal twisted and geniculate awn, the upper empty ones or those enclosing staminate flowers awnless. Palet 2-cleft or 2-toothed, narrow. Styles distinct. Grain deeply furrowed, usually pubescent.

Perennials, with rootstocks; empty glumes 5-12 $\mathrm{mm}$. long; lemma hairy at the base.

Empty glumes shorter than the flowers; panicle lax, narrow, and somewhat nodding; plant not tufted.

1. A. striata. 
Empty glumes longer than the flowers; panicle narrow and spike-like, strict; plant tufted.

Plant 1-1.5 dm. high; leaves strongly involute; callus of the lemma and prolongation of the rachilla long-hairy. 2. A. Mortoniana.

Plant 2-4 dm. high; leaves mostly flat; callus and rachilla short-hairy.

3. A. Hookeri.

Annuals; panicle open; empty glumes over $2 \mathrm{~cm}$. long; spikelets 2-4-flowered.

Lemma hairs, at least at the base; awn strongly twisted. $\quad 4$. A. fatua.

Lemma glabrous; awn scarcely twisted.

5. A. sativa.

1. A. striata Michx. Stem 3-6 dm. high, glabrous; leaf-blades $2-15 \mathrm{~cm}$. long, 3-6 mm. wide, scabrous above; panicle 7-12 cm. long; spikelets 3-6-flowered; empty glumes glabrous, the first 5-7 mm. long, 1-nerved, the second 6-8 $\mathrm{mm}$. long, 3-nerved; lemma 7-9 mm. long; awn 8-10 mm. long. In woods: N.B.Pa.-N.M.-B.C. Mont.-Subalp. Je-Au.

2. A. Mortoniana Seribn. Stem erect, 1-1.5 dm. high, glabrous, striate; leaf-blades $5-15 \mathrm{~cm}$. long, $2 \mathrm{~mm}$. wide or less, rigid, convolute, glabrous on both sides or pubescent above; panicle 2-4 cm. long; spikelets about $1 \mathrm{~cm}$. long, 2flowered; the first glume 1-nerved, the second 3-nerved; lemma 8-9 $\mathrm{mm}$. long, glabrous; awn 7-8 mm. long, twisted below and geniculate. Mountain tops: Colo. Alp.

3. A. Hookeri Scribn. Stem 3-6 dm, high; leaf-blades flat, firm, 5-15 cm. long, 1.5-3 mm. wide, glabrous, scabrous on the margins; panicle $8-12 \mathrm{~cm}$. long; spikelets 12-17 mm. long, 3-6-flowered; empty glumes about $1 \mathrm{~cm}$. long, thin, greenish; lemma about $8 \mathrm{~mm}$. long, brownish; awn over $1 \mathrm{~cm}$. long, bent and twisted. A. americana Scribn. Ridges and hillsides: Sask.-S.D.-Colo.Alta. Submont.-Mont. Je-Jl.

4. A. fatua L. Annual; stem 3-12 dm. high, stout, glabrous; leaf-blades flat, 1-3 dm. long, 5-15 mm. wide; panicle open, 1-3 dm. long; empty glumes 2$2.5 \mathrm{~cm}$. long, smooth; lemma $12-18 \mathrm{~mm}$. long, in the typical form covered with long brown hairs; awn $2-2.5 \mathrm{~cm}$. long. WILD OATs. A variety with lemma glabrous except at the base is $A$. fatua glabrata Peterm. Fields and waste places: Sask.-Wis.-Mo.-N.M.-Calif.-B.C.; native of Eurasia and established as a weed in grain fields. Plain-Submont.

5. A. sativa L. Erect annual, closely resembling the preceding; stem glabrous, 6-12 dm. high; panicle open, 1-3 dm. long, usually with drooping spikelets; empty glumes 2-3 cm. long, glabrous; lemma $15-20 \mathrm{~mm}$. long, glabrous; awn 2-3 cm. long. OAts. Occasionally escaped and established: Me.-Fla.Tex.-Yukon. My-S.

\section{ARRHENÁTHERUM Beatuv. OAT-GRASS.}

Tall perennials. Inflorescence paniculate. Spikelets 2-flowered, the lower flower staminate, the upper one perfect or pistillate, the rachilla articulated above the empty glumes and prolonged beyond the flowers. Empty glumes 2, persistent, thin-membranous, keeled. Lemma more rigid, somewhat toothed at the apex, that of the lower flower bearing near the base a long dorsal twisted and geniculate awn, that of the upper one awnless, or short-awned below the apex. Palet 2-keeled, hyaline, narrow. Stamens 3. Styles short, distinct; stigmas plumose. Grain hardly sulcate.

1. A. elatius (L.) Beauv. Perennial, with a cespitose rootstock; stem glabrous, 6-12 dm. high, ereet; leaf-blades flat, 5-30 $\mathrm{cm}$. long, 2-8 $\mathrm{mm}$. wide, scabrous; panicle 1-3 dm. long, narrow, with ereet bianches; lemmas about 8 $\mathrm{mm}$. long, that of the lower flower with a bent and twisted awn about $1 \mathrm{~cm}$. long. Fields and waste places: Me.-Ga.-Calif.-B.C.; nat. from Eu. Je-Jl.

\section{DANTHŌNIA DC. WILd OAT-GRAss.}

Usually perennial, all ours cespitose. Inflorescence a contracted or open diffuse panicle. Ligules usually represented by a hairy ring. Spikelets 3-manyflowered, the flowers perfect or the upper ones staminate, the rachilla pilose, articulated between the glumes and prolonged beyond them. Empty glumes 2, persistent, usually extending beyond the lemma, keeled, acute or acuminate. 
Lemma rounded on the back, the margins often ciliate, 2-toothed at the apex, the teeth often awned; awn arising between the teeth, more or less flattened, very often twisted at the base, and frequently geniculate. Palet obtuse or 2-toothed, 2-keeled, hyaline. Styles distinct; stigmas plumose.

Lemma hairy on the back; inflorescence spike-like, with short, erect branches. Empty glumes 15-20 mm. long, long-acuminate.

Empty glumes 8-13 mm. long, acute.

Empty glumes 11-13 mm. long, conspicuously nerved, broad; teeth of the lemma subulate, 1-2 $\mathrm{mm}$. long.

Empty glumes 8-10 mm. long, narrow; teeth of the lemma ovate, often only 0.5 mm. long.

Lemma glabrous on the back.

Empty glumes acute; inflorescence spike-like, with erect branches; stem-leaves erect.

4. $D$, intermedia.

Empty glumes long-acuminate; inflorescence racemiform or spikelet solitary: stemleaves spreading or ascending.

Lemma abruptly acuminate; spikelets usually 2-10, on spreading peduncles.

Lemma not abruptly acuminate; spikelet usually solitary, if more than one, the peduncles erect. 6 . D. unispicata.

1. D. Parryi Scribn. Stem 3-6 dm. high, invested by the marcescent leafsheaths at the base; leaf-blades $5-20 \mathrm{~cm}$. long, about $3 \mathrm{~mm}$. wide; spikelets 3-7 in the panicle, 5-7 flowered; lemma about $14 \mathrm{~mm}$. long, ovate; awn 12-14 mm. long, flat below, twisted. Mountain valleys: Alta.-N.M. Submont.-Mont. $\mathrm{Je}-\mathrm{Au}$.

2. D. thermalis Seribn. Stem $3-5 \mathrm{dm}$. high; sheaths papillate-pilose; lower leaf-blades hairy, the upper glabrous, $5-15 \mathrm{~cm}$. long, involute; spikelets 5-10, 5-7-flowered; lemma $5 \mathrm{~mm}$. long, thinly pilose on the back; awn about $7 \mathrm{~mm}$. long. D. spicata pinetorum Piper. Near hot springs and in woods: B.C.Wash.-Wyo. Submont.-Mont. Jl-Au.

3. D. spicata (L.) Beauv. Stems $3-7$ dm. high, glabrous; leaf-blades scabrous, $2-15 \mathrm{~cm}$. long, $2 \mathrm{~mm}$. wide, usually involute, of ten ciliate; panicle $3-5 \mathrm{~cm}$. long; spikelets 5-10,5-8-flowered; lemma sparingly pubescent with silky hairs; teeth usually about $0.5 \mathrm{~mm}$. long; awn $5-8 \mathrm{~mm}$, long. Woods and hillsides: Newf.-N.C.-N.M.-B.C. Submont.-Mont. My-Jl.

4. D. intermedia Vasey. Stem 3-5 dm. high; sheaths more or less pubescent at least at the mouth; panicle $3-6 \mathrm{~cm}$. long; spikelets $5-10$, about 5 -flowered, 12-15 $\mathrm{mm}$. long; empty glumes acute; lemma 6-8 $\mathrm{mm}$. long, hairy on the margin; teeth about $2 \mathrm{~mm}$. long; awn stout, $6 \mathrm{~mm}$. long. D. Cusickii (Williams) Hitche. Hillsides and mountains: Que.-N.M.-Calif.-B.C. Mont.-Alp. $\mathrm{Jl}-\mathrm{Au}$.

5. D. californica Bolander. Stems decumbent, 3-10 dm. long, glabrous; leaf-blades 5-20 cm. long, 3-5 mm. wide, flat, with involute tips; spikelets 5-10flowered; empty glumes lanceolate, purple, glabrous, $15-20 \mathrm{~mm}$. long; lemma glabrous, except the base and the margins, $7 \mathrm{~mm}$. long; awn $7-8 \mathrm{~mm}$. long. Wet meadows: B.C.-Calif.-Colo.-Mont. Submont.-Mont. My-Au.

6. D. unispicata Munro. Stems 1-3 dm. high, ascending or erect; sheaths villous with long white hairs, with papillose bases; leaf-blades $5-15 \mathrm{~cm}$. long, 2-3 mm. wide, flat, with involute tips; spikelets 4-7-flowered; empty glumes lanceolate, $12-20 \mathrm{~mm}$. long, glabrous; lemma about $8 \mathrm{~mm}$. long; awns 7-8 $\mathrm{mm}$. long. Meadows and hills: B.C.-Calif.-Wis.-Alta. Submont. Je-Au.

\section{SPARTINA Schreb. MarSh-GRASS.}

Tall perennials, with creeping scaly rootstocks. Spikelets. 1-flowered, crowded and imbricate in two rows, in one-sided spikes, the rachis extending beyond the spikelets. Empty glumes 2, firm-membranous, narrow, unequal, keeled. Lemma a little longer and broader than the second empty glume. Palet thin and almost hyaline, obscurely 2 -nerved, often exceeding the lemma. Styles elongate; stigmas thread-like, papillose or short-plumose.

First glume awn-pointed, equalling the lemma; second glume long-awned. 1. S. pectinata. First glume acute, shorter than the lemma; second glume acute. 
1. S. pectinata Bose. Stem 1-2 m. high, glabrous, stout; leaf-blades 3-6 dm. long, 6-15 mm. wide, scabrous on the margin, usually flat, becoming involute; spikes 5-30, often short-peduncled, $5-12 \mathrm{~cm}$. long; rachis rough on the margins; spikelets 12-14 $\mathrm{mm}$. long; first empty glume equalling the lemma. S. cynosuroides A. Gray, not Willd. S. Michauxiana Hitche. In swamps and streams: N.S.-N.J.-Tex.-Colo.-Ore.-Mack. Plain-Submont. Au-O.

2. S. gracilis Trin. Stem $3-10 \mathrm{dm}$. high, glabrous; leaf-blades $2-4 \mathrm{dm}$. long, 2-6 mm. wide, flat or involute; spikes 4-8, appressed, usually short-stalked, $3-5 \mathrm{~cm}$. long; spikelets $6-8 \mathrm{~mm}$. long; first glume half as long as the second and the lemma. Saline soil: B.C.-Calif.-Ariz.-Kans.-Sask. Plain-Submont. $\mathrm{Au}-\mathrm{S}$.

\section{BeCKmánnia Host. Slough Grass.}

Tall grasses with flat leaf-blades. Spikelets 1-2-flowered, orbicular, compressed, in two rows on several erect spikes. Empty glumes 2, membranous, saccate, obtuse or abruptly acute. Lemma narrow, thin-membranous. Palet hyaline, 2-keeled. Styles distinet; stigmas plumose. Grain oblong, free.

1. B. erucaeformis (L.) Host. Stem 4-10 dm. high, glabrous, simple; leaf-blades 7-20 $\mathrm{cm}$. long, 4-8 $\mathrm{mm}$. wide, scabrous; panicle simple or compound; spikes 1-2 cm. long; spikelets 2-3 mm. long, 1-2-flowered; empty glumes saccate, abruptly acute; lemma acute or awn-pointed. Wet ground: YukonCalif.-N.M.-Ia.-Ont. Plain-Mont. Jl-S.

\section{SCHEDONNÃRDUS Steud.}

Annuals, with involute, subulate leaf-blades. Spikelets 1-flowered, acuminate, sessile, alternate on opposite sides of the long rachis, forming several long, slender spikes. Empty glumes 2, persistent, narrow, acuminate, somewhat unequal. Lemma longer, rigid, enclosing the narrow shorter palet. Styles distinct; stigmas plumose.

1. S. paniculatus (Nutt.) Trelease. Annual; branched at the base; stems 2-5 dm. high, seabrous; leaf-blades $2-5 \mathrm{~cm}$. long, 1-2 mm. wide, flat, stiff; spikelets nearly $3 \mathrm{~mm}$. long, sessile and appressed; empty glumes hispid on the keel, the second much longer than the first and nearly equalling the lemma. S. texanus Steud. Sandy soil, especially river banks. Man.-III.-Tex.-N.M.Sask. Plain-Submont. J1-S.

\section{CHLÒRIS Sw.}

Usually perennials. Spikelets 1 -flowered, often sessile, with 1 or more empty usually awned glumes above the perfect flower, crowded in 2 rows, in verticillate or approximate spikes, the rachilla prolonged beyond the flower. Empty glumes 2 , persistent, unequal, keeled, narrow, acute or acuminate, awnless or awnpointed. Lemma acute, usually long-awned, rarely nearly awnless. Palet folded, 2-keeled. Styles distinct; stigmas plumose.

1. C. brevispica Nash. Perennial; stem 1-3 dm. high; leaf-blades 1-6 cm. long, 1-3 mm. wide, scabrous above and on the margins; spikes $6-10$, finally spreading, $2.5-4.5 \mathrm{~cm}$. long; spikelets (exclusive of the awns) about $2.8 \mathrm{~mm}$. long; empty glumes lanceolate, acute; lemma $2.5 \mathrm{~mm}$. long; awn about $2 \mathrm{~mm}$. long; the fourth glume (second lemma) empty, about $1.5 \mathrm{~mm}$. long, with an awn of about the same length. Sandy soil: Tex.-e Colo.-N.M. Son. Jl-Au.

\section{3. bouteloùa lag. Grama, Grama Grass, Mesquite Grass, Buffalo Grass}

Perennials or annuals, mostly tufted. Spikelets few or numerous, 1- or 2flowered, crowded in 2 rows and forming few to many one-sided, more or less curved sessile spikes; rachis usually conspicuously prolonged beyond the spikelets. Lower flowers perfeet; the upper when present staminate. Empty glumes 2, narrow, acute, unequal, keeled. Lemma usually thinner and broader, 3nerved, the nerves excurrent. Lemma of the upper 1-3 imperfect flowers borne at the end of a rachilla, 3-awned. Styles distinet; stigmas plumose. 
Spikes 1-4, rarely more; spikelets 25 or more.

Spikes usually more than one.

Awns manifestly arising from between the lobes of the lemma; annual.

1. B. polystachya.

Awns terminating the lobes of the lemma; cespitose tufted perennials.

Stem densely villous below.

2. B. eriopoda.

Stem glabrous.

Rachilla bearing the rudimentary glumes and awns glabrous: second glume strongly papillose-hispid on the keel. 3 . B. hirsuta.

Rachilla bearing the rudimentary glumes and awns with a tuft of long hairs at the apex; second glume scabrous and sparingly long-ciliate on the keel.

Spike solitary; tufted annual.

Spikes 12 or more; spikelets in each few, less than 12.

4. B. gracilis.

5. B. procumbens.

6. B. curtipendula.

1. B. polystachya (Benth.) Torr. Cespitose annual; stem geniculate, ascending, 1-3 dm. high; leaf-blades 1-5 cm. long, 1-2 mm. wide, flat, scabrous, ciliate with a few hairs; spikes $4-8$, about $2 \mathrm{~cm}$. long; spikelets $1.5-2.5 \mathrm{~mm}$. Jong; first glume very small, the second shorter than the lemma, purplish; awns not more than half as long as the glumes. Six-ween Grama. River valleys and sandy soil: Tex,-Colo,-Utah-Calif.; Mex. Son.

2. B. eriopoda Torr. Stems $3-6 \mathrm{dm}$. high, densely villous at least below; sheaths glabrous; leaf-blades 5-15 $\mathrm{cm}$. long, 1-2 mm. wide; spikes 2-5, erect on short woolly pedicels, $2-5 \mathrm{~cm}$. long; spikelets 2 -flowered, $6-8 \mathrm{~mm}$. long exclusive of the awns; empty glumes glabrous. Black Grama. Dry soil: Tex.-Colo.Utah-Calif.; Mex. Je-O.

3. B. hirsuta Lag. Stem 1-5 dm. high, glabrous; leaf-blades $2-12 \mathrm{~cm}$. long, $2 \mathrm{~mm}$. wide or less, flat, rough, sparingly papillose-hirsute near the base; spikes 1-4, 1-5 cm. long, the rachis conspicuously prolonged beyond the spikelets; spikelets numerous, 5-6 $\mathrm{mm}$. long; lemma 3-cleft to near the middle. HaIRY Grama. Dry or sandy soil: Minn.-Ill.-Tex.-Ariz.-S.D.; Fla.; Mex. Plain-Submont. Je-Au.

4. B. gracilis (H.B.K.) Lag. Stem 1.5-4 dm. high, smooth and glabrous; leaf-blades 3-10 cm. long, $2 \mathrm{~mm}$. wide or less, flat or when dry involute, usually glabrous; spikes 1-3, often strongly curved, $2-5 \mathrm{~cm}$. long; spikelets numerous, about $6 \mathrm{~mm}$. long; first glume about half as long as the second. B. oligostachya (Nutt.) Torr. Blue Grama. Plains and prairies: Man,-Wisc.-Miss.Ariz.-Alta.; Mex. Plain-Submont.

5. B. procumbens (Durand) Griffiths. Stems prostrate or ascending, 1-3 dm. high; leaf-blades 2-5 cm. long; spikes solitary, 1-3 cm. long; spikelets 4-5 $\mathrm{mm}$. long; first empty glume half as long as the seeond one; lemma pubescent on the veins, 3-lobed, the middle lobe 2-toothed; middle awn equalling the glumes and twice as long as the lateral ones. B. prostrata Lag. SIX-WEek Grama. Sandy plains: Tex.-Colo--Ariz.; Mex. Son.-Submont. Jl-D.

6. B. curtipendula (Michx.) Torr. Perennial, with more or less cespitose rootstocks; stem 3-10 dm. high, smooth and glabrous; leaves $5-15 \mathrm{~cm}$. long, 2-4 $\mathrm{mm}$. wide, scabrous above; spikes many, 6-15 $\mathrm{mm}$. long, spreading or reflexed; spikelets 4-12, divergent, 7-10 $\mathrm{mm}$. long; empty glumes scabrous especially on the keel; lemma 3-toothed at the apex. B. racemosa Lag. Atheropogon curtipendulum Fourn. Tall Grama. Dry soil: Ont.-N.J.-Tex.-Ariz.-Sask.; Mex. Plain-Submont. J1-S.

\section{LEPTÓCHLOA Beauv.}

Annuals or perennials. Spikelets small, ustally close, 2-several-flowered, rarely 1-flowered, flattened, sessile, in two rows, forming many long slender spikes. Empty glumes 2, keeled, a little unequal, usually shorter than the spikelets. Styles distinct; stigmas plumose.

1. L. filiformis (Lam.) Beauv. Annual, branched at the base; stems $3-10$ $\mathrm{dm}$. high, erect, glabrous; leaf-blades $5-20 \mathrm{~cm}$. long, 2-6 $\mathrm{mm}$. wide, seabrous; panicle 1-4 dm. long; spikes numerous, slender, ascending or spreading, the lower 5-15 cm. long; spikelets usually 3 -flowered, $2 \mathrm{~mm}$. long; lemma 2-toothed at the apex, ciliate on the nerves. L. mucronata (Michx.) Kunth. Dry soil: Fla.-Va.-Ill.-N.M.-Calif.; Mex., W. Ind. Son. Jl-S. 


\section{BƯlbilis Raf. Buffalo Grass.}

Creeping, stoloniferous, dioecious perennials. Staminate spikelets 2- or 3flowered, crowded in 2 rows on one side of the short, flattened rachis, in small spikes. Empty glumes 2, membranous, lanceolate. Lemma similar. Pistillate spikelet 1-flowered. First empty glume membranous, usually small, the second largest, firm, concave at the base, 3-lobed at the apex. Lemma narrow, nearly hyaline, enclosing a broad, 2-nerved, convolute palet. Styles distinet, long; stigmas elongate, short-plumose.

1. B. dactyloides (Nutt.) Raf. Stoloniferous perennial; stems bearing the staminate flowers 1-3 dm. high, erect, exceeding the leaves, glabrous; those bearing the pistillate flowers 1-10 $\mathrm{cm}$. long, shorter than the leaves; leaves 2-10 $\mathrm{cm}$. long, 1-2 mm. wide, papillose-hirsute; staminate spikelets 2 or 3 , approximate, $0.5-1.5 \mathrm{~cm}$. long; spikelets 4-5 $\mathrm{mm}$. long, flattened, 2-3-flowered; pistillate spikelets in the axils of the leaves, ovoid, the empty glumes indurate. Buchloe dactyloides (Nutt.) Engelm. Plains and prairies: Minn.-Ark-Tex--N.M.N.D.; Mex. Plain-Submont. Je-Jl.

\section{SCLEROPÒGON Philippi.}

Dioecious perennial herbs with tufted rootstocks. Spikelets in narrow panicl ss, very unlike. Staminate spikelets compressed, linear, many-flowered; empty glumes nearly equal, lanceolate; lemma 3-toothed at the apex or entire, about equalling the glumes and the palet. Pistillate spikelets cylindric, 3-5flowered; glumes lanceolate, the upper larger; lemma cylindric, rigid, enveloping the palet, 3-lobed and 3-awned.

1. S. Karwinskyanus (Fourn.) Benth. Stems ascending, 1-3 dm. high, glabrous; leaf-blades firm, flat, 1-4 cm. long, 1-2 mm. wide; inflorescence spikelike; staminate spikelets $2-5 \mathrm{~cm}$. long, 7-25-flowered; empty glumes $7-8 \mathrm{~mm}$. long; lemma almost as long, slightly 3 -toothed at the apex and awn-pointed; pistillate spikelets few-flowered; empty glumes very unequal, 7-14 mm. long; lemma about $1 \mathrm{~cm}$. long, with three awns often $5-6 \mathrm{~cm}$. long. Dry plains: Tex. -Colo.-Ariz.-Mex. Son. My-O.

\section{PHRAGMìtes Trin. Reed, Cane-grass.}

Tall perennials with long creeping rootstocks. Leaves broad and flat. Spikelets numerous in large terminal panicles, 3-several-flowered, the lower flower staminate, the rest perfect; rachilla articulated between the flowers and covered with long hairs. Empty glumes keeled, narrow, acute, the first much shorter than the second. Lemma similar, long-acuminate, 3-nerved. Palet hyaline, much shorter, 2-keeled. Styles short; stigmas plumose.

1. P. phragmites (L.) Karst. Stem glabrous, $1.5-5 \mathrm{~m}$. high, stout; leafblades $1.5-4 \mathrm{dm}$. long, $8-50 \mathrm{~mm}$. wide, flat, glabrous; panicle $1.5-3 \mathrm{dm}$. long, ample; spikelets numerous; lemma 10-12 mm. long, long-acuminate. $F$. communis Trin. Swamps: Newf.-Fla.-Calif-B.C.; Mex., W. Ind., Eurasia.
Plain-Submont. Au-O.

\section{MUNRÒa Torr. False Buffalo Grass,}

Low prostrate herbs, dichotomously branched and fasciculate at the nodes. Leaves short, rigid, crowded at the nodes and at the ends of the branches. Spikelets few, almost sessile in the axils of the leaves and almost concealed in the leaf-rosettes. Empty glumes hyaline, nerveless, acute. Lemmas larger, 3-nerved, retuse or 3-toothed at the apex, the upper one or two often sterile. Palet hyaline. Stamens 3. Styles elongated; stigmas barbellate or short-
plumose. Grain free.

1. M. squarrosa (Nutt.) Torr. Stems 1-2 dm. long; sheath short and inflated, long-hairy at the throat; leaf-blades 1-2.5 $\mathrm{cm}$. long, $1-2 \mathrm{~mm}$. wide, rigid, spreading, scabrous, pungent; spikelets $2-5$-flowered; empty glumes shorter than the lemma, which is about $5 \mathrm{~mm}$. long, 3-toothed and awn-pointed. Dry plains: Sask.-S.D.-Tex.-Ariz.-Alta. Plain-Submont. Au-O. 


\section{BLEPHARIDÁCHNE Hack.}

Low branched perennials or biennials, with erowded involute leaves. Spikelets few in subcapitate panicles, 4-flowered, the two lower flowers neutral, the uppermost reduced to a stipitate villous 3-cleft awn. Empty glumes membranous, carinate, 1-nerved, acute, glabrous, the first somewhat shorter. Lemma 3-nerved, villous on the nerves, 3 -lobed, with the middle lobe longest; lobes in the neutral flowers obtuse, in the perfect ones attenuate. Palet shorter, 2-keeled, 2-nerved, 2-toothed at the apex, imperfectly developed in the neutral flowers. Stamens 2. Styles 2; stigmas elongated, minutely hairy. Grain free. [Eremochloe S. Wats., not Eremochloa Buese.]

1. B. Kingii (S. Wats.) Hack. Stems $3-7 \mathrm{~cm}$. high, glabrous; leaf-blades 1-2 cm. long, rigid, revolute-setaceous, pungent; empty glumes $7 \mathrm{~mm}$. long, acuminate, purplish; lemma of the neutral flowers $4 \mathrm{~mm}$. long, very villous at the base; that of the perfect flower glabrous at the base, awned; rudiment 3awned. Dry barren foot-hills: Nev.-Utah-Ariz. Son. My.

\section{TRIPLÃ SIS Beauv. SAND-GRASS.}

Tufted perennials. Panicles in our species narrow. Spikelet short-pedicellate, 2-6-flowered, the flowers perfect or the uppermost staminate, the rachis glabrous, articulate between the flowers. Empty glumes keeled, 3-nerved, shorter than the lemma. Lemma dorsally rounded at the base, 3-nerved, deeply 2-lobed at the apex, with an awn arising between the lobes. Palet shorter, with 2 ciliate keels, compressed. Styles short; stigmas plumose.

1. T. purpurea (Walt.) Chapm. Tufted perennial (?); stem $3-10 \mathrm{dm}$. high, erect, prostrate or decumbent, branched below; leaf-blades 1-6 $\mathrm{cm}$. long, $2 \mathrm{~mm}$. wide, rigid, scabrous, sparsely ciliate; paniele $2-7 \mathrm{~cm}$. long; spikelets $2-5-$ flowered, 5-8 $\mathrm{mm}$. long; lemma oblong, 2-lobed at the apex, with erose-truncate lobes; midvein excurrent in a short point. Sandy places: Me.-Fla.-Tex.N.M.-Neb. Plain. Au-S.

\section{DASYÓCHLOA Willd.}

Stoloniferous perennials. Inflorescence densely paniculate. Spikelets flat, 5-10-flowered; flowers perfect. Empty glumes 2, membranous, ovate, nearly equal. Lemma oblong, more or less pubescent, at least on the veins, cleft to the middle, with an awn between the lobes, 3-nerved. Palet broad, prominently 2-keeled. Styles short, distinct; stigmas plumose.

1. D. pulchella (H.B.K.) Willd. Densely tufted; stem $3-10 \mathrm{~cm}$. high, fasciculately branched; leaf-blades 1-3 $\mathrm{cm}$. long, about $1 \mathrm{~mm}$. wide, involute, striate, curved, scabrous; inflorescence small and compact; spikelets 5-10flowered, 5-8 $\mathrm{mm}$. long; empty glumes white, lanceolate, $5-7 \mathrm{~mm}$. long, acuminate; lemma 4-6 mm. long, oblong, cleft to the middle. Triodia pulchella H.B.K. Hills and plains: Tex.-W Wyo,-Calif.; Mex. Son. Ap-O.

\section{ERIONEÙRON Nash.}

Tufted, low perennials. Panicles small, dense, subcapitate. Leaves thick, with thickened white margins. Spikelets several-flowered. Empty glumes narrow, acuminate. Lemma broad, 3-nerved, pubescent on the nerves below, with long silky white hairs, acuminate at the apex, entire or slightly 2-toothed, the terminal awn rising between the minute teeth. Style short.

1. E. pilosum (Buckley) Nash. Stem 0.5-3 dm. high, leafy mostly at the base; leaf-sheath pilose-ciliate at the summit; blades erect, thick, folded, papilloseciliate, 2-8 cm. long; spikelets 3-8, crowded, 1-1.5 cm. long; lemma 5.5-6 mm. long, acuminate, entire or slightly toothed at the apex; awn 1-1.5 mm. long. Tricuspis acuminata Munro. Triodia acuminata Vasey. Dry gravelly or sandy soil: Kans.-Nev.-Ariz.-Tex. Son.-Submont. Ap-O.

\section{TRIDENS R. \& S.}

Perennials with rootstocks, ours tufted. Panicles open, or in ours narrow, sometimes spike-like. Spikelets 3-many-flowered, the flowers perfect, or the 
upper one staminate. Empty glumes keeled, usually shorter than the lemma. Lemma 3-nerved, pilose on the nerves and the margins, entire or 2-toothed at the apex. Palet shorter, 2-keeled. Styles short; stigmas plumose.

Second empty glume 1-nerved.

Second empty glume 3-5-nerved.

1. T. muticus.

2. T. elongatus.

1. T. muticus (Torr.) Nash. Stem 2-5 dm. tall, glabrous; leaf-blades 2-12 $\mathrm{cm}$. long, 2-3 mm. wide, usually involute when dry, scabrous; panicle narrow, 6-15 cm. long; spikelets 6-9-flowered, 10-12 $\mathrm{mm}$. long; lemma 4-5 $\mathrm{mm}$. long, obscurely and irregularly lobed at the obtuse or rounded apex, not mucronate. Hills: Tex.-Colo.-Ariz.; Mex, Son. Je-O.

2. T. elongatus (Buckley) Nash. Stem $3-10 \mathrm{dm}$. tall, scabrous; leaf-blades erect or ascending, 4-25 $\mathrm{cm}$. long, 2-3 $\mathrm{mm}$. wide, long-acuminate, scabrous; panicle narrow, $12-25 \mathrm{~cm}$. long; spikelets 8-10-flowered, 10-14 $\mathrm{mm}$. long; lemma 5-6 mm. long, obtuse or minutely 2-toothed, mucronate. Plains: Mo.-Colo. -Ariz.-Tex. Austral-Son. Je-N.

\section{DIPLÁCHNE Beauv.}

Tall tufted perennials. Panicles composed of several long spike-like or raceme-like branches. Spikelets linear, sessile or nearly so, the flowers perfect or the uppermost staminate. Empty glumes persistent, keeled, acute, unequal. Lemma larger, 2-toothed and mucronate or short-awned between the teeth. Palet hyaline, 2-nerved and 2-keeled. Styles distinet; stigmas plumose.

1. D. acuminata Nash. Tufted perennial; stem $3-6 \mathrm{dm}$. high; leaf-blades erect, 1-3 dm. long, 3-4.5 $\mathrm{mm}$. wide, scabrous; racemes numerous, erect or ascending, the longer 7-15 cm. long; spikelets $10-12 \mathrm{~mm}$. long; empty glumes $8-11 \mathrm{~mm}$. long; lemma $6-7 \mathrm{~mm}$. long, acuminate; awn $0.75-1.33 \mathrm{~mm}$. long. Wet or meist ground: Ark.-Neb.-Colo. Plain. Je-Au.

\section{REDFik̀ldia Vasey. Blow-out Grass, Sand-Grass.}

Tall perennials, with long creeping scaly rootstocks. Panicles diffuse, with long capillary branches. Spikelets numerous, $1-3$-flowered, the flowers perfect. Empty glumes about equal, 1-nerved. Lemma large, compressed-keeled, with a basal ring of hairs, 3-nerved, awn-pointed or acute. Palet shorter, 2-nerved. Styles long; stigmas short, plumose.

1. R. flexuosa (Thurber) Vasey. Stem 4-12 dm. high; leaf-blades $3-6 \mathrm{dm}$. long, $2-4 \mathrm{~mm}$. wide, usually involute; panicle $2-5 \mathrm{dm}$. long; spikelets about 6 $\mathrm{mm}$. long, 1-3-flowered; lemma scabrous, twice as long as the acute glabrous empty glumes. Sand hills: S.D.-Okla.-Colo.-Wyo. Plain. Au-S.

\section{KOELÈria Pers. June Grass.}

Tufted annuals or perennials. Panicles narrow, contracted, spike-like. Spikelets numerous, erowded, 2-5-flowered, the flowers perfect or the uppermost one or two staminate, shining. Empty glumes narrow, unequal. Lemma similar to the second, the upper ones gradually smaller. Palet hyaline, 2-keeled, 2-toothed. Styles very short; stigmas plumose.

1. K. gracilis Pers. Stem 3-6 dm. high, slender, glabrous up to the inflorescence; leaf-blades narrow, 1-2 mm. wide, usually involute, glabrous or the lower short-pilose, 4-12 cm. long; panicle spike-like, 4-15 cm. long; spikelets shining, pale; empty glumes lanceolate, acute, scabrous; lemma similar, more hyaline and slightly shorter. $K$. cristata, in part. K. nitida Nutt. Prairies and plains: Ill.-Tex.-Calif.-B.C.; Eur. Plain-Submont. JI-S.

\section{ERAGRÓSTIS Beauv. Stink-Grass, SkUnk-grass.}

Tufted annuals or perennials, sometimes prostrate or creeping; some species dioecious. Spikelets numerous, singly or in fascicles, 2-many-flowered, the flowers perfect or unisexual. Empty glumes unequal. Lemma large, 3-nerved, usually broad. Palet shorter, prominently 2 -nerved and 2 -keeled, often ineurved and persistent on the rachis. Stamens 2 or 3 . Styles short; stigmas plumose. 
Plant extensively creeping, rooting at the nodes: plant dioecious.

Plant not creeping, not rooting at the nodes; flowers perfect.

Annuals, much branched, ascending or decumbent and geniculate at the base.

Spikelets about $3 \mathrm{~mm}$. broad; first empty glume only slightly shorter than the

Second.
Spikelets 1.5-2 mm. broad; first empty glume only two-thirds as long as the second.

Inflorescence open; branches at last more or less spreading; spikelets dark green or lead-colored.

Inflorescence narrow; branches erect or strongly ascending. Purshit. yellowish green.

Perennials, rigid, erect, often tufted.

Spikelets scattered on the long branches.

Branches of the panicle widely spreading in age.

Branches of the panicle erect or strongly ascending. Spikelets 3-9-flowered, on pedicels much longer. Spikelets clustered on short branches.

4. E. lutescens.
5. E. pectinacea.
6. E. trichodes.
7. E. neo-mexicana

8. E. secundiflora.

1. E. hypnoides (Lam.) B.S.P. Stem 5-45 em. long, branched, glabrous; floral branches erect, $3-15 \mathrm{~cm}$. high; leaves about $5 \mathrm{~cm}$. long or less, $1-2 \mathrm{~mm}$. wide, flat; spikelets 10-35-flowered, 4-15 $\mathrm{mm}$. long; empty glumes unequal, the first one-half to two-thirds as long as the second; lemma about $2.5 \mathrm{~mm}$. Iong; lateral veins prominent; glumes of the pistillate spikelets more acute than those of the staminate ones. E. replans Nees. Sandy or gravelly shores: Vt.-Ont, -Neb.-N.M.-Fla.-B.C.-Ida.-Calif.;Mex., W.Ind. Plain-Submont. Au-S.

2. E. megastachya (Koel.) Link. Stem 1-6 dm. tall; leaf-blades $7-18 \mathrm{~cm}$. long, 2-6 mm. wide, flat, smooth beneath, scabrous above; panicles $5-15 \mathrm{~cm}$. long; spikelets 8-35-flowered, 5-16 mm. long, very flat; empty glumes acute; lemma obtuse, 2-2.5 mm. long. E. major Host. STink Grass. Waste places and cultivated grounds: Ont.-Fla.-Calif.-Mont.; Mex.; nat. from Eu. Plain-Submont. My-S.

3. E. Purshii Schrad. Stem 1-4 dm. tall, smooth; leaf-blades 4-9 cm. long, 1-2 mm. wide; panicle open, $7-20 \mathrm{~cm}$. long; spikelets $5-15$-flowered, $3-8 \mathrm{~mm}$. long; lemma acute, firm, about $1.5 \mathrm{~mm}$. long. Dry or sandy places: Ont.-Fla. -Ariz.; Mex. Plain-Submont. Je-O.

4. E. lutescens Scribn. Stems 1-2 dm. high, glabrous; leaf-blades $2-5 \mathrm{~cm}$. long, $2-3 \mathrm{~mm}$. wide, flat; panicle narrow, 4-7 cm. long; spikelets $2-3 \mathrm{~mm}$. long, 3-12-flowered; first glume about $1 \mathrm{~mm}$. long, the second $1.3 \mathrm{~mm}$. long; lemma obtuse, about $2 \mathrm{~mm}$. long, 3-nerved. Sandy banks: Wash.-Ida.-Nev. San. JI-S.

5. E. pectinacea (Michx.) Steud. Stem 3-8 dm. high, ereet, rigid; leafblades 1-3 dm. long, 4-8 $\mathrm{mm}$. wide, flat, sparingly villous at the base; panicle $1.5-6 \mathrm{dm}$. long, purple or purplish, strongly bearded in the axils; spikelets $5-15-$ flowered, 3-8 mm. long; empty glumes acute, subequal; lemma $1.75-2 \mathrm{~mm}$. long. Dry or sandy soil: N.H.-Fla.-Tex.-N.M.-S.D. Plain. Au-S.

6. E. trichodes (Nutt.) Nash. Stem 6-12 dm. high; sheaths pilose at the throat; leaf-blades 1.5-7 dm. long, 2-4 mm. wide; panicle 2-7 dm. long, narrow; lower axils sometimes bearded; spikelets usually pale, 3-9-flowered, 5-9 mm. long; empty glumes subequal; lemma acute, $2-3 \mathrm{~mm}$. long. Sandy soil: Ohio-
Ark.-Tex.-N.M.-Neb. Plain-Son.

7. E. neomexicana Vasey. Stem 4-8 dm. high, usually branching near the base; leaf-blades flat, 4-10 mm. broad; panicle oblong, 2-4 dm. long, open; spikelets 5-8 mm. long, 8-15-flowered; lemma hispidulous on the keel near the acute apex; palet one-third shorter, ciliate. (?) E. limbata Fourn. (older name).

8. E. secundiflora Presl. Stems 1.5-10 dm. high, erect, simple; leaf-blades 5-30 $\mathrm{cm}$. long, 2-4 $\mathrm{mm}$. wide, flat; panicle 4-15 $\mathrm{cm}$. long, the branches erect or ascending; spikelets erowded, sessile or nearly so, strongly flattened, 8-40flowered, 6-20 mm. long, 3-5 mm. wide; empty glumes acute, equal; flowering glumes $3-3.5 \mathrm{~mm}$. long, acute, usually purple-margined. Dry or sandy soil: Mo.-La.-Tex.-N.M.-Colo.; Mex. Son. Au-S. 


\section{CATABRÒsA Beauv. Brook-Grass.}

Creeping or floating aquatic perennial. Panicles open, with slender spreading or reflexed branches. Spikelets 2- (rarely 3- or 4-) flowered, with the rachilla articulate between the flowers. Empty glumes unequal, broad, thin, very obtuse. Lemma strongly 3-nerved, longer than the empty glumes. Palet 2keeled, nearly as long. Styles distinct; stigmas plumose.

1. C. aquatica (L.) Beauv. Stem 1-3 dm. high, bright green, flaccid; leafblades $3-12 \mathrm{~cm}$. long, 2-6 mm. wide, flat, obtuse; panicle $3-20 \mathrm{~cm}$. long, open; branches whorled; spikelets $2.5-3.5 \mathrm{~mm}$. long; first glume about $1 \mathrm{~mm}$., the second nearly $2 \mathrm{~mm}$. long; lemma $2-2.5 \mathrm{~mm}$. long, 3-nerved, erose-truncate at the apex. In water: Lab.-Que.-Colo.-Utah-Alaska; Eurasia. Submont.Subalp. Je-Au.

\section{SPHENÓPHOLIS Scribn.}

Tall tufted perennials. Panicles usually narrow. Spikelets numerous, 2-3flowered, shining. First empty glume narrow, 1-nerved, acuminate, the second much broader, obovate when spread, obtuse or truncate, 3-nerved. Lemma narrower than the second glume, obtuse or acute. Palet narrow, 2-nerved. Styles short; stigmas plumose. [Eatonia Raf.]

Second empty glume much wider than the lemma, rounded or truncate and somewhat cucullate at the apex.

Intermediate nerves of the second glume almost as prominent as the lateral ones; leaf-blades firm, much broader than the sheaths and therefore with prominent auricles:"

1. $S$, robusta.

Intermediate nerves of the second glume faint, the lateral ones strong; leaf-blades soft, not much wider than the sheaths; auricles not prominent. 2 . S. oblusata. Second empty glume oblanceolate, not much wider than the lemma, obtuse or acute.

Second empty glume rather firm, as well as the lemma obtusish. 3. S. intermedia.

Second empty glume thin and with a broad, scarious margin, acutish; lemma acute.

4. S. pallens.

1. S. robusta (Vasey) Heller. Stem 4-10 dm. high, erect, glabrous; leafblades firm, dark green, 1-3 dm. long, 4-8 mm. wide, scabrous; panicle dense, usually decidedly lobed; spikelets $2.5-3 \mathrm{~mm}$. long; first glume linear-subulate, about $1.5 \mathrm{~mm}$. long, the second euneate, about $2 \mathrm{~mm}$. long, firm, very seabrous; lemma about $2 \mathrm{~mm}$. long, obtuse. Eatonia robusta Rydb. River banks: Neb.N.M.-Ariz.-Wash. Plain. My-Jl.

2. S. obtusata (Michx.) Scribn. Stem 3-7 dm. high, erect, glabrous; leafblades 3-20 cm. long, $2-5 \mathrm{~mm}$. wide, scabrous; panicle $5-15 \mathrm{~cm}$. long, dense and spike-like, strict; spikelets crowded, $2.5-3 \mathrm{~mm}$. long; first glume linear-subulate, the second cuneate, $1.5 \mathrm{~mm}$. long and about as broad; lemma $1.5-2 \mathrm{~mm}$. long, obtuse. E. obtusata A. Gray. Prairies, meadows and valleys: Mass.-Fla.Ariz-Mont.; Mex. Plain-Submont. Ap-Au.

3. S. intermedia Rydb. Stem 6-8 dm. high, striate, shining; leaf-blades $8-15 \mathrm{~cm}$. long, $3-5 \mathrm{~mm}$. wide, usually flat; inflorescence rather narrow and dense; first empty glume about $2 \mathrm{~mm}$. long, subulate, scabrous on the back. $E$. intermedia Rydb. Meadows: Sask.-N.M.-Wash. Plain-Submont. Jl-S.

4. S. pallens (Spreng.) Seribn. Stem glabrous, 3-10 dm. high; leafblades $5-15 \mathrm{~cm}$. long, $2-6 \mathrm{~mm}$. wide, scabrous; panicle $7-20 \mathrm{~cm}$. long, usually nodding, lax; spikelets $3-3.5 \mathrm{~mm}$. long; first empty glume subulate, slightly shorter than the second; lemma lanceolate, acute, about $3 \mathrm{~mm}$. long. E. pennsylvanica A. Gray. Open woods and among bushes: N.B.-Ga.- N.M.-B.C. Plain-Submont. Je-Au.

\section{MÉlica L. Melic-grass.}

Perennials with rootstocks, the stem often bulbous at the base. Panicles in our species narrow, often raceme-like. Spikelets rather few, erect or nodding, 1-several-flowered, the lower flowers perfeet, sometimes 1 or 2 staminate, and the upper neutral. Empty glumes membranous or hyaline, unequal in length. Lemma larger, membranous, the lateral nerves vanishing in the broad hyaline margins; upper empty lemmas gradually smaller, convolute and enclosing each other, forming an obovate or clavate mass. Palet shorter than the lemma, 2-keeled. Styles distinct; stigmas plumose. 
Lemma notched at the apex, awned.

Lemma neither notched nor awned.

Lemma attenuate at the apex.

First empty glume $4 \mathrm{~mm}$. long; second 5-6 mm. long. Lemma obtuse.

glume $6 \mathrm{~mm}$. long; second about $8 \mathrm{~mm}$. long.

Stem bulbous at the base.

Panicle narrow; lemma $7-8 \mathrm{~mm}$. long.

Spikelets usually nodding, flattened; second empty glume shorter than the first flower. $4 . M$. spectabilis. Spikelets erect, terete; second empty glume as long as the first flower.

Panicle open; lemma $6 \mathrm{~mm}$. long. Stem not bulbous at the base.

5. M. bella.

6. M. Macbridei.

7. M. Porteri.

1. M. Smithii (Porter) Vasey. Perennial with a rootstock; stem 7-12 dm. high, scabrous; leaf-blades 1-2 dm. long, 6-12 mm. wide, scabrous; panicle 1-3 dm. long, its branches at last spreading or reflexed; spikelets 3-6-flowered; first empty glume 4-6 mm. long, obscurely 3-nerved; second glume 6-8 $\mathrm{mm}$. long, 5-nerved; lemma about $10 \mathrm{~mm}$. long, strongly nerved; awn $3-5 \mathrm{~mm}$. long. $M$. retrofracta Suksd. Damp shady places: Mich.-Wyo.-Ore.-Wash. Mont. $\mathrm{Jl}-\mathrm{Au}$.

2. M. subulata (Griseb.) Scribn. Stem with a bulbous base, 5-10 dm. high, smooth; leaf-blades 1-2 dm. long, 5-12 mm. broad, scabrous; paniele narrow, the erect pedicels swollen just below the spikelets; spikelets 5 -6-flowered; empty glumes acute, scabrous on the keel and ciliate at the apex; lemma about $12 \mathrm{~mm}$. long, with scattered hairs below, attenuate. Woods: n Calif.-Mont.Alta.-Alaska. Mont. My-Au.

3. M. Pammelii Scribn. Stem with tuberous base, $5-10 \mathrm{dm}$. high; leaves flat, 1-3 dm. long; panicle flexuose, with ereet branches, scabrous; spikelets 3-6flowered, lanceolate or oblong; empty glumes obtuse or acutish; lemma 9-10 $\mathrm{mm}$. long, 9-nerved, lanceolate, acuminate, broadly scarious-margined; palet densely ciliate, fringed along the nerves. Parks: Wyo. Submont. Jl.

4. M. spectabilis Scribn. Stem 3-9 dm. high; leaf-blades 1-2 dm. long, $2-5 \mathrm{~mm}$. wide, scabrous; panicle narrow; spikelets $10-12 \mathrm{~mm}$. long, 5-7-flowered, usually purple; lower empty glume $5 \mathrm{~mm}$. long, the upper 6-7 $\mathrm{mm}$. long, acutish; lemma $7-8 \mathrm{~mm}$. long, minutely scabrous. M. scabrata Piper \& Beattie. Hillsides and meadows: B.C.-Ore-Colo,-Mont. Submont-Mont. Je-Au.

5. M. bella Piper. Stem 4-6 dm. high, simple; leaf-blades 1-3 dm. long, 3-5 $\mathrm{mm}$. wide, scabrous above; panicle narrow; spikelets $10-15 \mathrm{~mm}$. long, 6-9flowered; empty glumes obtuse, the first $6 \mathrm{~mm}$. long, the second about $8 \mathrm{~mm}$. long; lemma about as long, obtuse. $M$. bulbosa Geyer. Meadows and hillsides: Wash.-Ore.-Utah-Colo-Alta, Submont-Mont. My-Au.

6. M. Macbridei Rowland. Stem slender, 2-5 dm. high, as well as the sheaths hispidulous-scabrous; leaf-blades $1-4 \mathrm{~mm}$. wide, flat; panicle open; rays 1-3 at each node, some sessile, others peduncled and reflexed; spikelets 2-5flowered, 7-13 mm. long; first glume $4 \mathrm{~mm}$. long, 3-nerved; second glume $6 \mathrm{~mm}$. long, 5-nerved; lemma $6 \mathrm{~mm}$. long, thick, scabrous, obtusely 2-fid. Dry slopes: Ida. Je.

7. M. Porteri Scribn. Perennial, with a rootstock; stem 4-7 dm. high, smooth; leaf-blades 1-2 dm. long, 2-5 mm. wide, scabrous; panicle narrow, 12-15 em. long; spikelets 4-5-flowered, nodding, 10-13 mm. long; empty glumes obtuse or acutish, the first about $3 \mathrm{~mm}$., the second $5 \mathrm{~mm}$. long; lemma $3-5 \mathrm{~mm}$. long, scabrous. M. parviflora (Porter) Scribn. Plains and hills: Tex.-Kans.Colo.-Ariz, Submont.-Mont. Je-S.

\section{DÁCTYLIS L. ORChaRD-GRass.}

Tall perennials, with creeping rootstocks. Panicles contracted, with the spikelets crowded at the ends of the branches in unilateral head-like clusters. Spikelets 3-5-flowered, the flowers perfect or the uppermost staminate. Empty glumes unequal, 1-3-nerved, mueronate, the second the larger. Lemma more rigid, ciliate on the keel, mucronate or short-awned. Palet nearly as long, 2keeled. Styles distinct; stigmas plumose. 
1. D. glomerata L. Stem 6-12 dm. high, smooth; leaf-blades 7-25 $\mathrm{cm}$. long, 2-6 mm. wide, flat, scabrous; panicle 7-20 $\mathrm{cm}$. long; branches ascending or spreading in flower, ereet in fruit; lemma $5-6 \mathrm{~mm}$. long, pointed or short-awned. Fields and waste places: N.B.-Fla.-Calif-B.C.; nat. from Eu. PlainMont. Je-Jl.

\section{Brìza L. Quaking Grass, Quake-grass.}

Annuals or perennials, with open panicles. Spikelets few, nodding, flattened, broad, many-flowered, the flowers perfect. Empty glumes strongly concave, thin-membranous, 3-5-nerved, somewhat unequal. Lemmas imbricate, broader than the empty glumes, 5-many-nerved. Palet much shorter, hyaline, 2-keeled and 2-nerved. Styles distinct; stigmas plumose.

1. B. maxima L. Stem 3-5 dm. high, glabrous; leaf-blades 1-2 dm. long, $3-6 \mathrm{~mm}$. wide, scabrous on the veins; spikelets $2-10$, nodding, $1-2 \mathrm{~cm}$. long, 8-12 $\mathrm{mm}$. wide; empty glumes nearly orbicular, glabrous; lemma similar, but more or less pilose. Fields and waste places: Mass.-W. Ind.-Colo.-Calif.; adv. from Eurasia. Plain-Submont.

\section{Distíchlis Raf. Alkali Grass, Salt-grass, Spike-grass.}

Tufted dioecious perennials, with creeping scaly rootstocks. Inflorescence paniculate. Staminate spikelets many-flowered, very flat. Rachilla continuous. Empty glumes narrow, acute, keeled, membranous. Lemma broader, membranous. Pistillate spikelets few-flowered, less flattened. Lemma nearly coriaceous, broad. Palet compressed, the keels narrowly winged. Styles thickened at the base, moderately long; stigmas plumose.

Pistillate spikes 4-5 mm. wide; their floral glumes about $1.5 \mathrm{~mm}$. wide in side-view; palet scabrous-ciliate on the keels; leaf-blades $2 \mathrm{~mm}$. wide or less. $1 . D$. stricta.

Pistillate spikes $5-8 \mathrm{~mm}$. wide; their floral glumes about $2 \mathrm{~mm}$, wide in side-view: palet

distinctly dentate on the margins; leaf-blades usually over $2 \mathrm{~mm}$. wide. 2 . $D$. dentata.

D. stricta (Torr.) Rydb. Stem 1-4 dm. high, erect or decumbent at the base; leaf-blades erect, $5-15 \mathrm{~cm}$. long, more or less involute, long-attenuate; panicle of the pistillate plant 3-6 cm. long, dense and spike-like; spikelets 8-15 $\mathrm{mm}$. long; empty glumes lanceolate, acuminate, about $5 \mathrm{~mm}$. long; the second a little broader than the first, scarious-margined; lemma $5-6 \mathrm{~mm}$. long, acute, straw-colored with greenish nerves; palet 4-5 mm. long; panicle of the staminate plant looser, 3-10 cm. long; spikelets more flattened, $1-2.5 \mathrm{~cm}$. long, strawcolored; lemma narrower, 6-7 mm. long. D. spicata Coult \& Nels., not Greene. Alkaline soil: Sask.-Tex,-Ariz,-B.C.-Wash. Plain-Submont. Je-S.

2. D. dentata Rydb. Stem 1-3 dm. high, very leafy; leaf-blades $5-12 \cdot \mathrm{cm}$. long, 2-3.5 mm. wide, flat or slightly involute; panicle of the pistillate plant 4-8 $\mathrm{cm}$. long, 2-2.5 cm. wide; spikelets 1-2 cm. long, 5-8 mm. wide, 7-17-flowered; empty glumes lanceolate, about $5 \mathrm{~mm}$. long, short-acuminate; lemma ovate in lateral view, $6 \mathrm{~mm}$. long, short-acuminate; palet nearly as long; panicle of staminate plant nearly as in the preceding. Alkaline soil: Sask.-Wash.

\section{PÒa L. Blue-grass, Meadow-grass.}

Annuals or perennials, rarely dioecious, with paniculate inflorescence. Spikelets 2-6-flowered, flat, the flowers perfect or in some species unisexual, the rachis articulate between the flowers. Empty glumes persistent, strongly keeled, acute, the first usually 1-nerved, the second 3-nerved. Lemma usually longer, more or less keeled, acute or obtuse, awnless, 5-nerved, often pubescent on the keel and marginal nerve, as well as the rachis, the hairs near the base sometimes long and curled (cobweb). Palet shorter than the lemma, 2-keeled and 2-nerved. Styles short; stigmas plumose.

Annuals, but tufted; spikelets 3-5-flowered.

\section{ANNUAE.}

Cobweb at the base of the lemma present, although scant in some species; lemma acute or acutish, except in $P$ compressa and $P$. lanata, and usually strongly keeled.

Intermediate nerves of the lemma strong.

Branches of the inflorescence in fruit ascending, the lower in 3's or 4's; lemma acutish; cobweb copious; rootstock creeping.

II. Pratenses. 
Branches of the inflorescence in fruit reflexed or at least spreading; lemma usually acuminate or very acute; cobweb scant or sometimes none.

Spikelets many, light green; branches of the inflorescence numerous, the lower in 3's, or 4's, or 5's; rootstock creeping.

III. Platyphyllat.

Spikelets few, usually more or less purple, except in $P$. leptocoma; branches of the inflorescence few, the lower usually in 2's, racely in 3's, spikeletbearing towards the ends.

Intermediate nerves of the lemma faint or obsolete.

Stem compressed; lemma obtuse.

IV. REFLEXAE.

Stem not compressed; lemma acute or acuminate.

V. COMPRESSAE.

Branches of the panicles reflexed; rootstock creeping. VI. APERTAE.

Branches of the panicles not reflexed.

VII. TRIELORAE.

Cobweb wanting.

Spikelets rounded at the base; empty glumes very broad and their keel strongly arched; low tufted perennials, with short open panicle and broad leaves.

VIII. ALPINAE.

Spikelets acute at the base; empty glumes narrower, not strongly arched on their keels.

Plants with horizontal creeping rootstocks; not bunch-grasses.

Spikelets strongly compressed; lemma strongly keeled, strongly 5-nerved, conspicuously scabrous; glumes very acute. IX. WHEELERIANAE.

Spikelets not strongly compressed; lemma neither strongly compressed nor strongly nerved (except in $P$. pratensiformis), not conspicuously scabrous.

Lemma acuminate, dark purple; innovations extravaginal.

Lemma obtuse or acutish, green or merely tinged with purple; innovations both extra- and intravaginal. XI. ARIDAE.

Plants without extravaginal rootstocks; densely tufted bunch-grasses.

Lemma 3-4 mm. long.

Low alpine plants, with narrow panicles of few purplish spikelets; lemma ovate.

Slender plants, 4-5 dm. high, with open panicles; lemma narrowly lanceolate in side-view. XIII. MULTNomaE.

Lemma $5 \mathrm{~mm}$. long or more; plants comparatively robust.

Spikelets decidedly flattened; lemma acute and keeled on the back. Pubescence on the nerves of the lemma, if any, not stronger than on the internerves; flowers perfect.

Inflorescence dense and spike-like. XIV. EPILEs.

Inflorescence open; branches spikelet-bearing towards their ends. $\mathrm{XV}$. GRACILLIMAE.

Pubescence of the nerves of the lemma villous or pilose, that of the internerves none or almost none; plants dioecious.

XVI. Fendlerianae.

Spikelets little flattened; lemma rounded on the backs towards the apex, almost straight, obtuse.

XVII. BUCKLEYANAE.

\section{ANNUAE.}

Low, 1-2 dm. high; branches of the panicle spreading.

Taller, erect, $2-5 \mathrm{dm}$. high; branches of the panicle erect.

1. P. annua.

2. P. Bigelovii.

\section{Pratenses.}

Lemma 3-4 mm. long; ligule truncate.

3. P. pratensis.

Lemma $5 \mathrm{~mm}$. long; ligule not truncate.

4. $P$, rhizomata.

\section{Platyphyllate.}

Ligules truncate or abruptly acute.

Ligules lanceolate, long attenuate.

5. P. occidentalis.

6. P. callida.

\section{REFLEX.AE.}

Cobweb present but often scant.

Lemmas obtuse; cobweb dense.

Lemmas acute or acuminate; cobweb scant.

Internerves of the lemma more or less pubescent, at least below,

Spikelets 3-4-flowered; stem-leaves usually folded or involute; plant usually less than $3 \mathrm{dm}$. high, tufted.

Internerves of the lemma short-pubescent below; leaves filiform, involute; those of the sterile shoots usually arcuate. 8. P. cenisia.

Internerves of the lemma long-hairy, at least below; leaves $1-2 \mathrm{~mm}$. wide, usually conduplicate, rather firm.

Plant low, 1-3 dm. high, usually cespitose; lemma acute.

9. P. arctica.

Plant tall, 3-5 dm. high, not cespitose, with a creeping rootstock; floral glumes acuminate. 10 . P. longipila.

Spikelets 5-7-flowered; leaves all flat, 3-4 mm. wide; stem fully $3 \mathrm{dm}$. high.

11. P. callichroa.

Internerves of the lemma glabrous; plants with creeping rootstocks.

Intermediate nerves of the lemma pubescent; plant $3 \mathrm{dm}$. or less high; leaves mostly basal, firm; stem-leaves $1-2$, usually conduplicate.

12. P. pudica. 
Intermediate nerves of the lemma glabrous; plant usually over $3 \mathrm{dm}$. high; stem-leaves several, flat and flaccid.

Hairs of the midnerves and lateral nerves copious and spreading. Lemma ovate, abruptly acute, usually purple. 13. $P$. reflexa. Lemma lanceolate, gradually acute, usually pale green.

14. P. nervosa.

Hairs of the midnerves and lateral nerves few and appressed or none. 15. P. leptocoma.

Cobweb lacking; internerves and the intermediate nerves glabrous; midnerves and lateral nerves hairy; habit like $P$. arctica. 16. P. alpicola.

\section{COMPREsSAE.}

One species.

\section{ApERTAE.}

Branches of the inflorescence short, usually in pairs. Branches of the inflorescence very long, in 3's to 5's.

\section{P. compressa.}

18. P. aperta.

19. P. macroclada.

\section{TRIFLORAE.}

Lemma $5 \mathrm{~mm}$. long.

4. P. rhizomata.

Lemma $3 \mathrm{~mm}$. long or less.

Stem stout; leaves $2-5 \mathrm{~mm}$. wide; ligule $3-4 \mathrm{~mm}$. long, triangular; branches of the panicle at last spreading; second glume narrower than the lemma, threefourths as long or more.

20. P. triflora.

Stem slender; leaves seldom over $2 \mathrm{~mm}$. wide; ligule about $1 \mathrm{~mm}$. long, truncate; branches of the panicle ascending or erect.

Flowers green; the second empty glume with broad, scarious margins and strong lateral nerves

Inflorescence with erect branches; second empty glume narrower than the lemma.

21. P. subtrivialis.

Inflorescence with ascending branches; second empty glume not narrower than the lemma.

Flowers usually purple-tinged; scarious margin of the empty glumes scarcely evident and lateral nerves faint.

23. P. crocata.

One species.

VIII. ALPINAE.

24. P. alpina.

\section{WHEELERIANAE.}

Lower sheaths retrorsely strigulose.

Internerves of the acute lemma merely strigulose or scabrous.

Nerves of the lemma scabrous; ligules short, truncate. Branches of the inflorescence ascending. Branches of the inflorescence reflexed.

Nerves of the lemma silky or villous on the lower portion. Ligules $2 \mathrm{~mm}$. long, truncate; leaf-blades narrow, ascending.

27. P. Wheeleri.

Ligules 4-5 mm. long, lanceolate, acuminate; leaf-blades broad, spreading.

Internerves of the obtusish lemma villous, at least below.

28. P. Vaseyana.

29. P.tricholepis.

Leaf-sheaths all glabrous and smooth.

Ligules lanceolate, acute, $3 \mathrm{~mm}$. long.

Ligules truncate, about $1 \mathrm{~mm}$. long.

30. P. Tracyi.

31. $P$. curta.

\section{Phoeniceae.}

Plant tall, $4 \mathrm{dm}$. high or more; nerves and internerves of the lemma villous.

Plant low, usually less than $3 \mathrm{dm}$. high; internerves of lemma glabrous.

32. P. Grayana.

16. P. alpicola.

\section{ARIDAE.}

Internerves of the lemma pubescent, at least below; stem stout; inflorescence dense; ligules acute.

Intermediate nerves of the lemma strong; plant tall; glumes $5 \mathrm{~mm}$. long.

Intermediate nerves of the lemma weak; glumes $3-4 \mathrm{~mm}$. long. 33. P. pratensiformis.

Keel and the marginal nerves of the lemma villous; empty glumes equalling the lemma.

34. P. arida.

Keel and marginal nerves of the lemma short-hairy, with appressed hairs; empty glumes shorter than the lemma.

35. P. Sheldoni.

Internerves of the lemma glabrous; stem slender; inflorescence open; ligule obtuse.

\section{RUPICOLAE.}

36. P. glaucifolia.

Midnerve and lateral nerves of the lemma pubescent; plant strict, 1-5 dm. high.

Cobweb at the base of the flowers scant; stem slender and leafy, usually $3-5$ dm. high. Cobweb none; stem $1-2$ (seldom 3 ) dm. high, leafy most
Flowering glumes $3 \mathrm{~mm}$. long or less, firm, obtuse.
Flowering glumes about $4 \mathrm{~mm}$. long, acute, thin.

Nerves of the lemma glabrous; plant seldom over $5 \mathrm{~cm}$. high. 23. P. crocata.

athe base.

37. P. rupicola.

38. P. Pattersoni.

39. P. I.eltermani. 
One species.

\section{XiII. Multnomae.}

\section{EPILES.}

Plant green; lemma purple or dark green, abruptly acute; ligules acute.

Blades of the stem-leaves about $3 \mathrm{~mm}$. wide, flat; lemma more than $5 \mathrm{~mm}$. long. dark purple.

Blades of the stem-leaves 1-2 mm. wide; lemma 4-5 mm. long

Lemma purple, minutely scabrous, nearly smooth. $42 . P$. Cusickii.

Lemma green, only tinged with purple, hispidulous-scabrous.

43. P. epilis.

Plant pale; lemma very pale, long-attenuate or subcuspidate; leaves all filiform.

Ligules lanceolate, acuminate.

Panicle thick; branches with several 5-7-flowered spikelets: leaves very scabrous. 44. P. scaberrima.

Panicle narrow, slender; branches very short, with 1-2, only 2-4-flowered spikelets.

45. $P$, nematophylla.

Ligules oblong, $1 \mathrm{~mm}$. long, truncate; panicle dense and spike-like.

46. P. subaristata.

\section{GRACII.LIMAE.}

Lemma linear-lanceolate, 5-6 $\mathrm{mm}$. long.

47. P. idahoensis.

Lemma ovate, $4-5 \mathrm{~mm}$. long.

Plant 1-3 dm. high; panicle with ascending branches and many spikelets,

48. P. gracillima.

Plant 0.5-1.5 dm. high; panicle with divaricate branches and few spikelets.

49. P. Vaseyochloa.

\section{FendietrianaE.}

Ligules 5-7 mm. long, acute or acuminate.

Ligules short, rounded or truncate, or those of the innovations obsolete.

Leaf-blades erect; spikelets 3-5- (rarely 6-7-) flowered.

Lemma oblong; leaf-blades very slender, scabrous.

Lemma ovate; leaf-blades more rigid.

Panicle very narrow, its branches erect and spikelet-bearing to the base; lemma $4 \mathrm{~mm}$. long.

52. $P$. longipedunculata.

Panicle more open, its branchos ascending, usually naked at the base. Plant low; panicle short; lemma $3.5-4 \mathrm{~mm}$. long. 53. $P$. hrevipaniculata. Plant tall; panicle elongated; lemma $5 \mathrm{~mm}$. long. 54. P. Fendleriana.

Leaf-blades spreading; spikelets 7-9-(rarely 5-6-) flowered. 55. P. Eatoni.

\section{Buckleyanae.}

Ligules lanceolate, acuminate or attenuate.

Empty glumes strongly nerved, elongate-lanceolate, almost equalling the very scabrous or strigose lemma.

Leaves $4-6 \mathrm{~mm}$. wide, flat.

Leaves 1-3 mm. wide, conduplicate or involute.

Lemma strongly scabrous; leaves stiff; plant stout. .57. P. nevarensis.

Lemma strigose, at least below; leaves filiform, flaccid; plant slender.

58. P. Helleri.

Empty glumes not strongly nerved, ovate-lanceolate, usually much shorter than the lemma.

Plant yellowish green: spikelets yellowish or straw-colored.
Lemma merely scabrous.
59. $P$. laevigata.

Lemma more or less strigose on the lower portion.

60. P. lacida.

Plant dark green; spikelets dark green or purplish.

Leaf-blades almost $2 \mathrm{~mm}$. wide, flat or conduplicate; lemma more than $4 \mathrm{~mm}$. long.

61. P. Buckleyana.

Leaf-blades less than $1 \mathrm{~mm}$. wide, filiform, involute; lemma less than $4 \mathrm{~mm}$. long.

62. P. Sandbergii.

Ligules 1-2 mm. long, truncate, rounded or abruptly acute.

Plant $2-4 \mathrm{dm}$. high; leaves mostly basal and stiff, short, seldom $8 \mathrm{~cm}$. long; ligules rounded.

Plant taller, 4-10 dm. high, leafy; leaves longer.

Internerves of the lemma glabrous; nerves silky.

Internerves of the lemma as well as the nerves scabrous.

Leaves filiform, less than $1 \mathrm{~mm}$. wide.

Leaves flat or involute, but not filiform, $2-5 \mathrm{~mm}$. wide.

Ligules ovate or rounded, acute or obtuse; leaves soft.

Ligules truncate; leaves stiff.

Inflorescence very narrow; branches erect. $66 . P$
Inflorescence more open, lobed; branches ascending.

63. P. juncifolia.

36. P. glaucifolia.

64. P. brachyglossa.

65. P. confusa.

66. P. truncata.

67. P. ampla.

1. P. annua L. Stems usually decumbent and branched at the base or erect; ligules rounded at the apex, $2 \mathrm{~mm}$. long; leaf-blades flat, flaccid, $1-10 \mathrm{~cm}$. long, $1.5-3 \mathrm{~mm}$. wide; panicle 1-10 $\mathrm{cm}$. long; spikelets $3-5 \mathrm{~mm}$. long; empty glumes smooth, the first lanceolate, acute, $1.5 \mathrm{~mm}$. long, the second obtuse, 
nearly $2 \mathrm{~mm}$. long; lemma $2.5-3 \mathrm{~mm}$. long, the nerves pilose below. Waste places and cultivated ground: Lab.-Ga.-Calif,-B.C.; Mex.; nat. from Eu. Plain-Mont. My-O.

2. P. Bigelovii Vasey \& Seribn. Annual, usually more or less tufted; ligules lanceolate, $3 \mathrm{~mm}$. long; leaf-blades flat, flaccid, $5-10 \mathrm{~cm}$. long, 2-4 mm. wide; panicle 5-15 $\mathrm{cm}$. long, narrow; spikelets 4-6 mm. long, compressed; empty glumes glabrous, lanceolate, acute, nearly as long as the lemma; lemma 3-4 mm. long, subacute, villous on the midrib and marginal nerves; cobweb scant. Arid regions: Tex.-Colo.-Utah-Calif.-L. Calif. Son.-Submont.

3. P. pratensis L. Stem 3-12 dm. high, smooth; leaf-blades $1-6 \mathrm{~mm}$. wide, those of the stem 5-15 cm. long, the basal ones longer; panicle 5-20 cm. long, ovate or conical; spikelets 3-6-flowered, 4-5 mm. long; midvein and marginal veins of the lemma silky below, the intermediate ones glabrous. Meadows, fields and woods: Greenl.-Fla.-Calif.-Alaska; Eurasia. Plain-Subalp. $\mathrm{Je}-\mathrm{Au}$.

4. P. rhizomata Hitche. Perennial, with a creeping rootstock; stem 3-6 $\mathrm{dm}$. high, smooth; sheaths smooth, the lower loose and papery; ligules $2-3 \mathrm{~mm}$. long; blades mostly flat, $1-2 \mathrm{~mm}$. wide, $3-7 \mathrm{~cm}$. long; panicle $3-5 \mathrm{~cm}$. long; spikelets 3-4-flowered; first glume $3 \mathrm{~mm}$. long, the second $4 \mathrm{~mm}$. long; lemma $5 \mathrm{~mm}$. long, acutish, copiously webbed at the base; keel and marginal nerves short-pilose below; internerves sparingly scabrous. Damp woods: Calif.-Ida. Ap-Je.

5. P. occidentalis Vasey. Stem 3-10 dm. high; sheaths flattened, scabrous; leaf-blades $5-15 \mathrm{~cm}$. long, flat, $2-6 \mathrm{~mm}$. wide, scabrous; panicle large, $1.5-3$ $\mathrm{dm}$. long, loose; spikelets 2-4-flowered, 4-6 mm. long, light green; empty glumes acute, scarious margined, unequal; lemma 3-4 mm. long, slightly pubescent below and on the keel; cobweb scant. P. platyphylla Nash \& Rydb. Rich hillsides: N.M.-Colo.-Utah. Submont.-Subalp. My-Au.

6. P. callida Rydb. Stem 3-5 dm. high, somewhat flexuose; leaf-blades flat, flaccid, 5-12 cm. long, about $3 \mathrm{~mm}$. wide; panicle open, 1-1.5 dm. long; spikelets about $3 \mathrm{~mm}$. long, 2- or 3-flowered, light green; first empty glume subulate, $2 \mathrm{~mm}$. long, the second slightly broader, $2.5 \mathrm{~mm}$. long, glabrous; lemma $3 \mathrm{~mm}$. long, glabrous except the keel, which is slightly silky below; cobweb scant but long. Warm springs: Mont. Jl.

7. P. lanata Scribn. \& Merr. Perennial, with a creeping rootstock; stem 2.5-4 dm. high; sheath loose, the lower marcescent, scabrous; ligule $4 \mathrm{~mm}$. long, obtuse; blades 2-4 mm. wide, conduplicate or involute; inflorescence open; branches in pairs, 2-3 cm. long, with 1-3 spikelets near the ends; spikelets 3-6flowered; lemma purple, 6-7 $\mathrm{mm}$. long. Subarctic situations: Alaska-B.C. Subarct.

8. P. cenisia All. Stem 1-3 dm. high, slender; ligules 1-2 mm. long, truncate; blades 2-10 $\mathrm{cm}$. long, 1-2 mm. wide, involute; panicle 2-8 $\mathrm{cm}$. long, open; spikelets 2-4-flowered, 5-6 mm. long, purplish; empty glumes glabrous; lemma about $4 \mathrm{~mm}$. long. Aretic-alpine situations: Greenl.-Lab.-Colo.-Alaska; Eu. Alp. J-Au.

9. P. arctica R. Br. Stems 1-3 dm. high, smooth, erect or decumbent at the base; ligules erose-truncate; basal leaf-blades $5-10 \mathrm{~cm}$. long, 2-4 $\mathrm{mm}$. wide; stem-leaves shorter and often flat; panicle open, 5-10 cm. long; spikelets purple; empty glumes 3-3.5 mm. long, glabrous; lemma $4 \mathrm{~mm}$. long, acute. Alpinearetic situations: Aretic Sea-N.M.-Utah. Alp. Jl-Au.

10. P. longipila Nash. Stem $3-5 \mathrm{dm}$. high; ligules broad, obtuse or acutish; leaf-blades erect, acuminate, $3-8 \mathrm{~cm}$. long, 3-4 mm. wide, flat; panicle 6-9 $\mathrm{cm}$. long; spikelets 6-8 mm. long, 3-4-flowered, purple; lemma 5-6 $\mathrm{mm}$. long; cobweb copious and long. Wet places: Wyo.-Mont. Submont.

11. P. callichroa Rydb. Perennial, with a horizontal rootstock, but more or less matted; stem about $3 \mathrm{dm}$, high; blades of the lower leaves $6-10 \mathrm{~cm}$. long, firm, dark-green, strongly veined; blades of the upper leaves about $3 \mathrm{~cm}$. long, 
erect; panicle 6-9 $\mathrm{cm}$. long, open; spikelets 6-8 $\mathrm{mm}$. long, 5-7-flowered; empty glumes about $5 \mathrm{~mm}$. long, purple with greenish or brownish margins; lemma 4-5 mm. long, lanceolate, acuminate, green below, then purple, then brown, and white and scarious above; nerves and internerves more or less villous; cobweb scant. Mountain peaks: Colo.-Wyo. Subalp.-Mont. Au.

12. P. pudica Rydb. Stem 2-3 dm. high; lower leaves with short loose sheaths; ligules truncate, about $2 \mathrm{~mm}$. long; blades 4-5 $\mathrm{cm}$. long, usually conduplicate, strongly nerved; panicle 4-8 cm. long; spikelets 4-5 mm. long, mostly 3-flowered; empty glumes strongly veined, usually purple, acuminate; lemma lanceolate, sharp-acuminate, greenish below, then purplish, and scarious at the apex. Alpine meadows: Colo. Subalp.-Alp. Au.

13. P. reflexa Vasey \& Seribn. Stem 3-5 dm. high, slender, erect, smooth; ligules $2 \mathrm{~mm}$. long, obtuse; leaf-blades $5-15 \mathrm{~cm}$. long, 2-4 mm. wide; paniele 5-10 cm. long; spikelets 2-3-flowered, 3-4 $\mathrm{mm}$. long, usually purple; empty glumes acuminate, smooth; lemma very acute. Wet meadows: Alta.-N.M.Utah-Ore.-B.C. Submont.-Subalp.

14. P. nervosa (Hook.) Vasey. Stem 4-7 dm. high, slender, smooth; ligules truncate; blades of stem-leaves $2-7 \mathrm{~cm}$. long, 2-4 $\mathrm{mm}$. wide; those of the basal leaves 1.5-2.5 dm. long; panicle 5-12 cm. long, open; spikelets 3-8-flowered, flat, lax and flexuose; empty glumes linear-lanceolate, $4 \mathrm{~mm}$. long; lemma linearlanceolate, slightly scabrous on the nerves. Wet places: B.C.-Calif.-Mont. Mont.-Subalp.

15. P. leptocoma Trin. Stems 3-6 dm. high, smonth; ligules obtuse; leafblades flat, flaccid, 1-3 mm. wide, 4-10 $\mathrm{cm}$. long; panicle open, 5-10 $\mathrm{cm}$. long; spikelets 2-3-flowered, about $6 \mathrm{~mm}$. long, green or merely tinged with purple; first empty glume about $3 \mathrm{~mm}$. long, the second $3.5 \mathrm{~mm}$. long; lemma linearlanceolate, gradually acute. Boggy places: Alta.-Colo.-Wash.-Alaska. Mont.-Subalp. Jl-Au.

16. P. alpicola Nash. More or less tufted perennial; ligules acute, $2 \mathrm{~mm}$. long; leaf-blades $3-10 \mathrm{~cm}$. long, often involute or conduplicate, 1-2 mm. wide; inflorescence rather narrow, 3-5 cm. long; branches short; spikelets $5-7 \mathrm{~mm}$. long, 2-4-flowered, more or less tinged with purple; empty glumes subequal, glabrous, about $3 \mathrm{~mm}$. long; lemma ovate, acute, glabrous. $P$. laxa Thurber, not Haenke. Alpine: Colo.-Utah-(? Ida.) Alp. Jl-Au.

17. P. compressa L. Perennial, with a ereeping rootstock; stem 1.5-4 $\mathrm{dm}$. high, decumbent at the base, much flattened, smooth; ligules truncate; leaf-blades bluish green, stiff, erect, 2-10 $\mathrm{cm}$. long, about $2 \mathrm{~mm}$. wide, often convolute, scabrous above; panicle narrow, with ascending short branches, spikelet-bearing to near the base; spikelets 3-5-flowered, 3-9 mm. long; empty glumes acute, nearly equal; lemma 2-2.8 mm. long, obtuse; cobweb scant. Waste places, cultivated grounds, and woodlands: N.H.-N.C.-Calif.-B.C. -Yukon; Eurasia. Plain-Mont. Je-Jl.

18. P. aperta Scribn. \& Merr. Stem 4-5 dm. high, erect, wiry; ligules acute; leaf-blades firm, striate, minutely scabrous, glaucous, $5-15 \mathrm{~cm}$. long, $2 \mathrm{~mm}$. wide; panicle ovate; spikelets purplish, 5-6 mm. long, 3-4-flowered; lemma lanceolate, minutely pubescent throughout; cobweb conspicuous. Mountains: N.M.-Wyo. Mont.-Subalp. Au-S.

19. P. macroclada Rydb. Stem 6-8 dm. high; ligules ovate, acute; leafblades $7-10 \mathrm{~cm}$. long, $2 \mathrm{~mm}$. or less wide, flat, glabrous, firm and dark green; panicle 2-3 dm. long, open; spikelets often about $5 \mathrm{~mm}$. long; lemma lanceolate, acute or acuminate, glabrous, slightly purple-tinged; cobweb seant. Mountains: Colo, Mont.

20. P. triflora Gilib. Perennial, with a creeping rootstock; stem 4-12 dm. high, erect, smooth; leaf-blades 5-15 cm. long, $2-5 \mathrm{~mm}$. wide; panicle $1.5-3 \mathrm{dm}$. long, open; spikelets $3-5$-flowered, $3-5 \mathrm{~mm}$. long; empty glumes glabrous, scabrous on the keel; lemma obtuse, $2-3 \mathrm{~mm}$. long; midnerve and lateral nerves pubescent below. P. serotina Ehrh. P. flava Aıth., not L. Meadows and swampy places: Newf.-N.J.-Calif.-B.C.; Eurasia. Plain-Mont. Jl-Au. 
21. P. subtrivialis Rydb. Perennial, with a rootstock; stem slender, 4-6 dm. high, smooth; leaf-blades erect, flaccid, 8-15 $\mathrm{cm}$. long, about $2 \mathrm{~mm}$. wide, flat, dark green; panicle 1-2 dm. long; spikelets light green, 3-4 mm. long, 2-3flowered; lemma $2.5 \mathrm{~mm}$. long, glabrous; cobweb very scant. Meadows: Wyo. -Ida. Mont.

22. P. interior Rydb. Tufted perennial; stem slender, 3-6 dm. high; leafblades 2-8 cm. long, about $2 \mathrm{~mm}$. wide, glabrous; panicle $4-10 \mathrm{~cm}$. long; spikelets 2-5-flowered, 3-5 mm. long; lemma $2-2.5 \mathrm{~mm}$. long, scabrous on the midnerve and lateral nerves. $P$. nemoralis Scribn., not $\mathrm{L}$. Woods and copses: S.D.-Neb.-N.M.-Utah-Wash.-Alaska. Plain-Mont.

23. P. crocata Michx. Tufted perennial; stems strict, erect, 2-4 dm. high; leaf-blades narrow, erect, 1-2 mm. wide, 4-10 $\mathrm{cm}$. long, usually involute; panicle rather narrow, 5-15 cm. long; spikelets 2-4-flowered, about $4 \mathrm{~mm}$. long; lemma. about as long as the glumes, pubescent on the midnerve and lateral nerves. $P$. nemoralis strictior A. Gray. Dry hills and meadows: Lab.-Vt.-Minn.-Colo. -Ariz.-Alaska. Submont.-Subalp. Je-Au.

24. P. alpina L. Stem $0.5-4 \mathrm{~cm}$. high, erect or decumbent at the base; ligules truncate; leaf-blades $2-8 \mathrm{~cm}$. long, $2-4 \mathrm{~mm}$. wide, abruptly acute, flat; panicle $2-8 \mathrm{~cm}$. long; spikelets 3-5-flowered, 5-6 $\mathrm{mm}$. long; empty glumes broad, glabrous, acute, scabrous on the keel; lemma about $4 \mathrm{~mm}$. long, obtuse, its lower half pubescent. Alpine-aretic regions in wet places: Greenl.-Que.Colo.-Utah-Alaska; Eu. Mont.-Alp. Je-Au.

25. P. Olneyae Piper. Stem 3-8 dm. high, glabrous; blades of the basal leaves 1-2 dm. long, often conduplicate, $2-3 \mathrm{~mm}$. wide, those of the stem-leaves 3-6 cm. long, 2-3 mm. wide, flat; panicle pale green, about $1 \mathrm{dm}$. long, drooping, open; spikelets $7-10 \mathrm{~mm}$. long, 4-6-flowered; lemma ovate, $5 \mathrm{~mm}$. long. $P$. Wheeleri Auth., not Vasey. Pine woods and meadows: Mont,-Colo.-Ore.B.C. Submont. - Subalp. Jl-Au.

26. P. subreflexa Rydb. Stem ascending, 5-6 dm. tall; leaf-blades flat; flaccid, 7-10 cm. long, 3-4 mm. wide, spreading; panicle open, about $1 \mathrm{dm}$. long, spikelets pale green, 6-7 mm. long, 3- or 4-flowered; lemma lanceolate, $5 \mathrm{~mm}$. long. Wooded banks: Colo. Mont.-Subalp. Jl.

27. P. Wheeleri Vasey. Stem simple, 2-6 dm. high; leaf-blades $2-20 \mathrm{~cm}$. long, $3 \mathrm{~mm}$. wide, the lower involute or conduplicate; panicle open, $8-12 \mathrm{~cm}$. long; spikelets $6-7 \mathrm{~mm}$. long, 3-5-flowered, light green, rarely tinged with purple; lemma lanceolate, acute, $5 \mathrm{~mm}$. long. Meadows: Alta.-Colo.-Utah-B.C. Submont.-Subalp. Jl-Au.

28. P. Vaseyana Scribn. Stem 5-7 dm. high; leaf-blades flat, 5-30 cm. long, 4-5 mm. broad; panicle open, 10-15 $\mathrm{cm}$. long; spikelets often tinged with purple, 4-6-flowered, 8-10 mm. long; lemma 5.5-6.5 mm. long. Mountain meadows: Colo.-Wyo. Mont.-Subalp. Au.

29. P. tricholepis Rydb. Stem slender, 3-5 dm. high; leaf-blades 5-10 cm. long, a little over $1 \mathrm{~mm}$. wide, scabrous; stem-leaves $2-6 \mathrm{~cm}$. long, sometimes nearly $2 \mathrm{~mm}$. wide; ligules lanceolate, acuminate; panicle $6-8 \mathrm{~cm}$. long, open; spikelets 3-4-flowered, 5-8 mm. long; lemma about $4 \mathrm{~mm}$. long, green, bordered with purple and a scarious border. Mountains: Colo. Mont.-Alp. J1-Au.

30. P. Tracyi Vasey. Stem 3-8 dm. high; leaf-blades 6-12 cm. long, 2-6 $\mathrm{mm}$. wide, scabrous; panicle 1-2 dm. long; spikelets 3-5-flowered, light green, loose; lemma finely strigulose-scabrous, especially on the nerves, 4-5 mm. long. P. occidentalis (Vasey) Rydb., not Vasey. Mountains: N.M.-Colo.-Utah. Submont.-Subalp. J1-Au.

31. P. curta Rydb. Stem glabrous, 4-5 dm. high; leaf-blades $2-5 \mathrm{~cm}$. long, $3-5 \mathrm{~mm}$. wide, abruptly acute, dark green; inflorescence short, open, $4-5 \mathrm{~cm}$. long; spikelets light green, strongly compressed, about $6 \mathrm{~mm}$. long, 2-4-flowered; lemma lanceolate. Wooded banks: Wyo. Mont. Jl.

32. P. Grayana Vasey. Stem 5-6 dm. high, leafy; ligules triangularlanceolate or ovate, acute; blades $1-2 \mathrm{dm}$. long, about $2 \mathrm{~mm}$. wide; panicle 6-10 cm. long, open; spikelets 4-5-flowered, 6-7 mm. long; lemma lanceolate, green 
at the base, purple in the middle and brownish-searious at the top.

P. phoenicia Rydb. Mountains: Colo. Alp. Au.

33. P. pratensiformis Rydb. Stem 3-6 dm. high; leaf-blades flat, 2-6 $\mathrm{mm}$. wide, those of the stem $2-7 \mathrm{~cm}$. long, those of the sterile shoots $1.5-3 \mathrm{dm}$. long, scabrous on the margins; panicle 5-12 $\mathrm{cm}$. long, spreading in anthesis only; spikelets 3-5-flowered, 6-8 $\mathrm{mm}$. long; empty glumes nearly equal, acute; lemma obtuse, silky-hairy on the nerves to the middle and pubescent all over near the base. P. pseudopratensis Scribn. \& Rydb., not Beyer. Wet places: S.D.-Kans.-Utah. Plain-Submont. Je-Jl.

34. P. arida Vasey. Stem 2-6 dm. high; leaf-blades $2-15 \mathrm{~cm}$, long, erect, flat, or becoming somewhat involute, striate; panicle narrow, dense, $7-15 \mathrm{~cm}$. long; branches erect; spikelets $6-7 \mathrm{~mm}$. long, 5-9-flowered; lemma obtuse, scarcely compressed. $P$. andina Nutt. $P$. pratericola Rydb. Prairies and meadows: Kan.-N.M.-Utah-Wyo, Plain-Subalp.

35. P. Sheldoni Vasey. Stem rigid, 2-3 dm. high, smooth; blades of the basal leaves $5-10 \mathrm{~cm}$. long, 2-3 mm. wide, rigid, flat or conduplicate; panicle narrow, 3-7 cm. long; spikelets about $6 \mathrm{~mm}$. long, 3-4-flowered; lemma $4 \mathrm{~mm}$. long, subobtuse, short-pubescent near the base, scarious at the apex. Dry hills: Colo.-Wyo.-Utah. Mont.-Subalp. Je-Jl.

36. P. glaucifolia Seribn. \& Williams. Stem about $6 \mathrm{dm}$. high, smooth, except at the nodes; leaf-blades flat, glaucous, 1.5-2 dm. long, $2-4 \mathrm{~mm}$. wide; panicle open; spikelets compressed, 3-4-flowered; empty glumes ovate, obtuse or acutish, 3-nerved, scabrous on the back, about $4 \mathrm{~mm}$. long; lemma obtuse, pubescent on the keel and nerves, $3-4 \mathrm{~mm}$. long. Moist banks: S.D.-Colo.Mont. Submont.-Mont. Jl-Au.

37. P. rupicola Nash. Stems 1-3 dm. high, erect, rigid; ligules ovate, $2 \mathrm{~mm}$. long; leaf-blades 1-4 cm. long, about $1 \mathrm{~mm}$. wide, erect, involute; paniele $2-5$ $\mathrm{cm}$. long, with short ascending branches; spikelets 2-4-flowered, $3-5 \mathrm{~mm}$. long, purple; lemma with midvein and lateral nerves pubescent below, otherwise glabrous or scabrous. P. rupestris Vasey. High mountains: Mont.-Colo.Utah-Ore. Mont.-Alp. Jl-Au.

38. P. Pattersoni Vasey. Stem 5-40 $\mathrm{cm}$. high; ligules $1 \mathrm{~mm}$. long, truncate; leaf-blades $1-15 \mathrm{~cm}$. long, about $1 \mathrm{~mm}$. wide, conduplicate or flat, smooth; panicle dense; spikelets 4-6 $\mathrm{mm}$. long, 2-5-flowered, purple; lemma pubescent on the keel and lateral veins below, otherwise glabrous. P. Grayana Rydb. (Fl. Colo.), not Vasey, a large form. High mountains: Colo.-Wyo.-Utah. Alp. $\mathrm{Jl}-\mathrm{Au}$.

39. P. Lettermani Vasey. Stem 2-10 cm. high; ligules acute; leaf-blades mostly flat, 1-3 cm. long, 1-2 mm. wide; panicle 1-3 cm. long, dense, narrow; spikelets 3-4 mm. long, 2-4-flowered, purplish; lemma $2 \mathrm{~mm}$. long, ovate, acute, obscurely nerved, glabrous. P. Brandegei Scribn. Alpine peaks: Colo.-Wyo. -(? Wash.) Alp. Au.

40. P. Multnomae Piper. Stems 1-4 dm. high, very slender, glabrous; ligules 1-2 mm. long; leaf-blades narrow, flat or conduplicate, $8-12 \mathrm{~cm}$. long, 1-2 $\mathrm{mm}$. wide; panicle loose, $5-10 \mathrm{~cm}$. long, usually pale green; spikelets $5-7 \mathrm{~mm}$. long, 3-5-flowered; lemma narrow, lanceolate, glabrous, slightly puberulent on the keel and marginal veins below. Cliffs: Ore-Wash.-Mont. Submont. Je-Jl.

41. P. paddensis Williams. Stem erect, $3-5 \mathrm{dm}$. high, smooth; leaf-blades 5-8 cm. long; panicle erect, dense, oblong, 4-8 cm. long; spikelets about $8 \mathrm{~mm}$. long, 3-5-flowered, purple; empty glumes broadly searious-margined, about 4 $\mathrm{mm}$. long; lemma $6 \mathrm{~mm}$. long, minutely scabrous and villous at the base. $P$. purpurascens Vasey, not Spreng. P. subpurpurea Rydb. Mountains: B.C.Alta.-Colo.-Wash. Alp. Jl-Au.

42. P. Cusickii Vasey. Stem smooth, ereet, 3-5 dm. high; basal leaf-blades filiform, $1 \mathrm{~mm}$. wide, $7-12 \mathrm{~cm}$. long; those of the stem-leaves 5-7 cm. long, erect; panicle dense, oblong, 3-10 cm. long; spikelets 8-10 $\mathrm{mm}$. long, 3-5-flowered; 
lemma about $5 \mathrm{~mm}$. long, acute, scarious at the apex, finely scabrous-puberulent. Cañons: B.C.-Ida.-Ore. Submont.-Mont. My-Je.

43. P. epilis Scribn. Stem 4-6 dm. high; leaf-blades smooth, $2-20 \mathrm{~cm}$. Iong, flat, or involute when dry; panicle dense, oblong, $3-7 \mathrm{~cm}$. long; spikelets $3-4-$ flowered, about $5 \mathrm{~mm}$. long; empty glumes smooth, unequal, the first $2.5 \mathrm{~mm}$. long, the second $3 \mathrm{~mm}$. long; lemma about $4 \mathrm{~mm}$. long. Mountains: Mont.Colo.-Utah-B.C. Mont.-Alp.

44. P. scaberrima Rydb. Stem 3-5 dm. high, 2- or 3-leaved, glabrous; blades of the basal leaves $8-15 \mathrm{~cm}$. long, less than $1 \mathrm{~mm}$. wide; those of the stemleaves 1-5 cm. long, erect; panicle elliptic, dense, 4-7 cm. long; spikelets about $1 \mathrm{~cm}$. long; empty glumes ovate, nearly equal, 4-5 mm. long, glabrous; lemma ovate, acuminate, pale, slightly tinged with purple, 5-6 mm. long, strongly 5-nerved, and conspicuously scabrous. Hills: Ida. Submont. Je.

45. P. nematophylla Rydb. Stem about $3 \mathrm{dm}$. high; basal leaf-blades $1-1.5$ $\mathrm{dm}$. long, less than $0.5 \mathrm{~mm}$. wide; stem-leaves few, near the base; blades $3-5 \mathrm{~cm}$. long; spikelets 7-9 mm. long; empty glumes about $4 \mathrm{~mm}$. long, lanceolate, glabrous and shining; lemma about $6 \mathrm{~mm}$. long, light green, with a silvery scarious margin. Mountains: Colo.-Utah. Submont. Je-Au.

46. P. subaristata Scribn. Stem 1-4 dm. high; leaf-blades 5-10 cm. long, $0.5-1 \mathrm{~mm}$. wide, strongly involute, scabrous; panicle oblong, dense, $3-6 \mathrm{~cm}$. long; spikelets 4-7-flowered, 6-9 mm. long; empty glumes subequal, $5 \mathrm{~mm}$. long, lanceolate, 1-nerved; lemma $6 \mathrm{~mm}$. long, scabrous, acuminate or even cuspidate. High mountains: Sask.-Wyo.-Ida.-Alta. Mont.-Alp. My-Au.

47. P. idahoensis Beal. Stems $3-6 \mathrm{dm}$. high; ligules acute; basal leafblades filiform, $1.5-2.5 \mathrm{dm}$. long, flaccid, involute; those of the stem-leaves 2-5 $\mathrm{cm}$. long, erect; panicle loose, flexuose, 7-10 cm. long; spikelets compressed, 6-10 $\mathrm{mm}$. long, loosely 5-7-flowered; empty glumes nearly equal, acute, broadly scarious-margined, about $4 \mathrm{~mm}$. long; lemma scarious at the apex, minutely scabrous throughout. $P$. filifolia Vasey, not Schkuhr. $P$. scabrifolia Heller. Rocky banks: Ida.-Mont.-Ore. Submont. Ap-Je.

48. P. gracillima Vasey. Stems $3-5 \mathrm{dm}$. high, slender, erect; blades of the basal leaves filiform, flaccid, spreading, $5-12 \mathrm{~cm}$. long; those of the stem-leaves $2-5 \mathrm{~cm}$. long; panicle $5-10 \mathrm{~cm}$. long, open; spikelets $6-8 \mathrm{~mm}$. long, about 5flowered, lax; empty glumes ovate-lanceolate, acute, unequal; lemma 4-5 mm. long, acute, purplish, scarious at the apex, more or less scabrous and somewhat pubescent on the keel and marginal nerves. Mountains: B.C.-Calif.-Mont. -Alta. Jl-Au.

49. P. Vaseochloa Scribn. Stems slender, 0.5-1.5 dm, high, 1-2-leaved; basal leaves filiform, with thickened bases; panicle $3-5 \mathrm{~cm}$. long; spikelets purplish, 6-8 mm. long, 3-5-flowered; empty glumes scarious-margined, $2-3 \mathrm{~mm}$. long; lemma about $4 \mathrm{~mm}$. long, finely scabrous on the keel and veins. P. pulchella Vasey. River banks: Wash.-Alta.-Ida.-Ore. Submont.-Mont. ApJ.

50. P. longiligula Scribn. \& Williams. Stem $3-5 \mathrm{dm}$. high, with numerous persistent basal sheaths; blades of sterile shoots $1.5-2.5 \mathrm{dm}$. long, 1-2 mm. wide, flat or conduplicate; those of the stem-leaves shorter; panicle 6-12 cm. long; spikelets 4-6-flowered, 6-10 mm. long; lemma 4-5.5 mm. long, scabrous on the back, villous on the keel and marginal nerves below. Hillsides and plains: S.D. -N.M.-Calif.-Ore. Son.-Subalp. My-Jl.

51. P. scabriuscula Williams. Stem 2.5-3 dm. high, smooth; blades of the sterile shoots $8-12 \mathrm{~cm}$. long, $1-1.5 \mathrm{~mm}$. wide, flat or convolute; those of the upper stem-leaves seldom over $1 \mathrm{~cm}$. long; paniele open, subpyramidal, $5-7 \mathrm{~cm}$. long, 2-3.5 cm. broad; spikelets 5-7 mm. long; lemma oblong, obtuse, keeled, pale green or purplish, about $3.5 \mathrm{~mm}$. long. Mountains: Utah-Colo. My-Je.

52. P. longipedunculata Scribn. Stem smooth, 5-7 dm. high; blades of the sterile shoots $5-20 \mathrm{~cm}$. long, 1-2 mm. wide, involute; those of the stem-leaves $1-3 \mathrm{~cm}$. long, scabrous; spikelets green or tinged with purple, $6 \mathrm{~mm}$. long; lemma 
$4 \mathrm{~mm}$. long, minutely scabrous. Hills and mountain sides: Wyo.-N.M.Utah. Son.-Mont. My-Au.

53. P. brevipaniculata Scribn. \& Williams. Stem 1-3 dm. high, smooth; leaf-blades flat or conduplicate; those of the sterile shoots $1 \mathrm{dm}$. long or more; those of the stem much shorter; panicle 3-6 cm. long, 1-2 cm. wide; spikelets green or tinged with purple, 4-6-flowered, 4-6 mm. long; second glume $3.5 \mathrm{~mm}$. long; lemma obtusish or acutish, 3.5-4 mm. long. Perhaps not distinct from the next species. Dry meadows and mountain sides: Colo.-Utah-N.M.-Ariz. Son.-Mont.

54. P. Fendleriana (Steud.) Vasey. Stem 3-6 dm. high; leaf-blades flat or convolute, seabrous; those of the sterile shoots 1-2 dm. long, 1-2 mm. wide; panicle $5-10 \mathrm{~cm}$. long, open in anthesis; spikelets $7-8 \mathrm{~mm}$. long; empty glumes unequal, smooth, the second about $4 \mathrm{~mm}$. long; lemma keeled, obtuse, $5 \mathrm{~mm}$. long. Hills and tablelands: Colo.-N.M.-Calif. Son.-Subalp. My-Au.

55. P. Eatoni S. Wats. Stem 4-6 dm. high; leaf-blades flat, seabrous on both sides, those of the basal leaves $1-2 \mathrm{dm}$. long, $2-3 \mathrm{~mm}$. wide, those of the cauline leaves $2 \mathrm{~cm}$. long or less; panicle open, $7-8 \mathrm{~cm}$. long; spikelets $5-9$-flowered, obtuse 7-10 mm. long; empty glumes subequal, hispid on the keel; lemma 4-5 mm. long. Cañons: Utah-sw Colo.-Ariz. Submont.-Mont. Je.

56. P. Canbyi (Scribn.) Beal. Stem 5-10 dm. high, stout, smooth; leafblades 1-2 dm. long, 4-6 mm. wide, scabrous, flat; panicle narrow, 1-2 dm. long; spikelets 6-8 mm. long, 3-5-flowered; empty glumes unequal, acute; lemma about $4 \mathrm{~mm}$. long, strongly scabrous, its summit scarious-margined and obtuse. Meadows and bogs: Mont.-Wyo.-Wash. Submont.-Mont. Jl-Au.

57. P. nevadensis Vasey. Stem 5-10 dm. high, scabrous below the panicle; blades of the basal leaves 1.5-3 dm. long, 2-3 mm. wide, scabrous; those of the stem-leaves $3-10 \mathrm{~cm}$. long; panicle narrow and dense, 1-2 dm. long; spikelets 6-10 $\mathrm{mm}$. long, 3-8-flowered; empty glumes scabrous, 3-4 mm. long, nearly equal; lemma very seabrous, $4 \mathrm{~mm}$. long, obtuse, scarious-margined above. Plains, meadows and hillsides: Mont.-Colo.-Ariz.-B.C. Submont-Mont. Ap-Au.

58. P. Helleri Rydb. Stem slender, 4-6 dm. high, often purple-tinged below; leaf-blades very slender, flaccid, $5-15 \mathrm{~cm}$. long, $1 \mathrm{~mm}$. wide; panicle rather loose, $8-10 \mathrm{~cm}$. long; spikelets about $1 \mathrm{~cm}$. long, 4 - or 5 -flowered; empty glumes linear-lanceolate, 3-nerved, glabrous; lemma linear-lanceolate, about $5 \mathrm{~mm}$. long, scabrous on the upper part. Hillsides: Ida.

59. P. laevigata Seribn. Stem erect, smooth, 5-10 dm. high; blades of the basal leaves 1-2 dm. long, about $1 \mathrm{~mm}$. wide, involute; those of the stem-leaves $2-5 \mathrm{~cm}$. long; panicle narrow, 1-2 dm. long; spikelets appressed, 6-10 mm. long, about 5-flowered; empty glumes nearly equal, acute, thin, scarious-margined; lemma 4-5 mm. long, linear-oblong, the apex scarious and yellowish. $P$. laevis Vasey. Dry meadows and hillsides: Mont.-N.M.-B.C. Submont.-Mont.

60. P. lucida Vasey. Stem 3-6 dm. high, smooth; blades of basal leaves 12-15 $\mathrm{cm}$. long, 1-2 mm. wide, soft; those of the stem-leaves $5-7 \mathrm{~cm}$. long; panicle 1-1.5 dm. long, narrow; spikelets 6-8 mm. long, 3-4-flowered, shining, pale; empty glumes abruptly acute, unequal, 3-4 mm. long; lemma $2 \mathrm{~mm}$. long, obtuse. Dry hills: Alta.-S.D.-N.M. Submont. Je-Jl.

61. P. Buckleyana Nash. Stem 2-6 dm. high, rigid, smooth; leaf-blades 2-10 cm. long, about $2 \mathrm{~mm}$. wide, flat or becoming involute in drying; panicle 3-10 cm. long, narrow; spikelets 2-5-flowered, 4-6 mm. long, dark green and tinged with purple; empty glumes acute, nearly equal, scabrous on the keel; lemma 4-5 mm. long, obtuse, scabrous above, usually more or less pubescent below. P. tenuifolia Buckley, in part. (?) $P$. wyomingensis Scribn. Dry plains and hills: N.D.-Colo.-Utah-Wash. Plain-Alp. Je-Au.

62. P. Sandbergii Vasey. Stem $2-4 \mathrm{dm}$. high, very slender; ligules acute, 2-4 mm. long; basal leaf-blades 5-10 cm. long; those of the stem-leaves $1-2 \mathrm{~cm}$. long; panicle $3-7 \mathrm{~cm}$. long, very narrow; spikelets 2-4-flowered, about $6 \mathrm{~mm}$. long, often purplish; empty glumes lanceolate, subacute; lemma linear-oblong, 
obtuse, nearly $4 \mathrm{~mm}$. long, puberulent, somewhat villous towards the base. $P$, incurva Scribn. \& Merr. P. tenuifolia Buckley, in part. Plains and hills: Sask. -Wyo.-Colo.-Utah-n Calif.-B.C. Submont.-Mont. Je-Jl.

63. P. juncifolia Scribn. Stem glabrous $1.5-3 \mathrm{dm}$. high; blades of the sterile shoots about $5 \mathrm{~cm}$. long, involute; those of the stem 2-5 cm. long, 1-2 $\mathrm{mm}$. wide; panicle narrow; spikelets 3-5-flowered, 5-6 $\mathrm{mm}$. long; empty glumes ovate, usually obtuse, subequal, 3-4 $\mathrm{mm}$. long; lemma minutely scabrous on the back, 3-4 mm. long, obtuse. Plains and meadows: Wyo.-Colo.-Utah. Plain-Submont. Jl-Au.

64. P. brachyglossa Piper. Stem glabrous, smooth, 6-10 dm. high; ligules short, truncate; leaf-blades 5-20 cm. long, filiform, involute; panicle narrow, 1-2 $\mathrm{dm}$. long; spikelets 7-10 mm. long, 3-6-flowered; empty glumes smooth, scariousmargined, 4-5 mm. long, slightly unequal; lemma obtuse, smooth or nearly so. Plains and meadows: B.C. - n Calif.-Mont. Son.-Submont. Je-Jl.

65. P. confusa Rydb. Stem 6-9 dm. high; basal leaf-blades 1-2 dm. long, 2-3 mm. wide, flat or involute, puberulent; stem-leaves several; blades about 1 $\mathrm{dm}$. long; panicle narrow, 1-1.5 dm. long, dense; spikelets 7-8 mm. long, usually 4-flowered; empty glumes lanceolate, shining, minutely strigulose above; lemma narrow, about $3.5 \mathrm{~mm}$. long, yellowish green, with brownish scarious margins. Meadows and benchlands: Alta.-Neb.-Colo, Plain-Mont.

66. P. truncata Rydb. Stem about $9 \mathrm{dm}$. high, stiff; leaf-blades 1-2 dm. long, 2-3.5 mm. wide, scabrous on the back; panicle about $1.5 \mathrm{dm}$. long, narrow; spikelets 3-5-flowered, 7-9 $\mathrm{mm}$. long; empty glumes 5-6 $\mathrm{mm}$. long, tinged with purple, scabrous on the nerves; lemma narrow, about $5 \mathrm{~mm}$. long, straw-colored or tinged with purple, strigulose throughout. Hills and gulches: Colo.-Alta. Submont. Jl-Au.

67. P. ampla Merr. Stem 6-15 dm. high; leaf-blades flat, somewhat glaucous, $15-25 \mathrm{~cm}$. long, about $4 \mathrm{~mm}$. wide; panicle $2-3 \mathrm{~cm}$. thick and $1.5-3 \mathrm{dm}$. long; spikelets 7-10 mm. long, 3-6-flowered; empty glumes lanceolate, acute, scabrous on the keel and nerves; lemma 4.5-5 mm. long, lanceolate, scabrous throughout, hispidulous on the keel. P. laeviculmis Williams. Hills and valleys: B.C.-Ore.-Mont.-Ida. Submont. Je-Jl.

\section{SCOLÓCHLOA Link.}

Tall, aquatic perennials. Inflorescence paniculate. Spikelets 2-4-flowered; flowers perfect. Empty glumes 2, thin-membranous, 3-5-nerved. Lemma rigid, with a ring of hairs at the base, rounded on the back, 5-7-nerved. Palet usually equalling the lemma, 2-nerved. Styles very short; stigmas plumose. Grain hairy at the apex.

1. S. festucacea (Willd.) Link. Stem 1-2 m. high, smooth; leaf-blades 1.5-4 dm. long, 4-8 mm. wide, flat, scabrous on the margins; panicle open, 2-3 $\mathrm{dm}$. long; spikelets $6-8 \mathrm{~mm}$. long; empty glumes acute, unequal, 3-5-nerved, 6-8 mm. long; lemma narrow, $5-6 \mathrm{~mm}$. long. In water: Iowa-Neb.-Sask.Ore--B.C. Plain. Jl-Au.

\section{PANICULÀria Fabr. ManNa-Grass.}

Usually perennials with rootstocks (all ours), rarely annuals. Inflorescence paniculate. Spikelets usually numerous, ovate to linear, few-many-flowered, the glabrous rachilla articulate between the flowers. Empty glumes 2, obtuse or acute, unequal. Lemma obtuse or truncate, often denticulate, convex on the back, but not keeled, prominently nerved, hyaline at the apex. Palet 2-keeled. Styles short, distinet; stigmas plumose. [Glyceria R. Br.]

Spikelets ovate or oblong, $6 \mathrm{~mm}$. long or less.

Lemma 7-nerved, obscurely denticulate at the apex.

Spikelets 2-4 mm. long; lemma broadly oval, $1.5-2 \mathrm{~mm}$. long.

Leaf-blades flat and lax; lemma slightly scarious-margined; branches of the inflorescence long; empty glumes obtuse.

Plant slender; branches of the inflorescence strongly ascending, nodding.

1. P. nervata. 
Plant stout; branches of the inflorescence spreading or reflexed, not nodding. 2. P. elata.

Leaf-blades conduplicate, stiff, ascending; lemma distinctly scarious-margined; branches of the inflorescence short, strongly ascending, not drooping.

Spikelets 4-6 mm. long; lemma narrowly oval, 2-3 mm. long; inflorescence ample; branches finally spreading.

Lemma barely scarious-margined; empty glumes acute, lanceolate.

Lemma with broad scarious margins: empty glumes obtuse. 4. P. grandis,

5. P. pulchella.

Lemma. 5-nerved, distinctly dentate at the apex, broadly scarious-margined Spikelets 4-6-flowered. Spikelets 2-flowerer.

6. $P$. pauciflora.

7. P. Holmii.

Spikelets linear, $10 \mathrm{~mm}$. long or more; lemma 7-nerved, erose.

Spikelets 10-17 mm. long, on pedicels at least one-third their length.

Spikelets 15-20 mm. long, subsessile or nearly so.

8. P. borealis.

9. P. septentrionalis.

1. P. nervata (Willd.) Kuntze. Stem slender, 3-10 dm. high; leaf-blades 1.5-3 dm. long, 4-10 mm. wide, smooth beneath, scabrous above; panicle 7-20 cm. long, open; spikelets 3-7-flowered, 2-3 mm. long; lemma $1.5 \mathrm{~mm}$. long, obtuse or rounded at the apex, striate. Wet meadows and swamps: Lab.-Fla.Calif.-Alaska; Mex. Submont.-Mont. Je-Au.

2. P. elata Nash. Stem 5-15 dm. high, smooth; leaf-blades flat, scabrous on both sides, 2-4 dm. long, 6-10 mm. wide; panicle ample, 2-3 dm. long; spikelets 3-4 mm. long, ovate, 4-7-flowered; empty glumes hyaline, $1-1.5 \mathrm{~mm}$. long; lemma $2 \mathrm{~mm}$. long, its nerves vanishing near the apex. Shaded bogs: Mont.Wyo.-Calif.-B.C. Submont.-Mont. Jl-S.

3. P. rigida (Nash.) Rydb. Stem 3-4 dm. high; leaf-blades 5-15 cm. long, 3-4 mm. wide; inflorescence small, about $1 \mathrm{dm}$. long; spikelets about $3 \mathrm{~mm}$. long, 5-6-flowered; empty glumes about $1 \mathrm{~mm}$. long, purplish; lemma rounded-oval, usually purplish, about $1.5 \mathrm{~mm}$. long. Bogs and springs: Mont.-Ida.-Wyo. $\mathrm{My}-\mathrm{Jl}$.

4. P. grandis (S. Wats.) Nash. Stem stout, 1-2 m. high, smooth; leafblades $1.5-4 \mathrm{dm}$. long, 6-15 mm. wide, smooth beneath, scabrous above; panicle 2-4 dm. long, open; spikelets 4-7-flowered; lemma 2-2.5 mm. long. $P$. americana (Torr.) McMill. In water and wet places: N.B.-N.Y.-N.M.-Calif.Alaska, Plain-Submont. Je-Au.

5. P. pulchella Nash. Stem 4-6 dm. high, stout, smooth; leaf-blades $1,5-3$ $\mathrm{dm}$. long, 2.5-6 mm. wide, flat; panicle open, 1.5-3 dm. long; spikelets 4-6flowered; empty glumes brownish or purplish, scarious-margined, obtuse; lemma usually purple, scabrous, about $3 \mathrm{~mm}$. long. Swamps: Yukon-Mack.-N.M. Submont. -Subalp. J-S.

6. P. pauciflora (Presl.) Kuntze. Stem 3-10 dm. high; leaf-blades 1-3 dm. long, 6-10 mm. wide, scabrous on both sides; panicle 1.5-2 dm. long, loose; branches ascending or spreading; spikelets 4-5 $\mathrm{mm}$. long; empty glumes $1 \mathrm{~mm}$. long, rounded at the apex; lemma about $3 \mathrm{~mm}$. long, scabrous. Wet meadows and in water: Mont.-Colo.-Calif.-B.C. Submont.-Subalp. Jl-Au.

7. P. Holmii Beal. Stem 2.5-5 dm. high, pale; leaf-blades flat, 4-12 $\mathrm{cm}$. long, 4-7 mm. wide, scabrous; panicle open, lax, 5-8 cm. long; empty glumes hyaline, 1-1.3 mm. long; lemma scabrous, 2-2.2 $\mathrm{mm}$. long. Shaded streams: Colo. Mont. Jl.

8. P. borealis Nash. Stem glabrous, 6-15 dm. high; leaf-blades 1-2 dm, long, 2-10 $\mathrm{mm}$. wide, erect, scabrous on both sides; panicle narrow, 2-5 dm. long; branches erect, smooth; spikelets 7-13-flowered; empty glumes scarious-margined, 1-nerved, the first acute, the second obtuse, erose; lemma $3.5-4 \mathrm{~mm}$. long. Water and wet places: Me.-N.Y.-N.M.-Calif.-Alaska. Submont.Mont. Jl-Au.

9. P. septentrionalis Hitchc. Stem 1-1.5 m. high; blades 1-2.5 dm. long, 6-8 mm. wide; panicle 2-2.5 dm. long, subflexuose; spikelets 8-12-flowered; empty glumes obtuse; lemma 4-4.5 mm. long, hispidulous. Glyceria fluitans Am. auth., not R. Br. Shallow water: Newf.-Va.-Calif.-B.C. PlainSubmont. 


\section{PUCCINÉllia Parl. Meadow-grass.}

Perennials with rootstocks, ours tufted. Inflorescence paniculate. Spikelets 3-several-flowered; flowers perfect. Empty glumes 2, obtuse or acute, unequal. Lemma rounded on the back, obscurely 5-nerved. Palet nearly equalling the lemma. Styles wanting; stigmas sessile, plumose. Grain usually adherent to the palet.

Leaves mostly basal; panicle less than $1 \mathrm{dm}$. long.

Leaves scattered on the stem; panicle usually more than $1 \mathrm{dm}$. long.

Lemma 2-2.5 mm. long, distinctly nerved.

Lemma $2 \mathrm{~mm}$. long or less, obseurely nerved.

1. P. Lemmoni.

2. P. Nuttalliana.

3. P. tenuiflora.

1. P. Lemmoni (Vasey) Scribn. Stem 1-4 dm. high; leaves smooth, filiform, involute, short, the cauline ones few and reduced; panicle $5-10 \mathrm{~cm}$. long, becoming open; branches short, spreading; empty glumes both 1-nerved, 2-3 $\mathrm{mm}$. long; lemma $3 \mathrm{~mm}$. long, smooth. Glyceria Lemmoni Vasey. Alkaline flats: Calif.-B.C.-Sask. Plain-Submont. Je-Jl.

2. P. Nuttalliana (Schultes) Hitche. Stem 3-12 dm. high, ereet, strict; leaf-blades $5-10 \mathrm{~cm}$. long, $3 \mathrm{~mm}$. wide or less, usually involute or the upper flat; panicle open with spreading or ascending branches; spikelets scattered, 1-7flowered, 3-6 mm. long; empty glumes unequal, the first acute, 1-nerved, the second obtuse or acute, 3-nerved. P. airoides (Nutt.) Wats. \& Coult. G. distans airoides Nutt. Saline soil: Man.-Kans,-N.M.-Nev.-B.C.-Mack. Plain -Subalp. Je-Au.

3. P. tenuiflora (Griseb.) Scrib. \& Merr. Stems 4-6 dm. high; leaf-blades 6-9 cm. long, 1-2 mm. wide, involute; panicle 1-1.5 dm. long; branches capillary, ascending or spreading, scabrous, of ten $1 \mathrm{dm}$. long; spikelets $3-4 \mathrm{~mm}$. long, 3or 4-flowered. Atropis tenuiflora Griseb. Alkaline flats: Alaska-Sask. Boreal -Plain-Submont. Je-Au.

\section{FESTÙCA L. FESCUE-GRASS.}

Perennials, or annuals, usually tufted. Inflorescence paniculate. Spikelets 2-several-flowered, the flowers perfect or the upper ones staminate, the rachilla articulate between the flowers. Empty glumes 2, membranous, unequal, keeled, acute, the first mostly 1-nerved, the second 3-nerved. Lemma rounded on the back, at least below, acute, more or less awned, 3-7-nerved. Palet a little shorter than the lemma, 2-keeled. Stamens 1-3. Styles very short, distinct, terminal or nearly so; stigmas plumose, bilateral.

Perennials; stamens 3 .

Leaf-blades of the innovations narrow, $3 \mathrm{~mm}$. wide or less, involute.

Innovations extravaginal; $i . e_{.,}$plants with creeping rootstocks and stolons; leaves smooth.

Spikelets pubescent.

Spikelets glabrous or scabrous.

Body of the lemma $5-7 \mathrm{~mm}$. long; leaf-blades rather firm.

Stem-leaves with flat blades; innovations numerous.

Stem-leaves with filiform involute blades; innovations few.

3. F. vallicola.

Body of the lemma about $4 \mathrm{~mm}$. long; leaf-blades filiform, soft.

Innovations intravaginal; plants bunch-grasses.

4. F, Eerlei.

Ligules short, truncate or rounded.

Body of the lemma 3-8 mm. long; leaf-blades long, persistent on the sheaths; palet obtuse or 2-toothed at the apex.

Pulvini at the bases of the branches of the panicle none or obsolete; tufts easily separable.

Lemma (without the awns) 3-4-mm. long, not balf longer than the first glume: plant 1-2 (rarely 3) dm. high; inflorescence spike-like.

Lemma lanceolate, long-acuminate and long-awned; panicle dense; leaf-blades short, scarcely fliform.

Leaf-blades soft and sulcate, at least in age.

5. F. brachyphylla.

Leaf-blades firm and terete, even in age. 6. F. supina.

Lemma oblong-lanceolate, abruptly contracted into a short awn; panicle lax; leaf-blades narrowly filiform and soft.

7. F. minutiflora. 
Lemma (without the awns) $5-8 \mathrm{~mm}$. long; plant usually over $3 \mathrm{dm}$. high.

Old sheaths of the innovations brown and papery.

Otd sheaths of the innovations neither brown nor papery.

Basal leaf-sheaths short, remaining involute in age; blades of stem-leaves rarely $8 \mathrm{~cm}$. long.

Awn short, less than half as long as the lemma; inflorescence dense and narrow. $9 . F$, sarimontana.

Awn long, from nearly equalling to much exceeding the lemma: inflorescence open.

Awn little if at all exceeding the lemma in length; ovary glabrous.

Leaves scabrous. $10 . F$. ingrata.

Leaves smooth. 11. F. idahoensis.

Awn much exceeding the lemma; ovary hispidulous

at the apex. $12 . F$ occidentalis,

Basal sheaths long and becoming flattened in age, often 1 $\mathrm{dm}$. long; blades of the stem-leaves over $1 \mathrm{dm}$. long.

13. F, arizonica.

Pulvini at the bases of the branches of the panicle rather conspicuous; tufts separable with difflculty. $14 . F$. viridula.

Body of the lemma 8-12 mm. long: leaf-blades soon breaking off from the sheath; palet notched at the apex: bunch-grasses.

Branches of the panicle spreading or reflexed; spikelets shining; leaves smooth beneath.

15. F. allaica.

Branches of the panicle erest or ascending; spikelets rather dull; leaves very scabrous.

Plant 5-15 $\mathrm{dm}$. high: basal sheaths long, loose, in age more or less flattened; empty glumes narrowly lanceolate, acuminate; second glume shorter than the spikelet. 16. F. campestris.

Plant 3-5 dm. high: basal sheaths usually short and close even in age; empty glumes acute, lanceolate; second glume about equalling the spikelet.

Ligules elongate, 4-9 $\mathrm{mm}$. long, acute.

Leaf-blades all flat, $4 \mathrm{~mm}$. wide or more; perennials with rootstocks.

Lemma abruptly acute, not at all keeled. 19 . F elatior.

Lemma awned or awn-pointed, keeled at least above the middle.

Awn or awn-point shorter than the lemma.

Lemma distinctly 5-nerved; awn from the cleft apex; panicle ciliate.

Lemma with indistinct intermediate nerves; awn terminal; panicle not ciliate.

A wn longer than the lemma.

Annuals; stamens usually solitary.

Spikelets 5-13-flowered; both glumes subulate.

spikelets loosely 1-5-flowered; first glume subulate, the second 23 . F octoflora.

Branches of the short panicle normally divergent, a pulvinus at the base of at

Spikelets usually 3-5-flowered, only the main branches of the inflorescence divergent.

24. F pacifica.

Spikelets nsually 1-3-flowered; all branches divergent or reflexed.

Branches of the elongated narrow panicle erect and appressed.

25. F. reflexa.

26. F. megalura.

1. F. Kitaibeliana Schultes. Stem 2-5 dm. high; blades of stem-leaves flat, 3-12 cm. long; inflorescence narrow, often secund; spikelets 8-12 mm. long, 5-9-flowered; empty glumes unequal, 2-4 mm. long, lanceolate, glabrous; lemma narrowly lanceolate, 5-6 mm. long; awn scabrous, 2-4 $\mathrm{mm}$. long. Hills and mountain sides: Greenl.-N.B.-Wyo.-Ore.-Alaska; Eurasia. Submont. $\mathrm{Je}-\mathrm{Au}$.

2. F. rubra L. Stem $3-10 \mathrm{dm}$. high; blades soft, green or (in var. glaucoidea Piper) more or less glaucous; panicle 5-20 cm. long, often narrow; spikelets 4-6flowered, 7-8 mm. long, green or more or less glaucous, often purple-tinged; lemma 5-7 mm. long, lanceolate; awn scabrous, 1-4 mm. long. Hills: Greenl.Va.-Colo.-Alaska; Eurasia. Submont.-Subalp. Je-Au.

3. F. vallicola Rydb. Stem 4-10 dm. high, slender, light-colored, smooth and shining; leaf-blades all filiform, $5-10 \mathrm{~cm}$. long; panicle narrow, about $5 \mathrm{~cm}$. long; spikelets 4-7-flowered, 8-10 $\mathrm{mm}$. long; lemma about $5 \mathrm{~mm}$. long, lanceolate, indistinctly 5-7-nerved, smooth or minutely scabrous; awn 2-4 mm. long. Meadows: Mont.-Wyo. Submont. J1-Au.

4. F. Barlei Rydb. Stem about $3 \mathrm{dm}$. high, very slender; basal leaf-blades 5-10 cm. long, strongly involute, $0.5 \mathrm{~mm}$. wide or less; stem-leaves $3-5 \mathrm{~cm}$. long, 
$1 \mathrm{~mm}$. wide or less; panicle narrow and spike-like, $3-5 \mathrm{~cm}$. long; spikelets 2-3flowered, about $5 \mathrm{~mm}$. long; lemma narrowly lanceolate, smooth, usually awned; awn $1 \mathrm{~mm}$. or less long. Mountains: Colo. Mont. Jl.

5. F. brachyphylla Schultes. Stem 1-2 dm. (rarely $3 \mathrm{dm}$.) high; leafblades narı ow, involute, $1-5 \mathrm{~cm}$. long; panicle $2-5 \mathrm{~cm}$. long; spikelets $2-5$-flowered; lemma green or purplish, about $3 \mathrm{~mm}$. long, acuminate; awn scabrous, $2-3 \mathrm{~mm}$. long. F. brevifolia R. Br. Alpine-aretic regions: Greenl.-Vt.-N.M.-Ariz.Calif.-Alaska. Subalp.-Alp. Jl-S.

6. F. supina Schur. Stems 1-2 dm. high; leaf-blades stiff, involute, often arcuate-spreading; panicle $1-5 \mathrm{~cm}$. long, nearly simple; lemma lanceolate, $3-3.5$ $\mathrm{mm}$. long, acuminate, often tinged with red or brown; awn 1-3 mm. long. Alpine-arctic situations: Greenl.-Lab.-Colo.-B.C.; Eu. Alp. Jl-S.

7. F. minutiflora Rydb. Stem very slender, 1-1.5 (seldom 3) dm. high; leaves mostly basal; blades $1-10 \mathrm{~cm}$. long, narrow and flaccid, about $0.5 \mathrm{~mm}$. wide; panicle very narrow, lax, 2-4 $\mathrm{cm}$. long, with very short, erect branches; spikelets, excluding the awns, about $5 \mathrm{~mm}$. long, 2-3-flowered; lemma about $2 \mathrm{~mm}$. long, purple-tinged above; awn $1.5 \mathrm{~mm}$. long or less. Mountains: Colo. Mont. -Subalp. Je-Au.

8. F. calligera (Piper) Rydb, Stem pale, $1.5-5 \mathrm{dm}$. high; leaf-blades filiform, glaucous, strongly striate, $5-15 \mathrm{~cm}$. long, about $0.5 \mathrm{~mm}$. wide; sheaths of the stem-leaves looser; panicle narrow, $1-1.5 \mathrm{dm}$. long; branches ascending; spikelets 4-7-flowered; lemma about $5 \mathrm{~mm}$. long, abruptly acuminate; awn 1-2 $\mathrm{mm}$. long. $F$. ovina calligera Piper. Mountains: Ariz.-Nev.-Utah-Colo. Son.-Submont. Jl-Au.

9. F. saximontana Rydb. Densely tufted perennial; stem $2-4 \mathrm{dm}$. high, slender, glabrous; leaf-blades very slender, $3-10 \mathrm{~cm}$. long, less than half a millimeter wide, strongly involute; panicle 4-10 cm. long; spikelets 4-6-flowered; lemma lanceolate, $3-5 \mathrm{~mm}$. long, glabrous; awn 1-2 mm. long. Festuca pseudovina (Beal) Rydb., not Hack. Dry ridges: Mich.-Sask.-Colo.-B.C. Mont,-Alp. Je-Au.

10. F. ingrata (Hack.) Rydb. Stem 1-3 dm. high; leaf-blades filiform, involute, those of the sterile shoots $1.5-3 \mathrm{dm}$. long, $0.5 \mathrm{~mm}$. wide or less; panicle 8-15 cm. long; spikelets 3-8-flowered, 8-15 mm. long; lemma 6-8 mm. long, more or less scabrous; awn 3-4 mm. long. F. ovina ingrala Hack. Meadows and hillsides: Mont.-Colo.-Utah-B.C. Submont.-Subalp.

11. F. idahoensis Elmer. Stem 7-9 dm. high; leaf-blades filiform, involute, those of the sterile shoots $2-4 \mathrm{dm}$. long, less than $0.5 \mathrm{~mm}$. wide; inflorescence 7-12 cm. long, open; spikelets 3-5-flowered, about $1 \mathrm{~cm}$. long or less; lemma obscurely 5 -nerved, $6 \mathrm{~mm}$. long; awn about $3 \mathrm{~mm}$. long. Meadows: Ida. Submont. Jl.

12. F. occidentalis Hook. Stem slender, 5-8 dm. high; leaf-blades 5-20 $\mathrm{cm}$. long, glabrous; panicle loose, subsecund, flexuose, $8-20 \mathrm{~cm}$. long; spikelets 3-5-flowered, 6-10 $\mathrm{mm}$. long, pale green or purplish; lemma $5-6.5 \mathrm{~mm}$. long, scabrous towards the apex; awn of about the same length. Meadows and hillsides: B.C.-Calif.-Wyo.-Mont. Submont. Ap-Jl.

13. F. arizonica Vasey. Stem 4-7 dm. high; leaf-blades $1.5-2.5 \mathrm{dm}$. long, scabrous; panicle rather narrow, 7-12 cm. long; branches erect, somewhat secund, scabrous; spikelets 4-6-flowered, 10-13 $\mathrm{mm}$. long; lemma 6-7 mm. long, thick, acuminate; awn 1-2 mm. long. F. Vaseyana Hack. Hills and open woods: Colo.-N.M.-Ariz.-Utah. Mont. Jl-S.

14. F. viridula Vasey. Stem $3-6 \mathrm{dm}$. high; leaf-blades erect, the basal ones 1-3 dm. long, involute; those of the stem often flat, shorter; panicle loose, open, 1-1.5 dm. long; spikelets 3-6-flowered, 10-12 mm. long; lemma smooth and shining, 6-7 mm. long, pointed. Mountain meadows: B.C.-Ida.-Calif. Mont.-Subalp. Je-Au.

15. F. altaica Trin. Stem erect, smooth, $3-9 \mathrm{dm}$. high; leaf-blades involute, $1.53 \mathrm{dm}$. long; panicle loose and open, 1-2 dm. long; spikelets $3-5$-flowered, 
12-15 mm. long, green or more commonly copper-colored or purple; empty glumes smooth or nearly so; lemma ovate, attenuate, finely and densely scabrous, somewhat shiny, 10-12 mm. long. Subarctic regions: Alaska-Yukon-Canadian Rockies-(Mt. Albert) Que.-Lab.; Siberia. Subalp. Je-Au.

16. F. campestris Rydb. Stem 4-10 dm. high; leaf-blades $3-5 \mathrm{dm}$. long, scabrous; panicle $12-25 \mathrm{~cm}$. long; spikelets 10-12 mm. long, 2-4-flowered; empty glumes membranous, narrowly lanceolate, acuminate; lemma very scabrous, attenuate, thicker than the empty glumes, 9-10 mm. long. F. scabrella major Vasey. Plains and hills: Alta.-N.D.-Wash.-Yukon. Plain-Submont. Je$\mathrm{Au}$.

17. F. scabrella Torr. Stem 3-5 dm. high; blades of the basal leaves 1-2 $\mathrm{dm}$. long, scabrous, striate; those of the upper stem-leaves short, $3-5 \mathrm{~cm}$. long, often flat; panicle small, 5-15 cm. long; branches ascending; spikelets often purple-tinged, 3-4-flowered, about $1 \mathrm{~cm}$. long; lemma scabrous, 6-8 mm. long, acute. F. Hallii (Vasey) Piper. Mountains: Alta.-Mont.-Wash.-B.C.; Colo. Mont. Je-Jl.

18. F. Thurberi Vasey. Stem 6-10 dm. high; leaf-blades involute, 6-20 $\mathrm{cm}$. long, very seabrous; panicle 1-1.5 dm. long, loose, slightly drooping; spilielets 3-6-flowered, 8-12 mm. long; empty glumes smooth or scabrous on the keel; lemma finely scabrous near the margins or glabrous, cuspidate-acuminite, $7-8$ $\mathrm{mm}$. long. Poa festucoides and P. Keibensis M. E. Jones. Hillsides and mountains: N.M.-Wyo.-Utah. Mont.-Subalp. Jl-S.

19. F. elatior L. Stem smooth, 5-12 dm. high; leaf-blades 1-6 dm. long, 4-8 mm. wide, smooth beneath, scabrous above; panicle 1-2 dm. long, rather open in anthesis, narrowed in fruit; spikelets 3-13-flowered, usually 6-8-flowered, 9-11 mm. long; lemma 5-7 mm. long, scabrid towards the apex. Meadows and copses: N.S.-N.C.-N.M.-Calif.-B.C.; eult. and nat. from Eu. PlainSubmont. Je-Au.

20. F. dasyclada Hack, Stem erect, 2-4 dm. high; leaf-biades soft, often folded, glabrous, 5-15 cm. long; panicle open; spikelets 2-flowered, 6-7 mm. long; lemma about $6 \mathrm{~mm}$. long, scabrous-puberulent, 2-toothed at the apex; awn $3 \mathrm{~mm}$. long. Mountains: "Utah."

21. F. sororia Piper. Stem 6-9 dm. high, smooth and shining; leafblades thin, flat, spreading, 1-2.5 dm. long, 3-6 mm. wide, scabrous on the margins; panicle $1-1.5 \mathrm{dm}$. long, somewhat nodding, lax; spikelets $3-5$-flowered, 7-12 mm. long; empty glumes membranons; lemma 6-9 $\mathrm{mm}$. long, keeled at the base, scabrous; awn 0.5-2 mm. long. F. fratercula Piper, not Rupr. Open hillsides, cañons, and meadows. Colo.-Utah-Ariz.; Mex. Submont.-Subalp.

20. F. subulata Trin. Stem 4-12 dm. high; leaf-blades dark green above, flat, thin, 1-3 dm. long, 3-10 mm. wide, scabrous on both sides; panicle very loose, drooping, 1.5-4 dm. long; branches reflexed; spikelets 3-5-flowered, 7-12 $\mathrm{mm}$. long; lemma somewhat keeled, scabrous toward the apex, $5-7 \mathrm{~mm}$. long, attenuate into a scabrous awn $5-20 \mathrm{~mm}$. long. F. Jonesii Vasey. Woods: Alảska-Calif.-Utah-Colo.-Mont. Mont.-Subalp. Je-Au.

23. F. octoflora Walt. Usually tufted; stems $5-40 \mathrm{~cm}$. high, glabrous or retrorsely puberulent; leaf-hlades involute or rarely flat, $2-10 \mathrm{~cm}$. long; panicle narrow, erect, racemiform, 3-12 $\mathrm{cm}$. long; spikelets 5-10 $\mathrm{mm}$. long, rarely longer; lemma lanceolate, scabrous to glabrous, 4-5 mm. long, attenuate; awn straight, 1-7 mm. long. F. tenella Willd. In dry sandy soil: Que.-Fla.-Calif.-B.C. Plain-Mont. Ap-Jl.

24. F. pacifica Piper. Simple or somewhat tufted; stem 1-5 dm. high, glabrous; leaf-blades glabrous, loosely involute, $3-5 \mathrm{~cm}$. long; panicle more or less secund, 5-12 cm. long; branches solitary, bearing spikelets on the lower side; spikelets 3-6-flowered; lemma lanceolate, scabrous, except that of the lowest flower, which is smooth, 6-7 mm. long; awn seabrous, $10-15 \mathrm{~mm}$. long. River valleys and hills: B.C.-Utah-N.M.-Ariz.-L. Calif. Son. $\rightarrow$ Submont. Ap-Jl. 
25. F. reflexa Buckley. Simple or rarely tufted; stem erect, 2-5 dm. high; leaf-blades flat or loosely involute, $2-10 \mathrm{~cm}$. long; panicle $5-12 \mathrm{~cm}$. long; spikelets 1-3- (rarely 4- or 5-) flowered, 5-7 $\mathrm{mm}$. long; lemma lanceolate, smooth or scabrous, 4.5-6 mm. long, attenuate; awn scabrous, 2-12, usually 5-8 $\mathrm{mm}$. long. Dry places: B.C.-Utah-Calif. Son.-Submont. My-Je.

26. F. megalura Nutt. Simple or somewhat tufted; stems $2-6 \mathrm{dm}$. high, glabrous; leaf-blades involute or flat; panicle $1-3 \mathrm{~cm}$. long; spikelets 4-5-flowered, 8-11 $\mathrm{mm}$. long; lemma obscurely 5-nerved, 4-6 mm. long, scabrous and ciliate on its upper half; awn scabrous, $8-15 \mathrm{~mm}$. long. Dry soil: B.C,-Ida.-Ariz. -Calif.; Mex., Equador, Peru, and Chili. Submont. Ap-Je.

\section{HESPERÓCHLOA (Piper) Rydb.}

Dioecious perennials, densely tufted, producing both intravaginal innovations and stout extravaginal stolons. Panicle narrow. Spikelets 3-5-flowered, those of the staminate plant flattened, those of the pistillate one turgid. Empty glumes 2, lanceolate, subscarious, the lower 1-nerved, the upper 3-nerved. Lemma ovate, 5-nerved, acuminate. Palet shorter than the lemma. Ovary hispidulous at the apex, deeply sulcate; stigma elongate, the numerous short branches arising on all sides. Grain 2-dentate at the apex.

1. H. Kingii (S. Wats.) Rydb. Stems stout, striate, glabrous, 4-10 dm. high; leaf-blades firm, flat or loosely involute, coarsely striate, $1-3 \mathrm{~cm}$. long, 3-6 $\mathrm{mm}$. wide; panicle narrow, erect, $8-20 \mathrm{~cm}$. long; spikelets $6-10 \mathrm{~mm}$. long; empty glumes nearly smooth, shining, the first $3-4.5 \mathrm{~mm}$. long, the second $5-7 \mathrm{~mm}$. long; lemma ovate, abruptly acuminate, scabrous, 5-8 $\mathrm{mm}$. long. Poa Kingii S. Wats. Festuca confinis Vasey. Cañons and hillsides: Ore.-Calif.-Colo.Neb.-Mont. Submont.-Subalp. Je-Au.

\section{Bròmus L. Brome-grass, Chess, Cheat.}

Annuals or perennials, with paniculate inflorescence. Spikelets usually large, often drooping, several-many-flowered; flowers perfect or the upper ones imperfect. Empty glumes 2, membranous, persistent, narrow, unequal, acute or the second one sometimes short-awned. Lemma longer than the glumes, rounded or keeled on the back, usually awned, the awn dorsal and inserted just below the 2-toothed apex. Palet shorter than the lemma, 2-keeled. Ovary crowned with a villous appendage, at the base of which arise the lateral styles; stigmas plumose.

Second empty glume 5-7-nerved: first empty glume 3-nerved.

Lemma compressed-keeled.

Palet less than three-fourths as long as the lemma, which is scarcely toothed.

Sheaths and usually also the blades hairy; lemma pubescent or hispidulousscabrous.

Lemma hispidulous-scabrous.

Awns 10-15 mm. long.

Awn 4-6 mm. long.

1. B. Hookerianus.

Lemma pubescent; awns 4-8 $\mathrm{mm}$. long.

Lower branches of the panicle $7 \mathrm{~cm}$. long or less, in fruit erect.

Leaves flat, not canescent.
Leaves involute, canescent.

3. B. breviaristatus.

4. B. subrelutinus.
Lower branches of the panicle $1 \mathrm{dm}$. long or longer, spreading in fruit.

Sheaths and blades glabrous or minutely scabrous.

Panicle narrow, strict; awn 4-6 mm. long.

Panicle open, spreading and nodding; awn $6-7 \mathrm{~mm}$. long.

5. B. latior.

5. B. paniculatus.

Palet more than three-fourths as long as the lemma, which is distinctly toothed at the apex.

8 . B. unioloides.

Lemma rounded on the back, broadly elliptic: introduced tufted annuals or biennials. Lemma nearly as broad as long, awnless or with a very short awn.

Lemma much longer than broad, conspicuously awned.

9. B. brizaeformis.

Lemma and glumes glabrous.

Awn much shorter than the lemma, nearly erect,

Sheaths glabrous.

Sheaths densely pubescent.

10. B. secalinus.

Awn fully as long as the lemma, at maturity strongly divergent; sheaths pubescent.

12. B. patulus. 
Lemma and glumes more or less pubescent.

13. B. hordeaceus.

Second empty glume 3-nerved; first empty glume 1-nerved, except in B. Porteri.

Awns shorter than the lemma; plants perennial with rootstocks, all native except B. inermis.

Inflorescence more or less drooping.

Awn 6-9 mm. long; empty glumes sparingly pubescent or glabrous.

Awn $2-5 \mathrm{~mm}$. long.

14. B. eximius.

Empty glumes decidedly pubescent.

First empty glume 3-nerved; inflorescence narıow.

First empty glume 1-nerved; inflorescence open.

Sheaths with a ring of dense hairs at the base of the blades.

Sheaths without a ring of hairs. 16. B. latiolumis.

Empty glumes glabrous or merely scabrous on the nerves.

Lemma evenly pubescent on the back; sheaths densely hairy.

18. B. lanatipes.

Lemma ciliate on the margins, glabrous or sparingly hairy on the back; sheaths glabrous or the lower sparingly hirsute. 19. B. ciliatus,

Inflorescence not drooping.

Inflorescence narrow; its branches erect; lemma usually with awn $2-3 \mathrm{~mm}$. long.

20. B. Pumpelliants.

Inflorescence broad: its branches spreading: lemma usually awnless.

A wn longer than the lemma; introduced tufted annuals.

21. B. inermis.

Spikelets numerous on slender, recurved pedicels; lemma 8-12 mm. long.

Spikelets few; pedicels not recurved; lemma 12-30 mm. long. Awn less than $3 \mathrm{~cm}$. long.

A wn $3.5-4 \mathrm{~cm}$. long.

22. B. tectorum.

23. B. sterilis.

24. B. maximus.

1. B. Hookerianus Thurb. Annual or biennial; stem erect, 4-8 dm. high; leaf-blades flat, 1-2.5 dm. long, 5-12 mm. wide; panicle 2-4 dm. long; branches spreading; spikelets 5-10-flowered, 3-4 cm. long, 5-7 $\mathrm{mm}$. wide; empty glumes glabrous, 15-18 mm. long, gradually acuminate; lemma about $2 \mathrm{~cm}$. long, broadly hyaline-margined. Plains: B.C.-Ida.-Calif. Submont. My-Jl.

2. B. Flodmanii Rydb. Short-lived perennial; stem glabrous, 6-10 dm. high; leaf-blades 2-3 dm. long, 6-10 $\mathrm{mm}$. wide, minutely scabrous; panicle 1-2 dm. long; spikelets $2.5-3.5 \mathrm{~cm}$. long, 5-7 mm. wide; empty glumes lanceolate, about $1 \mathrm{~cm}$. long, glabrous, acute; lemma about $15 \mathrm{~mm}$. long, scabrous, narrowmargined, acuminate. Meadows: Mont. Submont.

3. B. breviaristatus (Hook.) Buckl. Tufted short-lived perennial; stem 6-12 dm. high; leaf-blades sparsely pilose throughout or glabrate, $1.5-2.5 \mathrm{dm}$. long, 6-12 mm. wide; panicle erect, narrow, 1-2 dm. long; spikelets $2.5-4 \mathrm{~cm}$. long, 5-7 mm. wide, 7-9-flowered; empty glumes scabrous or scabrous-puberulent; lemma 11-14 mm. long; awn 4-5 mm. long. B. marginatus Nees. Meadows: B.C.-Calif,-Colo.-Neb.-Alta. Submont.

4. B. subvelutinus Shear. Erect tufted perennial; stem pubescent above, 2.5-5 dm. high; leaf-blades linear, rigid, involute, canescent, with spreading hairs; panicle $5-10 \mathrm{~cm}$. long, narrow, erect; spikelets short-pediceled or subsessile, 5-7-flowered, 2-3 cm. long; empty glumes puberulent, 8-12 $\mathrm{mm}$. long; lemma appressed-pubescent; awn 3-4 mm. long. Arid regions: Nev.-Calif.Wash.-Ida. Son.

5. B. latior (Shear) Rydb. Stout perennial; stem 7-18 dm. high; leaf-blades 2-3 dm. long, 7-10 $\mathrm{mm}$. wide, more or less pilose; panicle 2-3 dm. long; spikelets $2.5-4 \mathrm{~cm}$. long, 6-8 mm. wide; empty glumes pubescent, about $1 \mathrm{~cm}$. long, acuminate; lemma densely pubescent, about $15 \mathrm{~mm}$. long, acuminate, slightly bifid; awn 6-7 mm. Iong. B. marginatus latior Shear. Meadows: Wash.Calif.-N.M.-Mont. Submont.-Mont. Je-Au.

6. B. polyanthus Scribn. Stout short-lived perennial; stem glabrous, or puberulent at the nodes; leaf-blades 1-2 dm. long, 4-8 $\mathrm{mm}$. wide, scabrous, especially above; panicle 1-2 dm. long; spikelets $3-3.5 \mathrm{~cm}$. long, densely 7-11flowered; empty glumes smooth or nearly so, subacute or obtuse; lemma smooth or minutely seabrous. Meadows: Mont.-N.M.-Utah-Ore. Submont.Subalp. Je-Au. 
7. B. paniculatus (Shear) Rydb. Tall leafy perennial; stem 6-10 dm. high; leaf-blades 2-3 dm. long, 8-12 mm. wide, scabrous; panicle 2-3 dm. long; spikelets loosely $5-7$-flowered, $2-3 \mathrm{~cm}$. long, $6-7 \mathrm{~mm}$. wide; empty glumes obtuse, glabrous; lemma glabrous, $11-14 \mathrm{~mm}$. long, scarious-margined, acute. $B$. polyanthus paniculatus Shear. Mountain meadows: Colo.-N.M.-Ariz.Utah. Submont. J1-Au.

8. B. unioloides (Willd.) H.B.K. Stout, more or less tufted annual; stems 3-10 dm. high, glabrous; sheath pilose-pubescent, rarely glabrous; panicle $1.5-3.5$ $\mathrm{dm}$. long; branches ascending or spreading; spikelets 2-3.5 $\mathrm{cm}$. long, 5-9 mm. broad, 7-11-flowered; empty glumes smooth or slightly scabrous; lemma broadly lanceolate, acute, nearly glabrous to strongly scabrous, $13-16 \mathrm{~mm}$. long; awn usually present, $2 \mathrm{~mm}$. long or less. Fields, prairies, and waste places: Fla.Colo.-Calif. Son. Ap-Au.

9. B. brizaeformis Fisch. \& Mey. Stem 3-6 dm. high, glabrous or slightly pubescent at the nodes; leaf-blades pubescent on both sides, $5-10 \mathrm{~cm}$. long, 2-5 $\mathrm{mm}$. wide; panicle 5-25 $\mathrm{cm}$. long, lax, secund, nodding; spikelets $15-25 \mathrm{~mm}$. long, ovate; empty glumes obtuse, smooth or minutely scabrous; lemma about $1 \mathrm{~cm}$. long, very broad, smooth or minutely scabrous, broadly scarious-margined. Waste places and fields: Mass.-Del.-Calif.-B.C.; adv. from Eurasia. Plain -Submont. Je-Jl.

10. B. secalinus L. Stem 3-7 dm. high, smooth or pubescent at the nodes; leaf-blades 1-2 dm. long, sparsely pubescent above, glabrous beneath; panicle 8-18 cm. long, at first erect, drooping in fruit; spikelets $10-18 \mathrm{~mm}$. long, 6-8 $\mathrm{mm}$. broad; lemma $6-8 \mathrm{~mm}$. long, obtuse, smooth or scabrous, its margins strongly incurved in fruit; awn 3-5 mm. long. CHEAт. Fields and waste places: Me,Fla.-Calif.-Wash.; nat. from Eu. Plain. Ap-Au.

11. B. racemosus L. Stem 3-7 dm. high, scabrous-puberulent under the inflorescence and pubescent at the nodes; leaf-blades 7-14 $\mathrm{cm}$. long, pilosepubescent; panicle simple, somewhat nodding; spikelets 15-20 mm. long, 5-9flowered, acute; lemma smooth or scabrous, $6-8 \mathrm{~mm}$. long, very shortly bidentate at the apex; awn 5-8 mm. long, straight. Waste places: N.S.-Ga.-N.M.Ore.-Wash.-Yukon; adv. from Eu. Plain-Submont. Je-Au.

12. B. patulus Mert. \& Koch. Stem somewhat geniculate at the base, 4-6 dm. high; leaf-blades pubescent, 4-10 cm. long, 2-4 mm. wide; panicle 12-20 $\mathrm{cm}$. long, diffuse, somewhat drooping; spikelets 2-2.5 $\mathrm{cm}$. long, $5-6 \mathrm{~mm}$. wide; lemma $7-9 \mathrm{~mm}$. long, hyaline-margined, emarginate, glabrous. Waste places: Mass.-Colo.-S.D.; adv. from Eu. Plains. Je-Jl.

13. B. hordeaceus L. Stem $2-8 \mathrm{dm}$. high, usually somewhat pubescent; leaf-blades $5-15 \mathrm{~cm}$. long, 3-5 $\mathrm{mm}$. broad, pilose or glabrate; panicle contracted, 5-10 $\mathrm{cm}$. long; spikelets 5-13-flowered, $12-15 \mathrm{~mm}$. long, 4-6 mm. wide; lemma obtuse, coarsely pilose, $8-9 \mathrm{~mm}$. long; awn stout, $6-9 \mathrm{~mm}$. long. $B$. mollis $\mathrm{L}$. Hairy Cheat. Waste places, roadsides, fields: Me.-N.C.-Calif.-B.C.; nat. from Eu. Plain-Submont. My-Jl.

14. B. eximius (Shear) Piper. Stem slender, 8-11 dm. high, somewhat pubescent, at least at the nodes; sheaths pilose; leaf-blades $1.5-2.5 \mathrm{dm}$. long, $5-9 \mathrm{~mm}$. wide, thinly pilose above; panicle $8-12 \mathrm{~cm}$. long, nodding; spikelets few, 15-25 $\mathrm{mm}$. long, 3-4 mm. wide; lemma 8-10 $\mathrm{mm}$. long, sparsely pubescent on the back, ciliate near the margins. B. vulgaris Shear, in part. Wet places: B.C.-Mont.-Wyo.-Calif. Submont. J1-Au.

15. B. Porteri (Coult.) Nash. Stem 5-9 dm. high, pubescent at the nodes; sheaths usually sparingly short-pilose; leaf-blades $7-30 \mathrm{~cm}$. long, 3-5 mm. wide, scabrous; paniele 1-2 dm. long, drooping; spikelets 2-2.5 $\mathrm{cm}$. long, 7-9-flowered; lemma $11-13 \mathrm{~mm}$. long, coarsely pubescent, the apex hyaline, slightly emarginate; awn 2-4 mm. long. Hillsides and meadows: Man.-N.M.-Ariz.-Alta. Plain -Subalp. Je-Au.

16. B. latiglumis (Shear) Hitchc. Stem 6-10 dm. high, very leafy, slightly pubescent at the nodes or glabrous; leaf-blades $1-3 \mathrm{dm}$. long, 5-8 mm. wide, scabrous and sometimes sparingly hairy above, with conspicuous auricles at the 
base; panicle 1-3 dm. long, open, somewhat nodding; spikelets $2-3 \mathrm{~cm}$. long, loosely 6-10-flowered; lemma about $1 \mathrm{~cm}$. long, broadly lanceolate, pilose, densely so toward the base; awn 4-5 mm. long. B. purgans latiglumis Shear. Meadows: Conn.-Pa.-Mo.-Neb.-Mont. Plain. Je-Au.

17. B. purgans L. Stem 7-14 dm. high, glabrous or pubescent at the nodes; leaf-blades $1.5-3 \mathrm{dm}$. long, $5-15 \mathrm{~mm}$. wide, somewhat auricled at the base, short-pilose on the veins above, scabrous or smooth beneath; panicle lax, nodding, 1.5-2.5 dm. long; spikelets 7-14-flowered, 2-2.5 cm. long; lemma acute, 10-12 $\mathrm{mm}$. long, sparsely pubescent across the back; awn 4-6 $\mathrm{mm}$. long, straight. Woods and shady banks: Que.-Ga.-Okla.-Wyo. Plain-Submont. My-Jl.

18. B. lanatipes (Shear) Rydb. Stem 4-10 dm. high, smooth, or pubescent at the nodes; leaf-blades 2-3 dm. long, $5-7 \mathrm{~mm}$. wide, scabrous on both sides; panicle open, 2-3 dm. long; branches ascending; spikelets $2-3 \mathrm{~cm}$. long, 7-11flowered; lemma about $1 \mathrm{~cm}$. long, obtuse, emarginate; awn 4-5 mm. long. Hillsides: Colo.-N.M.-Calif. Submont.-Mont. Jl-Au.

19. B. ciliatus L. Stem 6-13 dm. high, glabrous; leaf-blades $1.5-2.5 \mathrm{dm}$. long, 5-12 mm. wide, mostly scabrous above, glabrous beneath; panicle large, drooping, 1.5-2.5 dm. long; spikelets 2-3 cm. long, 6-11-flowered; lemma obtuse, emarginate, 12-15 mm. long; awn 3-5 mm. long, straight. B. Richardsoni Link. Meadows and hillsides: Sask.-N.M.-Ariz-Ore-B.C. Plain-Subalp. $\mathrm{Je}-\mathrm{Au}$.

20. B. Pumpellianus Scribn. Stem glabrous, or pubescent merely at the nodes; leaf-blades 1-2 dm. long, 5-10 mm. wide, smooth beneath, scabrous or slightly pubescent above, auricled at the base; spikelets erect, 7-11-flowered, 2-3 cm. long, 5-7 mm. wide; lemma 10-12 mm. long, coarsely ciliate along the margins and across the back at the base. Meadows and hillsides: Sask.-S.D. -Colo.-B.C.-Alaska. Submont.-Mont.

21. B. inermis Leyss. Stem 5-10 dm. high; leaf-blades smooth and glabrous, $1.5-2.5 \mathrm{dm}$. long, $5-10 \mathrm{~mm}$. wide; panicle $1-2 \mathrm{dm}$. long; spikelets $2-2.5 \mathrm{~cm}$. long, 4-5 mm. wide; lemma 9-12 $\mathrm{mm}$. long, obtuse, emarginate, typically glabrous. Fields and meadows: Man.-Ohio-N.M.-Wash.-Mont.; escaped from cultivation. Je-Au.

22. B. tectorum L. Stems $3-6 \mathrm{dm}$. high, glabrous; leaf-blades mostly pubescent throughout; panicle 6-15 $\mathrm{cm}$. long; spikelets $13-20 \mathrm{~mm}$. long; lemma lanceolate, seabrous-puberulent to pilose-pubescent, 11-13 $\mathrm{mm}$. long, narrowly 2-toothed at the apex; awn straight, 13-15 mm. long. Waste places and sandy soil: Mass.-Va.-Miss.-Colo.-Calif.-B.C.; adv. or nat. from Eu. PlainSubmont. My-Jl.

23. B. sterilis L. Stem erect or ascending, 5-10 dm. high; leaf-blades pubescent throughout; paniele 1-2 dm. long, lax, open; spikelets $2.5-3.5 \mathrm{~cm}$. long, 6-10-flowered; empty glumes lance-subulate, the first 7-9 mm. long, the second 11-13 mm. long; lemma linear-lanceolate, 12-16 $\mathrm{mm}$. long, scabrous; awn stout, very rough. Waste places: Mass.-D.C.-Colo.-Wash.-B.C.; adv. from Eu. Plain-Submont. My-Jl.

24. B. maximus Desf. Stem 2-4 dm. high, smooth; leaf-blades flat, $3-5$ $\mathrm{mm}$. broad, pilose on both sides; panicle erect, somewhat secund, 5-10 $\mathrm{cm}$. long; spikelets 5-7-flowered, $3.5-5 \mathrm{~cm}$. long, exclusive of the awns; lemma 5-nerved, 2.5-3 mm. long, harshly scabrous, 2-toothed at the apex. Waste places and fields: Calif.-Wash.-Ida.-B.C.; adv. from the Old World.

\section{Lôlium L. Darnel, Rye-grass.}

Perennials with rootstocks, or annuals, with terminal 2-sided spikes. Spikelets with the edge towards the rachis, compressed, several-many-flowered; flowers perfect or the upper ones imperfect; rachilla articulate between the flowers. Empty glumes in the terminal spikelet 2, in the lateral spikelets 1, facing the rachis, the inner one lacking. Lemma shorter and broader than the empty glume, rounded on the back. Palet shorter than the lemma, 2-keeled. Styles distinet, short; stigmas plumose. 
Empty glumes shorter than the spikelet; perennial. Empty glume longer than the spikelet; annual.
1. L. perenne.

2. L. iemulentum.

1. L. perenne L. Stem $2-8 \mathrm{dm}$. high, smooth; leaf-blades $5-12 \mathrm{~cm}$. long, 2-4 mm. wide, smooth; spike 7-20 cm. long; spikelets 5-10-flowered, 8-12 mm. long; empty glume strongly nerved; lemma 4-6 mm. long, acuminate, awnless. Waste places and cultivated ground: N.S.-Va.-N.M.-Calif.-B.C. nat. from Eurasia. Je-Au.

2. L. temulentum L. Stem $6-12 \mathrm{dm}$. high, smooth; leaf-blades $1-2.5 \mathrm{dm}$. long, 2-6 mm. wide, smooth beneath, rough above; spike 1-3 dm. long; spikelets 4-8-flowered, 10-18 $\mathrm{mm}$. long; empty glume strongly veined; lemma awned or awnless. Poisonous. Waste places and cultivated ground: N.B.-Ga.-Calif. -B.C.; nat. from Eu. Je-Au.

\section{AGROPỲRON Gaertner. WhEAT-GRAss, QUiTCH-GRASS, QUICK-GRASS.}

Perennials with terminal, 2-sided spikes; spikelets compressed, with the side of the spikelet towards the rachis, usually single at each node; flowers perfect, or the upper ones imperfect; rachilla articulate between the flowers. Empty glumes 2 , standing at right angles to the median plane of the spike, i. e., with one edge toward the rachis, usually firm. Lemma broader, rigid, rounded on the back, from obtuse to acuminate, awnless or awned. Palet shorter than the lemma, 2-keeled, ciliate on the keels. Styles very short; stigmas plumose. Fruit enclosed in the lemma, adherent to the palet.

Rachis of the spike breaking up at maturity, the internodes falling with the spikelets; lemma long-awned.

Rachis of the spike remaining continuous.

Tufted plants with intravaginal innovations; no horizontal stolons (except in $A$. arizonicum).

Lemma long-awned, $i$. e., the awn usually longer than the body of the lemma. Basal leaf-blades shorter than the upper ones; spikelets slightly compressed; awns somewhat spreading.

Basal leaf-blades longer than the upper ones.

Awn divergent.

Spikelets remote on the axis, more or less compressed.

Spikelets erect, empty glumes nearly equalling the spikelet.

3. A. Vaseyi.

Spikelets spreading or ascending; empty glumes half as long as the spikelet.

Empty glumes linear-oblong, acute or obtuse; stem-leaves 3 or 4 , not glaucous.

4. A. spicatum.

Empty glumes narrowly lanceolate, acuminate or awn-pointed; stem-leaves 6 or 7 , glaucous. 5 . A. arizonicum.

Spikelets crowded on the axis, subterete. 6. A. Bakeri.

Awns erect.

Plant tall, usually more than $3 \mathrm{dm}$. high, erect or ascending; empty glumes broadest below the middle; spike elongated.

Stem stout; spike 7-10 $\mathrm{mm}$. thick, erect, but usually unilateral; spikelets (exclusive of the awns) $15-25 \mathrm{~mm}$. long.

7. A. Richardsoni.

Stem slender; spike about $5 \mathrm{~mm}$. thick, seldom unilateral; spikelets (exclusive of the awns) about $1 \mathrm{~cm}$. long. 8. A. caninoides.

Plant 2-3 dm. high, decumbent at the base, geniculate; empty glumes broadest above the middle, scarious-margined; spike short and dense.

Lemma short-awned or awnless.

9. A. andinum.

Spikes stout and dense, 3-8 cm. long; empty glumes broadest above the middle.

Lemma densely pubescent; empty glumes conspicuously white-margined. 10. A. latiglume.

Lemma glabrous or scabrous; empty glumes not conspicuously whitemargined. 11. A. biflorum.

Spike slender and lax, 7-20 cm. Iong; empty glumes broadest below the middle.

Spikelets terete, appressed; empty glumes nearly as long as the spikelets. 12. A. tenerum.

Spikelets flattened; empty glumes much shorter than the spikelets. 13. A. inerme.

Stoloniferous plants with horizontal rootstocks, sometimes slightly tufted; innovavations extravaginal.

Lemma with a long, more or less divergent awn.

Lemma pubescent.

Lemma glabrous or scabrons.

Spikelets subterete, appressed.

14. A. albicans.

15. A. Griffithsii. 
Spikelets compressed, spreading.

5. A. arizonicum. Lemma awnless or with a very short erect awn; empty glumes usually narrowly lanceolate, acuminate.

Sheaths conspicuously pilose.

Sheaths glabrous or nearly so.

16. A. Palmeri.

Lemma glabrous or merely scabrous.

Spikelets erect, nearly cylindric or slightly compressed.

Spike elongate; empty glumes nearly equalling the spikelets.

17. A. pseudorepens.

Spike short; empty glumes about half as long as the spikelets.

18. A. riparium.

Spikelets much flattened, spreading. 19. A. Smithii.

Lemma from villous to hispidulous.

Lemma short-pubescent.

Spikelets compressed, more or less spreading: lemma acuminate or strongly acute.

20. A. molle.

Spikelets terete or nearly so, erect; lemma obtuse or acutish. Spike loose, elongate; lemma spar ingly pubescent.

21. A. lanceolatum.

Spike dense and short; lemma densely pubescent.

Lemma long-villous.

22. A. subrillosum.

23. A. dasystachyum.

1. A. Scribneri Vasey. Densely tufted perennial; stems decumbent and geniculate at the base, $2-5 \mathrm{dm}$. high; leaf-blades short, 3-10 $\mathrm{cm}$. long, 2-4 mm. wide, rigid, attenuate-pointed; spike 5-7 cm. long, flexuous; spikelets 3-6flowered; empty glumes linear-lanceolate or subulate, 3-5-nerved, smooth, longawned; lemma oblong-lanceolate, 8-10 mm. long, smooth, 5-nerved; awn divergent, scabrous, $1.5-2.5 \mathrm{~cm}$. long. This species connects the genus with Sitanion. High mountains: Mont.-N.M.-Ariz. Subalp.-Alp. Jl-Au.

2. A. Gmelini (Griseb.) Scribn. \& Smith. Stems 6-12 dm. high, glabrous, slender; blades of stem-leaves $12-30 \mathrm{~cm}$. long, flat or involute; those of the basal leaves 3-7 cm. long, 4-6 mm. wide; spike slender, 1-2.5 dm. long; spikelets 1020, 6-9 mm. long, 7-9-flowered; empty glumes unequal, 10-14 mm. long, oblonglanceolate, acuminate or short-awned; lemma oblong-lanceolate, acuminate, 10-12 $\mathrm{mm}$. long; awn scabrous, $15-30 \mathrm{~mm}$. long, at last divergent. Hillsides: Wash.-Alta.-Wyo.; Siberia. Submont. Jl-Au.

3. A. Vaseyi Scribn. \& Smith. Stem erect, 3-5 dm. high, wiry, glabrous; leaf-blades 3-15 cm. long, 1-2 $\mathrm{mm}$. wide, usually involute; spike slender, 5-10 $\mathrm{cm}$. long, of ten somewhat flexuose; spikelets 3-5-flowered; empty glumes oblanceolate or oblong, acute or acuminate, $6-8 \mathrm{~mm}$. long; lemma $8 \mathrm{~mm}$. long, lanceolate, acute; awn 8-10 mm. long. Hills and mountain sides: Wash.-Ore-Colo.-Mont. Submont. My-Au.

4. A. spicatum (Pursh) Scribn. \& Smith. Stem 3-10 dm. high, glabrous; leaf-blades 5-20 cm. long, 1-2 mm. wide, involute or rarely flat; spikes $8-20 \mathrm{~cm}$. long; spikelets 3-6-flowered, flattened; lemma 8-10 $\mathrm{mm}$. long, scabrous above; awn stout, $12-25 \mathrm{~mm}$. long. A. divergens Nees. Bunch Grass. Dry rocky hills and bench-lands: B.C.-Calif.-Ariz.-Colo--Mont. Plain-Submont. $\mathrm{Je}-\mathrm{Au}$.

5. A. arizonicum Scribn. \& Smith. Tufted, but occasionally with long stolons; stem 4-6 dm. high, minutely scabrous below; leaf-blades 1-3.5 dm. long, 4-6 mm. wide; spike 7-20 cm. long, usually nodding; spikelets 7-14, distant, 5-7-flowered, 2-3.5 $\mathrm{cm}$. long, 3-5-nerved; lemma 10-15 $\mathrm{mm}$. long, acuminate, scabrous; awn about $2.5 \mathrm{~mm}$. long. Mountains: Colo.-N.M.-Ariz.; n Mex. Submont.-Subalp. Au-O.

6. A. Bakeri F. Nels. Stem smooth, 3-5 dm. high; leaf-blades rigid, flat, 1-3 dm. long, 2-4 mm. wide; spike 9-12 $\mathrm{cm}$. long, dense, scarcely exserted; spikelets about 5-flowered, 15-19 mm. long; empty glumes 11-12 mm. long, scarious-margined, abruptly acuminate, short awned; lemma scabrous or nearly smooth, about $12 \mathrm{~mm}$. long, attenuate; awn 1-3.5 $\mathrm{cm}$. long. High mountains: Colo.-N.M. Mont. Au.

7. A. Richardsoni (Trin.) Sehrad. Stems smooth, 6-8 dm. high; leafblades 8-20 cm. long, 2-6 mm. wide, scabrous, flat, often with involute tips; spikes 7-10 cm. long, one-sided; spikelets 3-4-flowered; empty glume 12-16 mm. 
long, short-awned or awn-pointed; lemma 10-13 mm. long, scabrous on the margins. A. unilaterale Cassidy, not Beauv. Scarcely distinct from A, caninum L. of Eu. Meadows and among bushes: Sask.-Minn.-Iowa-N.M.-B.C. Plain-Mont. Je-S.

8. A. caninoides (Ramaley) Beal. Stem 3-10 dm. high; leaf-blades 1.5-3 $\mathrm{dm}$. long, $3 \mathrm{~mm}$. wide, erect, involute or nearly flat; spike 1-2 dm. long, dense; spikelets 1-2 cm. long, pale or purple-tinged; empty glumes 7-9 mm. long, short-awned or awn-pointed; lemma $7 \mathrm{~mm}$. long, scabrous. A. caninum Am. auth., mostly. Mountain meadows: N.S.-Mich.-N.M.-Calif.-Mont, Mont. -Subalp. JI-Au.

9. A. andinum (Seribn. \& Smith) Rydb. Stems 2-3.5 dm. high; leaf-blades 2-10 cm. long, 2-4 mm. wide, flat, glabrous beneath, pilose above; spike $3-8 \mathrm{~cm}$. long; empty glumes 8-10 mm. long; lemma 8-10 $\mathrm{mm}$. long, puberulent or glabrate; awn 4-10 mm. long. High mountains: Mont.-Colo. Mont.-Subalp. Jl-Au.

10. A. latiglume (Scribn. \& Smith) Rydb. Stems $2-4 \mathrm{dm}$. high, erect or often decumbent at the base; leaf-blades 3-10 $\mathrm{cm}$. long, 2-4 mm. wide, flat, or involute when dry, pubescent on both sides or sometimes glabrate; spike $3-5 \mathrm{~cm}$. long; spikelets 3-5-flowered; lemma oblanceolate, acute or short-awned. High mountains: Alta.-Mont.-Alaska. Subalp.-Alp.

11. A. biflorum (Brign.) R. \& S. Tufted perennial; stem $1.5-6 \mathrm{dm}$. high, often somewhat decumbent at the base; leaf-blades $5-15 \mathrm{~cm}$. long, 2-6 mm. wide, flat or somewhat involute; spike $2.5-10 \mathrm{~cm}$. long, 4-6 mm. wide; spikelets 3-6-flowered; lemma 5-7-nerved, 8-12 $\mathrm{mm}$. long, acuminate or short-awned. A. violaceum (Hornem.) Lange. Mountains: Greenl.-N.Y. -Neb.-N.M.Alaska; Eurasia. Subalp.-Alp. Jl-S.

12. A. tenerum Vasey. Stem 3-10 dm. high; leaf-blades $2-6 \mathrm{~mm}$. wide, $7-15 \mathrm{~cm}$. long, scabrous, flat or involute; spike slender, $1-1.5 \mathrm{dm}$. long, lax; spikelets 3-5-flowered; empty glumes 10-12 mm. long, acute to awn-pointed, 5nerved; lemma 8-10 mm. long, lanceolate; awn 1-4 mm. long or more. RYE Grass. Dry soil: B.C.-Calif.-N.M.-Minn. Plain-Submont. Je-Au.

13. A. inerme (Scribn. \& Smith) Rydb. Stems 3-10 dm. high, glabrous; leaf-blades erect, 1-2 dm. long, 2-4 mm. wide, more or less pubescent above, somewhat glaucous, flat or involute; spike 1-3 dm. long, lax; spikelets distant, 1.5-2 cm. long, 6-10-flowered; empty glumes 8-10 mm. long; lemma 10-12 mm. long, smooth, often mucronate or with a short awn-tip. Closely related to $A$. spicatum and A. Vaseyi. Plains and meadows: B.C.-Wash.-Utah-Wyo. Submont. Je-Au.

14. A. albicans Scribn. \& Smith. Stem erect, 3-6 dm. high, glaueous; leafblades rigid, ascending, involute, scabrous, $7-20 \mathrm{~cm}$. long, $2-3 \mathrm{~mm}$. wide; spike slightly nodding, 7-10 $\mathrm{cm}$. long; spikelets 8-10, 5-7-flowered, 15-18 mm. long; empty glumes pubescent, oblanceolate, acuminate, tipped with an awn 4-6 mm. long; lemma about $9 \mathrm{~mm}$. long, ovate-lanceolate; awn $12-15 \mathrm{~mm}$. long. Hills and benchlands. Mont.-Wyo.-w Neb.S.D. Submont. Je-Au.

15. A. Grifflthsii Scribn. \& Smith. Stem glabrous, $3-8 \mathrm{dm}$. high, striate; leaf-blades rather rigid, mostly involute, $5-12 \mathrm{~cm}$. long; spike erect, $8-15 \mathrm{~cm}$. long; spikelets pale, closely 5-7-flowered; empty glumes $8 \mathrm{~mm}$. long, with awns $3 \mathrm{~mm}$. long; lemma oblong, 8-10 $\mathrm{mm}$. long; awns $8-10 \mathrm{~mm}$. long. Plains: Wyo. -N.D.-S.D. Plain. Au.

16. A. Palmeri (Scribn. \& Smith.) Rydb. Stem 3-6 dm. high; leaf-blades glaueous, 1-2 dm. long, 3-4 mm. wide, at last involute, scabrous and often sparingly pubescent on both sides; spikes rather dense, 1-1.5 dm. Iong; spikelets compressed, $1.5-2 \mathrm{~cm}$. long; lemma about $1 \mathrm{~cm}$. long, acuminate, pilose to hispidulous-scabrous. Bottom-lands and hillsides: N.M.-Colo-Utah-Ariz. Son.-Submont. My-Jl.

17. A. pseudorepens Scribn. \& Smith. Stem 3-10 dm. high, glabrous; leaf-blades scabrous throughout, $12-20 \mathrm{~cm}$. long, $2-6 \mathrm{~mm}$. wide, flat, or involute when dry; spike 1-2.5 dm. long; spikelets rather distant, 10-16 mm. long, 3-7- 
flowered; lemma acuminate or awn-pointed, scabrous, about $1 \mathrm{~cm}$. long. Prairies and river valleys: Neb.-Tex.-Ariz.-B.C. Plain-Mont. Je-S.

18. A. riparium Scribn. \& Smith. Stem glabrous, erect, $4-6 \mathrm{dm}$. high; leaf-blades flat, becoming involute, $5-15 \mathrm{~cm}$. long, 2-4 mm. wide, seabrous throughout; spike 5-10 cm. long; spikelets 8-15, compressed, 5-7-flowered, spreading, 5-6 mm. long; lemma oblong-lanceolate, acute, scabrous towards the apex, acute or acuminate. River banks: Mont.-Colo. Submont.

19. A. Smithii Rydb. Stem 3-10 dm. high; leaf-blades spreading, rigid, bluish green, glaucous, smooth or minutely scabrous beneath, becoming involute, 1-3 dm. long, 4-6 mm. wide; spikes 7-18 cm. long; spikelets $7-13$-flowered, sometimes in pairs; lemma $8-12 \mathrm{~mm}$. long, lanceolate, acute or acuminate, seldom awn-pointed, smooth or nearly so. A. spicatum Seribn. \& Smith, in part. A occidentale Scribn. Blue-Jornt; Blue-stem. Prairies and plains: Man.-Mo. -Tex.-Ariz.-Ore-B.C. Plain-Mont. Je-S.

20. A. molle (Scribn. \& Smith) Rydb. Stems 4-8 dm. high; leaf-blades more or less glaucous, $1-3 \mathrm{dm}$. long, $2-4 \mathrm{~mm}$. wide, at last involute, scabrous; spike 1-2 dm. long, rather dense; spikelets about $2 \mathrm{~cm}$. long, 6-8-flowered; lemma 8-10 mm. long, densely hispidulous. River bottoms, especially in alkaline soil: Sask.-N.M.-Utah-Wash. Plain-Mont. JI-S.

21. A. lanceolatum Scribn. \& Smith. Stem 6-10 dm. high, smooth and shining; leaf-blades acuminate, $12-30 \mathrm{~cm}$. long, 4-6 mm. wide, flat, scabrous beneath, pilose above; spike 1-2 dm. long; spikelets $10-20 \mathrm{~mm}$. long, 4-7-flowered, erect; lemma 8-15 mm. long, broadly lanceolate, more or less short-pubescent. Banks and meadows: Wash.-Ida.-Ore. Je-Jl.

22. A. subvillosum (Hook.) E. Nelson. Stems 4-6 dm. high, slender, glabrous; leaf-blades 1-2 dm. long, 2-4 mm. wide, flat or at last involute, scabrous; spike rather crowded; spikelets compressed, 12-15 $\mathrm{mm}$. long; lemma 6-10 $\mathrm{mm}$. long, obtuse or acute. River banks and sandy soil: Sask.-Neb.-Colo.Nev.-B.C. Plain-Mont. Je-Au.

23. A. dasystachyum (Hook.) Seribn. Stem 3-10 dm. high; leaf-blades 5-20 cm. long, 2-6 mm. wide, flat, becoming involute in drying; spike 6-18 cm. long; spikelets slightly compressed, 4-8-flowered; lemma broadly lanceolate, 10 $12 \mathrm{~mm}$. long, acute or rarely short-awned. Sand-dunes: Hudson Bay-Mich.Wis.-Ida.-Sask. Plain-Boreal. J1-Au.

\section{TRÍticum L. WHEAT.}

Annuals or biennials with spicate inflorescence. Spikelets solitary at each node, alternate, 2-5-flowered; flowers mostly perfect. Empty glumes with one edge towards the rachis, broad, short, often toothed, but seldom awned at the apex. Lemma ventricose on the back, several-nerved, often awned or at least toothed at the apex. Palet shorter than the lemma, 2-keeled. Grain deeply furrowed, free, pubescent at the apex.

Empty glumes distinetly keeled only at the apex; grain dull, neither glossy nor semitranslucent.

Empty glumes distinctly keeled, almost winged, to the base; grain 1 . T. aesticum. what translucent.

1. often some-

1. T. aestivum L. Annual or biennial; stem about $1 \mathrm{~m}$. high, hollow, smooth; leaves at first rather light green, soft; spike 4-12 cm. long, 4-angled; spikelets mostly 4-flowered; lemma with or without awn. T. sativum Lam, WhEAT. Old fields and waste places: cult. and rarely escaped.

2. T. durum Desf. Annual or rarely biennial; stem $1 \mathrm{~m}$. high or more, usually with a pith; leaves smooth, whitish green, with hard euticle; spike almost terete, thicker than in the ordinary wheat, $5-10 \mathrm{~cm}$. long; lemma long-awned. Durum or Macaroni Wheat. Old fields and waste places: cult. and rarely escaped.

\section{SECÀLE L. RYE.}

Annuals or biennials, with spicate inflorescence. Spikelets solitary at each node, alternate, 2-flowered. Flowers all hermaphrodite and fertile. Empty glumes subulate, awn-pointed, with one edge towards the rachis. Lemma long- 
awned at the apex, keeled to the base. Grain slightly compressed laterally, deeply furrowed, free, pubescent at the apex.

1. S. cereale L. Annual or biennial; stem 1.5-3 m. high, glabrous; leaves scabrous, flat; spike 10-15 cm. long, 4-angled; spikelets 2-flowered; empty glumes subulate; lemma lanceolate, hispidulous-ciliate, 5-nerved, awned. Waste places and old fields: escaped from cultivation.

\section{5. hòrdeum L. Barley, Squirrel-tail, Foxtail.}

Annuals or rarely perennials, with spicate inflorescence. Spikelets alternately in 3's, rarely in 2's, at each node of the articulate rachis, sessile or shortpediceled, 1-flowered; flower perfect or in the lateral spikelets often imperfect or rudimentary; rachilla extending beyond the flower as a long slender bristle. Empty glumes 2, awnlike, subulate, or lanceolate, rigid, falling together with the rachilla-joint. Lemma lanceolate, rounded on the back, awned, lobed, or in the lateral spikelets awnless. Palet shorter, 2-keeled. Styles very short, distinct; stigmas plumose.

Lateral spikelets sessile; annuals.

Lemma not awned, the awns represented by chartaceous lobes. Lemma awned.

Lateral spikelets stalked; lemma awned.

Floret of the central spikelet sessile.

Empty glumes of the central spikelets lanceolate.

Empty glumes of central spikelet not lanceolate.

Inner empty glumes of the lateral spikelets broadened.

Empty glumes all setaceous.

Lateral floret not awned.

Plant low, 5-25 cm. high; upper sheaths inflated.

1. H. aegiceras.

2. H. vulgare.

Plant taller, 2-6 dm, high: pper sheath not, conspicuously. depressum.

Lateral floret neutral or staminate; lemma of the central floret 6-8 $\mathrm{mm}$. long.

3. H. pusillum.

4. H. marilimum.

Lateral floret usually perfect; lemma of the central flower $10 \mathrm{~mm}$. long.

Lateral florets long-awned.

Awn $2-3 \mathrm{~cm}$. long.

Awn $4-6 \mathrm{~cm}$. long.

Floret of the central spikelets stalked.

Empty glumes not ciliate.

7. H. boreale.

8. H. caespitosum.

9. H. jubatum.
Empty glumes or some of them ciliate.

1. H. aegiceras (E. Mey.) Royle. Stem 5-7 dm. high; leaf-blades glabrous, 1-1.5 cm. broad; spikes about $1 \mathrm{dm}$. long; spikelets all fertile; empty glumes lance-subulate, strigose; lemma 3 -lobed at the apex; lateral lobes lanceolate, acute, divergent; middle lobe ovate, obtuse, slightly hooded. PEARL Barley. Moist waste grounds: cult. and often escaped. Plain-Submont.

2. H. vulgare L. Annual or rarely biennial; stem 5-7 dm. high; leaf-blades broad, flat; ligules obsolete; spikes about $1 \mathrm{dm}$. long; empty glumes small, subulate, awned; spikelets all hermaphrodite; lemma lanceolate, long-awned, smooth. Barley. Waste places and old fields: sometimes eseaped from cultivation.

3. H. pusillum Nutt. Tufted annual; stem 1-4 dm. high, usually decumbent at the base; leaf-blades 1-7 $\mathrm{cm}$. long, 1-4 mm. wide; spike $3-7 \mathrm{~cm}$. long; central spikelets perfect, the lateral ones imperfect; inner empty glumes of the lateral spikelets lanceolate, the outer ones subulate, all awned; lemma smooth. that of the central spikelet 6-8 mm. long, short-awned, those of the latera! spikelets smaller and stalked. Dry soil: Ont.-Ga.-Calif.-B.C. PlainSubmont. Ap-Je.

4. H. maritimum With. Annual or perennial, branched at the base; branches decumbent below, then ascending, somewhat geniculate, 1-2 dm. high; sheaths loose, pubescent; spike short-exserted or the base included, $3-5 \mathrm{~cm}$. long; empty glumes setaceous except the inner ones of the lateral spikelets, which are sometimes staminate, distinctly awned; otherwise like $H$. nodosum. Saline soil: Calif.-Wash.-Ida.-Utah. My-Jl.

5. H. depressum (Seribn. \& Smith) Rydb. Tufted; stem 5-15 cm. high, geniculate at the base, which is covered by the sheaths; leaf-blades $1-3 \mathrm{~cm}$. long, 1-3 mm. wide, auricled at the base, finely pubescent; spikes $2-3 \mathrm{~cm}$. long; lemma 
of the central spikelet $7 \mathrm{~mm}$. long, smooth; awn of about the same length; lemma of the lateral spikelets about $4 \mathrm{~mm}$. long, acuminate or merely awn-pointed. H. nodosum depressum Scribn. \& Smith. Meadows: Wash.-Ida.-Calif. Submont. My-Je.

6. H. nodosum L. Tufted annual or perennial; stems $2-6 \mathrm{dm}$. high, erect or sometimes decumbent at the base; leaf-blades 4-12 $\mathrm{cm}$. long, 2-6 mm. wide, scabrous; spike $3-8 \mathrm{~cm}$. long; lemma of the central spikelet $6-8 \mathrm{~mm}$. long; awn 6-12 $\mathrm{mm}$. long; lemma of the lateral spikelets smaller. Meadows and waste places: Alaska-Calif.-Tex.-Yukon; Eu. Submont.-Mont. Ap-Au.

7. H. boreale Scribn. \& Smith. Rather simple perennial; stem 3-10 dm. high, lower sheaths often pubescent; leaf-blades 1-2.5 dm. long, 4-8 mm. wide, scabrous; spikes 7-10 cm. long; lemma of the central spikelet scabrous toward the apex; awn about $1 \mathrm{~cm}$. long; lemma of the lateral spikelets about $6 \mathrm{~mm}$. long, subulate-pointed. Meadows: Alaska-Calif.-Ida.-Colo. (?) Submont. Je-Jl.

8. H. caespitosum Scribn. Cespitose perennial; stem 3-6 dm. high, smooth; leaf-blades 5-15 cm. long, 3-5 mm. wide; spike $3-5 \mathrm{~cm}$. long; lemma of the central spikelet lanceolate, $6 \mathrm{~mm}$. long; awn about $12 \mathrm{~mm}$. long; lemma of the lateral spikelets 2-4 mm. long, with an awn of about the same length. Meadows and springy places: Sask,-S.D.-Kans.-N.M.-Ida.-Wash. PlainSubmont. Je-Au.

9. H. jubatum L. Tufted perennial; stem 2-8 dm. high, erect; leaf-blades 3-12 cm. long, 2-4 mm. wide, scabrous; spikes 5-10 cm. long; lemma of the central spikelet 6-8 mm. long, scabrous at the apex; awn 4-6 $\mathrm{cm}$. long; lemma of the lateral spikelets 4-6 mm. long, short-awned. Dry sandy soil and prairies: Lab.-N.J.-Tex.-Calif.-Alaska. Plain-Subalp. Je-S.

10. H. montanense Scribn. Erect biennial or perennial; stem 6-10 dm. high, smooth; spike 5-7 cm. long; leaf-blades 5-10 $\mathrm{cm}$. long, 4-6 mm. wide, scabrous; central spikelets usually 2 -flowered; lemma of the first flower about 1 $\mathrm{cm}$. long, lanceolate, scabrous; awn 16-18 mm. long; lemma of the second flower with the awn 12-14 mm. long; lateral spikelets similar to the central one, but the second flower rudimentary. Meadows: Mont. Submont.

11. H. murinum L. Tufted perennial; stem 2-6 dm. high, erect or decumbent at the base; leaves $3-15 \mathrm{~cm}$. long, 2-6 mm. wide, scabrous; spikes $5-10$ $\mathrm{cm}$. long; empty glumes of the central spikelet lance-subulate; outer glumes of the lateral spikelets setaceous and merely scabrous; awns $18-25 \mathrm{~mm}$. long; lemma 10-12 mm. long, scabrous toward the apex; awns about $25 \mathrm{~mm}$. long. Ballast and waste places: Calif.-B.C.-Ida.-N.M.; also along the eastern coast: N.Y.-D.C.; adv. and nat. from Eu. Son.-Submont. My-Au.

\section{SITĀNION Raf.}

Tufted perennials, with eylindric, spicate inflorescence. Spikelets sessile, several at each node of the articulate rachis, 1-5-flowered. Empty glumes 2, rarely entire, awn-like, usually $2-5$-cleft with subulate awned divisions. Lemma broader, entire, long-awned, or 2- or 3-cleft and short-awned. Palet shorter than the glume, 2-keeled. Styles very short, distinct; stigmas plumose.

Empty glumes lanceolate, scarious-margined.

Leaf-blades not white-margined.

Leaf-blades white-margined.

1. S. lanceolatum.

2. S. marginatum.

Empty glumes setaceous, or cleft into setaceous divisions, not scarious-margined.

Empty glumes setaceous, entire; lowest flower perfect. Lemma soft-pubescent. Lemma glabrous.

Empty glumes or some of them 2-cleft; lowest flower rudimentary. Lemma pubescent; sheaths and blades densely pubescent.

Blades and sheaths short-hairy, subvelutinous.

Awns at least 4 times as long as the lemma.

Awns 2-3 times as long as the lemma.

Blades and sheaths long-hairy.

3. S. pubiflorum.

4. S. elymoides.

emma glabrous or scabrous.

Empty glumes subulate-lanceolate, bifid about two-thirds their length. 
Empty glumes setaceous, or cleft to near the base into setaceous divisions. Sheaths and blades more or less long-pubescent.

Lemma glabrous.

Lemma scabrous.

9. S. molle.

10. S. strigosum. Sheaths and blades glabrous, scabrous, or puberulent; lemma smooth below, scabrous above.

Awns of the lemma $3-4 \mathrm{~cm}$. long, divergent; plant very low.

11. S. rigidum.

Awns of the lemma 4-7 cm. long; plant taller, more than $2 \mathrm{dm}$. high. Leaf-blades $2-5 \mathrm{~mm}$. broad, flat or slightly involute.

Plant perfectly glabrous; awn ascending.

Plant puberulent or scabrous; awns divergent.

Leaf-blades 1-2 mm. broad, strongly involute.

12. S. glabrum.

13. S. montanum.

14. S. basallicola.

1. S. lanceolatum J. G. Smith. Stem 3-5 dm. high, erect, smooth; leafblades $8-15 \mathrm{~cm}$. long, 2-3 mm. wide, rigid; spikes erect, $6-10 \mathrm{~cm}$. long, barely exserted; empty glumes 5-6 mm. long, usually 2-nerved, entire or unequally 2-cleft, the longer awn scabrous, divergent, 1-1.5 $\mathrm{cm}$. long; lemma $8-9 \mathrm{~mm}$. long, glaucous, entire or minutely 3-cleft; awns spreading, $2-5 \mathrm{~cm}$. long. Agropyron sitanioides J. G. Smith. Mountains: Mont.-S.D. Submont. Au.

2. S. marginatum Scribn. \& Merrill. Stem 2-3 dm. high; leaf-blades 3-9 $\mathrm{cm}$. long; spike 3-6 cm. long; empty glumes $5 \mathrm{~mm}$. long, entire; awn spreading, about $1.5 \mathrm{~cm}$. long; lemma glabrous, about $7 \mathrm{~mm}$. long; awn like those of the empty glumes. Bare mountain slopes: Wyo. Subalp. Jl.

3. S. pubiflorum J. G. Smith. Stem erect, 2-3 dm. high, strigose above; leaf-blades puberulent beneath, scabrous above, $2-10 \mathrm{~cm}$. long, spreading; spike exserted, $5 \mathrm{~cm}$. long; empty glumes $4-6 \mathrm{~cm}$. long; lemma of the lowest flower $7 \mathrm{~mm}$. long, scabrous and finely pubescent; awn scabrous, straight, ascending, 5-6 cm. long. Dry hills: Colo.-N.M.-Ariz. Son. Ap-Je.

4. S. elymoides Raf. Stem 3-6 dm. high, glabrous and glaucous; leafblades smooth and glaucous or puberulent, 1-2 dm. long, 2-4 mm. wide, flat or involute; spike somewhat nodding, exserted or enclosed at the base in the uppermost sheath; empty glumes 6-8 $\mathrm{cm}$. long; lemma 8-11 mm. long; awn scabrous, spreading, 5-6.5 cm. long. S. longifolium and S. brevifolium J. G. Smith. Hillsides and plains: Neb.-Kans--N.M.-Ariz--Nev--Mont. Plain-Mont. Je-S.

5. S. Hystrix (Nutt.) J. G. Smith. Stems 1-3 dm. high, erect, scabrous above; leaf-blades flat or at length involute, finely pubescent throughout, 2-12 $\mathrm{cm}$. long, 1-2 mm. wide; spike 5-7 cm. long, erect, flexuose; empty glumes scabrous, $3-4 \mathrm{~cm}$. long; lemma 7-8 mm. long, minutely pubescent, 3 -awned, the middle awn about $3 \mathrm{~cm}$. long. Dry hills and "sage plains": Colo.-Wyo.-Wash.Ore. Son.-Submont. My-Jl.

6. S. cinereum J. G. Smith. Stem 2-3 dm. high, densely grayish pubescent; leaf-blades involute, rigid; spike 4-5 cm. long; awns 2-3 cm. long; lemma 7-8 $\mathrm{mm}$. long, scabrous, 3-nerved towards the apex, 3-awned; lateral awns 2-4 $\mathrm{mm}$. long, the middle one 2-3 cm. long. Dry places: Wash.-Ida.-Nev. Son. My-Л.

7. S. ciliatum Elmer. Stem 1-2 dm. high, cinereous-pubescent just below the spike; leaf-blades $5-10 \mathrm{~cm}$. long, finely pilose, $3-4 \mathrm{~mm}$. wide; spikes $5-7 \mathrm{~cm}$. long; empty glumes about $1 \mathrm{~cm}$. long, gradually tapering into a divaricate awn, 3-4 mm. long; lemma $8 \mathrm{~mm}$. long, pubescent or scabrous on the nerves; awn 3-4 cm. long. Hills: Wash.-Wyo. Submont. Je.

8. S. insulare J. G. Smith. Stem slender, glabrous, 3-6 dm. high; leafblades 1-1.5 dm. long, glabrous below, pubescent on the veins above, involute; empty glumes 2-awned; awns divergent, scabrous, 1-2 cm. long; lemma $8 \mathrm{~mm}$. long, smooth and shining, 3-cleft; middle awn divaricate, 1-2 cm. long; lateral awns or teeth 1-2 mm. long. Arid places: Utah. Son. Je.

9. S. molle J. G. Smith. Stem 3-4 dm. high, pubescent; leaf-blades rigid, ascending, 8-15 $\mathrm{cm}$. long, 3-5 mm. wide; spike 7-8 cm. long, erect, exserted; empty glumes 4 , entire or unequally bifid, subulate-setaceous, $6-7.5 \mathrm{~cm}$. long, 
divaricate; lowest flower of the spikelet sterile, like the empty glumes; lemma of the second flower about $1 \mathrm{~cm}$. long, trifid or entire; awn 5-7 cm. long. Mountain sides: Colo.-N.M. Submont.-Subalp. Au.

10. S. strigosum J. G. Smith. Stem 3-6 dm. high, glabrous or minutely pubescent above; leaf-blades 1-2.5 dm. long, 3-6 mm. wide, flat, or the lower involute, pilose; spike stout, exserted, $8-12 \mathrm{~cm}$. long; empty glumes entire or bifid, subulate-setaceous, 5-6 $\mathrm{cm}$. long: lemma 8-10 $\mathrm{mm}$. long, 3-cleft above, the middle awn 5-7 $\mathrm{cm}$. long, the lateral ones 1-2 $\mathrm{mm}$. long. Valleys: Wash.Ore.-N.D.-S.D. Submont. Je-Au.

11. S. rigidum J. G. Smith. Stem 1-2 dm. high, glabrous; leaf-blades $3-8 \mathrm{~cm}$. long, $2-3 \mathrm{~mm}$. wide, rigid, involute, scabrous above; spike $2-8 \mathrm{~cm}$. long, exserted or included at the base; empty glumes 4, entire or two of them divided to the base, awned, strongly divaricate, $2-3 \mathrm{~cm}$. long; lowest floret usually sterile; lemma 7-9 mm. long, trifid; awn stout, divaricate. Mountains: Calif.Wash.-Mont.-N.M.-Ariz. Subalp.-Alp. Je-Au.

12. S. glabrum J. G. Smith. Stem 3-6 dm. high, smooth and shining; leaf-blades $7-15 \mathrm{~cm}$. long, $2-5 \mathrm{~mm}$. wide, flat, becoming involute; spike $5-8 \mathrm{~cm}$. long, sub-flexuose, the base usually enclosed in the uppermost sheath; empty glumes bifid to near the base, the lobes subulate-setaceous, $6-8 \mathrm{~cm}$. long; lemma 7-8 mm. long, entire or minutely bifid. Hills: Calif.-Wash.-Wyo.Utah. Subalp.-Alp. My-Au.

13. S. montanum J. G. Smith. Stem 2-4 dm. high, glabrous below, scabrous above; leaf-blades $5-10 \mathrm{~cm}$. long, 3-4 mm. wide; spike erect, 5-10 $\mathrm{cm}$. long; empty glumes subulate-setaceous, some of the lower usually bifid, divergent, 5-6 cm. long; lemma 10-11 mm. long, 3-fid, 3-awned. Hillsides: Mont.-Wyo. -Utah-Ore. Submont.-Mont. Je-Au.

14. S. basalticola Piper. Stem 1-3 dm. high, smooth; leaf-blades $3-10$ cm. long, 1-2 mm. wide, minutely scabrous on the nerves above; spike erect, 3-5 $\mathrm{cm}$. long, barely exserted; empty glumes subulate, or some cleft to near the base, spreading, 3-4 $\mathrm{cm}$. long; lemma 8-10 $\mathrm{mm}$. long, glabrous, glaucous, 3-fid; middle awn 3-3.5 cm. long, divergent, scabrous, the lateral ones about $1 \mathrm{~mm}$. long. Basaltic soil and sandy slopes: Wash.-Ida. Submont. Je.

\section{7. ÉLÝmUS L. Lyme-grass, Wild Rye, Rye-grass, Buffalo Rye.}

Perennials, with rootstocks and cylindric spikes. Spikelets sessile, usually 2 or 3 at each node, but in some species mostly single, 2-several-flowered. Empty glumes 2, inserted more or less obliquely, rigid, awn-like, subulate or lance-linear, persistent, awn-pointed or awned. Lemma oblong or lanceolate, rounded on the back, usually awned. Palet shorter than the glume, 2-keeled. Stvles very short, distinct; stigmas plumose.

\section{Lemma long-awned.}

Spike broad; spikelets spreading.

Empty glumes lanceolate to lanceolate-subulate; spike dense.

Empty glumes lanceolate, 5-7-nerved, thick and strongly curved at the base; spike erect.

Plant robust; spike scarcely exserted; lemma glabrous or nearly so.

Plant slender; spike Iong-exserted; lemma scabrous-hispidulous.

2. E. jejunus.

Empty glumes narrowly linear-lanceolate, neither conspicuously thickened nor curved at the base; spike often nodding.

Empty glumes usually minute, less than $15 \mathrm{~mm}$. long. 4. E. diversiglumis. Empty glumes $15-30 \mathrm{~mm}$. long.

Lemma hirsute or villous.

Lemma hispidulous-scabrous to glabrous.

Robust; spike usually included at the base; leaf-blades $8-15 \mathrm{~mm}$. wide.

Slender; spike long-exserted; leaf-blades seldom more than $5 \mathrm{~mm}$. wide.

6. E. brachystachys.

Empty glumes setaceous, hirsute; lemma hirsute; spike laxer.

7. E. striatus.

Spike narrow; spikelets erect, appressed.

Lemma pubescent.

Empty glumes lanceolate, 5-nerved.

Empty glumes lance-subulate, indistinctly veined.

8. E, vulpinus,

9. E. angustus. 
Lemma scabrous or glabrous.

Empty glumes lanceolate, acuminate or short-awned, 2-5-nerved.

Spike dense; spikelets more or less imbricate.

Plants not tufted, with rootstocks; leaf-blades spreading. Sheaths and blades glabrous; glumes scabrous, at least above.

Sheaths and lower leaf-blades pubescent: 10. E. glaucus.

Plants tufted; leaf-blades ascending. Spike lax; spikelets distant; glumes glabrous.

Empty glumes linear-subulate.

Spike 7-8 mm. thick; awns 30-40 mm. long.

Spike $5 \mathrm{~mm}$. thick; awns $5-10 \mathrm{~mm}$. long. $15 . E$. Macol
Lemma awnless or short-awned; awn less than one-third the length of the body.
Empty glumes strong.y 3-5-nerved.

11. E. marginalis,

12. E. nitidus.

13. E. Petersonii.

14. E. Saundersii.

15. E. Macounii.

Empty glumes strong1y 3-5-nerved.

Empty glumes thickened and strongly curved at the base, not scarious-margined.

Empty glumes neither thickened nor strongly curved at 16. E. curvatus. scarious-margined.

Empty glumes 1-nerved or indistinctly 3-nerved.

Lemma glabrous or hispidulous.

Empty glumes aristiform or narrowly subulate.

Plant stout, 1-2 m. high, tufted; spikelets $2-6$ at each joint; lemma scabrous-hispidulous.

Plant slender, 3-10 dm. high; spikelets 1 or 2 at each joint. Condensatus.

Lemma broadly lanceolate, acute or awn-pointed; rachis scabrous on the sharp angles; spikelets erect; plant with a horizontal rootstock. 19. E. triticoides.

Lemma narrowly lanceolate; rachis nearly terete, strigose; plant tufted. Spikelets usually in pairs; lemma awn-pointed. Lemma glabrous.

Lemma scabrous or scabro-strigose.

Lemma scabrous or scabro-strigose, 21 . E. strigosus.
Spikelets usually singly; lemma acuminate or acuce.

20. E. ambiguus.

Empty glumes lanceolate-subulate, tapering from the rather broad base; Lemma pubescent.

Plants tufted; lemma long-attenuate, short-awned. 24. E. villiflorus.

Plants not tufted, or somewhat so in $E$. cinereus, with horizontal rootstocks; lemma not long-attenuate.

Lemma appressed-pubescent.

Stem, sheath, and leaves glabrous or minutely strigulose.

Stem, sheath, and leaves densely $25 . E$. arenicola.

Lemma with spreading pubescent. 26. E. cinereus.

Spike long; empty glumes lanceolate, silky-villous.

Spike short; empty glumes subulate, scabrous. $\quad 27$. E. flavescens.

1. E. virginicus L. Stem $6-10 \mathrm{dm}$. high; sheath usually glabrous; leafblades 1-3 dm. long, 4-16 mm. wide, scabrous; spike 5-15 cm. long, thick, erect; lemma 6-8 mm. long, glabrous; awn scabrous, $5-18 \mathrm{~mm}$. long. Along streams: N.S.-Fla.-Tex.-Sask. Plain. Je-Au.

2. E. jejunus (Ramaley) Rydb. Stem slender, 3-6 dm. high; leaf-blades 1-2 dm. long, 2-5 mm. wide, scabrous; spike $2-6 \mathrm{~cm}$. long, strict; spikelets usually 2 at each node; lemma lanceolate, $7-8 \mathrm{~mm}$. long, scabrous, hispidulous; awn 3-10 $\mathrm{mm}$. long. E. virginicus minor Vasey. E. virginicus jejunus Ramaley. Sand hills and river banks: Minn.-Neb.-Wyo.-Mont. Plain-Submont. Je-Au.

3. E. diversiglumis Scribn. \& Ball. Stem 9-12 dm. high, glabrous; leafblades spreading, $1.5-2.5 \mathrm{dm}$. long, 6-12 mm. wide, scabrous on both sides; spikelets in pairs, 2-flowered; lemma linear-lanceolate, acute, $8-10 \mathrm{~mm}$. long, indistinctly 3-5-nerved, hirsute or scabrous, hispidulous; awn $2-3 \mathrm{~cm}$. long. Rich open places: Wis.-Wyo.-N.D. Plain-Submont. Jl.

4. E. canadensis L. Stem 6-15 dm. high, glabrous; leaf-blades $1-3 \mathrm{dm}$. long, 4-20 mm. wide, scabrous; spike 1-3 dm. long, usually long-exserted, nodding; spikelets spreading, 3-5-flowered; lemma 8-14 mm.long; awn 2-5 cm.long, rough. River banks and among bushes: N.S.-Ga.-N.M.-B.C. Plain-
Submont. Jl-Au.

5. E. robustus Scribn, \& Smith. Stem 1-2 m. high, smooth; leaf-blades 2-4 dm. long, 8-20 mm. wide, scabrous on both sides; spike $12-18 \mathrm{~cm}$. long, 2.5$4 \mathrm{~cm}$. thick; spikelets 3-4 at the nodes, 3-4-flowered; lemma $12-16 \mathrm{~mm}$. long, 
attenuate above; awn 3-4 cm. long. River valleys: Ill,-Mo.-N.M.-Mont. -Ida. Plain-Submont. Je-Au.

6. E. brachystachys Scribn. \& Ball. Stem 3-10 dm. high, smooth; leafblades 1-2 dm. long, 6-10 mm. wide, semi-involute, smooth or somewhat scabrous beneath, finely scabrous above; spike dense, nodding, $8-15 \mathrm{~cm}$. long; spikelets usually in 2's, 3-5-flowered; lemma 11-13 mm. long; awn scabrous, 2-4 cm. long. Prairies and plains: Mich.-Tex.-N.M.-(Black Hills) S.D.; Mex. Plain-Submont. Je-Au.

7. E. striatus Willd. Stem 3-9 dm. high; leaf-blades 1-2 dm. long, 4-10 $\mathrm{mm}$. wide, smooth or slightly scabrous beneath, pubescent above; spike exserted, nodding, 6-12 cm. long; spikelets divergent, 1-3-flowered; lemma about $6 \mathrm{~mm}$. long, hispid; awn 1.5-3 cm. long. Woods and river banks: Me,-N.C.-Tex.N.D. Plain-Submont. Je-Au.

8. E. vulpinus Rydb. Stem 5-7 dm. high, striate, erect; leaves $1-1.5 \mathrm{dm}$. long, 2-6 mm. wide, scabrous on the margins; spike exserted, 1-1.5 dm. long, 6-7 mm. thick, slightly nodding; spikelets $1-2$ at each node, 4-6-flowered; lemma linear-lanceolate, $8 \mathrm{~mm}$. long; awn 8-10 mm. long. Meadows: Alta.-Neb. Plain. Jl-Au.

9. E. angustus Trin. Stem 4-10 dm. high, striate, smooth; leaf-blades rigid, 7-15 $\mathrm{cm}$. long, 3-6 mm. wide, smooth beneath, scabrous above, with involute margins; spike rather slender, its base enclosed in the upper sheath; spikelets in pairs, 2-3-flowered, erect-appressed; lemma lanceolate, acuminate, 8-10 mm. long; awn scabrous, 4-6 mm. long. Banks: Wyo.-Ida.; Asia. Submont. Je.

10. E. glaucus Buckley. Stem 6-10 dm. high, smooth; leaf-blades flat, scabrous on both sides, 6-15 mm. wide, 5-20 cm. long; spike erect, 6-15 cm. long, $5-8 \mathrm{~mm}$. thick; spikelets in pairs, rarely in threes or single, 3-4-flowered; lemma scabrous towards the apex, 5-nerved, 7-10 mm. long, with a white margin, or in var. tenuis Vasey [E. americanus Vasey \& Seribn.] narrower and with purplish margin; awn scabrous, 7-15 mm. long. Among bushes and in meadows: Mich. -N.M.-Calif.-B.C. Submont.-Subalp. Je-Au.

11. E. marginalis Rydb. Stem 6-10 dm. high, glabrous or pubescent at the nodes; leaf-blades 1-2 dm. long, 7-10 mm. wide, flat, scabrous beneath, usually pilose above; spike $1.5-2 \mathrm{dm}$. long; spikelets usually in pairs, 4-5-flowered; lemma 10-12 mm. long, glabrous and shining; awns $8-20 \mathrm{~mm}$. long. Lake shores and banks: B.C.-Wash. Submont.-Mont. Je-Jl.

12. E. nitidus Vasey. Stem $7-10 \mathrm{dm}$. high, stout and leafy; leaf-blades 1.5-2 dm. long; spike about $1 \mathrm{dm}$. long, arect; spikelets $1-2$ at each node, 3-5flowered; lemma about $1 \mathrm{~cm}$. long, obscurely 5-nerved, smooth or nearly so, shining; awn scabrous, of about the same length. Mountains: Ore.-Wyo.B.C. Submont.-Mont. Jl-Au.

13. E. Petersonii Rydb. Stem 6-8 dm. high, slender, glabrous; leaf-blades flaccid, 1-1.5 dm. long, 4-5 mm. wide, light green, minutely scabrous on both sides, or sparingly pilose above; spikelets in pairs or single; lemma about $1 \mathrm{~cm}$. long; awn about $1 \mathrm{~cm}$. long. Mountains: B.C. (Selkirk Mts.) Mont. Au.

14. E. Saundersii Vasey. Stem 6-10 dm. high, smooth; leaf-blades $12-20$ $\mathrm{cm}$. long, becoming involute, finely scabrous; spike $12-18 \mathrm{~cm}$. long, somewhat nodding; spikelets usually in pairs, 2-4-flowered; lemma lanceolate, 5-nerved, finely scabrous, $10 \mathrm{~mm}$. long. Mountains: Colo. Mont.

15. E. Macounii Vasey. Stem 3-10 dm. high, smooth; leaf-blades erect, scabrous, 7-15 cm. long, 2-4 mm. wide; spike slender, 7-12 cm. long; spikelets often solitary at the nodes, 1-3-flowered; lemma scabrous above, $8-10 \mathrm{~mm}$. long, 5-nerved. Meadows: Man.-N.M.-Utah-Alta. Plain-Submont.

16. E. curvatus Piper. Stem erect, 6-10 dm. high, glabrous; leaf-blades 1-2 dm. long, 5-7 mm. wide, usually flat, scabrous on both sides; spike stout, erect, short-exserted, 5-12 cm. long; lemma 3-5-nerved, sparingly scabroushispidulous towards the apex, 8-12 mm. long, acuminate to short-awned; awn 
$2 \mathrm{~mm}$. long or less. E. virginicus submuticus Hook. River banks: Man.-Ills. -Kans.-Wash. Plain-Submont. Jl-Au.

17. E. Howellii Scribn. \& Merrill. Somewhat tufted perennial; stem 6-8 dm. high, glabrous; leaf-blades spreading, flat, $10-15 \mathrm{~cm}$. long, 4-8 $\mathrm{mm}$. wide, minutely scabrous; spike exserted, 7-10 $\mathrm{cm}$. long; spikelets usually in pairs, 2-4-flowered; lemma 10-12 mm. long, acuminate, usually awn-pointed, sparingly scabrous toward the apex. E. glaucus breviaristatus Davy. Grassy ground: Alaska-Ore. Jl-Au.

18. E. condensatus Presl. Stems tufted, 1-2 m. high, stout, striate, scabrous or scabro-puberulent above; leaf-blades 3-10 dm. long, 5-10 $\mathrm{mm}$. wide, more or less seabrous; spike 2-4 dm. long; lemma $12-15 \mathrm{~mm}$. long, acuminate or awn-pointed. Hills and alkaline ground: Alta.-Neb.-N.M.-Calif.-B.C. Plain-Mont. Je-Au.

19. E. triticoides Buckley. Stem slender, 6-8 dm. high; leaf-blades 1.5-3 $\mathrm{dm}$. long, about $7 \mathrm{~mm}$. wide, flat or somewhat involute, scabrous on the margins and nerves; spike about $1.5 \mathrm{dm}$. long, ereet; spikelets $12-18 \mathrm{~mm}$. long, 4-6flowered; lemma 8-10 mm. long, 9-nerved, glabrous, awn-pointed. Meadows, hillsides, and bottom lands: Alta.-N.M.-Calif.-Wash. Son.-Mont. Je$\mathrm{Au}$.

20. E. ambiguus Vasey \& Scribn. Tufted perennial; stem 6-10 dm. high, glabrous; leaf-blades 1-4 dm. long, 2-4 mm. wide, rigid, flat or at last involute, scabrous, especially above; spikes $7-12 \mathrm{~cm}$. long, erect; spikelets 5-9flowered, 12-18 mm. long; empty glumes about $12 \mathrm{~mm}$. long, scabrous; lemma 10-12 mm. long, obscurely 5-nerved; awn $3 \mathrm{~mm}$. or less long. Cañons and hillsides: Colo.-Utah. Submont.-Mont, Je-Au.

21. E. strigosus Rydb. A cespitose perennial; stem 5-7 dm. high; leafblades 1-2 dm. long, about $3 \mathrm{~mm}$. wide, flat or involute, scabrous; spike 1-1.5 $\mathrm{dm}$. long; empty glumes línear-subulate, $7-9 \mathrm{~mm}$. long, very scabrous; lemma lanceolate, about $1 \mathrm{~cm}$. long, awn-pointed or short-awned. Foot-hills and shaleslopes: Colo.-Wyo. Submont. Je-Jl.

22. E. salinus M. E. Jones. Tufted perennial; stem $3-6 \mathrm{dm}$. high, smooth; leaf-sheaths enlarged, long-remaining and becoming fibrous; leaf-blades thick, involute, puberulent near the throat, the basal ones 1-1.5 dm. long; stem-leaves 5-10 cm. long; spike 5-10 cm. long, narrow; spikelets about $12 \mathrm{~mm}$. long, 7-9flowered; empty glumes $4 \mathrm{~mm}$. long, somewhat falcate; lemma about $8 \mathrm{~mm}$. long. Saline soil: Utah-Wyo. Son.-Submont. Jl.

24. E. simplex Scribn. \& Williams. Stems tufted, 3-4 dm. high; leafblades 4-10 $\mathrm{cm}$. long, 3-6 $\mathrm{mm}$. wide, becoming involute, strigose-scabrous above; spikes 6-10 $\mathrm{cm}$. long; rachis flattened and scabrous on the edges; spikelets singly or sometimes in pairs, about $1.5 \mathrm{~cm}$. long, 5-7-flowered; empty glumes very rigid, unequal, 8-10 mm. long; lemma about $7 \mathrm{~mm}$. long, smooth, acuminate; awn 4-6 mm. long. Alkaline soil: Wyo.-N.M.-Ore. Submont,-Subalp. Je-Jl.

24. E. villiflorus Rydb. Stem 4-6 dm. high, finely retrorse-pubescent; leaf-blades $1-2 \mathrm{dm}$. long, about $2 \mathrm{~mm}$. wide, strongly involute, scabrous above; spike 1-1.5 dm. long; spikelets 1 or 2 at each node; lemma lanceolate, 5-nerved, villous-hirsute, about $1 \mathrm{~cm}$. long. Plains and foot-hills: Colo.-Alta. PlainSubmont. JI.

25. E. arenicola Scribn. \& Smith. Stem 8-15 dm. high, glabrous; leafblades $2-4 \mathrm{~mm}$. wide, $2-3 \mathrm{dm}$. long, strongly involute; spike slender, $1.5-2.5 \mathrm{dm}$. long; spikelets in pairs or singly, about 6-flowered; lemma acute, mucronate or awn-pointed, about $10 \mathrm{~mm}$. long, E. dasytachys litoralis Am. auth., not Griseb. Sand dunes: Wash.-Ida.-Ore. Son. Je-N.

26. E. cinereus Scribn. \& Merr. Stem densely short-pubescent, except where protected by the sheaths, about $1 \mathrm{~m}$. high; leaf-blades $2-3 \mathrm{dm}$. long, $5 \mathrm{~mm}$. wide, often involute; spike about $15 \mathrm{~cm}$. long; spikelets usually 2 at each node, 3-4-flowered; lemma 9-10 mm. long, strigose. Dry plains: Calif.-Nev.-Ida. Son. Je. 
27. E. flavescens Scribn. \& Smith. Stem 6-10 dm. high, glabrous, or pubescent just below the nodes; leaf-blades $2-4 \mathrm{dm}$. long, $4-8 \mathrm{~mm}$. wide, smooth beneath, scabrous or strigulose above; spike 1-2 dm. long, yellowish; spikelets 3-6-flowered, 1-2 cm. long; lemma 10-12 mm. long, mucronate or awn-pointed. Sand: Wash.-Ida.-Ore. Son. J1-Au.

28. E. innovatus Beal. Stem smooth, or pubescent just below the nodes; leaf-blades rather rigid, $5-18 \mathrm{~cm}$. long, 2-8 mm. wide, scabrous on the margins and nerves beneath; spike 4-10 $\mathrm{cm}$. long; spikelets 3-6-flowered, 10-15 mm. long; lemma densely pubescent, usually villous, $8-10 \mathrm{~mm}$. long; awns $2-4 \mathrm{~mm}$. long. E. Brownii Scribn. \& Smith. Hills: Sask.-S.D.-Wyo.-B.C. Submont. Je-Au.

\section{HÝSTRIX Moench.}

Perennials, with rootstocks and terminal spikes. Spikelets in pairs or 3's, spreading, 2-several-flowered; rachilla articulate below the lemmas. Empty glumes in the lowest spikelets subulate, minute, elsewhere wanting. Lemma lanceolate, rigid, convolute, rounded on the back, awned. Styles very short; stigmas plumose. Grain oblong, adherent to the palet.

1. H. Hystrix (L.) Millsp. Stem 6-12 dm. tall; leaf-blades $1-2.5 \mathrm{dm}$. long, 6-12 $\mathrm{mm}$. wide, smooth beneath, scabrous above; spike 7-18 $\mathrm{cm}$. long; spikelets at length spreading, 8-12 $\mathrm{mm}$. long, exclusive of the awns; lemma 8-12 $\mathrm{mm}$. long, acuminate; awn about $2.5 \mathrm{~cm}$. long. Asprella Hystix Willd. Rocky woods: N.B.-Ga.-Neh.-Sask. Plain. Je-Jl.

\section{Family 13. CYPeRACeAE. Sedge Family.}

Grass-like or rush-like plants, with mostly solid stems. Leaves 3-ranked, with closed sheaths and narrow blades. Flowers perfect or unisexual, in spikelets; bractlets (glumes or scales) 2-ranked or spirally arranged. Perianth composed of bristles, a sack-like organ (perigynium), or wanting. Stamens usually 3 , rarely 1 or 2 , or more than 3 ; filaments slender; anthers 2-celled. Gynoecium of 2 or 3 united carpels, but ovary 1-celled and 1ovuled; stigmas 2 or 3 . Ovules anatropous, erect. Fruit an achene; endosperm mealy.

Flowers all perfect, or at least one in each spikelet perfect.

Glumes of the spikelets 2-ranked.

Perianth represented by bristles; inflorescence axillary.

Perianth wanting; spikelets in terminal, solitary or umbellate heads,

Glumes of the spikelets spirally imbricate.

Base of the style persistent as a tubercle on the achene.

Basal empty glumes several.

Basal empty glumes wanting, or 1 or 2.

Spikelets solitary; stem leafless; bristles usually present.

Spikelets several or numerous; stem leafy; bristles none.

Base of the style not persistent as a tubercle.

Base of the style swollen; bristles none.

Base of the style not swollen; bristles usually present.

Flowers without any inner scales.

Bristles much elongating in fruit, silky.

Bristles 6, but each 4-6-cleft to near the base, therefore appearing numerous.

Bristles 6, simple, crisp.

7. ERIOPHORUM.

8. LEUCOCOMA.

Bristles short, or little elongating, rarely wanting. 9. SCIRPUS.

Flowers with a small inner scale between the flower and the rachis.

10. HEMICARPHA.

Flowers monoecious or dioecious.

Achenes not enclosed in a perigynium.

Spikes several, clustered; glumes subtending a single flower.

Spikes solitary: glumes subtending 2 flowers.

Achenes enclosed in a perigynium.

11. KOBRESLA.

12. EIYNA.

13. CarEX.

\section{DULÍCHIUM L. C. Rich.}

Tall perennials, with rootstocks and hollow jointed stems, leafy to the top. Leaves 3-ranked. Spikelets in axillary, simple or compound spikes, flat, linear, many-flowered; glumes 2-ranked, carinate, conduplicate, decurrent on the 
internode below. Flowers perfect. Perianth of 6-9 retrorsely barbed bristles. Stamens 3. Style persistent as a beak on the top of the achene. Stigmas 2. Achenes linear-oblong.

1. D. arundinaceum (L.) Britton. Stem stout, 3-10 dm, high; leaves numerous, flat, $2-8 \mathrm{~cm}$. long, 4-8 $\mathrm{mm}$. wide, spreading; lower sheaths bladeless; spikelets 12-25 mm. long, about $2 \mathrm{~mm}$. wide, 6-12-flowered; glumes lanceolate, acuminate, strongly nerved, brownish; bristles longer than the achenes. $D$. spathaceum Pers. Wet places: Newf.-Fla.-Tex.-Ore.-B.C.; C. Am. Plain. J1-O.

\section{Cypèrus L. Galingale, Nut-grass.}

Sub-scapose perennials or annuals. Leaves basal; blades narrow, grass-like. Scapes in our species simple, triangular, with one or more bracts at the summit, subtending a simple or compound, umbellate or capitate inflorescence; rays usually very unequal in length. Spikelets flat to nearly terete. Glumes 2ranked, concave, conduplicate or keeled. Flowers perfect; perianth none. Stamens 1-3. Styles deciduous from the summit of the achenes; stigmas 2 or 3. Achenes without a tubercle.

Glumes falling away from the persistent rachis of the flat spikelets.

Style 2-cleft; achenes lenticular.

Style 3-cleft; achenes 3-angled.

Wings of the rachis none or very narrow.

Annuals; stamen 1.

Glumes awned or mucronate.

Glumes acute, neither awned nor mucronate.

Perennials; stamens 2 or 3 .

Glumes tipped with a curved or bent awn; perennials with a rootstock.

1. C. diandrus.

4. C. Fendlerianus,

Glumes blunt or mucronate; perennials with a corm-like base.

Heads oblong; spikelets ascending; stem rough. 5. C. Schweinitzii.

Heads short; spikelets more or less spreading; stem smooth.

Glumies broadly ovate; achenes $1.5-2 \mathrm{~mm}$. long. 6. C. Houghtoni.

Glumes oblong-ovate; achenes $2-2.5 \mathrm{~mm}$. long. 7 . C. Bushii.

Wings of the rachis prominent and separating from it as interior scales.

8. C. erythrorhizos.

Spikelets wholly falling away, usually leaving the two lower glumes persistent.

9. C. strigosus.

1. C. diandrus Torr. Annual; stems tufted, 5-30 cm. high; leaves about $2 \mathrm{~mm}$. wide; bracts usually 3 , at least one much exceeding the spikelets; spikelets in terminal capitate clusters, linear-oblong, 8-18 $\mathrm{mm}$. long, flat, many-flowered; glumes ovate, green, brown, or with brown margins, obtuse, 1-nerved; stamens 2 or 3 ; achenes oblong, gray. Marshy places: N.B.-S.C.-Colo.-S.D. Plain - Submont. Au-O.

2. C. inflexus Muhl. Stems slender, tufted, $2-15 \mathrm{~cm}$. high; leaves $1-2 \mathrm{~mm}$. wide; bracts 2 or 3 , longer than the umbel; spikelets capitate or in 3-rayed, sessile umbels, linear-oblong, 6-10-flowered, 4-6 mm. long; glumes light brown, lanceolate, several-nerved. C. aristatus Rottb. Wet sandy soil: N.B.-Fla.-Calif. -B.C.; Mex. Plain-Submont. JI-S.

3. C. acuminatus Torr. Stems slender, tufted, $5-35 \mathrm{~cm}$. high; leaves usually less than $2 \mathrm{~mm}$. wide, light green; bracts much elongated; spikelets capitate, in 2-4-rayed umbels, flat, ovate-oblong, 4-8 mm. long; glumes oblong, pale green, 3-nerved, with short, more or less recurved tips. Wet soil: Ill.-La.Calif.-Wash. Plain. Jl-O.

4. C. Fendlerianus Boeckel. Stem slender, 3-5 dm. high, triangular above, scabrous on the angles; leaves flat, $2-6 \mathrm{~mm}$. wide, seabrous on the margins; bracts 3-6, the longer much exceeding the inflorescence; spikelets spicate, in simple, often subcapitate, few-rayed umbels, oblong to cylindric, 5-15 mm. long, 2-3 mm. thick; glumes orbicular-ovate, striate, pale greenish brown with brown or yellow margins. Wet places: w Tex.-Colo.-Ariz.; n Mex. Plain-Submont. Jl-S.

5. C. Schweinitzii Torr. Stems tufted, rough, 3-7 dm. high; leaves $2-5$ $\mathrm{mm}$. wide, rough-margined; bracts $3-7$, erect; spikelets spicate, in 3-9-rayed umbels, flat, linear-oblong, 6-12-flowered, 8-16 mm. long; glumes convex, light 
green, ovate, acute or acuminate, 9-13-nerved. Sandy soil: Ont.-Mo,-Kans. -(? N.M.) -S.D.-Sask. Plain. Au-O.

6. C. Houghtoni Torr. Stem smooth, 3-6 dm. high; leaves 1-2 mm. wide; bracts $3-5$, some much exceeding the inflorescence; spikelets loosely capitate in 1-5-rayed umbels, compressed, acute, $8-15 \mathrm{~mm}$. long, about $2 \mathrm{~mm}$. wide, $11-15-$ flowered; glumes chestnut brown, shining, oblong, obtuse, strongly 11-nerved. Sandy places: Mass.-Va.-Ark.-w S.D.-Man. Plain. J1-Au.

7. C. Bushii Britton. Stem smooth, 3-6 dm. high, longer than the leaves; leaves 3-4 mm. wide, smooth; spikelets capitate in 1-5-rayed umbels, flat, linear, acute, 8-15 mm. long; glumes oblong, mucronate, shining, 11-nerved. C. filiculmis Coult., not Vahl. Sandy soil: Minn.-Mo.-Tex.-Colo.-Ore.-Wash. Plain. Jl-S.

8. C. erythrorhizos Muhl. Annual; stems tufted, 0.7-6 dm. high; leaves 3-8 $\mathrm{mm}$. wide, rough-margined, the lower equalling or exceeding the stem; bracts $3-7$, some $3-5$ times as long as the inflorescence; spikelets spicate in mostly compound umbels, linear, subacute, 6-30 $\mathrm{mm}$. long, less than $2 \mathrm{~mm}$. wide, compressed, many-flowered; glumes bright chestnut-brown, oblong-lanceolate, mucronate, appressed. Wet places: Mass,-Fla.-Tex.-Calif.-Wash. Plain. $\mathrm{Au}-\mathrm{O}$.

9. C. strigosus L. Perennial, with a corm-like base, 3-10 dm. high; leaves rough-margined, 4-6 $\mathrm{mm}$. wide; some of the bracts exceeding the inflorescence; spikelets spicate or subcapitate in more or less compound umbels, flat, linear, 6-25 mm. long, $2 \mathrm{~mm}$. wide or less, 7-25-flowered; glumes straw-colored, oblonglanceolate, several-nerved, appressed; achenes linear-oblong, acute. Moist meadows: Me.-Fla.-Tex.-Calif.-Wash.-w S. D. Plain. Au-O.

\section{RYNCHÓSPORA Vahl. BEAKEd Rush.}

Caulescent perennials, with rootstocks. Spikelets oblong or fusiform; glumes spirally imbricate, the lower empty, usually mucronate or cuspidate by the excurrent midrib. Perianth of 1-24, mostly 6 , barbed or scabrous bristles, or rarely wanting. Stamens usually 3 . Stigmas 2, rarely wholly united. Achenes lenticular, smooth, cancellate or transversely wrinkled. Base of the style persistent, forming a tubercle, or the whole style persistent.

1. R. alba (L.) Vahl. Stems slender, glabrous, $1.5-2.5 \mathrm{dm}$. high; leaves. bristle-like, $0.5-1 \mathrm{~mm}$. wide; spikelets several, in 1-4 dense corymbose heads, narrowly oblong, 4-6 mm. long; glumes ovate or ovate-lanceolate, white, acute; bristles 9-15, equalling the achenes, which are obovate-oblong, lenticular, pale brown; tubercle triangular, flat. Bogs: Newf.-Fla.-Ky.-Ida.-Calif.Alaska; Eurasia. Boreal-Mont. Je-Au.

\section{ELEÓCharis R. Br. Spike-RUsh, Wire-grass.}

Annual or perennial scapose herbs. Leaves reduced to mere sheaths, or the lower rarely blade-bearing. Scape angled or terete. Spikelets solitary, terminal, erect. Glumes spirally arranged, imbricate. Perianth of 1-12 bristles, usually retrorsely barbed. Stamens 2-3. Stigmas 2 or 3 . Achene lenticular or triangular, sometimes obscurely so. Base of the styles persistent on the summit of the achenes, forming a tubercle.

Style-branches 2; achenes lenticular or biconvex.

Sheath hyaline, and scarious at the summit.

Sheath firm, not scarious at the summit.

Annuals, with fibrous roots.

Achenes black, shining.

Achenes pale brown, dull.

Spikelets narrowly oblong or subcylindric; glumes blunt, closely appressed.

Spikelets lance-ovoid or lance-oblong; glumes acutish, more spreading.

\section{E. thermalis.}

2. E. atropurpurea.

4. E. monticola.

Perennials, with rootstocks.

5. E. palustris.

Style-branches 3 ; achenes trigonous or turgid; perennials, with rootstocks.

Achenes cancellate and longitudinally ribbed; spikelets flat. $\quad 6$. E. acicularis.

Achenes smooth, papillose or reticulate. 
Tubercle of the achenes short-conic to depressed, plainly distinguishable from the achene.

Achenes papillose.

Stem filiform; glumes obtuse.

Stem flat; glumes acute.

Achenes finely reticulated.

7. E. tenuis.

8. E. acuminata.

9. E. arenicola.

Tubercle of the achenes long-conic, scarcely distinguishable from the body of the achene.

10. E. rostellata.

1. E. thermalis Rydb. Perennial, with a creeping rootstock; stems tufted, yellowish green, 3-10 $\mathrm{cm}$. high, somewhat flattened, striate; spikelet obovate, obtuse, $4 \mathrm{~mm}$. long, $3 \mathrm{~mm}$. thick; glumes very thin, ovate, acutish; achenes lenticular, broadly obovate, dark brown, smooth and shining, $1 \mathrm{~mm}$. long; tubercle conic. Hot springs and thermal waters: Mont.-Wyo. Mont. Jl-Au.

2. E. atropurpurea (Retz.) Kunth. Stems tufted, slender, $3-10 \mathrm{~cm}$. high; spikelet ovoid, subacute, $3-4 \mathrm{~mm}$. long, $2 \mathrm{~mm}$. thick; glumes ovate-oblong, obtuse, or the upper acute, purple-brown, with green midrib and narrow scarious margins; bristles 2-4, fragile, white, about as long as the achenes; achenes $0.5 \mathrm{~mm}$. long, smooth, lenticular; tubercles depressed-conic, constricted at the base. Moist soil: Ia.-Fla.-Tex.-(? Colo.); trop. Am.; Eurasia. A ustral. J1-S.

3. E. Engelmanni Steud. Stems $2-4.5 \mathrm{dm}$. high, tufted; spikelet obtuse, 5-15 mm. long, 2-3 mm. thick; glumes pale brown, with green midrib and narrow scarious margin, ovate, obtuse; bristles about 6 , not longer than the achenes, or none; achenes broadly obovate, smooth; tubercle broad, low, covering the top of the achene. Wet places: Mass.-N.J.-Tex.-Calif.-Wash. Plain-Submont. Jl-S.

4. E. monticola Fernald. Stems 1-2.5 dm. high, tufted; spikelets $6-9 \mathrm{~mm}$. long, 2-3.5 mm. thick, acutish; glumes chestnut-brown or purplish, with paler midribs and margins, acutish; bristles 6 , equalling or slightly exceeding the achenes, or (in var. leviseta) represented only by the unbarbed basal portion; achenes as in the preceding. Wet places: Calif.-Wash.; the var. leviseta: Wash.-Ida.Man. Submont.

5. E. palustris (L.) R. \& S. Stems striate, $3-15 \mathrm{dm}$. high; spikelets oblong to ovoid-cylindric, 6-25 $\mathrm{mm}$. long, 3-4 $\mathrm{mm}$. thick; glumes ovate-lanceolate or ovate-oblong, purplish brown with scarious margins and green midrib, or wholly green; bristles usually 4, longer than the achenes; achenes yellow, more than 1 $\mathrm{mm}$. long; tubercle conic, constricted at the base. E. glaucescens Willd., a slender form with narrower tubercle. In ponds and marshes: Lab.-Fla.-Tex.-Calif. -B.C.; Eurasia. Plain-Mont. Au-S.

6. E. acicularis (L.) R. \& S. Stems tufted, filiform, obscurely 4-angled, grooved, 5-20 $\mathrm{cm}$. high; spikelets narrowly ovate, acute, 3-10-flowered, 3-6 $\mathrm{mm}$. long; glumes oblong, obtuse, or the upper acute, pale green, often with two brown bands; bristles 3-4, fragile, fugaceous, shorter than the achenes; achenes obovoid, pale, obscurely 3 -angled; tuberele conic. Wet places: Newf.-N.J.N.M.-Calif.-B.C.; Mex.; Eurasia. Plain-Mont. Jl-S.

7. E. tenuis (Willd.) Schultes. Stems tufted, filiform, 4-angled, 2-4 dm. high; spikelets narrowly oblong, acute, $6-10 \mathrm{~mm}$. long, about $2 \mathrm{~mm}$. thick; glumes thin, obovate or obovate-oblong, obtuse, with greenish midvein and scarious margins; bristles 2-4, shorter than the achenes, fugaceous or wanting; achenes obovoid, obtusely 3-angled, yellowish brown; tuberele conic, short. Wet places: N.S.-Fla.-Tex.-Colo.-Sask. Plain-Submont. My-Jl.

8. E. acuminata (Muhl.) Nees. Stems tufted, flattened, striate, 2-6 dm. high; spikelets ovoid or oblong, obtuse, 6-12 $\mathrm{mm}$. long; glumes oblong or ovatelanceolate, acute or obtusish, purple-brown with green midrib and hyaline margins; bristles $1-5$, mostly shorter than the achenes; achenes obovoid, very obtusely 3-angled, light yellowish brown; tubercle depressed-conic. Wet places: Que.-Ga.-La.-Colo.-B.C. Je-Au.

9. E. arenicola Torr. Stems tufted, slender, 1.5-4.5 dm. high, grooved; spikelets oblong to ovoid-oblong, 4-12 $\mathrm{mm}$. long, 2.5-3.5 $\mathrm{mm}$. thick; glumes oblong or ovate, thin, blunt, with a brown apex and whitish margins; bristles 6 , persistent, the longer ones as long as the achenes; achenes 3 -angled, oblong- 
obovoid, faintly reticulate; tubercle thick, deltoid. Perhaps not distinet from E. montana H.B.K. Sandy shores: S.C.-Fla.-Tex.-Calif.-Colo. Son.Submont.

10. E. rostellata Torr. Stems slender, flattened, the sterile ones often reclining and rooting at the summit, grooved; spikelets oblong, 6-12 $\mathrm{mm}$. long, $2 \mathrm{~mm}$. thick; glumes ovate, obtuse, or the upper acute, green with a darker midvein; bristles 4-8, longer than the achenes; achenes obovoid, finely reticulate. Marshes and wet meadows: N.H.-Fla.-Tex.-Calif.-B.C.; Mex. PlainSubmont. Au-S.

\section{STENOPHÝLLUS Raf.}

Scapose annuals, with narrowly linear or filiform leaves. Spikelets umbellate, or eapitate, rarcly solitary; glumes spirally arranged, imbricate, deciduous, Flowers perfect; perianth wanting. Stamens 2 or 3 . Base of the style swollen, persistent, forming a tubercle; stigmas 2 or 3 . Achenes 3-angled or lenticular.

1. S. capillaris (L.) Britton. Annual; stems tufted, filiform, smooth, 5-25 $\mathrm{cm}$. high; leaves filiform, roughish; bracts 1-3, setaceous; spikelets narrowly oblong, 5-8 mm. long, less than $2 \mathrm{~mm}$. thick, in terminal, simple or compound umbels; glumes oblong, obtuse or emarginate, dark-brown with green keel; achenes yellowish, transversely wrinkled. River valleys: Me.-Fla.-Calif.-Ore. (but no specimens seen from the Rockies). J-S.

\section{FIMBRÍSTYLIS Vahl.}

Annual or perennial sub-scapose herbs, with grass-like leaves. Spikelets capitate or in ours umbellate, terete, several- or many-flowered; glumes spirally arranged, imbricate. Flowers perfect; perianth none: Stamens 1-3. Style usually enlarged at the base, but wholly deciduous at maturity; stigmas 2-3. Achenes lenticular or 3-angled.

1. F. interior Britton. Perennial, with short stolons; stem thickened at the base, striate, smooth, 3-6 dm. high; leaves rough-margined, involute; spikelets in somewhat compound umbels, ovoid or ovoid-oblong, acutish, $1 \mathrm{~cm}$. long or less; glumes yellowish-brown, ovate, striate, mucronate, dull; achenes broadly obovate, blunt, cancellate, ehestnut brown. $F$. castanea and $F$. thermalis of Fi. Colo. Meadows: Colo.-Neb.-Tex. Plain. Jl-Au.

\section{ERIÓPHORUM L. COTTON-GRASS.}

Perennial bog plants, with rootstocks. Stems triangular or terete. Leaves with linear blades or some of them reduced to bladeless sheaths. Spikelets terminal, solitary, or a few in heads or umbels. Glumes spirally arranged, all usually subtending perfect flowers. Perianth of 6 members, but each 4-6-cleft to the base into long soft, usually white bristles, exserted much beyond the glumes at maturity. Stamens 1-3. Styles deciduous; stigmas 3. Achenes 3-angled, oblong, ellipsoid or obovoid.

Spikelets solitary; involucre wanting.

Plant stoloniferous.

Glumes purplish-brown with narrow, pale margins.

Glumes purplish-brown with white, broad margins.

1. E. Scheuchzeri.

2. E. Chamissonis.

Plant tufted, not stoloniferous.

Upper sheaths inflated; stem rough above.

Upper sheaths not inflated; stem smooth.

Spikelets several, subtended by foliaceous bracts.

Leaf-blades triangular-channeled throughout.

3. E. callitrix.

4. E. opacum.

Leaf-blades flat, at least below the middle.

Midrib of the glumes not prominent at the tip of the glume.

Midrib of the glumes prominent to the very tip.

5. E. gracile.

6. E. angustifolium.

7. E. viridicarinatum.

1. E. Scheuchzeri Hoppe. Stem slender, 2.5-4 dm. high; sheaths all blade-bearing or the uppermost one bladeless; blades filiform, channeled. $E$. capitatum Host. Bogs: Lab. - Newf.-Wyo.-B.C.-Alaska. Mont. - Alp. $\mathrm{Jl}-\mathrm{O}$, 
2. E. Chamissonis C. A. Mey. Stems 1-7 dm. high, somewhat triangular; upper sheaths inflated, bladeless; leaf-blades filiform, triangular-channelled, 3-10 cm. long; bristles often reddish-brown. E. russeolatum Fries. Bogs: N.B.-Ont.-Wyo.-Ore.-B.C.; Eurasia. Mont.-Subalp. Je-Au.

3. E. callitrix Cham. Stems obtusely 3-angled, 2-5 dm. high; leaf-blades filiform, triangular-channeled; glumes thin, ovate-lanceolate or the lowest lanceolate, acuminate, pale brown. E. vaginatum Torr., not L. Bogs: Newf.Mass.-Pa.-Sask.-B.C.-Alaska. Boreal-Mont. Je-Au.

4. E. opacum (Björnstr.) Fernald. Stem terete or nearly so, 3-6 dm. high; basal leaves elongate, filiform, channeled; stem-leaves reduced to 2 or 3 close sheaths; glumes thin, ovate-lanceolate or the inner ones linear-lanceolate, acuminate. Bogs: Me.-Mass.-B.C.-Yukon; Eurasia. Boreal-Mont. My-Jl.

5. E. gracile Koch. Stem slender, smooth, terete, 3-6 dm. high; blades of the stem-leaves $2-3 \mathrm{~cm}$. long, the basal ones longer; bracts about $1 \mathrm{~cm}$. long; spikelets $2-6$, on pubescent peduncles; glumes ovate, gray or nearly black, acutish, with prominent midrib. Bogs: Que.-N.Y.-Colo--Calif.-B.C.; Eurasia. Plain-Mont. Je-Au.

6. E. angustifolium Roth. Stem smooth, obtusely triangular above, 3-6 $\mathrm{dm}$. high; blades rough-margined, $3-8 \mathrm{~mm}$. wide; bracts $2-4$, of ten black at the base; spikelets 2-12, ovoid or oblong; peduncles smooth; glumes ovate-lanceolate, acute or acuminate, purple-green or brown. $E$. polystachyon L., in part. $E$. ocreatum A. Nels. Bogs: Newf.-Me.-Ill.-N.M.-Ore.-Alaska; Eurasia. Submont.-Subalp. Je-Au.

7. E. viridicarinatum (Engelm.) Fernald. Stem 3-6 dm. high; leaf-blades 2-6 mm. wide, the upper $15 \mathrm{~cm}$. long or less; bracts not black at the base; spikelets 5-30; peduncles fine-hairy; glumes ovate-lanceolate; achenes oblong-obovoid. E. polystachyon Am. auth., mainly. Bogs and wet meadows: Newf.-Ga.Ohio-Wyo.-B.C. Submont. J1-Au.

\section{LeUCOCÒMA Ehrh. Alpine Cotton-Grass.}

Perennial bog plants, with rootstocks. Stems triangular. Spikelets solitary, usually subtended by a'subulate bract and attached slightly obliquely. Glumes spirally arranged, all usually subtending perfect flowers. Perianth of 6 white sof $t$ bristles, at maturity exserted far beyond the glumes. Stamens 3. Styles deciduous. Achenes obovoid, somewhat 3-angled, without tubercle. [Trichophorum Pers., in part.]

1. L. alpina (L.) Rydb. Stems numerous, not tufted, $1.5-2.5 \mathrm{dm}$. high; leaves subulate, 6-20 mm. long, triangular, channelled; lower sheaths often bladeless; glumes oblong-lanceolate, yellowish brown with slender midvein. Eriophorum alpinum L. Cold bogs: Newf.-Conn.-Mich.-B.C.; Eurasia. Mont.-Alp. Je-Au.

\section{9. scírpus L. Bulrush, Club-rush, Tule.}

Annual or perennial, caulescent or scapose herbs. Leaves grass-like, or in many species reduced to basal sheaths. Spikelets terete or somewhat flattened, solitary, eapitate or umbellate. Glumes spirally arranged, some of the lower often empty. Flowers perfect. Perianth of 1-6 barbed, pubescent or smooth bristles, rarely wanting. Stamens 2-3. Style wholly deciduous, not swollen at the base, or rarely its base persistent as a small tip. Stigmas 2-3. Achenes triangular or lenticular, rarely plano-convex.

Involucre of a single bract or wanting.

Spikelets solitary, rarely two together; plants tufted (except No. 5).

Annuals; stamens 2; bristles none.

Perennials, with rootstocks.

Involucre none.

Involucre present, consisting of one erect bract.

1. S. coloradensis.

2. S. pauciflorus.

Bract scarcely exceeding the spikelet, often shorter; bog plants. Bristles 6, longer than the achenes.

Bristles none.
Bract at least twice as long as the spikelet; aquatic plants.

3. S. caespitosus.

4.

5. S. subterminalis. 
Spikelets normally more than one, usually several, sometimes numerous.

Spikelets few, 1-12, appearing lateral, in a single capitate cluster.

Annuals, with fibrous roots, tufted; achenes dark, transversely wrinkled. Spikelets obtuse; achenes plano-convex. Spikelets acute; achenes 3 -angular.
erennials, with rootstocks; achenes plano-convex, obovate.

6. S. Hallit. Stem sharply 3 -angled.

Spikelets acute; bracts long; glumes awned.

Spikelets obtuse; bracts short; glumes mucronate. 9. S. Olneyí. Stem terete, striate.

10. S. nevadensis.

Spikelets numerous in small clusters of 1-7, arranged in compound umbels; perennials with stout rootstocks.

Style 2-cleft; achenes obovate and plano-convex, brown.

Achenes $2 \mathrm{~mm}$. long, nearly as long as the glumes; spikelets ovoid.

11. S. validus.

Achenes $3 \mathrm{~mm}$. long, distinctly shorter than the glumes; spikelet oblongcylindric.

12. S. occidentalis.

Style 3-cleft: achenes ohcordate, 3-angled, yellowish. 13. S. heterochaetus.

Involucre of two or more leaves with flat blades; perennials, with rootstocks.

Spikelets 3-10, capitate, relatively large. 14 . S. paludosus.

Spikelets numerous, in compound umbels or in umbellate heads, relatively small.

Bristles downwardly barbed, not much exceeding the fruit. Style-branches 2; achenes plano-convex; bristles mostly 4.

Style-branches 3 ; achenes oblong, 3-angular; bristles 6.

15. S. microcarpus.

Plant dark green; glumes acute; achenes pale brown. 16. S. atrovirens.

Plant pale; glumes rough-awned; achenes straw-colored.

17. S. pallidus.

Bristles 6, smootb, much exceeding the glumes at maturity; achenes 3-angled, whitish.

Spikelets all sessile; glumes brown.

Spikelets mostly pediceled; glumes mostly greenish black.

18. S. cyperinus.

19. S. atrocinctus.

1. S. coloradensis Britt. Annual; stems filiform, 2-5 em. high; spikelet bractless, linear-oblong, acutish, 3-5 mm. long, $2 \mathrm{~mm}$. thick; glumes lanceolate, acutish; keel green, bordered with two brown bands and scarious margins; achenes brown, obovate, $1 \mathrm{~mm}$. long, 3-gonous, finely papillose. Shores: Colo.; Nev. Plain.

2. S. pauciflorus Lightf. Rootstock filiform; stems 3-angled, filiform, leafless, 7-25 cm. high; spikelet oblong, compressed, 4-10-flowered, 4-6 mm. long; glumes brown with lighter margins and midrib, lanceolate, acuminate; bristles $2-6$, usually longer than the achenes; achenes obovoid, abruptly beaked, finely reticulate. Wet soil: Que.-Me.-N.Y.-N.M.-Calif.-B.C.; Eurasia. Mont. -Subalp. Jl-O.

3. S. caespitosus L. Stems light green, filiform, 1-4 dm. high; basal sheaths numerous, the upper one bearing a short blade; spikelet ovoid-oblong, $4 \mathrm{~mm}$. long; glumes yellowish brown, ovate, obtuse; achenes oblong, 3-angled, brown, acute. Bogs and wet places: Greenl.-Ill.-Colo.-Wash.-Alaska; Eurasia. Mont.-Alp. Je-Au.

4. S. pumilus Vahl. Stems terete, $1 \mathrm{dm}$. high or less, sheathed at the base; upper sheath with a short blade; spikelet rounded-ovoid; glumes ovate, acute or pointed, brown with green midrib and margins; achene 3-angular, smooth. S. alpinus Schleicher. Alpine wet places: Canadian Rockies; Alps. Jl-Au.

5. S. subterminalis Torr. Stem slender, terete, nodulose, 3-10 dm. high; leaves very slender, $1.5-6 \mathrm{dm}$. long, $0.5-1.5 \mathrm{~mm}$. wide; spikelet oblong-cylindric, 6-15 mm. long; bract subulate, erect, 1-2.5 cm. long; glumes ovate-lanceolate, acute, light brown with green midrib; bristles 6 , rarely equalling the achenes; these obovoid, 3-angled, dark brown, smooth. Ponds and streams: Newf.S.C.-Mich.-Ida.-Wash.-B.C. Submont. Jl-Au.

6. S. Hallii A. Gray. Stems slender, smooth, obtusely 3 -angular, $1-3 \mathrm{dm}$. high; upper sheath bearing a filiform blade $1-6 \mathrm{~cm}$. long; spikelets $1-7$, capitate, oblong-cylindric, obtuse, 6-12 mm. long; bract 2-10 $\mathrm{cm}$. long; glumes ovatelanceolate, greenish brown, acuminate; bristles none. Wet places: Mass.Fla.-Tex.-Colo.-Utah-Mex. Plain-Submont. JI-S.

7. S. saximontanus Fernald. Stems slender, smooth, 1-3 dm. high, tufted, short-leaved at the base; bract erect, one-half to one-fourth as long as the stem; 
spikelets 1-4, capitate, oblong-cylindric, acute, 5-12 mm. long; glumes ovate, cuspidate-acuminate, with pale brown margins; style 3-cleft. Wet places: Tex. -Wyo.-Utah-Mex. Plain-Submont.

8. S. americanus Pers. Stems erect, $3-12 \mathrm{dm}$. high; leaves $1-3$, narrowly linear, keeled; spikelets 1-7, oblong, acute, 8-25 mm. long; bract $2-10 \mathrm{~cm}$. long; glumes broadly ovate, brown, often emarginate or 2-cleft, awned; achenes smooth, dark brown. S. pungens Vahl. Fresh or saline swamps: Newf.-Fla.-Tex. -Calif.-B.C. Plain-Submont. Je-S.

9. S. Olneyi A. Gray. Stems stout, 6-20 dm. high; leaves 1-3, narrow, 2-12 $\mathrm{cm}$. long; spikelets 5-12, oblong, obtuse, 5-8 mm. long; bract short, stout, 1-4 $\mathrm{cm}$. long; glumes oval or orbicular, dark brown, with green midrib, emarginate or mucronate, brown. Salt marshes: N.H.-Fla.-Tex.-Calif.-Ore.; W. Ind.; Mex.; C. Am. Plain-Son. Je-S.

10. S. nevadensis S. Wats. Stems $2-4 \mathrm{dm}$. high; leaves several, mostly basal, convolute; spikelets 1-5, ovoid or ovoid-oblong, $6-18 \mathrm{~mm}$. long; bract flattened above, rough-margined; glumes broadly ovate, obtuse or acute, chestnut-brown, smooth and shining; achenes minutely reticulate. Wet places, especially in alkaline soil: Sask.-Wyo.-Calif.-Wash. Son. Je-Jl.

11. S. validus Vahl. Stems stout, terete, smooth, spongy, 1-3 m. high, sometimes $2 \mathrm{~cm}$. thick, sheathed below; spikelets 5-12 mm. long, 3-4 mm. thick; glumes ovate or suborbicular, slightly pubescent, with strong midrib; achenes plano-convex. S. lacustris Am. auth., not L. Common Bucrush. In water: Newf.-Fla.-Calif.-B.C.; W. Ind.; Mex. Plain-Mont. Je-S.

12. S. occidentalis (S. Wats.) Chase. Similar to S. valitus; basal sheaths fimbrillose on the margins; spikelets $20 \mathrm{~mm}$. long, $4 \mathrm{~mm}$. thick; glum?s ovate, short-awned, viscid above; achenes biconvex. S. lacustris occidenta'is S. Wats. Tule. In water: Newf.-N.Y.-Mo.-N.M.-Calif.-B.C. Plain-Submont. Jl-S.

13. S. heterochaetus Chase. Similar to $S$. validus; stem slender, 1-2 m. high, sheathed below; bracts glabrous; spikelets usually solitary on the slender ovate, glabrous, often erose-margined. In water: Vt.-Mass.-Neb.-Ida.Ore. Jl-S.

14. S. paludosus A. Nels. Stems slender, smooth, sharply triangular, 3-6 $\mathrm{dm}$. high; leaves pale green, smooth, $2-4 \mathrm{~mm}$. wide; bracts 2 or 3 ; spikelets oblong-cylindric, mostly acute, $15-25 \mathrm{~mm}$. long; glumes ovate, puberulent or glabrous, pale brown, 2-toothed at the apex, awned; achenes lenticular, obovate, yellowish brown. S. campestris Britt., not Roth. S. interior Britt. S. Brittonianus Piper. Salt marshes: Que.-N.J.-Kans.-Tex.-Calif.-Wash. Plain -Submont. My-Au.

15. S. microcarpus Presl. Stem 1-1.5 m. high; sheaths often tinged with red; leaves rough-margined, often $1 \mathrm{~m}$. long or more; spikelets ovoid-oblong, acute, $3-4 \mathrm{~mm}$. long; glumes brown with green midvein; stamens 2; achenes oblong-obovate, nearly white. S. rubrotinctus Fern. Swamps: Newf.-Conn. -N.M.-Calif.-Alaska. Plain-Submont. Jl-S.

16. S. atrovirens Muhl. Stem triangular, leafy, 6-14 dm. high; leaf-blades elongate, more or less nodulose, rough on the margins, dark green, $6-12 \mathrm{~mm}$. ovate-oblong, acute; bristles rarely wanting. Swamps: N.S.-Ga.-N.M.-La. -Sask. Plain-Submont. Je-Au.

17. S. pallidus (Britton) Fernald. Stem triangular, 1-1.5 m. high; leafblades elongate, pale, $6-15 \mathrm{~mm}$. wide, somewhat nodulose; spikelets oblong to oblong-eylindric; glumes pale, ovate, acute, tipped with an awn half as long as the body. Wet ground: Man.-Kans.-Tex.-N.M.-Wyo. Plain-Submont.

18. S. cyperinus (L.) Kunth. Stem smooth, obtusely 3 -angled or nearly terete, 6-18 dm. high; leaf-blades elongate, $4-6 \mathrm{~mm}$. wide, rough-margined; bracts $3-6$, their bases often brown or black; umbels irregularly compound; 
spikelets ovoid-oblong, obtuse, 3-10 mm. long; glumes ovate or lanceolate, acute or subacute. Swamps: Newf.-Fla.-La.-Sask. Plain. Au-S.

19. S. atrocinctus Fernald. Stem 5-12 dm. high, smooth, terete; leaves bright green, 2-5 mm. wide; bracts blackish at the base; spikelets $2.5-6 \mathrm{~mm}$. long; glumes lance-ovate, acute; achenes 3-angled, white, ovate. Swamps: Newf.-N.J.-Ia.-B.C. Submont.-Mont. Je-Au.

\section{HEMICÁRPHA Nees \& Arn.}

Dwarf annual tufted herbs. Leaves narrow, often setaceous, Spikelets terete, solitary or in small clusters. Glumes spirally arranged. Flowers perfect, each with a small translucent scale between it and the axis. Perianth wanting, $i$. e., bristles none. Stamen 1. Style 2-cleft, not swollen at the base.

1. H. aristulata (Coville) Smyth. Stem longer than the setaceous glabrous leaves, 5-20 $\mathrm{cm}$. high; bracts 1-3, sometimes $2 \mathrm{~cm}$. long; spikelets 4-8 $\mathrm{mm}$. long; glumes rhombic-obovate, brown, abruptly contracted into a subulate awn about as long as the body; achenes narrowly obovate, black. $H$. intermedia Piper. Sandy banks: Kans.-Tex.-Calif.-Wash. Son.-Submont. J1-S.

\section{KOBRESIA Willd.}

Sedge-like perennials, with monoecious flowers. Spikelets several-flowered, forming a terminal spike. Glumes spirally arranged, the lower usually enclosing a pistillate, the upper a staminate flower. Stamens 3. Perianth lacking. Style short; stigmas 3 . Achenes obtusely 3-angled.

1. K. bipartita (All.) Della Torre. Stems solitary or tufted, 1-3 dm. high, smooth; leaves about $1 \mathrm{~mm}$. wide, involute; spikets several in a spike, ascending, linear; glumes somewhat serrulate on the keel, fully $1 \mathrm{~mm}$. long. $K$. caricina Willd. Arctic-alpine situations: Greenl.-Alta.-B.C. Alp. Je-S.

\section{ELỲNA Schrad.}

Low, tufted, sedge-like monoecious plants. Leaves mostly basal, narrow. Spikelets 2-flowered, forming a terminal spike. Glumes of the spikelets 3 or 4, usually only one flower-bearing. Flowers 2, one staminate of 3 stamens, the other pistillate with a single pistil. Perianth none. Style slender, not jointed to the ovary; stigmas 3 . Achenes obtusely 3-angled.

1. E. Bellardi (All.) C. Koch. Densely tufted; stems slender, 1-4 dm. high; old sheaths fibrillose, brown; leaf-blades revolute; spikelet subtended by a short bract or bractless, 15-30 mm. long, 3-4 mm. wide; achenes appressed, ellipsoid, $2 \mathrm{~mm}$. long or less. Arctic-alpine situations: Greenl-Alta.-n N.M.-Ore.Alaska; Eurasia. Alp. Je-Au.

\section{CÃREX (Rupp.) L. Sedge.*}

Grass-like sedges, perennial by rootstocks. Culms mostly triangular, often strongly phyllopodic or aphyllopodic. Leaves 3-ranked, the upper (bracts) elongate or short, and subtending the spikes of flowers or wanting. Plants monoecious or sometimes dioecious; flowers solitary in the axils of scales (glumes). Spikes one to many, either wholly pistillate, wholly staminate, androgynous or gynaecandrous. Perianth none. Staminate flowers of three (or rarely two) stamens, the filaments filiform. Pistillate flowers of a single pistil, with a style and two or three stigmas. Achene completely surrounded by the perigynium, or rarely rupturing it in ripening, 3-angled, lenticular or plano-convex. Rhacheola occasionally developed.

Spike one, androgynous; perigynia glabrous, thin, not margined or triangular, beaked; style withering, not continuous with the achene; stigmas three.

Pistillate scales versistent; perigynia not stipitate, not becoming reflexed.

Spike linear or linear-oblong; perigynia not inflated. 1 . NARDINAE.

Spike orbicular to short-ovoid; perigynia inflated. 2 . INFLATAE.

Pistillate scales deciduous; perigynia stipitate, at least the lower reflexed at maturity. 3. ATHROCHLAENAE.

* Contributed by Mr. Kenneth K. Mackenzie. 
Spikes one to many; if one, plant not as above.

Achenes lenticular and stigmas two; lateral spikes sessile; terminal spike partly pistillate, or if staminate, the lateral spikes short, or heads dioecious.

Spike one.
Spike orbicular to short-ovoid.
Spike linear.
4. CAPITATAE.
5. DIOICAE.

Spikes more than one.

Perigynia not white-puncticulate.

Rootstocks long-creeping, the culms arising singly or few together.

Perigynia not thin or wing-margined, the beak obliquely cut.

Culms not branching.

Spikes densely aggregate into a globular-ovoid head, appearing like one spike. Spikes distinct.

Culms becoming decumbent and branching.

6. FOETIDAE.

7. DivisaE.

Perigynia thin or wing-margined, the beak bidentate.

8. CHORDORRHIZAE.

Rootstock not long-creeping, the culms ARENARIAE.

Spikes androgynous.

Perigynia abruptly contracted into the beak.

Spikes few (ten or less); perigynia green or tinged with reddish brown.

10. MUHLENBERgIANAE.

Spikes numerous; perigynia yellowish or brownish.

Perigynia yellowish; opaque part of leaf-sheath transversely rugulose.

11. MULTifLORAE.

Perigynia brownish; opaque part of leaf-sheath not transPerigynia versely rugulose.

12. Paniculatae.

Perigynia tapering into the beak.

13. STENORHYNCHAE.

Spikes gynaecandrous or pistillate or rarely staminate.

Perigynia at most thin-edged.

Perigynia spreading at maturity. 14. Stellulatae

Perigynia appressed.

Perigynia narrowly to broadly wing-margined.

Perigynia white-puncticulate.

15. DEWEYANAE.

16. OVALES.

17. CANESCENTES

Achenes triangular or lenticular; if lenticular, lower lateral spikes conspicuously peduncled, or terminal spike staminate and lateral spikes elongated.

Achenes strongly constricter at base, rounded at apex. 18. PHYLLOSTACHYAE.

Achenes not strongly constricted at base, pointed at apex.

Spike one; perigynia rounded and beakless at apex. 19. Polytrichoineae.

Spikes one or more; when one, perigynia not both rounded and beakless at the apex.

Perigynia both coriaceous and shining, the beak obliquely cut.

Spike solitary

Spikes several.

Perigynia not both coriaceous and shining.

20. OBTUSATAE.

ike one; perigynia triangular, glabrous, not reflexed or flattened.

Perigynia prominently beaked, finely many-nerved.

Perigynia nearly beakless, 2-keeled but oth. RUPESTRES.

Spikes one to many; FIRMICULMES.

Perigynia closely enveloping the achene, strongly tapering at base, pubescent or puberulent; bracts sheathless or nearly so. Spike normally one.

Spikes androgynous; leaf-blades very narrow.

Spikes dioecious. 24. FILIFoliAE.

Spikes two or more.

25. SCIRPINAE.

26. Montanae.

Perigynia not as above; or if so, bracts strongly sheathing.

Lowest bract long-sheathing, its blades rudimentary.

Leaf-blades flat; perigynia puberulent or pubescent.

Leaf-blades flliform; perigynia glabrous.

27. DigitataE.

Lowest bract sheathless or long-sheathing: ALBE.

blade well-developed.

Lowest bract strongly sheathing; perigynia never strongly bidentate with stiff teeth.

Achenes lenticular; stigmas two. 29. BICoLores.

Achenes triangular; stigmas three.

Scales not dark-tinged.

Pistillate spikes short-oblong to linear, erect.

Perigynia tapering at base, triangular, closely enveloping the achenes.

Rootstock long-creeping.

Rootstock not long-creeping.

31. LAXIFLORAE. 
Perigynia rounded at base, suborbicular in cross-section, loosely enveloping achenes.

32. GRANULARES.

Pistillate spikes elongate, linear to cylindric, slender peduncled, the lower drooping.

Culms strongly reddish tinged at base, aphyllopodic. 33. DEBILES.

Culms not strongly reddish tinged at base, phyllopodic.

Spikes slender, few-flowered; perigynia 4 $\mathrm{mm}$. long or less, not inflated, the beak not becoming bidentate.

34. Capillares.

Spikes dense, many-flowered; perigynia longer, more or less inflated, the beak becoming bidentate.

Scales dark-tinged.
Lowest bract sheathless, or sheathing, if sheathing. peri-

35. LONGIROSTRES. gynia strongly bidentate with stiff teeth.

Foliage pubescent; perigynia not bidentate.

37. Pallescentes.

Foliage glabrous, or if rarely pubescent, perigynia bidentate.

Perigynia rough-papillose. 38. ANOMALAE.

Perigynia at most granular-roughened.

Perigynia beakless or very short-beaked; achenes triangular.

Perigynia glaucous. 39. Lrmosae.

Perigynia not glaucous.

40. ATRATAE.

Perigynia with strongly bidentate beak, or if not, achenes lenticular.

Achenes lenticular; perigynia dull.

41. ACUTAE.

Achenes triangular, or if rarely lenticular. perigynia shining.

Perigynia coriaceous, little if at all inflated, often pubescent; bracts sheathless.

\section{HiRTAE.}

Perigynia glabrous, often inflated; if rarely coriaceous, the bracts sheathing.

Perigynia little inflated; lower bract strongly sheathing.

43. EXTENSAE.

Perigynia little to much inflated; lower bract not strongly sheathing.

Spike one. 44. PAUCIFLORAF.

Spikes more than one.

Perigynia finely and closely ribbed.

45. PSEUdO-CYPEREAE.

Perigynia coarsely ribbed or nerveless.

46. Physocarpaf.

1. NARDINAE.

Represented by one species in our range.

\section{InflataE.}

Represented by one species in our range.
1. C, Hepburnii.

2. C. Engelmannii.

\section{AthrochlannaE.}

Densely cespitose; leaf-blades involute, $1 \mathrm{~mm}$. wide; staminate flowers few; perigynia erect until full maturity.

Short-stoloniferous; leaf-blades flat, $1.5 \mathrm{~mm}$. wide or more; staminate flowers conspicuous; perigynia early deflexed.

Represented by one species.

\section{Capitatae.}

\section{DiOICAF.}

Represented by one species in our range.

4. C. nigricans.

5. C. capitata.

6. C. gynocrates.

6. FoetidaA.

Leaf-blades 2-3.5 mm. wide; perigynium little exceeding the scale at maturity.

7. C. vernacula.

Leaf-blades $1.5 \mathrm{~mm}$. wide or less; perigynium much exceeding the scale at maturity Perigynia membranous, not stipitate.

8. C. perglobosa.

Perigynia not membranous, stipitate.

9. C. incurviformis. 


\section{DIVISAE.}

Rootstocks slender, light brownish; culms obtusely triangular, normally smooth; leafblades narrowly involute.

Perigynia long-beaked; heads dioecious or nearly so.

Perigynia short-beaked; heads androgynous,

Rootstocks stout; culms acutely triangular, normally rough above.

10. C. Douglasii.

11. C. stenophylla.

Perigynia not strongly nerved ventrally; leaf-sheaths hyaline.

Perigynia chestnut, thick, the beak about one-fifth as long as the body.

12. C. simulata.

erigynia blackish in age, plano-convex, the beak one-third to one-half as long as the body. 13 . C. praegracilis.

Perigynia strongly nerved ventrally; upper leaf-sheaths green-striate opposite the blades.

Represented by one species in our range.

\section{CHORDORRHIZAE.}

9. Arenariae.

Represented by one species in our range.

\section{Múhlenbergianae.}

Sheaths tight, inconspicuously, if at all, septate-nodulose.

Densely cespitose; head ovoid, capitate; perigynia serrulate to the middle.

17. C. Hoodii.

Rootstocks elongate; head linear, interrupted; perigynia serrulate at the apex only. Scales obtuse to short-cuspidate, not concealing the spreading perigynia. Spikes with conspicuous staminate flowers; scales half as long as the perigynia. 18. C. vallicola.

Spikes with inconspicuous staminate flowers; scales about as long as the peri-

gynia.
Scales strongly cuspidate, concealing the appressed perigynia.

19. C. occidentalis.

Sheaths loose and membranous, easily breaking, conspicuously septate-nodulose.

\section{Multiflorae.}

21. C. gravida.

Represented by one species in our range.

22. C. vulpinoidea.

\section{Paniculatae.}

Culms loosely cespitose; sheaths not copper-tinged at the mouth; head little interrupted; perigynia 2-2.75 mm. long, shining, not concealed by the scales.

\section{C. diandra.}

Culms densely cespitose; sheaths copper-tinged at the mouth; head interrupted: perigynia $2.5-4 \mathrm{~mm}$. long, dull, concealed by the scales.

Leaves 1-2.5 mm. wide; perigynia 2.5-3 $\mathrm{mm}$. long; scales tinged with reddish brown.

Leaves 2.5-6 mm. wide; perigynia 3-4 mm. long; scales chestnut-tinged.

\section{STENORHYNCHAE.}

25. C. Cusickii.

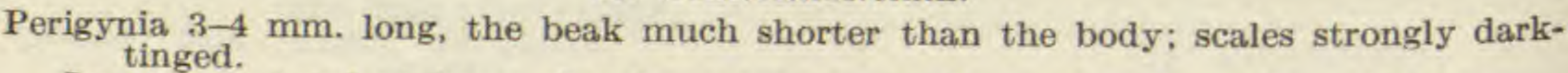

Leaves clustered at base; sheaths not cross-rugulose ventrally; culms slender.

Leaves not clustered at base; 26. C. Jonesii. y; culms stout.

Perigynia 4-6 mm. long, the beak longer than the body; scales 27. C. nervina.

\section{Stellulatae.}

28. C. stipata.

Spikes in a small (6-10 mm. long) densely capitate brownish black head.

Spikes more or less widely separate, not brownish black.

29. C. illota.

Perigynia broadest in middle, the beak sparingly serrulate; culms weak.

Perigynia broadest near base, the beak strongly 30. C. laeviculmis.

beak strongly serrulate; culms stiff. suture inconspicuous. Beak of the perigynia longer, strongly bidentate, the ventral suture conspicuous.
. C. interior.

32. C. angustior.

\section{Deweyanae.} Culms densely cespitose; perigynia tapering at base, 4-5 mm. long, the upper part of
the body covered by translucent scale.

Rootstocks slender, elongate; perigynia substipitate, $3.5-4.5 \mathrm{~mm}$. long.
.

Perigynia shallowly bidentate, the upper part of body not covered by the scale.

Perigynia deeply bidentate, the body $34 . C$, leptopoda.

\section{Ovales.}

Lower bract or bracts conspicuous, several-many times the length of the head.

Perigynia subulate, the beak much longer than body; lower bracts more than $1 \mathrm{dm}$. long, without yellowish brown margins at base.

36. C. sychnocephala. 
Perigynia lance-ovate, the beak shorter than the body; longer bracts less than $1 \mathrm{dm}$. long, with yellowish brown margins at base.

Perigynia nerveless ventrally, tawny at orifice.

Perigynia nerved ventrally, hyaline at orifice.

Bracts not conspicuous, rarely slightly exceeding the head.

37. C. athrostachya.

38. C. tenuirostris.

Beak of the perigynia flattened and serrulate to tip, often strongly bidentate.

Scales about the length of the perigynia and nearly of the same width above, the perigynia nearly entirely concealed.

Head stiff, the spikes approximate.

Perigynia less than $5.5 \mathrm{~mm}$. long, at most faintly nerved on inner face, loosely ascending; spikes suborbicular; lower bracts prominent, stiff.

39. C. adusta.

Perigynia 5.5-7 mm. long, finely many-nerved on inner face, appressed; spikes oblong-elliptic: bracts not stifr. $\quad 40$. C. petasata.

Head not stiff, flexuous or moniliform. 41 . C. aenea.

Scales shorter than perigynia and noticeably narrower above, the upper part of perigynia largely exposed.

Perigynia subulate to lanceolate, at least $21 / 2$ times as long as wide.

Perigynia subulate, the margin at the base almost obsolete.

Perigynia lanceolate, the margin conspicuous to the base.

42. C. Crawfordii.

43. C. scoparia.

Perigy nia ovate-lanceolate or broader, at most twice as long as wide.

Perigynia narrowly to broadly ovate, $3-4 \mathrm{~mm}$. long.

Perigynia brownish; spikes closely aggregate, rounded at base.

44. C. Bebbii.

Perigynia green; spikes contiguous to widely separate, usually tapering at base.

Leaf-blades $2.5 \mathrm{~mm}$. wide or less; perigynia spreading-ascending: culms slender.

45. C. tenera.

Leaf-blades $2-6 \mathrm{~mm}$. wide (averaging $4 \mathrm{~mm}$.); perigynia appressedascending; culms stout.

Perigynia ovate or broader, $3.75-6 \mathrm{~mm}$. long.

Perigynia thick, abruptly short-beaked; scales little, if at all, tinged with brownish red.

47. C. brevior.

Perigynia thin, tapering to the beak; scales strongly tinged with chestnut-brown.

48. C. Egglestonii.

Beak of the perigynia slender, terete and scarcely, if at all, serrulate towards tip, obliquely cut, at times becoming obscurely bidentate.

Scales about the length of the perigynia, and of nearly the same width above, the perigynia nearly entirely concealed.

Culms and head stiff and rigid.

Culms 1-3 dm. high, in large stools; scales strongly tinged with reddish brown; perigynia lanceolate.

49. C. phaeocephala.

Culms taller, not in large stools; scales lighter-colored; perigynia ovate, in age golden yellow at base.

Culms slender; head flexuous or moniliform.

Scales light reddish brown tinged.

Seales chestnut-brown tinged.

50. C. xerantica.

51. C. practicola.

52. C. Piperi.

Scales shorter than perigynia and noticeably narrower above, the upper part of perigynia largely exposed.

Perigynia thin and membranous, except where distended by the achene. Perigynia 3.5-5 mm. long; culms slender.

Perigynia lance-ovate, very narrowly margined, spreading; culms biennial.

53. C. microptera.

Perigynia ovate, strongly margined, appressed; culms annual.

Perigynia 4.5-6 mm. long; culms low.

54. C. festivella.

Perigynia lanceolate to broadly ovate, nerveless or nearly so on inner face, the beaks conspicuous; culms slender, ascending or decumbent. 55. C. nubicola.

Perigynia narrowly lanceolate, finely nerved on inner face, the beaks appressed; culms stiff, erect.

56. C. ebenea.

Perigynia strongly plano-convex, the walls thick.

Spikes densely capitate; beak of the perigynia obliquely cut, dark-tipped.

Spikes not capitate; beak of the perigynia bidentate, reddish-tipped.

58. C. Preslii.

\section{CANESCENTES.}

Spikes androgynous; perigynia unequally biconvex.

59. C. disperma.

Spikes gynaecandrous; perigynia plano-convex.

Lowest bract bristle-like, much prolonged, many times exceeding its 1-5-flowered spike; spikes widely separate.

60. C. trisperma.

Lowest bract much shorter or none; spikes several-many-flowered, the upper approximate.

Spikes $2-4$, subglobose, closely approximate, forming an ovate or subglobose head; perigynia scarcely beaked; scales white-hyaline. 61 . C. tenuiflora.

Spikes one-many, the lower more or less strongly separate; head elongate; perigynia shortly to strongly beaked; scales darker.

Perigynia broadest near middle; beak short, smooth or moderately serrulate 
Beak of the perigynia smooth or very nearly so; scales obtuse to acutish, strongly tinged with reddish brown or chestnut; spikes closely approximate.

Terminal spike strongly tapering at base; culms rough at apex only. 62. C. Lachenalii.

Terminal spike little tapering at the base; culms usually very rough. 63. C. Heleonastes.

Beak of the perigynia serrulate, or if smooth scales acutish to cuspidate and scarcely, if at all, tinged with reddish brown; lower spikes remote.

Plant glaucous; leaf-blades $2-4 \mathrm{~mm}$. wide; spikes many-flowered; perigynia scarcely beaked, appressed ascending, with emarginate or entire orifice.

64. C. canescens.

Plant not glaucous; leaf-blades $1-2.5 \mathrm{~mm}$. wide; spikes fewer-flowered: perigynia distinctly beaked, loosely spreading, with minutely biden-

65 . C. brunnescens,
Perigynia ovate, broadest near the base; beak conspicuous, strongly serrulate.
66 . C. arcta. 66. C. arcta.

\section{Phyllostachyae.}

Perigynia with long smooth beak; foliage deep green.

67. C. durifolia.

Perigynia with short sparingly serrulate beak; foliage light or glaucous green.

Represented by one species.

Represented by one species.

Represented by one species in our range.

\section{Polytrichoideae.}

\section{Obtusatae.}

21. Nitidae.

\section{RUPESTRES.}

Represented by one species.

\section{Firmiculmes.}

Represented by one species in our range.

24. Filifoliaf.

Leaf-blades fliform at base, $0.25-0.5 \mathrm{~mm}$, wide; culms flliform, obtusely triangular, smoothish; lowest scale rarely awned.

Perigynia sharply triangular below, obpyramidal; basal sheaths rarely filamentose. Perigynia rounded on the angles, obovoid 74 . C. elynoides. Perigynia rounded on the angles, obovoid to globose; basal sheaths filamentose.

Leaf-blades flattened at base, $1.5-2 \mathrm{~mm}$. wide; culms stoutish, 75 . C. filifolia. much roughened; lowest scale conspicuously awned.

\section{SCIRPINAE.}

Culms phyllopodic, the culm-leaves $6-10$; scales concealing perigynia.

Culms aphyllopodic, the culm-leaves 3-6; scales shorter 77 . C. pseudoscirpoidea. Perigynia lanceolate, flattish, $4 \mathrm{~mm}$. long.

Perigynia broader, triangular, $3 \mathrm{~mm}$. long or less.

Scales very minutely hyaline-margined; perigyni:

Scales very broadly hyaline-margined; perigyia

78. C. stenochlaena.

h-hirsute.

Basal spikes absent.

26. Montanae.

80. C. scirpiformis.

Long stoloniferous; scales about equalling the perigynia.

Without long stolons; scales much shorter than the perigynia.

Basal spikes present.

81. C. heliophila.

82. C. Peckii.

Lower bract exceeded by the culm, scale-like, hyaline-margined at base.

Lower bract normally exceeding the culm, leaf-like, not hyaline-margined at base.
Perigynia $2.75 \mathrm{~mm}$. long or less,

Perigynia $2.75 \mathrm{~mm}$. long or less, shallowly bidentate; rootstocks slender.

Perigynia longer, deeply bidentate; culms densely cespitose. C. dejtexa.

\section{Digrtatae.}

Basal spikes present; scales abruptly cuspidate.

Basal spikes absent; scales not abruptly cuspidate.

85. C. Rossii.

Staminate spike 3-6 mm. long: scales obtuse, one-half as long as the perigynia.

Staminate spike 8-22 mm. long; scales acute to acuminate, 87. C. concinna. to exceeding the perigynia.

Perigynia loosely pubescent, wider and longer than the scales; staminate spike nearly sessile; pistillate spikes few-flowered.

88. C. concinnoides.
Perigynia appressed-pubescent, narrower and shorter than the scales; staminate spike noticeably peduncled; pistillate spikes many-flowered.

89. C. Richardsonii. 
28. ALBAE.

Represented by one species in our range.

90. C. eburnea.

29. BICOLORES.

Mature perigynia whitish, ellipsoid, not fleshy or translucent. 91. C. Hassei, Mature perigynia orange or brownish, broader, fleshy, translucent.

92. C. aurea.

\section{Paniceat.}

Beak of the perigynia none or very short.

Sheaths of the bracts short; plant glaucous; leaf-blades involute; spikes approximate. 93. C. livida.

Sheaths of the bracts long; plant not glaucous; leaf-blades flat; spikes distant.

Fertile culm-blades 3-5, 2-3.5 mm. wide; perigynia $3.5 \mathrm{~mm}$. long or less; spikes

linear.
Fertile culm-blades 6-10, 3-7 mm. wide; perigynia longer; spikes oblong or linear-

94. C. tetanica. oblong. $\quad 95$. C. Meadii.

Beak of the perigynia straight, prominent. $\quad 96$. C. vaginata.

\section{LAXIFLORAE.}

Represented by one species in our range.

97. C. blanda.

32. Granulares.

Plants cespitose; bracts elongate, overtopping the spikes; staminate spike short-stalked. 98. C. Shriveri.

Plants with long-creeping rootstocks; bracts short, rarely overtopping the spikes; staminate spike long-stalked.

33. DEBILES.

Represented by one species in our range.

99. C. Crawei.

100. C. Assiniboinensis.

34. Capillares.

Represented by one species in our range.

101. C. capillaris.

\section{LONGIROSTRES.}

Represented by one species in our range.

102. C. Sprengelii.

36. Frigidae.

Terminal spike staminate or gynaecandrous, the lateral ones pistillate.

Terminal spike usually gynaecandrous, the lateral ones ovoid or short-oblong. 103. C. misandra.

Terminal spike staminate (or with a few perigynia), the lateral ones oblong or linearcylindric.

Perigynia triangular, slightly compressed.

Perigynia strongly compressed.

104. C. luzulina.

105. C. fissuricola.

Terminal spike androgynous, the upper lateral staminate, the lower pistillate.

Perigynia lanceolate, $1.5 \mathrm{~mm}$. wide, tapering to the apex; spikes 2-5, usually 4.

106. C. petricosa.

Perigynia oblong-oval, $2.25 \mathrm{~mm}$. wide, abruptly minutely beaked; spikes more numerous.

\section{Pallescentes.}

Represented by one species in our range.

107. C, Franklinii.

108. C. abbreviata.

\section{ANOMALAE.}

Represented by one species in our range.

109. C. amplifolia.

39. Limosae.

Pistillate spikes drooping.

Plants strongly stoloniferous; leaf-blades involute, glaucous, $3 \mathrm{~mm}$. wide or less; scales little exceeding the perigynia.

110. C. limosa.

Plant tufted; leaf-blades flat, not glaucous, wider; scales much exceeding the perigynia.

Pistillate spikes erect.

40. Atratae.

111. C. paupercula.

112. C. Buxbaumii.

Terminal spike in some plants pistillate and linear-cylindric or staminate only at apex, in others staminate.

Seales not long-pointed, little exceeding the perigynia; perigynia flattened, sharpedged.

113. C Parryana.

Scales long-pointed, 2-3 times as long as the perigynia; perigynia little flattened.

114. $C$. idahoa.

Terminal spike staminate or gynaecandrous, not pistillate and linear-cylindric.

Terminal spike staminate.

Culms few-leaved, strongly aphyllopodic, purplish tinged at base.

Staminate scales obtuse, the midvein nearly or quite obsolete. Staminate scales obovate; pistillate scales with obsolete (or nearly so) midvein; perigynia nerveless.

115. C. podocarpa.

Staminate scales linear-lanceolate; pistillate scales with strong midvein; perigynia 2 -nerved.

116. C. venustula.

Staminate scales with conspicuous more or less excurrent midvein.

117. C. spectabilis. 
Culms many-leaved, clothed at base with dried-up leaves of previous year, not purplish tinged at base.

Perigynia flat.

Perigynia round in cross-section, many-nerved.

Terminal spike gynaecandrous.

Perigynia triangular in cross-section, nerveless or nearly so, $2.5 \mathrm{~mm}$. long or less.

Perigynia longer, many-nerved or with two prominent marginal nerves, more or less strongly flattened.

Spikes contiguous, sessile or short-peduncled, forming a dense head; culms stiff, erect.

Perigynia subinflated-triangular, scarcely compressed, the beak $1 \mathrm{~mm}$. long.

Perigynia strongly compressed, the beak $0.5 \mathrm{~mm}$. long.

Lowest spike slightly separate, short-peduncled; scales black, with very conspicuous white hyaline apex and upper margins.

122. C. albo-nigra.

Spikes closely contiguous and sessile; scales black with inconspicuous hyaline apex and margins. $123 . C$. nova.

Lowest spike (or spikes) strongly peduncled, usually distant, erect or nodding.

Spikes $3-5$, not oblong-cylindric; walls of the perigynia not papery; perigynia 2.5-4.5 mm. long, nerveless or obscurely nerved on the face, dull green to brownish black; scales from a little shorter to a little longer than the perigynia.

Perigynia slightly inflated and sub-triangular, not strongly compressed.

Perigynia strongly compressed.

124. C. atrosquama.

Perigynia sharp-edged, the margins much narrower than the achene; lateral spikes linear.

Scales shining, with the midvein conspicuous the whole length, exceeded by the perigynia. 125. C. bella.

Scales dull with inconspicuous midvein, about covering the perigynia. 126. C. atratiformis.

Perigynia widely margined, the margins as wide as the achene; lateral spikes oblong or linear-oblong or ovoid.

Perigynia granular-roughened; achenes short-stipitate.

Upper pistillate scales exceeding the perigynia: lateral spikes ovoid; lowest peduncle less than the length of the spike.

127. C. chalciolepis.

Upper pistillate scales exceeded by the perigynia; lateral spikes oblong or linear-oblong; lowest pedumele $1-2$ times as long as the spike,

Perigynia smooth; achenes strongly stinitate.

128. C. atrata.

129. C. epapillosa.

Spikes 6-10, oblong-cylindric: walls of the perigynia papery; perigynia 5 mm. long, lightly 3-nerved, light green, much shorter than the perigynia.

Culms phyllopodic.

\section{ACUTAE.}

130. C. Mertensii.

Beak of the perigynia, if present, not deeply bidentate.

Lowest bract exceeded by the inflorescence; scales with obsolete or slender midvein; culms low, stiff, solitary or in small clumps, freely stoloniferous.

Perigynia plano-convex, puncticulate, appressed.

Perigynia soon turgid, papillose, spreading.

Scales ovate, exceeded by the perigynia.

Scales lanceolate, exceeding the perigynia.

131. C. concolor.

132. C. scopulorum.

133. C. chimaphila.

Lowest bract exceeding the inflorescence; scales usually with a slender midvein or broad light-colored center; culms taller, less stiff, in larger clumps.

Perigynia turgid, spreading.

Perigynia not turgid, appressed or ascending.

134. C. aperta.

Stolons absent; perigynia conspicuously nerved; leaf-blades $1-3 \mathrm{~mm}$. wide.

Perigynia substipitate, glaucous, granular-roughened all over, the body two-thirds as wide as long.

Perigynia strongly stipitate, green, granular-roughened at the apex only, the body half as wide as long. 136 . C. Kelloggii.

Stolons present, long: perigynia nerveless or inconspicuously nerved; leafblades 2-6 mm. wide.

Perigynia narrowly to very broadly elliptic, broadest below apex, less than $3 \mathrm{~mm}$. long, $1-1.5 \mathrm{~mm}$. wide. 137. C. aquatilis.

Perigynia strongly obovate, broadest at the apex, $3 \mathrm{~mm}$. long, $1.75 \mathrm{~mm}$.

wide.
Beak of the perigynia markedly bidentate, the body strongly ribbed.

138. C. substricta.

139. C. nebraskensis.

Fertile culms aphyllopodic.

Lower sheaths smooth; scales not blackish.

Lower sheaths strongly hispidulous; scales blackish.

140. C. Emoryi.

141. C. prionophylla.

42. Hirtae.

Beak of the perigynia much shorter than the body, the teeth $1 \mathrm{~mm}$. long or less.

Perigynia glabrous to sparsely pubescent.

142. C. lacustris. 
Perigynia densely or strongly pubescent.

Nerves of the perigynia obscured by pubescence, the teeth of beak short. Leaf-blades flat, more than $2 \mathrm{~mm}$. wide. 143. C. lanuginosa. Leaf-blades involute, $2 \mathrm{~mm}$. wide or less. Nerves of the perigynia prominent, the teeth of beak prominent, slender. 145. C. Houghtonii.

Beak of the perigynia including teeth nearly as long as body, the teeth $1.5 \mathrm{~mm}$. long or more.

Perigynia glabrous.

Perigynia ovoid, the teeth less than $2 \mathrm{~mm}$. long, erect or spreading; scales acute to aristate; leaf-blades glabrous. $146 . C$. laeviconica.

Perigynia lanceolate or ovoid-lanceolate, the teeth 2-4 mm. long, widely spreading; scales long-aristate; leaf-blades pubescent beneath.

Perigynia hairy.

147. C. atherodes

148. C. Sheldonii.

43. EXTENSAE.

Perigynia 2-3 mm. long, the beak scarcely half as long as the body.

\section{Pauciflorae.}

150. C. flava.

Rhacheola present, conspicuously exserted; culms with many leaves.

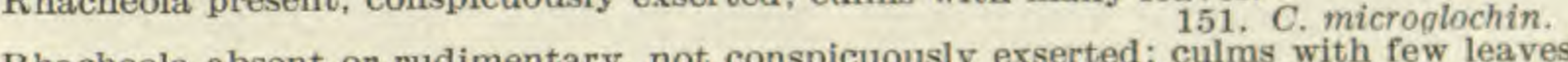

Rhacheola absent or rudimentary, not conspicuously exserted; culms with few lea

\section{PSEUdO-Cypereae.}

Perigynia suborbicular in cross-section, more or less inflated. 153. C, hystricina.

Perigynia obtusely triangular, scarcely inflated, closely enveloping achene.

\section{Physocarpae.}

Perigynia scarcely inflated; beak entire or emarginate; stigmas normally two and achenes lenticular.

Perigynia lanceolate; fertile culms fllamentose at the base; rootstocks creeping.

Perigynia ovoid; fertile culms rarely if ever filamentose at the base; plant loosely stoloniferous. 156 . C. saxatilis.

Perigynia from little to much inflated; beak bidentate; stigmas normally three and achenes triangular.

Pistillate spikes globose or short-oblong, 5-15-flowered.

Pistillate spikes oblong to cylindric, 15-many-flowered.

Lower perigynia not reflexed; bracts moderately exceeding the spikes.

Perigynia ascending; lower sheaths more or less strongly flamentose; culms sharply triangular.

Perigynia 6-8 $\mathrm{mm}$. long.

Perigynia oblong-ovoid, tapering into the beak; spikes loosely flowered at base.

158. C. Raeana.

Perigynia ovoid or globose-ovoid, contracted into the beak; spikes more closely flowered.

159. C. vesicaria.

Perigynia 8-10 mm. long, tapering into the beak. 160. C. exsiccata.

Perigynia spreading at maturity; lower sheaths not fllamentose; culms bluntly triangular below the spikes.

Lower perigynia reflexed; bracts many times exceeding the spikes.

162. C. retrorsa.

1. NardinaE Kükenth. Very densely cespitose. Leaf-blades filiform. Spike solitary, linear-oblong, androgynous, densely flowered, bractless. Perigynia ascending, biconvex, elliptic-ovate, not inflated, the walls thin, glabrous, striate, stipitate, the beak hyaline-tipped, in age bidentulate. Achenes lenticular or triangular. Stigmas 2 or 3.

1. C. Hepburnii Boott. Culms $2-15 \mathrm{~cm}$. high; sheaths strongly hyalinemargined above, abruptly contracted into the blades; spike 5-12 mm. long, with 1-10 perigynia; scales ovate, acutish, the midvein conspicuous; perigynia $3 \mathrm{~mm}$. long; achenes usually triangular. $C$. nardina Auth, in part. $C$. stantonensis M. E. Jones. Dry alpine slopes: Alta.-Colo.-Wash.-B.C. Alp.-Subalp. $\mathrm{Jl}-\mathrm{Au}$.

2. Inflatae Kükenth. Cespitose, the rootstocks elongate. Leaf-blades filiform. Spike solitary, ovoid, androgynous, densely flowered, bractless. Perigynia inflated, the walls very thin, slightly nerved, sessile, the smooth beak hyaline tipped, obliquely cut, in age bidentulate. Achenes triangular. Stigmas three.

2. C. Engelmannii Bailey. Culms $5-20 \mathrm{~cm}$. high; leaf-blades about 0.5 mm. wide; spike with 15-40 ascending perigynia; scales 1 -nerved, acute to cuspi- 
date; perigynia ovate, $4.5-5 \mathrm{~mm}$. long, tapering at apex; achenes $1.25 \mathrm{~mm}$. long. Isolated stations on mountain summits: Colo.; Wyo.; Wash. Alp. -Subalp. $\mathrm{Au}$.

3. Athrochlaenae Holm. Cespitose or with creeping rootstocks. Leafblades narrow. Spike solitary, androgynous, bractless, narrow, densely manyflowered. Pistillate scales soon falling. Perigynia slenderly strongly stipitate, widely spreading or the lower reflexed, obscurely triangular, nerveless, membranaceous, long-beaked, the beak obliquely cut, becoming bidentulate. Achenes usually triangular. Stigmas 3 , or occasionally 2 .

3. C. pyrenaica Wahl. Culms $3-20 \mathrm{~cm}$. high, wiry, slender, smooth; leaves $2-3$ to a fertile culm; spike $5-20 \mathrm{~mm}$. long, $3-5 \mathrm{~mm}$. wide; scales chestnut tinged; perigynia 3-4 mm. long. Alpine localities: Mack.-Colo.-Ore-CAlaska; Eurasia. Alp. -Subalp. J1-S.

4. C. nigricans C. A. Meyer. Culms 5-20 cm. high, stiff, firm, smooth; leaves 4-9 to a fertile culm; spike 8-15 mm. long, 6-9 mm. wide; scales dark brown tinged; perigynia $4 \mathrm{~mm}$. long. Alpine localities: Alta.-Colo.-Calif.Alaska. Alp.-Mont. Jl-S.

4. Capitatae Christ. Cespitose, the rootstocks somewhat elongate. Leafblades filiform. Spike solitary, ovoid, androgynous, densely flowered, bractless. Perigynia plano-convex, sharp-edged, not inflated, the walls thinnish, essentially nerveless, sessile, the smooth beak conspicuously hyaline-tipped, in age bidentulate. Achenes lenticular. Stigmas 2.

5. C. capitata L. Culms 1-2 dm. high; leaf-blades about $0.5 \mathrm{~mm}$. wide; spike with 6-25 ascending perigynia; scales ovate-orbicular, obtuse; perigynia $2-2.5 \mathrm{~mm}$. long, and about as broad, abruptly beaked. An arctic species also occurring very locally on mountain summits southward: Greenl.-Alaska; also N.H.; Alta.; Calif.; Nev.; Mex.; Eu. Alp. Je-Au.

5. DioICAe Tuckerm. Rootstocks elongate. Culms slender. Leaf-blades filiform. Spike solitary, bractless, staminate, pistillate or androgynous, narrow. Perigynia at length widely spreading, plano- or bi-convex, not inflated, subcoriaceous, glabrous, nerved, rounded and spongy at base, sharp-edged, strongly beaked, the apex hyaline, in age bidenticulate. Achenes lenticular. Stigmas 2.

6. C. gynocrates Wormskj. Culms 1-3 cm. high, smooth; rootstocks horizontal; spike 5-15 $\mathrm{mm}$. long, 2-5 mm. wide; scales sharp-pointed, reddish brown; perigynia few, $3 \mathrm{~mm}$. long, biconvex, nerved, narrowed into a rough beak half as long as the body. Sphagnum swamps: Greenl.-N.Y.- Mich.Colo.-Alaska; Siberia. Alp.-Mont. Southward local. My-Au.

6. Foetidae Tuckerm. Rootstocks elongate, dark-colored, the culms arising singly or a few together. Leaf-blades narrow. Spikes few to several, androgynous, aggregated into a dense subglobose or ovoid head. Perigynia spreading, plano-convex, membranaceous, usually obsoletely nerved, loosely enveloping the achene, rounded at the base, stipitate, - the beak obliquely cut, at times bidentulate. Achenes lenticular. Stigmas 2.

7. C. vernacula Bailey, Culms 1-2 dm. high, smooth; leaf-blades 5-12 cm. long, stiff; head very dense, globose, about $1 \mathrm{~cm}$. in diameter; perigynia ovoid, 3.5-4 mm. long, $1.5 \mathrm{~mm}$. wide, scarcely inflated, more or less nerved. Alpine slopes: Wyo.-Colo.-Calif.-Wash. Alp. Jl-Au.

8. C. perglobosa Mackenzie. Culms $1-1.5 \mathrm{dm}$. high, smooth; leaf-blades $2-8 \mathrm{~cm}$. long; head very dense, globose, about $1 \mathrm{~cm}$. in diameter; perigynia ovoid-elliptic, $4 \mathrm{~mm}$. long, $2.25 \mathrm{~mm}$. wide, membranous, not stipitate, more or less inflated. C. incurva Lightf. var, chartacea Kükenth. Alpine ridges: Colo.

9. C. incurviformis Mackenzie. Culms $2-5 \mathrm{~cm}$. high, smooth, obtusely angled; leaf-blades $2-4 \mathrm{~cm}$. long; head dense, globose, $7-9 \mathrm{~mm}$. in diameter; scales lance-ovate, chestnut with narrow hyaline margins, acuminate; perigynia 
elliptic-lanceolate, $3.5 \mathrm{~mm}$. long, $1.25 \mathrm{~mm}$. wide, finely conspicuously manynerved, not inflated, nor membranous, stipitate. Alpine ridges: Alta. Alp. Jl.

7. Divisae Christ. Rootstocks long-creeping, dark-colored, tough, the culms arising singly or in small clumps at intervals, mostly stiff, dark-tinged at the base, aphyllopodic. Leaf-blades narrow. Spikes few to many, more or less closely aggregated into an oblong or oblong-ovoid head, androgynous or dioecious, ovoid or oblong. Heads in some species dioecious or nearly so. Lowest one or several of the lower bracts developed, short-prolonged, the others bractlike. Perigynia appressed-ascending, plano-convex, smooth, often shining, coriaceous, more or less nerved on outer and nerved or nerveless on inner surface, sharp-edged but not wing-margined, rounded and spongy at base, the obliquely cut beak in age bidentulate. Achenes lenticular, closely enveloped. Stigmas 2.

10. C. Douglasii Boott. Culms 6-30 cm. high; leaf-blades 1-2.5 mm. wide; staminate spikes linear-elliptic, $8-15 \mathrm{~mm}$. long, $2.5-4 \mathrm{~mm}$. wide: pistillate spikes wider; scales ovate to lanceolate, yellowish-brown, with hyaline margins and lighter center, concealing the perigynia; perigynia lanceolate, strongly nerved, $4 \mathrm{~mm}$. long, $1.75 \mathrm{~mm}$. wide, light brownish; styles elongate. C. irrasa Bailey. Dry or alkaline soil: Man.-Neb.-N.M.-Calif.-B.C. Plain-Mont. My$\mathrm{Au}$.

11. C. stenophylla Wahl. Culms 5-20 cm. high; leaf-blades $1.5 \mathrm{~mm}$, wide at the base, involute above; spikes few, densely aggregated into a head $7-15$ $\mathrm{mm}$. long; scales broadly ovate, brownish with hyaline margins; perigynia few to a spike, ovate, lightly nerved on both surfaces, $3 \mathrm{~mm}$. long, $1.75 \mathrm{~mm}$. wide, blackish at maturity; styles short. C. Eleocharis Bailey. Dry soil: Man.Iowa-N.M.-Utah-Yukon; Eurasia. Plains-Mont. Je-Jl.

12. C. simulata Mackenzie. Culms 3-5 dm. high; leaf-blades 2-4 mm. wide, flat; head $12-25 \mathrm{~mm}$. long, 6-10 $\mathrm{mm}$. wide, the spikes densely aggregated, pistillate, staminate, or androgynous; scales brown with hyaline margins, concealing the perigynia; perigynia $2.25 \mathrm{~mm}$. long, $1.4 \mathrm{~mm}$. wide, round-truncate at base, abruptly beaked, serrulate above. C. Gayana N. Am. auth. Wet soil: Mont. -N.M.-Calif.-Wash. Submont.-Mont. My-S.

13. C. praegracilis $W$. Boott. Culms 2-5 dm. high; leaf-blades $1.5-3$ $\mathrm{mm}$. wide, flattened or channelled; head linear-oblong to ovate-oblong, $1-5 \mathrm{~cm}$. long, 6-12 mm. wide, the 5-15 spikes densely aggregated, androgynous, with 4-10 perigynia; scales ovate-lanceolate, acute to cuspidate, light brownish, with hyaline margins, nearly concealing the perigynia; perigynia $3-4 \mathrm{~mm}$. long, 1.5 mm. wide, dark brown at maturity, nerved on the outer, nearly nerveless on the inner surface. C. marcida Boott. C. usta Bailey. C. alterna (Bailey) Clarke. C. camporum Mackenzie. Meadows, widely distributed and variable: Man.-Iowa-Kans.-Calif.-B.C.; Mex. Prairie-Plains-Submont. My$\mathrm{Au}$.

14. C. Sartwellii Dewey. Culms 4-7 dm. high, rough above; leaf-blades 2.5-4 mm. wide, flat; head oblong, 3-5 cm. long, about $1 \mathrm{~cm}$. wide, the numerous spikes densely aggregated, the larger with 15 -20 perigynia; perigynia lance-ovate, 2.5-4 mm. long, $1.5-2 \mathrm{~mm}$. wide, finely nerved, the beak much shorter than the body. Marshes and bogs: Ont.-N.Y.-Ill.-Colo.-Mont. Plain-Submont. -Boreal. My-Au.

8. Chordorrhizae Fries, Culms elongate, prostrate, branching, the rootstocks and roots little developed. Leaf-blades narrow. Spikes 3-10, androgynous, few-flowered, closely aggregated into an ovoid head. Bracts absent or inconspicuous. Perigynia very thick, plano-convex, oblong-ovate, smooth, shining, coriaceous, closely many-nerved, rounded on the margins, rounded and spongy at the base, the short beak obliquely cut. Achenes lenticular, closely enveloped. Stigmas 2.

15. C. chordorrhiza Ehrh. Culms 1.5-3 dm. high; head 1-1.5 cm. long; perigynia 4-5 mm. long. Sphagnum bogs: Anticosti-Me.-Ind.-Sask.Mack.-B.C.; Eurasia. Boreal. My-Jl. 

22. C. vulpinoidea Michx. Culms $3-9 \mathrm{dm}$. high, very rough above, exceeding the leaves; leaf-blades long-tapering, 2-5 mm. wide; head 2-12 $\mathrm{cm}$. long, with very many small spikes; pistillate scales strongly awned; perigynia yellowish at maturity, 2-3 mm. long, the beak about the length of the body. Swampy places: N.B.-Fla.-Tex.-Colo.-Ore--B.C. Plains. Je-Au.

12. Paniculatae Kunth. Densely or loosely cespitose. Culms not flattened. Opaque part of sheaths strongly red-dotted. Spikes numerous, small, androgynous or pistillate, but never gynaecandrous, the lower compound or decompound. Bracts usually inconspicuous. Perigynia thick, strongly convex on the dorsal, and often somewhat convex on the ventral face, brownish or chestnut in age, ascending or spreading, coriaceous, spongy at base, stipitate, narrowly margined, more or less nerved, conspicuously rough-beaked, the beak bidentate. Achenes lenticular. Style-base more or less thickened. Stigmas 2.

23. C. diandra Schrank. Culms slender, sharply triangular, loosely cespitose, 3-7 dm. high; leaf-blades $1.25 \mathrm{~mm}$. wide; head $2.5-5 \mathrm{~cm}$. long, somewhat compound; the lower spikes more or less separated; scales acute, brownish, with lighter midvein and hyaline margins; perigynia somewhat biconvex, dark chestnut, shining, nerveless on inner face, spreading at maturity. Wet meadows: N.S.-Pa.-Colo.-B.C.-Alaska; Eurasia. Mont.-Bor. My-Jl.

24. C. prairea Dewey. Culms sharply triangular, 5-10 dm. high; leafblades with slightly revolute margins; head 4-8 $\mathrm{cm}$. long, decompound, the lower 3-5 branches separated; scales acute or acuminate, light brown, with broad light-colored center and hyaline margins; perigynia $1.25 \mathrm{~mm}$. wide, nerveless, or lightly nerved on inner face, ascending, plano-convex or nearly so, reddish brown, dull, the beak serrulate. Wet meadows: Que.-N.J.-Ia.-Sask. Boreal. $\mathrm{My}-\mathrm{Jl}$.

25. C. Cusickii Mackenzie. Culms sharply triangular, 7-12 dm. high; leafblades with slightly revolute margins; head 4-8 cm. long, decompound, the lower branches separated; scales chestnut brown, with lighter midvein and hyaline margins; perigynia $1.5 \mathrm{~mm}$. wide, lightly nerved at base on the inner face, somewhat biconvex, spreading in age, brownish black, dull, the beak setulose-serrulate. C. teretiuscula var. ampla Bailey. Wet meadows: B.C.-Mont.-Calif. Submont. My-S.

13. Stenorhynchae Holm. Densely cespitose or with more or less elongated rootstocks. Culms triangular or somewhat flattened. Opaque part of sheaths usually transversely rugulose or red-dotted. Spikes few to many, androgynous to pistillate, but never gynaecandrous, the lower from simple to compound. Bracts little developed. Perigynia plano-convex, yellowish or yellowish brown, appressed-ascending to spreading, not thick-walled, but strongly spongy at base, stipitate, strongly many-nerved, the margins nearly obsolete on the lower half, conspicuously beaked, the beak bidentate. Achenes lenticular. Style-base more or less thickened. Stigmas 2.

26. C. Jonesii Bailey. Culms 2-4 dm. high, slender, very rough above, densely cespitose from elongated rootstocks; leaves clustered near base, the blades 1-2 mm. wide; opaque part of sheath white, not cross-rugulose, truncate at mouth; spikes in a dense ovoid head 8-12 $\mathrm{mm}$. long; scales brown with inconspicuous midvein, exceeding the perigynia; perigynia $3.5 \mathrm{~mm}$. long, the beak nearly smooth. High mountains: Mont.-Wyo.-Calif.-Wash. Submont.Mont. Jl-Au.

27. C. nervina Bailey. Culms 5-6 dm. high, stout, little roughened above, densely cespitose from short elongated rootstocks, strongly aphyllopodic; leafblades clustered on the lower fourth of stem, $3.5 \mathrm{~mm}$. wide; opaque part of sheath olive-tinged, becoming cross-rugulose, rounded at the mouth; spikes in a dense ovoid or oblong head, $15-24 \mathrm{~mm}$. long; scales as in the last; perigynia $4 \mathrm{~mm}$. long, the beak slightly serrulate. High mountains: Wyo.-Calif.-Wash. J1-Au.

28. C. stipata Muhl. Culms 3-10 dm. high, strongly serrulate above, growing in dense clumps; leaf-blades 4-8 mm. wide, the opaque part of sheaths 
thin, cross-rugulose; head $2.5-10 \mathrm{~cm}$. long, the lower spikes often separate; scales light-brownish, hyaline-margined; perigynia serrulate. Swamps and wet meadows: Newf.-Fla.-Utah-Calif,-B.C. Plain-Submont. My-Au.

14. Stellulatae Kunth. Densely cespitose. Culms triangular. Sheaths not red-dotted' or cross-rugulose. Spikes 2-10, or by reduction one, gynaecandrous, pistillate, or in a few species staminate, not compound. Bracts inconspicuous. Perigynia plano-convex, with orbicular, ovate or broadly oval bodies, green, yellowish brown or brown, spreading or reflexed at maturity, $2.5-3.5 \mathrm{~mm}$. long, strongly spongy at base, sharp-edged nearly, if not entirely, to the rounded or truncate base, not puncticulate, nerved on the outer, nerved or nerveless on the inner surface, the beak bidentate or obliquely cut. Achenes lenticular. Stigmas 2 .

29. C. illota Bailey. Culms 1-2 dm. high, roughened above; leaf-blades short, $1.5-2 \mathrm{~mm}$. wide; spikes $3-4$, forming a dense capitate head $6-8 \mathrm{~mm}$. long; scales broadly ovate, obtuse, brownish black, with light midvein; perigynia ovate, $3 \mathrm{~mm}$. long, brownish black, at length spreading, the beak one-third the length of the body, smooth or nearly so. High mountains: Wyo.-Colo.Calif.-Wash. Alp. -Subalp. Jl-S.

30. C. laeviculmis Meinsh. Culms 3-7 dm. high, weak; leaf-blades $1.5-2 \mathrm{~mm}$. wide, flat, soft; spikes 3-8, widely separate or the upper approximate, suborbicular, with $3-10$, at length spreading perigynia; scales ovate, hyaline, with conspicuous green midvein; perigynia green or brownish green, ovate, $2.5-3 \mathrm{~mm}$. long, lightly nerved on inner surface, the beak slightly bidentate. C. Deweyana var. sparsiflora Olney. Wet shaded places: Alaska-Ida.-Calif.; Siberia. Mont. -Submont. Je-Au.

31. C. interior Bailey. Culms $2-3.5 \mathrm{dm}$. high, slender and wiry; leafblades 1-2 mm. wide; spikes $2-4$, the lateral pistillate, subglobose, with $3-10$ perigynia, the upper long-tapering and staminate at base; scales half the length of the perigynia, ovate-orbicular, very obtuse, brownish, hyaline-margined all around, the center lighter-colored, the midvein not reaching the tip; perigynia ovate, plump, abruptly beaked, $2.5 \mathrm{~mm}$. long, $1.5 \mathrm{~mm}$. wide, nerveless or obscurely nerved on the inner face, sparingly serrulate on the upper margins. Boggy places: Me.-Fla.-Ariz.-Calif.-B.C.; n Mex. Plain-Subalp. My$\mathrm{Au}$.

32. C. angustior Mackenzie. Culms very slender, 1-3 dm. high; leafblades $0.5-1.5 \mathrm{~mm}$. wide; spikes 2 or 3 , with $3-15$ perigynia, the terminal longclavate; scales as long as the body of perigynia, acute, acuminate or cuspidate, ovate, yellowish brown tinged, with hyaline margins and midvein prominent to tip; perigynia divaricate, $2.5-3.5 \mathrm{~mm}$. long, with raised margins, the beak serrulate. C. stellulata var. angustata Carey. Boggy places: N.S.-Md.-Colo.-Wash. Boreal-Submont. Je.

15. Deweyanar Tuckerm. Densely cespitose. Culms triangular. Sheaths not red-dotted or cross-rugulose. Spikes 3-8, gynaecandrous, pistillate or rarely staminate, simple. Lower one or two bracts often conspicuous. Perigynia plano-convex, with narrowly ovate or linear-oblong bodies, light or yellowish green, $3.5-5.5 \mathrm{~mm}$. long, appressed, strongly spongy at base, only upper half sharp-edged, round-tapering at base, nerved on the outer face, nerved or nerveless on the inner face, the beak bidenticulate to deeply bidentate. Achenes lenticular. Stigmas 2.

33. C. Deweyana Schwein. Culms slender, weak, 2.5-9 dm. high, little brownish-tinged at base, strongly roughened beneath head; leaf-blades 2-5 mm. wide; spikes 2-7, ovate-oblong or subglobose, the lower more or less separate, with 3-15 perigynia; lower bract conspicuous; scales white-hyaline, with green midvein, mostly cuspidate; perigynia nerveless on the inner face, shallowly bidentate. Woods: N.S.-Pa.-Ia.-Colo.-Ida.-Mack. Plain-Submont. My-
Au.

34. C. leptopoda Mackenzie. Culms slender, erect, 3-7.5 dm. high, little brownish-tinged at base, roughened beneath head; leaf-blades $2.5-5 \mathrm{~mm}$. wide; 
spikes 4-7, ovoid-oblong or linear-oblong, the lower 1-3 separate, with 6-18 perigynia; lower bracts usually shorter than the head; scales not reddish brown tinged, mostly cuspidate; perigynia nerved at base on inner face, shallowly bidentate. Woods: B.C.-Ida.-Calif. Submont.-Mont. Je-Au.

35. C. Bolanderi Olney. Culms slender, erect, 4-9 dm. high, brownishtinged at the base, little roughened beneath the head; leaf-blades $2.5-5 \mathrm{~mm}$. wide; spikes 4-8, linear-oblong or linear, the lower separate, with 8-20 perigynia; lower bracts usually shorter than the head; scales usually reddish brown tinged, mostly acute or mucronate; perigynia lanceolate, $4-4.5 \mathrm{~mm}$. long, nerved at base on the inner face. Woods: B.C.-Calif.-N.M.-Utah-w. Mont. Submont.-Mont.

16. Ovales Kunth. Densely cespitose or (rarely) with short-prolonged rootstocks. Culms triangular. Opaque part of sheaths not red-dotted or crossrugulose, but sometimes green-striate. Spikes two or three up to twenty, with several to many perigynia, the terminal gynaecandrous, the lateral pistillate or gynaecandrous, simple, the inflorescence varying from capitate to moniliform. Lower bracts from inconspicuous to very conspicuous. Perigynia varying from scale-like or flat (except when distended by the achene) to thick and plano-convex, the body subulate to reniform, narrowly to broadly wing-margined, appressed or ascending or spreading, little corky-thickened at base, prominently beaked, the beak bidentate, or obliquely cut becoming bidenticulate, usually serrulate on margins. Style-base scarcely thickened. Achenes lenticular. Stigmas 2.

36. C. sychnocephala Carey. Culms 1-6 dm. high, very smooth; leafblades $1.5-3 \mathrm{~mm}$. wide; spikes 6-15, densely aggregated into an oblong-ovoid head 1.5-3 cm. long; scales lanceolate, half the length of the perigynia; perigynia 5-6 mm. long, nerved on both faces, the beak deeply bidentate. Meadows and thickets: Ont.-N.Y.-Ia.-Mont. Plains. JI-Au.

37. C. athrostachya Olney. Culms 1-5 dm. high, roughened above; leafblades $2 \mathrm{~mm}$. wide; spikes 4-20, densely aggregated into an ovoid head 1-2 $\mathrm{cm}$. long; scales lance-ovate, somewhat shorter than the perigynia; perigynia $3-4 \mathrm{~mm}$. long, obsoletely nerved, the beak bidentate, reddish brown at mouth. Wet meadows and copses: Sask.-Colo.-Calif.-Alaska. Mont.-Submont. My-S.

38. C. tenuirostris Olney. Culms 6-9 cm. high, nearly smooth; leaf-blades 1.5-2.5 mm. wide; spikes 4-5, densely aggregated, ovoid, $5 \mathrm{~mm}$. long, $3-4 \mathrm{~mm}$. wide; scales ovate, acute, light brownish, with hyaline margins; perigynia 8-13, ascending, $3 \mathrm{~mm}$. long, $1 \mathrm{~mm}$. wide, lanceolate, nerved ventrally, tapering into a beak $1 \mathrm{~mm}$. long. C. macloviana f. involucrata Kükenth. Mountain meadows: Mont.-Colo.-Calif.-Wash. Mont.-Submont. My-Au.

39. C. adusta Boott. Culms 2.5-7 dm. high, nearly smooth; leaf-blades 2-3 mm. wide; spikes $3-15$, the lower only slightly separate; scales ovate, strawcolored, with greenish midvein; perigynia broadly ovate, 4-5 mm. long, 2-2.5 $\mathrm{mm}$. wide, rather abruptly beaked. C. pinguis Bailey. Dry soil: Newf.N.Y.-Minn.-Sask.-Mack. Plain. Je-S.

40. C. petasata Dewey. Culms $3-8 \mathrm{dm}$. high, nearly smooth; leaf-blades 2-3 mm. wide; spikes $3-6$, aggregated; scales ovate, reddish brown tinged and hyaline-margined; perigynia broadly lanceolate, $2.25 \mathrm{~mm}$. wide, round-tapering at base, tapering into the beak, which is $2 \mathrm{~mm}$. long. C. Liddonii Boott. Meadows and open woods: Sask.-Colo.-Nev.-Wash. Submont.-Mont. Je-S.

41. C. aenea Fernald. Culms 4-9 dm. high, rough beneath the head; leafblades 2.5-4 mm. wide; spikes 3-12, 7-24 mm. long, 5-7 mm. thick; scales ovate, light brownish tinged, hyaline-margined; perigynia ascending, ovate, $4 \mathrm{~mm}$. long, $2 \mathrm{~mm}$. wide, rounded at base, tapering into a beak half the length of the body. "C. foenea Willd." of our range. Dry places and open woods: Lab.Conn.-Alta.-B.C.-Yukon. Boreal-Mont. My-Jl.

42. C. Crawfordii Fernald. Culms 2-6 dm. high, rough beneath the head; leaf-blades $1-3.25 \mathrm{~mm}$. wide; spikes $3-12,5-11 \mathrm{~mm}$. long, $3-5 \mathrm{~mm}$, wide, rather closely aggregated, well-defined; scales lance-ovate, acute or acuminate, brownish; perigynia erect-ascending, brownish, $4 \mathrm{~mm}$. long, about $1 \mathrm{~mm}$. wide, obscurely 
nerved, tapering into a beak half the length of the body. Open places: Newf. -Conn.-Mich.-Ida.-B.C. Boreal. Je-S.

43. C. scoparia Schkuhr. Culms $2-8 \mathrm{dm}$. high, rough beneath the head; leaf-blades $1.5-3 \mathrm{~mm}$. wide; spikes 3-10,6-16 mm. long, 4-6 mm. wide, aggregate or scattered, clearly defined; scales ovate, acute, brownish tinged; perigynia erect-ascending, brownish, usually $5.5-6.5 \mathrm{~mm}$. (occasionally $4-5.5 \mathrm{~mm}$.) long, $1.2-1.9 \mathrm{~mm}$. wide, nerved, tapering into a beak half the length of the body. Moist soil: Newf.-Fla.-Colo.-B.C. Plain-Submont. My-Au.

44. C. Bebbii Olney. Culms 2-8 dm. high, rough beneath the head; leafblades $2-4.5 \mathrm{~mm}$. wide; spikes $5-10,4-9 \mathrm{~mm}$. long, $3-6 \mathrm{~mm}$. wide; scales ovate, acute, brownish; perigynia ascending, narrowly ovate, $3-4 \mathrm{~mm}$. long, $1.5-2 \mathrm{~mm}$. wide, rounded at base, obscurely nerved, tapering into a beak half the length of the body. Low ground: Newf.-N.J.-Mont.-B.C. Plain-Submont. Je$\mathrm{Au}$.

45. C. tenera Dewey. Culms 3-7 dm. high, slender, rough beneath head; spikes 3-8, 4-5 mm. thick; scales acutish, hyaline with green midvein, light brownish tinged; perigynia ascending or spreading, ovate, thick, $3-4 \mathrm{~mm}$. long, $1.5-2.5 \mathrm{~mm}$. wide, rounded at base, nerved, tapering into a beak half the length of the body. C. straminea Am. auth., in part. Woodlands: N.B.-Mass.-Ky. -Ark.-Mont.-Canadian Rockies. Apparently rare in our range. Mont.Boreal. Je-Au.

46. C. tincta Fernald. Culms $6-10 \mathrm{dm}$. high, rough beneath head; spikes 4-12, 6-9 mm. long, 5-8 mm. thick; scales ovate, acutish, reddish brownish with light midvein; perigynia 10-30, appressed, ovate, thick, $3.75-4.5 \mathrm{~mm}$. long, 1.5-2 $\mathrm{mm}$. wide, rounded at base, nerved, tapering into a beak less than half the length of the body. Woodlands: Que.-Me,-N.Y.-Mich.-Alta. Boreal -Plain. My-Jl.

47. C. brevior (Dewey) Mackenzie. Culms 3-12 dm. high, rough beneath head; leaf-blades 2-4 mm. wide; spikes 3-10, oblong to globose, 4-9 $\mathrm{mm}$. wide, 7-15 mm. long, aggregate or separate; scales acute; perigynia ovate to orbicular, thick, 4-5.5 mm. long, $2.5-3.5 \mathrm{~mm}$. wide, spreading or ascending, faintly nerved on inner face, the beak about one-third the length of the body. C. festucacea authors, in part. Dry soil: N.B.-Fla.-Tex.-N.M.-B.C. Plain-Submont. $\mathrm{Ap}-\mathrm{Au}$.

48. C. Egglestonii Mackenzie. Culms $49 \mathrm{dm}$. high, roughened beneath head; leaf-blades $2.5 \mathrm{~mm}$. wide; spikes $3-6$, closely aggregate, broadly ovoid, 10-14 mm. long, 6-10 mm. wide; scales ovate, acute, hyaline-margined; perigynia numerous, appressed-ascending, ovate, olive-green or brownish in age, $6-7 \mathrm{~mm}$. long, $3 \mathrm{~mm}$. wide, thin, obscurely nerved on inner face, strongly winged, rounded at the base, the beak one-third the length of the body. "Carex straminiformis Bailey" auth., in part. Dry soil: Wyo.-Colo.-Utah. Mont.-Subalp. J1Au.

49. C. phaeocephala Piper. Culms 1-3 dm. high, rough beneath head; leaves bunched at the base, the blades more oc less involute, $1.5-2 \mathrm{~mm}$. wide; spikes 2-5 (rarely 7 ), aggregate, 6-12 $\mathrm{mm}$. long, 5-8 $\mathrm{mm}$. wide; scales strongly hyaline-margined, acute; perigynia ascending, oblong-ovate, $1.8 \mathrm{~mm}$. wide, round-tapering at the base, obscurely nerved on inner face, contracted into a beak about $1 \mathrm{~mm}$. long. "C. Preslii Steud," Bailey. "C. petasata Dewey" Holm. C. leporina v. americana Olney. Mountain summits: Alta.-Colo.Calif.-B.C. Alp.-Mont. Jl-S.

50. C. xerantica Bailey. Culms 3-6 dm. high, nearly smooth; leaf-blades 2-3 mm. wide; spikes 3-6, approximate but distinet, ellipsoid, 8-14 $\mathrm{mm}$. long, $5 \mathrm{~mm}$. wide; scales silvery-hyaline, darker tinged; perigynia 4-5.5 mm. long, 2-2.5 $\mathrm{mm}$. wide, nearly nerveless on inner face, round-tapering at the base, tapering into a beak one-third the length of the body. Prairies and plains: Man. -Sask.-Colo.-Kans. Plains. Jl.

51. C. praticola Rydb. Culms slender, 2.5-6 dm. high, roughened beneath the head; leaf-blades $1-2 \mathrm{~mm}$. wide; spikes $2-6$, elliptic, $6-16 \mathrm{~mm}$. long, $5 \mathrm{~mm}$. wide; scales somewhat brownish-tinged, shining; perigynia appressed, ovate- 
lanceolate, $4.5-6.5 \mathrm{~mm}$. long, narrowly winged, round-tapering at the base, nearly nerveless on inner face, tapering to a short hyaline-tipped beak. $C$. pratensis Drejer. Meadows and open woods: Greenl.-Me.-Colo.-Calif.Alaska. Submont.-Mont.-Boreal. Je-Au.

52. C. Piperi Mackenzie. Culms slender, $3-8 \mathrm{dm}$. high, roughened beneath head; leaf-blades 2-3.5 mm. wide; spikes 3-9, elliptic, 10-18 $\mathrm{mm}$. long, 5-6 $\mathrm{mm}$. wide; scales ovate, chestnut-brown with lighter center and narrow hyaline margins, shining; perigynia 8-15, appressed, ovate-lanceolate, 4-5 mm. long, 1.75 $\mathrm{mm}$. wide, narrowly winged, round-tapering at base, nearly nerveless on inner face, contracted into the hyaline-tipped beak, $1.5 \mathrm{~mm}$. long. C. furva (Bailey) Howell. Damp meadows: Alta.-Wyo.-Ore.-B.C. Submont-Mont. JeAu.

53. C. microptera Mackenzie. Culms 3-10 dm. high, smooth or roughened beneath the head; leaf-blades $2-6 \mathrm{~mm}$. wide; spikes $5-20$, densely aggregate into a subglobose to oblong-ovoid head, the spikes ovoid, 5-8 mm. long, $4-6 \mathrm{~mm}$. wide; scales ovate-lanceolate, sharp-pointed, brown with light midvein; perigynia ascending, 15-30, 3.5-4.5 mm. long, 1-1.5 mm. wide, lanceolate, nerved ventrally, very narrowly winged, tapering into a beak one-third the length of the whole. Mountains: Alta.-Wyo.-Ore.-Wash. Submont.-Mont. Je-Au.

54. C. festivella Mackenzie. Culms rather stout, $2-7 \mathrm{dm}$. high, roughened above; leaf-blades $2.5-4 \mathrm{~mm}$. wide; spikes $3-8$, densely aggregate, ovoidorbicular, $5-9 \mathrm{~mm}$. long, $4-8 \mathrm{~mm}$. wide; scales ovate, dark reddish brown with narrow hyaline margins; perigynia numerous, appressed, $3.5-5 \mathrm{~mm}$. long, 1.75$2.75 \mathrm{~mm}$. wide, ovate, lightly nerved on the inner face, rounded at the base, narrowed into a beak one-third the length of the body. C. festiva authors, as to Rocky Mt. plant. Meadows and mountain sides: Alta.-N.M-Ariz.-Nev. -B.C. Submont.-Mont. Je-Au.

55. C. nubicola Mackenzie. Culms $12-35 \mathrm{~cm}$. high, nearly smooth; leafblades $2-3 \mathrm{~mm}$. wide; spikes $4-7$, densely aggregate, ovoid or subgloboce, 5-9 mm. long, 4.5-8 mm. wide; scales ovate, acute, blackish with a light center and nearly obsolete hyaline margins; perigynia 15-30, 4.5-5 mm. long, 2-2.75 $\mathrm{mm}$. wide, ovate, rounded at the base, abruptly beaked, the beak half the length of the body. C. Haydeniana Olney. C.festiva var. decumbens Holm. Mountain sides: Alta.-Colo.-Nev.-Ore. Mont.-Alp. Jl-S.

56. C. ebenea Rydb. Culms 2-5 dm. high, little roughened; leaf-blades 2-3 mm. wide; spikes 5-10, densely aggregate, ovoid-oblong, 7-12 $\mathrm{mm}$. long, $6 \mathrm{~mm}$. wide; scales lance-ovate, acute, brownish black with nearly obsolete hyaline margins; perigynia appressed, numerous, 5-7 $\mathrm{mm}$. long, $1.75 \mathrm{~mm}$. wide, lanceolate, round-tapering at the base, narrowed into a beak about $2 \mathrm{~mm}$. long. Mountain meadows: Wyo.-N.M.-Ariz.-Utah. Mont.-Alp. Je-Au.

57. C. pachystachya Cham. Culms rather slender, $3-8 \mathrm{dm}$. high, nearly smooth; leaf-blades $2-4 \mathrm{~mm}$. wide; spikes $4-8$, densely aggregate, ovoid or
subglobose, 5-8 mm. long, 4-6 mm. wide; scales ovate, reddish, with very narrow hyaline margins; perigynia $10-30,3.5-4 \mathrm{~mm}$. long, $1.5-2.25 \mathrm{~mm}$. wide, ovate, nerveless on the inner face, rounded at base, contracted into a beak half the length of the body. Mountains: Alaska-Alta.-Colo.-Ore. Submont.Mont. $\mathrm{My}-\mathrm{Au}$.

58. C. Preslii Steud. Culms $2.5-7.5 \mathrm{dm}$. high, rough beneath head; leafblades $1.5-4 \mathrm{~mm}$. wide; spikes $3-8$, well-defined, aggregate or the lower separate, 5-8 mm. long, slightly narrower, rounded at apex, rounded at the base, the terminal one tapering; scales ovate, reddish brown with green midvein and narrow margins; perigynia 10-25, ovate, thick, $3.5 \mathrm{~mm}$. long, $2 \mathrm{~mm}$. wide, obscurely nerved, rounded at base, abruptly beaked, the beak $1 \mathrm{~mm}$. Iong. C. festiva var. gracitis Olney. C. multimoda Bailey. Mountains: B.C.-Mont.-Calif. Mont. -Subalp. My-S.

17. Canescentes Fries. Cespitose, but in some species with slender stolons. Culms triangular. Sheaths not cross-rugulose. Spikes 1-10, with few to many perigynia, the terminal gynaecandrous, the lateral pistillate or gynaecandtous, 
simple. Bracts inconspicuous. Perigynia plano-convex, white-puncticulate, lanceolate, ovate, oval, or obovoid, appressed to spreading, beakless to prominently beaked, more or less nerved on both sides, not winged or margined, but acute-edged above, nearly or entirely filled by the lenticular achene. Stylebase not enlarged. Stigmas 2.

59. C. disperma Dewey. Culms weak, $1.5-6 \mathrm{dm}$. high, in large elumps, but with slender rootstocks; leaf-blades 1-1.5 mm. wide; spikes distant or the upper aggregate, 1-5-flowered; perigynia ovoid-elliptic, $2 \mathrm{~mm}$. long, $1.5 \mathrm{~mm}$. wide, finely nerved, the minute beak smooth. C. tenella Schk. Bogs: Newf.-N.J.Ind.-N.M.-Calif.-B.C.-Alaska; Eurasia. Submont.-Subalp. Je-Au.

60. C. trisperma Dewey. Culms filiform, weak, $1.5-8 \mathrm{dm}$. long, in large clumps, but with slender rootstocks; leaf-blades $1-2 \mathrm{~mm}$. wide; perigynia oblong, $2.5-4 \mathrm{~mm}$ long, nearly $2 \mathrm{~mm}$. wide, finely nerved, narrowed at the apex, the minute beak smooth or nearly so. Swamps and wet woods: Lab.-Md.(?Neb.) -Sask. Boreal. Je-S.

61. C. tenuiflora Wahl. Culms slender, weak, $2-6 \mathrm{dm}$. long, loosely cespitose and stoloniferous; leaf-blades $0.5-2 \mathrm{~mm}$. wide; perigynia oblong-obovoid, $2.5-3.5 \mathrm{~mm}$. long, $1.5 \mathrm{~mm}$. wide, obscurely nerved, Bogs: N.B.-Me.-Minn. -Alta.; Eurasia. Boreal. Je-Au.

62. C. Lachenalii Schkuhr. Culms stiff, erect, $0.7-4 \mathrm{dm}$, high; leaf-blades 1-3 mm. wide; spikes 2-6, many-flowered; perigynia $2-3.5 \mathrm{~mm}$. long, severalnerved, abruptly short-beaked. C. lagopina Wahl. Greenl.-Canadian Rockies-Alaska; Eurasia. Arctic. J1-Au.

63. C. Heleonastes Ehrh. Culms stiff, erect, 1-4.5 dm. high; leaf-blades $1-2 \mathrm{~mm}$. wide; spikes $2-5$, with $5-10$ perigynia; the latter $3 \mathrm{~mm}$. long, $1.25 \mathrm{~mm}$. wide, several-nerved, tapering into the short beak. Bogs: Ont.-Alta.-B.C.Mack.; Eurasia. Subalp,-Boreal. J1-Au.

64. C. canescens L. In large clumps, the culms slender, $2.5-8 \mathrm{dm}$. high; spikes 4-9, 3-12 $\mathrm{mm}$. long, 3-5 mm. wide; perigynia $1.8-2.8 \mathrm{~mm}$. long, 1-1.8 mm. wide, faintly few-nerved. Swamps and bogs: Lab.-Va.-Calif.-Alaska; Eurasia; S. Am.; Australia. Submont.-Subalp. My-Au.

65. C. brunnescens (Pers.) Poir. Culms slender, 2-5 dm. high; spikes 4-8, 4-10-flowered, subglobose, $4-13 \mathrm{~mm}$. in diameter; perigynia mostly smaller than in the preceding species. In wet places, banks and open woods: Lab.-N.C.Colo.-Wash.-Alaska; Eurasia. Submont.-Subalp. Je-Au.

66. C. arcta Boott. Culms slender, erect, 1.5-8 dm. high; leaf-blades 2-4 $\mathrm{mm}$. wide; spikes $5-15$, many-flowered, aggregate into a head $1.5-3 \mathrm{~cm}$. long; perigynia ascending or somewhat spreading, $2-3 \mathrm{~mm}$. long, many-nerved. $C$. canescens var. oregana Bailey. Swamps and wet woods: N.B.-N.Y.-Mont.Calif.-B.C. Submont. Je-Au.

18. Phyllostachyae Tuckerm. Culms densely cespitose, weak, compressed, dilated below the spikes, mostly much exceeded by the leaves. Spikes 2-4, androgynous, the rachis zigzag, dilated; one spike terminal, the others basal on often much elongated peduncles; staminate portion with small tight scales; pistillate portion loosely one-several-flowered, the scales elongated and conspicuous. Perigynia glabrous, 2-keeled, but otherwise nerveless, nearly round in cross-section, more or less beaked, the beak flattened-triangular, the orifice hyaline. Achenes triangular, stipitate, the sides convex, filling the perigynia, the apex rounded. Stigmas 3 , short. Style jointed at the base with achene, soon withering.

67. C. durifolia Bailey. Culms up to $2.5 \mathrm{dm}$. long; leaf-blades green, not glaucous, $1.5-3 \mathrm{dm}$. long, $2.5-6 \mathrm{~mm}$. wide; lower pistillate scales as in the next; perigynia $5-6 \mathrm{~mm}$. long, the body oval, the beak smooth, about as long as the body. C. Backii Boott. Woods: Que.-Mass.-N.Y.-Alta.-e B.C.

68. C. saximontana Mackenzie. Culms up to $1.5 \mathrm{dm}$. long; leaf-blades glaucous, $1.5-3 \mathrm{dm}$. long, $3-5 \mathrm{~mm}$. wide; lower pistillate scales leaf-like, saccate; perigynia $4 \mathrm{~mm}$. long, the body oblong-globose, the beak barely $1 \mathrm{~mm}$. long, 
the margins weakly serrulate. "C. Backii Boott" Fl. Colo. Woods and thickets: Colo.-Wyo.-w Neb. Submont. J1.

19. Polytrichoideae Tuckerm. Densely tufted. Culms slender. Leafblades narrow. Spike solitary, linear, androgynous, bractless. Rachis straight, not dilated. Perigynia appressed, membranaceous, the upper part empty, oblong-elliptic, many-nerved (not 2-ribbed), compressed-triangular, beakless. Achenes triangular. Style slender, flexuous, its base not enlarged. Stigmas 3, short.

69. C. leptalea Wahl. Rootstocks elongated; culms $2-6 \mathrm{dm}$. high, obscurely triangular; leaf-blades $0.5-1.25 \mathrm{~mm}$. wide; spike 4-15 $\mathrm{mm}$. long, 2-3 mm. wide; perigynia 1-10, 2.5-4.25 $\mathrm{mm}$. long, not concealed by scales. C. polytrichoides Willd. Bogs and wet meadows: Lab.-Fla.-Tex.-Colo.-Calif.-Alaska. Plain-Mont. Je-Jl.

20. Obtusatae Mackenzie. Rootstocks long, creeping. Culms low, slender. Leaf-blades involute. Spike solitary, linear, androgynous, bractless. Perigynia appressed-ascending, ovoid, glabrous, many-nerved, coriaceous, shining, substipitate, obscurely triangular, the beak hyaline-tipped, obliquely cut, at length bidentate. Achenes triangular. Stigmas 3.

70. C. obtusata Liljebl. Culms $6-20 \mathrm{~cm}$. high, rough above; sheaths sparingly filamentose; leaf-blades $1-1.5 \mathrm{~mm}$. wide; spike $5-12 \mathrm{~mm}$. long, $3-6 \mathrm{~mm}$. wide, the upper two-thirds staminate; perigynia 1-6, impressed nerved, 3-4 mm. long, exceeding the scales. Dry hills and ridges: Mont.-Colo.-B.C.; Eurasia. Mont, -Subalp. Je-Au.

21. Nitidae O. F. Lang. Culms slender, leafy at the base. Leaf-blades narrow. Terminal spike linear, staminate. Lateral spikes 1-3, small, pistillate, subglobose to oblong, few-many-flowered, sessile or short-peduncled. Lowest bract squamiform, sheathless or sub-sheathing. Seales reddish brown with hyaline margins. Perigynia ovoid, turgid-triangular, smooth, shining, coriaceous, round-tapering at the base, tipped with the short, cylindric, hyaline-tipped, obliquely cut beak. Achenes sessile, triangular, closely enveloped, short apiculate. Style short, jointed with the apex of achene, thickish. Stigmas 3, long.

71. C. supina Wahl. Long-stoloniferous; culms 6-25 cm. high; leafblades $1-1.5 \mathrm{~mm}$. wide; pistillate spikes $1-2$, sessile, 4-10-flowered, 4-8 mm. long, subglobose or short-oblong; perigynia nerveless (except keels), 2.5-3.5 mm. long. Dry soil: Greenl-_Mack., reported from Minn. and Sask.; Eurasia. Boreal-Arctic. My-Jl.

22. Rupestres Tuckerm. Stoloniferous. Culms low. Leaf-blades narrow, flattened. Spikes 1 and androgynous, or $2-4$, with the terminal staminate and linear, the lateral pistillate, approximate or more or less separate, fewflowered, sessile or short-peduncled. Bracts of the pistillate spike leaflet-like, sheathless or nearly so. Pistillate scales dark chestnut to purplish brown, with hyaline margins. Perigynia appressed-ascending, obovoid, glabrous, membranous, not polished, rounded and sessile at base, 2-ridged, obscurely triangular in cross-section, abruptly contracted into a hyaline-tipped, obliquely cut, straight beak. Achenes closely enveloped, triangular, with concave sides, apiculate. Style-base thickened. Stigmas 3.

72. C. rupestris All. Culms $7-10 \mathrm{~cm}$. high, sharply triangular, rough; sheaths not filamentose; leaf-blades $2-3 \mathrm{~mm}$. wide; spike $1-1.5 \mathrm{~cm}$. long, 3-6 $\mathrm{mm}$. wide, the upper half staminate; perigynia $6-15$, finely many-nerved, $4 \mathrm{~mm}$. long, concealed by the scales. Arctic-alpine situations: Greenl.-Que.-Colo.Alta.-Alaska; Eurasia. Alp. -Subalp. Je-Au.

23. Firmiculmes Kükenth. Culms wiry, triangular, aphyllopodic, the leaf-blades rudimentary at flowering time. Spike 1, androgynous, the staminate part in age short-peduncled, the pistillate loosely flowered; bracts absent; scales more or less chartaceous; perigynia 1 to several, obtusely triangular, smooth, 
2-keeled but otherwise nerveless, tapering at the base, very minutely beaked, the orifice truncate. Achenes triangular, with nearly flat sides, closely enveloped by the perigynia, tipped by the minute persistent base of the style, constricted at base. Stigmas 3, elongated.

73. C. Geyeri Boott. Rootstock woody, elongated; culms up to $3.5 \mathrm{dm}$. high, very rough; leaf-blades thick, $2-3.5 \mathrm{~mm}$. wide, those of the culm developing after flowering; perigynia $1-3,6 \mathrm{~mm}$. long. Dry mountain sides and open woods: Alta.-Colo.-Utah-Ore-Wash. Submont.-Subalp. My-Au.

24. Frlfroliae Tuckerm. Densely cespitose. Leaf-blades filiform or narrow. Spike solitary, linear or linear-oblong, androgynous, densely flowered, bractless. Perigynia more or less triangular, nerveless except for the two lateral ribs, not stipitate, puberulent or pubescent, the hyaline-tipped beak obliquely cut. Achenes triangular. Stigmas 3.

74. C. elynoides Holm. Culms 8-12 cm. high; spike 8-15 mm. long, with 4-8 ascending perigynia; pistillate scales with dingy white hyaline margins; perigynia $2.5-3 \mathrm{~mm}$. long, slightly puberulent above, slenderly beaked. $C$. filifolia var. misera Bailey. Mountain summits: Mont.-Colo.-Nev. Alp. Je-Au.

75. C. filifolia Nutt. Culms $8-30 \mathrm{~cm}$. high; spike $1-2 \mathrm{~cm}$. long, with $5-10$ perigynia; pistillate scales with broad bright white hyaline margins; perigynia $3 \mathrm{~mm}$. long, puberulent, abruptly and minutely stout-beaked. Plains and ridges: Sask.-Tex.-N.M.-Wash.-Yukon. Plains-Mont. Ap-Jl.

76. C. oreocharis Holm. Culms 1-2 dm. high; spike 1-2 cm. long, with 3-7 perigynia; pistillate scales ovate, acuminate; perigynia $4 \mathrm{~mm}$. long, broadly obovoid, minutely pubescent, abruptly short-beaked. C. filifolia var. valida Bailey. Dry slopes: Colo. Submont. Je.

25. Scirpinae Tuckerm. Rootstocks creeping. Culms leafy below. Leafblades narrow. Spike usually 1, linear, staminate or pistillate, many-flowered, occasionally with an additional spike and normally with an empty scarcely sheathing squamiform bract a short distance below the spike. Perigynia triangular or flattened-triangular, membranous, 2-keeled, pubescent or puberulent, tapering at the base, contracted at apex into the short cylindric entire or bidenticulate beak. Áchenes triangular, with flat sides, sessile. Style slender, slightly enlarged at the base, not jointed. Stigmas 3 , short.

77. C. pseudoscirpoidea Rydb. Rootstocks stout; eulms $1-3 \mathrm{~cm}$. high; leaf-blades $2-3 \mathrm{~mm}$. wide; spike $12-36 \mathrm{~mm}$. long, 2-5 mm. wide; scales brownish black; perigynia obovoid, strongly pubescent, triangular, $2.5 \mathrm{~mm}$. long, with bidenticulate beak. Mountain sides: Mont.-Colo.-Utah. Mont.-Subalp. Jl-Au.

78. C. stenochlaena (Holm) Mackenzie. Rootstocks stout, densely matted; culms 2.5-4 dm. high; leaf-blades $2-2.5 \mathrm{~mm}$. wide; pistillate spikes $1.5-3 \mathrm{~cm}$. long, 4-7 mm. wide; scales oblong-ovate, blackish, with narrow hyaline margins, ciliate; perigynia blackish at the apex. Mountains: Alaska-Alta.-Ida.Wash. Submont.-Mont. J-S.

79. C. scirpoidea Michx. Rootstocks stoutish; culms 2-3.5 dm. high; leaf-blades $1-2 \mathrm{~mm}$. wide; pistillate spikes $1.5-3 \mathrm{~cm}$. long, $2.5-5 \mathrm{~mm}$. wide; scales ovate, chocolate-brown, ciliate and puberulent; perigynia $3 \mathrm{~mm}$. long, not blackish. Arctic-alpine, along streams: Greenl.-N.H.-N.Y.-Mich.-Mont.B.C.-Alaska; Eurasia, where rare. Alp.-Subalp. Je-Au.

80. C. scirpiformis Mackenzie. Rootstocks stoutish; culms 2.5-4.5 dm. high; leaf-blades $2-3 \mathrm{~mm}$. wide; pistillate spikes $2-4 \mathrm{~cm}$. long, 4-5 $\mathrm{mm}$. wide; scales ovate, brownish, strongly pubescent and ciliate at the apex; perigynia $2.5 \mathrm{~mm}$. long, not blackish. Mountains: Alta.-N.D. Mont. Jl.

26. Montanae Fries. Culms slender, leafy at the base. Leaf-blades narrow, rough above. Terminal spike linear, normally staminate. Lateral spikes $1-5$, small, pistillate, or sometimes androgynous, subglobose to oblong, closely few-many-flowered, approximate and sessile or short-peduncled, or in some 
species radical and long-peduncled. Lowest bract squamiform or leaflet-like, sheathless or sub-sheathing. Scales often reddish brown tinged, acute to cuspidate. Perigynia membranaceous, ascending, the body pubescent, at least at the base of the beak, obovoid to elliptic, triangular, 2-keeled, strongly stipitate at the base, abruptly contracted into a cylindric or terete, emarginate to deeply bidentate beak, hyaline-tipped. Achenes normally triangular, the sides concave, closely enveloped, short-apiculate. Style short, jointed with apex of achene, thickish. Stigmas normally 3, long.

81. C. heliophila Mackenzie. Culms $12-25 \mathrm{~cm}$. high; leaf-blades 1-2 mm. wide; lowest bract squamiform; pistillate spikes 1-2 (rarely 3), subglobose, 5-15-flowered; perigynia $3.5 \mathrm{~mm}$. long, $2 \mathrm{~mm}$. wide, orbicular in cross-section, the beak deeply bidentate, in age strongly hyaline-tipped. "C. pennsylvanica vespertina Bailey," Fl. Colo. Prairies and plains: Man.-Ill.-Mo.-N.M.Colo. Plains-Submont. Je-S.

82. C. Peckii E. C. Howe. Loosely cespitose, the culms $1.25-6 \mathrm{dm}$. high; leaf-blades $3 \mathrm{~mm}$. wide or less; lowest bract short; staminate spike sessile, $3 \mathrm{~mm}$. long or less; pistillate spikes 2-4, subglobose, 2-8-flowered, closely contiguous or the lower a little separate; perigynia oblong-obovoid, 3-4 mm. long, $1 \mathrm{~mm}$. wide, grayish-pubescent, the beak one-fourth the length of the body; scales (except lower) half the length of the perigynia, reddish brown, with broad white hyaline margins. "C albicans Willd." authors. Open woods: Que.-Mass.N.Y.-Mich.-(Black Hills) S.D.-Alaska.

83. C. umbellata Schkuhr. Densely cespitose; culms up to $1.5 \mathrm{dm}$. high, much exceeded by leaves; leaf-blades $1.5-3 \mathrm{~mm}$. wide; non-basal pistillate spike usually present, oblong, globose; basal spike oblong; perigynia $2.25-3.25 \mathrm{~mm}$. long, $1.25 \mathrm{~mm}$. wide, rounded-triangular in cross-section, the beak obscurely bidentate, less than half the length of the body; achenes light brown. $C$. umbellata var. brevirostris Boott. Dry, sunny places: Que.-Del--Alta.-B.C. Plains-Submont. Ap-Jl.

84. C. deflexa Hornem. Loosely stoloniferous; culms very slender, 2-12 $\mathrm{cm}$. high; leaf-blades $1-2 \mathrm{~mm}$. wide; staminate spike inconspicuous, $2-4 \mathrm{~mm}$. long, 0.5-1 mm. wide; pistillate spikes subglobose, 2-8-flowered; perigynia 1 $\mathrm{mm}$. wide, nearly orbicular in cross-section. Dry soil: Greenl.-N.Y.-Mich.Sask.-B.C.-Alaska. Boreal. My-Au.

85. C. Rossii Boott. Rootstock stout; culms wiry, $5-25 \mathrm{~cm}$. high; leafblades $1-2.5 \mathrm{~mm}$. wide; staminate spike usually conspicuous, $3-10 \mathrm{~mm}$. long, 1 up to $3.4 \mathrm{~mm}$. long, $1.25 \mathrm{~mm}$. wide, nearly orbicular in cro

27. Digitatae Fries. Culms slender, leafy at the base. Leaf-blades narrow, the sheaths usually strongly purplish. Terminal spike linear, staminate. Lateral spikes 1-5, approximate, or separated or sometimes radical, oblong to linear, 5-20-flowered in few rows, the peduncles included or exserted. Bracts sheathing, more or less strongly purplish tinged, subspathaceous, the blade absent or rudimentary. Pistillate scales strongly purplish or reddish brown tinged. Perigynia membranaceous, appressed, oblong-obovoid, pubescent to glabrate, triangular, long-tapering into the stipitate base, abruptly contracted into the minute beak, the orifice entire or nearly so. Achenes triangular, closely enveloped. Style-base short, thickened, jointed with the apex of the achene. Stigmas 3 , early deciduous.

86. C. pedunculata Muhl. Densely matted, rather bright green; culms slender, diffuse, strongly purple tinged at the base, 0.7-3 dm. long; leaf-blades 2-3 mm. wide; terminal spike long-stalked, usually pistillate at the base; lateral spikes few-flowered, filiform-stalked, spreading or drooping, scattered, some appearing basal; perigynia sharply 3 -angled, puberulent or in age glabrate, stipitate, tipped with a minute entire beak; scales obovate, purplish, with green midrib, abruptly cuspidate. Dry woods: Anticosti-Va.-Ia.-e B.C. My-J. 
87. C. concinna R. Br. Strongly stoloniferous; culms $5-15 \mathrm{~cm}$. high; leafblades 2-2.5 mm. wide; pistillate spikes $2-3$, rather closely $4-10$-flowered; scales broadly ovate, hyaline-margined; perigynia densely pubescent, $3 \mathrm{~mm}$. long, nerveless. Dry soil: Que.-Sask.-Colo.-B.C.-Alaska. Mont.-Boreal. Je$\mathrm{Jl}$.

88. C. concinnoides Mackenzie. Strongly stoloniferous; culms $25 \mathrm{~cm}$. high or less; leaf-blades 2-4 mm. wide; pistillate spikes 1 or 2 , approximate, rather closely 5-10-flowered; scales narrowly ovate, hyaline-margined; perigynia 2.5-3 mm. long. Dry soil: B.C.-Alta.-Mont.-Ida.-Calif. Mont. My-Jl.

89. C. Richardsonii R. Br. Strongly stoloniferous; culms $30 \mathrm{~cm}$. high or less; leaf-blades $2-4 \mathrm{~mm}$. wide; pistillate spikes 2 or 3 , approximate or the lowest remote, rather closely 8-20-flowered; scales strongly hyaline-margined; perigynia 2.5-3 mm. long. Dry soil: Ont.-N.Y.-Ill.-S.D.-Sask. Mont.Boreal. My-Je.

28. Albae Aschers. \& Graebner. With long slender stolons. Culms very slender, obtusely triangular, leafy near the base. Leaf-blades of the fertile culm very narrow, involute. Terminal spike linear, staminate. Lateral spikes 2-3, oblong or linear, loosely 4-8-flowered, all long-peduncled, linear or oblong, often overtopping the staminate one. Bracts sheathing, subspathaceous, bladeless, white-hyaline above. Scales white-hyaline, yellowish tinged. Perigynia erect, obovoid, triangular, glabrous, nerved, tapering at the base, abruptly minutely beaked, the orifice entire, hyaline. Achenes triangular, closely enveloped, the sides concave. Style-base very short, bulbous-thickened, jointed with the achene, Stigmas 3, long.

90. C. eburnea Boott. Culms 1-3.5 dm. high; leaf-blades $0.5 \mathrm{~mm}$. wide or less; staminate spike sessile, $3-8 \mathrm{~mm}$. long; perigynia membranaceous, obsoletely nerved, $2 \mathrm{~mm}$. long, exceeding the scales. Dry sandy or rocky soil, especially limestone rocks: N.B.-Va.-Tenn.-Neb.-B.C.-Mack. Plain-Mont.; Boreal. $\mathrm{My}-\mathrm{Au}$.

29. Bicolores Tuckerm. Stoloniferous. Culms central, slender, leafy towards the base. Leaf-blades narrow. Basal sheaths light brown. Terminal spike linear, staminate or occasionally gynaecandrous. Lateral spikes 2-5, pistillate, rather closely few-many-flowered in few ranks on erect exserted peduncles. Bracts sheathing, not colored or dark-auricled, the blades elongated, leaf-like. Scales reddish or purplish brown tinged. Perigynia ascending, broadly oval or ellipsoid, circular in cross-section, nerved, glabrous, goldenyellow or white-pulverulent at maturity, tapering or rounded at the base, essentially beakless. Achenes lenticular, apiculate, closely enveloped. Style-base slender, short, jointed with the achene. Stigmas 2.

91. C. Hassei Bailey. Culms 1.5-6 dm. high; leaf-blades 2-4 mm. wide; pistillate spikes 6-20-flowered; scales usually purplish brown tinged; perigynia 2.5-3 mm. long, slightly pointed, less than $2 \mathrm{~mm}$. wide; style becoming shortexserted and somewhat persistent. River banks and wet rocks: Lab.-Me.Pa.-Alta.-Utah-Calif.-Yukon. Boreal-Submont.-Son.

92. C. aurea Nutt. Culms $0.3-4 \mathrm{dm}$. high; leaf-blades $2-4 \mathrm{~mm}$. wide; pistillate spikes 4-20-flowered; seales usually reddish brown tinged; perigynia subumbonate, $2 \mathrm{~mm}$. wide; style not exserted or persistent. Wet places: Newf. -Conn.-Mich.-N.M.-Calif.-B.C. Plain-Subalp. Je-Jl.

30. Paniceae Tuckerm. Stoloniferous. Culms central, slender, leafy towards the base. Basal sheaths brownish or purplish tinged. Terminal spike staminate, linear or linear-oblong. Lateral spikes $1-5$, pistillate, loosely to rather closely several-many-flowered, in few or several ranks, on erect, exserted or included peduncles. Bracts sheathing, not colored or dark-auricled, the blades developed. Seales purplish or reddish brown tinged. Perigynia ascending or spreading, ovoid or obovoid, membranaceous, obtusely triangular, slightly inflated, glabrous, puncticulate, light or olive green, pointed or beaked, the orifice entire or nearly so. Achenes triangular. Style-base slender, continuous with achene. Stigmas 3 . 
93. C. livida (Wahl.) Willd. Culms $1.5-5 \mathrm{dm}$. high; leaf-blades $2 \mathrm{~mm}$. wide or less; pistillate spikes closely 5-15-flowered; perigynia $3.75 \mathrm{~mm}$. long, $1.75 \mathrm{~mm}$. wide, faintly nerved, narrowed above, exceeding the scales. Sphagnum bogs: Lab.-N.J.-Mich.-Calif.-B.C.-Alaska. Boreal. My-Jl.

94. C. tetanica Schk. Rootstocks elongate, deep-seated, slender; culms $1.5-6 \mathrm{dm}$. high, slender; culm-leaves usually $3-5,2-3.5 \mathrm{~mm}$. wide; staminate spike long-stalked; pistillate spikes 1-3, linear, 6-20-flowered, distant, erect or the lower filiform-stalked and drooping; perigynia $3 \mathrm{~mm}$. long, $2 \mathrm{~mm}$. wide, obtusely triangular, prominently many-nerved, abruptly minutely beaked; scales usually shorter than the perigynia, obtuse or mucronate. Meadows and wet woods: Mass.-D. C.-Mo.-Sask. Plain.

95. C. Meadii Dewey. Resembling the last, but stouter; culms $2-5 \mathrm{dm}$. high; culm-leaves usually $6-10,3-7 \mathrm{~mm}$. wide; staminate spike long-stalked; pistillate spikes 1-3, oblong, densely 8-30-flowered, distant, erect, the lower long-stalked; perigynia more than $3 \mathrm{~mm}$. long, $2 \mathrm{~mm}$. wide, obtusely triangular, prominently many-nerved, tipped with a minute slightly bent beak; scales obtuse to cuspidate. Meadows and prairies: N.J.-Ga.-Neb.-Sask. Plain.

96. C. vaginata Tausch. Culms 1:5-8 dm. high, weak; leaf-blades $2-5$ $\mathrm{mm}$. wide; pistillate spikes loosely $3-20$-flowered; perigynia $4 \mathrm{~mm}$. long, nearly $2 \mathrm{~mm}$. wide, faintly nerved, the orifice purplish tinged, 2-toothed; seales purplish tinged, exceeded by the perigynia. Boggy woods: Lab.-N.Y.-Minn.-B.C.Alaska. Mont.-Boreal. Je-Au.

31. Laxiflorae Kunth. Cespitose. Fertile culms mostly lateral, the sterile shoots leafy, conspicuous. Basal sheaths brownish- or purplish-tinged. Terminal spike staminate, linear. Lateral spikes 2-5, pistillate or androgynous, loosely to closely few-many-flowered, in few-several ranks, on erect to drooping, included or exserted peduncles. Bracts sheathing, the sheaths green or purplishtinged, the blades leaf-like or sometimes reduced. Scales green with hyaline margins or more or less colored. Perigynia ascending, membranaceous, triangular, usually nerved, closely enveloping the achene, glabrous or hispidulous, tapering at the base, short-beaked or beakless, the orifice entire. Achenes triangular. Style-base slender, continuous with the achene. Stigmas 3.

97. C. blanda Dewey. Culms 1.5-6 dm. high, pale green, brownish at base; sterile shoots developing conspicuous culms; leaf-blades $3-14 \mathrm{~mm}$. wide, the sheaths with much crisped margins; staminate spike short-stalked or sessile, the scales rarely reddish brown tinged; pistillate spikes $2-4$, oblong or linearoblong, rather closely 8-25-flowered, the upper two contiguous, sessile or nearly so, the lower distant and stalked; perigynia obovoid, $2.5-3 \mathrm{~mm}$. long, strongly nerved, contracted into a short, stout, outwardly bent beak; scales with broad white scarious margins, the lower strongly awned. Me.-Va.-Ark.-w S.D. Plain. My-J.

32. Granulares Bailey. Culms central, slender, leafy. Leaf-blades flat. Basal sheaths brownish. Terminal spike staminate, linear. Lateral spikes 2-4, pistillate, closely many-flowered in several ranks, erect, on more or less strongly exserted peduncles. Bracts sheathing, not colored or dark-auricled, the blades leaf-like. Scales ovate, pointed, slightly ferruginous. Perigynia ascending, elliptic to ovoid, membranaceous, glabrous, with many elevated nerves, suborbicular in cross-section, loosely enveloping the achene, rounded at the base, short-tapering and minutely beaked, the orifice entire or sub-emarginate. Achenes triangular, strongly apiculate, jointed with the slender style. Stigmas 3, short.

98. C. Shriveri Britton. Culms 1.5-7 dm. high; leaf-blades 4-16 mm. wide, somewhat glaucous; staminate spike short-stalked; bracts overtopping the culms, the ligules little elongated; perigynia narrowly obovoid, $2.5 \mathrm{~mm}$. long, $1.5 \mathrm{~mm}$. wide, the beak minute, entire; apiculation of the achene abruptly bent. Moist meadows: Me.-Va.-w S.D.-Sask. Boreal. Je-Jl.

99. C. Crawei Dewey. Culms from long creeping rootstocks, stiff, glabrous or nearly so, $0.7-4 \mathrm{dm}$. high; leaf-blades 2-4 mm. wide, rather stiff; bracts similar, 
short, rarely overtopping the spikes; staminate spike long-stalked; pistillate spikes 1-4, distant, oblong, 10-45-flowered, sessile or stalked; perigynia ovoid, ascending, obscurely many-nerved, 3-3.5 mm. long, suborbicular in cross-section, rounded at the base, tapering into a very short beak; scales obovate, obtuse to cuspidate. Meadows and banks, limestone regions: N.S.-N.J.-Tenn.Wyo.-Alta. $\mathrm{My}-J$.

33. Denmess Carey. Culms aphyllopodic, strongly purplish tinged at base, tufted, slender, leafy. Leaf-blades flat. Terminal spike normally staminate. Lateral spikes 2-5, elongated, narrowly linear, slender-peduncled, the lower drooping. Bracts green-sheathing, the blades leaf-like. Perigynia appressed or ascending, lanceolate to ovoid, membranaceous, obsoletely nerved, rather closely enveloping the achene, tapering to a well-developed conic beak, obliquely cut at orifice and strongly hyaline-tipped, at length bidentate. Achenes triangular, apiculate, jointed with the slender style. Stigmas 3.

100. C. assiniboinensis W. Boott. Culms 2.5-7.5 dm. high; leaf-blades 1-2 mm. wide; staminate spike long-stalked; pistillate spikes loosely 1-8-flowered; perigynia narrowly lanceolate, $6 \mathrm{~mm}$. long, $2 \mathrm{~mm}$. wide; scales lanceolate, scariousmargined, awned. Wet soil: Man.-Minn.-S.D.-N.D., doubtfully in our range. Plain. Je.

34. Capillares Aschers \& Graebner. Culms phyllopodic, light brown and leafy at base, tufted, very slender. Blades narrow. Terminal spike staminate. Lateral spikes 2-4, linear, drooping on long capillary peduncles, few-flowered in few ranks. Bracts green-sheathing, the blades developed. Perigynia appressed, ovoid, membranaceous, triangular, closely enveloping the achene, tapering into the slender conic beak, truncate and entire at orifice. Achene triangular, shortapiculate, jointed with the slender style. Stigmas 3.

101. C. capillaris I. Culms $0.5-6 \mathrm{dm}$. high, obtusely triangular, smooth; leaf-blades flat, 1-2 mm. wide; pistillate spikes 2-12-flowered; scales broadly hyaline-margined; perigynia $2.5-3 \mathrm{~mm}$. long, the beak straight. Greenl.-N.H.Mich.-Colo.-Utah.-Nev.-Alaska; Eurasia. Alp.-Subalp. J1-Au.

35. Longirostres Kükenth. Culms phyllopodic, tufted, leafy towards the base. Blades flat. Terminal spike staminate. Lateral spikes 2-5, linearoblong or oblong-cylindric, peduncled, many-flowered in several ranks. Bracts green-sheathing, the blades developed. Perigynia appressed to spreading, membranaceous, globose-triangular, somewhat inflated, prominently beaked, the apex bidentate, the teeth weak, scarious. Achenes triangular, apiculate, the apiculation very abruptly bent, jointed with the slender style. Stigmas 3.

102. C. Sprengelii Dewey. Culms $2.5-9 \mathrm{dm}$. high, roughish above, strongly fibrillose at the base: leaf-blades $2.5-4 \mathrm{~mm}$. wide; pistillate spikes 10 -40-flowered; scales acute to cuspidate; body of the perigynia $2.5-3 \mathrm{~mm}$. long, short-oblong, exceeded by the slender beak. C. longirostris Torr. Alluvial banks: N.B.N.J.-Colo.-Alta. Plain-Submont. My-JI.

36. Frigidae Fries. Culms phyllopodic, tufted, the leaves clustered near the base. Spikes staminate, pistillate, androgynous or gynaecandrous. Bracts green-sheathing, the blades developed or rudimentary. Scales dark tinged, usually with light midvein and margins. Perigynia appressed or ascending, flat to flattened-triangular, not inflated, dark tinged, beaked, the beak hyaline at orifice, more or less bidentate. Achenes triangular, short apiculate, jointed with the straight slender style. Stigmas 3.

103. C. misandra R. Br. Culms $3-40 \mathrm{~cm}$. high; leaf-blades $2-3 \mathrm{~mm}$. wide, much shorter than the culms; sheaths purplish tinged, the blades short; lateral spikes 1-3, filiform-stalked, drooping, 6-14 $\mathrm{mm}$. long, $4 \mathrm{~mm}$. wide, closely 5-20flowered; scales blackish, with narrow hyaline margins; perigynia lanceolate, narrowed at both ends, serrulate above. High summits or aretic regions: Greenl. -Ont.-Alaska; Colo.; aretic Eurasia. Aret.-Alp. JI-S.

104. C. luzulina Olney. Culms densely cespitose, 1.5-7.5 dm. high; leaves in a basal rosette, the blades soon spreading, $3-7 \mathrm{~mm}$. wide, stiff; spikes $3-6$, the 
upper clustered, the lower widely separated, on long-exserted peduncles, the lateral pistillate, $6-8 \mathrm{~mm}$. wide, linear, not compound at base; seales dark reddish brown or black, obtuse or acutish; perigynium body compressed-triangular, closely enveloping achene, 3.75-5 mm. long, not inflated or hispidulous, contracted into the short, sparingly ciliate-serrulate, shallowly bidentate beak. C. ablata Bailey. C. owyheensis A. Nels. Mountain meadows and bogs: Mont.-Wyo.-Calif.B.C. Mont. -Subalp. Je-Au.

105. C. fissuricola Mackenzie. Culms 5-8 dm. high; leaves mostly clustered at the base, the blades 3-6 mm. wide, 7-14 cm. long; terminal spike sessile or short-stalked, often slightly pistillate; lateral spikes 4-5, the upper contiguous and sessile or short-peduncled, the lower separate and strongly peduncled; scales ovate, acute to cuspidate, brown, with lighter midrib conspicuous to apex, sparsely hairy when young; perigynium body narrowly ovate, much flattened, loosely enveloping the achene, $5 \mathrm{~mm}$. long, $2 \mathrm{~mm}$. wide, sparsely hairy when young, remotely ciliate-serrulate on the margins, contracted into a shallowly bidentate beak. C. luzulaefolia W. Boott, in part. Mountain meadows: (? Utah) Nev.-Calif. Mont.-Subalp.

106. C. petricosa Dew. Stoloniferous; culms $1.5-2 \mathrm{dm}$. high, obtusely triangular, smooth; leaf-blades $2 \mathrm{~mm}$. wide; spikes $3-5$, oblong, $10-15 \mathrm{~mm}$. long, closely flowered, the lower slender-peduncled; scales dark brown with hyaline margins; perigynia several-nerved, hispidulous, $4.5-5 \mathrm{~mm}$. long, the orifice of the beak obliquely cut. Mountain summits: B.C.-Alta. Alp.

107. C. Franklinii Boott. Stoloniferous; culms 6-9 dm. high, obtusely triangular, smooth; leaf-blades $2 \mathrm{~mm}$. wide; spikes $5-8$, oblong, $1.2 \mathrm{~cm}$. long, closely flowered, the lower slender-peduncled; scales brown with hyaline margins; perigynia with slender nerves, $4.5-5 \mathrm{~mm}$. long, rough on the margins, the beak with obliquely cut orifice, becoming bidenticulate. Mountain summits: Canadian Rocky Mts. (About Lat. $56^{\circ}$.) Alp.

37. Pallescentes Fries. Culms aphyllopodic, tufted, leafy towards the base. Leaves pubescent. Terminal spike staminate, linear. Lateral spikes pistillate, closely $10-30$-flowered in several rows. Bracts leaf-like, sheathless or nearly so. Perigynia green, rounded-triangular in cross-section, enveloping the achene, many-nerved, glabrous, rounded at the base, beakless or short-beaked. Achenes triangular, apiculate, the style thick, very short. Stigmas 3.

108. C. abbreviata Prescott. Culms 2.5-5 dm. high; leaflet-blades $1.5-3 \mathrm{~mm}$. wide; pistillate spikes 1-3, short-oblong, 6-16 mm. long, $6 \mathrm{~mm}$. wide, sessile or short-stalked, approximate; perigynia obovoid, $2.5-3 \mathrm{~mm}$. long, strongly nerved, depressed at the apex, tipped by a short slender entire beak. C. Torreyi Tuckerm. Dry soil: Man.-Minn.-Colo.-Sask. Plains-Submont. Je-Jl.

38. Anomalae Carey. Culms stout, leafy. Leaf-blades broad, flat, glabrous, not septate-nodulose. Terminal spike staminate, linear. Lateral spikes pistillate, linear-cylindric, scattered, closely many-flowered in several rows. Bracts leaf-like, sheathless. Perigynia ascending or in age spreading, obovoid, small, 2.5-4 mm. long, olive-green, nerved, tapering at the base, triangular, slightly inflated, abruptly beaked, the beak conic, shallowly bidentate. Achenes triangular, subapiculate, the style short, thickish, Stigmas 3.

109. C. amplifolia Boott. Stoloniferous; culms 5-10 dm. high, sharply triangular; sheaths hispidulous; leaf-blades 8-18 $\mathrm{mm}$. wide; pistillate spikes short-peduncled or nearly sessile, $3.5-8 \mathrm{~cm}$. long, 6-7 mm. wide; scales acute to mucronate; perigynia $3 \mathrm{~mm}$. long, nerveless except for the keels, glabrous. Wet soil: B.C.-Ida.-Calif. Submont. Je-Au.

39. Limosae Tuckerm. Culms slender, leafy below. Leaf-blades narrow. Terminal spike staminate, linear. Lateral spikes 1-4, pistillate, distant, oblong, closely several-many-flowered in several ranks, drooping, on slender peduncles. Bracts leaflet-like, essentially sheathless (in our species). Perigynia appressed, coriaceous, ovoid, or elliptic, glaucous, papillose, beakless or nearly so. Achenes triangular, closely enveloped, the style short, straight, exserted, its base not enlarged. Stigmas 3. 
110. C. limosa L. Culms $1.5-6 \mathrm{dm}$. high, sharply triangular; pistillate spikes 1-2.5 cm. long, 5-8 mm. thick, 8-30-flowered; scales acute or short-cuspidate; perigynia broadly ovate, flattened, 2-edged, $2.5 \mathrm{~mm}$. long, $2 \mathrm{~mm}$. wide, several-nerved. Sphagnum bogs: Lab.-N.J.-Ia.-Mont.-Wash.-Alaska; Eurasia. Boreal-Mont. My-Au.

111. C. paupercula Michx. Culms 1-8 dm. high, sharply triangular; pistillate spikes $0.5-2 \mathrm{~cm}$. long, 4-8 mm. thick, 6-25-flowered; scales long-acuminate or awned; perigynia subglobose, $2.5-3 \mathrm{~mm}$. long, $2.25 \mathrm{~mm}$. wide, fewnerved. C. magellanica Am. auth. Sphagnum bogs: Newf.-Pa.-Minn.-Colo. -Utah-Alaska; Eurasia. Submont.-Mont. Au.

112. C. Buxbaumii Wahl. Densely cespitose; culms $2-9 \mathrm{dm}$. high, slender but stiff, strongly reddish-purple at base; leaf-blades $2-4 \mathrm{~mm}$. wide; spikes $8-40$ $\mathrm{mm}$. long, $8 \mathrm{~mm}$. wide, the perigynia numerous, $3-4 \mathrm{~mm}$. long, glaucous-green, lightly many-nerved, the apex minutely bidentate; scales awned, exceeding the perigynia. C. Holmiana Mackenzie. Bogs: Greenl-Ga.-Ark.-Colo,-Calif. -Alaska; Eurasia. Mont.-Submont. My-Jl.

40. Atratae Kunth. Culms leafy below. Terminal spike staminate or gynaecandrous, the lateral 1-10, normally pistillate, from sessile, erect, and closely approximate, to long-peduncled, nodding, and distant. Bracts sheathless or nearly so, dark-colored at the base, the blades short. Scales dark-tinged. Perigynia membranaceous, straw-colored, often dark-tinged, elliptic to broadly obovate, circular in cross-section to much flattened, papillose to puncticulate, glabrous, abruptly short-beaked or beakless, the orifice entire or bidentate. Achenes triangular, the style slender, straight, often exserted, its base not enlarged. Stigmas 3.

113. C. Parryana Dewey. Stoloniferous, the culms $1-3.5 \mathrm{~cm}$, high, fibrillose at the base; leaf-blades $2.5-4 \mathrm{~mm}$. wide; spikes $1-5$, often all pistillate, or the terminal staminate below or throughout, the lateral oblong or linear-oblong, erect, approximate; scales obtuse to mucronate, concealing the perigynia; perigynia $2.5 \mathrm{~mm}$. long, $2 \mathrm{~mm}$. wide, flattened and sharp-edged, lightly few-nerved, the beak minute, bidenticulate. C. Elrodi M. E. Jones. Mountain meadows: Hudson Bay-N.D.-Colo.-Alta. Plain-Mont. My-Jl.

114. C. idahoa Bailey. Culms $2-3.5 \mathrm{dm}$. high, fibrillose at the base; leafblades 2-4 $\mathrm{mm}$. wide, flat; spikes usually 3 , approximate, erect, the terminal staminate above, the lateral pistillate, 1-2 cm. long, 4-6 mm. wide; scales ovate to lanceolate, acuminate, concealing the perigynia; perigynia $3 \mathrm{~mm}$. long, $2 \mathrm{~mm}$. wide, faintly nerved, the beak $1 \mathrm{~mm}$. long, bidenticulate. Mountain meadows: Mont.-Ida. Mont. Jl.

115. C. podocarpa R. Br. Culms aphyllopodic, triangular, slender, nearly smooth, 2-4 dm. high, from elongated tough rootstocks; leaf-blades $2-4 \mathrm{~mm}$. wide; pistillate spikes 2-4, drooping, oblong or linear-oblong, 1-2 cm. long, 4.5-6 $\mathrm{mm}$. wide, closely 15-30-flowered; perigynia ovate, flat, $4 \mathrm{~mm}$. long, $2 \mathrm{~mm}$. wide; achene stipitate. C. montanensis Bailey. Mountain sides and meadows: Alaska -Alta.-Mont.-Ida. Mont.-Subalp. J-Au.

116. C. venustula Holm. Culms sharply triangular, slender, nearly smooth, 2-5 dm. high, from stout rootstocks; leaf-blades erect-ascending, 2-4 $\mathrm{mm}$. wide; pistillate spikes 1-3, drooping, oblong or linear-oblong, $0.5-2 \mathrm{~cm}$. long, 4.5-7.5 mm. wide, closely 10-30-flowered; perigynia oblong-elliptic, flat, $4 \mathrm{~mm}$. long, $1.5 \mathrm{~mm}$. wide, sub-stipitate, exceeding the scales; achene short-stipitate. Mountains: Alta.-Alaska. Subalp. Л-Au.

117. C. spectabilis Dewey. Culms aphyllopodie, sharply triangular, 2.5-5 dm. high, from densely matted tough rootstocks; leaf-blades $2-3.5 \mathrm{~mm}$. wide; pistillate spikes 2-4, oblong, 1-2 $\mathrm{cm}$. long, $3.5-5 \mathrm{~mm}$. wide, closely $15-30-$ flowered; perigynia flat, $4 \mathrm{~mm}$. long, $2 \mathrm{~mm}$. wide; achene short-stipitate. $C$. nigella Boott. C. invisa Bailey. Mountains and meadows: Alaska-Mont.Calif. Mont.-Alp. Jl-S.

118. C. Tolmiei Boott. Culms phyllopodic, sharply triangular, rough above, $2.5-5 \mathrm{dm}$. high, from densely matted tough rootstocks; leaf-blades $2.5-$ 
$4.5 \mathrm{~mm}$. wide; pistillate spikes 3-6, oblong-cylindric, $1-3 \mathrm{~cm}$. long, 4-6 mm. wide, somewhat attenuate at the base, closely many-flowered; perigynia flat, $3 \mathrm{~mm}$. long; achene short-stipitate. Mountains: Alta.-Wyo.-Ida.-Wash. Mont. -Subalp. J1-Au.

119. C. Raynoldsii Dewey. Culms 2-4 dm. high, stout; rootstocks stout, stoloniferous; leaf-blades $3-8 \mathrm{~mm}$. wide; pistillate spikes 2 or 3 , approximate or the lowest separate, peduncled, erect, oblong, 1-2 $\mathrm{cm}$. long, 7-8 mm. wide, closely 15-40-flowered; scales blackish, with light midvein, exceeded by the perigynia; perigynia oblong-oval, round in cross-section, $4.5 \mathrm{~mm}$. long, $2 \mathrm{~mm}$. wide, the short beak bidentate. C. aboriginum M. E. Jones. Mountain meadows and bogs: Alta.-Colo.-Calif.-Wash. Mont.-Subalp. Je-Au.

120. C. Halleri Gunn. Culms 1.5-6 dm. high, slender; leaf-blades $1-3 \mathrm{~mm}$. wide; spikes 2-4, clustered, erect, sessile or short-peduncled, 4-10 mm. long, closely 8-25-flowered; scales black, shorter than the perigynia; perigynia minutely bidentate. C. alpina Sw. Rocky places: Greenl.-Ont.-N.M.-Alaska; Eurasia. Alp.-Mont. Jl-Au.

121. C. Nelsonii Mackenzie. Culms 2-4 dm. high, stiff, smooth, erect, fibrillose at base; leaf-blades 3-4 mm. wide; spikes 2 or 3 , oblong or obovoid, $10-12 \mathrm{~mm}$. long, 5-8 mm. wide, the lateral densely 15 -35-flowered; scales black, the midvein obsolete; perigynia $4 \mathrm{~mm}$. long, $1.5 \mathrm{~mm}$. wide, roughened on edges above, the conspicuous black beak sharply bidentate. Mountain meadows: Wyo.-Colo. Subalp.-Alp. JI-Au.

122. C. albo-nigra Mackenzie. Culms $1.5-3 \mathrm{dm}$. high, stiff, roughened above, slightly fibrillose at the base; leaf-blades $3 \mathrm{~mm}$. wide; spikes usually 3 , the lateral narrowly oblong, 8-10 mm. long, $4 \mathrm{~mm}$. wide, elosely 8-15-flowered, the terminal spike larger; scales with nearly obsolete midvein; perigynia blackish, $3 \mathrm{~mm}$. long, $2 \mathrm{~mm}$. wide, minutely roughened on margins. Mountain meadows: Mont.-Colo.-Ariz.-Utah. Subalp.-Alp. Jl-Au.

123. C. nova Bailey. Culms $1.5-6 \mathrm{dm}$. high, stiff, little roughened, fibrillose at the base; leaf-blades $2.5-5 \mathrm{~mm}$. wide; spikes $2-4$, broadly ovoid, $7-12 \mathrm{~mm}$. long, 6-10 mm. wide, closely flowered; scales with inconspicuous midvein; perigynia blackish, 3-4 mm. long, 2-3.5 mm. wide, minutely roughened on the margins. Mountain meadows: Mont.-N.M.-Utah-Ida. Mont-Alp. Je-Au.

124. C. atrosquama Mackenzie. Culms 3-4.5 dm. high, slender, often nodding, little roughened, slightly fibrillose at the base; leaf-blades $2.5-3.5 \mathrm{~mm}$. wide; spikes 3-4, approximate, the lower 1-2 slender-peduncled, oblong, 6-12 mm. long, $5 \mathrm{~mm}$. wide densely $15-30$-flowered; scales black with obsolete midbase, abruptly minutely beaked. Mountain meadows: Alta.-Mont.-Ida.B.C. Mont. Jl-S.

125. C. bella Bailey. Culms 5-9 dm. high, slender, nodding, roughened above; leaf-blades $3-6 \mathrm{~mm}$. wide; spikes $3-4$, gynaecandrous, $1-3 \mathrm{~cm}$. long, 4-6 $\mathrm{mm}$. wide, 15-30-flowered; scales brownish black, mostly shorter than the perigynia; perigynia green or olive-green, $4 \mathrm{~mm}$. long, $2 \mathrm{~mm}$. wide, rounded at the ends. Mountain meadows: Colo.-N.M.-Ariz.-Utah. Mont.-Alp. J1-Au.

126. C. atratiformis Britton. Culms $3-9 \mathrm{dm}$. high, slender, often nodding, roughened above, slightly fibrillose at the base; leaf-blades $3 \mathrm{~mm}$. wide; spikes 3-4, oblong, 1-2.5 cm. long, 4-6 mm. wide, closely 10-30-flowered; scales dark reddish brown; perigynia $2.5-3 \mathrm{~mm}$. long, $1.5 \mathrm{~mm}$. wide, rounded at the base, round-tapering at the apex. Along streams: Lab.-Me.-Alta.-Yukon. Mont.-Boreal. Je-Au.

127. C. chalciolepis Holm. Culms 2-7 dm. high, slender, smooth, or nearly so; leaf-blades 3-6 mm. wide, the uppermost bract-like, $2-6 \mathrm{~cm}$. below inflorescence; spikes 2-4, contiguous, oblong to broadly ovoid, 1-2 cm. long, 5-10 mm. wide, closely flowered in many rows; scales very thin, copper-colored, much narrower but longer than the perigynia, the midvein indistinet; perigynia 3-4 $\mathrm{mm}$. long, 2.5-3 mm. wide, with broadly oval or obovate body, rounded at ends; 
achenes short-stipitate. Mountain meadows: Mont.-Colo.-Ariz.-Nev.

128. C. atrata L. Culms $2-7 \mathrm{dm}$. high, sharply triangular, more or less roughened; leaves all towards culm base, the blades $2-8 \mathrm{~mm}$. wide; spikes $3-7$, at least the lowest separate, oblong or obovoid-oblong, 1-3 cm. long, 5-10 mm. wide, closely flowered in many rows; seales brownish black, narrower but mostly longer than the perigynia, the midvein indistinct; perigynia $3-3.5 \mathrm{~mm}$. long, oval; achenes $2 \mathrm{~mm}$. wide, granular-roughened, short-stipitate. Mountain meadows: Greenl.-Mont.-Wyo.-Alaska; Eurasia. Alp.-Subalp. Je-Au.

129. C. epapillosa Mackenzie. Culms $1.5-6 \mathrm{dm}$. high, stiff, sharply triangular, smooth; leaves all towards base of the culm, the blades $3-8 \mathrm{~mm}$. wide, nearly flat; spikes 3-6, approximate or the lowest a little separate, sessile or short-peduncled, oblong-obovoid, $1-2.5 \mathrm{~cm}$. long, 6-10 mm. wide, closely flowered in many rows; scales lance-ovate, sharp-pointed, brownish black, narrower than, but about equalling or exceeding the perigynia, the midvein more or less prominent; perigynia broadly oval or obovate, $3.5-4 \mathrm{~mm}$. long, $1.5-2 \mathrm{~mm}$. wide, obscurely nerved, not granular; achenes slender-stipitate. Mountain meadows: Wyo.-Utah-Calif. Mont.-Alp. Je-Au.

130. C. Mertensii Prescott. Culms $3-10 \mathrm{dm}$. high, sharply triangular, rough; leaf-blades flat, 4-7 mm. wide; spikes 1-4 cm. long, 7-10 mm. wide, gynaecandrous, the perigynia numerous, appressed-ascending; scales lance-ovate, acute, brown, with light midvein and margins; perigynia tapering at the apex, minutely beaked. Mountains: Alaska-Mont.-Calif. Mont.-Submont. Jl-

41. Acutae Fries. Culms leafy below, aphyllopodic or phyllopodic; terminal 1-several spikes staminate (rarely gynaecandrous), linear, the remaining pistillate, linear to cylindric or oblong, elosely many-flowered, sessile or peduncled. Bracts sheathless (rarely short-sheathing), leafy or squamiform, biauriculate and often darkened at the base. Perigynia membranaceous to coriaceous, plano- or bi-convex, or turgid, elliptic to obovate, puncticulate, margined, beakless or abruptly minutely beaked, the orifice entire to deeply bidentate. Achenes normally lenticular. Style slender, straight, sometimes exserted, its base not enlarged. Stigmas normally 2.

131. C. concolor $\mathrm{R}$. Br. Culms 1-5 dm. high, smooth; leaf-blades 3-7 $\mathrm{mm}$. wide, with revolute margins; terminal spike staminate, linear; lateral spikes short-stalked; scales obtuse or acutish, blackish with lighter midvein; perigynia $2.5-3 \mathrm{~mm}$. long, nerveless or nearly so, the orifice entire. C. rigida Good. C. Bigelovii Torr. Aretic-alpine regions: Greenl.-N.H.-Alta.-B.C.-Alaska;
Eurasia. Alp.

132. C. scopulorum Holm. Loosely stoloniferous; culms 1-4 dm. high, sharply triangular, smooth; leaf-blades $3-7 \mathrm{~mm}$. wide, with revolute margins; terminal spike androgynous or staminate; lateral spikes $2-3$, approximate, erect, sessile or short-stalked, pistillate or androgynous, $1-2.5 \mathrm{~cm}$. Iong, $6-7 \mathrm{~mm}$. wide; scales obtuse, black, the midvein obsolete; perigynia $2.5-3.5 \mathrm{~mm}$. long, with short but prominent beak, nerveless. Mountains: Mont.-Colo.-Wash.

133. C. chimaphila Holm. Loosely cespitose and stoloniferous; the culms 1-4 dm. high, scabrous, flattened, triangular; leaf-blades light green, 3-5 $\mathrm{mm}$. wide, with slightly revolute margins; spikes $3-4$, the upper approximate and sessile or short-peduncled, the lowest more distant, peduncled, the terminal staminate or androgynous, the lateral pistillate or androgynous, $1-3 \mathrm{~cm}$. long, 7-10 mm. wide; scales lanceolate, acute or acuminate, black, with lighter or obsolete midvein; perigynia $2.5-3.5 \mathrm{~mm}$. long, abruptly minutely beaked. Possibly merely a form of C. scopulorum Holm. Mountain slopes: Mont.-Colo.
Alp.-Subalp. Jl-Au.

134. C. aperta Boott. Stoloniferous; the culms 5-10 dm. high, sharply triangular, rough above; leaf-blades $2.5-5 \mathrm{~mm}$. wide; terminal spike staminate; 
lateral spikes 2-3, pistillate, sessile to slender-peduncled, approximate, 12-48 $\mathrm{mm}$. long, $5 \mathrm{~mm}$. wide; scales lanceolate, sharp-pointed; perigynia obovoid, nerveless, abruptly minutely beaked. Low ground: B.C.-Mont.-Utah-Calif. Submont. Je-S.

135. C. lenticularis Michx. Densely cespitose; culms $3-6 \mathrm{dm}$. high, somewhat roughened; staminate spikes $1-2$, often partly pistillate; pistillate spikes $2-5$, sessile or short-peduncled, approximate or lower remote, $1-5 \mathrm{~cm}$. long, 3-4 $\mathrm{mm}$. wide; scales obtuse, with broad light-colored center; perigynia $2.5 \mathrm{~mm}$. long, $1.5 \mathrm{~mm}$. wide, minutely beaked. River and lake shores: Lab.-Mass.-Minn. -Sask. Boreal. Je-S.

136. C. Kelloggii W. Boott. Cespitose; culms 3-7 dm. high, slender, somewhat roughened; staminate spike usually 1 ; pistillate spikes $3-5$, sessile or nearly so, approximate or slightly separate, linear, 1.5-4 cm. long, 4-6 mm. wide; scales obtuse or acutish, with broad light-colored center; perigynia $2.5 \mathrm{~mm}$. long, 1.25 $\mathrm{mm}$. wide, abruptly minutely beaked. C. vulgaris var. lipocarpa Holm. Alaska -Ida.-Colo.-Utah-Calif. Submont.-Mont. Je-Au.

137. C. aquatilis Wahl. Rootstock slender, stoloniferous; culms $2-7 \mathrm{dm}$. high, sharply triangular above, slender, reddened at the base; leaf-blades 2-4 mm. wide; staminate spikes 1-2, slender; pistillate spikes 2-4, sessile or shortpeduncled, separate, linear, 1.5-6 cm. long, 4-6 mm. wide; scales oblong-obovate to lanceolate, obtuse or acutish, blackish, 1-nerved; perigynia elliptic-obovate, $2.5 \mathrm{~mm}$. long, $1.25 \mathrm{~mm}$. wide, nerveless, but with a median ridge, sub-stipitate, puncticulate, reddish-dotted all over, granular, very minutely beaked. C. variabilis Bailey. C. rhomboidea Holm. Wet meadows and swamps: Lab.-Que.N.M.-Calif.-Yukon; Eurasia. Mont.-Subalp. Je-Au.

138. C. substricta (Kükenth.) Mackenzie. Cespitose and stoloniferous; culms 6-14 dm. high, sharply triangular, reddened at the base; leaf-blades often glaucous, 4-8 mm. wide; staminate spikes 2-3, slender; pistillate spikes $2-4$, sessile or short-peduncled, separate, linear, 2-7 cm. long, 4-6 mm. wide; seales lanceolate, sharp-pointed, reddish brown with broad light-colored center, narrower than the perigynia; perigynia $3 \mathrm{~mm}$. long, obovate, tapering to the stipitate base, obscurely nerved, but the marginal nerves prominent, resinousdotted, abruptly very minutely beaked. C. aquatilis Am. auth., not Wahl. Swamps: Me.-N.Y.-Neb.-Sask. Plain. Je-Au.

139. C. nebraskensis Dewey. Rootstocks creeping and stoloniferous; culms 2.5-10 dm. high; leaf-blades 4-8 mm. wide, flat; staminate spikes 1-2; pistillate spikes $2-5$, sessile or short-peduncled, $1.5-6 \mathrm{~cm}$. long, 6-9 mm. wide, contiguous or the lower separate; scales lanceolate, obtusish to acuminate, blackish with light midvein; perigynia ascending, $3-3.5 \mathrm{~mm}$. long, $2 \mathrm{~mm}$. wide, rounded at the base. Meadows and swamps: S.D.-Kans.-N.M.-Calif.B.C. Plain $\longrightarrow$ Submont. My-Jl.

140. C. Emoryi Dewey. Cespitose, long stoloniferous; culms 5-10 dm. high, sharply triangular, rarely reddened at the base; leaf-blades green, $3-7 \mathrm{~mm}$. wide; staminate spikes 1-3, slender; pistillate spikes 2-4, sessile or short-peduncled, more or less strongly separate, narrowly linear, 4-10 $\mathrm{cm}$. long, 3-5 mm. wide; scales lanceolate, sharp-pointed, with broad light-colored center and hyaline margins, narrower than the perigynia; perigynia very numerous, oval or ovate, $2.5 \mathrm{~mm}$. long, rounded at the base, sessile or substipitate, few-nerved, the marginal nerves not prominent, puncticulate, abruptly minutely but noticeably beaked. Swales and river banks: N.J.-D.C.-Tex.-N.M.-Colo.N.D.-Man. Plain-Submont.

141. C. prionophylla Holm. Rootstocks thick; culms 5-9 dm. high, strongly aphyllopodic and reddened at base, wing-angled and serrulate; leaf-blades lateral pistillate, contiguous or the lower separate, sessile or short-peduncled, 1-2 cm. long, 3-4 $\mathrm{mm}$. wide; lowest bract dark-auricled; seales oblong-ovate; perigynia appressed, $2.5 \mathrm{~mm}$. long, obovate, green, obscurely nerved, abruptly minutely beaked. Mountain streams: Ida.-Wash. Submont. Jl. 
42. Hrrtae Tuckerm. Culms stout, leafy. Rootstocks with long stolons. Leaves septate-nodulose. Spikes 3-10, the upper 1-5 staminate, slender, the others pistillate, many-flowered, erect. Bracts leaf-like, equalling or exceeding the culm, often sheathing. Pistillate scales acute or aristate, ovate or lanceolate. Perigynia mostly ascending, coriaceous, ovoid or oblong-ovoid, somewhat inflated, nearly orbicular in cross-section, many-nerved, of ten hairy, round-tapering at the base, tapering into a bidentate beak. Achenes triangular, often stipitate, the faces flat or deeply concave, apiculate, continuous with the straight or slightly flexuous slender style. Stigmas 3.

142. C. lacustris Willd. Culms stout, purplish-tinged and filamentose at the base, 6-12 dm. high; leaf-blades 5-12 mm. wide, somewhat glaucous; staminate spikes 1-5, slender; pistillate spikes 2-5, 3-10 cm. long, $1 \mathrm{~cm}$. wide; scales purplish tinged, acute to aristate; perigynia ovoid, $6 \mathrm{~mm}$. long, $2.5 \mathrm{~mm}$. wide, strongly nerved. In swamps: Newf.-Del.-Ia.-Man.-Ida. Boreal. Je-Jl.

143. C. lanuginosa Michx. Culms stoutish, more or less reddened and filamentose at the base, $6-9 \mathrm{dm}$. high, sharp-angled and rough above; staminate spikes 1-3, distant; pistillate spikes $1-3,1-5 \mathrm{~cm}$. long, $5-7 \mathrm{~mm}$. wide; scales acuminate or aristate; perigynia ovoid, the beak bidentate. C. Watsoni Olney. Swampy places: N.S.-D.C.-Mo.-N.M.-Calif.-B.C. Plain-Mont. Je-

144. C. lasiocarpa Ehrh. Culms slender but stiff, strongly reddened and filamentose at the base, 6-9 dm. high, obtusely angled, smooth; staminate spikes 1-3, distant; pistillate spikes $1-3,1-5 \mathrm{~cm}$. long, 5-7 mm. wide; scales acute or short-awned; perigynia oval-ovoid, $2 \mathrm{~mm}$. wide, the beak bidentate. $C$. filiformis Auth., not L. Swamps: Newf.-N.J.-Ia.-Colo.-Ida.-B.C.; Eurasia.
Plain-Submont.

145. C. Houghtonii Torr. Long-stoloniferous; culms stoutish, $3-8 \mathrm{dm}$. high; leaf-blades 3-7 mm. wide; staminate spikes 1-3, distant; pistillate spikes 2 or $3,1-4 \mathrm{~cm}$. long, $7-12 \mathrm{~mm}$. wide, rather loosely $15-35$-flowered; scales lance-
olate, short-awned; perigynia ovoid, $3 \mathrm{~mm}$. wide. Sandy or rocky soil: N.S.-
Me.-Minn Me.-Minn.-Sask. Boreal. My-Au.

146. C. laeviconica Dewey. Culms 6-12 dm. high, very rough above; leaf-blades 3-6 mm. wide, glabrous; sheaths puberulent towards the top, breaking and becoming filamentose; staminate spikes 2-6, distant; pistillate spikes 2-4, ovoid, glabrous, 8-10 mm. long, 3-4 mm. wide. Marshes: Ill.-Man.-Mo.Kans,-Mont.-Sask. Plain. My-Jl. 147. C. atherodes Spreng. Culms stout, $6-15 \mathrm{dm}$. high, often roughish
above; leaf-blades $5-12 \mathrm{~mm}$. wide, often pubescent beneath, as are the sheaths; staminate spikes 2-6, distant; pistillate spikes $3-5$, densely flowered except at the base, $3-10 \mathrm{~cm}$. long, $12-16 \mathrm{~mm}$. wide; perigynia $8-12 \mathrm{~mm}$. long. C. aristata R. Br. Marshes: N.Y.-Mo.-Colo.-Utah-Ore-Yukon. Plain-Submont.
Je-S.

148. C. Sheldonii Mackenzie. Strongly stoloniferous; culms very smooth below the spikes, 6-9 dm. high, neither bright-colored nor fibrillose at the base; leaves about four, the blades 5-6 mm. wide, 2-4 dm. long (or longer on sterile shoots), sparingly short-pubescent, as are the sheaths, the latter dark-tinged at the mouth, the basal breaking and slightly filamentose; staminate spikes 2-3, distant; pistillate spikes usually 2 , widely separate, sessile or short-peduncled, oblong-cylindric, 2-5 cm. long, 8-10 mm. wide, rather closely 25-60-flowered; perigynia 5-6 mm. long, short-pubescent, the beak bidentate, the teeth less than $1 \mathrm{~mm}$. long; scales ovate-lanceolate, acuminate or cuspidate. Swamps: Calif.

43. Extensae Fries. Culms slender, but strict, obtusely triangular, leafy towards the base. Leaves septate-nodulose, the blades narrow. Spikes 2-10, normally the terminal staminate, the others pistillate, suborbicular to oblong, densely flowered, $3 \mathrm{~cm}$. or less long, the upper sessile and approximate, the lower remote, peduncled, erect. Bracts leafy, more or less sheathing. Pis- 
tillate scales ovate, mostly reddish, copper- or chestnut-tinged. Perigynia ascending, spreading or deflexed, membranaceous, smooth, many-nerved, somewhat inflated, obscurely triangular, rounded at the base, contracted into a bidentate beak, the teeth very erect. Achenes triangular, with flat faces, continuous with the very slender erect or flexuous style. Stigmas 3.

149. C. viridula Michx. Densely cespitose, not yellowish green, the culms 0.7-4 dm. tall, smooth, bluntly triangular; leaf-blades $1.5-3 \mathrm{~mm}$. wide, canaliculate, the sheaths not prolonged at throat; staminate spike sessile or short-peduncled; pistillate spikes 2-10, aggregate or the lower separate and exsertpeduncled, 4-12 $\mathrm{mm}$. long, 4-7 $\mathrm{mm}$. wide; scales ovate, much shorter than the perigynia, obtuse or acutish; perigynia whitish-tipped, tapering at the base. $C$. Oederi Am. auth., in part. Lake and river banks: Newf.-N.J.-N.D.-Colo.Utah-B.C.-Calif. Plain-Mont. Je-Au.

150. C. flava L. Yellowish green; culms $1.5-6 \mathrm{dm}$. tall, smooth or nearly so; leaf-blades $2-5 \mathrm{~mm}$. wide; staminate spike sessile or stalked; pistillate spikes 1-4, aggregated or the lower separate, 6-18 $\mathrm{mm}$. long, 9-12 mm. wide; scales ovate, strongly reddish tinged, conspicuous at maturity; perigynia $5-6 \mathrm{~mm}$. long, the beak deflexed, reddish-tipped. Wet meadows: Newf.-N.J.-Ohio-Mont. -B.C. Mont.-Submont. Je-S.

44. Pauciflorae Tuckerm. Long-stoloniferous. Culms slender. Leafblades narrow. Spike solitary, androgynous, bractless, narrow. Pistillate scales soon falling. Perigynia few, short-stipitate, soon widely spreading or reflexed, obscurely triangular, straw-colored, subulate-beaked, obliquely cut. Achenes triangular, linear-oblong. Stigmas 3.

151. C. microglochin Wahl. Culms $8-25 \mathrm{~cm}$. high, smooth; culm-leaves 4-8; pistillate scales very quickly deciduous; perigynia $3-12,4-6 \mathrm{~mm}$. long, obscurely nerved, smooth. Arctic-alpine localities: Greenl,-Ont.-Alta.B.C.; reported from Colo.; Eurasia. Alp. Jl-Au.

152. C. pauciflora Lightf. Culms $10-25 \mathrm{~cm}$. high, rough on the angles; culmleaves 2-3; perigynia $1-6,6-7 \mathrm{~mm}$. long, obscurely several-nerved, smooth. Sphagnum swamps: Newf.-N.Y.-Mich.-Wash.-Alaska; Eurasia. (Not definitely known from our range.) Boreal-Mont. Je-Au.

45. Pseudo-Cypereae Tuckerm. Culms tall, generally stout, acutely angled, leafy below. Leaf-blades flat, septate-nodulose. Spikes 3-9, the upper 1-3 slender, staminate, the others normally pistillate, densely flowered, the upper approximate, the lower remote and strongly peduncled, often nodding. Bracts leaf-like, much exceeding the culms, mostly not sheathing. Pistillate scales aristate. Perigynia spreading or reflexed, membranaceous or stiff, triangular or circular in cross-section, 3-8 mm. long, closely many-ribbed, greenish strawcolor, smooth, stipitate, contracted into a rigid, slender beak. Achenes triangular, continuous with the slender often flexuous style. Stigmas 3, short.

153. C. hystricina Muhl. Culms 3-9 dm. tall, reddened at the base, rough above; leaf-blades $3-8 \mathrm{~mm}$. wide; staminate spike slender-stalked, the scales rough-awned; pistillate spikes 1-4, densely many-flowered, 1-6 cm. long, 10-14 $\mathrm{mm}$. wide, the lower slender-stalked; scales rough-awned; perigynia 5-6 mm. long, 15-20-nerved. Swampy soil: Newf.-Ga.-Tex.-Ariz.-Calif.-Alta. Plain. Je-Au.

154. C. comosa Boott. Culms stout, up to $15 \mathrm{dm}$. tall, sharply angled; leaf-blades 6-14 mm. wide; staminate spike as in the last; pistillate spikes as in the last but $12-14 \mathrm{~mm}$. wide; seales very rough-awned; perigynia rigid, closely many-ribbed, reflexed when mature. Swamps: N.S.-Minn.-Fla.-La.; Calif.-Wash.-Ida. Plain-Submont. Je-Au.

46. Physocarpae Drejer. Culms mostly tall and stout, leafy below. Leaves not hairy, septate-nodulose. Spikes 2-10, the upper 1-5 staminate, the others normally pistillate, subglobose to linear-cylindric, generally closely manyflowered, erect, short-peduncled, more or less remote. Bracts leaf-like, much 
exceeding the inflorescence, normally sheathless. Perigynia ascending, spreading, or even reflexed, membranaceous, smooth, from little to much inflated, suborbicular in cross-section, coarsely many-ribbed or nerveless, contracted into a beak, the beak entire to bidentate. Achenes much shorter than the perigynia, triangular or lenticular, continuous with the usually tortuous style. Stigmas 3 or 2 .

155. C. miliaris Michx. Culms 3-6 dm. tall, smooth, little filamentose at the base; leaf-blades $2 \mathrm{~mm}$. wide; staminate spikes 1 or 2 ; pistillate spikes $1-3$, oblong-cylindric, 8-25 mm. long, 5-7 mm. wide; perigynia at most faintly nerved, 2-3 mm. long, exceeding the scale. Border of lakes and streams: Lab.-Me.B.C. Boreal. Jl-Au.

156. C. saxatilis L. Culms $3-8 \mathrm{dm}$. tall, more or less roughened; leaf-blades 1.5-3.5 mm. wide; staminate spikes 1 or 2 ; pistillate spikes 1 or 2 , separate, oblongcylindric, $1.5-3.5 \mathrm{~cm}$. long, 6-8 mm. wide, closely $25-75$-flowered; scales ovatelanceolate, sharp-pointed, brownish with lighter midvein, hyaline at the apex; perigynia obscurely nerved, $4.5-5 \mathrm{~mm}$. long, $1.75-2.25 \mathrm{~mm}$. wide, exceeding the scales, minutely beaked. C. physocarpa Presl. Arctic and subaretic places: Colo.-Mack.-Alaska; Eurasia. Alp.-Mont. Je-Au.

157. C. oligosperma Michx. Long-stoloniferous; culms slender, 4.5-9 dm. high, exceeding the leaves; leaf-blades $3 \mathrm{~mm}$. wide, involute in age; staminate spike stalked, linear; pistillate spikes $1-2$, subglobose or short-oblong, mostly 5 -15-flowered; scales acute or slightly mucronate, much shorter than the perigynia; perigynia ovoid, inflated, strongly few-nerved, yellowish green, shining, $5 \mathrm{~m} \mathrm{n}$. long, $3 \mathrm{~mm}$. in diameter, the beak minutely bidentate. In bogs: Lab.Pa.-Ind. - Sask. Je-S.

158. C. Raeana Boott. Culms $3-6 \mathrm{dm}$. high, very slender, triangular and roughened above, reddened at the base; leaf-blades flat, $2 \mathrm{~mm}$. wide, little nodulose; staminate spikes 1 or 2 ; pistillate spikes $1-3$, narrowly cylindric, $1.5-5 \mathrm{~cm}$. long, $5 \mathrm{~mm}$. wide, short-peduncled; scales lanceolate, acuminate; perigynia 5-6 $\mathrm{mm}$. long, closely enveloping the achene, yellowish green, strongly few-nerved. (Probably a form of the next.) Lake and river shores: Me.-Que.-Sask.
Boreal. Je-Au.

159. C. vesicaria $\mathrm{L}$. Culms $3-9 \mathrm{dm}$. high, acutely angled and rough above; leaf-blades $3-6 \mathrm{~mm}$. wide; staminate spikes 2-4; pistillate spikes $1-3$, sessile or shor t-peduncled, erect, oblong-cylindric, $2.5-7 \mathrm{~cm}$. long, 6-15 mm. wide, manyflowered; scales ovate or lanceolate, acute, acuminate, or short-awned; perigynia 5-8 mm. long, yellowish green, 8-10-nerved. C. monile Tuckerm. Wet meadows and swamps: Que.-Pa.-Ohio-Calif.-B.C.; Eurasia. Plain. Je-Au.

160. C. exsiccata Bailey. Culms $3-10 \mathrm{dm}$. high, acutely triangular and rough above; leaf-blades $3-6 \mathrm{~mm}$. wide; staminate spikes $2-4$; pistillate spikes $1-3$, sessile or short-peduncled, erect, cylindric, 2-7 cm. long, 10-14 mm. wide, closely many-flowered; scales ovate, sharp-pointed; perigynia 7-9 mm. long, lanceolate, tapering into the beak, yellowish green, 8-10-nerved. " $C$. mirata Dewey" Holm. Wet places: Alaska-Mont.-Calif. Submont. Je-Au.

161. C. rostrata Stokes. Culms stout, 3-12 dm. high; leaf-blades $2-12 \mathrm{~mm}$. wide; staminate spikes $2-4$; pistillate spikes $2-4$, erect, cylindric, densely flowered, sessile or short-peduncled, 5-15 cm. long, 6-20 mm. wide; scales lanceolate, awned or acute; perigynia ovoid, spreading at maturity, few-nerved, 4-8 mm. long, abruptly beaked. C. utriculata Boott. Boggy places: Lab.-Del.-N.M. -Calif.-B.C.-Alaska; Eurasia. Plain-Mont. Je-S.

162. C. retrorsa Schw. Culms stout, $3-10 \mathrm{dm}$. high, smooth or slightly roughened above; leaf-blades $5-10 \mathrm{~mm}$. wide; staminate spikes $1-3$; pistillate spikes 3-8, contiguous and sessile or nearly so, or the lower distant and longstalked, cylindric, densely many-flowered, $2.5-7.5 \mathrm{~mm}$. long, $14-20 \mathrm{~mm}$. wide; scales lanceolate, acute or acuminate; perigynia ovoid, few-nerved, $7-10 \mathrm{~mm}$. long, places: Newf.-Pa.-Ia.-Colo.-Wash.-B.C. Plain-Submont. J1-O. 


\section{Family 14. ARACEAE. Arum Family.}

Fleshy, perennial, mostly acaulescent herbs, with rootstocks. Leaves basal, usually petioled, with broad, simple or rarely divided, reticulateveined blades, or narrowly linear with sheathing bases. Flowers perfect, monoecious or dioecious, borne in a dense fleshy spike (spadix); this subtended by or enclosed in a large foliaceous or colored bract (spathe). Perianth of scale-like members or wanting. Stamens $4-10$, with very short filaments and thick connectives. Gynoecium of a single carpel or of several united carpels. Ovaries 1-several-celled; stigmas terminal; ovules 1 to several in each cavity. Fruit a berry or a utricle.

Spadix terminal, with an oblong sheathing spathe; leaves petioled, with broad blades.

1. LYSICHITON,

Spadix borne somewhat laterally on the leaf-like scape; spathe leaf-like, continuous to the scape; leaves narrowly linear, equitant.

2. ACORUS.

\section{LYSÍChITON Schott. SKunk CabBage.}

Acaulescent perennial swamp plants, with short thick rootstocks. Leaves fleshy, petioled, with sheathing bases, the earlier reduced to merely inflated sheaths. Spathe sheathing at the base. Spadix cylindric, at last long-exserted. Flowers perfect, crowded. Perianth 4-lobed. Stamens 4, opposite. Pistil solitary; ovary 2-celled, 2-ovuled; stigma depressed. Ovules horizontal, orthotropous. Fruit fleshy.

1. L. kamtschatcensis Schott. Leaf-blades $3-7 \mathrm{dm}$. long, 7-25 cm. broad, elliptic to lance-oblong, acute at both ends; spathe oblong-lanceolate, 1-1.5 dm. long; peduncles $15-30 \mathrm{~cm}$. long; spadix 7-12 $\mathrm{cm}$. long, becoming 5-6 cm. thick. Swamps: Alaska-Mont.-Calif.; e Asia. Submont. My-Je.

\section{2. ácorus L. Sweet Flag, Calamus-root.}

Erect swamp plants, with long horizontal rootstocks. Leaves sword-shaped, equitant. Scapes 3-angled, bearing a lateral spadix and a foliaceous spathe, continuous with the scape. Flowers perfect, densely crowded on the spadix. Perianth with 6 membranous concave divisions. Stamens 6. Pistil solitary; ovary 2-4-celled, each 2-8-ovuled; stigma depressed-capitate. Fruit berry-like.

1. A. Calamus L. Leaves linear, erect, 5-20 dm. long, 1-2 cm. wide, longattenuate, 2-ranked; scape 1-2 $\mathrm{m}$. high; spathe $2-7.5 \mathrm{dm}$. long; spadix $5-7 \mathrm{~cm}$. long, about $1 \mathrm{~cm}$. thick, lance-cylindric; plant seldom fruiting. Swamps and streams: N.S.-Fla.-Tex.-Colo.-Ida.-Mont.; Eurasia. Plain. My-Jl.

\section{Family 15. LEMNACEAE. Duckweed Family.}

Minute floating perennial aquatics, consisting of a fleshy or membranaceous, loosely cellular thallus-like stem, without leaves and in our genera with one or more rootlets. The new stems or fronds are produced from two lateral depressions or pouches or a terminal one; the new frond being attached to the old one by a short, slender stalk, soon separating. Flowers very rare. Inflorescence consisting of 1 pistillate and 1 or 2 staminate flowers, borne on the edge on the upper surface of the frond. Staminate flower of a single stamen, with 2-4 pollen-sacks. Pistillate flowers of a single flasklike pistil, with 1-several ovules. Fruit a 1-6-seeded utricle.

Rootlets solitary, without a fibro-vascular bundle.

Rootlets several, each with a fibro-vascular bundle.

1. LEMNA.

2. SPIRODELA.

1. LËMNA L. DUCKWEED.

Frond disk-like, 1-5-nerved or nerveless. Stipe attached to the basal margins of the frond. Rootlet solitary, without fibro-vascular bundles. Anthers dehiscent transversely. 
Fronds long-stalked, mostly submerged, forming large masses

Fronds short-stalked or sessile, floating on the surface.

Frond pale and usually strongly gibbous beneath.

Fronds green or purplish, not gibbous beneath.

Frond oblong-obovate, indistinctly 3-nerved.

Frond oblong or elliptical, indistinctly 1-nerved or nerveless. Frond unsymmetrical, without papules.

Frond symmetrical, with a row of papules along the midvein 4 . L. cyclostasa.

1. L. trisulca.

2. L. gibba.

3. L. minor.

1. L. trisulca L. Fronds usually submerged, seldom floating, usually several generations attached together, oblong to oblong-lanceolate, slightly unsymmetrical and falcate, dentate towards the upper end, 5-10 mm. long, 2-3 mm. wide, In springs and running water: N.S.-N.J.-Tex.-Calif.-B.C.; Old World and Australia. Plain-Mont. Jl-Au.

2. L. gibba L. Fronds solitary or 2-4 in a group, orbicular to obovate, $2-5$ $\mathrm{mm}$. long and 2-4 mm. wide, thick, convex and slightly keeled above, with large air-cavities in the gibbous portion, unsymmetrical, 3-5-nerved. In ponds: Neb. -Tex.-Ariz.-Calif.; Mex.; Old World and Australia. Plain-Subalp.

3. L. minor L. Fronds solitary or a few together, round to oval, symmetrical, thickish, convex on both sides, sometimes slightly keeled above and with a row of papules along the midrib. In stagnant water and slow streams: Lab.-Fla.-Calif.-Alaska; Mex.; Old World and Australia. Plain-Mont.

4. L. cyclostasa (Eill.) Chev. Frond solitary or 2-8 in a group, oblong to obovate-oblong, usually somewhat falcate, $2.5-4.5 \mathrm{~mm}$. long, $1-1.5 \mathrm{~mm}$. wide, usually unsymmetrical at the base. L. valdiviana Philippi. In pools and streams: Mass.-Fla.-Calif.-Ida.; Mex.-S. Am. Plain-Submont.

5. L. minima Philippi. Fronds solitary or in groups of 2-4, oblong or elliptical, symmetrical, $1.5-4 \mathrm{~mm}$. long, 1-2.75 mm. wide, both surfaces convex or the lower flat, with a thin margin around the frond. In pools: Ga.-Kans.Wyo.-Calif.; Mex.-S. Am. Plain-Submont.

\section{SPIRODÈLA Schleiden. Larger Duckweed.}

Frond disk-like, several-nerved. Stipe attached peltately to the frond back of and under the basal margin. Rootlets several, each with a solitary fibrovascular bundle. Anthers dehiscent longitudinally.

1. S. polyrhiza (L.) Schleiden. Frond solitary or in colonies of $2-5$, roundish obovate, flat on both sides, green above, generally purplish beneath, 5-15nerved, $2.5-4.5 \mathrm{~mm}$. wide and $2.5-8 \mathrm{~mm}$. long; rootlets 4-16. In pools and ponds: N.S.-B.C.-Fla.-Mex.; Old World and S. Am. Plain.

\section{Family 16. COMMELINACEAE. Spiderwort FAMily.}

Somewhat succulent herbs, with fibrous or tuberous-thickened roots and alternate leaves sheathing at the base. Flowers perfect, subtended by leaflike sheathing bracts. Sepals 3 , herbaceous. Corolla regular or irregular, with 3 , usually showy, colored petals. Stamens 6 or 5 , sometimes 2 or 3 of these sterile. Gynoecium of 2 or 3 united carpels; ovary superior, 2- or 3-celled; styles united. Fruit a loculicidal capsule.

Petals all alike; perfect stamens 6 ; bracts leaf-like.
Petals unlike in shape and size; perfect stamens 3 or 2 ; bracts spathe-like.

1. Tradescantia.

\section{TRADESCÁNTIA (Rupp.) L. SPIDERWORT.}

2. Commelina.

Caulescent perennials, with alternate narrow leaves. Cymes umbel-like, terminal, subtended by usually 2 bracts, similar to the leaves. Sepals 3 , nearly equal, distinct. Petals 3 , showy, blue, rose-color or white, sessile, similar and equal, delicate. Stamens 6, all perfect; filaments filiform, in ours long-hairy. Capsule loculicidal, 3-valved. Seeds 3-6, more or less sculptured.

Sepals glandular-pilose; petals about $15 \mathrm{~mm}$. long; capsule decidedly ellipsoid.

Bracts broader than the leaves, strongly gibbous at the base; stem $2-3 \mathrm{dm}$. high, usually simple; pod densely glandular. 
Bracts not broader than the leaves, not strongly gibbous at the base; stem usually over $3 \mathrm{dm}$. high, branched.

Pod densely glandular-pubescent; sepals broadly lanceolate, densely glandular: plant bright green; branches shorter than the stem proper. 2. T. occidentalis. Pod glabrate, pubescent only in lines or at the apex.

Pedicels strongly glandular; pods pubescent in lines; branches almost equalling the stem.

3. $T$. larimiensis.

Pedicels glabrous or slightly glandular above; pods pubescent only at the apex.

Sepals glabrous or nearly so; petals about $10 \mathrm{~mm}$. long; capsule subglobose.

4. $T$. universitatis.

5. T. scopulorum.

1. T. bracteata Small. Stem erect, 1-3 dm. high, simple, or sparingly branched, glabrous; leaves linear, 1-2 dm. long, long-acuminate; sepals ovatelanceolate; corolla about $2.5 \mathrm{~cm}$. broad. Wet meadows: Minn.-Mo.-Kans.S.D. Plain-Submont.

2. T. occidentalis (Britton) Smyth. Stem stout, branched, erect, 2.5-4 $\mathrm{dm}$. high; leaves narrowly linear, 2-3 dm. long, attenuate, with rather loose sheaths, glabrous; bracts 5-15 cm. long; sepals ovate-lanceolate, acute, about 1 $\mathrm{cm}$. long; petals blue or rose-colored, 12-15 $\mathrm{mm}$. long. Wet meadows: Ia.-Mo. -Colo.-S.D. Plain-Submont.

3. T. larimiensis Goodding. Stem $3-4 \mathrm{dm}$. high, branched, erect, glabrous; leaves narrowly linear, 2-3 dm. long, spreading; bracts narrow, $2-3 \mathrm{~mm}$. broad; sepals lanceolate, acute, 10-12 $\mathrm{mm}$. long; petals dark blue, $15-20 \mathrm{~mm}$. long; filaments strongly woolly below. Wet places: Mont.-Colo.-Utah. Plain-Submont.

4. T. universitatis Cockerell. Stem 3-4 dm. high, branched; leaves ascending, linear, attenuate, 2-3 dm. long; bracts narrower, 1-2 dm. long; sepals narrowly lanceolate, about $1 \mathrm{~cm}$. long, acuminate; petals blue, broadly ovate, acute, $15 \mathrm{~mm}$. long. Scarcely distinct from the preceding. Wet places: Mont. -S.D.-Colo, Plain-Submont.

5. T. scopulorum Rose. Stem more or less branched, 3-4 dm. high; leaves erect, 1-2 dm. long, linear, attenuate; bract narrow, unequal, glabrous; sepals broadly lanceolate, $8 \mathrm{~mm}$. long; petals $1 \mathrm{~cm}$. long or less, blue. Wet places: Ariz.-Utah-Colo.-N.M. Son.-Submont.

\section{COMmelìna (Plum.) L. Day-Flower, Dew-Flower.}

Mostly perennials, with alternate leaves. Bracts usually spathe-like, folded. Flowers irregular, in small cymes. Sepals 3, unequal, the larger two more or less united. Petals 3, usually blue, two larger than the third. Fertile stamens 3 , rarely 2 ; filaments slender, glabrous; sterile stamens 2 or 3 , smaller than the fertile ones. Seeds 2, one above the other, or solitary.

1. C. crispa Wooton. Perennial, with tuberous roots; stem $3-8 \mathrm{dm}$. high, branched, finely villous-pubescent above; leaves linear-lanceolate, $3-7 \mathrm{~cm}$. long, 4-6 mm. wide; spathe $1.5-2 \mathrm{~cm}$. long, strongly eurved, pubescent and bearded at the base; sepals broadly elliptic-rotund, the upper one slightly narrower and half as long; upper two petals broadly reniform, 1-1.5 $\mathrm{mm}$. long, bright blue, the third white, lanceolate, $2-3 \mathrm{~mm}$. long; fertile stamens 3 ; staminodia 3 . Sandy places: Ind.-Neb.-Colo.-Ariz.-Tex. Plain.

\section{Family 17. PONTEDeriaceae. Pickerel-weed Family.}

Perennial bog or water plants, with rootstocks and alternate or basal leaves. Flowers perfect, more or less irregular. Sepals and petals each 3, both colored and partly united. Stamens 3-6; filaments partly adnate to the perianth. Pistil of 3 united carpels; ovary 3 -celled, or by abortion 1celled. Fruit a many-seeded capsule or a 1-seeded utricle.

Stamens unequal, the 2 posterior ones with ovate anthers, the third with a sagittate anther; capsule incompletely 3 -celled; leaf-blades broad, long-petioled.

1. Heteranthera.

Stamens all alike; anthers all sagittate; capsule 1-celled, with 3 parietal placentae; leafblades linear, translucent, sessile.

2. Zosterella. 


\section{HETERÁNTHERA R. \& P. Mud-Plantain.}

Creeping or floating water plants. Leaves long-petioled, with broad, ovate, cordate, rounded, or reniform blades, sometimes reduced to phyllodes. Flowers perfect, solitary or few, subtended by a spathe-like bract. Perianth white or blue, with a slender tube. Stamens 3; anthers introrse, that of the anterior stamen sagittate, those of the other two ovate. Ovary incompletely 3-celled; ovules numerous in two rows on each placenta.

1. H. limosa (Sw.) Willd. Stem floating, 1-5 dm. long, branched; leaves petioled; petioles $3-20 \mathrm{~cm}$. long; blades ovate to oblong-ovate, $1-3 \mathrm{~cm}$. long, rounded or subcordate at the base; spathe 1-flowered; perianth blue or white; tube 1.5-2 cm. long; lobes linear. Shallow water: Va.-Fla.--Mex.-Colo.S.D.; W. Ind. and Trop. Am. Plain. Je-Au.

\section{ZOSTERÉLla Small. Water Star-grass.}

Submersed grass-like plants. Leaves sessile, narrowly linear, translucent. Flowers perfect, 1 or 2, subtended by a bract. Perianth yellow, with a slender tube. Stamens 3; anthers all sagittate, introrse. Ovary 1-celled with 3 parietal placentae; ovules numerous, 2-ranked. [Schollera Schreb.]

1. Z. dubia (Jacq.) Small. Stem floating or ereeping, 2-10 dm. long, branched; leaves linear, flat, sheathing at the base, 1-2 dm. long; perianth-tube $1 \mathrm{~mm}$. thick; lobes linear, 8-12 mm. long. Heteranthera graminea (Michx.) Vahl. H. dubia (Jacq.) MacM. Still water: Ont.-Fla.-Mex.-Ore.; W. Ind. Plain. My-S.

\section{Family 18. MelanthaCeAE. Bunch-Flower Family.}

Leafy-stemmed perennials, with rootstocks or solid bulbs. Flowers racemose or paniculate, perfect, dioecious, or polygamous. Petals and sepals each 3, distinct or nearly so. Stamens 6; filaments often partly adnate to the base of the sepals and petals; anthers versatile. Pistil of 3 united carpels; ovary 3-celled; styles 3 . Fruit a septicidal capsule.

Plants with rootstocks (except in No. 3); petals and sepals glandless.

Anthers oblong or ovate, 2-celled.

Anthers intforse; flowers involucrate with 3 bractlets.

Anthers extrorse; flowers not involucrate.

Anthers cordate or reniform, confluently 1-celled.

Flowers racemose, perfect, nodding; plants glabrous, with narrow leaves,

Flowers paniculate, polygamous; more or less pubescent plants, with broad plaited leaves.

Plants with bulbs; petals and sepals with a more or less distinct gland

Ovary partly inferior; gland obcordate.

Ovary wholly superior; gland obovate or semiorbicular.

5. ANTICLEA.

6. TOXICOSCORDION.

\section{TOFIÈldia Huds. Scottish Asphodel.}

Perennial herbs, with short rootstocks, fibrous roots, 2-ranked linear equitant leaves, and small flowers in a terminal raceme. Flowers involucrate by 3 , more or less united bractlets below the calyx. Petals and sepals oblong or obovate, subequal, persistent, glandless. Stamens 6; anthers ovate, introrse. Capsule septicidal to the base, many-seeded.

Stem glabrous, scapiform; seed unappendaged.

Stem leafy at the base only; flowers short-pedicelled.

Stem with a leaf also at or above the middle; flowers sessile. Stem viscid-pubescent, at least above; seeds appendaged.

Bractlets broadly triangular, connate two-thirds their length.

Bractlets lanceolate-triangular, connate half their length or less.

1. T. palustris.

2. T. coccinea.

3. T. intermedia.

4. T. occidentalis.

1. T. palustris Huds. A glabrous plant, with a scape-like, leafless stem, $3-15 \mathrm{~cm}$. high, and a few basal leaves, $2-10 \mathrm{~cm}$. long; raceme in flower short, oblong, dense; flowers greenish; petals and sepals obovate, obtuse; capsule oblongglobose, minutely beaked. In wet places: Greenl.-Que.-Minn.-B.C.; Alaska; Eu. Alp. 一Suhalp. Je-Jl. 
2. T. coccinea Richardson. A glabrous plant; stem $5-10 \mathrm{~cm}$. high; basal leaves $2-6 \mathrm{~cm}$. long, 3-4 mm. wide; spike short-oblong or globose; flowers tinged with purple; fruit dark purple. In wet places: Mack.-Alta.-Alaska. Alp. $\mathrm{Jl}$.

3. T. intermedia Rydb. Stem leafy, 1.5-3 dm. high, viscid-pubescent above; leaves $5-20 \mathrm{~cm}$. long, $2-5 \mathrm{~mm}$. wide; raceme short, dense, $1-2 \mathrm{~cm}$. long. pedicels usually 3 together; flowers yellow; sepals obovate, $4-5 \mathrm{~mm}$. long; petals somewhat narrower and longer; capsule ovoid, about $5 \mathrm{~mm}$. long. Bogs: Sask; -Wyo.-Calif.-Alaska. Mont.-Alp. Je-Au.

4. T. occidentalis S. Wats. Stem leafy, 3-5 dm. high, viscid-pubescent above; leaves $5-20 \mathrm{~cm}$. long, 2-6 $\mathrm{mm}$. wide, acute; raceme $3-5 \mathrm{~cm}$. long; flowers as in the preceding, but sepals and petals narrower; capsule ovoid, about $8 \mathrm{~mm}$. long. In bogs: B.C.-Calif.-Ida. Mont. Je-Au.

\section{XEROPHÝlLUM Michx. TURKey-Beard, BeAR-GRASS, Moose-grass, Pine-Grass.}

Glabrous perennial plants, with thick rootstocks, numerous narrowly linear leaves with rough margins, and a single, dense and many-flowered raceme. Flowers perfect, whitish; petals and sepals subequal, ovate or oblong, 5-7-nerved, withering-persistent, claw- and gland-less. Anthers oblong, 2-celled, extrorse. Styles 3, reflexed. Capsule ovoid; seeds 2 in each cell, oblong.

Petals and sepals 7-10 mm. long.

Petals and sepals 4-6 mm. long.

1. X. tenax.

2. X. Douglasii.

1. X. tenax (Pursh) Nutt. A light green perennial, 5-15 dm. high; lower leaves very numerous, firm, strongly 1-nerved, 2-4 dm. long, 2-4 mm. wide; upper stem-leaves subulate, with broad scarious bases; pedicels slenđer, $3-5 \mathrm{~cm}$. long; petals and sepals narrowly oblong, shorter than the filiform filaments; capsule broadly ovate. On dry hillsides: Mont.-B.C.-Calif.-Ida. Mont. $\mathrm{Je}-\mathrm{Jl}$.

2. X. Douglasii S. Wats. Similar to the preceding; pedicels $1-3 \mathrm{~cm}$. long, more erect; sepals and petals equalling the stamens; capsule cordate-ovate. Dry hills: Ore.-Mont. Mont. Je-Jl.

\section{STENANTHÊLLA Rydb.}

Erect bulbous glabrous herbs, with few narrow leaves and racemose or paniculate, perfect, greenish, brownish, or purplish flowers. Petals and sepals each 3, subequal, withering-persistent, narrowly lanceolate, acuminate, with reflexed tips, without gland and distinct claw. Stamens 6, free, included; anthers reniform, confluently 1-celled. Capsule lance-ovoid, septicidal to the base, wholly superior. Seeds oblong, winged.

1. S. occidentalis (A. Gray) Rydb. Stem 3-5 dm. high; leaves linear or linear-oblanceolate, acute, 1-2 dm. long, 3-20 $\mathrm{mm}$. wide; raceme simple or branched below; flowers narrowly bell-shaped, 10-12 $\mathrm{mm}$. long; capsule about $2 \mathrm{~cm}$. long. Stenanthium occidentale A. Gray. In wet places: Alta.-B.C.Ore.-Ida. Mont.-Alp. Je-Au.

\section{VerÃtrum (Tourn.) L. White Hellebore, False Hellebore, SkUnk CabBage.}

Tall poisonous perennials, with broad strongly veined and plaited leaves, and stout rootstocks. Flowers paniculate, generally polygamous, $i$. $e_{\text {., }}$ the upper perfect and the lower staminate. Petals and sepals each 3 , subequal, glandless and clawless. Stamens 6 , free; anthers cordate, their sacks confluent. Fruit a many-seeded, slightly inferior capsule, Seeds flat, broadly winged.

Flowers greenish; bractlets foliaceous, often equalling or exceeding the flowers.

Fowers greenish; bractlets $V$. Eschscholtzianum. Flowers white or yellowish white; bractlets membranous, much shorter than the pedicels and flowers.

Petals and sepals oval or broadly oblanceolate.

Petals and sepals narrowly oblanceolate.

2. V. speciosum.

3. V. tenuipetalum. 
1. V. Eschscholtzianum (R. \& S.) Rydb. Stem 1-2 m. high; leaves from broadly round-oval to oblong, or the uppermost lanceolate, sessile and sheathing at the base, 2-3 dm. long; petals and sepals oblanceolate, $8-10 \mathrm{~mm}$. long, acute or obtuse, fully twice as long as the stamens. Closely related to $V$. viride Ait. of the East, which has longer bracts and stamens. In wet woods: Mont.-Ida.Ore--Alaska. Mont.-Subalp. Jl-S.

2. V. speciosum Rydb. Stem 1-3 m. high; leaves, except the uppermost, broadly oval, 2-3 dm. long, 1-2 dm. wide, finely soft-pubescent beneath, sessile and sheathing; petals and sepals yellowish white, mostly obtuse, 5-7-nerved, 8-10 mm. long. $V$. californicum S. Wats., not Durand. $V$. Jonesii Heller. Brook-and river-banks: Wash.-Calif.-N.M.-Mont. Submont.-Mont. Jl-Au.

3. V. tenuipetalum Heller. Like the last, but still more leafy; leaves very concave; panicle more compound and very many-flowered; petals and sepals mostly acute, 3-5-nerved, $6-8 \mathrm{~mm}$. long and about $2 \mathrm{~mm}$. wide. In mountain meadows: Colo, Submont.-Mont. Jl.

\section{ANTiClèA Kunth. White Camas.}

Bulbiferous glabrous perennials. Leaves linear, sheathing. Flowers perfect, greenish or yellowish white, in racemes or panicles. Petals and sepals nearly alike, elliptic to obovate, withering-persistent, bearing an obcordate gland within above the narrowed base, perigynous. Stamens free; anthers cordate or reniform. Ovary partly inferior. Seeds numerous, angled.

Base of the stem not covered by conspicuous scarious sheaths; plant not tufted.

Petals and sepals greenish, the former more or less contracted into a broad claw.

1. A. chlorantha.

Petals and sepals white or straw-colored, greenish only on the midrih, not at all clawed. Petals and sepals 7-13-nerved.

Stem more or less leaf $y, 3-6 \mathrm{dm}$. high; petals white, 7-8 mm. long.

Stem 2. A. elegans.

Stem scapiform, 1-2 dm. high; petals straw-colored, 5-6 mm. long.

Petals and sepals 5-6 mm. long, 3-7-nerved.

Inflorescence usually simple, few-flowered; petals and sepals usually nearly $6 \mathrm{~mm}$. long; flowers not recurved after anthesis.

3. A. alpina.

Inflorescence rs in length; flowers reflexed just after anthesis.

Base of the stem covered by numerous, conspicuous, scarious sheaths; plant growing in big clumps.

6. A. vaginata.

1. A. chlorantha (Richardson) Rydb. Stem glabrous, green, 3-10 dm. high; leaves 1-3 dm. long, 5-12 mm. wide, keeled; flowers paniculate, about 1 $\mathrm{cm}$. long; sepals and petals usually 7-nerved, elliptic; capsule ovoid. Zygadenus chloranthus Richardson. Z. glaucus Nutt., in part. Rocky or stony places, often on limestone: N.B.-N.Y.-Ill.-S.D.-Sask. Boreal. Je-Au.

2. A. elegans (Pursh) Rydb. Stem glabrous, light green, 3-6 dm. high; leaves 1-3 dm. long, 5-15 mm. wide, keeled; flowers racemose, or rarely paniculate, dirty white; bracts ovate to lanceolate, often membranous-margined; petals and sepals obovate or oval, obtuse; capsule ovoid. Z, elegans Pursh. Z. glaucus Nutt., in part. $Z$. dilatatus Greene. In meadows: Sask.-N.D.-N.M.Nev.-Alaska. Plain-Subalp. Je-Au.

3. A. alpina (Blankinship) Heller. Stem 1-2 dm, high, subscapiform with one or two bracts or small leaves; basal leaves 6-12 $\mathrm{cm}$. long, 2-4 mm. wide; bracts ovate, scarious, purple-veined; sepals and petals eream-colored, obovate; capsule narrow. Z. alpinus Blankinship. Mountains: Mont. Subalp. J1$\mathrm{Au}$.

4. A. coloradensis Rydb. A rather slender glabrous plant, 2-4 dm. high; leaves narrow, erect, about $2 \mathrm{dm}$. long, $3-5 \mathrm{~mm}$. wide; flowers racemose, yellowish white, tinged with brownish or purplish; bracts linear-lanceolate; petals and sepals oblong or narrowly obovate, acute; capsule ovoid. Mountains: N.M.-Colo.-Utah. Mont.-Subalp. Ji-Au.

5. A. porrifolia (Greene) Rydb. Stem slender, 3-6 dm. high; leaves thin, pale, 2-4 dm. long, 6-12 mm. wide; bracts lanceolate, green; pedicels $1-3 \mathrm{~cm}$. 
long; sepals and petals elliptic, not clawed, greenish white; capsule ovoid. 'Z. porrifolius Greene. Mountains and cañons: Ariz. - se Utah-N.M.-Mex. Submont. Jl-Au.

6. A. vaginata Rydb. Growing in clumps; stem 7-10 dm. high; leaves linear, 3-7 dm. long, 6-10 mm. wide, with numerous veins; inflorescence panicuate; bracts linear or subulate, 3-6 $\mathrm{cm}$. long, green, or the upper ovate, white; petals and sepals white, elliptic, 7-8 mm. long, 7-nerved. Loose soil under overhanging cañon walls: se Utah. Son. Au.

\section{TOXicoscòrdion Rydb. Poison Camas, Death Camas.}

Bulbiferous glabrous, more or less poisonous perennials, with narrow linear conduplicate leaves and yellowish racemose or paniculate flowers. Flowers perfect. Petals and sepals bearing an obovate or semiorbicular gland at or above the base of the blade. Ovary wholly superior. Stamens more or less adnate to the base of the petals and sepals; anthers sub-reniform, confluently 1-celled. Seeds numerous.

Petals and sepals rounded or obtuse at the apex.

Upper leaves without sheaths at the base; both petals and sepals distinctly clawed and subcordate at the base; gland with a thick, toothed margin. 1 . $T$. venenosum.

All leaves with distinct sheaths; petals long-clawed and subcordate at the base; sepals subsessule; margin of the gland ill-defined. 2. T. gramineum.

Petals and sepals acute or acuminate at the apex; all leaves with sheaths; sepals cuneate at the base and short-clawed or subsessile.

Leaves less than $5 \mathrm{~mm}$. wide; petals and sepals both cuneate at the base and shortclawed.

Leaves over $5 \mathrm{~mm}$. wide.

Raceme simple; petals comparatively long-clawed and subcordate at the base.

Raceme branched; petals short-clawed, not subcordate at the base.

4. T. falcatum.

5. T. paniculatum

1. T. venenosum (S. Wats.) Rydb. Stem 3-6 dm. high; leaves narrowly linear, striate, scabrous, $1.5-3 \mathrm{dm}$. long, 4-6 mm. wide; raceme many-flowered, in fruit elongate; petals and sepals about $5 \mathrm{~mm}$. long; claw about $1 \mathrm{~mm}$. long; blades of the sepals broadly ovate, those of the petals more elliptic-ovate. Zygadenus venenosus. S. Wats. Z . salinus A. Nels. Hillsides: Mont.-UtahCalif,-B.C. Plain-Submont. Je-Au.

2. T. gramineum Rydb. Stem 2-3.5 dm. high; leaves linear, 1-2 dm. long, 3-9 mm. wide; flowers light yellow; sepals broadly ovate, obtuse; petals ovate, obtuse, subcordate at the base. $Z$. gramineus and $Z$. intermedium Rydb. Hills and meadows: Sask.-S.D.-Colo.-Utah-Ida. Submont.

3. T. acutum Rydb. Stem 3-5 dm. high; leaves narrowly linear, seabrous on the margin, about $2 \mathrm{dm}$. long and 4-5 mm. wide; petals and sepals 4-5 $\mathrm{mm}$. long, both acute at the apex and at the base; glands obovate or cuneate. $Z$. acutus Rydb. Hillsides: (Black Hills) S.D. Submont. Je-Jl.

4. T. falcatum Rydb. Stem stout, 3-4 dm. high; leaves scabrous, 1.5-2.5 $\mathrm{dm}$. long, 5-8 $\mathrm{mm}$. wide; raceme short, in fruit elongate; petals and sepals about $5 \mathrm{~mm}$. long, acute; the former deltoid-ovate, acute at the base; glands semiorbicular, upper margin toothed, thin and not well defined. Z. falcatus Rydb. Hills and table-lands: Colo.--n N.M. Submont. Je-Au.

5. T. paniculatum (Nutt.) Rydb. Stem stout, 3-6 dm. high; leaves striate, scabrous, 2-4 dm. long, 5-10 $\mathrm{mm}$. wide; flowers panicled, rarely racemose, yellow; petals and sepals 4-5 mm. long; both ovate or deltate-ovate, acute at both ends and short-clawed; glands semi-orbicular, upper margins toothed, thin and ill-defined. Z. paniculatus S. Wats. On hills: Mont.-N.M. -Calif.-Wash. Son.-Submont. My-Je.

\section{Family 19. JUNCACEAE. Rush Family.}

Grass-like herbs. Flowers perfect, regular, inconspicuous; sepals and petals each 3 , similar, scale-like. Stamens 6 or 3 , rarely 4 or 5 ; anthers introrse. Pistil of 3 united carpels; ovary 1- or 3-celled; stigmas 3. Fruit a loculicidal capsule. Seeds 3-many, often apiculate or tailed. 
Leaf-sheaths open; capsule 1-3-celled, with axile or parietal placentae; seeds many.

Leaf-sheaths closed; capsule 1-celled, with basal placentae; seeds 3 .

1. JUNCUS.

2. JUNCOIDES.

\section{JÚNCUS (Tourn.) L. RUSh, Wire-grass.}

Caulescent or rarely scapose swamp plants, with glabrous leaves and stems. Leaves with laterally or vertically flattened, or terete leaf-blades, or the latter sometimes wanting; sheaths with free margins. Cymes paniculate, corymbiform or capitate. Flowers subtended by a bract and sometimes also by 2 bractlets. Stamens 6 or 3 . Capsule 1-celled or by the intrusion of the placentae 3-celled. Seeds often tailed or apiculate, reticulate or ribbed, many.

Lower bracts of the inflorescence terete, erect, appearing like a continuation of the stem; inflorescence therefore apparently lateral; stamens 6.

Flowers several in a more or less compound panicle; seeds apiculate or acute; perennials with long rootstocks.

I. EFFUSI.

Flowers 1-5, of which one is subsessile and the others peduncled; seeds caudate, $i$. $e$., with white tails at each end; densely cespitose perennials. II. SUBTRIFLORI.

Lower bracts not appearing as a continuation of the stem, or if so, channeled on the upper side; inflorescence terminal.

Leaves neither septate nor equitant.

Leaves not fistulose.

Flowers many.

Flowers bracteolate, inserted singly on the branches of the inflorescence; leaves narrowly linear, either flat or subterete and channeled; stamens 6.

Perennials, with short cespitose rootstocks; stems simple.

Annuals; stem branching; seed apiculate.

III. TENUES.

IV. BUFONII.

Flowers not bracteolate, in true heads on the branches of the inflorescence; leaves flat, often grass-like; perennials with stoloniferous rootstocks.

Flowers solitary on the scape; plant $2-3 \mathrm{~cm}$. high. VII. UNCIALES.
eaves fistulose (i.e., hollow); flowers few in small heads; lower sheath bladeless;

VI. GRAMINIFOLIS. seeds caudate; stamens 6 .

Leaves septate.

Leaves terete, not equitant.

Septa poorly developed; heads 1-3.

Septa poorly developed; heads 1-3.
Septa well developed; heads usually several (in $J$. Mertensianus usually

one).
Leaves equitant, laterally flattened so that one edge is towards the stem; seeds apiculate; perennials with creeping rootstocks.

IX. ENSIFOLII.

\section{EFFusi.}

Stem light green, striate when dry on account of the free hypodermal fibro-vascular bundles; sepals and petals green.

1. J. filiformis.

Stem dark green or at the base purplish, not striate; sepals and petals brown.

Stem terete; sheath naked or merely bristle-pointed; sepals and petals dark purplish brown.

Inflorescence congested; branches $1-3 \mathrm{~cm}$. long; petals and sepals acute or shortacuminate, almost equal in length.

2. J. ater.

Inflorescence open; branches 4-7 cm. long; sepals long-acuminate, much exceeding the acute petals.

Stem flattened; uppermost sheath often leaf-bearing; sepals and petals not very dark brown.

\section{SUBTRIFLORI.}

4. $J$, mexicanus.

Upper sheaths merely bristle-pointed; petals and sepals with green backs and dark brown margins.

5. J. Drummondii.

Upper sheaths leaf-bearing; green backs of the petals and sepals less prominent.

Sepals and petals linear-lanceolate, light brown; capsule acute, 6. J. Parryi.

Sepals and petals broadly lanceolate, very dark brown; capsule retuse.

\section{TENUES.}

\section{J. Hallii.}

Seeds long-caudate; leaves terete with a shallow groove above. $\quad 8 . J$. Vaseyi.

Seeds apiculate, not caudate; leaves flat, but usually involute, lunate in section.

Auricles at the summit of the sheaths membranous, whitish.

Auricles scarcely produced beyond the insertion, scarcely scarious; petals and sepals scarcely spreading.

Perianth 3-4 mm. long, equalling the capsule.

Perianth 4.5-5 mm. long, exceeding the capsule. 10. J. arizonicus.

Capsule oblong, narrow, 3-celled, equalling the perianth or nearly so; sepals and petals erect or appressed.

Stem stout; leaves short and broad $(1.5-2 \mathrm{~mm}$. wide); sepals and petals 4-5 $\mathrm{mm}$. long, scarious at the base only, stramineous; flowers in an open cyme. 
Stem slender; leaves narrow and long; sepals and petals $3.5-4 \mathrm{~mm}$. long, scarious to the apex, fuscous; flowers few, congested.

12. $J$. confusus.

Capsule ovate or oval, 1-celled, three-fourths as long as the petals or less; petals and sepals spreading.

13. $J$. tenuis.

Auricles cartilaginous, yellowish brown; inflorescence greenish; capsule ovate; petals and sepals spreading.

IV. BUFONII.

14. J. Dudleyi.

Capsule oblong to ovoid, trigonous, 3-4.5 mm. long, at maturity closely embraced by the ascending petals.

15. $J$. bufonius.

Capsule subglobose or short-ovoid, $2-3 \mathrm{~mm}$. long; petals and sepals at maturity loosely spreading, ascending, or squarrose.

16. J. sphaerocarpus.

\section{CASTANEI.}

Stem leafy only at the base, but the uppermost leaf often with a long sheath; perianth about $4 \mathrm{~mm}$. long; leaves about $1 \mathrm{~mm}$. in diameter; rootstock short, cespitose.

Lowest bract of the inflorescence more or less membranaceous, spreading: capsule obtuse or mucronate.

Lowest bract of the inflorescence foliaceous, erect; capsule deeply retuse.

18. J. biglumis,

Stem more or less leafy; leaves about $2 \mathrm{~mm}$. in diameter; perianth $5-6 \mathrm{~mm}$. long; rootstock longer, stoloniferous.

VI. Graminifolir.

19. J. castaneus.

Seeds caudate; ligules with lanceolate, acute auricles at the summit.

Stem slender, 3-5 dm. high; leaves 5-20 cm. long; auricles about $1 \mathrm{~mm}$. long.

20. J. Regelii.

Stem about $2 \mathrm{dm}$. high; leaves 3-6 cm. long, spreading; auricles of the ligules about

$2 \mathrm{~mm}$. long.

Seeds not caudate; ligules with rounded auricles or none.

Leaves long, erect; auricles present.

22. J. longistylis.

Leaves short and broad, ascending, spreading; auricles none. 23 . J. orthophyllus.

One species.

VII. UNCIALES.

VIII. NoDOsI.

24. $J$. uncialis.

Stamens 6 ; seeds not caudate, or slightly so in $J$. Meriensianus and $J$. nevadensis; perennials with creeping rootstocks.

Inflorescence with short branches; flowers echinate-spreading or the lowest of the heads reflexed; capsule narrowly lanceolate.

Heads 7-10 mm. in diameter; leaf-blades erect; petals usually longer than the sepals.

Heads 10-16 mm. in diameter; leaf-blades usually spreading; sepals longer than the petals.

26. J. Torreyi.

Inflorescence with elongated branches; flowers erect-ascending; capsule oblong.

Capsule shorter than or rarely equalling the acuminate sepals and petals. Flowers dark brown.

27. J. nevadensis.

Capsule truncate or obtuse.

Heads several; leaves terete; seeds not caudate. 28. J. truncatus.

Heads solitary, or rarely $2-3$; leaves somewhat flattened; seeds often caudate.

29. J. Mertensianus.

Flowers light brown or straw-colored.

Capsule longer than the obtuse or acutish petals and sepals. 36. J. columbianus.

Stamens 3 ; seeds long-caudate; perennials with cespitose rootstocks.

31. J, Richardsonianus.

IX. ENSIFOLII.

Styles long, exceeding the petals by $1 \mathrm{~mm}$. in length.

32. J. Tweedyi.

Style slightly, if at all exceeding the petals.

Flower-clusters numerous, small, 5-12-flowered, light colored.

Flower-clusters few, 15-25-flowered.

Flowers greenish or light brown; stamens 6 ; ligules of the sheaths usually without auricles.

Flowers fuscous or very dark brown.

Stamens 6; ligules of the sheaths usually produced into small auricles.

Stamens 3 ; ligules without auricles.

33. J. Tracyi.

34. J. brunnescens.

35. $J$. parous.

$36 . J$. saximontanus.

37. $J$. ensifolius.

1. J. filiformis L. Stem 1-5 dm. high, slender, 1-2 mm. thick; leaves basal and reduced to brown sheaths; inflorescence 6-10-flowered, open; sepals 4-5 mm. long, lanceolate, acute, slightly exceeding the obtuse or acutish petals; capsule obovoid, green, about equalling the petals, 3-celled; seeds acute, but scarcely apiculate. In wet places: Greenl.-Pa.-Utah-Wash.-Alaska; Eurasia. Plain-Submont. Je-Au.

2. J. ater Rydb. Stem dark green, 2-6 dm. high, about $2 \mathrm{~mm}$. thick; sheaths loose, dark brown; flowers 5-20; sepals and petals 5-6 $\mathrm{mm}$. long; capsule ob- 
pyramidal, long-mueronate, 3-celled. J. balticus montanus Engelm. Mountain valleys: Alaska-Calif.-N.M.-Neb.- Mont. Plain-Subalp. J1-Au.

3. J. vallicola Rydb. Stem rather stout, 6-8 dm. bigh, terete, $2-4 \mathrm{~mm}$. in diameter; sheaths at the base short, dark brown, bladeless; sepals narrowly lanceolate, slightly if at all scarious on the margins, about $6 \mathrm{~mm}$. long; petals broader and shorter, with broad scarious margins, about $5 \mathrm{~mm}$. long; capsules short-ovoid, obtusish and mucronate, shorter than the petals. $J$. balticus vallicola Rydb. Mountain valleys: B.C.-Wash.-Colo.-Mont. Plain-Submont. $\mathrm{Je}-\mathrm{Jl}$.

4. J. mexicanus Willd. Stem usually twisted, 3-6 dm. high; sheaths brown, short, except the uppermost, with a blade resembling the stems; inflorescence open; sepals light brown, 5-6 mm. long, lanceolate, longer than the scarious-margined petals; capsule ovate, triangular, mucronate, equalling the petals. J. compressus H.B.K., not Jacq. Mountains: N.M.-Utah-Calif.; Mex. L. Son. $\mathrm{My}-\mathrm{Au}$.

5. J. Drummondii E. Meyer. Stems 1-3 dm. high, slender; sheaths brown, short, striate, not inflated; blades reduced, bristle-like, 3-10 mm. (rarely $20 \mathrm{~mm}$.) long; sepals lanceolate, attenuate, $7 \mathrm{~mm}$. long; petals similar but usually slightly shorter; capsule oblong, triangular, obtuse, 3-celled. J. subtriflorus (E. Meyer) Coville. Mountain sides, especially in damp places: Alaska-Calif.-N.M.Alta. Mont. -Alp. Jl-Au.

6. J. Parryi Engelm. Stem 1-3 dm. high, terete, slender; sheaths brown, the upper with a sulcate blade 5-6 cm. (rarely $8 \mathrm{~cm}$.) long; sepals 5-7 mm. long, longer than the acute, scarious-margined petals; capsule oblong, triangular, 3-celled. Mountain sides: B.C.--Calif.-Colo.-Mont. Mont.-Alp. JI-Au.

7. J. Hallii Engelm. Stems slender, 2-3 dm. high, terete; sheaths brown; blades of the uppermost leaves 5-15 $\mathrm{cm}$. long; sepals 4-5 $\mathrm{mm}$. long, exceeding the similar petals; capsule dark brown, ovate, triangular, 3-celled, fully equalling the sepals. Mountains: Colo--Mont. Mont.-Subalp. J1-Au.

8. J. Vaseyi Engelm. Stems tall and stiff, 3-8 dm. high, terete; leaf-blades three-fourths as long as the stem; inflorescence $1-3.5 \mathrm{~cm}$. long, with erect 2-4flowered branches; sepals and petals $3.5-4 \mathrm{~mm}$. long, green or straw-colored, lanceolate, erect, acute and narrowly scarious-margined; capsule oblong-cylindric, obtuse. Moist shores and wet woods: Me.-Ia.-Colo.-Sask. PlainMont. Je-Au.

9. J. interior Wiegand. Stems tall, stout, 5-10 dm. high, nearly terete, coarsely grooved; leaves several, with blades one-third as long as the stem, 1-1.25 $\mathrm{mm}$. wide; inflorescence large and open, $3-10 \mathrm{~cm}$. long, many-flowered; sepals and petals 3-4 mm. long, nearly equal, lanceolate, very acute, narrowly scariousmargined, erect; capsule oblong, obtuse, imperfectly 3-celled. Dry woods and prairies: Ill.-Ark.-Tex.-N.M.-Wyo. Plain-Submont. My-Au.

10. J. arizonicus Wiegand. Stem 4-7 dm. high, terete, or slightly compressed, grooved; leaf-blades one-third to one-half as long as the stem, $1 \mathrm{~mm}$. wide; inflorescence many-flowered, 4-7 cm. long, with erect branches; sepals and petals $5 \mathrm{~mm}$. long, lance-subulate, very acute, erect; capsule ovate-oblong, obtuse, triangular above, imperfectly 3-celled. Prairies and plains: Tex.Colo.-Ariz. Son.-Submont. Ap-JI.

11. J. brachyphyllus Wiegand. Stem stout, 4-5 dm. high, slightly compressed, grooved; leaf-blades short, one-fourth to one-third as long as the stem, broad and flat, 1.5-2 mm. wide; inflorescence short, many-flowered, $2-6 \mathrm{~cm}$. long; sepals lanceolate, very acute, straw-colored; petals similar but scarious-margined all around; capsule narrowly oblong, obtuse or retuse. Meadows: Ark.Okla.-Ida. Plain-Submont. My-Jl.

12. J. confusus Coville. Stem slender, 4-5 dm. high, light green, slightly grooved; leaf-blades filiform, two-thirds as long as the stem or less, flat or involute; sepals and petals lanceolate, acute, straw-colored, with dark stripes on each side, scarious-margined; capsule oblong, a little shorter than the petals, retuse. J, tenuis congestus Engelm., in part. Meadows: B.C. -n N.M.-Neb. -Sask. Plain-Mont. Je-Au. 
13. J. tenuis Willd. Stem 2-6 dm. high, spreading, slightly flattened, striate; leaf-blades nearly as long as the stem, $1-1.25 \mathrm{~mm}$. wide, flat, soft; inflorescence open, 1-7 cm. long, with the flowers near the end of the branches; petals and sepals $3-4.5 \mathrm{~mm}$. long, lanceolate, very acute, green, with white scarious margins. Roadsides and meadows: Newf,-Fla.-Tex.-Mont.Ore.-Wash. Plain-Submont. My-S.

14. J. Dudleyi Wiegand. Stem 3-10 dm. high, stiff, erect, strongly striate; leaf-blades half as long as the stem or less, narrow, flat or involute; inflorescence small, dense, 2-5 cm. long; sepals and petals 4-5 $\mathrm{mm}$. long, lanceolate, acute, yellowish green, with scarious margins; capsule ovoid, somewhat shorter than the petals, rounded and apiculate at the apex, imperfectly 3-celled. Damp places and meadows: Me.-N.Y.-N.M.-Ariz.-Wash.-Alta.; Mex. Plain -Submont. My-Au.

15. J. bufonius L. Stem $0.5-2 \mathrm{dm}$. (seldom $3 \mathrm{dm}$.) high; leaf-blades flat, 0.25-1 mm. wide; flowers inserted singly on the branches; sepals 4-6 mm. long, narrowly lanceolate, subulate-attenuate, scarious-margined; petals somewhat shorter, less attenuate; capsule shorter than the petals, obtuse, 3-celled. Wet places: Greenl.-Fla.-Calif.-Alaska; Mex.; also Old World. Plain-Mont. Ap-S.

16. J. sphaerocarpus Nees. Stem $0.5-2 \mathrm{dm}$. high; leaf-blades $0.5 \mathrm{~mm}$. or less wide; sepals 3-4 mm. Iong, pale, lanceolate, acuminate, slightly longer than the petals, with broader scarious margins; capsule one-half to two-thirds as long as the petals, 3-celled. Wet places: Ore.-Calif-Colo.-Ida. Plain-Submont. Ap-J.

17. J. triglumis L. Stem $5-15 \mathrm{~cm}$. high, erect, terete, $1 \mathrm{~mm}$. or less thick; blades terete, 1-7 cm. Iong; sepals and petals ovate-lanceolate, obtuse, brown, about $4 \mathrm{~mm}$. long; capsule cylindric, trigonous, imperfectly 3-celled. Areticalpine regions: Greenl, $-\mathrm{n}$ N.Y.-N.M.-Alaska; Eurasia. Subalp.-Alp. JI$\mathrm{Au}$.

18. J. biglumis L. Stem erect, subterete, $3-10 \mathrm{~cm}$. (rarely $2 \mathrm{dm}$.) high; blades terete or nearly so, $2-7 \mathrm{~cm}$. long, about $1 \mathrm{~mm}$. thick; sepals and petals $3 \mathrm{~mm}$. long, oblong, rounded-obtuse, fuscous, with more greenish back; capsule trigono-cylindric, retuse, imperfectly 3-celled. Arctic-alpine regions: Greenl-B.C.-Alaska; Eurasia. Alp. Jl-Au.

19. J. castaneus J. E. Smith. Stems erect, terete, 1-3 dm. high, more or less leafy; blades channeled, 3-10 cm. long, 1-2 mm. thick; sepals linearlanceolate, about $5 \mathrm{~mm}$. long, acute, chestnut-brown; petals obtuse; capsule ovateprismatic, trigonous, acute, imperfectly 3-celled, almost black. Arctic-alpine regions: Greenl.-Newf.-N.M.-Alaska; Eurasia. Subalp.-Alp. Je-Au.

20. J. Regelii Buch. Stem erect, terete or compressed, $2-5 \mathrm{dm}$. high, leafy, 1-2 mm. thick; blades 5-20 cm. long, 1-3 mm. wide, soft, many-nerved; inflorescence consisting of 1-3 globose, several-flowered heads; bractlets scarious, broadly ovate, cuspidate; sepals 4-5 mm. long, lanceolate, acuminate, narrowly scariousmargined; petals ovate-lanceolate, acutish, broadly scarious-margined; capsule equalling the perianth, ovate, trigonous, obtuse, dark brown above. Mountain meadows: B.C.-Wash.-Utah-Mont. Mont.-Subalp. Jl-Au.

21. J. Jonesii Rydb. Stem about $2 \mathrm{dm}$. high, terete; leaf-blades $3-5 \mathrm{~cm}$. long, about $2 \mathrm{~mm}$, wide, spreading; inflorescence capitate, or rarely with a second head; sepals lanceolate, $5-6 \mathrm{~mm}$. long, acute or cuspidate, green on the back, brown on the sides, and with narrow scarious margins; petals ovate or ovatelanceolate, with broad margins; capsule dark brown, ellipsoid, retuse and apiculate. Mountain meadows: Utah. Mont. Au.

22. J. longistylis Torr. Stem erect, slender, compressed, 3-5 cm. high, 1-1.5 mm. thick; leaf-blades 1-2 mm. wide, 5-10 $\mathrm{cm}$. long; inflorescence of 1-6 heads; heads 5-12-flowered; sepals as in the preceding; petals broader, more obtuse and with broader margins; capsule shorter than the perianth, oblong, brown, trigonous above, obtuse. Meadows: Alta.-S.D.-N.M.-Calif.Ore.; Mex. Plain-Mont. Je-Au. 
23. J. orthophyllus Coville. Stem erect, 2.5-3 dm. high, compressed, 1-1.5 mm. thick; leaf-blades 5-10 $\mathrm{cm}$. long,-flat, 4-5 mm. broad, many-nerved, those of the stem-leaves narrower; inflorescence of 2-6 heads; heads 8-10-flowered; sepals as in the preceding; petals broader, acutish, with broad margins; capsule slightly shorter than the petals, oblong, trigonous, obtuse, mucronate, imperfectly 3-celled. J. longistylis latifolius Engelm. Mountains: Wash.-Calif.Utah. Plain-Submont. My־Au.

24. J. uncialis Greene. Annual, 2-3 cm. high, branched near the base, glabrous; leaves basal, flat, somewhat fleshy, linear, acute, 3-8 $\mathrm{mm}$. long; scapes 1-flowered, with a single minute bract; sepals and petals oblong-lanceolate, acute, hyaline, with a purplish or greenish midrib, about $1.5 \mathrm{~mm}$. long; capsule obtuse, slightly shorter; seeds apiculate. (?) J. triformis uniflorus Engelm. Wet places: Wash.-Utah-Calif. Plain-Submont. Je-Jl.

25. J. nodosus L. Stem 1.5-6 dm. high, erect, terete or somewhat compressed, leafy; leaf-blades erect, $0.5-1 \mathrm{~mm}$. thick, terete, $5-15 \mathrm{~cm}$. long, septate; heads 1-30, 8-20-flowered; sepals 2.5-3.5 mm. long, lanceolate, subulate; petals similar but slightly longer; capsule lanceolate-subulate, 3-gonous, 1-celled, strawcolored, exceeding the perianth. Wet soil: N.S.-Va.-N.M.-Nev.-B.C.Mack. Plain-Submont. Jl-S.

26. J. Torreyi Coville. Stem stout, 3-9 dm. high, 2-4 mm. thick, leafy; leaf-blades 1-3 mm. thick, terete, septate; heads 1-20, congested, 30 -80-flowered; sepals and petals lance-subulate, about $5 \mathrm{~mm}$. long; capsule subulate, 3-gonous, 1-celled. $J$. nodosus megacephalus Torr. Wet places, especially in sandy soil: w N.Y.-Miss.-Calif. Plain-Mont. JI-S.

27. J. novadensis S. Wats. Stem slender, erect, somewhat compressed, 2-4 dm. high, about $1 \mathrm{~mm}$. thick; leaf-blades nearly terete, $0.5-1.5 \mathrm{~mm}$. thick, septate; heads 2-11, 3-10-flowered; petals and sepals lanceolate, acute or mucronate, dark brown, with membranous margins; capsule slightly shorter than the perianth, brown above, acute. $J$. phaeocephalus gracilis Engelm. In meadows: B.C.-Calif.-Wyo.-(? Colo.)-Mont. Submont.-Mont. Je-S.

28. J. truncatus Rydb. Stems slender, 3-5 dm. high, terete or slightly flattened; leaves 1-3 dm. long, 1-2 mm. thick, septate; inflorescence open, 2-5 $\mathrm{cm}$. long, irregularly cymose, with 4-10 heads; heads 6-9 mm. in diameter, 5-10flowered; petals and sepals lanceolate, dark brown, about $3 \mathrm{~mm}$. long, acuminate, longer than the capsule. J. alpinus insignis Coult., in part. J. Mertensianus Auth., not Engelm. (?) J. badius Suskd. Mountain meadows: N.M.-Wyo.Ida. Submont.-Mont. Je-Au.

29. J. Mertensianus Bong. Stem erect, slender, 1-3 dm. high, 1-1.5 mm. thick; leaf-blades about $1 \mathrm{~mm}$. thick; inflorescence capitate, rarely with $2-3$ heads; head 10-12 mm. thick, 10-25-flowered; sepals and petals lanceolate, acute, almost black, the latter distinctly scarious-margined; capsule scarcely equalling the perianth, 3-gonous, obovate, 1-celled, dark brown above. Wet meadows: Alaska-Calif.-N.M.-Alta. Mont.-Subalp. J1-Au.

30. J. columbianus Coville. Stem 2-7 dm. high, terete, $1.5-2 \mathrm{~mm}$. thick; leaf-blades terete, 1-2 dm. long, inconspicuously septate, erect; inflorescence of 4-8 (rarely up to 20) heads; sepals and petals lanceolate, cuspidate, straw-colored or brownish, 3-3.5 mm. long; capsule equalling the perianth or a little shorter, oblong, acute or beaked. Meadows: Wash.-Ore-Mont. Submont. My-J1.

31. J. Richardsonianus Schult. Stem erect, 1.5-5 dm. high; blades terete or slightly compressed, septate, $0.5-1 \mathrm{~mm}$. thick; inflorescence with 5-25 heads, which are 4-6 mm. thick, 3-12-flowered; sepals 2-2.5 $\mathrm{mm}$. long, pale greenish, acutish; petals oblong, acute; capsule ovoid-oblong, slightly exceeding the perianth. J. alpinus insignis Fries. In wet soil: N.S.-Pa.-Neb.-Wash.Alaska. Plain-Mont. J-S.

32. J. Tweedyi Rydb. Stem strict, about $3 \mathrm{dm}$. high, light green, $2-3 \mathrm{~mm}$. thick; leaf-blades about $1 \mathrm{dm}$. long, terete or somewhat flattened, septate; inflorescence of 4-10 heads in a contracted panicle; heads 5-8-flowered; sepals and 
petals $4 \mathrm{~mm}$. long, lanceolate, acute or acuminate, light brown; capsule dark brown, oblong, acute, 3 -angled, about one-fourth longer than the perianth. $J$. canadensis coarctatus Coulter, not Engelm. J. canadensis Kuntzei Buch. Bogs and wet meadows: Mont.-Wyo.-Utah. Submont.-Mont. Jl.

33. J. Tracyi Rydb. Stem stout, 3-6 dm. high, compressed; blades 5-20 $\mathrm{cm}$. long, $2-4 \mathrm{~mm}$. wide; sheaths with a scarious margin which usually is produced into a very short auricle; inflorescence of 5-9 heads; these about $1 \mathrm{~cm}$. in diameter; sepals and petals lanceolate, acute, light brown, 3-4 mm. long, slightly scarious-margined; capsule oblong, mucronate, shorter than the perianth, imperfectly 3-celled. Meadows: Utah-Nev.-Ida. Submont. Jl-O.

34. J. brunnescens Rydb. Stem 4-6 dm. high, more or less winged; leaves $1-2.5 \mathrm{dm}$. long, $2-5 \mathrm{~mm}$. wide; sheaths with scarious margins, abruptly contracted above, but scarcely auricled; panicle open, $5-10 \mathrm{~cm}$. long, with 10-60 small heads; petals and sepals subequal, lanceolate, acuminate, about $3 \mathrm{~mm}$. long, light brown, with green midrib; capsule lance-ovoid, acute. Mountain meadows: Colo.-N.M.-Ariz.-Nev. Submont. Je-Jl.

35. J. parous Rydb. Stem 3-6 dm. high, distinctly winged; leaves $2-3 \mathrm{dm}$. long, $3-5 \mathrm{~mm}$. wide; petals and sepals lanceolate, sharply acuminate, subequal, light brown or greenish on the back; capsule oblong, acute, shorter than the petals. Mountain meadows: Colo.-N.M. Submont.-Subalp. Je-Jl.

36. J. saximontanus A. Nels. Stem winged, $2-5 \mathrm{dm}$. high; leaf-blades 3-20 cm. long, 2-4 mm. wide; inflorescence of 2-15 heads; these about $1 \mathrm{~cm}$. thick; sepals and petals lanceolate, acuminate, about $3 \mathrm{~mm}$. long, dark brown; capsule oblong, mucronate, a little shorter than the perianth, dark brown. $J$. xiphioides montanus Engelm. Meadows and wet places: B.C.-Calif.-N.M.Alta. Submont.-Mont. Je-S.

37. J. ensifolius Wikstr. Stem erect, 3-6 dm. high, winged; leaf-blades more or less falcate, $5-30 \mathrm{~cm}$. long, $3-6 \mathrm{~mm}$. wide; heads about $1 \mathrm{~cm}$. thick, about 25-flowered; sepals and petals dark brown, lanceolate, acuminate, about $3 \mathrm{~mm}$. long; capsule oblong, acute, often slightly exceeding the perianth, 3gonous. $J$. xiphiodes triandrus Engelm. Meadows and wet places: AlaskaCalif.-Utah-Alta. Submont. Je-Au.

\section{JUNCOİDES (Dill.) Adans. Wood-RUsH.}

Perennial caulescent herbs, with rootstocks, glabrous or sparingly pubescent. Leaf-sheaths closed; blades grass-like. Inflorescence umbel-like, capitate or spike-like. Flowers always subtended by usually lacerate or déntate bractlets. Stamens 6. Capsule 1-celled; ovules and seeds 3, basal. Seeds reticulate, sometimes apiculate but never tailed. [Luzula DC.]

Flowers on slender pedicels in a corymbiform inflorescence.

Petals and sepals $1.5-2 \mathrm{~mm}$. long.

Flowers and capsule pale green; leaves thin, shining; seeds brown, ellipsoid.

Flowers and capsule dark brown: leaves thick, dull; seeds yellow, constricted.

2. J. Piperi.

Petals and sepals $3-3.5 \mathrm{~mm}$. long.

3. J. glabratum.

Flowers subsessile in head-like or spike-like clusters.

Blades at least of the lower leaves flat, not attenuate into a subulate tip.

Spikelets peduncled, forming a corymb.

Flowers light yellow.

Flowers brown or ferruginous.

4. J. comosum.

5. $J$. intermedium.

Spikelets subsessile, forming a compound spike.

Plant tall, 4-5 dm. high; inflorescence subcapitate; stem-leaves broad and flat;
$6 . \mathrm{J}$. subcapitatum. bractlets not ciliate.

Plant 1-2, dm, rarely $4 \mathrm{dm}$. high.

Bractlets ciliate; spike usually elongate and often nodding: stem-leaves narrow, attenuate. $\quad 7 . J$. spicatum.

Bractlets lacerate, not ciliate: spike short, capitate. 8 . J. arcticum.

Blades of the leaves attenuate into subulate, almost pungent tips.

Spikelets many-flowered; the lower on suberect or ascending peduncles; leaves

erect. $9 . \mathrm{J}$. hyperboreum.

Spikelets few-flowered on arcuate-spreading peduncles; leaves arcuate-spreading. 10. J. arcuatum. 
1. J. parviflorum (Ehrh.) Coville. Stem erect, terete, $3-5 \mathrm{dm}$. high; leafblades broadly linear, 5-15 $\mathrm{cm}$. long, 5-12 $\mathrm{mm}$. wide, glabrous except the mouth of the sheath; flowers singly or rarely 2 or 3 together; sepals and petals lanceolate or ovate-lanceolate, acute; capsule ovate, 3-gonous, obtuse, exerted. Luzula spadicea parviflora E. Meyer. Meadows, hillsides, and thickets: Greenl.-N.Y. -N.M.-Calif.-Alaska; Eurasia. Mont.-Subalp. My-S.

2. J. Piperi Coville. Stem erect, 1-3.5 dm. high; leaves mostly basal, lance-linear, 2-4 mm. wide, glabrous except a few long hairs on the sheaths and margins; inflorescence 5-8 cm. long, nodding, diffuse; flowers solitary on the branches, rarely 2 or 3 together; sepals and petals about $1.5 \mathrm{~mm}$. long, ovate, acuminate; capsule ovate, acute, exserted. Sandy moraines: Wash.-Mont.-Ore. Alp.—Subalp. Jl-S.

3. J. glabratum (Hoppe) Sheld. Stems erect or ascending, terete, 2-5 dm. high; leaf-blades broadly linear to lanceolate, 3-10 $\mathrm{cm}$. long, 4-10 $\mathrm{mm}$. wide, glabrous; inflorescence open, ovoid, with branches often divaricate; flowers mostly singly; sepals and petals dark brown, lanceolate, acute; capsule almost black, ovate, acute, equalling the perianth. Luzula glabrata (Hoppe) Desv. Hillsides and mountains: Alaska-Wash.-Ida.-Mont.; Eu. Mont.-Subalp. $\mathrm{Jl}-\mathrm{Au}$.

4. J. comosum (E. Meyer) Sheld. Stem erect or ascending, 1-4 dm. high; leaves numerous, pale green; blades linear, $3-10 \mathrm{~cm}$. long, 3-6 mm. wide, glabrous; heads oblong, 6-7 $\mathrm{mm}$. thick; sepals and petals lanceolate, yellowish brown, acuminate, about $3 \mathrm{~mm}$. long, slightly exceeding the ellipsoid or subglobose capsule. L. comosa E. Meyer. Woods and copses: Alaska-Calif.-Colo.Mont: Submont.-Mont. My-Jl.

5. J. intermedium (Thuill.) Rydb. Stem slender, $2-5 \mathrm{dm}$. high; leaf-blades 5-10 cm. long, 1-4 mm. wide; inflorescence with erect or strongly ascending branches; heads 4-10, globose or oval, about $6 \mathrm{~mm}$. thick, 8-16-flowered; sepals and petals $2.5-3 \mathrm{~mm}$. long, lanceolate, mucronate, brown or reddish, with paler margins; capsule obovate, 3-gonous, obtuse or retuse, nearly equalling the perianth. L. campestris multiflora Celak. Hills and mountains: Greenl.-N.Y.N.M.-Calif.-B.C. Submont.-Mont. Je-Au.

6. J. subcapitatum Rydb. Stem 3-4 dm. high, glabrous; leaf-blades lanceolate, acuminate, glabrous, 4-10 cm. long, 5-10 mm. wide; inflorescence compact, consisting of 6-10 heads, conglomerate and forming an irregular head; sepals and petals subequal, $1.5-2 \mathrm{~mm}$. long, ovate, acuminate, dark brown, but lighter on the midrib; capsule broadly obovoid, obtuse, shorter than the petals. Mountains: Silver Plume, Colo. Subalp. Au.

7. J. spicatum (L.) Kuntze. Stem 1-3 dm. high, erect; leaf-blades 4-6 $\mathrm{cm}$. (rarely up to $12 \mathrm{~cm}$.) long, $1-3 \mathrm{~mm}$. wide; in florescence spike-like, usually nodding; sepals and petals $2-3 \mathrm{~mm}$. long, lanceolate, aristate-acuminate; capsule broadly ovoid, acute, about two-thirds as long as the perianth. L. spicata DC. Hills and mountain sides: Greenl.-N.H.-N.M.-Calif.-Alaska; Eurasia. Mont.-Alp. Jl-Au.

8. J. arcticum (Blytt) Coville. Stem erect, 5-10 cm. high, terete, slender; leaf-blades glabrous, $3-5 \mathrm{~cm}$. long, $2-4 \mathrm{~mm}$. wide; inflorescence spicate, erect, small; sepals and petals $1.5-2 \mathrm{~mm}$. long, lanceolate, fuscous; capsule ovate, 3gonous, exceeding the perianth. $J$. nivalis Coville, not $L$. nivalis Laest. t L. arctica Blyth. L. hyperborea minor Hook. Aretic-alpine regions: Greenl. - Canadian Rockies-Alaska; Seandinavia and Spitzbergen. Alp. Jl-Au.

9. J. hyperboreum (R. Br.) Sheld. Stem 1-2 dm. high, erect; leaf-blades narrow, 5-10 $\mathrm{cm}$. long, 1-2 mm. wide; inflorescence of a single erect head, or if heads $2-3$, the lowest erect and the upper sometimes nodding; sepals and petals lanceolate, acute, brown, $2-2.5 \mathrm{~mm}$. long; capsule about three-fourths as long as the perianth, 3-gonous, globose or ovate. L. hyperborea R. Br. Alpine-aretic regions: Greenl.-N.H.-Canadian Rockies-Alaska; Eu. Alp. Jl-Au.

10. J. arcuatum (Wahl.) Kuntze. Stem slender, about $1 \mathrm{dm}$. hrgh; leafblades 3-8 cm. long, narrow, 1-1.5 mm. wide, often curved; inflorescence of 2-10 
(rarely more) heads; the lower on slender curved peduncles; heads small, 3-5 $\mathrm{mm}$. thick; sepals and petals elongated-lanceolate, about $2.5 \mathrm{~mm}$. long, dark brown; capsule 3-gonous, globose, mucronate, shorter than the perianth. Arctic-alpine regions: Greenl.-Canadian Rockies-B.C.-Alaska; Eurasia. Alp. $\mathrm{Jl}-\mathrm{Au}$.

\section{Family 20. ALLIACEAE. Onion Family.}

Perennial scapose herbs, with bulbs or corms and narrow basal leaves. Flowers in terminal umbels subtended by or enveloped in a searious involucre. Sepals and petals each 3 , very similar, corolla-like, usually membranous. Stamens 6 . Pistil of 3 united carpels; ovary superior, 3-celled; styles united. Fruit a loculicidal, 3-celled capsule.

Perianth-segments distinct or nearly so; style articulate to the 3-lobed capsule; bracts broad, spathaceous.

1. Allium.

Perianth-segments united into a tube, with adnate filaments; style not articulate to the capsule; bracts not spathaceous, distinct.

Filaments not united into a tube; pedicels articulate; capsule ovate or oblong.

Filaments apparently in one series.

Filaments opposite to the petals wing-appendaged at the base; anthers basifixed; flowers subcapitate.

Filaments all deltoid; anthers versatile; flowers umbellate.

3. HESPEROSCORDION.

Filaments in two series; the inner adnate to the free part of the petals; anthers versatile.

4. TRITILELA.

Filaments united into a tube; pedicels not articulate: capsule triquetrous, subglobose.

5. ANDROSTEPHIUM.

\section{1. Állium (Tourn.) L. Onion, Garlic, Leek, Chives.}

Perennial bulbous plants, with a characteristic alliaceous smell. Bracts scarious, more or less connate. Petals and sepals free or slightly united at the base. Stamens adnate to the bases of the petals and sepals; anthers introrse. Ovary sessile, 3-celled; style filiform, usually deciduous; stigmas minute; ovules $1-6$ in each cell.

Bulb crowning a persistent rootstock; outer coat more or less fibrous.

Leaves terete and hollow; umbels dense, subcapitate.

1. A. sibiricum.

Leaves flat or channeled, not hollow.

Umbels rarely nodding; petals and sepals long-acuminate; capsule not crested. Stamens and styles exserted. 2 . A. validum. Stamens and styles included, half as long as the petals. 3. A. brevistylum.

Umbels nodding; petals and sepals obtuse or acute; capsule 6-crested; stamens and style exserted.

Leaves rounded-convex on the back, not keeled, Iunate in cross-section.

Leaves almost flat or keeled, somewhat broadly V-shaped in cross-section. Umbels many-flowered; leaves $3-5 \mathrm{~mm}$. wide. $\quad 5$. A.cernuum.

Umbels few-flowered; leaves less than $3 \mathrm{~mm}$. wide. 6. A. neo-mexicanum.

Bulbs without a rootstock.

Outer bulb-coat fibrous.

Umbels bulblet-bearing; flowers few or sometimes none.

Capsule with 6 rounded crests.

Capsule not crested.

Petals and sepals ovate.

Petals and sepals oblong-lanceolate.

Umbels not bulblet-bearing.

Capsule not crested; involucre usually 3-leaved.

Petals and sepals with a thick rounded keel.

Petals and sepals not thickened on the back.

Capsule crested.

Petals and sepals more than $1 \mathrm{~cm}$. Iong; peduncles often 2 or 3 ; sheaths loose; bracts 3 .

7. A. fibrosum.

8. A. rubrum.

9. A. canadense.

Petals and sepals less than $1 \mathrm{~cm}$. long; peduncles solitary; sheaths close.

Bracts broadly ovate, usually 2 , in flowers not reflexed; flowers white or light rose; several layers of the bulb-coat fibrous.

Plant 1-3 dm. high; pedicels 8-12 $\mathrm{mm}$. long; petals and sepals about $5 \mathrm{~mm}$. Iong. 13. A. textile.

Plant 2-6 dm. high; pedicels 12-25 mm. long; petals and sepals 6-8 $\mathrm{mm}$. long.

Bracts lanceolate, usually 3, soon reflexed; only outer bulb-coat flbrous; flowers red-purple.

Outer bulb-coat not fibrous, but of ten more or less reticulate.

Petals more or less serrulate or denticulate on the margins.

Petals and sepals acuminate, the former serrulate near the apex.

Petals and sepals long-acuminate, one-half longer than the stamens.

16. A. acuminatum. 
Petals and sepals abruptly acuminate, only slightly longer than the stamens.

mens.
Petals and sepals obtuse, delicately denticulate below with spreading papillae.

Petals entire, neither serrulate nor denticulate.

18. A. simillimum.

Ovary and capsule crestless or indistinctly 3-crested.

Petals and sepals obtuse or harely acutish. Leaves much longer than the scape. Leaves shorter than the scape.

Petals and sepals acute or acuminate.

Stamens exserted.

Stamens included.

Reticulations of the bulb-coat irregular, narrow, with curved sides; the outer coat in age becoming fimbrillate. 20. A. fibrillum.

Reticulations of the bulb-coat trapezoid, or elongated pent- or hexagonal; the sides not strongly curved; no fimbrillae.

Sepals and petals neither gibbous at the base, nor keeled on the back.

Involucres 3-leaved; petals and sepals little exceeding the stamens. 22 . A. tribracteatum.

Involucres 2-leaved; petals and sepals at least half longer than the stamens.

Petals and sepals half longer than the stamens; pedicels 8-15 mm. long. 23. A. Diehlii.

Petals and sepals twice as long as the stamens; pedicels about $4 \mathrm{~mm}$. long.

24. A. minimum.

Sepals and petals gibbous at the base and more or less keeled on the back below.

Scape flattened; leaf-blades $5-8 \mathrm{~mm}$. wide.

Scape much exceeding the leaves in length; stamens about equalling the petals and sepals.

25. A. Douglassii.

Scape low, often exceeded by the leaves; stamens much shorter than the petals and sepals.

Stamens two-thirds as long as the sepals; capsule scarcely crested. 26. A. Tolmiei.

Stamens half as long as the sepals; capsules with 3 small crests.

27. A. Cusickii.

Scape not flattened; leaf-blades $2-4 \mathrm{~mm}$. wide.

Petals about twice as long as the stamens; capsule not crested. 28. A. Brandegei.

Petals barely exceeding the stamens; capsule with minute thick crests.

29. A. Nïvii.

Ovary and capsule distinctly 6-crested.

Stamens and styles exserted; petals and sepals acute or obtuse.

Stamens and styles not exserted; petals and sepals 30 . A. stellatum.

Leaves more than one.

Reticulations of the bulb-coats sinuate: leaves shorter than the scape.

Bulb-coat thin, faintly reticulate; leaves 4-10 $\mathrm{mm}$. wide.

31. A. bisceptum.

Bulb-coat thick, strongly reticulate; leaves $1-3 \mathrm{~mm}$. wide.

32. A. Palmeri.

Reticulations of the bulb-coats straight; leaves longer than the scapes.

Leaves solitary, longer than the scape.

33. A. pleianthum.

Petals and sepals long-acuminate, nearly twice as long as the stamens. 34. A. cristatum.

Petals and sepals acute or short-acuminate, slightly longer than the stamens. 35 . A. nevadense.

1. A. sibiricum L. Bulb small, oblong-ovoid, often oblique, about $1 \mathrm{~cm}$. thick; scapes 3-6 dm. high; leaf-blades 6-20 $\mathrm{cm}$. long; bracts usually 2, ovate, about $2 \mathrm{~cm}$. long; petals and sepals bright rose-colored, with dark midrib, fully $1 \mathrm{~cm}$. long, lanceolate, acuminate; stamens included; capsule not erested. Rich soil: Me.-N.Y.-Colo.-Ore.-Alaska; Asia. Plain-Mont. Je-Au.

2. A. validum S. Wats. Bulb $2-4 \mathrm{~cm}$. thick; scape $3-7 \mathrm{dm}$. high, stout; leaves 2-4 dm. long, 4-12 mm. wide; bracts 2-4, ovate, about $1.5 \mathrm{~cm}$. long; sepals and petals dark rose-colored, 7-8 mm. long; capsule subglobose. Meadows: Wash.-Ida.-Nev.-Calif. Mont. J-Au.

3. A. brevistylum S. Wats. Bulbs obliquely elongate, lance-ovoid, 1-3 $\mathrm{cm}$. thick; scape 3-6 dm. high, stout; leaf-blades $1.5-3 \mathrm{dm}$. long, 4-6 mm. wide, flat; bracts usually solitary, ovate, $1.5-2 \mathrm{~cm}$. long; sepals and petals dark rose, lanceolate, 8-10 mm. long. Rich meadows and open woods: Mont.-Colo.Utah. Submont.-Subalp. Je-Au. 
4. A. recurvatum Rydb. Bulb oblong-ovoid, 1-1.5 cm. thick; scape slender, 3-5 dm. high, almost terete; leaf-blades 1-2 dm. long, 1-3 mm. wide, thick; involucre 2-leaved, almost $2 \mathrm{~cm}$. long; petals and sepals elliptic-ovate, obtuse, $5 \mathrm{~mm}$. long, rose, with darker midvein. A. cernuum obtusum Cockerell. Dry hills and mountain-sides. Alta.-S.D.--N.M.-B.C. Plain-Mont. My$\mathrm{Au}$.

5. A. cernuum Roth. Bulb lance-ovoid, 1-2 cm. thick, often purplish; scape 3-6 dm. high, stout; leaf-blades 1-2 dm. long, 3-7 mm. wide, rather thin; involucre 2-leaved, rarely more than $1 \mathrm{~cm}$. long; petals and sepals light pink or white, with faint midrib, otherwise as in the preceding. On banks and hillsides: N.Y.-W.Va.-Colo.-Wash.-Sask. Plain-Submont. Je-Au.

6. A. neomexicanum Rydb. Bulb oblong-ovoid, 1-2. cm. thick; coats membranous, only the outer slightly fibrous; scape $3-4 \mathrm{dm}$. high, slender, terete; leaf-blades narrow, 1-2 mm. wide, almost flat, slightly keeled; involucres very small, scarcely more than $5 \mathrm{~mm}$. long; petals and sepals oblong-ovate, nearly white, with very faint midrib. Dry mountains: s Colo.-N.M.-Ariz. Submont. Au-O

7. A. fibrosum Rydb. Bulb ovoid, about $1.5 \mathrm{~cm}$. thick; scape $2-3 \mathrm{dm}$.
h, striate, slender; leaf-blades flat, thick, $3 \mathrm{~mm}$. wide, $1-1.5 \mathrm{dm}$. long; bracts high, striate, slender; leaf-blades flat, thick, $3 \mathrm{~mm}$. wide, $1-1.5 \mathrm{dm}$. long; bracts
2 , ovate, about $1 \mathrm{~cm}$. long; petals and sepals lance-oblong, obtuse, $6 \mathrm{~mm}$. long. $A$. Geyeri M. E. Jones, not S. Wats. Mountain sides and meadows: Mont.-Wyo. -Ida.-(? B.C.) Submont.-Mont. Je-Jl.

8. A. rubrum Osterhout. Bulb ovoid, $1.5-2 \mathrm{~cm}$. thick; scape $2-3 \mathrm{dm}$. high, terete; leaf-blades $7 \mathrm{~mm}$. wide or less, concave; involucre 3 -leaved; petals and sepals ovate, obtuse, 6-7 $\mathrm{mm}$. long, with strong midrib; stamens and styles equalling the petals. In pastures and meadows: Colo. $\rightarrow \mathrm{s}$ Wyo. Submont. My-Jl.

9. A. canadense L. Bulbs ovoid, 1-2 cm. thick; scape 2-6 dm. high, stout; leaf-blades 1-5 dm. long, 3-8 mm. wide, rounded on the back; involucre 2- or 3-leaved; petals and sepals obtuse, pink or white, 4-6 mm. long; filaments as long as the petals. In meadows and fields: Me.-Fla.-La.-Colo.-Minn. Plain. My-Je.

10. A. aridum Rydb. Bulbs ovoid, about $1 \mathrm{~cm}$. thick, usually $2-4$ together; scape $1-1.5 \mathrm{dm}$. high, slender, striate; leaf-blades about $1-1.5 \mathrm{dm}$. long, often $1 \mathrm{~cm}$. long or less; sepals and petals about $6 \mathrm{~mm}$. long, lance-ovate, acute; filaments and style shorter than the petals. Dry hills in hard elay: Wyo. Plain. $\mathrm{Je}-\mathrm{Jl}$.

11. A. Nuttallii S. Wats. Bulb solitary, ovoid, about $1.5 \mathrm{~cm}$. thick; scape 1-3 dm. high; leaves 2-3 mm. wide, $1-1.5 \mathrm{dm}$. long; bracts 1-1.5 $\mathrm{cm}$. long; petals and sepals ovate or ovate-lanceolate, acute or acuminate, rose or white, 4-6 mm. long; stamens shorter than the petals. Plains and prairies: S.D.-Kans.-Ariz. -Ida. Plain. My-Je.

12. A. macropetalum Rydb. Bulb ovoid, solitary, about $2 \mathrm{~cm}$. thick; leaf-blades about $2 \mathrm{dm}$. long, almost equalling the scapes, 2-4 mm. wide; scapes $2 \mathrm{dm}$. high or more, stout, 3-4 mm. thick; bracts about $2 \mathrm{~cm}$. long; petals and sepals lanceolate, long-attenuate, white, with a purple or pink midrib; capsule with 6 conspicuous oblong crests. Mountains: Colo.-N.M. Submont. ApMy.

13. A. textile Nels. \& Macb. Bulbs usually solitary, ovoid, 1-2 cm. thick; scape slender, terete, 1-3 dm. high; leaf-blades $2-4 \mathrm{~mm}$. wide, 1-1.5 dm. long; bracts fully $1 \mathrm{~cm}$. long; petals and sepals ovate-lanceolate, acute or acuminate, 4-6 mm. long; capsule with 6 small rounded crests. A. reticulatum Fraser, not Presl. Plains and dry hills: Sask.-N.M.-Ariz.-Alta. Plain-Submont. Ap-S.

14. A. Geyeri S. Wats. Bulbs usually solitary, ovoid, $1.5-2.5 \mathrm{~cm}$. thick; scape 3-6 dm. high, rather stout; leaf-blades 2-4 mm. wide, 1-2 dm. long; bracts $1.5 \mathrm{~cm}$. long or more; petals and sepals pink or white, ovate-lanceolate, acuminate, 
6-8 mm. long; capsule with 6 rather prominent crests. A. reticulatum deserticola M. E. Jones. A. deserticola Woot. \& Standl. A. dictyotum Greene. Plains and valleys: Wash.-Ariz.-N.M.-S.D.-Mont. Plain-Mont. My-S.

15. A. Pikeanum Rydb. Bulb obliquely ovoid, about $1.5 \mathrm{~cm}$. long and 8-10 $\mathrm{mm}$. thick; scape $8-15 \mathrm{~cm}$. long, almost equalled by the narrowly linear leaves; bracts $8-10 \mathrm{~mm}$. long; petals and sepals subequal, ovate, acuminate, red-purple; capsule slightly crested above. Mountains: Pike's Peak and vicinity, Colo. Subalp.-Alp. Jl-Au.

16. A. acuminatum Hook. Bulbs solitary, nearly spherical, 1-1.5 cm. thick; outer coat rather thick, pitted, the 4-6-angled reticulations being very thick and raised; scapes 1-3 dm. high; bracts 2, 1-1.5 $\mathrm{cm}$. long; flowers 12-30; sepals dark rose or reddish purple, ovate-lanceolate, keeled on the back and gibbous at the base, 8-12 mm. long; petals similar but slightly shorter. Rich soil, prairies and rocky hillsides: B.C.-Calif.-Ariz.-Colo.-Mont. Submont. My-Jl.

17. A. cuspidatum (Fern.) Rydb. Bulb solitary, nearly globose, 1.5-2 cm. thick; outer coat thick; reticulations similar to those of the preceding, but less prominent; scape 2-3 dm. high, slender; leaf-blades less than $1 \mathrm{dm}$. long, $2 \mathrm{~mm}$. wide or less; sepals and petals more oblong and abruptly acuminate than in the preceding. A. acuminatum cuspidatum Fern. Rocky hillsides: e Wash.-W Ida. Submont. Ap-Jl.

18. A. simillimum Henderson. Bulbs ovate, nearly $1 \mathrm{~cm}$. thick; reticulations of the coat rectangular-hexagonal; scape $2.5-3 \mathrm{~cm}$. high, flattened and winged; leaf-blades 2, 8-9 $\mathrm{cm}$. long, $1 \mathrm{~mm}$. wide, falcate; bracts 2 ; flowers 6-9; sepals and petals narrowly oblong, pinkish white, with a strong green midvein; ovary slightly 3-crested. Open loose soil among rocks: Ida. Mont. Jl.

19. A. scilliloides Dougl. Bulb globose, about $1 \mathrm{~cm}$. thick, dark purplish brown; coat thin; reticulations fine and rectangular or square; scape about 2 $\mathrm{dm}$. high; bracts 2 , lanceolate, acuminate, fully $1 \mathrm{~cm}$. long; leaves 1 or 2 , about $15 \mathrm{~cm}$. long, $2 \mathrm{~mm}$. wide; sepals and petals ovate, about $7 \mathrm{~mm}$. long; the former saccate at base; capsule slightly 3 -ridged at the apex. Dry grounds: B.C.-Ida. - Ore. Submont. Je-Au.

20. A. incisum Nels. \& Macb. Bulb 1-1.5 $\mathrm{cm}$. thick; outer coat brown or pinkish, obseurely reticulate; scape $5-8 \mathrm{~cm}$. high, $1.5-2.5 \mathrm{~mm}$. broad, narrowly winged; leaves $3-5 \mathrm{~mm}$. wide, slightly faleate, exceeding the scape; bracts $2-$ several or the bracts cleft to the base; flowers many; pedicels $1-2 \mathrm{~cm}$. long; petals and sepals white, narrowly lanceolate, acute; capsule very obscurely crested. Barren clayey ground: Ida. Je.

21. A. fibrillum M. E. Jones. Bulb nearly spherical, $1-1.5 \mathrm{~cm}$. thick; leaves 2 or $3,1-1.5 \mathrm{dm}$. long, $2-4 \mathrm{~mm}$. wide; bracts 2 , ovate, fully $1 \mathrm{~cm}$. long; sepals ovate, acute, 6-8 mm. long; petals narrower, lanceolate; capsule slightly ridged. A. collinum Dougl., not Guss. Mountains: Wash.-Ore.-Ida.-W Mont. Plain-Mont. Je-Au.

22. A. tribracteatum Torr. Bulb ovoid or nearly globose, about $1 \mathrm{~cm}$. thick; reticulations transversely rectangular; scape $3-5 \mathrm{~cm}$. high, surpassed by the leaves; leaf-blades usually $2,4-10 \mathrm{~cm}$. long, 2-6 $\mathrm{mm}$. wide; sepals and petals oblong, acutish, with a purple midrib; capsule not crested. Mountains: Ore.Calif.-Utah-(? Colo.) Son. Ap.

23. A. Diehlii M. E. Jones. Bulb nearly globose; outer coat dark red; reticulations rectangular to linear-rectangular; scapes 5-7 cm. high; leaves 2; blades $1-1.5 \mathrm{dm}$. long and about $4 \mathrm{~mm}$. wide; bracts about $12 \mathrm{~mm}$. long; sepals ovate-lanceolate, acuminate; petals narrower; capsule spongy- and suleatecrested, the crests not evident in fruit. A. tribracteatum Diehlii M. E. Jones. Mountains: Utah. Mont. My.

24. A. minimum M. E. Jones. Bulb small, ovate, about $8 \mathrm{~mm}$. thick; outer coat very thin and membranous, the inner red; reticulations irregularly rectangular; scapes $7-10 \mathrm{~cm}$. high; leaves 2 ; bracts $6 \mathrm{~mm}$. long; flowers about 10 ; sepals and petals ovate, barely acute, $4 \mathrm{~mm}$. long, white, with green ribs 
below; capsule depressed-globose, crestless. Summits: Cuddy Mountains, Ida. Alp. Jl.

25. A. Douglasii Hook. Bulb ovoid, $1.5-2 \mathrm{~cm}$. thick; coats thin; reticulations obsolete; scape about $3 \mathrm{dm}$. high; bracts 2 , ovate, acuminate, $1.5-2 \mathrm{~cm}$. long; leaf-blades 1-1.5 dm. long, falcate; sepals and petals rose-colored, 6-8 mm. long, lanceolate, acuminate; capsule not crested. A. Hendersonii Robins. \& Seat. Hillsides and clay-banks. Wash.-Ore--Ida. Submont. Je.

26. A. Tolmiei Baker. Bulb ovoid, about $2 \mathrm{~cm}$. thick or less; reticulations obsolete; scape 5-10 $\mathrm{cm}$. high; leaf-blades 2, 1-1.5 dm. long, 4-8 $\mathrm{mm}$. wide; bracts 2 , nearly $2 \mathrm{~cm}$. long; flowers 20-30; sepals and petals pink with darker veins, about $8 \mathrm{~mm}$. long, lanceolate, acute or acuminate. A. anceps aberrans M. E. Jones. Arid places: Wash.-Ida.-Utah. Plain-Submont. Ap-Je.

27. A. Cusickii S. Wats. Bulb rounded-ovate, $1-1.5 \mathrm{~cm}$. thick; reticulations faint, rectangular; scape 5-10 $\mathrm{cm}$. high; leaves 2 , blades $1-1.5 \mathrm{dm}$. long, 4-7 $\mathrm{mm}$. wide; bracts ovate, acuminate; flowers rather many; sepals and petals pink, with darker veins, long-attenuate, $6-10 \mathrm{~mm}$. long. Valleys and mountain sides: Ore.-Ida. Plain-Mont. My-Jl.

28. A. Brandegei S. Wats. Bulb globose-ovoid, about $1 \mathrm{~cm}$. thick; outer coat very thin, inner ones purplish; reticulations transversely rectangular; seape less than $1 \mathrm{dm}$. high, often surpassed by the leaves; leaf-blades 2 , about $1 \mathrm{dm}$. long; bracts 2 ; sepals and petals rose-colored, broadly lanceolate, acuminate, 6-8 mm. long. Mountains: Ore.-Utah-Colo.-Ida. Submont.-Mont. Je-Au.

29. A. Nivii S. Wats. Bulb globose; coat white or reddish; reticulations transversely rectangular; scape $1.5-2 \mathrm{~cm}$. high, longer than the leaves; leafblades narrow; bracts 2 ; sepals and petals light rose-colored, lanceolate, acuminate, $6 \mathrm{~mm}$. long. Arid places: Wash.-Ida.-Ore. Submont. Je-Jl.

30. A. stellatum Ker. Bulb ovoid, 1-2 cm. thick; coats thin, mostly reddish; reticulations fine and close, elongated-rectangular; scapes $2-5 \mathrm{dm}$. high; leaves several; blades 1-3 dm. long, $1.5-2.5 \mathrm{~mm}$. wide, nearly flat; bracts 2, about $1 \mathrm{~cm}$. long; pedicels $1-2 \mathrm{~cm}$. long; sepals rose-colored, ovate, usually acute, 4-6 mm. long; petals ovate-oblong, mostly obtuse, slightly longer. On rocky banks: Ill.-Mo.-Kans.-Sask. Plain. Jl-S.

31. A. bisceptum S. Wats. Bulbs ovoid, 1-1.5 cm. thick; seapes often more than one, $2 \AA 4 \mathrm{dm}$. high, stout; leaf-blades broad, flat, 4-10 $\mathrm{mm}$. wide, $1.5 \mathrm{dm}$. long or more, attenuate; bracts 2; flowers numerous; petals and sepals broadly lanceolate, acuminate, white or pink, $7-8 \mathrm{~mm}$. long, not ribbed but slightly gibbous at the base. Moist soil: Utah-Nev.-Calif. Submont. MyJe.

32. A. Palmeri S. Wats. Bulb almost globose; scape 1.5-3 dm. high, slender; leaf-blades $1 \mathrm{dm}$. long or less; bracts 2, lanceolate, about $1 \mathrm{~cm}$. long; flowers 12-24; petals and sepals pink, ovate-lanceolate, slightly gibbous at the base, acute or acuminate. Dry regions: s Utah-Ariz.-N.M. L. Son.

33. A. pleianthum S. Wats. Bulb ovoid, 1-1.5 cm. thick; scape $5-12 \mathrm{~cm}$. high, flattened; leaf-blades 1-1.5 dm. long, 4-7 mm. wide, falcate; bracts 2; petals and sepals white or pink, lanceolate, acuminate, keeled and gibbous at the base, 8-10 mm. long. Valleys: Ore--Ida. Son. Ap-Je.

34. A. cristatum S. Wats. Bulb ovoid, about $\overline{2} \mathrm{~cm}$. thick; outer coat rather thick, brown; reticulations faint, irregularly quadrangular; scape less than $1 \mathrm{dm}$. high; leaf-blades $1 \mathrm{dm}$. long or less, $2-3 \mathrm{~mm}$. wide; bracts 2 or $3,1.5 \mathrm{~cm}$. long; petals and sepals light rose-colored, with darker midyeins, about $1 \mathrm{~cm}$. long, lanceolate; crests of the ovary very long, glandular-toothed. Dry places: Utah -Ariz. L. Son. Ap.

35. A. nevadense $\mathrm{S}$. Wats. Bulb nearly globose, $1-1.5 \mathrm{~cm}$. thick; outer coat thick and brown; reticulations irregular, with sinuate or eurved sides; scape less than $1 \mathrm{dm}$. high; leaf-blades $1 \mathrm{dm}$. or less, flat, $2-3 \mathrm{~mm}$. wide; bracts 2 , about $1.5 \mathrm{~cm}$. long; sepals and petals lanceolate, $6-8 \mathrm{~mm}$. long. Mountains and hillsides: Nev,-Utah-Ariz. Son.-Submont. My-Jl. 


\section{DIPTEROSTÈMON Rydb.}

Perennials, with fibrous-coated bulbs, few basal narrow leaves, and naked scapes. Flowers in subcapitate umbels, with 3-5 membranous colored bracts. Perianth funnelform or campanulate, purple; segments united half their length. Stamens 6; filaments subulate, adnate to the perianth-tube, those opposite the sepals naked, those opposite the petals with two lanceolate lobes or wings at the base; anthers basifixed. Capsule ovoid, 3-celled; cells many-seeded.

Perianth-tube funnelform, gradually widening into the limb; bracts broad, conspicuously exceeding the pedicels.

1. D. capitatus.

Perianth-tube cylindro-campanulate, abruptly widening into the limb; bracts narrow, often exceeded by some of the unequal pedicels.

2. D. pauciflorus.

1. D. capitatus (Benth.) Rydb. Scape $2-5 \mathrm{dm}$. high; leaves $2-4 \mathrm{dm}$. long, 6-12 $\mathrm{mm}$. wide; bracts ovate, lanceolate or elliptic, acute or obtuse, dark violetpurple; perianth purple, about $15 \mathrm{~mm}$. long. Brodiaea capitata Benth. Hillsides: Ore-Utah-Calif. Son. Ap-Je.

2. D. pauciflorus (Torr.) Rydb. Seape 1-3 dm. high; leaves 1-3 dm. long, 2-5 mm. wide; bracts lanceolate, $7-10 \mathrm{~mm}$. long, mostly white, tinged with lilac and purple-veined; perianth about $12 \mathrm{~mm}$. long, purple. B. capitata pauciflora Torr. Arid regions: N.M. $\rightarrow$ s Utah $\rightarrow$ s Calif. L. Son. Ap-Je.

\section{HESPEROSCÒRDUM Lindl.}

Plants with fibrous-coated bulb, few basal narrow leaves, and naked scapes. Flowers in bracted umbels; bracts $3-5$. Perianth openly turbinate; segments united one-third their length, white or lilac; lobes ascending. Stamens 6, adnate to the tube of the perianth; free portion of the filaments above the throat deltoid; anthers versatile, oblong. Capsule ovoid, stipitate, triangular in crosssection.

1. H. lacteum Lindb. Bulb globose, $15-18 \mathrm{~mm}$. thick; scape $3-5 \mathrm{dm}$. high; leaves 2-3 dm. long, 3-5 $\mathrm{mm}$. wide; bracts narrowly lanceolate, less than $1 \mathrm{~cm}$. long; flowers many; perianth white, with greenish or purplish veins, $12-15$ $\mathrm{mm}$. long; segments oblong or elliptic, obtuse. Brodiaea lactea S. Wats. Moist rich soil: B.C.-Ida.-Nev.-Calif. Submont. My-Je.

\section{TRITELÈIA Dougl. Wild Hyacinth.}

Plants with fibrous-coated bulbs, few basal elongated leaves, and naked scapes. Flowers in bracted umbels; bracts 3-5. Perianth from campanulate to narrowly funnelform, in ours blue or purple; segments united half their length or more; lobes aseending. Stamens 6 ; filaments adnate to the perianth-tube and the inner ones even to its lobes, making them apparently inserted in two distinct series; anthers distinctly versatile; capsule elongated-ovoid or ellipsoid, more or less distinctly stipitate, 3-valved, many-seeded.

1. T. grandiflora Lindl. Bulb globose, deep-seated, about $2 \mathrm{~cm}$. thick; scape 3-6 dm. high; flowers rather many; perianth about $2 \mathrm{~cm}$. long, campanulate; lobes elliptic or oval, obtuse. Brodiaea Douglasii S. Wats. Rich soil: B.C.Mont.-Wyo.-Utah-Ore. Submont. Ap-Jl.

\section{ANDROSTÉPHIUM Torr.}

Scapose herbs, with membranous-coated bulbs. Leaves basal, with elongated narrow blades. Bracts several. Flowers perfect, short-pedicelled. Petals and sepals blue, or rose-colored, united to about the middle into a funnelform tube. Stamens 6 , adnate to the perianth-tube; filaments united at least to the middle into a tube, which bears tooth-like lobes between the free portion of the filaments; anthers introrse. Ovary 3-celled; style filiform. Seeds several in each locule. Capsule 3-angled. Seeds few, black.

1. A. breviflorum S. Wats. Bulb ovoid, fibrous-coated, $1.5-2 \mathrm{~cm}$. broad; scape 1-3 dm. high; bracts lanceolate, scarious; flowers rather few; pedicels 1-2 cm. long; perianth 15-20 $\mathrm{mm}$. long; lobes oblong; lobes of the crown shorter than the anthers; pod $15-18 \mathrm{~mm}$. in diameter. Brodiaea Paysonii A. Nels. Dry regions: w Colo. $\rightarrow$ U Utah $\rightarrow$ S Calif. Son. Ap. 


\section{Family 21. Lillaceae. Lily Family.}

Perennial herbs, mostly caulescent, with bulbs, corms, or short rootstocks. Flowers in terminal racemes, corymbs, panicles, or rarely solitary. Sepals and petals each 3 , similar, petaloid, sometimes partly united. Stamens 6 . Pistils of 3 united carpels; ovary superior, 3-celled; styles united. Fruit a loculicidal capsule.

Plant with a short rootstock; flowers subumbellate on subterranean pedicels from the crown of the rootstock; petals and sepals united into a long tube.

1. LEUCOCRINUM.

Plant with bulbs or corms, either leafy-stemmed or scapiferous; petals and sepals distinct or nearly so.

Bulb scaly; plant tall, leafy.

Anthers versatile; petals and sepals oblanceolate, clawed, with a linear nectariferous groove.

2. LILIUM

Anthers fixed near the base, slightly if at all versatile; petals and sepals obovateoblanceolate, not clawed; nectary a shallow pit.

Styles distinct from the middle; flowers purple, mottled with yellowish green; fruit winged.

3. Fritillaria.

Styles connate to the summit; flowers yellow or orange; fruit not winged.

Bulb tunicated.

Anthers strictly basifixed.

Leaves 2, basal or nearly so; flowers nodding.

Leaves several, alternate; flowers not nodding.

5. ERYTHRONIUM.

Flowers in ours usually solitary; pedicels not jointed; dwarf alpine plant.

Flowers racemose; pedicels jointed below the middle; not alpine.

Anthers versatile; scapose plants with racemose flowers.

7. EREMOCRINUM.

8. QUAMASIA.

1. LeuCocrìnum Nutt. Star of Bethlehem, Mountain Lily, Wild Tuberose.

Low acaulescent herbs, with short rootstock and fleshy-fibrous roots. Leaves basal, numerous, surrounded by scarious sheaths. Flowers in umbel-like sessile clusters, with pedicels and ovaries under ground. Petals and sepals each 3, alike, united below into a long tube. Stamens 6; filaments adnate below to the tube of the perianth; anthers linear, attached near the base, introrse; style much elongated, filiform; stigma 3-lobed. Capsule triangular, obovoid.

1. L. montanum Nutt. Leaves thick, numerous, $1-2 \mathrm{dm}$. long, $2-8 \mathrm{~mm}$. broad; flowers 4-8; perianth white; tube $3-8 \mathrm{~cm}$. long; lobes linear-oblong, about $2 \mathrm{~cm}$. long; capsule truncate, $6-8 \mathrm{~mm}$. long, 12-18-seeded. Hills and plains: Mont.-S.D.-n N.M.-Calif.-Ore. Plain-Submont. My-Je.

\section{LÍlium (Tourn.) L. LiLy.}

Tall, leafy herbs, with thick-scaly bulbs and large funnelform or campanulate flowers. Petals and sepals each 3 , similar, distinct, each with a nectariferous groove at the base within. Stamens 6; filaments filiform or subulate; anthers linear, versatile, longitudinally dehiscent. Ovary 3-eelled, many-ovuled; style long, somewhat clavate; stigma 3-lobed. Capsule oblong or obovoid; seeds numerous, flat, horizontal, in 2 rows in each cavity.

Flower erect, solitary or subumbellate; petals and sepals unguiculate.

Leaves linear.

Leaves lanceolate.

1. L. umbellatum.

owers several, racemose, nodding; petals and sepals not unguiculate.

3. L. columbianum.

1. L. umbellatum Pursh. Stem leafy, 3-6 dm. high; leaves linear, acute, 4-7 $\mathrm{cm}$. long, $2-7 \mathrm{~mm}$. wide, mostly alternate and scattered, the uppermost forming one, seldom two whorls; flowers 1-3, umbellate; petals and sepals 5-6 $\mathrm{cm}$. long; blade oval, red or orange, spotted below, acute; capsule almost cylindrical, about $6 \mathrm{~cm}$. long, $15 \mathrm{~mm}$. thick. In dry open woods: Mich.-N.M.Ohio-Sask.-Ark. Plain-Submont. Je-Jl.

2. L. montanum A. Nels. A plant similar to the preceding, but with broader leaves; leaves, except the uppermost, alternate and scattered, $5-8 \mathrm{~cm}$. long, 6-10 mm. wide; whorl 1 , seldom 2; petals and sepals $5-6 \mathrm{~cm}$. long; blades 
oval, acute or short-acuminate; capsule cylindric-ovoid. Closely related to the eastern L. philadelphicum L. On hills and mountain-sides, among bushes: Mont.-N.M. Submont.-Mont. Je-Jl.

3. L. columbianum Hanson. Stem a meter or so high; leaves mostly verticillate, lanceolate, acute, $5-8 \mathrm{~cm}$. long, $6-15 \mathrm{~mm}$. wide; petals and sepals 3-4 $\mathrm{cm}$. long, in age reflexed, linear-lanceolate, red, spotted; capsule obovoid, 2-3 cm. long, $15 \mathrm{~mm}$. or more thick. L. parviflorum (Hook.) Holz. In open woods: B.C.-Ida.-Calif. Submont. Je-Au.

\section{FRITILLÀria L. Tiger LiLy, Leopard LiLy.}

Simple leafy herbs, with thick-scaly bulbs. Flowers open, campanulate, large, nodding; petals and sepals 3 , nearly equal, oblong or ovate, deciduous, each with a nectariferous pit at the base. Stamens 6 , hypogynous, free; anthers linear or oblong, attached at the base, not versatile. Ovary 3-celled; ovules numerous; style slender, 3-cleft. Capsule obovoid, globose or cylindric, 6-angled. Seeds numerous, flat, margined or winged.

Leaves lanceolate or linear-lanceolate.

Leaves narrowly linear.

1. F. lanceolata.

2. F. atropurpurea.

1. F. lanceolata Pursh. Stem stout, 3-6 dm. high, leafless below, leafy above, and 1-4-flowered; leaves in 1-3 verticils of 2's-4's, lanceolate or linearlanceolate, obtuse, 3-10 cm. long; flowers dark purple, mottled with greenish yellow; petals and sepals lanceolate or oblong, acutish, $2-3 \mathrm{~cm}$. long; capsule less than $2 \mathrm{~cm}$. long and fully $2.5 \mathrm{~cm}$. broad. In rich soil: B.C.-Calif.-Ida.Mont. Submont. Mr-My.

2. F. atropurpurea Nutt. Stem slender, 1-4 dm. high, leafless below, leafy above, 1-4-flowered; leaves mostly scattered, alternate or the upper verticillate, narrowly linear, $3-8 \mathrm{~cm}$. long, $3 \mathrm{~mm}$. wide; flowers dark purple, mottled with yellowish green; petals and sepals elliptic to linear, 5-25 mm. long; capsule about $15 \mathrm{~mm}$. long and as wide. F. linearis Coult. \& Fish. On hillsides among bushes: Wash.-Calif.-N.M.-N.D.-Neb. Plain-Submont. My-Je.

\section{OCHROCÒdON Rydb. Yellow Bell.}

Simple leafy herbs, with scaly bulbs. Leaves mostly scattered. Flowers yellow or orange, campanulate, nodding, solitary. Petals and sepals 3 , oblongspatulate, obtuse. Stamens 6, free; anthers attached at the base. Ovary 3celled; style undivided; stigma slightly 3-lobed. Capsule obovoid, 3-valved.

3. O. pudicus (Pursh) Rydb. Stem low, strict, 1-3 dm. high, generally 1-flowered; leaves 1-5, scattered or subverticillate, linear, 3-10 $\mathrm{cm}$. long, rather thick; flower yellow, or orange; petals and sepals oblong, obtuse, $12-20 \mathrm{~mm}$. long; fruit obovoid, $3-4 \mathrm{~cm}$. long, and 15-22 mm. thick, erect. Fritillaria pudica (Pursh) Spreng. In rich soil on hillsides: B.C.-Calif.-Utah-Wyo.-Mont. Submont.-Mont. Ap-My.

\section{ERYTHRÒNIUM L. Dog-tooth Violet, Adder-tongue,}

Low herbs, with membranous-coated corms and simple scapiform stems bearing two leaves below. Flowers solitary or few, nodding; petals and sepals lanceolate, distinct, with a nectariferous groove. Stamens 6, hypogynous, free; anthers oblong to linear, attached at the end. Ovary 3-celled; ovules numerous in each cell; style filiform, or thickened above, often 3-cleft. Capsule obovoid or oblong, in ours bluntly 3 -angled.

Style more or less clavate.

Anthers of the stamens subequal.

Anthers $3-4 \mathrm{~mm}$. long; rarely longer, light yellow.

Anthers 4-8 mm. long, usually purplish, in age yellowish.

1. E. parviflorum.

Petals $2-3 \mathrm{~cm}$. long; their veins almost equal and equally distributed.

Petals 3-5 cm. long (in secondary flowers sometimes smaller) E. obtusatum. inent, separated from the next veins by rather broad veinless spaces, side veins branched and arching towards the margin.

3. E. grandiflorum 
Anthers of the inner set of stamens much longer than those of the outer; veining of petals resembling that of $E$. grandiflorum.

Style filiform or nearly so; petals narrowly linear-lanceolate.

4. E. utahense.

5. E. leptopetalum.

1. E. parviflorum (S. Wats.) Goodding. Scape 1-3 dm. high, 1-4- (rarely 5-7-) flowered; sepals and petals lanceolate, acuminate, $2-3 \mathrm{~cm}$. long, bright yellow; capsule short, oblanceolate-oblong to nearly obovate, 3-4 cm. long, $1-1.5$ em. thick. E. grandiflorum parviflorum S. Wats. Rich soil: Colo--Wyo. -Utah. Submont.-Subalp. Ap-Au.

2. E. obtusatum Goodding. Scape 2-4 dm. high, 1-3-flowered; leaf-blades oblanceolate or oblong, broadest usually above the middle, obtuse and apiculate or acute, 1-2 dm. long; petals and sepals pale yellow, in age becoming whitish or purplish, 2-3.5 cm. long; filaments dilated at the base, subulate; capsule oblanceolate, $3.5-5 \mathrm{~cm}$. long, a little more than $1 \mathrm{~cm}$. thick. Rich soil: B.C.Wyo.-Mont. Submont.-Mont. Ap-Au.

3. E. grandiflorum Pursh. Scape 2-4 dm. high, 1-3-flowered; leaf-blades from lanceolate to oval or ovate-lanceolate, mostly acute, usually broadest at or below the middle, 1-2 dm. long; sepals and petals light yellow, $3-5 \mathrm{~cm}$. long; filaments slender but somewhat dilated below; capsule oblong, tapering at the base, 3-4 cm. long, about $12 \mathrm{~mm}$. thick. Rich soil: B.C.-Wash.-Wyo.Mont. Submont.-Mont. My-Jl.

4. E. utahense Rydb. Scape 1.5-3 dm. high, 1-3-flowered; leaf-blades oblanceolate, 1-2 dm. long, acute or obtuse, $1.5-4.5 \mathrm{~cm}$. wide; sepals and petals $2.5-3 \mathrm{~cm}$. long, narrowly lanceolate, acute or acuminate; filaments subulate, dilated below; capsule obovoid, about $2 \mathrm{~cm}$. long and $1 \mathrm{~cm}$. thick. Mountains: Utah. Submont.-Mont. My-Jl.

5. E. leptopetalum Rydb. Scape 1.5-2 dm. high, slender; leaf-blades broadly oval, about $12 \mathrm{~cm}$. long and $6 \mathrm{~cm}$. wide; sepals and petals narrowly lanceolate, about $3.5 \mathrm{~cm}$. long, $3-5 \mathrm{~mm}$. wide, acute, evenly veined; filaments strongly dilated below; stigma deeply 3-cleft, with slender recurved lobes. Mountains near Boise City, Ida. Je.

\section{LLÒYDIA Salisb. Atp LiLY.}

Dwarf caulescent herbs, with bulbs. Leaves narrow, grass-like. Flowers white in terminal racemes (often reduced to a single flower). Sepals and petals each 3 , nearly alike, with a transverse fold-like gland near the base. Stamens 6, distinct; filaments subulate; anthers basifixed, dehiscent by marginal slits. Ovary triangular, 3-celled; ovules numerous in 2 rows in each cell, anatropous; style persistent; stigma 3-lobed. Capsule loculicidal at the apex.

1. L. serotina (L.) Sweet: Bulb oblong, fibrous-coated, ending a creeping rootstock; stem 5-15 $\mathrm{cm}$. high; leaves several, 5-10 $\mathrm{cm}$. long, 1-2 $\mathrm{mm}$. wide; perianth about $1 \mathrm{~cm}$. long, broadly turbinate; petals and sepals oblanceolate, obtuse, yellowish white, purple-veined and tinged with rose on the back; capsule obovoid, $8 \mathrm{~mm}$. long. Alpine-arctic regions among rocks: Alta.-N.M. -Nev. -Alaska; Eurasia. Alp.

\section{EREMOCRINNUM M. E. Jones. Desert LiLy.}

Perennial herbs, with a small tunicated bulb. Stem more or less leafy at the base. Flowers racemose, scarious-bracted. Sepals and petals each 3, distinct, 3-nerved, spreading. Stamens 6; filaments linear, broader at the base; anthers linear, obtuse at the apex, subcordate at base, basifixed, in age incurved. Ovary 3-celled; style slender, elongated. Capsule loculicidal, each cell 2-seeded. Pedicels jointed near the base.

1. E. albomarginatum M. E. Jones. Bulb 5-6 mm. thick; stem 1-3 dm. high; leaves basal, $1-2 \mathrm{~cm}$. long, 1-3 mm. wide; bracts ovate, scarious, $10-12$ $\mathrm{mm}$. long; flowers $1-3$ at each node; pedicels 8-12 mm. long; perianth white, with green veins; petals and sepals $8-10 \mathrm{~mm}$. long. Desert regions: Utah. Son. My. 


\section{QUamásia Raf. Camash, Blue Camas, Wild Hyacinth, Swamp Sego.}

Perennial herbs, with scapiform stems and edible bulbs. Leaves basal, with elongated blades. Flowers in terminal racemes. Sepals and petals each 3, alike, distinct, blue, white, or purple. Stamens 6; filaments filiform, adnate to the base of the petals and sepals; anthers versatile, introrse. Ovary 3-celled; styles filiform; stigma 3-lobed; ovules numerous in each cavity. Capsule broad, 3 -angled. Seeds black, shining. Flowers somewhat oblique, about $2 \mathrm{~cm}$. long; divisions 3 -veined, or some of them 4 - or
5 -veined.

Flowers regular, about $3 \mathrm{~cm}$. long; divisions all 5-7-veined.

1. Q. Quamash.

2. Q. Suksdorfii.

1. Q. Quamash (Pursh) Coville. Bulb globose, $1.5-3 \mathrm{~cm}$. thick; scape 3-6 dm. high; leaves 6-15 mm. broad, 2-4 dm. long; petals and sepals linear, blue, about $2 \mathrm{~cm}$. long, exceeding the stamens, but slightly shorter than the style; capsules ellipsoid, $12-15 \mathrm{~mm}$. long, on almost erect pedicels. Camassia esculenta Lindl. Meadows: Mont.-Utah-Calif.-B.C. Plain-Submont. Ap-Je.

2. Q. Suksdorfii (Greenm.) Piper. Bulb ovate, 1-3 cm. thick; scape 3-7 $\mathrm{dm}$. high, few-flowered; leaves $2-3 \mathrm{dm}$. long, $0.5-2 \mathrm{~cm}$. broad; petals and sepals $3-3.5 \mathrm{~cm}$. long, $8 \mathrm{~mm}$. wide, blue; capsules $1.5-2.5 \mathrm{~cm}$. long, erect on pedicels which arch upwards. Meadows: Wash.-Ida.-Utah. Plain-Submont. My.

\section{Family 22. CONVALlaRIACEAE. Lily-of-the-Valley Family.}

Perennial herbs, with rootstocks and alternate, rarely basal leaves. Flowers perfect, in terminal or axillary racemes, panicles, umbels, or rarely solitary. Sepals and petals 3 or 2 , similar, distinct or partly united, inferior. Stamens 6 or 4 . Gynoecium of 3 or 2 united carpels; ovary 3- or 2-celled; styles united. Fruit in all our species a berry.

\section{Stem leafy; leaves alternate.}

Flowers white, in terminal racemes or panicles; anthers introrse; stem simple. Petals and sepals 3; stamens 6.

Petals and sepals 2 ; stamens $4 . \quad 2$. UNIFOLIUM.

Flowers extra-axillary or terminal and solitary or in small umbelliform clusters; anthers extrorse or opening laterally; stem branched.

Flowers extra-axillary, greenish white; fllaments slender; anthers acute. Corolla campanulate.
C. STREPTOPUs. Corolla rotate.
owers terminal, yellow; filaments dilated; anthers obtuse. 5. KRUHSEA.

Flowers terminal, yellow; filaments dilated; anthers obtuse. 5. DisPORUM.
Sepals and petals partially united into a tube; flowers axillary. Stem scapiform; leaves basal; flowers in terminal umbels, or solitary and terminal.

7. Clintonia.

\section{VÁGNera Adans. Wild Spikenard, Wild LiLy-of-the-Valley, False Solomon's Seal.}

Caulescent herbs, with elongated rootstocks. Leaves broad, several-nerved. Flowers in terminal racemes or panicles. Sepals and petals white or greenish white, distinct or nearly so. Stamens 6; filaments subulate; anthers introrse. Ovary 3-celled; styles short; stigma 3-lobed; ovules 2 in each cavity. Berry globose. Seeds 1 or 2, with a thin testa. [Smilacina Desf.]

Inflorescence paniculate.

Petals and sepals scarcely half as long as the stamens; fruii dark purple.

Pe Jals and sepals almost equalling the stamens; fruit red with purple 1. brachypetala.

Leaf-blades acuminate, the lower contracted at the base into distinct petioles;

style about $0.5 \mathrm{~mm}$. long.
Leaf-blades acute, all sessile and more or less clasping; style fully $1 \mathrm{~mm}$. long.

Inflorescence racemose.

Leaves 6-12, sessile.

Petals and sepals linear or linear-lanceolate.

Petals oblong-lanceolate.

3. V. amplexicaulis. Pedicels short, slightly if at all longer than the flowers or the fruit; leaves
lanceolate, acute.
5 . V. stellata.

5. V. stellata. 
Pedicels long, the lower often 2-3 times as long as the flowers or the fruit.

Raceme strict; pedicels strongly ascending; leaves narrowly lanceolate. long-attenuate.

6. V. liliacea.

Raceme zigzag; pedicels spreading; leaves broadly lanceolate, usually abruptly acuminate.

Leaves $2-4$, sheathing the low stem.

7. $V$. sessilifolia.

8. V. trifolia.

1. V. brachypetala Rydb. Stem stout, 5-8 dm. high, striate, puberulent; leaves subsessile or short-petioled, oval or ovate, 8-18 cm. long, 4-7 cm. wide, often short-acuminate and twisted at the apex; panicle rather dense; petals and sepals oblong, 1-1.5 mm. long; style about $0.5 \mathrm{~mm}$. long; berry about $4 \mathrm{~mm}$. in diameter. Hillsides: B.C.-Wash.-Ida. Submont.-Mont. My-Je.

2. V. racemosa (L.) Morong. Stem somewhat angled, finely puberulent above, 3-9 dm. high; blades elliptic or oval, 7-15 $\mathrm{cm}$. long, 3-6 $\mathrm{cm}$. wide, finely puberulent beneath; sepals and petals oblong, $2 \mathrm{~mm}$. long or more; berry $5-6$ mm. thick. Smilacina racemosa (L.) Desf. Woods and thickets: N.S.-Ga.Colo.-B.C. Plain-Submont. My-Jl.

3. V. amplexicaulis (Nutt.) Morong. Stem 3-7 dm. high; blades ovate to lanceolate, acute, puberulent, 6-15 $\mathrm{cm}$. long, 4-8 $\mathrm{cm}$. wide; sepals and petals oblong, about $2 \mathrm{~mm}$. long; filaments lanceolate-subulate; berry light red, dotted with purple, $5-6 \mathrm{~mm}$. thick. S. amplexicaulis Nutt. Hillsides and woods: B.C. -Calif.-N.M.-Alta. Submont.-Mont. My-Jl.

4. V. leptopetala Rydb. Stem 2-3 dm. high, erect, strict or the upper portion somewhat zigzag, striate and pale; leaves oblong-lanceolate, 6-8 cm. long, 1-2 cm. wide, light green, sessile, long-acute; raceme 3-6-flowered; pedicels $5-8 \mathrm{~mm}$. long; petals and sepals about $4 \mathrm{~mm}$. long and less than $1 \mathrm{~mm}$. wide, very thin, white. Cañons: Colo. Mont.

5. V. stellata (L.) Morong. Stem glabrous, $2-5 \mathrm{dm}$. high, striet; leaves sessile, minutely puberulent beneath, $5-13 \mathrm{~cm}$. long; sepals and petals $3-5 \mathrm{~mm}$. long; berry green, with 6 black stripes, turning black, 6-10 mm. thick. S. stellata (L.) Desf. In moist soil, meadows or copses: Newf.-Va.-Colo.-Alta. Submont. -Subalp. My-Jl.

6. V. liliacea (Greene) Rydb. Stem tall and strict throughout, 3-10 dm. high; leaves sessile, glabrous, 7-20 cm. long; raceme 4-10 cm. long, 3-10-flowered; sepals and petals oblong, obtuse, 5-7 mm. long; style about $1 \mathrm{~mm}$. long; berry purplish, 7-10 mm. thick. Unifolium liliaceum Greene. Wooded hills and shady places: B.C.-Calif.-N.M.-Mont. Submont.-Mont. My-Je.

7. V. sessilifolia (Nutt.) Greene. Stem 2-4 dm. high, more or less flexuose above; leaves sessile, $0.5-10 \mathrm{~cm}$. long, glabrous or nearly so; raceme $3-7 \mathrm{~cm}$. long; sepals and petals linear-oblong, obtuse, about $6 \mathrm{~mm}$. long; style about $1 \mathrm{~mm}$. long; berry red or purple, $8-10 \mathrm{~mm}$. in diameter. S. sessilifolia Nutt. Wouds: Yukon-Calif.-Wyo.-Mont. Submont. Je-Jl.

8. V. trifolia (L.) Morong. Stem slender, 0.5-4 dm. high; leaves sessile, oval, oblong, or oblong-lanceolate, with sheathing bases, acute or acuminate; raceme few-flowered, strict; sepals and petals oblong or oblong-lanceolate, obtuse, about $3 \mathrm{~mm}$. long; berry dark red, $5-6 \mathrm{~mm}$. in diameter. V. pumila Standl., a small form with rather short style. In bogs and wet woods: Lab.- N.J.Minn.-Mack. Boreal-Mont. My-Je.

\section{UNIfòliUm Adans. Two-leaved Solomon's Seal.}

Caulescent herbs, with slender rootstocks. Leaves mostly 2 or 3 , with broad, several-nerved blades. Inflorescence terminal, racemose. Sepals and petals white, similar, each 2, distinct, spreading. Stamens 4, hypogynous; filaments narrowly linear; anthers versatile, introrse. Ovary 2-celled; stigmas 2; ovules 2 in each cavity. Fruit a subglobose pulpy berry; seeds 1 or 2 . [Maianthemum Wigg.]

Leaves subsessile; blades cordate-clasping, with shallow and narrow sinuses.

Stem-leaves distinctly petioled; blades with deep and open sinuses.

. canadense.

2. U. dilatatum, 
1. U. canadense (Desf.) Greene. Stem slender, 1-3-leaved (usually 2leaved), $5-18 \mathrm{~cm}$. high, glabrous; leaves ovate or ovate-lanceolate, $2-8 \mathrm{~cm}$. long; berry pale red, speckled, about $4 \mathrm{~mm}$. thick. Moist woods and thickets: Lab. -N.C.-S.D.-Mack. Boreal-Submont. My-Jl.

2. U. dilatatum (Wood) Howell. Stem 2-3-leaved, 2-4 dm. high, glabrous; leaf-blades broadly cordate, acuminate, $5-10 \mathrm{~cm}$. long and nearly as broad; berry red, globose, about 6 mm. thick. Maianthemum bifolium dilatatum Wood. Swampy places: Alaska-Calif.-Ida.-Canadian Rockies. Submont.-Mont.

\section{STRÉPTOPUS Michx. TwISTED-STALK.}

Caulescent perennial herbs, with horizontal rootstocks. Leaves manynerved, broad, sessile or clasping. Flowers racemose on 1-3-flowered, extraaxillary peduncles. Sepals and petals much alike, greenish or purplish, each 3 , distinct, with spreading or recurved tips. Petals keeled. Stamens 6, hypogynous; filaments flattened, very short; anthers sagittate, opening by lateral slits. Ovary 3 -celled; stigmas 3 -lobed or entire; ovules in 2 rows in each cavity.

Plant branched; pedicels geniculate; berry white.

Plant simple; pedicels not geniculate; berry red.

1. S. amplexifolius.

2. S. curvipes.

1. S. amplexifolius (L.) DC. Stem 3-10 dm. high, flexuose-branched; leaves ovate or ovate-lanceolate, glabrous and glaucous, 5-13 cm. long; perianth campanulate, greenish white, $8-12 \mathrm{~mm}$. long; sepals and petals lanceolate, attenuate; berry globose-ellipsoid, 8-12 mm. long. Damp woods: Greenl.N.C.-N.M.-Ore-Alaska; Eu. Submont.-Subalp. Je-Au.

2. S. curvipes Vail. Perennial, with a rather slender rootstock; stem simple, 1-3 dm. high; leaves sessile, oval to oblong-lanceolate, $3-8 \mathrm{~cm}$. long, acuminate; perianth pale purple or rose-colored; sepals and petals lanceolate, $5-7 \mathrm{~mm}$. long, minutely glandular-pubescent inside; berry globose, 7-9 mm. thick. Open woods: B.C.-Ore.-Alaska. Submont.-Mont. Je-Jl.

\section{KRÙHSEA Regel.}

Caulescent perennial herbs, with rootstocks. Leaves broad, sessile or slightly clasping, several-nerved. Flowers usually solitary, inserted opposite the leaves. Flowers rotate; petals and sepals with greenish reflexed tips. Stamens 6 ; filaments very short; anthers 2-lobed. Ovary 3-celled, becoming a berry. Style none.

1. K. streptopoides (Ledeb.) Kearney. Stem glabrous, $5-15 \mathrm{~cm}$. high; leaves 4-8, bright green, ovate-lanceolate, acute, $3-5 \mathrm{~cm}$. long; pedicels recurved, $1 \mathrm{~cm}$. long or less; sepals and petals deeply wine-colored at the base, with yellowish green tips; fruit globose, bright red at maturity. Smilacina streptopoides Ledeb. Streptopus ajanensis Tiling. S. brevipes Baker. Kruhsea Tilingii Regel. Woods: B.C.; Siberia. Mont. My.

\section{DÍSPORUM Salisb.}

Caulescent branched perennial herbs, with rootstocks. Leaves broad, manynerved, sessile or clasping, often oblique. Flowers terminal, solitary or in small subumbellate clusters, drooping. Sepals and petals each 3 , whitish or greenish yellow, narrow, distinct. Stamens 6, hypogynous; filaments filiform, or somewhat flattened; anthers extrorse. Ovary 3-celled; stigmas entire or 3-cleft; ovules 2 or more in each cavity. Fruit thick, juicy, (in ours) bright red or orange.

Stigma 3-cleft; fruit deeply lobed, obtuse, papillose.

Stigma entire; fruit acutish, not papillose, but often pubescent.

1. D. trachycarpum (S. Wats.) Stem $3-6 \mathrm{dm}$. high, more or less flexuose, more or less pubescent; leaves sessile, ovate or oval to ovate-lanceolate, $3-9 \mathrm{~cm}$. long, short-acuminate; perianth narrowly campanulate, ochroleucous, 10-15 mm, long; fruit depressed-globose, deeply 3-lobed, $8-10 \mathrm{~mm}$. thick. Prosartes trachycarpa S. Wats, D. majus Britt., in part. Cañons and hillsides: Man.N.M.-Ariz-B.C. Plain-Subalp. My-Je. 
2. D. oreganum (S. Wats.) W. Miller. Stem 3-6 dm. high, with ascending branches; leaves ovate-lanceolate, more or less short-villous when young, $5-10$ $\mathrm{cm}$. long, long-acuminate; perianth campanulate, yellow, 10-15 mm. long; fruit obovoid, $10-12 \mathrm{~mm}$. long. $P$. oreganus $\mathrm{S}$. Wats. Cañons and river banks: B.C.-Mont.-Calif.-Ida. Submont. My-Je.

\section{POLYGonàtUM (Tourn.) Hill. Solomon's SEAL.}

Caulescent perennial herbs, with jointed rootstocks. Leaves in our species broad, many-nerved, sessile. Flowers in axillary 1-few-flowered racemes. Petals and sepals each 3, partly united, the free portion shorter than the tube, greenish or pinkish. Stamens 6, included; filaments partly adnate to the perianth-tube; anthers sagittate, introrse. Ovary 3-celled; stigma mostly eapitate; ovules $2-6$ in each cavity. Berry subglobose, dark blue or black. Seeds with a horny endosperm. [Salomonia Heist.]

1. P. commutatum (R. \& S.) Dietr. Stem 3-25 dm. high, glabrous; leaves ovate or oblong, partly clasping, 5-15 cm. long; peduncles 1-8-flowered; perianth white or greenish, 1-2 cm. long, drooping; filaments glabrous, adnate to the perianth about half its length; berries 8-12 $\mathrm{mm}$. thick, subglobose. $P$. giganteum Dietr. S. commutata Farwell. In woods: Ont.-Ga.-N.M.-Utah -Man. Plain-Submont. Je.

\section{CLINTÒNIA Raf.}

Subacaulescent perennial, with creeping rootstocks. Leaves basal or nearly so, broad, many-nerved. Flowers in terminal umbels, on an almost leafless scape, or in our species the umbel reduced to 1 or 2 flowers. Petals and sepals each 3 , similar, petaloid, distinct. Stamens 6 ; filaments filiform; anthers versatile. Ovary 2- or 3-celled; style slender; stigma 2- or 3-lobed. Berry ovoid, thin.

1. C. uniflora (Schult.) Kunth. Sparingly villous; leaves 2-5, oblanceolate, 1-2 dm. long, 3-5 cm. broad; scape shorter than the leaves; flowers 1 or 2, white, eampanulate, 18-22 mm. long, villous; sepals and petals oblanceolate, 9-11-nerved; fruit about $1 \mathrm{~cm}$. long, 6-10-seeded. Woods: Alaska-Mont.Calif. Mont. Je-Au.

\section{Family 23. DRACAenaCeae. Yucca Family.}

Shrubby plants or trees, with woody trunks or caudices, very leafy at the apex. Leaves narrow, rigid, often with marginal filaments or finely toothed. Flowers mostly perfect, or polygamo-dioecious, racemose or paniculate. Petals and sepals 3, similar. Stamens 6. Gynoecium of 3 united carpels. Ovary superior, 3-celled; styles very short, united or obsolete. Fruit a loculicidal capsule, or fleshy and indehiscent.

Flowers perfect, large; ovary many-ovuled and fruit many-seeded.

Styles evident; petals and sepals thin, petaloid, spreading in anthesis.

Styles wanting; petals and sepals tbick, inflexed.

1. YUCCA.

2. Clistoyucca. Flowers polygamo-dioecious; ovules 2 in each cell, but capsule often 1 -seeded.

3. Nolina.

\section{YÚCCA (Rupp.) L. YUCCA, Spanish Bayonet, Soap-WeEd,} Soap-root, Grass Cactus.

Coarse plants, with woody trunks or caudices. Leaves firm, narrow, rigidly pointed, commonly with thread-like fibers along the edges, or serrulate or entiremargined. Flowers in terminal racemes or panicles, drooping. Sepals and petals each 3 , distinet or slightly united at the base, usually white. Stames 6 , hypogynous; filaments enlarged above. Ovary 3-celled or imperfectly 6-celled, or 1celled; style turgid; ovules numerous. Capsule either dry and dehiscent, or fleshy and indehiscent. Seeds numerous, thin, flat. 
Fruit a dry capsule.

Leaves narrowly linear, very long.

Style stout, swollen, green.

Style not swollen, white.

Leaves linear-lanceolate, short; style not swollen, white. Leaves not papillose.

Fruit fleshy.

Leaves densely rough-papillose at least on the back.

1. Y. glauca.

2. $Y$. angustissima.

3. Y. Harrimaniae.

4. Y. Gilbertiana.

5. Y. baccata.

1. Y. glauca Nutt. Subacaulescent or branching with decumbent stems; leaves rigid, 6-12 $\mathrm{mm}$. wide, 2-4 dm. long, white-margined, finely but sparingly filiferous; inflorescence 1-2 m. high, simple or somewhat branched; sepals and petals greenish white, oval to lanceolate, acute, $4-5 \mathrm{~cm}$. long; capsule oblong, usually not constricted, somewhat roughened, brown. $Y$. angustifolia Pursh. Plains and hillsides: Ia.-Tex.-Ariz.-Mont. Plains-Submont. My-Jl.

2. Y. angustissima Engelm. Acaulescent, with a thick horizontal rootstock; leaves $2-4 \mathrm{dm}$. long, $2-5 \mathrm{~mm}$. wide, pungent, white-margined, very freely curly-filiferous; inflorescence $1-1.5 \mathrm{~m}$. high, racemose, or short-branched below; sepals and petals rather short, lanceolate, acute; capsule scarcely $5 \mathrm{~cm}$. long, rough, brown, constricted in the middle. Desert regions: Ariz.-s Utah. $L$. Son.

3. Y. Harrimaniae Trelease. Acaulescent, often cespitose; leaves linear to lanceolate, $6-40 \mathrm{~mm}$. wide, rigidly spreading, glaucous or green in age, pungent, narrowly brown-margined, with coarse curled fibers; inflorescence $2.5-5 \mathrm{dm}$. high, simple; sepals and petals greenish, oval, obtuse or acute; capsule brown, broadly oblong, about $4 \mathrm{~cm}$. long, eonstricted. Dry regions: Utah-w Colo.-W N.M. Son. Je.

4. Y. Gilbertiana (Trelease) Rydb. Acaulescent; leaves linear, about 4.5 $\mathrm{dm}$. long, $2 \mathrm{~cm}$. wide, openly concave, glaucous at least on the upper side, pungent, fibrous-filamentose on the margin; flowers about $4 \mathrm{~cm}$. long; segments narrow, acute; ovary papillate; style oblong, pale. Y. Harrimaniae Gilbertiana Trelease. Dry regions: w Utah. Au.

5. Y. baccata Torr. Low, usually with stout prostrate branched caudex; leaves rigid, spreading, about $6 \mathrm{dm}$. long and $5 \mathrm{~cm}$. wide, concave, shagreenroughened, with narrow brown margins, coarsely filiferous; sepals and petals lanceolate, about $7.5 \mathrm{~cm}$. long; style slender, elongate; fruit large, sometimes $2 \mathrm{dm}$. long, oblong- or conical-ovoid, pendent, fleshy. Dry plains: Tex. $\mathrm{s}$ Colo.-Nev. Son.-Submont. Ap-Je.

\section{CLISTOYÚCCA (Engelm,) Trelease. Joshua Tree.}

Large tree. Leaves short, thick, not filiferous. Flowers in panicles. Sepals and petals each 3 , thick, incurved at the end. Stamens 6 , hypogynous; filaments thick, curved outward; anthers sagittate, horizontal. Ovary 6-celled; stigma sessile, 6-lobed. Capsule 6-celled, spongy, indehiscent. Seeds numerous, flat, thin.

1. C. brevifolia (Engelm) Rydb. A tree $5-10 \mathrm{~m}$. high, with rough bark; leaves 1.5-2 dm. long, 6-15 mm. wide, rough, serrulate on the margin, spinetipped, concave above; flowers in sessile short panicles; perianth campanulate, 4-6 cm. long, greenish white; capsule 5-7 $\mathrm{cm}$. long. Y Ycca brevifolia Engelm. $Y$. arborescens Trelease. C. arborescens Trelease. Desert regions: \& Calif.-s Utah-Ariz. Son.

\section{NOLİNA Michx.}

Coarse herbs, with woody caudices. Leaves crowded, rigid, narrow, entire or serrulate, keeled, pungent-pointed. Flowers polygamo-dioecious, in open panicles. Sepals and petals each 3 , distinct, 1-nerved, similar, white. Stamens 6 , reduced to staminodia in the fertile flowers; filaments thick, short. Ovary 3-celled, abortive in the staminate flowers; styles obsolete during anthesis. Ovules 2 in each cavity. Capsule dry, 3-winged, tardily and irregularly opening. Seeds often solitary, thick. 
1. N. Greenei S. Wats. Leaves $6 \mathrm{dm}$. long, $1 \mathrm{~cm}$. or more wide, rounded and smooth on the back, slightly channelled and striate inside, minutely scabrous on the margin; peduncle $1-2 \mathrm{dm}$. long, shorter than the leaves; fruit about $6 \mathrm{~mm}$. wide; lobes almost orbicular. Dry mesa: Colo.-N.M. Son.

\section{Family 24. CalOChORTACEAE. Mariposa Lily Family.}

Perennial herbs, with coated corms and narrow leaves. Flowers perfect, regular, showy. Sepals 3, narrow, herbaceous. Petals 3, broad, glandbearing within near the base and often bearded within, petaloid. Stamens 6, hypogynous. Gynoecium of 3 united carpels; ovary 3-celled, manyovuled; styles united, almost none; stigmas 3, recurved. Fruit a septicidal, 3 -angled capsule.

\section{Calochórtus Pursh. Sego Lily, Mariposa Lily,} Butterfly Lily.

Characters of the family.

Capsule winged.

Petals $1.5-2.5 \mathrm{~cm}$. long, strongly arched and broadly pitted; leaves single; scape 1-4flowered; bracts lanceolate.

Stem 1-2 dm. high; gland broad.

Stem 3-4 dm. high; gland very small.

Petals $2.5-4 \mathrm{~cm}$. long, less arched, not pitted; leaves usually 2 ;

Purple spot of the petals almost orbicular.

Capsule not winged.

Flowers white or lilac.

Petals abruptly acuminate; gland oblong.

Petals lilac, purplish, or light blue, with greenish midvein. 5. C. macrocarpus.

Petals cream-colored, tinged with purple and sometimes with a purplish spot.

Petals rounded or merely acute at the apex.

Anthers acute; gland broader than long.

Anthers obtuse; gland not broader than long.

Stem erect, bulbiferous near the base.

Flowers y ellow.

Stem flexuose, not bulbiferous.

6. C. acuminatus.

1. C. elegans Lindl. A delicate, slender glabrous plant, 1-2 dm. high; leaf surpassing the scape, 1-2 dm. long, 2-9 $\mathrm{mm}$. wide; scape 1-3-flowered; petals oval or obovate, rounded or acute, $12-20 \mathrm{~mm}$. long, white, tinged with purple, or purplish with whitish margins, densely bearded within and ciliate on the margins; capsule $2 \mathrm{~cm}$. long, $12-15 \mathrm{~mm}$. wide. On shaded hillsides: Wash. -Mont.-Utah-Calif. Submont. My-Jl.

2. C. apiculatus Baker. A slender glabrous plant, 3-4 dm. high; leaf shorter than the scape, about $2 \mathrm{dm}$. long, and 8-18 $\mathrm{mm}$. wide; scape $2-3$-flowered; petals obovate, acute or short-acuminate, $2-3 \mathrm{~cm}$. long, white or cream-colored, tinged with purple, bearded within; capsule $2.5 \mathrm{~cm}$. long and about $1 \mathrm{~cm}$. wide. In rich woods: Alta.-Mont.-Ida.-Ore. Submont.-Mont. My-Jl.

3. C. pavonaceus Fernald. A rather stout plant, 3-6 dm. high; leaves shorter than the stem, the lower 2-3 dm. long, 5-12 mm. wide; flowers sub-umbellate; petals obovate, rounded or acute at the apex, more than $3 \mathrm{~cm}$. long, lilac; anthers tapering somewhat upwards, but obtuse; capsule $25 \mathrm{~mm}$. long, 15 $\mathrm{mm}$. wide. C. nitidus Henders., also Purdy, not Dougl. In open meadows: Mont.-Wash.-Ore.-Ida. Submont.-Mont. Jl.

4. C. eurycarpus S. Wats. A strict, glabrous plant, $3-5 \mathrm{dm}$. high; leaves usually 2 , the lower 1-2 dm. long, 2-12 mm. wide, much shorter than the stem; flowers subumbellate, resembling those of the preceding, but gland narrower; petals white or cream-colored with a round purple spot; anthers linear-oblong, obtuse; capsule as in the preceding. C. nitidus S. Wats., not Dougl. C. nitidus eurycarpus Henders. C. umbellatus A. Nels., not Wood. In open meadows: Wyo.-Mont.-Wash.-Ore. Submont.-Mont. J1-Au.

5. C. macrocarpus Dougl, A rather stout and strict plant, 3-5 dm. high; leaves several, linear, revolute, and at last curled, 5-10 $\mathrm{cm}$. long; bract similar; 
flowers usually 2 ; petals obovate, about $4 \mathrm{~cm}$. long; stamens tapering upwards, but obtuse; very variable in coloration and hairiness of the petals. C. cyaneus $\beta$. rels C. bruneaunis, and C. maculosus t. Nels. ${ }^{+m}$ Sage-brush plains: B.C.-Mont.Ida.-Ore. Plain-Submont. Je-Jl.

6. C. acuminatus Rydb. A low plant, 2-3 dm. high, bearing a bulblet $2-4 \mathrm{~cm}$. above the bulb; leaves very narrow, involute and curved, $3-15 \mathrm{~cm}$. long; flowers 1-2; petals obovate, about $3 \mathrm{~cm}$. long; gland broadly oblong; anthers gradually tapering upwards, obtuse. On dry hillsides: Mont.-Utah-Colo. Submont.-Mont. Je-Au.

7. C. Gunnisonii/ S. Wats. A strict plant, 2-5 dm. high, without bulblet; leaves several, slender, mostly involute, $5-15 \mathrm{~cm}$. long; flowers $1-2$; petals broadly cuneate-obovate, $2-4 \mathrm{~cm}$. long, white or cream-colored, tinged and streaked with purple, yellow and purple-dotted around the gland; capsule narrowed at both ends, about $3 \mathrm{~cm}$. long. In meadows: (Black Hills) S.D.-N.M.-Ariz.-Ida. Submont.-Mont. My-Jl.

8. C. Nuttallii Torr. \& Gray. A strict plant, similar to the preceding, 2-5 dm. high, but with a bulblet borne in the axil of the lowest leaf, 1-4 cm. above the bulb; leaves and flowers resembling those of the preceding, but petals of ten narrower, and sometimes acutish; capsule tapering at both ends. $C$. Watsoni M. E. Jones. Dry hillsides: (Black Hills) S.D.-N.M.-Calif.-Wash. Suhmont.-Mont. My-Jl.

9. C. flexuosus S. Wats. A decumbent or ascending, more or less flexuose and branched plant; leaves several, the lowest 1-2 dm. long, 2-3 mm. wide, the rest short, about $5 \mathrm{~cm}$. long, acuminate; flowers several; petals broadly cuneateobovate, $2.5-3 \mathrm{~cm}$. long, white with yellow base; gland orbicular. In dry places: s Utah-Calif.-Ariz. L. Son. Je.

10. C. aureus S. Wats. Low plant, 1-2 dm. high, 1-4-flowered; leaves 7-10 cm. long; bracts lance-linear, attenuate, scarious margined; sepals greenish yellow, lanceolate, purple-blotehed; petals broadly cuneate, about $3 \mathrm{~cm}$. long, bright yellow, with a circular densely hairy gland near the base, and a purplish lunate spot above; capsule narrowly oblong. Sand-cliffs: s Utah-Ariz.-N.M. L. Son. Ap-Je.

\section{Family 25. TRILliaceae. Trillium Family.}

Perennial caulescent or scapose herbs, with rootstocks. Leaves and bracts whorled, broad and often netted-veined. Flowers perfect, solitary, terminal, or in terminal umbels. Sepals 3 (or in exotic genera 4), green, distinct; petals of the same number, in ours white or purplish. Stamens 6-8; filaments short. Gynoecium of 3 or 4 united carpels; ovary 3- or 4-celled; stigmas sessile. Fruit a 3- or 4-celled, lobed berry.

\section{TRÍLLIUM L. WAKE-ROBIN, Birth-ROOT.}

Fleshy herbs, with short stout rootstocks and a whorl of 3 , netted-veined, leaves near the end of the scape. Flowers solitary, 3-merous, pedicelled or sessile. Sepals persistent. Petals early withering or deciduous, white or purple.

Flowers sessile; leaves long-petioled; blades rounded.

Flowers peduncled; leaves subsessile, rhombic.

1. T. petiolatum. 2. $T$. ovatum.

1. T. petiolatum Pursh. Rootstock corm-like; stem 1-2 dm. high; petioles 3-6 cm. long; leaf-blades 7-10 cm. long and 6-10 cm. wide; sepals 3-4.5 cm. long, linear-lanceolate; petals dark purple, linear-oblanceolate, slightly exceeding the sepals. Rich hillsides and copses: Wash.-Ida.-Ore. Son.-Submont. ApMy.

2. T. ovatum Pursh. Rootstock corm-like; stem $3-4 \mathrm{dm}$. high; leaves acuminate, 7-12 cm. long, 4-8 cm. wide; pedicels 4-5 cm. long, slender; sepals linear-lanceolate, $2.5-4 \mathrm{~cm}$. long; petals somewhat longer, obovate to narrowly lanceolate, pink or white, turning purple. T. Scouleri Rydb. T. crassifolium Piper. Woods: B.C.-Mont.-Colo.-Calif. Submont.-Mont. Mr-Jl. 


\section{Family 26. SmildaCACEAE. Smilax Family.}

Vines, with several-ribbed and netted-veined leaf-blades, articulate to the petioles. Flowers dioecious, in peduncled axillary umbels. Sepals and petals each 3, green, with spreading tips. Stamens 6; filaments flattened; anthers introrse. Gynoecium of 3 united earpels; stigmas 3, sessile. Fruit a berry, 1-6-seeded. Endosperm bony.

\section{NemÉxia Raf. Carrion Flower, Smilax.}

Unarmed vines, with herbaceous stems. Leaves membranous, broad. Ovules 2 in each cavity. Berry blue-black, with 3 bands of strengthening tissue. [Smilax, in part.]

1. N. lasioneuron (Hook) Rydb. A herbaceous vine, 1-2 m. long; petioles $2-5 \mathrm{~cm}$. long; leaf-blades ovate-cordate, abruptly short-acuminate, $5-10 \mathrm{~cm}$. long, 5-9-ribbed, rather thin, glabrous above, scabrous-hirsutulous on the veins beneath; peduncles 4-7 $\mathrm{cm}$. long; umbel many-flowered; flowers greenish; petals and sepals oblong, $4 \mathrm{~mm}$. long; fruit 8-10 $\mathrm{mm}$. thick, globose, purple with a bloom. Smilax lasioneuron Hook. S. herbacea Coult. Woods: Sask.-Kans. -Colo.-Wyo. Plain-Submont. My-Je.

\section{Family 27. AMARYLLIDACEAE. Amaryllis Family.}

Perennial fleshy plants, with bulbs, corms, rontstocks, or woody caudices. Leaves basal, usually sheathing. Flowers perfect, racemose, paniculate, umbellate or solitary. Sepals and petals each 3, epigynous, often united into a tube below, petaloid. Stamens 6. Gynoecium of 3 united carpels; ovary inferior, 3-celled, or rarely only partially so; styles united. Fruit a 3 -celled capsule or berry.

Perennial herbs, with fleshy leaves (often spiny-toothed), clustered on the caudex: anthers versatile; flowers in spikes or panicles.

1. AGAVE.

Perennial herbs, with grass-like leaves, from a subterranean corm or short rootstock; anthers erect; flowers in ours umbellate.

2. HYPOXIS.

\section{1. agãve L. American Aloe, Century Plant.}

Partially woody plants, with a more or less elongated caudex. Leaves crowded at the base, persistent several years, fleshy, thick, armed with spiny teeth, spine-tipped, channeled. Perianth withering-persistent. Stamens 6; filaments partly adnate to the perianth-tube; anthers versatile. Capsule 3-celled, thickwalled; seeds numerous, in 2 rows in each cell, black, flattened.

1. A. utahensis Engelm. Leaves very fleshy, 8-10 $\mathrm{cm}$. long, terminating in a long channeled spine, sinuate, with flat teeth; spike dense; flowers in pairs or 4's; perianth yellowish, fully $1 \mathrm{~cm}$. long; lobes oblong, obtuse, 3-4 times as long as the tube; capsule $18-20 \mathrm{~mm}$. long. Desert regions: s Utah-Ariz. $L$. Son.

\section{HYPÓXIS L. STAR-GRass.}

Acaulescent small herbs, with corms or short rootstocks and narrow grass-like basal leaves. Flowers perfect, regular. Sepals and petals each 3, equal, distinct above the ovary, yellow or whitish, the sepals green without. Stamens 6; filaments adnate only to the base of the perianth, short. Capsule 3-celled, thin.

1. H. hirsuta (L.) Coville. Leaves narrowly linear, $2-5 \mathrm{~mm}$. wide, longer than the scape, more or less villous; scape $5-15 \mathrm{~cm}$. high, 1-6-flowered; flowers umbellate, 6-10 mm. long, bright yellow within, villous without. $H$. erecta L. Meadows: Me.-Fla.-Tex.-Sask. Plain. My-O.

\section{Family 28. IRIDACEAE. Iris Family.}

Perennial herbs, with elongated or bulb-like rootstocks and narrow equitant, 2-ranked leaves. Flowers perfect, regular or nearly so. Sepals and 
petals each 3 , often dissimilar but both colored, distinct or united below. Stamens 3, opposite to the sepals; anthers extrorse. Gynoecium of 3 united carpels; ovary inferior, 3-celled; styles distinct, sometimes petal-like. Fruit a loculicidal capsule. Seeds numerous.

Styles alternate with the stamens; filaments more or less united; flowers rather small; sepals and petals similar.

Filaments united to near the top; flowers blue or white, rarely rose-purple.

Filaments united only at the base; flowers rose or purple.

1. SISYRINCHIUM.

2. OLSYNIUM. sepals and petals unlike.

3. IRIS.

\section{SISYRÍNCHIUM L. BLUE-Eyed Grass.*}

Perennial grass-like herbs, ours tufted, with short rootstocks and fibrous roots. Leaves narrowly linear. Scape 2-edged or 2-winged. Flowers in terminal clusters from spathes of 2 bracts. Petals and sepals in ours blue or white, alike, spreading. Filaments monadelphous. Style-branches filiform, alternate with the stamens. Ovules few in each cavity. Capsule subglobose, readily opening at the apex.

Stems bearing several peduncles from leaf-bearing nodes.

Stems simple and leafless, with sessile terminal spathe (casually with a terminal leafbearing node and a peduncle).

Outer bract of spathe little or not at all longer than the inner one, rarely surpassing it by more than one-third its length.

Small and slender; flowers $10 \mathrm{~mm}$. or less long; capsules less than $3 \mathrm{~mm}$. high.

Stouter; flowers $12 \mathrm{~mm}$, or more long: capsules $4 \mathrm{~mm}$ or malophilum. Outer bract $2-3 \mathrm{~cm}$. long; flowers becoming $14 \mathrm{~mm}$. long. 3. S. occidentale. Outer bract $3-6 \mathrm{~cm}$. long; flowers becoming $18 \mathrm{~mm}$. long. 4 . S. idahoense.

Outer bract of spathe conspicuously prolonged, sometimes 2-3 times longer than the inner one.

Plant developing capsules among the bases of the leaves different in form from those of the terminal spathes. 5. S. heterocarpum.

No basal capsules.

Stem winged or margined.

Perianth-segments not emarginate, narrowed to the aristulate tip.

Stems and leaves mostly 1-2 mm. wide; capsule obovoid-oblong, 6-7 mm. long.

6. S. alpestre.

Stems and leaves mostly under $1 \mathrm{~mm}$. wide; capsule obovoid or subglobose, 3-5 mm. long. 7 . S. septentrionale.

Perianth-segments more or less retuse or abruptly contracted to the aristulate apex.

Stems and leaves mostly $1.5-2.5 \mathrm{~mm}$. wide; capsules 4-6 mm. high.

Stems and leaves mostly $1.5 \mathrm{~mm}$. or less in width; S. angustifolium. high.

Bracts of spathe smooth; valves of capsule veinless,

Bracts of spathe minutely scabrellous; valves of capsule sparsely venose.

Stem practically marginless.

10. S. campestre.

11. S. inalatum.

1. S. radicatum Bickn. Stem erect, stout, $2-4 \mathrm{~mm}$. wide, pale, $3-4.5 \mathrm{dm}$. high; basal leaves 2-3 mm. broad, 1-2 dm. long, hyaline-margined; peduncles 5-10 cm. long, unequal; bracts subequal, acute, $17-22 \mathrm{~mm}$. long, scarious-margined; perianth violet-blue, about $10 \mathrm{~mm}$. long; segments short-aristulate; ovary and young capsule densely glandular-puberulent. Wet meadows: Wyo.Utah-Nev. Plain-Submont. My-Jl.

2. S. halophilum Greene. Stem erect, wiry and glaucous, 1-3 dm. high, very narrowly winged; leaves $1-2.5 \mathrm{~mm}$. wide; bracts $12-18 \mathrm{~mm}$. long, slightly scarious-margined; perianth-segments abruptly acuminate; capsule scabrouspuberulent. S. leptocaulon Bickn. (?) S. juncellum Greene. Alkaline meadows: Ida.-Colo.-Calif. Submont. My-Jl.

3. S. occidentale Bickn. Stem 1.5-3.5 dm. high, 1-2 mm. wide, stiff, erect, glaucescent; leaves $1-2.5 \mathrm{~mm}$. wide, very acute; bracts green or purplish, slightly scarious-margined, 2-3 cm. long, with broad margins; capsule subglobose glabrate. Wet meadows: Mont.-Colo.-Nev.-Ida. Plain-Mont. Je-Jl.

* Key and notes supplied by Mr. E. P. Bicknell. 
4. S. idahoense Bickn. Stem 2-4.5 dm. high, pale green and glaucous, often twisted, $1-3 \mathrm{~mm}$. wide, winged; leaves $1-3.5 \mathrm{~mm}$. broad; spathe often deflexed, green or faintly purple; outer bract $3-6 \mathrm{~cm}$. long, a little longer than the inner, both with narrow hyaline margins; perianth deep violet-blue, with a rather small yellow eye, abruptly cuspidate; capsule globose or ovoid. Wet meadows: Mont.-Wyo.-Ore.-B.C. Submont. My-Jl.

5. S. heterocarpum Bickn. Stem erect, 2-3 dm. high, 1-1.5 mm. wide, narrowly winged; leaves $1-2 \mathrm{~mm}$. wide, attenuate; spathe sometimes purpletinged, narrow, 1-3 mm. wide; outer bract $2.5-4.5 \mathrm{~cm}$. long, with hyaline margins below; inner bract 1.5-2 $\mathrm{cm}$. long, hyaline-margined to the apex; perianth violet-purple, about $1 \mathrm{~cm}$. long, with a large yellow eye; fruit of the terminal spathe 1-4, subglobose or somewhat obovoid, 5-7 mm. high; basal capsules among the leaves, 2-4, obovoid-pyriform, 7-10 mm. long, 4-5 mm. thick, with a narrow base, on slender pedicels $2.5-3.5 \mathrm{~cm}$. long. Moist meadows and sandy ground: Wyo. Jl-Au.

6. S. alpestre Bickn. Stem 1-2 dm. high, green and glaucous, 1-1.5 mm. wide, narrowly winged, distinctly broadened into the spathe; leaves $1-2 \mathrm{~mm}$. wide; spathe green; outer bract long and slender, $4.5-6.5 \mathrm{~cm}$. long, with narrow hyaline margins; inner bract $1.8-3 \mathrm{~cm}$. long; perianth 6-10 mm. long; segments white or tinged with purple. Alpine meadows: Colo. Mont. Au.

7. S. septentrionale Bickn. Stem 1-2.5 dm. high, slender, 0.5-1 mm. wide, barely margined; leaves $0.5-1 \mathrm{~mm}$. broad; spathe purplish or green; outer bract $2.5-4 \mathrm{~cm}$. long, the inner $1.5-2 \mathrm{~cm}$. long, both hyaline-margined; perianth 4-7 mm. long, pale rose or violet. Wet meadows: Man.-N.D.-Wash.B.C. Plain. Je-Jl.

8. S. angustifolium Miller. Stem stiff, glaucous, 1-5.5 dm. high, simple or rarely branched, 1-3 mm. wide, winged; leaves 1-3.5 $\mathrm{mm}$. wide; spathe green or slightly purplish; outer bract $2-6.5 \mathrm{~cm}$. long, obscurely hyaline-margined; inner bract $1.5-3 \mathrm{~cm}$. long, hyaline-margined; flowers deep violet, 10-12 mm. long; capsule ellipsoid to subglobose. S. montanum Greene. Meadows: Newf. -Va.-Colo.-B.C. Plain-Mont. Je-Au.

9. S. mucronatum Michx. Stems numerous, 1-4.5 dm. high, 0.5-1.5 mm. wide, margined or narrowly winged; leaves dull green, slender, $1-1.5 \mathrm{~mm}$., rarely $2 \mathrm{~mm}$. wide; spathe usually red-purple, rarely green; outer bract $1.8-5.5$ $\mathrm{cm}$. long; inner bract 1-1.5 $\mathrm{cm}$. long, searious-margined; perianth deep purplish blue, rarely white, 6-14 mm. long; capsules subglobose. Wet places: Ont.D.C.-Pa.-Alta. Plain. My-JI.

10. S. campestre Bickn. Stem usually 1.5-2 dm. high, ereet, stiff, glaucous, $0.5-1.5 \mathrm{~mm}$. wide, narrowly winged; leaves $1-1.5 \mathrm{~mm}$., rarely $2 \mathrm{~mm}$. wide; spathe pale purple or green; outer bract $2.5-4.5 \mathrm{~cm}$. long, narrowly hyaline-margined below; inner bract 1.2-2 cm. long, white-hyaline on the margins; perianth 8-14 $\mathrm{mm}$. long, pale blue or white; capsule trigonous-subglobose. Prairies: Wis.Mo.-La.-N.M.-N.D. Plain.

-11. S. inalatum A. Nels. Stem simple, 3-4 dm. high, wingless, 10-striate; leaves 9-15-nerved, 4-8 $\mathrm{mm}$. broad, often somewhat arcuate; outer spathe 4-6 $\mathrm{cm}$. long, many-nerved, scarious-margined; inner spathe 6-8-nerved, less than half as long; capsule 5-6 mm. long, obovoid-globose. Dry open hillsides: Ida. Submont. Je.

\section{OLSỲNIUM Raf.}

Perennial grass-like herbs, usually tufted. Leaves narrowly linear, equit ant. Seape flattened but not winged. Flowers in terminal clusters, subtended by a spathe of 2 bracts. Petals and sepals rose or purple, spreading, similar. Filaments united only at the broad bases. Styles cleft at the apex. Capsule globose.

1. O. grandifiorum (Dougl.) Raf. Stem erect, stout, 2-3 dm. high, 2-3 $\mathrm{mm}$. thick; outer bract $5-10 \mathrm{~cm}$. long, broadly scarious-margined; inner bract seareely half as long; corolla $15-20 \mathrm{~mm}$. long; segments slightly euspidate, obo- 
vate; filaments shorter than the style; fruit 7-8 mm. thick. Sisyrinchium grandiflorum Dougl. Wet meadows: B.C.-Ida.-Utah-Calif. Son.-Submont. Mr-Je.

\section{2. Îris L. Blue Flag, Fleur-de-Lis.}

Herbs, with creeping, horizontal rootstocks. Leaves sword-shaped or linear. Flowers solitary or in terminal panicles. Sepals and petals highly colored, in ours blue, the former spreading or recurved, the latter usually smaller and erect. Stamens 3; filaments adnate below to the base of the sepals. Ovary 3-celled; styles petal-like, arching over the stamens; stigmas under the usually 3-lobed tips. Ovules numerous. Capsule elongated, 3- or 6-angled. Seeds in 1 or 2 rows, vertically flattened.

1. I. missouriensis Nutt. Stem $2-10 \mathrm{dm}$. high, about $5 \mathrm{~mm}$. in diameter; leaves 1-5 dm. long, 5-10 $\mathrm{mm}$. broad; perianth pale blue, variegated, glabrous, crestless; sepals broadly oblanceolate, about $8 \mathrm{~cm}$. long; petals oblanceolate, ascending, about $6 \mathrm{~cm}$. long; capsule oblong-elliptic, about $4 \mathrm{~cm}$. long and 1.5 $\mathrm{cm}$. thick, 6-ridged. I. pelogonus Goodding. Meadows, marshes and along streams: N.D.-N.M.-Calif.-B.C. Plain-Mont. My-Jl.

\section{Family 29. ORCHIDACEAE. Orchis Family.}

Perennial herbs, usually succulent, with corms, bulbs, or rootstocks, and tuberous or fibrous roots. Flowers perfect, irregular. Sepals 3, similar or nearly so, the lower two sometimes united. Petals 3 ; the two lateral ones similar; the median one (the lip) usually very dissimilar, sometimes prolonged below into a spur, usually inferior by twisting of the ovary. Stamens 3 , of which 1 or 2 are abortive, adnate to the pistil and forming a column. Fertile anthers usually solitary, in a few genera 2, usually 2-celled, containing 2-3 waxy or powdery pollinia, these pollen-masses usually stalked and of ten attached at the base to a viscid gland. Gynoecium of 3 united carpels; ovary inferior, 1-celled, twisted. Capsule 3-valved. Seeds numerous. Endosperm wanting.

Fertile stamens 2; lip a large inflated sack.

Sepals distinct; lip with an almost conical obtuse prolongation below.

Lower sepals united; lip rounded-saccate.

1. Criosanthes.

2. CYPRIPEDIUM.

Fertile stamen 1.

Pollinia caudate at the base, attached to a viscid disk or gland.

Glands enclosed in a pouch-like fold; lip 3-lobed.

Glands not enclosed in a pouch.

Gland surrounded by a thin membrane; lip toothed at the apex.

Gland naked; lip entire.

Sepals 3-5-nerved; plants with rootstock or fibro-fleshy roots.

Stem scapiform; leaves 1-2, basal; anther-sacks divergent; plants in ours with rootstocks.

Basal leaves 2; ovary straight.

Basal leaf 1 ; ovary arcuate.

5. LYSIAS.

6. LYSIELLA.

roots.
ranther-cells parallel or nearly so; plants with fleshy-fibrous

roots.
Sepals 1-nerved; plants with rounded or oblong, undivided biennial corms.
8. PIPERIA.

Pollinia not produced into caudicles.

Pollinia granulose or powdery.

Anthers operculate; leaves alternate.

Green plants, with large leaves.

Plant white, turning brownish; leaves reduced, scale-like.

Anthers not operculate.

Leaves green, borne on the stem.

Leaves alternate; spike mostly twisted. 11. IBIDrum.

Leaves 2, opposite; spike not twisted.

Pollinia smooth or waxy.

12. OPHRYS.

13. Peramium.

Plants with corms or solid bulbs, rarely with coralloid roots; leaves not scalelike. 
Leaves unfolding before or with the flowers.

Lip flat; flowers racemed.

Leaves cauline; column short; pollinia clavate.

Leaves basal; column elongated; pollinia globose.

Lip saccate; flower solitary.

Leaf 1 , unfolding after the flowering time.

Plants with coralloid roots, bulbless; leaves reduced to scales.

15. LIPARIS.

16. CYTHEREA.

17. APLECTRUM.

18. Corallorrhiza.

\section{CRiosánthes Raf. Ram's-head, Ram's-head Ladies' Slipper.}

Perennial caulescent herbs, with rootstocks. Leaves sessile, alternate, several-veined, plaited. Flowers solitary, terminal. Sepals 3, distinct, spreading. Lateral petals narrow, spreading. Lips saccate, obtuse-conic, with the margin incurved, forming a rounded opening.

1. C. arietinum (R. Br.) House. Stem $2-3$ dm. high, 1-flowered; leaves 3 or 4, elliptic or lanceolate, $5-10 \mathrm{~cm}$. long; sepals lanceolate, $15-20 \mathrm{~mm}$. long, brownish; petals linear, greenish brown, about as long; lip about $1.5 \mathrm{~cm}$. long, white, veined and variegated with red. Cypripedium arietinum $\mathrm{R}$. Br. Cold damp woods: Que.-N.Y.-Minn.-Sask. Boreal. My-Au.

\section{CYPRIPÈDIUM L. LADIES' SLIPPER.}

Caulescent herbs, with rootstocks and fibrous roots. Leaves sessile, severalnerved, plaited. Flowers solitary or several in a terminal raceme. Sepals 3, the lateral two united under the lip. Lateral petals narrow, spreading. Lip conspicuous, an inflated round sack, with rounded opening, the margins incurved. Column declined, glabrous, bearing a fertile anther on each side, and a petalloid sterile stamen above, arching over the style. Pollen pulpy or granular, without tails or glands. Stigma terminal, broadest at the base. Capsule ribbed.

Leaves alternate; flowers solitary, terminal, or also several singly in the axils of the upper leaves.

Sepals obovate to broadly obovate or oval, not longer than the lip; sterilestamen elliptic-cordate.

Sepals lanceolate, attenuate, often longer than the lip.

Lip white, purple-veined; sterile stamen ovate or obovate.

Lip yellow; sterile stamen triangular, yellow and purple-spotted.

Lip 2-2.5 cm. long, broader than deep; lower sepal narrower than the upper one, exceeding the lip.

1. C. passerinum.

ip 3 , exceeding the lower sepal fully as broad parviforum. one or broader, usually shorter than the lip. 4 . C. veganum.

Leaves 2, opposite or nearly so; flowers usually several in a contracted bracted spike.

5. C. Knightae.

1. C. passerinum Richards. Stem 1-2.5 dm. high, often retrorsely villous; leaves oval to lanceolate, 5-10 dm. long, more or less viscid-villous; flowers 1-3; sepals 1-1.5 cm. long, the lower one slightly 2-cleft; petals oblong, obtuse, about $1.5 \mathrm{~cm}$. long; lip about $1.5 \mathrm{~cm}$. long, obovate, white, with purple spots inside. Pine woods: Ont.-Alta.-B.C.-Alaska-Mack. Boreal-Mont. Je-Jl.

2. C. montanum Dougl. Stem $3-5 \mathrm{dm}$. high, roughly glandular-puberulent, 1-3-flowered; leaves oval to lanceolate, $7-15 \mathrm{~cm}$. long, roughly glandularpuberulent; sepals linear-lanceolate, $4-5 \mathrm{~cm}$. long, greenish brown; petals narrowly linear-lanceolate; lip 2.5-3 cm. long. Open woods: B.C.-Calif.-Wyo. -Sask. Submont. Je-Jl.

3. C. parviflorum Salisb. Stem $2-6 \mathrm{dm}$. high, leafy, glandular-puberulent, usually 1-flowered; leaves oval to broadly lanceolate, of ten acuminate, $5-12 \mathrm{~cm}$. long, puberulent; upper sepal lanceolate, acuminate, about $3 \mathrm{~cm}$. long and $1 \mathrm{~cm}$. wide; petals narrowly linear-lanceolate, longer than the sepals. Woods: Newf. -Ga.-Colo.-B.C. Plain-Submont. My-Jl.

4. C. veganum Cockerell. Stem about $3 \mathrm{dm}$, high, leafy, puberulent, 1flowered; leaves broadly lanceolate, acuminate, 8-13 cm. long; sepals lanceolate, 3-4.5 cm. long; petals linear-lanceolate, $4.5-5.5 \mathrm{~cm}$. long. Cañons: N.M.-Colo. Submont. Je-Jl. 
5. C. Knightae A. Nels. Stem 3-10 cm. high, more or less villous-viscid in the inflorescence; leaves oval to nearly orbicular, $5-10 \mathrm{~cm}$. long, glabrous or nearly so; sepals and petals purplish, ovate-lanceolate, acuminate, about $2 \mathrm{~cm}$. long; lip 10-12 $\mathrm{mm}$. long, greenish yellow, with deep purple margins; sterile stamen oblong, obtuse. Open woods and hillsides: Wyo.-Utah-Colo. Submont. Ap-Je.

\section{ORCHIS (Tourn.) L. ORCHIS.}

Perennial herbs, with digitately cleft tubers, or in our species with rootstocks and fibrous roots. Flowers in terminal spikes. Sepals distinct, equal, spreading, 3-nerved. Petals ascending, in ours narrower. Lip connate with the column, produced below into a spur, usually 3-cleft. Column short. Fertile anther solitary, 2-celled; sacs contiguous and slightly diverging; pollinia granulose, one large mass in each sac, produced into a slender caudicle, attached to a small gland, which is enclosed in a pouch.

1. O. rotundifolia Pursh. Perennial, with a rather slender scaly rootstock; stem 1-2.5 dm. high, scape-like; leaf solitary, near the base, orbicular or oval, 3-7 cm. long; spike 2-6-flowered; flowers 12-15 mm. long; sepals elliptic, $6-7 \mathrm{~mm}$. long, rose-colored, the lateral ones spreading; upper petals similar, but slightly shorter; lip white, purple-spotted, 3-lobed, with a large middle lobe, notched at the apex; spur slender, curved, shorter than the lip. Cold damp woods: Greenl. -N.Y.-Minn.-B.C.-Yukon. Subalp.-Boreal. Je-Jl.

\section{COELOGLÓSSUM Hartman.}

Caulescent herbs, with 2-cleft biennial tubers. Leaves alternate, sessile. Flowers perfect, in elongated terminal spikes, greenish. Sepals distinct, converging, thus forming a hood. Lateral petals narrow, erect; lip obtuse, 2- or 3-toothed at the apex, produced below into a sack-like spur. Column short. Fertile anther solitary; anther-sacs 2. Pollinia solitary, with long caudicles. Gland small, surrounded by a thin membrane.

1. C. bracteatum (Willd.) Parl. Stem 1.5-6 dm. high; leaves 3-5, obovate, oblanceolate, oval, or the upper narrowly lanceolate, $5-15 \mathrm{~cm}$. long; bracts linearlanceolate, longer than the flowers; flowers green or greenish; sepals lanceolate, about $6 \mathrm{~mm}$. long; lip 6-8 $\mathrm{mm}$. long, oblong or somewhat cuneate, 3-toothed at the apex, the middle tooth smallest; spur less than half as long as the lip. Habenaria bracteata (Willd.) R. Br. Wet meadows and woods: N.B.-N.C.-Colo. -B.C. Mont.-Boreal. My-S.

\section{LÝSIAS Salisb.}

Subacaulescent herbs, with fleshy rootstocks or tubers. Leaves almost basal, 2 in number, broad and many-nerved. Flowers in terminal spikes, white or greenish. Sepals distinct, large, spreading; upper sepal in ours broadly cordate, the lateral ones obliquely ovate. Lateral petals small and narrow. Lip entire, narrow, produced below into a slender spur. Fertile anther solitary; sacks diverging, with beak-like bases projecting forward. Pollinia with their caudicles laterally affixed to orbicular naked glands. Stigma without append-
ages.

Leaves orbicular or rounded oval; spur slightly clavate at the apex.

Leaves oval or ovate; spur strongly clavate and curved at the apex.

1. L. orbiculata.

2. L. Menziesii.

1. L. orbiculata (Pursh.) Rydb. Scape stout, 3-6 dm. high, bearing several lanceolate bracts; basal leaves 1-1.5 cm. long, 8-12 cm. wide; raceme loosely many-flowered; lateral petals obliquely lanceolate; lip linear, 12-15 mm. long; spur 2-4 cm. long. Habenaria orbiculata (Pursh) Torr. Rich woods: Newf,N.C.-Minn.-Wash.-(? B.C.). Mont.-Boreal. My-Au.

2. L. Menziesii (Lindl.) Rydb. Scape 3-4 dm. high, with 1-2 lanceolate bracts; basal leaves 10-12 cm. long, 6-8 cm. wide; raceme lax; pedicels 7-10 mm. long; lateral petals narrowly lanceolate; lip narrowly linear, 8-10 mm. long; spur less than $2 \mathrm{~cm}$. long. Platanthera Menziesii Lindl. Wet woods: Mont.Ida.-B.C. Mont. Jl-Au. 


\section{LYSIÉLLA Rydb.}

Small herbs, with rootstocks. Stem scapiform, with a single obovate leaf at the base. Flowers greenish yellow. Upper sepal round-ovate, erect, surrounding the broad column; lateral sepals reflexed-spreading. Petals lanceolate, smaller; lip entire, linear-lanceolate, deflexed. Spur slightly curved, shorter than the ovary. Anther-sacs divergent, wholly adnate, arcuate; glands small, their faces incurved. Pod obovoid.

1. L. obtusata (Pursh) Rydb. Stem slender, 1-2.5 dm. high, glabrous; leaf 5-12 cm. long; spike 2-6 cm. long, loosely flowered; flowers about $1 \mathrm{~cm}$. long; spur longer than the lip, slender, straight. Habenaria obtusata Richards. Boggy places in the woods: Newf.-N.Y.-Colo.-Alaska. Mont,-Subalp. Je-Au.

\section{LIMNÓRCHIS Rydb. Bog Orchid.}

Leafy-stemmed plants, with elongated fusiform root-like tubers and fleshyfibrous roots. Flowers whitish or greenish or tinged with purple. Upper sepal ovate to almost orbicular, ereet, 3-7-nerved; lateral'sepals from linear to ovate-lanceolate, free from the lip, 3-nerved, seldom 4-5-nerved, spreading or often somewhat reflexed. Lateral petals erect, lanceolate, 3-nerved, oblique at the base. Lip entire, flat or slightly concave, reflexed, free, from linear to rhombic-lanceolate, obtuse. Column short and thick. Anther-sacs parallel, opening in front.

Lip more or less lanceolate, $i$. e., broad near the base.

Flowers greenish or purplish; lip not rhombic at the base.

Spur decidedly clavate, thickened and obtuse at the apex, shorter than the lip.

Petals purplish; spur only one-half to two-thirds the length of the lip, very saccate. Lip linear or nearly so, 5-7 mm. long; ovary slightly curved; spike usually
elongated.

$1 . L$. stricta.
Lip lanceolate, fleshy, 4-5 mm. long; ovary strongly curved; spike usually short.

$\begin{array}{ll}\text { Petals greenish; spur almost equalling the lip. } & 3 . \text { L. viridiflora. }\end{array}$

2. L. purpurascens.

ling order, scarcely thickened at all towards the apex, often acutish, equal-

large; sepals $4-6 \mathrm{~mm}$. long.

Florge; sepals 4-6 mm. long.

Spur only slightly if at all exceeding the lip lady dilated, subrhombic at the base.

Spur usually shorter than the lip and cla

Spur 5 . L. borealis.

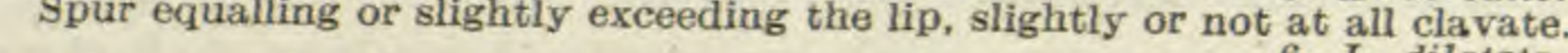

Spur from one-fourth to two-thirds Ionger than the lip.

6. L. dilatata.

Lip linear, $i$. e., not at all dilated at the base.

Spur shorter than the lip, decidedly saccate.
Spur much exceeding the lip, flliform.

Spike comparatively dense.

Spike very lax.

7. L. leucostachys.

1. L. stricta.

8. L. ensifolia.

9. L. laxiflora.

1. L. stricta (Lindl.) Rydb. Stem tall and strict, 3-10 dm. high; lower leaves oblanceolate, obtuse, 5-12 cm. long, the upper lanceolate, acute; spike 1-3 dm. long, lax; flowers 12-14 mm. long; lip linear, obtuse, 5-7 mm. long, thick, purple. Platanthera stricta Lindl. Habenaria gracilis S. Wats. Bogs and wet meadows: Alta.-N.M.-Ore-Alaska. Submont--Mont. Je-Au.

2. L. purpurascens Rydb. Stem stout, 3-5 dm. high; leaves ovate to lanceolate, acute, 6-10 cm. long, dark green; spike rather dense; flowers 10-12 $\mathrm{mm}$. long; lip about $5 \mathrm{~mm}$. long, scarcely at all dilated at the base. Damp wooded hillsides and brook-banks: Colo, Submont.-Subalp. Je-Jl.

3. L. viridiflora (Cham.) Rydb. Stem 2-5 dm. high; lower leaves 5-15 cm. long, oblanceolate, obtuse; spike short and dense; flowers 10-12 mm. long, light green; lip lanceolate, obtuse, less than $5 \mathrm{~mm}$. long. Habenaria hyperborea Coult., not R. Br. Bogs: Alta.-Colo.-Alaska. Submont.-Mont. Je-Au.

4. L. media Rydb. Stem very stout, 4-8 dm. high; leaves lanceolate, acute, 1-2 dm. long; spike long, densely flowered; flowers divaricate, about $15 \mathrm{~mm}$. long; lip about $6 \mathrm{~mm}$. long. Bogs: Que.-N.Y.-(Black Hills) S.D. BorealSubmont. 
5. L. borealis (Cham.) Rydb. Stem tall and leafy, 4-8 dm. high; lowest leaves oblanceolate and obtuse, the rest lanceolate, acute, $5-15 \mathrm{~cm}$. long; spike often rather dense, 1-2 dm. long; flowers 10-14 mm. long; lip rhombic-lanceolate, obtuse, about $5 \mathrm{~mm}$. long. Habenaria dilatata Coult., not Hook. Bogs: Mont. -Colo.-Wash.-Alaska. Submont.-Mont. Je-S.

6. L. dilatata (Pursh) Rydb. Stem slender, tall, leafy, 3-6 dm. high; leaves lanceolate, 7-20 cm. long, the lower obtuse, the upper acute; spike $5-25 \mathrm{~cm}$. long, usually rather lax; flowers white, $15-18 \mathrm{~mm}$. long; lip about $7 \mathrm{~mm}$. long. Habenaria dilatata (Pursh) Hook. Bogs: Lab.-N.Y.-Neb.-Sask. Boreal. Je-Au.

7. L. leucostachys (Lindl.) Rydb. Stem stout and tall, 6-10 dm. high; lower leaves oblanceolate, 1-2 dm. long; spike 1-3 dm. long, rarely very dense; flowers 15-20 mm. long; lip about $8 \mathrm{~mm}$. long. Habenaria leucostachys (Lindl.) S. Wats. Bogs: Alaska-Ida.-Utah-Calif. Submont. Je-Au.

8. L. ensifolia Rydb. Stem strict, 3-4 dm. high, light colored, few leaved; leaves linear-lanceolate, attenuate, slightly falcate, 1-1.5 dm. long; flowers greenish, about $15 \mathrm{~mm}$. long; lip linear, about $8 \mathrm{~mm}$. long, thick; spur about $1 \mathrm{~cm}$. long. Bogs: N.M. -Utah-Ariz. Son. Jl.

9. L. laxiflora Rydb. Stem slender, 4-6 dm. high; lower leaves oblanceolate, 8-10 cm. long; spike 1-2 dm. long, few-flowered; flowers greenish, $10-12 \mathrm{~mm}$. long; lip about $6 \mathrm{~mm}$. long; spur about $8 \mathrm{~mm}$. long, slightly clavate. Bogs: Ore.Colo.-Utah. Son.

\section{PIPÉRIA Rydb. WOOD ORCHID.}

Somewhat leafy-stemmed plants, but the leaves usually near the base and withering at or before the anthesis. Tubers spherical or rounded ellipsoid. Flowers greenish or white; sepals and petals 1-nerved or very obscurely 3-nerved; the upper erect, the lateral ones spreading. Lateral petals free, lanceolate or linear-lanceolate, oblique. Lip linear-lanceolate to ovate, obtuse, truncate or hastate at the base, concave, united with the bases of the lower sepals, bordered with an erect margin which connects the lip with the column. Anther-sacs parallel, opening nearly laterally.

Spur slightly exceeding the lip.

Spur 2-3 times as long as the lip, filiform.

1. P. unalaschensis.

Lip linear to lanceolate, about $6 \mathrm{~mm}$. long; spike dense; spur $15-18 \mathrm{~mm}$. long.

Lip ovate or ovate-lanceolate; spike looser; spur $10-12 \mathrm{~mm}$. long. 3 . P. Pultiflor

1. P. unalaschensis (Spreng.) Rydb. Stem strict, slender, $3-5 \mathrm{dm}$. high, leafy only near the base; leaves oblanceolate, obtuse or acutish, 1-1.5 dm. long; stem-leaves bract-like; spike long and lax, 1-3 dm. long; flowers greenish, 8-10 $\mathrm{mm}$. long; petals and sepals $2-4 \mathrm{~mm}$. long; lip oblong, obtuse; spur filiform or slightly clavate. Habenaria unalaschensis (Spreng.) S. Wats. Damp woods: Mont.-Colo.-Calif.-B.C.-(? Alaska); also Que. Submont.-Mont. Je-Au.

2. P. multiflora Rydb. Stem stout, 4-6 dm. high; basal leaves oblong or oblanceolate, obtuse or acutish, 1-1.5 dm. long; upper stem-leaves much reduced and bract-like; flowers greenish white, spreading, about $1.5 \mathrm{~cm}$. long; spur 15-18 mm. long, filiform. Damp woods: Wash.-Mont.-Calif. Submont. Je-Au.

3. P. elegans (Lindl.) Rydb. Stem slender, strict, 4-7 dm. high; basal leaves 2 or 3 ; blades lanceolate or oblanceolate or rarely oval, acute or obtuse, 8-15 cm. long; stem-leaves much reduced, lanceolate; spike usually lax, 1.5-3 dm. long; flowers greenish white, about $1 \mathrm{~cm}$. long: spur filiform. Habenaria. elemans (Lindl.) Bolander. Piperia elongata Rydb. Damp woods: B.C.-Ida.Calif. Submont. Je-Au.

\section{SERÃPiAs L. Helleborine.}

Caulescent herbs, with rootstocks and fibrous roots. Leaves alternate, plaited, many-nerved, clasping. Flowers in bracted terminal racemes. Sepals. 
distinct, strongly keeled. Lateral petals distinct, ovate. Lip free, not spurred, concave below, constricted in the middle, the terminal portion dilated and petal-like. Column short. Fertile anther 1, erect, operculate; its sacs contiguous. Pollinia granulose, 2-parted, becoming attached to the beaked stigma. [Epipactis R. Br.]

1. S. gigantea (Dougl.) A. A. Eat. Stem 3-10 dm. high, nearly glabrous, puberulent in the inflorescence; lower leaves ovate, sessile, the upper narrowly lanceolate, $5-20 \mathrm{~cm}$. long, acute or acuminate; flowers 3-10, greenish, veined with purple; lip 15-18 mm. long; the terminal portion ovate-lanceolate, many-crested; capsule oblong, $15 \mathrm{~mm}$. long. Epipactis gigantea Dougl. Rich woodlands: Mont. - w Tex.-Calif.-B.C. Son.-Submont. Je-Au.

\section{EBURÓPHYTON Heller.}

Saprophytic perennial herb, with branched creeping rootstock; whole plant white, leafless, scarious-bracted. Flowers racemose, almost sessile. Lateral sepals horizontally spreading, larger than the upper sepal and the petals, strongly keeled, somewhat concave. Upper sepal and petals erect, less strongly keeled. Lip free, shorter than the sepals, the saccate base with broad wing-like margins, articulate at the middle, with a callosity on each side; outer internode curved outward and downward, concave, grooved. Column twice as long as the anther. Stigma beakless. Pollen-masses not attached to the gland.

1. E. Austinae (A. Gray) Heller. Stem 3-6 dm. high; perianth about 12 $\mathrm{mm}$. long; distal portion of the lip suborbicular; nerves in center wavy-crested; column $4 \mathrm{~mm}$. long. Chloraea Austinae A. Gray. Cephalanthera oregana Reich. Pine woods: Calif.-Ida.-Wash. Mont. Je-Jl.

\section{IBÍdium Salisb. Ladies' Tresses.}

Perennial herbs, with tuberous thickened or fleshy-fibrous roots. Leaves alternate, in some species mostly basal. Flowers in terminal spiral spikes. Sepals distinct or coherent above or united with the similar lateral petals. Lip concave, sessile or slightly clawed, bearing two callosities at the base. Column oblique, arched. Fertile anther solitary, erect, without a lid. Pollinia one in each sac. Stigma with a beak. [Spiranthes L. C. Rich. Gyrostachys Pers.]

Callosities at the base of the lip obsolete; lower sepals coherent with the petals and upper sepals.

Callosities nipple-shaped, directed downwards; lower sepals free.

1. G. strictum.

2. G. porrifolium.

1. I. strictum (Rydb.) House. Stem 1.5-3.5 dm. high, glabrous; lower leaves 7-20 $\mathrm{cm}$. long, linear or linear-oblanceolate, the upper bract-like; spike 5-10 cm. long, 8-14 mm. thick, dense; flowers 3-ranked, white or greenish, 6-8 $\mathrm{mm}$. long, fragrant; lip oblong, broad at the base, contracted below the dilated crisp terminal portion. Gyrostachys stricta Rydb. Spiranthes Romanzoffana Coult., not Cham. Wet places and rich hillsides: Newf.-Pa.-Colo.-Calif.Alaska. Plain-Mont. My-S.

2. I. porrifolium (Lindl.) Rydb. Stem 2-4 dm. high, slender, glabrous; leaves narrowly oblanceolate or linear, rather thick, 1-2 dm. long; spike 5-10 $\mathrm{cm}$. long, 12-15 mm. thick, less dense; flowers greenish white; lip lanceolate, scarcely dilated at the apex. Spiranthes porrifolia Lindl. Marshes: Wash.Ida.-Colo.-Calif. Submont. Je-Au.

\section{2. ÒPHRYS (Tourn.) L. TWAY-BLAdE, Twifole.}

Perennials, with rootstocks and fleshy-fibrous roots. Leaves 2, opposite, near the middle of the stem. Flowers in terminal racemes, greenish or purplish. Sepals and lateral petals distinct, almost alike, reflexed. Lip notehed or 2-cleft at the apex, and often with a pair of teeth or auricles near the base. Fertile anther 1, erect, jointed to the back of the column, without a lid. Pollinia 2, powdery, attached to a minute gland. Column wingless. [Listera $\mathrm{R} . \mathrm{Br}$.] 
Lip broad, slightly 2-cleft at the apex, with or without a mucro in the sinus. Lip with distinct rounded auricles, slightly cleft at the apex; no mucro.

Lip with no auricles, but in their place two divergent 1 . O. borealis. present.

Lip unguiculate; lateral teeth small, without a papilla at the base.

Lip not unguiculate; lateral teeth prominent, 2 . O. convallarioides. Lip narrow, 2-cleft for about half its length into linear-laneeolate 3 . O. caurina.
. with narrow teeth at the base.

4. O. nephrophylla.

1. O. borealis (Morong) Rydb. Stem 7-15 $\mathrm{cm}$. high, pubescent above; leaves $1-3.5 \mathrm{~cm}$. long, elliptic-ovate, obtuse at both ends, borne above the middle of the stem; flowers about $1 \mathrm{~cm}$. long; lip 7-8 $\mathrm{mm}$. long, oblong-cuneate, with 2 obtuse lobes at the apex. L. borealis Morong. Damp woods: Mack.-Colo. -Yukon. Subalp. Je-Jl.

2. O. convallarioides (Sw.) Wight. Stem 1-2 dm. high, glabrous below, glandular above the leaves; leaves borne above the middle of the stem, broadly oval, obtuse, $3-5 \mathrm{~cm}$. long, rounded at the base; lip about $9 \mathrm{~mm}$. long, narrowly cuneate, retuse. L. convallarioides (Sw.) Torr. Moist woods: N.S.-Vt.-Mich. -Ida.-Calif.-Alaska. Mont. Je-Au.

3. O. caurina (Piper) Rydb. Stem 1-3 dm. high, glabrous below, densely glandular-pubescent above the leaves; leaves $3.5-7 \mathrm{~cm}$. long, oval to ellipticovate, rounded at the base, borne above or at the middle of the stem; lip 5-6 $\mathrm{mm}$. long, cuneate, retuse, with a blunt mucro in the sinus, sessile. L. caurina Piper. Damp mossy woods: B.C.-Mont.-Ida.-Ore. Mont. Je-JI.

4. O. nephrophylla Rydb. Stem slender, 1-2 dm. high, glabrous or slightly pubescent above the leaves; leaves inserted at the middle, rounded-reniform, about $2 \mathrm{~cm}$. long, $2-2.5 \mathrm{~cm}$. wide, strongly veined; flowers greenish, $5-6$ $\mathrm{mm}$. long; sepals and upper petals oblong, 1.5-2 $\mathrm{mm}$. long; lip $4-5 \mathrm{~mm}$. long. L. nephrophylla Rydb. Damp woods: Mont.-N.M.-Ore.-Alaska. Submont. -Subalp. Je-Au.

\section{PeràmiUm Salisb. Rattlennake Plantain.}

Caulescent perennial herbs, with rootstocks and fleshy-fibrous roots. Leaves alternate, mostly basal, strongly reticulate and often blotched. Flowers in terminal spikes, white or pink, inconspicuous. Lateral sepals distinct, spreading; the upper united with the lateral petals. Lip sessile, concave or gibbous, without callosities. Fertile anther solitary, short-stalked on the column, without a lid. Pollinia 2, one in each sac, attached to a small disk. Column straight, rather short. [Goodyera R. Br.]

Lip evidently saccate, with recurved margins.

Lip scarcely saccate, with incurved margins.

1. P. ophioides.

2. P. decipiens.

1. P. ophioides (Fernald) Rydb. Seape 1-2 dm. high, glandular-pubescent; leaves 1-2 cm. long, broadly ovate, dark green, usually with white blotches, most conspicuous along the cross-veins; flowers greenish white, $4-5 \mathrm{~mm}$. long; upper sepal concave, with a short strongly recurved tip; anthers blunt. Goodyera repens Am, auth. and var. ophioides Fernald. Cold mossy woods: N.S.N.C.-S.D.-N.M.-Alaska. Mont. Jl-Au.

2. P. decipiens (Hook.) Piper. Scape $2-4 \mathrm{dm}$. high, glandular-pubescent; leaves ovate-lanceolate, $4-6 \mathrm{~cm}$. long, acute at both ends, often without blotches; spike one-sided; flowers 7-9 mm. long; upper sepal concave, ovate-lanceolate, the tip long, often recurved; anthers ovate, long-pointed. G. Menziesii Lindl, P. Menziesii (Lindl.) Morong. Woods: Que.-N.H.-Minn.-Ariz.-Calif.Alaska. Submont.-Mont. Jl-S.

\section{MALÁXIS Soland, AdDer's Mouth.}

Caulescent perennial herbs, with corms. Leaves 2 or in our species 1 , on the stem. Flowers in terminal racemes, white or greenish. Sepals distinct, spreading. Lateral petals very narrow, often filiform, spreading. Lip broad, cordate 
or auricled at the base. Fertile anther 1, 2-celled, erect between the auricles. Pollinia 4, two in each sac, waxy, tail-less and without glands. Column embracing the lip. [Microstylis Nutt. Achroanthes Raf.]

Lip ovate, acuminate.

Lip broadly obcordate, with a tooth in the sinus.

1. M. monophylla.

2. M. unifolia.

1. M. monophylla (L.) Sw. Corm small, ovoid; stem 1-1.5 dm. high, glabrous, striate; leaf-blade $3-5 \mathrm{~cm}$. long, oval, elliptic, or ovate; pedicels $2-4$ $\mathrm{mm}$. long, nearly erect; capsule ellipsoid, $6 \mathrm{~mm}$. long. Microstylis monophylla Lindl. A. monophylla Greene. Woods: Que,-Pa.-Colo.-Man.; Eu. PlainSubmont. Jl-Au.

2. M. unifolia Michx. Corm globose; stem 1-2.5 dm. high; leaf-blade ovate or nearly orbicular, 2-6 $\mathrm{cm}$. long; flowers greenish, about $2 \mathrm{~mm}$. long; pedicels 6-10 mm. long. Microstylis ophioglossoides Nutt. Achroanthes unifolia Raf. Woods: Newf.-Fla.-Ala.-Neb.-Sask. Plain. Jl-Au.

\section{Líparis L. C. Rich. Twayblade.}

Low, scapose, perennial herbs, with corms. Leaves 2-6, basal. Flowers in terminal racemes, greenish. Sepals narrow, distinct. Lateral petals distinct, filiform. Lip dilated, often bearing two tubercles above the base. Column elongated, incurved, margined above. Fertile anther solitary, terminal, lidlike. Pollinia 4, two in each sac, waxy; each pair slightly united, without tails and glands. [Leptorchis Thouars.]

1. L. Loeselii (L.) L. C. Rich. Corm globose; scape $5-20 \mathrm{~cm}$. high, ribhed; leaves basal, elliptic or elliptic-lanceolate, $5-15 \mathrm{~cm}$. long, obtuse; flowers greenish; lip obovate, pointed, shorter than the sepals; capsule about $1 \mathrm{~cm}$. long, wide-angled on thick erect pedicels. Leptorchis Loeselii McMill. Woods and thickets: N.S.-Md.-Neb.-Sask. Plain.

\section{CYTherèa Salisb. Calypso, Venus' Slipper.}

Acaulescent perennial herbs, with corms. Leaf solitary, basal, petioled, with a broad blade. Flower solitary, terminal, showy. Sepals and lateral petals distinct, similar. Lip large, saccate, with two short spurs near the apex, hairy within. Column dilated, petal-like, bearing a lid-like anther just below the apex. Pollinia two in each sac, united, sessile on a broad gland. [Calypso Salisb.]

Beard of the lip yellow.

Beard of the lip white.
1. C. bulbosa.

2. C. occidentalis.

1. C. bulbosa (L) House. Corm nearly globose, $1 \mathrm{~cm}$. in diameter; scape 5-15 cm. high; leaf-blade rounded-ovate, $2-4 \mathrm{~cm}$. long, nearly as wide, acute at the apex, rounded or subcordate at the base; flowers variegated, purple, pink and yellow; petals and sepals $10-15 \mathrm{~mm}$. long, with 3 purple lines; lip large, 15$20 \mathrm{~mm}$. long. Calypso borealis Salisb. Cold woods: Lab.-Me.-Mich.-Colo. -Calif.-Alaska; Eu. Submont.-Subalp. My-Je.

2. C. occidentalis (Holz.) Heller. Corm rounded-ellipsoid; plant elosely resembling the preceding species, but the lip comparatively narrower and longer, usually fully $2 \mathrm{~cm}$. long, and sepals and petals less strongly purple-veined. Calypso bulbosa f. occidentalis Holz. Cold woods: Calif.-Ida.-B.C. Submont.-Mont. Ap-Je.

\section{7. apléctrum Nutt. Adam and Eve, Putty-Roor.}

Acaulescent perennial herbs, with a chain of corms, representing each a season's growth. Stem scape-like, leafless, a solitary long-petioled leaf being produced from the corm in the fall. Flowers in terminal racemes, showy. Sepals and lateral petals almost similar, narrow. Lip slightly clawed, spur-less, with 3 ridges. Fertile anther solitary, a little below the summit of the column. Pollinia 4. 
1. A. spicatum (Walt.) B.S.P. Scape glabrous, $3-6 \mathrm{dm}$. high, with a few scales; leaf-blade ovate or elliptic, or obovate, $1-1.5 \mathrm{~cm}$. long; flowers dull yellowish brown, streaked with purple, fully $2 \mathrm{~cm}$. long; lip shorter than the petals, obtuse, somewhat 3-lobed; capsule oblong-ovoid, $2 \mathrm{~cm}$. long. A, hyemale Nutt. Woods: Ont.-Ga.-Mo.-Sask. Boreal. My-Je,

\section{CORALLORRHİZA R. Br. CORAL-ROOT.}

Leafless saprophytic herbs, with coralloid roots. Stems scaly, colored. Flowers in terminal spikes. Sepals nearly equal, the lateral ones united with the foot of the column, and often forming a short spur, partly or wholly adnate to the top of the ovary. Lateral petals similar to the sepals. Lip broad, spreading, adnate to the base of the 2-edged or 2-winged column. Fertile anther solitary, terminal, lid-like. Pollinia 4, waxy, free.

Spur small, adnate to the ovary.

Lip entire, ovate, sinuate; whole plant yellow.

Lip with 2 lobes or teeth below the middle; plant brownish, 1 . C. ochroleuca.

Column about half as long as the petts plant brownish, rarely yellowish. Lip unspotted; teeth or lobes small; spur very small.

Lip spotted; lobes prominent; spur manifest. Column almost equalling the petals; sepals reflexed.
Spur lacking.

Petals and sepals 12-14 mm, long, elliptic.

Petals and sepals 7-8 mm. long, oblong.

2. C. Corallorrhiza.

3. C. multiflora.

4. C. Mertensiana.

5. C. striata.

6. C. Vreelandii.

1. C. ochroleuca Rydb. Stem 2-4 dm. high, not bulbous-thickened at the base; raceme 10-15-flowered; flowers 15-20 mm. long, light yellow, unspotted; petals and sepals 7-8 mm. long, oblong-lanceolate, acute, with prominent midvein. Woods: w Neb.-Colo.-Utah. Submont. Je-Jl.

2. C. Corallorrhiza (L.) Karst. Stem glabrous, 1-3 dm. high, usually yellowish; racemes 3-7 cm. long, 3-12-flowered; flowers greenish yellow or greenish brown, about $1 \mathrm{~cm}$. long; lip oblong, yellowish or whitish; spur a sack or small protuberance; capsule 8-12 mm. long. C. innata R. Br. Woods: N.S.-

3. C. multiflora Nutt. Stem 2-5 dm. high, purplish, with many scales; racemes 10-30-flowered; flowers 12-18 mm. long, brownish purple; lip white, spotted and lined with purple, oval in outline, deeply 3-lobed, crenulate, the middle lobe longer; spur about $2 \mathrm{~mm}$. long; capsule $15-20 \mathrm{~mm}$. long. Woods: N.S.-Fla.-Calif.-Alaska. Plain-Mont. Je-Au.

4. C. Mertensiana Bong. Scape $2-4 \mathrm{dm}$. high, glabrous, purple; raceme 10-20-flowered; flowers purplish; lip entire, broadly oblong, narrowed at the base, thin, concave; spur about $2 \mathrm{~mm}$. long, the lower half free from the ovary; capsule fully $2 \mathrm{~cm}$. long. Woods: Alaska-Mont.-Ida.-Calif. Mont. Je-

5. C. striata Lindl. Stem stout, 2-5 dm. high, purple; raceme 10-25flowered; flowers purple with dark veins; lip oval or obovate, entire, undulate, about as long as the petals; column half as long as the petals; capsule ellipsoid, reflexed, $15-20 \mathrm{~mm}$. long. Woods: Ont.-N.Y.-Mich.-Wyo.-Calif.-B.C.
Submont. My-Jl.

6. C. Vreelandii Rydb. Stem rather stout, 2-4 dm. high, dark purplish brown; flowers $6-15$, about $15 \mathrm{~mm}$. long, in fruit drooping; sepals with 3 purple stripes; petals slightly broader and with 4 stripes; lip ovate, entire. Wet woods: 


\section{Subclass 2. DICOTYLEDONES.}

Embryo mostly with 2 seed-leaves, if with only one seed-leaf, the first leaves opposite. Stem exogenous, $i$. e., differentiated into pith, wood, and bark; fibro-vascular bundles arranged in concentric layers around the pith, the new bundles being formed between the wood and the bark. Leaves usually pinnately or palmately veined, with ramifying veins. Parts of the flowers mostly in 5's, less commonly in 4's or 2's, seldom in 3's.

\section{Family 30 . SAlicaceae. Willow Family.}

Dioecious trees or shrubs, with soft wood and simple alternate leaves. Flowers in bracted aments, solitary in the axils of scale-like bractlets. Perianth represented by one or more glands or a cup-like disk. Stamens one or more. Pistil solitary, with 2-4 parietal placentae, becoming a dehiscent capsule; seeds numerous, bearing a tuft of hairs at the apex; endosperm wanting.

Bractlets incised; flowers with a cup-shaped disk; stamens usually more than 10; stigmas expanded; winter-buds with several scales Bractlets entire or denticulate; flowers with one or more glands; stamens $2-7$, in most species only 2 ; stigmas narrow; winter-buds with but 1 scale each. $\quad 2$. SALIX.

\section{PÓPUluS (Tourn.) L. Poplar, Cottonwood, Aspen.}

Trees, with furrowed bark and often resinous buds of more than one scale. Leaves petioled, usually with broad, toothed or even lobed blades, and caducous stipules. Flowers in drooping aments; bractlets membranous, lobed or fimbriate at the apex, usually caducous. Disk present, oblique, entire, toothed, or lobed. Stamens adnate to the disk; filaments distinct, glabrous; anthers purple, orange, or red. Ovary sessile in the disk; style short; stigmas 2-4, dilated. Ovules anatropous. Capsule opening by $2-4$ valves.

Leaves not white-tomentose beneath, toothed or rarely entire.

Petioles strongly flattened laterally.

Leaves suborbicular, acute or very short-acuminate, flnely crenate or subentire. Leaf-blades with' 2 conspicuous glands beneath at the base.

Leaf-blades not glandular at the base.

1. P. cercidiphylla.

2. P. tremuloides.

Leaves broadly deltoid, cordate, or ovate, abruptly acuminate, coarsely toothed, especially about the middle.

Cup of the pistillate flowers $6-8 \mathrm{~mm}$. broad.

Pedicels equalling or exceeding the capsules; leaf-blades longer than broad; teeth few, less than 10 on each side.

3. P. Wislizeni.

Pedicels shorter than the capsules; leaf-blades usually broader than long; teeth more than 10 on each side, sometimes obscure.

4. P. Fremontii.

Cup of the pistillate flowers less than $5 \mathrm{~mm}$. broad; teeth of the leaves many, more than 10 on each side; pedicels shorter than the capsule.

Leaves flabellate-cordate, with a broad, concave, entire sinus.

5. P. Sargentii.

Leaf-blades ovate, rounded or cuneate at the base, which is more or less toothed; only the blades of the young shoots cordate.

6. P. Besseyana.

Petioles terete or nearly so.

Petioles at least half as long as the blades; blades cordate, ovate, or broadly lanceolate.

Leaves green on both sides, abruptly long-acuminate.

Leaves paler beneath, acute or somewhat acuminate.

7. P. acuminata. Fruit sessile, usually 3-carpellary.

Ovary and capsule densely pubescent, subglobose. 8. P. trichocarpa. 
Ovary and fruit glabrous, but slightly warty, ovoid.

Fruit pedicelled, 2-carpellary, glabrous; capsule ovoid.

Twigs, petioles, and veins glabrous.

9. P. hastata. pulpeses and veins of the lower surface of the leaves more or

Petioles about one-third as long as the blade or less. Leaves cordate at the base.

Leaf-blades lanceolate, usually acute at the base.

Leaves white-tomentose beneath, of ten lobed.

11. P. candicans.

12. P. Tweedyi.

13. P. angustifolia.

14. $P$. alba.

1. P. cercidiphylla Britton. A small tree, with light grayish bark; petioles 1.5-2 cm. long; leaf-blades orbicular or somewhat reniform, slightly cordate at the base, dull green, somewhat paler beneath, entire or slightly undulate, about $3.5 \mathrm{dm}$. wide. Hoback Basin, Wyo. Submont.

2. P. tremuloides Michx. A slender tree, with light green or whitish bark, up to $30 \mathrm{~m}$. high; petioles 4-6 $\mathrm{cm}$. long; leaf-blades rounded or subcordate at base, 2-6 cm. broad, green and glabrous, ciliate on the margin; bracts silky, deeply 3-5-cleft into linear lobes; stamens 6-12; stigma-lobes linear; capsule conic, warty. The western tree may be distinct, and if so should be known as $P$. aurea Tidestrom. QUAKING Aspen. Cold places, sub-alpine forests: Newf. -N.J.-Tenn.-N.M.-Nev.-Alaska. Submont.-Subalp. Mr-My.

3. P. Wislizeni (S. Wats.) Sarg. A tree about $15 \mathrm{~m}$. high, with gray trunk and yellow branches; petioles glabrous, 4-7 $\mathrm{cm}$. long; leaf-blades truncate or broadly reniform, or sometimes broadly cuneate at the base; aments $5-10 \mathrm{~cm}$. long; bracts light red, fringed, with linear lobes; capsule ovoid, papillose. CoTTONwOoD. Valleys and river banks: Tex.-Colo.-Ariz.-n Mex. Son.Mont. Mr-My.

4. P. Fremontii S. Wats. A tree occasionally $35 \mathrm{~m}$. high, with dark brown trunk and gray branches; petioles $5-7 \mathrm{~cm}$. long; blades broadly cordate-deltoid, with an open rounded sinus at the base, 4-7 cm. long, 5-10 $\mathrm{cm}$. broad; aments 5-10 cm. long; capsule 8-12 mm. long. CotTonwood. Along rivers and in cañons: Calif.-s Utah-Ariz.-L. Calif. Son. F-Mr.

5. P. Sargentii Dode. A tree sometimes $30 \mathrm{~m}$. high, with gray trunk and straw-colored or light yellow branches; petioles about as long as the blades; leafblades broadly deltoid or cordate, abruptly acuminate at the apex, glabrous and shining, 5-10 cm. long; aments 5-8 cm. long; capsules ovoid, muricate, on pedirels 4-6 mm. long. P. occidentalis Rydb. Western or River CotTonwood. River bottoms: Sask.-Kans.-Ariz.-Alta. Plain-Submont. Mr-Ap.

6. P. Besseyana Dode. A tree about $10 \mathrm{~m}$. high, with gray trunk and yellowish terete branches; petioles about as long as the leaf-blades; blades abruptly - acuminate, 5-10 cm. long, glabrous and shining, slightly paler beneath; aments 7-8 cm. long; pedicels shorter than the fruit; capsule ovoid, about $5 \mathrm{~mm}$. long, muricate, 3-valved; stigma dilated. Valleys: Mont.-Ida. Submont. Ap-Je.

7. P. acuminata Rydb. A tree up to about $20 \mathrm{~m}$. high, with brownish or gray trunk and straw-colored branches; petioles $3-7 \mathrm{~cm}$. long; leaf-blades rhombic-lanceolate to avate, usually cuneate at the base, finely crenate, green and glabrous on both sides; aments $3-5 \mathrm{~cm}$. long, or the pistillate in fruit $10-15$ cm.; capsule ovoid, blunt, 6-8 mm. long, papillose; pedicels in fruit $3-5 \mathrm{~mm}$. long. RydberG's or SMooth-BARked CotTonwood. River banks: Sask.Tex.-Ariz.-Mont. Plain-Submont. Ap-My.

P. acuminata $\times$ Sargentii Sarg. Intermediate between the parents, with the fine serrations, cuneate base, and texture of the leaves of $P$. acuminata, but with the broader leaves and darker branchlets of $P$. Sargentii. P. Andrewsii Sarg. Colo.

8. P. trichocarpa T. \& G. A tree sometimes $60-70 \mathrm{~m}$. high, with gray trunk and orange or gray, pubescent branches; petioles $2-6 \mathrm{~cm}$. long; leaf-blades broadly ovate to ovate-lanceolate, acute or short-acuminate at the apex, cordate, truncate, or rounded at the base, $8-12 \mathrm{~cm}$. long, finely crenate, dark green above, pale beneath, usually pubescent when young; aments 4-7 cm. long. WesterN Balsam Poplar. River banks: Alaska-Mont.-Calif. Plain-Submont. ApMy. 
9. P. hastata Dode. A tree $10-20 \mathrm{~m}$. high, with gray trunk and branches; petioles 3-4 cm. long, glabrous; leaf-blades ovate, ovate-deltoid, or subcordate, dark green above, pale beneath, mostly acuminate, rounded or cordate at the base, crenulate, $6-10 \mathrm{~cm}$. long; aments $5-12 \mathrm{~cm}$. long; cup 4-5 mm. wide. Valleys: Alta.-Mont.-Ida. Submont.-Mont. Ap-Je.

10. P. balsamifera L. A tree sometimes $25 \mathrm{~m}$. high, with reddish gray trunk and light brown or gray branches; petioles $2-5 \mathrm{~cm}$. long; leaf-blades ovate to ovate-lanceolate, dark green and shining above, pale beneath, acute or acuminate at the apex, rounded or cuneate at the base, crenulate, 7-12 $\mathrm{cm}$. long; aments $5-10 \mathrm{~cm}$. long. Balsam Poplar. Along streams and lakes: Newf.N.Y.-Colo.-Nev.-Alaska. Submont.-Mont. Ap.

11. P. candicans Michx. A tree sometimes $30 \mathrm{~m}$. high, with gray trunk and round branches, pubescent when young, in age glabrate; petioles pubescent or ciliate; leaf-blades broadly ovate, acute or acuminate at the apex, cordate or truncate at the base, 6-15 $\mathrm{cm}$. long, 3-12 $\mathrm{cm}$. wide, dark green above, pale beneath, crenate; aments 6-12 $\mathrm{cm}$. long; capsule oblong-ovoid, smooth, shortstalked. BaLM OF GILEAD. Roadsides and river banks: Newf.-N.J.-S.D.Alta.-Alaska. Boreal. Ap-My.

12. P. Tweedyi Britton. A small tree, with yellowish twigs; petioles stout, $5-12 \mathrm{~mm}$. long; leaf-blades ovate to nearly round, acute, finely crenate, cordate or rounded at the base, 3-7 cm. long, dark green above, paler beneath; aments $3-4 \mathrm{~cm}$. long, in fruit $6 \mathrm{~cm}$.; capsules ovoid, densely papillose, $4 \mathrm{~mm}$. long; pedicels about $1 \mathrm{~mm}$. long. CotTonwood. River bottoms: Wyo, Submont.

13. P. angustifolia James. A slender tree, sometimes $20 \mathrm{~m}$. high, with upright branches and greenish bark; petioles 6-12 $\mathrm{mm}$. long; leaf-hlades lanceolate to ovate, acute or gradually acuminate at the apex, cuneate, rounded or rarely subcordate at the base, green above, paler beneath, finely crenate, 5-12 $\mathrm{cm}$. long; aments 2-6 $\mathrm{cm}$. long; capsule ovoid, rugose. $P$. coloradensis Dode. P. fortissima Nels. \& Macb. Narrow-Leaved or Black Cottonwood. Along streams: Sask.-Neb.-N.M.-Ida.; n Mex. Plain-Mont. Ap-My.

14. P. alba L. A large tree, sometimes $35 \mathrm{~m}$. high, with light gray bark; petioles shorter than the blades, subterete; leaf-blades densely white-tomentose on both sides, becoming glabrate and dark green above, broadly ovate or orbicular in outline, 3-5-lobed and irregularly toothed, 6-10 $\mathrm{cm}$. long; aments 3-6 cm. long; capsules elliptic, subsessile. White or Silver Poplar. In yards and along roadsides: N.B.-Va.-N.M.-Utah; cult, and escaped, native of Eurasia. Mr-My.

\section{SÀLIX (Tourn.) L. WILLOW.}

Trees or shrubs, usually with flaky bark and slender, flexible twigs; bud of only one scale. Leaves alternate, petioled or subsessile, pinnately veined, usually finely toothed. Bractlets of aments entire or rarely denticulate, with one or more gland-like nectaries at the base of the stamens or the pistil. Stamens $1-7$, usually 2 ; anthers usually yellow. Ovary more or less stipitate; stigmas 2, often 2-cleft, with narrow branches. Capsule dehiscent at the apex into 2 valves.

Capsule glabrous, or slightly silky when young in nos. 12, 14, and 16 .

Filaments hairy, at least below; bractlets caducous, light yellow; style very short, obsolete, or none, evident only in nos. 16 and 18 ; aments in all ours on short leafy branches.

Stamens $3-7$; stipe slender, 2-5 times as long as the nectaries. Petioles without glands; leaves remotely serrulate, thin. Petioles with glands; leaves densely glandular-serrate, firmer.

Stamens 2; stipes usually very short. Leaf-blades lanceolate, acuminate. Leaf-blades linear or linear-lanceolate, acute, rarely acuminate.

I. AMYgDalinaE.

II. Pentandrae.

III. Albae.

IV. LONGIFOLIAE.

Filaments glabrous; bractlets persistent, rarely light yellow.

Trees, or erect or ascending shrubs, several $\mathrm{dm}$. high; leaf-blades more than $1 \mathrm{~cm}$. long; style evident.

V. CORDATAE.

Depressed prostrate shrubs, $1-3 \mathrm{~cm}$. high; leaf-blades less than $1 \mathrm{~cm}$. long; style none.

VI. RETUSAE. 
Capsule hairy,

Filaments hairy; bractlets caducous; leaf-blades linear to lanceolate, not very veiny.

IV. LONGIFOLIAE.

Filaments glabrous, or if somewhat hairy, leaf-blades oval or orbicular, very veiny; bractlets persistent.

Capsule rostrate, distinctly stipitate; style none or short, always shorter than the stipe.

Stipe equalling or exceeding the bractlets; style $0.5 \mathrm{~mm}$. long or less.

Stipe shorter than the bractlets; style usually $1 \mathrm{~mm}$. long.

VII. Rostratae.

VIII. CAPREAE.

Capsule scarcely rostrate, subsessile or, if stipitate, stipe shorter than the style. Style evident, at least $0.5 \mathrm{~mm}$. long.

Leaves permanently silky or tomentose beneath.

Leaves neither silky-white nor tomentose beneath.

Style none; depressed or low shrubs, with entire strongly retict

Bractlets entire.

\section{Amygdalinae.}

IX. ARgENTEAE.

X. ARCTICAE.

XI. Reticulatae.

Leaves narrowly lanceolate; petioles short.

Bark of twigs brownish; aments long and lax; leaf-blades broadest below the middle, long-acuminate.

1. S. nigra.

Bark of twigs light yellow; aments short and dense; leaf-blades usually broadest at or above the middle, short-acuminate.

Leaf-blades broadly lanceolate; petioles slender, 6-15 mm. long.

Bractlets denticulate.

\section{Pentandrae.}

3. S. amygdaloides.

4. S. laevigata.

Leaves narrowly oblanceolate, acute, drying blackish; bractlets of the staminate aments ovate, and of pistillate lanceolate, neither toothed.

5. S, erythrocoma.

Leaves lanceolate to ovate; bractlets of the staminate aments obovate or spatulate, usually toothed; those of the pistillate aments oblong.

Bractlets densely white-villous; stipe of the capsules scarcely twice as long as the nectaries.

6. S. serissima.

Bractlets sparingly hairy; stipe of the capsules 3-4 times as long as the nectaries.

Leaves ovate-lanceolate or ovate; glands of the leaves very prominent; those on the petioles often stalked.

Leaves lanceolate; glands of the leaf-blades not very prominent; those on the petioles always sessile.

Leaf-blades usually less than $1 \mathrm{dm}$. long, green on both sides; aments short.

Mature leaf-blades often $1 \mathrm{dm}$. long, glaucous beneath; aments elongate.

9. S. Lyallii.

One species.

III. Albae.

10. S. alba.

\section{LONGIFOLIAE.}

Capsule glabrous or slightly silky when young.

Leaves with close serrations, glaucous and prominently veined beneath.

11. S. melanopsis.

Leaves entire or with distant serrations, neither glaucous nor strongly veined beneath. Styles none.

Leaves permanently silky.

Leaves $3-5 \mathrm{~mm}$. wide; ovary without a hairy swelling at the apex.

Leaves $2-3 \mathrm{~mm}$. wide; ovary with a hairy swelling at the apex.

Leaves glabrous in age, or nearly so.

Leaves linear-lanceolate; bractlets ovate or obovate, obtuse.

Leaves narrowly linear; bractlets lanceolate, acute.

14. S, interior.

Styles evident; aments dense; bractlets densely silky.

15. S. linearifolia.

Capsule permanently densely pubescent.

Stigma sessile; leaves entire or nearly so.

Stigma on a distinct style, which is $0.5 \mathrm{~mm}$. long; leaves dentate.

\section{Cordatae.}

16. S. sessilifolia.

17. S. argophylla.

18. S. macrostachya.

Leaves white-tomentose or white-villous beneath.

Leaves entire, or minutely denticulate; aments 3-4 cm. long; bractlets silky-pilose. Leaves permanently appressed-silky.

Leaves in age glabrous and shining, at least above.

19. S. Sandbergii.

Leaves usually crenate, villous, $3-8 \mathrm{~cm}$. long; aments $3-6 \mathrm{~cm}$. long; bractlets densely villous.

Leaves glabrous or hairy, but not densely white-pubescent beneath.

Branches without a bloom.

Capsule long-stipitate; stipe in fruit $1.5-6 \mathrm{~mm}$. long, equalling or exceeding the bractlets; style $0.5 \mathrm{~mm}$. long or less.

Leaves dark green above; young branches not light yellow; aments on short leafy branches. 
Mature leaves rather thin, dull; length of the blade less than three times its width. 22. S. balsamifera.

Mature leaves firm, dark green, shining above, pale beneath; length of the blade three times the width or more.

Stipe in fruit $2-4$ times as long as the bractlets; mature leaves slightly serrate.

Stipe slightly if at all exceeding the bractlets.

Mature leaves lanceolate, strongly serrate.

Mature leaves oblong or oblanceolate, entire.

23. S. Mackenziana.

24. S. cordata.

25. S. pedicillaris. tended by a few small leaves.

Leaves usually long-acuminate, serrate. 26. S. lutea.

Leaves acute or rarely short-acuminate, entire or indistinctly crenulate.

27. S. Watsonii.

Capsule short-stipitate or subsessile; stipe in fruit less than $1.5 \mathrm{~mm}$. long and much shorter than the bractlets; style $0.5-1 \mathrm{~mm}$. long.

Leaves more or less dentate, rarely subentire.

Young leaves and twigs rather densely pubescent with long white hairs; the former glandular-denticulate or dentate.

Bractlets fuscous.

Bractlets yellowish or light brown.

Young leaves glabrous or slightly pubescent

28. S. Barklayi.

Capsules 7-8 mm. long; leaf-blades broadly ovate or obovate, glandulardentate.

30. S. Tweedyi.

Capsule 4-6 mm, long; leaf-blades narrowly obovate to lanceolate. Leaves dark green above, not reticulate.

Leaves blackening in drying, finely glandular-dentate.

Leaves not blackening in drying.

31. S. conjuncta.

Leaves thin, ovate, elliptic, or obovate, light green and dull above; capsule ovoid.

32. S. padophylla.

Leaves thick, firm, shining above; capsule lance-ovoid.

Style $0.5-1 \mathrm{~mm}$. long; aments on short leafy branches, $2-3 \mathrm{~cm}$. long. 33 . S. monticola.

Style 1-1.5 mm. long; aments subsessile, 3-4 cm long.

34. S. curtiflora.

Leaves yellowish green, conspicuously reticulate, thin.

Leaves acute or acuminate, serrate. 35 , S. pseudomyrsinites.

Leaves obtuse or rounded at the apex, crenate.

36. S. myrtillifolia.

Leaves entire, linear, lanceolate, oblanceolate, or oblong; aments subsessile, naked.

Leaves permanently silky; a low shrub.

Leaves glabrous in age; tree or tall shrub.

Branches with a bloom, purple.

One species.

VI. Retusae.

37. S. Wolfii.

20. S. lasiolepis.

38. S. irrorata.

39. S. Dodgeana.

VII. Rostratae.

Leaves linear to lanceolate or oblanceolate.

Leaves sharply serrate, narrowly lanceolate, $5-10 \mathrm{~cm}$. long. $40 . S$. petiolaris.

Leaves entire or nearly so, linear, less than $5 \mathrm{~cm}$. long.

Leaves more or less silky, oblanceolate; branches purplish, usually with a bloom.

Leaves not silky, linear; branches without a bloom.

Leaves ovate to obovate or broadly oblanceolate.

Bracts fuscous, obovate or cuneate.

Bracts yellow, linear-oblong or lanceolate.

Mature leaves thin, glabrous.

Mature leaves firm, pubescent or tomentose beneath.

41. S. Geyeriana.

42. S. gracilis.

43. S. discolor.

44. S. perrostrata.

45. S. Bebbiana.

VIII. CAPREAE.

Capsule 8-10 mm. long; at least the staminate aments not leafy-bracted.

Leaves obovate, entire or nearly so, densely silky and fulvous, almost velutinous when young, in age glabrate above; bractlets fuscous, obovate.

46. S. Scouleriana.

Leaves oblanceolate, closely and finely serrulate, puberulent when young; bractlets yellow, oblong.

Capsule $6 \mathrm{~mm}$. long or less; aments leafy-bracted.

67. S. MacCalliana.

Bractlets black, thinly pilose; style about $1 \mathrm{~mm}$. long; leaves glabrate in age. 47. S. Lemmoni.

Bractlets brownish, villous; style about $0.5 \mathrm{~mm}$. long; leaves silvery-silky beneath.

IX. ARgentea.

54. S. argyrocarpa.

Aments more than $1 \mathrm{~cm}$. broad; ovary over $5 \mathrm{~mm}$. long.

Leaves obovate, ovate, or broadly oblanceolate.

Bractlets obovate, fuscous; leaves usually obovate.

Twigs white-villous; leaf-blades entire.

48. S. alaxensis. 
Twigs puberulent; leaf-blades usually glandular-denticulate.

Bractlets oblong, yellow; leaf-blades usually broadly oblanceolate. 49 . Sattiana.

Leaves oblanceolate or oblong-lanceolate; bractlets oblong.

Leaves silvery-silky beneath, not strongly reticulate; bractlets black.

Leaves white-tomentose beneath, strongly reticulate; bractlets brown.

Aments less than $1 \mathrm{~cm}$. broad; ovary less than $5 \mathrm{~mm}$. long.
Leaves broadly obovate.

51. S. candida.

Twigs puberulent; bractlets light brown; stamen 1.

Twigs glabrous; bractlets blackish; stamens 2 .

Leaves oblong, lanceolate, or oblanceolate.

Bractlets yellow or brown; stipes 3-4 times as long as the nectaries; style less than

$0.5 \mathrm{~mm}$. long.
Bractlets fuscous; stipes less than twice as long as the nectaries. Style about 0.5 mm. long; bractlets obtuse.
Style 1-2 mm. long.

Branches without a bloom; leaves tomentose beneath.

Branches with a bloom; leaves white-silky beneath. Aments peduncled and leafy-bracted. Aments sessile and naked.

56. S. pellita.

57. S. subcoerulea.

58. S. pachnophora.

\section{$X$. Arcticae.}

Aments on leafy peduncles.

Leaves grayish villous on both sides, less so on the upper.

Twigs white-villous or silky; branches yellow or grayish. Leaves villous; capsules densely pubescent.

Leaves silky; capsules finely and sparingly pubescent.

Twigs puberulent; branches usually purplish.

59. S. brachycarpa.

Bractlets black or with blackish tips.

Leaves oblong, 2-3 cm. long; bractlets obovate; branches divergent.

Leaves oblanceolate or obovate, $3-6 \mathrm{~cm}$. long: 61 . S. pseudolapponum. ascending.

Bractlets yellow, oblong.
Leaves glabrate or when young covered with white hairs glaucops.
S. Seemannii.

60. S. idahoensis.

Shrubs not creeping, although often depressed.

Leaves broadly oval, often minutely glandular-dentate.

Leaves narrower.

Leaves oblong or oblanceolate, or ovate.

Leaves $2-4 \mathrm{~cm}$. long; capsule $3-5 \mathrm{~mm}$. long.

Bractlets yellow or brown, oblong; leaves elliptic or oblanceolate, thin, darkening in drying; twigs purple. 65. S. desertorum.

Bractlets fuscous at the apex; leaves oblong, not blackening in

drying.
Leaves $4-6 \mathrm{~cm}$. long.

61. S. pseudolapponum.

Bractlets fuscous; leaves elliptic or oblong, obtuse or acute, usually reticulate; glabrous only in age.

62. S. glaucops.

Bractlets yellow or brown; leaves usually short-acuminate, glabrous except when very young, not reticulate.

Leaves entire or sparingly glandular-denticulate, oblanceolate.

Leaves finely serrulate, Austinae.

Leaves finely serrulate, elliptic, lanceolate, or oblanceolate.

Leaves linear-lanceolate.
Shrubs creeping; arctic or alpine.

67. S. MacCalliana.

Leaves obovate or oblanceolate; aments many-flowered.

$\begin{array}{ll}\text { Leaves narrowly oblanceolate; aments few-flowered. } & \text { 70. S. Setrophila. } \\ \text { cascadensis. }\end{array}$

Aments naked, from lateral buds.

Leaves oblanceolate, strongly veined.

Leaves elliptic, not strongly veined.

71. S. Nelsonii.

72. S. chlorophylla.

\section{Xi. Reticulatae.}

Leaves covered beneath with long white silky hairs.
Leaves at least in age not silky.

73. S. Fernaldii.

Leaf-blade over $1 \mathrm{~cm}$. long; aments comparatively many-flowered.

Filaments very hairy on the lower part; leaves strongly reticulate; bracts broadly obovate, fuscous, the upper portion almost glabrous.

Filaments almost glabrous; leaves less strongly reticulate $74, S$, orbicularis.

yellow, almost glabrous.
Leaf-blade $1 \mathrm{~cm}$. or less long; aments few-flowered; bractlets yellow, almost grab.

bracts cuneate-oblong, yellow, almost 
1. S. nigra Marsh. A tree $10-20 \mathrm{~m}$., rarely $30-40 \mathrm{~m}$. high; leaf-blades 6-12 cm. long, bright green on both sides, finely serrate, usually more or less falcate; aments appearing with the leaves, the staminate ones $4-6 \mathrm{~cm}$. long; bractlets ovate, finely villous; pistillate aments $4-8 \mathrm{~cm}$. or in fruit $10-12 \mathrm{~cm}$. long; bractlets oblong, finely pubescent; capsule about $3 \mathrm{~mm}$. long; stipe 1-1.5 mm. long. Black Willow. River banks and wet places: N.B.-Fla.-Tex.N.D. Plain. Ap-My.

S. amygdaloides $\times$ nigra Glattf. This hybrid is intermediate between the two parents, with narrower leaves, less glaucous beneath, and with shorter petioles than in $S$. amygdaloides, but broader leaves and with longer petioles than in $S$, nigra. In the eastern part of the range.

2. S. Wrightii Anders. A tree 8-10 m. high; bark of the stem flaky, gray; leaf-blades $5-15 \mathrm{~cm}$. long, light and usually yellowish green above, paler and sometimes glaucous beneath, finely serrate; aments 2-7 $\mathrm{cm}$. long; bractlets of the staminate aments ovate, finely pubescent, those of the pistillate ones oblong; capsule about $4 \mathrm{~mm}$. long; stipe 1-2 mm. long. River banks: Tex.-Colo.Nev.-s Calif.; n Mex. Son.-Submont. Ap-My.

3. S. amygdaloides Anders. A tree up to $20 \mathrm{~m}$. high; twigs yellowish; leaf-blades 8-12 cm. long, acuminate, finely serrate, paler and somewhat glaucous beneath; aments 3-5 $\mathrm{cm}$. long; bractlets oblong or lanceolate, somewhat pubescent; capsule about $5 \mathrm{~mm}$. long; stìpe 1-2 mm. long. Peach-Leaved Willow. River and lake banks: Que.-N.Y.-Mo.-Tex.-Ariz.-Ore.-B.C. Plain-Submont. Ap-My.

4. S. laevigata Bebb. A tree 5-15 m. high; trunk with brown fissured bark; twigs yellowish, pubescent when young; leaves lanceolate or lance-oblong, acute or acuminate, $7-15 \mathrm{~cm}$. long, dark green and glossy above, pale or glaucous beneath, minutely serrate; aments $5-10 \mathrm{~cm}$. long; bractlets villous, dentate, in the staminate aments obovate, in the pistillate ones narrower; stipe 3 to 4 times as long as the glands. Along streams: Ore-CUtah-Calif. Son. Ap-Je.

5. S. erythrocoma Barrett. A shrub or small tree (?); bark of the twigs dark, purplish brown; leaf-blades $3-5 \mathrm{~cm}$. long, finely glandular-serrate, reddish pubescent when young, in age glabrate on both sides; aments $2-4 \mathrm{~cm}$. long. $S$. arguta erythrocoma Anders. Banks of rivers and lakes: Man.-B.C.-Mack,

6. S. serissima (Bailey) Fern. A shrub 2-4 m. high; leaf-blades lanceolate, acute or acuminate, when mature dark green, shining above, pale beneath, thick and firm, 4-10 cm. long, closely and finely glandular-serrate; aments 1-2.5 $\mathrm{cm}$. long; capsules 7-12 mm. long. S. pallescens hirtisquama Anders. AUTUMN Wrllow. Swamps: Mass.-N.J.-Wis,-Minn.-Sask. Boreal. My-J1.

7. S. lucida Muhl. A tall shrub or sometimes a tree 6-8 m. high; leafblades mostly abruptly long-acuminate, acute or rounded at the base, sharply glandular-serrate, green and shining, slightly paler beneath, 7-12 cm. long; aments $2-5 \mathrm{~cm}$., or the pistillate even $7 \mathrm{~cm}$. long; bractlets sparingly pubescent; capsule $5 \mathrm{~mm}$. long. Shining Winlow. Swamps and banks: Newf.-N.J.Ky.-Neb.-Alta. Boreal. Ap-My.

8. S. Fendleriana Anders. A shrub or small tree, rarely $10 \mathrm{~m}$. high; leafblades lanceolate, long-acuminate, finely glandular-dentate, acute at the base, $6-15 \mathrm{~cm}$. long; aments $2-5 \mathrm{~cm}$. long; bractlets toothed towards the apex; stamens 5-9; capsule $5 \mathrm{~mm}$. long. S. lasiandra caudata (Nutt.) Sudw. Along mountain streams: B.C.-Alta.-(Black Hills) S.D.-N.M.-Calif. Submont.-Mont. Ap-My.

9. S. Lyallii (Sarg.) Heller. A tree sometimes $20 \mathrm{~m}$. high; bark brown or of the twigs yellow; leaf-blades broadly lanceolate, more or less acuminate, finely glandular-serrate, $6-20 \mathrm{~cm}$. long; aments $4-8 \mathrm{~cm}$. long, or the pistillate ones sometimes $10 \mathrm{~cm}$. long; bractlets toothed above; stamens 5-8; capsule about 6 $\mathrm{mm}$. long. S. lasiandra Lyallii Sarg. River and lake banks: B.C.-YukonMont.-Calif. Submont. Ap-My.

10. S. alba L. A large tree sometimes $30 \mathrm{~m}$. high; leaf-blades serrulate, silky-pubescent on both sides when young, pale beneath, $5-12 \mathrm{~cm}$. long; aments on short leafy branches, 3-6 $\mathrm{cm}$. long, 4-5 mm. thick; bractlets of the staminate 
aments obovate, those of the pistillate ones lance-oblong; capsule almost sessile, 4-5 mm. long. White WiLlow. Moist ground, along streams: N.B.-Pa.Colo.; escaped from cultivation, native of Eu. Plain. Ap-My.

11. S. melanopsis Nutt. A shrub or small tree; bark chestnut-brown; young branches puberulent; leaf-blades oblanceolate or elliptic, subsessile, about $5 \mathrm{~cm}$. long, $1 \mathrm{~cm}$. wide, silky-hairy when young, blackening in drying, somewhat glaucous, finely serrate; aments at the end of leafy branches, 5-7 cm. long, cylindric; bractlets linear-oblong, more or less erose; capsule lanceolate, glabrous. Dusky Willow. River banks: B.C.-Mont.-Ore. Submont. My-Jl.

12. S. exigua Nutt. A shrub or small tree sometimes $6-7 \mathrm{~m}$. high; twigs yellowish or light brown, silky-pubescent when young; leaf-blades linear to narrowly linear-lanceolate, $2-8 \mathrm{~cm}$. long, yellowish, silky; staminate aments $2-6 \mathrm{~cm}$, the pistillate ones $3-5 \mathrm{~cm}$. long; bractlets of the former obovate, of the latter broadly lanceolate; capsule elongate-ovoid, slightly silky when young, soon glabrate, 4-5 mm. long. S. luteosericea Rydb. SANDBAR WILlow. Sandbars: Sask.-Okla.-Ariz.-B.C.-Ore. Plain-Mont. My-Jl.

13. S. stenophylla Rydb. A shrub $2-5 \mathrm{~m}$. high; young shoots silverypubescent; leaves narrowly linear, 3-7 cm. long, acute, entire or minutely and distantly denticulate, silky-strigose; pistillate aments $3-4 \mathrm{~cm}$. long; bractlets oblanceolate; capsule glabrous, about $6 \mathrm{~mm}$. long; staminate aments $2-3 \mathrm{~cm}$. long; bractlets more obtuse and more villous. River banks: Colo.-N.M.Ariz. Plain-Submont. My-Л.

14. S. interior Rowley. A shrub 1-4 m. high, oceasionally a tree $6-9 \mathrm{~m}$. high; twigs pubescent when young; leaf-blades $6-10 \mathrm{~cm}$. long, less than $1 \mathrm{~cm}$. wide, lance-linear, remotely dentate; aments $2-5 \mathrm{~cm}$. long; bractlets glabrous or hairy toward the base, ovate or obovate, rarely oblong; capsule appressedsilky when young, soon glabrate. S. longifolia Muhl. SANDBAR WrLlow. River banks and shores: Que.-Va.-La.-Tex.-Sask. Plain. Je-Jl.

15. S. linearifolia Rydb. A low shrub, with reddish bark; leaf-blades narrowly linear, $4-10 \mathrm{~cm}$. long, remotely dentate; aments loosely flowered, 3-4 em. long; bractlets linear-lanceolate, acute, almost glabrous; capsule almost glabrous, 3-4 mm. long. S. rubra Richards. S. tenerrima (Howell) Heller. Sand-bars: Sask.-Okla.-Colo.-Wash. Plain. My-Je.

16. S. sessilifolia Nutt. A shrub or small tree sometimes $10 \mathrm{~m}$. high; young branches canescent; leaf-blades linear-lanceolate to linear or oblong, 5-10 $\mathrm{cm}$. long, sessile, obscurely and remotely denticulate or entire, silvery-canescent when young, in age more glabrate; aments $6-8 \mathrm{~cm}$. long, nearly $1 \mathrm{~cm}$. thick, often several together; capsule silky when young, glabrate in age. Sand-bars: (? Mont.) -Colo.—Calif.-Wash. Submont. Je-JI.

17. S. argophylla Nutt. A tree or large shrub, usually about $5 \mathrm{~m}$. high; young twigs yellow and puberulent, soon glabrate; leaf-blades narrowly linearlanceolate, about $5 \mathrm{~cm}$. long, sessile, densely white-silky on both sides; aments $3-5 \mathrm{~cm}$. long, 1-2 $\mathrm{cm}$. thick, of ten in pairs or threes; bractlets of the staminate aments oblong and obtuse, those of the pistillate aments lanceolate and acute; capsule densely silky, sessile. River banks: Mont.-Tex.-Calif.-Wash.
Plain-Submont. My-J.

18. S. macrostachya Nutt. A shrub or small tree 1-6 m. high; twigs densely villous; leaf-blades linear-oblanceolate, about $5 \mathrm{~cm}$. long, sessile, densely white-villous; aments often several together, $2-3 \mathrm{~cm}$. long, densely flowered; bractlets densely villous all over, oblong; capsule densely villous, sessile. River banks: Calif.-Ida.-B.C. Submont. My-Jl.

19. S. Sandbergii Rydb. A shrub or small tree; branches chestnut-brown; leaves oval or elliptic, $2-4 \mathrm{~cm}$. long, silky on both sides, grayish above, silvery spatulate, $3 \mathrm{~mm}$. long, white-pilose; capsule glabrous, $4-5 \mathrm{~mm}$. long; stipe about $1.5 \mathrm{~mm}$. long; style about $0.5 \mathrm{~mm}$. long. S. boiseana A. Nels. Valleys: Ida.

- Submont. Ap-Je. 
20. S. lasiolepis Benth. A tree $3-20 \mathrm{~m}$. high, with grayish brown, smooth bark; leaves oblanceolate, 10-15 cm. long, often obtuse, more or less short-villous when young, in age glabrous and shining above, glaucous or ferrugineous beneath, subcoriaceous in age; aments sessile or nearly so; bractlets rounded, dark, crisp-villous; filaments slightly united at the base; capsule glabrous; stipe short; style about $1 \mathrm{~mm}$. long. Along streams: Calif.-Utah-lda.-Wash. Son. $\mathrm{Mr}-\mathrm{Je}$.

21. S. Hookeriana Barrett. A shrub or tree up to $16 \mathrm{~m}$. high; twigs densely velvety-canescent when young; leaf-blades broadly obovate or oval, whitepubescent when young, in age dark green and more glabrate above, white-villous beneath; aments subsessile, naked or nearly so; bractlets obovate, fuscous, but usually hidden by the dense white-villous pubescence; capsule about $5 \mathrm{~mm}$. long; stipe short; style 0.5-1 mm. long. River banks: Sask.-Ore.-B.C. Submont. Ap-My.

22. S. balsamifera (Hook.) Barratt. Usually a shrub, about $3 \mathrm{~m}$. high, sometimes a small tree up to $8 \mathrm{~m}$. high; leaf-blades thin, ovate, oval, or obovate, acute or obtuse at the apex, rounded or subcordate at the base, dark green above, glaucous beneath, $5-8 \mathrm{~cm}$. long; aments $2-5 \mathrm{~cm}$. long; bractlets persistent, brownish or yellowish, silky-villous; capsule $6-8 \mathrm{~mm}$. long; stipe about $3 \mathrm{~mm}$. long; style very short. S. pyrifolia Anders. P. Columbiae Nels. \& Macb. Balsam Willow. Swamps: Lab.-N.Y.-Minn.-Mont. My.

23. S. Mackenziana Barratt. A small tree or shrub, sometimes $10 \mathrm{~m}$. high; bark brown, glabrous; leaf-blades oblanceolate or lanceolate, $5-10 \mathrm{~cm}$. long, acuminate at the apex, crenate or nearly entire, dark green above, pale beneath; aments $4-6 \mathrm{~cm}$. long; bractlets obovate, hairy towards the base; capsule glabrous, 5-7 mm. long; stipe 3-4 mm. long; style about $0.5 \mathrm{~mm}$. long. DIAMOND WrLLow. Along streams: Sask.-Man.-Ida.-Calif,-B.C.-Mack. Submont. Ap-Je.

24. S. cordata Muhl, A shrub 1.5-4 m. high; leaf-blades from oblonglanceolate and subcordate at the base to narrowly lanceolate and acute at the base [var. augustata (Pursh.) Anders., the form found in the Rocky Mountains], often somewhat silky-pubescent when young; staminate aments about $2 \mathrm{~cm}$. long, the pistillate ones 4-6 mm. long in fruit; bractlets fuscous, white-silky; capsule glabrous, 6-7 mm. long; stipe 1-2 mm. long; style minute. HEARTLeaved Willow. Wet ground: N.B.-Va.-Colo-Calif.-B.C. Plain-Mont. Ap-My.

25. S. pedicellaris Pursh. A shrub $1 \mathrm{~m}$. high or less; blades oblong, elliptic or sometimes oblanceolate, obtuse, entire, $2-4 \mathrm{~cm}$. long, $8-16 \mathrm{~mm}$. wide; aments about $2 \mathrm{~cm}$. long; bractlets obtuse, slightly villous; capsule glabrous, about $5 \mathrm{~mm}$. long; stipe about $2 \mathrm{~mm}$. long; style minute. S. myrtilloides Am. auth., not L. Bog Wrllow. In bogs: N.B.-N.J.-Ia.-Wash.-B.C. Mont. Ap-My.

26. S. lutea Nutt. A shrub or small tree 5-6 m. high, with gray bark; leaf-blades lanceolate, $3-7 \mathrm{~cm}$. long, more or less acuminate, somewhat pubescent when young; aments subsessile, $2-5 \mathrm{~cm}$. long; bractlets brownish, whitevillous; capsule about $5 \mathrm{~mm}$. long; stipe $1-2 \mathrm{~mm}$. long; style about $0.5 \mathrm{~mm}$. long. YeLLow WiLLow, River banks and wet places: Man.-Neb.-Utah-Mont.Alta. Submont.-Mont. My-Je.

27. S. Watsonii (Bebb) Rydb. A shrub or small tree 4-7 m. high; blades lanceolate, short-acuminate or acute, $3-7 \mathrm{~cm}$. long; aments $2-3 \mathrm{~cm}$. long, almost sessile; capsule ovate, about $6 \mathrm{~mm}$. long; stipe in fruit often $2 \mathrm{~mm}$. long; style about $0.5 \mathrm{~mm}$. long. S. flava Rydb. River banks: Mont.-N.M.-Calif. Submont. My-Je.

28. S. Barklayi Anders. A tall shrub 1-4 m. high; leaf-blades obovate, ovate or oval, $2-5 \mathrm{~cm}$. long, acute or short-acuminate, more or less glaucous beneath; aments on short leafy branches, $2-3 \mathrm{~cm}$. long, 8-10 mm. thick; bractlets oblong, obtuse, densely white-villous; capsule about $6 \mathrm{~mm}$. long, subsessile; style about $1 \mathrm{~mm}$. long. Mountain meadows: Alaska-Wash.-Mont.; (Gaspé Peninsula) Que. Subalp.-Alp. My-Au. 
29. S. commutata Bebb. A diffuse shrub 1-3 m. high; branches villous when young; leaves broadly oblanceolate or oblong, abruptly pointed; aments on short leafy branches, $2-4 \mathrm{~cm}$. long; bractlets woolly; capsule about $5 \mathrm{~mm}$. long, greenish or reddish; stipe short; style about $1 \mathrm{~mm}$. long. Alpine and subalpine bogs: Ore.-Ida.-B.C. Mont,-Alp. Jy-Au.

30. S. Tweedyi (Bebb) Ball. A tall shrub; twigs at first pubescent with gray hairs; leaf-blades acute or obtuse at the apex, from acute to subcordate at the base, yellowish green above, paler beneath; aments sessile and naked, appearing before the leaves, $4-6 \mathrm{~cm}$. long; bractlets obovate, black, white-silky; capsule green; stipe $1 \mathrm{~mm}$. long; style $1.5-2.5 \mathrm{~mm}$. long. Mountains: Mont.Wyo. Je-Jl.

31. S. conjuncta Bebb. A shrub 1-4 m. high; leaf-blades elliptic or obovate, $3-4 \mathrm{~cm}$. long, or on the young shoots $5-10 \mathrm{~cm}$. long, acuminate or acute at the apex, acute or rounded at the base, glabrous or slightly floccose when young; aments on leafy peduncles, $3-5 \mathrm{~cm}$. long; bractlets dark, acute, whitevillous; stipe and style about $1 \mathrm{~mm}$. each. Wet mountain meadows: Wash.Mont.-Alaska. Subalp. J1-Au.

32. S. padophylla Rydb. A shrub 1-7 m. high; leaf-blades oval or broadly elliptic, crenate, short-acute or obtusish, rounded at the base, $3-5 \mathrm{~cm}$. long; pistillate aments $3-4 \mathrm{~cm}$. long, densely flowered, borne on very short branches; bractlets obovate, fuscous, covered on the outside with white wool; capsule about $6 \mathrm{~mm}$. long; style about $1.5 \mathrm{~mm}$. long; staminate aments almost sessile, $2-3$ cm. long. S. padifolia Rydb., not Anders. Cherry Willow. River banks: N.M.-Mont.-Utah. Submont.-Mont. My-Je.

33. s. monticola Bebb. A shrub 2.5-3.5 m. high; leaf-blades lanceolate to obovate, acute or acuminate, $8-15 \mathrm{~cm}$. long, glabrous, pale or glaucous beneath, serrate or crenate; aments thick, $2-3 \mathrm{~cm}$. long; bractlets oval, silky with long hairs; capsule sessile or nearly so. Along streams: Colo.-Alta. Submont.-Mont. Je.

S. cordata $\times$ monticola. This has the capsule shorter than in $S$. cordata but longer than in S. monticola, the habit and bark of the latter, but the narrow leaves (although less serrate) and the bractlets of the Rocky Mountain form of the former; the capsule
usually remains undeveloped. Northern Utah.

34. S. curtiflora Anders. A tall shrub; twigs yellowish or rarely purplish; leaves oval-oblong or oblong-lanceolate, acute or short-acuminate at the apex, rounded or rarely subcordate at the base, green and shining above, glaucous beneath, finely serrate, 4-8 $\mathrm{cm}$. long; bracts black, white-pilose; capsule longrostrate; stipe very short; stamens light yellow. S. pseudo-cordata Anders. Wet places: Sask.-Colo--Alta. Submont. My-Jl.

35. S. pseudomyrsinites Anders. A shrub $1 \mathrm{~m}$. high or less; leaf-blades obovate or oblanceolate, $2-6 \mathrm{~cm}$. long, $8-25 \mathrm{~mm}$. wide, light green on both sides; aments on short leafy branches, $2-4 \mathrm{~cm}$. long; bracts obovate, fuscous, whitevillous; capsule $4-5 \mathrm{~mm}$. long; stipe about $1 \mathrm{~mm}$. long; style about $0.5 \mathrm{long}$. Mountain bogs: Lab.-Que.-Wyo.-Ore.-Alaska. Subalp.-Mont. Je-Jl.

36. S. myrtillifolia Anders. A shrub 1-6 dm. high; leaf-blades obovate, oblanceolate or oval, $1-3 \mathrm{~cm}$. long, acute to rounded at the base; aments on short leafy branches, $1-3 \mathrm{~cm}$. long; bractlets fuscous, obovate, glabrous, or villous only at the base; capsule 4-5 mm. long; stipe scarcely $1 \mathrm{~mm}$. long; style minute. BLUEBERry Willow. Wet places: Alaska-Alta.-Mack. Alp.-Subalp. My-Je.

37. S. Wolfii Bebb. A low shrub, less than $1 \mathrm{~m}$. high: leaf-blades oblong or elliptic, acute at both ends, $2-3 \mathrm{~cm}$. long, $7-10 \mathrm{~mm}$. wide, entire-margined; aments subsessile, but usually subtended by a few small leaves, $1-2 \mathrm{~cm}$. long, almost $1 \mathrm{~cm}$. thick; bractlets very dark, sparingly villous; capsule $4-5 \mathrm{~mm}$. long, subsessile; style fully $1 \mathrm{~mm}$. long. Mountain valleys: Colo.-Wyo.-Ida.
Mont.-Alp. My-Jl.

38. S. irrorata Anders. A shrub 2-3 m. high; leaf-blades linear-lanceolate, 6-10 $\mathrm{cm}$. long, glabrous, bright green and shining above, pale and glaucous beneath, remotely serrate or entire; aments subsessile, usually naked, appearing 
before the leaves, 2-4 $\mathrm{cm}$. long; bractlets dark, obtuse, white-villous; capsule subsessile; style about $0.5 \mathrm{~mm}$. long. Cañons and river banks: w Tex.-Colo. -Ariz. Submont.-Mont. Ap-My.

39. S. Dodgeana Rydb. A delicate suffruticose plant, scarcely more than $3 \mathrm{~cm}$. high; leaf-blades 4-5 mm. long, oblong or oval, glabrous, obtuse or acute, strongly veined, light green; staminate aments 3-4-flowered; pistillate aments usually 2-flowered; bracts oblong, truncate, sparingly villous; capsule subsessile, $3 \mathrm{~mm}$. long; style obsolete. The smallest willow in the world. Summits: Mont. -Wyo. Alp. Jl-Au.

40. S. petiolaris J. E. Smith. A shrub 1-3 m. high; leaf-blades acuminate at both ends, slightly silky when young, in age dark green and shining above, glaucous beneath; aments appearing before the leaves, naked or nearly so, about $2 \mathrm{~cm}$. long; bractlets yellow with dark tips, white-pilose; capsule 4-6 mm. long, subconic; stipe $2-3 \mathrm{~mm}$. long; style obsolete. Swamps: N.B.-Tenn.-Ills.S.D.-Sask. Boreal. My.

41. S. Geyeriana Anders. A shrub 2-3 m. high; leaf-blades linear-oblanceolate, 2-6 dm. long, densely silky-strigose when young, less so or sometimes glabrate in age, somewhat paler beneath; aments on very short leafy branches, 1-2 cm. long; bractlets oblong, yellowish, sparingly short-villous; capsule subconic, short-pubescent, 5-6 mm. long; stipe 1-2 mm. long; style obsolete. $S$. macrocarpa Nutt. Creek banks and mountain valleys: B.C.-Mont.-Colo.Ore. Submont.-Mont. Ap-Je.

42. S. gracilis Anders. A shrub 1-2 m. high; leaf-blades $3-5 \mathrm{~cm}$. long, about $4 \mathrm{~mm}$. wide, linear or lance-linear, at first tomentulose, soon glabrous and green above, slightly ghaucous beneath, entire or denticulate; aments on short leafy branches, lax, 2-3 cm. long; bractlets oblong, yellowish with dark apex; capsule elongate-conic, $5-6 \mathrm{~cm}$. long, grayish silky; stipe $3-4 \mathrm{~mm}$. long; style obsolete. S. rosmarinifolia Hook. River banks: Sask.-(? Wis.) Boreal.

43. S. discolor Muhl. A shrub or low tree up to $7 \mathrm{~m}$. high; leaf-blades oblong-oblanceolate, acute at both ends, irregularly serrate or entire, bright green above, glaucous beneath, glabrate, 4-10 cm. long, $1.5-3 \mathrm{~cm}$. wide; aments appearing before the leaves, dense, $3-5 \mathrm{~cm}$. long, or the pistillate ones $4-7 \mathrm{~cm}$. in fruit; eapsule elongated-conic, about $1 \mathrm{~cm}$. long, long-silky; stipe about $2 \mathrm{~mm}$. long; stigma obsolete. Pussy Wrllow. Swamps and wet places: N.S.-Del. -Mo.-S.D.-Sask. Boreal. Mr-Ap.

44. S. perrostrata Rydb. A shrub 1-4 m. high; leaf-blades obovatelanceolate or oblanceolate, when young finely silky, in age glabtate, 2-4 cm. long, $1-1.5 \mathrm{~cm}$. wide, undulate or entire, light green above, pale beneath; aments usually on very short leafy branches, 1-3 cm. long; bractlets sparingly silky; capsule elongated-conic, $7-8 \mathrm{~mm}$. long, finely pubescent; stipe $2-3 \mathrm{~mm}$. long; style obsolete. BEAKed WrLlow. River valleys: Hudson Bay-Neb.-Colo. -Utah-Alaska. Submont.-Mont. My-Je.

45. S. Bebbiana Sarg. A shrub 2-6 m. high, sometimes a tree $8 \mathrm{~m}$. high; leaf-blades elliptic, oblong, or oblong-lanceolate, acute, blunt, or short-acuminate, rounded at the base, sparingly serrate or entire; aments sessile, sometimes subtended by a few small leaves, $2-5 \mathrm{~cm}$. long; bractlets sparingly long-villous; capsule elongated-conic, finely pubescent, about $8 \mathrm{~mm}$. long; stipe $2-3 \mathrm{~mm}$. long; style obsolete. S. rostrata Richards. Valleys, river banks, and hillsides: Anticosti-N.J.-N.M.-Ariz.-Calif.-B.C. Plain-Mont. Ap-My.

46. S. Scouleriana Barratt. A shrub or tree, occasionally $9 \mathrm{~m}$. high; young twigs from densely velutinous to almost glabrous; leaf-blades obovate, rounded or abruptly acute at the apex, cuneate at the base, at maturity thin, dark yellowish green and lustrous above, pale, glaucous and more or less pubescent beneath, 4-10 cm. long; aments sessile, naked, 2-4 cm. long, about $1 \mathrm{~cm}$. thick; capsule subconic, about $1 \mathrm{~cm}$. long, densely white-villous; stipe short; style very short. S. flavescens Nutt. S. Nuttallii Sarg. Along streams: Sask.-N.M.-Calif.Yukon. Submont.-Mont. Mr-Je. 
47. S. Lemmoni Bebb. A shrub 1-5 m. high; branches at first pubescent, soon glabrate; leaves lanceolate, acute at both ends, entire or subserrulate, silky when young, soon glabrous, sometimes slightly glaucous beneath; aments on short leafy peduncles, $2-3 \mathrm{~cm}$. long; bractlets obovate; capsules grayish tomentose, 4-6 mm. long; stipe 2-3 times as long as the glands. Wet places: Calif.Nev.-Ida. Submont.-Mont. Je-Jl.

48. S. alaxensis (Anders.) Coville. A tree sometimes $9 \mathrm{~m}$. high, or a shrub 1-2 m. high; leaf-blades obovate to oblong-oblanceolate, acute or rounded at the apex, acute at the base, densely white-tomentose beneath, 5-10 cm. long, $2-4 \mathrm{~cm}$. wide; aments $3-6 \mathrm{~cm}$. long, sessile, naked, appearing with the leaves; capsule whitevillous, about $6 \mathrm{~mm}$. long, subsessile; style about $2 \mathrm{~mm}$. long. S. speciosa H. \& A. Subarctic and aretic regions: Alaska-Mack-Canadian Rockies. Sub-

49. S. Barrattiana Hook. A low shrub; leaf-blades obovate, acute at the apex, often subcordate at the base, $5-7 \mathrm{~cm}$. long, densely white-silky, in age greener above; aments appearing with the leaves, sessile and naked, $3-5 \mathrm{~cm}$. long; capsule white-silky, about $6 \mathrm{~mm}$. long, white-villous; stipe very short; style fully $1 \mathrm{~mm}$. long. S. albertana Rowley. Alpine swamps: Alta.-B.C.
Subalp. Je-J!

50. S. bella Piper. A shrub 2-4 m. high; leaf-blades mostly acute, 3-10 $\mathrm{cm}$. long, 1-2.5 $\mathrm{cm}$. wide, green and sparsely puberulent above, entire or repand; aments sessile, usually naked, appearing before the leaves, the pistillate ones $2-3 \mathrm{~cm}$. long or in fruit 4-6 $\mathrm{cm}$. long; capsule grayish sericeous, 5-6 mm. long, subsessile; style 1-1.5 mm. long. River banks: Wash.-Mont.-Ida. Sub-
mont. Ap.

51. S. candida Fluegge. A shrub 6-15 dm. high; leaf-blades oblong or oblong-lanceolate, thick, sparingly repand-denticulate or entire, acute at both ends, dark green above, $5-10 \mathrm{~cm}$. long, $6-16 \mathrm{~mm}$. wide; aments sessile and usually naked, appearing before the leaves, $2-5 \mathrm{~cm}$. long; capsule subconic, densely white-tomentose, 6-7 mm. long; stipe less than $1 \mathrm{~mm}$. long; style about 1 mm. long. Hoary Willow. Bogs: Lab.-N.J.-Colo.-Ida.-Alta. Mont. My,

S. cordata $\times$ candida. Resembling $S$. candida in leaf-form, but less densely hairy and thinner; aments more like those of $S$. cordata, borne on short branches; capsules
glabrous or nearly so. Collected at Ravalli, Mont.

52. S. sitchensis Sanson. A tree or shrub 2-9 m. high; leaf-blades $3-6 \mathrm{~cm}$. long, entire or remotely glandular-denticulate, acute or abruptly acuminate, at first tomentose, in age dark green, shining and glabrous above, densely whitesilky beneath; aments densely flowered, naked or on short leafy branches, the staminate ones $3-5 \mathrm{~cm}$. long, the pistillate ones $4-7 \mathrm{~cm}$. long; capsule grayish, short-silky, about $5 \mathrm{~mm}$. long; stipe and style about $0.5 \mathrm{~mm}$. each. SITKA Wrllow. River banks: Alaska-Calif.-Mont. Submont.-Mont. Ap-Je.

53. S. Drummondiana Barratt. A shrub; leaf-blades broadly obovate, 5-7 cm. long, 2-3 cm. wide, glabrous above, white-tomentose beneath, entiremargined; aments $2-4 \mathrm{~cm}$. long, subsessile, but usually subtended by a few small leaves; capsule 3-4 mm. long, white-silky, with short hairs, subsessile; style about $0.5 \mathrm{~mm}$. long. Marshes: Canadian Rockies. Subalp.

54. S. argyrocarpa Anders. An erect shrub 1-6 dm. high; leaf-blades oblong or oblanceolate, acute at both ends, entire or erenulate, bright green and glabrous above, silvery-silky beneath, 3-5 $\mathrm{cm}$. long, 6-12 $\mathrm{mm}$. wide; aments on short leafy branches, dense, $1-2.5 \mathrm{~cm}$. long; bractlets villous; capsule $2-3 \mathrm{~mm}$. long, white-villous; stipe 1-2 mm. long. SILver WILLOW. Mountains and hills: Lab.-N.H.-w Ont.-(? Sask.) -Mack. Boreal. Je-Jl.

55. $\mathbf{S}$. arbusculoides Anders. An erect shrub less than $1 \mathrm{~m}$. high; leafblades elliptic-lanceolate, acute at both ends, glabrous and green above, silky beneath, minutely serrulate or entire, $2-5 \mathrm{~cm}$. long; aments appearing with the leaves, $2-3 \mathrm{~cm}$. long, usually sessile, naked or subtended by a few leaves; capsule 3-4 mm. long, subsessile. Swamps: Hudson Bay-Canadian Rockies-
Alaska. Subalp. 
56. S. pellita Anders. A low shrub; leaf-blades oblanceolate, $3-7 \mathrm{~cm}$. long, with entire, somewhat revolute margins, acute or obtuse at the apex, tapering at the base, glabrous or slightly pubescent above when young; aments sessile and naked, 2-3 cm. long; bractlets obovate, brown, with black tip, or wholly blackish, silky; capsule 3-4 mm. long, villous, subsessile; style nearly $1 \mathrm{~mm}$. long. River banks: Me.-Que.-Sask.-Alta. Boreal. Je.

57. S. subcoerulea Piper. Shrub about $2 \mathrm{~m}$. high; leaf-blades oblanceolate, entire or nearly so, green and minutely pubescent above, $2-5 \mathrm{~cm}$. long, $1 \mathrm{~cm}$. wide or less; aments $2.5-4 \mathrm{~cm}$. long, less than $1 \mathrm{~cm}$. thick; capsule whitesilky, 2-3 mm. long, subsessile; style about $1 \mathrm{~mm}$. long. Blue Wrllow. River banks: B.C.-Mont.-Wyo.-Calif. My-Jl.

58. S. pachnophora Rydb. A shrub 2-3 m. high or perhaps sometimes higher; leaf-blades oblong-lanceolate or oblanceolate, $3-5 \mathrm{~cm}$. long, acute at both ends, densely white-silky beneath, glabrate above, rather thin; aments 1-3 cm. long; capsule grayish silky, ovoid, $3-5 \mathrm{~mm}$. long; style slender, about $1.5 \mathrm{~mm}$. long. River banks: Colo--N.M.-Utah. Submont.-Mont. My-Je.

59. S. brachycarpa Nutt. A shrub $1 \mathrm{~m}$. high or less; bark yellow; twigs densely villous; leaf-blades oblong to oval or oblanceolate, 1-3 cm. long, entiremargined; aments 1-2 cm. long; bracts yellow, obovate, villous; capsule 4-5 mm. long, villous, subsessile; style less than $0.5 \mathrm{~mm}$. long. S. stricta (Anders.) Rydb. Wet places in the mountains: B.C.-Colo.-Alta; Que. Submont.-Subalp. $\mathrm{Jl}-\mathrm{Au}$.

60. S. idahoensis (Ball) Rydb. Shrub 1-2 m. high; branches yellowish or light brown, silky when young; leaf-blades oblanceolate, $3-5 \mathrm{~cm}$. long, entire; aments 1-2 cm. long; bractlets obovate, brownish; capsules ovoid, subsessile, finely and sparingly pubescent; style about $1 \mathrm{~mm}$. long. $S$. Wolfii idahoensis Ball. Banks and marshes: Ore.-Wyo,-Wash. Submont.-Mont. Je-Jl.

61. S. pseudolapponum v. Seem. A shrub $1 \mathrm{~m}$. high or less; twigs brown, at first grayish pubescent; leaf-blades oblong or lance-oblong, acute at both ends, entire-margined, green above, gray below; aments appearing with the leaves, 1-2 $\mathrm{cm}$. long; bractlets brown below, with black tips; capsule grayish, villous, subsessile, about $5 \mathrm{~mm}$. long; style about $0.5 \mathrm{~mm}$. long. Summits: Colo. Subalp.-Alp. Je-J.

62. S. glaucops Anders. A shrub 1-2 m. high; twigs usually more or less villous; leaf-blades green above, paler beneath, entire-margined, $3-6 \mathrm{~cm}$. long; aments $2-3 \mathrm{~cm}$. long; bractlets fuscous, oblong, of ten acutish, short-villous; eapsule grayish villous, about $5 \mathrm{~mm}$. long, subsessile; style about $0.5 \mathrm{~mm}$. long. Mountains: Alta.-N.M.-Utah-Calif.-Yukon. Submont.-Subalp. Je-Jl.

S. glaucops $\times$ monticola. It resembles $S$. glaucops in the capsules and bractlets, but the former are less densely hairy; the leaves and bark are more like those of $\mathcal{S}$. monticola, the former being finely serrate, glabrate in age, and glaucous beneath; the young branches are somewhat villous. Big Cottonwood Cañon, Utah.

63. S. Seemannii Rydb. A shrub 3-4 m. high; young twigs villouspubescent; leaf-blades oval to oblong-lanceolate, 3-7 cm. long, rather firm, entiremargined, sometimes glabrate above in age; aments $2-7 \mathrm{~cm}$. long; bracts obtuse, villous; capsule about $8 \mathrm{~mm}$. long, densely white-villous, subsessile; style $0.5-1$ $\mathrm{mm}$. long. Mountains: Alaska-Yukon-Mont. Subalp. Je-Jl.

64. S. subcordata Anders. A low shrub, with erect stems; leaf-blades obovate, oval, or rounded, sometimes subeordate at the base, $2-5 \mathrm{~cm}$. long, 1-4 $\mathrm{cm}$. wide, paler and strongly reticulated beneath; aments $2-3 \mathrm{~cm}$. long; bractlets yellow, usually with darker tips; capsule white-villous, subsessile; style nearly $1 \mathrm{~mm}$. long. Mountains: Alta.-B.C. Mont. Jl-Au.

65. S. desertorum Richards. A shrub 1-2 m. high; leaf-blades 1-3 $\mathrm{cm}$. long, entire-margined, dark green above, glaucous beneath; aments $1-3 \mathrm{~cm}$. long; bracts obovate, brown or yellow, sparingly pubescent; capsule densely whitevillous, $3-4 \mathrm{~mm}$. long, subsessile; style about $0.5 \mathrm{~mm}$. long. BARREN-GROUND WiLlow. Wet places: Sask.-Alta.-Mack.; (Gaspé Peninsula) Que. Boreal -Subarctic. J1-Au. 
66. S. Austinae Bebb. A shrub 1-3 m. high; leaf-blades usually shortacuminate, 3-6 cm. long, glabrous or slightly pubescent but green above, glaucous beneath; aments $2-5 \mathrm{~cm}$. long; bractlets oblong, brown, sparingly white-silky; capsule elongate, subconic, 6-8 $\mathrm{mm}$. long; stipe very short; style nearly $1 \mathrm{~mm}$. long. S. glaucops glabrescens Anders. Wet places on the mountains: Alta.Wyo.-B.C.-Yukon. Submont.-Mont. Je-Jl.

S. Austinae $\times$ pseudolapponum. This has the glabrous leaves and yellowish or light-brown bractlets of $S$. Austinae, but the low habit, smaller leaves and short capsule of S. pseudolapponum. S. wyomingensis Rydb. Mountains: Wyo. Jl.

67. S. MacCalliana Rowley. A shrub 1-2 m. high; leaf-blades 6-7 cm. long, $1.5 \mathrm{~cm}$. wide, acute at both ends, puberulent when young, soon glabrous, green on both sides, finely serrulate; aments 3-4 cm. long; bractlets greenish or brown; capsule elongated-conic, white-velvety, 8-10 mm. long; stipe $1 \mathrm{~mm}$. long; style less than $1 \mathrm{~mm}$. long. Low ground: Alta. Mont.

68. S. saskatchewana v. Seem. A tall shrub or small tree; leaf-blades acute at both ends, $3-6 \mathrm{~cm}$. long, $1 \mathrm{~cm}$. broad or less, finely serrate, soon glabrate, dark green above, glaucous beneath; aments $2-5 \mathrm{~cm}$. long; bractlets brown, oval, sparingly villous; capsule grayish silky, with short hairs, about $5 \mathrm{~mm}$. long, nearly sessile; style scarcely $0.25 \mathrm{~mm}$. long. River banks and marshes: Sask, -Alta.-Yukon. Boreal. Je.

69. S. petrophila Rydb. A depressed creeping undershrub, less than 1 dm. high; leaf-blades 1-3 cm. long, obtuse, glabrous or sparingly silky at first, entire-margined, slightly paler and strongly veined beneath; aments $2-3 \mathrm{~cm}$. long; bractlets blackish, obovate, sparingly silky-villous; capsule white-villous, sessile, 5-7 mm. long; style fully $0.5 \mathrm{~mm}$. long. S. arctica petraea Anders. Rock Wrulow. Alpine peaks: B.C.-Calif.-N.M.-Mack. Alp.-Subalp. J1-Au.

70. S. cascadensis Cockerell. A depressed creeping undershrub, less than $1 \mathrm{dm}$. high; leaf-blades 1-2 cm. long, 2-5 mm. wide, light green on both sides, strongly veined beneath; aments about $1 \mathrm{~cm}$. long; bractlets black, obovate; capsule grayish villous, about $4 \mathrm{~mm}$. long, sessile; style about $0.5 \mathrm{~mm}$. long. $S$. tenera Anders. Alpine peaks: B.C.-Wash.-Utah-Wyo.-Mont. Alp.-
Mont. J-Au.

71. S. Nelsonii Ball. A shrub 1-3 m. high; leaf-blades acute at both ends, $8-15 \mathrm{~mm}$. wide, $3-6 \mathrm{~cm}$. long, entire or sparingly crenate, dark green and shining above, glaucous beneath; aments $1.5-3 \mathrm{~cm}$. long; bractlets black or nearly so, ovate, acute, long-silky; capsule silky-pubescent, sessile, $5-7 \mathrm{~mm}$. long; style nearly $0.5 \mathrm{~mm}$. long. Bogs and river banks: Colo.-Utah.-Alta. Mont. - Subalp. Je.

72. S. chorophylla Anders. A shrub 1-3 m. high; leaf-blades at first silky, soon glabrate, dark green and shining above, glaucous beneath, acute at both ends, usually entire, $2-5 \mathrm{~cm}$. long; aments $2-6 \mathrm{~cm}$. long; bractlets black, obovate, obtuse, silky-pilose; capsule sessile, $5-6 \mathrm{~mm}$. long, grayish silky; style about 0.5 mm. long. Mountain swamps: Lab.-N.H.-N.M.-Utah-Alaska. Mont.-

73. S. Fernaldii Blankinship. A low spreading shrub, up to $1 \mathrm{~m}$. high; leaf-blades oval, rarely ovate, rounded at both ends or sometimes acutish at the apex, 3-5 cm. long, glabrous and green above, silvery-silky and strongly veined beneath; margins sub-entire; aments at the ends of the leafy branches, $2-3 \mathrm{~cm}$. long; bractlets brown, short-villous, obovate; capsule short-ovoid, $2-3 \mathrm{~mm}$. long, sessile. Perhaps not distinct from the eastern S. vestita Pursh. Mountains: Alta.-Mont.-Ore.-B.C. Mont.-Subalp. Je-Au.

74. S. orbicularis Anders. Low creeping undershrub; leaf-blades oval or orbicular, $1.5-4 \mathrm{~cm}$. long, $1-4 \mathrm{~cm}$. wide, rounded at both ends or sometimes subcordate at the base, glabrous, dark green above, pale and somewhat glaucous beneath; aments at the ends of the leafy branches, $2-4 \mathrm{~cm}$. long; capsule shortovoid, 3-5 mm. long, short-villous, sessile. (Perhaps not distinct from S. reticulata L., which has narrower yellow bractlets and usually narrower leaves.) NETVEINED WILLOW. Aretic-alpine situations: Alaska-Canadian Rockies-Hudson Bay. Alp. Je-Au. 
75. S. saximontana Rydb. A densely cespitose, creeping undershrub, rarely over $5 \mathrm{~cm}$. high; leaf-blades light green above, glaucous beneath, glabrous, 1-2 cm. long, oblong or elliptic, commonly acutish at both ends; aments at the ends of the leafy branches, $1-2 \mathrm{~cm}$. long, loosely flowered; capsule ovoid, densely grayish pubescent with short hairs, sessile, $3 \mathrm{~mm}$. long; style obsolete. $S$. reticulata Porter \& Coulter, not L. S. aemulans v. Seem. Rocky Mountain Wrllow. High mountain tops: N.M.-Nev.-Wash.-Alta. Alp.-Mont. $\mathrm{Jl}-\mathrm{Au}$.

76. S. nivalis Hook. A cespitose, creeping undershrub, 1-5 cm. high; leafblades oval or orbicular, $1 \mathrm{~cm}$. long or less, glabrous, entire, dark green above, glaucous beneath; aments at the ends of the leafy branches, $1 \mathrm{~cm}$. long or less, few-flowered; capsule grayish, pubescent with short hairs, about $3 \mathrm{~mm}$. long, sessile. Snow Willow. High mountains: B.C.-Wash.-Mont.-Alta. Alp. $\mathrm{Jl}-\mathrm{Au}$.

\section{Family 31. FAgaceae. Beech Family.}

Monoecious trees or shrubs, with simple leaves. Staminate flowers in elongate or head-like aments; calyx of 4-7 partially united sepals; stamenis 4-20. Pistillate flowers in longer or shorter spikes; calyx of partly united sepals. Gynoecium of 3-7 united carpels; styles as many, but usually only one ovule maturing. Fruit a one-seeded nut, enclosed or seated in a scaly or spiny, in ours cup-like imvolucre.

\section{QUERRCUS (Tourn.) L. OAK.}

Trees or shrubs, with hard coarsely grained wood. Leaf-blades entire, toothed, or lobed, firm-membranous or leathery, sometimes evergreen. Staminate aments elongate, drooping, clustered; calyx campanulate, 4-7-lobed; stamens 6-12; filaments filiform. Pistillate flowers solitary or in lax spikes; calyx urnshaped or cup-shaped. Ovary usually 3 -celled; styles 3 ; ovules 2 in each cell, but seldom more than one maturing in each pistil. Fruit a leathery, 1-seeded nut (acorn), partly enclosed in an acerescent sealy involucre (cup).

Leaves lobed or divided, not evergreen; lobes rounded, obtuse or acute, but not spinulosetipped.

Leaves bright green, early deciduous.

Upper scales of the cup with caudate prolongations.

Upper scales of the cup not prolonged.

1. Q. macrocarpa.

Mature leaves softly pubescent, almost velvety beneath, deeply divided. Scales of the cup thin, not much thickened on the back.

Scales of the cup corky-thickened on the back.

2. Q. submollis.

3. Q. utahensis.

Mature leaves glabrate, puberulent, or somewhat pubescent, but not velvety beneath.

Cup flat, covering less than one-fourth of the acorn.

Cup hemispheric, covering one-third to one-half of the acorn.

Mature leaves very thin, glabrate beneath or puberulent only on the veins; cup covering about one-half of the acorn.

5. Q. leptophylla.

Mature leaves firm, puberulent beneath; cup covering about one-third of the acorn.

Leaves mostly oblong in outline, lobed half way to the midrib or less, rather dull.

6. Q. Gunnisonii.

Leaves obovate in outline, divided deeper than half way to the midrib, very shining above.

Lobes of the leaves broadly oblong, rounded at the apex.

Lobes of the leaves ovate or triangular, acute.

7. Q. Gambellii.

8. Q. novomexicana.

Leaves pale or bluish green, more persistent.

Leaves broadly obovate, with narrow sinuses.

Leaves oblong-obovate, or elliptic; sinuses broad.

Lobes oblong-ovate, obtuse or acutish, not mucronate.

Lobes triangular-ovate, mucronate.

9. Q. Eastwoodiae.

Leaves persistent, usually evergreen, entire, sinuate or dentate, or if more deeply lobed, the lobes with spinulose tips.

Cup hemispheric; acorns barrel-shaped. 
Scales of the cups decidedly corky-thickened on the back.

Leaves decidedly crisp, sinuately lobed; lobes distinctly spinulose-tipped.

Leaves flat, sinuate-dentate or entire; teeth mungens. spinulose-tipped.

Acorns 6-7 mm. thick; cup shallow, enclosing about one-third of the acorn; leaves usually sinuate-dentate. 13. Q. undulata.

Acorns about $1 \mathrm{~cm}$. thick or more; cup deeper, enclosing about half of the acorn.

Leaves usually entire, except those of the young shoots.

Leaves lobed, with few (5-7) lobes.

14. Q. grisea.

15. Q. panciloba.

Scales of the cups thin, only slightly thickened on the back; leaves glabrate and shining above in age.

Cup more or less turbinate; acorns elongated-ovoid.

16. Q. Wilcoxit.

1. Q. macrocarpa Michx. A tree $10-50 \mathrm{~m}$. high; leaf-blades obovate, irregularly round-lobed, usually pinnately divided below the middle, bright green and shining above, grayish tomentulose beneath, 1-2 dm. long; fruit shortpeduncled; cup hemispheric, 1-2.5 $\mathrm{cm}$. in diameter; scales floccose, thick, ovate or lanceolate, the upper subulate-tipped; acorns 1.5-2.5 $\mathrm{cm}$. long, ovoid. Bur OAK. MossY-CUP OAK. Rich soil: N.S.-Pa.-Tex.-(? Wyo.)-S.D.-Sask. Plain-Submont. My-Je.

2. Q. submollis Rydb. Shrub or small tree; leaf-blades obovate in outline, deeply pinnatifid at least two-thirds to the midrib, with oblong segments, rounded at the apex, glabrous and shining above, densely and softly pubescent beneath; fruit sessile; cup depressed-hemispheric, about $15 \mathrm{~mm}$. broad; acorn obtuse, 12 $15 \mathrm{~mm}$. long. Mountain sides: Ariz.-S Utah-N.M. Son.-Submont.

3. Q. utahensis (A. DC.) Rydb. A small tree, sometimes $10 \mathrm{~m}$. high, or more often only a shrub; leaf-blades $6-10 \mathrm{~cm}$. long, broadly obovate, deeply divided, often to near the midrib; lobes oblong, rounded at the apex, the larger usually again lobed or undulate; upper surface sparingly stellate, in age glabrate, dark green and glossy; fruit subsessile; cup hemispheric, 12-15 mm. in diameter; scales pubescent, ovate; acorn $15-20 \mathrm{~mm}$. long, light brown. UTAн ОАK. Hills and mountains: Utah-Colo.-N.M.-Ariz. Submont-Mont. My.

4. Q. Vreelandii Rydb. A small shrub $1-1.5 \mathrm{~m}$. high; young branches brown, puberulent; leaf-blades $5-7 \mathrm{~cm}$. long, obovate, deeply lobed about twothirds to the midrib, thick, firm; lobes rounded, the larger of ten lobed or sinuate; upper surface soon glabrate, bright green and rather dull; lower surface slightly paler; fruit subsessile; scales ovate and very corky on the back; acorn about 15 $\mathrm{mm}$. long, light brown. Hills and bench-lands: Colo.-N.M. Submont. My.

5. Q. leptophylla Rydb. A tree $10-15 \mathrm{~m}$. high; young twigs brownish or purplish, slightly pubescent at first; leaf-blades broadly obovate, very ${ }^{-}$thin, pinnately 5-9-lobed scarcely more than half way to the midrib; lobes rounded; upper surface soon glabrate, bright green, but not very glossy; lower surface paler; fruit subsessile; cup hemispheric, about $15 \mathrm{~mm}$. wide; scales ovate-lanceolate, obtuse, only slightly thickened on the back. Along mountain streams: Colo.-N.M. Submont.-Mont. My.

6. Q. Gunnisonii (Torr.) Rydb. A low shrub $1-3 \mathrm{~m}$. high, forming chapparels; leaf-blades with rounded lobes, usually directed forward, very thick, pale and bluish green above, soon glabrate, scarcely paler beneath; fruit subsessile; cup rather deep, 12-15 mm. in diameter, hemispheric; scales ovate, corkythickened on the back; acorns barrel-shaped, obtuse. Dry hillsides and tablelands: Colo.-N.M.-Ariz.-Utah. Submont. My.

7. Q. Gambellii Nutt. A shrub $3-5 \mathrm{~m}$. high; young twigs light brown and puberulent; leaf-blades broadly obovate in outline, thinner than in the preceding; upper surface glabrate, green, lower surface only slightly paler, lobes rounded; fruit subsessile; cup hemispheric or somewhat turbinate; acorn ovoid, acute or obtuse, about $15 \mathrm{~mm}$. long. Q. nitescens Rydb. Hills and table-lands: Wyo.N.M.-Utah. Submont.-Mont. My-Je.

8. Q. novomexicana (A. DC.) Rydb. A shrub 3-5 m. high; young branches light brown, or grayish, sparingly puberulent or glabrous; leaf-blades obovate in outline, deeply divided about three-fourths the distance to the midrib, very 
firm; upper surface soon glabrous, dark green and glossy; lower surface pale green, puberulent; fruit subsessile; cup hemispheric, $10-12 \mathrm{~mm}$. in diameter; scales ovate, moderately corky-thickened. Table-lands and hills: N.M.-Colo.Utah. Submont.-Mont. My.

9. Q. Eastwoodiae Rydb. A shrub $2-3 \mathrm{~m}$. high, not forming thickets; young branchlets densely stellate-pubescent, almost velvety; leaf-blades rounded at the apex, obtuse or acutish at the base, $6-8 \mathrm{~cm}$. long, $3-6 \mathrm{~cm}$. broad, pale bluish green, on the upper surface slightly stellate, especially on the veins, or glabrate, on the lower paler, strongly reticulate and decidedly stellate, with broad rounded lobes; fruit subsessile; cup hemispheric, 12-14 mm. in diameter; scales ovate, acutish, moderately corky-thickened on the back; acorn round-ellipsoid, mostly half included in the cup. Cañons: Utah. Son.

10. Q. venustula Greene. A small shrub 1-2 m. high; young twigs brown, puberulent or glabrate; leaf-blades $3-6 \mathrm{~cm}$. long, oblanceolate or elliptic in outline, lobed more than half way to the midrib, firm; upper surface pale bluish green, sparingly stellate, glabrate and glossy; lower surface paler, densely stellatepuberulent, very veiny and reticulate; fruits in peduncled spikes; scales of the cup ovate, corky-thickened on the back. Mountains: Colo.-N.M. Submont.Son.

11. Q. Fendleri Liebm. A shrub $1-3 \mathrm{~m}$. high, scarcely forming thickets; young branches brown, puberulent; leaf-blades lobed about half way to the midrib, firm, 3-7 cm. long; upper surface sparingly stellate or glabrate, pale bluish green and shining; lower surface light brownish, stellate-puberulent, strongly veined and reticulate; fruits $2-3$ together on a peduncle; cup hemispheric, covering about one-third of the acorn, $10-12 \mathrm{~mm}$. broad; scales ovate and much corkythickened; acorns 15-18 mm. long. Barren hills: Ariz.-Colo.-Tex. Son.Submont. My.

12. Q. pungens Liebm. A low shrub 1-3 m. high, rarely larger; younger twigs yellowish or brownish, densely stellate-pubescent; leaf-blades oval or broadly oblong, obtuse at the base, acute at the apex, deeply sinuately toothed, 3-5 cm. long, thick and firm; upper surface pale bluish or brownish green, rather dull, sparingly stellate; lower surface more or less densely stellate, pale yellowish or brownish; lobes triangular; cup hemispheric, $8-10 \mathrm{~mm}$. in diameter; acorns 10-13 mm. long. Holly ОАK. Hills: N.M.-Colo.-Utah-Ariz.; n Mex. Son. Mr-My.

13. Q. undulata Torr. A shrub $1-3 \mathrm{~m}$. high; young twigs sparingly stellate-pubescent; leaf-blades firm, pale bluish or brownish green and shining above, pale brownish beneath, stellate when young, almost glabrous in age on both sides, or sometimes densely stellate-pubescent beneath; cup hemispheric, $7-10 \mathrm{~mm}$. broad; acorn 10-15 mm. long, 6-7 mm. in diameter. LIVE OAK. Barren hills: Ariz.-Colo.-Tex. Son.-Submont. My.

14. Q. grisea Liebm. A shrub usually a few meters high, rarely a small tree; younger twigs yellowish and stellate-pubescent; leaves from oval to oblong or sometimes oblong-lanceolate, acute at the apex, cordate or rounded at the base, usually entire or undulate, sometimes on young shoots dentate, $2-5, \mathrm{~cm}$. long; upper surface pale bluish green, shining; lower surface densely stellate and fulvous; acorns about $15 \mathrm{~mm}$. long. Table-lands: Tex. $\rightarrow \mathrm{s}$ Utah-Ariz. Son Ap-My.

15. Q. pauciloba Rydb. Tree 4-5 m. high, rarely a shrub; young branches brown, pubescent; leaf-blades broadly oval, ovate, or obovate, $5-8 \mathrm{~cm}$. long, 3-5 $\mathrm{mm}$. wide, sinuately 5-7-lobed, pale bluish green above, pale brownish, strongly reticulate, and stellate-pubescent beneath; lobes broadly triangular, spinulosetipped; cup hemispheric, $12-18 \mathrm{~mm}$. in diameter; acorn sometimes $15 \mathrm{~mm}$. long. Cañons: Ariz. -s Utah. Son.

16. Q. Wilcoxii Rydb. A shrub or rarely a small tree 6-9 m. high; young branchlets fulvous-tomentulose; leaf-blades usually broadly oval, acute at the base, abruptly short-acuminate, thick and firm, 1-4 cm. long, when young deciduously fulvous stellate-tomentulose especially on the lower surface, dull 
white and punctate beneath, with many lateral veins and obsolete reticulations, usually entire or with a few spinulose-tipped teeth; those of the sterile shoots almost orbicular or round-ovate in outline, coarsely and deeply dentate with spinose-tipped teeth; cup hemispheric, 10-14 mm. in diameter; scales ovate, with brown acute tips; acorn ovoid, about $15 \mathrm{~mm}$. long. Mountains: N.M.Utah-Ariz.-Nev. Son.

17. Q. turbinella Greene. A shrub 1-3 m. high; young branchlets covered with a white stellate-pubescence and when young with fulvous tomentum; leafblades oblong, elliptic, oval or rarely ovate, $1-3 \mathrm{~cm}$. long, acute at the apex, usually sinuate-dentate with spinulose-tipped teeth, when unfolding covered with a fulvous tomentum, light bluish green and shining above, strongly reticulate, fulvous, stellate-pubescent beneath; cup $8-10 \mathrm{~mm}$. in diameter; scales deltoidovate, obtuse, moderately corky-thickened; acorn $15-20 \mathrm{~mm}$. long, $8 \mathrm{~mm}$. in diameter. Dry hills: Calif.-Utah-Ariz.; Sonora and L. Calif. Son, Ap-My.

\section{Family 32. Betulaceae. Birch Family.}

Monoecious trees or shrubs, with simple alternate leaves. Staminate flowers in long drooping aments, each bract subtending 2 or 3 flowers; calyx present. Pistillate flowers also in aments, but the aments seldom drooping, without calyx; pistils 2 or 3 at the base of each bract. Fruiting aments cone-like; fruit small nuts or samaras; seed solitary. Bracts of the mature pistillate aments membranous, in ours 3-lobed, deciduous with the
fruit.

Bracts of the mature pistillate aments thickened and woody, persistent.

1. BETULA.

\section{BÉtula (Tourn.) L. Birch.}

Shrubs or trees, with resinous aromatic bark; branchlets with transverse lenticels. Staminate aments slender, pendulous; calyx irregularly 2- or 4-lobed; stamens 2 , inserted at the base of the calyx; filaments very short, branched at the apex; anther-sacs separate. Pistillate aments erect or drooping, oblong or cylindric; bracts elongate, in ours 3-lobed, 3-flowered, accrescent, deciduous. Fruit small, samara-like or nut-like, flat; outer seed-coat thin, produced into a wing or margin; seeds solitary, pendulous.

Bark separating into layers or sheets, the very thin outer layer peeling into small shreds;
all trees.

Bark chalky white to silvery gray.

Leaves broadly ovate, with acute apex, mostly subcordate base, and spreading teeth; twigs mostly glabrous; middle lobe of the bractlets acute, slightly longer
than the rounded lateral ones.

Leaves narrowly ovate, with long-acute or acuminate apex, rounded or cuneate base, and teeth directed forward; twigs pubescent; middle lobe of the bractlets narrow, rounded at the apex, about twice as long as the acute or obtuse lateral ones.
2 . B p pyrifera.

Bark yellowish or reddish brown, often very dark; twigs very glandular.

Leaves ovate, very thin, dark green, acute at the apex, irregularly doubly-serrate,

with long-pointed, slender teeth.
Leaves deltoid or ovate, thick, bronze-green, long-acuminate at the apex, coarsely. and more regularly serrate. 4 . B. alaskana.

Bark not separating into layers; outer bark not peeling into shreds.

Samara-wing broader than the body.

Twigs and branchlets glandular-resiniferous, not hairy.

Lateral lobes of the bractlets spreading, obliquely ovate, auricled at the base;
trees.

Leaves very thin; fruiting aments narrowly cylindric, elongate, less than $1 \mathrm{~cm}$. thick; lateral Iobes of the bractlets obtuse or rounded; claw much shorter than the middle lobe.

Leaves thick; fruiting aments broadly cylindric stout, 5 . B. Piperi. thick; lateral lobes of the bractlets mostly acute: more than $1 \mathrm{~cm}$. middle lobe.

Lateral lobes of the bractlets ascending, obliquely rhombic, 6. B. utahensis. base; shrubs or trees.

Shrubs or small shrub-like trees; bark shining, dark red-brown, smooth; leaves broadly ovate, usually less than $4 \mathrm{~cm}$. long, coarsely and irregularly serrate, thin, dark green, obtuse or acute at the apex, mostly rounded at the base; twigs densely glandular-resiniferous.

7. B. fontinalis. 
Trees, often very large, never shrub-like; bark ashy gray or brown, roughened; leaves ovate, sometimes lobed, 4-7 cm. long, finely serrate, dull bronze-green, acute at the apex, truncate at the base; twigs but slightly glandular-resiniferous.

8. B. montanensis.

Twigs and branchlets more or less pubescent, not or sparingly glandular-resiniferous; shrubs or shrub-like trees.

Leaves oval or rhombic-ovate.

Leaves narrowly oval or rhombic-ovate, $6 \mathrm{~cm}$. long or more, sharply serrate or dentate; apex acute, base cuneate; twigs finely pubescent, not glandular: middle lobe of the bractlets triangular, obtuse; lateral lobes rounded. obliquely rhombic: fruiting aments $2-4 \mathrm{~cm}$. long. 9. B. Sandbergii.

Leaves broadly oval, less than $4 \mathrm{~cm}$. long, acute at both ends, serrate or serrate-crenate; twigs pubescent and sparingly glandular; middle lobe of the bractlets rounded, as broad as or broader than the ascending lateral ones; fruiting aments less than $2 \mathrm{~cm}$. long. 10. B. Elrodiana.

Leaves obovate, rounded at the apex, cuneate at the base; twigs puberulent and with scattered coarse hairs, sparingly glandular, 11. B. obovata.

Samara-wing narrower than the body; shrubs mostly low.

Twigs and branchlets pubescent, slightly glandular.

Leaves finely crenate or crenate-serrate, oval, acute at both ends; twigs at flrst puberulent, at length glabrate. 12. B. crenata.

Leaves coarsely serrate, obovate, acute or obtuse at the apex, cuneate at the base; twigs with long scattered coarse hairs.

13. B. glandulifera.

Twigs and branchlets glabrous, densely glandular-resiniferous; leaves obovate or orbicular, crenate-serrate.

14. B. glandulosa.

1. B. subcordata Rydb. A small tree; twigs reddish brown; leaf-blades 3-10 cm. long, pubescent when young, in age glabrate and dull bronze-green above, paler and pubescent beneath, irregularly toothed, with broad triangular teeth; pistillate aments short-peduncled on short lateral branches, 2-4 cm. long and $1 \mathrm{~cm}$. thick in fruit; body of the fruit elliptic, the wing of about the same width. White Birch. Mountain woods: Alta.-Mont.-Ida.-B.C. Mont,Submont. Ap.

2. B. papyrifera March. A tree up to $25 \mathrm{~m}$. high; leaf-biades $3-11 \mathrm{~cm}$. long, irregularly or doubly s errate, glabrous and dark green above, pubescent beneath; staminate aments $5-10 \mathrm{~cm}$. long, 2 or 3 at the ends of the branches; pistillate aments peduncled, solitary on small lateral leafy branches, $2-4 \mathrm{~cm}$. long. B. Andrewsii A. Nels. PAper Birch. Cold woods: Lab.-N.J.-Colo. -Alaska. Submont.-Subalp. Ap-My.

3. B. occidentalis Hook. A tree sometimes $30-40 \mathrm{~m}$. high; twigs brown, at first pubescent or puberulent; leaf-blades acute at the apex, rounded or sometimes subcordate or acute at the base, more or less glandular-resiniferous, pubescent along the veins and in their axils; staminate aments $7-10 \mathrm{~cm}$. long, usually several together; pistillate aments 1-4, on lateral leafy branches, in fruit 3-4 cm. long; terminal lobe of the bractlets lanceolate, longer than the subrhomboid, ascending lateral ones. Banks of streams and lakes: B.C.-w Mont. -Wash. Submont. My.

4. B. alaskana Sarg. A tree $10-12 \mathrm{~m}$., rarely $25 \mathrm{~m}$. high; twigs red-brown, verrucose with conspicuous resinous glands; leaf-blades from cuneate to cordate at the base, acuminate at the apex, entire at the base, glabrous and glandularresiniferous; staminate aments clustered, $2-4 \mathrm{~cm}$. long; pistillate aments in fruit 2-3 cm. long, 8-10 mm. thick; terminal lobe of the bractlets lanceolate, slightly longer than the rounded-obovate ascending lateral ones. River banks and woods: Alaska-Sask.-Mack. Boreal. My-Je.

5. B. Piperi Britton. A tree up to $15 \mathrm{~m}$. high; leaf-blades broadly ovate, thin, sharply and irregularly serrate, acute or short-acuminate, rounded or acute at the entire base; staminate aments $6-8 \mathrm{~cm}$. long; pistillate aments cylindric, in fruit 3-5 cm. long; terminal lobe of the bractlets triangular-lanceolate. River banks: Wash.-Mont.-Ida.-Ore. Submont. My-Je.

6. B. utahensis Britton. A tree 4-6 m. high; leaf-blades ovate to nearly orbicular, sharply toothed, with broad teeth, glabrate in age, thin, acute, 3-5 $\mathrm{cm}$. long, acute or truncate at the base, dull green; staminate aments about 5 $\mathrm{cm}$. long; pistillate ones in fruit 3-4 cm. long; terminal lobe of the bractlets triangular-lanceolate. Cañons and woods: Utah-Wyo.-Mont. Submont.Mont. Ap-Je. 
7. B. fontinalis Sarg. A tree occasionally 10-12 m. high, often growing in clumps and shrub-like; blades sharply double-serrate, entire towards the base, soon glabrous, $2-5 \mathrm{~cm}$. long; staminate aments $5-7 \mathrm{~cm}$. long, several; pistillate aments $2-3 \mathrm{~cm}$. long; terminal lobe of the bractlets lanceolate, decidedly longer than the lateral ones. B. occidentalis Nutt., not Hook. Mountarn Birch, Water Birch, Swamp Birch, Black Birch. River banks: Sask.-Neb.N.M.-Utah-Calif.-B.C.-Yukon. Plain-Mont. My-Je.

8. B. montanensis Butler. A large tree; leaf-blades $4-6.5 \mathrm{~cm}$. long, thick and firm, slightly lobed, finely serrate, glabrous above, conspicuously hairy beneath; fruiting aments $2.5-3.5 \mathrm{~cm}$. long; bractlets $5-7 \mathrm{~mm}$. long; middle lobe triangular-lanceolate, acute. Lake shores: Mont. Submont.

9. B. Sandbergii Britton. A shrub or shrub-like tree; leaf-blades up to 6 $\mathrm{cm}$. long, thick, firm, dull bronze-green above, paler and sparsely hairy beneath, rhombic-ovate or oval, acute at both ends; fruiting aments $2-4 \mathrm{~cm}$. long, slenderstalked; middle lobe of the bractlets longer than the ascending rounded lateral ones. Black Birch. Swampy places: Sask.-Minn.-Mont. Plain.

10. B. Elrodiana Butler. A low shrub; twigs slender, red-brown or gray; leaf-blades 1-3 cm. long, 1-2 cm. wide, oval or rhombic, rarely ovate or obovate, often suborbicular, shining, dark green above, dull green and reticulate beneath; fruiting aments $10-15 \mathrm{~mm}$. long, 6-8 mm. thick, cylindric or ellipsoid. Swampy places: w Mont. Submont.

11. B. obovata Butler. A coarse shrub; branchlets red-brown, becoming gray; leaf-blades $2-4 \mathrm{~cm}$. long, thick, firm, dark, shining above, paler and dull beneath, serrate or crenate-serrate; fruiting aments eylindrical or oval, $2-2.5$ $\mathrm{cm}$. long, 6-8 mm. thick; middle lobe of the bractlets long, ovate or triangular, obtuse, or acutish; lateral lobes obliquely rhombic. River banks: w Mont. Submont.

12. B. crenata Rydb. A shrub 2.5-4.5 m. high; branches puberulent and reddish when young; leaf-blades slightly pubescent when young, oval or elliptic, $1-3 \mathrm{~cm}$. long, $8-20 \mathrm{~mm}$. wide, crenate, dark green, shining, reticulate-veined above; pistillate aments $12-18 \mathrm{~mm}$. long, about $6 \mathrm{~mm}$. thick; terminal lobe of bractlets oblong or elliptic, obtuse or rounded at the apex; lateral lobes ascending, obliquely ovate or rhombic, obtuse; nut oval, nearly $2 \mathrm{~mm}$. long; wings of nearly the same width. Lake banks: w Mont. Submont. Je.

13. B. glandulifera (E. Regel) Butler. A shrub 1-5 m. high; leaf-blades dentate-crenate, with rounded-ovate or on the vigorous shoots triangular teeth, $1.5-3 \mathrm{~cm}$. long, sparingly hirsute when young, soon glabrous, dark green above, yellowish or reddish green beneath; pistillate aments $1-2 \mathrm{~cm}$. long, 6-7 mm. thick; bractlets glabrous; lobes all oblong and obtuse at the apex, of nearly the same length; wing one-fourth to one-half as wide as the oval nut. $B$. pumila glandulifera E. Regel. Boggy places: Ont.-Wis.-Minn.-Sask. Plain-Submont.
My.

14. B. glandulosa Michx. A shrub $0.3-2 \mathrm{~m}$. high; twigs brown and densely glandular-resiniferous; leaf-blades $1-2.5 \mathrm{~cm}$. long, rounded at both ends or sometimes acutish at the base, bright green above, paler beneath; staminate aments usually solitary, $1-1.5 \mathrm{~cm}$. long; pistillate aments $1-2.5 \mathrm{~cm}$. long, 4-5 $\mathrm{mm}$. thick; bractlets glabrous; lobes oblong, obtuse, the lateral ones shorter, spreading, ascending and curved upward; wing of the samara very narrow. Bog Birch, Scrub Birch. Wet places: Greenl.-Me.-Minn.-Colo.-Ore.Alaska. Submont,-Subalp. Je-Jl.

\section{2. ÁLNUS (Tourn.) Hill. Alder.}

Shrubs or trees, with astringent smooth bark. Staminate aments drooping; calyx irregularly lobed; stamens as many as the lobes and opposite to them; anthers introrse. Pistillate aments ovoid or oblong, cone-like; bracts subtending 2 flowers, becoming woody, truncate or lobed at the apex, persistent. Fruit minute, nut-like, winged or wingless, with thin outer coat. Seeds solitary. 
Nut bordered on each side with a membranous wing-margin, fully as broad as the nut; twigs resinous-granuliferous; stamens 4.

Leaves irregularly serrate, usually very oblique at the base, slightly paler beneath

Leaves incised and sharply double-serrate, green on both sides.

1. A. fruticosa.

Nut merely acute-margined.

2. A. sinuala.

Leaves distinctly lobed and doubly serrate; stamens 4.

Mature leaves pubescent, especially beneath, usually glaucous beneath; bark white-speckled.

3. A. incana.

Mature leaves glabrous, except on the veins beneath and in their axils, green on both sides; bark not speckled.

Leaves not lobed, merely sinuate and glandular-dentate; stamens $1-3$, usually 2.

5. A. rhombifolia.

1. A. fruticosa Rupr. A tree sometimes $12 \mathrm{~m}$. high; young twigs minutely puberulent, becoming brown and shining; leaf-blades broadly ovate, $6-10 \mathrm{~cm}$. long, short-acuminate or obtuse; staminate aments in pairs, $10-12 \mathrm{~cm}$. long; filaments longer than the calyx; pistillate aments elliptic, $12-15 \mathrm{~mm}$. long; nut oval, about $2 \mathrm{~mm}$. long. Alaska Alder. Along streams: Alaska-YukonB.C.-Wash.; e Siberia. Submont. My-Je.

2. A. sinuata (E. Regel) Rydb. A shrub 1-4 m. high; young twigs brown or greenish, glabrous or nearly so; leaf-blades ovate, $5-10 \mathrm{~cm}$. long, acute or shortacuminate at the apex, acute, rounded or rarely subcordate at the base, thin, glabrous or nearly so; staminate aments $3-8 \mathrm{~cm}$. long; filaments not exceeding the calyx; pistillate aments rounded-ellipsoid, 12-15 mm. long; nut elliptic. Mountain Alder. Mountain streams: B.C.-Ore-Wyo.-Alta. Mont. $\mathrm{My}-\mathrm{Jl}$.

3. A. incana (L.) Moench. Shrub or small tree, rarely $6 \mathrm{~m}$. high; leafblades broadly elliptic to ovate, rounded at the base, sharply and doubly serrate, dark green above, downy and ferruginous or glaucous, prominently veined bəneath, 5-13 cm. long; staminate aments $3-8 \mathrm{~cm}$. long, the pistillate in fruit 1-1.5 cm. long; nut orbicular, thick-margined. SPECKLEd Alder. Swamps and along streams: Newf.-Pa.-Neb.-Sask.; Eurasia. Boreal. Ap-My.

4. A. tenuifolia Nutt. A tall shrub or small tree, sometimes $8-10 \mathrm{~m}$. high; twigs pubescent when young; leaf-blades ovate or oval, obtuse or acute at the apex, rounded or subcordate at the base, 5-10 $\mathrm{cm}$. long; staminate aments 2.5$4.5 \mathrm{~cm}$. long, filaments equalling the calyx; pistillate aments when ripe 1-2 cm. long, ellipsoid; nut $2.5 \mathrm{~mm}$. long. A. incana virescens $\mathrm{S}$. Wats. RIVEr AldDER. Along streams: Alaska-Calif.-N.M.-Yukon. Submont.-Mont. Ap-My.

5. A. rhombifolia Nutt. A tree sometimes $25 \mathrm{~m}$. high; young twigs green and pubescent; leaf-blades oval or rarely ovate, 5-12 $\mathrm{cm}$. long, hairy on both sides when young, often glabrate in age and dark green above, paler beheath; staminate aments 6-15 cm. long, yellow; pistillate aments ellipsoid, $1.5-2 \mathrm{~cm}$. long; nut oval, about $2.5 \mathrm{~mm}$. long. Along streams: B.C.-Ida.-Calif. Submont. D-Ja.

\section{Family 33. COR ylaceae. Hazelnut Family.}

Monoecious trees or shrubs, with simple alternate leaves. Staminate aments elongate, drooping, each bract subtending a single flower; calyx wanting; filaments distinct, branched at the apex. Pistillate aments short; bracts foliaceous at maturity, each subtending 2 or 3 flowers; calyx present, sometimes represented by a cup. Fruit 1-3 nuts, enclosed in the bracts. Seeds solitary by suppression.

Pistillate flowers many in a cylindric ament; nuts small, enclosed in a bladdery bract.

Pistillate flowers few in a head-like ament; nut large, in a leaf-like involucre.

1. OSTRYA.

2. CORYLUS.

\section{1. Óstrya (Mich.) Scop. Ironwood, Hop-hornbeam.}

Trees with close-grained, hard wood and sealy bark. Staminate aments clustered, drooping; bracts subtending 3-14 stamens; filaments very short, 
branched at the tips; anther-sacs separate, pilose above. Pistillate aments terminal, solitary; bracts subtending two flowers, developing into bladdery sacks. Calyx denticulate. Nut ovoid, flattened, obscurely ribbed.

1. O. virginiana (Mill.) K. Koch. A tree 6-18 m. high; twigs light green and pubescent at first; leaf-blades ovate or oblong-lanceolate, acuminate at the apex, sharply serrate, $7-15 \mathrm{~cm}$. long; staminate aments $3-7 \mathrm{~cm}$. long; bractlets triangular-ovate, acuminate; pistillate aments about $8 \mathrm{~mm}$., in fruit 4-6 $\mathrm{cm}$. long; nut 5-8 mm. long, shining. Dry woods: N.S.-Fla.-Tex.-(Black Hills) S.D. Submont. Ap-My.

\section{CóRYLUS (Tourn.) L. HAZELnUt.}

Shrubs or trees, with branched stem and smooth bark. Staminate aments pendulous, very long, solitary or in clusters; bracts enclosing 4-8 stamens; filaments short, forked at the apex; anther-sacs separate, pilose at the apex. Pistillate aments inconspicuous, clustered at the tips of the branches; each bract enclosing 2 bractlets and an incompletely 2-celled ovary. Nut large, enclosed in a leafy involucre formed by the more or less united bracts. Twigs glabrous or nearly so; beak of the involucre fully twice as long as the nut, strongly
ribbed.

Twigs decidedly hirsute, sometimes somewhat glandular : 1 . C. rostrata.

than half longer than the nut, not strongly ribbed.

1. C. rostrata Ait. A shrub 1-2 m. high, with brown branches; leaf-blades ovate or oval, sharply serrate, glabrous or with scattered hairs above, sparingly pubescent especially on the veins beneath, $5-12 \mathrm{~cm}$. long; involucral bracts bristly hairy, united and prolonged into a tubular beak, laciniate at the summit; nut ovoid, scareely compressed, striate. BEAKED HAZLENUT. Thickets: N.S, -Ga.-Colo.-N.D. Submont. Ap-My.

2. C. californica (A. DC.) Rose. A shrub, or small tree, up to $12 \mathrm{~m}$. high, with brown pubescent branches; leaf-blades broadly ovate to suborbicular, $2.5-7 \mathrm{~cm}$. long, cordate or rounded at the base, double-toothed, rough and pubescent above, soft-pubescent and paler beneath; involucral bracts bristly hairy, united into a tube, cleft at the apex; nut rounded-ovoid, $1.5 \mathrm{~cm}$. in diameter. Woods: Calif.-B.C. Son.-Submont.

\section{Family 34. ULmaCeae. Elm Family.}

Monoecious, polygamous, or hermaphrodite trees or shrubs, with simple leaves, of ten 2-ranked and oblique at the base. Flowers in cymes or racemes. Calyt of 3-8 sepals, more or less united at the base, imbricate. Stamens of the same number, opposite the sepals. Pistil of 2 united carpels; ovary 2-celled. Fruit a samara, drupe, or nut. Endosperm scant or wanting.

Fruit a samara; embryo straight.

Fruit a drupe; embryo with conduplicate cotyledons.

1. ULmus.

\section{1. ÜLMUS (Tourn.) L. ELM.}

Trees or shrubs, with furrowed, often corky bark. Leaves 2-ranked, oblique, straight-veined, serrate, deciduous. Flowers perfect, in axillary elusters. Calyx membranous, 4-9-lobed, usually 5-lobed, campanulate. Stamens exserted; filaments filiform or slightly flattened; anthers extrorse, emarginate at both ends. Ovary sessile or short-stalked, 1-celled or rarely 2-celled; stigmas often ineurved, introrse. Samaras orbicular or oblong, winged all around. Seeds flattened.

1. U. americana L. A large tree, sometimes $35 \mathrm{~m}$. high, with glabrous or sparingly pubescent twigs; leaves oval or obovate, abruptly acuminate at the apex, obtuse or acutish at the oblique base, sharply, usually doubly serrate, slightly rough above, pubescent or glabrate beneath, 5-12 cm. long; samara ovate-oval, reticulate-veined, $10-12 \mathrm{~mm}$. long, glabrous except the ciliate margins. American or White Elm. Moist soil: Newf.-Fla.-Tex, - se Mont.Sask. Plain-Submont. Mr-Ap. 


\section{CÉLtis (Tourn.) L. HackBerry.}

Shrubs or trees, with thin smooth or corky-ridged bark. Leaves oblique, sarrate or entire, 2-ranked, membranous or leathery. Flowers polygamomonoecious or monoecious, axillary, the staminate solitary or clustered; the pistillate usually solitary. Calyx 4 - or 5-lobed, deciduous. Stamens 4 or 5 ; filaments incurved; anthers extrorse. Ovary sessile, 1-celled, with 2 recurved stigmas. Drupe globose or ellipsoid, with scant pulp and bony stone.

Leaf-blades neither coriaceous nor pale beneath, nor st rongly rugose.

Leaves smooth above.

Leaves very rough, pustulate-scabrous above.

1. C. occidentalis. Leaf-blades coriaceous, 2 . Crassifolia. green.

Leaf-blades strongly pubescent beneath.

Pedicels 15-20 mm. long, more than twice as long as the fruit; leaf-blades toothed. 3. C. rugulosa.

Pedicels 4-10 mm. long, usually less than twice as long as the fruit; leaf-blades

subentire.
Leaf-blades glabrous beneath, or slightly hispidulous on the veins and in their axils.

subentire.
Leaf-blades glabrous beneath, or slightly hispidulous on the veins and in their axils.

5. C. Douglasii.

1. C. occidentalis L. A small tree, sometimes $20 \mathrm{~m}$. high; bark of the suem gray, corky-ridged; leaf-blades ovate to ovate-lanceolate, pubescent on the veins beneath, thin, very oblique at the base, usually sharply serrate, shortacuminate, $3-10 \mathrm{~cm}$. long; pedicels in fruit $1-2 \mathrm{~cm}$. long, nearly glabrous; fruit globose, 7-10 mm. in diameter, purple or blackish. Rocky places: Que.-N.C. -Okla.-w Neb.-Man. Plain. Ap-My.

2. C. crassifolia Lam. A tree occasionally $40 \mathrm{~m}$. high; bark corky-roughened and warty; leaf-blades ovate or ovate-lanceolate, dark green, short-acuminate, usually coarsely toothed, 3-10 $\mathrm{cm}$. long, hirsute beneath, especially on the veins; pedicels in fruit 1-2 cm. long; fruit globose or nearly so, 8-10 $\mathrm{mm}$. in diameter, black. Woods and hillsides: Mass.-S.C.-Colo.-S.D. PlainSubmont. Ap-Je.

3. C. rugulosa Rydb. A tree $5-10 \mathrm{~m}$. high, with round crown; twigs somewhat pubescent when young; leaf-blades broadly ovate, oblique, 4-7 cm. long, somewhat cordate at the base, short-acuminate, sharply serrate except at the base and apex, dark green, shining and slightly scabrous above, brownish or yellowish green and dull beneath; fruit globose, about $8 \mathrm{~mm}$. in diameter, brownish; style short but evident. C. rugosa Rydb., not Newberry. Valleys in the foothills: Colo. Submont. My.

4. C. reticulata Torr. A shrub 1-5 m. high; bark gray, corky-ridged; branchlets densely pubescent, brownish gray; leaf-blades broadly ovate, acute, cordate at the base, 2-4 cm. long, entire or with a few broad teeth, shining above, pale brown and densely hirsutulous beneath; fruit globose, 6-10 mm. in diameter, red. Dry rocky places: Tex.-Kans.-Colo.-N.M. Son.-Staked Plains. Ap.

5. C. Douglasii Planch. A low tree or shrub 5-10 m. high; twigs sparingly pubescent; leaf-blades oblique, lance-ovate or ovate, gradually acuminate or acute, more or less serrate, $2-6 \mathrm{~cm}$. long, dark green above, light yellowish green and reticulate beneath; pedicels 10-15 mm. long; fruit greenish brown to nearly black, about $6 \mathrm{~mm}$. in diameter, somewhat ellipsoid; style obsolete. Hills: Ore.-Utah-Ida.-B.C. Submont.-Son. Ap-Je.

\section{Family 35. Cannabinaceae. Hemp Family.}

Herbs or vines, with mostly opposite leaves and persistent stipules. Staminate flowers in panicled racemes; sepals and stamens 5. Pistillate flowers in bracted spikes, with a cup-like calyx; pistil of 2 united carpels, but ovary 1-celled. Fruit an achene; seed solitary, pendulous.

Erect herbs; leaves digitately divided to near the base; pistillate flowers in axillary stiff

spikes.
Twining vines; leaves merely digitately lobed; pistillate flowers in drooping ament-lik, spikes with imbricate bracts.

2. HUMULU, $_{\mathrm{S}}$ 


\section{CÁnNaBis L. Hemp.}

Erect annual dioecious herbs. Leaves alternate or opposite, digitately 5-11divided into serrate divisions. Staminate flowers in paniculate racemes; sepals 5, imbricate; stamens 5 . Pistillate flowers in leafy-bracted spikes; perianth undivided; pistil solitary. Fruit a slightly flattened achene.

1. C. sativa L. Stem branched, 1-4 m. high, rough-pubescent; leafblades divided into 5-11 linear, serrate, acuminate divisions, 5-15 cm. long. Waste places: N.B.-Ga.-Tenn.-Colo.-Minn.; escaped from cultivation; native of Eurasia.

\section{HÙMULUS L. Hops.}

Perennial, twining herbaeeous vines. Leaves opposite, 3-7-lobed, serrate. Stipule persistent, free. Staminate flowers in panicled racemes; sepals 5, imbricate; stamens 5; filaments short, erect. Pistillate flowers in ament-like, drooping spikes, 2 together, subtended by a bract; ovary 1-celled. Achenes a little flattened. Embryo spirally coiled.

Leaf-blades 3-7-lobed about half-way to the base, with ovate, acute or short-acuminate lobes; those of the inflorescence 3-lobed or undivided.

Leaf-blades 5-7-divided to near the base, with lanceolate, long-acuminate divisions; those of the inflorescence 5-cleft.

2. H. neomexicanus.

1. H. Lupulus L. A vine 5-10 m. high; leaf-blades cordate in outline, dark green, scabrous above, glabrous beneath except the pubescent veins; lobes coarsely toothed, with ovate teeth; bracts of the pistillate flowers broadly ovate, from obtuse to short acuminate. Common Hops. Rocky banks and copses: N.S.-Ga.-Kans.-Wyo.-Mont.; Eurasia; extensively cultivated. Plain-Submont.

2. H. neomexicanus (A. Nels. \& Cockerell) Rydb. A vine $5-10 \mathrm{~m}$. high; leaf-blades light green, minutely scabrous above, nearly glabrous beneath; bracts of the pistillate flowers narrower, lanceolate or ovate, acute or acuminate. $H$. Lupulus neomexicanus A. Nels. \& Cockerell. WILD Hops. Among bushes: Wyo.-Utah-Ariz.-N.M. Plain-Submont. Jl-Au.

\section{Family 36. URticaceae. Nettle Family.}

Monoecious, dioecious, or polygamous herbs (ours), often armed with stinging hairs. Leaves simple, alternate or opposite, with stipules. Flowers greenish, in axillary cymes. Calyx of 2-5 distinct or partly united sepals. Stamens $2-5$, in the pistillary flowers reduced to staminodia or wanting. Pistil solitary; ovary 1-celled. Fruit an achene. Endosperm scant, oily, or wanting; emb yo straight.

Herbs with stinging hairs; leaves opposite; flowers not involucrate.

1. URTICA.

Plants without stinging hairs; leaves alternate; flowers involucrate by leafy bracts.

\section{URTİCA (Tourn.) L. Netrle.}

2. Parietaria.

Annual or perennial herbs, with stinging hairs. Leaves opposite, with membranous, toothed, 5-7-veined blades and free stipules. Plants dioecious or monoecious; flowers in axillary, paniculate cymes; sepals 4 , nearly distinct, in the pistillate flowers two of them larger. Staminate flowers with 4 stamens and a rudimentary ovary, the pistillate ones with an equilateral ovary and tufted stigmas. Achenes flattened. Seeds with membranous coats, often adherent to the pericarp. All our species dioecious and perennial with a rootstock.

Stipules membranous, oblong or broadly lanceolate, obtuse or acutish, often $1 \mathrm{~cm}$. long. Stem and leaves densely pubescent.

Stem and lower surface of the leaves coarsely velvety.

Stem finely strigose; lower surface of the leaves finely short-pubescent.

Stem nearly glabrous; leaves puberulent, in age becoming glabrate.

2. U. Breweri.

3. U. Lyallii. 
Stipules narrowly lanceolate or linear, attenuate.

Teeth of the leaves ovate, strongly directed forward

Stem glabrous except the presence of a few bristles; leaves thin, almost glabrous, not strongly veined.

Petioles one-third to one-half as long as the cordate or broadly ovate leafblades. leaf-blades.

or ovate-lanceolate 5. U. viridis.

Stem more or less strigose or hirsute; leaves decidedly hairy, especially on the very strong veins.

Leaf-blades lanceolate, scarcely cordate at the base. Stem sparingly strigose and bristly. Stem densely strigose, scarcely at all bristly.

Leaf-blades broad, deeply cordate at base.

Teeth of the leaves broadly triangular, not strongly directed forward; stem and leaves glabrous or nearly so.

6. U. gracilis.

7. U. strigosissima.

S. dioice.

9. U. gracilenta.

1. U. holosericea Nutt. Plant densely velvety; stem 1-3 m. high; leafblades thick, ovate or the lower cordate, coarsely toothed, 5-10 $\mathrm{cm}$. long, pale beneath; staminate flowers in loose panicles, nearly equalling the upper leaves, the pistillate ones in shorter and denser clusters; inner sepals ovate, about equalling the achenes. Alluvial soil: Wash.-Ida.-Calif. Son.-Submont. Jl-Au.

2. U. Breweri S. Wats. Stem 1-2 m. high; leaf-blades lanceolate to cordate, coarsely toothed, rather thin, somewhat paler beneath; panicles shorter than in the preceding, the staminate ones shorter than the leaves, the pistillate slightly exceeding the petioles; sepals obovate, about twice as long as the achenes. River valleys: Wash.-Utah-Calif. Submont. Je-Au.

3. U. Lyallii S. Wats. Perennial, dioecious; stem 1-2 m. high; leaf-blades thin, coarsely toothed, 3-15 cm. long, ovate or cordate; panicles shorter than the leaves, the pistillate ones scarcely exceeding the petioles; sepals ovate, usually shorter than the achenes. Along streams: Alaska-Wash.; Newf.-Conn. Submont. My-S.

4. U. cardiophylla Rydb. Stem about $1 \mathrm{~m}$. high; lower leaf-blades cordate, the upper lance-ovate, $6-10 \mathrm{~cm}$. long, coarsely toothed, very thin, shining, dark green, glabrous; panicles small, few-flowered, much shorter than the leaves; sepals ovate, about equalling the achenes. Wooded creek banks: Mont.-Alta. -B.C.-Ida. Submont. Je-Au.

5. U. viridis Rydb. Stem 1-1.5 m. high, slender; blades coarsely toothed, 4-10 $\mathrm{cm}$. long, thin, light green; panicles many-flowered, often equalling the upper leaves; sepals oval or ovate, usually half longer than the achene. River bottoms: Ida.-Wyo.-Alta. Submont. Je-Au.

6. U. gracilis Ait. Stem slender, $0.5-3 \mathrm{~m}$. high, sharp-angled; leaf-blades finely serrate, acuminate, $7-15 \mathrm{~cm}$. long, about as wide as the length of the petioles; flower-clusters slender, but shorter than the leaves; sepals ovate, about equalling the achenes. Alluvial soil and waste places: N.S.-N.C.-N.M.Alaska. Plain-Mont. Ap-S.

7. U. strigosissima Rydb. Stem $1 \mathrm{~m}$. high or more; petioles $2-3 \mathrm{~cm}$. long; leaf-blades sharply serrate, long-acuminate, 5-10 cm. long, $1.5-5 \mathrm{~cm}$. wide; flower-clusters slender, the upper almost equalling the leaves; sepals ovate, about equalling the achenes. River banks: Ida.-Utah. Submont. July.

8. U. dioica L. Stem $0.5-1.5 \mathrm{~m}$. high, strongly bristly and somewhat hispidulous above, obtusely angled; leaf-blades thin, very bristly, coarsely toothed, acute or short-acuminate, 3-10 $\mathrm{cm}$. long, usually twice as broad as the length of the petioles; flower-clusters about half as long as the leaves. Waste places: N.S.-S.C.-Colo.-Minn.; nat. from Eu. Plain-Submont. JI-S.

9. U. gracilenta Greene. Stem slender, 1-2 m. high, strigose or hirsutulous, as well as bristly; petioles slender, $2-8 \mathrm{~cm}$. long; leaf-blades lanceolate, longacuminate, rounded at the base, $5-15 \mathrm{~cm}$. long, more or less pubescent, with salient teeth; flower-clusters slender, slightly exceeding the petioles. Along streams and in cañons: S.D.-Wyo.-Ariz.-Tex.; Mex. Son.-Submont. AuS. 


\section{PARIetària (Tourn.) L. Pellitory.}

Annual or perennial herbs, with diffusely branched, often pellucid stems, polygamous. Leaves alternate, with 3-veined blades. Involucres of 2-6, more or less united bracts. Flowers in axillary cymes. Perianth of 4 , rarely 3 , more or less united sepals. Stamens 4, rarely 3, in the perfect and the staminate flowers, in the pistillate ones wanting. Pistils solitary, in the staminate flowers rudimentary; stigmas tufted. Achenes included, with a crustaceous pericarp.

Leaf-blades lanceolate, $2-7 \mathrm{~cm}$. long, twice as long as the petioles or longer.

Plant comparatively dark green; stem densely puberulent; sepals lanceolate, acute.

Plant very light gen i. P. pennsylvanica.

Plant very light green; stem long-villous; sepals ovate, often obtuse.
2. occidentalis.

Leaf-blades oblong or ovate-oblong, $0.5-2 \mathrm{~cm}$. long, not twice as long as the petioles.
3 . obtusa.

1. P. pennsylvanica Muhl. Annual, slender; stem weak, ascending, 1-4 $\mathrm{dm}$. high, simple or branched; leaf-blades thin and flimsy, obtuse or acuminate at the apex, acute or acuminate at the base; bracts of the involucre linear, 4-5 $\mathrm{mm}$. long. Shaded banks or rocks: Ont.-Fla.-Mex.-B.C. Plain-Submont. My-Au.

2. P. occidentalis Rydb. Annual; stem slender, erect, simple or branched at the base, 1-4 dm. high; leaf-blades thin, light green, acute at the base, obtusish at the apex, $1-4 \mathrm{~cm}$. long, $5-18 \mathrm{~mm}$. wide, sparingly pubescent; bracts of the involucre linear, obtuse. Moist shaded places: Wash.-Ida.-Nev. Submont. $\mathrm{My}-\mathrm{Au}$.

3. P. obtusa Rydb. Annual; stem usually branched at the base, spreading, 5-20 cm. long, finely villous; leaf-blades obtuse; bracts of the involucres oblong or narrowly oblong, obtuse; sepals ovate, obtuse, rarely acutish. Shady places: Colo.-Utah-s Calif,-Tex. Son.-Submont. F-Jl.

\section{Family 37. POLYgonaceae. Buckwheat Family.}

Herbs or shrubs, or in the tropics trees or vines, with alternate leaves. Flowers perfect or rarely unisexual. Calyx inferior, of $2-6$ more or less united sepals, often corolloid. Corolla wanting. Stamens 2-9. Pistil of 2 or 3 united carpels, but ovary 1-celled, in fruit becoming a 1-seeded, triangular or lenticular achene.

Leaves without stipules; flowers or flower-clusters subtended by involucres of partly united bracts; stamens mostly 9 .

Involucres from tubular to campanulate, of several united bracts.

Involucres awnless, campanulate or turbinate, 4-8-toothed or -lobed.

Involucres awn-pointed.

1. ERIOGONUM.

Involucres herbaceous; flowers exserted; achenes Ienticular.

Involucres leathery or horny; flowers included 2 . OxYTHECA.

uded; achenes 3-angled.

dichotomous $3-6$ awn-tipped spurs near the base, 1-3-flowered, in open

Involucres without spurs, 1-flowered.

Involucres 6-angled, sulcate; fllaments adnate to the base of the perianth.

3. Centrostegia.

Involucres 3-angled; flaments adnate to the whole 4. CHORIZANTHE.

Involucres bract-like, 2-cleft.

tube of the perianth.

6. PTEROSTEGIA.

Stigmas tufted.

Sepals 6; styles 3 ; achenes triangular.

Sepals 4 ; styles 2 ; achenes lenticular.

Stigmas not tufted.

Leaf-blades jointed at the base; ocreae 2-lobed, becoming lacerate; fllaments, at least the inner, dilated.

Leaf-blades not jointed at the base; ocreae not 2-lobed; flam 9. PoLYGoNUM. Ocreae cylindric, truncate.

Ocreas oblique, more or less open on the side facing the leaf.

Herbs, not climbing or twining; sepals neither winged nor keeled. Flowers in simple spike-like racemes; plants with thickened tuberous
rootstocks. 
Flowers in several racemes or panicles; rootstocks not tuberous-thickened.

Racemes in terminal corymbs; plants smooth.

Embryo in the center of the endosperm; leaves sagittate or cordate. 12. FAGOPYRUM.

Embryo at one side of the endosperm; leaves neither sagittate nor cordate. 13 . ACONOGONUM.

Racemes not in terminal corymbs; plant prickly; embryo at one side of the endosperm. 14. TracaULON.

Herbaceous vines, with twining stems; sepals winged or keeled.

15. BILDERDYKIA.

\section{1. eriógondm Michx. Umbrella Plant.}

Annual or perennial herbs or shrubby plants, with basal or cauline, alternate, opposite, or whorled leaves and no stipules. Blades entire. Flowers perfect or polygamo-monoecious, in involucrate clusters variously disposed. Involucres turbinate or campanulate, rarely nearly cylindric, 4-8-lobed. Perianth more or less colored, jointed to a short pedicel. Segments 6, in two series. Stamens 9; filaments filiform, often hairy at the base. Ovary 1-celled, 3-angled or 3-winged; styles 3 .

Achenes 3-winged; perianth not accrescent; perennials with a thick taproot and short crown.

Achenes merely 3-angled; perianth accrescent in fruit.

Perianth with a stipe-like base; bracts verticillate, leaf-like.

Involucres in branching cymes; perennials with a branched woody caudex; flowering branches scapiform.

II. ERIANTHA.

Involucres in simple or compound umbel-like or head-like clusters.

Perianth pubescent.

Perianth yellow; leaf-blades spatulate or oblanceolate.

Involucres undulate-dentate, tomentose, many, umbellate; embryo straight; perennials with a cespitose caudex. III. FLAVA.

Involucres deeply lobed, solitary, or 2 or 3 together; embryo curved; perennials, subacaulescent or suffruticose. IV. CAEsPITOSA.

Perianth white; leaf-blades ovate or elliptic; cespitose subacaulescent perennials.

V. PYROLAEFOLIA.

Perianth glabrous; perennials with a cespitose caudex, with the leaves clustered at the ends of the branches.

VI. UMBELLATA.

Perianth without stipe-like base.

Ovaries and fruit pubescent; involucres few, capitate or subcymose; perennials with scapiform stems.

Ovaries and fruit glabrous or nearly so.

Involucres in head-like or umbellate clusters.

Perianth-lobes very unequal; perennials with a pulvinate-cespitose woody caudex.

Perianth-lobes equal or nearly so.

VIII. HETEROSEPALA.

Heads solitary or, if more than one, proliferous-umbellate, with the central head sessile; cespitose perennials.

Heads several, paniculate, corymbose or cymose-umbellate. Herbs with perennial caudices; heads paniculate, almost ebracteate; perennials with a stout rootstock.

$\mathrm{X}$. Elata.

Leafy undershrubs, with fascicled leaves; heads cymose-umbellate; suffruticose perennials. XI. FAsciculata.

Involucres in open cymes.

Bracts scale-like.

Involucres, except those of the forks of the inflorescence, sessile, the uppermost conglomerate.

Cymes repeatedly dichotomous or trichotomous. Perianth-lobes very dissimilar; perennials.

Perianth-segments not very dissimilar.

Perennials, shrubby at least at the base.

Annuals, with a strict herbaceous stem.

XII. Dichotoma.

XiII. CORYMrosa.

Cymes with more or less raceme-like branches. Perennials.

Annuals.

XIV. ANNUA.

XV. RACEMOSA.

XVI. VIRGATA.

Involucres all peduncled, never conglomerate; scapose annuals (except E. tenellum); leaves basal, petioled. XVII. PEDUnCUlata. Bracts leaf-like.

Primary stem-leaves scale-like, with a pair or a fascicle of secondary well-developed leaves in their axils; caulescent annuals.

XVIII. DIVARICATA.

Primary stem-leaves well-developed, also often with secondary leaves in their axils.

Perianth petaloid, not closely investing the achenes; involucres toothed or lobed. 
Involucres sessile; leaves basal, petioled; bracts sessile, elliptic; scapose annuals.

XIX. Puberula.

Involucres peduncled; leaves and bracts similar, verticillate, linear; caulescent annuals. $\mathrm{XX}$. SPERGULINA.

Perianth herbaceous, closely investing the achene; involucre divided

to near the base; leaves spatulate; caulescent annuals.

\section{Alata.}

XXI. SAlsuginosa.

Involucres hairy, 3-3.5 mm. long and 1.5-2 mm. wide; stem and leaves manifestly hirsute and tomentose.

Involueres glabrous, $2-2.5 \mathrm{~mm}$. glabrous.

stem and leaves nearly

2. E. triste.

II. ERIANTha.

Perianth whitish; style hairy at least to the middle.

Perianth yellow; style hairy only at the base.

Involucres 6-8 mm. long; leaf-blades oblong or oblanceolate.

Involucres 9-10 mm. long; leaf-blades suborbicular to oval.

3. E. Jamesii.

III. Flava.

Perianth (externally) pubescent throughout.

Involucre elongated-obconic, $6-8 \mathrm{~mm}$. long.

Involucre turbinate, 4-5 $\mathrm{mm}$. long.

4. E. Bakeri.

5. E. arcuatum.

Stipe-like base of the perianth very short; old leaf-bases permanently tomentose.

Leaf-bases thickened; perianth copiously pubescent; leaf-blades silky above; involucres usually several.

Leaf-bases not thickened; leaf-blades slightly floccose above; involucres few. Perianth 6-7 mm. long.

Perianth about $4 \mathrm{~mm}$. long.
Stipe-like base of the perianth slender; old leaf-bases glabrous.

Perianth pubescent at the base only.

10. E. xanthum.

11. E. androsaceum.

IV. Caespitosa.

Involucres with comparatively short, ovate, merely spreading lobes, long-peduncled;

leaves linear or nearly so, revolute; stems short, leafy. $12 . E$. thymoides.

Involucres with long reflexed lobes.

Densely cespitose, subacaulescent; involucre solitary.

Perianth in flowers $3-4 \mathrm{~mm}$. long.

Perianth in flowers $2 \mathrm{~mm}$. long.

Caulescent, suffruticose; involucres $1-5$.

13. E. caespitosum.

Perianth greenish yellow, 6-8 mm. long; leaves spatulate or oblanceolate.

Perianth ochroleucous, $5 \mathrm{~mm}$. long; leaves linear or linear-oblanceolate. 15 . sphacephalum.

One species.

\section{Pyrolaefolia.}

16. E. fasciculifolium.

Leaf-blades ovate or cordate.

\section{UMBELlati.}

Leaf-blades from obovate or orbicular to oblanceolate,

Involucres solitary.

Involucres several, umbellate.

Perianth deeply yellow.

Leaves not densely tomentose beneath.

Umbels simple; leaves spatulate. 20. E. neglectum.

Umbels more or less compound; leaves oblanceolate.

Leaves densely tomentose beneath.

21. E, biumbellatum.

Inflorescence more or less compound.

Inflorescence simple.

22. E. stellatum.

Leaf-blades obovate-spatulate or oval; perianth 6-7 mm. long.

Leaf-blades rhombic-ovate or rhombic-oval. 23. E. umbellatum.

perianth $7-8 \mathrm{~mm}$. long.

Perianth ochroleucous, in age turning purplish rose-colored.

24. E. Rydbergii.

Scape naked up to the umbel; leaves spatulate.

Perianth about $6 \mathrm{~mm}$. long; leaf-blades spatulate-oblong or elliptic, glabrous above at maturity.

Perianth about $8 \mathrm{~mm}$. long; leaf-blades oval or ovate, permanently tomentose above.

Scape with at least one whorl of leaves below the $26 . E$. aridum. late.

VII. LACHNOGYNA.

el; leaf-blades oblanceo-

27. E. heracleoides.

Leaves and scape silky; the latter elongate, $1 \mathrm{dm}$. high or more; perennials with a taproot and cespitose crown.

Inflorescence irregularly branched.

Inflorescence subcapitate.

28. E. lachnogynum.

Leaves lanate, subsessile, obtuse; scape short, less than 39 . E. Tetraneuris. cespitose perennials; involucres capitate. 
Leaf-blades elliptic or oval, not strongly revolute; scape $1-3 \mathrm{~cm}$. long.

Perianth yellow; lobes of the involucres lanceolate, more than twice as long as the tube.

30. E. longilobum.

Perianth white or pinkish; lobes of the involucres not twice as long as the tube.

Lobes of the involucres oblong or ovate, with a more or less scarious white or pink margin.

Lobes of the involucres triangular, not scarious-margined. 31. E. Shockleyi.

32. E. pulvinatum.

Leaf-blades linear-oblong, strongly revolute; scape none or very short.

33. E. acaule.

\section{Heteroserala.}

34. E. proliferum.

Heads several, cymose-proliferous, the central head sessile.

Heads solitary.

Involucres about $7 \mathrm{~mm}$. long; leaf-blades oval.

Involucres 4-5 $\mathrm{mm}$. long.

35. E. orthocaulon.

Perianth bright yellow or in age purplish; leaf-blades about as broad as long.

Perianth cream-colored, ochroleucous, or isabel-colored. Perianth 2.5-3.5 mm. long; leaf-blades rounded-oval or ovate.

Perianth 4-5 mm. long; leaf-blades elliptic, oblong, or spatulate. 36. E. ovalifolium.

37. E. depressum.

38. E. ochroleucum.

\section{Capitata.}

Perianth yellow.

Bracts and involucres membranous; the former broadly lanceolate; the lobes of the latter ovate or triangular; densely pulvinate-cespitose perennials.

$\begin{array}{ll}\text { Perianth bright yellow. } & 39 \text {. E. chrysops. } \\ \text { Perianth ochroleucous, sometimes tinged with rose. } & 40 . \text { E. Kingii. }\end{array}$

Bracts and involucres firm; the former subulate or narrowly lanceolate (except in $E$. medium); the lobes of the latter lanceolate; perennials with a cespitose woody caudex.

Perianth ochroleucous.

Perianth golden yellow.

41. E. loganum.

Leaf-blades oblanceolate or oblong, tomentose on both sides.

42. E. chrysocephalum.

Leaf-blades linear or narrowly linear-oblanceolate, in age greener above.

43. E. medium.

Perianth white or rose-colored.

Perianth glabrous; perennials with a cespitose woody caudex.

Lobes of the involucres lanceolate, acute, not scarious-margined.

Heads about $1 \mathrm{~cm}$. broad; perianth fully $3 \mathrm{~mm}$. long; leaf-blades $3-8 \mathrm{~cm}$. long. 44. E. Brandegei.

Heads about $0.5 \mathrm{~cm}$. broad; perianth about $2 \mathrm{~mm}$. long; leaf-blades $1-2 \mathrm{~cm}$. long.

45. E. depauperatum.

Lobes of the involucres oval to orbicular, scarious-margined.

Leaves glabrate above; perianth $3-5 \mathrm{~mm}$. long; involucres in small heads. Lobes of the involucres much shorter than the tube.

Lobes of the involucres about as long as the tube.

46. E. coloradense,

47. E. pauciflorum.

Leaves white-tomentose on both sides; perianth $2.5 \mathrm{~mm}$. long; involucres solitary.

Perianth pubescent.

48. E. mancum.

Suffruticose leafy-stemmed perennial, with decumbent branches, villous.

Pulvinate perennial, acaulescent, silky-hirsute.

49. E. multiceps.

50. E. villiflorum.

\section{Elata.}

One species.

\section{Fasciculata.}

51. E. elatum.

One species.

\section{DichотомA.}

52. E. polifolium.

Stem leafy, suffrutescent; outer perianth-segments suborbicular.

Stem scapiform, with a cespitose woody caudex; outer perianth-segments oval.

Inflorescence more or less floccose.

Involucres 5-6 mm. long; branches of the inflorescence ascending-spreading.

54. E. dichotomum.

Involucres 3-4 mm. long; branches of the inflorescence strongly ascending, almost erect.

Inflorescence glabrous.

XIII. Corymbosa.

55. E. lachnostegium.

56. E. strictum.

Branches of the inflorescence not grooved.

Perianth yellow.

Plants more than $2 \mathrm{dm}$. high; leaves not heath-like.

Leafy shrubs; inflorescence shorter than the stem. Leaf-blades elliptic, oval, or broadly spatulate; involucres glabrous.

Leaf-blades oblanceolate; involucres tomentose. 
Undershrubs, leafy only at the base; inflorescence longer than the stem.

Involucres villous-tomentose; leaf-blades equally white on both sides. Leaf-blades narrowly oblanceolate; branches of the inflorescence strongly ascending. 59. $E$. orendense.

Leaf-blades broadly spatulate; branches of the inflorescence more spreading.

60. E. lagopus.

Involucres glabrate: leaves usually less tomentose above.

Leaf-blades oblanceolate or broadly oblong, not strongly revolute. Involucres strongly angled, all sessile. 61. E. Thompsonae. Involucres not strongly angled; those of the forks peduncled. Leaf-blades linear or narrowly linear. campanulatum.

Leaf-blades linear or narrowly linear-oblanceolate, usually with revolute Involucres in the forks peduncled. Involucres all sessile.

63. E. brevicaule. eaves.

65. E. contortum.

Perianth white or rose-colored.

Suffruticose plants, leafy only at the base; inflorescence longer than the stem.

Involucres tomentose, all sessile.

Involucres glabrous, at least in age.

66. E. spathulatum.

Leaf-blades spatulate or elliptic.

Pedicels of the lower forks scarcely longer than the involucres; lobes of the latter as broad as long; perianth $3 \mathrm{~mm}$. long.

67. E. spathuliforme.

Pedicels of the lower forks several times as long as the involucres; lobes of the latter longer than broad; perianth $2 \mathrm{~mm}$. long.

Leaf-blades narrowly oblanceolate to linear.

68. E. Ostlundi.

Involucres all sessile.

Leaves mostly flat; involucres narrowly turbinate; perianth 2-2.5 mm. long.

69. E. lonchophyllum.

Leaves mostly revolute; involucres campanulate; perianth $3-3.5$

$\mathrm{mm}$. long.
Involucres in the forks of the inflorescence, at least the lower, distinctly peduncled.

Involucres broadly campanulate, about as wide as long.

Involucres turbinate, decidedly longer than 71. E. scoparium. Branches of the inflorescence almost erect.

Branches of the inflorescence ascending-spreading.

Leaf-blades narrowly linear-oblanceolate or linear, usually revolute.

Leaf-blades spatulate to oblanceolate, flat.

73. E. tristichum.

Shrubby plants, with the leafy stem usually longer than 74 . E. salicinum.

Leaves not revolute or scarcely so, distinctly petioled.

Leaf-blades relatively broad, oblong to rounded-oval or obovate, obtuse.

Involucres 4-5 $\mathrm{mm}$. long.

Involueres $2-3 \mathrm{~mm}$. long.

Branches of the inflorescence divaricate.

Branches of the inflorescence ascending.

75. E. Fendlerianum.

Leaf-blades rounded or subcordate at the base, decidedly crisp.

Leaf-blades acutish at the base, not crisp, except sometimes the margins.

Inflorescence and stem loosely floccose, in age inclined to become glabrate. 78. E. corymbosum. Inflorescence and stem permanently and densely white-
tomentose.

Leaf-blades narrow, spatulate to linear, mostly acute at the apex.

Inflorescence many times compound, copiously branched; internodes long.

Inflorescence tomentulose, broom-like, with strongly ascending branches; involucresabout $1.5 \mathrm{~mm}$. long. 80 . E. effusum.

Inflorescence glabrous, lax and with spreading branches; involucres

$2-2.5 \mathrm{~mm}$. long.
Inflorescence less compound; branches and internodes short, mostly spreading.

Involucres in the forks peduncled; peduncles slightly floccose.

Involucres all sessile; peduncles densely white-tomentose.

82. E. nebraskense.

Leaves linear or linear-oblanceolate, strongly revolute, subsessile.

Peduncles not thickened upwards.

Leaves glabrous or loosely floccose above.

Stem 1-4 dm. high; leaves floccose above. 83. E. Simpsoni.

Stem less than $1 \mathrm{dm}$. high; leaves glabrous above.

84. E. Mearnsii. 
Leaves densely villous on both sides.

Peduncles clavate-thickened upwards.
Branches of the inflorescence strongly angled and deeply grooved.

5. E. bicolor

86. E. clavellatum.

87. E. sulcatum.

One species.

XIV. ANNUA.

88. E. annuum.

XV. RACEMOSA.

Leaves crowded on the short branches of the caudex; blades abruptly narrowed at the base or subeordate. 89. E. racemosum.

Leaves scattered on the fruticose branches; blades tapering at the base.

Leaf-blades elliptic or oblanceolate.

90. E. Wrightii.

Leaf-blades linear.

91. E, leptocladon,

\section{VIRgata.}

Stem neither divaricately branched, nor densely floccose.

Involucres cylindric; perianth-segments oblong or oval; plant with few branches. Involucres about $3 \mathrm{~mm}$. long. Involucres about $2 \mathrm{~mm}$. long.

92. E. vimineum.

93. E. Baileyi.

Involucres campanulate, 1-1.5 mm. long; perianth-segments cuneate, flabellate, or fiddle-shaped; plants with numerous branches.

Branches not incurved in age; leaf-blades ovate or oblong.

Branches incurved in age; leaf-blades orbicular or 94. E. densum.

Stem divaricately branched, densely floccose.

form.

95. E. nidularium.

96. E. Plumatella.

\section{XVir. Pedunculata.}

Perennials with a woody caudex.

Annuals.

Perianth glabrous or in E. Thomasii and E. nutans somewhat pubescent; segments mostly obtuse or rounded at the apex.

Peduncles not glandular.

Scape and its branches glabrous.

Peduncled reflexed or at least divaricate; leaves tomentose on both sides, less so above.

Involucres $1.5-2 \mathrm{~mm}$. long; perianth 1.5-2 mm. long.

Peduncles shorter than the involucres; outer perianth-lobes ovate or subreniform.

Perianth pale yellow; outer segments subreniform.

Perianth white; outer segments ovate. 98. E. Hookeri.

Peduncles longer than the involucres; outer perianth-segments obovate or panduriform; perianth white or pinkish

Involucres $0.5 \mathrm{~mm}$. long; perianth 1-1.5 mm. long, yellowish with reddish veins.

Peduncles erect or ascending.

Leaves more or less tomentose beneath.

Involucres $1.5-2 \mathrm{~mm}$. long.

Perianth yellow; segments similar. 102. E. pusillum.

Perianth white or rose-colored; segments unlike.

Involucres campanulate; outer perianth-segments flabellate. 103. E, rotundifolium.

Involucres turbinate; outer perianth-segments not flabellate. Outer perianth-segments oblong-ovate, the inner ones entire. 104. E, insigne.

Outer perianth-segments subreniform, the inner ones 3toothed, much smaller. 105. $\vec{E}$, turbinatum.

Involucres scarcely $1 \mathrm{~mm}$. long; perianth yellowish or white, usually somewhat hispidulous at the base. 106. E. Thomasii.

Leaves green, glabrate or sparingly pilose.

Scape more or less pubescent, at least at the nodes. Leaves white-lanate beneath.

Leaves green on both sides, sparingly pilose.

107. E. Gordonii.

108. E. subreniforme.

109. E. trinervatum.

Peduncles glandular; leaves tomentose

Outer perianth-segments oval, emarginate or retuse, the inner ones oblong.

110. E. nutans.

110. E. nutans.

Perianth pubescent; segments ovate or lanceolate, acute.

Peduncles and usually also the scape glandular; leaves green, merely hirsute beneath.

Peduncles and scape not glandular.

Leaves floccose or tomentose beneath.

Leaves green, merely pilose or hirsute.

112. E. glandulosum.

113. E. Ordii.

Accessory branches at the lower forks of the inflorescence many and nearly as strong as the primary ones; all divaricate. 


\begin{abstract}
Scape strongly inflated under the first node. 115. E. fusiforme.
Accessory branches of the lowest node of the inflorescence few and small
or none; branches ascending; scape usually inflated. or none; branches ascending; scape usually inflated.

XVIII. Divaricata.
\end{abstract}

Leaves green, puberulent; involucres 5-cleft. usually sessile. Leaves floccose beneath; involucres 5 -toothed, peduncled.

xix. Puberula.

One species.

XX. SPERgULINA.

Leaves green, merely pilose; scape glandular.

Leaves tomentose beneath; scape finely pubescent.

One species.

XXI. SALSUGINOSA.

tufte. alatum Torr. Stems erect, 3-10 dm. high; leaves mostly basal, eblanceolate, 3-10 cm. long; hirsute above, glabrous beneath, except the strong midrib; panicle open; involucres in small cymes; perianth campanulate, greenish yellow, $2 \mathrm{~mm}$. high, glabrous; achenes 5-7 mm. long, glabrous. Plains and table-lands: Neb.-Tex.-Ariz.-Wyo. Son.-Plain-Mont.
Je-Au.

2. E. triste S. Wats. Stems $3-5 \mathrm{dm}$. high, sparingly hirsute or glabrate; leaves mostly basal, oblanceolate, $8-10 \mathrm{~cm}$. long, eiliate on the margins, otherwise glabrous; inflorescence paniculate; involucres in cymes; perianth glabrous, campanulate, $2 \mathrm{~mm}$. long, brownish red; achenes $5-6 \mathrm{~mm}$. long. E. alatum glabriusculum Torr. Sandy soil: Tex.-s Colo.-s Utah-Ariz. Son.-Mont.

3. E. Jamesii Benth. Stems decumbent at the base, $1-3 \mathrm{dm}$. high, tomentose; leaves mostly basal, petioled, 3-8 cm. long; blades elliptic-spatulate, thick, green, densely white-tomentose beneath; involucres deeply campanulate, $5 \mathrm{~mm}$. high, tomentose; perianth 4-5 mm., becoming 7-8 mm. long; inner lobes slightly longer than the outer; achenes $4 \mathrm{~mm}$. long, pubescent at the base. Plains and hills: Tex.-Kans.-Colo.-Ariz. Plain-Mont. J1-S. 4. E. Bakeri Greene. Stems scapiform, 1-3 dm. high; leaves basal, petioled,
$2-5 \mathrm{~cm}$. long, somewhat tomentose above, but in age more glabrate and greenish, densely white-tomentose beneath; involucres campanulate, tomentose; perianth silky-villous. E. Jamesii flavescens S. Wats. E. vegetius (T. \& G.) A. Nels. Hills: Wyo.-N.M.-Ariz.-Utah. Submont.-Mont.

5. E. arcuatum Greene. Stems scapiform, about $1 \mathrm{dm}$. high, tomentose; leaves basal, petioled, $2-5 \mathrm{~cm}$. long, tomentulose but greenish above, whitetomentose beneath; involucres tomentose; perianth 6-7 $\mathrm{mm}$. long, silky below. Mountains: Colo.-Utah. Submont.-Subalp. Jl.

6. E. Piperi Greene. Stems scapiform, 1-3 dm. high, villous; leaves basal, petioled, 3-10 cm. long; blades thin, oblanceolate or elliptic-oblanceolate, green and villous above, white-tomentose beneath; perianth yellow, $5-6 \mathrm{~mm}$. long,
turbinate; filaments hairy below; achenes villous at the apex. Open valleys:
Wash.-Wyo.-Mont. Submont.-Mont. Wash.-Wyo.-Mont. Submont.-Mont.

7. E. flavum Nutt. Stems 1-2 dm. high, scapiform, white-tomentose; leaves thick, petioled, 3-5 cm. long; blades oblanceolate, densely tomentose on both sides, greenish in age above, snowy-white beneath; perianth yellow; filaments villous at the base; achenes $4 \mathrm{~mm}$. long, villous. 'E. sericeus Pursh. E. crassifolius Benth. Dry hills, mountains and cañons: Man.-Neb.-Colo.-

8. E. chloranthum Greene. Stems scapiform, 1-2 dm. high, tomentose; leaves basal, not very thick, petioled, $3-5 \mathrm{~cm}$. long; blades oblanceolate, somewhat tomentose, but green above, white-tomentose beneath; perianth orange or greenish orange. E. aureum Nutt., not M. E. Jones. E. flavum A. Nels., in part. Mountains: Colo.-Wyo. Subalp. Jl-Au.

9. E. polyphyllum Small. Stems scapiform, 1-1.5 dm. high; leaves basal, numerous, 1-3 cm. long; blades villous but green and glabrate above, densely 
and finely white-tomentose beneath, spatulate or oblanceolate; perianth deep yellow, sometimes tinged with red, appressed-silky; filaments villous below the middle; achenes sparingly villous at the tip, $2 \mathrm{~mm}$. long. Mountains: Alta.Mont.-Ore. Mont.-Subalp. Jl-Au.

10. E. xanthum Small. Stems scapiform, 3-5 cm. high, tomentose; leaves numerous, basal, 2-3 cm. long; blades spatulate, obtuse, somewhat floccose, but greenish above, densely villous-tomentose beneath; perianth yellow, becoming $8 \mathrm{~mm}$. long, silky-pubescent throughout; achenes about $5.5 \mathrm{~mm}$. long, pubescent at the apex. E. flavum A. Nels., in part. Mountain tops: Colo.-Wyo. Alp. $\mathrm{Au}$.

11. E. androsaceum Benth. Stems scapiform, 2-10 $\mathrm{cm}$. high, whitetomentose; leaves basal, short-petioled, 1-2 $\mathrm{cm}$. long; blades spatulate or oblanceolate, loosely tomentose, but soon glabrate above, densely white-tomentose beneath; perianth light yellow, turbinate, barely stipitate, $4-5 \mathrm{~mm}$. long; achenes glabrous. Hills and mountains: Alta.-Mont.-B.C. Submont.-Mont. Je$\mathrm{Au}$.

12. E. thymoides Benth. Stems $1-2 \mathrm{dm}$. high; leaves $4-8 \mathrm{~mm}$. long, linear, white-tomentose beneath, cinereous above; peduncles $3-6 \mathrm{~cm}$. long, slender, with a whorl of leaves below the middle; involucre solitary, turbinate, villous, about $5 \mathrm{~mm}$. long; perianth 3-4 mm. long, villous, pale yellow, turning purplish; lobes obovate; ovary pubescent. Rocky places: Wash.-Ida. Son. My-Jl.

13. E. caespitosum Nutt. Stems scapiform, $3-6 \mathrm{~cm}$. high, tomentulose or in age glabrate; leaves basal, oval or elliptic, short-petioled, $5-10 \mathrm{~cm}$. long, whitetomentose on both sides, more or less revolute on the margins; involuere turbinate, tomentose; tube about $3 \mathrm{~mm}$. long; lobes elliptic or linear; perianth yellow, turning purplish brown in age, villous below; achenes hirsute at the apex. Hills: Mont.-Wyo.-Colo.-Nev.-Ida. Mont.-Subalp. My-Je.

14. E. andinum Nutt. Stems scapiform, 2-4 cm. high, floccose; leaves numerous, basal, oblanceolate or spatulate, $1 \mathrm{~cm}$. long or less, loosely villousfloccose on both sides; involuere turbinate, tomentose; tube 2-2.5 mm. long; perianth turbinate, bright yellow. Dry hills: Mont.-Wyo.-Ida.-Nev. Mont. Je-Jl.

15. E. sphaerocephalum Dougl. Stem with decumbent cespitose branches, rising 1-2 dm. above ground; leaves and bracts verticillate, narrowly oblanceolate, $1-3 \mathrm{~cm}$. long, white-tomentose beneath, with more or less revolute margins, floccose or glabrate above; involucres solitary or 2 or 3 , turbinate, the lateral ones sometimes bracted; tube about $3 \mathrm{~mm}$. long; lobes oblong, fully as long; perianth-lobes oblanceolate. (?) E. cupreum Gand. Rocky hills: n Calif.Ida.-Wash. Son. Je-Jl.

16. E. fasciculifolium A. Nels. Leaves fasciculate or verticillate on the enlarged nodes, 1-3 cm. long, petioled, pale green and glabrate above, obscurely tomentose beneath; involucres in few-rayed umbels, campanulate; lobes ovateoblong, reflexed, as long as the tube, sparsely silky-villous; perianth slightly silky-villous; lobes broadly obovate. Dry mountain sides: Ida. Submont. Au.

17. E. pyrolaefolium Hook. Leaves clustered at the base, petioled; petioles long-villous; leaf-blades oval or broadly spatulate, sparingly villous or glabrous, coriaceous; scape $1 \mathrm{dm}$. long or less; umbels few-rayed; bracts mostly 2 or 3 ; involucres campanulate, villous, sinuately toothed; perianth white or pinkish, 4-5 mm. long, long-villous. Mountains: Wash.-Ida.-Calif. Mont. - Alp. Au-S.

18. E. compositum Dougl. Floral stems scapiform, 2-4 dm. high; leaves basal, 5-15 cm. long, petioled; blades $3-8 \mathrm{~cm}$. long, 3-4 cm. wide, loosely floccose above, densely white-tomentose beneath; inflorescence compound-umbellate; bracts linear or lanceolate; involucres broadly campanulate, villous or glabrous (var. leianthum Benth.), $4 \mathrm{~mm}$. high; perianth ochroleucous, $3-4 \mathrm{~mm}$. long, campanulate; achenes hairy above. Rocky soil and dry plains: Wash.-Ida.Calif. Son,-Submont. Ap-Au. 
19. E. Porteri Small, Floral stems scapiform, $2-7 \mathrm{~cm}$. high; leaves basal, numerous, petioled, 1-2 cm., slightly floccose when young, soon green and glabrous; blades suborbicular or rhomboidal; involucres solitary, glabrous, turbinate; perianth yellow, 6-8 $\mathrm{mm}$. long; outer lobes oblong-spatulate, the inner cuneatespatulate, slightly longer. Mountain slopes: Utah. Mont. Jl-S.

20. E. neglectum Greene. Floral stems scapiform, 1-3 dm. high; leaves petioled, $2-6 \mathrm{~cm}$. long; blades spatulate or elliptic or oval, loosely tomentose when young, glabrous or nearly so and green at maturity; involucres campanulate; tube $2-2.5 \mathrm{~mm}$. long; perianth about $8 \mathrm{~mm}$. long; lobes spatulate to oblongobovate, the inner longer than the outer; achenes about $5 \mathrm{~mm}$. long. $E$. umbelliferum Small. E. glaberrimum aureum Gand. Mountains: Wyo.-Colo.-Nev. Submont. -Subalp. Jl-Au.

21. E. biumbellatum Rydb. Flowering stems scapiform, $2-3 \mathrm{dm}$. high; leaves short-petioled, oblanceolate, finely tomentose on both sides when young, soon glabrate and green; involucres $2 \mathrm{~mm}$. long, slightly tomentose; perianth yellow, 4-6 mm. long; lobes elliptic, obtuse, the outer slightly longer. Hillsides: Utah. Submont. Jl-Au.

22. E. stellatum Benth. Flowering stems scapiform, 1-3 dm. high, sometimes with a single leaf; leaves petioled, 3-8 $\mathrm{cm}$. long; blades oval or roundedoval, obtuse, tomentose when young, glabrate in age above; involucres turbinate; tube $2-2.5 \mathrm{~mm}$. long; perianth $5-6 \mathrm{~mm}$. long; outer lobes oblong, the inner ones cuneate-spatulate; achenes $4 \mathrm{~mm}$. long, sparingly villous at the apex. $E$. croceum Small. Mountains: Wash.-Ida.-Colo.-Utah-Calif. Submont.Subalp. Jl-S.

23. E. umbellatum Torr. Flowering stems scapiform, 1-3 dm. high; leaves $2-6 \mathrm{~cm}$. long, petioled; blades rather thick, loosely white-floccose when young, in age glabrate above; involucres turbinate, tomentose; tube $3-4 \mathrm{~mm}$. long; divisions of the perianth spatulate, the inner somewhat longer. (?) $E$. marginale Gand. Mountains and dry valleys: Wyo.-Colo.-Calif.-Wash. Submont.-Subalp. Je-Au.

24. E. Rydbergii Greene. Flowering stem scapiform, $1.5-2.5 \mathrm{dm}$. long; leaves $2-3 \mathrm{~cm}$. long, petioled, rather persistently floccose above; involucres campanulate, tomentose; tube 3-4 $\mathrm{mm}$. long; outer lobes of the perianth elliptic, the inner longer, obovate; achenes villous at the apex. $R$. umbellatum cladophorum Gand. R. rhomboideum A. Nels. Loose soil and geyser basins: $\mathrm{n}$ Wyo. Mont. Au.

25. E. subalpinum Greene. Flowering stems scapiform, 1-3 dm. high; leaves $2-5 \mathrm{~cm}$. long, petioled, densely white-tomentose beneath; involucres tomentose, turbinate; tube $3 \mathrm{~mm}$. long; perianth in age turning rose-colored; lobes obovate, the inner longer; achenes about $5 \mathrm{~mm}$. long. $E$. umbellatum majus Benth. Sulphur Plant, Dry mountains: Alta,-Colo.-Nev.-B.C. Submont.-Mont. Je-S.

26. E. aridum Greene. Flowering stems scapiform, 1.5-2.5 dm. long, floccose; leaves $2-6 \mathrm{~cm}$. long, white-tomentose beneath; involucres tomentose, campanulate, $4 \mathrm{~mm}$. high; perianth purplish in age; outer lobes elliptic, the inner ones spatulate, somewhat longer; achenes villous at the apex. E. latum Small. Dry gravelly soil: Mont.-Colo--Nev.-Wash. Submont.-Mont. Je-Au.

27. E. heracleoides Nutt. Flowering stems $2-4 \mathrm{dm}$. high; leaves $5-10 \mathrm{~cm}$. long, short-petioled, loosely floccose above, densely white- or yellowish-tomentose beneath; inflorescence compound-umbellate; involucres campanulate, villous; tube $3 \mathrm{~mm}$. long; perianth $4 \mathrm{~mm}$. long; achenes hairy above. Dry slopes: Mont.-Wyo.-Utah-Nev.-B.C. Submont.-Mont.

28. E. lachnogynum Torr. Flowering stems scapiform, 1-3 dm. high; leaves crowded, basal, oblanceolate or oblong-oblanceolate, petioled, acute, silvery-silky above, grayish tomentose beneath, with revolute margins; bracts lanceolate or subulate, rarely verticillate; involucres silky-tomentose, 3-4 mm. high, campanulate; lobes oblong; perianth campanulate, tomentose, $3 \mathrm{~mm}$. high, yellow; fruit villous. Dry plains and cañons: Kans.-Colo.-Ariz.-Tex. Son.-Plain. Je-Au. 
29. E. Tetraneuris Small. Flowering stems scapiform, 1-1.5 dm. high; leaves basal, petioled, elliptic or oblong, 1-3 cm. long, acute, silky-strigose above, white-tomentose beneath, somewhat revolute-margined; involucres campanulate, $3.5 \mathrm{~mm}$. long, silky; perianth lemon-yellow, about $6 \mathrm{~mm}$. long, silky without; lobes oblong, the inner broader than the outer; ovary densely pubescent. Dry mesas: Colo. Plain-Submont. My.

30. E. longilobum M. E. Jones. Leaves tufted, petioled, densely villoustomentose; blades oblanceolate or spatulate, about $1 \mathrm{~cm}$. long, slightly revolute, obtuse; involucres $3-5$, densely villous, campanulate; lobes about $4 \mathrm{~mm}$. long, erect; perianth white-woolly on the outside, sparingly villous within, yellow, campanulate; lobes obovate-oblong, barely $3 \mathrm{~mm}$. long; achenes very woolly. Sand and dry places: Utah. Son.-Submont. Je-Jl.

31. E. Shockleyi S. Wats. Leaves spatulate, $8-10 \mathrm{~mm}$. long, rarely longer, densely tomentose, thick; bracts small; involucres densely white-tomentose, campanulate, about $4 \mathrm{~mm}$. long; perianth villous, white, with green midveins, 3-4 mm. long; lobes oblong; ovary villous. Mountains: Nev.-Utah. Son.Submont. My-Je.

32. E. pulvinatum Small. Leaves crowded, spatulate or oval, villoustomentose on both sides, slightly revolute, short-petioled; involucres turbinatecampanulate, 3-4 mm. high, white-tomentose; perianth oblong-campanulate, 2.5-3 mm. long, villous on both sides; lobes oblong, obtuse, erect, twice as long as the tube, the inner narrower; achenes $2 \mathrm{~mm}$. long, densely villous. Dry hills: Utah-Ariz. Submont. Je-Jl.

33. E. acaule Nutt. Leaves crowded, subsessile, white-tomentose on both sides, 3-6 $\mathrm{mm}$. long; involucres villous, turbinate, $3 \mathrm{~mm}$. long; lobes rounded, obtuse; perianth yellow, campanulate, 2-2.5 $\mathrm{mm}$. long, tomentose without, especially below; achenes villous. Dry hills: Wyo-Colo.-Nev.-Ida. Submont.-Son. Je-S.

34. E. proliferum T. \& G. Scape 1.5-3 dm. high, tomentose; leaves basal, petioled, white-tomentose on both sides; blades oval to nearly orbicular, 1-2 $\mathrm{cm}$. long; involucres campanulate, $2.5-3 \mathrm{~mm}$. long, pubescent; perianth white, turning purplish (a yellow-flowered form is also usually included, which may be distinct), about $4 \mathrm{~mm}$. long; outer lobes broadly obovate or oval, the inner narrowly cuneate. River flats: Wash.-Ida.-Calif. Son. Je.

35. E. orthocaulon Small. Scapes 1-3 dm. high; leaves clustered at the ends of short branches, petioled; blades oval, mostly $1-1.5 \mathrm{~cm}$. long, or rarely smaller, densely felty-tomentose on both sides; bracts subulate; involucres turbinate, floccose; lobes short, rounded; perianth ochroleucous, becoming 4.5-5 $\mathrm{mm}$. long; outer lobes suborbicular to ovate-orbicular, the inner cuneate, about as long as the outer and half as wide. Dry hills: Alta,-Colo.-Utah-Ida. Submont. Je-Au.

36. E. ovalifolium Nutt. Scape 1-1.5 dm. high; leaves numerous, clustered, petioled, white- or yellowish-tomentose, almost felty; blades usually about $1 \mathrm{~cm}$. long; involucres about $5 \mathrm{~mm}$. long, campanulate, villous-tomentose; perianth 4 $\mathrm{mm}$. long; outer lobes broadly oval or suborbicular, the inner cuneate, scarcely half as wide. $E$. dichroanthum Gand. Silver Plant. Dry plains and hills: Alta.-N.M.-Calif.-Wash. Son.-Subalp.

37. E. depressum (Blankinship) Rydb. Scape $1 \mathrm{dm}$. high or less; leaves densely clustered, petioled; blades 3-10 $\mathrm{mm}$. long, densely white-tomentose; involucres campanulate, about $4 \mathrm{~mm}$. long; lobes triangular; perianth 2.5-3.5 $\mathrm{mm}$. long; outer lobes oval, the inner cuneate, about half as broad. $E$. ovalifolium depressum Blankinship. E. rubidum frigidum Gand. Dry hills: Mont. -Ore. Mont.-Alp. My-Au.

38. E. ochroleucum Small. Scape 3-4 dm. high, loosely floccose; leaves densely crowded, petioled; blades 1-2 cm. long, obtuse, densely tomentose on both sides; involucres $5 \mathrm{~mm}$. long, campanulate, tomentose, ribbed; outer perianth-segments elliptic, the inner spatulate-oblong, slightly longer. Dry hills: Mont.-Colo.-Nev.-Ida. Submont. My-Jl. 
39. E. chrysops Rydb. Scape $2-5 \mathrm{~cm}$. high, floccose; leaves numerous, clustered, oblanceolate or spatulate, 1-2 cm. long, white-floccose on both sides; inflorescence 1-1.5 $\mathrm{cm}$. in diameter; involucres campanulate, membranous, 3 $\mathrm{mm}$. long; lobes as long as the tube; perianth $2.5-3 \mathrm{~mm}$. long, campanulate; lobes cuneate, slightly emarginate, the outer somewhat broader. High mountains: Ore.-w Ida. Submont.-Alp. Je-S.

40. E. Kingii T. \& G. Seape less than $1 \mathrm{dm}$. high; leaves crowded on the ends of the caudex, obovate or spatulate, $0.5-2 \mathrm{~cm}$. long, white-woolly; heads about $1 \mathrm{~cm}$. in diameter; bract lanceolate, membranous; involucre turbinatecampanulate, deeply 6-7-toothed, membranous; perianth about $3 \mathrm{~mm}$. long; lobes cuneate, emarginate. Mountains: Nev.-Ida. Mont. Jl-Au.

41. E. loganum A. Nels. Scape $5-20 \mathrm{~cm}$. high, white-tomentose; leaves basal, petioled, $2-5 \mathrm{~cm}$. long; blades oblanceolate or spatulate, densely whitetomentose on both sides, obtuse; involucre tubular-campanulate, 4-5 mm. long, white-villous; lobes short, ovate; perianth $2-2.5 \mathrm{~mm}$. long; lobes elliptic, subequal; filaments pubescent below; achenes glabrous. Mountains: n Utah. Submont.

42. E. chrysocephalum A. Gray. Scape 4-15 $\mathrm{cm}$. high; leaves petioled, $3-10 \mathrm{~cm}$. long; involucre turbinate, ribbed, $3 \mathrm{~mm}$. long; perianth $2.5-3 \mathrm{~mm}$. long, campanulate; lobes obovate-oblong, the outer usually slightly longer. E. latifolium (T. \& G.) A. Nels. Dry hills: Neb.-Colo.-Utah-Ida. PlainMont. Jl-Au.

43. E. medium Rydb. Scape 1-2 dm. high; leaves narrowly linear, oblanceolate, 3-10 $\mathrm{cm}$. long, densely white-tomentose beneath, with somewhat revolute margins, loosely floceose and greenish above; inflorescence capitate or subumbellately branched, with a sessile involucre in each fork and small heads on the branches; bracts ovate, acuminate, membranous-margined; involucres turbinate, $4 \mathrm{~mm}$. high, loosely floccose or glabrate; perianth golden yellow, 4 $\mathrm{mm}$. long, glabrous; segments oblong-obovate. Mountains: Utah. Submont.Mont. J1-Au.

44. E. Brandegei Rydb. Scape 1-2 dm. high, floceose; leaves narrowly oblanceolate, white-tomentose beneath, floccose above; inflorescence capitate; bracts subulate, occasionally one of them elongated; involucres turbinate, about $4 \mathrm{~mm}$. long, slightly floceose; lobes lanceolate; perianth rose-colored, $3 \mathrm{~mm}$. long; segments oblong, truncate or emarginate; fruit glabrous. Cañons: Colo. Son. S.

45. E. depauperatum Small. Scapes erect, 5-10 cm. high; leaves crowded, petioled; blades thinnish, linear-spatulate, $2-6 \mathrm{~cm}$. long, revolute-margined, glabrous above, tomentose beneath; bracts scale-like, lanceolate-subulate; involucres $3.5-4.5 \mathrm{~mm}$. high, densely tomentose; lobes about half as long as the angled tube; perianth glabrous; lobes unequal, the outer oblong or obovate or cuneate, the inner cuneate and narrower. Dry hills: (Black Hills) S.D. Submont. Je-Au.

46. E. coloradense Small. Scape tomentose, about $1 \mathrm{dm}$. high; leaves crowded, petioled; blades narrowly spatulate to linear-spatulate, $2-5 \mathrm{~cm}$. long, slightly revolute; bracts subulate; involucres campanulate, about $5 \mathrm{~mm}$. long, thinly woolly without; lobes suborbicular or rarely reniform; perianth-lobes blunt, the outer ovate or orbicular-ovate, the inner smaller, oblong. Mountains: Colo. Mont. Au-S.

47. E. pauciflorum Pursh. Scape $1 \mathrm{dm}$. high or less; leaves crowded, short-petioled, 3-8 cm. long; blades linear or linear-oblanceolate, revolutemargined, white-tomentose beneath; bracts lance-subulate, sometimes membranous-margined; involucres 4-5 mm. high; lobes petaloid, elliptic; perianthlobes elliptic, nearly equal. Sandy soil and dry places: Wyo.-Colo.-S.D. Submont.-Mont. J1-S.

48. E. mancum Rydb. Pulvinate perennial; scape 2-4 cm. long, slender, floccose; leaves narrowly spatulate, densely white-tomentose on both sides, 1-1.5 $\mathrm{cm}$. long; inflorescence capitate; head 5-8 mm. in diameter, sometimes with only 1 involucre; bracts ovate, membranous, floccose; involucres $2.5 \mathrm{~mm}$. 
long, floccose; teeth triangular; perianth pinkish, $1.5 \mathrm{~mm}$. long; segments oblong; fruit glabrous. Hills: Mont. Submont. Je-Jl.

49. E. multiceps Nees. Scape $5-15 \mathrm{~cm}$. long, white-tomentose; leaves slender-petioled, $3-8 \mathrm{~cm}$. long, densely white-tomentose on both sides, with appressed tomentum; blades from linear-oblanceolate to spatulate; inflorescence capitate or rarely umbellate; bracts subulate, or sometimes one or more of them elongate and foliaceous; involucres tubular-campanulate, tomentose, 3-4 mm. long; lobes triangular; perianth-lobes oblong or cuneate-oblong, rounded. $E$. gnaphaloides Benth. Dry plains and "bad-lands": Sask.-N.D.-Neb.-Colo. -Ida. Plain-Submont. Jl-Au.

50. E. villiflorum A. Gray. Scape $2-4 \mathrm{~cm}$. long, silky-tomentose; leaves crowded at the ends of the short branches, oblanceolate or spatulate, acute, white-silky on both sides, revolute-margined, 6-10 mm. long; bracts linear or subulate; involucres campanulate, 3-4 $\mathrm{mm}$. long; lobes 6-8, oblong; perianth campanulate, white, sericeous without; lobes oblong, subequal. Arid places: s Utah. Son.

51. E. elatum Dougl. Stem scapiform, branched, 3-10 dm. high, glabrous; leaves basal, long-petioled, 1-2 dm. long; petioles and midvein hirsute, ferruginous; blades ovate, oblong-ovate, or lanceolate, cordate, truncate, or cuneate at the base, softly villous-pubescent on both sides, almost velutinous beneath, 7-15 $\mathrm{cm}$. long; involucres in small capitate clusters at the ends of the branches, or sometimes solitary in the forks; involucres eampanulate, $3 \mathrm{~mm}$. long, repandly 5-dentate; perianth campanulate, $3 \mathrm{~mm}$. long, pubescent below; lobes oval. Dry gravelly soil: Wash.-Ida.-Nev.-Calif. Son. Jl-Au.

52. E. polifolium Benth. Stem 3-6 dm. high, more or less tomentulose; leaves fasciculate, on short lateral branches, oblanceolate, 1-2 cm. long, sparingly villous above, white-tomentose beneath, slightly revolute-margined; peduncles 1-1.5 dm. long, tomentulose; involucres campanulate, pubescent, about $3 \mathrm{~mm}$. long, with 5 broadly triangular teeth; perianth campanulate, pubescent at the base and along the midveins, white or pinkish; lobes oval. Dry places: Calif,Utah-Ariz. L. Son. My-Au.

53. E. niveum Dougl. Stems 2-4 dm. high, leafy below; leaves ovate or oblong, white-tomentose; inflorescence tomentose, di- or tri-chotomous; bracts foliaceous, oblong; involucres sessile, villous, turbinate; lobes triangular, acute; perianth glabrous, 3-4 mm. long; inner perianth-segments cuneate. Hills and plains: Ore.-Ida.-B.C. Son.-Submont. My-Au.

54. E. dichotomum Dougl. Stem 2-3 dm. high, trichotomous; ultimate branches short; leaves near the base, petioled, 2-8 cm. long; blades spatulate or elliptic, white-floccose on both sides, or glabrate above; branches short; bracts minute, subulate; involucres cylindro-campanulate; lobes triangular, obtuse; perianth glabrous, $3 \mathrm{~mm}$., or in fruit, $5-6 \mathrm{~mm}$. long; inner lobes cuneate or spatulate. Dry places: Wash.-Mont.-Ida. Son.-Submont. Je-Jl.

55. E. lachnostegium (Benth.) Rydb. Seape floccose, 1.5-3 dm. high, trichotomously branched; leaves petioled, $2-4 \mathrm{~cm}$. long; blades elliptic or spatulate, white-tomentose on both sides; bracts minute, subulate; involucral lobes triangular; perianth white or straw-colored, turning pink, glabrous, $3 \mathrm{~mm}$. long, or in fruit longer; inner lobes oblong, longer than the outer. E. strictum lachnostegium Benth. Dry benches and hills: Mont.-Ida. Submont. Jl-S.

56. E. strictum Benth. Stem about $3 \mathrm{dm}$. high; leaves near the base, petioled; blades oval, elliptic or spatulate, $1-4 \mathrm{~cm}$. long, glabrate in age above, densely white-tomentose beneath; inflorescence mostly trichotomous; involucres 3-4 mm. long, almost columnar, angled; lobes lanceolate; perianth white, glabrous, $3.5-4 \mathrm{~mm}$. long; segments unequal, the outer broadly oval, the inner narrower, cuneate-elliptic, slightly longer. Hillsides: Ore.-Ida.-Wash. Son. Je-Jl.

57. E. aureum M. E. Jones. Shrubby, 3-10 dm. high; leaves short-petiioled; blades $1.5-3 \mathrm{~cm}$. long, densely woolly-tomentose beneath; peduncles $3-6$ $\mathrm{cm}$. long, loosely tomentose; inflorescence with spreading branches; involucres 
sessile, about $2 \mathrm{~mm}$. long; perianth $2 \mathrm{~mm}$. long; outer lobes oval, obtuse, the inner elliptic or oblong. E. fruticosum A. Nels. Sand: s Utah. Son. S.

58. E. idahoense Rydb. Shrub, 4-6 dm. high; branches tomentose, erect; leaves $2-3 \mathrm{~cm}$. long, short-petioled; blades oblanceolate, white-tomentose beneath, loosely floccose and glabrate above; involucres in the lower forks peduncled, turbinate, about $3 \mathrm{~mm}$. long; perianth about $2 \mathrm{~mm}$. long, glabrous. Hills: Ida. Submont. Jl.

59. E. orendense A. Nels. Stems white-tomentose, 7-15 cm. long; leaves numerous, 1-3 cm. long, petioled, white-tomentose on both sides; lower involucres with peduncles nearly $1 \mathrm{~cm}$. long, erect; involucres turbinate, about 3 $\mathrm{mm}$. long; perianth $2 \mathrm{~mm}$. long; lobes oblong, obtuse. Dry hills: Wyo. Submont. Je-Au.

60. E. lagopus Rydb. Stems scape-like, about $3 \mathrm{dm}$. high, floccose, trichotomous; leaves crowded on the ends of the branches of the caudex, spatulate, 2-3.5 $\mathrm{cm}$. long, tomentose on both sides; bracts subulate; involucres turbinate, tomentose, 3-3.5 mm. long, those of the lower forks peduncled; lobes triangular; perianth golden yellow, $2.5 \mathrm{~mm}$. long, glabrous; segments elliptic, the outer slightly larger; filaments pubescent below; achenes glabrous. Plains: Wyo. Plain.

61. E. Thompsonae S. Wats. Caudex woody, eespitose; branches tomentose; leaves long-petioled; blades broadly oblong, 3-4 cm. long, acute at each end, glabrous above, white-tomentose beneath; peduncle $2-3 \mathrm{dm}$. high, glabrous; involucres sessile, strongly 5 -angled, $3-4 \mathrm{~mm}$. long, glabrous; lobes short-ovate; perianth glabrous, $2-3 \mathrm{~mm}$. long; lobes subequal, oval. Sand eliffs: s Utah. Son.

62. E. campanulatum Nutt. Branches short; peduncle 1-3 dm. long; leaves basal, petioled; blades tomentose on both sides, but less densely so above; inflorescence with ascending branches; involucres campanulate, $2-2.5 \mathrm{~mm}$. long, glabrous or nearly so; perianth about $2 \mathrm{~mm}$. long. $E$. sabulosum M. E. Jones. Dry hills and plains: Neb.-Colo--Utah. Plain-Submont. Je-Au.

E. campanulatum $\times$ multiceps. Like E. multiceps in habit, pubescence, and leafform, but the panicle is tristichous-cymose as in E. campanulatum and the flowers yellow. Neb.

63. E. brevicaule Nutt. Leafy branches short; seapes 1-3 dm. high, soon. glabrous; leaf-blades 4-7 $\mathrm{cm}$. long, densely white-tomentose beneath, loosely floccose and greener above; involucres about $3 \mathrm{~mm}$. long, campanulate, glabrous, angled; lobes ovate, acutish; perianth campanulate, $2-2.5 \mathrm{~mm}$. long, glabrous; lobes oval, obtuse. Dry hills and plains: Mont.-Colo.-Utah. Plain-Submont. Je-S.

E. chrysosepalum $\times$ brevicaule. Like $E$. brevicaule, but the leaves broader and the branches of the inflorescence bearing capitate clusters, with somewhat tomentose involucres. Utah.

64. E. micranthum Nutt. Scape 1-3 dm. high; leaves 4-8 $\mathrm{cm}$. long, densely white-tomentose beneath, less densely so above; involucres turbinatecampanulate, $3 \mathrm{~mm}$. long; lobes ovate, acutish or obtuse; perianth $2 \mathrm{~mm}$. long; lobes oval, obtuse. Hillsides: Utah-Ida. Submont. Je-Jl.

E. medium $\times$ micranthum. The branches of the inflorescence bearing capitate clusters of more tomentose involucres. Utah.

F. chrysocephalum $\times$ micranthum. Like the last hybrid, but leaves rather densely tomentose above. Utah.

65. E. contortum Small. Scape 1-2 dm. high, tomentulose; leaves thick, clavate, about $1 \mathrm{~cm}$. long, strongly revolute, tomentose on both sides; involucres turbinate, glabrous, $2 \mathrm{~mm}$. long; lobes ovate; perianth $2-2.5 \mathrm{~mm}$. long; lobes essentially equal, oblong-cuneate; fruit glabrous. Dry hills: w Colo. Son. My.

66. E. spathulatum A. Gray. Scape 2-3 dm. high; leaves all near the base, petioled; blades spatulate or oblanceolate, densely white-tomentose on 
both sides, 2-5 cm. long; involucres tomentose, 3-4 mm. long; lobes ovate; perianth white, glabrous, $3 \mathrm{~mm}$. long; lobes oblong, obtuse, unequal; fruit scabrous on the angles. (?) E. Kearneyi Tidest. Dry valleys: Utah. Son. Jl.

67. E. spathuliforme Rydb. Perennial, shrubby at the base; scape 2-3 $\mathrm{dm}$. high; leaves all near the base, petioled; blades elliptic to spatulate, $2-3.5 \mathrm{~cm}$. long, white-tomentose on both sides, densely so beneath; involucres glabrous, turbinate, $3 \mathrm{~mm}$. long; lobes rounded, scarious and slightly floccose on the margins; perianth white, glabrous; segments equal, obovate. Sandy washes: Utah. Son. Au.

68. E. Ostlundi M. E. Jones. Scape about $2 \mathrm{dm}$. high; leaves all near the base, petioled; blades elliptic, $1-1.5 \mathrm{~cm}$. long, floccose above, white-tomentose beneath; involucres turbinate, $2.5 \mathrm{~mm}$. long, glabrous; lobes oval, scariousmargined; perianth white or pink; segments obovate. Clay banks: Utah. Son. $\mathrm{Je}-\mathrm{Au}$.

69. E. lonchophyllum T. \& G. Caudex with leafy branches, $1 \mathrm{dm}$. long or more; leaf-blades $6-10 \mathrm{~cm}$. long, densely white-tomentose beneath, loosely floccose or glabrate above; inflorescence elongate, 2-3 dm. long, glabrous; involucres $3 \mathrm{~mm}$. long, glabrous, turbinate; perianth-lobes oval or obovate, round. E. wasatchense M. E. Jones. Plains and hills: Colo.-N.M.-Utah. Son.Submont. Jl.

70. E. nudicaule (Torr.) Small. Stem scapiform, 1-2 dm. high; leaves short-petioled; blades 3-5 cm. long, white-tomentose beneath, floccose or sometimes glabrate above, mostly revolute; involucres campanulate, $3-4 \mathrm{~mm}$. high, glabrous; perianth-lobes cuneate-obovate. E. effusum nudicaule Torr. Plains and hills: Kans.-Tex.-Utah. Son.-Submont. J-Au.

71. E. scoparium Small. Stem scapiform, 1-2 dm. high, glabrous; leaves petioled; blades linear to linear-spatulate, $2-5 \mathrm{~cm}$. long, revolute, densely whitelanate beneath, floccose above; involucres $2.5-3 \mathrm{~mm}$. long, and almost as wide; lobes broad; perianth becoming $3.5-4 \mathrm{~mm}$. long; lobes oblong or obovate. Plains and valleys: Colo.-N.M. Submont. JI-S.

72. E. grangerense M. E. Jones. Stem scapiform, 1-3 dm. high; leaves petioled; blades revolute, densely white-tomentose beneath, permanently whitefloceose above, 4-6 cm. long, 2-4 mm. wide; involueres turbinate, $3 \mathrm{~mm}$. long, glabrous; lobes triangular, acute; perianth campanulate, glabrous, $2 \mathrm{~mm}$. long; lobes elliptic, obtuse. E. confertifolium Stansburyi Benth. Barren hills: Wyo. -Utah. Son.

73. E. tristichum Small. Stem scapiform, 1-3 dm. high; leaves nearly basal, short-petioled; blades $2-7 \mathrm{~cm}$. long, floccose above, densely white-tomentose beneath; involucres 2.5-3 $\mathrm{mm}$. long; lobes broad, rounded, much shorter than the tube; perianth becoming $4 \mathrm{~mm}$. long; lobes obovate or oblong-obovate. Plains and valleys: Colo.-N.M. Submont. Je-S.

74. E. salicinum Greene. Stem scapiform, 3-4 dm. high; leaves near the base, short-petioled; blades about $4 \mathrm{~cm}$. long, densely white-tomentose beneath, loosely floccose and glabrate above, 3-4 dm. long; involucres broadly turbinatecampanulate, $3 \mathrm{~mm}$. long, with 5 rounded teeth; perianth about $2 \mathrm{~mm}$. long; lobes oval, obtuse. Cañons: Colo. Submont. Jl.

75. E. Fendlerianum (Benth.) Small. Low shrub, 1-5 dm. high, with tomentose branches; leaves short-petioled; blades oval to oblong, $2-4 \mathrm{~cm}$. long, 5-18 mm. wide, densely white-tomentose beneath, loosely floccose above; infloreseence $0.5-2 \mathrm{dm}$. high, floccose when young, soon glabrous, with ascending branches; involucres deeply-turbinate, sparingly floccose or glabrate; lobes rounded, scarious-margined; perianth campanulate, $3.5-4 \mathrm{~mm}$. long; lobes unequal, the outer oval, slightly longer than the elliptic inner ones. E. microthecum Fendlerianum Benth. Plains: Colo.-N.M. Son. Au-O.

76. E. divergens Small. Low shrub, 3-6 dm. high, with densely whitetomentose branches; leaves short-petioled; blades oval or elliptic, 1-2.5 $\mathrm{cm}$. long, densely white-tomentose beneath, loosely floccose above; inflorescence $1-5 \mathrm{~cm}$. 
high; involucres 2-2.5 mm. long, campanulate, tomentose; lobes rounded; perianth campanulate, $2-2.5 \mathrm{~mm}$. long; lobes unequal, the outer obovate, truncate or emarginate, the inner elliptic. E. corymbosus divaricatus Torr. Plains: Colo. -N.M.-Ariz.-Nev. Son. Jl-Au.

77. E. Jonesii S. Wats. Shrubby; stem 3-8 dm. high, tomentose; leaves scattered, petioled; blades $1-3 \mathrm{~cm}$. long, densely white-tomentose beneath, floccose above; inflorescence with ascending branches; the lowermost bracts sometimes foliaceous; involucres all sessile, or rarely the lower peduncled, tomentosevillous, about $3 \mathrm{~mm}$. long; perianth eampanulate, about $2.5 \mathrm{~mm}$. long; lobes obovate. Arid regions: Ariz.-Utah. Son.-Submont. J1-Au.

78. E. corymbosum Benth. Shrub, 3-10 dm. high, with tomentose branches; leaf-blades oval, $2-3 \mathrm{~cm}$. long, 1-1.5 $\mathrm{cm}$. wide, densely white-tomentose beneath, loosely floccose above; inflorescence $0.5-2 \mathrm{dm}$. high, with ascending branches; involucres sessile, tomentose, $2-2.5 \mathrm{~mm}$. long, campanulate; perianth about $3 \mathrm{~mm}$. long, eampanulate; lobes elliptic, nearly equal. Dry plains: Colo. -Utah-N.M. Son. Je-S.

79. E. salinum A. Nels. Low shrub, with shreddy bark; branches whitetomentose, leafy; leaves narrowly lanceolate, mostly erect, white-tomentose beneath, floccose above, $2-3 \mathrm{~cm}$. long; inflorescence about $1 \mathrm{dm}$. high, flattopped, with short, spreading branches; involucres turbinate; lobes acute; perianth-lobes obtuse or apiculate, the outer oblong-elliptic, the inner longer, obovate. Saline plains: Wyo.-Colo. Plain-Submont. Je-Jl.

80. E. effusum Nutt. Shrub, $2-5 \mathrm{dm}$. high; leaves short-petioled; blades linear-oblanceolate, $2-4 \mathrm{~cm}$. long, 4-8 mm. wide, white-tomentose beneath, floccose above, 3-10 cm. long, tomentulose; involucres short-peduncled, or the upper sessile, $2 \mathrm{~mm}$. long, tomentulose; lobes ovate; perianth campanulate, $2 \mathrm{~mm}$. long; outer lobes obovate, the inner elliptic. Dry plains and hills: Neb.-N.M.Utah-Mont. Son.-Plain-Submont. J1-S.

81. E. microthecum Nutt. Low shrub, 2-6 dm. high; leaves scattered, short-petioled; blades linear, oblong, or oblanceolate, densely white-tomentose beneath, floccose above, $1-2 \mathrm{~cm}$. long, $3-5 \mathrm{~mm}$. wide; inflorescence $2-7 \mathrm{~cm}$. long, floccose, small; branches short, spreading or ascending-spreading; involucres, at least those of the lower forks, peduncled, tomentulose, turbinate, $2.5 \mathrm{~mm}$. long; lobes rounded, scarious-margined; perianth turbinate, $2.5-3 \mathrm{~mm}$. long; lobes obovate, rounded, truncate or even emarginate. E. myrianthum, E. intricatum, $E$. heliochrysoides, and E. sarothriforme Gand. Plains and table-lands: Mont.Neb.-Colo.-Ariz.-Calif.-Wash. Son.-Plain-Mont. Je-S.

82. E. nebraskense Rydb. A low shrub, 2-3 dm. high; branches and inflorescence tomentose; leaves short-petioled, oblanceolate, $2-3 \mathrm{~cm}$. long, densely white-tomentose on both sides; inflorescence less than $1 \mathrm{dm}$. high, trichotomously or verticillately branched; branches short, more or less spreading; involucres tomentose, $2-3 \mathrm{~cm}$. high, turbinate; lobes triangular; perianth rosecolored, glabrous or slightly pubescent, $2.5 \mathrm{~mm}$. long; segments oblong to obovate; fruit glabrous. Plains: w Neb. Jl.

83. E. Simpsoni Benth. Low shrub, 1-4 dm. high; leaves scattered; blades 1-2 $\mathrm{cm}$. long, 1-2 $\mathrm{mm}$. wide, densely white-tomentose beneath; inflorescence $2-5 \mathrm{~cm}$. long, floccose, with ascending or spreading branches; involucres of the lower forks short-peduncled, $2.5 \mathrm{~mm}$. long, turbinate, slightly floccose; lobes ovate; perianth turbinate, $2 \mathrm{~mm}$. long; outer lobes obovate, rounded or emarginate, the inner somewhat narrower. E. effusum foliosum Torr. (?) E. effusum leptophyllum Torr. Dry plains: Tex.-Colo.-Utah-Ariz. Son. J-Au.

84. E. Mearnsii Parry. Depressed undershrub, with lanate twigs; leaves crowded, more or less fascicled, linear, $5-10 \mathrm{~mm}$. long, revolute, tomentose beneath, glabrous above, acute; inflorescence of few involucres, about $1 \mathrm{~cm}$. long; involucres short-peduncled, $3 \mathrm{~mm}$. high, slightly tomentose or glabrate; lobes rounded; perianth turbinate, $2.5-3 \mathrm{~mm}$. high; lobes obovate or spatulate, the outer broader. Rocks: Ariz.-Utah. Son. O. 
85. E. bicolor M. E. Jones. Depressed undershrub, tufted, $1 \mathrm{dm}$. high or less; leaves linear, revolute, $10-15 \mathrm{~mm}$. long, about $2 \mathrm{~mm}$. wide; inflorescence $1-3 \mathrm{~cm}$. long, sometimes subcapitate, with few involucres, which are turbinate, tomentose, $3 \mathrm{~mm}$. long; lobes rounded, scarious-margined; perianth $4 \mathrm{~mm}$. long, campanulate; outer lobes broadly obovate or suborbicular, the inner elliptic. $E$. Batemani and (?) E. friscanum M. E. Jones. Clayey hills: Utah. Son. My-Je.

86. E. clavellatum Small. Undershrub, with a thick woody caudex and thinly tomentose branches; leaves fleshy, strongly revolute, cylindric-clavate, 1-1.5 cm. long, glabrous without; involucres campanulate, $4 \mathrm{~mm}$. long, ribangled, glabrate; lobes acute, erect; perianth $3.5 \mathrm{~mm}$. long, urn-shaped; segments saccate at the base, the outer fiddle-shaped, the inner linear-cuneate. Rocky hills: se Utah. Son. Jl.

87. E. sulcatum S. Wats. Low shrub, $2-3 \mathrm{dm}$. high, intricately branched, with tomentose branches; leaves petioled; blades narrowly oblanceolate, $1 \mathrm{~cm}$. long or less, tomentose on both sides, less so above, rather thin; inflorescence about $1 \mathrm{~cm}$. long, its divaricate branches deeply sulcate, glabrate; involucres sessile, 1-1.5 mm. long, glabrous. Dry hills: sw Utah-Nev. Son. Ap-My.

88. E. annuum Nutt. Stem simple, leafy, 3-10 dm. high, floceose throughout; leaves petioled; blades oblong or oblanceolate, obtuse, slightly revolute, densely white-tomentose beneath, floccose above, $3-5 \mathrm{~cm}$. long; inflorescence cymose, flat-topped, somewhat irregularly branched; involucres turbinate, 2-3 $\mathrm{mm}$. long, white-tomentose; teeth short, obtuse; perianth white or whitish, 1.5-2 $\mathrm{mm}$. long, campanulate; lobes obovate. E. Hitchcockii Gand. Sandy places: S.D.-Tex.-Mex.-Mont. Submont.-Plain. Je-O.

89. E. racemosum Nutt. Scapose perennial; scape more or less branched, white-tomentose, 3-8 dm. high; leaves basal, long-petioled; blades ovate or oval, densely white-tomentose beneath, floccose above, $2-6 \mathrm{~cm}$. long; involucres sessile, 3-4 mm. long, white-tomentose; perianth pink or white, turbinate, $3 \mathrm{~mm}$., but accrescent, becoming 4-6 mm. long; lobes obovate. Dry plains and hills: Colo. -Tex,-Ariz.-Utah. Son.-Submont. Jl-S.

90. E. Wrightii Torr. Shrub or undershrub, 3-6 dm. high, with tomentose short branches; leaves scattered, short-petioled or subsessile; blades whitetomentose on both sides, 1-2 cm. long; inflorescence cymose, irregularly branched, 2-3 dm. long; involucres elongate-turbinate, 2-3 mm. long, tomentose; lobes ovate or lanceolate, acute; perianth 3-4 mm. long; outer lobes suborbicular or broadly oval; the inner oval or elliptic. Dry plains: Colo.-Tex.-Calif.; Mex. Son. Je-N.

91. E. leptocladon Torr. Shrubby; stems several, $3-8 \mathrm{dm}$. high, diffusely branched, white-floccose; leaves short-petioled, 2-4 cm. long, white-tomentose on both sides; margin slightly revolute; inflorescence much branched, lower nodes flowerless; involucres near the ends, sessile and secund, about $2 \mathrm{~mm}$. long, tomentose; perianth glabrous, campanulate, $2 \mathrm{~mm}$. long; divisions broadly oval, white, with rose-colored base. E. ramosissimum Eastw. E. Eastwoodiae M. E. Jones. Sandy mesas: se Utah-nw N.M. Son. Jl-Au.

92. E. vimineum Dougl. Branched annual; leaves basal, slender-petioled; blades orbicular or subreniform, densely white-tomentose beneath, floccose above, 1-2 cm. long; inflorescence 1-3 dm. high, slightly floccose when young, snon glabrate; branches glabrous; involucres about $3 \mathrm{~mm}$. long, glabrous; lobes very short; perianth $1.5-2 \mathrm{~mm}$. long, campanulate, glabrous, pink or white. $E$. shoshonense A. Nels. Hills: Wash.-Ida.-Calif. Son. My-S.

93. E. Baileyi S. Wats. Branched annual, 2-3 dm. high; leaves basal, petioled; blades orbicular or broadly ovate, $1-2 \mathrm{~cm}$. long, floccose-tomentose on both sides; inflorescence glabrous and glaucous; involucres sessile, glabrous, oblong-campanulate; teeth obtuse; perianth glabrous, pinkish-white, 1-1.5 $\mathrm{mm}$. long; lobes obovate or spatulate. Dry hills: Wash.-Ida.-Ariz.-se Calif. Son. My-Au.

94. E. densum Greene. Diffusely branched annual, 1-2 dm. high; leaves basal, petioled; blades ovate or oblong, about $1 \mathrm{~cm}$. long, white-tomentose; 
inflorescence floccose; involucres sessile, 1.5-2 mm. long, glabrate; lobes oblong; perianth rose-colored, campanulate, $1.5 \mathrm{~mm}$. long. Dry mountains: N.M.Utah-Nev.-Ariz. Son. My-S.

95. E. nidularium Coville. Profusely branched annual; leaves basal, slender-petioled; blades orbicular, often subcordate at the base or subreniform, floccose on both sides; inflorescence 1-2 dm. high; involucres turbinate, 1-15 mm. long, sessile; perianth yellowish, turbinate, about $2 \mathrm{~mm}$. long. (?) $E$. nummulare M, E. Jones. Sandy or stony hills: Ida.-w Ariz.-se Calif. Son. My-Au.

96. E. Plumatella Dur. \& Hilg. Divaricately branched annual; leaves clustered near the base, tomentose, short-petioled, spatulate; inflorescence 2-4 $\mathrm{dm}$. long, tomentose; bracts subulate: involucres obconic, glabrous, $2.5 \mathrm{~mm}$. long; lobes rounded, ciliolate; perianth white, about $2 \mathrm{~mm}$. long, glabrous; segments oval. Desert regions: s Utah-s Calif. L. Son.

97. E. tenellum Torr. Scapose, cespitose perennial, with woody caudex; leaves basal, petioled; blades orbicular or ovate, densely and finely white-tomentose on both sides, $0.5-1 \mathrm{~cm}$. long; scapes 2-4 dm. high, glabrous; peduncles slender, erect, glabrous, 1-2 cm. long; involucres turbinate, glabrous, $3 \mathrm{~mm}$. long; lobes triangular-ovate; perianth white, $2.5-3 \mathrm{~mm}$. long; outer lobes broadly obovate, the inner oblong or cuneate, both emarginate. Arid or rocky places: Tex.-Colo.-Utah-N.M.; n Mex. Son. Ap-N.

98. E. Hookeri S. Wats. Scape $2-4 \mathrm{dm}$. high; leaf-blades orbicular, $2-6$ $\mathrm{cm}$. broad; involucres nearly $2 \mathrm{~mm}$. long; lobes broadly ovate; perianth $1.5-2$ $\mathrm{mm}$. long; lobes oblong, much smaller than the outer. Cañons and sandy places: Nev.-Wyo.-Utah-Ariz. Son. Au-S.

99. E. deflexum Torr. Scape glabrous, 2-4 dm. high; blades orbicular, subcordate at the base, $1-3 \mathrm{~cm}$. broad; involucres campanulate, glabrous, 1.5 $\mathrm{mm}$. long; lobes rounded-ovate; perianth white, 1.5-2 mm. long; inner lobes much smaller than the outer, ovate or lance-ovate. Arid regions: Ariz. - s Utah-Calif. L. Son. My-S.

100. E. cernuum Nutt. Scape glabrous, $2-4 \mathrm{dm}$. high; leaf-blades orbicular or oval, $1-2 \mathrm{~cm}$. broad; peduncles $0.5-2 \mathrm{~cm}$. long; involueres glabrous, campanulate, $1.5-2 \mathrm{~mm}$. long; lobes ovate, obtuse; perianth white or pinkish, about $2 \mathrm{~mm}$. long; inner lobes elliptic-cuneate, narrower, but almost as long as the outer. "Bad-lands," hills, and cañons: Sask.-Neb.-N.M.-Ariz.-Ida. -Alta. Plain-Mont. Je-S.

101. E. Wetherillii Eastw. Scape 1-2 dm. high, glabrous; leaf-blades orbicular, obtuse or obliquely truncate at the base, about $1 \mathrm{~cm}$. wide; peduncles reflexed or divaricate, about $5 \mathrm{~mm}$. long; lobes of the involucres 4 , obtuse; outer lobes of the perianth obovate, the inner oblong, slightly longer. Sandstone cliffs: N.M.-Utah. Son.

102. E. pusillum T. \& G. Scape $1-3 \mathrm{dm}$. high, glabrous; blades suborbicular, 1-3 cm. broad, slightly floccose, but green above; peduncles $1-4 \mathrm{~cm}$. long, erect; involucres hemispheric, glandular-puberulent, 3-4 mm. broad; lobes rounded-ovate; perianth yellow, campanulate, $1-1.5 \mathrm{~mm}$. long, glabrous or slightly puberulent; segments elliptic. Hills and washes: Calif.-s Utah-Ariz. Son. Ap-Au.

103. E. rotundifolium Benth. Scape $1-3 \mathrm{dm}$. high, glabrous; leaf-blades orbicular, 1-2 $\mathrm{cm}$. broad; peduncles $4-20 \mathrm{~mm}$. long; perianth white, glabrous; inner lobes narrowly oblong. Dry plains: Tex.-Colo.-N.M.-Mex. L. \& U. Son. Ap-O.

104. E. insigne S. Wats. Scape stout, 3-10 dm, high; leaf-blades reniform, 2-4 cm. broad; involucres somewhat angled, $2 \mathrm{~mm}$. long, glabrous; lobes rounded; perianth rose-colored, nearly $2 \mathrm{~mm}$. long. Hills: s Utah-Nev. L. Son. Je.

105. E. turbinatum Small. Seape erect, 2-4 dm. high; leaf-blades suborbicular or reniform, 1-4 cm. broad, deeply cordate at the base; involucres 2 $\mathrm{mm}$. long; lobes broadly ovate, obtuse, scarious-margined; perianth pink, $2 \mathrm{~mm}$. long. Mesas: Ariz. $\rightarrow$ Utah. L. Son. Mr-My. 
106. E. Thomasii Torr. Scape 1-2 dm. high; leaf-blades orbicular or rounded-ovate, $0.5-2 \mathrm{~cm}$. long; peduncles capillary, 6-12 $\mathrm{mm}$. long; involucres glabrous, turbinate; lobes rounded; outer perianth-lobes oval or elliptic, shorter than the elliptic or oblong inner ones. Desert regions: Ariz. $\rightarrow$ Utah-Calif.; n Mex. L. Son. Mr-Jl.

107. E. Gordonii Benth. Scape 2-4 dm. high, slender, glabrous; leafblades coriaceous, glabrous, orbicular, $1-3 \mathrm{~cm}$. broad; peduncles $1-3 \mathrm{~cm}$. long, erect; involucres turbinate-campanulate, about $1 \mathrm{~mm}$. long, glabrous; lobes rounded; perianth white or pinkish, $2-2.5 \mathrm{~mm}$. long, glabrous; outer lobes oblongovate, the inner oblong, slightly if at all shorter. E. Visheri A. Nels. Dry plains and bad-lands: S.D.-Colo.-Utah-Wyo, Plain-Submont. Je-S.

108. E. subreniforme S. Wats. Scape slender, 1-3 dm. high, more or less silky-pilose or villous, especially at the nodes; leaf-blades rounded-reniform, 1-2 $\mathrm{cm}$. wide; peduncles capillary, ascending, 5-20 mm. long; involueres glabrous, turbinate-campanulate, $1 \mathrm{~mm}$. long; lobes rounded-ovate; perianth rosecolored, glabrous or slightly hispid, 1-1.5 mm. long; lobes subequal, elliptic. Arid regions: Ariz.-s Utah-N.M. L. Son.

109. E. trinervatum Small. Scape about $3 \mathrm{dm}$. high, more or less villous or pilose; leaf-blades suborbicular or rounded-ovate, $1-2 \mathrm{~cm}$. broad, truncate or subcordate at the base, conspicuously 3-nerved; peduncles spreading, 6-15 $\mathrm{mm}$. long, glabrous; involucres campanulate, glabrous, 1-1.5 mm. long; perianth deep-pink, glabrous, nearly $2 \mathrm{~mm}$. long; lobes subequal in length, elliptic or oval, the inner broader. Arid places: Colo.-Utah. Son.-Submors. Je-Au.

110. E. nutans T. \& G. Scape 1-2 dm. high; leaf-blades orbicular, 1-2 cm. broad, glabrous; peduncles reflexed, $5-10 \mathrm{~mm}$. long; involucres campanulate, $2.5-3$ $\mathrm{mm}$. long; lobes broadly ovate; perianth rose-colored, $2-2.5 \mathrm{~mm}$. long. $\quad E$. rubiflorum M. E. Jones. Arid regions: Utah-Nev. Son. Je.

111. E. Parryi A. Gray. Scape about $2 \mathrm{dm}$. high; blades rounded-reniform, 1-3 $\mathrm{cm}$. broad; peduncles $5-10 \mathrm{~cm}$. long, spreading or somewhat reflexed; involueres turbinate, oblique, glandular; lobes rounded-ovate; perianth campanulate, white, green on the midveins. Arid regions: s Utah $\rightarrow$ s Calif. $L$. Son. My-Je.

112. E. glandulosum Nutt. Scape about $2 \mathrm{dm}$. high; leaf-blades orbicular or reniform, cordate at base, 1-3 cm. broad; peduncles capillary, 1-3 cm. long, spreading or reflexed, abruptly bent above the middle; involucres broadly turbinate, glabrous, $2 \mathrm{~mm}$. long, deeply cleft; lobes ovate; perianth yellow, $2-2.5$ $\mathrm{mm}$. long. E. flexum M. E. Jones. Slopes and hills: Colo.-Utah. Son. Je.

113. E. Ordii S. Wats. Scape $3-6 \mathrm{dm}$. high; leaf-blades elliptic, $2-4 \mathrm{~cm}$. long; peduncles filiform, $1-2 \mathrm{~cm}$. long, glabrous; involucres turbinate, $1 \mathrm{~mm}$. long; lobes ovate; perianth white, tipped with pink, $2 \mathrm{~mm}$. long. Sand dunes: Ariz. -Utah. Son. Ap-Jl.

114. E. trichopodum Torr. Scape $3-5 \mathrm{dm}$. high; leaf-blades cordate to oval, subcordate at the base, $1-3 \mathrm{~cm}$. broad, glabrous above, hirsute beneath; peduncles capillary, about $1 \mathrm{~cm}$. long; involucres glabrous, $1 \mathrm{~mm}$. long or less, turbinate; lobes rounded; perianth yellowish, $1-1.5 \mathrm{~mm}$. long. Arid and sandy places: N.M.-s Utah-Calif.; n Mex. L. Son. Mr-Jl.

115. E. fusiforme Small. Seape $2-5 \mathrm{dm}$. high; leaf-blades suborbicular, $1-5 \mathrm{~cm}$. in diameter, with scattered hairs on both sides; peduncles capillary, spreading, 1-2 cm. long; involucres turbinate, barely $1 \mathrm{~mm}$. long; lobes ovate, shorter than the tube; perianth white or yellowish; lobes ovate, $1.5 \mathrm{~mm}$. long. Bluffs and sandy places: Colo.-Utah-Ariz. Son. My-Je.

116. E. inflatum Torr. Scape 3-6 dm. high; leaf-blades reniform or orbicular, hirsute-pubescent or sometimes glabrate; peduncles $1-3 \mathrm{~cm}$. long, spreading; involucres turbinate, glabrous, $1-1.5 \mathrm{~mm}$. long; lobes ovate; perianth $1.5 \mathrm{~mm}$. long, densely pubescent. Arid places: N.M.-Colo.-Calif. Son. My-J.

117. E. divaricatum Hook. Stem 1-2 dm. high, divaricately branched, minutely pubescent; basal leaves petioled; blades spatulate to orbicular, $1-2 \mathrm{~cm}$. 
broad, pilose on both sides; secondary leaves with orbicular blades; involucres turbinate; perianth whitish or yellowish, 1-1.5 mm. long; lobes oblong, subequal. Clay hills: Wyo.-Colo.-Ariz.-Utah. Son.-Submont.' Je-S.

118. E. angulosum Benth. Stem 1-4 dm. high, di- or tri-chotomously branched; basal leaves petioled, spatulate, $2-5 \mathrm{~cm}$. long; primary stem-leaves lanceolate, stipule-like; secondary ones fascicled, oblong, linear, or oblanceolate; peduncles 1-3 cm. long, divaricate; involucres shortly turbinate, $2 \mathrm{~mm}$. long, minutely glandular; lobes rounded; perianth rose-colored or white, deeply 5cleft, about $2 \mathrm{~mm}$. long, the outer lobes ovate, the inner ones oblong or lanceolate, obtuse. Arid regions: Ariz.-Ida.-Calif. Son. Ap-O.

119. E. puberulum S. Wats. Scape $5-15 \mathrm{~cm}$. high, canescent, dichotomously branched; leaf-blades obovate to broadly oval or suborbicular, 5-15 $\mathrm{mm}$. broad, grayish short-pubescent; bracts more or less foliaceous, narrowly oblong, 3-5 mm. long; involucres sessile in the forks, very small, 4-lobed; perianth glabrous, rose-colored, $1.5-2 \mathrm{~mm}$. long; lobes oblong. Sandy soil: Utah. Son.-Submont. Je.

120. E. spergulinum A. Gray. Stem 1-3 dm. high, slender, dichotomously branched, glandular-pruinose and more or less hirsute below; leaves and bracts verticillate, linear, green on both sides, hirsute; involucres on slender reflexed peduncles, glabrous, 4-cleft, 1-1.5 mm. long; perianth white, pilose at the base, $2 \mathrm{~mm}$. long. Sunny slopes: Calif.-Nev.-Ida.-Ore. Son. J1-Au.

121. E. pharnaceoides Torr. Stem slender, 1-3 dm. high, villous; leaves and bracts verticillate, linear, revolute-margined, villous above, tomentose beneath; involucres on slender peduncles, turbinate, $3 \mathrm{~mm}$. long, villous; lobes lanceolate, as long as the tube; perianth rose-colored, $2.5-3 \mathrm{~mm}$. long; outer segments oval, saccate below, glabrous; the inner ones oblong. Rocky hills: N.M.-Utah-Ariz. Son. JI-S.

122. E. salsuginosum Hook. Stem branched from the base, $1-2 \mathrm{dm}$. high, trichotomous, leafy; basal leaves fleshy, spatulate, $2-4 \mathrm{~cm}$. long; stem-leaves linear; involucres partly sessile in the forks, partly long-peduncled, of nearly distinct lanceolate bracts; perianth yellowish, hirtellous without; lobes oblonglanceolate; filaments and pistils glabrous. Clayey hills: Wyo.-N.M.-Utah. Son. $\rightarrow$ Submont. My-Jl.

\section{OXYTHEेCA Nutt.}

Diffuse dioecious or monoecious annuals, more or less glandular. Leaves rosulate at the base. Inflorescence trichotomously cymose. Bracts ternate, foliaceous and more or less connate, often awned. Involucres few-flowered, campanulate or turbinate, herbaceous, 3-5-cleft; lobes ereet or spreading, ending in straight awns. Perianth 6-parted. Stamens 9, inserted near the base of the perianth. Achenes lenticular.

Stem-leaves and bracts lanceolate, connate only at the base; involucres pedicelled. 1. O. foliosa. Stem-leaves and bracts connate, forming a nearly circular disk; involucres sessile.

2. O. perfoliata.

1. O. foliosa Nutt. Stem 1-3 dm. high, with ascending branches; basal leaves linear-oblanceolate, $3-6 \mathrm{~cm}$. long, pilose; involueres 1-2 $\mathrm{mm}$. long; lobes somewhat unequal, the awns very unequal and varying in length; perianth light rose-colored; lobes 6 , obovate, $0.5-0.75 \mathrm{~mm}$. long. Dry regions: Wash.-Wyo.Nev. Son. Je-Jl.

2. O. perfoliata T. \& G. Annual; stem dichotomously branched, sparingly glandular, 1-2 dm. high; basal leaves spatulate, 1-4 cm. long, glabrous; stemleaves and bracts 3 at each joint, forming a disk 1-2 $\mathrm{cm}$. broad, with 3 bristle points; involucres in the forks; lobes subulate-lanceolate, ending in an awn of their own length; flowers 4-6, pedicellate; perianth pubescent. Arid regions: Nev.Ariz. -s Utah. L. Son. Je.

\section{CENTrostżgia A. Gray.}

Branched annuals. Leaves basal, spatulate. Inflorescence cymose-paniculate. Bracts usually 3-fid; lobes spinulose-cuspidate. Involucres sessile, 
solitary, 1-3-flowered, tubular, 5-6-dentate, with 3-6 spinulose-tipped spurs below. Perianth 6-lobed. Stamens 9, inserted near the base of the perianth.

1. C. Thurberi A. Gray. Diffusely branched annual, 5-15 $\mathrm{cm}$. high; leaves spatulate, glabrous, 1-2 cm. long; involucre 1-2-flowered, chartaceous, venose, 5-toothed at the apex; spurs 3 , large, divergent, conic, as well as the teeth shortcuspidate; segments of the perianth linear-spatulate, hirsute towards the base. Arid regions: Ariz. $\rightarrow \mathrm{s}$ Utah-Calif. L. Son. My-Je.

\section{CHORIZĀNTHE R. Br.}

Low annual or perennial herbs, with sessile cymosely arranged involucres and opposite or verticillate leaves, or the lower leaves sometimes alternate. Involucres 1-flowered, gamophyllous, with angular or costate tube and 2-6 cuspidate or aristate teeth or lobes. Perianth corolla-like, 6-lobed or 6-parted. Stamens 9 , rarely 6 or 3 . Achenes 3 -angled.

Involucre not strongly sulcate, 5-toothed; filaments adnate to the perianth nearly up to the base of the lobes.

1. C. Watsoni.

Involucres strongly sulcate, 6-toothed; filaments adnate only to the lower part of the perianth-tube.

Leaves linear-oblanceolate to linear.

Lower leaves broadly spatulate.

2. C. brevicornu.

3. C. spathulata.

1. C. Watsoni A. Gray. Low branched annual, appressed-canescent; stem 2-5 cm. high; leaves linear or linear-spatulate, canescent; involucres eylindric, 5-6 mm. long; teeth 5, unequal, acerose-subulate, recurved; perianth with a cylindric tube; stamens 9 ; embryo straight; cotyledons linear. Desert regions: Wash.-Ida.-Nev.-Calif. Son. My-Jl.

2. C. brevicornu Torr. Branched annual; stem 5-20 cm. high, strigose; lower leaves narrowly linear-oblanceolate, 2-7 cm. long, strigose; bracts small, with a hooked mucro; involucres narrowly prismatic, about $5 \mathrm{~mm}$. long; lobes subequal, subulate-aristate, recurved; perianth $1.5 \mathrm{~mm}$. long, 5-lobed; lobes ovate, entire; stamens 3 . Desert regions: Ariz. $\rightarrow$ Stah-Nev. $\rightarrow$ se Calif. $L$. Son. Ap-My.

3. C. spathulata Small. A branched annual; stem strigose-canescent, $5-20 \mathrm{~cm}$. high; lower leaves $1.5-3 \mathrm{~cm}$. long, spatulate, hirsute-strigose on both sides; involucre prismatic, $5 \mathrm{~mm}$. long, strigose; lobes 6 , subulate, recurved, spinulose-tipped, the alternating narrower; perianth $2 \mathrm{~mm}$. long; lobes ovate; stamens mostly 3. Desert regions: Ida.-Nev. Son. My-Je.

\section{ACANTHÓGONUM Torr.}

Dwarf annuals, with obovate leaves. Bracts spinescent-subulate. Involucres axillary, sessile, subtended by a 3-fid bractlet, 1-flowered, 3-cleft to near the base; tube short, 3-angled; segments unequal, lanceolate, tapering into a subulate pungent tip. Flowers hermaphrodite, sessile; perianth equally 6toothed, closed in fruit. Stamens 6-9, adnate to the whole tube of the perianth. Styles 3, short; stigmas capitate. Achenes ovate, 3-angled.

1. A. rigidum Torr. Plant at first lanate; stem 1-3 cm. high; leaves longpetioled, white-tomentose beneath; involucres with elongated aristiform or subulate spinescent bracts; perianth with a cylindric tube and obtuse base; stamens 9. Chorizanthe rigida (Torr.) A. Gray. Desert regions: N.M. $\rightarrow$ s Utah -Nev. - - Calif.; n Mex. L. Son. Ap-My.

\section{PTEROSTÈGIA F. \& M.}

Slender annuals, diffusely branched, dichotomous, with opposite leaves and foliaceous bracts. Involucres axillary, sessile, consisting of a single 2-lobed bract, enlarged in fruit, scarious and reticulate, loosely enclosing the achene, 2 -gibbous on the back. Perianth 6-parted, or rarely 5-parted. Stamens 3 or 6. Achenes triangular, glabrous.

1. P. drymarioides F. \& M. Stem 1-3 dm. long; lower leaves long-petioled, flabelliform, obcordately 2-lobed or emarginate, those of the upper branches rounded-obovate or spatulate; fruiting involucre $2-3 \mathrm{~mm}$. long, deeply 2-lobed, 
dentate or laciniate on the margin. Rocky places: Ariz.-s Utah-Calif. $L$. Son. Mr-My.

\section{RÙMEX L. Dock, Sorrel.}

Perennial, or rarely annual, caulescent herbs, with thick roots. Leaves alternate, entire or wavy, with thin brittly ocreae. Flowers green, perfect, polygamo-monoecious or dioecious, pedicelled in distant or contiguous whorls. Sepals 6, the inner three usually developing entire, toothed, or spiny crests and one or more sometimes bearing a tubercle or callosity. Stamens 6. Ovary 1-celled, sessile; styles 3 ; stigmas peltate, tufted. Achenes 3-angled, usually invested by the accrescent calyx, margined or winged.

Flowers dioecious; foliage acid.

Leaves with auricled or hastate bases.

Inner perianth-lobes not developed into wings in fruit; achenes granular.

Inner perianth-lobes developed into wings in fruit; achenes smooth.

1. $R$. Acetosella.

2. R. Acetosa.

Leaves narrowed at the base, neither auricled nor hastate.

3. R. paucifolius.

Flowers perfect, or andro-polygamous; foliage not acid.

Inner perianth-lobes entire, undulate, or denticulate.

Inner perianth-lobes in fruit without tubercles. Inner perianth-lobes in fruit more than $2 \mathrm{~cm}$. broad; plants perennial, with
deep-seated woody rootstock.

4. $R$. venosus.

Inner perianth-lobes in fruit less than $1.5 \mathrm{~cm}$. in diameter.

Plants perennial, with clusters of tuberous roots; inner perianth-lobes in fruit $1-1.5 \mathrm{~cm}$. broad.

Achene $7 \mathrm{~mm}$. long or more; inner perianth-lobes in fruit broader than long; plant low.

5. R. salinus.

Achenes about $5 \mathrm{~mm}$. long; inner perianth-lobes in fruit longer than broad.

6. R. hymenosepalus.

Plants with taproots or thickened rootstocks; inner perianth-lobes in fruit 5-10 mm. broad.

Plants low, less than $3 \mathrm{dm}$. high, perennial, with short tuber-like rootstock; fruit maturing before the inner perianth-lobes become enlarged.

7. $R$. praecox.

Plants tall, perennial, with a taproot, not with a tuber-like rootstock; inner perianth-lobes well enlarged in fruit. Basal leaves $2-3 \mathrm{~cm}$. wide, acute or rarely rounded at the base.

8. R. hesperius.

Basal leaves 5-20 cm. wide, rounded, cordate, or truncate at the base.

Inner perianth-lobes in fruit with rounded apex, not conspicuously punctate.

Inner perianth-lobes in fruit $8-10 \mathrm{~mm}$. wide.

Inner perianth-lobes in fruit 5-6 mm. wide.

9. R. confinis.

10. $R$. occidentalis.

Inner perianth-lobes abruptly pointed, conspicuously punctate.

Fruiting inner perianth-lobes about as broad as long, sinuate on the margin. $11 . R$. densiflorus.

Fruiting inner perianth-lobes longer than broad, sharply dentate. $12, R$. subalpinus.

Inner perianth-lobes or at least one of them bearing a tubercle in fruit; perennials with a taproot.

Only one perianth-lobe tubercled.

Leaves dark green, more or less crisp; fruiting inner perianth-1obes 8-9 $\mathrm{mm}$. broad, reniform. $13, R$. Patientia.

Leaves pale green, not crisp; fruiting inner perianth-lobes $5-6 \mathrm{~mm}$. broad, deltoid-ovate.

14. R. altissimus.

All three perianth-lobes bearing tubercles.

Leaves dark green, erisp; fruiting perianth-lobes ovate to reniform, denticulate.

Leaves pale green, not crisp; fruiting perianth-lobes deltoid, entire.

16. R. mexicanus.

Inner perianth-lobes in fruit spinulose-toothed on the margin.

Tall plants; lower leaf-blades cordate at the base; one tubercle.

Low plants; lower leaf-blades narrowed at the base; three tubercles.

18. R. maritimus.

1. R. Acetosella L. Perennial, with a creeping rootstock; stem erect, glabrous, 1-6 dm. high; leaf-blades hastate, $2.5-15 \mathrm{~cm}$. long, obtuse or acute, with entire or 1- or 2-toothed auricles; upper stem-leaves linear; perianth green or purplish; achenes ovoid, 3-angled, $1.5 \mathrm{~mm}$.long, exceeding the persistent peri- 
anth. Sheep Sorrec. Waste places, old fields, etc.: Lab.-Fla.-Calif.Alaska, nat. from Eu. Plain-Submont. Ap-Au.

2. R. Acetosa L. Perennial, with a short rootstock; stem erect, $3-10 \mathrm{dm}$. high; leaf-blades oblong-hastate or ovate-sagittate, $3-12 \mathrm{~cm}$. long, acute at the apex, with acute auricles, the basal ones petioled, the upper cauline ones sessile; perianth green, $2 \mathrm{~mm}$. long, in fruit winged, broadly ovate or orbicular, cordate, $5 \mathrm{~mm}$. long, with delicate callosities at the base. Sour Dock. Waste places: Lab.-N.Y.-Mont.-Alaska; adv. from Eu. Plain-Submont. Je-Au.

3. R. paucifolius Nutt. Perennial, with a taproot and short rootstock, somewhat tufted; stem 2-5 dm. high; leaf-blades lanceolate or oblanceolate or sometimes elliptic, the lower petioled, $5-12 \mathrm{~cm}$. long, the upper sessile; perianth yellowish green or reddish, $1.5 \mathrm{~mm}$. long; divisions winged, in fruit about $4 \mathrm{~mm}$. in diameter, rounded, sometimes with a small basal callosity. $R$. Geyeri (Meisn.) Trelease. Meadows: Alta.-Colo.-Calif.-B.C. Submont.-Mont. My-Au.

4. R. venosus Pursh. Stem stout, erect or decumbent at the base, 1.5-4 $\mathrm{dm}$. high, somewhat fleshy; leaf-blades ovate, ovate-lanceolate, or oblong, 3-12 $\mathrm{cm}$. long, fleshy, somewhat glaucous; panicle rather dense, conic; perianth red, pedicelled, about $5 \mathrm{~mm}$. long; inner lobes in fruit much enlarged, orbicular, 2-5 $\mathrm{cm}$. broad, venose, cordate at the base; achene $7 \mathrm{~mm}$. long. WILD BEGONIA, Sour Greens, Wild Hydrangea. Sandy soil: Sask.-Mo.-Nev.-Wash. -Alta. Plain-Submont. Ap-Je.

5. R. salinus A. Nels. Stem stout, $2-4 \mathrm{dm}$. high, glabrous; leaf-blades moderately thick, somewhat crisp, the lower oblanceolate-oblong, $10-15 \mathrm{~cm}$. long, the upper lanceolate; perianth red, about $3 \mathrm{~mm}$. long; inner lobes in fruit enlarged, reniform-cordate. $R$. tuberosus A. Nels. Alkaline soil: w Wyo.Colo. Submont. Je.

6. R. hymenosepalus Torr. Stem 3-10 dm. high, glabrous; leaf-blades somewhat fleshy, somewhat crisp, $5-20 \mathrm{~cm}$. long, elliptic or oblanceolate; perianth yellowish green, 3-4 mm. long; inner lobes in fruit much enlarged, cordate, longer than broad, with an open sinus. Dry or sandy soil: Tex.-Okla.-Utah -Calif.; n Mex. Son.-Mont. Mr-My.

7. R. praecox Rydb. Stem $2-3 \mathrm{dm}$. high, striate; basal leaves petioled, rather thick, oval or elliptic, 4-10 cm. long, rounded at both ends; perianth-lobes oval, rounded at the apex, the inner $3-5 \mathrm{~mm}$. long, without tubercles. Along streams, in the mountains: Colo.-Wyo. Mont. Je.

8. R. hesperius Greene. Stem 3-6 dm. high; leaf-blades lanceolate or linear-lanceolate, slightly warty; panicle small; perianth purplish or greenish, 3 $\mathrm{mm}$. long; inner lobes in fruit 4-5 $\mathrm{mm}$. long, deltoid or reniform-deltoid, more or less reticulate, denticulate on the margins. Bottom lands: Alta.-Wyo.Wash. Submont. My-Jl.

9. R. confinis Greene. Stem stout, 4-15 dm. high; blades of the basal leaves 1-3 dm. long, oblong-lanceolate to oblong-ovate, cordate at the base; panicle large; flowers greenish; perianth $4 \mathrm{~mm}$. long; inner lobes suborbicular or rounded-cordate, crenate-dentate, rather strongly reticulate. Wet places: B.C. -Mont.-Wash. Son. Je-Jl.

10. R. occidentalis S. Wats. Stem 5-20 dm. high; blades of the basal leaves oblong-lanceolate, truncate or subcordate at the base, 1-3 dm. long; panicle narrow, elongate; perianth greenish, $3-4 \mathrm{~mm}$. long; inner lobes in fruit broadly cordate, denticulate towards the base; achenes $3 \mathrm{~mm}$. long. $R$. polyrrhizus Greene, in part. Wet places: Lab.-N.D.-N.M.-Calif.-B.C. Plain-Mont. Jl-Au.

11. R. densiflorus Osterh. Stem 5-10 dm. high, grooved; blades of the basal leaves elliptic or oblong-lanceolate, cordate at the base, $1.5-3 \mathrm{dm}$. long, 10-15 $\mathrm{cm}$. wide; flowers polygamous; perianth often red, $3 \mathrm{~mm}$. long; inner lobes broadly ovate-cordate, reticulate. R. Bakeri Greene. Wet ground: Colo. -Wyo.-Ida. Plain-Mont. Jl-Au.

12. R. subalpinus M. E. Jones. Stem erect, sulcate, 1-2 m. high; blades of basal leaves $2-4 \mathrm{dm}$. long, $5-20 \mathrm{~cm}$. wide, oblong-lanceolate to elliptic, entire, 
not crisp; flowers perfect; perianth greenish, $3 \mathrm{~mm}$. long; inner lobes in fruit deltoid or deltoid-cordate, 5-8 cm. long, acute or short-acuminate. Swampy grounds in the mountains: Colo.-Utah. Submont.-Mont. Jl-Au.

13. R. Patientia L. Stem erect, grooved, $5-15 \mathrm{dm}$. high; blades of basal leaves ovate-lanceolate, 1-4 dm. long; pedicels jointed below the middle; flowers perfect; perianth green, 4-5 $\mathrm{mm}$. long; inner lobes in fruit 6-7 $\mathrm{mm}$. long, roundedcordate, sinuate on the margins; achenes $3 \mathrm{~mm}$. long. $R$. Brittannica of western reports, not L. Patience. Waste places: Newf.-N.J.-Utah; cultivated and oceasionally escaped; native of Eu. Plain-Submont. Je-Jl.

14. R. altissimum Wood. Stem grooved, 5-12 dm. high; blades of the basal leaves lanceolate or oblong-lanceolate, $5-25 \mathrm{~cm}$. long, acute at both ends, papillose; flowers perfect; pedicels jointed near the base; perianth light green, 2 $\mathrm{mm}$. long; inner lobes in fruit triangular-cordate, $4-5 \mathrm{~mm}$. long, reticulate, entiremargined. Along streams: Mass.-Md.-N.M.-N.D. Plain. Ap-Je.

15. R. crispus L. Stem 3-10 dm. high, erect, simple; blades of the basal leaves oblong to linear-lanceolate, $1.5-3 \mathrm{dm}$. long, cordate, rounded, obtuse or acute at the base, more or less papillose; flowers perfect; pedicels jointed at the base; perianth dark green; inner lobes in fruit $3-5 \mathrm{~mm}$. long. CURLEd Dock. Waste places: Newf,-Fla.-Calif.-B.C. Plain. Je-Au.

16. R. mexicanus Meisn. Stem 3-6 dm. high; blades of the basal leaves lanceolate or linear-lanceolate, pale, $5-15 \mathrm{~cm}$. long, $1-2.5 \mathrm{~cm}$. wide; flowers perfect; perianth pale green, 2-3 mm. long; inner lobes in fruit $5-6 \mathrm{~mm}$. long, truncate at the base. R. salicifolius Am. auth., not Weinm. Along rivers: Lab. -Me.-Mo.-N.M.-B.C.; Mex. Plain-Mont. My-Au.

17. R. obtusifolius L. Perennial, with a taproot; stem stout, 5-12 dm. high, grooved; blades of the basal leaves broadly ovate, $1.5-3 \mathrm{dm}$. long; pedicels jointed below the middle; perianth greenish or purplish, $3 \mathrm{~mm}$. long; inner lobes in fruit about $5 \mathrm{~mm}$. long, hasstate or deltoid, strongly reticulate. Waste places: N.S.-Fla.-N.M.-Ore--B.C.; nat. from Eu. Plain-Son. Ap-Au.

18. R. maritimus L. Annual; stem $3-10 \mathrm{dm}$. high, leafy; leaf-blades lanceolate or linear-lanceolate, $3-25 \mathrm{~cm}$. long, undulate and erisp; pedicels jointed at the base; perianth greenish, 1-1.5 mm. long; inner lobes in fruit about $2 \mathrm{~mm}$. long, with 1-3 bristle-like teeth on the margins. $R$. persicarioides Am. auth., not L. Golden Dock. Sandy shores: N.B.-N.C.-Calif.-B.C. Plain-Submont. J-S.

\section{OXÝria Hill, Mountain Sorrel.}

Low perennials, with acid juice and thick fleshy taproots. Leaves alternate, but mostly basal. Flowers perfect, in verticils, arranged in panicled racemes. Sepals 4; the outer larger than the inner; stamens 6; filaments short-subulate. Ovary 1-celled; ovules solitary; styles 2, short; stigmas fimbriate. Achenes thin, lenticular, nearly flat, broadly winged.

1. O. digyna (L.) Hill. Stem scapiform, 5-30 cm. high; blades of the basal leaves reniform or rounded-reniform, $1-3 \mathrm{~cm}$. in diameter, sometimes emarginate at the apex; panicle narrow, racemiform; perianth red or green, 1.5-2 mm. long, the inner in fruit erect, reniform-orbicular, 4-6 mm. broad; achenes in fruit broadly winged. Aretic-alpine regions among rocks: Greenl.-N.H.-Alta.N.M.-Calif.-Alaska; Eurasia. Alp.-Mont. Jl-S.

\section{POLÝGoNuM (Tourn.) L. KNotweed, Doorweed, Knotgrass.}

Perennial or annual, sometimes somewhat shrubby herbs, with alternate leaves and somewhat fleshy or leathery leaf-blades articulate to the ocreae. Ocreae at first 2-lobed, soon lacerate, hyaline. Inflorescence of axillary small clusters. Calyx of 5 or rarely 6 , partially united sepals, mostly green with white, pink, or yellowish margins. Stamens $3-8$, usually 5 or 6 ; filaments, at least the inner ones, dilated. Ovary 1-celled, 1-ovuled; styles 3, usually distinct. Achenes 3 -angled, brown or black; endosperm horny; cotyledons incum-
bent. 
Fruit erect.

Inflorescence of small axillary clusters scattered more or less thoroughout the plant: all except $P$. minimum with elongated stems or branches; perianth-lobes never keeled near the apex.

Plants copiously leafy throughout; upper leaves scarcely reduced and more crowded.

Very slender and low annuals, with red wiry, terete, non-striate stems.

1. P. minimum.

Stouter and larger plants, often perennial, with prominently striate stems, usually 3-8 dm. long.

Perianth-lobes with yellowish green margins; plant erect, with spreading branches in age; leaves broad, yellowish green.

2. P. erectum.

Perianth-lobes with white, pink or purplish margins; plant prostrate or diffusely spreading; leaves from bright to pale bluish green.

Leaves thick, prominently veined, oblong, oval, or spatulate, obtuse or rounded at the apex, usually pale; ocreae very conspicuous: faces of the achenes granular.

3. P. buxiforme.

Leaves thin, not prominently veined, bright green; ocreae not conspicuous; faces of the achenes finely striate.

Perianth 2.5-3.5 mm. long; achenes 2.5-3 mm. long, acute; leaves $2-4 \mathrm{~cm}$. long.

4. P. aviculare.

Perianth 2-2.5 mm. long; achenes $2-2.5 \mathrm{~mm}$. long, acuminate; leaves mostly less than $2 \mathrm{~cm}$. long.

5. P. neglectum.

Plants with the upper leaves more scattered and reduced; mostly erect perennials. Upper bracts not subulate; achenes mostly dull.

Lobes of the perianth with yellowish margins; perianth $3-4 \mathrm{~mm}$. long: achenes about $3 \mathrm{~mm}$. long, nearly smooth.

6. P. ramosissimum.

Lobes of the perianth with whitish or pinkish margins; perianth $2-3 \mathrm{~mm}$. long; achenes $2-2.5 \mathrm{~mm}$. long, distinctly granulate or striate.

Plant copiously branched and broom-like; leaf-blades linear or nearly so; achenes granulate.

7. P. prolificum.

Plant sparingly branched, mostly below; leaf-blades oblanceolate to elliptic; achenes finely striate.

Upper bracts subulate; achenes smooth and shining.

8. P. rubescens.

9. P. sawatchense.

Inflorescence aggregate at the ends of the branches, or more scattered in $P$. paronychioides, in which, however, some of the perianth-lobes are keeled near the apex; bracts leaf-like and usually broader than the narrowly linear leaves; plants dwarf annuals.

Perianth-lobes not keeled.

Leaves several, gradually merging into the bracts; achenes blunt-angled and strongly striate. 10. P. Watsonii.

Leaf usually solitary and much longer than the bracts; achenes sharp-angled and obscurely striate.

Some of the perianth-lobes keeled near the apex.

Bracts herbaceous or the uppermost with a very narrow scarious margin.

Bracts linear; ocreae conspicuous; inflorescence interrupted.

12. P. paronychioides.

Bracts oblong or narrowly oblong; ocreae inconspicuous; inflorescence contiguous and dense.

Fruit reflexed.

Bracts with broad white petaloid margins.

13. P. Kelloggii.

14. $P$. polygaloides.

Upper bracts much reduced and subulate.

Perianth 1.5-2.5 $\mathrm{mm}$. long; leaves narrowly linear.

15. P. Engelmannii.

Perianth 3-5 mm. long.

Outer perianth-lobes oblong, obtusish, thickened and green or purplish on the back; lower leaves oblanceolate to linear-oblanceolate.

16. P. Douglasii.

Outer perianth-lobes obovate, rounded at the apex, merely with a narrow midrib; lower Ieaves linear.

Inflorescence long, lax, virgate; ocreae of the bracts inconspicuous.

Inflorescence dense, crowded at the ends of the branches; ocreae of the bracts contiguous and conspicuous.

18. P. spergulariforme.

Upper bracts foliaceous, relatively broad lanceolate or oblong.

Perianth $3.5-4 \mathrm{~mm}$. long; lower leaves oblong or nearly so.

Achenes included.

Achenes exserted.

Perianth 2-2.5 mm. long; lower leaves obovate, very acute.

19. P. montanum.

20. P. commixtum.

21. P. Austinae.

1. P. minimum S. Wats. Annual; stem erect or spreading, $3-20 \mathrm{~cm}$., rarely $30 \mathrm{~cm}$. high, branched mostly at the base; leaves obovate, sometimes ovate or elliptic, $0.5-2 \mathrm{~cm}$. long, evenly distributed or erowded above; perianthsegments $1.5-2 \mathrm{~mm}$. long, greenish with rose-colored margins; achenes 2-2.3 $\mathrm{mm}$. long, smooth and shining. P. Torreyi S. Wats. Dry or sandy slopes: B.C.-Mont.-Colo.-Calif. Submont. JI-S.

2. P. erectum L. Annual; stem usually erect, $2-6 \mathrm{dm}$. high, yellowish green; leaves oval, elliptic or obovate, 1-6 cm. long; flowers in small axillary 
clusters; perianth $3 \mathrm{~mm}$. long; achenes dark brown, granular and dull. Waste places: Me.-Ga.-Ark.-N.M.-Alta.; (? Ida.) Plain. Je-S.

3. P. buxiforme Small. Annual or perennial; stem usually prostrate, 3-12 $\mathrm{dm}$. long; leaves oblong, elliptic or oblanceolate, $0.5-2.5 \mathrm{~cm}$. long, usually obtuse, often erisp on the margin; perianth $2-2.5 \mathrm{~mm}$. long; achenes $2-2.5 \mathrm{~mm}$. long, dark brown, mostly dull, granular. Sandy or alkaline soil: Ont.-Va.Tex.-Nev.-B.C. Plain-Mont. Je-S.

4. P. aviculare L. Annual or sometimes perennial; leaves oblong-lanceolate, acute at both ends, petioled, dull bluish green, rather thin, 1-3 cm. long; flowers pedicelled; perianth $2.5-3.5 \mathrm{~mm}$. long; achenes dark, rugulose-striate, dull. Waste places: Newf.-Va.-Calif.-B.C.; nat. or adv. from Eu. Plain-Submont. My-O.

5. P. neglectum Besser. Annual or perennial; stems with short internodes, strongly striate, usually minutely roughened; leaves firm, narrowly ellipticlanceolate, or the upper rarely linear; margins often revolute when dry; perianth $2-2.5 \mathrm{~mm}$. long, venose; segments with usually purplish margins; achenes reddish brown, apiculate-acuminate. P. aviculare angustissimum Meisn. Waste places: Me.-Fla.-Ark.-N.M.-Alta.; nat. or adv. from Eu.; more common than P. aviculare. Plain-Submont. Je-N.

6. P. ramosissimum Michx. Annual; stem 2-10 dm. high, somewhat virgate, yellowish green; leaves lanceolate, oblong, or linear-oblong, 1-4 cm. long, yellowish green, the upper ones much reduced in size; perianth about $3 \mathrm{~mm}$. long; achenes $3 \mathrm{~mm}$. long, black, not shining. River valleys and sandy soil: Man.Ills.-N.M.-Nev.-Wash.-B.C. Plain-Mont. Jl-S.

7. P. prolificum (Small) B. L. Robins. Annual; stem 3-5 dm. high, much branched, strongly striate, dark green or reddish; leaves linear-oblong or linear, thick, obtuse or acute, strongly veined beneath, dark green, $1-2 \mathrm{~cm}$. long; perianth about $2 \mathrm{~mm}$. long; achenes brown, $2 \mathrm{~mm}$. long, concave on the lanceolatedeltoid faces, shining. (?) P. flexile Greene. Sandy places: Me.-Va.-Colo.

8. P. rubescens Small. Annual or perennial; stem erect, ultimately branched, 1-5 dm. high; leaves thick, narrowly oblong or elliptic, $1-2.5 \mathrm{~cm}$. long, the upper reduced; perianth $3 \mathrm{~mm}$. long; achenes $2-2.5 \mathrm{~mm}$. long, dull. Sandy soil: Sask.-Colo.-Nev.-Ida. Plain-Submont. Je-S.

9. P. sawatchense Small. Annual; stems erect, striate, obscurely 4-angled, branched from the base, 5-30 cm. high; lower leaves oblanceolate, 1-2 cm. long, acute or obtuse at the apex, often more or less revolute, with a prominent midvein; perianth-segments green, only slightly lighter on the margins, $2 \mathrm{~mm}$. long; achenes rather blunt at both ends, smooth and glossy. Hillsides and mountains: S.D.-N.M.-Calif.-Wash. Submont.-Mont. J-Au.

10. P. Watsonii Small. Annual; stem erect, $5-15 \mathrm{~cm}$. high, sparingly branched, 4-angled, glabrous; leaves linear, 1-5 cm. long; bracts reduced, 0.5-1 $\mathrm{cm}$. long, linear-lanceolate; perianth-segments green, pinkish on the margins, 2 mm. long; achenes nearly black, narrowly ovoid, strongly striate. $P$. imbricatum Nutt., not Raf. $P$. confertiflorum Nutt. Wet places: B.C.-Sask.-N.M.Calif. Plain-Mont. Je-Au.

11. P. unifolium Small. Annual, dwarf; stem 1-3 cm. high, simple, or nearly so; well developed leaf mostly solitary, linear, erect, $7-10 \mathrm{~mm}$. long; bracts several, crowded, imbricate, linear or linear-lanceolate; perianth-segments about $1.5 \mathrm{~mm}$. long, white or pinkish, with green ribs; achenes about $1.3 \mathrm{~mm}$. long, shining, included. Wet places: Mont.-Colo.-Utah. Plain-Mont. Ji-Au.

12. P. paronychioides Small. Annual, bushy; stem copiously branched at the base, $8-15 \mathrm{~cm}$. long; leaves linear, $8-10 \mathrm{~mm}$. long; perianths short-pedicelled, solitary or a few together in the axils; segments green, with pale or pink margins,
becoming fully $2 \mathrm{~mm}$. long; lobes slightly keeled, acutish; achenes rhombic, about $2 \mathrm{~mm}$. long, granular. Wet places: Mont.-Wyo. Submont. Au.

13. P. Kelloggii Greene. Annual; stem erect, $3-8 \mathrm{~cm}$. high, branched at the base; leaves linear, acute, 5-10 cm. long, spreading; perianth-segments $1.5-2$ 
$\mathrm{mm}$. long, greenish, with white or cream-colored margins; achenes $1.5 \mathrm{~mm}$. long, rhombic-ovoid, light brown, granular, somewhat striate, dull. In wet soil: Wash.-Mont.-Colo.-Calif. Submont.-Mont. Jl-S.

14. P. polygaloides Meisn. Annual, glabrous; stem slender, erect, 1-2 dm. high, with ascending branches; leaves narrowly linear, 1-3 cm. long, strict; floral leaves oblong or elliptic; perianth-segments $2 \mathrm{~mm}$. long, white or pinkish, with dark midribs; outer segment longer than the inner; achenes about $1.5 \mathrm{~mm}$. long. Wet places: Wash.-Mont.-Wyo.-Ore. Submont. Je-Au.

15. P. Engelmannii Greene. Annual; stem often diffusely branched at the base, 0.5-3 dm. high; lower leaves linear-oblanceolate, 0.5-2 cm. long, the upper reduced, bract-like, subulate; perianth-segments oblong, obtuse, with whitish margins; achenes $2-2.5 \mathrm{~mm}$. long, ovoid, black, smooth and shining. $P$. tenue microspermum Engelm. Hillsides and mountains: B.C.-Mont.-Colo. Plain-Mont. Jl-S.

16. P. Douglasii Greene. Annual; stem erect, 2-4 dm. high, with ascending branches; lower leaves oblanceolate, $2-5 \mathrm{~cm}$. long, mostly obtuse or acutish; the upper linear and reduced, scattered; perianth-segments white or rose-colored on the margins; achenes 3-4 mm. long, black, smooth and shining. $P$. consimile Greene. (?) P. emaciatum A. Nels. P. pannosum S. S. Sharp. Hillsides and in sandy soil: Vt.-N.Y.-N.M.-Calif.-B.C.; probably only introduced east of the Rockies. Plain-Mont. Je-Au.

17. P. majus (Meisn.) Piper. Annual; stem wiry, terete, 2-4 dm. high, with ascending branches; leaves $2-6 \mathrm{~cm}$. long; bracts linear-subulate, remote; perianth 4-5 mm. long; segments white, with green midrib; achenes black, shining, smooth, 3-3.5 mm. long. P. coarctatum majus Meisn. Stony soil: Wash. -Mont.-Wyo.-Ore. Plain-Submont. Je-S.

18. P. spergulariaeforme Meisn. Annual, scurfy throughout; stem erect, 1-3 dm. high, branched from the base; leaves $1-3 \mathrm{~cm}$. long, usually somewhat revolute; bracts rather crowded, subulate; perianth $3.5-4 \mathrm{~mm}$. long, pink; achenes about $3.5 \mathrm{~mm}$. long, black, smooth and shining except the granular apex and angles. P. coarctatum Dougl., not Willd. Ridges: B.C. - W Wyo.-Calif. Plain-Submont. J1-Au.

19. P. montanum (Small) Greene. Annual; stem branched from the base, 1-3 dm. high, floriferous from near the base; lower leaves elliptic or oblongoblanceolate, 1-3 cm. long, 1-nerved; upper leaves smaller, lanceolate or oblong; perianth-segments oblong, dark green or purplish, with white or pinkish margins; achenes black, shining, striate. Mountains: Alta.-N.M.-Calif. Submont.Subalp. Jl-Au.

20. P. commixtum Greene. Annual; stem 0.5-1.5 dm. high, glabrous, branched from the base, glabrous; leaves oval, oblanceolate, or lanceolate, abruptly cuspidate-mucronate, 1-2.5 cm. long, 1-nerved, glabrous; perianth about $3 \mathrm{~mm}$. long; segments elliptic, green, with yellowish white or purplish margins; achenes almost black, smooth and shining. Mountains: Colo.-Mont. Submont.Subalp. Jl-Au.

21. P. Austinae Greene. Annual; stem mostly erect, $0.5-1 \mathrm{dm}$. high, branched from the base; leaves ovate-lanceolate to oblanceolate, $0.5-1.5 \mathrm{~cm}$. long, the upper much reduced; perianth green, $2.5 \mathrm{~mm}$. long, drooping; segments narrowly oblong, obtuse, dark green, with white margins; achenes $2.5-3 \mathrm{~mm}$. long, black, smooth and shining. Sandy places: Alta.-Wyo.-Calif. Submont. Au-S.

\section{Perricària (C. Bauhin) Mill. Smartweed, Lady's Thumb, Water Pepper.}

Perennial or annual, caulescent herbs, not twining, with alternate leaves and entire leaf-blades, continuous with the ocreae. The latter cylindric, mostly membranous, truncate. Racemes spike-like; pedicels articulate below the calyx. Calyx more or less colored, white or greenish, glandular-punctate; perianth-segments mostly 5. Stamens 4-8, filaments not dilated. Ovary 1-celled, 1-ovuled; 
styles mostly 2 , sometimes 3 , usually partially united; stigmas capitate. Achenes mostly lenticular, sometimes 3-angular, usually black, smooth or granular. Endosperm horpy; cotyledons accumbent.

Racemes terminal only and usually solitary; plants aquatic perennials.

Ocreae without spreading foliaceous tops.

Plant usually floating, or decumbent and rooting; leaves of an oblong type, glabrous, acute or obtuse.

Plant usually diffuse and emersed; leaves of a lanceolate type, pubescent, acuminate.

Ocreae with spreading foliaceous tops; leaf-blades narrowly oblong or lanceolate

(broader in floating forms), pubescent.
3. P. Hartwrightii.

Racemes axillary as well as terminal, numerous; annuals.

Ocreae without marginal bristles.

Racemes erect; glands on the branches and inflorescence numerous, stalked.

Racemes drooping: glands on the $P$. omissa. Styles united only at the base.

Styles united to about the middle.

Leaves deep green on both sides.

Leaves pale beneath.

Ocreae bristle-fringed.

5. P. incarnata.

6. P. lapathifolia.

7. P. incana.

Racemes oblong or cylindric, about $1 \mathrm{~cm}$. thick in fruit; perianth not punctate, usually pink to red-purple. 8 . P. Persicaria.

Racemes slender, loosely flowered, about $5 \mathrm{~mm}$. thick in fruit; perianth white or pale green, copiously punctate.

Racemes erect; achenes smooth and shining.

Racemes nodding at least in fruit; achenes granular and dull.

9. P. punctata.

10. P. Hydropiper.

1. P. coccinea (Muhl.) Greene. Perennial, glabrous, or the young shoots somewhat pubescent; stem 5-50 dm. long; leaves oblong or elliptic, 3-10 cm. long, glossy, obtuse or acute at both ends, or when growing in mud more elongate, elliptic-lanceolate and acute; raceme spike-like, 1-3 cm. long; perianth light rosecolored; achenes lenticular, black. Polygonum amphibium Hook., not L. Persicaria plattensis, $P$. subcoriacea, $P$. psychrophila, $P$. oregana, and $P$. laetevirens Greene. In water or rarely in mud: Me.-N.J.-N.M.-Calif.-Alaska. Plain-Mont. Je-Au,

2. P. Muhlenbergii (Meisn.) Small. Perennial, more or less strigosehispid throughout; stem erect or creeping at the base, 3-8 dm. high, simple; leaf-blades broadly lanceolate, $5-20 \mathrm{~cm}$. long, acuminate or acute; racemes spikelike, linear or linear-oblong, 3-10 cm. long; perianth dark rose-colored, rarely pink, $4 \mathrm{~mm}$. long; achenes lenticular, black, granular but shining. Polygonum Muhlenbergii (Meisn.) S. Wats. P. emersum (Michx.) Britton. Persicaria emersa (Michx.) Small. $P$. propinqua and $P$. Wardii Greene. In swamps and shallow water: Me.-Va.-N.M.-Calif.-B.C.; Mex. Plain-Submont. Je-S.

3. P. Hartwrightii (A. Gray) Greene. Perennial, more or less hispid throughout; stem ascending or suberect, 3-7 dm. long, or rarely floating in water; leaf-blades narrowly lanceolate or oblong-lanceolate or oblong, 6-18 cm. long; raceme spike-like, oblong or ovoid, 1-3 cm. long, erect; perianth rose-colored, 3-4.5 cm. long; achenes lenticular, $2.5 \mathrm{~mm}$. long, black, smooth and shining. Polygonum Hartwrightii A. Gray. Persicaria muriculata and P. villosula Greene. Wet places and shallow water. Me.-Pa.-Calif.-Wash.-Sask. PlainSubmont. Je-S.

4. P. omissa Greene. Annual; stem 3-6 dm. high, with copious stipitate glands; oereae short, cup-shaped; leaf-blades 5-10 cm. long, lanceolate or oblonglanceolate, glabrous, punctate; racemes short-oblong or ellipsoid, 1-2 cm. long; perianth deep pink, about $4 \mathrm{~mm}$. long; achenes round-ovate, black and shining, nearly flat on one side. Polygonum omissum Greene. Wet ground and driedup ponds: Kans.-Colo. Plain. JI-S.

5. P. incarnata (EIl.) Small. Annual, nearly glabrous throughout; stem erect, 6-10 dm. long, more or less thickened at the nodes; leaf-blades lanceolate or linear-lanceolate, $5-20 \mathrm{~cm}$. long, acuminate or acute; racemes linear, 3-8 cm. long, drooping; perianth whitish, green, or rose-colored, 2-3 mm. long; achenes lenticular, rarely 3 -angled, dark brown or black, shining, smooth. Polygonum incarnatum Ell. Wet places: Vt.-Fla.-Calif.-Ida. Plain-Submont. Jl-O. 
6. P. lapathifolia (L.) S. F. Gray. Annual, glabrous or nearly so; stem erect, 3-6 dm. high, thickened at the nodes; leaf-blades broadly or narrowly lanceolate, 5-20 $\mathrm{cm}$. long, attenuate, punctate and ciliolate on the margins; racemes linear-oblong, 2-8 $\mathrm{cm}$. long, drooping, dense; perianth flesh-colored or whitish, 2-2.5 mm. long; achenes lenticular or rarely 3-angled, black or dark brown, slightly granular, shining. Polygonum lapathifolium L. Wet places: Que.-Fla.-Calif.-B.C.; Mex., W.Ind.; Eurasia. Plain-Submont. Jl-O.

7. P. incana (Schmidt) S. F. Gray. Annual; stem erect, 1-4 dm. high, slightly scurfy; leaf-blades lanceolate or oblong, acute or obtuse; racemes oblong, 1-3 $\mathrm{cm}$. long, erect or only slightly nodding; peduncles with sessile glands; perianth 2-2.5 mm. long, greenish or pinkish white; achenes lenticular, dark brown, shining. Polygonum incanum Schmidt. Wet places and swamps: Newf.N.Y.-Colo.-B.C.; Eu. Plain-Submont. Je-S.

8. P. Persicaria (L.) Small. Annual, glabrous or puberulent; stem erect, $2-8 \mathrm{dm}$. high, usually branched; leaf-blades lanceolate or linear-lanceolate, $2-18$ $\mathrm{cm}$. long, acuminate, conspicuously punctate, usually with a lunar or triangular spot in the middle; racemes oblong or ovoid, $1-3 \mathrm{~cm}$. long, $0.5-1 \mathrm{~cm}$. thiek, mostly erect; perianth abo.t $2.5 \mathrm{~mm}$. long, pink or purple; achenes lenticular or 3-angled, smooth and shining. Polygonum Persicaria L. Lady's Thumb. Waste places and rich soil: Newf.-Fla.-Calif.-B.C.; Mex.; Eu. Plain-Submont. $\mathrm{My}-\mathrm{S}$.

9. P. punctata (Ell.) Small. Annual or perennial, mostly glabrous throughout; stem erect, or creeping at the base, 3-10 dm. high, more or less branched; leaf-blades lanceolate to linear-lanceolate, $5-15 \mathrm{~cm}$. long, acuminate, conspicuously punctate; raceme linear, erect, 1-6 $\mathrm{cm}$. long, somewhat interrupted below; perianth greenish, about $2 \mathrm{~mm}$. long, conspicuously glandular-punctate; achenes lenticular or 3-angled, black, smooth and shining. Polygonum punctatum Ell. P. acre H.B.K., not Lam. Smartweed. Swamps and wet places: Me.-Fla.Calif.-Wash.; Mex., C.Am., W.Ind., and S.Am. Plain. Mr-D.

10. P. Hydropiper (L.) Opiz. Annual, glabrous; stem erect or assurgent, 2-6 dm. high, simple or branched, sometimes reddish; leaf-blades ovate-lanceolate or lanceolate, $1.5-9 \mathrm{~cm}$. long, acute, more or less papillose, punctate; racemes linear, $2-6 \mathrm{~cm}$. long, interrupted and drooping; perianth greenish, 2.5-3 $\mathrm{mm}$. long, glandular; achenes lenticular or 3-angled, dark brown, strongly granular and dull. Polygonum Hydropiper L. Water Pepper. Wet places: Nerff. -Ga.-Calif.-B.C.; Mex. and C.Am.; nat. from Eu. Plain. Je-S.

\section{BISTÓRTA (C. Bauhin) Mill. Bistort.}

Perennials, with thickened horizontal rootstocks and simple stems. Basal leaves long-petioled; stem-leaves short-petioled or sessile, narrow, entire. Ocreae cylindric, hyaline, never eiliate, oblique at the summit. Inflorescence a solitary spike-like raceme, sometimes bearing bulblets at the base. Pedicels articulate at the base of the perianth. Perianth 5-parted, not glandular-punctate. Stamens 8, exserted. Style usually 3-parted; achenes triangular or rarely lenticular. Endosperm horny; cotyledons accumbent.

Racemes not viviparous, not bulblet-bearing, oblong, 1-2 cm. thick.

Perianth 5-6 mm. long; leaf-blades lanceolate, oblong, or oblanceolate.

Perianth 3-4 mm. long; basal leaf-blades linear.

Racemes viviparous, bulblet-bearing below, linear, $5-8 \mathrm{~mm}$. thick.

1. B. bistortoides.

2. B. binearifolia.

3. B. vivipara.

1. B. bistortoides (Pursh) Small. Stem erect, $2-7 \mathrm{dm}$. high, simple; blades of the basal leaves $10-25 \mathrm{~cm}$. long, $0.5-3 \mathrm{~cm}$. broad, acute or obtuse, glabrous on both sides or scabrous-puberulent beneath; stem-leaves lanceolate, sessile; raceme oblong, 1-6 cm. long, 1-1.5 cm. thick, densely flowered; perianth light rose-colored to white; achenes light brown, smooth and shining. Polygonum bistortoides Pursh. B. calophylla, B. glastifolia, and B. lilacina Greene. Wet meadows and swamps: Mont.-N.M.-Calif.-B.C. Alp.-Mont. Je-S.

2. B. linearifolia (S. Wats.) Greene. Stem slender, 1-3 dm. high; basal leaf-blades 3-4 cm. long, acute; cauline leaves linear-lanceolate to linear, sessile; 
raceme ovoid, less than $2 \mathrm{~cm}$. long; perianth mostly white; achenes smooth and shining. Polygonum Bistorta linearifolium S. Wats. B. jejuna Greene. Alpine swamps: Mont.-Colo.-Utah-Nev. Alp.-Mont. Je-Au.

3. B. vivipara (L.) S. F. Gray. Blades of the basal leaves oblong or lanceolate, $2-10 \mathrm{~cm}$. long, 1-2.5 cm. wide; stem-leaves lanceolate to linear; raceme narrowly cylindric, $2-10 \mathrm{~cm}$. long, $0.5-1 \mathrm{~cm}$. thick; perianth pale rose-colored or white; achenes dark brown, granular and dull. Polygonum viviparum L. B. scopulina Greene. Alpine, arctic, and subarctic swamps: Greenl.-N.H.N.M.-Alaska; Eurasia. Alp.-Mont. Je-Au.

\section{FAGOPỲRUM (Tourn.) Mill. BuckwheAT.}

Caulescent glabrous annuals. Leaves alternate, petioled; blades hastate or cordate; ocreae oblique, entire. Flowers perfect, several in corymbiform cymes, with slender pedicels subtended by an ocreola. Calyx corolloid; sepals 5, equal. Stamens 8. Styles 3; stigmas capitate. Achenes 3-angled, margined or erested. Embryo S-shaped, central.

1. F. Fagopyrum (L.) Karst. Stem 1-9 dm. high, branched, pubescent at the nodes; leaf-blades hastate, $2.5-8 \mathrm{~cm}$. long; ocreae fugacious; perianth whitish; achenes ovoid, $5 \mathrm{~mm}$. long, with pinnately striate faces, acute-angled. $F$. esculentum Moench. Escaped from cultivation; native of Eurasia.

\section{ACONÓGONUM Reichenb.}

Caulescent herbaceous or rarely suffrutescent plants, with horizontal rootstocks. Leaves fleshy or thin. Inflorescence of axillary and terminal racemes or panicles. Ocreae funnelform, oblique. Pedicels articulate below the perianth. Perianth 5-parted, not glandular-punctate. Stamens 5-8, included. Style 3-parted; achenes 3-angled, smooth. Endosperm horny; cotyledons accumbent.

1. A. phytolaccaefolium (Meisn.) Small. Perennial; stem erect, 1-2 m. high, channeled, branched; leaf-blades lanceolate, $5-15 \mathrm{~cm}$. long, 1-4 cm. wide, acute or acuminate at both ends, slightly crisped, ciliate on the margins; inflorescence paniculate, leafy; perianth greenish or whitish, $3 \mathrm{~mm}$. long; segments obovate or oblong, rounded; achenes $4 \mathrm{~mm}$. long, broadly ovoid or oval, light chestnut-colored, shining. Polygonum polymorphum and P. alpinum Am. auth. Subalpine and alpine regions: Alaska-Ida.-Nev.-Calif.; Asia. Submont. Jl-S.

\section{TRACAÙlON Raf. Tear-thumb.}

Annual or rarely perennial, prickly-armed herbs, with weak 4-angled stems. Leaves alternate; blades hastate or cordate, membranous, the petioles and veins prickly. Ocreae oblique. Flowers in terminal or axillary spikes, or capitate clusters. Sepals 4 or 5, somewhat colored, neither keeled nor winged. Stamens 5-8; filaments not dilated. Ovary 1-celled; styles 2 or 3 , partially united. Achenes lenticular or 3-angled, smooth and shining. Endosperm horny; cotyledons accumbent.

1. T. sagittatum (L.) Small. Annual; stem slender, decumbent or reclining, 3-15 dm. high, branched, 4-angled, armed on the angles with sharp recurved prickles; leaves lanceolate or oblong, sagittate at the base, 1-12 cm. long, $0.5-3 \mathrm{~cm}$. broad, the lower petioled, the uppermost sessile; perianth white, green, or red, $4 \mathrm{~mm}$. long, 5-parted; achenes 3-angled, black or brownish. Polygonum sagittatum L. Wet meadows: Newf.-Fla.-Tex.-Sask. Plain. Jl-S.

\section{Bilderdỳkia Dum. False Buckwheat, Bindweed.}

Annual or perennial twining herbaceous vines. Leaves alternate, with cordate or hastate blades. Ocreae oblique, naked or fringed. Racemes loosely flowered, terminal or axillary, often paniculate. Sepals 5, green, white, or yellowish, the outer two sepals and the intermediate one keeled or winged. Pedicels slender, reflexed and articulate. Stamens 8; filaments short, converging. Ovary 1-celled; styles 3 , short or almost wanting; stigmas capitate. Achenes 
3-angled, dark brown or black. Endosperm horny. Cotyledons accumbent. [Tiniaria Reichenb.]

Outer sepals merely keeled at maturity.

Outer sepals developing conspicuous wings.

1. B. Convolvulus.

2. B. scandens.

1. B. Convolvulus (L.) Dum. Annual, glabrous but scurfy, pale green; stem ascending and twining, 1-12 dm. long; leaf-blades ovate-sagittate or deltoid, $2-6 \mathrm{~cm}$. long, acuminate at the apex; racemes 1-6 cm. long; perianth green, 3.5-4 $\mathrm{mm}$. long; segments oblong, obtuse; achenes 3-angled, $3.5 \mathrm{~mm}$. long, black, granular. Polygonum Convolvulus L. Tiniaria Convolvulus Webb. \& Moq. Bindweed. Among bushes: N.S.-Fla.-Calif.-B.C.; nat. from Eu. Plain -Mont. My-S.

2. B. scandens (L.) Greene. Perennial, glabrous, somewhat scurfy; stem extensively twining, 5-30 dm. high; leaf-blades ovate-cordate to oblong-cordate, 1-12 cm. long, short-acuminate, long-petioled; perianth greenish yellow, $1 \mathrm{~cm}$. long; segments ovate, obtuse; achenes $3.5-4.5 \mathrm{~mm}$. long, black, smooth and shining. Polygonum scandens L. Tiniaria scandens (L.) Small. False Buckwhent. Thickets: N.S.-Fla.-La.-Colo--Mont. Plain-Submont. Jl-O.

\section{Family 38. Chenopodiaceae. Goosefoot Family.}

More or less fleshy herbs or shrubs, with alternate or opposite leaves, without stipules. Flowers usually clustered in spikes, cymes, or panicles, usually greenish. Calyx of $2-5$ sepals. Corolla wanting. Stamens opposite the sepals; anthers introrse. Pistils of 2-5 united carpels; ovary 1-celled; styles 2-5. Fruit a 1-seeded utricle. Embryo curved or spiral.

Embryo annular.

Stems and branches not jointed; leaves not scale-like.

Flowers perfect, all with perianth, not inclosed in a pair of bracts.

Fruit inclosed in the calyx.

Calyx in fruit not transversely winged.

Sepals $3-5$; stamens $1-5$.

Fruiting calyx herbaceous.

Fruiting calyx fleshy, red. Sepals 1 ; stamens 1 .

Calyx in fruit transversely winged.

Flowers paniculate; leaves ample, sinuate, flat. 4. Cycloloma.

Flowers spicate; leaves linear, terete.

Fruit laterally flattened, exserted from the marcescent calyx.

1. CHENOPODIUM.

2. BLITUM.

3. MONOLEPIS.

5. KOCHIA.

6. CoRiospermum.

Flowers monoecious or dioecious; the pistillate inclosed in two accrescent bractlets. Pericarp not hairy.

Bracts compressed; leaves more or less farinose; testa mostly coriaceous.

Pistillate flowers without perianth.

7. ATRIPLEX.

Pistillate flowers with 2-3 hyaline sepals shorter than the bracts.

8. ENDOLEPIS.

Bracts ob-compressed; testa membranous.

Pericarp hastate with crested margins, 2-toothed apex; herbs more or less farinaceous, with toothed leaves.

9. SUCKLEYA.

Pericarp obovate or orbicular, entire; undershrubs with entire leaves.

10. GRAYIA.

Pericarp densely hairy, conic; low and tomentose shrubs. 11. EuRotra.

Stems and branches fleshy, jointed; leaves scale-like; flowers sunk into the rachis of the spike.

Flower-clusters decussately opposite; branches opposite.

Flowers spirally arranged; branches alternate.

12. SALICORNIA.

13. Allenrolfia.

Embryo spirally coiled.

Shrubs with monoecious bractless flowers; staminate flowers in spikes, without perianth; pistillate ones solitary, axillary; fruiting calyx transversely winged.

Herbs with perfect bracteolate flowers.

Fruiting calyx transversely winged; leaves spiny.

Fruiting calyx not winged; leaves fleshy, not spiny.

14. Sarcobatus.

1. Chenopòdium (Tourn.) L. Goosefoot, Pigweed, LAMB'S QUARTER.

Annual (all ours) or perennial herbs, usually with mealy-coated or glandular foliage. Leaves alternate, with entire, toothed or lobed blades. Flowers per- 
fect or rarely dioecious, in small axillary or terminal spikes or glomerules. Sepals persistent, flat or keeled. Stamens 1-5; filaments filiform. Ovary usually depressed, 1-celled; styles 2-5; stigmas filiform or subulate. Utricle containing one horizontal or vertical seed. Endosperm mealy.

Leaves more or less mealy or glabrate, never glandular or sweet-scented, sinuately lobed, dentate or entire; embryo forming a complete ring.

Stamens 5; calyx not at all fleshy in fruit.

Leaves entire or sinuately toothed, but not with large, acute (except in C. murale), divaricate teeth; seeds $1-1.5 \mathrm{~mm}$. in diameter.

Calyx-lobes carinate; at least the upper panicles exceeding the leaves. Pericarp easily separating from the seeds.

Leaves linear or oblong, entire or slightly sinuately toothed.

Whole plant almost perfectly glabrous; glomerules 1-4-flowered, in very lax spikes; leaves narrowly linear. 1 1. C. subglabrum.

Leaves more or less mealy beneath; glomerules several-flowered; spikes denser.

Leaves thin; inflorescence not very dense; spikes somewhat interrupted below.

Leaves all narrowly linear, 1-nerved, entire. 2. C. leptophyllum. Lower leaves at least oblong or lanceolate, 3-nerved and often somewhat hastately toothed. 3 . C. pratericola.

Leaves thick; inflorescence dense and crowded; leaves oblong.

Plant densely mealy, yellowish. 4 . C. desiccalum.

Plant only slightly mealy, dark green. 5. C. aridum.

Leaves broadly ovate or triangular, more or less hastate at the base.

Plant densely farinose.

Plant low and spreading. 6. C. incanum.

Plant tall and erect.

Plant sparingly farinose or glabrate, tall.

Leaves very thin, distinctly hastate; inflorescence lax.

8. C. Fremontii.

Leaves thick, only slightly hastate, rounded at the apex.

Pericarp firmly attached to the seeds.

9. C. atrovirens.

Leaves subentire or merely hastately toothed.

Leaves linear; calyx closed in fruit.

10. C. inamoenus.

Calyx open in fruit; plant ill-scented. 11. C. hians

Calyx closed in fruit.

Leaves thick, more or less farinose, none of them cuspidate.

Leaves thin, glabrate: inflorescence lax.

Seeds $1 \mathrm{~mm}$. in diameter; upper leaves cuspidate.

13. C. Berlandieri.

Seeds about $1.5 \mathrm{~mm}$. in diameter; upper leaves long-acuminate.

14. C. lanceolatum.

Leaves more or less sinuately dentate; inflorescence dense.

Leaves densely mealy.

Leaves green or nearly so.

15. C. album.

16. C. paganum.

Calyx-lobes not carinate; panicles mostly axillary, shorter than the leaves.

Leaves glabrate; seeds horizontal. 17 . C. murale.

Leaves farinose and glaucous beneath; seeds vertical. 18. C. salinum.

Leaves with large divaricate acute lobes; seeds about $2 \mathrm{~mm}$. in diameter.

Stamens 1-2; calyx reddish and slightly fleshy in fruit.

19. C. hybridum.

Plant usually more than $1 \mathrm{dm}$. high, erect; leaves usually more or less toothed. 20. C. rubrum.

Plant less than $2 \mathrm{dm}$. high, prostrate; leaves entire or merely hastately toothed. 21. C. humile.

Leaves glandular, sweet-scented, pinnately lobed; embryo horseshoe-shaped.

Lobes of the leaves rounded or broadly oblong, more or less toothed. 22. C. Botrys.

Lobes of the leaves lanceolate, entire.

23. C. incisum.

1. C. subglabrum (S. Wats.) A. Nels. Stem $2-4 \mathrm{dm}$. high, branched, striate, obtusely angled; leaves 1-nerved, 2-10 $\mathrm{cm}$. long, 1-3 $\mathrm{mm}$. (rarely $4 \mathrm{~mm}$.) wide, entire, light green; seeds black, shining, about $1.5 \mathrm{~mm}$. in diameter. Sandy soil: S.D.-Neb.-Utah-Wash.-Ore. Plain. Jl-Au.

2. C. leptophyllum Nutt. Stem $2-5 \mathrm{dm}$. high, striately angled; leaves 1-6 dm. long, 1-6 mm. wide, green above, rather densely mealy beneath; sepals strongly carinate, scarcely covering the seed; seeds shining, fully $1 \mathrm{~mm}$. broad. Sandy or dry soil: Man.-Mo.-N.M.-Ariz.-Ore.-B.C.; adv. in the East: Me. -N.J. Son.-Plain-Submont. Je-S.

3. C. pratericola Rydb. Stem 3-6 dm. high, striate and angled, nearly glabrous; leaves petioled; blades $2-6 \mathrm{~cm}$. long, 4-18 $\mathrm{mm}$. wide; sepals scarious- 
margined, green on the back, slightly carinate; seeds black, shining, about 1.5 $\mathrm{mm}$. in diameter. Sandy soil, fields and waste grounds: Neb.-Mo.-N.M.Ariz.-Wash.; n Mex. Plain. J-S.

4. C. desiccatum A. Nels. Stem 2-5 dm. high; leaves short-petioled; blades obtuse or acutish, 1-4 cm. long, 4-10 $\mathrm{mm}$. wide, thick, mealy on both sides; sepals slightly carinate; seeds black, shining, $1.5 \mathrm{~mm}$. broad. C. oblongifolium (S. Wats.) Rydb. C. desiccatum was described from a depauperate form. Arid ground: N.D.-Mo.-Tex.-Calif.-Wash. Plain-Submont. Jl-S.

5. C. aridum A. Nels. Stem erect, 3-4 dm. high; leaves moderately thick, dark green; blades 1-3 cm. long, oblong to ovate-lanceolate, entire or rarely slightly hastately toothed, obtuse; seeds scarcely $1 \mathrm{~mm}$. in diameter, black, shining. C. Wolfii Rydb. Arid ground: Colo.-Wyo. Submont.-Mont. Jl-Au.

6. C. incanum (S. Wats.) Heller. Stem divaricately branched, 1-3 dm. high, mealy, obtusely angled; leaf-blades rhombic or broadly ovate, hastately lobed, 3-ribbed, 1-2 cm. long and nearly as broad; flowers in dense clusters; sepals very mealy, slightly carinate; seeds black, shining. Dry ground, especially in "prairie-dog towns:". Neb.-Kans.-N.M.-Ariz.-Utah. Plain-Son. $\mathrm{My}-\mathrm{Au}$.

7. C. albescens Small. Stem erect, 5-12 dm. high, mealy when young, angled; leaf-blades $2-4 \mathrm{~cm}$. long, sharply acute or bristle-tipped, hastately lobed or toothed, 3-ribbed; inflorescence rather lax; sepals mealy, barely keeled; seed 1-1.5 mm. broad, black, shining. Dry soil: Tex.-N.M.-Colo. Son.Submont. Je-Jl.

8. C. Fremontii S. Wats. Stem 2-8 dm. high, with slender branches, green; leaf-blades broadly triangular or rhombic, sinuate-dentate, $1-5 \mathrm{~cm}$. long and nearly as wide, rounded and mucronate at the apex; sepals strongly carinate, nearly covering the fruit; seed black, shining, fully $1 \mathrm{~mm}$. broad. In cañons and among bushes: Sask.-N.M.-Ariz.-Nev.-B.C.; n Mex. Plain-Mont. $\mathrm{Jl}-\mathrm{S}$.

9. C. atrovirens Rydb. Stem $3-5 \mathrm{dm}$. high, striate and obtusely angled; leaf-blades broadly ovate, the upper mucronate at the apex, 3-ribbed, $1-3 \mathrm{~cm}$. long, 5-15 mm. wide; flowers in short dense spikes, sparingly mealy; seeds black, shining, $1 \mathrm{~mm}$. broad. Foot-hills: Mont.-Wyo.-Nev. Submont. Jl-Au.

10. C. inamoenus Standl. Stem erect, 1-8 dm. high, much branched; petioles very short; leaf-blades $1-3 \mathrm{~cm}$. long, 1-5 mm. wide, obtuse, 1-nerved, thick, densely farinose, becoming glabrate above; flowers in large glomerules in dense erect paniculate spikes; sepals ovate, slightly carinate; seeds $0.8 \mathrm{~mm}$. broad, black, shining. Dry places: Wyo.-N.M.-Nev,-Ore.; n Mex. Au-S.

11. C. hians Standl. Stem 4-8 dm. high, copiously mealy; petioles half as long as the leaf-blade or shorter; blade $1.2-3 \mathrm{~cm}$. long, rounded and shortapiculate at the apex, green above, densely white-mealy beneath; flowers in large glomerules in paniculate spikes; sepals rounded-oblong or ovate, obtuse, obtusely carinate, mealy; seeds black, $1 \mathrm{~mm}$. broad, shining. Dry hillsides: N.M.Wyo. Au.

12. C. Watsoni A. Nels. Stem stout, 2-6 dm. high; leaf-blades $1-2 \mathrm{~cm}$. long, oval, ovate, or oblong, obtuse, dark green and sparingly mealy; inflorescence narrow, dense; seed 1.25-1.5 mm. in diameter. $C$. olidum S. Wats. Dry places: Mont.-N.M.-Ariz. Son.-Mont. Au-O.

13. C. Berlandieri Moq. Stem erect, 3-9 dm. high, much branched; leafblades lanceolate, oblong, or ovate, sometimes somewhat rhombic, $1.5-4 \mathrm{~cm}$. long; inflorescence open, interrupted, lax; sepals barely keeled; seeds black, punetate. Dry soil: N.C.-Fla.-Tex.-Colo.; n Mex. Plain-Mont. Jl-S.

14. C. lanceolatum Muhl. Stem 4-12 dm. high, branched, blunt-angled; lower leaf-blades ovate or lanceolate, coarsely toothed, those of the inflorescence linear-lanceolate, entire; inflorescence open and interrupted; sepals merely keeled; seeds black, shining. C. viride Auth., not $L$. Waste places and fields: Mass.-Fla.-La.-Sask.; B.C. Plain. Jl-S. 
15. C. album L. Stem erect, 6-30 dm. high; leaf-blades ovate or lanceolate, more or less rhombic, $2-8 \mathrm{~cm}$. long, acute or obtuse, usually hastately lobed; inflorescence dense; sepals with light margins, enclosing the fruit; seed black, shining. Fields, waste places, and thickets: Newf.-Fla.-Calif.-B.C.Yukon; Eurasia. Plain-Submont. JI-S.

16. C. paganum Reichenb. Stem erect, $0.5-3 \mathrm{~m}$. high; leaf-blades ovate to broadly lanceolate, 3-15 cm. long, coarsely sinuate-dentate, acute at the apex, thin; inflorescence dense, much-branched; sepals sharply carinate, enclosing the fruit; seeds black, rugulose-pitted. Waste places: Mass.-Va.-N.M.-Colo.; adv. from Eu. Plain-Submont. Jl-S.

17. C. murale L. Stem erect or decumbent, 1-6 dm. long, widely branching; leaf-blades thin, rhombic-ovate, $2-8 \mathrm{~cm}$. long, acute, coarsely sinuate-dentate, cuneate or truncate at the base; flower-clusters small, shorter than the leaves; sepals oblong, obtuse; seeds firmly adherent to the pericarp, sharp-angled. Waste places: Me.-Fla.-Calif.-B.C.; Mex. and W. Ind.; adv. or nat. from Eu. Plain-Submont. Mr-O.

18. C. salinum Standl. Stem prostrate, decumbent or ascending, freely branched, more or less fleshy; leaf-blades broadly lanceolate to triangular-ovate or oblong, acute, $2-3 \mathrm{~cm}$. long, sinuately toothed and somewhat hastate; flowers in small axillary spikes shorter than the leaves; sepals obovate, rounded at the apex; seeds finely tuberculate. C. glaucum Am. auth., mainly. Alkaline soils: Alta.-Neb.-Colo.-Utah-Ore. Plain-Submont. Jl-S.

19. C. hybridum L. Stem erect, 6-13 dm. high; leaf-blades rhombic-ovate or triangular-ovate, long-acuminate, sharply sinuate-dentate, with 1-4 large teeth on each side, or the uppermost entire, 1-2 dm. long; flowers in large open panicles; sepals oblong, slightly keeled; seeds firmly attached to the pericarp, acute-margined, punctate. Woods, thickets and waste places: Que.-Vt.N.Y.-Ky.-N.M.-Calif.-B.C.; nat. from Eu. Plain -Submont.

20. C. rubrum L. Stem erect, branched, $3-8 \mathrm{dm}$. high; leaf-blades thick, triangular-hastate to lanceolate, $3-10 \mathrm{~cm}$. long, coarsely sinuate-dentate or the upper entire, nearly glabrous, dark green; flower-clusters densely spicate on short branches; sepals $2-5$, obtuse, rather fleshy; seeds easily separating from the pericarp, less than $1 \mathrm{~mm}$. in diameter. C. succosum A. Nels. CoAst Blite. Alkaline or saline soil: Newf.-N.J.-Mo.-N.M.-Ariz.-B.C.; Eu. Plain-Submont. Jl-S.

21. C. humile Hook. Stem decumbent or spreading, divaricately branched; leaf-blades obovate, spatulate, or lanceolate, the upper linear, 1-3 cm. long, fleshy, glabrous or nearly so; flower-clusters in small axillary spikes; sepals oblong, obtuse, somewhat fleshy; seeds less than $1 \mathrm{~mm}$. broad, easily separating from the pericarp. Alkali Blite. Alkaline meadows: Sask.-Neb.-Colo.Calif.-B.C. Plain-Submont. Je-N.

22. C. Botrys L. Stem erect, 1-6 dm. high, branched; leaf-blades 1-5 cm. long, oblong or ovate, irregularly pinnatifid; flower-clusters in small, axillary cymes; seeds horizontal or vertical, $0.8 \mathrm{~mm}$. broad, adherent to the pericarp. JERUSAr.m OAK. Waste places: N.S.-Ga.-Tex.-Calif.-B.C.; Mex.; nat. from Eu. Plain-Mont. J-O.

23. C. incisum Poir. Stem 2-5 dm. high, branched; leaves lanceolate or ovate in outline, $2-4 \mathrm{~cm}$. long, sinuate-pinnatifid or sinuate-dentate, with entire lobes or teeth; flowers in axillary cymes; sepals acute, carinate; seeds about 0.5 mm. broad, obtusely margined. C. cornutum (Torr.) B. \& H. Dry places: Colo.-N.M.-Ariz.; Mex. Son.-Submont. Je-S.

\section{Blitum L. Strawberry Blite, Strawberry Pigweed.}

Annual fleshy herbs, with light green, glabrous, toothed leaves. Flowers small, green or reddish, aggregate in small axillary, head-like clusters, or the upper clusters forming an interrupted spike. Calyx 2-5-lobed, becoming fleshy and bright red in fruit. Stamens 1-5, mostly 2. Ovary 1-celled; styles 2-5; 
stigmas slender. Seed vertical, shining, separating from the pericarp. Endosperm mealy.

Leaves more or less dentate, truncate or broadly cuneate at the base; inflorescence dense; glomerules $5-10 \mathrm{~mm}$. in diameter.

Inflorescence naked above; seeds with acute margins.

Inflorescence leafy throughout; seeds round-margined.

1. B. capitatum

eaves entire, except the hastate teeth at the cuneate bach

2. B. virgatum.

naked above; glomerules $3-6 \mathrm{~mm}$. in diameter.

3. B. hastatum.

1. B. capitatum L. Stem simple or branched from the base, $3-6 \mathrm{dm}$. high; leaves broadly triangular to lanceolate, $3-7 \mathrm{~cm}$. long; the uppermost entire, rather thick; flowers in rather large clusters in the axils of the upper leaves and in a terminal spike; sepals acute or acutish. In rocky soil: N.S.-N.J.-N.M.Calif.-Alaska; Eurasia. Submont.-Mont. My-Au.

2. B. virgatum L. Stem branched throughout, $1.5-8 \mathrm{dm}$. high; leaf-blades triangular to rhombic-oblong, 2-9 cm. long, coarsely laciniate-dentate, the upper smaller and sharply hastate; glomerules large, all axillary; sepals rounded. Waste places: Ore.-Ida.-Wash.; Mass.-N.Y.; adventive from the Old World.

3. B. hastatum Rydb. Stem slender, 2-4 dm. high; leaves very thin; blades $3-7 \mathrm{~cm}$. long, ovate or ovate-lanceolate in outline, the upper ones smaller, not hastate: flowers in the upper axils and in a slender interrupted terminal spike. Stony ground: Wyo.-Colo.-Nev. Submont.-Mont. Jl-S.

\section{MONÓlepis Schrad. Poverty Weed.}

Low branching annuals, with alternate leaves. Flowers small, perfect or polygamous, in small axillary clusters, without bracts. Calyx of a single persistent sepal. Stamen 1. Ovary 1-celled; styles 2; stigmas filiform. Seed vertical, flattened. Endosperm copious, mealy.

Leaves lanceolate, hastately lobed; flower-clusters several-flowered; pericarp somewhat fleshy.

I reaves spatulate to linear-spatulate, entire; pericarp thin.

Flower-clusters 10-20-flowered; pericarp easily separating from the seed.

Flower-clusters 1-3-flowered; pericarp adherent to the seed.

2. M. spathulata.

3. M. pusilla.

1. M. Nuttalliana (Schultes) Engelm. Annual; stem decumbent or ascending, divaricately branched, 1-3 dm. high; leaves short-petioled or subsessile; blades thick, $2-7 \mathrm{~cm}$. long, acute at both ends, sparingly sinuate-dentate or entire; sepal fleshy and foliaceous, oblanceolate or spatulate; pericarp adherent to the seed. M. chenopodioides Moq. Saline soils: Man.-Minn.-Tex.-N.M.Calif.-Wash.; Sonora; Siberia. Plain-Mont. Mr-S.

2. M. spathulata A. Gray. Stem decumbent or ascending, branched at the base, 7-15 $\mathrm{cm}$. long; leaves short-petioled, 1-2 $\mathrm{cm}$. long; blades spatulate, thick, acute, entire; sepal spatulate, obtuse; seed $0.5 \mathrm{~mm}$. broad. Saline soil: Calif.-Ida.-Ore. Son.

3. M. pusilla Torr. Stem erect, dichotomously branched, 5-15 cm. high, somewhat mealy, glabrate; leaves subsessile, oblong-spatulate, obtuse, 5-15 $\mathrm{mm}$. long, entire; seeds less than $0.5 \mathrm{~mm}$. broad. Alkaline valleys and sandy plains: Wyo.-Colo.-Calif.-Wash. Son.-Submont. My-J.

\section{4. cyclolòma Moq. Winged Pigweed, Tumbleweed.}

Diffusely branched coarse annuals, with alternate toothed leaves. Flowers polygamous, $i$. e., perfect and pistillate, in paniculate spikes, without bracts. Sepals 5, keeled, each at maturity with a horizontal wing. Stamens 5. Ovary 1-celled, hairy; styles 2 or 3, partially united. Utricle depressed, enclosed in the calyx. Seed flat, horizontal. Endosperm mealy.

1. C. atriplicifolium (Spreng.) Coult. Stem erect, divaricately branched, 3-6 dm. high; leaves short-petioled or sessile; blades lanceolate or ovate, coarsely sinuately dentate, acute at the apex, cuneate at the base, $2-7 \mathrm{~cm}$. long; wing of the calyx irregularly lobed and toothed, $4-5 \mathrm{~mm}$. in diameter, covering the 
utricle. C. platyphyllum (Michx.) Moq. Sandy soil: Ont.-Ark.-Tex.-N.M. -Ariz.-Mont. L. Son.-Plain-Submont. Je-S.

\section{KÒCHIA Roth.}

Perennial or annual herbs, or undershrubs, with alternate narrow leaves. Flowers solitary or few together in the upper axils, perfect or pistillate, sometimes bracteolate. Calyx herbaceous, 5-cleft, persistent, at length developing a horizontal wing. Stamens $3-5$, usually exserted; filaments linear. Ovary ovoid, narrowed upwards; stigmas 2. Pericarp not adherent to the inverted seed. Endosperm scanty.

Perennial undershrubs; leaves linear-filiform, fleshy.

Branches tomentulose, soon glabrate; leaves somewhat hairy when young; fruit nearly glabrous.

Branches and leaves densely and permanently hairy; fruit very pubescent,

Annual; leaves lanceolate, not fleshy.

2. K. vestita.

3. K. scoparia.

1. K. americana S. Wats. Low undershrub; stems 1-4 dm. high; leaves 6-25 mm. long, acute, ascending, puberulent or glabrate; ovary ovate, tomentose at the apex, shorter than the calyx and styles. Foot-hills and alkaline flats: Wyo.-Colo.-N.M.-Calif. Plain-Submont. Je-S.

2. K. vestita S. Wats. Low undershrub; stems 1-4 dm. high; leaves 6-20 $\mathrm{mm}$. long, villous, nearly erect, acute; ovary oblong, nearly equalling the calyx. Foot-hills and alkaline flats: Wyo.-Colo.-Calif.-Ore. Plain-Submont. My$\mathrm{Jl}$.

3. K. scoparia (L.) Schrad. Branches annual; stems sparingly pubescent or glabrous, 3-10 dm. high; branches strongly ascending; leaves lanceolate, or the upper linear, the lower 3-nerved, entire; flowering branches and calyces villous. Waste places and fields: Vt.-Pa,-Colo.; adv. from the Old World. Plain. Jl-S.

\section{CORISPÉRMUM (A. Juss.) L. BUG-SEED.}

Caulescent annuals, with narrow sessile leaves and diffusely branched stems. Flowers solitary, in the axils of more or less leaf-like bracts. Sepals 1-3, unequal, scarious. Stamens $1-3$, rarely 5 , hypogynous, one longer than the rest; filaments dilated. Ovary 1-celled; styles 2. Utricle more or less flattened, in ours acutely margined or winged. Pericarp adherent to the vertical seed. Endosperm fleshy.

Fruit with a distinct wing, about $0.5 \mathrm{~mm}$. wide.

Spike lax; lower bracts much narrower than the fruit. 1 . C. nitidum.
Spikes dense; lower bracts usually overtopping, and rarely narrower than the fruit.

Fruit merely acute-margined, scarcely at all winged.

Plant glabrous.

Plant more or less villous.

2. C. marginale.

1. C. nitidum Kit. Stem branched, 3-6 dm. high, glabrous; leaves linearfiliform, 2-5 cm. long, $1 \mathrm{~mm}$. wide or less; lower bracts subulate, about $1 \mathrm{~cm}$. long, 1-1.5 $\mathrm{mm}$. broad at the base; the upper lanceolate, shorter; fruit about $2 \mathrm{~mm}$. broad and $3 \mathrm{~mm}$. long. C. hyssopifolium microcarpum S. Wats. On sand-hills and in cañons: IIl.-Tex.-N.M.-N.D.; Eurasia. Son--PlainSubmont. Л-S.

2. C. marginale Rydb. Stem glabrous, much branched, $2-5 \mathrm{dm}$. high; leaves narrowly linear, $2-5 \mathrm{~cm}$. long, $1.5-2 \mathrm{~mm}$. wide; lower bracts lanceolate, about $1 \mathrm{~cm}$. long, the upper ovate, $5 \mathrm{~mm}$. long, all with conspicuous scarious margins; fruit about $4 \mathrm{~mm}$. long and $2.5 \mathrm{~mm}$. wide. C. imbricalum A. Nels. Sandy soil: Wyo.-N.M, Plain-Submont. Au-0.

3. C. emarginatum Rydb. Stem branched near the base, 3-4 dm. high; leaves narrowly linear, $2-4 \mathrm{~cm}$. long, $1-2 \mathrm{~mm}$. wide, cuspidate-pointed; bracts except the lowest ovate, $5-7 \mathrm{~mm}$. long, acuminate, searious-margined; fruit $2.5-3 \mathrm{~mm}$. long and about $2 \mathrm{~mm}$. wide. Sandy valleys: Alta.-Colo.-Nev, Submont. 
4. C. villosum Rydb. Stem 2-4 dm. high, diffusely branched from near the base; leaves linear, 2-4 cm. long, 1-3 mm. wide, cuspidate-mucronate; spikes rather dense; bracts more or less imbricate, the lower linear-lanceolate, 5-10 $\mathrm{mm}$. long, the upper ovate, acuminate, 4-5 mm. long, with broad scarious margins; fruit $2.5-3 \mathrm{~mm}$. long, $2 \mathrm{~mm}$. wide. Sandy valleys and fields: Sask.N.M.-Ariz.-Ore,-Wash. Plain-Submont. J-S.

\section{7. Átriplex (Tourn.) L. Orache, Salt-bush, Shad-scales.}

Annual or perennial herbs or low shrubs, with scaly or scurfy, often silvery pubescence. Leaves alternate or some opposite. Flowers monoecious or dioecious, in axillary or terminal panicles, or congested axillary spikes. Staminate flowers without bracts; sepals $3-5$; stamens $3-5$; filaments distinct or united; anthers 2-celled, opening lengthwise. Pistillate flowers subtended by 2, more or less united bracts, which are entire or toothed, often crested, tuberculate, or winged on the back. Calyx wanting. Ovary 1-celled; stigmas 2, subulate or filiform. Utricle wholly or partly enclosed in the accrescent bracts. Seeds erect or nearly horizontal. Endosperm mealy.

Annuals.

Bracts united only at the base; radicle inferior.

Bracts thin, rounded-ovate, mueronate.

Bracts thick, deltoid or lanceolate, acute.

Leaves not hastate.

Leaves more or less hastate.

Bracts united to about the middle; radicle superior.

1. A. hortensis.

Bracts lanceolate or lance-oblong, not tubercled below.

Bracts broader; if narrow, broadest above the middle.

Bracts broadly cuneate, truncate at the apex, seldom with tubercles. Leaves triangular or cordate-ovate.

Plant low, decumbent, $1 \mathrm{dm}$. high or less; leaves less than $2 \mathrm{~cm}$. long.

5. A. subdecumbens.

Plant larger, 3-10 dm. high; leaves $1.5-2.5 \mathrm{~cm}$. long.

2. A. lapathifolia.

3. A. hastata.

back; often laciniate

4. A. phyllostegia.

Bracts subentire, corky at the apex; fruit short-peduncled; leaves cordate-ovate. 6 . A. saccaria.

Bracts bluntly 3-toothed at the herbaceous apex; fruit subsessile; Leaves linear. leaves more triangular-ovate. 7 . A. truncata.

Bracts rhombic-orbicular to triangular, conspicuously toothed on the margins and usually appendaged or tubercled on the back.

Bracts with linear, subulate, or oblong appendages on the back.

Staminate flowers few, mixed with the pistillate ones.

Staminate flowers in terminal clusters.

9. A. Caput-Medusae.

Bracts with triangular lobes and appendages.

Leaves thin, more or less toothed or hastate.

Bracts ovate, acute, longer than broad; branches terete or nearly so.

10. A, rosea.

Bracts suborbicular, as broad as Iong; branches distinctly roundangled.

Leaves subsessile, only the lowest with short-winged petioles, very thin, usually cuspidate-acuminate; staminate spikes, if present, elongated.

11. A. expansa.

Leaves petioled, firmer, acute; staminate spikes, if present, very short.

12. A. argentea.

Leaves ovate or oblong, entire, usually less than $2 \mathrm{~cm}$. long.

Leaves more or less 3-ribbed; branches ascending.

Leaves strongly ribbed; faces of the bracts with short thick appendages.

13. A. Powellii.

Leaves obscurely ribbed; bracts without dorsal appendages.

Leaves 1-ribbed; branches spreading, slender.

14. A. Rydbergit.

Leaves ovate or oblong, $2-7 \mathrm{~mm}$. long; bracts ovate, tubercled below the middle.

15. A. tenuissima

Leaves linear, 7-17 mm. long; bracts ovate-oblong, tubercled at or above the middle.

16. A. Greenei.

Perennials.

Bracts not winged on the back.

Plant monoecious; lateral wings decurrent on the pedicels. 17. A. gracilliflora.

Plant dioecious; lateral wings not decurrent.

Bracts with entire or merely wavy (rarely slightly denticulate) margins, without appendages on the back.

Bracts small, 3-4 mm. long, longitudinally veined.

Bracts united to above the middle; shrub not spinescent.

18. A. lentiformis. 
Bracts nearly free; shrub spinescent.

Bracts larger, 5-10 mm. long, not veined.

19. A. Torreyi.

Leaves reniform, coarsely sinuately dentate; free portion of the bracts reniform.

Leaves entire; bracts not reniform.

20. A. hymenolytra.

Leaves broadly oval or obovate; bracts obovate or suborbicular. Bracts entire.

Bracts dentate or denticulate, at least near the base.

22. A. collina.

Leaves oblanceolate; bracts lance-oblong. $\quad 23$. A. subconferta.

Bracts with a distinctly toothed margin or appendaged on the back. Bracts broadest above the middle.

Bracts more or less toothed on the margin, only rarely tuberculate on the back.

Bracts 3-toothed at the apex, the middle tooth the longest. Bracts oblong-cuneate; leaves oblanceolate-cuneate.

Bracts broadly obovate-cuneate; leaves linear.

4. A. Gardneri.

Bracts several-toothed at the apex.

25. A. tridentata.

26. A. pabularis.

Bracts entire, spongy, strongly tuberculed or appendaged on the back.

27. A. corrugata.

Bracts broadest below the middle, strongly tuberculate or appendaged.

Leaves oblanceolate to spatulate.

Leaves oblanceolate, oblong, or narrowly spatulate, subsessile, or short-petioled.

Plant low; staminate flowers brown, in panicles; leaves shortpetioled.

28. A. oblanceolata.

Plant usually tall; staminate flowers yellow, in interrupted spikes; leaves sessile.

Bracts ovate, sessile or nearly so; leaf-blades oblanceolate to oblong.

29. A. Nuttallii.

Bracts fusiform, stalked; leaf-blades oblong-linear to linear.

Leaves broadly spatulate, conspicuously petioled; staminate flowers brown, in interrupted spikes. 31 . A. cuneata.

Bracts broadly 4-winged.

Leaves oval, sessile. $\quad 32$. A. buxifolia.

Leaves oval, abruptly acuminate.

Leaves from oblong or spatulate to linear, not acuminate.

Wings thick, laciniate-toothed.

Wings thin, sinuately dentate or subentire.

33. A. Garrettii.

34. A. aptera.

Wings when fully developed 4-6 mm. wide, distinctly dentate.

Leaves comparatively broad, linear-oblong to spatulate, 4-10 mm. wide; sinus at the apex of the fruit narrow; free portion of the bract one-half to three-fourths as long as the width of the wing.

35. A. canescens.

Leaves very narrow, linear, 2-5 mm. wide; sinus of the strongly reticulate bract broad; free portion of the bract less than half as long as the width of the wing.

36. A. tetraptera.

Wing very broad and thin, fully $8 \mathrm{~mm}$. wide, merely sinuate; leaves linear.

37. A. occidentalis.

1. A. hortensis L. Stem 1-1.5 m. high; leaves petioled; lower leaf-blades from cordate or hastate to ovate, sinuately toothed, 1-2 dm. long, the upper lanceolate and entire; bracts rounded-ovate, about $1 \mathrm{~cm}$. in diameter, thin, reticulate. Waste places: N.Y.-Colo.-Utah-Mont.; escaped from cultivation; native of Eu. Plain-Submont. Jl-Au.

2. A. lapathifolia Rydb. Stem strict, 4-6 dm. high; leaves petioled; blades somewhat fleshy, dark green, lanceolate, $3-6 \mathrm{~cm}$. long, entire; bracts in fruit about $4 \mathrm{~mm}$. long and $5 \mathrm{~mm}$. wide, of ten slightly hastate, sometimes with 1 or 2 tubercles on the back, thin, veiny, acute. Alkaline flats: Mont.-Wyo.Neb. Plain. Au-S.

3. A. hastata L. Stem branched, 5-10 dm. high, subglabrous; leaf-blades fleshy, rarely sinuately-toothed, 3-7 em. long; flowers numerous, in large fleshy clusters forming interrupted spikes; fruiting bracts triangular-ovate, about $5 \mathrm{~mm}$. long and broad, usually with 1 or 2 small teeth on each margin, and sometimes with 1 or 2 fleshy tubercles on the back. A. carnosa A. Nels. A. subspicata Rydb., a low spreading form. Alkaline meadows or flats: Alta.-Kans.-N.M. -Nev.-Ida. Plain-Son. Au-S.

4. A. phyllostegia (Torr.) S. Wats. Stem stout, 2-6 dm. high, simple or branched; leaves thin, rhombic-triangular, hastate, or ovate, $2-5 \mathrm{~cm}$. long, entire; flower-clusters axillary and in short naked spikes at the ends; bracts 
nearly free, linear-lanceolate, becoming 8-12 mm. long, strongly 3-nerved, somewhat hastately lobed. Obione phyllostegia Torr. Endolepis phyllostegia Rydb., in part. A. Draconis M. E. Jones. Valleys and foot-hills: Utah-Nev. Son.Submont. My-Jl.

5. A. subdecumbens M. E. Jones. Stem 5-20 cm. long, much branched at the base, mealy throughout; leaves barely petioled; blades ovate to lanceolate, 12-18 mm. long, entire, thin; flower-clusters small, axillary; fruiting bracts about $2 \mathrm{~mm}$. long, obseurely dentate on the margin. Gravelly meadows: Utah. Mont. Au.

6. A. saccaria S. Wats. Stem ascending, 1-1.5 dm. high, diffusely branched, densely scurfy; leaves short-petioled or sessile; blades 1-2 cm. long; flowerclusters axillary; fruiting bracts about $3 \mathrm{~mm}$. long, cuneate, reticulate on the sides. A. cornuta M. E. Jones. Arid regions:" Nev.-Wyo.-N.M.-Ariz. Son.

7. A. truncata (Torr.) A. Gray. Stem stout, 3-10 dm. high, sparingly branched; leaves sessile or the lower short-petioled; blades broadly triangularovate, $2-4 \mathrm{~cm}$. long, truncate or subcordate at the base; inflorescence leafy; bracts $3 \mathrm{~mm}$. long; faces not reticulate and rarely tubercled. A. Nelsonii M. E. Jones. Alkaline flats: Mont.-N.M.-Calif.-B.C. Plain-Submont. Jl-S.

8. A. Wolfii S. Wats. Stem 1-2 dm. high, slender, branching from the base, scurfy; leaves sessile, linear, 1-1.5 cm. long, acute, scurfy; flowers in small axillary clusters (monoecious); fruiting bracts $1-1.5 \mathrm{~mm}$. long, cuneate-obovate; summit foliaceous, 3-toothed. Alkaline flats: Wyo--Colo.-Utah. PlainSubmont. Je-S.

9. A. Caput-Medusae Eastw. Stem with several, erect branches from the base, 4-5 dm. high, much branched; leaves petioled; blades vertical, thin, deltoid or hastate; fruiting bracts orbicular, becoming hard, 4-5 mm. long, thickly beset with flat horny acuminate processes. River banks: se Utah-sw Colo.N.M. Son.

10. A. rosea L. Stem erect, freely branching, often $1 \mathrm{~m}$. high; leaf-blades ovate, $2-5 \mathrm{~cm}$. long, coarsely and irregularly toothed; flowers in axillary clusters, staminate and pistillate mixed; fruiting bracts about $5 \mathrm{~mm}$. long, hastately toothed near the base, the faces with slender green appendages. A* spatiosa A. Nels. Alkaline flats and railroad embankments: Wyo.-Kans-Chihuahua -Calif.--Wash.; N.Y.-Fla.; adv. from the Old World. Plain-Son. Au-S.

11. A. expansa S. Wats. Stem divaricately branched, $3-18 \mathrm{dm}$. high; leaves thin, triangular-hastate; pistillate flowers in axillary clusters; fruiting bracts coarsely toothed on the margins and somewhat tuberculate on the faces. Alkaline soil: Tex.-(? Colo.)-Calif.; n Mex. Son. JI-O.

12. A. argentea Nutt. Stem divaricately branched, angled, 2-10 dm. high; leaf-blades ovate, triangular-ovate, or subrhombic, $2-5 \mathrm{~cm}$. long; pistillate flowers in axillary clusters; fruiting bracts suborbicular, usually deeply toothed and with projections on the faces. A. rolutans A. Nels. SALT-Bush. Alkaline flats: Sask.-N.D.-Colo.-B.C. Plain-Son. Jl-S.

13. A. Powellii S. Wats. Stems $2-5 \mathrm{dm}$.. high, freely branched; leaves silvery white, petioled; leaf-blades $0.8-2 \mathrm{~cm}$. long; flowers in small clusters in the axils, the staminate and pistillate usually mixed or the staminate ones above; fruiting bracts suborbicular, about $5 \mathrm{~mm}$. broad, irregularly toothed; the faces with short thick appendages. A. philonitra A. Nels. Alkaline flats and dry lakes: Alta.-S.D.-N.M.-Ariz.-Mont. Son.-Submont. JI-S.

14. A. Rydbergii Standl. Stem erect, branched, 2-4 dm. high, subterete; leaves petioled or the upper subsessile; blades ovate or rhombic-ovate to elliptic, $1.5-3.5 \mathrm{~cm}$. long, obtuse or acute at the apex, cuneate at the base, entire, grayish; pistillate flowers solitary or in small clusters in the axils, sometimes mixed with staminate ones, the staminate ones mostly in interrupted terminal spikes; fruiting bracts flabelliform, deeply and coarsely dentate on the margins. Dry roadsides and hills: se Utah. Son. Jl. 
15. A. tenuissima A. Nels. Stem branched from the base, $2-3 \mathrm{dm}$. high; branches slender, decumbent; flower-clusters small, axillary; fruiting bracts very small, less than $2 \mathrm{~mm}$. long, triangular-ovate, with thick appendages on the faces. Arid ground: Utah. Submont. S.

16. A. Greenei A. Nels. Stem 1.5-4 dm. high, much branched; branches strongly ascending, finely furfuraceous; flowers in small axillary clusters; fruiting bracts ovate-oblong or oblong, $2 \mathrm{~mm}$. long, minutely tuberculate, 3 -nerved. Arid ground: Wyo. Submont.

17. A. gracilliflora M. E. Jones. Annual (?) or perennial; stem diffusely branched, 3-6 dm. long, round, sparingly mealy; leaves petioled; blades cordateovate, $1-2 \mathrm{~cm}$. long, entire, fleshy; pistillate flowers in small axillary clusters, the staminate ones in terminal panicles; fruiting bracts orbicular, entire, about 1 $\mathrm{cm}$. broad. Alkaline soil: Utah. Son. Jl.

18. A. lentiformis (Torr.) S. Wats. Shrubby perennial; stems diffusely branched, 6-35 dm. high; leaves short-petioled; blades ovate or oblong-rhombic, $1-3.5 \mathrm{~cm}$. long, entire, cuneate at the base; flowers paniculate; fruiting bracts orbicular, obscurely crenate, 4-5 mm. broad. Alkaline flats: Ariz.-s UtahCalif.; n Mex. L. Son. S-F.

19. A. Torreyi S. Wats. Shrubby perennial; stem diffusely branched, 6-15 $\mathrm{dm}$. high; leaves short-petioled; blades ovate or oblong-triangular, often subhastate, 1-3 $\mathrm{cm}$. long, bluish gray; flowers densely paniculate; fruiting bracts orbicular or reniform, obscurely denticulate, $3-4 \mathrm{~mm}$. broad. Desert valleys: Nev. - s Utah-Ariz.-Calif. L. Son. Jl-S.

20. A. hymenolytra (Torr.) S. Wats. Shrubby perennial; stem 6-10 $\mathrm{dm}$. high; leaves petioled; blades 2-3 $\mathrm{cm}$. long; flowers usually in small panicles, but also in axillary clusters; fruiting bracts reniform, entire, about $1 \mathrm{~cm}$. broad. Alkaline plains: N.M.-Utah-Calif. Son. D-Ap.

21. A. confertifolia (Torr.) S. Wats. Shrubby dioecious perennial; stem $3-15 \mathrm{dm}$. high; branches terete, spinescent; leaf-blades ovate or obovate to orbicular, 0.5-2 cm. long, short-petioled; flowers in axillary clusters; fruiting bracts broadly ovate or suborbicular, about $1 \mathrm{~cm}$. broad. SHAD-sCALES. Alkaline valleys and bluffs: N.D.-N.M.-Calif.-Ore. Son.-Plain-Submont. My$\mathrm{Au}$.

22. A. collina Woot. \& Standl. Shrubby dioecious perennial; stem 2-3 dm. high, much branched; branches spinose; leaf-blades oval-oblong to obovate, $1-2.5 \mathrm{~cm}$. long; flower in axillary clusters, forming densely leafy spikes; fruiting bracts ovate-orbicular, $5-8 \mathrm{~mm}$. long, acute or acutish. Dry hillsides: Colo.N.M.-Ariz.-Utah. Son.

23. A. subconferta Rydb. A low dioecious shrub, with ascending, rather slender, spinescent branches; leaf-blades oblanceolate, acutish or obtuse, 1-2 $\mathrm{cm}$. long, short-petioled, entire; flowers in axillary clusters; fruiting bracts lanceoblong, usually acute, $5-8 \mathrm{~mm}$. long, entire. Dry bench-lands: Ida. Submont. Jl.

24. A. Gardneri (Moq.) Standl. Suffruticose perennial; stems decumbent at the base, $2-4 \mathrm{dm}$. high; leaves sessile or nearly so; blades $3-6 \mathrm{~mm}$. wide, $1.5-3$ $\mathrm{cm}$. long; flowers in axillary capitate clusters or the staminate more paniculate above; fruiting bracts 5-6 mm. long; faces smooth and reticulate; staminate flowers brown. A. Gordoni Hook. A. fruticulosa and A. eremicola Osterh. Alkaline flats or dry lake beds: Wyo.-Colo, Plain. My-Jl.

25. A. tridentata O. Kuntze. Suffruticose dioecious perennial; stem with ereet branches, 3-8 dm. high; leaves sessile, linear, 3-6 cm. long, 2-5 mm. wide, entire; flowers in axillary clusters. Saline soil: Utah-Wyo.-Colo. Son.

26. A. pabularis A. Nels. Suffruticose perennial; stem with erect branches, 2-5 dm. high; leaves sessile or nearly so; blades oblong to almost linear, $1-5 \mathrm{~cm}$. long; flowers in leafy panicles; fruiting bracts cuneate-obovate, usually 5-toothed at the apex; faces smooth. Alkaline flats: Wyo. Jl-S.

27. A. corrugata S. Wats. Suffruticose perennial; stem much branched, 2-3 dm. high; leaf-blades linear-oblanceolate to oblong, entire, $6-18 \mathrm{~mm}$. long; 
pistillate flowers in axillary clusters, the staminate ones in short crowded terminal spikes; fruiting bracts about $4 \mathrm{~mm}$. long. Alkaline valleys: Colo. Son. $\mathrm{My}-\mathrm{Au}$.

28. A. oblanceolata Rydb. Suffruticose perennial, with decumbent base and ascending branches, about $2 \mathrm{dm}$. high; leaves $2-3 \mathrm{~cm}$. long, obtuse or acutish; pistillate flowers in small axillary clusters; fruiting bracts ovate in outline, slightly dentate, tubercled or irregularly crested on the back. Alkaline or clayey flats: Mont.-Colo. Plain. Jl-Au.

29. A. Nuttallii S. Wats. Suffruticose or shrubby perennial; stems 3-6 $\mathrm{dm}$. high, branching near the base; leaves 2-5 $\mathrm{cm}$. long; pistillate flowers in axillary clusters; fruiting bracts ovate or orbicular, 3-4 $\mathrm{mm}$. Iong, irregularly toothed, muricate or tooth-crested on the faces. Plains, bad-lands, and arid valleys: Sask.-Neb.-Colo.-Nev.-Ida. Plain-Submont. Je-S.

30. A. falcata (M. E. Jones) Standl. Suffruticose perennial; stem 2-5 $\mathrm{dm}$. high, with ascending branches; leaves $1.5-5 \mathrm{~cm}$. long, 2-7 mm. wide; flowerclusters both axillary and in terminal spikes; fruiting bracts $5-8 \mathrm{~mm}$. long, entiremargined or sparsely dentate at the apex, united to near the tip, often muricate or tuberculate below. A. Nuttallii falcata and A. Nuttallii anomala M. E. Jones. Plains and hillsides: Wash.-Ida.-Utah-Nev. Son.

31. A. cuneata A. Nels. Suffruticose perennial; stem branched near the base, decumbent; leaves numerous, petioled; leaf-blades 1-3 cm. long; pistillate flowers in axillary clusters; fruiting bracts ovate or suborbicular, irregularly toothed and with thick flattened processes on the faces. Arid plains: sw Colo. -Utah-N.M.-Ariz. Submont. Je-Jl.

32. A. buxxifolia Rydb. Suffruticose perennial; stem branched near the base, with simple branches, 3-4 dm. high; leaves thick, 1-2 $\mathrm{cm}$. long; pistillate flowers in axillary clusters; fruiting bracts ovate, acute, 4-5 mm. long, toothed on the margins and with thick, often flattened processes on the faces. Dry plains: Wyo. Submont. Au.

33. A. Garrettii Rydb. A low shrub, with straw-colored branches; leaves short-petioled, oval, grayish on both sides; flowers in axillary and terminal clusters; bracts $8 \mathrm{~mm}$. long and as broad, 4-winged, coarsely toothed, sometimes with processes on the back; free portion 1-2 mm. long. Hills: se Utah. Son. Jl.

34. A. aptera A. Nels. A shrubby perennial; stems with shining, white, more or less flaky bark, 1-4 dm. high; leaves narrowly oblanceolate to oblong, acute or obtuse, 2-4 cm. long, entire; pistillate flowers axillary: fruiting bracts 3-4 mm. broad, reticulate and ribbed. A. odontoptera Rydb. Saline flats: Alta. - Colo. Plain-Submont. Jl-Au.

35. A. canescens (Pursh) Nutt. Shrubby perennial; leaves 2-5 cm. long; pistillate flowers axillary, short-pedicelled, the staminate clusters in subterminal spikes; fruiting bracts orbicular in outline, when fully developed $12-15 \mathrm{~mm}$. broad. Dry mesas and alkaline valleys: S.D.-Kans.-N.M.-Calif.-Ore. Plain-Submont. Je-Au.

36. A. tetraptera (Benth.) Rydb. Shrubby perennial; stem 6-10 dm. high, white, branched; leaves 2-4 cm. long; pistillate flowers axillary, the staminate clusters forming subterminal spikes; fruiting bracts about $1 \mathrm{~cm}$. broad, strongly reticulate, Desert regions: s Utah-Ariz. $-\mathrm{s}$ Calif.-Nev. L. Son. Ap-J.

37. A. occidentalis (Torr.) D. Dietr. Shrubby perennial; stem $5-20 \mathrm{dm}$. high, divaricately branched and somewhat spinose; leaves $2-4 \mathrm{~cm}$. long, $2-5 \mathrm{~mm}$. wide, linear or oblanceolate, obtuse or even retuse; pistillate flowers axillary, the staminate clusters forming terminal panicles; fruiting bracts $16-18 \mathrm{~mm}$. broad. Arid plains: Tex.-Colo.-Utah-Ariz.; n Mex. Son. My-Jl.

\section{ENDÓLEPIS Torr.}

Monoecious or dioecious annual herbs. Staminate flowers ebracteate in glomerate terminal spikes; calyx gamosepalous, urceolate, 5-lobed, each lobe 
with a gibbosity at its base. Stamens 5; filaments subulate. Pistillate flowers solitary or clustered in the axils of the leaves, 2-bracted; bracts ovate, membranous, united, forming a sack enclosing the flower, or nearly free. Calyx of 2-3 distinct sepals. Utricle ovate, compressed. Radicle superior.

Leaves thin, Ianceolate, 1-nerved.

Leaves thick, ovate, or ovate-lanceolate; the lower 3-nerved.

1. E. Suckleyi,

2. E. dioica.

1. E. Suckleyi Torr. Low annual; stem erect, with ascending branches, 1-3 dm. high, almost glabrous; leaves sessile, $2-3 \mathrm{~cm}$. long, entire; staminate clusters both axillary and forming short terminal spikes; fruiting bracts ovate, $2 \mathrm{~mm}$. long, membranous, pubescent. Atriplex Endolepis S. Wats. A. Suckleyana Rydb. Plains: Sask.-Mont.-S.D. Plain. Jl.

2. E. dioica (Nutt.) Standl. Low annual, usually less than $1 \mathrm{dm}$. high, rarely $2-3 \mathrm{dm}$; stem branched; leaves usually less than $1 \mathrm{~cm}$. long; staminate flowers in small clusters in the axils of the upper leaves or at the end of the branches. Kochia dioica Nutt. E. ovata Rydb. Plains: Mont.-Wyo. Plain. Je-S.

\section{SUCKLÈYA A. Gray.}

Monoecious fleshy annuals. Flowers axillary, the staminate above. Calyx 3-4-parted to the base. Stamens 3 or 4, distinct; anther 2-celled. Fruiting bracts subhastate, obcompressed, herbaceously eristate on the margins, 2-cleft at the apex. Radicle superior.

1. S. Suckleyana (Torr.) Rydb. Prostrate or ascending annual; stem diffusely branched, 1-4 dm. long, sparingly scurfy; leaves petioled; blades orbicular to rhombic-ovate, 1-3 cm. broad, acutely sinuate-dentate; fruiting bracts 5-6 mm. long, ovate-rhombic and subhastate, with crenate ridges. Obione Suckleyana Torr. Suckleya petiolaris A. Gray. Along streams: Mont.-Colo. Plain-Submont. J1-Au.

\section{GRAỲIA H. \& A. HoP SAgE.}

Subspinescent or unarmed undershrubs or shrubs, with alternate leaves, dicecious or monoecious. Flowers small, in axillary clusters and terminal spikes. Staminate flowers bractless; calyx 4-parted; stamens 4 or 5; filaments short, subulate. Bracts of the pistillate flowers obcompressed, membranous, united into a sack with a narrow opening at the apex; calyx none. Ovary 1-celled; styles 2. Seeds vertical; embryo annular; radicle inferior. [Eremosemium Greene.]

Plant spiny; leaves i-3 cm. long, spatulate; bracts $8-12 \mathrm{~mm}$. wide. Plant not spiny; leaves 2.5-5 cm. long, linear-oblanceolate; bracts 4-6 mm. wide.

1. G. spinosa

2. G. Brandegei.

1. G. spinosa (Hook.) Moq. Erect diffusely branched shrub, $3-10 \mathrm{dm}$. high; leaf-blades fleshy, glabrous or at first somewhat mealy, $1-3 \mathrm{~cm}$. long, obtuse or acute; fruiting bracts smooth, emarginate, white or pink. $G$. polygaloides H. \& A. Alkaline plains or hills: Mont.-Wyo.-Utah-Calif.-Wash. Son.-Submont. Ap-Je.

2. G. Brandegei A. Gray. Unarmed shrub, with erect branches, $3-5 \mathrm{dm}$. high; leaves sessile or short-petioled, 4-6 mm. wide, scurfy; fruiting bracts scarcely emarginate, scurfy. Arid hills, among rocks: w Colo.-se Utah. Son. Jl.

\section{EURÒtia Adans. White Sage, Winter Sage, Winter Fat.}

Low pubescent undershrubs, with alternate, entire leaves, either polygamomonoecious or dioecious. Flowers in small axillary clusters. Staminate flowers bractless; calyx 4-parted; stamens 4; filaments slender. Pistillate flowers bibracteate; bracts sessile, somewhat obeompressed, united to the apex, not winged, 2-horned, densely long-hairy on the sides. Ovary hairy, oblong-ovate, membranous; stigmas 2 , elongate. Seeds vertical, obovate; radicle inferior.

Branches erect, not spinescent; monoecious or some plants only pistillate; pubescence of mixed stellate and simple hairs.

1. E. lanata.

Branches ascending or spreading, becoming more or less spinescent; dioecious; pubescence of stellate hairs only.

2. E. subspinosa. 
1. E. lanata (Pursh) Moq. Undershrub, white or later rufous-tomentose, 2-10 $\mathrm{dm}$. high; leaves linear, with revolute margins, $2-4 \mathrm{~cm}$. long, $2-5 \mathrm{~mm}$. wide; staminate flower-clusters above the pistillate ones, in some individuals much more numerous, in others few or none; fruiting bracts 4-6 $\mathrm{mm}$. long, lanceolate; horns about $1 \mathrm{~mm}$. long. Plains and hills: Sask.-Tex.-Calif.-Wash. Son.-PlainMont. Je-S.

2. E. subspinosa Rydb. Dioecious shrub, 6-10 dm. high; leaves linear or oblong, obtuse, entire, 1-3 cm. long; flower-clusters of the staminate plant crowded and forming simple, leafy spikes; fruiting bracts lanceolate, about 6 $\mathrm{mm}$. long; horns usually about $2 \mathrm{~mm}$. long. Rocky hills in desert regions: s Utah-Ariz.-Calif.; Sonora. Son. Ap-S.

\section{SAlicòrnia (Tourn.) L, Glasswort, Samphire.}

Annual or perennial, fleshy, glabrous herbs, with scale-like leaves; branches and leaves opposite; internodes very short. Flowers perfeet or polygamous, in cylindric spikes, sunk in cavities of the internodes, 3-7 together. Calyx fleshy, with a truncate or 3-4-toothed border. Stamens 2, rarely 1; filaments filiform or subulate. Utricle oblong or ovoid, included in the spongy perianth. Seeds erect; endosperm wanting; embryo conduplicate.

Annual with a taproot.

Perennial with a creeping rootstock.

1. S. rubra.

2. S. utahensis.

1. S. rubra A. Nels. Stem erect, divaricately branched throughout, 1-2 dm. high; scale-like leaves short, broadly triangular, wider than long; fruiting spikes 2-4 cm. long; internodes very short, scarcely exceeding the middle flower of the nodes below. Border of alkaline lakes: Sask.-Kans.-Colo.-Nev.B.C. Plain. Au-S.

2. S. utahensis Tidest. Stems 1-2 dm. high, with short branches; scalelike leaves connate, broadly triangular, about $3 \mathrm{~mm}$. long, scarious-margined; internodes 1-2 cm. long or the lower shorter, 3-4 mm. thick; spikes on short lateral branches, 8-15 $\mathrm{mm}$. long, 4-5 $\mathrm{mm}$. thick; bracts broader than long. Alkaline and saline soil: Utah. Son. Je.

\section{ALLENRÓlfia Kuntze. Burro Weed.}

Fleshy, jointed shrubs, with alternate branches and scale-like leaves. Flowers perfect, arranged spirally in crowded spikes. Calyx of 4 , or 5 concave, carinate, imbricate sepals, more or less united. Stamens 1-2; filaments slender, exserted. Ovary oblong; styles 2 or 3, distinct. Fruit with a membranous pericarp, free from the seed. Albumen copious; radicle inferior, basal. [Spirostachys S. Wats., not Sond.]

1. A. occidentalis (S. Wats.) Kuntze. Shrub 6-15 dm. high, fleshy; scalelike leaves broadly triangular, amplexicaul; spikes numerous, cylindric, $1-2 \mathrm{~cm}$. long; bracts broadly rhombic; flowers small, erowded; seeds less than $0.5 \mathrm{~mm}$. long. Spirostachys occidentalis S. Wats. Salt marshes: Utah-Ariz.-Calif. -Nev. Son. J-S.

\section{SARCobÃtús Nees. Greasewood, Сhico.}

Spinescent branched shrubs, with fleshy narrow leaves, monoeeious or dioecious. Staminate flowers in terminal spikes, without calyx; stamens arranged around the base of a peltate scale. Pistillate flowers axillary, solitary, with a closed compressed calyx, margined by a narrow border, which develops into a broad membranous horizontal wing. Ovary thin and hyaline; embryo spiral; endosperm scant or none.

1. S. vermiculatus (Hook.) Torr. Erect shrub, 1-3 m. high, divaricately branched and spinescent; leaves linear or linear-filiform, fleshy, 1-4 cm. long; aments of the staminate flowers cylindric, $0.5-3 \mathrm{~cm}$. long; stamens 3 ; fruiting calyx about $6 \mathrm{~mm}$. Iong, its wing-margin $6-12 \mathrm{~mm}$. broad. Alkaline flats: Sask.-Tex.-Calif.-Wash. Son.-Plain-Mont. My-S. 


\section{Sälsola L. Saltwort, Russian Thistle.}

Annual or perennial herbs, or shrubs, bushy-branched, with narrow, entire, spine-tipped, rigid leaves. Flowers perfect, solitary or several together in the axils, with 2 bractlets. Sepals 5, appendaged with a horizontal wing at maturity. Stamens 5, rarely less; filaments linear or subulate. Ovary 1-celled, more or less depressed; styles 2. Utricle flattened; seeds erect; endosperm wanting; embryo spiral in form of a cone.

1. S. Pestifer A. Nels. Divaricately branched annual; stem $3-10 \mathrm{dm}$. high; leaves filiform, somewhat fleshy, 2-6 cm. long, spine-tipped; bracts subulate, 5-10 $\mathrm{mm}$. long, with stout spines; calyx membranous, conspicuously veiny, 6-7 $\mathrm{mm}$. in diameter. S. Tragus Reichenb., not L. Waste places, fields, and loose sandy soil: Ont.-N.J.-Tex.-Calif.-Wash. Plain-Submont. JI-S.

\section{Dóndia Adans. Sea Bltte.}

Annual or perennial herbs, or shrubby plants, more or less fleshy, with alternate, narrow, terete leaves. Flowers perfect or polygamous, solitary or clustered in the upper axils, bracteate. Sepals 5, keeled or narrowly winged at maturity. Stamens 5; filaments short. Ovary 1-celled, rounded or flat on the top; styles often 2. Utricle surrounded by the calyx; seeds horizontal or vertical; endosperm wanting or scant. Embryo coiled in a flat spiral. [Swaeda Forskal.]

Sepals more or less fleshy, but none of them carinate; leaves narrowed at the base.

Plant perennial, stout.

Seeds tubercled.

Seeds not tubercled.

Plant annual, more slender.

Sepals very fleshy, one or two decidedly carinate.

Leaves subulate, broadest at the base; flowers crowded. Plant depressed, spreading.

Plant erect, strict.

Leaves narrowed at the base; spike slender; flowers not crowded.

1. D. Torreyana.

2. D. intermedia.

3. D. nigra.

4. D. depressa.

5. D. erecta.

6. D. occidentalis.

1. D. Torreyana (S. Wats.) Standl. Undershrub, woody at the base; herbaceous branches $6-10 \mathrm{dm}$. high, glabrous or somewhat pubescent, with strongly ascending branchlets; leaves subterete, filiform, $1-4 \mathrm{~cm}$. long, acute; bracts similar but shorter; calyx deeply cleft; seeds $1.5 \mathrm{~mm}$. broad. Swaeda Torreyana S. Wats. S. Moquini (Torr.) A. Nels., in part. Salt marshes: Wyo.-Tex.-N.M.-Calif. -Nev. Son.-Submont. Je-S.

2. D. intermedia (S. Wats.) Heller. Undershrub, woody at the base; herbaceous branches $2-5 \mathrm{dm}$. high, glabrous, with branchlets ascending but not strongly so; leaves narrowly linear, narrowed at the base, 1-2 cm. long; bracts shorter and broader; calyx deeply cleft, not appendaged; seeds small, less than $1 \mathrm{~mm}$. broad. Swaeda intermedia S. Wats. Alkaline soil: Ida.-Utah-Ariz.Calif. Son.

3. D. nigra (Raf.) Standl. Erect or ascending annual; stem diffusely branched, 3-5 dm. high; branches long and flexuose; leaves filiform, terete, 1-3 $\mathrm{em}$. long, acute; bracts similar, but much shorter, usually less than $1 \mathrm{~cm}$. long; calyx cleft to just below the middle, fleshy; seeds vertical, $1 \mathrm{~mm}$. broad, smooth. Swaeda diffusa S. Wats. D. diffusa (S. Wats.) Heller. Sage plains and alkaline soil: Wyo.-N.M.-Ariz.-Ore.; n Mex. Plain. Jl-S.

4. D. depressa (Pursh) Britton. Low and decumbent annual; stems branching at the base, 2-10 dm. long; leaves linear, subulate, 1-3 $\mathrm{cm}$. long; bracts 5-10 mm. long, rather crowded on the branchlets; calyx cleft to the middle; seeds about $1 \mathrm{~mm}$. broad, slightly reticulate. Chenopodium calceolariforme Hook. Suaeda depressa S. Wats. Dondia calceolariformis Rydb. Saline or alkaline soil: Sask.-Kans,-Nev.-Mont. Plain-Submont. Jl-S.

5. D. erecta (S. Wats) A. Nels. Erect annual; stems rather simple or with short erect branches, very leafy; leaves slender, $2-4 \mathrm{~cm}$. long; bracts often more than $1 \mathrm{~cm}$. long; calyx cleft below the middle; seeds smooth, nearly $1.5 \mathrm{~mm}$. broad. Alkaline or saline flats: Sask.-Colo-Nev-Mont. Plain-Mont. J-S. 
6. D. occidentalis (S. Wats.) Heller. Erect or spreading annual; stem 6-35 $\mathrm{cm}$. high, with flexuose ascending or spreading branches; leaves linear, 1-2.5 $\mathrm{cm}$. long, $1 \mathrm{~mm}$. wide; bracts similar only slightly shorter; flowers 1-3 in each axil; seeds smooth, black and shining. Alkaline meadows: Wyo.-Colo.Ore.-Wash. Son.

\section{Family 39. Amaranthaceae. Amaranth Family.}

Coarse herbs, with alternate or opposite leaves, without stipules. Flowers inconspicuous, perfect, moneocious, dioecious, or polygamous, subtended by more or less imbricate bracts. Calyx of 2-5 scarious or herbaceous sepals. Corolla wanting. Stamens 5 or fewer, opposite the sepals. Pistil solitary, 1-celled; style 1, terminal, or wanting. Fruit a membranous utricle or pyxis.

Anthers 2-celled; green plants with alternate leaves.

Perianth present in all flowers.

Perianth wanting in the pistillate flowers.

1. Amaranthus.

Anthers 1-celled; stellate or woolly plants with mostly opposite leaves.

Filaments united into a short cup at the base; calyx neither crested nor spiny; plants stellate, diffuse.

3. TIDESTROMIA.

Filaments united into a long tube; calyx crested and tuberculate or spiny at maturity; plants woolly, erect.

4. Froelichia.

\section{1. amaránthus (Tourn.) L. Amaranth, Pigweed, Tumbleweed.}

Annual weedy herbs, with alternate, flat, pinnately veined, entire or undulate leaves. Flowers monoecious, dioecious, or polygamous, in dense spikes or clusters, each subtended by usually 3 , conspicuous, green, red or purple bracts. Sepals 2-5, distinct; anthers 2-celled, opening lengthwise. Ovary 1-celled; styles or stigmas 2 or 3 . Ovules solitary. Utricles circumscissile, irregularly splitting, or indehiscent. Seeds lenticular, shining. Embryo annular.

Sepals clawed; flowers in terminal and axillary spikes.

Monoecious; sepals fimbriate; utricle circumscissile; leaf-blades linear or linearlanceolate.

Dioecious; sepals not fimbriate; utricle indehiscent; leaf-blades lanceolate-ovate or obovate.

Bracts lanceolate, not exceeding the flowers; spike not very long.

Bracts subulate, pungent, exceeding the flowers; spikes very long.

A. Torreyi.

3. A. Palmeri.

Sepals not clawed

Plants tall, simple; flowers in terminal and axillary panicles; sepals 5.

Stamens 3; sepals 1-2 mm. long; bracts $5 \mathrm{~mm}$. long or more. 4. A. Powellii.

Stamens 5; sepals $2-3 \mathrm{~mm}$. long; bracts $3-5 \mathrm{~mm}$. long.

Spikes stout, 8-14 mm. thick, strict; pistillate sepals obtuse or truncate. Inflorescence tinged with red; pistillate sepals $1.5-2 \mathrm{~mm}$. long; plant glabrous. 5 . A. Wrightii. Inflorescence pale green; pistillate sepals $3 \mathrm{~mm}$. long; plant villous.

6. A. retroflexus.

Spike slender, 4-6 mm. thick, usually drooping; stem glabrous; pistillate sepals acute.

7. A. hybridus.

Plant low, much branched; flowers in small axillary spike-like panicles, shorter than the leaves.

Sepals 3-5, well developed.

Sepals 4-5; bracts lanceolate, a little longer than the sepals; plant prostrate.

Sepals 3 ; bracts much longer than the sepals, pungent.

Plant erect, glabrous.

Plant prostrate or diffuse, pubescent.
Sepals of the pistillate flowers, all except one, minute or wanting.

8. A. blitoides.

9. A. graecizans.

10. A. pubescens.

11. A. californicus.

1. A. fimbriatus (Torr.) Benth. Stem 3-10 dm. high, glabrous; leaves short-petioled; blades $3-7 \mathrm{~cm}$. long; flowers in a loose spike; bracts shorter than the perianth, narrow, acute; sepals of the staminate flowers oblong, those of the pistillate ones broadly fan-shaped, 2-3 mm. long. Sandy places: s Utah-Nev. -Calif.; n Mex. L. Son. Au-S.

2. A. Torreyi (A. Gray) Benth. Stem 3-10 dm. high, somewhat pubescent or glabrate; leaves long-petioled; blades lanceolate or oblong-lanceolate, strongly veined beneath; flowers in a rather lax paniele; sepals of the staminate plant 
lanceolate, spinulose-cuspidate, more or less scarious-margined; sepals of the pistillate plants obovate-spatulate, rounded at the apex. Sandy soil: Ia.-Tex. -Calif.-Nev. Plain-Son. J1-Au.

3. A. Palmeri S. Wats. Stem erect, $6-10 \mathrm{dm}$. high, branching; leaves longpetioled; blades rhombic-lanceolate or obovate, $2-5 \mathrm{~cm}$. long, strongly veined beneath; sepals of the staminate flowers lanceolate, spinulose-cuspidate, those of the pistillate flowers $2-3 \mathrm{~mm}$. long, oblong or somewhat spatulate, distinct or nearly so. Banks and river valleys: Kans.-Tex.-Colo-Calif.; $n$ Mex. Son.-Submont.

4. A. Powellii S. Wats. Stem 3-15 dm. high, glabrous, simple or with erect branches; leaves slender-petioled; blades lanceolate or ovate, $3-10 \mathrm{~cm}$. long; bracts subulate, spinulose-cuspidate, $3 \mathrm{~mm}$. long; sepals $1-2 \mathrm{~mm}$. long, lanceolate, mucronate. Loose or sandy soil: N.M.-Wyo.-Ore.-Calif.; n Mex. Son.-Mont. Jl-S.

5. A. Wrightii S. Wats. Stem $2-10 \mathrm{dm}$. high, simple or branched at the base; leaves slender-petioled; blades lance-elliptic to rhombic-ovate, $1.2-6 \mathrm{~cm}$. long, yellowish green, paler beneath; bracts linear-lanceolate or subulate, longer than the sepals, pungent; sepals $1.5-2 \mathrm{~mm}$. long, rounded or truncate and retuse at the apex. Sandy soil: N.M. - s Colo.-Ariz. Son.

6. A. retroflexus L. Stem erect or ascending, usually branched, 3-30 dm. high; leaves petioled; leaf-blades ovate or rhombic-ovate to lanceolate, $5-15 \mathrm{~cm}$. long; bracts subulate, twice as long as the oblong, scarious sepals. PIGWEED. Waste places and fields: Vt.-Fla.-Calif.-B.C.; Mex.; nat. from Eu. PlainSubmont. Je-O.

7. A. hybridus L. Stem branched, $6-25 \mathrm{dm}$. high; leaves petioled; leafblades ovate, 4-10 cm. long, darker green above, scabrous-puberulent; bracts subulate, twice as long as the oblong acute sepals. Waste places: R.I.-Fla.Colo.-Calif.-Alta.; Mex.; W. Ind.; nat. from Eu. Plain-Son. Mr-S.

8. A. blitoides S. Wats. Stem 3-10 dm. long, glabrous or nearly so, profusely branched; leaf-blades broadly spatulate, obovate or oblanceolate, $1-3 \mathrm{~cm}$. long; bracts short-acuminate, $2-3 \mathrm{~mm}$. long; sepals obtuse and mucronate or acute; utricle not rugose. Dry ground, roadsides, and waste places: Minn.La.-Calif.-B.C.; Mex.; adv. eastward to Me. and N. J. L. Son.-PlainMont. Jl-S.

9. A. graecizans L. Stems bushy-branched, whitish, 2-6 dm. high; leafblades oblong or spatulate, 1-4 cm. long, papillose, mucronate-cuspidate; flowers polygamous; sepals membranous. A. albus $\mathrm{L}$. Tumble WeEd. Waste places and cultivated ground: R.I.-Fla.-Calif.-B.C.; W. Ind.; Mex.; and Old World. Plain-Submont. Jl-S.

10. A. pubescens (Uline \& Bray) Rydb. Stem spreading, pubescent with a viscid pubescence; leaf-blades spatulate, $1-3 \mathrm{~cm}$. long, very erisp, mucronate; sepals thicker than in A. graecizans. Sandy places: N.M.-Colo--Ariz. Son.

11. A. californicus (Moq.) S. Wats. Stem prostrate, glabrous, branching at the base, 2-5 dm. long; leaf-blades obovate or oblong, 5-20 mm. long, often with white veins and margins; bracts lanceolate, membranous, acuminate; sepals of the staminate flowers $1.5 \mathrm{~mm}$. long, the single one of the pistillate flowers shorter, lateral; utricle rugose. A. carneus Greene. Cultivated or loose ground: Calif.-Nev.-Alta.-Wash. Jl-S.

\section{ACNİDA L. WATER-HEMP.}

Annual coarse herbs, with branching stem and alternate, narrow, entire, pinnately veined leaves. Flowers dioecious, subtended by 1-3 bracts, in terminal or axillary, continuous or interrupted spikes. Staminate flowers with 5 scarious mucronate sepals. Stamens 5; filaments distinct, subulate; anthers 2-celled. Pistillate flowers without calyx. Ovary 1-celled; stigmas 2-5, papillose or plumose. Ovules solitary. Utricle circumscissile or opening irregularly, or indehiscent. Seeds smooth, erect, shining. 
Pistillate inflorescence of slender interrupted spikes; fruit circumscissile. 1. A. tamariscina. Pistillate inflorescence of closely clustered spikes; fruit indehiscent or irregularly splitting. 2. A. altissima.

1. A. tamariscina (Nutt.) Wood. Stem erect, much branched, $1-2 \mathrm{~m}$. long; leaf-blades lanceolate or ovate-lanceolate, obtuse or notched at the apex, entire or undulate; bracts lanceolate, spinulose-tipped, scarious-margined. Swamps and alluvial soil: Ill.-S.D.-Colo.-N.M.-La. Plain. Jl-S.

2. A. altissima Riddell. Stem 1-3 m. high, with flexuose branches; leafblades lanceolate to rhombic-ovate, entire; bracts rigid, acuminate; sepals of the staminate flowers lanceolate, acuminate. A. tuberculata Moq. Swamps: Ont. -S.D.-Colo.-Ohio. Plain. Л-S.

\section{TIDESTRÒMIA Standl.}

Annual or perennial herbs, with stellate pubescence and mostly opposite, entire or merely undulate, short-petioled leaves. Flowers perfect, subtended by 3 bracts, solitary or clustered in the axils. Sepals 5, unequal, pubescent. Stamens 5; filaments united at their bases; anthers 1-cellod. Ovary 1-celled; styles short; stigmas capitate or 2-lobed. Ovules solitary. Utricle subglobose, indehiscent. [Cladothrix Nutt., not Cohn.]

1. T. lanuginosa (Nutt.) Standl. Annual; stems diffusely branched; branches ascending or prostrate, $1-6 \mathrm{dm}$. long; leaf-blades rhombic-ovate to orbicular, entire, $0.5-2 \mathrm{~cm}$. long; flowers in axillary clusters; bractlets obtuse; utricle glabrous, included in the calyx: Cladothrix lanuginosa Nutt. Dry soil: Tex.-Kans.-Utah-Ariz.; Mex. Son. Jl-S.

\section{FROELÍCHIA Moench.}

Annual or biennial herbs, with woolly or silky pubescence and opposite, entire or undulate leaves. Flowers perfect, subtended by 3 bracts, in dense spikes. Calyx 5-lobed, woolly; tube longitudinally crested or tubercled at maturity. Stamens 5, included; filaments united into a tube; anthers 1-celled. Ovary 1-celled; styles short or wanting; stigmas capitate or brush-like. Utricle indehiscent, enclosed in the tube of the filaments.

Stout, 4-12 dm. tall; crest of fruiting calyx continuous, dentate. 1. F campestris. Slender, $2-5 \mathrm{dm}$. high; crest of fruiting calyx interrupted, forming distinct spines.

2. F. gracilis.

1. F. campestris Small. Biennial or annual; leaves numerous and approximate below; blades spatulate to oblong or broadly linear, acute, whitewoolly beneath; spikes $1-10 \mathrm{~cm}$. long. F floridana Coult. \& Nels., not Moq. Dry or sandy soil: Minn.-Ill.-Okla.-N.M.-Colo. Plain-Son. Je-S.

2. F. gracilis Moq. Annual or perhaps biennial; stem usually branched at the base, 2-3 dm. high; leaves numerous near the base of the plant, of ten clustered; blades linear-oblanceolate or linear-oblong, 1-5 $\mathrm{cm}$. long, acute, whitewoolly; spikes 1-3 cm. long. Sandy valleys: Ia.-Ark.-Tex-Ariz.-Colo.; Mex. Plain-Son. JI-S.

\section{Family 40, nYCtaginaceae. Four-o'clock Family.}

Annual or perennial herbs (all ours), usually with swollen nodes, and alternate or opposite leaves, without stipules. Flowers regular, perfect, often subtended by bracts forming a calyx-like involucre. Perianth simple, corolla-like, campanulate or funnelform. Stamens 1-many. Pistil solitary; ovary 1-celled, surrounded by the perianth-tube. Fruit indehiscent, angled, ribbed, or winged.

Bracts distinct.

Fruit crested or winged; bracts in a whorl at the base of the head-like cluster; perianth salverform. Bracts conspicuous.
Wings not completely encircling the fruit, interrupted above and below.
1 . ABRONIA. 
Wings completely encircling the fruit.

Bracts inconspicuous or lacking.

2. TRIPTEROCALYX.

3. SELINOCARPUS.

Fruit globular, neither crested nor winged; bracts attached each to a pedicel of the umbel-like or corymbose inflorescence; perianth funnelform. 4. HERMIDIUM. Bracts united.

Fruit neither strongly tubercled nor winged.

Fruit not ribbed; involucre herbaceous, little if at all enlarging in fruit, not becoming membranous.

Stamens usually 5; involuere campanulate, not enlarged in fruit. Flowers several in each involucre. 5 . QUAMOcLIDION. Flowers solitary in each involucre.

Stamens 3 ; involucre rotate, somewhat enlarged in fruit in the manner of the

next genus, but not membranous.
Fruit ribbed; involucre rotate, in fruit becoming much enlarged and membranous. 8. Allionia.

Fruit with two rows of strong tubercles on the back and surrounded by two-toothed inflexed wings.

9. WEDELTELLA.

\section{1. abrònia Juss. Sand Verbena, Sand Puffs.}

Annual or perennial herbs, with opposite petioled leaves. Leaf-blades entire and oblique at the base. Flowers several in heads, surrounded by five or more distinct bracts. Perianth colored and corolla-like, salver-shaped, with an elongated tube, and expanding above into a 5-lobed limb. Stamens 3-5, included. Fruit leathery, 3-5-winged, or 3-5-ribbed. Seed filling the pericarp and adherent to it.

Fruit biturbinate, $i$. $e_{\text {, }}$ tapering at both ends, irregularly ridged or crested.

Flowers about $2 \mathrm{~cm}$. long; limb 5-10 $\mathrm{mm}$. wide.

Bracts broadly obovate, over $1 \mathrm{~cm}$. long.

Bracts ovate-lanceolate, less than $1 \mathrm{~cm}$. long.

1. A. fragrans.

2. A. nudala.

Flowers about $1 \mathrm{~cm}$. long; limb 3-5 mm. wide; bracts ovate to lanceolate-ovate, $5-8$ mm. long.

Petioles of the stem-leaves shorter than the very thick blades; plant low, about 1 dm. high.

3. A. pumila.

Petioles of the stem-leaves much longer than the moderately thick blades; plant slender, 2-4 dm. high.

Fruit turbinate or obpyramidal, $i$. $e$, almost truncate above, distinctly winged, the wings very broad above.

Plant almost acaulescent; stem and leaves greatly surpassed by the long peduncles.

Plant with an elongated stem.

5. A. nana.

Bracts broadly ovate or obovate, acute or obtusish.

Stem distinctly viscid-pubescent; leaves scabrous-puberulent; bracts $1-1.5 \mathrm{~cm}$. long.

Blades of the stem-leaves elliptic; bracts broadly obovate, $12-15 \mathrm{~mm}$. wide, obtusish.

Blades of the stem-leaves lanceolate; bracts oval, acute, about 6-7 $\mathrm{mm}$. wide.

7. A. fallax.

Stem finely puberulent or glabrous; leaves glabrous; bracts $5-8 \mathrm{~mm}$. long.

Stem puberulent; leaves long-petioled; bracts 8-15 mm. long.

Stem glabrous; leaves short-petioled; bracts $5 \mathrm{~mm}$. long. 8. A. elliptica.
A. glabra.

Bracts oblong-lanceolate or lanceolate, attenuate or cuspidate. Stem glabrous.

Stem more or less pubescent.

Stem puberulent; wings with double lamina, coriaceous.

Stem villous; wings with single lamina, membranous.

10. A. lanceolata.

11. A. Carletoni.

12. A. villosa.

1. A. fragrans Nutt. Perennial; stems several; branches erect, $15-25 \mathrm{dm}$. high, glabrous below, puberulent and subviscid above; leaves glabrous or nearly so, petioled; blades oval, ovate, or elliptic, rounded at the apex, 3-6 $\mathrm{cm}$. long; fruit about $8 \mathrm{~mm}$. long, $4 \mathrm{~mm}$. broad, one-third from the apex. Dry soil: S.D. -Ia.-Kans.-N.M.-Ida.-Mont. Plain-Submont. My-Ji.

2. A. nudata Rydb. Perennial; stems very long and decumbent, sparingly hispidulous; leaf-blades broadly lanceolate, thick, glabrous, $2-5 \mathrm{~cm}$. long; flowers many, about $2 \mathrm{~cm}$. long; limb 5-6 $\mathrm{mm}$. wide; achenes thickest a little above the middle, erested, $8-10 \mathrm{~mm}$. long, those of the marginal flowers very obliquely ovoid-fusiform, scarcely at all crested. Barren hills: e Mont. Plain. S.

3. A. pumila Rydb. Perennial, caespitose; stems ascending, about $1 \mathrm{dm}$. long, puberulent; leaf-blades $1.5-3 \mathrm{~cm}$. long, thick, minutely puberulent, oval, elliptic or somewhat ovate; fruit bipyramidal, broadest one-third from the apex, merely crested or the inner ones somewhat winged. Cañons: Utah. Je-Jl. 
4. A. ammophila Greene. Glandular-puberulent perennial; stem 3-4 dm. high, decumbent, branched; leaf-blades $1.5-2 \mathrm{~cm}$. long, oblong-elliptic, obtuse, thick; flowers greenish or yellowish white; fruit bi-turbinate, with about 5 low rounded erests. A. arenaria Rydb. A. cheradophila A. Nels. A. Nelsonii Heimerl. Sandy places: Yellowstone Park. Submont.-Mont. Au.

5. A. nana S. Wats. Dwarf cespitose perennial, with thick caudex; stems less than $1 \mathrm{dm}$. long; leaf-blades 8-20 mm. long, oval, rough-puberulent; involueres of 4 or 5 , ovate or lanceolate bracts, $6-10 \mathrm{~mm}$. long; flowers greenish, 12 $14 \mathrm{~mm}$. long; fruit cuneate-turbinate, with 5 hollow wings. Dry ravines and valleys: s Utah-Ariz.-Calif. Son. Je.

6. A. salsa Rydb. Perennial; stem ascending, 3-4 dm. high, densely viscidpubescent; leaf-blades oval or elliptic, very thick, puberulent, obtuse, or the lowest rounded-oval, $3-5 \mathrm{~cm}$. long, 1-3 $\mathrm{cm}$. wide; bracts about $15 \mathrm{~mm}$. long; flowers many, about $2 \mathrm{~cm}$. long; limb about $4 \mathrm{~mm}$. wide; fruit about $1 \mathrm{~cm}$. long. Sandy beaches of salt lakes: Utah. Son. My-Jl.

7. A. fallax Heimerl. Perennial; stem erect, almost shrubby below, branched, straw-color or white, viscid-pubescent above; leaf-blades thick, puberulent, oval, those of the upper long-lanceolate, $2-5 \mathrm{~cm}$. long, $1-1.5 \mathrm{~cm}$. wide; flowers many, about $15 \mathrm{~mm}$. long; fruit with the wings about $6 \mathrm{~mm}$. wide and $8 \mathrm{~mm}$. long, cuneate-obpyramidal. Sandy places: Utah. Son. Au.

8. A. elliptica A. Nels. Perennial, with a thick root; stems several, ascending, 1-3 dm. long; leaf-blades fleshy, glabrous, elliptic or oval, $1.5-3 \mathrm{~cm}$. long; bracts obovate, subacute, $8-15 \mathrm{~mm}$. long; flowers greenish white, $15-20 \mathrm{~mm}$. long; fruit obscurely pubescent, turbinate, truncate or somewhat obcordate, with 5 wings, $7 \mathrm{~mm}$. long. Clay hills: Wyo.-Colo.-Utah. Son.-Submont. My-Jl.

9. A. glabra Rydb. Perennial; stem ascending, about half a meter high; leaf-blades oval to oblong, thick, 1-4 cm. long, obtuse; bracts obovate, about $5 \mathrm{~mm}$. long, acute; flowers $12-15 \mathrm{~mm}$. long, numerous; fruit cuneate-obpyramidal, with the wings 4-5 mm. wide; wings very thick, of two lamina, semi-cordate at the apex. Arid places: Colo. Son. Л.

10. A. lanceolata Rydb. Perennial; stem glabrous, decumbent, several decimeters long; leaf-blades oblong-oval, rather thick, glabrous, 2-5 cm. long, 1-1.5 cm. wide; bracts 6-8, lanceolate, about $1 \mathrm{~cm}$. long; flowers numerous, about $1.5 \mathrm{~cm}$. long, with a limb 4-5 mm. wide; fruit with the thin wings about $8 \mathrm{~mm}$. wide, cuneate-obpyramidal. Drifting sand: Ida. Son. Jl.

11. A. Carletoni Coult. \& Fisher. Perennial, with a thick root; stems decumbent, glandular-puberulent, 2.5-4 dm. high; leaf-blades thick, linear-oblong or oblong-ovate, $3-5 \mathrm{~cm}$. long; bracts rose-colored, $6 \mathrm{~mm}$. long; flowers rose-colored; fruit turbinate, with 5 coarsely reticulate wings. Plains: Colo. Plain. My-Je.

12. A. villosa S. Wats. Perennial; stems weak and slender, decumbent or ascending, densely villous; leaf-blades $0.5-3 \mathrm{~cm}$. long, ovate or elliptic, obtuse or acute; bracts 6-8 $\mathrm{mm}$. long; flowers pink, $15-20 \mathrm{~mm}$. long; fruit with $3-5$ broad wings, membranous, with a simple lamina, truncate above. Sandy places: Ariz, -s Utah-Calif. L. Son. Ap-Au.

\section{TRIPTEROCÀlYX Hook. SAND PUfFS.}

Branched annuals, with opposite petioled leaves. Blades entire and usually oblique at the base. Flowers perfect, in heads surrounded by 4-6 distinct bracts. Perianth corolla-like, salverform, with elongated tube and 5-lobed limb. Stamens 5, regularly adnate to the perianth-tube. Fruit almost orbicular in outline, completely surrounded by $2-4$, strongly reticulate, membranous wings. Seeds cylindric-ellipsoid.

Flowers $3 \mathrm{~cm}$. or more long; limb about $1 \mathrm{~cm}$. wide; peduncles longer than the leaves.

Flowers $1.5-2 \mathrm{~cm}$. long; limb about $5 \mathrm{~mm}$. wide.

Stem glabrous or nearly so; peduncles often nearly equalling the leaves. Stem densely pubescent; peduncles at least in flower much shorter than the leaves. 
1. T. cyclopterus (A. Gray) Standl. Annual; stem stout, $2-5 \mathrm{dm}$. long, puberulent; leaf-blades elliptic, lance-elliptic, or oval, 2-5 cm. long, more or less pubescent; bracts lanceolate, $8-10 \mathrm{~mm}$. long; fruit with the wings $2-3 \mathrm{~cm}$. in diameter, emarginate at each end; body usually 3-nerved. Abronia cycloptera A. Gray. Plains: Tex.-Colo.-Calif. Son. My-Au.

2. T. pedunculatus (M. E. Jones) Standl. Annual; stem $2-3 \mathrm{dm}$. long, glabrous or nearly so; leaf-blades elliptic or oval, $2-5 \mathrm{~cm}$. long; bracts ovate, about $4 \mathrm{~mm}$. long, acuminate or abruptly acute; fruit about $18 \mathrm{~mm}$. long, often red; body 3-nerved. A. micrantha pedunculata M. E. Jones. Perhaps not specifically distinct from the next. Sandy or gravelly places: Utah. Son. Ap-Je.

3. T. micranthus (Torr.) Hook. Annual; stem branched at the base, decumbent or ascending, 1-3 dm. high, more or less pubescent; leaf-blades 2-4 $\mathrm{cm}$. long, elliptic, about equalling the petioles; bracts ovate, acuminate, 4-5 mm. long; fruit with the wings 1-1.5 (rarely 2) $\mathrm{cm}$. broad; body spongy-reticulate, not nerved. A. micrantha Torr. Dry plains and in sandy soil: Sask.-Kans.N.M.-Mont. Plain-Mont. My-Jl.

\section{SELINOCÃRPUS A. Gray.}

Perennial herbs or somewhat shrubby plants. Leaves opposite, thick and sometimes fleshy. Flowers solitary in the axils of the leaves or clustered at the ends of the branches. Bracts when present small and inconspicuous, distinct. Perianth funnelform with a spreading limb. Stamens 2-5, exserted. Fruit with 3-5 prominent membranous wings.

1. S. diffusus A. Gray. Perennial, with a woody caudex, cespitose at the base; stems 1-2 dm. high, scabrous-hispidulous, canescent; leaf-blades ovate to suborbicular [var. nevadensis Standl.] obtuse, 1-3 cm. long, hispidulous on both sides; flowers about $3 \mathrm{~cm}$. long, greenish, hispidulous; fruit about $7 \mathrm{~mm}$. long; wings $2 \mathrm{~mm}$. wide. Arid regions: Tex. $\rightarrow$ Stah. L. Son.

\section{HERMÍDIUM S. Wats.}

Perennial glabrous herbs, with entire, opposite, short-petioled leaves. Flowers perfect, 3 together, subtended by as many leaf-like distinct bracts. Perianth campanulate, purplish, slightly lobed. Stamens 5-7, about as long as the perianth. Fruit subglobose, smooth, glabrous. Seed enclosed in the pericarp.

1. H. alipes S. Wats. Stem stout, ascending, 3-6 dm. high; leaf-blades 2-6 $\mathrm{cm}$. long, broadly ovate, subcordate, short-petioled; bracts $12-20 \mathrm{~mm}$. long, ovate-cordate, acute, more or less colored; heads about 6-flowered; calyx campanulate, light purple, somewhat 5-lobed; fruit globular, narrowly 3-winged. Foot-hills: Utah-Nev.-Calif. Son. My.

\section{QUAMOCLÍDION Choisy: FOUR-o'ClOCK.}

Perennial herbs, with opposite, thick, entire leaves. Flowers perfect, usually large, several in umbels, surrounded by a gamophyllous involucre. Perianth corolla-like, funnelform or trumpet-shaped. Stamens 5, exserted. Fruit hard, smooth, ellipsoid or subglobose, glabrous. Pericarp adherent to the seed.

1. Q. multiflorum Torr. Perennial, with a thick root; stem stout, spreading or ascending, 6-10 dm. long; leaf-blades broadly ovate or subcordate, acute, 3-7 $\mathrm{cm}$. long; involucre large, its braets united half way up or further, acute or acuminate; heads usually 6 -flowered; perianth broadly funnelform, rose-colored to purple, 4-5 cm. long; fruit ovate-oblong, 6-8 mm. long, 10-furrowed toward the base. Mirabilis multiflora A. Gray. Valleys: Tex.-Colo.-Utah-Calif. Son.-Mont. Je-S.

\section{HESPERÕNIA Standl.}

Perennial herbs, with opposite, entire leaves. Involucres campanulate, of 5 bracts united at their base, not enlarged in fruit. Flowers solitary in each involucre. Perianth eampanulate, white or purplish. Stamens usually 5, distinct. Fruit ellipsoid or globose, neither angled nor ribbed, glabrous. 
1. H. limosa (A. Nels.) Standl. A perennial with a woody base; stems ascending 3-6 dm. high, nearly glabrous; leaf-blades thick, rounded-ovate to cordate, 1-3 cm. long; involueres 4-6 mm. long; calyx rose-colored or purple, campanulate, about $1 \mathrm{~cm}$. high; fruit ovate, smooth, $3 \mathrm{~mm}$. long. Mirabilis glutinosa and $M$. limosa A. Nels. Dry hillsides: Utah-Ariz.-Calif.-Nev. Son. F-Je.

7. ALLIONIÉLLA Rydb.

Branched perennial herbs, with opposite petioled leaves. Bracts five, united into a gamophyllous viscid rotate involucre, which enlarges somewhat in fruit, but does not become membranous. Flowers in each involucre 3 . Perianth open, short funnelform, 5-lobed. Stamens 3, distinct. Fruit ellipsoid, neither angled nor ribbed, very indistinctly tubercled, glabrous.

1. A. oxybaphoides (A. Gray) Rydb. Perennial; stems diffusely branched, procumbent; leaf-blades cordate, often somewhat acuminate, $2-5 \mathrm{~cm}$. long, more or less puberulent; involucre deeply 5-cleft, glandular-viscid, $6 \mathrm{~mm}$. long; perianth campanulate, $7-8 \mathrm{~mm}$. long. Ravines and valleys: Tex.-Colo.-UtahAriz. Son.-Submont. Je-S.

\section{ALLiònia Loefl. Umbrella-Wort.}

Perennial herbs, with rather fleshy, entire, opposite leaves. Flowers perfect, 1-5 in each involucre, in ours rose-colored or white. Involucre gamophyllous, 5 -lobed, in fruit enlarging and membranous. Perianth campanulate or funnelform, often oblique. Stamens 2-5, unequal; filaments very slender and united at the base. Fruit club-shaped, 5-angled or 5-ribbed, usually pubescent and minutely tuberculate. Periearp adhering to the seed. Endosperm mealy. [Oxybaphus L'Her.]

Leaves cordate to broadly ovate-lanceolate, all distinctly petioled.

Leaf-blades cordate or deltoid.

Leaf-blades ovate, rounded or cuneate at the base.

Stem glabrous: leaves thin and soft; inflorescence not bracteate. 2. A. floribunde.

Stem hirsute; leaves thick and fleshy; inflorescence bracteate. 3. A. polyatricha.

Leaves ovate-lanceolate, oblong, or linear, sessile, or only the lower short-petioled.

Stem more or less hirsute as well as viscid.

Fruit pubescent.

Leaves ovate or broadly oblong, as well as the stem conspicuously hirsute.

Leaves linear-lanceolate, almost glabrous; stem sparingly hirsute, or glabrous except under the nodes.

Fruit glabrous.
glabrous below, not hirsute, viscid-puberulent above.

5. A. pilosa.

6. A. Carletoni.

Flowers solitary in the involucre, on short slender pedicels; fruit nearly glabrous.

Flowers $2-3$ in the involucres, subsessile; fruit decidedly pubescent. 7. A. glabra.

Lower leaves ovate, rounded at the base,

Leaves of the cymes much reduced and bract-like; upper portion of the stem densely and finely puberulent.

Leaves of the cymes neither much reduced nor bract-like.

Leaves erect or ascending; lobes of the involucre rounded or broadly triangular-ovate.

Plant prostrate or diffuse: involucres and branches of the inflorescence densely viscid-hairy. 10 . A. diffusa.

Plants more simple, erect or ascending; branches of the inflorescence usually merely viscid-puberulent.

Leaves from ovate- or obovate- to linear-lanceolate, usually over $5 \mathrm{~mm}$. wide. 11 . A. decumbens.

Leaves narrowly linear, less than $5 \mathrm{~mm}$. wide, 12. A. linearis. Leaves divergent, distinctly petioled; lobes of the involucre elliptic or
oval.

1. A. nyctaginea Michx. Stems 3-10 dm. tall, stout, dichotomously branched; leaf-blades 2-10 cm. long; inflorescence paniculate; involucres in fruit about $1.5 \mathrm{~cm}$. broad, pubescent; lobes ovate or triangular; perianth red, hairy without. Oxybaphus nyctagineus Sweet. Rich soil: Sask.-Ill.-La.-N.M.Wyo. Plain. My-Au.

2. A. floribunda (Choisy) Kuntze. Stems 3-9 dm. high, stoutish, swollen at the nodes; leaf-blades ovate to lanceolate, $2-5 \mathrm{~cm}$. long; inflorescence panicu- 
late, pubescent; fruiting involucres fully $1.5 \mathrm{~cm}$. broad, glabrate; lobes triangular; perianth usually white; fruit obovoid, constricted near the base. A. ovata Pursh. O. floribundus Choisy. Dry soil: S.D.-Mo.-Tex.-N.M.-Wyo. Plain. $\mathrm{Jl}-\mathrm{S}$.

3. A. polyatricha Standl. Stem sparingly branched, hirsute below; branches and inflorescence soft-pubescent; leaf-blades glabrous or sparingly pilose, ovate, the uppermost narrowly so, obtuse or rounded at the apex; involucre about $1 \mathrm{~cm}$. wide; lobes broadly ovate, more or less densely pubescent. Cañons: Colo. Jl-Au.

4. A. hirsuta Pursh. Stem strict, 4-8 dm. high, glandular in the paniculate inflorescence; involucre glandular-pubescent, in fruit $1.5 \mathrm{~cm}$. wide; lobes broadly ovate; perianth purple or pink, pubescent without. A. aggregata (Ortega) Speng., a form with axillary involueres. Sandy soil: Sask.-Minn.Neb.-N.M.-Wyo. Plain-Submont. Je-Au.

5. A. pilosa (Nutt.) Rydb. Stem erect or decumbent at the base, 3-12 dm. high; leaf-blades lanceolate or oblong, $2-9 \mathrm{~cm}$. long, thick, nearly glabrous; inflorescence cymose, glandular; fruiting involucres $1.2-2 \mathrm{~cm}$. broad; lobes triangular-ovate; perianth purplish. Dry sandy soil: Sask.-Wisc.-La.-Tex.Colo.-N.D. Plain-Submont. J-Au.

6. A. Carletoni Standl. Stem about $1 \mathrm{~m}$. high, simple below, softpubescent throughout; leaves sessile or nearly so, lanceolate, very thick, acutish, wavy-margined, strongly veined, $7 \mathrm{~cm}$. long, puberulent on both sides; involucres about $15 \mathrm{~mm}$. wide, copiously soft-pubescent, the lobes rounded; fruit $5 \mathrm{~mm}$. long, with 5 prominent smooth ribs. Plains: Kans.-Colo--Okla. Plain. Je-Jl.

7. A. glabra (S. Wats.) Kuntze. Stem 6-10 dm. high, ereet, branched, glabrous; leaf-blades linear, 6-12 cm. long, thick, glabrous, sessile; inflorescence a large panicle; flowers solitary; fruiting involucre about $1 \mathrm{~cm}$. broad, glabrous; lobes triangular, thin, veiny. Dry soil: s Utah-Colo.-N.M.-Ariz.; Chihuahua. Son. Au-S.

8. A. Sessilifolia Osterh. Stem stout, 5-10 dm. high, erect, branched above, angled; leaves thickish, sessile, $6-8 \mathrm{~cm}$. long, $4 \mathrm{~cm}$. wide; involucre densely hirsute, in fruit $1 \mathrm{~cm}$. broad; perianth purple or pink. Valleys: Colo. Submont.

9. A. bracteata Rydb. Stem 4-12 dm. high, erect or ascending; leaf-blades oblong to linear-lanceolate or linear, $3-9 \mathrm{~cm}$. long, thick; involucres often numerous, in terminal eymes, $10-14 \mathrm{~mm}$. wide; lobes broadly ovate, obtuse; perianth white or pale, about $10 \mathrm{~mm}$. broad. Dry and rocky soil: Mo.-Ala.-
S.D. Plain.

10. A. diffusa Heller. Stem $2-3 \mathrm{dm}$. long; leaves sessile, linear-lanceolate, often narrowly so, $5-6 \mathrm{~cm}$. long, thick; fruiting involueres $7-10 \mathrm{~mm}$. wide; lobes triangular-ovate; perianth rose-colored to white, $6 \mathrm{~mm}$. long; fruit inconspicuously ribbed. A. glandulifera A. Nels. A. viscida (Eastw.) Cockerell. Gravelly hills and sandy plains: N.D.-Kans.-N.M.-Ariz.-Wyo. Son.-PlainMont. Je-Au.

11. A. decumbens Nutt. Stem erect or ascending, 4-15 dm. high; leafblades $3-10 \mathrm{~cm}$. long, very thick, obtuse or blunt at the apex; involucres numerous, usually in terminal cymes, $1-1.5 \mathrm{~cm}$. wide; lobes rounded-ovate, sometimes acutish; perianth pink, about $10 \mathrm{~mm}$. broad. A. decumbens was originally described from a form with axillary involucres. A. Aanceolata Rydb. Tenn.-Tex.-N.M.-Wyo. Plain-Submont. My-S.

12. A. linearis Pursh. Stem slender, 3-15 dm. high, terete or 4-angled below, erect or ascending; leaf-blades thick, linear, 2.5-10 cm. long, undulate, sessile, or the lower sometimes short-petioled; perianth finely pubescent, purple. $O$. angustifolius Sweet. A. montanensis Osterh. A. Bodini (Holz.) Morong., a form with axillary involucres. Dry soil: Minn.-La.-Ariz.-Mont.; Mex. Plain-Mont. J-O. 
13. A. divaricata Rydb. Stems usually solitary, erect, 6-10 dm. high; leaf-blades glabrous, linear to linear-lanceolate, acute, $5-10 \mathrm{~cm}$. long; involucres numerous, in terminal eymes, about $1.5 \mathrm{~cm}$. wide; lobes elliptical or oval, obtuse; perianth pink, about $8 \mathrm{~mm}$. wide. Sandy valleys: N.M.-Colo.-Ariz. Son.Submont. J-Au.

\section{WEDELIÉLLA Cockerell.}

Annual or perennial prostrate herbs, with opposite petioled leaves; blades entire, oblique at the base. Flowers perfect, 3 in each involucre, which is composed of 3 sepal-like bracts united at the base, Perianth corolla-like, with a short oblique tube and a 4-lobed limb. Fruit leathery, winged on each side, smooth or rarely erested on the inner face and with two rows of glands on the outer. Seeds filling the pericarp to which it adheres. Endosperm mealy. Stamens 4; filaments slender. [Wedelia Loeffl. Allionia L., in part.]

1. W. incarnata (L.) Cockerell. Perennial; stem diffusely branched at the base, prostrate, 1-5 dm. long; leaf-blades thick, ovate or oblong, 1-3 $\mathrm{cm}$. long, undulate; bracts of the involucre oval or orbicular, 4-6 $\mathrm{mm}$. long, reticulate, ciliate; calyx rose or white, $5-6 \mathrm{~mm}$. long; fruit $3-4 \mathrm{~mm}$. long. Allionia incarnata L. Wedelia incarnata (L.) Kuntze. Valleys: Tex.-Colo--Utah-Ariz.; Mex.; Trop. Am., and S. Am. Son. My-N.

\section{Family 41. tetragoniaceae. Carpet-weed Family.}

More or less succulent herbs, with opposite or whorled leaves. Flowers in ours perfect, regular. Sepals 4 or 5 . Corolla wanting in our species. Stamens 4 or 5, or many, hypogynous. Gynoecium of 2 or more united carpels; ovary 2-several-celled or by reduction 1-celled, superior or partly inferior; styles as many as the cells of the ovary. Fruit a circumscissile or loculicidal capsule.

Hypanthium wanting; capsule loculicidal; leaves whorled. Hypanthium manifest; capsule circumscissile; leaves opposite.

1. Mollugo.

2. Sesuvium.

\section{Mollùgo L. Indian Chickweed, Carpet-weed.}

Annual herbs, with verticillate leaves and hyaline stipules. Flowers perfect, in axillary clusters, cymes, or racemes, pedicelled, usually white. Sepals 5, persistent, with hyaline margins. Stamens 3 , opposite the angles of the ovary, or 5 , alternating with the sepals; filaments filiform or subulate. Ovary 3-5-celled, superior; styles 3-5, distinet; stigmas entire. Capsule 3-5-valved.

1. M. verticillata L. Annual; stem branched at the base, prostrate, $0.5-3$ $\mathrm{dm}$. long; leaves in whorls of 4-8, short-petioled; blades unequal, spatulate to linear-oblanceolate, $1-3 \mathrm{~cm}$. long, entire; sepals $2 \mathrm{~mm}$. long, oblong, with white margins; capsule oblong or oval, $4-5 \mathrm{~mm}$. long. Waste places and cultivated ground: Ont.-Fla.-Tex.-Calif.-Wash.; Mex.; W. Ind., C. Am., and S. Am. Plain-Son. Ja-D.

\section{Sesùvium L. Sea Purslane.}

Annual or perennial herbs or shrubby plants, with fleshy opposite leaves, without stipules. Flowers axillary. Hypanthium in ours turbinate. Sepals 5 , usually horned on the back near the tip. Stamens 1-many, perigynous. Ovary 3-5-celled, half-inferior; styles 3-5, distinct, filiform; ovules numerous. Fruit a circumscissile capsule; seeds several or many in each cavity.

1. S. sessile Pers. Perennial, with a thick root; stems diffuse, branched at the base, prostrate or ascending, 1-8 dm. long; leaf-blades spatulate or oblanceolate, 1-3 cm. long; sepals ovate-oblong, 8-10 mm. long; stamens many; capsule oblong, $6 \mathrm{~mm}$. long. River banks and saline plains: Wyo.-Kans.-Tex.Calif.; Mex. and S. Am. Son. Ap-N. 


\section{Family 42 . PORtulacaceae. Purslane Family.}

Succulent plants, with opposite or alternate leaves. Flowers perfect, regular. Sepals 2 , or in Lewisia 6-8. Petals 4 or 5 , rarely more, imbricate. Stamens as many as the petals. Gynoecium of $2-5$ united carpels; ovary 1-celled, usually superior; styles $2-5$, distinct or partly united. Fruit a valvate or cireumscissile capsule.

Ovary wholly superior.

Styles or stigmas 3-8; sepals not accrescent; inflorescence not secund.

Sepals deciduous, scarious; capsule 3-valved; plant with fleshy rootstock or root; ours with terete leaves.

Sepals persistent, at least in part herbaceous.

1. TAIINUM. Capsule 3-valved; styles 3 .

Plants with a corm, or a fleshy root, crowned with a short caudex; cauline leaves opposite; ovules usually 6.2 . Claytonia.

Plants annual, or perennial, with slender rootstocks; ovules usually 3. Stem-leaves opposite.

Stem-leaves a single pair; plant neither rooting at the nodes nor

flagelliferous.
Stem-leaves of several pairs; plant floating and rooting at the nodes.

3. LIMNIA. usually flagelliferous.

4. CRUNOCALlis. Stem-leaves alternate.

Leaves very fleshy; perennials, with bulblets and creeping stems or stolons.

5. NAIOCRENE.

Leaves not fleshy; erect annuals, without bulblets and stolons.

Capsule circumscissile near the base.

6. Montiastrum.

Sepals 6-8; scape jointed above the middle, with 2 or more subulate bracts at the joint.

Sepals 2; scape not jointed near the middle.

7. LEWISIA.

Plants with a thick perennial root, bearing one or several short caudices. 8. OREOBROMA.

Plants with a globular corm and a slender stem bearing 2-3 verticillate leaves.

9. EROCAllis.

Styles or stigmas 2; capsule 2-valved; sepals scarious and accrescent; inflorescence secund.

10. SPRAgUEA.

Ovary partly inferior, circumscissile; ours low spreading leafy annuals, with flat leaves.

11. Portulaca.

\section{TALİNUM Adans. FAME-FLOWER.}

Perennial herbs or shrubby plants, ours with fleshy rootstocks. Leaves alternate or nearly opposite, in ours terete. Flowers in terminal cymes, or in some species axillary. Sepals 2, scarious, deciduous. Petals 5 or more, early withering. Stamens usually more numerous than the petals. Ovary superior; styles 3, more or less united. Capsules 1-celled, 3-valved, parchment-like. Seeds flattened, reniform, shining.

Plant scapose, from a corm-like rootstock.

Flowers about $1 \mathrm{~cm}$. wide; stamens 5-10.

Flowers $2-3 \mathrm{~cm}$. wide; stamens 30 or more.

1. T, parviflorum.

2. T. calycinum.

Plant low and spreading, from a branched rootstock; flowers axillary. $3 . T$. brachypodum.

1. T. parviflorum Nutt. Scape usually $1 \mathrm{dm}$. high or less; leaves numerous, basal, terete, $2-5 \mathrm{~cm}$. long, glabrous; sepals ovate, $2-3 \mathrm{~mm}$. long; petals rose or whitish, 5-7 mm. long; capsule ellipsoid, 3-4 mm. long. Rocky soil: Minn.S.D.-Ariz.-Tex.; Mex. Son.-Plain-Submont. Jl-Au.

2. T. calycinum Engelm. Seape 1-2 dm. high; leaves 1-5 cm. long, glabrous; sepals ovate-orbicular, $5 \mathrm{~mm}$. long, tardily deciduous; petals $8-10$, pink, 10-12 mm. long; eapsule subglobose, 6-7 mm. long. Sandy soil: Ark.-Mo.Neb.-N.M.; Mex. Plain-Son. Je-S.

3. T. brachypodum S. Wats. Lower leaves seale-like, the others linear, fleshy, 5-12 mm. long; pedicels very short, 2-5 $\mathrm{mm}$. long, articulate below; sepals ovate, acutish, 4-5 mm. long; petals bright pink, $8-10 \mathrm{~mm}$. long; stamens 10; capsule ovate, $4 \mathrm{~mm}$. long. Barren hills and mesas: s Utah-N.M.-Ariz. Son. Jl-Au.

\section{Claytônia (Gronov.) L. Spring Beauty, Ground-nut.}

Perennial fleshy herbs, with tuber-like corms or a thick fleshy root and short caudex. Basal leaves solitary or few, or clustered on the caudex; stem-leaves 
either 2, opposite, or a few alternate. Flowers in terminal racemes. Sepals 2, persistent. Petals 5. Stamens 5, adnate to the petals at the base. Ovary superior; styles 3, mostly united. Capsule 1-celled, 3-valved.

Plants with corms; basal leaves few.

Stem-leaves linear or narrowly lanceolate, 1-ribbed or indistinctly 3-ribbed.

Corolla orange.

Corolla white or pink.

Sepals oblong to oval, rounded at the apex; corms usually with 1 or 2 stems. Stem-leaves petioled; corolla white, with rose-colored veins.

Stem-leaves sessile; flowers pink.

Sepals rhombic-ovate; corms with several stems.

Stem-leaves broadly lanceolate, distinctly triple-ribbed.

Plants with a short caudex and a fleshy taproot; basal leaves clustered.

2. C. virginica.
3. C. rosea.
4. C. multiscapa.
5. C. lanceolata.

6. C. megarrhiza.

1. C. chrysantha Ġreene. Corm 1-1.5 cm. thick, globose; basal leaves usually solitary; blades narrowly oblong or oblanceolate; stem 1-2 dm. high; stem-leaves sessile, inserted below the middle of the stem; sepals rhomboidal or suboval, scarious-margined; petals $8-10 \mathrm{~mm}$. long, broadly oval. C. aurea A. Nels., not O. Kuntze. Wet flats: Ida.-Wash.-B.C. Mont-Subalp. Je.

2. C. virginica $\mathrm{L}$. Corm globose, $1-2 \mathrm{~cm}$. in diameter; stems 1-2.5 dm. high; basal leaves usually several; blades linear or narrowly linear-lanceolate, $5-12 \mathrm{~cm}$. long; sepals $5-7 \mathrm{~mm}$. long, acute or obtuse; petals oblong, 8-10 $\mathrm{mm}$. long, white, or in the East often pinkish, with rose-colored veins. Rich woods or among bushes: N.S.-Ga.-Tex.-Colo.-Mont. Plain-Mont. Mr-Au.

3. C. rosea Rydb. Corm 10-15 mm. in diameter; stem about $1 \mathrm{dm}$. high, slender; basal leaves rare; blades 1-2 $\mathrm{cm}$. long, spatulate; stem-leaves $2-5 \mathrm{~cm}$. long; sepals rounded-ovate, rounded at the apex, about $5 \mathrm{~mm}$. long; capsule shorter than the sepals. Hills and valleys: Colo.-Utah-Wyo. Submont.Mont. My-Je.

4. C. multiscapa Rydb. Corm 1-1.5 cm. thick, globose; stems $5-15 \mathrm{~cm}$. long; basal leaves usually several; blades narrowly oblong or oblanceolate, 3-5 $\mathrm{cm}$. long; stem-leaves sessile, lanceolate, $2-4 \mathrm{~cm}$. long, at the middle of the stem; petals broadly elliptic or oval, 7-10 mm. long, white, with purplish veins. $C$. multicaulis A. Nels., not O. Kuntze. Gravelly slopes and bottom lands: Mont. -Wyo.; apparently also Ia. Plain-Submont. My-Jl.

5. C. lanceolata Pursh. Corm about $1 \mathrm{~cm}$. thick; stem $0.5-2 \mathrm{dm}$. high; basal leaves solitary; blade oblong-lanceolate; stem-leaves sessile, $2-5 \mathrm{~cm}$. long; sepals elliptic, 3-6 mm. long, acute or obtuse; petals obovate, from rounded to obcordate at the apex, rose-colored, with purple veins. Rich wet soil: Sask.N.M.-Calif.-B.C. Submont.-Subalp. Ap-Jl.

6. C. megarrhiza (A. Gray) Parry. Root 1-4 cm. thick; basal leaf-blades spatulate to nearly orbicular, with the wing-margined petioles $2-15 \mathrm{~cm}$. long, fleshy; stem-leaves alternate, linear or narrowly spatulate; sepals ovate, acute, 5-6 mm. long; petals pink or white, purple-veined, 6-8 $\mathrm{mm}$. Iong. Rock-slides, in the higher mountains: Mont.-N.M.-Utah-Wash. Mont.-Alp. Jl-Au.

\section{Limmia L. Spanish Lettuce, Squaw Lettuce, Souaw Cabbage, Miners' Lettuce.}

Annuals, or perennials, with slender rootstocks, rarely stoloniferous or bulbiferous in the basal leaf-axils. Basal leaves several; stem-leaves opposite, a single pair, often more or less united. Inflorescence racemose. Sepals 2, somewhat unequal, persistent; petals 5, emarginate or obcordate. Stamens 5, opposite the petals. Styles 3. Capsule 3-valved from the apex; seeds 2-3.

Plants with perennial scaly rootstocks; stem-leaves not united.

1. L. asarifolia.

Plants annual, or perennial by offsets.

Stem-leaves free; bractlets present.

Stem-leaves rounded or rhombic-ovate.

Stem-leaves linear.

2. L. sibirica.

3. L. arenicola.

Stem-leaves more or less united; bractlets lacking. or only one below the lowest pedicel. Stem-leaves broadly ovate to orbicular.

Blades of the basal leaves reniform or rhombic to spatulate. Racemes elongate; flowers more or less fascicled; seeds about $2 \mathrm{~mm}$. long.

4. $L$. perfoliata. 
Racemes short, only slightly exceeding the subtending leaves; seeds about $1 \mathrm{~mm}$. long.

5. L. depressa.

Blades of the basal leaves linear to spatulate; seeds $1 \mathrm{~mm}$. Iong or less.

Racemes elongate.

Racemes very short.

Stem-leaves 1-2 cm. long; seeds minutely muricate. 7. L. utahensis.

Stem-leaves less than $1 \mathrm{~cm}$. long; seeds conspicuously granulated.

Stem-leaves linear.

8. L. spathulata.

9. L. exigua.

1. L. asarifolia (Bong.) Rydb. Stem 2-3 dm. high, slender; basal leaves long-petioled; blades reniform to rhombic-ovate, $2-8 \mathrm{~cm}$. long; cauline leaves closely sessile, broadly ovate or rounded; inflorescence bractless; petals white, 6-10 mm. long, obcordate. Claytonia asarifolia Bong. Springy ground: Mont. -Utah-Calif.-Alaska. Mont. My-Au.

2. L. sibirica (L.) Haw. Annual, or perennial with offsets; stem slender, 1-4 dm. high; basal leaves petioled; blades rhombic-ovate to lanceolate, $2-5 \mathrm{~cm}$. long; racemes elongate, lax, usually with linear or oblong bracts; petals rosecolored or white, about $6 \mathrm{~mm}$. long. C. sibirica L. Springy places and banks: Mont.-Utah-Calif.-Alaska; Siberia. Submont.-Subalp. My-Au.

3. L. arenicola (Henders.) Rydb. Annual; stem 5-15 cm. long; basal leaves petioled; blades narrowly linear-oblanceolate, $2-5 \mathrm{~mm}$. broad, $2-5 \mathrm{~cm}$. long; racemes rather many-flowered; petals pinkish, 5-6 mm. long, emarginate. $C$. arenicola Henders. Sandy river banks and in pine woods: Wash.-Ida. Son.-Submont. Ap-My.

4. L. perfoliata (Donn) Haw. Annual; stem 1-3 dm. high; basal leaves petioled; blades 2-7 cm. wide; stem-leaves connate into a rounded, 2-lobed cup; sepals orbicular, in fruit $4 \mathrm{~mm}$. long; petals white, slightly longer than the calyx; seeds minutely granulate. C. perfoliata Donn. Banks and springy places: Mont.-Utah-Calif.-Alaska. Submont.-Mont. Mr-Je.

5. L. depressa (A. Gray) Rydb. Annual; stem 5-10 cm. long; leaf-blades 5-15 mm. wide; stem-leaves connate, but usually less so on one side; calyx about $2 \mathrm{~mm}$. long; pedicels 3-4 $\mathrm{mm}$. long. C. parviflora depressa A. Gray. Montia Viae A. Nels. Banks and springy places: S.D.-Colo--Ariz.-Calif,-B.C. Submont. $\mathrm{My}-\mathrm{Jl}$.

6. L. parviflora (Dougl.) Rydb. Annual; stem 1-2 dm. high, slender; stem-leaves connate, forming a rounded disk, with 2 short-acuminate lobes; pedicels in fruit usually much longer than the calyx; petals pink or white; seeds scarcely granulate. C. parviflora Dougl. Banks and springy places: Ida.-Utah -Calif.-B.C. Submont.-Son. Ja-Je.

7. L. utahensis Rydb. Annual; stem 2-15 cm. long; basal leaves petioled; blades spatulate to linear, 1-3 cm. long, 2-6 mm. wide; stem-leaves connate, forming an oblique, 2-lobed disk, 1-2 cm. broad; inflorescence corymbiform; sepals ovate, equalling the pedicels; seed $1 \mathrm{~mm}$. in diameter. Sandy soil: 8 Utah. Son.

8. L. spathulata (Dougl.) Heller. Annual; stem 2-10 $\mathrm{cm}$. long; basal leaves 2-3 cm. long; stem-leaves ovate to lanceolate, connate on one side, 4-8 $\mathrm{mm}$. long; inflorescence short and corymbiform; petals white, 3-4 mm. long. Hillsides and saline ground: B.C.-Calif.-Utah. Son.-Submont. Ap-Je.

9. L. exigua (T. \& G.) Heller. Annual; stems several, $2-8 \mathrm{~cm}$. high; basal leaves linear or linear-oblanceolate, 2-4 cm. long; stem-leaves connate on one side, 1-2 cm. long; petals white, obcordate, twice as long as the sepals; seeds minutely muricate. C.exigua T.\& G. Hills: B.C.-Ida.-Calif. Son. Ap-Je.

\section{CRUNOCÁLlis Rydb. Water Spring-Beauty.}

Floating or creeping perennials, rooting at the nodes, usually flagelliferous, bearing winter buds at the ends of the flagella. Leaves opposite, several pairs. Inflorescence racemose. Sepals 2. Petals 5, equal. Styles 3 ; ovules 3. Capsule 3-valved; seeds $2-3$, round-reniform, muriculate.

1. C. Chamissonis (Ledeb.) Rydb. Perennial; leaves spatulate or oblanceolate, 1-4 cm. long; raceme 1-9-flowered; pedicels recurved in fruit; petals pale 
rose-color, 6-8 mm. long; seeds densely muricate. Claytonia Chamissoi Ledeb. Montia Chamissonis Greene. Wet places and in springs: Alaska-Calif.-N.M. -Minn. Plain-Mont. Je-Au.

\section{NAIOCRÈNE (T. \& G.) Rydb.}

Perennials, with very fleshy leaves, decumbent or sarmentose, producing axillary bulblets. Stem-leaves numerous; alternate. Inflorescence racemose. Sepals 2, broadly obovate, unequal. Petals 5. Stamens 5, adnate to the base of the petals. Styles 3 ; ovules 3 . Capsule 3-valved, usually 3 -seeded.

1. N. parviftora (Moq.) Rydb. Perennial, with a rootstock; stems several, ascending or décumbent at the base, 1-3 dm. high; leaves fleshy, the lower petioled, the blades spatulate, $5-20 \mathrm{~mm}$. long, the upper sessile, oblong and bractlike; petals obovate or obcordate, 8-10 mm. long, rose-colored or white. Claytonia parviflora Moq. Montia parviftora Greene. Moist rocks: Alaska-Mont. -Calif. Sübmont.-Mont. My-Au.

\section{MONTIÁSTRUM (A. Gray) Rydb.}

Leafy-stemmed annuals, with narrow, alternate leaves, partly scarious at their insertion. Infloreseence racemose, secund. Sepals 2. Petals 5, obviously unequal, unguiculate at their bases. Stamens 3. Styles 3. Capsule 3-valved, 2-3-seeded. Seeds lenticular, thin-edged, very shining.

1. M. lineare (Dougl.) Rydb. Annual; stems branched at the base, slender, erect, $0.5-3 \mathrm{dm}$. high; leaves linear-filiform, $1-5 \mathrm{~cm}$. long; sepals in fruit $3-4 \mathrm{~mm}$. long, rounded; seeds $2 \mathrm{~mm}$. in diameter, black and shining. Claytonia linearis Dougl. Montia linearis Greene. Moist ground: Mont.-Calif--B.C. Submont. Ap-Je.

\section{Lewísia Pursh. Bitter-Root, Red-head Louisa.}

Low acaulescent, succulent perennials, with a thick fleshy taproot. Seapes 1-flowered, jointed near the middle and with a whorl of 2 or more subulate bracts at the joint. Sepals 6-8, distinct, marcescent-persistent. Petal 8-16, large and showy. Stamens numerous. Styles 5-8, united at the base. Capsule circumscissile at the base, then bursting irregularly, many-seeded. Seeds black and shining. Cotyledons accumbent.

1. L. redofviva Pursh. Leaves numerous, terete or nearly so, more or less elavate, 1-4 cm. long; involucre of 5-7 subulate, scarious bracts; sepals 6-8, strongly imbricated, rounded-oval; petals $12-16$, rose-colored, purplish, or rarely white, oval or spatulate, $1.5-3 \mathrm{~cm}$. long; stamens about 40 . Stony ridges: Mont.-Colo.-Ariz.-Calif.-B.C. Submont.-Subalp. Ap-Je.

\section{OREOBRÒMA Howell. BREAD-ROOT.}

Low acaulescent perennials, with fleshy taproots, with or without a multicipital caudex. Leaves tufted at the base, fleshy. Scapes few-many-flowered. Sepals 2. Petals 3-10 or more. Stamens 5-20, usually not of the same number as the petals. Styles 2-7. Capsules membranous, circumscissile at the base, many-seeded. Cotyledons incumbent. [Calandrinia A. Gray, in part.]

Bracts neither sepal-like nor closely subtending the calyx.

Sepals not erose-denticulate.

Petals 10-12 mm. long; leaves usually more than $2 \mathrm{~mm}$. wide. 1. O. nevadensis.

Petals less than $10 \mathrm{~mm}$. long; leaves $2 \mathrm{~mm}$. wide or less. 2 . 0 . minima.

Sepals erose-denticulate.

Bracts 2, sepal-like and closely subtending the calyx.

3. O. pygmaea.

4. O. brachycalyx.

1. O. nevadensis (A. Gray) Howell. Root fusiform, 1-3 cm. long; leaves linear, 5-10 cm. long; scape stout, 4-10 cm. long; bracts lanceolate, near the base of the scape; sepals rounded-ovate, in fruit $1 \mathrm{~cm}$. long; petals white, $10-12 \mathrm{~mm}$. long. C. nevadensis A. Gray. Mountains: Wash.-Colo.-N.M.-Calif. Submont.-Mont. Je-Jl.

2. O. minima A. Nels. Root napiform, 5-20 mm. long; leaves several, narrowly linear, 4-7 cm. long; scape rarely equalling the leaves; bracts one-third 
from the base, lanceolate; sepals oval, abruptly acuminate; petals white. Lewisia minima A. Nels. Creek banks: n Wyo.-Mont.-Ida. Submont. Jl.

3. O. pygmaea (A. Gray) Howell. Root usually elongated-conic, $2-8 \mathrm{~cm}$. long; leaves many, narrowly linear, $2-7 \mathrm{~cm}$. long; scape $2-5 \mathrm{~cm}$. high; bracts scarious, lanceolate, inserted at the middle of the scape; sepals rounded-ovate, short-acuminate; petals 6-8, pink or white, $8-10 \mathrm{~mm}$. long. C. pygmaea A. Gray. O. Grayi (Britt.) Rydb. Gravelly hills and mountain sides: Mont.-Colo-Calif.-Wash. Mont.-Alp. Je-Au.

4. O. brachycalyx (Engelm.) Howell. Leaves spatulate or oblanceolate, spreading, 3-7 cm. long, contracted into a margined petiole; scape $2-5 \mathrm{~cm}$. long; bracts elliptic, about $6 \mathrm{~mm}$. long, equalling the oval sepals; petals $7-9$, cuneate or obovate, white, 1-2 cm. long; stamens 10-15. C. brachycalyx Engelm. Mountains: s Utah-N.M. $\rightarrow$ S Calif. Ap-Je.

\section{EROCÁLLIS Rydb.}

Perennial, with globular corms. Radical leaf usually solitary, not present at flowering time. Stem low, with 2 or 3 whorled leaf-like bracts. Sepals 2, somewhat unequal. Petals 3-10, oblong. Capsule oblong-conical, circumscissile.

1. E. triphylla (S. Wats.) Rydb. Corm globose, $5-8 \mathrm{~mm}$. thick; stem $2-10$ $\mathrm{cm}$. high, slender; basal leaves solitary or none; stem-leaves 2-4, verticillate, linear-filiform, $1-5 \mathrm{~cm}$. long; inflorescence 2-20-flowered; petals 3-10, oblong, $4 \mathrm{~mm}$. long. Claytonia triphylla S. Wats. Lewisia triphylla B. L. Robins. Mountains: Wyo.-Colo.-Calif.-Wash. Mont. Je-Au.

\section{SPRÃGUEA Tort. PUSSY-PAws.}

Biennial or perennial herbs, with rosulate leaves. Flowers in dense scorpioid spikes clustered in an umbel-like or subcapitate inflorescence. Sepals 2, orbiclar, scarious-hyaline, accrescent and persistent. Petals 4, somewhat unequal. Stamens 3, opposite to the three larger petals. Ovary 8-10-ovuled. Styles 2, united to near the apex. Capsule 2-valved, membranous. Seeds black, shining.

1. S. multiceps Howell. Perennial, with a cespitose caudex, forming cushions; basal leaves numerous, petioled; blades spatulate, fleshy, $0.5-5 \mathrm{~cm}$. long; flowering stems scape-like, $3-15 \mathrm{~cm}$. long; stem-leaves small, oblanceolate; flowers in a dense head-like inflorescence; sepals with broad, scarious, white or pink margins, orbicular or somewhat reniform, in fruit 7-8 mm. broad. Volcanie sand and geyser formations: Wash.-Mont.-Wyo. Mont.-Alp. Je-Au.

\section{PORtulàca (Tourn.) L. Purslanf, Pussley.}

Annual or perennial fleshy herbs, mostly with diffusely branched stems. Leaves terete or flat, opposite or alternate, with bristle-like or scarious stipules. Sepals 2 , deciduous. Petals 4-6, fugaceous. Stamens 8 or more. Ovary partly or wholly inferior; styles 3-8, slender. Capsule 1-celled, circumscissile. Seeds flattened, reniform.

Leaf-blades flat, glabrous in the axils or nearly so: petals yellow.

Stem prostrate; sepals pointed in the bud; seeds obscurely granulate. 1. P. oleracea.

Stem ascending; sepals obtuse in the bud; seeds echinate-tuberculate. 2. $P$, retusa. Leaf-blades terete or nearly so, pilose in the axils; petals red or purple. $3 . P$. pilosa.

1. P. oleracea $L$. Annual; stem diffusely branched at the base, prostrate, 1-6 dm. long; leaves fleshy, sessile or nearly so, euneate or obovate, 1-3 cm. long, rounded at the apex; buds flattened; stamens 7-12. Cultivated grounds and waste places: Me.-Fla.-N.M.-Wash.; Mex. and W. Ind.; nat. from the Old World. Plain. Ja-D.

2. P. retusa Engelm. Annual; stem ascending, branched near the base; leaves cuneate, $1-2.5 \mathrm{~cm}$. long, of ten retuse, fleshy, sessile; sepals carinately-winged; petals minute; stamens 10-19. Sandy soil: Ark.-Utah-N.M. Son.-Submont. Jl-S.

3. P. pilosa L. Annual; stem ascending, branched; leaves nearly terete, linear or linear-subulate, $1 \mathrm{~cm}$. long or less, with numerous hairs in the axils; petals carmine to purple, $3-4 \mathrm{~mm}$. long, retuse; capsule globose. Sandy soil: Fla.-Mo.-Colo.-Calif.; Trop. stral-Son. 


\section{Family 43. CORRIGIOLACEAE. Whitlow-wort Family.}

Herbs, with narrow opposite leaves with scarious stipules. Flowers perfect, inconspicuous, in dichotomous eymes. Sepals 4-5, distinct or partly united. Corolla wanting. Stamens 4 or 5. Pistil solitary; ovary 1-celled. Fruit a utricle or an achene.

\section{PARONÝCHIA (Tourn.) Adans. WHITLOW-WORT.}

Annual or perennial herbs, with stems often branched at the base. Leaves opposite, narrow. Sepals 5, narrow, concave or hooded at the awn-tipped apex. Stamens 5, included; filaments inserted at the base of the ovary, alternating with 5 small staminodia. Styles partially united. Utricle included. Radicle ascending.

Flowers solitary; leaves scarcely exceeding the bracts; plants densely pulvinate.

Leaves elliptic, thick, not spinulose-tipped.

Leaves linear, chartaceous, spinulose-tipped.

Leaves straight, ascending; spinules of the sepals less than $1 \mathrm{~mm}$. long.

Leaves arcuate-spreading; spinules of the sepals more than $1 \mathrm{~mm}$. long.

3. P. sessiliflora.

Flowers more or less clustered; leaves much longer than the bracts.

Plants low and diffuse, less than $1 \mathrm{dm}$. high; calyx fully $3 \mathrm{~mm}$. long.

Inflorescence much contracted; bracts exceeding the flowers. 4. P. depressa.

Inflorescence more open; bracts shorter than or merely equalling the flowers.

lants taller, $1 \mathrm{dm}$. or more high; stems erect or ascending; calyx $2-2.5 \mathrm{~mm}$. long.

Branches of the cymes ascending; calyx about $2.5 \mathrm{~mm}$. long; sepals lanceolate, gradually acuminate.

Branches of the cymes divaricate; calyx about $2 \mathrm{~mm}$. long; sepals oblong, abruptly acuminate.

7. $P$. Wardii.

1. P. pulvinata A. Gray. Pulvinate-cespitose perennial, $3-5 \mathrm{~cm}$. high; stipules ovate, silvery; leaves thick, 3-5 $\mathrm{mm}$. long; flowers solitary in the upper axils; sepals broadly scarious-margined, ovate, about $3 \mathrm{~mm}$. long. Exposed mountain tops: N.M.-Wyo.-Utah. Subalp.-Alp. Jl-Au.

2. P. brevicuspis (A. Nels.) Rydb. Pulvinate-cespitose perennial; leaves 3-5 mm. long, linear, with short spine-tips; flowers sessile in the upper axils; sepals $2-3 \mathrm{~mm}$. long, brown, scarcely scarious-margined. $P$. sessilifolia brevicuspis A. Nels. Dry hills: Wyo.-Colo.-Nev. Submont. Jl.

3. P. sessiliflora Nutt. Pulvinate-cespitose perennial, $4-10 \mathrm{~cm}$. high; leaves linear or linear-subulate, spinulose-tipped, 4-6 mm. long; sepals lanceolate brown with narrow scarious margins, spine-tipped, about $3 \mathrm{~mm}$. long. Dry ridges: Sask.-Tex.-Utah-Alta. Plain-Mont. Je-Au.

4. P. depressa Nutt. Cespitose perennial, somewhat woody at the base; stems diffuse, much branched; leaves linear, $5-8 \mathrm{~mm}$. long, scabrous, spinulosetipped; sepals linear, $2.5-3 \mathrm{~mm}$. long, usually exceeded by the bracts. Dry hills or plains: S.D.-Neb.-Wyo. Plain-Submont. Je-Au.

5. P. diffusa A. Nels. Cespitose perennial, somewhat woody at the base; stems $5-15 \mathrm{~cm}$. long; leaves linear, 7-10 mm. long, spinulose-tipped, scabrous; sepals linear, $2.5-3 \mathrm{~mm}$. long; spine-tips $0.5 \mathrm{~mm}$. long. Dry plains, hills, and mountains: S.D.-Kans.-Colo.-Wyo.-Alta. Plain-Alp. Je-S.

6. P. Jamesii T. \& G. Perennial, shrubby and branched at the base; stems erect, 1-3 dm. high, forking above; leaves strongly ascending, 1-2 $\mathrm{cm}$. long, callous-mucronate; sepals about $2.5 \mathrm{~mm}$. long, lanceolate; spine-tips strongly ascending. Dry plains and hills: Neb.-Tex.-N.M.-Wyo. Plain-Mont. $\mathrm{Je}-\mathrm{Au}$.

7. P. Wardii Rydb. Perennial, shrubby and branched at the base; stems erect, 1-2 dm. high; leaves narrowly linear or linear-filiform, $0.7-2 \mathrm{~cm}$. long, early deciduous, mucronate, minutely scabrous. Dry stony soil: Kans.-Tex.N.M.-Colo. Plain-Submont. Jl-O. 


\section{Family 44. alsinaCeat. Chickweed Family.}

Herbs with opposite leaves, with or without stipules. Flowers perfect, usually cymose. Sepals 4 or 5 , distinct. Petals 4 or 5, clawless, rarely wanting. Stamens twice as many as the sepals or fewer. Gynoecium of $2-5$ united carpels; ovary partly or completely $2-5$-celled; styles $2-5$. Fruit a capsule, opening with as many or twice as many valves as carpels. Seed several to many on a central placenta. Embryo curved.

Stipules wanting.

Capsule opening with twice as many valves or teeth as there are styles; petals deeply 2-cleft.

Capsule short, ovate or oblong, opening with usually 6 valves; styles usually 3 .

Capsule long, cylindric, often curved, opening with usually 10 teeth at the apex; styles usually $5 . \quad 2$. CERASTIUM.

Capsule opening with as many, entire or at length 2-cleft, valves as there are styles; petals entire or merely notched at the apex (except in Arenaria Kingii).

Styles fewer than the sepals, or rarely of the same number and then opposite them.

Flowers with a rather prominent, glandular, 10-1obed disk under the ovary; plants fleshy.

3. AMMODENIA.

Flowers with no or a very inconspicuous disk; plants scarcely fleshy. Seeds with a basal membranous appendage (strophiole) at the hylum.

Seeds not strophiolate.

Valves of the capsule entire.

Valves of the capsule at last 2-cleft.

Styles as many as the sepals and alternate with them.

Stipules present.

Leaves whorled; styles 5 .

Leaves opposite; styles usually 3 .

Styles distinct; sepals not spinulose-tipped.

Stigmas sessile; sepals spinulose-tipped.

\section{ALSìne L. Chickweed, Starwort.}

Annual or perennial herbs, with weak spreading stems and alternate leaves. Flowers usually in open cymes. Sepals 5, rarely 4 . Petals 5 or 4, deeply 2cleft, or rarely wanting. Stamens 10 or fewer, hypogynous. Ovary 1-celled; styles 3 , rarely 4 or 5 , opposite the sepals, if of the same number. Capsule relatively short, opening by twice as many valves as there are styles. Seeds flattened or globose. [Stellaria L.]

Plant not viscid.

Basal leaf-blades spatulate to rhombic-obovate, petioled; plants annual.

Leaf-blades all ovate or rhombic-ovate.

Flowers cymose.

Stem-leaves small, lanceolate.

1. A media

18. A. washingtoniana.

2. A. nitens.

All leaves sessile.

Upper bracts at least scarious; perennials with rootstocks.

Petals minute or none.

Leaves oblong-lanceolate; branches of the inflorescence at last reflexed.

Leaves linear; branches of the inflorescence ascending.

3. A. baicalensis.

Petals equalling or exceeding the sepals.

4. A. alpestris.

Leaves broadest at about the middle, narrowed at the base.

Leaves broadest near the base.

5. A. longifolia.

Calyx 4-5 mm. long; stem not villous.

Stem 2-3 dm. high, many-flowered; leaves narrowly lanceolate to nearly linear.

Sepals lanceolate, very acute, nearly equalling the capsule.

6. A. strictiflora.

Sepals ovate or ovate-lanceolate, obtuse or mucronate, scarcely more than half as long as the mature capsule; pedicels in fruit spreading.

7. A. longipes.

Stem 3-15 cm. high, usually 1-3-flowered, rarely 4-6-flowered.

Leaves narrowly lanceolate; sepals lanceolate, very acute.

Leaves ovate or ovate-lanceolate; sepals ovate-lanceolate, obtusish.

9. A. Edwardsii.

Calyx 2-3 mm. long; stem $1 \mathrm{dm}$. high or less, 3-10-flowered, usually villous. 
None of the bracts scarious.

Leaves linear to lanceolate, more than four times as long as broad; plants perennial, with running rootstocks.

Petals equalling or exceeding the sepals.

Plant low, less than $1 \mathrm{dm}$. high, bluish green.

Plant slender, light green, more than $1 \mathrm{dm}$. high.

8. A. laeta.

11. A. crassifolia.

Petals much shorter than the sepals, or none.

Sepals with narrow scarious margins, acute; leaves oblong-lanceolate, narrowed at the base; midrib not unusually strong; petals usually lacking.

12. A. borealis.

Sepals with broad scarious margins, acuminate; leaves linear-lanceolate. with a strong midrib; petals usually present.

Leaves $2-8 \mathrm{~mm}$. wide, broadest near the base.

Leaves 8-15 mm. wide, broadest near the middle.

13. A. brachypetala.

14. A. oxyphylla.

Leaves ovate-lanceolate, ovate or oval, less than four times as long as broad: cespitose perennials, except No. 18.

Leaves thin.

Stem glabrous or nearly so.

Sepals acute or acuminate.

15. A. crispa.

Sepals obtuse.

16. A. obtusa.

Stem distinctly pubescent.

Leaves sessile; flowers more or less cymose. 17. A. calycantha,

Leaves short-petioled; flowers solitary in the axils.

18. A. washingtoniana.

Leaves thick.

Petals equalling or exceeding the sepals; branches simple, ascending.

Leaves ovate, bluish green, with strong midrib; petals longer than the obtusish sepals. A. Edwardsii.

Leaves oval, bright green; midrib not strong; petals equalling the acute sepals.

19. A. Palmeri.

Petals shorter than the sepals; branches divaricately branched, spreading.

20. A. polygonoides.

Plant more or less viscid, especially the upper portion; perennials with rootstocks.

Plant tall, 1-3 dm. high, erect; leaves linear to lanceolate.

Leaves linear or linear-lanceolate, $2-5 \mathrm{~mm}$, wide.

Leaves lanceolate, 5-10 $\mathrm{mm}$. wide.

Plant low, diffusely cespitose; leaves ovate.

21. A. Curtisii.

22. A. Jamesiana.

23. A. americana.

1. A. media L. Stem diffusely branched, prostrate or ascending, 1-4 dm. long, glabrous except the pubescent lines; leaf-blades $0.5-3.5 \mathrm{~cm}$. long; sepals oblong, glandular-pubescent, about equalling the capsule; petals shorter than the sepals. S. media Cyrill. CHוckwEED. Waste places, cultivated grounds, etc.: Greenl.-Fla.-Calif.-B.C.; W. Ind.; nat. from Eu. Ja-D.

2. A. nitens (Nutt.) Greene. Stem branched near the base, glabrous or somewhat pubescent below, erect, 1-2 dm. high; basal leaf-blades ovate, acute, 4-5 $\mathrm{mm}$. long; stem-leaves 6-10 $\mathrm{mm}$. long; sepals lanceolate, acute, 3-4 mm. long, 3-nerved at the base; petals about half as long as the sepals, or sometimes wanting. S. nitens Nutt. S. praecox A. Nels. Wet places: w Mont.-Utah -Calif.-B.C. Son.-Submont. Mr-Je.

3. A. baicalensis Coville. Stem weak, ascending, or decumbent at the base, 3-30 $\mathrm{cm}$. high; leaves 6-20 $\mathrm{mm}$. long; bracts lanceolate; sepals $2-2.5 \mathrm{~mm}$. long, glabrous, scarious-margined. S. umbellata Turez. Around springs and brooks: Mont.-N.M.-Calif.-Ore.; Siberia. Submont.-Alp. Jl-Au.

4. A. alpestris (Fries) Rydb. Stem 2-4 dm. high, angled; leaves sessile, linear, 2-4 cm. long, 2-4 $\mathrm{mm}$. wide; bracts lanceolate, the lower foliaceous; sepals lanceolate, about $3 \mathrm{~mm}$. long, very acute; petals about half as long or less, or lacking. S. alpestris Fries. Wet places: Ont.-Sask.-Colo.-Utah-Alta.; n Eu. Submont.-Mont. Je-Au.

5. A. longifolia (Muhl.) Britton. Stem sharply 4-angled, 2-5 dm. high; leaves sessile, lance-linear, often ciliate towards the base, 2-6 $\mathrm{cm}$. long, 2-6 mm. wide; bracts lanceolate; branches of the cyme and pedicels spreading; sepals lanceolate, acute, 3 -nerved, about $3 \mathrm{~mm}$. long, shorter than the petals. $S$. longifolia Muhl. Low meadows and swamps: Lab.-Newf.-Md.-N.M.-Alaska; Eurasia. Plain-Subalp. My-Au.

6. A. strictiflora Rydb. Stem 2-5 dm. high, angled; leaves linear-lanceolate, $2-4 \mathrm{~cm}$. long, $2-4 \mathrm{~mm}$. wide, spreading; pedicels strongly ascending or 
almost erect; calyx 4-5 mm. long; sepals narrowly scarious-margined; petals 5-6 mm. long. Stellaria stricta Richards. S. longipes Am. auth., not Goldie. Wet meadows: w Ont.-Colo.-Calif.-B.C. Plain-Subalp. My-Au.

7. A. longipes (Goldie) Coville. Stem much branched, 4-angled, 1-3 dm. high; leaves linear-lanceolate, $1-3 \mathrm{~cm}$. long, glabrous, rather firm, shining; pedicels $2-5 \mathrm{~cm}$. long; calyx $4-5 \mathrm{~mm}$. long; sepals broadly scarious-margined; petals slightly exceeding the sepals. S. longipes Goldie. S. valida Goodding. Wet places: Greenl.-Que.-Colo-Calif.-Alaska. Submont.-Mont. Jl-Au.

8. A. laeta (Richards.) Rydb. Stem $5-15$, rarely $20 \mathrm{~cm}$. long, densely leafy; leaves 1-2 $\mathrm{cm}$. long, 2-4 mm. wide, bluish green, sometimes glaucous, shining; bracts foliaceous, or (in several flowered plants) the upper scarious; pedicels erect; sepals narrowly lanceolate, very acute, almost equalling the capsule; petals about $5 \mathrm{~mm}$. long. Wet places in the mountains: Hudson Bay-N.M.Calif.-Alaska-Arctic Sea. Mont.-Alp. My-Au.

9. A. Edwardsii (R. Br.) Rydb. Stem 3-10 cm. high, glabrous or somewhat pubescent; leaves $3-10 \mathrm{~mm}$. long, erowded, thick and keeled; bracts all foliaceous or the upper with scarious margins; calyx about $4 \mathrm{~mm}$. long; sepals 3-nerved, with narrow scarious margins; petals $5-6 \mathrm{~mm}$. long. S. Edwardsii R. Br. Aretic-alpine situations: Greenl.-Lab.-Hudson Bay-B.C.-Alaska. Subalp.-Alp. JI-Au.

10. A. subvestita (Greene) Rydb. Stem branched at the base, 5-10 cm. high, usually somewhat pilose; leaves numerous, linear-lanceolate, firm, 8-15 $\mathrm{mm}$. long, 1-nerved; bracts ovate, scarious; calyx 2-3 $\mathrm{mm}$. long; sepals ovatelanceolate, usually obtuse, scarious-margined, slightly shorter than the petals and capsule. S. subvestita Greene. Open places: Hudson Bay-Alta.-B.C.Alaska. Subalp.-Boreal. Je-Jl.

11. A. crassifolia (Ehrh.) Britton. Stem weak, ascending, with short internodes, 2-4 dm. long; leaves small, 6-20 mm. long, lanceolate or oblong-lanceolate, acutish; cymes few-flowered; sepals ovate-lanceolate, acuminate, about $3 \mathrm{~mm}$. long, exceeded by the petals. S. crassifolia Ehrh. Wet ground: Lab.-Pa.Colo.-Alta. Mont.-Subalp. Je-Au.

12. A. borealis (Bigel.) Britton. Stem erect, $1.5-4 \mathrm{dm}$. high, glabrous or nearly so; leaves 1-4 cm. long; cyme leafy, several-flowered; pedicels often deflexed; sepals ovate-lanceolate, $3-4 \mathrm{~mm}$. long. S. borealis Bigel. Wet places: Lab.-N.J.-Colo.-Calif.-Alaska, Submont.-Mont. J-S.

13. A. brachypetala (Bong.) Howell. Stem erect, 3-6 dm. high, sharply 4-angled; leaves linear-lanceolate, broad at the base, 2-6 cm. long; inflorescence leafy; pedicels reflexed in fruit; calyx about $5 \mathrm{~mm}$. long; sepals narrowly lanceolate, very acute, about twice as long as the petals. S. brachypetala Bong. Wet places: Mont.-Wyo.-Utah-Calif.-Alaska, Submont,-Mont. My-Au.

14. A. oxyphylla (B. L. Robins.) Heller. Stem decumbent and rooting at the base, $3-5 \mathrm{dm}$. high, glabrous except the pubescent lines; leaves elongatelanceolate, narrowed at the base, caudate-attenuate, 5-12 $\mathrm{cm}$. long, sparingly ciliate on the margin; pedicels at length deflexed; sepals about $6 \mathrm{~mm}$. long, lanceolate, attenuate, somewhat scarious-margined; petals about two-thirds as long. S. oxyphylla B. L. Robins. Wet places: Ida. Submont. Jl.

15. A. crispa (Cham. \& Schlecht.) Holz. Stems weak, decumbent, 1-3 dm. long; leaves ovate, usually crisp on the margins, $5-20 \mathrm{~mm}$. long, short-acuminate; flowers axillary, solitary; sepals lanceolate, acute, scarious-margined, exceeding the acute capsule; petals minute or none. S. crispa Cham. \& Schlecht. A. viridula Piper is a form with slightly ciliate petioles. Mountains, in wet places: Alta.-Wyo.-Calif.-Alaska. Submont.-Mont. Ap-JI.

16. A. obtusa (Engelm.) Rose. Stems numerous, glabrous, decumbent or prostrate, 5-15 $\mathrm{cm}$. long, angled; leaves ovate, thin, acute, $8-10 \mathrm{~mm}$. long; flowers axillary, solitary; sepals ovate, obtuse, searcely at all searious, shorter than the obtuse capsule. S. obtusa Engelm. Wet places in the mountains: Alta.-Colo.-Utah-Wash.-B.C. Mont. Je-Au. 
17. A. calycantha (Bong.) Rydb. Stems numerous, decumbent, more or less pubescent; leaves ovate-lanceolate, ciliolate at least at the base, $5-15 \mathrm{~mm}$, long; sepals lanceolate, acute, about equalling the rounded-ovoid or subspheric, obtuse capsule. S. calycantha Bong. Wet places in the mountains: Mont.Colo.-Calif.-Alaska. Mont.-Alp. Jl-S.

18. A. washingtoniana (B. L. Robins.) Heller. Delicate annual (?); stems decumbent, quite simple, more or less pubescent; leaf-blades ovate, acute, shortpetioled, thin, 8-10 $\mathrm{mm}$. long, finely ciliate near the base; peduncles spreading; sepals four, ovate, acute, $2-3 \mathrm{~mm}$. long, slightly scarious-margined; petals none; capsule ovoid. S. washingtoniana B. L. Robins. Woods and dry ground: Wash. -Ida. Submont.-Mont. J1-Au.

19. A. Palmeri Rydb. Stems spreading, $5 \mathrm{~cm}$. high or less, glabrous; leaves ovate or ovate-lanceolate, $2-5 \mathrm{~mm}$. long, fleshy, acute; cyme 3-5-flowered; sepals laneeolate, $2.5-3 \mathrm{~mm}$. long, acute; petals about equalling the sepals. Valleys: s Utah. Son.

20. A. polygonoides Greene. Stem diffuse, $3-10 \mathrm{~cm}$. long; leaves thick, ovate, $6-12 \mathrm{~mm}$. long; cymes several-flowered, with 'short branches and pedicels; sepals narrowly lanceolate, slightly scarious-margined, $4 \mathrm{~mm}$. long, acute, nearly twice as long as the petals. High mountains: Colo.-Utah. Subalp. Jl-Au.

21. A. Curtisii Rydb. Stem sharply 4-angled, erect, branched, $2-6 \mathrm{dm}$. high, glabrous, except in the inflorescence; leaves rounded and half clasping at the base, $3-6 \mathrm{~cm}$. long; sepals about $3 \mathrm{~mm}$. long, thick, ovate-oblong, obtuse or acutish, with a narrow white margin; petals about $7 \mathrm{~mm}$. long, Open woods: Wyo.-Colo.-Ariz.-Nev. Submont.-Mont. Je-Au.

22. A. Jamesiana (Torr.) Heller. Stem strongly angled, $2-5 \mathrm{dm}$. high, viseid above; leaves elongate-lanceolate, $5-12 \mathrm{~cm}$. long, broadest near the base; inflorescence leafy; sepals oblong or elliptic, thin, $4-5 \mathrm{~mm}$. long; petals $7-8$ $\mathrm{mm}$. long. S. Jamesiana Torr. Moist woodlands: Wyo.-Tex.-Calif.-Ida. Submont.-Mont. My-Au.

23. A. americana (Porter) Rydb. Stems branched, very leafy, 1-2 dm. high, viscid-puberulent; leaves sessile, ovate, obtusish, $1-3 \mathrm{~cm}$. long; cymes very leafy; pedicels short; sepals ovate, obtuse, $3-4 \mathrm{~mm}$. long; petals about 6 $\mathrm{mm}$. long. S. dichotoma americana Porter. Rock slides: Mont. Subalp. JeAu.

\section{Cerástium L. Mouse-ear Chickweed.}

Annual or perennial herbs, with pubescent, often viscid foliage. Leaves opposite. Flowers cymose. Sepals 5, rarely 4. Petals as many, white, 2-cleft. Stamens usually 10. Ovary one-celled; styles as many as the sepals and opposite them, rarely fewer. Capsule eylindric, often eurved, opening by 10 , rarely 8 , tooth-like valves.

Annuals; pod 2-3 times as long as the calyx.

Pedicels in fruit $1-3$ times as long as the calyx, straight or nearly so.

1. C. brachypodum.

Pedicels in fruit 5 times as long as the calyx or longer; strongly curved above.

Perennials or rarely annuals; pods 1-2 times as long as the calyx.

2. C. nutans.

Leaves oblong, oval, or ovate, mostly obtuse, or barely acutish.

Petals $1 \mathrm{~cm}$. long or more, fully twice as long as the sepals.

Sepals, at least the outer ones, oval, obtuse, scarious-margined at the tip as well as on the sides.

Sepals lanceolate, acute, scarious mostly on the margins only.

Leaves and stem distinctly, although not copiously villous.

Leaves and stem finely pilose. Alpinum.

Petals less than $1 \mathrm{~cm}$. long.

5. C. Earlei.

Petals much exceeding the sepals.

Leaves thick with a prominent midrib.

Plant tall, 4-5 dm. high; leaves linear-oblong. 12. C. Leibergii.

Plant low, depressed, less than $1 \mathrm{dm}$, high; leaves ovate-lanceolate.

Leaves thin; midrib not prominent.

18. C. thermale.

Sepals tinged with purple; stem depressed, 1-3-flowered.

6. C. Beeringianum. 
Sepals light green; plant not depressed, 3-12-flowered.

7. C. variabile.

Petals scarcely if at all exceeding the sepals; branches erect or ascending. Plant low and cespitose; leaves rather thick, all subsessile.

Plant taller and simple: leaves thin, the lower spatulate C. Buffumae. petioles.
9 . C. vulgatum.

Leaves, at least the lower ones, linear or linear-lanceolate, acute.

Leaves of the inflorescence short, broadly ovate, the rest linear.

10. C. oreophilum.

Leaves all linear or lanceolate, or rarely linear-oblong.

Inflorescence racemose-cymose, with almost erect branches, as well as the calyx copiously viscid.

Inflorescence cymose, with ascending or spreading branches.

Lower leaves linear-oblong, 5-8 $\mathrm{mm}$. wide; often obtuse.

12. C. Leibergii.

Leaves linear or linear-lanceolate, usually less than $5 \mathrm{~mm}$. wide, all acute or acuminate.

Petals 12-14 mm. long, more than twice as long as the sepals.

13. C. graminifolium.

Petals $10 \mathrm{~mm}$. long or less, rarely twice as long as the sepals.

Stem villous with reflexed hairs.

Leaves thin and flaccid, those of the sterile shoots and fascicles much narrower than those of the main stem.

14. C. angustatum.

Leaves firm, with a thick midrib, all alike or those of the sterile shoots broader.

15. C. campestre.

Stem finely glandular-puberulent.

Leaves thin and soft, all linear or narrowly linear-lanceolate; midrib not prominent.

Leaves thick and firm; midrib prominent.

Stem $1 \mathrm{dm}$. high or more; plant green; leaves not coriaceous, acute.

17. C. striclum.

Stem depressed, less than $1 \mathrm{dm}$. high; plant yellowish green; leaves coriaceous, the lower often obtuse.

18. $C$, thermale.

1. C. brachypodum (Engelm.) B. L. Robins. Annual; stem often branched at the base, finely villous-viscid, 1-3 dm. high; leaves oblanceolate or oblong, obtuse, 1-3 cm. long, viscid-villous; flowers in rather open cymes. Dry sandy soil: S.D.-Mo.-Alta.-Tex.-Ariz.-Ore.; Mex. Plain-Submont. Ap-J.

2. C. nutans Raf. Annual; stem often branched at the base, $2-5 \mathrm{dm}$. high, viscid-villous; leaves oblong or oblong-lanceolate, usually acute, or the lower oblanceolate, $2-7 \mathrm{~cm}$. long; flowers in open cymes; sepals about $4 \mathrm{~mm}$. long, lanceolate; petals slightly longer. $C$. longipedunculatum Muhl. $C$. Bakeri Greene. Wet places: N.S.-N.C.-Ariz.-Ore--B.C. Plain-Mont. $\mathrm{My}-\mathrm{Au}$.

3. C. pulchellum Rydb. Low decumbent; stems $5-10 \mathrm{~cm}$. long, finely viscid-pubescent; leaves about $1 \mathrm{~cm}$. long and $4 \mathrm{~mm}$. wide, viscid-pubescent on both sides; peduncles 1-1.5 $\mathrm{cm}$. long; petals $10-12 \mathrm{~mm}$. long. Alpine peaks: Colo. Alp. Jl.

4. C. alpinum L. Cespitose perennial; stems ascending or decumbent at the base, 1-2 dm. high; leaves 5-20 $\mathrm{mm}$. long, obtuse; cymes usually 1-3-flowered; pedicels long, erect; calyx 7-8 mm. long, villous; petals about $1 \mathrm{~cm}$. long. Areticalpine situations: Greenl.-Que.-Alta.-Alaska; Eurasia. Alp.-Subalp. JeAu.

5. C. Earlei Rydb. Perennial with a rootstock; stems weak, ascending, 2-3 dm. high, viscid-puberulent, branched; leaves obtuse, $1.5-3 \mathrm{~cm}$. long, 3-8 $\mathrm{mm}$. wide; inflorescence open; bracts ovate or ovate-lanceolate, not scarious; pedicels $2-2.5 \mathrm{~cm}$. long; sepals lanceolate, acute, about $5 \mathrm{~mm}$. long; petals not deeply cleft. Wet places among rocks in the mountains: Colo. Mont. $\rightarrow$ Subalp.

6. C. Beeringianum Cham. \& Schlecht. Depressed cespitose perennial; stems decumbent or ascending, $5-15 \mathrm{~cm}$, high, more or less viscid-puberulent; leaves 5-15 mm. long, more or less viscid-puberulent; cymes 1-3-flowered; sepals 4-5 mm. long, ovate, thick, acute; petals 6-8 mm. long. Mountain summits, among rocks: Alta.-N.M.-Ariz.-Alaska; Gaspé, Que. Mont.-Alp. $\mathrm{J}-\mathrm{Au}$. 
7. C. variabile Goodding. Cespitose perennial; stems many, erect, $15-25$ $\mathrm{cm}$. high, viscid-pubescent; leaves from spatulate to oblong or lanceolate, 1-3 $\mathrm{cm}$. long; sepals oblong or lance-oblong, acute, $6-7 \mathrm{~mm}$. long; petals $7-8 \mathrm{~mm}$. long. $C$. pilosum Greene, not Ledeb. Moist places among rocks: Colo.Utah. Mont.-Subalp. Ap-Au.

8. C. Buffumae A. Nels. Cespitose perennial; stems numerous, $7-15 \mathrm{~cm}$. long, glandular-puberulent, leafy; leaves oblong or elliptic, 5-12 mm. long; cymes dense, 3-10-flowered; sepals green, barely scarious-margined at the tips, oblong, obtusish, 4-5 mm. long; petals 6-7 mm. long. Mountains: Wyo.-ne Utah. Mont.

9. C. vulgatum L. Perennial, cespitose at the base; stems $1-4 \mathrm{dm}$. high, viscid-pubescent; leaves oblong or elliptic, obtuse, $1-3 \mathrm{~cm}$. long, villous; cymes elongate; bracts foliaceous; at least the lower pedicels exceeding the sepals in fruit; sepals about $5 \mathrm{~mm}$. long, obtuse, scarious-margined; petals about as long. Roadsides and fields: Lab.-Fla.-Ida.-Wash.-Alaska. Plain. My-Jl.

10. C. oreophilum Greene. Cespitose perennial; stems decumbent at the base, 1-2 dm. high, glandular-pubescent; leaves $1-3 \mathrm{~cm}$. long, viscid-pubescent; cymes many-flowered; calyx about $5 \mathrm{~mm}$. long, glandular; sepals ovate-lanceolate, acute, more or less scarious-margined; petals $8-9 \mathrm{~mm}$. long. 'Wet places in the mountains: Colo.-nw N.M. Submont.-Subalp. My-Jl.

11. C. elongatum Pursh. Cespitose perennial; stems much branched, decumbent at the base, 2-3 dm. high, short-pubescent with white reflexed hairs below, very glandular above; leaves narrowly linear, rather stiff, with prominent midnerve, $1.5-3 \mathrm{~cm}$. long; sepals 4-5 mm. long, ovate, acute, scarious-margined; petals about $7 \mathrm{~mm}$. long. Hills: Mont.-n Wyo.-Wash. Plain-Submont. $\mathrm{Jl}-\mathrm{Au}$.

12. C. Leibergii Rydb. Perennial, with a slender branched rootstock; stems simple, 4-5 dm. high, sparingly villous and viscid-puberulent; leaves 2.5-3 $\mathrm{cm}$. long, 6-7 mm. wide, 1-nerved, thin, inflorescence viscid-puberulent; sepals about $5 \mathrm{~mm}$. long, lanceolate, viscid-pubescent; petals scarcely twice as long as the sepals. Open forests: Ida.-Mont. Submont. Je.

13. C. graminifolium Rydb. Perennial, with a slender branched rootstock; stems 3-5 dm. high, densely short-villous and somewhat viseid, erect; leaves $2-3 \mathrm{~cm}$. long, 1 -nerved, short viscid-villous, mostly spreading; sepals narrowly lanceolate, viscid-pubescent, only slightly scarious-margined, acute, 5-6 $\mathrm{mm}$. long. Bottom lands: Wash.-Mont.-Wyo.-Ore. Submont. Ap-Je.

14. C. angustatum Greene. Cespitose perennial; stems $2-3 \mathrm{dm}$. high, erect or ascending; primary leaves of the stem linear-lanceolate or linear, 2-4 $\mathrm{cm}$. long, villous; inflorescence many-flowered, somewhat glandular; sepals about $4 \mathrm{~mm}$. long, lanceolate, acute, light green, only slightly viscid. Hillsides: Man.-S.D.-Wyo.-Mont. Plain-Submont. Je-Jl.

15. C. campestre Greene. Cespitose perennial; stems decumbent at the base or ascending, 1-2 dm. high; leaves 1-2 cm. long, linear-lanceolate, ascending, or the lower ones oblanceolate; sepals lanceolate, about $5 \mathrm{~mm}$. long; petals about twice as long. Plains and hills: Man.-S.D.-Colo.-Yukon. Plain-Submont.

16. C. scopulorum Greene. Cespitose perennial; stems 1-2.5 dm. high; leaves $1.5-2 \mathrm{~cm}$. long, more or less glandular-puberulent; cymes several-flowered; calyx 4-5 mm. long, glandular-puberulent, acute; corolla about twice as long. (?) C. effusum Greene. Mountains: Alta.-N.M. Submont.-Mont. My-Jl.

17. C. strictum L. Cespitose perennial; stems decumbent at the base, 1-2 dm. high; leaves 1-2 cm. long, linear-oblong, acute, ascending, glandularpuberulent; cymes 5-15-flowered, rather short; sepals about $5 \mathrm{~mm}$. long, scariousmargined, acute, viscid-puberulent; petals about twice as long. $C$. occidentale Greene. Mountains and dry hills: Mont.-S.D.-Colo.-Utah-Wash.-B.C.; Eurasia. Plain-Subalp. My-Au.

18. C. thermale Rydb. Densely cespitose perennial; stem decumbent, 5-12 cm. long, viscid-puberulent; leaves less than $1 \mathrm{~cm}$. long, lanceolate and 
acute, or the lower oblong, with very thick midrib, viscid-puberulent; sepals $4 \mathrm{~mm}$. long, ovate, scarious-margined; petals $5 \mathrm{~mm}$. long; capsule slightly curved. C. fuegianum A. Nels., not Alboff. Geyser basins: nw Wyo. Mont. Jl-Au.

\section{AMMODÈnIA J. G. Gmel.}

Perennial fleshy herbs, growing in saline soil, with broad opposite leaves and rather small flowers solitary and subsessile in the leaf-axils and the forks. Sepals 5. Petals 5, entire. Stamens 8-10. Disk under the ovary prominent, 8-10lobed, glandular. Styles 3-5. Capsule subglobose, fleshy, 3-5-valved when mature, the valves entire. Seeds numerous, obovate, not strophiolate.

1. A. oblongifolia (T. \& G.) Pydt: Perennial, with a horizontal rootstock; stems glabrous, 1-6 dm. high, fleshy, simple or sparingly branched; leaves oblong or oblanceolate, acute, $2-3 \mathrm{~cm}$. long; flowers axillary; sepals lance-ovate, acute, 4-5 $\mathrm{mm}$. long; petals oblong-spatulate or oblanceolate, acute, about equalling the sepals. Honkneya oblongifolia T. \& G. Arenaria peploides major Hook. Saline soil: Ore.-Wyo.-Alaska; e Asia. Submont. My-Jl.

\section{MOEHRÍNGIA L.}

Low perennials, with slender rootstocks. Leaves opposite, sessile or nearly so, soft. Flowers solitary in the axils or in terminal cymes. Sepals and petals 4 or 5 . Petals entire. Stamens 8 or 10 . Capsule oblong or ellipsoid, at first 3-celled, opening by 3 two-cleft valves. Seeds few, smooth and shining, appendaged at the hilum by a membranous broad strophiole.

Stem terete; leaves oval or elliptic-oblong; sepals obtuse or acutish. 1. M. Lateriflora. Stem angled; leaves lanceolate or oblanceolate; sepals very acute or acuminate.

2. M. macrophylla.

1. M. lateriflora (L.) Fenzl. Stems puberulent, decumbent at least at the base, 1-2 dm. high; leaves obtuse or rounded at the apex, puberulent, ciliolate on the margins and ribs, 1-3 cm. long; cymes corymbiform, 1-6-flowered; sepals ovate, $2.5 \mathrm{~mm}$. long; petals obovate, 4-6 mm. long. Arenaria lateriflora L. Wet places among bushes: Lab.-N.J.-N.M.-Ore.-Alaska; n Eurasia. Submont.-Mont. Je-Au.

2. M. macrophylla (Hook.) Torr. Stems decumbent at the base, finely puberulent; leaves usually acute or acuminate at both ends, $2-7 \mathrm{~cm}$. long; cymes 1-5-flowered; sepals ovate-lanceolate, about $4 \mathrm{~mm}$. long, usually exceeding the petals. A. macrophylla Hook. Wet places among bushes: Lab.-Vt. $-\mathrm{n}$ N.M. -Calif.-B.C. Submont.-Subalp. My-Au.

\section{ALSINÓPSIS Small. SANDWORT.}

Annual or perennial herbs, often tufted. Leaves opposite, without stipules, sometimes fascicled. Flowers in terminal cymes or rarely solitary in the axils. Sepals 5, often thick. Petals 5, white, entire or merely notched. Stamens 10. Ovary 1-celled; styles usually 3. Capsule ovoid, opening with as many entire valves as there are styles. Seeds several or many, not strophiolate. [Alsine Gaertn., not L.]

Annuals.

Plant puberulent above; petals exceeding the sepals.

Plant glabrous; petals scarcely equalling the sepals. Cespitose perennials.

Sepals acute or acuminate.

Leaves pungent, arcuate-spreading; sepals 1-nerved or indistinctly 3 -nerved.

Leaves not pungent; sepals distinctly 3-nerved.

Petals 6-8 mm. long, much exceeding the sepals. 4. A. macrantha.

Petals small, scarcely equalling the sepals.

Plant densely glandular-puberulent.

Plant glabrous or nearly so.

Leaves 3-nerved, acutish, flat.

Leaves linear-subulate, usually over $1 \mathrm{~cm}$. long; plant cespitose, but not densely tufted, 3-10 cm. high. 6. A. verna.

Leaves linear-lanceolate, less than $1 \mathrm{~cm}$. long; plant densely tufted, about $2 \mathrm{~cm}$. high.

7. A. quadrivalvis. 
Leaves usually 1-nerved, obtuse, more or less triangular in cross-secSepals obtuse. tion, fleshy.

8. A. Rossii.

Petals equalling or somewhat exceeding the sepals; plant $1-5 \mathrm{~cm}$. high,

9. A. obtusiloba.

Petals twice as long as the sepals; plant about $1 \mathrm{dm}$. high. 10. A. laricifolia.

1. A. tenella (Nutt.) Heller. Stem branched from the base, $5-20 \mathrm{~cm}$. high; leaves subulate, often arcuate, $5-10 \mathrm{~mm}$. long; pedicels slender; sepals strongly 3-ribbed, lanceolate, about $3 \mathrm{~mm}$. long. Arenaria tenella Nutt. Rocky places: Mont.-Wyo.-Ore.-B.C. Submont. My-Jl.

2. A. dawsonensis (Britton) Rydb. Stem branched from the base, 1-3 dm. high; leaves filiform or linear-subulate, 1-2 cm. long; cyme open, with slender pedicels; bracts lanceolate or subulate, green; sepals oblong-lanceolate, acute, 3-nerved, $4 \mathrm{~mm}$. long; petals oblong. Hillsides: Yukon-Alta.-S.D. Submont.-Subalp. Je-Jl.

3. A. occidentalis Heller. Stems loosely matted, ascending or erect, glandular throughout; leaves 6-10 mm. long; cymes open, many-flowered, with ascending or spreading branches; sepals lanceolate, 4-5 $\mathrm{mm}$. long, long-attenuate; petals shorter than the sepals. Arenaria pungens Nutt., not Clem. $A$. Nuttallii Pax. Dry mountains: Alta.-Wyo.-Utah-Calif.-B.C. Submont. -Mont.

4. A. macrantha Rydb. Stem diffusely branched and spreading, perfectly glabrous; branches $1 \mathrm{dm}$. long or less; leaves subulate-filiform, obtuse, $5-10 \mathrm{~mm}$. long, 1-nerved; sepals lanceolate, 4-5 mm. long, very acute, scarious-margined. Sandy soil in the mountains: Colo. Mont. Jl.

5. A. propinqua (Richards.) Rydb. Stems branched from the base, 3-10 $\mathrm{cm}$. high; leaves linear-subulate, flat, 3-nerved, ascending, 5-10 $\mathrm{mm}$. long; cyme open, branches ascending; sepals lanceolate, $3 \mathrm{~mm}$. long; petals about $4 \mathrm{~mm}$. long. Arenaria propinqua Richards. A. aequicaulis A. Nels. Sandy soil: Hudson Bay-N.M.-Calif.-B.C.-Mack. Submont.-Alp. Jl-Au.

6. A. verna (L.) Cockerell. Stems branched from the base, decumbent below, $1 \mathrm{dm}$. high or less, glabrous; leaves linear-subulate, flat, rather soft; cyme open, 1-3- (rarely 5-) flowered, with slender pedicels; sepals ovate, 3-3.5 mm. long. Arenaria verna L. Sandy and rocky places: Greenl.-Que.-Alta.Alaska; n Eu. Subalp.-Alp. Jl-Au.

7. A. quadrivalvis (R. Br.) Rydb. Stems tufted, $2-5 \mathrm{~cm}$. high; leaves lanceolate, flat, glabrous; flowers usually solitary; sepals lanceolate, scariousmargined, about $3 \mathrm{~mm}$. long. Arenaria quadrivalvis $\mathrm{R}$. Br. Aretic-alpine situations: Aretic coast and Colo. Alp. Jl-Au.

8. A. Rossii (Richards.) Rydb. Stems tufted, 1-5 cm. high, glabrous; leaves linear, 5-8 mm. long, glabrous; flowers usually solitary; sepals $3 \mathrm{~mm}$. long. Arenaria Rossii R. Br. Alpine-aretic situations: Mack.-Colo.-Wash.Alaska. Alp. Je-Au.

9. A. obtusiloba Rydb. Caudex much branched, woody; stems decumbent, very leafy below, glandular-pubescent, 1-5 $\mathrm{cm}$. high; leaves subulate, rigid, with a strong midrib, obtusish, $2-6 \mathrm{~mm}$. long; flowers solitary or rarely 2 or 3 ; sepals elliptic-oblong, 4-5 mm. long, glandular-pubescent, strongly 3-nerved, obtuse; petals spatulate, 6-7 mm. long. Arenaria obtusa Torr., not All. $A$. sajanensis B. L. Robins, not Willd. Exposed mountains: Alta.-N.M.-UtahB.C. Mont.-Alp.

10. A. laricifolia (L.) Heller. Stems woody at the base, decumbent below, very leafy; leaves linear-filiform, somewhat pungent, ciliolate or glabrous; flowers 1-4 on each branch; sepals oblong, obtuse, 3-nerved, puberulent, 5-6 $\mathrm{mm}$. long. Arenaria laricifolia L. Arctic-alpine situations: Mont.-Alaska; also in the Old World. Alp. 'Jl.

\section{ARENÃRIA L. SANDWORT.}

More or less diffusely branched annuals or perennials, sometimes woody at the base. Leaves opposite, without stipules, often also fasciculate ones in their 
axils. Flowers in open or subcapitate cymes, or solitary in the leaf-axils. Sepals 5 , often strongly ribbed. Petals white, entire or notched, in one species 2-cleft, sometimes wanting. Stamens normally 10. Ovary 1-celled; styles 3 , rarely 2, or 4 or 5 . Capsule globose or oblong, opening by 3 two-cleft valves. Seeds numerous, not strophiolate.

Annuals; leaves ovate, 4-7 mm. long.

Perennials.

1. A. serpyllifolia.

Leaves neither narrowly linear nor pungent. Plant low and spreading; stems less than $1 \mathrm{dm}$. long; leaves ovate-oblong, less
than $1 \mathrm{~cm}$. long.

Sepals obtuse or acute; midrib not very prominent; leaves glabrous.

Sepals acuminate; midrib very prominent; leaves puberulent. A. cylindrocarpa.

Plant taller; stems 2-4 dm. long; leaves oblong or linear-obi. A. polycaulos.

long.

Leaves narrowly linear, more or less rigid and pungent.

Sepals ovate or ovate-lanceolate.

Inflorescence contracted and head-like.

Bracts ovate, not scabrous-ciliolate, only scarious-margined.

Bracts narrowly lanceolate, scabrous-ciliolate, 5 . A. congesta. midrib. Inflorescence more open.

Sepals obtuse, or some acutish, or apiculate. Plant glabrous.

Bracts linear-lanceolate, scarcely scarious-margined.

Bracts ovate-lanceolate or ovate, broadly 8 . A. nardifolia. green midrib. Plant more or less glandular.

9. A. lithophila.

Sepals 4-5 $\mathrm{mm}$. long; petals about twice as long as the sepals.

Sepals $2-3 \mathrm{~mm}$. long; petals half longer than 10 . A. formosa.

Sepals distinctly acute or acuminate.

Petals deeply 2-cleft.

Petals not deeply 2-cleft.

11. A. salmonensis.

Plant with a cespitose perennial caudex; all bracts usually broadly lanceolate and broadly scarious-margined.

Capsule scarcely exceeding the sepals; leaves ascending.

Flowers all pedicelled, in open regular cymes; inflorescence more or less glandular.

Leaves distinctly pungent; plant sparingly glandularpuberulent.

Sepals 4-5 $\mathrm{mm}$. long; plant not densely tufted.

Sepals $3 \mathrm{~mm}$. long; plant low, densely. Aintahensis.

14. A. compacta.
. densely glandular-pubescent; inflorescence and calyx densely glandular-pubescent. 15. A. Tweedyi.

Flowers mostly subsessile, in small glomerules at the ends of the branches of the very irregular cymes.

Capsule almost twice as long as the sepals; 16 . A. Burkei.

Plant suffrutescent the

dm.

Sepals narrowly lanceolate, acuminate.

Cymes open, not densely congested.

Plant more or less glandular. Branches of the inflorescence long and ascending-spreading; sepals
equalling or exceeding the petals.
19. A. laxiflora.

Branches of the inflorescence comparatively short and strongly ascend-
ing; sepals usually shorter

Plant perfectly glabrous. shorter than the petals. 20. A. Fendleri.

Cymes densely congested, subcapitate.

21. A. Eastwoodiae.

Caudex of numerous procumbent branches covered

sepals long-acuminate, longer than the petals.
Caudex multicipital; sepals short-acuminate, shorter

with dried leaves: 22. A. Franklinii.

Caudex multicipital; sepals short-acuminate, shorter than the petals.

1. A. serpyllifolia L. Stem branched from near the base, decumbent or ascending, 1-3 dm. high, finely puberulent; leaves $4-7 \mathrm{~mm}$. long, ovate, acute or acuminate, distinetly 3-5-nerved, the lowest short-petioled, the rest sessile; 
sepals acuminate, about $3 \mathrm{~mm}$. long; petals small, scarcely $2 \mathrm{~mm}$. long. Sandy soil: Que.-Fla.-Ore.-B.C.; W. Ind.; nat. from Eu. My-S.

2. A. cylindrocarpa Fernald. Stems ascending or spreading, $2-10 \mathrm{~cm}$. long, minutely puberulent; leaves ovate or oblong, $2-6 \mathrm{~mm}$. long, acute; flowers 1-3; pedicels 4-10 $\mathrm{mm}$. long; sepals ovate, $3-4 \mathrm{~mm}$. long, about equalling the petals. A. ciliata humifusa B. L. Robins., not Hornem. A, norvegica Am. auth., not Gunner. Rich soil: Greenl.-Que.-Alta.-B.C. Subalp.-Alp. Je$\mathrm{Au}$.

3. A. polycaulos Rydb. Stems numerous, prostrate or spreading, about $1 \mathrm{dm}$. long; leaves ovate or ovate-lanceolate, spreading, about $5 \mathrm{~mm}$. long; sepals ovate-lanceolate, 3-4 mm. long; petals $5-6 \mathrm{~mm}$. long, obovate, entire. A. saxosa Coult, not A. Gray. Dry hills: N.M.-Colo--Ariz. Mont. Je-Jl.

4. A. confusa Rydb. Stems diffuse, slender, branched, $4-6 \mathrm{dm}$. long, finely puberulent; leaves with a strong midrib, puberulent, 1-2 $\mathrm{cm}$. long; sepals linearlanceolate, acuminate, about $3 \mathrm{~mm}$. long; petals about three-fourths as long. Sandy soil, especially in cañons: Colo.-N.M.-Ariz. Submont.-Subalp. Je-S.

5. A. congesta Nutt. Stems somewhat woody at the base, glabrous, 1-3 $\mathrm{dm}$. high; leaves filiform-subulate, 1-6 $\mathrm{cm}$. long, strongly ascending or almost erect; sepals carinate, obscurely 3-nerved, more or less searious, $4 \mathrm{~mm}$. long; petals oblong, fully twice as long. Dry plains: Mont.-Colo.-Calif.-Wash. Plain-Mont. Je-Au.

6. A. cephaloidea Rydb. Stems strict, $2-4 \mathrm{dm}$. high, glabrous; leaves erect, filiform-subulate, $3-10 \mathrm{~cm}$. long; flowers in dense heads; bracts often 1 $\mathrm{cm}$. long; sepals similar, but broader, 4-5 mm. long; petals oblong, about half longer than the sepals. Hills: Wash.-Ida. Submont. Je-S.

8. A. nardifolia Ledeb. Stems decumbent at the base, otherwise erect, 1-3 dm. high; leaves filiform, $2-8 \mathrm{~cm}$. long, those of the stem nearly erect; sepals oval, obtuse, 4-5 mm. long, with scarious, often purple-tinged margins; petals about twice as long. A. capillaris Am. auth. Grassy slopes: Alta.-B.C.Arctic Sea; Siberia. Submont.-Subalp. Jl.

9. A. lithophila Rydb. Stems erect, strict, 1-3 dm. high, glabrous; leaves filiform, mostly erect, $2-5 \mathrm{~cm}$. long; sepals oval, $3-4 \mathrm{~mm}$. long, obtuse, scariousmargined, sometimes tinged with brown or purple; petals $4-6 \mathrm{~mm}$. long. $A$. subcongesta Rydb., in part, and var. lithophila. Hillsides and rocky ridges: Sask. -Wyo.-Ida. Submont.-Subalp. My-Jl.

10. A. formosa Fischer. Stems somewhat woody at the base, erect, or decumbent at the base, 1-2 dm. high; leaves filiform, mostly erect, $2-7 \mathrm{~cm}$. long; bracts lanceolate, more or less scarious-margined; sepals oval, obtuse, with scarious or more or less colored margins; petals $6-9 \mathrm{~mm}$. long. A. capillaris Am. auth. Mountains and hills: Alta.-Utah-Calif.-B.C. Submont.Mont. Je-Au.

11. A. salmonensis Henderson. Stems more or less woody at the base, 6-10 cm. high; leaves filiform, 1-3 $\mathrm{cm}$. long, glabrous or scabrous-ciliolate; bracts scarious, ovate; sepals $2-3 \mathrm{~mm}$. long, ovate, obtuse, scarious-margined. Dry plains and ridges: Mont.-Ida.-Ore.-Wash. Submont.-Subalp. J1$\mathrm{Au}$.

12. A. Kingii (S. Wats.) M. E. Jones. Stems somewhat woody and glabrous below, glandular above; leaves subulate, ascending-spreading, 1-3 cm. long, often scabrous-ciliolate; bracts ovate, scarious; sepals lanceolate, acute, about $4 \mathrm{~mm}$. long, glandular-puberulent, searious-margined; petals about $5 \mathrm{~mm}$. long. Mountains: Nev.-Utah. Mont. Je-Jl.

13. A. uintahensis A. Nels. Stems decumbent at the base, 1-2 dm. high, glabrous below, glandular-puberulent above; leaves filiform, somewhat acerose, 1-3 cm. long; sepals ovate-lanceolate, acute, scarious-margined; petals oblong, about $5 \mathrm{~mm}$. long. Dry hills: Wyo.-Calif.-Ore. Submont. Je-J.

14. A. compacta Coville. Densely tufted perennial, with woody caudex; floral stems $2-10 \mathrm{~cm}$. long, few-leaved; leaves mostly basal, densely clustered, 
subulate, 3-6 mm. long; inflorescence open, few-flowered; bracts lance-subulate; sepals lanceolate, $3 \mathrm{~mm}$. long, scarious-margined, glandular on the thick midrib; petals 3-4 mm. long. Dry mountains: Utah-Calif. Submont. Jl-S.

15. A. Tweedyi Rydb. Stem with somewhat ligneous base, usually less than $1 \mathrm{dm}$. high, glandular-puberulent especially in the inflorescence; leaves linear-filiform, $2-3 \mathrm{~cm}$. long, less than $1 \mathrm{~mm}$. wide; pedicels about $1 \mathrm{~cm}$. long; sepals lanceolate, acute, about $5 \mathrm{~mm}$. long, scarious-margined and decidedly glandular-puberulent; petals about $8 \mathrm{~mm}$. long. Mountains: Colo. Subalp.
Jl.

16. A. Burkei Howell. Stems woody at the base, 1-2 dm. high; leaves filiform, ascending, somewhat acerose, 1-3 cm. long, glabrous; sepals ovate, acute or acuminate, scarious-margined, $4 \mathrm{~mm}$. long; petals about $5 \mathrm{~mm}$. long. $A$, congesta subcongesta $\mathrm{S}$. Wats. A. subcongesta Rydb. Mountains: Wash.-Calif, -Colo--Mont. Mont.-Submont. My-Jl.

17. A. aculeata S. Wats. Stems woody and decumbent at the base, 1-2 $\mathrm{dm}$. high, leafy at the base; leaves subulate-filiform, pungent, glabrous and glaucous; sepals ovate, acute, $4 \mathrm{~mm}$. long; petals $5-6 \mathrm{~mm}$. long. Arid mountains: Ore.-Ida.-Ariz.-Nev. Son.-Submont. Jl-Au.

18. A. glabrescens (S. Wats) Howell. More or less shrubby perennial; herbaceous branches 2-3 dm. long, glabrous; leaves glabrous, filiform, erect or ascending, 2-4 cm. long; sepals ovate-lanceolate or ovate, acute; petals $6-7 \mathrm{~mm}$. long; capsule nearly twice as long as the calyx. A. Fendleri glabrescens S. Wats. A. congesta macradenia M. E. Jones, not A. macradenia S. Wats. Arid regions in the mountains: Utah-Nev.-Ariz. Mont. Je-Au.

19. A. laxiflora Rydb. Cespitose, tufted perennial; stems numerous, 2-4 $\mathrm{dm}$. high, glabrous below, glandular-pubescent above, usually thickened at the nodes; leaves filiform, slender, $5-10 \mathrm{~cm}$. long; pedicels long; lower bracts linearsubulate, the upper lanceolate; sepals 5-7 mm. long. A. Fendleri diffusa Porter. Mountains: Colo. Submont.-Mont. Je-Au.

20. A. Fendleri A. Gray. Stems 1-3 dm. high, strict, glabrous beneath, glandular above; leaves filiform, glabrous, more or less glaucous, rather firm, $3-8 \mathrm{~cm}$. long; pedicels rather short; sepals $4-5 \mathrm{~mm}$. long. Mountains and dry hills: Wyo.-N.M.-Ariz. Submont.-Alp. Je-Au.

21. A. Eastwoodiae Rydb. Stems about $2 \mathrm{dm}$. high; leaves filiform, stiff, pungent, $1-2 \mathrm{~cm}$. long, $0.5 \mathrm{~mm}$. wide, minutely scabrous-ciliolate on the margins below; pedicels erect, 1-2 cm. long, glabrous; sepals about $6 \mathrm{~mm}$. long, glabrous, equalling or slightly exceeding the petals. Dry hills: N.M.-Colo.-Utah.

22. A. Franklinii Dougl. Stems about $1 \mathrm{dm}$. high, angular in drying; leaves subulate, acerose, $1-2 \mathrm{~cm}$. long, arcuate-spreading; bracts lance-subulate, searious-margined at the base; sepals linear-lanceolate, $8-12 \mathrm{~mm}$. long. Sandy soil: Wash.-Ida.-Ore. Plain-Submont. My-Je.

23. A. Hookeri Nutt. Caudex woody, tufted; stems 4-15 cm. high, terete, more or less pubescent; leaves subulate, ascending or spreading, $0.5-5 \mathrm{~cm}$. long, pungent; bracts lanceolate, scarious-margined; sepals lanceolate, 6-9 mm. long; petals oblong. A. pinetorum A. Nels. Dry hills: Mont.-Neb.-Colo. Plain

\section{SAgìna L. Pearlwort.}

Low matted annuals or perennials. Leaves opposite, filiform or subulate. Flowers axillary, on more or less elongated pedicels. Sepals 4 or 5 , persistent. Petals 4 or 5 , white, entire or notched, or wanting. Stamens usually 5 , alternate with the sepals. Capsule 4 - or 5 -valved, the valves opposite the sepals. Seeds usually numerous, not strophiolate.

Stem short, forming sterile rosettes at the base; perennials.

Basal leaves filiform; petals shorter than the green sepals.

Basal leaves subulate; petals longer than the purple-tinged sepals. 2. 2. S. nivalis.
Stem slender, 5-10 cm. high, without sterile rosettes

3. S. occidentalis. 
1. S. saginoides (L.) Britton. Stem $2-10 \mathrm{~cm}$. high, decumbent, often rooting; leaves filiform, 5-15 mm. long; pedicels $5-20 \mathrm{~mm}$. long, often curved at the summit; sepals oval, obtuse, $1.5-2 \mathrm{~mm}$. long. S. Linnaei Presl. Wet places among rocks: Greenl.-Que.-N.M.-Calif.-Alaska; Eurasia. Mont.—Subalp. Je-Au.

2. S. nivalis Fries. Stems $1-3 \mathrm{~cm}$. high; leaves subulate, $3-8 \mathrm{~mm}$. (rarely $1 \mathrm{~cm}$.) long; pedicels $3-10 \mathrm{~mm}$. long, straight or nearly so; sepals broadly oval, rounded, purple-edged, $2 \mathrm{~mm}$. long. Wet places on the summits: Greenl.Lab.-Alaska; Colo.; n Eur. Alp. Jl.

3. S. occidentalis S. Wats. Stem 5-10 $\mathrm{cm}$. high, branched near the base, decumbent or ascending; leaves narrowly linear, acute; pedicels $15-25 \mathrm{~mm}$. long; calyx rounded at the base; sepals 5 ; capsule $3 \mathrm{~mm}$. long. Low ground: B.C.Ida.-Calif. Submont.

\section{Spérgula L. Spurry, Corn Spurry.}

Somewhat succulent annuals. Leaves whorled and commonly clustered, thick, narrow, with stipules. Flowers in terminal cymes. Sepals 5, persistent. Petals 5, white, entire. Stamens 10, rarely 5. Ovary 1-celled; styles 5. Capsule 5 -valved, the valves opposite the sepals. Seeds narrowly winged.

1. S. arvensis L. Annual; stems slender, branched from the base, 1.5-5 $\mathrm{dm}$. high; leaves linear-filiform, sparingly villous or glabrate, $3-5 \mathrm{~cm}$. long; cymes terminal, loose, many-flowered; pedicels reflexed in fruit; sepals ovate, $3-4 \mathrm{~mm}$. long; petals equalling or slightly exceeding the sepals. Cultivated grounds and waste places: N.S.-Fla.-Calif.-Alaska; adv. or nat. from Eu. Je-S.

\section{TÍssa Adans. SANd Spurry.}

Low annual, biennial, or perennial herbs, usually rather succulent. Leaves opposite, with stipules, often with secondary leaves fascicled in their axils. Flowers in terminal, racemiform cymes. Sepals 5, persistent. Petals 5, rarely fewer, or wanting, pink or whitish, entire. Stamens 2-10. Ovary 1-celled; styles 3. Capsule 3-valved to the base. Seeds often margined, smooth or tubercled. [Spergularia J. \& C. Presl.]

Stipules lanceolate or ovate-lanceolate, longer than broad.

Stipules broadly triangular, as broad as long or broader.

1. T. rubra.

Stipules triangular, about as long as broad; internodes of the stem much shorter than the leaves; seeds rough.

2. T. salina.

Stipules very broadly triangular, almost twice as broad as long; middle internodes about equalling the nodes; seeds smooth. ? z

1. T. rubra (L.) Britton. Annual or perennial; stem spreading, much branched from the base, glabrous or more or less glandular above; leaves flat or slightly grooved, linear-filiform, 8-12 $\mathrm{mm}$. long; stipules attenuate, 4-6 $\mathrm{mm}$. long; sepals oblong-lanceolate, scarious-margined, $3-4 \mathrm{~mm}$. long; petals scarcely equalling the calyx. Spergularia rubra J. \& C. Presl. Sandy soil and waste places: Newf.-Va.-O.; Calif.-Mont.-B.C.; Eu. Plain. My-Au.

2. T. salina (Presl.) Greene. Annual; stem usually diffuse, branched, more or less pubescent, 1-2 dm. high; leaves linear-filiform, fleshy, terete, 1-4 cm. long; sepals ovate, acutish or obtuse, 4-5 mm. long; petals pink, shorter than the sepals. S. salina J. \& C. PresI. T. marina Britton. Saline soil: N.B.-Fla.Sask.; Alaska-Calif. Ap-S.

3. T. sparsiflora Greene. Annual; stems somewhat branched, ascending or diffuse, glandular-pubescent; leaves linear-filiform, acute, 1-2.5 $\mathrm{cm}$. long; sepals ovate, obtusish, about $4 \mathrm{~mm}$. long, glandular-pubescent; petals lilac. Saline soil: Mont.-Colo.-Nev.-B.C. Plain. My-S.

\section{LOEFLINAGIA L.}

Small diffusely branched, glandular or glabrous annuals. Leaves subulate, with stipules. Flowers solitary or fascicled in the axils. Sepals 5, rigid, keeled, awn-pointed. Petals $2-5$, minute, without claws, or wanting. Stamens 3-5, 
perigynous. Ovary 1-celled, many-ovuled; stigmas sessile. Capsule 3-valved. Cotyledons accumbent.

1. L. texana Hook. Annual, branched at the base, 5-15 cm. high; leaves 4-6 $\mathrm{mm}$. long; flowers on secund recurved branches; sepals straight or slightly curved; capsule shorter than the calyx; seeds obovate. Dry hills: Tex.-Neb. Plain. Ap-Je.

\section{Family 45. CARYOPHyllaceae. Pink Family.}

Herbs with narrow opposite leaves, without stipules, often connate at the base. Flowers perfect, polygamous, or dioecious, cymose. Calyx of 5 or 4 united sepals. Petals 5 or 4 , distinct, with a narrow claw, often with scale-like appendages (the crown) at the junction of the claw with the blade. Stamens usually twice as many as the sepals. Gynoecium of $2-5$ united carpels; styles $2-5$. Fruit a 1-celled or partially 2-5-celled capsule, opening by $2-5$ valves at the apex.

Calyx with at least twice as many ribs (usually 10) as calyx-teeth, running both into the teeth and the sinuses.

Styles 5, alternate with the foliaceous calyx-lobes.

Styles either 5 and opposite the short calyx-lobes or fewer than 5. Styles mostly 3 ; capsule usually septate at the base. Styles 5; capsule 1-celled to the base.

Calyx 5-angled or 5-ribbed.

Petals with a crown; calyx not strongly angled.

Petals without a crown; calyx strongly 5-angled.

1. Agrostemma.

2. SILENE.

3. WAHLBERGELLA.

\section{1. agrostémma L. Corn Cockle, Corn Campion.}

Annual pubescent herbs, with opposite leaves. Flowers solitary at the end of the branches. Calyx oblong, not inflated, 10-ribbed, 5-lobed; lobes linear, elongate and foliaceous. Petals 5, clawed, without appendages or crown; blade obovate or cuneate, emarginate. Stamens 10. Styles 5, opposite the petals. Capsule 1-celled. Seeds numerous.

1. Agrostemma Githago L. Stem erect, $3-10 \mathrm{dm}$. high, densely pubescent; leaves linear-lanceolate, ereet, $5-10 \mathrm{~cm}$. long; calyx-lobes $2-3 \mathrm{~cm}$. long; petals red; blade $1.5-2 \mathrm{~cm}$. long. Waste places and grain fields: Newf.-Fla.-Calif. -B.C.; nat. from Eu. Jl-S.

\section{Silkìne L. Catchfly, Campion.}

Annual or perennial herbs. Leaves opposite, flat, entire. Flowers perfect, in terminal cymes, or rarely solitary. Calyx with a more or less inflated tube, 10-many-nerved, with short, erect, or spreading lobes. Petals 5, red, pink, or white, with a crown, and usually cleft or divided. Stamens 10 . Ovary 1-celled, but usually with partial partitions at the base. Styles 3, seldom more. Capsule opening by twice as many tooth-like valves as there are styles. Ovary with a more or less developed stipe. Seeds tuberculate or echinate.

Annuals.

Glabrous or nearly so, or the upper nodes glutinous.

Viscid-pubescent or hirsute throughout.

1. S. antirrhina. Perennials.

Calyx mostly 10-nerved, rarely strongly inflated in fruit, not constricted at the mouth.

Caulescent herbs, rather tall, not densely matted, with rootstocks.

Inflorescence paniculate or thyrsoid at the end of the stem, not leafy; flowers more than $1 \mathrm{~cm}$. long.

Blade of the petals 2-parted and cleft into 4-6 linear segments.

Blades of the petals bifid; each lobe sometimes with a 3 . oregana. Blade small, scarcely exceeding the small appendages; plant viscidtomentose. 4. S. Spaldingii.

Blades conspicuous, much longer than the appendages; plant viscidpuberulent or glabrous.

Stipe of the capsule over $5 \mathrm{~mm}$. long; fruiting calyx distinctly contracted below.

5. S. repens.

Stipe of the capsule short, less than $5 \mathrm{~mm}$. long; calyx slightly if at all contracted below. 
Flants comparatively few-flowered; inflorescence not verticillately racemose or spicate; branches mostly ascending and bracts shorter than the calyx.

Stem nearly glabrous; flowers solitary or 3-5 in an open cyme: leaves grass-like.

6. S. monantha.

Stem puberulent throughout or viscid above; leaves not grasslike.

Calyx short, its lobes rounded, with dilated scarious margins.

7. S. columbiana.

Calyx long, its lobes ovate; margins searcely dilated.

Calyx inflated in fruit, purple-veined; stem viscid above.

Plant very viscid; leaves thick, the basal ones narrowly linear-oblanceolate; calyx less inflated. Plant usually viscid only above; leaves thin, the basal ones oblanceolate or spatulate; calyx much inflated and rounded below.

9. S. multicaulis.

Calyx scarcely inflated in fruit, narrowed downward;

veins green; plant not viscid. 10 . S. Douglasii.
Plants many-flowered, more or less verticillately racemose or spicate, with erect branches; lower bracts longer than
the calyx.

Claw and auricles of the petals narrow; the latter laciniate. Claw and auricles of the petals broad: 11. S. Scouleri.

Inflorescence leafy; flowers borne in the axils of the branches, 12 . Hallii.

ciliate. long.

Plant subacaulescent, densely cespitose-pulvinate.

Calyx 15-20 es, less than I cm. 13. S. Menziesii. 14. S. acaulis. mouth.
15. S. vulgaris.

1. S. antirrhina L. Stem $1.5-5 \mathrm{dm}$. (rarely $6-10 \mathrm{dm}$.) high, finely puberulent below; branches strongly ascending or nearly erect, usually more or less viscid about the middle of the internodes; lower leaves oblanceolate, $5-10 \mathrm{~cm}$. long, the upper linear to lanceolate; calyx in flower fusiform, 8-10 mm. long; lobes lanceolate or ovate-lanceolate, usually acute, often purple-tipped; petals purple or rose-tipped, exceeding the sepals and with a 2-cleft blade, or shorter and with a truncate blade, or wanting; fruit broadly ellipsoid, $6-8 \mathrm{~mm}$. long, about $4 \mathrm{~mm}$. thick. Sleepy Catchrly. Waste places, fields, etc.: Newf.Fla.-Calif.-B.C. Plain-Submont. Ap-Au.

2. S. noctiflora L. Stem stout, viscid-pubescent, 3-10 dm. high; lower leaves obovate or oblanceolate, 5-12 cm. long, obtuse, viscid-hirsute, shortpetioled; upper leaves lanceolate, acuminate, sessile; calyx 2-3 cm. long, at first nearly tubular; petals white or pinkish, about $3 \mathrm{~cm}$. long, somewhat exceeding the calyx, 2-cleft; eapsule sessile, ellipsoid. Night-Blooming Catchfly. Waste places and cultivated ground: N.S.-Fla.-Utah-Wash.; nat. from Eu. Plain-Submont. My-Au.

3. S. oregana S. Wats. Stem $3-5 \mathrm{dm}$. high, more or less viscid-puberulent; lower leaves oblanceolate, $5-10 \mathrm{~cm}$. long, viscid-puberulent, the upper linearlanceolate; calyx oblong-cylindric, about $15 \mathrm{~mm}$. long; petals white, fully $2 \mathrm{~cm}$. long; claws auricled above; capsule stipitate, ovoid. Mountain valleys: Mont. -Wyo.-Ore.-Wash. Submont.-Subalp. J-S.

4. S. Spaldingii S. Wats. Stems stout, leafy, viscid-villous, $3-5 \mathrm{dm}$. high; lower leaves oblanceolate, the upper lanceolate, densely viscid-pubescent; calyx oblong-cylindric, $15-20 \mathrm{~mm}$. long; petals not exceeding the calyx, greenish white; claw broad, auricled; capsule stipitate, ovate-oblong. Mountains: Wash.Mont.-Ida.-Ore. Submont. Au-S.

5. S. repens Patrin. Stems several, finely puberulent, decumbent below; leaves linear-lanceolate or nearly linear, densely and finely pubescent; calyx cylindric or somewhat elavate, villous, usually more or less purplish, 10-12 mm. long; petals rose-colored, $15-18 \mathrm{~mm}$. Iong; blade bifid. S. purpurata Greene. Valleys: Mont.-Yukon-Alaska; Siberia. Submont,-Mont, J1-Au.

6. S. monantha S. Wats. Stem weak, $2-3 \mathrm{dm}$. high; leaves linear or narrowly oblanceolate, $4-7 \mathrm{~cm}$. long, acuminate; calyx inflated, thin, about 12 $\mathrm{mm}$. long; teeth triangular, acutish, scarious-margined; petals about $18 \mathrm{~mm}$. 
long, white or pinkish; claw naked, narrowly auricled; blade bifid, with rounded lobes. Mountains: Calif.-Utah-Wash. Submont.

7. S. columbiana Howell. Stems $2-3 \mathrm{dm}$. high, puberulent, not viscid; leaves narrowly oblanceolate or linear, puberulent, 4-6 $\mathrm{cm}$. long; calyx campanulate, inflated, 8-12 $\mathrm{mm}$. long, puberulent; petals white, $15-18 \mathrm{~mm}$. long; claws with broad auricles; blades deeply 2-cleft, with rounded lobes; capsule shortstipitate. S. Douglasii brachycalyx B. L. Robins. Hillsides: Wash.-Ida.Utah. Submont.-Mont. Je-Au.

8. S. Lyallii S. Wats. Stem 1-3 dm. high, minutely puberulent below, glandular above; leaves linear-lanceolate or oblanceolate, 5-7 cm. long, puberulent; calyx 8-10 $\mathrm{mm}$. long, usually purple-tinged; lobes short-ovate, obtuse; petals $12-15 \mathrm{~mm}$. long, white or brownish purple; claws broadly auricled; blades bifid, with a linear tooth on each side; appendages oblong or quadrate. $S$. Macounii S. Wats. S. tetonensis E. Nels. Mountains: Alta.-Wyo.-UtahOre.-B.C. Submont.-Alp. Jl-Au.

9. S. multicaulis Nutt. Stems 2-4 dm. high, puberulent; lower leaves oblanceolate or spatulate, 3-7 cm. long, thin; upper leaves linear; calyx about $15 \mathrm{~mm}$. long; lobes ovate, obtuse or acute; petals $2-2.5 \mathrm{~cm}$. long, white, 2-cleft; claw broad and auricled. Mountains: Alta.-Wyo.-Ore.-B.C. PlainMont. Jl-Au.

10. S. Douglasii Hook. Stems 3-5 dm. high, puberulent; leaves narrowlyoblanceolate to linear, more or less puberulent, $5-10 \mathrm{~cm}$. long; cyme few-flowered; calyx 15-18 mm. long, puberulent; lobes ovate, obtuse; petals $2-2.5 \mathrm{~cm}$. long, pink or white; capsule stipitate, ovoid. Mountains: Mont-Utah-Calif. -B.C. Submont.-Subalp. My-Au.

11. S. Scouleri Hook. Stems simple, 3-7 dm. high, puberulent and glandular above; lower leaves narrowly oblanceolate, $5-10 \mathrm{~cm}$. long, densely puberulent, the upper ones linear or linear-lanceolate; inflorescence 1.5-2 dm. long; calyx oblong-clavate, strongly veined; petals $15-20 \mathrm{~mm}$. long, white or purplish; blades bifid; appendages blunt; capsule stipitate. Mountains: Mont.-Colo.Ore.-B.C. Submont.-Mont. Jl-S.

12. S. Hallii S. Wats. Stems $2-4 \mathrm{dm}$. high, puberulent and more or less glandular; lower leaves narrowly oblanceolate, $5-10 \mathrm{~cm}$. long, finely pubescent; upper leaves linear; calyx oblong or campanulate, strongly striate, about $15 \mathrm{~mm}$. long; lobes triangular, acute, with scarious margins; petals purple, slightly exceeding the calyx; capsule short-stipitate. Mountains: Colo.-N.M. Submont. $\rightarrow$ Subalp. Jl-Au.

13. S. Menziezii Hook. Stems erect or ascending, 1-3 dm. high, dichotomously branched, very leafy, retrorsely hirsutulous and more or less glandularvillous, especially above; leaves ovate-lanceolate to linear-lanceolate, acuminate at both ends, 3-8 $\mathrm{cm}$. long; calyx turbinate-obovoid, 5-8 $\mathrm{mm}$. long; petals 2cleft, white, $6-10 \mathrm{~mm}$. long, without a crown (always?); capsule sessile, ellipsoid, slightly exceeding the calyx. S. stellarioides Nutt., a narrow-leaved form. Among bushes: Sask.-Mo.-N.M.-Calif.-Mont. Submont.-Subalp. My-S.

14. S. acaulis L. Leaves linear, more or less glandular-ciliolate, 5-10 $\mathrm{mm}$. long (in var. subacaulescens 1-4 cm. long); flowers polygamo-dioecious, the pistillate ones usually somewhat smaller, in the typical form on peduncles 1-4 $\mathrm{cm}$. long or (in var. excapa) sessile or nearly so; calyx oblong, $5-6 \mathrm{~mm}$. long, rounded or sunken or rarely acute at the base; petals pink or purple, exceeding the calyx, emarginate or 2-lobed, rarely entire; capsule cylindric, exceeding the calyx, sessile, or (in the var. excapa) ovoid or subglobose. Moss CAMpION. Alpine-aretic situations: Greenl.-N.H.-N.M.-Ariz.-Alaska; Eurasia. Mont.-Alp. Je-Au.

15. S. vulgaris (Moench) Garcke. Cespitose caulescent perennial; stems glabrous or nearly so, $2-4 \mathrm{dm}$. high; leaves lanceolate, acute, $3-5 \mathrm{~cm}$. long, glabrous; flowers polygamo-dioecious; calyx campanulate to subglobose; petals white or pink, 2-cleft, almost without crown. S. inflata Smith. BLADDER CAMPION. Fields, roadsides, and waste places: N.B.-N.J.-Colo.-Alta.; Calif.-Wash.; adv. or nat. from Eu. Plain-Submont. My-S. 


\section{WAHLBERGÉLLA Fries.}

Perennial herbs, with opposite leaves. Calyx ovoid, more or less inflated, 5-toothed, 10-nerved. Petals inconspicuous, often included, with small crowns and 2-cleft blades. Stamens 10. Styles 5, rarely 4, alternating with the petals. Ovary strictly 1-celled. Capsule opening by twice as many valves as there are styles. Seeds laterally attached; embryo curved. [Lychnis Am. auth. in part.]

Tall, usually $3 \mathrm{dm}$. high or more, several to many-flowered, in narrow cymes.
Petals included.
Ovary sessile; blades of the petals emarginate.
Ovary stipitate; blades of the petals 2-cleft.
1. W. Drummondii.
2. W. striata.
3. W. Parryi.

Low, about $1 \mathrm{dm}$. high; flowers solitary, or 2 or 3 ; seeds winged.

Flowers in anthesis erect; fruiting calyx not much inflated.

Petals usually exserted; claw broad; blade short and broad, emarginate.

Claws of the petals and the filaments naked; plant glandular-villous.

Claws of the petals and the filaments ciliate; plant puberulent.

Petals usually included; claws and blades narrow; the latter bifld; fllaments glabrous.

Flowers in anthesis nodding; fruiting calyx much inflated.

Petals slightly exserted; calyx-lobes broadly lanceolate; five of the stamens adnate to the petals for one-third their length.

Petals included; calyx-lobes short, rounded-ovate; five of the stamens only slightly adnate to the petals at the base.

8. W. apetala.

1. W. Drummondii (Hook.) Rydb. Stems viscid-puberulent throughout, 2-4 dm. high; basal leaves oblanceolate, petioled, 5-10 $\mathrm{cm}$. long, grayish puberulent, early deciduous; stem-leaves linear, attenuate; calyx oblong-cylindric, with green nerves, glandular-viscid, $10-12 \mathrm{~mm}$. long; petals white or purplish; blade narrower than the claw. Silene Drummondii Hook. L. Drummondii S. Wats, Dry hillsides and plains: Man.-N.M.-Ariz.-B.C. Plain-Mont. $\mathrm{Je}-\mathrm{Au}$.

2. W. striata Rydb. Stems 3-5 dm. high, finely puberulent and more or less viscid above; basal leaves and lower stem-leaves narrowly oblanceolate, 5-15 cm. long; upper stem-leaves sessile and linear-lanceolate; calyx densely viscid-puberulent, strongly 10-nerved, 10-12 mm. long; lobes oblong, obtuse; petals about $15 \mathrm{~mm}$. long; claw long, narrowly cuneate. $L$. striata Rydb. Hillsides: Wyo.-Colo.-Utah.-Alta. Mont. Jl-Au.

3. W. Parryi (S. Wats.) Rydb. Stem slender, about $3 \mathrm{dm}$. high, finely pubescent, glandular above; leaves linear, 3-6 cm. long; calyx inflated, ovateoblong, about $12 \mathrm{~mm}$. long; teeth broad, acute; petals purplish, about $16 \mathrm{~mm}$. long; claw broadly auricled. L. Parryi S. Wats. Hills: Wyo. Submont.

4. W. affinis (Vahl.) Fries. Stem 1-3 dm. high, glandular-villous throughout; leaves linear or narrowly linear-oblanceolate, $1-3 \mathrm{~cm}$. long, glandular-villous; calyx ellipsoid, usually contracted at the mouth, in flower 8-10 mm. long; teeth short, acutish; petals white or pink; claws auricled. L. affinis Vahl. High mountains: Greenl.-Lab.-Alta.; Eurasia. Alp.-Subalp. Jl-Au.

5. W. Kingii (S. Wats.) Rydb. Stems erect, 1-2 dm. high, densely puberulent and glandular above; leaves narrowly linear-oblanceolate; calyx about 12 $\mathrm{mm}$. long; lobes ovate, rounded at the apex; petals exserted; appendages oblong. L. Kingii S. Wats. Mountains: Utah. Subalp. Jl.

6. W. montana (S. Wats.) Rydb. Stem nearly glabrous below, glandular above, slender, $0.5-1 \mathrm{dm}$. high; leaves linear-oblanceolate, $3-5 \mathrm{~cm}$. long, ciliate on the petioles; calyx ovate-campanulate, $10-12 \mathrm{~mm}$. long; teeth short, acute. L. montana S. Wats. Mountain peaks: Colo.-Wyo. Subalp.-Alp.

7. W. attenuata (Farr.) Rydb. Stem 1-1.5 dm. high, slender, sparingly villous; leaves linear, $2-7 \mathrm{~cm}$. long, light green, sparingly pubescent; flowers $1-2$, nodding in anthesis; calyx ellipsoid, somewhat inflated, narrowed at the mouth, densely villous; petals purple; blades cuneate, bifid. High mountains: Alta.B.C. Subalp. J-Au.

8. W. apetala (L.) Fries. Stems $0.5-2 \mathrm{dm}$. high, puberulent and more or less glandular-viscid; flowers at first drooping, erect in fruit, perfect or pistillate; 
calyx ellipsoid, much inflated, $12-15 \mathrm{~mm}$. long, glandular-pubescent; lobes very broad, rounded-ovate; petals included; blades very short, bifid; claws auricled. High mountains: Greenl.-Lab.-Mont.-Colo.-Utah-Alaska; Eurasia. Alp. -Subalp. Jl-Au.

\section{SAPONÃria L. Soapwort, Bouncing Bet.}

Perennial herbs, with opposite broad leaves. Calyx 5-toothed, obscurely 5-nerved. Petals 5, long-clawed, with appendages (crown). Stamens 10. Ovary 1-celled or incompletely 2-4-celled; styles 2. Capsule dehiscent by 4 apical teeth or valves.

1. S. officinalis L. Glabrous perennial; stem $3-6 \mathrm{dm}$. high; leaves oval or ovate, $5-8 \mathrm{~cm}$. long, 3-5-ribbed; flowers in dense corymbiform cymes; calyx tubular, 1.5-2 cm. long; petals pink or white; blades obcordate; capsule oblong. Roadsides and waste places: N.S.-Fla.-N.M.-Colo.; nat. from Eu. Plain -Submont. Jl-S.

\section{VACCÃria Medic. Cow-herb, Cow Cockle.}

Annual caulescent herbs, with glabrous and glaucous, opposite, often thickish, clasping leaves. Flowers in dichotomous cymes. Calyx somewhat inflated, strongly 5-angled and 5-nerved; lobes very short. Petals conspicuous, longer than the calyx, without a crown. Stamens 10. Ovary 1-celled; styles 2. Capsule opening by 4 apical, tooth-like valves. Seeds laterally attached; embryo slightly curved.

1. V. Vaccaria (L.) Britton. Annual; stem 3-10 dm. high, branched; leaves ovate to lanceolate, connate at the base, $2-8 \mathrm{~cm}$. long; calyx with the sharp angles herbaceous, and the intervening parts scarious and white, $1-1.5 \mathrm{~cm}$. long; petals rose-colored, erenulate. Saponaria Vaccaria L. In waste places: Ont.Fla.-Calif.-Alaska.; nat. from Eu. Plain-Submont. Je-Au.

\section{Family 46. CERATOPHYLlaCeAe. Hornwort Family.}

Submerged aquatic herbs, with verticillate leaves, thrice dissected dichotomously into filiform stiff divisions. Flowers monoecious, inconspicuous, sessile, axillary. Sepals 6-12, herbaceous, valvate. Petals wanting. Stamens 10-24, with very short filaments. Pistil 1; ovary 1-celled. Fruit nut-like, with a persistent style. Seeds pendulous; embryo straight.

\section{CERATOPHÝlLUM L. HoRnWort.}

Characters of the family.

1. C. demersum L. Stems 3-12 dm. long; leaves rather rigid, 6-9 in each whorl, 1-3 $\mathrm{cm}$. long, once, twice, or thrice forking, the ultimate segments spinytoothed; achenes oblong, slightly flattened, $5 \mathrm{~mm}$. long, tipped with the persistent style and armed with spreading spines at the base. Ponds and still water: Newf.-Fla.-Calif.-Wash.; W.Ind., Mex., Eurasia. Plain. Je-Jl.

\section{Family 47. NYMPhaEACEAE. Water Lily Family.}

Perennial acaulescent water plants, with stout elongate rootstocks. Leaves with elongate petioles and broad leathery floating blades cordate or sagittate at the base. Flowers solitary, long-pedicelled, perfect. Sepals 4-7, green or partly colored. Petals numerous, often passing into staminodia and stamens. Stamens numerous. Gynoecium of several more or less united carpels, forming a compound pistil; stigmas united into a disk. Ovules numerous, parietal. Fruit a leathery berry. 


\section{NYMPhaÈA (Tourn.) L. Yellow Pond Lily, Spatter-dock.}

Flowers yellow. Sepals 5-7, leathery, concave. Petals 10-20, small filament-like. Filaments flattened, inserted under the ovary. Stigmas forming an 8-24-radiate disk. Fruit with a leathery pericarp; seeds pendulous. [Nuphar Sibth.]

Leaves 1-3 dm. long, the sinus extending about one-third their length; petals cuneate to oblanceolate, truncate; stigma 10-25-rayed.

Sepals $9-12$; flowers $6-10 \mathrm{~cm}$. in diameter; stamens red,

Sepals usually 6 ; flowers $4-7 \mathrm{~cm}$. in diameter; stamens yellow.

1. N. polysepala.

thin; stigma 7-10-rayed; flowers about $2.5 \mathrm{~cm}$. in diameter.

1. N. polysepala (Engelm.) Greene. Leaf-blades oval, 2-3 dm. long, 1.5-2 $\mathrm{dm}$. wide, with a narrow or closed sinus; sepals $6-12$, yellow, reddish tinged; petals 12-18, cuneate, $1-1.5 \mathrm{~cm}$. long; stigma 15-25-rayed, crenate; fruit about $3.5 \mathrm{~cm}$. in diameter, with a constricted neck. Lakes and slow streams: Mont.(Black Hills) S.D.-Colo.-Calif.-Alaska. Plain-Subalp. Ap-Au.

2. N. variegata (Engelm.) G. S. Miller. Leaf-blades rounded-ovate or broadly oval in outline, 1-2 dm. long, 8-15 $\mathrm{cm}$. wide, with a narrow or closed sinus; outer sepals green, the rest with bright yellow edges, red or maroon towards the base within; petals oblanceolate; stigma 10-16-rayed; fruit scarcely constricted into a neck. N. americana (Prov.) Mill. \& Standl. Lakes and slow streams: Lab.-N.J.-Wyo.-B.C. Plain-Submont. Je-Au.

3. N. microphylla Pers. Leaf-blades $3-10 \mathrm{~cm}$. long, oval or ovate, with a very deep sinus; sepals about 5 , mostly yellow, $12-15 \mathrm{~mm}$. long; petals $4 \mathrm{~mm}$. long; stigma usually deep red, distinctly lobed; fruit $12-15 \mathrm{~mm}$. in diameter, with a narrow neck. N. Kalmiana (Michx.) Sims. Ponds: Newf.-Pa.Sask. Boreal. Jl-Au.

\section{Castàlia Salisb. Water Limy, Pond Lily.}

Flowers in ours white. Sepals 4. Petals numerous, imbricate in several series, grading into staminodia and stamens. Stamens numerous, epigynous. Stigma 12-35-rayed, with a globular projection in the middle. Fruit with a leathery pericarp, maturing under water. Seeds numerous, surrounded by a sack-like aril. [Nymphaea L., in part.]

1. C. Leibergii Morong. Leaves broadly obovate in outline, $6-10 \mathrm{~cm}$. long, 4-6 cm. wide; sinus deep, often extending more than half the length of the leaves; basal lobes acute; flowers 4-6 $\mathrm{cm}$. wide; sepals green outside, elliptic, often acutish; petals 8-10, white, purple-veined, obtuse; stamens 20-30; stigma 7-8rayed. Ponds: Ida.-w Ont. and northward. Mont.-Boreal. J1-Au.

\section{Family 48. RANUNCULACEaE. Crowfoot Family.}

Herbs or climbing shrubs. Leaves alternate, except in Clematis, Viorna, and Atragene, simple or compound, without stipules. Flowers regular or irregular. Sepals 3-15, usually green and caducous, or in genera without petals persistent and more or less petaloid, imbricate, or in Clematis, etc., valvate. Petals as many as the sepals or wanting. Stamens usually many, rarely 5. Carpels numerous or few, distinct, rarely solitary, 1-celled, 1many-ovuled. Fruit of achenes, follicles, or berries.

Carpels 1-ovuled; fruit of achenes.

Petals wanting; sepals often petal-like.

Sepals imbricate in the bud; leaves all alternate, or only those subtending the inflorescence opposite.

Flowers subtended by opposite or verticillate leaf-like bracts. Styles short, not elongating in fruit. 1 . ANEMONE. Styles much elongating in fruit, plumose.

2. Anemone.

Flowers not subtended by opposite or verticillate bracts. Leaves ternately compound.

Leaves palmately cleft.

3. THALICTRUM.

4. TrautVetTeria.

Sepals valvate in the bud; leaves all opposite. 
Stamens erect; sepals thickish, more or less converging; staminodia wanting:

Stamens spreading; sepals spreading from the base.

6. VIORNA.

Flowers mostly paniculate; sepals white or yellow, firm, without a border; staminodia wanting.

Flowers solitary; sepals blue or purple, thin; staminodia usually present.

Petals usually present.

7. ATRAGENE.

Sepals spurred; small annuals with basal linear leaves; receptacle in fruit elongatecylindrical; stamens 5.

8. MYosurus.

Sepals not spurred; plant usually bearing cauline as well as basal leaves; receptacle in fruit spherical, conical or short-cylindric; stamens more than 5 .

Achenes transversely wrinkled; petals white.

9. BATRACHIUM.

Achenes not transversely wrinkled.

Achenes not ribbed.

Petals yellow, at least without; sepals deciduous.

Achenes without an empty upper portion; plants not scapose.

10. RANUNCULUS.

Achenes with the lower half enclosing the seed; the upper portion empty, flattened and spongy; plants scapose.

11. Coptidum.

Petals pink, rose-colored, or white; sepals marcescent-persistent.

Achenes longitudinally ribbed; petals yellow.

12. BECKWITHIA.

Achenes compressed; leaves simple, crenate or lobed.

Achenes terete; leaves compound.

13. HALERPESTES.

14. CYRTORHYNCHA.

Carpels with several ovules; fruit of follicles or berries.

Hypanthium not developed; petals wholly superior.

Flowers regular.

Petals inconspicuous or none, not spurred.

Fruit of follicles; flowers sonitary.

Follicles sessile: leaves simple or cleft.

Petals wanting; leaf-blades entire or merely toothed.

Petals presènt, but small, linear; leaf-blades palmately parted and toothed.

16. Trollius.

Follicles stipitate; petals clawed; leaves compound or dissected.

Petals hooded and nectariferous at the summit; leaves ternate.

Petals fliform or linear beyond the COPTIS.

nately dissected.
Fruit a berry; leaves twice or thrice ternately compound.

pit: leaves pin

Fruit a berry; 19 . ACTAEA.

Petals conspicuous, produced into a spur or at least saccate at the base; leaves ternately compound.

20. AQUILEgIA.

Flowers irregular.

Posterior sepal spurred. 21. DelphInUM.

Posterior sepal hooded, helmet-shaped or boat-shaped. 22. ACONITUM.

Hypanthium somewhat developed, lined at the mouth by a fleshy perigynous disk.

23. Paeonia.

\section{ANEMÒNE (Tourn.) L. Wind-FLOWER, ANEMONE.}

Perennial herbs, usually with horizontal rootstocks and erect scapes. Leaves basal, petioled, palmately divided or dissected. Bracts verticillate, usually 3, similar to the leaves, remote from the flower. Flowers terminal, solitary or cymose. Sepals 4-20, mostly 5, petal-like. Petals wanting. Stamens numerous. Pistils usually numerous. Achenes compressed, 1-seeded. Stigmas introrse, unilateral.

Plants with tuberous roots; sepals 6-20.

Plants with a rootstock; sepals $5-6$, rarely more.

Achenes densely villous.

Style filiform, usually deciduous; heads of fruit spherical or nearly so; involucral leaves short-petioled or subsessile.

Leaves ternate; segments broadly cuneate or flabelliform, crenate or slightly cleft.

2. A. parviflora.

Leaves 2-4 times ternate; segments linear to oblong or oblanceolate.

Styles 1-3 mm. long; leaves 2-3 times ternate.

Achenes merely strigose on the back, densely villous on the sides; styles 2-3 mm. long; leaf-blades glabrate; segments oblanceolate.

Achenes villous all over; style 1-2 mm. Iong.

3. A. tetonensis.

Leaffets thick, glabrate, strongly veined; segments oblanceolate, acutish.

4. A. lithophila.

Le tf-blades thin, usually long-hairy, not strongly veined; segments linear to lanceulate, acute.

5. A. globosa. 
Styles 4-6 mm. long; leaves 3-4 times ternate; segments narrowly linear.

6. A. Drummondii.

Styles subulate, persistent; heads of fruit from rounded oblong to cylindric; involucral leaves long-petioled.

Heads elongate, cylindric; styles about $1 \mathrm{~mm}$. long; flowers usually subumbellate.

7. A. cylindrica.

Heads of fruit rounded-oblong; styles about $2 \mathrm{~mm}$. long; flowers truly cymose. Petals greenish white, $1 \mathrm{~cm}$. long or less; styles in fruit divergent.

Petals white, $1.5 \mathrm{~cm}$. long; styles suberect.

8. A. virginiana.

Achenes not villous.

Achenes wing-margined; plant stout.

Sepals yellow; styles very long, reflexed.

Sepals white or pink; styles not reflexed.

9. A. riparia.

Flowers cymose; achenes sparsely hirsute when young, sessile; styles long. straight.

10. A, Richardsoni.

Flowers subumbellate; achenes glabrous, stipitate; styles short, curved. 12. A. zephyra.

Achenes not wing-margined, pilose; style minute; plant slender; flowers solitary. 13. A. Piperi.

1. A. tuberosa Rydb. Stem 1-3 dm. high; basal leaves twice ternate; divisions rhombic-cuneate in outline, ternately cleft and toothed; involucral leaves similar, but short-petioled; peduncle solitary or a second one with a smaller involucre; sepals white or purplish, oblong-linear, 1-2 cm. long; head of fruit ellipsoid; achenes densely woolly; style filiform, about $1.5 \mathrm{~mm}$. long. A. sphenophylla Britton, not Poepp. Dry plains and hills: N.M.-Utah-Calif. L. Son. F-Ap.

2. A. parviflora Michx. Stem $5-20 \mathrm{~cm}$. high; leaves ternate, thick, and firm, glabrous above, silky-strigose beneath; divisions cuneate, 1-2 cm. long; sepals white or tinged with bluish or rose, oval, 8-18 $\mathrm{mm}$. long; head of fruit spherical. In aretic-alpine situations: Lab.-Ont.-Mont.-Colo.-Alaska; Asia. Mont.-Subalp. My-Au.

3. A. tetonensis Porter. Stem silky, 1-3 dm. high, 1-3-flowered, the secondary peduncles with smaller involucres; leaf-blades twice ternate, $2-5 \mathrm{~cm}$. broad; involucral leaves similar, but sessile; sepals oval, 6-10 mm. long, of ten dark purple, more rarely white, and tinged with blue on the outside; head of fruit hemispherical, $10-15 \mathrm{~mm}$. in diameter. A. stylosa A. Nels. Mountains: Alta.-Wyo.-Utah-Wash.-B.C. Submont. $\rightarrow$ Subalp. J1-Au.

4. A. lithophila Rydb. Stem 1-2 dm. high, sparingly pubescent with long silky hairs; basal leaves thickish, shining, somewhat glaucous; divisions about $3 \mathrm{~cm}$. long, deeply 3-cleft, again cleft and toothed; sepals silky, ochroleucous, tinged with blue, $12-15 \mathrm{~mm}$. long, broadly obovate or oval; head of fruit globose. Rocky mountain tops: Mont.-Wyo.-Utah. Submont.-Subalp. Jl$\mathrm{Au}$.

5. A. globosa Nutt. Stem 2-5 dm. high, 'silky-villous, 1-3-flowered; leafblades 5-12 $\mathrm{cm}$. broad, thrice eleft; sepals oval, 6-12 mm. long, pink or purplish or ochroleucous, tinged with bluish on the outside; heads of fruit globose or ovoid, 10-12 mm. in diameter. A. multifida Hook., in part, not Poir. Meadows and hillsides: Alaska-Calif.-Colo.-S.D.-Sask.-Mack. Plain-Subalp. My-S.

6. A. Drummondii S. Wats. Stem 1-2 dm. high, usually 1-flowered, silkyhirsute; leaf-blades 2-6 cm. broad, silky-hirsute; sepals oval, $8-10 \mathrm{~mm}$. long, tinged with blue; heads of fruit spherical, about $1 \mathrm{~cm}$. thick; achenes densely woolly. High mountains: B.C.-Alta.-Ida.-Calif. Mont,-Subalp. Jl-Au,

7. A. cylindrica A. Gray. Stem 3-6 dm. high, 1-10-flowered; leaf-blades strigose-pubescent, $3-8 \mathrm{~cm}$. wide, ternate or quinnate; divisions rhombic-cuneate, 3-cleft and again cleft or toothed, with ovate or lanceolate teeth or lobes; involucral ones similar, clustered together with those of the secondary peduncles, the lowest node of which usually is very short or obsolete, the inflorescence therefore becoming umbelliform; sepals greenish white, oblong, 8-10 mm. long; heads in fruit 2-4 cm. long, about $1 \mathrm{~cm}$. thick. Meadows, hillsides, and river banks: N.B.-N.J.-Ariz.-B.C. Plain-Submont. Je-Au.

8. A. virginiana L. Stem 6-10 dm. high, hirsute, 1-7-flowered; leaf-blades $10-15 \mathrm{~cm}$. broad, ternate or quinate, more or less silky-hirsute; divisions rhom- 
bic-obovate, 3-cleft and coarsely toothed; inflorescence cymose; sepals greenish white, $1 \mathrm{~cm}$. or less long; heads of fruit 1-2.5 $\mathrm{cm}$. long, 12-15 mm. thick. Woods and river banks: N.S.-S.C.-Kans.-Wyo.-Alta. Plain-Submont. Je-Au.

9. A. riparia Fernald. Stem 6-10 dm. high, somewhat pubescent, 1-5flowered; leaf-blades ternate or quinate; divisions lanceolate, cuneate at base, 3 -cleft and toothed; inflorescence cymose; head of fruit subcylindric, $2-3 \mathrm{~cm}$. long, $1 \mathrm{~cm}$. thick. River banks: Me.-Va.-Alta. Plain-Submont. Je-Jl.

10. A. Richardsoni Hook. Basal leaf-blades round-reniform, deeply 5-cleft into cuneate-obovate incised divisions; involucres of 3 , dilated, cuneate, 3 -lobed, dentate leaves; sepals sulphur-yellow, elliptic, $8-15 \mathrm{~mm}$. long; heads of fruit subglobose; achenes comparatively few. Arctic and subarctic regions: Greenl. -Hudson Bay-Alta.-Alaska. Subalp. My-Jl.

11. A. canadensis L. Stem strigose, 2-6 dm. high, 1-3-flowered; leafblades 10-12 cm. wide, 3-5-parted; divisions oblanceolate, 3-cleft and toothed; involucral leaves similar but larger, often $15 \mathrm{~cm}$. long or more, sessile and more deeply cleft; sepals obovate or oval, $12-18 \mathrm{~mm}$. long, white; head of fruit globose. Low ground: Lab.-Md.-N.M.-Alta. Plain—Submont. My-Au.

12. A. zephyra A. Nels. Stem 1-4 dm. high; leaf-blades more or less silkyvillous, but in age often glabrate, $5-8 \mathrm{~cm}$. wide, ternate or quinate; divisions cuneate to broadly obovate in outline, twice cleft into obtuse lobes; involucral leaves much smaller, sessile and 3-cleft; petals white, broadly obovate, 10-15 mm. long; head of fruit about $15 \mathrm{~mm}$. broad, spherical; achenes flat,broadly spatulate in outline. A. narcissiflora Am, auth. Alpine-arctic regions: Colo.-Wyo.Alaska. Mont.-Alp. Jl-Au.

13. A. Piperi Britton. Stem 1.5-3 dm. high, slender, very sparingly appressed-silky; basal leaves ternate; middle lobe rhombic-obovate or rhombiccuneate, coarsely toothed above the middle, $2-7 \mathrm{~cm}$. long, the lateral ones broader, obliquely ovate, 2-cleft to about the middle; sepals elliptic-obovate to oval, about $15 \mathrm{~mm}$. long, white, glabrous. Hillsides: Ida,-Wash. Submont. My-JI.

\section{2. pulsatílla Adans. Pasque-flower, Blue Tulip, Wild Crocus, Lion's Beard (Fruit).}

Perennial scapose herbs, with a thick taproot and short caudex. Leaves basal, palmately or rarely pinnately divided or dissected. Bracts of the seape somewhat similar to the leaves, 3 in number, verticillate, often connate. Flowers mostly solitary. Sepals 5-7, colored blue, purple, or white. Petals wanting. Stamens numerous, the outer often changed into staminodia. Pistils numerous. Fruit of numerous achenes, with much elongated, persistent, plumose styles.

Flowers purple or violet, seldom white; involucral leaves sessile, palmately divided into linear lobes.

1. P. ludoviciana.

Flowers white or tinged with purple; involucral leaves petioled, ternate and twice pinnately dissected.

2. P. occidentalis

1. P. ludoviciana (Nutt.) Heller. Leaf-blades ternate and repeatedly dissected into linear divisions, $5-10 \mathrm{~cm}$. in diameter, villous-hirsute or in age glabrate; scape 1-4 dm. high, villous; sepals ovate-oblong, 25-35 $\mathrm{mm}$. long; achenes silky, their styles about $3 \mathrm{~cm}$. long. Anemone patens Nuttalliana A. Gray. P. hirsutissima Britton. Prairies, plains, and hillsides: Ill--Tex.-Utah-Wash. -Alaska. Plain-Subalp. Mr-S.

2. P. occidentalis (S. Wats.) Freyn. Leaf-blades ternate and then twice pinnate-dissected, sparingly silky-hirsute; scape 1-6 dm. high, silky-villous; sepals oval or oblong, $2-2.5 \mathrm{~cm}$. long; achenes silky, in fruit reflexed, their style $3 \mathrm{~cm}$. long or more. Anemone occidentalis S. Wats. On gravelly or stony hills and mountains: Alaska-Calif.-Mont.-Alta. Submont.-Mont. Je-Au.

\section{Thalíctrum L. Meadow Rue, Matd-of-the-Mist.}

Perennial herbs, with rootstocks. Leaves alternate, ternately decompound; petioles with dilated bases. Flowers perfect, dioecious, or polygamous, in panieles or racemes. Sepals greenish white, 4 or 5 . Petals wanting. Stamens 
numerous; filaments often clavate or dilated. Pistils few; stigmas elongate, unilateral. Achenes stipitate or sessile, ribbed or nerved.

Flowers perfect.

Plant $2 \mathrm{dm}$. or less (rarely $3 \mathrm{dm}$.) high; achenes turgid; filaments filiform.

Plant 3-10 dm. high; achenes flat and very oblique; filaments clavate.

1. T. alpinum.

2. T. sparsiflorum.

Flowers dioecious or polygamous.

Achenes turgid, thick-walled; ribs thick and almost corky, separated by acute grooves.

Plants polygamous; stem-leaves subsessile, the basal ones petioled.

Achenes, petiolules, and lower surfaces of the leaves decidedly viscid-pubescent.

3. T. dasycarpum.

Achenes, petiolules, and the lower surfaces of the leaves glabrous or slightly viscid-puberulent.

Plants dioecious; all leaves petioled.

Achenes equally acutish at both ends; leaves very thin and not strongly veined.

Achenes more acute at the upper end than at the lower; leaves firm, strongly veined.

Achenes more or less flattened, thin-walled; ribs not thick, separated by wide, shallow, rounded grooves.

Achenes sessile.

Achenes more than twice as long as broad, slightly if at all oblique.

Achenes about 4 times as long as broad, 6-8 mm. long, $1.5-2 \mathrm{~mm}$. wide.

Achenes less than 3 times as long as broad.

Achenes 6-8 mm. long, 2.5-3.5 $\mathrm{mm}$. wide.

Achenes 4-5 mm. long, $1.5-2 \mathrm{~mm}$. wide.

Achenes not quite twice as long as broad, decidedly oblique.

Achenes stipitate.

7. T. occidentale.

8. T. megacarpum.

9. T. columbianum.

10. T. Fendleri.

11. T. stipitatum.

1. T. alpinum L. Stem glabrous; leaves mostly basal, $2-10 \mathrm{~cm}$. long, pinnate, with the lower primary divisions ternate; leaflets cuneate-obovate to orbicular, firm, 3-10 mm. long, 3-5-lobed at the apex; inflorescence usually a raceme; anthers oblong-linear; achenes few, lance-obovoid, turgid, with thick ribs. T. scopulorum, T. cheilanthoides, T. subspensum, T. leiophyllum, and $T$. duriusculum Greene. Bogs: Greenl.-Newf.-Colo.-Calif.-Alaska; n Eurasia. Mont.-Alp. Je-Jl.

2. T. sparsiflorum Turcz. Stem glabrous, leafy; leaves bi- or tri-ternate, the lower petioled, the uppermost sessile; leaflets thin, pulverulent-glandular beneath, cordate, usually 3-cleft and the divisions 3-lobed, 1-2 cm. long; achenes $6-12$, half rhombic with a straight back, glandular-pulverulent, with about three faint ribs, 5-6 mm. long, 3-4 mm. wide. T. utahense Greene. Moist places: Alaska-Calif.-Colo.-Hudson Bay; n Asia. Submont.-Mont. Je-Au.

3. T. dasycarpum Fisch. \& All. Stem tall, 5-20 dm. high; leaves 3-5 times ternate; leaflets ovate or obovate, rather thick, dark green above, paler and strongly veined beneath; achenes obliquely oblanceolate, about $5 \mathrm{~mm}$. long and $2 \mathrm{~mm}$. wide, Copses and meadows: Ont.-Ia.-n N.M.-Sask. Plain-Mont. $\mathrm{Je}-\mathrm{Au}$.

4. T. purpurascens L. Stem tall, glabrous, $3-20 \mathrm{dm}$. high; leaves $3-5$ times ternate, glabrous or nearly so; leaflets rather thin, ovate or subcordate at the base, rather light green; achenes obliquely oblanceolate, 4-5 mm. long and about $2 \mathrm{~mm}$. wide. Copses and woodlands: N.S.-Fla.-Colo.-Sask. Plain -Submont. Je-Au.

5. T. dioicum L. Stem 3-6 dm. high, slender; leaves 3-4 times ternate; leaflets 1-3 cm. long, thin, pale beneath, rounded or sometimes cordate at the base, with 3-9 rounded lobes; filaments filiform; achenes oblong, about $4 \mathrm{~mm}$. long. Woods: Lab.-Ala.-Mo.-Sask. Boreal. My-Je.

6. T. venulosum Trelease. Stem 2-5 dm. high, glabrous; leaves $3-4$ times ternate; leaflets rounded in outline, $5-15 \mathrm{~mm}$. long, strongly veined, $3-5$-lobed and erenate, bluish green, paler beneath; panicle narrow and dense; filaments filiform; achenes about $5 \mathrm{~mm}$. long, oblong. $T$. campestre Greene. Open mountain woods: Man.-Colo.-Utah. Plain-Mont. Je-Au. 
7. T. occidentale A. Gray. Stem 3-10 dm. high; leaves 3-4 times ternate; leaflets very thin, orbicular to obovate-cuneate, 3 -lobed and coarsely crenate, $1-3 \mathrm{~cm}$. long; filaments filiform; achenes lanceolate, tapering at both ends, $6-8$ mm. long, $1.5-2 \mathrm{~mm}$. wide. Woods and copses: B.C.-Calif.-Utah.-Alta.
Submont.-Mont. Je-Au.

8. T. megacarpum Torr. Plant closely resembling the preceding; stem 3-8 dm. high; leaves 3-4 times ternate; leaflets thin, pale beneath; filaments filiform; achenes lance-oblong, acute at both ends, 6-7 mm. long, 2.5-3.5 mm. wide, with more prominent ribs than in the preceding. T. propinquum and $T$. omissum Greene. Copses, woods and river banks: Ida. - Utah-Colo-Mont, Submont.-Mont. My-Au.

9. T. columbianum Rydb. Stem 3-5 dm. high; leaves 3-4 times ternate; leaflets rather crowded, thick and veiny, 1-2 cm. long, cuneate to nearly orbicular, 3-lobed and deeply toothed; inflorescence narrow; achenes oblong- or ovate-lanceolate, somewhat flattened, 4-5 mm. long, 1.5-2 mm. wide. Meadows: Wash.-Ore.-Wyo.-Ida. Submont.-Mont. Jl-Au.

10. T. Fendleri A. Gray. Stem 3-6 dm. high; leaves $3-4$ times ternate, glabrous; leaflets obliquely orbicular or subcordate, pale beneath, $1-2 \mathrm{~cm}$. long, 3 -lobed and erenate; inflorescence open and leafy; filaments filiform; achenes obliquely obovate, 3-ribbed, with the median rib strong. Mountains: Wyo.-
N.M.-Ariz.-Utah. Submont.-Mont. Je-Au.

11. T. stipitatum Rydb. Stem 4-6 dm. high, glabrous, leafy; leaves 3-4 times ternate, glabrous, paler beneath, all except the very uppermost petioled;
leaflets $1-2 \mathrm{~cm}$. long, orbicular, with a rounded or subcordate base, 3 -lobed and
crenate; inflorescence leafy and crenate; inflorescence leafy and open; achenes short-stipitate, the body broadly and obliquely oblong-lanceolate, about $6 \mathrm{~mm}$. long, $2.5-3 \mathrm{~mm}$. broad, flat with
slender ribs. Woods: c Colo. Mont. Jl.

\section{TRAUTVETtÉRIA F. \& M. FAlse Bugbane,}

Perennial herbs, with horizontal rootstocks and tall stems. Leaves mainly basal, palmately lobed, long-petioled. Flowers perfect, corymbose-paniculate. Sepals $3-5$, petaloid, greenish white, caducous. Petals wanting. Stamens numerous, with white filaments. Pistils numerous, 1 -ovuled. Achenes sharply angled, inflated, tipped with a minute style; stigma introrse. Embryo large;
endosperm fleshy. Styles in fruit about one-third as long as the body of the achenes; flaments broader than
the anthers.

Styles in fruit less than one-fourth as broader than the anthers.

fliaments not

1. T. grandis Nutt. Stem 3-10 d. T. media.

leaf-blades reniform in outline, $1-2 \mathrm{dm}$. high, glabrous up to the inflorescence; larly serrate; filaments clavate, $5-6 \mathrm{dm}$. wide, palmately 7-9-lobed and irregubase, $3 \mathrm{~mm}$. long. T. saniculifolia Greene achenes ovoid, rounded at the Mont. Je-Au.

2. T. media Greene. Stem 5-10 dm. high, glabrous; leaf-blades reniform, 5-9-cleft; the divisions often again lobed and irregularly toothed; filaments slightly clavate, about $5 \mathrm{~mm}$. long; achenes fully $3 \mathrm{~mm}$. long, less rounded at the base. Mountain woods: N.M. $-\mathrm{s}$ Utah. Mont. Jl-Au.

\section{Clématis L. Virgin's Bower, White Clematis, Traveler's Joy, Pipe-Stem.}

Climbing vines. Leaves opposite, pinnately compound or decompound, with entire, toothed, or incised leaflets. Flowers in broad, paniculate eymes or rarely solitary, perfect, dioecious, or polygamo-dioecious. Sepals rather small, petaloid, usually white, valvate, without a border, spreading. Petals and staminodia wanting. Stamens numerous, spreading; anthers short and blunt. Pistils several or many. Fruit of 1-seeded achenes, with silky or plumose,
elongate styles. 
Plant dioecious; flowers white, paniculate.

Inflorescence usually longer than the leaves, its branches and the pedicels strongly ascending; leaflets lanceolate or ovate-lanceolate; sepals oblanceolate.

1. C. ligusticifolia.

Inflorescence shorter than the leaves, its branches and the pedicels more spreading: leaflets broadly ovate, usually subcordate at the base; sepals spatulate.

$\begin{array}{ll}\text { Plant with perfect yellowish flowers, solitary in the axils. } & \text { 2. C. brevifolia. }\end{array}$

1. C. ligusticifolia Nutt. A woody vine, $3-6 \mathrm{~m}$. high; leaves pinnately 5-7-foliolate; leaflets petiolate, in the typical form lanceolate to ovate, rounded or truncate at the base, usually more or less acuminate, $3-8 \mathrm{~cm}$. long, sparingly strigose; cymes with nearly erect branches; sepals white, nearly $1 \mathrm{~cm}$. long, oblong-oblanceolate; filaments of the staminate flowers linear-filiform, those of the pistillate flowers broader, linear, somewhat dilated, with sterile anthers; achenes numerous, obovate, pubescent; styles plumose, 4-5 $\mathrm{cm}$. long. Very variable species. Copses and eañons among bushes: B.C.-N.D.-N.M.-Calif. Plain -Submont. My-Au.

2. C. brevifolia (Nutt.) Howell. A woody vine, $2-5 \mathrm{~m}$. high, resembling the last; leaves pinnately $5-7$ fololiate; leaflets broadly ovate, acute at the apex, usually cordate at the base, double-toothed, 2-5 cm. long, nearly glabrous, rather firm; inflorescence subumbellate or corymbiform, with more spreading short branches; sepals straw-colored, 8-9 mm. long; achenes obovate, pubescent; styles plumose, 2-3 cm. long. Among bushes: Wash.-Mont.-Utah-Ore. Submont. My-Jl.

3. C. orientalis $\mathrm{L}$. Climbing vine, $3-5 \mathrm{~m}$. high; leaves twice or thrice ternate; leaflets thin, shining, 3-parted with small, ovate, incised divisions; sepals yellow, tinged with green, somewhat reflexed; styles plumose. $C$. crux-flava Cockerell. (?) C. aurea Nels. \& Macb. Among bushes: Ont.-N.M. -Ida.; escaped from cultivation, native of India.

\section{VIÒRNA Reichenb. VASE-Vine, Leather-Flower, Old Man's WhisKers AND LION's BEARD (fruit).}

Climbing vines or (all ours) erect perennial herbs. Leaves opposite, in ours pinnately compound or decompound. Sepals 4, rarely 5, valvate, petaloid, bluish or purplish, erect and connivent at the base or throughout. Petals and staminodia wanting. Stamens numerous, erect; anthers long and narrow, pointed; filaments hairy. Pistils many. Fruit 1-seeded achenes, with long persistent, in ours plumose styles.

Sepals not or indistinctly dilated above.

Calyx rounded-urceolate; sepals broadly ovate, merely the tips spreading.

Leaf-segments ovate to ovate-lanceolate, $2-5 \mathrm{~cm}$. long. $1 . \quad V$. Scottii.

Leaf-segments linear to lanceolate, $1-2 \mathrm{~cm}$. long. $\quad$ 2. $V$. Bakeri.

Calyx elongated-campanulate; sepals oblong-lanceolate, about one-fourth or more of their length spreading.

Middle and upper leaves subsessile, thrice ternate; ultimate segments linear or linear-lanceolate. $3 . \mathrm{V}$. hirsutissima.

Middle and upper leaves distinctly petioled, twice ternate; ultimate segments lanceolate. 4 . V. Wyethii.

Sepals decidedly dilated at the apex.

Sepals acute or short-acuminate; plant in age glabrate; leaf-segments lanceolate.

5. V. Jonesii.

Sepals obtuse or merely acutish; plant permanently villous; leaf-segments linear.

1. V. Scottii (Porter) Rydb. Stem erect, 2-4 dm. high, more or less villous when young; leaves twice pinnately divided, spreading; peduncles about $1 \mathrm{dm}$. long; sepals purplish brown, 2.5-3.5 cm. long, more or less villous outside; achenes obovate, flattened, densely short-pubescent; their styles 4-5 cm. long. Clematis Scottii Porter. C. Douglasii Scottii Coulter. Hillsides: N.M.-S.D.-Wyo. Submont.-Mont. My-Jl.

2. V. Bakeri (Greene) Rydb. Stem erect, 3-6 dm. high, simple, slightly villous, strongly striate; leaves short-petioled, twice or thrice pinnate; sepals dark purplish brown, villous outside, less than $2 \mathrm{~cm}$. long; fruit unknown. $C$. Bakeri Greene. Hillsides: Los Pinos, Colo.-N.M. Submont. My. 
3. V. hirsutissima (Pursh) Heller. Stem simple, erect, $3-7 \mathrm{dm}$. high; lower leaves petioled, the earliest entire, the rest dissected, mostly thrice pinnate; sepals brownish purple, $3-4.5 \mathrm{~cm}$. long; achenes obliquely ovate, densely canescent, their styles 5-6 cm. long. C. hirsutissima Pursh. C. Douglasii Hook. Hillsides and valleys: Wash.-Wyo.-Mont. Submont.-Mont. My-Je.

4. V. Wyethii (Nutt.) Rydb. Perennial; stem simple, 2-4 dm. high, villous; leaves twice pinnately divided, with usually broader divisions than in the preceding; sepals dark brownish purple, $2.5-3.5 \mathrm{~cm}$. long, villous outside; achenes obliquely ovate, canescent; their styles $3-5 \mathrm{~cm}$. long. $C$. Wyethii Nutt. Hills: Mont.-Wyo.-Ida. Submont.-Subalp. Ap-J.

5. V. Jonesii (Kuntze) Rydb. Stems 3-6 dm. high; leaves twice pinnately divided, 1-1.5 dm. long, rather firm; segments $1-5 \mathrm{~cm}$. long, acutish; calyx campanulate, brown; sepals $2-2.5 \mathrm{~cm}$. long, ovate, the upper half with wavy dilated margins; achenes about $5 \mathrm{~mm}$. long, densely silky; styles 4-5 cm. long. Clematis Douglasii var. Jonesii Kuntze. Clematis plattensis A. Nels. Hillsides and gulches: Colo.-Nev. Submont-Mont. Je-Jl.

6. V. eriophora Rydb. Stems and leaves prominently white-villous, the former 3-5 dm. high; leaves distinctly petioled, twice pinnately divided; segments 1-3 cm. long; calyx villous, campanulate, about $3 \mathrm{~cm}$. long; sepals oblong, long; tails about $4 \mathrm{~cm}$. long. Foot-hills and cañons: N.M.-Wyo.-Utah. Submont. My-Je.

\section{Atrágene L. Bell Rue, Purple Virgin's Bower.}

Perennial climbing or creeping vines. Leaves opposite, compound. Flowers large and showy, solitary in the axils or at the end of the branches. Sepals large, petal-like, mostly membranous, blue or purple, spreading from the base. Petals or staminodia small, spatulate, usually present. Stamens numerous, spreading; filaments pubescent, the outer ones dilated; anthers short. Pistils many. Fruit 1-seeded achenes, with persistent, long, plumose styles.

\section{Leaves merely ternate.}

Staminodia usually decidedly spatulate; leaflets variously toothed or cleft, not long-
acuminate. Lobes or teeth

Lobers rounded or obtuse at the apexate.

Lobes or teeth of the leaves acute or acuminate; sepals lanceolate. diversiloba.

Staminodia linear or none; leaflets entire or crenate above the middle, long-acuminate.

Leaves twice or thrice ternate; staminodia usually linear or lacking.
Secondary leaflets merely toothed or cleft.

Secondary leaflets broadly ovate, with broadly ovate teeth. 4. A. repens.

Secondary leaflets lanceolate, with lanceolate or ovate-lanceolate lobes or teeth.

Secondary leaflets divided to near the midrib.

5. A. pseudoalpina.

1. A. diversiloba Rydb. A low vine; leaves glabrous or slightly hairy when young, ternate; leaflets ovate in outline, obtuse, $1-3 \mathrm{~cm}$. long, the lateral ones usually 2-cleft, the terminal one 3 -cleft; sepals red-purple, lanceolate, about 2.5

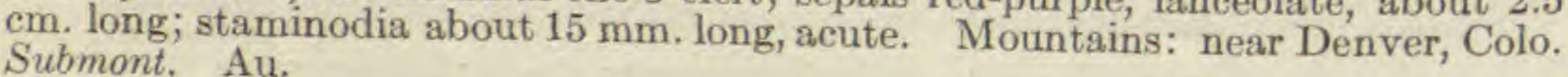

2. A. grosseserrata Rydb. Trailing or climbing over bushes; leaves ternate; leaflets broadly ovate, oblique, somewhat cordate at the base, $3-4 \mathrm{~cm}$. long, coarsely toothed and often somewhat lobed; sepals about $4 \mathrm{~cm}$. long, 10-13 $\mathrm{mm}$. wide, acute; staminodia about $18 \mathrm{~mm}$. long, a little exceeding the stamens; achenes small, sparingly hirsute; styles about $3 \mathrm{~cm}$. long, plumose throughout. Mountain meadows among bushes: Ida.-Mont.-Wash. Submont.-Mont.
Je.

3. A. columbiana Nutt. Rather tall vine, climbing over bushes; leaves ternate; leaflets thin, 3-10 cm. long, obliquely cordate at the base; sepals purple or blue, $3-5 \mathrm{~cm}$. long, lanceolate, acuminate; achenes rather densely pubescent; styles plumose, $4-5 \mathrm{~cm}$. long. A. occidentalis Rydb., not Hornem. Clematis 
verticillaris columbiana A. Gray. Woods and among bushes: B.C.-Alta.Colo.-Utah-Wash. Submont.-Mont. My-Jl.

4. A. repens (Kuntze) Rydb. Plant trailing; leaves biternate, glabrous; leaflets subsessile or the terminal short-stalked, broadly ovate, 3-4 $\mathrm{cm}$. long, abruptly short-acuminate; sepals ovate-lanceolate, about $4 \mathrm{~cm}$. long, acute; staminodia linear; achenes about $5 \mathrm{~mm}$. long, pubescent; styles about $4 \mathrm{~cm}$. long. Cañons: Utah-Wyo. Submont. Jl.

5. A. pseudoalpina (Kuntze) Rydb. Vine climbing over bushes; leaves biternate; leaflets lanceolate to ovate-lanceolate, acuminate, 2-4 cm. long, deeply toothed or often 2-3-cleft; sepals lanceolate, $3-5 \mathrm{~cm}$. long, purple or blue, rarely white; staminodia linear or often lacking; achenes nearly glabrous at maturity; styles 3-4 cm. long, plumose. Clematis alpina occidentalis A. Gray. C. pseudoatragene pseudoalpina Kuntze. Hillsides among shrubs: Colo.-Utah-N.M. Submont.-Mont. Ap-Je.

6. A. tenuiloba (A. Gray) Britton. Mostly trailing vine; leaves biternate; secondary leaflets 1-3 cm. long, usually divided to near the midrib into lanceolate or ovate divisions; these more or less toothed, acuminate; sepals 2.5-3.5 cm. long, lanceolate, acuminate, blue or purple; achenes densely pubescent; styles 4-5 cm. long. Woods: S.D.-Colo.-Ariz.-Mont. Submont.-Subalp. $\mathrm{My}-\mathrm{Jl}$.

\section{MYOSÛRUS L. MoUse-TAIL.}

Small acaulescent annual mud plants, with fibrous roots. Leaves basal, linear or filiform. Scapes 1-flowered. Sepals 5, rarely 6 or 7 , long-spurred at the base. Petals 5-7, narrow, greenish yellow, or wanting, the claws nectariferous at the summit. Stamens 5-25. Pistils numerous, borne on a receptacle, which becomes elongated and cylindric at maturity. Achenes aristate or apiculate, numerous, 1-seeded, tardily dehiscent. Seeds suspended; embryo minute.

Achenes with a flat back, only slightly carinate, and tipped with a very short appressed beak.

Achenes strongly carinate on the back, tipped with a subulate, ascending beak.

Beak more than half as long as the achene proper; spike short and dense

Beak very short; spike of the achenes long and slender.

2. M. aristatus.

3. M. lepturus.

1. M. minimus L. Leaves filiform or nearly so, glabrous, $3-10 \mathrm{~cm}$. long, blunt; scape $3-15 \mathrm{~cm}$. long; sepals oblong, about $3 \mathrm{~mm}$. long; spurs 1-2 $\mathrm{mm}$. long; petals spatulate, long-clawed, sometimes lacking; fruiting spike $3-6 \mathrm{~cm}$. long. In mud and shallow water: Ont.-Fla.-Calif.-Wash.; Eu. and $n$ Africa. Plain-Submont. Ap-Je.

2. M. aristatus Geyer. Leaves filiform to narrowly linear-oblanceolate, blunt; scape $2-6 \mathrm{~cm}$. long; sepals $2 \mathrm{~mm}$. or less long; spurs about $1 \mathrm{~mm}$. long; petals often lacking; carpel-spike $3-20 \mathrm{~mm}$. long. (?) $M$. nitidus Eastw. In mud: B.C.-Mont.-Neb.-N.M.-Calif. Plain-Mont. Ap-Jl.

3. M. lepturus (A. Gray) Howell. Leaves filiform, 3-5 cm. long, glabrous; scape $3-10 \mathrm{~cm}$. long; sepals about $2 \mathrm{~mm}$. long; spurs about $1 \mathrm{~mm}$; carpel-spike 1-4 cm. long, slender. In mud and dry ponds: B.C.-Sask.-Mont.-Calif. Plain-Submont. My-Je.

\section{BAtràchium S. F. Gray. White Water Crowfoot.}

Perennial aquatic herbs, with floating or creeping stems. Leaves alternate, palmately dissected or lobed, the submerged ones usually with filiform divisions. Flowers perfect, solitary, borne opposite the leaves. Sepals and petals usually 5 , the latter white, sometimes with a yellowish base, bearing a small pit on the claw. Stamens several or numerous. Pistils many in a globular head. Achenes oblique, compressed, not margined, transversely wrinkled, short-beaked or almost beakless.

Leaves all submerged and finely dissected, with linear to capillary divisions.

Divisions of the leaves rather few, flat, $0.5-1.5 \mathrm{~mm}$. wide.

Divisions of the leaves very slender, fliform or capillary.

Beak of the achenes nearly $1 \mathrm{~mm}$. long.

1. B. Porteri.

2. B. longirostre. 
Beaks of the achenes minute or none.

Petals 5-7 mm. long, broadly obovate; stamens many.

Primary divisions of the leaves $1-1.5 \mathrm{~cm}$. long, rather rigid, scarcely collapsing when withdrawn from the water. 3 . B. trichophyllum.

Primary divisions of the leaves $1.5-3 \mathrm{~cm}$. long, flaccid, collapsing when

withdrawn from the water.
Petals less than $5 \mathrm{~mm}$. long, oblong-obovate; stamens 5-12.

Stem slender, but not capillary; leaves not very flaccid.

Stem capillary-filiform; leaves very flaccid.

4. B. flaccidum.

5. B. Drouetii.

Upper leaf-blades floating, reniform, merely cleft or toothed, the rest submersed and
with with capillary divisions.
7. B. Grayanus.

1. B. Porteri Britton. Stem $1 \mathrm{~m}$. long or more; leaves all submerged; petioles 1-2 cm. long, dilated at the base; blade 4-5 cm. broad, repeatedly ternately divided, with narrowly linear, attenuate divisions; petals $3-4 \mathrm{~mm}$. long; achenes 6-12 in a head, obliquely oval, nearly $2 \mathrm{~mm}$. long, almost beakless. In water: Henry's Fork, e Ida.

2. B. longirostre (Godr.) F. Schultz. Stem very leafy and branched; petioles very short; blades $2-4 \mathrm{~cm}$. broad; petals broadly ovate, $5-7 \mathrm{~mm}$. long; head of fruit globose; achenes many, about $1.5 \mathrm{~mm}$. long. Ranunculus circinatus A. Gray, in part, not Sibth. Ponds and slow streams: Ont.-N.Y.-N.M. -Utah-S.D. Plain. Je-Au.

3. B. trichophyllum (Chaix.) Bosch. Stem $3 \mathrm{dm}$. long or more; petioles $1-1.5 \mathrm{~cm}$. long; blades $2-3 \mathrm{~cm}$. wide, usually with spreading divisions; petals about $8 \mathrm{~mm}$. long; head of achenes globose, $4 \mathrm{~mm}$. thick; achenes many, about $1.5 \mathrm{~mm}$. long. Ponds and slow streams: N.S.-N.C.-Calif.-B.C.; Mex.; Eurasia. Plain-Mont. Je-S.

4. B. flaccidum (Pers.) Rupr. Stem long and slender; leaves rather distant; leaf-blades $3-5 \mathrm{~cm}$. broad, with usually ascending segments; petals $5-8 \mathrm{~mm}$. long, white; head of fruit about $4 \mathrm{~mm}$. wide; achenes often nearly $2 \mathrm{~mm}$. long. In streams, rarely in ponds: Lab.-N.C.-L. Calif,-Wash. Plain-Mont. My-S.

5. B. Drouetii (F. Schultz) Nym. Similar in habit to B. trichophyllum, but more slender; leaf-blades $1.5-3 \mathrm{~cm}$. wide; petals $3-5 \mathrm{~mm}$. long; head of achenes about $4 \mathrm{~mm}$. thick, globose; achenes about $1.5 \mathrm{~mm}$. long. In streams: Vt.-R.I.-N.M.-L. Calif.-Alaska; Eurasia and Africa. Plain-Submont. Je-S.

6. B. confervoides Fries. Stem 1-2 dm. long, very slender; leaf-blades $2-4 \mathrm{~cm}$. wide; petals about $3 \mathrm{~mm}$. long, oblong; achenes about $1 \mathrm{~mm}$. long. In cold pools and lakes: Man.-Colo.-Alaska; Eu. Mont. Au.

7. B. Grayanus (Freyn) Rydb. Stem long and slender; submerged leaves short-petioled, finely dissected into capillary divisions, $3-8 \mathrm{~cm}$. in diameter; floating leaves with petioles $2-3 \mathrm{~cm}$. long; blades reniform, 1-3 cm. broad, 3-cleft; middle lobe cuneate, usually 3-lobed; lateral lobes broadly cuneate-obovate, usually twice 2-lobed; petals $5-7 \mathrm{~mm}$. long, obovate; achenes hairy, nearly $2 \mathrm{~mm}$. long. Ranunculus aquatilis A. Gray, not L. R. Grayanus Freyn. In water: Alaska-Mont.-Calif. Submont. Ap-JI.

\section{RANÚNCUlus (Tourn.) L. Crowfoot, Buttercup.}

Annual or most all of ours perennial herbs, with a cluster of fleshy-fibrous roots. Leaves alternate, entire, lobed, divided or dissected. Flowers solitary or cymose. Sepals mostly 5 , deciduous. Petals 5 or more, in ours yellow, each with a nectariferous pit and a scale at the base of the blade. Pistils several or many, 1-ovuled. Achenes flattened, smooth, papillose, or echinate, tipped with the style, not striate.

Achenes smooth.

Leaves linear to oval, entire, or merely denticulate or crenate, none divided or cleft.

Some of the leaves at least cleft.

Sepals black-hairy.

Sepals not black-hairy.

Some of the basal leaves entire.

Basal leaves linear or divided into 3 linear divisions.

I. FLAMMULAE.

II. Nivales.

V. Digitati. 
Basal leaves elliptic to reniform.

III. GLABERRIMI.

None of the leaves entire.

Neither floating water plants nor creeping mud plants, if rooting at the nodes, the leaves not palmately lobed or dissected.

Achenes turgid, marginless.

Petals much exceeding the sepals.

Basal leaves not divided to the base.

Leaves all divided to the base; achenes glabrous.

Leaves ternate, with simple linear divisions; plants very low, $0.5 \mathrm{dm}$. or less. $\mathrm{V}$. Digitati.

Leaves 2-3 times ternate; plants $5-20 \mathrm{~cm}$. high.

Petals scarcely exceeding the sepals.

Plants low, less than $1 \mathrm{dm}$. high.

Plants taller, 3-6 dm. high.

VI. TRITERNATI.

Achenes compressed, with a distinct margin.

VII. Pygmaei.

Beak of the achenes strongly hooked; heads of fruit globose.

IX. RECURVATI.

Beak of the achenes straight or nearly so; achenes in ours glabrous. Beak short.

Leaves, at least the basal ones, pinnately ternate, the terminal division at least petioled. Leaves palmately divided.

Beak long,

Immersed aquatics or creeping mud plants, with palmately lobed, divided, or dissected leaves.

Achenes prickly: annuals.

$\mathrm{X}$. REPENTES.

XI. ACRES.

XIII. MULTIFIDI.

XIV. MURICATI.

Plants rooting at the nodes.

Stem filiform, prostrate; petals about $3 \mathrm{~mm}$. long.

1. $R$. reptans.

Stem not fliform, at first ascending; petals about $5 \mathrm{~mm}$, long. 2 . $R$. unalaschensis.

Plants erect or ascending, not rooting at the nodes.

Leaves appressed-pubescent on the lower side. $\quad 3 . R$, microlonchus.

Leaves glabrous.

Blades of the basal leaves acute at the base.

Petals spatulate or oblong, usually $6-8,6-8 \mathrm{~mm}$. long. 4. R. alismaefolius.

Petals obovate, usually only 5 .

Petals $7-10 \mathrm{~mm}$. long; plants over $2 \mathrm{dm}$. high; leaves not very thin.

Petals 5-6 mm long: plant low, seldom $2 \mathrm{dm}$, high; $5 . R$. Bolanderi.

6. R. alismellus.

Blades of the basal leaves cordate or at least rounded at the base.

7. R. Populago.

II. Nivales.

8. R, Macauleyi.

Leaf-blades spatulate or elliptic, 2-4-toothed at the apex.

Leaf-blades of the basal leaves reniform or flabelliform, 3-5-lobed or 3-5-cleft.

\section{GLABERRIMI.}

One species.

IV. AFFINES.

10. R. glaberrimus.

Achenes pubescent, with a short recurved beak; heads oblong to cylindric.

Some of the basal leaf-blades merely crenate, the rest mostly 3 -cleft at the apex, with a narrow middle lobe.

Sepals densely villous.

Petals broadly obovate, about $1 \mathrm{~cm}$. long.

Petals wanting.

11. $R$. cardiophyllus.

29. $R$, apetalus.

Sepals not densely villous; petals oblong-obovate, 3-6 mm. long.

Petals 5-6 mm. long; heads of achenes oblong. 12. $R$, inamoenus.

Petals 3-5 $\mathrm{mm}$. long; heads of achenes cylindric.

Basal leaf-blades digitately or pedately cleft with acute lobes.

Basal leaf-blades reniform or rounded-cordate.

Basal leaf-blades cuneate-flabelliform.
nes glabrous; beak straight, usually slender.

13. R. micropetalus,

Plant glabrous, except the more or less villous sepals.

Petals 7-12 mm. long; lobes of the basal leaves acutish.

Basal leaf-blades cuneate-flabelliform; head of achenes somewhat oblong, 5-10 $\mathrm{mm}$. long.

Basal leaf-blades cleft half way down or less.

14. $R$, affinis.

15. $R$. saxicola.

Basal leaf-blades cleft more than half way down.

Basal leaf-blades reniform or at least truncate at the base, divided more than half way down; heads of achenes globular. 17. R. Suksdorfii.

Petals 4-8 mm. long; Iobes of the basal leaves obtuse or rounded.

Heads of fruit decidedly oblong; basal leaf-blades orbicular, seldom reniform, the earliest not cleft more than half way down.

Leaves thick; petals about $4 \mathrm{~mm}$. long.

Leaves thin; petals about $6 \mathrm{~mm}$. long.

18. $R$, utahensis.

19. $R$, alpeophilus.

Heads of achenes spherical or nearly so; basal leaf-blades decidedly reniform, cleft deeper than half way down. 
Lobes of the upper stem-leaves elliptical, oval or obovate.

Lobes of the upper stem-leaves linear to oblong. 20. R. Eschscholtzii. Stem about $2 \mathrm{dm}$. high; lateral lobes of the basal leaves 2-3-toothed. Stem less than $1 \mathrm{dm}$, high; lateral lobes of the 21. $R$. Helleri.

Plant more or less pubescent.

One species.

\section{Digitati.} 22. $R$. vericundus. 23. $R$, ovalis.

\section{Plant less than Triternati.}

24. R. Jovis.

Plant less than $1 \mathrm{dm}$. high; petals about $5 \mathrm{~mm}$. long; segments of the leaves very short. Plant usually more than 1 decurved

25. $R$. Drummondii. or more long; beak slender, not recurved.

Primary division; beak slender, not recurved.

Primary divisions of the basal leaves petiolate; segments linear, somewhat narrowed
downward; stems usually several Primary divisions of thually several-flowered; roots fibrous, $26 . R$. stenolobus. form, not narrowed downward; stems 1 -2-flowered; roots fleshy-fibrous.
fivest fili-

\section{Pygmaei.}

27. $R$. adoneus.

Sepals glabrous or nearly so; lateral lobes of the basal leaves 2-3-toothed,

Sepals copiously pubescent; lateral lobes of the basal leaves $4-5$-toothed.

VIII. A Bortivi.
Basal leaves, at least some of them, merely crenate.

22. $R$. verecundus.

Achenes pubescent; heads oblong to cylindrical.

Petals present; sepals not petaloid.

Petals wanting; sepals with petaloid margins.
Achenes glabrous, with a minute beak; heads subglobose.
Basal leaf-blades cordate at the bat

Basal leaf-blades rarely cordate at the base; plant, spreading hairs.

All the leaves divided or lobed; annuals.

13. $R$, micropetalus.

29. $R$. apetalus.

30. $R$, abortivus.

cially the stem, with 31. R. micranthus.

32. $R$, sceleratus.

Flowers small; petals only $2-5$ IX. RECURvati. cuneate-obovate, cleft divisions.

Petals $2-3 \mathrm{~mm}$. long.

Stem glabrous; achenes glabrous.
Stem hairy; achenes usually hirsute when young

Petals 4-5 mm. long; achenes glabrous, when young. $\quad 34 . R$. Bongardi.

Flowers larger; petals $5-12 \mathrm{~mm}$, long: $35, R$. Earlei.

lanceolate, ovate, or cuneate divisions; leaves often biternately. cleft into linear,

Pubescence of the stem appressed.

Pubescence of the stem appressed.

ubescence of the stem spreading.

36. $R$, acriformis,

Stem low and slender, seldom more than $3 \mathrm{dm}$. high; petals oblong to oval.

Stem tall, 5-10 dm. high; petals broadly obovate.

37. $R$. occidentalis.

38. $R$. montanensis.

Petals less than $1 \mathrm{~cm}$. long.

$\mathrm{X}$. REPENTES.

Plant glabrous or nearly so.

Plant decidedly pubescent.

Heads of achenes decidedly oblong, about $5 \mathrm{~mm}$. thick.

Heads of achenes globose, $7-12 \mathrm{~mm}$. thick.

39. $R$. oreganus.

Plants not stoloniferous; primary segme

beak half as long as the body of the achene.

40. R. pennsylvanicus. of the lower leaves more or less trooting at the nodes; primary segments

one-third as long as the body of the achene.
Petals more than $1 \mathrm{~cm}$. long; stem ereeping. one-third as long as the

42. $R$. rivularis.

43. $R$. repens.

One species.

\section{ACRES.}

XII. HispID:.

Petals obovate: divisions of the leaves lanceolate or ovate.

Petals elliptic; divisions at least of the upper leaves linear.
44. $R$, acris.

45. $R$. platyphyllus.

46. $R$. orthorhynchus,

\section{MUltifidi.} Leaves deeply cordate at the base, their primary divisions lobed or dissected; style about
two-thirds as long as the achene.

Achenes callous-margined.

Achenes marginless.

Stem glabrous.

Stem pubescent.

47. $R$. delphinifolius.

48. R. Purshii.

49. $R$. limosus. 
Leaves truncate or slightly cordate at the base, their primary lobes entire or merely crenate; styles minute.

Floating water plants; at least some of the leaves cordate at the base.

Rooting mud plants; none of the leaves cordate at the base.

50. $R$. intertextus.

51. R. hyperboreus.

One species.

XIV. MURICATI.

1. R. reptans L. Stem filiform, 1-3 dm. long; leaves $1-5 \mathrm{~cm}$. long, linearfiliform and glabrous to oblanceolate and strigose (var. strigulosus Freyn); peduncles 1-3 $\mathrm{cm}$. long, filiform; petals obovate, 2-4 $\mathrm{mm}$. long; head of fruit spherical; achenes glabrous, with a minute beak. $R$. flammula reptans $\mathrm{E}$. Meyer. Shores: Lab.-N.J.-N.M.-Ore.-Alaska. Plain-Mont. My-S.

2. R. unalaschensis Bess. Stem 3-6 dm. long, at first ascending, later decumbent and rooting at the nodes; leaves 4-10 $\mathrm{cm}$. long, petioled, sparingly strigose or glabrous; blade lanceolate or oblanceolate, sometimes more than 1 $\mathrm{cm}$. wide; petals obovate, 5-7 $\mathrm{mm}$. long; head of fruit globose; achenes glabrous, with a minute beak. R. Flammula intermedius Hook. Shores and wet pastures: Alaska-Ida.-Calif.-Ont.-(? Newf.) Submont. My-Jl.

3. R. microlonchus Greene. Stem $7-15 \mathrm{~cm}$. high; basal leaves slenderpetioled; blades narrowly lanceolate, entire, 3-5 $\mathrm{cm}$. long; cauline leaves few, relatively broader; flowers about $8 \mathrm{~mm}$. broad; petals $5-8$, obovate; achenes few in a depressed globose head, obliquely obovoid, tipped with a stout style, glabrous. Wet places: n Ida. Au.

4. R. alismaefolius Geyer. Stem glabrous or slightly hairy on the peduncles, 1-2 dm. (seldom $3 \mathrm{dm}$.) high, with rather spreading branches; basal leaves $1 \mathrm{dm}$. or less long, glabrous, petioled, oval to lanceolate, entire or denticulate; cauline leaves subsessile or short-petioled, lanceolate; petals obovate-oblong, 6-8 mm. long; head of achenes depressed-globose; achenes glabrous; beak subulate, curved. $R$. calthaefolius Greene. $R$. unguiculatus Greene, a form with somewhat clawed petals. Wet cold soil, below the snow or in open woods: Wyo.-Colo.-Nev.Wash. Mont.-Subalp. Je-Au.

5. R. Bolanderi Greene. Stem stout, 3-10 dm. high, glabrous, or the peduncles strigose; basal leaves 1-2 dm. long, petioled, glabrous, lanceolate, thick, callous-denticulate or entire; stem-leaves similar, subsessile; petals 5 , broadly obovate, $7-10 \mathrm{~mm}$. long; achenes in a globose head, numerous, nearly $3 \mathrm{~mm}$. long, with a subulate slightly curved beak. Wet places and shallow water: B.C.-Ida.-Calif. Submont. Ap-Je.

6. R. alismellus (A. Gray) Greene. Stem 1-2 dm. high, slender; basal leaves $1 \mathrm{dm}$. long or less, glabrous, long-petioled, oval to elliptic, acute at both ends; stem-leaves similar; petals obovate, 5-6 mm. long; head of fruit globose, 4-5 mm. broad, glabrous, with a subulate beak. $R$. alismaefolius alismellus A. Gray. Wet meadows and along streams: Wash.-Mont.-Wyo.-Calif. Submont.-Mont. Je-Au.

7. R. Populago Greene. Stem 1.5-2 dm. high, glabrous, slender; basal leaves long-petioled, glabrous; blades about $2 \mathrm{~cm}$. wide, oval, to nearly round, cordate or rounded at the base, $2-3 \mathrm{~cm}$. long, subentire, thin; stem-leaves shortpetioled or subsessile, ovate, obtuse; petals 5-6, oblong-obovate; achenes glabrous, in a globose head. R. Cusickii M. E. Jones. Mountains: Ore--Ida.Wash. Submont. J-Au.

8. R. Macauleyi A. Gray. Stem 1-1.5 dm. high, glabrous or sparingly hairy above, the base surrounded by the remnants of old leaves; basal leaves thick, $0.5-2 \mathrm{~cm}$. wide, petioled, glabrous; blades oblong or elliptic or spatulate, few-toothed at the apex; stem-leaves oblong-cuneate, sessile; petals broadly obovate, deep yellow; heads of achenes ovoid, about $5 \mathrm{~mm}$. broad; achenes glabrous; beak $0.5 \mathrm{~mm}$. long, subulate, nearly straight. Alpine peaks among rocks: s Colo.-n N. M. Mont. -Subalp. Je-Jl.

9. R. nivalis L. Stem more or less black-hairy, at least above; basal leafblades $0.5-2 \mathrm{~cm}$. wide, reniform or flabelliform, usually 3 -cleft; middle lobe entire or 3-toothed and the lateral ones 2-4-toothed; petals about $1 \mathrm{~cm}$. long, broadly 
obovate; head of fruit ovoid; achenes glabrous; beak about $1 \mathrm{~mm}$. long. Aretic regions and alpine summits: Greenl.-Alta.-Alaska; Eurasia. Alp. Je-Au.

10. R. glaberrimus Hook. Stem $1 \mathrm{dm}$. high or less, glabrous, more or less fleshy; basal and lower cauline leaves petioled, thick, glabrous; blades reniform to rounded-oval, usually more or less 3-lobed at the apex; upper stem-leaves cuneate or oblanceolate, entire or 3 cleft; petals rounded-oval, $8-12 \mathrm{~mm}$. long; heads of achenes globose; achenes glabrous, with an only slightly curved beak. $R$. ellipticus Greene, a form with thinner, more entire basal leaves. Wet places: Wash.-Mont.-N.M.-Calif. Plain-Submont. Mr-My.

11. R. cardiophyllus Hook. Stem $1.5-3 \mathrm{dm}$. high, more or less villous; basal leaves petioled, thick, pubescent when young; blades $2-4 \mathrm{~cm}$. wide, reniform or cordate; stem-leaves divided into linear lobes; heads of achenes usually oblong or ellipsoid. R. affinis validus A. Gray. Wet meadows, bogs, and along streams: Sask.-Neb.-Colo.-Wash.-Alta. Plain-Mont. My-Au.

12. R. inamoenus Greene. Stem $2-3 \mathrm{dm}$. high, sparingly silky or in age glabrate; basal leaves petioled; blades $2-5 \mathrm{~cm}$. wide, from orbicular to flabelliform or obovate in outline, the later leaves sometimes pedately 5-divided, with oblanceolate-cuneate divisions; stem-leaves 3-divided, with cuneate or oblanceolate divisions, or the upper with linear lobes; sepals sparingly pubescent; petals oval; heads of achenes $1 \mathrm{~cm}$. long or less, over $5 \mathrm{~mm}$. thick. R. affinis A. Gray, not Hook. Meadows and along streams: Mont.-N.M.-Utah-Ida. Submont.-Mont. $\mathrm{My}-\mathrm{Au}$.

13. R. micropetalus (Greene) Rydb. Stem slender, $2-3 \mathrm{dm}$. high, sparingly hairy or glabrate; leaves similar to those of the preceding, but usually thinner; petals light yellow; heads of achenes in well-developed specimens often $2 \mathrm{em}$. long, about $4 \mathrm{~mm}$. thick. $R$. affinis leiocarpus $\mathrm{S}$. Wats., in part, not Trautv. $R$. affinis micropetalus Greene. Wet meadows and along streams: Colo.-Utah -Ariz.-N.M. Submont.-Subalp.

14. R. afflnis $\mathrm{R}$. Br. Stem slender, $1.5-3 \mathrm{dm}$. high, sparingly silky or glabrate; basal leaf-blades $2-4 \mathrm{~cm}$. wide, the earliest 3 -cleft and coarsely toothed or rarely merely toothed, the rest pedately divided into cuneate to oblong or linear, cleft segments; stem-leaves sessile, with linear divisions; petals oval; head of fruit oblong or ovoid, $5-10 \mathrm{~mm}$. long. (?) $R$. oreogenes Greene. Bogs and wet meadows: Baffins Bay-Sask.-Colo.-Alaska. Subalp.-Mont. My-Au.

15. R. saxicola Rydb. Stem about $1 \mathrm{dm}$. long, decumbent or ascending, glabrous; basal leaf-blades $2-4 \mathrm{~cm}$. wide, 3 -cleft, the middle lobe narrow, entire or slightly 3 -toothed, the lateral ones very oblique, coarsely 3-4-toothed; stemleaves sessile, pedately 3-7-cleft into linear lobes; sepals obovate, half as long as the broadly obovate petals; achenes usually more or less pubescent. Among rocks in the mountains: Alta.-Mont.-Wyo.-Utah. Mont. Je-Jl.

16. R. eximius Greene. Stem glabrous or nearly so, 1-2 dm. high, erect; basal leaf-blades $2-4 \mathrm{~cm}$. wide, pedately 3-7-cleft, with lanceolate divisions; stemleaves sessile, with linear divisions; sepals oval or oblong; petals broadly cuneateobovate, $10-12 \mathrm{~mm}$. long, often overlapping. Below snowdrifts: Mont.-Colo. Mont.-Subalp. J1-S.

17. R. Suksdorfii A. Gray. Stem about $1 \mathrm{dm}$. high, glabrous; basal leafblades $1.5-3 \mathrm{~cm}$. wide, deeply $3-5$-cleft, with cleft acute divisions; petals roundobovate, retuse, 8-12 mm. long. Damp ground in the mountains: Wash.-Alta. -Mont. Mont.-Subalp. Je-Au.

18. R. utahensis Rydb. Stems 1-2 dm. high, branched above; basal leafblades almost orbicular, rather thick, crenate or round-lobed; stem-leaves sessile, deeply cleft or divided into 4-5 oblong or elliptic, obtuse segments; sepals elliptic to obovate, at last reflexed; petals exceeding the sepals; beak rather short. Wet places in the mountains: Utah. Mont. Jl.

19. R. alpeophilus A. Nels. Stem $1.5-3 \mathrm{dm}$. high, branched above; basal leaf-blades $1.5-4 \mathrm{~cm}$. wide, orbicular or flabelliform, the later ones often deeply 3-lobed, with a narrow middle lobe; divisions of the sessile upper stem-leaves 

with linear or oblong divisions; sepals $2-3 \mathrm{~mm}$. long, oblong; petals oblong. Wet places and open woods: Lab.-Fla,-Colo--B.C. Plain-Submont. Ap-Jl.

31. R. micranthus Nutt. Stem 1.5-4 dm. high, branched; basal leaf blades 1-4 $\mathrm{cm}$. wide, the later 3 -cleft or 3-divided, with oblanceolate-cuneate to obovate divisions; upper stem-leaves with linear divisions, sessile; flowers and achenes as in the preceding. $R$. abortivus micranthus A. Gray. Rich woods: Que.-Pa. Colo.-Sask. Plain-Mont. Ap-Je.

32. R. sceleratus L. Stem glabrous or nearly so, stout, more or less fleshy, 1.5-6 dm. high, freely branching; blades of the basal leaves $3-10 \mathrm{~cm}$. wide, reniform, 3-cleft or 3-5-parted; segments round-lobed; upper stem-leaves sessile and with linear lobes; sepals 3-4 mm. long, hairy; petals elliptic; head of achenes oblong, with numerous small glabrous achenes; beak minute. $R$. eremogenes Greene. Shallow water and swamps: N.B.-Fla.-N.M.-S.D.; Eurasia. Plain -Mont. Ap-Au.

33. R. Douglasii Howell. Stem 3-7 dm. high, usually slender; blades of basal leaves $2-6 \mathrm{~cm}$. wide, the middle division 3 -cleft and toothed, the lateral ones twice 2-cleft; petals elliptic or spatulate, slightly exceeding the sepals; achenes rather few, glabrous. $R$. tenellus Nutt. $R$. Nelsonii tenellus A. Gray. $R$. arcuatus Heller. Wet places among bushes and open woods: Alaska-Mont. -Colo.-Calif. Submont.-Mont. Ap-JI.

34. R. Bongardi Greene. Stem stout, 4-8 dm. high; basal leaf-blades 3-10 $\mathrm{em}$. wide, more distinctly eordate at the base, with broader divisions; flowers and fruit as in the preceding, but the achenes usually hirsute when young. $R$. occidentalis Lyallii A. Gray. R. Lyallii Rydb. R. Greenei Howell. Open rich woods: Alaska-Mont,-Colo--Ore. Submont.-Mont. Ap-Jl.

35. R. Earlei Greene. Like the two preceding; stem sparingly hairy or glabrous, 3-5 dm. high; leaves resembling those of $R$. Bongardi; petals ellipticobovate, nearly twice as long as the sepals; achenes glabrous. Along mountain streams: Colo. Mont. Je.

36. R. acriformis A. Gray. Stem strict, 3-5 dm. high; leaf-blades $2-6 \mathrm{~cm}$. wide, strigose, bi- or tri-ternately cleft into lanceolate or linear divisions, the uppermost merely ternate and sessile; sepals strigose, elliptic, about $6 \mathrm{~mm}$. long; petals about $8 \mathrm{~mm}$. long, broadly obovate, of ten retuse. Bogs and wet meadows: Ida.-Mont.-Colo. Submont.-Mont. Je-Au.

37. R. occidentalis Nutt. Stem usually ascending, hirsute, $2-3 \mathrm{dm}$. high; basal leaf-blades $2-4 \mathrm{~cm}$. wide, densely pubescent, deeply 3 -parted; terminal segment cuneate, 3-lobed and often toothed; lateral ones obiquely ovate, cleft and toothed; upper stem-leaves small and with linear divisions; petals 10-12 $\mathrm{mm}$. long, more than twice as long as the sepals. $R$. Nelsonii A. Gray, in part. Open woods and low ground: Alaska-Mont.-Wyo.-Ore. Submont. Ap-Je.

38. R. montanensis Rydb. Stem stout, $3-5 \mathrm{dm}$. high, sparingly hirsute; basal leaf-blades $3-6 \mathrm{~cm}$. wide, silky-hirsute, ternately divided, the divisions again parted and cleft into linear or lanceolate segments; upper stem-leaves sessile, with few linear segments; petals $7-10 \mathrm{~mm}$. long. $R$. MacCallae Davis, a slender, less leafy form. Wet meadows: Alta.-Mont.-Ida. Submont.Mont. Je-Au.

39. R. oreganus (A. Gray) Howell. Annual; stem erect, glabrous or with a few scattered hairs, 2-10 dm. high; leaves ternate, glabrous; divisions broadly ovate, deeply 3-lobed and serrate; petals obovate, $6-8 \mathrm{~mm}$. long, twice as long as the reflexed sepals; heads of fruit oblong or oval. Wet places: Ore.-Ida.Wash. Submont. Je-Au.

40. R. pennsylvanicus L. f. Mostly annual; stem erect, branching, hirsute, 3-8 dm. high; leaf-blades $5-15 \mathrm{~cm}$. wide, very hairy, ternate; divisions petioled (especially the terminal one), ternately or pinnately divided, cleft and toothed, with lanceolate teeth; petals oblong, 2-4 mm. long, shorter than the reflexed sepals; beak broad, flat, less than half as long as the achene. Wet places and shallow water: N.S.-Ga.-N.M.-Wash.-B.C. Plain-Submont. Je-Au. 
41. R. Macounii Britton. Stem 2-6 dm. high, usually very hirsute, at first usually erect, but later decumbent, branched and leafy; leaf-blades $5-15 \mathrm{~cm}$. wide, ternate, hirsute, especially beneath; segments petiolate, especially the terminal one, rhombic-obovate, twice ternately cleft and toothed; petals obovate, 5-7 mm., equalling or somewhat exceeding the sepals. Wet meadows: Ont.Ia.-N.M.-Utah-B.C. Plain-Submont. Je-Au.

42. R. rivularis Rydb. Stem hirsute, sometimes more than $1 \mathrm{~m}$. long, rooting at the nodes and there producing plantlets; leaves ternate, $5-15 \mathrm{~cm}$. wide; divisions petiolate, ovate, 3 -cleft and coarsely toothed; petals rounded-obovate, about $4 \mathrm{~mm}$. long, scarcely equalling the sepals. R. repens $\mathrm{S}$. Wats., not L. River banks and along ditches: Nev.-Ariz.-Neb. Plain-Submont. Au.

43. R. repens L. Stem strigose or nearly glabrous, at first ascending, then decumbent and creeping; leaf-blades 3-8 $\mathrm{cm}$. wide, ternate or the lower biternate, strigose or glabrate; divisions petiolate or the lateral ones sometimes subsessile, ternately or biternately cleft and toothed; petals broadly obovate or flabelliform, fully twice as long as the sepals; beak about one-fourth as long as the achene. Meadows and roadsides: Newf.-Va.-Utah-Wash.; adv. or nat. from Eu. Plain-Submont.

44. R. acris L. Stem erect, strigose or somewhat hirsute, or nearly glabrous, $3-9 \mathrm{dm}$. high; blades of the basal leaves $3-8 \mathrm{~cm}$. wide, palmately $3-5$-divided to near the base, more or less hairy; divisions broadly rhombic in outline, twice cleft into lanceolate lobes; petals broadly obovate, $1 \mathrm{~cm}$. long or more, more than twice as long as the sepals; beak slightly curved, about one-fourth as long as the achene. Fields, meadows, and roadsides: Newf.-N.C.-Mo.-B.C.; nat. from Eu. Plain-Submont.

45. R. platyphyllus (A. Gray) A. Nels. Stem 3-6 dm. high, stout, striate, more or less hirsute; basal leaves 6-15 $\mathrm{cm}$. wide, biternate or pinnate, with the lower divisions deeply $2-3$ divided; divisions ovate in outline, eleft and toothed; divisions of the upper leaves lanceolate; sepals reflexed; petals 8-12 mm. long; heads of fruit oblong or subglobose, $12-18 \mathrm{~mm}$. long and $10-12 \mathrm{~mm}$. thick. $R$. orthorhynchus platyphyllus A. Gray. Wet places: Utah-Calif.-Wash. Submont.-Mont. Ap-Au.

46. R. orthorhynchus Hook. Stem slender, hirsute to nearly glabrous; lower leaves pinnate; divisions cleft into oblong or lanceolate to linear lobes; petals elliptic, $8-12 \mathrm{~mm}$. long; head of fruit globose. Wet ground: B.C.-Wyo. - Ore. Submont. My-Je.

47. R. delphinifolius Torr. Plant glabrous or slightly hairy when young; immersed leaves 5-10 $\mathrm{cm}$. wide, finely dissected into capillary divisions, shortpetioled; floating or emerged leaves $2-5 \mathrm{~cm}$. wide, with longer petioles, repeatedly ternate, with linear lobes; leaves when growing in mud (var. terrestris) with much shorter and broader divisions, the lobes oblong or lance-ovate; petals $5-8 \mathrm{~mm}$. long, obovate; head of fruit globose or slightly oblong. $R$. multifidus Pursh. Shallow water or mud: Me.-N.C.-Kans.-Utah-B.C. Plain. Je-Au.

48. R. Purshii Richards. Leaf-blades $1-3 \mathrm{~cm}$. wide, cordate at the base, palmately divided in 3-7 more or less cuneate and lobed or eleft divisions, or the immersed ones dissected into filiform divisions; petals oboyate, 4-5 $\mathrm{mm}$. long; head of fruit globose, $5-6 \mathrm{~mm}$. broad. Water or mud: N.S.-Ont.-Colo. -Ore.-Alaska. Plain-Mont. Je-S.

49. R limosus Nutt. Leaf-blades 1-3 cm. wide, reniform in outline, palmately divided into more or less cuneate, cleft or lobed divisions; petals obovate, 4-5 $\mathrm{mm}$. long; head of fruit globose, 4-5 mm. thick. Shallow water and mud: Mont.-Wyo.-Utah-Wash. Submont. Jl-Au.

Ranunculus limosus $\times$ sceleratus, with the habit of $R$. sceleratus and the leaves and pubescence of $R$. limosus, has been collected in Idaho.

50. R. intertextus Greene. Leaf-blades $1-3 \mathrm{~cm}$. wide, rounded or slightly reniform, usually truncate at the base, palmately 3-7-lobed, with rounded entire lobes; petals obovate, 3-4 mm. long; head of fruit globose, 4-5 mm. thick; beak 
minute. R. natans A. Gray, not C. A. Mey. Water: Colo.-Wyo.-Ida. Mont. Je-Au.

51. R. hyperboreus Rottb. Creeping mud plant, glabrous, usually less than $1 \mathrm{dm}$. long; leaf-blades less than $1 \mathrm{~cm}$. broad, palmately 3-5-lobed, cuneate or rounded at the base; petals $2-3 \mathrm{~mm}$. long; heads of achenes about $3 \mathrm{~mm}$. thick; beak minute. In mud: Greenl.-Lab.-Mont.-Alaska. Alp.-Subalp. $\mathrm{Jl}-\mathrm{Au}$.

52. R. arvensis L. Stem glabrous or sparingly pubescent, branched above, 3-4 dm. high; lower leaves petioled; blades cuneate, 3-5-lobed at the apex; the rest of the leaves short-petioled, twice or thrice ternate; primary divisions distinctly petioluled, the ultimate ones laneeolate or linear; sepals lanceolate, yellowish, membranous, long-pilose, $5 \mathrm{~mm}$. long; petals obovate, strongly veined, 6-7 $\mathrm{mm}$. long; achenes few, obliquely ovate, compressed, 7-10 mm. long, spiny; beak 3-4 mm. long, flat, subulate, slightly curved. Waste places: N.J.-O.Utah; adv. from Eu. Je-Au.

\section{Coptídium Beurl:}

Scapose perennial herbs, with slender, stoloniferous rootstocks. Leaves basal, petioled, with reniform, 3-parted blades, the divisions of which are again lobed. Scape 1-flowered. Sepals and petals 5, the latter yellow. Pistils rather few; styles long. Achenes obliquely ovate, the lower half enclosing the seeds, the upper portion empty, flattened, somewhat spongy.

1. C. lapponicum (L.) Gand. Stem scapiform, about $1 \mathrm{dm}$. high, filiform, glabrous, naked or with a single small leaf; basal leaf-blades $2-5 \mathrm{~cm}$. wide, glabrous, ternately divided; divisions cuneate, $3-5$-lobed; petals elliptic, about 5 $\mathrm{mm}$. long, equalling the sepals; achenes about $5 \mathrm{~mm}$. long, $2 \mathrm{~mm}$, wide, acute at both ends; beaks about $1.5 \mathrm{~mm}$. long, hooked. Ranunculus lapponicus L. Anemone nudicaulis A. Gray. In moss: Lab.-Ont.-Minn.-Alta.-Alaska; Eu. Subalp.-Subarctic-Boreal. Je-JI.

\section{BECKWÎTHIA Jeps.}

Perennial herbs, with fibrous, fascicled roots. Leaves alternate, palmately dissected. Flowers perfect, solitary or few. Sepals marcescent, persistent. Petals large, broad and overlapping, white or rose-colored, nectariferous and with a rudimentary scale. Pistils many. Achenes thin-walled, utricular, compressed, narrowly scarious-margined, apiculate.

Scape 1-flowered, bractless; achenes 8-10 mm. long, inflated. Scape $2-3-$ 1. B. Andersonii. Scape 2-3-flowered, with a leaf-like bract; achenes $3-4 \mathrm{~mm}$. long, not inflated.

1. B. Andersonii (A. Gray) Jeps. Scape about $1.5 \mathrm{dm}$. high; leaves fleshy, glabrous, bi- or triternate and parted into linear or lanceolate lobes; sepals broadly elliptic; petals orbicular, pink, $10-15 \mathrm{~mm}$. long; achenes flattened, but inflated. Ranunculus Andersonii A. Gray. In rocky mountains: Ore.-Ida.Utah-Calif. Submont.-Mont. Ap-My.

2. B. juniperina (Jones) Heller. Seape $2-3 \mathrm{dm}$. high; leaves basal, petioled, triternately divided, with short lanceolate lobes; sepals greenish, broadly obovate and enclosing the fruit; petals first white, veined with pink, becoming purple and 10-15 mm. long, broadly oval or orbicular; achenes flat. Ranunculus Andersonii tenellus S. Wats. Gravelly mountain sides: Utah. Mont. Ap.

\section{HALERPÉSTES Greene.}

Perennial herbs, with runners. Leaves mainly basal, petioled, cleft or toothed. Stem more or less scapiform. Flowers small, perfect, cymose or solitary. Sepals usually 5, spreading, tardily deciduous. Petals 5-12, each with a nectariferous pit at the base. Stamens and pistils numerous. Achenes compressed, thin-walled, longitudinally striate.

1. H. Cymbalaria (Pursh) Greene. Leaves glabrous, more or less fleshy; blades rounded-cordate or reniform, erenate, 4-18 $\mathrm{mm}$. long; scapes 2-30 $\mathrm{cm}$. 
long; flowers 1-7; sepals yellowish green, oval or oblong, 3-7 $\mathrm{mm}$. long; petals oblong-spatulate, slightly shorter; heads of fruit rounded-oblong, 6-16 mm. long. Ranunculus Cymbalaria Pursh. Wet sandy or alkaline soil: Lab.-N.J.-N.M. -Calif.-Alaska; Mex. and S. Am. Son.-Plain-Mont. My-Jl.

\section{CYRTORHÝNCHA Nutt.}

Perennial herbs, with fascicled fleshy-fibrous roots. Leaves alternate, biternate, the basal ones long-petioled. Flowers cymose, perfect. Sepals membranous, yellowish, deciduous. Petals 5-9, narrow, pale yellow, bearing a callosity on the inner face, or wanting. Stamens 10-20. Pistils several; style recurved. Achenes oblong or ellipsoid, terete, prominently 10-costate, subcoriaceous, filled by the oblong erect seed.

Sepals spatulate or oblong-ovate, more or less contracted at the base.

Leaf-segments thick, mostly acute; inflorescence corymbiform.

Leaf-segments thin, broad; inflorescence not corymbiform.

Sepals broadly round-ovate, not at all clawed; petals usually wanting.

1. C. ranunculina. 2. C. rupestris,

3. C, neglecta.

1. C. ranunculina Nutt. Stems 1-2 dm. high; basal leaves long-petioled; blades 4-6 $\mathrm{cm}$. broad; divisions deeply parted and cleft into lanceolate or oblong lobes; stem-leaves with scarious stipules, short-petioled and with linear lobes; sepals 3-5 mm. long, yellowish; petals spatulate or oblanceolate, clawed; Ranunculus Nuttallii A. Gray. Foot-hills and draws: Colo.-Wyo. Submont. Ap-Jl.

2. C. rupestris Greene. Stem about $3 \mathrm{dm}$. high; leaves long-petioled; blades biternate, thin, with broad divisions; flowers few, 5 or 6 , on slender pedicels; petals variable, some obovate, some spatulate and long-clawed. Moist cliffs: Black Cañon, Colo. Submont. Je.

3. C. neglecta Greene. Stem $3 \mathrm{dm}$. or more; leaves like those of $C$. ranunculina; divisions less dissected and with broader lobes; sepals $3 \mathrm{~mm}$. long; petals usually none, or few and narrowly spatulate; stamens few, usually about 10. Dry ravines: Colo. Submont. My.

\section{Cáltha (Rupp.) L. Marsh-marigold, Meadow-Gowan.}

Perennial herbs, somewhat fleshy. Leaves few, mostly basal, petioled; blades elliptic, oval, cordate or reniform, entire or crenate. Sepals 5-15, large, more or less petal-like, deciduous, yellow, white, or pink. Petals wanting. Stamens numerous; filaments short. Carpels numerous or several, sessile; ovules numerous, in 2 rows on the ventral suture. Fruit follicles, dehiscent on the ventral suture.

Stem scapiform or rarely with a small leaf, erect; sepals white or greenish white.

Plant 1-3 dm. high, often 2-flowered; leaf-blades orbicular or oval, 3-10 cm. long. Filaments narrower than and twice as long as the anthers; follicles erect.

1. C. leptosepala.

Filaments broader than the anthers and only slightly longer; follicles ascending

or more or less spreading above.
Plant $5-8 \mathrm{~cm}$. high, one-flowered; leaf-blades $1-2 \mathrm{~cm}$. long; flaments broader than the anthers and 2-3 times as long. $\quad 3$. C, chelidonii.
Stem leafy, creeping or floating.
4. C. natans.

1. C. leptosepala DC. Glabrous perennial, with a short erect rootstock; leaf-blades oval in outline, with a shallow sinus, sinuately toothed or crenate; petals oblong, 10-18 mm. long; follicles about $15 \mathrm{~mm}$. long; beak somewhat curved, nearly $1 \mathrm{~mm}$. long. C. Macounii Greene. Swamps and marshy meadows: Wash.-B.C.-Mont.-Alta. Mont.-Alp. Jl-Au,

2. C. rotundifolia (Huth) Greene. Glabrous perennial, with a short usually erect rootstock; leaves mostly basal, long-petioled, 2-3 dm. long; blades of the earliest sometimes orbicular, with a deep closed sinus, the rest or all more elongate, with an open sinus, dentate, crenate, or subentire; peduncles 2-3 dm. high; sepals 6-10, oblong or rarely oval, $12-20 \mathrm{~mm}$. long; follicles $15-20 \mathrm{~mm}$. long, straight; beak about $1 \mathrm{~mm}$., straight. $C$. leptophylla rotundifolia Huth. C. chionophila Greene. Swamps and under the snow: Wyo.-N.M.-Utah. Mont.-Subalp. Je-Au. 
3. C. chelidonii Greene. Dwarf perennial; leaves mostly basal, $3-4 \mathrm{~cm}$. long, short-petioled; blades broadly cordate to oval or ovate in outline, with a short open sinus, mostly entire; petals $5-8,10-12 \mathrm{~mm}$. long, oblong. C. uniflora Rydb., a dwarf form with a large flower. Along alpine streams and below the snow: B.C.-Mont. Alp. Jl-Au.

4. C. natans Pallas. Stem slender, floating or creeping, rooting at the nodes, $1.5-5 \mathrm{dm}$. long; lower leaves long-petioled; blades cordate-reniform, 3-5 $\mathrm{cm}$. wide, entire or crenate, with a narrow sinus; upper leaves short-petioled and smaller; sepals white or pinkish, 6-8 mm. long, oval, obtuse; follicles about 4 mm. long; beak minute. In water: Minn.-Alta.-Alaska; Siberia. Mont.Boreal. Jl-Au.

\section{TRÓLLIUS L. GLOBE-FLOWER.}

Glabrous perennials, with rootstocks. Leaves alternate, palmately lobed or divided. Flowers solitary, or few, terminal, regular, perfect. Sepals 5-15, yellow, lilac, or in ours white, petaloid, deciduous. Petals 5-8, small, tubular at the base. Stamens numerous, hypogynous. Pistils numerous, forming a subglobose head. Fruit of numerous subcylindric, many-seeded follicles, opening along the ventral suture. Seeds numerous in two rows.

1. T. albiflorus (A. Gray) Rydb. Stem erect, $2-6 \mathrm{dm}$. high, 2-4-leaved; lower leaves Iong-petioled, the uppermost subsessile; blades palmately divided, $5-10 \mathrm{~cm}$. wide, nearly orbicular in outline; divisions rhombic or obovate, cleft and incised; sepals 5-7, ovate or broadly oval, white; petals clawed, $3-5 \mathrm{~mm}$. long, linear; follicles $10-20$, about $1 \mathrm{em}$. long. T. laxus albiflorus A. Gray. Wet meadows and along streams: Alta.-B.C.-Wash.-Colo. Mont.-Subalp. $\mathrm{Je}-\mathrm{Au}$.

\section{CóPtis Salisb. Gold-THREAd.}

Low scapose perennial herbs, with slender rootstocks. Leaves basal, petioled, ternately compound. Scape slender, 1 -flowered. Sepals 5-7, oval, petallike, deciduous, white, with yellowish bases. Petals shorter than the stamens, club-shaped, hollowed and nectariferous at the thickened summit. Stamens numerous. Pistils 3-7. Fruit of as many stipitate follicles, forming an umbellike cluster. Seeds smooth and shining.

1. C. trifoliata (L.) Salisb. Leaves $5-10 \mathrm{~cm}$. long, ternate; leaflets evergreen, broadly obovate, slightly 3-5-lobed and crenate, shining; scape $5-12 \mathrm{~cm}$. long; sepals white, with yellow base; petals $2-3 \mathrm{~mm}$. long; stipe of the follicles 7-8 $\mathrm{mm}$. long; body about $6 \mathrm{~mm}$. Woods and bogs: Greenl.-Md.-Minn.B.C.-Alaska; n Eurasia. Mont.-Boreal. My-Au.

\section{CHRYSOCÓPTIS Nutt.}

Low scapose perennials, with rootstocks. Leaves basal, petioled, pinnately 3-5-foliolate, with lobed or dissected leaflets. Scapes 2-4-flowered. Flowers perfect, regular. Sepals $\mathbf{5}$ or 6 , linear or ligulate, attenuate, greenish or yellowish white, deciduous. Petals filiform or ligulate beyond the nectariferous portion. Pistils several. Fruit of stipitate follicles. Seeds several, smooth and shining.

1. C. occidentalis Nutt. Leaves $1-1.5 \mathrm{dm}$. long, long-petioled, pinnately ternate; divisions broadly ovate, pinnately $3-5$-lobed and serrate, shining, $3-6$ $\mathrm{cm}$. long; main peduncle about $1 \mathrm{dm}$. long; petals and sepals subulate; stipe of the follicles about $6 \mathrm{~mm}$.; body about $12 \mathrm{~mm}$. long. Woods: Mont.-Ore--Wash. Submont.-Mont. My-Je.

\section{ACTAÈA L. BANEBERRY.}

Perennial herbs, with thick rootstocks and erect stems. Leaves basal and cauline, ternately decompound. Flowers small, in terminal racemes. Sepals $3-5$, petal-like, usually white. Petals 4-10, small, narrow, elawed. Stamens numerous; filaments flattened, white. Pistil solitary, sessile; style none; stigma 2-lobed, depressed. Fruit berry-like, with depressed, horizontal seeds. 
Filaments whitish; raceme short; pedicels in fruit $1-3 \mathrm{~cm}$. long. Fruit white, ellipsoid, $9-12 \mathrm{~mm}$, long.

Fruit red.

Fruit ellipsoid, 10-12 $\mathrm{mm}$. long.

Fruit spherical or nearly so, 5-7 mm. long.

Filaments greenish; raceme elongate; pedicels very short, even in fruit less than $1 \mathrm{~cm}$. long; fruit red.

1. A. eburnea.

2. A, rubra.

3. A, arguta.

4. A. viridiflora.

1. A. eburnea Rydb. Stem 6-10 dm. high, glabrate or villous-puberulent above; leaves ternate or twice ternate, the divisions pinnate; leaflets ovate, usually 3-5-lobed, and sharply serrate; pedicels slender; sepals orbicular, early deciduous; petals narrowly rhombic-spatulate, acute; fruit about 12-seeded; seeds obliquely pear-shaped, about $4 \mathrm{~mm}$. long. In rich woods: B.C.-Ore.-Utah-Colo.S.D.; n N.Y.-Newf. Submont.-Mont. My-Je.

2. A. rubra (Ait.) Willd. Like the preceding, but lower, 3-6 dm. high; leaflets shorter and broader, firmer, darker, acute or short-acuminate; teeth coarser, less sharp; pedicels more divaricate; petals spatulate, acute; seeds about $3 \mathrm{~mm}$, long. Rich woods: N.S.-N.J.-Ia.-Mont.-Alta. Boreal-Mont. $\mathrm{My}-\mathrm{Je}$.

3. A. arguta Nutt. Very similar to A. eburnea in habit, fully as tall; leaflets very thin and light green, long-acuminate and very sharply toothed; sepals with long claws and rhombic acute blades; seeds about 10 , about $3 \mathrm{~mm}$. long. Woods: Alaska-Calif.-N.M.-S.D.-Alta. Submont.-Mont. My-Je.

4. A. viridiflora Greene. Stems usually several from the rootstock, fully as tall as in the preceding; leaflets darker green, ovate-lanceolate, more regularly toothed, more pubescent when young; petals clawed; blades ovate, obovate or lanceolate, usually greenish; fruit red, 10-12-seeded. A. multicaulis Greene. Rocky woods: Ariz.-Colo.-N.M. Submont.-Mont. Je-Jl.

\section{AQUILÈGIA (Tourn.) L. ColUMbine.}

Perennial herbs, with rootstocks and branching stems. Leaves basal and cauline, ternately decompound. Flowers perfect, usually large and showy, regular. Sepals 5, petal-like, deciduous. Petals concave, produced below into a hollow spur, or at least saccate. Stamens numerous, the inner reduced to staminodia; filaments more or less flattened. Pistils 5, sessile, many-ovuled. Fruit follicles, many-seeded, with slender styles. Seeds numerous, smooth and shining, with a hard coat.

Plant very low; stem scapiform and 1-flowered; spur curved; flower blue or purple.

Stem more or less leafy.

1. A. Jonesii.

Petals merely saccate, not spurred at the base; terminal leaflet rhombic, acute.

Petals spurred; all leaflets obtuse.

2. A. Eastwoodiae.

Lamina of the petals longer than the strongly curved spurs, truncate.

Stems many times exceeding the basal leaves; styles in fruit about one-fourth as long as the follicles.

3. A, brevistyla.

Stem only slightly exceeding the basal leaves; styles in fruit about half as long as the follicles.

Plant perfectly glabrous; flowers blue.

4. A. saximontana.

Peduncles and follicles sparingly hairy; flowers sulphur-yellow or greenish.

Lamina of the petals shorter than the slightly curved or straight spurs.

5. A. larimiensis.

Spur not over $2 \mathrm{~cm}$. long; flowers nodding.

Sepals and spurs red; spur usually straight (except in No. 9).

Lamina of the petals small, less than $4 \mathrm{~mm}$. Iong or none; sepals spreading or reflexed.

Sepals $10-15 \mathrm{~mm}$. Iong, shorter than or rarely equalling the spurs.

6. A. truncata.

Sepals 15-25 mm. long, exceeding the spurs. 7. A. columbiana.

Lamina of the petals $6-12 \mathrm{~mm}$. long.

Sepals spreading or reflexed, longer than the spurs. 8. A. formosa

Sepals ascending, usually shorter than the spurs.

Sepals much longer than the lamina of the petals; spur incurved.

9. A. latiuscula.

Sepals equalling or little exceeding the lamina of the petals; spur straight.

Spur gradually tapering to the apex; follicles glabrous.

10. A. rubicunda. 
Spur cylindric-filiform for some distance near the apex; follicles pubescent.

Sepals and spurs wholly yellow; spur

Leaves thick, densely pur, spur usually slightly curved. rowed near the base.

Leaves thin, glabrous or glabrate; spur 12 . A. micrantha. apex.

Spur 2.5-6 cm. long; flowers in anthesis usually erect, tapering to near the 13. A. flavescens.

Basal leaves usually twice ternate; spur 3-4 cm. long.

Sepals blue or white, ovate-lanceolate, acute or obtuse; spur $3-5 \mathrm{~cm}$. long.

Stem (except the upper part) and petioles glabrous. Plant 3-5 dm. high; leaflets thin, rather large, not conspicuously
glaucous.

Plant 1-2 dm. high; leaflets thick, small and conspicuously glaucous. 15. A. scopulorum.

Stem and petioles glandular and villous throughout.

Sepals yellow, lanceolate, somewhat acuminate 16. A. pallens. spur $2.5-3 \mathrm{~cm}$. long.
17 . A. oreophila.

Spur 4-5 4m follicles strongly curved outward. $2 \mathrm{~cm}$. long, ovate-lanceolate, acute: Spur 5-7 cm 18. A. thalictrifolia. acuminate; follicles almost straight. lanceolate to ovate-lanceolate,

1. A. Jonesii Parry. Acaulescent plant, with a densely cespitose short caudex; basal leaves 2-10 cm. long, pubescent, biternate; blades $1-2 \mathrm{~cm}$. in diameter, glaucous; divisions broadly cuneate, deeply $3-5$-cleft; scape $2-5 \mathrm{~cm}$., rarely $10 \mathrm{~cm}$. long; flower erect; sepals about $1.5 \mathrm{~cm}$. long; lamina of the petals broad, rounded at the apex, about $8 \mathrm{~mm}$. long; spur $8-10 \mathrm{~mm}$. long, somewhat incurved; follicles $1.5-2 \mathrm{~cm}$. long. Exposed rocky summits: Wyo.-Alta. Subalp. - Alp. Je-Jl.

2. A. Eastwoodiae Rydb. Stem 4-6 dm. high, glandular-puberulent above; leaves biternate; leaflets 1-2 cm. long, with oblong obtuse lobes; flowers white or roseate; sepals lanceolate, acute, spreading; petals nearly like the sepals; follicles about $12 \mathrm{~mm}$. long; styles 6-7 mm. A. ecalcarata Eastw. A. mancosana (Eastw.) Cockerell. Cañons: Colo. Son. Je-Jl.

3. A. brevistyla Hook. Stem 4-10 dm. high, pubescent or glandular above; basal leaves biternate; stem-leaves ternate or the upper simple and 3-lobed; leaflets 3 -lobed and coarsely crenate; sepals blue, lanceolate, acute, about 15 $\mathrm{mm}$. long; lamina of the petals yellowish white; spur $6-8 \mathrm{~mm}$. long; follicles $2-2.5$ $\mathrm{cm}$. long. Meadows and open woods: Yukon-Alta.-S.D.-Minn. PlainSubmont. Je-Jl.

4. A. saximontana Rydb. Stem 1-2 dm. high; leaves all biternate; leaflets obovate, 2-3-cleft; sepals greenish or blue, obtuse or acutish; lamina of the petals yellowish; spur $5 \mathrm{~mm}$. long or less; follicles 1-1.5 cm. long. A, vulgaris brevistyla A. Gray. A. brevistyla Coulter, not Hook. Among rocks: Colo,e Utah. Mont.-Subalp. JI-Au.

5. A. larimiensis A. Nels. Stem 2-3 dm, high, branched; leaves, except the uppermost biternate; leaflets obovate or cuneate, $1.5-2.5 \mathrm{~cm}$. long, 2-3-cleft and again round-lobed; sepals ovate, acute; lamina of the petals cream-colored;

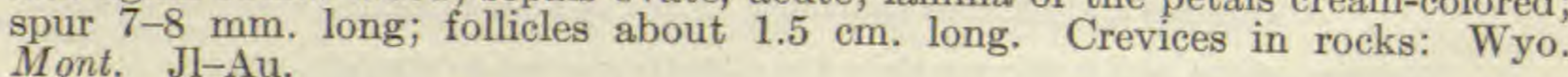

6. A. truncata Fisch. \& Mey. Stem 3-7 dm. high, sparingly pubescent or glabrate; lower leaves biternate, the upper ternate; leaflets obovate, $2-6 \mathrm{~cm}$. long, usually pale and pubescent beneath, 3-eleft and round-lobed; sepals scarlet, lanceolate, acute or acuminate; lamina very short, rounded or obsolete, yellowish; spur scarlet, narrow, elongate-conic, $1.5-2 \mathrm{~cm}$. long, merely with a knob at the end; follicles pubescent, about $2 \mathrm{~cm}$. long. Shady places along streams: B.C.-Calif.-s Utah. Submont.-Mont. My-Jl.

7. A. columbiana Rydb. Stem 6-10 dm. high, glabrous or sparingly pubescent above; leaves twice ternate; leaflets obovate, $2-3 \mathrm{~cm}$. long, more or less glaucous beneath, 2-3-cleft and deeply crenate at the apex; sepals and spurs very bright red; sepals ovate-lanceolate, acute; lamina yellowish, scarcely $3 \mathrm{~mm}$. 
long, truncate; spur 12-18 mm. long; follicles ereet, densely pubescent. Meadows and open woods: Alaska-Ore.-Ida.-Alta. Submont.-Mont. My-Au.

8. A. formosa Fisch. Very similar to the last; leaflets often $4 \mathrm{~mm}$. long; sepals about $2 \mathrm{~cm}$. long, ovate-lanceolate, acuminate; lamina yellow, 6-10 $\mathrm{mm}$. long, truncate; spur $12-18 \mathrm{~mm}$. long, more gradually tapering; fruit as in the preceding. Wooded hillsides and banks of streams: Alaska $-\mathrm{n}$ Calif.-Mont. Submont.-Mont. Je-Au.

Aquilegia flavescens $\times$ formosa. This resembles $A$. flavescens most in habit and the shape of the flowers, but the sepals and spurs are more or less tinged with red. Mont.

9. A. latiuscula Greene. Stem $2-6 \mathrm{dm}$. high, glabrous or sparingly glandular-pubescent above; leaves biternate; leaflets obovate or cuneate, $2-4 \mathrm{~cm}$. long, deeply 3-cleft and round-lobed or crenate, glaucous beneath; sepals ovate-lanceolate, acute, $10-12 \mathrm{~mm}$. long, purplish red; lamina 8-10 $\mathrm{mm}$. long, yellow, rounded at the apex; spur 12-15 mm. long, abruptly narrowed at the middle, more or less incurved; follicles pubescent, about $2 \mathrm{~cm}$. long. A. vulgaris hybrida Hook. A. vulgaris violacea Nutt. Closely related to A, coccinea Small. Open woods: Iowa-Kans.-S.D. Plain-Submont.

10. A. rubicunda Tidest. Stem 1-3 dm. high, pubescent; basal leaves long-petioled, triternate; leaflets $1 \mathrm{~cm}$. long or less, truncate or cuneate at the base, with rounded lobes; sepals ovate, acute, reddish, $1 \mathrm{~cm}$. long or less; lamina of the petals pale yellow, $5-7 \mathrm{~cm}$. long, rounded; spur $2 \mathrm{~cm}$. long. Among rocks: Utah. Mont.

11. A. elongatula Greene. Stem $2-4 \mathrm{dm}$. high, usually with but a single leaf; leaves biternate; leaflets $1.5-2.5 \mathrm{~cm}$. long, deeply 3-cleft and again roundlobed; sepals erect, ovate-lanceolate, acute, greenish or scarlet, about equalling the lamina; this rounded or truncate at the apex, yellow, $8-10 \mathrm{~mm}$. long; spur scarlet, straight, $1.5-2 \mathrm{~cm}$. long. Closely related to A. canadensis L. Wooded hillsides, especially in rocky places: Colo.-N.M.-Utah. Submont.-Subalp.

12. A. micrantha Eastw. Stem 4-5 dm. high, densely glandular-pubescent above; leaves biternate, the upper reduced and more simple; leaflets broadly cuneate, 1-2 cm. long; sepals oval, about $1 \mathrm{~cm}$, long, yellowish or tinged with red; lamina truncate, $7-8 \mathrm{~mm}$. long; spur straight or slightly recurved, 12-15 $\mathrm{mm}$. long; follicles glandular, about $1.5 \mathrm{~cm}$. long, arcuate-spreading above. Cañons: s Utah. Son. Jl.

Aquilegia elegantula $\times$ micrantha. This resembles $A$, micrantha most, but the spurs are less slender and as well as the sepals tinged with red. se Utah.

13. A. flavescens S. Wats. Stem $2-7 \mathrm{dm}$. high; leaves biternate, or the upper only ternate or simple; leaflets $2-4 \mathrm{~cm}$. long, 3-cleft and round-lobed; sepals light yellow or ochroleucous, or tinged with scarlet, lanceolate, 10-18 $\mathrm{mm}$. long; lamina cream-colored, 5-8 mm. long; spur 10-15 mm. long, usually slightly incurved-hooked; follicles about $2 \mathrm{~cm}$. long, pubescent. A. canadensis aurea Regel. A. aurea Junka. A. depauperata M. E. Jones. Open woods: B.C.-Ore.-Utah-Wyo.-Alta. Submont.-Mont. Je-Au.

14. A. coerulea James. Stem $2-6 \mathrm{dm}$. high, from glabrous or nearly so to glandular-pubescent above; leaves except the uppermost biternate; leaflets deeply 2-3-cleft and round-lobed, 1-3 cm. long, glabrous; sepals 2-4 cm. long, blue, rose, or white, ovate-lanceolate; lamina $1.5-2.5 \mathrm{~cm}$. long, rounded at the summit, white or cream-colored; spur straight, $3-5 \mathrm{~cm}$. long; follicles about $3 \mathrm{~cm}$. long, pubescent. A. leptocera Nutt., white-flowered form. ColoRado State Flower. Woods and hillsides: N.M.-Mont.-Ida.-Calif. (in Mont. and Ida., mostly represented by the white form). Submont.-Subalp. Je-Au.

A. coerulea $\times$ elegantula. This resembles $A$. coerulea, but the flowers are smaller, the spurs and sepals shorter and tinged with red. se Utah,

A. coerulea $X$ flavescens. Like $A$. flavescens, but usually lower, with large pale yellow flowers, longer spur and sometimes slightly tinged with blue. Utah.

15. A. scopulorum Tidest. Stem 1-2 dm. high, glabrous or somewhat pubescent above; basal leaves biternate; leaflets crowded, sessile, $1 \mathrm{~cm}$. long or 
less, 3-lobed; stem-leaves few, small, ternate; sepals ovate-oblong, pale blue or pale purple; lamina of the petals white, oblong, rounded; spurs slender, $3-5 \mathrm{~cm}$. long; follicles pubescent. Mountains: Utah. Mont.-Subalp. My-Jl.

16. A. pallens Payson. Stem slender, erect; lower leaves biternate; leaflets cuneate to suborbicular, inclined to be revolute-margined, glaucous, viscid and pubescent beneath; sepals $1.5 \mathrm{~cm}$. long, white or pale blue, lanceolate; petals white; lamina truncate, $8 \mathrm{~mm}$. long, $6 \mathrm{~mm}$. broad; spur slender, straight, $3 \mathrm{~cm}$. long; follicles pubescent. A. coerulea calcarea M. E. Jones. Moist sandstone cliffs: s Utah-w Colo. Son. Je.

17. A. oreophila Rydb. Very similar to $A$. coerulea, but with usually smaller yellow flowers; leaves usually coarser; leaflets $2.5-3 \mathrm{~cm}$. long; lamina about $1.5 \mathrm{~cm}$. long; spur $2.5-3 \mathrm{~cm}$; follicles $2.5 \mathrm{~cm}$. A. coerulea alpina A. Nels. A. coerulea flavescens Jones. On naked summits: Wyo.-Utah. Subalp.-Alp. $\mathrm{Jl}-\mathrm{Au}$.

18. A. thalictrifolia Rydb. Stem $2-5 \mathrm{dm}$. high, glabrous below, finely viscid-puberulent above; leaves twice ternate; leaflets broadly obovate-cuneate, 2-3-cleft and crenate at the apex, 1-1.5 cm. long, bluish green; flowers yellow; laminae of the petals $7-12 \mathrm{~mm}$. long, truncate or rarely rounded at the apex; spur very slender from the base; follicles about $3 \mathrm{~cm}$. long, strongly reticulate and pubescent. Rocky ravines: Tex.-Colo.-Utah-Ariz. Submont.-Subalp. $\mathrm{Je}-\mathrm{Au}$.

19. A. chrysantha A. Gray. Stem 3-10 dm. high, glabrous, or viscidpuberulent above; leaves triternate or the upper ternate; leaflets broadly cuneate, 3-cleft and round-crenate at the apex, 1.5-4 cm. long; flowers yellow; lamina about $2 \mathrm{~cm}$. long, rounded at the apex; follicles about $3 \mathrm{~cm}$. long, narrower and straighter than in the preceding. Along streams and in ravines: N.M.-(? Culo.) -Ariz. Submont. My-S.

\section{DELPHINIUM (Tourn.) L. LARKsPUR.}

Annual or perennial herbs, usually with erect branching stems. Leaves alternate, mostly cauline, palmately lobed or divided. Flowers in racemes or panicles, perfect, irregular, zygomorphic. Sepals 5, the posterior produced below into a spur. Petals 2 or 4 , the two posterior spurred, the lateral ones, if present, small, all in most species 2-cleft at the apex. Stamens numerous. Pistils $1-5$, in ours mostly 3 , many-ovuled; stigmas introrse. Fruit many-seeded follicles.

A. Carpels and follicles 3 , rarely 4 or 5 .

I. Pedicels erect or nearly so.

a. Sepals white or merely tinged with blue or with a blue spot; follicles more than $1 \mathrm{~cm}$. long, about four times as long as broad; seeds squamellate. (I. CAROLINIANA.)

Lobes of the lateral petals divergent; lower pedicels elongate; spur mostly erect; stem strigose-canescent throughout. $1 . D$. Penardii.

Lobes of the lateral petals not divergent; lower pedicels not elongate; spur mostly horizontal; stem usually glabrous below, viscid above.

2. D. virescens.

b. Sepals dark blue; follicles less than $1 \mathrm{~cm}$. long, only 2-3 times as long as broad; seeds not squamellate, but wing-margined. (II. STRICTA.)

Lower petals blue and bearded; perennials with fasciculate tuberous roots. Stem glabrous below.

Stem glabrous throughout; pedicels equalling or exceeding the spur. Leaves pubescent; follicles glabrous. $\quad 27$. D. Brownit.

Leaves glabrous and glaucous; follicles strigose.

Stem puberulent above; follicles viscid-villous. Pedicels shorter than the spurs. Pedicels longer than the spurs.

25. D. elongatum.

3. D. distichum.

4. D. megacarpum. Stem more or less pubescent throughout, finely so below, viscid above.

Spur with reflexed tip; upper petals with a lanceolate, 2-cleft apex: inflorescence appressed-pubescent.

5. D. simplex.

Spur straight; upper petals with an obliquely ovate-triangular apex, slightly 2-toothed; inflorescence villous. $\quad 6 . D$. cyanoreios.

Lower petals white; roots fleshy, fusiform.

Stem leafy throughout, viscid.

Stem leafy only at the base, glabrous below.

7. D. diversicolor.

8. D. Burkei. 
II. Pedicels ascending or spreading.

a. Inflorescence few-flowered; the lower pedicels elongate; sepals broad, spreading, dark blue; leaf-segments narrow; root short and thickened, often tuber-like, (III. BICOLORIA.)

Upper petals as well as the lower blue; pod straight.

9. D. Helleri.

Upper petals white or yellowish, only veined with blue, the lower mostly blue. Follicles 1.5-2 cm. long, more or less arcuate, the upper portion divergent.

Roots fascicled, thick, but not tuber-like; stem usually viscid, at least above; blades of the lateral petals about $10 \mathrm{~mm}$. long.

Spur fully half longer than the obtuse lateral sepals.

Spur only slightly longer than the acute lateral sepals.

10. D. Leonardi.

11. D. bicolor.

Roots tuber-like; stem not viscid; blades of the lateral petals about 5 $\mathrm{mm}$. long.

Stem with long, soft reflexed hairs.

Stem appressed-strigose or glabrous.

Flowers dark blue.

Flowers light blue.

12. D. Menziesii.

13. D. Nelsonii.

14. D. dumetorum.

Follicles less than $1 \mathrm{~cm}$. long, only the tips divergent; stem strigose; root tuber-like.

Segments of the leaves all narrow.

Segments of the leaves all narrow.
Segments of the basal leaves oblong to cuneate. 15. D. Nepauperatum.

b. Lower pedicels not elongate; plant with a long woody taproot or a rootstock.

1. Segments of the basal leaves obtuse, mucronate. (IV. SCAPOSA.)

Sepals light blue; lobes of the first basal leaves linear-oblong; spur a little

longer than the upper petals.

17. D. coelestinum.

Sepals dark blue; lobes of the first basal leaves rounded to oblong; spur nearly twice as long as the upper petals.

Follicles glabrous or sparingly viscid; stem usually scapiform.

Follicles strigose; stem leafy.

18. D. scaposum.

19. D. xylorhizum.

2. Segments of all the leaves acute or acuminate.

a. Plant not all viscid.

* Follicles pubescent. ( $\mathrm{V}$. RoBUSTA.)

Stem grayish strigose throughout.

Leaves divided into cuneate, merely cleft, segments.

Leaves repeatedly divided into linear lobes.

Stem 3-5 dm, high; bractlets oblong, close under the calyx.

21. D, Geyeri.

Stem 5-20 dm. high; bractlets subulate, $2-3 \mathrm{~mm}$, below the calyx.

Stem glabrous and glaucous, at least below.

Plant cespitose, 2-4 dm. high.

Plant not cespitose, 5-20 dm, high.

24. D. robustum.

Inflorescence dense; follicles scarcely at all arcuate.

Leaf-segments $3-7$, broad, cuneate, merely cleft into broadly lanceolate lobes.

Sepals yellowish white or light blue.

Sepals dark blue.
Leaf-segments narrow, repeatedly dissected into linear

22. D. cucullatum. or linear-lanceolate divisions.

Inflorescence paniculate, strigose-puberulent; leafsegments linear.

24. D. robustum.

Inflorescence racemose, simole, glabrous or nearly so; leaf-segments narrowly lanceolate.

Inflorescence lax; follicles strongly arcuate.

25. D. elongatum.

26. D. ramosum.

** Follicles glabrous. (VI. GLAUCA.)

$b$. Plant more or less viscid, especially the pedicels.

* Plant tall, 4-20 dm. high, not cespitose.

Leaves dissected into linear lobes; follicles densely strigose. VISCIDA.)

28. D. viscidum.

Leaves divided into cuneate or rhomboid, merely cleft, divisions.

Follicles viscid-pubescent. (VIII. OCCIDENTALIA.)

Flowers light blue, or yellowish, tinged with blue or purple.

Flowers dark blue.

Follicles glabrous. (IX. SUBALPINA.)

Sepals obtuse.

29. D. multiflorum.

30. D. occidentale.

Sepals acute or acuminate.

Sepals at most equalling the spur. 32. D, Barbeyi.

Sepals much longer than the spur. 33. D. attenuatum.

** Plant less than $4 \mathrm{dm}$. high, cespitose. (X. Alpestria.)

Stem 2-4 dm. high, puberulent or glabrous. 34 . D. glaucescens.

Stem about $1 \mathrm{dm}$. high, viscid-pubescent. 35. D. alpesire.

B. Carpels and follicles solitary; petals 2, united. (XI. COASOLIDAE.)

36. D. Ajacis. 
1. D. Penardii Huth. Stem 2-4 dm. high; lower leaves numerous, with broad, often oblong or lanceolate divisions; upper stem-leaves few and with narrow lobes; inflorescence short; pedicels strongly curved above, bringing the spur in a nearly erect position; follicles pubescent, fully $2 \mathrm{~cm}$. long, erect, and nearly straight. D. camporum Greene. Dry plains: Tex.-Colo.-Ariz. Plain-Submont. Ap-Jl.

2. D. virescens Nutt. Stem 3-15 dm. high; leaves finely dissected, with linear or linear-oblong divisions; racemes long, sometimes $5-6 \mathrm{dm}$.; spur stout, tinged with blue, usually horizontal; follicles pubescent, cylindric, about $2 \mathrm{~cm}$. long, nearly straight and ascending. D. albescens Rydb. Prairies and river valleys: Ill.-Man.-S.D.-Colo.-Tex.-Mo. Plain. My-Jl.

3. D. distichum Geyer. Stem 3-6 dm, high (rarely higher), strict; blades of the lower leaves rather thick and veiny, divided into cuneate divisions and these again cleft into oblong or lanceolate acute lobes; upper leaves with linear divisions; inflorescence very narrow and spike-like, viscid; sepals oval, obtuse, slightly villous; upper petals white, tinged with blue, obtuse; spur straight, about $15 \mathrm{~mm}$. long; follicles erect, viscid-pubescent. Meadows: Wash.-Mont.-Ore. Submont. Jl-Au.

4. D. megacarpum Nels. \& Macbr. Stem 2-5 dm. high, at first cinereouspuberulent, becoming glabrate below; lower leaves long-petioled; blades suborbicular in outline, divided into cuneate divisions cleft into linear lobes, puberulent, slightly ciliate; stem-leaves few and reduced; inflorescence in simple or fewbranched racemes; sepals dark blue, softly hirsute; upper sepals brownish white; follicles 2-2.5 cm. long, erect. Among sage-brush: Ore.-Ida.-Wash. Submont. Je.

5. D. simplex Dougl. Stem about $3 \mathrm{dm}$. high; blades of the lower leaves rather thick and finely pubescent, divided into three cuneate divisions; these with oblong, obtuse lobes; lobes of the upper leaves linear; inflorescence strict, narrow, and spike-like; sepals pubescent, oblong, obtuse; upper petals with bluish base and brownish white apex; follicles pubescent, when mature $6-8 \mathrm{~mm}$. long. $D$. strictum A. Nels. Meadows: Ore-Wash.-Wyo. Submont. Au.

6. D. cyanoreios Piper. Stem 3-6 dm. high; leaves usually with much narrower divisions than in the preceding, those of the stem-leaves narrowly linear; sepals brighter blue and the straight spur lighter in color; upper petals yellowish white, only tinged with blue; otherwise as the preceding. $D$. simplex A. Gray, not Dougl. Damp prairies and wet rocky places: B.C.-Ida.-Ore. Submont. Je-Au.

7. D. diversicolor Rydb. Stem about $4 \mathrm{dm}$. high, simple, strict; leafblades finely pubescent, palmately dissected into linear lobes; inflorescence a narrow raceme; sepals oblong-oval, obtuse, $10-13 \mathrm{~mm}$. long, slightly pubescent; petals all white, with blue veins and yellowish below; follicles densely hairy. Bogs: Mont. Mont. Je.

8. D. Burkei Greene. Stem leafy only near the base, villous-hirsute above; leaf-blades rather fleshy, divided into linear or oblong-linear, obtusish divisions; racemes long and narrow; sepals pubescent exteriorly; follicles appressed-villous. Arid hills: Ida. Submont.

9. D. Helleri Rydb. Stem about $3 \mathrm{dm}$. high, viscid-pubescent throughout, few-leaved; leaf-blades more or less viscid-pubescent, $3-5 \mathrm{~cm}$. broad, the lower dissected into linear obtuse, the upper into narrowly linear acute divisions; sepals more or less pubescent, oval; lower petals with acute crenate lobes; follicles viscidpubescent, nearly straight, about $2 \mathrm{~cm}$. long. Plains: Ida. Plain.

10. D. Leonardi Rydb. Stem 2-5 dm. high; leaf-blades 4-5 cm. wide, dissected into oblong, obtuse divisions, more or less viscid-pubescent; upper leaves with narrowly linear, acute divisions; sepals oblong, obtuse, or the upper acute; lower petals with short lobes; follicles over $2 \mathrm{~cm}$. long, eurved, viscid-pubescent, or in age glabrate. River banks and beaches: Utah. Submont. Ap-My.

11. D. bicolor Nutt. Stem 2-5 dm. high, few-leaved; leaf-blades $2-4 \mathrm{~cm}$. broad, puberulent or glabrate, thick, dissected into linear or linear-oblong obtuse 
divisions; sepals ovate-lanceolate, acute or acuminate, about $15 \mathrm{~mm}$. long; upper petals pale brownish yellow, with blue veins, usually uncleft; lower petals with obtuse wavy lobes; follicles from densely viscid-pubescent to glabrous, $1.5-2 \mathrm{~cm}$. long. Dry ground in the mountains: Wash.-Sask.-Wyo.-Utah-Ore. Plain -Mont. Ap-J.

12. D. Menziesii DC. Closely resembling the preceding, but more or less long-hairy throughout; stem $2-5 \mathrm{dm}$. high; divisions of the basal leaves shorter and broader and often acutish; lower petals scarcely longer than the upper; blades rounded and only slightly cleft; follicles glabrous or pubescent, arcuate. On hills: B.C.-Ida.-Calif. Son.-Submont. Ap-Je.

13. D. Nelsonii Greene. Closely resembling D. bicolor in habit, but usually.more slender; stem $2-5 \mathrm{dm}$. high, finely strigose-puberulent; leaf-blades dissected into linear obtuse divisions; sepals oblong or oval, usually obtuse; petals as those of $D$. bicolor but shorter; follicles abqut $15 \mathrm{~mm}$. long, strigose or glabrous. D. pinetorum Tidest. Hills and grassy slopes: N.M.-Neb.-Alta.Wash.-Mont.-Utah. Submont.-Mont.

14. D. dumetorum Greene. Stem 4-6 dm. high, glabrous or slightly pubescent above, few-leaved; leaf-blades glabrous, $5 \mathrm{~cm}$. broad, 5 -divided to the base, the divisions again cleft into broadly linear lobes; sepals pale lavender, blue, or white tinged with blue, oblong or oval, obtuse, about $12 \mathrm{~mm}$. long; petals white tinged with yellow; follicles puberulent, more or less spreading. Dry hills: Colo. Submont. Je.

15. D. Nuttallianum Pritzel. Resembling D. Nelsonii, but more slender; stem strigose-puberulent or glabrous, 2-4 dm. high; leaf-blades about $3 \mathrm{~cm}$. wide, strigose or glabrate, dissected into narrowly linear lobes; sepals oblong, 8-10 mm. long, obtuse; upper petals whitish, obtuse and merely notched; lower petals with obtuse lobes; follicles 7-8 mm. long, glabrous. D. pauciflorum Nutt. Dry places in the mountains: Wash.-Mont.-Wyo.-Utah-Ore. Submont.Subalp. My-Au.

16. D. depauperatum Nutt. Stem about $3 \mathrm{dm}$. high, viscid-puberulent, rather simple; basal leaf-blades orbicular in outline, $1-4 \mathrm{~cm}$. broad, 5-cleft; divisions usually cuneate, with 2 or 3 oblong lobes; stem-leaves reduced and with narrower divisions, oblong, obtuse; upper petals notched; follicles nearly straight, 6-7 mm. long, viscid. Poor soil: Ore--Ida.-Calif. Son. Je-Jl.

17. D. coelestinum Rydb. Stem 4-5 dm. high, glabrous or slightly pubescent above, leafy; leaves long-petioled; blades about $3 \mathrm{~cm}$. broad, sparingly pubescent, divided to the base into 3-5 narrowly euneate divisions, these again eleft into linear-oblong lobes; sepals oblong, obtusish, about $1 \mathrm{~cm}$. long; upper petals yellowish white; lower petals light blue, with obtusish wavy lobes; follicles 8-10 mm. long, slightly puberulent, nearly straight. Arid regions: s UtahAriz. L. Son. My.

18. D. scaposum Greene. Stem $2-5 \mathrm{dm}$. high; leaves basal, fleshy, petioled; blades of the earliest reniform in outline, about $3 \mathrm{~cm}$. broad, 3-cleft and the divisions round-lobed, those of the later leaves more deeply cleft; sepals dark blue, ovate, acutish, 10-12 mm. long; upper petals yellowish, tinged with blue; lower petals dark blue, with sinuate obtuse lobes; follicles glabrous or sparingly viseid. Dry ground: N.M. $\rightarrow$ S Colo. $\rightarrow \mathrm{s} \mathrm{Utah}-A$ Ariz. Son. Ap-Je.

19. D. xylorhizum Rydb. Stem not scapose, $2-3 \mathrm{dm}$. high, glabrous; leafblades of the basal leaves fleshy, divided into 3 broadly cuneate, cleft and lobed divisions; stem-leaves with linear-oblong lobes; sepals dark blue, oval, obtuse, pubescent outside; upper petals yellowish, with very obtuse lobes; lower petals blue, with sinuate, obtuse lobes. Dry elayey hills: Lima, Mont. Submont. Je-Jl.

20. D. geraniifolium Rydb. Stem stout, $3-4$ dm. high, leafy; leaves grayish strigose; blades $4-6 \mathrm{~cm}$. broad, mostly 5 -divided to the base; ultimate lobes oblong or lanceolate, acute; sepals dark blue, oval, acute; upper petals yellowish, tipped with blue, acute, scarcely cleft; lower petals with acute lobes; follicles strigose. Dry hills: Ariz.-Colo. Submont. Au. 
21. D. Geyeri Greene. Stem 2-7 dm. high, leafy mostly towards the base; leaves grayish strigose; blades $5-8 \mathrm{~cm}$. broad; sepals deep blue, oblong to oval, 1-1.5 cm. long; upper petals yellow, tinged with blue, obtuse or acutish, entire, the lower deep blue, with sinuate obtuse lobes; follicles about $15 \mathrm{~mm}$. long, nearly straight, canescent. Dry mesas and rocky hills: Colo.-Wyo.-Utah. Submont. $\mathrm{My}-\mathrm{Jl}$.

22. D. cucullatum A. Nels. Stem 6-15 dm. high, finely puberulent above; leaf-blades 1-2 dm. broad, finely puberulent; inflorescence narrow and dense; sepals pubescent, but not glandular; upper petals yellowish, undivided; lower petals blue, with obtuse sinuate lobes; follicles about $15 \mathrm{~mm}$. long, villous, thick, straight. (?) D. abietinum Tidest. Wet meadows: Mont.-Ida.-Utah-Colo. Submont.-Mont. Jl-Au.

23. D. canmorense Rydb. Stem more than $5 \mathrm{dm}$. high; leaf-blades 8-10 cm., densely puberulent; sepals acute, fully $1 \mathrm{~cm}$. long, strigose outside; upper petals brownish; lower petals dark blue, with lanceolate acute lobes. Rocky mountains: Canmore, Alta. Mont. Jl.

24. D. robustum Rydb. Stem leafy, often $2 \mathrm{~m}$. high or more, puberulent throughout, often $1 \mathrm{~cm}$. in diameter at the base; leaf-blades puberulent on both sides, divided to the base into 5-7, twice cleft segments; ultimate lobes linear; sepals dark blue, paler at the base, all except the upper one obtuse, $12-15 \mathrm{~mm}$. long; upper petals narrow, light brownish; lower petals with slender claws bent at right angles, bearded only within; follicles densely pubescent. Meadows: Colo.-N.M. Submont.-Mont. Jl-Au.

25. D. elongatum Rydb. Stem tall, slightly strigose in the inflorescence; leaf-blades digitately divided into about 7 divisions, glabrous and glaucous beneath; ultimate lobes lanceolate, acute; sepals and petals dark blue, the former oval, about $1 \mathrm{~cm}$. long; follicles erect, 12-15 mm. long, strigose-puberulent. Hills and mountains: Colo.-Mont.-Alta. Submont.-Mont. Au.

26. D. ramosum Rydb. Stem often $2 \mathrm{~m}$. high, often tinged purplish or bluish; leaf-blades glabrous above, finely puberulent beneath, divided to near the base into 5-7 cleft segments; ultimate lobes oblong or lanceolate; inflorescence with slender branches, puberulent; sepals dark blue, slightly brownish at the base, about $1 \mathrm{~cm}$. long, ovate, puberulent; upper petals dirty white, tinged with brown and blue, about $8 \mathrm{~mm}$. long; lower petals dark blue, bearded, only slightly 2-lobed at the apex; follicles $12-15 \mathrm{~mm}$. long, somewhat spreading and with divaricate beaks. Cañons: Colo.-Wyo. Submont.-Mont. J1.

27. D. Brownii Rydb. Stem about $1 \mathrm{~m}$. high, glabrous and shining throughout; leaf-blades palmately divided into about 5 divisions, puberulent; divisions 4-6 cm. long, oblanceolate in outline, eleft into lanceolate, acute, somewhat spreading lobes; inflorescence a rather lax raceme; sepals dark blue or purple, oblong-oval, obtuse, 10-12 mm. long; lateral petals also blue or purplish; upper petals of the same color or paler, acute; follicles erect, glabrous. Meadows: Sask.-Mont.-Alaska. Submont. J1-Au.

28. D. viscidum Rydb. Stem about $3 \mathrm{dm}$. high, grayish strigose below, densely glandular-viscid above; leaf-blades 5-7 cm. broad, densely grayish strigose; inflorescence branched; sepals dark blue, $12-15 \mathrm{~mm}$. long, oblong, acute; upper petals yellowish, tinged with blue, obtuse, entire; lower petals dark blue, with obtuse sinuate lobes; spur 10-12 mm. long, somewhat S-curved. Plains: Wyo. Plain. J-Au.

29. D. multiflorum Rydb. Stem about $1 \mathrm{~m}$. high or more, glabrate below; leaf-blades glabrous and glaucous, pubescent only on the margins and veins; segments $5-7 \mathrm{~cm}$. long, cleft into lanceolate, ovate, or oblong acute lobes; inflorescence long and dense, often branched; sepals light blue, with darker median lines or blotches towards the tips, oblong-oval, obtuse, or the upper acutish, finely puberulent; petals of the same color as the sepals; follicles erect. Along streams, damp meadows, etc.: Wash.-Ida.-Colo. Submont.-Mont. Ji-Au.

30. D. occidentale S. Wats. Stem $1 \mathrm{~m}$. or more high, glabrous below; leafblades 1-1.5 dm. wide, pubescent on both sides, divided into $3-7$ rhombic, twice 
cleft divisions; inflorescence many flowered and usually branched; sepals dark blue, oval, obtuse or the upper acute, viscid outside; upper petals yellowish, tinged with blue, obtuse, entire; lower sepals with broad acute sinuate lobes; follicles about $15 \mathrm{~mm}$. long, straight. D. quercetorum Greene. Higher mountains: Ida.-Utah-Colo.-Wyo. Mont.-Subalp. J-Au.

31. D. reticulatum (A. Nels.) Rydb. Stem 6-12 dm. high, glabrous and glaucous below; leaf-blades $8-10 \mathrm{~cm}$. broad, pubescent, divided into $3-5$ broadly cuneate, 3-cleft, toothed divisions; inflorescence mostly simple; sepals usually dark blue, of ten streaked with yellow, viscid-villous outside; upper petals usually blue, variegated with yellow; lower petals with acutish sinuate lobes; follicles fully $1 \mathrm{~cm}$. long, straight. Moist glades and open woods: Ida.-Wyo.-Colo. Submont.-Mont. J1-Au.

32. D. Barbeyi Huth. Stem 3-10 dm. high, stout, usually pubescent throughout; leaf-blades $7-15 \mathrm{~cm}$. broad, pubescent; divided or cleft into about 5 variously cleft divisions; inflorescence short and dense; sepals dark blue, acuminate, viscid-pubescent with yellowish hairs; upper petals yellow, tinged with blue; lower petals with broad acute sinuate lobes. D. subalpinum (A. Gray) A. Nels. Grassy parks and open woods: Wyo.-Colo.-Utah. Mont.-Alp. Jl-Au.

33. D. attenuatum (M. E. Jones) Rydb. Closely related to the preceding, but the raceme compound, resembling $D$. glaucum in leaf-form; stem about $1 \mathrm{~m}$. high; sepals dark blue, long-attenuate, about $25 \mathrm{~mm}$. long and about 3 times as long as the petals, nearly glabrous; upper petals white and veiny, the lower light blue. Along brooks: Utah. Subalp. Jl-Au.

34. D. glaucescens Rydb. Stems 3-5 dm. high, from a thick cespitose caudex; leaf-blades $5-7 \mathrm{~cm}$. wide, finely puberulent, divided into $5-8$ cuneate divisions, these 3-cleft, with lanceolate lobes; raceme simple, short; sepals dark blue, oval, obtuse, about $1 \mathrm{~cm}$. long; upper petals yellowish white, tipped and variegated with blue; lower petals dark blue, with short acute lobes; ovary densely pubescent. Among rocks: Mont.-Ida.-Wyo. Subalp. Jl-Au.

35. D. alpestre Rydb. Stems several, about $1 \mathrm{dm}$. high, puberulent and viscid above, densely leafy; leaf-blades digitately divided into about 5 divisions, finely and sparingly puberulent when young, dark green; divisions cuneate-obovate, divided half-way into oblong mucronate lobes; inflorescence short and fewflowered; sepals dark blue, oblong, obtuse or the upper acute, viscid-puberulent; upper petals blue and yellowish; lower petals 2-cleft; lobes lanceolate; follicles viscid-puberulent. Among rocks: Colo.-N.M. Alp. Jl.

36. D. Ajacis L. Annual; stem erect, 3-7 dm. high, branched, glabrous below, viscid-puberulent above; leaf-blades glabrous, finely dissected into narrowly linear lobes; flowers blue or purple, rarely white; sepals obovate, 1-1.5 $\mathrm{cm}$. long, slightly pubescent; follicles $12-15 \mathrm{~mm}$. long, pubescent, with a very short beak. Around dwellings: N.Y.-Va.-Tex.-Mont.; cultivated and escaped from gardens.

\section{ACONítum L. Aconite, Monkshood, Wolfsbane.}

Perennial herbs, with rootstocks or tubers. Leaves alternate; blades palmately lobed or divided. Flowers large, perfect, irregular, zygomorphic. Sepals 5 , the upper or posterior one hooded or helmet-shaped. Petals 2-5, small, the posterior two hooded, clawed, concealed in the posterior sepal, the other three when present minute. Stamens numerous, hypogynous. Pistils 3-5, sessile, many-ovuled. Fruit many-seeded follicles.

Hood boat-shaped, slightly saccate, almost semicircular in outline; stem slender, scarcely more than $3 \mathrm{dm}$. high; perennials with tubers.

U.

Ultimate divisions of the basal leaves lanceolate. 1. A. tenue.

2. A. delphinifolius.

Hood helmet-shaped, deeply saccate; stem stout, 4-10 dm, high; root fleshy, usually fusiform.

Stem, at least the upper portion, viscid-pubescent.

Primary divisions of the leaves cleft or toothed; upper end of pedicels not glabrous. Front-line of the hood strongly concave, $i$. $e .$, the beak porrect, almost horizontal. 
Lower sepals one-half to two-thirds as long as the lateral ones.

Beak of the hood almost as long as the portion below; inflorescence usually simple; follicles erect.

3. A. porrectum.

Beak of the hood seldom one-half as long as the portion below; inflorescence branched; follicles ascending-spreading. 4. A. divaricatum.

Lower sepals at least three-fourths as long as the lateral ones; leaf-segments rather broad. 5. A. Bakeri.

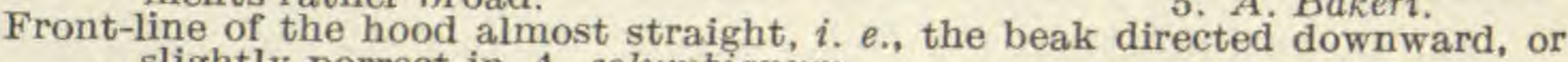
slightly porrect in $A$. columbianum.

Segments of the leaves linear-lanceolate.

Segments of the leaves lanceolate.

6. A, ramosum.

Lateral sepals very oblique; upper margin semi-reniform.

Lateral sepals moderately oblique; cave.

Flowers blue.

Flowers ochroleucous, pedicels glabrous.

Whole plant glabrous.

9. A lutescens.

10. A, patens.

11. A. glaberrimum.

1. A. tenue Rydb. Stem very slender, about $3 \mathrm{dm}$. high; leaves few; blades glabrous, thin, shining, almost pentagonal in outline, 5-7-divided to near the base, divisions rhombic, 3-cleft and often again cleft; inflorescence racemose, 2-6-flowered; hood 15-18 mm. long; lateral sepals rounded-ovate, $10-12 \mathrm{~mm}$. long; lower sepals oblong, obtuse. Damp cañons: Black Hills, S.D. Mont. Ji.

2. A. delphinifolium DC. Stem erect, 3-7 dm. high, finely pubescent or glabrate; leaf-blades pentagonal in outline, glabrous, deeply divided to the base, and again cleft; inflorescence few-flowered; hood 2-2.5 cm. long; beak very short; lateral sepals broadly rounded-obovate, a little longer and about 3 times as broad as the oblong lower ones. Wet places: Alaska-Alta.-B.C. Subalp.Alp. Jl-Au.

3. A. porrectum Rydb. Stem stout, 6-7 dm. high, leafy; basal leaves glabrous; blades reniform-pentagonal in outline, 6-10 cm. wide, 5-7-divided to near the base, divisions rhombic-oblanceolate, variously cleft above; inflorescence mostly racemose; sepals dark blue, ciliate on the margins; lateral sepals broadly obovate or semi-reniform, very oblique; lower sepals lanceolate or oblong. Moist places: Wyo.-N.M.-Ariz.-Utah. Submont.-Mont, Je-Au.

4. A. divaricatum Rydb. Stem 6-10 dm. high; leaf-blades about $1 \mathrm{~cm}$. broad, finely pubescent, or in age glabrate, divided into about 5 rhombic-oblanceolate divisions, again cleft into broadly lanceolate or ovate-lanceolate lobes; inflorescence branched; sepals purplish or blue; hood narrow, 18-20 mm. long, with a short porrect beak $6-10 \mathrm{~mm}$. long; lateral sepals obovate and somewhat oblique; lower sepals lanceolate; follicles about $15 \mathrm{~mm}$. long, finely viscid. Creek banks: Ida.-Utah-(Yellowstone Park) Wyo. Submont-Mont. Jl-Au.

5. A. Bakeri Greene. Stem 4-6 dm. high; leaf-blades about $6 \mathrm{~cm}$. broad, glabrous, divided into 5-7 rhombic-cuneate divisions, twice cleft into broadly lanceolate lobes; inflorescence almost spike-like; sepals dark blue, more or less pubescent; hood about $18 \mathrm{~mm}$. long; lateral sepals very obliquely obovate; lower sepals oblong, obtuse; follicles nearly erect. A. atrocyaneum Rydb. Wet places in the mountains: Colo. Mont.-Subalp. Jl.

6. A. ramosum A. Nels. Stem 3-5 dm. high; leaf-blades $5-8 \mathrm{~cm}$. broad, sparsely short-pubescent, divided into 3-5 oblanceolate divisions, these variously cleft into linear-lanceolate lobes; sepals blue, short-pubescent; hood 12-16 mm. long; lateral sepals obovate, somewhat oblique; lower sepals oblong or spatulate, about three-fourths as long and one-fourth to one-third as broad as the lateral ones; follicles $15-20 \mathrm{~cm}$. long, more or less pubescent, straight. Open grassy ground: S.D.-Wyo. Submont.-Mont. Jl-Au.

7. A. columbianum Nutt. Stem 6-12 dm. high; leaf-blades 5-15 cm. broad, glabrous or nearly so, divided into 3-5 rhombic divisions, these cleft and toothed with lanceolate teeth or lobes; sepals blue or purple, more or less pubescent; hood 15-20 mm. long; follicles usually more or less pubescent, $15-20 \mathrm{~mm}$. long. A. vestitum Greene. Moist meadows: B.C:-Mont.-N.M.-Calif. Submont.-Subalp. Je-S. 
8. A. insigne Greene. Stem 6-10 dm. high; leaf-blades $1-1.5 \mathrm{dm}$. broad, sparingly pubescent, divided into about 5 divisions, which usually are narrower, more deeply cut, more long-acuminate than in the preceding; sepals dark blue, rather long-pubescent; hood about $2 \mathrm{~cm}$. long; follicles sparingly pubescent, 15$18 \mathrm{~mm}$. long. Mountain meadows: Colo.-Alta. Submont.-Subalp. Jl-Au.

9. A. lutescens A. Nels. Stem 4-8 dm. high; leaf-blades $5-10 \mathrm{~cm}$. broad, resembling those of $A$. columbianum; flowers like those of $A$. insigne, but smaller, ochroleucous. A. ochroleucum (A. Nels.) Rydb. Along mountain streams: N.M.-Mont.-Ida. Mont. Jl.

10. A. patens Rydb. Stem $1.5 \mathrm{~m}$. or more high; leaf-blades glabrous, those of the upper leaves divided into 3-5 lanceolate entire divisions; inflorescence much branched, with slender pedicels; sepals light blue, glabrous; hood about 2 $\mathrm{cm}$. long, narrow, straight, with a rounded apex; beak porrect, 6-8 $\mathrm{mm}$. long; lateral petals obliquely broadly obovate; lower ones oblong, usually very obtuse. Along streams: Ida.-Utah. Jl-Au.

11. A. glaberrimum Rydb. Stem almost $1 \mathrm{~m}$. high; leaves 5 -divided, thin, divisions oblanceolate to rhombic-oblanceolate in outline, 5-10 cm. long, irregularly doubly cleft above; inflorescence compound; branches and pedicels spreading or divergent, glabrous; flowers blue; lower sepals lanceolate; lateral ones very oblique, as broad as long, rounded; hood about $2 \mathrm{~cm}$. long, deeply saccate, elongate helmet-shaped; beak long-attenuate, very porrect or even ascending. Along streams: Utah-Ariz.

\section{PAEÒnIA L. PAEONY.}

Perennial herbs, with fascicled fleshy roots. Leaves ternately compound or dissected. Flowers perfect, regular. Sepals mostly 5. Receptacle somewhat concave, bearing a perigynous fleshy disk. Petals 5 or of ten more numerous. Stamens numerous, perigynous. Pistils few; styles short or none. Fruit consisting of few, coriaceous, many-seeded follicles. Seeds anatropous, with the seed-coat fleshy externally.

1. P. Brownii Dougl. Low glabrous and usually glaucous perennial; stem 2-4 dm. high; leaves ternately or biternately divided, the divisions parted and cleft into oblong or oblanceolate lobes; sepals rounded, concave, green or purplish; petals 5-6, thick, dull brownish red; disk many-lobed; follicles $3-5$, oblong, glabrous, about $2 \mathrm{~cm}$. long and $1 \mathrm{~cm}$. broad. Dry ground: Calif.-B.C.-Ida.Utah. Submont.-Mont. Ap-J.

\section{FAMily 49. BERBERIDACEAE. BarberRy FAmily.}

Shrubs, with yellow wood and inner bark. Leaves alternate, leathery, pinnately compound or simple, usually spinose-toothed. Flowers small, yellow, racemose or paniculate. Sepals 6, in two series, subtended by 2 or 3 bractlets. Petals 6, in two series, imbricate, with glands near their bases. Stamens 6 ; anthers opening by 2 valves. Ovary 1-celled; stigmas peltate; ovules few, erect or ascending. Fruit a few-seeded berry, in one species rather dry. Endosperm present.

Primary leaves reduced to spines; secondary ones fascicled in their axils, simple or unifoliolate. Primary leaves pinnately compound, evergreen, no secondary ones in their axils.

2. ODOSTEMON.

\section{BÉRBERIS (Tourn.) L. BARBERRY.}

Spiny shrubs. Primary leaves transformed into simple or triple spines; secondary leaves fascicled in their axils, unifoliolate or apparently simple, in ours deciduous. Racemes drooping, simple. Filaments toothless. Berries red, without a bloom, acid, edible.

1. B. Fendleri A. Gray. A shrub, 1-2 m. high, with shining purplish branches; spines weak, $8-15 \mathrm{~mm}$. long; leaves short-petioled; blades spatulate 
or oblanceolate, 2-6 cm. long, spinulose dentate or entire, shining; racemes 6-10-flowered; sepals ovate to obovate, the inner 5-6 mm. long; berry ellipsoid, about $6 \mathrm{~mm}$. long. Mountains: Colo.-N.M. Son.-Submont. My-Je.

\section{ODOSTÈMON Raf. Oregon Grapes.}

Unarmed shrubs. Leaves pinnately compound, with spinose-toothed evergreen leaflets. Flowers in erect fascicled or branched racemes. Filaments in ours with a pair of divergent teeth near the apex. Berries usually with a bloom. [Mahonia Nutt.]

Fruit becoming dry and inflated at maturity; leaflets less than $3 \mathrm{~cm}$. long.

Fruit 1 . 0 . Fremontii.

Fruit fleshy, not inflated at maturity, dark blue with a bloom; leaflets $3-10 \mathrm{~cm}$, long.

Leaflets $3-11$; bud-scales ovate or rounded, deciduous.

Prostrate, rising only 1-3 dm. over ground; leaves not very shining.

Erect, 3-15 dm. high; leaves very shining.

2. O. Aquifolium.

Leaflets 13-17; bud-scales large, lanceolate, coriaceous, persistent. 4. O. nutvosus.

1. O. Fremontii (Torr.) Rydb. Shrub or small tree, 1-4 m. high, with furrowed bark; leaflets 3-7 (rarely 9-11), coriaceous, ovate or oblong, gravish green, 1-3 cm. long, sinuately 3-9-toothed; petioles very short; racemes 3-8flowered; berries at first blue, ovate-globose, 6-8-seeded. Berberis Fremontii Torr. Dry regions: w Tex.-Colo.-Nev.-s Calif.; n Mex. Son. Ap-Je.

2. O. Aquifolium (Pursh) Rydb. Stoloniferous dwarf shrub; leaflets 3-7, oval or rarely ovate, acute to rounded at the apex, rounded or obliquely truncate at the base, coriaceous, pale and strongly reticulate beneath, sinuately 9-19toothed, 3-9 cm. long; racemes many-flowered; berry ellipsoid-globose, 7-8 mm. long. B. Aquifolium Pursh. B, repens Lindl. B. nana and B. brevipes Greene. Hills and mountain sides: Alta.-Neb.-N.M.-Calif,-B.C. Submont,-Mont. Ap-Je.

3. O. nutkanus (DC.) Rydb. A shrub, with yellowish smooth branches; leaflets 5-11, coriaceous, ovate or lance-ovate, 5-10 cm. long, only slightly paler beneath, less strongly reticulate, acute at the apex, usually obliquely truncate at the base, sinuately 11-25-toothed; raceme many-flowered; berry globose, about $1 \mathrm{~cm}$. thick. B. Aquifolium Lindl., not Pursh. Hilly woods Ore:-Ida.w Mont.-B.C. Submont. Ap-Je.

4. O. nervosus (Pursh) Rydb. Stoloniferous shrub; stems 1-4 dm. high, with light brown bark; leaflets shining, glaucescent, thick-coriaceous, ovate to lanceolate, acute or acuminate at the apex, rounded at the base, spinulosedentate, with 15-30 teeth; racemes many-flowered, 1-2 dm. long; berry roundedellipsoid, 8-10 mm. long. B. nervosa Pursh. Woods: B.C.-Ida.-Calif. Submont. Ap-My.

\section{Family 50. PAPAVeraCeae Juss. Poppy Family.}

Annual or perennial herbs, or rarely shrubby plants, with colored sap and narcotic or acrid properties. Flowers perfect, regular. Sepals 2, or rarely 3 , caducous. Petals 4,8 , or 12 . Stamens numerous; filaments distinct, often dilated. Gynoecium of 2 to many united carpels, forming a 1-celled ovary; placentae parietal; ovules numerous, anatropous. Fruit a capsule; seeds numerous, with a fleshy or oily endosperm.

Hypanthium not developed; calyx not calyptrate; pod not elongate, 3-20-carpellary.

Ovary many-lobed, in fruit breaking up into many follicles, which at maturity break off into 1-seeded joints; leaves opposite.

Ovary of two to many completely united and not separating carpels; leaves alternate. Capsule opening by valves, at least at the summit.

Unarmed herbs; sepals neither horned nor hooded.

Petals in age thin, scarious-persistent; leaves basal, entire.

2. ARCTOMECON. Petals not scarious-persistent; stem leafy; leaves pinnately divided or
lobed.

lobed.
Prickly-leaved leafy-stemmed herbs; sepals hooded or horned; petals deciduous.

4. ARGEMONE. 
Capsule opening by dentiform lids under the stigma.
Hypanthium more or less developed: Papaver. into a funnelform body lifted into a funnelform body, lifted off by the expanding petals; capsule elongate, 2-valved usually from the base to the apex.

6. Eschscholtzia,

\section{Platystèmon Benth. Cream-cups.}

Small annuals, with opposite linear, entire leaves. Sepals 3 , ovate, caducous. Petals 6, rarely more, yellow or yellowish. Stamens numerous; filaments usually dilated upwards, especially the outer ones; anthers linear to oval, dehiscent laterally. Pistils many, soon separate, torulose. Carpels in fruit moniliform and usually breaking up into 1-seeded joints.

1. P. californicus Benth. Low annual, 1-3 dm. high, hispid with long spreading hairs; leaves closely sessile, linear, obtuse, nerved; peduncles about 1 $\mathrm{dm}$. long or more; sepals varying from yellow to nearly white, $1-2.5 \mathrm{~cm}$. long. Includes $P$.rigidulus, $P$.remotus, $P$.termini and two score or more species proposed by Greene and Fedde. Desert and arid regions: Calif.-s Utah-Ariz. L. Son.

\section{ARCTOMEेCON Torr. \& Frem.}

Low, almost scapose annuals. Leaves basal or nearly so. Sepals 2. Petals 4, in age thin-scarious, persistent. Flowers perfect, drooping in the bud. Stamens numerous. Styles short; stigmas united, cordate-bilobed, 3-6, usually 4. Capsule ovoid or obovoid, 3-6-valved; valves alternating with the nerviform placentae. Seeds oblong with sinuose coat.

1. A. humilis Coville. Low annual, 1-2 dm. high; leaves erect, lanceolate, usually 2-3-dentate at the apex, hirsute-ciliate and sparsely villous; scape 1-3flowered; petals 4 , suborbicular, white, about $18 \mathrm{~mm}$. long; filaments flattened; capsule $8 \mathrm{~mm}$. long and $6 \mathrm{~mm}$. thick; style short. Desert regions: Utah. Son.

\section{Chelddònium (Tourn.) L. Celandine.}

Glabrous perennial herbs, with rootstocks. Leaves pinnately divided, crenately lobed, alternate. Sepals 2 , yellowish green. Petals 4, yellow, imbricate in two series. Stamens many. Pistil formed of 2 carpels; ovary linear; style present; stigmas 2-lobed. Capsule linear, torulose, glabrous, 2-valved, dehiscent from the base, separating from the persistent placentae.

1. C. majus L. Stem 3-10 dm. high; leaf-segments 5-7, obovate-oblong, crenately lobed; petals $7.5-10 \mathrm{~mm}$. long, rounded; capsule $2-5 \mathrm{~cm}$. long, $2-3 \mathrm{~mm}$. thick. Waste places: N.S.-N.C.-Utah; adv. from Eu. Ap-S.

\section{ARGemòne L. Prickly Poppy, Thistle Poppy.}

Annual or perennial herbs, or rarely shrubby, with yellow or white sap. Leaves alternate, clasping, pinnatifid or lobed, the divisions spinose-tipped. Flowers ereet in bud, perfect. Sepals 2-3, hooded or horned, deciduous. Petals $4-6$, showy, yellow or white. Stamens numerous; filaments slender. Ovary with 4-6 nerviform placentae; stigma sessile; ovules numerous. Capsule oblong, opening at the top by 4-6 valves. Seeds numerous, pitted; endosperm oily. [Enomegra A. Nels,]

Corolla yellow; leaves with light blotches.

Corolla white; leaves not blotehed.

Prickles of the fruit not squarrose.

Stem unarmed, prickly, or bristly, but not hispidulous.

Leaves acutely lobed; horns of the sepals glabrous.

Leaves round-lobed; horns of the sepals bristly. Stem hispidulous-pubescent as well as densely prickly.

Prickles of the fruit strong, recurved-spreading, squarrose.

1. A. mexicana.

1. A. mexicana L. Stem 3-6 dm. high, glabrous or sparingly prickly; leaves sinuate-pinnatifid, with spinulose dentate lobes; flowers sessile; calyx slightly bristly, its horns terete, glabrous, with stout spines; petals yellow, $1.5-2.5 \mathrm{~cm}$. long; capsule ellipsoid, $2.5-3 \mathrm{~cm}$. long, sparingly prickly, with stout spreading prickles. Hillsides, cultivated ground and waste places: W.Ind.-Fla.-Tex. S.Am.; Africa, East Indies and Australia. Cult. and escaped, reported from
Colo. Ja-D. 
2. A. intermedia Sweet. Stem stout, $3-10 \mathrm{dm}$. high, sparingly but strongly prickly; leaves bluish green, glaucous, erisp, 1-3 dm. long; flowers usually shortpeduncled; sepals sparingly prickly; horns conical, spreading, $5-8 \mathrm{~mm}$. long; petals $3-4 \mathrm{~cm}$. long; capsule oblong-fusiform, about $4 \mathrm{~cm}$. long, with rather few strong prickles. Plains: S.D.-Tex.-n Mex.-(? Utah)-Wyo. Plain-Submont. Je-Au.

3. A. rotundata Rydb. Stem stout, densely and strongly prickly, but otherwise glabrous; leaves oval in outline, the cauline ones sessile and broadly auricled; flowers short-pedicelled or subsessile; calyx very bristly, its horns erect or slightly spreading, flattened; petals fully $4 \mathrm{~cm}$. long; pod oblong-fusiform, $4 \mathrm{~cm}$. long, densely bristly. Sandy soil: Utah-Nev. Son.-Submont. Je-Jl.

4. A. hispida A. Gray. Stem 3-6 dm. high; leaves deeply pinnately cleft, with oblong, coarsely spinulose-dentate lobes, prickly on the veins and hispidulous between; calyx densely bristly, its horns $8-10 \mathrm{~mm}$. long, triangular, bristly; petals $3-4 \mathrm{~cm}$. long; capsule oblong-fusiform, densely prickly with rather spreading prickles. A. bipinnatifida Greene. Enomegra bipinnatifida A. Nels. E. hispida A. Nels. Plains and hillsides: Kans.-N.M.-Utah-Wyo. Son.Mont. Je-Jl.

5. A. squarrosa Greene. Stem 4-10 dm. high, prickly and hispid; leaves glaucescent, sinuate-pinnatifid and spinulose-dentate, hispid, 4-10 cm. long; flowers sessile; calyx densely bristly; horns broadly triangular, prickly and hispid; capsule nearly $5 \mathrm{~cm}$. long. Plains: N.M.-Colo.-Kan. Son.

\section{PAPĀVER (Tourn.) L. Poppy.}

Annual or in ours perennial herbs, with milky sap. Leaves alternate or in ours basal, lobed or dissected. Flowers drooping in the bud, perfect. Sepals 2, rarely 3 . Petals 4 , rarely 6 . Stamens numerous. Ovary with 4-20 septiform placentae; style none; stigma disk-like; ovules numerous. Capsule globose or pyriform, opening by $4-20$ tooth-like lids under the margin of the stigma. Seeds scrobiculate, naked.

Leaves densely hirsute; lobes lanceolate or oblong.

Leaves glabrous or with a few bristles; lobes rounded.

1. $P$. radicatum.

2. P. pygmaeum.

1. P. radicatum Rottb. A cespitose and scapose perennial; leaves basal, numerous, 2-10 $\mathrm{cm}$. long; blades 1-4 $\mathrm{cm}$. long, usually twice ternately or pinnately dissected, coarsely hirsute; scape $5-15 \mathrm{~cm}$. long, blackish hirsute; calyx densely black-hirsute, elliptic in bud; petals yellow, 1-3 $\mathrm{cm}$. long; pod obovoid, fully $1 \mathrm{~cm}$. long, $P$. coloradense Fedde. Exposed summits and bare hills: Greenl.-Lab.-N.M.-Alaska; arctic and subarctic Eurasia. Alp.-Subalp. $\mathrm{Jl}-\mathrm{Au}$.

2. P. pygmaeum Rydb. A cespitose and scapose perennial; leaves all basal, numerous, $2-3 \mathrm{~cm}$. long; blade broadly ovate in outline, deeply cleft, sparingly hispid or glabrous; seape 4-6 $\mathrm{cm}$. high, sparingly hirsute; calyx obovate in bud; petals yellow, $1 \mathrm{~cm}$. or less long; pod obovoid, about $1 \mathrm{~cm}$. long, densely bristly. P. pseudocorydaliforme Fedde. Exposed summits: Mont.-Alta.-B.C. Alp. J1-Au.

\section{6. eschschóltzia Cham. California Poppy.}

Annual or perennial herbs, with dissected leaves, watery juice, and yellow flowers. Sepals 2, completely united into a cap, pushed off by the expansion of the petals. Petals 4, deciduous. Hypanthium more or less developed. Stamens numerous. Styles short and stout; stigmas 4-6, subulate. Capsule 2 -valved, rarely 3 -valved, usually from the base to the apex, the nerviform placentae remaining attached to the valves. Seeds globular, unappendaged.

Petals 8-25 mm. long, broadly cuneate; stem scapiform; stamens many.

Seeds superficially reticulate; lobes of the leaves oblong or linear, 1-2 mm. wide.

Seeds deeply pitted; lobes of the leaves linear-filiform, about $0.5 \mathrm{~mm}$. wide.

Petals 3-6 mm. long, obovate; stem usually more or less leafy; stamens few.

2. E. glyptosperma.

3. E. minuscula. 
1. E. mexicana Greene. Stout subacaulescent annual, glabrous, glaucescent; leaves coarsely dissected, with ascending divisions; scapes 1-2.5 dm. high; calyx firm, opaque, ovoid, taper-pointed, 14-16 mm. long; petals light yellow, $1-2.5 \mathrm{~cm}$. long, spreading; receptacle with a reflexed margin; stamens 20 or more. Arid regions: Ariz. $\rightarrow$ S Utah-n Mex. L. Son. F-My.

2. E. glyptosperma Greene. Acaulescent annual, glabrous and glaucous; leaves numerous; blades rounded in outline, twice pedately ternate; peduncles 5-15 cm. long; calyx 8-10 mm. long, broadly ovoid, conic, shortly taper-pointed; petals $8-15 \mathrm{~mm}$. long, spreading; receptacle not with an obvious rim; stamens 30 or more. Arid regions: Calif.-Nev. - s Utah-Ariz. L. Son. F-Ap.

3. E. minuscula Greene. Slender caulescent annual, 1-3 dm. high, branched near the base, leafy; leaves twice or thrice ternate, with linear spreading divisions; calyx about $4 \mathrm{~mm}$. long, ovate, acute or acuminate; petals orange, spreading; receptacle without rim; stamens 8 or 12 . E. ludens Greene. Arid regions: Nev.-Utah-Ariz.-Calif. Son. Ap-Je.

\section{Family 51. FUMARIACEAE. Fumitory Family.}

Herbs, with alternate usually finely dissected leaves. Flowers perfect, irregular, in racemes or panicles. Sepals 2, scale-like. Petals 4, the outer ones spreading above, one or both spurred at the base, the inner smaller, thickened above, enclosing the stigmas. Stamens 6; filaments diadelphous. Gynoecium of 2 united carpels; ovary 1-celled, with 2 parietal placentae. Fruit a capsule, rarely indehiscent.

Both of the outer petals spurred at the base.

1. Bicuculla. One of the outer petals spurred.

Ovules several or many; fruit an elongated capsule.

Ovules solitary; fruit an indehiscent nut.

2. CAPNOIDES.

3. Fumaria.

\section{Bicucúlla Adans. Dutchman's Breeches, Bleeding Heart.}

Perennial herbs, with horizontal, granular or tuberous rootstocks. Leaves basal, long-petioled, repeatedly ternately divided. Flowers perfect, irregular, in terminal racemes or panicles. Two outer petals spurred, loosely united, deciduous, their tips spreading, the inner petals crested, clawed, cohering by their tips. Stamens 6, in two bundles, opposite the outer petals; filaments diadelphous at the base. Ovary with two parietal placentae; style filiform. Capsule elongate, opening by two valves. Seeds 10-20, crested. [Dicentra Bernh.]

Flowers racemose; spur elongate, oblong, divergent. Flowers solitary; spur very short and rounded.

1. B. occidentalis. 2. B. uniflora.

1. B. occidentalis Rydb. Perennial, with a very short rootstock bearing numerous tubers; scape and leaves perfectly glabrous; leaf-blades twice ternate, the divisions twice pinnately divided into linear-oblong lobes, $1-2 \mathrm{~cm}$. long; scape about $3 \mathrm{dm}$. high; petals pink, the outer about $1 \mathrm{~cm}$. long, their spurs about $12 \mathrm{~mm}$., divergent; crest of the inner petals prominent; capsule fusiform, with the style about $1.5 \mathrm{~cm}$. long. D. occidentalis Fedde. Shady hillsides: Wash.-Ida.-Ore. Submont. Ap.

2. B. uniflora (Kellogg) Howell. Acaulescent perennial, with fascicled fusiform roots and a tuber-bearing crown; leaves twice or thrice ternate, with oblong divisions, slightly pubescent, about $1 \mathrm{dm}$. long; scape $1 \mathrm{dm}$. long or less, 1 -flowered; corolla flesh-colored, about $15 \mathrm{~mm}$. long; spurs represented by rounded sacks; outer petals strongly recurved. D. uniflora Kellogg. . Mountains: Wash.Wyo.-Utah-Calif. Submont.-Mont. Ap-Au.

\section{CAPNOİdes Adans. Corydalis.}

Annual, biennial, or perennial, caulescent herbs. Leaves alternate, bipinnately dissected. Flowers perfect, irregular, in racemes. Outer petals dissimilar, distinct, one of them spurred at the base, the two inner narrower, winged or crested, coherent at the apex. Stamens 6, in two bundles, opposite the outer 
petals; filaments united above the middle. Ovary with two parietal placentae; style filiform. Fruit an elongated 2-valved capsule. Seeds numerous, crested. [Corydalis Vent.]

Annuals or biennials.

Plants low, ascending or diffuse; corolla yellow.

Pod glabrous.

Bracts narrowly lanceolate; pod pendulous, torulose.

Bracts ovate-lanceolate, ovate, or obovate; pod erect, not torulose.

Pod covered with translucent vesicles.

2. C. montanum.

3. C. crystallinum.

Plants erect, tall, usually 3-6 dm. high; corolla rose or purplish, with purple tips.

Perennials with thickened roots; corolla white or tinged with purple.

Bracts spatulate or oblanceolate, about $1 \mathrm{~cm}$. long; dorsal crest of the hood narrow. Sepals reniform, laciniate.

Sepals narrowly hastate, with large toothed basal lobes.

5. C. Cusickii.

6. C. hastatum.

Bracts linear; dorsal crests of the hood obsolete.

Corolla $2 \mathrm{~cm}$. long; sepals broadly ovate, obtuse, their auricles subentire; pod lance-obovoid.

7. C. Brandegei.

Corolla $1.5 \mathrm{~cm}$. long; sepals ovate, acute, their auricles toothed; pod broadly

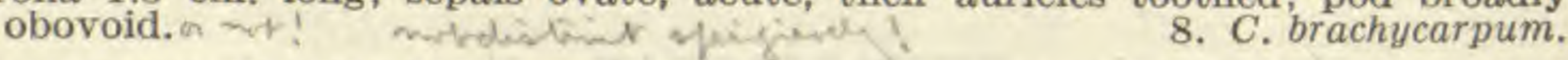

1. C. aureum (Willd.) Kuntze. Glabrous and more or less glaucous annual or biennial, diffusely branched, 1-4 dm. high; racemes $1-5 \mathrm{~cm}$. long; leaves thrice pinnate; corolla $12-15 \mathrm{~mm}$. long, golden yellow; spur one-half to twothirds as long as the body, curved downward; pods $2-3 \mathrm{~cm}$. long, about $2 \mathrm{~mm}$. thick. Corydalis aurea Willd. C. Engelmanii, C. macrorrhiza, and C. Albertae Fedde. River banks, hillsides, and open woods: N.S.-Pa.-Tex.-Calif.Alaska. Plain-Mont. My-Au.

2. C. montanum (Engelm.) Britton. Glabrous and glaucous biennial, branched at the base, $2-5 \mathrm{dm}$. high; leaves as in the preceding; corolla $15-20 \mathrm{~mm}$. long, golden yellow; spur usually almost as long as the body, decidedly saccate at the end and somewhat turned upward; pod usually curved at the base, 2-3 $\mathrm{cm}$. long, $3 \mathrm{~mm}$. thick. Corydalis aurea occidentalis Engelm. C. curvisiliquaeformis, C. bilimbata, and (?) C. hypecoiformis Fedde. River banks, cañons, and copses: S.D.-Tex.-Ariz.-Utah; Mex. Plain-Submont. Mr-Au.

3. C. crystallinum (Engelm.) Kuntze. Glabrous and slightly glaucous annual, branched at the base, 1-3 dm. high; leaves thrice pinnatifid, with oblong small divisions; bracts ovate or ovate-lanceolate; corolla golden yellow, 12-15 $\mathrm{mm}$. long; spur nearly as long as the body; pod erect, about $2 \mathrm{~cm}$. long and 3 mm. thick. Fields and open grounds: Mo.-Ark.-Kans.-Mont. PlainMont. Ap-Je.

4. C. sempervirens (L.) Borkh. Glabrous and glaucous biennial, simple, 3-6 dm. high; leaves twice or thrice pinnatifid, with obovate divisions; racemes 3-10 cm. long; corolla 12-15 $\mathrm{mm}$. long; spur short, one-third as long as the body or less; pod ascending, 3-4 cm. long, $1.5 \mathrm{~mm}$. thick. Corydalis glauca Pursh. Rocky woods: N.S.-N.C.-Mont.-B.C.-Alaska. Plain-Boreal. My-Au.

5. C. Cusickii (S. Wats.) Heller. Stout glabrous perennial, 6-15 cm. high; leaves thrice pinnatifid, 2-10 dm. long; ultimate divisions ovate or lanceolate, acuminate; corolla with the spur about $2 \mathrm{~cm}$. long, white or lilac, with the tips of the inner petals violet; capsule ellipsoid, 1-1.5 $\mathrm{cm}$. long. Mountains along water-courses: e Ore-Ida. Submont. Je-Jl.

6. C. hastatum Rydb. Glabrous green perennial, 1-1.5 m. high, branched above; leaves 2-4 dm. long, thrice pinnatifid; ultimate divisions elliptic or oval, mucronate; corolla with the spur 15-18 mm. long, salmon-pink; hood barely crested. (?) Corydalis Hendersonii Fedde. Along water-courses: Ida.-Wash.

7. C. Brandegei (S. Wats.) Heller. Glabrous perennial, scarcely glaucous, 6-15 dm. high; leaves 2-3 dm. long, thrice pinnatifid, with oval or obovate, mucronate divisions; corolla $2 \mathrm{~cm}$. long, with almost erect spur; pods pendent, $1.5 \mathrm{~cm}$. long, $4 \mathrm{~mm}$. thick. Mountains: Colo.-n N.M. Mont. Je-Au.

8. C. brachycarpum Rydb. Glabrous and glaucous perennial, with a thick root; stem 3-6 dm. high, branched above; leaves 2-3 dm. long, thrice pinnatifid; ultimate divisions lanceolate or lance-elliptic; corolla yellowish, the inner 
petals tipped with purple or brown; spur horizontal; pod horizontal or reflexed, about $1 \mathrm{~cm}$. long and $6 \mathrm{~mm}$. wide. High mountains: Utah. Subalp.

\section{FUMÃRIA (Tourn.) L. FUMiTory.}

Annual caulescent herbs. Leaves alternate, finely dissected. Flowers perfect, irregular, in terminal or lateral racemes. Outer petals dissimilar, one of them spurred at the base. Stamens in two bundles, opposite the outer petals. Ovary subglobose, 1-ovuled; style filiform. Fruit a 1-seeded nut. Seed not crested.

1. F. officinalis L. Glabrous, diffusely branched annual, 2-10 dm. high; leaves finely dissected into linear-oblong to spatulate divisions; corolla purplish, together with the short spur 6-8 $\mathrm{mm}$. long; pod spherical, 2-2.5 $\mathrm{mm}$. in diameter, minutely tuberculate. Waste places: N.S.-Fla.-Utah; adv. from Europe. Plain. My-Au.

\section{Family 52. BRASSICACEAE. Mustard Family.}

Herbs or rarely shrubby plants, with alternate, entire to finely dissected leaves. Flowers perfect, regular or nearly so, in spikes or racemes. Sepals 4 , mostly erect. Petals 4 , with spreading blades. Stamens usually 6 , tetradynamous, $i$. e., the inner 4 longer, or rarely 4 or 2 . Gynoecium of 2 united carpels; ovary 2-celled or rarely 1-celled, superior or (in Subularia only) partly inferior. Fruit a capsule, rarely indehiscent. Seeds without endosperm. [CRUCIFERAE.]

I. Pod sessile, or short-stipitate (in no. 48-53); sepals erect, ascending, or connivent in anthesis (except in 32,33 and 53); anthers not twisted (except in no. 48 and 50 53 ).

A. Pod compressed or flattened contrary to the narrow partition.

Pod not didymous; plants not densely stellate, except in Smelowskya.

Pod orbicular, oval, oblong or cuneate, strongly flattened; plant not stellate. Pod 1-celled, winged all around.

Pod 2-celled, not winged all around.

Cells of the pod 1-seeded.

Pods ovate-cordate, acute at the apex, neither winged nor retuse. $\begin{array}{ll}\text { apex, usually winged above. } & \text { 3. LEPIDIUM. }\end{array}$

Cells of the pods 2-seeded.

Pods more or less winged; cotyledons accumbent; hairs of the plant simple or none.

Pods wingless; cotyledons incumbent.

4. THLASPI.

Pods cuneate; plants with branched hairs. 5. BURSA,

Pods elliptic; plants glabrous or minutely stellate.

6. HUTCHINSIA.

Pod ovate or lanceolate, not strongly flattened; plant stellate.

7. SMELOWSKYA.

Pod more or less didymous; plants stellate.

Seeds solitary in each cell; pods strongly flattened.

Seeds several in each cell; pods more or less inflated.

B. Pod neither compressed nor flattened contrary to the partition.

8. DITHYREA.

9. Physaria.

1. Anthers not sagittate at the base, not twisted.

a. Pod terete or tetragonal.

$t$ Pod short, scarcely more than twice as long as broad.

Cotyledons accumbent; valves of the pods nerveless.

Pubescence stellate or canescent with branched hairs; seeds flat. Petals white, 2-cleft. Petals yellow or tinged with red, not 2-cleft.

Pubescence not stellate; seeds terete.

35. BERTEROA.

10. Lesquerella.

Petals white; stout perennials with a thick taproot.

14. ARMORACLA.

Petals yellow or ochroleucous, rarely white; annuals, or perennials with rootstocks.

15. RADICULA.

Cotyledons incumbent or folded transversely; valves of the pod 1nerved; pubescence if any not densely stellate.

Submerged water plants, with subulate leaves; pods subglobose or elliptical.

11. SUBULARIA.

Land plants with ample leaves.

Capsule obovoid, dehiscent, many-seeded.

12. Camelina. 
Capsule globose, indehiscent, 1-2-seeded. 13. Nesisa.

$\dagger \dagger$ Pod long, several times as long as broad.

* Pod scarcely beaked, merely tipped by a short style or a sessile stigma.

$\ddagger$ Pod terete or nearly so.

Pubescence of simple hairs.

Seeds in two rows in each cell of the pod.

Seeds globose or oblong, turgid; valves of the pod nerveless; cotyledons accumbent.

Petals with a median nectary, usually yellow. 15. RADICULA.

Petals without nectary, white. 16. SISYMBRIUM.

Seeds flattened; valves of the pod 1-nerved; cotyledons partly incumbent.

Seeds in 1 row in each cell of the pod.

17. TURRITIS.

Pod subulate, tapering from the base to the apex.

Pod cylindric or tapering both ways.

18. ERYSIMUM.

Perennials with creeping rootstocks.

Annuals, or perennials with taproots.

46. SCHOENOCRAMBE.

Septum of the pod nerved, with longitudinal reticulations.

Septum of the pod nerveless, with transverse reticulations. 20 , BRAYA.

Pubescence of forked hairs.

Flowers pedicelled, yellow to straw-colored, rarely white; leaves pinnatifid or lobed.

Flowers sessile, rose or white; leaves toothed or entire.

¥ Pod 4-angled.

Stem-leaves clasping by a cordate base.
Stem-leaves not clasping.

Corolla white.

Corolla yellow or purplish.

Seeds plump; leaf-blades entire or toothed.

Hairs of the stem and leaves appressed, 2-branched, attached near the middle; partition of the pod not cross-veined.

25. CHEIRINIA.

Hairs of the stem and leaves spreading, branched, attached at the end; partition of the pod crossreticulate. 26 . HESPERIS.

Seeds flat; leaf-blades pinnatifid. 27. CAMPE.

** Pod with a long distinct beak.

Pods indehiscent, constricted between the seeds, which are separated from each other by false, spongy, transverse partitions.

28. RAPHANUS.

Pods opening by valves, without transverse partitions.

Beak flat and sword-like, 4-angled, or two-edged, contiguous with an internode, containing 1 seed.

Valves of the pod with 3 strong nerves. 29. SINAPIS.

Valves of the pod with 1 strong nerve. 30. ERucA.

Beak elongated-conic, seedless. 31 . BRAssicA.

b. Pod flattened parallelly to the broad partition.

Fruit orbicular, 1-celled, 1-seeded, indehiscent; sepals somewhat spreading.

Fruit not winged; pubescence of branched hairs, those of the fruit uncinate.
32. ATHYSANUS.

Fruit winged, usually marked with fenestrations or sinuations on the margin; pubescence of simple hairs.

33. THYSANOCARPUS.

Fruit 2-celled, 2-several-seeded, dehiscent (in some species of Draba tardily so); sepals erect.

Pod orbicular.

Valves convex; fllaments dilated and toothed near the base; plants stellate, leafy.

Pod suborbicular, with flat margins; petals entire or nearly so.

34. Alyssum.

Pod oblong, slightly if at all compressed; petals notched.

35. BERTEROA.

Valves flat; filaments not toothed; plant scapose, with simple hairs. 36. IDAHOA.

Pod oblong, ovate or linear, rarely nearly orbicular; valves flat, or if convex not with flattened margins; filaments unappendaged.

Valves nerveless.

Valves elastically dehiscent; seeds in one row; pod long.

Stem naked below, 2-3-leaved; cotyledons thick, very unequal.

Stem leafy; cotyledons flat, equal.

37. DENTARIA.

38. CARDAMINE.

short.

two rows; pod usually

Valves nerved and reticulate, not elastically dehiscent. 
Anthers not subsagittate at the base.

Pod short, from orbicular to linear-oblong.

Pod elongated-linear.

Cotyledons accumbent.

Cotyledons incumbent.

Anthers subsagittate at the base.

39. DRABA.

40. ARABIS.

23. Conringla.

Stigma 2-lobed; seeds margined; cotyledons strictly accumbent.

41. PARRYa.

Stigma entire, capitate; seeds marginless; cotyledons obliquely accumbent.

42. PhXENICAULIS.

2. Anthers sagittate at the base.

Calyx urn-shaped, closed; blades of the petals narrow, undulate-crisp.

Cotyledons accumbent; stem not succulent; flowers small.

43. Cartiera.

Cotyledons incumbent; stem more or less succulent; flowers comparatively large.

Calyx campanulate, open; petals ample.

44. Caulanthus.

Pod flat; anthers neither curved nor twisted.

Stigma 2-lobed.

Lobes of the stigma over the placentae; perennials.

41. PARRYA.

Lobes of the stigmas over the valves; annuals. 45. STREPTANTELLA. Stigma entire, capitate; seeds marginless.

Cotyledons obliquely accumbent; low perennials, with pink or purplish flowers.

42. PHAXENCAULIS.

Cotyledons incumbent; tall leafy plants, with greenish flowers.

46. Chlorocrambe.

Pod terete or tetragonal; anthers curved or twisted (except in Schoenocrambe).

Sepals unequal, the lower longer; hairs, at least some of them, stellate or branched.

Sepals equal or nearly so; hairs simple or none.

Sepals erect or ascending in anthesis.

Stigma distinctly lobed, its lobes expanded over the septum.

Plants with creeping rootstocks.

Plants with taproots.

47. SCHOENOCRAMBE.

48. THELYPODIOPSIS.

Stigma entire or, if distinctly lobed, the lobes expanded over the valves.

Stigma conical; outer sepals gibbous at the base.

50. HESPERIDANTHUS.

Stigma truncate; sepals scarcely gibbous at the base.

Septum of the pod without a distinct midrib.

Septum of the pod with a strong midrib.

51. THELYPODIUM.

52. Pleurophragma.

Sepals strongly spreading or reflexed in anthesis, soon deciduous.

53. STANIEYELLA.

II. Pod terete, long-stipitate; sepals spreading or reflexed in anthesis; anthers curved and spirally twisted.

54. STANLEYA.

\section{ISÃTIS L. WOAD.}

Annual to perennial herbs. Flowers perfect, racemose. Sepals equal, ascending-spreading, not gibbous at the base. Petals yellow, entire, equal. Stamens 6; filaments not dilated, on a disk. Pod indehiscent, 1-celled, 1-(rarely 2-) seeded, oval to oblong, flattened contrary to the partition, winged all around, without style. Cotyledons incumbent.

1. I. tinctoria L. Biennial; stem 3-10 dm. high; leaves blue-green, the lower oblanceolate, entire or denticulate, the upper sagittate-clasping; racemes several; pod oblong, 12-15 mm. long, 5-7 mm. wide, rounded or retuse at the apex. Waste places: Utah; adv. from Eu.

\section{CARDÃRIA Desv.}

Perennial eaulescent herbs. Leaves alternate, toothed, the upper elasping. Flowers perfect, in terminal panicles. Petals white. Stamens 6. Ovary sessile; styles slender, but short. Pod ovate, cordate at the base, acute at the apex, neither winged nor retuse; valves strongly convex. Seeds solitary in each cavity. Cotyledons incumbent.

1. C. Draba (L.) Desv. Erect perennial, 2.5-5 dm. high, hoary-pubescent, branched above; lower leaves oblanceolate, petioled, the upper oblong, ovate, or cordate, clasping, usually dentate; pod $3 \mathrm{~mm}$. long and $4 \mathrm{~mm}$. broad, papillose; style 1-2 mm. long. Lepidum Draba L. Waste places and cultivated ground: N.Y.-Fla.-Calif.-Ida.; adv, or nat. from Eurasia. Ap-Je. 


\section{Lepídium L. Peppergrass, Canary-grass, Bird-seed.}

Annual, biennial or perennial herbs. Pubescence if any of simple hairs. Leaves alternate, entire, toothed, lobed, or disseeted. Flowers perfect, in racemes or panicles. Sepals 4, equal. Petals small, white or greenish, or wanting. Stamens often less than 6. Ovary sessile; styles short or wanting; ovules solitary in each cell, pendulous. Pods short, oblong to orbicular, transversely flattened, wing-margined or at least acute on the margins, notched at the apex. Seeds solitary in each cavity. Cotyledons incumbent or rarely obliquely accumbent.

Style evident, at least equalling the wing-margins.

Introduced annuals or biennials.

Upper leaves entire, perfoliately clasping.

Leaves all pinnatifid, none clasping.

1. L. perfoliatum.

Native perennials.

Pods 2-4 mm. wide.

None of the leaves pinnatifid.

Basal leaves oblanceolate, entire-margined, thick; stamens 2 .

Basal leaves more or less toothed, thinner; stamens 6 . Basal leaves truncate and 3-toothed at the apex, 4. L. Vaseyanum.

Basal leaves oblanceolate, acute at the apex, serrate-crenate.

5. L. crenatum.

Basal leaves at least pinnatifid.

Segments of the basal leaves short, obovate or oblanceolate in outline; petals obovate.

Styles $2-3$ times as long as the wing-margins; racemes in age more or less elongate.

Styles about 3 times as long as the wing-margins; leaves coriaceous; segments entire or merely round-toothed, obtusish; plant glabrous; stem few-leaved. $\quad$ 6. L. scopulorum.

Styles about 2 times as long as the wing-margins; leaves not coriaceous; segments usually cleft or deeply toothed, acute.

Upper stem-leaves linear, entire; plant glabrous or the upper part of the stem slightly puberulent. 7. L. Crandallii.

Leaves usually all pinnatifid; stem puberulent throughout. Stem glandular-puberulent; pod oval or ovate, narrowed towards the apex.

8. L. montanum. Stem densely papillose-puberulent; pod orbicular.

9. L. papilliferum.

Styles slightly exceeding the wing-margins; racemes numerous, short; plant puberulent.

10. L. brachybotryum.

Segments of the basal leaves elongate, linear, oblong, or lanceolate.

Only the lower leaves pinnatifid; pod broadly oval; style scarcely longer than the width of the wing-margins; petals orbicular. 11. L. alyssoides.

Stem leaves except the uppermost also pinnatifid; pod narrower, acutish at both ends; style about twice as long as the width of the wingmargins; petals obovate to elliptic.

Plant low, $3 \mathrm{dm}$. high or less; leaves or their lobes narrowly linear. 12. L. Jonesii.

Plant tall, 4-10 dm. high; upper leaves broadly linear or oblong. 13. L. Eastwoodiae.

Pods $6-8 \mathrm{~mm}$. wide.

14. L. Fremontii.

Style obsolete, or at least shorter than the width of the wing-margins; annuals or biennials.

Wing-margins of the fruit not produced at the apex into distinct lobes or teeth. Pods glabrous or rarely minutely puberulent when young.

Petals conspicuous, at least equalling the sepals, spatulate or obovate.

Style distinct, but short: blades of the petals broadly obovate, much exceeding the sepals.

Style none; blades of the petals spatulate.

Pubescence, if any, of cylindrical or subulate hairs: petals well exceeding the sepals, at least in the earlier flowers.

Stem glabrous or nearly so.

Cotyledons accumbent; petals broadly spatulate.

16. L. virginicum.

Cotyledons incumbent; petals narrowly spatulate or oblanceolate.

Stem densely pubescent.

17. L. texanum.

18. L. hirsutum.

Pubescence of the stem of short, clavate hairs; petals about equalling the sepals.

Stem low, 1-3 dm. high, branched below; primary basal leaves oblanceolate, serrate.

19. L. ramosum.

Stem taller, 4-6 dm. high, simple below, branched above; primary basal leaves pinnatifid.

20. L. simile.

Petals none or minute, scarcely more than half as long as the sepals, linear or linear-spatulate. 
Plants branched near the base; petals usually present (except in $L$. divergens).

Racemes usually numerous, on short branches from the axils of the upper leaves; pods broadest below the middle; wing-margins narrow. Axillary racemes very short and dense, usually shorter than the leaves; petals more than half as long as the sepals.

21. L. ramosissimum.

Axillary racemes at last elongate; petals very minute or lacking.

22. L. ditergens.

Racemes elongate, terminal; pods broadest above the middle; wingmargins fully $0.5 \mathrm{~mm}$. wide at the apex. $23, L$. elongatum.

Plant simple below, branched above; petals none; racemes elongate, terminal.

24. L. densiflorum.
Pods hirsute, at least on the margins.
Stem-leaves linear, mostly entire.
Stem-leaves spatulate, toothed or laciniate.
25. L. pubecarpum.
26. L. Georginum.
Wing-margins of the fruit produced at the apex into acute lobes or teeth.

Stem erect, $3-5 \mathrm{dm}$. high.

Pod obovate or elliptic; stamens 2; leaves linear or linear-spatulate.

Pod obovate or elliptic; stamens 2; leaves linear or linear-spatulate. 28 . L. Bourgeauanum.

Pod ovate; stamens 4; basal leaves often pinnatifid. 29. L. dictyotum.

1. L. perfoliatum L. Annual or biennial; stems suberect, 2-4 dm. high, more or less pilose; lower leaves bipinnatifid into linear divisions; upper stemleaves entire, cordate or reniform, clasping, glabrous; petals yellow, fully $1 \mathrm{~mm}$. long; stamens 6 ; pod $4 \mathrm{~mm}$. long, orbicular, broadly ovate, or rhombic-elliptic, slightly emarginate; style about equalling the width of the wings. Waste places: Utah; nat. from Eu. My-Je.

2. L. sativum L. Glabrous, bright green annual; stem $3-5 \mathrm{dm}$. high, branched; lower leaves twice pinnate, $5-20 \mathrm{~cm}$. long, with obovate or oblanceolate, toothed divisions; petals spatulate, white or pinkish, $2 \mathrm{~mm}$. long; stamens 6 ; pod obovate, $5 \mathrm{~mm}$. long, glabrous, strongly winged above, emarginate; wing partly adnate to the style. Waste places: Que.-N.Y.-Mont.-B.C.; escaped from gardens, native of Eu. Plain-Submont. My-Au.

3. L. integrifolium Nutt. Stems few, 2-5 dm. high, simple below, glabrous; leaves entire, fleshy; petals $2.5 \mathrm{~mm}$. long, obovate; pod 4-5 mm. long, elliptic; style scarcely $1 \mathrm{~mm}$. long. L. utahense Jones. L. Zionis A. Nels. Plains: Wyo.-s Wash.-Ariz. Son. Je.

4. L. Vaseyanum Thellung. Fruticose at the base; stems $2-4 \mathrm{dm}$. high, glabrous; lower leaves cuneate, $2-10 \mathrm{~cm}$. long, the upper oblanceolate, entire, glabrous; petals clawed, $2 \mathrm{~mm}$. long; pod ovate, $3-3.5 \mathrm{~mm}$. long; style about 0.5 mm. long. L. spathulatum Vasey, not Phil. Mountains and hills: Colo.-W Tex.-N.M. Son. Je-S.

5. L. crenatum (Greene) Rydb. Stem 5-9 dm. high, glabrous, simple; basal leaves 5-15 cm. long, petioled; upper stem-leaves sessile and more entire; petals short-clawed, $3 \mathrm{~mm}$. long; pods ovate, 3-4 mm. long; style about twice as long as the wing-margins. Thelypodium crenatum Greene. Sage plains: Colo. Son. J.

6. L. scopulorum M. E. Jones. Somewhat woody at the base; stems several, rather simple, glabrous, 1.5-3 dm. high; leaves coriaceous, glabrous, shining, with broad, obovate, entire or round-toothed divisions; petals clawed, $2 \mathrm{~mm}$. long; pod 3-4 mm. long, ovate; style $1 \mathrm{~mm}$. long. Mountains: UtahAriz.-(? Wyo.) Submont.-Mont. J1-Au.

7. L. Crandallii Rydb. Stems several, branched and leafy throughout, glabrous or puberulent above, $3-5 \mathrm{dm}$. high; lower leaves pinnatifid, $5-7 \mathrm{~cm}$. long, glabrous, with oblanceolate or oblong, entire or slightly toothed divisions; upper stem-leaves oblanceolate or linear, entire or toothed; petals clawed, about 3 $\mathrm{mm}$. long, white; pods oval or ovate, about $4 \mathrm{~mm}$. long, glabrous, slightly wingmargined above; style $1 \mathrm{~mm}$. long. Valleys: Colo. Submont. My-Je.

8. L. montanum Nutt. Stems often several from the same root, $2-4 \mathrm{dm}$. high, more or less puberulent or hirsutulous; lower leaves bipinnatifid, with oblong or obovate divisions, the upper pinnatifid or toothed; petals clawed, $2 \mathrm{~mm}$. long; pod ovate, 3-3.5 $\mathrm{mm}$. long; style about $0.75 \mathrm{~mm}$. long. (?) L. philonitrum Nels. \& Macb. Plains: Wyo.-N.M.-Calif.-Ida.; Mex. Son.-Mont. My-S. 
9. L. papilliferum (Henders.) Nels. \& Macbr. Biennial; stem intricately branched, 1-2 dm. high, bushy; leaves pinnatifid, with oblong, acute divisions, 2-4 em. long; raceme short and dense; petals white, twice as long as the sepals; pedicels in fruit spreading or recurved; pod suborbicular, notched at the apex, $3 \mathrm{~mm}$. long, slightly papillose; style $0.6 \mathrm{~mm}$. long. L. montanum papilliferum Henders. Sage-brush plains: Ida. Son. My-Je.

10. L. brachybotryum Rydb. Stem $2-3 \mathrm{dm}$. high, branched, puberulent throughout; basal leaves puberulent, bipinnatifid, with elliptic or obovate lobes; stem-leaves oblanceolate, pinnatifid or toothed; petals white, clawed, $2 \mathrm{~mm}$. long; fruiting racemes short; pod rounded-ovate, $3 \mathrm{~mm}$. long, wing-margined above. Dry. valleys: Utah. Son. Je-Jl.

11. L. alyssoides A. Gray. Stems usually several, 2-5 dm. high, corymbosely branched, puberulent above; lower leaves pinnatifid with linear divisions, glabrous; upper leaves entire, narrowly linear; petals distinctly clawed, $2-3 \mathrm{~mm}$. long; pod ovate, rarely oval or elliptic, about $4 \mathrm{~mm}$. long; style about $0.5 \mathrm{~mm}$. long. Plains and river valleys: Tex.-Ariz.-Utah-Colo. Son. Ap-S.

12. L. Jonesii Rydb. Perennial, with a short woody caudex; stems 2-3 dm. high, branched, glabrous; lower leaves pinnatifid with linear acute divisions; upper leaves entire, narrowly linear; racemes rather short and dense; petals white, about $3 \mathrm{~mm}$. long, much exceeding the sepals; stamens 6; pod oval, about $4 \mathrm{~mm}$. long and slightly over $2 \mathrm{~mm}$. wide, glabrous, retuse; style about $1 \mathrm{~mm}$. long. Dry places: Utah-Nev. Son.-Submont. Ap-Je.

13. L. Eastwoodiae Wooton. Perennial, with a woody base; stems 5-10 $\mathrm{dm}$. high, corymbosely branched above; lower leaves $3-5 \mathrm{~cm}$. long, pinnately divided, with oblong acute divisions; upper cauline leaves oblong-lanceolate to linear, usually entire; racemes short and crowded; petals elliptic, white, $3 \mathrm{~mm}$. long, clawed; pods elliptic-ovate, emarginate. In rocky places: N.M.-Utah. Submont. Je.

14. L. Fremontii S. Wats. Shrubby below, 3-10 dm. high; stem glabrous and shining; lower leaves glabrous, pinnatifid, with linear divisions, the upper entire, linear, more or less fleshy; petals clawed, $3 \mathrm{~mm}$. long; blades rhombicobovate; pods $5-7 \mathrm{~mm}$. long and fully as broad, orbicular or obcordate, scarcely winged; style $0.5-0.7 \mathrm{~mm}$. long. Rocky and arid ground: Utah-Ariz.-Calif. L. Son. Ap-Je.

15. L. idahoense Heller. Stem $2-5 \mathrm{dm}$. high, sparingly and minutely pubescent, simple below, branched above; basal leaves spatulate, coarsely toothed or pinnatifid; lower stem-leaves oblanceolate, laciniately dentate, the upper linear and entire; petals white, clawed, about $2 \mathrm{~mm}$. long; pod orbicular, about $3 \mathrm{~mm}$. long. River banks, cañons, and foot-hills: Ida.-Colo. Son.-Submont. My-Je.

16. L. virginicum L. Annual or biennial; stem erect, more or less pubescent, leafy, corymbosely branched above; basal leaves lyrate-pinnatifid, more or less hirsute; lower stem-leaves oblanceolate, incised, the upper narrower, remotely dentate; petals clawed, about $1.5 \mathrm{~mm}$. long; stamens 2-6; pod suborbicular, 3 $\mathrm{mm}$. long, winged above, with rounded lobes. Waste places, fields, and roadsides: Que.-Fla.-Tex.-Utah; Mex., W. Ind., C. Am., S. Am.; naturalized in the Old World. Plain-Submont. Ja-D. (in the Rockies, My-Au).

17. L. texanum Buckl. Annual; stems glabrous or nearly so, 3-5 dm. high, branched above; lower leaves obovate or oblanceolate, somewhat pubescent, coarsely toothed; upper stem-leaves linear, mostly entire, glabrous and shining; petals slightly more than $1 \mathrm{~mm}$. long; stamens mostly 2; pod orbicular, $3 \mathrm{~mm}$. long, narrowly wing-margined above. $L$. intermedium A. Gray. $L$. medium Greene. Sandy soil: Mo.-Ala.-Tex.-Calif.-B.C.; Mex. Son. Ap-Au.

18. L. hirsutum Rydb. Annual or biennial; stem strict, 3-5 dm. high; lower leaves lyrately pinnatifid, with broad, toothed lobes, densely hirsute; upper leaves oblanceolate, coarsely and saliently toothed; petals white, $1 \mathrm{~mm}$. long, clawed; stamens usually 2 ; pod rounded-oval, $3-3.5 \mathrm{~mm}$. long. L. inter- 
medium pubescens Greene. River banks and waste places: Colo.-Utah-Mex. Son.-Mont. Ap-Au.

19. L. ramosum A. Nels. Biennial; stem 1.5-3 dm. high, minutely granular-puberulent; basal leaves oblanceolate, coarsely serrate or pinnatifid; upper cauline leaves narrowly oblanceolate or linear, entire; petals about $1 \mathrm{~mm}$. long; stamens 2; capsule orbicular, $3 \mathrm{~mm}$. long, narrowly winged at the summit. Sandy soil: Mont.-Colo. Submont.-Mont. Je-Au.

20. L. simile Heller. Annual; stem 3-5 dm. high, more or less puberulent, lower leaves oblanceolate, pinnately lobed or parted, puberulent; upper stem-leaves entire, oblanceolate to linear; petals greenish white, $1.5 \mathrm{~mm}$. long; stamens usually 2 ; pod fully $3 \mathrm{~mm}$. long, winged above, obovate, notched, puberulent on the margin. River banks: Ida.-Wash.-B.C. Son. My-Jl.

21. L. ramosissimum A. Nels. Biennial; stems 2-4 dm. high, slightly puberulent, profusely branched; basal leaves pinnately lobed or toothed or incised; stem-leaves oblanceolate, all except the uppermost more or less toothed; petals white, narrowly spatulate; stamens 2 ; pod ovate, $3 \mathrm{~mm}$. long. Mesas and mountains: Colo.-Wyo. Submont.-Mont. Je-Au.

22. L. divergens Osterh. Biennial; stems 1.5-3 dm. high, branclted from the base, minutely puberulent; basal leaves spatulate, coarsely toothed; stemleaves linear or oblanceolate, few-toothed above or entire; petals none; stamens 2 ; pod elliptic, $3 \mathrm{~mm}$. long; fruiting racemes numerous and short. Mountains: Colo.-Utah. Submont.-Mont. Jl.

23. L. elongatum Rydb. Annual or biennial; stem branched near the base, about $3 \mathrm{dm}$. high, granular-pruinose above; basal leaves spatulate or oblanceolate, about $4 \mathrm{~cm}$. long, coarsely toothed; stem-leaves oblanceolate, entire or with a few small teeth, acutish; petals minute, linear-oblanceolate, or lacking; pods nearly orbicular, about $3 \mathrm{~mm}$. broad, glabrous or slightly pruinose. Sandy soil and rocky hilltops: Ida.-Wash. Son. My-Je.

24. L. densiflorum Schrad. Annual or biennial; stem 2-5 dm. high, puberulent, with short hairs, simple below, branched above; basal leaves oblanceolate or oblong, deeply incised-serrate or more or less pinnatifid, puberulent; stem-leaves mostly sharply toothed; petals rudimentary, linear-oblong, or none; stamens 2 or 4 ; pod obovate, about $3 \mathrm{~mm}$. long. L. apetalum A. Gray, not Willd. Plains, prairies, waste places: Hudson Bay-Vt.-N.Y.-N.M.B.C. Plain-Mont. Ap-O.

25. L. pubecarpum A. Nels. Annual; stem usually branched near the base, 8-30 cm. high, minutely puberulent; basal leaves oblanceolate, toothed; stemleaves linear or oblanceolate, entire, or the lower remotely toothed; petals wanting; stamens 2 ; pod finely pubescent, broadly oval to orbicular, $2.5-3 \mathrm{~mm}$. long. Dry rocky slopes and roadsides: Mont.-Wyo.-Utah-Nev. My-Jl.

26. L. Georginum Rydb. Apparently biennial, 1-2 dm. high; stems hirsute with short spreading hairs; lower leaves $1-5 \mathrm{~cm}$. long, deeply pinnately divided with ovate lobes, more or less pubescent; petals spatulate, slightly exceeding the sepals; pods pubescent, rarely almost glabrous, rounded oval, $4 \mathrm{~mm}$. long, broadly winged above, forming at the apex two broadly ovate obtuse lobes, over $0.5 \mathrm{~mm}$. long. L. lasiocarpum Coult. \& Nels., not Nutt. L. Wrightii Auth., not A. Gray. Arid regions: w Colo--Ariz.-Nev. Son. Ap-Je.

27. L. Fletcheri Rydb. Annual or biennial; stem erect, 3-5 dm. high, puberulent with short cylindric spreading hairs; leaves narrow, pinnatifid, with linear divisions or saliently toothed, $2-5 \mathrm{~cm}$. long, puberulent; petals none; stamens usually 2 ; pod glabrous, scarcely $3 \mathrm{~mm}$. long, obovate in outline, glabrous; lobes of the wings nearly $0.5 \mathrm{~mm}$., triangular-ovate, acutish or obtuse. Roadsides: Man.-Sask. Plain.

28. L. Bourgeauanum Thellung. Annual or biennial; stems decumbent, 1-1.5 dm. long; leaves linear or narrowly linear-spatulate, entire, pubescent with thickened hairs; petals rudimentary; stamens 2; pod obovate or elliptic, deeply notched at the apex; lobes of the wings acute and somewhat porrect. Plains: Sask. Plain. 
29. L. dictyotum A. Gray. Annual; stems branched at the base, spreading, 3-10 cm. long, hirsute; basal leaves either linear, entire, or pinnatifid with distant linear lobes; stem-leaves narrowly linear; petals none or rudimentary; stamens 4 ; pod ovate, wing-margined, with prominent acute lobes, hirsute, 3 mm. long. Sandy places: Wash.-Ida.-Utah-Calif. Son. Mr-Je.

\section{Thláspi (Tourn.) L. Penny Cress, Penny-grass. Wild Sweet Alyssum.}

Glabrous annuals or perennials, with undivided and often clasping leaves. Flowers racemose, perfect. Sepals equal. Petals white, or rarely pink or purplish, obovate or oblanceolate. Stamens free, unappendaged; anthers short, oval. Styles slender or none; stigma small, entire. Capsules orbicular, oblong or cuneate; valves strongly keeled, often winged, especially towards the apex. Seeds $2-8$ in each cell.

Pods orbicular in outline, broadly wing-margined and deeply notched at the apex; sepals green; annuals.

Pods obovate or oblanceolate-cuneate in outline, with narrow margins, acute, truncate or slightly notched at the apex; sepals with white or rarely purplish margins; perennials.

Petałs $2.5-3 \mathrm{~mm}$. long; pod oblanceolate-cuneate, 2-2.5 mm. wide. 2 , $T$. parviflorum.

Petals 4-7 mm. long; pods cuneate or obovate-cuneate, $3 \mathrm{~mm}$, or more wide. Pods acutish at the apex, neither emarginate nor retuse.
Pods rounded or truncate at the apex, emarginate or retuse.

Pods rounded at the apex; sinus narrow.

Caudex rather slender; stem 1-2 dm. high; petals spatulate, about $5 \mathrm{~mm}$. long.

3. T. californicum.

Caudex obovate, $6-7 \mathrm{~mm}$. long.

Pods truncate or nearly so at the apex; sinus very broad and open.

Stem 2-3 dm. high; stem-leaves ample, broader than the basal ones; sepals green, with white margins.

Stem $1 \mathrm{dm}$, or less; stem-leaves reduced; sepals and often also petals purplish.

7. T. purpurascens.

1. T. arvense L. Annual, glabrous; stem 1.5-4.5 dm. high; basal leaves early deciduous, petioled; blades oblanceolate; stem-leaves oblong or elliptic, dentate, the upper auricled and clasping at the base; petals about $4 \mathrm{~mm}$. long, oblanceolate or spatulate; pod 12-18 mm. long, 10-15 mm. broad. Waste places and roadsides: Lab.-Fla.-Colo.-Utah-B.C.; adv. or nat. from Eu. Plain -Submont. My-Jl.

2. T. parviflorum A. Nels. Stems few, 1-3 dm. high; lower leaves rosulate at the base, glabrous, $5-20 \mathrm{~mm}$. long, short-petioled, elliptic or oval; stem-leaves 5-12 mm. long, oblong, sagittate and clasping at the base; petals oblanceolate; pod 5-7 mm. long, scarcely winged, slightly emarginate. Open valleys: Wyo.Mont. Submont,-Mont. Je.

3. T. californicum S. Wats. Stems 1-2 dm. high, simple; basal leaves petioled, $1-3 \mathrm{~cm}$. long, oval or spatulate; stem-leaves oval, $5-10 \mathrm{~mm}$. long, sagittate and clasping at the base; petals spatulate, $4-5 \mathrm{~mm}$. long; pod cuneate, 5-7 $\mathrm{mm}$. long. Mountain valleys: Mont.-Utah-Calif.-Wash. Submont.-Subalp. Je-Au.

4. T. Nuttallii Rydb. Stems solitary or few, 1-2 dm. high, leafy; basal leaves petioled, 1-2 cm. long, glabrous, oval, spatulate, or obovate; stem-leaves rounded-oval, about $1 \mathrm{~cm}$. long, cordate and clasping at the base; pod cuneateobcordate, about $7 \mathrm{~mm}$. long. Valleys and hillsides: Mont.-Colo.-Wash. Submont.-Mont. My-Jl.

5. T. coloradense Rydb. Stems $2-8 \mathrm{~cm}$. long; basal leaves broadly spatuate, $1-2 \mathrm{~cm}$. long, fleshy, sinuately crenate or subentire; stem-leaves oblong or obovate, $3-10 \mathrm{~mm}$. long, obtuse; pod obovate, about $6 \mathrm{~mm}$. long; wing-margins very narrow. Alpine peaks: Colo.-Utah. Alp.-Mont. Jl-Au.

6. T. glaucum A. Nels. Stems leafy, 1-3 dm. high; basal leaves petioled, 2-3 cm. long, oval or obovate, glabrous and glaucous, entire or repand; stem-leaves ovate-oblong, cordate and clasping at the base; petals about $6 \mathrm{~mm}$. long; pod cuneate, wing-margined above. Valleys: Mont.-Colo.-Utah. Submont. -Subalp. Je-Jl. 
7. T. purpurascens Rydb. Stems generally several, less than $1 \mathrm{dm}$. high; basal leaves oval or broadly spatulate, $2-3 \mathrm{~cm}$. long, petioled, usually more or less sinuate-dentate; stem-leaves ovate, obtuse, with a truncate base, closely sessile; petals about $6 \mathrm{~mm}$. long; pod triangular-obovate, distinctly winged above, 7-8 mm. long. Alpine peaks: Colo.-Utah-Ariz.-N.M. Subalp.-Alp. My-Jl.

\section{BÚRSA Weber. Shepherd's Purse.}

Annual caulescent herbs, pubescent with branched hairs. Leaves alternate, entire, lobed, or pinnatifid. Flowers perfect, in elongate racemes. Petals white, spatulate. Stamens free and unappendaged. Styles almost none; stigma simple. Pod strongly flattened contrary to the narrow septum, cuneate or obcordate, more or less deeply notched at the apex, the valves boat-shaped. Seeds numerous in each cavity, marginless. Cotyledons accumbent.

1. B. Bursa-pastoris (L.) Britton. Annual or winter biennial; stem 1-5 $\mathrm{dm}$. high; lower leaves usually lyrate-pinnatifid, lobed or merely dentate; stemleaves sessile, hastate or sagittate at the base; petals white, $2 \mathrm{~mm}$. long, spatulate; pods 6-8 mm. long, triangular. Capsella Bursa-pastoris Medic. Waste places: Lab.-Fla.-Calif.-B.C.; S. Am.; nat. from Eurasia. Plain-Subalp. Ja-D.

\section{HUTCHINSIA R. Br.}

Low spreading annuals, minutely stellate or glabrous. Leaves alternate, entire to pinnately lobed. Flowers perfect, in at last elongate racemes. Stigma sessile. Petals minute, narrow, white. Pods strongly flattened contrary to the narrow septum, elliptic, not at all obcordate or notched at the apex. Seeds numerous in each cell. Cotyledons accumbent.

1. H. procumbens (L.) Dev. Stems branched at the base, slender, $5-20 \mathrm{~cm}$. long; lower leaves pinnatifid, lobed, toothed, or entire, minutely stellate; upper leaves entire, oblanceolate or linear; sepals and petals about $1 \mathrm{~mm}$. long; fruiting pedicels divaricate; pod elliptic, about $4 \mathrm{~mm}$. long. Moist ground: Lab.-Newf.-Colo-Calif.-B.C. Plain-Submont. Mr-Je.

\section{SMELÓWSKIA C. A. Meyer.}

Low cespitose perennials, with a suffruticose eaudex and cinereous stellate pinnatifid leaves. Flowers perfect, racemose. Sepals subequal, somewhat spreading. Petals obovate, exserted, white or ochroleucous or tinged with purple. Pod lanceolate or ovate, more or less obcompressed; valves strongly keeled. Stigma sessile.

Basal leaves merely lobed, cuneate to oblanceolate in outline; pod 5-6 mm. long, tapering towards the base.

Leaves all deeply pinnatifid.

Pod ovate, 4-5 mm. long, obtuse at the base; calyces and pedicels densely villous;

Pod lanceolate or oblanceolate, 7-12 mm. long, tapering at each end. Segments of the basal leaves spatulate or oblong.

Segments of the basal leaves linear or linear-oblong.

1. S. lobata Rydb. Stems $1 \mathrm{dm}$. or less high; stem-leaves pinnatifid; sepals densely villous, $3 \mathrm{~mm}$. long, ovate, acute; petals white, clawed, rounded-obovate; pod glabrous, about 5-6 mm. long, oblanceolate; style very short. High mountains: Alta.-Mont. Subalp. Je-Jl.

2. S. ovalis M. E. Jones. Stems about $1 \mathrm{dm}$. high, densely white-villous and stellate; basal leaves floccose-stellate, pinnately divided into 5-7 oblong, entire, or 2-3-cleft divisions; petals clawed, with rounded-obovate blades; pods obtuse at the base. High mountains: Wash.-Alta.-Calif. Mont.-Subalp. $\mathrm{Jl}-\mathrm{Au}$.

3. S. americana Rydb. Stems 1-2 dm. high; leaves finely but not densely stellate; petals long-clawed, spatulate; pod 7-12 $\mathrm{mm}$. long, tapering at both ends. High mountains: Mont.-Colo--Utah-Ida. Mont.-Alp. Je-Jl.

4. S. lineariloba Rydb. Stems about $1 \mathrm{~cm}$. high, few-leaved; leaves 2-5 $\mathrm{cm}$. long, finely stellate, the petioles also ciliate; petals clawed, $5-6 \mathrm{~mm}$. long, 
broadly spatulate; fruit $11-12 \mathrm{~mm}$. long and about $1 \mathrm{~mm}$. wide, tapering at both ends. High mountains: Colo.-Utah-Alta. Alp.-Subalp.

\section{DITHYRÈA Harv.}

Stellate caulescent annuals or perennials. Flowers perfect, racemose. Sepals ovate or oblong, erect or spreading, pubescent. Petals broadly spatulate, with slender claws, white or purplish. Stamens 6, free and unappendaged; anthers sagittate, linear. Pods didymous, strongly obcompressed; cells suborbicular. Stigma sessile, large, simple. Cotyledons accumbent.

1. D. Wislizeni Engelm. Perennial or biennial with a taproot; stems cinereous-stellate, $3-6 \mathrm{dm}$. high; leaves numerous, lanceolate, sinuately dentate, cinereous-stellate, 3-6 $\mathrm{cm}$. long; petals light yellow, $6 \mathrm{~mm}$. long, long-clawed; pedicels in fruit divaricate; cells of the fruit obliquely obovate, flat, margined, about $5 \mathrm{~mm}$. wide. Arid regions: Tex.-Ariz.-Utah. Son.

\section{PhYSÃria A. Gray. Double Bladder-pod.}

Stellate, cespitose perennials with taproots. Flowers perfect, racemose. Sepals oblong, erect or ascending, equal at the base. Petals spatulate, yellow. Stamens 6; anthers sagittate, linear. Fruit more or less distinctly didymous, inflated or obcompressed. Styles slender. Cotyledons accumbent.

Cells of the pods much inflated, the upper sinus acute, narrow.

Pods deeply cordate at the base; lower sinus almost as deep as the upper. Pubescence short and close.

Pubescence long and loose.
Pods not cordate at the base or slightly so; lower sinus none or very shallow.

1. P. didymocarpa.

Cells of the pods $5-10 \mathrm{~mm}$. in diameter, without ridges on the sides.

Some of the basal leaves more or less fiddle-shaped.

Leaves of the decumbent flowering stems reduced; terminal lobe of the basal leaves rounded or reniform, very obtuse, entire. Leaves of the ascending flowering stems ample; terminal lobes of the basal leaves rhombic or ovate, acute or sometime obtuse, sinuate.

None of the basal leaves fiddle-shaped.

4. P. floribunda.

Basal leaves oblanceolate or spatulate, acute, 2-4 cm. Iong; pods slightly cordate at the base. 5 . P. acutifolia,

Basal leaves rounded-obovate, 4-10 $\mathrm{cm}$. long; pod acutish at the base.

Cells of the pods $10-18 \mathrm{~mm}$. in diameter when fully developed, ridged on the sides.

Cells of the pods not much inflated, the upper sinus shallow, open. 8. P. Newberryi.

1. P. didymocarpa (Hook.) A. Gray. Stems numerous, $3-15 \mathrm{~cm}$. long, decumbent to erect; basal leaves 1-8 cm. long, with margined petioles and broadly obovate, entire or sinuately toothed blades, finely and closely stellate; petals 8-14 mm. long, spatulate; pod 7-15 mm. in diameter. $P$. macrantha Blankinship. Sandy or rocky hills and plains: Sask.-Colo.-Utah-Alta. PlainMont. $\mathrm{My}-\mathrm{Jl}$.

2. P. lanata (A. Nels.) Rydb. Stems erect or ascending, 1-2 dm. high; basal leaves numerous, 4-8 cm. long; blades broadly obovate to flabelliformspatulate, sinuate-dentate; petals about $8 \mathrm{~mm}$. long, oblanceolate; pods about $12 \mathrm{~mm}$. in diameter. $P$. didymocarpa lanata A. Nels. Rocky slopes and rolling plains: n Wyo. Submont. Je-Jl.

3. P. vitulifera Rydb. Stems ascending or decumbent, 1-2 dm. high; basal leaves numerous, the larger 4-5 cm. long; terminal lobe nearly orbicular to broadly obovate, sub-entire, obtuse; lateral lobes 1-2 pairs, much smaller; petals clawed, 8-9 mm. long; fruit obtuse at the base, deeply divided above; cells $5 \mathrm{~mm}$. in diameter. Dry places in the mountains: Colo. Mont. My-Jl.

4. P. floribunda Rydb. Stems numerous, ascending or almost erect, 1-2.5 $\mathrm{dm}$. high; basal leaves less crowded and more erect than in the preceding, oblanceolate or spatulate, sinuately toothed, usually acute, $5-10 \mathrm{~cm}$. long; petals bright yellow, 8-9 mm. long; fruit obtuse or slightly cordate at the base, deeply divided above; cells about $8 \mathrm{~mm}$. in diameter. Sandy soil, in mountain valleys: Colo. Submont.-Mont. Ap-Jl. 
5. P. acutifolia Rydb. Stems $4-6 \mathrm{~cm}$. long, ascending or depressed; basal leaves numerous, oblanceolate or obovate, acute, entire or slightly wavy, very finely stellate; fruit small, obtuse or slightly cordate at the base, deeply divided above, 4-6 mm. in diameter. (?) Lesquerella pruinosa Greene. Mountains: Colo.-Wyo. Submont.-Mont.

6. P. brassicoides Rydb. Stems about $1 \mathrm{dm}$. high, ascending; basal leaves large, with winged petioles almost orbicular in outline, sinuate-dentate, 2.5-5 $\mathrm{cm}$. in diameter; fruit almost obcordate, acute at the base, deeply divided above, 8-10 mm. long and 5-8 mm. in diameter. Cañons and bad lands: Neb.-N.D. Plain. Je.

7. P. Newberryi A. Gray. Stems $8-20 \mathrm{~cm}$. high, decumbent at the base; basal leaves $3-10 \mathrm{~cm}$. long, with margined petioles, finely stellate-eanescent, obovate or spatulate, entire or sinuate-dentate; petals oblanceolate, about $1 \mathrm{~cm}$. long; pod deeply cleft above, slightly so below. Dry mountains and hills: N.M. -Ariz.-Nev.-Utah. Submont.-Mont. My-Je.

8. P. Geyeri (Hook.) A. Gray. Stems ascending or decumbent, $5-15 \mathrm{~cm}$. long; basal leaves $2-5 \mathrm{~cm}$. long, with margined petioles, obovate to nearly orbicular, finely stellate, sinuately-toothed or entire; petals 8-12 mm. long, spatulate; pods obcordate, about $6 \mathrm{~mm}$. wide and $3 \mathrm{~mm}$. thick. Dry hillsides: Wash.Mont.-Wyo. Submont. My-Jl.

\section{LESQUERÉLLA S. Wats. BLADDER-POD.}

Annual or tufted perennial, stellate herbs. Leaves entire or lobed, the hlades linear to broadly spatulate or orbicular, the basal ones clustered. Flowers perfect, racemose. Sepals oblong, equal at the base; petals spatulate, yellow. Stamens 6; anthers linear, sagittate. Pods inflated, subglobose, ellipsoid, or ovoid; style slender; stigma entire; cells $2-16$-seeded. Seeds rarely margined. Cotyledons accumbent.

Ovary and pod stellate-pubescent.

Pod ovoid or ellipsoid.

Pod distinctly compressed and acute at the apex.

Pod 6-8 mm. long; plant usually more than $1 \mathrm{dm}$. high.

Basal leaves broadly oval; septum of the pod elliptic in outline; style equalling the pod

1. L. Shearis.

Basal leaves oblanceolate to obovate; septum of the pod ovate in outline; style much shorter than the pod.

2. L. curvipes.

Pod 3-5 mm. long; plant usually $1 \mathrm{dm}$. or less high.

Basal leaves linear-oblanceolate or linear. Pod strongly compressed above.

Leaves narrowly linear-oblanceolate; plant pulvinate.

3. L. alpina.

Leaves narrowly linear; plant multicipitous, with a subterranean woody caudex. Pods slightly compressed.

Basal leaves spatulate; pod not strongly compressed above.

Plant densely pulvinate, $2-5 \mathrm{~cm}$. high; leaves $2 \mathrm{~cm}$. long or less; pedicels erect or nearly so.

4. L. parvula.

5. L. intermedia.

6. L. condensata.

Plant cespitose, 5-10 cm. high; leaves about $2 \mathrm{~cm}$. long or more; basal leaves oblanceolate-spatulate; pedicels spreading, S-curved.

7. L. spatulata.

Pod not compressed above.

Basal leaf-blades rounded or broadly spatulate.

Stem-leaves small, generally less than $1 \mathrm{~cm}$. long, linear-oblanceolate.

Basal leaf-blades obovate-spatulate; style shorter than the pod.

8. L. prostrata.

Basal leaf-blades rhombic-ovate; style longer than the very acute pod.

9. L. Wardii.

Stem-leaves oblanceolate or obovate, 1-2 cm. long.

10. L. montana.

Basal leaf-blades linear-oblanceolate; stem-leaves narrowly so.

11. L. arenosa.

Pod globose.

Plant perennial.

Pod 2-3 $\mathrm{mm}$. in diameter.

Basal leaf-blades spatulate or oblanceolate.

Stem very slender; stem-leaves oblanceolate, 1-3 cm. long.

Plant $5 \mathrm{~cm}$. or less high; pod less than $2 \mathrm{~mm}$. broad; petals purple.

12. L. rosea.

Plant usually more than $5 \mathrm{~cm}$. high; pod 2-3 mm. broad; petals yellow. 
Pedicels ascending.

Pedicels in fruit recurved.
13. L. versicolor.

11. L. arenosa.

Stem stouter, strict; stem-leaves linear, 2-6 cm. long. 14. L. ludoviciana. Basal leaf-blades broadly oval, ovate, or elliptic.

Basal leaves repand-dentate; stems stout; raceme loose; pedicels recurved.

Basal leaves entire; stem slender; racemes congested; pedicels upcurved.

16. L. utahensis.

17. L. macrocarpa.

18. L. Gordoni.

Plant annual.

Ovary and pod glabrous, globose.

Plant annual.

Plant perennial.

18. L. Gordoni.

Basal leaf-blades oblanceolate; stem-leaves narrowly so.

Plants usually more than $3 \mathrm{dm}$. high; flowers and fruit corymbose.

19. L. Engelmanni.

Plant usually less than $3 \mathrm{dm}$. high; inflorescence at least in fruit elongate, racemose.

Basal leaf-blades broadly oval.

21. L. ovalifolia.

1. L. Shearis Rydb. Stems several, ascending, 1-2 dm. high; basal leaves 3-4 cm. long; blades broadly oval or ovate; stem-leaves oblanceolate, about 2 $\mathrm{cm}$. long, subsessile; pedicels in fruit bent S-shaped; pods erect, 7-8 mm. long, acute, compressed above. Creek banks and foot-hills: Colo. Submont. Je-Jl.

2. L. curvipes A. Nels. Stems tufted, numerous, adsurgent, $1.5-3 \mathrm{dm}$. high; basal leaves with oblanceolate to obovate blades; stem-leaves linear or oblanceolate; pedicels S-curved, about $1 \mathrm{~cm}$. long; pod ovate in outline, gibbous at the base, flattened at the apex, about $8 \mathrm{~mm}$. long. Dry mountains: Colo.Mont. Submont.-Mont. My-Je.

3. L. alpina (Nutt.) S. Wats. Stem $2-10 \mathrm{~cm}$. long, erect or adsurgent; basal leaves $2-5 \mathrm{~cm}$. long; stem-leaves narrowly linear; petals about $6 \mathrm{~mm}$. long; pods usually erect, ovoid; body about $4 \mathrm{~mm}$. long; style slightly longer; septum usually perforated. Dry hills and plains: Mont.-Utah-Colo.-N.D. Submont.Subalp. Je-Jl.

4. L. parvula Greene. Stems $1-4 \mathrm{~cm}$. high; leaves all narrowly linear, silvery stellate; pods ovate, 4-5 $\mathrm{mm}$. long, erect; style slightly longer; septum usually perforated. High mountains: Colo. Subalp.-Alp. Je-Jl.

5. L. intermedia (S. Wats.) Heller. Pulvinate-cespitose; stems numerous, 5-10 cm. high, leafy; leaves oblanceolate or linear-oblanceolate; petals fully 1 $\mathrm{cm}$. long; pedicels in fruit erect; pod 4-5 $\mathrm{mm}$. long, ovoid; style of about the same length; septum usually entire. Arid regions: N.M.-Ariz.-Utah. Son. $\mathrm{My}-\mathrm{Je}$.

6. L. condensata A. Nels. Stems numerous, $3-5 \mathrm{~cm}$. (rarely $7 \mathrm{~cm}$.) high; leaves spatulate, 8-20 $\mathrm{mm}$. long; inflorescence short and corvmbiform; petals 6-7 mm. long; pod ovoid, slightly compressed, $5 \mathrm{~mm}$. long and about equalling the style; septum usually with a narrow perforation. Rocky slopes of the foothills: Mont.-Wyo. Submont. My-Je.

7. I. spatulata Rydb. Stems $3-10 \mathrm{~cm}$. high; stem-leaves few, linear; petals spatulate, $7-8 \mathrm{~mm}$. long; pod ovoid, about $5 \mathrm{~mm}$. long; style slightly shorter; septum not perforated. (?) L. nodosa Greene. Dry hills: Man.-Neb.-Utah -Mont. Plain-Submont. Je-Jl.

8. L. prostrata A. Nels. Stems many, spreading; petals about 7-8 mm. long; pedicels in fruit ascending, recurved; pod 5-6 mm. long, ovoid; septum mostly perforated. Gravelly slopes: Sask.-Colo. Plain-Submont. Je.

9. L. Wardii S. Wats. Stems decumbent; basal leaves long-petioled; blades 1-3 cm. long, 1-2 cm. wide; petals 7-9 mm. long; fruiting pedicels ascending; pod ellipsoid, terete or obcompressed; body $6 \mathrm{~mm}$. long. Mountains: Utah. Mont.-Subalp. Je-Jl.

10. L. montana (A. Gray) S. Wats. Stems decumbent, 1-2 dm. high; blades ovate or broadly spatulate, often sinuate; petals spatulate, about $1 \mathrm{~cm}$. long; fruiting pedicels more or less S-curved; pod ellipsoid, 7-10 $\mathrm{mm}$. long, not compressed; style slightly shorter. L. rosulata A. Nels., a depauperate form. Mountains: Wyo.-N.M.-Utah. Submont.-Subalp. My-Je. 
11. L. arenosa (Richards.) Rydb. Stems slender, decumbent or ascending, 1-3 dm. high; petals 6-8 mm. long; fruiting pedicels spreading, recurved; pod globose or slightly ellipsoid, 4-5 mm. long, shorter than the style. L. Lunellii A. Nels. Hills and plains: Man.-S.D.-Colo--Mont.-Sask. Plain-Submont. Je-Jl.

12. L. rosea Greene. Stems slender, $5 \mathrm{~cm}$. or less high; basal leaves about $1 \mathrm{~cm}$. long; blades ovate or ovate-lanceolate; stem-leaves few, oblanceolate, sessile; petals rose-purple; pod $2 \mathrm{~mm}$. thick, shorter than the style. Plains: Sask.-Alta. Plain. Je.

13. L. versicolor Greene. Stems decumbent, 2-3 dm. high; basal leaves few and small; blades oval or oblanceolate, entire or toothed; stem-leaves oblanceolate; petals sulphur-yellow, changing into pink; pod $3 \mathrm{~mm}$. thick; style $4 \mathrm{~mm}$. long. Stony mountains: Man.-Sask. Plain. Je.

14. L. Iudoviciana (Nutt.) S. Wats. Stems erect or decumbent at the base, 1-4 dm. high; basal leaves linear-oblanceolate, $3-10 \mathrm{~cm}$. long, entire or repand; petals $7-8 \mathrm{~mm}$. long; pedicels in fruit spreading and recurved; pods 4-5 mm. long; style about the same length. L. argentea (Pursh) MacMill., not S. Wats. Plains and hills: Man.-Kans.-Colo.-Mont. Plain-Submont. My$\mathrm{Jl}$.

15. L. Macounii Greene. Stems several, decumbent, 1-1.5 dm. high; basal leaf-blades oval or elliptic, repand-dentate; pedicels spreading, recurved; petals pale yellow; pods $3-4 \mathrm{~mm}$. long, slightly shorter than the styles. Dry plains: Alta. Plain. Au.

16. L. utahensis Rydb. Stems ascending, 5-10 cm. (seldom $15 \mathrm{~cm}$.) high; basal leaves 3-4 cm. long; blades oval or obovate; stem-leaves smaller, oblanceolate or spatulate; petals yellow, about $8 \mathrm{~mm}$. long; pedicels in fruit ascending; pod a most spherical or slightly obcompressed, 3-4 mm. wide; style $4-5 \mathrm{~mm}$. long, much longer than the pod. Dry hills: Utah. Submont.-Mont. Je-Jl.

17. L. macrocarpa A. Nels. Stems decumbent, 7-15 $\mathrm{cm}$. high; basal leaf-blades orbicular or obovate; petals 5-7 $\mathrm{mm}$. long, spatulate; pedicels in fruit spreading, recurved; body of pod 5-8 $\mathrm{mm}$. thick; style $2-3 \mathrm{~mm}$. long. Clay flats and ridges: Wyo. Plain. Je.

18. L. Gordoni (A. Gray) S. Wats. Annual or perhaps biennial; stems 1-3 dm. high, erect, slender; leaves narrowly oblanceolate, entire or repand; petals 6-7 mm. long; fruiting pedicels somewhat recurved; pod slightly stipitate, globose, $4 \mathrm{~mm}$. thick, sparingly stellate; style slightly shorter. Sandy soil: Tex.-Calif. -Utah. Son. Mr-My.

19. L. Engelmanni (A. Gray) S. Wats. Cespitose perennial; stems erect, 3-5 dm. high; petals often $1 \mathrm{~cm}$. long; fruiting pedicels ascending or the lower spreading; pod 6-8 mm. thick; style about $8 \mathrm{~mm}$. long. Rocky hills and plains: Tex.-N.M.-Colo. Son. Ap-My.

20. L. stenophylla (A. Gray) S. Wats. Stems many, very leafy; petals about $8 \mathrm{~mm}$. long; fruiting pedicels ascending, $1-1.5 \mathrm{~cm}$. long; pod $4-5 \mathrm{~mm}$. thick; style of about the same length. L. Fendleri Coulter \& Nels, not S. Wats. Dry plains and hills: Tex.-Ariz.-Colo.; n Mex. Son. My-Je.

21. L. ovalifolia Rydb. Stems ereet, 1-2 dm. high; basal leaves petioled, 1-2 cm. long; stem-leaves sessile, linear-oblanceolate; inflorescence corymbiform; petals 8-10 $\mathrm{mm}$. long, obovate; fruiting pedicels ascending; pods $5-6 \mathrm{~mm}$. thick; style of about the same length. L. ovata Greene. L. Engelmanii Coult. \& Nels., not S. Wats. Dry plains and hills: Neb.-Kans.-N.M.-Colo. Plain -Son. My-Je.

\section{SUBULĀRIA L.}

Small aquatic perennials, scapose and with subulate basal leaves. Flowers perfect, racemose. Sepals ovate, equal, spreading. Petals oblong or spatulate, without claws, white. Stamens 6, scarcely unequal; anthers oval. Pod short, subglobose or pear-shaped, turgid. Seeds few. Embryo folded above the radicle. 
1. S. aquatica L. Submerged perennial; leaves $10-20$, erect or nearly so, 2-7 cm. long, subulate; scape 2-10 cm. long; submersed flowers cleistogamous; fruit obovate. Ponds: Newf.-N.H.-Calif.-B.C. Mont.

\section{Camelìna Crantz. False Flax.}

Annual caulescent herbs, glabrous or with branching hairs. Leaves alternate, entire or toothed, often clasping. Flowers perfect, in elongate racemes. Sepals equal. Petals yellowish or greenish. Pod short, inflated, nearly terete, obovoid; valves 1-nerved; style slender; stigma capitate. Seeds in two rows, usually few, marginless. Cotyledons incumbent.

Stem glabrous.

stem pubescent.
1. C. sativa.

2. C. microcarpa.

1. C. sativa (L.) Crantz. Stem 3-6 dm. high, branched above; lower leaves petioled, 5-8 cm. long, lanceolate; upper stem-leaves sagittate at the base and clasping; petals light yellow, 5-6 mm. long; pod pear-shaped 6-8 $\mathrm{mm}$. long. Waste places: N.S.-N.Y.-Calif.-Mont.; adv. from Eu. Plain-Submont. $\mathrm{Je}-\mathrm{Jl}$.

2. C. microcarpa Andrz. Stem 3-6 dm. high; lower leaves lanceolate, more or less hirsute; stem-leaves sagittate at the clasping base; petals about $4 \mathrm{~mm}$. long; pod 4-6 mm. long, pear-shaped, strongly margined. Waste places: R.I.Va.-Ariz.-B.C.; nat. from Eu. Plain-Submont. My-Jl.

\section{NẾSLIA Desv.}

Leafy-stemmed annuals. Flowers perfect. Sepals short, equal at the base. Petals spatulate, clawed. Stamens 6, free and unappendaged. Fruit globose, indehiscent, usually 1-celled by obliteration of the partition; style elongate; stigma simple. Seeds 1 or 2, neither winged nor margined. Cotyledons incumbent.

1. N. paniculata (L.) Desv. Slender branched annual; stems $3-6 \mathrm{dm}$. high, rough-hispid; leaves lanceolate, sagittate at the base, $2-6 \mathrm{~cm}$. long; racemes elongate in fruit; petals bright yellow, $2 \mathrm{~mm}$. long; pod subglobose, reticulate and muricate, about $2 \mathrm{~mm}$. thick. Waste places: Que.-S.D.-B.C.; adv. from Eu. Plain-Submont. Jl-Au.

\section{ARMORÃCIA Gaertn. HoRSE-RAdisH.}

Tall glabrous perennials, with thick pungent taproot and leafy stem. Leaves crenate or sinuately lobed. Flowers perfect, in dense racemes or panicles. Petals white, clawed. Stamens 6, free and unappendaged. Pod short, roundellipsoid or subglobose; style short; stigma subcapitate.

1. A. Armoracia (L.) Cockerell. Stem 6-10 dm. high; basal leaves $1.5-3 \mathrm{dm}$. long, glabrous, oblong; stem-leaves lanceolate, serrate or crenate; flowers $4-8 \mathrm{~mm}$. wide, showy. Nasturtium Armoracia Fries. Around dwellings: Que.-Fla.Tex.-Mont.; escaped from cultivation. J-S.

\section{Radícula Hill. Yellow Water-cress, Marsh-cress.}

Annual or perennial herbs, of wet situations. Leaves alternate, pinnately dissected or lobed. Flowers perfect, in terminal or axillary racemes. Sepals spreading during anthesis. Petals yellow, or rarely white or wanting, clawed. Stamens 2-6. Pods terete, from subglobose to short-cylindric; valves usually 1-nerved. Seeds in 2 rows, turgid. Cotyledons accumbent. [Nasturtium R. Br., in part. Roripa Scop.]

Perennials with rootstocks; petals much exceeding the sepals.

Pods papillose.

Pods ovate; leaves coarsely toothed.

Pods lance-oblong or linear, mostly curved; leaves pinnatifid. Leaves thin; petals white; fruit recurved.

Leaves thick; petals yellow; fruit erect.

Pods not papillose.

1. R. calycina.

2. R. trachycarpa.

3. R. Columbiae.

4. R. sinuata. 
Annuals or biennials.

Pods thickened towards the apex and truncate, curved, longer than the pedicels.

Pods not thickened towards the apex, acute or obtuse,

5. $R$. clavata.

Pods spherical to oblong-ellipsoid, in the latter case shorter than the pedicels. Pedicels $4-10 \mathrm{~mm}$. long.

Pods 5-8 mm. long, 2-3 mm. thick; stem sparingly hirsute.

Pods $3-5 \mathrm{~mm}$. long (rarely $6-7 \mathrm{~mm}$. in $R$. palustris), 1.5 . $R$. pacifica. Stem more or less hirsute.

Stem glabrous.

Stem tall, 3-8 dm. high; stigma prominent, 2-lobed.

Stem low, divaricately branched, 8 . R. terrestris. thicker than the style. 9. . R. alpina.

Pedicels 2-5 mm. long, pod globose. $10 . R$. sphaerocarpa.

Pods oblong to linear-cylindrical, equalling or longer than the short pedicels.

Style about $1 \mathrm{~mm}$. long.

Leaves nearly all pinnatifid, with obtuse divisions. $11, R$. obtusa.

Leaves mostly sinuate, or if pinnatifid, with acute divisions.

Pods short-ellipsoid, straight on straight pedicels. $10 . R$. sphaerocarpa. Style minutelongate-ovoid, curved, on curved pedicels. 12. $R$. curvipes.

Pods $1.5 \mathrm{~mm}$. thick or less, distinctly pedicelled; seeds tuberculate.

Petals about $2 \mathrm{~mm}$. long or more; pods linear, $1 \mathrm{~mm}$, or less thick, strongly curved.

Leaves divided to near the midrib, their segments obtuse.

13. R. curvisiliqua.

etals rarely more than with acute segments. 14. R. Nuttallii. , long; pods usually slightly tapering

Leaves pinnatifid.

Low, slender, less than $2 \mathrm{dm}$. high; leaves not auricled at the base.

Taller and stouter, over $2 \mathrm{dm}$, high; petioles $15, R$. lyrata.

aller and stouter, over $2 \mathrm{dm}$. high; petioles of the stem-leaves
auricled at the base. $16 . R$. Underwoodii.

Leaves entire or merely sinuate.

Pods fully $2 \mathrm{~mm}$. thick, almost sessile;

17. $R$. integra.

18. R. sessilifiora.

1. R. calycina (Engelm.) Greene. Stem hirsute, erect, $2-3 \mathrm{dm}$. high; leaves oblong or oblanceolate, sessile and even subclasping, coarsely toothed; racemes rather dense; pedicels ascending, $5-8 \mathrm{~mm}$. long; petals light yellow, slightly exceeding the sepals; pod erect, ovate, $3-5 \mathrm{~mm}$. long; style more than half as long. Nasturtium calycinum Engelm. Sandy bottoms: Mont. Plain. Jl.

2. R. trachycarpa (A. Gray) Rydb. Stem branching, papillose-puberulent or glabrous; leaves lyrate-pinnatifid, with many oblong divisions, nearly glabrous; petals white, $5 \mathrm{~mm}$. long; pedicels spreading; pod oblong-linear, curved, ascending. N. trachycarpum A. Gray. Wet places: s Colo. Plain-Submont. Je.

3. R. Columbiae (Suksd.) Greene. Stem branched, 1-3 dm. high, papillose or glabrate; leaves pinnatifid, with many oblong often toothed divisions; petals yellow, spatulate, $4 \mathrm{~mm}$. long; pedicels ascending or spreading; pod ascending or erect, curved, $5-8 \mathrm{~mm}$. long; style nearly $2 \mathrm{~mm}$. long. Roripa calycina Rydb., not Nasturtium calycinum Engelm. River banks and wet sandy places: Mont.-Neb.-N.M.-Wash. Plain-Submont. Je-Jl.

4. R. sinuata (Nutt.) Greene. Stems 1-4 dm. high, glabrous or nearly so; leaves glabrous, pinnately divided or cleft, with numerous oblong or lanceolate, often toothed divisions; petals yellow, 4-5 mm. long; pod curved upwards, glabrous, $1-1.5 \mathrm{~cm}$. long, $2 \mathrm{~mm}$. thick; style $3 \mathrm{~mm}$. long. $N$. sinuatum Nutt. River valleys: Sask.-Minn.-Ill.-Tex.-Ariz.-Wash.; Ont. Plain. Ap-Au.

5. R. clavata (Rydb.) J. M. Macoun. Biennial, perfectly glabrous; stem 6-10 dm. high, simple up to the inflorescence; leaves lyrate-pinnatifid, $5-10 \mathrm{~cm}$. long, more or less auricled at the base; lobes oblong to ovate, broadly dentate; pedicels in fruit $5-10 \mathrm{~mm}$. long, divaricate; petals spatulate, about $3 \mathrm{~mm}$. long; pod 10-12 mm. long, 2.5-3 mm. thick; style nearly $1 \mathrm{~mm}$. long. Roripa clavata Rydb. River valleys: Ida.-Ore-Alaska. Submont. Ap-S.

6. R. pacifica (Howell) Greene. Annual or biennial; stem 3-10 dm. high, glabrous, or slightly hairy, branching above; leaves lyrately pinnatifid or pinnately lobed, with oblong-lanceolate or triangular, toothed divisions; petals 
yellow, about, $2.5 \mathrm{~mm}$. long, spatulate; pedicels in fruit spreading; pod 7-10 $\mathrm{mm}$. long, $2 \mathrm{~mm}$. thick; style $0.5-0.75 \mathrm{~mm}$. long. Roripa pacifica Howell. Wet places: Alaska-Wash.-Utah-Alta. Submont. My-Au.

7. R. hispida (DC.) Heller. Biennial; stem stout, branched above, $3-12 \mathrm{dm}$. high; leaves lyrate-pinnatifid, with lanceolate or ovate, toothed divisions; petals spatulate, yellow, $2 \mathrm{~mm}$. long; fruiting pedicels ascending or spreading; pod 4-6 $\mathrm{mm}$. long, $2 \mathrm{~mm}$. thick, glabrous; style about $1 \mathrm{~mm}$. long. $N$. hispidum DC. Water and wet places: N.B.-Fla.-N.M.-Wash.-Utah-Alaska. PlainSubmont. Je-Au.

8. R. terrestris (R. Br.) Woot. \& Standl. Annual or biennial; stem branched above, 3-10 dm. high; leaves lyrate-pinnatifid, with oblong or lanceolate, toothed divisions; petals yellow, spatulate, $2 \mathrm{~mm}$. long; fruiting pedicels usually spreading; pod 5-7 mm. long, $2 \mathrm{~mm}$. thick; style $1 \mathrm{~mm}$. long. Sisymbrium amphibium palustre L. N.terrestre R. Br. N. palustre DC. Radicula palustris (L.) Moench. Water and wet places: Lab.-Ga.-N.M.-Alaska; Eurasia, Mex. PlainSubmont. Ap-O.

9. R. alpina (S. Wats.) Greene. Biennial; stem branched below, 1-3 dm. high; leaves sinuately lobed, rarely pinnatifid, elliptic or oblanceolate, obtuse; petals spatulate, $2.5 \mathrm{~mm}$. long; pedicels spreading; pod about $5 \mathrm{~mm}$. long, $2 \mathrm{~mm}$. thick; beak about $0.5 \mathrm{~mm}$. long. $N$. obtusum alpinum $\mathrm{S}$. Wats. Wet places in the mountains: Mont.-Colo.-Utah-Ida. Submont.-Subalp. Jl-Au.

10. R. sphaerocarpa (A. Gray) Greene. Annual or biennial; stem diffusely branched from the base, 1-3 dm. high, glabrous; leaves sinuately or lyrately lobed, with rounded lobes; petals yellow, $1.5 \mathrm{~mm}$. long; pedicels $2-3$, rarely $5 \mathrm{~mm}$. long; pod $2-3 \mathrm{~mm}$. long, nearly $2 \mathrm{~mm}$. thick; style about $0.5 \mathrm{~mm}$. long. $N$. sphaerocarpum A. Gray. Along streams: Ill.-Tex.-Calif.-Wyo. PlainSubmont. Jl-S.

11. R. obtusa (Nutt.) Greene. Annual; stem diffusely branched at the base, 1-3 dm. high, glabrous; leaves pinnatifid, with obovate or rounded, sinuately toothed divisions; petals narrowly spatulate, $1 \mathrm{~mm}$. long; pedieels ascending or spreading; pod 4-8 mm. long, 1-2 mm. thick; style about $1 \mathrm{~mm}$. long. $N$. obtusum Nutt. Wet places: Mich.-Mo.-Tex.-Utah-Wash. PlainSubmont. Je-S.

12. R. curvipes Greene. Annual; stems 1-3 dm. high, diffusely branched; leaves lyrate-pinnatifid or lobed, usually with acute divisions; petals about 1 $\mathrm{mm}$. long; pedicels spreading or recurved; pod about $5 \mathrm{~mm}$. long, somewhat curved, about $2 \mathrm{~mm}$. thick, acute at the apex. Roripa curvipes Greene. Wet places in the mountains: Utah-Wyo.-N.M. Submont.-Subalp. Jl-S.

13. R. curvisiliqua (Hook.) Greene. Annual or biennial; stem diffusely branehed, 1-3 dm. high, glabrous; leaves pinnately divided, with many oblong, mostly obtuse divisions, glabrous; petals yellow, $2.5 \mathrm{~mm}$. long, oblanceolate; pedicels 4-5 mm. long; pod curved, 8-12 mm. long, about $1 \mathrm{~mm}$. thick. Sisymbrium curvisiliquum Hook. N. curvisiliquum Nutt., in part. Wet places: Mont. -Wyo.-Ore.-Wash. My-S.

14. R. Nuttallii (S. Wats.) Greene. Biennial; stems solitary or several, erect, rather simple, 3-4 dm. high, glabrous; leaves pinnately lobed or toothed, with lanceolate or triangular lobes or teeth, or the lower ones with linear divisions; petals 2-2.5 mm. long, oblanceolate; pedicels 2-4 mm. long; pod 8-15 $\mathrm{mm}$. long, $1 \mathrm{~mm}$. thick, somewhat curved. N. curvisiliqua Nuttallii S. Wats. N. Nuttallii Rydb. Wet places: Wash-Calif.-(? Mont.)

15. R. Iyrata (Nutt.) Greene. Annual; stems diffusely branched, 1-3 dm. high, glabrous; leaves pinnately divided, with oblong to ovate, coarsely toothed divisions; petals scarcely $1 \mathrm{~mm}$. long; pedicels $1-3 \mathrm{~mm}$. long, ascending; pod 6-15 mm. long, 1-1.5 mm. thick. N. lyratum Nutt. Wet places: Mont.-Colo. -Calif.-Wash. Plain-Submont. J1-Au.

16. R. Underwoodii (Rydb.) Heller. Biennial; stem $2 \mathrm{dm}$, or more high, divaricately branched, perfectly glabrous; leaves $3-5 \mathrm{~cm}$. long, lyrately pinnatifid, thin; lobes oblong, obtuse, the terminal one elliptic to broadly oval, sinu- 
ately toothed; pedicels short, in fruit scarcely more than $4 \mathrm{~mm}$. long, diverging or reflexed; petals light yellow, not quite $1 \mathrm{~mm}$. long; fruit 5-6 mm. long, slightly thicker at the base; style not $0.5 \mathrm{~mm}$. long. Wet places, in the mountains: Colo. Subalp. S.

17. R. integra (Rydb.) Heller. Biennial, glabrous; stems few, strict, branched above; stem-leaves spatulate or rhombic-spatulate, 1-2 $\mathrm{cm}$. long, not auricled at the base; petals $1.5 \mathrm{~mm}$. long, scarcely exceeding the sepals; pedicels $1-3 \mathrm{~mm}$. long, ascending; pod about $8 \mathrm{~mm}$. long, somewhat curved; style about $0.5 \mathrm{~mm}$. long. Roripa integra Rydb. Wet places, in the mountains: Utah. Mont. $\mathrm{Au}$.

18. R. sessiliflora (Nutt.) Greene. Annual or biennial; stem usually erect, branched, glabrous; leaves lobed or eleft, with rounded lobes, or merely coarsely crenate; petals 1.5-2 mm. long; pedicels $1-2 \mathrm{~mm}$., or sometimes almost none; pod 6-12 mm. long, fully $2 \mathrm{~mm}$. thick; beak short and thick. Nasturtium sessiliflorum Nutt. Wet places; Ill.-Fla.-Tex.-Neb. Plain. Ap-S.

\section{SISÝMBRIUM (Tourn.) L. WATER-CRESS.}

Aquatic perennials, with floating or creeping stems, rooting at the nodes. Leaves odd-pinnate. Flowers perfect, in racemes. Sepals equal at the base, spreading during anthesis. Petals white, without nectaries. Pods cylindric; valves 1-nerved. Styles slender; stigma 2-lobed. Seeds in 2 rows, turgid. Cotyledons accumbent.

1. S. Nasturtium-aquaticum L. Aquatic perennial; leaves pinnate, with 1-11 orbicular to oblong-lanceolate sinuate leaflets; sepals oblong, about $2 \mathrm{~mm}$. long; petals white, spatulate, about $4 \mathrm{~mm}$. long; fruiting pedicels divaricate; pod 1-2 $\mathrm{cm}$. long, $3 \mathrm{~mm}$. thick, somewhat curved; beak about $1 \mathrm{~mm}$. long. In water and mud: N.S.-Va.-Calif.-B.C.; Mex., W. Ind., S. Am.; nat. from Eu. Plain-Subalp. My-S.

\section{TURRİtis L. TOWer Mustard.}

Caulescent herbs, with partly clasping, auricled stem-leaves. Flowers in elongate racemes. Sepals erect, two of them slightly saccate at the base. Petals yellowish white, small. Pods erect, linear-cylindric, terete or slightly flattened, 1-nerved and veined; stigma cupulate. Seeds flattened, partially incumbent, $i$. e., radicle oblique.

1. T. glabra L. Biennial; stem erect, 6-15 dm, high, hirsute below; basal leaves oblanceolate, sinuately toothed or somewhat lyrate, hirsute-stellate, $5-15 \mathrm{~cm}$. long; stem-leaves glabrous, lanceolate, sagittately clasping, $2-10 \mathrm{~cm}$. long; sepals and petals greenish white, $3 \mathrm{~mm}$. long; pedicels erect, 4-12 $\mathrm{mm}$. long; pod erect, 4-10 cm. long, 1.5-2 mm. wide. Arabis perfoliata Lam. A. glabra (L.) Bernh. Waste places: Que.-Pa.-Calif.-B.C.; nat. from Eu. PlainSubmont. Ap-Au.

\section{ER ÝSimum L. Hedge Mustard.}

Annual caulescent herbs. Leaves alternate, pinnately lobed. Flowers perfect, in racemes. Sepals subequal, ascending. Petals small, pale yellow. Filaments unappendaged. Pod subulate, tapering from the base to the apex. Style almost none; stigma 2-lobed. Cotyledons incumbent. Seeds in one row, marginless.

1. E. officinale L. Annual; stem branching, hirsute, at least below; leaves hirsute, pinnatifid or the uppermost merely hastate; terminal lobes of the lower leaves rounded and toothed, those of the upper lanceolate; petals pale yellow, spatulate, $3 \mathrm{~mm}$. long; pods erect, on very short pedicels, $1.5-2 \mathrm{~cm}$. long, glabrous or pubescent. Sisymbrium officinale Scop. Waste places: N.S.-Fla.Calif.-B.C.; nat. from Eu. Plain-Submont. My-S.

19. NÓRta Adans. Tumble Mustard.

Caulescent leafy annuals, with runcinately pinnatifid or toothed leaves, pubescent with simple hairs. Flowers perfect, in elongate racemes. Sepals 
subequal, ascending. Petals light yellow, clawed. Stamens 6; filaments unappendaged. Pod elongate, narrowly cylindric, terete; style none; stigma slightly 2-lobed. Seeds in one row, numerous, marginless. Cotyledons incumbent. [Sisymbrium L., in part.]

18. N. altissima (L.) Britton. Tall annual; stem freely branching, 6-12 $\mathrm{dm}$. high, sparingly ciliate; leaves pinnatifid, the lower with oblong or lanceolate, the upper with narrowly linear divisions; sepals oblong, $5 \mathrm{~mm}$. long; petals yellowish white, spatulate, 6-8 $\mathrm{mm}$. long; pedicels and pods ascending-spreading, the latter, 7-10 cm. long, $1 \mathrm{~mm}$. thick, sessile. Sisymbrium altissimum L. Waste places: Que.-D.C.-N.M.-Calif.-B.C.; nat. from Eu. Plain. My$\mathrm{Au}$.

\section{BRAỲA Sternb. \& Hoppe.}

Perennials, with a stout root, cespitose at the base. Flowers perfect, racemose. Sepals short, ovate, equal at the base. Petals obovate, clawed. Fruit oblong, flattish; valves faintly 1-nerved; style short; stigma more or less 2-lobed; partition with transversely elongated reticulations. Cotyledons incumbent.

1. B. purpurascens (R. Br.) Bunge. Perennial, with a taproot; leaves fleshy, spatulate or oblanceolate, glabrous, or ciliate towards the base, $1-2 \mathrm{~cm}$. long; stems several, scapiform, $1 \mathrm{dm}$. high or less, more or less pubescent; sepals purplish, $2 \mathrm{~mm}$. long; petals white or pinkish, broadly spatulate; pods oblong, 8-10 mm. long, sparingly hairy. Alpine-arctic stations: Greenl.-Lab.-Alta. -Alaska; Spitzbergen. Alp. Jl-Au.

\section{SÓPHIA Adans. Tansy Mustard.}

Annual or biennial (all ours), or perennial herbs, or rarely suffruticose, pubescent with short branched hairs. Leaves usually twice pinnatifid to finely dissected, or in one of our species merely pinnately lobed or toothed. Flowers in elongate racemes. Sepals narrow, subequal, ascending, early deciduous. Petals yellow or yellowish white, rarely pure white. Pod linear or club-shaped; style short; stigmas minute, entire; valves one-nerved. Seeds in 1 or 2 rows in each cell. Cotyledons incumbent.

Leaves all pinnately dissected; pod not twisted.

Pedicels ascending or spreading.

Pods linear, $1 \mathrm{~mm}$. wide, somewhat curved; seeds uniserial.

Stem simple or with erect-ascending branches; pods $8-25 \mathrm{~mm}$. long.

Pods 15-25 mm. long; leaves mostly thrice pinnatifid.

Inflorescence elongate; pods nearly erect; pedicels about $1 \mathrm{~cm}$. long.

Inflorescence short; pods spreading; pedicels about $0.5 \mathrm{~mm}$. long.

Pods 8-15 mm. long; leaves once or twice pinnatifid.

Stem glabrous, or sparingly stellate or glandular puberulent.

Leaf-segments all narrow, linear or oblong, or those of the lower

leaves broad and obtuse, more or less grayish stellate.
Stem grayish stellate, not at all glandular; leaf-segments all narrow.

3. S. gracilis.

Stem very sparingly stellate, often glandular-puberulent; segments of the lower leaves broad, very obtuse.

4. S. californica.

Leaf-segments all broad, lanceolate or ovate, thin and bright green.

Pods divergent; primary segments of the uppermost leaves often entire.
5. S. leptophylla.

Pods ascending; primary segments of the leaves all sharply cutlobed. $\quad$ 6. S. incisa.

$\begin{array}{ll}\text { Stem densely glandular-pubescent. } & \text { 7. S. viscosa. }\end{array}$

Stem diffusely branched; pods 5-8 mm. long. $\quad$ 8. S. purpurascens.

Pods more or less clavate, 5-12 mm. long, 1-2 mm, wide; seeds usually more or less biserial.

Pods 8-12 mm. long, mostly erect on spreading pedicels.

Leaves and stem green, only sparingly stellate.

Stem divaricately branched; branches making with the stem an angle of 45 degrees or more; pedicels $7-10 \mathrm{~mm}$. long, usually shorter

than the pod.
Stem simple or with almost erect or strongly ascending branches.

Petals much exceeding the sepals.

Terminal segments of the upper leaves usually elongate, linear, entire; segments all narrow.

10. S. filipes. 
Terminal segments not greatly elongate; segments of the lower leaves obovate.

11. S. magna.

Petals not much exceeding the sepals; segments narrow; terminal segments of the upper leaves not elongate. 12. S. intermedia. Leaves and stem cinereous-stellate.

Petals longer than the sepals, about $2 \mathrm{~mm}$. long; uppet leaves mostly once pinnate, with elongate, broad terminal segments.

13. S. andrenarum.

Petals not longer than the sepals, about $1.5 \mathrm{~mm}$. long; upper leaves usually more dissected; terminal segment narrow, not elongate.

Pods 5-8 mm. long.

14. S, halictorum.

Pods acute above, acuminate below; style obsolete.

Pods ascending or spreading.

Pods erect; leaves sparingly stellate.

Pedicels erect.

Pods over $1 \mathrm{~mm}$. thick.

Plant green and almost glabrous.

Plant cinereous-pubescent. cence, or glabrous.

Lower leaves merely coarsely toothed or lobed; pod twisted.

19. S. Hartvegiana.

15. S. pinnata.

17. S. leptostylis.

18. S. procera.

pecially the inflores-

21. S. perplexa.

1. S. Sophia (L.) Britton. Stem much branched, 3-10 dm. high, minutely pubescent; leaves thrice pinnate, with narrowly linear divisions; petals creamcolored; pod ereet, somewhat curved, glabrous, about $2 \mathrm{~cm}$. long, less than 1 mm. thick, torulose. Sisymbrium Sophia L. Waste places: N.B.-N.Y.Utah-Ore.-Wash.; nat. from Eu. Je-Jl.

2. S. sophioides (Fisch.) Heller. Stem $3-5 \mathrm{dm}$. high, slightly viscid-puberulent; leaves thrice pinnate, with linear or oblong divisions, nearly glabrous; petals spatulate, cream-colored; pod 2-2.5 cm. long, $1 \mathrm{~mm}$. thick, filiform. Sisymbrium sophioides Fisch. Subarctic regions: Hudson Bay-Man.-B.C.-Alaska. Subalp. Jl.

3. S. gracilis Rydb. Stem slender, 1-3 dm. high, finely stellate, somewhat branched; leaves 1-5 cm. long, once or twice pinnatifid, with linear or oblong lobes; petals $2-2.5 \mathrm{~mm}$. long, light yellow; pedicels ascending; pods 1-1.5 long, $1 \mathrm{~mm}$. thick, more or less curved. Hills and meadows: Wyo.-Wash.-Mack. Submont. My-Jl.

4. S. californica (T. \& G.) Rydb. Stem 3-4 dm. high; leaves twice pinnate, the lower with oblong obtuse divisions, the upper with linear ones; petals light yellow, 3-4 mm. long; pedicels ascending; pod filiform, 1-1.5 mm. (rarely $2 \mathrm{~mm}$.) long, $1 \mathrm{~mm}$. thick, erect. Sisymbrium canescens californicum T. \& G. Waste places: Calif.-B.C.-Mont. Son.-Submont. Ap-Je.

5. S. leptophylla Rydb. Stems $5-7 \mathrm{dm}$. high, sparingly glandular; leaves very thin, only once pinnate; segments of the lowest leaves rounded, those of the middle lanceolate and somewhat incised, those of the upper entire; petals bright yellow, about $1.5 \mathrm{~mm}$. long; pod linear, $8-10 \mathrm{~mm}$. long, much less than $1 \mathrm{~mm}$. thick, torulose, spreading, arcuate, curved up. Foot-hills: Colo.-Mont. Submont.-Mont. Ji-Au.

6. S. incisa (Engelm.) Greene. Stem 3-10 dm. high, usually branched, slightly stellate or glabrate; leaves thin, pinnate or the lower twice pinnate; segments lanceolate, deeply toothed, acute; petals bright yellow, $3 \mathrm{~mm}$. long; pedicels usually spreading; pod filiform, 1-1.5 cm. long, scarcely $1 \mathrm{~mm}$. thick, somewhat curved. Sisymbrium incisum Engelm. Hills and cañons: N.M.Wyo.-Utah. Submont.-Mont. My-J.

7. S. viscosa Rydb. Stem 5-10 dm. high, at least the upper part decidedly glandular or viscid-villous; leaves $3-10 \mathrm{~cm}$. long, twice pinnatifid, densely pubescent; primary divisions of the lower leaves ovate and obtuse, those of the upper lanceolate and acute; secondary divisions oblong, acute or obtuse; petals bright yellow, spatulate, $2-3 \mathrm{~mm}$. long; pod over $1 \mathrm{~cm}$. long and less than $1 \mathrm{~mm}$. thick. Cañons and grassy slopes: Wyo.-Nev.-B.C. Son. Je-Au.

8. S. purpurascens Rydb. Stem very slender, diffusely branched above, glabrous and purplish; upper leaves simply pinnate, with linear-oblong divisions, slightly stellate; pedicels ascending in fruit, 4-5 $\mathrm{mm}$. long; fruit very slender, 
5-8 mm. long, $0.75 \mathrm{~mm}$. thick, linear, nearly eylindrical, tapering somewhat at both ends, slightly torulose. Mountains: Colo. Submont. S.

9. S. ramosa Rydb. Stems 3-6 dm. high, finely but sparingly stellate; leaves once or twice pinnate; divisions linear or linear-oblong; petals oblanceolate, pale yellow, slightly longer than the sepals; pod somewhat clavate, $8-10 \mathrm{~mm}$. long, erect or strongly ascending, about $1 \mathrm{~mm}$. thick. Mountains: Colo. Mont. S.

10. S. filipes (A. Gray) Heller. Stem branched, 3-6 dm. high, almost glabrous; leaves once to twice pinnatifid, sparingly stellate or glabrous; segments linear or oblong, often lobed; petals bright yellow, $3 \mathrm{~mm}$. long or more; pedicels 1-2 $\mathrm{cm}$. long; pods clavate, erect, $12-15 \mathrm{~mm}$. long, $1.5-2 \mathrm{~mm}$. thick. Mountains, cañons, and plains: Sask.-N.D.-Colo.-Utah-Wash.-B.C. Submont. $\mathrm{Ap}-\mathrm{Jl}$.

11. S. magna Rydb. Stem branched, 5-10 dm. high, sparingly stellatepuberulent or glabrous, stout; basal leaves twice to thrice pinnatifid, 1-2 dm. long, nearly glabrous; segments obovate, often toothed; petals spatulate, nearly $3 \mathrm{~mm}$. long, rather light yellow; pod glabrous, more or less clavate, $12-15 \mathrm{~mm}$. long, $1.5-2 \mathrm{~mm}$. thick. River bluffs: Colo. Mont.

12. S. intermedia Rydb. Stem 3-7 dm. high, often glandular above; leaves twice or thrice pinnatifid; segments linear or linear-oblong; petals spatulate, slightly if at all exceeding the sepals; pedicels in fruit 1-1.5 cm. long, usually spreading; pods clavate, glabrous, 8-12 mm. long, $1.5 \mathrm{~mm}$. thick, nearly erect. Prairies, plains, and waste places: Mich.-Tenn.-Colo-Calif.-B.C. PlainMont. My-Jl.

13. S. andrenarum Cockerell. Stem 3-7 dm. high; lower leaves twice pinnatifid, with small oblong or ovate divisions, the upper more simple and with linear elongated divisions; petals spatulate; pod ascending or erect, elavate, about $1 \mathrm{~cm}$. long, $1.5 \mathrm{~mm}$. thick. Dry ground: Mont.-N.M.-Ariz.-Wash. Plain-Mont. My-Jl.

14. S. halictorum Cockerell. Stem branching, 3-5 dm. high; leaves twice pinnate, with short linear or oblong divisions; pedicels $5-10 \mathrm{~mm}$. long; pods clavate, nearly $1 \mathrm{~cm}$. long, erect or nearly so. Dry regions: Tex.-Colo.-Utah -Ariz. Son--Submont. Ja-Je.

15. S. pinnata (Walt.) Howell. Stem 3-6 dm. high; leaves thrice or twice pinnatifid into short, obovate, oval, or elliptic divisions; petals pale yellow; pedicels spreading, 7-12 $\mathrm{mm}$. long; pod clavate, 5-8 $\mathrm{mm}$. long. Sisymbrium canescens Nutt. Sandy or dry soil: Va.-Fla.-Ariz.-Colo. Plain. Mr-Je.

16. S. Nelsonii Rydb. Stems $2-4 \mathrm{dm}$. high; leaves pinnatifid or bipinnatifid, with linear or oblong divisions; petals light yellow, spatulate, $1.5 \mathrm{~mm}$. long; fruiting pedicels ascending, 4-6 $\mathrm{mm}$. long; pods clavate, 5-8 mm. long, glabrous, slightly over $1 \mathrm{~mm}$. thick. Gravelly flats, sandy plains, \&c.: Wyo.-Utah. Plain-Submont.

17. S. leptostylis Rydb. Stem 3-6 dm. high, rather simple below, sparingly stellate or glabrous; leaves $3-10 \mathrm{~cm}$. long, twice pinnatifid into oblong divisions; petals spatulate, slightly surpassing the sepals; pedicels in fruit 5-8 $\mathrm{mm}$. long; pod about $5 \mathrm{~mm}$. long, tapering at both ends; style $0.5-0.7 \mathrm{~mm}$. long. Mountain valleys: Utah. Mont. Je-Au.

18. S. procera Greene. Stem 5-20 dm. high, simple below; leaves twice pinnatifid, with lanceolate, toothed segments, or the lower ones with obovate segments; petals spatulate, about $2 \mathrm{~mm}$. long; pedicels $5-8 \mathrm{~mm}$. long; pods $6-10$ $\mathrm{mm}$. long, over $1 \mathrm{~mm}$. thick, tapering at both ends; style nearly $0.5 \mathrm{~mm}$. long. Sandy valleys and hills: Colo.-Utah-Wyo. Submont.-Mont. Jl-S.

19. S. Hartvegiana (Fourn.) Greene. Stem 6-20 dm. high; leaves twice pinnatifid, with lanceolate divisions; petals spatulate, light yellow, $2.5-3 \mathrm{~mm}$. long; pedicels $5-8 \mathrm{~mm}$. long; pod linear, $10-15 \mathrm{~mm}$. long, $1 \mathrm{~mm}$. thick. $S$. brevipes (Nutt.) Rydb. River banks, waste grounds, and sandy valleys: Sask. -Minn.-Colo.-Utah-B.C. Plain-Submont. J1-Au. 
20. S. glandulifera Rydb. Stem simple below, about $6 \mathrm{dm}$, high; branches spreading, with upwardly curved ends; leaves pubescent and viscid, bipinnately divided; segments linear-lanceolate, or those of the upper leaves filiform; petals scarcely exceeding the sepals; pedicels in fruit 4-6 mm. long; pods 8-10 mm. long, erect, more or less curved, scarcely exceeding $0.7 \mathrm{~mm}$. in width; style slender, short, about $0.5 \mathrm{~mm}$. long. Rolling plains: Wyo.-Colo. Plain-Submont. $\mathrm{Je}-\mathrm{Jl}$.

21. S. perplexa (Henders.) Rydb. Stem 1.5-4 dm. high, with ascending branches, stellate-pubescent; basal leaves 1-3 $\mathrm{cm}$. long, petioled; blades spatulate or oblanceolate, repand-dentate or coarsely lobed; cauline oblanceolate, sessile; petals white, $3 \mathrm{~mm}$. long; pedicels $5-8 \mathrm{~mm}$. long, spreading; pod linear, torulose, about $1 \mathrm{~cm}$. long, usually twisted. Sisymbrium perplexum Henders. Slopes: Ida. Submont. J1.

\section{MALCÓLimia R. Br.}

Leafy-stemmed annuals, with branched hairs. Flowers perfect, racemose or (in ours) spicate. Sepals erect, usually saccate at the base. Petals white or rose-colored. Longer stamens coherent. Fruit cylindric, dehiscent, with 1 or 2 rows of seeds.

1. M. africana (Willd.) R. Br. Annual; stem 2-4 dm. high, with ascending-spreading branches; leaves oblanceolate or lanceolate, 4-8 $\mathrm{cm}$. long, usually sinuate-dentate, hirsute with branched hairs; flowers sessile; sepals linear, 3 $\mathrm{mm}$. long; petals pinkish, veined, long-clawed; pods ascending, 5-6 cm. long, 1-1.5 mm. thick. Sandy or alkaline ground: Utah; adv. from $\mathrm{n}$ Africa. Je-Jl.

\section{CONRÍNGIA (Heist.) Link. HaRE's-eAR.}

Glabrous annuals, with sessile clasping leaves. Flowers perfect, in elongate racemes. Sepals subequal, long and narrow, ascending. Petals light yellow. Pod elongate-linear, more or less 4-angled; style short; stigma simple or nearly so. Seeds in a single row in each cell, oblong, thick, not margined. Cotyledons incumbent.

1. C. orientalis (L.) Dum. Glabrous annual; stem 3-6 dm. high; leaves oval or elliptic, deeply cordate-clasping, 4-10 cm. long; petals oblanceolate, yellowish white, $8 \mathrm{~mm}$. long; pod ascending, $8-10 \mathrm{~cm}$. long, fully $2 \mathrm{~mm}$. thick; beak $1.5 \mathrm{~mm}$. long. Waste places and along roads: N.S.-Del.-Colo.-Utah -Ore.-B.C.; adv. from Eu. Plain. My-Jl.

\section{ARABIDÓpSis (DC.) Schur. Mouse-ear Cress.}

Annual or perennial herbs, with branched hairs. Leaves entire or toothed. Flowers perfect, small, in terminal racemes. Sepals equal, not saccate at the base. Petals white. Style very short; stigma 2-lobed. Pod narrow, linear, with rounded, nerveless or finely nerved valves. Seeds in 1 row in each cell. Cotyledons incumbent. [Pilosella (Thal) Kostel. Stenophragma Celak.]

Stem-leaves not auriculate-clasping or sagittate at the base.

Annual.
Perennial.

Stem-leaves auriculate-clasping or sagittate at the base.

Pubescent biennials or perennials. Pod $2 \mathrm{~mm}$. thick; style obsolete.

Pod $1 \mathrm{~mm}$. thick; style $0.5 \mathrm{~mm}$. long.

Glabrous annual.

1. A. Thaliana.

2. A. Richardsonii.

3. A, virgata.

4. A. stenocarpa.

5. A, glauca.

1. A. Thaliana (L.) Schur. Stem simple or branched, $2-4 \mathrm{dm}$. high, sparingly pubescent; basal leaves oblanceolate or spatulate, usually petioled, $2-5 \mathrm{~cm}$. long, sparingly hirsute-stellate; petals white, oblanceolate, $3-4 \mathrm{~mm}$. long; pods ascending, glabrous, $1-1.5 \mathrm{~cm}$. long, $0.75 \mathrm{~mm}$. wide; style very short. Arabis Thaliana L. Sisymbrium Thalianum A. Gray. Stenophragma Thalianum Celak. Wastè places: Mass.-Ga.-Kans.; Utah; nat. from Eu. Plain-Son. Ap-Je.

2. A. Richardsonii Rydb. Stem branched and decumbent at the base, 1-2 dm. high; basal leaves spatulate, thick, 1-3 cm. long, stellate, often 
coarsely toothed; petals clawed, spatulate, $4 \mathrm{~mm}$. long; pods erect, stellate, 2-3 $\mathrm{cm}$. long, about $1 \mathrm{~mm}$. wide, torulose; style about $0.5 \mathrm{~mm}$. long. Sisymbrium humile Hook., not Meyer. Pilosella Richardsonii Rydb. Sandy plains: Mack. -Alta.-(? Ore.)-B.C.-Alaska. Boreal-Mont. Je-Jl.

3. A. virgata (Nutt.) Rydb. Stem 2-4 dm. high, simple or branched; hirsute with branched hairs; basal leaves $2-5 \mathrm{~cm}$. long, oblanceolate, spatulate, or oblong, stellate and somewhat hirsute; petals about $4 \mathrm{~mm}$. long, spatulate; pod erect, $2-3 \mathrm{~cm}$. long, nearly $2 \mathrm{~mm}$. wide, style obsolete. Sisymbrium virgatum Nutt. Arabis Brebneriana A. Nels. Plains and hills: Wyo.-Colo. Plain-Submont. Je.

4. A. stenocarpa Rydb. Stem hirsute with branched hairs; basal leaves oblanceolate, 2-3 cm. long, sinuate-dentate, short-petioled, hirsute-stellate; petals spatulate, $3 \mathrm{~mm}$. long; pod 2.5-4 cm. long, glabrous, scarcely $1 \mathrm{~mm}$. wide. Pilosella stenocarpa Rydb. Dry plains: Sask.-Colo.-Wyo. Plain. Je-Jl.

5. A. glauca (Nutt.) Rydb. Stem 2-3 dm. high, glabrous; basal leaves spatulate, entire; stem leaves lanceolate, sagittate at the base; petals spatulate, $2 \mathrm{~mm}$. long; pod erect, about $1.5 \mathrm{~cm}$. long, nearly $1 \mathrm{~mm}$. wide, glabrous; style obsolete. Sisymbrium glaucum Nutt. Prairies: Colo.-Ida.-Alta. PlainSubmont.

\section{Cheirínia Link. Wild Wali-flower, Prairie-rocket, Yellow PhLOX.}

Annual, biennial, or perennial leafy-stemmed herbs, with appressed 2-branched hairs (the hairs appearing as if attached near the middle). Flowers perfect in terminal racemes, usually rather large. Sepals erect, the outer two gibbous at the base. Petals yellow, brown, or purple, clawed, with spreading blades. Filaments free, unappendaged. Pods elongate-linear, more or less 4-angled, or at least with a strong midrib. Style short; stigma 2-lobed. Seeds in one row in each cell, numerous, marginless or margined at the apex. Cotyledons in our species incumbent or nearly so. [Erysimum L., in part.]

Petals less than $1 \mathrm{~cm}$. long.

Petals 4-5 $\mathrm{mm}$. long.
Petals 6-10 $\mathrm{mm}$. long.

Perennials or biennials; pods ascending.

Petals more than pods spreading.

Petals light yellow.

Biennials or short-lived perennials, not cespitose.

Pods almost terete, slightly compressed, tapering into a style more than $2 \mathrm{~mm}$. long.

Pods 4-angled; style only slightly narrower, very short.

Basal leaves, as well as whole plant, grayish-strigose, not silvery.

Pods widely spreading, 4-8 cm. long, stout; stem-leaves usually sinuatedentate. 5 . C. aspera.

Pods strongly ascending or almost erect, $8-12 \mathrm{~cm}$. long (except in $C$. brachycarpa).

Stem-leaves usually sinuately dentate.

Stem-leaves entire or rarely denticulate.

Stem-leaves linear or nearly so; pod usually twisted, slender.

Stem-leaves oblanceolate; pod straight, stout.

Pod about $8 \mathrm{~cm}$. long, $1.5 \mathrm{~mm}$. thick. 8 . C. oblanceolata.

$\begin{array}{ll}\text { Pod 4-6 cm. long, } 2.5 \mathrm{~mm} \text {. thick. } & 8 . \text { C. Oblanceolata. }\end{array}$

Basal leaves, at least, silvery white; stem-leaves narrowly linear.
Plant 2-3 dm. high; stem-leaves sinuate-dentate.

Plant 1-2 dm high, stem-leaves C. Bakeri.

Low cespitose perennials.

Leaves entire-margined or minutely denticulate.

Petals varying from orange to brown or purple.
Plant simple, $3-5$ dm.

Plant cespitose, $1-2 \mathrm{dm}$. high

Perennial with a branched basal leaves $2-4 \mathrm{~cm}$. long, spatulate.

Biennial; stem in flower a few $\mathrm{cm}$. the base.
11. C. argillosa.

12. C. nivalis.

13. C. radicata.

in fruit, leafy only at 16. C. Pallasii. 
1. C. cheiranthoides (L.) Link. Annual; stem 3-6 dm. high, finely strigose; leaves lanceolate or linear-lanceolate, $2-10 \mathrm{~cm}$. long, entire or sinuate-denticulate; petals 4-5 mm. long; fruiting pedicels spreading or ascending; pod 2-3 $\mathrm{cm}$. long, 1-1.5 mm. thick, erect. Erysimum cheiranthoides L. WORMSEEd MusTARD. Waste places and river bottoms: Newf.-N.C.-Utah-Alaska; Eu. Plain-Mont. Je-Au.

2. C. inconspicua (S. Wats.) Rydb. Biennial; stem 3-6 dm. high, angled; leaves linear or oblanceolate, mostly entire, canescent; petals pale yellow, 8-10 $\mathrm{mm}$. long, claw shorter than the sepals; pedicels strongly ascending; pods ereet, $1.5-5 \mathrm{~cm}$. long, about $2 \mathrm{~mm}$. thick. E. asperum inconspicuum S. Wats. E. parviflorum Nutt. Dry soil: Minn.-Colo--Nev.-B.C. Plain-Submont. Je-Au.

3. C. repanda (L.) Link. Annual; stem $3-4 \mathrm{dm}$. high, much branched; leaves lanceolate or oblanceolate, 3-8 $\mathrm{cm}$. long, repand-dentate or the lower coarsely toothed; petals $6-9 \mathrm{~mm}$. long, light yellow; pods $4-8 \mathrm{~cm}$. long, about $2 \mathrm{~mm}$. thick; style very short and stout. E. repandum L. Waste places: Ohio -Kans.-Ariz.-Utah; also as a ballast plant at sea-ports; adv. or nat. from Eu. Plain-Son. My-Jl.

4. C. arida (A. Nels.) Rydb. Biennial; stem branched at the base, $3-4 \mathrm{dm}$. high; leaves oblanceolate, entire or nearly so, $4-8 \mathrm{~cm}$. long, grayish green; petals 16-20 $\mathrm{mm}$. long, pale yellow; pedicels ascending; pod ascending, subterete, 8-12 $\mathrm{cm}$. long; style $2 \mathrm{~mm}$. long. Cheiranthus aridus A. Nels. Desert regions: Wyo. -Utah. Je.

5. C. aspera (Nutt.) Rydb. Biennial; stem $2-4 \mathrm{dm}$. high, mostly simple; leaves lanceolate or linear-lanceolate, usually somewhat sinuately dentate; petals light yellow, 15-18 mm. long; pedicels divergent; pods divergent, $2 \mathrm{~mm}$. thick; beak about $1 \mathrm{~mm}$. long, thick. Cheiranthus asper Nutt. E. asperum DC. Plains: Man.-Kans.-e N.M.-e Mont. Plain-Submont. Je-Au.

6. C. elata (Nutt.) Rydb. Biennial; stem $3-10 \mathrm{dm}$. high, strigose; leaves linear, deeply sinuate-dentate, sometimes almost lyrate-pinnatifid, or the basal ones oblanceolate; petals usually bright yellow, $15-18 \mathrm{~mm}$. long; pedicels ascending; pods usually erect, $4-6 \mathrm{~cm}$. long, $2 \mathrm{~mm}$. thick; beak nearly $2 \mathrm{~mm}$. long. $E$. elatum Nutt. Hills and plains: Sask.-S.D.-N.M.-Calif.-Wash. Submont. -Mont. My-Jl.

7. C. asperrima (Greene) Rydb. Biennial; stems $2-5 \mathrm{dm}$. high, usually simple; leaves linear, 5-8 $\mathrm{cm}$. long; petals $10-15 \mathrm{~mm}$. long, usually pale yellow; pedicels ascending; pods strictly erect, $5-8 \mathrm{~cm}$. long, 1-1.5 mm. thick; beak 1 $\mathrm{mm}$. long. Cheiranthus asperrimus Greene. Dry hills: S.D.-N.M.-Ariz.Mont. Submont. 'My-Au.

8. C. oblanceolata Rydb. Biennial; stem 4-6 dm. high; leaves narrowly oblanceolate, $5-12 \mathrm{~cm}$. long; petals yellow, about $15 \mathrm{~mm}$. long; blades almost orbicular; fruiting pedicels ascending or spreading; pod ascending, about $8 \mathrm{~cm}$. long, about $1.5 \mathrm{~mm}$. thick; style about $1 \mathrm{~mm}$. long. E. oblanceolatum Rydb. Mountains: Colo.-Wyo.-Utah. Submont.-Subalp. My-Au.

9. C. brachycarpa Rydb. Biennial; stem 3-6 dm. high, grayish canescent; leaves linear-spatulate or oblanceolate, $5-10 \mathrm{~cm}$. long, the lower petioled and minutely denticulate; petals nearly $2 \mathrm{~cm}$. long, bright yellow; fruiting pedicels about $8 \mathrm{~mm}$. long, strongly ascending; pod erect. Hills: Utah. Submont. Je-Au.

10. C. Bakeri (Greene) Rydb. Biennial or perhaps perennial; stem $3-5 \mathrm{dm}$. high; leaves narrowly linear; petals bright yellow, $15-18 \mathrm{~mm}$. long; pedicels strongly ascending, nearly $1 \mathrm{~cm}$. long; pod ereet. Cheiranthus aridus Greene, not A. Nels. C. Bakeri Greene. Hills: N.M.-Colo. Submont. Ap-Je.

11. C. argillosa (Greene) Rydb. Biennial; stem usually simple, 1-3 dm. high; leaves linear-lanceolate or linear, erowded below; petals pale yellow, about $15 \mathrm{~mm}$. long; pedicels ascending, 5-8 mm. long; pods erect, 5-7 em. long, $2 \mathrm{~mm}$. thick. Cheiranthus argillosus Greene. Clayey bluffs and bad lands: S.D.Colo. Plain. My-Je. 
12. C. nivalis (Greene) Rydb. Cespitose perennial; stems 1-2 dm. high, very leafy; leaves narrowly oblanceolate to linear, $3-5 \mathrm{~cm}$. long, sparingly pubescent; petals bright yellow, about $15 \mathrm{~mm}$. long; pedicels about $5 \mathrm{~mm}$. long, ascending; pods erect, $3-5 \mathrm{~cm}$. long. Cheiranthus nivalis Greene. Summits: Colo. Mont.-Alp. J1-Au.

13. C. radicata Rydb. Perennial, branched at the base; stems $1.5 \mathrm{dm}$. or less high; leaves linear-oblanceolate, sinuately toothed, 4-7 $\mathrm{cm}$. long; petals light yellow, about $15 \mathrm{~mm}$. long; fruiting pedicels ascending; pods ascending, tetragonal, about $4 \mathrm{~cm}$. long. E. radicatum Rydb. High mountains: Colo. Subalp. -Alp. Jl.

14. C. Wheeleri (S. Wats.) Rydb. A tall strigose biennial or perennial; stem strict, simple, 3-6 dm. high, striate; basal leaves 2-7 mm. wide, subentire or sinuately denticulate, grayish strigose; stem leaves mostly narrowly linear, the upper sessile; pedicels short, ascending; petals with slender claws, about 15 $\mathrm{mm}$. long, varying from orange or brown to rose-purple; pods four-angled, slender, erect, $7-8 \mathrm{~cm}$. long and $1.5 \mathrm{~mm}$. in diameter; beak about $2 \mathrm{~mm}$. long, stout. E. Wheeleri Rothr. E. alpestre Rydb., in part. Mountains: Colo.N.M.-Ariz.-Utah. Submont.-Subalp. My-Jl.

15. C. amoena (Greene) Rydb. Cespitose perennial; stem 1-3 dm. high; leaves linear-oblanceolate, 4-6 cm. long, more or less sinuate-dentate; petals 15-18 mm. long, brown, purple, or rose, with whitish claws; pedicels ascending; pods erect, $3-5 \mathrm{~cm}$. long. Cheiranthus nivalis amoenus Greene. Erysimum asperum alpestre Cockerell. E. Cockerellianum Daniels. High mountains: Colo. Mont.-Alp. Je-Jl.

16. C. Pallasii (Pursh) Rydb. Dwarf biennial; stem $2-10 \mathrm{~cm}$. high, densely leafy; leaves linear-oblanceolate or linear, 1-2 cm. long, sinuate-dentate; sepals scarious-margined; petals deep purple, $10-16 \mathrm{~mm}$. long; pedicels ascending; pods ascending, 4-5 cm. long, $2 \mathrm{~mm}$. thick. Cheiranthus Pallasii Pursh. Aretic regions: Greenl.-Alta.-Alaska. Alp.-Subalp. Je-Jl.

\section{5. hÉSPERIS (Tourn.) L. Dame's Rocket, Dame's VIolet.}

Perennial or biennial herbs, with forked hairs. Leaves simple, dentate. Flowers large, racemose, perfect. Sepals equal, not saccate at base. Petals purple or white, with long claws and broad blades. Pod elongate, nearly cylindric; valves keeled and 1-nerved. Stigma with 2 erect lobes. Seeds in a single row in each cell, globose, wingless. Cotyledons incumbent.

1. H. matronalis L. Stem erect, simple; branched above, 3-10 dm. high; leaves $5-20 \mathrm{~cm}$. long, ovate or ovate-lanceolate, dentate, pubescent on both sides; petals purple, pink, or white; pod 5-10 cm. long, ascending or spreading, somewhat torulose when ripe. Fields and roadsides: N.S.-Pa.-Ia.-Mont.; escaped from cultivation; native of Eurasia. My-Au.

\section{CÁmpe Dulac. Winter Cress, Scurvy Grass.}

Biennial or perennial herbs with angled stem, and alternate lyrate-pinnatifid leaves. Flowers perfect in racemes or panicles. Sepals erect, the outer two slightly saccate at the base. Petals yellow, spatulate, clawed. Pod elongate, linear, somewhat 4-angled, style short; stigma more or less 2-lobed. Seeds in one row in each cell, flattish, marginless. Cotyledons accumbent. [Barbarea
R. Br., not Scop.]

Pod obtusely angled; leaves with 1-4 pairs of divisions.
Divisions of the basal leaves 1-2 small pairs; pod slender, ascending.

Divisions of the basal leaves 3-4 pairs; pod stouter, erect anding. ${ }_{1 .}$. . americana. Pod sharply 4-angled; leaves with 4-8 pairs of divisions.

2. C. stricta.

1. C. americana (Rydb.) Cockerell. Biennial; stem $3-5 \mathrm{dm}$. high, glabrous, strict; divisions of the basal leaves broadly elliptic; stem-leaves with the petioles auriculate-clasping; petals $2-4 \mathrm{~mm}$. long, light yellow; pod $2-2.5 \mathrm{~cm}$. long, 
scarcely $2 \mathrm{~mm}$. wide. $B$. americana Rydb. Wet places in the mountains: Mont.-Colo.-Utah-Wash.-B.C. Plain-Mont. Je-Jl.

2. C. stricta (Andrz.) W. F. Wight. Biennial; stem erect, $3-6 \mathrm{dm}$. high, glabrous; petals light yellow; pods about $2.5 \mathrm{~cm}$. long, stout, erect and appressed against the rachis. B. stricta Andrz. Waste places: Que.-Sask,-Wyo.-Fla.; Wash.-Ida.-Calif,; nat. from Eurasia. Ap-Je.

3. C. verna (Michx.) Heller. Biennial; stem branched, 3-6 dm, high; leaves with rounded or elliptic divisions; petals yellow, about $5 \mathrm{~mm}$. long; fruiting pedicels ascending, stout, angled; pods $5-6 \mathrm{~cm}$. long, straight or nearly so, ascending, sharply angled. B. praecox (J. E. Smith) R. Br. Waste places: N.Y.Fla.-Colo.; Calif.-Wash.; adv. from Eu. My-Je.

\section{RÁPHANUS L, RADISH.}

Leafy annuals or biennials. Flowers perfect, in racemes. Sepals erect, the lateral ones somewhat saccate at the base. Petals large, pale yellow, white or light purple. Pod terete, tapering into a distinct beak, one-celled or transversely divided by several false partitions, more or less moniliform. Seeds globular, pendulous. Cotyledons conduplicate. Stamens unappendaged.

1. R. sativus L. Annual or biennial; stem branched, 4-5 dm. high, glabrous or nearly so; lower leaves lyrate-pinnatifid with rounded, crenate divisions, more or less hairy, the uppermost lanceolate; petals $15-20 \mathrm{~mm}$. long, with long claws, white and tinged with yellow; pod $4-5 \mathrm{~cm}$. long; body $7-8 \mathrm{~mm}$. thick, gradually tapering into a long beak. Waste places: Que.-B.C.-Calif.-Fla.; -W. Ind.; escaped from cultivation. Plain-Submont. F-N.

\section{SinĀpis L. Mústard, Charlock.}

Annual or biennial, caulescent herbs, more or less hirsute. Flowers perfect, in racemes or panicles. Leaves alternate, runcinate-pinnatifid or lobed. Sepals more or less spreading, equal or the outer slightly saccate at the base. Petals yellow, longer than the sepals, clawed. Filaments not appendaged. Pods elongate, nearly terete, more or less constricted between the seeds, the upper portion, containing one seed, produced into a broad and sword-shaped or more or less 4-angled beak. Seeds in one row in each cell, globose, marginless and wingless. Cotyledons conduplicate.

Beak sword-shaped, constituting more than half the length of the pod. 1. S. alba.

length of the pod.

1. S. alba.

2. S. arvensis.

1. S. alba L. Annual; stem 3-6 dm. high, more or less hispid; leaves more or less hirsute, the lower pinnatifid, with rounded toothed divisions, the uppermost often entire; petals yellow, about $1 \mathrm{~cm}$. long; pedicels in fruit spreading; pod densely hispid, about $3 \mathrm{~cm}$. long. Waste places and fields: Me.-Fla.Calif.-B.C.; nat. from Eu. Plain-Submont. Mr-Au.

2. S. arvensis L. Annual; stem 3-6 dm. high, more or less hirsute, or glabrous above; lower leaves lyrate-pinnatifid, with a rounded toothed terminal lobe, usually hispid on the veins beneath; upper leaves oblong or lanceolate, merely toothed; petals bright yellow, $8 \mathrm{~mm}$. long; pedicels ascending, about 5 $\mathrm{mm}$. long; pods ascending, $3-4 \mathrm{~cm}$. long; beak about $5 \mathrm{~mm}$. long. Brassica arvensis (L.) B.S.P. B. Sinapistrum Bois. Fields and waste places: Me.-Fla. -Calif.-Wash.; W. Ind.; nat. from Eu. Plain-Submont. My-S.

\section{ERŨCA (Tourn.) Mill. Garden Rocket.}

Annual or biennial, branching herbs. Leaves pinnately lobed or toothed. Flowers perfect, large, racemose. Petals yellowish or purplish, with brown or violet veins. Pod linear, with a long sword-shaped beak; valves with a single strong and several faint nerves; seeds in two rows.

1. E. Eruca (L.) Britton. Annual; stem glabrous, 3-4 dm. high; lower leaves pinnatifid or lobed, the upper of ten merely dentate; petals strongly veined; pod $1.5 \mathrm{~cm}$. long or more, erect on erect pedicels. E. sativa Lam. Waste places: Ont.-Pa.-Mo.-N.M.-Mont.; adv. from Eu. My-O. 


\section{BRÁssica L. Cabbage, Rape, Turnip, Black Mustard,}

Annual, biennial, or perennial herbs, caulescent, with alternate leaves. Flowers perfect, in elongate racemes or panicles. Sepals ascending, equal or the outer somewhat saccate at the base. Petals yellow or white, clawed. Filaments free, unappendaged. Pods elongate, linear, terete or somewhat 4-angled, with an elongate-conic seedless beak, the valves 1-3-nerved; stigma truncate or 2lobed. Seeds in one row in each cell, subglobose, marginless. Cotyledons conduplicate.

None of the leaves clasping.

Pod slender, 4-angled, erect, appressed to the stem.

Pod ascending, terete, but with a strong midvein.

Upper stem-leaves clasping.

Leaves glaucous, all glabrous except the very earliest ones; petals cream-colored, long-clawed.

Leaves not glaucous, the basal ones distinctly hairy; petals bright yellow, shortclawed.

4. B. Rapa.

1. B. nigra (L.) Koch. Annual; stem 5-20 dm. high, branching, glabrous or nearly so; lower leaves pinnatifid, with a large rounded or oval terminal lobe and a few small lateral ones; uppermost leaves lanceolate or oblong, entire; sepals yellowish; petals bright yellow, spatulate, $7-8 \mathrm{~mm}$. long; pod $1.5-2 \mathrm{~cm}$. long, a little over $1 \mathrm{~mm}$. thick; beak slender. BLACK MUSTARD. Waste places and fields: Me.-Fla.-Calif.-B.C.; W. Ind.; nat. from Eu. Plain-Submont. Ap-S.

2. B. juncea (L.) Cosson. Annual or biennial (?); stem erect, 3-12 dm. high, branched, glabrous or nearly so; lower leaves 1-1.5 dm. long, lyrate-pinnatifid, with a large oval dentate end lobe, the upper lanceolate or linear; petals yellow, 8-10 mm. long, broadly spatulate; pod $3.5-5 \mathrm{~cm}$. long, $2-3 \mathrm{~mm}$. thick; beak 5-8 $\mathrm{mm}$. long. Fields and waste places: N.S.-Va.-N.M.-Sask.; adv. or nat. from Asia. Plain-Submont. Jl-S.

3. B. campestris L. Annual or biennial; stem 3-10 dm. high, glabrous; basal leaves lyrate-pinnatifid, with a large toothed end lobe; stem-leaves lanceolate, entire; petals cream-colored, spatulate, 6-7 mm. long; pod 5-7 $\mathrm{cm}$. long, about $3 \mathrm{~mm}$. thick; beak about $1 \mathrm{~cm}$. long. Rape, Rutabaga, Swedish TURNips. Fields and waste places: N.S.-Mont.-Colo.; escaped from cultivation. Plain -Submont. Ap-O.

4. B. Rapa L. Annual or biennial, closely resembling the preceding, but greener and more hairy, and with smaller and bright yellow flowers. TURNIP. Waste places: west to Wyo. and Mont.; escaped from cultivation. Plain. ApO.

\section{ATHYSĀNUS Greene.}

Small annuals, branched near the base, with toothed or pinnatifid leaves. Flowers perfect, minute in elongate racemes. Sepals ovate-rounded, spreading, equal at the base. Petals minute, linear, or wanting. Stamens subequal, with slender filaments. Anthers short. Fruit orbicular, 1-celled, 3-4-ovuled, but 1 -seeded, wingless, covered with uncinate hairs.

1. A. pusillus (Hook.) Greene. Delicate annual; stem branched near the base, pubescent with branched hairs; leaves oblanceolate or obovate, toothed, $8-15 \mathrm{~cm}$. long, stellate; petals white, spatulate, $1.5 \mathrm{~mm}$. long, or in the later flowers usually wanting; fruiting pedicels recurved, $2-3 \mathrm{~mm}$. long; pod orbicular, Submont. F-My.

\section{THYSANOCÁRPUS Hook.}

Slender caulescent annuals, with alternate leaves. Flowers perfect, in slender racemes. Sepals ovate, rounded, spreading. Petals spatulate, white or purplish. Stamens subequal, with slender filaments. Pods orbicular, 1-celled, 1-ovuled, 1 -seeded, indehiscent, winged, the wing often toothed on the margins like a cogwheel or perforated by round holes near the margins; style slender, but short. Pubescence of simple hairs or none. 
Pods pubescent; plant glabrous and glaucous.

Pods glabrous.

1. T. trichocarpus.

Plant more or less hirsute; pod entire-margined, fenestrate, or with thin round

areas.
Plant glabrous; pod toothed, rarely with fenestrations or thin 2 . T. elegans.

1. T. trichocarpus Rydb. Stem 1-3 dm. high; lower leaves oblanceolate or oblong, sinuately dentate; uppermost leaves linear or linear-lanceolate, entire; petals slightly over $1 \mathrm{~mm}$. long; pedicels in fruit about $5 \mathrm{~mm}$. long, recurved; pod nearly orbicular, about $4 \mathrm{~mm}$. wide, short-pubescent; wing-margins crenate or lobed, not fenestrate. Dry places: Utah-Ida. Son.-Submont. My.

2. T. elegans F. \& M. Stem 3-6 dm. high; basal leaves oblanceolate, 3-10 cm. long; upper leaves lanceolate, sagittate at the base; petals spatulate, $2 \mathrm{~mm}$. long, white or pinkish; pod nearly orbicular, $5 \mathrm{~mm}$. wide; wing with $12-14$ fenestrations or thinner areas. Sandy or rocky ground: Calif.-Wash.-Ida. Son. Mr-My.

3. T. amplectens Greene. Stem 3-5 dm. high; basal leaves oblanceolate, coarsely sinuate-dentate, $2-5 \mathrm{~cm}$. long; stem-leaves linear-lanceolate, auriculate at the base; petals spatulate, about $1.5 \mathrm{~mm}$. long; pods orbicular, with a short cuneate base, crenate on the margin, $5 \mathrm{~mm}$. broad. Sandy places: Ariz.Utah-N.M. Son.-Submont. Mr-Je.

\section{AlÝYSSUM L. Alyssum, Sweet Alyssum.}

Densely stellate annuals or perennials, with alternate leaves. Flowers perfect in racemes. Sepals ovate or oblong, more or less spreading. Petals whitish, obovate or cuneate to linear. Stamens 6; filaments commonly dilated at the base, in our species not toothed. Fruit orbicular, 2-celled, dehiscent; valves convex. Cotyledons accumbent.

1. A. alyssoides (L.) Gouan. Branched annual; stems 1-3 dm. high; leaves linear-oblong or spatulate, 1-3 cm. long, densely stellate-canescent, entire; petals white, or at first yellowish, $3.5 \mathrm{~mm}$. long; pod orbicular in outline, $3 \mathrm{~mm}$. broad, notched at the apex. A. calycinum L. Fields and waste places: N.H.N.J.-Utah-Calif.-B.C.; nat. from Eu. Plain-Submont. My-Je.

\section{BERTERÒA DC. HoAry Alyssum.}

Annual or perennial herbs, stellate or canescent with forked hairs. Leaves alternate, entire. Flowers racemose, perfect. Sepals ascending in anthesis, equal. Petals white, notched. Stamens 6; filaments 2-toothed at the base. Pod oblong (in ours) to nearly globose, only slightly compressed. Seeds winged, several. Cotyledons accumbent.

1. B. incana (L.) DC. Stem 3-6 dm. high, branched; leaves numerous, entire, lanceolate or lance-elliptic, pale green, or the lower oblanceolate, petioled; petals $2-3 \mathrm{~mm}$. long, white; pod oblong, $6-8 \mathrm{~mm}$. long, $2.5-3.5 \mathrm{~mm}$. thick, canescent. Waste places and around dwellings: Me.-N.J.-Mo.-Mont.; adv. or nat. from Eu. Je-S.

\section{IDAHÒA Nels. \& Macb. Flat-PoD.}

Low scapose annual, with lyrate basal leaves. Flowers perfect, solitary. Sepals broad, erect. Petals small, spatulate, white. Pods suborbicular, strongly flattened parallelly to the partition. Seeds in two rows, reticulate, broadly winged. Cotyledons accumbent. [Platyspermum Hook., not Hoffm.]

1. I. platysperma (Hook.) Nels. \& Macb. Acaulescent, scapiferous annual; leaves basal, petioled, with hastate or lyrate or rarely entire and ovate blades; scapes $2-15 \mathrm{~cm}$. long; sepals $2 \mathrm{~mm}$. long, nearly equalling the white spatulate petals; pod rounded-ovate, $6-10 \mathrm{~mm}$. long, $5-8 \mathrm{~mm}$. wide; seeds broadly winged, $5 \mathrm{~mm}$. broad. Platyspermum scapigerum Hook. Prairies and hillsides: Ore. -Calif.-Nev.-Ida. Ap-My.

37. DENTÃria L. Toothwort, Milk Maids.

Erect scapose, perennial herbs, with often thickened rootstocks. Leaves basal; blades palmately cleft or divided. Bracts leaf-like, subopposite or sub- 
verticillate. Flowers perfect, in terminal racemes or corymbs. Sepals equal at the base, erect or nearly so. Petals white or purplish, with slender claws and spreading blades. Pods elongate, linear, flattish or nearly terete, the valves with faint or no midnerve, elastically dehiscent from the base; style slender; stigma entire or rarely 2 -lobed. Seeds in one row in each cell, somewhat flattened, but not margined. Cotyledons accumbent.

1. D. rupicola (O. E. Schulz) Rydb. Perennial, with tuberous rootstock; stem glabrous, 1-3 dm. high; basal leaves palmately divided into 3-5 mucronate oval divisions; stem-leaves or bracts 1-3, 3-5-divided, with elliptic-oblong divisions; petals $10 \mathrm{~mm}$. long, white; pods about $3 \mathrm{~cm}$. long, nearly $2 \mathrm{~mm}$. wide, tapering at both ends; beak $5-6 \mathrm{~mm}$. long. Cardamine californica rupicola O. E. Schulz. Mountains: Mont. Submont-Mont. Jl.

\section{Cardámine L. Bitter Cress.}

Annual or perennial herbs, with alternate, entire or pinnate leaves. Flowers perfect, in racemes or panicles. Sepals equal at the base, erect or ascending. Petals white or purple, obovate to narrowly spatulate. Pods elongate, manyseeded, narrow, flattened, the valves nerveless or nearly so, elastically dehiscent at maturity. Seeds in one row in each cell, not margined. Cotyledons accumbent.

Leaves all entire.

Plant dwarf, less than $1 \mathrm{dm}$. high, with a slender rootstock; leaf-blades oval, usually entire-margined.

Plant more than $1 \mathrm{dm}$. high; blades at least of the stem-leaves sinuately toothed.

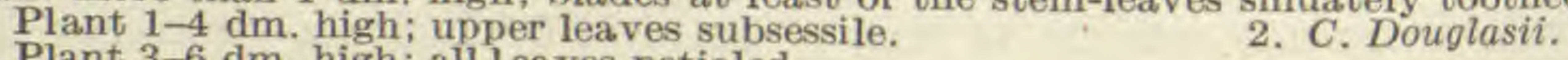
Plant 3-6 dm. high; all leaves petioled.

Flowers about $1 \mathrm{~cm}$. long; leaves not thick. Plant glabrous or nearly so.

Stem densely pilose; leaves also hairy.
Flowers about $0.5 \mathrm{~cm}$. long; leaves thickish, sinuately round-lobed.

Some of the leaves at least pinnate.

5. C. Leibergii.

Petals 5-12 mm. long.

Petals 8-12 mm. long; leaflets 3, rhombic, 3-lobed or sinuately 3-toothed.

Petals about $5 \mathrm{~mm}$. long; leaflets $1-9$, the terminal one much larger, cordate, ovate, or reniform, sinuately toothed.

Beak of the fruit about $2.5 \mathrm{~mm}$. long.

Beak of the fruit about $1 \mathrm{~mm}$. long.

Only a few of the leaves pinnate.

Petals $2-4 \mathrm{~mm}$. long.

5. C. Leibergii.

Leaflets of the stem-leaves usually only 3 .

Leaflets of the stem-leaves $5-11$.

Leaves glabrous; seeds small, more than 12 in each pod. Beak of the pod less than $1 \mathrm{~mm}$. long.

Stem few-leaved; petals $3-4 \mathrm{~mm}$. long; racemes contracted, corymbiform, shorter than the subtending leaves. $10 . C$. umbellata. Stem very leafy; petals $2-3 \mathrm{~mm}$. long; raceme elongate.

Leaves thin; leaflets usually broad; stem glabrous or nearly so.

Leaves thick; leaflets of the 11.C. pennsylvanica. stem densely hairy below. $12, C$, multifolia. Beak of the pod more than $1 \mathrm{~mm}$. long.

12. C. mullifolia.

Leaves with scattered hairs; seeds large, 6-12 in each pod. 14. C. oligosperma.

1. C. bellidifolia L. Dwarf tufted perennial; stems branching, $5-15 \mathrm{~cm}$. high; leaves petioled, simple; blades 5-10 mm. long; petals spatulate, 3-4 mm. long; pods erect, $2-2.5 \mathrm{~cm}$. long, fully $1 \mathrm{~mm}$. wide, on short pedicels. Arcticalpine situations: Greenl.-N.H.-Wash.-Alaska; Eu. Alp. Jl-Au.

2. C. Douglasii (Torr.) Britton. Perennial, with a slender tuberiferous rootstock; stem more or less pubescent, 1.5-4 dm. high; leaves simple, the lower blades cordate, $1-3 \mathrm{~cm}$. broad, sinuate, the upper ovate, usually coarsely dentate; petals obovate, pink or purple, $8-12 \mathrm{~mm}$. long; pod 2-3 $\mathrm{cm}$. long; beak $3-4 \mathrm{~mm}$. long. C. rhomboidea purpurea Torr. C. purpurea (Torr.) Britt., not Cham. \& Schlecht. Springy places: Que.-Md.-Mo.-Alta, Boreal. Ap-My.

3. C. cordifolia A. Gray. Perennial, with a rootstock; stem 3-6 dm. high; leaf-blades cordate, $2-5 \mathrm{~cm}$. long, sinuately toothed; petals about $1 \mathrm{~cm}$. long, 
white, obcordate or obovate; pods erect on ascending pedicels, $2-3 \mathrm{~cm}$. long, 1.5 $\mathrm{mm}$. wide; beak very short. Springs and river banks: Wyo.-N.M.-Ariz.Ida. Submont.-Mont. Je-Au.

4. C. infausta Greene. Stem stout, 3-10 dm. high; leaf-blades roundedcordate or the lower reniform, simple, coarsely sinuately toothed, $3-4 \mathrm{~cm}$. broad; petals white, broadly spatulate, about $8 \mathrm{~mm}$. long; pedicels in fruit spreading; pods $2.5-3.5 \mathrm{~cm}$. long, ascending, $1.5 \mathrm{~mm}$. wide. C. cardiophylla Rydb., not Greene. C. incana (A. Gray) A. Nels. River banks and in water: Colo.-Utah. Submont.-Mont. Je-Au.

5. C. Leibergii Holz. Perennial, with a horizontal rootstock; stems glabrous, erect, 1-3 dm. high; leaves simple or the lower divided into 3-5 segments, thick; leaf-blade or terminal segment orbicular or oval, sinuately 5-9-lobed or toothed; petals white, $4 \mathrm{~mm}$. long; pods $2-2.5 \mathrm{~cm}$. long, $1 \mathrm{~mm}$. wide, erect on ascending pedicels; beak very short. $C$. callosicrenata $\cdot$ Piper. Moist places in the mountains: Ida.-Mont. Submont.-Mont. Je-Au.

6. C. angulata Hook. Perennial, with a strong rootstock; stem glabrous, 4-6 dm. high; leaves pinnate, with 3 , rarely 5 , petiolulate divisions; divisions of the basal leaves rounded, coarsely toothed, those of the upper leaves rhombicovate or -lanceolate, with large, acute lobes; petals white, 8-12 mm. long; pod about $2 \mathrm{~cm}$. long; nearly $2 \mathrm{~mm}$. thick. Wet places and shallow water: B.C.Ore.-Wyo. Submont. My-Je.

7. C. vallicola Greene. Perennial, with a rootstock; stems erect, 3-5 dm. high, glabrous; leaves pinnate, with 5-9 divisions; terminal divisions rounded, or ovate, often cordate at the base, $2-4 \mathrm{~cm}$. wide; pods erect, $3-3.5 \mathrm{~cm}$. long, 1.5 $\mathrm{mm}$. wide, on ascending pedicels; beak $2.5-3 \mathrm{~mm}$. long. (?) C. foliacea Greene. Wet places: Wyo.-Colo. Submont. My-Au.

8. C. Breweri S. Wats. Perennial, with a rootstock; stem erect, 3-6 dm. high, glabrous or nearly so; terminal division of the leaves oval to rounded, acute, truncate or rarely cordate at the base, $1.5-4 \mathrm{~cm}$. broad, toothed; petals 5-6 mm. long; pods 3-3.5 $\mathrm{cm}$. long, $1.5 \mathrm{~mm}$. wide. Wet places: Mont.-Wyo. -Calif.-B.C. Submont.-Mont. Je-Jl.

9. C. unijuga Rydb. Perennial, with a slender rootstock; stem $2-3 \mathrm{dm}$. high, glabrous, simple; basal leaves simple, broadly cordate or reniform, $5 \mathrm{~mm}$. wide, sinuately 3-lobed; stem-leaves pinnately ternate, with oblong divisions, or the terminal one rhomboid; petals spatulate, $2 \mathrm{~mm}$. long; pod erect, $1.5-2 \mathrm{~cm}$. long, about $1 \mathrm{~mm}$. wide; seeds 8-12; beak $1 \mathrm{~mm}$. long or less. Wet places: Mont. -Wyo. Submont.-Mont. J-Au.

10. C. umbellata Greene. Perennial, with a rootstock; stems 2-5 dm. high, glabrous or nearly so; leaves with 3-7 oval to oblong divisions, or the terminal one rounded or reniform, glabrous; petals spatulate; pods $2-3 \mathrm{~cm}$. long, 1 $\mathrm{mm}$. wide, erect, on ascending pedicels; beak minute. C. kamtschatica (Regel) Schulz. Wet places: Alaska-Calif.-Colo--Alta. Subalp. My-Au.

11. C. pennsylvanica Muhl. Perennial, with a horizontal rootstock; stem glabrous or nearly so, branched, 2-8 dm. high; leaves with 5-17 oblong, oval, or obovate divisions, or the terminal one orbicular; pod ereet or ascending, 2-3 $\mathrm{cm}$. long, $1 \mathrm{~mm}$. wide. Wet places: Newf.-Fla.-Colo.-Ore.-B.C. PlainMont. Ap-Au.

12. C. multifolia Rydb. Perennial, with a rootstock; stem about $2 \mathrm{dm}$. high, very leafy; leaflets $7-13$, those of the lower leaves oblong to oblong-obovate or oval, entire or sinuate-dentate, the terminal one larger and obovate; pedicels ascending; pod erect, about $2 \mathrm{~cm}$. long and $0.75 \mathrm{~mm}$. wide. Wet places: B.C.Utah-Mont. Plain-Mont. My-Je.

13. C. acuminata (Nutt.) Rydb. Perennial, with a rootstock; stems 2-6 $\mathrm{dm}$. high, somewhat pubescent below; leaves with $7-15$ oblong to oval divisions, or the terminal one broader, orbicular; petals about $3 \mathrm{~mm}$. long; pod erect or nearly so, $2.5-3 \mathrm{~cm}$. long, $1 \mathrm{~mm}$. wide. Wet places: Mack.-Alta.-(? Wyo.) -Wash.-Alaska. Submont. Je-Au. 
14. C. oligosperma Nutt. Perennial; stem 1-4 dm. high, pubescent; leaves with 5-11 oval or orbicular, stalked divisions; petals spatulate, about $2.5 \mathrm{~mm}$, long; pods erect, on ascending pedicels, $2-3 \mathrm{~cm}$. long, over $1 \mathrm{~mm}$. wide; beak about $0.5 \mathrm{~mm}$. long. Wet places: B.C.-Calif.-Ida. Submont.-Mont. $\mathrm{Mr}-\mathrm{Jl}$.

\section{Dràba L. Whitlow Grass, Draba.}

Annual or perennial herbs, mostly low, often with stellate or branched pubescence. Flowers perfect, in racemes. Sepals equal at the base. Petals yellow or white, longer than the sepals. Pods elliptic to linear, flat; valves nerveless; stigma capitate. Seeds in 2 rows in each cell, neither margined nor winged. Cotyledons usually accumbent.

Winter annuals.

Style slender, $12 \mathrm{~mm}$. long; fllaments dilated.

Style obsolete.

Pods hairy.

Leaves all crowded on the lower part of the stem; flowers white; racemes short, on long naked peduncles.

Pods linear, appressed-hirsute; leaves entire.

Inflorescence even in fruit corymbiform; petals minute or none.

Inflorescence in fruit elongate; petals conspicuous.

2. D. micrantha.

3. D. coloradensis.

Pods oblong or elliptic, with spreading branched pubescence, often stellate; leaves usually toothed. $\quad 4$. D. cuneifolia.

Leaves more or less scattered on the stem; flowers yellow or in age sometimes white.

Basal leaves obovate, ovate, or oblong; stem-leaves ample; pedicels longer than the pods. 5 . D. nemorosa.

Basal leaves oblanceolate to oblong; stem-leaves smaller, oblong-lanceolate; pedicels shorter than the pods.

Pedicels divergent; leaves hirsute. $\quad$ 6. D. montana.

Pods glabrous.

Pedicels ascending; leaves stellate, not hirsute. $\quad$ 7. D. praealta.

Pedicels in fruit reflexed; petals white. $\quad 8, D$. deflexa.

Pedicels ascending or spreading; petals yellow. "

Stem more or less leafy.

Pods 2-4 mm. long; stem-leaves thick.

Pods 6-8 mm. long; leaves thin.

Basal leaves obovate; stem-leaves several, broad; pedicels twice as long as the pod.

Basal leaves oblanceolate; stem-leaves very few and small; pedicels slightly, if at all, longer than the pod. 11. D. nitida.

Stem scapiform or with a single leaf; leaves in a basal rosette.

Basal leaves spatulate; pods more than $1 \mathrm{~cm}$. long.

Basal leaves broadly spatulate, finely stellate; petals white.

Basal leaves spatulate, but not broadly 12. D. Macouniana. petals yellow. (Depauperate forms of) 11. D. nitida.

Basal leaves oblanceolate to linear, hirsute or glabrate; pods $5-8 \mathrm{~mm}$. long.

Basal leaves oblanceolate or spatulate, hirsute. 13. D. crassifolia.

Basal leaves narrowly linear-oblanceolate, glabrous, except the very sparingly ciliate margins, 14. D. Parryi,

Perennials; style usually evident

Plants scapose or nearly so.

Pod 16-20 mm. long and 7-8 mm. wide. 15. D. eurycarpa.

Pod less than $12 \mathrm{~mm}$. long and $5 \mathrm{~mm}$. wide.

Petals yellow.

Pods about twice as long as broad, 5-12 mm, long.

Pods glabrous or nearly so.

Leaves not stellate, glabrous, except the ciliatemargin. (Depauperate variety of) $41 . D$. streptocarpa.

Leaves more or less stellate over the whole surface.

Leaves broadly spatulate, long-ciliate, especially on the margin; midrib weak. 16. D. alpina.

Leaves linear-oblanceolate, scarcely ciliate; midrib strong.

Pods pubescent.

17. D. glacialis.

Leaves obovate, densely and finely white-stellate; midrib indistinct.

Ieaves spatulate 18 . D. argyrea. midrib.

Plant cespitose, but not densely pulvinate; leaves oblanceolate or spatulate, rather finely stellate, spreading, not densely imbricate. 
Plant densely pulvinate; leaves linear-oblong, villous-hispid as well as stellate, densely imbricate. 20 . D. densifolia.

Pods only slightly longer than broad.

Leaves stellate or with branched hairs.

Pod ovate or elliptic, compressed.

Pods densely stellate, about $5 \mathrm{~mm}$. long, fully $4 \mathrm{~mm}$. wide; midrib of the leaves indistinct.

Leaves densely and closely stellate, thick.

Leaves sparingly long-hairy or glabrate above.

21. D. ventrosa.

22. D. sobolifera.

Pods sparingly puberulent or glabrous, not more than $3 \mathrm{~mm}$. wide, $3-5 \mathrm{~mm}$. long.

Leaves oblong to linear; midvein strong.

Plants not densely pulvinate; leaves linear or linear-oblanceolate, 5-10 mm. long.

23. D. oligosperma.

Plant densely pulvinate; leaves oblong or linear-oblong, less than $5 \mathrm{~mm}$. long, densely imbricate.

Leaves obovate, thick; midvein indistinct.

24. D. andina.

Pod globose.

25. D. uncinalis.

Leaves glabrous except the unbranched ciliations on the margins.

Leaves densely imbricate, short.

Pod pubescent; midvein of the leaves obsolete.

Pod glabrous; midvein of the leaves prominent.

27. D. sphaerula.

28. D. pectinata.

Leaves not densely imbricate; pod pubescent, $3-6 \mathrm{~mm}$. long.

Petals white.

29. D. Nelsonii.

Leaves finely stellate.

Leaves linear or linear-oblanceolate.

Midrib of the leaves strong; pods 4-5 $\mathrm{mm}$. long.

Midribs of the leaves not strong; pods $6-8 \mathrm{~mm}$. long.

23. D. oligosperma.

30. D. lapponica.

Leaves broadly spatulate or obovate.

Pod oblong to linear, 6-12 $\mathrm{mm}$. long.

Pods 6-8 mm. long, not twisted.

31. D. nivalis.

Pods $10-15 \mathrm{~mm}$. long, more or less twisted. 32 . D. lonchocarpa.

Pods broadly obovate, 3-4 mm. long. 25. D. uncinalis.

Leaves hirsute-ciliate on the margins, oblanceolate.

Style obsolete.

Plant leafy-stemmed.

Style about $1 \mathrm{~mm}$. long.

33. D. fladnizensis.

34. D. oreibata.

Petals white.

Petals about $3 \mathrm{~mm}$. long: pods $5-8 \mathrm{~mm}$. long.

Plant 1-2 dm. high, densely grayish-stellate; pods longer than the pedicels.

35. D. cana.

Plants about $3 \mathrm{dm}$. high, greener; pods shorter than the pedicels.

36. D. McCallae.

Petals about $2 \mathrm{~mm}$, long; pods more than $1 \mathrm{~cm}$, long. $37 . D$. columbiana.

Petals yellow.

Plants glabrous, except the margins of the leaves, which are occasionally ciliate.

Leaves linear or narrowly linear-oblanceolate, thin.

Leaves much shorter than the flowering stem; pods lance-linear.

Leaves almost equalling the flowering stem; pods ovate.

38. D. chrysantha.

39. D. graminea.

Leaves spatulate or broadly oblanceolate, thick.

40. D. crassa.

Plant decidedly hairy.

Pubescence long-hirsute, with simple or slightly branched hairs.

Pubescence short, mostly of stellate or branched hairs

41. D. streptocarpa.

Styles 1.5-2 mm. long; pods glabrous or slightly puberulent.

Pod not twisted; pubescence rather sparse or minute; stem-leaves usually sharply toothed.

Stem more or less hirsute.

Stem minutely appressed-stellate.

42. D. spectabilis.

43. D. oxyloba.

Pod twisted; pubescence dense and grayish; stem-leaves entiremargined or minutely denticulate.

Style $1 \mathrm{~mm}$. long; pods densely pubescent.

44. D. Helleriana.

Stem ereet or nearly so.

Leaves thin, the basal ones usually over $2 \mathrm{~cm}$. long, the cauline ovate to lanceolate.

Petals $5 \mathrm{~mm}$, or more long.

Petals pale yellow; stem-leaves often dentate.

45. D. luteola. 
Petals bright yellow; stem-leaves entire-margined.

46. D. surculifera.

Petals 3-4 mm. long, pale yellow; stem-leaves entire-margined. 47 . D. aureiformis.

Leaves thick, the basal ones oblanceolate, $1-2 \mathrm{~cm}$. long, the cauline lanceolate or oblong. $\quad 48$. D. aurea. Stem decumbent.

Leaves finely stellate; pods twisted. 49, D. decumbens.

Leaves coarsely hairy, with branched hairs; pods not twisted.

50. D. brachystylis.

1. D. asprella Greene. Winter annual, scapose or nearly so; scapes 1 to several, 5-10 cm. high, hirsute with branched hairs; leaves basal, rosulate, oblanceolate, 2-3 cm. long, densely hairy; petals yellow, 4-5 mm. long; pod rather turgid, $5 \mathrm{~mm}$. long or more. Mountains: Ariz. - Utah. My.

2. D. micrantha Nutt. Annual; stems 5-10 cm. high, branched at the base, more or less pubescent; leaves $5-15 \mathrm{~mm}$. long, ovate or elliptic, entire, stellate; petals shorter than the hairy sepals, or none, sometimes in the earlier flowers 2.5-3 mm. long, 2-cleft at the apex; pedieels ascending; pod hispid, 6-12 $\mathrm{mm}$. long, $4 \mathrm{~mm}$. wide. D. caroliniana mierantha A. Gray. Dry plains: Ill.Tex:-Ariz.-Wash. Plain. Mr-Au.

3. D. coloradensis Rydb. Annual, leafy below, often branched, 5-10 cm. high; leaves obovate, entire, $1-2 \mathrm{~cm}$. long, $0.5-1 \mathrm{~cm}$. wide, subsessile, coarsely hirsute; petals white, $3-3.5 \mathrm{~mm}$. long, spatulate, emarginate; pods linear-oblong, 10-12 mm. long and nearly $2 \mathrm{~mm}$. wide. Plains and hillsides: N.M.-Colo.S.D. Plain-Submont. Ap-My.

4. D. cuneifolia Nutt. Annual; stem 5-20 cm. high, branched; leaves obovate or cuneate, $1-4 \mathrm{~cm}$. long, usually coarsely toothed above the middle, stellate; racemes elongate in fruit; petals white, $3-4 \mathrm{~mm}$. long; pod 7-15 $\mathrm{mm}$. long, $2 \mathrm{~mm}$. wide, rarely glabrate. Grassy places and plains: Ill.-Fla.-Calif.

5. D. nemorosa L. Winter annuals; stem leafy, $0.5-3 \mathrm{dm}$. high, branched below; leaves often more or less dentate; petals light yellow, $2-3 \mathrm{~mm}$. long;
fruiting pedicels divaricate, $1-2 \mathrm{~cm}$. long; pods oblong, $5-10 \mathrm{~mm}$. long, $2 \mathrm{~mm}$. wide. Hills, prairies, and plains: Mich.-Colo.-Nev.-Ore.-B.C.; Eurasia. Plain-Mont. Ap-Au.

6. D. montana S. Wats. Winter annual; stem branched or simple, leafy, 1-2 dm. high; basal leaves rosulate, entire or sparingly toothed, hirsute with branched hairs; stem-leaves lanceolate; racemes elongate; petals yellow, $2-3 \mathrm{~mm}$. long; fruiting pedicels $5-8 \mathrm{~mm}$. long; pod erect, oblong, petals yellow, $6-10 \mathrm{~mm}$. long, $2 \mathrm{~mm}$. wide. Mountains: (? N.M.)-Colo.-Utah. Submont.-Mont. Je-S.

7. D. praealta Greene. Winter annual; stems usually several from the base, leafy; basal leaves lanceolate or oblanceolate, stellate, 1-3 cm. long, entire or slightly dentate; stem-leaves ovate, small; petals white, spatulate, $2-3 \mathrm{~mm}$. long; fruiting pedicels $5-7 \mathrm{~mm}$. long; pods oblong, about $1 \mathrm{~cm}$. long, $2-3 \mathrm{~mm}$. wide. $D$. yellowstonensis A. Nels. D. lapilutea A. Nels. Mountain slopes: Wyo.-Alta.-B.C. Submont. Je-Jl. 8. D. deflexa Greene. Winter annual; stem stout, $7-10 \mathrm{~cm}$. high, racemose
almost from the base; leaves mostly basal, oblong-lanceolate, entire or sparingly
toothed, hirsute-ciliate on the mar toothed, hirsute-ciliate on the margins; petals white; pedicels spreading, much exceeding the pod; pod elliptic, 6-8 $\mathrm{mm}$. long. Dry places: Wyo.

9. D. brachycarpa Nutt. Annual; stem usually much branched, stellate; leaves ovate to lanceolate, entire, $1 \mathrm{~cm}$. long or less, thick, finely stellate; petals yellow or whitish, $2 \mathrm{~mm}$. long; pedicels $3-4 \mathrm{~mm}$. long; pod oblong, 2-5 mm. Mr-My.

10. D. lutea Gilib. Winter annual of the habit of $D$. nemoralis; stems $1-4$ dm. high, branched; basal leaves obovate or oblanceolate, densely and coarsely stellate; stem-leaves ovate, usually coarsely toothed; petals yellow, or in age paler, 2-3 mm. long; fruiting pedicels $15-30 \mathrm{~mm}$. long, ascending or spreading; pod oblong, 5-10 mm. long, $2 \mathrm{~mm}$ wide. D. nemorosa leiocarpa Lindb. (?) $D$. 
dictyota Greene, Hills and plains: Hudson Bay-Mich.-Colo.-Ore.-Alaska; Eurasia. Plain-Mont. My-Jl.

11. D. nitida Greene. Winter annual, often branched at the base; stems 1-3 dm. high, erect; basal leaves rosulate, oblanceolate, $1-3 \mathrm{~cm}$. long, nearly glabrous above, densely stellate beneath; stem-leaves oblong or lanceolate, usually entire; petals yellow, about $2 \mathrm{~mm}$. long; fruiting pedicels ascending, 6-15 mm. long; pod glabrous, ereet, $8-15 \mathrm{~mm}$. long, $2 \mathrm{~mm}$. wide. D. stenoloba S. Wats., not.Ledeb. Mountains: Alta,-Colo.-Calif.-B.C. S'ubmont.-Subalp.

12. D. Macouniana Rydb. Annual, almost seapose; stems ascending or decumbent, less than $1 \mathrm{dm}$. high, glabrous and shining; basal leaves numerous, broadly spatulate or obovate, $5-10 \mathrm{~mm}$. long, finely stellate; stem-leaf usually one, oval, obtuse, $5 \mathrm{~mm}$. long; petals white, less than $3 \mathrm{~mm}$. long; pod oblonglinear, erect, about $1 \mathrm{~cm}$. long and $2 \mathrm{~mm}$. wide. Summits of the Rocky Mountains: B.C. Submont.-Subalp. J1-Au.

13. D. crassifolia Graham. Biennial or short-lived perennial; stems $2-10$ $\mathrm{cm}$. long, ascending, usually scapiform; basal leaves oblanceolate, $5-15 \mathrm{~mm}$. long; petals yellow, soon turning white, $2-2.5 \mathrm{~mm}$. long; fruiting pedicels ascending, 4-7 mm. long; pod glabrous, $6-7 \mathrm{~mm}$. long, $2 \mathrm{~mm}$. wide. D. albertina Greene. Alpine-arctic damp places: Greenl.-Lab.-Colo.-Alaska. Subalp.-Alp. Jl$\mathrm{Au}$.

14. D. Parryi Rydb. Annual, perfectly glabrous, except a few eilia on the petioles; stems several, usually less than $1 \mathrm{dm}$. high, scapiform or rarely with one stem-leaf; basal leaves numerous, linear or narrowly linear-oblanceolate, $1.5-2.5 \mathrm{~cm}$. long; petals searcely $2 \mathrm{~mm}$. long, white or at first light yellow; pods erect, oblong, 5-8 mm. long, 1.5-2 $\mathrm{mm}$. wide. Alpine peaks: Colo.-Wyo. Subalp.-Alp. Jl-Au.

15. D. eurycarpa A. Gray. Densely cespitose; branches short and very leafy; leaves oblanceolate, about $12 \mathrm{~mm}$. long, densely stellate; scape scarcely exceeding the leaves, few-flowered; pod oblong-ovate, acute, glabrous; style 2 $\mathrm{mm}$. long: High mountains: Calif.-Nev.-Ida. Alp.-Subalp.

16. D. alpina L. Scapose perennial; leaves basal, rosulate, oblanceolate, $1-3 \mathrm{~cm}$. long, nearly glabrous above, sparingly stellate beneath; scapes $5-15 \mathrm{~cm}$. long, stellate; petals yellow, spatulate, $5-7 \mathrm{~mm}$. long; pod lance-oblong, $7-10$ $\mathrm{mm}$. long, $3 \mathrm{~mm}$. wide. Arctic and alpine ridges: Greenl.-Lab.-B.C.—Alaska; aretic Eurasia. Alp. Je-Jl.

17. D. glacialis Adams. Seapose perennial; leaves basal, rosulate, stellate on both sides, $1-3 \mathrm{~cm}$. long; seape 5-15 $\mathrm{cm}$. high; petals yellow, 5-6 mm. long; fruiting pedicels ascending; pod lance-oblong, $6-8 \mathrm{~mm}$. long, $3 \mathrm{~mm}$. wide $D$. laevicapsula Payson. Alpine-arctic situations: Greenl.-Wyo.-Wash.-Alaska; Asia. Subalp,-Alp. Je-Jl.

18. D. argyrea Rydb. A cespitose tufted perennial, with underground horizontal stems; basal leaves obovate, $3-7 \mathrm{~mm}$. long, in dense rosettes, almost silvery; petals yellow, $3 \mathrm{~mm}$. long, obovate; pedicels in fruit $5-8 \mathrm{~mm}$. long; pods lanceolate, $6-7 \mathrm{~mm}$. long, $2.5-3 \mathrm{~mm}$. wide, minutely stellate. Crevices of rocks: Ida. Subalp. Jl.

19. D. incerta Payson. Cespitose, acaulescent, pulvinate perennial; leaves basal, oblanceolate or linear-oblanceolate, $5-15 \mathrm{~mm}$. long, firm, with a strong midrib; petals yellow, obovate, emarginate, 4-5 mm. long; scapes 5-10 $\mathrm{mm}$. long; fruiting pedicels ascending; pods lance-oblong, pubescent, $6-7 \mathrm{~mm}$. long, $2.5-3 \mathrm{~mm}$. wide. Rocky mountain summits: Alta.-Mont.-Wyo. Mont. 一Alp.

20. D. densifolia Nutt. Densely pulvinate cespitose perennial; leaves basal, rosulate, densely imbricate, less than $1 \mathrm{~cm}$. long, with thick midrib, stellate and hispid; scape $1-5 \mathrm{~cm}$. long, villous; petals yellow, about $5 \mathrm{~mm}$. long; pedicels ascending; pod elliptic, $6-8 \mathrm{~mm}$. long, $3-4 \mathrm{~mm}$. wide, densely stellate. D. Mulfordae Payson, typical form with elongate inflorescence and 
coarse pubescence. D. glacialis $\gamma$ Hook. D. vestita Payson, more common form with corymbose inflorescence and softer pubescence. Rocky places, high mountains: Alta.-Wyo.-Alaska. Mont.-Alp. Je-Jl.

21. D. ventrosa A. Gray. Densely cespitose pulvinate perennial; leaves numerous and imbricate, obovate or spatulate, $1 \mathrm{~cm}$. or less long; scape $1-2 \mathrm{~cm}$. long, villous-stellate; petals yellow, about $5 \mathrm{~mm}$. long; pod densely stellate, 4-5 $\mathrm{mm}$. long, $4 \mathrm{~mm}$. wide. High mountains: Wyo,-Utah. Mont.-Subalp. Jl-Au.

22. D. sobolifera Rydb. A low cespitose perennial, but the leafy stolons often somewhat elongate; basal leaves oblanceolate, obtuse or spatulate, $1-2 \mathrm{~cm}$. long and 3-4 mm. wide, thick; peduncles $3-6 \mathrm{~cm}$. long, stout, rather many-flowered; petals yellow, obovate, about $4 \mathrm{~mm}$. long; pedicels in fruit 7-8 $\mathrm{mm}$. long; pod ovate, about $6 \mathrm{~mm}$. long, 3-4 mm. wide. Alpine peaks: Utah. Subalp.Alp. Jl.

23. D. oligosperma Hook. Cespitose perennial, profusely branched; leaves 5-15 mm. long, somewhat imbricate; scape in fruit 5-10 $\mathrm{cm}$. high; petals yellow or whitish, $5 \mathrm{~mm}$. long, broadly spatulate; pedicels ascending, $3-5 \mathrm{~mm}$. long; pod ovate, about $4 \mathrm{~mm}$. long, $3 \mathrm{~mm}$. wide. D. saximontana A. Nels. Mountains and dry hills: Mack.-Utah-Calif.-Alaska. Mont.-Alp.

24. D. andina (Nutt.) A. Nels. Cespitose-pulvinate perennial; leaves basal, densely imbricate, about $5 \mathrm{~mm}$. long, oblong or linear-oblong; seape 1-3 $\mathrm{cm}$. high; petals yellow, 4-5 mm. long; fruiting pedicels ascending; pod roundedovate, $3-3.5 \mathrm{~mm}$. long, $2.5-3 \mathrm{~mm}$. wide. D. glacialis $\delta \& \&$ Hook. D. oligosperma andina Nutt. D. oligosperma microcarpa Blankinship. Dry hills and mountains: Alta.-Wyo.-Utah-B.C. Mont.-Alp. My-Je.

25. D. uncinalis Rydb. Small cespitose and pulvinate perennial; flowering stems scapiform, $2-3 \mathrm{~cm}$. high, sparingly stellate; basal leaves in dense tufts, thick, rounded-obovate, 3-4 mm. long, sparingly stellate; inflorescence corymbiform, few-flowered; pod ovate, $3-4 \mathrm{~mm}$. long and $3 \mathrm{~mm}$. wide. Mountains: Utah. Subalp.-Alp.

26. D. sphaerocarpa Macbr. \& Payson. Much branched cespitose perennial; leaves tufted, oblong or obovate, obtuse, 4-7 mm. long, finely and densely stellate, the midveins indistinet; fruiting racemes elongate; pods 8-12, globose, scarcely at all flattened, ovate, stellate, $2-5 \mathrm{~mm}$. long; style $1 \mathrm{~mm}$. long. Granite washes: Ida.

27. D. sphaerula Macbr, \& Payson. Densely pulvinate cespitose perennial; leaves $2 \mathrm{~mm}$. long, densely clustered and imbricate, broadly linear, acute; scape slightly longer than the leaves; petals slightly longer than the sepals; fruiting inflorescence corymbose; pods few, broadly lanceolate, $3 \mathrm{~mm}$. long, compressed, stellate; style $1 \mathrm{~mm}$. long. Alpine slopes: Ida. Alp. J.

28. D. pectinata (S. Wats.) Rydb. Cespitose pulvinate perennial; leaves oblong, thick, $3-4 \mathrm{~mm}$. long; midrib very prominent; scape $1-2 \mathrm{~cm}$. long; petals $4 \mathrm{~mm}$. long; pedicels ascending; pod $3-4 \mathrm{~mm}$. long, $2-2.5 \mathrm{~mm}$. wide. D. globosa Payson. Dry hills and mountains: Utah-Nev. Subalp.-Alp. Jl.

29. D. Nelsoni Macbr. \& Payson. Cespitose perennial; leaves linear, 5-7 $\mathrm{mm}$. long, $1 \mathrm{~mm}$. wide or less, glabrous, except the strong marginal cilia, the midvein prominent; petals yellow, twice as long as the sepals; fruiting raceme elongate; pods $6-15$, broadly lanceolate, $3-6 \mathrm{~mm}$. long, $2-3 \mathrm{~mm}$. wide, pubescent with simple hairs; style about $1 \mathrm{~mm}$. long. Exposed ridges: Wash.-Ida.Calif. Subalp.-Alp. Je-Au.

30. D. lapponica Willd. Cespitose tufted perennial; basal leaves 5-15 $\mathrm{mm}$. long; scape $3-7 \mathrm{~cm}$. long; petals $3 \mathrm{~mm}$. long, obovate, white; pedicels $2-4$ $\mathrm{mm}$. in fruit; pod oblong, 6-8 mm. long, $2 \mathrm{~mm}$. wide, glabrous. Alpine-aretic regions: Greenl.-B.C.; Eu. Alp.

31. D. nivalis Liljeb. Cespitose tufted perennial; leaves $5-8 \mathrm{~mm}$. long, densely stellate; scape $1-5 \mathrm{~cm}$. long; petals white, obovate, $3 \mathrm{~mm}$. long; pedicels ascending; pod 6-8 mm. long, $2 \mathrm{~mm}$. wide. Arctic-alpine situations: Greenl.Lab.-Utah-Alaska; Eu. Subalp.-Alp. Je-Au. 
32. D. lonchocarpa Rydb. Densely cespitose perennial; leaves basal, numerous, spatulate, $3-5 \mathrm{~mm}$. long, densely stellate; petals white, $2-2.5 \mathrm{~mm}$. long, obovate; scape 1-10 cm. long; pedicels almost erect; pod linear, $1-1.5 \mathrm{~cm}$. long, $1.5 \mathrm{~mm}$. wide, usually more or less twisted. D. laevipes Hook., not DC. D. nivalis elongata $\mathrm{S}$. Wats. Alpine regions in wet places: Alta.-Mont.-Wash. -B.C. Subalp. -Alp. My-Jl.

33. D. fladnizensis Wulfen. Cespitose acaulescent perennial; leaves spatulate or oblanceolate, $1 \mathrm{~cm}$. or less long, rosulate, hirsute-ciliate on the margins or nearly glabrous; peduncles $1-5 \mathrm{~cm}$. long; petals white, $3 \mathrm{~mm}$. long; pod oblong, glabrous, 4-5 $\mathrm{mm}$. long, $2 \mathrm{~mm}$. wide. Alpine-aretic situations: Greenl.-Que.-Colo.-Utah-B.C.; Eu. Subalp.-Alp. Jl-Au.

34. D. oreibata Macbr. \& Payson. Cespitose perennial; leaves oblonglinear, obtuse, 4-6 mm. long, ciliate on the margins, the midvein evident; petals white; fruiting raceme elongate; pod narrowly elliptic, $8-10 \mathrm{~mm}$. long, $2-3 \mathrm{~mm}$. broad; style slender, $1 \mathrm{~mm}$. long. Alpine summits: Ida.-Utah. Subalp.Alp. $\mathrm{My}-\mathrm{Jl}$.

35. D. cana Rydb. Perennial, with a taproot and short caudex, densely grayish stellate; stem 1-2 dm. high; basal leaves numerous, oblanceolate or spatulate, 1-1.5 cm. long, densely stellate; stem-leaves lanceolate to ovate, about $1 \mathrm{~cm}$. long; pedicels short, nearly erect; petals white, about $3 \mathrm{~mm}$. long; pod linear-oblong, 6-8 mm. long, densely pubescent. D. valida Goodding. Foothills and mountains: Alta.-N.M.-B.C. Submont.-Mont. Je-Jl.

36. D. McCallae Rydb. Perennial with a cespitose base, sparingly stellate but green; stems several, simple, about $3 \mathrm{dm}$. high; basal leaves spatulate, 10-18 mm. long, entire or nearly so; stem-leaves ovate, sharply dentate or entire; pedicels in fruit erect; petals white, 4-5 $\mathrm{mm}$. long; pod ovate, densely but finely pubescent. Along brooks: Alta. Mont. Au.

37. D. columbiana Rydb. Perennial, with a cespitose base, sparingly and finely stellate; stems slender, about $2 \mathrm{dm}$. high, simple; basal leaves many, ciliate on the margin, oblanceolate, $10-15 \mathrm{~mm}$. long, denticulate or entire; stemleaves ovate to lanceolate; raceme elongate; pedicels ascending; petals slightly over $2 \mathrm{~mm}$. long, white; pods linear-oblong, finely pubescent, over $1 \mathrm{~cm}$. long. Along rivers, in the mountains: B.C.-Yukon. Subalp. My-Jl.

38. D. chrysantha S. Wats. Cespitose perennial; stems decumbent, 5-15 $\mathrm{cm}$. high, few-flowered; basal leaves narrowly oblanceolate, $2-6 \mathrm{~cm}$. long, entire, ciliate, thin; stem-leaves small; petals $4 \mathrm{~mm}$. long; pods glabrous, $8-12 \mathrm{~mm}$. long; style slender, $1 \mathrm{~mm}$. long. Mountains: Colo.-N.M.-Ariz. Submont.Subalp. Au.

39. D. graminea Greene. Cespitose perennial; stem $1 \mathrm{dm}$. or less high; lower leaves numerous, narrowly linear, ciliate, $5 \mathrm{~cm}$. long, $1 \mathrm{~mm}$. wide; stemleaves few; petals pale yellow, $4 \mathrm{~mm}$. long; pod glabrous, $7 \mathrm{~mm}$. long, $3 \mathrm{~mm}$. wide. High mountains: Colo. Mont.-Subalp. Jl.

40. D. crassa Rydb. Cespitose perennial; stems ascending or decumbent, 5-15 cm. high, sparingly pubescent; basal leaves 2-4 cm. long, rather thick, generally entire, sparingly ciliate; stem-leaves similar, smaller; petals yellow, 3-5 mm. long; pod ovate-oblong, 8-10 mm. long, about $4 \mathrm{~mm}$. wide; style $1 \mathrm{~mm}$. long. High mountains: Mont.-Colo. Mont.-Subalp. Jl-Au.

41. D. streptocarpa A. Gray. Perennial, with a densely cespitose caudex; stems more or less hirsute, $1-20 \mathrm{~cm}$. high, leafy; basal leaves oblanceolate; stem-leaves lanceolate or oblong; inflorescence often branched; pedicels erect, 8-10 $\mathrm{mm}$. long; petals yellow, 5-6 $\mathrm{mm}$. long; pod lance-linear, about $1 \mathrm{~cm}$. long, $2 \mathrm{~mm}$. wide, glabrous, usually twisted; style $1.5-2 \mathrm{~mm}$. long. Mountains: Colo. -N.M. Submont.-Alp.

42. D. spectabilis Greene. Cespitose perennial; stems leafy, $1.5-3 \mathrm{dm}$. high; basal leaves obovate or spatulate, $2-3 \mathrm{~cm}$. long, rather sparingly stellate; stemleaves ovate, thin; petals 6-8 mm. long, spatulate, golden yellow; fruiting pedicels ascending or spreading, about $1.5 \mathrm{~cm}$. long; pod $8-10 \mathrm{~mm}$. long, glabrous or hirtellous, 2-2.5 mm. wide. Mountains: Colo.-Wyo. Mont. -Subalp. Je-Jl. 
43. D. oxyloba Greene. Cespitose perennial; stems 2-5 dm. high, leafy; basal leaves $2-4 \mathrm{~cm}$. long, oblanceolate, remotely dentate or entire, finely appressed-stellate; stem-leaves ovate or lanceolate; petals golden yellow, 4-5 mm. long; pedicels ascending-spreading, about $8 \mathrm{~mm}$. long; pods $8-10 \mathrm{~mm}$. long, $2 \mathrm{~mm}$. wide, finely pubescent. Mountains: Colo. Submont.-Mont. Jl.

44. D. Helleriana Greene. Cespitose perennial; stems 2-4 dm. high, hirsute, with branched hairs; basal leaves spatulate or oblanceolate, $2-3 \mathrm{~cm}$. long, loosely stellate; stem-leaves oblong or lanceolate; petals golden yellow, $6 \mathrm{~mm}$. long; pedicels about $1 \mathrm{~cm}$. long, ascending; pod nearly $1 \mathrm{~cm}$. long. $D$. aurea stylosa A. Gray. Cañons in the mountains: N.M.-Colo.-Utah. Submont.Mont. My-Jl.

45. D. luteola Greene. Cespitose perennial; stem 1.5-4 dm. high, cinerousstellate; basal leaves oblanceolate, usually entire, $2-5 \mathrm{~cm}$. long; stem-leaves entire or dentate; petals $5-6 \mathrm{~mm}$. long, light yellow; pedicels ascending, 7-8 $\mathrm{mm}$. long; pod ereet, $10-18 \mathrm{~mm}$. long, $3 \mathrm{~mm}$. wide, stellate. Mountains: Colo.-Utah. Mont.-Alp. J.

46. D. surculifera A. Nels. Cespitose perennial; stems 2-4 dm. high, stellate and villous; basal leaves $3-5 \mathrm{~cm}$. long, oblanceolate, finely and rather sparingly stellate; petals $5 \mathrm{~mm}$. long, golden yellow; pedicels $3-4 \mathrm{~mm}$. long; pod lanceolate, 8-12 mm. long, finely stellate, straight or somewhat twisted. Mountains: Wyo.-S.D. Submont.-Mont. Jl-Au.

47. D. aureiformis Rydb. A slender, cespitose, grayish stellate plant; stem strict, 2-4 dm. high; basal leaves spatulate, $2-3 \mathrm{~cm}$. long, acute, entire; stem-leaves elosely sessile, oblong-lanceolate; pedicels ascending; pod erect, linear to oblong-lanceolate, $10-15 \mathrm{~mm}$. long, about $3 \mathrm{~mm}$. wide, slightly if at all twisted, stellate. D. Bakeri Greene. Mountains: Utah-Colo--S.D. Mont. -Alp. Je-Au.

48. D. aurea Vahl. Cespitose perennial; stem 1-4 dm. high; basal leaves oblanceolate, 1-2 $\mathrm{cm}$. long, thick, densely stellate; petals yellow, 4-6 $\mathrm{mm}$. long; pedicels in fruit about $5 \mathrm{~mm}$. long; pods lanceolate, $10-12 \mathrm{~mm}$. long, 2-3 $\mathrm{mm}$. wide, often twisted, pubescent. $D$. uber A. Nels. Mountains and arctic regions: Greenl.-Lab.-Colo.-Ariz.-B.C.; Eu. Alp.-Mont.

49. D. decumbens Rydb. Perennial with a short cespitose caudex; stems decumbent, 1-2 dm. high, sparingly pubescent, few-leaved; basal leaves numerous, broadly spatulate, entire, $2-4 \mathrm{~cm}$. long, finely grayish stellate, rather thick; stem-leaves ovate to ovate-lanceolate, sessile, entire; petals pale yellow, about $4 \mathrm{~mm}$. long; pedicels very short; pod oblong, 8-15 mm. long, densely pubescent. Summits: Colo. Alp. Au.

50. D. brachystylis Rydb. Perennial; stems several, decumbent or ascending, with divergent branches, 1-1.5 dm. high, hirsute; basal leaves oblanceolate or spatulate, $1.5-2 \mathrm{~cm}$. long; stem-leaves few, oblong or lanceolate, sessile; pedicels short; pod oblong, finely stellate, $8-12 \mathrm{~mm}$. long, ascending; style almost obsolete. Mountains: Utah. Subalp. J.

\section{0. ÁRABIS L. Rock Cress, Wind Candytuft,}

Annual or perennial herbs, glabrous, or pubescent with branched hairs. Leaves alternate, in ours mostly toothed. Flowers perfeet, in terminal or axillary racemes. Sepals equal or nearly so, sometimes saccate at the base. Petals white, rarely yellowish, pink, or purple, mostly clawed. Stamens 6; filaments free, unappendaged. Pods sessile, elongate, flat, the valves sometimes nerved, not elastically dehiscent; stigma capitate or 2-lobed. Seeds in 1-2 rows in each cell, marginless, margined, or winged. Cotyledons accumbent or nearly so.

Basal leaves lyrately lobed; perennials.

Basal leaves entire-margined or toothed.

Pods erect or nearly so.

Leaves coarsely hirsute.

Stem-leaves neither cordate nor auricled at the base,

Stem-leaves cordate or auricled at the base; biennials.

I. LYRATAE.

II. Furcatae.

III. HIRSUTAE. 
Leaves not coarsely hirsute; perennials.

Pubescence, if any, sparse and consisting of 2-forked or rarely 3-forked hairs.

Pubescence of at least the lower leaves decidedly stellate.

IV. Drummondanae.

Pods spreading or reflexed.

Pods and calyx stellate.

Pods not stellate.

Pods 3-4 mm. wide.

Pods 1-2.5 mm. wide.

Pods spreading or somewhat recurved on spreading pedicels.

Pods only 1-1.5 mm. wide.

Pods $1.5-2.5 \mathrm{~mm}$. wide.

Perennials, with a caudex.

Plant tall, $3 \mathrm{dm}$. or more high, suffruticose at the base.

Plant low, 1-2 dm. high, cespitose. X. RECoNDrTAE

IX. PERENNANTES.

Stout biennials or short-lived perennials, $3 \mathrm{dm}$, high or more

Pods and pedicels reflexed.

XII. RETROFRACTAE.

\section{LYRATAE.}

Pods about $0.75 \mathrm{~mm}$. wide; style more than $0.5 \mathrm{~mm}$. long.

Pods fully $1 \mathrm{~mm}$. wide; style almost obsolete.

1. A. lyrata,

2. A. ambioua.

\section{Furcatae.}

Seeds not winged; leaves hairy; pods $1 \mathrm{~mm}$. wide or less.

Seeds winged at the lower end; leaves merely ciliate on the margins; pods $1.5-2 \mathrm{~mm}$. wide.

\section{HIRSUTAE.}

3. A. Nuttallii.

4. A. furcata.

All sepals narrowly oblong; two of them with slightly saccate bases; petals $3-5 \mathrm{~mm}$. long, yellowish white, less than twice as long as the sepals.

5. A. ovata.

Two of the sepals with strongly saccate bases, almost twice as broad as the others; petals 6-10 mm. long, pure white, fully twice as long as the sepals.

6. A. rupestris.

\section{DRUmmondianaE.}

Stems $3 \mathrm{dm}$. high or more, solitary or 2 or 3 from the same root. Pods about $1.5 \mathrm{~mm}$. wide.

Pods about $3 \mathrm{~mm}$. broad.

Stems less than $3 \mathrm{dm}$. high, several from a cespitose caudex.

Pods strictly erect, blunt.

Pods rather ascending, acute.

\section{MICROPHYLLAE.}

Stems more than $3 \mathrm{dm}$, high; basal leaves $3-10 \mathrm{~cm}$. long.

7. A. Drummondii.

8. A. connexa.

9. A. alberiina.

10. A. Lyallii.

11. A, oblanceolata. leaves $1-2 \mathrm{~cm}$. long. Stems usually less than $3 \mathrm{dm}$. high, from a branched caudex; basal leaves ote-lanceolate. Plant green; petals $7-8 \mathrm{~mm}$. long; pods fully $2 \mathrm{~mm}$. wide; stem-leaves ovate-lanila.
$12 . A$. oreophila.

Plant grayish; petals about $5 \mathrm{~mm}$. long; pods $0.75-1.5 \mathrm{~mm}$. wide; stem-leaves oblong or linear, the lower oblanceolate.

Flowers few; pods more than $1 \mathrm{~mm}$. wide; seeds somewhat 2-ranked; stem hirsuteciliate below or glabrous.

Flowers many; pods less than $1 \mathrm{~mm}$. wide; seeds strictly in one row; stem finely stellate.

\section{Pulchrae.}

Seeds distinctly in two rows; stem-leaves not auricled.

Petals purple, 8-10 mm. long.

Petals white, $10-12 \mathrm{~mm}$. long.

14. A. Crandallii.

15. A. pulchra.

16. A. formosa.

Seeds in one row; stem-leaves more or less auricled; petals $5-8 \mathrm{~mm}$. long.

Leaves usually coarsely toothed; petals pink, 6-8 mm. long. 17. A. subpinnatifida.

Leaves entire; petals white, 5-6 mm. long.

18. A. MacDougalii.

VII. SUFFRUTESCENTES.

Stems suffrutescent at the base; pods reflexed.

Stems not suffruticose; pods spreading.

19. A. suffrutescens.

20. A, drepanoloba.

VIII. Macounianae,

Petals about $4 \mathrm{~mm}$. long; pod $3-4 \mathrm{~cm}$. long; basal leaves $1-2 \mathrm{~cm}$. long.

Petals about $8 \mathrm{~mm}$. Iong; pod 4-6 cm. long; basal leaves 4-6 cm. long.

21. A. Macounii.

22. A arcoidea.

ix. Perennantes.

One species.

X. RECONDITAE.

23. A. perennans.

Leaves finely stellate.

Leaves thick, canescent; stems simple.

Pod about $1.5 \mathrm{~mm}$. wide, acute.

24. A. Lemmonii. 
Pod about $2 \mathrm{~mm}$. wide, obtuse.

Leaves thin, green; stem branched.

Leaves densely hairy. with branched hairs or merely ciliate on the margins.

Leaves densely hairy.

Leaves sparingly hairy or merely ciliate.

27. A, setulosa.

Plant green, not glaucous; pods $3 \mathrm{~cm}$.

Leaves firm, ciliate or somewat so in one row

Leaves thin, almost perfectly glabrous. $\quad 28$. A. rugocarpa.

Plant glaucous or bluish-green; pods $4-5 \mathrm{~cm}$. long; seeds in two rows.

Pedicels and calyx long-ciliate.

\section{Arcuatae,}

Pedicels glabrous or merely stellate.

30. A. spatifolia.

Calyx more or less stellate; petals $8 \mathrm{~mm}$. long.

Stem 3-6 dm. high; basal leaves $2-4 \mathrm{~cm}$. long, entire.

Stem 5-10 dm. high; basal leaves 5-10 cm. long, denticulate.

Calyx glabrous or nearly so.

Leaves decidedly stellate; plants biennial.

31. A. perelegans.

Pods straight or slightly curved upwards, ascending-spreading.

Pods more or less arcuate and somewhat drooping.

Pods 8-10 cm. long; petals 8-10 mm. long.

32. A. brachycarpa.

Pods 4-6 cm. long; petals $5-8 \mathrm{~mm}$. long.

Stem-leaves narrowly lanceolate.

Petals 8-10 mm. long, purple.

Petals about $5 \mathrm{~mm}$. long, white or pinkish.

Leaves coarsely stellate-hirsute; plants perennial.

35. A. Stokesiae.

A. Bourgovii.

34. A. Selbyi.

Stem-leaves conspicuously sagittate at the base; sepals linear-oblong.

Stem-leaves with inconspicuous auricles at the 39. A. gracilenta.

Basal leaves sparingly hirsute;

Basal leaves sparingly htem-leaves lanceolate, $1.5-3 \mathrm{~cm}$. long.

Basal leaves densely hairy; stem-leaves oblong-lanceolate, i-1.5 cm. long.

36. A. divaricarpa.

37. A. densicaulis.

38. A. fructicosa.

XII. RETROFRACTAE.

27. A. setulosa.

Stem-leaves decidedly sagittate at the base.

Plants not densely cespitose; stem mostly solitary (except in A. lignifera); biennials.
Pedicels of the fruit merely recurved.

Leaves dentate.

Leaves entire.

41. A. consanguinea.

Seeds in one row; pod $3-4 \mathrm{~cm}$, long; sepals stellate. 42. A. lignifera.

Seeds in two rows; pod less than $3 \mathrm{~cm}$. long; sepals glabrous.

Pedicels in fruit strictly reflexed.

43, A, brevisiliqua.

Seeds in one row; pods 4-7 cm. long.

Petals 6-10 mm. long; stem-leaves usually ample.

Racemes not secund.

Racemes secund.
Petals about $5 \mathrm{~mm}$. long; stem-leaves narrow, serrulate.

Seeds in two rows; pod $1.5-3.5 \mathrm{~cm}$. long.
Plant densely cespitose; basal leaves linear-oblanceolate; perennials.

44. A, rhodantha.

45. A. retrofracta.

46. A. lignipes.

7. A. caduca.

Stem-leaves scarcely sagittate at the base.

48. A. canescens.

Plant $3 \mathrm{dm}$. high or more, sparingly stellate; flowers numerous.

Plant 1-2 dm. high, densely stellate below; flowers few.

49. A. exilis.

50. A. pendulocarpa.

1. A. lyrata L. Stem 1-3 dm. high, glabrous or sparingly pubescent below; basal leaves $2-5 \mathrm{~cm}$. long, sparingly hairy or glabrate; stem-leaves spatulate to linear, 1-2.5 cm. long; petals 6-8 mm. long, white; fruiting pedicels ascending or spreading, 6-8 mm, long; pods $1.5-3 \mathrm{~cm}$. long. Rocky places: Conn. S.C. -Mo.-Sask. Boreal. Ap-JI.

2. A. ambigua DC. Stem branched at the base, $2-4 \mathrm{dm}$. high, glabrous or nearly so; basal leaves glabrous or sparingly pubescent, 2-4 cm. long; stemleaves spatulate, entire or toothed; petals white, about $6 \mathrm{~mm}$. long; pedicels in fruit ascending, about $1 \mathrm{~cm}$. long; pods erect or nearly so, $2-3 \mathrm{~cm}$. long. Wet rocky places: Alta.-Mont.-Wash.-Alaska; e Asia. Subalp. My-Au.

3. A. Nuttallii B. L. Robins. Biennial or perennial, more or less cespitose; stems 1-3 dm, high, sparingly hirsute below; basal leaves short-petioled, spatulate, 1-3 cm. long; stem-leaves oblanceolate, sessile; petals white, 4-6 mm. long; pedicels 8-15 mm. long; pods $1-3 \mathrm{~cm}$. long. A. spathulata Nutt., not DC. Mountains: Mont.-Utah-Wash. Submont.-Mont. My-Jl. 
4. A. furcata S. Wats. Perennial, with a cespitose caudex or rootstock; stems 1-3 dm. high, glabrous; basal leaves spatulate, $2-4 \mathrm{~cm}$. long, often ciliate on the margin; stem-leaves oblong or oblanceolate; petals 7-8 mm. long; pedicels 5-15 mm. long; pods 2-3.5 cm. long. A. Bridgeii M. E. Jones. Mountains: Wash.-Mont.-Ore. Submont.-Mont. My-Au.

5. A, ovata (Pursh) Poir. Stem simple or branched above; basal leaves oblanceolate or spatulate, $1-8 \mathrm{~cm}$. long, slightly toothed or entire; stem-leaves lanceolate, cordately or sagittately clasping, usually sinuate-dentate, $2-8 \mathrm{~cm}$. long; petals 4-5 mm. long; pedicels $5-7 \mathrm{~mm}$. long; pods $3-4 \mathrm{~cm}$. long, $1 \mathrm{~mm}$. wide; style very short. A. hirsuta Hook., not Scop. Among rocks and in waste places: N.B.-Ga.-Calif.-Alaska. Plain-Mont. My-Au.

6. A. rupestris Nutt. Stems simple, hirsute, 3-5 dm. high; basal leaves spatulate, $\Sigma-5 \mathrm{~cm}$. long, sinuately toothed; stem-leaves lanceolate, cordateclasping; petals $6-10 \mathrm{~mm}$. long; pedicels $5-10 \mathrm{~mm}$. long; pod $4-6 \mathrm{~cm}$. long, more than $1 \mathrm{~mm}$. wide. Dry places and among rocks: Sask.-(? Colo.)-Utah-Ore. -Alaska. Submont. Ap-Je.

7. A. Drummondii A. Gray. Stems simple and strict, 3-6 dm. high; basal leaves oblanceolate, $2-4 \mathrm{~cm}$. long, glabrous or somewhat pubescent; stem-leaves lanceolate, sagittate-clasping, glabrous and glaucous; petals white or pink, 6-10 $\mathrm{mm}$. long; pedicels 5-10 mm. long; pod 5-8 cm. long, $1.5-2 \mathrm{~mm}$. wide; seeds winged, in two rows. Streptanthus angustifolius Nutt. Turritis stricta Grah. Arabis philonipha A. Nels. A. oxyphylla Greene. Mountains: Alta.-N.M.Utah. Submont.-Subalp. My-Au.

8. A. connexa Greene. Closely resembling the preceding and perhaps not distinct, differing in the stronger and more branched caudex, spatulate basal leaves, shorter, less acuminate stem-leaves, and broader pod, which is $5-8 \mathrm{~cm}$. long. Mountains: Alta.-Colo.-Utah. Mont. Je-Jl.

9. A. albertina Greene. Stem 1-2 dm. high, glabrous, simple; basal leaves oblanceolate, $1-2 \mathrm{~cm}$. long; stem-leaves narrowly lanceolate, auriculate-clasping; inflorescence short; petals purple or rose-colored, about $8 \mathrm{~mm}$. long; pedicels $5-10 \mathrm{~mm}$. long, erect; pod 2-6 cm. long, $2 \mathrm{~mm}$. wide. A. Drummondii Wardii A. Gray. Mountains: Alta.-Wyo.-Utah-Wash. Submont.-Mont. J1-Au.

10. A. Lyallii S. Wats. Perennial, with a branched caudex; stems 1-2 dm. high, ereet or ascending; basal leaves narrowly oblanceolate, the petioles ciliate; stem-leaves few, lanceolate; petals purple, $7-8 \mathrm{~mm}$. long; pedicels $5-10 \mathrm{~mm}$. long, ascending or rarely erect; pods $4-5 \mathrm{~cm}$. long, $2 \mathrm{~mm}$. wide. Mountains: B.C.-Mont.-Calif. Submont.-Subalp. My-Au.

11. A. oblanceolata Rydb. Stem branched at the base, $3 \mathrm{dm}$. or more high; basal leaves sparingly stellate-pubescent, oblanceolate, entire; stem-leaves sessile, lanceolate, sagittate-auricled at the base; sepals white-hairy near the apex; petals dark reddish purple, $7-8 \mathrm{~mm}$. long; pods ascending, about $5 \mathrm{~cm}$. long and $2 \mathrm{~mm}$. wide, glabrous; seeds in two rows. Mountains: Colo. Mont.Subalp. S,

12. A. oreophila Rydb. Stems 1-2 dm. high; basal leaves numerous, broadly oblanceolate or spatulate, stellate-pubescent; petals yellowish white below, upper portion rose or purplish; pods glabrous, $3-6 \mathrm{~cm}$. long, slightly arcuate; beak obsolete; seeds in two rows, winged above. Arabis Drummondii alpina S. Wats., in part. A. oreocallis Greene. Mountains: Utah-Wyo.Mont, Mont.-Subalp.

13. A. microphylla Nutt. Stems ereet, $1-3 \mathrm{dm}$. high; basal leaves oblanceolate or spatulate, $0.5-3 \mathrm{~cm}$. long, entire, stellate; sepals stellate; petals mostly white, $5 \mathrm{~mm}$. long; pedicels $5-10 \mathrm{~mm}$. long, ascending; pods ascending, $2-4 \mathrm{~cm}$. long. Hills and mountains: Mont.-Utah-Ore.-Wash. Submont.-Mont. Je-S.

14. A. Crandallii B. L. Robins. Stems 2-4 dm. high; basal leaves narrowly oblanceolate, $2-4 \mathrm{~cm}$. long, densely stellate; stem-leaves lanceolate or linear, slightly clasping; sepals stellate; petals $6 \mathrm{~mm}$. long, white; pedicels $5-10$ 
$\mathrm{mm}$. long, erect; pods 4-5 cm. long. A. stenoloba Greene. Mountains: Colo. Submont. My-Je.

15. A. pulchra M. E. Jones. Perennial; stem erect, 3-6 dm. high, stellatecanescent; basal leaves oblanceolate, entire, $3-4 \mathrm{~cm}$. long, densely stellate; stemleaves linear or linear-lanceolate, not auricled; sepals densely stellate, oblong, 5-6 mm. long; petals dark purple, with light claws, 8-10 $\mathrm{mm}$. long; pods $4-6 \mathrm{~cm}$. long, $3 \mathrm{~mm}$. wide; seeds in two rows. Valleys: Nev.-Calif.-s Utah. Son. My-Je.

16. A. formosa Greene. Perennial, somewhat woody at the base; stem about $3 \mathrm{dm}$. high, densely stellate; lower leaves linear-oblanceolate, $2-4 \mathrm{~cm}$. long, densely stellate, thick; stem-leaves linear, sessile; sepals stellate, broadly elliptic, rounded and slightly scarious at the apex; petals white, $10-12 \mathrm{~mm}$. long; pod $4-5 \mathrm{~cm}$. long, $2-2.5 \mathrm{~mm}$. wlde; seeds in two rows. River valleys: n N.M.Utah-(? Colo). Son. Ap-Je.

17. A. subpinnatifida S. Wats. Biennial or perennial; stem $1.5-5 \mathrm{dm}$. high; basal leaves linear-oblanceolate, entire or sparingly toothed, $2-4 \mathrm{~cm}$. long; stem-leaves numerous, lanceolate, coarsely toothed; pedicels recurved, 5-10 mm. long; pod 4-7 $\mathrm{cm}$. long, 2-3 $\mathrm{mm}$. wide; seeds in one row. Dry regions: Calif.Ore.-Ida.-Nev. Son.

18. A. MacDougalii Rydb. Perennial; stem 4-6 dm. high, densely stellate; basal leaves narrowly oblanceolate, $2-4 \mathrm{~cm}$. long, entire or denticulate, densely stellate; stem-leaves linear or linear-lanceolate, sagittate at the base; pedicels reflexed, $5-10 \mathrm{~mm}$. long; pods reflexed, 4-5 $\mathrm{cm}$. long, $1.5 \mathrm{~mm}$. wide; seeds in one row. Mountains: Mont.-Nev. Mont. Je.

19. A. suffrutescens S. Wats. Suffrutescent perennial; shoots of the season 1-3 dm. long, glabrous; leaves narrowly oblanceolate, glabrous, or nearly so, thick and shining, 3-5 cm. long; upper stem-leaves lanceolate, somewhat sagittate at the base; petals purplish, $6 \mathrm{~mm}$. long; pods 4-7 cm. long, glabrous, about $4 \mathrm{~mm}$. wide, tapering into a short beak. Mountains: Wash.-Ida.Calif. Submont.-Mont. Je-Au.

20. A. drepanoloba Greene. Perennial, with several decumbent stems, 2-3 dm. high; basal leaves oblanceolate, 1-3 cm. long, minutely stellate; stemleaves lance-oblong, sagittate, glabrous; petals rose or pink, 6-8 mm. long; pedicels spreading, $5 \mathrm{~mm}$. long; pods $3-5 \mathrm{~cm}$. long, $3 \mathrm{~mm}$. wide; style very short. Mountains: Alta. Mont. N-Au.

21. A. Macounii S. Wats. Biennial or perennial, branched at the base; stems $2-3 \mathrm{dm}$. high, sparingly hirsute below, glabrous above; basal leaves stellate, oblanceolate, 1-2 $\mathrm{cm}$. long; stem-leaves linear, sagittate at the base, glabrous; petals $4 \mathrm{~mm}$. long, rose-colored; pedicels spreading; pods glabrous, slightly curved, mostly divaricate, $3-4 \mathrm{~cm}$. long; seeds in one row. Valleys: B.C. Submont. My.

22. A. arcoidea A. Nels. Perennial, with a woody taproot, and short branched caudex; stems erect, $2-5 \mathrm{dm}$. high, densely hirsute below, glabrate above; leaves entire, the basal ones petioled, narrowly linear-spatulate, densely sub-stellate; stem-leaves auriculate-clasping, linear; pedicels ascending; petals purple or violet; pod arcuate-spreading; seeds in a single row, broadly winged. Dry sandy soil: Ida. My.

23. A. perennans S. Wats. Perennial, with a branching caudex, often suffruticose at the base; stems 3-4 dm. high; lower leaves $2-3 \mathrm{~cm}$. long, petioled; spatulate or linear-spatulate, stellate; sepals stellate; petals 4-5 mm. long, pale; pods $4-6 \mathrm{~cm}$. long, areuate, on spreading pedicels; seeds in one row. Dry plains and valleys: Wash.-Utah-Ariz.-s Calif. Son-Submont. Ap-My.

24. A. Lemmonii S. Wats. Stems $1-2 \mathrm{dm}$. high, ascending or erect; basal leaves spatulate, 1-3 $\mathrm{cm}$. long; stem-leaves lanceolate or oblong, sometimes auricled; sepals stellate; petals rose or purple, 5-6 mm. long; pedicels $2-6 \mathrm{~mm}$. long, spreading; pods somewhat arcuate-spreading, $3-4 \mathrm{~cm}$. long, glabrous; style obsolete. L. bracteolata Greene, a form with short stem-leaves. Mountains: Mont.-Utah-Calif.-B.C.-Submont.-Mont. Jl-Au. 
25. A. Egglestonii Rydb. Stems several, about $1 \mathrm{dm}$, high, decumbent at the base, glabrous; basal leaves crowded, spatulate, thick, 1-2 em. long; stemleaves elliptic or lanceolate, less than $1 \mathrm{~cm}$. long, more or less auricled at the base; petals light purple, about $4 \mathrm{~mm}$. long; pods spreading on short spreading pedicels, glabrous, $2-2.5 \mathrm{~cm}$. long, obtuse at the apex. High mountains: Colo. Alp. Jl.

26. A. recondita Greene. Stems glabrous, about $3 \mathrm{dm}$. high, branched; basal leaves thin, obovate, more or less dentate; stem-leaves lanceolate, auriculateclasping; sepals with scattered stellate hairs; petals rose-purple, $5 \mathrm{~mm}$. long; pedicels spreading, about $8 \mathrm{~mm}$. long; pod curved, glabrous, $2.5-3.5 \mathrm{~cm}$. long. Mountains: Colo.-Ariz. Submont. Je.

27. A. setulosa Greene. Stems $2-3 \mathrm{dm}$. high; basal leaves oblanceolate, 1-2 cm. long; stem-leaves glabrous, somewhat sagittate at the base; sepals sparingly stellate; petals white, 6-7 mm. long; pedicels spreading, curved; pod spreading or recurved, 3-4 cm. long; seeds slightly 2-rowed. A. Fendleri A. Nels., not Greene. A. Diehlii M. E. Jones. Dry hills: Wyo.-Colo.-Utah. Submont. $\mathrm{My}-\mathrm{Je}$.

28. A. rugocarpa Osterhout. Stems 1-2 dm. high; basal leaves oblanceolate, 2-3 cm. long; stem-leaves small, linear, often with small auricles at the base; petals $5 \mathrm{~mm}$. long, rose or pale purple; pod $3 \mathrm{~mm}$. long, spreading or pendulous. A. aprica A. Nels. Mountains: Colo.-Wyo. Submont.-Mont. Je.

29. A. oxylobula Greene. Stems about $1 \mathrm{dm}$, high; basal leaves narrowly linear-oblanceolate, about $2 \mathrm{~cm}$. long; petals pink, $4 \mathrm{~mm}$. long; pedicels about $5 \mathrm{~mm}$. long, spreading; pods $1.5-2.5 \mathrm{~cm}$. long; seeds almost in one row. Mountains: Colo. Submont. Je.

30. A. spatifolia Rydb. Stems 2-3 dm. high; basal leaves narrowly oblanceolate, $2-3 \mathrm{~cm}$. long; stem-leaves linear-lanceolate, sagittate at the base; petals 4-5 mm., pinkish; pedicels spreading or somewhat reflexed, 8-10 $\mathrm{mm}$. long; pods 4-5 cm. long; style obsolete. Mountains: Colo. Submont. Jl.

31. A. perelegans A. Nels. Biennial; stem strict, 5-7 dm. high, hirsute with branched hairs below, glabrous above; basal leaves oblanceolate, more or less dentate, finely stellate, 3-5 cm. long; stem-leaves linear-lanceolate, sagittate at the base, glabrate; petals dark purple to nearly white, $8-10 \mathrm{~mm}$. long; pedicels $5-8 \mathrm{~mm}$. long, ascending or spreading; pods arcuate-spreading, $6-8 \mathrm{~cm}$. long, nearly $2 \mathrm{~mm}$. wide. A. arcuata subvillosa $\mathrm{S}$. Wats. A. elegans A. Nels. Open woods and slopes: Mont.-Wyo.-Utah-Wash. Son.-Submont. Ap-Je.

32. A. brachycarpa (T. \& G.) Britton. Stem 4-6 dm. high; basal leaves oblanceolate, usually dentate, $2-5 \mathrm{~cm}$. long; stem-leaves lanceolate, sagittate at the base, glabrous; petals pink, about $8 \mathrm{~mm}$. long; pedicels about $5 \mathrm{~mm}$. long, spreading or ascending; pods usually spreading, $2-5 \mathrm{~cm}$. long, $2 \mathrm{~mm}$. wide; seeds in two rows. Dry ledges: Que.-Mich.-Alta. Plain. My-Au.

33. A. Bourgovii Rydb. Stem 3-6 dm. high; basal leaves oblanceolate, finely stellate, almost entire, $2-4 \mathrm{~cm}$. long; stem-leaves lanceolate, sagittate at the base; petals pink, $8 \mathrm{~mm}$. long; pedicels spreading, 5-7 $\mathrm{mm}$. long; pods sometimes pendulous, $4-8 \mathrm{~cm}$. long, $2 \mathrm{~mm}$. wide; seeds more or less in two rows. Turritis patula Grah. A. dacotica Greene, small form. Meadows and hills: Man.-Wyo.-Ida.-Alta. Plain-Submont. Ap-Jl.

34. A. Selbyi Rydb. Perennial, with a basal rosette of leaves; these oblanceolate, 5-10 cm. long, short-petioled, acute, sinuate-denticulate, green but stellate on both sides; stem-leaves linear-lanceolate, sagittate at the base; petals red-purple; fruiting pedicels 3-4 $\mathrm{mm}$. long, divergent; pods divergent, about 3 $\mathrm{cm}$. long and $2 \mathrm{~mm}$. wide, obtuse at both ends; seeds in two rows. Cañons: Colo. Mont.

35. A. Stokesiae Rydb. Biennial; stem 5-7 dm. high, retrorse-pubescent below; basal leaves oblanceolate, $2-3 \mathrm{~cm}$. long, finely stellate; stem-leaves lanceolate, sagittate at the base, 4-7 cm. long, glabrous; petals pink or purple; pedicels spreading, 7-10 mm. long; pod glabrous, $2 \mathrm{~mm}$. wide. Cañons and hills: Mont. -Utah-Ida. Son.-Submont. My-Je. 
36. A. divaricarpa A. Nels. Biennial or perhaps perennial, often branched at the base; stems 5-7 dm. high, sparingly retrorse-hairy below; basal leaves 2-4 cm. long, stellate, oblanceolate; stem-leaves lanceolate, sagittate at the base; pedicels $1 \mathrm{~cm}$. or less, spreading; pods straight or slightly arcuate; seeds more or less in two rows. Mountains: Colo.-Utah-Wyo.-Ida. Mont. Je-Jl.

37. A. densicaulis A. Nels. Biennial; stems several, 3-5 dm. high, glabrous or slightly hirsute near the base; basal leaves oblanceolate, $2-3 \mathrm{~cm}$. long, finely stellate; stem-leaves glabrous, linear, auriculate-clasping at the base; pedicels about $1 \mathrm{~cm}$. long, spreading; pods arcuate, often somewhat drooping; seeds in one row. Wooded gravelly slopes: Wyo. Jl.

38. A. fructicosa A. Nels. Biennial; stems several, $3-5 \mathrm{dm}$. high; basal leaves oblanceolate, stellate, entire or denticulate; petals white, $7 \mathrm{~mm}$. long; pedicels 5-7 mm. long, spreading; pods areuate, 4-5 cm. long, $2 \mathrm{~mm}$. wide; seeds mostly in one row. Dry roadsides: Wyo.-Ida. Mont. Jl.

39. A. gracilenta Greene. Perennial; stems 2-4 dm. high, ascending; basal leaves narrowly oblanceolate, entire; stem-leaves glabrous, linear or linearoblong; petals $4-5 \mathrm{~mm}$. long, rose-colored or white; pedicels $8-10 \mathrm{~mm}$. long, spreading; pods arcuate, $3-5 \mathrm{~cm}$. long; seeds more or less in two rows. Cañons, plains and mountains: N.M.-Colo.-Utah. Submont. Ap-My.

40. A. Fendleri (S. Wats.) Greene. Biennial or short-lived perennial; stem. 2-5 dm. high; basal leaves oblanceolate, 1-3 cm. long; stem-leaves glabrous, linear-lanceolate; petals 6-7 mm. long, pink or whitish; pedicels $1-2 \mathrm{~cm}$. long, ascending to somewhat recurved; pods somewhat areuate, $4-6 \mathrm{~cm}$. long, $2 \mathrm{~mm}$. wide; seeds 2-rowed. Mountains: N.M.-S.D.-Wyo. Submont.-Mont. My-Je.

41. A. consanguinea Greene. Biennial or maybe perennial; stems erect, 3-4 dm, high, stellate-canescent; basal leaves $2-3 \mathrm{~cm}$. long, oblanceolate, serrate, finely stellate; stem-leaves lance-oblong, stellate; sepals stellate; petals $5-6 \mathrm{~mm}$. long, pinkish; pedicels about $1 \mathrm{~cm}$. long; pods pendent, $4-5 \mathrm{~cm}$. long, $2 \mathrm{~mm}$. wide; seeds more or less in two rows. Mountains: Colo.-N.M. Submont. My-Je.

42. A. lignifera A. Nels. Perennial, often branched at the base; stems 2-4 dm. high, minutely stellate below; basal leaves narrowly oblanceolate, entire, 3-6 cm. long, finely stellate, petioled; stem-leaves oblong, 2-4 cm. long; petals white or pinkish, 7-8 mm. long; pods usually pendulous, $3-4 \mathrm{~cm}$. long, $2 \mathrm{~mm}$. wide; seeds in one irregular row. Among sage-brush and on hillsides: Wyo.Colo.-Utah. Submont.-Mont. Je-Jl.

43. A. brevisiliqua Rydb. Biennial; stems 3-4 dm. high, sparingly strigosestellate below, otherwise glabrous; basal leaves narrowly oblanceolate, $1-2 \mathrm{~cm}$. long, finely stellate; stem-leaves linear, glabrous; petals purplish, about $6 \mathrm{~mm}$. long; pod 2-4 cm. long, $2 \mathrm{~mm}$. wide; seeds in two rows. Mountains: Alta.B.C. Submont. Ji-Au. 44. A. rhodantha Greene. Biennial; stem erect, 4-6 dm. high, stellate
below, otherwise glabrous; basal leaves oblanceolate, 1-5 cm. long, stellate; upper stem-leaves oblong, sagittate at the base; petals pink, $8-10 \mathrm{~mm}$. long; pedicels about $1 \mathrm{~cm}$. long, reflexed; pods pendent, 5-7 $\mathrm{cm}$. long, $2 \mathrm{~mm}$. wide. Scarcely distinct from the next. Mountains and hills: Colo.-Utah. Submont.-Mont.
Je-Jl. 45. A. retrofracta Grah. Biennial or perennial; stems $3-5 \mathrm{dm}$. high,
usually stellate throughout; basal leaves oblanceolate, $1-3 \mathrm{~cm}$. long, densely
stellate, usuatly entire; stem-leaves lanceolate stellate, usually entire; stem-leaves lanceolate, sagittate at the base; sepals stellate; petals 6-8 mm. long, white or pinkish; pedicels $1 \mathrm{~cm}$. long, abruptly reflexed; pods $3-6 \mathrm{~cm}$. long, $2 \mathrm{~mm}$. wide. A. Holboellii Am. Auth. A. Kochii Blankinship. (?) A. demissa Greene. Plains, hills, and mountains: Mack.Man.-Neb.-Utah-Calif.-B.C. Plain-Mont. My-Jl. 46. A. lignipes A. Nels. Short-lived perennial; stems $3-5 \mathrm{dm}$. high,
finely stellate below, glabrous above; basal leaves entire, narrowly oblanceolate,
densely stellate-pubescent, $1-2 \mathrm{~cm}$, revolute; sepals stellate; $1-2 \mathrm{~cm}$. long; stem-leaves almost linear, auriculate, revolute; sepals stellate; petals $5-6 \mathrm{~mm}$. long, white or purplish; pedicels abruptly 
reflexed; pod 6-8 $\mathrm{cm}$. long, $2 \mathrm{~mm}$. wide. Sandy or stony ground: Wyo.-Mont. -Ida. Submont.-Mont. Je-Jl.

47. A. caduca A. Nels. Biennial or perennial; stem 2-4 dm. high, slender, sparingly stellate; basal leaves narrowly oblanceolate, $1-2 \mathrm{~cm}$. long, densely and finely stellate; stem-leaves linear, mostly revolute; sepals stellate; petals white, $5 \mathrm{~mm}$. long; pedicels abruptly reflexed; pod $1.5-3.5 \mathrm{~cm}$. long, nearly $2 \mathrm{~mm}$. wide. Mountains: Wyo.-Utah. Submont. J-Au.

48. A. canescens Nutt. Perennial; stems $2-3 \mathrm{dm}$. high, finely stellate; basal leaves densely stellate-canescent, 1-2 cm. long; stem-leaves linear; sepals stellate; petals white or pale purplish, 4-5 mm. long; pedicels recurved; pods pendulous, $3-5 \mathrm{~cm}$. long, $1.5-2 \mathrm{~mm}$. wide; seeds more or less in two rows. (?) $A$. puberula Nutt. Dry plains: Wyo.-Mont.-Ore. Submont. Ap-Je.

49. A. exilis A. Nels. Biennial; stems strict, slender, 3-4 dm. high; basal leaves small, 1-2 cm. long, oblanceolate or oblong-spatulate; stem-leaves lanceolate; sepals stellate; petals white or purplish, 5-6 mm. long; pedicels reflexed; pods pendent, $4-6 \mathrm{~cm}$. long, $2 \mathrm{~mm}$. wide; seeds in two rows. Sage-brush plains: Wyo.-Mont.-Utah. Son.-Mont. Je-Au.

50. A. pendulocarpa A. Nels. Perennial; stem simple, about $2 \mathrm{dm}$. high; basal leaves oblong-oblanceolate, $1 \mathrm{~cm}$. or less long; stem-leaves linear-oblong or lanceolate, $5-10 \mathrm{~mm}$. long; petals about $5 \mathrm{~mm}$. long, white or tinged with purple; pedicels recurved; pod 4-6 $\mathrm{cm}$. long, $2 \mathrm{~mm}$. wide; seeds in two rows. Cliffs and rocky ridges: Wyo. Submont. Je.

\section{PÁRRYA R. Br.}

Acaulescent perennials, with branched caudex. Flowers perfect, racemose. Sepals oblong, erect, the lateral ones gibbose at the base. Petals pink or purple, with long claws and broad blades. Anthers included, oblong, sagittate at the base. Pods with flat, 1-nerved, reticulate valves; stigma 2-lobed. Seeds margined or winged; cotyledons strictly accumbent.

1. P. platycarpa Rydb. Leaves basal, runcinate, more or less glandularhirsutulous, thick, 6-8 cm. long, oblanceolate in outline; scape 1-1.5 cm. long, glandular-hirsutulous; petals $15-18 \mathrm{~mm}$. long, purplish; fruiting pedicels 8-15 $\mathrm{mm}$. long, ascending; pod erect, glandular-hispidulous, $\bullet-4 \mathrm{~cm}$. long, $6-7 \mathrm{~mm}$. wide, acute at both ends; seeds broadly winged, $3-4 \mathrm{~mm}$. wide. $P$. macrocarpa S. Wats., not R. Br. High mountains: Utah. Alp. -Subalp. Jl-Au.

\section{PHOEN}

Low leafy perennials, with thick caudex. Flowers perfect, racemose. Sepals erect, the lateral gibbose at the base. Petals purple or pink, long-clawed. Pods flat, with 1-nerved, reticulate valves, few-seeded, tapering into a slender style; stigma nearly entire, capitate. Seeds marginless; cotyledons obliquely accumbent.

Pod linear-lanceolate, 3-5 mm. wide; seed-coat not cellular.

Pod lanceolate, $7-10 \mathrm{~mm}$. wide; seed-coat cellular.

1. P. cheiranthoides,

1. P. cheiranthoides Nutt. Stem 1-3 dm, high; basal leaves numerous, petioled, densely white stellate-tomentose, oblanceolate, entire, 5-10 $\mathrm{cm}$. long; stem-leaves small, ovate to lance-linear, in age glabrate; petals about $8 \mathrm{~mm}$. long; fruiting pedicels $1-1.5 \mathrm{~cm}$. long, divaricate; pod horizontal, $2-4 \mathrm{~cm}$. long, glabrous. Parrya Menziesii (Hook,) Greene. Mountains: Wash.-Ida.Nev.-Calif, Submont.-Mont. Ap-Je.

2. P. Huddelliana (A. Nels.) Rydb. Perennial, with a branched sbender deep rootstock; leaves rosulate, narrowly spatulate, $12-25 \mathrm{~mm}$. long, densely stellate-pubescent; flowers corymbose; branches 1-1.5 $\mathrm{cm}$. long; pod lanceolate, 2-3 cm. long, tapering into a short style. Parrya Huddelliana A. Nels. High mountains among loose rocks: Ida. Alp. Jl.

\section{CARTIÈra Greene.}

Glabrous perennials, with fleshy leaves, the cauline ones cordate-clasping. Flowers perfect, in elongate racemes. Calyx urn-shaped; lateral sepals saccate 
at the base, all erect, constricted at the throat and with spreading tips. Petals undulate-crisp, with a narrow blade. Stamens 6, distinct; anthers linear, sagittate at the base. Pods flat, linear. Cotyledons accumbent.

1. C. cordata (Nutt.) Greene. Stems glabrous, 3-6 dm. high; basal leaves spatulate, thick, usually coarsely toothed, especially towards the summit, pale green; cauline leaves oblong, elliptic or ovate, cordate-clasping; petals linearlanceolate, a little exceeding the sepals; pod flat, 5-7 cm. long, $4 \mathrm{~mm}$. wide; Streptanthus cordatus Nutt. S. argutus and S. crassifolius Greene. S. coloradensis A. Nels. Cartiera arguta and C. crassifolia Greene. Dry places: Wyo.N.M.-Calif.-Ore. Son.-Submont. Je-JI.

\section{CAULĀNTHUS S. Wats. Wild CabBage.}

More or less succulent biennials or perennials. Flowers perfect, in elongate racemes. Sepals oblong, often colored, the lateral ones more or less saccate at the base, erect, with spreading tips; calyx closed and more or less urn-shaped. Petals undulate-crisped, with a broad claw and a small narrow blade. Stamens 6 ; anthers linear, sagittate at the base. Pods somewhat flattened or nearly terete, linear; valves 1-nerved, often reticulate-veined; stigmas 2-lobed. Cotyledons incumbent.

Stem glabrous; upper leaves reduced.

Stem inflated.

Calyx densely villous.

Calyx as well as the whole plant glabrous.

Stem not inflated.

Stem hirsute, leafy.

1. C. crassicaulis.

2. C. glaber.

3. C. procerus.

4. C. pilosus.

1. C. crassicaulis (Torr.) S. Wats. Biennial or perhaps perennial; stem inflated, fistulose, 1-2 cm. thick, glabrous, 3-10 dm. high; basal leaves lyrate, glabrous and glaucous, 1-1.5 dm. long; stem-leaves linear or linear-oblanceolate; petals linear, nearly $2 \mathrm{~cm}$. long; pod ascending, terete, $6-9 \mathrm{~cm}$. long, $2 \mathrm{~mm}$. thick. Rocky places and hills: Ida.-Utah-Calif. Son.-Submont. My-Je.

2. C. glaber (M. E. Jones) Rydb. Biennial or perennial; stem fistulose, $1-1.5 \mathrm{~cm}$. thick, glabrous, $3-5 \mathrm{dm}$. high; basal leaves lyrate, about $1 \mathrm{dm}$. long, glabrous; stem-leaves reduced, linear; petals linear, $15 \mathrm{~mm}$. long; pod unknown. C. crassicaulis glaber M. E. Jones. Dry hills: s Utah-e Nev. Son. My-Je.

3. C. procerus (Brewer) S. Wats. Perennial or biennial; stems slender, 4-6 dm, high; basal leaves runcinate, glabrous, or the earliest entire, spatulate; stem-leaves narrowly linear to lanceolate; sepals glabrous or nearly so; petals oblong-spatulate, acuminate, with a blunt apex. C. crassicaulis major M. E. Jones, Hills and mountain slopes: Calif.-(? Utah). Son, Je.

4. S. pilosus S. Wats. Biennial; stem 6-12 dm. high, leafy; lower leaves coarsely toothed or pinnatifid, hirsute, $8-20 \mathrm{~cm}$. long; petals slightly longer than the sepals; pod $1.5 \mathrm{~mm}$. wide, widely spreading or recurved. Sandy soil: B.C.Ida.-Calif. Son.-Submont.

\section{STREPTANTHÉLLA Rydb.}

Glabrous annual herbs, with entire leaves and branched stems. Flowers perfect in slender racemes. Sepals erect, the outer saccate at the base. Petals erisp and with narrow blades. Stamens distinct; anthers subsagittate at the base. Pod flat, with a long beak. Stigma 2-cleft, with the lobes over the valves. Seeds wing-margined.

1. S. longirostris (S. Wats.) Rydb. Stem glabrous, with ascending branches, 2-4 dm. high; basal leaves ovate-spatulate, soon deciduous; stem-leaves linear or linear-oblanceolate, glabrous; pedicels short, horizontal, or in fruit reflexed; petals oblanceolate, $4 \mathrm{~mm}$. long; pod pendulous, about $5 \mathrm{~cm}$. long; style $3-5$ mm. long. Arabis longirostris S. Wats. Streptanthus longirostris A. Gray.

\section{CHLOROCRĀMBE Rydb.}

Perennial glabrous herbs; stem simple at least up to the inflorescence. Racemes lax, with slender horizontal or reflexed pedicels. Leaves thin, peti- 
oled, with usually hastate blades. Sepals greenish, ascending. Petals greenish white, with short claws and lanceolate dentate blades. Anthers sagittate at the base, linear-oblong, at last curved, greenish. Pod slender, somewhat torulose, short-stipitate and short-styled; stigma minute, entire.

1. C. hastatus (S. Wats.) Rydb. Perennial; stem glabrous, terete, 6-10 dm. high, simple or branched above; leaves petioled; blades of all except the uppermost leaves hastate, glabrous, thin, $5-12 \mathrm{~cm}$. long; flowers drooping or horizontal; petals $5-6 \mathrm{~mm}$. long; pod terete, $6-9 \mathrm{~cm}$. long; stipe and style about $2 \mathrm{~mm}$. each. Caulanthus hastatus S. Wats. Cañons and mountain valleys: Ore.-Utah. Submont.-Mont. Je-Jl.

\section{SCHOENOCRĀMBE Greene.}

Glabrous perennials or slightly pubescent, with creeping rootstocks. Flowers perfect in elongate racemes. Sepals slightly saccate at the base. Petals light yellow, rather large. Pods sessile, linear-cylindric. Stigmas nearly circular, but 2-lobed. Anthers sagittate at the base. Cotyledons incumbent.

Plant tall, 3-6 dm. high, glabrous.

Leaves all linear, entire.

Plant decumbent, slender; pods ascending, more or less arcuate; style about $1 \mathrm{~mm}$. long.

$1 . S$. decumbens.
Plant erect, stouter; pods erect or nearly so, straight; style obsolete, $0.5 \mathrm{~mm}$, or $\begin{array}{ll}\text { less long. } & 2 \text {. S. linifolia. } \\ & \end{array}$

Some of the leaves pinnatifid.

Plant low, 1-2 dm, high, pubescent; leaves pinnatifid.

3. S. pinnata.

4. S. pygmaea.

1. S. decumbens Rydb. Perennial; stems slender, decumbent, 2-3 dm. long, as well as the whole plant perfectly glabrous, more or less branched; leaves 2-6 cm. long, 1-3 mm. wide, glaucous; petals yellow, 6-7 mm. long, spatulate or oblanceolate; pods $3-4 \mathrm{~cm}$. long, about $0.75 \mathrm{~mm}$. in diameter. Plains and hills: Mont.-Colo.-Utah. Plain-Submont. Je-Au.

2. S. linifolia (Nutt.) Greene. Stems erect, glabrous, or with a few hairs at the base; leaves glabrous, 4-7 cm. long; petals yellow, spatulate, $8 \mathrm{~mm}$. long; pod erect on ascending pedicels, $3-5 \mathrm{~cm}$. long, $1 \mathrm{~mm}$. thick. Sisymbrium linifolium Nutt. Dry plains: Mont.-N.M.-Utah-B.C. Son.-Submont. My-
Je.

3. S. pinnata Greene. Stems simple, 3-5 dm. high; lower leaves pinnatifid, with oblong to linear divisions, glabrous and glaucous, the upper linear and entire; petals light yellow, $7-10 \mathrm{~mm}$. long; pod 5-6 cm. long, $1 \mathrm{~mm}$. thick, erect on ascending pedicels. Plains and hills: Mont.-Colo.-Utah-Wash. Son.Submont. My-Jl.

4. S. pygmaea (Nutt.) Greene. Stem low, about $1 \mathrm{dm}$. high, sparingly pubescent; leaves except the uppermost pinnatifid, with lanceolate or linear divisions; petals yellow, about $6 \mathrm{~mm}$. long, spatulate. Dry soil: Mont.

\section{THELYPODIÓPSIS Rydb.}

Biennials, with rather thick and glaucous foliage and glabrous except the lower part of the stem. Basal leaves spatulate or oblanceolate; stem-leaves auriculate-clasping with rounded auricles. Sepals thin, erect or ascending, not gibbous. Petals more or less clawed, white or purplish or in one species yellow. Anthers long, linear, sagittate at the base, soon spirally curved. Pod slender, terete, more or less torulose, usually with a short stipe and style; stigma 2-lobed, the lobes expanded over the septum; cotyledons obliquely incumbent.

Stipe very short, less than $1 \mathrm{~mm}$. long or almost none; petals white or tinged with purple.

Style $2 \mathrm{~mm}$. or nearly so.

Pod 7-9 cm. long.
Pod about $4 \mathrm{~cm}$. iong.

Style less than $1 \mathrm{~mm}$. long; pod $5-7 \mathrm{~cm}$. long.

Stipe 2-5 mm. long; petals and sepals yellow.

1. $T$. elegans.

2. T. Bakeri.

3. T. wyomingensis.

1. T. elegans (M. E. Jones) Rydb. Stem 6-15 dm. high, erect, simple or branched, glabrous or slightly hairy below; basal leaves oblanceolate or spatulate, dentate, $2-4 \mathrm{~cm}$. long; stem-leaves ovate or lanceolate; petals $8-10 \mathrm{~mm}$. long, 
$1 \mathrm{~mm}$. wide. Thelypodium elegans M. E. Jones. Sandy soil and adobe plains: Colo.-Utah. Submont. My-Je.

2. T. Bakeri (Greene) Rydb. Stems several, branched, 2-4 dm. high, sparingly hairy at the base; basal leaves petioled, oblanceolate, denticulate, 2-4 cm. long; stem-leaves 1-2 cm. long, glabrous and glaucous, ovate; petals white, 6-8 mm. long; pod about $1.5 \mathrm{~mm}$. thick, torulose. Thelypodium Bakeri Greene. Valleys: Colo. Submont. My-Je.

3. T. wyomingensis (A. Nels.) Rydb. Stem single or several, branched, $2-5 \mathrm{dm}$. high, glabrous or nearly so; basal leaves obovate or oblanceolate, toothed, $2-5 \mathrm{~cm}$. long; cauline leaves glaucous, ovate or oblong, 4-7 cm. long; petals white, sometimes pinkish, 10-12 mm. long; pod nearly sessile, $1.5 \mathrm{~mm}$. wide. Streptanthus wyomingensis A. Nels. Dry desert regions: Wyo.-Utah-Colo. Son.-Submont. Je.

4. T. aurea (Eastw.) Rydb. Stem 3-10 dm. high, branching, sparıngly retrorse-hairy at the base; basal leaves oblanceolate, dentate, with margined petioles; eauline leaves ovate, entire, glaucous; sepals and petals yellow; petals about $8 \mathrm{~mm}$. long; pod 4-7 cm. long, somewhat over $1 \mathrm{~mm}$. wide. Thelypodium aureum Eastw. Arid regions: Colo. Submont. Je.

\section{HETERÓTHRIX (B. L. Robins.) Rydb.}

Slender biennials, more or less pubescent, at least below, with stellate or branched hairs. Basal leaves oblanceolate, more or less toothed; stem-leaves lance-linear or linear, entire. Racemes elongate, slender. Calyx more or less oblique, the lower sepals being longer than the upper, all ascending, rather firm and more or less purplish. Petals oblanceolate or spatulate, indistinetly or broadly clawed. Filaments subulate; anthers linear, sagittate at the base, spirally curved. Pod slender, terete, sessile; stigma minute, entire or slightly lobed, the lobes expanding over the septum; cotyledons obliquely incumbent. [Thelypodium § Heterothrix B. L. Robins.]

1. H. micrantha (A. Gray) Rydb. Stems branched, 3-6 dm. high; basal leaves $2-5 \mathrm{~cm}$. long; upper stem-leaves linear, often glabrate; raceme elongate, narrow; petals $3-4 \mathrm{~mm}$. long, cuneate-spatulate; pedicels and pods erect, the latter 3-4 cm. long, less than $1 \mathrm{~mm}$. thick. Thelypodium micranthum A. Gray. Mountains: Colo.-Tex.-Ariz.; Mex. Son.-Submont. J1-O.

\section{HESPERIDÁNTHUS (B. L. Robins.) Rydb.}

Erect, slender, glabrous perennials, with pale foliage, corymbosely branched above. Basal leaves obovate, toothed; stem-leaves linear, entire. Sepals rather firm, erect, the outer strongly saccate at the base. Petals purple, with obovate blades. Anthers linear, sagittate at the base, strongly curved. Stigma conical or ovate, neither truncate nor 2-lobed. Pod terete, linear, short-stipitate. [Thelypodium § Hesperidanthus B. L. Robins.]

1. H. linearifolium (A. Gray) Rydb. Stem erect, 6-15 dm. high; basal leaves $5-10 \mathrm{~cm}$. long, oblanceolate or spatulate, thick, pale; stem-leaves sessile, linear, entire; petals purplish, $12-15 \mathrm{~mm}$. long; pedicels in fruit $1-2 \mathrm{~cm}$. long; pod 5-10 $\mathrm{cm}$. long, $1.5 \mathrm{~mm}$. wide. Streptanthus linearifolius A. Gray. Thelypodium linearifolium A. Gray. Dry hills and plains: Colo.-Tex.-Ariz.; Mex. Submont.-Mont. F-Je.

\section{THELYPÒDIUM Endl.}

Perennial, biennial, or annual leafy-stemmed plants. Flowers perfect, in elongate racemes. Sepals oblong to linear, erect, scarcely gibbose at the base. Petals white or purplish, with a well-developed blade, clawed. Stamens with long, slender, exserted filaments; anthers linear, sagittate at the base, curved and twisted. Pods slender, linear, more or less distinetly stipitate, terete; stigma entire or nearly so, truncate. Cotyledons incumbent.

Upper leaf-blades auriculate at the base.

Pods $3-5 \mathrm{~cm}$. long.

Petals 6-9 mm. long, about twice as long as the sepals. 
Pods 2-3 cm. long; basal leaves oblanceolate or spatulate.

Petals 5-6 mm. long; blades spatulate; pedicels nearly erect.

Petals 7-9 mm. long; blades obovate; 1 . T. Palmeri.

Petals 7-9 mm. long; blades obovate; pedicels spreading or ascending.

Pods 1-2 cm. long; basal leaves oval.

Petals 10-15 mm. long, about three times as long as the sepals.

Pods 4-5 cm. long, $1 \mathrm{~mm}$. wide.

Pods about $3 \mathrm{~cm}$. long, nearly $2 \mathrm{~mm}$. wide.

Pods 5-10 cm. long, arcuate, spreading or ascending.

2. T. sagittatum.

3. ovalifolium.

4. T. macropetalum.

5. T. Nuttallii.

Stem stout; lower leaves coarsely sinuate-dentate; petals obovate, more than 2

$\mathrm{mm}$. wide.
Stem slender; lower leaves entire or slightly sinuate; petals narrowly spatulate,
barely $2 \mathrm{~mm}$. broad. barely $2 \mathrm{~mm}$. broad.

Upper leaf-blades attenuate at the base; leaves mostly laciniate.

Petals narrowly linear-oblanceolate.

Pods divergent; raceme lax.

Pods erect; raceme dense.

Petals spatulate; pods reflexed; raceme lax.

7. T. eucosmum.

1. T. Palmeri Rydb. Biennial, with a taproot; stem 3-5 dm. high, sparingly hirsute below, glabrous above; basal leaves $2-4 \mathrm{~cm}$. long, more or less hirsute beneath, especially on the veins; stem-leaves sagittate, $2-4 \mathrm{~cm}$. long, glabrous or nearly so; inflorescence usually branched; petals white or rose; pod about 2-5 cm. long, $1 \mathrm{~mm}$. wide. Arid regions: s Utah. Son.

2. T. sagittatum (Nutt.) Endl. Biennial; stem 3-6 dm. high, branched above, glabrous or nearly so; basal leaves oblanceolate, $2-6 \mathrm{~cm}$. long, glabrous or sparingly hirsute; stem-leaves sagittate, $2-6 \mathrm{~cm}$. long, glabrous; petals white or purplish; pods $1 \mathrm{~mm}$. wide, nearly erect, somewhat torulose. T. paniculatum A. Nels. T. torulosum Heller. Sage plains and alkali soil: Mont.-Colo.Utah-Ida. Son.-Submont. Je-Au.

3. T. ovalifolium Rydb. Biennial or perennial, perfectly glabrous; stems terete, $3-5 \mathrm{dm}$. high; earliest basal leaves about $5 \mathrm{~cm}$. long, petioled, with broadly oval blades, the later ones oblanceolate; stem-leaves sagittate, $2 \mathrm{~cm}$. long, thick; petals about $5 \mathrm{~mm}$. long, with spatulate blades; pedicels in fruit 4-5 mm. long, spreading; pods ascending, about $1 \mathrm{~mm}$. wide, somewhat torulose. Plains:
Utah. Son. Au-S.

4. T. macropetalum Rydb. A glabrous perennial, 4-6 dm. high; basal leaves oblanceolate or spatulate, $2-5 \mathrm{~cm}$. long; lower stem-leaves oblong, obtuse, sessile, 5-6 cm. long; upper leaves lanceolate-sagittate, acute; pedicels divaricate; petals purple, spatulate; pods $1 \mathrm{~mm}$. wide, ascending or erect and somewhat incurved. Hills and plains: Utah-Ida. Submont. My-Je. 5. T. Nuttallii S. Wats. Biennial, glabrous and glaucous; stem $4-10 \mathrm{dm}$.
high; basal leaves $5-15 \mathrm{~cm}$. long, lanceolate; stem-leaves sagittate, $2-10 \mathrm{~cm}$. long; petals lilac or whitish, $10-15 \mathrm{~mm}$. long; pod nearly $2 \mathrm{~mm}$. thick; style 1 mm. long. Streptanthus sagittatus Nutt. T. sagittatum Heller, not Endl. Plains and valleys: Wyo.-Utah-Ore.-Wash. Son. Je-Au.

6. T. ambiguum S. Wats. Stout biennial, glabrous; stem 6-15 dm. high; radical leaves thick, coarsely toothed, $1-2 \mathrm{dm}$. long, oblanceolate; stem-leaves $4-5 \mathrm{~cm}$. long, subentire; petals purplish, about $1 \mathrm{~cm}$. long; blade obovate; pod $2 \mathrm{~mm}$. thick; style very short. Arid regions: s Utah-Ariz. Son. 7. T. eucosmum B. L. Robins. Glabrous biennial or perennial (?); lower
leaves oblong, entire or slightly sinuate, the upper lanceolate, clasping, 3-7 cm. long; racemes several, many-flowered; pedicels 4-6 mm. long, spreading; petals deep purple, $8 \mathrm{~mm}$. long; pod arcuate, ascending. Mountains: Ore.-Ida.

8. T. leptosepalum Rydb. Annual or biennial, glabrous throughout; stem 4-6 dm. high, branched; leaves thin, glabrous, 6-10 cm. long, lyrate-pinnatifid, with lanceolate divergent lobes; petals with scarcely any distinction between blade and claw, $8 \mathrm{~mm}$. long, $0.5 \mathrm{~mm}$. wide or less. Rocky banks: Ida. Son.

9. T. milleflorum A. Nels. Glabrous biennial, 1-2 m. high; leaves coarsely and irregularly dentate to entire, oblong or lanceolate below to linear above; inflorescence often 4-6 dm. long; flowers numerous, crowded; petals white, twice 
as long as the sepals; pods filiform, 6-10 cm. long, erect or nearly so; stipe and style each 2-3 mm. long. Rich slopes: Ida.-Wash.-Ore.-Nev. Son. MyJe.

10. T. utahense Rydb. Annual or biennial; stem 4-6 dm. high, sparingly pubescent below; leaves all lanceolate in outline, , $-10 \mathrm{~cm}$. long, lanceolate, glabrous; segments oblong-lanceolate to triangular; pedicels very short, in fruit scarcely more than $1 \mathrm{~mm}$. long; petals spatulate, $4 \mathrm{~mm}$. long, white; pod about $3 \mathrm{~cm}$. long. Arid regions: s Utah. L. Son. Ap.

\section{PLEUROPHRÁGMA Rydb.}

Tall glabrous perennials or biennials, with paniculate inflorescence and thick entire leaves. Basal leaves oblanceolate or spatulate; stem-leaves linear-lanceolate, sessile, but not clasping. Sepals ascending, thin, more or less petaloid. Petals white or purplish, with slender claws. Filaments subulate, white, with conspicuous glands at their bases; anthers linear, sagittate at the base, curved. Receptacle dilated. Pod slender, terete, torulose; stipe short; style short, slender; stigma minute, entire; septum with a strong midrib.

Pedicels not flattened, about $1 \mathrm{~cm}$. long.

Stipe $0.5-1 \mathrm{~mm}$. long; inflorescence short.

Stipe $2-3 \mathrm{~mm}$. long; inflorescence elongate.

Pedicels flattened at the base, about $3 \mathrm{~mm}$. long; stipe 1-2 mm. long.

1. P. integrifolium.

2. P. gracilipes.

3. P. platypodum.

1. P. integrifolium (Nutt.) Rydb. Perennial, with a taproot; stem simple, strict or branched above, 6-20 dm. high; basal leaves $5-30 \mathrm{~cm}$. long; stem-leaves 4-10 cm. long; inflorescence paniculate, at first corymbiform; pedicels in fruit spreading; petals 6-7 mm. long; pod 2.5-3 cm. long, 1-1.5 mm. thick. Thelypodium integrifolium Endl. ? T. lilacinum Greene. Dry plains: Neb.-N.M. -Calif.-Wash. Plain-Submont. J-Au.

2. P. gracilipes (Robins.) Rydb. Perennial, resembling the preceding, but more slender, about $5 \mathrm{dm}$. high; inflorescence more elongate; flowers smaller; pod more slender, less than $1 \mathrm{~mm}$. thick, and with longer stipe. Thelypodium integrifolium gracilipes Robins. Wet ground: Colo.-N.M. Son.

3. P. platypodum Rydb. Glabrous perennial, with a taproot; stem simple up to the inflorescence, $1-2 \mathrm{~m}$. high; basal leaves $5-10 \mathrm{~cm}$. long, entire; stem-leaves 3-6 cm. long; inflorescence paniculate; racemes dense, at first corymbiform, in fruit about $1 \mathrm{dm}$. long; petals white, $6-7 \mathrm{~mm}$. long; pod $1.5-2 \mathrm{~cm}$. long, 1-1.5 $\mathrm{mm}$. thick, torulose. Arid regions: Utah-Ariz. Son.

\section{STANLEYÉLLA Rydb.}

Tall branched biennials. Leaves thin, the lower ones lyrately pinnatifid, the upper entire. Sepals thin, petaloid, white, oblong or linear, spreading or even reflexed in anthesis. Petals white, with oblanceolate or spatulate blades gradually tapering into a short claw. Filaments distinct, filiform; anthers linear, sagittate at the base, soon more or less spirally recurved. Pod slender, terete with short stipe and short style; stigma small, truncate or nearly so. Cotyledons incumbent and somewhat conduplicate.

1. S. Wrightii (A. Gray) Rydb. Biennial; stem 6-15 dm. high, much branched, sparingly hairy below; basal leaves 1-1.5 dm. long, lyrate-pinnatifid, with lanceolate or elongate, triangular toothed lobes; stem-leaves less lobed or the upper entire, linear-lanceolate; petals white, $6 \mathrm{~mm}$. long; pedicels in fruit divergent, $10-15 \mathrm{~mm}$. long; pod 5-7 $\mathrm{cm}$. long, less than $1 \mathrm{~mm}$. thick. Thelypodium Wrightii A. Gray. River bottoms: Colo.-N.M.-Ariz.-Utah. Son. -Submont. Je-Au.

\section{STANLèYA Nutt. Prince's Plume.}

Leafy perennials, usually more or less glaucous. Flowers perfect in elongate, many-flowered racemes. Sepals oblong, widely spreading in anthesis. Petals with long claw and narrow elongate blades. Stamens 6; filaments elongate, 
spreading; anthers linear, curved and spirally coiled. Pods long-stipitate, elongate-linear, terete; valves 1-nerved. Stigma sessile, small, simple. Seeds in one row, oblong; cotyledons incumbent.

Middle cauline leaves sessile by an auriculate base.

Stem winged; petals greenish.

Stem not winged; petals yellow.

Middle cauline leaves petioled or sessile with a narrowed base. Plant white-villous.

Plant not white-villous.

1. S. viridiflora,

2. S. confertiflora.

Blades of the petals linear-oblong to elliptic, bright yellow.

Blades of the petals one-third to two-thirds as long as the claws. Pod arcuate, not tortuose.

Leaves sparingly hirsute.

Filaments hairy; lower leaves pinnatifid, with lanceolate or oblong lobes. 4 4. S. pinnata.

Filaments glabrous; lower leaves runcinate, with triangular lobes.

Leaves glabrous.

Pod decidedly tortuose.

Blades of the petals as long as the claws.

Leaves glabrous.

Leaves broadly lanceolate, the lower with short broad lobes; blades

of the petals oblong; pod ascending.
Leaves linear-lanceolate, usually all entire; blades of integrifolia. elliptic; pod recurved.

Leaves finely puberulent.

Blades of the petals rounded-oval, ochroleucous.
5. S. runcinata.

7. S. glauca.

6. S. bipinnata
9. S. arcuata.

10. S. canescens.

11. S. albescens.

1. S. viridifiora Nutt. Stem glabrous, 3-10 dm. high; basal and lower cauline leaves glabrous or short-pubescent, 7-20 cm. long, oblanceolate or spatulate; petals 12-15 mm. long; claws subulate, about as broad as the linear blades; filaments glabrous; stipe 5-8 $\mathrm{mm}$. long; pod spreading, somewhat arcuate and torulose, 4-5 cm. long. S. heterophylla Nutt. Bare hills: Wyo.-Mont.-Ore. -Nev. Submont. My-Ji.

2. S. confertiflora (B. L. Robins.) Howell. Stem glabrous, terete, 4-6 dm. high; basal leaves glabrous, 4-6 cm. long, oblanceolate; petals yellow, about 12 $\mathrm{mm}$. long; claw about equalling the linear blades; pods 4-5 cm. long, ascending, not torulose; stipe about $6 \mathrm{~mm}$. long. Foot-hills: Ida.-Ore. Submont. Ap-My.

3. S. tomentosa Parry. Stem terete, woolly below, $8-15 \mathrm{dm}$. high, angled above; lower leaves lyrately pinnatifid; terminal segment lanceolate, $3-7 \mathrm{~cm}$. long; lateral segments ovate-oblong; petals cream-colored; pedicels of the pod equalling the stipe. Dry slopes: Wyo. Submont.

4. S. pinnata (Pursh) Britton. Stem sparingly hairy or glabrate, 3-10 dm. high, terete; leaves thick, commonly pinnatifid, with oblong or lanceolate divisions, or the upper entire, more or less pubescent; petals $10-15 \mathrm{~mm}$. long; pod 6-7 cm. long, spreading; stipe 10-15 mm. long, twice as long as the pedicels. S. pinnatifida Nutt. Plains: S.D.-Neb.-Utah. Plain. My-Au.

5. S. runcinata Rydb. Stem stout, glabrous; basal leaves about $2 \mathrm{dm}$. long, lanceolate in outline, runcinately divided, softly pubescent, with long white hairs; lobes broadly triangular or the lowest ones oblong; stem-leaves ovate to oblanceolate, more glabrous; pods almost erect and straight, $6-7 \mathrm{~cm}$. long, 1.5 mm. wide, on spreading pedicels about $1 \mathrm{~cm}$. long. (?) S. rara A. Nels. Plains:
Ida. Son.

6. $\mathbf{S}$. bipinnata Greene. Stem flexuose, 2-6 dm. high, terete, glabrous; leaves except the uppermost pinnatifid, with oblong or linear, of ten lobed divisions; petals yellow, 8-10 mm. long; pod 4-5 cm. long, torulose and tortuose; stipe Colo,-Kans. Plain equalling the pedicels. Plains and dry draws: Wyo.-

7. S. glauca Rydb. Stem 4-6 dm. high, bluish green; lower leaves 1-1.5 $\mathrm{dm}$. long, more or less pinnatifid, with linear-lanceolate or oblong lobes, the terminal usually much longer than the rest; upper leaves usually entire, linearlanceolate; petals lemon-yellow, about $1 \mathrm{~cm}$. long; claws pubescent; pedicels about $1 \mathrm{~cm}$. long, more or less spreading; stipes about $1.5 \mathrm{~cm}$. long; pod proper about $5 \mathrm{~cm}$. long and $1.5 \mathrm{~mm}$. thick, somewhat arcuate. Dry hills and tablelands: Colo.-N.D.-Wyo. Plain-Submont. 
8. S. integrifolia James. Stem glabrous, 3-6 dm. high; leaves 5-10 cm. long, thick, glabrous, the upper entire, the lower with triangular to oblong lobes; petals sulphur yellow, about $12 \mathrm{~mm}$. long; pod 5-6 cm. long; stipe 12-15 mm. long, about equalling the pedicels. Dry plains and hills: S.D.-Kans.-Colo.Wyo. Plain-Submont. Je-Jl.

9. S. arcuata Rydb. Stem 4-10 dm. high, perfectly glabrous, light green and shining, in age straw-colored; leaves thick, 5-12 cm. long; pedicels rather short, in fruit about $1 \mathrm{~cm}$. long; petals yellow, 7-8 $\mathrm{mm}$. long, broadly elliptic; pods $7-10 \mathrm{~cm}$. long, strongly areuate, and spreading. Dry plains and valleys: Wyo.-N.M.-Calif.-Nev. Son. Je-Jl.

10. S. canescens Rydb. Stem $0.5-1 \mathrm{~m}$. high, light green, finely puberulent or glabrate, terete; leaves grayish puberulent, the upper entire and oblanceolate, 5-7 cm. long, the lower pinnatifid, with oblong lateral lobes and a large oval or elliptic end-lobe; pedicels short, in fruit divergent; blades of the yellow petals linear-oblong, about as long as the claw; pods arcuate, spreading, 5-7 cm. long. Dry ground: Utah-Ariz. Son.-Submont. Je.

11. S. albescens M. E. Jones. Stem 3-10 dm. high; lower leaves $10-15 \mathrm{~cm}$. long, lyrate-pinnatifid, with oblong or elliptic lobes, the upper hastate at the base; petals fully $1 \mathrm{~cm}$. long; blades broadly oval, about equalling the pubescent claws; pod about $5 \mathrm{~cm}$. long; stipe somewhat longer than the pedicels. Draws and river banks: Colo.-Utah-Ariz.-N.M. Son. Ap-Je.

\section{Family 53. CAPParidaceae. Caper Family.}

Herbs with alternate, digitately compound or rarely simple leaves. Flowers perfect, regular or irregular, usually in racemes. Sepals 4, distinct or united at the base. Petals 4, rarely more, clawed. Receptacle often thickened or produced between the stamens and the petals. Stamens 6 or more. Gynoecium of 2 united carpels, 1-celled, with 2 parietal placentae, sessile or stalked. Fruit in ours dehiscent, the valves separating from the frame-like placentae (replum).

Pods elongate, linear; receptacle with an appendage or gland.

Appendages tubular; petals cuneate-flabelliform, laciniate, very unequal.

Appendages solid; petals entire, emarginate or 3 -toothed, but not 1. CRIsTATELLA. Stamens 12-32; capsule sessile or short-stipitate. Stamens 6 ; capsule long-stipitate.
Pods short; receptacle without appendages.

Pod oblong, flattened parallelly to the replum.

Pod broader than long, more or less flattened contrary to the replum.

\section{CRistatélla Nutt.}

2. JACKSONIA.

3. Peritoma.

4. Celome.

5. Cleomella.

Slender glandular annuals. Leaves alternate, without stipules, palmately trifoliolate, with narrow entire leaflets. Flowers perfect, small, white or yellowish, in terminal racemes. Sepals 4 , united at the base, deciduous. Receptacle produced between the posterior petals and the ovary into a tubular appendage, as long as the smaller petals. Petals 4, more or less fan-shaped, clawed, laciniate at the apex, the posterior larger. Stamens 6-14, declined; filaments filiform, distinct; anthers sagittate. Capsule elongate, flattened. Seeds numerous.

1. C. Jamesii T. \& G. Erect annual; stem 1-4 dm. high; glandular-puberulent, branched above; leaflets 3 , linear or linear-oblong, $8-25 \mathrm{~mm}$. long; petals cream-colored, $3-4 \mathrm{~mm}$. long; stipe about $4 \mathrm{~mm}$. long; body of the capsule about $2 \mathrm{~cm}$. long and $4 \mathrm{~mm}$. wide, glandular, oblanceolate or oblong. Sandy soil: Ia. -Ark.-Colo. Plain. Je-Au.

\section{JACKSÒnia Raf. Clammy-Weed.}

Glandular, clammy annuals. Leaves alternate, without stipules, palmately trifoliolate or sometimes simple. Flowers perfect, somewhat irregular, in ter- 
minal racemes. Receptacle inconspicuous, with a solid gland on the upper side. Sepals 4, imbricate, deciduous. Petals 4, imbricate, entire or notched at the apex, with slender claws. Stamens 12-32; filaments purple, more or less declined; anthers introrse. Capsule elongate, flattened, sessile, 2-valved at the apex. Seeds numerous. [Polanisia Raf.]

1. J. trachysperma (T. \& G.) Greene. Stem 3-8 dm. high, usually branched; leaflets 3 , oblanceolate, elliptic or oval, $2-5 \mathrm{~cm}$. long; petals long-clawed, 8-12 $\mathrm{mm}$. long; stamens about 16; filaments purple; pods sessile, linear, 4-5 cm. long, 6-7 mm. wide. P. trachysperma T. \& G. Sandy soil and eañons: Sask.-Ia.Tex.-Ariz.-B.C. Plain-Submont. Je-Au.

\section{Peritòma DC. Bee Flower, Indian Pink, Stink Flower.}

Tall glabrous or pubescent annuals. Leaves palmately trifoliolate, petioled, alternate. Flowers perfect, in terminal racemes, nearly regular. Sepals 4, united below, valvate; calyx deciduous by circumscission at base. Receptacle with a solid appendage opposite the upper sepal. Petals 4, nearly equal, convolute, scarcely clawed. Stamens 6; filaments filiform, unequal, more or less declined; anthers spirally coiled. Capsule elongate, stalked, 1-celled, 2-valved. Seeds numerous, pendulous, conduplicate. [Cleome L., in part.]

Petals yellow.

Petals purple, pink, or white.

1. P. luteum.

Petals 8-12 mm. long, usually 3-toothed.

Stamens exserted.

Pods $2.5-5 \mathrm{~cm}$. long, broadly linear; calyx-lobes lanceolate to ovate, longer than broad.

2. $P$. serrulatum.

Pods 6-7 cm. long, narrowly linear; calyx-lobes broadly triangular, abruptly acuminate, broader than long.

Stamens included.

Petals about $4 \mathrm{~mm}$, long, entire,

3. $P$. angustum.

4. $P$. inornatum.

5. P. Sonorae.

1. P. luteum (Hook.) Raf. Stem 3-6 dm. high; leaflets 3-7, linear-oblanceolate to oblong, entire, 3-5 cm. long; petals yellow, oblanceolate, $6-8 \mathrm{~mm}$. long; pedicels about $1 \mathrm{~cm}$. long, spreading; stipe $1-2 \mathrm{~cm}$. long; body of the pod 1-5 cm. long. Cleome lutea Hook. River bottoms and and banks: Neb.N.M.-Ariz.-Ore.-Wash. Plain-Submont. My-Au.

2. P. serrulatum (Pursh) DC. Stem 6-15 dm. high; leaves 3-foliolate; leaflets lanceolate to obovate-oblong, entire or rarely denticulate, $3-10 \mathrm{~cm}$. long, minutely pubescent or glabrous; petals fully $1 \mathrm{~cm}$. long, purplish, rose-colored, or white; stipe of the pod $1.5-2 \mathrm{~cm}$. long; body $2.5-5 \mathrm{~cm}$. long, 4-6 mm. thick. Cleome serrulata Pursh. C. integrifolia T. \& G. Prairies, sand-draws, and waste places: Sask.-Kans.-N.M.-Ariz.-Ore, Plain-Mont. My-Au.

3. P. angustum (M. E. Jones) Rydb. Stem 5-10 dm. high; leaflets 3, lanceolate, entire, $5-10 \mathrm{~cm}$. long, glabrous; petals $8-10 \mathrm{~mm}$. long, rose-colored or white; stipe of the fruit $1.5-2 \mathrm{~cm}$. long; body 6-7 cm. long, about $4 \mathrm{~mm}$. thick, tapering gradually at each end. Cleome integrifolia angusta M. E. Jones. Valleys: Utah-Ariz.-N.M. Son. Je-Jl.

4. P. inornatum Greene. Stem 3-6 dm. high, branched; leaflets 3, broadly lanceolate, acute, entire, $2-3 \mathrm{~cm}$. long, glabrous above, sparingly pubescent beneath; calyx-teeth broadly triangular, cuspidate; petals $7-8 \mathrm{~mm}$. long, white or faintly purplish. Dry valleys: Colo. Submont. Au.

5. P. Sonorae (A. Gray) Rydb. Stem 3-6 dm. high, often simple, glabrous; leaflets 3 , linear, $1-2 \mathrm{~cm}$. long, glabrous; petals white or purplish; stamens of about the same length; stipe somewhat reflexed, $6-8 \mathrm{~mm}$. long; body of the pod 10-15 mm. long, $2.5 \mathrm{~mm}$. thick, acute at both ends. Dry plains and saline soil: N.M.-Colo. Sonora. Son. J.

\section{CELÒME Greene.}

Hirsute annuals. Leaves petioled, digitately trifoliolate, alternate. Flowers regular, perfect, in bracted terminal racemes. Receptacle glandless. Sepals 4, distinct, deciduous, linear. Petals 4, spatulate, not clawed. Stamens 6; filaments filiform, distinct; anthers spirally coiled. Pod long-stipitate, broad, flat, with the seeds distinctly in two rows. 
1. C. platycarpa (Torr.) Greene. Stem 3-5 dm. high; leaflets 3 , oval or oblong, petiolulate, $1.5-4 \mathrm{~cm}$. long; bracts unifoliolate, petioled, elliptic; sepals linear-subulate; petals golden yellow, 6-7 mm. long; stipe of the fruit $10-15 \mathrm{~mm}$. long; body elliptic, $12-15 \mathrm{~mm}$. long, 6-7 mm. wide, pubescent; style slender, 3 mm. long. Cleome platycarpa Torr. Alkaline and lava soil: Ore.-Ida.-Nev. -n Calif. Son. My-Je.

\section{CLEOMÉLLA DC.}

Glabrous annuals. Leaves alternate, without stipules, digitately trifoliolate, petioled. Flowers small, yellow, in terminal bracted racemes, nearly regular. Receptacle elongate, without appendage. Sepals 4, distinct, thin, imbricate, deciduous. Petals 4, entire, sessile, deciduous. Stamens 6; filaments filiform, equal, distinct. Capsule short, broader than long, inflated, with two helmetlike valves. Seeds usually 2 on each placentae, pendulous.

Stipe longer than the pod; leaflets linear to oblong.

Seeds rugose or tessellate; leaflets linear; pod rhombic.

Petals 3-5 mm. long; pod about $6 \mathrm{~mm}$. wide; seed transversely rugose.

Petals 2-3 mm, long; pod 3-4 mm. wide; seed tessellate.

1. C. angustifolia.

Seeds smooth and unmarked.

Pod broadly rhombic; leaflets oblong or oblanceolate. Stem 2-3 dm, high; pod with sharp angles. Stem less than $1 \mathrm{dm}$. high; pod with rounded angles. Pod ovate; leaflets linear.

Stipe shorter than the pod; leaflets oval or broadly oblong.

2. C. plocosperma.

3. C. cornuta.

4. C. nana.

5. C. oocarpa.

6. C. Palmerana.

1. C. angustifolia Torr. Stem glabrous, branched, 3-6 dm. high; leaflets acuminate or acute, $3-4 \mathrm{~cm}$. long; sepals lanceolate, $1 \mathrm{~mm}$. long; petals yellow, $5 \mathrm{~mm}$. long, oblanceolate; pedicels ascending, $10-15 \mathrm{~mm}$. long; stipes spreading, $5-6 \mathrm{~mm}$. long; body of the pod rhombic, about $5 \mathrm{~mm}$. long, $6 \mathrm{~mm}$. broad, with rounded angles. River valleys and plains: Neb.-Tex.-Utah. Plain-Son. $\mathrm{Jl}-\mathrm{S}$.

2. C. plocosperma S. Wats. Stem $3-5 \mathrm{dm}$. high, diffusely branched; leaflets 3 , linear, $1-2 \mathrm{~cm}$. long; sepals ovate, $0.5 \mathrm{~mm}$. long; petals yellow, $4 \mathrm{~mm}$. long; pedicels divaricate, $6-8 \mathrm{~mm}$. long; stipe $3-5 \mathrm{~mm}$. long; body of the pod rhombic, 3-4 mm. long and as wide. Desert regions: Utah-Nev. Son. Jl-S.

3. C. cornuta Rydb. Stem 2-3 dm. high, branched below, glabrous; leaflets 1-2 cm. long, oblong or oblong-oblanceolate, obtuse, mucronate; sepals ovate, cuspidate; petals light yellow, narrowly oval, clawless, about $3 \mathrm{~mm}$. long; pedicels very slender, almost $1 \mathrm{~cm}$. long; pod broadly rhombic, about $3 \mathrm{~mm}$. long and $4 \mathrm{~mm}$. broad, the corners often produced into short processes; stipe 6-8 mm. long. Dry places: Utah. Son. Л.

4. C. nana Eastw. Stems 3-8 em. high, simple or branched from the base; leaflets $6-10 \mathrm{~mm}$. long, entire; pedicels $5-10 \mathrm{~mm}$. long; sepals subulate-aristate; petals yellow, oval, $4.5 \mathrm{~mm}$. long, obtuse; stipe deflexed, $6 \mathrm{~mm}$. long; pod rhombic, $4 \mathrm{~mm}$. long, $5 \mathrm{~mm}$. wide. Dry regions: Utah. Son. My.

5. C. oocarpa A. Gray. Stem diffusely branched, 2-3 dm. high; leaflets linear, obtuse, 1-3 cm. long; petals yellow, $6 \mathrm{~mm}$. Iong; pedicels $6 \mathrm{~mm}$. long; stipe about $6 \mathrm{~mm}$. long; pod ovate, $4 \mathrm{~mm}$. long and about as wide. Arid regions: Colo.-Nev. Son.

6. C. Palmerana M. E. Jones. Stem 5-25 $\mathrm{cm}$. high, branched from the base; leaflets obtuse, $1-2 \mathrm{~cm}$. long; pedicels $6-8 \mathrm{~mm}$. long, reflexed; petals orange, $4 \mathrm{~mm}$. long, oblong-oblanceolate; stipe $2 \mathrm{~mm}$. long; pod 4-5 mm. long, 8-10 mm. wide; seeds smooth, spotted. (?) C. Montrosae Payson. Dry regions: UtahColo. Son. My.

\section{Family 54. DROSERACEAe. Sundew Family.}

Mostly subacaulescent herbs, with glandular-viscid leaves, which are either filiform and circinate in the bud or with broadened sensitive blades. Flowers perfect, regular, racemose or spicate. Sepals 4-8, imbricate. 
Petals as many, convolute. Stamens 5-8, mostly 5. Gynoecium of 2-5 united carpels; ovary 1-celled, with 2-5 parietal placentae, rarely 2-3-celled, loculicidally $2-5$-valved.

\section{DRÓSERA L. SUNdew.}

Perennials, in ours scapose, with basal leaves. Sepals, petals, and stamens 4-8. Petals white or pink, spatulate or oblanceolate. Filaments subulate or filiform; anthers extrorse. Ovary 1-celled, superior; styles 2-5, distinct. Capsule 2-5-valved.

Leaf-blades suborbicular or broader than long.

Leaf-blates elongate.

Leaf-blades spatulate or oblanceolate; seeds smooth.

Leaf-blades linear or linear-oblanceolate; seeds muricate.

1. D. rotundifolia.

1. D. rotundifolia L. Rosulate perennial; leaf-blades $6-10 \mathrm{~mm}$. wide; scape glabrous, 1-3 dm. high; raceme secund; calyx about $3 \mathrm{~mm}$. long; lobes ovate-oblong; petals about $4 \mathrm{~mm}$. long, white; capsule erect, about $5 \mathrm{~mm}$. long; seeds smooth. Sphagnum bogs: Lab.-N.J.-Ida.-Calif.-Alaska; Eurasia. Boreal-Mont. Je-S.

2. D. longifolia L. Rosulate perennial; leaf-blades spatulate or oblanceolate, $1.5-3 \mathrm{~cm}$. long, about 4-5 mm. wide; scape $1-3 \mathrm{dm}$. high; ealyx about 4 $\mathrm{mm}$. long; lobes oblong; petals white, $5 \mathrm{~mm}$. long; pods $7-8 \mathrm{~mm}$. long. $D$. anglica Huds. Bogs: Newf.-Ont.-Ida.-Calif.-B.C.;Eurasia. Boreal-Mont. My-Au.

3. D. linearis Goldie. Rosulate perennial; leaf-blades linear or narrowly linear-oblanceolate, $1.5-4 \mathrm{~cm}$. long, 2-3 mm. wide; scape $3-10 \mathrm{~cm}$. high, 1-4flowered; calyx 3-4 mm. long, lobes ovate; petals white, $5-6 \mathrm{~mm}$. long; capsule 5-6 mm. long. Bogs: Que.-Mich.-Alta. Boreal. Jl-Au.

\section{Family 55. CRASSUldaceat. Stone-Crop Family.}

Herbs or rarely shrubby plants, mostly fleshy or succulent, without stipules. Flowers mostly cymose, perfect, regular. Calyx persistent; sepals 4 or 5 , usually free, rarely united. Petals 4 or 5 , free or more or less united, rarely wanting. Stamens as many or twice as many as the petals. Pistils as many as the sepals, distinct or united at the base. Fruit of follicles, dehiscent on their ventral suture.

Stamens twice as many as the sepals.

Flowers axillary, arranged in elongate racemes or spikes; petals rose-colored, distinct.

Flowers terminal, in cymes or one-side racemes.

Petals more or less united, erect; corolla tubular.

Petals distinct.

Flowers polygamous or dioecious; carpels erect; petals in ours purplish.

Flowers perfect; carpels spreading; petals in ours yellow.
Stamens as many as the sepals; minute annual mud or water plants.

1. Clementsia.

2. Gormania.

3. RHODIOLA.

4. SEDUM.

5. TILlLaEAstrum.

\section{Cleméntsia Rose. Red Orpine.}

Perennial herbs, with elongate rootstocks. Stem-leaves numerous. Flowers in dense spikes or racemes. Sepals distinct, linear or linear-lanceolate. Petals distinet, rose-colored. Stamens 10 , the 5 opposite to the petals adnate to them up to the middle. Carpels 5, erect.

1. C. rhodantha (A. Gray) Rose. Stems several from the thick rootstock, simple, 1.5-3.5 dm. high; leaves linear-oblong or oblanceolate, sessile, $1.5-3 \mathrm{~cm}$. long, entire or few-toothed; raceme very dense, $2-6 \mathrm{~cm}$. long; petals linearlanceolate, twice as long as the sepals. Sedum rhodanthum A. Gray. Mountain meadows: Mont.-N.M.-Ariz. Mont.-Alp. Je-Au.

\section{GORMÁNIA Britton.}

Perennial herbs, with horizontal rootstocks, Leaves spatulate, obovate, or orbicular, the basal ones numerous, the cauline ones similar but smaller. Flow- 
ers perfect, eymose or thyrsoid. Sepals distinct or nearly so. Petals 5, united below the middle, yellow or red, acute or acuminate. Stamens 10 , adnate to the corolla; anthers mostly oblong. Carpels 5, united below, erect or nearly so, many-seeded.

1. G. debilis (S. Wats.) Britton. Perennial, with a slender rootstock; stems often decumbent at the base, 3-12 $\mathrm{cm}$. high; leaves ovate-orbicular, or the upper ones oblong, obtuse, sessile; cyme $2-5 \mathrm{~cm}$. broad; corolla yellow; lobes lanceolate, 6-8 mm. long. Sedum debile S. Wats. Rocky ridges: Utah-Nev.-Ore. -Ida. Submont.-Mont. Je-Au.

\section{RHODIOLA L. ROSE-ROOT, ROSE-WORT.}

Perennial, with a thick, red, somewhat branching rootstock. Flowers polygamous or dioecious, 4- or 5-merous. Leaves broad and soft, not very thick. Sepals distinct, oblong or lanceolate. Petals rather narrow, distinct, yellowish or greenish, or in our species purplish. Carpels erect, only the beaks spreading.

Petals acute; follicles 3-5 mm. long, the beak $0.5 \mathrm{~mm}$. long, divergent or recurved; dioecious.

1. $R$. integrifolia.

Petals abruptly acuminate; follicles $6-8 \mathrm{~mm}$. long; the beak $1 \mathrm{~mm}$. long, ascending; polygamo-dioecious.

2. R. polygama.

1. R. integrifolia Raf. Stems usually less than $1 \mathrm{dm}$. high; leaves flat, 1-1.5 cm. long, obovate or oblong-obovate, often dentate above the middle; sepals lanceolate, acute, $1.5-2 \mathrm{~mm}$. long, dark purple or rarely greenish; petals oblanceolate or oblong, acute, about $3 \mathrm{~mm}$. long, usually dark purple. Sedum Rhodiola Coult. S. frigidum Rydb. Alpine-arctic situations, among rocks: Alta. -Colo.-Calif.-Alaska. Alp.-Subalp. Je-Au.

2. R. polygama (Rydb.) Britt. \& Rose. Stem 1-3 dm. high: leaves obovate or oblanceolate,-acute, sessile, flat, entire or minutely denticulate, $1.5-2.5 \mathrm{~cm}$. long; sepals lanceolate, $2 \mathrm{~mm}$. long, acute; petals oblanceolate, dark purple, about $3 \mathrm{~mm}$. long. Sedum polygamum Rydb. Alpine peaks: Colo.-N.M. Alp.-Mont. Je-Au.

\section{SËDUM L. STONE-CROP, ORPINE.}

Annual or perennial, fleshy herbs. Leaves mostly alternate, often imbricate, entire or dentate. Flowers perfect, in terminal, often one-sided cymes. Sepals distinet or somewhat united, 4 or 5 . Petals 4 or 5, distinet, or rarely slightly united at the base. Stamens 8-10, the alternate ones often adnate to the base of the petals. Carpels 4 or 5 , distinct, or united at the very base, more or less spreading or at least ascending, usually many-seeded.

Leaves linear, linear-oblanceolate, or oblong, terete or nearly so. Leaves lanceolate to oblong or spatulate, more or less flattened.

Leaves of the flowering stems lanceolate, broadest at the base.

Leaves spatulate or obovate, narrow at the base.

1. S. stenopetalum.

2. S. Douglasii.

3. S. Leibergii.

1. S. stenopetalum Pursh. Perennial, tufted; flowering stems $8-18 \mathrm{~cm}$. high; leaves crowded, but scarcely imbricate, except on the sterile shoots, sessile, linear, 6-16 mm. long; cymes forked; petals yellow, narrowly lanceolate; follicles about $4 \mathrm{~mm}$. long, ascending, with divergent tips, $S$. subalpinum Blankinship. On rocks: Sask.-Neb.-N.M.-Calif.-Alta. Plain-Mont. Je-Au.

2. S. Douglasii Hook. Perennial, with a branching rootstock; stems erect or ascending, 1-3 dm. high; leaves narrowly lanceolate or linear-lanceolate, acuminate, sessile, 1-2.5 $\mathrm{cm}$. long, flat above; cyme forked; petals 6-12 $\mathrm{mm}$. long, yellow, longer than the stamens; follicles $3-4 \mathrm{~mm}$. long, widely divergent from the base. Rocky places: Mont.-Ida.-Calif.-B.C. Submont.-Mont. $\mathrm{Je}-\mathrm{Au}$.

3. S. Leibergii Britton. Perennial, with a rootstock; stem simple, about $2.5 \mathrm{~cm}$. high; leaves, except those of the inflorescence, oblanceolate or spatulate, 1-1.5 mm. long; cyme open; flowers sessile; petals yellow, narrowly lanceolate, acuminate, 7-9 $\mathrm{mm}$. long; follicles divergent from the united bases. Sedum divaricatum S. Wats., not Ait. Rocky places: Ore-W Wash.-Ida. Son. My-Je. 


\section{TILLAEÁSTRUM Britton.}

Small glabrous aquatic annuals. Leaves opposite, entire. Flowers perfect, small, solitary, axillary. Sepals 4, distinet. Petals usually 4, distinet or united at the base. Stamens 4. Carpels 4, distinct, several-seeded; styles short.

1. T. aquaticum (L.) Britton. Stem $1-8 \mathrm{~cm}$. high; leaves linear-oblong, connate at the base, $4-6 \mathrm{~mm}$. long; flowers subsessile; petals greenish, about twice as long as the sepals; follicles ovoid, 8-10-seeded. Tillaea aquatica L. In mud or water: N.S.-Md.-La.-Tex.-L. Calif.-Wash.; Eurasia. PlainMont.

\section{Family 56. PARNASSIACEAE. Grass of Parnassus Family.}

Scapose perennials, with rootstocks and basal petioled entire leaves. Flowers solitary on the scape, perfect, regular. Sepals 5, imbricate. Petals 5 , imbricate, white or nearly so, conspicuously veined. Stamens 5 , alternate with the petals and with 5 clusters of united gland-tipped staminodia. Gynoecium of 3 or 4 united carpels; ovary superior or half inferior, with 3 or 4 parietal placentae; style obsolete; stigmas 3 or 4 . Fruit a 1-celled capsule, loculicidal at the apex.

\section{PaRnássia. Grass of Parnassus.}

Characters of the family.

Petals fimbriate on the sides, at least below; free portions of the staminodia very short and stout; leaf-blades reniform or cordate, usually broader than long.

Petals obovate, 5-nerved; staminodial scales with 5-9 lobes; sepals elliptic

1. P. fimbriata.

Petals oblong, 3-nerved; staminodial scales with 3-5 lobes; sepals narrowly lanceolate.

Petals entire, not fimbriate; free portion of the staminodia long.

2. P. rivularis.

Petals 5-9-veined, usually exceeding the sepals; capsule less than twice as long as the sepals; bract some distance from the base.

Staminodia 7-15 in each fascicle; basal leaf-blades cordate or rounded at the base.

Petals nearly twice as long as the sepals; hypanthium inconspicuous; staminodia usually 9-15 in each fascicle.

Petals only slightly exceeding the sepals; hypanthium conspicuous, obconic, fully half as long as the sepals and nearly as broad as high; staminodia 7-9 in each fascicle. 4 . P. montanensis. Staminodia 5-7 in each fascicle; basal leaf-blades acute at the base.

5. P. parviflora.

Petals 3-veined, thin, scarcely equalling the sepals; capsule twice as long as the sepals; bract none or near the base.

6. P. Kotzebuei.

1. P. fimbriata Konig. Leaf-blades reniform or broadly cordate, $2-4 \mathrm{~cm}$. wide, thin; scape 2-3 dm. high; sepals 5-6 mm. long, elliptic or oval, obtuse, and of ten crenulate at the apex; petals obovate, $7-8 \mathrm{~mm}$. long; capsule $1 \mathrm{~cm}$. long or more. Springy places in the mountains: Alta.-Colo.-Calif.-Alaska. Mont. -Subalp. Ji-S.

2. P. rivularis G. E. Osterhout. Leaf-blades reniform or broadly cordate, thin, about 7 -ribbed, $1-2 \mathrm{~cm}$. wide; scape slender, about $1 \mathrm{dm}$. high; sepals narrowly lanceolate, acute, about $3 \mathrm{~mm}$. long; petals oblong, about $6 \mathrm{~mm}$. long; capsule ovoid. Springy places in the mountains: n Colo. Mont.

3. P. palustris L. Leaf-blades cordate, $1-3 \mathrm{~cm}$. wide; scape $1-3 \mathrm{dm}$. high; sepals oblong or elliptic, 4-6 mm. long; petals oval, 8-12 $\mathrm{mm}$. long; capsule ovoid, about $1 \mathrm{~cm}$. long. Wet places: Lab.-Que.-Mich.-Wyo.-Alaska; Eurasia. Mont. J-Au.

4. P. montanensis Fern. \& Rydb. Leaf-blades ovate, with a subcordate or rounded base, 1-2 $\mathrm{cm}$. long, $8-18 \mathrm{~mm}$. wide; scape about $2 \mathrm{dm}$. high; sepals oblong to lanceolate, acute, $7-9 \mathrm{~mm}$. long; petals oval to elliptic; capsule roundedovoid, about $1 \mathrm{~cm}$. long. Wet river banks: Mont.-B.C.-Sask. Submont.Mont. Jl-Au.

5. P. parviflora DC. Leaf-blades oval or ovate, 1-3 cm. long, $0.75-2 \mathrm{~cm}$. wide; scape slender, 1-3 dm. high; sepals oblong, 5-8 mm. long; petals elliptic 
or oval, 6-10 $\mathrm{mm}$. long; capsule ovoid, about $1 \mathrm{~cm}$. long. Wet places and swamps: Lab.-Que.-S.D.-Colo.-Utah-Alta. Plain-Mont. Jl-S.

6. P. Kotzebuei Cham. Leaf-blades broadly ovate or somewhat cordate, 1-2 cm. long; scape slender, about $1 \mathrm{dm}$. (seldom $2 \mathrm{dm}$.) high; staminodial seales short, with 3-5 filiform short filaments; sepals oblong, 5-7 mm. long; capsule ovoid, about $12 \mathrm{~mm}$. long. Wet places: Greenl.-Que.-Wyo.-Alaska; ne Asia. Subalp. Jl-Au.

\section{Family 57. SAXIFRAGACEAE. Saxifrage Family.*}

Herbs, usually without stipules. Leaves alternate, rarely opposite, often all basal. Flowers perfect, regular or nearly so. Hypanthium often well developed, from flat to cylindric, often more or less adnate to the ovary. Sepals 5, rarely 4, distinct. Petals as many or wanting. Stamens as many or twice as many as the sepals, in one genus only 3. Gynoecium of 2, rarely of 3 or 4 , carpels, more or less united, rarely wholly distinct; placentae parietal, basal, or axial. Fruit a capsule or follicles.

Placentae parietal, sometimes nearly basal.

Flowers solitary and axillary to leaf-like bracts, or 2-4 in small corymbs, each subtended by a leaf-like bract; sepals 4 ; petals wanting.

Flowers in more or less elongate racemes or panicles.

Gynoecium of 2 or 3 equal or essentially equal carpels.

Flower-stalk axial, from a slender bulbiferous rootstock; gynoecium 3-carpellary.

2. LITHOPHRAGMA.

Flower-stalk a lateral shoot from a stout scaly rootstock; gynoecium 2-carpellary.

Inflorescence racemose.

Petals pinnately cleft or pinnatifid.

Hypanthium deeply campanulate or urn-shaped, deeper than the length of the sepals; capsule tapering into a beak.

3. TELIIMA.

Hypanthium saucer-shaped or open campanulate, shallower than the length of the sepals; capsules abruptly beaked or beakless.

Ovary more than half superior; disk inconspicuous; stigmas entire, terminating distinct styles.

Stamens 10; placentae almost basal, bearing few ovules.

4. Mitella.

Stamens 5; placentae parietal, bearing many ovules.

5. Mitellastra.

Ovary wholly inferior, covered with the prominent disk; stigmas sessile, 2-lobed; stamens 5.

Potals entire, toothed or 3-cleft above; stamens 5.

Hypanthium campanulate during anthesis; ovary half inferior.

7. OzOMELIS.

Hypanthium turbinate during anthesis; ovary almost wholly inferior. 8 . Conimitella.

Inflorescence paniculate; stamens 5 ; petals broadened upward.

Gynoecium of 2 very unequal carpels.

9. HEUCHERA.

Placentae axial.

Hypanthium well-developed, and accrescent, at maturity longer than the sepals.

Stamens 5.

Plants with short bulblet-bearing rootstocks; flower-stalk axial.

Ovary half inferior; blade of the basal leaf ternately divided; stamens borne on the outer edge of a thickened disk. 11. HEMIEvA.

Ovary two-thirds inferior or more; blade of the basal leaf merely crenate;

Plants with horizontal rootstocks; flower-stalk a lateral shoot.

Sepals imbricate; petals marcescent; seeds winged. 13. SULLrvanTIA.

Sepals valvate; petals deciduous; seeds wingless. 14. THEROFON.

Stamens 10.

Petals clawed; styles partially united: plants with thick rootstocks.

Petals clawless; styles distinct; plants with slender rootstocks, often with offsets.

Plants without caudices, producing only annual flowering stems.

Plants with perennial very leafy caudices, often with offsets, the flowering stems very different from the caudices.

* Adapted and abbreviated from Small \& Rydberg in North American Flora, Vol. 22. 
Leaves of the caudex with lobed blades, the margins poreless.

17. MUSCARIA.

Leaves of the caudex with serrate blades, each tooth with an encrusted pore.

18. CHONDROSEA.

Hypanthium only slightly developed, unchanged at maturity, or if slightly accrescent, then flat and plants acaulescent.

Leaves alternate, sometimes all basal.

Plants acaulescent.

Corolla essentially regular, the petals about equal in shape and length.

19. MICRANTHES.

Corolla irregular, except sometimes that of the terminal flower, 3 of the petals with blades of an ovate or lanceolate type and 2 of them narrower and longer.

Plants caulescent.

Leaves without stipules.

Carpels distinct; leaf-blades toothed.

20. SPATUlaRIA.

Carpels partially united; leaf-blades entire or rarely with 3 apical tooth-

like lobes.
Leaves with reniform or orbicular, shallowly lobed blades and wing-like stipules at the base of the petioles. 23. HETERISIA.

Leaves opposite, except sometimes on the flower-stalks. 24. ANTIPHYLLA.

\section{ChrysosplèniUm (Tourn.) L. Golden Saxifrage,}

Water Carpet.

Low, somewhat succulent herbs, mainly semi-aquatic; all North American species, with perennial rootstocks. Flowers small, axillary or terminal, solitary or in small corymbs. Hypanthium saucer-shaped or campanulate, adnate to the lower portion of the gynoecium and usually lined with a disk. Sepals normally 4. Petals none. Stamens 4-8 (rarely 10), inserted on the margin of the disk. Gynoecium 1-celled, 2-lobed; styles 2, usually short; placentae parietal, many-ovuled.

Leaves all alternate; flowers clustered near the ends of the stems; stamens 4.

Lower leaves opposite; flowers solitary in the leaf-axils; stamens mostly 8 .

2. C. americanum.

1. C. tetrandrum Th. Fries. Perennial, with a stoloniferous rootstock; stem 1.5-8 $\mathrm{cm}$. high; leaf-blades thick, reniform, 4-12 mm. wide, crenate with $3-5$ broad teeth; sepals usually 4 ; stamens opposite to the sepals. Wet places, aretic-alpine situations: Aretic coast-Colo. Subalp. Jl-S.

2. C. americanum Schwein. Perennial, with a slender, stoloniferous rootstock; stem decumbent, forked above, glabrous or nearly so, 7-20 cm. long; leafblades broadly obovate, orbicular or rarely reniform, 4-20 mm. wide. Wet shady places: N.S.-Ga.-Minn.-Sask. Plain. Ap-Au.

\section{LithophrÁGMa Nutt. Star-Flower, Prairie Star, WOODLAND STAR.}

Perennial herbs, with slender bulblet-bearing rootstock and axial leafy flowering shoots. Flowers racemose, perfect; hypanthium campanulate or hemispheric and adnate to the very base of the ovary, to elongate-turbinate and adnate to the lower half thereof. Sepals 5 , valvate, rounded to triangular. Petals white or rose-colored, clawed, digitately or pinnately divided, toothed, or entire, much exceeding the sepals. Stamens 10, included; filaments short; anther cordate. Gynoecium 1-celled with 3 parietal placentae, 3-valved at the apex; styles 3 , short. Seeds many.

Hypanthium campanulate or hemispheric, mostly rounded at the base, adnate only to

the base of the ovary.
Stem-leayes seldom bulbiferous in the axils; stipules long and narrow, the free portion triangular or lanceolate, not fimbriate.

Hypanthium with the sepals $2-3 \mathrm{~mm}$. long; petals about $2 \mathrm{~mm}$. Iong.

Pedicels short, in fruit not exceeding the capsule in length; seeds smooth.

Pedicels in fruit much longer than the capsule; seeds muriculate.

Hypanthium with the sepals $3-4 \mathrm{~mm}$. Iong; petals $3-5 \mathrm{~mm}$. long. 2 . Llabra.

2. L. glabra.

Stem-leaves usually bulbiferous in their axils; stipules short and broad, the free portion rounded and fimbriate. 4 . L. bulbifera.

Hypanthium deeply obconic, adnate to the lower half of the ovary. 5. L. parvifiora. 
1. L. tenella Nutt. Stem slender, 1-1.5 dm. high, glandular-puberulent throughout; leaf-blades less than $1 \mathrm{~cm}$. broad, orbicular-flabellate in outline, glandular-puberulent, 3-cleft half their length; lobes cuneate, 3-toothed; pedicels about $2 \mathrm{~mm}$. long; hypanthium almost hemispheric, together with the sepals $2 \mathrm{~mm}$. long; petals 3 -cleft at the apex. Rocky banks and hillsides: Alta. -Wyo. Submont,-Mont. My-Je.

2. L. glabra Nutt. Stem 1-2 dm. high, minutely glandular-puberulent or glabrous; leaf-blades ternately divided to near the base, puberulent; divisions cuneate, 0.5-1.5 cm. long, 3-lobed; hypanthium campanulate, puberulent, together with the sepals $2.5-3 \mathrm{~mm}$. long; petals 3-cleft at the apex. Damp ground: Ore.-Wyo.-Mont. Submont. Je.

3. L. australis Rydb. Stem 1-2 dm. high, stout, glandular-puberulent; leaf-blades ternately divided to near the base; divisions $1.5-2 \mathrm{~cm}$. long, rhombic or cuneate, deeply cleft and toothed; pedicels $2-5 \mathrm{~mm}$. long; hypanthium campanulate, slightly striate, with the sepals $3-4 \mathrm{~mm}$. long; petals broadly cuneate, deeply 3-5-cleft. Hillsides and drier meadows: N.M.-Wyo.-Utah-Ariz. Submont.-Mont. My-Je.

4. L. bulbifera Rydb. Stem 1-2 dm. high, glandular-puberulent; leafblades ternately divided to the base; divisions $0.5-1 \mathrm{~cm}$. long, cuneate or obovate, 3-cleft and toothed; pedicels $3-5 \mathrm{~mm}$. long, or in fruit $1 \mathrm{~cm}$. long; hypanthium campanulate, together with the sepals 3-4 mm. long; petals 4-7 mm. long, 3-5-cleft, white or sometimes rose-colored. Dry hills: S.D.-Colo.-Calif.B.C. Submont.-Subalp. Ap-Jl.

5. L. parviflora (Hook.) Nutt. Stem 1-3 dm. high, glandular-puberulent and somewhat hirsutulous; leaf-blades more or less hirsutulous, divided to the base into $3-5$ divisions, which are $1-3 \mathrm{~cm}$. long, twice ternately cleft into oblong or linear lobes; pedicels 2-4 mm. long; hypanthium together with the sepals 5-8 $\mathrm{mm}$. long; petals deeply 3-5-cleft into narrowly oblong divisions. Rocky or gravelly places: Alta.-S.D.-Colo.-Calif.-B.C. Submont.-Mont. Ap-Jl.

\section{TELLIMA $\mathrm{R}$. Br.}

Coarse hirsute perennials, with thick scaly rootstock and axillary leafy flowering shoots. Stipules present but small. Hypanthium urn-shaped or deeply campanulate, adnate only to the base of the gynoecium. Sepals ovate, erect, valvate in bud. Petals white or tinged with purple, spreading, with a cuneate claw and pinnately divided blade. Stamens 10, short, included; anthers 2-celled. Gynoecium 1-celled, with 2 parietal many-seeded placentae; styles 2; stigmas capitate. Capsule opening between the beaks. Seeds horizontal.

1. T. grandiflora (Pursh) Dougl. Flowering branches $3-6 \mathrm{dm}$. high, hirsute with long hairs, glandular above, leafy; blades of basal leaves reniform, sparingly hirsute, round-lobed, 4-10 cm. broad; stem-leaves short-petioled, with more or less developed stipules; hypanthium glandular-puberulent, cylindrocampanulate, 8-10 mm. long; petals purplish or pink; claw ereet; blade spreading or reflexed; ovary united with the hypanthium only at the base. Rich moist woods: Alaska-B.C.-Calif. Submont. Ap-Jl.

\section{Mitélla (Tourn.) L. Miterwort, Bishop's Cap.}

Low perennials, with scaly rootstocks and lateral flowering branches. Inflorescence racemose. Hypanthium saucer-shaped or open-campanulate, adnate to the base of the gynoecium. Sepals triangular or ovate, valvate in aestivation. Petals 5, pectinately pinnatifid. Stamens 10 , included; filaments short, subulate. Gynoecium mostly superior, 1-celled, with 2 parietal placentae, ovuliferous only at the base; styles distinct, short; stigma obtuse, simple. Capsule 2-valved at the summit, few-seeded.

1. M. nuda L. Perennial, producing long runners later in the season; flowering branches scapiform, $0.5-2 \mathrm{dm}$. high, sparingly hairy; leaf-blades reniform, $2-5 \mathrm{~cm}$. in diameter, rounded-crenate or slightly round-lobed; calyx about $6 \mathrm{~mm}$. wide; sepals yellowish green, triangular-ovate; petals about twice as long 
as the sepals. Cold woods and peat-bogs: Lab.-Newf.-B.C.-Mont.; e Asia. Boreal-Mont. My-Jl.

\section{Mitellástra (T. \& G.) Howell.}

Slender glandular pubescent perennials, with scaly rootstocks and lateral leafy flowering shoots. Inflorescence racemose. Hypanthium saucer-shaped, adnate only to the base of the gynoecium. Sepals 5, triangular, valvate in aestivation. Petals pectinately pinnatifid, with filiform divisions. Stamens 5, opposite the sepals; filaments slender, about two-thirds as long as the sepals. Gynoecium nearly wholly superior, with 2 parietal many-ovuled placentae. Styles 2 , distinct, slender, tapering into the stigmas. Capsule as in Mitella.

1. M. caulescens (Nutt.) Howell. Flowering branches 1-3-leaved, puberulent and somewhat hirsute, 1.5-3 dm. high; basal leaf-blades broadly cordate or reniform, 5-7-lobed, with triangular-ovate lobes and crenate, hirsute on both sides, $3-5 \mathrm{~cm}$. broad; stem-leaves similar but short-petioled, alternate; flowers yellowish green; hypanthium with the calyx about $5 \mathrm{~mm}$. wide; sepals broadly triangular. Mitella caulescens Nutt. Shady woods: B.C.-Mont.-Ida.Calif, Submont. My-JI.

\section{PECTIÁNTHIA Raf.}

Low perennials, with scaly rootstocks and lateral, scapiform flowering branches. Inflorescence racemose. Hypanthium saucer-shaped, wholly adnate to the depressed ovary. Sepals 5, triangular or ovate, reflexed, valvate in aestivation. Petals 5, pectinately pinnatifid, with filiform divisions. Stamens 5, on the margin of a distinct disk, which eovers the ovary; filaments very short, inflexed; anthers reniform. Gynoecium 1-celled, depressed, mostly inferior, with 2 parietal, but almost basal placentae. Stigmas 2, subsessile, 2-lobed at the apex. Seeds numerous.

Stamens opposite to the petals.

1. P. pentandra. Stamens opposite to the sepals.

2. P. Breweri.

1. P. pentandra (Hook.) Rydb. Flowering branches scapiform, naked, 1-3 dm. high; blades of the basal leaves broadly cordate, coarsely crenate, and with 9-11 more or less distinct round lobes, thin, 3-6 cm. in diameter; raceme lax, with the flowers not rarely in pairs; hypanthium with the calyx 3-3.5 mm. wide, green, often purplish inside; sepals broadly triangular. Mitella pentandra Hook. Mossy banks, in the woods: Alaska-Alta.-Colo.-Calif. Mont.Subalp. Je-Au.

2. P. Breweri (A. Gray) Rydb. Flowering branches 1-2 dm. high, scapiform, leafless, very sparingly hairy; blades of the basal leaves reniform, with many shallow rounded lobes, serrate-erenate, thin, sparingly hairy on both sides or glabrous, 4-7 cm. broad; flowers green, occasionally in pairs; hypanthium with the calyx 3-4 mm. wide; sepals very broadly ovate, obtuse. M. Breweri A. Gray. Damp woods in the mountains: Alta.-Ida.-Calif.-B.C. Mont.-Subalp. $\mathrm{Je}-\mathrm{Au}$.

\section{OZOMÈLIS Raf. Mitrewort.}

Perennials, with scaly rootstocks and lateral scapiform flowering shoots. Leaves basal, long-petioled, with rounded-reniform or cordate blades. Inflorescence racemose. Hypanthium campanulate, adnate to the lower half of the ovary. Sepals 5, ovate or oblong, erect, valvate in aestivation. Petals 5 or lacking, 3-cleft, toothed or entire. 'Stamens 5, opposite to the sepals; disk obsolete; filaments short, erect; anthers reniform. Gynoecium half-inferior, 1-celled, with 2, parietal, many-ovuled placentae; styles 2, very short; stigmas capitate.

Midvein of the sepals branched; side-veins simple; petals cuneate or oblanceolate, with lanceolate lobes or entire.

Petals cuneate, about twice as long as the sepals, 3-fid with subequal divisions.

Petals oblanceolate, slightly exceeding the sepals, entire or slightly and unequally toothed.

2. O. violacea.

Midveins of the sepals simple; lateral veins branched; petals filiform or 3-fid, with filiform divisions, 1-nerved. 
Petals 3-fid to the middle; hypanthium with the sepals $4-5 \mathrm{~mm}$. long.

P. O. stauropetala.

Petals entire or 3 -fld only at the apex; hypanthium with the sepals $1.5-3 \mathrm{~mm}$. long.

Hypanthium with sepals $2-3 \mathrm{~mm}$. long; leaf-blades indistinctly lobed and with shallow crenulations; petals often entire.

4. O. stenopetala.

Hypanthium with the sepals $1.5-2 \mathrm{~mm}$. long; leaf-blades distinctly lobed and deeply crenate; petals 3 -cleft.

5. O. Parryi.

1. O. trifida (Graham) Rydb. Flowering branches $2-3 \mathrm{dm}$. high, naked, glandular-puberulent; leaf-blades reniform, 2-4 cm. broad, 7-9-lobed, with broad shallow rounded lobes and crenate, sparingly hairy on both sides; raceme short, 2-6 cm. long; hypanthium with the sepals $3 \mathrm{~mm}$. long; sepals green, triangular-ovate. Mitella trifida Graham. Wet woods: Alta.-B.C. Mont. $\mathrm{My}-\mathrm{Au}$.

2. O. violacea Rydb. Flowering branches $2-3 \mathrm{dm}$. high, naked, glandularpuberulent; leaf-blades broadly cordate in outline, slightly 5 -7-lobed with rounded, finely crenate lobes; racemes short, with almost sessile flowers; hypanthium with the sepals $3 \mathrm{~mm}$. long and $2 \mathrm{~mm}$. wide; sepals ovate, obtuse. $M$. violacea Rydb. Mossy banks in woods: Mont. Submont. Je-Jl.

3. O. stauropetala (Piper) Rydb. Flowering branches naked, 3-5 $\mathrm{dm}$. high, glandular-puberulent throughout, or slightly hirsute below; leaf-blades rounded-reniform, indistinctly 5-9-lobed, with round crenate lobes, sparing hirsute on both sides; racemes rather elongate; pedicels about $1 \mathrm{~mm}$. long; sepals oblong-ovate; petals fully twice as long as the sepals. $M$. stauropetala Piper. Springy places in woods: Mont.-Colo.-Ore.-Wash. Mont. My-Jl.

4. O. stenopetala (Piper) Rydb. Flowering branches leafless, $3-5 \mathrm{dm}$. high, puberulent; leaf-blades rounded-reniform, $2-6 \mathrm{~cm}$. wide, ciliate on the margin, indistinctly round-lobed and crenate; raceme secund, of ten $1 \mathrm{dm}$. long; flowers almost sessile; sepals whitish, oblong, obtuse; petals about half longer than the sepals. M. trifida S. Wats. M. stenopetala Piper. Damp places: Utah
-Colo.-Wyo. Mont. Je-Jl.

5. O. Parryi (Piper) Rydb. Flowering branches leafless, 1.5-3 dm. high, glandular-puberulent above, slightly hairy below; leaf-blades $2-3 \mathrm{~cm}$. wide,
reniform, sparingly hairy on the veins and the margin, more distinctly lobed than in the preceding, deeply crenate; racemes $2-7 \mathrm{~cm}$. long, of ten secund; flowers nearly sessile; sepals whitish, rounded-oblong, obtuse; petals about half longer than the sepals. M. stenopetala Parryi Piper. Mountains: Wyo.-
Colo.-Utah. Mont. My-Au.

\section{CONIMITÉLLA Rydb.}

Perennials, with sealy cespitose rootstocks and scapiform lateral flowering branches. Inflorescence racemose. Leaves basal, long-petioled, with reniform of the ovary. Sepals 5, oblong, erect. Petals 5, long-clawed, spatulate, entire. 2 parietal placentae and short. Gynoecium mostly inferior, one-celled, with 2 parietal placentae and numerous ovules; stigmas subsessile, capitate. Seeds

1. C. Williamsii (D. C. Eaton) Rydb. Flowering branches leafless, 4-6 dm. high, glandular-puberulent; leaf-blades reniform, thick, shining, 3-4 cm. wide, indistinctly round-lobed and crenate, hispid-ciliate on the margin, of ten tinged with red; raceme short, $3-10 \mathrm{~cm}$. long, 6-12-flowered; hypanthium $3-4 \mathrm{~mm}$. (in fruit 8-10 mm.) long, finely puberulent; sepals oblong, $1 \mathrm{~mm}$. long, obtuse, yellowish;
petals 5-6 mm. long, narrowly spatulate. Heuchera Williamsii D. C. Eaton.
Tellima nudicaulis Greene. Tellimg Greene. Hillsides and open Tellima pentandra Canby. Lithophragma Williamsii Jl.

\section{HEÙCHERA L. AlUM-ROOT, KaLispell.} Perennials, with scaly rootstocks and lateral flowering branches, which are
either scapiform or leafy. Basal leaves petioled, with palmately veined, broad
blades. Inflorescence paniculate. blades. Inflorescence paniculate. Hypanthium eylindric to saucer-shaped, 
most often campanulate, adnate to the lower part of the gynoecium, often more or less oblique. Sepals 5, often very unequal. Petals 5, often more or less clawed. Stamens 5, opposite to the sepals; filaments usually filiform. Gynoecium partly inferior, 1-celled, with 2 parietal, many-ovuled placentae; styles 2 , distinct, elongate. Capsule opening between the two more or less divergent beaks.

Stamens equalling or exceeding the sepals.

Panicle open, not spike-like.

Hypanthium turbinate, about as broad as long; stamens at least twice as long as the sepals.

1. H. glabra.

Hypanthium deeply campanulate or urceolate, about twice as long as broad; stamens slightly exceeding the sepals.

Hypanthium strongly oblique.

Hypanthium with the sepals more than $1 \mathrm{~cm}$. long; petioles glabrous or sparingly short-hairy.

2. H. Richardsonii.

Hypanthium with the sepals less than $1 \mathrm{~cm}$. long; petioles long-hispid.

Hypanthium not strongly oblique.

Panicle contracted, dense, spike-like.

3. H. hispida.

4. H. rubescens.

tamens shorter than the sepals.

Hypanthium short-campanulate to saucer-shaped, together with the sepals $3-5 \mathrm{~mm}$. long.

Petioles more or less hirsute.

6. H. novomexicana.

Petioles glabrous or puberulent.

Hypanthium campanulate, yellowish or pinkish; sepals almost erect.

Leaf-blades deeply lobed; lobes again lobed and toothed; petals narrowly oblanceolate, nearly twice as long as the sepals.

7. H. gracilis.

Leaf-blades merely once 5-7-lobed and toothed; petals spatulate, from equalling to half longer than the sepals.

Base of the leaf-blades with an open sinus, or almost cuneate; plant 1-3 dm. high.

8. H. Hallii.

Base of the leaf-blades with a narrow sinus; plant $3-5 \mathrm{dm}$. high.

Hypanthium saucer-shaped; sepals spreading.

9. H. grossulariffolia.

Hypanthium with the sepals $4 \mathrm{~mm}$. high, yellowish; blades of the petals rhombic.

10. $H$. flavescens.

Hypanthium with the sepals $2-3 \mathrm{~mm}$. high, greenish; petals oblanceolate or spatulate.

Leaf-blades with shallow lobes.

Sinus of the leaf-blades closed, the basal lobes often overlapping; petals not exceeding the sepals.

11. H. utahensis.

Sinus of the leaf-blades open; petals exceeding the sepals.

12. $H$. parvifolia.

Leaf-blades cleft at least one-half to the base. 13. $H$. flabellifolia.

Hypanthium deeply campanulate or urceolate, with the sepals $5-10 \mathrm{~mm}$. long.

Flowering branches and petioles pubescent.

Flowers greenish: leaf-blades reniform or rounded, deeply cordate at the base

lobes and teeth rounded; petioles long-hairy. 14. H. chlorantha.

Flowers yellowish; leaf-blades broadly oval to orbicular, truneate or slightly cordate at the base.

Leaf-blades thick, densely glandular-pubescent, $1.5-4 \mathrm{~cm}$. wide, rarely cordate at the base. $15 . H$. ovalifolia.

Leaf-blades thin, glabrous, or hairy only on the veins, $3-6 \mathrm{~cm}$. wide, cordate at the base. 16 . H. cylindrica.

Flowering branches and petioles glabrous or finely puberulent.

Flowers yellowish; leaf-blades rounded-oval to orbicular, truncate or slightly cordate at the base, only the earliest reniform. 17. H. glabella.

Flowers greenish; leaf-blades thin, reniform or rarely rounded, with deeply cordate base.

1. H. glabra Willd. Flowering branches 1-5 dm. high, glabrous, 1-3leaved, rarely scapiform; leaf-blades cordate or round-cordate, deeply 5-7lobed, sparingly hispidulous when young, soon glabrate, thin and shining, 3-10 cm. broad; lobes triangular-ovate, doubly serrate; panicle lax; hypanthium with the sepals $2.5-3 \mathrm{~mm}$. long; petals broadly spatulate or ovate, with a slender claw, about twice as long as the sepals. Damp shady rocks: Yukon-Alta.Ore.-Alaska. Mont. Je-S.

2. H. Richardsonii R. Br. Flowering branches $3-4 \mathrm{dm}$. high, scapiform, sparingly short-hirsute and glandular-puberulent above; leaf-blades roundedcordate, 3-6 $\mathrm{cm}$. broad, with rounded lobes and broadly ovate teeth, sparingly hispidulous, ciliate on the margins; petals spatulate, purplish, slightly exceeding the oblong sepals. Hills: Man.-S.D.-B.C. Plain-Submont. Je. 
3. H. hispida Pursh. Flowering branches scapiform, usually densely hispid, 6-12 dm. high; leaf-blades orbicular-cordate or reniform, 4-7 cm. wide, 5 -9-lobed, with shallow rounded lobes and broad teeth, hirsute beneath and ciliate on the margins; petals spatulate, equalling or shorter than the sepals. $H$. ciliata Rydb. Woods and hillsides: Ont.-Va.-Kans.-Wyo.-Mont. Plain -Mont. My-Jl.

4. H. rubescens Torr. Flowering branches scapiform, naked, 2-4 dm. high, straw-colored, shining; leaf-blades reniform or rounded-cordate, $2-4 \mathrm{~cm}$. wide, glabrous or minutely puberulent, thick, shining, rounded 5-lobed and with rounded bristle-tipped teeth; hypanthium campanulate, pinkish, glandularpuberulent, with the sepals $5 \mathrm{~mm}$. long; petals linear-oblanceolate, acute, about twice as long as the sepals. Mountains: Utah-Calif-Ore, Son.-Mont. $\mathrm{Je}-\mathrm{Au}$.

5. H. bracteata (Torr.) Seringe. Flowering branches usually about $1 \mathrm{dm}$. seldom $3 \mathrm{dm}$. high, glandular-puberulent or glabrate, usually with a few minute leaves; leaf-blades rounded-reniform, 1-3 cm. in diameter, more or less roundlobed, and with ovate cuspidate-tipped teeth, glandular-puberulent, and minutely ciliate on the margins; hypanthium deeply campanulate, glandular-puberulent, together with the oblong sepals $3-4 \mathrm{~mm}$. long; petals oblanceolate or spatulate, Je-Au.

6. H. novomexicana Wheelock. Flowering branches scapiform, glandularpuberulent or slightly hirsute below, $3-5 \mathrm{dm}$. high; leaf-blades reniform above, hairy on the veins beneath, ciliate $7-9$ rounded lobes and broadly ovate teeth, glabrous campanulate, glandular-pubeath, ciliate on the margins; hypanthium turbinatesepals 3-4 mm. Mountains: N.M.-s Utah-Ariz. Mont

7. $\mathrm{H}$. Mont.

dm. high, finely glandular-pubwering branches scapiform, very slender, about 4 glabrous, about $3 \mathrm{~cm}$. broad very short and narrow; hypanthium 5 -7-lobed; teeth bristle-pointed; panicles sepals about $4 \mathrm{~mm}$, long. hypanthium yellowish, with the erect oblong obtuse

8. H. Hallii A. Gray. Jl.

minutely puberulent, $1-3 \mathrm{dm}$. high; leaf-blades scapiform, naked, glabrous or sinus, deeply 5-7-lobed and with ovate, bristle-tipded-reniform, with an open glabrous or minutely glandular-puberulent; infle-tipped teeth, 1-3.5 cm. wide, thium yellowish or pinkish, together with inflorescence narrow, short; hypanlong. Mountain sides: Colo. Submer with the rounded-ovate sepals 4-5 mm.

9. H. grossularififolia Rydb. Submont. Subalp. Jl-Au.

naked, glabrous or sparingly or reniform, with a deep sinu glandular-puberulent; leaf-blades rounded-cordate puberulent, 5-7-lobed, with rounded the base, thin, glabrous or minutely glandularinflorescence very short and narrow; lobes and round-ovate bristle-tipped teeth; sepals $4 \mathrm{~mm}$. long. Rocky hillsides: hypanthium yellow, together with the ovate

10. H. flavescens Rydb. Flowering branches.-Ida.-Ore. Mont. Je-Jl.

puberulent, $4-6 \mathrm{dm}$, high; leaf-blades reniform or scapiform, naked, glandularexcept the ciliate margins, round-lobed and or rounded-cordate, thin, glabrous, teeth, 3-6 cm. wide; inflorescence elongate with very broadly ovate mucronate ceeding the sepals. Rocky hills ano elongate; sepals triangular-ovate; petals exSubalp. Je-Jl.

11. H. utahensis Rydb. Flowering branches 5-6 dm. high, minutely puberulent; leaf-blades reniform, $5-8 \mathrm{~cm}$. broad, almost glabrous and shining, and cañons: Utah. Submont. Je-th; inflorescence narrow, but open. Hills

12. H. parvifolia Nutt. Je-Au.

pubescent, 1-4 dm. high; leaf-bladering branches scapiform, naked, glandularcrenate with round teeth; inflorescen reniform, with 7-9 shallow, rounded lobes, 
yellowish, spatulate, with a broad, short claw. Hills: Alta.-N.M.-Ariz.Ore. Submont.-Alp. My-Au.

13. H. flabellifolia Rydb. Flowering branches slender, $2-3 \mathrm{dm}$. high, glandular-puberulent, subscapose; leaf-blades $1.5-3 \mathrm{~cm}$. broad, rounded-reniform, cleft one-third to one-half to the base into 7-9 somewhat cuneate lobes, which are rounded-crenate at the apex, the sinuses between the lobes of the leaves very narrow and rounded at the bottom, the lobes often overlapping. H. parvifolia dissecta M. E. Jones. Hills and mountain sides: Alta.-Mont. $\mathrm{n}$ Wyo. Plain-Mont. My-Au.

14. H. chlorantha Piper. Flowering branches scapiform, villous with long (in age brown) hairs, 5-7 dm. high; leaf-blades reniform or rounded-cordate, $5-8 \mathrm{~cm}$. wide, round-lobed and with ovate cuspidate teeth; inflorescence dense; hypanthium hirsute and glandular, together with the oblong sepals $7-8 \mathrm{~mm}$. or in fruit over $1 \mathrm{~cm}$. long; petals minute or usually lacking. H. cylindrica T. \& G., not Dougl. Low ground and river banks: B.C.-Ore,-Ida. Submont. JlAu.

15. H. ovalifolia Nutt. Flowering branches scapiform, naked, densely glandular-pubescent, with short hairs; leaf-blades rounded-oval, $1.5-4 \mathrm{~cm}$. broad and $2-5 \mathrm{~cm}$. long, truncate, rounded or slightly cordate at the base, roundlobed, and crenate; hypanthium together with the broadly oblong sepals about $7 \mathrm{~mm}$. long; petals usually wanting. H. cylindrica alpina $\mathrm{S}$. Wats. H. saxicola E. Nels. Rocky banks and hillsides: Alta.-Wyo,-Ore.-B.C. Submont.-Alp. $\mathrm{Je}-\mathrm{Au}$.

16. H. cylindrica Dougl. Flowering branches scapiform, naked, hirsute with white hairs, about $5 \mathrm{dm}$. high; leaf-blades orbicular or nearly so, deeply cordate at the base, glabrous or ciliate on the margins and veins, thin and shining, 3-6 cm. broad, round-lobed and crenate; inflorescence spike-like; hypanthium together with the oblong sepals $6-9 \mathrm{~mm}$. long. H. columbiana Rydb. Hills: Ore.-Ida.-Mont.-B.C. Submont. My-Jl.

17. H. glabella T. \& G. Flowering branches seapiform, 4-6 dm. high, glandular-puberulent or glabrous; leaf-blades rounded-oval or orbicular, slightly cordate or truncate at the base, $2-5 \mathrm{~cm}$. wide, glabrous or minutely glandularpuberulent, with ciliate margins, round-lobed and with rounded teeth; inflorescence narrow, elongate; hypanthium together with the broadly oblong sepals about $7 \mathrm{~mm}$. long. Rocky hills: Alta.-Mont.-Ore.-Wash. Submont. Je-Au.

18. H. tenuifolia (Wheelock) Rydb. Flowering branches scapiform, 4-6 dm. high, glabrous or minutely glandular-puberulent; leaf-blades reniform or rounded, deeply cordate at the base, thin, glabrous, round-lobed and crenate; hypanthium together with the oblong obtuse sepals about $6 \mathrm{~mm}$. long; petals oblanceolate, shorter than the sepals. H. cylindrica tenuifolia Wheelock. Hillsides: Ida.-Wash.-Ore. Submont. My-Au.

\section{0. tiaréllla L. Fatse Miterwort.}

Perennial herbs, with scaly rootstocks and lateral leafy flowering branches. Leaves petioled; blades cordate in outline. Stipules present. Inflorescence racemose or paniculate. Hypanthium small, short-campanulate, almost free from the gynoecium. Sepals 5, ovate or lanceolate. Petals clawed, with oblong or elliptic blades, or else clawless and filiform. Stamens 10, exserted, with long filiform filaments. Gynoecium 1-celled, with 2 parietal nearly basal placentae. Capsule membranaceous, with 2 very unequal valves. Seeds few.

1. T. unifoliata Hook. Flowering branches $1.5-4 \mathrm{dm}$. high, glabrous or viscid-puberulent above, or slightly hirsute, 1-4-leaved; leaf-blades broadly cordate, sparingly hirsute or in age glabrate, 4-10 cm. wide, coarsely 3-5-lobed, with broadly ovate, acute, doubly crenate, mucronate teeth; inflorescence a narrow panicle; sepals whitish, ovate-oblong; petals linear-subulate, white, fully 3 times as long. Shaded ravines and woods: B.C.-Alta.-Ida.-Calif. Mont. $\mathrm{My}-\mathrm{S}$. 


\section{HEMIÈVA Raf.}

Glandular-puberulent perennials, with a very short bulbiferous rootstock and fibrous roots. Blades of basal leaves ternately divided, with crenate lobes; stemleaves with more or less developed stipules. Flowers in a corymbiform panicle. Hypanthium campanulate, adnate to the lower half of the ovary. Sepals 5, triangular-lanceolate. Petals 5, obovate, short-clawed. Stamens 5, opposite to the sepals, erect, inserted on the outer margin of a thick disk; filaments filiform. Gynoecium half inferior, 2-celled, with axial placentae; styles distinct.

1. H. ranunculifolia (Hook.) Raf. Stem about $2 \mathrm{dm}$. high, more or less glandular-pubescent; lower leaf-blades ternately divided to the base, the middle division broadly cuneate, $1-2.5 \mathrm{~cm}$. long, and rounded 3-lobed, the lateral ones oblique and 4-lobed; uppermost leaves sessile, 3-lobed at the apex; hypanthium about $2 \mathrm{~mm}$. long; sepals about $2 \mathrm{~mm}$. long; petals white or ochroleucous. Saxifraga ranunculifolia Hook. Wet rocks in the mountains: Alta.-B.C.-Mont. -Ore. Mont.-Subalp. Je-J.

\section{SUKSDÓRFIA A. Gray.}

Slender, glandular-pubescent perennials, with a bulblet-bearing rootstock; flowering shoots axial, leafy. Blades of basal leaves reniform, merely crenate; stem-leaves with stipules. Inflorescence a few-flowered panicle. Hypanthium deeply campanulate or urn-shaped, adnate to the larger portion of the gynoecium. Sepals 5, lanceolate, erect. Petals 5, long-clawed, purple or rose, occasionally lobed, imbricate. Stamens 5, opposite to the sepals; disk obsolete; anthers almost sessile. Gynoecium 2-celled, with axial, many-ovuled placentae, almost wholly inferior; style short; stigma truncate. Capsule dehiscent between the

1. S. violacea A. Gray. Stem 2-3 dm. high, more or less glandular-pubescent; leaf-blades 1-3 $\mathrm{cm}$. wide, more or less puberulent; upper stem-leaves subsessile, cuneate, and 1-4-toothed at the apex; hypanthium $2.5 \mathrm{~mm}$. long, in fruit 6-7 mm. long; sepals about $2 \mathrm{~mm}$. long; petals pink, $5-7 \mathrm{~mm}$. long. Wet cliffs near streams: Wash.-Mont.-Ida.-Ore. Submont. Ap-Je.

\section{SULLIVĀNTIA T. \& G.}

Perennial acaulescent slender herbs, with small rootstocks and scape-like stems. Leaves alternate, mostly basal, only one on the lower part of the stem; blades reniform to orbicular in outline, shallowly lobed and often coarsely toothed, cordate at the base, long-petioled. Flowers in panicled cymes. Hypanthium campanulate, longer than the calyx. Sepals 5, erect. Corolla white or whitish, regular. Petals 5, persistent, clawed. Stamens 5; filaments subulate. Ovary fully half-inferior, the carpels united up to the beaks. Follicles erect, well included in the drooping hypanthium. Seeds winged.

1. S. Hapemanii (Coult. \& Fisch.) Coulter. Stems 1-2 dm. tall, sparingly glandular-pubescent; leaf-blades reniform or orbicular-reniform, $2-8.5 \mathrm{~cm}$. in diameter, rather shallowly lobed, the lobes coarsely toothed; sepals ovate or oblong-ovate, $1.5-2 \mathrm{~mm}$. long; petals $3 \mathrm{~mm}$. long; follicles $4-5 \mathrm{~mm}$. long. Heuchera Hapemanii Coult. \& Fisch. Boykinia Purpusii Brand. Therofon Purpusii Heller. S. halmicola A. Nels. Rocky places: Wis.-Minn.-Wyo,-Colo.
Mont. J1.

\section{THERROPHON Raf.}

Glandular-pubescent perennial herbs, with scaly rootstocks. Flowers perfect, paniculate, on leafy lateral shoots. Leaf-blades reniform, variously cleft or lobed; stipules usually present. Hypanthium adnate to the lower half of the ovary. Sepals 5, lanceolate or ovate-lanceolate. Petals 5, white, obovate or spatulate, of ten short-clawed. Stamens 5, with short filaments, opposite to the sepals. Ovary and capsule usually 2-celled, opening between the beaks; styles 2 , distinct and in fruit forming two divergent beaks. Placentae axial; seeds numerous, with a shining minutely punctate testa. [Boykinia Nutt., not Raf.] 
1. T. majus (A. Gray) Wheelock. Stems 3-10 dm. high, more or less glandular-villous with brown hairs; leaf-blades reniform in outline, glabrous, except the veins beneath, $5-15 \mathrm{~cm}$, in diameter, 7-cleft about half way down, again cleft and coarsely serrate; middle stem-leaves with large foliaceous stipules; hypanthium campanulate, 2-3 mm. long, glandular-puberulent; sepals lanceolate, $3 \mathrm{~mm}$. long; petals white, 5-7 mm. long. B. occidentalis elata A. Gray. B. major A. Gray. Woods: Mont.-Ida.-Wash.-s Calif. Mont. Je-S.

\section{TELESÒNIX Raf.}

Low glandular-pubescent perennials, with thick scaly rootstocks. Leafblades reniform, deeply and doubly crenate. Flowers in a contracted, leafy, somewhat secund panicle. Hypanthium turbinate-campanulate, adnate to the lower half of the ovary. Sepals 5, ovate-lanceolate. Petals 5, red or purple, with long claws. Stamens 10; filaments subulate. Ovary 3-celled; styles more or less united. Fruit dehiscent between the beaks, which are not divergent. Seeds numerous.

Petals twice as long as the sepals; blades almost orbicular; beaks of the pistils united almost to the top.

Petals equalling or slightly exceeding the sepals; blades obovate-spatulate; beaks of the pistils united halfway up.

2. T. heucheriformis.

1. T. Jamesii (Torr.) Raf. Stems usually less than $1 \mathrm{dm}$. high, glandularpubescent; leaf-blades round-reniform, deeply and doubly crenate, $2-3.5 \mathrm{~cm}$. wide, or the upper ones flabellate-cuneate, with winged petioles, or subsessile; hypanthium $8 \mathrm{~mm}$. long; sepals ovate-lanceolate, 4-5 mm. long; petals reddish purple. Saxifraga Jamesii Torr. Boykinia Jamesii Engler. Among rocks: Colo. Mont.-Alp. Jl.

2. T. heucheriformis Rydb. Closely resembling the preceding; stem 1-2 $\mathrm{dm}$. high; hypanthium usually smaller, 6-7 mm. long, more hirsute; petals dark violet. Boykinia heucheriformis A. Nels. Rocky mountain sides: Alta.-B.C. -(Black Hills) S.D.-Wyo. Mont.-Subalp. Jl-S.

\section{SAXÍFRAGA (Tourn.) L. SAXIFrage.}

Perennial caulescent herbs, from a small rootstock. Leaves alternate, not crowded, but sometimes tufted at the base of the plants; blades more or less 3lobed, or in diminutive plants nearly entire, mostly petioled. Flowers solitary or in terminal cymes. Hypanthium turbinate or campanulate, longer than the calyx, at least at maturity. Sepals 5, erect, usually with a terminal gland. Petals 5, white, somewhat narrowed at the base, but usually clawless. Stamens 10 ; filaments subulate. Ovary about half-inferior, the carpels united to above the middle. Follicles well united, erect except the more or less spreading tips.

Flowers normal, none of them represented by clusters of bulblets.

Petals not abruptly narrowed into claws; leaf-blades thick, the lower ones mainly.

3-lobed.
Petals abruptly narrowed into claws; leaf-blades thin, the lower ones 5 - S-lobed.

Flowers below the terminal one replaced by clusters of bulblets.

2. S. debilis.

Lobes of the stem-leaves linear to triangular-lanceolate; petals cuneate.

Lobes of the 3 . S. cernua. shaped.
4 . S. Simulata.

1. S. rivularis L. Stems $3-8.5 \mathrm{~cm}$. tall, tufted, glabrous or finely glandularpubescent; leaf-blades reniform in outline, $3.5-12 \mathrm{~mm}$. broad, thick; those of the stem-leaves sometimes entire; hypanthium 2-3.5 mm. long at maturity; sepals ovate, $1.5-2.5 \mathrm{~mm}$. long, obtuse; petals oblong, 3-5 mm. long. Wet places: Greenl.-N.H.-Wyo.-B.C.-Alaska; Eurasia. Alp.-Subalp.

2. S. debilis Engelm. Stems $3-14,5 \mathrm{~cm}$. tall, loosely tufted, glabrous or nearly so; leaf-blades suborbicular or reniform in outline, 6-17 $\mathrm{mm}$. wide, thin, mainly 5-lobed; hypanthium 3-4.5 mm. long at maturity; sepals ovate, $1.5-2$ $\mathrm{mm}$. long, obtuse; petals cuneate to oblong, 3-7 mm. long. Wet rocks: Mont.Wyo.-Colo.-Utah. Mont.-Alp. Je-Au. 
3. S. cernua L. Stems $8-19 \mathrm{~cm}$. tall, somewhat glandular-pubescent; leafblades reniform in outline, 9-23 $\mathrm{mm}$. wide, prominently 5 -7-lobed, the lobes linear to triangular-lanceolate; upper stem-leaves with 3-5-lobed blades; hypanthium $3.5-5 \mathrm{~mm}$. long at maturity; sepals oblong to oblong-lanceolate, $3-4.5$ $\mathrm{mm}$. long; petals cuneate, $6-8 \mathrm{~mm}$. long. Wet rocks: Greenl.-Lab. - N.M.Utah-Alaska; Eurasia. Alp.-Subalp, Je-Jl.

4. S. simulata Small. Stems 9-22 cm. tall, sparingly glandular-pubescent; leaf-blades reniform or orbicular-reniform in outline, $8-21 \mathrm{~mm}$. wide, 5-7-lobed, the lobes much broader than long; upper stem-leaves with 3-5-lobed blades; sepals oblong-ovate, $3-3.5 \mathrm{~mm}$. long; petals fiddle-shaped, $6-7 \mathrm{~mm}$. long. Wet rocks: Black Hills, S.D.-Colo. Mont.-Alp. Jl.

\section{MUSCÀria Haw. Saxifrage,}

Perennial caulescent matted herbs, with copiously leafy caudices and sparingly leafy flower-stalks. Leaves alternate; blades 3-lobed, or rarely 5-7-lobed, narrowed at the base. Flowers solitary or few in terminal cymes. Hypanthium turbinate or campanulate, longer than the calyx, at least at maturity. Sepals 5, erect. Corolla white, regular. Petals 5, relatively broad, clawless. Stamens 10; filaments subulate. Ovary about one-half inferior, the carpels united to above the middle. Follicles erect, the tips sometimes slightly spreading.

Leaves of the caudex with entire or slightly 3 -toothed blades.

Leaves of the caudex with 3 -cleft or prominently 3 -lobed blades.
Petals less than $2 \mathrm{~mm}$. long.

Petals over $2 \mathrm{~mm}$. long.

Petals $2.5-3.5 \mathrm{~mm}$. long.

Petals $4.5-7 \mathrm{~mm}$. long. Sepals oblong-lanceolate to triangular-lanceolate;
during anthesis.

1. M, adscendens.

2. M. micropetala.

3. M, delicatula. thesis.
tly ovate to half-orbicular; hypanthium campanulate during an

1. M. adscendens (L.) Small. Plants $2.5-11 \mathrm{~cm}$. tall, somewhat glandularpubescent; leaf-blades $3-8 \mathrm{~mm}$. long, mainly cuneate to spatulate, 3 -toothed, or those on the flower stalks sometimes entire; sepals ovate or oblong-ovate, $1.5-2.5$ dens L. S. oregonensis (Raf) oblong-cuneate, $3-3.5 \mathrm{~mm}$. long. Saxifraga adscenB.C.; Eu. Alp.-Mont. J-Au. A. Nels, Wet rocks: Alta.-Colo.-Utah-

2. M. micropetala Small. Plants $2-6 \mathrm{~cm}$, tall, rather copiously glandularpubescent; leaves compactly crowded on the caudices, 5-9 $\mathrm{mm}$. long, 3-lobed at the apex, the lobes linear or oblong-linear; flower stalks 1-3-flowered, each bearing 2 or 3 leaves; hypanthium about $3 \mathrm{~mm}$. long at maturity; sepals broadly micropetat $2 \mathrm{~mm}$. long; petals oval or oval-obovate, about $1.5 \mathrm{~mm}$. long. $S$. micropetala Fedde. High mountains: Wyo.-Utah. Subalp. Jl-Au.

3. M. delicatula Small. Plants $1-3.5 \mathrm{~cm}$. tall, sparingly glandular-pubescent; leaves crowded on the caudices, 5-16 mm. long, 3-lobed at the apex, the lobes lanceolate to oblong or linear; flower-stalks slender, 1-2-flowered, each bearing 1 or 2 leaves; hypanthium 2-2.5 mm. long at maturity; sepals oblong to oblong-lanceolate, $2-2.5 \mathrm{~mm}$. long, obtuse; petals oblong, 2.5-4 mm. long. Ji-Au. 4. M. monticola Small. Plants $4.5-16 \mathrm{~cm}$. tall, finely glandular-pubescent;
leaves crowded on the caudices, $7-18 \mathrm{~mm}$. long, 3-lobed at the apex, the lobes
linear to oblong-ovate, acute; flower-s. 1 to 3 leaves; hypanthium 3.5-4 flower-stalks slender, 3 -5-flowered, each bearing petals obovate, about $4-5.5-4 \mathrm{~mm}$. long at maturity; sepals $2-2.5 \mathrm{~mm}$. long; Fedde. Mountains: B.C.-Mont.-Alta. Saxifraga exarata Hook. S. monticola

\section{M. caespitosa (L.) Haw. Plants Subalp. Jl-Au.}

leaves erowded on the caudices; blades 8 5-16 $\mathrm{cm}$. tall, glandular-pubescent; lobes lanceolate or linear; flower-stalks $8-17 \mathrm{~mm}$. long, 3-lobed at the apex, the leaves; hypanthium 3.5-4.5 mm. long at maturity; 3 -fered, each bearing 2 or 3 narrowly obovate or oblong-obovate, $5-7$ turity; sepals $2-3.5 \mathrm{~mm}$. long; petals 
High mountains: Greenl.-Lab.-Que.-B.C.-Alaska; Eu. Alp.-Subalp. $\mathrm{Je}-\mathrm{Au}$.

\section{CHONDRÒSEA Haw.}

Perennial caulescent herbs, with a densely leafy short caudex and offsets, and sparingly leafy flower-stalks. Leaves alternate; blades serrate, each tooth terminating in an encrusted pore. Flowers in terminal compound cymes. Hypanthium turbinate to campanulate, at maturity longer than the calyx. Sepals 5, erect. Corolla white, regular. Petals 5, clawless. Stamens 10; filaments lanceolate or lanceolate-subulate. Ovary about half-inferior, the carpels united to above the middle. Follicles united to the spreading tips.

1. C. Aizoon (Jacq.) Haw. Stems 1-4 dm. tall; basal leaves linear-oblong to spatulate, $1.5-4 \mathrm{~cm}$. long; stem-leaves few, remote, more abruptly broadened than those on the caudex; sepals ovate, $1.5-2 \mathrm{~mm}$. long; petals oval, oval-obovate or oval-oblong, 3.5-4 mm. long, sessile. Saxifraga Aizoon Jaeq. Wet rocks: Lab.-N.S.-Vt.-Sask.; Eurasia. Boreal-Subarctic. Je-Jl.

\section{MICRĀNTHes Haw. SAXIfrage.}

Perennial acaulescent herbs, with very short caudices and solitary or tufted scapes, sometimes bulblet-bearing at the base. Leaves basal; blades fleshy, entire or toothed. Flowers in terminal cymes disposed in narrow or broad panicles. Hypanthium rather flat, shorter than the calyx. Sepals 5, erect or reflexed. Corolla essentially regular. Petals 5, mostly white. Stamens 10 . Ovary slightly inferior, the carpels partially united, often only at the base. Follicles spreading or with spreading tips.

Filaments subulate or filiform-subulate, or sometimes narrowly linear.

Cymules wholly or mainly aggregate into a head or spike, 1 or 2 lower ones sometimes remote or peduncled.

Petals shorter than the sepals or about equalling them.

Lower cymules sessile; petals about equalling the sepals.

Lower cymules peduncled; petals shorter than the sepals. Petals obovate to oval or orbicular-oval.

Petals oblong to cuneate.

Petals larger than the sepals.

Sepals ovate to triangular.

Sepals oval, rounded at the apex.

Cymules in narrow pyramidal panicles.

Corolla present.

Petals white.

Leaves with blades narrowed into petiole-like bases. $\quad 6$. M. Greenei.

Leaves without petiole-like bases.

Panicle wide; peduncles of the lower cymules elongate. Petals with claw-like bases. Petals without claw-like bases.

1. M. Rydbergii.

2. M. crenatifolia.

3. M. columbiana.

4. M. rhomboidea.

5. M. austrina.

7. M. arnoglossa.

8. M. oregana.

Panicle narrow: peduncles permanently very short. 9. M. brachypus. Petals greenish.

Corolla wanting or obsolete.

Filaments clavate or spatulate.

Leaf-blades flabellate.

Leaf-blades ovate, oval, broadly oblong, or orbicular,

Leaf-blades narrowed at the base, neither cordate nor of an orbicular type. Cymules permanently compact. Cymules lax and open.

Leaf-blades orbicular or nearly so.

Petals with elliptic-oblong or ovate blades, the claws stout. 15. M. aestivalis. Petals with suborbicular or reniform blades, the claws slender.

16. $M$, arguta.

1. M. Rydbergii Small. Leaves spreading, 2-4 cm. long, oblong to ovate, obtuse, undulate or repand-dentate, glabrous or nearly so, paler beneath; scapes solitary, erect, $5-10 \mathrm{~cm}$. tall, purplish, glandular-puberulent; sepals ovate or triangular-ovate; petals oblong-oval, 1-1.5 mm. long. Saxifraga Rydbergii Small. Mountain summit: Mont. Alp. Au.

2. M. crenatifolia Small. Leaves spreading, $2-3 \mathrm{~cm}$. long, obovate, cuneate or orbicular-flabellate, coarsely crenate, glabrous or nearly so; scapes erect, about $15 \mathrm{~cm}$. tall, closely glandular-pubescent; sepals deltoid or ovatedeltoid, obtuse; petals about $1.5 \mathrm{~mm}$. long, rounded at the apex. S. crenatifolia Fedde. High mountains: Mont.-B.C. Mont. My-Jl. 
3. M. columbiana (Piper) Small. Leaves $2-10 \mathrm{~cm}$. long, oblong to elliptic, varying to ovate, shallowly undulate or denticulate, glabrous or nearly so on both sides; scapes erect, 1-3.5 dm. tall, rather copiously glandular-pubescent throughout; sepals ovate to oblong; petals $1.4-2 \mathrm{~mm}$. long. S. columbiana Piper. Slopes: Wash.-Ida.-Mont.-Ore. Submont. Ap-Je.

4. M. rhomboidea (Greene) Small. Leaves $2-6 \mathrm{~cm}$. long, ovate or rhombicovate, sometimes oblong-ovate, obtuse, crenate or dentate-serrate, nearly glabrous except the ciliate margins; scapes erect, $8-30 \mathrm{~cm}$. high, glandular-pubescent; sepals ovate to triangular, $1.5-3.5 \mathrm{~mm}$. long; petals white, obovater to oblong-obovate, $2.5-4 \mathrm{~mm}$. long, commonly notched at the apex. S. nivalis Am, auth., not L. S. rhomboidea Greene. Among rocks: Mont.-Wyo.-N. MJ
Mont.-Alp. My-Au.

5. M. austrina (A. Nels.) Rydb. Leaf-blades $3-5 \mathrm{~cm}$. long, ovate, elliptice, or rhomboid-ovate, crenate or entire; scape $1-3 \mathrm{dm}$. high, glandular-pubescent; obovate, $2-3 \mathrm{~mm}$. long; tips of the follicles strongly divaricate. S. austrina A. Nels. Damp soil: Colo. Mont. Je-Jl.

6. M. Greenei Blankinship. Leaves $2-6 \mathrm{~cm}$. long, ovate to oblong-ovate, or oval-oblong, crenate, obtuse at the apex, ciliolate or sometimes almost glabrous; scapes erect, solitary, glandular-pubescent throughout; sepals 1-2 mm. long, reflexed, ovate; petals white, $2-3 \mathrm{~mm}$. long, ovate, oval, or obovate. High
mountains: Mont.-Utah-Nev. Mont. Je-Jl.

7. M. arnoglossa (Greene) Small. Leaves 6-19 cm. long, oblong to elliptic, sometimes narrowly so, remotely glandular-denticulate, ciliolate; scapes erect, $30-70 \mathrm{~cm}$. tall, stout, glandular-pubescent, rather widely paniculate above; sepals broadly ovate to deltoid, $1.5-3 \mathrm{~mm}$. long, eciliate; petals white, mainly oblong to elliptic, $3-3.5 \mathrm{~mm}$. long. S. arnoglossa Greene. Hills and mountains: Mont.-Ida.-Colo. Submont.-Subalp. Je-Au.

8. M. oregana (Howell) Small. Leaves $3-11 \mathrm{~cm}$. long, oblong or elliptic, crenulate or minutely glandular-denticulate, glabrous except the ciliolate margins; scape $3-10 \mathrm{dm}$. high, densely glandular-pubescent, paniculate aboye; sepals ovate to semi-orbicular, about $2 \mathrm{~mm}$. long; petals white, oval, $-3.5-4 \mathrm{~mm}$. long, clawless. S. oregana Howell. Wet places: Wash.-Ida.-Calif. Sub-
mont. My-Jl.

9. M. brachypus Small. Leaves spreading, $6-13 \mathrm{~cm}$. long, oblong to elliptic, remotely glandular-denticulate, the margins ciliolate; scapes solitary, eciliate; petals white, oblong or nearly eeiliate; petals white, oblong or nearly so, $3-3.5 \mathrm{~mm}$. long, clawless. S. brachypus Fedde. High mountains: Colo.-Nev. Alp.-Subalp. Jl-Au.

10. M. montanensis Small. Leaves erect or ascending, $3.5-14 \mathrm{~cm}$. long, often ovoid-oval, narrowly oblong-lanceolate and spatulate on the same plant, entire or glandular-denticulate, often sparingly pubescent; seapes erect, stout, $25-60 \mathrm{~cm}$. tall, finely glandular-pubescent throughout, paniculate above; sepals ovate to triangular-ovate, $1-2 \mathrm{~mm}$. long; petals greenish, nearly oblong or elliptic, 1-2.5 mm. long, clawless. S. montanensis Small. Mountains: Mont. Mont. Je.

11. M. subapetala (E. Nels.) Small. Leaves $3-17 \mathrm{~cm}$. long, narrowly oblong to oblong-spatulate, the early ones relatively shorter and broader, all undulate or remotely glandular-toothed, eiliolate; scapes erect, $28-50 \mathrm{~cm}$. tall, thinly glandular-pubescent, narrowly paniculate above; sepals ovate, $1-2 \mathrm{~mm}$. long; petals wanting or minute, oval, white or red-tinged. S. subapetala E. Nels,

12. Mos: Mont.-Wyo.-Ida. Mont.-Alp. Je-Au. 12. M. Lyallii (Engler) Small. Leaves $1.5-6.5 \mathrm{~cm}$. long, flabellate, varying
to suborbicular, cuneate at the base, coarsely few-toothed above, glabrous or
nearly so, the petiole-like bases often longer then the glabrous or nearly so; ; bases often longer than the blades; scapes 8-36 em. tall, to oblong-ovate, $1.5-3 \mathrm{~mm}$. long, few-flowered, or flowers solitary; sepals ovate blotches below the middle, $3-4.5 \mathrm{~mm}$, labrous, reflexed; petals white, with 2 yellow Lyallii Engler, Along brooks: Alaska- long, broadly oblong to suborbicular $S$. 
13. M. occidentalis (S. Wats.) Small. Leaves spreading, $2-6.5 \mathrm{~cm}$. long, ovate to oblong or oval, dentate or crenate-dentate, usually minutely pubescent beneath; scapes $4-19 \mathrm{~cm}$. tall, copiously glandular-pubescent, very densely so above; sepals ovate, $1.5-2 \mathrm{~mm}$. long, obtuse, occasionally sparingly ciliolate, reflexed; petals white, $2-3.5 \mathrm{~mm}$. long, rounded at the apex, oval to oval-ovate, rather abruptly narrowed below. S. occidentalis S. Wats. Wet places and grassy slopes: Alta.-Mont. Submont.-Mont. Je-Au.

14. M. saximontana (E. Nels.) Small. Leaves spreading, $3-9 \mathrm{~cm}$. long, ovate, varying to oblong-ovate or occasionally oblong, dentate or crenate, sparingly pubescent; seapes 9-19 $\mathrm{cm}$. tall, glandular-pubescent throughout, corymbosely branched; sepals ovate to oblong-ovate, $1.5-2 \mathrm{~mm}$ long, sometimes eiliolate, reflexed; petals white, with 2 yellow blotches, $2-3 \mathrm{~mm}$ long, oval to ovate. S. saximontana E. Nels. Moist places: Mont.-Wyo.-Ida.-B.C. Mont.-Submont. My-Au.

15. M. aestivalis (Fisch. \& Mey.) Small. Leaves $4-16 \mathrm{~cm}$. long, the blades suborbicular to reniform, $2-5.5 \mathrm{~cm}$. in diameter, coarsely few-toothed, deeply cordate at the base, glabrous or nearly so; scapes mostly erect, 9-27 cm. tall, somewhat corymbosely branched; sepals oblong to oblong-ovate, $1-1.5 \mathrm{~mm}$. long, ciliate, reflexed; petals white, $3-4.5 \mathrm{~mm}$. long, mostly notched at the apex; blades elliptic-oblong or ovate. S. aestivalis Fisch. \& Mey. Along brooks and in wet places: Alaska-Alta.-Wash.; ne Siberia. Submont.-Mont. Jl.

16. M. arguta (D. Don) Small. Leaves erect or ascending, 9-28 cm. long, the blades suborbicular to orbicular-reniform, $3-9 \mathrm{~cm}$. in diameter, crenate or crenate-dentate, deeply cordate at the base, usually glabrous or nearly so; scapes 14-46 cm. tall, glabrous or somewhat glandular-pubescent near the top, paniculate above; sepals lanceolate to oblong, $1.5-2 \mathrm{~mm}$. long, sometimes glandularciliolate, reflexed; petals white, with 2 yellow blotches below the middle, $2.5-3.5$ $\mathrm{mm}$. long, the blades suborbicular or reniform. 'S. arguta D. Don. S. punctata Auth. S. denudata Nutt. Springy places: B.C.-Mont.-N.M.-Calif. Submont.-Subalp. Jl-Au.

\section{SPATULÀria Haw. Saxifrage.}

Perennial acaulescent herbs, with erect branching scapes from a caudex. Leaves basal; blades of a spatulate type, or broadest above the middle, toothed, at least near the apex, or rarely entire. Flowers in open cymes, sometimes changed into bulblets. Hypanthium much shorter than the calyx. Sepals 5, reflexed at maturity. Corolla irregular, white. Petals clawed, the three upper with ovate, lanceolate or sagittate blades, the two lower with elliptic or spatulate blades, or in species bearing a single terminal flower, this difference less pronounced. Filaments subulate. Ovary chiefly superior, the carpels united at the base or to below the middle. Follicles erect, with ascending or diverging tips.

\section{Inflorescence with bulblets.}

Plants with all the flowers represented by clusters of bulblets, or with a single flower

terminating the main axis.
Plants with many flowers and some bulblets, at least with a flower terminating each branch of the stem.

Inflorescence without bulblets.

2. S. Brunoniana.

3. S. ferruginea.

1. S. Vreelandii Small. Plant $0.6-2 \mathrm{dm}$. tall, minutely glandular-pubescent; leaves crowded on the short caudex, the blades spatulate to linear-spatulate, 1.5-6 $\mathrm{cm}$. long, sharply toothed near the apex or above the middle; scape loosely paniculate above or rarely with congested cymes; bracts similar to the leaves, but smaller. High mountains: B.C.-Mont.-Colo. Submont.-Alp. Au.

2. S. Brunoniana (Bong.) Small. Plants $1-4 \mathrm{dm}$. tall, glandular-pubescent; leaves crowded on the short caudex, the blades spatulate to oblanceolate-spatulate, $2-8 \mathrm{~cm}$. long, sharply or sometimes broadly toothed above the middle; scapes rather widely paniculate; bracts much smaller than the leaves; sepals oblong-ovate to triangular-ovate, $1-1.5 \mathrm{~mm}$. long; petals $3.5-6 \mathrm{~mm}$. long, the 3 upper with lanceolate or oblong-lanceolate blades, the 2 lower with elliptic or spatulate-elliptic blades. S. nootkana Moç. S. Bongardi Presl. Mountain sides: Alaska-B.C.-Mont.-Ore. Mont.-Subalp. Jl-S. 
3. S. ferruginea (Graham) Small. Plants 1-1.5 dm. tall, pubescent throughout with ultimately reddish hairs; leaves crowded on the short eaudex, the blades spatulate to oblanceolate, $1.5-6.5 \mathrm{em}$. long, prominently toothed above the middle, copiously pubescent; scapes corymbosely branched above; bracts much smaller than the leaves; sepals ovate, $1.5-2 \mathrm{~mm}$. long, sparingly ciliate; petals $3.5-4 \mathrm{~mm}$. long, the 3 upper with lanceolate-cordate blades, the 2 lower with Subarctic. J-Au.

\section{LEPTARRHÈNIA $\mathrm{R}, \mathrm{Br}$.}

Perennial caulescent herbs, with short leafy caudices. Leaves alternate, with leathery toothed blades narrowed into short petioles. Flowers in thyrsoidpaniculate cymes. Hypanthium flattened. Sepals 5, erect. Corolla regular, Petals white, persistent. Stamens 10; filaments subulate. Ovary slightly inferior; carpels almost distinct. Follicles erect, with slightly spreading tips.

1. L. pyrolifolia (D. Don.) R. Br. Caudex horizontal, clothed with dried leaf-blades; leaf-blades oblong, 3-9 cm. long, obtuse, serrate, deep green and shining above, pale beneath; floral stalks $1-5 \mathrm{dm}$. high, with 1 or 2 clasping leaves; sepals ovate, as long as the hypanthium, each with an apical gland and $\mathrm{mm}$. long. mm. long. Wet places: Alaska-Mont.-Wash. Alp.-Subalp. Je-Au.

\section{Leptásea Haw. Yfllow Saxifrage, Spotted Saxifrage.}

Perennial matted caulescent herbs, with copiously leafy caudices and offsets. Leaves alternate, fleshy or parchment-like; blades entire, ciliate or rarely with 3 pound cymes. Hypanthium solitary or in terminal simple or comoften spreading or reflexed small, much shorter than the calyx. Sepals 5, claws. Stamens 10; filaments mostly superior, the carpels united to (in all ours) or club-shaped. Ovary spreading tips.

Leaf-blades not spine-tipped at the a pex, more or less ciliate.
Petals suborbicular or oval, $5.5-7 \mathrm{~mm}$

cliw; plant less than $6 \mathrm{~cm}$. high.

Petals elliptic to oblong, 9-13 mm. long, clawless; plant more 1. L. chrysantha.

plant more than $6 \mathrm{~cm}$. high.

Petals oblong, oblong-lanceolate,

2. L. Hirculus.

Leaf-blades entire,

Leaf-blades not ciliate, single spine at the apex. caudices.

larger leaves than the -blades ciliate, parchment-like; flower-stalks bearing 3, L. Van-Bruntiae.

the caudices.

Leaf-blades 3 -toothed at the apex, the teeth spine-tipped.
Petals broadly obovate; plants with runners produstromonta
5. Luspidata.

6. L. flagillaris.

long, thick, spatulate, (A. Gray) Small. Leaves of the caudices $4.5-10 \mathrm{~mm}$. sparingly glandular-pubescent, bearing few glabrous leaves; sepals ovate or yellow. Saxifraga chrysantha A. Glandular-ciliate, obtuse; petals goldenAlp.-Subalp. Jl-Au.

2. L. Hirculus (L.) Small. Leaves of the caudices 9-41 mm. long; blades flat, elliptic or elliptic-spatulate, glabrous, obtuse, often long-petioled; flowerstalks 6-30 cm. tall, more or less pubescent, mostly 1-flowered; sepals oblong to petals yellow. S. Hirculus L. copiously ciliate, obtuse, reflexed at maturity; Eu. Alp.-Subalp. J1-Au. I. In wet places: Greenl.-Colo.-B.C.-Alaska;

3. L. Van-Bruntiae Small. Leaves of the caudices $3.5-8.5 \mathrm{~mm}$. long, the stades very thick, flattish, glabrous or sparingly ciliate, spine-tipped; flowerstalks 4-9 cm. tall, finely glandular-pubescent; sepals ovate to oblong-ovate, 
3-3.5 mm. long, glabrous; petals deep yellow, oblong, 4-4.5 mm. long, more or less erose at the apex. S. Van-Bruntiae Small. Along mountain streams: Alta. -B.C. Mont. Jl-S.

4. L. austromontana (Wiegand) Small. Leaves of the caudices 7-14 $\mathrm{mm}$. long, parchment-like, crowded, but more or less spreading, the blades narrowly lanceolate to subulate, slenderly spine-tipped, ciliate; flower-stalks 8-15 cm. tall, glabrate or finely glandular-pubescent; sepals ovate, $1.5-3 \mathrm{~mm}$. long, glabrous or sparingly ciliate, obtuse; petals white, often yellow-spotted, oblong to oblonglanceolate, 5-6.5 mm. long. Saxifraga bronchialis Am. auth. S. austromontana Wiegand. S. cognata E. Nels. On rocks: Alta.-B.C.-Wash.-Utah-N.M. Submont.-Alp. Je-S.

5. L. tricuspidata (Retz.) Haw. Leaves of the caudices 7.5-21 mm. long, parchment-like, crowded, spreading, the blades linear to cuneate-linear, 3-toothed, ciliate; flower-stalks $5.5-18 \mathrm{~cm}$. tall, sometimes sparingly glandular-pubescent, sepals ovate, $1.5-3 \mathrm{~mm}$. long, obtuse, ciliate; petals white, oblong-elliptic to oval; 6-7 mm. long. S. tricuspidata Retz. Aretic regions or high mountains: Greenl. -Iab.-Mich.-Alta.-Alaska. Arctic-Alp. Jl-Au.

6. L. flagellaris (Willd.) Small. Leaves of the caudices 7-16 $\mathrm{mm}$. long, crowded, more or less spreading, some of them subtending slender arching offsets, the blades cuneate, oblong-cuneate or spatulate, spine-tipped, glandularciliate; flower-stalks 4-15 cm. tall, glandular-pubescent, 1-few-flowered; sepals ovate or oblong-ovate, 4-5.5 mm. long, glandular-ciliate, obtuse; petals yellow, cuneate or obovate, $6.5-9 \mathrm{~mm}$. long. S. flagellaris Willd. Alpine-arctic situations: Greenl.-N.M.-Ariz.-Alaska; Eurasia. Alp.—Subalp. Jl-Au.

\section{HETERÍSIA Raf.}

Perennial caulescent herb with a short caudex. Leaves alternate, but approximate, mostly near the base, with thin membranous stipules; blades somewhat fleshy, palmately lobed; lobes 3-toothed. Flowers in open cymes, often replaced by bulblets. Hypanthium flat. Sepals 5, ovate to oblong, strongly reflexed. Corolla white, regular; petals 5 , ovate with a narrow claw. Stamens 10; filaments clavate. Ovary slightly inferior, the carpels united below the middle. Fruit nodding, the tips of the follicles spreading or slightly recurved.

1. H. Mertensiana (Bong.) Small. Leaves $4.5-21 \mathrm{~cm}$. long, the blades suborbicular to reniform, deeply cordate at the base, glabrous, shallowly lobed, the lobes usually broadly 3-toothed; scapes 11-32 cm. tall, sparingly pubescent, bright green, paniculately branched; cymules mainly reduced to bulblets along the slender peduncles, terminating in a single flower; sepals oblong to oblongovate, 2-3 mm. long, sometimes glandular-ciliolate, usually glabrous, reflexed; petals white, 3-4 mm. long. Saxifraga Mertensiana Bong. S. heterantha Hook. Mountains: Alaska-Alta.-Mont.-Ida.-Calif. Mont. My-Jl.

\section{ANTIPhýllla Haw. Purple or Mountain Saxifrage.}

Perennial caulescent densely matted herbs, with copiously leafy stems and sterile branches, and naked or sparingly leafy flower-stalks. Leaves opposite, except sometimes on the flower-stalks, often 4-ranked, imbricate; blades relatively broad, conspicuously ciliate, mostly with an almost apical pore, keeled, sessile. Flowers solitary, erect. Hypanthium shorter than the calyx. Sepals 5 , strongly ciliate. Corolla regular; petals 5 , blue or purple, much longer than the sepals, narrowed into claw-like bases. Filaments subulate to triangular. Ovary more than half superior, the carpels united to above the middle. Follicles erect, with more or less spreading tips.

1. A. oppositifolia (L.) Fourr. Plants in dense mats; leaves densely imbricate, 4-ranked, the blades obovate to spatulate, 3-5 $\mathrm{mm}$. long, ciliate, keeled; flower-stalks 1-3 cm. long, leafy; sepals oblong to ovate, $2.5-3 \mathrm{~mm}$. long, ciliate all around; petals elliptic to oval, 8-9 mm. long. Saxifraga oppositifolia L. Rocks and stony places: Greenl.-Vt.-Wyo.-B.C.-Alaska; Eurasia. Mont. $-A l p$. Je-Au. 


\section{Family 58. hydRANGEACEAE. Hydrangea Family.}

Shrubs or trees, or rarely vines. Leaves opposite, without stipules. Flowers commonly perfect, in cymes. Hypanthium well developed, usually ribbed. Sepals 4-10. Petals as many. Stamens from 8 to many. Gynoecium of $2-5$, rarely 10 , united carpels. Ovary partly or wholly inferior; styles distinct or united, sometimes wanting. Fruit a capsule.

Cansule obovoid or obconic, the beaks rising abruptly from the body.

Capsule conic or ovoid, the beaks tapering gradually from the body.

Filaments and anthers unappendaged; sepals and petals 5. Leaf-blades toothed; hypanthium short during anthesis. Leaf-blades entire; hypanthium long during anthesis.

Filaments appendaged under the anthers; anthers appendaged at the top: sepals and petals 4 .

\section{Philladelphus.}

\section{PhiladéllphuS L. Mock Orange, Syrtnga.}

Branching shrubs. Leaves toothed or entire. Flowers perfect, borne at the ends of short leafy branches, solitary or in cymes. Sepals 4 , rarely 5 , valvate, persistent, more or less tomentose within. Petals 4 , rarely 5 , convolute, white or ochroleucous. Stamens usually many, 25-60; filaments flat,-subulate, free or more or less united below; anthers short, didymous. Ovary at least two-thirds inferior and adnate to the hypanthium, 4-celled; styles elongate, distinct or more or less united; stigmas distinct or more or less united. Ovules numerous, pendulous. Capsule more or less woody, loculicidal, the septa separating in the center. Seeds numerous; coat reticulate; albumen fleshy.

Leaf-blades thin, not leathery, usually toothed or denticulate, more than $3 \mathrm{~cm}$. long: flowers several.

Petals ovate-lanceolate, acute or obtuse at the apex.

Petals oblong to rounded-oval; rounded at the apex.

1. P. Helleri

Leaf-blades 3-5-ribbed, the lateral ribs or if 5 -ribbed the second or stronger pair meeting the midrib some distance from the base of the blade.

Bark of the second season red or chestnut-brown, with conspicuous crosscracks, at last peeling off.

2. P. Lewisii.

Bark of the second season gray or yellowish, neither cross-cracked nor peeling off.

Leaf-blades 5-ribbed, all ribs originating at the base of the blade.

Leaf-blades small, $0.5-2 \mathrm{~cm}$. long, entire; flowers mostly solitary.

Hypanthium 4-5 mm. high.

Hypanthium about $2 \mathrm{~mm}$. high, or in fruit 3-4 $\mathrm{mm}$. high.

Styles wholly united or nearly so; stigmas sometimes also partly united.

Styles distinct for at least half their length; stigmas distinct,

4. P. Gordonianus.

5. P. microphyllus.

6. $P$. occidentalis.

7. P. minutus.

1. P. Helleri Rydb. Shrub $2-3 \mathrm{~m}$. high, with ascending branches; bark of the young branches brownish, glabrous, and of the second year yellowish or gray, not exfoliating; leaf-blades ovate or lance-ovate, denticulate or rarely entire, 4-7 cm. long, glabrous, or sparingly hairy along the veins beneath; flowers 5-11, falsely racemose; sepals $7-8 \mathrm{~mm}$. long, short-acuminate; petals white, $15-18 \mathrm{~mm}$. long; styles united to near the apex. Hills: Ida. Submont. Jl.

2. P. Lewisii Pursh. Shrub 1-2 m, high, with ascending branches; bark of the young twigs red, glabrous; leaf-blades ovate-lanceolate or ovate, glabrous above, hairy on the veins and in their axils beneath, entire or denticulate; sepals lance-ovate, abruptly acuminate; petals white, $10-15 \mathrm{~mm}$. long; styles united half their length; capsule about $1 \mathrm{~cm}$. long. (?) $P$. intermedius A. Nels. River banks and hills: B.C.-Mont.-Ida.-Ore. Submont.-Mont. My-Ji.

3. P. columbianus Koehne. Shrub $2-3 \mathrm{~m}$. high, with ascending branches; bark of the young twigs mostly yellowish, glabrous or pubescent; leaf-blades lanceolate to ovate, more or less acuminate, denticulate or entire, more or less hairy on both sides; flowers 3-9, falsely racemose; sepals lance-ovate, acuminate; petals white, $15-20 \mathrm{~mm}$. long; styles united half their length; capsule about 12 $\mathrm{mm}$. long, somewhat 4-angled below. River banks and copses: B.C.-Ida.Calif. Submont. My-Jl. 
4. P. Gordonianus Lindl. Shrub $2-4 \mathrm{~m}$. high, with ascending branches; bark of the young twigs red or chestnut, at first slightly pubescent, that of the second year grayish, not exfoliating; leaf-blades ovate, more or less acuminate at the apex, rounded or subcordate at the base, usually coarsely dentate, more or less pubescent on both sides; sepals lance-ovate, abruptly acuminate; petals white, $15-20 \mathrm{~mm}$.long; styles usually united to near the apex; capsule $8-10 \mathrm{~mm}$. long, abruptly contracted below. Hills and along streams: B.C.-Ida.-Calif. Submont. My-Jl.

5. P. microphyllus A. Gray. Shrub 5-15 dm. high, with ascending branches; bark of the young twigs brown, strigose, exfoliating the second year; leaf-blades oblong or oblong-lanceolate, entire, leathery, 1-3 cm. long, shining and glabrous or strigose above, pale and strigose beneath; sepals ovate, $5-6 \mathrm{~mm}$. long, glabrous or strigose without; petals white, about $15 \mathrm{~mm}$. long, obovate; stamens about 40; styles united; stigmas oblong, often more or less united; capsule about $8 \mathrm{~mm}$. long. Dry hills and among cliffs: N.M.-Colo.-Ariz. Submont. Je-J.

6. P. occidentalis A. Nels. Shrub $5-10 \mathrm{dm}$. high, with spreading branches; bark of the young twigs brown, hirsute-strigose, exfoliating the second year; leaf-blades oblong or elliptic-ovate, entire, 1-2 cm. long, strigose on both sides, paler beneath, less shining than in the related species; hypanthium strigose; sepals ovate, usually acute; capsule 6-7 $\mathrm{mm}$. long. Cañons and hillsides: Utah-Wyo.-Colo, Submont. Jl-Au.

7. P. minutus Rydb. Shrub about $1 \mathrm{~m}$. high, with divergent branches; bark of the twigs brown and finely strigose, exfoliating the second year; leafblades oblong, 8-18 $\mathrm{mm}$. long, leathery, densely hirsute-strigose beneath, slightly so or glabrous and shining above; hypanthium strigose or rarely glabrate; sepals about $5 \mathrm{~mm}$. long, ovate; petals obovate, $10-12 \mathrm{~mm}$. long. P. nitidus A. Nels. Cañons: Colo.-Utah. Son.-Submont. Je.

\section{EDWÍNIA Heller.}

Shrubs, with erect terete branches; bark exfoliating. Leaves opposite, toothed, pubescent at least beneath. Flowers perfect, cymose, rather large. Hypanthium turbinate, becoming hemispheric. Sepals 5. Petals 5, convolute, with a clawlike base, white, pubescent within. Stamens 10; filaments narrow, subulate; anther didymous. Ovary conic, partially 3-5-celled; styles 3-5, distinct; stigmas terminal. Ovules numerous. Capsule half-inferior, with a rounded base, 3-5valved; beaks slender. [Jamesia T. \& G., not Raf.]

Sepals slightly longer than the hypanthium at maturity.

Sepals several times longer than the hypanthium at maturity.

1. E. americana.

2. E. macrocalyx.

1. E. americana (T. \& G.) Heller. Shrub 0.5-2 m. high; bark of young twigs brown, pubescent; leaf-blades oval or suborbicular, $1.5-6 \mathrm{~cm}$. long, serrate, finely pale- or white-tomentose beneath; hypanthium during anthesis turbinate, becoming 2-3 mm. long; sepals acute, becoming $2-3 \mathrm{~mm}$. long; petals cuneate; body of capsule 4-4.5 mm. long, rounded at the base. Jamesia americana T. \& G. Cliffs: N.M.-Wyo.-Utah. Submont.-Mont. My-Jl.

2. E. macrocalyx Small. Shrub less than $1.5 \mathrm{~m}$. high; young twigs finely pubescent, pale red; leaf-blades oval or ovate, $1-2.5 \mathrm{~cm}$. long, serrate, palestrigose beneath; hypanthium flattish in anthesis, becoming 3-3.5 $\mathrm{mm}$. long and turbinate-campanulate in fruit; sepals acute, becoming 5-6 mm. long; petals white, obovate; body of capsule 4-5 mm. long, narrowly turbinate at the base. Cliffs: Utah. Mont.-Subalp. Au.

\section{FENDLERÉLLA Heller.}

Shrubs low and depressed, with somewhat shreddy bark. Leaves opposite, entire, nearly sessile. Flowers perfect, small, in compound eymes. Hypanthium turbinate-campanulate, becoming turbinate. Sepals and petals 5 , the latter white, narrowed into broad claws, entire. Stamens 10, alternately longer and shorter; filaments subulate; anthers didymous. Ovary conic, 3-celled; styles 3, distinet; stigmas slightly introrse. Ovules several in each eavity. Capsule 
half-inferior, narrowed at both ends, 3-valved, septicidal. Seeds solitary in each cavity.

1. F. utahensis (S. Wats.) Heller. A diffuse shrub, usually less than a meter high; branches, leaves, and young parts strigillose; leaf-blades oblong or elliptic to oblong-spatulate, 6-16 mm. long; hypanthium pubescent; sepals lanceolate, 1-1.5 mm. long, ciliate; petals oblong or elliptic, 3-4 mm. long; body of eapsule $4 \mathrm{~mm}$. long. Cañons and eliffs: Utah-Nev.-Ariz. Submont.Mont. Jl.

4. FÉNDLERA Engelm. \& Gray.

Shrubs, with exfoliating bark, becoming striate. Leaves opposite, deciduous, entire, 3-ribbed, sessile or nearly so. Flowers solitary or 2 or 3 together, perfect, rather large. Hypanthium turbinate, 8-ribbed. Sepals 4, valvate. Petals 4, white, clawed, with ovate-deltoid, erose blades. Stamens 8; filaments flattened, with 2 narrow appendages; connective prolonged beyond the anthers, which are slightly elongate. Ovary 4-celled; styles 4, distinct; stigmas minute, nearly terminal. Ovules numerous, pendulous. Capsule less than half inferior, septicidal. Seeds few in each cavity.

Hypanthium and lower surface of the leaves strigose, the upper surface hispidulous.

Hypanthium and leaves sparingly strigose or glabrous.

1. F. tomentella.

2. F. falcata.

1. F. tomentella Thornber. Shrub $1-1.5 \mathrm{~m}$. high, with reddish or strawcolored, pubescent twigs; leaves lanceolate, $1.5-3 \mathrm{~cm}$. long, dull green, strongly 3-ribbed; petals 15-20 mm. long; capsule 10-12 mm. long. F. rupicola of Fl. Colo. Among rocks: N.M.-Colo.-Utah-Ariz. Son.-Submont. Ap-Au.

2. F. falcata Thornber. Shrub $1.5-2 \mathrm{~m}$. high, with reddish, glabrate twigs; leaves $1.5-4 \mathrm{~cm}$. long, lanceolate, often narrowly so, revolute on the margins; pedicels and hypanthium glabrous or sparingly strigose and glabrate; petals 17-22 mm. long; eapsule 11-16 mm. long. Mountains: N.M.-Colo. Son.-Mont. My-Jl.

\section{Family 59. GROSSUlariaceae. Gooseberry Family.}

Shrubs, with palmately veined leaf-blades; stipules none or adnate to the petioles. Inflorescence racemose. Flowers regular, perfect. Hypanthium more or less developed, from saucer-shaped to tubular. Sepals 5, rarely 4. Petals as many as the sepals, small. Stamens as many as and alternate with the petals, inserted in the mouth of the hypanthium. Gynoecium of 2 united carpels; ovary 1-celled, with 2 parietal placentae, inferior; styles 2. Fruit a pulpy berry.

Leaf-blades plicate (folded like a fan) in vernation; flowers regular; style not inclined.

Plant armed with nodal spines and usually also bristly.

Pedicels not jointed near the flowers; bractlets if present enclosed in the bract; hypanthium-tube well developed, deeply campanulate to cylindric.

1. Grossuliaria.

Pedicels jointed below the short stipe-like base of the flower, bearing the bractlets. just below the node; hypanthium-tube short, saucer-shaped. Plant unarmed; pediceis jointed just under the flowers; bractlets if present borne
just under the node. Leaf-blades convolute (rolled in) in vernation; flowers slightly irregular; styles somewhat
declined.

4. CHRYsobotrya.

\section{Grossulària (Tourn.) Mill. Gooseberries.}

Shrubs, normally armed with simple or 3-forked nodal spines. Leaves in ours rounded or reniform, or more or less pentagonal in outline, 3-5-cleft and crenate or dentate. Flowers bracteate in few-flowered racemes; pedicels not jointed. Hypanthium distinctly produced beyond the ovary; tube campanulate to cylindric. Fruit a berry, with rather tough skin, in ours smooth, only. somewhat glandular-hispid in $G$. setosa, but in species from other regions often spiny. 
Sepals white; filaments more than twice as long as the petals; style pubescent below.

Filaments and anthers glabrous; ribs of the leaves distinct to the base.

1. G. missouriensis.

Filaments and usually also the anthers hairy; ribs of the leaves united at the base on the lower surface.

2. G. nivea.

Sepals mostly green or purplish; filaments not more than twice as long as the petals.

Tube of the hypanthium externally glabrous; styles hairy towards the base.

Hy panthium-tube cylindric, usually longer than the sepals. 3. G. setosa.

Hypanthium-tube campanulate or turbinate, not longer than the sepals. Stamens equalling the petals.

Peduncles well exserted from the bud-scales; hypanthium and sepals together 8-10 $\mathrm{mm}$. long.

4. G. irrigua.

Peduncles and pedicels together scarcely longer than the bud-scales; hypanthium and calyx together 5-7 mm. long.

Stamens about twice as long as the petals.

Peduncles glabrous; bracts glabrous.

Peduncles puberulent and often glandular; bracts pubescent and glandularciliate.

5. G. oxyacanthoides.

6. G. inermis.

7. G. Purpusi.

Tube of the hypanthium pubescent; styles wholly glabrous; stamens about equalling the petals.

Length of the flowers $8 \mathrm{~mm}$. or more; tube of the hypanthium cy lindric, not shorter than the sepals.

Length of the flower $7 \mathrm{~mm}$. or less; tube of the hypanthium campanulate, shorter than the sepals.

1. G. missouriensis (Nutt.) Cov. \& Britt. A shrub 1-2 m. high, with glabrous branches; spines reddish brown, 1-2 $\mathrm{cm}$. long, straight; leaf-blades 2-6 $\mathrm{cm}$. broad, thin, sparingly pubescent or glabrous above, densely pubescent beneath; peduncles slender, longer than the petioles; hypanthium cylindric, pubescent, about $2.5 \mathrm{~mm}$. long, greenish; sepals linear, 2-3 times as long as the hypanthium, greenish white; petals much shorter than the sepals, erose; berry purple or brownish, about $1 \mathrm{~cm}$. in diameter. Ribes missouriense Nutt. River banks: Ill.-Tenn.-Kans.-S.D. Plain. Ap-Je.

2. G. nivea (Lindl.) Spach. A shrub 1-3 m. high; branches glabrous, reddish or brown; spines 1-3, stout, brown, 1-2 cm. long; leaves sparingly pubescent or glabrate; peduncles nodding, shorter than the leaves; hypanthium campanulate, white, about $2 \mathrm{~mm}$. long; sepals white, narrowly lanceolate, 6-8 $\mathrm{mm}$. long; petals white, cuneate, erose; berry glabrous, bluish black, about $8 \mathrm{~mm}$. thick. R. niveum Lindl. River banks: Wash.-Ida.-Nev.-Ore. Son.-Submont. Ap-My.

3. G. setosa (Lindl.) Cov. \& Britt. A shrub, usually less than $1 \mathrm{~m}$. high, with bristly branches; spines subulate, usually less than $1 \mathrm{~cm}$. long; leaf-blades thin, cordate or truncate at the base, $1-4 \mathrm{~cm}$. wide, finely pubescent; peduncles shorter than the leaves; hypanthium-tube $5-8 \mathrm{~mm}$. long, about twice as long as the white sepals; petals one-half to two-thirds as long as the sepals and as long as the stamens; berry red to black, somewhat bristly or smooth, 8-12 mm. in diameter. $R$. setosum Lindl. R. saximontanum E. Nels. Plains and hills: Sask.-Neb.-Colo.-Ida.-Alta. Plain.-Submont. Ap-Je.

4. G. irrigua (Dougl.) Cov. \& Britt. A shrub 1-3 m. high; young shoots usually pubescent; spines subulate, about $1 \mathrm{~cm}$. long; leaf-blades thin, $3-7 \mathrm{~cm}$. wide, glabrous or nearly so above, pubescent and minutely glandular beneath; peduncles nodding, shorter than the leaves; hypanthium greenish, glabrous, 3-4 $\mathrm{mm}$. long; sepals greenish white, $5-8 \mathrm{~mm}$. long; petals obovate, white, about half as long as the sepals; berry smooth, globose, $7-13 \mathrm{~mm}$. in diameter. $R$. irriguum Dougl. Mountains: B.C.-Mont.-Ida.-Ore. Submont. My-Je.

5. G. oxyacanthoides (L.) Mill. A low shrub, less than $1 \mathrm{~m}$. high, usually very bristly; spines subulate, rather strong, $1 \mathrm{~cm}$. long or less; leaf-blades $2-4 \mathrm{~cm}$. broad, cordate or broadly cuneate at base, more or less pubescent, somewhat glandular; pedicels also very short; hypanthium greenish white, glabrous; sepals white, glabrous, $2.5-4 \mathrm{~mm}$. long, a little longer than the hypanthium; petals obovate, two-thirds as long as the sepals; berry smooth, about $1 \mathrm{~cm}$. in diameter. $R$. oxyacanthoides L. Copses: Hudson Bay-Mich.-Mont.-B.C.-Yukon. Boreal-Submont. My-Je.

6. G. inermis (Rydb.) Cov. \& Britt. Shrub with glabrous stem; nodal spines few, $1 \mathrm{~cm}$. long or less, or none; leaves truncate or cordate at the base, glabrous or somewhat puberulent and glandular; peduncles exserted but short, 
glabrous, 1-4-flowered; bract small and glabrous; hypanthium glabrous; tube 2.5-3.5 mm. long, a little longer than the glabrous sepals; berry red-purple, glabrous, about $8 \mathrm{~mm}$. thick. R. inerme Rydb. R. vallicola Greene, a more pubescent form. Mountains: B.C.-Alta.-N.M.-Utah-Calif. Submont.Mont. My-Jl.

7. G. Purpusi (Koehne) Rydb. Shrub with fine puberulent branches; nodal spines $1 \mathrm{~cm}$. long or less; leaves mostly truncate at the base, decidedly pubescent and slightly glandular; peduncles short; hypanthium glabrous; tube about $3 \mathrm{~mm}$. long, as long as the sepals, which usually bear a few seattered hairs on the lower side; berry glabrous, purple. R. Purpusi Koehne. Mountains: Colo.N.M. Submont. My-Je.

8. G. leptantha (A. Gray) Cov. \& Britt. A shrub 1-2 m. high, the branches sometimes bristly; spines $0.5-1.5 \mathrm{~cm}$. long; leaves reniform-orbicular in outline, crenate-dentate, truncate at the base, $0.5-2 \mathrm{~cm}$. broad, glabrous or pubescent on both sides; peduncles 1-2-flowered, shorter than the leaves; pedicels very short; hypanthium greenish, 4-6 mm. long, about half as thick; sepals greenish white, pubescent; petals spatulate, white or pinkish, about half as long as the sepals; berry 6-8 mm. in diameter. R. leptanthum A. Gray. Mountains: N.M.-Colo. -Ariz.-Utah. Submont.-Mont. Ap-Je.

9. G. velutina (Greene) Cov. \& Britt. A shrub 1-2 m. high; young shoots finely pubescent but not bristly; spines $0.5-2 \mathrm{~cm}$. long, straight or slightly curved; leaf-blades erenate, $1-1.5 \mathrm{~cm}$. broad, cordate or truncate at the base, finely pubescent on both sides; hypanthium about $2 \mathrm{~mm}$. long and $3 \mathrm{~mm}$. thick; sepals yellow, about $3 \mathrm{~mm}$. long; petals oblong or obovate, yellow, $2-2.5 \mathrm{~mm}$. long; berry yellow, about $7 \mathrm{~mm}$. thick. R. leptanthum brachyanthum A. Gray. R. velutinum Greene. Mountains: Ore.-Utah-Ariz.-Calif. Son.-Submont. Ap-Jl.

\section{LIMNOBÒtRYA Rydb. Swamp CuRRants.}

Shrubs, armed with pectinately divided nodal spines, usually also bristly, Leaves more or less pentagonal in outline, palmately veined and quinately-cleft and incised or toothed. Flowers perfect, usually several, in bracted racemes; pedicels jointed just under the short stipe-like base of the flower, usually with 2 minute bractlets just below the node. Hypanthium slightly produced beyond the ovary; tube saucer-shaped. Sepals 5, ascending, oval or rounded. Petals reniform-flabellate, clawed, erect. Stamens not exceeding the petals. Fruit a

Leaves glabrous or nearly so; fruit black.

Lobes of the leaves acute, incised, the terminal one decidedly longer; basal sinus open;
stem usually densely bristly.

Nodal spines densely bristly.

almost obsolete: ptronger than the bristles; stipitate base of the flowers finely villous.

Nodal spines usually much stronger than the bristles; stipe-like b. L. lacustris, evident, $0.5-1 \mathrm{~mm}$. at all villous. Lobes of the leaves obtusish, toothed, the terminal one scarcely longer; basal sinus
usually narrow; stem except in depaus stipe-like base of the flower about $0.5 \mathrm{~mm}$ forms usually only slightly bristly;

Leaves pubescent and glandular on both sides; fruit bright red. $\begin{array}{ll}\text { 1. L. lacustris (Pers.) Rydl } & \text { 3. L. parvula. } \\ \text { 1. montigena. }\end{array}$ 3. L. parvula.
4. montigena. der, 2-4 mm. long; petioles fourth their length; divisions rhombic, incised $2-5 \mathrm{~cm}$. long, cleft about three4-10, light green or purplish; stamens shorter into oblong acute teeth; flowers diameter; densely glands; stamens shorter than the petals; berry 6-8 $\mathrm{mm}$. in Newf.-Mass.-Pa.-(Black Hills) S.D. Pibes lacustre (Pers.) Poir. Swamps:

2. L. echinata (IindI) Rydb. Bareal-Submont. My-J.

paratively stout, $3-8 \mathrm{~mm}$. long and Shrub 1-2 m. high; spines usually compreceding; peduncles and long; flowers 6-20, often purplish; stamens glandless; bractlets about $0.5 \mathrm{~mm}$. 8-10 mm. in diameter, sparingly; stamens usually equalling the petals; berry Lindl. Swamps: Alaska-Maringly glandular-hispid or glabrous. R. echinatum 
3. L. parvula (A. Gray) Rydb. Low shrub, $1 \mathrm{~m}$. high or less; spines slender, 2-4 mm. long, rarely much stronger than the bristles; leaves usually fully as broad as long, cleft about two-thirds to the base; flowers usually purplish, 4-8 in the raceme; stamens equalling the petals; berry $8-10 \mathrm{~mm}$. in diameter, usually densely glandular-hispid. R. lacustre parulum A. Gray. Mountains, among rocks and along streams: Yukon-Alta.-Colo.-Utah. Mont.-Alp. My-Au.

4. L. montigena (MeClatchie) Rydb. A straggling shrub, 3-6 dm. high; stems with short stout nodal spines, and more or less bristly; leaves $1-4 \mathrm{~cm}$. wide, reniform, pubescent, the divisions obovate to elliptic, incised; racemes rather short and few-flowered; tube of the hypanthium glandular-bristly; sepals 3-4 mm. long, veiny; berry densely glandular-bristly. $R$. lacustre molle A. Gray. $R$. lentum (M. E. Jones) Cov. \& Rose. R. montigenum McClatchie. High mountains: N.M.-Calif.-B.C.-Mont. Mont.-Alp.

\section{RİES L, CURRANTs.}

Unarmed shrubs. Leaves alternate, palmately veined and usually also palmately lobed, plicate in vernation, mostly deciduous. Inflorescence several- to many-flowered; pedicels jointed beneath the flowers, a pair of small bractlets often present at the node. Flowers perfect or in some exotic species dioecious. Hypanthium-tube more or less developed, from saucer-shaped to cylindric. Fruit a berry, with rather thin skin, with or without glands, never spiny, disarticulating from the pedicel.

Hypanthium-tube rather poorly developed, saucer-shaped or open-campanulate.

Berry not glandular-hispid.

Berry red, without glands; racemes drooping; bracts short-ovate.

1. R. triste.

Berry black, with sessile glands; racemes erect; bracts subulate-linear.

Racemes 6-12-flowered; bracts 2-5 mm. long; leaves firm, villous-pubescent beneath, with a shallow or no basal sinus.

Racemes 25-50-flowered; bracts minute, 1-2 $\mathrm{mm}$. long; leaves thin, essentially glabrous, usually with a deep basal sinus.

Berry glandular-hispid.
Berry red; sepals 2-2.5 mm. long, glabrous without.

Berry black or dark-purple; sepals $3-4 \mathrm{~mm}$. long, hairy without.

Sepals without gland-hairs; berry with a bloom. $\quad 5 . R$. laxiflorum.

Sepals with gland-hairs; berry without a bloom.

Hypanthium-tube well developed, deeply campanulate to tubular.

Fruit glabrous, black.

Fruit glandular-hispid.

Hypanthium-tube campanulate or urceolate; fruit black or blue.

Leaves glabrous or essentially so: fruit globose, with a bloom.

Hypanthium-tube greenish white, about $1 \mathrm{~mm}$. long, less than half as long as the sepals.

Hypanthium-tube rose-colored or purplish, about $2 \mathrm{~mm}$. long, more than

half as long as the sepals.
Leaves pubescent and usually very glandular; fruit ellipsoid, without a bloom.

Hypanthium-tube cylindric; fruit red.

Leaves merely glandular-pruinose, not hairy; flowers whitish.

Leaves decidedly pubescent as well as glandular.

Bracts cuneate-obovate, the rounded or truncate summit several lobed; flowers whitish: styles pubescent.

Bracts oblong or rhombic, entire or glandular-dentate; flowers pinkish; styles glabrous.

13. $R$. inebrians.

1. R. triste Pall. A shrub about $1 \mathrm{~m}$. high; leaf-blades thin, reniformorbicular, 6-10 cm. wide, usually 3-lobed, rarely 5-lobed, dark green and glabrous above, pale and pubescent or glabrate beneath, with conspicuous veins and coarsely dentate-serrate lobes, cordate or rarely truncate at the base; racemes somewhat glandular, usually shorter than the leaves; flowers more or less purplish; sepals obtuse, spreading; berry smooth, glabrous, red, $6-8 \mathrm{~mm}$. in diameter. R. albinerium Michx. R. rubrum A. Gray, not L. Woods: Newf.-N.J.-S.D. -Ore.-Alaska. Boreal.—Submont. My-Je.

2. R. hudsonianum Richards. A shrub 1-1.5 m. high; leaf-blades reniform, broader than long, $3-10 \mathrm{~cm}$. wide, more or less pubescent and resinousdotted, their lobes ovate, obtuse or acutish, coarsely dentate; racemes $3-6 \mathrm{~cm}$. 
long, loosely flowered; bracts setaceous, nearly equalling the pedicels; sepals oval, obtuse, spreading; fruit globose, glabrous, 5-10 mm. in diameter. Wooded places: Hudson Bay-Ont.-Minn.-Mont.-B.C.-Alaska. Boreal.-Mont. My-Je.

3. R. petiolare Dougl. A shrub $1-1.5 \mathrm{~m}$. high; leaf-blades cordate, mostly 5-lobed, thin, glabrous or slightly pubescent when young, resinous-dotted beneath; the lobes ovate, acute, sharply serrate; racemes erect, 5-12 dm. long; pedicels 3-6 mm. long, much longer than the subulate bracts; sepals white, ovate, obtuse, puberulent, $7 \mathrm{~mm}$. long; berry subglobose, without bloom, about $1 \mathrm{~cm}$. in diameter. Wooded mountain sides: B.C.-Ore.-Utah-Wyo.-Alta. Submont.-Mont. My-Jl.

4. R. glandulosum Grauer. A shrub, with decumbent or spreading branches, $1 \mathrm{~m}$. long or less; leaf-blades thin, fetid, glabrous above, puberulent on the veins beneath, orbicular in outline, cordate at the base, $3-8 \mathrm{~cm}$. wide, deeply $5-7-$ lobed, the lobes ovate, acute, incised-serrate; racemes 8-12-flowered, ascending, shorter than the leaves, puberulent; pedicels much longer than the narrow, glandular bracts; tube of the hypanthium short-campanulate; sepals 2-2.5 mm. long, pubescent without; fruit 6-8 mm. in diameter. $R$. prostratum L'Her. Woods: Newf.-N.C.-Wis.-B.C.-Mack. Boreal. My-Je.

5. R. laxiflorum Pursh. A shrub, with decumbent stems and puberulent young shoots; leaf-blades suborbicular in outline, cordate at the base, $5-10 \mathrm{~cm}$. wide, thin, deeply 5-lobed, glabrous above, somewhat puberulent beneath, the lobes ovate, serrate; racemes erect-spreading, 6-12-flowered, pubescent and glandular; pedicels much longer than the lanceolate bracts; petals fan-shaped. Woods: Alaska-Alta.-Ida.-n Calif. Mont. My-Jl.

6. R. coloradense Coville. A shrub, with decumbent or procumbent stems; leaf-blades thin, broader than long, $5-8 \mathrm{~cm}$. wide, deeply cordate at the base, mostly 5-lobed, glabrous above, sometimes sparingly pubescent on the veins beneath, and with minute glands, the lobes ovate or triangular, irregularly crenate-dentate; raceme erect, puberulent and glandular; pedicels longer than the linear-lanceolate bracts; sepals greenish or purplish, $3-4 \mathrm{~mm}$. long, spreading; Colo.-N.M.-Utah. Mont.-Subalp. Je-Jl.

7. R. americanum Mill. A shrub 1-1.5 m. high; young shoots somewhat pubescent and glandular-dotted; leaves suborbicular in outline, cordate at the base, with an open sinus, 3-8 cm. broad, glabrate above, more or less pubescent (at least on the veins) and glandular-dotted beneath, with ovate serrate-dentate lobes; petioles long-ciliate towards the base; bracts linear or linear-lanceolate; hypanthium urceolate-cylindric, $3-4 \mathrm{~mm}$. long, greenish, sparingly pubescent; sepals obtuse, a little longer than the hypanthium; petals oblong, greenish, twothirds as long; fruit 6-10 mm. in diameter. R. floridum L'Her. Thickets and damp woods: N.S.-Va.-N.M.-Alta. Plain-Submont. My-Je. 8. R. Wolfii Rothr. A shrub 1-3.5 m. high, glabrous, or the young shoots
finely pubescent; leaves suborbicular in outline, cordate at the base, with an
open sinus, 3-5-lobed, $4-9$. open sinus, 3-5-lobed, 4-9 cm. broad; lobes acute or obtuse, serrate-dentate; racemes erect, few-flowered, puberulent and glandular; bracts oblong or oblongspatulate; hypanthium puberulent, $1.5 \mathrm{~mm}$. long; sepals greenish-white, ovateoblong, 3-4 mm. long, spreading; petals white, spatulate, much shorter than the sepals; berry black, 8-12 mm. in diameter. Mountains: Colo.-N.M.-Ariz.-
Utah. Submont.-Subalp. My-Je. 9. R. nevadense Kellogg. A shrub, glabrous, or the young shoots puberu-
lent; leaves thin, paler beneath, sparingly pubescent or glabrate, orbicular, with
obtuse crenate lobes, cordate or truncate obtuse crenate lobes, cordate or truncate at the base, $47 \mathrm{~cm}$. broad, long-ciliate towards the base; racemes nodding; bracts thin, pink or greenish, obtuse or berry blue, $8 \mathrm{~mm}$. in berry blue, $8 \mathrm{~mm}$. in diameter. Mountains: Calif.-Nev.-Ida.-Ore. Sub10. R. viscosissimum Pursh. A shrub $1 \mathrm{~m}$. high or less, with the young
shoots and the inflorescence glandular-pubescent; leaves orbieular-reniform in 
outline, pubescent and glandular on both sides, $5-8 \mathrm{~cm}$. broad; lobes rounded, short and broad, crenate; racemes spreading or ascending, few-flowered; bracts oblanceolate, entire; hypanthium cylindro-campanulate, 6-7 $\mathrm{mm}$. long, greenish or pinkish; sepals oblong, obtuse, about as long as the hypanthium; berry black, about $1 \mathrm{~cm}$. in diameter. Mountain woods: B.C.-Mont.-Colo.-Calif. Submont.-Mont. My-Jl.

11. R. reniforme Nutt. A robust shrub, usually $1.5-2.5 \mathrm{~m}$. high, with glabrous shoots; leaf-blades reniform-orbicular, $2.5-5 \mathrm{~cm}$. wide, not pubescent, glandular-pruinose on both sides; racemes 4-7-flowered, nearly as long as the leaves, glabrous; bracts light green, rhombic or obovate, nearly entire, glandular; tube of the hypanthium cream-white, about $8 \mathrm{~mm}$. long, with stalked glands, but not pubescent; sepals oblong, recurved; petals white, reniform-orbicular; styles glabrous; fruit 6-8 mm. in diameter. Dry hills: Mont.-Wash.-Ore. Submont. Ap-Je.

12. R. cereum Lindl. A much branched shrub, $1 \mathrm{~m}$. high or less, the young shoots finely puberulent; leaf-blades round-reniform, 1-4 cm. wide, puberulent and somewhat glandular, the lobes rounded, crenate; racemes short, puberulent, few-flowered, drooping; hypanthium-tube cylindric, pubescent, 6-8 $\mathrm{mm}$. long, white, greenish, or cream-colored; sepals ovate, about $2 \mathrm{~mm}$. long; petals minute, orbicular; fruit bright red, $6-7 \mathrm{~mm}$. in diameter. Dry hills: Calif.-UtahMont.-B.C. Son.-Submont. My-Jl.

13. R. inebrians Lindl. A low scraggling shrub, $0.5-1 \mathrm{~m}$. high; leaf-blades round-reniform, $1-3 \mathrm{~cm}$. wide, the lobes rounded, crenate; racemes few-flowered, pendulous, puberulent and usually glandular; tube of the hypanthium 5-8 mm. long, usually pink or pinkish; sepals ovate, acutish; fruit $6-8 \mathrm{~mm}$. in diameter. R. pumilum Nutt. Dry hills: S.D.-w Neb.-N.M.-Ariz.-Ida. PlainSubmont. My-J.

\section{ChRYSOBÒtrya Spach. Flowering, Golden, Missouri, or} Buffalo Currants.

Unarmed erect shrubs. Leaves palmately veined, palmately 3-5-lobed, convolute in vernation. Inflorescence racemose, several-flowered; pedicels jointed beneath the flower. Flowers perfect, slightly irregular. Hypanthium well developed, yellow, tubular, slightly oblique. Petals erose or denticulate at the apex. Fruit a berry, disarticulating from the pedicel.

Sepals less than half as long as the hypanthium-tube.

Sepals more than half as long as the hypanthium-tube.

1. C. odorata.

2. C. aurea.

1. C. odorata (Wendl.) Rydb. A shrub 1-2 m. high, with pubescent young shoots and gray bark on the old stems; leaves obovate or suborbicular in outline, cuneate at the base, $2-5 \mathrm{~cm}$. broad, deeply 3-5-lobed and coarsely dentate, glabrous on both sides; racemes 4-8-flowered; bracts ovate or oval, longer than the pubescent pedicels; hypanthium $10-15 \mathrm{~mm}$. long; petals $2-3 \mathrm{~mm}$. long, erose; berry black, globose, about $8 \mathrm{~mm}$. in diameter. Ribes odoratum Wendl. $R$. longiflorum Nutt. Chrysobotrya revoluta Spach. Hillsides: S.D.-Tex. Plain.

2. C. aurea (Pursh) Rydb. Erect shrub, 1-2 m. high; leaves reniformorbicular to obovate in outline, firm, 3-5-lobed and dentate, from cuneate to subcordate at the base, $3-5 \mathrm{~cm}$. broad, glabrous or essentially so; racemes $5-15-$ flowered; bracts oblong or obovate, 5-12 $\mathrm{mm}$. long; tube of the hypanthium 6-10 mm. long; petals oblong, erose, yellow, of ten tipped with red; fruit black, red, or amber-yellow, 6-8 mm. in diameter. Ribes aureum Pursh. Chrysobotrya Lindleyana and $C$. intermedia Spach. Hills and river banks: Wash.-Sask.S.D.-N.M.-Calif. Submont.

\section{Family 60, ROSACEaE. Rose Family.}

Herbs, shrubs or trees, usually with alternate leaves and stipules. Flowers perfect, rarely dioecious or monoecious, regular or nearly so. Hypanthium usually well developed, from flat or saucer-shaped to urn-shaped, 
salverform, or tubular. Sepals normally 5 , rarely 4 or $6-9$, of ten subtended by as many bractlets. Petals as many as the sepals or rarely wanting. Stamens 1-many, most commonly 20, in three series. Gynoecium of 1many usually wholly distinct carpels. Fruit of achenes, follicles, or drupelets.

A. Fruit consisting of $1-5$ dehiscent follicles.

Carpels alternate with the sepals, or less in number; stipules none or deciduous.

Carpels $1-5$, if more than one more or less united below; seeds shining, pear-shaped, with a bony coat; endosperm present.

1. OPULASTER.

Carpels usually 5, distinct; seeds dull, linear or linear-lanceolate, with a thin coat; endosperm lacking.

Stamens inserted on the margin of the hypanthium; flowers perfect; shrubs or undershrubs with simple leaves.

Filaments free; leaves entire or toothed.

Carpels dehiscent on the ventral suture; shrubs with deciduous leaves.

Carpels dehiscent on both sutures; 2 . SPIRAEA. persistent leaves.

Flowers racemose, rarely somewhat paniculate; stamens 20.

3. PETROPHYTUM.

Flowers solitary, nearly sessile at the ends of the short branches;

Filaments united at the base; leaves twice or thrice $3-$ cleft. K

4. KF.LSEYA.

5. LUETKEA.
LUtall herbs with twice or thrice compound leaves.

Carpels opposite to the sepals; stipules present, persistent; leaves pinnately dissected.
Cater.

B. Fruits consisting of indehiscent achenes or drupelets.

7. CHAMAEBATIARIA.

I. Carpels not enclosed in a fleshy hypanthium.

a. Fruits of dry achenes.

1. Ovules 2, one above the other; achenes usually 1-seeded and more or less flattened, arranged in a single circle; shrubs with simple leaves. 2. Ovules and seeds solitary; achenes usually turgid and, if many, spira.lly
arranged.

a. Seeds inserted at the distal end of the ovary, $i$. e., opposite the origin of the style, pendulous or in genera with basal styles ascending;
radicle superior.

Disk at the mouth of the hypanthium annular or obsolete; leaves and branches alternate.

Style articulated to the ovary; hypanthium from campanulate to almost flat, neither contracted at the throat nor closely investing the achenes; flowers cymose or solitary.

Style not basal.

Style terminal or nearly so; ovules pendulous and anatropous.

Stamens separated from the receptacle by an open space: no indication of an annular thickening at the base of the filaments.

Hypanthium saucer-shaped to deeply campanulate; petals oblanceolate to obcordate or cuneate; pistils usually more than 2 .

Filaments dilated, petaloid. 9. Horkelia.

Filaments filiform. 10. IvEsIA.

Hypanthium wheel-shaped; petals narrowly linear; pistils 2

pistils 2.
Stamens inserted very near the base of the receptacle on a more or less evident annular thickening.

Style lateral; ovules ascending and amphitropous. POTLA.

Achenes glabrous; herbs.

Achenes numerous; stamens about 20.

Leaves odd-pinnate.

Receptacle not enlarged in fruit; petals yellow, obtuse or retuse; leaves interruptedly pinnate. 13. ARGENTINA.

Receptacle somewhat enlarged in fruit, becoming spongy; petals red, acute or acuminate; leaves regularly pinnate.

Leaves trifoliolate; receptacle much enlarged and usually red in fruit, pulpy; petals white or pinkish.

pinkish.;
Achenes 10-15; stamens 5 ; leaves trifoliolate.

Achenes hairy; shrubs; style club-shaped; leaves pinnate; petals (in ours) yeliow. 17. DASIPHORA. 
Style nearly basal; ovules ascending or nearly erect, orthotropous. Stamens and pistils numerous; bractlets present; leaves pinnate. 18. DRYMOCALLIS.

Stamens 5; bractlets wanting; leaves twice or thrice ternate. 19. Chamaerhodos.

Style not articulate to the ovary; inflorescence spicate, racemose or paniculate; hypanthium indurate, closely investing the achenes in fruit.

Hypanthium not prickly; petals lacking.

Perennials, with rootstocks; stigmas muricate-papillose; leaflets toothed. 20. SANGUISORBA.

Annuals or biennials, with taproots; stigmas brush-like; leaflets pectinate-pinnatifid. 21 . POTERIDIUM.

Hypanthium prickly; petals present; prickles of the hypanthium hooked.

22. AGRIMONLA.

Disk at the mouth of the hypanthium produced into a cylindric tube, separating the stamens from the pistils; shrubs with opposite leaves and branches.

23. COLEOGYNE

b. Seeds inserted at the proximal end of the ovary, $i$. e., perfectly basal; radicle inferior.

Styles wholly deciduous.

Styles partly or wholly persistent.

24. WALDSTEINIA.

Hypanthium hemispheric, campanulate or turbinate, persistent.

Pistils several or many.

Flowers 8-10-merous; low depressed undershrubs with crenate or entire leaf-blades.

25. DRYAS.

Flower usually 5-merous.

Sepals valvate: perennial herbs, with rootstocks; leaves pinnate: bractlets present.

Style conspicuously bent and distinctly geniculate above, the upper hairy portion readily deciduous. 26. GEUM.

Style neither conspicuously bent nor distinctly geniculate, the upper glabrous portion persistent or tardily deciduous.

Styles conspicuously elongating in fruit, plumose below. 27 . SIEVERSIA.

Styles not much elongating in fruit, not plumose. 28. ACOMASTYLIS.

Sepals imbricate in bud; shrubs; leaves dissected into narrow lobes.

Bractlets present; pistils numerous.

Bractlets wanting; pistils few. 30. CowANIA.

Pistils usually solitary; shrubs with 3 -cleft leaves.

31. Purshia.

Hypanthium salver-shaped, the limb deciduous; the tube persistent and closely investing the fruit; shrubs. 32. CERCOCARPUS.

D. Fruits of more or less fleshy drupelets; ovules 2, collateral.

Styles club-shaped: stigmas slightly 2-lobed; receptacle flat; unarmed shrubs with exfoliating bark and simply digitately ribbed and lobed leaves.

Drupelets capped by a hard pubescent cushion; styles glabrous.

Drupelets without cushion; styles hairy.

33. RUBACER.

34. OREOBATUS.

Styles filiform, glabrous; stigmas capitate; receptacle convex, hemispheric or nipple-shaped; drupelets without cushion; leaves in most species compound and stem prickly or bristly.

35. RUBUS.

II. Carpels enclosed in the hypanthium which becomes fleshy in fruit. 36. ROSA.

\section{OPULÄSTER Medic. NINE-BARK.}

Shrubs with exfoliating bark. Leaves alternate, 3-5-ribbed, more or less lobed and usually with more or less stellate hairs. Flowers in terminal corymbs. Hypanthium hemispheric or nearly so. Sepals 5, persistent. Petals 5, white or rarely pinkish, spreading. Stamens $20-40$ on a disk, clothing the mouth of the hypanthium. Pistils 1-5, more or less united at the base; styles filiform, terminal; stigmas capitate; ovules 2-4. Follicles more or less inflated, opening along both sutures; seeds obliquely pear-shaped, shining with a bony coat; endosperm copious. [Physocarpus Maxim.]

Carpels $3-5$, united only at the base, turgid.

Mature carpels glabrous, ovate, usually 5 ; leaves of the sterile shoots scarcely longer than broad.

Mature carpels stellate, short-ellipsoid, abruptly acute, usually 3 or 4 .

1. O. capitatus.

Leaf-blades deeply lobed, as broad as long, cordate at the base; western species.

Leaf-blades shally 2. $O$. cordatus.

Leaf-blades shallowly round-lobed, not cordate at the base, usually longer than broad; eastern species.

3. O. intermedius. 
Carpels 2, united half their length, or only 1.

Carpels usually 2 ; stamens similar or nearly so.

Mature carpels more or less turgid; styles more or less spreading.

Bracts obovate or spatulate, often foliaceous and more or less persistent.

4. O. bracteatus.

Bracts linear or linear-oblanceolate, membranous and caducous.

Pedicels and the hypanthium almost glabrous; sepals stellate only on the inner surface and near the margin; shrub $1 \mathrm{~m}$. high or more.

Pedicels, hypanthium and calyx densely stellate; shrub 0.5 . glabratus. Leaves green on both sides, almost glabrous. Leaves paler and densely stellate beneath.

Mature carpels flattened and decidedly keeled; styles erect.

Carpels usually solitary; every other filament longer and with more dilated bas
leaves small, finely stellate.
9 . Olternans.

6. O. monogynus.

7. O. Hapemanii.

8. O. malvaceus.

1. O. capitatus (Pursh) Kuntze. Shrub, with surculose branches, sometimes even $7 \mathrm{~m}$. high; branches glabrous or slightly stellate; leaf-blades broadly rounded-ovate or pentagonal in outline, distinctly 3-5-lobed, with incised or doubly serrate lobes, sparingly pubescent or glabrous above, stellate-pubescent beneath, 3-10 cm. long and usually fully as broad; sepals ovate-acute, stellate; petals orbicular, about $4 \mathrm{~mm}$. long; carpels $8-10 \mathrm{~mm}$. long, ovate, rather longacuminate. Spiraea capitata Pursh. Woods: B.C.-Ida.-Calif. Submont. $\mathrm{My}-$ Л.

2. O. cordatus Rydb. Tall shrub; branches brown, glabrous and shining; leaf-blades rounded-cordate to somewhat reniform in outline, 4-10 cm. long and about as broad, 3-5-lobed, with rounded or acute lobes, serrate, with roundedovate teeth, glabrous on both sides or with scattered hairs beneath; inflorescence dense; sepals ovate, acute, densely stellate, 3-4 mm. long; carpels 8-9 mm. long, abruptly acute. Open woods: w Ida.-n Calif. Submont. Je-Jl.

3. O. intermedius Rydb. Shrub 1-1.5 m. high; branches glabrous or nearly so; blades ovate to orbicular in outline, usually shallowly $3-l o b e d, 2-6 \mathrm{~cm}$. long, doubly crenate, glabrous or nearly so above, usually sparingly hairy beneath; inflorescence dense; bracts linear-oblanceolate, caducous; sepals ovate, acute, densely stellate on both sides; petals $4 \mathrm{~mm}$. long; carpels united at the base, rounded-ellipsoid, abruptly acuminate, 7-8 mm. long. $O$. Ramaleyi A. Nels., mainly. P. intermedius C. K. Schneider. Creek banks and hillsides: w N.Y.-Mo.-Colo.-S.D. Plain-Submont. Je-Jl.

4. O. bracteatus Rydb. Shrub 1-2 m. high; branches yellowish green, glabrous; leaf-blades $2-7 \mathrm{~cm}$. long, broadly ovate or subcordate in outline, more or less deeply 3-lobed, doubly crenate, glabrous or nearly so, somewhat paler beneath; corymb many-flowered; sepals ovate, acute, densely stellate on both sides, about $3 \mathrm{~mm}$. long; petals 4-5 mm. long; carpels densely stellate, united at least half their length. O. Ramaleyi A. Nels., in part. P. Ramaleyi A. Nels. Mountains: Colo. Submont. Je-Jl.

5. O. glabratus Rydb. Shrub about $1 \mathrm{~m}$. high; leaf-blades rounded-ovate, orbicular or sometimes slightly reniform, $2-3 \mathrm{~cm}$. long, glabrous, slightly paler beneath, 3-5-lobed, doubly crenate; sepals oval or rounded-ovate, obtuse, about $3 \mathrm{~mm}$. long; petals about $4 \mathrm{~mm}$. long, pink or white; follicles 2, densely stellate. Mountains: Colo, Submont.-Mont. Je-J.

6. O. monogynus (Torr.) Kuntze. Shrub usually less than $1 \mathrm{~m}$. high, with usually decumbent stems; blades $1-3 \mathrm{~cm}$., rounded-ovate to reniform in outline, usually rather deeply 3-5-lobed, incised; sepals lance-ovate to elliptic, usually obtuse; petals about $3 \mathrm{~mm}$. long; follicles densely stellate, 3-4 mm. long, with ascending-spreading beaks. P. Torreyi Maxim. P. monogynus Coult. Mountains: (Black Hills) S.D.-Wyo.-N.M.-Nev. Submont.-Mont. My-Jl.

7. O. Hapemanii Rydb. Low shrub, $1 \mathrm{~m}$. or less high; blades roundedovate to reniform in outline, $1-2 \mathrm{~cm}$. broad, rather deeply 3 -lobed, incised, obtuse or rounded at the apex, stellate on both sides, paler beneath; sepals broadly ovate, obtuse, about $3 \mathrm{~mm}$. long; petals about $3 \mathrm{~mm}$. long; follicles 2 , densely stellate; beaks ascending-spreading. Mountains: Wyo.-Utah. Mont. Je-JI.

8. O. malvaceus (Greene) Kuntze. Shrub 1-2 m. high; leaf-blades orbicular or rounded-ovate in outline, more or less distinctly 3-5-lobed, doubly crenate, 
glabrous or stellate on both sides, thin, 2-6 $\mathrm{cm}$. long and about as broad; bracts spatulate or cuneate, caducous; sepals ovate, 4-5 mm. long; petals often $5 \mathrm{~mm}$. long; follicles 2, united nearly two-thirds their length, about $5 \mathrm{~mm}$. long, dehiscent after falling. $O$. pubescens Rydb. P. malvaceus Kuntze. P. pubescens Coult. \& Nels. Mountains, hillsides, and rocky banks: B.C.-Ore.-Utah-Wyo.-Mont. Submont.-Mont. My-Jl.

9. O. alternans (M. E. Jones) Heller. Low shrub, with divaricate, gray, finely stellate branches; blades orbicular or reniform, about $1 \mathrm{~cm}$. long, more or less deeply 3-lobed, doubly crenate, rounded or obtuse at the apex, stellatepubescent on both sides, densely so beneath; bracts oblanceolate, usually laciniate, caducous; sepals densely stellate on both sides, ovate, obtuse; petals about $3 \mathrm{~mm}$. long. Niellia alternans M. E. Jones. Mountains: Utah-Nev. Submont. -Mont. Je-Jl.

\section{SPIRAÈa L. Meadow Sweet.}

Shrubs, with simple, feather-veined leaves, which are usually serrate, and no stipules. Inflorescence racemose, corymbose or paniculate. Flowers in ours perfect. Hypanthium hemispherical, campanulate, or turbinate. Sepals 5, valvate or slightly imbricate. Petals 5, imbricate, white to red. Stamens $15-70$, inserted in 1-several series under the margin of a more or less developed disk. Pistils 5, rarely 3-8, distinct, inserted in the bottom of the hypanthium; styles terminal; stigmas capitate or discoid; ovules 2-several, anatropous, pendulous. Follicles leathery, not inflated, opening along the ventral suture; seeds several, in ours usually 4 , pendulous, linear-lanceolate or oblong, tapering at both ends; endosperm none or almost none.

Panicle flat-topped; sepals erect or merely spreading.

Petals pink or rose-colored; corymb small.

Petals white, seldom tinged with rose; corymb larger.

Panicle elongate, conical or ovoid, or lanceolate.

Sepals merely spreading; disk obsolete.

Inflorescence glabrous; leaf-blades broadly oblanceolate to obovate.

Inflorescence pubescent; leaf-blades narrowly oblanceolate.

3. S. latifolia.
4. S. alba.

Sepals soon reflexed; disk usually rather conspicuous.

Leaves not tomentose beneath.

Stem glabrous; leaves serrate to near the base.

Stem more or less pubescent; leaves toothed above the middle.

Leaves tomentose beneath.

1. S. densiflora.

2. S. lucida.

5. S. idahoensis.

6. S. Menziesii.

7. S. Douglasii.

1. S. densiflora Nutt. Low shrub, 2-6 dm. high, with ascending branches; bark of the twigs dark reddish brown, glabrous; leaf-blades oval or elliptic, rounded at both ends, glabrous or essentially so, bright green above, somewhat paler beneath, erenate or serrate above the middle, $1.5-3 \mathrm{~cm}$. long; sepals ovate, obtuse; petals nearly $1.5 \mathrm{~mm}$. long, obovate; follieles glabrous and shining. Mountains: B.C.-Ore.-Wyo.-Mont. Submont.-Mont. Jl-Au.

2. S. lucida Dougl. Low shrub, with creeping rootstock; stems and branches erect, often dying down annually to near the base, 3-10 dm. high; blades of the lower leaves obovate, of the upper oval, often acutish, 2-6 cm. long, thin, glabrous, shining above, paler beneath, coarsely serrate or incised; sepals triangular, acute; petals white, orbicular, about $2 \mathrm{~mm}$. long; follicles glabrous, shining. Mountains: B.C.-Ore.-Wyo.-Sask. Submont.-Mont. My-Jl.

3. S. latifolia (Ait.) Borkh. A shrub, 1-20 dm. high, branched; bark of the twigs glabrous, chestnut; leaf-blades broadly oblanceolate or obovate, thin, 2-8 $\mathrm{cm}$. long, acute, obtuse or rounded at the apex, sharply and sometimes doubly serrate; inflorescence $0.5-2 \mathrm{dm}$. long and about half as wide; bracts sometimes ciliate; sepals triangular, acute; petals white or a little pinkish in bud; follicles glabrous and shining. Meadows: Newf.-N.C.-w Pa. Sask. Boreal. Je-S.

4. S. alba DuRoi. A shrub, 1-2 m. high; bark of the twigs brown; leafblades rather firm, more or less puberulent on the veins, sharply serrate, acute at both ends, 3-6 cm. long; inflorescence 5-20 cm. long; sepals triangular, acute; petals white, about $2 \mathrm{~mm}$. long; follicles glabrous, shining. S. simplex Greene. Swamps and wet ground: Newf.-N.C.-Ia.-N.D.-Sask. Boreal. Je-Au. 
5. S. idahoensis A. Nels. A shrub, 1-2 m. high, branched below; leaves ovate or oval, rarely elliptic, serrate except the very base, 5-9 $\mathrm{cm}$. long; inflorescence paniculate, cylindric or pyramidal, dense, only slightly pubescent on the branches; sepals reflexed, triangular-ovate; petals rose-colored, about 2 $\mathrm{mm}$. long, ovate; follicles obovate-oblong. Mountains and foot-hills: Ida. Submont. Au.

6. S. Menziesii Hook. A shrub, 1-1.5 m. high; bark of the twigs brown and usually puberulent; leaf-blades elliptic, oblong, or oval, serrate above the middle, acute, obtuse or rounded at either end, glabrous or puberulent on the veins, 3-10 cm. long; inflorescence very dense, long and narrow, spike-like; sepals pubescent, ovate; petals rose-colored, $1.5 \mathrm{~mm}$. long; follicles glabrous. Along streams: s Alaska-B.C.-Ore.-Ida. Submont. Je-Au.

S. densiflora $\times$ Menziesii. Resembling most $S$. densiflora, but the inflorescence more conic and the sepals reflexed; inflorescence shorter and more open and leaves finer serrate than in S. Menziesii. S. roseata Rydb. Ida.

s. lucida $\times$ Menziesii. Intermediate between the two parents, having the leafform of the former, the size of the plant and reflexed sepals of the latter; inflorescence intermediate, pyramidal and open and the petals white or pale pink. S. pyramidata Greene. B.C.-Ida.-Ore.

7. S. Douglasii Hook. A shrub, 1-2.5 m. high; bark of twigs brown and more or less tomentose; leaf-blades elliptic, oblong, oval, or oblong-cuneate, 3-10 $\mathrm{cm}$. long, serrate above the middle, dark green above, white-tomentose beneath; inflorescence very long and narrow; sepals tomentose outside, ovate; petals rose-colored, about $1.5 \mathrm{~mm}$. long; follicles glabrous and shining. Lowlands: B.C. -Calif. Submont. Je-Au.

\section{PETRÓPHYTUM (Nutt.) Rydb.}

Densely cespitose and depressed undershrubs, with prostrate branches, growing on rocks. Leaves oblanceolate or spatulate, entire, coriaceous, evergreen, crowded on the short branches. Inflorescence racemose, rarely compound. Flowers perfect. Hypanthium hemispheric. Sepals 5, valvate. Petals 5, imbricate, white. Stamens about 20 ; filaments filiform, distinct, about twice as long as the sepals. Disk evident, entire, margined. Pistils 3-5; ovary and lower part of the style very hairy; style filiform, terminal; ovules $2-4$, pendulous. Follicles leathery, dehiscent along both sutures; seeds linear.

Leaves spatulate, spreading; racemes short, 1-4 cm. long; bracts usually shorter than the flowers.

1. P, caespitosum.

Leaves narrowly oblanceolate, erect or ascending; inflorescence 4-10 cm. long, often branched; bracts usually exceeding the flowers.

2. P. elatius.

1. P. caespitosum (Nutt.) Rydb. Season's shoots very short; leaves spatulate, 5-12 mm. long, 2-4 mm. wide, densely silky, 1-ribbed, obtuse or mueronate; sepals ovate-lanceolate, acute, $1.5 \mathrm{~mm}$. long; petals spatulate, obtuse, 1.5 $\mathrm{mm}$. long; follieles 3-5,2 mm. long. Spiraea caespitosa Nutt. Rocks: (Black Hills) S.D.-N.M.-Ariz.-Calif.-Ida.-Mont. Plain-Mont. Jl-S.

2. P. elatius (S. Wats.) Heller. Shoots of the season of ten $2-3 \mathrm{~cm}$. long, erect; leaves silky, oblanceolate, acute, $1.5-2 \mathrm{~cm}$. long, $3-4 \mathrm{~mm}$. wide, usually with more distinct petioles; sepals lanceolate, $2 \mathrm{~mm}$. long, acute or acuminate; petals oblanceolate, $2-3 \mathrm{~mm}$. long. Spiraea caespitosa elatior S. Wats. Mountains: Utah-Ariz. Son.-Mont. Jl-S.

\section{KELSÈYA (S. Wats.) Rydb.}

Densely cespitose, pulvinate undershrubs, with short branches. Leaves entire, crowded, leathery, persistent. Flowers perfect, solitary, almost sessile, enclosed in the rosettes of the leaves. Hypanthium hemispheric. Sepals 5, valvate. Petals 5, imbricate. Stamens about 10; filaments filiform, about twice as long as the sepals; anthers didymous. Disk inconspicuous, entire. Pistils about 5 ; styles terminal; stigmas minute; ovules $3-4$, pendulous. Follicles leathery, not inflated, opening along both sutures; seeds elongate-fusiform.

1. K. uniflora (S. Wats.) Rydb. Leaves crowded, $2-3 \mathrm{~mm}$. long, more or less silky-pubescent; sepals oblong, obtuse, $1.5 \mathrm{~mm}$ : long; petals narrowly spatu- 
late, nearly $3 \mathrm{~mm}$. long, white; follicles $2-2.5 \mathrm{~mm}$. long. Cliffs in the mountains: Mont.-n Wyo.-Ida. Submont.-Mont. Jl.

\section{LUÈTKEA Bong.}

Cespitose undershrubs, with decumbent or creeping, stoloniferous branches. Leaves twice or thrice ternately dissected, grooved above. Flowers perfect, racemose. Hypanthium hemispheric. Sepals 5, valvate. Petals 5, while in bud contorted. Stamens about 20; filaments subulate, connate at the base; anthers didymous. Disk thickened, about 10-lobed. Pistils 4-6, usually 5, distinct; styles terminal, deciduous; stigmas truncate; ovules several, pendulous. Follicles coriaceous, dehiscent on both sutures. Seeds linear-lanceolate, acute at both ends.

1. L. pectinata (Pursh) Kuntze. Flowering shoots $5-15 \mathrm{~cm}$. high, leafy, glabrous; leaves $1-1.5 \mathrm{~cm}$. long, dissected into linear, acute divisions, glabrate; raceme short, 1-5 cm. long; bracts ternate or the upper ones entire; hypanthium about $2 \mathrm{~mm}$. wide; sepals ovate, acute, $2 \mathrm{~mm}$. long, glabrous; petals white, orbicular or rounded-obovate, 3-3.5 mm. long; earpels about $4 \mathrm{~mm}$. long. Eriogynia pectinata Hook. Spiraea pectinata T. \& G. Mountains: Alaska-Ore.Alta. Mont. J-S.

\section{6. arúncus (L.) Adans. Goat's Beard.}

Perennial herbs, with thick rhizomes, twice or thrice ternate-pinnatisect leaves, and no stipules. Inflorescence a large panicle with spike-like branches. Flowers dioecious. Hypanthium of the staminate flowers flat or saucer-shaped, pentagonal. Sepals triangular, valvate. Petals 5, orbicular to spatulate, white. Stamens 15-30; filaments subulate, distinct, long-exserted; anthers didymous. Disk 5-lobed. Pistils 3-5, rudimentary, style-less. Pistillate flowers much smaller. Petals elliptic to oblanceolate. Stamens rudimentary; filaments short; anthers minute, empty. Pistils $3-5$, distinct; styles short, obliquely terminal; stigmas capitate; ovules $8-12$, pendulous. Follicles oblong, cartilaginous, dehiscent along the ventral suture and then splitting dorsally at the apex, in our species reflexed. Seeds few, attenuate at both ends.

1. A. acuminatus (Dougl.) Rydb. Stem 1-2 m. high, glabrous; leaflets 3-12 $\mathrm{cm}$. long, lanceolate, long-acuminate at the apex, truncate or subcordate at the base, sharply and doubly serrate; panicles terminal and axillary, $1-4 \mathrm{dm}$. long; petals of the staminate flowers broadly rounded-obovate, about $1 \mathrm{~mm}$. long, those of the pistillate flowers slightly smaller, elliptic; follicles about $3 \mathrm{~mm}$. long and $1 \mathrm{~mm}$. thick, shining. A. sylvester Coult. \& Nels., not Kost. Moist woods and along streams: Ore.-Alaska-B.C. Mont. Je S.

\section{Chamaebatiària (Porter) Maxim. Fern-Bush.}

Low shrubs, more or less stellate-pubescent and scurfy, with bipinnatisect leaves and paniculate flowers. Hypanthium turbinate. Sepals 5, erect, imbricate. Petals 5, rounded, erect. Stamens about 60, inserted on the margin of the disk. Pistils 5, more or less united below; styles terminal; stigmas capitate; ovules about 8 , pendulous, Follicles coriaceous, dehiscent on the ventral suture and at the apex on the dorsal one; seeds few, terete, not appendaged.

1. C. Millefolium (Torr.) Maxim. A densely branehed shrub, less than $1 \mathrm{~m}$. high; leaves $2-4 \mathrm{~cm}$. long, crowded at the ends of the branches, glabrous above, stellate-tomentose beneath, oblong in outline; primary divisions about 20 pairs, 4-8 mm. long; secondary divisions 15-17 pairs, decurrent, about 0.5 $\mathrm{mm}$. long, entire, obovate; panicle $3-10 \mathrm{~cm}$. long, leafy below; sepals lanceolatedeltoid, acute, $3 \mathrm{~mm}$. long; petals white, rounded-obovate, about $5 \mathrm{~mm}$. long, wavy and crenulate; follicles about $5 \mathrm{~mm}$. long. Spiraea Millefolium Torr. Among rocks: Ida.-Nev.-Ariz.-s Calif. Submont.-Mont. Jl-S.

8. Sericothèca Raf, Ocean Spray, Mountain Spray.

Shrubs, with simple toothed or lobed leaves. Sepals 5, 3-nerved, valvate in the bud, in fruit erect. Petals 5, white or pinkish, short-elawed. Stamens 
about 20. Achenes inclosed in the calyx, short-stipitate, long-hairy, membranaceous, indehiscent, caducous, strongly arched on the lower suture; seeds broadly oblong, with a double coat. [Holodiscus Maxim.]

Leaves grayish- or whitish-tomentose and villous beneath.

Inflorescence ample, well-compound; leaves usually over $3 \mathrm{~cm}$. long.

Leaf-blades abruptly contracted below, scarcely decurrent on the petioles, 4-10 cm. long.

$\mathrm{cm}$. long.
$2-5 \mathrm{~cm}$. long.

Inflorescence small and narrow, simple, racemose, or with a few short, spreading branches; leaves usually less than $2 \mathrm{~cm}$. long, finely pubescent and green above,

white silky-villous and tomentose beneath.
Leaves glandular-atomiferous and slightly hairy on the veins beneath, not at all tomen$\begin{array}{ll}\text { tose, 1-1.5 cm. long, glabrous or sparingly pubescent. } & \text { 4. S. glabrescens. }\end{array}$

1. S. discolor (Pursh) Rydb. Shrub 1-4.5 m. high; leaf-blades roundedovate or oval, usually double-toothed, with broadly ovate, mucronate teeth, acute at the apex, truncate, rounded, or cuneate at the base, 4-10 cm. long, thin, green and sparingly pubescent, or in age glabrate above, more or less densely villous and tomentose beneath; infloreseence conical or ovate, $10-20 \mathrm{~cm}$. long. twice or thrice compound; sepals oblong; petals white, elliptic, $1.5 \mathrm{~mm}$. long or more; stamens $15-20$; pistils usually 5 ; carpels semi-ovate, $1-5 \mathrm{~mm}$. long. Holodiscus discolor (Pursh) Maxim. H. ariaefolius (Smith) Howell. Hills and river banks: B.C.-Cal.-Ida.-w Mont. Submont. Je-Au.

2. S. dumosa (Nutt.) Rydb. Shrub 6-10 dm. high; leaf-blades obovate, $2-5 \mathrm{~cm}$. long, obtuse or acute at the apex, often double-toothed above, green and short-hairy above, white and densely villous and tomentose beneath; inflorescence usually twice compound, ovoid, $5-20 \mathrm{~cm}$. long; sepals ovate or lanceovate; petals elliptic or oval, about $2 \mathrm{~mm}$. long; stamens about 20 ; pistils 5 ; earpels about $1.5 \mathrm{~mm}$. long. $H$. discolor (Nutt.) Heller. $H$. australis Heller. Mountains: Wyo-Utah-N.M.-Chihuahua. Submont.-Mont. Je-S.

3. S. microphylla Rydb. A low diffuse shrub, 3-10 dm. high; leaf-blades spatulate-cuneate, $1-1.5 \mathrm{~cm}$., rarely $2 \mathrm{~cm}$. long, evenly serrate above the middle, obtuse at the apex, cuneate at the base; inflorescence small, $3-5 \mathrm{~cm}$. long; sepals about $1 \mathrm{~mm}$. long, ovate, villous; petals broadly obovate or oval, a little exceeding the sepals; stamens 20 ; carpels about $1.5 \mathrm{~mm}$. long. H. microphyllus Rydb. Mountains: Colo.-Wyo.-Utah; apparently also in Calif. Submont.-Mont.
Je-Au.

4. S. glabrescens (Greenm.) Rydb. A diffuse shrub, 6-12 dm. high; leafblades cuneate-obovate, $1-1.5 \mathrm{~cm}$. long, decurrent on the short petioles, evenly toothed above the middle; inflorescence more or less compound, $3-6 \mathrm{~cm}$. long; the branches short and spreading; sepals ovate, $1.5 \mathrm{~mm}$. long; petals white, oval, $2 \mathrm{~mm}$. long; stamens 20 ; carpels $1.5 \mathrm{~mm}$. long. Spiraea discolor glabrescens Greenm. H. glabrescens Heller. Mountains: Ore.-n Calif.-Utah. Submont.
-Mont. Je-Au.

\section{HORKÈLIA Cham. \& Schlecht.}

Perennial herbs, with scaly rootstocks or caudices. Leaves pinnately compound, usually with many leaflets. Inflorescence cymose-paniculate. Hypanthium deeply campanulate to saucer-shaped. Bractlets, sepals, and petals 5 . Petals strap-shaped, oblanceolate, obovate, cuneate, or obcordate, often unguiculate, white or light yellow. Stamens 10, inserted in the throat of the hypanthium; filaments dilated and more or less petaloid, persistent, triangular, subu-
late, with a distinct midrib. Receptacle generally conic or hemispheric, with
numerous pistils. Style long and slendr numerous pistils. Style long and slender, articulated to the achene and deciduous. Ovule and seed inserted near the base of the style, pendulous and
anatropous.

Leaflets ovate or oval, 2-3 cm. long; bracts generally exceeding the inflorescence. Leaflets obovate or cuneate, usually less than $2 \mathrm{~cm}$. long; bracts shorter than th
inflorescence.

3. H. fusca. 
1. H. parviflora Nutt. Perennial, with a short woody caudex; stem erect, densely glandular, 1-2 dm. high; leaflets $5-8$ pairs, densely pilose and glandular, obovate or nearly orbicular, coarsely crenate; cyme subcapitate; hypanthium cup-shaped, $2-3 \mathrm{~mm}$. broad, tinged with purple; sepals lanceolate, $2-3 \mathrm{~mm}$. long; bractlets linear, much shorter; petals broadly cuneate, emarginate. Sagebrush lands and mountain sides: Calif.-Nev.-Ida.-Ore. Submont. Jl-Au.

2. H. capitata Lindl. Perennial; stem erect, rather simple, 4-6 dm. high, nearly glabrous below, glandular-hirsute above; basal leaves $2-3 \mathrm{dm}$. long, pinnate, nearly glabrous; leaflets 5-7 pairs, obovate or oval, $2-3 \mathrm{~cm}$. long, deeply incised-toothed; stem-leaves similar, but the upper with narrower oblanceolate acute leaflets; hypanthium glandular-hirsute, deeply cup-shaped; bractlets linear, nearly equalling the triangular-lanceolate acuminate sepals; petals broadly cuneate, 5-6 mm. long, truncate at the apex. Mountains: Ore.-Ida. Submont. Je-Jl.

3. H. fusca Lindl. Perennial, with a short woody caudex; stems several, 2-6 dm. high, more or less glandular, of ten more or less tinged with brown or purple; basal leaves 1-2 $\mathrm{cm}$. long, somewhat glandular-pubescent or glabrate; leaflets 5-7 pairs, obovate or cuneate, toothed or incised toward the apex, 1-2 $\mathrm{cm}$. long; hypanthium glandular-villous, cupulate; bractlets linear, much shorter than the ovate-lanceolate sepals; petals broadly cuneate, $3-4 \mathrm{~mm}$. long, truncate at the apex. Ore.-Calif.-Nev.-Ida. Son.-Submont. Je-Au.

\section{IVESIA T. \& G.}

Perennials, with thick erect rootstocks and short, often woody caudices. Leaves mostly basal and numerous, pinnately divided usually into numerous small more or less crowded and imbricate leaflets. Inflorescence cymose. $\mathrm{Hy}$ panthium from deeply campanulate or turbinate to saucer-shaped. Bractlets, sepals, and petals 5. Petals usually oblanceolate and more or less clawed, but sometimes nearly orbicular and practically clawless, white or yellow. Stamens $5-20$, inserted in the throat of the hypanthium; filaments filiform. Receptacle from hemispheric to flat, usually poorly developed and bearing $3-1,5$ pistils surrounded by a ring of prominent bristles. Styles long and slender, terminal or nearly so. Ovules and seeds pendulous and anatropous.

Leaflets numerous, more or less crowded, usually divided to near the base.

Stem leafy; stamens 20; claws of the white petals obsolete.

Stem few-leaved or scapiform; stamens 5; petals yellow or yellowish, clawed.

Cyme corymbiform; hypanthium cup-shaped.

Bractlets linear; stem decumbent.

Bractlets oblong or lanceolate; stem erect.

Cyme subcapitate; hypanthium campanulate.

Leaflets comparatively few, obovate, merely incised.

2. I. utahensis.

3. I. mutabilis.

4. I. Gordonii.

5. I. beneolens.

1. I. Kingii S. Wats. Perennial, with a thick, deep and woody root, crowned with a very short erect caudex; stems several, leafy, glabrous, prostrate, $2-4 \mathrm{dm}$. long; basal leaves numerous, glabrous, pinnate, with 20-25 pairs of crowded leaflets, glabrous; leaflets 3-5 $\mathrm{mm}$, long, divided to the base into 2-4 ovate or oblong segments; cyme narrow; hypanthium saucer-shaped, in fruit $3-4 \mathrm{~mm}$. in diameter; petals white, obovate or broadly spatulate, much exceeding the sepals; stamens 20. Desert regions: Nev.-w Utah. Son. Je-Au.

2. I. utahensis S. Wats. Perennial, with a woody but not very thick root, crowned by a cespitose caudex; stems several, about $1 \mathrm{dm}$. high, glabrous below, glandular above; basal leaves glabrous, pinnate, with 15-20 pairs of crowded leaflets, these $2-4 \mathrm{~mm}$. long, cleft to the base into 3 to 5 , broadly oblong to spatulate segments; stem-leaves few and very small; hypanthium somewhat glandularpuberulent, cup-shaped, veiny, $3 \mathrm{~mm}$, in diameter; petals yellowish, spatulate, scarcely exceeding the sepals; stamens 5. Mountains: Utah. Mont.-Subalp. Au.

3. I. mutabilis (Brand.) Rydb. Perennial, with a very thick woody root and short caudex; stems several, $3 \mathrm{dm}$. high, somewhat villous or nearly glabrous; basal leaves numerous, pinnate, with numerous leaflets, villous and somewhat glandular; leaflets sessile, more or less imbricate, $2-5 \mathrm{~mm}$. long, usually 
divided to near the base into obovate-oblong divisions; cyme much branched, open; hypanthium $4 \mathrm{~mm}$. broad, glandular-puberulent and sparingly hirsute; petals yellow, shorter than the sepals, oblanceolate; stamens 5 ; pistils 2-7. Mountains: Nev.-Utah. Son,-Submont.

4. I. Gordonii (Hook.) T. \& G. Perennial, with a thick and deep root and short woody cespitose caudex; stem subscapose, minutely glandular-puberulent or glabrous, 1-2 dm. high, seldom $3 \mathrm{dm}$.; basal leaves numerous, finely puberulent or glabrate, pinnate; leaflets $10-20$ rather approximate pairs, $5-12 \mathrm{~mm}$. long, divided into $3-5$ segments or again divided; segments broadly oblong to linear; hypanthium campanulate, $3-4 \mathrm{~mm}$. in diameter, villous-puberulent and somewhat glandular, yellowish; petals yellow, spatulate or oblanceolate, shorter than the sepals. Mountains: Wash.-Calif.-Colo.-Mont. Submont.-Subalp. $\mathrm{Je}-\mathrm{Au}$.

$$
\text { (mes + moels. }
$$

5. I. beneolens (A. Nels.) Rydb. Perennial, with thick woody caudex, densely covered with remains of old leaves; stems several, 7-15 $\mathrm{cm}$. long, viscidpuberulent; basal leaves numerous, about $1 \mathrm{dm}$. long, with 5-9, obovate, flabelliform or suborbicular leaflets; these $5-15 \mathrm{~mm}$. long, parted and incised into oblong lobes, viscid-puberulent; stem-leaves with 3-5 smaller leaflets; flowers cymose; hypanthium saucer-shaped, 5-angled, with a disk; sepals ovate; petals white, linear-oblanceolate; stamens 5; pistils 3-5. Hookelia beneolens A Nels. $\mathrm{Crev-}$ ices of basalt eliffs: Ida. Son. Je.

\section{COMARÉLLA Rydb.}

Perennial herbs, with very thick woody taproots and short thick scaly caudices. Leaves pinnate with numerous crowded leaflets. Inflorescence cymosepaniculate, with slender branches. Hypanthium wheel-shaped, i.e., the central portion turbinate, enclosing the ovaries, and beset on its inner surface with long bristles, the lateral portion flat, pentagonal in outline. Petals dark purple, narrowly linear, shorter than the calyx. Stamens 5, inserted at the outer margin of the flat portion of the hypanthium; filiments filiform, bent inward; anthers small. Pistils two; styles long and filiform, terminal.

1. C. sabulosa (M. E. Jones) Rydb. Stem several from the caudex, ascending, less than $2 \mathrm{dm}$. high, slender, glabrous; leaves glabrate, pinnate; leaflets about 15 rather approximate pairs, $3-5 \mathrm{~mm}$. long, 2-3-cleft into oval segments; hypanthium glabrous, $3-4 \mathrm{~mm}$. in diameter, in age 5-angled; bractlets linear-subulate, thickish, much smaller than the ovate-lanceolate acuminate sepals. Potentilla sabulosa M. E. Jones. Mountains: Utah. Son. Au-S.

\section{POtentílla L. Cinquefoil, Five-Finger.}

Annuals, or perennial herbs, with rootstocks. Leaves pinnately or digitately compound. Inflorescence usually cymose-paniculate. Hypanthium concave, mostly hemispheric. Bractlets, sepals, and petals 5 (sometimes 4). Petals deciduous, obcordate, obovate, rotund, or cuneate, as a rule not unguiculate, yellow, white, or dark-purple. Stamens most commonly 20 , in three series, viz., 10,5 , and 5 , respectively, sometimes more, sometimes fewer; filaments filiform or subulate, neither flattened nor dilated. Receptacle hemispheric or conic, bearing usually numerous pistils. Style usually long and filiform, attached near the apex of the ovary, deciduous. Seeds inserted near the base of the style, pendulous and anatropous. Cymes very leafy, many-flowered; annuals or biennials, rarely short-lived perennials;
styles fusiform and glandular at the base.

Cymes not very leafy, generally rather few-flowered; perennials with rootstocks.

Leaves digitate.
Basal leaves $5-9$-foliolate.

Basal leaves without an additional pair of leaflets on the petioles.

Plants more than $2 \mathrm{dm}$. high.

Leaves green on both sides, sparingly hairy, not at all tomentose.

Leaves either densely hairy or more or less tomentose II. NUTTALLIANAE. Leaflets merely crenate or cut-toothess tomentose beneath. half-way to the midrib. 
Leaflets densely pubescent beneath, if at all tomentose, the tomentum hidden under the long hairs, green and sparingly pubescent on the upper side. II. NUTTALLIANAE.

Leaflets principally tomentose beneath, only slightly hairy.

V. GRACILES.

Leaflets cleft more than half-way to the midrib into linear, oblong, or lance-oblong divisions.

Stems ascending or decumbent at the base; stem-leaves few, reduced, with $3-5$ leaflets.

Stems leafy; most of the stem-leaves 7-foliolate.

Plants less than $2 \mathrm{dm}$. high.

Leaves neither tomentose nor silky, green. VII. AUREAE.

Leaves tomentose or silky, at least beneath.

VIII. CONCINNAE.

Basal leaves digitately 5-foliolate, with an additional pair of smaller leaflets on the petiole.

Basal leaves 3 -foliolate.

Leaves more or less tomentose beneath. IX. NIVEAE.

Leaves not tomentose.

X. FRIGIDAE.

Leaves odd-pinnate.

Style much longer than the mature achene, fliform.

Leaves with 1-3 more or less approximate pairs of leaflets; plants low.

Leaves not at all tomentose.

Style subterminal.

Style attached below the apex of the achene.

Leaves more or less tomentose beneath.

VII. AUREAE.

XI. BREVIFOLIAE.

XII. RUBRICAULES.

Leaves with 3-13 pairs of leaflets; plants usually comparatively tall.

Leaves grayish or whitish, silky or tomentose, at least beneath.

Leaves green on both sides or merely strigose.

XIII. LEUCOPHYLLAE.

Leaves green on both sides or merely strigose. XIV. MULTIJUGAE.

Style not longer than the mature achene, thickened and glandular below; leaves usually more or less tomentose beneath.

XV. Multifidae.

\section{SUPINAE.}

Achenes with a corky gibbosity on the upper suture; leaves all pinnate with 3-5 pairs of leaflets.

Achenes not gibbous.

Lower leaves pinnate with 2 approximate pairs of leaflets, the upper ternate; stem strict; inflorescence cymose.

1. P. paradoxa.

Leaves all digitate; the basal ones rarely pinnate in $P$. monspeliensis.

Leaves ternate.

Petals about half as long as the sepals; achenes whitish, smooth; hypanthium in fruit $5 \mathrm{~mm}$. wide or less.

Stem slender; petals cuneate or obovate; sepals and bractlets $3-4 \mathrm{~mm}$. long. Stem with diffuse, spreading branches; leaflets cuneate; inflorescence cymose.

3. P. millegrana.

Stem with erect or strongly ascending branches; inflorescence inclined to be falsely racemose; leaflets broadly obovate; plant decidedly glandular-puberulent.

4. P. biennis.

Stem stout; petals obcordate; sepals and bractlets $5 \mathrm{~mm}$. long; plants densely glandular. $\quad$ 5. P. Kelseyi.

Petals equalling the sepals or nearly so; hypanthium in fruit about $7 \mathrm{~mm}$. wide; stamens $15-20$.

6. $P$. monspeliensis.

Lower leaves digitately 5-foliolate, or ternate with the lateral leaflets 2-cleft to near the base; stamens 5 .

7. P. pentandra.

\section{NuttallianaE.}

Calyx and leaves more or less glandular-atomiferous; whole plant yellowish or brownish green; leaves with strong ribs.

Leaflets dissected into linear or oblong divisions.

Leaflets coarsely toothed with lanceolate teeth.

8. P. brunnescens.

9. P. Nuttallii.

Calyx and leaves not glandular-atomiferous; plant neither yellowish nor brownish; ribs of the leaves not prominent.

Pubescence of the stem and petioles appressed.

Leaflets coarsely toothed.

Leaflets obovate or oblanceolate, toothed to near the base,

10. P. jucunda.

Leaflets cuneate-obovate, the middle ones mostly toothed above the middle, entire at the base.

Leaflets dissected at least half-way to the midrib.

Leaves rather densely silky beneath.

Leaves glabrous except the veins.

31. P. glaucophylla.

Pubescence of the stem and petioles spreading; leaflets loosely hairy, often slightly tomentose beneath.

13. P. dascia.

III. CANDIDAE.

Segments of the leaflets lanceolate, acute; tomentum sparse. 22. P. viridescens.

Segments of the leaflets oblong to linear, obtusish; tomentum dense.

Pubescence of the petioles and stems appressed. 
Leaves densely yellowish silky above, snow-white, tomentose and silky beneath.

Leaves green and sparingly silky above, tomentose, but 14. P. candida.

silky beneath.
15. P. Pecten. Pubescence of the petioles and stem spreading.

16. P. Bakeri.

\section{iV. Pectinisectae.}

Leaves green, finely silky beneath, slightly if at all tomentose. 17. P. pectinisecta.

Leaves white-tomentose beneath.

Divisions of the leaflets scarcely revolute; petals $7-10 \mathrm{~mm}$. long.

Leaves loosely villous-tomentose above.

Leaves appressed-silky above.

18. P. longiloba.

Divisions of the leaflets narrowly linear, revolute; petals $5-7 \mathrm{~mm}$. P. Bl $\mathrm{Bl}$.

\section{Graciles.}

20. P. flabelliformis.

Leaflets cut-toothed or cleft with lanceolate teeth.

Leaflets with a cuneate entire base; tomentum sparse.

Leaflets toothed or cleft along cheir whole margins.

Petioles with appressed or ascending hairs.

Stem slender, $3-5 \mathrm{dm}$. high; inflorescence open, scarcely leafy.

Stem stout, 4-7 dm. high, erect, leafy as well as the inflorescencidescens.

21. P. intermittens.

Leaves grayish green beneath, only slightly tomentose.

Leaves densely white-tomentose beneath; stem densely hairy. 23 . glota.

Petioles with spreading hairs.

24. P. dichroa.

Leaflets of at least the stem-leaves oblanceolate, sparingly hairy or glab
above; petals often $1 \mathrm{~cm}$. long.
Leaflets obovate, densely hairy above; plant $3-4 \mathrm{dm}$. high; pracilis.
long.
26. . $P$. camporum

Leaflets merely crenate with rounded or ovate teeth.

27. P. filipes.

One species.

VI. SUbJUGae.

VII. AUREAE.

28. P. subjuga.

Leaflets toothed, the toothing not deeper than half-way to the midrib.

Leaflets crenate with rounded or rounded-ovate, obtuse teeth.

Leaflets closely toothed or cleft with lanceolate or ob. P. Vreelandii. teeth or segments.

Leaflets spatulate or

Leaflets cuneate or obovate; teeth usually spreading. $35 . P$. concinnaeformis. ing. Leaves rather densely silky-strigose, the basal ones often inclined to be pin-
nate.

Leaves slightly pubescent, in age glabrous and somewhat glaucous, diveria.

Leaflets cleft or divided, the divisions extending two-thirds to the midrib or further.
. Placophlla.

Leaflets cleft into oblong or lanceolate divisions, slightly silky-strigose, in further.

Leaflets divided into linear divisions, permanently strigose. 33 . P. Perdissecta.
3ultisecta.

VIII. CONCINNAE.

Leaflets densely silvery-silky on both sides, only slightly if at all tomentose beneath.
Leaflets deeply dissected.

Leaflets merely toothed.

Inflorescence many-flowered and dense.

Inflorescence few-flowered and open.
Leaflets densely white-tomentose beneath.

Leaflets merely crenate or serrate.

Leaflets obovate to oblanceolate, toothed except at the very base.
Sepals ovate, acute.

Sepals lanceolate, acuminate.

Leaflets obovate, few-toothed. (Occasional forms of) 42. P. nivea.

Leaflets oblanceolate, many-toothed. (Depauperate forms of)

Leaflets oblong, with entire margins, only 3 -toothed (seldom $P$. filipes. apex. Leaflets deeply dissected.

37. P. bicrenata.

Bractlets lanceolate or linear-lanceolate, acute; petals light yellow.

Plant diffuse; sepals ovate; leaves more or less grayish above.

Plant erect or ascending; sepals lanceolate, $\quad 38$. P. divisa.

Bractlets linear, obtuse; petals 4. P. quinquefolia.
39. dense.

low; inflorescence rather

40. P. modesta. 


\section{NIVEAE.}

Leaflets oblanceolate or obovate, toothed or cleft, except at the very base; stem usually 1-2 dm. high, more or less leafy, several-flowered.

Leaflets deeply cleft, the clefts extending at least half-way to the midrib. Inflorescence dense and congested.

Inflorescence open, with slender pedicels.

41. P. Hookeriana.

Leaflets coarsely toothed, the toothing rarely extending half-way to the midrib. 42. $P$. nivea.

Leaflets broadly cuneate, toothed only above the middle; stems usually less than $1 \mathrm{dm}$. high, scapiform, 1-2-flowered (rarel y 3 -flowered). 43. P. uniflora.

\section{Frigidae,}

Stem less than $1 \mathrm{dm}$. high, decumbent; leaflets obovate, short-pilose; petals $5-8 \mathrm{~mm}$.

Stem 1-3 dm. high, erect; leaflets cuneate, flabelliform; petals $8-10 \mathrm{~mm}$. long.

One species,

\section{BRevifoliae.}

45. P. flabellifolia.

\section{RUBRICAULES.}

46. P. brevifolia.

Leaves mostly greenish above, tomentose beneath.

Segments of the leaves linear; stem nearly ereet, slender; sepals almost linear,

Segments of the leaves lanceolate or oblong; sepals lanceolate.

47. $P$, tenerrima.

Plant densely cespitose; segments of the leaves obtuse.

Segments lanceolate, acute; leaflets only slightly tomentose beneath.

Segments oblong to orbicular, obtuse.

Segments of the leaves narrowly oblong.

Segments of the leaves oval to orbicular.
Plant with spreading branches; segments of the leaves acute.

61. P. viridior.

48. P. saximontana.

49. $P$. minutifolia.

38. P. divisa.

Leaves densely silky on both sides.

Leaves with 2 or 3 pairs of leaflets; bractlets much shorter than the sepals; stem strict. 50. $P$. filicaulis.

Leaves with $3-5$ pairs of leaflets; bractlets little if at all shorter than the sepals; stem decumbent-ascending.

Leaflets deeply cleft.

Leaflets merely toothed.

51. P. Macounii.

\section{LeUCOPHYLLAE.}

52. P. proxima.

Pistils 20 or fewer; bractlets much shorter than the acuminate sepals; tomentum if any loose and not dense.

Plant tomentose throughout.

Plant green and nearly glabrous up to the inflorescence.

53. P. coloradensis.

Pistils usually more than 20 .

Leaves white-tomentose beneath; pubescence of the stem and petioles mostly appressed.

Leaves almost equally white-pubescent on both sides,

Bractlets much shorter than the acuminate sepals.

Leaflets not closely approximate, finely tomentose. 55. P. effusa.

Leaflets closely approximate, coarsely appressed-silky as well as tomentose.

Bractlets at least three-fourths as long as the acute sepals. 56. P. lupina. Inflorescence open; leaves silky and shining. Inflorescence dense; leaves loosely tomentose and rather dull.

Leaves green and merely silky above.

57. P. Hippiana.

Leaflets usually 9, all usually ascending, the upper pair decurrent.

Leaflets 5-7, the lower spreading or reflexed, the upper p. P. propinqua. Leaflets densely white beneath; teeth ovate. Leaflets thin, sparingly tomentose beneath; teeth lanceolate.

Leaves green beneath, only slightly tomentulose when young; pubescence of the stems and petioles spreading.

62. P. ambigens.

\section{MUltijugae.}

Pedicels at least in fruit arcuate-spreading; stems usually diffuse or spreading; leaflets pinnately divided, with several or many, oblong or lanceolate divisions.

Pedicels erect or ascending, straight; stem erect or ascending.
Leaflets dissected to near the midrib.

63. P. plattensis.

Stem and mature leaves glabrate; leaflets cuneate, cleft above the middle into oblong or ovate divisions.

Stem 1-3 dm. high; leaflets elongate-cuneate, with oblong divisions.

64. P. Nelsoniana,

Stem about $1 \mathrm{dm}$. high; leaflets short-cuneate, merely toothed at the apex.

65. P. decurrens. 
Stem and mature leaves more or less hairy; leaflets obovate, at least the upper pinnatisect.

Divisions of the leaflets long, narrowly linear; stem $2-3 \mathrm{dm}$. high; leaflets many. 66 . P. wyomingensis.

Divisions of the leaflets oblong or oblanceolate; stem less than $2 \mathrm{dm}$. high; leaflets few.

Leaflets not dissected to near the midrib.

67. P. ovina.

Leaves not densely grayish-strigose.

Sepals ovate or lance $\rightarrow$ ovate; bractlets lanceolate or oblong.

Stem about $1 \mathrm{dm}$. high; leaflets $1 \mathrm{~cm}$. long or less, toothed only at the apex.

65. $P$. decurrens.

Stem 2-4 dm. high; leaflets more than $2 \mathrm{~cm}$. long. 68. P. Drummondii.

Sepals linear-lanceolate, acuminate; bractlets linear-subulate.

Leaves densely grayish-strigose or silky.

54. $P$. rupincola.

Stem 1-4 dm. high, ascending or decumbent; leaflets cuneate or linear-oblong, conduplicate, toothed at the apex only.

Stem stout, 6-7 dm, high; leaflets obovate-oblong, coarsely serrate.

\section{Multifidae.}

62. P. ambigens.

Pubescence of the under side of the leaves silvery-white.

Petioles and lower part of the stem silky villous with spreading hairs.

Petioles and stem tomentulose and silky strigose.

70. P. paucijuga.

Segments of the leaflets linear or linear-oblong; branches of the inflorescence usually short and ascending.

Leaflets usually white on both sides; petals and sepals 4-6 $\mathrm{mm}$. long. Stem decumbent or ascending, 0.5-1 dm. high; leaflets 2 or 3 rather approximate pairs.

Stem erect, 3-5 dm. high; leaflets 3-7 usually rather remote pairs.

Leaflets green above; petals and sepals about $3 \mathrm{~mm}$. long.

72. P. bipinnatifida.

73. P. virgulata.

Segments of the leaflets lanceolate or oblong, usually green above; branches of the inflorescence long and erect.

Pubescence of the under side of the leaves grayish.

74. P. platyloba.

Petioles and stem appressed-pubescent.

Segments of the leaflets narrowly linear; petals and sepals about $3 \mathrm{~mm}$. long.

73. $P$. virgulata.

Segments of the leaflets ovate, lanceolate, or oblong; petals and sepals 4-6 mm. long.

Leaves glandular-pruinose above and sometimes with scattered long hairs.

Leaves short-strigose above.

Margins of the leaf-segments not revolute.

Margins of the leaf-segments revolute.

Petioles and stem with spreading hairs.

Flowers distinctly pedicelled; upper leaflets of the basal leaves with 9-13 segments; pubescence of the stem and petioles long.

Plant dark green; leaves scarcely paler beneath.

Plant not dark green; leaves decidedly paler beneath. $79 . P$. strigosa.

Flowers usually subsessile, densely conglomerate; upper leaflets of the basal leaves with 15-21 segments; pubescence of the stem short and dense.

80. P. lasiodonta.

1. P. paradoxa Nutt. Stem spreading or ascending, seldom erect, about $2-5 \mathrm{dm}$. high, leafy; leaves in age nearly glabrous, light green in color; leaflets obovate-cuneate, deeply erenate or cleft, $1-2 \mathrm{~cm}$. long; flowers about $7 \mathrm{~mm}$. in diameter; bractlets and sepals oblong-ovate, acute or mucronate, about equal in length; petals yellow, obovate-cuneate, truncate or slightly emarginate; stamens 15-20. Low ground: N.Y.-Ont.-N.M.-Utah-Wash.; Mex., e Asia. Plain -Submont. Je-Au.

2. P. rivalis Nutt. Stem erect and simple, finely villous-hirsute, leafy; leaflets $2-5 \mathrm{~cm}$. long, obovate, with coarse ovate teeth; flowers less than $5 \mathrm{~mm}$. in diameter; bractlets oblong, obtuse or acute, rather shorter than the ovate acute sepals; petals cuneate, much shorter than the sepals; stamens about 10 . River valleys: B.C.-Sask.-Mex. Plain-Submont. Je-Au.

3. P. millegrana Engelm. Stem slender, 4-8 dm. high, divaricate, softly pubescent, sometimes nearly glabrous; leaves ternate, finely pubescent; leaflets oblong-cuneate, deeply serrate, $1-6 \mathrm{~cm}$. long, the middle one often petiolulate; flowers 3-4 mm. in diameter; bractlets and sepals oblong-ovate, acute, of about the same length; petals oblong-cuneate, about half as long as the sepals, lightyellow; stamens generally 10 ; achenes smooth, light-colored, small. $P$. leuco- 
carpa Rydb, River valleys: Ill.-Man.-Wash.-Calif.-N.M. Plain-Submont. $\mathrm{My}-\mathrm{S}$.

4. P. biennis Greene. Annual or biennial; stems often several from the root, $3-5 \mathrm{dm}$. high, finely and rather densely pubescent, often tinged with red or purple; leaves all ternate; leaflets broadly obovate, coarsely crenate, $2-4 \mathrm{~cm}$. long; flowers small, about $5 \mathrm{~mm}$. in diameter; bractlets ovate-lanceolate or oblong, acute, a little shorter than the ovate acute sepals; petals yellow, obovate-cuneate, much shorter than the sepals; stamens about 10 ; ripe achenes whitish, smooth. Waste places: B.C.-Sask.-Colo.-Ariz.-L. Calif. Plain-Submont. My-S.

5. P. Kelseyi Rydb. Biennial; stem stout, 6-7 dm. high, glandular-villous; leaves ternate; leaflets obovate or cuneate-obovate, $3-5 \mathrm{~cm}$. long, incised-crenate, sparingly pubescent on both sides; inflorescence rather short and compact; hypanthium $5 \mathrm{~mm}$. wide; bractlets and sepals subequal, $5 \mathrm{~mm}$. long, linearlanceolate; petals obcordate, apparently white, about half as long as the sepals. Perhaps a hybrid of $P$. biennis and $P$. monspeliensis. Waste places: Mont. Submont. Je.

6. P. monspeliensis $\mathrm{L}$. Stems stout and very leafy, $3-8 \mathrm{dm}$. high, often several from the annual or biennial root, hirsute; leaves digitately 3 -foliolate, or in luxuriant forms the lower sometimes digitately or pinnately 5 -foliolate; leaflets usually obovate, $3-10 \mathrm{~cm}$. long, serrate; flowers about $1 \mathrm{~cm}$. in diameter; bractlets and sepals oblong-lanceolate, acute, nearly of the same length; petals light yellow, obovate, or cuneate, truncate, nearly equalling the sepals; stamens generally 20 , sometimes only 15 ; achenes usually rugulose when ripe. $P$. norvegica hirsuta Michx. Rich soil and waste places: Lab.-D.C.-Kans.-Mex.Calif.-Alaska; Eurasia. Plain-Submont. My-S.

7. P. pentandra Engelm. Annual; stems stout, very leafy, 3-7 dm. high, finely hirsute and much branched above; leaflets $2-10 \mathrm{~cm}$. long, oblong to oblanceolate or cuneate, deeply serrate, pubescent on both sides; flowers less than $5 \mathrm{~mm}$. in diameter; bractlets oblong, acute, about $3 \mathrm{~mm}$. long, nearly as long as the ovate acute sepals; petals pale yellow, obovate, scarcely half as long as the sepals; achenes smooth, brownish. Bottom-land: Mo.-A Ark.-Sask.-Alta.Neb. Plain. Je-Au.

8. P. brunnescens Rydb. Stem 4-5 dm. high, with spreading pubescence; petioles villous with spreading hairs; leaflets $4-7 \mathrm{~cm}$. long, broadly oblanceolate in outline; segments linear, obtuse; hypanthium and calyx villous-strigose; bractlets linear, obtuse, about half as long as the ovate-lanceolate acute sepals; petals yellow, $5-6 \mathrm{~mm}$. long, obovate; stamens 20 . Mountains: Colo.-Mont. Submont. $\mathrm{My}-\mathrm{Au}$.

9. P. Nuttallii Lehm. Stem 6-8 dm. high, stout, sparingly hirsute; basal leaves digitate, sparingly hirsute, not at all tomentose beneath; petioles with appressed hairs; leaflets 5-10 $\mathrm{cm}$. long, oblanceolate, toothed or divided nearly halfway to the midrib; hypanthium hirsute, in fruit about $1 \mathrm{~cm}$. in diameter; bractlets linear to lanceolate, generally shorter than the ovate-lanceolate sepals; petals yellow, obovate, emarginate, $6-8 \mathrm{~mm}$. long. Mountain valleys: Sask.Colo.-Ore.-B.C. Plain-Mont. My-Au.

10. P. juncunda A. Nels. Stem slightly appressed-pubescent, slender, 4-7 dm. high; basal leaflets 4-7 cm. long, obovate-oblanceolate, green on both sides, nearly glabrous above, slightly appressed-silky beneath, coarsely serrate; hypanthium softly pubescent; bractlets linear-lanceolate, a little shorter than the broadly lanceolate sepals; petals broadly obcordate, $8-10 \mathrm{~mm}$. long. Mountains: Mont.-Colo.-Utah-Ida. Submont.-Mont. Je-Au.

11. P. rectiformis Rydb. Stem 6-10 dm. high, densely strigose; leaflets oblanceolate or spatulate, 4-6 $\mathrm{cm}$. long, coarsely cut-toothed with lanceolate teeth curved forward, appressed-pubescent on both sides or glabrate above; hypanthium strigose; bractlets linear-lanceolate, 5-7 mm. long, about equalling the ovate-lanceolate acuminate sepals; petals obcordate, 6-7 mm. long. Valleys: Wash.-Ida.-Mont. Plain-Submont. Je-Jl. 
12. P. glabrata (Lehm.) Rydb. Stems slender, 4-6 dm. high; leaflets $2-5 \mathrm{~cm}$. long, oblanceolate or obovate-oblanceolate, glabrous except the veins beneath, cut-toothed about halfway to the midrib; hypanthium strigose; bract lets linear or linear-lanceolate, 3-4 mm. long; sepals ovate, acuminate, 5-7 mm. long; petals obcordate, slightly exceeding the sepals. Valleys: Ore.-Wash.w Wyo. Submont. Je-Jl.

13. P. dascia Rydb. Stem single, erect, 4-7 dm. high, hirsute; leaflets obovate to oblanceolate, $3-10 \mathrm{~cm}$. long, coarsely and rather densely pubescent on both sides, coarsely cut-toothed about halfway to the midrib; hypanthium hirsute, in fruit 7-8 mm. broad; bractlets linear to lanceolate, 4-5 mm. long; sepals lanceolate, $5-6 \mathrm{~mm}$. long; petals obcordate, 7-8 mm. long. Meadows:
Wash.-Calif.-Mont. Submont. Jl-Au.

14. P. candida Rydb. Stem low, $1-2 \mathrm{dm}$. high, densely white silky-strigose; leaflets 7-9, obovate in outline, $2-4 \mathrm{~cm}$. long, rather thick, deeply incised or cleft; flowers about $1 \mathrm{~cm}$. in diameter; hypanthium white-silky; bractlets lanceolate, much shorter than the ovate sepals, which are about $5 \mathrm{~mm}$. long; petals yellow, obcordate, a little exceeding the sepals. Dry places: Nev.-s Utah.
Submont. Je.

15. P. Pecten Rydb. Stem $2-3 \mathrm{dm}$. high, ascending or decumbent at the base, grayish silky-strigose; leaflets $3-4 \mathrm{~cm}$. long, elliptic-ovate or oblanceolate, green and appressed-hairy above, tomentose and silky beneath, dissected onehalf to two-thirds to the midrib into oblong acute divisions; bractlets $2-3 \mathrm{~mm}$. at all exceeding the sepals. Mountains: Mont.-Wyo.-Utah. Submont. Je-Au.

16. P. Bakeri Rydb. Stem $3-5 \mathrm{dm}$. high, usually decumbent at the base, loosely hirsute; leaflets oblanceolate, $3-5 \mathrm{~cm}$. long, strongly veined, coarsely appressed-silky on both sides and tomentose beneath, cleft about three-fourths to the midrib into oblong, acutish or obtusish divisions; hypanthium 5-6 mm. broad in fruit; bractlets linear-lanceolate, about $3 \mathrm{~mm}$. long and about half as long as the ovate or ovate-lanceolate sepals; petals obcordate, a little exceeding the sepals. Mountain valleys: Wyo.-Colo.-e Calif.-Ida. Submont.-

17. P. pectinisecta Rydb. Stem slender, $3-4 \mathrm{dm}$. high, finely silky-strigose or rarely hirsute; leaflets appressed-silky on both sides and sometimes slightly tomentulose beneath, obovate, deeply pectinately divided into oblong or linear segments; hypanthium appressed-silky, in fruit 6-7 mm. broad; bractlets linearlanceolate, shorter than the broadly lanceolate sepals; petals yellow, obcordate, 7-8 mm. long. Dry places: Utah-Wyo.-n Ariz. Son.-Submont. My-J.

18. P. longiloba Rydb. Stem stout, $3-5 \mathrm{dm}$. high, hirsute-strigose and woolly; leaflets $3-5 \mathrm{~cm}$. long, dissected to near the midrib into linear or linearlanceolate divisions, loosely villous above, densely white-tomentose beneath; hypanthium in fruit $8 \mathrm{~mm}$. broad; bractlets linear-lanceolate, usually equalling w Mont. -n Ida. Son. Submont obcordate, about $8 \mathrm{~mm}$. long. Meadows:

19. P Blaschlson. Submont. My-J.

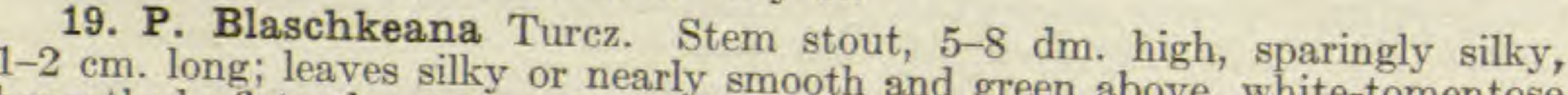
beneath; leaflets about $5 \mathrm{~cm}$. long, obovate in outline, deeplye, white-tomentose oblong divisions, often divergent; hypanthium silky, in fruit often over $1 \mathrm{~cm}$. in
diameter; bractlets oblong-lanceolate, lanceolate or ovate sepals; petals broadly obeordach shorter than the broadly much longer than the sepals. Potentilla ctenophora Rydb. Meadows: B.C.-n Calif.-n Wyo.-Alta. Submont.-Mont. My-Jl.

20. P. flabelliformis Lehm. Stem slender, but strict, 4-6 dm. high, silkystrigose; leaves densely silky above, white-tomentose beneath; leaflets $3-5 \mathrm{~cm}$. long, pectinately divided into narrowly linear lobes; hypanthium silky-villous; sepals; corolla 10-12 mm. in diameter; than the triangular-lanceolate acuminate sepals. Meadows: B.C.-Sask-W - w 
21. P. intermittens Rydb. Stems ascending, about $3 \mathrm{dm}$. high, sparingly hairy; leaflets cuneate-oblanceolate, most of them sharply cut-toothed, with lanceolate teeth directed forward, sparingly silky above, grayish tomentose beneath; inflorescence few-flowered; bractlets linear, $4 \mathrm{~mm}$. long; sepals laneeolate, acuminate, $5-6 \mathrm{~mm}$. long; petals obcordate, $6-7 \mathrm{~mm}$. long. Perhaps a hybrid between $P$. glaucophylla and $P$. filipes. Mountains: Alta.-Colo.Nev. Submont.-Mont. Je-Au.

22. P. viridescens Rydb. Stem 5-7 dm. high, sparingly silky with appressed or slightly spreading hairs; leaves silky, but green above, silky and somewhat tomentulose beneath; leaflets oblanceolate or spatulate, deeply toothed or divided nearly half way to the midrib, with lanceolate often somewhat divergent teeth; hypanthium silky; bractlets lanceolate, a little shorter than the ovate-lanceolate sepals; corolla $10-15 \mathrm{~mm}$. in diameter; petals obcordate, equalling or slightly exceeding the sepals. Valleys: Man.-Alta.-Wyo. Submont.-Mont. My-Au.

23. P. glomerata A. Nels. Stem stout, $4-8 \mathrm{dm}$. high, softly pubescent with appressed or slightly spreading hairs; leaflets $4-8 \mathrm{~cm}$. long, oblanceolate or narrowly obovate, cut-toothed, green, but densely appressed-hairy above, more or less tomentose beneath; sepals broadly lanceolate, acuminate, $5-8 \mathrm{~mm}$. long; petals rounded-obcordate, $6-8 \mathrm{~mm}$. long. River bottoms: Wash.-Calif.Wyo.-Mont. Submont.-Mont. Je-Au.

24. P. dichroa Rydb. Stems strict, 4-6 dm. high, densely white-strigose; leaflets oblanceolate, $3-6 \mathrm{~cm}$. long, green and appressed-silky above, white-tomentose and silky beneath, eut-toothed nearly halfway to the midrib; hypanthium silky; bractlets lanceolate, $3-4 \mathrm{~mm}$. long; sepals ovate, acute, $6 \mathrm{~mm}$. long; petals obcordate, 7-8 mm. long. Meadows: w Mont.-Ore.-Nev.-Utah. Submont. Je-Au.

25. P. gracilis Dougl. Stem 4-7 dm. high, slender, slightly silky-villous; leaflets $3-6 \mathrm{~cm}$. long, oblanceolate, green and nearly glabrous above, densely and finely white-tomentose beneath, divided about halfway to the midrib; bractlets lanceolate, a little shorter than the ovate-acuminate sepals; corolla 15-20 mm. in diameter; petals obcordate, deeply emarginate, often over $1 \mathrm{~cm}$. long, much exceeding the sepals. Meadows: B.C. -w Mont.-Ore. Submont. Je-S.

26. P. camporum Rydb. Stem simple, strict, $3-4 \mathrm{dm}$. high, hirsute with spreading or reflexed hairs; leaflets obovate or broadly oblanceolate, $2-5 \mathrm{~cm}$. long, cut-toothed, densely hirsute-strigose above, white-tomentose and silky beneath; bractlets lanceolate, $3-4 \mathrm{~mm}$. long; sepals ovate-lanceolate, $4-5 \mathrm{~mm}$. long; petals obcordate, 5-6 mm. long. Meadows: (Black Hills) S. D.-Man. Plain. Je-Jl.

27. P. filipes Rydb. Stems 3-5 dm. high, slender, silky-hirsute or silkystrigose; leaflets obovate to oblanceolate, obtuse, coarsely crenate, $2-6 \mathrm{~cm}$. long, green and sparingly strigose above, white-tomentose beneath; bractlets linearlanceolate, a little shorter than the lanceolate acute sepals; petals yellow, broadly obeordate, 6-8 mm. long, exceeding the sepals. P. Hippiana pulcherrima S. Wats. P. gracilis Porter \& Coulter, not Dougl. Mountains, valleys: Man. -N.M-Utah-Alta. Submont.-Mont. Je-Au.

28. P. subjuga Rydb. Tufted; stems many, 1-3 dm. high, silky-villous, few-leaved; leaflets 1-4 cm. long, oblong or obovate, deeply incised into oblong, rather obtuse segments, silky and green above, silky and white-tomentose beneath; bractlets oblong, obtuse or acute, about a third shorter than the triangular-lanceolate sepals; petals broadly obcordate, exceeding the sepals. Mountains: Colo. Mont.

29. P. Vreelandii Rydb. Stems ascending, $1.5-2 \mathrm{dm}$. high, glabrous and straw-colored below, sparingly pubescent above; basal leaves 5 -foliolate, digitate, or pinnate with closely approximate leaflets; leaflets cuneate or obovate-cuneate, glabrous or ciliate on the margins and veins, more or less glaucous, 1-2 cm. long, erenate with rounded-ovate teeth at the apex; inflorescence 1-4-flowered; bractlets elliptic or oblong, obtuse, about $3 \mathrm{~mm}$. long; sepals ovate, acute, 4-5 $\mathrm{mm}$. long; petals broadly obcordate, about $7 \mathrm{~mm}$. long. Mountains: Mont. Subalp. Au. 
30. P. diversifolia Lehm. Stem erect, few-leaved, smooth or strigose, 1-2 $\mathrm{dm}$. (rarely $3 \mathrm{dm}$.) high; basal leaves digitate, or often pinnate with approximate leaflets, or both in the same plant, more or less silky-strigose, especially beneath; leaflets most commonly 7, oblanceolate, cuneate, or sometimes obovate, more or less toothed; bractlets and sepals lanceolate, acute, $3.5-5 \mathrm{~mm}$. long; petals obcordate or obovate and emarginate, $6-7 \mathrm{~mm}$. long, about one-third longer than the sepals. P. dissecta Nutt., not Pursh. Mountain valleys: Sask.-B.C. -Calif.-Colo. Submont.-Alp. Je-Au.

31. P. glaucophylla Lehm. Stems 1.5-4 dm. high, glabrous below, sparingly strigose above; leaflets oblanceolate-cuneate, 1-5 cm. long, coarsely serrate, with acute teeth directed forward, strigose when young, soon glabrate, glaucous; cyme 3-12-flowered; bractlets lanceolate, 3-5 mm. long, acute; sepals ovate, acuminate, $5-7 \mathrm{~mm}$. long; petals obcordate, $6-10 \mathrm{~mm}$. long. $P$. diversifolia glaucophylla Lehm. P. dissecta glaucophylla S. Wats. Mountain valleys: B.C.-Sask.-N.M.-Utah. Submont.-Subalp. Je-Au.

32. P. perdissecta Rydb. Stems $0.5-2 \mathrm{dm}$. high, when young slightly silky-strigose, glabrate in age; leaflets $1-3 \mathrm{~cm}$. long, obovate in outline, the two lower much smaller, all deeply cleft into oblong or lanceolate acute divisions, glabrous or nearly so, shining; bractlets oblong, obtuse, much shorter than the ovate-lanceolate acute sepals; petals much longer than the sepals, $5-8 \mathrm{~mm}$. long. High mountains: B.C.-Alta.-Wyo--Utah. Submont.-Mont. Je-Au.

33. P. multisecta (S. Wats.) Rydb. Stem erect, slender, 1-2 dm. high, more or less silky-strigose; leaves more or less silky, digitate, or pinnate with approximate leaflets; leaflets 3-7, the lower smaller, all dissected into linear or linear-oblong divisions; bractlets and sepals oblong-lanceolate, acute, $3-4 \mathrm{~mm}$. long; petals obcordate, about one-half longer than the sepals. $P$. diversifolia multisecta S. Wats, P. dissecta multisecta S. Wats. High mountains: Mont.B.C.-Wyo.-Nev. Mont. Je-Jl.

34. P. fastigiata Nutt. Stem low, 1-3 dm. high, ascending, generally quite densely silky, rather simple; leaves silky-villous with rather long hairs on both sides and slightly tomentose beneath; leaflets obovate, $1-3 \mathrm{~cm}$. long, coarsely crenate or somewhat incised; cyme usually rather dense; bractlets linear-lanceolate, shorter than the triangular-ovate acute sepals; corolla $10-15 \mathrm{~mm}$. in diameter; petals broadly obcordate, a little exceeding the sepals. Meadows: Mont.-Wyo.-Nev. Submont. Je-Jl.

35. P. concinnaeformis Rydb. Stems about $1 \mathrm{dm}$. high, ascending, slightly silky-strigose, subscapose; basal leaves numerous, densely silvery-silky on both sides and slightly tomentose beneath; leaflets $1-2 \mathrm{~cm}$. long, oblongcuneate, crenate except at the base; bractlets oblong-lanceolate, about a third shorter than the broadly lanceolate sepals; petals yellow, obcordate, a third longer than the sepals. Mountains: Ariz.-s Utah. Subalp. Je-Jl.

36. P. concinna Richards. Stems many, spreading, more or less tomentose; leaves densely white-tomentose beneath, silky and slightly tomentose above when young, digitate (sometimes approximately pinnate); leaflets obovate or cuneate, more or less deeply toothed, 1-3 cm. long; sepals ovate, acute, 4-5 $\mathrm{mm}$. long; petals obcordate, a little exceeding the sepals, about $6 \mathrm{~mm}$. long. Dry hills and mountains: Colo.-Sask.-Alta.-Ida. Plain-Mont. My-Jl.

37. P. bicrenata Rydb. Stem erect to spreading, 5-7 cm. high, about equalling the leaves, 1-3-flowered; basal leaves digitately 5-foliolate, silky and greenish above, white-tomentose beneath; leaflets $0.5-3 \mathrm{~cm}$. long, oblong-cuneate; sepals ovate or lance-ovate, about $4 \mathrm{~mm}$. long; petals obovate, truncate or emarginate, 5-6 mm. long. Dry hills: N.M.-Wyo. Submont. Je.

38. P. divisa Rydb. Stems spreading or diffuse, 5-10 $\mathrm{cm}$. long, pubescent with long white hairs; basal leaves 5 -foliolate, digitate, or pinnate with approximate leaflets; leaflets 1-2 cm. long, obovate or oblanceolate in outline, deeply cleft, with oblong or lanceolate divisions, pubescent above with long white hairs, densely white-tomentose beneath; sepals ovate, about $4 \mathrm{~mm}$. long; petals broadly cuneate, emarginate, about $5 \mathrm{~mm}$. long. $P$. nivea dissecta $\mathrm{S}$. Wats. $P$. concinna 
divisa Rydb. Dry hills: (Black Hills) S.D.-Sask.-Alta,-Colo. Submont.Alp. Je-Jl.

39. P. quinquefolia Rydb. Stems generally several, ascending, 1.5-2 dm. high, rather loosely silky-villous; basal leaves rather many, 5- (seldom 3-) foliolate, usually with the terminal leaflet short-petiolulate, silky-villous above, whitetomentose beneath; leaflets broaaly obovate, cleft about halfway to the midrib into oblong segments, $1.5-3 \mathrm{~cm}$. long; sepals lanceolate, $4 \mathrm{~mm}$. long; petals obovate, emarginate, a little exceeding the sepals. $P$. nivea pentaphylla Lehm. $P$. nivea quinquefolia Rydb. P. subquinata Rydb. Mountains and hills: Sask. -B.C.-Colo-Utah. Plain-Alp. Je-Jl.

40. P. modesta Rydb. Stems ascending, about $1 \mathrm{dm}$. high, several-flowered; basal leaves digitately 5-foliolate, or 3-foliolate; leaflets broadly obovate, 1-1.5 $\mathrm{cm}$. long, silky, but green above, white-tomentose beneath, deeply cleft into oblong or lanceolate divisions; inflorescence few-flowered, rather dense, the pedicels short: sepals lance-ovate, acute, $3 \mathrm{~mm}$. long; petals $3-4 \mathrm{~mm}$. long, obeordate. High mountains: Utah. Submont.-Subalp. My-Jl.

41. P. Hookeriana Lehm. Stems several from the caudex, 1-2 dm. high, white-tomentose and silky-villous, ascending; leaves ternate, or occasionally with a pair of small extra leaflets, white on both sides, silky-villous above, densely tomentose beneath; leaflets obovate in outline, 1-2 cm. long, deeply cleft to near the midrib into oblong lobes; flowers in small dense cymes, about $8-10 \mathrm{~mm}$. in diameter; sepals lanceolate, acute; petals obcordate, generally a little exceeding the sepals; styles short, a little thickened and glandular at the base. Hills and plains: Sask.-Alta.-Mont. Plain-Submont. Je-Jl.

42. P. nivea L. Stems several, 1-2 dm. high, more or less tomentose or villous, few-leaved; leaves ternate, glabrate or slightly villous above, densely white-tomentose beneath; leaflets oblong-cuneate or obovate, $2-3 \mathrm{~cm}$. long, generally coarsely crenate; cyme 2-6-flowered; flowers $12-15 \mathrm{~mm}$. in diameter; sepals lanceolate, acute, 5-6 mm. long; petals obcordate, exceeding the sepals, 6-8 mm. long. Aretic and alpine regions: Alaska-Greenl.-Que.-Colo.; Eurasia. Alp.-Subalp. Jl-Au.

43. P. uniflora Ledeb. Stems about $5 \mathrm{~cm}$. high, slightly villous or tomentose, 1-2-flowered; leaves crowded, ternate, silky or glabrate above, densely white-tomentose beneath; leaflets $1-1.5 \mathrm{~cm}$. long, broadly cuneate or rhombicobovate, deeply cut from the apex into coarse oblong-lanceolate teeth; sepals ovate-lanceolate, acute, 4-5 mm. long; petals yellow, obcordate, 6-8 mm. long. Arctic-alpine regions: Alaska-Ore--Hudson Bay-Colo.; Asia. Alp.-Subalp. $\mathrm{Je}-\mathrm{Au}$.

44. P. emarginata Pursh. Stems 2-10 cm. high, generally 1-2-flowered, pilose or softly villous-hirsute; leaves ternate, pilose on both sides; leaflets 0.5 $1.5 \mathrm{~cm}$. long, broadly obovate, with a cuneate base and broad teeth; sepals acute, ovate; petals broadly obcordate, a little exceeding the sepals, $5-8 \mathrm{~mm}$. long. $P$. nana Willd. Arctic-alpine regions: Lab.-Greenl--Alaska-Canadian Rocky Mountains; Siberia and Spitzbergen. Alp. Jl-Au.

45. P. flabellifolia Hook. Stems $2-3 \mathrm{dm}$. high, minutely puberulent, fewleaved; leaves ternate, very thin, short-pubescent or glabrate; leaflets cuneateflabelliform, deeply serrate, with obtuse teeth, entire towards the base; bractlets oval, obtuse or acutish, equalling the sepals, $5-6 \mathrm{~mm}$. long; petals obovatecuneate, deeply emarginate, $8-10 \mathrm{~mm}$. long. $P$. trina A. Nels. Mountains: B.C.-Ida.-c Calif. Submont.

46. P. brevifolia Nutt. Stems less than $1 \mathrm{dm}$. high, slender, 1-2-leaved, glandular-puberulent; leaflets suborbicular, with cuneate base, 2-3-cleft and crenate, $0.5-1 \mathrm{~cm}$. long; sepals broadly ovate and acute or slightly mucronate, $4 \mathrm{~mm}$. long; petals a little longer than the sepals, yellow, obovate, and often a little notched. High mountains: Ore.-W Wyo. Mont.-Subalp. Au.

47. P. tenerrima Rydb. Stems many, very slender, generally tinged with red, 1-1.5 dm. high, sparingly strigose; leaves pinnate, with 2 pairs of leaflets, finely silky and a little grayish-tomentulose beneath; leaflets obovate or oblan- 
ceolate in outline, divided to near the midrib into linear acute segments; sepals narrowly lanceolate, about $4 \mathrm{~mm}$. long; petals obovate, slightly retuse, a little exceeding the sepals. Mountains: Colo. Subalp. J1.

48. P. saximontana Rydb. Stems ascending or prostrate, generally not much over $1 \mathrm{dm}$. high, appressed silky-strigose, more or less leafy and branched; leaves pinnate, with 2-3 approximate pairs of leaflets, silky above, more or less white-tomentulose beneath; leaflets $5-20 \mathrm{~mm}$. long, obovate or oblong in outline, deeply dissected into narrowly oblong segments; cyme rather few-flowered; sepals lanceolate, acute, 4-5 $\mathrm{mm}$. long; petals obcordate, $6-8 \mathrm{~mm}$. long. $P$. rubricaulis Rydb., not Lehm. P. rubripes Rydb. Alpine regions: Utah-Colo. -Alta. Alp.-Subalp. Je-Au.

49. P. minutifolia Rydb. Stems about $1 \mathrm{dm}$. long, slender, 1 - or 2-leaved, sparingly silky or nearly glabrous; basal leaves very small, slightly grayish beneath, pinnate, with two pairs of leaflets, the upper pair and the sessile odd leaflet about $5 \mathrm{~mm}$. long, the lower pair only $2-3 \mathrm{~mm}$; leaflets obovate, incised, with oval rounded segments; flowers 1 or 2 ; sepals lanceolate, obtuse or acutish, about $4 \mathrm{~mm}$. long; petals obcordate, about half longer than the sepals. Mountains: Colo. Alp.-Mont. Jl.

50. P. filicaulis (Nutt.) Rydb. Stems several from the caudex, erect or ascending, $1 \mathrm{dm}$. high or less, silky-strigose, few-leaved; basal leaves many, pinnate, with 2 or 3 pairs of approximate leaflets, or subdigitately 5 -7-foliolate, densely silky on both sides and slightly tomentose beneath; leaflets cuneate, 1-2 cm. long, coarsely serrate, with ovate teeth; cyme few-flowered; sepals ovate or ovate-lanceolate, acute, 4-5 mm. long; petals obcordate, $5-6 \mathrm{~mm}$. long. $P$. effusa filicaulis Nutt. Mountains: Colo--Ida. Mont. J.

51. P. Macounii Rydb. Stems usually more than one from the caudex, ascending, silky-villous, less than $1 \mathrm{dm}$. high, 1- or 2-leaved; basal leaves many, pinnate, with 3-5 pairs of rather approximate leaflets, silky on both sides and somewhat tomentose beneath; leaflets cuneate, about $1 \mathrm{~cm}$. long, deeply cleft into oblong segments; eyme few-flowered; sepals ovate, 4-5 $\mathrm{mm}$. long; petals obcordate, 5-7 mm. long. Rocky slopes: Alta.-Mont. Submont.-Mont. Je-Au.

52. P. proxima Rydb. Stems less than $1 \mathrm{dm}$. high, decumbent or ascending, grayish silky-strigose; basal leaves pinnate, with 7 approximate leaflets; leaflets 7-15 mm. long, obovate, serrate, silky on both sides and white-tomentose beneath; sepals lanceolate, $4 \mathrm{~mm}$. long; petals obcordate, $5 \mathrm{~mm}$. long. Mountains: Utah-Ariz. Subalp. Jl-Au.

53. P. coloradensis Rydb. Stems several, rather slender, silky-tomentose, in age glabrate, about $3 \mathrm{dm}$. high, branched; leaflets 9-13, finely tomentose, or in age more glabrate; leaflets cuneate-oblanceolate, incisely serrate, with triangular acute teeth; bractlets linear-lanceolate; sepals lanceolate acuminate, about $4 \mathrm{~mm}$. long; petals obcordate, scarcely exceeding the sepals; pistils $10-15$ (rarely 20). Mountains: Colo.-Wyo. Mont. J1-Au.

54. P. rupincola Osterhout. Stems slender, 2-3 dm. high, glabrous except for a few stiff pointed hairs, erect or nearly so; leaflets of the basal leaves 5-7, narrowly cuneate, $1-1.5 \mathrm{~cm}$. long, sharply serrate above, glabrous, except the ribs and margins, which are slightly ciliate; sepals narrowly lanceolate, acuminate, 3-4 $\mathrm{mm}$. long; petals broadly obovate, retuse, about the length of the sepals; pistils about 6. Mountains: n Colo. Submont.-Mont. J-Au.

55. P. effusa Dougl. Stems many, $2-4 \mathrm{dm}$. high, slightly silky, ascending or diffuse; basal leaves usually interruptedly pinnate, grayish tomentose on both sides; leaflets 5-11, cuneate-oblong or oblanceolate, the upper often confluent, crenate, with broad usually ovate teeth; sepals lanceolate-acuminate, 4-5 mm. long; petals obovate, retuse, a little longer than the calyx. Plains and hills: Alta.-Sask.-Neb.-N.M. Plain-Mont. Je-Au.

56. P. lupina Rydb. Stem 3-4 dm, high, nearly erect, densely grayish pubescent with coarse ascending hairs; basal leaves pinnate, with about 7 approximate leaflets; leaflets oblanceolate, $2-5 \mathrm{~cm}$. long, coarsely crenate, densely 
grayish pubescent on both sides and tomentulose beneath; bractlets lanceolate, about $3 \mathrm{~mm}$. long; sepals lance-ovate, acuminate, $5-7 \mathrm{~mm}$. long; petals obcordate, about equalling the sepals. Mountain slopes: Wyo. Submont.-Mont. $\mathrm{Jl}-\mathrm{Au}$.

57. P. Hippiana Lehm. Stem erect, 3-5 dm. high, more or less silkycanescent or white with appressed hairs, leafy; basal leaves several; leaflets 7-11, gradually diminishing downward, white- or grayish-silky on both sides and tomentose beneath, obovate or cuneate-oblong, 2-5 cm. long, deeply obtusely toothed, the upper often confluent; sepals ovate-lanceolate, $5-7 \mathrm{~mm}$. long; petals 6-8 mm. long, obovate, retuse. Plains and hills: Alta.-Sask.-N.M.Ariz. Plain-Mont. Jl-Au.

58. P. argyrea Rydb. Stems erect or nearly so, white-tomentose and silky; basal leaves pinnate, with 7-9 leaflets; leaflets oblanceolate or oblong-obovate, 1-3 cm. long, white-tomentose on both sides, coarsely crenate; sepals ovate, acute, 4-5 mm. long; petals obcordate, $5 \mathrm{~mm}$. long. Plains: Sask.-N.D. Plain. Je-Jl.

59. P. propinqua Rydb. Stems decumbent, ascending, or erect, finely silky-strigose, 2-5 dm. high; basal leaves pinnate, with 9-11 leaflets; leaflets oblanceolate, 1-6 cm. long, coarsely crenate, green and silky above, whitetomentose beneath, the upper two pairs usually more or less decurrent on the rachis; sepals ovate-lanceolate, $5-6 \mathrm{~mm}$. long; petals obcordate, $6-8 \mathrm{~mm}$. long. $P$. diffusa A. Gray, not Willd. P. Hippiana pulcherrima S. Wats., in part. Mountain meadows: Alta.-(Black Hills) S.D.-N.M.-Ariz. Submont.-Mont. $\mathrm{Je}-\mathrm{Au}$.

60. P. pulcherrima Lehm. Stems erect or ascending, 4-6 dm. high, pubescent with ascending hairs; basal leaves pinnate, with 5-7 approximate leaflets; leaflets oblanceolate, 2-7 cm. long, crenate, green and silky above, densely whitetomentose beneath, the lower two pairs spreading or the lowest reflexed, usually very close together; sepals ovate-lanceolate, acuminate, 5-7 mm. long; petals obcordate, 6-8 mm. long. P. Hippiana pulcherrima S. Wats. P. Wardii Greene. Mountains: Alta.-Sask.-N.M.-Utah. Submont.-Mont. Je-Au.

61. P. viridior Rydb. Stems erect or ascending, glabrous or nearly so, 2-3 dm. high; basal leaves pinnate, with $5-7$ leaflets; leaflets $0.5-3 \mathrm{em}$. long, obovate, green and slightly silky above, paler, silky and sparingly tomentulose beneath, deeply serrate, with lanceolate acute teeth; sepals lanceolate, 4-6 mm. long; petals obcordate, 6-8 mm. long. Mountains: Colo. Subalp. J-Au.

62. $\mathbf{P}$. ambigens Greene. Stem stout, 6-7 dm. high, more or less striate, densely silky-villous, with long spreading hairs; basal leaves irregularly pinnate, silky villous beneath, especially on the rachis and the veins, slightly tomentulose when young, more glabrate above; leaflets 9-15, obovate-oblong, 3-6 cm. long, coarsely serrate, more or less decurrent on the rachis, the uppermost confluent; sepals lanceolate, acute, 6-7 $\mathrm{mm}$. long; petals about $8 \mathrm{~mm}$. long, obcordate, about a fourth longer than the sepals. Mountains: N.M.-Wyo. Submont. $\mathrm{J}$-Au.

63. P. plattensis Nutt. Stems 1-2 dm. high, decumbent or spreading; basal leaves many, pinnate; leaflets 9-17, light green in color, appressed-strigose or glabrate, obovate-oblong in outline, deeply pinnatifid, with oblong obtuse to nearly linear, acutish lobes, $5-8 \mathrm{~mm}$. long; flowers in few-flowered, rather open cymes; sepals and bractlets lanceolate, long-acuminate; sepals $3-4 \mathrm{~mm}$. long; petals yellow, obovate, slightly retuse, longer than the sepals. Valleys: N.M.-Utah-Sask. Submont.-Mont. Je-Au.

64. P. Nelsoniana Rydb. Stems erect or ascending, $1.5-3 \mathrm{dm}$. high, glabrous or sparingly strigose; basal leaves pinnate, with 9-15 leaflets, the earlier appressed-pubescent, the rest glabrate; leaflets cuneate, 1-3.5 $\mathrm{cm}$. long, the upper three pinnately cleft, with 5-7 lance-oblong divisions, the rest $2-3$ cleft at the apex or some entire; sepals lance-ovate, 4-5 mm. long, acute; petals obovate, emarginate, 5-6 mm. long. $P$. pinnatisecta A. Nels., not $P$. diversifolia pinnatisecta S. Wats. Mountains: Wyo.-n Utah-Colo. Submont.-Subalp. Jl-Au. 
65. P. decurrens (S. Wats.) Rydb. Perennial; stems glabrous up to the inflorescence, less than $1 \mathrm{dm}$. high, ascending; basal leaves pinnate, with 11-13 leaflets, which are broadly cuneate, usually 3 -toothed at the apex, $1 \mathrm{~cm}$. long or less; cymes 4-10-flowered; sepals lanceolate, acute, 4-5 mm.long; petals obovate, $5 \mathrm{~mm}$. long. P. dissecta decurrens S. Wats. Mountains: Utah. Alp.-Mont. Jl.

66. P. wyomingensis A. Nels. Stems 1-2.5 dm. high, strigose, erect or ascending; basal leaves crowded, pinnate, with 7-19 leaflets, white silky-strigose when young, sometimes glabrate in age; leaflets $1 \mathrm{~cm}$. long or less, the upper pinnatifid, the lower 3-5-fid, with linear or linear-oblong divisions; sepals ovatelanceolate, acuminate, 4-5 mm. long; petals broadly obovate, retuse, 6-8 $\mathrm{mm}$. long. P. monidensis A. Nels. Mountains: Wyo.-Mont.-Ida. Submont.Mont. Je-Jl.

67. P. ovina J. M. Macoun. Stems mostly erect or ascending, usually less than $1 \mathrm{dm}$. high, strigose, with 2 or 3 reduced leaves, 3-6-flowered; basal leaves crowded, 2-4 cm. long, appressed-hoary, especially when young, pinnate, with 7-11 crowded leaflets; leaflets deeply cleft into oblong obtuse lobes; sepals lanceolate, $4 \mathrm{~mm}$. long, acute or acuminate; petals obcordate, about a third longer than the sepals. P diversifolia pinnatisecta S. Wats. High mountains: Alta.Wyo.-Utah. Submont.-Subalp. Je-Au.

68. P. Drummondii Lehm. Stem erect, 3-6 dm. high, slightly hairy, fewleaved, branched above; basal leaves pinnate, hairy, especially when young; leaflets 5-11, somewhat crowded, often verticillate and the upper confluent, veined, $2-6 \mathrm{~cm}$. long, obovate-cuneate, deeply and sharply serrate; sepals ovatelanceolate, acuminate, 6-7 mm. long; petals 6-10 mm. long, obcordate, longer than the sepals. Mountains: Alta.-B.C.-n Calif.-Ida. Submont--Mont.
J-S.

69. P. crinita A. Gray. Stems several, ascending, $2-3 \mathrm{dm}$. high, often diffusely few-branched, silky-pilose; basal leaves many, pinnate, silky-villous (pubescence projecting far beyond the tips of the leaflets), nearly glabrous on the upper surface; leaflets 11-15, approximate, cuneate, $1.5-2 \mathrm{~cm}$. long, toothed at the apex, generally remaining conduplicate; sepals ovate-lanceolate, acute, about $4 \mathrm{~mm}$. long; petals obovate, deeply retuse, exceeding the calyx. Dry places: Colo.-Utah-Ariz.-N.M. Submont. JI-S.

70. P. paucijuga Rydb. Stems about $2 \mathrm{dm}$. high, tinged with purple, somewhat villous-hirsute, ascending or decumbent; basal leaves pinnate, with 5 leaflets; terminal leaflet broadly obovate, $2-2.5 \mathrm{~cm}$. long, sessile, green, but densely hairy above, white-tomentose and silky beneath, divided two-thirds to the midrib into linear or oblong, acutish divisions; lateral leaflets similar, but smaller; sepals lanceolate, acute, $5 \mathrm{~mm}$. long; petals yellow, broadly obovate, emarginate, about $6 \mathrm{~mm}$. long. Mountains: se Utah. Subalp. $-A l p$. Jl.

71. P. pseudosericea Rydb. Stems several from the caudex, ascending or decumbent, 5-10 $\mathrm{cm}$. high, few-leaved, grayish silky; leaves pinnate, with 5-9 approximate leaflets, grayish silky or hirsute above, white-tomentose and silky beneath; leaflets 1-2 $\mathrm{cm}$. long, obovate in outline, divided to near the midrib into linear obtuse segments; sepals ovate or ovate-lanceolate, 4-5 mm. long; petals obovate, about equalling the sepals. Mountains: Wyo.-Colo.-Nev.
Submont. Jl-S.

72. P. bipinnatifida Dougl. Stems several, erect or ascending, finely white silky-villous, $3-5 \mathrm{dm}$. high; basal leaves many, pinnate, with $7-9$ approximate leaflets, densely and finely silky above, white-tomentose beneath; leaflets 2-4 $\mathrm{cm}$. long, obovate in outline, pectinately divided to near the midrib into almost linear, mostly obtuse segments; sepals ovate, 4-5 $\mathrm{mm}$. long; petals obovate, cuneate, truncate, about equalling or slightly exceeding the sepals. Plains and hills: Man.-Minn.-Colo.-Alta. Plain-Mont. Jl-Au.

73. P. virgulata A. Nels. Stems 1 or 2 , simple, erect, strict, 3-4 dm. high, slightly appressed-pubescent; basal leaves pinnate, with 5 -7 leaflets; leaflets obovate in outline, $1-2 \mathrm{~cm}$. long, green and sparingly appressed-silky above, 
grayish or white beneath, dissected into narrowly linear divisions, with revolute margins; cyme congested; sepals lanceolate, $2-3 \mathrm{~mm}$. long; petals small, orbicular, about $4 \mathrm{~mm}$. long, slightly emarginate. Wet grassy flats: Wyo.-UtahAlaska. Submont. Jl.

74. P. platyloba Rydb. Stems several, erect or ascending, 3-5 dm. high, pubescent with white appressed hairs; leaves pinnate, usually with but two pairs of leaflets; leaflets obovate, $2-6 \mathrm{~cm}$. long, greenish and silky-strigose above, white-tomentose beneath, cleft into broad lanceolate or oblong divisions; stemleaves short-petioled and often subdigitate; sepals ovate, acute; petals about equalling the sepals, obovate. Plains: Hudson Bay-Colo.-Alta. PlainMont. Je-S.

75. P. glabrella Rydb. Stem erect and strict, rather low, 1-2 dm. high, glabrate or sparingly pubescent; leaves pinnate, with 5-11 rather approximate leaflets, glabrate or glandular-pruinose, sparingly hairy on the veins and margins; leaflets obovate to oblanceolate, the lower ones smaller, very deeply dissected into oblong, acute or obtuse segments; sepals broadly ovate, rather strongly veined, about $5 \mathrm{~mm}$. long; petals obovate, about equalling the sepals. $P$. pennsylvanica glabrata S. Wats. Mountains: Sask,-Alta.-Wyo. Submont. J1Au.

76. P. pennsylvanica L. Stem generally erect, strict, 4-8 dm. high, more or less appressed-pubescent and tomentulose; leaves pinnate, with 7-15 leaflets, gravish tomentose and veiny beneath, short-strigose and green above; leaflets gradually reduced downward, often somewhat decurrent, oblong or oblanceolate in outline, divided halfway to the midrib into oblong divisions; sepals ovatetriangular, acute, usually not prominently veiny, about $5 \mathrm{~mm}$. long; petals obovate, cuneate, slightly emarginate or truncate, about $6 \mathrm{~mm}$. long. Plains: Hudson Bay-Yukon-Colo. Plain-Mont. Jl.

77. P. arachnoidea Dougl. Stems densely pubescent, with partly short, partly longer appressed hairs, 1-3 dm. high, erect, strict; basal leaves pinnate, with 9-13 leaflets; leaflets obovate or oblanceolate, 1-3 $\mathrm{cm}$. long, green and rather densely short-puberulent above, grayish tomentose and silky on the veins beneath, deeply cleft into lanceolate or linear divisions, with revolute margins; inflorescence congested; sepals lance-ovate; petals broadly obovate, emarginate, 4-5 mm. long. P. pennsylvanica arachnoidea Lehm. Dry plains and hills: N.M.-Ariz.-Mont. Plain-Submont. Jl-Au,

78. P. atrovirens Rydb. Stem stout, $2-3 \mathrm{dm}$. high, with erect branches, dark colored, densely pilose; leaves very dark green, densely pilose on both sides, strongly veined, pinnate, with 7-9 leaflets; these obovate to oblanceolate, coarsely dissected about halfway to the midrib into oblong segments; sepals and bractlets subequal, about $5 \mathrm{~mm}$. long, ovate, exceeded by the cuneate-obovate bright yellow petals. Plains: Minn.-Wyo.-Colo. Plain. Je-Jl.

79. P. strigosa Pall. Stems 1-4 dm, high, densely puberulent and with long spreading hairs; basal leaves pinnate, with $7-11$ leaflets; leaflets obovate or oblanceolate, 1-5 cm. long, densely silky-pubescent, but yellowish green above, densely grayish-tomentose and silky beneath, deeply cleft into lanceolate or linear, revolute divisions; sepals ovate, slightly longer, strongly ribbed; petals obovate or orbicular, about equalling the sepals. Plains: Hudson Bay-Kans. -N.M.-B.C. Plain-Submont. Je-Au.

80. P. lasiodonta Rydb. Stem strict, 3-4 dm. high, densely pubescent, with short spreading pubescence; basal leaves pinnate, with 11-15 leaflets; leaflets oblong, 1-4 cm. long, green and densely short-pubescent, almost velvety above, grayish tomentose beneath, deeply serrate; sepals ovate, acute, strongly ribbed, about $6 \mathrm{~mm}$. long; petals rounded-obovate, slightly if at all exceeding the sepals. Plains: Sask.-S.D.-Alta. Plain. Jl-Au.

\section{3. argentìna Lam. Silver-Weed, Goose Tansy.}

Perennial herbs, with slender prostrate stolons. Leaves interruptedly pinnate, with many leaflets. Flowers solitary in the axils of small leaves or scales 
on the stolons. Hypanthium almost flat. Bractlets, sepals, and petals normally 5. Petals yellow, broadly elliptic or almost orbicular, not at all unguiculate. Stamens 20-25, in three series, inserted as in Potentilla; filaments filiform; anthers didymous, dehiscent by a longitudinal slit. Receptacle hemispheric, bearing very numerous pistils. Styles filiform, lateral, scarcely deciduous. Mature achenes with thick pericarp. Seeds ascending and amphitropous.

Achenes corky, with a deep groove; stem and petiole and rachis of the leaves densely pubescent, with at first ascending and later spreading hairs.

Leaves silvery on both sides.

Leaves green and glabrate above.

1. A. argentea.

Achenes not corky, without a groove; stem and petiole and the rachis of A. Anserina. brous or slightly appressed-hairy and glabrate; hypanthium acute at the base.

3. A. subarctica.

1. A. argentea Rydb. Basal leaves 1-2 dm. long, pinnate, with 11-25 larger leaflets and smaller ones interposed; larger leaflets $1-3 \mathrm{~cm}$. long, obovate, rounded at the apex, serrate, white-silky on both sides or slightly greener above; bractlets usually entire, about equalling the ovate or ovate-lanceolate sepals; petals obovate or broadly oval, 6-9 mm. long. Wet places: Mack. S.D.N.M.-Ariz,-Ore-B.C. Plain-Mont. My-Au.

2. A. Anserina (L.) Rydb. Leaves 1-2 dm. long, interruptedly pinnate, with 9-31 larger leaflets and smaller ones interposed, spreading or flat on the ground, slightly silky and green above, white-silky and tomentose beneath; larger leaflets 1-4 cm. long, oblong or oblanceolate, usually acute, deeply and sharply serrate; bractlets simple and lanceolate, or ovate-lanceolate, toothed or divided, generally a little longer than the broadly ovate sepals; petals oval, 7-10 $\mathrm{mm}$. long. Wet places: Newf.-N.Y.-Calif.-Alaska; Eurasia. Plain-Mont. $\mathrm{My}-\mathrm{Au}$.

3. A. subarctica Rydb. Basal leaves 7-15 cm. long, ascending; rachis silky, with appressed or ascending hairs; larger leaflets 15-19, dark green and sparingly silky above, densely white-silky and tomentose beneath, deeply serrate, the upper leaflet $1.5-2 \mathrm{~cm}$. long; hypanthium about $5 \mathrm{~mm}$. wide, silky and tomentulose, acute at the base; bractlets linear-lanceolate, 3-6 mm. long; sepals ovate, $5-6 \mathrm{~mm}$. long; petals oval or suborbicular, about $8 \mathrm{~mm}$. long. Wet places: Alaska-Yukon-Ida.-Mont. Mont.-Subalp. Je-Au.

\section{Cómarum L. Marsh Crnetchotl, Purple Marshlocks, Cowberry.}

Aquatic perennials, with long creeping rootstocks and pinnate leaves. Inflorescence cymose. Hypanthium almost flat or slightly saucer-shaped, enlarging in fruit, more or less tinged with red. Bractlets, sepals, and petals 5 . Petals red, ovate, acuminate. Stamens $20-25$, inserted near the base of the receptacle; filaments filiform, stout; anthers flat, cordate at the base, attached by the back, and opening by longitudinal marginal slits. Receptacle hemispheric, enlarging in fruit and becoming ellipsoid or hemispheric and spongy. Pistils numerous. Styles lateral, filiform. Seeds amphitropous.

1. C. palustre L. Stem ascending, 2-5 dm. high, more or less hirsute, with short spreading hairs, somewhat glandular on the upper portion; leaves pinnate, with 5-7 more or less approximate leaflets, green above, paler and purple-veined beneath, sparingly hairy, in age glabrate; leaflets elliptic or oval, mostly acute at both ends, to linear-oblong, $5-8 \mathrm{~cm}$. long and only $1-2 \mathrm{~cm}$. wide, obtuse or rounded at the apex; hypanthium in flower $7-\delta \mathrm{mm}$., in fruit about $15 \mathrm{~mm}$. in diameter, short-pilose and glandular-pubescent; sepals ovate to lanceolate, acuminate, about $1 \mathrm{~cm}$. long in flower and $1.5 \mathrm{~cm}$. in fruit; petals spatulate or ovate, acuminate or acute, scarcely half as long as the sepals. Wet bogs: Greenl. -Lab.-N.H.-Wyo.-Calif.-Alaska. Mont. Jl-S.

\section{FrAGÀria L. StraWberry.}

Perennial acaulescent herbs, with scaly rootstock, and producing runners which root and form new plants. Leaves (in all ours) ternate, basal. Hypanthium almost flat. Bractlets, sepals, and petals normally 5. Petals white, or 
in one species reddish, broadly obovate, elliptic, or almost orbicular, obtuse, never emarginate. Stamens about 20, in three series as in Potentilla, closely surrounding the base of the receptacle; filaments short; anthers dehiscent by a longitudinal slit. Receptacle hemispheric or conic, bearing very numerous pistils, in fruit becoming enlarged, very juicy, and delicious in taste. Styles filiform, but rather short, attached near the middle of the ovaries. Seeds ascending and amphitropous.

Pubescence of scape and petioles divaricate, $i$. $e_{\text {. }}$ generally spreading at right angles or somewhat reflexed (scanty and less spreading in no, 3).

Leaflets sessile; achenes superficial on the receptacle.

Flowers pinkish, nodding from the beginning. $\quad$ 1. F. Helleri.

Flowers white, erect or spreading, nodding only in fruit.

Calyx in fruit spreading or ascending; scape generally with long divaricate hairs and a leafy bract.

2. F. bracteata.

Calyx in fruit reflexed; leaflets rhombic-obovate, acute; scape and petioles sparingly hairy; hairs more ascending or appressed. 3 . F. americana.

Leaflets usually petiolulate; achenes set in usually deep pits.

Plant more or less glaucous; petals usually orbicular and twice as long as the sepals.

Sepals and bractlets elliptic.

4. F. truncata.

Sepals and bractlets lanceolate.

Sepals linear-lanceolate; leaflets cuneate, somewhat coriaceous, sharply toothed at the apex.

5. F. cuneifolia.

Sepals broadly lanceolate; leaflets broadly obovate or broadly cuneate, only a little longer than broad, with coarse acute teeth.

6. F. platypetala.

Plant not glaucous; petals elliptic, generally exceeding the sepals by one-half, usually over $10 \mathrm{~mm}$. long; achenes set in shallow pits; leaves firm.

7. F. grandiflora.

Pubescence of the scape and petioles appressed or ascending; achenes in pits.

Plants not glaucous.

Leaflets usually more than $3 \mathrm{~cm}$. long, very veiny beneath; runners many.

Leaflets usually $1-3 \mathrm{~cm}$. long, not very veiny; runners few.

8. F. prolifica.

lants more or less glaucous.

Leaves rather thin.

Leaflets obovate; scape several-flowered.

Leaflets oblong-cuneate; scape 1-4-flowered.

Leaves rather thick, firm; leaflets oblong-cuneate.

10. F. glauca.

11. F. pauciflora.

12. F. ovalis.

1. F. Helleri Holz. Leaflets rounded-obovate or rhombic-obovate, coarsely serrate, very thin, glabrate above, finely silky beneath; scape $1.5-2 \mathrm{dm}$. high, often with a foliaceous unifoliolate bract; flowers $1.5-2 \mathrm{~cm}$. in diameter; sepals ovate; petals nearly orbicular, twice as long as the sepals. Woods: Ida.-Wash. Submont. Je-Jl.

2. F. bracteata Heller. Leaflets broadly rhombic-obovate, acute, coarsely toothed, $2-5 \mathrm{~cm}$. long, very thin, somewhat glaucous, silky when young, glabrate in age; scape often over $1 \mathrm{dm}$. high, often exceeding the leaves, 2-8-flowered; flowers 1.5-2 cm. in diameter; sepals and bracts lanceolate, acute; petals roundedobovate, often nearly twice the length of the sepals; fruit ovoid or semi-ellipsoid, red, about $7.5 \mathrm{~mm}$. in diameter and $10 \mathrm{~mm}$. long. Fragaria retrorsa Greene. Woods: B.C.-Calif.-N.M.-Mont. Submont.-Subalp. My-S.

3. F. americana (Porter) Britton. Leaflets $3-8 \mathrm{~cm}$. long, rhombic-obovate, mostly acute, sharply and deeply serrate, very thin, very soon glabrate on both sides; scape slender, seldom over $1.5 \mathrm{dm}$. high, seldom much exceeding the leaves, very rarely leafy-bracteate; fruit elongate-ovoid, $5-7.5 \mathrm{~mm}$. in diameter and 1-1.5 cm. long. Fragaria vesca americana Porter. Woods: Newf.-Man.N.M.-Va. Submont.-Mont. Je-Au.

4. F. truncata Rydb. Leaflets petiolulate, $1.5-4 \mathrm{~cm}$. long, roundedobovate, round-crenate above the middle, with the middle tooth smaller, thin, silky on both sides, but in age glabrate above; scape slender, few-flowered, seldom exceeding $1 \mathrm{dm}$. in height, and rarely leafy-bracteate; flowers $1-2 \mathrm{~cm}$. in diameter; bractlets and sepals elliptic or ovate, obtuse or acutish; petals obovate, exceeding the sepals by about a third. Mountains: Calif.-Nev.-Ida. Submont. Je.

5. F. cuneifolia Nutt. Leaflets cuneate to obovate, obtuse or truncate, toothed only at the apex, $1.5-4 \mathrm{~cm}$. long, firm and somewhat coriaceous, silky 
above when young, glabrate in age, densely silky and slightly tomentulose beneath; scape slender, less than $1 \mathrm{dm}$. high; flowers $1.5-2 \mathrm{~cm}$. in diameter; bractlets and sepals linear-lanceolate; petals obovate-cuneate, a third longer than the sepals; fruit subglobose, about $1 \mathrm{~cm}$. in diameter, villous. Mountains: B.C.-Ore.-Ida. Submont. My-Jl.

6. F. platypetala Rydb. Leaflets broadly cuneate or obovate, $2-8 \mathrm{~cm}$. long, coarsely serrate or crenate above the middle, moderately thick, glabrous and glaucous above and appressed-silky beneath; scape about $1 \mathrm{dm}$., seldom 2 $\mathrm{cm}$. high, often leafy-bracteate; flowers large, $1.5-2.5 \mathrm{~cm}$. in diameter; sepals and bractlets lanceolate; petals almost orbicular, usually twice as long as the sepals; fruit hemispheric, $1-1.5 \mathrm{~cm}$. in diameter. $F$. latiuscula Greene. Hills: Alaska-Calif.-Utah-Wyo.-Mont. Submont.-Mont. My-Jl.

7. F. grandiflora Ehrh. Leaflets $4-15 \mathrm{~cm}$. long, broadly obovate, coarsely toothed, usually rounded at the apex, rather firm, very dark green, glabrate and somewhat shining above, paler beneath and silky on the veins; scape 1-2 $\mathrm{dm}$. high, usually shorter than the leaves; flowers over $2 \mathrm{~cm}$. in diameter; bractlets lanceolate, about equalling the ovate acuminate sepals; petals rounded-obovate, over $1 \mathrm{~cm}$. long; fruit 2-3 cm. in diameter, of ten acutish at the apex, sometimes laterally flattened or irregular in outline. Waste places: Calif.-B.C.; in the East; escaped from cultivation; native of S.Am. My-Jl.

8. F. prolifica Baker \& Rydb. Leaflets obovate, rounded at the apex, coarsely toothed with very broad teeth, rather thin and dark green, glabrous above, sparingly silky or glabrate and strongly veined beneath; runners very numerous; seapes many-flowered, appressed-strigose, seldom over $1 \mathrm{dm}$. high; flowers about $1 \mathrm{~cm}$. in diameter; sepals and bractlets ovate-lanceolate; petals obovate, a little exceeding the sepals; fruit hemispheric, $1-1.5 \mathrm{~cm}$. in diameter. Mountains: Colo. Submont.-Mont. My-Au.

9. F. pumila Rydb. Leaflets oblong or narrowly obovate, 1-3 cm. long, erenate, small and thick, dark green and silky above when young, soon glabrate, silky-strigose and finely puberulent beneath; scape few-flowered, usually about by about a half; fruit searcely $1 \mathrm{~cm}$. in diameter. Dry hills: N.D.-Colo. -Wyo. Submont.-Subalp. My-Jl.

10. F. glauca (S. Wats.) Rydb. Leaflets broadly obovate, $3-5 \mathrm{~cm}$. long, coarsely toothed, thin, glaucous and almost glabrous above, silky or at last
glabrate beneath; scape slender, rarely exceeding the leaves; flowers $1.5-2 \mathrm{~cm}$.
in diameter. in diameter; petals obovate, exceeding the sepals by about a half; fruit subglobose, $1-1.25 \mathrm{~cm}$. in diameter. Fragaria virginiana (?) glauca S. Wats. Mountains: B.C.-Nev,-N.M.-S.D.-Mack. Plain-Subalp. My-Au. 11. F. paucifiora Rydb. Leaflets cuneate, subsessile, coarsely toothed
above the middle, the lateral ones scarcely at all oblique at the base, thin and glaucous, almost glabrous above and soon glabrate beneath; scape 2-4-flowered, $5-15 \mathrm{~cm}$. long, seldom exceeding the leaves; flowers $1-1.5 \mathrm{~cm}$. in diameter; petals obovate; fruit subglobose, about $1 \mathrm{~cm}$. in diameter; achenes set in very deep pits. Hills: Hudson Bay-Colo.-Alta. Plain-Mont. Je-Au.

12. F. ovalis (Lehm.) Rydb. Leaflets subsessile or short-petiolulate, oblong or cuneate, $2-3 \mathrm{~cm}$. long, toothed above the middle, thick and firm, somewhat glaucous, glabrate above, rather densely silky beneath; scape short, not much over $5 \mathrm{~cm}$. high; flowers $1-1.5 \mathrm{~cm}$. in diameter; petals obovate, exceeding the sepals by a half; fruit subglobose, about $1 \mathrm{~cm}$. in diameter. F. firma Rydb. Dry hills: Ariz.-N.M.-Wyo. Son.-Mont. Je-Au.

\section{SIBBẢLDIA L.}

Low, tufted perennial herbs, with short cespitose caudices or rootstocks and ternate leaves. Hypanthium saucer-shaped or cup-shaped, small. Bractlets, sepals, and petals 5 . Petals yellow, obovate, cuneate, or oblanceolate, scarcely equalling the sepals. Stamens 5, inserted not very close to the small receptacle; 
filaments filiform, but short, inclined. Pistils 5-20; styles lateral. Ovule and seed attached near the base of the style, ascending and amphitropous.

1. S. procumbens L. Stems less than $1 \mathrm{dm}$. high, more or less hirsutestrigose; leaflets sparingly appressed-pilose, $1-2 \mathrm{~cm}$. long, broadly cuneate, 3-5toothed at the apex; flowers few in rather dense eymes; bractlets and sepals subequal, broadly oblong or ovate; petals yellow, spatulate, shorter than the sepals. Aretic and alpine regions: Greenl.-N.H.-Colo.-Calif.-Alaska; arctic and alpine Eurasia. Alp. -Subalp. Je-Au.

\section{Dasíphora Raf. Shrubby Cinqueform, Yellow Rose.}

Shrubs, with scarious sheathing stipules, pinnate leathery leaves, and axillary flowers. Hypanthium saucer-shaped. Bractlets, sepals, and petals 5. Petals in ours yellow, nearly orbicular, neither unguiculate nor emarginate. Stamens about 25 , in 5 festoons on a pentagonal disk; filaments filiform; anthers oblong, flat, not didymous, dehiscent by a longitudinal slit along the margin. Receptacle hemispheric, with numerous pistils; styles club-shaped, thick and glandular upward, inserted near or below the middle of the ovaries; stigmas large and evidently four-lobed; achenes densely covered with long straight hairs. Seeds ascending and amphitropous.

1. D. fruticosa (L.) Rydb. Shrub 3-15 dm. high; branches with brownish shreddy bark; leaves pinnate, with 3-7 approximate leaflets, silky above, silky and whitish beneath; leaflets oblong or linear-oblong; flowers in small loose eymes or solitary, large, $1.5-3 \mathrm{~cm}$. in diameter; petals yellow, orbicular, often twice as long as the sepals. Cold valleys and among rocks: Lab.-Alaska-Calif.N.M.-N.J.; w Eu.; e Asia. Submont.—Subalp. Je-Au.

\section{DRYMOCÁLLIS Fourr.}

Perennial herbs, with scaly rootstocks, glandular foliage, pinnate leaves, and cymose inflorescence. Hypanthium saucer-shaped or hemispheric. Bractlets, sepals, and petals 5 . Petals obovate, elliptic, or nearly orbicular, neither unguiculate nor emarginate, yellow or white. Stamens 20-30, in 5 festoons on the much thickened pentagonal disk around the receptacle; filaments filiform; anthers oblong, truncate at each end or cordate at the base, flat and dehiscent by longitudinal marginal slits. Receptacle hemispheric or semi-ellipsoid, with very numerous pistils. Style nearly basal, in all our species except one thickened and glandular a little below the middle and tapering to each end; stigma minute. Seed attached near the base of the ovary, ascending and orthotropous.

Style fusiform, less than twice as long as the ovary.

Sepals ovate to lanceolate, acute, rarely acuminate.

Petals white or cream-colored, often, however, turning more yellowish in drying.

Petals slightly if at all exceeding the sepals; inflorescence many-flowered, dense.

Leaves densely hairy: petals orbicular or nearly so, 7-8 mm. long; cyme short and dense; stem densely short-hairy. 1 1. D. agrimonioides.

Leaves sparingly hairy; petals obovate, $5-6 \mathrm{~mm}$. long.

Cyme short, flat-topped; leaflets rounded-obovate to flabelliform; stem and petioles not conspieuously long-hairy. $2, D$. corymbosa.

Cyme elongate, narrow; leaflets more or less rhombic-obovate; stem and petioles conspicuously long-hairy, especially below.

3. D. convallaria.

Petals much exceeding the sepals; cyme open, few-flowered; stem slender.

Petals yellow in anthesis.

Leallets with ovate teeth.

Petals much exceeding the sepals in length.

Bractlets lanceolate to linear; sepals lanceolate or ovate-lanceolate.

Plant tall, 3-10 dm. high; cyme flat-topped.

Leaflets rhombic-obovate, acute, at least the terminal one; inflorescence leafy. 5 . D. foliosa.

Leaflets of the basal leaves orbicular to obovate, obtuse; upper leaves reduced.

6. D. valida.

Plant low, 2-3 dm. (rarely $4 \mathrm{dm}$.) high; cyme narrow, leafy; leaflets orbicular or rounded-obovate.

7. D. fissa.

Bractlets elliptic or oval; sepals ovate; stem 1-1.5 dm. high, almost scapose.

8. D. pumila. 
Petals slightly if at all exceeding the sepals, 5-7 $\mathrm{mm}$. Iong.

Bractlets linear-lanceolate, about two-thirds as long as the lanceolate sepals; leaflets obovate, irregularly or doubly toothed.

Bractlets oblong or oblong-lanceolate; sepals ovate- 9. glandulosa. more evenly simple-tootled, the lar.

Leaflets incised, with lanceolate teeth.
Sepals oval or broadly ovate, rarely lanceolate, rounded and mucronate at the apex.
Petals $7-8 \mathrm{~mm}$. long, ascending incisa.

inclined to be orbicu-

Petals 7-8 mm. long, ascending in anthesis; leaves densely hairy; plant stout.

Petals less than $6 \mathrm{~mm}$. long, spreading or reflexed in anthesis. D. agrimonioides.

Petals 4-6 mm. long; calyx and hypanthium in fruit toget

petioles conspicuously long-hairy; petals yellow.

Petals 2-4 mm. long; calyx and hypanthium in fruit 12 . D. oregana. petioles mostly short-hairy Petals obovate; sepals twice as long as broad.

Petals orbicular or nearly so; sepals half longer than 13 . D. albida.

13. $D$.

Style filiform or nearly so, more than twice as long as the ovary; plant about 2 dm. high;
petals much exceeding the petals much exceeding the sepals; leaflets rhombic-obovate. 15. D. rhomboidea.

1. D. agrimonioides (Pursh) Rydb. Stem stout and erect, 3-10 dm. high, striate, generally densely glandular- or viscid-hirsute; basal leaves many; leaflets $7-11$, strongly veined, densely pubescent on both sides; upper three leaflets larger than the others, usually 4-5 cm. long, doubly serrate, the odd one commonly rhomboid, the others usually obliquely ovate; flowers $12-18 \mathrm{~mm}$. in diameter; bractlets lanceolate, much smaller than the oblong-ovate, acute or mucronate sepals. Potentilla arguta Pursh. Meadows and rocky places: N.B. -D.C.-Colo.-Mack. Plain-Submont. Je-Au.

2. D. corymbosa Rydb. Stem $3-8 \mathrm{dm}$. high, branched above; basal leaves pinnate, with $7-11$ leaflets; upper leaflets broadly obovate, $3-5 \mathrm{~cm}$. long, usually rounded at the apex, sparingly short-hairy, coarsely and deeply doubly serrate, $5 \mathrm{~mm}$. long. Meadows: Alta.-B.C.-n Colo.-Wash. Submont.-Mont. Je-Au.

3. D. convallaria Rydb. Stem tall, erect, 4-10 dm. high, long-villous; basal leaves several, pinnate; leaflets $9-11$, slightly long-pubescent or glabrate, the upper $3-5 \mathrm{~cm}$. long, rhombic-obovate and acute, coarsely serrate and inobovate, white, a little longer than flowers $10-18 \mathrm{~mm}$. in diameter; petals broadly Mont.-N.M. Submont.-Mont. Je-Au.

4. D. pseudorupestris Rydb. Stem

or in lower meadows (var. intermedia) 7-9, sparingly and finely pubescent or glabrate, the terminal one obovate to cuneateserrate and incised; flowers $15-20 \mathrm{~mm}$; stem-leaves few and small, the leaflets $3-5$ and more rhombic; a third; sepals ovate-lanceol petals broadly obovate, exceeding the sepals by Submont. -Subalp. Je-Au.

5. D. foliosa Rydb. Stem stout, 4-5 dm. high; basal leaves 1-1.5 dm. long, with about 9 leaflets, the upper leaflets rhombic-obovate, $4-5 \mathrm{~cm}$. long, sparingly leaflets more rounded; upper stem- coarsely and more or less doubly serrate; lower rhombic leaflets; cyme rather open and $3-5$-foliolate, all with rather large and acuminate, 5-6 mm. long; petals yellow corymbiform; sepals lanceolate, acute or Mountains: Mont.-Wyo,-ne Utah. Submided-obovate, about $8 \mathrm{~mm}$. long.

6. D. valida (Greene) Piper. Stemont,-Mont. Je-Au.

leaves pinnate; leaflets 7-11, more or less the terminal one broadly obovate, the lateral ones or glabrate, 3-6 cm. long, orbicular, all coarsely serrate; stem-leaves with fewer, sometimes more rhombic pointed; petals yellow, broadly elliptic or nearly orbicular, $8-10 \mathrm{~mm}$. long.
D. glutinosa (Nutt) Rydb. Meadows.

7. D. fissa (Nutt.) Rydb. Stem : B.C.-Ida.-n Utah-Wash. Submont. very leafy; basal leaves with shom low, $2-3 \mathrm{dm}$., or sometimes $4 \mathrm{dm}$. high, 
orbicular, except the upper ones, which are somewhat rhombic, all deeply incised and doubly serrate; stem-leaves similar, only the upper ones slightly reduced; flowers $15-20 \mathrm{~mm}$. in diameter; sepals triangular-lanceolate, long-acuminate; petals orbicular, very concave, much exceeding the sepals. Mountains: (Black Hills) S.D.-Alta.-Utah-Colo. Submont.-Subalp. My-Au.

8. D. pumila Rydb. Cespitose; stem about $1.5 \mathrm{dm}$. high, sparingly viscidpuberulent or glabrate; basal leaves 4-7 $\mathrm{cm}$. long, with 9-11 leaflets; terminal leaflets broadly obovate or flabelliform-cuneate, about $1 \mathrm{~cm}$. long and broad, serrate above the middle; lateral leaflets broader, often broader than long; stemleaves $1-3$, the uppermost often with but 3 leaflets; inflorescence small, corymbiform; sepals $5 \mathrm{~mm}$. long; petals rounded-obovate or orbicular, $7-8 \mathrm{~mm}$. long, yellow. Mountains: Ore.--Utah-Calif. Mont. Je-Au.

9. D. glandulosa (Lindl.) Rydb. Stem strict, 3-6 dm. high; basal leaves pinnate, sometimes interruptedly so; leaflets $7-9$, sparingly hairy, obovate, obtuse, simply or doubly serrate, with broad teeth, the upper 1-3 cm. long; stemleaves smaller, short-petioled, 3-7-foliolate; flowers in an open many-flowered cyme, 10-15 mm. in diameter; sepals oblong or ovate-lanceolate; petals obovate, about equalling the sepals. Mountains: (Black Hills) S.D.-B.C.-Calif.N.M. Submont.-Mont. Je-Au.

10. D. arizonica Rydb. Stem $3-5 \mathrm{dm}$. high, sparingly viscid-villous, often tinged with red; basal leaves 1-1.5 dm. long, with about 9 leaflets; upper leaflets broadly obovate, coarsely serrate with ovate teeth, the lateral leaflets almost orbicular; lower stem-leaves similar, the upper 3-foliolate; cyme rather dense, few-flowered; sepals ovate-lanceolate, acuminate, $5 \mathrm{~mm}$. long, in fruit $7 \mathrm{~mm}$. long; petals nearly orbicular, about equalling the sepals. Mountains: Ariz.s Utah. Son. Je-Jl.

11. D. incisa (Lindl.) Rydb. Stems $3-5 \mathrm{dm}$. high; basal leaves about $1 \mathrm{dm}$. long, with 7-9 leaflets; terminal leaflet rhombic-obovate, about $3 \mathrm{~cm}$. long and $2 \mathrm{~cm}$. wide, sparingly pubescent or glabrate above, softly pubescent beneath; lower leaflets more obovate and smaller; upper stem-leaves reduced, 3 -foliolate; sepals lanceolate, acuminate, $5-6 \mathrm{~mm}$. long, in fruit 8-9 $\mathrm{mm}$. long; petals roundedobovate, often pale yellow, about $6 \mathrm{~mm}$. long. Meadows: Wash.-Ida.-Calif. Submont. Je-J.

12. D. oregana (Nutt.) Rydb. Stem 6-7 dm. high; basal leaves $1.5-2 \mathrm{dm}$. long, with about 9 leaflets; terminal leaflets rounded-obovate, with cuneate base, $3-4 \mathrm{~cm}$. long, 2-3 cm. wide, doubly serrate, the lateral leaflets somewhat smaller and more rounded; upper leaves reduced and with 3 oblanceolate leaflets; sepals ovate, mucronate, $5-6 \mathrm{~mm}$. long. Dry copses and sand bars: Mack.-B.C.Ore.-Ida. Submont. My-Au.

13. D. albida Rydb. Stems usually several; basal leaves $1-1.5 \mathrm{dm}$. long, pinnate, with usually 7 leaflets; terminal leaflets $2-4 \mathrm{~cm}$. long, obovate, usually acutish, sparingly pubescent, usually doubly serrate; lateral leaflets more roundedobovate; stem-leaves 3-5-foliolate, the upper somewhat smaller; inflorescence open; sepals elliptic-ovate, mucronate, about 4-5 $\mathrm{mm}$. long, usually shorter than the sepals. Copses: B.C.-Wash. Submont. Je-Jl.

14. D. micropetala Rydb. Stem 4-6 dm. high, sparingly viscid-villous; basal leaves pinnate, with 5-7 leaflets; terminal leaflet obovate, with cuneate base, $2-3 \mathrm{~cm}$. long, coarsely serrate; lateral leaflets smaller and more rounded; upper stem-leaves 3-5-foliolate; inflorescence rather dense; sepals ovate, mucronate, about $4 \mathrm{~mm}$. long; petals $2-3 \mathrm{~mm}$. long. Cañons: Utah-Ida. Submont. Je-Ji.

15. D. rhomboidea Rydb. Stem low and slender, about $2 \mathrm{dm}$. high, simple, about 3-leaved; basal leaves many, short-petioled; leaflets about 7 , smooth or beset with a few scattered hairs, rhombic-ovate, mostly acute, serrate, the largest leaflets $1.5 \mathrm{~cm}$., seldom $2 \mathrm{~cm}$. long; upper stem-leaves 3 -foliolate and subsessile; flowers few in open cymes, about $1 \mathrm{em}$. in diameter; sepals 4-5 $\mathrm{mm}$. long, broadly ovate, slightly mueronate; petals yellow, obovate, a little exeeeding the sepals. Mountains: Ore.-Wash.-w Mont. Submont. 


\section{CHAMAÈRHODOS Bunge.}

Perennial or biennial herbs, with taproots, 2-4 times ternately divided leaves, and small cymose flowers. Hypanthium cup-shaped, small. Petals and sepals 5; bractlets wanting. Petals obovate or cuneate, somewhat clawed. Stamens 5, opposite the petals; filaments subulate, short, persistent; anthers didymous, opening by a slit. Pistils $5-10$, or more; styles basal, filiform. Seed inserted near the base of the style, ascending and nearly orthotropous.

1. C. Nuttallii Pickering. Plant 1-3 dm. high, erect, branching and leafy, hirsute and glandular; basal leaves numerous and rosulate, 2 -4-ternately divided into linear or oblong divisions; inflorescence many-flowered; hypanthium 2-3 $\mathrm{mm}$. in diameter, hispid; sepals narrowly lanceolate, equalling or somewhat shorter than the white obovate-cuneate petals. C. erecta Hook., not Bunge. Plains: Sask.-S.D.-Colo-_Alaska. Plain-Mont. Jl-Au.

\section{SANGUISÓRBA L. BURNET.}

Leafy perennial herbs, with thick rootstocks. Leaves odd-pinnate, with adnate stipules and toothed leaflets. Flowers perfect or some of them pistillate, in dense spikes. Hypanthium urn-shaped, contracted at the-mouth, angled, and usually winged. Sepals 4, petaloid, deciduous, very concave. Petals none. Stamens in ours 4, opposite to the sepals. Pistils solitary; styles terminal; stigmas muricate-papillose; ovule solitary, suspended. Achenes dry, enclosed in the indurate 4-angled smooth hypanthium.

1. S. sitchensis C. A. Meyer. Stem leafy, 2-12 dm. high; leaves odd-pinnate, the lower with 11-21 leaflets; leaflets $2-7 \mathrm{~cm}$. long, $1.5-5 \mathrm{~cm}$. wide, coarsely serrate, rounded at the apex, those of the lower leaves deeply cordate at the base; spike $2-10 \mathrm{~cm}$. long, in age cylindric; sepals oval, $2.5-3 \mathrm{~cm}$. long, white or slightly tinged with purple. S. canadensis latifolia Hook. Moist places: AlaskaYukon-Ida.-Wash. Submont. J1-Au.

\section{POTERIDIUM Spach.} Leafy branched annuals or biennials, with taproots. Leaves odd-pinnate,
with adnate stipules and pectinately pinnatifid leaflets. Flowers greenish, per-
fect, in dense, fect, in dense, oblong spikes. Hypanthium urn-shaped, contracted at the
mouth, 4-winged. Sepals 4, green, with white-scarious margins. Stamens 2 or
4 , opposite to all or the inner terminal; stigm or the inner two sepals; filaments short. Pistils solitary; styles in the 4-winged in brush-like. Ovules solitary, suspended. Achenes enclosed in the 4-winged, indurate, dry hypanthium.

1. P. occidentale (Nutt.) Rydb. Stem branched, leafy, 2-10 dm. high; leaves glabrous, odd-pinnate; leaflets of the lower leaves $11-15$, obovate, the larger $1-2 \mathrm{~cm}$, long, pectinately pinnatifid into $9-15$ narrowly linear acute divisions; spikes globose to oblong-cylindric, $0.5-2.5 \mathrm{~cm}$., or in fruit even $3-4 \mathrm{~cm}$. long, 7-8 mm. thick; sepals oval, white-margined, green in the middle, $2 \mathrm{~mm}$. long; stamens 2, opposite the inner sepals; fruiting hypanthium lance-ovoid, 4-angled, with narrow, thick wings, reticulate on the faces. Poterium annuum Hook., Ida.-Calif. Sanguisorba occidentulis Nutt. Moist places: Wash.-Mont.-

\section{AGRIMÒNIA L. AgRIMONY.}

Perennial herbs, with rootstocks. Leaves odd-pinnate, with smaller leaflets interposed between the larger ones. Flowers in narrow racemes, regular, perfect. Hypanthium hemispheric to obconic, constricted at the throat and enclosing the achenes in fruit, usually 10-grooved longitudinally, above with a ring of hooked bristles. Sepals 5 , after anthesis more or less connivent, forming a nipplefilaments slender. Pistils. Petals 5, small, yellow, clawless. Stamens 5-15; Fruiting hypathis acuminate with tips incurved in series of bristles, the lower bristles reflexed; sepals Fruiting hypanthium with spreading; sepals acute. $2-4$ series of bristles, the latter erect, ascending or merely

2. A. striata. 
1. A. gryposepala Wallr. A perennial, with short thick rootstocks; stem 3-18 dm. high, sparingly hirsute and glandular-granuliferous; principal leaflets $5-9$, oval or obovate, or those of the upper leaves narrower, coarsely serrate, acute, glabrous or sparingly strigose above, hirsute and glandular-granuliferous beneath, 4-12 cm. long; petals $2.5-3 \mathrm{~mm}$. long, bright yellow; fruiting hypanthium 4-5 mm. long, abruptly contracted at the base, strigose, strongly grooved. A. hirsuta Bickn. Thickets: N.S.-N.D.-N.M.-S.C.; Calif.; Mex. PlainSubmont. Je-Au.

2. A. striata Michx. A perennial, with stout rootstock and fibrous roots; stem 3-20 dm. high, hirsute and glandular-papillose; principal leaflets 7-13, hispidulous or seabrous above, copiously glandular-granuliferous and somewhat pubescent beneath, lanceolate, elliptic, or oblanceolate, or rhombic-obovate, acuminate, sharply serrate, $3-10 \mathrm{~cm}$. long; petals deep yellow, obovate, $3 \mathrm{~mm}$. long; fruiting hypanthium $5 \mathrm{~mm}$. long, turbinate, strongly ribbed, glandulargranuliferous. A. Brittoniana Bickn. Roadsides and copses: N.S.-B.C.N.M.-W.Va. Plain-Submont. J1-Au.

\section{COLEÓGYNE Torr. Black Bush.}

Shrubs, with linear-clavate, entire, opposite, crowded leaves and opposite spinescent branches; leaf-blades deciduous. Flowers solitary, terminating short branches. Calyx coriaceous, yellowish or brownish; sepals 4, connate at the base, persistent. Corolla wanting. Stamens $30-40$; filaments slender, distinct, except at the very base, there slightly adnate to a tubular sheath-like prolongation of the disk, separating the stamens from the pistil. Gynoecium of a single pistil; ovary 1-ovuled, 1-celled; style lateral, filiform, bent and twisted, very villous, exserted, stigmatose on one side; ovules hemitropous. Fruit an achene.

1. C. ramosissima Torr. A shrub, 1-2 m. high, with divergent opposite branches, with at first ashy, in age black bark; leaves clavate, strigose, 5-15 $\mathrm{mm}$. long, flat above, 4-grooved beneath; sepals yellowish or brownish, 7-8 mm. long, the outer lanceolate, acute, the inner ovate or obovate, acuminate; tubular sheath 4-5 mm. long; style villous. Desert mesas and foothills: sw Colo.s Calif,-Ariz. Son. Ap-My.

\section{WALDSTEİNIA Willd, Barren Strawberry.}

Herbs, with perennial rootstocks and membranous stipules. Leaves basal, palmately 3-5-foliolate or 3-7-lobed. Stem in our speeies scapiform. Hypanthium mostly obconic. Sepals 5, valvate, spreading. Petals 5, yellow, obovate. Stamens numerous; filaments subulate, flattened below. Pistils 1-6, inserted on a short villous receptacle; styles filiform, terminal, deciduous. Achenes obliquely ovoid, pubescent. Seeds erect.

1. W. idahoensis Piper. Leaf-blades orbicular, slightly 5-7-lobed, cordate at the base, coarsely and doubly crenate-dentate, sparsely hirsute above and on the margin, 2-5 cm. broad; seapes 1-2.5 dm. long, glabrous or nearly so; inflorescence glandular-puberulent, 2-7-flowered; hypanthium obconic, $4 \mathrm{~mm}$. long; sepals triangular-lanceolate, acute, $5-6 \mathrm{~mm}$. long; petals yellow, orbicular, equalling the sepals. Mountains: Ida. Submont. Jl.

\section{DRỲas L. Dryad, Mountarn Avens.}

Low depressed undershrubs, strongly cespitose, with short horizontal branches, Leaves alternate, petioled, simple, crenate or entire, white-tomentose beneath. Flowers solitary on naked peduncles. Hypanthium saucer-shaped, little developed. Bractlets wanting. Sepals $8-10$, persistent. Petals $8-10$, obovate or oval. Stamens numerous, inserted in the mouth of the hypanthium; filaments subulate. Pistils numerous, sessile; style terminal, persistent, elongate and plumose in fruit. Fruit indehiscent, 1 -seeded. Seeds basal, ascending.

Sepals linear or linear-lanceolate; petals white, spreading.

Leaf-blades entire or with a few acutish teeth, shining and not conspicuously rugose

above, broadest near the base.
Leaf-blades coarsely round-crenate, dull, strongly rugose and impressed-reticulat above, broadest near the middle. 
Sepals ovate or ovate-lanceolate; petals yellow, strongly ascending.

Hypanthium and calyx densely hairy with black glandular hairs, only slightly tomentose.

Hypanthium and calyx densely white-tomentose, not glandular.

3. D. Drummondii.

4. D. tomentosa.

1. D. integrifolia Vahl. Leaf-blades lanceolate or elliptic-lanceolate, rounded, truncate, or subcordate at the base, acutish at the apex, 6-25 $\mathrm{mm}$. long, usually with entire revolute margins, densely white-tomentose beneath, glabrate and shining above; scapes 5-15 cm. long, tomentose; hypanthium and calyx tomentose and usually more or less densely black- or brown-hairy; sepals linear or linear-lanceolate, $5 \mathrm{~mm}$. long; petals white, elliptic, 8-12 $\mathrm{mm}$. long. Ridges: Greenl.-Lab.-N.H.-B.C.-Alaska. Alp. Je-Jl.

2. D. octopetala L. Leaf-blades oblong, elliptic or oval, white-tomentose beneath, glabrate and dull above, 6-25 $\mathrm{mm}$. long, rounded or obtuse at both ends, or subcordate at the base; scape $5-20 \mathrm{~cm}$. long, tomentose and more or less black-hairy; hypanthium black-hairy and tomentose; petals white, elliptic or obovate-elliptic, $1-1.5 \mathrm{~cm}$. long. Ridges: Greenl.-Colo.-Wash.-Alaska; alpine and aretic Eurasia. Alp.-Subalp. Je-Au.

3. D. Drummondii Richards. Leaf-blades elliptic or obovate, $1-3 \mathrm{~cm}$. long, white-tomentose beneath, dark green, dull, slightly tomentose or glabrous above, veiny and somewhat rugose, coarsely crenate, acute at the base and rounded at the apex; scape $5-20 \mathrm{~cm}$. long, tomentose and somewhat black-hairy above; petals yellow, about $1 \mathrm{~cm}$. long, elliptic-spatulate or obovate. Ridges: Que.-Mont.-Ore.-B.C.-Mack. Alp.-Subalp. Je-Au.

4. D. tomentosa Farr. Leaf-blades obovate or elliptic, 1-2 cm. long, coarsely crenate, acute at the base, rounded at the apex, tomentose on both sides, grayishgreen above, white beneath; scape 5-10 cm. long, densely white-tomentose; sepals ovate, $5 \mathrm{~mm}$. long; petals yellow, spatulate, $8 \mathrm{~mm}$. long. Ridges: Alta.-
B.C. Subalp. Jl.

\section{GÈUM L. AvENS.}

Perennial herbs, with rootstocks. Basal leaves lyrately odd-pinnate, with large terminal divisions; stem-leaves few, reduced, most often 3 -fid or the upper bract-like. Stipules persistent, adnate to the elasping bases of the petioles. Flowers cymosely corymbose. Hypanthium turbinate, hemispheric, or saucershaped. Bractlets 5, sometimes reduced. Sepals 5, imbricate or valvate. ous, in several serios; fovate, or cuneate, yellow, white, or red. Stamens numerclavate receptacle; styles filif free, filiform. Pistils numerous, inserted on a above, the upper ; styles filiform, terminal, strongly curved and geniculate Seed erect.

Sepals reflexed; upper internode of the style less than one-third as long as the lower.
Petals white or ochroleucous; receptacle long-hairy; hairs at least half as long as achenes.

Petals bright or golden yellow; receptacle short-hairy.
Leaflets of the stem-leaves decurrent

Upper internodeleaves not decurrent.

node hirsute below, style hirsute, the hairs about $1 \mathrm{~mm}$. long; lower inter-

node hirsute below, not glandular; petals orbicular, rounded at the base.

Upper internode of the style short-hispide 3. G. strictum. usually cuneate at the of the style glandular-puse, except in G. perincisum; lower internode Divisions of the glandular-puberulent.

cence corymbiform, usualleaves ample, rhombic or cuneate; inflores-

Divisions of the upper usually with short branches. 4. G. macrophyllum. inflorescence open, with stem-leaves oblanceolate or rarely obovate: Leaflets doubly serrate with siender branches. rounded or reniform. or dentate; terminal leaflet of the basal leaves Leaflets es or reniform.

5. $G$. oregonense. leaflet of the basal of the upper leaves deeply incised; terminal Sepals ascending or merely spreading; upper internoder, ovate, or subcordate.
6 . G. perincisum.

as lower internode, hirsute; petals flesh-colored internode of the style at least half as long 1. G. 1. G. canadense Jacq. Stems $3-10 \mathrm{dm}$. high, finely pubescent or glabrate;
blades of the earlier basal leaves reniform or rounded-cordate, round-lobed and 
dentate, those of the later usually ternate, with rhombic or obovate leaflets; upper stem-leaves often simple and subsessile, ovate, acute, and 3-lobed; petals white, elliptic or oblong, seldom exceeding the sepals; fruiting head 10-12 $\mathrm{mm}$. in diameter. Geum album J. F. Gmel. Banks and among bushes: N.S.-Ga.Tex.-S.D.; Mex. Plain. Je-S.

2. G. decurrens Rydb. Stem more or less pubescent, but not conspicuously hirsute; basal leaves and lower stem-leaves interruptedly pinnate, sparingly pubescent; leaflets 5-9, oblanceolate to obovate, 1-5 $\mathrm{cm}$. long, eleft and more or less doubly toothed; upper stem-leaves ternate and short-petioled; sepals triangular-lanceolate, 5-6 mm. long; petals orbicular or broadly oval, about $6 \mathrm{~mm}$. long. Mountains: Ariz.-N.M.-Colo. Submont.-Mont. Jl.

3. G. strictum Soland. Stem 5-15 dm. high, strongly hirsute; basal leaves interruptedly lyrate-pinnate; principal leaflets 5-9, cuneate, obovate, or on the young shoots the terminal leaflet rounded or reniform, $2-10 \mathrm{~cm}$. long, cleft or divided and doubly toothed; uppermost stem-leaves 3 -foliolate and short-petioled; petals orbicular, 5-8 $\mathrm{mm}$. long, bright yellow; fruiting head 15-18 mm. in diameter. G. scopulorum Greene. Low meadows: Newf.-Pa.-Mo.-Ariz.B.C.; Mex. Plain-Submont. Je-Au.

4. G. macrophyllum Willd. Stem very hirsute, especially below, with yellowish hairs; basal leaves interruptedly lyrate-pinnate; principal leaflets $5-15$, the terminal one reniform or rounded, often 3-lobed, 5-10 cm. broad, the lateral ones obovate or rounded, $1-5 \mathrm{~cm}$. long, hirsute on both sides, doubly toothed; petals bright yellow, obovate or obcordate, 4-7 mm. long; fruiting head $15-18 \mathrm{~mm}$. in diameter. Wet meadows: Newf.-N.H.-Mont.-Calif.-Alaska; e Siberia. Submont.-Mont. My-Au.

G. macrophyllum $\times$ strictum. With the habit and leaves of G. macrophyllum, but the stem less leafy and the petals broad and rounded at the base as in G. strictum. Mont.

5. G. oregonense (Scheutz) Rydb. Stem 4-7 dm. high, densely hirsute, with yellowish hairs; basal leaves interruptedly lyrate-pinnate; principal leaflets 5-9; terminal leaflet reniform or rounded, $5-10 \mathrm{~cm}$. broad, doubly dentate; lateral leaflets obovate or cuneate, 1-5 cm. long, more or less hirsute on both sides; upper stem-leaves small, usually ternate or 3-cleft, with obovate or oblanceolate divisions, or simple; petals pale yellow, $4-5 \mathrm{~mm}$. long, obovate; fruiting head about $15 \mathrm{~mm}$. in diameter. G. urbanum oregonense Scheutz. Meadows: Mack.-Minn.-N.M.-Calif.-B.C. Submont.-Mont. My-S.

G. macrophyllum $\times$ oregonense. With the more numerous and smaller flowers of $G$. oregonense and the long yellow pubescence characteristic of that species, but the stem more leafy and the upper stem-leaves with the broad lobes characteristic of $G$. macrophyllum. Wyo.-Mont.-B. C.

G. oregonense $\times$ strictum. Resembling $G$. oregonense in habit, leaf-form, long yellow pubescence, and structure of the styles, but more robust and with the broad, large, rounded petals of G. strictum. Utah-Mont.

6. G. perincisum Rydb. Stem strict, 4-6 dm. high, conspicuously hirsute, with divaricate hairs; basal leaves interruptedly pinnate; principal leaflets 5-11, 1-6 $\mathrm{cm}$. long, obovate or rhombic-obovate, or the terminal one ovate or cordate and then deeply 3 -cleft, all cleft and incised; upper stem-leaves 3 -foliolate; leaflets oblanceolate; petals pale yellow, oval or obovate, about $5 \mathrm{~mm}$. long. Meadows: Mack.-Mich.-Alta.-Yukon. Subalp.-Mont. Je-Jl.

7. G. rivale L. Stems 3-6 dm. high, simple, more or less hirsute; basal leaves lyrate-pinnate; leaflets obovate or cuneate or the terminal one rounded or reniform, 2-10 $\mathrm{cm}$. long, bidentate or biserrate; stem-leaves ternate, with oblanceolate or obovate leaflets; petals flesh-colored or sometimes tinged with yellow, purple-veined, elawed, flabelliform, emarginate, 7-10 mm. long. In swamps and low ground: Lab.-Newf.-N.J.-Mo.-N.M.-B.C.; Eurasia. Plain-Subalp. My-Au.

G. macrophyllum $\times$ rivale. Resembling $G$. rivale in habit and foliage, but the flowers smaller and more numerous, the sepals widely spreading or somewhat reflexed, and the petals golden-yellow, obovate, and less clawed. G. pulchrum Fernald. Que.Vt. - Alta. 
G. rivale $\times$ strictum. With the habit of $G$. strictum, but differing in the petals, which are golden-yellow, obcordate, clawed at the base and emarginate at the apex, longer than the reflexed sepals; the basal leaves are those of G. rivale. G. aurantiacum Fries, B.C.-Alta.-n N.Y.

\section{SIEVÉRSIA Willd. OLD MAN's WHISKERS.}

Perennial herbs, with rootstocks or suffruticose bases. Basal leaves usually numerous, lyrately or odd-pinnately divided, usually with smaller segments interposed between the larger ones; stem-leaves usually reduced; stipules usually large, adnate to the petioles. Flowers solitary or corymbose-cymose. Hypanthium turbinate or hemispheric. Bractlets usually present. Sepals 5, valvate. Petals 5, white, light yellow, pinkish, or purplish. Stamens many, inserted on a disk in the mouth of the hypanthium. Pistils numerous, inserted on a short carpophore. Styles not articulate or obsoletely so, the lower portion plumose, elongate in fruit, not at all hooked or rarely slightly so, the upper portion glabrous, persistent or withering and then deciduous, but not falling off early at a distinct node. Fruit a hairy achene. Seed erect, basal. [Erythrocoma Greene.]

Leaflets cuneate, toothed at the apex.

Hypanthium at least in flower acute at the base; bractlets much exceeding the lanceolate sepals; petals elliptic.

Hypanthium in flower rounded or sunken shorter than the ovate or ovate-lanceolate sepals; petals broadly elliptic.
Bractlets linear or linear-subulate, equalling the sepals

Bractlets linear or linear-subulate, equalling the sepals or slightly exceeding them.

Bractlets oblong-linear or lanceolate, shorter than the sepals. $\quad 2$. S. grisea.

Leaflets dissected at least half way into linear or linear-lone sepals. . 3. S. canescens.

Bractlets longer than the sepals; hypanthium and sepalste divisions. tinged.

Bractlets shorter than the sepals; hypanthium and 4. S. ciliata. purple-tinged.

Leaflets, except in depauperate soecimens, 2-4 cm. long, ascending, scarcely glandular.

Leaflets less than $1.5 \mathrm{~cm}$. long, spreading, conspicuula 5 . S. flavula. hirsute.

6. S. brevifolia.

1. S. triflora (Pursh) R. Br. Stem finely pilose and somewhat hirsute, 2-4 dm. high, cymosely 3 -flowered; basal leaves $1-2 \mathrm{dm}$. long; principal leaflets $7-15$, at the apex 2 - or 3 -cleft less than half their length, finely puberulent; hypanthium densely pilose, more or less turbinate at the base; bractlets linear-subulate, 12$18 \mathrm{~mm}$. long; sepals lanceolate; petals yellowish or flesh-colored. Geum triflorum Pursh. Erythrocoma triflora, E. cinerascens, and E. affinis Greene. Hills: Newf.-N.Y.-Hl.-Neb.-Mont.-Alta. Plain-Submont. My-Jl.

2. S. grisea (Greene) Rydb. Stem 2-3 dm. high, purple-tinged, pilose throughout; basal leaves 5-15 $\mathrm{em}$. long; principal leaflets cuneate or obovateeuneate, $1-2 \mathrm{~cm}$. long, pilose on both sides, yellowish green, usually 3 -cleft to near the middle and again toothed; bractlets linear-subulate, about $1 \mathrm{~cm}$. long; hypanthium hemispheric or slightly sunken at the base, tinged with scarlet or rose; sepals triangular-lanceolate or lance-ovate, petals elliptic or oblong-spatulate, about equalling the bractlets. Erythrocoma grisea, E. arizonica, E. tridentata, and $E$. aliena Greene. Mountains: Mont.-Wash.-Ore.-N.M.; Chi-
huahua. Submont.-Mont. My-Jl.

3. S. canescens (Greene) Rydb. out, usually 3 -flowered; basal leaves $8-15 \mathrm{~cm}$. $\mathrm{dm}$. high, finely pilose through$1-2.5 \mathrm{~cm}$. long, densely pilose and ciliate on the long; leaflets obovate-cuneate, toothed or sometimes merely 3-5-toothed at the margins and veins, 2-3-cleft and lanceolate, $6-8 \mathrm{~mm}$. long; hypanthium hemispheric or; bractlets oblong-linear or broadly ovate-lanceolate or ovate, acute; petals or sunken at the base; sepals slightly exceeding the sepals. Scarcely distinet from elliptic or elliptic-obovate, Greene. Mountains: Wash.-Ida.-Calif.' Submont. preceding. E. canescens

4. S. ciliata (Pursh) G. Don. Stem $2-5 \mathrm{dm}$. high, finely pilose and silkyhirsute, cymosely $3-15$-flowered; basal leaves $1-2 \mathrm{dm}$. long; principal leaflets ciliate on the veins and margins; bractlets linear-subure or less densely silkyovate-lanceolate; petals broadly elliptic or oval, flate; sepals finely pilose, 
Geum ciliatum Pursh. Erythrocoma dissecta, and E. ciliata Greene. Mountains and hills: Alta.-N.M.-Utah-Wash.-B.C. Submont.-Subalp. My-Au.

\section{S. ciliata $\times$ grisea. Intermediate between the two species. E. australis Greene.}

5. S. flavula (Greene) Rydb. Stem 2-3 dm. high, rather slender, yellowish, only slightly tinged with red, finely pilose; basal leaves $5-15 \mathrm{~cm}$. long; principal leaflets cuneate or rhombic-cuneate, finely puberulent, and ciliate on the margins and veins, yellowish green; hypanthium low, hemispheric; bractlets linear-subulate; sepals deltoid-lanceolate, yellow, merely purple-veined; petals yellow, oval, barely exceeding the sepals. Scarcely distinct from $S$. ciliata. E. flavula Greene. Mountains: Wyo.-Mont. Mont. My-Au.

6. S. brevifolia (Greene) Rydb. Stem 1-2 dm. high, with few reduced leaves, pilose; basal leaves numerous, short, 4-8 cm. long; principal leaflets cuneate in outline, about $1 \mathrm{~cm}$. long, hirsute and glandular-pruinose; hypanthium hemispheric; bractlets linear; sepals elliptic or lance-elliptic, purple-veined; petals yellow, elliptic or oval. Closely related to $S$. ciliata. E. brevifolia Greene. Mountains: c.Utah. Submont.-Mont. Je-Jl.

\section{ACOMASTỲLIS Greene.}

Low cespitose perennials, with strong rootstocks. Basal leaves numerous, pinnately divided, with numerous cleft or toothed divisions; stem-leaves few, reduced and with few divisions. Flowers terminal, solitary or in 2-4-flowered cymes. Hypanthium more or less turbinate. Bractlets and sepals 5. Petals 5 , obovate, oval, or suborbicular, yellow. Stamens numerous, inserted in the mouth of the hypanthium. Pistils numerous; ovaries hirsute, lanceolate, tapering into the glabrous, persistent styles, which do not elongate in fruit; ovules basal.

Leaves densely silky-canescent.

Leaves puberulent, somewhat glandular-granuliferous or glabrate, not silky.

1. A. sericea.

2. A. turbinata.

1. A. sericea Greene. Stem 1-3 dm. high, slender, silky; basal leaves 5-10 cm. long, densely silky-villous; segments $15-25$, cuneate in outline; stem-leaves 1-3; hypanthium short-turbinate, 4-5 $\mathrm{mm}$. high and broad; bractlets lanceolate; sepals triangular-ovate; petals yellow, orbicular, $8-10 \mathrm{~mm}$. long. Geum sericeum Greene. Sieversia sericea Greene. Mountains: Nev.-Ida.-Wyo.-Mont.

2. A. turbinata (Rydb.) Greene. Stem slender, 0.5-3 dm. high, silkystrigose or glabrate; basal leaves .5-15 cm. long; segments 11-33, oblanceolate, obovate, or cuneate in outline, with lanceolate or oblong lobes; stem-leaves 1-3; hypanthium obconic-turbinate, about $5 \mathrm{~mm}$. high and broad; bractlets lanceolate; sepals ovate, short-acuminate; petals yellow, broadly obovate or obcordate, 6-8 mm. long. Potentilla nivalis Torr. Geum turbinatum Rydb. Sieversia turbinata Greene. S. scapoidea A. Nels, A. arapahoensis Daniels, Mountains: Mont.-N.M.-Ariz.-Nev. Mont.-Alp. Je-Au.

\section{FAllùgia Endl. Apache Plume.}

Low shrub, with straw-colored branches and flaky bark. Leaves pinnately dissected into linear divisions, revolute on the margins, and with small stipules. Flowers solitary or few at the ends of the branches, peduncled. Hypanthium hemispheric, persistent, villous within. Sepals 5, imbricate. Bractlets present. Petals 5, white, rounded, spreading. Stamens numerous, inserted on the margin of the hypanthium in three series. Pistils numerous, villous, on a conic receptacle; style terminal; ovules solitary, erect, basal. Fruit of coriaceous, villous, oblong achenes, with (in fruit) elongate, plumose, persistent styles.

1. F. paradoxa (D. Don) Endl. A shrub 5-10 dm. high, much branched; bark white, in age somewhat shreddy; leaves pinnatifid, with $3-7$ linear, revolute divisions, puberulent, villous or in age glabrate, rusty-lepidote beneath, $1-2 \mathrm{~cm}$. long; flowers few, in corymbiform cymes; hypanthium hemispheric, 4-5 mm. high, silky-villous; sepals 8-10 $\mathrm{mm}$. long, often rose-tinged, villous; outer ones lanceolate or ovate, long-acuminate-caudate, 3-cleft at the apex, or entire; petals 
obovate to elliptic, $1.5-2 \mathrm{~cm}$. long, obtuse; pistils numerous; styles in fruit 3-4 cm. long. Hills and cañons: Tex.-Colo.-Utah-Ariz.; n Mex. Son.-Mont. $\mathrm{Ap}-\mathrm{Au}$.

\section{CoWÃnta D. Don. Clifff Rose.}

Shrubs or small trees. Leaves alternate, toothed or pinnatifid, or entire, coriaceous, glandular-dotted, mostly with revolute margins and tomentulose beneath. Flowers solitary, terminal, on short branches. Hypanthium wholly persistent, more or less turbinate. Sepals 5, imbricate, persistent. Petals 5, obovate, spreading. Stamens numerous in two series, inserted in the throat of the hypanthium. Pistils 4-12, or in one species only 1-3, distinct, sessile, densely villous-hirsute; style terminal, plumose, persistent, elongate in fruit; ovules solitary.

1. C. Stansburiana Torr. A shrub 1-3.5 m. high; bark of the stem gray and shreddy, that of the young branchlets reddish-brown and glandular; leaves obovate in outline, 8-15 mm. long, glandular-punctate and green above, more or less tomentulose beneath, revolute-margined, pinnately 3-5-divided; flowers solitary, terminal; hypanthium turbinate-funnelform; petals sulphur-yellow or eream-colored, broadly obovate, $8-10 \mathrm{~mm}$. long. C. mexicana A. Gray, not D. Don. Dry hills: N.M. - s Colo.-Nev.-s Calif.; n Mex. Son.-Submont. $\mathrm{My}-\mathrm{N}$.

\section{PÚRSHIA DC.}

Shrubs, with spreading branches. Leaves alternate, crowded, apparently fascicled, deeply 3 -cleft, with revolute margins. Flowers solitary, terminating short branches. Hypanthium turbinate or funnelform, persistent. Sepals 5, imbricate. Petals 5, yellow. Stamens about 25, in one series, inserted on the margin of the hypanthium. Pistils 1 , rarely 2 , lance-oblong, tapering into a short persistent style, which does not greatly elongate in fruit; ovule solitary,
basal, erect. [Kunzia Spreng.]

1. P. tridentata (Pursh) DC. Shrub 1-3 m. high; bark chestnut-brown or grayish; leaves cuneate in outline, 5-30 $\mathrm{mm}$. long, 3-lobed at the apex, whitetomentose and revolute-margined beneath, glabrate or slightly tomentose above when young; flowers solitary; hypanthium funnelform; sepals oblong or elliptic; petals spatulate-obovate, $7-9 \mathrm{~mm}$. long. Hills: Mont,-N.M.-Calif.-B.C.' Son.-Submont. My-Au.

\section{CERCOCÁRPUS H.B.K. Mountain Mahogany.}

Shrubs or trees with hard wood. Leaves alternate, simple, toothed or entiremargined. Flowers axillary, solitary or fasciculate. Hypanthium with a cylindric persistent tube, abruptly widening into a turbinate or campanulate, deciduous limb. Sepals 5 , from broadly triangular to nearly subulate. Corolla wanting. Stamens 15 or more, inserted at different heights on the limb of the hypanthium. Pistil solitary, inserted in the bottom of the hypanthium; ovary eylindrie-fusiform, sessile; style terminal, elongate, plumose; stigma undivided,
terminal. Seed eylindrie, solitary, basal.

Leaves serrate or dentate.

Hypanthium and leaves villous, with spreading hairs; leaves broadly obovate, 1.5-3
$\mathrm{cm}$. long. $\begin{array}{ll}\mathrm{cm} \text {. long. } & \text { 1. } \mathrm{C} \text {. montanus. }\end{array}$

Leaves obovate-flabelliform, 1-2 cm. Iong.

$\begin{array}{ll}\text { Leaves oblanceolate or obovate, } 2-4 \mathrm{~cm} \text {. long. } & \text { 2. C. flabellifolius } \\ \text { Leaves entire, from linear to elliptic, coriaceous, with more or less revolute margin }\end{array}$

2. C. flabellifolius. resinous.

Leaf-blades $1.5-3 \mathrm{~cm}$. long; tail of fruit $4-6 \mathrm{~cm}$. long. Leaf-blades elliptic, only slightly revolute, in age merely tomentulose beneath;
petioles $3-5 \mathrm{~mm}$. long.

Leaf-blades linear, strongly revolute, permanemtly 4. C. ledifolius. neath; petioles $1-2 \mathrm{~mm}$. long.

Leaf-blades 5-1.5 mm. long, narrowly linear, strongly revolute, 5, C. hypoleucus. lower surface exposed; tail of fruit $3-4$ strongly revolute, only the midrib of the Leaves short-villous when young.

Leaves glabrous from the beginning.

6. C. arizonicus.

7. C. intricatus. 
1. C. montanus Raf. Shrub $1-2 \mathrm{~m}$. (rarely $3 \mathrm{~m}$.) high; leaf-blades $2-5 \mathrm{~cm}$. long, coarsely serrate, with ovate teeth, pale and finely tomentose beneath; tube of the hypanthium about $1 \mathrm{~cm}$. long, pilose; limb campanulate or somewhat turbinate, together with the sepals $6-7 \mathrm{~mm}$. wide. C. parvifolius Nutt. Hills and mountain sides: S.D.-W Kans.-N.M.-Utah-Mont. Plain-Mont. $\mathrm{My}-\mathrm{Jl}$.

2. C. flabellifolius Rydb. Low shrub, with gray smooth flaky bark; leafblades $1-2 \mathrm{~cm}$. long and nearly as broad, coarsely dentate above the middle, pale beneath; tube of the hypanthium silky-strigose; limb campanulate, puberulent within, together with the sepals $5 \mathrm{~mm}$. wide. Hills and cañons: Utah-N.M.

3. C. argenteus Rydb. Shrub $2-3 \mathrm{~m}$. high, with gray bark; leaf-blades oblanceolate or obovate, $2-4 \mathrm{~cm}$. long, obtuse or rarely rounded at the apex, crenate above and at the middle, silvery-white beneath; teeth rounded-ovate, obtuse; tube of the hypanthium 8-10 mm. long, silky; limb silky without, turbinate, together with the sepals $6-7 \mathrm{~mm}$. wide. Hills: Colo.-Tex.-N.M. Son.Submont. Je-Jl.

4. C. ledifolius Nutt. Aromatic tree, sometimes $12 \mathrm{~m}$. high, with red-brown, furrowed bark; leaf-blades narrowly lanceolate, lance-elliptic, or oblanceolate, entire, with revolute margins, villous-puberulent when young, glabrate in age above, pale or rufous, and tomentulose beneath, $1-3 \mathrm{~cm}$. long, $5-10 \mathrm{~cm}$. broad, persistent; tube of the hypanthium 5-7 mm. long, white-villous-tomentose; limb turbinate, together with the ovate sepals $5-6 \mathrm{~mm}$. wide. Hills: Mont.-Colo. $\rightarrow$ Calif.-Wash. Submont.-Mont. My-Jl.

5. C. hypoleucus Rydb. Shrub or small tree, 1-5 m. high, with ashy bark; leaf-blades linear-lanceolate or linear-elliptic, acute at both ends, $1-2 \mathrm{~cm}$. long, 3-4 mm. wide, green above, at first villous, in age glabrate, densely white villoustomentose beneath; tube of the hypanthium $4-5 \mathrm{~mm}$., in fruit $5-6 \mathrm{~mm}$. long, white-villous; limb turbinate, together with the sepals $4 \mathrm{~mm}$. broad. Hills: Mont.-Wyo.-Ore. Son.-Submont. Je-Jl.

6. C. arizonicus M. E. Jones. Intricately branched, spinose shrub, with ashy bark; young branches white villous-tomentose; leaves linear, $5-15 \mathrm{~mm}$. long, strongly revolute, villous-canescent on both sides, glabrate above, entire, acute at both ends; flowers solitary; tube of the hypanthium in fruit $6 \mathrm{~mm}$. long, short-villous; achenes $6 \mathrm{~mm}$. long. Cañons: e Utah-Ariz.-Nev.

C. arizonicus $\times$ ledifolius. Most resembling $C$. arizonicus in habit, but the leaves broader and less revolute, $1-1.5 \mathrm{~cm}$. long and $2-3 \mathrm{~mm}$. wide. Utah.

7. C. intricatus S. Wats. Intricately branched shrub, with fissured ashy bark, more or less spinescent; young branches strigose, soon glabrous; leafblades linear, entire, strongly revolute on the margins; tube of the hypanthium strigose, $4 \mathrm{~mm}$. long, in fruit $6 \mathrm{~mm}$. long; limb turbinate, together with the sepals $3 \mathrm{~mm}$. wide; achenes about $7 \mathrm{~mm}$. long, hirsute. Cañons and hills: Utah -Nev.-Ariz.

\section{RUBÃCer Rydb. Flowering Raspberry, Thimbleberry, Salmon Berry.}

Unarmed shrubs, with more or less shreddy bark, more or less glandularhispid above. Leaves petioled, simple, digitately ribbed and lobed, with acute or acuminate lobes and cordate at the base, resembling the leaves of certain maples. Flowers showy, in small panicles. Sepals 5, ovate, with long slender acuminations. Petals 5, pink or white. Stamens numerous, in several series; filaments slender. Pistils numerous; styles glabrous, club-shaped; stigmas slightly 2-lobed. Drupelets numerous, eoherent with each other and separating from the flat receptacle, capped with a dry, rather hard, finely and densely pubescent cushion, the style inserted under its margin.

1. R. parviflorum (Nutt.) Rydb. Stem ereet, shrubby, 5-20 dm. high, with flaky bark; leaf-blades reniform in outline, $5-20 \mathrm{~cm}$. broad, $3-5$-lobed, the lobes triangular; sepals broadly ovate, abruptly caudate-acuminate, about 1.5 $\mathrm{em}$. long, densely glandular on the back; petals white, broadly oval, or ovate, 
15-30 mm. long; fruit convex, red, 15-20 mm. wide. Rubus parviflorus Nutt. Rubus nutkanus Moc. Bossekia parviflora Greene. Open woods and among bushes: Mich.-w Ont.-S.D.-N.M.-Calif.-s Alaska; n Mex. Submont.-Mont. My-Jl.

\section{OREOBÃTUS Rydb.}

Prostrate or reclining or erect shrubs, with light-colored shreddy bark. Leaves petioled, simple, maple- or gooseberry-like, digitately ribbed or lobed. Flowers showy, usually solitary. Sepals 5, ovate or ovate-lanceolate, acuminate or with foliaceous tips, in fruit erect. Petals white, pink, or purple, broadly obovate. Stamens very numerous, in several series, hiding the rather few pistils. Receptacle flat or nearly so. Styles club-shaped, densely pubescent, curved; stigma somewhat 2-lobed. Drupelets rather few, fleshy, without hairy cushions.

1. O. deliciosus (Torr.) Rydb. Stems mostly decumbent or prostrate, or ascending; young branches almost velvety; leaf-blades reniform in outline, more or less distinctly $3-7$-lobed, $2-6 \mathrm{~cm}$. broad; lobes very broad and rounded, dentate; flowers mostly solitary; sepals $10-15 \mathrm{~mm}$. long, acuminate or with foliaceous tips; petals oval, white, $1.5-3 \mathrm{~cm}$. long; fruit hemispheric, dark purple, 10-15 mm. broad. Rubus deliciosus Torr. Bossekia deliciosa A. Nels. Mountains: Colo. Submont.-Mont. Je-S.

\section{RÙBUS (Tourn.) L. Raspberry, Blackberry, Cloudberry.}

Perennial plants, ours either shrubs with biennial, prickly or bristly stems, or herbaceous plants, with rootstocks or creeping stems, unarmed. Leaves alternate, usually pinnately or pedately compound or rarely simple. Flowers racemose, paniculate or rarely solitary, perfect, dioecious or polygamo-dioecious. Hypanthium flat or saucer-shaped. Sepals 5, rarely $6-8$, without bractlets. Petals as many, deciduous. Stamens numerous, inserted on a disk at the margin of the hypanthium. Pistils many, inserted on a convex or nipple-shaped, dry or fleshy receptacle. Fruit of several or many fleshy drupelets. Ovules 2, collateral, one abortive.

Stem herbaceous, never prickly, rarely bristly; floral branches directly from the rootstock or from stolons; stipules broad, free or nearly so.

Petals spreading or ascending; flaments not dilated.

Plants dioecious; drupelets many, coherent; petals large and broad; leaves merely lobed.

Plants with perfect flowers; drupelets few, distinct; petals narrow; leaves pedately 5 -foliolate.
2 . $R$. pedatus.

Petals erect; filaments dilated.

Petals pink or rose-color; plants not stoloniferous; floral branches directly from the rootstock.

Petals oblanceolate or obovate, 10-15 mm. long, distinctly clawed; stem less than $1 \mathrm{dm}$. high, usually 1 -flowered; leaflets rounded at the apex.

Petals broadly obovate, rounded or emarginate, scarcely clawed, $10 \mathrm{~mm}$. long or less; stem leafy, 1-3 dm. high, 1-5-flowered; stem-leaves with rhombic acute leaflets.

Petals white; plant stoloniferous.

Plant wholly unarmed; flowers solitary or racemose. $\quad 5 . R$. pubescens.

Plant sparingly glandular-hispid above and sometimes with a few weak bristles; flowers corymbose.

Stem more or less woody, biennial of perennial, usually prickly or bristly, if unarmed or merely bristly, then the stipules narrow and more or less adnate.

Stipules broad, free or nearly so; stem decumbent, prickly. 7. R. nivalis.

Stipules narrow, linear-lanceolate or subulate, adnate to the petioles.

Carpels united into a thimble-shaped aggregate fruit, separating from the dry receptacle.

Flowers solitary or few; petals purplish, large, much exceeding the sepals; leaves green on both sides.

Flowers clustered; petals white, usually shorter than the sepals; leaves more or less tomentose or at least glaucous beneath.

Inflorescence corymbiform; fruit black or purple; stem prickly; leaves, when having more than 3 leaflets, pedately compound.

Prickles of the inflorescence not flattened, straightish; leaflets dark green above, acuminate, with small teeth; stem usually dark bluish, with a bloom.

9. $R$. occidentalis.

Prickles of the inflorescence strongly flattened and curved; leaflets yellowish green above, acute, with coarse teeth; branches usually straw-colored.

10. R. leucodermis. 
Inflorescence racemose; fruit red; leaves, when having more than 3 leaflets, pinnately compound.

Plant not at all glandular-hispid; inflorescence with weak prickles, villous.

11. R. melanotrachys.

Plant more or less glandular-hispid, especially in the inflorescence.

Sepals narrowly lanceolate, gradually acuminate; leaves glabrate beneath in age.

Stem sparingly bristly; leaflets neither strongly plicate nor strongly veined. $12 . R$. peramoenus.

Stem densely bristly; leaves strongly plicate and strongly veined.

Sepals ovate or ovate-lanceolate, 13 . R. viburnifolius.

13. R. viburnifolius.

Young stems, petioles, and inflorescence neither densely tomentose nor puberulent.

14. $R$. melanolasius.

Young stems, petioles and inflorescence densely tomentose or puberulent.

Carpels coherent to the fleshy receptacle; plant dioecious $15 . \pi$. acalyphaceus. and 1-3-foliolate green leaves. $16 . R$. macropetalus.
.

1. R. Chamaemorus L. A herbaceous perennial, with creeping rootstock; stem 1-3 dm. high, 1-3-leaved; leaf-blades reniform, with 3-7 rounded lobes, palmately veined; flowers solitary; petals white, obovate, 8-12 mm. long; stamens numerous, in the pistillate flowers without anthers; fruit at first red, when ripe yellow or golden. Cloud-Berry. Baked-Apple Berry. Arctic and subarctic sphagnum swamps: Greenl.-N.H.-B.C.-Alaska; Eurasia. Boreal. J1-Au.

2. R. pedatus Smith. An unarmed herbaceous perennial, with flagelliform creeping branches; flowering branches very short, 2-4-leaved; leaflets thin, irregularly incised, obovate, or rhombic, $1-5 \mathrm{~cm}$. long; flowers solitary; petals white, obovate-oblong, spreading or reflexed; stamens many; pistils 1-6; fruit purple; drupelets short-stipitate. Woods: n Calif.-Ida.-Alta.-Yukon-Alaska. Boreal-Mont. Je-S.

3. R. acaulis Michx. An unarmed herbaceous, subdioecious perennial, with creeping rootstock; stem 3-12 cm. high, 2-4-leaved; leaflets 3, broadly obovate to flabelliform, unevenly serrate; petals rose-colored, with yellowish claws; fruit red; drupelets 20-30, coherent. Arctic and subarctic swamps and tundras: Lab.-Newf.-Minn.-Alaska. Boreal-Subalp. Je-Au.

4. R. arcticus L. An unarmed herbaceous perennial, with a rootstock; stem $0.5-2 \mathrm{dm}$. high, 2-6-leaved, more or less flexuose: leaflets 3 , obovate to rhombic, coarsely dentate, $1.5-4 \mathrm{~cm}$. long; petals rose-colored, clawless, sometimes denticulate; fruit red, globose; drupelets 20-40, coherent. Bogs: Lab.-Alta.; Eurasia. Boreal-Subalp. J-Au.

5. R. pubescens Raf. An unarmed perennial, with flagelliform, procumbent shoots, 1-10 dm. long; leaves ternate, rarely quinate; leaflets $3-10 \mathrm{~cm}$. long, green on both sides, sharply and doubly serrate, the lateral ones obliquely ovate, the terminal one rhomboid; petals elliptic or oblanceolate; fruit red, globose; drupelets rather few, large, slightly coherent. $R$. triflorus Richards. R. americanus (Pers.) Britt. Damp woods and swamps: Newf,-N.J.-Ia.-Mont.B.C.; Colo. Boreal-Mont. My-J.

6. R. transmontanus Focke. A mostly herbaceous perennial, with a creeping rootstock; shoots creeping, flagelliform, slightly bristly or glanidularhispid; leaves ternate; leaflets rhombic-ovate, 3-7 cm. long, acute at the base, acuminate at the apex, rather coarsely serrate; inflorescence 1 -3-flowered; petals erect, white, oblanceolate, $4 \mathrm{~mm}$. long; pistils 20-50; fruit hemispheric, red. Perhaps a hybrid of $R$. pubescens with some species of the $R$. strigosus group. Woods: B.C. Mont. My-Jl.

7. R. nivalis Dougl, A perennial; stems more or less woody, creeping, terete, puberulent, 3-12 dm. long, sparingly armed with curved or hooked prickles; leaves simple or sometimes ternate, bluish green and shining; blades of the simple leaves 3-6 cm. long, ovate-cordate or rounded-cordate, more or less distinctly 3-lobed, dentate; lower leaflets of the ternate leaves obliquely ovate, the terminal one broadly rhombic-ovate, somewhat larger; flowers usually solitary; hypanthium short-turbinate, more or less prickly; petals white, linear-lanceolate, tapering at both ends; pistils few, not all maturing; drupelets pubescent, large, red. Mountains: (?) n Calif.-Ore.-Ida.-B.C. Mont.-Subalp. Je-Jl. 
8. R. spectabilis Pursh. Stems perennial, shrubby, $2-5 \mathrm{~m}$. high, unarmed when young or with small straight prickles; leaves usually 3 -foliolate; leaflets thin, incisedly double-serrate; terminal leaflet 4-10 $\mathrm{cm}$. long, often deltoid- or rhombic-ovate; lateral leaflets obliquely ovate, subsessile; flowers mostly solitary; petals reddish purple or rose-colored, elliptic, $15-20 \mathrm{~mm}$. long; fruit large, ovoid, $15-20 \mathrm{~mm}$. long, red or yellow. SALMon-Berry. Along streams: $\mathrm{s}$ Alaska-Ida,-Calif. Submont. Äp-Je.

9. R. occidentalis L. Stems biennial, 1-3 m. long, recurved, at length rooting at the tips, usually purplish or bluish; leaves of the shoots 3 -foliolate, or some of them pedately 5 -foliolate; median leaflet ovate to broadly cordate, sometimes more or less lobed, doubly serrate, acuminate at the apex, rounded to cordate at the base, $5-8 \mathrm{~cm}$. long, white-tomentose beneath; lateral leaflets in the 5 -foliolate leaves similar, but narrower; outer leaflets subsessile, often oblique and sometimes 2-lobed; floral branches green, their leaves 3-foliolate; leaflets similar, but rarely cordate at the base; corymbs few-flowered; sepals ovate-lanceolate, long-acuminate, 7-8 mm. long; petals white, elliptic, shorter than the sepals; fruit dark bluish purple, with a bloom, hemispheric. BLACK RASPBERry, Black-CaP. Copses: N.B.-Que.-Ga.-Colo-Minn. Plain-Submont. Je-Jl.

10. R. leucodermis Dougl. Stems biennial, erect, $1-2 \mathrm{~m}$. high, yellowish and glaucous, armed with stout, flat, recurved prickles; leaves of the shoots usually pedately 5 -foliolate; terminal leaflet broadly ovate, 6-10 cm. long, acute, double-serrate, rounded or subcordate at the base; lateral leaflets similar, but narrower and merely rounded at the base; lower leaflets usually subsessile; floral branches usually with yellowish bark, their leaves 3 -foliolate and leaflets smaller; corymbs usually few-flowered; pedicels tomentose, prickly, but not glandular; sepals lanceolate, long-acuminate, in fruit merely spreading; petals white, oblong or elliptic, shorter than the sepals; fruit hemispheric, dark reddish purple or nearly black, with a bloom. Purple Raspberry. Copses: B.C.-Mont.Utah-Calif. Submont. Je-Jl.

R. leucodermis $\times$ melanolasius. Resembling $R$. leucodermis in habit and in the prickly stem, but the upper part of the branches, the peduncles, pedicels, and petioles
more or less glandular-hispid. B.C.-Mont.

11. R. melanotrachys Focke. Stems biennial, erect, 1-2 m. high, purplish, glabrous, short-bristly; leaves pinnately ternate; leaflets coarsely and somewhat doubly serrate, acuminate, green and glabrous above, densely white-tomentose beneath; inflorescence short, almost corymbiform; pedicels villous, not at all glandular, armed with purple, curved, strong bristles or weak prickles; hypanthium and calyx tinged with purple, bristly and villous, not glandular; petals white, elliptic, or spatulate, $5 \mathrm{~mm}$. long; fruit red, hemispheric. Woods: Ida.
Jl.

$$
\text { Tiedde }
$$

12. R. peramoenus (Greene) Ryelb. Stems biennial, erect, 1-2 m. high, usually glabrous and shining, rather sparingly bristly; leaves of the turions pinnately 3-5-foliolate, green on both sides, only sparingly grayish-puberulent beneath when young; terminal leaflet cordate or ovate, sometimes 3-lobed, sharply and doubly serrate; lateral leaflets sessile, obliquely ovate; leaves of the floral branches usually ternate, their leaflets usually smaller and broader; racemes short, few-flowered; pedicels and hypanthium rather densely glandular-hispid and glandular-puberulent; petals white, erect, spatulate, $6 \mathrm{~mm}$. long; fruit red, hemispheric, $12 \mathrm{~mm}$. broad. Batidaea peramoena Greene. Damp woods: e Ore. -Wash.-w Mont. Submont. My-Jl.

13. R. viburnifolius (Greene) Rydb. Stems biennial, yellowish or brownish, seldom purplish, more or less densely bristly with fine bristles, about $1 \mathrm{~m}$. high; leaves of the turions often 5 -foliolate, those of the floral branches 3 -foliolate; leaflets green on both sides or sparingly tomentulose beneath when young, incised-serrate; terminal leaflet rhombic-ovate or ovate, $4-6 \mathrm{~cm}$. long, the lateral ones somewhat smaller, obliquely ovate; racemes short, few-flowered; pedicels, hypanthium, and calyx densely glandular-hispid and somewhat bristly; petals white, erect, 5-7 mm. long; fruit hemispheric, red or yellowish. Batidaea viburni- 
folia Greene. Perhaps not distinct from the next. Woods: Alaska-Mack.Mont.-B.C. Submont. Je-Jl.

14. R. melanolasius Focke. Stems biennial, erect, $0.5-1 \mathrm{~m}$. high, purple, or yellow, and often glaucous, densely bristly and more or less glandular; leaves of the shoots pinnately $3-5$-foliolate; leaflets ovate or lanceolate, short-acuminate or acute at the apex, usually rounded or cuneate at the base, sharply doubleserrate, light green and sparingly and minutely pubescent above, finely and densely white-tomentose beneath; leaves of the floral branches similar, but always 3 -foliolate; flowers in small terminal and axillary racemes; peduncles, pedicels, hypanthium, and calyx densely bristly and glandular-hispid; petals white, elliptic, 5-6 $\mathrm{mm}$. long, erect; fruit red or purplish red, hemispheric, very sour. $R$. strigosus of Western reports. B. laetissima, B. dacotica, B. unicolor, and B. Sandbergii Greene. Red Raspberry. Mountains: B.C.-Alta.-Colo.-Utah-Ore. Submont.-Mont. Je-Jl.

15. R. acalyphaceus (Greene) Rydb. Stem biennial, erect, $0.5-1 \mathrm{~cm}$. high, brown or purple, in age exfoliating, tomentose or pilose as well as densely armed with strong bristles often flattened; leaves of the shoot pinnately, 3-5-foliolate; leaflets ovate or the terminal subcordate, rather prominently veined and plicate, incisedly double-toothed, abruptly acuminate, densely white-tomentose beneath, 2-4 cm. long; leaves of the floral branches always 3 -foliolate, with shorter leaflets; flowers in short few-flowered racemes; petals white, erect, about $5 \mathrm{~mm}$. long; fruit red, acid, hemispheric. Perhaps not distinet from $R$. melanolasius. $B$. acalyphacea, B. subcordata, B. cataphracta, and B. filipendula Greene. Mountains: Mont.-Wyo.-Ida.-Nev.

16. R. macropetalus Dougl. Stem biennial, terete, often purplish, elimbing or decumbent, sparingly hirsute or glabrous, armed with small, slightly retrorse prickles; leaves ternate; terminal leaflet broadly ovate or subcordate, often more or less lobed, double-serrate, green and sparingly hirsute on both sides; lateral leaflets ovate, subsessile; inflorescence corymbose, armed with weak prickles and slightly glandular; petals of the staminate flowers $12-16 \mathrm{~mm}$. long, elliptic, white, those of the essentially pistillate flowers oval, 7-10 $\mathrm{mm}$. long; fruit hemispheric or slightly elongate, black, sweet. Creeping Blackberry. Low woods: B.C.-Ida.-n Calif. Submont, My-Je.

\section{RÒSA (Tourn.) L. Rose.}

Shrubs or vines, usually prickly. Leaves alternate, pinnate, with more or less adnate stipules, and serrate leaflets. Flowers perfeet, solitary or corymbose. Hypanthium well-developed, urceolate, globose, ellipsoid or turbinate, contracted at the mouth, enclosing the achenes, becoming fleshy in fruit. Sepals 5 (rarely 4 ), with or without bractlets. Petals normally 5 (rarely 4), or by the transformation of the stamens numerous, spreading, usually obcordate. Stamens numerous, inserted on the thickened margin of the hypanthium. Pistils numerous or several, inserted in bottom of the hypanthium or also on the inside walls of the same. Styles ventral, reaching the mouth of the hypanthium or long-exserted, sometimes united into a column. Achenes bony.

Pistils numerous; styles as well as the upper part of the hypanthium persistent; sepals in fruit erect or ascending, persistent.

Infrastipular prickles not present; branches mostly unarmed and young shoots bristly, but not prickly.

Inflorescence corymbose, terminating the stems (or rarely the branches); plant suffruticose; stem usually dying back to near the ground; leaflets 9-11.

Leaves glabrous or nearly so.

Leaflets mostly $2-5 \mathrm{~cm}$. long, not glaucous, decidedly acute; plant $3 \mathrm{dm}$. high or more; flowers corymbose.

1. $R$. arkansana

Leaflets rarely more than $2 \mathrm{~cm}$. long, mostly counded at the apex, somewhat glaucous beneath; plant 1-2 dm. high; flowers 1-3.

Leaves densely pubescent, especially beneath.

2. R. Lunellii.

Upper stipules and bracts not densely glandular; leaflets $1.5-4 \mathrm{~cm}$. long: plant 3-5 dm, high.

3. R. suffulta.

Upper stipules and bracts densely glandular: leaflets seldom more than $1.5 \mathrm{~cm}$. long; plant $1-3 \mathrm{dm}$. high.

4. R. alcea.

Inflorescence of solitary or few corymbose flowers at the end of lateral branches; plant shrubby; leaflets usually 5 or 7 , or 9 only on the young shoots. 
Hypanthium decidedly pear-shaped or elliptic, acute at the base, with a distinct neck at the top.

Sepals rarely more than $1 \mathrm{~cm}$.long; bark yellowish green, 5. R. collaris.

Sepals $2-3 \mathrm{~cm}$. long; bark brown.

Leaflets conspicuously glandular-granuliferous, but searcely at all hairy beneath, rounded-oval, double-toothed.

6. $R$. Engelmannii.

Leaflets densely pubescent, but rarely slightly if at all glandular-granuliferous beneath, mostly elliptic, simple-toothed.

Hypanthium subglobose, almost without a neck.

7. $R$. acicularis.

Hypanthium subglobose, alm
Infrastipular prickles usually present.

8. $R$, Bourgeauiana.

Flowers mostly solitary : petals usually $2.5 \mathrm{~cm}$. long or more; fruit $12-20 \mathrm{~mm}$ thick. Prickles straight or nearly so.

Hypanthium densely prickly.

Hypanthium not prickly or rarely slightly so.

9. R. MacDougali.

Leaflets more or less double-toothed, more or less glandular-granuliferous beneath; stipules and rachis glandular.

Leaflets very thin, pale and slightly glandular-granuliferous, but not muriculate beneath.

10. R. nutkana.

Leaflets thicker, dark green on both sides, conspicuously glandularmuriculate beneath.

Leaflets simple-toothed, puberulent but not $11 . R$. muriculata.

beneath; rachis rarely glandular. 12 . $R$. Spaldingii.

Prickles more or less distinctly curved.

Hypanthium prickly.

Stem stout, $1 \mathrm{~m}$. high or more; leaflets usually more than $3 \mathrm{~cm}$. long.

Stem 13. R. Underwoodii.

$2 \mathrm{~cm}$. long.

Hypanthium smooth.

usually not more than

Prickles very large and flat; twigs densely glandular and pubescent.

Prickles short and slender, not spicuously glandular, mostly glabrous.

Leaflets perfectly glabrous or merely glandular-granuliferous beneath.

Stem $1 \mathrm{~m}$. high or more; leaflets usually more than $2 \mathrm{~cm}$. long, pale or light green, rather firm, rarely double-serrate, not glandular-granuliferous beneath; calyx not densely glandular.

Stem usually less than $3 \mathrm{dm}$ hig. 15. R. melina. $\mathrm{em}$. long, dark green 3 dm, high; leaflets usually less than 2 landular-double-toothed; calyx usually

Leaflets sparin with stalked glands.

16. $R$. aciculata.

Leaflets sparingly pubescent beneath.
Flowers mostly corymbose, if solitary the petals $2 \mathrm{~cm}$, long or less; fruit rarely more than $1 \mathrm{~cm}$. thick.

Prickles more or less curved.

Leaflets finely puberulent or glandular-granuliferous, or both beneath.

Hypanthium ellipsoid; young shoots with rather few strong curved prickles.

$18 . R$. neomexicana.
Hypanthium globose; young shoots with fine, often rather many prickles. 19 . $R$. puberulenta.

Leaflets perfectly glabrous.

Prickles straight or nearly so.

20. R. manca.

Hypanthium globose; neck usually obsolete.

Stipules, petioles, and rachis conspicuously glandular.

Stipules, petioles, and rachis not 21. R. Fendleri. glandless.

Leaflets glabrous or nearly so.

Leaves yellowish green; fruit orange; corymb several-flowered.

Leaves dark green above, paler beneath $22, R$. chrysocarpa. flowers 1-3.

Leaflets more or less pubescent beneath.

23. R. Woodsii.

Leaflets elliptic or oval, equally green on both sides.

Leaflets broadly oval, thin, $2-5 \mathrm{~cm}$. long; plant nearly unarmed.

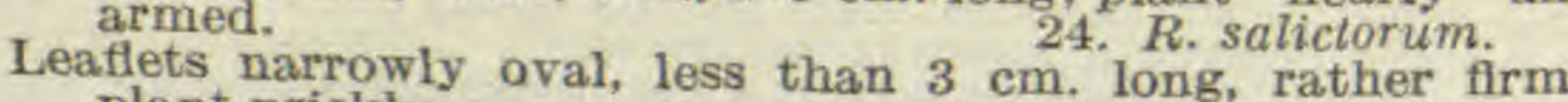
plant prickly. 25. R. ultramontana.

Leaflets obovate, or if elliptic, more or less glaucous beneath.

Leaflets thin, very sharply serrate, equally green on both sides; sepals with a few slender bristles near the margins; prickles very slender. $26 . R$. pratincta. Leaflets firmer, paler beneath; sepals without bristles; prickles
stouter.

Hypanthium elongate, pear-shaped, with a distinct neck. 27. R. Macounii.

Pistils few; styles deciduous with the upper part of the $28 . R$, pyrifera. ring. 
Leaflets very thin, scarcely paler beneath, with distinct reticulations.

Leaflets not very thin, pale and indistinctly reticulate beneath 29 . $R$. oymnocarpa.

30. R. leucopsis.

1. R. arkansana Porter. Stem erect, 2-4 dm. high, copiously bristly, mostly simple, killed back to near the root; glabrous or nearly so, glandulartoothed; rachis and petiole glabrous or sparingly pilose, sometimes glandular; leaflets elliptic, $1.5-6 \mathrm{~cm}$. long, glabrous and shining, coarsely and sharply serrate; hypanthium subglobose, glabrous, without a neck, in fruit $12-15 \mathrm{~mm}$. broad; sepals somewhat glandular on the back; petals obcordate, 2-2.5 cm. long. Plains and cañons: Colo.-Kans.-Wis.-Minn. Plain-Submont. Je-Jl.

2. R. Lunellii Greene. Stem erect, simple, 1-3 dm. high, densely bristly; sepals glabrous or nearly so, sometimes glandular, entire or gland-toothed on the margins; petiole and rachis glabrous or sparingly puberulent, sometimes glandular; leaflets elliptic or oval, serrate, $1-2.5 \mathrm{~cm}$. long, glabrous on both sides or sparingly pubescent on the veins beneath; hypanthium globose, glabrous, in fruit orange-red and 10-12 mm. thick; sepals glandular on the back; petals rarely $2 \mathrm{~cm}$. long, obcordate. Plains and hills: Man.-N.D.-S.D. PlainSubmont. Je-Jl.

3. R. suffulta Greene. Stem erect, $3-5 \mathrm{dm}$. high, usually simple, dying back to near the ground, densely bristly, green; stipules densely and finely pubescent, glandular-dentate on the margins; leaflets obovate, $1.5-4 \mathrm{~cm}$. long, light green, finely and rather densely pubescent on both sides or in age glabrate above, densely serrate; rachis and petiole finely pubescent; hypanthium globose, glabrous or rarely bristly, in fruit about $1 \mathrm{~cm}$. broad; sepals somewhat glandular on the back; petals obcordate, $2-2.5 \mathrm{~cm}$. long. $R$. arkansana $\mathrm{S}$. Wats., not Porter. $R$. pratincola and $R$. heliophila Greene, Prairies and plains: Ill.-Tex.-N.M. -Wyo.-Alta.-Man. Plain-Submont. Je-Au.

4. R. alcea Greene. Stem low, 1-3 dm. high, terete, densely bristly, even the floral branches; stipules puberulent, and glandular-hispid and even bristly on the back, glandular-ciliate on the margins, rather broad; rachis and petiole puberulent and glandular; leaflets obovate, 1-2 cm. long, serrate above the middle, glabrous above, finely and densely pubescent and strongly veined beneath; hypanthium globose, glandular-bristly; sepals glandular-hispid on the back; petals obcordate, $15 \mathrm{~mm}$. long. Plains: Sask.-N.D.-Man.-Colo. Plain.

5. R. collaris Rydb. Stem bristly, but not copiously so, yellowish green, about $1 \mathrm{~m}$. high; stipules glandular-dentate, slightly puberulent; petiole and rachis somewhat puberulent and glandular; leaflets mostly 5, oval, coarsely serrate, 1-3 cm. long, glabrous above, finely puberulent beneath; hypanthium small, ellipsoid, contracted into a rather long neck, glabrous; sepals $8-10 \mathrm{~cm}$. long, lanceolate, attenuate, with rather short tips, glabrate on the back. River banks: Ida. Jl.

6. R. Engelmannii S. Wats. Stem low, 3-5 dm. high, densely bristly, but rarely prickly; stipules rarely pubescent, eonspicuously glandular-granuliferous and glandular-ciliate; petiole and rachis more or less glandular; leaflets 5 or 7 , oval, $1-3 \mathrm{~cm}$. long, doubly glandular-serrate, shining above, paler beneath; hypanthium decidedly ellipsoid or pear-shaped, in fruit 8-10 mm. thick, and 12$15 \mathrm{~mm}$. long, with a distinct neck; sepals slightly if at all glandular; petals broadly obcordate, about $2.5 \mathrm{~cm}$. long. Woods: Colo. $-\mathrm{s}$ Mont.-N.D. Submont.Mont. Je-Jl.

7. R. acicularis Lindl. Stem low, about $1 \mathrm{~m}$. high, densely covered with straight bristles or weak prickles; stipules pubescent, more or less glandulargranuliferous and glandular-ciliate; leaflets 3-7, usually 5 , elliptic or oval, $1.5-5$ $\mathrm{cm}$. long, simply and regularly serrate, dull and glabrous above, pale and finely and densely pubescent beneath; hypanthium glabrous, pear-shaped or elliptic, in fruit $1-1.5 \mathrm{~cm}$. broad and $1.5-2 \mathrm{~cm}$. long, usually with a neck; sepals pubescent and more or less glandular on the back; petals obcordate, $2-2.5 \mathrm{~cm}$. long. Woods: Alaska-Wyo.-Mich.-N.Y. Boreal-Mont. Je-Au. 
R. acicularis $\times$ nutkana. This hybrid has the bristly stems, the elongate hypanthium, and the narrow, elliptic leaflets of $R$. acicularis, but the bristles are stronger, some of them stout and nearly $1 \mathrm{~cm}$. long, the leaflets are often double-toothed and much less hairy beneath than in $R$. acicularis. Mont.

8. R. Bourgeauiana Crep. Stem usually low, 3-10 dm. high, densely covered with straight bristles or weak prickles; stipules slightly, if at all, pubescent, glandular-dentate; petiole and rachis somewhat pubescent and glandular; leaflets usually 5 or 7 , broadly elliptic, $1.5-5 \mathrm{~cm}$. long, usually rounded or obtuse at both ends, more or less double-serrate, thin, glabrous or nearly so above, slightly pubescent and glandular-granuliferous beneath; hypanthium glabrous, in fruit 12-15 mm. broad; sepals slightly, if at all, glandular; petals broadly obcordate, $2-2.5 \mathrm{~cm}$. long, rose-colored. $\quad R$. Sayi S. Wats., not Schwein. Woods: Ont.-Colo.-Mont,-Mack. Boreal-Submont.-Mont. Je-Jl.

R. Bourgeauiana $\times$ nutkana. This resembles $R$. Bourgeauiana in the numerous bristles or rather weak prickles, but the prickles are stronger than in that species and many of them have broadened bases; the leaves are also firmer and conspicuously doubletoothed as in $R$. nutkana. Mont.

9. R. MacDougali Holz. Stem erect, 1-2 m. high, usually armed with paired straight, rather stout infrastipular prickles, 7-10 $\mathrm{mm}$. long; floral branches with weaker prickles or unarmed; stipules puberulent and somewhat glandular beneath, glandular-dentate; petiole and rachis puberulent and slightly glandular; leaflets usually 7 , oval, $1.5-5 \mathrm{~cm}$. long, coarsely and rather regularly toothed, glabrous or nearly so above, puberulent beneath; pedicels more or less glandularbristly; hypanthium subglobose, densely bristly or prickly, without a neck, in fruit 12-18 $\mathrm{mm}$. broad; sepals glandular on the back; petals broadly obcordate, 2-3 cm. long, rose-colored. R. nutkana hispida Fern. Woods: Ida.-W Mont. -n Utah-Wash.-B.C. Submont. My-Je.

10. R. nutkana Presl. Stems stout, erect, usually $1-1.5 \mathrm{~m}$. high, armed usually with paired large straight prickles, which are somewhat flattened below, 6-12 mm. long; floral branches glabrous, with smaller infrastipular prickles; stipules mostly glabrous, strongly glandular-dentate on the margins; petiole and rachis glandular-puberulent; leaflets $5-9$, usually 7 , rounded-ovate, rounded at the both ends or acute at the apex, double-serrate, with glandular teeth, $1.5-5$ $\mathrm{cm}$. long; hypanthium glabrous; sepals glabrous or rarely glandular on the back; petals rose-colored, rarely white, broadly obcordate, $2-3.5 \mathrm{~cm}$. long. Woods: Alaska-w Mont.-Wyo.-n Calif. Submont.-Mont. My-Jl.

11. R. muriculata Greene. Stem stout, erect, $1 \mathrm{~m}$. high or more, armed with paired infrastipular prickles, which are straight, stout, slightly ascending, 8-10 mm. long, flattened below; floral branches unarmed or with weak prickles; stipules densely glandular-muricate; petioles and rachis strongly glandular and more or less prickly; leaflets 5 or 7 , broadly oval or subrotund, rounded at the apex, glandular double-toothed, dark green on both sides, $1.5-3 \mathrm{~cm}$. (rarely 4 cm.) long; hypanthium subglobose, glabrous, in fruit $12-15 \mathrm{~mm}$. in diameter; sepals glandular-hispid on the back; petals obcordate, $2-2.5 \mathrm{~cm}$. long. Woods: B.C.-Mont.-Ore. Submont.

12. R. Spaldingii Crep. Stem erect, about $1 \mathrm{~m}$. high, usually armed with straight paired prickles, 5-10 mm. long; floral branches glabrous, somewhat prickly; stipules finely puberulent and somewhat glandular-toothed; petiole and rachis grayish-puberulent and sometimes slightly glandular; leaflets 5-7, oval or rounded, coarsely and usually regularly toothed, $1.5-5 \mathrm{~cm}$. long, pale and puberulent beneath; hypanthium glabrous; sepals glabrous or very rarely glandular on the back; petals rose-colored, $2-3 \mathrm{~cm}$. long; hypanthium in fruit globose, without neck, $12-18 \mathrm{~mm}$. thick. Woods: B.C.-Wyo-Utah-Ore. My-J.

13. R. Underwoodii Rydb. Stem 1-2 m. high, glabrous, armed with stout, recurved, paired infrastipular prickles (and also often with scattered ones) $5-10 \mathrm{~mm}$. long; stipules puberulent, glandular-dentate; petiole and rachis puberulent and with sessile glands; leaflets 5-7, obovate or oval, 2-4 cm. long, somewhat irregularly or doubly serrate, glabrous on both sides or finely puberulent and paler beneath; hypanthium more or less pear-shaped, sparingly bristly, in fruit about $2-3 \mathrm{~cm}$. long and $1.5-2 \mathrm{~cm}$. broad; sepals glandular and pubescent on 
the back; petals obcordate, about $2.5 \mathrm{~cm}$. long and fully as wide. Mountains: s Colo. Submont. Je.

14. R. Durandii Crep. Stem terete, armed with very stout prickles, which are about $1.5 \mathrm{~cm}$. long, very flat, curved, puberulent; branches pubescent and densely glandular-hispid; stipules copiously glandular on the back, densely glandular-eiliate; petiole and rachis unarmed, pubescent and very glandular; leaflets $5-9$, broadly oval, rounded at the base, acute at the apex, glabrous above, densely glandular-granuliferous beneath, double-toothed, with gland-tipped teeth; pedicels densely glandular; hypanthium smooth or slightly glandular at the base, globose, in fruit 12-15 mm. broad; sepals glandular on the back. Banks: Ore.-w Ida. Je.

15. R. melina Greene. Stem stout, about $1 \mathrm{~m}$. high, glabrous, armed with curved prickles, which are $3-8 \mathrm{~mm}$. long, flattened at the base; stipules glandulardenticulate on the margins, usually glandular-granuliferous on the back; petiole and rachis more or less glandular; leaflets mostly 7 , oval or obovate, coarsely serrate, $1.5-3 \mathrm{~cm}$. long, glabrous or essentially so on both sides; hypanthium glabrous, globose, in fruit about $12 \mathrm{~mm}$. thick; sepals sparingly glandular-hispid on the back; petals rose-colored, obcordate, $2-2.5 \mathrm{~cm}$. long. $R$. pandorana Greene. Mountains: Utah-Colo. Submont-Mont. Je-Jl.

16. R. aciculata Cockerell. Stem low, much branched, 1-3 dm. high, armed with curved prickles, which are $3-5 \mathrm{~mm}$. long and flattened at the base; branches less than $1 \mathrm{dm}$. long, usually armed; stipules densely glandular on the margins and the back; rachis and petiole copiously glandular; leaflets 5 or 7 or on the young shoots 9 , oval, acute or obtuse, $1-2 \mathrm{~cm}$. long, more or less doubleserrate, especially those of the young shoots, with ovate gland-tipped teeth; flowers solitary; pedicels glabrous or often more or less glandular-hispid; hypanthium globose, glabrous or glandular-hispid; sepals densely glandular-hispid; petals rose-colored or white, obcordate, about $2.5 \mathrm{~cm}$. long. Hillsides: Colo.se Utah. Mont. Jl-Au.

17. R. oreophila Rydb. Stem $2-3 \mathrm{~m}$. high, glabrous, mostly armed with weak curved prickles $5 \mathrm{~mm}$. long, or rarely unarmed; stipules finely puberulent and glandular-denticulate; rachis and petiole finely pubescent and with sessile glands; leaflets $5-7$, oval or ovate, $2-3.5 \mathrm{~cm}$. long, glabrous and dark green above, sparingly and finely pubescent and paler beneath, coarsely and simply serrate; flowers mostly solitary; hypanthium glabrous, obovate, usually acute at the base, without distinct neck, when ripe fully $2 \mathrm{~cm}$. long and 15-18 mm. broad; sepals finely pubescent on the back; petals obcordate, $2-2.5 \mathrm{~cm}$. long, rose-colored. R. Bakeri Rydb., not Desegl. Mountains: Colo.-Utah. Submont. J1.

18. R. neomexicana Cockerell. Stem $1-2 \mathrm{~m}$. high, terete, armed with usually paired infrastipular prickles, which are $5-10 \mathrm{~mm}$. long, more or less recurved; stipules glabrous or finely pubescent, somewhat glandular-dentate on the margins; rachis puberulent and sometimes glandular; leaflets $5-7$, obovate or on the young shoots elliptic, 1-3.5 $\mathrm{cm}$. long, puberulent or nearly glabrous, glandular-pruinose and rather pale beneath, with ovate teeth; hypanthium ellipsoid, tapering at the base, glabrous, purple, in fruit 8-10 mm. thick, $15 \mathrm{~mm}$. long; sepals glabrous without; petals $1.5-2 \mathrm{~cm}$. long, obcordate. Hillsides and cañons: Ariz.-N.M. - S Colo.-Utah. Son.-Submont. Je.

19. R. puberulenta Rydb. Stem 1-2 m. high, brown, terete, slender, armed with slender, slightly curved prickles about $5 \mathrm{~mm}$. long; young shoots bristly; stipules finely puberulent; petiole and rachis puberulent, unarmed; leaflets $5-7$ or on the new shoots sometimes 9 , broadly oval, light green, glabrous above, finely puberulent beneath, coarsely serrate, not glandular, $2-4 \mathrm{~cm}$. long; hypanthium glabrous, globose, in fruit $12-13 \mathrm{~mm}$. thiek; sepals puberulent on the back; petals about $2 \mathrm{~cm}$. long, rose-colored. Cañons and banks: Nev.Utah-Ida. Son.-Mont. Je-Au.

20. R. manca Greene. Stem low, $2-10 \mathrm{dm}$. high, terete, armed with rather few curved prickles $3-5 \mathrm{~mm}$. long and flattened at the base; stipules glandulardenticulate; petiole and rachis more or less glandular; leaflets mostly 7 , rarely $2 \mathrm{~cm}$. long, oval or obovate, thin, more or less double-toothed, with gland-tipped 
teeth, glabrous on both sides; flowers solitary; hypanthium glabrous, globose, in fruit about $1 \mathrm{~cm}$. thick; sepals glabrous or sparingly glandular; petals rosecolored, 1.5-2 cm. long. Cañons: Colo.-e Utah-Ariz. Submont.-Mont. $\mathrm{Je}-\mathrm{Au}$.

21. R. Fendleri Crep. Stem low, $1 \mathrm{~m}$. high or less, terete, armed with a few prickles, which are straight, slender, $5 \mathrm{~mm}$. long or less; stipules glandularpruinose on the back, more or less glandular-dentate; rachis and petiole densely glandular-puberulent and often somewhat glandular-hispid or with weak prickles; leaflets 5-7, elliptic, oval, or obovate, 1-3 cm. long, rather thin, green and glabrous above, slightly paler, puberulent and glandular-pruinose beneath, often double-serrate; hypanthium globose, glabrous, in fruit $8-10 \mathrm{~mm}$. broad; sepals sparingly glandular on the back; petals rose-colored, obcordate, about $1.5 \mathrm{~cm}$. long, Woods and copses: N.M.-Ariz.-S.D.-Mont. Plain-Submont. My-
Jl.

R. Bourgeauiana $\times$ Fendleri. This resembles $R$. Fendleri in habit, the corymbose inflorescence and the small flowers and fruit, but the plant is much more prickly, the

22. R. chrysocarpa Rydb. Stem tall, 1-3 m. high, terete, at first lightyellowish green, armed with straight prickles, somewhat retrorse, terete, $3-7$ $\mathrm{mm}$. long, some of them infrastipular, others scattered; young shoots copiously armed with bristle-like prickles; stipules glandular-dentate or ciliate; petiole and rachis glabrous, sometimes with a few prickles; leaflets 5-7, elliptic or oval, thin, glabrous on both sides, yellowish green, coarsely serrate throughout, 1-4 $\mathrm{cm}$. long; hypanthium globose, at first glabrous, light green, in fruit about $1 \mathrm{~cm}$. thick and orange; sepals glabrous or nearly so on the back. Cañons: Utah-
Ida. Son.-Submont. Je.

23. R. Woodsii Lindl. Stem terete, glabrous, $0.5-2 \mathrm{~m}$. high, armed with rather numerous, straight or slightly curved prickles, $4-8 \mathrm{~mm}$. long; stipules glabrous, usually glandless, entire or somewhat toothed; rachis and petiole glabrous, occasionally with a few prickles or stalked glands; leaflets 5 -7, obovate, cuneate at the base, serrate above, glabrous on both sides, glaucous beneath, $1-2 \mathrm{~cm}$., rarely $3 \mathrm{~cm}$. long; hypanthium globose, glabrous, in fruit $8-10 \mathrm{~mm}$. thick; sepals glabrous or slightly glandular on the back. R. Macounii Rydb. (Fl. Colo.), not Greene. R. Sandbergii, and (?) R. fimbriatula Greene. R. deserta Lunell. River banks and copses: Sask.-N.D.-Kans.-Colo.-Utah-B.C.

24. R. salictorum Rydb. Stem 3-5 m. high, unarmed or nearly so, except the new shoots; infrastipular prickles if present small and straight; stipules more or less toothed, finely puberulent; leaflets $5-7$, broadly oval, coarsely and evenly serrate, glabrous above, finely puberulent beneath, $2-4 \mathrm{~cm}$. long; hypanthium glabrous, globose, in fruit about $1 \mathrm{~cm}$. broad; sepals glabrous on the back; petals pink, about $15 \mathrm{~mm}$. long. Among willows: Nev.-Ida.-(? Utah.) Jl.

25. R. ultramontana (S. Wats.) Heller. Stem tall, 1-3 m. high, rarely $5 \mathrm{~m}$. high, terete, armed with straight prickles, $5-7 \mathrm{~mm}$. long; stipules puberulent and often pruinose on the back, usually denticulate; leaflets usually 7 , oval, usually rounded at both ends, serrate, with broad teeth, $2-4 \mathrm{~cm}$. long, green and dull on both sides, rather firm, glabrous above, puberulent and often also pruinose beneath; hypanthium globose, glabrous, in fruit $8-10 \mathrm{~mm}$. thick; sepals glabrous or slightly puberulent on the back (in the related $R$. pisocarpa of the Pacific Coast glandular on the back); petals obcordate, $1.5 \mathrm{~cm}$. long or a little more. R. californica ultramontana S. Wats. Woods and copses: Ore--Mont.

26. R. praetincta Cockerell. Stem about $1.5 \mathrm{~m}$. high, armed with numerous often bristle-like prickles, which are terete, $5-8 \mathrm{~mm}$. long; stipules slightly puberulent or glabrate, often more or less toothed; rachis and petiole finely puberulent, thin, 1-3 cm. long, sharply serrate, with leaflets obovate or rarely oval, very glabrous above, finely puberulent on the veins thium glabrous, globose; sepals glabrous on the and pruinose beneath; hypanthium glabrous, globose; sepals glabrous on the back; petals about $2 \mathrm{~cm}$. long, 
broadly obcordate. R. aciculata Rydb. (Fl. Colo.), not Cockerell. Banks and copses: N.M.-Colo. Son.-Submont. Je.

27. R. Macounii Greene. Stem $0.5-2 \mathrm{~m}$. high, usually armed with straight terete prickles, $5-8 \mathrm{~mm}$. long; new shoots bristly; stipules entire or glandulardenticulate, puberulent on the back; rachis and petiole finely puberulent, unarmed; leaflets obovate, serrate, $1-3 \mathrm{~cm}$. long, green and glabrous above, pale or glaucous, finely puberulent ano sometimes pruinose beneath; hypanthium globose, without a neck, glabrous, 8-10 mm. thick; sepals glabrous or sparingly pubescent on the back; petals about $2 \mathrm{~cm}$. long, obcordate, rose-colored. $R$. Woodsii S. Wats., not Lindl. R. grosseserrata E. Nels. R. Maximiliani Rydb., not Nees. Banks and copses: Sask.-Neb.-w Tex.-N.M.-Utah-e Wash. Plain-Submont. My-Jl.

R. Bourgeauiana $\times$ Macounii. This resembles $R$. Macounii in habit and flowers, but the young shoots are exceedingly bristly and the leaflets, especially those of the shoots. are very broad and rounded, with broad occasionally double teeth, and slightly glandular-

28. R. pyrifera Rydb. Stem $1 \mathrm{~m}$. high or more, armed with slender, straight prickles $5-8 \mathrm{~mm}$. long; stipules finely puber slent and usually glandular-granuilferous on the back; petiole and rachis puberulent and often glandular; leaflets about 7, oval, 2-4 cm. long, coarsely serrate, dark green and glabrous above, finely puberulent and more or less glandular-granuliferous beneath; hypanthium pyriform or ellipsoid, acute at the base, with a distinct neck at the apex, in fruit $10-12 \mathrm{~mm}$. thick and $15-20 \mathrm{~mm}$. long; sepals glandular on the back; petals obcordate, about $2 \mathrm{~cm}$. long. Banks: Mont.-Wyo.-Utah-Calif.-Wash. Submont. Je-Jl.

29. R. gymnocarpa Nutt. Stem slender, 1-3 m. high, terete, often very bristly and with infrastipular prickles, which are very slender, terete, sometimes not larger than the scattered bristles, sometimes $1 \mathrm{~cm}$. long; stipules glabrous on the back, glandular-ciliate and dentate on the margin; rachis and petiole usually glandular-hispid; leaflets $5-7$ (rarely 9), from suborbicular to elliptic, 1-3.5 $\mathrm{cm}$. long, thin, shining above, dull beneath, glabrous on both sides, doubleserrate, with gland-tipped teeth; flowers usually solitary; hypanthium ellipsoid, in fruit 7-9 mm. thick, $8-10 \mathrm{~mm}$. long; sepals 5-8 mm., sometimes $10 \mathrm{~mm}$. long, purplish, glabrous on the back; petals $10-18 \mathrm{~mm}$. long, obcordate. Woods: B.C.-Mont.-Ida.-Calif. Son.-Submont. My-J.

30. R. leucopsis Greene. Closely related and scarcely distinct from $R$. gymnocarpa. Stem $1 \mathrm{~m}$. high or more, sparingly bristly, with ascending bristles; stipules glandular-ciliate and glandular on the back; petiole and rachis glandularhispid; leaflets oval or obovate, deeply double-serrate, with gland-tipped teeth, glabrous on both sides, pale; flowers solitary; hypanthium glabrous, ellipsoid, becoming globose or pear-shaped in fruit, $4-6 \mathrm{~mm}$. thick; sepals glabrous on the back; petals obcordate, $10-12 \mathrm{~mm}$. long. Woods and copses: Ore.-Ida.Mont.-B.C. Submont. My-Jl.

\section{Family 61. malaceae. Apple Family.}

Trees or shrubs, with simple or pinnate, alternate leaves, with stipules. Flowers perfect, regular. Hypanthium well developed, adnate to the ovary, becoming fleshy, and constituting a part of the fruit. Sepals and petals mostly 5. Stamens numerous, distinct, inserted on the margins of the receptacle. Gynoecium of 1-5 united carpels; cells of the ovary and styles as many, the latter distinct or partly united. Fruit a more or less fleshy pome.

Cells of the fruit by false partitions twice as many as the styles.

Flowers racemose; styles $3-5$, rarely 2 .
Flowers solitary or in 2- or 3-flowered corymbs; styles 2.

Cells of the fruit as many as the styles.

Leaves pinnately compound; carpels leathery at maturity.
Leaves simple, more or less pinnately lobed; carpels bony at maturity

1. AMELANCHIER.

2. Peraphyllum.

3. SORBUS.

4. Crataegus. 


\section{AMelánChier Medic. Service-berry, June-berry, Shadberry.}

Shrubs or small trees. Leaves alternate, simple, petioled, toothed or entiremargined. Flowers in ours racemose. Hypanthium campanulate, becoming globose, adnate to the ovary. Sepals 5, reflexed, persistent. Petals 5, white. Stamens many; filaments subulate. Styles 3-5, rarely less. Ovary inferior or nearly so, the cells becoming twice as many as the styles, by false partitions intruding from the back. Ovules solitary in each cell, erect. Pome berry-like, 6-10-celled.

Top of the ovary, winter buds, and leaves glabrous from the beginning; fruit juicy; styles mostly 5 .

Sepals mostly sparingly hairy within.

Petals oblanceolate, $18-20 \mathrm{~mm}$. long; leaves thin, green.

Petals oblong, 10-15 mm. long; leaves firmer, pallid.

Sepals perfectly glabrous on both sides; petals $10-12 \mathrm{~mm}$. long.

Leaves green; styles 5 , all united; twigs brown.

Leaves moderately toothed; lower one-third of the blade entire; teeth rarely over $2 \mathrm{~mm}$. long.

Leaves coarsely toothed to near the base; teeth 3-4 mm. long.

1. A. Cusickii.

2. A. basalticola.

Leaves bluish-green; styles 4 , two and two united; twigs gray.

4. A. pumila.

11. A, Jonesiana,

Top of the ovary and usually the winter buds pubescent; leaves hairy beneath, at least when young.

Fruit glabrous, in age purple, juicy; styles mostly 5 , rarely 4 .

Leaves glabrous above, white-tomentose but soon glabrate beneath.

Leaves mostly acute at the apex, toothed to near the base.

Leaf-blades elliptic, finely toothed, short-acuminate.

Leaf-blades oval, coarsely toothed, acute or obtuse.

5. A. canadensis.

Leaves truncte 6. humilis.

Leaf-blades thin, usually oval.

Leaf-blades firm, usually suborbicular.

Leaves more or less permanently pubescent on both sides, more or less pale.

Leaves neither coarsely toothed nor strongly veined. 9. A. oreophila.

Leaves coarsely toothed and strongly veined. 10. A. mormonica. Fruit even in age more or less pubescent, orange or yellow, not juicy; styles mostly
3 or 2 .

Leaves coarsely toothed; branches gray.

Leaf-blades suborbicular, truncate at the apex. Leaves dentate; teeth acute.

Leaves crenate, teeth broad, rounder.

Leaf-blades oval, acute to rounded at the apex.

Leaves finely toothed; branches brown or cherry-red.

12. A. Bakeri.

13. A. crenata.

14. A. utahensis.

15. A. prunifolia.

1. A. Cusickii Fernald. A shrub $2-6 \mathrm{~m}$. high, with smooth reddish bark; leaves about $3 \mathrm{~cm}$. long, ovate-oblong, rounded at the apex, or the smaller acutish, serrate, with rather coarse teeth, to near the base; racemes about 6-flowered; sepals lanceolate, acuminate; fruit about $1 \mathrm{~cm}$., scarlet, tardily turning black. Stony hillsides: B.C.-Mont.-(? Utah)-Ore. Submont. Ap-Je.

2. A. basalticola Piper. A small shrub, with grayish bark; leaves orbicular or oval, mostly truncate at both ends, usually coarsely serrate only above the middle, 1.5-2 cm. long; racemes short, few-flowered; sepals lanceolate, attenuate; stamens 20; fruit 8-9 mm., dark purple. Bluffs and copses: Wash.-Ida. Son. Ap-Jl.

3. A. polycarpa Greene. A shrub 1-3 m. high or according to original description a small tree, with reddish bark; leaves broadly oval, $2-4 \mathrm{~cm}$. long, deep green above, pale beneath; racemes short; sepals triangular-lanceolate, acuminate; fruit depressed, globose, 8-9 mm. broad, dark purple, juicy. Hills and table lands: Wyo.-N.M.-Utah. Submont.-Son. My-Jl.

4. A. pumila Nutt. A low shrub, 0.5-1 m. high, with depressed branches and dark brown twigs; leaves glabrous, broadly oval, rounded at both ends, rather thin, 2-5 cm. long; racemes few-flowered; sepals narrowly lanceolate, attenuate; petals oblong, about $1 \mathrm{~cm}$. long; fruit purple, about $7 \mathrm{~mm}$. thick. Mountains: Wyo.-Utah-Colo. Submont. Je-Jl.

5. A. canadensis (L.) Medic. A bushy tree, 5-10 m. high, or sometimes a tall shrub; leaves rounded or cordate at base, usually acuminate, sharply and finely serrate, white-tomentose when young, glabrate in age; racemes $3-5 \mathrm{~cm}$. long; sepals broadly oblong-lanceolate, abruptly pointed, tomentose; petals 
oblong, 10-14 mm. long; fruit purple, not very juicy. Copses: Me.-S.C.Ark.-Minn.-Alta. Boreal-Mont.

6. A. humilis Wieg. A stoloniferous shrub, $0.5-1.5 \mathrm{~m}$. high, with grayish brown twigs; leaves oval-oblong or oval, $2.5-5 \mathrm{~cm}$. long, subcordate or rounded at the base, green above, tomentose when young beneath, becoming glabrate and glaucous; racemes 4-5 cm. long; sepals triangular-lanceolate; petals obovateoblong, 7-10 mm. long; fruit almost black, glaucous, juicy. Banks and hills: Vt.-Neb.-Alta.-(? Mack.) Plain-Mont. Je.

7. A. florida Lindl. A shrub or low tree, $2-5 \mathrm{~m}$. high, not stoloniferous, with grayish or brownish twigs; leaves elliptic or oval, glabrous above, floccose beneath when young, but soon glabrate, $2-4 \mathrm{~cm}$. long; racemes $4-8 \mathrm{~cm}$. long; sepals lanceolate, acute; petals $12-15 \mathrm{~mm}$. long, oblanceolate; fruit juicy, purple, with a bloom, $1 \mathrm{~cm}$. broad. A. elliptica A. Nels. River banks and hillsides: B.C.-Alta.-Colo.-Calif. Submont. Ap-Je.

8. A. alnifolia Nutt. A low shrub, 1-2 m. high, with dark gray twigs; leaves suborbicular or round-oval, $2-5 \mathrm{~cm}$. long, glabrous above, somewhat tomentose beneath; raceme 2-4 $\mathrm{cm}$. long; sepals lanceolate; petals oblanceolateoblong, about $1 \mathrm{~cm}$. long; fruit purple, juicy, with a bloom, 8-9 mm. thick. Banks and hills: Sask.-Neb.-Colo.-Ida.-Yukon; Mich. Plain-Mont. My-Jl.

9. A. oreophila A. Nels. A low, branched shrub, 1-2 m. high, growing in clumps; leaves broadly oval, or obovate, $2-4 \mathrm{~cm}$. long, rounded at the apex; racemes short and dense; sepals narrowly lanceolate; petals oblanceolate or spatulate, about $8 \mathrm{~mm}$. long; fruit globose, purplish black, little juicy. Open stony slopes: Mont.-N.M.-Nev. Submont.-Mont. My-Je.

10. A. mormonica C. K. Schneider. A low shrub; leaves rounded-oval, rounded at both ends, $2-3.5 \mathrm{~cm}$. long, coarsely dentate, dark green above, grayish green beneath; racemes few-flowered; sepals lanceolate; petals oblong-lanceolate, about $1 \mathrm{~cm}$. long; fruit globose, slightly juicy; styles 4 or 5 . Hillsides: Ariz.-Wyo.-N.M. Son.-Submont. My-Je.

11. A. Jonesiana C. K. Schneider. A low shrub; leaves rounded-oval, truncate at the apex, irregularly dentate from below the middle to the apex, about $2 \mathrm{~cm}$. long; racemes short, few-flowered; sepals elongate-lanceolate, acuminate; petals ovate-oblong, about $11 \mathrm{~mm}$. long; stamens 8-10. Cañons: Utah-Ariz. (acc. to Schneider). Submont. My.

12. A. Bakeri Greene. A shrub, divaricately branched, with reddish puberulent bark; leaf-blades orbicular, $1.5-2 \mathrm{~cm}$. long, coarsely toothed, except the entire subcordate base, finely tomentulose; racemes $2-3 \mathrm{~cm}$. long; sepals lanceolate, villous on both sides; petals $7-8 \mathrm{~mm}$. long, elliptic; fruit orange, not juicy. A. Purpusi Koehne. Hills: Colo,-N.M. Submont.-Mont. My.

13. A. crenata Greene. A low shrub, divaricately branched; leaf-blades suborbicular or broadly oval, $1.5-2.5 \mathrm{em}$. long and nearly as broad, crenate except at the base, tomentulose on both sides, paler beneath; racemes very short; sepals lanceolate, villous; petals $6-7 \mathrm{~mm}$. long, oblanceolate; fruit unknown. Rocks: N.M.-(? Ariz.)-se Utah-s Colo. Son. Ap.

14. A. utahensis Koehne. A shrub $0.5-5 \mathrm{~m}$. high, with gray or brown twigs; leaves elliptic or oval, 1-3 cm. (rarely $3.5 \mathrm{~cm}$.) long, finely tomentulose, coarsely serrate; racemes $2-3 \mathrm{~cm}$. long; sepals narrowly lanceolate, villous on both sides; petals elliptic, about $7 \mathrm{~mm}$. long; fruit puberulent, yellow or orange, not juicy, $7-8 \mathrm{~mm}$. broad. Hills: Ida.-Colo.-N.M.-Ariz. Son,-Submont. My-Je.

15. A. prunifolia Greene. A shrub, 0.5-3 m. (according to Greene even $5 \mathrm{~m}$.) high, with brown, or on account of the pubescence grayish twigs, much branched; leaves $1-3 \mathrm{~cm}$. long, elliptic, ovate, or oval, or rarely obovate, finely crenate-serrate, thick, finely einereous on both sides; raceme $2-3 \mathrm{~cm}$. long; sepals narrowly lanceolate, villous on both sides; petals elliptic, $8 \mathrm{~mm}$. long; fruit puberulent when young, in age yellow or golden, not juicy, 6-7 mm. broad. A. rubescens Greene. Hills and arroyos: Colo.-Utah-N.M. Submont.-Mont. Ap-Je. 


\section{PeraphÝllium Nutt. Squaw Apple, Wild Crab,}

Low shrub, with gray branches. Leaves alternate, but crowded at the ends of the branches, serrulate or entire, simple. Flowers perfect, regular, solitary or 2 or 3 together. Hypanthium subglobose, adnate to the ovary. Sepals 5, persistent. Petals 5, broad. Ovary of 2 earpels, but 4-celled by false partitions intruded from the back. Pome fleshy, middle-sized, bitter; carpels cartilaginous. Stamens about 20.

1. P. ramosissimum Nutt. A low shrub, 1-2 m. high; leaves narrowly oblanceolate, obtuse or acute at the apex, acute at the base, $2-4 \mathrm{~cm}$. long, sparingly appressed-silky when young, coriaceous in age, sinuately crenate; teeth when young tipped with deciduous glands; sepals triangular, reflexed, pubescent within; petals orbicular, pale pink; fruit $15-18 \mathrm{~mm}$. thick, glabrous, exceedingly bitter. Dry hills: w Colo. - s Utah-n Calif.-Ore. Son.-Submont. My-Je.

\section{SÓRBUS L. Mountain Ash.}

Trees or shrubs. Leaves alternate, pinnate; leaflets several, more or less toothed; stipules deciduous. Flowers perfect, regular, in terminal compound cymes. Hypanthium urn-shaped. Sepals 5, erect or spreading, in ours deciduous. Petals white, spreading. Stamens many. Ovary inferior, adnate to the hypanthium; styles usually 3 , distinct; cells of the ovary as many, with 2 ovules each. Fruit small, berry-like, in ours red and very acid; carpels cartilaginous.

Leaflets acute or acuminate at the apex, serrate to near the base; inflorescence broad and flat-topped.

Leaflets linear-lanceolate, gradually acuminate, at least five times as long as broad.

Leaflets elliptic or oblong, abruptly acuminate or acute, 2-3 times as long as broad.

2. S. scopulina.

Leaflets mostly rounded at the apex, entire towards the base; inflorescence small, usually
round-topped.

1. S. angustifolia Rydb. A shrub $2-5 \mathrm{~m}$. high; young twigs and inflorescence sparingly pilose; leaflets usually 13 , acute at the base, gradually acuminate at the apex, 3-7 cm. long, 7-15 mm. broad, finely and sharply serrate throughout, glabrous, slightly paler beneath; inflorescence broad, flat-topped; sepals triangular, acute; petals white, orbicular; fruit red, ellipsoid. Pyrus sitchensis Piper, not Sorbus sitchensis Roemer. Mountain slopes: n Ida.-W Mont.-Wash. Submont. Jl.

2. S. scopulina Greene. A shrub 1-4 m. high; young twigs, petioles and inflorescence sparingly villous; leaflets 11-13, elliptic or elliptic-lanceolate, rounded at the base, abruptly acute or acuminate, $3-6 \mathrm{~cm}$. long, sharply and doubly serrate, glabrate, pale beneath; fruit red, subglobose, $7-8 \mathrm{~mm}$. broad. Pirus sambucifolia Porter, not Cham. \& Sehlecht. Hillsides and ravines: Alta.N.M.-Ariz.-Ore.-B.C. Submont.-Mont. Je-Jl.

3. S. occidentalis (S. Wats.) Greene. A shrub 1-3 m. high; young twigs, petioles, and inflorescence finely pubescent; leaflets 9-11, oblong, acutish at the base, rounded or obtuse at the apex, $3-5 \mathrm{~cm}$. long, paler beneath, rather evenly serrate above, entire towards the base; fruit red, ellipsoid, 7-8 $\mathrm{mm}$. long, 6-7 $\mathrm{mm}$. broad. (?) S. sitchensis Roemer. Hills: Yukon-Mont.-Ore-Alaska. Submont.-Mont. Je-Au.

\section{CRataggus L.* Haw or Hawthorn.}

Small trees or shrubs, usually armed with thorns or spines. Leaves alternate, petioled, simple, toothed and usually more or less lobed. Flowers in terminal clusters, cymose or corymbose. Hypanthium cup-shaped or campanulate, adnate to the ovary. Sepals 5, reflexed after anthesis. Petals 5, white or pink, spreading, rounded. Stamen 5-25, inserted on the margin of the hypanthium; filaments slender, incurved. Ovary inferior, of 1-5 carpels; styles 1-5, distinct. Pome globose, pear-shaped, or ellipsoid, yellow, red, blue, or black, containing $1-5$, bony and 1 -seeded carpels.

* With the assistance of Mr. W. W. Eggleston. 
Fruit black or nearly so when ripe; nutlets irregularly pitted on the faces; leaves glabrate beneath, more or less pubescent above.

Inflorescence glabrous; spines mostly slender.

Leaf-blades narrow, rhombic-oblanceolate or elliptic, scarcely lobed.

Leaf-blades crenate; fruit $7-8 \mathrm{~mm}$. in diameter; nutlets 5. 1. C. saligna.

Leaf-blades irr egularly serrate; fruit 8-10 mm. in diameter; nutlets usually 4.

Leaf-blades broad, rhombic, lobed and incised.

2. C. rivularis.

nflorescence pubescent; spines short and stout; leaf-blades broad, ovate or obovate, somewhat lobed above the middle.

Fruit red or red-purple; leaves pubescent beneath, at least on the veins.

Teeth of the leaves not glandular; nutlets deeply pitted on the faces.

Teeth of the leaves glandular; nutlets not pitted.

Leaf-blades suborbicular.

5. C. succulenta.

Leaf-blades ovate, oval or obovate, more or less cuneate at the base.

Leaf-blades mostly $5-9 \mathrm{~cm}$. long, with shallow, acute lobes. 7. C. Williamsii.

Leaf-blades $2-6 \mathrm{~cm}$. long, with deep, often acuminate lobes.

8. C. columbiana.

1. C. saligna Greene. A tree $3-6 \mathrm{~m}$. high, with spreading branches; spines 5-25 mm. long; leaf-blades thick, rhombic-oblanceolate, $1.5-5 \mathrm{~cm}$. long, those of the floral branches usually obtuse, those of the shoots acute or acuminate, crenate, with short gland-teeth, paler beneath; sepals triangular, glabrous; anthers 20, yellow; fruit blue-black. $C$. Wheeleri A. Nels. River banks: Colo. Submont. $\mathrm{My}-\mathrm{Je}$, fruit Au.

2. C. rivularis Nutt. A tree $3-6 \mathrm{~m}$. high, with ascending branches; spines slender, 1.5-4 cm. long; leaves lanceolate, rhombic-lanceolate or elliptic, 2.5-8 $\mathrm{cm}$. long, cuneate at the base, acuminate to obtuse at the apex, slightly doubletoothed, paler beneath; sepals lanceolate, long-pointed, remotely glandulartoothed; anthers 20, yellow; fruit dark crimson, becoming black. $C$. Wheeleri Rydb., not A. Nels. C. tennowana A. Nels., a form with short spines. Valleys: Wyo.-Colo.-Nev.-Ida. Submont. My-Je.

3. C. erythropoda Ashe. A small tree, 2-5 m. high, widely branched; spines rather stout, $2-3 \mathrm{~cm}$. long, morocco red; leaf-blades broadly oval or rhombic, $3-5 \mathrm{~cm}$. long, coarsely glandular-serrate, acute or acuminate; sepals with a broad gland-margined acumination; stamens 1-8; anthers purple; styles 5; fruit dark cherry red, becoming black or dark brown. C. cerronis A. Nels. Banks: Wyo. Submont. My-Je.

4. C. Douglasii Lindl. A tree 5-12 m. high, with ascending branches; spines red, stout, $1-3 \mathrm{~cm}$. long; leaf-blades ovate or obovate to broadly oval, 2-7 cm. long, short-acuminate, doubly-toothed and somewhat lobed above; sepals acuminate, long-hairy above; anthers 10-20, light yellow; fruit black. C. brevispina (Dougl.) Farwell. River banks: B.C.-Mich.-Wyo.-Calif. -N.M. Submont. My-Je.

5. C. succulenta Schrad. A small tree, 4-7.5 m. high, with ascending branches; branches glabrous or hairy; spines numerous, $3-10 \mathrm{~cm}$. long; leaves rhombic-ovate to obovate, $3-9 \mathrm{~cm}$. long, acute at the apex, broadly cuneate at base, doubly serrate, dark green and shining above; corymb slightly villous; sepals lanceolate, acuminate, glandular-laciniate, villous; stamens $10-20$; anthers pink, rarely yellow or white; fruit dark red, villous, about $1 \mathrm{~cm}$. thick. $C$. macrantha (Lindl.) Lodd. C. occidentalis Britton. C. coloradensis A. Nels. $C$. Colorado Ashe and $C$. coloradoides Ramaley, the variety with hairy twigs. Hillsides and eañons: N.S.-N.C.-Colo.-Sask. Plain-Submont. My-Je.

6. C. chrysocarpa Ashe. A round-topped shrub or tree, 2-7 m. high; spines $2-7 \mathrm{~cm}$. long, numerous; leaves orbicular or rounded-obovate, $3-5 \mathrm{~cm}$. long, acute at the apex, broadly cuneate at the base, with 3 or 4 pairs of triangular lobes and doubly serrate; sepals lanceolate, acuminate, glandular-margined; stamens 5-10; fruit depressed-globose, about $1 \mathrm{~cm}$. thick, red. Crataegus rotundifolia (Ehrh.) Borckh., not Lam. C. Sheridana A. Nels. C. Doddsii Ramaley, a form with glandular petioles and dark fruit. Cañons and banks: N.B.-N.C. -N.M.-Wyo.-Sask. Plain-Submont. My, fr. Au-S.

7. C. Williamsii Eggleston. A round-topped shrub or tree, $4 \mathrm{~m}$. high; spines $3-6 \mathrm{~cm}$. long; leaf-blades ovate or oval, 4-9 $\mathrm{cm}$. long, acute or rarely 
acuminate at the apex, euneate at the base, with 2-4 shallow lobes towards the apex, serrate, with gland-tipped teeth, slightly pubescent above and at the junctions of the veins beneath; corymb pilose; sepals pubescent within, ovate, acuminate, sometimes with stalked glands; stamens 10 ; styles 3 or 4 ; fruit globose, $8-10 \mathrm{~mm}$. thick, red, slightly pubescent. Banks: nw Mont. Submont. $\mathrm{My}-\mathrm{Jl}$.

8. C. columbiana Howell. A shrub or small tree, much branched; leaves rather thin, obovate or ovate, 2-6 $\mathrm{cm}$. long, cuneate at the base, with 3 or 4 pairs of sharp lobes, sharply and doubly toothed, sparingly long-hairy, especially along the veins; corymb sparingly long-hairy; sepals triangular, long-pointed, slightly long-hairy within, glandular-toothed; stamens about 10 ; fruit pearshaped or ellipsoid, 8-12 mm. long, scarlet. C. Piperi Britton, a form with hairy corymb and fruit. River banks: B.C.-N.D.-Ida.-Ore. Submont.

\section{Famlly 62. AMYgdalaceae. Plum Family.}

Trees or shrubs, with alternate simple leaves and deciduous stipules. Flowers perfect, in ours regular. Hypanthium well developed, mostly cupshaped, with an angular disk at the mouth bearing the stamens. Sepals and petals 5. Stamens in ours 10 or more. Pistils usually solitary. Fruit a drupe.

Drupe with pulpy exocarp; leaves not fascicled.

Drupe with almost dry exocarp, pubescent; leaves fascicled.
1. PRUNUS.

2. EMPLECTOCLADUS.

\section{PRÙnUS L. Plums, Cherries.}

Shrubs or trees. Leaves alternate, deciduous, usually toothed. Flowers perfect, either solitary, umbellate or corymbose from scaly buds, or corymbose or racemose at the ends of leafy branches. Hypanthium in ours campanulate or turbinate. Sepals 5, imbricate. Petals 5, imbricate, inserted with the stamens on a disc in the throat of the hypanthium. Stamens 15-30; filaments filiform, distinet. Drupe, with a fleshy exocarp, often with a bloom; stone bony, smooth.

Flowers few, umbellate or corymbose.

Fruit with a ventral groove and flat stone. (PLUMS.)

Leaves oval or orbicular, rounded at the apex.

Leaves lanceolate to obovate, acute or acuminate.

Trees or shrubs, usually spiny; leaves serrate to near the base.

Low undershrub, unarmed; leaves entire at the base. Fruit without a ventral groove; stone subglobose. (CHERries.)
Creeping shrub; flowers umbellate.

Erect shrubs or trees.

Hypanthium decidedly obconic; flowers umbellate from naked lateral buds.

Hypanthium campanulate or turbinate; flowers more or less corymbose.
5. . ignota.

Leaves acute, serrate. Corymbs naked.

Corymb usually subtended by 1 or 2 leaves.

Leaves obtuse or rounded at the apex, crenulate. Leaves glabrous. Leaves pubescent.

Flowers many, racemose on leafy branches.

(ChOKe Cherries.)

2. $P$. americana.

3. P. prunella.

4. P. Besseyi.

6. P. pennsylvanica.

7. P. corymbulosa.

8. $P$. emarginata.

9. P. prunifolia.

Leaves more or less pubescent beneath.

Peduncles stout; pedicels pubescent, shorter than the fruit, deciduous; leaves thick.

Peduncles slender; pedicels glabrous, $10, P$, valida. glabrous, longer than the fruit, persistent; leaves Leaves glabrous on both sides.

11. $P$. demissa.

12. $P$. melanocarpa.

1. P. subcordata Benth. Tree up to $8 \mathrm{~m}$. high, with stout spreading branches, finely pubescent, becoming glabrous; leaves oval to orbicular, $2.5-7$ $\mathrm{cm}$. long, finely double-toothed, pale beneath; sepals entire, rounded; fruit 2-3. $\mathrm{cm}$. long, dark red or yellow. Rocky hills: Ore,-Ida.-Calif. Submont. $\mathrm{Mr}-\mathrm{My}$. 
2. P. americana Marsh. Tree $5-11 \mathrm{~m}$. high, or rarely a shrub $1-5 \mathrm{~m}$., more or less spiny, with glabrous twigs; leaves firm, lanceolate, elliptic, or obovate, 4-10 $\mathrm{cm}$. long, acute or rounded at the base, acuminate at the apex, sharply toothed, glabrous, or somewhat hairy along the veins beneath; fruit subglobose or round-ellipsoid, $2-2.5 \mathrm{~cm}$. long, orange, bright red, or purplish. Along rivers and in thickets: N.Y.-Fla.-Tex.-Colo.-Mont. Plain-Submont. Mr-My.

3. P. prunella Daniels. Undershrub, thornless, trailing or ascending, 3-6 $\mathrm{dm}$. high; twigs reddish; leaves lanceolate, $3-5 \mathrm{~cm}$. long, sharply serrate, except the entire acuminate base, glossy green above, paler beneath; fruit ellipsoid, $1.3-1.5 \mathrm{~cm}$. long and $1 \mathrm{~cm}$. thick, black-purple, with a slight bloom. Table land: Colo. Submont.

4. P. Besseyi Bailey. Shrub, with spreading or prostrate branches, $0.5-1.5$ $\mathrm{m}$. long; leaves oblanceolate or elliptic, cuneate at the base, acute at the apex, serrate; flowers in sessile umbels, opening with the leaves; fruit $12-16 \mathrm{~mm}$. in diameter, globose, black, often mottled, somewhat astringent. Sand hills: Man. -Minn.-Kans.-Colo.-Wyo. Plain. My-Je.

5. P. ignota A. Nels. "Shrubby or possibly becoming tree-like; branches slender, none of them becoming indurated or thorny; leaves glabrous from the first, simply and sharply serrate; flowers white [or pinkish], appearing with or after the leaves, solitary or 2 or 3 in a cluster; ealyx [hypanthium] turbinate; lobes entire, glabrous within and nearly so without; petals obovate." [Perhaps one of the cultivated Japanese cherries, escaped, but species not identified.] Banks: Colo. Plain. My.

6. P. pennsylvanica L. f. A small tree, or shrub, sometimes $12 \mathrm{~m}$. high; leaves oval to lanceolate, acute or acuminate at the apex, rounded or acute at the base, glabrous and shining on both sides, serrulate; inflorescence corymbose, leafless, peduncled or sessile, unfolding with the leaves; fruit globose, red, 4-6 $\mathrm{mm}$, in diameter, sour. Rocky woods and along streams: Newf.-Ga.-Colo.N.D. Plain-Submont. Ap-Je.

7. P. corymbulosa Rydb. A small shrub, 1-2 m. high; leaves glabrous and shining, 4-6 cm. long, ovate-lanceolate, acute or acuminate, finely serrulate; corymbs 3-6-flowered, peduncled, usually subtended by 1 or 2 small leaves; sepals erose; petals more or less pubescent; fruit globose, red. Cerasus trichopetala Greene. Hills: Mont.-Wyo. Submont. My-Je.

8. P. emarginata (Dougl.) Walp. A tree up to $8 \mathrm{~m}$. high, with glabrous, red, shining branches; leaves elliptic, obovate, or oblanceolate, $3-8 \mathrm{~cm}$. long, rounded or obtuse at the apex, erenate, with gland-tipped teeth, dark green above, paler beneath; sepals rounded at the apex, entire; petals obovate, greenish white; fruit 8-12 mm. in diameter, dark red or almost black to lemon-yellow. Cerasus padifolia Greene. Hillsides: B.C.-Ida,-Nev.-Calif. Submont. Ap-Je.

9. P. prunifolia (Greene) Shafer. A tree rarely $15 \mathrm{~m}$. high, with grayish brown branches, at first finely pubescent, in age glabrous; leaves elliptic or obovate, or rarely oval, 4-9 $\mathrm{cm}$. long, rounded or obtuse, or on vigorous shoots acute at the apex, crenate, with gland-tipped teeth, dark green above, paler and villous beneath; sepals blunt, villous; petals white, obovate; fruit $8-12 \mathrm{~mm}$. in diameter, bright red or purple. Cerasus mollis Dougl. C. prunifolia Greene. P. mollis Walp., not Torr. Hills and copses: B.C.-Ida.-Ariz.-Calif. Submont. Ap-Je.

10. P. valida (Woot. \& Standl.) Rydb. Tree $5-8 \mathrm{~m}$. high; branches stout, dark reddish brown, densely and finely pubescent when young; leaf-blades obovate, oval, or elliptic, 5-7 $\mathrm{cm}$. long, rounded or subcordate at base, green and glabrous above, glaucescent and pubescent beneath, serrulate with inflexed teeth; peduncle stout, pubescent, often recurved above; fruit black, 10-12 $\mathrm{mm}$. thick. Padus valida Woot. \& Standl. Cañons: N.M.--se Utah. Submont. Je.

11. P. demissa (Nutt.) Walp. Tree up to $15 \mathrm{~m}$. high; twigs densely pubescent when young; leaves obovate or oblong-obovate, $5-10 \mathrm{~cm}$. long, rounded or subcordate at the base, sharply toothed, paler and pubescent at least on the veins beneath; peduncles $7-10 \mathrm{~cm}$. long, more or less pubescent; petals about 5 
$\mathrm{mm}$. long; fruit globose, $8-10 \mathrm{~mm}$. in diameter, purplish or red. Cerasus demissa Nutt. River banks: B.C.-Ida.-Calif.; apparently also Black Hills of S. D., but there a mere low shrub (f. Rydbergii Koehne). Submont. My-Je.

12. P. melanocarpa (A. Nels.) Rydb. Tree or shrub up to $10 \mathrm{~m}$. high; twigs reddish brown, glabrous; leaves obovate or oval, abruptly acuminate at the apex, mostly rounded at the base, rather firm, paler beneath, glabrous on both sides; peduneles slender, glabrous or rarely minutely puberulent, manyflowered; petals about $6 \mathrm{~mm}$. long; fruit dark purple or black, 6-8 mm. thick, sweet, slightly astringent, shorter than the pedicels. Cerasus demissa melanocarpa A. Nels. Hills and river banks: Alta.-N.D.-Kans.-N.M.-Calif. -B.C. Plain-Submont. My-Je.

\section{EMPLECTOCLĀDUS Torr. WiLd Almonds.}

Low shrubs, with divaricate, spinescent branches. Leaves fasciculate on short branchlets, entire. Flowers 1-3, in axillary umbels, perfect. Hypanthium campanulate, hairy within. Sepals and petals 5, imbricate. Stamens 10-15; filaments slender, distinct. Drupe pubescent, with rather dry exocarp, which splits on one side. Stone bony, flattened.

1. E. fasciculatus Torr: A shrub $0.5-1 \mathrm{~m}$. high, with divaricate branches, more or less spinescent; leaves fascicled on short branchlets, spatulate, nearly sessile, $5-10 \mathrm{~mm}$. long, finely puberulent or glabrate; flowers sessile or nearly so; petals linear-oblanceolate, white, $3 \mathrm{~mm}$. long; stamens 10-15; fruit subglobose, pubescent, about $1 \mathrm{~cm}$. long. Prunus fasciculata A. Gray. Amygdalus fasciculatus Greene. Desert regions: Calif. $\mathrm{s}$ Utah-Ariz. L. Son. Mr-Ap.

\section{Family 63. mimosaceae. Mimosa Family.}

Herbs, shrubs, or trees, usually with twice or thrice pinnately compound leaves, with stipules, the latter often modified into spines. Flowers mostly perfect, regular, in heads or spikes. Sepals $3-6$, partly united, valvate. Petals as many, valvate, distinct or partly united. Stamens of the same number, twice as many, or numerous. Pistil solitary, in fruit becoming a legume.

Legumes flat; valves not separating from the continuous margins.

Legumes 4-angled; valves separating from the continuous margins.

1. ACUAN.

2. Morongia.

\section{1. ĀCUan Medic. Prairie Mimosa,}

Perennial unarmed herbs, rarely somewhat shrubby. Leaves bipinnate, with numerous leaflets. Flowers in peduncled heads or head-like spikes, perfect or the lower ones staminate, sometimes without petals. Calyx 5-lobed. Petals 5 , distinct, or slightly united at the base. Stamens 5 or 10 , exserted; filaments distinct or nearly so. Ovules numerous. Pod elongate, unarmed. [Desmanthus
Willd.]

1. A. illinoensis (Michx.) Kuntze. Erect or ascending herb, 3-10 dm. high, glabrous or nearly so; leaves bipinnate, with $20-30$ pinnae; leaflets numerous, linear-oblong, $2.5-3.5 \mathrm{~mm}$. long; peduncles $2.5-8 \mathrm{~cm}$. long, longer than the pods; stamens 5; pods $4-6 \mathrm{~mm}$. wide, in compact heads, slightly spirally twisted. N.M.-S.D. Plain. My-Je.

\section{MORÓNGia Britton. Sensitrve Brier.}

Perennial herbs or shrubs, with spreading prickly stems. Leaves bipinnate, usually sensitive; leaflets numerous, usually small. Flowers perfect or polygamous, in axillary peduncled heads. Calyx 4 - or 5 -lobed. Petals 4 or 5 , united to about the middle. Stamens 8-10, exserted; filaments distinct or nearly so. Ovules numerous. Pod narrow, 4-angled, prickly all over, finally 4-valved, the valves separating from the margins. [Schrankia Willd., not Medie.] 
1. M. uncinata (Willd.) Britton. Herbs; stem $3-15 \mathrm{dm}$. long, armed with recurved prickles; leaves bipinnate; pinnae 6-12; leaflets numerous, oblong, 3-6 $\mathrm{mm}$. long, apiculate, prominently veined beneath; peduncles prickly; pod $3-15$ $\mathrm{cm}$. long, more or less densely prickly, beaked. Schrankia uncinata Willd. Prairies and dry soil: Va.-Fla.-Tex.-Colo. Plain. Je-S.

\section{Family 64. Caesalpiniaceae. Senna Family.}

Trees, shrubs or herbs. Leaves alternate, usually with stipules, simple or compound. Flowers mostly perfect, regular or irregular. Calyx of 5 , more or less united sepals. Petals usually 5, imbricate, the upper one enclosed by the lateral ones in the bud. Stamens 10 or fewer, filaments distinct or monadelphous. Ovary 1-celled. Fruit a 2-valved legume or indehiscent.

Leaves bipinnate; anthers opening lengthwise.

Leaves simply pinnate; anthers opening by terminal pores.
1. HofFmanseggia.

2. CHAMaEcrista.

\section{HOFFMANSÉGGIA Cav.}

Herbs, sometimes somewhat woody at the base. Leaves bipinnate; leaflets several to many, often glandular-punctate. Flowers perfect, racemose. Calyxlobes equalling or exceeding the tube. Petals 5, yellow or yellowish, imbricate. Stamens 10, slightly declined; filaments distinet, glandular at the base; anthers opening lengthwise. Pod flat, often more or less curved, few-seeded.

Leaves, flowers, and pods with black glandular dots; pod short, straight on the back or nearly so.

Leaves, flowers, and pods without glandular dots.

Pod about $7 \mathrm{~mm}$. wide, strongly arcuate.

Pod 12-14 mm. wide, straight or nearly so.

1. H. Jamesii.

2. H. depranocarpa.

1. H. Jamesii T. \& G. Herb, with fusiform root; stem branched at the woody base, 1-3.5 dm. high, finely pubescent and more or less glandular; leaves with 5-7 pinnae, each bearing 10-20 leaflets, which are oblong or oblong-ovate, 3-5 mm. long, obtuse; calyx-lobes oblong or linear-oblong, 7-9 mm. long; petals about $1 \mathrm{~cm}$. long, clawed; pod $2.25 \mathrm{~cm}$. long. Plains: Kans.-Tex.-Ariz.Colo. Son. My-Au.

2. H. depranocarpa A. Gray. Herb, perennial, with a thick root; stem branched, 1-2 dm. high, puberulent; leaves with 5-11 pinnae, each with 8-20 leaflets; these sub-falcate, nerveless, crowded; petals obovate, glandless, about $1 \mathrm{~cm}$. long; pod 3-4 cm. long, 9-10-seeded, glabrous or minutely puberulent. Plains: N.M.-Colo.-Ariz. Son. Je-Au.

3. H. repens (Eastw.) Cockerell. Perennial, with a woody rootstock, 1-1.5 dm. high, canescent; leaves with 5-7 pinnae, each with 4-6 leaflets, which are obovate, 5-7 mm. long, strigose; lower sepal oblanceolate, the rest lanceolate; petals obovate, short-clawed, 8-12 mm. long; filaments hairy below, but not glandular; pod flat, broad, oblong or elliptic, rarely suborbicular. Caesalpinia repens Eastw. Bluffs and washes: Utah. Son. My.

\section{Chamaecrísta Moench. Partridge Pea, Sensitive} Pea, Wild Sensitive Prant.

Herbs or shrubs. Leaves pinnate; rachis with 1 or 2 glands at the base. Flowers solitary or clustered, axillary or supra-axillary; pedicels twisted. Calyx 5-lobed. Corolla irregular; petals 5, one of the lateral ones (banner) and the lower one (one of the wings) larger than the rest. Stamens 10, all perfect or some of them redueed to staminodia; anthers unequal in size, opening by terminal pores, Pod linear, flat, dehiscent with elastic valves.

1. C. fasciculata (Michx.) Greene. Erect herb; stem glabrous, 3-6 dm. high, glabrous; leaflets $16-28$, oblong-elliptic, about $1.5 \mathrm{~cm}$. long, $3 \mathrm{~mm}$. wide; petiolar gland sessile; peduncles supra-axillary, 3-5-flowered; sepals lanceolate, fully equalling the petals; pods linear, pubescent, $5 \mathrm{~cm}$. long, $5 \mathrm{~mm}$. wide. Cassia chamaecrista Am. auth. Meadows: Me.-Fla.-Mex.-Colo.-Minn. Plain. $\mathrm{Je}-\mathrm{S}$. 


\section{Family 65 . Fabaceae. Pea Family.}

Herbs, shrubs, or trees, with alternate, mostly pinnately or palmately compound leaves with stipules. Flowers perfect, rarely polygamo-dioecious, irregular, zygomorphic. Calyx of 5 , or rarely 4 , more or less united sepals, or sometimes by the complete union of some of the sepals becoming 2-lipped. Corolla papilionaceous, $i$. e., consisting of 5 more or less united or distinct petals, of which the upper (banner or standard) is broader and surrounds the rest, the 2 lateral ones (wings) are curved upwards, and the 2 lowest (keel) more or less united, forming a boat-shaped organ. Stamens usually 10 , sometimes 9 or 5 ; filaments diadelphous ( 9 and 1 ), monadelphous, orrarely distinct. Pistil 1, superior. Fruit a 2-valved or indehiscent legume, 1-celled or by the intrusion of the sutures 2 -celled, or a loment, $i$. e., divided by false cross-partitions into several cells.

Filaments distinct.

Leaves pinnate.

Leaves digitately 3-foliolate.

Tribe I. SOPHOREAF.

Filaments monadelphous or diadelphous.

Tribe II. PODALYRIEAE.

Rachis of the leaves not produced into a tendril or bristle-like appendage, representing the terminal leaflet.

Fruit 2-valved or indehiscent, not a loment.

Foliage not glandular-dotted.

Anthers of 2 kinds; fllaments monadelphous; leaves digitate; calyx 2lipped. Tribe III. GENISTEAE.

Anthers all alike; filaments diadelphous; calyx 5-toothed.

Leaflets toothed. Tribe IV. TRIFOLIEAE.

Leaflets not toothed.

Filaments all or at least 5 of them (alternately) dilated above; flowers umbellate, or solitary. Tribe V. LOTEAE.

Filaments all filiform; flowers racemose or capitate.

Herbs, shrubs, or trees; keel of the corolla neither curved nor coiled.

Tribe VII. GALEgEAE.

Herbaceous vines; keel of the corolla in ours coiled or at least

Tribed. XI. PHASEOLEAE.
Filaments all filiform; leaves odd-pinnate; flowers racemose or capitate.

Foliage glandular-dotted.

Pod prickly.

Fruit a loment, prickly.

Tribe VII. GALEGEAE.

internodes.
Rachis of the leaves produced into a tendril or bristle-like appendage.

Tribe VIII. GLYCYRRHIZEAE.

Tribe VI. Psoraleak.

Tribe $X$. VICIEAE.

One genus.

One genus.

One genus.

Leaves digitate, in most 3 -foliolate.

TRIBE I. SOPHOREAE.

TRIBE II. PODALYRIEAE.

TRIBE III. GENISTEAE.

TRIBE IV. TRIFOLIEAE.

Leaves pinnately 3 -foliolate.

Pod curved or coiled.

Pod straight.

Tribe V. LOTEAE.

Keel prolonged into an incurved beak; leaves odd-pinnate. Stipules foliaceous; flowers in umbels.

Stipules gland-like; flowers mostly solitary.

Keel blunt, not beaked.

Legumes straight or nearly so, acute, dehiscent.

Stipules foliaceous; leaves regulaly odd-pinnate.

Stipules gland-like; leaves irregularly even-pinnate.

Legumes curved, indehiscent, caudate-acuminate.

TRIBE VI. PSORALEAE.

Petal 1 (standard); leaves odd-pinnate.

Petals 5.

Wings and keel free from the flament-tube; ovules solitary; leaves digitate.

13. Psoralea.
1. SOPHORA.

2. THERMOPSIS,

3. LUPINUS.

4. TRIFOLIUM.

5. medicago.

6. Melilotus.

7. LotUs.

8. ACMISPON.

9. HosACKIA.

10. ANISOLOTUS.

11. SYRMATIUM.

12. AMORPHA. 
Wings and keel more or less adnate to the fllament-tube; ovules 2-6; leaves oddpinnate.

Stamens 9 or 10 .

14. Parosela.

Stamens 5 .

15. Petalostemon.

TRIBE VII. GALEGEAE.

Leaflets with stipels; pods margined on one edge; trees or shrubs.

Leaflets without stipels; pods not margined; herbs or undershrubs.

Stipules modified into spines.

Stipules not modified into spines.

Keel (lower petal) not produced into a beak.

Leaves odd-pinnate, or unifoliolate or simple.

Pods papery, strongly inflated.

Pods strictly 1-celled.

Pods 2-celled.

Pods terete or nearly so.

Pods sharoly 3-angled in cross-section. 20 .

16. ROBINIA.

17. Peteria.

Pods 2-celled with a perfect or nearly perfect partition.

Pods fleshy, indehiscent or very tardily dehiscent.

Pods membranous, leathery or woody, dehiscent.

21. GEOPRUMNON.

Pods ovoid or oblong, rarely almost didymous, terete or vertically flattened, leathery or woody.

Pods linear, somewhat laterally flattened, membranous.

Pods 1-celled, the partition, if any, rudimentary.

23. HaMosA.

Lower suture strongly intruded, making the pod sagittate or obcordate in cross-section; pod membranous, rarely leathery.

24. TIUM.

Lower suture not intruded or merely slightly so; pods in the latter case woody.

Pods woody or chartaceous, never flattened laterally; both sutures not prominent.

Pods more or less stipitate.

Pods with two grooves on the upper side, strictly 1-celled.

25. DiHOLCOS.

Pods without grooves on the upper side, usually with a partial partiton.

Leaves unifoliolate.

Leaves odd-pinnate.

26. JONESIFLILA.

27. RYDBERGIELLA.

Pods sessile, usually without even a rudimentary partition.

Valves of the pods not winged.

Pods with a fleshy epicarp, in fruit cross-ribbed; leaflets obscurely articulated to the rachis, fleshy, narrow.

28. Ctenophyllum.

Pods without fleshy epicarp; leaflets distinctly articulated to the rachis.

Calyx cylindrical; flowers large; plant mostly low and cespitose. 30. XYLOPHACOS.

Calyx campanulate; flowers small.

Corolla yellow; calyx-lobes linear-lanceolate, equalling the tube; stipules united; stem low. 29. CNEMIDOPHACOS.

Corolla purple; calyx-lobes triangular, much shorter than the tube; stipules free or nearly so; stem tall and slender.

31. MicRophacos.

Valves of the pods winged.

32. Pterophacos.

Pods membranous, usually somewhat flattened laterally, if terete, both sutures prominent.

Partial partition present.

Partial parcition wanting.

Leaflets not spinulose-tipped; pods several-seeded.

Leaflets spinulose-tipped; pods 1-2-seeded

33. Atelephragma.

34. Homalobus.

Leaves digitately 3 -foliolate.

Flowers racemose.

Flowers capitate (some species of).

35. KENTROPHYTA.

Keel (lower petals) produced into a beak.

36. OREOPHACA.

4. TRIFOLIUM.

37. Aragallus.

\section{TRIBE VII. GLYCYRRHIZEAE.}

One genus.

TRIBE IX, HEDYSARIEAE.

Leaves odd-pinnate, with several pairs of leaflets, without stipels.

Pods 4-several-seeded, neither spiny nor dorsally toothed.

Pods 1-2-seeded, more or less spiny or toothed.

Leaves 3 -foliolate, with stipels.

38. GLyCYrRhiza.

39. HEDYSARUM.

40. ONOBRYCHIS.

41. Meibomia. 
TRIBE $\mathrm{X}$. VICIEAE.

Style fliform, hairy all around and below the apex; stamen-tube usually oblique at the summit. 42. VICIA.

Style flattened towards the apex, hairy on the inner side; stamen-tube usually truncate or nearly so.

Tribe XI. PHASEOLEAE.

Leaves 5-7-foliolate; style glabrous.

Leaves 3 -foliolate; style bearded along the inner side. 43. LATHYRUS.

44. ApIOS.

45. STROPHOSTYLES.

\section{SOPHÒRA L.}

Trees or shrubs, or (ours) perennial herbs, with rootstocks. Leaves oddpinnate, with bristle-like stipules. Flowers perfect, in racemes. Calyx campanulate, 5-lobed. Petals clawed, white, yellow, or violet, nearly equal in length; banner suborbicular, notched at the apex; keel 2-beaked at the apex. Stamens 10; filaments distinct or nearly so. Pod nearly terete, usually moniliform, indehiscent or tardily dehiscent. Seeds globose.

1. S. sericea Nutt. Perennial, with a creeping rootstock; stem 1-3 dm. high, silky-canescent, leafy; leaflets 15-23, elliptic or obovate, canescent; calyx gibbous on the upper side; lobes lanceolate to triangular; corolla about $15 \mathrm{~mm}$. long, ochroleucous; keel with two subulate beaks; pod $3-5 \mathrm{~cm}$. long, constricted between the seeds. Dry prairies, plains, and hills: S.D.-Tex.-Ariz.-Wyo. Plain-Submont. Ap-Je.

\section{Thermópsis R. Br. Yellow Pea, Golden Pea, Pratrie Bean.}

Perennial herbs, with creeping rootstocks. Leaves alternate, with foliaceous stipules, digitately 3 -foliolate, with entire leaflets. Flowers perfect, in racemes. Calyx campanulate, 5-lobed, the lobes nearly equal, or the upper two united. Corolla in ours yellow; banner with a broad spreading blade and reflexed margins; keel as long as the wings or longer. Stamens 10, distinct; anthers nearly alike. Pod narrow, flat, 2-valved, many-seeded.

Legume erect or ascending.

Fruit straight.

Legume strictly erect and appressed to the peduncle, densely pubescent.

Leaves strongly ascending; leaflets lance-oblong or oblanceolate; stipules lanceolate of oblong, more than twice as long as broad; raceme dense.

Leaves spreading: leaflets rhombic-elliptic to elliptic-oblong 1. T. montana. least ovate, very oblique less than to elliptic-oblong; lower stipules at Raceme lax; legume straight.

Raceme dense; legume somewhat curved. ovata.

Raceme dense; legume somewhat curved. $\quad 4$. T. xylorrhiza.

2. $T$. ovata.
4. $T$. xlorrhiza
few-flowered.

Fruit arcuate with spreading tips.

Legume $4-6 \mathrm{~cm}$. long.

Legume 8-10 cm. long.

Legume strongly divaricate or reflexed; inflorescence short.

Fruit mostly horizontal, merely arcuate.

Fruit reflexed, curved into half a circle or more.

Leaves glabrous above.

$\begin{array}{lr}\text { Leaves silvery on both sides. } & \text { 8. T. Thombifolia. } \text {. } \\ \text { 1. T. monulocarpa. }\end{array}$

3. $T$, pinetorum.

4. T. xylorrhiza.

5. T. divaricarpa.

6. $T$. arenosa.

7. T. rhombifolia.

8. T. annulocarpa.

sparingly hairy; leaflets $3-6 \mathrm{~cm}$. long, glabrous above, sparsely pubescent beneath; inflorescence rather dense, $1-1.5 \mathrm{dm}$. long; corolla $15-20 \mathrm{~mm}$. long; pod linear, 4-6 cm. long, $5 \mathrm{~mm}$. wide. T. stricta Greene. Meadows: Mont.-Colo.-Utah -Ore.-Wash. Submont.-Mont. My-Jl.

2. T. ovata (B. L. Robins.) Rydb. Stem 3-7 dm. high, strict, branched above; leaflets rhombic-elliptic or elliptic-oblong, 6-10 cm. long, glabrous; racemes 1-2 dm. long; corolla $2-2.5 \mathrm{~cm}$. long; pod straight, about $6 \mathrm{~cm}$. long, Utah. Submont. Ap-Je.

3. T. pinetorum Greene. Stem 2-4 dm. high, striate, glabrous or sparingly pubescent above; stipules ovate, $2-4 \mathrm{~cm}$. long; leaflets oblong or obovateoblong, 3-5 cm. long, obtusish, glabrous above, sparingly pubescent beneath; racemes short, 3-5 cm. long; fruit linear, 5-7 cm. long, $6 \mathrm{~mm}$. wide, appressed- 
pubescent, straight, about 10-seeded. In woods: Colo.-Utah-N.M. Submont.-Mont. Je-Jl.

4. T. xylorrhiza A. Nels. Stem erect, 4-7 dm. high, glabrate and striate; stipules ovate or obovate, $2-4 \mathrm{~cm}$. long; leaflets oval or elliptic, 4-8 $\mathrm{cm}$. long; raceme 10-20-flowered, dense; pod sparingly pubescent, somewhat arcuate, 4-6 cm. long. Shady slopes: Idag, Mont.

5. T. divaricarpa A. Nels. 'Stem erect, 5-8 dm. high; stipules large, ovate, or on the branches narrower, $2-5 \mathrm{~cm}$. long; leaflets rhombic-oblanceolate or elliptic, glabrous above, pubescent beneath, $5-10 \mathrm{~cm}$. long; corolla fully $2 \mathrm{~cm}$. long; pod linear; finely pubescent, about 15-seeded. Creek banks and open slopes: Wyo.-Colo. Submont.-Subalp. Je-Jl.

6. T. arenosa A. Nels. Stems several, 2-4 dm. high, glabrous or slightly pubescent above; stipules ovate to suborbicular, 2-4 cm. long; leaflets oblong, oblanceolate, or obovate, 3-4 cm. long, glabrous on both sides, or sparingly hairy beneath; pod spreading, 4-7 cm. long, more or less torulose, 8-13-seeded. Sandy or gravelly places: Sask.-Colo.-Mont. Plain-Mont.

7. T. rhombifolia (Nutt.) Richards. Stems several, glabrous or strigose above, 1-3 dm. high; stipules ovate to suborbicular, 1-2 $\mathrm{cm}$. long, often obtuse; leaflets rhombic-obovate to oblong-oblanceolate, 2-3 cm. long; corolla $15-20 \mathrm{~mm}$. long; pod 5-6 cm. long, grayish strigose, 10-13-seeded. Sandy places, especially in draws: Sask.-Neb.-Colo.-Mont. Plain-Submont. Ap-Je.

8. T. annulocarpa A. Nels. Stems single or two, 2-4 dm. high, strigose; stipules broadly ovate or rhombic, $2-3 \mathrm{~cm}$. long; leaflets elliptic, oblong or broadly oblanceolate, mostly obtuse, $3-5 \mathrm{~cm}$. long; pod often forming a nearly complete ring, 7-10 cm. long, strigose-canescent, 7-12-seeded. Among rocks: Wyo. Mont. Je.

\section{LUPINNUS (Tourn.) L. Lupine, Wolf's Bean, Blue Bonnet, QUAKER BonNeT.}

Annual or perennial herbs, or rarely shrubs. Leaves alternate, with narrow stipules, digitately 5-15-foliolate, rarely 1 - or 3 -foliolate. Flowers perfect, in terminal racemes. Calyx 2-lipped, the upper lip of 2 partially, and the lower of 3 partially or usually wholly united sepals. Corolla in most of our species blue, purple, or white, in a few yellow; banner broad, with reflexed margins; wings curved; keel sickle-shaped. Stamens monadelphous; anthers alternately larger and smaller. Pods flat, 2-valved, dehiscent; ovules and seeds 2-many.

Perennials with rootstocks; cotyledons petioled after germination.

Plant tall, $3 \mathrm{dm}$. high or more.

Stem with appressed hairs.

Leaves glabrous above, at least in age.

Flowers large, over $12 \mathrm{~mm}$. long.

Stem rather low and stout, canescent-strigose; leaflets broadly oblanceolate.

I. Plattenses.

Stem glabrous or almost so, tall; leaflets narrowly oblanceolate.

Flowers small, less than $12 \mathrm{~mm}$. long.

X. POLYPHYLI.

Leaves permanently pubescent above.

Flowers yellow or ochroleucous.

Flowers blue, purple, or white.

Caly x produced backwards into a distinet spur or sack. Spur of the caly $\times 2-3 \mathrm{~mm}$. long.

Spur of the calyx $1 \mathrm{~mm}$. long or less. IV. AR
alyx merely gibbous at the base, not produced backwards.
Plant green, usually not densely hairy; pubescence

II. Parviflori.

V. SULPHUREI.

Plant green, usually not densely hairy; pubescence short, or if longer, very sparse.

Keel moderately curved, Iunate, the upper portion longer than the lower.

VI. AlbicAUles.

Keel strongly curved, the upper portion shorter than the lower.

Plant densely silvery or canescent with long hairs.
Stem leafy; pubescence of the leaves appressed.

VII. Foliosi.

VIII. ORNATI.

Stem leafy at the base only, pubescence of the leaves longer and Iooser.

Stem with spreading pubescence.

XIV. LEPIDI. 
Leaflets glabrous above, at least in age; flowers large.

Bracts linear-subulate, long-attenuate, almost setaceous, much exceeding the flower-buds.

Bracts lanceolate, scarcely exceeding the flower-buds.

Stem tall, leafy throughout; leaflets narrowly oblanceolate, acute.

$\mathrm{X}$. POLYPhyll.

Stem low, stout, leafy mostly towards the base; leaflets broadly oblanceolate or spatulate, mucronate. XI. AMNOPHILI.

Leaflets permanently pubescent above.

Pubescence of the stem of one kind, usually short, except in $L$. comatus.

XII. CYANEI.

Pubescence of the stem of two kinds, viz., a short and dense under-pubescence and scattered long silky hairs.

Plant low, less than $3 \mathrm{dm}$. high, densely cespitose.

XIII. LEUCOPHYLL.

Inflorescence much exceeding the leaves.

Leaves mostly basal; petioles many times longer than the leaflets.

Leaves mostly couline: petioles of the XIV. LePIDI. mostly cauline; petioles of the cauline leaves only slightly, if at all, exceeding the leaflets in length.

Leaves densely canescent.

Leaves green.

Annuals.

Inflorescence not exceeding the leaves.

XV. CANDICANTES. XVI. MONTICOLAE.

Cotyledons after germination petioled; pods 3-4-seeded. XVIII. ConcINNI.

Cotyledons after germination sessile, persistent, clasping the stem; pod 2-seeded.

XIX. PUSILLI.

One species.

\section{Plattenses.}

1. L. plattensis.

II. PARViflori. Calyx spurred or saccate at the base, appressed-silky; banner pubescent on the back;
keel ciliate.

Leaflets oblanceolate, flat; racemes comparatively dense; flowers numerous, subverticillate.

Leaflets linear, conduplicate; flowers scattered in a lax raceme.

2. I. pseudoparviflorus.

Calyx somewhat gibbous at the base, but not produstenophllus.

Inflorescence, pedicels, and calvees finely produced backwards into a spur or sack.

Flowers $15 \mathrm{~mm}$. long; corolla white.
Flictly appressed

Flowers $12 \mathrm{~mm}$. long or less; corolla purple or blue.

Banner somewhat silky on the back: lower lip of the calyx twice as long as the upper; keel ciliate on the margins.

Banner glabrous; keel not ciliate.

Lower lip of the calyx only slightly longer than the upper; flowers about $10 \mathrm{~mm}$. long; plant green.

$10 \mathrm{~mm}$. long; plant green.
Lower lip of the calyx much longer than the upper; corolla about $8 \mathrm{~mm}$.

Inflorescence, pedicels, and calyces more loosely pubescent; hairs at least in age spread-
ing. ing.

Banner pubescent on the back; plant silvery.

Banner glabrous; plant green.

8. L. argenteus.

Calyx strongly gibbous at the base; keel glabrous; stem purplish.

Calyx not strongly gibbous; stem green.

9. L. rubricaulis.

Banner blue or purplish, not dark-spotted.

Lower lip of the calyx about twice as broadly oblanceolate.

10. L. spathulatus. narrow slightly longer than the upper; leaflets

Banner light blue with a dark spot.
Flowers about 6 mm

11. L. alpestris.

12. L. maculatus.

Leaflets narr

Lips of the ohlanceolate.

Lips of the calyx acutely 2- and 3-toothed.

Lips of the calyx obtuse, merely retuse.

13. L. floribundus.

14. L. leptostachyus.

15. L. parviflorus.

Une species

\section{Calcarati.}

IV. ARgOPHYLL.
Lower lip of the calyx about half longer than the upper; leaflets linear-oblanceolate.

16. L. calcaratus.

Petals and calyx-lobes narrow; wings fully twice as long as broad; lower lip of calyx narrowly lanceolate; plant greener; inflorescence lax.
17. L. laxiflorus.

Petals and calyx-lobes broad; lower lip of the ealyx broadly lanceolate; plant
white; inflorescence dense.

Lower lip of the calyx about twice as long as the upper; leaflets broadly lanceolate.
Leaflets equally silvery white curved.

Leaflets grayish canescent, greener above, flat.

19. $L$. argentinus.

20. L. lupinus. 


\section{SULPHUREI.}

Flowers 12-14 mm. long; uoper lip of calyx about $8 \mathrm{~mm}$. long. 21 . L. flavescens.

Flowers $1 \mathrm{~cm}$. long or less; upper lip of calyx very short, only $4 \mathrm{~mm}$. long.

Inflorescence loosely pubescent; flowers about $10 \mathrm{~mm}$. long. 22 . L. sulphureus. Inflorescence finely appressed-silky; flowers about $8 \mathrm{~mm}$. long.

\section{Albicaules.}

23. L. lucidulus.

One species.

VII. Foliosi.

Flowers ahout $15 \mathrm{~mm}$. long; pubescence long, sparse.

Flowers 8-12 mm. long; pubescence short.

Banner glabrous.

Bracts linear-subulate, long-attenuate, 8-12 $\mathrm{mm}$. long, longer than the buds.

Flowers dark blue, ascending, in lax racemes; calyx appressed-silky.

25. $L$. adscendens.

Flowers white in dense racemes, spreading; calyx with spreading hairs.

26. L. ingratus.

Bracts lanceolate, short-acuminate, 4-7 mm. long; flowers spreading; calyx with short spreading hairs.

Flowers dark blue or dark purple; stems simple, low, 1-3 dm. high, from a cespitose caudex.

Pubescence of the stem and leaves short.

Pubescence of the stem and leaves rather long. 70. L. monticola.

27. L. Macounii.

Flowers lilac or rose-colored, rarely white; plant tall, 3-8 dm. high, branched.

Banner more or less pubescent.

Corolla light blue or lilac, $7-8 \mathrm{~mm}$. long; keel glabrous. 29. L. laxus.

Corolla 8-10 mm. long; keel ciliate on the margins.

Corolla dark blue or purple; stems mostly simple.

Corolla light blue, or lilac, or pink; stem much branched.

\section{ORNATI.}

Bracts subulate, much longer than the flower-buds.

Bracts ovate or lanceolate, rarely exceeding the flower-buds.

Flowers less than $12 \mathrm{~mm}$. long.

Flowers 6-7 mm. long.

Flowers 8-10 mm. long.

Flowers over $12 \mathrm{~mm}$. long.

Stem few-leaved, only slightly exceeding the long petioles of the basal leaves.

Pubescence of the leaves long and rather loose, hirsute rather than silky.

34. L. Rydbergii.

Pubescence of the leaves fine and short, strictly appressed and silky.

Pubescence of the calyx and pedicels short, loose and spreading.

35. L. humicola.

Pubescence of the calyx and pedicel densely and finely appressed-pubes-

cent, silky.
Stems very leafy, many times exceeding the basal leaves.

36. L. Hellerae,

Flowers 15-20 $\mathrm{mm}$. long; pubescence at least on the inflorescence brownish in age. 37 . L. ornatus.

Flowers 10-14 mm long; pubescence white-silky. 38. L. leucopsis.

\section{Cytisoides.}

Stem arachnoid-villous; flowers $18-20 \mathrm{~mm}$. long.

Stem sparingly hairy or glabrous; flowers $10-15 \mathrm{~mm}$. long.

Stem decidedly pubescent with long spreading hairs.

Banner only slightly shorter than the wings; plant $2-7 \mathrm{dm}$. high.

40. L. Wyethii.

Banner much shorter than the wings; plant about $10 \mathrm{dm}$. high.

Racemes dense; flowers about $12 \mathrm{~mm}$. long, dark blue, verticillate, leaflets oblanceolate, long-hairy beneath.

41. L. amplus.

Racemes lax; flowers about $10 \mathrm{~mm}$. long, light blue or white, mostly singly; leaflets narrowly oblanceolate, short-hairy beneath.

Stem glabrous or nearly so.

Calyx and bracts villous.

Calyx and bracts appressed-silky.

42. L. marianus.

\section{Polyphylli.}

Stem decidedly hairy; leaflets oblanceolate.

Stem glabrous or nearly so; leaflets narrowly oblanceolate.

43. L. Burkei.

44. L. cytisoides.

\section{AMMOPHII.}

Keel ciliate on the margins; leaves rather thick.

Keel glabrous; leaves thin.

\section{CYANET.}

Pubescence of the stem long; leaves greener.

Pubescence rather short, leaves canescent or silvery.

45. L. glabratus.

46. L. polyphyllus.

47. L. ammophilus.

45. L. glabratus.

48. L. comatus. 
Pubescence of the leaves appressed.

Corolla blue; banner with a light spot.

Bracts linear-lanceolate to subulate, 5-8 $\mathrm{mm}$. long.
Corolla $12-14 \mathrm{~mm}$. long; leaflets $3-7 \mathrm{~cm}$. long.
49. L. sericeus.

Corolla $10 \mathrm{~mm}$. long or less; leaflets $2-3 \mathrm{~cm}$. long. 50 . L. apronosus.

Bracts lanceolate, 3-5 mm. long.

Leaflets densely pubescent above; corolla about $12 \mathrm{~mm}$. long.

51. L. Bakeri.

Leaves sparingly pubescent or glabrate above; corolla about $10 \mathrm{~mm}$. long.

52. L. cyaneus.

Corolla at first white; banner turning purplish; no light spot.

53. L. dichrous.

Pubescence of the leaves long and loose; corolla light purple or pink; banner with a dark spot.

\section{LEUCOPHYLLI.}

54. L. flavicaulis.

Racemes elongate, 1-3 dm. long, terminal.

Flowers numerous in a very long and dense raceme.

Bracts lanceolate, not much longer than the buds.

Pubescence not very dense.

Pubescence on the leaves appressed.

Pubescence on the leaves short, spreading.
Pubescence very dense, in age more or less rusty, and rather loose.

55. L. macrostachys.

$57 . \mathrm{L}$. leucophyllus.
Bracts subulate, much exceeding the buds; flowers about $16 \mathrm{~mm}$. long.

Pubescence of the leaves long and loose. $58 . I$ plumosus.

Pubescence of the leaves short, appressed.

Flowers in a long, but lax raceme.
Racemes short, $3-5 \mathrm{~cm}$. long, terminating short divaricate branches.

59. L. Jonesii.

61. L. ramosus.

\section{LEPIDI.}

Stem trailing or decumbent.

Stem erect or ascending, if at all decumbent, only so at the base.

Pubescence of the stem and leaves loose.
Pubescence of the stem and leaves appressed.

62. L. depressus.

63. L. aridus.

Flowers 7-10 mm. long; stem mostly 1-leaved or leafless; pubescence short. Racemes short, dense, $2-5 \mathrm{~cm}$. long; flowers about 10 long.

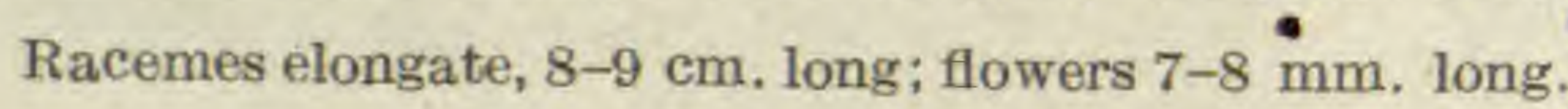

64. L. minimus,

Flowers $12 \mathrm{~mm}$. long or more; stem with several stem-leaves; pubescence

XV. CANDICANTES.

66. L. lepidus.

Flowers 9-10 mm. long or more.

Peduncles short; raceme elongate.

Peduncles elongate; racemes short.

Flowers 6-7 mm. long.

67. L. psoralioides.

68. L. candicans.

69. L. Evermannii.

\section{MONTICOLAE.}

Flowers 9-10 mm. long; petads dark blue; banner with a light spot.

Flowers 7-8 mm. long; petals light rose, turning yellowish. $\quad 71$. L. roseolus.

\section{Caespitosi.}

Plant loosely pubescent with long hairs.

Racemes very short and dense, sessile; bracts lanceolate, about equalling the flowers; pubescence rather appressed.

Racemes elongate; bracts subulate, exceeding the flowers; pubescence spreading.

Plant densely canescent.

One species.

\section{Concinni.}

73. L. Watsonii.

Racem. Pusilli.

75. L. micensis.

Racemes dense, subcapitate; lower lip of the calyx 2-3-toothed.

Plant almost stemless; lower lip of the calyx oval or ovate. 76 . L. brevicaulis.

Plant with distinct leafy stem; lower lip of the calyx oblong-lanceolate.

Racemes more elongate and less dense; lower lip of the calyx entire.
Peduncles much exceeding the leaves.

Peduncles very short, shorter than the petioles.

78. L. scaposus.

Racemes lax, usually much exceeding the leaves; lower part of the calyx and

pedicels glabrous.
Racemes dense, slightly if at all exceeding the leaves; calyx and pedicels densely

pedicels glabrous.
Racemes dense, slightly if at all exceeding the leaves; calyx and pedicels densely hirsute.
80. L. pusillus.

1. L. plattensis S. Wats. Stem short, densely leafy, 2-5 dm. high; leaflets $7-9$, oblanceolate, obtuse or acutish, thick, somewhat glaucous, grayish silky-strigose beneath, 2-4 cm. long; racemes 1-1.5 dm. long; bracts lanceolate, 
equalling the calyx, deciduous; calyx only slightly gibbous at the base; lips lanceolate, about $8 \mathrm{~mm}$. long; corolla pale blue; banner with a dark spot, about 12 $\mathrm{mm}$. long; legume $2.5-3.5 \mathrm{~cm}$. long. L. crassus Payson. Plains and hills: Neb. -Wyo.-Colo.-Kans. Plain-Submont. Je-Jl.

2. L. pseudoparviflorus Rydb. Stems several from a short woody caudex, 3-6 dm. high; leaflets $8-10$, oblanceolate, $3-5 \mathrm{~cm}$. long, acute or mucronate, finely silky-strigose beneath; racemes 1-1.5 dm. long; bracts subulate, shorter than the ealyx, deciduous; corolla blue, $8-10 \mathrm{~mm}$. long; banner lighter in the middle, equalling the wings; legume $2 \mathrm{~cm}$. long, 3-5-seeded. Open woods: Mont.-Ida. Plain-Submont. My-Jl.

3. L. stenophyllus (Nutt.) Rydb. Stem slender, probably $1 \mathrm{~m}$. high; leaflets about $5,3 \mathrm{~cm}$. long, green, sparingly silky-strigose beneath; bracts lanceolate, shorter than the calyx, deciduous; calyx densely silky-strigose; upper lip shorter than the lower; corolla light blue, 7-8 mm. long. Meadows: Mont.Nev.-Ore. Plain-Submont. Jl.

4. L. leucanthus Rydb. Stem about $6 \mathrm{dm}$. high; leaflets 5-7, narrowly oblanceolate, 4-5 cm. long, acute or short-acuminate, sparingly appressed-hairy beneath; raceme lax; bracts lanceolate, acuminate, about equalling the pedicels, 6-8 $\mathrm{mm}$. long; lower lip of the calyx about one-third longer than the upper one; corolla white, with a brownish spot on the banner, the latter glabrous. Meadows: Utah. My.

5. L. Scheuberae Rydb. Stem 4-6 dm. high; leaflets 7-8, oblanceolate, 5-7 cm. long, acute and mucronate, green, sparingly appressed-pubescent beneath; racemes 1-1.5 dm. long, not dense; bracts lanceolate, 7-8 mm. long, deciduous; flowers 10-12 mm. long; lower lip fully twice as long as the upper; corolla 11-12 $\mathrm{mm}$. long, dark purple but lighter towards the base; banner slightly longer than the wings; pod 2-4-seeded, $2 \mathrm{~cm}$. long. Woods: Mont.-Wyo.-Utah. Submont. Je-Au.

6. L. laxispicatus Rydb. Stems 3-4 dm. high; leaflets $7-10$, narrowly oblanceolate, acute, green, strigose beneath, $4-5 \mathrm{~cm}$. long; inflorescence lax; bracts lanceolate, shorter than the calyx, deciduous; upper calyx-lip slightly shorter than the lower; corolla blue, about $10 \mathrm{~mm}$. long. Mountains: Ida.-Utah.

7. L. tenellus Dougl. Stems several, 4-6 dm. high; leaflets narrowly linear or linear-oblanceolate, acute at both ends, silky-strigose beneath, usually conduplicate, 1-3 cm. long; raceme slender, lax; bracts lanceolate, shorter than the buds; corolla blue; legume 3-5-seeded. L. Jonesii Blankinship, not Rydb. $L$. Blankinshippii Heller. Meadows and hillsides: Wash.-Calif.-Colo.-Mont. Submont.-Mont. My-Jl.

8. L. argenteus Pursh. Stems diffusely branched, 5-10 dm. high; leaflets 7-8, narrowly oblanceolate and usually conduplicate, or in var. argentatus broader and flat, $2-5 \mathrm{~cm}$. long; bracts linear-lanceolate, about equalling the flower-buds; lower lip of the calyx longer than the upper; corolla light violet, rose or white, about $1 \mathrm{~cm}$. long; legume about $2 \mathrm{~cm}$. long, 5-6-seeded. $L$. decumbens Torr. L. leptostachys Greene. Plains and hills: N.D.-Neb.-Colo,-Calif.-Ore. Plain -Mont. Je-Au.

9. L. rubricaulis Greene. Stems from a short woody caudex, $3-5 \mathrm{dm}$, high; leaflets $6-10$, oblanceolate or elliptic, thick, acute, silky-strigose beneath, 2-3.5 $\mathrm{cm}$. long; racemes short, $5-10 \mathrm{~cm}$. long; corolla dark blue, about $8 \mathrm{~mm}$. long; pods about $2 \mathrm{~cm}$. long. Moist open slopes: Colo. Mont. Jl.

10. L. spathulatus Rydb. Stem 8-10 dm. high; leaflets 7 , about $4 \mathrm{~cm}$. long, mucronate; bracts lanceolate, attenuate, deciduous, longer than the buds; lower calyx-lip lanceolate, about twice as long as the upper; corolla dark blue, with lighter keel, $8 \mathrm{~mm}$. long. Cañons: Colo.-Utah. Mont. Je-Au.

11. L. alpestris A. Nels. Stems erect, 4-6 dm. high; leaflets 5-9, from narrowly linear-oblanceolate to ovate-oblanceolate, obtuse, mucronate, $2-7 \mathrm{~cm}$. long, strigose beneath; racemes 1-2 dm. long, loosely flowered; upper calyx-lip lance-ovate, $5 \mathrm{~mm}$. long; lower lip lanceolate, $6 \mathrm{~mm}$. long; corolla usually blue; banner glabrous, $8-10 \mathrm{~mm}$. long; keel slightly ciliate; legume $2-3 \mathrm{~cm}$. long, 3-5- 
seeded. L. alsophilus Greene. Hillsides, border of woods, and mountain valleys: Mont.-Colo.-Utah. Submont.-Subalp. Je-Au.

12. L. maculatus Rydb. Stem 4-6 dm. high; leaflets 5-7, those of the lower leaves obovate-oblanceolate, mucronate, those of the upper oblanceolate and acute, sparingly appressed-hairy beneath, $3-5 \mathrm{~cm}$. long; bracts ovate-lanceolate, acuminate, deciduous; lips of the calyx ovate-lanceolate, the lower $7 \mathrm{~mm}$. long, the upper $6 \mathrm{~mm}$. long; flowers $10-12 \mathrm{~mm}$. long; banner light purple, with a dark spot, glabrous, much shorter than the white or purple-tinged wings; keel white, with purple tip; pods oblong, 2.5-3.5 $\mathrm{cm}$. long, 4-6-seeded. Hillsides: e Utah-w Colo. Submont.-Mont. Jl-Au.

13. L. floribundus Greene. Stems branched, leafy; leaflets 7-9, narrowly oblanceolate, acute, 3-6 $\mathrm{cm}$. long, strigose beneath; bracts lanceolate, shorter than the calyx; upper lip of the calyx $3 \mathrm{~mm}$. long, lance-ovate; lower lip lanceolate, $4 \mathrm{~mm}$. long; corolla darker or lighter, blue or violet, about $6 \mathrm{~mm}$. long; petals subequal; pod 1.5-2 cm. long, 3-4-seeded. L. myrianthus Greene. (?) L. fulvomaculatus Payson. Mountain meadows: Colo.-Wyo.-Utah. Mont. Jl-Au.

14. L. leptostachyus Greene. Stems leafy, 3-6 dm. high; leaflets 7-9, narrowly linear-oblanceolate, $3-5 \mathrm{~cm}$. long, strigose, but green beneath; bracts lanceolate, about equalling the calyx; upper lip of the latter $3 \mathrm{~mm}$., the lower 4 $\mathrm{mm}$. long, both ovate, obtuse, merely retuse at the end; corolla pale blue, $6 \mathrm{~mm}$. long, the banner somewhat darker than the other petals, with a brownish eye. Ledges: Colo. Submont. Je-Jl.

15. L. parviflorus Nutt. Stems slender, 5-10 dm. high, branching; leaflets $5-11$, broadly oblanceolate to obovate, obtuse, $3-5 \mathrm{~cm}$. long, slightly strigose beneath, green; racemes 1-3 dm. long; bracts linear-subulate, equalling the calyx, deciduous; lips of the calyx nearly equal, $6 \mathrm{~mm}$. long, broadly lanceolate; corolla light blue, sometimes white, about $6 \mathrm{~mm}$. long; banner glabrous; legume $2-2.5$ $\mathrm{cm}$. long, 3-4-seeded. Meadows and among bushes: S.D.-Colo.-UtahMont. Submont.-Alp. Je-S.

16. L. calcaratus Kell. Stems 4-7 dm. high; leaflets 7-11, linear-oblanceolate, $3-5 \mathrm{~cm}$. long, pubescent above, silvery-silky beneath; racemes slender, 6-12 $\mathrm{cm}$. long; bracts subulate, caducous; calyx appressed-silky; lower lip longer than the upper; corolla from nearly white to purple, sometimes bi- or tri-colored; banner slightly pubescent on the back; pod 2-5-seeded. L. multitinctus A. Nels. Hills and plains: Calif.-Utah-Ida.-Ore. My-Je.

17. L. laxiflorus Dougl. Stems erect, $3-6 \mathrm{dm}$. high, slender; leaflets $6-10$, narrowly linear-oblanceolate, 3-5 cm. long, acute, short-strigose on both sides, green; racemes lax, 1-2 dm. long; bracts subulate, shorter than the calyx; calyx appressed-silky; upper lip lance-ovate, $5 \mathrm{~mm}$. long, the lower lanceolate, $6 \mathrm{~mm}$. long; corolla blue, 8-10 mm. long; petals sub-equal; legume about $2 \mathrm{~cm}$. long, 4-6-seeded. Meadows: Wash.-Calif.-Ariz.-Mont. Submont.-Mont. My=Jl.

18. L. aduncus Greene. Stems $3-10 \mathrm{dm}$. high, silky-canescent; leaflets $7-9$, narrowly oblanceolate, $2-3 \mathrm{~cm}$. long, acute, appressed-silky on both sides, often conduplicate; raceme $1-2.5 \mathrm{dm}$. long; bracts ovate-lanceolate, shorter than the calyx; calyx densely appressed-silky; lower lip lanceolate, $7 \mathrm{~mm}$. Tong, the upper ovate-lanceolate, nearly as long; corolla dark blue, about $10 \mathrm{~mm}$. long; petals subequal; pod $2-3 \mathrm{~cm}$. long, 5-6-seeded. L. decumbens argophyllus A. banks: Neb.-N.M.-Utah-Wyo. Submont.-Mont. My-Jl.

19. L. argentinus Rydb, Stem 4-6 dm. high; leaflets about 7 , oblanceolate, densely silky on both sides, $3-5 \mathrm{~cm}$. long; inflorescence rather short and dense; bracts ovate-lanceolate, short, deciduous; flowers 10-12 $\mathrm{mm}$. long; calyx and pedicels densely white-silky; lower lip lanceolate, $7-8 \mathrm{~mm}$. long, the upper ovate, $5-6 \mathrm{~mm}$. long; corolla bluish purple; banner pubescent on the back; pods about $3 \mathrm{~cm}$. long and 5-6-seeded. L. holosericeus utahensis S. Wats. Hills: Utah -Neb. Son.-Submont. Je-Au.

20. L. lupinus Rydb. Stem 3-6 dm. high, densely canescent; leaflets 5-9, oblanceolate, usually flat, $3-6 \mathrm{~cm}$. long, appressed-canescent on both sides; 
racemes 5-10 cm. long; bracts lanceolate, 3-4 mm. long, deciduous; calyx silvery; upper lip scarcely $3 \mathrm{~mm}$. long, the lower $5 \mathrm{~mm}$. long; corolla about $1 \mathrm{~cm}$. long, dark blue or purple; banner with a light spot; pod $3 \mathrm{~cm}$. long, 3-seeded. Along streams and in meadows: Utah. Submont.-Mont. Jl-Au.

21. L. flavescens Rydb. Stem about $3 \mathrm{dm}$. high; leaflets about 7 , oblanceolate, 3-4 cm. long, appressed-silky on both sides; inflorescence short; bracts lanceolate, early deciduous; calyx densely pubescent with short spreading hairs, gibbous at the base, its lips almost equal in length, about $8 \mathrm{~mm}$. long; corolla pale yellow; banner with a darker spot, glabrous. Prairies: Ida.-Mont. Je.

22. L. sulphureus Dougl. Stems 4-8 dm. high; leaflets 7-10, oblanceolate, yellowish green, softly strigose on both sides, 3-5 cm. long; raceme 1-2 dm. long, rather lax; bracts lanceolate, shorter than the ealyx; calyx more or less spurred at the base, short-pubescent with spreading hairs; lower lip lanceolate, about 6 $\mathrm{mm}$. long, the upper ovate, $5 \mathrm{~mm}$. long; seeds 4-5. Plains: Ida.-Wyo.-UtahOre. Son.-Submont. Je-Au.

23. L. lucidulus Rydb. Stem 5-6 dm. high, branched above, especially the upper portions, leafy; leaflets $7-8$, linear-oblanceolate, silky and silvery on both sides, about $3 \mathrm{~cm}$. long; raceme 1-2 dm. long, lax; flowers scattered; pedicels and calyx densely pubescent with short strictly appressed silky hairs; lower lip of the calyx about $5 \mathrm{~mm}$. long, lanceolate, almost twice as long as the short ovate upper one; corolla yellow or light pink; banner slightly exceeding the wings, with a darker spot. Hills: Wyo. Submont. Au.

24. L. albicaulis Dougl. Stem 3-10 dm. high, straw-colored; leaflets oblanceolate, $3-5 \mathrm{~cm}$. long, short-pubescent on both sides; bracts subulate; calyx with short spreading hairs; lips subequal; petals 10-14 mm. long, blue, violet or whitish; banner glabrous; pods 3-6-seeded. Plains: Wash.-Ida.-Calif. Je-Jl.

25. L. adscendens Rydb. Stem 4-6 dm. high, appressed-silky, leafy; leaflets about 7, linear-oblanceolate, 4-5 $\mathrm{cm}$. long, acute, appressed-silky on both sides, but green; racemes elongate, narrow; flowers about $12 \mathrm{~mm}$. long; ealyx grayish silky; lower lip $8 \mathrm{~mm}$. long, slightly longer than the upper, both lanceolate; bract linear-subulate, much longer than the buds, equalling the calyx in length; corolla dark bluish purple; banner glabrous, with a lighter spot. Mountains: Wyo.-Utah. Submont. JI.

26. L. ingratus Greene. Stems several, 3-6 dm. high, sparingly strigose; leaflets $7-9$, narrowly oblanceolate, sparingly appressed-pubescent on both sides, 2-4 cm. long; inflorescence many-flowered; upper calyx-lip ovate, $3 \mathrm{~mm}$. long, the lower lanceolate, $4 \mathrm{~mm}$. long; corolla white, $8 \mathrm{~mm}$. long, the banner with a brownish spot; pod 1.5-2 cm. long, 4- or 5-seeded. Hills: N.M.-(? Colo.). Submont. Jl-S.

27. I. Macounii Rydb. Stems several, 3-6 dm. high, somewhat branched; leaflets about nine, linear-oblanceolate, $2-3 \mathrm{~cm}$. long, usually conduplicate, silkystrigose on both sides; racemes dense, $5-10 \mathrm{~cm}$. long; calyx gibbous at the base; lower lip lanceolate, 6-7 mm. long, the upper hardly $4 \mathrm{~mm}$. long, ovate; corolla 8-9 mm. long, dark blue, the banner with a lighter spot, somewhat shorter than the wings; legume about $2 \mathrm{~cm}$. long, 3-4-seeded. Plains and mountains: Sask. -Wyo.-Mont. Plain.

28. L. foliosus Nutt. Stems erect, 3-8 dm. high, branched, usually with erect branches; leaflets narrowly oblanceolate, usually conduplicate, silkystrigose on both sides, $2-5 \mathrm{~cm}$. long; calyx densely silky-canescent; lower lip lanceolate, $6-7 \mathrm{~mm}$. long, upper lance-ovate, $5-6 \mathrm{~mm}$.; corolla about $1 \mathrm{~cm}$. long; petals subequal; legume about $2 \mathrm{~cm}$. long, 3-4-seeded. Hills and plains: Wash. -Ida.-Colo.-Mont. Je-Au.

29. L. laxus Rydb. Stem 4-6 dm. high, slender; leaflets 7-9, linear or linear-oblanceolate, 3-4 cm. long, green, but appressed-silky on both sides; racemes slender and lax; bracts lanceolate, short-acuminate, not longer than the buds; pedicels and calyx rather long-hairy; calyx not spurred; lower lip Ianceolate, $5 \mathrm{~mm}$. long, the upper slightly shorter; corolla light bluish purple; banner broad, somewhat shorter than the wings. Meadows: Mont.-Wyo. Submont. Jl. 
30. L. pulcherrimus Rydb. Stems $3-6 \mathrm{dm}$. high, leafy; leaflets $7-9$, linearoblanceolate, acute, appressed-silky on both sides, but green; raceme more or less elongate and rather dense; bracts lanceolate, short-acuminate, shorter than the buds, deciduous; calyx grayish silky; lips lanceolate, the lower $6 \mathrm{~mm}$. long, the upper somewhat shorter; corolla dark purple; banner with a light spot, pubescent on the back; pods 3-3.5 cm. long, 5-6-seeded. Meadows: B.C.Colo.-Utah-Mont. Mont.-Subalp. My-Au.

31. L. flexuosus Lindl. Stem 4-5 dm. high, striate, leafy; leaflets 7-10, narrowly oblanceolate or linear-oblanceolate, densely appressed-silky on both sides, $2-4 \mathrm{~cm}$. long; raceme dense, $1-1.5 \mathrm{dm}$. long; calyx appressed silky-canescent, scarcely gibbous; lower lip $8 \mathrm{~mm}$. long, narrowly lanceolate, the upper ovate-lanceolate, $6 \mathrm{~mm}$. long; corolla dark blue, with keel and a spot on the banner, light-colored, about $1 \mathrm{~cm}$. long; banner rather densely pubescent without. L. subulatus Rydb. Plains: Mont.-Wash.-(? Utah). Plain-Submont.

32. L. tenuispicus A. Nels. Stem 3-7 dm. high, silvery-silky; leaflets 6-9, narrowly oblanceolate, $4-6 \mathrm{~cm}$. long, silvery-silky, with long hairs; spike slender, erowded, 5-15 cm. long; bracts linear-lanceolate, shorter than the calyx; lips subequal; corolla blue or purple, $6-7 \mathrm{~mm}$. long; banner pubescent on the back; pods 1-3-seeded. Mountains: Ore--Wash.-Ida. Au.

33. L. Greenei A. Nels. Stems several, usually erect; leaflets $7-10$, narrowly oblanceolate, densely appressed silky-canescent, $2-5 \mathrm{~cm}$. long, obtuse, mucronate; calyx densely canescent; lower lip lanceolate, $6-7 \mathrm{~mm}$. long, the upper slightly shorter; corolla 7-9 mm. long; petals subequal, dark bluish purple; banner hairy outside, with a light brownish spot; pod about $1.5 \mathrm{~cm}$. long, 3-seeded. L. oreo-
philus Greene. River banks and benchland: Ore.-Nev.-Utah-Colo.-Wyo.
Submont. My-Jl.

34. L. Rydbergii Blankinship. Stems several, about $3 \mathrm{dm}$. high; leaflets 8-10, oblanceolate, $2-4 \mathrm{~cm}$. long, coarsely canescent; racemes 8-14 cm. long; bracts linear, scarcely exceeding the buds; calyx canescent, gibbous; lower lip $7 \mathrm{~mm}$., upper lip about $5 \mathrm{~mm}$. long; corolla dark blue, about $10 \mathrm{~mm}$. long; banner with a light spot, glabrous; legumes 3-5-seeded. Hills: Mont.-Ida. Plain-
Submont. My-Je.

35. L. humicola A. Nels. Stems several, erect or ascending, 3-6 dm. high, few-leaved; leaflets 7-12, narrowly oblanceolate, appressed-silky on both sides, 4-7 $\mathrm{cm}$. long; raceme dense, 1-2 dm. long; bracts lanceolate, shorter than the buds; corolla blue, about $1 \mathrm{~cm}$. long; banner glabrous, with a light spot; pod $2.5-4 \mathrm{~cm}$. long, normally 6 -seeded. Hills and mountain slopes: Colo--Mont.
Submont.-Mont. Je-Au.

36. L. Hellerae Heller. Stems several, clustered, erect, 3-4 dm. high, fewleaved; leaflets $7-9$, narrowly oblanceolate, $4-5 \mathrm{~cm}$. long, acute; bracts narrowly lanceolate, shorter than the buds; calyx-lobes lanceolate, the lower $8 \mathrm{~mm}$., the upper $7 \mathrm{~mm}$. long; corolla dark blue, $12-15 \mathrm{~mm}$. long; banner with a lighter spot, Ida. Submont. My.

37. L. ornatus Dougl. Stem erect or decumbent at the base, leafy, 5-10 $\mathrm{dm}$. high; leaflets 5-9, oblanceolate, 4-8 cm. long, acute, appressed silky-canescent; racemes $7-20 \mathrm{~cm}$. long; bracts lanceolate, usually shorter than the buds; lanceolate, 9-10 $\mathrm{mm}$; ; corolla dark blue; banner with a light spot, somewhat pubescent on the back; legume $2.5-3.5 \mathrm{~cm}$. long, 5-7-seeded. Hillsides and plains: Ida.-(? Mont.) -Wash. Plain-Submont. Ap-Je. 38. L. leucopsis Agardb. Stems $4-8 \mathrm{dm}$. high; leaflets $6-12$, densely ap-
pressed silky-canescent, oblanceolate, $3-6 \mathrm{~cm}$. long; raceme dense, 1-2 dm. long;
bracts lanceolate, slightly exceding bracts lanceolate, slightly exceeding the flower-buds; ealyx densely canescent; lower lip lanceolate, 7-8 mm. long, the upper ovate-lanceolate, about $6 \mathrm{~mm}$. long; corolla blue; banner with a light spot, densely hairy outside; pod $2.5-3 \mathrm{~cm}$. Plains: Wash.-Ore.-Nev,-Wyo-Cas., in part. L. axillaris Blankinship. 
39. L. nootkatensis Donn. Stem 3-6 dm. high, stout, more or less decumbent at the base, arachnoid-long-villous, especially upwards; leaflets 6-8, oblanceolate, obtuse and mucronate or acutish, $3-5 \mathrm{~cm}$. long, glabrous above, long-villous beneath; raceme dense, nearly sessile; bracts linear-lanceolate, equalling the calyx; calyx densely villous; lower lip $10 \mathrm{~mm}$., upper lip $8 \mathrm{~mm}$. long; corolla dark blue, glabrous; wings and banner subequal; legume about 4 cm. long, 9-12-ovuled. Wet places: Vancouver Island-Alta.-Alaska. Subalp. Je-Jl.

40. L. Wyethii S. Wats. Stem $2-7 \mathrm{dm}$. high, few-leaved, sparingly longvillous, with spreading hairs; leaflets $8-12$, narrowly oblanceolate, $3-6 \mathrm{~cm}$. long, acute, glabrous above, sparingly long-hairy beneath; calyx villous; upper lip ovate, $5 \mathrm{~mm}$. long, 2-toothed; lower lip laneeolate, 6-7 $\mathrm{mm}$. long, entire; corolla dark blue; wings $12 \mathrm{~mm}$. long; banner glabrous, slightly shorter; keel slightly ciliate; legume 3-4 cm. long, 7-8-ovuled. Grassy hillsides: B.C.-Wash.Ida.-Mont. Submont. My-Je.

41. L. amplus Greene. Stem clustered, 4-10 dm. high, sparingly hairy with long spreading hairs; leaflets $9-10$, oblanceolate, $5-12 \mathrm{~cm}$. long, glabrous above, long-hairy beneath; racemes 1-2.5 dm. long; calyx villous; upper lip 3-5 $\mathrm{mm}$. long, ovate, the lower lanceolate, $5-6 \mathrm{~mm}$. long, entire; corolla dark blue, veined; banner glabrous; keel ciliate. Mountains: Colo. Mont. Je.

42. L. marianus Rydb. Stem 5-10 dm. high, hirsute-villous, with rather short hairs, slender; leaflets 6-8, narrowly oblanceolate, 3-7 cm. long, acute, glabrous above, appressed short-hairy beneath; inflorescence lax, $1-1.5 \mathrm{dm}$. long; calyx villous; lips lanceolate, the upper $7 \mathrm{~mm}$., the lower $8 \mathrm{~mm}$. long; banner slightly pubescent on the back, 8-10 mm. long, light-blue or white, with a darker spot; wings light blue or white, $10-12 \mathrm{~mm}$. long; legume $3-4 \mathrm{~cm}$. long. River banks: Utah. Submont. Jl.

43. L. Burkei S. Wats. Stem 3-8 dm. high, few-leaved, sparingly hairy, with long spreading hairs or nearly glabrous; leaflets about 8 , oblanceolate, 4-8 $\mathrm{cm}$. long, glabrous above, sparingly pubescent or glabrate beneath; raceme dense, 1-3 dm. long; calyx villous; upper lip $5 \mathrm{~mm}$., the lower $7 \mathrm{~mm}$. long; corolla light blue, with dark veins; banner glabrous, about $10 \mathrm{~mm}$. long; wings $12 \mathrm{~mm}$. long; legume $3-4 \mathrm{~cm}$. long, 6-8-seeded. Meadows: B.C.-Wash.-Nev.-Wyo.Mont. Submont.-Mont. Je-Jl.

44. L. cytisoides Agardb. Stem stout, ereet, 6-15 dm. high, leafy, branching, glabrous or nearly so; leaflets 7-10, oblanceolate, 4-12 cm. long, glabrous above, appressed short-hairy beneath, thin; raceme $2-6 \mathrm{dm}$. long; calyx appressedsilky; upper lip $6 \mathrm{~mm}$. long, ovate; lower lip lanceolate, $8 \mathrm{~mm}$. long; corolla blue; wings about $12 \mathrm{~mm}$; banner glabrous, about $10 \mathrm{~mm}$. long; legume $4-5 \mathrm{~cm}$. long, 8-11-seeded. L. rivularis S. Wats., not Dougl. Banks: B.C.-s Calif.Ida. Son.-Submont. My-Je.

45. L. glabratus (S. Wats.) Rydb, Stem 3-4 dm. high, leafy, slender, villous, with spreading hairs; leaflets $7-8$, thin, light green, glabrous above, longciliate beneath, narrowly oblanceolate, $2-3.5 \mathrm{~cm}$. long, acute; inflorescence rather dense, 1-1.5 dm. long; calyx villous; upper lip ovate, $4 \mathrm{~mm}$. long, the lower lanceolate, $5 \mathrm{~mm}$. long; corolla light blue or whitish, tinged with blue; wings 10 $\mathrm{mm}$. long; banner glabrous, slightly shorter; keel glabrous or slightly ciliate. $L$. ornatus glabratus S. Wats. Hills: Colo.-Wyo. Submont. Je.

46. L. polyphyllus Lindl. Stem stout, ereet, 6-15 dm. high, leafy; leaflets 8-16, narrowly oblanceolate, glabrous above, appressed-pubescent or glabrous beneath, $5-12 \mathrm{~cm}$. long, acute; raceme often $3-6 \mathrm{dm}$. long; calyx villous, gibbous; lower lip 7-8 mm. long, lanceolate, the upper ovate, 6-7 mm.; corolla blue or purple, seldom white; wings $12-15 \mathrm{~mm}$. long; banner glabrous, slightly shorter; keel glabrous; pod 4-5 cm. long, about 9-seeded. Meadows: B.C.-Mont.c Calif. Submont.-Mont. My-Je.

47. L. ammophilus Greene. Stem low, $2-6 \mathrm{dm}$. high, mostly leafy at the base, hirsute with long spreading hairs; leaflets $7-11$, obovate or oblanceolate, obtuse or acute, light green and glabrous above, sparsely hirsute beneath, thick, 
2-4 cm. long; racemes 1-2 dm. long; bracts lanceolate, about equalling the calyx; calyx hirsute; upper lip ovate, $5 \mathrm{~mm}$. long, the lower lanceolate, $8 \mathrm{~mm}$. long; corolla blue or purple; banner glabrous, $10-11 \mathrm{~mm}$. long, with a yellowish or reddish spot; wings 11-12 $\mathrm{mm}$. long; keel ciliate on the margin; pod 3-4 $\mathrm{cm}$. long, 4-6-seeded. Sandy bottoms and dry banks: Colo.-Utah-N.M. Submont.-Mont. Ap-Je.

48. L. comatus Rydb. Stem 3-7 dm. high, pubescent with long spreading silky hairs; leaflets narrowly oblanceolate, acute, $2.5-4 \mathrm{~cm}$. long, green, pubescent on both sides; raceme short and dense, 5-15 cm. long; bracts lanceolate-subulate, equalling or exceeding the buds; calyx densely pubescent with spreading hairs; lips almost equal, ovate-lanceolate, $6 \mathrm{~mm}$. long; flowers $8-10 \mathrm{~mm}$. long; corolla bluish purple, rarely white; banner slightly shorter than the broad wings; pod about $4 \mathrm{~cm}$. long, 4-8-seeded. (?) L. habrocomus Greene. Mountains: Colo. -Utah. Mont. Je-Jl.

49. L. sericeus Pursh. Stem erect, 3-6 dm. high, densely silky-hirsute, leafy; leaflets 5-10, narrowly oblanceolate, densely silky, acute, 3-7 cm. long; raceme 1-2 dm. long, rather dense; calyx silky-hirsute; lower lip narrowly lanceolate, 7-9 $\mathrm{mm}$. long; upper lip ovate, 6-7 $\mathrm{mm}$. long; corolla dark blue; banner with a light spot, pubescent on the back; legume about $3 \mathrm{~cm}$. long, 4-6-seeded, Plains and hills: Ore.-Ida.-Wyo.-S.D.-Mont. Submont. My-Au.

50. L. aphronosus Blankinship. Stems 2-4 dm. high, densely pubescent, with short spreading hairs; leaflets 6-8, oblanceolate, densely silky on both sides, 2-3 cm. long, acute; raceme 5-10 $\mathrm{cm}$. long, dense; calyx silky, with short spreading hairs; lower lip linear-lanceolate, $6 \mathrm{~mm}$. long; upper lip ovate, $5 \mathrm{~mm}$. long; corolla blue; banner with light spot, pubescent outside. Fields and plains: Mont. J1-Au.

51. L. Bakeri Greene. Stems several, leafy, 6-10 dm. high, densely hirsutulous, with short spreading hairs; leaflets $7-9$, oblanceolate, densely silky on both sides, acute, $3-6 \mathrm{em}$. long; raceme 1-2 dm. long; calyx densely silky-hirsute with short hairs; lower lip linear-lanceolate, about $8 \mathrm{~mm}$. long; upper lip ovate, $6 \mathrm{~mm}$. long; corolla dark blue to reddish purple; banner with a light spot, sparingly pubescent without; legume $2.5-3 \mathrm{~cm}$. long, 5-6-seeded. $L$. arcentinus Greene. Mountains: Colo. Submont. My-Je.

52. L. cyaneus Rydb. Stem 4-9 dm. high, densely short-villous, very leafy; leaflets $7-11$, oblanceolate, $3-9 \mathrm{~cm}$. long, glabrous or nearly so above, almost velvety beneath, acute; raceme dense, 1.5-2 dm. long; calyx white-velvety; lower lip about $8 \mathrm{~mm}$. long; banner slightly hairy on the back, light blue, with a light brownish spot at the center, about $8 \mathrm{~mm}$. long; wings light blue, about $1 \mathrm{~cm}$. long; pod about $25 \mathrm{~mm}$. long, 4-5-seeded. Mountains: Mont. Jl.

53. L. dichrous Greene. Stem erect, about $1 \mathrm{~m}$. high, densely pubescent with short spreading hairs, leafy; leaflets $7-8$, narrowly oblanceolate, 4-5 $\mathrm{cm}$. long, densely silky-canescent, acute; raceme lax, 1.5-3 dm. long; bracts lanceolate, shorter than the buds; calyx densely pubescent, with short spreading hairs; lower lip linear-lanceolate, $7 \mathrm{~mm}$. long; upper lip ovate-lanceolate, $5 \mathrm{~mm}$. long; corolla 10-12 $\mathrm{mm}$. long; banner shorter than the wings, pubescent without; legume about $3 \mathrm{~cm}$. long, about 5-seeded. Mountains: Colo. Submont. Je.

54. L. flavicaulis Rydb. Stems several, densely pubescent, with short yellowish spreading hairs, almost velutinous, $3-5 \mathrm{~cm}$. high; leaflets $7-10$, narrowly oblanceolate, usually conduplicate, densely silky on both sides, acute, $2-4 \mathrm{~cm}$. long; racemes dense, $5-10 \mathrm{~cm}$. long; bracts subulate, shorter than the buds; calyx villous; lower lip lanceolate, $7 \mathrm{~mm}$. long; upper lip ovate, 5-6 $\mathrm{mm}$. long; corolla about $10 \mathrm{~mm}$. long; legume $2-2.5 \mathrm{~cm}$. long, 3-4-seeded. River bottoms: Wyo.-Utah. Submont.

55. L. macrostachys Rydb. Stem 5-10 dm, high, puberulent and with long silky spreading or reflexed hairs; leaflets 7-8, linear-oblanceolate, acuminate, 3-6 $\mathrm{cm}$. long, appressed-silky on both sides; raceme dense, 2-3 dm. long; calyx velutinous; lower lip broadly lanceolate, obtuse, about $8 \mathrm{~mm}$. long; upper lip ovate, almost as long; corolla $10-12 \mathrm{~mm}$. long, dirty white, tinged with blue; 
banner with a darker spot; legumes fully $2 \mathrm{~cm}$. long, 4-5-seeded. Along river banks: Mont. Submont.

56. L. retrorsus Henders. Stem 6-9 dm. high, hirsute, with reflexed hairs; leaflets greenish-villous above, white-villous beneath, 4-7 cm. long, narrowly oblanceolate; racemes 6-30 $\mathrm{cm}$. long; flowers 8-12 $\mathrm{mm}$. long; upper calyx lip shorter than the lower; banner pubescent; keel ciliate; pod $2 \mathrm{~cm}$. long, 3-6seeded. Grassy places: Ida. Au.

57. L. leucophyllus Dougl. Stem 6-10 dm. high, leafy, branched, velutinous and with scattered longer, spreading or reflexed hairs; leaflets $7-10$, oblanceolate, $3-7 \mathrm{~cm}$. long, densely silky-canescent on both sides, in age fulvous; racemes dense, $1.5-3 \mathrm{dm}$. long, sessile or nearly so; calyx velutinous; lower lip lanceolate, 8-9 mm. long, the upper lance-ovate, 7-8 mm. long; corolla 10-12 mm. long, light blue, pink, or white, with darker striations; banner with a lighter spot, densely hairy without; legume about $2.5 \mathrm{~cm}$. long, 5-6-seeded. Meadows and hills: Wash.-Calif.-Utah-Wyo.-Mont. Submont.-Mont. My-Jl.

58. L. plumosus Dougl. Stem stout, erect, 5-8 dm. high, densely pubescent partly with short, partly with long shaggy, reflexed or spreading hairs; leaflets $5-9$, oblanceolate, densely long-silky on both sides, acute, $3-5 \mathrm{~cm}$. long; racemes dense, 1-2 dm. long; calyx gibbous, shaggy-silky; lower lip lanceolate, $7 \mathrm{~mm}$. long, the upper ovate, $6 \mathrm{~mm}$. long; corolla light blue or pink; banner with a yellowish spot, densely hairy without; legume $2-2.5 \mathrm{~cm}$. long, 4-5-seeded. Meadows: Wash.-Ore.-Utah-Ida. Submont. Je-Jl.

59. L. Jonesii Rydb. Stem over $1 \mathrm{~m}$. high, densely pubescent with a short pubescence and long spreading silky hairs; leaflets $7-9$, oblanceolate, densely appressed-pubescent, with short yellowish hairs on both sides, 4-7 cm. long; raceme long and dense, many-flowered; flowers about $16 \mathrm{~mm}$. long; calyx yellowish, silky; lips ovate-lanceolate, the lower about 8-9 $\mathrm{mm}$. long, the upper 6-7 $\mathrm{mm}$. long; corolla white or ochroleucous, rarely pinkish; banner with a faint brownish spot; legume about $3 \mathrm{~cm}$. long, 6-7-seeded. Sandy plains and mountains: Utah. Je-Au.

60. L. barbiger S. Wats. Stem 5-7 dm. high, densely pubescent, with short stiff hairs and some longer ones; leaflets $5-7$, narrowly oblanceolate, silky on both sides, 4-7 cm. long; bracts setaceous, longer than the calyx; lower calyxlip narrow, lanceolate, entire, slightly longer than the ovate upper one; corolla $1 \mathrm{~cm}$. long, mostly ochroleucous; petals subequal; keel copiously ciliate; pod about 7-seeded. Meadows: s Utah.

61. L. ramosus E. Nels. Stems several, 2-4 dm. high, with divaricate branches, finely canescent and sparingly villous; leaflets 5-8, narrowly oblanceolate, densely soft-silky on both sides, 2-4 cm. long; bracts ovate or lanceolate, $2 \mathrm{~mm}$. long; flowers about $1 \mathrm{~cm}$. long; ealyx silky, the lower lip a little longer than the upper; banner silky on the back, pale blue, with a yellowish white spot; pod 3-5-seeded. Dry banks: Wyo. Au.

62. L. depressus Rydb. Plant cespitose; stems decumbent, 1-2 dm. long, appressed silvery silky pubescent; leaflets about 7 , oblanceolate, usually obtusish, $1.5-2 \mathrm{~cm}$. long, densely appressed silvery canescent; racemes short; bracts lanceolate; flowers 8-9 mm. long; calyx long-villous; lips ovate-lanceolate, the lower about one-third longer than the upper; corolla light bluish purple; banner glabrous, slightly shorter than the wings. Gravelly mountain slopes: Ida. Jl.

63. L. aridus Dougl. Densely cespitose; stems 1-2 dm. high, loosely hirsute, leafy at the base; inflorescence loose, $5-10 \mathrm{~cm}$. long; bracts subulate, about equalling the buds; calyx long-silky; lips lanceolate, subequal, about $6 \mathrm{~mm}$. long; corolla purple or violet, about $1 \mathrm{~cm}$. long; pod $1 \mathrm{~cm}$. long, 3-4-seeded. Dry prairies: Wash.-Ore.-Canadian Rockies. Subalp. My-Jl.

64. L. minimus Dougl. Densely cespitose, subacaulescent perennial, 1-1.5 dm. high; leaflets 5-9, oblanceolate or obovate, acute, densely silky canescent, $0.5-1.5 \mathrm{~cm}$. long; raceme short, dense, $2-5 \mathrm{~cm}$. long; bracts lanceolate, acuminate, shorter than the buds; calyx canescent; lips lanceolate, the lower $6 \mathrm{~mm}$., the 
upper $5 \mathrm{~mm}$. long; corolla blue or purple, $9-10 \mathrm{~mm}$. long. L. ovinus Greene. Plains and hills: Wash.-Ore.-Ida.-Alta. Jl-Au.

65. L. erectus Henders. Cespitose perennial; stems 2.5-3.5 dm. high; basal leaves many; leaflets $5-8$, linear-oblong to narrowly oblanceolate, acute, $1.5-4 \mathrm{~cm}$. long, appressed silky-canescent; cauline leaves 1-2; bracts persistent, lanceolate to subulate, equalling the calyx; calyx silky; lips subequal; banner obovate, silky, reflexed. Dry ground: Ida. Submont.-Mont. Jl.

66. L. lepidus Dougl. Densely cespitose perennial; stems 1-4 dm. high, leafy mostly at the decumbent base; leaflets $7-9$, oblanceolate, $1-3 \mathrm{~cm}$. long, silky but green, acute; racemes rather lax, 5-20 cm. long; bracts lance-subulate, about equalling the buds; calyx silky-canescent; lips lanceolate, the lower $6 \mathrm{~mm}$. long, the upper slightly shorter; corolla about $1 \mathrm{~cm}$. long, violet, whiter at the base; legume 1.5-2 cm. long, 4-6-seeded. Meadows: B.C.-Calif.-Ida. Submont. Je-Jl.

67. L. psoraleoides Pollard. Perennial, with a cespitose caudex, subacaulescent; stem 1-1.5 dm. high, densely villous with long white hairs; leaflets $5-7$, oblanceolate, acute, $2-3 \mathrm{~cm}$. long, long-villous; raceme dense, almost sessile, scarcely surpassing the leaves; bracts linear, scarious; corolla about $1 \mathrm{~cm}$. long, violet-purple; banner shorter than the keel; legume $1.5 \mathrm{~cm}$. long, few-seeded. Gravelly soil: Colo. Submont. Au.

68. L. candicans Rydb. Low cespitose perennial, densely white-silky throughout; stems ascending, 1.5-2 dm. high; leaflets about 7, 1.5-2.5 cm. long, oblanceolate, acute, mucronate, mostly conduplicate; raceme rather dense, 3-8 $\mathrm{cm}$. long; calyx densely silky-villous; lower lip about $6 \mathrm{~mm}$., the upper $4 \mathrm{~mm}$. long; corolla dark blue; banner with a light brown spot, glabrous, about $7 \mathrm{~mm}$. long; wings about $9 \mathrm{~mm}$. long; pod $3-4$-seeded. Dry hills and mountains: Mont.-Wyo. Submont. My.

69. L. Evermannii Rydb. Perennial and densely cespitose; stems about $1.5 \mathrm{dm}$. high, slender, erect or ascending, leafy, appressed-hairy; leaflets oblanceolate to linear-oblanceolate, $1-2.5 \mathrm{~cm}$. long, densely canescent on both sides;
raceme very short-peduncled, dense and short; bracts lanceolate, short; flowers 6-7 mm. long; calyx with spreading hairs; lips ovate-lanceolate, the lower about $5 \mathrm{~mm}$. long, the upper $4 \mathrm{~mm}$. long; corolla purplish blue; banner with a light spot, glabrous. Mountains: Ida.-Wyo. Subalp.

70. L. monticola Rydb. Stems numerous, 1-2 dm. high, grayish-strigose, leafy; leaflets $7-9$, narrowly oblanceolate, $2-4 \mathrm{~cm}$. long, acute or acuminate, grayish silky-strigose on both sides; racemes $3-6 \mathrm{~cm}$., densely flowered; bracts $5-8 \mathrm{~mm}$. long, subulate, equalling the calyx; calyx silky-villous; lower lip lanceolate, $7 \mathrm{~mm}$. long, the upper ovate, 2 -toothed, $6 \mathrm{~mm}$. long; flowers dark blue, about $10 \mathrm{~mm}$. long; petals subequal; banner with a light brown spot; legume $2 \mathrm{~cm}$. long, 4-6-seeded. Rocky places in the mountains: 'Mont.-Wyo. Mont.-
Subalp. Jl-Au.

71. L. roseolus Rydb. Stems ascending or decumbent, about $1 \mathrm{dm}$. high, sparingly strigose; leaflets about 7, narrowly linear-oblanceolate, acute, 1-2 cm. long, sparingly silky, short-strigose; raceme $2-4 \mathrm{~cm}$. long; bracts subulate, shorter than the buds; calyx with short spreading hairs; lips broadly lanceolate, subequal, $5-6 \mathrm{~mm}$. long; corolla nearly white, tinged with rose; pod perhaps 1.5
$\mathrm{~cm}$. long. Mountains: Wyo. Mont.

72. L. caespitosus Nutt. Cespitose, almost stemless; leaflets 5-7, oblanceolate, $1-2 \mathrm{~cm}$. long, sparingly pubescent on both sides, with long hairs; raceme subsessile, $1-4 \mathrm{~cm}$. long; bracts setaceous, equalling or slightly exceeding the buds; calyx silky; lower lip lanceolate, about $6 \mathrm{~mm}$. long; upper lip ovate, $3-4$ $\mathrm{mm}$. long; corolla pale blue, lilac or white, 7-8 mm. long; legume $1-1.5 \mathrm{~cm}$. long, Au.

73. L. Watsonii Heller. Stems short, decumbent at the base, with few stem-leaves, long-silky, $1-2 \mathrm{~cm}$. long; leaflets $5-7$, narrowly oblanceolate, loosely ciliate on both sides, with in age brown hairs; raceme 5-12 $\mathrm{cm}$. long; calyx long- 
silky; lower lip lanceolate, $6 \mathrm{~mm}$. long, the upper somewhat shorter and broader; corolla purplish, $8 \mathrm{~mm}$. long; legumes about $1 \mathrm{~cm}$. long, 4-seeded. L. aridus utahensis S. Wats. Mountain sides: Utah-Wyo.-Colo. Submont. J-Au.

74. L. Cusickii S. Wats, Stems densely strigose, 5-8 cm. long; leaflets 5-8, oblanceolate, densely canescent on both sides, $0.5-2 \mathrm{~cm}$. long; racemes $2-3 \mathrm{~cm}$. long; bracts subulate, about equalling the buds; calyx canescent; lower lip lanceolate, $5 \mathrm{~mm}$. long, the upper lance-ovate, $4 \mathrm{~mm}$.; corolla about $7 \mathrm{~mm}$. long, purple; banner glabrous; pod about $1 \mathrm{~cm}$. long, about 3-seeded. Sterile hillsides: Ore.-Ida.-Utah. Son.-Submont. Jl.

75. L. micensis Jones. Branching from the base; branches decumbent, $5-15 \mathrm{~cm}$. long, silky-villous, with long spreading hairs; leaflets obovate, oblanceolate or spatulate, $1-1.5 \mathrm{~cm}$. long, silky-villous, with long spreading hairs, obtuse; racemes $2-5 \mathrm{~cm}$. long; bracts lanceolate, persistent; calyx long-hairy; lips subequal, broadly lanceolate, $4 \mathrm{~mm}$. long; corolla about $7 \mathrm{~mm}$. long, reddish purple; legume about $1.5 \mathrm{~cm}$. long, 3-4-seeded. Sandy or gravelly slopes: Nev.-Utah -Ariz. Son. Ap-My.

76. L. brevicaulis S. Wats. Subacaulescent; leaflets 7-8, cuneate-obovate or spatulate, rounded at the apex, sparingly ciliate on both sides, $7-15 \mathrm{~mm}$. long; peduncles $2-5 \mathrm{~cm}$. long; bracts lanceolate, short, persistent; calyx ciliate; lips ovate, subequal, $3-4 \mathrm{~mm}$. long; corolla $6-8 \mathrm{~mm}$. long, blue; pods 1-1.5 $\mathrm{cm}$. long. On hills: Ore.-Calif.-N.M.-Colo. Son.-Submont.

77. L. Kingii S. Wats. Stem branched near the base, 1-1.5 dm. high, with silky-villous, spreading hairs; leaflets oblanceolate, $1-2.5 \mathrm{~cm}$. long, silky-villous on both sides; racemes 1-3 cm. long; bracts lanceolate, shorter than the buds, persistent; calyx ciliate, lower lip 7-8 mm. long, oblong-lanceolate, the upper broadly ovate; corolla purplish, $8 \mathrm{~mm}$. long; pod ciliate, $1 \mathrm{~cm}$. long. L. Sileri S. Wats. L. capitatus Greene. Dry soil: Utah-Colo-Ariz. Son--Submont. Je-Jl.

78. L. scaposus Rydb. Stem branched at the base, 1-1.5 dm. high, sparingly ciliate; leaflets about 7 , spatulate, $1 \mathrm{~cm}$. long, sparingly silky-hirsute on both sides or glabrous above; raceme 1-4 cm. long; bracts lanceolate, short; calyx ciliate, the lower lip broadly lanceolate, $5 \mathrm{~mm}$. long, the upper ovate; corolla purplish, $6 \mathrm{~mm}$, long, paler at the base; banner shorter than the wings; legume $1 \mathrm{~cm}$. long. Sandy soil: Colo. Son.

79. L. rubens Rydb. Stem ciliate, tinged with red, branched near the base, about $1 \mathrm{dm}$. high; leaflets $6-7$, spatulate, 1-1.5 $\mathrm{cm}$. long, ciliate on both sides or glabrous above, acute; raceme lax, $5-10 \mathrm{~cm}$. long; bracts minute, subulate; calyx ciliate, the lower lip lanceolate, $5 \mathrm{~mm}$. long, the upper barely $3 \mathrm{~mm}$. long; corolla $7 \mathrm{~mm}$. long; banner dark purple, with a yellow spot; wings and keel lighter. Sandy soil: s Utah. L. Son.

80. L. pusillus Pursh. Stem with branches decumbent near the base, stout, $0.5-2.5 \mathrm{dm}$. high, hirsute; leaflets 5-8, oblong-oblanceolate, glabrous above, sparingly hirsute beneath, $2-3 \mathrm{~cm}$. long, rounded at the apex; racemes shortpeduncled, 3-8 $\mathrm{cm}$. long; calyx hirsute-ciliate; lower lip broadly lanceolate, 6 $\mathrm{mm}$. long, the upper $4-5 \mathrm{~mm}$. long; corolla tinged with rose or purple, or almost white, $8-10 \mathrm{~mm}$. long; legume nearly $2 \mathrm{~cm}$. long. Plains and sandy places: Wash.-Nev.-N.M.-Kans.-Sask. Son.-Plain. My-Jl.

\section{TRIFÒliUM (Tourn.) L. Clover, Trefoil.}

Annual or perennial herbs. Leaves alternate, digitately 3 -foliolate, rarely 5-7-foliolate, with toothed (in ours mostly finely denticulate) or rarely entire leaves. Flowers perfect, in heads or short dense racemes, bracted at the base. Calyx pedicelled, campanulate; lobes 5 , elongate, often subequal, or the upper broader and more or less united. Corolla in ours purple, pink, or white; banner in ours straight; wings narrow and longer than the keel. Stamens 10, diadelphous; anthers all alike. Pod flattish or terete, included in the persistent corolla, often indehiscent; seeds few or solitary. 
Heads not involucrate; bracts inconspicuous.

Leaflets 5-7.

Leaflets 3.

I. MACROCEPHALA.

Plants mostly tall; stem leafy; perennials with rootstocks.

Corolla yellow. Corolla white, red, or purple.

Calyx hairy

Heads oblong.

Heads spherical.

Heads sessile; corolla red-purple; free portion of the stipules ovate,

III. Pratensia.

Calyx glabrous. stipules elongate-lanceolate.

Peduncles terminal; corolla dark red or purple. V. Altissima.

Peduncles axillary; corolla white or rose-colored. VI. REPENTIA.

Plants low, pulvinate-cespitose perennials; stems scapiform.

Calyx glabrous; leaflets minutely denticulate.

Calyx pubescent.

Leaflets oval or obovate, strongly veined, and sharply dentate.

VIII. GYMNOCARPA. Leaflets lanceolate or linear-lanceolate, entire-margined and not strongly
veined.

IX. DASYPHYLA.

Heads more or less involucrate by rather conspicuous, usually more or less united bracts.

Plants low, densely cespitose, subacaulescent; bracts if at all united only at the base, not aristate.

Plant densely pubescent.

Plants glabrous.

X. Andina.

XI. PARRYANA.

Plants with elongated leafy stem; bracts united to a monophyllous involucre; leaflets in ours spinulose denticulate.

XII. INVOLUCRATA.

One species.

One species.

One species.

\section{MacROCEPHALA.}

II: PlumosA.

III. Pratensia.

IV. LONGIPEDIA.
1. T. macrocephalum.

2. T. plumosum.

3. T. pratense.

Stem with spreading villous pubescence.

Calyx two-thirds as long as the corolla; teeth 2-3 times as long as the calyx-tube.

4. T. eriocephalum.

Calyx scarcely half as long as the corolla; teeth only slightly longer than the tube. Stem appressed-pubescent or glabrous.

5. T. villiferum.

Banner broad, obtuse; calyx about one-third as long as the corolla.

6. T. macilentum.

Plarrow, acute or acutish; calyx one-half to one-third as long as the corolla. Plant cespitose from a woody root; stem ascending; corolla salmon-colored.

Plant erect, with a creeping rootstock.

7. T. Rusbyi.

Calyx-teeth a little longer than the tube, the upper ones scarcely exceeding it in length; plant usually less than $1.5 \mathrm{dm}$. high; corolla white.

Calyx-teeth much exceeding the tube, 8 . T. orbiculatum. the lower twice as long or nearly so; plant usually over $1.5 \mathrm{dm}$. high.

Lower part of the calyx glabrous, upper part and the teeth villous, with spreading hairs; corolla rose or purple.

Flowers 13-15 mm. long, reflexed in fruit.

Flowers 10-12 $\mathrm{mm}$. long.

Flowers reflexed in fruit; lateral veins of leaves arched.

10. T. harneyense.

Flowers not reflexed; lateral veins of the leaves not arched.

Calyx hairy throughout; corolla white or yellowish white, rarely pinkish.

Flowers not reflexed in fruit. $12 . T$. longipes.

Flowers reflexed in fruit.

Pedicels 1.5-3 mm. long; leaflets broadly oval, ovate, or obovate.

Stem low, decumbent, 1-3 dm. high; leaflets usually broadly obovate or oval.

Stem tall, ereet, 3-4 dm. high; leaflets ovate.

13. T, latifolium.

Pedicels al. T. Aitonii.

narrowly oval.

\section{Altissima.}

15. T. Rydbergii.

Calyx-teeth twice as long as the tube, contorted; leaflets linear to elliptic.

Calyx-lobes scarcely longer than the tube: leaflets $16 . T$. Douglasii. Leaflets broad and obtuse; flowers about $1.5 \mathrm{~cm}$. long.

17. $T$, Beckwithii. 
Upper leaflets lanceolate, acuminate; flowers about $1 \mathrm{~cm}$. long.

\section{REPENTIA.}

18. T. Kingii.

Plant ascending; corolla rose or pink, rarely white,

Plant creeping; corolla white or tinged with pink.

19. T. hybridum.

20. T. repens.

VII. NANA.

Heads 1-3-flowered; flowers not reflexed; calyx-teeth lanceolate; caudex thick, densely cespitose, with short branches. 21 . T. nanum.

Heads several-flowered; flowers reflexed; calyx-teeth subulate; branches of the caudex more slender and elongate.

Corolla purple, $15-20 \mathrm{~mm}$. long.

Corolla white or light rose, 10-15 $\mathrm{mm}$. long.

22. T. Brandegei.

23. T. Haydenii.

Flowers 10-12 $\mathrm{mm}$. long.

Flowers about $8 \mathrm{~mm}$. long.

\section{GYMNOCARPA.}

\section{DASYPHYLLA.}

24. T. subacaulescens. 25. T. gymnocarpon.

Flowers reflexed in fruit; bracts minute, truncate and toothed.

Calyx two-thirds to three-fourths as long as the corolla its teeth fully twice as long as the tube.

26. T. stenolobum.

Caly $x$ about half as long as the corolla, its teeth only slightly longer than the tube. Banner acuminate; leaflets linear-lanceolate.

27. $T$. attenuatum.

Banner obtuse, minutely mucronate; leaflets oblong-Ianceolate to elliptic.

Flowers not reflexed in fruit; bracts more conspius, 28 . T, bracteolatum. attenuate, except in the first species.

Leaves as well as the whole plant densely silvery-white.

Leaves green or brown, though somewhat silky.

Bracts narrow, 1-nerved; leaflets broadest at or below the middle.

Calyx-teeth only slightly longer than the tube; bracts glabrous, much exceeding the calyx-tube.

30. T. lividum.

Calyx-teeth fully twice as long as the tube; bracts pubescent, slightly if any exceeding the calyx-tube.

Banner white or ochroleucous, merely tinged with purple; wings and keel dark purple; pubescence rather loose.

31. T. dasyphyllum.

Banner as well as the other petals reddish purple; pubescence appressed.

Bracts broader, 3-nerved; leaflets broader above the middle.

32. T. scariosum.

33. T. uintense.

One species.

X. Andina.

34. T. andinum.

XI. Parryana.

Banner long-acute, much exceeding the wings; bracts ovate, exceeding the calyx, strongly

purple-veined.
Banner blunt, slightly exceeding the wings.

35. T. salictorum.

Calyx-teeth only slightly unequal; bracts exceeding the calyces; upper stipules broadly obovate.

36. T. Parryi.

Upper calyx-teeth much shorter than the lower; bracts not exceeding the calyces; upper stipules ovate.

Peduncles 1-2 dm. long; bracts ovate.

37. T. inaequale.

Peduncles less than $1 \mathrm{dm}$. Iong; bracts obovate in outline. 38. $T$. montanense.

\section{Perennials.}

\section{INVOLUCRATA.}

Banner white; wings and keel tipped with dark purple; calyx-teeth twice as long as the tube.

39. T. spinulosum.

Banner as well as the other petals purple; calyx-teeth a little longer than the tube. Corolla 12-15 mm. long; involucres to about the middle. $40 . T$. Fendleri.

Corolla about $10 \mathrm{~mm}$. long; involucres cleft to below the middle.

Annuals.

41. T. oxydon.

Involucres much shorter than the flowers, not scarious; teeth long.

Leaflets obovate or elliptic.

Flowers $7-8 \mathrm{~mm}$. long.

Flowers more than $1 \mathrm{~cm}$. long.

Leaflets linear.

42. T. variegatum.

43. T. subsalinum.

44. $T$. oliganthum.

Involueres almost equalling the flowers, scarious at least below, its teeth short or

none.
Involucres glabrous, $8-10 \mathrm{~mm}$. high, its lobes toothed; calyx-teeth ternately

divided, with setiform branches.
Involucres hairy, $5-7 \mathrm{~mm}$. high, its lobes entire; calyx-teeth simple. 45. $T$. cyanthiferum.

46. T. microcephalum.

One species.

XIII. Agraria.

47. T. procumbens. 
1. T. macrocephalum (Pursh) Poir. Perennial; stem 1-2 dm. high, stout, somewhat villous; leaflets $5-7$, villous on both sides, or soon glabrate above, cuneate or obovate, strongly veined, 1-2 $\mathrm{cm}$. long; head short-peduncled; calyx villous, lobes subulate, plumose, about $1 \mathrm{~cm}$. long; corolla purplish, about $2 \mathrm{~cm}$. long; pod stipitate. T. megacephalum Nutt. Wet meadows: Wash.-Ida.Calif. Son. Ap-My.

2. T. plumosum Dougl. Perennial; stem erect, $3-8 \mathrm{dm}$. high, densely pubescent with short ascending hairs; leaflets linear to oblanceolate, $3-5 \mathrm{~cm}$. long, acute, finely strigose; head elongate, $4-5 \mathrm{~cm}$. long, $2 \mathrm{~cm}$. thick; calyx-tube $4 \mathrm{~mm}$. long, densely villous; teeth setaceous, $8 \mathrm{~mm}$. long, plumose; corolla white or pink, about $15 \mathrm{~mm}$. long. Meadows: Ida.-Ore. Submont.-Mont. Jl.

3. T. pratense L. Stem erect or decumbent, 2-6 dm. high, more or less pubescent; leaflets oval or obovate, $2-3 \mathrm{~cm}$. long, rounded or retuse at the apex, often with a purplish spot in the middle; heads globose or nearly so, subsessile; calyx-tube about $3 \mathrm{~mm}$. long, sparingly hairy; teeth subulate, $3 \mathrm{~mm}$. long; corolla about $1.5 \mathrm{~cm}$. long. Meadows, roadsides, and fields: Newf.-Fla.Calif.-B.C.; W.Ind.; cult. and nat.; native of Eu. My-S.

4. T. eriocephalum Nutt. Stem erect or decumbent, 2-4 dm. high; leaflets oblong, acute, more or less villous, $2-3.5 \mathrm{~cm}$. long; flowers reflexed in age; calyx villous; tube $2 \mathrm{~mm}$. long; teeth setaceous, $6-9 \mathrm{~mm}$. long, plumose; corolla ochroleucous, about $12 \mathrm{~mm}$. long. Wet prairies: Wash.-Ida.-Calif.

5. T. villiferum House. Stem slender, erect, 2.5-3.5 dm. high; leaflets oblong-oblanceolate, $2.5-4 \mathrm{~cm}$, long, obtuse at the base, acute at the apex, pubescent on both sides; peduncles $6-13 \mathrm{~cm}$. long; flowers reflexed in fruit; calyx densely villous, especially towards the apex; tube $2 \mathrm{~mm}$. long; teeth subulate, equal, plumose, 3-4 mm. long; corolla pink-purple, 12-14 mm. long. Wet

\section{T. macilentum}

lets of the basal retuse, $2-3.5 \mathrm{~cm}$ leaves ovate or broadly ovate, coarsely dentate, truncate or retuse, $2-3.5 \mathrm{~cm}$. long, thin, glabrous; those of the stem-leaves narrowly lanceteeth setaceous, about $2 \mathrm{~mm}$. Utah-n Ariz. L. Son.

7. T. Rusbyi Greene. Stems several, decumbent, 1-3 dm. long; leaflets oblong to obovate, $1-2 \mathrm{~cm}$. long, glabrous or slightly pubescent beneath; peduncles about $1 \mathrm{dm}$. long; flowers in age reflexed; calyx villous, usually purple-tinged; tube $2 \mathrm{~mm}$. long; teeth subulate-setaceous, $3-4 \mathrm{~mm}$. long; corolla $10-12 \mathrm{~mm}$, long. T. longipes pygmaeum A. Gray. Meadows: Ariz.-SW Colo.-Nev.-Calif.
Submont.-Mont. Je-Jl.

8. T. orbiculatum Kenn, \& MeDerm. Stem 1-2 dm. high, short-pubescent; leaflets $1-2.5 \mathrm{~cm}$. long, oblong or ovate, rounded or cuspidate at the apex, somewhat pubescent on the lower side; peduncles 4-10 $\mathrm{cm}$. long; flowers reflexed in age; calyx dull green, $7-9 \mathrm{~mm}$. long, short-pubescent; teeth $4-5 \mathrm{~mm}$. long; corolla about $17 \mathrm{~mm}$. long. Meadows: Mont. Je.

9. T. confusum Rydb. Stems erect, simple, 2-3 dm. higb, glabrous below, sparingly strigose above; leaflets of the lower leaves oval and rounded at the apex, of the upper ones lanceolate, and acute, $2-3 \mathrm{~cm}$. long, glabrous or nearly so; peduncles 5-7 cm. long; calyx-tube $2 \mathrm{~mm}$. long, glabrous except the villous margin; teeth villous, 4-5 mm. long, subulate-setaceous. Meadows: s Utah.

10. T. harneyense Howell. Stem ' $2-3 \mathrm{dm}$. high, glabrous or nearly so; leaflets linear, $3-6 \mathrm{~cm}$. long, $2-5 \mathrm{~mm}$. wide, denticulate; heads mostly solitary; calyx-lobes filiform, silky-hairy, longer than the scarious tube; banner with Son. Je.

11. T. pedunculatum Rydb, Stems $2-4 \mathrm{dm}$. high, rather slender, striate, glabrous or nearly so; leaflets oblanceolate to linear, acute, $2-3.5 \mathrm{~cm}$. long; 
peduncles $1 \mathrm{dm}$. or more long; flowers $10-12 \mathrm{~mm}$. long; calyx-tube $2 \mathrm{~mm}$. long, glabrous below, pubescent towards the throat; calyx-teeth subulate, the lower 3-3.5 mm. long. Valleys: Ida. Submont. Jl.

12. T. longipes Nutt. Stem solitary, erect, simple, 1-3 dm. high, sparingly strigose above; leaflets lanceolate or oblong, acute, $2-4 \mathrm{~cm}$. long, or the lower elliptic-obovate, obtuse, glabrous above, pubescent beneath; peduncles 1-2 dm. long; calyx pubescent; tube $2 \mathrm{~mm}$. long; teeth setaceous, $5-7 \mathrm{~mm}$. long; corolla white, $10-12 \mathrm{~mm}$. long. Meadows: Wash.-Ida.-Calif. Submont.Mont. Je-Jl.

13. T. latifolium (Hook.) Greene. Stems strigose, decumbent, 1-2 dm. high; leaflets oval or obovate, $1-2 \mathrm{~cm}$. long; peduncles $5-10 \mathrm{~cm}$. long; calyx villous throughout; tube $2 \mathrm{~mm}$. long; teeth subulate, about $3 \mathrm{~mm}$. long; corolla 12-15 $\mathrm{mm}$. long. T. longipes latifolium Hook. (?) T. brachypus Blankinship. Grassy slopes: Ida.-Wash.-Ore. Submont.-Mont, My-Je.

14. T. Aitonii Rydb. Stem 3-4 dm. high, glabrous below, strigose above; leaflets ovate, thin, obtuse or rounded and mucronate at the apex, $2-4.5 \mathrm{~cm}$. long, glabrous above, sparingly hairy beneath; peduncles several, 1-2 dm. long; calyx pubescent throughout; tube $2 \mathrm{~mm}$. long; teeth subulate, about $4 \mathrm{~mm}$. long; corolla about $12 \mathrm{~mm}$. long. Meadows: Ida. Submont. Je.

15. T. Rydbergii Greene. Stems usually erect, usually single, $2-4 \mathrm{dm}$. high, glabrous below, strigose above; leaflets lanceolate to oval, $2-4 \mathrm{~cm}$. long or those of the basal leaves shorter and broader, usually acute, sharply denticulate, glabrous or slightly pubescent beneath; peduncles $5-10 \mathrm{~cm}$. long; calyx pubescent; tube $2 \mathrm{~mm}$. long; teeth subulate-setaceous, 4-5 mm. long; corolla white, about $15 \mathrm{~mm}$. long. T'. longipes reflexum A. Nels. . Wet meadows: Ida.-Utah -Colo.-Mont. Submont.-Mont. Je-Au.

16. T. Douglasii House. Stem erect, strict, glabrous, $3-7 \mathrm{dm}$. high; leaflets veiny, glabrous, $2-6 \mathrm{~cm}$. long; those of the lower leaves broader and shorter; peduncle 5-10 cm. long; head usually somewhat ellipsoid; flowers somewhat reflexed in fruit; calyx glabrous, veiny; tube nearly $3 \mathrm{~mm}$. long; teeth subulate, about $5-6 \mathrm{~mm}$. long; corolla $12-15 \mathrm{~mm}$. long. T. altissimum Dougl., not Loisel. Low prairies and meadows: Wash.-Ida.-Calif. Submont. Je-J.

17. T. Beckwithii Brewer. Stem stout, erect, glabrous, $3-5 \mathrm{dm}$. high; leaflets elliptic or oval, the upper acute, the lower rounded at the apex, strongly veiny, glabrous, $2-4 \mathrm{~cm}$. long; peduncles $1-2 \mathrm{dm}$. long; heads globose; flowers reflexed in age; calyx glabrous; tube nearly $3 \mathrm{~mm}$. long; teeth subulate, 3-4 mm. long; corolla reddish purple. Wet meadows: S.D.-Mont.-Ore.-Calif, Plain -Mont. Je-Jl.

18. T. Kingii S. Wats. Stem erect, $2-3 \mathrm{dm}$. high, glabrous; leaflets of the lower leaves oval or elliptie, rounded at the apex, dentate, veined, glabrous, 1.5$4 \mathrm{~cm}$. long, those of the upper leaves linear-lanceolate, sharply dentate, acuminate; peduncles 8-10 $\mathrm{cm}$. long, glabrous; heads globose; flowers reflexed in fruit; calyx glabrous or nearly so; tube nearly $3 \mathrm{~mm}$. long; teeth subulate, about 4 $\mathrm{mm}$. long; corolla reddish purple. Wet meadows: Utah. Mont. Je-Au.

19. T. hybridum L. Stems several, glabrous, ascending or erect, $3-6 \mathrm{dm}$. high; leaflets broadly obovate, 1-3 cm. long, glabrous, rounded or rarely emarginate at the apex; peduncles $5-10 \mathrm{~cm}$. long; heads globose; flowers reflexed in fruit; calyx glabrous; tube $1.5-2 \mathrm{~mm}$. long; teeth subulate, $2-3 \mathrm{~mm}$. long. Pastures and waste places: N.S.-Fla.-Calif.-Wash.-W. Ind.; cultivated and escaped, native of Eu. Je-S.

20. T. repens L. Stems creeping, 1-6 dm. long, glabrous; leaflets obovate, emarginate or obcordate, $0.5-2 \mathrm{~cm}$. long; glabrous; peduncles $1-3 \mathrm{dm}$. long; flowers reflexed in age; calyx glabrous or essentially so; tube about $2 \mathrm{~mm}$. long; teeth lance-subulate, $1.5 \mathrm{~mm}$. long; corolla $7-8 \mathrm{~mm}$. long. Waste places, roadsides and pastures: N.S.-Fla.-Calif.-B.C.; W. Ind.; cult. and escaped; native of Eurasia. Ap-O.

21. T. nanum Torr. Leaflets from linear-oblanceolate to cuneate-oblong, glabrous, strongly veined, $5-10 \mathrm{~mm}$. long; peduncles 1-3 $\mathrm{cm}$. long; heads 1-3- 
flowered; flowers ascending; calyx glabrous; tube about $4 \mathrm{~mm}$. long; teeth lanceolate, about $2 \mathrm{~mm}$. long; corolla reddish purple or rose, nearly $2 \mathrm{~cm}$. long. High mountains: Mont.-Colo.-Utah. Mont.-Alp. Jl-Au.

22. T. Brandegei S. Wats. Leaflets from broadly obovate to elliptic, rounded and short-mucronate at the apex, glabrous, $1-3 \mathrm{~cm}$. long; peduncles $5-15 \mathrm{~cm}$. long; heads loosely flowered; calyx glabrous or sparingly hairy, usually purple; tube $2 \mathrm{~mm}$. long; teeth lance-subulate, $3-4 \mathrm{~mm}$. long. High mountains: Colo. Subalp.-Alp. Jl-Au.

23. T. Haydenii Porter. Subacaulescent; leaflets broadly obovate or suborbicular, rather coarsely denticulate, $5-20 \mathrm{~mm}$. long, glabrous; peduncles $5-15$ $\mathrm{cm}$. long, slender; flowers reflexed in age; calyx glabrous; tube fully $2 \mathrm{~mm}$. long; teeth subulate, $3 \mathrm{~mm}$. long. Mountain meadows and wet slopes: Mont.-Wyo. Submont.-Mont. Jl-Au.

24. T. subacaulescens A. Gray. Leaf-blades oval or elliptic, $1-2.5 \mathrm{~cm}$. long, bright green and glabrous above, silky-canescent beneath; peduncles $2-5$ $\mathrm{cm}$. long, strigose; heads globose; flowers reflexed in age; calyx canescent; tube 2.5-3 mm. long; teeth subulate, about $2.5 \mathrm{~mm}$. long; corolla purplish or salmoncolored, 10-12 mm. long. T. nemorale Greene. Open pine woods: Colo.N.M. Submont. My-Je.

25. T. gymnocarpon Nutt. Leaflets oval to elliptic, glabrous above, strigose beneath, 5-10 $\mathrm{mm}$. long; peduncles $1-4 \mathrm{~cm}$. long; flowers reflexed in age; calyx strigose; tube about $1.5 \mathrm{~mm}$. long; teeth subulate, $1.5-2 \mathrm{~mm}$. long; corolla ochroleucous, about $8 \mathrm{~mm}$. long; pod globose, hirsute, reticulate-rugose, dehiscent. Dry hills: Mont.-Colo.-Utah. Submont. My-Je.

26. T. stenolobum Ryeb. Leaflets narrowly lanceolate or oblanceolate, $1.5-4 \mathrm{~cm}$. long, finely strigose, very acute or acuminate; scape $1-1.5 \mathrm{dm}$. long; calyx-tube silky-strigose, 4-5 mm. long; teeth almost filiform, 7-9 $\mathrm{mm}$. long; banner about is mm. long, obtuse, mucronate. Alpine peaks: Colo. Subalp. -Alp. Jl.

27. T. attenuatum Greene. Leaflets narrowly linear, attenuate, $1-4 \mathrm{~cm}$. long, entire, with scattered hairs; peduncles $5-7 \mathrm{~cm}$. long, sparingly strigose; calyx sparingly villous; tube $2.5-3 \mathrm{~mm}$. long; teeth subulate, $2-3 \mathrm{~mm}$. long; corolla reddish purple, $15-18 \mathrm{~mm}$. long. High mountains: Colo. Alp. Au.

28. T. bracteolatum Rydb. Leaflets bright green, elliptic or lanceolateoblong, acute at each end, $1-2.5 \mathrm{~cm}$. long, strigose; peduncle $5-12 \mathrm{~cm}$. long; calyx densely strigose; tube $3 \mathrm{~mm}$. long; teeth subulate-filiform, 4-6 $\mathrm{mm}$. long; corolla pale rose-purple or lilac, in age turning light brownish, about $1 \mathrm{~cm}$. long. T. lilacinum Rydb., not Greene. T, petraeum Greene. High mountains: Colo. Subalp.-Alp. Jl.

29. T. anemophilum Greene. Leaflets linear-oblanceolate, $1-2 \mathrm{~cm}$. long, entire, acuminate; peduncles $1-3 \mathrm{~cm}$. long; bracts short, 3-5 $\mathrm{mm}$. long, lanceolate or ovate, acuminate or 3-dentate at the apex; calyx canescent; tube $2 \mathrm{~mm}$. long; teeth subulate, about $4 \mathrm{~mm}$. long; corolla reddish purple, about $15 \mathrm{~mm}$. long. Dry rocky hillsides: Wyo. Submont. My-Je.

30. T. lividum Rydb. Leaflets linear-lanceolate or oblanceolate, very acute at both ends or cuspidate at the apex, 3-4 cm. long, glabrous above, sparingly appressed-hairy beneath; peduncles $1-1.5 \mathrm{dm}$. high; bracts linear-subulate to almost filiform; calyx-tube $2.5-3 \mathrm{~cm}$. long; teeth subulate-filiform, $4-5 \mathrm{~mm}$. long; corolla about $12 \mathrm{~mm}$. long, light purple, with a darker keel. High peaks: Colo.-Wyo. Subalp.-Alp. Ji-Au.

31. T. dasyphyllum Torr. Leaflets linear-oblong, acuminate or attenuate at both ends, 1-3 cm. long; peduncles 2-10 $\mathrm{cm}$. long; bracts linear-lanceolate, more or less searious-margined; calyx loosely pubescent; tube $3 \mathrm{~mm}$. long; teeth subulate, about $6 \mathrm{~mm}$. long; corolla $12-15 \mathrm{~mm}$. long. High mountains: Colo. Submont.-Alp. Je-Au.

32. T. scariosum A. Nels. Leaflets narrowly linear-oblong, short-acuminate at both ends, $1.5-2.5 \mathrm{~cm}$. long; peduncles 4-6 cm. long; bracts linear-lance- 
olate, scarious-margined, abruptly long-acuminate; calyx canescent-strigose; tube about $3 \mathrm{~mm}$. long; teeth subulate, about $8 \mathrm{~mm}$. long; corolla about $15 \mathrm{~mm}$. long. Stony slopes: Wyo.-Utah-Mont. Submont.-Mont. Je-Jl.

33. T. uintense Rydb. Leaflets oblanceolate, acute and mucronate, entire, 1-2 cm. long, sparingly pubescent or glabrate above; peduncle about $6 \mathrm{~cm}$. long; bracts lanceolate, $5-8 \mathrm{~mm}$. long, slightly if at all scarious-margined; calyx only slightly pubescent; tube $2.5 \mathrm{~mm}$. long; teeth subulate-setaceous, about $7 \mathrm{~mm}$. long; corolla purple, about $15 \mathrm{~mm}$. long. Mountains: Utah. Subalp.

34. T. andinum Nutt. Stems $1-5 \mathrm{~cm}$. long, scapiform, with two leaves close under the heads, strigose-canescent; leaflets oblanceolate to cuneate-oblong, 5-10 $\mathrm{mm}$. long, densely canescent on both sides; heads sessile; calyx canescent; tube 3-4 mm. long; teeth subulate, $4 \mathrm{~mm}$. long; corolla ochroleucous, $8 \mathrm{~mm}$. long, 1-seeded. Stony hillsides and mountains: Wyo.-Utah. Submont. Je-Jl.

35. T. salictorum Greene. Leaflets elliptic, acute or obtuse, 1-2 cm. long; peduncles 4-10 $\mathrm{cm}$. long; bracts ovate or obovate, $5-10 \mathrm{~mm}$. long, acute, more or less toothed or cleft at the apex; calyx-tube $3 \mathrm{~mm}$. long; teeth unequal, the upper 1.5-2 mm., the lower 3-4 mm. long; corolla bluish purple, about $15 \mathrm{~mm}$. long. High mountains: Colo. Subalp.-Alp. Jl.

36. T. Parryi A. Gray. Leaflets from oblanceolate to oval or obovate, usually sharply denticulate, 1-4 cm. long, acute or obtuse; peduncles $5-15 \mathrm{~cm}$. long; bracts usually obovate, purple-veined and more or less toothed; calyxtube $2.5-3 \mathrm{~mm}$. long; teeth lanceolate, 2-3 mm. long; corolla purple, 15-17 mm. long. High mountains: Wyo,-Utah-Colo. Subalp.-Alp. J1-Au.

37. T. inaequale Rydb. Leaflets oblanceolate or oblong, acute or obtuse, minutely denticulate, rather fleshy, $1.5-3 \mathrm{~cm}$. long; peduncles 1-2 dm. long; bracts ovate or lanceolate, $5-7 \mathrm{~mm}$. long; calyx-tube $3 \mathrm{~mm}$. long; teeth unequal, the upper 2-2.5 mm., the lower 3.5-4 mm. long, lance-subulate; corolla purple, about $15 \mathrm{~mm}$. long. Mountains: Utah. Subalp.-Alp.

38. T. montanense Rydb. Leaflets $0.5-2 \mathrm{~cm}$. long, obovate, rounded and mucronate at the apex; peduncles 2-10 $\mathrm{cm}$. long; ascending or decumbent; head 8-20-flowered; bracts obovate, often bluntly toothed, obtuse or acute; sepals subulate, the lower fully $3 \mathrm{~mm}$., the upper scarcely $2 \mathrm{~mm}$. long; corolla dark purple, about $12 \mathrm{~mm}$. long. High mountains: Mont.-Wyo. Subalp.-Alp. Jl.

39. T. spinulosum Dougl. Stems decumbent, $3-5 \mathrm{dm}$. long, glabrous; leaflets oblong to oval, acute at each end, $1.5-2.5 \mathrm{~cm}$. long; involucre about 8 $\mathrm{mm}$. high, cleft about halfway down, again incised, with lanceolate spinulose teeth; calyx glabrous; tube $3 \mathrm{~mm}$. long; teeth lanceolate-subulate, $5-7 \mathrm{~mm}$. long; corolla 12-15 mm. long. Wet meadows: Wash.-Ida.-Calif. Submont. $\mathrm{Je}-\mathrm{Jl}$.

40. T. Fendleri Greene. Stem erect or decumbent, $2-5 \mathrm{dm}$. high; leaflets of the lower leaves obcordate or obovate and emarginate, about $1 \mathrm{~cm}$. long; leaflets of the upper leaves oblong or oblanceolate, about $3 \mathrm{~cm}$. long; peduncles 5-15 cm. long; involucre 5-8 $\mathrm{mm}$. high, whitish at the base; calyx glabrous, about $3 \mathrm{~mm}$. long; teeth subulate, $4 \mathrm{~mm}$. long, subequal. Wet meadows: Colo, -Utah-Ariz.-N.M.; Mex. Son.-Submont.

41. T. oxyodon Greene. Stem ascending, 1-2 dm. high; leaflets oblong to linear-oblanceolate, acute or the lower obtuse, $0.5-2 \mathrm{~cm}$. long; peduncles $1-3 \mathrm{~cm}$. long; involucres 6-7 mm. high; ealyx glabrous; tube $2 \mathrm{~mm}$. long; teeth subulate, $3 \mathrm{~mm}$. long; corolla purple. Meadows: Colo. Submont. Au.

42. T. variegatum Nutt. Glabrous; stems decumbent or ascending, often branched; leaflets obovate or oblong-obovate, rounded or emarginate at the apex, minutely 5-10 $\mathrm{mm}$. long; involucre $2-3 \mathrm{~mm}$. high, cleft to about the middle and laciniately spinulose-lobed; calyx glabrous; tube $2 \mathrm{~mm}$. long; teeth lanceolate, spinulose-acuminate, $2 \mathrm{~mm}$. long; corolla dark purple, tipped with white. Grassy slopes: B.C.-Calif.-Utah-Mont. Son.-Submont. My-Au.

43. T. subsalinum Greene. Glabrous; stem hollow, flaccid, prostrate, 1-6 dm. long; leaflets obovate or obovate-oblong, mostly $1.5-2 \mathrm{~cm}$. long, obtuse, 
none emarginate; peduncles slender, twice as long as the leaves; involucre only slightly lobed, laciniate. Subsaline ponds: Nev.-Wyo. Plain.

44. T. oliganthum Steud. Glabrous; stem erect, slender, 2-4 dm. high. branched; leaflets of the lower leaves cuneate-oblong, of the upper linear or lancelinear, acute; involucre $3 \mathrm{~mm}$. high; divided below the middle and laciniately spinulose-toothed; head few-flowered; calyx-tube $2.5 \mathrm{~mm}$. long; teeth lanceolate, spinulose, acuminate, $2 \mathrm{~mm}$. long; corolla dull purple, $6-7 \mathrm{~mm}$. long. T. pauciflorum Nutt., not Urv. T. filipes Greene. Roadsides, hills, and banks: B.C.Calif.-Ariz.; Mex. Submont. Ap-Je.

45. T. cyathiferum Lindl. Glabrous; stem prostrate or ascending, $3-5 \mathrm{dm}$. long; leaflets obovate-cuneate to elliptic, $1-2 \mathrm{~cm}$. long; peduncles $5-10 \mathrm{~cm}$. long; involucre white at the base, $8-10 \mathrm{~mm}$. high, with rounded, spinulose dentate lobes; calyx glabrous; tube inflated, veiny, $3-4 \mathrm{~mm}$. long; teeth ovate; corolla rose-colored. Moist places: B.C.-Ida.-Calif. Submont.

46. T. microcephalum Pursh. Annual; stems ascending or procumbent, branched, usually sparingly villous, $2-4 \mathrm{dm}$. high; leaflets obcordate or obovatecuneate, emarginate, $.5-15 \mathrm{~mm}$. long, sparingly villous; peduncles $3-5 \mathrm{~cm}$. long; involucre white at the base, with ovate acuminate lobes; calyx pubescent; tube and subulate teeth each about $2 \mathrm{~mm}$. long; corolla about $6 \mathrm{~mm}$. long, purplish. Hillsides and wet places: B.C.-L. Calif.-Nev.-Mont. Submont. My-Au.

47. T. procumbens L. Decumbent annual; stem 1.5-4 dm. long; leaflets obovate, truncate or emarginate at the apex, finelý denticulate, $1-1.5 \mathrm{~cm}$. long, the terminal one petiolulate; flowers reflexed in fruit; corolla yellow, striate, marcescent. Fields and roadsides: N.S.-Fla.-Tex.-Colo.-Minn.; adv. or nat. from Eu. My-S.

\section{Medicàgo (Tourn.) L. Medick, Alfalfa, Lucerne, Nonesuch.}

Mostly perennial herbs, sometimes shrubby plants. Leaves alternate, pinnately trifoliolate, with commonly toothed leaflets. Flowers perfect, in elongate or head-like racemes. Calyx pedicelled, campanulate; lobes slender, nearly equal. Corolla purplish or yellow; banner oblong, subsessile; wings nearly oblong; keel obtuse, shorter than the wings. Stamens 10, diadelphous; anthers all alike. Stigma oblique. Pods curved or spirally coiled, often spiny, reticulate, indehiscent.

\section{Pod unarmed.}

Perennial, erect; corolla violet or blue; fruit spirally coiled in 2-3 turns.

Annual, prostrate; corolla yellow; fruit merely curved. Pod prickly, densely spirally coiled, in 2-3 turns; corolla yellow.
1. M. sativa.
2. M. lupulina.

1. M. sativa L. Perennial; stem decumbent or ascending at the base, sparingly hairy, in age glabrous, branched, 3-10 dm. high; leaflets oblong, oblanceolate, or cuneate-obovate, $1-3 \mathrm{~cm}$. long, sharply denticulate towards the apex, obtuse or truncate, mucronate; racemes oblong, 1-5 cm. long; corolla $8-10 \mathrm{~mm}$. long; pods pubescent, twisted into 2-3 spires. AlfFALFA, Lucerne. Fields and fence rows: Me.-Va.-Calif.-B.C.; Eu.; cult. and escaped. My-S.

2. M. lupulina L. Annual; stem prostrate, branched at the base, $3-6 \mathrm{dm}$. long, sparingly pubescent; leaflets usually broadly obovate or obcordate, denticulate above the middle, emarginate and mucronate, sparingly hairy, 4-15 $\mathrm{mm}$. long; raceme dense, short and head-like, less than $1 \mathrm{~cm}$. long; corolla about 3 $\mathrm{mm}$. long; pod pubescent, strongly reticulate. Nonesuch. Fields and waste places: N.S.-Fla.-Mex.-Calif.-Wash.; nat. from Eurasia; rare in the Rocky
Mountains. Mr-D.

3. M. hispida Gaertn. Annual; stem branched at the base, with ascending or spreading branches, glabrous or sparingly strigose; leaflets obovate, rounded to few-flowered heads; corolla yellow; pods several-seeded, reticulate, armed on the edges with curved prickles. M. denticulata Willd. Bur Clover. Waste places: N.S.-Fla.-Tex.-Mont.; Calif.-Wash.; adv. from Eu. Je-Au. 


\section{Melilòtus (Tourn.) Hill. Sweet Clover, Honey Clover.}

Annual or perennial herbs, sweet-scented. Leaves alternate, pinnately trifoliolate, with toothed leaflets. Flowers perfect, in elongate lax racemes. Calyx pedicelled, campanulate, teeth 5, nearly equal. Corolla yellow or white, free from the filaments; banner abruptly contracted at the base, subsessile; wings narrow, cohering with the short obtuse keel. Stamens 10, diadelphous; anthers equal. Stigma terminal. Pods short and thick, straight, often subglobose, indehiscent or nearly so, in ours reticulate.

Corolla white; banner a little longer than the wings.

Corolla yellow; banner about equalling the wings.

1. M. alba.

2. M. officinalis.

1. M. alba Desv. Stem 1-3 m. high, erect, branched, glabrous, or puberulent when young; leaflets obovate, oblanceolate or oblong, denticulate except at the base, $1.5-2.5 \mathrm{~cm}$. long, usually truncate at the apex; corolla white, $4-6 \mathrm{~mm}$. long. Waste places and roadsides: N.S.-D.C.-N.M.-Calif.-Wash.; adv. or nat. from Eurasia, or escaped from cultivation. My-S.

2. M. officinalis (L.) Lam. Stem erect, 1-3 m. high, glabrous, or slightly pubescent when young; leaflets from broadly obovate to oblong, sharply denticulate, except at the base, about $2 \mathrm{~cm}$. long, rounded or obtuse at the apex; raceme lax and slender; corolla light yellow, 5-7 mm. long. Waste places and roadsides: N.S.-Fla.-Colo.-Utah-Ida.-Mont.; adv. or nat. from Eu., or escaped from cultivation. Je-S.

\section{LÒTUS (Tourn.) L. BIRD'S-FOOT TrefoIL.}

Perennial herbs, mostly with decumbent stems. Leaves alternate, oddpinnate, with foliaceous stipules. Flowers perfect, yellow, in head-like umbels; banner orbicular, spreading; keel prolonged into an incurved beak. Stamens 10, diadelphous; filaments dilated above; anthers equal. Pods elongate, linear, usually straight, dehiscent, many-seeded.

1. L. tenuis Waldst. \& Kit. Perennial, with taproot; stem branched at the base; branches slender, widely spreading, prostrate, with assurgent tips, 1.5-5 $\mathrm{dm}$. long; leaflets 3 , narrowly oblong or oblanceolate, 6-15 mm. long; flowers eapitate, 3-7; calyx-tube obconic; lobes linear-subulate, about as long as the tube; corolla yellow, about $1 \mathrm{~cm}$. long; pod $2-2.5 \mathrm{~cm}$. long, $2 \mathrm{~mm}$. broad. $L$. tenuifolius (L.) Reich. L. Macbridei A. Nels. Bottom lands: Ida.; introduced from Eu. Je.

\section{ACMÍsPON Raf.}

Leafy-stemmed annuals. Leaves alternate, pinnately 1-5-foliolate, with small gland-like stipules. Flowers perfect, usually solitary, on bracted axillary peduncles. Petals usually pinkish, slightly exceeding the calyx; claws equally approximate to each other; banner rounded; wings oblong; keel narrowed above into a rather short acute, incurved beak, equalling or exceeding the wings. Stamens diadelphous; filaments alternately dilated under the subequal anthers. Pods linear, straight or nearly so, somewhat compressed, readily dehiscent, many-seeded.

Leaves subsessile; petiolule of the terminal leaflet ascending.

Leaves distinctly petioled; 1. americanus.

at least spreading.

2. A. elatus.

1. A. americanus (Nutt.) Rydb. Stem 3-5 dm. high, silky when young, much branched, with strongly ascending branches; leaves 1-3-foliolate; leaflets lanceolate or linear-lanceolate, acute, silky-villous, in age glabrate, 1-2 cm. long; peduncles 7-25 mm. long; bracts linear-lanceolate; calyx-teeth subulate, subequal, $4 \mathrm{~mm}$. long, nearly equalling the pinkish corolla. Hosackia Purshiana Benth. Lotus americanus (Nutt.) Bishop. Prairies, especially in sandy soil: Minn.-Ark.-Tex.-Sonora-Ida. Plain-Submont. Je-Au.

2. A. elatus (Nutt.) Rydb. Stem sparingly silky-villous, with ascendingspreading branches, 3-6 dm. high; leaves 1-3-foliolate; lateral leaflets obliquely oblong-lanceolate, acutish or obtuse, 1-2 cm. long, silky-villous; terminal leaf- 
let elliptic or oval; peduncles 1-3 cm. long; bracts ovate; calyx--teeth subulate, about $3 \mathrm{~mm}$. long, one-fourth or one-third shorter than the whitish corolla. Hosackia elata Nutt. Sandy soil: Wash.-Ida.-Ore. Son.-Submont. Je-Jl.

\section{HOSÁCKIA Dougl. BIRD's-Foot.}

Perennial herbs, with leafy stems. Leaves alternate, regularly odd-pinnate, with foliaceous stipules. Flowers perfect, in bracted several-flowered umbels or heads. Calyx campanulate; lobes subequal. Banner broad, its claw remote from the others; wings partially coherent to the very obtuse keel. Stamens 10, diadelphous, the alternate filaments dilated below the anthers. Pods linear, straight, or nearly so, 5-20-seeded, tardily dehiscent.

1. H. bicolor Hook. Glabrous perennial; stem erect or decumbent at the base, $2-4 \mathrm{dm}$. high; stipules ovate, more or less scarious; leaves pinnate; leaflets 5-9, obovate to elliptic, $1-2 \mathrm{~cm}$. long, obtuse or acute; peduncles 4-10 $\mathrm{cm}$. long, 3-7-flowered; bracts usually lacking; flowers sessile; calyx-tube $4 \mathrm{~mm}$. long, the lower three teeth subulate, $2 \mathrm{~mm}$. long, the upper two lanceolate and more or less united; corolla light yellow or the wings white; pod 6-8 $\mathrm{cm}$. long, glabrous. Lotus pinnatus Dougl. Wet places: B.C.-Ida.-Calif. Submont. Ap-Je.

\section{ANISOLÒtUS Bernh. DEer-WEed.}

Annuals or perennials, with leafy stems. Leaves alternate, pinnate, with an even number (2-10) of leaflets, which, however, are rather irregularly arranged on the rachis; stipules gland-like. Flowers solitary or in small umbels or heads, on axillary peduncles. Calyx campanulate; teeth or lobes nearly equal. Petals free from the staminal tube; banner ovate or rounded; wings oblong; keel acute or rounded at the apex. Stamens 10 , diadelphous, the alternating filaments dilated above. Pod flat, linear, straight, dehiscent, mostly many-seeded.

Annual; plant villous; flowers subsessile in the axils of the leaves. 1. A. brachycarpus. Perennials; plant appressed-pubescent; flowers mostly several together, on a peduncle
(except often in No. 2).

Leaflets closely crowded on the very short rachis, oblanceolate to linear; peduncles less than $5 \mathrm{~cm}$. long; stem erect.

Inflorescence 1-2-flowered, usually subsessile in the axils of the leaves; calyx-teeth equalling the tube. Inflorescence 2-5-flowered, distinctly peduncled; calyx-teeth shorter than the
tube.

Leaflets not crowded on the evident rachis; stem decumbent.

Flowers about $1 \mathrm{~cm}$. long; peduncles $1-2 \mathrm{~cm}$. long; leaflets linear-oblong.

Flowers 12-15 mm, long: 4 . A. nummularius.

Leaflets linear to oblong; bracts longer than $4-10 \mathrm{~cm}$. flexed.

列 ascending.

6. A. rigidus.

1. A. brachycarpus (Benth.) Rydb. Stem decumbent or prostrate, diffusely branched, 1-3 dm. long, densely villous; leaves about $2 \mathrm{~cm}$. long, subsessile; leaflets usually 4, oval, 6-10 $\mathrm{mm}$. long, densely villous on both sides; flowers solitary, sessile; calyx-lobes lance-subulate, about $4 \mathrm{~mm}$. long; corolla yackia brachycarpa Benth oblong, about $1 \mathrm{~cm}$. long, villous, 2-3-seeded. Hosackia brachycarpa Benth. Lotus humistratus Greene. Hills: s Utah-Ariz.Calif, Son. Mr-Jl.

2. A. Wrightii (A. Gray) Rydb. Stems numerous, erect or ascending, grayish strigose; leaflets $3-6$, crowded, grayish strigose, linear or linear-oblong, solitary or 2 or 3 , sometimes flowers usually subsessile in the axils of the leaves, linear; calyx-teeth subulate $4 \mathrm{~mm}$. 1-3-flowered peduncles; bracts 1-foliolate, orange, turning red; pod linear . long; corolla about $15 \mathrm{~mm}$. long, yellow or Hills: s Colo- red; pod linear, strigose, $2.5 \mathrm{~cm}$. long. L. Wrightii Greene.

3. A. puberulus (Benth) Son--Submont. My-Au. 3. A. puberulus (Benth.) Woot. \& Standl. Stems erect, $2-3 \mathrm{dm}$. high,
strigose; leaves sessile; leaflets from spatulate to linear, $7-15 \mathrm{~mm}$. long, strigose;
peduncles $2-4 \mathrm{~cm}$. long, $2-5$-flowered; $2-3 \mathrm{~mm}$. long; corolla about 1 clowered; bracts $1-3$-foliolate; calyx-teeth subulate, 
pod linear, 2-3 cm. long, strigose. H. puberula Benth. Sandy places in the mountain valleys: Utah-n Ariz.-N.M. Son.-Submont. J-S.

4. A. nummularius (M. E. Jones) Woot. \& Standl. Stem 1-2 dm. high, diffusely branched, often prostrate; leaves short-petioled or the upper subsessile, ashy gray; leaflets oblong to linear-oblong, 0.5-1.5 $\mathrm{cm}$. long or those of the lower leaves still smaller and rounded-oval; peduncles mostly 1-flowered; calyx-teeth subulate, $3 \mathrm{~mm}$. long; corolla light yellow; pod 1.5-2 cm. long, strigose. $H$. rigida nummularia M. E. Jones. Sandy soil: Utah-Ariz.-N.M. Son. Ap-My.

5. A. longebracteatus Rydb. Stems 2-3 dm. long, diffusely branched, grayish strigose; leaflets 4-5, thick, grayish strigose, linear to oblong, or of the lowest leaves obovate, $1-1.5 \mathrm{~cm}$. long, or the lower shorter; peduncles $4-5 \mathrm{~cm}$. long, 1-2-flowered; bracts linear, about equalling the ealyx; calyx-teeth about 4 $\mathrm{mm}$. long, subulate; corolla-about $14 \mathrm{~mm}$. long, strongly curved upwards; pod linear, straight, $2.5-3 \mathrm{~cm}$. long, pubescent. L. longebracteatus Rydb. Cañons and rocky places: Nev.-s Utah-Ariz. Son. Ap-Je.

6. A. rigidus (Benth.) Rydb. Stems more or less suffruticose, decumbent at the base, branched, strigose, 3-6 dm. high; leaves short-petioled; leaflets 3-5, obovate or cuneate, obtuse or rounded or retuse at the apex, 4-10 $\mathrm{mm}$. long; peduncles 5-15 cm. long, 1-3-flowered; bracts minute; calyx-teeth lance-subulate, $3 \mathrm{~mm}$. long; pod erect or ascending, 2-4 cm. long, sparingly strigose or glabrate. $H$. rigida Benth. Sandy soil: N.M. - S Utah-Ariz.; Mex. Son.

\section{SYRMÀTIUM Vogel.}

Perennial herbs. Leaves alternate, pinnately 3 - or 5-foliolate, with glandlike stipules. Flowers perfect, in 1-few-flowered umbels. Calyx campanulate, deciduous with the pods; teeth 5, nearly equal. Petals free; banner ovate or rounded, its claw remote from those of the other petals; wings obovate; keel broad and obtuse. Stamens diadelphous; the alternate filaments dilated and thickened below the anthers; anthers subequal. Pods usually small, arcuate, slender-pointed, indehiscent, few-seeded.

1. S. decumbens (Benth.) Greene. Cespitose perennial; stems several, ascending to procumbent, 3-7 dm. long, hirsute-strigose; leaflets 3-5, obovate, 5-10 mm. long, rounded to acutish at the apex, villous; peduncles $1 \mathrm{~cm}$. long or less; heads 3-10-flowered, usually with a 1-3-foliolate leafy bract; calyx-teeth setaceous, $2.5 \mathrm{~mm}$. long; corolla yellow, about $8 \mathrm{~mm}$. long; pod curved in a halfcircle, strigose; body nearly $1 \mathrm{~cm}$. long; beak about $5 \mathrm{~mm}$. long. Hosackia decumbens Benth. Lotus Douglasii Greene. Prairies, shores and hillsides: Wash. -Ida.-Calif. Submont. My-Au.

\section{Amórpha L. False Indigo, Shoe-strings.}

Shrubs, with glandular-punctate foliage. Leaves alternate, odd-pinnate. Flowers perfect, incomplete, in spike-like racemes. Calyx subcampanulate; lobes 5, short. Corolla incomplete; banner erect, clawed, folded around the stamens, blue, purple or white; wings and keel lacking. Stamens 10; filaments united at the base only. Ovary 2-ovuled. Pods short, 1-2-seeded, nearly indehiscent.

Tall shrub; leaflets $2-5 \mathrm{~cm}$. long; pods usually 2-seeded; leaves petioled; pod curved.

Low shrubs; leaflets $0.5-1.5 \mathrm{~cm}$. long; pods 1 -seeded.

1. A. angustifolia.

Glabrous or nearly so; spikes usually solitary at the end of the branches; leaves petioled; pod straight.

2. A. nana.

Densely canescent; spikes usually clustered; leaves subsessile; pod curved.

3. A. canescens.

1. A. angustifolia (Pursh.) Boynton. Branched shrub, $1.5-5 \mathrm{~m}$. high; young growth finely strigose-canescent; leaflets 9-27, oval to oblong, 2-4 cm. long, mostly acute at both ends, minutely puberulent; racemes $5-20 \mathrm{~cm}$. long; calyx about $3.5 \mathrm{~mm}$. long; upper two lobes rounded, the others triangular, pointed, the lowest almost twice as long as the rest; banner broadly obovate, short-clawed, 4.5-5 mm. long; pod 6-7 mm. long. A. fruticosa Coult., not L. Banks of streams: Ia.-Ark,-Tex.-Ariz.-Mont. Plain. My-Jl. 
2. A. nana Nutt. Undershrub, 1-4 dm. high, glabrate or minutely strigose; leaflets 15-31, elliptic or oval, rounded at both ends, mucronate, $5-10 \mathrm{~mm}$. long; racemes solitary, 3-6 cm. long; calyx about $3 \mathrm{~mm}$. long, glabrous; lobes lanceolate, acuminate, subequal; banner broadly obovate, purple; pod about $5 \mathrm{~mm}$. long. A, microphylla Pursh. Hills and prairies: Man.-Ida.-Colo.-Wyo. Plain-Submont. My-Je.

3. A. canescens Pursh. Undershrub, 3-10 dm. high, white-canescent; leaflets $15-47$, crowded, oval or ovate-lanceolate, $9-18 \mathrm{~mm}$. long, rounded at the base, acute or obtuse at the apex; racemes clustered, dense, $5-18 \mathrm{~cm}$. long; calyx about $5 \mathrm{~mm}$. long; lobes lance-subulate; banner obovate, $5 \mathrm{~mm}$. long, blue; pod about $4 \mathrm{~mm}$. long. Dry prairies and plains: Man.-Mich.-La.-N.M.Mont. Plain. Je-Au.

\section{PSORÃlea L. Pomme de Pratrie, Pomme Blanche, BREAD-ROOT, INDIAN TURNIP.}

Perennial herbs (all ours) or shrubs, with glandular-punctate foliage. Leaves alternate, 3-5-foliolate, with entire or toothed leaflets. Flowers perfect, in peduncled spikes or racemes. Calyx campanulate, lobes equal, or the lower longer. Corolla in ours white or purplish; banner usually broad and auricled at the base; wings clawed, scythe-shaped; keel shorter than the other petals, incurved. Stamens diadelphous or monadelphous; anther alike. Pods broad, indehiscent, or circumscissile or bursting irregularly, mostly 1-seeded; ovules 1 or 2 .

Flowers small, less than $8 \mathrm{~mm}$. long, in racemes or interrupted spikes; root not tuberous; pod indehiscent. (PSORALIDIUM.)
Stem-leaves reduced to scales.
Stem leaves all $3-5$-foliolate.

Flowers in racemes, $i$. e., distinctly pedicelled.

Pods globose; corolla white, only the keel tipped with purple,

Racemes short and dense, elliptic or oblong; calyx-lobes obtuse.

Leaflets linear to lance-oblong; fruit glabrous or sparingly strigose.

Leaflets lance-oblong to linear.

Leaflets narrowly linear.

Leaflets spatulate or obovate; fruit long-villous.

Racemes lax, elongate, calyx-lobes acute.

Leaves oblanceolate; pod densely villous.

Leaves narrowly linear; pod strigose.

Pods ovoid; corolla blue or purplish; raceme elongate, lax.

2. P. lanceolata.

4. P. Purshii.

5. P. stenostachys.

6. P. stenophylla.

Leaflets from linear-oblanceolate to obovate; pods with short beaks.

Leaflets narrowly linear; pods with longer beaks. $\quad$ 7. P. tenuiflora.

Flowers in interrupted spikes; pods with longer beaks.

Leaves not silvery below; flowers about $6 \mathrm{~mm}$. long; bracts minute.

Leaves silvery-white at least below: 9 . $P$. collina. as long as the calyx.
silvery-white at least below; flowers $7-8 \mathrm{~mm}$. long; bracts at least half

Leaflets oval; bracts lanceolate, acuminate; calyx not inflated in fruit.

Leaflets linear; bracts Leaflets linear; bracts obovate; calyx inflated in fruit. 11. P. digitata.
Flowers large, over $1 \mathrm{~cm}$. long, in dense, head-like spikes; plant with a deep-seated,
tuberous, farinaceous root; pod long-beaked, circumscissile or bursting irregularly. (PEDIOMELUM.)

Tall, leafy and branched, usually over $4 \mathrm{dm}$. high; strigose throughout; lower calyx-

teeth cuspidate-acuminate.
Low and more simple, $1-3 \mathrm{dm}$. high; lower calyx-teeth not cuspidate- P. cuspidata.

Plants with long scattered hairs, lower calyx-teeth not cuspidate-acuminate.

Stem and peduncles hirsute, not cinereous; leaflets linear to obovate. mith spreading pubescence; lower calyx-lobe not

stem larger than the rest. 13. P. esculenta. , short peduncles and pedicels, with appressed pubescence; lower calyx-

Plant cinereous, with short an the rest. 14. P. hypogaea. rounded-spatu short appressed pubescence; leaflets broadly obovate or Lowest calyx-10 Petioles with not much longer than the rest.

Petiol 15. P. megalanth

Lowest calyx-lobe obovate or spatulate, obtuse, much larger than the rest.

17. P. castorea.

1. P. juncea Eastw. Stem 6-10 dm. high, with virgate branches, glabrous or sparingly strigose; basal leaves, if present, digitately $3-5$-foliolate; leaflets 
lanceolate, $2-3 \mathrm{~cm}$. long, grayish strigose and strongly veined; stem-leaves reduced to small lance-subulate scales, $3-4 \mathrm{~mm}$. long; flowers in interrupted spikes terminating the branches; calyx canescent; upper teeth rounded, the lower three broadly triangular; corolla dark blue, $5 \mathrm{~mm}$. long; pod subglobose, $4 \mathrm{~mm}$. thick, canescent. In sand: se Utah.

2. P. lanceolata Pursh. Stem very glandular-punctate, glabrous or sparingly strigose, $1.5-4 \mathrm{dm}$. high; leaflets $1.5-4 \mathrm{~cm}$. long, strigose with scattered hairs or glabrate; peduncles 1-3 cm. long; calyx-tube $1.5 \mathrm{~mm}$. long, campanulate; lobes ovate, obtuse, $0.5 \mathrm{~mm}$. long; corolla $5-6 \mathrm{~mm}$. long; pod $4 \mathrm{~mm}$. thick. Sandy plains: Sask.-Kans.-N.M.-Ariz.-Mont. Plain-Submont. My-Au.

3. P. micrantha A. Gray. Stem very glandular-dotted, glabrous or strigose; leaflets $1-5 \mathrm{~cm}$. long, 1-3 mm. wide, glabrous or nearly so; peduncles $2-4 \mathrm{~cm}$. long; calyx-tube $1 \mathrm{~mm}$. long; lobes rounded-oval, $0.5 \mathrm{~mm}$. long; corolla scarcely $5 \mathrm{~mm}$. long. Sandy plains: Okla.-Tex.-Ariz. $-\mathrm{s}$ Utah. Son. Ap-Jl.

4. P. Purshii Vail. Stems adsurgent, branched, sparingly strigose or glabrate, 1-6 dm. high; leaflets $1.5-4 \mathrm{~cm}$. long, retuse, rounded or acute, and mucronate, sparingly strigose or glabrate; peduncles $2-5 \mathrm{~cm}$. long; calyx and corolla as in P. lanceolata; pod 4-5 mm. thick. Sandy soil: Wash.-Ida.-Ariz.-Calif. Son.-Submont. My-S.

5. P. stenostachys Rydb. Stem adsurgent or erect, sparingly strigose and glandular-dotted, 3-5 dm. high, branched; leaflets $2-4 \mathrm{~cm}$. long, rounded to acute and mucronate at the apex, sparingly strigose; peduncles $5-15 \mathrm{~cm}$. long; calyxtube $1.5 \mathrm{~mm}$. long; teeth $0.5 \mathrm{~mm}$. long; corolla white, $4 \mathrm{~mm}$. long. Sandy soil: Utah. Son. Jl.

6. P. stenophylla Rydb. Stem simple, about $5 \mathrm{dm}$. high, slender, sparingly strigose and glandular-dotted; leaflets $2.5-5 \mathrm{~cm}$. long, about $2 \mathrm{~mm}$. wide, sparingly strigose; peduncle $8-10 \mathrm{~cm}$. long; calyx-lobes triangular, acute, $0.5 \mathrm{~mm}$. long; corolla about $4 \mathrm{~mm}$. long. Sandy river banks: Utah. Son. Je-Jl.

7. P. tenuiflora Pursh. Stems ereet, diffusely branched, striate and strigose; leaflets 1-4 cm. long, glabrous above, strigose beneath; racemes slender, $2-10 \mathrm{~cm}$. long, rather few-flowered; calyx strigose, usually purplish; tube $1.5 \mathrm{~mm}$. long; calyx-lobes lanceolate, $1 \mathrm{~mm}$. long, acute; corolla light blue, $4-5 \mathrm{~mm}$. long; pod ovoid, $8 \mathrm{~mm}$. long. Prairies and plains: S.D.-Tex.-Ariz.-Mont. Plain -Submont. $\mathrm{Je}-\mathrm{O}$.

8. P. linearifolia T. \& G. Stem 4-10 dm. high, widely branching, sparingly strigose; leaflets $2-6 \mathrm{~cm}$. long, 2-3 mm. wide, sparingly strigose beneath, glabrous above; calyx-tube campanulate, $2-2.5 \mathrm{~mm}$. long; teeth lanceolate, acute, 1-1.5 $\mathrm{mm}$. long; corolla blue, $7-8 \mathrm{~mm}$. long; pod ovoid, $8 \mathrm{~mm}$. long. Plains and hills: Neb.-Ark.-Tex.-Colo. Plain. Je-S.

9. P. collina Rydb. Stem 4-6 dm. high, branched, strigose; leaflets oblongoblanceolate, obtuse, $1.5-2.5 \mathrm{~cm}$. long, glabrous or nearly so above, grayish strigose beneath; bracts lanceolate, 2-4 mm. long; calyx densely silky-strigose; tube and the lanceolate lobes each $2 \mathrm{~mm}$. long; corolla blue, about $6 \mathrm{~mm}$. long. Hills: w Neb. Plain. Jl.

10. P. argophylla Pursh. Stem erect, 3-6 dm. high, branched above, strigose-canescent; leaflets $1.5-4 \mathrm{~cm}$. long, 6-20 mm. wide, obovate or oval, obtuse, densely white-silky on both sides, or grayish strigose above; spike rather short; calyx silvery; tube about $2 \mathrm{~mm}$. long; upper teeth 2-3 $\mathrm{mm}$. long, lanceolate, the lower one narrower, $6 \mathrm{~mm}$. long, in fruit over $1 \mathrm{~cm}$. long. Prairies and plains: Sask.-Wis.-Mo.-N.M.-Alta. Plain. Je-Au.

11. P. digitata Nutt. Stem erect, simple below, branched above, canescent, 3-6 dm. high; leaflets 2-3.5 cm. long, 3-5 mm. wide, densely strigose-canescent beneath, sparingly strigose when young, soon glabrate above; spike lax; bracts $5 \mathrm{~mm}$. long; calyx silky; tube in flowers $3-4 \mathrm{~mm}$. long; lobes lanceolate, abruptly acuminate, the upper $2 \mathrm{~mm}$., the lowest one $4 \mathrm{~mm}$. long; corolla $7-8 \mathrm{~mm}$. long, blue; pod ovoid, 6-7 mm. long. P. campestris Nutt. Sandy plains: S.D.Ark.-Tex.-Colo. Plain. My-Jl. 
12. P. cuspidata Pursh. Stems strigose or glabrate, erect, 4-6 dm. high, with spreading branches; leaflets $5,2-4 \mathrm{~cm}$. long, obovate to elliptic, glabrate above, grayish strigose beneath; spikes head-like, 2-5 cm. long; calyx strigose, enlarged in fruit; tube in flowers $4-5 \mathrm{~mm}$. long, gibbous above; lobes ovate to lanceolate-acuminate, the upper two united half their length, $4 \mathrm{~mm}$. long, the lower long-cuspidate, 6-9 mm.; corolla blue, 15-20 mm. long; pod strigose, about $8 \mathrm{~mm}$. long, ovoid. Sandy soil, hillsides: Minn.-Ark,-Tex.-N.M.-Mont. Plain. Ap-Jl.

13. P. esculenta Pursh. Stem erect, 1-3 dm. high, hirsute; leaflets $5,2-6$ $\mathrm{cm}$. long, obovate to oblong, glabrous above, strigose beneath; spike short and dense, 2-8 cm. long; calyx-tube about $5 \mathrm{~mm}$. long, gibbous above, lobes in anthesis lanceolate, the upper four $6 \mathrm{~mm}$. long, the lowest $8 \mathrm{~mm}$.; corolla about $15 \mathrm{~mm}$. long; body of the pod ovoid, $6 \mathrm{~mm}$. long; beak $15 \mathrm{~mm}$. long. Prairies and plains: Sask.-Wis.-Mo.-Okla.-Mont. Plain-Submont. My-Jl.

14. P. hypogaea Nutt. Stem very short, strigose; leaflets $5-7,2-5 \mathrm{~cm}$. long, linear or linear-lanceolate, glabrous or nearly so above, strigose beneath; peduncles 1-5 cm. long, strigose; spike head-like; calyx-tube $4 \mathrm{~mm}$. long, gibbous above; upper 4 lobes lance-subulate, $5 \mathrm{~mm}$. long, the lowest broadly-lanceolate, in flowers 7-10 mm. long; corolla about $12 \mathrm{~mm}$. long. Dry plains: Neb.-Tex.N.M.-Mont. Plain. Je.

15. P. megalantha Woot. \& Standl. Stem very short; leaflets 5-6, obovate, $1-3 \mathrm{~cm}$. long, densely white-strigose beneath, less densely so above; peduncles 1-4 cm. long; raceme $2 \mathrm{~cm}$. long; calyx-tube $5-6 \mathrm{~mm}$. long, gibbous above; lobes all subulate. Hills: n N.M.-w Colo.-e Utah. Son. Je.

16. P. mephitica S. Wats. Stem very short; leaflets 5 , obovate or spatulate, $1.5-2.5 \mathrm{~cm}$. long, grayish strigose on both sides, rounded or retuse at the apex; peduncles $1-5 \mathrm{~cm}$. long, hirsute; spike head-like; calyx-tube $8 \mathrm{~mm}$. long, gibbous above; upper 4 lobes subulate, $6 \mathrm{~mm}$. long, the lowest lanceolate, $8-10$ $\mathrm{mm}$. long; pod about $1 \mathrm{~cm}$. long, with a straight beak. Arid regions: Ariz.s Utah. Son. My-Je.

17. P. castorea S. Wats. Stem $1.5 \mathrm{dm}$. or less high, strigose-canescent; leaflets 3-5, broadly obovate-cuneate, rounded or retuse at the apex, grayish strigose on both sides; peduncles $2-5 \mathrm{~cm}$. long, strigose; spike head-like; calyxtube $3 \mathrm{~mm}$. long, the upper 4 teeth subulate, 6-7 mm. long, the lowest $8-10 \mathrm{~mm}$. long; corolla about $1 \mathrm{~cm}$. long; pod obovoid, $8 \mathrm{~mm}$. long; beak about $1.5 \mathrm{~cm}$. long. Arid regions: s Utah-Ariz.-s Calif.-Nev. Son. My.

\section{PAROSÈLA Cav.}

Perennial or annual herbs or shrubby plants, with glandular-punctate foliage. Leaves alternate, odd-pinnate, with small leaflets. Flowers perfect, in terminal or lateral spikes. Calyx campanulate, its lobes nearly equal. Corolla white, purple, or yellow; banner broad, long-clawed, auricled at the base; wings and keel usually longer than the banner, their claws adnate to the staminal tube. Stamens 10 or 9 , monadelphous; anthers alike. Pods usually included in the calyx, indehiscent, 2-3-ovuled, but usually 1-seeded. [Dalea Willd.]

Wing- and keel-petals inserted at the base of the staminal tube; pods exceeding the
calyx; shrubs. (XYLODALEA.)

Calyx-lobes shorter than the tube.

Leaflets $1-7$, oblong or elliptic.

Leaflets 5-11, linear or linear-oblanceolate.

Calyx-lobes equalling the tube, all lanceolate, nearly similar.

1. P. Fremontii.

2. P. Johnsoni.

Winaly $\quad$ 3. P. amoena. base; pod shorter than the inserted on the staminal tube, some distance from the Stem and leaves glabrous.

Annual; spike dense, cylindric.

Perennial; spike either rather lax or few-flowered. sistent, enclosing spike lax, elongate, several-flowered; bracts obovate, perPlant shrubby; spike head-like, 2-10-flowered, 5 . P. enneandra.

Stem and leaves pubescent.

; bracts ovate, de-

Calyx-lobes short, ovate, not subulate-tipped; spike lax; prostrate or decumbent villous herbs.

7. P. lanata. 
Calyx-lobes subulate-tipped, longer than the tube; plants erect or decumbent, with a short cespitose caudex; spike dense.

Leaves 3-foliolate.

8. P. Jamesii.

Leaves 5-foliolate.

Stem low, 1-2 dm. high, decumbent at the base; spike sessile or short-peduncled.

9. P. carnescens.

Stem tall, 3-5 dm. high, with the upper leaves reduced and spike rather long-peduncled.

10. P. aurea.

1. P. Fremontii (Torr.) Vail. Shrub with white stems; branches eanescentstrigose, somewhat spiny; leaflets often somewhat decurrent on the slightly winged rachis, 5-10 $\mathrm{mm}$. long; spike elongate; calyx strigose; lobes lanceolate, $2 \mathrm{~mm}$. long; corolla indigo-blue; keel about $8 \mathrm{~mm}$. long; banner $6 \mathrm{~mm}$. long; pod ovoid; body $1 \mathrm{~cm}$. long, strigose. Rocky places: s Utah-Nev.-Calif. L. Son. $\mathrm{My}-\mathrm{Je}$.

2. P. Johnsoni (S. Wats.) Vail. Shrub, with light-colored bark; branches strigose; leaflets 8-15 mm. long, $1 \mathrm{~mm}$. wide, strigose-canescent; spike $5-7 \mathrm{~cm}$. long, lax; calyx finely puberulent or glabrous; tube $3-4 \mathrm{~mm}$. long; lobes $2 \mathrm{~mm}$. long, the upper ovate-lanceolate, the rest lanceolate; corolla bluish purple; keel $8 \mathrm{~mm}$. long; banner slightly shorter; pod minutely strigose; body $8 \mathrm{~mm}$. long. Rocky hills: Ariz.-s Utah-Nev. Son. My.

3. P. amoena (S. Wats.) Vail. Branched shrub; branches strigose; leaflets 7-11, narrowly linear, 6-8 mm. long, obtuse, strigose-canescent; spike loose, few-flowered; calyx pilose; tube $4 \mathrm{~mm}$. long; teeth lance-subulate, $4 \mathrm{~mm}$. long; corolla dark purple; keel $10 \mathrm{~mm}$. long; banner slightly shorter; pod densely pubescent. Arid places: s Utah-Nev--Ariz. L. Son. Ap.

4. P. alopecuroides (Willd.) Rydb. Annual; stem erect, glabrous, with ascending branches, 2-6 dm. high; leaflets $15-41$, oblong, cuneate, or oblanceolate, $3-8 \mathrm{~mm}$. long, obtuse at the apex; spike $2-7 \mathrm{~cm}$. long; bracts ovate to lanceolate, acuminate, hyaline-margined; calyx-lobes linear-lanceolate, long-acuminate, plumose; corolla $2.5-3 \mathrm{~mm}$. long, white, tinged with rose or lilac. Dalea alopecuroides Willd. P. Dalea Britton. Prairies: S.D.-Ill.-Ala.-Tex.-N.M. Plain. Je-S.

5. P. enneandra (Nutt.) Britton. Perennial, with a taproot; stem simple below, branched above, 3-10 dm. high, flat-topped; leaflets $5-11$, linear, linearoblong, or oblanceolate, $5-10 \mathrm{~mm}$. long, glabrous, conspicuously glandulardotted; spikes 2-11 cm. long; calyx silky; lobes filiform-subulate, plumose, about $6 \mathrm{~mm}$. long; corolla white; banner about $12 \mathrm{~mm}$., keel $15 \mathrm{~mm}$. long. D. laxiflora Pursh. Prairies: N.D.-Ia.-Mo.-Tex-Colo. Plain. My-Au.

6. P. formosa (Torr.) Vail. Divaricately branched shrub, 3-6 dm. high; leaflets $9-13$, glabrous, cuneate to oblong, $2-4 \mathrm{~mm}$. long, thick, retuse at the apex, revolute; bracts acuminate, ciliate, $5 \mathrm{~mm}$. long; calyx villous; teeth $8 \mathrm{~mm}$., subulate-setaceous, plumose; corolla reddish purple; keel $12-15 \mathrm{~mm}$. long; banner 7-8 mm. long. Dry soil: s Colo.-Utah-Ariz.-Tex. Son. Ap-O.

7. P. lanata (Spreng.) Britton. Stems branched at the base, decumbent, $2-6 \mathrm{dm}$. long, densely short-villous; leaflets $9-13$, cuneate, 4-12 mm. long, obtuse, truncate or retuse, densely short-villous; spikes slender, $2-10 \mathrm{~cm}$. long, manyflowered; bracts ovate, acuminate, 3-4 mm. long; calyx 3-3.5 mm. long, velutinous; lobes lanceolate, shorter than the tube; corolla purple, rarely white; keel nearly $5 \mathrm{~mm}$. long; banner $3 \mathrm{~mm}$. long. Dry soil: Kans.-Tex.-N.M.-Colo.; Mex. Son. Je-Au.

8. P. Jamesii (T. \& G.) Vail. Stems silky-strigose, ascending or decumbent, $5-20 \mathrm{~cm}$. high; leaflets obovate, $5-15 \mathrm{~mm}$. long, appressed silky-canescent; spike short-peduncled, 2-3 cm. long, dense; bracts ovate, acuminate, $8-10 \mathrm{~mm}$. long; corolla yellow, in age turning purplish; keel $10-12 \mathrm{~mm}$. long; banner about half as long. P. Porteri A. Nels. Dry plains and hills: Colo.-Tex.-N.M. Son.-Submont. $\mathrm{My}-\mathrm{Au}$.

9. P. carnescens Rydb. Stems 2-4 dm. high, strigose-canescent; leaflets $3-7$, oblong-obovate, sparingly silky-canescent, $5-12 \mathrm{~mm}$. long; spike dense, oblong, 1-2 cm. long; bracts ovate, acuminate; corolla yellow, turning reddish; 
keel about $8 \mathrm{~mm}$. long, nearly twice as long as the banner. Dalea nana elatior "Torr."; Port. \& Coult., in part. P. rubescens Coult. \& Nels., not D. rubescens S. Wats. Dry soil: Tex,-Colo.-Ariz. Son. Jl.

10. P. aurea (Nutt.) Britton. Stems few, strigose-canescent; leaflets 5-9, oblong, obovate, or oblanceolate, $6-18 \mathrm{~mm}$. long, obtuse or mucronate, silverycanescent; spikes $2-7 \mathrm{~cm}$. long; bracts broadly ovate, short-acuminate; corolla yellow, not turning red or purple; keel about $12 \mathrm{~mm}$. long, about twice as long as the banner. Plains and hills: S.D.-Mo.-Tex.-Colo. Plain. Je-Au.

\section{Petalostimon Michx. Prairie Clover.}

Perennial (all ours), or annual caulescent herbs, with glandular-dotted foliage. Leaves alternate, odd-pinnate. Flowers perfect, in spikes, not subtended by involucres. Calyx campanulate; teeth short and broad. Corolla white, purple, pink, or yellowish; banner broad, clawed; wing- and keel-petals similar to each other, narrower, distinct, inserted at the mouth of the staminal tube, between the stamens. Stamens 5, monadelphous. Pods short, indehiscent, mostly 2-ovuled, but 1 -seeded.

Calyx glabrous except the teeth; corolla white.

Spikes compact; bracts longer than the buds; leaflets $1.5-2.5 \mathrm{~cm}$. long.

Spikes looser; bracts shorter than the buds; leaflets usually less than $P_{.}$candidus.

Calyx pubescent.

$1.5 \mathrm{~cm}$. long.

Corolla white or yellow; spike long and compact.

Leaves glabrous; corolla white or ochroleucous.

Leaves sparingly silky; corolla yellow.

Corolla rose or purple, very rarely white.

Leaflets mostly 5 , linear or nearly so.

Pubescence of the calyx long silky-pilose; bracts lanceolate, acute; leaflets of the lower leaves oblong, obovate, or cuneate.

Bracts glabrous or short-pilose.

Bracts silky, long-pilose.
Pubescence of the calyx dense and short; bracts ovate, $P$. ornatus.

5. P. Searlsiae.

3. P. compactus.

4. P. flavescens. subulate glabrous acumination.

Leaflets linear, conspicuously glandular-dotted; bracts longer than the calyces.

Stem and leaves glabrous or sparingly hairy. Stem and leaves densely villous.

7. P. purpureus.

Leaflets spatulate-linear, not glandular-dotted; bracts 8. P. mollis. calyces.

Leaflets 7-17, oblong.

shorter than the

9. P. pubescens.

10. P. villosus.

1. P. candidus (Willd.) Michx. Stems several, erect, $3-7 \mathrm{dm}$. high, glabrous; leaflets 7-9, linear, oblong or oblanceolate, 1-3 cm. long, acute or mueronate, glabrous; spike $2-10 \mathrm{~cm}$. long, compact; bracts subulate-tipped; calyx 3 $\mathrm{mm}$. long; lobes triangular to lanceolate, shorter than the tube; corolla white. Prairies: Ind.-La.-Tex.-Sask. Plain. Je-Jl.

2. P. oligophyllus (Torr.) Rydb. Stems erect or decumbent, $3-10 \mathrm{dm}$. high, branched, glabrous; leaflets 5-9, firm, linear, oblanceolate, or elliptic, acute or mueronate, glabrous; spike oblong, becoming more or less cylindric and looser, 1-7 $\mathrm{cm}$. long; bracts with filiform tips; calyx-lobes $3 \mathrm{~mm}$. long, triangular, acute; corolla white. P. gracilis oligophyllus Torr. Plains, prairies, and cañons: Minn. -Ia.-Tex.-Ariz.-Alta. Plain-Submont. Je-Au.

3. P. compactus (Spreng.) Sweezy. Stems few, glabrous, 3-8 dm. high; leaflets 5-7, oblong-oblanceolate or linear-oblong, 8-25 mm. long; spike longpeduncled, cylindric, compact, 4-15 cm. long, about $13 \mathrm{~mm}$, thick; calyx silkyvillous, $4 \mathrm{~mm}$. long; teeth lanceolate, acute; corolla ochroleucous. P. macrostachyus Torr. Sand hills and plains: Neb.-Colo. Plain. Jl-Au.

4. P. flavescens S. Wats. Stem glabrous, about $3 \mathrm{dm}$. high; leaflets narrowly oblong, obtuse, 6-12 mm. long, sparingly silky; spike dense, long-peduncled, $2.5-4.5 \mathrm{~cm}$. long; calyx silky-villous; teeth subulate. Dry rocky hills: s Utah.
Son. Jl.

5. P. Searlsiae A. Gray. Stem glabrous, branched below, 3-5 dm. high; leaflets 5-7, linear-oblanceolate to cuneate or owate, obtuse, rounded or retuse at 
the apex, glabrous, 5-20 $\mathrm{mm}$. long; spike oblong, dense, 2-4 $\mathrm{cm}$. long; bracts lanceolate, shorter than the calyx, acuminate; calyx villous, $4 \mathrm{~mm}$ long; teeth subulate; corolla rose-colored. Hills: Utah-Ariz. Son. Je.

6. P. ornatus Dougl. Stem 3-6 dm. high, glabrous, simple or slightly branched; leaflets 5-7, oblong to obovate, obtuse or retuse at the apex, 5-15 $\mathrm{mm}$. long, glabrous; spike short and dense, $2-4 \mathrm{~cm}$. long, about $1.5 \mathrm{~cm}$. thick; bracts and calyx silky-pilose, with long brownish hairs; calyx-teeth triangular, subulate; corolla rose-colored. Mountain slopes: Ore.-Ida.-Nev. Son.-Submont. $\mathrm{My}-\mathrm{Jl}$.

7. P. purpureus (Vent.) Rydb. Stems several, erect or ascending, 3-10 $\mathrm{dm}$. high; leaflets $3-5$, narrowly linear, 8-20 $\mathrm{mm}$. long, strongly involute; spikes oblong or cylindric, 1-5 cm. long; bracts oblanceolate, abruptly acuminate; calyx densely silky-velutinous, $3 \mathrm{~mm}$. long; teeth triangular; corolla violet or purple, rarely white. $P$. violaceus Michx. Prairies, plains or hills: Ind.-Ark.N.M.-Sask. Plain-Submont. Je-Jl.

8. P. mollis Rydb. Stems several, erect, densely villous, 3-4 dm. high; leaflets 5 , densely short-villous, linear, $10-15 \mathrm{~mm}$. long, $1.5-2 \mathrm{~mm}$. wide, obtuse; spike cylindric or oblong, 2-4 cm. long; calyx densely silky-villous, yellowish or ferruginous; teeth lanceolate; corolla rose-purple. Dry plains and hills: Mont.Colo. Je-Au.

9. P. pubescens A. Nels. Stem 1-2 dm. high, sublanate; leaflets 5, nearly glabrous above, sublanate beneath, $10-14 \mathrm{~mm}$. long; spike oblong, $2-5 \mathrm{~cm}$ long, less than $1 \mathrm{~cm}$ thick; calyx 4-5 mm long; lobes shorter than the tube; corolla light purple. Plains: Colo Plain.

10. P. villosus Nutt. Perennial, with a taproot; stems several, ascending or decumbent, 3-6 dm. high, densely villous; leaflets $7-17$, approximate, linear to oblong, silky-villous, $6-12 \mathrm{~mm}$. long; spikes cylindric, $2.5-8 \mathrm{~cm}$. long; calyx densely villous; teeth subulate; corolla rose-purple, pink, or rarely white. Sand hills: Minn.-Mo.-Tex.-Colo.-Sask. Plain. Jl-S.

\section{ROBÍNIA L. Locust-tree.}

Shrubs or trees, often with spine-like stipules. Leaves alternate, odd-pinnate, with entire leaflets. Flowers in axillary or terminal racemes. Calyx campanulate, 5-lobed, the two upper lobes more united than the rest. Corolla white, pink, or purplish; banner with a broad reflexed blade; wings eurved, free; keelpetals incurved, united at the base. Stamens 10, diadelphous, or the upper filament united with the tube up to the middle. Pods narrow, flat, short-stalked, many-seeded; seeds oblique, with a crustaceous coat.

Inflorescence, leaves and fruit glabrous.

Inflorescence and fruit hispid; leaves finely puberulent.

1. R. Pseudacacia.

2. $R$, neomexicana.

1. R. Pseudacacia L. Tree 6-35 m. high, with firm brown bark, and spreading branches; stipular spines $3-10 \mathrm{~mm}$. long; leaflets $9-19$, thin, $2.5-4.5$ $\mathrm{cm}$. long, elliptic or oval, glabrous; calyx finely silky-strigose; teeth triangular, $2 \mathrm{~mm}$. long; corolla $15-20 \mathrm{~mm}$. long, white, except a yellow spot on the banner; pods 5-10 $\mathrm{cm}$. long, $10-15 \mathrm{~mm}$. wide. (?) $R$. coloradensis Dode. Woods: Pa.Ia.-Okla.; cult. and nat. as far as Ont.-Ida.-Utah. My-JI.

2. R. neomexicana A. Gray. Tree $6-8 \mathrm{~m}$. high, with ascending branches; stipular spines 5-20 mm. long, often curved; leaflets 9-19, elliptic, oval, or ovate, 2-3 cm. long, strigose-puberulent; calyx glandular-hirsute and strigillose; teeth lanceolate, or the upper two ovate, $3 \mathrm{~mm}$. long; corolla about $2 \mathrm{~cm}$. long, pale rose-colored; pod 5-8 $\mathrm{cm}$. long, nearly $1 \mathrm{~cm}$. wide. Along streams: Colo.N.M.-Ariz.-Nev. Submont. My-Je.

\section{PETÈRIA A. Gray.}

Perennial herbs or undershrubs. Leaves alternate, odd-pinnate, with entire leaflets and the stipules transformed into diverging spines. Flowers drooping, in virgate racemes terminating the branches. Calyx tubular, gibbous on the upper side; teeth triangular-subulate or lanceolate, the upper two more or less 
united at the base. Corolla yellow or straw-colored; banner obovate, emarginate, recurved; wings oblong, obtuse; keel incurved, very obtuse, shorter than the wings. Stamens 10, diadelphic. Style filiform, barbate at the apex; stigma terminal, barbate. Legume linear; flat, short-stipitate, few-seeded. Seeds oval, compressed.

Leaflets linear-elliptic or lanceolate, acute and mucronate, 2-6 mm. long, or wanting: corolla $12-15 \mathrm{~mm}$. long.

1. P. scoparia.

Leaflets broadly elliptic, oval, or obovate, rounded and mucronate at the apex, 8-15 $\mathrm{mm}$. long.

2. P. Thompsonae.

1. P. scoparia A. Gray. Stem woody at the base, 5-10 dm. high, with ascending branches; stipular spines slender, 3-5. $\mathrm{mm}$. long; leaflets $9-15$, linearelliptic or lanceolate, acute at both ends, $2-6 \mathrm{~mm}$. long, sparingly strigose; some of the leaves reduced to merely the slender rachis; racemes $2-3 \mathrm{dm}$. long, lax; ealyx about $1 \mathrm{~cm}$. long; teeth half as long as the tube; legume about $5 \mathrm{~cm}$. long or more, about $6 \mathrm{~mm}$, wide. Valleys: w Tex. - sw Colo.-N.M.-Chihuahua. Son. Je-Jl.

2. P. Thompsonae S. Wats. Herbaceous, with rather simple stem, sparingly strigose when young, 3-4 dm. high; leaflets $13-21$, oval or obovate or broadly elliptic, rounded at both ends, $8-15 \mathrm{~mm}$. long, grayish strigose on both sides, mucronate; raceme dense; pedicels and calyx glandular, as well as strigose; calyx $10-15 \mathrm{~mm}$. long, the lanceolate or subulate teeth equalling the tube; corolla 15-20 $\mathrm{mm}$. long; legume about $5 \mathrm{~cm}$. long and $4 \mathrm{~mm}$, wide. Dry rocky cliffs: Utah. Son. My-Jl.

\section{8. phàca L. Rattle-weed, Rattle-pod.}

Perennial or annual herbs, caulescent or rarely almost stemless. Leaves alternate; stipules nearly free from the petioles, often partially united with each other; leaflets many or few, entire, or in one species often none. Flowers perfect, racemose, or in one species subsessile in the axils of the leaves. Calyx campanulate. Corolla ochroleucous or purple; banner rather broad; wings longer than the keel; the latter beakless. Stamens 10, diadelphous; anthers alike. Pod membranous, inflated, sessile or stipitate, 1-celled, with neither suture intruded, without even a partial partition. Seeds numerous.

Upper suture of the pod not acute; pod circular or oval in cross-section.

Pod stipitate.

Pod long-stipitate, not mottled; stipe longer than the calyx.

Pod pendent; flowers ochroleucous.

Pod on an ascending stipe; flowers purplish.

Pod short-stipitate; stipe scarcely exceeding the calyx. Pod not mottled, erect or ascending.

Pod ashy-strigose, with minute hairs.

Pods sulcate above; leaflets broad.

Pod not sulcate; leaflets narrow.

1. P. americana.

2. P. ampularia.

Pod glabrous.

Flowers purplish; racemes long-peduncled; pods about $2 \mathrm{~cm}$. long.

3. P. Wetherillii.

4. P. allochroa.

Flowers white; racemes short-peduncled; pods $3-4 \mathrm{~cm}$. long.

Pod mottled, spreading or reflexed.

Leaflets linear or none; plant grayish pubescent.

Terminal leaflet none, represented by the much produced rachis; lateral leaflets often also lacking.

Leaflets present; rachis not produced.

Stem canescent, 1-2 dm. high; calyx-teeth subulate.

8. P. picta.

Stem glabrous or nearly so, 3-5 dm. high; calyx-teeth triangular.

Leaflets elliptic to broadly oval or obcordate.

Plant glabrous.

Plant canescent.

9. P. Cusickii.

Pod sessile.

10. P. artipes.

11. P. Hookeriana.

Pod more than $12 \mathrm{~mm}$. long.

Plant densely cespitose, almost stemless; pod $3.5-5 \mathrm{~cm}$. long.

Plant distinctly caulescent and leafy; pod $3 \mathrm{~cm}$ long or 12. $P$. megacarpa.

Whole plant glabrous.

Plant, including the pods, pubescent.

13. P. Wardii.

Calyx-teeth very short, scarcely one-third as long as the tube.

14. P. subcinerea. 
Calyx-teeth subulate, fully as long as the tube.

Plant appressed-pubescent, cespitose and much branched.

Stem ascending.

Inflorescence scarcely equalling the leaves; pod $2-2.5 \mathrm{~cm}$. long; corolla ochroleucous. 15. P. Candolleana.

Inflorescence exceeding the leaves; pod 12-15 $\mathrm{mm}$. long: corolla purple. 16. P. cerussata.

Stem decumbent. 17. P. serpens.

Plant with short spreading pubescence; stem simple, elongate.

Pod 8-12 mm. long.

Stem slender and much branched, usually more than $1 \mathrm{dm}$. high; leaflets more than $5 \mathrm{~mm}$. long, flat, oblong, oval, or obovate.

Leaflets 5-11 pairs.

Plant slightly strigose.

Pod ovoid; plant 3-6 dm. high; racemes many-flowered.

19. P. Bodinii.

Pod ellipsoid; plant usually less than $3 \mathrm{dm}$. high; racemes fewflowered.

Plant densely hirsutulous.

20. P. leptalea.

18. P. Silerana. Leaflets 4-6 pairs; plant more or less grayish-pubescent; pod globose-ovoid.

Stem densely pulvinate-cespitose, with a thick caudex, only a few centimeters high; leaflets minute, linear or lanceolate, conduplicate, 1-4 mm. long.

Rachis of the leaves not spinose; pod slightly puberulent, mottled, $1 \mathrm{~cm}$. long.

22. P. jejuna.

long.

23. P. humillima.

Upper suture of the pod straight or curved upwards, acute; pod in cross-section obovate, triangular-obovate, or slightly cordate.

Plant, including the pods, perfectly glabrous, $2 \mathrm{dm}$. high or more; pods stipitate, somewhat leathery.

Corolla ochroleucous; calyx-teeth nearly equalling the tube.

Corolla purple; calyx-teeth much shorter than the tube.

Plant, including the pods, more or less hairy; pods sessile.

Pods much over $1 \mathrm{~cm}$. long, usually not mottled.

Pods strongly inflexed; flowers white or ochroleucous, tinged with purple.

26. $P$. pubentissima.

Pods not strongly incurved; upper suture straight or nearly so; flowers ochroleucous.

Plant strictly annual.

Plant cinereous, with short hairs; pods puberulent. 27. P. annua.

Plant, including the pods, grayish hoary.

24. P. Beckwithii.

25. P. artemisiarum.

Plant perennial or at least biennial, cespitose, low.

Flowers mostly subsessile in the axils of the leaves; racemes if peduncled 2-3-flowered; leaflets mostly over $1 \mathrm{~cm}$. long, appressed-hairy.

29. P. elatiocarpa.

Flowers in peduncled several-flowered racemes; leaflets mostly less than $1 \mathrm{~cm}$. long, loosely hairy beneath, glabrateabove. 30 . $P$. lotiflora.

Pods about $1 \mathrm{~cm}$. long, mottled; plant diffusely cespitose. 31. P. sesquiflora.

1. P. americana (Hook.) Rydb. Perennial; stems single or two or three, erect, 3-10 dm. high; leaflets 7-17, oval, elliptic, or oblong, obtuse, thin, $2-4 \mathrm{~cm}$. long, glabrous above, sparingly pubescent beneath; raceme short; ealyx glabrous or nearly so; tube campanulate, $4 \mathrm{~mm}$. long; teeth obsolete; corolla ochroleucous, about $12 \mathrm{~mm}$. long; pod glabrous; stipe about $5 \mathrm{~mm}$. long; body ellipsoid, acute, $2 \mathrm{~cm}$. long, 7-8 mm. wide. Astragalus frigidus americanus S. Wats. Along streams and in wet copses: Que.-Wyo.-Yukon. Submont.-Mont. J1-Au.

2. P. ampularia (S. Wats.) Rydb. Perennial; stem short, ascending, strigose; leaflets $7-11$, obovate, $8-12 \mathrm{~mm}$. long, emarginate, glabrous above, strigose beneath; racemes short and dense; calyx-tube cylindro-campanulate, 5-6 mm. long; teeth nearly obsolete; banner $15-18 \mathrm{~mm}$. long; pod oblong, on a long stipe, glabrous. Astragalus ampullarius S. Wats. Wet places: s Utah. L. Son. Ap-My.

3. P. Wetherillii (M. E. Jones) Rydb. Cespitose perennial; stems ascending, 3-4.5 dm. long, glabrous or sparingly strigose above; leaflets $9-17$, oval or obovate, rounded or retuse at the apex, $8-10 \mathrm{~mm}$. long, glabrous; inflorescence 6-8-flowered; calyx-tube campanulate, $3 \mathrm{~mm}$. long; teeth subulate, $2 \mathrm{~mm}$. long; corolla white, tipped with pink, $8 \mathrm{~mm}$. long; body of the legume ovoid, about 2 $\mathrm{cm}$, long, sulcate above, puberulent. A. Wetherillii M. E. Jones. Dry places: Colo. Son. My.

4. P. allochroa (A. Gray) Rydb. Perennial; stem 1-3 dm. high, strigose, ascending; leaves 5-10 cm. long; leaflets $13-15$, oblong, strigose, obtusish, 8-10 
$\mathrm{mm}$. long; corolla purplish, or ochroleucous tipped with purple, 10-12 $\mathrm{mm}$. long; calyx-teeth triangular-subulate; legume ellipsoid, $2.5-3.5 \mathrm{~cm}$. long, strigose, stipe about equalling the calyx. A. allochrous A. Gray. Hillsides: Ariz.-Ida. Son. Ap-Je.

5. P. Eastwoodiae (M. E. Jones) Rydb. Perennial, with a cespitose woody caudex; stem about $1.5 \mathrm{dm}$. high, glabrous; leaflets about 21 , narrowly oblanceolate or linear, $4-10 \mathrm{~mm}$. long; calyx-tube about $6 \mathrm{~mm}$. long, glabrous; corolla purple; stipe of the pod about $2 \mathrm{~mm}$. long; body ovoid, $2 \mathrm{~cm}$. long, glabrous, sulcate on the upper side. River valleys: Utah-Colo. Son. My.

6. P. Iutosa (M. E. Jones) Rydb. Perennial, with fleshy taproot, and several scaly stolons; leaflets about 12 pairs, mostly folded, oval, $6 \mathrm{~mm}$. long, obtuse, strigose; flowers 1-4, in almost sessile axillary clusters; bracts hyaline; corolla white; fruit glabrous, sulcate on both sutures, but less so on the dorsal one. A. lutosus M. E. Jones. River bottoms: Utah. Son. My.

7. P. longifolia (Pursh.) Nutt. Perennial, with horizontal rootstocks; stem erect, $1.5-4 \mathrm{dm}$. high; leaves $5-15 \mathrm{~cm}$. long, grayish canescent; leaflets often none, the terminal represented by the prolonged rachis or contiguous with it, slightly if at all flattened; the lateral ones if present $1-4$, linear-filiform, $1-2.5$ $\mathrm{cm}$. long; raceme few-flowered; calyx strigose; tube campanulate, $2 \mathrm{~mm}$. long; teeth subulate, $1.5 \mathrm{~mm}$. long; pod ellipsoid, papery, $2-3 \mathrm{~cm}$. long, $12-18 \mathrm{~mm}$. broad, mottled, glabrous. A. pictus filifolius A. Gray. Sand hills: S.D.-Ida, -N.M.-Ariz. Plain-Son. My-JI.

8. P. picta A. Gray. Perennial, with a horizontal rootstock; stems $1-2 \mathrm{dm}$. long, slender, grayish strigose-canescent; leaves 3-8 cm. long; leaflets 9-15, linear, strigose-canescent, 5-20 mm. long; racemes 3-10-flowered; calyx strigose, with white, or mixed white and black hairs; tube campanulate, $2 \mathrm{~mm}$. long; teeth subulate, $1.5 \mathrm{~mm}$. long; corolla ochroleucous, $7 \mathrm{~mm}$. long; pod elliptic, mottled, $15-18 \mathrm{~mm}$. long, $8 \mathrm{~mm}$. wide, acute at both ends. A, ceramicus Sheld. Dry sandy places: Colo.-N.M.-Utah. Son.-Submont. My.

9. P. Cusickii (A. Gray) Rydb. Perennial, with a persistent caudex; stems $3-5 \mathrm{dm}$. high, sparingly strigose or glabrous; leaflets 7-13, narrowly linear, 4-20 mm. long; raceme lax; calyx strigose, with black hairs; tube campanulate, $3 \mathrm{~mm}$. long; teeth triangular, $1 \mathrm{~mm}$. long; corolla white; pod $2-3 \mathrm{~cm}$. long, mottled, ovoid, glabrous. A. Cusickii A. Gray. Dry ground: Ida.-Ore.
Son.

10. P. artipes (A. Gray) Rydb. Perennial, with a cespitose eaudex; stems 1-3 dm. high, glabrous; leaflets 11-17, oval or obovate to oblong, retuse, $7-12$ $\mathrm{mm}$. long, glabrous; raceme short, few-flowered; calyx glabrous, or with a few scattered black hairs; tube campanulate, about $5 \mathrm{~mm}$. long; teeth subulate, 3 $\mathrm{mm}$. long; corolla white, $15 \mathrm{~mm}$. long; pod mottled, about $3 \mathrm{~cm}$. long, ovoid, short-acuminate, the upper suture nearly straight. A. artipes A. Gray. Mountains: Colo.-Utah-Ariz. Submont.-Mont. Je.

11. P. Hookeriana T. \& G. Perennial, with a deep root and cespitose caudex; stems einereous, 1-2 dm. high, decumbent; leaflets 13-19, oblong, strigosecanescent on both sides, $5-10 \mathrm{~mm}$. long; racemes short, few-flowered; calyx-tube $3-4 \mathrm{~mm}$. long, more or less black hairy; teeth subulate, $2 \mathrm{~mm}$. long; corolla ochroleucous, $8-10 \mathrm{~mm}$. long; pod obovoid, 2-3 $\mathrm{cm}$. long, mottled, glabrous; stipe about as long as the calyx. Hills and ridges: Ore.-Ida.-Nev.-Colo. Submont.-Mont. My-Jl.

12. P. megacarpa Nutt. Subacaulescent, cespitose perennial; leaflets 9-13, broadly oval, $8-12 \mathrm{~mm}$. long, sparingly strigillose, in age glabrate, rounded or retuse at the apex; racemes 3-6-flowered, calyx sparingly strigillose, with black hairs, $8 \mathrm{~mm}$. long; teeth lanceolate, $3 \mathrm{~mm}$. long; corolla ochroleucous, about 2 $\mathrm{cm}$. long; legume elongate-ovoid, $1.5-2 \mathrm{~cm}$. broad, papery, glabrous. $A$. megacarpus (Nutt.) A. Gray. Plains and dry draws: Wyo.-Utah. Son.-
Submont.

13. P. Wardii (A. Gray) Rydb. Perennial, with a cespitose caudex; stems 3-4 dm. high, glabrous, leafy; leaflets 9-17, oblong, obtuse or retuse, $6-12 \mathrm{~mm}$. 
long; raceme lax, 4-15-flowered; calyx with scattered short black hairs; tube campanulate, $2 \mathrm{~mm}$. long; teeth subulate, $2 \mathrm{~mm}$. long; corolla cream-colored or white (according to Gray sometimes purple), about $8 \mathrm{~mm}$. long; pod ovoid, glabrous, about $2 \mathrm{~cm}$. long, $1.5 \mathrm{~cm}$. wide. A. Wardii A. Gray, Dry hills: Utah. Submont.-Mont. Je-Au.

14. P. subcinerea (A. Gray) Rydb. Cespitose perennial; stems erect, 2-4 dm. high, einereous-canescent; leaflets $15-21$, linear or oblong, 6-10 mm. long, retuse, cinereous on both sides; raceme short; calyx cinereous; tube $3 \mathrm{~mm}$. long; teeth subulate, $1 \mathrm{~mm}$. long or less; corolla greenish, with purple tip, $6 \mathrm{~mm}$. long: pod ovoid-globose, puberulent, $1.5-2 \mathrm{~cm}$. long, acute. A. subcinereus A. Gray. Dry places: Ariz.-s Utah. L. Son. My-Je.

15. P. Candolleana H.B.K. Cespitose perennial; stems 1-3 dm. high, branched, strigose, erect or spreading; leaflets 11-15, oblong, 6-15 $\mathrm{mm}$. long, obtuse, truncate, or retuse at the apex, grayish strigose or hirsute; raceme short; calyx strigose; tube $2 \mathrm{~mm}$. long; teeth subulate, nearly $2 \mathrm{~mm}$. long; corolla ochroleucous, $6-7 \mathrm{~mm}$. long; pod ellipsoid, $2-2.5 \mathrm{~cm}$. long, $1-1.5 \mathrm{~cm}$. broad, sparingly pubescent, not mottled. A. triflorus A. Gray, not D.C. Hills and mountains: w Tex.-Colo.-Calif.-n Mex, Son. Ap-Je.

16. P. cerussata (Sheld.) Rydb. Perennial; stems 2-3 dm. high, erectspreading, striate, sparingly strigose; leaflets $11-17$, oblong to obovate, emarginate, $5-12 \mathrm{~mm}$. long, pilose-strigose on both sides, or glabrate above; racemes lax, 3-7-flowered; calyx strigose; tube and the subulate teeth each $2 \mathrm{~mm}$. long; corolla ochroleucous, tipped with purple, 8-9 mm. long; pod ellipsoid, 12-16 mm. long, finely pubescent. A.cerussatus Sheld. Cañons: Colo. Submont. My-Je.

17. P. serpens (M. E. Jones) Rydb. Perennial, with a thick woody root and cespitose caudex; stems decumbent or ascending, 3-20 cm. long; leaflets 11-15, crowded, elliptic or oval, folded, 4-6 mm. long, grayish strigose; racemes 2-6-flowered; calyx strigose-canescent; tube $2 \mathrm{~mm}$. long; teeth triangular-subulate, $1 \mathrm{~mm}$. long; corolla greenish purple, $7 \mathrm{~mm}$. long; pod broadly ellipsoid, about $15 \mathrm{~mm}$. long, $1 \mathrm{~mm}$. broad, mottled, glabrous. A. serpens M. E. Jones. Dry mountains: Utah. Submont.-Mont, J1.

18. P. Silerana (M. E. Jones) Rydb. Perennial; stems many, decumbent, 5-8 dm. long, hirsutulous; leaflets about 9 pairs, $1-1.5 \mathrm{~cm}$. long, oblanceolate, obovate or oblong, notched at the apex, hirsutulous; flowers subcapitate; calyxteeth subulate; corolla $7 \mathrm{~mm}$. long, light yellow; keel dark-tipped; pods purplespotted, sessile, short-pubescent, $12-15 \mathrm{~mm}$. long. A. Sileranus M. E. Jones. Among brush, on hillsides: Utah. Submont.-Mont. Je-Jl.

19. P. Bodinii (Sheld.) Rydb. Perennial, scarcely cespitose; stems slender, glabrous, 3-6 dm. high, decumbent, branched; leaflets 11-17, oval to lanceolate, acute, 7-18 $\mathrm{mm}$. long, glabrous or sparingly strigose beneath; raceme lax, 4-16flowered; calyx strigose, with black hairs; tube $3 \mathrm{~mm}$. long; teeth subulate, $2 \mathrm{~mm}$. long; corolla purple, 10-12 mm. long; pod ovoid, black-strigose, $8 \mathrm{~mm}$. long, 4 $\mathrm{mm}$. wide. A, Bodinii Sheld. Meadows: Neb,-Wyo.-Colo. J1-Au.

20. P. leptalea (A. Gray) Rydb. Cespitose perennial, with a rootstock; stems ascending, 1-3 dm. high, branched; leaflets 15-21, lanceolate to linearlanceolate, acute, 5-10 mm. long, glabrous or sparingly strigose; racemes 1-4flowered; calyx black-strigose; tube $2.5 \mathrm{~mm}$. long; teeth subulate, $2-2.5 \mathrm{~mm}$ long; corolla white, tipped with purplish, about $1 \mathrm{~cm}$. long; legume oblongelliptic, strigillose with black hairs, $1 \mathrm{~cm}$. long, $4 \mathrm{~mm}$. broad. A. leptaleus A. Gray. P. pauciflora Nutt., not Pers, Mountains: Colo. Submont.-Mont. $\mathrm{Jl}-\mathrm{Au}$.

21. P. microcystis (A. Gray) Rydb. Perennial, with a taproot and cespitose caudex; stems numerous, ascending or procumbent, canescent-strigose; leaflets 9-13, oblong or lance-oblong, obtuse, strigose on both sides, or glabrate above; raceme lax; calyx strigose; tube and the subulate teeth each $1.5 \mathrm{~mm}$. long; corolla violet or nearly white, 6-7 $\mathrm{mm}$. long; legume globose-obovoid, 6-8 $\mathrm{mm}$. long, densely canescent. A. microcystis A. Gray. Hillsides and sandy shores: B.C.-Mont.-Wash. Plain-Submont. J-Au. 
22. P. jejuna (S. Wats.) Rydb. Pulvinate-cespitose; stems $1-4 \mathrm{~cm}$. long, densely covered by scarious stipules and numerous leaves; leaves $1-3 \mathrm{~cm}$. long, stiff; leaflets 11-15, linear, 2-4 mm. long, strigose; peduncles 1-3 cm. long, 1-3flowered; calyx strigose; tube $1 \mathrm{~mm}$. long; teeth subulate, $1 \mathrm{~mm}$. long; corolla purple, $5 \mathrm{~mm}$. long; legume about $1 \mathrm{~cm}$. long, mottled, puberulent. A. jejunus S. Wats. Dry hills: Wyo.-Utah. Submont. My-Au.

23. P. humillima (A. Gray) Rydb. Pulvinate-cespitose; stems $1-2 \mathrm{~cm}$. long, covered by searious stipules; leaves $1-3 \mathrm{~cm}$. long; rachis persistent and more or less pungent; leaflets 9-11, oblong, canescent, 1-2 mm. long; peduncles short, 1-3-flowered; calyx-teeth subulate, half shorter than the tube; corolla pale; legume ovoid, 4-6 mm. long, white-pubescent. Dry table land: Colo. Submont. Je-Jl.

24. P. Beckwithii (T. \& G.) Piper. Cespitose perennial; stems glabrous, 2-4 dm. high, branched; leaflets obovate, $6-12 \mathrm{~mm}$. long, glabrous, rounded or retuse at the apex; raceme short, many-flowered; calyx glabrous or minutely black-hairy; tube 4-5 mm. long; teeth subulate, $3-5 \mathrm{~mm}$. long; corolla 18-20 $\mathrm{mm}$. long; stipe of the pod $5 \mathrm{~mm}$. long; body lance-oblong, about $2 \mathrm{~cm}$. long, mottled; upper suture prominent, wing-margined; lower suture strongly curved, rounded or even somewhat sulcate. A. Beckwithii T. \& G. Gravelly hillsides: Utah-Ida.-Nev. Submont. My-Je.

25. P. artemisiarum (M. E. Jones) Rydb. Resembling the preceding; stems erect, 2-3 dm. high; leaflets $13-25$, rhombic-obovate, 8-12 $\mathrm{mm}$. long, rounded or retuse at the apex, glabrous; raceme 6-10-flowered; calyx with scattered short black hairs; tube 5-6 $\mathrm{mm}$. long; teeth subulate, $2 \mathrm{~mm}$. long; corolla purple, about $18 \mathrm{~mm}$. long; pod as in the preceding but thicker and said to be filled with a mucilaginous pulp when young. A. Beckwithii artemisiarum M. E. Jones. Mountains: w Utah. Son. Je.

26. P. pubentissima (T. \& G.) Rydb. Perennial, with a taproot; stems much branched from the base, grayish strigose, about $1 \mathrm{dm}$. high; leaflets $7-17$, obovate to oblong, obtuse, densely canescent-hirsute; calyx grayish hirsute; tube $3 \mathrm{~mm}$. long; teeth subulate, $2 \mathrm{~mm}$. long; corolla $8 \mathrm{~mm}$. long; keel tipped with purple; legume obliquely ovoid, strongly curved, $1-5 \mathrm{~cm}$. long, silkyhirsute. A. pubentissimus T. \& G. (?) A. Peabodyanus M. E. Jones. Dry hills: Utah-Wyo.-Colo. Son.-Submont. My.

27. P. annua Geyer. Annual; stem $1 \mathrm{dm}$. high or less, branched, erect; leaflets linear to oblong, 5-15 mm. long, grayish strigose, truncate, rounded or retuse at the apex; racemes short, 3-6-flowered; calyx-tube $1-1.5 \mathrm{~mm}$. long; teeth subulate, $1 \mathrm{~mm}$. long; corolla ochroleucous, $5 \mathrm{~mm}$. long; legume obliquely ovoid, $1.5 \mathrm{~cm}$. long; finely strigose. A. Geyeri A. Gray. Sandy flats and banks: Wyo. -Ore.-Calif. Son.-Submont. Je-Jl.

28. P. sabulonum (A. Gray) Rydb. Annual; stem branched, $1 \mathrm{dm}$. high or less; leaflets 9-13, oblong, 8-15 mm. long, hirsute-canescent; racemes short, 3-5flowered; calyx hirsute-canescent; tube $2 \mathrm{~mm}$. long; teeth subulate, $2-2.5 \mathrm{~mm}$. long; corolla about $6 \mathrm{~mm}$. long; legume obliquely ovoid, $15 \mathrm{~mm}$. long, hirsute. A. sabulonum A. Gray. Sandy ridges: Nev.-Utah. Son.

29. P. elatiocarpa (Sheld.) Rydb. Perennial, with a taproot; stems numerous, a few centimeters long; leaflets oblong or lance-oblong to obovate, strigose on both sides or glabrate above; peduncles of the earlier flowers $1-3 \mathrm{~cm}$. long, of the later searcely any; calyx hirsute-strigose; tube $3 \mathrm{~mm}$. long; teeth subulate, 3 $\mathrm{mm}$. long; corolla ochroleucous, about $1 \mathrm{~cm}$. long; legume elongate-ovoid, hirsute-strigose. A. latiflorus brachycarpus A. Gray. A. elatiocarpus Sheld. Plains: Sask.-Minn.-Tex.-N.M.-Mont. Plain. My-Au.

30. P. lotiflora (Hook.) Nutt. Perennial, with a taproot; stems many, 1 $\mathrm{dm}$. or less long, hirsute; leaves $5-10 \mathrm{~cm}$. long; leaflets oblong or lanceolate, acute, $8-15 \mathrm{~mm}$. long, light green, silky-hirsute beneath, glabrate above; peduncles $\mathrm{mm}$. long; teeth subulate, $4 \mathrm{~mm}$. long; legume elongate-ovoid, $2 \mathrm{~cm}$. long, 8 $\mathrm{mm}$. thick, hirsute-villous; upper suture acute, straight. A. lotiflorus Hook. Hills and plains: Sask.-Neb.-Colo.-Wyo. Plain. My-Je. 
31. P. sesquiflora (S. Wats.) Rydb. Cespitose perennial; stems $1 \mathrm{dm}$. or less long, silky strigose-canescent; leaflets 5-11, linear-lanceolate, strigose-canescent, $5-8 \mathrm{~mm}$. long; racemes 1-2-flowered; calyx-tube $2.5 \mathrm{~mm}$. long; teeth subulate, $2.5 \mathrm{~mm}$. long; corolla purple, about $7 \mathrm{~mm}$. long; pod about $1 \mathrm{~cm}$. long, 4 $\mathrm{mm}$. broad, minutely strigose, mottled, somewhat curved. A. sesquiflorus $\mathrm{S}$. Wats. Dry hills: s Utah. L. Son. Je.

\section{CÝSTIUM Stev.}

Cespitose perennials, with branched rootstocks. Leaves alternate, oddpinnate, with several pairs of leaflets, most commonly glabrous or sparingly pubescent. Stems mostly decumbent or prostrate, rarely ascending or erect. Flowers white or purplish, in rather few-flowered spikes. Calyx short-cylindric or campanulate; teeth mostly subulate. Pods membranous, much inflated, ovoid, ellipsoid, or globose, perfectly 2-celled by the intrusion of both sutures, several-seeded.

Plant cespitose, less than $1 \mathrm{dm}$. high, canescent, nearly stemless; pod not curved.

Plant with elongate stems, 1-4 dm. high.

Plant silvery canescent-strigose; corolla pinkish.

1. C. platytrope,

Plant glabrous or slightly strigose, not silvery.

Corolla purple.

Corolla white or yellowish, purple only at the tip.

Pod more than $1.5 \mathrm{~cm}$. long.

Pod short-ovoid, only slightly curved.

Pod elongate-ovoid, strongly curved.

Calyx-teeth at least half as long as the tube; corolla $8-9 \mathrm{~mm}$. long.

5. C. lentiginosum.

Calyx-teeth about one-fourth as long as the tube; corolla about $12 \mathrm{~mm}$. long.

Pod 1-1.5 cm. long.

6. C. araneosum.

1. C. platytrope (A. Gray) Rydb. Stems 1-3 em. long; leaves erowded at the base; leaflets 7-11, obovate or oblanceolate, 5-10 $\mathrm{mm}$. long; spike fewflowered, capitate; calyx strigose; tube $3 \mathrm{~mm}$. long; teeth subulate, $2 \mathrm{~mm}$. long; corolla white or yellowish, tipped with purple, $7 \mathrm{~mm}$. long; pod ovoid, $2 \mathrm{~cm}$. long, sessile, cinereous-puberulent, mottled. Astragalus platytropis A. Gray. Mountains: Nev.-Mont. Mont. J1.

2. C. Coulteri (Benth.) Rydb. Stem 3-4 dm. high, white silky-strigose, branched; leaflets $9-19$, broadly obovate, $8-15 \mathrm{~mm}$. long, rounded or retuse at the apex; spike lax; calyx-tube about $5 \mathrm{~mm}$. long; teeth lance-subulate, $2 \mathrm{~mm}$. long; corolla about $12 \mathrm{~mm}$. long; pod ovoid, cinereous-strigose, about $2 \mathrm{~cm}$. long. A. Coulteri Benth. Arid regions: s Utah-Ariz.-s Calif. F-Ap.

3. C. diphysum (A. Gray) Rydb. Stems ascending or decumbent, 2-4 dm. high; leaflets 19-21, oblong or elliptic, glabrous, fleshy, rounded or retuse at the apex, 6-10 $\mathrm{mm}$. long; spike dense, oblong; calyx glabrous; tube 5-6 $\mathrm{mm}$. long; teeth subulate, $2 \mathrm{~mm}$. long; corolla $15 \mathrm{~mm}$. long; pod ovoid, acuminate, and somewhat incurved at the apex, about $2 \mathrm{~cm}$. long, glabrous, somewhat sulcate on both sutures. A. diphysus A. Gray. Hills: N.M.-Colo.-Utah-Ariz. Son. My-Jl.

4. C. heliophilum Rydb. Perennial, with a deep taproot and a short cespitose caudex; stems decumbent or ascending, sparingly strigose, 1-4 dm. high; leaflets rather fleshy, light green, obovate, sparingly strigose, 7-10 mm. long, rounded, retuse or emarginate at the apex; raceme short, oblong; calyx strigose; tube about $5 \mathrm{~mm}$. long; teeth lance-subulate, $2-3 \mathrm{~mm}$. long; corolla ochroleucous, 12-14 mm. long; pod ovoid, acute, somewhat sulcate on both sutures, about 2 $\mathrm{cm}$. long, $1 \mathrm{~cm}$, in diameter, short-acuminate. Phaca inepta Rydb., in part. Astragalus ineptus Coult. \& Nels. Hills and mountain sides: Mont.-Wyo.Utah. Submont. My-Jl.

5. C. lentiginosum (Dougl.) Rydb. Stems decumbent or diffusely spreading; leaflets 11-19, obovate or obcordate to elliptic, 8-12 $\mathrm{mm}$. long, slightly strigose or glabrate; raceme short and dense; calyx strigose; tube $3-4 \mathrm{~mm}$. long; teeth subulate, $2 \mathrm{~mm}$. long; corolla ochroleucous or white, $8-9 \mathrm{~mm}$. long; pod 
about $2 \mathrm{~cm}$. long, usually mottled. A. lentiginosus Dougl. Arid regions: Wash.-Ida.-Utah-Calif. Son. My-Jl.

6. C. araneosum (Sheld.) Rydb. Stems $2-5 \mathrm{dm}$. long, decumbent or erect, strigose; leaflets $15-19$, fleshy, obovate to oval, rounded or retuse at the apex, 7-12 mm. long; spike short, 12-15-flowered; calyx with a few scattered black hairs; tube 4-5 mm. long; teeth subulate, about $1.5 \mathrm{~mm}$. long; corolla whitish, tipped with purple; legumes about $2.5 \mathrm{~cm}$. long, sulcate on both sutures, strongly curved, often mottled. A. araneosus Sheld. Dry plains: c Utah. Son.-Submont. Je.

7. C. salinum (Howell) Rydb. Stems many, ascending or decumbent, 1-3 dm. high, sparingly strigose; leaflets $9-17$, obovate to oblong, obtuse or retuse, 8-12 mm. long, glabrous or nearly so; peduncles shorter than the leaves; calyxtube $3 \mathrm{~mm}$. long; teeth subulate, less than $2 \mathrm{~mm}$. long; corolla ochroleucous, about $1 \mathrm{~cm}$. long; pod glabrous, ovate, short-acuminate, with the beak curved upwards. A. salinum Howell. Saline soils and river flats: Ore.-Ida. Son. Je.

\section{0. ÒNIX Stev.}

Cespitose perennials, with rootstocks or caudices. Stem mostly decumbent. Leaves alternate, odd-pinnate, with many leaflets. Flowers racemose, white or purplish. Calyx campanulate or hemispheric; lobes subulate. Pod mostly stipitate, membranaceous, inflated, but triangular in cross-section, perfectly 2 -celled, the upper suture acute, the lower sulcate; seeds many.

1. O. Mulfordae (M. E. Jones) Rydb. Stems decumbent, 1-2 dm. long; leaflets 13-17, linear, 4-6 mm. long, glabrate; racemes 5-10-flowered; calyx strigose; tube campanulate or hemispheric, $2 \mathrm{~mm}$. long; teeth subulate, 1-1.5 $\mathrm{mm}$. long; corolla about $7 \mathrm{~mm}$. long, white; pod strigose; stipe $2-3 \mathrm{~mm}$. long; body 10-12 mm. long; upper suture straight. Astragalus Mulfordae M. E. Jones. Dry ground: Ida. Son. Je.

\section{Geoprúmnon Rydb. Buffalo Beans, Ground Plums,} Buffalo Peas, Prairie Apples.

Perennial tufted herbs, with decumbent or ascending stems. Leaves alternate, odd-pinnate; leaflets numerous, entire, not notched. Flowers perfect, in dense racemes; calyx deeply campanulate or nearly cylindric, 5-lobed; lobes nearly equal. Corolla white or purplish, rarely ochroleucous; banner with a rather narrow, erect blade, longer than the wings and keel; keel-petals wholly united, not produced into a beak. Stamens 10; filaments diadelphous. Pods globose or ellipsoid, fleshy, becoming spongy, 2-celled, the partition formed by the intruded lower suture, which meets the upper suture. Seeds numerous.
Pods pubescent, abruptly pointed.
Pods glabrous, pointless.
Corolla purple; leaflets oblong to linear.
Corolla yellowish-white, with purple keel; leaflets oval or obovate,
1. G. plattense.
2. G. crassicarpum.
3. G. succulentum.

1. G. plattense (Nutt.) Rydb. Stems diffusely branched, 1-4 dm. long, decumbent, strigose; leaflets 13-23, oblong, elliptic or cuneate, 5-15 mm. long, acute, rounded or retuse at the apex; racemes few-flowered, head-like; calyxtube strigose, $5 \mathrm{~mm}$. long; teeth subulate, $2 \mathrm{~mm}$. long; corolla about $15 \mathrm{~mm}$. long, yellowish white, tipped with purple; pod ovoid, $1-1.5 \mathrm{~cm}$. in diameter. Astagalus plattensis Nutt. Prairies: Ind.-Ala.-Tex--N.D. Plain. Ap-Je.

2. G. crassicarpum (Nutt.) Rydb. Stems strigose, branched, prostrate, 1-4 dm. long; leaflets 13-27, oblong to linear, 8-20 mm. long, acute or obtuse, strigose beneath, glabrous above; raceme few-flowered; calyx-tube about $5 \mathrm{~mm}$. long, strigose, at least some of the hairs black; corolla violet-purple, $1.5-2 \mathrm{~cm}$. long; pod subglobose, $1.5-2 \mathrm{~cm}$. thick. A. caryocarpus Ker. A. crassicarpus Nutt. Prairies: Man.-Mo--Tex--Mont. Plain. Ap-My.

3. G. succulentum (Richards.) Rydb. Stems prostrate, spreading, branched, 2-4 dm. long, finely strigose; leaflets $17-25$, elliptic or broadly oblong, obtuse, 
truncate or emarginate, $1-1.5 \mathrm{~cm}$. long, strigose beneath, glabrous above; raceme short; calyx strigose, sometimes with dark hairs; tube 7-8 $\mathrm{mm}$. long; teeth subulate, $2 \mathrm{~mm}$. long; corolla $2 \mathrm{~cm}$. long; pod rounded-ellipsoid, over $1.5-2 \mathrm{~cm}$. in diameter. A. succulentus Richards. A. prunifer Rydb. Plains and hills: Sask. -Colo.-Mont. Plain-Submont. My-Je.

\section{AStrágalus (Tourn.) L. Loco Weed, Milk Vetch.}

Perennial or annual herbs. Leaves alternate, odd-pinnate. Flowers perfect, racemose. Calyx campanulate to cylindric, 5-lobed; lobes usually distinctly unequal. Corolla purplish or white, or rarely ochroleucous; banner with an erect blade, usually longer than the wings and the keel; keel not beaked, its petals wholly united. Stamens 10; filaments diadelphous; anthers alike. Pods ovoid to oblong, leathery or woody, turgid, 2-celled, dehiscent; partition formed by the intruded lower suture. Seeds usually many.

Plants cespitose, subscapose, villous-pubescent; pods sulcate on both sutures.

Plants with elongate leafy stems.

I. MOLLISSIMI.

Pods not sulcate or slightly so on the Iower suture, round or nearly so in cross-section.

Pod deeply sulcate on the lower suture, cordate or triangular in cross-section.

Leaves and stems strigose or glabrate; pods several-seeded. III. HYPOGLOTTIDES.

Leaves and stem villous; pods few-seeded.

IV. SPALDINGIANI.

Pod glabrous, deeply sulcate.

\section{Mollissimi.}

Pod villous, slightly sulcate.

Calyx densely villous; leaflets $6-12$ pairs.

Pods perfectly 2-celled; raceme elongate.

The cells of the pod confluent at the apex; raceme short.

Calyx sparingly nigrescent; leaflets $3-6$ pairs.

1. A. mollissìmus.

2. A. Bigelovii.

3. A. Thompsonae.

4. A. anisus.

Pod straight or nearly so.

II. Uliginosi.

Calyx-tube 4-6 mm. long, 3-4 mm. wide.

Bracts linear-lanceolate, long-attenuate, the lower almost as long as the calyces; calyx-teeth all narrow, subulate, fully half as long as the tube; pod glabrous. 5. A. canadensis.

Bracts ovate to lanceolate, scarcely half as long as the calyces; calyx-teeth short, less than half as long as the tube, the upper broader; pod more or less hairy (except sometimes in the first).

Upper calyx-teeth only slightly broader than the lower; bracts lanceolate. Calyx not black-hairy; pod not sulcate. 6 . A. oreophilus, Calyx more or less black-hairy; pods somewhat sulcate on the lower suture. 7. A. Mortoni.

Upper calyx-teeth about twice as broad as the lower, broadly triangular at the base; pod not sulcate.

Calyx-tube about $3 \mathrm{~mm}$. long, less than $2 \mathrm{~mm}$. wide.

Pod decidedly arcuate.

\section{HYPOGLOTTIDES.}

8. A. spicatus.

9. A. ursinus.

18. A. palans.

Pod with appressed gray or black pubescence.

Calyx-teeth short and broad; corolla purple.

10. A. terminalis.

Calyx-teeth subulate.

Corolla purple or pink, seldom white; calyx-teeth much shorter than the tube.

Corolla sulphur-yellow, white, or pinkish; calyx-teeth almost A. Atriatus.

Lats ellipic apualling the tube.

Leaflets broadly obovate; pubescence looser. 13. A. oreganus.

Pod villous with long spreading hairs.

Corolla ochroleucous; bracts broadly spatulate to linear, obtuse.

14. A. virgultulus.

Colla purple; bracts ovate-lanceolate or oblong-lanceolate, often acutish.

Calyx biack-hairy; teeth decidedly shorter than the tube. 15. A. goniatus.

Calyx not black-hairy; teeth about equalling the tube. 16. A. agrestis.

One species.

IV. SPALDINGIANI.

17. A. Spaldingii.

1. A. mollissimus Torr. Stems less than $1 \mathrm{dm}$. long, decumbent, densely villous; leaves mostly basal; leaflets $23-29$, obovate to oval, 6-25 $\mathrm{mm}$. long, silky-villous; racemes short; calyx-tube cylindric, silky, $7-9 \mathrm{~mm}$. long; teeth subulate, about $3 \mathrm{~mm}$. long; corolla bright purple, about $18 \mathrm{~mm}$. long; pod oylindric, $2 \mathrm{~cm}$. long, curved upwards. Prairies and plains: Neb.-Tex.-N.M.Wyo.-(? Mont.). Plain. My-Jl. 
2. A. Bigelovii A. Gray. Stems less than $1 \mathrm{dm}$. long, ascending or decumbent, densely villous; leaves mostly basal; leaflets $15-25$, broadly obovate or oval, 7-20 mm. long, densely silky-villous; raceme short; calyx-tube 7-8 mm. long, villous; teeth subulate, $3 \mathrm{~mm}$. long; corolla $15-18 \mathrm{~mm}$. long, bright purple; pod elongate-ovoid, curved upwards, $1.5 \mathrm{~cm}$. long. Plains: Tex.-Colo.-Ariz.; Mex. Son. Ap-Je.

3. A. Thompsonae S. Wats. Stem very short, densely villous; leaflets 11-31, oblong to obovate, 4-8 $\mathrm{mm}$. long, densely villous on both sides; racemes rather dense; calyx-tube cylindric, $8-10 \mathrm{~mm}$. long; teeth subulate, $2-3 \mathrm{~mm}$. long; corolla purple, nearly $2 \mathrm{~cm}$. long; legume obliquely ovoid, somewhat curved, 12-16 mm. long, acuminate. Dry regions: Utah. Son. My.

4. A. anisus M. E. Jones. Stems short, usually less than $1 \mathrm{dm}$. long, silkypubescent; leaflets 7-13, silky-pubescent, obovate or oval, 4-6 mm. long; peduncles longer than the leaves; calyx-tube broadly cylindric, $8 \mathrm{~mm}$. long; teeth subulate, very short; pods oval, obtuse at each end, finely corrugated, usually somewhat sulcate on both sutures. Dry plains: Colo, Son.

5. A. canadensis L. Stem erect or ascending, 3-12 dm. high, sparingly strigose; leaflets 15-25, elliptic, oblong, or oblong-lanceolate, $2-4 \mathrm{~cm}$. long, usually obtuse at the apex, strigose on both sides or glabrate above; peduncles 5-10 cm. long; raceme 5-20 cm. long; calyx-tube strigose, $5 \mathrm{~mm}$. long; teeth subulate, the upper $1.5 \mathrm{~mm}$., the lower $2 \mathrm{~mm}$. long; corolla ochroleucous, about $12 \mathrm{~mm}$. long; pod oblong, $1-1.5 \mathrm{~cm}$. long. River banks and hillsides: Que.Fla.-Utah-B.C. Plain-Submont. Je-Au.

6. A. oreophilus Rydb. Stem sparingly strigose, 3-6 dm. high; leaflets $7-23$, oblong or elliptic, about $3 \mathrm{~cm}$. long, strigose on both sides or glabrate above; infloreseence $5-10 \mathrm{~cm}$. long; calyx-tube about $5 \mathrm{~mm}$. long, gibbous above, white-pubescent; lower calyx-teeth subulate, about $1.5 \mathrm{~mm}$. long, the upper lanceolate, shorter and slightly broader; pod oblong, about $1.5 \mathrm{~cm}$. long and $5 \mathrm{~mm}$. thick. Hills, among bushes: Colo. Submont. J1-Au.

7. A. Mortoni Nutt. Stem 3-6 dm. high, sparingly strigose or glabrate; leaflets 9-21, elliptic or oval, obtuse, rounded, or emarginate at the apex, $1.5-3.5$ $\mathrm{cm}$. long, strigose beneath; peduncles 1-2 dm. long; raceme short and dense, 2-5 $\mathrm{cm}$. long; calyx-tube 4-5 $\mathrm{mm}$. long; lower teeth subulate, $1.5 \mathrm{~mm}$. long, the upper ones lanceolate, $1 \mathrm{~mm}$. long; corolla ochroleucous, $12-15 \mathrm{~mm}$. long; pod cylindrie, $1.5 \mathrm{~cm}$. long, 4-5 mm. thick. River banks: B.C.-Mont.-n Calif. Son.-Submont. Je-Au.

8. A. spicatus Nutt. Stems $2-4 \mathrm{dm}$. high, strigose; leaflets oblong to oval, obtuse or rounded at the apex, $1-2.5 \mathrm{~cm}$. long, strigose on both sides or glabrate above; peduncle 1-1.5 dm. long; flowers often reflexed; calyx-tube $6 \mathrm{~mm}$. long; lower teeth subulate, $2 \mathrm{~mm}$. long, the upper ones triangular, $1.5 \mathrm{~mm}$. long; corolla ochroleucous, $12-15 \mathrm{~mm}$. long; pod cylindric, $1 \mathrm{~cm}$. long, 4-5 $\mathrm{mm}$. thick. A. Mortoni Coult., not Nutt. Meadows: Mont.-S.D.-Wyo.-Nev.-Ida. Submont.-Mont. Je-Au.

9. A. ursinus A. Gray. Stem erect, flexuose, $3 \mathrm{dm}$. high or more, striate, sparingly strigose; leaflets $11-15$, obovate, emarginate, $8-10 \mathrm{~mm}$. long, glabrous or nearly so; peduncles $3-6 \mathrm{~cm}$. long; racemes $2-5 \mathrm{~cm}$. long; tube about $3 \mathrm{~mm}$. long; upper teeth triangular, $0.5 \mathrm{~mm}$. long, the lower more subulate, nearly 1 $\mathrm{mm}$. long; legume oblong, about $1 \mathrm{~cm}$. long, terete, slightly eurved. Valleys: Utah. Son.

10. A. terminalis $\mathrm{S}$. Wats. Stem slender, $1.5-3 \mathrm{dm}$. high, strigose-canescent; leaflets $13-15$, linear-oblong to oblong-obovate, obtuse, $6-10 \mathrm{~mm}$. long, strigosecanescent; racemes open; flowers reflexed; corolla purplish, about $1 \mathrm{~cm}$. long; pod coriaceous, sessile, straight, narrowly oblong, about $12 \mathrm{~mm}$. long. Gravelly banks: Mont. Submont. J.

11. A. striatus Nutt. Stems 1-4 dm. high, strigose, decumbent or ascending; leaflets 9-19, oblong or elliptic, acute or obtuse, $1-2 \mathrm{~cm}$. long, grayish strigose; peduncles 7-10 $\mathrm{cm}$. long; spike dense, $2-6 \mathrm{~cm}$. long; calyx-tube $5 \mathrm{~mm}$. long, strigose, with mixed black and white hairs; teeth subulate, $2-3 \mathrm{~mm}$. long; corolla 
12-14 mm. long; pod ovoid, 8-19 mm. long, strigose. A. adsurgens Hook., not Pall. A. nitidus Dougl. A. Crandalii Gand. Plains and hills: Sask.-Minn. -Colo.-Ore--B.C. Plain-Mont. Je-Jl.

12. A. sulphurescens Rydb. Stems ascending, about $4 \mathrm{dm}$. high, angled, glabrous; leaflets $13-19$, elliptic, obtuse or acutish, mucronulate, $12-30 \mathrm{~mm}$. long; spike dense and elongate; calyx white-strigose, with scattered black hairs; tube about $5 \mathrm{~mm}$. long; lobes almost filiform, $5 \mathrm{~mm}$. long; corolla light yellow, white, or pinkish; banner 15-18 $\mathrm{mm}$. long, much exceeding the wings and keel; pod about $1 \mathrm{~cm}$. long, 3-4 mm. wide, strigose, with black hairs. Mountains: Colo.-Mont. Submont.-Mont. Je-Au.

13. A. oreganus Nutt. Stem ascending or erect, branched, grayish-canescent; leaflets 9-21, broadly obovate, 7-20 $\mathrm{mm}$. long, canescent with crisp hairs on both sides; peduncles $5-8 \mathrm{~cm}$. long; spike at first short, in age elongate, $10-20$ flowered; calyx-tube about $6 \mathrm{~mm}$. long, more or less black- and white-hairy; teeth subulate, $2 \mathrm{~mm}$. long; corolla $16-18 \mathrm{~mm}$. long; pods sessile, slightly curved. A. ventorum A. Gray. Sand hills: Wyo--Ida. Plain-Submont. Je.

14. A. virgultulus Sheld. Stems $1.5-2 \mathrm{dm}$. high, erect or ascending, striate, glabrous or nearly so; leaflets $13-19$, oblong or oblong-lanceolate, $5-8 \mathrm{~mm}$. long, obtuse or acute, glabrous above, sparingly strigose beneath; peduncles $5-10 \mathrm{~cm}$. long; spike short, 2-3 cm. long; calyx-tube 6-7 mm. long, black- and white-hairy; teeth subulate, 3-4 mm. long; corolla ochroleucous, $12-15 \mathrm{~mm}$. long; pod 10-12 mm. long. A. hypoglottis bracteatus Osterhout. River banks; Colo.-Wyo. Submont. Je-Jl.

15. A. goniatus Nutt. Stems 1-2 dm. (rarely $3 \mathrm{dm}$.) high, strigose, decumbent or ascending, zigzag; leaflets $15-21$, linear-oblong to elliptic, obtuse or retuse, $5-10 \mathrm{~mm}$. long, sparingly strigose on both sides or glabrate; peduncles about $5 \mathrm{~cm}$. long; spike globose or oblong, $2-3 \mathrm{~cm}$. long; calyx-tube $6-7 \mathrm{~mm}$. long, usually with black hairs; teeth $2-3 \mathrm{~mm}$. long, subulate; corolla about 15 $\mathrm{mm}$. long; pod villous, about $1 \mathrm{~cm}$. long, ovoid. A. hypoglottis Richards., not L. A. agrestis M. E. Jones, not Dougl. Meadows and river valleys: Hudson Bay -N.M.-Utah-Ore-B.C. Plain-Mont. Je-Au.

16. A. agrestis Dougl. Stems decumbent or ascending, about $2 \mathrm{dm}$. high, glabrous or nearly so; leaflets oblong or oblong-lanceolate, $7-15 \mathrm{~mm}$. long, obtuse or retuse, sparingly strigose or glabrate; peduncles $5-10 \mathrm{~cm}$. long; spikes oblong or globose, 2-3 cm. long; calyx-tube 5-6 mm. long; teeth subulate, 4-5 mm. long; corolla purple, $15-18 \mathrm{~mm}$. long; pod as in the preceding. Meadows: Man.Sask.-Mont. Plain. Je.

17. A. Spaldingii A. Gray. Stem 2-4 dm. high, villous; leaves $5-7 \mathrm{~cm}$. long; leaflets 21-25, lanceolate or lance-linear, villous; peduncles $5-10 \mathrm{~cm}$. long; spike oblong, 2-4 cm. long; calyx villous; tube $3-4 \mathrm{~mm}$. long; teeth setaceous, 4-5 mm. long; corolla light yellow, 9-10 mm. long; pod villous, ovate, coriaceous, turgid, scarcely sulcate; cells 3-4-ovuled, but often only 1 -seeded. Plains: Wash.-Ida.-Ore. Plain. My-Jl.

18. A. palans M. E. Jones. Stems ascending, glabrous throug̊hout; leaflets 17-25, obovate or elliptic, 6-15 mm. long, obtuse or retuse, glabrous; peduncles about $1 \mathrm{dm}$. long; racemes 6-10-flowered; calyx sparsely nigrescent; tube $4 \mathrm{~mm}$. long; teeth $3 \mathrm{~mm}$. long, subulate; corolla pink, about $15 \mathrm{~mm}$. long; legume linear, acuminate, arcuate, sulcate on both sides, less so on the lower side; lower suture inflexed, forming a not quite complete septum. Cañons: Utah-Ariz. Submont. Je.

\section{HAMÒSA Medic.}

Annual, biennial, or perennial herbs, with decumbent or tufted stems. Leaves alternate, odd-pinnate; stipules almost free and distinct; leaflets numerous, entire, usually truncate or notehed at the apex. Flowers perfect, in short racemes, few. Calyx short-campanulate, 5-lobed; lobes subulate, nearly equal. Corolla usually purplish; banner with rather broad blade, erect; wings usually longer than the unbeaked keel. Stamens 10; filaments diadelphous; anthers 
alike. Pods linear, laterally flattened, dehiscent, membranous, completely 2celled by the intrusion of the lower suture. Seeds numerous.

Plant acaulescent, silvery white.

Racemes several-flowered; calyx-teeth triangular-lanceolate, about one-third as long as the tube.

Racemes 1-2-flowered; calyx-teeth elongate-lanceolate, more than half as long as the tube.

Piant caulescent, not silvery.

Legume curved.

Plant glabrous or strigose.

Pod less than $3 \mathrm{~mm}$. wide, not mottled; corolla 5-6 mm. long. Leaflets lanceolate or oblong; pod finely strigose. Leaflets cuneate or oblong, emarginate; pod glabrous. Pod $6 \mathrm{~mm}$. wide, mottled; corolla about $1.5 \mathrm{~cm}$. long.

Plant hirsute; pod over $4 \mathrm{~mm}$. wide.

3. H. austrina.

4. H. Nuttalliana.

5. H. amplexa. Legume straight.

Racemes short, subcapitate; corolla light bluish purple; leaflets oblong to obcordate, green.

7. H. leptocarpa.

Racemes elongate, lax; corolla cream-colored; leaflets narrowly oblong or linear, grayish strigose.

8. H. atratiformis.

1. H. scaposa (A. Gray) Rydb. Cespitose, nearly acaulescent perennial; leaflets 5-9, obovate or elliptic, silvery-cinereous, 7-12 $\mathrm{mm}$. long; peduncles 8-10 cm. long; raceme 3-12-flowered; calyx cinereous; tube about $5 \mathrm{~mm}$. long; teeth 1-1.5 mm. long; corolla purple, about $12 \mathrm{~mm}$. long; pod oblong, slightly curved, cinereous-strigillose, $12-15 \mathrm{~mm}$. long, $4 \mathrm{~mm}$, wide. Astragalus scaposus A. Gray. Sandy soil: Wyo.-N.M.-Ariz.-Utah. Son. Ap-Je.

2. H. calycosa (Torr.) Rydb. Cespitose perennial, nearly acaulescent; leaflets 3-9, obovate, oblanceolate, or oblong, silvery-sericeous, $5-10 \mathrm{~mm}$. long; peduncles $2-5 \mathrm{~cm}$. long; raceme 1 -3-flowered; calyx cinereous; tube $4 \mathrm{~mm}$. long; teeth lanceolate, 2-4 mm. long; corolla purple or cream-colored, about $1 \mathrm{~cm}$. long; pod sessile, cinereous-strigillose, oblong, somewhat curved, $15-20 \mathrm{~mm}$. long, $4 \mathrm{~mm}$. wide. A. calycosus Torr. A. brevicaulis A. Nels. Gravelly soil: Ida. -Utah-Calif. Submont.-Mont. Ap-Jl.

3. H. austrina Small. Annual; stem branched at the base; branches ascending or decumbent, $1-4 \mathrm{dm}$. long, strigillose; leaflets $9-11$, strigose on both sides, oblong or oval, 2-6 mm. long; peduncles $1-4 \mathrm{~cm}$. long; raceme head-like, few-flowered; calyx-tube $2 \mathrm{~mm}$. long; teeth subulate, $2 \mathrm{~mm}$. long; corolla purplish, 5-6 mm. long; pod linear, $1.5-2 \mathrm{~cm}$. long, strongly curved at the base. $A$. Nutlallianus trichocarpus T. \& G. Plains and prairies: Tex.-Utah-Calif.; n Mex. Son. Ja-Je.

4. H. Nuttalliana (DC.) Rydb. Annual; stem simple or branched at the base, erect or ascending, sparingly strigillose or glabrate, $0.5-3 \mathrm{dm}$. high; leaflets 11-21, oblong, obovate or cuneate, usually notched at the apex, 2-10 $\mathrm{mm}$. long, glabrous or sparingly strigose; peduncles $2-5 \mathrm{~cm}$. long; raceme short and few-flowered; calyx-tube and the lance-subulate teeth each about $2 \mathrm{~mm}$. long; corolla purplish, 5-6 mm. long; pod linear, about $2 \mathrm{~cm}$. long, slightly curved, glabrous. A. Nuttallianus DC. Dry soil: Ark.-Colo.-Ariz.-Tex. Son. $\mathrm{Mr}-\mathrm{My}$.

5. H. amplexa (Payson) Rydb. Biennial or short-lived perennial; stems several, 3-4 dm. high, sparingly pubescent, erect or spreading, flexuose; leaflets 17-21, oblanceolate, truncate or retuse at the apex, 9-12 $\mathrm{mm}$. long, 4-6 $\mathrm{mm}$. wide; raceme 12-15-flowered; calyx-tube $6 \mathrm{~mm}$. long, nigrescent; teeth linear, 2-3 mm. long; corolla violet; pod sparsely pubescent, $2-2.5 \mathrm{~cm}$. long, $6 \mathrm{~mm}$. wide, mottled along the dorsal suture, curved. A. amplexus Payson. Dry hillsides: w Colo. Submont. My.

6. H. malacra (A. Gray) Rydb. Perennial, cespitose; stems 1-3 dm. high, decumbent or erect, hirsute; leaflets $13-15$, obovate, retuse, $1-1.5 \mathrm{~cm}$. long, villous-hirsute; peduncles longer than the leaves; calyx-tube black-hairy, nearly $1 \mathrm{~cm}$. long; teeth subulate, $3 \mathrm{~mm}$. long; corolla purple, fully $1.5 \mathrm{~cm}$. long; pod flattened laterally, strongly curved, loosely villous-hirsute, $3 \mathrm{~cm}$. long, about $5 \mathrm{~mm}$. wide, somewhat mottled. A. malacrus A. Gray. A. obfalcatus A. Nels. Hills: Calif.-Nev.-Ida.-Ore. Son. Ap-My. 
7. H. leptocarpa (T. \& G.) Rydb. Annual; stem erect, simple or branched at the base, with ascending branches, 1-3 dm. high; leaflets 9-19, glabrous or nearly so, oblong to cuneate, $3-8 \mathrm{~mm}$. long, notched at the apex; peduncles $3-7$ $\mathrm{cm}$. long; raceme few-flowered; calyx-tube and the lanceolate teeth each $2 \mathrm{~mm}$. long; corolla purplish, $8-10 \mathrm{~mm}$. long; legume linear, $2.5-3 \mathrm{~cm}$. long, straight or nearly so, glabrous. A. leptocarpus T. \& G. Dry soil: Tex.-Colo.-Ark. Son. Mr-Ap.

7. H. atratiformis Rydb. Perennial; stem $2-3 \mathrm{dm}$. high, erect, branched, strigose; leaflets $13-19$, oblong, strigose below, glabrous above, 4-6 mm. long; peduncles 5-7 $\mathrm{cm}$. long; raceme lax, 2-3 $\mathrm{cm}$. long; calyx black-strigose; tube about $2 \mathrm{~mm}$. long; teeth subulate, $1 \mathrm{~mm}$. long; corolla ochroleucous, about 7 $\mathrm{mm}$. long; pod linear, straight, minutely strigillose. (?) A. straturensis M. E. Jones. Dry soil: s Utah. L. Son.

\section{TÎUM Medic.}

Perennial caulescent herbs. Leaves alternate, with nearly free and distinct stipules; leaflets numerous, entire. Flowers perfect, in racemes. Calyx campanulate; teeth nearly equal, usually rather long. Corolla purple, white or ochroleucous; banner with a rather broad, erect, often notched blade. Stamens 10, diadelphous; anthers alike. Pod narrow, tapering at each end, more or less stipitate, usually membranous, 1-celled, obcordate, or inverted V-shaped in cross-section, the lower suture strongly sulcate, rarely with a narrow partial partition. Seeds numerous.

Stipe exceeding the calyx; pod not incurved.

Pod not black-hairy; corolla white or ochroleucous.

Pod erect, glabrous.

Stipe much longer than the calyx.

Stipe scarcely exceeding the calyx.

Pod with a partial septum.

Pod glabrous; stipe 3-4 mm. long.

Pod strigose; stipe $1 \mathrm{~mm}$. long.

Pod reflexed.

Pod without septum.

1. T. eremiticum.

Plant villous; pod cordate in cross-section.

2. T. atropubescens,

3. T. obscurum.

4. T. arrectum.

Plant appressed-pubescent or glabrous; pod more or less triangular or inverted $\mathrm{V}$-shaped in eross-section.

Pod 2-3 cm. long; corolla $15-20 \mathrm{~mm}$. long.

Calyx not black-hairy; pod straight.

Calyx black-hairy; pod arcuate.

Pod less than $1.5 \mathrm{~cm}$. long; flowers $6-8 \mathrm{~mm}$. long.

Pod black-hairy; corolla violet or purple.

Stipe shorter than the calyx or almost none; pod incurved.

Pod mottled; plant green, very slender.

Stem slender, spreading.

Raceme 1-5-flowered, short; leaflets obovate or orbicular.

Raceme 5-10-flowered; leaflets linear.

10. T. sparsiflorum.

Stems stout, erect; raceme 5-15-flowered.

Leaflets obovate or orbicular.

Leaflets narrowly elliptic.

Pod not mottled; plant cinereous.

Pod appressed-pubescent.

Pod hirsute-villous, with spreading hairs.

6. T. racemosum.
7. T. scopulorum.
8. T. Rusbyi.
9. T. alpinum.

1. T. eremiticum (Sheld.) Rydb. Stems several, 2-4 dm. high, glabrous or nearly so; leaflets 13-19, 8-12 $\mathrm{mm}$. long, oblong to obovate, obtuse; peduncles 8-10 $\mathrm{cm}$. long; raceme $5-10 \mathrm{~cm}$. long, loosely $5-10$-flowered; calyx strigose, with black hairs; tube 5-6 mm. long; teeth subulate, 1-2 $\mathrm{mm}$. long; corolla ochroleucous, $13-15 \mathrm{~mm}$. long; stipe of the pod 10-12 mm. long; body oblong, 1.5-2 $\mathrm{cm}$. long and $5 \mathrm{~mm}$. thick. Astragalus eremiticus Sheld. A. arrectus M. E. Jones. A. boiseanus A. Nels. Mountains and hillsides: Ida.-Ariz,-Nev. Son.

2. T. atropubescens (Coult. \& Fish.) Rydb. Stems sêveral, erect, branched, strigose or glabrous; leaflets 16-25, oblong, about $1 \mathrm{~cm}$. long, obtuse, glabrate above, strigose beneath; peduncles about $1 \mathrm{~cm}$. long; raceme rather lax; calyx strigose, with black hairs; tube about $4 \mathrm{~mm}$. long; teeth lance-subulate, $1.5 \mathrm{~mm}$. long; corolla sulphur-yellow, 12-14 mm. long; body of the pod 15-18 mm. long, 
$4 \mathrm{~mm}$. thick, glabrous. A. atropubescens Coult. \& Fish. A. Kelseyi Rydb. Hills: Mont. Son.-Submont. Je-Jl.

3. T. obscurum (S. Wats.) Rydb. Stem with a woody base, ascending, $2-3 \mathrm{dm}$. high, strigose; leaflets $11-15$, oblong to oval, 5-10 mm. long, sparingly strigose; peduncles 5-10 $\mathrm{cm}$. long; racemes short; ealyx strigose, with partly black hairs; tube about $3 \mathrm{~mm}$. long; teeth subulate, 1-1.5 $\mathrm{mm}$. long; corolla yellowish, about $1 \mathrm{~cm}$. long; pod linear, about $2 \mathrm{~cm}$. long, $3 \mathrm{~mm}$. thick, strigose. $A$. obscurus S. Wats. Dry regions: Ore--Ida.-Nev.-Calif. Son. My-Je.

4. T. arrectum (A. Gray) Rydb. Stems several, 3-6 dm. high, more or less strigose, striate; leaflets 25-31, linear to elliptic, obtuse, $8-16 \mathrm{~mm}$. long, grayish strigose on both sides or glabrate above; peduncles 1-2 dm. long; raceme lax; calyx strigose with black hairs; tube $4-5 \mathrm{~mm}$. long; teeth subulate, about $2 \mathrm{~mm}$. long; corolla white or nearly so, $12-15 \mathrm{~mm}$. long; stipe of the pod $3-4 \mathrm{~mm}$. long; body oblong, $1.5-2 \mathrm{~cm}$. long, $5 \mathrm{~mm}$. broad. A. arrectus A. Gray. A. palousiensis Piper. A. Liebergii M. E. Jones. Hills: Ida.-Wash.-Ore. Son.Submont. My-Je.

5. T. Drummondii (Dougl.) Rydb. Stems 3-7 dm. high, villous; leaflets $25-31$, elliptic to linear-oblong, obtuse, about $1 \mathrm{~cm}$. long, glabrous or nearly so above, softly long-villous beneath; peduncles $5-10 \mathrm{~cm}$. long; raceme $3-10 \mathrm{~cm}$. long, at first dense, soon elongate; calyx hirsute-villous, with mixed black and white hairs; tube 5-6 mm. long; teeth subulate, 1.5-2 mm. long; corolla 15-20 $\mathrm{mm}$. long, cream-colored; stipe of the pod about $8 \mathrm{~mm}$. long; body linear, 2-2.5 em. long, glabrous, $3-4 \mathrm{~mm}$. thick. A. Drummondii Dougl. Plains and hills: Sask,-Neb.-Colo.-Alta. Plain-Submont. My.

6. T. racemosum (Pursh) Rydb. Stems 3-6 dm. high, strigose; leaflets 15-31, pale green, linear or oblong, obtuse, $1.5-3 \mathrm{~cm}$. long, glabrous above, strigose beneath; peduncles about $1 \mathrm{dm}$. long; raceme lax, 1-2 dm. long, manyflowered; calyx strigose; tube $5-8 \mathrm{~mm}$. long; teeth subulate, $4-6 \mathrm{~mm}$. long; eorolla white, $15-20 \mathrm{~mm}$. long; stipe of the pod about $5 \mathrm{~mm}$. long; body linear, about $2.5 \mathrm{~cm}$. long, $4 \mathrm{~mm}$. broad, glabrous. A. racemosus Pursh. Plains and hills: N.D.-Okla.-N.M. Plain.

7. T. scopulorum (Porter) Rydb. Stems $3-5 \mathrm{dm}$. high, strigose, angled; leaflets 15-27, oblong to obovate or oval, glabrous above, sparingly strigose beneath; peduneles 5-8 cm. long; raceme short, $5-10 \mathrm{~cm}$. long; calyx-tube about $6 \mathrm{~mm}$. long; teeth subulate, $3 \mathrm{~mm}$. long; corolla ochroleucous, $15-20 \mathrm{~mm}$. long; stipe of the pod about $8 \mathrm{~mm}$. long; body linear, curved, glabrous, $2.5 \mathrm{~cm}$. long, $3 \mathrm{~mm}$. wide. A. scopulorum Porter. A. rarus Sheld. A. subcompressus A. Gray. Mountains, usually in open woods: Colo.-Utah-N.M. Submont.-Mont. My-Je.

8. T. Rusbyi (Greene) Rydb. Stem branched, 3-6 dm. high, glabrous or nearly so; leaflets $17-27$, oblong, $5-15 \mathrm{~mm}$. long, obtuse or truncate, sparingly strigose below, glabrous above; raceme elongate, long-peduncled; calyx-tube black-hairy, about $2 \mathrm{~mm}$. long; lobes subulate, less than $1 \mathrm{~mm}$. long; corolla yellowish or with purplish banner, $7-8 \mathrm{~mm}$. long; pod straight, linear, about 2 $\mathrm{cm}$. long, glabrous, with a broad, partial partition. A. Rusbyi Greene. Mountains: Ariz.-Utah-N.M. Submont. My-Jl.

9. T. alpinum (L.) Rydb. Stems decumbent or ascending, 1-3 dm. (rarely $4 \mathrm{dm}$.) high, glabrous or nearly so; leaflets $13-25$, oval or elliptic, obtuse or retuse, 6-12 $\mathrm{mm}$. long, pilose on both sides; peduncles 5-10 $\mathrm{cm}$. long; raceme short, $1-4 \mathrm{~cm}$. long; calyx black-hairy; tube about $3 \mathrm{~mm}$. long; teeth subulate, $1.5 \mathrm{~mm}$. long; corolla $8-12 \mathrm{~mm}$. long; stipe of the pod $3 \mathrm{~mm}$. long; body oblong, about $1 \mathrm{~cm}$. long, $3 \mathrm{~mm}$. thick. A. alpinus L. Alpine-aretic regions: Lab.Vt.-Colo.-Ida.-Alaska; Eurasia. Mont.-Alp. Je-Au.

10. T. sparsiflorum (A. Gray) Rydb. Stems slender, 1-3 dm. long, sparingly strigose, diffuse; leaflets $9-13$, obovate or suborbicular, rounded or retuse at the apex, 3-6 mm. long, strigose beneath, glabrous above; peduncles $1-3 \mathrm{~cm}$. long; raceme short, $1-5$ flowered; calyx black-hairy; tube short, $2 \mathrm{~mm}$. long, very oblique; teeth 1-1.5 mm. long, subulate; corolla white, tinged with violet, 
5-6 $\mathrm{mm}$. long; pod strigose; stipe about $1 \mathrm{~mm}$. long; body $6-8 \mathrm{~mm}$. long, lunatefalcate, mottled. A. sparsiflorus A. Gray. Mountains: Colo. Submont.Mont. Jl.

11. T. owyheense (Nels. \& Macbr.) 'Rydb. Stems several, prostrate, spreading, strigillose; leaflets 5-13, linear; racemes exceeding the leaves; calyx strigillose; teeth one-third as long as the tube; corolla 8-10 mm. long, white; pod oblong-linear, 10-18 mm. long, straight or slightly curved, strigillose; dorsal suture only slightly intruded. A. owyheensis Nels. \& Macbr. Sage-brush plains: Ida.

12. T. variegatum Rydb. Stems numerous, strigose, more or less mottled with purplish brown; leaflets obovate to nearly orbicular, rounded or retuse at the apex, thick, sparingly strigose, soon glabrate, 5-10 $\mathrm{mm}$. long; raceme short, 5-15 flowered; calyx black-hairy; tube 2-2.5 mm. long; teeth subulate, 1-2 mm. long; corolla ochroleucous, 6-7 mm. long; pod scarcely stipitate, about $2 \mathrm{~cm}$. long, $4 \mathrm{~mm}$. broad, oblong, slightly arcuate, acute on the upper suture, mottled with purplish brown and minutely strigose. Cañons. Colo. Submont.-Mont.

13. T. naturitense (Payson) Rydb. Perennial; stem grayish strigose; stipules scarious, ovate, free; leaflets 9-11, narrowly elliptic, more densely pubescent beneath, 6-7 mm. long; raceme short, subcapitate at first, 6-10flowered; calyx $7 \mathrm{~mm}$. long, sparsely nigrescent; teeth triangular-subulate; corolla 12-15 mm. long; banner white; wings and keel red-tipped; pod subsessile, $2 \mathrm{~cm}$. long, $6 \mathrm{~mm}$. wide, cordate in section, with red and purplish blotches. $A$. naturitensis Payson. Mesas: w Colo. Submont.

14. T. humistratum (A. Gray) Rydb. Stems procumbent, $2-5 \mathrm{dm}$. long, grayish strigose; leaflets 13-17, linear, linear-oblong, or oblanceolate, silkystrigose on both sides, or glabrate above, $7-15 \mathrm{~mm}$. long; peduncles $5-8 \mathrm{~cm}$. long; raceme $2-5 \mathrm{~cm}$. long; calyx strigose with long hairs; tube $3 \mathrm{~mm}$. long; teeth subulate, $4 \mathrm{~mm}$. long; corolla 9-11 mm. long, violet, the banner with purple veins; pod strigose, linear-lanceolate, $15-18 \mathrm{~mm}$. long, arcuate. A. humistratus A. Gray. Dry hills: N.M.-Calif.-s Colo. Son. Ap-Jl.

15. T. desperatum (M. E. Jones) Rydb. Stems very short, covered with the large scarious stipules; leaflets $11-15$, narrowly lanceolate to oval, 4-12 mm. long, strigose on both sides; peduncles 3-10 cm. long; raceme rather lax, 2-6 cm. long; calyx strigose; tube $4 \mathrm{~mm}$. long; teeth subulate, $2 \mathrm{~mm}$. long; corolla about $12 \mathrm{~mm}$. long, purple, darker towards the tip; pod sessile, reflexed, falcate, 12 $\mathrm{mm}$. long, $4 \mathrm{~mm}$. wide, long-hairy. A. desperatus M. E. Jones. Sandy river banks: Utah-Colo. Son.

\section{DIHÓLCOS Rydb.}

Stout erect perennial herbs, forming clumps. Leaves alternate, odd-pinnate, with numerous thick leaflets, strigose beneath, glabrous above; stipules lanceolate, free. Raceme many-flowered, dense, spike-like; bracts subulate. Calyx campanulate, gibbous at the base on the upper side; teeth subulate-setaceous. Corolla purple, white, or ochroleucous. Pod coriaceous, stipitate, oblong, straight, rounded on the lower suture, deeply 2-grooved above and with a prominent upper suture, 1-celled.

Pod glabrous; body about $1.5 \mathrm{~cm}$. long; upper calyx-teeth 3-4 mm. long; corolla white.

Pod strigose; upper calyx-teeth less than $3 \mathrm{~mm}$. long.

Body of the pod $12-15 \mathrm{~mm}$. long; corolla usually purple.

1. D. decalvans.

Body of the pod rarely $10 \mathrm{~mm}$. long; corolla white or straw-colored, only the keel sometimes tipped with purple.

Pod distinetly cross-ribbed.

Corolla more than $1 \mathrm{~cm}$. long; pod very acute at both ends; stipe $5 \mathrm{~mm}$. long.

3. D. scobinatulus.

Corolla less than $1 \mathrm{~cm}$. long; pod obtusish or abruptly acuminate at both ends;

stipe $3 \mathrm{~mm}$. long.
Pod not cross-ribbed; corolla $6 \mathrm{~mm}$. long.

4. D. Haydenianus.

5. D. micranthus.

1. D. decalvans (Gand.) Rydb. Stem 3-6 dm. high, sparingly strigose or glabrate; leaflets 19-29, oval or elliptic, 1-2 cm. long; raceme many-flowered; calyx sparingly strigose, with black or white hairs; tube $4 \mathrm{~mm}$. long; teeth almost 
equal, subulate; corolla $15-18 \mathrm{~mm}$. long; stipe of the pod about $5 \mathrm{~mm}$. long; body 12-16 $\mathrm{mm}$. long, $5 \mathrm{~mm}$. wide. Astragalus bisulcatus decalvans Gand. Plains and foot-hills: Colo,-Wyo. Submont. Je.

2. D. bisulcatus (Hook.) Rydb. Stems erect or decumbent at the base, sparingly strigose or glabrate, $3-7 \mathrm{dm}$. high; leaflets $17-27$, elliptic or rarely oval, $1-2.5 \mathrm{~cm}$. long; racemes many-flowered; calyx strigose, tinged with purple; tube $4 \mathrm{~mm}$. long; teeth subulate or lance-subulate, the upper 1.5-2 $\mathrm{mm}$. long, the lower 2-3 mm.; corolla 12-15 mm. long; legume strigose. A. bisulcatus A. Gray. Plains, hills, and river valleys: Sask.-Neb.-Colo-_Alta. Plain-Submont. $\mathrm{Je}-\mathrm{Au}$.

3. D. scobinatulus (Sheld.) Rydb. Stems 3-6 dm. high, erect; leaflets 15-21, elliptic or oblong or oval, 8-20 $\mathrm{mm}$. long, obtuse; raceme rather short; calyx sparingly strigose; tube $4 \mathrm{~mm}$. long; upper teeth triangular-subulate, 1-1.5 $\mathrm{mm}$. long; lower subulate, about $2 \mathrm{~mm}$. long; corolla fully $1 \mathrm{~cm}$. long, creamcolored; keel purple-tipped. A. Haydenianus major Jones. A. scobinatulus Sheld. A. Haydenianus Nelsonii Gand. Alkali flats and dry ground: Utah-Wyo.
Plain. Je.

4. D. Haydenianus (A. Gray) Rydb. Stems erect, 3-9 dm. high; leaflets 15-29, linear to elliptic, 7-20 mm. long; racemes elongate; calyx strigose, usually with black hairs; tube $3-4 \mathrm{~mm}$. long; upper teeth triangular-subulate, $1 \mathrm{~mm}$. long, the lower subulate, $1.5-2 \mathrm{~mm}$. long; corolla 7-9 mm. long. A. Haydenianus A. Gray. Dry soil: Colo.-Wyo.-Utah. Submont. Je-Ji.

5. D. micranthus Rydb. Stems erect or ascending, sparingly strigose or glabrate, 2-4 dm. high; leaflets 17-25, linear or lance-oblong, acute at both ends, $7-20 \mathrm{~mm}$. long; racemes many-flowered; calyx strigose; tube $2-2.5 \mathrm{~mm}$. long; teeth subulate-filiform, 1-2 mm. long, the upper somewhat shorter; corolla 6-7 $\mathrm{mm}$. long, ochroleucous; stipe $3-4 \mathrm{~mm}$. long; body scarcely $1 \mathrm{~cm}$. long, very acute. Dry table lands: Colo. Submont. My-Jl.

\section{JONESIÉLLA Rydb.}

Stout perennial, with a woody root and simple stems. Leaves unifoliolate, thick and veiny; stipules broadly triangular, thin. Racemes 6-8-flowered, axillary. Calyx cylindric, somewhat gibbous, with triangular teeth. Corolla ochroleucous, with a purple spot on the keel. 'Pod stipitate, coriaceous, elliptic, turgid, partially 2-celled by the inflexion of the upper suture.

1. J. asclepiadoides (M. E. Jones) Rydb. Stems 4-6 dm. high, erect or ascending, glabrous and glaucous; leaves orbicular-ovate or cordate, entire, veiny, thick, $3-5 \mathrm{~cm}$. in diameter; raceme 6-8-flowered; calyx about $1 \mathrm{~cm}$. long; corolla $2 \mathrm{~cm}$. long; pod glabrous; stipe about $1 \mathrm{~cm}$. long; body ovoid, $2.5 \mathrm{~cm}$. long, fully $1 \mathrm{~cm}$. wide. Astragalus asclepiadoides M. E. Jones. Sand-bars: Utah-Colo. Son. Je.

\section{RYDBERGIÉLLA Fedde \& Sydow.}

Stout erect glabrous perennials, more or less branched at the woody base. Leaves pinnate, with numerous leaflets; stipules ovate, almost free. Racemes rather many-flowered; flowers nearly sessile; bracts lanceolate. Calyx campanulate; lobes lanceolate-subulate, nearly equalling the tube, at last with spreading tips. Corolla ochroleucous, with purple-tipped keel; banner and wings narrow. Pod oblong-ovate, coriaceous, somewhat inflated, with a more or less distinet partial partition formed by the inflexion of the upper suture, more or less stipitate. [Phacopsis Rydb.]

Pod with a broad partition, almost 2-celled, except at the apex.

Pod with a narrow, sometimes obsolete partial partition.

Stipe of the pod 4-8 $\mathrm{mm}$. long. Leaflets oblanceolate or oblong.
Leaflets obovate.

Stipe of the pod $1-2 \mathrm{~mm}$. long; leaflets oblong to oval.

Plant glabrous; leaflets oblong, retuse.

Plant hispidulous-strigose on the upper parts of the stem and of the leaves.

1. R. scaphoides.

2. R. arcta.

3. R. Preussii.

4. $R$. praelonga,

the lower surface

5. R. Pattersonii. 
1. R. scaphoides (M. E. Jones) Rydb. Stem coarse, strigose, 5-7 dm. high; leaflets about 11, elliptic, 1-2.5 cm. long, grayish-strigose beneath, glabrous above; calyx black-hairy, $8 \mathrm{~mm}$. long; teeth $2 \mathrm{~mm}$. long, triangular-subulate; corolla white; pod coriaceous, glabrous, reticulate; stipe about $1 \mathrm{~cm}$. long; body oblong, acute, about $15 \mathrm{~mm}$. long. Astragatus arrectus scaphoides M. E. Jones. Sage-brush plains: Mont. Plain-Submont. Je.

2. R. arcta (Sheld.) Rydb. Perennial, with woody base, much branched, 1.5-5 dm. high, striate, glabrous; leaflets 13-21, rather distant, oblanceolate, 4$10 \mathrm{~mm}$. long, glabrous, or nearly so; calyx about $10 \mathrm{~mm}$. long; teeth subulate; corolla purplish, about $18 \mathrm{~mm}$. long; pod oblong-ellipsoid, $2-2.5 \mathrm{~cm}$. long, tapering at both ends; stipe 5-8 $\mathrm{mm}$. long, somewhat sulcate on the ventral side. A. Preussii latus Jones. A. Preussii arctus Sheld. Sandy soil: Utah. Son. My-Je.

3. R. Preussii (A. Gray) Rydb. Stems glabrous, 3-4 dm. high; leaflets $13-17$, fleshy, obovate or rounded, usually retuse, $1-2 \mathrm{~cm}$. long, glabrous; calyx minutely strigose or glabrate; tube $7-8 \mathrm{~mm}$. long; teeth subulate, $1.5 \mathrm{~mm}$. long; corolla purple, $20-25 \mathrm{~mm}$. long; stipe of the pod $4 \mathrm{~mm}$. long; body oblong, acute at both ends, $2.5 \mathrm{~cm}$. long. A. Preussii A. Gray. River banks: Utah-Ariz. -s Calif.-Nev. Son. Mr-My.

4. R. praelonga (Sheld.) Fedde \& Sydow. Stems 4-10 dm. high, glabrous or nearly so; leaflets $15-21$, oval, 1-3.5 $\mathrm{cm}$. long, glabrous or nearly so, often retuse; raceme densely flowered; ealyx sparingly strigillose; tube $6 \mathrm{~mm}$. long; teeth subulate, 2-3 mm. long; corolla ochroleucous, $16-18 \mathrm{~mm}$. long; pod ovoid, abruptly acute, $2-3 \mathrm{~cm}$. long, $10-12 \mathrm{~mm}$. thick, glabrous, indistinctly reticulate. A. praelongus Sheld. A. sabulosus M. E. Jones. Dry ground: Colo.-N.M.Calif. Son.-Submont. Ap-My.

5. R. Pattersonii (A. Gray) Fedde \& Sydow. Stems $3-6$ dm. high, more or less strigose; leaflets 11-21, oblong, thick, acute or obtuse, 1-2 cm. long, glabrous above, strigose beneath; flowers usually nodding; calyx strigose; tube about 8 $\mathrm{mm}$. long; teeth subulate, $3-4 \mathrm{~mm}$. long; corolla ochroleucous, $18-20 \mathrm{~mm}$. long; pod ovoid, long-acuminate, $2-2.5 \mathrm{~cm}$. long, $7-8 \mathrm{~mm}$. thick, glabrous, reticulate. A. Pattersonii A. Gray. Foot-hills and plains: Colo.-Utah. Son.-Submont. My.

\section{CTENOPHÝLLUM Rydb.}

Stout perennials, with often several stems rising from the same root and more or less stoloniferous. Leaves pinnate, with 11-19 leaflets, which usually are indistinctly jointed to the rachis; stipules ovate, free from the petioles, but (especially the lower) united back of the stem. Peduncles usually equalling the leaves; raceme short. Calyx cylindro-campanulate, very gibbous at the base on the upper side. Corolla ochroleucous, with narrow petals; keel almost straight. Pod oblong, terete, coriaceous, with a subfleshy epicarp, in age cross-wrinkled, with thick and prominent sutures, neither of which is inflexed.

\section{Leaflets narrow.}

Leaflets filiform or nearly so, 2-4 cm. long, 1-2 mm. wide.

Leaflets linear, $2-3 \mathrm{~cm}$. long, $3-4 \mathrm{~mm}$. wide.

Leaflets oblong to broadly obovate.

1. C. pectinatum.

2. C. Grayi.

3. C. adanum.

1. C. pectinatum (Hook) Rydb. Stems 3-5 dm. high, erect or decumbent at the base; leaflets $15-21$, minutely strigose when young, soon glabrate; raceme short and dense, 5-20-flowered; calyx sparingly black-strigose; tube 5-7 $\mathrm{mm}$. long; teeth subulate, $2 \mathrm{~mm}$. long; corolla ochroleucous, about $2 \mathrm{~cm}$. long; pod oblong-ellipsoid, $1.5-2 \mathrm{~cm}$. long, terete, $8 \mathrm{~mm}$. in diameter. Astragalus pectinatus Dougl. Dry plains: Man.-Kans.-Colo.-Alta. Plain-Submont. MyJe.

2. C. Grayi (Parry) Rydb. Stems 3-4 dm. high, strigose; leaflets 7-13, obtuse, glabrous above, sparingly strigillose beneath; raceme short and dense; calyx strigillose, with blackish hairs; tube $7 \mathrm{~mm}$. long; teeth subulate, $2-3 \mathrm{~mm}$. long; corolla ochroleucous, $2-2.5 \mathrm{~cm}$. long; legume oblong-ovoid, glabrous. $A$. Grayi Parry. Dry draws and hills: Wyo. Plain. Je. 
3. C. adanum (A. Nels.) Rydb. Sterns many, glabrate, striate, $2-4 \mathrm{dm}$. high; leaflets $13-25$, rather thin, from oblong to broadly obovate, $7-14 \mathrm{~mm}$. long, glabrous above, sparingly strigose beneath; racemes 5 - 15 -flowered, shortpeduncled; calyx partly black-hairy; pod narrowly ovoid, with short incurved, compressed apex, about $1 \mathrm{~cm}$. long. A. adanus A. Nels. Hills: Ida. Je.

\section{CNEMIDOPHÃCOS Rydb.}

Cespitose perennials with a woody caudex; stems short, 1-2 dm. high. Leaves pinnate, with many narrow leaflets, cinereous; stipules slightly united with the petioles, but almost wholly united behind the stem, forming a sheath. Racemes strict and many-flowered. Calyx deeply campanulate; lobes linear-lanceolate, equalling the tube. Corolla yellow, with narrow petals. Pod coriaceous, oblong, ovoid, rounded below, somewhat depressed above, one-celled, without a partial partition or rarely with a rudimentary one; upper suture usually prominent.

Pod with a rudimentary partition.

Pod without a partition.

Calyx densely black-villous.

Calyx not black-hairy or with a few scattered black hairs. Calyx strigose with rather short hairs. Corolla yellow. Corolla pinkish.

Calyx silky-pilose or hirsute with long loose hairs. Corolla purple; calyx-teeth 4-5 mm. long. Corolla ochroleucous; calyx-teeth $2 \mathrm{~mm}$. long.
1. C. reventoides.

2. C. reventus.

3. C. flavus.

4. C. confertiflorus.

5. C. argillosus.

6. C. urceolatus.

1. C. reventoides (M. E. Jones) Rydb. Stems adsurgent or erect, 1-1.5 $\mathrm{dm}$. high, canescent-strigose; leaflets $15-25$, oval to oblong, 6-12 mm. long, silvery-strigose on both sides; raceme head-like, 3-4 cm. long; calyx black-hairy; tube $4 \mathrm{~mm}$. long; teeth $1 \mathrm{~mm}$. long, obtuse; corolla yellowish, about $1 \mathrm{~cm}$. long; pod oblong-ovoid, $8-10 \mathrm{~mm}$. long, $6 \mathrm{~mm}$. thick. Astragalus reventoides Jones. Dry hills and sage-brush flats: Mont. Plain. Je.

2. C. reventus (A. Gray) Rydb. Stems $2-4$ dm. high, numerous, sparingly strigose; leaflets 21-37, oblong to linear, 1-1.5 cm. long, grayish strigose on both sides or glabrate above; raceme short; calyx black-villous; tube $5 \mathrm{~mm}$. long; teeth subulate, $3 \mathrm{~mm}$. long; corolla ochroleucous or whitish, nearly $2 \mathrm{~cm}$. long; pod ovate-oblong, glabrous, acute, $15-20 \mathrm{~mm}$. long, 7-8 mm. wide, neither suture very prominent. A. reventus A. Gray. Mountain sides: Wash.-Ida.Ore. Plain-Submont. Ap-My.

3. C. flavus (Nutt.) Rydb. Stems canescent-strigose, decumbent or ascending, 1-3 dm. high; leaflets 5-11, oblong to linear, grayish strigose beneath, slightly strigose or glabrate above, $1-3 \mathrm{~cm}$. long; raceme rather dense; calyx strigose with white hairs; tube 4-5 mm. long; teeth subulate, about $2 \mathrm{~mm}$. long; corolla yellow, 10-12 mm. long; pod ovoid, strigose, 12-15 mm. long, sessile. A. flavus Nutt. Dry plains: Wyo,-N.M.-Utah. Submont. Ap-My.

4. C. confertiflorus (A. Gray) Rydb. Stems erect, 1.5-3 dm. high, canescent-strigose; leaflets 11-13, narrowly linear, $15-25 \mathrm{~mm}$. long; racemes $5-8 \mathrm{~cm}$. long; calyx strigose, with white hairs; tube scarcely $4 \mathrm{~mm}$. long; teeth subulate, $2 \mathrm{~mm}$. long; corolla pale lilac, $1 \mathrm{~cm}$. long; keel tipped with purple; legume ovaloblong, strigose, 10-12 mm. long. A. confertiflorus A. Gray. Dry places: Utah.

5. C. argillosus (M. E. Jones) Rydb. Stems 1-2 dm. long, ascending, canescent-strigose with long hairs; leaflets $9-13$, narrowly linear to oblonglinear, 1-2 cm. long; raceme short, dense; calyx silky-pilose with long hairs; tube $4 \mathrm{~mm}$. long; teeth subulate-filiform, 4-5 mm. long; corolla about $1 \mathrm{~cm}$. long, purplish; pod sessile, ovoid, obcompressed. A. argillosus M. E. Jones. Clayey soil: Utah. Son. My.

6. C. urceolatus (Greene) Rydb. Stems 3-4 dm. high, decumbent at the base, sparingly strigose; leaflets $11-21$, narrowly linear, $1-3 \mathrm{~cm}$. Iong, $1-3 \mathrm{~mm}$. wide, sparingly strigose beneath, glabrate above; raceme short, head-like, denselyflowered; calyx densely silky-hirsute; tube $5 \mathrm{~mm}$. long; teeth subulate, $2 \mathrm{~mm}$. 
long; corolla ochroleucous, $12 \mathrm{~mm}$. long. A. urceolatus Greene. Mountains: Colo. Submont. Je.

\section{XYLOPHĀCOS Rydb. SHEeP-POD.}

Perennial herbs, mostly low, usually copiously hairy, often canescent, with short stems. Leaves alternate, with nearly free and distinct stipules; leaflets few or more numerous, entire. Flowers in short, often subcapitate racemes. Calyx cylindric; lobes much shorter than the tube. Corolla purple, rarely ochroleucous or in one species crimson; banner narrow, slightly longer than the wings. Stamens 10; filaments diadelphous; anthers alike. Pods fusiform, or ovoid, leathery or woody, 1-celled, without partition; the lower suture sometimes slightly sulcate. Seeds numerous.

Pod strigose or glabrous.

Exocarp of the fruit not spongy; stem evident, but often short.

Pod more or less curved.

Plant sparingly hairy or glabrous, scarcely canescent; stem usually more or less elongate.

Calyx-tube about $10 \mathrm{~mm}$, long, white-hairy; plant sparingly silky.

1. $X$. stipularis.

Calyx-tube $5-8 \mathrm{~mm}$. long, black-hairy; plant strigose or glabrous.

Pod $2-2.5 \mathrm{~cm}$. long, abruptly acute at both ends. 2. X. cuspidocarpus.

Pod 2.5-4 cm. long, long-acuminate at both ends. 3 . $X$. cibarius.

Plant densely canescent, with white silky appressed hairs; stem low, decumbent.

Pod elongate; dorsal suture distinctly sulcate.

Pod tapering at the base, not very thick.

Calyx-teeth subulate, about half as long as the tube.

Calyx-teeth less than half as long as the tube. $5 . \underset{X}{X}$. aragalloides.

Pod not tapering at the bases.

Calyx with black hairs; leaflets oval; corolla white or cream-colored.

6. $X$. eurekensis,

Calyx without black hairs; leaflets rounded-obovate; corolla purple.

Pod short-ovoid; neither suture distinctly sulcate.

7. $X$. Shortianus.

Pod mottled.

Pod very strongly curved and vertically flattened at the middle; leaflets oval, acute, strigose. $\quad 8 . X$. Zionis.

Pod slightly curved; leaflets oblong, rounded or truncate at the apex, villous.

Pod not mottled, slightly curved and turgid.

Calyx-teeth subulate, about half as long as the tube; leaflets oblongoval. 10. A. argophyllus.

Calyx-teeth lanceolate, one-fourth as long as the tube; leaflets

Pod straight or nearly so; plant canescent.

11. $X$. uintensis.

Pod obcompressed, somewhat triangular; ventral suture only prominent,

Pod compressed; both sutures prominent.

Corolla purple; calyx with black hairs.

12. $X$. vespertinus.

13. X. missouriensis hairs. 14 . X. cymboides.

Exocarp of the fruit spongy at least in age; plant sub-acaulescent, less than $5 \mathrm{~cm}$. high.

Leaflets $7-11$, rounded-obovate, obtuse.

Pod villous.

Leaflets $1-3$, broadly lanceolate, acute.

15. $X$. pygmaeus.

16. $X$. musinensis.

Pod densely woolly, short-ovoid; plant canescent.

Pubescence of the leaves strictly appressed.

Leaflets elliptic to obovate; calyx-teeth one-fourth as long as the tube.

Leaflets obovate, obtusish; peduncles much shorter than the leaves.

17. $X$. Newberryi.

Leaflets oblanceolate, acute; peduncles about equalling the leaves.

18. $X$. consectus.

Leaflets broadly obovate-cuneate, rounded, truncate, or retuse at the apex;

calyx-teeth half as long as the black-villous tube. 19. X. Watsonianus,

Pubescence of the leaves loosely woolly.

Stems $1 \mathrm{dm}$. Iong or less; bracts ovate or oblanceolate, only slightly exceeding the pedicels.

Leaflets broadly obovate, rounded at the apex; plant densely floccose.

20. $X$, utahensis.

Leaflets oblanceolate or oblong, acute; plant hirsute-rillous. Corolla ochroleucous; only the keel purple-tipped. 21. X. Purshii. Corolla purple.

22. $X$. glareosus.

Stems $2-4 \mathrm{dm}$. high; bracts subulate, at least half as long as the calyx.

Pod sparingly villous, elongate; plant not canescent.

23. $X$. inflexus

24. X. Parryi. 
1. X. stipularis (M. E. Jones) Rydb. Stems 5-15 cm. long; leaflets 9-17, elliptic to obovate, $8-15 \mathrm{~mm}$. long, rounded or retuse at the apex, silky beneath, glabrate above; raceme subcapitate, 5-12-flowered; calyx silky-villous with white hairs; tube about $1 \mathrm{~cm}$. long, teeth lance-subulate, $4-5 \mathrm{~mm}$. long; corolla purple, about $2 \mathrm{~cm}$. long; pod 2.5-3 cm. long, $8-10 \mathrm{~mm}$. thick, rounded at the base, short-acuminate at the apex, reticulate, glabrate. Astragalus arietinus stipularis M. E. Jones, Hills: s Colo. Submont. Je.

2. X. cuspidocarpus (Sheld.) Rydb. Stems 1-2 dm. high, decumbent at the base; leaflets $10-17$, oblong to obovate, $8-12 \mathrm{~mm}$. long, usually retuse, glabrous above, strigose beneath; raceme 7-9-flowered, subcapitate; calyx-teeth subulate, $1.5 \mathrm{~mm}$. long; corolla ochroleucous, tinged with purple; legumes $2.5-3$ $\mathrm{cm}$. long, abruptly acute at both ends. A. cuspidocarpus Sheld. A. thermalis Greene. Hills: Mont.-n Wyo. Submont.-Mont. My-Je.

3. X. cibarius (Sheld.) Rydb. Stems 1-3 dm. long, decumbent at the base, strigose and striate; leaflets 11-17, oblong-obovate to nearly orbicular, rounded or retuse at the apex, 5-15 $\mathrm{mm}$. long, glabrous above, strigose beneath; raceme short, 8-12 flowered; calyx-tube 6-8. mm. long; teeth subulate, $2 \mathrm{~mm}$. long; corolla 12-18 mm. long, purplish or ochroleucous, with purple-tipped keel; pod cross-reticulate; lower suture sulcate. A. cibarius Sheld. A. arietinus M. E. Jones. Hills: Utah-Colo.-Mont. Submont.

4. X. aragalloides $R y d b$. Stems $1 \mathrm{dm}$. or less long, decumbent at the base; leaflets 11-19, lanceolate to elliptic, silky-canescent, 5-12 mm. long, acute; raceme short, 4-10-flowered; calyx ascending, strigose with black and white hairs; tube about $8 \mathrm{~mm}$. long; teeth subulate, $3.5-4 \mathrm{~mm}$. long; corolla purplish, about $2 \mathrm{~cm}$. long; pod about $4 \mathrm{~cm}$. long, tapering, rather deeply sulcate below, transversely reticulate; upper suture prominent. Arid regions: s Utah. L. Son.

5. X. amphioxys (A. Gray) Rydb. Stems spreading, 1-5 cm. long; leaflets 15-25, obovate or oval, 4-10 mm. long; raceme short, 8-12-flowered; calyx strigose with mixed white and black hairs; tube $7-8 \mathrm{~mm}$. long; teeth subulate, about $2 \mathrm{~mm}$. long; legume crescent-shaped, acute at both ends, $3-5 \mathrm{~cm}$. long, strigose, cross-reticulate; lower suture deeply sulcate. A. amphioxys A. Gray. Gravelly hills: Tex.-Colo.-Utah-(? Ida.)-Ariz. Son.

6. X. eurekensis (M.E.Jones) Rydb. Stems less than $1 \mathrm{dm}$. high, sometimes almost wanting; leaflets elliptic or oval, about $1 \mathrm{~cm}$. long, coarsely silky; calyx $6 \mathrm{~mm}$. long; teeth subulate; corolla about $25 \mathrm{~mm}$. long; keel tipped with purple; pod 3-5 cm. long, acuminate, appressed long-hairy, sulcate on both sutures. $A$. glareosus M. E. Jones. A. eurekensis M. E. Jones. Valleys and hillsides among sage brush: Utah. Son. My.

7. X. Shortianus (Nutt.) Rydb. Stem 1-10 cm. long; leaflets 11-15, obovate or oval, $1-2.5 \mathrm{~cm}$. long; peduncles shorter than the leaves; raceme short, 5-15-flowered; calyx strigose, usually with white hairs; tube 8-10 mm. long; teeth lance-subulate, about $3 \mathrm{~mm}$. long; corolla violet or purple, $18-25 \mathrm{~mm}$. long; pod elongate-ovoid, arcuate, $3-5 \mathrm{~cm}$. long, $12-14 \mathrm{~mm}$. wide, sulcate on the lower suture, strigose. A. Shortianus Nutt. Plains and mesas: Neb.Ariz.-Wyo. Plain-Mont. My-Je.

8. X. Zionis (M. E. Jones) Rydb. Stems spreading or prostrate, $5-30 \mathrm{~cm}$. long; leaflets about 21 , ovate to lanceolate, about $12 \mathrm{~mm}$. long, acute; peduncles as long as the leaves; calyx-tube about $6 \mathrm{~mm}$. long; corolla pink-purple; legume arcuate, abruptly long-acuminate, about $3 \mathrm{~cm}$. long, slightly sulcate, triangular in cross-section; ventral suture prominent. A. Zionis M. E. Jones. Sandy or gravelly places: Utah. Son.-Submont. Mr-My.

9. X. puniceus (Osterhout) Rydb. Stems decumbent, about $4 \mathrm{dm}$. long; leaflets elliptic or oblong, 8-15 mm. long, rounded or retuse at the apex, ashypubescent beneath, sparingly strigose above; raceme about 10 -flowered; calyx silky-hirsute; tube 5-6 mm. long; teeth subulate, $2 \mathrm{~mm}$. long; corolla purple, about $15 \mathrm{~mm}$. long; pod elongate-ovoid, 15-20 mm. long, $7 \mathrm{~mm}$. wide, pubescent; lower suture slightly suleate. A. puniceus Osterhout. Dry hills: Colo. Submont. Je. 
10. X. argophyllus (Nutt.) Rydb. Stems short, decumbent, 5-10 cm. long; leaflets 15-17, lanceolate, 8-15 mm. long, acute; raceme 3-8-flowered; calyxtube 8-10 mm. long; teeth subulate, about 4-5 mm. long; corolla $15-20 \mathrm{~mm}$. long, purplish; pod oblong-ovoid, with a curved point, about $2 \mathrm{~cm}$. long, transversely wrinkled, rounded on both sutures. A. argophyllus Nutt. Hills and valleys: Mont.-Wyo.-Utah-Nev. Submont. Je-Jl.

11. X. uintensis (M. E. Jones) Rydb. Stems prostrate or decumbent, 5-10 $\mathrm{cm}$. long; leaflets lance-oblong to elliptic, 5-10 mm. long, acute; raceme short, few-flowered; calyx-tube about $8 \mathrm{~mm}$. long; teeth subulate, $1.5-2 \mathrm{~mm}$. long; corolla purple, $2-2.5 \mathrm{~cm}$. long; pod ovoid, $2-2.5 \mathrm{~cm}$. long, obcompressed; ventral suture slightly sulcate. A. uintensis M. E. Jones. Dry ground: Colo. -Nev,-Ariz. Son.-Submont. My-Je.

12. X. vespertinus (Sheld.) Rydb. Stems 4-6 $\mathrm{cm}$. high, decumbent, striate; leaflets 11-13, obovate-elliptic, obtuse, 4-12 mm. long; raceme short, 3-6-flowered; calyx strigose with mixed black and white hairs; tube about $8 \mathrm{~mm}$. long; teeth subulate, about $1.5 \mathrm{~mm}$. long; corolla $2-3 \mathrm{~cm}$. long, purplish; pod $2.5-3 \mathrm{~cm}$. long, coriaceous, oblong, obcompressed-triangular in section; upper suture prominent. A. vespertinus Sheld. (?) A. panguicensis M. E. Jones. Dry hills: Colo.-N.M. Submont. My.

13. X. missouriensis (Nutt.) Rydb. Stems $5-10 \mathrm{~cm}$. long; leaflets 11-21, elliptic to obovate, $5-15 \mathrm{~mm}$. long; raceme short, 5 - 15 -flowered; calyx-tube $7-8$ $\mathrm{mm}$. long; teeth subulate, $2-2.5 \mathrm{~mm}$. long; corolla purple, $15-20 \mathrm{~mm}$. long; pod oblong, $1.5-2.5 \mathrm{~cm}$. long, $7-8 \mathrm{~mm}$. broad, neither suture sulcate, rather prominent in age. A. missouriensis Nutt. Plains and hills: Sask.-Kans.-N.M.Mont. Plain-Mont. My-Je.

14. X. cymboides (M. E. Jones) Rydb. Stems decumbent, 5-15 cm. long, and matted; leaflets 9-11, elliptic, obtuse, usually about $6 \mathrm{~mm}$. long; calyx-tube about $6 \mathrm{~mm}$. long; legume oblong-ovoid, $6 \mathrm{~mm}$. wide, $16 \mathrm{~mm}$. long, somewhat 4 -angled, with rather prominent sutures in age. A. cymboides M. E. Jones. Gravelly or clayey ground: Utah. Submont. Je-Jl.

15. X. pygmaeus (Nutt.) Rydb. Plant almost stemless; leaflets 7-11, broadly oval, obovate, or orbicular, $5-10 \mathrm{~mm}$. long; raceme short, subcapitate, few-flowered; calyx strigose with short, partly black hairs; tube about $8 \mathrm{~mm}$. long; teeth $2 \mathrm{~mm}$. long; corolla ochroleucous or purple, about $1.5 \mathrm{~cm}$. long; pod obliquely ovoid, $2-3 \mathrm{~cm}$. long, somewhat mottled, pulpy when young, in age with a membranous, transversely reticulate outer coat and a thicker inner one. Phaca pygmaea Nutt. Astragalus Chamaeluce A. Gray. A. Cicadae M. E. Jones: Hills: Colo.-Wyo.-Utah. Submont. My.

16. X. musinensis (M. E. Jones) Rydb. Plant nearly acaulescent; leaflets 1-3, lanceolate, or elliptic-lanceolate, $2 \mathrm{~cm}$. or less long; pod ovate, $18 \mathrm{~mm}$. long, 6-8 $\mathrm{mm}$. broad, strigillose, with incurved acute apex, sulcate ventrally at the base; outer coat loose. A. musinensis M. E. Jones. Clayey slopes: Utah. Submont. Je.

17. X. Newberryi (A. Gray) Rydb. Subacaulescent; leaflets 3-7, obovate, 6-10 mm. long; raceme short, 2-6-flowered; calyx-tube about $12 \mathrm{~mm}$. long; teeth subulate, $3 \mathrm{~mm}$. long; corolla $2.5-3 \mathrm{~cm}$. long, ochroleucous, tipped with purple; pod ovoid, about $2 \mathrm{~cm}$. long, somewhat eurved, not sulcate. A. Newberryi A. Gray. Dry hills: sw Colo.-N.M.-Ariz.-Utah. Son. Ap.

18. X. consectus (Sheld.) Rydb. Subacaulescent; leaflets 5-11, oblancelate, acute, 1-2 cm. long; raceme short, 6-8-flowered; calyx-tube about $10 \mathrm{~mm}$. long; teeth subulate, $3-4 \mathrm{~mm}$. long; corolla about $2 \mathrm{~cm}$. long, purplish or ochroleucous tipped with purple; legume ovoid, about $2.5 \mathrm{~cm}$. long, with rather long beak, neither suture suleate. A. consectus Sheld., in part. A. eriocarpum M. E. Jones, not S. Wats. Dry ground: Utah. Son.-Submont. Ap-My.

19. X. Watsonianus (Kuntze) Rydb. Subacaulescent; leaflets broadly obovate-cuneate, rounded or retuse at the apex, 10-15 mm. long; flowers capitate; calyx villous with black hairs; tube $12-15 \mathrm{~mm}$. long; teeth subulate, $5 \mathrm{~mm}$. long; corolla purplish, nearly $3 \mathrm{~cm}$. long; pod $2.5 \mathrm{~cm}$. long, strongly curved above 
the middle, scarcely sulcate. A. eriocarpus S. Wats. Mountains: Nev.(? Utah). Submont. My.

20. X. utahensis (T. \& G.) Rydb. Stems usually less than $1 \mathrm{dm}$. long, densely floccose; leaflets $9-17$, obovate or orbicular, rounded at the apex, 5-10 $\mathrm{mm}$. long, densely white-floccose; raceme 3-10-flowered, dense; calyx densely villous; tube about $12 \mathrm{~mm}$. long; teeth subulate, about $4 \mathrm{~mm}$. long; corolla $25-$ $28 \mathrm{~mm}$. long, violet or purple; pod ovoid, about $2 \mathrm{~cm}$. long, somewhat curved, only slightly sulcate on the sutures. A. utahensis T. \& G. A. nudisiliquus A. Nels. Pink Lady-Fingers. Hills and benchlands: Mont.-Wyo.-UtahNev. Submont. Ap-My.

21. X. Purshii (Dougl.) Rydb. Stems usually less than $5 \mathrm{~cm}$. long, villous; leaflets $9-13$, oblanceolate or oblong, acute, $8-15 \mathrm{~mm}$. long, villous; calyx densely villous; tube about $1 \mathrm{~cm}$. long; teeth subulate, about $3 \mathrm{~mm}$. long; corolla $2-2.5$ cm. long, ochroleucous; keel tipped with purple; pod ovoid, densely woolly, about $2 \mathrm{~cm}$. long, slightly eurved, scarcely sulcate. A. Purshii Dougl. A. Booneanus A. Nels, in part. Dry plains and hills: Mont.-Colo.-Calif.-B.C. Son.-Submont. My-Je.

22. X. glareosus (Dougl.) Rydb. Stems usually less than $1 \mathrm{dm}$. long; leaflets 11-17, oblong, canescent-hirsute, 4-10 $\mathrm{mm}$. long, acute; peduncles very short; racemes 3-8-flowered; calyx-tube $8-9 \mathrm{~mm}$. long; teeth subulate, $2 \mathrm{~mm}$. long; corolla purple, about $2 \mathrm{~cm}$. long; pod villous, ovoid, about $2.5 \mathrm{~cm}$. long. A. glareosus Hook. A. Booneanus A. Nels., in part. Hills and flats: Wash,Mont.-Wyo.-Utah. Plain-Submont. My-Je.

23. $\mathbf{X}$. inflexus (Dougl.) Rydb. Stems 2-4 dm. long, decumbent, whitevillous; leaflets $15-25$, obovate or elliptic to oblanceolate, $7-15 \mathrm{~mm}$. long, whitevillous; raceme 5-10-flowered, capitate, calyx long-villous; tube 10-12 $\mathrm{mm}$. long; teeth subulate-setaceous, 6-7 mm. long; corolla light purple, $20-25 \mathrm{~mm}$. long; pod oblong-ovoid, strongly curved, villous, deeply sulcate on both sutures, 2.5 cm. long. A. inflexus Dougl. Plains and river-bars: Wash.-Mont.-Ore. Son.
-Plain. My-Je.

24. X. Parryi (A. Gray) Rydb. Stems 0.5-2 dm. long, hirsute-villous; leaflets $15-27$, obovate or oblong, 4-15 mm. long, sparingly hirsute on both sides; raceme short, 6-10-flowered; calyx sparingly hirsute; tube 5-6 mm. long; teeth 4-5 mm. long; corolla ochroleucous, $15-18 \mathrm{~mm}$. long; keel tipped with purple; pod 2.5-3 cm. long, $7 \mathrm{~mm}$. broad, long-beaked, arcuate, hirsute; lower suture slightly more suleate than the upper. Mountains: Wyo.-Colo.-n Tex. Sub-
mont.-Mont. My-Jl.

\section{MICROPHĀCOS Rydb.}

Subcinereous perennials, with very slender stems. Leaves pinnate, with 7-21 linear to oblong leaflets; stipules very broad, triangular, free from the petioles and only the lower more or less united with each other. Racemes many-flowered. Calyx short-campanulate, about $2 \mathrm{~mm}$. long, with very short and broad teeth. Corolla purple, 5-6 mm. long, all petals strongly curved. Pod 6-8 mm. long, coriaceous, eross-wrinkled, wholly 1-celled, 6-7-ovuled, boat-shaped, $i$. e., upper suture prominent, strongly curved, lower suture nearly straight or curved up-
wards, flat or slightly sulcate. Pod slightly sulcate on the lower suture, transversely veined; leaflets narrowly linear,
obtuse.

Pod merely flattened on the lower suture, cross-wrinkled; leaflets linear-oblong or linear-

cuneate, truncate or emarginate.
$2 . M$. microlobus,

1. M. parviflorus (Pursh) Rydb. Stem minutely strigose, 3-6 dm. high; leaflets 11-21; racemes very slender, lax; calyx-tube $1 \mathrm{~mm}$. long; teeth triangular, $0.5 \mathrm{~mm}$. long; corolla purplish, $5-6 \mathrm{~mm}$. long; pod pendent, straight, ovoid, $5-7$ mm. long. Astragalus gracilis Nutt. Plains and hills: N.D.-Tex.-Wyo.
Plain. Je-Jl.

2. M. microlobus (A. Gray) Rydb. Stem branched, $3-4 \mathrm{dm}$. high, finely strigose; leaflets $7-17$, minutely strigose; raceme lax, short; calyx-tube $1.5-2 \mathrm{~mm}$. long; teeth triangular, $0.5 \mathrm{~mm}$. long; corolla about $7 \mathrm{~mm}$. long, purplish; pod 
6-10 mm. long, ovoid. A. microlobus A. Gray. Plains and hills: S.D.-Kans.Colo.-Mont. Plain-Submont. Je-Jl.

\section{PTEROPHÃCOS Rydb.}

Perennial glabrous or strigose herbs. Leaves alternate, odd-pinnate, with nearly free and distinct stípules; leaflets linear or linear-filiform, scarcely broader than the rachis. Flowers perfect, in short racemes. Calyx-tube oblong-campanulate, with short subulate-setaceous teeth. Corolla white; banner narrow. Stamens 10; filaments diadelphous; anthers alike. Legume woody, one-celled, 2 -valved, the valves winged on the back, the sutures acute or even winged. Seeds many.

1. P. tetrapterus (A. Gray) Rydb. Stem about $3 \mathrm{dm}$. high, glabrous, striate; leaflets 15-21, narrowly linear, 12-20 mm. long, 1-2 mm. wide; raceme short, 5-9-flowered; calyx-teeth setaceous-subulate, about half as long as the tube; corolla white, about $15 \mathrm{~mm}$. long; pod 3-4 $\mathrm{cm}$. long, arcuate, glabrous, 4-winged, $8 \mathrm{~mm}$. wide. A. tetrapterus A. Gray. Dry ground: s Utah. Son.

\section{ATELOPHRÄGMA Rydb.}

Caulescent leafy slender perennial herbs, with rootstocks. Stipules nearly free both from each other and from the petioles. Leaves pinnate, usually with numerous leaflets. Inflorescence a spike-like raceme. Calyx short, campanulate; lobes slender, subulate. Corolla white or purplish. Pod membranous or papery, more or less compressed laterally, in the typical species decidedly flattened and stipitate; dorsal suture intruding in the pod and forming a partial partition.

\section{Pod stipitate, flat.}

Partial partition broad, making the pod almost 2-celled.

Partial partition narrow, less than one-third the width of the pod.

Pod long-stipitate, glabrous at least in age.

Plant loosely short-villous.

Plants appressed-silky or glabrous.

Leaflets oblong.

Leaflets linear.

Plant grayish silky.

Pod short-stipitate, hairy.

Upper leaves not reduced; pod black-hairy.

Upper leaves reduced, often unifoliolate; pod not black-hairy,

2. A. aboriginum.

3. A. Forwoodii.

4. A. lineare.

5. A. glabriusculum.

6. A. Macounii.

7. A. ibapense.

Pod sessile, more turgid.

Racemes many-flowered; leaflets oblong; partition of the pod narrow.

Racemes elongate; pod short-obovoid.

Racemes short; pod oblong.

Racemes few-flowered; leaflets linear; partition of the pod broad.

8. A. elegans.

9. A. Shearii.

10. A. Brandegei.

1. A. Arthuri (M. E. Jones) Rydb. Stems 3-4 dm. high, finely strigose; leaflets 21-35, oblong-elliptic, obtuse or retuse, 5-10 $\mathrm{mm}$. long, glabrous above, minutely strigose beneath; racemes about $1 \mathrm{dm}$. long; calyx black-hairy; tube $5 \mathrm{~mm}$. long; teeth $3 \mathrm{~mm}$. long; corolla $10-12 \mathrm{~mm}$. long, white; pod strigose; stipe 8-10 mm. long; body linear, 3-3.5 cm. long, tapering at both ends. Astragalus Arthuri M. E. Jones. Basalt hillsides: Ida. Son.-Submont. Je.

2. A. aboriginum (Richards.) Rydb. Stems 2-4 dm. high, short-villous; leaflets 9-15, linear-oblong to elliptic or lanceolate, 1-2 cm. long; raceme short; calyx more or less black-hairy; tube 3-4 mm. long; teeth 2-3 mm. long; corolla ochroleucous, 9-11 $\mathrm{mm}$. long; pod glabrous; stipe 5-8 $\mathrm{mm}$. long; body oblanceolate, acute at both ends, 1.5-2 cm. long; lower suture almost straight. Astragalus aboriginorum Richards. Mountains: Sask.-Colo.-Nev.-Yukon. Submont.-Mont. My-Je.

3. A. Forwoodii (S. Wats.) Rydb. Stems ascending, minutely strigose, 1-3 dm. high; leaflets 9-17, oblong or oblanceolate, strigose on both sides or glabrous above, 1-1.5 cm. long; raceme short; calyx more or less black-hairy; tube $3 \mathrm{~mm}$. long; teeth $2 \mathrm{~mm}$. long; legume glabrous, flat; stipe $3-5 \mathrm{~mm}$. long; body 2-2.5 cm. long, lunate-oblanceolate; lower suture usually somewhat concavely 
curved. Astragalus Forwoodii S. Wats. Hills: S.D.-Wyo.-Mont. Submont. -Mont. Je-Jl.

4. A. lineare Rydb. Stem grayish strigose, often tinged with purple, 2-4 dm. high; leaflets 9-15, linear, 1-2 $\mathrm{cm}$. long, 1-2 mm. wide, grayish strigose; raceme short; calyx densely black-hairy; tube $3 \mathrm{~mm}$. long; teeth $2 \mathrm{~mm}$. long; corolla about $8 \mathrm{~mm}$. long, ochroleucous or tinged with purple; keel tipped with dark purple; legume glabrous, stipitate; stipe 4-5 mm. long; body $25-28 \mathrm{~mm}$. long, convexly curved on both sutures, but much more strongly so on the upper. Dry slopes: Man.-Alta.-Yukon. Boreal-Mont. Je.

5. A. glabriusculum (Hook.) Rydb. Stem 2-4 dm. high; leaflets linear or nearly so, $15-25 \mathrm{~mm}$. long, glabrous or nearly so; raceme short, in fruit elongate; calyx black-hairy; tube $3 \mathrm{~mm}$. long; corolla ochroleucous, $8 \mathrm{~mm}$. long; keel tipped with dark purple; pod glabrous; stipe $4-5 \mathrm{~mm}$. long; body $2 \mathrm{~cm}$. long; lower suture straight or nearly so. Phaca glabriuscula Hook. A. glabriusculus A. Gray. Gravelly slopes: Alta.-S.D.-Wyo. Submont.-Mont. Je.

6. A. Macounii Rydb. Stem $5-6 \mathrm{dm}$. high, finely and sparingly strigose or glabrate; leaflets $9-17$, very thin, oblong or oval, $15-25 \mathrm{~mm}$. long, obtuse, glabrous above, sparingly strigose beneath; calyx black-hairy; tube about $3 \mathrm{~mm}$. long; teeth $1 \mathrm{~mm}$. long; corolla about $8 \mathrm{~mm}$. long, cream-colored or white, tinged with purple; stipe of the pod 2-3 mm. long; body acute at both ends, $15-18 \mathrm{~mm}$. long, $5 \mathrm{~mm}$. wide. Astragalus Macounii Rydb. Mountains: B.C.-Alta.Colo. Submont.-Mont. My-Jl.

7. A. ibapense (M. E. Jones) Rydb. Stem slender, grooved, minutely strigose; leaflets 1-7, elliptic or linear, the lower obtuse, the upper acute, 4-12 $\mathrm{mm}$. long, minutely strigose, or the single one of the upper leaves $2.5-4 \mathrm{~cm}$. long; raceme 1-3-flowered; calyx strigose; tube $2 \mathrm{~mm}$. long; teeth $1 \mathrm{~mm}$. long; corolla $6 \mathrm{~mm}$. long, white; keel purple-tipped; pod short-stipitate, $12 \mathrm{~mm}$. long, $3 \mathrm{~mm}$. wide, densely strigose, flat; lower suture straight. Astragalus ibapensis M. E. Jones. Mountains: w Utah. Je.

8. A. elegans (Hook.) Rydb. Stem finely strigose or glabrous, erect or decumbent at the base, $2.5-6 \mathrm{dm}$. high; leaflets 9-17, oblong to linear, 15-20 $\mathrm{mm}$. long, obtuse; raceme lax, 5-10 cm. long, in fruit even 15-20 $\mathrm{cm}$. long; calyx black-hairy; tube $2.5 \mathrm{~mm}$. long; teeth $1 \mathrm{~mm}$. long; corolla 6-8 mm. long, purple, or ochroleucous and tinged with purple; pod ellipsoid, pendent, slightly inflated, sessile, black-hairy, 8-15 mm. long. Phaca elegans Hook. Astragalus oroboides americanus A. Gray. A. minor M. E. Jones. A. eucomus B. L. Robins. Mountains and woods: Lab.-Que.-S.D.-Colo.-Ida.-Alta. Submont,-Alp. Je$\mathrm{Jl}$.

9. A. Shearii Rydb. Stems slender, strigose and striate, about $2 \mathrm{dm}$. high; leaflets $13-19,5-8 \mathrm{~mm}$. long, oblong, obtuse or retuse at the apex, glabrate above, grayish strigose beneath; raceme short, 5 -10-flowered; calyx-tube about $4 \mathrm{~mm}$. long, strigose, partly with black hairs; teeth short; corolla reddish purple, nearly $1 \mathrm{~cm}$. long; pod oblong, 12-14 mm. long, glabrous, reticulate, sessile. Astragalus Shearii Rydb. Mountains: Colo. Mont. Au.

10. A. Brandegei (Porter) Rydb. Stems adsurgent or ascending, branched, strigose; leaflets 9-11, distant, linear, obtuse, $5-15 \mathrm{~mm}$. long, glabrous above, strigose beneath; raceme short, 2-5-flowered; calyx strigose; tube scarcely $2 \mathrm{~mm}$. long; teeth $1 \mathrm{~mm}$. long or less; corolla about $5 \mathrm{~mm}$. long, white or cream-colored, tinged with purple; legume oblong, 10-12 mm. long, strigose. A. Brandegei Porter. Hills and bluffs: Colo.-Utah-Ariz. Submont. Je-J.

\section{HOMÁLOBUS Nutt.}

Perennial herbs, with rootstocks or woody caudices. Leaves alternate, oddpinnate, or sometimes simple. Flowers racemose, purple or ochroleucous. Calyx campanulate. Keel obtuse. Pod several- or many-seeded, usually narrow, perfectly 1-celled, without trace of a partition, with both sutures prominent, usually more or less compressed, often flat. 
Legumes decidedly flattened laterally.

Leaves simple or some of them rarely 3-foliolate; plants pulvinate-cespitose; pod sessile.

Leaves several-foliolate,

Pod sessile or short-stipitate; stipe seldom exceeding the calyx.

Legume oval, ovate, broadly oblong, or elliptic,

Pod without long black hairs.

Pod with long black hairs.

Legume linear, $1.5 \mathrm{~cm}$. long or longer.

Pod long-stipitate; stipe decidedly longer than the calyx.

Calyx not gibbous at the base, less than half as long as the corolla; pod membranous; leaflets linear or filiform.

Ca yx strongly gibbous at the base, more than half as long as the corolla; pod more coriaceous.

Legumes nearly terete.

Pod sessile or short-stipitate; stipe if any shorter than the calyx.

Pod long-stipitate; stipe longer than the calyx.

VII. FLEXUOSI.

VIII. MACROCARPI.

\section{SIMPLICIFOLII.}

Calyx-teeth about half longer than the calyx-tube; corolla ochroleucous or whitish.

Calyx glabrous.

Calyx pubescent.

Leaves almost filiform, sparingly hairy, pungent-pointed; pods mottled.

Leaves narrowly linear-oblanceolate, canescent, not pungent; pods not mottled.

Calyx-teeth about as long as the tube; corolla purple or pink.

Peduncles 1-flowered; bracts subulate, longer than the flowers. 4. H. uniflorus.

Peduncles 3-10-flowered; bracts ovate to narrowly lanceolate, shorter than the flowers.

Pods long-acute; bracts narrowly lanceolate; leaves usually narrowly oblanceolate.

Pods abruptly acute; bracts short, ovate to lanceolate, 5, H. caespitosus. oblanceolate or spatulate.

Pod strictly sessile

Leaflets narrowly linear, often wanting.

\section{TENELLI.}

6. H. brachycarpus.

Leaflets oblong to oval.

Stems densely cespitose, 1-2 dm. high; racemes short, few-flowered.

Racemes 2-6-flowered, shorter than the leaves; leaflets oblong to oblanceolate, acute, canescent. Racemes 5 -12-flowered, exceeding the leaves; leaflets oblong to elliptic, green,
glabrate above.
$10 . \mathrm{H}$. miser.

Stems more simple, $2 \mathrm{dm}$. high or more; racemes elongate.

Pods erect, on long pedicels.

Pods spreading or reflexed, on short pedicels.

Pods glabrous; plant canescent.

Pod short-stipitate. Pods glabrous; plant can
Pods hairy; plant green.

10. H. miser.

Corolla white, tinged with purple.

Both sutures of the pod curved.

Lower suture of the pod straight.

11. H. grallator.

12. H. wingatanus.

13. H. Clementis.

Corolla ochroleucous.

Legume glabrous.

Stipe rarely exceeding the tube of the calyx; leaves usually spreading in age; leaflets oblong to oval, obtuse and mucronate.

14. H. acerbus.

15. H. Dodgeanus.

Stipe of the mature legume usually exceeding the calyx-teeth; leaves strongly ascending; leaflets narrowly linear to linear-oblong, mostly acute.

Stipe 3-4 mm. long; leaflets linear or linear-oblong; stem usually conspicuously strigose; calyx-teeth half as long as the tube.

Stipe 5-7 mm. long: leaflets narrowly linear: stem 17. H. tenellus. calyx-teeth usually nearly equalling the tube glabrous or nearly so;

Legume strigose.

\section{DeBILES.}

18. H. stipitatus.

19. H. strigulosus.

Stem very slender, filiform and decumbent; pod sessile, ovate or oval.

Stem erect or ascending; pods stipitate and long-acute at both ends.

20. H. debilis.

\section{IV, CAMPestres.}

21. H. Bourgovii.

Corolla ochroleucous, usually without any tinge of purple; upper leaves reduced to fliform phyllodes or the rachis greatly produced, without a terminal leaflet; canescent rush-like plants, with deep-seated roots and stem branched below the surface; calyx-lobes less than half as long as the tube.

Calyx more or less black-hairy; legumes tapering towards the base.

Calyx-lobes subulate, much longer than broad; leaves linear-subulate to linear, very acute.

22. H. campestris. 
Calyx-teeth about as broad as long, triangular; leaflets linear or linear-oblong. obtuse.

23. H. junciformis. Calyx white-hairy; teeth triangular; legumes linear; leaflets, if any, narrowly linear
to filiform.

Coralla white, pink, purplish, or rarely ochroleucous, at least the keel tipped with dark purple; terminal leaflet usually well developed; leafy plants with a cespitose caudex.

Legume strigose, rarely becoming glabrate in age.

Legume arcuate.

Leaflets 5; plant pulvinate-cespitose.

Leaflets 7-11; plant cespitose, decumbent, but not pulvinate.

Legume straight, or the end slightly curved upwards in $H$. oblongifolius.
Leaflets strigose on both sides, usually densely canescent.

Leaflets narrowly linear or narrowly lance-linear.

Calyx-teeth almost as long as the tube; corolla purplish; plant $2-4 \mathrm{dm}$. high.

26. H. strigosus.

Calyx-teeth much shorter than the tube; corolla ochroleucous, only the keel tipped with purple; plant less than $2 \mathrm{dm}$. high.

Leaflets narrowly lanceolate or lance-oblong, 4-8 27. H. tenuifolius.

wide; plant less than $1 \mathrm{dm}$. high.
$28 . H$. divergens.

Leaflets usually glabrous above, green.

Calyx white-hairy, its teeth one-third as long as the tube; leaflets linear to lance-oblong; racemes long and lax.

29. H. serotinus.

Calyx usually black-hairy, its teeth fully half as long as the tube.

Legumes $2-2.5 \mathrm{~cm}$. long; corolla about $1 \mathrm{~cm}$. long; leaflets ample; plant erect, 2-4 dm. high.

Leaflets elliptic or oblong, obtuse, the terminal one short-stalked and similar to the rest; lower suture of the legume decidedly curved.

30. H. oblongifolius.

Leaflets lanceolate or oblanceolate, somewhat faicate, the terminal one long-stalked, longer and tapering into the rachis without a distinct articulation. 31. $H$. decurrens.

Legumes less than $2 \mathrm{~cm}$. long; corolla 6-8 mm. long; leaflets small, less than $1 \mathrm{~cm}$. long; plant decumbent-cespitose, less than $2 \mathrm{dm}$. high.

Leaflets $1-5$, the terminal narrowly oblanceolate, falcate, gradually tapering into the rachis.

32. H. paucijugus.

Leaflets 7-17, the terminal one resembling the rest, short-stalked. Legumes linear with parallel sutures, $3 \mathrm{~mm}$. wide.

33. H. microcarpus.

Legumes obliquely oblanceolate, fully $3.5 \mathrm{~mm}$. wide near the

apex. 34. H. humilis.

Legume glabrous from the beginning.

Legumes about $1.5 \mathrm{~cm}$. long; calyx-teeth less than half as long as the tube; leaflets linear or narrowly lance-linear.

$35 . H$. Palliseri.

Legumes $2-2.5 \mathrm{~cm}$. long; calyx-teeth more than half as long as the tube; leaves lanceolate to oval.

\section{STENOPHYLLI.}

Calyx-teeth obtuse; leaflets many, the terminal one present. 36. H. hylophilus.

\section{Calyx-teetr
rachis.}

Pod straight.

Pod curved one-half to two-thirds of a circle.

\section{Colitini.}

\section{Flexuosi.}

Pod oblong, over $5 \mathrm{~mm}$. in diameter.

Inflorescence short; flowers about $15 \mathrm{~mm}$. long; pod glabrous. 41. H. Hallii.

Inflorescence elongate and lax; flowers about $10 \mathrm{~mm}$. long; pod pubescent.

Pod linear, 2-3 mm. in diameter.

Pod abruptly contracted into a short or obsolete stipe.

Stem decumbent; stipe minute or obsolete.

Stem erect; stipe almost equalling the calyx.

Pod gradually tapering into the short stipe.

42. H. Fendleri.

43. H. flexuosus.

44. H. proximus.

45. H. Salidae.

VIII. MACROCARPI.

One species.

46. H. macrocarpus.

1. H. lingulatus (Sheld.) Rydb. Leaves numerous, simple, 2-3.5 cm. long, lingulate or linear-spatulate; peduneles slender, shorter than the leaves, 1-2flowered; calyx-tube striate; teeth subulate, spreading; corolla about $1 \mathrm{~cm}$. long. Astragalus lingulatus Sheld. Foot-hills: Wyo. Submont.

2. H. exilifolius (A. Nels.) Rydb. Leaves numerous, narrowly linear to filiform, pungent, 2-4 cm. long, sparingly strigose; peduncles about equalling 
the leaves, 1-2-flowered; calyx sparingly strigose; tube 3-4 mm. long; teeth subulate, $2 \mathrm{~mm}$. long; corolla $15-20 \mathrm{~mm}$. long, whitish, tipped with purple; pod oblong, 12-15 mm.long, mottled. A. exilifolius A. Nels. Desert regions: Wyo. Submont. My-Jl.

3. H. simplicifolius (Nutt.) Rydb. Leaves linear-oblanceolate, $5-10 \mathrm{~mm}$. long, canescent-strigose; peduncles very short, 1-2-flowered; calyx strigose; tube $3 \mathrm{~mm}$. long; teeth $1 \mathrm{~mm}$. long; corolla ochroleucous, about $8 \mathrm{~mm}$. long, tipped with purple; pod glabrate, slightly longer than the calyx. A. simplicifolius Nutt. Dry hills: Wyo.-Ida. Submont. Je-Jl.

4. H. uniflorus Rydb. Leaves oblanceolate or linear-spatulate, appressed silky-canescent, 1-2 cm. long, 1-3 mm. wide; peduncles 1-2 cm. long; calyx silky-canescent; tube $2 \mathrm{~mm}$. long; teeth subulate, of about the same length; corolla $8 \mathrm{~mm}$. long. Dry hillsides: Wyo. Plain-Submont. My.

5. H. caespitosus Nutt. Leaves $2-5 \mathrm{~cm}$. long, appressed silky-canescent, either simple, linear-oblanceolate, or some of them with $3-5$, linear-oblanceolate leaflets; peduncles 3-7 cm. long; racemes short, 2-10-flowered; calyx strigose; tube $2 \mathrm{~mm}$. long; teeth of about the same length; corolla about $8 \mathrm{~mm}$. long; pod lance-oblong, about $1 \mathrm{~cm}$. long, acute, finely strigose. A. caespitosus A. Gray. A. spatulatus Sheld. Dry hills and plains: Sask.-Neb.-Colo.-Utah-Mont. Plain-Submont. My-Je.

6. H. brachycarpus Nutt. Leaves spatulate or oblanceolate, 1-2 cm. long, silky-canescent; peduncles 2-4 cm. long; racemes short, 2-7-flowered; calyx silky-strigose; tube $2 \mathrm{~mm}$. long; teeth subulate, almost as long; corolla $7-8 \mathrm{~mm}$. long; pod oblong, abruptly acute, about $7 \mathrm{~mm}$. long, strigose. Dry plains: Wyo.-Utah. Submont. My-Je.

7. H. detritalis (M. E. Jones) Rydb. Cespitose perennial, growing in small mats; stems prostrate, 3-5 cm. long, ashy-strigose; leaves basal, $5-7 \mathrm{~cm}$. long; leaflets mostly 5, cinereous-strigose, linear-oblanceolate, about $18 \mathrm{~mm}$. long, aristately-tipped, or those of the earlier leaves oblanceolate, 6-8 mm. long; flowers few; calyx-tube $4 \mathrm{~mm}$. long, acute at the base; teeth subulate; corolla purple, 15-16 mm. long; pod arcuate, about $2.5 \mathrm{~cm}$. long, $2 \mathrm{~mm}$. wide, mottled with brown spots. A. detritalis M. E. Jones. Clayey slopes: Utah. Son.

8. H. lancelarius (A. Gray) Rydb. Stems erect, flexuose, branched, glabrous, 4-5 dm. high; leaflets 5-9, 1-2 cm. long, about $1 \mathrm{~mm}$. wide, cinereouspuberulent, sometimes lacking, especially the terminal one, when the rachis is produced; racemes elongate, many-flowered; calyx sparingly short-hairy; tube $3 \mathrm{~mm}$. long; teeth triangular-subulate, $1 \mathrm{~mm}$. long; corolla $8 \mathrm{~mm}$. long, white, tipped with purple; legume oblong, $15-20 \mathrm{~mm}$. long, $6 \mathrm{~mm}$. wide, acute at both ends, glabrous. A. lancelarius A. Gray. Dry places: Utah-Ariz.-(? Colo.) Son.

9. H. vexilliflexus (Sheld.) Rydb. Stems strigose-canescent, decumbent, branched, 1-3 dm. high; leaflets 7-11, strigose-canescent, oblong or oblanceolate, acute, 5-18 mm. long; calyx strigose; tube $1.5 \mathrm{~mm}$. long; teeth subulate, $1.5 \mathrm{~mm}$. long; corolla purplish, 6-8 mm. long; pod oblong, strigose, abruptly acute, 8 $\mathrm{mm}$. long, $3 \mathrm{~mm}$. wide. A. pauciflorus Hook. A. vexilliflexus Sheld. Hills and mountains: Sask.-Wyo.-B.C. Plain-Submont. My-Jl.

10. H. miser (Dougl.) Rydb. Stems 1-3 dm. high, sparingly strigose; leaflets 11-15, linear-oblong to elliptic, obtuse, sparingly strigose below, glabrate above, 8-12 $\mathrm{mm}$. long, 2-4 $\mathrm{mm}$. wide; calyx as in the preceding; corolla purple, about $8 \mathrm{~mm}$. long; pod similar to that of the preceding, but more acute. $A$. miser Dougl. (?) A. amphidoxus Blankinship. Stony banks and hills: w Mont. -Wash. Submont. Jl-Au.

11. H. grallator (S. Wats.) Rydb. Stem decumbent, about $5 \mathrm{dm}$. high, glabrous; leaflets about 20, finely strigose or glabrate, 1-2 cm. long, oblong; racemes loose, exceeding the leaves; calyx-teeth narrow, shorter than the tube; corolla white or pale rose-colored, $6 \mathrm{~mm}$. long; pod $1 \mathrm{~cm}$. long, transversely rugose, glabrous. A. grallator S. Wats. River banks: Colo. Submont, Jl. 
12. H. wingatanus (S. Wats.) Heller. Stems $1-3 \mathrm{dm}$. high, finely strigose; leaflets $7-13$, linear to oblong, $5-15 \mathrm{~mm}$. long, sparingly strigose beneath, glabrate above; raceme $7-12$-flowered; calyx strigose, with mixed black and white hairs; tube $1.5 \mathrm{~mm}$. long; teeth subulate, $1 \mathrm{~mm}$. long or less; corolla purplish, 6 $\mathrm{mm}$. long; pod oblong, sessile, about $1 \mathrm{~cm}$. long, $4 \mathrm{~mm}$. wide. A. wingatanus S. Wats. Dry hills: N.M.-Colo.-Utah. Submont.

13. H. Clementis Rydb. Stem glabrate or slightly strigose, about $2 \mathrm{dm}$. high; leaflets 11-21, oblong or lanceolate, acute, 7-12 mm. long, glabrous above and sparingly strigose beneath; inflorescence 8-12-flowered; calyx-tube about 3 $\mathrm{mm}$. long, strigose with black hairs; teeth lanceolate-subulate, about half as long; corolla bluish-purple, about $8 \mathrm{~mm}$. long; pod oblong, about $1 \mathrm{~cm}$. long, 3-4 mm. wide, black-hairy, with very short hairs. Mountains: Colo. Mont. Jl.

14. H. acerbus (Sheld.) Rydb. Stems erect, strigose, branched, 3-4 dm. high; leaflets 5-7, linear, 4-20 mm. long, 1-2 mm. wide; raceme lax, 5-14-flowered; calyx strigose; tube slightly over $1 \mathrm{~mm}$. long; teeth triangular-subulate, $0.5 \mathrm{~mm}$. long; corolla $5 \mathrm{~mm}$. long; legume glabrous; body oblong, 10-12 $\mathrm{mm}$. long; stipe about $1 \mathrm{~mm}$. long. A. acerbus Sheld. Hills: Colo,-N.M. Submont.-Mont. Je.

15. H. Dodgeanus (M. E. Jones) Rydb. Stems slender, flexuose, 1.5-6 dm. high, minutely pubescent; leaflets $9-11$, narrowly elliptic to linear, 5-10 $\mathrm{mm}$. long; racemes lax; calyx strigose, with black hairs; teeth triangular; corolla about $8 \mathrm{~mm}$. long; keel purple-tipped; pod short-stipitate, linear-oblong. $A$. Dodgeanus M. E. Jones. Rocky slopes: Utah-Colo. Submont. My.

16. H. dispar Nutt. Stem 3-4 dm. high, sparingly strigose or glabrate; leaflets oblong to oval, rarely linear-oblong, obtuse, often mucronate, glabrous above, sparingly strigose beneath, 8-20 mm. long; raceme 5-15-flowered; calyx strigose or glabrous; tube $2 \mathrm{~mm}$. long; teeth lance-subulate, $1 \mathrm{~mm}$. long; corolla 8-10 $\mathrm{mm}$. long; legume short-stipitate; body oblong, 10-13 $\mathrm{mm}$. long, abruptly contracted into the stipe. Hills and mountains: w Neb.-Colo.-Utah. Plain -Mont. Je-Jl.

17. H. tenellus (Pursh) Britton. Stems erect, $2-4 \mathrm{dm}$. high, more or less strigose, branched; leaflets 6-10 pairs, linear or linear-oblong, glabrous above, more or less strigose beneath, 8-15 $\mathrm{mm}$. long, 1-4 mm. wide; racemes 4-20-flowered; calyx strigose; tube nearly $2 \mathrm{~mm}$. long; teeth triangular-subulate, $1 \mathrm{~mm}$. long or less; corolla 8-9 mm. long; body of the pod oblong, 8-12 mm. long, 3-5 $\mathrm{mm}$. wide, gradually tapering into the stipe. A. multiflorus (Pursh.) A. Gray. Hills and mountain sides: Sask,-Neb,-Colo,-Utah-Yukon. Plain-Mont. Je-Jl.

18. H. stipitatus Rydb. Stems slender, $3-4 \mathrm{dm}$. high, erect; leaflets $9-15$, narrowly linear, $1-2 \mathrm{~cm}$. long, 1-2.5 $\mathrm{mm}$. wide, glabrous or sparingly strigose beneath; racemes lax, 5-20-flowered; calyx strigose; tube about $1.5 \mathrm{~mm}$. long; teeth subulate, about as long; corolla 8-10 mm. long; body of the pod oblong, about $1 \mathrm{~cm}$. long, $3 \mathrm{~mm}$. wide, acute, gradually tapering into the stipe. Dry hills: Sask,-Minn.-S.D. Plain.

19. H. strigulosus Rydb. Stems erect or ascending, 1-3 dm. high, strigillose; leaflets linear, acute, 8-12 $\mathrm{mm}$. long, 1-2 mm. wide, thick, glabrous above, strigose beneath; raceme lax, 4-7-flowered; calyx strigillose; tube $1.5 \mathrm{~mm}$. long; teeth subulate, less than $1 \mathrm{~mm}$. long; corolla about $6 \mathrm{~mm}$. long; body of the pod oblong, $7-8 \mathrm{~mm}$. long, $3 \mathrm{~mm}$. wide, rather gradually contracted into the stipe, which is about $3 \mathrm{~mm}$. long. Dry places: Utah-Nev. Son.

20. H. debilis (Nutt.) Rydb. Stem 1-2 dm. long, sparingly strigose; leaflets cuneate-oblong or elliptic, truncate or emarginate, minutely strigose beneath; raceme short, subeapitate; calyx strigose, with grayish or blackish hairs; tube $2 \mathrm{~mm}$. long; teeth subulate, about as long; corolla purple, $8-10 \mathrm{~mm}$. long; pod black-hairy, with rounded base, acute. A. debitis (Nutt.) A. Gray. Along streams: Wyo.-Ida.-Yukon-Mack. Boreal-Mont. Jl.

21. H. Bourgovii (A. Gray) Rydb. Stems numerous, decumbent or ascending, $0.5-3 \mathrm{dm}$. long, minutely strigose; leaflets oblong or elliptic to lance-linear, 4-12 mm. long, strigose; raceme lax, 3-10-flowered; calyx strigose, with black 
hairs; tube about $3 \mathrm{~mm}$. long; teeth 1-2 mm. long, subulate; corolla 8-10 mm. long, dark purple; pod lance-oblong, slightly stipitate, about $15 \mathrm{~mm}$. long, blackhairy, with a round ridge on each side. A. Bourgovii. A. Gray. Mountains: Alta.-S.D.-Mont.-B.C. Submont.-Mont. Jl-Au.

22. H. campestris Nutt. Stems often single, 2-4 dm. high, branched; rachis of the leaves $5-10 \mathrm{~cm}$. long, sometimes broadened at the end into a narrowly oblanceolate blade, but usually long-attenuate; lateral leaflets of the lower leaves narrowly linear or linear-subulate, 5-30 mm. long, those of the upper leaves usually lacking; raceme lax, 3-10-flowered; calyx-tube $3 \mathrm{~mm}$. long; teeth $1 \mathrm{~mm}$. long; corolla about $1 \mathrm{~cm}$. long; pod about $3 \mathrm{~cm}$. long, 3-4 mm. wide, strigose. A. campestris A. Gray. A. convallarius Greene. Sandy plains and bench-land: Wyo.-Colo-Utah. Plain-Submont. Je.

23. H. junciformis (A. Nels.) Rydb. Stems several, 2-4 dm. high, branched; leaves either reduced to a naked slender rachis, 4-7 cm. long, or bearing 5-7 distant linear-oblong or linear leaflets, 8-15 mm. long; raceme lax, 3-10-flowered; calyx-tube $3 \mathrm{~mm}$. long; teeth triangular, $0.5 \mathrm{~mm}$. long; corolla about $1 \mathrm{~cm}$. long; pod about $3 \mathrm{~cm}$. long, strigose. A. junciformis A. Nels. Sandy or stony plains: Wyo. Submont. Je.

24. H. junceus Nutt. Stems single or few, 3-6 dm. high, canescent-strigose, branched; lower leaves with 3-5, narrowly linear or oblanceolate-linear leaflets 1-3 cm. long, the upper usually reduced to the long slender rachis, curved at the tip; racemes 3 -10-flowered, lax; calyx-tube $3 \mathrm{~mm}$. long; teeth triangular, $1 \mathrm{~mm}$. long or less; pod strigose, linear, $2.5-3 \mathrm{~cm}$. long, $4 \mathrm{~mm}$. wide. A. junceus A. Gray. A. diversifolius A. Gray. Sandy plains: Mont.-Wyo.-(? Colo.)Ariz.-Ida. Plain-Submont. Je-Jl.

25. H. decumbens Nutt. Stems decumbent, 1-2 dm. high, sparingly strigose or glabrate; leaflets 7-11, narrowly linear-lanceolate, 5-10 mm. long, about $1 \mathrm{~mm}$. wide, strigose on both sides; raceme short, but loose, 5-10-flowered; calyx-tube about $2 \mathrm{~mm}$. long; teeth subulate, scarcely $1 \mathrm{~mm}$. long; corolla ochroleucous, tipped with purple; pod linear, arcuate, $2-2.5 \mathrm{~cm}$. long, $3 \mathrm{~mm}$. wide, finely strigillose. A. decumbens A. Gray. Sandy plains: Wyo.-Mont.-Wash. $\mathrm{Je}-\mathrm{Jl}$.

26. H. strigosus (Coult. \& Fish.) Rydb. Stems decumbent or ascending, 1.5-3.5 dm. high, strigose; leaflets 13-21, narrowly linear or linear, 1-2 cm. long, strigose on both sides; raceme slender, lax, 10-20-flowered; calyx-tube $2.5 \mathrm{~mm}$. long; teeth subulate, of the same length; corolla $1 \mathrm{~cm}$. long; pod sessile, linear, about $2 \mathrm{~cm}$. long, $3-3.5 \mathrm{~mm}$. broad, strigose. A. strigosus Coult. \& Fish. A. griseopubescens Sheld. Dry ground: Mont.-Wash. Plain-Submont. Je-Jl.

27. H. tenuifolius Nutt. Stems decumbent, less than $2 \mathrm{dm}$. high, strigose-canescent; leaflets 7-13, linear or subulate, 5-15 $\mathrm{mm}$. long, about $1 \mathrm{~mm}$. wide, strigose-canescent on both sides; raceme short, lax, 3-8-flowered; calyx-tube campanulate, about $2 \mathrm{~mm}$. long; teeth $0.5-0.7 \mathrm{~mm}$. long; corolla $6-8 \mathrm{~mm}$. long; pod linear, strigose, $12-15 \mathrm{~mm}$. long, 2.5-3 mm. wide. A. campestris Coult. \& Nels., not A. Gray. Dry hills and mountains: Mont.-Colo.-Utah. Submont. -Mont. Je-Jl.

28. H. divergens (Blankinship) Rydb. Stems numerous, 1-1.5 dm. (rarely $2 \mathrm{dm}$.) high, grayish strigose, decumbent; leaflets 9-15, canescent-strigose, linear to lance-oblong, 4-8 $\mathrm{mm}$. long, 1-2.5 $\mathrm{mm}$. wide; racemes 6 -15-flowered; calyx strigose with dark hairs; tube scarcely $2 \mathrm{~mm}$. long; teeth subulate, fully $1 \mathrm{~mm}$. long; corolla $6 \mathrm{~mm}$. long, white, purple-tinged, with purple veins and purpletipped keel; pod linear, 12-15 mm. long, 2-2.5 mm. wide. A. divergens Blankinship. Homalobus camporum Rydb., in part. Dry hills and mountain tops: Mont.-Wyo.-Utah. Plain-Mont.

29. H. serotinus (A. Gray) Rydb. Stems ascending or erect, slender, 2-4 $\mathrm{dm}$. high, strigose; leaflets 9-21, linear to lance-oblong, acute, glabrous above, strigose beneath, 1-3 cm. long, 2-4 mm. wide; racemes lax, 5-15-flowered; calyxtube about $2.5 \mathrm{~mm}$. long; teeth subulate, less than $1 \mathrm{~mm}$. long; corolla purplish, 
$1 \mathrm{~cm}$. long; keel with a deeply purple tip; pod $2-2.5 \mathrm{~mm}$. long, $3 \mathrm{~mm}$. wide, minutely strigose or in age glabrous. A. serotinus A. Gray. Mountain slopes: B.C.-Wash.-Mont. Submont. My-Jl.

30. H. oblongifolius Rydb. Stems ascending, branched, $2-3 \mathrm{dm}$. high, glabrous or nearly so; leaflets $11-19$, usually oblong, but varying from elliptic to linear-oblong, 1-2 cm. long, 3-6 mm. wide, glabrous above, sparingly strigose beneath, rounded at the apex; raceme short, 5-10-flowered; calyx-tube 2-2.5 $\mathrm{mm}$. long; teeth subulate, fully $1 \mathrm{~mm}$. long; corolla $1 \mathrm{~cm}$. long, white, tinged with purple; keel with a narrow dark-purple tip; pod 2-2.5 $\mathrm{cm}$. long, strigose, $4 \mathrm{~mm}$. wide. Mountains: Colo. Mont. My-Je.

31. H. decurrens Rydb. Stems erect, $3-4 \mathrm{dm}$. high, slightly strigose and angled; leaflets $11-15,2-4 \mathrm{~cm}$. long, linear-oblong to oblanceolate, sparingly strigose below, glabrate above; racemes slender, lax, 5-10-flowered; ealyx-tube about $2.5 \mathrm{~mm}$. long; teeth nearly $2 \mathrm{~mm}$. long and subulate; pod fully $2 \mathrm{~cm}$. long and $3 \mathrm{~mm}$. wide, at length often glabrous. Wooded hills: Colo. Mont. Je-Au.

32. H. paucijugus Rydb. Stems 1-2 dm. high, sparingly strigose; leaflets $1-5$, the lateral ones lanceolate to linear-subulate, $1 \mathrm{~cm}$. or less long, glabrous above, sparingly strigose beneath, or none, the terminal one $1-2 \mathrm{~cm}$. long, linear or linear-oblanceolate; racemes short, 3-6-flowered; calyx strigose with black hairs; tube about $2 \mathrm{~mm}$. long; teeth subulate, fully $1 \mathrm{~mm}$. long; pod 12-15 mm. long, $2 \mathrm{~mm}$. wide. Sheltered places in the mountains: Utah. Mont.-Subalp.

33. H. microcarpus Rydb. Stems decumbent, about $1 \mathrm{dm}$. high, strigose; leaflets $9-15$, elliptic to linear, $5-15 \mathrm{~mm}$. long, $1-3 \mathrm{~mm}$. wide, glabrous above, sparingly strigose beneath; racemes short, 3-8-flowered; calyx strigose with black hairs; tube about $2 \mathrm{~mm}$. long; teeth about $1 \mathrm{~mm}$. long, subulate; pod $12-$ $18 \mathrm{~mm}$. long, $3 \mathrm{~mm}$. wide. H. camporum Rydb., in part. Mountains: Colo. Submont.-Mont.

34. H. humilis Rydb. Stems $2-10 \mathrm{~cm}$. long, grayish strigose, decumbent or spreading; leaflets $11-15$, oblong, 3-6 $\mathrm{mm}$. long, about $2 \mathrm{~mm}$. wide, grayish strigose beneath, glabrate above; raceme short, 3-8-flowered; calyx strigose with black hairs; tube 1.5-2 mm. long; teeth triangular or triangular-subulate, $1-1.5$ $\mathrm{mm}$. long; corolla purple, $7-8 \mathrm{~mm}$. long; pod about $1.5 \mathrm{~cm}$. long, $3 \mathrm{~mm}$. wide. Mountains: Utah. Mont.-Subalp.

35. H. Palliseri (A. Gray) Rydb. Stems adsurgent, 2-4 dm. high, sparingly strigose; leaves $8-12 \mathrm{~cm}$. long; leaflets 9-19, linear or lance-linear, sparingly strigose below, glabrate above, 1-2 cm. long; raceme 7-12-flowered, lax; calyx strigose with black hairs; tube $2.5 \mathrm{~mm}$. long; teeth triangular-subulate, $0.5 \mathrm{~mm}$. long; pod linear, about $1.5 \mathrm{~cm}$. long, $2 \mathrm{~mm}$. broad, glabrous, tapering at both ends. Mountains: Alta.-B.C.-Wash.-Mont. Submont. Jl.

36. H. hylophilus Rydb. Stems slender, leafy, sparingly strigose; leaflets 13-25, elliptic to lance-oblong, 1-2 em. long, glabrous above, sparingly strigose beneath; raceme short, 6-12-flowered; calyx strigose, with dark hairs; tube $3 \mathrm{~mm}$. long; teeth subulate, $1-1.5 \mathrm{~mm}$. long; corolla about $1 \mathrm{~cm}$. long, white, tinged with purple at the tip; keel purple-tipped; pod linear, $2-2.5 \mathrm{~cm}$. long, 3-4 mm. wide. Open woods: Mont.-Wyo,-Utah-Ida. Submont.-Mont. $\mathrm{Je}-\mathrm{Au}$.

37. H. stenophyllus (T. \& G.) Rydb. Stem erect, glabrous, 5-7 dm. high; leaflets $9-17$, narrowly linear, glabrous or sparingly strigose, $1-1.5 \mathrm{~cm}$. long, $1-2$ $\mathrm{mm}$. wide; raceme lax, many-flowered; calyx-tube 3-4 mm. long; teeth triangular, $1 \mathrm{~mm}$. long; corolla ochroleucous or white, about $2 \mathrm{~mm}$. long; stipe of the pod about $1 \mathrm{~cm}$. long; body oblong, about $2 \mathrm{~cm}$. long, $4 \mathrm{~mm}$. wide. A. stenophyllus T. \& G. Plains: Mont.-B.C.-Ore.-(? Utah). Son.-Plain. Je.

38. H. Episcopus (S. Wats.) Rydb. Stems glabrous or slightly appressedhairy, 4-6 dm. high, branched; leaflets $0-7$, narrowly linear, 8-12 mm. long, sparingly strigose; raceme lax; calyx strigose, with more or less blackish hairs; tube about $4 \mathrm{~mm}$. long; teeth subulate, about $1 \mathrm{~mm}$. long; corolla reddish purple, 12-15 mm. long; pod glabrous; stipe 5-8 $\mathrm{mm}$. long; body linear-oblanceolate, 
2.5-3 cm. long, about $5 \mathrm{~mm}$. wide. A. Episcopus S. Wats. A. Coltoni M. E. Jones. Hills: Utah. Son.

39. H. collinus (Dougl.) Rydb. Stems erect, cinereous-pilose; leaflets 15-23, linear or linear-oblong, obtuse or retuse, $7-15 \mathrm{~mm}$. long, villous-hirsutulous beneath, glabrate above; raceme $5-10 \mathrm{~cm}$. long; calyx villous; tube about $8 \mathrm{~mm}$. long; lower teeth lance-subulate, the upper triangular, all about $2 \mathrm{~mm}$. long; corolla ochroleucous, about $15 \mathrm{~mm}$. long; pod densely pilose; stipe about $1 \mathrm{~cm}$. long; body linear, straight, about $2 \mathrm{~cm}$. long, tapering at both ends. $A$. collinus Dougl. Mountain sides: B.C.-Ida.-Ore. Son. My-Je.

40. H. curvicarpus (Sheld.) Heller. Stem 3-6 dm. high, cinereous-pilose, with crisp hairs, branched and often flexuose; leaflets 9-17, obovate or obovatecuneate, truncate to emarginate at the apex, $8-15 \mathrm{~mm}$. long, more or less pubescent on both sides, with crisp hairs; calyx densely pilose; tube $7-8 \mathrm{~mm}$. long; teeth triangular, 1-1.5 mm. long; pod finely pubescent; stipe 10-12 mm. long; body curved, $3 \mathrm{~cm}$. long, $4 \mathrm{~mm}$. wide, tapering at both ends. A. speirocarpus falciformis A. Gray. Sandy or dry soil: Ida.-Nev.-Calif.-Wash. Son. My-J.

41. H. Hallii (A. Gray) Rydb. Stems adsurgent, 2-4 dm. high, strigose, leafy; leaflets 19-25, linear-oblong to elliptic-cuneate, truncate or retuse, $5-10$ $\mathrm{mm}$. long, strigose beneath, glabrous above; raceme dense; calyx strigose; tube 4-5 mm. long; teeth triangular-subulate, $1 \mathrm{~mm}$. long; corolla purple, $12-15 \mathrm{~mm}$. long; pod 2-2.5 cm. long, oblong-elliptic, tapering at both ends, short-stipitate, glabrous, $5 \mathrm{~mm}$. thick, A. Hallii A. Gray. Mountains: Colo. Submont.Mont. Jl-Au.

42. H. Fendleri (A. Gray) Rydb. Stems adsurgent, 3-5 dm. high, glabrous or nearly so; leaflets $13-25$, oblong or linear-oblong, obtuse or retuse, $8-20 \mathrm{~mm}$. long, sparingly strigose beneath, glabrous above; calyx strigose, with dark hairs; tube $3 \mathrm{~mm}$. long, lanceolate or triangular, $1 \mathrm{~mm}$. long; corolla $10-12 \mathrm{~mm}$. long, purple; pod oblong-obovoid, about $2 \mathrm{~cm}$. long, 7-8 mm. in diameter, strigillose or glabrate. Phaca Fendleri A. Gray. A. Fendleri A. Gray. River bottoms in the mountains: N.M.-Colo. Submont. My-Je.

43. H. flexuosus (Dougl.) Rydb. Stems erect to decumbent, usually flexuose, strigose, 3-6 dm. long; leaflets 13-21, linear-oblong to elliptic-cuneate, obtuse or retuse, glabrous above, strigose beneath, 5-15 mm. long; racemes lax; calyx strigose; tube $3 \mathrm{~mm}$. long; teeth subulate, $1 \mathrm{~mm}$. long; corolla purple, or white tinged with purple; pod eylindric, $1.5-2 \mathrm{~cm}$. long, $4 \mathrm{~mm}$. thick, strigose, acute at both ends, straight or slightly curved. Phaca elongata Hook. A. flexuosus Dougl. Dry plains: Sask.-Minn.-Kans.-N.M.-Utah-Alta. Plain-Mont.

44. H. proximus Rydb. Stems erect, 2-3 dm. high, grayish strigose; leaflets $5-11$, linear or linear-oblong, obtuse, 5-11 $\mathrm{mm}$. long, grayish strigose; calyx about $2.5 \mathrm{~mm}$. long, strigose; corolla $4-5 \mathrm{~mm}$. long, white or ochroleucous; pod oblong-linear, terete, glabrous, about $12 \mathrm{~mm}$. long and $3 \mathrm{~mm}$. in diameter. Dry places: Colo. Submont. Je.

45. H. Salidae Rydb. Stem $3 \mathrm{dm}$. or more long; leaflets 15-21, oblongoblanceolate to narrowly linear, 8-15 $\mathrm{mm}$. long, strigose; racemes lax; calyx strigose and slightly black-hairy, about $3 \mathrm{~mm}$. long; teeth short, triangular; corolla about $8 \mathrm{~mm}$. long, purple-veined; pod narrowly linear-oblanceolate, terete or nearly so, $2-2.5 \mathrm{~cm}$. long, $2 \mathrm{~mm}$. in diameter, finely strigose, very acute at the apex. Dry places: Colo. Submont. Au.

46. H. macrocarpus (A. Gray) Rydb. Stems 4-8 dm, high, strigosecanescent; leaves 5-10 $\mathrm{cm}$. long, the upper often reduced to filiform phyllodes; leaflets $0-5$, linear to filiform, strigose-canescent, 1-3 cm. long; raceme lax, 2-4 $\mathrm{dm}$. long; calyx strigose-canescent; tube about $7 \mathrm{~mm}$. long; teeth lanceolate, $1.5-2 \mathrm{~mm}$. long; pod long-stipitate, glabrous; stipe about $1 \mathrm{~cm}$. long; body lancelinear, tapering at both ends, $3-4 \mathrm{~cm}$. long, $4-5 \mathrm{~mm}$. thick, A. lonchocarpus A. Gray. (?) A. duchesnensis M. E. Jones. A. macer A. Nels. Sandy places: N.M. -Colo.-Utah. My-Je. 


\section{KENTRÓPHYTA Nutt.}

Perennial, diffusely branched herbs. Leaves pinnately 3-7-foliolate; leaflets linear or subulate, inarticulate, rigid, spinulose-tipped; stipules more or less united. Flowers small, 2 or 3 together in the axils. Calyx campanulate, deeply 5-cleft; teeth equal, subulate. Corolla ochroleucous or purplish; banner oblong, reflexed; keel obtuse, shorter than the wings. Legume ovate, one-celled, flat, with both sutures prominent, 1- or 2-seeded.

Stipules united only at the base, more or less herbaceous.

Plant 3-4 dm. high, usually erect; stipules lanceolate, with long spinulose tips.

Plant low; stipules lance-subulate, not spinulose-tipped. Stipules united for about half their length, scarious.

Leaflets linear-filiform, scarcely narrowed at the base; corolla ochroleucous, subsessile in the axils of the leaves. $3, K$. montana.

Leaflets lanceolate or oblanceolate, distinctly narrowed at the base.

Corolla ochroleucous, about $4 \mathrm{~mm}$. long, the keel usually purple-tipped; leaflets less than $5 \mathrm{~mm}$. long.

Flower-clusters subsessile or short-peduncled; calyx-lobes shorter than the tube.

Leaves short-hairy; stipules with long spreading tips; leaflets about $3 \mathrm{~mm}$. long. $\quad$ 4. K. minima. Leaflets long-hairy; stipules not with spreading tips; leaflets $4-5 \mathrm{~mm}$. long.

Flower-clusters on peduncles much exceeding the leaves; calyx-lobes . Wolfiling or exceeding the tube.

Corolla purple, about $6 \mathrm{~mm}$. long; leaflets over $5 \mathrm{~mm}$. long. 6. K. tegetaria.
7. K. aculeata.

1. K. impensa (Sheld.) Rydb. Stems ereet or ascending, 3-4 dm. high, simple or with short branches; leaflets 5-7, subulate or linear-lanceolate, 8-15 $\mathrm{mm}$. long, strigose, strongly ribbed and pungent; calyx-tube $1.5 \mathrm{~mm}$. long; teeth $1 \mathrm{~mm}$. Iong; corolla ochroleucous, $4 \mathrm{~mm}$. long. Astragalus Kentrophyta elatus S. Wats, A. viridis impensus Sheld. Dry valleys: Nev.-w Colo.-Ariz. Son.Submont. My-S.

2. K. viridis Nutt. Stems diffusely spreading and much branched, 1-3 dm. long; leaflets usually 5, subulate, pungent, 8-18 mm. long; calyx-tube $1.5-2 \mathrm{~mm}$. long; teeth $1.5 \mathrm{~mm}$. long; corolla ochroleucous, $5 \mathrm{~mm}$. long. A. Kentrophyta A. Gray, in part. Plains, bad-lands, and hills: Wyo.-Colo. Plain-Submont. My-Je.

3. K. montana Nutt. Stems diffusely spreading, and intricately branched; stipules ovate, 1-3 $\mathrm{mm}$. long; leaflets 5-7, subulate, pungent, 8-15 mm. long; calyx-tube $1.5-2 \mathrm{~mm}$. long; teeth $1 \mathrm{~mm}$. long; corolla ochroleucous, $4-5 \mathrm{~mm}$. long. A. Kentrophyta A. Gray, in part. Bad lands, cañons, and sandy hills: Sask.-Neb.-Utah-Alta. Plain-Submont. Je-Au.

4. K. minima Rydb. Perennial forming cushions $1 \mathrm{dm}$. in diameter; stems 1-2 cm. high; stipules lanceolate, 1-3 mm. long; leaflets 5-9, linear-lanceolate, conduplicate, pungent, 3-4 mm. long; flowers usually solitary; calyx-tube 1-1.5 mm. long; teeth scarcely $1 \mathrm{~mm}$. long; corolla about $3 \mathrm{~mm}$. long. Mountains: Yellowstone Park, Wyo. Mont. Au.

5. K. Wolfii Rydb. Stems intricately branched, less than $1 \mathrm{dm}$. long; stipules triangular; leaflets 5, approximate, 3-4 mm. long, lanceolate, strongly conduplieate; calyx-tube scarcely $2 \mathrm{~mm}$. long; teeth about $1 \mathrm{~mm}$. long; corolla about 4 $\mathrm{mm}$. long. High mountains: Colo. Mont.-Subalp. Jl.

6. K. tegetaria (S. Wats.) Rydb. Stems diffuse-procumbent, $5-15 \mathrm{~cm}$. long, much branched; stipules lanceolate, acuminate, $3-5 \mathrm{~mm}$. long; leaflets $7-11$, narrowly linear-lanceolate, pungent, 4-6 mm. long; calyx-tube scarcely $1.5 \mathrm{~mm}$. long; teeth fully $1.5 \mathrm{~mm}$. long; corolla $4-5 \mathrm{~mm}$. long. A. tegetarius S. Wats. Mountains: Nev.-(? Utah). Mont, Jl.

7. K. aculeata (A. Nels.) Rydb. Stems less than $1 \mathrm{dm}$. long, diffusely spreading or decumbent; stipules ovate, 4-5 $\mathrm{mm}$. long; leaflets 5-9, narrowly linear-lanceolate, conduplicate, 4-8 mm. long; calyx-tube about $1.5 \mathrm{~mm}$. long; teeth subulate, $1 \mathrm{~mm}$. long; corolla $5-6 \mathrm{~mm}$. long. A. aculeatus A. Nels. A. tegetarius implexus Canby. High mountains: Mont.-Colo.-Utah-Ida. Submont.-Mont. Jl-Au. 


\section{OROPHĀCA (T. \& G.) Britton.}

Cespitose, silvery or villous perennials, with branched woody caudices and deep roots. Leaves crowded, digitately 3 -foliolate (rarely 5-foliolate), with scarious sheathing stipules. Flowers few, capitate or racemose. Calyx campanulate to cylindric. Corolla yellowish or purplish. Keel blunt. Pod coriaceous, 1-celled, without partition, ovoid or elliptic, few-seeded, villous or puberulent, partly included in the calyx.

Flowers sessile in the axils of the leaves, $12 \mathrm{~mm}$. or more long: corolla ochroleucous; calyx-tube longer than the teeth; plant pulvinate-cespitose.

Corolla $2 \mathrm{~cm}$. or more long, glabrous; calyx-tube cylindrical, more than thrice as long as the teeth.

1. O. caespitosa.

Corolla 15-18 mm. long, pubescent on the outside; calyx-tube short-cylindric, about twice as long as the teeth.

2. O. argophylla.

Flowers in small, neduncled 1-3-flowered racemes, purple or turning yellowish in age, less than $10 \mathrm{~mm}$. long; calyx-tube campanulate, not longer than the tube-teeth.

Plant pulvinate-cespitose; flowers 8-10 mm. long; inflorescence not exceeding the leaves.

Flowers about $10 \mathrm{~mm}$. long; pods puberulent. Flowers about $8 \mathrm{~mm}$. long; pods hoary.

3. $O$, tridactylica.

4. $O$. aretioides.

Plant broadly cespitose, with prostrate branches; flowers about $6 \mathrm{~mm}$. long; peduncles usually exceeding the leaves; pods hoary.

5. O. sericea.

1. O. caespitosa (Nutt.) Britton. Stems $5 \mathrm{~cm}$. or less, densely covered with leaves and scarious stipules; leaflets elliptic to narrowly oblanceolate, $0.5-2$ $\mathrm{cm}$. long, appressed silvery-silky on both sides; calyx silky; tube cylindric, 10-15 $\mathrm{mm}$. long; teeth 3-4 mm. long; corolla 2-3 cm. long; legume oblong-ovate, terete, silky-villous. Phaca caespitosa Nutt. Astragalus triphyllus Pursh. Dry gravelly hills: Sask.-Neb.-Wyo.-Mont. Plain. My-Je.

2. O. argophylla (Nutt.) Rydb. Stems less than $5 \mathrm{~cm}$. high, densely covered with scarious, ovate stipules; leaflets elliptic or obovate to oblanceolate, 5-15 $\mathrm{mm}$. long, 3-5 mm. wide, appressed white-silky on both sides; calyx white silkyvillous; tube cylindric, $6-8 \mathrm{~mm}$. long; teeth subulate, $3 \mathrm{~mm}$. long; corolla $15-18$ $\mathrm{mm}$. long; legume short and rounded-ovate, densely villous. Phaca argophylla Nutt. Astragalus hyalinus M. E. Jones. Dry hills and bad lands: w Neb.Wyo.-Colo. Plain. J-Au.

3. O. tridactylica (A. Gray) Rydb. Stems less than $5 \mathrm{~cm}$. high, densely covered with leaves and scarious, pubescent stipules; leaflets broadly or narrowly oblanceolate, $0.5-2 \mathrm{~cm}$. long, 3-4 mm. wide, densely silky on both sides; calyx silky; tube $3 \mathrm{~mm}$. long; teeth $4 \mathrm{~mm}$. long, subulate; corolla about $1 \mathrm{~cm}$. long; legume globose-ovoid, 6-8 $\mathrm{mm}$. Iong. A. tridactylicus A. Gray. Hills and plains: Colo. Submont. My-Je.

4. O. aretioides (M. E. Jones) Rydb. Stems more elongate than in the preceding; leaflets broadly oblanceolate, $0.5-1 \mathrm{~cm}$. long, 3-4 $\mathrm{mm}$. wide; calyx densely silky; tube about $2 \mathrm{~mm}$. long; teeth subulate, $2 \mathrm{~mm}$. long; corolla 7-8 mm. long; legume ovoid. A. sericoleucus aretioides M. E. Jones. Dry hills: Wyo.-Colo. Submont. My-Je.

5. O. sericea (Nutt.) Britton. Branches of the caudex often 1-2 dm. long; annual branches $2-4 \mathrm{~cm}$. long, densely covered with leaves and ovate scarious pubescent stipules; leaflets oblanceolate to cuneate-obovate, $5-8 \mathrm{~mm}$. long, 2-3 $\mathrm{mm}$. wide, densely white-silky; calyx densely silky; tube $1.5 \mathrm{~mm}$. long; teeth about $1.5 \mathrm{~mm}$. long; corolla purple, 6-7 mm. long; legumes ovoid. Phaca sericea Nutt. A. sericoleucus A. Gray. Dry hills: Neb.-Wyo.-Colo. PlainSubmont.

\section{ARAGÁLLUS Necker. Loco-WEED.}

Perennial herbs, mostly acaulescent. Leaves alternate, odd-pinnate. Flowers racemose or spicate Calyx campanulate, its teeth almost equal. Petals clawed; banner erect, ovate or oblong; wings oblong; keel produced at the apex into a porrect point. Stamens 10, diadelphous; anthers all alike. Pods sessile or stipitate, coriaceous, often more or less 2-celled by the intrusion of the upper suture. [Oxytropis DC.] 
Stipules adnate to the petioles only slightly at the base; pods pendent, 1-celled, many times exceeding the calyx; plant often caulescent. I. DEFLEXI.

Stipules decidedly adnate to the petioles; pods not pendent; plant acaulescent. Leaves strictly pinnate; leaflets opposite.

Fruiting calyx inflated, enclosing the fruit; plants densely cespitose, less than $1.5 \mathrm{dm}$. high.

Fruiting calyx not inflated, much exceeded by the pod.

Inflorescence 1-3-flowered; plants dwarf, pulvinate. Pods inflated, 1-celled, ovoid.

Pods not inflated, oblong, almost 2-celled.

II. NANI.

III. INFLATI.

IV. PARRYANI.

Leaflets verticillate.

I. DEFLEXI.

high, not pulvinate;

V. CAMPESTRES.

VI. VERTICILLARES.

Plant more or less caulescent; racemes at least in fruit elongate; pods $1.5-1.8 \mathrm{~cm}$. long.

Plant subacaulescent; racemes short and head-like; pods about 1 . A. deflexus.

\section{NANI.}

2. A. foliolosus.

Peduncles scarcely exceeding the leaves, 1-3-flowered; bracts broadly ovate.

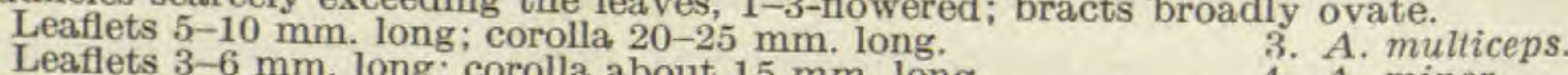

Peduncles decidedly long; corolla about $15 \mathrm{~mm}$. long.

4. A. minor. lanceolate. Pubescence of the peduncles appressed or merely ascending; pods included in the
calyx.

Peduncles erect, strict; spike oblong, over $2 \mathrm{~cm}$. long. Corolla yellow or whitish, more than $2 \mathrm{~cm}$. long.

Corolla purple, less than $2 \mathrm{~cm}$. long.
Peduncles ascending, curved; spike subcapitate.

5. A. collinus.

6. A. Blankinshipii.

Pubescence of the peduncles 7 . A. nanus.

mewhat exserted.

Leaflets 11-23.

III. INFLATI.

8. A. Lagopus.

Leaflets sparingly appressed-hirsute.

Leaflets densely canescent.

Leaflets 5-11, densely canescent.

One species.

Plant not viscid.

IV. Parryani.

9. A. podocarpus.

10. A. Hallii.

11. A. oreophilus.

Corolla purple, rarely white.

Calyx with spreading hairs.

Calyx white-hairy; corolla usually light purple.

Plant loosely pubescent; peduncles with long spreading hairs.

Plant silky-canescent; peduncles with 8. A. Lagopus.

Plant low, densely cespitose; $5 \mathrm{~cm}$. high; spike capitate; peduncles ascending, curved, less than

Plant taller, over 1 dm. high; spike elongate. Calyx long-hairy; wings broad.

Calyx short-hairy; wings narrow.
Calyx black-hairy; corolla dark, bluish purple.

Plant white or grayish villous.

Plant silky, with appressed hairs, green.

12. A. Parryi.

13. A. argophyllus.

14. A. Besseyi.

21. A. alberlinus.

15. A. atropurpureus.

16. A. melanodontus.

Calyx with appressed hairs. Legumes about $3 \mathrm{~cm}$. long, short-stipitate and long-acuminate; corolla over 2
$\mathrm{~cm}$. long.

Legume $2 \mathrm{~cm}$. long or less, sessile.

17. A. Bigelovii. Legumes villous, almost 2-celled; caudices densely white-hairy; corolla 12
mm. long.

Legumes appressed-silky or short-hairy; caudices not conspicuously white-
hairy. hairy.

Legume nearly 2-celled; leaves white-silky.

Corolla 12-15 $\mathrm{mm}$. long; wings slightly emarginate.

Corolla about $2 \mathrm{~cm}$. long; wings broadly and deeply emarginate.

Legumes only half 2-celled.

Leaves white-silky benea

20. A. sericeus.

Leaves green or only slightly silky.

Legumes spreading; leaves elliptic or oblong: corolla $15 \mathrm{~mm}$. long. 22 . A. dispar.

Legumes erect or strongly ascending; leaflets lanceolate or linearlanceolate, very acute.

Leaves spreading; pod is $\mathrm{mm}$. long, abruptly contracted into a short spreading beak; corolla $15 \mathrm{~mm}$. long.

Leaves erect; pod 20 23. A. angustatus. straight; 24. A. Lambertii. 
Corolla yellow, ochroleucous or white, with a purple spot on the keel. Peduncles decumbent, curved, $1 \mathrm{dm}$. long or less. Peduncles erect, $2 \mathrm{dm}$. high or more.

Peduncles with long loose hairs.

Peduncles appressed-hairy.

Flowers 12-15 $\mathrm{mm}$. long.

Lower leaves with conspicuously shorter and broader leaflets; flowers

more or less spreading. 22. A. dispar.

25. A. alpicola.

26. A. villosus.

ing. 27. A. gracilis.

Flowers 18-25 mm. long; pods coriaceous.

Corolla yellow; banner and wings narrower than in the next, slightly notched; legume nearly 2-celled. 28. A. spicatus.

Plant more or less viscid.

rolla white or straw-colored, banner and wings fully $1 \mathrm{~cm}$. wide, deeply notched; legume half 2-celled. $\quad 29$. A. albiflorus.

Calyx not black-hairy; pods abruptly acuminate; base of the plant with long yellow hairs.

Calyx black-hairy; pods long-acuminate; base of the plant not yellow-hairy.

\section{VERTICILLATI.}

Bracts usually shorter than the flowers.

Leaflets lance-oblong to elliptic, densely silky-pubescent.

Leaflets linear-lanceolate, rather sparingly silky.

Bracts much exceeding the flowers,

32. A. Richardsonii.

33. A. galioides.

34. A. splendens.

1. A. deflexus (Pall.) Heller. Stem 1-4 dm. high, villous, flexuose; leaflets 25-41, lanceolate or ovate, green, loosely villous, 5-20 mm. long, rounded at the base, acute at the apex; raceme usually lax, 5-10 cm. long; calyx black-hairy, tube $4 \mathrm{~mm}$. long; teeth subulate, $3 \mathrm{~mm}$. long; corolla 6-9 mm. long, dirty white below, blue at the apex; pod oblong, black-hairy. O. deflexa (Pall.) DC. Damp places: Sask.-S.D.-N.M.-Ida.-Alaska. Mont.-Subalp. Je-Au.

2. A. foliolosus (Hook.) Rydb. Subacaulescent; leaflets 13-31, ovate or elliptic, 3-8 $\mathrm{mm}$. long, villous, green, acutish or obtuse; calyx black-villous; tube $5-6 \mathrm{~mm}$. long; teeth subulate, $3 \mathrm{~mm}$. long; corolla bluish purple, $8-10 \mathrm{~mm}$. long; legume ellipsoid, black-hairy. O. foliolosa Hook. High mountains: Alta.Colo.-Yukon. Subalp. J1-Au.

3. A. multiceps (Nutt.) Heller. Pulvinate perennial; leaflets 7-9, elliptic to lanceolate, densely canescent, with appressed silky hairs, 5-10 $\mathrm{mm}$. long, acute; peduncles 1-4 cm. long, 2-3-flowered; calyx silky-villous; tube 8-10 $\mathrm{mm}$. long; teeth lanceolate, $3 \mathrm{~mm}$. long; corolla reddish purple; keel with a very short porrect beak; legume ellipsoid, silky-strigose, $1 \mathrm{~cm}$. long, with a very narrow partial partition. O. multiceps Nutt. Hills and mountains: Neb.-(? Mont.)-Wyo. - Colo. Plain-Submont. My-Je.

4. A. minor (A. Gray) Cockerell. Pulvinate perennial; leaflets 5-9, lanceolate or oblong, 3-6 mm. long, acute, silky, but pubescence somewhat looser than in $A$. multiceps; peduncles $0.5-3 \mathrm{~cm}$. long; calyx silky-villous; tube $6-7 \mathrm{~mm}$. long; teeth lanceolate, $2-3 \mathrm{~mm}$. long; corolla dark purple; keel with a slender ascending beak; legume ovoid, thin, silky, about $8 \mathrm{~mm}$. long; partial partition narrow. O. multiceps minor A. Gray. High mountains: Colo.-Wyo. Submont.-Mont. My-Jl.

5. A. collinus A. Nels. Plant very hairy at the base; leaflets $7-13$, oblong to linear-lanceolate, acute, 1-3 cm. long, densely white-silky, with long appressed hairs; scapes several, 1-2 dm. high; spike 10-20-flowered; calyx villous with long silky hairs; tube $7 \mathrm{~mm}$. long; teeth lanceolate, $3 \mathrm{~mm}$. long; corolla $18-20 \mathrm{~mm}$. long; keel with a dark spot and a short porrect tip; legume oblong-elliptic, villous, nearly filling the ealyx. Mountains: Wyo.-(? Mont.). Submont. Jl.

6. A. Blankinshipii A. Nels. Leaflets $7-17$, oblong, acute at both ends, 8-16 $\mathrm{mm}$. long, canescent with appressed hairs; scapes erect, 5-10 $\mathrm{cm}$. long; spike in fruit $2-5 \mathrm{~cm}$. long; calyx villous with long hairs; tube $6-7 \mathrm{~mm}$. long; teeth triangular or lanceolate, $2-3 \mathrm{~mm}$. long; corolla dark purple, about $15 \mathrm{~mm}$. long; legumes ovoid, about $1 \mathrm{~cm}$. long, coriaceous, only partly 2-celled. Hills and plains: Mont,-Wyo.-Ida. Submont. My-Je.

7. A. nanus (Nutt.) Greene. Pulvinate perennial; leaves usually spreading; leaflets 7-13, oblong or lanceolate, $5-10 \mathrm{~mm}$. long, appressed silky; peduncles decumbent or ascending, $2-5 \mathrm{~cm}$. long; calyx villous, often with partly black hairs; tube about $6 \mathrm{~mm}$. long; teeth lanceolate, $3 \mathrm{~mm}$. long; corolla dark purple, 
$15 \mathrm{~mm}$. long; legume ovoid, $1 \mathrm{~cm}$. long, densely villous, nearly half 2-celled. 0 . nana Nutt. Mountains: Mont.-Wyo. Plain-Submont. Je.

8. A. Lagopus (Nutt.) Greene. Pulvinate perennial; leaflets 9-15, elliptic, oblong or lanceolate, acute, 5-15 mm. long, loosely canescent; scape 2-7 $\mathrm{cm}$. long, silky villous, decumbent to erect; spike head-like; calyx densely long-villous; tube about $6 \mathrm{~mm}$. long; teeth often dark, subulate, $3 \mathrm{~mm}$. long; corolla dark bluish purple; legume long-villous, oblong-ovoid, long-acuminate, $15 \mathrm{~mm}$. long or less, thin, half 2-celled. O. Lagopus Nutt. Dry hills and bench lands: Mont.-Wyo.-Ida. Plain-Submont. My-Je.

9. A. podocarpus (A. Gray) Greene. Pulvinate perennial; leaflets 11-33, linear-lanceolate or oblong, 3-8 mm. long, acute; peduncles 1-3 $\mathrm{cm}$. long, sparingly hairy, 1-2-flowered; calyx dark, villous with white hairs; tube 6-7 mm. long; teeth lanceolate, $2-3 \mathrm{~mm}$. long; corolla dark bluish purple, about $15 \mathrm{~mm}$. long; legume stipitate, finely black-hairy; body ellipsoid, $15-20 \mathrm{~mm}$. long, abruptly contracted into a short beak. $O$. podocarpa A. Gray. Aretic-alpine regions: Lab.-Alta.-Colo.-Ida.-B.C.-Yukon. Subalp._Alp. Je-Jl.

10. A. Hallii (Bunge) Rydb. Pulvinate perennial; leaflets 11-19, narrowly oblong or lanceolate, densely silky-canescent, about $5 \mathrm{~mm}$. long; peduncles 1-3 $\mathrm{cm}$. long, grayish strigose; calyx black, villous with white hairs; tube searcely 5 $\mathrm{mm}$. long; teeth lanceolate; corolla bluish purple, about $1 \mathrm{~cm}$. long. $O$. Hallii Bunge. High mountains: Colo. Subalp.-Alp. Je.

11. A. oreophilus (A. Gray) A. Nels. Pulvinate perennial; leaflets 7-11, lanceolate or oblong, densely white-silky, 4-8 $\mathrm{mm}$. long; peduncles $1-3 \mathrm{~cm}$. long; spike 3-8-flowered, capitate; calyx densely hirsute-villous, partly black-hairy; tube about $5 \mathrm{~mm}$. long; teeth subulate, $2-3 \mathrm{~mm}$. long; corolla purple, $10-12 \mathrm{~mm}$. long; legumes papery, grayish villous, about $1 \mathrm{~cm}$. long. O. oreophila A. Gray. Mountains: Utah-Ida. Mont.-Subalp. Jl.

12. A. Parryi (A. Gray) Greene. Pulvinate perennial; leaflets 15-19, oblong-lanceolate, 4-8 mm. long, acute, grayish silky-strigose; peduncles $1-5 \mathrm{~cm}$. long, decumbent or ascending, 1-4-flowered; calyx villous, partly with black hairs, 6-7 mm. long; teeth subulate, $3 \mathrm{~mm}$. long; corolla purple, about $15 \mathrm{~mm}$. long; pod cylindric, coriaceous, densely canescent, about $2 \mathrm{~cm}$. long, $6 \mathrm{~mm}$. thick. O. Parryi A. Gray. High mountains: N.M.-Colo.-(? Mont. ). Mont. -Alp. Jl.

13. A. argophyllus Rydb. Leaflets $7-11$, linear-lanceolate, generally less than $1 \mathrm{~cm}$. long, silvery white, with appressed pubescence, mostly involute; calyx silky villous, $6-7 \mathrm{~mm}$. long; teeth subulate, $3-4 \mathrm{~mm}$. long; corolla purple; wings rather narrow, deeply emarginate; pod similar to that of the next, but scarcely $15 \mathrm{~mm}$. long. Dry hillsides: Mont. Submont. Je-Jl.

14. A. Besseyi Rydb. Leaflets 11-25, oblong-lanceolate, 1-2 cm. long, acute, silky-canescent; scape 1-2 dm. high; spike dense, $3-5 \mathrm{~cm}$. long; calyx silky-villous with long hairs; tube $5-6 \mathrm{~mm}$. long; teeth subulate, $4-5 \mathrm{~mm}$. long; corolla
purple, about $2 \mathrm{~cm}$. long; wings very broad, deeply emarginate; pod ovate-oblong,
nearly $2 \mathrm{~cm}$. long, $5 \mathrm{~mm}$. nearly $2 \mathrm{~cm}$. long, $5 \mathrm{~mm}$. thick, silky-villous, half 2-celled. O. argentata Pursh, not Pers. A. Blankinshipii A. Nels., in part. A ventosus Greene. Dry hillsides: Mont.-Wyo. Je-Jl.

15. A. atropurpureus Rydb. Leaflets oval to oblong, canescently silkyvillous, $5-15 \mathrm{~mm}$. long, obtuse or acute; scape $6-10 \mathrm{~cm}$. long, loosely villous; raceme short and head-like; calyx dark, villous, with mixed black and white hairs; teeth black-tairy, subulate, $4 \mathrm{~mm}$. long; corolla dark-purple, about 15 $\mathrm{mm}$. long; wings deeply emarginate; pod ovoid, less than $1.5 \mathrm{~cm}$. long, with a spreading beak, villous, thin, half 2-celled. Mountains: Wyo. Submont. Jl.

16. A. melanodontus Greene. Leaflets elliptic, often obtuse, 5-10 mm. long, appressed silky; scape 1-2 dm. high, minutely strigose; raceme $2-3 \mathrm{~cm}$. long; calyx densely pubescent, with partly black hairs; tube $5 \mathrm{~mm}$. long; teeth lanceolate, $2 \mathrm{~mm}$. long; corolla purple, about $12 \mathrm{~mm}$. long; wings rather narrow, slightly emarginate; keel with a porrect tip. Oxytropis Lambertii $\beta$ Hook. Dry
banks: Sask.-Alta. Plain. 
17. A. Bigelovii (A. Gray) Greene. Leaflets 9-17, lanceolate or oblonglanceolate, acute at both ends, 2-3 $\mathrm{cm}$. long, 5-8 mm. wide, green, short-strigose on both sides; peduncles 2-3 dm. high, finely strigose; raceme 1-2 dm. long; flowers more or less spreading; calyx-tube about $7 \mathrm{~mm}$. long; teeth lanceolate, 2-3 mm. long; corolla purple, 20-22 $\mathrm{mm}$. long; wings very broad, slightly emarginate; legume stipitate, ascending, lance-cylindric, about $3 \mathrm{~cm}$. long, fully half 2-celled. Oxytropis Lambertii Bigelovii A. Gray. Plains and hillsides: w Tex. -s Colo. Submont.-Mont. Je-Jl.

18. A. plattensis (Nutt.) Rydb. Leaflets 11-15, elliptic or oblong-lanceolate, 4-10 $\mathrm{mm}$. long, densely silky-canescent, with rather loose hairs, acute; scape 4-8 $\mathrm{cm}$. long, with rather loose hairs; raceme 3-5 $\mathrm{cm}$. long; calyx-tube $5 \mathrm{~mm}$. long; teeth subulate, $2 \mathrm{~mm}$. long; corolla purple, about $12 \mathrm{~mm}$. long; legume villous, about $15 \mathrm{~mm}$. long, coriaceous, half 2-celled. $O$. plattensis Nutt. Dry hills: Wyo.-Neb. Submont. Je.

19. A. monticola (A. Gray) Greene. Leaflets 7-11, elliptic, or oblong, 6-20 $\mathrm{mm}$. long, sericeous-canescent; scape $5-15 \mathrm{~cm}$. high; raceme short, $3-6 \mathrm{~cm}$. long; calyx densely and finely silky-strigose; tube $5 \mathrm{~mm}$. long; teeth triangular, 1.5 $\mathrm{mm}$. long; corolla purple, $12-15 \mathrm{~mm}$. long; wings slightly emarginate; legume erect, lance-cylindric, nearly $2 \mathrm{~cm}$. long, long-acuminate, rather thin, sulcate on the upper suture, 2-celled. $O$. monticola A. Gray. Dry plains and bottom land: Wyo.-Colo. Submont. Jl.

20. A. sericeus (Nutt.) Greene. Leaflets $7-13$, elliptic or oblong, 1-3 cm. long, shining, with white silky-appressed hairs; scape 1-1.5 dm. high, stout; raceme $5-10 \mathrm{~cm}$. long; flowers rather spreading; calyx about $7 \mathrm{~mm}$. long; teeth lanceolate, about $3 \mathrm{~mm}$. long; corolla light purple; wings very broad and deeply emarginate; pod cylindric, erect, about $2 \mathrm{~cm}$. long, long-acuminate, nearly 2celled. O. sericea Nutt. Hills: Neb.-Colo.-Wyo. Plain. My-Jl.

21. A. albertinus Greene. Leaflets 17-23, lanceolate, broadest near the base, $15-20 \mathrm{~mm}$. long, sparingly silky and light green above, densely silky beneath, the margins somewhat involute; scape slender, 1-2 dm. high; raceme about $1 \mathrm{dm}$. long; calyx short-silky, with rather loose hairs; tube $5-6 \mathrm{~mm}$. long; teeth 2-3 mm. long; corolla about $15 \mathrm{~mm}$. long, white below, sky-blue at the end; pod lance-ovoid, ereet, dark, long-acuminate, thin, half 2-celled. Exposed rocky places: Man.-Sask, Plain. Au.

22. A. dispar A. Nels. Leaves spreading or ascending; leaflets $9-17$, elliptic or oblong, acutish at both ends, 1-2 $\mathrm{cm}$. long, $4-6 \mathrm{~mm}$. wide, those of the lower leaves often shorter and broader, somewhat silyery, with closely appressed hairs; scape 1-1.5 dm. high; raceme short; bracts linear-lanceolate to lanceolate, 5-8 $\mathrm{mm}$. long; flowers usually spreading; ealyx sparingly appressed-silky with short hairs, often somewhat tinged with purple above; tube 5-7 mm. long; teeth subulate, $3 \mathrm{~mm}$. long; corolla dark bluish purple to rarely ochroleucous, about $15 \mathrm{~mm}$. long; wings broad, slightly emarginate; keel with a very dark purple spot; pod ascending-spreading, thin-coriaceous, nearly straight, less than $2 \mathrm{~cm}$. long, longacuminate, minutely strigose, half 2-celled. A. patens Rydb. A. formosus Greene, a coarse form. Plains and hills: N.D.-Neb.-Colo.-Wyo. PlainSubmont. My-S.

23. A. angustatus Rydb. Leaflets $7-13$, narrowly linear-lanceolate to narrowly linear, 1-2 $\mathrm{cm}$. long; scape about $1 \mathrm{dm}$. high; raceme $3-5 \mathrm{~cm}$. long; calyx finely silky-strigose; tube $5-6 \mathrm{~mm}$. long; teeth subulate; wings broad and slightly emarginate; legume ovoid, coriaceous, half 2-celled. A. Aven-Nelsonii Lunell. Plains and hills: N.D.-Neb.-Colo. Plain-Submont. J1-Au.

24. A. Lambertii (Pursh) Greene. Leaflets 11-17, narrowly lanceolate, 1.5-4 $\mathrm{cm}$. long, 3-5 $\mathrm{mm}$. wide, acute at both ends, green, silky on both sides; scape $1.5-2 \mathrm{dm}$. high; racemes elongate, $5-10 \mathrm{~cm}$. long; flowers usually somewhat ascending; calyx-tube about $7 \mathrm{~mm}$. long; teeth subulate, $2 \mathrm{~mm}$. long; corolla usually dark bluish purple; wings slightly emarginate; legume almost erect, lance-oblong, half 2-celled. Oxytropis Lambertii Pursh. A. falcatus Greene. Dry plains and prairies: Minn.-Mo.-Colo.-Mont. Plain-Submont. My-Au. 
25. A. alpicola Rydb. Depressed acaulescent perennial; leaflets 9-13, oblong or elliptic, obtuse or acutish, $5-8 \mathrm{~mm}$. long, white silky-strigose; scapes 2-6 cm. long, strigose; spike short, 3-8-flowered, subcapitate; calyx usually very dark from the intermixed black hairs; tube 5-6 mm. long; teeth subulate, $2 \mathrm{~mm}$. long; corolla ochroleucous, about $15 \mathrm{~mm}$. long; wings broad and broadly emarginate; pod about $15 \mathrm{~mm}$. long, subcoriaceous, ovoid, short-beaked, nearly 2-celled. High mountains: Alta.-Mont.-B.C. Mont.-Alp. Je-Au.

26. A. villosus Rydb. Leaflets 25-31, rather crowded, $1-1.5 \mathrm{~cm}$. long, lanceolate, very acute, densely but somewhat loosely silky; seape about $1.5 \mathrm{dm}$. long, loosely silky; spike dense, 4-5 $\mathrm{cm}$. long; calyx white silky-villous; tube 6 $\mathrm{mm}$. long; teeth very short, about $2 \mathrm{~mm}$. long; corolla ochroleueous, without any purple, 12-15 mm. long; pod thin, almost perfectly 2-celled, white-silky, about $1.5 \mathrm{~cm}$. long. A. invenustus Greene. Hills: Mont.-S.D. Submont.-Mont.

27. A. gracilis A. Nels. Leaves erect; leaflets 21-31, oblong-lanceolate, appressed-silky, $1-2.5 \mathrm{~cm}$. long, acute; scapes 2-4 dm. high; spike elongate, 5-10 cm. long; calyx densely silky, sometimes somewhat blackish; tube $6-7 \mathrm{~mm}$. long; teeth linear-subulate, 3-4 mm. long; corolla ochroleucous, about $15 \mathrm{~mm}$. long; wings slightly emarginate; pod oblong-ovate, about $2 \mathrm{~cm}$. long, semi-membranous, nearly 2 -celled. A. albertinus Greene, in part. Open woodlands: Man.S.D.-Ida.-Alta. Submont.-Mont. Je-J.

28. A. spicatus (Hook.) Rydb. Leaflets oval to oblong, 8-25 mm. long, 4-8 mm. wide, usually obtuse, silky-strigose; scape 1-1.5 dm. long; spike 4-10 $\mathrm{cm}$. long; calyx silky-strigose, often with intermixed black hairs; tube 6-7 $\mathrm{mm}$. long; teeth lanceolate, $3 \mathrm{~mm}$. long; corolla $18-20 \mathrm{~mm}$. long; pod short-hairy, often with some black hairs, oblong, about $2 \mathrm{~cm}$. long. O. campestris spicata Hook. A. cervinus Greene. A. Macounii Greene. Plains and hills: Sask.S.D.-Wyo.-Alta. Plain-Mont. My-Jl.

29. A. albiflorus A. Nels. Leaflets 13-21, oblong, elliptic, or lanceolate, 1.5-2.5 cm. long, grayish strigose; scape 1.5-3 dm. long; spike elongate, 5-10 $\mathrm{cm}$. long; calyx silky, with intermixed black hairs; tube $7-8 \mathrm{~mm}$. long; teeth pod densely pubescent, oblong, about $2 \mathrm{~cm}$. long, rather abruptly acuminate, Mont.-Colo. Submont. saximontanus A. Nels. A. majusculus Greene. Plains:

30. A. viscidus

or rarely ovate and rounded Greene. Leaflets 31-57, oblong-lanceolate, acute villous; spike $3-8 \mathrm{~cm}$ rounded at the apex; seape $5-15 \mathrm{~cm}$. long, erect, hirsute$3 \mathrm{~mm}$. long; corolla violet, calyx villous; tube about $5 \mathrm{~mm}$. long; teeth subulate, $12-15 \mathrm{~mm}$. long, minutely, rarely white, about $12 \mathrm{~mm}$. long; pod oblong, ovoid, tains: Mont.-Wyo.-Nev. Mont. J-Au.

31. A. viscidulus Rydb. Leaflets $17-31$, oblong, obtuse or acutish, 5-10 $\mathrm{mm}$. long, sparingly villous; seape $0.5-2 \mathrm{dm}$. high, sparingly silky-villous; spike
dense, $2-5 \mathrm{~cm}$. long; calyx densely hairy, viscid and more or less blackish; tube about $5 \mathrm{~mm}$. long; teeth lanceolate, $2.5 \mathrm{~mm}$. long, glandular; corolla dark bluish purple, with yellowish base, about $12 \mathrm{~mm}$. long; pod membranous, oblong-ovate, $1-1.5 \mathrm{~cm}$. long, finely black-hairy, about half 2 -celled. Hills and mountains:
Alta.-Wyo.-Utah-Yukon. Mont.

32. A. Richardsonii (Hook.) Greene. Leaflets numerous, verticillate, elliptic to lance-oblong, acute or obtuse, $8-20 \mathrm{~mm}$. long, densely silky; scape $1-2$ $\mathrm{dm}$. high, villous; spike dense, $5-10 \mathrm{~cm}$. long; bracts linear or lanceolate, often blue, 10-12 mm. long; legume tube $5 \mathrm{~mm}$. long; teeth $2 \mathrm{~mm}$. long; corolla dark tically 2-celled. O. splendens Richardsoni Hook. Mountains: Sask.-Colo.-
Yukon. Submont.-Mont. Je-

33. A. galioides Greene.

cillate, linear-lanceolate, very acute $5-15$ rather sparingly silky, numerous, vertivillous; spike 5-10 
calyx villous; tube $5 \mathrm{~mm}$. long; teeth subulate, about $2.5 \mathrm{~mm}$. long; corolla dark blue, about $12 \mathrm{~mm}$. long; pod ovoid, villous, about $1 \mathrm{~cm}$. long, nearly 2-celled. Banks and hills: n Sask.-Alta.-Yukon. Mont,-Boreal. Je-Jl.

34. A. splendens (Dougl.) Greene. Leaflets very numerous, linear-lanceolate, 1-2.5 $\mathrm{cm}$. long, very acute, white, silky-villous; scape $2-3 \mathrm{dm}$. high; spike dense or in age laxer, 4-10 cm. long; bracts narrowly linear to subulate, silkyvillous, 1-2 $\mathrm{cm}$. long; calyx densely white-villous; tube about $6 \mathrm{~mm}$. long; teeth about $5 \mathrm{~mm}$. wide; corolla $12-15 \mathrm{~mm}$. long, dark blue; legume densely longvillous, $1 \mathrm{~cm}$. long, ovoid, short-beaked, nearly 2-celled. O. splendens Dougl. A. caudatus Greene. Plains and hills: Man.-Minn.-Mont.-B.C. BorealMont. J1.

\section{GLYCYRRHİZA (Tourn.) L. LIQUORICE.}

Perennial herbs, with thick sweet roots and glandular-dotted foliage. Leaves odd-pinnate. Flowers perfect, in spikes or heads. Calyx with the two upper teeth somewhat shorter and partly united. Banner oblong or narrowly ovate, clawed; keel acute or obtuse. Stamens diadelphous, 9 and 1; anthers alternately smaller and larger. Pod sessile, indehiscent, covered with prickles or in exotic species with glands.

1. G. lepidota Nutt. Tall leafy perennial, 3-10 dm. high; leaflets $11-19$, lanceolate or oblong, entire, $2-3.5 \mathrm{~cm}$. long, mucronate-pointed, scaly when young; spikes many-flowered; corolla yellowish white, $12-13 \mathrm{~mm}$. long; pod 12$15 \mathrm{~mm}$. long, with hooked prickles. Copses and rich meadows: Ont.-N.Y.Ariz.-Calif.-Wash.; Mex. Son.-Plain-Submont. My-Au.

\section{HEDÝSARUM (Tourn.) L. HEDYSARUM.}

Perennial herbs, rarely shrubby, with odd-pinnate leaves, with several leaflets and no stipels. Flowers showy, in axillary, peduncled racemes, perfect. Calyx bracteolate, campanulate, nearly equally 5-toothed. Banner obovate or orbicular, clawed; wings oblong, shorter than the other petals; keel obliquely truncate, obtuse. Stamens diadelphous (9 and 1). Legume flat, divided transversely into rounded or subrhombic indehiscent internodes.

Calyx-teeth shorter than the tube; reticulations of the pods polygonal.

Corolla sulphur-yellow; fruit glabrous.

1. H. sulphurescens.

Corolla purple, rose, or rarely white.

Fruit glabrous, except as to a few hairs on the margins; internodes $6-8 \mathrm{~mm}$. long.

Fruit distinctly appressed-pubescent; internodes $8-15 \mathrm{~mm}$. long.

2. $H$. americanum.

Corolla 12-15 mm. long; bracts linear-subulate, $5 \mathrm{~mm}$. or more long. Leaflets oblong, elliptic, or oval, less than $3 \mathrm{~cm}$. long. 3 . $H$. boreale. Leaflets lanceolate, fully $3 \mathrm{~cm}$. long.

4. H. lancifolium.

Corolla 15-20 mm. long; bracts lanceolate, 2-4 mm. long. 5. H. marginatum.

Calyx-teeth subulate, Ionger than the tube; reticulavions of the pods transversely elongate. usually reaching from the middle to the margins, without cross-veins.

Flowers 15-20 mm. long.

Calyx sparingly strigose; loments with 4-7 internodes; nodes more than half as wide as the internodes.

Calyx canescent; loments with 2-5 internodes; nodes less than half as broad as the internodes.

Flowers 10-15 mm. long.

Leaves glabrous above, at least in age.

Leaflets elliptic-oblong, not fleshy; flowers 12-15 $\mathrm{mm}$. long, purple; bracts lanceolate-subulate, $3-5 \mathrm{~mm}$. long; internodes of the loments $3-5$.

8. H. pabulare.

Leaflets linear-oblong, somewhat fleshy; flowers about $10 \mathrm{~mm}$. long, rosepurple; bracts lanceolate, $1.5-2 \mathrm{~mm}$. long; internodes of the fruit 1-3.

Leaves canescent on both sides.

9. H. carnosulum.

10. H. cinerascens.

1. H. sulphurescens Rydb. Stem erect, 3-5 dm. high, glabrous or sparingly strigose; leaflets $11-15$, oblong or elliptic or oval, $1-4 \mathrm{~cm}$. long, glabrous or nearly so, shining; racemes lax; calyx-tube about $3 \mathrm{~mm}$. long; teeth lanceolate, 1-2 $\mathrm{mm}$. long; corolla about $15 \mathrm{~mm}$. long; loment glabrous; internodes 2 or 3 , 8-15 mm. long, 6-8 mm. wide, wing-margined; nodes $2.5-4 \mathrm{~mm}$. wide. $H$. flavescens Coult. \& Fish. Open woods and copses: Alta.-Wyo.-Ida.-B.C. Submont.-Mont. Je-Jl. 
2. H. americanum (Michx.) Britton. Stem 2-7.5 dm. high, glabrous or nearly so; leaflets $11-21$, oblong, $1.5-3 \mathrm{~cm}$. long, rounded at both ends, glabrous above, sparingly hairy beneath; raceme lax; calyx-tube $2 \mathrm{~mm}$. long; teeth triangular, 1-2 mm. long; corolla violet, rarely white, $12-18 \mathrm{~mm}$. long; loment glabrous or nearly so; internodes $3-5$, about $5 \mathrm{~mm}$. wide. $H$. alpinum americanum Michx. $H$. philoscia A. Nels., a white-flowered form. Rocky places and open woods: Lab.-Vt.-S.D.-Wyo.-Alaska. Boreal-Mont. Je-Au.

3. H. boreale Nutt. Stem 3-7 dm. high, strigose especially above; leaflets oblong or lanceolate, rounded to acute at the apex, $1.5-3 \mathrm{~cm}$. long, glabrous above, sparingly pubescent or glabrate beneath; racemes lax; calyx-tube $2 \mathrm{~mm}$. long; teeth triangular, $1-1.5 \mathrm{~mm}$. long; corolla violet or reddish purple to nearly white; loment finely strigose; internodes $2-4,6-8 \mathrm{~mm}$. long, 5-6 $\mathrm{mm}$. wide. Banks and thickets: Sask.-S.D.-Wyo.-Mack. Boreal-Mont. Jl-Au.

4. H. lancifolium Rydb. Stem $5 \mathrm{dm}$. high or more, sparingly strigose; leaflets 13-21, lanceolate, acute, about $3 \mathrm{~cm}$. long, $8 \mathrm{~mm}$. wide, slightly strigose or glabrate; raceme lax; calyx strigose; tube about $3 \mathrm{~mm}$. long; lower teeth 2.5 $\mathrm{mm}$. long, the upper shorter; corolla about $15 \mathrm{~mm}$. long, rose-purple; loment somewhat strigose; internodes $2-4$, broadly oval, $12-15 \mathrm{~mm}$. long, $8 \mathrm{~mm}$. wide. Mountain woods: Mont.-Alta. Mont. J.

5. H. marginatum Greene. Stem 6-10 dm. high, minutely strigose; leaflets $11-23$, from oblong to oval or ovate, obtuse to emarginate, $1-3 \mathrm{~cm}$. long, minutely appressed-pubescent on both sides or glabrate above; racemes rather short; calyx-tube $3 \mathrm{~mm}$. long; upper teeth triangular, $1 \mathrm{~mm}$. long, the lowest lanceolate, $2 \mathrm{~mm}$. long; corolla rose-purple; loment strigose; internodes $2-5$, 8-15 mm. long, 6-8 mm. wide. H. uintahense A. Nels. Draws and copses: Wyo.-Colo. Mont. Je-J.

6. H. Mackenzii Richards. Stem 2-4 dm. high, strigose above; leaflets $7-15$, elliptie, $1-2.5 \mathrm{~cm}$. long, finely grayish strigose beneath, glabrate above; raceme short; calyx-tube $3 \mathrm{~mm}$. long; teeth 4-5 mm. long; corolla $18-20 \mathrm{~mm}$. long, rose-purple; loments minutely strigose; internodes $5-7 \mathrm{~mm}$. long, about 5 mm, wide, Meadows: N. W. Terr-Alta-Yukon. Boreal-Subarct. Je.

7. H. utahense Rydb. Stem 4-6 dm. high, finely strigose; leaflets 11-17, elliptic, oval, or oblong, usually rounded at both ends, $1-3 \mathrm{~cm}$. long, glabrous above, finely cinereous-strigose beneath; ealyx-tube nearly $3 \mathrm{~mm}$. long; teeth $5 \mathrm{~mm}$. long, attenuate; corolla rose-purple, $15-18 \mathrm{~mm}$. long; loments minutely strigose; internodes 6-8 $\mathrm{mm}$. long, $5-6 \mathrm{~mm}$. wide. Hills among bushes: UtahIda. Submont.-Mont. My-Jl.

8. H. pabulare A. Nels. Stems 4-7 dm. high, finely strigose; leaflets 9-15, oblong or elliptic, 1-2 cm. long, glabrous above, cinereous-strigose beneath; calyx-tube about $2 \mathrm{~mm}$. long; teeth $3-4 \mathrm{~mm}$. long; loments minutely puberulent; internodes $5-7 \mathrm{~mm}$. long, $5-6 \mathrm{~mm}$. wide. Copses, cañons, and among sage-brush: Mont.-N.M.-Utah. Submont. My-Jl.

9. H. carnosulum Greene. Stems flexuose, 2-4 dm. high; leaflets 9-11, pale green, thick, linear-oblong to elliptic, $6-15 \mathrm{~mm}$. long, glabrous above, cinereous-strigose beneath; raceme lax; calyx-tube $2 \mathrm{~mm}$. long; teeth $2-3 \mathrm{~mm}$. long; loments minutely strigose; internodes $7-8 \mathrm{~mm}$. long, $5-6 \mathrm{~mm}$. wide. Dry hills: Colo.-Utah-N.M. Submont. Je-JI.

10. H. cinerascens Rydb. Stems 3-5 dm. high, strigose-canescent or glabrate below; leaflets $9-15$, oblong or elliptic, 1-2 cm. long, silvery canescentstrigose on both sides; calyx-tube about $3 \mathrm{~mm}$. long; teeth $5 \mathrm{~mm}$. long; corolla reddish-purple, about $15 \mathrm{~mm}$. long; loment strigose; internodes $3-4,6-8 \mathrm{~mm}$. long, about $6 \mathrm{~mm}$, wide. 'H. canescens Nutt., not L.' Dry hills: Sask.-N.D.Wyo.-Utah-Ida.-Alta. Submont. Je-Jl,

\section{ONOBRỲCHIS Scop. SAND-FOIN.}

Herbs or undershrubs. Leaves odd-pinnate, without stipels. Flowers perfect, in spikes or racemes. Calyx-tube campanulate; teeth subulate, subequal, the lower smaller. Banner obcordate or obovate, sessile; wings shorter; 
keel equalling the banner. Stamens partly diadelphous, $i$. $e$, the tenth stamen united with the rest at the middle, but free at the base. Legume flat, 1-2-seeded, half-round, or spirally coiled, not jointed, pectinately prickly.

1. O. Onobrychis (L.) Rydb. Perennial herb; stem erect, $3-5 \mathrm{dm}$. high; leaflets 11-23, elliptic; calyx-lobes subulate, subequal; corolla rose-colored, striate; wings about half as long as the banner; legume brown, obliquely semiorbicular, keeled above, the lower suture and apex with short broad pricklepoints. O. sativa Lam. Cultivated and occasionally escaped: Mont.-Colo.Utah-Ida.

\section{MEIBŌMIA Heister. Tick-trefoll, Beggar's Ticks.}

Herbs (all ours), shrubs or vines. Leaves alternate, pinnately 3-foliolate, rarely 1 - or 5 -foliolate; leaflets stipellate. Flowers perfect, in racemes or panicles. Calyx with bractlets at the base, campanulate; lobes unequal, the two upper ones more or less united. Corolla in ours reddish purple; banner more or less clawed; wings oblique, more or less coherent with the keel. Stamens monadelphous or partly diadelphous; anthers alike. Pod divided transversely into several indehiscent internodes, flat, in ours retrorsely hispid. [Desmodium Desv.]

Leaflets neither coriaceous nor strongly reticulate beneath. Leaflets coriaceous, strongly reticulate beneath.

1. M. canadensis.

2. M. illinoensis.

1. M. canadensis (L.) Kuntze. Stem erect, 5-20 dm. high, pubescent; leaflets elliptic or oblong-lanceolate, appressed-pubescent and paler beneath, hispidulous or glabrate above; flowers paniculate, 11-17 mm. long, purple; loments about $2.5 \mathrm{~cm}$. long; internodes $3-5$, somewhat triangular, straight or nearly so on the upper suture, uncinate-pubescent. Desmodium canadense (L.) DC. Thickets and river banks: N.B.-N.C.-Okla.-(Black Hills) S.D.-Man. Plain-Submont. JI-S.

2. M. illinoensis (A. Gray) Kuntze. Stem 5-12 dm, high, uncinatepubescent; leaflets lanceolate or ovate-lanceolate, hispidulous above, cinereous beneath, 2.5-9 $\mathrm{cm}$. long; flowers paniculate, 6-9 mm. long, purple; loments 1-2.5 $\mathrm{cm}$. long; internodes 3-6, oval or orbicular, densely uncinate. $D$. illinoense A. Gray. Prairies: III.-Kans.-S.D. Plain. Je-S.

\section{Vícia L. Vetch, Wilid Pea.}

Perennial or annual herbaceous vines. Leaves alternate, abruptly pinnate, usually with tendrils or these represented by a tip. Flowers axillary, racemose or sessile. Calyx somewhat oblique and gibbous at the base, the upper two teeth shorter. Banner obovate or oblong, emarginate; wings obliquely oblong, adherent to the curved keel. Stamens diadelphous (9 and 1); tube oblique at the summit; anthers all alike. Style slender, with a tuft or ring of hairs at the summit. Pod flat, dehiscent, 2-valved, few- or several-seeded.

Racemes 3-40-flowered; flowers 1-2.5 cm. long.

Racemes one-sided, dense, 15-40-flowered.

Racemes lax, 3-10-flowered.

1. V. cracca.

Leaflets linear to oblong; stipules usually narrow, semi-sagittate and often entire. Leaves decidedly pubescent, rather thick and strongly veined. Stem low; leaflets linear to oblong. $2 . V$. trifida. Stem tall; leaflets oblong or elliptic, only those of the lower leaves sometimes linear.

Leaves glabrous or siightly pubescent when young.

3. $V$. oregana. Leaflets elongate, narrowly linear; plant low and erect. 4. V. sparsifolia. Leaflets, at least the upper ones, oblong or linear-oblong; plant tall and climbing. 5. V. dissitifolia.

Leaflets broad; stipules broadly semi-sagittate or semi-orbicular in outline, sharply toothed.

Leaflets usually oval, thin and not strongly veined, mostly entire and acute or rounded at the apex.

Racemes $1-2$ toothed at the apex.

6. V. americana.

Leaflets obovate-cuneate, firmer and more strongly veined, truncate and toothed at the apex. $\quad 7$. V. pumila.

Flowers $1-1.8 \mathrm{~cm}$. long, subsessile in the axils; annual.

Flowers 6-8 mm. long, on a distinct peduncle; perennial.

8. $V$. angustifolia.

9. V. producta. 
1. V. cracca L. Stem weak, 3-12 dm, high; stipules narrowly semi-sagittate, entire; leaflets 18-24, thin, linear or linear-oblong, mucronate, $1.5-2 \mathrm{~cm}$. long, finely pubescent; corolla bluish purple, $11-13 \mathrm{~mm}$. long; pod $1.8-2.5 \mathrm{~cm}$. long. Dry soil: Newf.-N.J.-Kans.-Ida.-B.C.; nat. from Eu. Je-Au.

2. V. trifida Dietr. Stem low, 1-4 dm, high, more or less pubescent when young; stipules broadly semi-sagittate, often toothed; leaflets 8-12, linear or narrowly oblong, acute at both ends or truncate at the apex, mucronate or cuspidate, dark green; racemes 3-6-flowered; corolla bluish purple, 15-18 mm. long; pod $2 \mathrm{~cm}$. long, puberulent or glabrate. $V$. tridentata Sehwein. $V$. caespitosa A. Nels., a depauperate form. V. callianthema Greene. Wet meadows: w Ont.-Kans.-Tex.-Nev.-B.C. Plain-Mont. My-Au.

3. V. oregana Nutt. Stem $3-8 \mathrm{dm}$. high, somewhat pubescent when young, or glabrate, angled; stipules usually narrowly semi-sagittate, mostly toothed; leaflets 8-12, elliptic or those of the lower leaves linear, often truncate and somewhat toothed at the apex, 1-2.5 cm. long, dark green, appressed-pubescent, at least below; raceme 3-8-flowered; corolla pink-purple or bluish purple, 15-20 $\mathrm{mm}$. long; pod about $3 \mathrm{~cm}$. long. $V$. vexillaris Greene. Meadows: Sask.N.M.-Calif,-B.C. Plain-Mont. My-Au.

4. V. sparsifolia Nutt. Stem low, $2-5 \mathrm{dm}$. high, glabrous; leaflets 8-12, narrowly linear, firm, strongly veined, acute at both ends, mucronate, glabrous or nearly so, 2-4 cm. long, 1-3 mm. wide; raceme 2-6-flowered; corolla bluish purple, about $18 \mathrm{~mm}$. long; pod $3 \mathrm{~cm}$. long, $6-7 \mathrm{~mm}$. broad. V. linearis (Nutt) Greene. Prairies and plains: Man.-Okla.-N.M.-Calif.-B.C. Plain-Mont. $\mathrm{My}-\mathrm{Au}$.

5. V. dissitifolia (Nutt.) Rydb. Stem tall, slender, 3-7 dm. high, glabrous; leaflets $8-12$, linear or narrowly oblong, $1.5-5 \mathrm{~cm}$. long, $2-5 \mathrm{~mm}$. wide, rather thin, not strongly veined, acute at both ends, mucronate; raceme 3-6flowered; corolla violet-purple, $15-18 \mathrm{~mm}$. long. Lathyrus dissitifolius Nutt. Confused with and grading into $V$. oregana. Valleys: w Neb.-Colo.-Utah. Plain-Mont. Je-Au.

6. V. americana Muhl. Stem glabrous or nearly so, 3-10 dm. high; leaflets 8-12, oval or elliptic, or those of the lower leaves linear-oblong, thin, glabrous, usually rounded at both ends or retuse at the apex, mucronate, 1.5-3.5 $\mathrm{cm}$. long, not strongly veined; racemes shorter than the leaves, 3-9-flowered; corolla bluish purple, $15-20 \mathrm{~mm}$. long; poa glabrous, $2.5-3 \mathrm{~cm}$. long. Meadows: N.B.-Va.-Ariz.-B.C. Plain-Mont. My-Au.

7. V. pumila Heller. Stem low, 2-4 dm. high, ascending, sparingly pubescent; leaflets 6-14, 10-15 $\mathrm{mm}$. long, 4-6 mm. wide, truncate, cuspidate, and sometimes toothed at the apex, appressed-pubescent on both sides, prominently veined; racemes 3-6-flowered; corolla violet-purple, $15-18 \mathrm{~mm}$. long. V. californica Rydb., not Greene. Valleys and river banks: Colo.-Calif.-B.C. Submont. $\mathrm{Je}-\mathrm{Au}$.

8. V. angustifolia (L.) Reichard. Annual; stem glabrous, 3-5 dm. high; leaflets 5-11, those of the lower leaves oblong, truncate, those of the upper linear, mucronate, $1.5-3 \mathrm{~cm}$. long; corolla purple or rose-colored; pod $4-5.5 \mathrm{~cm}$. long, 5-7 mm. wide. Fields, meadows, and waste places: Ida.; also in the East; nat. from Eu.

9. V. producta Rydb. Stems slender, decumbent or ascending, 2-3 dm. high; stipules narrow, semi-hastate, entire; leaflets $7-11$, oblong to linear, $5-15$ $\mathrm{mm}$. long, obtuse, mueronate; peduncles 2-4 $\mathrm{cm}$. long, produced beyond the upper flowers; corolla yellowish white, tipped and tinged with purple. $V$. Thurberi S. Wats., in part. Among bushes: Colo,-N.M.-Ariz.-Utah. Submont. $\mathrm{My}$-Je.

\section{LÄTHYRUS (Tourn.) L. VETCHLING.}

Herbaceous vines, rarely erect herbs, mostly perennials, with horizontal rootstocks. Leaves alternate, abruptly pinnate, the rachis usually tendrilbearing at the apex, or the tendril represented by a tip or an appendage. Flowers 
racemose (raceme sometimes 1-flowered), perfect. Calyx obliquely campanulate, gibbous at the base, its teeth nearly equal, or the upper shorter. Banner obovate, emarginate, clawed; wings obliquely oblong, adherent to the shorter curved keel. Stamens diadelphous (9 and 1), monadelphous below; tube usually truncate at the apex. Style curved, flattened, hairy along its inner side. Legumes linear, more or less flattened, dehiscent, 2-valved. Seeds usually several.

Corolla purple.

Stem winged; leaflets linear, lanceolate, or oblong; flowers about $15 \mathrm{~mm}$. long.

Stem wingless.

Racemes 1-flowered.

Racemes several- to many-flowered.

1. L. palustris.

Tendrils much reduced; stem mostly erect.

Leaflets 1 or 2 pairs; flowers $8-10 \mathrm{~mm}$. long.

Leaflets narrowly linear.

Leaflets oval or oblong.

Leaflets 3 or 6 pairs; flowers $20-25 \mathrm{~mm}$. long.

Plant glabrous or nearly so.

Plant decidedly villous-pubescent.

11. L. Torreyi.

rils usually well developed; plant more or less climbing.

Corolla less than $18 \mathrm{~mm}$. long.

Leaflets linear to oblong-elliptic, thick, veiny.

Leaflets oblong-elliptic.

Leaflets linear.

Leaflets broadly oval or ovate.

Tendrils usually 3-cleft; leaflets moderately firm, strongly veined.

Stipules large, often half as long as the small, $1-3 \mathrm{~cm}$. long leaflets.

8. L. Schaffneri.

Stipules very small in comparison with the large $2-7 \mathrm{~cm}$. long leaflets.

9. L. venosus.

Tendrils simple; leaflets not strongly veined. 10. L. Nuttallii.

Corolla $2 \mathrm{~cm}$. long or more.

Stipules large and broad, about half as long as the leaflets.

Leaflets not linear.

Leaflets rounded-oval, obtuse or rounded and mucronate at the apex. 12. L. utahensis.

Leaflets elliptic, acute at both ends, cuspidate at the apex.

13. L. pauciflorus.

Leaflets narrowly linear.

Stipules narrow, less than half as long as the leaflets.

Leaflets elliptic to oval. 15. L. decaphyllus.

Leaflets linear-oblong or oblanceolate. 16. L. brachycalyx.

Corolla white or yellowish.

Tendrils well developed.

Stipules large and broad, often half as long as the leaflets; corolla about $15 \mathrm{~mm}$. long.

17. L. ochroleucus.

Stipules smaller, much less than half as long as the leaflets; corolla about $20 \mathrm{~mm}$. long.
18. L. laetivirens.

Tendrils reduced; stipules narrow and small.

Corolla about 15-20 $\mathrm{mm}$. long.

Leaflets ovate or oval or obovate.

Leaflets linear or lance-linear.

Corolla 10-15 $\mathrm{mm}$. long.

Leaflets oval.

Leaflets linear.

19. L. obovatus.

4. L. ornatus.

20. L. leucanthus.

21. L. arizonicus.

1. L. palustris L. Stem glabrous or nearly so, 3-6 dm. high; leaflets 2-4 pairs, $2.5-6 \mathrm{~cm}$. long; tendrils usually branched; inflorescence $7-15 \mathrm{~cm}$. long, 2-6-flowered; corolla purple, 12-15 mm. long; pod linear, 4-5 cm. long. Wet places: Lab.-N.Y.-S.D.-Ore-Alaska; Eurasia. Plain-Submont. My$\mathrm{Au}$.

2. L. Sandbergi (White) Howell. Stem 2-3 dm. high, angled, glabrous, erect; leaflets 5-10 $\mathrm{cm}$. long, 2-4 mm. wide, glabrous; inflorescence 2-5 mm. long, 1-3-flowered; corolla purplish, about $1 \mathrm{~cm}$. long, L. bijugatus Sandbergi White. Hillsides and copses: Ida.-Wash. Submont. My-Je.

3. L. bijugatus White. Stem erect or decumbent at the base, $2-3 \mathrm{dm}$. high, glabrous; leaflets thin, 2-5 cm. long, 6-12 $\mathrm{mm}$. wide, mucronate; inflorescence 2-5 cm. long, 1-2-flowered; corolla purplish, 8-10 mm. long; pod 6-seeded. Hillsides and rocky ground: Mont.-Ida.-Wash. Submont. Je.

4. L. ornatus Nutt. Stem erect, glabrous or nearly so, 2-4 dm. high; leaflets linear or lance-linear, $1.5-4 \mathrm{~cm}$. long, 3-5 mm. wide, glabrous; peduncles 
about $5 \mathrm{~cm}$. long; raceme 3-5-flowered; corolla purple or rarely yellowish, 2-2.5 $\mathrm{cm}$. long; pod 4-5 cm. long. Plains and prairies: S.D.-Okla,-Colo.-Wyo. Plain-Submont. My-Jl.

5. L. incanus (Smith \& Rydb.) Rydb. Stem erect, 1-3 dm. high, more or less densely villous with short hairs; leaflets 3-4 pairs, linear or linear-oblong, 1-4 $\mathrm{cm}$. long, $3-5 \mathrm{~mm}$. wide, usually densely villous with short hairs; corolla as in the preceding; pod 3-4 cm. long. L. ornatus incanus Smith \& Rydb. Dry sandy plains: Neb.-Colo.-Wyo. Plain-Submont. My-Jl.

6. L. coreaceus White. Stem flexuose, quadrangular, 2-6 dm. high, glabrous; leaflets $3-6$ pairs, thick and coriaceons, strongly venulose, elliptic to linear-lanceolate, 3-6 $\mathrm{cm}$. long, 6-15 mm. wide; tendrils branched, but usually short; inflorescence $1 \mathrm{dm}$. long or less, 3-10-flowered; corolla 10-15 mm. long, purple or nearly white. Open woodlands, in the mountains: Utah-Ore.-Nev. Submont.-Mont. Je-Jl.

7. L. graminifolius (S. Wats.) White. Stem erect, 3-6 dm. high, nearly terete, glabrous; leaflets 1-3 pairs, narrowly linear, 5-10 $\mathrm{cm}$. long, 1-3 mm. wide, glabrous, firm; tendrils of the lower leaves reduced, of the upper ones branched; raceme 2-4-flowered; corolla about $1 \mathrm{~cm}$. long; pod linear, 4-6 cm. long. Hillsides: N.M.-Utah-Ariz. Submont. My-S.

8. L. Schaffineri Rydb. Stem angled, glabrous, erect or decumbent, 3-6 $\mathrm{dm}$. long; leaflets 4-6 pairs, oval or rhombic-oval, or elliptic, 1-3 $\mathrm{cm}$. long, thick and veiny; peduncles 5-10 $\mathrm{cm}$. long; raceme 6-12-flowered; corolla purple, 12-18 $\mathrm{mm}$. long; pod $3-4 \mathrm{~cm}$. long, glabrous. L. parviflorus S. Wats. Meadows: s Utah-Calif.-Mex. Son. Je-S.

9. L. venosus Muhl. Stem 6-10 dm. high, erect, usually finely villous, 4-angled; leaflets 4-7 pairs, oval, often very veiny, glabrous above, finely pubescent beneath; peduncles 5-10 $\mathrm{cm}$. long; raceme short and dense, 12-16-flowered; corolla purple, $12-15 \mathrm{~mm}$. long; pod 4-5 $\mathrm{cm}$. long, glabrous. River banks and wet places: Ont.-Ga.-La.-Kans.-Mont.-Sask. Plain-Submont. My-Jl.

10. L. Nuttallii S. Wats. Stem 3-6 dm. high, more or less villous-pubescent, angled; leaflets $3-6$ pairs, elliptic or oval, acutish, 2-4 $\mathrm{cm}$. long, 1-2 $\mathrm{cm}$. wide, nearly glabrous above, more or less villous beneath; peduncles 3-6 $\mathrm{cm}$. long; raceme 3-6-flowered, short; corolla purple, $12-16 \mathrm{~mm}$. long; pod glabrous, 2.5-4 cm. long. Woods and meadows: Calif.-Ida.-B.C. Submont. Ap-Jl.

11. L. Torreyi S. Wats. Stem decumbent, branched from the base, pubescent, 1-3 dm. high; leaflets 4-6 pairs, broadly oval, $5-15 \mathrm{~mm}$. long, mucronate, villous-pubescent on both sides; tendrils reduced to short tips; corolla about 1 $\mathrm{cm}$. long, blue with white keel; pod oblong, $2.5-3 \mathrm{~cm}$. long. Woods: Wash.Calif.-Ida. Ap-Jl.

12. L. utahensis M. E. Jones. Stem angled, glabrous, about $1 \mathrm{~m}$. high or more; leaflets $4-6$ pairs, broadly oval, $2-5 \mathrm{~cm}$. long, $1-3 \mathrm{~cm}$. wide, firm and veiny, glabrous; peduncles 5-15 $\mathrm{cm}$. long; racemes 3-8-flowered; corolla purple, rarely white, about $2 \mathrm{~cm}$. long; pod glabrous, $5-6 \mathrm{~cm}$. long. L. Bradfieldianus A. Nels. Woods: Ida.-Utah-Colo. Submont. My-J1.

13. L. pauciflorus Fernald. Stem glabrous, $4-6 \mathrm{dm}$. high or more, angled; leaflets $3-6$ pairs, thick, veiny, elliptic, acute and cuspidate, $1-4 \mathrm{~cm}$. long; peduncles $5-10 \mathrm{~cm}$. long; raceme 2-5-flowered; corolla about $2 \mathrm{~cm}$. long; pod 5-6 $\mathrm{cm}$. long. Hillsides: Wash.-Ida.-Ore. Son.-Submont. Ap-Je.

14. L. tenuior (Piper) Rydb. Stem flexuose, 3-6 dm. high, glabrous, angled; leaflets $3-5$ pairs, narrowly linear, $3-7 \mathrm{~cm}$. long, 4-10 $\mathrm{mm}$. wide, glabrous or nearly so; peduncles 5-10 $\mathrm{mm}$. long; raceme short, 2-5-flowered; corolla purple, about $2 \mathrm{~cm}$. long; pod glabrous, about $4 \mathrm{~cm}$. long. L. pauciflorus tenuior Piper. Hillsides: Ore.-Ida.-Wash. Son.-Submont. Je.

15. L. decaphyllus Pursh. Stem erect, $2-5 \mathrm{dm}$. high, angled; leaflets $2-5$ pairs, thick and veiny, elliptic or lance-oblong, acute, somewhat glaucous, glabrous, or finely pubescent beneath; stipules of the lower leaves reduced; peduncles 
5-10 cm. long; racemes short, 3-5-flowered; corolla purple, 2.5-3 cm. long; pod 4-5 cm. long. Plains and prairies: Neb.-N.M.-Ariz. Plain-Submont. $\mathrm{My}-\mathrm{Jl}$.

16. L. brachycalyx Rydb. Stem simple or slightly branched, $1.5-3 \mathrm{dm}$. high, usually finely pubescent, sharply 4 -angled; leaflets $2-5$ pairs, linear-oblong or oblanceolate, firm, strongly veined, finely pubescent, 1-3 cm. long, $2-8 \mathrm{~mm}$. wide; tendrils of the lower leaves reduced to mere tips; peduncles $5-10 \mathrm{~cm}$. long; raceme short, 2-6-flowered; corolla purple, $2-2.5 \mathrm{~cm}$. long; pod glabrous, $3-4 \mathrm{~cm}$. long. Mountains: Utah. Submont.-Mont. Je-Au.

17. L. ochroleucus Hook. Stem 4-10 dm. high, terete, glabrous; leaflets $3-4$ pairs, broadly oval or ovate, $2-5 \mathrm{~cm}$. long, thin, glabrous, somewhat glaucous beneath; peduncles $2-5 \mathrm{~cm}$. long; racemes 5-10-flowered; corolla ochroleucous, about $15 \mathrm{~mm}$. long; pod about $4 \mathrm{~cm}$. long, glabrous. Woods and river banks: Hudson Bay-Que.-N.J.-Wyo.-B.C.-Mack. Plain-Submont. My-Au.

18. L. laetivirens Greene. Stem branched, climbing, 4-6 dm. high; leaflets $3-5$ pairs, oval or ovate, obtuse and mucronate, light green and glabrous, $2-5 \mathrm{~cm}$. long, 1-2.5 $\mathrm{cm}$. wide; peduncles about $5 \mathrm{~cm}$. long; raceme short, $3-6-$ flowered; corolla ochroleucous, about $2 \mathrm{~cm}$. long; pod about $4 \mathrm{~cm}$. long. Mountains: Colo. Submont.-Mont. Je.

19. L. obovatus (Torr.) White. Stem finely pubescent or glabrous, 2-4 $\mathrm{dm}$. high; leaflets $2-4$ pairs, ovate or oval, $2-5 \mathrm{~cm}$. long, obtuse or acute, thin; corolla white or nearly so, $15-20 \mathrm{~mm}$. long; pod about $4 \mathrm{~cm}$. long. L. nevadensis S. Wats., in part. Mountains: Wash.-Ida.-Calif. Son. My-Je.

20. L. leucanthus Rydb. Stem about $3 \mathrm{dm}$. high, angled, glabrous; leaflets $2-4$ pairs, elliptic, veiny, glaucous, acute, mucronate, $1-3 \mathrm{~cm}$. long, $3-10$ $\mathrm{mm}$. wide; inflorescence short, in the axils of the middle leaves, $3-4 \mathrm{~cm}$. long, $2-$-flowered; corolla white, about $15 \mathrm{~mm}$. long. Open woods: Wyo.-N.M.
Mont. My-J.

21. L. arizonicus Britton. Stem $2-4 \mathrm{dm}$. high, glabrous; leaflets usually 2 pairs, glabrous or nearly so, narrowly linear, $3-8 \mathrm{~cm}$. long, $2-10 \mathrm{~mm}$. wide; peduncles 2-4 cm. long; racemes 2-3-flowered; corolla white, $10-15 \mathrm{~mm}$. long. Open woods: Colo.-N.M.-Ariz. Mont.-Subalp. My-Jl.

\section{4. ÀPIOS Moench. Ground-NuT.}

Twining vines, with large tuberous roots. Leaves alternate, pinnate, with small stipules. Flowers perfect, in racemes. Upper two ealyx-teeth united, the lateral ones very small, and the lowest one longer. Corolla red, purple, or brown; banner reflexed; keel elongate, spirally twisted. Stamens diadelphous. Style glabrous. Pod elongate, curved, flattened.

1. A. Apios (L.) MacMill. Stem 3-20 dm. long; leaflets 5-9, ovate to lanceolate, $3-10 \mathrm{~cm}$. long, acute or acuminate; calyx-tube $2-4 \mathrm{~mm}$. long; corolla brownish purple; banner with a broad blade, about $1 \mathrm{~cm}$. long; pod linear, 6-12 Plain-Submont.

\section{STROPHOSTỲles EII. Wild Bean.}

Herbaceous vines, twining or trailing. Leaves alternate, pinnately 3 -foliolate, with stipules. Flowers perfect, in dense clusters on long axillary peduncles. Calyx subequally 5-toothed, or the upper two teeth partially united. Corolla white or purplish; banner with a broad blade; keel curved. Stamens diadelphous. Style bearded, bent. Pod narrow, flat, straight or nearly so. Seeds truncate.

1. S. pauciflora (Benth.) S. Wats. Annual; stem 3-10 dm. long; leaflets linear to lanceolate, $1.5-3.5 \mathrm{~cm}$. long, rarely sinuately lobed; peduncles longer than the leaves; calyx $1.5 \mathrm{~mm}$. long; lobes subequal; corolla pale purple; pod 2-3 cm. long, strigose. Phaseolus pauciflorus Benth. River banks: Minn.Ind.-La.-Tex.-Colo. Plain. 


\section{Family 66. Geraniaceae. Geranium Family.}

Herbs, with opposite leaves with stipules; blades in ours palmately lobed or divided. Flowers perfect, regular, cymose, or subumbellate. Sepals 5, imbricate. Petals 5, deciduous. Stamens 10, rarely 5; filaments monadelphous. Gynoecium of 5 carpels, the styles of which are adnate to an elongate central column, from which they separate at maturity. Carpels 2-ovuled, but 1-seeded.

Carpels rounded, their tails (styles) glabrous within, merely recoiling at maturity; leaves in ours palmately veined and lobed. 1 . GERANIUM.

Carpels spindle-shaped, their tails (styles) pubescent within, spirally coiled at maturity: leaf-blades in ours pinnately veined, pinnately lobed or dissected. 2 . ERoDIUM.

\section{Gerànium (Tourn.) L. Cranebill, Wild Geranidu.}

Annual or perennial herbs, with opposite leaves. Leaf-blades palmately lobed or parted. Flowers eymose, perfect, regular. Sepals 5, usually awntipped. Petals 5, often pubescent near the base, not clawed. Stamens 10, rarely only 5 ; filaments ciliate at the base, more or less united, monadelphous. Style column usually beaked, the styles glabrous within, recoiled but not spirally twisted, when freed from the axis. Carpels turgid, permanently attached to the styles. Seeds smooth, reticulate or pitted.

Petals 2-7 mm. long, at most slightly exceeding the calyx; plants annual or biennial, or sometimes perennial in $G$. thermale.

Sepals not bristle-tipped; seeds smooth.

Carpels wrinkled; stamens 10 .

Carpels finely pubescent; stamens 5 .

Sepals awn-tipped; seeds reticulate or pitted.

Awn-tips less than $1 \mathrm{~mm}$. Iong.

Seeds reticulate; pedicels slightly hirsute, not glandular. 3. G. thermale.

$\begin{array}{ll}\text { Seeds pitted; pedicels glandular-pubescent. } & \text { 4. G. rotundifolium. }\end{array}$

A wn-tips 1-2 mm. long.
Beak and branches of the style less than $3 \mathrm{~mm}$. long.

Beak and branches of the carolinianum.

Beak and branches of the style more than $4 \mathrm{~mm}$. long; inflorescence open.

Petals 1-3 cm. long; plants perennial, with rootstocks or caudices; seed reticulate.

Petals white; style-column and carpels glandular. Leaf-blades thin, sparingly hirsute beneath; upper petioles retrorsely hirsute or
glabrous; sepals slightly if at all glandular.

Leaf-blades thick, strigillose beneath; upper petioles canescent; Richardsonii. glandular-pubescent.

Leaf-blades with long lanceolate lobes; veins of the petals very strong.

Leaf-blades with short ovate lobes; veins of the petals rather weak.
. G. nervosum.

Petals purple or rose.

17. G. Cowenii.

Plants with simple rootstocks or caudices; stem erect and simple below; stylecolumn glandular-pubescent.

Stem and petioles glandular-viscid; petals strongly veined.

Stem and petioles retrorsely hairy, not glandular-viscid.

Petioles of the upper leaves minutely puberulent; petals strongly veined.

Petioles of the upper leaves with long hairs; petals 10. G. strigosum.

Stem nearly glabrous, sparingly hirsute; leaves short-strigose; inflor-

escence open.
Stem and leaves densely hairy: inflorescence incisum.

11. G. incisum.

Plants with cespitosely branched caudices; stems usually diffusely branched.

Petals obcordate to broadly obovate, light purple, with darker veins.
Stem glandular-villous with long spreading hairs.

Divisions of the leaves much longer than broad, with ovate or lanceolate. acute teeth.

acute teeth.
Divisions of the leaves about as broad as long, with broadly ovate,

Stem, petioles, and calyx with short grayish pubescence. 14 . Pattersonii.

Pedicels and style-column densely glandular-pubescent.

Leaves with broadly ovate teeth; petals distinctly emarginate.

Leaves with lanceolate or lance-ovate teeth. 15. G. Fremontii.

ginate.
Pedicels not glandular-pubescent; style-column rarely so. 
Basal leaves 4-6 $\mathrm{cm}$. broad; middle division broadly spatulate, 3-lobed; lobes notched; sepals over $1 \mathrm{~cm}$. long.

17. G. Cowenii.

Basal leaves 2-3 cm. broad; middle division cuneate, 3-toothed at the apex; sepals less than $1 \mathrm{~cm}$. long. 18. G. marginale.

Petals narrowly obovate or oblong, dark purple. 19. G, atropurpureum.

1. G. molle L. Stem spreading or decumbent, branched, 1-5 dm. long, finely pubescent; leaf-blades reniform or rounded-reniform, 2-6 em. broad, the lower 6-9-cleft, the upper 3-5-cleft or parted, the divisions toothed or lobed at the apex; sepals elliptic or ovate, $3-4 \mathrm{~mm}$. long; petals deep-purple, obovate, truneate or emarginate; style-column short-beaked. Waste places and around dwellings: Me.-B.C.-Calif.-N.C.; nat. from Eu. My-Jl.

2. G. pusillum Burm. Stem decumbent or prostrate, branched, $1-5.5 \mathrm{dm}$. long, puberulent; leaf-blades reniform, 1.5-5 $\mathrm{cm}$. broad, 5-7-parted, the divisions toothed or lobed at the apex; sepals elliptic, $2.5-4 \mathrm{~mm}$. long; petals violet, often pale, cuneate, notched; style-column short-beaked. Waste places: Ont.-B.C. -Utah-Va.; nat. from Eu. Plain. My-Au.

3. G. thermale Rydb. Stem branched at the base, with diffusely spreading branches 1-1.5 dm. long, puberulent and finely pubescent; leaf-blades 1-2 cm. broad, mainly 3-parted, the divisions more or less deeply lobed; sepals broadly ovate or oval, about $0.5 \mathrm{~mm}$. long; petals rose-purple, hardly as long as the sepals; carpels villous-hirsute and puberulent. Around warm springs: Lo-Lo Hot Springs, Mont. Submont.

4. G. rotundifolium L. Stems decumbent, branched, 1-6 dm. long, softly pubescent with gland-tipped hairs; leaf-blades rounded-reniform in outline, 1.5-4 $\mathrm{cm}$. broad, cleft to about the middle; divisions 3-5-toothed at the apex; sepals 4-5.5 mm. long, oblong or elliptic; tips minute; petals purple, longer than the sepals; style-column 12-15 mm. long, minutely glandular; carpels glandularpubescent. Waste places: N.Y.-Mich.-Colo.; adv. from Eu, Plain-Submont. $\mathrm{Mr}-\mathrm{S}$.

5. G. carolinianum L. Stem branched above, more or less glandularpubescent; leaf-blades $3-6 \mathrm{~cm}$. broad, reniform in outline; divisions cleft or parted, with oblong or linear-oblong lobes; inflorescence congested; sepals ovate, with long awn-tips; petals pink or whitish; style-column with spreading glandular hairs; carpels pilose; seeds reticulate. Meadows and waste places: Newf.Alaska-Calif.-Fla.; Mex. and W. Ind. Plain-Submont. Ap-Jl.

6. G. Bicknellii Britton. Stem with ascending branches and loose spreading hairs; leaf-blades pentagonal or the lower rounded, $2-7 \mathrm{~cm}$. broad, the division incised or cleft into oblong or lanceolate segments; petioles, peduncles, and pedicels glandular-pubescent; sepals lanceolate or oblong-lanceolate; petals rosepurple, about as long as the sepals; style-column glandular-hirsute; carpels sparingly hirsute. G. carolinianum longipes S. Wats. G. longipes Goodding. Meadows: N.S.-N.Y,-Utah-Wash.-B.C.-Yukon. Plain-Submont. My$\mathrm{Au}$.

7. G. Richardsonii Fisch. \& Trautv. Stems erect, 4-9 dm. high, pubescent with spreading hairs or glabrous; leaf-blades thin, pentagonal in outline, $3-5$ parted, the divisions incised or toothed; pedicels glandular-pubescent; sepals awn-tipped, 8.5-11.5 mm. long, elliptic, pubescent and sometimes glandularciliate; petals white, $12-20 \mathrm{~mm}$. long; style-column $19-23 \mathrm{~mm}$. long. G. albiflorum Hook. G. gracilentum Greene. Mountain valleys: Sask. S.D.-N.M. -Calif.-B.C. Mont.-Submont. My-Au.

8. G. nervosum Rydb. Stems 4-8 dm. high, minutely retrorsely strigose, in age more glabrate; leaf-blades reniform in outline, $8-12 \mathrm{~cm}$. in diameter, divided to near the base into 5-7 obovate-cuneate or oblanceolate-cuneate 2-3-cleft and coarsely toothed divisions; sepals oval, $8-9 \mathrm{~mm}$. long, awn-tipped; petals broadly obovate, $15-18 \mathrm{~mm}$. long, pale violet or almost white, with dark purple streaks; column nearly $2 \mathrm{~cm}$. long. Mountains: Wyo.-Colo.-Ore. Mont.-Submont. JI. 
9. G. viscosissimum F. \& M. Stem $2.5-6 \mathrm{dm}$. high; leaf-blades pentagonal in outline, 4-11 cm. wide, hirsute, 3-5-parted, the divisions sharply and irregularly incised; sepals $12-15 \mathrm{~mm}$. long, oblong-lanceolate, finely hirsute, awntipped; petals pink-purple, $17-20 \mathrm{~mm}$. long; carpels glandular-pilose. Woods and among bushes: S.D.-Colo.-Calif.-B.C. Mont.-Submont. My-S.

10. G. strigosum Rydb. Stem 4-8 dm. high; leaf-blades reniform in outline, $5-12 \mathrm{~cm}$. in diameter, finely strigose on both sides, deeply 3-7-cleft; divisions rhombie in outline, 3-cleft and toothed; sepals densely glandular, oval, about $8 \mathrm{~mm}$. long; bristle-tipped; petals broadly obovate, rose or light violet; carpels glandular-hirsute. Woods: Sask.-Colo.-Nev.-Wash. Mont.-Submont. $\mathrm{My}-\mathrm{Au}$.

11. G. incisum Nutt. Stem 3-9 dm. high; leaf-blades pentagonal in outline, $6-15 \mathrm{~cm}$. broad, 5-parted, the divisions cleft and coarsely toothed; pedicels glandular-hirsute; sepals awn-tipped, 11-12 $\mathrm{mm}$. long, lanceolate, short-hirsute; petals purple, $15-23 \mathrm{~mm}$. long; carpels $5 \mathrm{~mm}$. long, sparingly pubescent. $G$. oreganum Howell. Mountain valleys: B.C.-Mont.-n Calif. Submont. My$\mathrm{Au}$.

12. G. canum Rydb. Stem 3-7 dm. high; leaf-blades suborbicular in outline, 6-12 cm. wide, densely hoary, 3-5-parted, the divisions sharply incised; pedicels glandular-hirsute; sepals awn-tipped, 13-15 mm. long, lanceolate, glandular-ciliate; petals purple, $13-18 \mathrm{~mm}$. long; carpels $5 \mathrm{~mm}$. long, minutely pubescent. G. incisum Howell, not Nutt. Valleys: Wash.-Ore.-Wyo.-Alta. Submont. Je-Jl.

13. G. Parryi (Engelm.) Heller. Stems tufted, 2-6 dm. long; leaf-blades thickish, pentagonal, $2.5-6 \mathrm{~cm}$. broad, canescent-strigillose, more or less glandular, 3-5-parted, the divisions incised or lobed; pedicels glandular-hirsute; sepals awn-tipped, 8.5-9.5 mm. long, elliptic to ovate, glandular-ciliate; petals pinkpurple, 12-15 mm. long; style-column $18-23 \mathrm{~mm}$. long; carpels glandular-hirsute. G. Fremontii Parryi Engelm. Mountains: Wyo.-Colo-Ariz. Mont.-Submont. Je-Au.

14. G. Pattersonii Rydb. Stems ascending or diffuse, 2-4 dm. long; leafblades reniform in outline, about $3 \mathrm{~cm}$. broad, glandular-villous on both sides, deeply 5-7-cleft; lobes broadly obovate-cuneate, 3-toothed; pedicels and calyx glandular long-villous; sepals long, oval, with a short bristle-tip; petals obovate, about $1 \mathrm{~cm}$. long, light purple or rose, with darker veins; style-column about 2 cm. long; carpels pubescent. Mountains: Colo. Mont.-Subalp. Je-S.

15. G. Fremontii T. \& G. Stems tufted, $2-5 \mathrm{dm}$. long, ascending or spreading, retrorsely pubescent, somewhat glandular above; leaf-blades thick, pentagonal, 2-4.5 cm. wide, 3-5-parted, eanescent, the divisions coarsely toothed or lobed; sepals awn-tipped, 10-11 mm. long, oblong or oblong-lanceolate, ciliate and glandular; petals pink-purple, $12-15 \mathrm{~mm}$. long; style-column $2-2.5 \mathrm{~mm}$. long; carpels pilose. Mountains: Colo.-N.M.-Ariz.-Utah. Submont. Jl$\mathrm{S}$.

16. G. caespitosum James. Stems $1.5-4 \mathrm{dm}$. long, retrorsely pubescent; leaf-blades thick, pentagonal or suborbicular, $2-6 \mathrm{~cm}$. wide, canescent or strigillose, 3-5-parted, the divisions incised or lobed; sepals awn-tipped, 9-11 $\mathrm{mm}$. long, oblong-elliptic, ciliate; petals rose-purple, $14-17 \mathrm{~mm}$. long; style-column $18-20 \mathrm{~mm}$. long. Plains, foot-hills, and the lower mountains: Colo.-Wyo.Utah. Plain-Mont. My-Jl.

17. G. Cowenii Rydb. Stems few, erect, 3-5 dm. high, retrorsely pubescent; leaf-blades pentagonal in outline, $2.5-6 \mathrm{~cm}$. wide, $3-5$-parted, the divisions eleft or toothed, canescent; pedicels more or less hirsute; sepals awn-tipped, 10$12 \mathrm{~mm}$. long, elliptic, ciliate; petals pink-purple, 12-18 mm. long; style-column Submont. Je-J.

18. G. marginale Rydb. Stems erect or ascending, 1-4 dm. high, minutely retrorsely strigose; leaf-blades pentagonal in outline, $2-3 \mathrm{~cm}$. wide, minutely pubescent, $3-5$-parted, the divisions, at least the terminal one, cuneate, and mostly 
3-toothed at the apex; pedicels retrorsely pubescent; sepals awn-tipped, 8-9.5 $\mathrm{mm}$. long, elliptic-lanceolate, minutely pubescent; petals light pink or rosecolored, 12-15 mm. long; style-column 15-18 mm. long, minutely hirsute; carpels sparingly pubescent. Mountain plateaus: Utah. Mont. Au.

19. G. atropurpureum Heller. Stems tufted, spreading, 1-9 dm. long, retrorsely pubescent; leaf-blades thick, 3-5-parted, strigillose-pubescent, 2-5 $\mathrm{cm}$. wide, the lower reniform, the upper pentagonal in outline; divisions incised or coarsely toothed; pedicels retrorsely pubescent, not glandular; sepals awntipped, 10-11.5 mm. long, oblong, finely pubescent and ciliate; petals purple, 12-15 mm. long, oblong or narrowly obovate, not notched; style-column $19-23$ mm. long, minutely pubescent; carpels pilose. G. gracile Engelm., not Ledeb. Plains and hills: Colo.-Utah-N.M.-n Mex. Submont. Je-S.

\section{2. eròdium L’Her. Storkbill, Alfilarta, Pin Clover, Filaree.}

Annual or perennial herbs, with opposite leaves. Leaf-blades pinnately divided or lobed, or if merely toothed, pinnately veined, long-petioled. Sepals 5 , usually awn-tipped. Petals 5, those of the later flowers often reduced. Stamens 5 , alternating with 5 staminodia. Style-column very elongate, the styles pubescent within, and spirally coiled, when freed from the central axis. Carpels narrow, spindle-shaped. Seeds smooth.

1. E. cicutarium (L.) L'Hér. An annual, with low spreading stem; leafblades pinnately divided; segments oblong to ovate, pinnatifid or incised; peduncles and pedicels more or less hirsute, rarely glandular, sepals oblong, 6-7 mm. long, the short tips with 1 or 2 bristle-like appendages; petals slightly longer than the sepals, pink, with darker veins; anther-bearing filaments toothless; stylecolumn 3-4 cm. long. Waste places and fields: N.S.-N.J.-N.M.-Calif.B.C.-Alta.; Mex. and C. Am.; nat. from Eu. Plain-Submont. My-Au.

\section{Family 67. OXALIDACEAE. Wood-Sorrel Family.}

Mostly herbs, with elongate or bulb-like rootstocks. Leaves alternate, sometimes all basal, compound, in ours palmately trifoliolate. Flowers perfect, regular or nearly so, cymose. Sepals and petals 5 . Stamens 10, in 2 series, monadelphous. Gynoecium of 5 united earpels; styles distinct or coherent. Fruit a valvate capsule.

Acaulescent herbs, with bulb-like rootstocks; petals violet or purple. 1. IONOXALIS.

Caulescent plants, with slender horizontal rootstocks or with an annual taproot; petals yellow.

2. XaNTHOXALIS.

\section{IONÓXALIS Small. VIOLET WOOD-SORREL.}

Perennial succulent herbs, with scaly bulbs, scapose. Leaves basal, with elongate petioles; blades palmately 3 -9-foliolate. Flowers in umbel-like cymes, subtended by several bracts. Sepals 5 , each with one or two pairs of apical tubercles. Petals 5, violet, blue, red, or white. Stamens 10; filaments united at the base, the longer sometimes appendaged on the back. Capsules erect.

1. I. violacea (L.) Small. Plant 1-4 dm. high; bulb-scales 3-ribbed; petioles glabrous; leaflets 3 , obreniform, $1-2.5 \mathrm{~cm}$. broad, glabrous, bright green above, slightly paler beneath; scape and pedicels glabrous, the former 4-19-flowered; sepals oblong to ovate-oblong, 4-6 mm. long, glabrous; petals violet, 14-20 mm. long; filaments pubescent; capsule globose-ovoid, 4-5 mm. long. Oxalis violacea L. Rich soil: Me.-Fla,-Tex.-Colo, Plain-Submont. Ap-S.

\section{XANTHÓXALIS Small. Yellow WOOD-SORREL.}

Herbs, perennial, with horizontal rootstocks or annual taproots, or rarely shrubs. Stem leafy. Leaves alternate, sometimes clustered at the nodes. Leaves palmately 3 -foliolate; leaflets mostly obcordate (in our species), or rarely broadest at the base, sessile. Flowers in umbel-like or dichotomous cymes. Sepals 5, herbaceous or petaloid. Petals 5, yellow or purplish, deciduous. 
Stamens 10; filaments united into a tube at the base. Ovary elongate; styles filiform or subulate. Capsule columnar or oblong, prismatic, erect.

Stem appressed-pubescent; capsule pubescent.

Stem loosely pubescent, or nearly glabrous; capsule glabrous.

1. $X$. stricta.

2. X. Bushii.

1. X. stricta (L.) Small. Stems erect or decumbent in age, $0.5-5 \mathrm{dm}$. long, strigillose; leaflets $15-20 \mathrm{~mm}$. wide; peduncles longer than the petioles; sepals 4-5 $\mathrm{mm}$. long; petals pale yellow, 5-10 $\mathrm{mm}$. long; capsule columnar, 16-30 $\mathrm{mm}$. long, rather abruptly pointed. Oxalis stricta L. Woods, roadsides, and cultivated grounds: N.S.-Fla.-N.M.-Wyo.; Mex. Plain-Submont. Ap-N.

2. X. Bushii Small. Stem slender, erect, 1-2 dm. high, villous; leaflets broadly obcordate, glabrous, 8-20 $\mathrm{mm}$. long; peduncles very slender, about 5 $\mathrm{cm}$. long; inflorescence cymose, but often reduced to 2-3 flowers and umbel-like; sepals 4-5 mm. long, oblong; petals 6-7 mm. long; capsule columnar, $12-15 \mathrm{~mm}$. long. Oxalis Bushii Small. Oxalis and Xanthoxalis coloradensis Rydb. River bottoms: N.S.-Ga.-Colo.-S.D. Plain-Mont. My-Au.

\section{Family 68. LinaCeat. Flax Family.}

Herbs with alternate leaves, with or without stipules. Flowers perfect, regular, racemose or paniculate. Sepals and petals 5 , rarely 4 or 6 . Stamens as many as the sepals, monadelphous. Gynoecium of 5, sometimes 2 or 3, united earpels. Fruit a capsule, opening by twice as many valves as there are carpels.

Stigmas introrse and more or less elongate; sepals glandless; flowers in ours blue, rarely white.

Stigmas terminal and capitate; sepals, at least the inner ones, with marginal glands; flowers in ours yellow.

2. CATHartolinum.

\section{1. lìnum l. Flax, Blue Flax.}

Annual or perennial glabrous plants, sometimes woody at the base. Leaves alternate, without stipules or stipular glands, narrow, entire. Sepals 5, persistent. Petals 5 , in ours blue, or rarely white, unappendaged and entire at the base. Stamens 5; filaments dilated and united at the base, each sinus with a short staminodium. Gynoecium 5-carpellary, not cartilaginous at the base; styles 5, elongate, distinct or united; stigmas elongate, introrse. Capsules 5celled, the carpels with incomplete false partitions. Seeds flat, elongatelenticular.

Inner sepals eiliate; stigmas much elongate; introduced annual. Sepals not ciliate; stigmas rather short; native perennials.

1. L. usitatissimum.

Sepals over $5 \mathrm{~mm}$. long at maturity, more than one-half as long as the capsule.

Sepals less than $5 \mathrm{~mm}$. Iong, less than one-half as long as the capsule.

2. L. Lewisii.

3. L. pratense.

1. L. usitatissimum L. Stem 2-8 dm. high, glabrous; leaves narrowly linear-lanceolate, 3-nerved, sessile; sepals acuminate, the outer elliptic or ellipticlanceolate, the inner elliptic-ovate or ovate, ciliate, 7-9 $\mathrm{mm}$. long, all 3-nerved at the base; petals blue $1-1.5 \mathrm{~cm}$. long; capsule 6-8 mm. long. Waste places and old fields; occasionally escaped from cultivation, native of Eu. My-S.

2. L. Lewisii Pursh. Stem 2-7 dm. high, often branched at the base, obscurely striate; leaves erect, linear or nearly so, $1-2 \mathrm{~cm}$. long; sepals $5.5-7 \mathrm{~mm}$. long, the outer ovate, short-acuminate, the inner broader, mucronate; petals blue or rarely white, $1.5-2 \mathrm{~cm}$. long. Plains and hills: Man.-Neb.-Tex.Calif.-Alaska; n Mex. Plain-Mont. My-Au.

3. L. pratense (Norton) Small. Stem 1-6 dm. high, striate in age, commonly branched at the base; leaves commonly numerous and crowded towards the base, narrowly linear or subulate, $0.5-1 \mathrm{em}$. long, rather succulent; bracts subulate; sepals mostly $4-5 \mathrm{~mm}$. long, ovate to oblong-ovate, the outer acute or shortacuminate, the inner broader, mucronulate; petals blue, $1-1.5 \mathrm{~cm}$. long. Dry plains: Sask,-Tex,-Ariz,-Nev.-Wyo. Plain-Submont. My-S. 


\section{CATHARTOLİNUM Reichenb. Yellow Flax.}

Annual or perennial herbs. Leaves alternate or occasionally opposite, without stipules, but often with stipular glands, mostly narrow, entire or serrulate. Sepals 5, persistent or deciduous, at least the inner ones with gland-tipped teeth. Petals 5, yellow or white. Stamens 5; filaments united at the base, monadelphous, the free portion more or less dilated at the base, sometimes with short staminodia in the sinuses. Gynoecium 5-carpellary, rarely 2-carpellary, Styles filiform, distinct or united; stigmas terminal, capitate. Capsule ovoid or depressed, 5-celled, rarely 2-celled, or completely or incompletely 10-celled by false septa. Seeds flattened, often lunate.

Styles distinct; capsules without cartilaginous thickenings at the bases of the sepals; sepals ovate, scarcely as long as the capsule; leaves oblong or oblong-linear; flowers in fastigiate cymes.

Outer sepals obtuse or merely acutish at maturity; capsule $3 \mathrm{~mm}$. long.

Outer sepals acuminate at maturity; capsule $4 \mathrm{~mm}$. long.

1. C. sedoides.

2. C. Kingii,

Styles more or less united; capsule with cartilaginous thickenings at the base of the sepals; sepals lanceolate, much exceeding the capsule; leaves linear-lanceolate to subulate.

Outer sepals copiously gland-toothed; staminodia none or entire.

Stem, branches, and pedicels densely puberulent.

Stem, branches, and pedicels not densely puberulent, usually glabrous.

Sepals not more than half longer than the capsule, the inner ones with relatively coarse and conspicuously gland-tipped teeth.

Petals 5-9 mm. long.

Outer sepals with lateral ribs faint near the base; branches blunt-angled.

4. C. australe.

Outer sepals with lateral ribs prominent throughout; branches wingangled.

Petals 10-20 mm. long.

False septa of the capsule slightly thickened; sepals becoming 6-8 mm.

long; petals $11-15 \mathrm{~mm}$. long.
False septa thickened half their width; sepals becoming $9-11 \mathrm{~mm}$. long; petals $17-20 \mathrm{~mm}$. long.

Sepais twice as long as the capsule, long-acuminate, aristate, the inner ones with very numerous, fine, inconspicuously gland-tipped teeth.

Outer sepals entire or with few scattered teeth; staminodia 2-lobed.

8. C, aristatum.

9. C. subteres.

1. C. sedoides (Porter) Small. Perennial, with a woody base; stems or branches mostly less than $1 \mathrm{dm}$. long; leaves very numerous, approximate, near the base of the stem, more or less imbricate, erect or ascending, clavate, the upper short-linear, 3-9 mm. long; outer sepals ovate, about $4 \mathrm{~mm}$. long, with few gland-tipped teeth; petals bright yellow; capsule ovoid, $3 \mathrm{~mm}$. long. $L$. Kingii sedoides Porter. L. Kingii pinetorum M. E. Jones. High mountains: Utah. Subalp. Jl.

2. C. Kingii (S. Wats.) Small. Perennial, with a woody base; stem and branches more or less tufted, $0.5-3 \mathrm{dm}$. high; leaves numerous, spreading, thick, the lower linear-spatulate, the upper linear, 1-2 cm. long; outer sepals ovate, about $4 \mathrm{~mm}$. long, sparingly gland-toothed, the inner ones broader, abruptly short-pointed; petals bright yellow; capsule ovoid, $4 \mathrm{~mm}$. long. Linum Kingii S. Wats. High mountains: Utah-Wyo. Submont..-Mont. Jl-Au.

3. C. puberulum (Engelm.) Small. Pale green, often glaucous, perennial; stem $0.5-3 \mathrm{dm}$. high, usually branched throughout; leaves numerous and crowded at the base, erect or ascending, thick, the lower linear or linear-spatulate, entire, the upper linear or subulate, often gland-toothed below the middle; sepals narrowly lanceolate, becoming 7-9 mm. long, acuminate, the inner ones shorter than the outer, and more coarsely toothed towards the apex; petals light yellow, 12-17 $\mathrm{mm}$. long. L. rigidum puberulum Engelm. Dry plains and hills: Colo.-Tex. -Ariz.-Nev. Plain-Submont. Ap-Au.

4. C. australe (Heller) Small. Pale green perennial, glabrous or nearly so; stem 1.5-5 dm. high, simple below, the branches erect or ascending; leaves scattered, early deciduous, thick, serrulate; sepals lanceolate or oblong-lanceolate, becoming 6-8 mm. long, evenly glandular-toothed, long-acuminate; inner slightly broader than the outer; petals pale yellow, 6-9 mm. long. L. australe Heller. 
Dry plains and hills: Colo.-N.M.-Ariz.-Utah; n Mex. Son.-Submont. Ap-Au.

5. C. compactum (A. Nels.) Small. Dull-green perennial; stem 1-2 dm. high, branched at the base; leaves numerous towards the base, but early deciduuous, the upper more persistent, erect or ascending, entire; sepals lanceolate, becoming $6-8 \mathrm{~mm}$. long, acuminate, evenly glandular-toothed, the inner much shorter than the outer; petals yellow, 7-9 mm. long; capsule ovoid, $4 \mathrm{~mm}$. long. L. compactum A. Nels. Dry plains: N.D.-Mo.-Wyo.-Mont. Plain-Submont. Je-Au.

6. C. rigidum (Pursh) Small. Glabrous, bright green perennial; stem 1-5 $\mathrm{dm}$. high, simple at the base, corymbosely branched above, prominently striateangled; leaves relatively few, erect, early deciduous, linear to linear-lanceolate, $0.6-3 \mathrm{~cm}$. long, acute or acuminate, the upper ones glandular-ciliate or glandularserrulate; sepals lanceolate, becoming 6-8 $\mathrm{mm}$. long, acuminate, evenly glandular-toothed, the inner ones shorter and broader than the outer ones; petals yellow; capsule ovoid, $4-5 \mathrm{~mm}$. long. $L$. rigidum Pursh. Plains and hills: Man.-Tex.-Colo-Alta. Plain-Submont. Je-O.

7. C. Berlandieri (Hook.) Small. Bright green glaucescent perennial; stem $0.5-3.5 \mathrm{dm}$. high, simple at the base, branched and angled above; leaves rather few, spreading or ascending, linear to linear-lanceolate, mostly $1.5-4 \mathrm{~cm}$. long, acuminate, entire, the lateral veins marginal; sepals lanceolate, becoming 9-11 $\mathrm{mm}$. long, evenly glandular-toothed, acuminate and minutely spinulose-tipped, the inner ones shorter; petals light yellow, 17-20 mm. long; capsule ovoid, $4-4.5$ $\mathrm{mm}$. long. L. Berlandieri Hook. L. arkansanum Osterhout. Sandy soil: Neb. -Tex.-Colo. Plain-Son. Ap-Ji.

8. C. aristatum (Engelm.) Small. Glaucescent perennial; stem 2-4 dm. high, corymbosely branched above, striate or somewhat angled, glabrous; cymes few-flowered; leaves few, ereet, thickish, the lower linear or narrowly linearspatulate, about $1 \mathrm{~cm}$. long, the upper subulate, slender, with involute margins, entire; sepals linear-lanceolate, becoming 9-10 mm. long, aristately tipped, the inner shorter than the outer, more finely toothed; petals yellow, $13-15 \mathrm{~mm}$. long; capsule about $3 \mathrm{~mm}$. long, ovoid. L. aristatum Engelm. Sandy soil: w Tex. -se Utah-n Mex. Son. J-Au.

9. C. subteres (Trelease) Small. Glaucous perennial; stem 2-3 dm. high, branched at the base, terete or nearly so; leaves crowded at the base and on the main bianches, erect, thick, succulent, the lower linear-spatulate, the upper linear or subulate, $1-1.5 \mathrm{~cm}$. long; sepals lanceolate, becoming $6-7 \mathrm{~mm}$. long, abruptly pointed, the inner shorter, with several teeth; petals yellow, 10-13 mm. long; capsule ovoid, $4 \mathrm{~mm}$. long. L. aristatum subteres Trelease. Sandy places: Nev.-Utah. Son.-Submont. My-Au.

\section{FAMILY 69. BALSAMINACEAE. JeWEL-WEed FAMILY.}

Herbs, with more or less succulent leaves and swollen nodes. Flowers perfect, irregular, zygomorphic. Sepals 3 , rarely 5 , the posterior one petaloid, strongly saccate or spurred at the base. Petals 5, or by union of two and two only 3 . Stamens 5, alternate with the petals; anthers more or less united around the stigma. Gynoecium of 5 united carpels; styles obsolete. Pod a 5-celled capsule, elastically dehiscent.

\section{IMPÀTIENS L. TOUCH-ME-NOT, JEWEL-WEED.}

All our species annual. Sepals in ours 3. Lateral petals each united with the adjacent posterior one. Capsule elastically dehiscent. Seeds usually many, pendulous above each other in a single row.

Spur present.

Spur porrect, $i$. e., bent at a right angle to the sack, one-fourth as long as the same or less; sack as broad as long, pale yellow, unspotted or minutely so.

1. I. pallida. 
Spur strongly incurved, one-third as long as the sack or more; sack longer than broad. Sack at least two-thirds as broad as long, abruptly contracted into the spur; flowers orange or pinkish, with large spots or rarely unspotted. 2. I. biflora.

Sack one-half as broad as long or less, gradually tapering into the spur; flowers unspotted.

Sack about $2 \mathrm{~cm}$. long; flowers light yellow. Spur wanting.

Sack about $12 \mathrm{~mm}$. long; flowers golden-yellow.

3. I. occidentalis.

4. I. aurella.

5. I. ecalcarata.

1. I. pallida Nutt. Stem usually light green, 1-2 m. high; leaf-blades thin, bright green, oval or ovate, $3-15 \mathrm{~cm}$. long, crenate-dentate; lateral sepals broadly ovate, acuminate, light green, 5-7 mm. long; posterior sepal light sulphur-yellow, usually unspotted, broadly conic, about $15 \mathrm{~mm}$. long; spur 3-8 $\mathrm{mm}$. long; petals of the same color as the spur or lighter, usually dotted, the anterior one broadly obovate, emarginate, 7-8 mm. long. River banks: N.S.-Ga.-Kans.-Sask. Plain.

2. I. biflora Walt. Stem 1-1.5 m. high, often tinged with red; leaf-blades oval or ovate, $2-10 \mathrm{~cm}$. long, green or purplish; lateral sepals light green or purplish, obovate, short-acuminate, $5-6 \mathrm{~mm}$. long; posterior sepal orange, or rarely pink, usually copiously spotted with red or purple, sometimes wholly unspotted, elongate-helmet-shaped, $15-18 \mathrm{~mm}$. long; spur about $1 \mathrm{~cm}$. long; petals of the same color as the posterior sepal, the anterior one nearly orbicularly obcordate, 6-7 mm. long. I. maculata Muhl. I. fulva Nutt. River banks: Newf. -Fla.-Ala.-Ida.-Mack. Plain-Submont.

3. I. occidentalis Rydb. Stem light green or straw-colored, about a meter high; leaf-blades oval, thin, light green, $2-10 \mathrm{~cm}$. long, acute at the apex, acute to subcordate at the base, erenate-dentate; lateral sepals obovate, abruptly acuminate, about $6 \mathrm{~mm}$. long; posterior sepal conic-trumpetshaped, somewhat curved, about $2 \mathrm{~cm}$. long, pale yellow; spur $8-10 \mathrm{~mm}$. long, cylindric; anterior petals broadly obovate, emarginate, $7 \mathrm{~mm}$. long, fully $10 \mathrm{~mm}$. wide. Wet places: Wash.-Alaska-(? Ida).

4. I. aurella Rydb. Stem slender, light green, 5-6 dm. high; leaf-blades ovate or oval, thin, bright green, a little paler beneath, $2-8 \mathrm{~cm}$. long, coarsely dentate; lateral sepals ovate, 4-5 $\mathrm{mm}$. long; posterior sepal orange, unspotted, conic, $10-15 \mathrm{~mm}$. long; spur about $8 \mathrm{~mm}$. long; anterior petal triangular-obovate, emarginate, $5 \mathrm{~mm}$. long, $8 \mathrm{~mm}$. wide. Wet places: Mont.-Ida.-Wash.-BC.

5. I. ecalcarata Blankinship. Stem glabrous, light green, 9-12 dm. high; leaf-blades ovate or ovate-elliptic, 2-10 $\mathrm{cm}$. long, dentate, light green above, paler beneath; lateral sepals obliquely oval, $6 \mathrm{~mm}$. long; posterior sepal orange or sometimes paler yellow, unspotted, helmet-shaped, unspurred, 8-10 $\mathrm{mm}$. deep, 10-13 mm. wide; petals of the same color as the sack; anterior sepals orbicular or reniform, notched; petals oblanceolate or oblong, $6 \mathrm{~mm}$. long. Wet places: Mont.-Wash.-B.C.

\section{Family 70. Limnanthaceae. False Mermaid Family.}

Herbs of wet places, with pinnately dissected leaves. Flowers perfect, regular. Hypanthium present, but small, saucer-shaped. Sepals 3-5, persistent, valvate or nearly so. Petals $3-5$, marcescent. Stamens 6-10. Gynoecium of 2-5 carpels; ovaries distinct, but the styles united to near the top, arising between the ovaries. Fruit of semi-drupaceous nutlets.

\section{FLoÈrkea Willd. False Mermatd.}

Low slender annuals. Leaves simply pinnately dissected. Flowers inconspicuous on axillary peduncles. Sepals 3 , slightly imbricate, spreading in fruit. Petals 3, white, about half as long as the sepals. Stamens 6; filaments subulate, distinct, those opposite the petals shorter; anthers didymous, introrse, opening longitudinally. Ovaries 2 or 3; style 2- or 3-cleft at the apex; stigmas capitate.

1. F. occidentalis Rydb. Very slender glabrous annual; stem slightly branched, less than $1 \mathrm{dm}$. high, ascending or decumbent; leaves $1-3 \mathrm{~cm}$. long, 
pinnate, glabrous; divisions $3-5$, oblong or oblanceolate to nearly linear, 5-15 $\mathrm{mm}$. long; sepals ovate, $2 \mathrm{~mm}$. or in fruit $3 \mathrm{~mm}$. long; petals oblanceolate or oblong, usually less than $1 \mathrm{~mm}$. long; carpels usually 2 . Wet places: Colo.Wyo.-Calif.-Wash.

\section{Family 71. ZYGOPHYLlaCEAE. Caltrop Family.}

Perennial herbs, shrubs, or trees, with articulate stems. Leaves alternate or opposite, digitate or evenly pinnate, with inequilateral punctate leaflets. Flowers perfect, regular or nearly so. Sepals 5 , rarely 4 or 6 , usually imbricate. Petals as many, hypogynous. Stamens twice as many. Gynoecium of $2-5$ united carpels; ovary 2-5-celled, rarely 10-12-celled, angled or winged; styles wholly united. Fruit a capsule or splitting into as many or twice as many nutlets as there are carpels.

Leaves digitately 1-7-foliolate; stipules spiny; stamens with scale-like appendages.

Leaves abruptly pinnate; stipules in ours not spiny.

1. FAGONIA.

Shrubs with endosperm; fruit woolly; stamens

Herbs without endosperm; corolla mostly yellow; stame-like appendages. 2 . CoviLLEA. dages.

Fruit dividing into 5 (by abortion sometimes fewer) carpels, each with $3-5$ oneseeded compartments, spiny. Fruit dividing into $8-12$ (twice as many as the original carpels) one-seeded nutlets,
merely tubercled.

4. KALLSTROEMIA.

\section{FAGÒNIA L.}

Branching, diffuse, spreading, or prostrate undershrubs. Stems spinulose on the upper angles. Leaves opposite, digitately 1-7-foliolate; leaflets entire, callous-mucronate or spinulose-tipped; stipules often spinescent. Flowers solitary, pedunculate. Sepals 5, imbricate, eaducous. Petals 5, imbricate, unguiculate, caducous. Stamens 10; filaments filiform, naked. Style subulate; stigma simple; ovary 5-celled. Fruit pyramidate-ovoid, deeply 5 -angled, the 1 -seeded carpels at length separating from the axis and dehiscing on the inner
edge.

1. F. californica Benth. A low dichotomously branched undershrub; stems $2-5 \mathrm{dm}$. long, diffuse, much branched, glabrous; stipules $2-5 \mathrm{~mm}$. long, arcuate-spreading; leaflets 3 , lanceolate or ovate-lanceolate, glabrous or nearly so, 3-10 mm. long; petals spatulate, $5-8 \mathrm{~mm}$. long; fruit ovate or spindle-shaped in outline, $4-5 \mathrm{~mm}$. long, $7-8 \mathrm{~mm}$. broad, finely pubescent. Sandy soil: Calif.s Utah.-Sonora-L. Calif. L. Son.

\section{Covíllea Vail. Creosote Bush, Hediondilla.}

Low, evergreen, strong-scented, balsamiferous shrubs. Leaves opposite, consisting of a single pair, rarely of several pairs of small inequilateral leaflets; stipules persisting. Peduncles 1-flowerea. Sepals 5, imbricate, unequal, caducous. Petals 5, yellow, obovate or lanceolate-spatulate, more or less unguiculate. Stamens 10, inserted on the base of the small disc. Anthers oblong. Pistil of 5 united carpels. Ovary short-stipitate, globose, pilose, 5-celled, the cells alternate with the petals; styles united, sometimes separable. Fruit villose or tomentose, globose, 5-angled. [Larrea Cav., not Ort.]

1. C. glutinosa (Engelm.) Rydb. A diffusely branched resinous shrub, 1-3.5 m. high; stems densely leafy, angled, silky-pubescent; leaves nearly sessile; leaflets obliquely lanceolate or lunate, falcate, $5-10 \mathrm{~mm}$. long, coriaceous, resinous, yellowish, silky-pubescent, becoming glabrate, 3-ribbed; petals slightly unguiculate, spatulate-oblong, bright yellow; fruit subglobose or elliptic, $4-5 \mathrm{~mm}$. broad, densely rusty-villous. L. glutinosa Engelm. L. mexicana Torr., not Moric. C. tridentata Vail, in part. Dry plains and hills: Tex.-s Utah-Calif.; n Mex.
L. Son. 


\section{TRÍBULUS L. BUR-NUT.}

Diffuse herbs, with weak, often prostrate, stems and branches. Leaves abruptly pinnate, opposite. Stipules lanceolate or subulate, membranaceous. Flowers solitary on axillary peduncles. Sepals 5, lanceolate, herbaceous, soon caducous. Petals 5, obovate, yellow, orange, or rarely white, spreading, deciduous. Stamens 10, hypogynous; filaments filiform, naked, the 5 inner alternate with the petals, shorter than the outer, subtended by a small gland. Ovary sessile, 5-celled, surrounded at the base by an urceolate 10-lobed disk. Styles united into a short stout column; stigmas 5, more or less connate. Fruit depressed, 5-angled, tuberculate or spinose, separating at maturity into 5 bony carpels. Seeds oblong-obovate. Endosperm wanting.

1. T. terrestris L. A diffuse trailing annual herb; stems hirsute and slightly swollen at the nodes; leaflets about 5-7 pairs, somewhat oblique, oblong or elliptic, 3-13 mm. long; petals obovate, about $4 \mathrm{~mm}$. long, light yellow; carpels 5 , bony, each with 2 divergent stout spines and 2 or more smaller ones, sparingly hispid. Waste places and sandy soil: S.C.-Ill.-Neb.-Ariz.; Mex. and W. Ind.; nat. from Eu. Plain-Son.

\section{KaLlstrok̀mia Scop. Caltrop.}

Diffuse and branching herbs. Stems procumbent. Leaves opposite, abruptly pinnate, the terminal pair larger. Flowers solitary, orange or yellow. Peduncles axillary. Sepals 5 or 6 , mostly persisting. Petals 4-6, obovate or obcordate, spreading, caducous. Stamens 10 or 12 , hypogynous; filaments filiform, those opposite the petals adnate to the petals, the alternate ones smaller and subtended externally by a small gland. Ovary sessile, 8-12-celled, without transverse septa; styles united, columnar, or subulate from a conic base; stigma capitate; fruit roughened or tuberculate, separating at maturity into 8-12 bony, indehiscent, 1 - rarely 2 -seeded tuberculate nutlets, leaving a more or less persistent thick styliferous central axis.

Plant sparingly pubescent or glabrate; petals 3-5 mm. long; beak much shorter than the

body of the fruit.
Plant densely hirsute; petals $5-6 \mathrm{~mm}$. long; beak slightly shorter than the body.

2. K. hirsutissima.

1. K. brachystylis Vail. A profusely branched annual; stems $2-3 \mathrm{dm}$. long or more, very brittle; leaflets 3-4 pairs, obliquely elliptic or oval, 6-15 mm. long, slightly falcate, ciliate on the margins; sepals lanceolate, caducous; petals 4-5 $\mathrm{mm}$. long, orange to pale yellow, sometimes shorter than the sepals; fruit minutely pubescent; beak persistent, glabrous, 1-2 mm. long; nutlets with rounded tubercles on the back, strongly reticulate on the faces. Sandy soil: N.M. $\rightarrow$ S Colo.L. Calif.; Mex. Son.

2. K. hirsutissima Vail. A much branched annual; branches stout, trailing, 4-7 dm. long, appressed cinereous-pubescent and hirsute with longer spreading hairs; leaflets 3-4 pairs, elliptic, 8-20 mm. long, shaggy-hirsute, at least beneath; sepals linear-lanceolate, $4-6 \mathrm{~mm}$. long; petals obovate-oblong, $5-6 \mathrm{~mm}$. long, yellow or orange, fading whitish, retuse; fruit canescent-strigose; beak pubescent, conic at the base, $3-4 \mathrm{~mm}$. long; carpels 10 . Sandy soil: Tex.Kans.-Colo.-Mex. Son.

\section{Family 72. RUTACEAE. Rue Family.}

Aromatic trees or shrubs, with secreting glands in the foliage. Leaves mostly digitately or pinnately compound; leaflets usually inequilateral. Flowers perfect, polygamous or dioecious. Calyx with 3-5 lobes or sepals, rarely wanting. Petals $3-5$, imbricate. Stamens as many as the petals or twice as many, sometimes more, inserted on a hypogynous disk. Gynoecium of $1-5$, or more, free or united carpels. Fruit various, of follicles, a capsule, samara, or drupe. 
Fruit a samara; cells of ovary 2-ovuled; trees or shrubs with digitately compound leaves.

Fruit a capsule; cells of ovary 5- or 6-ovuled; undershrubs or 1 1. PTELEA. leaves.

2. T

1. ptèlea l. Hop-tree, Shrubby Trefoil.

Unarmed shrubs or trees. Leaves alternate, rarely opposite, 3-foliolate, rarely 4 - or 5-foliolate; leaflets entire or toothed, pellucid-punctate. Flowers polygamous, in corymbose or paniculate cymes. Sepals 4 or 5 , rarely 6 . Petals as many, greenish or yellowish white. Stamens 4 or 5 , rarely 6 , hypogynous, abortive in the pistillate flowers. Gynoecium of 2 or 3 united carpels; ovules 2 in each cavity. Fruit a 2 -celled or rarely 3 -celled samara with reticulate wings, surrounding the body.

1. P. Baldwinii T. \& G. A shrub or small tree, $3-8 \mathrm{~m}$. high; leaflets usually 3 , narrowly lanceolate to oval or obovate, $1.5-6 \mathrm{~cm}$. long, crenulate or entire, somewhat pubescent beneath; fruit 1-2 cm. long, with thin oblong to nearly orbicular wings. $P$. angustifolia Benth. $P$. crenulata Greene. Woods and cañons: Fla.-Tex,-Colo.-Calif.; Mex. Son.-Submont.

\section{THAMNÓSMA Torr, \& Frem.}

Strong-scented glandular shrubs or undershrubs. Leaves simple, alternate, entire. Flowers perfect, racemose. Sepals 4. Petals 4, imbricate. Disk present, cup-like, entire or crenate. Stamens 8 , inserted on the disk; filaments subulate or filiform. Gynoecium of 2, rarely 3, united carpels; ovary 2- or 3lobed; style filiform; ovules 5-6 in each cavity. Capsule leathery, 2- or 3-celled, opening at the apex.

Shrubby; corolla $8-10 \mathrm{~mm}$, long; capsule distinctly stipita te.
Herbaceous from a woody base; corolla about $4 \mathrm{~mm}$. long; capsule sessile or subsessile.

2. T. texana.

1. T. montana Torr. \& Frem. A glandular shrub, 3-6 dm. high, often spinose; leaves few, early deciduous, linear to spatulate or oval; petals purple, N.M. - or oval; filaments filiform; seeds 3 or by abortion solitary. Arid regions: M. - U Utah-Nev.-se Calif.; Mex. Son.

2. T. texana (A. Gray) Torr. A low undershrub, 1-5 dm. high; leaves linear-oblong to narrowly linear, 5-15 mm. long, entire, sessile; sepals ovate or oval, obtuse or retuse; petals oval or elliptic, greenish yellow or whitish, tinged with purple; capsule lobed to the middle, 3-7 mm. high. Rutosma purpurea Woot. \& Standl. Arid regions: Tex.-Colo.-Ariz.; Mex. Son.

\section{Family 73. POLYGalaceae. Milkwort Family.}

Herbs, or rarely shrubs or trees, with alternate, opposite, or whorled leaves; stipules wanting. Flowers irregular, Sepals 5 , free, imbricate, the two inner petaloid, called wings. Petals 5 or 3 , the lower one concave, often beaked or crested, called keel, the others more or less united. Stamens usually 8; filaments usually united into a tube, cleft on the back; anthers becoming 1-celled, opening by terminal pores or cracks. Gynoecium usually of 2 , rarely 5 , united carpels. Fruit usually a 2-celled capsule.

\section{POLÝGGLA (Tourn.) L. MiLKWort.}

Filaments united. Capsule compressed laterally, 2-celled. Seeds caruncled.

Plants herbaceous, unarmed; keel with a fimbriate crest.

Annuals; leaves verticillate, narrowly linear.

Leaves linear or linear-oblanceolate.

More or less spiny undershrubs.

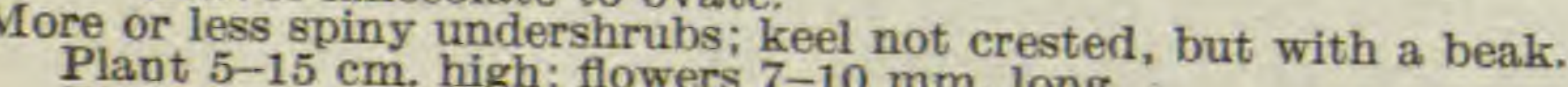

Plant $5-15 \mathrm{~cm}$. high; flowers $7-10 \mathrm{~mm}$. long.

Plant 3-10 dm. high; flowers $3-4 \mathrm{~mm}$. long.

1. $P$, verticillata.

2. P. alba.

3. P. Senega.

4. P. subspinosa.

5. P. acanthoclada. 
1. P. verticillata L. Stem $0.5-3 \mathrm{dm}$. high, angled, with numerous spreading branches; leaves in 4's or 5's, 1-3 cm. long; racemes spike-like, narrowly conic; flowers greenish or greenish white; wings ovate, about $1 \mathrm{~mm}$. long; keel crested with several thick processes; eapsule about $2 \mathrm{~mm}$. long. Dry soil: Que.-Fla.-Mex.-Wyo.-Sask. Plain-Submont. Je-S.

2. P. alba Nutt Stems several from the base, erect or ascending, 1-5 dm. high, angled, simple; leaves 1-2.5 $\mathrm{cm}$. long; racemes spike-like, 4-6 mm. thick; wings oval or obovate, $2-3 \mathrm{~mm}$. long; corolla white; keel with a fimbriate crest; capsule ovoid, $2-3 \mathrm{~mm}$. long. Dry plains: Minn.-Kans.-Tex.-Ariz.-Colo. -Mont.; Mex. Plain. Ap-O.

3. P. Senega L. Stems several from a thick root, erect, $1-5 \mathrm{dm}$. high, simple; leaves numerous, lanceolate to lance-elliptic or (in var. latifolia) ovatelanceolate or ovate, scabrous on the margin; racemes spike-like, $2-6 \mathrm{~cm}$. long; wings orbicular-ovate, 2-3 mm. long; corolla greenish white, $3-4 \mathrm{~mm}$. long; keel erested with thick processes; capsule flat, broader than long. Dry soil: N.B.N.C.-Ark.-(Black Hills) S.D.-Alta. Submont, My-JI.

4. P. subspinosa S. Wats. Spinescent undershrub, intricately branched, puberulent; leaves lance-oblong to elliptic or spatulate, 1-2 cm. long, firm; inflorescence a few-flowered raceme; wings elliptic-oblong, acutish, as well as tips of the lateral petals rose-colored; keel yellow, with a blunt beak; capsule obovate, retuse, veiny, glabrous. Foot-hills: Colo.-Ariz.-Nev. Son. - Submont. Мy-Jl.

5. P. acanthoclada A. Gray. Spinescent shrub, with white or yellowish bark, intricately branched; leaves 6-12 $\mathrm{mm}$. long; oblanceolate or spatulate; racemes few-flowered, with a stout peduncle produced into a spine; flowers yellowish white, or the petals tipped with purplish; wings obovate; keel with a very short blunt, often obsolete, beak; fruit oblong-ovate, $5 \mathrm{~mm}$. long, deeply notched. Arid regions: Colo.-Ariz.-Nev. Son. Je.

\section{Family 74. EUPHORbiaceae. Spurge Family.}

Monoecious or dioecious herbs (all ours), or shrubs or trees, often with milky sap, and alternate, opposite, or verticillate simple leaves. Flowers with or without petals, sometimes much reduced and subtended by a calyxlike involucre. Stamens few or many; filaments united or distinct. Ovary usually 3-celled. Styles as many as the cells of the ovary, simple, divided, or many-cleft. Capsule separating at maturity into three 2-valved carpels.

Flowers not in involucres; calyx of several sepals.

Corolla present in either the staminate or pistillate flowers, or in both.

Stamens 5 or 6 ; fllaments distinct.

Stamens 10; filaments monadelphous.

1. CRoton.

2. Ditaxis.

Corolla wanting.

3. Tragia.

Flowers in involucres; calyx represented by a minute scale on the fllament-like pedicels.

Glands of the involucres with petal-like appendages, these however sometimes much reduced.

Leaves all opposite.

Leaf-blades oblique at the base, inequilateral; glands 4. 4. ChamaEsyce. Leaf-blades equilateral, not oblique at the base; glands 5 .

5. ZYGOPHYLIDIUM.

Leaves alternate or scattered, at least below the inflorescence; annuals or bienenials; bracts petal-like.

6. LEPADENIA.
naked, sometimes with crescent-shaped horns.

Stem topped by an umbel; stipules none; involucres in open cymes, each with 4 glands and entire or toothed lobes.

7. TITHYMALUS.

Stem not topped by an umbel; stipules gland-like; involucres in conglomerate cymes, each with a single gland, or rarely 4 glands and fimbriate lobes.

\section{CRÒTON L. CROTON.}

8. Poinsetita.

Herbs (ours) or shrubs, monoecious or rarely dioecious, heavy-scented, stellate-pubescent or scaly, sometimes more or less glandular. Leaves mostly alternate, entire, toothed or lobed. Flowers in axillary or terminal clusters. Stam- 
inate flowers uppermost. Sepals 4-6, usually 5. Petals usually present, but often small, alternating with the glands. Stamens 5 or more, inflexed in bud. Pistillate flowers below the staminate ones. Sepals 5-10. Petals usually wanting. Ovary 3-celled; ovules solitary in each cell; stigmas once, twice, or thrice 2cleft. Capsule mostly splitting into three 2 -valved carpels. Seeds smooth or minutely pitted.

Annual; leaf-blades linear, lanceolate, or oblong, 3-5 times as long as the petioles.

Perennial; leaf-blades elliptic or oval, only a little longer than the petioles, 1 . texensis.

2. C. longipes.

1. C. texensis (Klotzsch) Muell. Arg. Lepidote, dioecious annual; stem 4-16 dm. high, di- or tri-chotomously branched; the staminate plant usually more slender than the pistillate one and with narrower leaves; leaf-blades linear, lanceolate, or oblong, 4-12 cm. long, entire; staminate racemes $1-3 \mathrm{~cm}$. long; sepals oblong to ovate-oblong; stamens 8-12; pistillate flowers $2-4$ together or solitary; sepals triangular; capsule globose or oval, $4-6 \mathrm{~mm}$. long, warty. Plains and prairies: Ill.-Ala.-Tex.-Ariz.-Wyo.; Mex. Plain. My-Au.

2. C. longipes M. E. Jones. Perennial, woody at the base, $3-6 \mathrm{dm}$. high, white, lepidote-stellate; leaf-blades $2-3 \mathrm{~cm}$. long, densely stellate beneath, sparingly so or glabrate above; staminate flowers $2 \mathrm{~mm}$. wide; pistillate ones 6 $\mathrm{mm}$. wide; sepals in both triangular; capsule globose, densely stellate. Sand: Utah-Nev. Son.-Submont. Ap-My.

\section{DITÁXIS Vahl.}

Monoecious or rarely dioecious herbs or shrubs, often with rootstocks. Leaves alternate, silky or pilose, entire or rarely toothed, often strongly veined. Flowers in axillary and terminal clusters, usually bracted. Staminate flowers usually crowded at the ends of the racemes. Sepals 4 or 5 , valvate. Petals 4 or 5. Stamens of the same number, or twice or thrice as many; filaments united into a column, Pistillate flowers with imbricate sepals and rudimentary petals. Ovary 3-celled, each cell with a solitary ovule. Styles 3, 2-cleft. Capsule 3 -lobed, depressed, separating into three 2-valved carpels. Seeds subglobose, wrinkled or crested.

1. D. humilis (Engelm. \& Gray) Pax. Perennial, with a woody root and caudex; stems much branched, pubescent, spreading, 1-3 dm. long; leaf-blades ovate, oblong, or oblanceolate, 1-3 cm. long, entire; capsule short-pedicelled, depressed, 4-6 mm. in diameter; seeds oval-globose, $2 \mathrm{~mm}$. long, muricate. Prairies: Kans.-La.-Tex.-N.M. Son. My-O.

\section{TRÀGIA (Plum.) L.}

Perennial monoecious herbs, or shrubs, usually armed with stiff, stinging hairs. Leaves alternate, entire, toothed, or lobed, mostly cordate, petioled. Flowers in racemes or spicate racemes, bracteolate, apetalous. Staminate flowers with 3-5 sepals, and mostly 1-3 stamens. Pistillate flowers with 3-8 sepals. Ovary 3-celled; ovules solitary. Styles 3 , often united to above the middle. Capsule 3-lobed, separating into three 2-valved earpels. Seeds subglobose.

1. T. ramosa Torr. Light green perennial, with a woody caudex, hispid; stem $0.5-3 \mathrm{dm}$. high, usually much branehed; leaf-blades lanceolate to triangularlanceolate, 1-5 cm. long, coarsely and sharply serrate; staminate flowers with 4-5 sepals and 5-6 stamens; pistillate flowers solitary, with 5 sepals subtended by a 3-lobed bract; capsule depressed, $6-8 \mathrm{~mm}$. thick, orange, more or less variegated. Dry soil: Mo.-Tex.-Ariz.-Colo. Son.-Submont. Ap-Au.

\section{Chamaes Ỳ CE S. F. Gray. Spurge, Carpet-weed.}

Annual or perennial herbs, or in the tropies shrubs. Stems often radially branched at the base, ascending or prostrate, forking. Leaves opposite, entire or toothed, more or less oblique at the base; stipules delieate, entire or fringed. Involueres solitary in the axils or in axillary eymes. Glands 4, sessile or stalked, 
naked or usually with an appendage; one sinus of each involucre usually glandless. Capsule 3-lobed, smooth, with sharp or rounded angles. Seeds angled, the faces smooth or transversely wrinkled.

Leaf-blades entire.

Annuals or biennials.

Plants prostrate; leaves oblong to orbicular.

Leaf-blades manifestly longer than broad, usually more than twice as long.

Leaf-blades as broad as long or nearly so.

1. C. Geyeri.

2. C. serpens.

Plants more or less ascending or erect; leaf-blades linear or linear-lanceolate.

Capsule less than $1.5 \mathrm{~mm}$. long.

Capsule about $2 \mathrm{~mm}$. long or more.

Appendages of the glands conspicuous, white.

Appendages inconspicuous, greenish white, or obsolete.

Stems low and erect; stipules subulate-setaceous; seeds finely granulate, obscurely angled.

5. C. Parryi.

Stems long and ascending; stipules triangular; seeds smooth, 3-angled.

Perennials.

6. C. flagelliformis.

Leaves glabrous.

Appendages fan-shaped, white, petaloid; stipules triangular, fimbriate.

7. C. albomarginata.

Appendages crescent-shaped or semi-orbicular, greenish, pinkish, or yellowish; stipules subulate-setaceous.

Appendages crescent-shaped, much narrower than the gland; leaves broadly deltoid-ovate; seeds transversely ridged; plant prostrate.

8. C. Greenei.

Appendages conspicuous, semi-orbicular, fully as broad as the glands; leaves ovate or ovate-lanceolate; seeds irregularly pitted; plant erect.

Leaves toothed, but sometimes only at the apex; stems and branches prostrate; annuals.

Capsules glabrous.

Seeds strongly transversely wrinkled.

Seeds pitted or irregularly and faintly wrinkled.

Seeds deeply and irregularly pitted.

Seeds faintly pitted or wrinkled.

Leaves oblong; seeds usually with a white bloom.

Leaves linear; seeds brownish, usually without a bloom.

11. C. glyptosperma.

12. C. rugulosa.

13. C. serpyllifolia.

14. C. albicaulis,

Capsule pubescent.

Leaf-blades and involucres glabrous or sparingly pubescent. 15. C, maculata.

Leaf-blades and involucres copiously hirsute.

16. C. stictospora.

1. C. Geyeri (Engelm.) Small. Plant green; stem branched at the base; branches $0.5-4 \mathrm{dm}$. long; leaf-blades oblong to ovate, 4-12 $\mathrm{mm}$. long, obtuse, usually mucronulate, truncate or subcordate at the base; involucres turbinate, $1.5 \mathrm{~mm}$. high; glands $0.3 \mathrm{~mm}$. broad; appendages inconspicuous, white or red; seeds narrowly ovoid, $1.5 \mathrm{~mm}$. long, nearly terete, ash-colored. Euphorbia Geyeri Engelm. On plains and prairies: Ill. - Mo. - Tex. - Neb. - Minn. Plain. Je-S.

2. C. serpens (H.B.K.) Small. Plant pale green; stems branched at the base, 5-30 $\mathrm{cm}$. long; leaf-blades orbicular to oval, 2-6 $\mathrm{mm}$. long, obtuse or emarginate, rounded or subeordate at the base; involueres nearly $1 \mathrm{~mm}$. high; appendages minute, irregular, erenate; capsules nodding, depressed-globose, $2 \mathrm{~mm}$. broad; seeds $1 \mathrm{~mm}$. long, smooth, obtusely 4-angled, light gray. E. serpens H.B.K. On prairies and plains: Ont.-Fla.-Ariz.-S.D.; Mex. Plain-Son. Je-O.

3. C. revoluta (Engelm.) Small. Plant delicate; stem very slender, 8-20 $\mathrm{cm}$. high; leaves few; blades narrowly linear, 1-3 $\mathrm{cm}$. long, usually about $1 \mathrm{~mm}$. broad, acute; involucres $1 \mathrm{~mm}$. long; glands minute, broader than long, purple; appendages white or reddish, oblong or ovate, obtuse, entire; capsules about 1 $\mathrm{mm}$. long, rather sharply 3 -angled; seeds oblong, less than $1 \mathrm{~mm}$. long, sharply 4-angled, the faces irregularly wrinkled, E. revoluta Engelm. Hillsides: Tex.Colo.-N.M.; n Mex. Son. Jl-Au.

4. C. petaloidea (Engelm.) Small. Plant pale green; stem 1-6 dm. high; leaf-blades linear, oblong or linear-lanceolate, 1-2.5 cm. long, obtuse; involueres oblong-campanulate, $2 \mathrm{~mm}$. long; glands about as long as the lobes; appendage white, reniform, ovate or suborbicular, entire or undulate; capsules globosereniform, fully $2 \mathrm{~mm}$. long; seeds oblong-ovoid, nearly $2 \mathrm{~mm}$. long, ash-colored, 

minutely pitted, nearly terete. E. petaloidea Engelm. Plains, in sandy soil:
Ia.-Mont.-Tex. Plain. Jl-S.

5. C. Parryi (Engelm.) Rydb. Plant pale; stems slender, about $1 \mathrm{dm}$. high; leaf-blades linear, acute or acutish at both ends, 1-2 cm. long, 1-2 mm. wide, rolled inward when drying; involucres $1.5-2 \mathrm{~mm}$. long; appendages unequal, small, greenish, truncate; capsules sharp-angled; seeds $1.5 \mathrm{~mm}$. long, ovate. $E$. Parryi Engelm. Loose sand: se Utah-Nev. L. Som.

6. C. flagelliformis (Engelm.) Rydb. Plant glabrous, pale; stems prostrate or ascending, branched, 1-4 dm. long; leaf-blades linear or oblong-linear, entire, acutish at both ends, $8-15 \mathrm{~mm}$. long, $2 \mathrm{~mm}$. wide; involucres broadly campanulate; glands 2-4, concave; appendages obsolete or a mere margin; capsule broadly triangular; seeds gray, acute. Sandy valleys: N.M.-Colo.-Utah-Ariz. Son.

7. C. albomarginata (T. \& G.) Small. Plant glabrous; stems diffusely branched from the base, $2-15 \mathrm{~cm}$. long; leaf-blades suborbicular or ovate-orbicular, 4-8 mm. long, truncate or subcordate at the base; involucres fully $1 \mathrm{~mm}$. high; glands transversely oval; appendages irregular, entire or lobed; capsule globoseovoid, $2 \mathrm{~mm}$. long, sharply 3 -angled; seeds oblong-ovoid, $1-1.3 \mathrm{~mm}$. long. $E$. albomarginata T. \& G. Dry soil: Tex.-Colo.-Utah-Calif.; Mex. Son. Mr-N.

8. C. Greenei (Millsp.) Rydb. Perennial from a woody root; stems numerous, prostrate, diffuse, branched, 1-2 $\mathrm{cm}$. long; leaves 4-7 mm. long and nearly as broad, glabrous, very oblique; involueres $1.5-2.5 \mathrm{~mm}$. long; glands thick, purple; appendages thick, minutely 2-lobed; capsules $2.5-3 \mathrm{~mm}$. thick; seeds ovoid, white, angled. E. Greenei Millsp. Confused with C. Fendleri. Dry or sandy plains: Neb.-Wyo.-Colo.-Ida. Plain-Submont. Je-Au.

9. C. Fendleri (T. \& G.) Small. Plant cespitose, usually pale green; stems erect or ascending, about $1 \mathrm{dm}$. high; leaf-blades ovate to lance-ovate, $4-6 \mathrm{~mm}$. long, 2-5 mm. wide; involucres $1.5-2.5 \mathrm{~mm}$. high; appendages yellowish or purplish, often crenate-toothed; capsule $3 \mathrm{~mm}$. in diameter; seeds ovoid, $1.5 \mathrm{~mm}$. long. E. Fendleri T. \& G. Plains: Tex,-Ariz.-Utah. Son. Ap-O.

10. C. lata (Engelm.) Small. Stems branched from a woody root, spreading or ascending, $5-15 \mathrm{~cm}$. long, pubescent; leaf-blades ovate to lanceolate, $5-10$ $\mathrm{mm}$. long, canescent-pubescent, revolute-margined; involucre $1 \mathrm{~mm}$. long; appendages narrowly crescent-shaped, undulate; capsule rounded 3 -angled, $2 \mathrm{~mm}$. thick; seeds oblong, $1.5 \mathrm{~mm}$. long, 4-angled and transversely wrinkled. $E$. lata Engelm. Plains: Kans.-Tex.-N.M.-Colo. Son.

11. C. glyptosperma (Engelm.) Small. Plant pale green, glabrous; stem $0.5-4 \mathrm{dm}$. long; leaf-blades oblong, linear-oblong, or rarely ovate, $2-12 \mathrm{~mm}$. long, obtuse or subcordate at the base, serrulate towards the apex; involucres $1 \mathrm{~mm}$. long, with 4 dark ribs; appendages narrow, erescent-shaped, often crenulate; capsule less than $2 \mathrm{~mm}$. thick; seeds oblong, $1 \mathrm{~mm}$. long, ash-colored, strongly 4-angled. E. glyptosperma Engelm. Sandy soil: Ont.-Mo.-Tex.-Mex.B.C. Plain-Submont. My-S.

12. C. rugulosa (Engelm.) Rydb. Plant light green; leaf-blades oblong, elliptic, or oval, 5-8 mm. long, semi-cordate at base, serrulate above the middle; involucres turbinate-campanulate, $1 \mathrm{~mm}$. long; appendages whitish, broadly crescent-shaped or semi-orbicular, usually lobed; capsule $1.5-2 \mathrm{~mm}$. thick; seeds oblong-ovoid, obtusely angled, ashy, with purplish pits, nearly $1 \mathrm{~mm}$. long. $E$. serpyllifolia rugulosa Engelm. Sandy soil: s Calif.-Wyo.-Colo. Je-O.

13. C. serpyllifolia (Pers.) Small. Plant dark green or reddish; stems 1-4 $\mathrm{dm}$. long; leaf-blades oblong or spatulate, $3-12 \mathrm{~mm}$. long, obtuse or retuse, appendages narrow, crescent-shaped, lobed; capsules $2 \mathrm{~mm}$. broad; seeds ovoid, hardly $1 \mathrm{~mm}$. long, obtusely 4-angled. E. serpyllifolia Pers. Plains and in dry soil: Mich.-Tex.-Calif.-B.C.-Alta.; Mex. Plain-Submont. Ap-O.

14. C. albicaulis Rydb. Plant pale green; stems straw-colored or light greenish yellow, shining; leaf-blades linear, minutely callous-toothed towards the apex, $1-1.5 \mathrm{~cm}$. long, $2-3 \mathrm{~mm}$. wide; involucres about $1 \mathrm{~mm}$. fong, turbinate 
appendages white, crescent-shaped, crenulate; pod $2 \mathrm{~mm}$. thick; seeds light olivebrown, oblong, acutely 4-angled, $1.3-1.5 \mathrm{~mm}$. long, less than $0.5 \mathrm{~mm}$. broad. $E$. albicaulis Rydb. Cultivated or sandy soil: Neb.-Mont.-N.M. Plain. Jl-Au.

15. C. maculata (L.) Small. Plant dark green; stems 5-40 cm. long, often dark red, villous; leaf-blades oblong or ovate-oblong, 4-16 mm. long, more or less serrate, usually blotched, oblique, semi-cordate at base; involucres $1 \mathrm{~mm}$. long; appendages semiorbicular, white, crenulate; capsules about $2 \mathrm{~mm}$. thick, pubescent; seeds ovoid-oblong, less than $1 \mathrm{~mm}$. long, obtusely angled, ash-colored, minutely pitted and inconspicuously transversely wrinkled. $E$. maculata L. Dry ground and waste places: Ont.-Fla.-Tex.-Wyo.; introduced in Calif. Plain. $\mathrm{Mr}-\mathrm{O}$.

16. C. stictospora (Engelm.) Small. Plant yellowish green; stems $5-30 \mathrm{~cm}$. long, villous; leaf-blades oblong to suborbicular, densely villous, 4-6 mm. long, obtuse, dentate-serrate above the middle; involucres campanulate, $1 \mathrm{~mm}$. high; appendages narrow, crescent-shaped; capsules $1.5-2 \mathrm{~mm}$. in diameter; seeds narrowly ovoid, $1.2-1.5 \mathrm{~mm}$. long, pointed, pitted, ash-colored, sharply angled. E. stictospora Engelm. Dry soil: Kans.-Colo.-Ariz.-Tex.-Mex. Son. Ap-N.

\section{ZYGOPHYLLÍDIUM Small. SPURge.}

Annual herbs, with erect, forking stems. Leaves mostly opposite, narrow, equilateral, not oblique at the base. Stipules gland-like, often obsolete. Involucres short-peduncled in the upper forks. Glands 5, broader than long, with petal-like appendages. Capsule long-pedicelled, 3-lobed. Seeds terete, narrowed upwards, more or less papillose.

Leaves entire; appendages of the glands triangular-ovate.

Leaves serrate; appendages of the glands semi-orbicular.

1. Z. hexagonum.

2. Z. exstipulatum.

1. Z. hexagonum (Nutt.) Small. Plant yellowish green; stem slender, 1-5 $\mathrm{dm}$. high, with ascending almost filiform branches; leaves linear, oblong, or lanceolate, short-petioled; involucres $2-3 \mathrm{~mm}$. long, ciliate; appendages green or whitish; capsule $4 \mathrm{~mm}$. thick; seeds ovoid or oblong, $3 \mathrm{~mm}$. long, terete, papillose. Euphorbia hexagona Nutt. On sandy prairies and river valleys: Ia.Tex.-N.M.-Mont. Plain. Jl-S.

2. Z. exstipulatum (Engelm.) Woot. \& Standl. Plant light green; stem erect, branched, glabrous, 1-3 dm. high; leaf-blades linear to lanceolate or on the branches ovate, sharply serrate, 1-3 cm. long, glabrous; involucres fully 1 $\mathrm{mm}$. high; appendages white, 2-4-lobed; capsule rounded, $3 \mathrm{~mm}$. thick; seeds ash-colored, tubercled and with $2-3$ cross ridges, round-angled, $2 \mathrm{~mm}$. long. $E$ : exstipulata Engelm. E. Aliceae A. Nels. Dry regions: Wyo.-Tex.-Ariz. Son.-Submont. Au-S.

\section{LEPADÈnia Raf. SnOW-ON-THe-Mountain.}

Annual herbs, with erect stems. Leaves scattered below the umbel-like inflorescence, often very showy and petal-like in the inflorescence. Stipules fugaceous. Involucres campanulate; lobes fimbriate. Glands 5, peltate, with pink or white petal-like appendages. Capsule 3-lobed, pubescent, round-lobed. Seeds narrowed upwards, reticulate. [Dichrophyllum K1. \& Garke.]

1. L. marginata (Pursh) Niewl. Stout annual; stem 3-9 dm. tall, usually pilose; leaves ovate or obovate, $2-9 \mathrm{~cm}$. long, sessile; bracts large, white-margined; involucres campanulate, $4 \mathrm{~mm}$. long, usually pubescent; appendages reniform, white; capsule depressed-globose, $6 \mathrm{~mm}$. in diameter, usually pubescent; seeds ovoid-globose, terete, $4 \mathrm{~mm}$. long, dark ash-colored, reticulate-tuberculate. $E$. marginata Pursh. Dicrophyllum marginatum (Pursh) Kl. \& Garke. Prairies, plains, and river valleys: Minn.-Tex.-Colo.-Mont.; introduced eastward. Plain-Submont. JI-S.

\section{TITHÝMALUS (Tourn.) Adans. SpURge.}

Annual or perennial herbs, rarely shrubby, with simple or branched stems. Leaves below the inflorescence scattered, without stipules, entire or toothed, 
often broadened upwards. Bracts of the umbel-like inflorescence different from the stem-leaves. Involucres sessile or peduncled; lobes often toothed. Glands 4, transversely oblong, reniform, or crescent-shaped, with the horn-like appendages pointing upwards. Capsule 3-lobed; lobes rounded, acute or keeled. Seeds pitted.

Leaves entire; glands of the involucres with processes, except in the first species.

Perennials with a woody base; processes short and blunt, or none.

Stem-leaves linear; capsule rough; seeds smooth.

1. T. Cyparissias.

Stem-leaves from oblong or oblanceolate to orbicular; capsule smooth or slightly wrinkled; seeds pitted.

Glands crenulate, obscurely horned; leaves small, ascending.

2. T. luridus.

Glands distinctly horned; horns larger than the teeth (if any) between them; leaves large, spreading.

Bracts rhombic-ovate, cuspidate; stem rather slender. 3. T. philorus.

Bracts rhombic-reniform, mucronate; stem stout. 4 . T. robustus.

Annuals or perennials by means of sobols (suckers); processes of the glands long and horn-like.

Seeds with small deep pits; leaves very thin.

Seeds with broad shallow pits; leaves firm.

5. T. commutatus.

6. T. mancus.

Leaves distinctly serrulate; plants annual or biennial; glands without processes.

Upper stem-leaves merely sessile; bracts manifestly longer than broad.

7. T. arkansanus.

Upper stem-leaves with small auricles at the base; bracts mostly broader than long.

8. T. missouriensis.

1. T. Cyparissias (L.) Lam. Bright green, cespitose perennial; stems erect, usually simple, $2-3 \mathrm{dm}$. high, very leafy; leaves $1.5-3 \mathrm{~cm}$. long, $0.5-3 \mathrm{~mm}$. broad; bracts reniform or nearly orbicular; involueres $2 \mathrm{~mm}$. long; glands crescentshaped; appendages none; capsule subglobose, $3 \mathrm{~mm}$. thick; seeds oblong, $2 \mathrm{~mm}$. long. E. Cyparissias L. Waste places and around dwellings: Mass.-Va.Colo.-Mont.; escaped and nat. from Eu. My-O.

2. T. luridus (Engelm.) Woot. \& Standl. Stems several from the woody caudex, 1.5-3 dm. high, strict, very leafy; leaves oblanceolate or obovate, obtuse or mucronate, $8-15 \mathrm{~mm}$. long; bracts oblanceolate to rounded; involucres $2 \mathrm{~mm}$. long, hirsute within; glands transversely oblong; capsule $3 \mathrm{~mm}$. thick; seeds cylindric-ovoid, $2.4 \mathrm{~mm}$. long. E. lurida Engelm. Arid regions: N.M. - s Utah -Ariz. Son. Je-Jl.

3. T. philorus Cockerell. Glabrous, cespitose perennial; stems branched, erect, 1-3 dm. high; leaves ovate, lanceolate, or broadly oval, $0.5-2 \mathrm{~cm}$. long; involucres $2 \mathrm{~mm}$. high; glands $0.5 \mathrm{~mm}$. long, $1 \mathrm{~mm}$. wide; capsule depressed-ovoid, $3 \mathrm{~mm}$. high, $3.5 \mathrm{~mm}$. wide; seeds ovoid-oblong, $2 \mathrm{~mm}$. long, ash-colored. $E$. montana Engelm., not Raf. Mountains: Colo.-Utah-Mex.-Tex. Son.Submont. Mr-JI.

4. T. robustus (Engelm.) Small. Robust, cespitose perennial; stems 1-3 dm. high; usually glabrous; stem-leaves oblong to broadly ovate, $1-2 \mathrm{~cm}$. long, often nearly as broad; involucres $2.5 \mathrm{~mm}$. high, $1.5 \mathrm{~mm}$. wide, hirsute inside; glands often dentate between the short horns, 1-2 mm. wide; capsule depressedovoid, 4-4.5 $\mathrm{mm}$. wide; seeds ovoid, $2.3 \mathrm{~mm}$. long, with shallow pits. E. montana robusta Engelm. Mountains: S.D.-Mont.-Ariz.-N.M.-Neb. Plain -Submont. My-Jl.

5. T. commutatus (Engelm.) Kl. \& Garke. Annual or perennial by means of shoots from the decumbent stems, $1.5-3 \mathrm{dm}$. high, branched at the base; stem-leaves obovate, obtuse or retuse, $0.5-3 \mathrm{~cm}$. long; those of the sterile branches oblanceolate; bracts triangular-reniform; glands $1-1.5 \mathrm{~mm}$. wide, yellow or brown when old; horns white, twice as long; capsule $3 \mathrm{~mm}$. thick; seeds subglobose. E. commutata Engelm. River valleys and sandy soil: Pa.-N.C.Tex.-Wis.-Mont. Plain. My-Л.

6. T. mancus (A. Nels.) Heller. Annual; stems 1-3 dm. high, branched at the base, erect, or decumbent below; leaves spatulate or obovate, obtuse, 1-2 $\mathrm{cm}$. long; bracts ovate-reniform, connate especially on the outside, 1-2 cm. wide and more than half as long; glands $2 \mathrm{~mm}$. wide, with divergent horns; capsule $4 \mathrm{~mm}$. long, somewhat broader; seeds oblong-ovoid. E. manca A. Nels. Valleys: Colo.-Ariz. 
7. T. arkansanus (Engelm. \& Gray) Kl. \& Garke. Annual or biennial; stem slender, $2-5 \mathrm{dm}$. high, branched; leaves few, cuneate or spatulate, acute, serrulate, 1-3 cm. long, 5-10 $\mathrm{mm}$. wide; bracts broadly triangular-ovate to oblong, mucronate, serrulate, the larger $1 \mathrm{~cm}$. wide, $1-2 \mathrm{~cm}$. long; involucres $1 \mathrm{~mm}$. high; glands transversely elliptic, yellow, less than $1 \mathrm{~mm}$. wide; capsule depressed globose, verrucose, 2.5-3 mm. wide; seeds ovoid-lenticular, brown or purplish, wrinkled, reticulate, nearly $1.5 \mathrm{~mm}$. long. $E$. arkansana Engelm. \& Gray. Plains and sandy places: N.D.-Mo.-Ala.-Tex.-Ariz.-Wyo.; Mex. Plain. Ap-Je.

8. T. missouriensis (Norton) Small. Annual or biennial, olive-green; stem 3-6 dm. high, stout; stem-leaves spatulate, $2-3.5 \mathrm{~cm}$. long, obtuse, serrate to below the middle; bracts ovate, inequilateral, acute, serrate; involucres less than $2 \mathrm{~mm}$. high; glands transversely oblong; capsules $3-3.5 \mathrm{~mm}$. wide, bearing elongated warts; seeds ovoid, distinctly and regularly reticulate, purplishbrown. E. arkansana missouriensis Norton. Dry plains: Minn.-Kans.-N.M. -Wash. Plain. My-Jl.

\section{POINSÉTtita Graham. Spurge.}

Annual or perennial herbs, or shrubby plants, with green or partially colored foliage. Leaves alternate below, opposite above. Stipules gland-like. Involucres in axillary or terminal cymes, or solitary; lobes fimbriate. Glands fleshy, solitary, or rarely 3 or 4 , without appendages. Capsule 3 -lobed, lobes rounded. Seeds narrowed upwards, tuberculate.

Gland or glands of the involucre stalked; bracts and upper leaves slightly if at all discolored.

Seeds not prominently tubercled; glands of the involucre 3-4; leaf-blades linear or linear-lanceolate.

the the 1. Puphusperma. eeds prominently tubercled; gland of the involuere solitary: lanceolate (linear-lanceolate only in one variety). $\quad 2$. P. dentata.

Gland of the involucre sessile or nearly so; bracts and upper leaves discolored at the base;

leaf-blades very variable, the upper usually fiddle-shaped. $\quad 3$. P. heterophylla.

1. P. cuphusperma (Boiss.) Small. Simple annual; stem 2-4 dm. high, more or less pubescent, especially upwards, erect; leaf-blades $2-8.5 \mathrm{~cm}$. long, entire or denticulate; involucres erowded at the ends of the branches, almost 4 $\mathrm{mm}$. long; capsule $5 \mathrm{~mm}$. in diameter; seeds narrowly ovoid, $3 \mathrm{~mm}$. long, irregularly 4-angled, ridged and slightly tuberculate. E. cuphusperma Boiss. Plains and prairies: S.D.-Colo.-Ariz.-Tex.-Mex. Son.-Submont. Au$\mathrm{S}$.

2. P. dentata (Michx.) Small. Pubescent annual; stem erect or ascending, $2-4 \mathrm{dm}$. high, somewhat woody at the base, branched; leaf-blades from ovate to nearly linear or orbicular-oblong, $1-9 \mathrm{~cm}$. long, coarsely dentate; involucres about $3 \mathrm{~mm}$. long; capsule glabrous, 4-5 mm. in diameter; seeds ovoid-globose, ash-colored, inconspicuously 4-angled. E. dentata Michx. Dry soil: S.D.Pa.-La.-Mex. Plain-Submont. Je-S.

3. P. heterophylla (L.) Small. Bright green annual or biennial, pubescent or nearly glabrous; stem erect, $3-10 \mathrm{dm}$. high, woody below; leaf-blades linear to orbicular, the lower ones often entire, the upper undulate, sinuate, or dentate, the uppermost often fiddle-shaped and like the bracts blotched with red; involucres $3 \mathrm{~mm}$. long, with 5 ovate or oblong laciniate lobes, one sinus bearing a sessile gland; capsule glabrous or minutely pubescent, $6 \mathrm{~mm}$. broad; seeds oblongovoid, 3-4 mm. long, transversely wrinkled and tuberculate. E. heterophylla L. Sandy soil: Ill.-Fla.-Tex.-Mont.; Mex. and trop. Am. Plain. Ja-D.

\section{Family 75. CaLlitrichaceae. Water Starwort Family.}

Small aquatic caulescent annuals or perennials, with opposite, entire leaves, of ten crowded towards the end of the branches. Flowers inconspicuous, solitary in the axils of the leaves, polygamous. Calyx wanting. Corolla none. Stamens solitary; anthers 2-celled; cells sometimes con- 
fluent. Pistils solitary; ovary 4-celled; styles united in pairs. Fruit leathery, indehiscent, 4-lobed, 4-seeded. Endosperm fleshy, embryo straight, axile, terete.

\section{Callittriche L. Water Starwort.}

Characters of the family.

Upper floating leaves obovate or spatulate, 3-nerved; flowers subtended by a pair of bracts.

All leaves linear, 1-nerved; flowers bractless.

1. C. palustris.

1. C. palustris L. Aquatic annual; stems usually floating, 2-30 cm. long; submerged leaves sessile, linear, 1-nerved, 1-1.5 $\mathrm{cm}$. long; floating leaves petioled; blades 5-10 mm. long; fruit obovoid, $1.5 \mathrm{~mm}$. long, slightly notched, grooved and winged, especially above. C. verna L. Shallow water: Newf.-Fla.Calif.-Alaska; Mex., S. Am., and Eurasia. Plain-Mont. Je-Au.

2. C. autumnalis L. Submerged aquatic annual; stem slender, $1-4 \mathrm{dm}$. long; leaves all linear, retuse or bifid at the apex, $0.5-2 \mathrm{~cm}$. long; fruit orbicular or rounded ellipsoid, 1-2 mm. in diameter, grooved and winged. C. bifida (L.) Morong. In water: Que.-N.Y.-Colo.-Utah-Ore.;Eu. Plain-Mont. JI-S.

\section{Family 76. Cellastraceae. Staff-tree Family.}

Shrubs, trees, or twining vines, sometimes spiny, with opposite, whorled, or alternate, simple leaves, with or without stipules. Inflorescence normally cymose. Flowers perfect, polygamous, or dioecious. Sepals 4 or 5 , imbricate. Petals 4 or 5, usually inserted under the fleshy disk, imbricate. Stamens 4 or 5 under the disk, on the margin thereof, or on top of it. Gynoecium of a compound pistil. Ovary 2-5-celled; style short or wanting; stigma 2-5-lobed. Fruit a capsule, drupe, or berry. Seeds often surrounded by a brightly colored aril.

Stamens as many as the petals and sepals.

Fruit a loculicidal capsule; seeds with an aril.

Shrubby vines, with alternate leaves; ovary free from the disk; aril crimson.

Shrubs, with opposite leaves; ovary immersed in the disk. Capsule 3-5-celled, 3-5-lobed; aril orange or scarlet. Capsule 2-celled, unlobed; aril white or nearly so.

Fruit indehiscent, by abortion 1-seeded; aril wanting. Stamens more numerous than the sepals or petals; ovary 1-celled.

1. Celastrus.

2. EUONYMUS.

3. PACHYSTIMA.

4. MoRTONIA.

5. Forsellesia,

\section{Celiástrus L. Waxwork, Shrubby Bittersweet, Staff-tree.}

Usually twining vines or shrubs, Leaves alternate, entire or toothed; stipules minute. Flowers in axillary or terminal racemes, or panicles. Sepals 5 . Hypanthium urn-shaped. Petals 5, inserted under the disk, which is cup-shaped, 5-lobed. Stamens 5, inserted in the sinuses of the disk. Gynoecium of a compound pistil; ovary 2-4-celled, sometimes incompletely so; style short and stout; stigma 2-4-lobed. Ovules 2 in each cavity, erect. Capsule globose or ellipsoid, leathery, 2-4-celled, loculicidal. Seeds 1 or 2 in each cavity, surrounded by a scarlet aril.

1. C. scandens L. A climbing shrub, usually with twining branches; leafblades elliptic, oval, oblong, or ovate, 6-10 $\mathrm{cm}$. long, acuminate, crenate, glabrous or nearly so; petals oblong or obovate, greenish, erose; capsule subglobose, $1 \mathrm{~cm}$, in diameter, finely wrinkled, orange, opening by 3 valves. Along streams and in thickets: Que.-Fla.-N.M.-Mont. Plain. My-Je.

\section{EUONYMUS (Tourn.) L. BuRning Bush, Wahoo.}

Shrubs or trees, commonly with 4-angled branches. Leaves opposite, entire or toothed, deciduous; stipules caducous. Flowers solitary or cymose. Sepals 4 or 5 . Petals as many, inserted under the disk. Stamens 4 or 5 , inserted on the disk; filaments very short; anthers 2-celled. Disk flat, 4- or 5-lobed. Gynoe- 
cium of a compound pistil; ovary 3-5-celled; stigma with as many inconspicuous lobes; ovules 2 in each cavity, ascending. Capsule 3-5-lobed, angled or winged, loculicidal. Seeds 2 in each cavity, surrounded by an orange or scarlet aril.

1. E. atropurpureus Jacq. A shrub or small tree, 1-8 $\mathrm{m}$. high; leafblades elliptic to ovate or obovate, $5-16 \mathrm{~cm}$. long, acuminate, puberulent, crenateserrate; flowers trichotomously cymose; corolla dark purple; petals 4 , suborbicular, 2-3 mm. long; capsule 4-lobed, pendulous, not warty, depressed, the lobes wing-like; seeds 8-10 mm. long, with a scarlet aril. River banks: N.Y.Fla.-Okla.-Mont. Plain. Je.

\section{PACHÝSTIMA Raf. Mountain Lover.}

Low, depressed evergreen shrubs. Leaves opposite, leathery, toothed or entire. Flowers solitary or clustered in the axils of the leaves. Sepals 4. Petals 4, greenish. Stamens 4, inserted under the flat, 4-angled disk; filaments short. Ovary 2-celled; style very short; stigma obscurely 2 -lobed. Ovules 2 in each cavity, erect. Capsule 2-celled, somewhat flattened, not lobed, 2-valved. Seeds surrounded by a white aril.

Leaves decussately spreading; petioles abruptly contracted into the midrib; petals nearly as broad as long; stigma rounded. 1 . P. Myrsinites.

Leaves arranged in one plane; petioles thickened, the thickening continued into the

midrib; stigma 2-lobed.
Stigma slightly 2-lobed; anthers equalling the filaments.

Stigmas deeply 2-cleft; anthers much shorter than the filaments.

2. P. macrophylla.

3. P. Schaefferi.

1. P. Myrsinites (Pursh) Raf. Shrub 2-5 dm. high; branches usually ascending, brown, with 4 dark ridges; leaf-blade oval or elliptic, with dentate, thickened, and revolute margins, yellowish green, $1-3 \mathrm{~cm}$. long; lateral veins 3-4 pairs; flowers numerous, odorless; sepals broadly oval, with faint midribs, obtuse; petals oval or ovate; filaments twice as long as the anthers. Wooded hills and mountains: Alta.-N.M.-Calif.-B.C. Submont.-Mont. My-Au.

2. P. macrophyllum Farr. Shrub 4-6 dm. tall; branches cinnamonbrown, with 4 dark brown ridges, loosely spreading; leaf-blades oval-elliptic or oblanceolate, $2-4 \mathrm{~cm}$. long, with 6 pairs of lateral veins, bluish green above, bright green beneath; margins serrate and revolute; flowers few; sepals ovate, with prominent midrib, pointed; petals ovate; filaments equalling the anthers. Mountains: B.C. Mont. My-Je.

3. P. Schaefferi Farr. Shrub about $5 \mathrm{dm}$. high; branches spreading, dark brown; leaf-blades lanceolate to linear-lanceolate, the veins 6-7 pairs, blunttoothed above, not revolute, bright green; flowers fragrant, numerous; sepals and petals as in the preceding; filaments 1.5-2 times as long as the anthers. Mountains: B.C. My-Je.

\section{MORTÒNIA A. Gray.}

Intricately branched low shrubs, with often hispid twigs. Leaves alternate, thick, entire, 1-nerved, with abortive stipules. Flowers cymose or paniculatecymose, perfect. Sepals and petals 5. Stamens 5. Pistil compound; ovary 5-celled; style short, terminal; stigma 5-lobed; ovules 2 in each cell. Fruit dry, oblong, 1-celled and 1-seeded by abortion; seed filling the cavity, without an aril.

1. M. utahensis (Coville) Rydb. A shrub about $1 \mathrm{~m}$. high, with spreading branches and yellow bark; twigs scabrous-hispidulous; leaf-blades thick, scabrous-hispidulous, oval, 8-13 $\mathrm{mm}$. long, entire; panicles narrow, raceme-like, $3-5 \mathrm{~cm}$. long; sepals lanceolate-triangular, $2 \mathrm{~mm}$. long; petals $3 \mathrm{~mm}$. long, broadly obovate, crenulate on the margins, white. Arid regions: Utah-Nev.-Ariz. Son.

\section{FORSELLESIA Greene.}

Small shrubs, with green, glabrous, spinescent branches. Leaves alternate, small, entire, with adnate setaceous stipules. Flowers axillary, subsolitary, perfect. Sepals and petals 4-6. Stamens more numerous, usually twice as 
many as the sepals and petals. Gynoecium of a compound pistil; stigma sessile, slightly notched; ovary 1-celled, with 2 basal anatropous ovules. Fruit follicular, 1- or 2-seeded; seeds with a minute aril or caruncle at the base. [Glossopetalon A. Gray.]

Stamens 5-7.

Stamens 10.

1. F. meionandra.

2. F. spinescens.

1. F. meionandra (Koehne) Heller. A low intricately branched spinescent shrub; leaves grayish green, blades up to $15 \mathrm{~mm}$. long, cuneate oblong or oblanceolate; sepals ovate; petals $5-6 \mathrm{~mm}$. long, $2 \mathrm{~mm}$. wide, spatulate. Glossopetalon meionandrum Koehne. Hills: w Colo. Submont. My.

2. F. spinescens (A. Gray) Greene. An intricately branched, spinescent shrub 3-12 dm. high; leaves glaucous, glabrous, oblanceolate or linear-oblanceolate, $5-10 \mathrm{~mm}$. long, acute; sepals oblong-ovate, $2 \mathrm{~mm}$. long; petals narrowly linear, 4-5 mm. long; capsule ovoid, somewhat flattened, strongly striate. $G$. spinescens A. Gray. Mountain ravines and eliffs: Ore--Calif,-Tex.-Colo.; Mex. Son. F-My.

\section{Family 77. ANAChardiaCeae. Sumach Family.}

Polygamous, monoecious, or dioecious, or rarely hermaphrodite shrubs or trees, with alternate, simple or pinnate leaves, without stipules. Inflorescence paniculate, or spicate, or racemose. Flowers regular. Sepals $3-5$, distinct. Petals 3-5, usually inserted on a hypogynous disk, imbricate or rarely valvate. Stamens $3-5$, rarely more, alternate with the petals. Gynoecium of 1 , or 4 or 5 united or nearly distinct carpels; styles united, sometimes distinct; stigmas entire. Fruit a drupe or a berry; seeds solitary.

Drupe with pubescent exocarp; stone smooth.

Drupe with glabrous, smooth exocarp; stone ribbed.

1. RHUS.

2. TOXICODENDRON.

\section{RHÚS (Tourn.) L. SUmach, Skunk-bush.}

Shrubs or trees, not poisonous. Leaves alternate, odd-pinnate, rarely unifoliolate; leaflets more or less toothed. Flowers in terminal panicles, polygamous or dioecious. Sepals commonly 5. Petals as many, imbricate. Ovary 1-celled; ovules pendulous. Drupe red, covered with acid-secreting hairs. Stone smooth. Stamens 5, inserted under the edge or between the lobes of the flattened disk. Flowers greenish white or yellowish.

Leaflets 11-21; inflorescence terminating leafy shoots.

Leaflets light green or yellowish green, rather dull, subsessile.

Leaflets dark green above, shining, strictly sessile.

Leaflets $1-3$, rarely 5; inflorescence axillary.

Leaves densely villous.

Leaves puberulent or glabrous.

Leaves 3-foliolate, rarely 5-foliolate.

Branchlets and leaves puberulent, at least when young. 4. R. trilobata. Branchlets and leaves glabrous, except a few scattered cilia on the petioles
and veins. Leaves 1 -foliolate, or rarely some of them 3 -foliolate with
and a broad terminal one. small lateral leaflets

6. $R$. utahensis.

1. R. cismontana Greene. Shrub 1-2 m. high; branches glabrous, often reddish, somewhat glaucous; leaves $1.5-2 \mathrm{dm}$. long; leaflets $11-15$, usually pallid green, often lighter along the veins, glaucescent beneath, $5-10 \mathrm{~cm}$. long, lanceolate, abruptly acuminate, sharply serrate, thin; panicle about $1 \mathrm{dm}$. long; branches usually spreading, finely pubescent; calyx-lobes $1 \mathrm{~mm}$. long; petals greenish yellow, $2-2.5 \mathrm{~mm}$. long. $R$. sambucina, R. tessellata, R. albida, and $R$. asplenifolia Greene. Along streams: S.D.-Mo.-N.M.-Ariz.-Wyo. Plain-Submont.
My-Jl.

2. R. occidentalis (Torr.) Blankinship. Shrub 1-3 m. high; branches glabrous and glaucous; leaves ascending, often $3 \mathrm{dm}$. long; leaflets 11-21, oblonglanceolate, $6-8 \mathrm{~cm}$. long, sharply serrate up to the long acumination, very glau- 
cous beneath; panicles 1-2 dm. long, branches usually strongly ascending, rather densely pilose; calyx-lobes $1.5 \mathrm{~mm}$. long; petals yellowish, $3 \mathrm{~mm}$. long; fruits $4 \mathrm{~mm}$. wide. $R$. glabra occidentalis Torr. $R$. arguta Greene. $R$. nitens Greene. Along streams: Ore.-B.C.-Mont.-Utah. Son. My-Jl.

3. R. Osterhoutii Rydb. Shrub about $1 \mathrm{~m}$. high; leaves trifoliolate; leaflets sessile, $1-2.5 \mathrm{~cm}$. long, cuneate, 3-5-lobed and some of the Iobes with rounded teeth, dark green above, pale beneath. Schmaltzia pubescens Osterh. Hills: Colo. Submont. Je.

4. R. trilobata Nutt. Shrub $1-2 \mathrm{~m}$. high, blooming before the leaves; leaves trifoliolate, with unpleasant odor; leaflets 1-3 cm. long, dark green above, paler and minutely pubescent beneath, the lateral ones elliptic or cuneateobovate, the terminal one euneate-spatulate, usually more or less 3-lobed and crenate; petals obovate, $2 \mathrm{~mm}$. long; fruit globose, $5-6 \mathrm{~mm}$. thick, more or less densely short-pubescent. Schmaltzia trilobata, S. Bakeri, S. cognata, S. glomerata, S. subpinnata, and S. glabrata Greene. Hills and plains: Sask.-Mo.-Tex.Calif.-Wash. Plain-Submont. Ap-Je.

5. R. oxyacanthoides (Greene) Rydb. Low shrub, about $1 \mathrm{~m}$. high; leaves 3 -foliolate; leaflets obovate-cuneate, or the terminal one rhombic-obovate, rather thin, rounded-crenate, the terminal one $2-4 \mathrm{~cm}$. long, and often 3-lobed, the lateral ones 1.5-3 cm. long; fruit bright red, puberulent. Schmaltzia oxyacanthoides Greene. Hills and cañons: w Colo.-Utah-(? Mont.) Submont. $\mathrm{Ap}-\mathrm{My}$.

6. R. utahensis Goodding. A shrub $1-1.5 \mathrm{~m}$. high, diffusely branched; leaves simple, the blades usually suborbicular or reniform, truncate at the base, crenate, or rarely 3 -lobed, $1.5-3 \mathrm{~cm}$. long, finely pubescent beneath; inflorescence few-flowered; fruit rather large, $5-8 \mathrm{~mm}$. thick, short-pubescent. $R$. canadensis simplicifolia Greene. Schmaltzia simplicifolia and S. affinis Greene. Desert regions: Utah-Ariz.-L. Calif. Son. Ap.

\section{TOXICODÉNDRON (Tourn.) Mill. POISON Ivy, POISON OAK, PoIsON SUMACH.}

Shrubs, trees, or vines, with a resinous sap, poisonous to touch. Leaves alternate, pinnately 3 -several-foliolate, with coarsely toothed or entire leaflets. Flowers polygamous, paniculate. Sepals 4-6, persistent. Petals 4-6, imbricate, yellowish or greenish. Disk annular. Stamens $4-6$ or 10 . Ovary 1-celled; ovules pendulous. Drupe whitish, smooth, shining, glabrous. Stone striately ribbed.

Leaflets thick, the terminal one decidedly longer than broad, its petiolule usually $1-2 \mathrm{~cm}$. long; petals $3 \mathrm{~mm}$. long.
Leaflets thin, the terminal one nearly as broad as long, its petiolule $3-4 \mathrm{~cm}$. long; petals

$2.5 \mathrm{~mm}$. long.

2. T. longipes.

1. T. Rydbergii (Small) Greene. A single-stemmed shrub, usually less than $1 \mathrm{~m}$. high; leaves pinnately 3 -foliolate; leaflets $3-10 \mathrm{~cm}$. long, rhombic-ovate, thick, bright green, strongly veined beneath, glabrous, usually coarsely and broadly toothed; flowers in dense axillary panicles; petals whitish yellow, with greenish veins; fruit depressed-globose, $5-6 \mathrm{~mm}$. in diameter. T. hesperinum Greene, a large form. Hillsides and open woods: S.D.-Kans.-N.M.-Ariz.Ore.-B.C. Plain-Submont. Je-J.

2. T. longipes Greene. Erect single-stemmed shrub; leaves pinnately 3foliolate; leaflets thin, light green, the lateral ones broadly obliquely ovate, $7-10$ $\mathrm{cm}$. long, the terminal one almost orbicular, abruptly short-acuminate, coarsely toothed; inflorescence racemose, lax, rarely with 1 or 2 branches below; petals reflexed, greenish white, with dark veins. Cañons: Utah. Submont. Je.

\section{Family 78. ACERACEAe. Maple Family.}

Shrubs or trees, with opposite, simple or compound leaves, without stipules. Flowers perfect or polygamous, rarely dioecious or monoecious, regular. Sepals 4 or 5, rarely 6-9, imbricate, often colored. Petals of the 
same number, inserted on the margins of an indistinct disk, or very often wanting. Stamens 4-9, often 8. Gynoecium of two united carpels; styles united. Fruit of 2 winged carpels, united below (samaras).

Leaves palmately lobed or rarely palmatedly compound; flowers polygamous or perfect.

Leaves pinnately compound; flowers dioecious.

1. ACER.

2. NegUNDO.

\section{1. ÃCER (Tourn.) L. MAPLe.}

Trees or rarely shrubs. Leaves opposite, petioled, more or less palmately lobed or cleft, rarely palmately compound. Flowers polygamous or rarely perfect, regular, in axillary or terminal racemes or corymbs. Sepals 4 or 5 , rarely 6-9. Disk cup-shaped, lobed, or more commonly obsolete or wanting. Stamens 4-9. Petals as many as the sepals or wanting. Samaras 2, with reticulate wings. Flowers in racemes or corymbs; petals and sepals both present; disk well developed;
lobes of the leaves toothed.

Flowers in long racemes, appearing after the leaves; leaves long-acuminate, with small lateral lobes; petals longer than the sepals.

Flowers corymbose, appearing with the leaves; leaves not long-acuminate, deeply $3-5$-cleft; terminal lobe only slightly larger; petals and sepals greenish, sub-
equal. Bark of the one-year-old branches grayish; leaves and their lobes acuminate, not
dotted beneath.

Sinuses between the leaf-lobes shallow, open; terminal lobe broadly triangularovate.
2. A. Douglasii.

Sinuses between the leaf-lobes deep and narrow; terminal lobe rhombic.

Bark of the one-year-old 3. A. glabrum. inate, with more or less numerous glandular red dots beneath.
inte, not acum-

Flowers in umbels, appearing with the leaves; petals lacking; lobes of the leaves sinuate.

5. A. grandidentatum.

1. A. spicatum Lam. Shrub or small tree, sometimes $10 \mathrm{~m}$. high, with thin smooth bark; twigs somewhat velutinous-puberulent or glabrate in age; leaf-blades longer than broad, cordate, 3-lobed, glabrate above, paler and pubescent beneath; petals linear or spatulate; samaras about $2 \mathrm{~cm}$. long; wings ascending-spreading at about $90^{\circ}$; backs nearly straight. Rocky woods and mountain slopes: Newf.-Ga.-Minn.-Sask. Boreal. My-Je.

2. A. Douglasii Hook. Shrub or small tree, sometimes $10 \mathrm{~m}$. high; twigs glabrous, purplish or red; older branches grayish; leaf-blades broadly cordate in outline, $3-10 \mathrm{~cm}$. long and about as broad, 3-5-lobed, or on young shoots and vigorous twigs sometimes 3 -divided to the base, glabrous on both sides; samaras 3-4 cm. long, ascending, usually incurved on the back; sinus usually rounded. A. subserratum Greene. Hills and mountain sides: Alta.-Wyo.-Ore.-B.C. Submont.-Mont. Ap-Je.

3. A. glabrum Torrey. Usually a small tree, $5-15 \mathrm{~m}$. high; twigs glabrous, reddish; older branches gray; leaf-ble des broadly cordate or rounded-reniform in outline, $4-8 \mathrm{~cm}$. long, 4-10 cm. wide, glabrous, 5-7 lobed, or usually on young shoots and vigorous branches or sometimes on the whole tree 3-divided to the base; samaras $2.5-3 \mathrm{~cm}$. long, usually straight on the back; sinus usually acute. A. neomexicanum Greene. Mountains, usually along streams: S.D.-N.M.Utah-Wyo. Submont.-Mont. My-Je.

4. A. tripartitum Nutt. Shrub 1-5 m. high; twigs reddish, glabrous; leaf-blades rounded-reniform in outline, glabrous above, more or less puberulent beneath, shining, 3-5-lobed or -cleft or sometimes [as in the type specimens] 3parted to the base, the terminal lobe more or less rhombic, coarsely toothed, $2-4 \mathrm{~cm}$. long, 2-5 cm. wide; samaras $2-2.5 \mathrm{~cm}$. long, ascending, incurved on the back, forming with each other a narrow angle. Dry hills: Wyo.-Utah-s

5. A. grandidentatum Nutt. Shrub or rarely a small tree, $5 \mathrm{~m}$. high, with light brown twigs and gray branches; leaves reniform or orbicular in outline, deeply 3-5-lobed, with rounded sinuses, glabrous, pale and velutinous 
beneath, 4-8 $\mathrm{cm}$. long, 5-10 $\mathrm{cm}$. wide; lobes rhombic-lanceolate; hypanthium long-hairy; samaras divergent, about $3 \mathrm{~cm}$. long, forming with each other an angle of about $120^{\circ}$. Cañons: w Tex.-Wyo.-Ida.-Ariz. Son.-Submont. Ap-My.

\section{NEGÚNDo (Ray) Ludwig. Box-eider, Ash-leaved Maple.}

Trees, with light green twigs, widely branching. Leaves opposite, odd-pinnate, usually with toothed leaflets. Flowers dioecious, appearing before the leaves, the staminate in drooping small clusters, the pistillate racemose. Sepals 4 or 5, very small. Petals wanting. Stamens 4 or 5 . Disk obsolete. Samaras 2, with reticulate wings. [Rulac Adans.]

Branchlets glabrous, usually with a bloom; anthers acute, tapering into a tip one-half to one-fourth $\mathrm{mm}$. long.

Branchlets pubescent; anthers obtuse, merely mucronate.

Wings of the carpels terminal, scarcely at all decurrent on the body; racemes seldom over $1 \mathrm{dm}$. long in fruit.

2. $N$, interius.

Wings of the carpels extending down on the inner side almost to the bottom of the sinus; racemes in fruit $1.5-2 \mathrm{dm}$. long.

3. $N$, Kingii.

1. N. Nuttallii (Nieuwl.) Rydb. Tree up to $15 \mathrm{~m}$. high, with spreading branches; bark of the twigs and younger branches light green; leaflets usually 3 , lanceolate or ovate, long-acuminate, usually rounded at the base, coarsely toothed or often more or less lobed, sparingly hairy or in age glabrate above, more densely so beneath, and often with tufts of hairs in the axils of the veins; fruit glabrous, gradually tapering below; wing scarcely decurrent. River valleys: Mich.-Ia.-Kans.-Colo.-Mont.; often cultivated. Plain. Ap-My.

2. $\mathbf{N}$. interius (Britton) Rydb. Tree up to $12 \mathrm{~m}$. high; leaflets lanceolate or ovate, or the terminal rhombic, 5-12 cm. long, long-acuminate, usually lobed, coarsely toothed, otherwise as in the preceding; fruit as in the preceding. $A$. interior Britton. Along streams and in cañons, mostly in the foot-hills and mountains: Sask.-Man.-Neb.-N.M.-Ariz.-Mont. Plain-Submont. My-Je.

3. N. Kingii (Britton) Rydb. Tree perhaps $10 \mathrm{~m}$. high; twigs grayish green; leaflets lanceolate, long-acuminate, $5-10 \mathrm{~cm}$. long; pubescence as in the preceding; fruit glabrous; wings less spreading than in the two preceding. $A$. Kingii Britton. Cañons: Utah-(? Ariz.). Submont.-Mont. My-Je.

\section{Family 79. RHAMnACEAE. Buckthorn Family.}

Shrubs or trees, with alternate, rarely opposite, simple, usually severalribbed leaves and small stipules. Flowers greenish, perfect or polygamous, rarely dioecious. Sepals 4 or 5 , valvate. Hypanthium somewhat developed, lined or filled with a thickened disk. Petals 4 or 5 . Stamens of the same number, inserted on the disk, opposite the petals. Gynoecium of 2 or 3 united carpels; ovary 2- or 3-celled, partly immersed in the disk. Styles and stigmas more or less united. Fruit a capsule, a drupe, or rarely a samara.

Fruit pulpy; petals small, clawless, or wanting; stigmas usually 2. Fruit dry; petals hooded and long-clawed; stigmas 3 .

1. RHAMNUS.

2. CEANOTHUS.

\section{RHÁMNUS (Tourn.) L. BUCKTHORN.}

Shrubs or trees, unarmed, or with spinose branchlets. Leaves alternate, entire or toothed, several-ribbed; stipules deciduous. Flowers perfect or polygamo-dioecious, axillary, often clustered, in racemes, cymes or umbels. Sepals 4 or 5 , keeled within. Disk cup-shaped, lining the hypanthium. Petals 4 or 5 , or wanting, clawless, inserted on the margin of the disk. Stamens of the same number, on the edge of the disk; filaments very short. Ovary 2-4-celled; styles 2-4, united at the base. Drupe berry-like, with 3-4 nutlets. Endosperm fleshy.

Flowers solitary or in sessile umbels, usually polygamo-dioecious or dioecious; winterbuds scaly.

Shrub spinose; introduced species.

1. R. carthartica. 
Shrub not spinose; native species.

Flowers 4-merous; petals present; seeds 2, grooved; leaves not strongly veiny. Leaves broadly lanceolate, acuminate with a blunt apex. $2 . R$. lanceolata. Leaves narrowly lanceolate, not acuminate.

3. R. Smithii.

Flowers 5-merous, apetalous; seeds 3 , scarcely grooved; leaves strongly veiny.

Flowers in peduncled umbels or corymbs, perfect; winter-buds not scaly, pubescent. Peduncles longer than the pedicels; leaves merely callous-denticulate. 5 . R. Purshiana.

Peduncles shorter than the pedicels, sometimes almost none; leaves finely but distinctly serrate.

6. R. betulaefolia.

1. R. carthartica L. Shrub or low tree, $2-7 \mathrm{~m}$. high, with-rough bark; leaves petioled; blades glabrous or nearly so, broadly ovate or oval, $3-6 \mathrm{~cm}$. long, crenate; flowers dioecious, greenish, 4-merous; petals lanceolate; drupe globose, about $8 \mathrm{~mm}$. in diameter; seeds $3-4$, grooved. Around dwellings: Ont.-Va.Colo.; cult. and occasionally escaped; native of Eu. Je.

2. R. lanceolata Pursh. Unarmed shrub or small tree; leaves short-petioled; blades lanceolate or ovate-lanceolate, acuminate, with a blunt apex, minutely crenate, glabrous above, puberulent beneath, $3-8 \mathrm{~cm}$. long; flowers $2-3$ in the axils of the leaves, greenish, dioecious; petals lanceolate, shorter than the sepals; drupe black, $6 \mathrm{~mm}$. in diameter. Wet ground: Pa.-Ala.-Tex.-Neb. Plain. My-Je.

3. R. Smithii Greene. Unarmed shrub, with densely leafy branches and yellowish or grayish bark; leaves short-petioled; blades yellowish green, lanceolate, obtuse or acutish, finely crenate, $2-4 \mathrm{~cm}$. long; flowers greenish, dioecious; drupe subglobose, 6-7 $\mathrm{mm}$. in diameter, black. Mountain valleys: Colo.N.M.-Ariz.-Utah. Submont. Je.

4. R. alnifolia L'Her. Unarmed shrub, 1-2 m. high; branches gray, finely pubescent; leaves short-petioled; blades oval or elliptic, from obtuse to somewhat acuminate, coarsely crenate-serrate, finely pubescent when young, soon glabrate, $3-10 \mathrm{~cm}$. long, strongly veined; flowers solitary or 2 or 3 umbellate; sepals spreading; drupe black, 7-8 mm. in diameter. Swamps: Me.-N.J.Wyo.-n Calif.-B.C. Submont. My-Je.

5. R. Purshiana DC. Unarmed shrub or small tree, $3-10 \mathrm{~m}$. high; leaves short-petioled; blades broadly oval, rounded or subcordate at the base, obtuse or abruptly short-acuminate, $3-12 \mathrm{~cm}$. long, short-villous beneath and on the veins above; flowers 5-merous, perfect; petals minute; drupe depressed-globose, purple or black, 3-seeded; seeds plano-convex, without a groove. Woods: Mont.-Calif.-B.C. Submont. My-Je.

6. R. betulaefolia Greene. Unarmed low shrub, 1-3 m. high; branches pubescent; leaves short-petioled; blades oval or elliptic or obovate-lanceolate, acute or obtuse at the apex, 5-10 $\mathrm{cm}$. long, puberulent and in age glabrate above, pubescent beneath, especially on the strong veins; flowers corymbose, few; drupe purplish black, $8 \mathrm{~mm}$. broad, 3-seeded. Under cliffs and along streams: N.M.-Ariz. - s Utah. Son.-Submont. My-Jl.

\section{Ceanòthus L. New Jersey Tea, Mountain Laurel.} Snow Brush, Deer Brush.

Shrubs or small trees, often with spinulose branches. Leaves alternate, commonly 3-ribbed; stipules caducous. Flowers perfect, crowded in terminal panicles, cymes, or umbels. Hypanthium urn-shaped, filled by the disk. Sepals 5 , deciduous, white. Petals 5, inserted under the disk, long-clawed and strongly hooded. Stamens 5; filaments filiform, exserted. Ovary immersed in the disk, 3-celled. Styles short, united below; stigmas 3. Fruit dry, 3-lobed, separating into 3 nutlets. Seeds flattened; endosperm fleshy.

Leaves alternate, thin, triple-nerved.

Leaf-blades rounded-oval, often cordate at the base, closely glandular-dentate or Peduncles often naked from lateral buds; leaves sparingly pubescent beneath,
soon glabrate.

Leaves 3-6 cm. long; young branches long-hairy, soon glabrate.

Leaves 1-2.5 cm. long; young branches flnely puberulent.

1. C. sanguineus.

2. C. Martini. 
Peduncles on leafy branches of the present season; leaves velutinous beneath.

Leaf-blades oblong to elliptic or ovate, glandular-serrate to subentire. 3. C. velutinus.

Umbels panicled, mostly terminal; leaves dull beneath, glabrate or villous. Leaves thin, glossy above, sparingly hairy when young, glabrate in age; peduncles finely viscid-puberulent.

Leaves thick, veiny, dull, as well as the peduncles more or less permanently villous.

Umbels mostly axillary; leaves silky beneath.

Leaf-blades distinctly glandular-serrate; plant not spiny.

Leaf-blades obsoletely denticulate or entire; branches often ending in spines.

Leaves opposite, very small and thick, not triple-nerved.

Leaves entire or nearly so; petals white.

Leaves spinulose-toothed; petals bluish.

5. C. pubescens.

6. C. subsericeus.

7. C. Fendleri.

8. C. Greggii.

9. C. prostratus.

1. C. sanguineus Pursh. Tall shrub, 1-3 m. high; young twigs greenish, those of preceding season red or purple; leaf-blades oval, rounded at the apex, rounded or cordate at the base, glabrate; petals white, spatulate; fruit obovoid, 3-lobed above, not crested, $4 \mathrm{~mm}$. thick. Hillsides and copses: Mont. $-\mathrm{n}$ Calif.-B.C. Submont. Ap-Jl.

2. C. Martini M. E. Jones. Branched unarmed shrub, 1-2 m. high; twigs and branches grayish, the former finely and closely pubescent; leaf-blades broadly oval or subrotund, glabrous, except the veins beneath, minutely glandulardentate; inflorescence small, 1-3 cm. long; petals white, broadly spatulate. Mountain sides: Utah-Nev. Son.-Submont. Je-J.

3. C. velutinus Dougl. Shrub $1-3 \mathrm{~m}$. high, with olive twigs and brown branches; leaf-blades thick, broadly oval, often subcordate at base, glabrous and shining above, pale and velutinous beneath, 4-8 cm. long; inflorescence paniculate, ample; petals white, broadly spatulate; fruit obovoid, $5 \mathrm{~mm}$. in diameter, deeply 3-lobed on the top. Hillsides: Mont.-S.D.-Colo.-Utah-B.C. Submont.-Mont. My-Jl.

4. C. ovatus Desf. Shrub 2-10 dm. high; branches brownish; leaf-blades narrowly oblong to oval or ovate, $1.5-4 \mathrm{~cm}$. long, serrate with gland-tipped teeth; petals spatulate-dippershaped, $1.5-2 \mathrm{~mm}$. long; fruit $4-4.5 \mathrm{~mm}$. in diameter, depressed globose, 3-lobed. C. ovalis Bigel. 'Sandy soil: Vt.-Ga.-Tex.Colo.-(Black Hills) S.D.-Man. Plain-Submont. Ap-Je.

5. C. pubescens (T. \& G.) Rydb. Shrub 5-10 dm. high; leaf-blades from oblong to lanceolate or oval, $2-5 \mathrm{~cm}$. long, glabrate except the veins above, villous beneath, glandular-serrate; petals white, $1.5 \mathrm{~mm}$. long, spatulate; fruit subglobose, $5-6 \mathrm{~mm}$. in diameter, slightly 3-lobed. C. ovatus pubescens $\mathrm{T}$. \& G. Sandy soil: Mich.-Mo.-Tex.-Colo.-S.D. Plain-Submont. My-Jl.

6. C. subsericeus Rydb. Small shrub; leaves short-petioled; leaf-blades elliptic or elliptic-lanceolate, acute at both ends, 2-3 cm. long, 3-ribbed, sparingly strigose above, grayish-silky beneath; petals white, broadly spatulate, clawed, $1.5 \mathrm{~mm}$. long; fruit dark brown, about $4 \mathrm{~mm}$. in diameter, slightly 3 -lobed above. Foot-hills: Colo. Submont. Jl.

7. C. Fendleri A. Gray. Low spinescent shrub, 1-5 dm. high, with canescent twigs; leaf-blades elliptic, 3-ribbed, entire-margined, 7-30 $\mathrm{mm}$. long, green and strigose or glabrate above, pale and silky-canescent beneath; petals white, 1.5 $\mathrm{mm}$. long, spatulate; fruit $4 \mathrm{~mm}$. wide, subglobose, somewhat 3 -lobed. Woods and hillsides: S.D.-N.M.-Ariz.-Utah-Wyo. Submont.-Mont. Je-Au.

8. C. Greggii A. Gray. Intricately branched spinescent shrub, 1-2 m. high; branches gray or olive-green, at first finely tomentose; leaves short-petioled; blades 5-15 mm. Inng, 1-ribbed, elliptic or oval, entire or nearly so, coriaceous, glabrate above, tomentulose beneath; petals white, obovate-spatulate, $1.5 \mathrm{~mm}$. long; capsule slightly elongate, $4 \mathrm{~mm}$. in diameter. Arid mountain sides: Tex. -Nev.-Mex. Son. F-Je.

9. C. prostratus Benth. Intricately branched prostrate shrub; leaves 5-25 mm. long, coriaceous, obovate or oblong-cuneate, spinulose dentate, glabrous or bose, about $5 \mathrm{~mm}$. thick. Mountains: Ore.-Ida.-Nev.-Calif. Submont.Mont. Ap-Je. 


\section{Family 80. Vitaceae. Grape Family.}

Woody vines, elimbing by means of tendrils. Flowers perfect, polygamous, or dioecious, in axillary clusters. Sepals and petals 4 or 5 , the latter valvate. Stamens as many as the petals and opposite them. Gynoecium of 2, or rarely 3-6, united carpels; styles united; stigmas capitate or peltate. Fruit a berry; seeds 1 or 2 in each cavity.

Hypogynous disk present; leaves in our species simple, palmately veined and usually
lobed. Hypogynous disk wanting; leaves palmately 5 -7-foliolate.

1. VITIS,

\section{VİTIS (Tourn.) L. Grape.}

Climbing or trailing vines, with shreddy bark and simple tendrils. Leaves alternate, simple, palmately lobed, petioled; stipules small and caducous. Flowers dioecious, polygamo-dioeceous, or rarely perfect. Disk hypogynous. Calyx minute. Petals caducous, coherent at the apex as a cap. Stamens exserted. Ovary 2-celled, rarely 5- or 4-celled. Berry pulpy. Seeds few, pear-shaped.

Twigs and leaves somewhat puberulent when young, glabrate in age, except the veins

and their axils beneath; vine high-climbing.
Twigs and leaves white-floccose when young; plant scarcely climbing.
2.

1. V. vulpina L. High elimbing vine; leaf-blades thin, broadly cordate, with a broad sinus, often somewhat 3-lobed, deeply and irregularly serrate, $5-12 \mathrm{~cm}$. long, 6-15 cm. wide; panicles 5-12 cm. long; berries $1 \mathrm{~cm}$. or less in diameter, bluish or purplish black, with a bloom, very sour. Woods and river banks: N.B.-W.Va.-Tex.-N.M.-Wyo. Plain-Mont. Ap-Je.

2. V. arizonica Engelm. Weak, branched vine, scarcely climbing; leafblades cordate-ovate, with a broad sinus, usually indistinctly lobed, dentate, with numerous small teeth, white-floccose when young, becoming more glabrate in age; panicles $5-8 \mathrm{~cm}$. long; berries black, about $1 \mathrm{~cm}$. in diameter, pleasanttasting. (?) $V$. boulderensis Daniels. River banks and cañons: N.M.-Colo-Utah-s Calif.; Mex. Son.-Submont. Ap-Je.

\section{PARThenocíssus Planch. Virginia Creeper, American Ivy, WOODBINE.}

Climbing or trailing vines, with forking tendrils, their branches often with adhesive disks. Leaves alternate, palmately $5-7$-foliolate. Flowers perfect or polygamo-dioecious, in compound cymes. Sepals and petals 5. Disk obsolete or wanting. Stamens 5. Ovary 2-celled, sessile. Berries with scant pulp, inedible. Seeds more or less 3 -angled. [Psedera Neck.]

Aerial rootlets present; tendi ils with disks.

Aerial rootlets lacking; tendrils without disks.

1. P. quinquefolia.

1. P. quinquefolia (L.) Planch. Tall vine, climbing; branches warty; leaves usually 5 -foliolate; leaflets ovate or obovate to oblong-lanceolate, acute or short-acuminate, serrate above the middle, teeth directed forward; corymbs 8-12 $\mathrm{cm}$. broad; berries subglobose, 8-9 $\mathrm{mm}$. in diameter, blue, with a scant bloom. Woods and banks: Que.-Fla.-Tex.-S.D.-Man. Plain-Submont. Je-Jl.

2. P. vitacea (Knerr) Hitchcock. Straggling vine, with long tendrils, and smoother bark; leaflets 5-6, thin, 4-10 $\mathrm{cm}$. long, lanceolate or oval, acuminate, serrate, with large, often flaring, lanceolate teeth; corymb about $5 \mathrm{~cm}$. broad; berries 5-7 mm. in diameter, bluish black. P. quinquefolia laciniata Planch. Woods and banks: Mich.-Ohio-N.M.-Ariz.-Wyo. Plain-Submont. Je-
J.

\section{Family 81. MalvaCeae. Mallow Family.}

Herbs (all ours), or rarely shrubs or trees, with alternate, palmately ribbed and usually lobed leaves, often with stellate or branched pubescence. Flowers perfect, regular. Calyx of 5, more or less united valvate sepals. Petals 
5, convolute. Stamens many, monadelphous. Gynoecium of several, usually united carpels. Fruit a several-celled capsule, or the carpels separating at maturity.

Style-branches filiform, stigmatose longitudinally on the exterior side.

Stamens simply monadelphous; flowers involucelled.

Petals notched at the apex; carpels beakless, without internal processes.

1. MaLVA.

Petals not emarginate at the apex; carpels beaked, with an internal process above the seed. 2 . CALLIRrHOE.

Stamens more or less united in falanges in a double series; flowers without involucels.

Style-branches terminated by capitate stigmas.

Lower seed at least from an ascending ovule: calyx more or less bracteolate.

Carpels strongly reticulate on the lower part of the sides facing the adjacent earpels, this portion enclosing the seeds, the upper part of the carpels smooth and empty.

4. SPHAERALCEA.

Carpels not differentiated in an upper and lower portion.

Carpels thin-walled, loosely investing the 2 or 3 seeds, hirsute; tall perennials with maple-like leaves.

5. PHYMosia.

Carpels reticulate, the rather thick walls closely surrounding the single seed; annuals with round-lobed leaves.

Lower seed at least resupinate-pendulous; calyx without involucels or these represented by 1-3 setaceous bractlets.

Carpels 1-ovuled, the cell filled with the seed; bractlets present.

Carpels 3-9-ovuled, several-seeded, dehiscent apically and dorsally; bractlets absent.

8. ÁBUTILON.

\section{1. málva (Tourn.) L. Mallow, Cheeses (fruit).}

Annual or perennial herbs. Leaves alternate, with pubescent, lobed or dissected, reniform or suborbicular blades. Flowers solitary or clustered in the axils of the leaves, or rarely in terminal racemes or spikes, subtended by 2 or 3 bractlets, perfect and regular. Calyx of 5 partly united sepals. Petals 5, emarginate. Carpels many, 1-celled, reniform, indehiscent, beakless, arranged around a central axis. Seeds ascending; embryo circular.

Corolla scarcely exceeding the calyx; carpels rugose-reticulate on the back, and with acute or winged margins.

Calyx becoming much enlarged, and spreading under the fruit, nervose-reticulate; angles of the carpels margined and denticulate. 1. M. parviflora.

Calyx not much enlarged in fruit, mostly erect, not reticulate; carpels merely acute
2. M. pusilla.

on the margins.
Corolla about twice as long as the calyx; carpels not rugose on the backs, round-margined.

Plant decumbent; leaves scarcely crisp: carpels smooth.

Plant erect; leaves very crisp; carpels veiny-reticulate.

3. M. rotundifolia.

4. M. crispa.

1. M. parviflora L. Annual; stem erect or ascending, branched, glabrous or sparingly hairy; leaf-blades reniform in outline, with about 7 rounded crenate lobes, $2-10 \mathrm{~cm}$. in diameter; calyx-lobes rounded, mucronate; corolla lilac, about $5 \mathrm{~mm}$. long; carpels glabrous or pubescent. Waste places: N.D.-Tex.-Calif.; also on the Atlantic Coast; Mex.; adv. or nat. from Eu. F-O.

2. M. pusilla Smith. Annual; stem erect, branched, 1-3 dm. high; leafblades reniform, $2-5 \mathrm{~cm}$. broad, obscurely round-lobed and crenate; calyx-lobes ovate, in fruit mostly erect; corolla white; carpels pubescent or glabrate. $M$. borealis Wallm. Waste places: Mont.-Calif.; adv. from Eu. J1-Au.

3. M. rotundifolia L. Annual; stems procumbent; leaf-blades roundedreniform, more or less distinctly round-lobed and crenate, usually more or less pubescent; calyx not much accrescent, its lobes ovate; corolla pale lilac or whitish, about $1 \mathrm{~cm}$. long; carpels puberulent. Waste places: Mass.-N.C.-Calif.Wash.; nat. from Eu. My-S.

4. M. crispa L. Annual; stem erect, 5-20 dm. high; leaf-blades reniform in outline, $5-20 \mathrm{~cm}$. in diameter, distinctly lobed and double-crenate; flowers nearly sessile; calyx accrescent, in fruit becoming membranous and veiny, but not spreading; corolla purplish or white, about $1 \mathrm{~cm}$. long; carpels not at all rugose. Waste places and around dwellings: N.S.-N.J.-Colo.-Minn; ; escaped from cultivation. $\mathrm{Jl}-\mathrm{S}$. 


\section{CALlírRhö Nutt. Poppy Mallow.}

Perennial herbs, with thick, farinaceous roots. Leaves alternate, with lobed or cleft blades or the upper stem-leaves palmately or pedately dissected. Flowers solitary, axillary, or sometimes in terminal racemes, subtended by 1-3 bractlets. Sepals 5, united below. Petals 5, crimson to white, cuneate at the base, or fan-shaped. Carpels 10-20, 1-celled, 1-seeded, beaked. Seeds ascending; embryo curved.

1. C. involucrata (T. \& G.) A. Gray. Cespitose perennial, with a napiform thick root; stems procumbent, more or less hirsute; leaf-blades rounded in outline, palmately or pedately 5-7-parted, the cuneate divisions deeply cleft into lanceolate or oblong lobes; peduncles surpassing the leaves; calyx subtended by 3 linear or oblong bractlets half as long as the lanceolate calyx-lobes; petals crimson or purple, $2-3 \mathrm{~cm}$. long. Plains: Minn.-Mo.-Tex.-Utah-Wyo. Plain. Je-Au.

\section{SIDÁldeEA A. Gray. Wild Hollyhock, False Mallow, Rose Mallow.}

Erect perennial (ours) or annual herbs, with palmately or digitately lobed or cleft leaf-blades. Flowers in terminal spikes or racemes, purple, or pink, or yellowish white, occasionally polygamous by the abortion of the stamens in some flowers, without bractlets. Sepals 5, united below. Petals 5, emarginate or truncate. Stamens in two more or less distinct series, the outer of 5 phalanges, each of 4-10 stamens, the inner of 10 phalanges of 2 stamens. Carpels 5-9, at maturity separating from the axis, beakless or apiculate.

Corolla yellowish white; plant with a creeping rootstock; leaves glabrous.

Corolla pink, rose-colored, or lilac, S. candida. cent.

Pubescence, especially that of the calyx and stem, stellate, without any longer hairs.

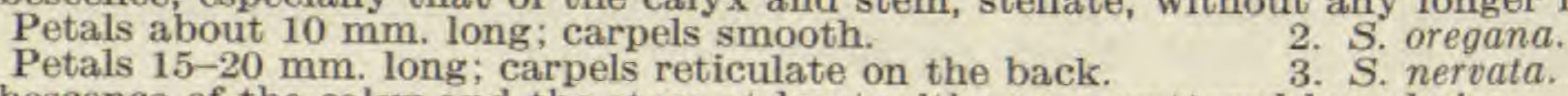

Pubescence of the calyx and the stem at least with some scattered long hairs. Calyx-lobes lanceolate; stem mostly single, erect.

Calyx stellate, with longer hairs on the margins; carpels puberulent, reticulate

on the back.
Calyx hirsute, with branched hairs; carpels smooth and glabrous.

4. S. campestris.

Calyx-lobes ovate, glandular-puberulent and with a few scattered long hairs;
stems usually several, decumbent at the base.

1. S. candida A. Gray. Stem glabrous and shining, 5-10 dm. high; blades of the basal leaves rounded, 5-9-lobed, and crenate, 4-10 $\mathrm{cm}$. broad, those of the upper stem-leaves still larger, sometimes almost $2 \mathrm{dm}$. in diameter, cleft into lanceolate divisions; calyx minutely stellate, about $7 \mathrm{~mm}$. long; lobes ovate, acute; petals $15-20 \mathrm{~mm}$. long; carpels smooth, nearly glabrous. Along streams and in wet meadows: Wyo.-N.M.-Utah. Submont.-Subalp. J1-S.

2. S. oregana (Nutt.) A. Gray. Stem 6-15 dm. high; basal leaf-blades rounded-reniform, 7-9-cleft, with erenate or lobed divisions, 4-10 cm. wide; uppermost stem-leaves divided into linear divisions; inflorescence spiciform; calyx about $6 \mathrm{~mm}$. Iong; lobes triangular-ovate, abruptly short-acuminate; petals lilac or rose. S. digitata A. Nels. Open places: Wash.-Ida.-n Calif. $\mathrm{My}-\mathrm{Au}$.

3. S. nervata A. Nels. Stems usually single; leaf-blades sparingly pubescent, with short branched hairs above, minutely stellate beneath, those of the basal leaves orbicular-reniform, 4-8 cm. broad, usually 5-9-lobed, sometimes obscurely so, each lobe with 2-3 broad teeth, those of the upper stem-leaves deeply cleft into cuneate, lobed divisions; calyx 6-7 $\mathrm{mm}$. long; lobes triangularlanceolate, acute; petals rose-colored. Hills and mountain valleys: Wyo.Utah-Ida. Submont. Je-Jl.

4. S. campestris Greene. Stem 3-10 dm. high; leaf-blades rather coarsely pubescent, with branched or stellate hairs; those of the basal leaves orbicularreniform, about 9-lobed, the lobes 3-5-toothed, those of the upper stem-leaves 
with lanceolate or linear lobes; calyx 8-9 $\mathrm{mm}$. long, its lobes lanceolate, longacuminate; petals rose or lilac, $15-20 \mathrm{~mm}$. long. Hills and plains: B.C.-Mont. -Ida. $-\mathrm{n}$ Calif. My-Je.

5. S. neomexicana A. Gray. Stem 6-20 dm. high; blades of the basal leaves rounded-reniform, 3-10 $\mathrm{cm}$. wide, hirsute, crenate and more or less distinctly 5-9-lobed, those of the upper stem-leaves divided into linear or oblong divisions; petals lilac, rarely rose or white, $12-18 \mathrm{~mm}$. long. Mountain valleys: Wyo.N.M.-Ariz.-Ida.; Mex. Submont.-Mont. Je-S.

6. S. crenulata A. Nels. Stems $2-5 \mathrm{dm}$. high, green, nearly glabrous, with a few scattered hairs; leaf-blades sparsely appressed-pubescent, with forked hairs, those of the basal leaves orbicular-reniform, $2-5 \mathrm{~cm}$. broad, crenate, those of the stem-leaves 5-9-lobed or cleft, the uppermost with linear divisions; inflorescence racemose; calyx about $6 \mathrm{~mm}$. long; lobes lanceolate, acute, or shortacuminate; petals $12-15 \mathrm{~mm}$. long; carpels smooth or slightly reticulate on the back. Meadows and draws: Utah-Nev. Son. Je-Jl.

\section{Sphatrálcea St. Hil. Globe Mallow, Scarlet Mallow.}

Mostly perennial herbs, often einereous, with stellate or branched hairs. Leaves alternate, with palmately lobed or dissected blades. Flowers mostly in terminal spike-like racemes, subtended by 1-3 bractlets. Sepals 5 , partially united. Petals 5, golden, pink, or scarlet, usually notched. Stamens monadelphous in a single series. Stigmas truncate or capitate. Carpels 5 or more; the lower portion of each enclosing 1 or 2 seeds, reticulate on the sides facing the adjacent carpels, the upper portion of the carpels smooth and empty. [Malvastrum A. Gray.]

Leaves lanceolate; fruit ellipsoid to ovate.

Carpels with a cusp.

Carpels rounded at the apex.

1. S. cuspidata.

2. S. angustifolia.

Leaves rounded or rhomboid to reniform in outline; fruit depressed-globose to broadly ellipsoid.

Leaves merely toothed or round-lobed, or at most cleft half-way down.

Plant low and depressed, 1 or rarely $2 \mathrm{dm}$. high; leaf-blades rounded-rhombic, coarsely toothed.

3. S, caespitosa.

Plant tall, 3-6 dm. high; leaf-blades round-lobed.

Calyx-lobes 5-7 mm. long, acuminate, longer than the fruit; inflorescence more racemiform.

4. S. ambigua.

Calyx-lobes 3-4 mm. long, merely acute, not longer than the fruit; inflorescence thyrsoid.

Leaves lobed less than half-way down.

Capsule separating from the axis by means of a thread; leaves coarsely few-toothed; terminal lobe mostly acute. 5. S. Munroana.

Carpels without a thread; leaves densely crenate; terminal lobe rounded. Calyx sparingly stellate, except at the base and on the margins of the lobes.

Calyx densely stellate throughout.

6. S. marginala.

7. S. arizonica.

Leaves 3-cleft half-way down, the terminal lobe acute.

8. S. subrhomboidea.

Leaf-blades divided to near the base.

Upper seedless portion of the carpels at least as large as the lower reticulate and seed-enclosing portion.

Plant green, only slightly stellate; bractlets about two-thirds as long as the calyx; fruit ellipsoid.

9. S. Rusbyit.

Plant grayish or whitish, densely stellate; bractlets scarcely half as long as the calyx; fruit depressed-globose.

Primary divisions of the leaves cuneate, with rounded-ovate lobes; corolla about $12 \mathrm{~mm}$. long. 10.S. grossulariaefolia.

Primary divisions of at least the upper leaves with linear divisions; corolla 9-10 $\mathrm{mm}$. Iong. 11 . S. digitata.

Upper smooth seedless portion of the carpels very small, much smaller than the lower reticulate portion.

Primary divisions of the leaves rather broad, cleft or lobed.

Leaves 3-parted; lateral segments deeply 2-cleft; lobes broadly oblong, oblanceolate, or obovate.

Plant low, 1-2 dm. high; middle segment of the leaves slightly longer than the others; raceme crowded. $12 . S$. coccinea.

Plant tall, 3-4 dm. high; middle segment of the leaves usually half longer than the others; raceme elongate.

Leaves 5-parted to the base; segments all cleft into linear or linear-oblong lobes.

Primary divisions of the leaves linear, not lobed.

14. S. dissecta.

15. S. leptophylla. 
1. S. cuspidata Torr. Perennial, with a woody base; stem $3-10 \mathrm{dm}$. high, stellate-pubescent; leaf-blades lanceolate or linear-lanceolate, crenulate, $5-10 \mathrm{~cm}$. long, sometimes hastately lobed at the base; flowers axillary; sepals ovate, acute; petals pink, $6-8 \mathrm{~mm}$. long; carpels $5-6 \mathrm{~mm}$. long, strongly rugose at the base. Plains: Tex.-Kans.-Colo.-Ariz.; n Mex. Son. Ap-Au.

2. S. angustifolia (Cav.) Don. Perennial, with a somewhat woody base; stem 5-15 dm. high, leafy, subcanescent; leaf-blades 5-12 $\mathrm{cm}$. long, lanceolate or linear-oblong, crenate, the lower sometimes hastately lobed; flowers clustered in the axils; sepals lanceolate or ovate-lanceolate, acute or short-acuminate; petals pink, 8-10 mm. long; carpels $5-6 \mathrm{~mm}$. long, only the lower fourth or less rugose. Plains and dry places: Tex.-Colo.-Utah-Ariz.; Mex. Son.-Submont. Ap-Au.

3. S. caespitosa M. E. Jones. Caespitose, with a thick woody root and caudex; stem 5-15 $\mathrm{cm}$. high, rarely higher, densely stellate; leaves rhombicovate or -obovate, $2-3.5 \mathrm{~cm}$. long, coarsely serrate, thick, densely white-stellate; calyx sharply angled; lobes triangular; corolla red, fully $2 \mathrm{~cm}$. long; fruit depressed-globose; carpels 2-seeded. Volcanic soil: w Utah. Son. Je.

4. S. ambigua A. Gray. Perennial, woody at the base; stem $3-10 \mathrm{dm}$. high, tomentulose-canescent; leaf-blades rounded-cordate or orbicular, often obscurely 3-5-lobed, irregularly crenate; inflorescence racemiform; calyx densely stellate, its lobes lanceolate, $8-10 \mathrm{~mm}$. long; petals rose-colored or white, 1-2 $\mathrm{cm}$. long; carpels about $6 \mathrm{~mm}$. long, cuspidate-acuminate. Desert regions: Ariz.s Utah-Calif.-L. Calif. L. Son. Mr-Je.

5. S. Munroana (Dougl.) Spach. Perennial, with a woody root; stem leafy, $3-6 \mathrm{dm}$. high, minutely canescent; leaf-blades rounded-cordate, more or less distinctly 3-5-lobed, coarsely toothed; inflorescence thyrsoid-glomerate; calyx densely stellate, its lobes ovate, acute; petals scarlet to rose-red, about $1 \mathrm{~cm}$. long; earpels about $3 \mathrm{~mm}$. long, merely acutish above. Malvastrum Munroanum A. Gray. Dry plains: B.C.-Ida.-Utah-Ore. My-Je.

6. S. marginata York. Perennial; stem usually branching from the base, 2-6 dm. tall, densely stellate-canescent; leaf-blades subrotund, rounded-ovate or subcordate, $1.5-4 \mathrm{~cm}$. long, crenate, slightly 3-5-lobed, densely stellate; flowers borne in narrow panicles; calyx-lobes ovate, acute, or acuminate, in fruit 4-5 mm. long; petals pink, obovate, $10-12 \mathrm{~mm}$. long; earpels $3-4 \mathrm{~mm}$. long, cuspidate, the lower half reticulate. Dry places: Colo.-Utah-N.M. Son.Submont. My-Je.

7. S. arizonica Heller. Perennial, with a woody caudex; stem branching from the base; leaf-blades reniform to cordate, $3-5 \mathrm{~cm}$. long, densely stellate on both sides, obscurely lobed and crenate; inflorescence paniculate, dense, with short branches; calyx-lobes ovate, acute, about $3 \mathrm{~mm}$. long; petals pink, about $1 \mathrm{~cm}$. long; carpels about $4 \mathrm{~mm}$. long and $1.5 \mathrm{~mm}$. wide, mucronate or shortcuspidate, oblong, with only about the lowest fourth reticulate. Desert regions: Ariz.-s Utah. L. Son. Ap-Je.

8. S. subrhomboidea Rydb. Perennial, with a woody caudex; stems branched at the base, stellate, 2-4 dm. high; leaf-blades rhombic in outline, 2-5 $\mathrm{cm}$. long, grayish green, cuneate at the base, 5-ribbed, the divisions 2-4lobed; inflorescence a dense virgate panicle; calyx densely stellate, $4-5 \mathrm{~mm}$. long; lobes broadly ovate, obtusish; corolla scarlet, $8-9 \mathrm{~mm}$. long; carpels nearly round, obtuse, the lower half reticulate on the faces; seeds solitary. Valleys: Utah. Mont. Jl-Au.

9. S. Rusbyi A. Gray. Perennial, with a woody eaudex; stems 4-6 dm. high, glabrous or sparingly stellate, often tinged with purple; leaf-blades reniform in outline, $2-3.5 \mathrm{~cm}$. broad, 5 -divided to the base; divisions obovate, cleft into oblong or linear lobes; flowers in a narrow, virgate panicle; calyx 7-8 $\mathrm{mm}$. long, stellate; lobes lanceolate, acute; corolla searlet, $15-18 \mathrm{~mm}$. long; carpels mueronate, only the basal one-third reticulate on the faces. Dry places: Ariz. -Utah. Son. My.

10. S. grossulariaefolia (H. \& A.) Rydb. Perennial, with a woody caudex; stem 2-6 dm. high; leaf-blades cordate in outline, stellate-canescent, deeply 3-5- 
cleft, 2-4 cm. long; divisions rhombic-cuneate, lobed or coarsely toothed; inflorescence paniculate; calyx-lobes ovate, acute, 3-4 mm. long; petals brick-red to pink, $10-15 \mathrm{~mm}$. long; carpels reniform, $3 \mathrm{~mm}$. long, rounded at the apex. $S$. pedata Torr. Sida grossulariaefolia Hook. \& Arn. Plains, open hillsides, and valleys: Wyo.-Ariz.-Nev.-Ida. Son.-Submont. My-Au.

11. S. digitata (Greene) Rydb. Perennial, with woody caudex; stems 2-6 dm. high; leaves digitately or pedately 5-divided, or the uppermost 3-divided; divisions of the lower leaves oblanceolate or cuneate, usually 3-cleft, with oblong lobes, those of the upper leaves narrow, linear or with linear lobes; inflorescence a narrow virgate panicle; calyx-lobes lanceolate-acute; corolla scarlet, $9-10 \mathrm{~mm}$. long; carpels obliquely reniform, lower half reticulate on the faces. S. pedata angustiloba A. Gray. Malvastrum digitatum Greene. Dry mesas and sandy soil: w Tex.-N.M.-Utah-Ariz. Son. My-Au.

12. S. coccinea (Nutt.) Rydb. Perennial, with a woody base; stems several, 1-3 dm. high; leaf-blades 3-cleft to the base and the lateral divisions again deeply 2-parted; divisions rhombic-cuneate to spatulate, usually 3-cleft at the apex, with oval or oblong lobes; inflorescence dense, short, raceme-like; sepals ovate, about $3 \mathrm{~mm}$. long, villous-stellate; petals usually brick-red, $8-12 \mathrm{~mm}$. long; carpels reniform, $3 \mathrm{~mm}$. high. Malvastrum coccineum (Nutt.) A. Gray. Dry plains and sandy valleys: Man.-Ia.-Tex.-Utah-Ore. Plain-Mont. $\mathrm{My}-$ $\mathrm{Au}$.

13. S. elata (E. G. Baker) Rydb. Perennial, with a woody caudex; stems 2-4 dm. high; leaf-blades cordate in outline, 3-cleft to the base and the lateral divisions again 2-cleft; middle division oblanceolate, 3-5-lobed above the middle, the lateral divisions 2-3-lobed or entire; calyx-lobes lanceolate, 3-4 mm. long; petals about $12 \mathrm{~mm}$. long, brick-red; carpels 3-4 $\mathrm{mm}$. long. Malvastrum coccineum elatum E. G. Baker. Dry plains: N.M.-Colo. Son. My-J.

14. S. dissecta (Nutt.) Rydb. Perennial, with a cespitose woody base; stems 1-3 dm. high, densely cinereous-stellate; leaf-blades $1-3 \mathrm{~cm}$. broad, dissected to the base into 5 divisions; these rhombic in outline and twice eleft; inflorescence racemiform; petals searlet, 10-12 $\mathrm{mm}$. long; earpels reniform, strongly reticulate, $3 \mathrm{~mm}$. long. Malvastrum coccineum dissectum Nutt. $M$. Cockerellii A. Nels. Dry rocky hills: Wyo.-Ariz.-Utah. Son. My-Je.

15. S. leptophylla (A. Gray) Rydb. Perennial, with a thick woody taproot and caudex; stems 1-4 dm. high, numerous, silvery-lepidote; leaf-blades divided into 3 narrowly linear divisions, or the upper entire, linear-filiform, silvery-lepidote; inflorescence racemiform; calyx-lobes ovate, acute; petals copperred, $1 \mathrm{~cm}$. or less long; carpels tomentulose, $3 \mathrm{~mm}$. long. Malvastrum leptophyllum A. Gray. Dry places: w Tex. $\rightarrow$ s Colo.-s Utah-Ariz. Son. My-Au.

\section{PhYmòsia Desv. Wild Hollyhock, Maple-leaved Mallow.}

Tall leafy perennials, with rootstocks. Leaves alternate, palmately ribbed and lobed, with acute lobes, and maple-like in appearance. Flowers large, clustered in the upper axils or interruptedly spicate or corymbose at the summit, subtended by bractlets. Sepals united at the base. Petals rose-colored, purplish, or white, obcordate. Stamens monadelphous in single series. Carpels oblong, hirsute, thin, not reticulate, 2- or 3-seeded. [Iliamna Greene.]

Sepals lanceolate or ovate-lanceolate, long-attenuate; bractlets subulate, three-fourths

as long as the sepals.

1. P. Crandallii.

Sepals broadly triangular-ovate, acute; bractlets scarcely more than half as long as the

sepals.
Calyx and pedicels stellate; bractlets subulate; petals $2-2.5 \mathrm{~cm}$. long Plant sparingly stellate, green. Plant densely stellate-canescent.

2. P. rivularis.

3. P. acerifolia.

Calyx and pedicels hirsute with branched hairs; bractlets lanceolate; petals $3 \mathrm{~cm}$. or more long.

4. $P$. grandiflora.

1. P. Crandallii Rydb. Stem simple, about 6 dm. high; sparingly stellate; leaf-blades cordate in outline, 5-lobed, about $5 \mathrm{~cm}$. in diameter; lobes lanceolate, coarsely toothed; pedicels and ealyx sparingly and finely stellate; petals white or 
nearly so, about $2.5 \mathrm{~cm}$. long, euneate and slightly emarginate. Sphaeralcea Crandallii Rydb. Mountains: Colo. Submont.

2. P. rivularis (Dougl.) Rydb. Stem 6-20 dm. high, sparingly stellate; leaf-blades cordate or reniform in outline, 5-7-lobed, $5-15 \mathrm{~cm}$. long and about as wide; lobes triangular or broadly lanceolate, usually coarsely toothed; pedicels and calyx stellate; petals pink or white, $2-2.5 \mathrm{~cm}$. long. $S$. rivularis Torr. $I$. rivularis and $I$. angulata Greene. Along streams: Alta.-S.D.-Colo.-Nev.B.C. Submont.-Mont. J-S.

3. P. acerifolia (Nutt.) Rydb. Stem 5-10 dm. high; leaf-blades cordate or reniform in outline, 5-7-lobed, 5-10 $\mathrm{cm}$. broad; lobes triangular, coarsely serrate; petals rose-colored, $2-2.5 \mathrm{~cm}$. long. Sphaeralcea acerifolia Nutt. Along streams: Mont.-Ida.-Ore. Submont. Je.

4. P. grandiflora Rydb. Stem glabrous below, stellate above, 1-2 m. high; blades cordate or reniform in outline, 9-15 $\mathrm{cm}$. wide, deeply 5-7-lobed; lobes lanceolate or triangular, coarsely toothed, with triangular teeth; pedicels and calyx densely hirsute-pubescent, with long stellate hairs; petals pinkish, 3 $\mathrm{em}$. or more long. Sphaeralcea grandiflora Rydb., not Phil. Mountains: Colo. -Utah. Submont.-Mont. Je.

\section{EREMĀLCHE Greene.}

More or less hispid or hirsute annuals, not stellate. Leaves alternate, reniform, palmately ribbed, crenate or lobed. Flowers solitary, axillary, longpeduncled, subtended by 3 slender bractlets. Sepals 5, partially united. Petals 5 , purplish. Stamens monadelphous, in a single series. Carpels orbicular, rugose, pointless, closely investing the single seed.

1. E. exilis (A. Gray) Greene. Annual; stem branched, spreading or decumbent, more or less pubescent, with branched hairs; leaves long-petioled; blades reniform, 5-7-lobed, 1-2 cm. wide; lobes cuneate, with 3-5 rounded teeth; sepals triangular-lanceolate, acuminate; petals white or pink, $6-10 \mathrm{~mm}$. long; carpels $2 \mathrm{~mm}$. long, reniform, with thick rugose backs. Malvastrum exile A. Gray. Sandy places: Ariz. $\rightarrow \mathrm{s}$ Utah-Calif.; n Mex. L. Son. Ap-Je.

\section{DISÉLLA Greene.}

Canescent, stellate perennials. Leaves alternate, pubescent, reniform, or hastate. Flowers perfect, solitary or clustered in the axils of the leaves. Bractlets 1-3. Sepals 5, united into a usually angular base. Petals 5; carpels five to many, 1-celled. Styles filiform; stigmas capitate. Carpels 1-seeded, indehiscent or partially 2 -valved, obtuse or short-acuminate. Seeds pendulous, 3-angled.

Leaves reniform or orbicular.

Leaves lanceolate, hastate.

1. D. hederacea.

2. D. sagitlaefolia.

1. D. hederacea (Dougl.) Greene. Perennial, with a cespitose caudex or rootstock; stems decumbent or spreading, branched, 1-4 dm. long, scurfycaneseent; leaf-blades reniform or suborbicular, dentate, scurfy-canescent, 1-5 $\mathrm{cm}$. wide; petals pale yellow or white, about $1 \mathrm{~cm}$. long; fruit short-conic, tomentulose. Sida hederacea (Dougl.) Torr. Low banks and salt-flats: Wash.-Utah -Ariz.-W Tex.-Mex. Son.-Submont. Je-S.

2. S. sagittaefolia (A. Gray) Greene. Cespitose perennial; stems spreading or decumbent 1-4 dm. long, scurfy-lepidote; leaf-blades sinuate-dentate, $2-5 \mathrm{~cm}$. long, scurfy-lepidote, silvery when young; petals yellowish white, tinged with rose or purple, about $12 \mathrm{~mm}$. long; fruit depressed. Sida lepidota sagittaefolia A. Gray. Plains: w Tex. - s Colo. - s Calif.; n Mex. Son. My-N.

\section{8. abŨtilon (Tourn.) Mill. Indian Mallow, Velvet Leaf.}

Herbs (ours), shrubs, or trees. Leaves alternate, softly pubescent, entire, toothed, or lobed, usually cordate at the base. Flowers perfeet, mostly axillary. Involucel wanting. Sepals 5, united below. Petals 5, distinct, usually yellow. Styles filiform or club-shaped, with terminal stigmas. Carpels 1-celled, leathery 
or parchment-like, more or less prominently beaked, 2-valved at the apex and on the back, with 1-6 reniform seeds.

1. A. parvulum A. Gray. Cespitose perennial, with woody base; stems 2-4 dm. high, cinereous-stellate, spreading; leaf-blades rounded to ovate-cordate, dentate, sometimes obscurely 3-lobed, 1-3 cm. long, stellate-canescent; flowers axillary; calyx-lobes 3-4 mm. long, lanceolate, in fruit reflexed; petals $3-5 \mathrm{~mm}$. long, brick-red or pinkish; fruit 7-8 $\mathrm{mm}$. long and about as wide, minutely stellate. Dry soil: Tex.-Colo.-Ariz. Ap-S.

\section{FAmILY 82. HYPERICACEAE. ST. John's-Wort FAmLY.}

Herbs or shrubby plants, with opposite, rarely whorled, entire or nearly so, pellucid-punctate leaves, without stipules. Flowers cymose, perfect, regular or nearly so. Sepals 4 or 5, herbaceous, equal or unequal. Petals 4 or 5, yellow or flesh-colored. Stamens few or many, usually 3- or 5delphous. Gynoecium of several united carpels. Ovary 1-celled, with parietal placentae, or 3-7-celled, with central placentae. Styles distinct or united; stigmas of ten capitate. Fruit a septicidal capsule.

\section{HYPÉRICUM (Tourn.) L. St. JoHn's-Wort.}

Herbs (all ours), or shrubs. Leaves opposite, rather thick, usually sessile, entire or nearly so, more or less punetate. Flowers cymose. Sepals 5, slightly unequal. Petals 5, yellow, convolute. Stamens numerous, more or less distinctly 3 - or 5-delphous. Ovary 1-celled, with 3 (all ours) or 5 parietal placentae, or 3- or 5-celled. Styles 3-5, sometimes coherent. Seeds numerous.

Petals more than twice as long as the sepals, both usually margined with black glands; stamens numerous; erect perennials.

$\begin{array}{ll}\text { Sepals acuminate or at least decidedly acute. } & \text { 1. H, formosum. }\end{array}$

Sepals obtuse or acutish.

Stem 3-5 dm. high; petals $8-10 \mathrm{~mm}$. long.

Stem about $1 \mathrm{dm}$. high; petals $10-15 \mathrm{~mm}$. long.

2. H. Scouleri.

3. H. Nortonae.

Petals slightly exceeding the sepals; black glands none; stamens 5-20; annuals or no. 4 often perennial, rooting at the nodes.

Procumbent, often forming mats; leaves broadly oval.

Erect and simple; leaves oblong to lanceolate.

4. $H$. anagalloides.

5. H. majus.

1. H. formosum H.B.K. Perennial, with a horizontal rootstock; stem simple, 3-6 dm. high; leaves oval or elliptic, 2-3 $\mathrm{cm}$. long, sessile; sepals 4-5 mm. long, black-dotted on the margin and usually also on the back, acuminate or acute; petals 10-12 $\mathrm{mm}$. long, oval; capsule 3 -lobed, $8 \mathrm{~mm}$. long; stamens numerous. Mountains and hillsides: N.M.-Wyo.-s Calif.-Mex. Submont.-Mont. J-Au.

2. H. Scouleri Hook. Perennial, with a horizontal rootstock; stem 4gonous above, $2-5 \mathrm{dm}$. high; leaves oblong or elliptic to ovate, somewhat clasping, 1-2 cm. long; sepals ovate, obtuse, with a few black dots along the margin; petals 8-10 mm. long, oval; eapsule 3-lobed; stamens numerous. Copses and hillsides: Mont.-Wyo.-Calif.-B.C. Submont.-Mont.

3. H. Nortonae M. E. Jones. Perennial, with a slender rootstock; stem barely angled; leaves oval or rounded-oval, obtuse, $1.5-2.5 \mathrm{~cm}$. long, cordate at the base; flowers 1-3; sepals ovate-obtuse, about $2.5 \mathrm{~mm}$. long; petals narrow, strongly many-nerved; pod 3-lobed at the apex. Moist alpine places: Mont. Alp.

4. H. anagalloides Cham. \& Schlecht. Diffusely branched annual or perennial, rooting at the nodes; branches $5-30 \mathrm{~cm}$. long, procumbent or ascending; leaves elliptic to broadly oval, 5-7-ribbed, 5-15 $\mathrm{mm}$. long, not dotted; sepals elliptic, unequal; petals 3-4 mm. long, oval; stamens $15-21$, in 3 clusters; capsule 1-celled, ovate. H. tapetoides A. Nels. Wet ground: B.C.-Mont.Ida.-L. Calif. Je-Jl.

5. H. majus (A. Gray) Britton. Erect annual, simple below; stem 2-9 dm. high; leaves lanceolate or oblong-lanceolate, 2-6 cm. long, 5-7-ribbed; sepals 
lanceolate, acuminate; petals oval or obovate, $2-3 \mathrm{~mm}$. long; stamens $5-10$; capsule narrowly conic. H. canadense majus A. Gray. Wet places: Me.N.J.-Colo.-Wash.-B.C. Plain-Submont. J1-Au.

\section{Family 83. ELATINACEAE. Water-Wort Family.}

Herbs or shrubby plants, ours low water herbs, with opposite or whorled leaves, with stipules. Flowers inconspicuous, perfect, regular, solitary or clustered in the axils of the leaves. Sepals 2-5, imbricate. Petals as many, hypogynous. Stamens 2-5, or sometimes 10 . Gynoecium of $2-5$ united carpels. Ovary 2-5-celled, with central placentae; stigmas $2-5$, distinct. Fruit a septicidal capsule.

\section{1. eldatìne L. Water-Wort, Mud-purslane.}

Low water plants. Leaves opposite or whorled, entire. Flowers usually solitary, axillary. Sepals 2-4, membranous, obtuse, nerveless. Petals and stamens as many as the sepals or the latter twice as many. "Ovary and fruit 2-4-celled. Styles 2-4. Capsule membranous, 2-4-valved.

Flowers sessile; stamens $2-3$, as many as the petals.

Leaves oblanceolate; flowers usually 3 -merous.

Leaves obovate.

Flowers 3-merous; plant red; leaves $2 \mathrm{~mm}$. long.

Flowers 2-merous; plant green; leaves 4-6 $\mathrm{mm}$. long. Flowers pedicelled; stamens 6-8, twice as many as the sepals and petals.

1. E. triandra.

2. E. rubella.

3. E. americana.

4. E. Williamsii.

1. E. triandra Schkur. Immersed water plant, flaccid; stems $5-10 \mathrm{~cm}$. long; leaves opposite, oblong or oblanceolate; flowers sessile; sepals usually 2; seeds slightly curved, little sculptured. Shallow water: Ill.-Colo.-Wash.; Eu. Plain-Submont.

2. E. rubella Rydb. Low and depressed annual, whole plant reddish; stems scarcely more than $5 \mathrm{~mm}$. long; leaves opposite, broadly obovate-spatulate, fleshy; flowers sessile; pod depressed-globose, $1.5 \mathrm{~mm}$. in diameter; seeds curved, sculptured as in the next. Wet volcanic sand: Yellowstone National Park. Mont.

3. E. americana (Pursh) Arn. Diffuse rooting annual; stems 1-4 cm. long; leaves obovate, very obtuse, $2-6 \mathrm{~mm}$. long; petals in the terrestrial form rosecolored; pod globose, $1 \mathrm{~mm}$. in diameter; seeds slightly curved, sculptured with 9-10 longitudinal and 20-30 cross-bars. Mud and shallow water: Que.-Va.Tex.-Calif.-B.C. Plain-Submont. Jl-S.

4. E. Williamsii Rydb. Slender diffuse annual; stems $3-5 \mathrm{~cm}$. long; leaves broadly spatulate, distinctly petioled, $5-8 \mathrm{~mm}$. long, thin, indistinctly 3 -nerved; flowers on pedicels 1-2 mm. long; capsule $1.5 \mathrm{~mm}$. in diameter; seeds curved into a hook, less than $0.5 \mathrm{~mm}$. long, with numerous cross-lines. Shallow water: Mont. Au-S.

\section{Family 84. Frankeniaceae. Frankenia Family.}

Low herbs or undershrubs, with opposite or whorled, entire, thick leaves, with a stipular membrane connecting their bases. Flowers small, perfect, regular. Sepals 4 or 5 , united into a tube. Petals as many, clawed. Gynoecium of 3 or 4 united carpels; ovary 1-celled, with as many parietal placentae. Fruit a capsule, septicidal, enclosed in the calyx.

Characters of the family.

\section{FRANKËENA L.}

1. F. Jamesii Torr. Erect shrub, 3-6 dm. high, thickly branched; branches scabrous-puberulent; leaves nearly glabrous, linear, 5-10 $\mathrm{mm}$. long, with revolute margins, fascicled; petals white; blades $4 \mathrm{~mm}$. long, cuneate, erose-truncate; 
stamens usually 6 ; anther-cells elongate, oblong. Bluffs and plains: w Tex.Colo.-Sonora. Son. Je-Jl.

\section{Family 85. CistaCEAE. Rock-Rose Famly.}

Shrubs or undershrubs. Leaves alternate or opposite. Flowers nearly regular, usually perfect, solitary, racemose, clustered, or paniculate. Sepals $3-5$, persistent. Petals 5 or 3 , sometimes wanting, fugaceous. Stamens 8, hypogynous. Gynoecium of several united carpels; ovary sessile, 1-severalcelled; ovules orthotropous; styles united; stigma entire or 3-lobed. Fruit a capsule. Seeds several or numerous. Embryo slender; endosperm starchy or fleshy.

\section{CROCÁNTHEMUM Spach. Frost-WeEd.}

Undershrubs. Leaves more or less coriaceous, entire, flat or revolute-margined. Flowers of two kind, viz., some with large fugaceous petals and many stamens, the others cleistogamous, apetalous or with small petals, and 3-10 stamens. Styles obsolete or short; stigmas capitate or 3-lobed. Fruit a capsule. Embryo eurved.

1. C. majus (L.) Britton. Hoary canescent herbs, slightly woody at the base, 3-6 dm. high; leaves oblanceolate or oblong-lanceolate, $1.5-3.5 \mathrm{~cm}$. long, stellate on both sides, canescent beneath, greener above; petaliferous flowers 5-12, in terminal cymes; sepals densely canescent, the outer nearly as long as the inner, petals yellow, 7-9 mm. long, oval; apetalous flowers clustered in the axils of the leaves, nearly sessile. Helianthemum majus (L.) B.S.P. H. canadense Walkerae W. H. Evans. Dry soil: Me.-Va.-Tex.-Colo-S.D. Plain-Submont. $\mathrm{J}-\mathrm{Au}$.

\section{Family 86. VIOLACEAe. Violet Family.}

Low herbs, or in the tropics woody. Leaves simple, alternate or basal, with stipules. Flowers perfect, irregular. Sepals and petals 5; the latter imbricate in bud, the lowermost spurred or saccate at the base. Stamens 5 ; anthers united or connivent. Gynoecium of 3 united carpels. Ovary 1-celled, with 3 parietal placentae. Capsule loculicidal; seeds anatropous.

Sepals auricled at the base; corolla spurred.

1. VIOLA. Sepals not auricled at the base; lowest petal merely saccate at the base. 2. CALCEOLARIA.

\section{1. viola (Tourn.) L. Violet, Hearts-ease, Pansy.*}

Usually perennial herbs, either bearing leaves and 1-flowered scapes from the crown of the rootstock, or stemmed, with manifest internodes between the leaves, and with axillary 1-flowered peduncles. Flowers usually of two kinds, those of spring with showy petals and those of summer with petals rudimentary or lacking, the latter never opening, but self-fertilized within the closed calyx; petaliferous flowers nodding, pentamerous and irregular as to calyx, corolla and stamens. Sepals 5, persistent in fruit, auricled at the base. Petals 5, the lowest one spurred. Stamens distinct, but more or less coherent, the two lower furnished with nectar-bearing appendages projecting into the spur. Capsule ovoid to cylindric, 3 -valved, bearing $20-60$ obovate seeds $1-3 \mathrm{~mm}$. long.

Plants acaulescent, or without manifest stems.

Plants without stolons.

Flowers violet-puiple.

Rootstock thick.

Leaves not lobed nor parted.

Leaves and scapes glabrous. Spurred petal glabrous, rounded at the apex.

Peduncles of cleistogamous flowers usually 1-3. cm. long, prostrate under the soil or dead leaves. 1. V. papilionacea.

* Contributed by Prof. Ezra Brainerd. 
Peduncles of cleistogamous flowers usually 4-6 $\mathrm{cm}$. Iong, erect or ascending.

2. V. pratincola.

Spurred petal more or less bearded, retuse or emarginate.

Spurred petal somewhat bearded, mostly retuse.

3 . V. retusa.

Leaves and scapes hirsutulous.

Leaves $2-3$-ternately parted.

Rootstock slender.

Flowers white.

Plants stoloniferous.

Flowers not yellow.

Flowers white or lilac; petioles glabrous.

Flowers white; petioles after flowering pilose. Flowers yellow.

Stolons several, long, prostrate, leafy.

Stolons few, short, ascending, with 1-3 leafy bracts.

Plants caulescent, or with manifest stems.

4. V. nephrophylla

5. V. septentrionalis.

6. $V$. pedatifida.

7. V. Selkirkii.

8. V. renifolia.

9. V. palustris.

10. V. Macloskeyi.

11. V. sempervirens.

12. V. orbiculata.

Leaves compound or much dissected.

Upper petals deep violet, the lower pale violet, with yellow base.

All the petals pale vellow.

13. V. Beckwithii.

Leaves simple, not dissected.

14. V. Sheltonii.

Flowers yellow.

First peduncles from the base of the stems.

Basal leaves round, 5-7-lobed or -toothed.

Basal leaves ovate to lanceolate, denticulate.

Basal leaves 5-9 cm. long, ovate to elliptic.

Basal leaves $2-5 \mathrm{~cm}$. long.

Basal leaves narrowly ovate, obtuse.

Basal leaves lanceolate, acute or subacute.

First peduncles from the upper half of the stem.

Style and lateral petals beardless.

Style and lateral petals bearded.

Upper part of stem and its leaves nearly glabrous.

Upper part of stem and its leaves densely short-pubescent.

15. V. venosa.

16. V. linguaefolia.

17. V. vallicola.

18. V. Nuttallii.

19. V. biflora.

20. V. glabella.

21. V. pubescens.

Flowers not yellow.

Petals white on the inner face, with a yellow base, on the outer face usually purplish.

Underground stolons present.

Stolons lacking.

Stems usualily $15-35 \mathrm{~cm}$. bigh.

Petals violet or purple. $15 \mathrm{~cm}$. high

Stipules sharply or bristly toothed; perennials.

Plant dwarf; leaves cuneate, glabrous.

Plant over $1 \mathrm{dm}$. high, usually puberulent. Leaves $2-3 \mathrm{~cm}$. long, seeds $1.5 \mathrm{~mm}$. long. Leayes $3-5 \mathrm{~cm}$. long, seeds $2 \mathrm{~mm}$. long.

Stipules leaf-like, pectinate at base; annuals.

22. V. rugulosa,

23. V. canadensis.

24. V. scopulorum.

25. V. bellidifolia.

26. $V$, adunca.

27. V. montanensis.

28. V. Rafinesquii.

1. V. papilionacea Pursh. Plants robust and hardy from a stout branching rootstock, usually glabrous, but petioles sometimes sparsely pubescent; blades when fully grown often $12 \mathrm{~cm}$. wide, reniform or broadly ovate-cordate, acute or abruptly pointed; outer sepals ovate-lanceolate; upper and lateral petals broadly obovate, 8-10 mm. wide. Fields and groves: Mass.-Ga.-Okla. -Minn.; apparently introduced in gardens and along irrigation ditches in Denver, Colo., and vicinity.

2. V. pratincola Greene. Plant every way smaller than the preceding; leaves deeply cordate-ovate, tapering gradually to a subacute apex, $2-3 \mathrm{~cm}$. wide at petaliferous flowering, 5-8 cm. wide at maturity; petals spatulate, 4-6 mm. wide; peduncles taller than the leaves. Hills and prairies: Colo.-Wyo.-N.D. Plain-Submont.

3. V. retusa Greene. Glabrous throughout; leaves at flowering time broadly cordate-deltoid, finely serrate; later leaves much dilated, with a shallow sinus, more or less decurrent on the petiole, often abruptly acuminate; cleistoga- mous flowers on erect peduncles; capsules ellipsoid, green; seeds brown, 2 mm. long. Borders of streams: Kans.-Colo. Plain. My-Je.

4. $\nabla$. nephrophylla Greene. Leaves broadly cordate-ovate to reniform, obtuse or bluntly short-pointed; petals large, the upper pair often sparsely pubescent; sepals ovate to lanceolate, obtuse; cleistogamous flowers on erect 
peduncles; capsules green, short-ellipsoid; seeds olive-brown, $2 \mathrm{~mm}$. long, $V$. cognata Greene. Bogs and borders of cold streams: Que.-Conn.-Wis.-N.M. -Utah-Wash.-B.C. Plain-Mont. My-Jl.

5. V. septentrionalis Greene. Basal stipules often $1 \mathrm{~cm}$. long, bristly ciliolate and more or less glandular; leaves cordate-ovate, somewhat acuminate, the apex obtuse; flowers large; sepals obtuse, finely ciliate; cleistogamous flowers sagittate, on ascending peduncles; their capsules subglobose, usually purple. Woodlands: P.E.I.-Conn.-Pa.-Wash.-B.C. Boreal.

6. V. pedatifida G. Don. Leaves 3-parted, the divisions variously cleft and incised into linear lobes, usually truncate or cuneate at the base, the margins and midrib hirsutulous; peduncles of the petaliferous flowers taller than the leaves, those of the apetalous flowers shorter, but erect. $\quad V$. delphinifolia Nutt. Prairies and valleys: Sask.-Ohio-N.M.-S.D. Plain-Mont. Ap-Je.

7. V. Selkirkii Pursh. Leaves broadly cordate-ovate, the basal lobes converging or overlapping, the margins crenate-serrate, the upper surface hirtellous; petals pale violet, all beardless; spur $3-5 \mathrm{~mm}$. long, with an enlarged rounded end; capsule subglobose; seeds small, buff. Woods: N.B.-Pa.-Minn.-B.C. -Colo. Mont.

8. V. renifolia Gray. Pubescent throughout, or often subglabrous, especially on the upper surface of the leaf; blades reniform, those of summer often ending in a short blunt tip; petals white, all beardless; capsule ellipsoid; cleistogamous flowers on horizontal pedicels, their capsules purple. Cold forests: Newf. -Pa.-Minn.-Colo.-Mack. Mont. Ap-My.

9. V. palustris L. Scapes and leaves glabrous throughout, arising from the ends of scaly creeping rootstocks; blades cordate-ovate to orbicular, remotely and lightly crenate-serrate; petals pale lilac to white, the lateral slightly bearded, the spur short and thick; seeds dark brown, $1.5 \mathrm{~mm}$. long. $V$. cyclophylla and V. eucycla Greene. Cold bogs and wet borders of rivulets: Lab.-N.H.-S.D.Colo.-Utah-Alaska. Mont.-Subalp. My-Au.

10. V. Macloskeyi Lloyd. Stolons slender, leafy, bearing at the end the following spring a tuft of leaves and scapes; blades ovate-orbicular, slightly cordate, rounded at the apex, obscurely and remotely crenulate, bearing at maturity on the lower surface and petioles white crinkled hairs; seeds olivebrown, $1 \mathrm{~mm}$. long. Wet places in the mountains: Alta.-B.C.-Calif. Submont.-Mont. Je-Jl.

11. V. sempervirens Greene. Stolons often $30 \mathrm{~cm}$. long, bearing cleistogamous flowers in summer; leaves usually remaining green through the dry season, the blades round-cordate, with open sinus, those of the stolons nearly as large as those of the rootstock; petals $1 \mathrm{~cm}$. long; spur very short; capsule globose, $7 \mathrm{~mm}$. long, brown or sometimes green. V. sarmentosa Dougl., not Bieb. Woods: B.C.-W Mont.-Calif. Submont.

12. V. orbiculata Geyer. Rootstock stout and jagged with stumps of former leaves; blades orbicular, crenate-serrate, somewhat hirtellous above, the sinus usually closed by the overlapping basal lobes; stolons $5-10 \mathrm{~cm}$. long, ascending, bearing petaliferous and cleistogamous flowers, and 1-3 small leaves with brown searious stipules. Alta.-Ida.-Wash.-B.C. Submont.-Mont.

13. V. Beckwithii T. \& G. Stems several, mostly underground from a deep-seated rootstock; leaves 2-3-ternately parted into linear entire obtuse lobes, glabrous or sometimes hirsutulous; lateral petals bearded; spur short and thick. Valleys: Utah-Calif.-Ore. Son.-Submont. Ap-Je.

14. V. Sheltonii Torr. Stems as in the preceding; leaves hirsutulous or nearly glabrous, palmately 3 -divided, the middle division palmately, the lateral divisions pedately, 3-parted, and often again variously cleft into obtuse linear lobes; lateral petals bearded; capsule globose, $8 \mathrm{~mm}$. long, brown, glabrous; seeds buff, $2.5 \mathrm{~mm}$. long. V. biternata Greene. Rocky hillsides: Colo.-Ore.Calif. Mont. Ap-Je.

15. V. venosa (S. Wats.) Rydb. Minutely puberulent; crown of verticaI rootstock usually $3-12 \mathrm{~cm}$., underground; stems sometimes elongating $12 \mathrm{~cm}$. 
above the ground; its leaves ovate to lanceolate, gradually smaller upward, the margins nearly entire; petaliferous flowers from the lower axils, cleistogamous from the upper; outer petals madder-brown. V. atriplicifolia Greene. V. Thori A. Nels. Cliffs and hillsides: Mont.-Colo.-Calif.-Ore. Submont.-Mont. Ap-Jl.

16. V. linguaefolia Nutt. Pubescence variable, from villous to subglabrous; stems tardily developed, 1-3 dm. long; first flowers petaliferous, the upper petals reddish brown; later apetalous flowers from the upper axils; capsule globose, usually glabrous; seeds $3 \mathrm{~mm}$. long. V. flavovirens Pollard. V. erectifolia A. Nels. V. gomphopetala Greene. Valleys: Mont.-Colo--Calif.-Wash. Submont.-Subalp.

17. V. vallicola A. Nels. Glabrous or pubescent; leaves nearly entire, ovate to lanceolate, obtuse, the base often obliquely rounded; petals yellow, the two upper often tinged with purple; cleistogamous flowers borne on the upper part of the stem; capsule short-ellipsoid; seeds $2 \mathrm{~mm}$. long. $V$. physalodes Greene. Moist valleys in the mountains: Colo.-Sask.-Wash.-B.C. Plain -Mont. My-Je.

18. V. Nuttallii Pursh. More or less pubescent; stems commonly numerous, in moist situations elongating $15-25 \mathrm{~cm}$.; leaves except the few earliest lanceolate to linear-lanceolate, tapering at the base into margined petioles, the apex acute or subacute, obscurely and remotely denticulate; seeds brown, $3 \mathrm{~mm}$. long. On the foot-hills and plains: Man.-Mo.-Ariz.-Mont. Plain-Submont. Ap-Je.

19. V. biflora L. Stems several, slender, 2-3-leaved and 2-3-flowered; leaves somewhat hirtellous, reniform, narrowly cordate at base, rounded at apex, 2-4 cm. wide; cauline stipules ovate; flowers small, eitrous-yellow; spur short-conical; stigma margined on two sides. In wet moss and in fine gravel along rivulets: Colo.; Alaska, and n Eurasia. Mont.-Subalp. Ap-Jl.

20. v. glabella Nutt. Rootstock stout, jagged, usually horizontal; stems $1-4$, leafy only toward the top; root-leaves $1-2$, the blades reniform, crenateserrate, short-pointed, nearly glabrous, $6-8 \mathrm{~cm}$. wide; eauline leaves $2-4$, the upper much smaller and ovate; capsules ellipsoid, $1 \mathrm{~cm}$. long; seeds nearly black, $2 \mathrm{~mm}$. long. Woods: Alaska-Mont.-Ida.-Calif. Submont.-Mont.

21. V. pubescens Ait. Stem often solitary; root-leaves few or none; stemleaves short-petioled; blades reniform to ovate, cordate or truncate-decurrent, the apex slightly blunt-pointed; stipules large, obliquely ovate; capsules often white-woolly; seeds $3 \mathrm{~mm}$. long. Rich woodlands: N.S.-Va.-Neb.-(Black Hills) S.D. Plain-Submont.

22. V. rugulosa Greene. Stems $2-6 \mathrm{dm}$. high; root-leaves cordate-reniform, abruptly short-pointed, often $10 \mathrm{~cm}$. wide, densely hirsutulous beneath; lower stem-leaves similar, the upper successively smaller and shorter-petioled, becoming ovate-acuminate; capsules ovoid to subglobose, often puberulent, $6-10$ $\mathrm{mm}$. long; seeds brown, $2 \mathrm{~mm}$. long. V. Rydbergii Greene. Woods: Man.-Ia. -Colo.-Alaska. Plain-Mont. My-Jl.

23. V. canadensis L. Stems several, $15-35 \mathrm{~cm}$, high; leaves broadly cordate-ovate, abruptly acuminate, serrate with incurved teeth, nearly glabrous, or the smaller upper leaves murieulate to hirtellous, especially on the veins underneath; petals often purplish with age; spur short and rounded; capsule ovoid, usually glabrous; seeds brown, $2 \mathrm{~mm}$. long. $V$. neomexicana and $V$. geminiflora Greene. Moist, wooded, and steep mountdin slopes: N.B.-S.C.-N.M.-Ariz. -B.C. Submont,-Mont. My-Jl.

24. V. scopulorum (A. Gray) Greene. Stems numerous, more or less spreading, 10-20 $\mathrm{cm}$. high; leaves cordate-deltoid, about $2 \mathrm{~cm}$. wide, gradually tapering into an acute apex; upper surface often minutely scabrous; flowers about $1 \mathrm{~cm}$. broad, on long axillary peduncles, and often later numerous cleistogamous flowers on axillary branches; seeds $1.5 \mathrm{~mm}$. long. Moist groves and shady river banks: Colo. Submont.-Mont. 
25. V. bellidifolia Greene. Plants cespitose, with short obscure stems; leaves glabrous, round-ovate, truncate or cuneate at base, obtuse at apex, 8-15 $\mathrm{mm}$. wide; stipules linear-lanceolate, with $2-6$ bristly teeth on either margin; capsule $5 \mathrm{~mm}$. long; seeds $1.5 \mathrm{~mm}$. long. $V$. demissa Greene. Mountain sides: Mont.-Colo.-Ida. Mont.-Subalp. Je-Au.

26. V. adunca J. E. Smith. Stems numerous, often short at first flowering; leaves subcordate-ovate, obtuse, crenulate, glabrous to puberulent or scaberulous, 2-3 cm. wide; stipules linear-subulate, with setulose teeth near the base; spur 5-7 mm. long, often hooked or straight on the same plant. $V$. monticola Rydb. V. retroscabra, V. albertina, V. cordulata, V. mamillata, V. oxypetala, $V$. subvestita, $V$. stenantha, $V$. Tidestromii, and $V$. unguiculata Greene. $V$. inamoena Greene, a glabrate form. (?) V. Clarkae A. Nels. Hills and valleys: Que.-N.H.-Alta.-Colo.-Calif.-Alaska. Submont.-Subalp.

27. V. montanensis Rydb. Stems slender, 1-2 dm. high, scabrous; leaves broadly ovate, subcordate, obtuse at the apex, $3-4 \mathrm{~cm}$. wide; stipules linearlanceolate; petals light violet; capsule ellipsoid, $1 \mathrm{~cm}$. long; seeds $2 \mathrm{~mm}$. long. $V$. retroscabra Greene, in part. V. odontophora Rydb,. a form with toothed spur. Colo.-Utah-Mont. Submont.-Mont. Je-JI.

28. V. Rafinesquii Greene. A subglabrous annual, 10-25 $\mathrm{cm}$. high, often branching from the base; lower leaves round, upper ovate to spatulate, attenuate at the base; stipules foliaceous, pectinate, the terminal segment elongate, entire; petals cream-colored, about twice the length of the sepals. Fields and waste places: N.Y.-Ga.-Tex.-Colo.-Mich. Plain. Ap-My.

\section{CALCeolària Loefl. Green Violet.}

Perennial herbs or rarely shrubs, with alternate or opposite leaves. Flowers axillary and solitary or racemose, perfect. Sepals equal, not auricled. Petals unequal, the lowest largest and gibbous at the base; stamens 5; anthers connivent but distinct; the two lower filaments glandular at the base. Capsule 3valved, opening elastically. [Hybanthus Jacq. Ionidium Vent.]

1. C. verticillata (Ortega) Kuntze. Low perennial herb; stems clustered, 1-4 dm. high, slightly pubescent; leaves alternate, but often fascicled; stipules subulate or wanting; blades linear, 2-4 cm. long; flowers solitary, nodding; petals white, 4-6 mm. long. Dry ground: Kans.-Tex.-Ariz.-Colo.; Mex. Son.

\section{FAMILY 87. LOASACEAE. LOASA Family.}

Usually scabrous-pubescent herbs, rarely shrubs, with opposite or alternate leaves, without stipules. Flowers perfect, regular, cymose. Hypanthium well developed, turbinate to cylindric, enclosing the ovary. Sepals 4 or 5 , imbricate or convolute. Petals as many, yellow or red. Stamens numerous; filaments filiform or dilated, sometimes passing into staminodia closely resembling the petals. Gynoecium of $2-5$ united carpels, enclosed in the hypanthium. - Ovary 1-celled, with parietal placentae.

Stamens numerous; styles seyeral, more or less distinct; seeds several or many.

Styles and placentae 3 ; flowers subsessile.

Placentae with horizontal lamellae between the seeds; these in two rows.

Filaments 3-cleft at the apex, the middle tooth bearing the anther, the lateral ones cuspidate; seeds angled or with folds, not winged; annuals.

1. BICUSPIDARIA.

Filaments not cleft; seeds very flat, more or less winged; perennials or biennials.

Placentae without lamellae; seeds usually prismatic.

2. Nutrallia.

Placentae fliform; ovules in one row, 10-40; seeds minutely muricate, not striate; fllaments free or nearly so. 3 . ACRolasia.

Placentae broad, band-like; ovules in 1-2 rows, few; seeds distinctly striate, often rugose; filaments at the base united with the petals into a ring.

Styles and placentae 5; flowers distinctly pedicelled.

4. Mentzelita.

Stamens 5; styles simple; seed solitary.

5. EUCNIDE.

6. Petalonyx. 


\section{BICUSPIDÃRIA (S. Wats.) Rydb.}

Annuals, scabrous, with rather large flowers. Sepals 5, persistent. Petals 5 , free, light yellow. Stamens 80-130; filaments dilated, 3-cleft at the apex, the middle tooth bearing the anther, the lateral teeth cuspidate. Hypanthium cylindric; placentae with horizontal lamellae between the ovules and vertical wings; ovules in 2 rows, $15-40$ on each placenta. Capsule thin-walled, inflated, sessile. Seeds angled or with folds, not winged.

1. B. tricuspis (A. Gray) Rydb. Annual; stem 1-2 dm. high, branched near the base, hispid and pilose; leaves petioled, lanceolate, acute or acuminate, sinuately dentate; bracts 2, pinnatifid or toothed; petals light yellow, obovate, $3 \mathrm{~cm}$. long; fruit ellipsoid, about $18 \mathrm{~mm}$. long and half as thick. Mentzelia tricuspis A. Gray. Dry regions: s Utah-s Calif. L. Son. My.

\section{NUtTállia Raf. Sand Lily, Blazing Star.}

Scabrous pubescent, biennial or perennial herbs, with barbed or hooked hairs, mostly stout. Leaves alternate, toothed or pinnatifid, rarely entire. Sepals 5, persistent. Petals 5, or apparently 10 , on account of the petaloid staminodia, yellow to straw-colored, usually conspicuous. Stamens numerous; filaments filiform, or the outer ones dilated. Hypanthium oblong-cylindric; ovules in two rows on each of the three parietal placentae. Capsule stout; seeds numerous, horizontal, flattened, winged or margined, separated by horizontal lamellae. [Touterea Eat. \& Wright, Hesperaster Cockerell.]

Petal-like staminodia present; petals therefore apparently 10 or nearly that number.

Petals golden or greenish yellow, rarely more than $2 \mathrm{~cm}$. long.

Seeds irregularly angled on the faces; petals greenish yellow.

Seeds not angled on the faces; petals golden yellow.

Upper leaves entire, narrowly linear.

All leaves pinnatifid or lobed.

Petals obtuse; seeds broadly winged.

Lower leaves at least deeply pinnatifid, with linear-oblong or lanceolate

lobes.
3. N. multiflora.

1. N. lutea.

2. N. multicaulis.

Leaves sinuately lobed or toothed, with triangular-ovate lobes or teeth. Stem glabrous; all leaves oblanceolate; capsule somewhat turbinate at the base.

4. N. lobata.

Stem pubescent; upper leaves lanceolate, with broad clasping bases; Petals acute. capsule rounded at the base.

5. N. pterosperma.

Capsule 7-10 $\mathrm{mm}$. long; lobes of the leaves narrowly linear.

6. N. humilis.

Capsule over $12 \mathrm{~mm}$, long; lobes of the leaves not narrowly linear.

Plants low, less than $4 \mathrm{dm}$. high; leaves less than $6 \mathrm{~cm}$. long; petals less than $15 \mathrm{~mm}$. long; seeds broadly winged.

Leaves sinuately dentate or crenate, the lower ones oblanceolate or spatulate, the upper ovate-lanceolate. 7. N. integra.

Leaves mostly pinnatifid.

Plant simple below; lobes of the leaves short, broadly oblong.

8. $N$, pumila.

Plant much branched and suffruticose at the base; lobes of the leaves narrow, linear or lanceolate. 9. $N$. densa.

Plants tall, usually $4 \mathrm{dm}$. high, or more; leaves often $1 \mathrm{dm}$. Iong; petals $15-20 \mathrm{~mm}$. long; seed less broadly winged.

Leaves divided to near the midrib into linear-oblong or narrowly lanceolate lobes. $10 . N$. laciniata.

Leaves sinuate or lobed halfway to the midrib; lobes triangular or ovate.

Stem erect; leaves tapering at the base, lobed.

Stem decumbent at the base; leaves, at least the upper ones, rounded at the base, sinuate.

Petals straw-colored, usually more than $2 \mathrm{~cm}$. long.

12. $N$. crysantha.

Outer filaments dilated; petals $2-3 \mathrm{~cm}$. long.

Petals about $2 \mathrm{~cm}$. long; upper leaves with broad bases, long-acuminate.

Petals nearly $3 \mathrm{~cm}$. long; none of the leaves broad at the base. Plant branched below; flowers subtended by solitary entire bracts.

Plant simple below; flowers subtended by several toothed bracts.

Filaments all filiform; petals 4-5 cm. long. 15. N. stricta. 16. N. decapetala. 
Petal-like staminodia none; petals 5 , yellow; a few of the outer flaments slightly dilated. Stem glabrous or nearly so, white and shining; upper stem-leaves neither with a broad base, nor long-acuminate. 17. N. laevicaulis.

Stem pubescent throughout, straw-colored, rather dull; upper stem-leaves longacuminate and with a broad base.

Petals 5-7 cm. long; leaves coarsely hirsute-scabrous.

Petals 2.5-3 cm. long; leaves finely scabrous-puberulent.

18. N. acuminata.

19. N. parviflora.

1. N. Iutea Greene. Stout biennial, 6-9 dm. high, with a fusiform fleshy root; lower leaves sinuate-pinnatifid, the upper sinuate-dentate; petals elliptic, short-clawed, acute; petaloid staminodia about three-fourths as long; capsule thick-walled. Mentzelia lutea Greene. Alkaline soil: Colo. Submont. S.

2. N. multicaulis Osterhout. Much branched perennial; stems many, white, shining, 2-4 dm. high; lower leaves pinnatifid, with oblong divisions; flowers opening at sundown; sepals lanceolate, acuminate, $1 \mathrm{~cm}$. long; petals spatulate, $17-20 \mathrm{~mm}$. long; petaloid staminodia about half as large; capsule fully $1 \mathrm{~cm}$. long; seeds smooth, margined. T. multicaulis Osterhout. Dry soil: Colo. Submont. Je-Jl,

3. N. multiflora (Nutt.) Greene. Corymbosely branched perennial or biennial; stems bright white and shining, scabrous-puberulent, 3-6 dm. high; petals spatulate, $12-20 \mathrm{~mm}$. long; petaloid staminodia slightly smaller; capsule 15-20 mm. long, acute at the base. Bartonia multiflora Nutt. Dry plains: w Tex,-Colo.-Ariz.-Utah-Mex. Submont.-Mont. Ap-S.

4. N. lobata Rydb. Perennial, with a thick root; stems strict, white and shining, 3-4 dm. high; leaves 5-8 cm. long; sepals lanceolate, acuminate, 8-10 mm. long; flowers diurnal; petals spatulate, $12-18 \mathrm{~mm}$. long; petaloid staminodia similar and almost as large; capsule $15 \mathrm{~mm}$. long. Sandy soil: s Utah. L. Son. Jl.

5. N. pterosperma (Elastwood) Greene. Biennial; stem white, 1-3 dm. high, divaricately branched; lower leaves spatulate, $2.5-3 \mathrm{~cm}$. long, sinuately dentate, with broad, usually obtuse teeth; petals oblanceolate, $1-1.5 \mathrm{~cm}$. long; petaloid staminodia similar; capsule about $1 \mathrm{~cm}$. long. Sandy valleys: Colo.Utah. Son. Je-Jl.

6. N. humilis (A. Gray) Rydb. Low branched perennial or biennial; stem 2-4 dm. high, scabrous-puberulent; leaves pinnatifid; petals oblanceolate, 8-10 $\mathrm{mm}$. long, bright yellow; petaloid staminodia almost as large; capsule $7-10 \mathrm{~mm}$. long, rounded at the base. M. multiflora humilis A. Gray. Dry soil: w Tex.Colo.-N.M. Son.

7. N. integra (M. E. Jones) Rydb. Rather simple biennial; stem puberulent, 2-3 dm. high; lower leaves 4-5 cm. long; sepals lanceolate, 7-8 mm. long; petals oblanceolate, $15-18 \mathrm{~mm}$. long; staminodia similar, slightly smaller; capsule 12-15 mm. long, acute at the base. $M$. multiflora integra M. E. Jones. Sandy or clayey soil: Utah. Son. My-S.

8. N. pumila (Nutt.) Greene. Low biennial; stem scabrous-puberulent, 2-3 dm. high; leaves oblanceolate, 4-8 cm. long, sinuately pinnatifid; petals oblanceolate, acute, 10-12 mm. long; staminodia similar, but somewhat smaller; capsule fully $1 \mathrm{~cm}$. long, acute at the base. $M$. pumila Nutt. Barren hills and sandy flats: Wyo.-Colo.-Utah. Submont. Je.

9. N. densa Greene. Low perennial, with thick root and several stems; stems white, puberulent, 2-4 dm. high, branched; leaves oblanceolate, $3-6 \mathrm{~cm}$. long, deeply pinnatifid; sepals lanceolate, acuminate, nearly $1 \mathrm{~cm}$. long; petals about $15 \mathrm{~mm}$. long; staminodia similar, scarcely smaller; capsule about $15 \mathrm{~mm}$. long. Hillsides, cañons, and dry table-lands: Colo.-Utah-N.M. Son.-Mont. $\mathrm{Je}-\mathrm{Au}$.

10. N. laciniata (Rydb.) Woot. \& Standl. Biennial or short-lived perennial; stems 3-4 dm. high, white, puberulent; leaves 5-10 $\mathrm{cm}$. long; petals 15-20 $\mathrm{mm}$. long, short-clawed, oblanceolate; staminodia similar; capsule 15-18 $\mathrm{mm}$. long. Touteria laciniata Rydb. Hillsides: Colo. Submont. Je-J1.

11. N. speciosa (Osterhout) Greene. Stout perennial; stem whitish, puberulent, corymbosely branched, 3-8 dm. high; leaves linear or oblong-lanceolate, 10- 
$15 \mathrm{~cm}$. long; flowers vespertine; petals $2 \mathrm{~cm}$. long, oblanceolate, sometimes whitish without, golden yellow within; staminodia about half their size; capsule fully $2 \mathrm{~cm}$. long. $M$, aurea and $M$. speciosa Osterhout. Hills and dry valleys: Colo. -Wyo. Submont.-Mont. Jl-Au.

12. N. chrysantha (Engelm.) Greene. Decumbent biennial 3-4 dm. high; stems stout, white-pubescent, much branched; lower leaves $10-15 \mathrm{~cm}$. long, lanceolate or oblanceolate; upper leaves broadly lanceolate, or even ovate; petals 15-20 mm. long, oblanceolate; staminodia similar; capsule $2.5-3 \mathrm{~cm}$. long. $T$. sinuata Rydb. N. sinuata Daniels. Cañons: Colo. Submont. S.

13. N. Rusbyi (Wooton) Rydb. Erect biennial; stem stout, scabrous, 1-1.5 m. high; lower leaves long-lanceolate, 1-2 dm. long, sinuate-dentate, with triangular teeth; flowers with two pinnatifid bracts; petals light yellow, oblanceolate, acute, $16-20 \mathrm{~mm}$. long; petaloid staminodia narrower and shorter; capsule $3 \mathrm{~cm}$. long, acute at the base; seeds winged. M. Rusbyi Wooton. Plains and valleys: N.M.-Wyo.-Ariz. Son.-Submont. Je-S.

14. N. nuda (Pursh) Greene. Stout perennial or biennial; leaves oblanceolate, $5-15 \mathrm{~cm}$. long, sinuately lobed, with oblong or ovate lobes, less hispid above; petals spatulate, acute, about $2 \mathrm{~cm}$. long; staminodia nearly as large, similar; capsule about $3 \mathrm{~cm}$. long; seeds winged. Bartonia nuda Pursh. $M$. nuda T. \& G. Plains and hillsides: w Neb.-Colo-Wyo. Plain-Submont.
J-Au.

15. N. stricta (Osterhout) Greene. Strict, rather simple perennial; stem 5-10 dm. high, branched above; leaves linear-lanceolate, 5-10 cm. long, sinulong; petaloid staminodia similar; capsule 2-3 cm. long; seeds wing-margined. Hesperaster strictus Osterhout. Plains and foot-hills: w Neb.-Tex.-Colo.Wyo. Plain-Submont. Je-O.

16. N. decapetala (Pursh) Greene. Stout biennial; stem 5-10 dm. high, leafy, very scabrous; lower leaves oblanceolate, $1-3 \mathrm{dm}$. long, the upper lanceolate, pinnately lobed, with lanceolate lobes; flowers subtended by several pinnatifid bracts; petals $4-5 \mathrm{~cm}$. long, oblanceolate, acute; petaloid staminodia almost as large; capsule about $4 \mathrm{~cm}$. long; seeds with a narrow wing. Bartonia decapetala Pursh. M. ornata T. \& G. Cañons: S.D.-Tex.-Nev.-Alta. Plain-Sub-

17. N. laevicaulis (Dougl.) Greene. Stout biennial; stem $3-10 \mathrm{dm}$. high; lower leaves oblanceolate, sinuately dentate, with triangular teeth, $1-1.5 \mathrm{~cm}$. long; upper stem-leaves ovate-lanceolate, densely scabrous; flowers diurnal, subtended by toothed bracts; petals narrowly oblanceolate, $5-6 \mathrm{~cm}$. long; seeds wing-margined. Bartonia laevicaulis Dougl. $M$. laevicaulis T. \& G. Cañons and river valleys: Wash.-Ida.-Utah-Calif. Son.-Submont. Je-Au.

18. N. acuminata Rydb. Stout biennial; stem 3-10 dm. high, strawcolored; lower leaves oblanceolate, 1-2 dm. long, sinuately dentate, densely scabrous, with triangular teeth; upper stem-leaves lanceolate, pinnatifid, with lanceolate or rarely triangular lobes; flowers diurnal, their bracts narrowly linear, entire or with a few narrow lobes; capsule $4 \mathrm{~cm}$. long; seeds winged. River valleys: Wash.-Mont.-Wyo.-Utah. Son.-Submont. Je-S.

19. N. parviflora (Dougl.) Greene. Divaricately branched biennial; stem white; lower leaves oblanceolate, coarsely sinuately toothed, with triangular teeth; the upper lanceolate; flowers diurnal; bracts narrowly linear, mostly entire; petals oblanceolate, $2.5-3 \mathrm{~cm}$. long; capsule about $2 \mathrm{~cm}$. long; seeds winged. Bartonia parviflora Dougl. (?) M. Brandegei S. Wats. Along rivers: B.C.-Wash.-Ore. Son.-Submont. Je-Ji.

\section{ACROLÀ̃SIA Presl.}

Seabrous pubescent annuals. Leaves alternate, rarely some opposite, narrow, from entire to pinnatifid. Sepals 5, persistent. Petals 5, yellow, rather inconspicuous. Stamens many, free, or nearly so; filaments filiform. Hypan- 
thium cylindric; placentae 3 , filiform; ovules $10-40$, in a single row on each placenta. Capsule slender, linear-cylindric or linear-clavate. Seeds rather few, pendulous, more or less prismatic, muricate, not striate, not separated from each other by horizontal lamellae.

Inflorescence congested; bracts broad, 3-lobed, membranous at the base.

Inflorescence open; bracts neither 3-lobed nor membranous.

1. A. congesta.

Seeds rather strongly muricate; upper leaves narrow; sepals lanceolate-subulate, half as long as the petals or longer.

Petals 3-6 mm. long.

Leaves pinnatifid with many lobes; petals $5-6 \mathrm{~mm}$. long.

Leaves divided to near the midrib, with ascending lobes; plant erect.

Leaves divided one-half or one-third to the midrib, with divergent lobes; plant ascending or diffuse. 3 . A, ctenophora.

Only the middle leaves pinnatifid with few lobes, or seldom all entire; petals 3-4 mm. long. 4 . A. albicaulis.

Petals 2-3 mm. long; plant very slender.

Leaves deeply pinnatifid, with narrow lobes. $\quad$ 5, A. Tweedyi.

Leaves narrowly linear, entire. 6. A. tenerrima.

Seeds minutely muricate (tubercles seen only under strong magnification); at least the upper leaves broadly ovate.

Petals $5 \mathrm{~mm}$. long; sepals about half as long, lanceolate, acute; plant tall and stout.

7. A. latifolia.

Petals 3-4 mm. long; sepals linear, obtuse, only one-third as long as the petals. Plant tall, 3-5 dm. high; capsules 2-3 cm. long; lower leaves lanceolate or linear, some of them usually toothed. 8. A. dispersa.

Plant low, less than $2 \mathrm{dm}$. high; capsule $12-15 \mathrm{~mm}$. long; leaves all ovate, entire.

9. A. compacta.

1. A. congesta (Nutt.) Rydb. Stems white, 1-4 dm. high, somewhat pilose; lower leaves linear, entire, 4-6 cm. long; the upper ones lanceolate, sometimes sinuately toothed; sepals $2-3 \mathrm{~mm}$. long; petals rounded-obovate; capsule $8 \mathrm{~mm}$. long, clavate-oblong, about 20-seeded. Hills: Ida.-Nev.-Calif. Son.

2. A. gracilis Rydb. Stem $3-5 \mathrm{dm}$. high; leaves $5-10 \mathrm{~cm}$. long, deeply pinnatifid to near the midrib; floral leaves lanceolate, sessile, pinnatifid or toothed, rarely entire; sepals $4-5 \mathrm{~mm}$. long; petals obovate, $6-7 \mathrm{~mm}$. long, strongly striate; capsule linear-cylindric, $2.5-3 \mathrm{~cm}$. long. Foot-hills and plains: Colo.-Wyo.Nev.-Wash. Son.-Submont. My-Jl.

3. A. ctenophora Rydb. Stems 3-6 dm. long; lower leaves linear or linearlanceolate in outline, often $2 \mathrm{dm}$. long, the upper lanceolate, with a broad base, all pectinately laciniate; sepals ovate-lanceolate, acute, 4-5 $\mathrm{mm}$. long; petals obovate, light yellow, about $8 \mathrm{~mm}$. long. $M$. ctenophora Rydb. Sandy soil: Mont.-Neb.-N.M.-Ariz.-B.C. Plain-Submont. Mr-Au.

4. A. albicaulis (Dougl.) Rydb. Stem white, glabrous, erect, or decumbent at the base, 1-4 dm. high; lower leaves linear-oblanceolate, usually dentate or entire; middle leaves with 1-5 pairs of linear lobes, the upper linear, usually entire; sepals lanceolate-subulate, $2-2.5 \mathrm{~mm}$. long; petals obovate, $3-4 \mathrm{~mm}$. long, golden yellow, rather prominently veined; capsule linear-cylindric, 10-15 $\mathrm{mm}$. long, $2 \mathrm{~mm}$. thick. M. albicaulis Dougl. Sandy soil: Mont.-Neb.-N.M. -Ariz.-B.C. Plain-Submont. Mr-Au.

5. A. Tweedyi Rydb. Stem very slender, erect, 1-3 dm. high, pilose when young; leaves lanceolate or linear in outline, those of the inflorescence almost entire; sepals $1 \mathrm{~mm}$. long; petals oblanceolate, light yellow, 2-3 mm. long; capsule linear-elavate, $15 \mathrm{~mm}$. long. M. Tweedyi Rydb. Pine woods: Mont,B.C. Plain-Submont. My-Je.

6. A. tenerrima Rydb. Stem very slender, ascending, branched, strawcolored, 3-5 dm. high; leaves 2-3 cm. long, pilose; sepals linear-lanceolate, $1 \mathrm{~mm}$. long; petals oblanceolate, lemon-yellow, 2-3 mm. long; capsule $15 \mathrm{~mm}$. long. M. tenerrima Rydb. Mountain sides and dry valleys: Mont.-Utah-Ida. Submont.-Mont. My-Au.

7. A. latifolia Rydb. Stem 3-5 dm. high, branched; leaves sessile, ovate or ovate-lanceolate, coarsely toothed or entire, $5-10 \mathrm{~cm}$. long; sepals $2.5-3 \mathrm{~mm}$. long; petals obovate-spatulate, about $5 \mathrm{~mm}$. long; capsule linear-cylindric, 2.5-3 $\mathrm{cm}$. long. Foot-hills and mountains: Colo. Submont. Je-Au. 
8. A. dispersa (S. Wats.) Rydb. Stem erect; lower leaves entire, the middle ones lanceolate, entire or dentate, the uppermost ovate, entire; petals $3-4 \mathrm{~mm}$. long, obovate, bright yellow; capsule $2-3 \mathrm{~cm}$. long. M. albicaulis integrifolia $\mathrm{S}$. Wats. M. dispersa S. Wats. Sandy soil: Mont.-Colo.-Calif.-B.C.; Mex. Son.-Submont. My-Au.

9. A. compacta (A. Nels.) Rydb. Stem whitish, pilose; leaves numerous, $2-3 \mathrm{~cm}$. long, rough-hirsute; petals obovate, $3-4 \mathrm{~mm}$. long; capsule linear-clavate, 10-13 mm. long, 10-12-seeded. M. compacta A. Nels. Plains and foot-hills: Wyo.-Colo.-Ida.-Wash. Son.-Submont. Je-Au.

\section{MentZìlia (Plum.) L. Stick-Leaf.}

Annual or biennial, or in the tropics even perennial herbs, scabrous, with barbed hairs. Leaves alternate, relatively broad, sinuate or lobed. Flowers perfect, eymose. Sepals 5, persistent. Petals also 5, deciduous. Stamens numerous; filaments filiform, united at the base with each other and with the petals into a ring. Hypanthium short, tapering at the base. Placentae 3, broad and band-like, bearing the ovules in 1 or 2 rows. Capsule 3-valved at the top. Seeds rather few, ellipsoid, angled, striate, neither winged, nor separated by horizontal lamellae.

1. M. oligosperma Nutt. Perennial, with a fusiform root; stem strawcolored, rough-hirsute; leaves ovate or ovate-lanceolate, or sometimes rhombic, coarsely dentate and often somewhat lobed, $1-6 \mathrm{~cm}$. long; sepals 5-8 $\mathrm{mm}$. long, linear-subulate; petals 10-15 $\mathrm{mm}$. long, obovate-cuneate, cuspidate, golden yellow; stamens about 20; capsule about $8 \mathrm{~mm}$. long, $2 \mathrm{~mm}$. thick, about 3seeded. M. Nelsonii Greene, a small-flowered form. Rocky places and hillsides: Ill.-La.-Tex.-N.M.-N.D.; Mex. Plain-Submont. Je-Au.

\section{EUCNİDE Zuce.}

Annual or biennial herbs. Leaves alternate, broad, toothed or lobed, longpetioled, armed with stinging barbed hairs. Flowers solitary or in cymes. Sepals 5, persistent. Petals 5, deciduous, united at the base. Stamens numerous; filaments united below and adnate to the petals. Styles 5 , distinct above. Placentae 5, parietal; ovules numerous. Capsule broadened upwards, 5-valved at the top; seeds numerous, longitudinally striate.

1. E. urens Parry. Stem very hispid, with stinging bristles, straw-colored; leaf-blades suborbicular or broadly ovate, $4-5 \mathrm{~cm}$. long, the lower petioled, the upper sessile; sepals lanceolate, $15-20 \mathrm{~mm}$. long; petals obovate, $3-4 \mathrm{~cm}$. long, light yellow, short-acuminate. Sandstone cliffs: s Utah-Nev. L. Son. My.

\section{PETALÒNYX A. Gray.}

Erect perennial herbs, shrubby at the base, or low shrubs, scabrous with short barbed hairs. Leaves alternate, entire or toothed. Flowers small, in terminal heads or short spikes. Hypanthium small, cylindric. Sepals 5, linear, deciduous. Petals 5, yellowish, long-clawed, spatulate. Stamens 5; filaments free, filiform. Ovary 1-celled. Style simple. Stigma entire. Ovule solitary, pendulous. Capsule oblong, bursting irregularly. Seed smooth.

Leaves of the branches reduced, less than $1 \mathrm{~cm}$. long.

Leaves of the branches not reduced, about $2 \mathrm{~cm}$. long.

1. P. Thurberi.

2. P. Parryi.

1. P. Thurberi A. Gray. Perennial, more or less shrubby at the base; stems $3-6 \mathrm{dm}$. high, finely scabrous-pubescent; leaves $6-20 \mathrm{~mm}$. long, ovate or triangular-ovate, thick, finely scabrous, sessile, entire or few-toothed; spikes short, 1-4 cm. long; bracts 2, small, linear; sepals linear, $1 \mathrm{~mm}$. long; petals white, 4-5 mm. long, slender-clawed; blades ovate; fruit ovate, $2.5 \mathrm{~mm}$. long. Dry sandy soil: Ariz.-s Utah-s Calif.; Mex. L. Son. My-Jl.

2. P. Parryi A. Gray. A low shrub; bark of the stems gray and fissured, that of the twigs straw-colored and scabrous-puberulent; leaves subsessile, ovate or rhombic, or the lower spatulate, crenate, $1-3 \mathrm{~cm}$. long, very scabrous; 
bracts lanceolate, crenate; sepals linear, $3 \mathrm{~mm}$. long, twice as long as the hypanthium; petals yellowish, about $1 \mathrm{~cm}$. long, long-clawed; blades spatulate. Desert region: s Utah. L. Son.

\section{Family 88. CaCtaceae. Cactus Family.}

Succulent shrubby plants, usually spiny, the spines arising from small hairy or bristly cushions (areolae); leaves usually wanting, if present, in ours small and deciduous. Flowers perfect, in ours regular, solitary. Hypanthium well developed, enclosing the ovary. Sepals usually many, imbricate, the inner often petal-like. Petals many, in two or more series. Stamens numerous, in several series. Gynoecium of several united carpels; ovary inferior, 1-celled, with several parietal placentae. Fruit a fleshy or rather dry berry.

Leaves evident, but small and deciduous; flowers without definite tube; seeds with a bony aril; stems jointed.

1. OPUNTIA.

Leaves wanting; flowers with a more or less definite tube; seeds without aril; stems not conspicuously jointed.

Flowers borne near the spine-bearing areolae.

Plant-body more or less cylindric; spines arranged on definite ribs; flowers arising from near fully developed areolae, hence lateral on the stem. 2. ECHINOCEREUS.

Plant-body usually globular or ellipsoid or short cylindric; fruit not spiny; stem tubercled or ribbed, if ribbed the flowers arising near young areolae, hence nearly terminal on the stem.

Flowers large; fruit covered with bracts; seeds smooth. 3. EcHINOcACTUs.

Flowers small; fruit naked or nearly so; seeds roughened; stems tubercled.

4. PEDIOCACTUS.

Flowers borne remote from the spines, at the base of the tubercles of the stem.

5. CORYPHANTHA.

\section{OpÚntia Hill.* Prickly Pear, Cholla, Indian fig, Tree Cactus.}

Fleshy plants with conspicuously jointed stems, the joints flat or terete. Leaves scale-like, eaducous, spirally arranged. Areolae axillary, usually spinebearing. Flowers lateral, arising from the upper part of some spine-bearing areolae. Hypanthium bearing areolae, not produced beyond the ovary. Sepals spreading, in several rows. Style cylindric; stigma 5-8-lobed. Berry more or less pear-shaped, fleshy or rather dry. Seeds disk-like and flattened. Embryo curved around the endosperm.

Internodes cylindrical; spines covered with a delicate sheath.

Internodes very fleshy, turgid, easily detached.

Internodes less fleshy, not easily detached.

Fuit dry; seeds angular.

Fruit fleshy; seeds not angular.

Plants tall (1 to 3 meters high); flowers red:

Plants low and spreading (less than 1 meter high).

Spines yellow; flowers olive-green.

Spines white; flowers yellow.

Internodes flat and broad; spines not covered by a sheath.

1. O. echinocarpa.

2. O. acanthocarpa.

3. O. arborescens.

4. O. Davisii.

5. O. Whipplei.

Pulvini not densely woolly.

Fruit dry when mature, usually very spiny.

Internodes very fleshy, often terete in section, the terminal one easily breaking loose.

6. O. fragilis.

Internodes never terete in section, but always much broader than thick. Internodes somewhat turgid; spines very long. $\quad 7$. O. rutila. Internodes flat; spines medium length.

Petals normally yellow.

Spines stout, dark brownish.

Spines weak, white.

Petals red.

Filaments red.

Filaments yellow.

Fruit juicy, usually naked or nearly so.

Internodes pubescent, always spineless.

Internodes glabrous.

Internodes often naked or sometimes bearing long, stout spines. Internodes pale, somewhat glaucous. Internodes deep green.

8. O. polyacantha.

9. O. Schweriniana.

10. $O$, rhodantha.

11. O. xanthostemma.

12. $O$. basilaris.

13. O. humifusa.

14. O. Greenei.

* Key prepared by Dr. J. N. Rose. 
Internodes generally bearing several spines from each areole.

Spines twisted.

15. O. tortispina.

Low and procumbent; internodes 5 to $10 \mathrm{~cm}$. broad.

16. O. camanchica.

Stout and somewhat ascending; internodes $12 \mathrm{~cm}$. or more broad.

Pulvini densely long-woolly.

Plant erect; one spine deflexed.

Plant prostrate; all spines deflexed.

17. O. utahensis.

18. O. Palmeri.

19. O. rubrifolia.

1. O. echinocarpa Engelm. A low shrub, 1.5-4.5 dm. high, with numerous spreading branches; internodes ovate, $2.5-6 \mathrm{~cm}$. long, less than $2.5 \mathrm{~cm}$. thick, with ovate crowded areolae, $8-10 \mathrm{~mm}$. long; pulvini with few straw-colored bristles; larger spines about 4, whitish, 18-25 $\mathrm{mm}$. long; smaller ones 8-16, spreading; flowers greenish yellow, $3.5-4 \mathrm{~cm}$. broad; fruit dry, depressed-globose, very spiny. Desert regions: Ariz. $-\mathrm{s}$ Utah-Calif. L. Son.

2. O. acanthocarpa Engelm. Erect and arborescent, 1.5-2 m. high, with few alternate branches; internodes eylindric, $1-2 \mathrm{dm}$. long, $2.5 \mathrm{~cm}$. thick; areolae oblong, 18-20 mm. long; pulvini with short wool and seanty bristles; spines 8-25, spreading in all directions, the inner $2.5-3 \mathrm{~cm}$. long; flowers copper-colored; fruit depressed-globose, with few stout spines. Desert regions: Ariz.-s Utahse Calif.-Sonora. Son.

3. O. arborescens Engelm. Erect, arborescent, $1.5-8 \mathrm{~m}$. high, with vertieillate branches; internodes cylindric, $0.5-1.5 \mathrm{dm}$. long, $2 \mathrm{~cm}$. thick; areolae oblong, 15-30 mm. long; pulvini short-woolly, but scarcely bristly; spines 8-30, terete, spreading, the inner often $2.5 \mathrm{~cm}$. long; flowers purple, 6-7.5 $\mathrm{cm}$. broad; fruit subglobose, prominently tuberculate, unarmed. TREe CACTUS. Foot-hills and plains: Tex.-Colo.-Utah-Sonora. Son.-Submont.

4. O. Davisii Engelm. Spreading or procumbent, with divaricate branches; internodes slender, narrowed towards the base, $10-15 \mathrm{~cm}$. long, with linearoblong areolae, 14-16 $\mathrm{mm}$. long; inner spines 4-7, subtriangular, reddish brown, $2.5-3.5 \mathrm{~cm}$. long, the lower 5 or 6 slender, $6-12 \mathrm{~mm}$. long; flowers yellowish; fruit ovoid, $2.5 \mathrm{~cm}$. long, spiny. Arid regions: Tex. $\rightarrow$ S Colo. $-\mathrm{s}$ Calif. Son.

5. O. Whipplei Engelm. Stem erect, rarely spreading, $2-20 \mathrm{dm}$. high, with divaricate branches; internodes cylindric, 5-30 $\mathrm{cm}$. long, 1-2 cm. thick, with ovate areolae, $10 \mathrm{~mm}$. long; pulvini sparingly woolly, scarcely bristly; spines short, the longer 1-4 divaricate, $6-18 \mathrm{~mm}$. long, and 2-8 smaller ones deflexed; flowers red; fruit subglobose, lightly tuberculate, unarmed. Desert regions: N.M. - s Utah-Calif.-L. Calif. L. Son.

6. O. fragilis (Nutt.) Haw. Decumbent; internodes $3.5-5 \mathrm{~cm}$. long, ovate, only slightly compressed or subterete; pulvini large, white woolly and with few bristles; spines 1-4, divaricate, the uppermost stout, angular, 12-20 $\mathrm{mm}$. long; flowers pale yellow, about $5 \mathrm{~cm}$. broad; fruit ovate, almost naked, about $2.5 \mathrm{~cm}$. long. Plains and hills: B.C.-Minn.-Wis.-Kans.-Utah. Plain-Submont.

7. O. rutila Nutt. Stems ascending or diffuse; internodes thick, ovate, 5-10 $\mathrm{cm}$. long, $2.5-7.5 \mathrm{~cm}$. broad; pulvini crowded, white-woolly and bristly; spines $3-5$, reddish gray, $1-4 \mathrm{~cm}$. long, the central one longer, spreading or declined, the upper erect, the rest reflexed; flowers rose-red or pink; fruit ovate, dry, spinulose, $2.5-3 \mathrm{~cm}$. long. Plains: w Wyo.-Calif.-Ariz. Son.-Submont.

8. O. polyacantha Haw. Stem prostrate; internodes broadly obovate or orbicular, pale green, $5-15 \mathrm{~cm}$. long, about $12 \mathrm{~mm}$. thick; pulvini densely bristly; spines $5-15$, rather stout, $1-5 \mathrm{~cm}$. long, variegated, the $3-5$ inner stout, reddish brown, $3-5 \mathrm{~cm}$. long, some deflexed, some spreading; flowers yellow; fruit ovoid, spiny, $2.5 \mathrm{~cm}$. long. O. missouriensis DC. Plains and prairies: Sask.-Wis.Mo.-N.M.-Utah-B.C. Plain. My-Je.

9. O. Schweriniana K. Schum. Diffuse; internodes oblong, small, only $5 \mathrm{~cm}$. long and $3.5 \mathrm{~cm}$. wide; pulvini with brown bristles; spines $7-10$, only on the lower side of the pulvini, the larger only about $1 \mathrm{~cm}$. long, at last all reflexed; flowers $4 \mathrm{~cm}$. broad, yellow or greenish yellow; filaments green or yellow; fruit ovoid. Hillsides: Colo. Submont. 
10. O. rhodantha K. Sehum. Stem erect; internodes obovate or more oblong, 7-12 $\mathrm{cm}$. long, 5-10 $\mathrm{cm}$. wide; pulvini with reddish brown bristles; spines $2-4$, soon becoming gray, up to $3 \mathrm{~cm}$. long, the larger flattened, porrect or erect, the lower deflexed; flowers carmine; style rose-red; stigma green; fruit obovate, bristly, soon unarmed. Table-lands: Colo.-w Neb.-Wyo. Submont. Je.

11. O. xanthostemma K. Schum. Stem erect, $3 \mathrm{dm}$. high; internodes obovate, bright green; pulvini woolly at first, with reddish brown bristles; lower ones spineless, the upper with 2-4 large spines, which are terete, $4 \mathrm{~cm}$. long, the upper dark brown, porrect, the lower reflexed, and 2-4 dark smaller ones; flowers $5 \mathrm{~cm}$. broad, carmine-red; style white at the base; stigma green; fruit obovoid, prickly. Table-lands: Colo. Submont. Je.

12. O. basilaris Engelm. Ascending; internodes obovate, glaucescent, minutely pubescent, 1-2 dm. long; pulvini depressed, with yellow wool and numerous reddish brown bristles, without proper spines; flowers purple, 6 $\mathrm{cm}$. broad; fruit short-obovate, pubescent. Desert regions: Ariz.-Utah-Nev. - se Calif.-Sonora. Son.

13. O. humifusa Raf. Stem diffuse; internodes obovate or suborbicular, 7.5-12 $\mathrm{cm}$. long; pulvini with slender reddish brown bristles, mostly unarmed; spines when present few, only marginal, stout, straight, white, usually reddish at the base and apex, the longest $1.5-2.5 \mathrm{~cm}$. long; flowers sulphur-yellow, 6-8.5 $\mathrm{cm}$. broad; fruit clavate, naked, $3.5-5 \mathrm{~cm}$. long, with purplish pulp. O. Rafinesquii Engelm. Sandy soil: Tex.-Colo.-Minn. Plain.

14. O. Greenei Engelm. Stem diffuse; internodes orbicular-obovate; pulvini with numerous reddish brown bristles, unarmed, or armed with 1-3 spines, the upper one stout, terete, $2.5-3.5 \mathrm{~cm}$. long, brownish red, at least at the base; fruit ovate, $3 \mathrm{~cm}$. long, unarmed. Dry plains: Colo.-Ariz. Son.-Submont.

15. O. tortispina Engelm. Stem prostrate; internodes orbicular-obovate, 1.5-2 dm. long; pulvini with yellowish bristles, armed with 3-5 yellowish, angled, usually twisted spines, the longer ones $3-6 \mathrm{~cm}$. long, with 2-4 slender ones below; flowers sulphur-yellow, $6-7.5 \mathrm{~cm}$. broad; fruit ovate, $4.5-5 \mathrm{~cm}$. long. Plains: Miss.-Neb.-Tex.-Colo. Plain-Son.

16. O. camanchica Engelm. Stem prostrate; internodes obovate-orbicular; pulvini with few greenish or yellowish brown bristles, armed with 1-3 (or the marginal ones 3-6) spines, which are reddish brown or blackish brown, with paler tips, 3.5-7.5 $\mathrm{cm}$. long, the upper erect, the rest deflexed; fruit oval, 3.5-5 cm. long, deep red, sweet. Plains and hillsides: Tex.-Colo.-Ariz. PlainSubmont.

17. O. utahensis Purpus. Stem prostrate; internodes elliptic or obovate, dark green; pulvini with yellowish white wool and yellowish bristles; spines 1-4, the longest $4 \mathrm{~cm}$. long; flowers up to $9 \mathrm{~cm}$. broad, earmine; fruit cylindric, $4 \mathrm{~cm}$. long and $2 \mathrm{~cm}$. thick. Mountains: Utah. Submont.

18. O. Palmeri Engelm. Stem erect; internodes oval, not tuberculate, pale, glaucous, $20-25 \mathrm{~cm}$. long, $15-20 \mathrm{~cm}$. broad; pulvini with pale brownish or gray persistent wool, and few straw-colored bristles; spines 5-7 larger ones and a few smaller ones on the upper pulvini, $1-3$ on the lower ones, $2.5-3 \mathrm{~cm}$. long, erect or spreading or the upper ones deflexed. Arid regions: s Utah. L. Son. Je.

19. O. rubrifolia Engelm. Prostrate; internodes ovate, $12-15 \mathrm{~cm}$. long and $10 \mathrm{~cm}$. broad; pulvini with brownish gray persistent wool and numerous yellowish bristles; spines mostly 2 or 3 , slender, angular and often twisted, 2.5-6 cm. long, all deflexed. Arid regions: s Utah. L. Son.

\section{EChinocitreus Engelm. Hedgehog Cereus.}

Plants with cylindric or rarely oblong stems, ribbed, or if tubercled, the tubercles more or less connected in vertical rows. Leaves none. Spine-bearing 
areolae on the ribs or the tubercles. Flowers arising close above the spine-bearing, fully developed areolae, hence appearing lateral on the stem. Hypanthium prolonged beyond the ovary, scaly. Style filiform. Fruit fleshy. Seeds tubercled, endosperm scanty; embryo straight.

Corolla greenish; ribs of the stem about 13 .

Corolla red or purple; ribs usually less than 13.

1. E. viridiflorus.

Ribs of the stem 8-12.

Flowers scarlet; central spines 2-7.

Central spines all terete; flowers 4-6 cm. long, yellowish inside.

Lower central spine quadrangular: 2 . E. aggregatus,
2.

Flowers purple or violet.

Central spines 4-5, straight.

Central spines solitary, bulbous at the base.

3. E. Roemeri.

Central spine terete; radials $12-25 \mathrm{~mm}$. long, the lower stouter.

Central spine angular; radials $2-5 \mathrm{~cm}$. long, the lateral 5. E. Fendleri.

Ribs of the stem 5-7.

6. E. mojavensis. Central spine present, $8 \mathrm{~cm}$. long, angled and grooved; radials $6-8$, strongly
angled.

Central spine wanting; radials $3-59$, almost terete.

8. E. paucispinus.

1. E. viridiflorus Engelm. Stem globose or sometimes oblong-cylindric, 2.5-7.5 $\mathrm{cm}$. high; ribs 13, acute; central spines solitary, stout, straight or curved, and radiating, $2-6 \mathrm{~mm}$. long; flowers $2.5 \mathrm{~cm}$. wide, greenish brown without, yellowish green within; fruit elliptic, $10-12 \mathrm{~mm}$. long. Plains and hills: Tex.Wyo.-N.M. Son.-Submont.

2. E. aggregatus (Engelm.) Rydb. Ovate or subglobose, obtuse, 3.5-7.5 $\mathrm{cm}$. high, 3-5 $\mathrm{cm}$. thick, cespitose in hemispheric tufts; ribs 8-11, tubercled; spine slender, straight, terete; radials $8-12$, white, 6-12 $\mathrm{mm}$. long, the upper shorter; central spines 1-3, stouter, 1-2 cm. long; flowers deep scarlet, $3.5-6 \mathrm{~cm}$ long, $2.5-3.5 \mathrm{~cm}$. broad. Cereus coccineus and C, phoeniceus Engelm. Hillsides and plains: Tex.-Colo.-Ariz.; n Mex. Son.-Submont.

3. E. Roemeri (Muhlenph.) Engelm. Stem ovoid, 7.5-10 cm. high, sparingly branched; ribs 9-11, obtuse, tubercled; spines whitish or straw-colored, with bulbose bases; radials 8-12, slender, straight, the upper 4-10 $\mathrm{mm}$. long, the lateral $12-30 \mathrm{~mm}$. long; central spines $3-5$, very bulbose, the lowest quadrangular, dusky when young, $2.5-7.5 \mathrm{~cm}$. long, porrect or reflexed; flowers scarlet, 8-10 $\mathrm{cm}$. long, 3.5-5 cm. broad. Cereus Roemeri Muhlenph. C. conioides Engelm. Plains: N.M.-Colo.-Calif.; n Mex. Son.

4. E. Engelmanni (Parry) Lem. Stem elliptic-cylindric, 12-30 cm. high, $5-7 \mathrm{~cm}$. thick, simple or sparingly branched; ribs $10-12$, rarely 13 , tuberculate; radial spines 12-14, slender, 6-12 $\mathrm{mm}$. long, white, with dark tips, the upper setaceous and the lower stoutest; central spines 4 (or 5 ), straight and angled, $2.5-5 \mathrm{~cm}$. long, the 3 upper yellow, straight, the lowest white, porrect or reflexed; flower purple, $5-7 \mathrm{~cm}$. long; fruit ovate, $4 \times 2.5 \mathrm{~cm}$. Cereus Engelmanni Parry. Deserts: Utah-Calif.-L. Calif.-Sonora. L. Son.

5. E. Fendleri (Engelm.) Rumpl. Stem ovoid or ovoid-cylindric, 7.5-20 cm. high, $5-7.5 \mathrm{~cm}$. in diameter, cespitose; ribs 9-12, tubereulate; radial spines $5-10$, straight or curved, the lowest stoutest, white and angular, $12-25 \mathrm{~mm}$. long; central spine 1 , stout and bulbose at the base, curved upwards, reddish black, $2.5-5 \mathrm{~cm}$. long; flowers violet-purple, $6-8.5 \mathrm{~cm}$. broad; fruit ovate-globose, $2.5-3$ $\mathrm{cm}$. long, purple-green, edible. Cereus Fendleri Engelm. Dry plains: Tex.-
Utah-Ariz.; n Mex. Son.

6. E. mojavensis (Bigel. \& Engelm.) Rumpl. Stem ovate, glaucous, 5-8 $\mathrm{cm}$. high, densely tufted, forming masses $1 \mathrm{~m}$. wide; ribs $8-12$, slightly tubercled; central spine angular, dusky, curved upwards, $3.5-6 \mathrm{~cm}$. long; radials $5-8$,
stout, curved, and interlocked, white or with tawny tips, the upper and lower
$2-3 \mathrm{~cm}$. long, the lateral ones $3-5 \mathrm{~cm}$. $2-3 \mathrm{~cm}$. long, the lateral ones $3-5 \mathrm{~cm}$. long; flowers deep crimson, $5-7 \mathrm{~cm}$. long;
fruit oblong, $2.5-3 \mathrm{~cm}$. long. Deserts: Calif.-Utah-Ariz. Son. 
7. E. goniacanthus (Engelm.) Lem. Stems ovoid, 7.5-12.5 cm. high, simple or sparingly branched at the base; ribs 7 , rarely 8 or 9 , tuberculate; spines stout, angular, straight, or curved; radials 8 , the lower $16-24 \mathrm{~mm}$. long, the rest 2-3 $\mathrm{cm}$. long, yellow at the base and dark-tipped, the upper one and the solitary central one stout, 6-7-angled, 3-6 $\mathrm{cm}$. long, $2 \mathrm{~mm}$. broad; flowers scarlet, about $6 \mathrm{~mm}$. long. Cereus goniacanthus Engelm. Sandy hills: Colo.-N.M. Submont.

8. E. paucispinus (Engelm.) Rumpl. Stem ovoid or ovoid-cylindric, 12$25 \mathrm{~cm}$. high, 5-10 $\mathrm{cm}$. thick, simple or somewhat branched, deep green; ribs 5-7, tubercled; spines stout, with a bulbose base, straight or somewhat curved; radials 3-7, reddish or dark, at last blackish, $18-32 \mathrm{~mm}$. long; central one wanting or rarely a stout subangular one, 3-4 cm. long, porrect; flowers purplish red, 2.5-3 cm. broad. Cereus paucispinus Engelm. Rocks and limestone hills: Tex.-Colo.-N.M. Submont.

\section{ECHINOCÁCTUS Link \& Otto. Hedgehog CACtUS, Barrel Cactus.}

Fleshy plants, with globular, or oblong, or sometimes cylindric stems, with spine-bearing ribs, or these divided into spiral or vertical rows of tubercles. Leaves none. Flowers borne just above young spine-bearing areolae, hence appearing almost terminal on the stem. Hypanthium produced beyond the ovary, more or less scaly, not spiny. Style columnar; stigmas slender. Fruit a fleshy or dry berry, scaly. Seeds smooth, or nearly so, with an endosperm; embryo eurved.

Stem with definite ridges, not tuberculate.

Scales of the hypanthium subulate, copiously woolly in their axils; fruit dry and clothed with wool.

Uppermost central spine the broadest; ribs of the stem 15-20.

Le 1 . E. polycephalus.

Scales of the hypanthium ovate, orbicular, or not woolly.

One or more of the central spines strongly hooked, neither annulate nor strongly compressed.

Central spines except the hooked one, flattened, glabrous.

Central spines all terete, pubescent.

3. E. Whipplei.

4. E. pubispinus.

One or more of the central spines distinctly annular, strongly broadened, flattened above, slightly if at all hooked.

Radial spines 9-13; upper central spine angled.

Radial spines over 20: upper three spines terete.

5. E. cylindraceus.

6. E. Wislizeni.

Stem with the ribs more or less divided into tubercles.

Tubercles terete.

Radial spines 8-9; central ones 1-3; tubercles $1 \mathrm{~cm}$. high.

Radial spines 10-14; central spines 4; tubercles low.

Tubercles rhombic in cross-section; radial spines 13-15.

7. E. subglaucus.

8. E. Johnsoni.

9. E. Sileri.

1. E. polycephalus Engelm. \& Bigel. Globose to ovate or cylindric, 15-70 $\mathrm{cm}$. high, $12.5-25 \mathrm{~cm}$. in diameter, branched at the base; ribs 15-21; spines 8-15, very stout, compressed, more or less recurved, reddish; radials 4-11, comparatively slender, $2.5-5 \mathrm{~cm}$. long; centrals 4 , very unequal, $2-9 \mathrm{~cm}$. long, the uppermost broadest, curved upward, the lower longest and decurved; flowers yellow; fruit globose, $15-20 \mathrm{~mm}$. in diameter. Stony or gravelly ground: Ariz. -Utah-s Calif. L. Son.

2. E. xeranthemoides Engelm. Stem globose, $2.5-12.5 \mathrm{~cm}$. high; ribs 13 , sharp and interrupted; spines 10-15, straight or slightly curved; radials small, about $3 \mathrm{~cm}$. long; centrals 4 , slender, $3-5 \mathrm{~cm}$. long, the lowest broadest and porrect, otherwise as the preceding. Desert regions: s Utah-Ariz. L. Son.

3. E. Whipplei Engelm. Stem globose-ellipsoid, 7-13 cm. high, 5-10 cm. thick; ribs 13-15, compressed and somewhat interrupted; radial spines $7-11$, white or the lower dusky, 12-36 $\mathrm{mm}$. long; central spines 4, the uppermost flattened, straight, $2.5-4 \mathrm{~cm}$. long, $1-2.5 \mathrm{~mm}$. broad at base, turned upwards, the others $2.5-3 \mathrm{~cm}$. long, 4-angled, dark brown, the lateral straight, the lowest sharply hooked downward: flowers greenish red, $2-3 \mathrm{~cm}$. long. Sandy soil: Utah-Colo. -Ariz. Son. 
4. E. pubispinus Engelm. Small, turbinate or ellipsoid, $5 \mathrm{~cm}$. high, 2.5-3 $\mathrm{cm}$. in diameter; ribs 13 , compressed, tuberculate; spines velvety pubescent, in age glabrate; radial spines 5-6 below, 9-12 above, $2-8 \mathrm{~mm}$. long, straight to hooked; central spines wanting or solitary, longer, 10-12 $\mathrm{mm}$. long, strongly hooked. Valleys: Utah. Son.

5. E. cylindraceus Engelm. Globose to ovoid or ovate-cylindric, simple or branching at the base, up to $9 \mathrm{dm}$. high and $3 \mathrm{dm}$. thick; ribs 13-27, obtuse and tuberculate; spines stout, compressed, more or less curved, reddish; radials about $12,2.5-5 \mathrm{~cm}$. long, the lowest stouter and hooked; centrals 4, very stout, 4-angled, about $5 \mathrm{~cm}$. long, the uppermost broadest, straight and erect, the lowest decurved; flowers yellow; fruit subglobose, pale green, $2.5 \mathrm{~cm}$. thick. Desert regions: Tex.-S Utah-Calif,-L. Calif. L. Son.

6. E. Wislizeni Engelm. At first globose, at last cylindric, 5-12 dm. high; ribs 21-25, or sometimes less, acute and oblique, more or less tubercled; radial spines $1.5-5 \mathrm{~cm}$. long, the 3 upper and 3-5 lower stouter, the lateral ones bristlelike; centrals 4 , stout, angled, red, $3.5-7.5 \mathrm{~cm}$. long, the 3 upper straight, the lowest and strongest up to $12 \mathrm{~cm}$. long, flat and hooked downwards; flowers yellow or sometimes red, 5-6.5 cm. long; fruit ovate, yellow. Desert regions: w Tex. $\rightarrow$ U Utah-Calif,; n Mex. L. Son.

7. E. subglaucus Rydb. Simple, depressed-globose or ellipsoid; ribs 8-13, with conical tubercles; radial spines $8-9$, white or with darker tips, straight, up to $15 \mathrm{~mm}$. long; central spines 1-3, curved, dark brown; flowers $3 \mathrm{~cm}$. broad, rose-red; fruit pear-shaped, $1 \mathrm{~cm}$. high. E. glaucus K. Schum., not Karw. High table-land: Colo. Submont.

8. E. Johnsoni Parry. Stem oval, 1-1.5 dm. high; ribs 17-21, rounded, interrupted into low rounded tubercles; radial spines $10-14,1.5-3 \mathrm{~cm}$. long, the upper strongest; central spines 4, stout, recurved, reddish gray, $3.5-4 \mathrm{~cm}$. long; flowers 5-6.5 cm. long, deep red to pink; seeds pitted. Arid regions: Utah. Son.

9. E. Sileri Engelm. Globose; ribs 13, prominent, densely crowded with short rhombic-angled tubercles; radial spines 11-13, white; centrals 3 , black with pale base, $18 \mathrm{~mm}$. long, the uppermost slightly longer; flowers scarcely $2.5 \mathrm{~cm}$. long, straw-colored. Desert regions: s Utah. L. Son.

\section{PEDIOCÁCTUS Britton \& Rose.}

Stem globose, leafless, tubercled; the tubercles arranged in spiral rows, nipple-shaped. Flowers borne on the tubercles, near the areolae. Hypanthium funnelform, bearing a few scales. Petals numerous, pink. Stamens numerous. Fruit globose, irregularly bursting, nearly or quite scaleless. Seed tubercled, with a basal hilum.

1. P. Simpsoni (Engelm.) Britton \& Rose. Subglobose or turbinate at the base, sometimes clustered, $7.5-12.5 \mathrm{~cm}$. in diameter; ribs 8-13, with prominent nipple-shaped tubercles, which are $12-16 \mathrm{~mm}$. long; radial spines 20-30, slender, straight, 8-12 mm. long; central spines 8-10, stouter, yellowish to black, 10-14 $\mathrm{mm}$. long; flowers $16-20 \mathrm{~mm}$. long, and nearly as broad, yellowish green or purple; fruit green, 6-7 mm. long, suborbicular. Echinocactus Simpsoni Engelm. Table-lands and plains: Nev.-Utah-Colo. Submont.-Subalp.

\section{CORYPHÁNTHA (Engelm.) Lem.}

Fleshy plants, with globular or oval, solitary or clustered stems, covered by spirally arranged tubercles with spine-bearing areolae at the end. Leaves none. Flowers borne near woolly areolae in the axils or near the base of the tubercles. Hypanthium produced peyond the ovary, campanulate or funnelform, naked. Style filiform. Berry fleshy. [Mamillaria Haw.]

Larger spines curved upwards; tubercles not grooved; flowers borne at the base of older tubercles, hence lateral on the stem.

Spines all straight; tubercles grooved; flowers borne at the base of young tubercles, hence nearly terminal. 
Flowers yellowish or greenish, merely tinged with red; central spines 1 ; berry scarlet, Stem usually simple or nearly so; central spines stout, porrect; flowers about 2.5

$\mathrm{cm}$. long.
Stems tufted; central spine often wanting or small; flowers $3-4 . C$. missouriensis.

Flowers purple; central spines several; berry green, ellipsoid.

Stems tufted, depressed-globose; central spines 3-4.
Stems usually simple, ellipsoid or oblong; central spines 4-12, vivipara.

C.

4. C. vivipara.

5. C. radiosa.

1. C. Grahami (Engelm.) Rydb. Stem simple or clustered, globose, becoming ellipsoid, $3-8 \mathrm{~cm}$. high; tubercles ovate, $6 \mathrm{~mm}$. long; radial spines $15-30$, white, often dusky-tipped, 6-12 mm. long; central spines 1-3, blackish, with a paler base, the lower one stouter and longer, 6-18 $\mathrm{mm}$. long, hooked upwards; flowers 2-2.5 cm. long, rose-colored; fruit 2-2.5 cm. long; seeds $1 \mathrm{~mm}$. long, black. M. Grahami Engelm. Rocky places: Tex, $-\mathrm{s}$ Utah-s Calif,; Sonora. L. Son.

2. C. missouriensis (Sweet) Britton \& Rose. Stem mostly simple, globose, 3-5 cm.; tubercles $12-15 \mathrm{~mm}$. long, in about 8 spiral rows; spines gray, $10-20$ together; central spine 10-12 mm. long; corolla greenish yellow or tinged with reddish; berry globose, $6-8 \mathrm{~mm}$. in diameter, ripening the next spring; seeds black, $1 \mathrm{~mm}$. long. M. missouriensis Sweet. M. Notesteinii Britton. Cactus missouriensis Kuntze. Plains and hills: S.D.-Mont,-Colo.-Kans. Plain. My.

3. C. similis (Engelm.) Britton \& Rose. Stems clustered, forming masses $3 \mathrm{dm}$. broad; tubercles $1.5-2 \mathrm{~cm}$. long, in 8 spiral rows; radial spines gray, $12-$ 15, puberulent, the central one often lacking, not larger than the rest; corolla yellowish, 3-5 cm. long; berry globose, $8-10 \mathrm{~mm}$.; seeds $1.5-2 \mathrm{~mm}$. long. $M$. simitis Engelm. Cactus missouriensis similis Coulter. Plains: Kans.-Colo.Tex. Son.

4. C. vivipara (Nutt.) Britton \& Rose. Stems usually tufted, $3-5 \mathrm{~cm}$. high; tubercles terete, ellipsoid, slightly grooved; central spines $3-4$, slender, reddish brown, 8-12 mm. long, one of them deflexed, the others ascending; radial spines 12-20, white, often dark-tipped, $6-8 \mathrm{~mm}$. long; flowers about $3.5 \mathrm{~cm}$. long, bright purple; fruit pale green, $12-18 \mathrm{~mm}$. long; seeds yellowish brown, obliquely pearshaped, $1.5 \mathrm{~mm}$. long. Cactus viviparus Nutt. M. vivipara Haw. Plains: Man. -Alta.-Colo.-Kans. Plain.

5. C. radiosa (Engelm.) Rydb. Stems mostly simple, ellipsoid or cylindric, 5-12 cm. high and $5 \mathrm{~cm}$. thick; tubercles 8-12 mm. long; central spines 4-12, tawny or purplish, 8-12 mm. long, the upper the longer, the lowest small and porrect; radial spines 20-30, white, 6-8 mm. long; flowers $3.5-5 \mathrm{~cm}$. long, dark purple; seeds $2 \mathrm{~mm}$. long. M. radiosa Engelm. Cactus radiosus Coulter. Plains: Kans.-s Utah-Sonora-Tex. Son.

\section{Family 89. elaeagnaceae. Oleaster Family.}

Shrubs or trees, with silvery, scaly, or stellate pubescence. Leaves entire, alternate or opposite. Flowers in axillary clusters, perfect, polygamous or dioecious. Hypanthium in the pistillate flowers tubular or urn-shaped, adnate to and enclosing the ovary. Sepals 4, deciduous. Corolla none. Stamens 4 or 8. Disk present, annular or lobed. Ovary 1-celled, 1-ovuled. Fruit drupe-like.

Stamens 4; flowers perfect or polygamous; leaves alternate.

Stamens 8; flowers dioecious; leaves opposite.

1. EllaEAgNus.

2. LEPARgYraEA.

\section{1. ellakágNus (Tourn.) L. Silver-berry, Silver-Bush.}

Silvery-scaly shrubs or trees. Leaves alternate, petioled. Flowers solitary or 2-4 together, axillary, perfect or polygamous. Hypanthium tubular, constricted over the ovary. Sepals 4, deciduous, valvate. Stamens 4. Fruit drupe-like. 
1. E. commutata Bernh. Shrub or small tree, $2-5 \mathrm{~m}$. high, with brownscurfy twigs; leaf-blades oblong or elliptic, densely silvery, scurfy on both sides, $2-10 \mathrm{~cm}$. long; flowers $1-3$ in the axils, fragrant, $12-16 \mathrm{~mm}$. long; perianth silvery without, yellowish within; sepals ovate, $2 \mathrm{~mm}$. long; fruit ellipsoid, silvery, 8-12 $\mathrm{mm}$. long; stone 8-striate. E. argentea Pursh. Banks and hillsides: Que.Minn.-S.D.-Utah-Yukon. Plain-Submont. Je-JI.

\section{LEPARGYRAÈA Raf. BUFFalo-BerRy, BULl-BerRy.}

Shrubs, with silvery or brown, scaly or stellate pubescent. Leaves opposite, petioled. Flowers small, dioecious, in small clusters at the nodes of preceding season. Hypanthium of the pistillate flowers urn-shaped or ovoid, bearing an 8-lobed disk at its mouth. Stamens 8, alternate with the lobes of the disk. Fruit drupe-like. [Shepherdia Nutt.]

Leaves green above; shrub not thorny.

Leaves silvery white on both sides; plant usually thorny.

Leaves oblong; fruit ellipsoid; tall shrub or small tree.

Leaves rounded-oval or ovate; fruit globular; low shrub.

1. L. canadensis.

2. L. argentea.

3. L. rotundifolia.

1. L. canadensis (L.) Greene. A thornless shrub, 1-3 m. high, with brown scurfy branches; leaves ovate or oval, silvery stellate and brown-scurfy spotted beneath; flowers brown without, greenish yellow within; fruit rounded-ellipsoid, red or yellowish, 4-6 mm. long, insipid. Shepherdia canadensis (L.) Nutt. Woods and banks: Newf.-N.Y.-Mich.-Colo.-Utah-Ore.-Alaska. Submont.-Subalp. Ap-Je.

2. L. argentea (Nutt.) Greene. A shrub or small tree, 2-7 m. high, with whitish, more or less thorny branches; leaves oblong, $2-5 \mathrm{~cm}$. long, rounded at the apex, acute at the base; flowers brown; fruit rounded-ellipsoid, sour, scarlet, red, or golden yellow, 4-6 mm. long. S. argentea Nutt. River banks: Sask.Man.-Kans.-N.M.-Nev.-Alta. Plain-Submont. Ap-My.

3. L. rotundifolia (Parry) Greene. Low densely branched shrub, with silvery tomentose branches; leaves persistent, rounded-oval or ovate, $1-3 \mathrm{~cm}$. long; staminate flowers in 3's, the pistillate solitary, silvery without; fruit globular, scurfy. S. rotundifolia Parry. Bare clayey soil: s Utah. Son. Mr.

\section{FAmily 90. LYTHRACEAE. Loosestrife Family.}

Herbs, rarely shrubs or trees, with opposite or alternate, mostly entire leaves. Flowers perfect, solitary or in axillary clusters or cymes. Hypanthium from globose or campanulate to cylindric, enclosing but free from the ovary. Sepals 4 or 5 , often accompanied by as many accessory teeth. Petals 4 or 5, or wanting. Stamens few or many, in one or several series. Gynoecium of several united carpels; ovary 2-6-celled, rarely 1-celled; styles united. Fruit a capsule, rarely indehiscent.

Hypanthium campanulate or turbinate, in fruit becoming globose or hemispheric.
Capsule bursting irregularly.

Capsule septicidal.

Hypanthium eylindric.

2. ROTALA.

\section{AMMÁNIA (Houston) L.}

Annual herbs, with 4-angled stems. Leaves opposite, entire, usually auricled at the base. Flowers solitary or cymosely clustered in the axils. Hypanthium campanulate, 4 -angled, becoming subglobular. Sepals 4 , usually with as many small teeth in the sinuses between them. Petals 4, early deciduous. Stamens 4-8. Ovary subglobose, usually 2-4-celled; styles filiform; stigmas capitate.

1. A. coccinea Rottb. Annual; stem erect, glabrous, branched below, 1.5-5 dm. high, glabrous; leaves linear or linear-lanceolate, acutish at the apex, aurso; petals purple, early deciduous; style elongate, very slender, usually more 
than half as long as the capsule. A. latifolia T. \& G., not L. (?) A. alcalina Blankinship. Swamps and wet places: Ind.-Fla.-Tex.-Wyo.-Mont.; Mex.; Brazil. Plain. Jl-S.

\section{ROTÃLA L.}

Annual or biennial swamp herbs, with 4-angled stems. Leaves opposite, narrow, entire. Flowers perfect, usually solitary in the axils. Hypanthium campanulate, becoming subglobose in fruit. Sepals 4, very small. Petals usually 4. Stamens 4; filaments short. Ovary subglobose, 4-celled; styles very short; stigma entire or nearly so. Capsule 4-celled, subglobose, septicidally 4-valved.

1. R. ramosior (L.) Koehne. A glabrous annual, $5-25 \mathrm{~cm}$. high; leaves oblong or linear-oblong, 1-3 cm. long, obtuse, acute at the base; flowers usually solitary in the axils; calyx 3-4 mm. long; lobes acuminate; petals minute; capsule ellipsoid. Wet places: Mass.-Fla.-Tex.-Neb.-Calif.-Ida.-Wash.; W. Ind. and Mex. Jl-S.

\section{LÝTHRUM L. LOOSESTRIFE.}

Herbs or shrubs, with angled stem; ours perennial herbs. Flowers solitary in the axils, or in spikes or racemes. Hypanthium cylindric, ribbed or grooved. Sepals 4-6, accompanied with as many accessory teeth. Petals 4-6, obovate or oblanceolate. Stamens 8-12, in one series; filament filiform. Ovary 2-celled; stigma capitate. Capsule membranous, 2-celled, or becoming 1-celled, septicidally 2-valved or bursting irregularly.

1. L. alatum Pursh. Perennial; stem glabrous, 3-12 dm. high, 4-angled or -winged; leaves sessile, alternate or the lowest opposite, lanceolate or oblong, rounded at the base, acute at the apex, 2-3 cm. long; flowers solitary in the upper axils; petals deep purple, ascending; disk fleshy; calyx $5-6 \mathrm{~mm}$. long in fruit, ribbed. Low ground: Ont.-Mass.-D.C.-Tex.-Wyo.-B.C. Plain. Je-Au.

\section{Family 91. ONAGRACeat. Evening-Primrose Family.}

Herbs, or rarely shrubs, with simple alternate or opposite leaves. Flowers perfect, axillary or in terminal racemes. Hypanthium often elongate, enclosing and adnate to the ovary. Sepals 2-6, usually 4 . Petals 2-9, usually 4 , convolute in the bud, rarely wanting. Stamens as many or twice as many as the sepals. Gynoecium of $1-6$, usually 4 , united carpels. Ovary 1-6-celled, inferior; styles united. Fruit capsular or nut-like.

\section{Flowers 4-merous.}

Fruit a many-seeded capsule, opening by valves.

Seeds with a tuft of silky hairs.

Hypanthium not prolonged beyond the ovary; flowers large.

Hypanthium somewhat prolonged beyond the ovary.

Hypanthium-tube cylindric, not inflated above the ovary, without scales within; flowers neither showy nor scarlet.

Flowers regular; stamens and style not declined; petals purplish, pink or white, in ours yellow only in one species.

Flowers irregular; stamens and style somewhat declined; petals yellowish. 3 . CORDYLOPHORUM.

Hypanthium-tube inflated above the ovary, bearing 8 scales within; flowers irregular, showy scarlet.

Seeds without a tuft of silky hairs, naked or tuberculate.

Hypanthium not produced beyond the ovary; flowers minute.

Stamens 8; sepals deciduous; capsule linear. 5 . G.

Stamens 4; sepals persistent; capsule obovoid or turbinate.

Hypanthium prolonged beyond the ovary into a cylindric or funnelform tube.

Anthers attached near the base, erect; petals never yellow.

Calyx-lobes erect; petals minute, elawless; capsule membranous.

Calyx-lobes reflexed; petals showy, clawed; capsule coriaceous. Fertile stamens 4 , the alternate ones rudimentary: petals 3 -lobed. 8. ClLARKIA. 
Fertile stamens 8 ; petals entire, rhombic. Anthers attached near the middle and versatile.

Stigma divided into 4 linear lobes.

Stamens equal in length; capsule terete or round-angled.

Ovules and seeds horizontal, inserted in 2 or rarely more rows, prismatic-angled; petals yellow.

10. OENOTHERA.

Ovules and seeds ascending, in one row, not angled; buds drooping; petals white or pink.

11. ANOGRA.

Stamens unequal in length, the alternate longer: capsule crested or winged; plant acaulescent or low-stemmed.

Capsules with more or less distinct double crests on the angles; seed furrowed along the raphe. 12. PACHYLOPHUS.

Capsules winged or at least sharply angled on the angles. Plants acaulescent, cesvitose. 13. LAvAUXIA.

Plan is caulescent, with wiry diffuse stems.

Stigma discoid or capitate.

14. Gaurella.

Stigma discoid; hypanthium-tube funnelform above.

Hypanthium-tube longer than the ovary; stigma entire.

15. GALPINSIA.

Hypanthium-tube shorter than the ovary; stigma 4-toothed.

Stigma capitate.

16. MERIOLIX.

Plant acaulescent; capsules 4 -winged; hypanthium-tube tubularcylindric.

17. TARAXIA.

Plant caulescent; capsules not winged; hypanthium-tube obconic or funnelform.

Capsule linear, sessile, narrowed above,

18. SpHafrostigma.

Fruit indehiscent, nut-like.

and obtuse.

Hypanthium-tube fliform; filaments unappendaged; ovary 1-celled.

Hypanthium-tube obconic; fllaments with scales at the base; 20 . STENOSIPHON.

Flowers 2-merous; fruit indehiscent, obovoid and bristly with hooked hairs.

22. Circaea.

\section{Chamaenterion (Gesn.) Boehmer-Ludwig. Fire-Weed.}

Perennial herbs, somewhat woody at the base. Leaves alternate, narrow, entire. Flowers perfect, somewhat irregular, showy, in terminal racemes. Hypanthium not prolonged beyond the ovary. Sepals 4, deciduous. Petals 4 , purple, forming an oblique cross, entire. Stamens 8 , with declined filaments. Stigma 4-lobed. Capsule elongate, nearly linear, obtusely 4-angled, loculicidal. Seeds with a tuft of hairs (coma) at the upper end.

Style pubescent at the base; leaves lanceolate or linear-lanceolate, with the lateral veins confluent in marginal loops.

Petals 15-20 mm. long; stem-leaves usually obtuse at the base.

Petals 8-12 mm. (rarely $15 \mathrm{~mm}$.) long; leaves all acute at the base.

Style glabrous; lateral veins of the leaves obsolete, not looped.

Leaves lanceolate to ovate, entire or nearly so; pod about $3 \mathrm{~mm}$. thick.

Leaves narrowly linear-lanceolate, denticulate; pod about $2 \mathrm{~mm}$. thick.

1. C. exaltatum.

2. C. spicatum.

3. C. latifolium.

4. C. subdentatum.

1. C. exaltatum Rydb. Stem 1-3 m. high, glabrous or nearly so; leaves linear-lanceolate, 1-2 dm. long, 2-3 cm. wide, short-petioled, minutely denticulate or entire, slightly paler beneath; lateral veins numerous, at almost right angles to the midrib; petals purple, broadly obovate; styles exceeding the stamens, bearded some distance above the base; capsule $5-8 \mathrm{~cm}$. long, spreading. Hillsides: Alaska-Mont.-Ida.-Wash. Submont. Je-J,

2. C. spicatum (Lam.) S. F. Gray. Stem $0.5-2.5 \mathrm{~m}$. high, glabrate below, puberulent above; leaves lanceolate or linear-lanceolate, $5-15 \mathrm{~cm}$. long, paler beneath; petals purple, rose-colored or rarely white; style exceeding the stamens, hairy at the base; capsule $5-7.5 \mathrm{~cm}$. long. Epilobium angustifolium $\beta \mathrm{L} . \quad C$. angustifolium Scop. Edges of woods and copses, burnt-over ground, etc.: Greenl. -N.C.-Ill.-N.M.-Calif.-Alaska. Submont.-Mont. Je-S.

3. C. latifolium (L.) Sweet. Perennial, with a cespitose rootstock; stem 1-4 dm. high, glabrous below; leaves $2-5 \mathrm{~cm}$. long, ovate or ovate-lanceolate, pale; inflorescence usually short; petals $1.5-3 \mathrm{~cm}$. long, rose-colored, pale purple, 
or white, purple-veined; style shorter than the stamens, glabrous; capsule 5-8 em. long. Epilobium latifolium L. Wet places, especially along mountain streams: Greenl.-Que.-S.D.-Colo.-Wash.-Alaska. Subalp.-Alp. Je-Au.

4. C. subdentatum Rydb. Stem $2-3 \mathrm{dm}$. high, finely puberulent; leaves narrowly lance-linear, more or less distinctly denticulate, $2-4 \mathrm{~cm}$. long, 3-8 $\mathrm{mm}$. wide, finely puberulent, the midvein strong, but the lateral ones obscure; sepals lance-linear, $12 \mathrm{~mm}$. long, purplish; petals oblanceolate, about $15 \mathrm{~mm}$. long, rose or white; style shorter than the stamens, glabrous; capsule 3-6 $\mathrm{cm}$. long, $2 \mathrm{~mm}$. thick. Banks: Alta.-B.C. Subalp.

\section{EPILÒBIUM (Gesn.) L. WILLOW-HERB, COTTON-WEED.}

Caulescent herbs, rarely shrubby. Leaves alternate or opposite, with often toothed blades. Flowers perfect, racemose or spicate, or rarely solitary. Hypanthium prolonged beyond the ovary into an obconic short tube. Sepals and petals 4 , the latter often notched, purplish, pink or white, rarely yellow. Stamens 8, not declined. Stigma club-shaped, subentire, slightly notched, or rarely 4-lobed. Capsule elongate, subcylindric, slightly fusiform or clavate, 4-celled, 4-sided, loculicidal. Seeds with a tuft of hairs (coma) at the upper end.

Petals purple, pink or white.

Perennials; stigma entire or merely notched.

Leaves oblong, oval, ovate, or lanceolate, usually dentate or denticulate.

Plants with rosettes or turions: leaves ovate or lanceolate, usually broadest below the middle, and distinctly denticulate or dentate (except sometimes in nos. 8,9 , and 16 )

Stem pubescent throughout; leaves also pubescent, at least when young. Pubescence consisting of long silky hairs.

Pubescence short and dense, crisp or glandular.

Petals $7-8 \mathrm{~mm}$. long.

Petals 4-5 $\mathrm{mm}$. long.

1. E. ursinum.

Leaves ovate, permanently glandular, dark green.

Leaves lanceolate, glabrous in age, pale green.

2. E. Sandbergii.

3. E. Palmeri.

13. E. stramineum.

Stem glabrous below; leaves glabrous or nearly so.

Flowers 7-8 mm. long; petals purple or dark pink; leaves ovate-lanceolate.

Leaves sessile or nearly so; innovations by turions. Seeds without apiculations; coma sessile.

Plant tall, 5-10 dm. high; leaves dark green, sharply dentate.

4. E. glandulosum.

Plant low, 2-4 dm. high; leaves light green, more indistinctly

denticulate.
Seeds with a pale hyaline beak at the apex. 5 . $E$. Oratifolium.

Leaves short-petioled; innovations by rosettes. 7. E. occidentale.

Flowers $3-5 \mathrm{~mm}$. long.
Leaves all except the uppermost, short-petioled.

Leaves all except the uppermost, short-petioled.
Seeds pellucid-apiculate; leaves not very thin; pods strongly ascending or nearly erect.

Innovations by rosettes.

Leaves narrowly lanceolate, pale green; corolla white.

8. E. americanum.

Leaves broadly lanceolate, not pale; corolla usually pink.

Innovations by turions.

9. E. adenocaulon.

Seeds not apiculate; leaves very thin; pods ascending-spreading.

11. E. MacDougalii.

Leaves all sessile or only the very earliest sometimes short-petioled.

Leaf-blades rounded at the base, broadly lanceolate to ovate.

Petals purple, 5-8 mm. long, leat-blades usually ovate.

Petals white, $4 \mathrm{~mm}$. long; leaf-blades lanceolate.

5. E. ovatifolium,

Leaf-blades acute at the base.

12. E. rubescens.

Petals white or rarely pale pink.

Leaf-blades ample, ovate or broadly lanceolate.

Plant tall, 3-6 dm. high; pod and inflorescence more or less glandular.

13. E. stramineum.

Plant 1-2 dm. high; whole plant perfectly glabrous, except the slightly crisp hairy decurrent lines.

14. E. saximontanum.
Leaf-blades narrowly lanceolate, almost erect; plant slender, 1-3 dm. high.

15. E. Drummondii. 
Petals pink-purple.

16. E. delicatum.

Plants with stolons or soboles, low, 1-2 (seldom 3) dm. high; leaf-blades oval or oblong, indistinctly denticulate.

Leaves more or less distinctly petioled.

Petals white; plant 1-3 dm. high, stoloniferous. 17. E. alpinum.

Petals purple or pink.

Plant 1-3 dm. high, soboliferous; flowers 5-7 $\mathrm{mm}$. long.

18. E. Hornemannii.

Plant usually less than $1 \mathrm{dm}$. high, stoloniferous; flowers less than $5 \mathrm{~mm}$. long.

Flowers nodding in the bud; pods cylindric; seeds smooth.

Flowers ascending in the bud; pods somewhat clavate; seeds

papillose.
Leaves sessile; plant glabrous up to the hypanthium.

Stem somewhat angled by the decurrent lines; plant stoloniferous; leaves oblong or linear, less than $1.5 \mathrm{~cm}$. long.

21. $E$. oregonense.

Stem terete, without decurrent lines; plant more or less glaucous, soboliferous.

Stem-leaves linear-lanceolate.

Leaves narrow, lineaves ovate or ovate-lanceolate. 23. E. platyphyllum.

22. E. glaberrimum. cinereous.

Innovations of long subterranean shoots, bearing at their ends ovoid turions; petals white.

Leaves and lower part of the stem glabrous.

Leaves and stem crisp-pubescent.
Innovations leafy rosettes; petals pale; leaves $5-15 \mathrm{~mm}$. long.

24. E. wyomingense.

m. long.

Annuals with more or less shreddy, straw-colored bark; stigma 4-cleft.
Seeds smooth;

elliptic elliptic; calyx (with the tube of the hypanthium) about $2 \mathrm{~mm}$. long.

Seeds muriculate; stem glabrous 27. E. Lindleyi.

narrowly linear-lanceolate; calyx usually over $2 \mathrm{~mm}$. long.

Tube of the hypanthium funnelform, 1-3 $\mathrm{mm}$. (rarely $4 \mathrm{~mm}$.) long.

Petals white, only slightly exceeding the calyx, 2-3 $\mathrm{mm}$. long; capsule glabrous; tube of hypanthium 1-1.5 mm. long.

Petals pink or purple, $3.5-7 \mathrm{~mm}$. long, about twice as long as the calyx.

Capsule and pedicels glabrous or sparingly puberulent.

Leaves and bracts very thick, horny at the apex, the latter very short; capsule glabrous; pedicels short. 29 . E. subulatum.

Leaves and bracts not very thick, not horny at the apex; capsule usually puberulent, at least when young; pedicels slender. 30. E. paniculatum.

Capsule and pedicels glandular-pubescent; pedicels very short.

Tube of the hypanthium 4-8 mm. long, cylindric or nearly so, abruptly widen-
. ing into the calyx.

Tube of the hypanthium about $4 \mathrm{~mm}$. long; petals $6-7 \mathrm{~mm}$. long.

Tube of the hypanthium $7-8 \mathrm{~mm}$. long; petals $10-12 \mathrm{~mm}$. long.

Petals yellow; perennials; stigma 4-cleft.

33. E. Hammondii.

34. E. luteum.

1. E. ursinum Parish. Perennial, with turions (subterranean bulb-like winter-buds); stem 1-3 dm. high, pilose with long silky hairs; inflorescence minutely glandular; leaves $2-3 \mathrm{~cm}$. long, ovate or broadly lanceolate, serrate or serrulate, rounded at the base, sessile, pilose throughout; petals white or lavender, about $5 \mathrm{~mm}$. long; capsule $3 \mathrm{~cm}$. long, soon glabrous; seeds $1.5 \mathrm{~mm}$. long, short-beaked, with a white scant coma. Wet meadows: Wash.-Ida.-s Calif.

2. E. Sandbergii Rydb. Perennial by means of turions; stem obtusely angled, $6-10 \mathrm{dm}$. high, finely puberulent throughout; leaves sessile, ovate, acute, dentate, 3-7 cm. long, pubescent on both sides, or glabrate below, except the petals rose, $7-8 \mathrm{~mm}$. long; pod $4-6 \mathrm{~cm}$. long, glandular-pilose; seeds $1.5 \mathrm{~mm}$. long, almost beakless; coma tawny. Moist places: Ida.-Mont. Submont.

3. E. Palmeri Rydb. Perennials propagating by turions or oceasionally by rosettes; stem $4-6 \mathrm{dm}$. high, glandular-pilose, usually reddish or brownish; leaves sessile or nearly so, ovate or ovate-lanceolate, denticulate, $3-4 \mathrm{~cm}$. long, 
more or less pubescent; petals pink or light purple, rarely white, about $5 \mathrm{~mm}$. long; pod 4-6 $\mathrm{cm}$. long; seeds papillose, without a beak; coma white or in age somewhat tawny. Wet meadows: Utah-Colo.-Mont.-Ida. Submont. Jl-S.

4. E. glandulosum Lehm. Stem 3-9 dm. high, somewhat angled, glabrous below, crisp-pubescent and glandular above; leaves ovate, 5-12 $\mathrm{cm}$. long, acute or acuminate, sessile, darkening in drying; petals $5-7 \mathrm{~mm}$. long, purple; capsule about $6 \mathrm{~cm}$. long, more or less pubescent; coma dingy. E. Treleaseanum Lev., a large-flowered form. Wet places, usually in edges of woods: Sask.-Wyo.Alaska. Submont.-Mont. Jl-Au.

5. E. ovatifolium Rydb. Stem 2-6 dm. high, glabrous except the crisphairy decurrent lines; leaves sessile or nearly so, ovate or ovate-lanceolate and acute, or the lowest oval and obtuse, 3-4 cm. long, glabrous; petals purple or rarely rose, 5-7 mm. long; capsule 5-6 cm. long, crisp-hairy; coma white. Wet places in the mountains: Colo.-Utah-N.M. Mont.-Alp. Je-Au.

6. E. brevistylum Barbey. Stem 2-6 dm. high, glabrous below, crisppubescent above; leaves 3-6 cm. long, ovate or elliptic-lanceolate, drying pale, sessile; petals pink or purple, about $5 \mathrm{~mm}$. long; capsules 4-6 $\mathrm{cm}$. long, shortpedicelled, almost glabrous; coma dingy. Springs and along brooks: Mont.Colo.-Calif.-Wash. Submont-Mont. Je-Au.

7. E. occidentale (Trelease) Rydb. Stem 3-10 dm. high, somewhat angled, glabrous below, crisp and glandular-pubescent above; lower leaves short-petioled, the upper subsessile; blades ovate to triangular-lanceolate, 3-7 cm. long; petals purple or rose, 5-6 mm. long; capsule 4-6 $\mathrm{cm}$. long, more or less pubescent; seeds beakless; coma white. E. adenocaulon occidentale Trelease. Wet places: Alta.-S.D.-Colo-Calif.-B.C. Submont.-Mont. J1-Au.

8. E. americanum Haussk. Stem 3-6 dm. high, slightly angled, glabrous below, slightly crisp-hairy above; leaves short-petioled, $2-4 \mathrm{~cm}$. long, glabrous and pale, denticulate or subentire; petals about $4 \mathrm{~mm}$. long, white; capsules glabrous or sparingly pilose when young, 3-5 $\mathrm{cm}$. long; coma white. $E$. adenocaulon perplexans Rydb., scarcely Trelease. Wet places: Sask.-N.D.-Wyo. -Ida.-B.C. Je-Au.

9. E. adenocaulon Haussk. Stem erect, 3-10 dm. long, somewhat angled, glabrous below, crisp and glandular in the inflorescence; leaves glabrous or the upper puberulent, ovate-lanceolate or elliptic-lanceolate, $3-6 \mathrm{~cm}$. long; petals about $4 \mathrm{~mm}$. long; capsules $4-5 \mathrm{~cm}$. long, glabrate in age; coma white or nearly so. Wet places: N.B.-Pa.-Colo.-Nev.-Yukon. Plain-Mont. Je-Au.

10. E. latiusculum Rydb. Stem 2-4 dm. high, more or less tinged with purple, glabrous or with pubescent lines below, more or less crisp-hairy above; leaves ovate-lanceolate, $2-4 \mathrm{~cm}$. long, acute at the apex, rounded at the base, glabrous; petals pink or rose-colored, about $4 \mathrm{~mm}$. long; capsules 4-5 $\mathrm{cm}$. long, minutely glandular-puberulent, soon glabrate; seeds obtuse at each end, with a very short apiculation; coma sparse, tawny. E. Drummondii latiusculum Rydb. Wet places: B.C.-Ida.-Wyo. Submont.-Subalp. J-Au.

11. E. MacDougalii Rydb. Perennial, with fleshy rosettes; stem $3-5 \mathrm{dm}$. high, glabrous, with pubescent lines; leaves with very short petioles; blades lanceolate or ovate-lanceolate, glabrous, very thin, 5-7 cm. long, acutish at both ends, denticulate; corolla white, about $4 \mathrm{~mm}$. long; capsule $6-7 \mathrm{~cm}$. long, on pedicels about $1 \mathrm{~cm}$. long; seeds acute at the base, obtuse at the apex; coma scant, white, about $6 \mathrm{~mm}$. long. Lake shores: w Mont. J.

12. E. rubescens Rydb. Perennial, with turions; stem $3-4 \mathrm{dm}$. high, strict and simple, often more or less reddish, glabrous below, crisp-hairy above and more or less on the decurrent lines; leaves $3-4 \mathrm{~cm}$. long, lanceolate, very acute, slightly crisp-hairy beneath when young; petals about $4 \mathrm{~mm}$. long; pods 4-5 cm. long, more or less crisp-pubescent; seeds without neck; coma white. Springs: Colo.-Utah. Submont.-Mont. J-Au.

13. E. stramineum Rydb. Stem 5-6 dm. high, simple, straw-colored, glabrous or somewhat puberulent below, pubescent and glandular in the inflorescence; leaves sessile, light green, lanceolate, tapering at both ends, 4-5 cm. long; 
petals 4-5 mm. long; pod 4-5 cm. long, more or less crisp and glandular; seeds without a neck; coma white. Wet places: Colo.-Wyo.-Utah. Submont.Subalp. Л-Au.

14. E. saximontanum Haussk. Perennial, with turions; stem simple, ascending or suberect, 1-2 dm. (rarely $3 \mathrm{dm}$.) high; leaves pale green, glabrous, 1-3 cm. long, the lower ovate, entire, the upper ovate-lanceolate, denticulate; petals 3-5 mm. long; capsules glabrous, about $4 \mathrm{~cm}$. long, short-pedicelled; seeds acute at each end. Near springs: Alta.-Wyo.-B.C. Submont.-Subalp. J-Au.

15. E. Drummondii Haussk. Perennial, with turions; stem strict, erect, $2-4 \mathrm{dm}$. high, pale, glabrous; leaves pale, $2-4 \mathrm{~cm}$. long, repand-dentate; petals $4 \mathrm{~mm}$. long; capsule $3-5 \mathrm{~cm}$. long, slender-pedicelled; seeds acute at each end, minutely apiculate; coma dingy. Wet places: Sask.-S.D.-Colo.-UtahB.C. Submont.-Mont. Je-Au.

16. E. delicatum Trelease. Perennial, with turions; stem slender, 1-3 dm. high, glabrous, with crisp-hairy lines above; leaves $2-7 \mathrm{~cm}$. long, mostly spreading, lanceolate, obtuse, undulate-denticulate, thin and pale; petals about $5 \mathrm{~mm}$. long; capsule 4-6 cm. long, slender-pedicelled; seeds papillose, apiculate; coma dingy. Wet places: Wash.-Mont.-Wyo.-Ore. Jl-Au.

17. E. alpinum L. Stem ascending or decumbent at the base, $1-3 \mathrm{dm}$. high, glabrous; leaves elliptic, rather obtuse, $2-5 \mathrm{~cm}$. long, glabrous, the upper often alternate; petals about $3 \mathrm{~mm}$. long; capsules slender, about $5 \mathrm{~cm}$. long, with long pedicels; seeds smooth, beaked. E. lactiflorum Haussk. E. canadense Lev., a somewhat puberulent form. Wet places in the mountains and in arctic regions: Greenl.-N.H.-S.D.-Colo.-Calif.-Alaskd; n Eu. and ne
Asia. Mont.-Alp.

18. E. Hornemannii Reichenb. Stem 1-3 dm. high, ascending, somewhat erisp-hairy on the decurrent lines and in the inflorescence; leaves $2-4 \mathrm{~cm}$. long, elliptic or oval, mostly obtuse; flowers few, erect; petals 5-7 mm. long; capsule $5 \mathrm{~cm}$. long, on slender peduncles; seeds usually rough, short-apiculate; coma dingy. Wet places on the mountain sides and in arctic regions: Greenl.-N.H. S.D.-Colo.-Calif.-Alaska; n Eurasia. Mont.-Subalp. Je-Au.

19. E. anagallidifolium Lam. Stem about $1 \mathrm{dm}$. high, usually S-bent, somewhat crisp-hairy, at least on the decurrent lines; leaves 1-2 cm. long, oval or oblong, obtuse; petals lilac or rose, 4-5 mm. long; capsules 2-4 cm. long, slender-pedicelled, cylindric; seeds short-apiculate; coma dingy. In wet places in alpine-aretic situations: Greenl.-Lab.-Alta.-Colo.-(? Calif.)-Alaska; Eurasia. Subalp.-Alp. Je-Au.

20. E. clavatum Trelease. Stems ascending or decumbent, $1 \mathrm{dm}$. high or less, glabrate or sparingly glandular; leaves 1-2 $\mathrm{cm}$. long, divergent, broadly oval, obtuse; petals rose-colored, about $5 \mathrm{~mm}$. long; capsule about $2.5 \mathrm{~cm}$. long, more or less areuate; seeds fusiform, papillose; coma dingy. Alpine peaks: Alta.-Colo.-Utah-B.C. Mont.-Alp. Jl-Au.

21. E. oregonense Haussk. Stem 1-2 dm. high, simple, erect, glabrous, often purplish above, 1-few-flowered; leaves obtuse, glabrous, entire or remotely and minutely denticulate, $1-1.5 \mathrm{~cm}$. long; petals violet or rose, $3-5 \mathrm{~mm}$. long; capsules $2-4 \mathrm{~cm}$. long, on pedicels of about the same length; seeds apiculate. Bogs: B.C.-Ida.-Nev.-Calif. Mont.-Subalp. Je-Au.

22. E. glaberrimum Barbey. Stems erect, simple, $3-6 \mathrm{dm}$. high, glabrous, terete; leaves ascending, 2-5 cm. long, the lowest oblanceolate, entire or repand, narrowed at each end; petals purplish, rose, or rarely white, $5-8 \mathrm{~mm}$. long; capsule $7.5 \mathrm{~cm}$. long, linear-falcate, distinctly pedicelled; seeds very rough; coma dingy. Wet places: Wash.-Ida.-Calif. Mont. J-Au.

23. E. platyphyllum Rydb. Stems ascending or erect, glabrous, without decurrent lines, terete; leaves rounded or subcordate at the base, acute, or the lower obtuse, entire or minutely denticulate, $1.5-2.5 \mathrm{~cm}$. long; petals pale, about $4 \mathrm{~mm}$. long; capsules glabrous, about $5 \mathrm{~cm}$. long, on short pedicels; seeds not 
apiculate; coma white or dingy. E. glaberrimum latifolium Barbey. Wet places: B.C.-Utah-Calif. Submont.-Mont. J1-Au.

24. E. wyomingense A. Nels. Stem slender, erect, branched, glabrous below, minutely puberulent above; leaves thin, 3-5 $\mathrm{cm}$. long; midrib evident, but lateral veins obscure; petals $3-4 \mathrm{~mm}$. long; capsules 4-7 $\mathrm{cm}$. long, minutely cinereous; seeds fusiform, scarcely beaked; coma white. E. palustre albiflorum Lehm. In bogs and along streams: Sask.-S.D.-Colo.-Utah-Yukon. Plain-Submont. J-Au.

25. E. lineare Muhl. Stem erect, branched, 2-4 dm. high; leaves Jinear, short-pubescent, with erisp hairs, revolute on the margins, $2-5 \mathrm{~cm}$. long; flowers numerous; petals about $4 \mathrm{~mm}$. long; capsule $4-5 \mathrm{~cm}$. long, canescent, often slender-pedicelled; seeds fusiform, short-apiculate; coma dingy. Swamps: N.B.Del.-Colo.-Ida.-B.C. Plain-Submont, Jl-S.

26. E. davuricum Fischer. Stem 1-2 dm. high, sparingly crisp-hairy; leaves 5-15 mm. long, crowded at the base, distant above, linear or narrowly oblong, obtuse, remotely denticulate, sessile; flowers at first nodding; capsule erect, $4 \mathrm{~cm}$. long, on slender pedicels; coma white. Bogs: Alaska-B.C.; e Siberia. Subalp.

27. E. minutum Lindl. Stem 1-3dm. high, without decurrent lines, branched; leaves mostly opposite, short-petioled, rather fleshy, more or less strigose; flowers numerous, 3-4 mm. long; petals white or rose-colored; capsules clavate, tortuose, 1-2 cm. long; seeds rounded at the apex. Crossostigma Lindleyi Spach. $E$. adscendens Suksdorf. Hills and rocky places: Athabasca-Nev.-Calif.-B.C. Submont. Ap-Jl.

28. E. Tracyi Rydb. Stem 3-8 dm. high, perfectly glabrous, straw-colored; leaves 2-4 cm. long, linear, entire, glabrous; tube of the hypanthium 1-1.5 mm. long; calyx-lobes about $2 \mathrm{~mm}$. long, very acute; capsule more or less clavate, about $1.5 \mathrm{~cm}$. long; seeds obovoid, $1.5 \mathrm{~mm}$. long. Sandy soil: B.C.-Ore.Utah-Mont. Son.

29. E. subulatum (Haussk.) Rydb. Stem slender, 3-6 dm. high, muchbranched, brownish, glabrous; leaves linear or linear-subulate, 2-3 em. long; tube of hypanthium about $2 \mathrm{~mm}$. long; calyx-lobes $2-2.5 \mathrm{~mm}$. long; petals $3.5-5$ $\mathrm{mm}$. long, rose; capsule about $2 \mathrm{~cm}$. long; seeds brown, $1.5 \mathrm{~mm}$. long, obovate; coma tawny. E. paniculatum subulatum Haussk. Sandy soil: B.C.-Ida.Utah-Calif. Son.-Plain. Jl-Au.

30. E. paniculatum Nutt. Stem branched, 4-8 dm. high, glabrous, strawcolored; leaves linear or linear-lanceolate, $3-5 \mathrm{~cm}$. long; pedicels Ionger than the bracts; tube of hypanthium $2-3 \mathrm{~mm}$. long; calyx-lobes about as long; petals lilac or rose-colored, $5-7 \mathrm{~mm}$. long; pods clavate, about $2 \mathrm{~cm}$. long; seeds brown, $2 \mathrm{~mm}$. long; coma tawny. Sandy soil: Alta.-Colo.-Calif.-B.C. PlainMont. Jl-Au.

31. E. adenocladon (Haussk.) Rydb. Stem rigid, 4-8 dm. high, glabrous and straw-colored below, the smaller branches and pedicels densely glandular; leaves linear or linear-lanceolate, mostly entire, 2-4 cm. long; tube of the hypanthium about $3 \mathrm{~mm}$. (rarely $4 \mathrm{~mm}$.) long; calyx-lobes $2-3 \mathrm{~mm}$. long; petals purple or rose, 5-7 mm. long; capsule clavate, $1.5-2.5 \mathrm{~cm}$. long; seeds blackish brown, obovoid, $2 \mathrm{~mm}$. long; coma tawny. E. paniculatum adenocladon Haussk. Sandy soil: S.D.-Colo.-Utah-Mont. Plain-Submont.

32. E. laevicaule Rydb. Stem glabrous, 6-10 dm. high, glabrous and shining; leaves linear or linear-lanceolate, 3-6 cm. long, the upper mostly involute; calyx-lobes 3-4 mm. long; petals rose-colored; pods clavate, about $3 \mathrm{~cm}$. long, glabrous or almost so; seeds obovoid, dark; coma dingy. Sandy valleys: Ida.-Mont.-Wash. Plain. Jl-Au.

33. E. Hammondii Howell. Stem 6-10 dm. high, glabrous, with shreddy bark, paniculate-branched; leaves linear, 2-5 cm. long, the upper involute, pale green, entire; calyx-lobes about $5 \mathrm{~mm}$. long; petals rose or purplish; capsule somewhat clavate, 3-4 cm. long. Rocky places: Ore.-Ida. Au-S. 
34. E. luteum Pursh. Perennial, with a rootstock and turions; stem 2-8 $\mathrm{dm}$. high, terete and glabrous below, pubescent on the decurrent lines above; leaves sessile, glabrous or nearly so, 4-8 cm. long, dentate, ovate or lance-ovate; tube of the hypanthium very short, campanulate; sepals $1 \mathrm{~cm}$. long or more; petals yellow, slightly exceeding the sepals; style exserted; capsule glabrescent, 4-6 cm. long; seeds obovoid; coma reddish. Wet places: Alaska-Alta.-Wash. Mont.-Subalp. Jl-Au.

\section{CORDYLÓPHORUM (Nutt.) Rydb.}

Suffruticose perennial herbs, branched at the base. Leaves mostly opposite, narrow, entire. Flowers perfect, axillary, irregular. Hypanthium prolonged beyond the ovary into a broadly funnelform tube. Sepals 4 . Petals 4 , unequal, pale yellow, nótched at the apex. Stamens 8, declined. Style slightly declined, long-exserted; stigma deeply 4-lobed. Capsule fusiform, elongate, 4-valved. Seeds with a deciduous coma.

1. C. suffruticosum (Nutt.) Rydb. Suffruticose perennial; stems many, decumbent or ascending, more or less strigose, terete; leaves sessile, lanceolate, acute, entire, 1-3 cm. long, cinereous-strigose; tube of hypanthium about $3 \mathrm{~mm}$. long; calyx-lobes about $5 \mathrm{~mm}$. long; petals slightly exceeding the calyx, pale yellow; capsule 1.5-2.5 cm. long; seeds obovoid-oblong, $2.5-3 \mathrm{~mm}$. long; coma tawny. Epilobium suffruticosum Nutt. Stony places: Mont.-Wy.-Wash. $\mathrm{Jl}-\mathrm{Au}$.

\section{ZAUSCHNÈRIA Presl.}

Perennial cespitose herbs, sometimes shrubby at the base. Leaves, except those of the inflorescence, opposite, toothed. Flowers perfect, somewhat irregular, racemose, showy. Hypanthium inflated above the ovary, then funnelform, with 4 erect and 4 reflexed scales in the throat. Sepals and petals 4 , the latter scarlet, retuse, obcordate, or deeply cleft. Stamens 8 , the alternate ones inserted with the petals lower down. Styles elongate and exserted; stigma peltate or capitate, 4-lobed. Capsule elongate-fusiform, obtusely angled, loculicidal, 4-valved. Seeds with a coma.

Leaves ovate; lateral veins strong.

Leaves oblanceolate; lateral veins faint.

1. Z. Garrettii.

2. Z. crassifolia.

1. Z. Garrettii A. Nels. Stems erect from a decumbent base, $1.5-3 \mathrm{dm}$. high, with pale shreddy bark below, softly hirsute above; leaves sessile; elliptic, oval, or ovate, $2-3 \mathrm{~cm}$. long, remotely dentate, sparsely soft-hirsute; tube of hypanthium red, 12-16 mm. long; petals deep-red, obovate-obcordate; capsule minutely glandular-puberulent on the angles. Dry hills: Utah. Submont.Mont. Au,

2. Z. crassifolia Rydb. Stems 2-4 dm. high, pilose; bark in age exfoliating; leaves sessile, oblanceolate or elliptic-oblanceolate, $1.5-3 \mathrm{~cm}$. long, acute at each end, denticulate, pilose or in age glabrate; flowers crimson; hypanthium trumpet-shaped, $2 \mathrm{~cm}$. long; sepals narrowly lanceolate, $8 \mathrm{~mm}$. long; petals about $1 \mathrm{~cm}$. long, oblanceolate; eapsule about $2 \mathrm{~cm}$. long, cylindric. Cañons and sandy soil: Ariz. $\rightarrow \mathrm{s}$ Utah. Son. S-N.

\section{GAYÓPHYTUM A. Juss. BABY's BREATH.}

Cauleseent annuals. Leaves very narrow, linear, entire. Flowers axillary, minute, perfect. Hypanthium not produced above the ovary. Sepals 4, reflexed, deciduous. Petals 4 , small, obovate or spatulate, white or rose-colored. Stamens 8, those opposite the petals shorter and with sterile anthers. Stigmas capitate or clavate. Capsule clavate or linear, 2-celled, 4-valved. Seeds without a coma.

Seeds canescent.

Petals $3-6 \mathrm{~mm}$. long.

Petals about $1 \mathrm{~mm}$. long.

1. G. eriospermum.

Plant diffusely branched, glabrous throughout, or upper part of the stem and capsules strigillose; capsule distinctly pedicelled. $\begin{aligned} & \text { 2, G. lasiospermum. } \\ & \text {. }\end{aligned}$ Plant with strict branches, hirsutulous; pedicel of capsule very short or almost
none.

3. G. Helleri. 
Seeds glabrous.

Capsules torulose, less than three times as long as the pedicels, usually more or less clavate.

Petals $3-6 \mathrm{~mm}$. long; capsules scarcely longer than the pedicels.

Petals 1-3 mm. long.

4. G. diffusum.

Plant pubescent with spreading hairs.

5. G. caesium.

Plant glabrous throughout or the young capsules strigillose.

Petals 1.5-2.5 mm. long, rose with yellow base; capsules 8-12 $\mathrm{mm}$. long, nearly twice as long as the pedicels.

Petals about $1 \mathrm{~mm}$. long, rose or white.

Capsules decidedly clavate, rounded at the apex, seldom longer than the pedicels, spreading or reflexed.

6. G. intermedium.

Capsules only slightly if at all clavate, narrow, 7. G. ramosissimum. the pedicels, and erect.

Capsules neither torulose nor clavate; pedicel very short. Capsules narrow, scarcely flattened, with suberect seeds.

Capsules broader, flattened contrary to the septum, with oblique seeds. usually longer than 8. G. Nuttallii.

\section{G. racemosum.}

10. G. pumilum.

1. G. eriospermum Coville. Stem 3-5 dm. high, widely branched, glabrous; leaves narrowly linear, 3-5 cm. long; pedicels 5-10 mm. long, erect; sepals 3-4 mm. long, strigose; petals rose-colored in age; capsule strigose, ereet, about $1 \mathrm{~cm}$. long, torulose, 8-10-seeded. Sandy soil: Ore.-Ida.-Calif. Son. Jl-S.

2. G. lasiospermum Greene. Stem 3-6 dm. high; leaves narrowly linear, 1-3 cm. long; pedicels erect, 2-4 $\mathrm{mm}$. long; petals white, often turning rosecolored; capsules erect, slightly clavate, scarcely torulose, glabrous or strigillose, 6-10 mm. long. Sandy soil: Wash.-Mont.-Utah-Calif. Plain-Submont. Je-Au.

3. G. Helleri Rydb. Stem 1-3 dm. high; leaves linear, $0.5-2 \mathrm{~cm}$. long, softly hirsutulous; pedicels very short, even in fruit scarcely more than $1 \mathrm{~mm}$, long; petals scarcely $1 \mathrm{~mm}$. long; capsules linear, erect, $8-10 \mathrm{~mm}$. long, almost sessile, hirsutulous, not torulose. Sandy places: Ida.-Wyo.-Calif. Submont. Je-Jl.

4. G. diffusum T. \& G. Stem dichotomously branched, 3-6 dm. high, glabrous or nearly so; leaves linear, $2-6 \mathrm{~cm}$. long, glabrous, or strigillose when young; sepals about $2 \mathrm{~mm}$. long; capsule clavate, torulose, 5-10 $\mathrm{mm}$. long, usually erect. Sandy places: Mont.-Wyo.-Utah-Calif.-Wash. Submont. -Mont. Je-Au.

5. G. caesium T. \& G. Stem 1-5 dm. high; branched; leaves linear or narrowly linear-oblanceolate, $2-5 \mathrm{~cm}$. long, sepals and petals $1-2 \mathrm{~mm}$. long; capsule clavate, torulose, 8-10 mm. long; erect, short-pedicelled. Sandy places: Mont. -Wyo.-Utah-Calif.-Wash. Son.-Submont. Je-Au.

6. G. intermedium Rydb. Stem white and shining, with more or less peeling bark, profusely branched, 3-7 dm. high, erect; leaves linear or nearly so, light green; sepals about $1.5 \mathrm{~mm}$. long, yellowish; capsule somewhat clavate and torulose, somewhat strigose when young. Sandy soil: Mont.-Colo.-Calif.Wash. Submont.-Mont. Jl-Au.

7. G. ramosissimum T. \& G. Stem diffusely branched, 3-6 dm. high; leaves linear, 2-4 cm. long; petals white or rose-colored; capsule $3-8 \mathrm{~mm}$. long, decidedly torulose, spreading or usually reflexed. Sandy places and on hillsides: Mont.-S.D.-Colo.-Ariz.-Calif.-B.C. Submont.-Mont. My-Au.

8. G. Nuttallii T. \& G. Stem $2-5 \mathrm{dm}$. high, glabrous, branched; leaves 1-3 cm. long, acute; capsule linear, $7-15 \mathrm{~mm}$. long, somewhat torulose; pedicels 2-4 mm. long. Sandy or dry soil, hillsides, etc.: S.D.-Colo.-Ariz.-Calif.Wash. Submont. JI-S.

9. G. racemosum T. \& G. Stem 1-3 dm. high, more or less branched, glabrous or slightly strigose above; leaves linear, $2-4 \mathrm{~cm}$. long, usually glabrous; sepals and petals mostly less than $1 \mathrm{~mm}$. long; capsule narrowly linear, 1-1.5 cm. long, glabrous, erect, almost sessile. Sandy soil: S.D.-Colo.-Calif.Wash. Submont. Subalp. Je-Au.

10. G. pumilum S. Wats. Stem 1-2 dm. high, glabrous or nearly so, simple or branched at the base; leaves narrowly linear-oblanceolate, acute, 2-4 
$\mathrm{cm}$. long; sepals and petals about $1 \mathrm{~mm}$. long; capsules erect, flat, glabrous or nearly so, 6-12 mm. long. Low sandy soil: Wash.-Ida.-Utah-Calif. Mont. $\mathrm{Je}-\mathrm{Au}$.

\section{6. isnárdia L. Marsh Purslane.}

Succulent caulescent herbs, with creeping or floating stems. Leaves few, petioled, opposite. Flowers perfect, axillary, sessile. Hypanthium not produced beyond the ovary. Sepals 4, erect and persistent. Petals 4, small, reddish, or wanting. Stamens 4, with short filaments. Capsule short, truncate at the apex, mostly obpyramidal or obovoid. Seeds without a coma.

1. I. palustris L. Stem branching, 1-5 dm. long; leaf-blades oval, ovate, or spatulate, $1-2.5 \mathrm{~cm}$. long, slender-petioled; flowers solitary; bractlets none; sepals triangular, acute; capsule 4-sided, slightly longer than broad, 3-4 mm. long. Muddy places and shallow water: N.S.-Fla.-Calif.-Ore.; Mex. and the Old World.

\section{BOISDUVÁLLIA Spach.}

Erect caulescent annuals. Leaves alternate, simple, sessile. Flowers in leafy spikes. Hypanthium produced above the ovary into a funnelform deciduous tube. Sepals 4, erect. Petals 4, sessile, 2-lobed, purple or white. Stamens 8, those opposite the petals shorter; anthers all perfect, oblong, attached near the base. Styles filiform; stigma with 4 cuneate lobes. Capsule oblong, membranous, 4-celled, 4-valved to the base. Seeds without a coma, smooth.

Capsule loculicidal, a considerable portion of the septa remaining attached to the valves at dehiscence; leaves mostly alike.

Leaves ovate or ovate-lanceolate, dentate, glabrous or nearly so. 1 . B. glabella.

Leaves narrowly lanceolate, entire or remotely denticulate, softly pubescent.

Capsule septicidal; septa adherent to the placenta, rendering the latter 4 -winged: upper floral leaves broader.

3. B, salicina.

1. B. glabella (Nutt.) Walp. Stem 1-3 dm. high, simple, or branched near the base, glabrous or nearly so; leaves and bracts $1-2 \mathrm{~cm}$. long, acute, serrulate; corolla about $2 \mathrm{~mm}$. long, violet; capsule slender, nearly straight, about $7 \mathrm{~mm}$. long, 4-ribbed, seeds sub-fusiform, about $1 \mathrm{~mm}$. long. Damp ground: Sask.-Nev.-Calif.-B.C. Plain-Submont. Je-Jl.

2. B. parviflora Heller. Stem 1-3 dm. high, branched below, pubescent with spreading white hairs; leaves 1-2.5 $\mathrm{cm}$. long; petals red, about $3 \mathrm{~mm}$. long; capsule about $7 \mathrm{~mm}$. long, slightly curved; seeds somewhat flattened. Sandy soil: Wash.-Ida.-Ore. Submont. My-Au.

3. B. salicina (Nutt.) Rydb. Stem simple, $2-5 \mathrm{dm}$. high, grayish strigose; leaves linear or linear-lanceolate, $2-3 \mathrm{~cm}$. long, canescent, entire-margined or nearly so; bracts ovate-lanceolate or ovate, 1-2 $\mathrm{cm}$. long; corolla 4-5 $\mathrm{mm}$. long, purple or rarely white; capsule about $1 \mathrm{~cm}$. long, slightly 4-angled; seeds concave on the inner face. Oenothera densiflora $\beta$ T. \& G. O. salicina Nutt. Low ground: B.C.-Ida.-Ore. Plain-Submont. Ji-S.

\section{Clárkia Pursh. Clarkia, Pink Fatries.}

Annual caulescent, brittle herbs. Leaves alternate, narrow. Flowers showy, in terminal racemes, perfect. Hypanthium produced beyond the ovary into an obconic tube, which is deciduous. Sepals 4, reflexed. Petals 4, clawed, 3-cleft, purple. Perfect stamens 4, with a linear scale at the base on each side; the alternate ones rudimentary, filiform; perfect anthers oblong. Stigmas with 4 broad lobes. Capsule elongate, 4-angled, 4-celled, and 4-valved to the middle. Seeds angled or margined, without a coma.

1. C. pulchella Pursh. Stem $2-6 \mathrm{dm}$. high, puberulent; leaves linearlanceolate to linear, $3-7 \mathrm{~cm}$. long, entire, glabrous or nearly so; calyx $1-1.5 \mathrm{~cm}$. long; petals purple, 12-25 mm. long, with long slender claws and 3-cleft limb; capsule linear, 16-24 $\mathrm{mm}$. long, 8-angled. Dry plains and hillsides: B.C.Alta.-Mont.-Ore. Son.-Submont. Je-Jl. 


\section{PHAEOSTÒMA Spach.}

Annual caulescent herbs. Leaves alternate, narrow. Flowers in terminal racemes. Hypanthium-tube above the ovary obeonic. Sepals 4, reflexed. Petals 4, rhomboidal, with a broad short blade, entire, purple. Stamens 8, all perfect, with hairy scales at the bases. Stigma with broad lobes. Capsule elongate, somewhat fusiform, 4-angled, 4-celled, 4-valved to the middle. Seeds without a coma, obliquely prismatic.

1. P. rhomboidea (Dougl.) A. Nels. Stem puberulent or glabrous, 3-6 $\mathrm{dm}$. high; leaves petioled; blades oblong-lanceolate or oblong-ovate, $3-5 \mathrm{~cm}$. long; petals purple, $5-7 \mathrm{~mm}$. long, short-clawed, the claw often with a tooth on each side; blades rhombic, entire; capsule 15-25 mm. long, 4-angled, nearly glabrous. Clarkia rhomboidea Dougl. Ospianthes gauroides (Don.) Lilja. Sandy soil and hillsides: B.C.-Mont.-Utah-Calif. Submont. Ap-Jl.

\section{OENOTHÈRA L. EvENING-PRIMROSE.}

Biennial or annual stout herbs, with taproots. Leaves alternate, undulate or toothed. Flowers in terminal spikes, nocturnal, from erect buds. Hypanthium-tube above the ovary funnelform. Sepals 4, reflexed. Petals 4, usually obcordate, yellow, or in age turning purplish. Stigmas with 4 linear lobes. Stamens 8. Capsule usually tapering upwards, 4-celled, loculicidal, 4-valved. Seeds in two or more rows, horizontal. [Onagra Adans.]

Free tube of the hypanthium 1.5-4 cm. long.

Petals turning pink or purplish in age, $3-4 \mathrm{~cm}$. long.

Free tips of the sepals about $4 \mathrm{~mm}$. long; pubescence of the leaves short, that of the calyx not very copious.

1. O. Hookeri.

Free tips of the sepals 2-2.5 $\mathrm{mm}$. long; pubescence of the leaves long and loose, that of the calyx copious.

Petals not turning pink or purplish in age, less than $3 \mathrm{~cm}$. long.

Free tips of the sepals $3 \mathrm{~mm}$. long or longer. Spike not conspicuously leafy-bracted; bracts lance-linear, none except the very lowest ones exceeding the hypanthium-tube or the fruit in length.

Spike conspicuously leafy-bracted; bracts, even the upper ones, exceeding th hypanthium-tube or the fruit in length. Bracts caudate-acuminate, with twisted tips; plant canescent; corolla
about $15 \mathrm{~mm}$. long.

Bracts not caudate-acuminate.

Petals 10-12 mm. long; plant green.

$\begin{array}{ll}\text { Petals } 10-12 \mathrm{~mm} \text {. long; plant green. } & \text { 5. O. muricata. } \\ \text { Petals } 20-30 \mathrm{~mm} \text {. long: plant canescent. } & \text { 6. O. ornata. }\end{array}$

Free tips of the sepals about 2 mm. long.

Stem erect; petals $12-20 \mathrm{~mm}$. long.

Stem decumbent; petals about $10 \mathrm{~mm}$.

Free tube of the hypanthium 8-15 cm. long.

Leaves linear, entire.

Leaves ovate or lanceolate, sinuate-dentate. 4. O. Cockerellii.
6. O. ornata.
7. O. strigosa.
8. O. depressa.

1. O. Hookeri T. \& G. Biennial, with a taproot; stem 5-10 dm. high, erect, angled, more or less hirsute and canescent; leaves lanceolate, repand-dentate, hirsute and canescent, 5-20 $\mathrm{cm}$. long; free tube of the hypanthium 3.5-4 $\mathrm{cm}$. long; sepals about $3 \mathrm{~cm}$. long, more or less hirsute; petals $3-4 \mathrm{~cm}$. long; capsules $4-5 \mathrm{~cm}$. long, hirsute and more or less canescent. Onagra Macbridei A. Nels. Valleys: Mont.-N.M.-Calif.-B.C.; n Mex. Submont.-Mont. Je-S.

2. O. hirsutissima (A. Gray) Rydb. Biennial, with a taproot; stem 3-6 $\mathrm{dm}$. high, grayish pubescent, as well as coarsely hirsute, sometimes almost hispid; leaves lanceolate or linear-lanceolate, entire, or merely denticulate, 5-10 $\mathrm{cm}$. long, densely hirsute; bracts linear-lanceolate, shorter than the hypanthiumtube; free part of the hypanthium about $3 \mathrm{~cm}$. long; sepals about $3 \mathrm{~cm}$. long; petals $3-4 \mathrm{~cm}$. long; capsule $2.5-3 \mathrm{~cm}$. long. Oenothera biennis hirsutissima A. Gray. Valleys: N.M.-Colo.-Ariz.-Chihuahua. JI-S.

3. O. subulifera Rydb. Biennial; stem 3-6 dm. high, sparingly hirsute; leaves lanceolate or the lower oblanceolate, densely pubescent, somewhat cinereous, 5-15 cm. long, minutely denticulate; free tube of the hypanthium 1.5-2.5 $\mathrm{cm}$. long; calyx-lobes about $2 \mathrm{~cm}$. long, sparingly hirsute, somewhat glandular; free tips 3-4 mm. long, slender; petals $1.5-2 \mathrm{~cm}$. long; capsule $2.5-3.5 \mathrm{~cm}$. 
long, sparingly hirsute. Onagra strigosa subulata Rydb. O. Oakesiana Rydb. (Fl. Colo.). Valleys: Mont.-Colo. Submont. Jl-Au.

4. O. Cockerellii De Vries. Biennial, with a taproot; stem erect, strigosecanescent; leaves lanceolate, caudate-attenuate, strigose-canescent, entire, 5-8 $\mathrm{cm}$. long; bracts similar, with involute, curved and twisted tips; calyx-lobes about $2 \mathrm{~cm}$. long, strigose-canescent; free tips about $3 \mathrm{~mm}$. long; petals yellow; capsule about $3 \mathrm{~cm}$. long. Valleys: Colo. Submont.

5. O. muricata L. Biennial, with a taproot; stem erect, $2-8 \mathrm{dm}$. high, very leafy, puberulent and usually hirsute, the hairs with reddish pustulate bases; leaves lanceolate, ascending, entire or sinuately denticulate, more or less pubeseent; inflorescence dense; calyx-lobes 15-18 mm. long; petals light yellow, $12-15 \mathrm{~mm}$., rarely $2 \mathrm{~cm}$. long; capsule $2.5-3 \mathrm{~cm}$. long, more or less hirsute. Sandy places: Newf.-N.Y.-Colo.-Mont. Plain-Submont. J-S.

6. O. ornata (A. Nels.) Rydb. Stout biennial; stems adsurgent, 4-6 dm. high, very leafy, densely and finely pubescent as well as hirsute; leaves lanceolate or linear-lanceolate, 5-15 cm. long, densely canescent, sinuate-dentate; bracts lanceolate, acute; hypanthium and calyx densely canescent; sepals $2-2.5 \mathrm{~cm}$. long; petals deep yellow or orange, $2-2.5 \mathrm{~cm}$. long; capsule $2-3 \mathrm{~cm}$. long, slightly tapering upwards. Onagra ornata A. Nels. Sandy soil: B.C.-Wyo.-Ida.

Submont. Je-Jl.

7. O. strigosa (Rydb.) Mack. \& Bush. Biennial or annual; stem erect, 3-10 dm., grayish strigose and hirsute; lower leaves spatulate, the other lanceolate, $5-10 \mathrm{~cm}$. long, more or less repand-dentate; inflorescence leafy; calyx-lobes $1.5-2 \mathrm{~cm}$. long, grayish-hirsute; capsule $2.5-3 \mathrm{~cm}$. long, grayish hirsute. O. biennis canescens T. \& G. Onagra strigosa Rydb. Valleys and sandy places: Minn.-Kans.-Utah-Wash.-B.C. Plain-Submont. Je-Au.

8. O. depressa Greene. Annual or biennial; stems decumbent, 3-8 dm. long, densely canescent; leaves lanceolate, repand-denticulate, densely whitecanescent; inflorescence leafy-bracted; calyx and hypanthium densely canescent; sepals about $12 \mathrm{~mm}$. long; capsule about $3 \mathrm{~cm}$. long, densely canescent. This may be a form of the preceding, produced by cultivation. Dry sandy soil: Mont.
Jl-Au.

9. O. longissima Rydb. A tall biennial; stem strict, 5-10 dm. high, densely canescent, with short crinkled hairs as well as sparingly hirsute; leaves linear or narrowly linear-lanceolate, $1-1.5 \mathrm{dm}$. long, densely canescent, entire, acute at only slightly widening upwards; sepals linear-lanceolate, about $4 \mathrm{~cm}$. long; free tips about $4 \mathrm{~mm}$. long; petals golden yellow, $4 \mathrm{~cm}$. long; capsule about $4 \mathrm{~cm}$. long, densely canescent, slightly tapering upwards. Cañons: Utah.-Ariz.

10. O. Jamesii T. \& G. Biennial; stem decumbent or erect, canescent; leaves ovate, or lanceolate-acuminate, sinuate-dentate, cinereous-canescent; inflorescence leafy, few-flowered; free tube of the hypanthium 8-15 cm. long, more or less pubescent; calyx-lobes $4-6 \mathrm{~cm}$. long; free tips 5-7 mm. long; petals $4-5 \mathrm{~cm}$. long, yellow, turning rose-colored; capsule $2.5-3 \mathrm{~cm}$. long. River valleys: Tex.-Colo.-Ariz. Son. Jl-Au.

\section{ANÒGRA Spach. White Evening-Primrose.}

Annual or perennial caulescent herbs, often with white flaky bark. Leaves alternate, usually pinnatifid or toothed. Flowers axillary, usually diurnal, from drooping buds. Hypanthium produced beyond the ovary into a cylindrie tube. Sepals 4, narrow, reflexed. Petals white, turning pink, obcordate, showy. Stigma with 4 linear lobes. Capsule cylindric, slightly angled, loculicidal, 4-valved, many-seeded. Seeds terete in one row in each cavity of the ovary.

Calyx in bud merely acutish; tips not free or slightly so in no. 4.

Pubescence at least in part consisting of long silky hairs. Capsule divergent or reflexed.

Blades of the upper leaves rhombic-lanceolate to ovate in outline. 
Blades of all the leaves deltoid-lanceolate, sinuate-dentate, acuminate or acute; capsule reflexed.

1. A. deltoidea.

Blades of the lower leaves spatulate, sinuate or round-lobed, obtuse; capsules divergent.

2. A. Engelmannii.

Blades of all leaves linear, oblanceolate or oblong in outline.

Leaf-blades linear or the lower linear-oblanceolate, sinuately dentate; calyx with a few long hairs

3. A. Buffumi.

Leaf-blades oblanceolate or oblong in outline, sinuately pinnatifid, with oblong lobes; calyx densely silky villous.

Capsule erect or ascending.

Seeds narrow, smooth, very acute at the apex; petals $1-1.75 \mathrm{~cm}$. long.

Seeds ovoid, ridged and tubercled, rather blunt at the apex.

5. A. trichocalyx.

Branches erect; petals $1.5-2 \mathrm{~cm}$. long.

6. A. perplexa.

Branches decumbent or merely ascending; petals $2.5-4 \mathrm{~cm}$. long.

7. A. albicaulis.

Pubescence wholly cinereous-strigose.

8. A. Bradburiana.

Calyx in bud acuminate or acute; tips free.

Capsule linear-cylindric; throat of the corolla glabrous.

Leaves all long-petioled, oblanceolate, subentire; plant dwarf. 9. A. simplex.

Stem-leaves short-petioled or sessile; plant not dwarf.

Calyx sparingly long-hairy, glandular-puberulent, or glabrous, not strigose.

Stem-leaves deeply pinnatifid.

Plant perennial with a rhizome.

Plant biennial, with a taproot.

10. A. rhizomata.

Stem-leaves subentire, dentate or short-lobed.

Capsules strongly ascending, straight; leaves linear or lance-linear, entire or nearly so, strigose beneath. 11. A. Nuttallii.

Capsules divergent, usually curved upwards; leaves usually denticulate or sometimes lobed.

Leaves glabrous, except the margins.

Calyx glabrous or nearly so; tips slender.

Leaves lanceolate to linear-lanceolate. 12. A. pallida.

Leaves linear or very narrowly linear-oblanceolate.

Calyx pilose; tips very short.

Leaves pubescent on both sides.

13. A. leptophylla.

14. A. Vreelandii.

15. A. cinerea.

Calyx and hypanthium densely grayish strigose; leaves cinereous.

Leaves linear-lanceolate, deeply pinnatifid; petals rhombic.

16. A. runcinata.

Leaves ovate or oblong, rarely lanceolate, dentate; petals obcordate.

17. A, latifolia.

Capsules oblong; throat of the corolla hairy; leaves deeply pinnatifid.

18. A. coronopifolia.

1. A. deltoidea (Torr. \& Frem.) Small. Annual or biennial; stems often branched at the base, 1-3 dm. high, decumbent below; leaves petioled; blades 3-10 cm. long, densely canescent above, hirsute beneath; tube of the hypanthium 3-4 cm. long, densely hirsutulous; calyx-lobes $1.5-2.5 \mathrm{~cm}$. long, hirsutulous; petals 2-3 cm. long; capsule 3-4 cm. long, $2 \mathrm{~mm}$. thick. Dry regions: Ariz.s Utah-s Calif. L. Son. Ap-Je.

2. A. Engelmannii (Small) Woot. \& Standl. Biennial; stem erect, $3-6 \mathrm{dm}$. high; basal leaves petioled, 7-10 $\mathrm{cm}$. long; stem-leaves sessile, lanceolate or ovate, sinuately toothed, 2-4 $\mathrm{cm}$. long, canescent on both sides, and hirsute on the veins; tube of the hypanthium $1.5-2 \mathrm{~cm}$. long, caneseent and hirsutulous; calyx-lobes about $1.5 \mathrm{~cm}$. long, hirsute; petals about $2 \mathrm{~cm}$. long; pod $3-5 \mathrm{~cm}$. long, 2.5-3 mm. thick. Dry places: w Tex.-Utah. Son. Je-Jl.

3. A. Buffumi A. Nels. Annual; stem erect, $2-3 \mathrm{dm}$. high, usually simple, sparingly puberulent and with seattered long hairs, or nearly glabrate; basal leaves petioled, $6-12 \mathrm{~cm}$. long; petals about $2.5 \mathrm{~cm}$. long; capsule spreading and curved, $2-3 \mathrm{~cm}$. long. River valleys: Wyo. Submont. Au.

4. A. violacea A. Nels. Biennial, with a taproot; stems several, erect, 2-3 $\mathrm{dm}$. high, violet or purple, finely puberulent or glabrous; basal leaves linearoblanceolate, entire or dentate; stem-leaves puberulent, $4-8 \mathrm{~cm}$. long; tube of hypanthium 2-2.5 $\mathrm{cm}$. long, sparingly hairy; ealyx-lobes $1.5-2 \mathrm{~cm}$. long; capsule divergent, about $3 \mathrm{~cm}$. long, $2 \mathrm{~mm}$. thick, usually strongly eurved. Sandy soil: Wyo.-Colo. Plain-Submont. My-Je.

5. A. trichocalyx (Nutt.) Small. Biennial or perennial; stems erect, 1-2 $\mathrm{dm}$. high, somewhat puberulent; leaves more or less deeply sinuate-pinnatifid, cinereous and with seattered long hairs; tube of hypanthium 2-2.5 $\mathrm{mm}$. long, 
cinereous; sepals $1.5 \mathrm{~cm}$. long, cinereous and silky-villous; capsule erect, $2-3 \mathrm{~cm}$. long, $2 \mathrm{~mm}$. thick, nearly straight. O. trichocalyx Nutt. Dry places: Wyo.Colo.-Nev. Plain-Submont. My-Jl.

6. A. perplexa Rydb. Biennial; stem 1-2 dm. high, more or less cinereous and with scattered hairs, branched at the base, with ereet branches; leaves 2-6 dm. long, oblanceolate in outline, hirsute and somewhat canescent, the basal ones dentate, the cauline ones strongly ascending, deeply pinnatifid, with narrowly linear, more or less ascending lobes; tube of the hypanthium $1.5-2 \mathrm{~cm}$. long, hirsute; calyx-lobes $1.5-1.75 \mathrm{~cm}$. long, hirsute; capsule about $3 \mathrm{~cm}$. long, and fully $3 \mathrm{~mm}$. thick, erect. Plains: Neb.-Kans.-Colo.-Wyo. PlainSubmont. Je-Jl.

7. A. albicaulis (Pursh) Britton. Annual or biennial; stem 1-3 dm. long, branched at the base; basal leaves spatulate, obtuse, merely toothed; stem-leaves 5-12 $\mathrm{cm}$. long, deeply pinnatifid, with lanceolate or linear, rather divergent divisions; tube of hypanthium about $3 \mathrm{~cm}$. long, sparingly pubescent; calyx-lobes about $3 \mathrm{~cm}$. long, sparingly silky-hirsute or sometimes glabrous; pod $3.5-5 \mathrm{~cm}$. long, about $3 \mathrm{~mm}$. thick. Oenothera pinnatifida Nutt. O. albicaulis Pursh. Hillsides and in sandy soil: S.D.-Tex.-Ariz.-Mont.; n Mex. Plain-Submont. My-Jl.

8. A. Bradburiana (Nutt.) Rydb. Annual or biennial; stem erect, 1-2 dm. high, finely cinereous-strigose; leaves $3-5 \mathrm{~cm}$. long, oblanceolate in outline; the basal ones subentire or dentate, the cauline ones deeply pinnatifid, cinereousstrigose; tube of hypanthium and calyx-lobes cinereous, each nearly $2 \mathrm{~cm}$. long; petals fully $2 \mathrm{~cm}$. long. O. Bradburiana Nutt. Sandy places: Wyo.-S.D.

9. A. simplex Small. Annual; stem simple, 1-1.5 dm. high; leaves petioled, oblanceolate, sinuately toothed or entire, 5-10 $\mathrm{cm}$. long, grayish strigose; tube of hypanthium 2-2.5 cm. long, canescent; calyx-lobes about $2 \mathrm{~cm}$. long, strigose, their free tips fully $1 \mathrm{~mm}$. long; petals $2.5-3 \mathrm{~cm}$. long, white, turning rose, with yellow bases. Dry places: s Utah-L. Calif. L. Son.

10. A. rhizomata A. Nels. Perennial, with a rootstock; stems $1-2 \mathrm{dm}$. long, often pinkish or violet, strigose and sparingly hirsute; leaves oblanceolate in outline, 3-5 cm. long, strigose and hirsute, the lowermost entire or dentate; tube of hypanthium 1.5-2 cm. long; calyx-lobes silky-hirsute, $1.5-2 \mathrm{~cm}$. long; free tips scarcely $1 \mathrm{~mm}$. long; capsules spreading, about $3 \mathrm{~cm}$. long. Dry sandy places: Wyo.-Colo. Plain-Submont. My-Jl.

11. A. Nuttallii (Sweet) A. Nels. Perennial; stem 3-10 dm. high; leaves 5-10 cm. long; tube of hypanthium glabrous or sparingly glandular-puberulent, 3-4 cm. long; calyx-lobes 1.5-2 cm. long, glabrous or sparingly hirsute; free tips $3 \mathrm{~mm}$. long; capsule $3 \mathrm{~cm}$. long; petals $2-2.5 \mathrm{~cm}$. long. Oenothera albicaulis Nutt. In sandy soil: Sask.-Minn.-Colo.-Ida.-B.C. Plain-Mont. Je$\mathrm{Au}$.

12. A. pallida (Dougl.) Britton. Perennial, with a horizontal rootstock; stem 3-5 dm. high, glabrous; leaves perfectly glabrous, entire, dentate, or the upper somewhat sinuate-pinnatifid, 3-10 cm. long; tube of the hypanthium 2-3 $\mathrm{cm}$. long; calyx-lobes $1.5-2 \mathrm{~cm}$. long; free tips $1.5-2 \mathrm{~mm}$. long; petals obcordate, $1.5-2 \mathrm{~cm}$. long; pod 2.5-3 cm. long, $3 \mathrm{~mm}$. thick. Sandy places: Mont.-Utah - Calif.-B.C. Plain-Submont. Je-JI.

13. A. leptophylla (Nutt.) Rydb. Perennial; stem 2-4 dm. high, glabrous, shining; Jeaves $2-5 \mathrm{~cm}$. long, pubescent on the margins, otherwise glabrous; tube of hypanthium 1.5-2 cm. long; calyx-lobes about $1.5 \mathrm{~cm}$. long, glabrous or with scattered hairs; free tips $1.5 \mathrm{~mm}$. long; petals scarcely $1.5 \mathrm{~cm}$. long; capsule less than $2 \mathrm{~cm}$. long and scarcely $2 \mathrm{~mm}$. wide. Sandy places: Wyo.-Utah-Ida. Son.-Submont. Je-Jl.

14. A. Vreelandii Rydb. Perennial; stem erect, strict, $3-5 \mathrm{dm}$. high; leaves narrowly lanceolate, about $5 \mathrm{~cm}$. long, glabrous, sinuate-dentate; petals about $2 \mathrm{~cm}$. long, white, turning pink; pod cylindric, usually somewhat curved upwards, $3 \mathrm{~cm}$. long, $2 \mathrm{~mm}$. thick. Hills and cañons: Colo.-Utah. Son. Je. 
15. A. cinerea Rydb. Branched perennial; stem 3-4 dm. high, cinereousstrigose when young; leaves lanceolate to ovate-lanceolate, mostly subsessile, $3-5 \mathrm{~cm}$. long, sinuate-dentate or denticulate, cinereous; tips of the calyx free and rather long; petals 15-18 $\mathrm{mm}$. long; pods $3-3.5 \mathrm{~cm}$. long, $3 \mathrm{~mm}$. thick, almost straight. Dry soil: S.D.-w Neb.-Ida.-Colo. Plain-Submont. Je-Jl.

16. A. runcinata (Engelm.) Woot. \& Standl. Perennial; stem much branched, $2-4 \mathrm{dm}$. high, cinereous; leaves lanceolate to linear, canescent-strigose, $2-6 \mathrm{~cm}$. long, pinnatifid, with triangular-lanceolate, divergent lobes; tube of hypanthium and calyx-lobes each $1.5-2 \mathrm{~cm}$. long; free tips about $1 \mathrm{~mm}$. long; petals $1.5-2 \mathrm{~cm}$. long; pod divergent, $3-4 \mathrm{~cm}$. long, 2-3 mm. thick, often twisted. $O$. albicaulis runcinata Engelm. Dry places: Tex.-Utah-Ariz. Son. Ap-S.

17. A. latifolia Rydb. Perennial, whole plant strigose-canescent; stem divaricately branched, 2-6 dm. high; leaves ovate, oblong or lanceolate, sinuatedentate, $2-6 \mathrm{~cm}$. long; tube of hypanthium and calyx-lobes about $2 \mathrm{~cm}$. long; free tips 1.2-2 mm. long; petals nearly $2 \mathrm{~cm}$. long; capsule divaricate, usually curved, $3 \mathrm{~cm}$. long, $3 \mathrm{~mm}$. thick. Sandy soil: Neb.-Kans.-Utah-Ida. Plain - Mont.

18. A. coronopifolia (T. \& G.) Britton. Perennial, with a rootstock; stem 1-3 dm. high, strigose; leaves $1-6 \mathrm{~cm}$. long, pinnatifid, with linear divisions, or the basal ones spatulate and merely dentate; tube of hypanthium $1-2 \mathrm{~cm}$. long, strigose; calyx-lobes $1.5-2 \mathrm{~cm}$. long; free tips less than $1 \mathrm{~mm}$. long; petals $1-1.5 \mathrm{~cm}$. long; capsule oblong, $1-1.5 \mathrm{~cm}$. long, $4 \mathrm{~mm}$. thick. O. coronopifolia T. \& G. Prairies and plains: S.D.-Kans.-N.M.-Ariz.-Ida. Plain-Mont. $\mathrm{Je}-\mathrm{Au}$.

\section{PAChÝlophus Spach. Rock Rose, Mountain Primrose.}

Acaulescent or short-stemmed perennials. Leaves mostly crowded, toothed, lobed, or pinnatifid. Flowers axillary, perfect, night-blooming. Hypanthium much elongated beyond the ovary into a narrowly funnelform tube. Sepals 4, elongate, reflexed. Petals white, turning pink, showy. Stamens 8. Stigma with 4 linear lobes. Capsule lance-ovoid or ovoid-oblong, large, 4-angled, with more or less wavy-crested angles, woody, tardily loculicidal. Seeds many, in 1 or 2 rows in each cell.

Plant glabrous, or nearly so.

1. P. caespitosum.

Plant hairy.

Plant not canescent-stri, 50 se.

Leaves lyrate-pinnatifid; apex and lobes rounded or obtuse; hairs with pustulate bases.

2. P. Johnsoni.

Leaves sinuately lobed or toothed, acute; hairs not pustulate at the bases.

Hypanthium, calyx, and fruit glabrous, slightly strigose or with a few scattered long hairs.

Tube of the hypanthium 3-6 cm. long; pubescence short and usually appressed.

3. P. montanus.

Tube of hypanthium 6-12 $\mathrm{mm}$. long. Plant acaulescent, cespitose; pod short, conic-ovoid, with very thick ridges.

4. P. macroglottis. Plant more or less caulescent; pod elongate, conic-ovoid, with low ridges.

Hypanthium, calyx, and fruit densely hirsute.

Fruit subsessile, conic-ovoid, obtuse at the base. Plant acaulescent; ridges of the fruit slightly tuberculate. Hypanthium 8-12 cm. long; petals $3-4 \mathrm{~cm}$. long. 6. P. hirsutus. Hypanthium about $5 \mathrm{~cm}$. long; petals about $2 \mathrm{~cm}$. long.

7. P. crinitus.

Plant more or less caulescent; ridges of the fruit with lobed, more or less foliaceous crests.

8. $P$. eximius.

Fruit more or less stipitate, fusiform, tapering at both ends, with slightly tuberculate ridges; plant of ten more or less caulescent. 9 . $P$. marginatus.

Plant densely canescent-strigose throughout. 10. P. canescens.

1. P. caespitosus (Nutt.) Raim. Cespitose acaulescent perennial; leaves with winged petioles, 1-2 dm. long; blades oblanceolate, glabrous, sinuate-dentate, with triangular teeth; tube of the hypanthium 5-10 $\mathrm{cm}$. long, glabrous; petals 3-4 cm. long; fruit lance-ovoid, $3 \mathrm{~cm}$. long, with low rounded tubercles on the angles. Oenothera caespitosa Nutt. P. glabra A. Nels., a depauperate form. Dry hills: Sask.-Neb.-N.M.-Utah-Mont. Plain-Mont. Je-Au. 
2. P. Johnsoni (Parry) Rydb. Cespitose perennial, acaulescent; leaves lyrate-pinnatifid, 4-7 cm. long, short-pubescent; terminal lobe oval or ovate, dentate-crenate, about $2 \mathrm{~cm}$. long; larger lateral lobes 6-8 $\mathrm{mm}$. long, oblong, the smaller ones deltoid; hypanthium about $3 \mathrm{~cm}$. long, sparingly pilose; petals 1.5-2 $\mathrm{cm}$. long; capsule sessile, lance-oblong, about $2 \mathrm{~cm}$. long, with a double row of strongly tuberculate ridges on each angle. O. Johnsoni Parry. Dry regions: s Utah-s Calif. Son.

3. P. montanus (Nutt.) A. Nels. Cespitose, acaulescent perennial; leaves short-petioled, $5-10 \mathrm{~cm}$. long; leaf-blades oblanceolate, coarsely sinuate-toothed, canescent-pubescent on the margins, otherwise glabrous or sparingly strigose; petals $2-3 \mathrm{~cm}$. long; capsule sessile, ovoid, obtusely tubercled on the blunt angles, 2 cm. long. O. montana Nutt. Dry hills: Sask.-Neb.-Colo.-Nev.-Ida. Plain-Submont. My-Au.

4. P. macroglottis Rydb. Acaulescent or nearly so; leaves $8-15 \mathrm{~cm}$. long, tapering into a margined petiole, puberulent, and villous ciliate on the margins and the veins, very thin; tube of hypanthium gradually widening into a funnelform throat, $1 \mathrm{~cm}$. in diameter; sepals lanceolate, gradually long-acuminate, $3-5$ $\mathrm{cm}$. long; petals about $3.5 \mathrm{~cm}$. long, and fully as wide; capsule with rather strong sinuate ridges, 3-4 cm. long, lance-ovoid. Hillsides: Colo.-Wyo. Submont.Mont. Je-Au.

5. P. caulescens Rydb. More or less eaulescent perennial; stem 1-2 dm. high, angled; leaves with the long petioles about $2 \mathrm{dm}$. long, about $3 \mathrm{~cm}$. wide, pubescent on the margins and veins, sinuately dentate; hypanthium-tube about $9 \mathrm{~cm}$. long, glabrous, at the throat nearly $1.5 \mathrm{~cm}$. wide; petals about $2.5 \mathrm{~cm}$. long, obovate; pod sessile, about $3 \mathrm{~cm}$. long, lance-ovoid, with rounded low ridges. Hillsides and river banks: Colo. Submont. My-Je.

6. P. hirsutus Rydb. Cespitose, almost acaulescent perennial; leaves oblanceolate, 1-2 dm. long, more or less petioled, runcinately lobed or divided, hirsute-villous, especially on the margins and the veins; hypanthium at the throat 1-1.5 $\mathrm{cm}$. wide; sepals $3-4 \mathrm{~cm}$. long; capsule 4-5 $\mathrm{cm}$. long, lance-ovoid, about $1 \mathrm{~cm}$. in diameter, sessile; ridges low and rounded, slightly if at all tubercled. Hillsides:-Wyo.-N.M.-Utah. Submont.-Mont.

7. P. crinitus Rydb. Strongly cespitose, acaulescent perennial, the eaudex branching below ground; leaves oblanceolate in outline, $2-4 \mathrm{~cm}$. long, densely hirsute, sinuately toothed, acute; sepals linear-lanceolate, about $18 \mathrm{~mm}$. long, densely pilose; petals obcordate, $2 \mathrm{~cm}$. long, or a little more; pod (not fully developed), sessile, ovoid, scarcely tubercled on the ridges, densely hairy. Dry places: Utah. Submont. Je-Au.

8. P. eximius (A. Gray) Woot. \& Standl. Caulescent perennial; stem stout, 1-3 dm. high, leafy; leaves oblanceolate or spatulate in outline, 1-2 dm. long, more or less hirsute, especially on the margins and veins, sinuate-dentate or lobed; tube of hypanthium 1-1.5 dm. long, hirsute; petals $2.5-4 \mathrm{~cm}$. long; capsule 3-4 cm. long, lance-ovoid. O eximiq A. Gray. P. exiguus Rydb. (Fl. Colo., misprint). Hills and banks: S.D.-N.M. Plain-Submont. Je-Au.

9. P. marginatus (Nutt.) Rydb. Cespitose acaulescent or short-stemmed perennial; leaves oblanceolate, sinuate-dentate, or runcinate, 1-1.5 dm. long, villous-hirsute, especially on the margins and veins; tube of the hypanthium 7-10 $\mathrm{cm}$. long; petals $3-4 \mathrm{~cm}$. long; pod $3-4 \mathrm{~cm}$. long, with rather prominent tubercles on the angles. O. marginata Nutt. O. idahoensis Mulford. On hills: Ida.Colo.-Utah-Ore. Son.-Submont. My-Jl.

10. P. canescens Piper. Acaulescent cespitose perennial, canescent with fine appressed pubescence; leaves pale green, oblanceolate, sinuate-dentate or subentire; tube of hypanthium 5-8 cm. long, canescent; petals $2-4 \mathrm{~cm}$. long; capsule 2-3 cm. long, lance-ovoid, canescent, strongly tubercled. Dry hills and bench-lands: Mont.-W Neb.-Calif.-Wash. Son.-Submont. Je-Jl.

\section{LAVAÙXIA Spach.}

Perennial or annual, mostly acaulescent herbs. Leaves mostly basal, numerous, pinnatifid or lobed. Flowers few, axillary. Sepals narrow, reflexed. Petals 
white, pink, or yellow. Stamens 8 . Hypanthium produced beyond the ovary into a slightly funnelform tube. Stigmas with 4 linear lobes. Capsule short, sharply 4-angled or 4-winged above, few-seeded.

Leaves strigose-canescent.

Leaves green, glabrous or puberulent, with eiliate margins,
1. L. brachycarpa.

2. L. flava.

1. L. brachycarpa (A. Gray) Britton. Cespitose acaulescent perennial, canescent-strigose throughout; leaves oblanceolate or spatulate, sinuate-pinnatifid to entire, $5-15 \mathrm{~cm}$. long; tube of the hypanthium 1-1.5 dm. long, petals yellow, turning rose-colored, 4-5 $\mathrm{cm}$. long; capsule 15-30 $\mathrm{mm}$. long, canescent. Oenothera brachycarpa A. Gray. O. Howardii M. E. Jones. Plains and hills: Kans.-Tex.-N.M.-Utah. Plain-Submont. My-J.

2. L. flava A. Nels. Acaulescent perennial; leaves oblong-lanceolate in outline, deeply runcinate-pinnatifid, $15-25 \mathrm{~cm}$. long, glabrous or a little pubescent on the margins; tube of hypanthium 4-7 cm. long; petals yellow, turning pink, 12-18 mm. long; capsule 2-3 cm. long, narrowly winged. Oenothera triloba ecristata M. E. Jones. Valleys: Sask.-Neb.-Colo.-Calif.-Wash. Submont. -Mont. Je-Au.

\section{GaUréllia Small. Spotted Primrose.}

Low caulescent perennials, with branching stems. Leaves alternate, entire or distantly toothed. Flowers perfect, axillary, sessile. Hypanthium produced beyond the ovary into a slightly funnelform tube. Sepals elongate, reflexed. Petals 4, obovate, white or pink, spotted or striped with red. Style short, slightly clavate; stigma with 4 linear lobes. Capsule short, 4-angled, with a short curved beak. Seeds few, angled, striate.

1. G. canescens (Torr. \& Frem.) A. Nels. Cespitose perennial; stems 1-5 $\mathrm{dm}$. long, strongly branched, decumbent or ascending, strigose; leaves lanceolate or oblong, $8-16 \mathrm{~mm}$. long, repand-denticulate or entire; petals white, turning pink, spotted, about $1 \mathrm{~cm}$. long; capsule $8-10 \mathrm{~mm}$. long, angled. Oenothera canescens Torr. \& Frem. O. guttulata Geyer. Prairies: Neb.-Tex.-N.M.Colo. Plain.

\section{GALPINSIA Britton.}

Suffruticose perennials, with branched stems. Leaves alternate, narrow. Flowers perfect, axillary to foliaceous bracts. Hypanthium produced beyond the ovary into a more or less funnelform tube. Sepals 4, reflexed. Petals 4, yellow. Stamens 8. Strgma disk-like, entire. Capsule eylindric or somewhat fusiform, narrowed at the base, more or less curved. Seeds often tuberculate.

Whole plant strigose-cinereous.

Stem and hypanthium more or less hirsute.
1. G. Lavandulaefolia. 2. G. interior.

1. G. lavandulaefolia (T. \& G.) Small. Cespitose perennial, with a woody base; stems 1-2 dm. high, decumbent or ascending, canescent; leaves numerous, crowded, linear or linear-spatulate, entire or nearly so, finely pubescent; hypanthium gradually dilated; tube $3-4 \mathrm{~cm}$. long; petals $13-19 \mathrm{~mm}$. long; capsule 2-2.5 cm. long. Oenothera lavandulaefolia T. \& G. Plains and prairies: Neb.Kans.-Tex.-Ariz.-Wyo. Plain-Son. My-Jl.

2. G. interior Small. Cespitose perennial, with a woody base; stems 2-3 $\mathrm{dm}$. high, hirsute as well as puberulent; leaves oblong, $1-2.5 \mathrm{~cm}$. long, entire, partly clasping; hypanthium elongate, gradually dilated, $2-3.5 \mathrm{~cm}$. long; petals $1.5-2.5 \mathrm{~cm}$. long; capsule $1.5-2 \mathrm{~cm}$. long. Plains and prairies: Neb.-Kans.Tex. Plain. My-Au.

\section{MERÌOLIX Raf.}

Biennial or perennial herbs, with branched stems, sometimes suffruticose at the base. Leaves alternate, narrow or sharply serrate. Flowers perfect, regular, axillary. Hypanthium produced beyond the ovary, funnelform, the free portion rather short. Sepals 4, keeled on the back. Petals yellow, often spotted at the base. Stamens 8. Stigma disk-like, 4-toothed. Capsule linear, 4-angled, sessile. Seeds numerous, longitudinally grooved. 
Throat of the hypanthium dark purple within, 5-6 mm. broad at the mouth.

Throat of the hypanthium orange within, sometimes $1 . M$. melanoglottis the stamens, $3-4 \mathrm{~mm}$. broad at the mouth.

1. M. melanoglottis Rydb. Perennial, shrubby and branched at the base; stems 2.5-4 dm. high, the upper portion as well as the leaves grayish strigose; leaf-blades spatulate to almost linear, $2.5-6 \mathrm{~cm}$. long, shallowly serrate; petals 10-12 mm. long; capsule straight, $2 \mathrm{~cm}$. long, copiously pubescent. Dry soil: Tex.-Colo. Plain.

2. M. serrulata (Nutt.) Walp. Perennial, woody at the base; stem 1-5 $\mathrm{dm}$. high, branched and leafy, more or less canescent; leaf-blades spatulate to linear-oblong or linear, 2-5 cm. long, serrate, canescent-strigose; petals obovate, 8-12 mm. long, crenulate; capsule 1.5-2 cm. long. Oenothera sermulata Nutt. Dry soil, plains and hills: Man.-Mo.-Tex.-Ariz.-Alta. Plain-Submont. $\mathrm{Je}-\mathrm{Au}$.

\section{TARÁXIA Nutt.}

Acaulescent perennial herbs, with a short caudex. Leaves crowded at the base, pinnatifid or entire. Flowers perfect, regular, axillary. Hypanthium prolonged beyond the ovary into a slender cylindric tube, marcescent. Petals 4, yellow or white. Stamens 8 . Stigma capitate, entire or 4-toothed. Capsule sessile, oblong, 4-winged. Seeds in a double row in each cell of the ovary.

Leaves entire or merely toothed.

Leaves pinnatifid.

Hypanthium 2-5 cm. long; petals about $5 \mathrm{~mm}$. long.

Hypanthium 6-10 cm. long; petals $10-14 \mathrm{~mm}$. long.

1. T. subacaulis.

2. T. breviflora.

1. T. subacaulis (Pursh) Rydb. Acaulescent perennial; leaves oblance olate or lanceolate, $7-15 \mathrm{~cm}$. long, entire or repand, glabrous; tube of hypanthium 3-4.5 cm. long, slender; petals pale yellow, 8-12 mm. long; capsule ovate-ellipsoid, $1.5-2 \mathrm{~cm}$. long. Oenothera heterantha Nutt. Plains and valleys: Mont.Colo.-Calif. Submont. Je-Au.

2. T. breviflora Nutt. Acaulescent perennial; leaves deeply pinnatifid, 5-12 cm. long, minutely pubescent; sepals and yellow petals about $5 \mathrm{~mm}$. long; capsule about $1.5 \mathrm{~cm}$. long, lance-ovoid, tuberculate. O. breviflora T. \& G. Plains and valleys: Alta.-Wyo--Utah-B.C. Plain-Submont. Je-Au.

3. T. longiflora Nutt. Acaulescent perennial; leaves narrowly oblanceolate in outline, sinuately pinnatifid to near the midrib, 8-15 cm. long, sparsely strigose; sepals narrowly lance-oblong, $8 \mathrm{~mm}$. long; petáls emarginate or rounded, yellow; capsule lance-ovoid, round-ridged. $O$. Nuttallii T. \& G. T. tikurana A. Nels. Meadows: Calif,-Ida.-Wash. Submont. Je-Au.

\section{SPHAEROSTÍGMA F. \& M.}

Annual or perennial caulescent herbs. Leaves alternate, entire or pinnatifid. Flowers small or minute, in bracted or leafy spikes. Hypanthium produced beyond the ovary into an obconie short tube. Sepals 4. Petals 4, yellow, white, or pink, entire or emarginate. Stamens 8, slightly unequal. Stigma capitate, entire. Capsule sessile, linear, terete or 4-angled, often more or less twisted and curved, 4-celled. Seeds linear-oblong, smooth.

Corolla yellow, turning reddish or greenish.

Capsule fusiform.

Capsule linear.

Leaves narrowly linear.

Plant glabrous, or nearly so.

Pods straight, erect.

Pods curved, often reflexed.

Plant more or less pubescent, at least when young.

Plant strigillose; leaves usually dentate. linear.

Leaves oval, lanceolate, or oblong.

1. S. andinum.

Petals $1-2 \mathrm{~mm}$ long.

Plant dwarf, only a few centimeters high, strigillose; capsule about $2 \mathrm{~cm}$. long.

4. S. parvulum.

5. S. flexuosum.

6. S. strigulosum.

leaves usually entire, 8. S. pubens. 
Plant taller, 1-4 dm. high, often viscid above; capsule about $5 \mathrm{~cm}$. Iong.

Petals 5-6 mm. long.

Corolla white to ochroleucous or rose-colored.

11. S. chamaenerioides.

12. S. alyssoides.

Capsule enlarged at the base, tapering upwards; bark shreddy.

Plant glabrous; leaf-blades oblanceolate.

Plant more or less glandular; leaf-blades ovate.

2. S. decorticans.

3. S. Boothii.

Plant strigose or puberulent. base, cylindric; plant pubescent; bark not shreddy.

Leaves linear.

Leaves elliptic, spatulate or lanceolate.

Petals $1-2 \mathrm{~mm}$. long.

Petals 5-6 mm. long.

7. S. refractum.

Plant villous.

10. S. tortum.

12. S. alyssoides.

Leaf-blades $3-5 \mathrm{~cm}$. long, obovate, sparsely villous; petals $7-8 \mathrm{~mm}$. long.

Leaf-blades $1-2.5 \mathrm{~cm}$. long, densely villous; petals $3-5 \mathrm{~mm}$. S. macrophy
14. S. utahense.

1. S. andinum (Nutt.) Walp. Small annual; stem 3-10 cm. high, branched, canescent-puberulent; leaves linear or linear-oblanceolate, 1-3 cm. long, entire, more or less strigose; flowers minute, numerous; tube of the hypanthium less than $1 \mathrm{~mm}$. long; petals about $1 \mathrm{~mm}$. long; capsule $6-7 \mathrm{~mm}$. long, canescent. Oenothera andina Nutt. Hills: Sask,-Wyo.-Utah-Calif.-Wash. Son.Submont. My-Jl.

2. S. decorticans (H. \& A.) Small. Originally described as perennial, but apparently only biennial or annual; stem $2-4 \mathrm{dm}$. high, sparingly branched, glabrous, somewhat glandular-puberulent in the inflorescence; leaves lanceolate or oblanceolate, $2-6 \mathrm{~cm}$. long, entire or denticulate; tube of the hypanthium about $4 \mathrm{~mm}$. long; petals white or cream-colored, turning pink, 3-4 mm. long; capsule about $2 \mathrm{~cm}$. long, $2 \mathrm{~mm}$. thick, more or less curved and twisted. Gaura decorticans H. \& A. O. gauriflora T. \& G. Sandy places: s Utah-Ariz.-Calif. Son,-Submont. Ap-Je.

3. S. Boothii (Dougl.) Walp. Annual; stem in age glabrate, shining, with white shreddy bark; leaves petioled; blades ovate, dentate, acute or acuminate, glabrous above or nearly so, hirsute beneath, $2-3 \mathrm{~cm}$. long; tube of hypanthium $5 \mathrm{~mm}$. long, glandular-pubescent; petals $4-5 \mathrm{~mm}$. long; capsule 1-1.5 $\mathrm{cm}$. long, $1.5-2 \mathrm{~mm}$. thick at the base. O. Boothii Dougl, Gravelly hills: Wash.-Ida. -Nev.-Calif, Son. Je.

4. S. parvulum (Nutt.) Walp. Slender annual; stem $5-10 \mathrm{~cm}$. long, branched; leaves narrowly linear, almost filiform, entire, $1-3 \mathrm{~cm}$. long, less than $1 \mathrm{~mm}$. wide; tube of hypanthium $1.5 \mathrm{~mm}$. long; petals $2-3 \mathrm{~mm}$. long; capsule linear-cylindric, 2-2.5 mm. long, $1 \mathrm{~mm}$. thick, erect, straight, glabrous. O. parvula Nutt. Sandy plains and rocky hills: Wyo.-Utah-Ida. Son.-Submont. My-Je.

5. S. flexuosum A. Nels. Small annual; stem $1 \mathrm{dm}$. high or less, with few branches; leaves narrowly linear, entire, $2-3 \mathrm{~cm}$. long, about $1 \mathrm{~mm}$. wide; tube of hypanthium $1.5 \mathrm{~mm}$. long; capsules linear-cylindrie, 2-3 $\mathrm{cm}$. long, S-curved. S. contortum flexuosum A. Nels. Dry soil: Wyo.-Utah. Son. Je.

6. S. strigulosum Fisch. \& Mey. Annual; stem 1-3 dm. high, branched near the base, with spreading or ascending branches; leaves linear or oblong, 1-3 $\mathrm{cm}$. long, 1-3 $\mathrm{mm}$, wide, in depauperate specimens narrow and subentire; tube of hypanthium $2 \mathrm{~mm}$. long; petals 3-4 mm. long; capsule linear-cylindric, $1 \mathrm{~mm}$. thick, $2-3 \mathrm{~cm}$. long, ascending, only slightly curved. O. strigulosa T. \& G. Sandy places: B.C.-Ida.-Calif. Son. My-Jl.

7. S. refractum (S. Wats.) Small. Annual; stem erect, diffusely branched, 2-4 dm. high, somewhat glandular-puberulent; leaves linear or narrowly linearlanceolate, $2-5 \mathrm{~cm}$. long; tube of the hypanthium about $4 \mathrm{~mm}$. long; petals cream-colored, 5-6 mm. long; capsule slender, 2-3 cm. long, more or less twisted, abruptly reflexed. O. refracta S. Wats. Arid regions: s Utah-Ariz, Son.

8. S. pubens (S. Wats.) Rydb. Annual; stem 1-3 dm. high; leaves linear, entire or rarely minutely denticulate, $1-3 \mathrm{~cm}$. long, $1-2 \mathrm{~mm}$. wide; tube of hypanthium 1-1.5 mm. long; corolla $3-4 \mathrm{~mm}$. long; capsule linear-cylindric, 2-3 $\mathrm{cm}$. long, $1 \mathrm{~mm}$. thick, spreading at the base, arching upwards. (?) S. filiforme A. Nels. Dry places: Ida.-w Colo--Ariz.-Calif.-B.C. Son. My-J. 
9. S. minus A. Nels. A small annual; stems simple or with a few branches at the base, $3-10 \mathrm{~cm}$. high, puberulent; leaves $1-2.5 \mathrm{~cm}$. long, mostly shortpetioled; tube of the hypanthium $1.5-2 \mathrm{~mm}$. long; petals $1-1.5 \mathrm{~mm}$. long; capsule nearly straight or somewhat contorted, $2 \mathrm{~cm}$. long, $1 \mathrm{~mm}$. thick. S. Nelsonii Heller. Dry hills: Wyo. My.

10. S. tortum (Lev.) A. Nels. Annual; stems branched near the base, 1-3 dm. high, more or less strigose; leaves petioled; blades oblanceolate or linearoblong, strigose or nearly glabrous, 2-4 cm. long; tube of hypanthium 1-2 mm. long; petals ochroleucous, $1-2 \mathrm{~mm}$. long; capsule $2 \mathrm{~cm}$. long, variously twisted. S. minutiflora (S. Wats.) Rydb. Sandy soil and dry hills: Wyo.-Colo.-Utah Ore. My-Je.

11. S. chamaenerioides (A. Gray) Small. Annual; stem slender, 1-4 dm. high, somewhat viscid-puberulent above; lower leaves petioled, the uppermost sessile; blades lanceolate or oblanceolate, repand-denticulate or entire, 3-6 cm. long; tube of the hypanthium $2 \mathrm{~mm}$. long; petals yellow, 1.5-2 $\mathrm{mm}$. long; capsule linear-cylindric, 3-5 $\mathrm{cm}$. long, $1 \mathrm{~mm}$. thick, straight or slightly curved. Dry places: Tex.-s Utah-Ariz. Son. $\mathrm{Mr}-\mathrm{My}$.

12. S. alyssoides (H. \& A.) Walp. Annual; stem branched, 1-3 dm. high, more or less strigose; leaves petioled; blades oblanceolate or elliptic, $2-6 \mathrm{~cm}$. long, more or less strigose; tube of hypanthium 5-7 mm. long, strigose; petals white or ochroleucous, $5-6 \mathrm{~mm}$. long; capsule linear-cylindric, $2-2.5 \mathrm{~cm}$. long, $1 \mathrm{~mm}$. thick, more or less twisted. S. implexa A. Nels. Sandy places and hills: Ida.-Utah-Calif.-Ore. Son. My-Je.

13. S. macrophylla (Small) Rydb. Annual; stem 1-3 dm. high, sparingly villous, branched; leaves petioled; blades obovate or broadly spatulate, $3-5 \mathrm{~cm}$. long, more or less villous; tube of the hypanthium $5-6 \mathrm{~mm}$. long, villous; petals white, $7-8 \mathrm{~mm}$. long, broadly obovate. Saline or alkaline soil: Utah-Nev. Son.

14. S. utahense Small. Annual; stem erect, $2-10 \mathrm{~cm}$. high, simple or with ascending branches, sparingly villous; leaves short-petioled; blades spatulate or obovate or oval, $1-2.5 \mathrm{~cm}$. long, densely villous, entire or nearly so; calyx-tube 7-9 mm. long; petals obovate, 3-5 mm. long; capsule filiform, $1.5 \mathrm{~cm}$. long, spirally twisted at the base. Sandy soil: Utah. Son. My-Je.

\section{CHYLÍSMIA Nutt.}

Caulescent annual herbs. Leaves pinnatifid, but sometimes reduced to the terminal segment. Flowers in terminal racemes, except in one species. Hypanthium produced beyond the ovary into an obconic or funnelform tube. Sepals 4, reflexed. Petals 4, entire, yellow or ochroleucous, sometimes turning purplish. Stamens 8 ; anthers oblong, attached to the middle. Stigma capitate, entire. Capsule linear or clavate, membranous, peduncled. Seeds in a single row in each cell.

Flowers axillary; delicate plant $1 \mathrm{dm}$, high or less.

Flowers in terminal racemes or panicles.

Leaf-blades simple, sinuate or entire, or pinnate with the lower leaflets much reduced.

Plant glabrous, puberulent, minutely strigose, or glandular.

Petals 3-5 mm. long; leaves glabrous.

Petals 7-10 mm. long; leaves grayish-strigose when young. 3 , C. cruciformis.

Plant more or less hirsute or villous, with long white hairs.

Leaves simple or with a few (1 or 2 pairs, rarely more) small lobes on the petioles; leaves and stem sparingly hair y.

Petals 10-12 mm. long; pod linear, 5-6 cm. long. 4. C. brevipes.

Petals 2-7 mm. long; pod clavate, less than $1.5 \mathrm{~cm}$. long. Petals 6-7 mm. long.

Petals 2-5 $\mathrm{mm}$. long.

5. C. Parryi.

Petals 4-5 mm. long; stem tall, $3 \mathrm{dm}$. high or more, branched.

Petals 2-3 mm. long; stem low, about $1 \mathrm{dm}$. high, simple.
7 . C. Walkeri.

Leaves interruptedly pinnate, with several leaflets.

Petals 8-10 mm. long; leaves and lower part of the stem densely hairy.

8. C. venosa. 
Petals 4-6 mm. long; leaves and stem sparingly hairy or glabrate.

9. C. parviflora.

Leaves interruptedly pinnate, the larger alternate pairs 12 or more, not reduced.

10. C. multijuga.

1. C. pterosperma (S. Wats.) Small. Stem slender, $5-10 \mathrm{~cm}$. high, branched, hirsute; leaves oblong-lanceolate, 1-2 $\mathrm{cm}$. long, entire, hispidulous; tube of hypanthium $1 \mathrm{~mm}$. long; petals obcordate, rose-colored, $1.5-2 \mathrm{~mm}$. long; capsule cylindric-clavate, $12-18 \mathrm{~mm}$. long; seeds $2 \mathrm{~mm}$. long, the margins thin, incurved, cellularly tuberculate. Oenothera pterosperma S. Wats. Foot-hills: Utah-Calif. Son. My-Je.

2. C. scapoidea Nutt. Stem glabrous, 1-3 dm. high, simple or branched at the base; leaves petioled, simple or pinnate, with small lateral leaflets; blade or terminal leaflet ovate or elliptic, 1-4 $\mathrm{cm}$. long, dentate or entire, glabrous, veiny; tube of the hypanthium 2-3 mm. long; petals bright yellow, $3-5 \mathrm{~mm}$. long; capsule $1.5-2 \mathrm{~cm}$. long, $2 \mathrm{~mm}$. thick. O. scapoidea Nutt. Hills and river banks: Wyo.-Colo.-Ariz.-Calif.-Ore. Son.-Submont.

3. C. cruciformis (Kellogg) Howell. Stem 2-4 dm. high, finely puberulent or glabrate; leaves interruptedly pinnate; leaflets $5-15$, lanceolate or ovate, $0.5-4 \mathrm{~cm}$. long, veiny; tube of hypanthium 4-5 $\mathrm{mm}$. long; petals $7-10 \mathrm{~mm}$. long; capsule about $2 \mathrm{~cm}$. long, $2 \mathrm{~mm}$. thick. O. cruciformis Kellogg. Dry regions: Ore.-Colo--Ariz.-Calif. Son. Mr-Je.

4. C. brevipes (A. Gray) Small. Stem branched at the base, 2-3 dm. high, usually densely white-hirsute; leaves simple, or pinnate with small lateral leaflets; blade or terminal leaflet ovate, $3-5 \mathrm{~cm}$. long, dentate, veined, hirsute; tube of the hypanthium $5 \mathrm{~mm}$. long; petals yellow; eapsule spreading on short pedicels. O. brevipes A. Gray. Arid regions: s Utah-Ariz.-Calif.-Nev. Son. Ap-Je.

5. C. Parryi (S. Wats.) Small. Stem branched, $2-3 \mathrm{dm}$. high, sparingly ciliate; leaves simple, petioled; blades ovate or oblong-lanceolate, $2-5 \mathrm{~cm}$. long, entire or sinuate, pubescent with scattered long spreading hairs, especially on the veins; free tube of hypanthium $1 \mathrm{~mm}$. long; petals yellow or orange, $6-7 \mathrm{~mm}$. long; capsule 8-12 mm. long, ascending. Clayey hills: s Utah. L. Son.

6. C. tenuissima (M. E. Jones) Rydb. Stem much branched, 3-10 dm. high; leaves mostly simple; blade lanceolate, sparingly dentate, acute at each end, veiny beneath, sparingly pilose, about $1 \mathrm{~cm}$. long; inflorescence racemes or panicles, axillary, with ascending-spreading branches; tube of the hypanthium about $1 \mathrm{~mm}$. long; petals $2-5 \mathrm{~mm}$. long, yellow; capsule clavate, 4-6 mm. long, on divergent pedicels. O. tenuissima M. E. Jones. Barren clay soil: Utah. Son. S.

7. C. Walkeri A. Nels. Stem slender, 1-2 dm. high, minutely glandularpubescent and with some long white hairs; leaves simple, entire, ovate to oblonglanceolate, white-hirsute; tube of hypanthium $0.5 \mathrm{~mm}$. long; petals yellow, oval; capsule clavate, $10-14 \mathrm{~mm}$. long, on a filiform spreading pedicel of the same length. Gypsum hills: w Colo. Son. Л.

8. C. venosa Nels. \& Kenn. Stem 3-5 dm. high, villous, becoming glabrate in the inflorescence; leaves 1-2 dm. long, interruptedly pinnate; terminal leaflet orbicular or ovate, $2-4 \mathrm{~cm}$. long, finely canescent above, hirsute beneath, veiny, irregularly serrate; the lateral ones smaller and lanceolate; tube of hypanthium $2.5 \mathrm{~mm}$. long; petals yellow, turning purple, $8 \mathrm{~mm}$. long; capsule 2 em. long, almost glabrous. Cañons and river valleys: Nev.-Utah. Son. My-Je.

9. C. parviflora (S. Wats.) Rydb. Annual; stem $2-3 \mathrm{dm}$. high, glabrous or sparingly pubescent; leaves interruptedly pinnate, glabrous or nearly so; terminal leaflet ovate, 2-4 cm. long, sharply serrate, strongly-veined, the lateral ones lanceolate, smaller; tube of hypanthium $2 \mathrm{~mm}$. long or less; petals light yellow, 4-6 $\mathrm{mm}$. long; eapsule about $3 \mathrm{~cm}$. long, $2 \mathrm{~mm}$. thick. O. brevipes parviflora S. Wats. Arid regions: s Utah-Ariz. L. Son.

9. C. multijuga (S. Wats.) Small. Stem branched, glabrous, $2-3 \mathrm{dm}$. high; leaves interruptedly pinnate; larger leaflets 12 pairs or more, of nearly 
the same size, ovate, $2-3 \mathrm{~cm}$. long, glabrous, veiny, sharply serrate; free tube of hypanthium $3 \mathrm{~mm}$. long; petals yellow, about $1 \mathrm{~cm}$. long; pod linear, spreading. O. multijuga S. Wats. Dry places: s Utah. Mr.

\section{STENOSİPHON Spach.}

Perennial herbs, with erect leafy stem. Leaves alternate, sessile, narrow. Flowers perfect, in elongate terminal spikes. Hypanthium much produced beyond the ovary into a filiform tube. Sepals 4, reflexed. Petals white, clawed. Stamens 8, declined, without scales at the base. Ovary 1-celled; stigma 4-lobed, surrounded by a cup-like border. Fruit 8-ribbed, indehiscent, 1-celled, 1-seeded.

1. S. linifolium (Nutt.) Britton. Stem slender, glabrous, $6-15 \mathrm{dm}$. high; leaves lanceolate to linear, $2.5-5 \mathrm{~cm}$. long, entire, acuminate; spikes elongate, sometimes $3 \mathrm{dm}$. long; tube of the hypanthium about $1 \mathrm{~cm}$. long; petals white, long-clawed, about $5 \mathrm{~mm}$. long; fruit ovoid, hirsutulous, rugose, 3-4 mm. long. Dry plains and prairies: Neb.-Ark.-Tex.-Colo.; Mex. Jl-S.

\section{Gaùra L. Butterfly Weed.}

Annual, biennial, or perennial caulescent herbs, with branching stems. Leaves alternate, usually narrow. Flowers perfect, in terminal racemes or panicles, or spikes. Hypanthium prolonged beyond the ovary into a slender but short tube. Sepals 4, rarely 3. Petals clawed, unequal. Stamens usually 8 , declined, with a small scale at the base of the filament. Ovary 4-celled; style declined; stigma 4-lobed, with a cup-like border below. Fruit nut-like, indehiscent, ribbed or angled, 4-celled, but some of the cells usually empty. Seeds $1-4$.

Anthers oval, attached near the middle; fruit fusiform, sessile, almost equally 8-ribbed. Anthers linear or nearly so attached 1 . G. parviflora. above.

Fruit sessile, broadly fusiform; tall biennials.

Fruit prolonged below into a stipe-like base.

Stipe-like base slender; fruit fusiform; tall herbaceous plant. 3 . G. coloradensis. neous base.

Plants more or less pubescent.

Leaves canescent, the lower usually oblong and sinuately toothed.

Leaves sparingly strigose, all linear or nearly so and entire.

4. G. coccinea.

Plant glabrous or nearly so, except the strigose hypanthium.

5. G. parvifolia.

6. G. glabra.

1. G. parviflora Dougl. Biennial; stem 6-15 dm. high, silky-pilose, with long spreading hairs; leaves lanceolate, ovate-lanceolate, or elliptic, $3.5-10 \mathrm{~cm}$. long, acute or acuminate, repand-dentate, softly pilose; spike very long; petals 2.5-4 mm. long; fruit 6-8 mm. long, glabrous or nearly so. Plains, valleys, and prairies: S.D.-Mo.-La.-Ariz.-Wash.; Mex. Plain-Submont. My-O.

2. G. neomexicana Wooton. Perennial; stems usually more than one from the woody root, 4-7 dm. high, villous, somewhat glandular in the inflorescence; leaves lanceolate, $5-10 \mathrm{~cm}$. long, entire or sinuately toothed; flowers sessile; tube of hypanthium $1 \mathrm{~cm}$. long; petals $1 \mathrm{~cm}$. long, rose-pink; fruit obovoid-pyramidal, 7-8 mm. long, 3-4 mm. broad, sessile. Valleys: N.M.-Colo. Submont. Je.

3. G. coloradensis Rydb. Herbaceous biennial or perennial, with fusiform root; stem 5-7 dm. high, strict, but somewhat branched, finely strigose, more or less red; leaf-blades narrowly oblanceolate, 5-10 cm. long, gradually tapering below into a short petiole, or the upper sessile, callous-denticulate, finely strigose; hypanthium about $2 \mathrm{~cm}$. long, finely strigose; petals about $8 \mathrm{~mm}$. long, spatulate, pink; fruit 8-10 mm. long. Meadows: Colo. Submont. Jl.

4. G. coccinea Nutt. Stems several, branched, strigose or puberulent and more or less hirsute, 1-5 dm. high; leaves numerous, sessile, oblong or lanceolate, the upper linear-lanceolate, repand-dentate or entire, 1-3.5 cm. long, eanescent; tube of hypanthium 6-8 $\mathrm{mm}$. long; petals from pink or white to scarlet, 
4-6 mm. long; capsule 5-7 mm. long, canescent. G. marginata Lehm. Plains and prairies: S.D.-Tex.-Ariz.-Mont.; Mex. Plain-Submont. Ap-Jl.

5. G. parvifolia Torr. Stem 3-4 dm. high, with ereet branches, sparingly strigose or in age glabrate; leaves $1-2.5 \mathrm{~cm}$. long; tube of hypanthium $5 \mathrm{~mm}$. long; petals 4-5 mm. long, scarlet; capsule 6-7 mm. long. Dry hills and plains: Tex,-Colo.-N.M. Son.-Submont. J1-Au.

6. G. glabra Lehm. Stem 2-4 dm, high, in age straw-colored and shreddy; leaves oblong or lanceolate, or those of the branches linear-lanceolate; tube of hypanthium 6-7 mm. long; petals pink or brick-red, rarely white; fruit $5-6 \mathrm{~mm}$. long. Dry plains and prairies: S.D.-Colo-Ariz,-Mont. Plain-Submont. $\mathrm{Je}-\mathrm{Au}$.

\section{Circatea L. ENChanter's Nightshade.}

Low perennial herbs, with succulent but slender stems. Leaves opposite, petioled. Flowers small, in racemes. Hypanthium slightly produced beyond the ovary into a slender short tube. Sepals 2. Petals 2, notched, white. Stamens 2, alternate with the petals. Fruit 1-2-celled, 1-2-seeded, obovoid, indehiscent, usually covered with hooked hairs.

Plant 1-2 dm. high; leaves sharply dentate, usually cordate at the base. Plant 1-2 dm. high; leaves sharply dentate, usually cordate at the base. 1 . C. alpina.
Plant $3-6 \mathrm{dm}$. high; leaf-blades sinuately denticulate, usually truncate or rounded at
the base.

2. C. pacifica.

1. C. alpina L. Stem $0.5-2 \mathrm{dm}$. high, glabrous or pubescent above; leafblades cordate, $2.5-5 \mathrm{~cm}$. long; pedicels $3-4 \mathrm{~mm}$. long, reflexed in fruit; fruit narrowly obovoid, about $2 \mathrm{~mm}$. long. Cold woods: Lab.-Ga.-S.D.-Colo.Alaska; Eurasia. Mont. Jl-S.

2. C. pacifica Asch. \& Magn. Stem mostly glabrous, $1.5-3 \mathrm{dm}$. high; leafblades ovate, $3-6 \mathrm{~cm}$. long; fruit obovoid, fully $2 \mathrm{~mm}$. long, spraingly pubescent. Woods: Mont.-Colo.-Calif.-B.C. J-Au.

\section{Family 92. haloragidaceae. Water Milfoll Family.}

Perennial or rarely annual, caulescent herbs, aquatic or amphibious, with alternate, opposite, or whorled leaves, the submerged ones often finely divided. Flowers perfect or monoecious, solitary or clustered, either axillary or in terminal spikes. Sepals 2-4. Petals usually wanting or small, 2-4. Stamens 1-8. Gynoecium of 1-4, somewhat united carpels. Ovary 1-4-celled, inferior, angled or winged; style wanting. Fruit a nutlet or drupe.

Flowers monoecious or polygamous, 4-merous; stamens 4 or 8 ; submerged leaves finely pinnatifid. Flowers perfect, without sepals and petals; stamen 1 ; leaves all entire. 2 . HiPPURIs.

\section{MYRIOPHÝlLUM (Vaill.) L. Water Milfoil.}

Aquatic herbs, with slender stems, usually floating. Leaves alternate or whorled, the emersed ones entire or pectinately lobed, the submerged ones finely pectinately dissected into filiform divisions. Flowers monoecious or polygamous, axillary or in terminal spikes, the upper ones usually staminate, with short hypanthium, 2-4 sepals, 2-4 small petals and 4-8 stamens; the intermediate ones often perfect; the lower ones pistillate, with 4 minute sepals, 4 small petals, or none, and a 2-4-celled ovary; stigmas 2-4, plumose. Fruit bony, splitting into 2 or 4 , angled nutlets. Seeds solitary in each nutlet.

Floral leaves ovate, entire or dentate, usually shorter than the flowers.

Floral leaves pinnatifid, much longer than the flowers.

1. M. spicatum.

2. M. verticillatum.

1. M. spicatum L. Stem submerged, 3-20 dm. long; leaves verticillate in 4 's or 5's, 1-3 cm. long, pinnatifid into filiform divisions; flowers verticillate in an interrupted spike; stigmas rounded, sessile, not elongate; sepals of the staminate flowers usually deep purple. Still water and slow streams: Newf.-Conn. -Kans.-N.M.-Calif.-Alaska; Eurasia. Plain-Submont. Je-Au. 
2. M. verticillatum L. Stem $3-20 \mathrm{dm}$. long; leaves flaccid, verticillate in 3's or 4's, 1.5-4 cm. long, pinnatifid, the rachis usually broader than the filiform divisions; floral leaves or bracts similar, but shorter and firmer, 6-20 $\mathrm{mm}$. long; stigmas elongate, recurved; sepals of the staminate flowers pale green or pinkish. Still water and slow streams: Que.-N.Y.-Neb.-Ida.-B.C. PlainSubmont. Je-Au.

\section{HIPPÙRIS L. MARE'S-TAIL.}

Aquatic perennial herbs, with simple stems. Leaves narrow, entire, verticillate. Flowers perfect, axillary. Hypanthium adherent to the ovary, with a minute entire limb. Sepals and petals none. Stamen solitary. Pistil solitary; style filiform, stigmatic its whole length, placed in a groove of the anther; Fruit 1-celled, 4-seeded.

1. H. vulgaris $\mathrm{L}$. Stem simple, 2-6 dm. high; leaves in whorls of 6's-12's, linear, acute, $1-3 \mathrm{~cm}$. long; stamen with a short thick filament and large anther; fruit nearly $2 \mathrm{~mm}$. long. Swamps and ponds: Greenl.-N.Y.-Neb.-N.M.Calif.-Alaska; Eurasia. Plain-Mont. Je-Au.

\section{Family 93. AMmiaceae. Carrot Family.}

Herbs, with usually hollow stems. Leaves alternate, usually compound or decompound, rarely simple, with dilated sheathing leaf-bases. Flowers perfect or polygamous, in simple or compound umbels, or rarely in heads or head-like clusters, the umbels commonly subtended by involucres and involucels, consisting of several bracts or bractlets. Hypanthium adnate to the ovary. Sepals 5, usually small. Petals 5, usually with an inflexed tip, often emarginate. Stamens 5, inserted on an epigynous disk; anthers versatile. Gynoecium of 2 united carpels, each 1-ovuled. Styles 2, distinct, borne on a more or less developed thickened base (stylopodium). Fruit of two 1-seeded carpels, separating at maturity; each carpel usually with 5 principal ribs, sometimes with 4 secondary ribs; the faces where the two carpels meet are called the commissures, and the sinuses between the ribs, intervals; the pericarp usually containing oil-tubes in the intervals and on the commissural side; some or all the ribs often winged.

A. Fruit with the secondary ribs most prominent, in ours ellipsoid, armed with prickles; oil-tubes under the secondary ribs; leaves pinnately compound.

Stylopodium obsolete; calyx-teeth obsolete; fruit flattened dorsally.

Stylopodium conical; calyx-teeth prominent; fruit flattened laterally.

B. Fruit with primary ribs only, or ribs wanting; oil-tubes (rarely lacking) in the intervals between the ribs.

I. Fruit scaly or spiny.

Fruit ovoid, covered with hyaline scales or tubercles; leaves coriaceous, spinosely toothed or divided; flowers in dense heads.

3. ERYNGIUM.

Fruit with hooked spines, subglobose; flowers in simple or compound few-rayed umbels; leaves not spinose, palmately or pinnately divided.

II. Fruit not spiny, only bristly on the ribs in Osmorrhiza.

4. SANICULA.

a. Fruit linear, linear-oblanceolate, or linear-lanceolate in outline.

Stylopodium present; oil-tubes obsolete in the mature fruit; fruit thickened above; leafy-stemmed plants with aromatic thick roots and ternately decompound leaves with toothed segments.

Fruit attenuate at the base, bristly on the ribs.

Fruit glabrous, obtuse at the base.

5. OSMORRHIZA.

6. GLYCOSMA.

Stylopodium wanting; oil-tubes small but evident; fruit thickest below; acaulescent plants, with globose corms and ternate leaves with linear segments.

b. Fruit oblong to orbicular in outline.

7. LEIBERGLA.

1. Fruit not compressed dorsally, terete in cross-section or somewhat compressed laterally; wings of the lateral ribs (if present) rarely much broader than those of the dorsal ribs.

a. Ribs not conspicuously winged.

* Ribs at least the dorsal ones filiform or more prominent, but not corky. 
I Ribs unlike, the dorsal ones filiform; the lateral ones corky and inflexed towards those of the other carpel; commissure with a corky projection which connects the carpels to the gynophore, leaving two air spaces between the carpels, this projection, and the lateral wings; plants with corms. 8. OROGENIA.

†† Ribs all nearly alike; commissure not with corky projection. ¥ Stylopodium conic.

Leafy plant with white or pinkish flowers.

Plants with fascicled tuberous roots and few narrow, mostly entíre leaf-segments.

Seed-face concave with a longitudinal ridge; oil-tubes several in the intervals. 9. EuLOPHus.

Seed-face plane; oil-tubes solitary in the intervals.

Plants with taproots or rhizomes. 10. ATENIA.

Fruit round, with sub-globose carpels and very slender inconspicuous ribs; leaves pinnate; oil-tubes several. 11 . BERULA.

Fruit ovate or oblong, with more prominent ribs.

Oil-tubes solitary in the intervals; leaves twice or thrice pinnately compound. 12. CARUM.

Oil-tubes several in the intervals; leaves ternately or ternate-pinnately compound or decompound. 13. LIGUSTICUM.

Acaulescent plants with yellowish green flowers and simply pinnate leaves; oil-tubes several in the intervals.

$\ddagger \ddagger$ Stylopodium flat or wanting; flowers 14. LIGUSTICELLA.

Leaves simple; oil-tubes wanting or continuous around the seed cavity.

15. BUPLEURUM.

Leaves compound, or only the basal ones simple; oil-tubes present and not continuous in the intervals.

Caulescent perennials, with taproots.

Oil-tubes solitary in the intervals; stylopodium wanting; root neither deep-seated nor conspicuously thickened; leaves ternately compound or the basal ones simple, cordate.

16. ZiZIA.

Oil-tubes several in the intervals; stylopodium flat; root deep-seated and usually decidedly thickened, fusiform. 17. MUSINEON.

Acaulescent cespitose perennials, with short branched caudices.

Oil-tubes 2 or 3 in each interval; divisions of the leaves filiform. 18. DAUCOPHYLLUM.

Oil-tubes solitary in the intervals; divisions of the leaves elliptic, ovate, or obovate.

* Ribs all corky. 19. Aletes. Cespitose perennials with branched caudices; flowers yellow or
yellowish.

Fruit not tubercled; dwarf acaulescent plants.

Fruit tubercled; stem about $3 \mathrm{dm}$. high, few-leaved.

21. HARBOURLA.

Not cespitose perennials, with short rootstocks and fibrous roots: flowers white; tall plants.

Ribs equal and prominent. 22. Srum.

Ribs unequal; the dorsal ones very low and broad; the lateral ones prominent and thick.

$\beta$. Ribs conspicuously winged.

23. Cicuta.

Plant pseudo-scapose* from a deep-seated fleshy root; leaves fleshy.

with obtuse segments.

Seed-face deeply grooved.

Seed-face shallowly concave.

Plant from a cespitose caudex or rootstock.

Seed-face deeply grooved; segments of the leaves ovate or lanceolate.

Seed-face broadly and shallowly concave; 26. CorIOPHYLLUS. ulate or linear-filiform divisions.

Ribs broadly winged; main divisions of the leaves ternate: stylopodium wanting; flowers yellow, except in one species.

Ribs narrow; leaves bipinnate; stylop 27. PTERYXIA. flowers white.

28. Pseudoreoxis.

* Stem mostly subterranean, but rising somewhat above ground and bearing at the end a cluster of leaves and peduncles. 
2. Fruit flattened strongly dorsally, with the lateral ribs more or less prominently winged.

a. Stylopodium wanting.

Dorsal and intermediate ribs or some of them winged.

Wings thickened and corky towards the margin; plants pseudoscapose from a thick deep-seated root.

Wings not thickened towards the margin.

29. CyMOPTERUS.

Leafy-stemmed plants with a taproot; calyx-teeth small and equal; leaf-segments thin, not pungent.

30. Pseudocymopterus.

Acaulescent plants with a cespitose caudex; calyx-teeth large and unequal, one or two much larger than the rest; leafsegments thick and pungent. 31 . PsEUDOPTERYXIA.

Dorsal ribs filiform (or in one species of Cogswellia somewhat margined).

Lateral wings thin, not corky; plants mostly small.

Lateral wings thick and corky; plants large.

$\beta$. Stylopodium present.

32. Cogswelitia.

Stylopodium depressed.

Dorsal ribs more or less winged.

Plant acaulescent or low-stemmed, with narrow leaf-segments; sepals evident; petals yellow. 34. CYNOMARATHRUM.

Plant caulescent, with broad leaf-segments; sepals obsolete; petals white. 35 . ANGELICA.

Dorsal ribs filiform; plant caulescent; sepals obsolete; petals yellow. Stylopodium conical.

36. Pastinaca.

Plants villous at least in the inflorescence; sepals obsolete.

Leaves ternate, with rounded-cordate leaflets; oil-tubes prominent, inversely clavate, only in the upper half of the carpels. 37. HERACLEUM.

Leaves once or twice pinnate; oil-tubes not prominent, running through the whole length of the carpels.

38. SPHENOSCLADIUM.

Plants glabrous, with linear or lanceolate leaf-segments.

Sepals obsolete; leaves in ours three or four times compound; oil-tubes several in the lateral intervals.

39. Conioselinum.

Sepals evident; leaves in our species simply pinnate; oil-tubes solitary in all intervals. 40. OXYPOLIS.

\section{DAÛCUS (Tourn.) L. CARrot.}

Bristly annuals or biennials. Leaves pinnately decompound. Flowers white or rarely pinkish, in compound umbels. Bracts foliaceous and pinnately cleft; bractlets entire or toothed. Calyx-teeth obsolete. Fruit oblong, flattened dorsally. Primary ribs 5, slender, bristly; secondary ribs 4, strong, each bearing a row of strong, barbed prickles. Stylopodium depressed or wanting. Oil-tubes solitary under the secondary ribs, 2 on the commissure. Seeds flattened dorsally; face more or less concave.

1. D. pusillus Michx. Annual; stem repeatedly pinnately dissected into short linear divisions; bracts bipinnate, with linear divisions; bractlets linearfiliform; fruit ovoid-oblong, 3-5 mm. long. Dry or sandy soil and waste places: S.C.-Fla.-Calif.-B.C.-Ida. Son. Mr-Au.

\section{CAÙCALIS L.}

Mostly hispid annuals (ours). Leaves pinnately dissected. Flowers white, in umbels. Bracts in ours foliaceous, divided; bractlets entire or toothed. Calyx-teeth prominent. Stylopodium thick and conic; fruit ovate or oblong, flattened laterally; primary ribs 5, filiform, 2 of them pushed down on the commissural side, the other 3 bristly; secondary ribs 4 , winged and with barbed or hooked prickles. Oil-tubes solitary under the secondary ribs, and 2 on the commissural side. Seed-face deeply grooved.

1. C. microcarpa Hook. \& Arn. Slender annual; stem $2-4 \mathrm{dm}$. high, glabrous or sparingly hispid; leaves repeatedly pinnatifid into numerous linear divisions, glabrous or sparingly hairy; bracts foliaceous, pinnatifid; bractlets small, usually entire; fruit oblong, 4-6 mm. long, armed with rows of hooked prickles. Hills and river-banks: Wash.-Ida.-Ariz.-Calif. Son. Mr-Je. 


\section{ERÝNGiUM (Tourn.) L. Rattlesnake-Master, Eryngo.}

Glabrous caulescent perennials. Leaves usually rigid, coriaceous, spinosely toothed or divided. Flowers white or blue, in dense, bracted heads. Bractlets intermixed with the flowers. Sepals very prominent, rigid, persistent. Stylopodium wanting. Fruit ovoid or oblong, laterally flattened, covered with hyaline scales or tubercles; ribs obsolete. Oil-tubes usually 5 , of which 3 are on the dorsal and 2 on the commissural side. Seed-face plane.

1. E. articulatum Hook. Stem 3-7 dm. high, dichotomously branched, usually with a peduncled head in the forks; basal and lower cauline leaves with nodose petioles, 7-25 cm. long; leaf-blades lanceolate, spinulose-serrate or entire, or in submerged leaves lacking; upper stem-leaves sessile and opposite, more or less laciniate at the base; heads globose or ellipsoid; bracts euspidate, spinytoothed below, as long as the heads; bractlets 3-cuspidate; fruit 4-5 mm. long; sepals cuspidate. Wet places: Wash.-Ida.-Calif. Son. Je-S.

\section{SANícula (Tourn.) L. SNake-root, Sanicle.}

Smooth perennials, with rootstocks and few-leaved stems. Leaves palmate or rarely pinnate, with incised or pinnatifid divisions. Flowers greenish yellow or purple, in irregularly compound, few-rayed umbels. Involucres and involucels present. Calyx-teeth foliaceous, persistent. Fruit globose, densely covered with hooked bristles; ribs none. Stylopodium wanting. Oil-tubes from 3 to many; usually 5 ; of these 3 dorsal and 2 commissural. Seed-face plane or coneave.

Leaves palmately or pedately $3-7$-divided.

Styles longer than the bristles; staminate flowers often in separate umbels.

Styles shorter than the bristles; staminate flowers always intermixed with thandica. ones.

Leaves pinnately twice or thrice ternate.

2. S. canadensis.

2. S. canadensis.

3. S. septentriomalis.

1. S. marilandica L. Stem 4-12 dm. high; basal leaves long-petioled; blades 3-5-divided to the base and the lateral divisions 2-cleft; divisions oblanceolate or obovate, sharply cut and serrate, $5-10 \mathrm{~cm}$. long; the stem-leaves shortpetioled or the upper sessile; involucres of few more or less leaf-like bracts; involucels of small bractlets; fruit sessile, 6-7 mm. long, including the bristles. Rich woods: Newf.-Ga.-Colo.-Wash.-B.C. Plain-Submont. Je-S.

2. S. canadensis L. Stem more or less branched, 3-12 dm. high; basal leaves long-petioled, palmately 3-divided to the base; lateral divisions 2-parted; divisions incised; the upper leaves short-petioled or subsessile; umbels irregular, few-rayed; involucres and involucels of few small bracts and bractlets; fruit 3-6 mm. long, including the bristles. Rich woods: Vt.-Fla.-Tex.-Wyo. Plain-Submont. Je-S.

3. S. septentrionalis Greene. Perennial, with a fusiform root; stem 1-4 $\mathrm{dm}$. high; basal leaves small, ternate or bi-ternate; divisions 1-2 cm. long, obovate, cleft and coarsely serrate; stem-leaves few, their lobes sharply laciniate; bracts of the involucres pinnatifid, leaf-like; bractlets small, oblong, acute, more or less united; flowers yellow; fruit sessile, $4 \mathrm{~mm}$. long. NIGGER-BABIES. S. apiifolia Greene. Open woods and hillsides: Mont.-Ida.-Calif.-B.C. Submont. $\mathrm{My}-\mathrm{Jl}$.

\section{OSMORRHİZA Raf. SWeEt Cicely.}

Glabrous or hirsute perennials, with thick aromatic roots and more or less leafy stems. Leaves ternately decompound, with broad, lanceolate or ovate, toothed leaflets. Flowers white or purplish, in few-rayed umbels. Involucres and involucels few-leaved or wanting. Calyx-teeth obsolete. Fruit linearclavate, attenuate at the base, bristly on the equal ribs. Stylopodium conic or depressed. Oil-tubes obsolete in the mature fruit. Seed-face concave to deeply grooved. [Washingtonia Raf.]

Involucels of several bractlets.

Involucels lacking or of a single small bractlet.

1. O. longistylis.

Fruit obtuse at the apex, without a neck.

2. O. obtusa. 
Fruit more or less constricted at the apex into a short neck.

Pedicels longer than the fruit.

Stylopodium short, broad and flat, making the fruit almost truncate at the apex; plants almost glabrous.

Corolla purple.

Corolla white.

3. O. purpurea.

4. O. Leibergii.

Stylopodium as well as the neck tapering above, the fruit therefore ending in a short beak.

Branches of the umbel in fruit ascending; fruit $15 \mathrm{~mm}$. or more long; beak $2 \mathrm{~mm}$. or more.

Branches of the umbel in fruit divaricate; fruit 12-13 scarcely more than $1 \mathrm{~mm}$. long.

Pedicels shorter than the fruit. 5. O. intermedia. $\mathrm{mm}$. long; beak 6. O. divaricata.

7. O. brevipes.

1. O. longistylis (Torr.) DC. Stem stout, glabrous or nearly so, $3-10 \mathrm{dm}$. high; leaves twice to thrice ternate; ultimate leaflets $3-7 \mathrm{~cm}$. long, acuminate, sparingly hirsute; involucre and involucels of few narrowly lanceolate-acuminate bracts; fruit $2-3 \mathrm{~cm}$. long, with a slender attenuation at the base; stylopodium elongate-conical, $1 \mathrm{~mm}$. long; styles $2 \mathrm{~mm}$. long. W. longistylis Britton. Damp woods: N.S.-Ga.-Colo.-Alta. Plain-Submont. My-Jl.

2. O. obtusa (Coult. \& Rose) Fernald. Stem 3-6 dm. high, glabrous or more or lesś pilose, with spreading or reflexed hairs; leaves twice or thrice ternate; ultimate leaflets ovate or lanceolate, mostly acuminate; umbels with spreading branches; fruit about $15 \mathrm{~mm}$. long; stylopodium flattened, $0.5 \mathrm{~mm}$. long or less; styles very short, recurved. W. obtusa Coult. \& Rose. Woods in the mountains: Alta.-N.M.-Calif.-B.C.; Gaspe, Que. Submont.-Subalp. Je-Au.

3. O. purpurea (Coult. \& Rose) Suksd. Stem 2-6 dm. high, nearly glabrous; leaves twice ternate; leaflets ovate or lanceolate, acute or acuminate, $2-7$ $\mathrm{cm}$. long; branches of fruiting umbels widely spreading; fruit slightly hispid at the base, $10-12 \mathrm{~mm}$. long, slightly beaked at the apex; styles over $0.5 \mathrm{~mm}$. long. W. pupurea Coult. \& Rose. Woods: Alaska-Mont.-Ore. Mont. Je-Au.

4. O. Leibergii (Coult. \& Rose) Blankinship. Stem 3-6 dm. high, almost glabrous; leaves twice or thrice ternate; leaflets thin, ovate or lanceolate, acuminate; umbels with ascending branches; fruit slightly hispid at the base; styles less than $0.5 \mathrm{~mm}$. long. W. Leibergii Coult. \& Rose. Moist woods: Ida.B.C.-Alta,-Wash. Submont.-Mont. J-Au.

5. O. intermedia (Rydb.) Blankinship. Stem 4-8 dm. high, sparingly villous or glabrous; ultimate leaflets rhombic-ovate, acute, somewhat pubescent; branches of umbel ascending in fruit; fruit about $15 \mathrm{~mm}$. long; stylopodium 0.5 $\mathrm{mm}$. long; styles very short. W. intermedia Rydb. Woods and copses: Mont. -Colo.-Utah-Alaska. Submont.-Mont. Je-Au.

6. O. divaricata Nutt. Stem slender, 3-6 dm. high, sparingly pubescent; leaves twice or thrice ternate; ultimate leaflets $2-6 \mathrm{~cm}$. long, ovate, acute or acuminate, more or less pubescent; branches of the umbels very long and divaricate in fruit; fruit $12-13 \mathrm{~mm}$. long; stylopodium $0.25 \mathrm{~mm}$. long; styles of about the same length. W. divaricata Britton. Woods: B.C.-Ore.-Utah-S.D.; also Gaspe, Que. Submont.-Mont. Je-Л.

7. O. brevipes (Coult. \& Rose) Suksd. Stem 3-8 dm. high, pubescent, with short retrorse hairs; leaflets broadly ovate, $2-5 \mathrm{~cm}$. long, obtuse or acutish, more or less pubescent; branches of the umbels 3-7, ascending; pedicels 4-12 mm. long; fruit 14-16 mm. long, with slender attenuation at the base and a distinct beak $2 \mathrm{~mm}$. long; stylopodium conic, less than $0.5 \mathrm{~mm}$. long; style short. $W$. brevistylis Coult. \& Rose. Woods and thickets: B.C.-Mont.-Wyo.-Calif. Submont.-Mont. My-Jl.

\section{GLYCÓSMA Nutt.}

Caulescent perennials, with rootstocks, more or less pubescent, at least at the nodes. Leaves ternately decompound, with lanceolate, toothed leaflets. Flowers yellow, in few-leaved umbels. Calyx-teeth obsolete. Stylopodium conic or depressed. Fruit linear-clavate, glabrous, obtuse at the base; oil-tubes obsolete in the fruit; seed-face concave or grooved.

Fruit 12-16 mm., rarely $18 \mathrm{~mm}$. Iong, on erect pedicels.

Fruit $20 \mathrm{~mm}$. long or more, on spreading pedicels.

1. G. occidentalis.

2. G. maxima. 
1. G. occidentalis Nutt. Stem stout, usually puberulent, 6-12 dm. high; leaves twice or thrice pinnately ternate; leaflets oblong-lanceolate, $3-10 \mathrm{~cm}$. long, acute, serrate; pedicels 2-8 $\mathrm{mm}$. long; fruit distinctly beaked; stylopodium conic, nearly $1 \mathrm{~mm}$. long. Osmorrhiza occidentalis Torr. Hillsides and valleys: Alta.-Colo-Calif.-B.C. Submont.-Mont. Je-Au.

2. G. maxima Rydb. Stem $1 \mathrm{~m}$. high or more, puberulent or glabrous, pilose at the nodes; lower leaves twice compound, first pinnate and the lower primary divisions ternate; the upper leaves ternate or twice ternate; leaflets oblong-lanceolate, $5-10 \mathrm{~cm}$. long, minutely puberulent; pedicels in fruit 1-1.5 $\mathrm{cm}$. long; fruit contracted above into a beak, $2 \mathrm{~mm}$. long; stylopodium conic, $0.5 \mathrm{~mm}$. long. Mountains: Utah-Mont. Submont. Jl-Au.

\section{LEIBÉRGIA Coult. \& Rose.}

Slender glabrous acaulescent plants, from small globose corms. Leaves ternately divided into long filiform leaflets. Flowers white, in irregular umbels. Calyx-teeth obsolete. Stylopodium wanting. Fruit slightly flattened laterally, linear, beaked, glabrous. Ribs filiform. Oil-tubes small, solitary in each interval, 2 on the commissural side. Seed-face broad, slightly concave, but in drying becoming involute.

1. L. orogenioides Coult. \& Rose. Stem 1-5 dm. high; branches of the umbels $3-10$, often spreading, $2-12 \mathrm{~cm}$. long; pedicels very short; fruit $8 \mathrm{~mm}$. long, 1 $\mathrm{mm}$. broad. Cogswellia orogenioides M. E. Jones, in part. Wet grounds, pine woods: Ida.-Wash. My-Je.

\section{OROGÉnIA S. Wats. TURKey Peas.}

Dwarf glabrous acaulescent perennials, with tuberous or fusiform corms or roots. Leaves ternate, with linear divisions. Flowers white, in small subcompound umbels with very unequal rays. Calyx-teeth minute. Stylopodium depressed. Fruit oblong, slightly flattened laterally, glabrous. Carpels strongly flattened dorsally. Dorsal and intermediate ribs filiform; lateral ribs strongly corky thickened and inflexed towards the other carpel, leaving empty cavities between them, the carpels, and a thick corky projection from the middle of the commissure of each carpel. Oil-tubes very small, 3 in each interval, 2-4 on the commissural side. Seed-face slightly concave.

Stem from a deep-seated round corm.

Stem from a fusiform long root.

1. O. linearifolia.

2. O. Leibergii.

1. O. linearifolia S. Wats. Stem scapiform, usually about $1 \mathrm{dm}$. high; leaves 2-3, ternate or biternate, slender-petioled, glabrous; divisions entire, linear, $2-5 \mathrm{~cm}$. long, $2-6 \mathrm{~mm}$. wide; umbels 2-10-rayed; flowers sessile or nearly so; fruit $3-4 \mathrm{~mm}$. long; ribs rather prominent. Mountain sides and ridges: Wash.-Ore.-Utah-Colo. Submont.-Mont. Mr-Je.

2. O. Leibergii (Coult. \& Rose) Rydb. Stem scapiform, 3-4 dm. high, glabrous; leaves twice or thrice ternate; divisions $2-4 \mathrm{~cm}$. long, linear. O. fusiformis Leibergii Coult. \& Rose. Sand hills: Ida. Je.

\section{EÙLOPHUS Nutt.}

Glabrous caulescent perennials, with fascicled tuberous roots. Leaves pinnately or ternately compound, with narrow, linear to oblong-linear leaflets, of which the terminal one usually is elongate. Bracts lanceolate or rarely wanting; bractlets lanceolate, several, subscarious. Flowers white or pinkish, in long-peduncled umbels. Calyx-teeth prominent. Stylopodium conic; styles long, recurved. Fruit laterally flattened, ellipsoid to linear-oblong, glabrous. Ribs filiform; pericarp thin. Oil-tubes $1-5$ in the intervals, $4-8$ on the commissural side. Seed-face broadly concave, with a central longitudinal ridge.

1. E. Bolanderi (A. Gray) Coult. \& Rose. Stem 3-6 dm. high; lower leaves twice pinnately compound; leaflets entire or divided into linear or oblong divisions, $1-3 \mathrm{~cm}$. long, the upper less compound or simple; umbels 10-25rayed; involucres and involucels of oblanceolate, acuminate, scarious bracts 
and bractlets; fruit oblong, $3 \mathrm{~mm}$. long, $1 \mathrm{~mm}$. broad; oil-tubes $2-5$ in each interval, 6 on the commissure. Meadows and ridges: Ore,-Ida,-Nev.-Calif. Son. My-Jl.

\section{ATÈNIA H. \& A. YAMP, SQUAW-ROOT.}

Smooth slender herbs, with tuberous or fusiform-fascicled roots. Leaves pinnate, with few linear or linear-lanceolate divisions. Flowers white. Involucres of few or several bracts, rarely wanting; involucels present. Calyx-teeth prominent. Stylopodium conic. Fruit orbicular to oblong, flattened laterally. Ribs filiform, inconspicuous. Oil-tubes large and solitary in each interval, 2 on the commissural side. Seeds somewhat flattened dorsally; face plane.

Leaflets of all the leaves filiform to linear-lanceolate.

Leaflets filiform.

Leaflets linear-lanceolate.

Leaflets of the basal leaves ovate-lanceolate or broadly lanceolate.

1. A. Gairdneri.

2. A. montana.

1. A. Gairdneri H. \& A. Stem 3-10 dm. high; leaves pinnate; leaflets narrowly linear to filiform, $5-15 \mathrm{~cm}$. long; fruit nearly orbicular, usually less than $2 \mathrm{~mm}$. long; calyx-teeth ovate, very small; stylopodium low-conic. Carum Gairdneri (H. \& A.) A. Gray. Meadows and valleys: Alta.-N.M.-Calif.B.C. Plain-Submont. Au-S.

2. A. montana (Blankinship) Rydb. Stem $8-12 \mathrm{dm}$. high; leaves $2-3 \mathrm{dm}$. long, pinnate, with 7-11 leaflets; leaflets often cleft into 1-4 lanceolate or linearlanceolate divisions; sepals as long as the depressed conic stylopodium; fruit fully $2 \mathrm{~mm}$. long, orbicular. Carum montanum Blankinship. Low thickets: Alta.Wyo,-Ida. Submont. J1-S.

3. A. Garrettii (A. Nels.) Rydb. Stem 6-8 dm. high, glabrous; basal and lower cauline leaves pinnate, with $3-7$ leaflets; leaflets $3-5 \mathrm{~cm}$. long, $1-2 \mathrm{~cm}$. wide, ovate or ovate-lanceolate, entire; upper cauline leaves with narrower leaflets or reduced to broad sheaths; bracts and bractlets filiform-subulate; fruit about $2 \mathrm{~mm}$. long, orbicular; stylopodium low-conic, longer than the sepals. Carum Garrettii A. Nels. Valleys: Utah. Submont. Au-S.

\section{BÉRULA Hoffm. Water Parsnip.}

Smooth aquatic perennials, with rootstocks. Flowers white, umbellate. Leaves simply pinnate, with toothed or incised leaflets. Bract and bractlets conspicuous, but narrow. Calyx-teeth minute. Stylopodium conic. Fruit nearly suborbicular, flattened laterally, emarginate at the base, glabrous. Ribs slender, inconspicuous. Oil-tubes numerous and contiguous, closely surrounding the seed cavity. Seeds subterete.

1. B. erecta (Huds.) Coville. Stem 2-10 dm. high, glabrous; leaves pinnate, with 11-19 leaflets; leaflets ovate to linear, sharply serrate, incised or laciniately lobed, 1-7 cm. long; fruit scarcely $2 \mathrm{~mm}$. long. B. angustifolia (L.) Mert. \& Koch. Swamps and streams: Ont.-Ill--N.M.-Calif.-B.C. Plain-Submont. Jl-S.

\section{CÀrum L. Caraway.}

Biennials or perennials with taproot, leafy-stemmed. Leaves twice or thrice pinnatifid, with filiform divisions. Involueres and involucels present. Flowers white, in many-rayed umbels. Calyx-teeth prominent. Stylopodium conie. Fruit oblong, somewhat flattened laterally. Ribs rather strong. Oil-tubes solitary in the intervals, 2-6 on the commissural side. Seed-face plane.

1. C. carui L. Stem 3-6 dm. high; leaves 3-4 times pinnatifid, with lanceolate to filiform acute segments; involucres of 1-3 linear bracts; involucels usually none; fruit oblong, about $4 \mathrm{~mm}$. long, with conspicuous ribs. Waste places: Newf.-Pa.-Colo.-Alta.; escaped from cultivation; native of Europe. Plain -Mont. My-Jl.

\section{LIGỨSTICUM L.}

Smooth caulescent perennials, with large aromatic roots. Leaves large, ternately or ternate-pinnately compound or decompound. Flowers white or 
pinkish, in many-rayed umbels. Bracts usually wanting; bractlets narrow. Calyx-teeth small or obsolete. Stylopodium conic. Fruit oblong or ellipsoid, flattened laterally if at all, glabrous. Ribs all prominent and equal, acute, sometimes slightly winged. Oil-túbes $2-6$ in the intervals, $6-10$ on the commissural side. Seeds with rounded or angled back; face from plane to deeply concave.

Stem leafy; divisions of the leaves not fliform.

Ultimate divisions of the leaves $2-3 \mathrm{~cm}$. wide; involucels none. 1. L. verticillatum.

Ultimate divisions of the leaves less than $2 \mathrm{~cm}$. wide, laciniate or pinnatifid.

Ultimate divisions of the leaves ovate to lanceolate.

Lateral primary divisions less than half as long as the terminal one; leaves therefore appearing pinnate; oil-tubes in the intervals 3 , on the commissure 6-8.
3. L. simulans.

Lateral primary divisions at least two-thirds as long as the terminal one; the leaves therefore appearing ternate; oil-tubes in the intervals $4-6$, on commissure 6-10.

Secondary leaflets not cleft to near the midrib; fruit $4 \mathrm{~mm}$. long.

2. L. Canbyi.

Secondary leaflets cleft to near the midrib; fruit $5-6 \mathrm{~mm}$. Iong. Leaves thin and dark green.

Fruit almost $5 \mathrm{~mm}$. long; stylopodium conic. 4. L. Leibergii.

Fruit about $6 \mathrm{~mm}$. long; stylopodium low and broad.

Ultimate lobes of the leaves lanceolate, 5-10 $\mathrm{mm}$. long.

5. L. Porteri.

Ultimate lobes of the leaves ovate or oblong-ovate, usually less than $5 \mathrm{~mm}$. long.

Leaves thicker, pale green.

7. L. affine.

6. L. brevilobum.

Ultimate divisions of the leaves or teeth linear or linear-lanceolate.

8. L. filicinum.

Plant subscapose or with a single leaf; ultimate divisions of the leaves linear-fliform.

9. L. tenuifolium.

1. L. verticillatum (Geyer) Coult. \& Rose. Stem 6-7 dm. high; leaves once or twice ternate, then pinnate; leaflets $2.5-7.5 \mathrm{~cm}$. long, ovate to oblong, serrate, pale beneath, glabrous; umbels many-rayed, compact; involucels none; fruit oblong, $6 \mathrm{~mm}$. long; ribs winged; stylopodium low-conic. Borders of woods: Ida. Submont. Je-J.

2. I. Canbyi Coult. \& Rose. Stem about $6 \mathrm{dm}$. high; leaves mostly basal, biternate; leaflets lanceolate, $7.5-10 \mathrm{~cm}$. long, pinnately parted below, toothed above; bractlets linear; fruit $4 \mathrm{~mm}$. long; ribs winged; stylopodium slenderconic; oil-tubes 5 or 6 in the intervals, 6-8 on the commissure. Low ground: Mont.-Ida.-Wash.-B.C. Submont.-Mont. Jl-S.

3. L. simulans Coult. \& Rose. Stem 6-9 dm. high; leaves mostly basal, twice pinnate; leaflets oblong or lanceolate, toothed or cleft; bracts and bractlets linear; fruit oblong, 4-5 mm. long; ribs with narrow thin wings; stylopodium lowconic. Wet meadows: Wyo. Mont. Au.

4. L. Leibergii Coult. \& Rose. Stem glabrous, $1 \mathrm{~m}$. or more high; leaves twice ternate, then pinnate; leaflets lanceolate, acuminate, laciniately cleft into lanceolate, pointed, sometimes toothed lobes; peduncles often verticillate around a central one, $1-4 \mathrm{dm}$. long; involucels few, subulate; fruit oblong, 4-5 mm. Iong; ribs with narrow wings; stylopodium conie; oil-tubes 4-6 in the intervals. Rich soil: Ida.-Wash. Submont-Mont. Je-Au.

5. L. Porteri Coult. \& Rose. Stem 6-10 dm. high, leafy; leaves large, biternate and then pinnate; leaflets numerous, lanceolate or ovate, pinnatifid or toothed, with oblong-lanceolate divisions or teeth; bracts and bractlets usually lacking; fruit oblong, 6-7 $\mathrm{mm}$. long; ribs prominently winged; stylopodium broad and low; oil-tubes $4-6$ in the intervals. Woods: Wyo.-N.M.-Ariz. Mont.-Subalp. J1-Au.

6. L. brevilobum Rydb. Stem 6-8 dm. high, glabrous; leaves twice ternate and then pinnate; segments cleft into ovate or oblong-ovate lobes which are. seldom more than $5 \mathrm{~mm}$. long, prominently veined; involucres and involucels usually wanting; fruit short-oblong, nearly as in the preceding; stylopodium low-conic. Open woods: e Utah. Mont.-Subalp. J1-Au.

7. L. affine A. Nels. Stem 5-10 dm. high; leaves biternate, then once or twice pinnate; leaflets ovate-oblong, deeply cleft into linear-oblong or linear- 
lanceolate divisions; bractlets few, linear-subulate, caducous; fruit elliptic, 5 $\mathrm{mm}$. long; ribs winged; oil-tubes usually 5 in the intervals; stylopodium low. Open hillsides: Wyo.-Colo. Submont.-Mont. Jl-Au.

8. L. filicinum S. Wats. Stem 3-10 dm. high, leafy; leaves once or twice ternate, then bipinnate; leaflets pinnatifid into linear or narrowly linear-lanceolate, acute divisions; bracts and bractlets solitary or few, small, linear; fruit narrowly oblong, 6-7 mm. long; ribs somewhat winged; stylopodium conic; oiltubes 3-5 in the intervals. Mountain valleys: Wyo-Utah-Mont. Submont. -Mont. Je-Au.

9. L. tenuifolium S. Wats. Stem 2-6 dm. high, naked or with a single leaf; leaves ternate, then pinnately decompound; leaflets pinnately divided or laciniate into narrowly linear lobes; bractlets 1 or 2 , narrowly linear; fruit oblong, $3-4 \mathrm{~mm}$. long, with narrow ribs; oil-tubes $3-5$ in the intervals. Mountain woods: Colo.-Ida.-Ore. Mont.-Subalp. Au.

\section{LIGUSTICÉLLA Coult. \& Rose.}

Low glabrous acaulescent perennials. Leaves simply pinnate. Flowers yellowish green, in few-rayed compact umbels. Bracts none, or 1 or 2 , caducous; bractlets broad and toothed. Calyx-teeth evident; Stylopodium conic. Fruit flattened laterally, glabrous. Oil-tubes 2 or 3 in the intervals, 4 on the commissural side. Ribs filiform. Seeds broader than thick; face nearly plane.

1. L. Eastwoodae Coult. \& Rose. Leaves pinnate; leaflets 7-13, oval, orbicular or obovate, 2- or 3-lobed, again cleft and toothed, 1-1.5 $\mathrm{cm}$. long; bracts $0-2$; bractlets obovate or cuneate, $3-5$-toothed; fruit ovoid, $3 \mathrm{~mm}$. long, with small ribs; stylopodium conic; oil-tubes $2-3$ in each interval. Ligusticum Eastwoodiae Coult. \& Rose. Mountains: Colo.-Wyo. Submont.-Subalp. Je$\mathrm{Au}$.

\section{BUPLEÙRUM L.}

Annuals or perennials, with entire, clasping or perfoliate stem-leaves. Flowers yellow, in small umbels. Involueres present or wanting; involucels of 5 or more ovate bractlets. Calyx-teeth obsolete. Fruit oblong, flattened laterally. Ribs equal, slender or prominent. Stylopodium prominent and flat. Oil-tubes wanting or continuous around the seed-cavity. Seed-face plane or nearly so.

Plant usually over $1 \mathrm{dm}$. high; bractlets lanceolate, acute, yellowish green; fruit about $5 \mathrm{~mm}$. long.

Plant usually loss than 1 dm; bicanum.

fruit $3 \mathrm{~mm}$. long; flowers usually purplish.

1. B. americanum Coult. \& Rose. Perennial, with a woody caudex; stem 1-3 dm. high, glabrous; basal leaves linear-lanceolate, tapering into a short petiole, parallel-veined; stem-leaves clasping, oblong to linear; petals light yellow; oil-tubes about 4 in each interval. Mountains: Alaska-Ida.-Wyo.Mack. Mont.-Subalp. Jl-Au.

2. B. purpureum Blankinship. Perennial, with a woody caudex; stem 1 $\mathrm{dm}$. high or less, glabrous; basal leaves linear-lanceolate, $2-5 \mathrm{~cm}$. long, the cauline ones lanceolate or oblong, elasping; petals purple, rarely yellow; oil-tubes 3 or less in each interval. High mountains: Mont. Mont.-Alp. J1-Au.

\section{Zízia Koch. Alexanders, Meadow Parsnip.}

Smooth caulescent perennials. Leaves simple or ternately compound, with broad serrate leaflets. Flowers yellow, umbellate. Bracts wanting; bractlets small. Calyx-teeth prominent. Stylopodium wanting; styles long, ereet. Fruit flattened laterally, ellipsoid or oblong, glabrous. Ribs filiform. Oiltubes large, solitary in each broad interval, 2 on the commissural side. Seed pentagonal in cross-section; face plane.

Basal leaves, at least the earlier ones, simple, cordate. Basal leaves ternate.

1. Z. cordata.

1. Z. cordata (Walt.) Koch. Stem 3-7 dm. high, glabrous; basal leafblades cordate or rounded-cordate, $2-10 \mathrm{~cm}$. long, crenate; stem-leaves ternate, 
with ovate to lanceolate, serrate or incised leaflets; fruit ovate, $3 \mathrm{~mm}$. long. Wet meadows and open woods: Conn.-Ga.-Utah-Ore.-B.C. PlainSubmont. My-Au.

2. Z. aurea (L.) Koch. Stems $3-10 \mathrm{dm}$. high; leaves all except the uppermost twice or thrice ternate; leaflets ovate to lanceolate, sharply serrate, 2-10 $\mathrm{cm}$. long; fruit oblong, about $4 \mathrm{~mm}$. long. Fields and meadows: N.B.-Fla.Tex.-Wyo.-Mont. Sask. Plain-Submont. My-Jl.

\section{MUSINEON Raf.}

Low glabrous or seabrous perennials, with thick elongated roots and dichotomously branched stems. Leaves pinnately decompound, usually with more or less winged rachis. Flowers yellow, rarely white, in long-peduncled umbels. Bracts wanting; bractlets few and narrow. Calyx-teeth prominent. Stylopodium depressed. Fruit ovate or ovate-oblong, flattened laterally. Ribs equal and filiform. Oil-tubes usually 3 in each interval, unequal in size, 2-4 on the commissural side. Seed-face broadly concave. [Musenium Nutt.]

Divisions of the leaves obovate or oblong, toothed; rachis dilated.

Fruit glabrous or slightly puberulent.

Plant evidently caulescent; basal leaf-sheath not scarious, slightly dilated.

Plant with the 1. M. divaricatum.

Plant with the stem above ground very short; basal sheath strongly dilated and scarious.

Fruit strongly scabrous-puberulent.

Divisions of the leaves obtuse.

Divisions of the leaves acute or acuminate.

2. M. pedunculatum.

Divisions of the leaves linear or linear-oblong, entire; rachis not dilated; leaf-sheath strongly dilated.

5. M. vaginatum.

1. M. divaricatum (Pursh) Coult. \& Rose. Stems ascending or decumbent, 1-2 dm. high; leaves bipinnatifid; segments obovate, 3-5-toothed; branches of the umbels 10-25, 1-2 $\mathrm{cm}$. long; pedicels very short; fruit $4 \mathrm{~mm}$. long. Dry ground: Sask.-Neb.-Colo-CAlta. Plain-Submont. My-Jl.

2. M. pedunculatum A. Nels. Stem very short, less than $1 \mathrm{dm}$. high; peduncles $1-2 \mathrm{dm}$. long; leaves thick, somewhat glaucous, bipinnate; the ultimate divisions obovate, $2-5$-toothed; rays of the umbels $10-20,1.5-2.5 \mathrm{~cm}$. long; fruit 4-5 mm. long. Clayey soil: Wyo. Submont. Je.

3. M. trachyspermum Nutt. Perennial, with a thick fusiform deep-seated root; stems decumbent or ascending, 0.5-2 dm. long, somewhat puberulent; leaves bipinnatifid; divisions obovate, obtusish, 3-5-toothed; flowers yellow; fruit $2-3 \mathrm{~mm}$. long, scabrous-tuberculate, with prominent ribs. $M$. divaricatum Hookeri T. \& G. Dry plains: Sask.-Neb.-Colo--Alta. Plain-Submont. $\mathrm{My}-\mathrm{Jl}$.

4. M. angustifolium Nutt. Stem decumbent or ascending, $1.5 \mathrm{dm}$. long or less, puberulent; leaves bipinnatifid; rachis with very narrow wings; segments lanceolate, acute, 3-5-toothed or eleft; fruit about $3 \mathrm{~mm}$. long, scabrous-tuberculate, with rather prominent ribs. Sandy and gravelly plains: Sask.-Colo.Alta. Plain-Submont. My-Jl.

5. M. vaginatum Rydb. Stem less than $1 \mathrm{dm}$. high, glabrous; leaves twice or thrice ternate; divisions linear or linear-oblong, obtuse, about $5 \mathrm{~mm}$. long; stem-leaves with a scarious-margined sheath; petals white or sometimes yellowish; fruit oblong, $3 \mathrm{~mm}$. long; seed-face plane. Mountains: Mont.Wyo. Submont.-Mont. Je-Jl.

\section{DAUCOPHÝLLUM (Nutt.) Rydb.}

Low cespitose perennials, acaulescent or nearly so, with a branched caudex. Leaves numerous, basal, or 1 or 2 cauline, pinnate or bipinnate, with filiform or narrowly linear divisions. Flowers cream-colored to yellow, in dense umbels. Bracts wanting; bractlets few, narrow, linear. Calyx-teeth prominent. Stylopodium wanting. Fruit ovoid or oblong, granular on the intervals. Ribs equal, rather strong, but not at all winged. Oil-tubes 2 or 3 in the intervals, $4-6$ on the commissural side. Seeds terete or somewhat depressed; face plane. 
Leaves bi- or tri-pinnate; segments fliform; bractlets not exceeding the pedicels; seeds subterete.

1. D. tenuifolium.

Leaves pinnate; segments narrowly linear; bractlets longer than the pedicels; seeds somewhat depressed.

2. D. linearis.

1. D. tenuifolium (Nutt.) Rydb. Leaves glaucous; peduncles $1-2.5 \mathrm{dm}$. high, glabrous; flowers cream-white or ochroleucous; fruit 3-4 mm. long, puberulent or nearly glabrous; oil-tubes 2 or 3 in the intervals. Musenium tenuifolium Nutt. Dry hills and plains: S.D.-Neb.-Wyo. Plain-Submont. My-Jl.

2. D. linearis Rydb. Stems glabrous, weak, 1-2 dm. high; leaf-segments entire, 1-3 cm. long; branches of the umbels $2-4 \mathrm{~mm}$. long; fruit nearly sessile, oblong, 3-4 mm. long, strongly ribbed; oil-tubes 2 or 3 in the intervals. Aletes tenuifolia Coult. \& Rose. Mountains: Utah. Submont. J.

\section{ALÈTES Coult. \& Rose.}

Low cespitose, acaulescent perennials. Leaves pinnate, with broad, sharply toothed or cleft, distant leaflets. Flowers yellow, in small umbels. Calyx-teeth prominent. Stylopodium wanting. Fruit flattened laterally, oblong, glabrous. Ribs equal and prominent, but not winged. Oil-tubes large and solitary in each broad interval, 2 on the commissural side, and a small one in each rib. Seeds sulcate beneath each oil-tube; face slightly concave or plane.

Peduncles longer than the leaves; branches of the umbels short.

Leaflets rounded-obovate in outline; their teeth ovate; fruit $5-6 \mathrm{~mm}$. long.

Ieaflets rhombic- A. obovata.

fruit 4-5 mm. long.
Peduncles shorter than the leaves; branches of the umbels nearly as long as the peduncles.

2. A. acaulis.

1. A. obovata Rydb. Peduncles 1-3 dm. high; leaves 1-2 dm. long, pinnate with 4-5 pairs of leaflets; these broadly obovate, $1-2 \mathrm{~cm}$. long, more or less cleft and toothed, with short ovate teeth, strongly veined beneath; branches of the umbel $2-2.5 \mathrm{~cm}$. long in fruit; fruit $5-6 \mathrm{~mm}$. long and $1.5 \mathrm{~mm}$. in diameter; ribs rather thick, Mountains: Colo. Submont. Ap-Je.

2. A. acaulis (Torr.) Coult. \& Rose. Peduncles $1-3 \mathrm{~cm}$. high; leaflets rhombic or rhombic-ovate, cut with lanceolate-acuminate teeth; branches of the umbels $1-2 \mathrm{~cm}$. long; fruit 4-5 mm. long, almost sessile. High mountains: Colo.-N.M. Submont.-Mont. My-Au.

3. A. humilis Coult. \& Rose. Peduncles $2-5 \mathrm{~cm}$. long; leaflets usually 5 , entire or few-toothed, elliptic to obovate; branches of umbels spreading, 2.5-3 $\mathrm{cm}$. long; fruit ovate, $3 \mathrm{~mm}$. long. Mountains: Colo. Mont. Je.

\section{OREÓXIS Raf.}

Acaulescent cespitose perennials. Leaves pinnate, the leaflets cut into lanceolate, acute divisions. Flowers yellow or yellowish, in small umbels. Involueres none; involucels of narrow bractlets. Calyx-teeth prominent. Fruit globose to oblong, slightly flattened laterally. Ribs prominent, thick and corky. Stylopodium wanting. Oil-tubes $1-3$, in the very narrow intervals, 2 on the commissural side. Seeds slightly depressed, somewhat sulcate under the oil-tubes; face plane or nearly so.

Oil-tubes more than one in each interval; plant less than $1 \mathrm{dm}$. high, glabrous.

Bractlets linear, entire.

Bractlets obovate or oblanceolate, toothed.

1. O. humilis.

Oil-tubes solitary in each interval.

Plant less than $1 \mathrm{dm}$. high, more or less puberulent, at least the upper part of the peduncle; leaflets cleft into 1-7 linear divisions, which are $4-5 \mathrm{~mm}$. long; fruit 4-5 $\mathrm{mm}$. long.

3. O. alpina.

Plant 1-2 dm. high, glabrous; leaflets ovate or lanceolate, few-toothed, $5-15 \mathrm{~mm}$. long; fruit oblong, 6-7 mm. long.

4. O. MacDougali.

1. O. humilis Raf. Leaves 4-7 cm. long; leaflets cut into $3-7$ linear-lanceolate divisions; peduncles $2-7 \mathrm{~cm}$. long, glabrous or slightly puberulent below the umbel; flowers bright yellow; fruit $3-4 \mathrm{~mm}$. long; oil-tubes 2 or 3 (rarely 1 ) in the intervals. High mountain peaks: Colo. Subalp. $-A l p$. Je-Au. 
2. O. Bakeri Coult. \& Rose. Leaves $2-7 \mathrm{~cm}$. long, glabrous; leaflets divided into 3-5 linear or linear-lanceolate lobes; peduncles 3-8 cm. long; fruit 3-4 mm. long; oil-tubes $2-5$ in the intervals. High mountain peaks: Colo.-Utah. Subalp.-Alp. J1-Au.

3. O. alpina (A. Gray) Coult. \& Rose. Leaves pale green, $2-7 \mathrm{~cm}$. long; leaflets divided into 1-7 linear divisions; peduncles $2-8 \mathrm{~cm}$. long, puberulent or sometimes nearly glabrous; bractlets usually narrowly lanceolate, more or less united at the base; flowers pale yellow or nearly white; fruit 4-5 $\mathrm{mm}$. long, puberulent, at least when young. Cymopterus alpinus A. Gray. High mountain peaks: Colo.-Utah. Subalp,-Alp. Jl-Au.

4. O. MacDougali (Coult. \& Rose) Rydb. Leaves 5-15 $\mathrm{cm}$. long; leaflets $3-7$, obovate, ovate, or cuneate in outline, with $2-5$ coarse teeth; peduncles $1-1.5$ $\mathrm{dm}$. long, glabrous; bractlets few, linear; flowers yellow; fruit oblong, retuse at each end, 6-7 mm. long. Aletes MacDougali Coult. \& Rose. Cañons: n Ariz. -s Utah. Son. Je-Jl.

\section{HARBOÙRIA Coult. \& Rose.}

Glabrous cespitose perennials, with few-leaved stems and woody caudex. Leaves ternately decompound, with narrowly linear or filiform divisions. Flowers yellow, in long-peduncled umbels. Bracts and bractlets few, subulate. Calyx-teeth evident. Stylopodium depressed or wanting. Fruit ovate, flattened laterally, with narrow commissure, tuberculate-roughened. Ribs broad, obtuse, prominent. Oil-tubes large, solitary in each interval, 2 on the commissural side. Seed nearly round in cross-section.

1. H. trachypleura (A. Gray) Coult. \& Rose. Stem 3-6 dm. high, glabrous; leaves several times ternately decompound into filiform, mucronulate divisions; umbels 15-25-rayed; flowers yellow; fruit broadly ovate, $4 \mathrm{~mm}$. long. Cicuta trachypleura A. Gray. Mountains: Colo.-Wyo. Submont.-Mont. My-Jl.

\section{SİUM (Tourn.) L. WATER PARSNIP.}

Smooth caulescent perennials, with rootstocks, growing in water or wet places. Leaves pinnate, with serrate or pinnatifid leaflets. Flowers white in large umbels. Bract and bractlets numerous, narrow. Calyx-teeth minute. Stylopodium depressed; styles short, recurved. Fruit flattened laterally, oval in outline, glabrous. Ribs equal, prominent and corky. Oil-tubes 1-3 in each interval, 2-6 on the commissural side. Seed not compressed; face plane.

1. S. cicutaefolium Gmel. Stem 6-10 dm. high; leaves pinnate, with 7-17 leaflets, or if growing in water the submerged leaves twice or thrice pinnatifid; leaflets in the emersed leaves linear or lanceolate, $3-10 \mathrm{~cm}$. long, sharply serrate; fruit $3 \mathrm{~mm}$. long, with prominent ribs. Water and wet places: Newf.-Va,Calif.-B.C. Plain-Mont. Je-Au.

\section{Cicûta l. Cow Bane, Poison or Water hemlock.}

Smooth poisonous marsh plants, with short often erect rootstock and leafy stems. Leaves pinnate or bipinnate, with serrate leaflets. Flowers white, in compound umbels. Bracts few or none. Bractlets several and slender. Calyxteeth rather prominent. Stylopodium low, but sometimes low-conic. Fruit oblong to orbicular, flattened laterally, glabrous. Ribs strong, corky, flattish, the lateral ones largest. Oil-tubes solitary in the intervals, 2 on the commissure. Seed-face plane or nearly so.

Axils of the leaves not bearing bulblets; leaflets lanceolate.

Bractlets scarious-margined.

Bractlets not scarious.

1. C. cinicola.

Fruit orbicular in outline; rootstock usually horizontal or ascending.

2. C. vagans.
3. C. occidentalis.
narrowly linear.

Fruit oval in outline; rootstock exceedingly short, erect.
Axils of the leaves (especially the upper ones) bearing bulblets; leaflets narrowly linear.

4. C. bulbifera.

1. C. cinicola A. Nels. Stem stout, $2 \mathrm{~m}$. high; lower leaves bipinnate, with some of the larger pinnae bifoliolate; leaflets ovate or broadly lanceolate, 
1-2 dm. long, coarsely serrate; upper stem-leaves 3 -foliolate or simple, with linear-lanceolate leaflets, $2-3 \mathrm{~cm}$. long; involucre none, or of 1-3 scarious-margined linear bracts; bractlets lance-linear; fruit laterally compressed, $3 \mathrm{~mm}$. long. Near brooks in volcanic soil: Ida. Son. Jl.

2. C. vagans Greene. Stem stout, $5-15 \mathrm{dm}$. high; leaves twice or thrice pinnate; leaflets thin, lanceolate or linear-lanceolate, $3-7.5 \mathrm{~cm}$. long, remotely serrate, not strongly reticulate; fruit orbicular, $2-3 \mathrm{~mm}$. long; ribs broad; intervals narrow; oil-tubes small. Swamps, lakes, and wet meadows: B.C.-Mont. -Ida.-Calif. Son.-Submont. Jl-Au.

3. C. occidentalis Greene. Stem stout, 1-2 m. high; leaves twice pinnate; leaflets lanceolate or linear-lanceolate, $5-8 \mathrm{~cm}$. long, sharply serrate; fruit ellipsoid, $3 \mathrm{~mm}$. long, constricted at the commissure; oil-tubes large. (?) C. subfalcata Greene. Swamps and wet meadows: Alta.-S.D.-N.M.-Calif.B.C. Plain-Submont. Je-S.

4. C. bulbifera L. Stem slender, 3-9 dm. high; leaves twice or thrice ternate; leaflets linear, sparsely toothed, $2-5 \mathrm{~cm}$. long; fruit rather rare, orbicular, $2 \mathrm{~mm}$. long, constrieted at the commissure; ribs broad and low; intervals narrow. Swamps: Me.-Md.-Ore.-B.C. Plain. Jl-S.

\section{AULOSPÉRMUM Coult. \& Rose.}

Perennial herbs, with deep-seated fleshy root. Stem partly subterranean, covered at the base by scarious sheath and bearing at the end a cluster of leaves and naked scapes. Leaves pinnately dissected, fleshy, with obtuse segments. Flowers yellow or white or purple. Bracts mostly wanting; bractlets small, narrow. Calyx-teeth evident. Stylopodium wanting. Fruit oblong in outline. Ribs or most of them with thin broad wings; intervals broad. Oil-tubes several in each interval and on the commissural side. Seeds not dorsally flattened; face with a narrow and deep groove.

Involucres present.

Involucres wanting.

1. A. glaucum.

Corolla yellow.

Rachis of the primary leaf-segments dilated; secondary segments confluent, broad, toothed or merely cleft. 2 2. A. longipes.

Rachis of the primary leaf-segments not dilated; secondary segments distinct, finely dissected into oblong lobes.
3. A. angustum.

Corolla white.

Corolla purple.

4. A. ibapense.

5. A. planosum.

1. A. glaucum (Nutt.) Coult. \& Rose. Leaves twice or thrice pinnatifid, glaucous; segments crowded, obovate, toothed; bracts and bractlets linear-subulate; flowers white or ochroleucous (at least in age); fruit about $6 \mathrm{~mm}$. long; wings narrow. Cymopterus glaucus Nutt. Dry places: Mont.-Ida. Plain. Je.

2. A. longipes (S. Wats.) Coult. \& Rose. Naked portion of stem $5-15 \mathrm{~cm}$. long; leaves glaucous, pinnate or bipinnate, the ultimate divisions oval or obovate, mueronate; fruiting peduncles $1-2.5 \mathrm{dm}$. long; bractlets subulate; fruit 6-8 $\mathrm{mm}$. long; wings broad and thin. C. longipes $\mathrm{S}$. Wats. Dry hills and benchlands: Utah-Colo.-Wyo.-Ida. Son.-Submont. Ap-My.

3. A. angustum Osterhout. Stem about $1 \mathrm{dm}$. long; leaves ovate in outline, thrice pinnatifid, glaucous; ultimate divisions small, obovate or oblong, acute; bractlets subulate; fruit 6-7 mm. long; wings very narrow. River valleys: Colo. Submont. Je.

4. A. ibapense (M. E. Jones) Coult. \& Rose. Leaves tripinnate, glaucous, the ultimate divisions crowded, oblong, obtuse; bractlets linear, acute; fruit 4-5 $\mathrm{mm}$. long; wings broad and somewhat thickened at the insertion. C. ibapense M. E. Jones. Dry places: Utah-Nev. Son. My-Je.

5. A. planosum Osterhout. Stem 5-7 cm. long; leaves glaucous, ovate in outline, $7-8 \mathrm{~cm}$. long, tripinnatifid, with small oblong or obovate divisions; bractlets few, subulate; fruit oblong, $6 \mathrm{~mm}$. long, broadly winged. Dry places: Colo. Submont. Je. 


\section{PHELLÓPTERUS Nutt.}

Perennial herbs, with deep-seated fleshy roots, a subterranean stem merely reaching the surface of the ground and there bearing a cluster of leaves and naked peduncles. Leaves from once to thrice pinnate, rather fleshy. Flowers white or purplish. Calyx-teeth evident. Stylopodium wanting. Fruit oblong to orbicular in outline, nearly orbicular in cross-section. Ribs or most of them with thin broad wings, which sometimes are somewhat thickened at the insertion; the lateral distinct from those of the other carpel. Oil-tubes usually more than one in each interval. Seeds more or less flattened dorsally; face broadly and shallowly concave.

Wings of the fruit thin and broad, scarcely rugose.

Peduncles even in fruit shor ter than the leaves; wings thickened at the insertion. Flowers white; fruit 6-8 mm. long. $\quad 1, P$, montanus, Flowers purple; fruit 10-14 mm. long.

1. $P$, montanus.

Peduncles at least in fruit equalling or exceeding the leaves; wings not thickened at the insertion; fruit more than $8 \mathrm{~mm}$. long.

Involucels 1-3-nerved; corolla purplish. Fruit oblong. Fruit orbicular.

Involucels 5-13-nerved. Bracts white with green middle; corolla white or pink. Bracts and corolla purple.

Wings of the fruit thick, somewhat corky and rugose.

3. P. bulbosus.

4. P. utahensis.

5. $P$. camporum.

6. $P$. multinervatus.

7. P. Jonesii.

1. P. montanus Nutt. Leaves twice or thrice pinnate, with oblong toothed divisions, somewhat glaucous; peduncles 1-5 cm. long; involucre inconspicuous, hyaline and lobed; involucels conspicuous, of obovate entire distinct bractlets; fruit broadly elliptic to nearly orbicular, $6-8 \mathrm{~mm}$. long. Cymopterus montanus T. \& G. Dry plains: S.D.-Kans.-Colo.-Wyo. Plain-Submont. Ap-My.

2. P. macrocarpus Osterhout. Leaves narrow in outline, $1 \mathrm{dm}$. long, glaucous, bipinnate, with oblong divisions; flowers purple; involueres small, scarious, divided; bractlets distinct, white and scarious, with green midrib; fruit orbicular or rounded-oval, $10-14 \mathrm{~mm}$. long; oil-tubes $3-5$ in the intervals and usually 6 on the commissure. Dry plains: Colo. Plain. Ap-My.

3. P. bulbosus (A. Nels.) Coult. \& Rose. Leaves bipinnatifid; divisions cleft into oblong lobes, crowded; peduncles 5-10 cm. long; involuere of broad hyaline bracts united at the base; involucels of obovate hyaline bracts, with greenish midribs; fruit elliptic, $8 \mathrm{~mm}$. long. C. bulbosus A. Nels. Clayey hills: Wyo. Submont. My-Je.

4. P. utahensis (M. E. Jones) Woot. \& StandI. Leaves twice or thrice pinnatifid, with obovate or oblong, toothed or lobed divisions; peduneles 1-1.5 $\mathrm{dm}$. long; involucres and involucels conspicuous, of white or purplish bracts, with 1-3 green or purple veins; fruit orbicular or oval, 10-12 mm. long. P. purpurascens Coult. \& Rose. C. utahensis M. E. Jones. Clayey or gravelly soil: N.M.-Colo.-Ida.-Nev.-Ariz. Son. Ap-My.

5. P. camporum Rydb. Leaves twice to thrice pinnatifid, petioled, palegreen; ultimate divisions oblong, obtusish, 3-6 mm. long; peduncles $5-20 \mathrm{~cm}$. long, usually exceeding the leaves; involucres of white hyaline bracts; bractlets orbicular, 5-7 mm. long; fruit with the very broad wings $10-13 \mathrm{~mm}$. long and 9-11 mm. wide. Dry mesas: Colo. Son.-Submont. My.

6. P. multinervatus Coult. \& Rose. Leaves as in the preceding; peduncles about $1 \mathrm{dm}$. long; involucres low hyaline-lobed sheaths or sometimes resembling the involucels, which are composed of broad bracts united at the base; fruit orbicular, 12-15 mm. long. C. purpurascens M. E. Jones. Dry places: N.M.Utah-Nev.-s Calif. F-My.

7. P. Jonesii (Coult. \& Rose) Rydb. Leaves somewhat fleshy, oblong to ovate in outline; leaflets 3 , the lateral ones deeeply 2-cleft, the terminal one 3-cleft; divisions cleft and crenate; umbels solitary; bractlets distinct to near the base, ovate, acuminate; fruit $3 \mathrm{~mm}$. long. Rhysopterus Jonesii Coult. \& Rose. Dry places: Utah. Submont. Ap. 


\section{CORIOPHÝlluUs (M. E. Jones) Rydb. Indian Parsnip.}

Perennial herbs, with more or less fleshy roots, somewhat branched rootstocks covered with fibrous sheaths, and leafy stems. Flowers yellow to purple. Bracts none; bractlets present, but narrow. Leaves pinnately dissected, subcoriaceous, rigid, not fleshy, with ovate or lanceolate, cuspidate or spinulose-tipped lobes. Calyx-teeth evident. Stylopodium wanting. Fruit orbicular to oval in outline, usually emarginate at both ends, compressed laterally if any. Ribs with broad wings. Oil-tubes $1-5$ in the intervals, $2-8$ on the commissural side. Seeds little if at all flattened dorsally; face deeply grooved. [Cymopterus $\S$ Coriophyllus M. E. Jones.]

Wings thickened at the insertion.

Leaves ternately bipinnatifid; oil-tubes solitary in each interval. 1. C. Jonesii.

Leaves pinnate, with lobed or divided leaflets; oil-tubes several in each interval. Leaves ovate to ovate-oblong in outline; flowers pedicelled. $\begin{array}{ll}2 & \text { 2. C. Rosei. }\end{array}$ Leaves reniform to oblong-cordate in outline; flowers sessile. 3 . C. basalticus. Wings not thickened at the insertion.

Flowers purplish; oil-tubes on the commissure 8.

Flowers greenish yellow; oil-tubes on the commissure 4.

4. C. purpureus,

5. C. Betheli.

1. C. Jonesii (Coult. \& Rose) Rydb. Leaves ternate, then pinnate or bipinnate; ultimate segments broad, obovate, with spinulose-tipped teeth; bractlets lanceolate, small; flowers purple; fruit globose, $8 \mathrm{~mm}$. long; wings broad, but very thick at the insertion. Cymopterus and Aulospermum Jonesii Coult. \& Rose. Dry places: Utah. Submont. Je.

2. C. Rosei (M. E. Jones) Rydb. Leaves leathery, smooth, pinnate, with obovate-triangular, toothed, mucronate segments; peduncles $5-10 \mathrm{~cm}$. long; bractlets lanceolate, purplish, barely united at the base; flowers purple; fruit broadly elliptic, $8-10 \mathrm{~mm}$. long; wings broad, thin, slightly thickened at the insertions. A. Rosei M. E. Jones. Slopes and mesas in alkaline soil: Utah. Submont. Je.

3. C. basalticus (M. E. Jones) Rydb. Leaves 5-7 cm. long; blades 2.5-4 $\mathrm{cm}$. long, reniform or oblong-cordate in outline, 3-5-lobed; lobes pinnatifid and fan-shaped, with apiculate teeth; peduncles thick, 1-1.5 dm. long; flowers white or purplish, sessile; involucels of 8 oval or triangular bractlets; fruit broader than long, emarginate at both ends, $4 \mathrm{~mm}$. long, 3-winged. Cymopterus basalticus M. E. Jones. Bare knolls: Utah. Submont.

4. C. purpureus (S. Wats.) Rydb. Leaves broadly triangular in outline, ternate, then pinnate or bipinnate; divisions obovate, dentate, with mucronate teeth; peduncles 1-2.5 dm. high; bractlets lanceolate, united at the base; fruit 8-10 mm. long; wings broad, scarcely thickened at the insertions. Cymopterus purpureus S. Wats. A. purpureum Coult. \& Rose. Dry plains: Colo.-N.M. -Ariz.-Utah. Son.-Submont. Ap-Je.

5. C. Betheli (Osterhout) Rydb. Leaves broadly ovate in outline, first ternate, the main divisions bipinnate; leaflets broad, coarsely toothed; peduncles $5-10 \mathrm{~cm}$. long; bractlets linear, acuminate; fruit 7-8 mm. long, 6-7 mm. wide; oil-tubes $3-5$ in the intervals. A. Betheli Osterhout. Cymopterus duchesnensis M. E. Jones may be the same. Dry hills: Colo.-Utah. Submont. My-Je.

\section{PTERÝXIA Nutt.}

Low cespitose perennials, clothed at the base with fibrous sheaths. Leaves finely dissected, the main divisions being ternate, then repeatedly pinnate, with short linear or subulate, pungent divisions. Bracts mostly wanting; bractlets narrow, not at all hyaline. Flowers yellow or in one species white. Calyx-teeth evident. Stylopodium wanting. Fruit oblong to orbicular in outline, nearly round in cross-section. Ribs all or most of them more or less winged, the lateral ones at least broad-winged; wings thin throughout. Oil-tubes several in the intervals. Seeds usually strongly flattened dorsally; face broadly and shallowly concave. 
Dorsal ribs with narrow wings.

Leaves oblong or ovate in outline.

Pinnae very small and distant.

Petals white.
2. P. Elrodi.
3. P. petraea.
4. P. calcarea.
5. P. albiflora.

1. P. foeniculacea Nutt. Stem few-leaved below or nearly scapiform, 1-3 $\mathrm{dm}$. high; leaves 3-4 times ternate, then pinnatifid into oblanceolate-toothed divisions, which are scarcely salient; fruit broadly oval, 6-7 $\mathrm{mm}$. long, wings broad, scarcely undulate. Cymopterus foeniculaceus T. \& G. Gravelly soil and dry places: Wyo.-Colo.-Utah-Ore-Wash. Son.-Submont. Ap-Jl.

2. P. Elrodi (M. E. Jones) Rydb. Stem few-leaved below, about $3 \mathrm{dm}$. high; leaves ovate or deltoid in outline, ternate, then pinnately decompound; segments filiform, pungent, about $2.5 \mathrm{~mm}$. long; bractlets needle-shaped and short; fruit about $9 \mathrm{~mm}$. long and half as wide, truncate at the apex and slightly emarginate at the base; oil-tubes 5 in the intervals and 14 on the commissure. Cymopterus Elrodi M, E. Jones. Among loose rocks and gravel: Mont. J.

3. P. petraea (M. E. Jones) Coult. \& Rose. Stem few-leaved, $3 \mathrm{dm}$. high; leaves mostly basal, twice pinnate, with distant pinnae, and then pinnately divided into short narrow segments; fruit narrowly oval, 4-6 $\mathrm{mm}$. long; lateral wings half as broad as the body; dorsal wings still narrower. $C$. petraeus $\mathrm{M}$. E. Jones. Dry places: Ore--Ida.-Nev. Son.-Submont. Je-Jl.

4. P. calcarea (M. E. Jones) Coult. \& Rose. Stem few-leaved, $2-3 \mathrm{dm}$. high; leaves 3-4 times pinnately dissected into linear crowded divisions; fruit elliptic, 6-7 mm. long; dorsal wings rather narrow. C. calcarea M. E. Jones. Stony draws and foot-hills: Wyo.-Utah-Nev.-Ore. Submont. Je-Jl.

5. $\boldsymbol{P}$. albiflora Nutt. Stem 1-2 dm. high; leaves twice or thrice ternate, the ultimate divisions divaricate and 3-cleft; involucels of several linear bractlets; fruit nearly orbicular, $4 \mathrm{~mm}$. long; wings more or less undulate. C. albiflorus T. \& G. Mountains: Mont.-Ida.-Wyo. Submont. Jl.

\section{PSEUDOREÓXIS Rydb.}

Low cespitose acaulescent perennials, with branched caudex. Leaves bipinnate, the segments cleft into small lance-oblong to linear-oblong divisions. Flowers white, in small umbels; bracts wanting; bractlets obovate or oblanceolate, cuspidate or acuminate, white, with green midrib. Calyx-teeth evident, but small. Stylopodium low and flat; styles reflexed. Fruit somewhat flattened laterally, oblong. Ribs all with narrow wings, the lateral wings scarcely wider than the dorsal ones. Oil-tubes 3 or 4 in the intervals, 6-8 on the commissure. Seed-face slightly concave.

1. P. bipinnatus (S. Wats.) Rydb. Leaves $5-8 \mathrm{~cm}$. long, glaucous, more or less puberulent, rarely glabrous; peduncles 1-2 dm. high; flowers white; fruit 3-4 mm. long. Cymopterus bipinnatus S. Wats. Pseudocymopterus bipinnatus Coult. \& Rose. Cynomarathrum Macbridei A. Nels. Dry mountains: Mont.-Wyo.-Ore. Submont.-Mont. Je-Jl.

\section{CYMÓPTERUS Raf.}

Dwarf subacaulescent perennials, with deep-seated thick root. Leaves pinnate or bipinnate. Bracts wanting or rarely few, small and linear; bractlets conspicuous, foliaceous. Flowers white or yellow. Calyx-teeth obsolete or evident. Fruit flattened dorsally, oval, in ours glabrous. Dorsal and intermediate ribs filiform or some of them usually winged; the lateral ones with broad thickened corky wings. Stylopodium wanting. Oil-tubes 4-12 in the intervals, 8-14 on the commissure (in ours). Seed-face plane.

Umbels dense, globular; petals white; involucre wanting.

Involucels of linear to oblong bractlets.

Ultimate divisions of the leaves linear or linear-oblong, acutish; fruit orbicular, 6-8 mm. long.

1. C. acaulis.

Ultimate divisions of the leaves short, broadly oblong, obtuse; fruit 7-10 mm. long. Bractlets oblong, rarely lanceolate, obtuse; fruit orbicular, 8-10 $\mathrm{mm}$. broad; wings strongly thickened.

2. C. Parryi. 
Bractlets linear or lanceolate, acute; fruit oval, 6-8 mm. broad; wings moderately thickened.

3. C. lucidus.

Involucels of broad membranous, more or less 3-cleft bractlets; fruit fully $10 \mathrm{~mm}$. long, broadly elliptic.

Umbels open; petals yellow; involucre present, although often a mere vestige.

Divisions of the leaves narrow.

Divisions of the leaves broad.

5. C. Fendleri.

6. C. Newberryi.

1. C. acaulis (Pursh) Rydb. Stem above ground less than $1 \mathrm{dm}$. high; leaves clustered, bipinnatifid; segments entire or few-toothed; peduncles shorter than the leaves; bractlets linear, entire, more or less united, foliose; fruit 6-8 $\mathrm{mm}$. long; wings of the fruit broad, moderately thick throughout. Dry arid places: Sask.-Kans.-Colo.-Alta. Plain-Submont. Ap-Je.

2. C. Parryi (Coult. \& Rose) M. E. Jones. Leaves bipinnatifid, with oblong or oval obtuse segments; branches oblong or lanceolate, obtuse, united below; fruit $8-10 \mathrm{~mm}$. long, with broad thick wings. Coloptera Parryi Coult. \& Rose. Hills: Mont.-Colo. Plain-Submont. My-Je.

3. C. lucidus Osterhout. Leaves narrowly ovate in outline, bipinnate, glabrous, with ovate ultimate divisions; flowers in close head-like umbels; bractlets united at the base; wings of fruit 3 or 4 , moderately thickened in the outer portion. Dry plains: Colo. Plain. Ap-Je.

4. C. Leibergii Coult. \& Rose. Leaves tripinnate, with short obtuse segments; peduncles as long or longer than the leaves; fruit broadly elliptic, $10 \mathrm{~mm}$. long. Dry places: Ore.-Ida. Je.

5. C. Fendleri A. Gray. Leaves twice or thrice pinnate, with obovate lobed divisions; involucre of a short sheath toothed or sometimes with linear lobes; bractlets united at the base, exceeding the flowers; fruit 8-10 $\mathrm{mm}$. long; wings thin at the margin and at the insertion. C. decipiens M. E. Jones. Gravelly hills: N.M.-Colo.-Utah. Son. My.

6. C. Newberryi (S. Wats.) Jones. Leaves shorter than the peduncles, pinnately $3-5$-foliolate; leaflets obovate, cleft into broad obovate lobes; bractlets conspicuous, oblong to obovate, foliaceous; fruit sessile or nearly so, 6-8 $\mathrm{mm}$. long; lateral wings broad and thick; dorsal ribs narrowly winged or some filiform. Sandy places: Utah-Colo.-N.M. Son. My-Je.

\section{PSEUDOCYMÓPTERUS Coult. \& Rose.}

Perennial herbs, with taproots and leafy stems (in two species very short). Leaves bipinnate, with narrow, but not filiform, soft divisions. Flowers yellow or purplish, in small umbels. Bracts usually wanting; bractlets present and linear. Calyx-teeth evident but minute. Stylopodium wanting. Fruit oval, flattened dorsally, glabrous. Dorsal and intermediate ribs prominent and acute, or some of them usually more or less winged; the lateral ones with wings which are distinct from those of the other carpel. Seed-face plane.

Petals light yellow; bractlets linear-subulate, longer than the flowers.

Plant over $1 \mathrm{dm}$. high, with distinct leafy stems.

Ultimate divisions of the leaves short, ovate or lanceolate; leaves ovate in outline.

Ultimate divisions of the leaves linear, elongate.

Leaves, at least the basal ones, ovate in outline.

Leaves, at least the basal ones, broadly rhombic in outline.
Plant slender; leaves mostly twice compound, with very long and few divisions.

divisions,
Plant low; leaves thrice pinnate with shorter, more numerous divisions.

Plant less than $1 \mathrm{dm}$. high, nearly acaulescent.

1. P. montanus.

2. P. sylvaticus.

4. P. multifidus.

Petals purple, or orange tinged with purple; bractlets linear-lanceolate or lanceolate, shorter than the flowers.

Stem $2-3 \mathrm{dm}$. high; ultimate leaf-segments narrowly linear.
Stem $0.5-1.5$. $\mathrm{dm}$. versicolor.
high, nearly leafless; ultimate divisions of the leaves short, oblong or lanceolate.

7. P. purpureus.

1. P. montanus (A. Gray) Coult. \& Rose. Stem 3-6 dm. high, few-leaved; leaves pinnate; leaflets deeply divided into short ovate or lanceolate divisions; fruit 4-5 $\mathrm{mm}$. long; lateral wings nearly as broad as the body; dorsal ribs with 
narrow or no wings. Thaspium montanum A. Gray. Mountain woods: Wyo.N.M.-Ariz. Submont.-Subalp. Je-Au.

2. P. sylvaticus A. Nels. Stem glabrous, $3-8 \mathrm{dm}$. high; leaves few, oblong or ovate in outline, bipinnate; segments linear, acute, long; fruit broadly elliptic, $5 \mathrm{~mm}$. long; lateral wings thin, as broad as the body; the dorsal ribs usually narrowly winged. Woods: Colo,-Wyo. Mont.-Subalp. Je-Jl.

3. P. tenuifolius (A. Gray) Rydb. Stem 3-6 dm. high; leaves ternate, then pinnatifid into narrowly linear, rather stiff divisions; fruit broadly oval, 5 $\mathrm{mm}$. long; lateral ribs slightly narrower than the body; dorsal ribs with narrow or no wings. Thaspium montanum tenuifolium A. Gray. Woody hillsides: Colo.-N.M.-Ariz. Submont.-Mont. F-Jl.

4. P. multifidus Rydb. Stem 1-3 dm. high, few-leaved; leaves twice or thrice pinnatifid into linear divisions; fruit about $4 \mathrm{~mm}$. long, nearly orbicular; lateral wings thick, as broad as the body; dorsal ones narrow. Hills and open woods: Colo.-N.M. Submont.-Mont. Je-Jl.

5. P. Tidestromii Coult. \& Rose. Mostly acaulescent perennial; leaves pinnate, less than $1 \mathrm{dm}$. long, bipinnatifid into narrowly lanceolate or linear divisions; peduncles 1-2 dm. high; fruit about $4 \mathrm{~mm}$. long; ribs thick, acute. High mountains: Utah. Subalp.-Alp. Jl-Au.

6. P. versicolor Rydb. Stem glabrous, about $3 \mathrm{dm}$. high, few-leaved; leaves 1-2 dm. long, broadly ovate in outline, thrice pinnatifid into linear divisions; rays $1-2 \mathrm{~cm}$. long; petals orange, tipped with reddish purple; fruit oval, about 4 $\mathrm{mm}$. long; lateral ribs nearly as broad as the body, the dorsal ones narrower. Hillsides: Utah. Mont.

7. P. purpureus (Coult. \& Rose) Rydb. Plant almost acaulescent, 5-15 $\mathrm{dm}$. high; leaves less than $1 \mathrm{dm}$. long, twice to thrice pinnatifid into short oblong or lanceolate divisions; flowers usually dark purple, but sometimes rose or orange, tinged with purple; fruit nearly $5 \mathrm{~mm}$. long, rounded-oval; wings rather thick. P. montanus purpureus Coult. \& Rose. Mountains: Ariz.-Utah. Mont.Subalp. Je-Au.

\section{PSEUDOPTERÝXIA. ?}

Densely cespitose acaulescent strong-scented perennials, with multicipital caudices covered with numerous sheaths of old leaves. Leaves pinnatifid or bipinnatifid, with thick and firm pungent divisions. Flowers yellow; involucres wanting; bractlets linear-subulate. Calyx-teeth very prominent, one or two of them much larger than the rest. Stylopodium wanting. Fruit oblong, glabrous. Dorsal and intermediate ribs sharp or some of them winged, the lateral ones with broad wings, distinct from those of the other carpel. Carpels flattened dorsally. Oil-tubes $1-3$ in the intervals, $2-4$ on the commissural side. Seed-face plane.

Leaves with long petioles; scape 1-3 dm. high.

Primary divisions of the leaves once or twice dissected, with narrowly linear divisions. Ultimate divisions of the leaves $5-10 \mathrm{~mm}$. long; fruit about $6 \mathrm{~mm}$. long.

Ultimate divisions of the leaves 3-5 mm. long; fruit about $4 \mathrm{~mm}$. long.

2. P. anisata.

Primary divisions broad, cuneate-flabellate, cleft or toothed, with short, ovate or lanceolate teeth.

Leaves on short petioles; divisions linear; scape less than $1 \mathrm{dm}$. high.

3. P. aletifolia.

4. $P$. Hendersonii.

1. P. longiloba Rydb. Leaves twice pinnatifid, with linear-subulate, pungent divisions; peduncles $2-3 \mathrm{dm}$. high, stout; fruit about $6 \mathrm{~mm}$. long; lateral wings thick, narrow; some of the wings of the dorsal ribs often fully as broad; calyx-teeth less prominent than in P. anisata. Dry hills: Utah. Son.

2. P. anisata (A. Gray) Rydb. Leaves pinnate, the primary leaflets once or twice pinnatifid, with linear, divergent divisions; peduncles 1-3 dm. high; fruit about $4 \mathrm{~mm}$. long; lateral wings thick, narrower than the body; dorsal ribs either prominent or with narrow wings. Pseudocymopterus anisatus Coult. \& Rose. Cymopterus asinatus A. Gray. Mountains among rocks: Wyo.Colo.-Utah-Nev. Mont.-Subalp. Je-J. 
3. P. aletifolia Rydb. Leaves once or twice pinnate, dark green, glabrous, stiff and shining, 1-2 dm. long; leaf-segments obovate to rhombic-cuneate, deeply cleft; lobes usually 3 -toothed with lanceolate acuminate teeth; scapes $1-1.5 \mathrm{dm}$. long; sepals in fruit 1-2 mm. long; fruit 5-6 mm. long, $2.5-3 \mathrm{~mm}$. wide; lateral wings evident but rather narrow; dorsal ribs acute or slightly winged. Psudocymopterus aletifolius Rydb. Mountains among rocks: Colo. Submont. -Mont. My-Je.

4. P. Hendersonii (Coult. \& Rose) Rydb. Leaves short-petioled, very pale, pinnate; leaflets ovate in outline, deeply cleft into $3-5$ linear entire segments; peduncles longer than the leaves; bractlets linear, entire. Pseudo-cymopterus Hendersonii Coult. \& Rose. Mountains: Ida. Alp. Au.

\section{COGSWÉllia Spreng. Cous, Biscuit Root, WHISK-BROOM PARSLEY.}

Acaulescent or short-stemmed perennials, with thickened, tuberous roots. Leaves ternately, rarely pinnately, dissected. Flowers yellow, white, or purple. Bracts wanting; bractlets usually present. Calyx-teeth usually obsolete. Stylopodium wanting. Fruit strongly flattened dorsally. Dorsal and intermediate ribs filiform, close together, the lateral ones winged, the wings coherent to those of the other carpel till maturity. Oil-tubes solitary or few in the intervals, 2-10 on the commissural side. Seed-face plane or rarely slightly concave. [Peucedanum Am. auth. Lomatium Raf.]

Plants slender with thick rounded corms.

Corolla white.

Bracts not scarious.

Fruit puberulent.

Fruit glabrous.

Divisions of the leaves oblong, very short, $5 \mathrm{~mm}$. long or less; oil-tubes solitary in the intervals.

Divisions of the leaves linear, $1-7 \mathrm{~cm}$. Iong.

Wings of the fruit more than half as broad as the body; oil-tubes none.

Wings of the fruit less than half as broad as the body; oil-tubes several.
4 . C. farinosa.

Bracts scarious-margined. (See $C$. orientalis, $C$. nevadensis, \&c.)

Corolla yellow.

Fruit linear in outline.

Divisions of the leaves few, long and linear.

Umbellets open; pedicels 4-8 $\mathrm{mm}$. long.

Umbellets compact; fruit nearly sessile.

Divisions of the leaves filiform.

Fruit oval in outline; divisions of the leaves oblong.

Caulescent; fruit glabrous; oil-tubes solitary in the intervals.

Acaulescent or nearly so.

Fruit puberulent; oil-tubes solitary in the intervals.

Fruit glabrous; oil-tubes several in the intervals.
5. C. ambigua.
6. C. leptocarpa.
7. C. bicolor.

\section{C. circumdata.}

9. C. Cous.

10. C. montana.

Plant generally stouter from a thickened root or rootstock, rarely corm-like.

Bractlets of the involucels many, conspicuous, often broad, or united at the base.

Bractlets obováte or spatulate; whole plant glabrous; corolla yellow.

Involucre present, consisting of a scarious sheath, sometimes produced into linear green lobes. 11 . C. concinna.

Involucre wanting.

10. C. montana.

Bractlets lanceolate, oblong or linear.

Corolla white.

Bractlets scarious-margined, as well as the whole plant puberulent or rarely glabrate.

Fruit glabrous; oil-tubes solitary in the intervals. 12. C. orientalis.

Fruit pubescent; oil-tubes several in the intervals. 13. C. nevadensis. Bractlets not scarious-margined, villous.

14. C. macrocarpa.

Corolla yellow or purple.

Wings of the fruit half as wide as the body or broader.

Bractlets more or less united, densely villous; corolla yellow.

Bractlets distinct, less densely villous; corolla often tinged with purple. 16. C. Jonesii.

Wings of the fruit less than half as wide as the body; bractlets linear, distinct. 17 . C. MacDougalii.

Bractlets of the involucels none or very few, linear or subulate.

Leaves finely dissected, with numerous small divisions.

Fruit oval in outline. 
Plant glabrous throughout.

Divisions of the leaves filiform.

Divisions of the leaves oblong or broadly linear.

Flowers white; dorsal ribs of the fruit somewhat wing-margined.

19. C. lapidosa.

Flowers yellow; dorsal ribs of the fruit not wing-margined.

20. C. Donnellit.

Plant puberulent.

Leaf-sheath with broad white scarious margins; fruit puberulent.

Leaf-sheath not broadly scarious-margined; fruit glabrous.

21. C. Sandbergii.

22. C. juniperina.

Fruit oblong-linear in outline; leaves finely dissected into filiform divisions, slightly puberulent.

7. C. bicolor.

Leaves simply or doubly (rarely 3 or 4 times) ternate, with comparatively large divisions; flowers yellow.

Leaf-divisions linear or narrowly linear-lanceolate, mostly attenuate.

Wings of the fruit as broad as the body or broader. Fruit glabrous; leaflets usually linear-lanceolate, 23, C. simplex. Fruit puberulent; leaflets usually narrowly linear. 24. C. leptophylla. Wings of the fruit narrower than the body.

Ovary and fruit glabrous.

Ovary and young fruit puberulent.
Leaf-divisions from linear-oblong to oval, obtuse or acutish.

Fruit puberulent; leaf-segments many; peduncles not thickened.

Fruit glabrous; leaf-segments few; peduncles in fruit usually inflated at the apex.

Fruit elliptic; oil-tubes solitary in the intervals; leaflets at least twice as long as broad.

28. C. nudicaulis.

Fruit oval; oil-tubes several in each interval; leaflets usually not twice as long as broad.

29. C. platyphylla.

1. C. Gormani (Howell) M. E. Jones. Corm small; leaves bipinnate, with the ultimate segments linear or oblong; bractlets few, setaceous, or none; fruit sessile or nearly so, rough puberulent, ovate, $6 \mathrm{~mm}$. long; wings more than half as broad as the body. Peucedanum Gormani Howell. P. confusum Piper. Mountains: Ore.-Ida.-Wash. Ap-My.

2. C. Canbyi (Coult. \& Rose) M. E. Jones. Corm 1-2.5 cm. thick; scape 7-20 cm. high; leaves ternate, then pinnatifid; bractlets narrowly linear, scariousmargined; fruit ovate-oval, glabrous, $8 \mathrm{~mm}$. long, $5 \mathrm{~mm}$. broad; wings about half as broad as the body. P. Canbyi Coult. \& Rose. Stony ground: Ore.Ida.-Wash. Son.-Submont. Ap-My.

3. C. Geyeri (S. Wats.) M. E. Jones. Corm small, globular; scape 1-4 dm. high; leaves once or twice ternate, then pinnate; segments linear, $1-5 \mathrm{~cm}$. long; bractlets numerous, purplish, lanceolate, acuminate, united; fruit oval, 8-10 $\mathrm{mm}$. long, $5 \mathrm{~mm}$. broad; wings membranous. $P$. Geyeri $\mathrm{S}$. Wats. Sandy or gravelly ground: Wash.-Ida.-B.C. Son. My-Je.

4. C. farinosa (Hook.) M. E. Jones. Corm globose or sometimes several corms in succession; stem scapiform or few-leaved, $2-3 \mathrm{dm}$. high; leaves ternate or biternate; leaflets 1-8 $\mathrm{cm}$. long; bractlets several, linear, acuminate; fruit linear-oblong, glabrous, $6-8 \mathrm{~mm}$. long, $2-3 \mathrm{~mm}$. wide. $P$. farinosum Hook. Rocky places: Ore.-Ida.-B.C. Submont. Ap-My.

5. C. ambigua (Nutt.) M. E. Jones. Corm sometimes globose, sometimes fusiform, occasionally with several successive thickenings; sheaths very conspicuous; leaf-blades once or twice ternate, with elongate linear or linear-filiform leaflets; bractlets none; pedicels $4-8 \mathrm{~mm}$. long; fruit narrowly oblong, 6-8 $\mathrm{mm}$. long, $2 \mathrm{~mm}$. wide, very narrowly winged. $P$. ambiguum Nutt. Sandy or gravelly hillsides or valleys: B.C.-Mont.-Wyo.-Utah-Ore. Son.-Submont. $\mathrm{My}-\mathrm{Au}$.

6. C. leptocarpa (Nutt.) M. E. Jones. Corm globose; plant subacaulescent; scape 2-3 dm. high; leaves ternate, then once or twice pinnate, with elongate linear divisions; bractlets small, linear-subulate; fruit nearly sessile, 9-10 $\mathrm{mm}$. long, $2 \mathrm{~mm}$. broad, with very narrow wings. $P$. leptocarpum Nutt. $P$. bicolor gumbonis M. E. Jones. Stony hillsides and plains: Ore.-Ida.-Colo.Calif. Plain-Submont. My-Je. 
7. C. bicolor (S. Wats.) M. E. Jones. Corm napiform; stem 1-4.5 dm. high, glabrous or slightly puberulent; leaves ternate, then repeatedly pinnate, with numerous filiform divisions; sheath inflated; bractlets 1-8, linear-subulate; pedicels very short; fruit linear-oblong, glabrous, $10-12 \mathrm{~mm}$. long, $2-5 \mathrm{~mm}$. wide; wings very narrow. P. bicolor S. Wats. Hillsides: Utah-Ida.-Mont. Son.-Submont. My-Je.

8. C. circumdata (S. Wats.) M. E. Jones. Corm subglobose; stem 2-3 dm. high, more or less leafy; leaves ternate, then once or twice pinnate; ultimate segments linear, 2-12 $\mathrm{mm}$. long; sheath of the stem-leaves broadly dilated; bractlets oblanceolate, becoming scarious; fruit oblong-elliptic, $6-8 \mathrm{~mm}$. long, , 3 $\mathrm{mm}$. wide, with narrow wings. P. circumdatum S. Wats. Hillsides: Wash.Mont.-Ida.-Ore. Submont. Ap-Je.

9. C. Cous (S. Wats.) M. E. Jones. Corm globose or napiform, $1-2.5 \mathrm{~cm}$. thick; stem scapiform, $5-15 \mathrm{~cm}$. high; leaves ternate, then twice pinnately dissected; ultimate segments short, linear, entire or few-toothed; bractlets broadly oblanceolate, scarious-margined; fruit elliptic, scabrous-puberulent, 6-8 $\mathrm{mm}$. long, $3-4 \mathrm{~mm}$. wide, with narrow wings. $P$. Cous $\mathrm{S}$. Wats. Stony ridges: Ore. -Ida.-Wash. Plain-Submont. Ap-Je.

10. C. montana (Coult. \& Rose) M. E. Jones. Corm napiform or fusiform, or plant sometimes with thickened roots; seape 1-3 dm. high; leaves usually ternate and then once or twice pinnate; leaflets short-oblong, erowded; bractlets obovate or oblanceolate, with white or purplish scarious margins; fruit elliptic, glabrous, $5-6 \mathrm{~mm}$. long, $2-3 \mathrm{~mm}$. wide; wings about half as broad as the body. Lomatium montanum Coult. \& Rose. L. purpureum A. Nels. Hillsides: Ore.-Wyo.-N.D. Submont.-Mont. My-Je.

11. C. concinna Osterhout. Perennial, from a fleshy root; stem $2-3 \mathrm{dm}$. high, much branched near the ground; leaves sheathing at the base, $1 \mathrm{dm}$. long, ovate in outline, glabrous, twice pinnately divided into linear-oblong divisions; peduncles 1-2 dm. long, decumbent at the base; bractlets united, forming a single leaf, divided into oblong lobes; fruit oval, $7-8 \mathrm{~mm}$. long; wings broad; oil-tubes 5-10 in the intervals, 8-15 on the commissure. Hills: Colo. Submont. My.

12. C. orientalis (Coult. \& Rose) M. E. Jones. Perennial, with a thick taproot; stem often scapiform, 1-3 dm. high; leaves bipinnate; segments oblong or lanceolate, pinnately cleft into short oblong divisions, grayish-pilose with short hairs; bractlets lanceolate, distinet, scarious-margined; fruit glabrous, oval, $5 \mathrm{~mm}$. long, $4 \mathrm{~mm}$. wide; wings not as broad as the body. $P$. nudicaule Nutt. in part. Lomatium orientale Coult. \& Rose. Dry plains: Minn.-Kans.N.M.-Ariz.-Mont. Plain-Submont. Ap-Je.

13. C. nevadensis (S. Wats.) M. E. Jones. Perennial, with a fusiform root; stem short, 1-4 dm. high, puberulent; leaves twice or thrice pinnatifid, grayish-pilose, with small oblong divisions; bractlets linear-lanceolate, usually distinct; fruit oval or ovate, somewhat pubescent, 6-10 $\mathrm{mm}$. long, 4-8 $\mathrm{mm}$. wide; wings almost as broad as the body. P. nevadense $\mathrm{S}$. Wats. Mountains: Ore-Utah-Ariz,-Calif. Son.-Submont. Ap-My.

14. C. macrocarpa (Nutt.) M. E. Jones. Perennial, with an elongate fusiform root; stem 1-6 dm. high, more or less pubescent, branched at the base; leaves three or four times pinnately (or the first division ternately) dissected into short linear or oblong divisions, more or less pubescent; bractlets somewhat foliaceous, lanceolate or linear, often united and unilateral; calyx-teeth evident; fruit elliptic, glabrous, $1-2 \mathrm{~cm}$. long, $5-7 \mathrm{~mm}$. wide; wings nearly as broad as the body. P. macrocarpum Nutt. Hills and plains: Sask.-Colo-Calif.B.C. Plain-Submont. Ap-Je.

15. C. villosa (Raf.) Schultes. Perennial, with a fusiform root; leaves finely dissected, first ternate, then several times pinnate, villous; segments numerous, linear, crowded; bractlets conspicuous, lanceolate, more or less united, very tomentose; pedicels $2-6 \mathrm{~mm}$. long; fruit oval, puberulent or pilose, $5-8 \mathrm{~mm}$. long, 4-5 mm. wide. L. villosum Raf. Dry plains and hills: Sask.-W Kans.--. Wyo.-Alta. Plain-Submont. My-Je. 
16. C. Jonesii (Coult. \& Rose) M. E. Jones. Perennial, with a fusiform root, aeaulescent; scape 1-2 dm. high; leaves ternate and then repeatedly pinnate, villous, with very small crowded, oblong segments; bractlets linear, distinct, villous; pedicels 3-12 mm.; flowers yellow or tinged with purple; fruit oval, pubescent, $8 \mathrm{~mm}$. long, 6-7 mm. wide. L. Jonesii Coult. \& Rose. Dry plains and eañons: Alta.-Utah-Ida. Plain-Submont. Ap-My.

17. C. MacDougalii (Coult. \& Rose) M. E. Jones. Perennial, with a fusiform root, acaulescent; scape 1-2 dm. high; leaves first ternate, then several times pinnate, with numerous very small linear segments, densely pilose, with short hairs; bractlets linear, distinct or nearly so, hirsute; fruit elliptic, somewhat pubescent, 6-7 mm. long, $4 \mathrm{~mm}$. wide. L. MacDougalii Coult. \& Rose. Dry places: Ariz.-Utah-Nev. Son. Mr-My.

18. C. Grayi Coult. \& Rose. Perennial, with a fusiform root, glabrous throughout; scapes 1-4 dm. high; leaves ternate, then repeatedly pinnate; segments very numerous, linear-filiform; bractlets linear-subulate, distinct; flowers yellow; fruit oval, $10-16 \mathrm{~mm}$. long, $7-9 \mathrm{~mm}$. wide; wings nearly as broad as the body. Peucedanum millefolium S. Wats., not Sonder. P. Grayi Coult. \& Rose. Plains and hills: Wyo.-Colo.-Utah-Ore-Wash. Plain-Submont. Mr-My.

19. C. lapidosa (M. E. Jones) Rydb. Perennial, with a fusiform deepseated root; stem barely rising above ground, bearing a crown of leaves and peduncles; leaves $5-10 \mathrm{~cm}$. long, bipinnate, with crowded obovate cleft divisions; bracts and bractlets several, linear; fruit oblong, glabrous, $6-7 \mathrm{~mm}$. long, 2-2.5 $\mathrm{mm}$. broad; lateral wings half as broad as the body; dorsal ribs prominent, but not winged; calyx-teeth evident; stylopodium depressed. Peucedanum and Cymopterus lapidosus M. E. Jones. Among rocks: Utah-Wyo. My-Je.

20. C. Donnellii (Coult. \& Rose) M. E. Jones. Perennial, with a fusiform root; stem 1.5-3 dm. high, glabrous; leaves ternate and then twice or thrice pinnatifid; ultimate lobes linear or oblong, glabrous; bractlets linear, acuminate; fruit oval, glabrous, 7-8 mm. long, 4-6 mm. wide; wings less than half as wide as the body. P. Donnellii Coult. \& Rose. Dry valleys and sage-brush flats: Ore.-Ida. Son. My-Je.

21. C. Sandbergii (Coult. \& Rose) M. E. Jones. Perennial, with an elongate taproot; stem 1-3 dm. high, rough-puberulent; leaves ternate and then repeatedly pinnately dissected into short linear divisions, more or less puberulent; sheaths much enlarged and with conspicuous white scarious margins; bractlets distinet, linear-lanceolate; flowers bright yellow; fruit oval, puberulent, 4-5 mm. long, $3 \mathrm{~mm}$. wide; wings narrow. $P$. Sandbergii Coult. \& Rose. Mountains: Alta.-Mont.-Ida.-B.C. Plain-Submont. Je-Au.

22. C. juniperina M. E. Jones. Perennial, with a fusiform root; stems more or less purplish, ashy puberulent, 1-3 dm. high; leaves ternate or biternate and then bipinnate; ultimate segments linear to lanceolate, $2-5 \mathrm{~mm}$. long; sheath enlarged; bractlets several, lanceolate to filiform-subulate; flowers yellow; fruit elliptie, 6-8 mm. long, $4 \mathrm{~mm}$. wide; wings narrower than the body. P. juniperinum M. E. Jones. Among junipers on hills: Utah-Wyo. Son. My-Je.

23. C. simplex (S. Wats.) 9 pyctb. Perennial, with an elongate taproot; stem stout, 2-5 dm. high, puberulent; leaves ternate or biternate; leaflets linearlanceolate, $5-10 \mathrm{~cm}$. long, puberulent beneath; fruit broadly elliptic to nearly orbicular, 6-12 mm. long, 4-10 $\mathrm{mm}$. wide. $P$. simplex Nutt. Lomatium platycarpum (Torr.) Coult. \& Rose. Cogswellia platycarpa M. E. Jones. C. altensis M. E. Jones, a form with narrow leaf-segments. Mountains and hillsides: Alta. -Colo.-Utah-Ore.-Wash. Submont. My-Je.

24. C. leptophylla (Hook.) Rydb. Perennial, with taproot; stems more or less puberulent, 3-4 dm. high; leaves usually twice ternate; leaflets linear, sometimes almost filiform, 2-7 cm. long, 1-4 mm. wide, puberulent; fruit puberulent, 6-7 mm. long, $3.5-4.5 \mathrm{~mm}$. wide. P. triternatum leptophyllum Hook. Hills and mountains: Mont.-Ida. Submont. Ap-Je.

25. C. triternata (Pursh) M. E. Jones. Perennial, with an elongate taproot; stem 3-7 dm. high, puberulent; leaves biternate or triternate; leaflets linear 
to linear-lanceolate, $5-10 \mathrm{~cm}$. long; pedicels 2-4 mm. long; fruit narrowly oblong; glabrous, 6-12 mm. long, 3-4 mm. wide. P. triternatum (Pursh) Nutt. Hillsides: Calif,-Wyo--Alta.-B.C. Submont. My-Je.

26. C. robustior Coult. \& Rose. Perennial, with a taproot; stem 3-6 dm. high; leaves puberulent below, three to four times ternate, with linear-lanceolate to oblong divisions, $1-3 \mathrm{~cm}$. long; fruit oblong, $12-14 \mathrm{~mm}$. long, $5 \mathrm{~mm}$. wide. $P$. triternatum macrocarpum Coult. \& Rose. P. triternatum robustius Coult. \& Rose. Valleys: Ore.-Ida.-Wash. Son-Submont. Ap-Je. 27. C. anomala M. E. Jones. Perennial, with a large taproot; stem $3-5$
dm. high, stout, somewhat puberulent; leaves ternate, then bipinnate; leaflets linear-oblong or oblanceolate, mostly obtuse, 1-7 cm. long; bractlets linear or setaceous; fruit elliptic, $10-12 \mathrm{~mm}$. long, $4-5 \mathrm{~mm}$. broad; wings not half as broad as the body. Lomatium anomalum M. E. Jones. Hillsides and slopes: Ida.-Ore. Submont. My-Je.

28. C. nudicaulis (Pursh) M. E. Jones. Perennial, with a long fleshy taproot; stem 3-6 dm. high, glabrous; leaves biternate, ternately quinate, or sometimes ternate; leaflets thickish, ovate or lanceolate, $2.5-5 \mathrm{~cm}$. long, entire or toothed at the apex; bractlets none; fruit narrowly elliptic, $9-14 \mathrm{~mm}$. long, 3-6 $\mathrm{mm}$. wide, narrowly winged. Gravelly soil: Calif.-Ida.-B.C. Son. - Submont. My-Je.

29. C. platyphylla Coult. \& Rose. Perennial, with a taproot; stem 2-4 $\mathrm{dm}$. high; leaves once or twice ternate; leaflets ovate, orbicular or obovate, entire or toothed at the apex; bractlets none; fruit 8-12 $\mathrm{mm}$. long, $5-6 \mathrm{~mm}$. wide; wings narrow. P. latifolium Nutt. P. Nuttallii S. Wats. Lomatium platyphyllum Coult. \& Rose. Dry plains: Ore.-Nev.-Ida.-Wash. Son.-Submont. Ap-
Je.

\section{LEPTOTAÈNIA Nutt. WILD PARSNIP.}

Tall, stout, acaulescent perennials, with thick fusiform roots. Leaves large, pinnately decompound. Flowers yellow or purplish, in large umbels. Bracts few or none; bractlets numerous, small. Calyx-teeth obsolete or minute. Fruit strongly flattened dorsally, oblong or elliptic, glabrous. Stylopodium wanting. Dorsal and intermediate ribs filiform or obscure, the lateral ones with thick and corky wings. Oil-tubes $3-6$ in the intervals, $4-6$ on the commissural side, mostly small, sometimes obsolete. Seeds very flat; face plane or slightly concave.

Flowers yellow or salmon-colored.

Foliage puberulent; dorsal ribs faint; flowers yellow.

Fruit sessile or nearly so; staminate flowers with long pedicels. 1. L. foliosa.

Fruit with pedicels longer than those of the staminate flowers.

Fruit 8-12 mm. long, usually without oil-tubes; leaves finel linear divisions.

Fruit 14-18 mm.

Foliage glabrous; dorsal ribs strong.

Fruit broadly oblong, 5-6 mm. broad.
Fruit narrowly oblong, $4 \mathrm{~mm}$. broad.

Flowers purple.

1. L. foliosa (Hook.) Coult. \& Rose. Stem about $6 \mathrm{dm}$. high; leaves twice or thrice ternately compound, then twice or thrice pinnatifid, with linear lobes, slightly puberulent; bracts several, linear; bractlets few, linear; fruit almost sessile; staminate flowers on slender pedicels. Hillsides: Ida. Submont. My-Je.

2. L. multifida Nutt. Stem 3-10 dm. high; leaves twice or thrice ternate, then three or four times pinnatifid into linear divisions, more or less puberulent; involucre usually none; bractlets few, linear-filiform; fruit 8-12 mm. long; dorsal ribs almost obsolete. Rich soil in the mountains: Alta.-Colo.-Calif.-B.C.

3. L. Eatoni Coult. \& Rose. Stem 3-10 dm. high; leaves twice ternate, then once or twice pinnate; leaflets ovate, cleft and lobed, with oblong or lanceoblong divisions; bracts few, linear-subulate, or none; fruit $14-18 \mathrm{~mm}$. long, tains in rich soil: Wyo.-Colo.-Nev.-Ida. Submont.-Mont. Je-Jl. 
4. L. salmoniflora Coult. \& Rose. Stem 3-5 dm. high, glabrous; leaves large, biternate, then twice or thrice pinnately decompound, with short linearfiliform segments, glabrous; bracts none; bractlets filiform; flowers salmoncolored; fruit oblong, $10 \mathrm{~mm}$. long; dorsal ribs strong but low; oil-tubes solitary in the intervals. Basaltic rocks: Ida.-Wash. Submont. Ap-My.

5. L. filicina M. E. Jones. Stem about $1 \mathrm{~m}$. high, glabrous; leaves with inflated petioles, ternate, then pinnately decompound into filiform short divisions; bractlets few, inconspicuous; fruit $12-15 \mathrm{~mm}$. long, $4 \mathrm{~mm}$. wide; lateral wings very narrow; oil-tubes solitary in the intervals, $2-4$ on the commissural side; seed-face nearly flat. Mountains: Ida. Submont. Jl.

6. L. purpurea (S. Wats.) Coult. \& Rose. Stem about $3 \mathrm{dm}$. high; leaves twice or thrice ternately disseeted into linear or filiform divisions, perfectly glabrous; involucres usually none; bractlets several, linear, acuminate; fruit 18-24 $\mathrm{mm}$. long, as long as the pedicels; lateral ribs very corky; oil-tubes 3 in the intervals, 4 on the commissure; dorsal ribs evident. Rich soil: Ore.-Alta.-B.C. Submont. My-Je.

\section{CYNOMARĀTHRUM (Nutt.) Coult. \& Rose.}

Acaulescent perennial, with multicipital caudices densely covered by old leafsheaths. Leaves narrow in outline, pinnately dissected, with very narrow divisions. Flowers yellow or perhaps sometimes white. Calyx-teeth evident. Stylopodium evident, flat, apparently somewhat spongy. Fruit strongly flattened dorsally, oblong. Dorsal and intermediate ribs sharp or more or less winged, the lateral ones broadly winged. Oil-tubes mostly several in each interval, or obscure. Seed-face plane.

Leaves glabrous.

Leaves bipinnate.

Leaf-segments linear.

Pedicels in fruit $1-6 \mathrm{~mm}$. long.

Divisions of the leaves elongate-linear, 1-5 cm. long; bractlets 5-10 mm.

long.
Divisions of the leaves less than $1 \mathrm{~cm}$. long; bractlets $3-4 \mathrm{~mm}$. long.

Divisions of the leaves less than $1 \mathrm{~cm}$. long; bractlets $3-4 \mathrm{~mm}$. long.

Pedicels in fruit 8-16 mm. long; divisions of the leaves short, usually less than

$5 \mathrm{~mm}$. long. $\quad 3$. C. Parryi.

Leaf-segments lanceolate. $\quad$ 4. C. latilobum.

Leaves biternate. $\quad 5$. C. brecciarum.

Leaves scabrous.

Pedicels 12-18 mm. long; wings of the fruit about as broad as the body.

Pedicels 2-6 mm. long; wings of the fruit half as broad as the bod 6 . C. Eastwoodae. 7 .

1. C. Nuttallii (A. Gray) Coult. \& Rose. Scape 2-5 dm. high; leaves pinnate or bipinnate; leaflets cuspidate, $1-5 \mathrm{~cm}$. long, ascending; bractlets lanceolate, often more or less united below; petals yellow; pedicels in fruit $2-6 \mathrm{~mm}$. long; fruit elliptic, $8-10 \mathrm{~mm}$. long, $4 \mathrm{~mm}$. wide, narrowly winged. Peucedanum graveolens S. Wats. P. Kingii S. Wats. Dry hills: w Neb.-Wyo.-Utah. Plain -Mont. My-Jl.

2. C. megarrhizum A. Nels. Scape 1.5-3 dm. high; leaves pinnate or bipinnate; leaflets few; ultimate segments linear or oblong, cuspidate, 5-10 mm. long; petals pale yellow; fruit elliptic, $6-8 \mathrm{~mm}$. long, $3-4 \mathrm{~mm}$. broad; wings scarcely half as broad as the body. P. megarrhizum A. Nels. Dry hills: Wyo. Submont. Je.

3. C. Parryi (S. Wats.) Coult. \& Rose. Scape $2-3 \mathrm{dm}$. high, glabrous; leaves twice pinnate, 1-3 dm. long; leaflets linear, cuspidate, more or less arcuatespreading, 4-8 mm. long; bractlets green, linear and entire or some oblanceolate and toothed at the apex; fruit oblong, $10-12 \mathrm{~mm}$. long; lateral wings about half as broad as the body. P. Parryi S. Wats. Rocky ledges: s Utah-Nev.Calif. Son. Ap-My.

4. C. latilobum Rydb. Scape 1-1.5 dm. long, stout; leaves about $1 \mathrm{~cm}$. long, pinnate, glabrous; leaflets entire or 2- or 3-cleft into broadly lanceolate, reticulate, pointed segments, 5-15 mm. long, thick; rays $1-2 \mathrm{~cm}$. long; bractlets 
linear or lance-linear, 5-6 mm. long; flowers apparently straw-colored or ochroleucous; fruit about $9 \mathrm{~mm}$. long, $6 \mathrm{~mm}$. wide; lateral wings about as broad as the body; oil-tubes $2-4$ in the intervals, $4-6$ on the commissure, rather obscure. Cañons: Utah. Son. Jl.

5. C. brecciarum (M. E. Jones) Rydb. Leaves biternate; leaflets $2.5 \mathrm{~cm}$. long, tapering at both ends, narrowly linear, glabrous; rays few and unequal; bracts none; involucels setaceous; pedicels $4-5 \mathrm{~mm}$. long; flowers greenish yellow, turning purplish; fruit over $1 \mathrm{~cm}$. long, with narrow and thick lateral wings; dorsal ribs sharp, raised; oil-tubes 2 in the intervals. Cogswellia brecciarum M. E. Jones. High mountains: Mont. Mont. Au.

6. C. Eastwoodae Coult. \& Rose. Leaves very narrow in outline, once or twice pinnate, very scabrous; segments short and narrow, cuspidate; pedicels 12-18 $\mathrm{mm}$. long; bractlets several, linear, entire; fruit glabrous, $8-10 \mathrm{~mm}$. long; wings nearly as broad as the body. Hills and plains: Colo. Submont. My-Je.

7. C. scabrum Coult. \& Rose. Scape 1-2 dm. high, scabrous throughout; leaves very scabrous, narrowly lanceolate in outline, bipinnate; ultimate divisions short, ovate, cuspidate; bractlets sêtaceous, somewhat scarious and united at the base; pedicels $2-6 \mathrm{~mm}$. long; flowers yellow; fruit oval, glabrous, 7-9 $\mathrm{mm}$. long, 4-6 mm. wide; wings half as broad as the body. Dry hills: Utah. Son.Submont. Ap-Je.

\section{ANGÉlica L. ANGELICA.}

Stout perennials, with a woody root. Leaves ternate-pinnately or pinnately compound, usually with broad segments. Flowers white, or rarely greenish yellow or purplish, in large umbels. Bracts scanty or none, in one species foliaceous; bractlets small or wanting. Calyx-teeth mostly wanting. Stylopodium conic. Fruit flattened dorsally, ovate or oblong, glabrous or pubescent, with a prominent crenulate disk. Dorsal and intermediate ribs strong, the lateral ones broadly winged; wings distinct from those of the other carpel. Oil-tubes one to several in each interval, or indefinite, $2-10$ on the commissural side. Seed-face plane or slightly concave.

Oil-tubes mostly solitary in the intervals, not continuous around the seed; rays of the umbels ascending.

Involucre and involucels of several foliaceous, lacerately toothed bracts.

Involucre none or consisting of 1-2 small bracts.

Involucels of many bractlets.

Bractlets lanceolate, acuminate.

Bractlets linear-filiform.

Involucels none, or of a few linear-subulate or filiform bractlets.

Plant glabrous up to the inflorescence.

Fruit glabrous or nearly so.

Fruit 3-3.5 mm. long: oil-tubes solitary in the interval, except in the lateral ones, where they are usually in pairs. 4 . A. leporina.

Fruit over $5 \mathrm{~mm}$. long; oil-tubes solitary in all the intervals.

Leaves once pinnate, or the lower primary divisions short-petioled and again pinnate.

1. A. Dawsoni.

Leaves ternate and then pinnate, the lower primary divisions lon. petiolate.

Divisions of the leaves and their teeth lanceolate, acuminate.

6. A. arguta.

Divisions of the leaves and their teeth ovate, acute or obtuse. Teeth of the leaves acute; plant perfectly glabrous.

7. A. Lyallii.

Teeth of the leaves obtuse, with a callous mucro; leaves slightly pubescent on the sheaths, leaf-stalks, and veins beneath. 8 . A. Piperi.

Fruit hispid; leaves twice compound.

8. A. Piperi.

Rays numerous; leaflets broadly ovate or obovate; pedicels longer th
the fruit.

Rays few; leaflets lanceolate or linear-lanceolate; pedicels and fruit subequal.

10. A. Kingii.

Plant more or less scabrous or pubescent, at least on the sheath, leaf-stalks, and veins beneath.

Fruit glabrous; leaves sparingly short-hispid on the sheaths, petioles, and veins.

Fruit hispid or rough-puberulent; leaves rough-pubescent.

Oil-tubes solitary in the intervals; pedicels and fruit rough-puberulent.

11. A. Roseana. 
Oil-tubes in pairs in the lateral intervals; pedicels and fruit hispid.

12. A. Wheeleri.

Oil-tubes many, continuous around the seeds; rays of the umbels widely spreading.

1. A. Dawsoni S. Wats. Stem 3-9 dm. high, slender, glabrous; leaves twice or thrice ternate; leaflets lanceolate, $2-5 \mathrm{~cm}$. long, sharply and finely serrate, yellowish green, acute or acuminate; umbels solitary; bracts and bractlets foliaceous, oblanceolate, lacerate-toothed; flowers greenish ochroleucous; fruit glabrous, $5 \mathrm{~mm}$. long; stylopodium minute. River banks and rocky places: Alta.-Mont.-Ida.-B.C. Mont. J1-Au.

2. A. Grayi Coult. \& Rose. Stem stout, $2-6 \mathrm{dm}$. high, glabrous up to the inflorescence; leaves once or twice ternate, but with the middle division larger, then pinnate; leaflets oblong or ovate, $2-3 \mathrm{~cm}$. long, acute, serrate; bractlets about $1 \mathrm{~cm}$. long, longer than the pedicels; fruit oblong, glabrous, 4-5 $\mathrm{mm}$. long; wings prominent and rather thick. Selinum Grayi Coult. \& Rose. Mountains: Colo.-s Wyo. Mont.-Alp. Jl-Au.

3. A. genuiflexa Nutt. Stem glabrous up to the puberulent peduncles, 6-12 dm. high; leaves twice ternate, the lateral divisions often deflexed; leaflets ovate or broadly lanceolate, acuminate, irregularly and sharply serrate; fruit 3-4 $\mathrm{mm}$. long; dorsal wings low; lateral wings broader than the body; stylopodium conic. Wet places: Ore.-B.C.-Alaska. Submont. J-S.

4. A. leporina S. Wats. Stem glabrous, 3-9 dm. high; leaves bipinnate; leaflets linear to lanceolate, long-acuminate, distantly serrate, $3-8 \mathrm{~cm}$. long; fruit glabrous, about $3 \mathrm{~mm}$. long; wings rather prominent, the lateral ones narrower than the body. Wet places: Utah. Son.-Submont. Jl-Au.

5. A. pinnata $\mathrm{S}$. Wats. Stem glabrous, $6-10 \mathrm{dm}$. high; leaves simply pinnate, or the lower pairs sometimes again pinnate; leaflets lanceolate, sharply serrate, $3-15 \mathrm{~cm}$. long; flowers yellowish or purplish; fruit oblong, glabrous, 4-6 $\mathrm{mm}$. long; wings thick and prominent, the lateral ones scarcely as wide as the body; stylopodium slightly conic. Wet meadows: Alta.-N.M.-Utah. Plain-Mont. J1-Au.

6. A. arguta Nutt. Stem glabrous up to the inflorescence, 5-10 dm. high; leaves ternate and then pinnate or bipinnate; leaflets mostly small, ovate or lanceolate, $2-5 \mathrm{~cm}$. long, acute, sharply serrate; fruit elliptic, glabrous, $6-8 \mathrm{~mm}$. long; dorsal wings low and thick; lateral wings fully as broad as the body, more or less corky. Wet places: Ore--Ida.-Mont.-Wash. Submont. Jl-Au.

7. A. Lyallii S. Wats. Stem stout, $6-15 \mathrm{dm}$. high; leaves ternate and then twice pinnate; leaflets ovate to lanceolate, acute, serrate, with ovate teeth; fruit oblong, glabrous, $4-6 \mathrm{~mm}$. long; dorsal wings low and thick; lateral wings as broad or broader than the body. Wet meadows: Alta.-Wyo.-Utah-Ore.B.C. Submont.-Mont. Jl-Au.

8. A. Piperi Rydb. Stem about $1 \mathrm{~m}$. high, stout, glabrous or nearly so; leaves ternate and then twice pinnate; leaflets ovate, $5-15 \mathrm{~cm}$. long, coarsely toothed, with rounded-ovate teeth; rays $10-25$, mostly scabrous-puberulent, $2-6$ $\mathrm{cm}$. long; bractlets 1 or 2, subulate; fruit elliptic, 5-6 mm. long; dorsal wings low and thick; lateral wings about as broad as the body. Wet woods: Wash.-Ids. Submont.-Mont. Je-Au.

9. A. dilatata A. Nels. Stem 5-15 dm. high; lower leaves ternate, then pinnate; the upper simply pinnate; leaflets broadly obovate or ovate, obscurely or irregularly serrate; umbels 10-30-rayed; fruit sparingly scabrous, oblongelliptic, $5 \mathrm{~mm}$. long or less. Along streams: Utah. Jl-Au.

10. A. Kingii (S. Wats.) Coult. \& Rose. Stem glabrous up to the inflorescence, 3-6 dm. high; lower leaves bipinnate, the upper ones simply pinnate; leaflets lanceolate to linear-lanceolate, $3-7 \mathrm{~cm}$. long, coarsely and unevenly serrate; fruit broadly oval, hispid, 4-6 mm. long; wings thick and rather low; stylopodium low-conic. Wet meadows: Calif.-Ida.-Nev. Son. Jl,-Au.

11. A. Roseana Henderson. Stem low and stout, 3-6 dm. high, glabrous up to the scabrous inflorescence; leaves twice or thrice ternate, then pinnate; 
leaflets broadly ovate to lanceolate, thick, with prominent veins, sharply serrate, with salient mucronate or cuspidate teeth, $2-4 \mathrm{~cm}$. long, obtuse or acute; flowers greenish or tinged with purple; fruit broadly elliptic, more or less scabrous, 4-5 $\mathrm{mm}$. long; dorsal ribs nearly as prominent as the lateral ones. Mountains: Mont.-Wyo.-Utah-Ida. Submont.-Mont. Jl-Au.

12. A. Wheeleri S. Wats. Stem tall and stout, puberulent; leaves biternate; leaflets ovate-oblong, 5-7 cm. long, acute, incisely serrate, with broad, mucronulate teeth; pedicels hispid; fruit broadly elliptic, $6 \mathrm{~mm}$. long, somewhat pubescent; dorsal ribs thick, narrower than the thick lateral ones. Wet places: Utah. Son.

13. A. ampla A. Nels. Stem stout, $1.5-2.5 \mathrm{~m}$. high, glabrous, purplish; leaves ternate, then twice pinnate; leaflets ovate or obovate, short-acuminate, serrate or toothed, 5-20 cm. long; bractlets setaceous; fruit broadly oblong, glabrous, 5-7 mm. long; dorsal ribs sharp, hardly winged; lateral wings narrow and thin. Wet meadows and stream banks: Wyo.-Colo. Jl-S.

\section{PASTINÃCA L. Parsnip.}

Stout caulescent biennial, with thick taproot. Leaves pinnately compound, with broad leaflets. Flowers yellow in large umbels. Calyx-teeth obsolete. Stylopodium flat. Dorsal and intermediate ribs slender, the lateral ones strongly winged. Fruit oval or elliptic, glabrous. Seed-face plane.

1. P. sativa L. Biennial, with a fusiform root; stem 6-15 dm. high; leaves pinnate; leaflets ovate or oval, sessile, $2-12 \mathrm{~cm}$. long, lobed and incised or dentate; fruit broadly oval, 5-7 mm. long, 4-6 mm. broad, glabrous. Roadsides and waste places: Vt.-Fla.-Calif.-B.C..; escaped from cultivation; native of $\mathrm{Eu}$.

\section{7. heraclèum L. Cow Parsnip, Cow Cabbage.}

Tall stout leafy-stemmed perennials. Leaves ternately compound, with large, broad leaflets. Flowers white, in large umbels. Bracts deciduous; bractlets numerous. Calyx-teeth small or obsolete. Stylopodium thick, conic. Fruit broadly obovate, strongly flattened dorsally, pubescent. Dorsal and intermediate ribs filiform; lateral ribs with broad wings, contiguous to those of the other carpel, strongly nerved towards the outer margin. Oil-tubes solitary in the intervals, conspicuous, about half as long as the carpels, 2-4 on the commissural side. Seeds very strongly flattened; face plane.

1. H. lanatum Michx. Tall perennial; stem stout, $1-2.5 \mathrm{~m}$. high, villous, especially above; leaves ternate; sheaths much dilated; leaflets stalked, roundcordate, 1-3 dm. broad, palmately cleft and incised; bracts and bractlets subulate; fruit obcordate, about $1 \mathrm{~cm}$. long, somewhat pubescent. Wet ground: Vt.-N.C.-Calif.-Alaska. Plain-Mont. Je-Au.

\section{SPHENOSCIÃdIUM A. Gray.}

Thick-rooted perennials, with stout stems, glabrous up to the inflorescence. Leaves once or twice pinnate, with much dilated petioles. Flowers white or sometimes purplish, in umbellate heads. Calyx-teeth obsolete. Stylopodium small, at first flat, becoming conic. Fruit flattened dorsally, cuneate-obovate, hirsute. Carpels strongly flattened, strongly ribbed below, winged above; the dorsal and intermediate wings narrow, the lateral ones broader. Oil-tubes solitary in the intervals, 2 on the commissural side. Seed-face plane.

1. S. capitellatum A. Gray. Perennial, with a short caudex and thick root; stem stout, 3-15 dm. high; leaves twice pinnate, glabrous; leaflets lanceolate to oblong or nearly linear, serrate to laciniate, or of the lower leaves entire; inflorescence white-villous; branches 4-15, $2.5-5 \mathrm{~cm}$. long; fruit cuneate-obovoid, about $5 \mathrm{~mm}$. long. Wet meadows: Ore.-Ida.-Calif. Son. Jl-Au.

\section{CONIOSELiñm Fisch. Hemlock-Parsley.}

Glabrous perennials, with a thick root. Leaves ternate, and then pinnately decompound, with toothed leaflets. Flowers white, in large umbels. Bracts 
more or less conspicuous, or wanting; bractlets numerous, elongate, narrow. Calyx-teeth obsolete. Stylopodium slightly conic. Fruit oblong, dorsally flattened, glabrous. Dorsal and intermediate ribs prominent, sometimes narrowly winged, the lateral ones broadly winged and thick. Oil-tubes usually solitary in the dorsal intervals, 1-several in the lateral ones, and 2-8 on the commissural side. Seed-face plane or slightly concave.

Fruit fully $6 \mathrm{~mm}$. long; oil-tubes 1 or 2 in each interval. Fruit about $5 \mathrm{~mm}$. long; oil-tubes $2-5$ in each interval.

1. C. scopulorum. 2. C. coloradense.

1. C. scopulorum (A. Gray) Coult. \& Rose. Stem 6-10 dm. high, glabrous; leaves twice or thrice ternate and then once or twice pinnate; leaflets ovate, pinnately cleft into oblong divisions; bractlets several, linear, elongate; fruit elliptic or oval, about $6 \mathrm{~mm}$. long. Mountain woods: Colo.-N.M.-Ariz. -Ore. Mont.-Subalp. J-Au.

2. C. coloradense Osterhout. Stem 5-6 dm. high; lower leaves biternate and the upper ternate, then pinnate; segments narrowly ovate, cleft; bracts and bractlets few, subulate, scarious; fruit broadly oval, $5 \mathrm{~mm}$. long. Mountain woods: Colo.-Wyo. Mont.-Subalp. Jl-Au.

\section{OXÝPOLIS Raf.}

Smooth, erect, swamp plants, with fascicled tubers. Leaves simply pinnate, or ternate, or reduced to phyllodia. Flowers white. Bract few or none; bractlets numerous, small, or wanting. Calyx-teeth evident. Stylopodium short, thick, conic. Fruit flattened laterally, ovate to obovate, glabrous. Dorsal and intermediate ribs filiform; wings of the lateral ribs closely continuous to those of the other carpel. Oil-tubes solitary in the intervals, 2-6 on the commissural side. Seed-face plane. [Tiedemannia DC.]

1. O. Fendleri (A. Gray) Heller. Stem simple, 3-6 dm. high; leaves pinate; leaflets 5-9, ovate or oblong, or those of the upper leaves linear-lanceolate, 3-5 cm. long, coarsely serrate; bracts and bractlets none; fruit ovoid, scarcely $4 \mathrm{~mm}$. long; wings thick, about half as broad as the body. T. Fendleri A. Gray. Wet creek-banks in the mountains: Wyo.-N.M. Mont.-Subalp. Je-Au.

\section{Family 94. araliaceae. Ginseng Family.}

Aromatic herbs, shrubs, or trees. Leaves alternate or whorled, simple or compound. Flowers inconspicuous, variously disposed, the ultimate divisions of the inflorescence usually umbellate, perfect or polygamous, regular. Sepals 5 , often minute. Petals 5 or 10 , valvate, or imbricate, inserted in the margin of an epigynous disk. Stamens 5 or 10, alternate with the petals; filaments short, distinct; anthers introrse. Gynoecium of 2-5 united carpels; ovary 2-5-celled; styles usually as many; stigmas simple. Ovules solitary in each cavity, anatropous. Fruit a berry or a drupe. Endosperm copious, fleshy. Embryo straight.

Petals imbricate; drupe 5-celled; leaves pinnately or ternately compound; ours unarmed herbs.

Petals valvate in the buds; drupe 2- or 3-celled; leaves simple, palmately lobed; prickly shrubs.

\section{1. arầlia (Tourn.) L. Sarsaparilla, Spikenard, Wild Ginseng.}

Perennial herbs (ours), or shrubs or trees. Leaves alternate, petioled, pinnately or ternately compound, with toothed leaflets. Flowers perfect or polygamous, in racemose or paniculate umbels, or in compound umbels. Sepals 5, often obsolete. Petals 5, imbricate, with obtuse or inflexed tips. Stamens 5; filaments incurved. Ovary 5-celled; styles 5, spreading. Drupe 5-lobed, 5-celled, black, fleshy. Seeds flattened.

1. A. nudicaulis L. Acaulescent perennial herb, with a long rootstock; eaves ternate, long-petioled; primary divisions pinnately 3 -5-foliolate; leaflets 
oval or ovate, acuminate, finely serrate, $5-13 \mathrm{~cm}$. long; peduncles $2-3 \mathrm{dm}$. long; flowers greenish; fruit globose, purplish black. Woods: Newf.-N.C.-Colo.Ida.-B.C. Submont.-Mont. My-Je.

\section{2. échinopànaX Dec. \& Planch. Devil's Club, Devil's WALKING-STICK.}

Prickly shrubs. Leaves simple, palmately lobed. Flowers in paniculate umbels. Calyx-teeth obsolete. Petals 5, greenish, valvate in the buds. Stamens 5; filaments filiform; anthers oblong. Ovary 2-celled, rarely 3-celled. Styles usually 2, filiform. Fruit laterally flattened. [Fatsia Benth. \& Hook., in part, not Dec. \& Planch.]

1. E. horridum (J. E. Smith) Dec. \& Planch. A shrub, 1-4 m. high, densely prickly, leafy above; leaf-blades nearly orbicular in outline, $1.5-6 \mathrm{dm}$. broad, cordate at the base, palmately 3-7-lobed, with scattered prickles on both sides, sharply serrate; inflorescence terminal, 1-3 dm. long; fruit 4-5 mm. long, scarlet. F. horrida Benth. \& Hook. Rocky woods: Mich.-Mont.-Ore--Alaska. Boreal-Mont. Je.

\section{Family 95. CORNaCeae. Dogwood Family.}

Shrubs or trees, rarely perennial herbs. Leaves alternate or opposite, without stipules, often firm, usually entire. Flowers perfect or unisexual, in cymes or heads, or the staminate ones in ament-like spikes. Sepals 4 or 5 . Petals 4 or 5 , or rarely numerous, imbricate or valvate, inserted at the base of the epigynous disk, or wanting. Stamens as many as the petals; anthers attached at the base or the back. Gynoecium of 1-4 united carpels; styles united; stigmas entire, lobed, or cleft. Ovules usually solitary in each cavity, anatropous, pendulous. Fruit a drupe; stone 1-4-celled. Endocarp fleshy.

Flowers dioecious; stigmas lateral; staminate flowers in ament-like spikes.

Flowers perfeet, cymose or umbellate; stigmas terminal. 1. GARRYA.

Flowers in open cymes, not subtended by an involucre; shrubs.

Flowers in head-like umbels, subtended by an involucre of 2 . SviDA. rootstocks.

1. GÁRRYA A. Gray.

Shrubs, with 4-angled branches. Leaves opposite, persistent, entire or slightly lobed. Flower dioecious; the staminate ones in ament-like spikes, with 4 narrow sepals, no petals, 4 stamens, and a rudimentary pistil. Pistillate flowers with 2 sepals, and 1-celled ovary, 2 stigmas, and 2 pendulous ovules. Fruit drupaceous, with persistent styles. Seeds 3 , rarely 1, flattened.

1. G. flavescens S. Wats. Shrub $1-3 \mathrm{~m}$. high, branched from the base; bark gray or that of the young branches yellow; leaves short-petioled; blades obovate or oblanceolate, or oval, $3-5 \mathrm{~cm}$. long, appressed-pubescent on both sides, becoming glabrate above, paler beneath; fruit 6-8 mm. long, densely grayish pubescent. Rocky hills and cañons: s Utah-Ariz.-Nev. Son. My.

\section{SvìdA Opiz. CoRnel, Dogwood, Kinnikinnik.}

Shrubs or trees, with hard wood and mostly opposite branches. Leaves opposite or rarely alternate, entire. Flowers perfect in naked, open, dichotomous cymes. Sepals 4, usually small. Petals 4, valvate, white. Stamens 4; filaments filiform or subulate. Ovary 2-celled, or rarely 5-celled. Fruit drupaceous, with thin pulp; stone bony, usually 2-celled. Seeds flattened. [Cornus L., in part.]

Young branches and inflorescence villous.

Leaves broadly oval or ovate, the larger obtuse at the base, densely villous beneath; inflorescence long-villous; stone usually broader than long.

1. S. pubescens. 
Leaves ovate or ovate-lanceolate, acute at the base, silky beneath or slightly villous on and near the veins; inflorescence short-villous; stone as long as broad or longer.

Young branches appressed-strigose or nearly glabrous.

2. S. interior.

3. S. instolonea.

1. S. pubescens (Nutt.) Standl. Shrub $2-4.5 \mathrm{~m}$. high; branches smooth, purplish; leaves oval or ovate, usually somewhat acuminate, strigose above, villous beneath, 3-12 cm. long; sepals minute; fruit white; stone compressed, mostly oblique, $4 \mathrm{~mm}$. high, $5 \mathrm{~mm}$. broad, furrowed on the edge, the sides usually with ridges. Cornus pubescens Nutt. C. occidentalis Coville. Along streams and in wet places: Calif.-Ida.-B.C. Submont. My-Jl.

2. S. interior Rydb. A shrub, 2-5 m. high; bark of the old stems grayish; leaves elliptic or oval, acute at both ends, 5-9 $\mathrm{cm}$. long, finely short-strigose on both sides and more or less villous on the veins and in their angles beneath; sepals minute; fruit white, about $5 \mathrm{~mm}$. in diameter; stone elliptic, slightly oblique, longer than broad, nearly smooth. River banks: N.D.-Kans.-Colo.Yukon. Plain-Submont. Je-Jl.

3. S. instolonea A. Nels. Shrubs, $2-5 \mathrm{~m}$. high, not stoloniferous; bark of the old stems gray; young twigs brownish; leaves usually oval or elliptic, acute, thin, light green and less pale beneath than in the eastern $S$. stolonifera, lanceolate to oval, acute or short-acuminate, obtuse or acute at the base, strigose on both sides, 3-12 $\mathrm{cm}$. long; fruit white; stone higher than broad, $5 \mathrm{~mm}$. long, 3-3.5 mm. broad, smooth. S. stolonifera riparia Rydb. River banks: Man.Kans.-N.M.-Calif.-Alaska. Plain-Mont. My-Jl.

\section{ChAMAEPERICLÍMENUM Aschers. \& Graebn. BunchBerRy.}

Low perennial herbs, with rootstocks. Leaves opposite, or the upper whorled, entire. Flowers perfect in close head-like clusters, subtended by 4 petal-like bracts. Sepals 4, tipped each with a short deciduous bristle. Petals 4, valvate. Stamens 4. Ovary 2-celled, sessile. Ovules solitary in each cell. Drupe globular, red; stone 2-celled. [Cornella Rydb.]

Flowers greenish; st one smooth, higher than broad.

Flowers purple; stone ridged on each side, as broad as long.
1. C. canadense.

2. C. unalaschkense.

1. C. canadense (L.) Aschers. \& Graebn. Stem simple, 5-20 cm. high; leaves subsessile, mostly in an apparent whorl of 4-6 at the summit, oval, ovate, or obovate, acute at each end, 3-7 $\mathrm{cm}$. long, and a pair of smaller ones at about the middle of the stem; bracts 4, white or cream-colored. Cornus canadensis L. Cornella canadensis Rydb. Woods: Lab.-N.J.-Minn.-N.M.-Calif.-Alaska. Submont.-Mont. My-Au.

2. C. unalaschkense (Ledeb.) Rydb. Stem 10-15 cm. high, simple, rarely branched; leaves usually subverticillate at the summit, with two smaller ones below, or sometimes in pairs, oval, ovate, or obovate, acute at each end; bracts 4 , white, ovate, $8-18 \mathrm{~mm}$. long; petals purple or at least purple-tipped; fruit 4-8 mm. in diameter, red. Cornus unalaschkensis Ledeb. C. canadensis intermedia Farr. Woods: Alaska-B.C. Boreal-Mont. My-Je.

\section{Family 96. PYROLACEAe. Wintergreen Family.}

Perennial, mostly evergreen herbs, with elongated rootstocks. Leaves basal or crowded on the short stem or at the end of the branches, thick and leathery, entire or toothed. Flowers perfect, often slightly irregular, in racemes or corymbs. Sepals 4-5, persistent. Petals 4-5, wax-like. Stamens twice as many as the petals; filaments usually subulate; anthers introrse, becoming inverted in anthesis, opening by pores or slits. Gynoecium of 4 or 5 united carpels; ovary superior, 4- or 5-celled; styles united; stigma 5-lobed. Capsule loculicidal, valvate. Seeds minute, numerous.

Plants leafy-stemmed; flowers corymbose; style very short and ending in the peltate stigma; fllaments dilated and hairy at the middle. 1. ChIMAPHILa. Plant scapose, with a basal rosette of leaves; flowers racemose or solitary; style evident; filaments subulate, naked. 
Flowers solitary; petals spreading; valves of the capsule not cobwebby on the margins.

T. MONESES.

Flowers racemose; petals more or less converging, concave; valves of the capsule cobwebby on the margins when opening.

Flowers without hypogynous disk; petals without tubercles. Style exserted, deflexed, curved; stigma narrower than the style.

Style short, straight; stigma thicker than the style, peltate. Flowers with a 10-lobed hypogynous disk; petals with a pair of
base.

3. Pyrola.

4. ERXLEBENIA.

tubercles at the

\section{Chimáphila Pursh. Pipsissewa, Prince's Pine.}

Perennial herbs, with more or less cespitose, horizontal rootstock and short leafy stems. Leaves persistent, coriaceous, opposite or whorled, short-petioled and serrate. Flowers perfect, in terminal corymbs. Sepals 5, persistent. Corolla white or pink, wax-like; petals 5 , broad, concave, sessile. Stamens 10; filaments very short; anthers incurved; sacs opening by pores at the ends of the basal ascending beaks. Ovary 5-celled; stigma orbicular, peltate, barely 5crenate; style very short. Capsule 5-celled, the latter loculicidal from the top; valves not cobwebby on the margins; seeds many.

Leaves lanceolate to ovate, broadest below the middle, usually pale-mottled along the

midveins; dilated portion of the filaments hairy
Leaves oblanceolate, broadest above the middle; dilated portion of the filaments hairy only along the margins.

2. C. occidentalis.

1. C. Menziesii Spreng. Stem about $1 \mathrm{dm}$. high; leaves $2-5 \mathrm{~cm}$. long, serrulate, acute; peduncles 1-3-flowered, 3-6 $\mathrm{cm}$. long; bracts ovate or rotund; sepals orbicular, crenulate; petals orbiculate, not ciliate; capsule globose, $6 \mathrm{~mm}$. in diameter. Woods: B.C.-Ida.-Calif. Je-Jl.

2. C. Occidentalis (Rydb.) Stems 1-2 dm. high, terete; leaves whorled; blades 3-10 cm. long, oblanceolate, acute, sharply serrate, dark green and shining above, pale beneath; peduncles $5-10 \mathrm{~cm}$. long, corymbosely 4-7-flowered; bracts narrow; sepals suborbicular or orbicular-ovate, $2 \mathrm{~mm}$. long, rounded and erose-ciliate; petals nearly orbicular, ciliate on the margin; capsule depressedglobose, 5-6 mm. in diameter. C. umbellata Am. Auth., in part, not Nutt. In dry woods: Mont.-N.M.-Calif-Alaska. Submont.-Mont. Je-Au.

\section{Monèses Salisb. One-Flowered Wintergreen, Single Beauty.}

Perennial herbs, scapose or short-stemmed, with slender rootstocks. Leaves persistent, coriaceous, opposite or in 3's, short-petioled, crenate or serrate. Flowers perfect, solitary, on a long peduncle, nodding. Sepals 5 (rarely 4), persistent. Petals white or rose-colored, 5 (rarely 4), orbicular or broadly ovate, spreading. Stamens 10 or 8; filaments short, subulate, somewhat dilated, incurved. Ovary 4-5-celled; style straight; stigma peltate, with 4-5 narrow, at first erect, at length radiating lobes. Capsule depressed-globose, 4-5-celled, loeulicidally 4-5-valved from the summit; valves not woolly on the edges.

Leaf-blades orbicular or obovate, crenate, usually rounded at the apex. 1. M. uniflora. Leaf-blades ovate, strongly reticulate, serrate, usually acute or acutish at the apex.

2. $M$. reticulata.

1. M. unifiora (L.) A. Gray. Stem $5-15 \mathrm{~cm}$. high; leaves mostly crowded near the base; blades $8-25 \mathrm{~mm}$. long, acute or rounded at the base, thin; sepals oval, obtuse, $3 \mathrm{~mm}$. long, ciliolate; petals ovate to orbicular, obtuse, $8-12 \mathrm{~mm}$. long; capsule 6-8 mm. in diameter, In woods: Greenl.-Pa.-Colo.-Ore.Alaska; Eurasia. Mont.-Subalp. Je-Au.

2. M. reticulata (Nutt.) Stem $5-10 \mathrm{~cm}$. high; leaf-blades rounded-ovate, $1-2.5 \mathrm{~cm}$. long, strongly veiny and coarsely toothed; sepals oval, ciliolate; petals white, ovate, obtuse, about $1 \mathrm{~cm}$. long; capsule about $1 \mathrm{~cm}$. in diameter. Shady woods: Wash.-Mont.-Alaska. Mont.

\section{Pýrola (Tourn.) L. Wintergreen.}

Scapose perennials, with slender, stoloniferous rootstocks. Leaves persistent, firm, subcoriaceous, mainly basal, or in one species usually none and replaced by scales. Flowers racemose, nodding, perfect. Sepals 5 , persistent, spreading. 
Petals 5, concave, sessile. Stamens 10; filaments declined; anthers contracted under the terminal pores. Ovary 5-celled; hypogynous disk none; style long, declined and curved upwards towards the end, which is enlarged, truncate and concave and forming a ring or collar; stigma much narrower, 5-lobed. Capsule 5 -celled, 5-lobed, loculicidally 5-valved; valves opening from the base and cobwebby on the margins.

Leaves ample, not scale-like.

Leaves not mottled.

Leaves not spatulate, dark green.

Petals pink or purplish.

Leaf-blades crenulate, not callous-denticulate, obtuse. Leaf-blades round-reniform to orbicular.

Leaf-blades orbicular to round-ovate.

Leaf-blades more or less distinctly callous-denticulate by the protruding ends of the veins, rounded-ovate, acute. 3 . bracteata.

Petals white or greenish.

Leaf-blades oval, longer than the petioles.

Leaf-blades orbicular, usually shorter than the petioles.

Leaves spatulate, pale or yellowish green.

Leaves mottled.

Leaves reduced to lanceolate scales,

4. P. elliptica.

5. P. chlorantha.

6. P. dentata.

7. P. picta.

8. $P$. aphylla.

1. P. asarifolia Michx. Leaf-blades reniform to orbieular, usually broader than long, shining, finely crenulate, $2.5-6 \mathrm{~cm}$. wide; scape $1-3 \mathrm{dm}$. high; bracts lanceolate; sepals lanceolate, acute or acuminate, about $2 \mathrm{~mm}$. long; petals oval, pink or purplish, $5-6 \mathrm{~mm}$. long. Wet woods and swamps: N.B.-N.Y.-Minn. -N.M.-B.C. Submont.-Mont. Je-J.

2. P. uliginosa Torr. Leaf-blades broadly oval to orbicular, usually longer than broad, shining, finely crenulate, $2-6 \mathrm{~cm}$. broad, $2.5-8 \mathrm{~cm}$. long; scape 1-3 $\mathrm{dm}$. high; bracts lanceolate, usually purplish; sepals ovate or triangular-lanceolate, acute or short-acuminate, about $2 \mathrm{~mm}$. long; petals oval or obovate, pink or purplish, 5-7 mm. long. P. rotundifolia incarnata A. Gray, scarcely DC. Wet woods and bogs: N.S.-N.Y.-Minn.-Colo.-Calif.-B.C. Submont.Subalp. Je-Jl.

3. P. bracteata Hook. Leaf-blades ovate, acute, shining, $2.5-6 \mathrm{~cm}$. wide, 3-8 cm. long; scape 2-4 dm. high; bracts lanceolate, acuminate, the lower at least much exceeding the petioles; sepals lanceolate, acuminate, $3 \mathrm{~mm}$. long or more; petals pink or purplish, oval or obovate, 7-9 $\mathrm{mm}$. long. In wet woods: Alaska-Ore.-B.C.-Yukon. Submont. Je-Au.

4. P. elliptica Nutt. Leaf-blades oval, acute at the base, rounded, retuse or short-acuminate at the apex, rather thin, crenulate and the teeth often callous-mucronate, $1.5-6 \mathrm{~cm}$. wide, $2-8 \mathrm{~cm}$. long; bracts narrowly lanceolate to subulate; sepals triangular-ovate, acute or acuminate, often less than $2 \mathrm{~mm}$. long; petals greenish white, oval, $5-6 \mathrm{~mm}$. long. Rich woods: N.S.-D.C.Minn.-N.M.-B.C. Submont.-Mont. Je-Au.

5. P. chlorantha Swartz. Leaf-blades orbicular to broadly oval or obovate, crenulate, thick, but rather dull, rounded or acute at the base, 1-4 cm. wide; sepals triangular-ovate, about $1.5 \mathrm{~mm}$. long, obtuse or acute; petals greenish white, oval, about $7 \mathrm{~mm}$. long. In woods and swampy places: Lab.-D.C.Calif.-B.C.; n Eu. Submont,-Subalp. Je-Jl.

6. P. dentata Smith. Leaf-blades spatulate or oblanceolate, tapering at the base, acute or obtuse at the apex, callous-denticulate, thick, dull, 1-2 cm. wide, $1.5-4 \mathrm{~cm}$. long; sepals triangular-ovate, acute, about $1.5 \mathrm{~mm}$. long; petals oval, 5-6 mm. long, greenish or purplish. In woods: B.C.-Calif.-Mont. Submont.-Mont. Je-Au.

7. P. picta Smith. Leaf-blades ovate or oval, acute at both ends, callousdenticulate, firm and coriaceous, blotehed white above and purple beneath, 1-5 $\mathrm{cm}$. wide, 1-6 cm. long; sepals triangular-ovate, acute, about $1.5 \mathrm{~mm}$. long; petals oval, greenish or purplish, about $6 \mathrm{~mm}$. long. Woods: B.C.-Calif.Ariz.-Colo.-Mont. Submont.-Mont. J1-Au.

8. P. aphylla Smith. Proper leaves usually replaced by lanceolate scales, only on sterile shoots sometimes producing small lanceolate green leaf-blades; 
sepals ovate or' lanceolate, acute, $2-3 \mathrm{~mm}$. long; petals obovate or oval, white or greenish, 7-10 mm. long. In coniferous woods: B.C.-Calif.-w Mont. Submont. Je-Au.

\section{ERXLEBËNIA Opiz.}

Scapose perennials, with stoloniferous rootstocks. Leaves persistent, basal, firm, petioled. Flowers racemose, perfect. Sepals 5, persistent, spreading. Petals 5, concave. Stamens 10; filaments erect, connivent; anthers opening by oblique pores at the end, not produced into tubes. Oyary 5-celled; style straight, erect, in ours short, without a collar; stigma peltate, thicker than the style, with 5 marginal papillae. Capsule as in Pyrola.

1. E. minor (L.) Rydb. Leaf-blades oval or orbicular, 1-3 cm. wide, 1-4 $\mathrm{cm}$. long, finely crenulate, light green; sepals ovate or triangular-ovate, $1.5 \mathrm{~mm}$. long, acute or acutish; petals white or pinkish, orbicular, 4-5 $\mathrm{mm}$. long; capsule 5-6 mm. in diameter. Pyrola minor L. In woods: Greenl.-Conn.-Colo.Calif.-Alaska; Eurasia. Mont.-Subalp. Je-Au.

\section{RAMÍsCHIA Opiz.}

Perennials, usually with a short leafy stem and slender, stoloniferous rootstocks. Leaves persistent, but thin. Flowers racemose, nodding and decidedly secund. Sepals 5, persistent, spreading. Petals oblong, erect, with a pair of tubercles at the base within. Stamens 10; filaments slender, not declined, all equally connivent; anthers not contracted beneath the pores. Ovary 5-celled; hypogynous disk present and 10-lobed; style long and straight; stigma peltate, 5-lobed. Capsule 5-celled, 5-lobed, loculicidally 5-valved; valves opening from below, cobwebby on the margins.

1. R. secunda (L.) Garcke. Leaf-blades ovate, oval or lanceolate, thin, acute at both ends or rarely obtuse, $2-5 \mathrm{~cm}$. long, $1-3 \mathrm{~cm}$. wide, crenulate or serrulate; sepals less than $1 \mathrm{~mm}$. long, triangular; petals oblong, greenish white, about $4 \mathrm{~mm}$. long. Pyrola secunda L. In woods: Lab.-D.C.-Calif.-Alaska; Eurasia. Mont.-Subalp. Je-Au.

\section{FAmily 97. MONOTROPACEAE. Indian Pipe Family.}

Saprophytic herbs or root-parasites, with densely matted roots. Leaves scale-like, destitute of chlorophyll. Flowers perfect, usually drooping. Sepals 2-6, distinct, imbricate, deciduous. Petals distinct or partially united, rarely wanting. Stamens 6-12, hypogynous; filaments distinct or united at the base; anthers 2 -celled or with confluent sacs, opening by valves or pores. Gynoecium of 1-6 united carpels; ovary 1-6-celled, superior; styles united; stigma capitate, disk-like, or funnelform. Ovules numerous, anatropous. Fruit a 1-celled loculididal capsule. Seeds numerous.

Flowers in elongate racemes; corolla gamopetalous, globular or nearly so; anther 2-awned. 1 . PTEROSPORA. Flowers in short, few-flowered racemes, or solitary; corolla of 4-6 erect, distinct petals; anthers awnless.

Flowers solitary; stigma naked.

2. MoNOTROPA.

Flowers racemose; terminal flower 5-merous, the lateral ones 3 - or 4-merous; stigma glandular or hairy on the margins.

3. HYPOPITYS.

\section{Pteróspora Nutt. Pine-drops, Giant Bird's-nest.}

Purplish or brown plants, without proper leaves, and with numerous roots forming rounded masses often $5 \mathrm{~cm}$. or more in diameter. Flowers in long, many-flowered racemes. Sepals 5, oblong. Corolla globose, gamopetalous, with 5 reflexed lobes. Stamens 10, included; filaments subulate, glabrous; anthers introrse, the sacs longitudinally dehiscent. Ovary 5-lobed, 5-celled; style short, straight; stigma capitate, 5-lobed. Capsule depressed-globose, 5 -valved. Seeds with a terminal reticulate wing. 
1. P. Andromedea Nutt. Plant $2-15 \mathrm{dm}$. high, viscid-hairy; scales lanceolate or linear, numerous; sepals oblong, obtuse; corolla $6-8 \mathrm{~mm}$. long, whitish; capsule 8-12 $\mathrm{mm}$. in diameter. In rich woods: Que.-Pa.-S.D.-N.M.Calif.-B.C.; n Mex. Submont. Je-Au.

\section{MONÓtROPA L. Indian Pipe.}

White or pink, leafless plants, with sessile scales. Flowers perfect, solitary, nodding, but in fruit erect. Sepals 2-4, similar to the upper bracts. Petals 5 or 6, somewhat dilated at the apex, erect, tardily deciduous. Stamens 10-12; filaments linear-subulate, more or less pubescent; anthers becoming equally and transversely 2-valved. Hypogynous disk 10-12-toothed. Ovary 5-celled; styles very short; stigma funnelform, crenate on the edge. Capsule 5-celled, loculicidally 5 -valved, erect. Seeds numerous; testa produced at both ends.

1. M. uniflora L. Plant 1-3 dm. high, white or pink, turning black in drying; flowers $1.5-2 \mathrm{~cm}$. long; petals abruptly dilated above, strigillose within. Deep woods: Newf.-Fla.-Calif.-B.C.; Mex.; Japan to India. Submont. Je$\mathrm{Au}$.

\section{HYPÓPITYS (Dill.) Adans. Pinesap.}

Yellowish or reddish, violet-scented, leafless plants, with sessile scales. Flowers perfect, few or several in a raceme, the terminal one 5-merous, the lateral ones 3-4-merous. Calyx regular; sepals not resembling the bracts. Petals distinct, as many as the sepals, saccate at the base. Stamens 6-10; anthers horizontal, opening by two transverse, unequal valves. Hypogynous disk, 6-10toothed. Ovary 3-5-celled; style short; stigma funnelform or disk-like. Capsule 3-5-celled, erect, loculicidally 3-5-valved. Seeds numerous.

1. H. latisquama Rydb. Plant pink, 1-3 dm. high, more or less shortpubescent above; scales of the stems broadly ovate, obtuse, $1-1.5 \mathrm{~cm}$. long; sepals spatulate or cuneate, $8-10 \mathrm{~mm}$. long, abruptly acuminate, ciliate; petals cuneate or obovate, 11-12 mm. long, rounded and sinuate at the apex, pubescent and ciliate. Woods: Mont.-N.M.-B.C. Submont. J.

\section{Family 98. ericaCeae. Heath Family.}

Perennial herbs, shrubs, or trees, with alternate, opposite, or whorled leaves, commonly leathery and persistent, without stipules. Flowers perfect. Sepals 4 or 5, or rarely 6-10, distinct or partially united. Corolla regular or slightly irregular; petals as many as the sepals, usually more or less united. Stamens as many or twice as many, hypogynous; anthers two-celled, sometimes prolonged into terminal tubes; opening by terminal pores or lengthwise, often with horn-like awns. Gynoecium of 2-5 united carpels; ovary with as many cells; styles united; stigma capitate or peltate. Fruit usually a capsule, sometimes a berry or drupe.

Fruit a capsule.

Fruit septicidal; valves separating from the central columella, which bears the placentae; anther awnless.

Petals distinct, spreading; flowers from separate strobilaceous buds.

Petals united, forming a gamopetalous corolla.

1. LEDUM.

Corolla without sacs for the anthers.

Corolla large, white, rotate or rotate-campanulate.

Corolla small, urceolate or campanulate.

Heath-like evergreen undershrubs, with the flowers umbellately or racemosely arranged at the ends of the branches, from the axils of the leaves.

3. PHYLLODOCE.

Deciduous-leaved shrubs, with the flowers from strobilaceous buds, ending the branches of the preceding year.

Corolla rotate, with 10 sacs enclosing the anthers in bud.

4. MENZIESIA.

5. KALMIA.

Fruit loculicidal; the valves carrying with them the partitions; anthers in our genera awned.

Calyx and hypanthium neither accrescent, nor enclosing the capsule, nor berrylike. 
Sepals or calyx-lobes valvate in bud; corolla globose-urceolate; shrubs; leaves neither imbricate nor scale-like.

6. ANDROMEDA.

Sepals imbricate in the bud; corolla campanulate; undershrubs, with scale-like imbricate leaves.

Calyx and hypanthium accrescent, enclosing the capsule, berry-like.

8. Gaultheria.

Fruit a drupe or berry.

Leaves thin, deciduous; fruit juicy.

Leaves evergreen, leathery; fruit mealy.

9. Arctous.

10. Arctostaphylos.

\section{LÈDUM L. Labrador Tea.}

Resinous shrubs, with scaly buds and fragrant foliage. Leaves alternate, thick and leathery, with more or less revolute margins. Flowers in terminal corymbs. Bracts deciduous. Calyx persistent; sepals 5. Petals 5, obtuse, spreading, imbricate in the bud. Stamens 5-10, exserted; filaments filiform; anthers didymous, the sacs opening by terminal pores. Disk annular, 8-10lobed. Ovary 5-celled, usually covered by scales; style filiform; stigma 5-lobed. Capsule oblong or ovate, 5-celled, septicidally 5-valved from the base.

Leaves densely ferruginous-tomentose beneath and with strongly revolute margins.

1. L. groenlandicum.

Leaves glabrous on both sides, paler and glandular-punctate beneath, not revolute.

2. L. glandulosum.

1. L. groenlandicum Oeder. Shrub 3-10 dm. high, with rusty tomentose twigs; leaf-blades oblong or elliptic, obtuse at both ends, $1.5-5 \mathrm{~cm}$. long, $0.5-2 \mathrm{~cm}$. wide, dark green above, densely tomentose beneath, with rusty hairs; pedicels 2-2.5 $\mathrm{cm}$. long, in fruit recurved; sepals minute, triangular; petals white, about $5 \mathrm{~mm}$. long; capsule lance-ovoid, puberulent, $5-7 \mathrm{~mm}$. long, $2-3 \mathrm{~mm}$. thick. $L$. latifolium Ait. In bogs: Greenl.-N.J.-Wash.-Alaska. Boreal-Subarctic. $\mathrm{Je}-\mathrm{Jl}$.

2. L. glandulosum Nutt. Shrub, 3-10 dm. high, with glabrous or minutely puberulent branches; leaf-blades elliptic or oval, $1.5-3 \mathrm{~cm}$. long, 1-2 cm. wide, green above, pale and minutely resiniferous beneath; sepals oblong, obtuse, about $1.5 \mathrm{~mm}$. long; petals white, broadly oval, 5-7 mm. long; capsule ovoid, 4-5 mm. long, 3-4 mm. thick. Mountain swamps: B.C.-Calif.-Utah-Alta. Mont.-Subalp. Je-Au.

\section{AZALIĀSTRUM (Planch.) Rydb. White Rhododendron,} AzALEA.

Shrubs, with erect branches and deciduous leaves. Flowers perfect, in 1-3flowered umbels, from lateral scaly buds. Sepals 5, membrano-foliaceous. Corolla open-campanulate or saucer-shaped, 5-lobed. Stamens 10, included; filaments bearded at the base; anthers awnless, opening by terminal pores. Ovary 5-celled; style included; stigma peltate, 5-lobed. Capsule ovoid, 5-celled, septicidal.

Leaves hirsute with brown hairs.

Leaves glabrate, only glandular-ciliolate on the margins.

1. A. albiflorum.

2. A. Warrenii.

1. A. albifiorum (Hook.) Rydb. Shrub 0.5-2 m. high, with branches glandular-strigose when young, in age glabrous; leaf-blades membranous, oblanceolate, oval or oblong, pale green, 4-7 cm. long, $1.5-2 \mathrm{~cm}$. wide; sepals oblong, 8-10 mm. long, glandular-pubescent, obtuse; corolla white, $12-20 \mathrm{~mm}$. long; lobes rounded; capsule woody, about $8 \mathrm{~mm}$. in diameter. In woods: B.C.Wash.-Mont.-Alta. Mont. J-Au.

2. A. Warrenii A. Nels. A low shrub, $3 \mathrm{dm}$. or less, with grayish bark on the stem and brown twigs; leaves ovate, oval, or obovate, 1-2 $\mathrm{cm}$. long; flowers axillary, solitary or a few close together; sepals narrowly elliptic, 7-10 $\mathrm{mm}$. long, covered with short gland-tipped hairs; corolla $10-15 \mathrm{~mm}$. long, white; lobes orbicular. Mountain slopes: Colo. Mont. Jl.

\section{PHYLlódoce Salisb. Mountain Heath.}

Evergreen low branching shrubs, with alternate crowded leaves, thick, grooved beneath, the margin revolute-thickened. Flowers in terminal umbels, 
perfect. Sepals normally 5, imbricate, persistent. Corolla open-campsnulate to urn-shaped, 5-lobed. Stamens 10, included; anthers dehiscent by oblique chinks. Ovary 5-celled; style filiform; stigma capitate or obscurely 5-lobed. Capsule subglobose, septicidal, 5 -valved to the middle; seeds numerous, with coriaceous testa.

Corolla not contracted at the throat, open-campanulate, rose-colored to scarlet; sepals obtuse.
1. P. empetriformis. Corolla urceolate, contracted at the throat, yellow; sepals acute. $\quad \begin{aligned} & \text { 1. P. P. empetriformis. } \\ & \text { glandiflora. }\end{aligned}$

1. P. empetriformis (Smith) G. Don. Branched shrub, 1-3 dm. high; leaves subsessile, linear, rather crowded on the branches, 5-12 mm. long, 1-1.5 mm. wide, thick, grooved on both sides, glabrous, scabrous, denticulate on the margins; sepals oblong or ovate, obtuse, about $2 \mathrm{~mm}$. long, usually pink or scarlet; corolla 6-8 mm. long, glabrous. ReD or Purple Heather. Mountain sides and swamps: Alaska-n Calif.-Colo.-Alta. Subalp.-Alp. J-Au.

P. empetriformis $\times$ glanduliflora. Where the two species grow together, hybrids often occur. These are of two forms, both having cylindraceous corolla. On one, $P$. intermedia (Hook.) Rydb., the corolla is pink and the sepals acute, in the other, P. hybrida Rydb., the corolla is yellowish and the sepals obtuse.

2. P. glanduliflora (Hook.) Coville. Branched shrub, 1-3 dm. high; leaves subsessile, linear-oblong, obtuse, 4-8 mm. long, $1.5-2 \mathrm{~mm}$. wide, otherwise as in the preceding; sepals lanceolate, very acute, 4-5 mm. long, glandular-hairy; corolla about $8 \mathrm{~mm}$. long, sulphur-yellow and more or less glandular-puberulent. Yellow Heather. Mountain sides and swamps: Alaska-Wash.-Wyo-Alta. Subalp.-Alp. Je-Au.

\section{MENZIÈsIA Smith.}

Shrubs, with erect branching stems and alternate deciduous leaves. Flowers perfect, in terminal clusters from early buds. Calyx 4-5-lobed, often obsolete. Corolla urn-shaped, campanulate or globose, usually 4-lobed. Stamens 5-10, mostly 8, included; filaments subulate, flattened; anthers linear-sagittate, awnless, opening by terminal oblique pores or chinks. Disk 8-10-lobed. Ovary 4- (rarely 5-) celled; style included; stigma truncate, with 4 or 5 lobes. Capsule septicidal, 4-valved.

Pedicels and petioles glandular-puberulent; seeds tailed at both ends; leaf-blades obtuse.

Pedicels and petioles glandular-hirsute; seeds merely apieulate at the 1 . M. glabella.

acute.

ends; leaf-blades

1. M. glabella A. Gray. Erect shrub, 2-3 m. high; leaf-blades obovate or elliptic, 3-6 cm. Iong, 1-3 cm. wide, green and sparingly short-hairy above, glabrous or nearly so and pale beneath; corolla urceolate, $8-9 \mathrm{~mm}$. long; capsule ovoid, about $6 \mathrm{~mm}$. long, glabrous or minutely puberulent. Woods: B.C.-Ore. -Wyo.-Alta. Submont. Je-Jl.

2. M. ferruginea Smith. Erect shrub, 2-3 m. high; leaf-blades broadly oblanceolate, hirsute-strigose and green above, pale and glabrous beneath, except the veins and margin, 3-5 cm. long, 1-2.5 $\mathrm{cm}$.-wide; corolla cylindrourceolate, $8-10 \mathrm{~mm}$. long, 6-7 $\mathrm{mm}$. wide; capsule ovoid, about $8 \mathrm{~mm}$. long, glabrous or with scattered hairs. M. urceolaria Salisb. Woods: Alaska-Ore. -Wyo.-Mont. Submont.-Mont. My-Jl.

\section{Kálmia l. American Laurel, Swamp Laurel.}

Evergreen shrubs or trees, with alternate, opposite, or whorled leaves. Flowers perfect, in terminal or axillary corymbs or umbels, with early deciduous bracts. Sepals 5, persistent, leathery. Corolla rotate, pink or white, with 10 pouches at first enclosing the anthers, 10-keeled and rounded 5-lobed. Stamens 10; filaments shorter than the corolla, straightening elastically at maturity; anther s awnless, opening by terminal pores. Disk 1-lobed. Ovary 5-celled. Capsule globose, depressed at the apex, septicidal, 5-valved.

1. K. microphylla (Hook.) Heller. Low branched shrub, 1-3 dm. high; leaves opposite, with very short petioles; leaf-blades $1-1.5 \mathrm{~cm}$., seldom $2.5 \mathrm{~cm}$. 
long, 5-10 mm. wide, oval, glabrous, dark green above, glaucous beneath, somewhat revolute on the margins; sepals ovate, concave, about $3 \mathrm{~mm}$. long, purple; corolla bluish purple, 10-14 mm. wide. Cold bogs: Alaska-Calif.-Colo.Alta. Mont.-Subalp. Je-Au.

\section{ANDRÓMEDA L. Bog Rosemary.}

Glabrous evergreen shrubs, with coriaceous, entire, revolute-margined leaves. Flowers perfect, in terminal umbels. Sepals 5, persistent. Corolla globoseurceolate, 5-toothed, with recurved teeth. Stamens 10, included; filaments bearded, unappendaged; anthers short, ovate, obtuse; sacs opening by a terminal pore, each with an ascending awn. Disk 10-lobed Ovary 5-celled; style columnar; ovules many. Capsule subglobose, 5-angled, 5-valved, loculicidal. Seeds with smooth testa, coriaceous, shining.

1. A. polifolia L. Shrub, 1-3 m. high, with acid foliage; leaf-blades oblong to linear, 3-5 $\mathrm{cm}$. long, 3-8 $\mathrm{mm}$. wide, dark green above, white beneath, mucronulate, the margins usually strongly revolute; bracts ovate, glaucous; pedicels $5-10$ $\mathrm{mm}$. long; sepals triangular, acute, about $1 \mathrm{~mm}$. long; corolla pink, about $9 \mathrm{~mm}$. long. In swamps: Lab.-N.J.-Ida.-Wash.-Alaska; Eurasia. Je-Jl.

\section{Cassiope D. Don. Moss-plant, White Heather.}

Evergreen low branching shrubs, with thick, opposite, crowded, imbricate, 4-ranked leaves and axillary nodding flowers. Sepals usually 5, not bracted, imbricate, thickened at the base. Corolla campanulate, usually 5-lobed. Stamens 8-10, included; anthers attached to the filaments near the apex; sacs opening by large terminal pores and tipped with recurved awns. Disk 10crenate. Ovary 4-5-celled; style slender, somewhat thickened below. Capsule globose or ovoid, loculicidal, 4-5-valved.

Leaves with a deep furrow on the back.

Leaves without furrow on the back.

1. C. tetragona (L.) D. Don. Tufted shrub, with ereet or ascending branches, 1-3 dm. high; leaves very thick, ovate, $2-5 \mathrm{~mm}$. long, more or less pubescent; peduncles $1-2.5 \mathrm{~cm}$. long, glabrous or nearly so; sepals ovate, $2-2.5$ $\mathrm{mm}$. long, acute; corolla white or rose-eolored, $5-6 \mathrm{~mm}$. long. Wet places: Greenl.-Lab.-B.C.-Alaska; Eurasia. Subalp.-Alp. Jl-Au.

2. C. Mertensiana (Bong.) D. Don. Tufted shrub, with ascending branches, 1-3 dm. high; leaves ovate, 2-4 mm. long, round-keeled on the back, glabrous or nearly so; peduncles $1-1.5 \mathrm{~cm}$. long, glabrous or puberulent; sepals $2-3 \mathrm{~mm}$. long, ovate, usually pinkish, acute; corolla $5-8 \mathrm{~mm}$. long, white or slightly tinged with rose. Wet places in the mountains: Alaska-n Calif-Mont.-Alta. Subalp.-Alp. Jl-Au.

\section{GaUlthìria (Kalm) L. Creeping Wintergreen.}

Shrubs or undershrubs, with alternate evergreen leaves. Flowers perfect, solitary, axillary, or in axillary racemes. Hypanthium and calyx enlarging and becoming fleshy, enclosing the capsule and forming a berry-like fruit. Sepals 5 . Corolla campanulate or urn-shaped. Stamens 10; filaments dilated below, included; anther-sacs opening by terminal pores, 2-awned or 2-pointed. Disk 10-toothed. Ovary and capsule 5-celled, 5-lobed,

Glabrous; leaves oval or orbicular.

Calyx, pedicels, and upper part of the stem sparingly hirsute; leaves ovate.

1. G. humifusa.

2. G. ovatifolia,

1. G. humifusa (Graham) Rydb. Cespitose, depressed, procumbent undershrub, 3-10 $\mathrm{cm}$. high, glabrous; leaf-blades finely crenate or entire-margined, 1-2 $\mathrm{cm}$. long; corolla open-campanulate, 5 -lobed, white, about $3 \mathrm{~mm}$. long; filaments glabrous; fruit scarlet, $5-6 \mathrm{~mm}$. in diameter. G. Myrsinites Hook. Wooded mountain sides: B.C.-Calif.-Colo.-Alta. Submont.-Subalp. Jl.

2. G. ovatifolia A. Gray. Low depressed shrub, 1-2 dm. high, with more or less hirsute stems; leaf-blades ovate, acute, serrate, glabrous, rather thick, 
1.5-3.5 $\mathrm{cm}$. long; pedicels one-flowered; corolla white, about $4 \mathrm{~mm}$. long; fruit searlet, 7-8 mm. in diameter. Woods: B.C.-Ore.-Ida. Submont. Je-J.

\section{ARCtòus (A. Gray) Niedzu. Alpine Bearberry.}

Low cespitose shrubs, with shreddy bark and alternate deciduous leaves, clustered towards the ends of the branches. Flowers few, in fascicles from terminal scaly buds. Sepals 4-5, short. Corolla globose-urceolate, 4-5-toothed. Stamens 8-10, included; anther-sacs with 2 recurved dorsal awns. Fruit drupaceous, with 4-5 1-seeded nutlets. [Mairiania Neck.]

Fruit black; corolla-lobes ciliate; leaves less than $3 \mathrm{~cm}$. long. Fruit red; corolla-lobes not ciliate; leaves usually more than $3 \mathrm{~cm}$. 1ong.

1. A. alpina.

2. A. erythrocarpa.

1. A. alpina (L.) Niedzu. Depressed-prostrate shrub, with branches 5-12 $\mathrm{cm}$. high; leaf-blades spatulate or obovate, tapering below into short petioles, $2-3 \mathrm{~cm}$. long, 1-1.5 cm. wide, crenate, strongly veined, glabrous, except the ciliate margin; corolla white or pink; fruit 5-7 mm. in diameter, bluish black when ripe. Arctostaphylos alpina (L.) Spreng. In alpine-arctic localities: Greenl.-N.H.B.C.-Alaska; Eurasia. Subalp.-Alp. My-Je.

2. A. erythrocarpa Small. A depressed shrub, 1-2 cm. high; leaf-blades spatulate, $3-6 \mathrm{~cm}$. long, tapering below into short petioles, crenate, glabrous, not ciliate; corolla white or pinkish, turning yellowish; fruit 7-10 $\mathrm{mm}$. in diameter, bright red. Mountains: Alta.-B.C.-Yukon. Subalp.-Alp. My-Je.

\section{ARCTOStÁPhylos Adans. Bearberry, Kinnikinick, Manzanita.}

Shrubs or small trees, with alternate, thick, evergreen leaves. Flowers perfect in terminal, bracteolate racemes, often pendulous. Sepals 5 , persistent. Corolla urn-shaped, with 4-5 recurved lobes. Stamens 8-10; filaments dilated and hairy at the base; anthers with 2 reflexed awns on the backs, opening by terminal pores. Ovary 4-10-celled, with a single pendulous ovule in each cell. Fruit drupaceous, either with a 1-8-seeded stone or 1-8 one-seeded more or less coalescent stones. [Uva-ursi Mill.]

Depressed creeping glabrous plant, with spatulate leaves.

Erect shrubs or trees, 1-6 m. high, with oval leaves.

Young branches puberulent; leaves usually pungent-cuspidate,

Branches glabrous; leaves usually not cuspidate.

1. A. Uva-ursi.

2. A. pungens.

3. A. platyphylla.

1. A. Uva-ursi (L.) Spreng. 'Depressed and trailing, diffusely branched shrub, forming patches 1-2 m. across; leaves short-petioled, coriaceous; blades spatulate, entire-margined, obtuse, glabrous or nearly so, 1-3 cm. long, finely reticulate; racemes short and crowded; sepals ovate, acute; corolla ovoid-urnshaped, white, about $4 \mathrm{~mm}$. long; fruit rather dry, insipid, mealy, red, 6-10 mm. in diameter. Woods: Lab.-N.J.-Colo.-Calif.-Alaska; Eurasia. Submont. -Mont. My-Je.

2. A. pungens H.B.K. Shrub 1-7 m. high, with puberulent branches; leaf-blades very thick, entire-margined, elliptic or oval, rounded at the base, pungent, acuminate at the apex, glabrous above, minutely puberulent beneath, $1.5-3 \mathrm{~cm}$. long; sepals ovate; corolla 5-6 mm. long; fruit $8 \mathrm{~mm}$., rarely $10 \mathrm{~mm}$. in diameter. Wooded mountains: Mex.-N.M. - s Utah - s Calif. Son. Ap-My.

3. A. platyphylla (A. Gray) Rydb. Shrub about $1 \mathrm{~m}$. high, with glabrous branches; leaf-blades ovate, entire-margined, merely acute, 2-4 cm. long, thick and light green; sepals ovate, obtuse or acutish; corolla about $6 \mathrm{~mm}$. long; fruit usually $1 \mathrm{~cm}$. or more in diameter. Woody mountain sides: e Colo.-UtahCalif. Son.-Mont. My-J.

\section{Family 99. VACCiniaceae. Huckleberry Family.}

Shrubs or small trees, or rarely delicate vines. Leaves alternate, simple, sometimes evergreen. Flowers perfect, clustered or solitary. Hypanthium well developed, more or less completely enclosing and adnate to the ovary. 
Sepals 4 or 5. Corolla usually gamopetalous, 5- or 4-lobed, rarely of free petals. Stamens twice as many as the lobes of the calyx or corolla. Gynoecium of 5 or 4 united carpels. Ovary 4-10-celled, inferior, crowned by an epigynous disk. Fruit a berry or drupe, pulpy.

Petals united into a gamopetalous corolla.

Ovary half-inferior; berry white, acute; low creeping plants.

Ovary wholly inferior; berry blue, black, or red, rounded; shrubs or undershrubs. Filaments glabrous; anthers 2-awned on the back; leaves deciduous.

Filaments pubescent; anthers awnless.

2. VACCINIUM.

Ovary and berry incompletely 10-celled, by a false partition, intruding from the back of each cell; leaves thin, deciduous.

3. OYanOCOCCUS. Ovary and berry 4 - or 5-celled; no false partitions; leaves leathery, persistent,

Petals distinct; delicate prostrate vines.

4. VITIS-IDAEA.

5. OXYCOCCUS.

\section{Chiógenes Salisb. Creeping Snowberry, Moxie Plum, Capillatre.}

Evergreen shrubs, with prostrate stems. Leaves alternate, 2-ranked. Flowers solitary, subtended by two bracts. Sepals 4, free. Corolla campanulate, with 4 rounded lobes. Stamens 8, included; filaments rough; anthers awnless; sacs not prolonged into tubes at the apex. Ovary and berry 4-celled, the latter white, mealy.

1. C. hispidula (L.) T. \& G. Stems slender, creeping, 1-3 dm. long, strigose; leaves short-petioled, dark green and glabrous above, pale and with scattered brown appressed hairs beneath, ovate, acute, $3-6 \mathrm{~mm}$. long; pedicels very short; corolla short-campanulate, $1.5-2 \mathrm{~mm}$. long; berry hispid, $5-6 \mathrm{~mm}$. in diameter. Cold woods: Newf.-N.C.-Mich.-Ida.-B.C. Boreal. My-Je.

\section{Vaccínium L. Bilberry, Whortleberry, Huckleberry.}

Low shrubs, with alternate, thin, deciduous leaves. Flowers on drooping pedicels, solitary or two to four together. Calyx-lobes 5 or 4 , small. Corolla more or less urceolate, 5- or 4-toothed, rose-colored or white. Filaments glabrous; anthers 2-awned on the back, included. Stamens 8-10. Ovary and fruit 4-5-celled, without false partitions. Fruit sweet and edible, blue, black, or red, with or without a bloom.

Branches not angled.

Leaves entire-margined.

Leaves broadly obovate or oval, strongly reticulate.

Leaves oblong-obovate to oblanceolate, $1 . V$. uliginosum.

Leaves serrate.
ranches angled.

2. V. occidentale.

3. V. caespitosum.

Fruit purplish, black, or blue; leaves more than $1 \mathrm{~cm}$. long.

Corolla depressed-globular; fruit purple; leaves obtuse or acute, crenulate or subentire.

Corolla rounded-ovoid.

Leaves subentire, obtuse; fruit blue, with a bloom. Leaves serrate, acute or acuminate; fruit black, without a bloom.
Shrub tall; leaves $2-5 \mathrm{~cm}$. long; fruit 8-10 $\mathrm{mm}$. in diameter.

4. V. globulare.

5. V. ovalifolium.

hrub low, 1-3 dm. high; leaves $1-1.5 \mathrm{~cm}$. long; frit

6. $V$, membranaceum.

Fruit bright red; leaves usually less than $1 \mathrm{~cm}$. long.

Leaves serrate, light green on both sides.

Leaves entire, dull and pale, especially beneath.

5-8 $\mathrm{mm}$. in diameter.

7. V. oreophilum.

8. V. scoparium.

9. V. parvifolium.

1. V. uliginosum L. Shrub 1-6 dm. high; leaves glabrous, green above, pale beneath, 1-2 cm. long; corolla pink, ovoid-urceolate, only slightly contracted at the throat, 4-5-toothed; berry blue, with a bloom, globose-ellipsoid, about 6 $\mathrm{mm}$. in diameter. Bogs: Greenl,-N.Y.-B.C.-Alaska; Eurasia. My-Jl.

2. V. occidentale A. Gray. Shrub 2-10 dm. high; leaves thin, $1-2 \mathrm{~cm}$. long, only slightly paler beneath; corolla ovoid-urceolate, about $5 \mathrm{~mm}$. long; berry blue, with a bloom, 4-5 $\mathrm{mm}$. in diameter. Wet places in the mountains: B.C.-Calif.-Utah-Mont. Submont.-Mont. Je-Au. 
3. v. caespitosum Michx. Shrub 0,5-3 dm. high; leaves rather thin, obovate, cuneate or oblanceolate, glabrous; corolla ovoid-urceolate, 4-5 mm. long; berry blue, with a bloom, $6-8 \mathrm{~mm}$. in diameter. Alpine-arctic situations: Lab.-N.H.-Colo.-B.C. Subalp.-Alp.

4. V. globulare Rydb. Shrub 3-8 dm. high; leaf-blades $1-4 \mathrm{~cm}$. long, thin, broadly oval or obovate, somewhat paler beneath; corolla yellowish white, about $6 \mathrm{~mm}$. in diameter; berry dark purplish blue, $6-8 \mathrm{~mm}$. in diameter. Woods: B.C.-Ore-Utah-Mont. Submont-Mont. My-Jl.

5. v. ovalifolium Smith. Shrub $2-3.5 \mathrm{dm}$. high; leaf-blades elliptic, oval, or oblong-oval, entire-margined, bright green above, pale beneath, $3-5 \mathrm{~cm}$. long; corolla ovoid-urceolate, about $8 \mathrm{~mm}$. long and $5-6 \mathrm{~mm}$. in diameter; berry 8-10 $\mathrm{mm}$. in diameter. Woods: Alaska-Ore.-Mich.-Que. Submont.-Mont, My-J.

6. V. membranaceum Dougl. Shrub 3-15 dm. high; leaf-blades thin, oval, only slightly paler beneath, $3-5 \mathrm{~cm}$. long; corolla ovoid-urceolate, about $5 \mathrm{~mm}$. long, $4 \mathrm{~mm}$. wide; berry $8-10 \mathrm{~mm}$. in diameter. V. myrtilloides Hook. Woods: B.C.-Calif.-Wyo.-Mich. Submont.-Mont. Je-Jl.

7. V. oreophilum Rydb. Shrub 1-3 dm. high; leaf-blades ovate or oval, thin, veiny, green on both sides, $1-1.5 \mathrm{~cm}$. long; corolla ovoid-urceolate, about $4 \mathrm{~mm}$. long; berry $5-8 \mathrm{~mm}$. in diameter. V. Myrtillus Hook., not L. Mountain woods: B.C.-N.M.-Alta. Mónt.-Alp. Je.

8. V. scoparium Leiberg. Shrub 1-2 dm. high; leaf-blades light green, thin, $1 \mathrm{~cm}$. or less, ovate or lance-ovate, acute at both ends, serrulate; corolla ovoid-urceolate, $3 \mathrm{~mm}$. or less long; berry red, about $5 \mathrm{~mm}$. in diameter. $V$. erythrococcum Rydb. Grouse-Berry. Mountain sides: B.C.-Calif.-Colo.Alta. Submont,-Subalp. Je-ת.

9. V. parvifolium Smith. Shrub 2-4 m. high; branches green, sharply angled; leaves oblong or oval, obtuse or rounded at both ends, pale and dull, entire, 6-20 $\mathrm{mm}$. long; corolla globular; pedicels nodding in fruit; berry light red, rather dry. Shady woods: Calif.-Ida.-B.C.-Alaska. Submont.-Mont.

\section{Cyanocôccus (A. Gray) Rydb. Blueberry.}

Shrubs with alternate, thin, deciduous leaves. Flowers in fascicles or very short racemes, developed with the leaves, from separate scaly buds; bracts and bractlets sealy, mostly deciduous. Calyx-lobes 5, usually small. Corolla in ours campanulate, white or slightly rose-colored; lobes 5 . Stamens 10; filaments hairy; anthers awnless. Ovary and fruit incompletely 10-celled, by false partitions or projections from the back of each carpel; berry blue or black, with a bloom, sweet and edible, many-seeded.

Leaves entire, as well as the branches pubescent.
Leaves serrate, glabrous, except sometimes the veins and margins; branches glabrous or with pubescent lines.

2. C. pennsylvanicus.

1. C. canadensis (Richards.) Rydb. Shrub 3-6 dm. high; leaves broadly lanceolate, acute at both ends, softly pubescent, especially beneath, $2-4 \mathrm{~cm}$. long, 8-18 mm. wide; corolla cylindro-campanulate, about $4 \mathrm{~mm}$. long and $3 \mathrm{~mm}$. in diameter; berry bluish black, with a bloom, $5-8 \mathrm{~mm}$. in diameter. Vaccinium canadense Richards. Moist places: Lab.-Va.-Ill.-Sask. Boreal. My-Je.

2. C. pennsylvanicus (Lam.) Rydb. Shrub 1-4 dm. high, with warty branches; leaves oblong or oblong-lanceolate, slightly pubescent on the veins beneath and the margins, acute at both ends, $2-4 \mathrm{~cm}$. long; corolla as in the preceding; berry 6-10 $\mathrm{mm}$. in diameter, bluish black, with a bloom, very sweet. V. pennsylvanicum Lam. Hillsides and woods: Newf.-N.J.-Ill.- Sask. Boreal. $\mathrm{My}-\mathrm{Je}$.

\section{Vìtis-IDAÈA (Tourn.) Moench. Mountain Cranberry, SWedish Cranberry.}

Low shrubs, with coriaceous, persistent leaves. Flowers in short racemes from separate buds. Calyx-teeth small, 4 or 5 . Corolla urceolate or campanu- 
late, 4- or 5-toothed. Stamens 8-10; filaments hairy; anthers awnless. Ovary and fruit 4-5-celled, without false partitions. Fruit in ours red, sour.

1. V. Vitis-Idaea (L.) Britton. Low shrub, 1-5 dm. high; leaves thick, persistent, dark green and shining above, pale and black-dotted beneath, glabrous, obovate or oval, obtuse or rounded at the apex; 5-15 mm. long, with revolute margins; corolla eampanulate, about $4 \mathrm{~mm}$. long, 4-lobed; stamens 8; berry 8-10 $\mathrm{mm}$. in diameter, red. Vaccinium Vitis-Idaea L. Rocky places and open woods: Greenl.-Mass.-Alta.-Alaska; Eurasia. Je-Jl.

\section{OXYCócCus (Tourn.) Hill. Cranberry.}

Delicate trailing or creeping vines. Leaves alternate, persistent, entire, leathery, with more or less revolute margins. Flowers solitary or few together, on slender pedicels. Sepals 4. Petals 4, pink or red, distinct, narrow, and recurved. Stamens 8; anther-sacs produced into slender tubes, opening with terminal pores. Ovary and fruit 4-celled. Fruit globose or ellipsoid, red, sour.

Leaves ovate or lanceolate, 4-8 mm. long; fruit globose; bracts subulate or filiform.

Leaves strongly revolute, acute; fruit 6-9 mm. in diameter; flowers strictly terminal.

Leaves not revolute, mostly obtusish; fruit $10-12 \mathrm{~mm}$ i. O. Oxycoccus. surpassed by a leafy shoot.

Leaves elliptic or oblong, obtuse, 6-14 mm. long; flowers mostly iateral; bractlets lanceolate or oblong, foliaceous; fruit rounded-ellipsoid. $\quad 3.0$. macrocarpus.

1. O. Oxycoccus (L.) MacM. Stems slender, creeping and rooting, 1-4 dm. long; leaves thick, rounded or cordate at the base, dark green above, white beneath, 4-6 mm. long; flowers in small umbel-like corymbs from sealy terminal buds; petals oblong, 5-7 mm. long; berry globose, $6-9 \mathrm{~mm}$. in diameter, usually spotted. Vaccinium Oxycoccus L. Oxycoccus palustris Pers. Cold bogs: Greenl.-N.J.Mich.-Wash.-Alaska. Boreal-Subarctic. My-Jl.

2. O. intermedius (A. Gray) Rydb. Stems coarser than in the preceding, 3-6 dm. long; leaves thick, broadly ovate or oval, rounded or cordate at the base, green above, white beneath, slightly revolute, $8-12 \mathrm{~mm}$. long; berry globose, $10-$ $12 \mathrm{~mm}$. in diameter. V. Oxycoccus intermedius A. Gray. In bogs: AlaskaWash.-Ida.; e Asia. My-Je.

3. O. macrocarpus (Ait.) Pers. Stems 3-10 dm. long; leaves oblongelliptic, usually rounded at both ends, $8-15 \mathrm{~mm}$. long, green above, pale beneath, slightly revolute; inflorescence racemose from a terminal bud, nearly always produced into a leafy branch; berry nearly always longer than broad, 10-18 $\mathrm{mm}$. in length, not spotted. Bogs: Newf.-N.C.-Minn.-Sask. Boreal. Je-Au.

\section{Family 100. PRImUlaceae. Primrose Family.}

Caulescent or scapose herbs. Leaves opposite, alternate, or whorled, without stipules. Flowers perfect, in ours regular. Sepals'4-9, partially united. Corolla hypogynous, usually gamopetalous, or rarely wanting; lobes 4-9. Stamens as many as the calyx-lobes and alternate with them, partly adnate to the corolla-tube or the calyx; filaments sometimes united at the base. Pistil single; ovary free or nearly so, 1-celled, with a central placenta. Fruit a 1-celled capsule, opening by 2-8 valves.

Ovary wholly superior and free.

Corolla present.

Corolla-lobes erect or spreading; stamens distinct, except in Lysimachia.

Corolla salverform or funnelform, its lobes imbricate; stamens included; plants scapose; leaves in rosettes, either on the basal crown or at the ends of short branches of the caudex.

Corolla-tube equalling or exceeding the calyx; style filiform.

Truly scapose perennials, simple, bearing a single tuft of leaves on the short crown; seeds numerous.

1. Primula.

Low suffruticose perennials; leaves rosulate or imbricate at the ends of the branches of the caudex; seeds few. 2 . DOUglasia.

Corolla-tube shorter than the calyx, its throat constricted; style very short. Cespitose, rosulate perennials; capsule few-seeded. 3. DROSACE. 
Scapose annuals; capsule many-seeded.

4. ANDROSACE.

Corolla rotate, its lobes convolute or involute in bud; stamens exserted; plants leafy-stemmed.

Capsule opening lengthwise; erect plants.

Flowers mostly 7-merous; corolla white; proper leaves clustered near the top of the stem, the lower ones reduced. 5. TRIENTALIS.

Flowers mostly 5-merous; leaves scattered on the stem, opposite or verticillate.

Staminodia wanting; filaments united at the base; flowers solitary or racemose.

6. LYSIMACHIA.

Staminodia present; filaments distinct.

Flowers solitary; staminodia conspicuous; corolla-lobes broad.

7. STEIRONEMA.

Flowers in short axillary spikes; staminodia tooth-like; corollalobes long and linear.

8. NAUMBURGia.

Capsule circumscissile; low depressed herbs.

Corolla longer than the calyx; fllaments pubescent, adnate to the base of the corolla.

9. ANagallis.

Corolla shorter than the calyx; filaments glabrous, adnate to the corolla-

tube.
Corolla-lobes reflexed; stamens more or less monadelphous; plants scapose.

10. Centunculus.

12. DODEcatheon.

Corolla wanting; calyx with 5 petaloid lobes; flowers solitary, sessile, axillary.

Ovary partly inferior, the lower portion included in and adnate to the hypanthium; plant leafy-stemmed.

13. SAMOLUS.

\section{Prímula L. Primrose, Cowslip.}

Perennial scapose herbs. Leaves all in a basal rosette. Flowers in ours umbellate. Calyx tubular, campanulate or funnelform, persistent, usually angled, 5-lobed, the lobes imbricate. Corolla salver-shaped or trumpet-shaped, with a funnelform throat, the tube longer than or equalling the calyx. Stamens 5 , distinct, inserted in the tube or the throat of the corolla. Style filiform; stigma capitate. Capsule 1-celled, 5-valved at the apex, many-seeded.

Bracts of the involucres more or less gibbous at the base; lobes of the corolla deeply 2cleft.

Plant usually less than $1 \mathrm{dm}$. high, rarely mealy.

Calyx about one-half as long as the corolla-tube; lobes oblong, obtuse; leaves thin.

1. P. mistassinica.

Calyx at least two-thirds as long as the corolla-tube; lobes acutish; leaves rather

thick.
Plant taller, 1-4 $\mathrm{dm}$. Migh, usually more or less mealy; leaves oblong or oblong-spatu-

2. P. MacCalliana. late.

Bracts lanceolate, thick, obtusish.

3. $P$. incana.

Bracts linear-subulate, thin.

4. P. specuicola.

Bracts of the involucres not gibbous below; lobes of the corolla merely emarginate or notched, or entire.

Plant less than $1 \mathrm{dm}$. high, 1-few-flowered; flowers less than $2 \mathrm{~cm}$. long.

Scape usually 1 -flowered, rarely 2 -flowered; bracts subulate, small, less than $5 \mathrm{~mm}$. long.

Scapes 2-4-flowered; bracts conspicuous, oblong, more than $5 \mathrm{~mm}$. long.

Plant 1.5-5 dm. high, many-flowered; flowers more than $2 \mathrm{~cm}$. long.

6. P. Broadheadae.

$$
\text { 7. P. Parryi. }
$$

1. P. mistassinica Michx. Leaf-blades spatulate or obovate, denticulate or repand, 1-3 cm. long, obtuse or rounded at the apex; seape $1-1.5 \mathrm{dm}$. high, slender; bracts subulate; calyx-lobes nearly as long as the tube; corolla pink or pale purple; lobes of the limb usually 4-5 mm. long, obcordate. Wet banks: Greenl.-Nev.-Minn.-Alta. Boreal. My-Jl.

2. P. MacCalliana Wiegand. Leaf-blades broadly spatulate or obovatecuneate, rather thick, $1-2.5 \mathrm{~cm}$. long, obtuse or rounded and crenate at the apex; scape 5-12 cm. high; bracts subulate, $5 \mathrm{~mm}$. long; corolla deep rich blue, with a large orange eye; lobes $5-6 \mathrm{~mm}$. long, broadly obcordate. Wet places in the Rockies: Alta.-B.C. Mont. Je.

3. P. incana M. E. Jones. Leaf-blades oblong or oblong-oblanceolate or spatulate, $2-8 \mathrm{~cm}$. long, obtuse at the apex, sinuate-dentate or subentire, more or less mealy beneath; scape 1-3 dm. high; bracts 6-10 mm. long; calyx 6-8 mm. long, nearly equalling the corolla-tube, more or less mealy; lobes oblong, obtuse or acutish; corolla lilac, $8-9 \mathrm{~mm}$. long; lobes obcordate, $2-3 \mathrm{~mm}$. long. $P$. amer- 
icana Rydb. Swamps and wet meadows: Sask.-Colo.-Utah-Alta. Submont. Je-Au.

4. P. specuicola Rydb. Leaves $5-13 \mathrm{~cm}$. long, thin, slightly farinose when young, in age glabrate, spatulate or elliptic, obtuse at the apex, sinuate-dentate; scape $1-1.5 \mathrm{~cm}$. long; umbels $10-20$-flowered; bracts $5-10 \mathrm{~mm}$. long; calyx densely farinose; tube deeply campanulate, $3-5 \mathrm{~mm}$. long; lobes linear-oblong, $2.5-3.5$ $\mathrm{mm}$. long, obtusish; corolla-tube yellowish; lobes cuneate, merely emarginate, with a broad sinus, dark violet, about $3 \mathrm{~mm}$. long. Under overhanging eliffs: s Utah. Son. F-Je.

5. P. angustifolia Torr. Leaf-blades from linear-oblanceolate to spatulate, 1-5 cm. long, glabrous and fleshy, entire-margined, obtuse; scape $1-5 \mathrm{~cm}$. high, usually 1-flowered; calyx three-fourths as long as the corolla-tube to almost equalling it; calyx-tube obconic; lobes linear-lanceolate, acute; corolla about $1 \mathrm{~cm}$. long; lobes emarginate, $5-8 \mathrm{~mm}$. long. Alpine peaks: Colo. Alp. Je-Jl.

6. P. Broadheadae M. E. Jones. Leaf-blades elliptic, $2-8 \mathrm{~cm}$. long, glabrous, entire-margined, rather thick, rounded at the apex; scape $5-10 \mathrm{~cm}$. high, 1-4-flowered; calyx half as long as the corolla-tube, about $6 \mathrm{~mm}$. long; lobes lanceolate, acute; corolla purple; lobes rounded, emarginate, 4-6 $\mathrm{mm}$. long. Marshy places: Ida.-Utah. Submont.-Mont. My-Je.

7. P. Parryi A. Gray. Leaf-blades oblong or oblanceolate, 5-15 cm. long, fleshy, puberulent, callous-denticulate or entire, acute or obtuse and mucronate; scape 1-3 dm. high, several- to many-flowered; bracts lanceolate, $0.5-2 \mathrm{~cm}$. long; calyx usually shorter than the corolla-tube; lobes lanceolate, acuminate; corolla strongly scented, $12-15 \mathrm{~mm}$. long, purple; lobes rounded, notched. Wet places among rocks and along streams: Mont.-Colo.-Ariz.-Ida. Submont.-Subalp.

\section{DOUglásia Lindl. Mountain Pink.}

Depressed and tufted perennials, with suffruticose bases. Leaves imbricate and crowded at the ends of the branches. Flowers in small umbels, sometimes reduced to one flower. Calyx campanulate, persistent, 5-lobed. Corolla salvershaped; tube equalling or surpassing the calyx; throat more or less contracted, and 5-fornicate within. Stamens included, with short filaments. Style filiform; ovary 1-celled, 5-ovuled. Capsule 1-2-seeded.

Peduncles with several flowers in an umbel; leaves stellate-pruinose, not ciliate.

Peduncles 1-3-flowered; leaves ciliolate on the margins.

1. D. nivalis.

2. D. montana.

1. D. nivalis Lindl. Plant 5-10 cm. high, 3-4-chotomously branched, with several successive tufts of leaves; leaves thick, sessile, linear, obtusish, stellatepruinose, not ciliate, $6-12 \mathrm{~mm}$. long; bracts similar to the leaves, but shorter; calyx shorter than the corolla-tube; lobes lanceolate, acute; corolla 7-8 $\mathrm{mm}$. long; lobes oval, about $4 \mathrm{~mm}$. long. High mountains: B.C.-Wash.-Alta. Alp.

2. D. montana A. Gray. Cespitose perennial; leaves $3-8 \mathrm{~mm}$. long; peduncles $0.5-3 \mathrm{~cm}$. long; bracts subulate; calyx equalling the corolla-tube; lobes lanceolate; corolla purple or lilac, 6-8 mm. long; lobes cuneate or obovate, 3-4 $\mathrm{mm}$. long. D. biflora A. Nels. Mountain tops and dry hills: Mont.-Wyo.Ore. Submont.-Subalp. My-Jl.

\section{DRÓSACE A. Nels.}

Tufted perennials, with a cespitose caudex. Leaves rosulate at the ends of the branches. Flowers umbellate, on short scapes. Calyx campanulate, persistent. Corolla white, with a yellow eye, short salver-shaped; tube shorter than the calyx; throat more or less constricted. Stamens 5, included. Style short; stigma capitate. Capsule few-seeded.

Leaves without thickened midrib, linear-oblanceolate, about $1 \mathrm{~cm}$. Iong; pedicels much longer than the calyx, nearly equalling the bracts.

Leaves oblanceolate, about $5 \mathrm{~mm}$. long, at least the

1. D. albertina. on the under side; pedicels shorter than the calyx.

2. D. carinata. 
1. D. albertina Rydb. Cespitose perennial, but scarcely pulvinate; leaves narrowly oblanceolate, about $1 \mathrm{~cm}$. long, sparingly ciliate; seape $5-10 \mathrm{~cm}$. long, slender, sparingly hairy; bracts linear-lanceolate, 3-4 mm. long; calyx-lobes elliptic, obtuse; corolla-lobes 2-3 mm. long. Androsace albertina Rydb. High mountains: Alta.-Mont. Subalp. Je-Au.

2. D. carinata (Torr.) A. Nels. Densely tufted and pulvinate perennial; leaves numerous, crowded, oblanceolate, $4-6 \mathrm{~mm}$. long, acute, ciliate; scape 1-5 $\mathrm{cm}$. high, white-hirsute; bracts oblong or linear, about $5 \mathrm{~mm}$. long; calyx-lobes oval or oblong, obtuse; corolla white or yellowish, with a yellow eye; lobes oval, 3-4 mm. long. A. Chamaejasne A. Gray, not Host. A. carinata Torr. Douglasia Johnstoni A. Nels. High mountains: Colo.-Utah-Alta. Mont.-Alp. $\mathrm{Je}-\mathrm{Jl}$.

\section{ANDRÓSACE (Tourn.) L.}

Small scapose annuals. Leaves rosulate at the base of the stem. Flowers umbellate, inconspicuous. Calyx campanulate or turbinate, persistent, 5 -lobed or 5-parted. Corolla salver-shaped, almost funnelform; tube shorter than the calyx; throat constricted; lobes of the limb 5, imbricate in the bud. Stamens 5, included, with short filaments. Style very short; stigma capitate. Capsule short, 5-valved; seeds usually many.

Calyx-tube in fruit obpyramidal, its green teeth surpassing the capsule.

Bracts of the involucre ovate or oblong.

Calyx-teeth longer than the tube; leaves linear-oblanceolate, thin.

Calyx-teeth shorter than the tube; leaves spatulate or oblanceolate, thicker. $\begin{array}{ll}\text { Scapes and pedicels several, diffuse or ascending. } & \text { 2. A. occidentais } \\ \text { Scape single, 1-4-flowered, erect; pedicels almost erect. } & \text { 3. A. simplex. }\end{array}$

Bracts of the involucre lanceolate or subulate.

Calyx-teeth erect, lanceolate, usually shorter than the tube.

Peduncles, pedicels and calyx-lobes densely puberulent, the latter exceeding the fruit.

4. A. puberulenta.

Peduncles and pedicels sparingly puberulent or glabrous; calyx-lobes glabrous or nearly so, not exceeding the fruit.

Corolla longer than the calyx.

Peduncles 1-2 dm. high, many times longer than the strongly ascending

or suberect pedicels.
Calyx-lobes triangular, less than half as long as the calyx-tube.

5. A. septentrionalis.

Calyx-lobes lanceolate, more than half as long as the calyx-tube.

Peduncles less than $3 \mathrm{~cm}$. high, often equalled or exceeded in length by the spreading pedicels. 7 . A. subumbellata.

Corolla shorter than the calyx.

8. A. diffusa.

Calyx-teeth more or less spreading, ovate-triangular, foliaceous, equalling or exceeding the whitish tube; corolla shorter than the calyx. 9. A. subulifera. Calyx-tube in fruit hemispherical; teeth broadly triangular.

10. A. filiformis.

1. A. arizonica A. Gray. Leaves oblanceolate, 5-15 mm. long, acute, entire or denticulate, thin, minutely puberulent; scapes usually few, ascending or erect, slender, $3-8 \mathrm{~cm}$. high; bracts broadly spatulate or oval, usually acute, 2-6 mm. long; pedicels ascending; calyx-lobes lanceolate to ovate, $2-3 \mathrm{~mm}$. long, rather spreading; corolla much shorter than the calyx. Plains and valleys: Ariz.-Utah. Son. Mr-My.

2. A. occidentalis Pursh. Leaves oblanceolate or spatulate, $5-15 \mathrm{~mm}$. long, entire or denticulate, puberulent; scapes $2-6 \mathrm{~cm}$. high, puberulent; bracts spatulate, obtuse, about $5 \mathrm{~mm}$. long; pedicels ascending or spreading; calyx-lobes lanceolate, ascending; corolla much shorter than the calyx. In dry or sandy soil: Man.-Ill.-Mo.-Tex.-B.C. Plain-Submont. Ap-Je.

3. A. simplex Rydb. Leaves oblanceolate, $3-6 \mathrm{~mm}$. long, acute, entire, minutely puberulent; scape 2-7 $\mathrm{cm}$. high; bracts oval or lance-oval, 2-4 mm. long; pedicels suberect; calyx-lobes lanceolate, about $1.5 \mathrm{~mm}$. long, acute; corolla small, shorter than the calyx. Poor soil: B.C.-Utah-Alta. Son.-Submont. Ap-My.

4. A. puberulenta Rydb. Leaves oblanceolate, 1-3 cm. long, acute, entire or sinuatelý denticulate; peduncles $3-10 \mathrm{~cm}$. long; bracts narrowly lanceolate, 3-4 mm. long; pedicels spreading; calyx-lobes lanceolate, strongly keeled; corolla 
white, about equalling the calyx. Hills and mountains: Yukon-Sask.-N.M. -Ariz. Plain-Submont.

5. A. septentrionalis L. Leaves oblanceolate or oblong, acute, dentate or entire, rather thick, 1-2 $\mathrm{cm}$. long; scapes $1-2 \mathrm{dm}$. high, slightly puberulent; bracts subulate, $3-4 \mathrm{~mm}$. long; calyx-lobes triangular, scarcely $1 \mathrm{~mm}$. long, glabrous or nearly so; corolla about $4 \mathrm{~mm}$. long, exceeding the calyx. Sandy plains and banks: Hudson Bay-Alta.-Wyo.-Ida.-Alaska; Eurasia. Boreal. MyJe.

6. A. pinetorum Greene. Closely resembling the preceding and scarcely distinet; scapes more numerous, 1-1.5 dm. high; calyx-lobes longer and narrower, sometimes $1.5 \mathrm{~mm}$. long. Pine woods: Colo.-N.M. Submont.-Subalp. $\mathrm{My}-$ Jl.

7. A. subumbellata (A. Nels.) Small. Leaves oblanceolate, acute, thin, entire or denticulate, puberulent, 1-2 $\mathrm{cm}$. long; bracts subulate, $2-3 \mathrm{~mm}$. long; pedicels $1-5 \mathrm{~cm}$. long; calyx-lobes lanceolate, scarcely $1 \mathrm{~mm}$. long; corolla nearly $4 \mathrm{~mm}$. long, slightly exceeding the calyx. Mountains, especially in gravelly soil: Hudson Bay-Colo.-Ariz.-B.C. Submont.-Subalp. Jl-S.

8. A. diffusa Small. Leaves oblanceolate, acute, entire or denticulate, puberulent; scapes many, ascending, $3-15 \mathrm{~cm}$. high; bracts subulate, $2-3 \mathrm{~mm}$. long; pedicels glabrous, spreading, $2-7 \mathrm{~cm}$. long; calyx-lobes lanceolate, nearly 1 $\mathrm{mm}$. long; corolla scarcely $3 \mathrm{~mm}$. long, shorter than the calyx. A. elongata Richards., not L. Hills and plains: Mack.-N.M.-Ariz.-B.C. Submont.Mont. My-Jl.

9. A. subulifera (A. Gray) Rydb. Leaves oblanceolate, thin, acute, puberulent, usually dentate, acute at the apex, 1-4 cm. long; scapes several, $5-15 \mathrm{~cm}$. long, slightly puberulent or glabrous; bracts subulate, $2-7 \mathrm{~mm}$. long; pedicels $3-$ $10 \mathrm{~cm}$. long, spreading; calyx-lobes 1-3 mm. long, more or less foliaceous; corolla shorter than the calyx. A. septentrionalis subulifera A. Gray. Cañons and valleys: Alta.-Colo. Plain-Mont. Je-Au.

10. A. filiformis Retz. Leaves ovate-lanceolate or spatulate, $5-15 \mathrm{~mm}$. long, thin, usually dentate, glabrous; scapes several, 2-10 $\mathrm{cm}$. high, filiform; bracts subulate, 1-2 mm. long; pedicels $1-3 \mathrm{~cm}$. long, spreading; calyx-tube about $1 \mathrm{~mm}$. long, in fruit almost hemispheric; corolla slightly exceeding the calyx. A. capillaris Greene. Sandy or gravelly river shores or in mud: Wash. -Colo.-Mont.; Asia. Submont. $\rightarrow$ Subalp. Je-Au.

\section{TRIENTÀlis L. Starflower.}

Low perennial herbs, with rootstocks and simple stems. Leaves mostly clustered at the end of the stem, the lower leaves being much reduced or even seale-like. Flowers in the upper axils, with filiform pedicels. Sepals mostly 7 , nearly distinct, linear, imbricate. Corolla white or pinkish, rotate, deeply 5-7parted to near the base, with convolute lobes. Stamens mostly 7 ; filaments long and slender, slightly united into a ring at the base. Style filiform. Capsule with about 5 revolute valves. Seeds few.

Lower reduced leaves lanceolate to linear-subulate, acute, scale-like.

Verticillate leaves lanceolate, long-acuminate.
Verticillate leaves broadly oval or obovate, acute or abruptly acuminate.

Lower reduced stem-leaves oblanceolate or spatulate, obtuse.

1. T. americana.

2. T. latifolia.

3. $T$, arctica.

1. T. americana Pursh. Stem 1-2.5 dm. high, naked below or with a few scale-like lanceolate leaves, at the summit with a verticil of 5 -10 short-petioled or sessile leaves; blades 3-10 cm. long, thin, entire-margined or minutely crenulate; corolla 8-12 mm. wide; lobes ovate or lanceolate, acuminate. Damp woods and thickets: Lab.-Va.-Ill.-Sask. Boreal. My-Je.

2. T. latifolia Hook. Stem $0.5-2 \mathrm{dm}$. high, with a few scales below and a verticil of 4-7 short-petioled or subsessile leaves at the summit; blades 3-7 cm. long; corolla white or pinkish, $10-15 \mathrm{~mm}$. wide; lobes ovate or lanceolate, abruptly acuminate. Woods: B.C.-Calif.-Ida. Submont. Mr-My. 
3. T. arctica Fisch. Stem about $1 \mathrm{dm}$. high; upper leaves verticillate, obovate, rounded or obtuse at the apex, cuneate at the base, 1-4 cm. long, entire or nearly so; corolla $10-15 \mathrm{~mm}$. in diameter; lobes ovate. Wet places: AlaskaYukon-B.C.-Ore. Subalp. My-Jl.

\section{LYSIMÃCHIA (Tourn.) L. Loosestrife.}

Perennial or rarely annual caulescent herbs. Leaves opposite or whorled, entire, glandular-punctate. Flowers axillary, solitary or in terminal or axillary racemes. Sepals 5, practically distinct. Corolla rotate or short-funnelform, yellow, its lobes entire, convolute. Stamens 5; staminodia wanting; filaments united at the base; anthers short. Styles filiform; ovary 1-celled. Capsule globose, few-several-seeded.

1. I. terrestris (L.) B.S.P. Glabrous perennial, with a rootstock, and often bulbiferous in the axils; leaves opposite or some of them alternate, lanceolate, acute at both ends, usually black-punctate, $2-8 \mathrm{~cm}$. long; flowers in terminal bracted racemes; corolla rotate, deeply parted, yellow with purple streaks or dots, nearly as long as the sepals. L. stricta Ait. In swamps: Newf.-Ga.Ark.-Sask.-B.C. Boreal. Jl-S.

\section{STEIRONÈMA Raf. Fringed LoOsestrife.}

Perennial, caulescent herbs. Leaves opposite, or whorled above, entire, with ciliate petioles, without glandular dots. Flowers axillary, solitary, on nodding pedicels. Sepals 5 , essentially distinct. Corolla rotate, yellow, 5-lobed, the lobes erose-denticulate. Stamens and staminodia 5; filaments distinct; anthers linear. Style filiform; ovary 1-celled. Capsule round, 10-20-seeded.

1. S. ciliatum (L.) Raf. Perennial, with a horizontal rootstock; stem 3-12 $\mathrm{dm}$. high, glabrous; leaves with ciliate petioles; blades ovate or lanceolate, acute or acuminate at the apex, acute, rounded, truncate, or subcordate at the base, $5-15 \mathrm{~cm}$. long, glabrous except the ciliolate margins; peduncles axillary, $1-5 \mathrm{~cm}$. long; corolla $1.5-2.5 \mathrm{~cm}$. broad, yellow; lobes erose-denticulate, broadly obovate. Moist thickets and swamps: N.S.-Ga.-Ariz.-B.C. Plain-Submont. Je$\mathrm{Au}$.

\section{NAUMBÚRgia Moench. TUfted Loosestrife.}

Erect perennial caulescent water-herbs. Leaves opposite, entire, narrow. Flowers in axillary spikes. Sepals 5-7, linear, imbricate. Corolla yellow, deeply 5-7-parted, with narrow segments. Stamens 5-7, alternating with as many tooth-like staminodia; filaments slender, glabrous. Style slender; stigma capitate. Capsule 5-7-valved, few-seeded.

1. N. thyrsiflora (L.) Duby. Perennial, with a rootstock; stem 3-8 dm. high, simple, glabrous or slightly villous; leaves sessile, $5-10 \mathrm{~cm}$. long, lanceolate to linear-lanceolate, acute; racemes $1-2.5 \mathrm{~cm}$. long; flowers nearly sessile, crowded; corolla 4-6 mm. broad, yellow, with black spots; divisions linear. In water and swamps: N.S.-Pa.-Colo.-Calif.-Alaska; Eurasia. Plain-Submont. My$\mathrm{Jl}$.

\section{ANAGÁLlis (Tourn.) L. PoOr Man's or Shepherd's Weatherglass, Pimpernel.}

Annual or rarely perennial decumbent, eaulescent herbs. Leaves mostly opposite or whorled, entire. Flowers axillary, solitary, on slender pedicels. Calyx 5-cleft, persistent. Corolla blue, pink, or white, rotate; lobes 5, entire, convolute. Stamens 5; filaments slender, adnate to the base of the corolla, sometimes pubescent. Style filiform; stigma eapitate; ovary 1-celled; ovules half-anatropous. Capsule circumscissile, subglobose; seeds numerous.

1. A. arvensis L. A glabrous annual; stems spreading, 5-30 $\mathrm{cm}$. long, 4-angled; leaf-blades ovate or oval, 5-20 mm. long, entire, sessile or clasping; peduncles axillary, filiform, 1-2 cm. long; corolla scarlet, pink, or white, 5-7 mm. broad. Waste places: Newf.-Fla.-Calif.-B.C.; Mex.; nat. from Eurasia and Africa. Je-Au. 


\section{Centúnculus L. False Pimpernel, Chaffweed.}

Small depressed caulescent annuals. Leaves alternate or the lower opposite. Flowers minute, axillary, solitary. Sepals 4 or 5 , united below, persistent. Corolla not exceeding the calyx; tube subglobose; lobes entire, spreading. Stamens 4 or 5 , inserted in the throat; filaments dilated; anthers cordate. Ovary 1-celled; style filiform; stigma capitate. Ovules numerous, half-anatropous. Capsule subglobose, circumscissile; seeds numerous.

1. C. minimus L. Slender annual, $2-15 \mathrm{~cm}$. high; leaves subsessile, obovate or oblong, 4-8 $\mathrm{mm}$. long; flowers sessile or nearly so; sepals linear or linearlanceolate, acuminate; corolla pink; lobes lanceolate. Moist soil: Ill.-Fla.L. Calif.-B.C.; Eu. and S. Am. Plain-Submont. Ap-S.

\section{GlaúX (Tourn.) L. Black Saltwort, Sea Milkwort.}

Small caulescent herbs, perennial. Leaves opposite, entire, sessile. Flowers small, axillary. Calyx campanulate, 5-lobed; the lobes petaloid, pink or white, imbricate in the bud. Corolla wanting. Stamens 5 , inserted at the base of the calyx, alternate with its lobes; filaments filiform-subulate; anthers cordate. Capsule 5-valved at the top, few-seeded.

1. G. maritima L. Succulent leafy perennial; stems $0.5-3 \mathrm{dm}$. high, glabrous; leaves sessile, from oval to linear-oblong, 4-12 $\mathrm{mm}$. long; calyx campanulate, about 3-4 mm. long, pinkish or white; lobes oval, rounded. Saline soil: Newf.-N.J.-Colo.-Ore.-Alaska; Eurasia. Plain-Submont. Je-Au.

\section{DODECÃtheON L. Shooting Star, American Cowslip, BIRD-BILLS.}

Scapose perennials, with short rootstocks. Leaves in basal rosettes. Flowers umbellate on solitary scapes, nodding. Calyx-lobes 4 or 5 , longer than the tube, reflexed in flower. Corolla hypogynous; tube very short; lobes 5 or 4 , imbricate in the bud, reflexed, many times as long as the tube. Stamens 5 or 4, exserted; filaments usually united; anthers attached by their bases. Ovary 1-celled, free; style filiform; stigma capitate. Ovules numerous, half-anatropous. Capsule partially 5 -valved, the very apex in some species separating off as a lid. Seeds numerous.

Anthers subsessile or nearly so; tube of the flaments if any less than $0.5 \mathrm{~mm}$. long.

Leaf-blades thin, ovate, sinuately dentate, truncate, subcordate or obtuse at the base; anthers strictly sessile.

Leaf-blades thicker, linear, oblanceolate or oval, entire or minutely denticulate, gradually tapering at the base.

Filaments purple; plant with a distinct, often bulbiferous rootstock.

Leaf-blades linear or narrowly linear-oblanceolate, entire.

Plant low; corolla-lobes 10-18 mm. long.

Plant tall; corolla-lobes 20-25 mm. long. $\quad 3$. D. Jefreyi.

Leaf-blades broadly oblanceolate or elliptic; margins callous-denticulate. Filaments yellow; rootstock merely a short vertical crown, bearing the leaves and
fleshy roots; bulblets none.

Leaves glabrous.

Leaves distinctly petioled.

Scape low, few-flowered; capsule circumscissile near the apex; connective rugose.

Leaf-blades oval, elliptic, or obovate; capsule 10-12 mm. long.

Leaf-blades oblanceolate or oblong, spatulate; capsule $15-20 \mathrm{~mm}$. long.
6 . D. cylindrocarpum.

Scape tall, many-flowered; capsule opening by valves from the apex; connective
Leaves subsessile.

Leaves pubescent.

valves from the ap

8. D. pulchrum.

9. D. pubescens.

Anthers not subsessile; filaments united into a distinct tube, $1-3 \mathrm{~mm}$. long.
Leaves glabrous.

Capsule circumscissile near the apex; anthers more than twice as long as the tube of the filaments.

Filaments and throat of the corolla indigo blue; leat-blades obovate.

Filaments and throat of the corolla yellow. Petals oblong-lanceolate, obtuse or acutish.

10. D. Hendersoni.

6. D. cylindrocarpum. 
Petals lanceolate, long-acuminate.

11. D. acuminatum.

Capsule opening by valves from the apex.

Anthers more than twice as long as the short filaments.

Leaf-blades oval or oblong; bracts oblong, mostly obtuse; plant slender; flowers 1-3 (rarely 4-5).

12. D. philoscia.

Leaf-blades oblanceolate; bracts lanceolate, acute; plant usually stout and many-flowered.

Anthers less than twice as long as the filaments.

13. D. radicatum.

Whole plant glabrous.

Bracts lanceolate, acute; anthers 4-5 $\mathrm{mm}$. long, half Ionger than the filament-tube.

14. D. pauciflorum.

Bracts oblong, obtuse; anthers 3-4 mm. Iong, only slightly longer than the filament-tube. $15 . D$. salinum.

Bracts, upper part of the peduncle, and pedicels puberulent; bracts small, lanceolate, acute; anthers 3-4 mm. long. 16. D. puberulentum.

Leaves pubescent.

Plant 1-2 dm. high, usually more than one-flowered; leaves with long petioles.

17. D. Cusickit.

Plant about $5 \mathrm{~cm}$. high, usually 1-flowered; petioles obsolete. 18. D. uniflorum.

1. D. dentatum Hook. Leaves with winged petioles, $3-10 \mathrm{~cm}$. long; blades elongate-ovate, sinuate-dentate, obtuse, 3-10 cm. long, very thin, glabrous; scape 2-3 dm. high, few-flowered; calyx-tube about $5 \mathrm{~mm}$. long, glabrous; lobes lanceolate, acuminate, about $4 \mathrm{~mm}$. long; corolla white; lobes oblong, obtuse, $8-10 \mathrm{~mm}$. long; anthers about $5 \mathrm{~mm}$. long, tapering upwards, but obtuse; connective purple, smooth; capsule oblong, about $1 \mathrm{~cm}$. long, opening by valves from the apex. D. Meadia latilobum A. Gray. Rich wet soil in woods: Ore.Utah-Ida.-B.C. Je-Jl.

2. D. alpinum (A. Gray) Greene. Leaves linear-oblanceolate, $3-15 \mathrm{~cm}$. long, 5-10 mm. wide, glabrous, obtuse at the apex, entire; scape 1-3 dm. high, usually few-flowered; calyx-tube $2 \mathrm{~mm}$. long; lobes lanceolate, acute, 3-4 mm. long; corolla bluish purple; lobes lanceolate, 10-18 mm. long; anthers linear, about $7 \mathrm{~mm}$. long; connective purple, smooth; capsule oblong-ellipsoid, about $7 \mathrm{~mm}$. long, opening by valves from the summit. Mountain valleys: Calif.Utah. Submont.-Mont. Je-Au.

3. D. Jeffreyi Moore. Leaves linear or linear-oblanceolate, 1-2 dm: long, 1-2 cm. wide, glabrous, acutish, entire; scape 2-4 dm. high, several-flowered; calyx-tube 4-5 mm. long; lobes lanceolate, acute; corolla bluish purple; lobes $2-2.5 \mathrm{~cm}$. long, lanceolate; anthers about $1 \mathrm{~cm}$. long; connective smooth, purple; capsule opening by valves from the summit. ? D. dispar A. Nels. Mountain valleys: Calif.-Ida.-B.C. Submont.-Mont. Je-Au.

4. D. viviparum Greene. Leaves oblong to oblanceolate, 6-15 $\mathrm{cm}$. long, acute or obtuse, sinuately toothed; scape $1.5-4 \mathrm{dm}$. high; calyx-tube $3-4 \mathrm{~mm}$. long; lobes lanceolate, acute or acuminate; corolla purple; lobes linear, $1-2 \mathrm{~cm}$. long, acute or obtuse; anthers linear, 7-9 mm. long; connective narrow, purple; capsule circumscissile near the apex and later splitting, ovoid, about $1 \mathrm{~cm}$. long. D. crenatum Greene. Wet places in the mountains: Alaska-Mont.-Ore. Submont.-Mont. J1-Au.

5. D. conjugens Greene. Leaves glabrous, oval, elliptic, or rarely obovate, 1.5-4 cm. long, 1-2 cm. wide, rounded at the apex, abruptly contracted at the base; scape 1-2 dm. high, 1-4-flowered; calyx-tube $4 \mathrm{~mm}$. long; lobes lanceolate, acute, about $5 \mathrm{~mm}$. long; corolla from deep purple to rose or white; lobes linear, acute, 15-18 mm. long; anthers 7-8 mm. long, mostly obţuse; connective broad, lanceolate, white, rugose; capsule oblong, 10-12 mm. long, circumscissile near the apex. Moist places: Ore.-Wyo.-Mont. Submont.-Mont. Ap.

6. D. cylindrocarpum Rydb. Leaf-blades oblanceolate, or oblong-spatulate, glabrous, 4-10 $\mathrm{cm}$. long, 1-2 cm. wide, obtuse at the apex, gradually tapering below; scape 1-2 dm. high, glabrous; calyx-tube $3-4 \mathrm{~mm}$. long; lobes $3-4 \mathrm{~mm}$. long; corolla purple or white; lobes linear to lanceolate, 1-2 cm. long; anthers 5-7 mm. long, usually acute; connective lanceolate, white, rugose; capsule 15-20 $\mathrm{mm}$. long, circumscissile near the apex. D. albidum Greene. Wet places: e Wash.-Mont. Mont. My.

7. D. multiflorum Rydb. Leaves about $2 \mathrm{dm}$. long, sinuate-denticulate, obtusish, narrowly oblanceolate, tapering below; scape stout, 3-4 dm. high; 
flowers 10-20; calyx-tube 5-6 mm. long; lobes lanceolate, about $5 \mathrm{~mm}$. long; corolla bluish violet, paler in the throat, but without any markings; lobes oblong, obtuse; anthers narrowly linear-lanceolate, acute, 7-8 $\mathrm{mm}$. long; connective narrow, lance-subulate; capsule about $12 \mathrm{~mm}$. long, eylindric-ovoid, septicidal from the apex. River valleys: Colo.-Wyo. Mont. Je-Jl.

8. D. pulchrum Rydb. Leaves glabrous, obovate-elliptic, 7-8 cm. long, without distinct petioles, thin, wavy, acute or obtuse; scape about $2 \mathrm{dm}$. high, 5-7-flowered; corolla rose or purplish, with a deep purple wavy line in the throat; lobes about $2 \mathrm{~cm}$. long, broadly oblong; anthers 6-7 $\mathrm{mm}$. long, obtuse; connective purple, lanceolate, rugose at the base. Creek-banks: Yellowstone Park. Mont. Je.

9. D. pubescens Rydb. Leaves $2-4 \mathrm{~cm}$. long, elliptic or broadly spatulate, densely and finely pubescent, obtuse at the apex, abruptly contracted into short petioles; scape about $1 \mathrm{dm}$. long, 2-5-flowered; calyx-lobes lanceolate, acute, about $4 \mathrm{~mm}$. long; corolla bluish purple; lobes linear-oblong, acutish, about 7 $\mathrm{mm}$. long; anthers about $5 \mathrm{~mm}$. long, acute; connective lanceolate, yellow, rugose; capsule cylindric about $1 \mathrm{~cm}$. long. Wet places: w Mont. Submont. Ap.

10. D. Hendersoni A. Gray. Leaves thick, 4-10 cm. long; blades orbicular, oval, broadly oval or obovate, entire or callous-denticulate, rounded at the apex, abruptly contracted into short petioles; scape 2-3 dm. high, 6-12-flowered; calyx-tube 4-5 mm. long; lobes lanceolate, acuminate, about $4 \mathrm{~mm}$. long; corolla with a dark indigo lobed center; outer part of the throat light-colored; lobes oblong, obtuse, $15-20 \mathrm{~mm}$. long, purple or lilac; anthers linear, 4-5 $\mathrm{mm}$. long, obtuse; capsule oblong, about $1 \mathrm{~cm}$. long. Hillsides: B.C.-Calif.-Ida. Submont. Mr-My.

11. D. acuminatum Rydb. Leaves $5-6 \mathrm{~cm}$. long, rather fleshy, glabrous or minutely puberulent; blades entire-margined, oblong-elliptic, usually obtuse at the apex, tapering into short petioles; scape $1-1.5 \mathrm{dm}$. high, 3-5-flowered; calyx-lobes lanceolate; corolla whitish, tinged with purple or rose; lobes lanceolate, 12-15 mm. long, acuminate; anthers 6-7 $\mathrm{mm}$. long; connective purple, broad and rugulose at the base. Wet open slopes: Mont.-Wyo. Submont. Ap-Jl.

12. D. philoscia A. Nels. Leaves $3-10 \mathrm{~cm}$. long, rather thin, glabrous; blades oval to oblong, obtuse or rounded at the apex, contracted into short petioles; seape 1-2 dm. high, slender, 1-3-flowered (rarely 4-6-flowered); calyxtube about $2 \mathrm{~mm}$. long; lobes lanceolate, $2-3 \mathrm{~mm}$. long; corolla purple or violet, usually with a dark wavy line in the throat; lobes linear-oblong or linear, acute or obtuse, 12-18 $\mathrm{mm}$. long; anthers linear, acute, about $6 \mathrm{~mm}$. long; capsule oblong, 8-10 mm. long. Gravelly margins of streams: Wyo.-Colo. Submont. -Mont. Je-Au.

13. D. radicatum Greene. Leaves 5-20 $\mathrm{cm}$. long; blades oblanceolate, or rarely elliptic, entire-margined or (in the v. sinuatum) sinuate, obtuse or acutish at the apex, tapering below into short petioles; scape 1-4 dm. high, 5-15 flowered; calyx-tube 3-4 mm. long; lobes linear-lanceolate, about $6 \mathrm{~mm}$. long; corolla purple, with a very dark wavy line in the throat; lobes linear or oblong, obtuse, 15-18 $\mathrm{mm}$. long; anthers linear, acute, $5-6 \mathrm{~mm}$. long; capsule oblong-ovoid, about $12 \mathrm{~mm}$. long. Wet meadows: S.D.-Kans.-N.M.-Wyo. PlainMont. My-Jl.

14. D. pauciflorum (Durand) Greene. Leaves glabrous, 3-10 cm. long; blades oblanceolate, entire-margined, obtuse at the apex, tapering into more or less elongate petioles; scape 1-4 dm. high, 1-10-flowered; calyx-tube $2 \mathrm{~mm}$. long; lobes lanceolate, about $4 \mathrm{~mm}$. long; corolla purple, with a very dark wavy line in the throat; anthers 4-5 mm. long, linear, usually obtuse; capsule elongateoblong, 12-15 mm. long. Wet meadows: Mack.-Sask.-Colo--Wash.-B.C. Plain-Mont. Je-Au.

15. D. salinum A. Nels. Leaves $2-4 \mathrm{~cm}$. long, spreading, glabrous; blades elliptic or oblanceolate, rarely obovate, obtuse, thin, entire-margined, tapering 
below into petioles; scape slender, 1-2 dm. high, purplish above, glabrous, 3-12flowered; calyx-tube about $2 \mathrm{~mm}$. long; lobes lanceolate, $3 \mathrm{~mm}$. long; corolla lilac-purple, with yellowish throat, often with a wavy purple line; lobes oblong, obtuse or acutish; anthers purple, often with whitish margins, acutish; capsule oblong, about $8 \mathrm{~mm}$. long. Saline flats: Sask.-N.D.-Utah-Ida. Submont. -Mont. My-Jl.

16. D. puberulentum Heller. Leaves $3-8 \mathrm{~cm}$. long; blades oblanceolate or spatulate, glabrous, entire-margined, obtuse, contracted below into short petioles; scape 1-2 dm. high, puberulent above; calyx-tube $2 \mathrm{~mm}$. long; lobes lanceolate, acute; corolla purplish, with the throat yellowish; lobes oblong, 8-10 mm. long; capsule about $8 \mathrm{~mm}$. long. Wet places: Ida. Submont. Ap.

17. D. Cusickii Greene. Leaves $3-7 \mathrm{~cm}$. long, puberulent; blades oblanceolate or oblong or rarely obovate, obtuse, rounded or acutish at the apex, contracted below into winged petioles; scape 1-3 dm. high, puberulent; calyx-tube 2-3 mm. long; lobes lanceolate, acuminate; corolla purple, with a yellow throat; lobes oblong or elliptic, acutish, about $1 \mathrm{~cm}$. long; anthers $3-5 \mathrm{~mm}$. long, acute; capsule cylindric, about $8 \mathrm{~mm}$. long. D. Meadia puberulum Nutt. Grassy slopes: B.C.-Wash.-Mont.-Alta. Submont. Ap-My.

18. D. uniflorum Rydb. Leaves spatulate or oblanceolate, almost sessile, densely puberulent, 1-2 cm. long, obtuse or acutish; scape $5 \mathrm{~cm}$. or less; calyxlobes linear-lanceolate, 2-3 mm. long; corolla dark bluish purple, with a yellow throat, which has or has not a dark wavy line; lobes oblong, about $1 \mathrm{~cm}$. long; anthers $3 \mathrm{~mm}$. long, dark purplish blue, with yellowish sides; capsule cylindric, 6-10 $\mathrm{mm}$. long, splitting into valves. Mountain sides: Mont. Mont.-Subalp. Je-Jl.

\section{SÁmoluS (Tourn.) L. Water Pimpernel, Brookweed.}

Annual or perennial, caulescent herbs. Leaves alternate, entire. Flowers in terminal racemes or panicles. Sepals united at the base, persistent. Hypanthium more or less developed. Corolla perigynous, short-salverform; tube very short; lobes rounded, imbricate. Stamens 5, adnate to the corolla-tube; staminodia sometimes present, narrow; anthers cordate. Ovary 1-celled; stigma capitate. Ovules numerous, half-anatropous. Capsule short, 5-valved at the apex. Seeds numerous.

1. S. floribundus H.B.K. Stem 1-6 dm. high; leaves few, spatulate, or oval, obtuse, 3-15 cm. long, narrowed into winged petioles; upper stem-leaves subsessile and ovate; sepals ovate or triangular; corolla white, $3 \mathrm{~mm}$. broad; staminodia 5, at the sinuses of the corolla. Wet places: Newf.-Fla.-Calif.B.C.; Mex. Plain. Je-Au.

\section{Family 101. Oleaceae. Olive Family.}

Shrubs or trees, rarely herbs. Leaves opposite, exceptionally alternate or whorled, without stipules, simple or pinnately compound. Flowers mostly paniculate, perfect, polygamous, or dioecious, regular, complete or incomplete. Sepals usually 4, partially united, rarely wanting. Petals 2-6, distinct or partially united, narrow, imbricate or valvate, or wanting. Stamens 2 or 4, adnate to the base of the corolla, if the latter is present. Gynoecium of 2 united carpels; ovary 2-celled, free; stigmas capitate or 2-lobed. Fruit a loculicidal, 2-valved capsule, a samara, or a berry. Seeds usually solitary, sometimes 2-4.

Fruit indehiscent; plant dioecious or polygamous; corolla in ours wanting; calyx-lobes 4. Fruit a samara.

Fruit a drupe.

1. Fraxinus.

Fruit a dit a druper calyx 5-15-lobed.

\section{FRÁXINUS (Tourn.) L. AsH.}

Trees or shrubs. Leaves opposite, usually odd-pinnate, rarely simple. Flowers inconspicuous, polygamous or dioecious, usually in panicles. Calyx small, 
4-lobed, or wanting. Corolla in ours wanting, otherwise rarely present, of 4 distinct or more or less united petals. Stamens 2 , rarely 3 or 4 ; filaments short or elongate, inserted at the base of the petals, or hypogynous; anthers linear or oblong, introrse. Ovary 2-celled; styles united; stigma 2-cleft; ovules 2 in each cell, pendulous. Fruit a samara.

Flowers polygamous; leaves simple or rarely 3-foliolate.

Flowers dioecious; leaves pinnately 5 -9-foliolate.

Leaflets sessile, rather thin.

Leaflets petiolulate, thick, subcoriaceous.

1. F. anomala.

2. F. campestris.

3. F. coriacea.

1. F. anomala Torr. A small tree, $5-10 \mathrm{~m}$. high, with 4-angled twigs; leaves simple, slightly pubescent when young, soon glabrate, petioled, ovate, rounded, rhombic-ovate or even subcordate, acute to rounded at the apex, $3-5$ $\mathrm{cm}$. long, or rarely 3 -foliolate, with rhombic-ovate or rhombic-lanceolate leaflets; calyx campanulate, with 4 erose teeth; samara oblong or obovate, $1.5-2 \mathrm{~cm}$. long; wing extending around the body. Cañons: s Utah-sw Colo-Ariz. Son.-Submont. Ap-My.

2. F. campestris Britton. A tree, $8-12 \mathrm{~m}$. high, with round twigs; leaves mostly 7 -foliolate; leaflets ovate to lanceolate, usually long-acuminate, toothed, more or less hairy beneath or glabrous on both sides, 3-10 cm. long; calyx small, 4-toothed; samara spatulate, about $3 \mathrm{~cm}$. long; wing narrow, decurrent on the body to the middle or below. Valleys and hillsides: Man.-Kans.-Wyo.Sask. Plain.

3. F. coriacea $\mathrm{S}$. Wats. A tree, $10-12 \mathrm{~m}$. high; twigs light gray, somewhat hairy; leaves 5 -foliolate, rarely 3 -foliolate; leaflets thick, rhombic-lanceolate, oblong, or elliptic, 5-8 cm. long, usually more or less acuminate at both ends, somewhat toothed to nearly entire, smooth and shining above, more or less pubescent beneath; calyx campanulate, with lanceolate teeth; samaras narrowly oblanceolate, $2-3 \mathrm{~cm}$. long, $5 \mathrm{~mm}$. wide; wing decurrent on the body to about the middle. Dry regions: Nev.-Utah-Ariz. $\rightarrow$ s Calif. Son. Ap-My.

\section{FORESTIÈRA Poir.}

Shrubs or trees, often widely branching. Leaves opposite, simple. Flowers inconspicuous, polygamo-dioecious, appearing before the leaves. Calyx usually present, but small, 4-6-lobed. Corolla usually wanting, rarely with 1 or 2 deciduous petals. Stamens 2-4; anthers extrorse. Ovary 2-celled; stigma thick, sometimes 2-lobed; ovules 2 in each cavity. Fruit a drupe; seeds solitary, rarely 2. Endosperm fleshy. [Adelia P. Br.]

1. F. neomexicana A. Gray. Shrub, 1.5-3 m. high, glabrous; leaves spatulate-oblong, obtuse or obtusely acuminate, $1-4 \mathrm{~cm}$. long, obsoletely crenate; pistillate flowers in sessile fascicles, pedicelled; calyx minute, persistent; drupe black, ellipsoid, obtuse; staminate flowers fasciculate, sessile, with yellowish deciduous bud scales. Adelia neomexicana Kuntze. Dry regions: w Tex.Colo.-Utah-Ariz. Son. Ap.

\section{MENODÒRA H.B.K.}

Shrubs or undershrubs, rarely herbs. Leaves opposite or alternate, simple, entire, toothed, or lobed. Flowers solitary at the ends of the branches, sometimes cymose. Calyx persistent; tube very short; lobes $5-15$, narrow. Corolla white, yellow, or reddish, rotate to campanulate; lobes 5 or 6 , imbricate. Stamens 2 or 3, exserted. Ovary 2-celled; stigmas capitate; ovules 4, rarely 2. Capsule membranous, didymous. Seeds usually 2 in each cavity.

1. M. scabra A. Gray. An undershrub, woody and branched at the base; herbaceous stems 1-3 dm. high, flax-like; leaves mostly alternate, linear or oblong, entire, 1-2 cm. long, scabrous, thick, subcoriaceous; flowers cymose; corolla rotate, bright yellow; lobes obovate, 6-8 mm. long; calyx-lobes 7-15, linear or subulate; fruit didymous-obcordate, $7-8 \mathrm{~mm}$. high. Dry and arid regions: w Tex.-s Utah-Ariz. Son.-Submont. My-Au. 


\section{Family 102. LOGANIACEAE. Logania Family.}

Herbs, shrubs, or vines. Leaves opposite or whorled, simple. Flowers perfect, regular, in cymes or panicles. Calyx inferior, 4- or 5-lobed. Corolla gamopetalous, 4- or 5-lobed; lobes imbricate or convolute. Stamens 4 or 5, alternate with the corolla-lobes. Anthers opening lengthwise. Ovary superior, 2-celled (rarely 3-5-celled); styles more or less united. Ovules solitary or two (rarely numerous) in each cavity, amphitropous or anatropous. Fruit sometimes capsular, 2-valved, or a berry or drupe.

\section{BUDDLEेIA L.}

Shrubs or trees, or undershrubs. Leaves opposite, with more or less developed stipules. Flowers in dense heads, rarely in panicles. Calyx campanulate, 4lobed or 5-lobed. Corolla rotate-campanulate to salverform. Stamens 4, rarely 5; filaments adnate to the corolla-tube. Ovary 2-celled; styles united. Capsule globular or oblong, septicidal, 2-valved.

1. B. utahensis Coville. Shrub 2-3 dm. high; young branches, leaves, and calyces densely tomentose; leaves linear-oblong, irregularly undulate, revolutemargined, thick, venose-reticulate, $1.5-2 \mathrm{~cm}$. long, obtuse; inflorescence of 2-9 verticels, about $1.5 \mathrm{~cm}$. in diameter; calyx-lobes 1-nerved; corolla purple or brownish purple; tube tomentose without; lobes rounded, spreading; anthers sessile in the throat of the corolla. Rocky places: Utah-Nev. Son.

\section{Family 103. Gentianaceae. Gentian Family.}

Annual or perennial caulescent herbs, or in warmer climates rarely shrubs. Leaves normally opposite, sometimes connate at the base. Inflorescence cymose. Flowers regular, perfect. Calyx of 2, 4, or 5, more or less united sepals. Corolla of 4 or 5 more or less united petals; lobes convolute or imbricate, entire or fringed. Stamens as many as the corolla-lobes and alternate with them, partly adnate to the corolla. Gynoecium of two united carpels; ovary 1-celled, superior, with 2 parietal placentae. Fruit a capsule.

\section{Corolla not spurred.}

Style filiform, mostly deciduous.

Corolla small, red, rose, or yellowish; tube surpassing the calyx; filaments spirally twisted.

1. CENTAUREUM.

Corolla large, blue, purple, or white; tube much shorter than the calyx; stamens recurved.

Style stout, short, persistent, or none.

Corolla without nectariferous pits, glands (except in species of Amarella), or scales. Corolla campanulate, funnelform, or salver-shaped; calyx 4-or 5-lobed; stamens inserted in the corolla-tube.

Corolla without plaits or lobes in the sinuses; calyx without an inter-calycine membrane; sepals imbricate.

Flowers 4-merous, rather large, usually more than $3 \mathrm{~cm}$. long; corollalobes more or less fringed or toothed; inner sepals broader, membranous-margined.

3. ANTHOPOGON.

Flowers 5-merous (rarely 4-merous), small, less than $2 \mathrm{~cm}$. long; outer sepals broader; corolla-lobes never fringed, rarely toothed.

Corolla plicate in the sinuses, the plaits more or less extended in membranous lobes or teeth; calyx with an inter-calyeine membrane; its lobes valvate.

Anthers cordate-versatile; dwarf annuals or biennials, with terminal solitary flowers. Anthers linear or oblong, extrorse; perennials, with mostly axillary
flowers. Corolla rotate; calyx parted to near the base; stamensinserted on the base of
the corolla.
7. PLEUROGYNE.

Corolla rotate, with nectariferous pits, glands, or scales.

Style none; leaves opposite, rarely alternate; corolla without a crown at the
base. base.

Style manifest; leaves opposite or verticillate.

Each division of the corolla with a single gland; capsule flattened parallelly to the valves. 
Corolla without a crown; leaves not white-margined.

9. Frasera.

Corolla with a decurrent crown contiguous with the gland; leaves white-margined.

10. LEUCOCRASPEDUM.

Each division of the corolla with a pair of oblong glands and a separate crown below; capsule flattened contrary to the valves.

Corolla spurred.

11. Tessaranthium.

12. TetragonanthUS.

\section{Centaùreum Hill. Centaury.}

Annual, biennial, or rarely perennial caulescent herbs. Leaves opposite, entire, sessile or clasping. Flowers in terminal cymes, pedicelled. Calyx with 4 or 5 keeled lobes. Corolla salver-shaped, rose-colored, pink, white, or yellow; lobes 4 or 5 , convolute. Stamens 4 or 5 , partially adnate to the corolla-tube; filaments short; anthers at last twisted. Ovary 1-celled; placentae 2, sometimes intruding. Capsule oblong or fusiform, 2-valved. Seeds many, reticulate. [Erythraea Neck.]

Corolla-lobes 4-6 mm. long, about half as long as the tube; annuals.

Corolla-lobes oblong, obtuse.

Corolla-lobes ovate or lanceolate, acute.

1. C. exaltatum.

Corolla-lobes 7-10 mm. long, about three-fourths as long as the tube; perennials.

3. C. arizonicum.

1. C. exaltatum (Griseb.) M. F. Wight. Stem 1-3 dm. high, slender, glabrous, with erect or strongly ascending branches; leaves sessile, oblong to linear, 1.5-4 cm. long; corolla-tube yellow, 8-10 $\mathrm{mm}$. long; lobes rose-colored, 4-5 mm. long. Erythraea Douglasii A. Gray. E. exaltata (Griseb.) Coville. Wet meadows and river bars: Wash.-Calif.-Utah-Neb. Plain-Submont. My-J1.

2. C. Nuttallii (S. Wats.) Heller. Stem 1.5-4 dm. high, with strongly ascending branches; leaves oblong, acute; corolla-tube yellowish, about $10 \mathrm{~mm}$. long; lobes 5-6 mm. long. Erythraea Nuttallii S. Wats. Valleys: Utah-Nev. -Ida. Submont. J1-S.

3. C. arizonicum (A. Gray) Heller. Stem angled, 2-4 dm. high; basal leaves spatulate; stem-leaves oblong to linear, usually acute, $2-5 \mathrm{~cm}$. long; corolla-tube about $12 \mathrm{~mm}$. long, yellow; lobes elliptic or oblong, acute, 9-12 mm. long. Erythraea calycosa arizonica A. Gray. River bottoms: Ariz. - s Utah. Son. Je-Au.

\section{EUSTÒMA Salisb.}

Annual caulescent herbs, or perennials by means of rosettes. Leaves opposite, sessile or clasping, glaucous. Flowers in terminal cymose panicles, or solitary. Calyx with 4 or 5 narrow keeled lobes. Corolla deeply campanulate, blue, purple, or white; lobes 5 or 6 , convolute in bud, erose-denticulate. Stamens 5 or 6 , adnate to the corolla-tube; filaments filiform; anthers versatile. Ovary 1-celled; stigmas 2. Seeds numerous, pitted.

1. E. Russelianum (L.) Griseb. Annual, or perennial with rosettes, with a taproot; stem 3-6 dm. high; leaves ovate to lanceolate or oblong, 3-ribbed, 2-4 em. long; calyx 15-20 mm. long; lobes subulate; corolla deep purple, rarely white, 3-4 cm. long; lobes obovate. E. Andrewsii A. Nels. Meadows: Neb.Tex.-N.M.-Colo. Plain-Submont. Je-Au.

\section{ANThopŌgon Necker. Fringed Gentian.}

Annual, biennial, or perennial caulescent herbs. Leaves opposite, entire, sessile. Flowers solitary at the end of the stem or its branches, perfect, 4-merous. Calyx large; lobes keeled, the inner distinctly wider than the outer, scarious- or hyaline-margined. Corolla showy, funnelform; lobes erose or fimbriate, without plaits in the sinuses, convolute. Stamens with glands at the base of the filaments. Ovary 1-celled; ovules numerous, Capsule stipitate.

Annuals or biennials; flowers on naked long peduncles terminating the branches, not bracteate.

Corolla enclosed in the ventricose wing-angled calyx.

Corolla much longer than the merely angled calyx.

1. A. ventricosus.

Inner calyx-lobes ovate, fully twice as broad as the outer linear-lanceolate ones; stem-leaves linear. 
Filaments hairy at the middle.

Filaments glabrous.

2. A. Macounii.

3. A. tonsus.

All calyx-lobes lanceolate, the inner not twice as broad as the outer ones; stemleaves oblong or lanceolate.

Inner calyx-lobes decidedly broader than the outer; corolla-lobes distinctly fringed on the sides.

4. A. thermalis.

Inner calyx-lobes slightly broader than the outer; corolla-lobes dentate, rarely with a few bristles on the sides.

5. A. simplex.

Perennials with a taproot; flowers short-peduncled in the axils of two bract-like leaves.

6. A. barbellatus.

1. A. ventricosus (Griseb.) Rydb. Stem simple or branched above, 2-3 $\mathrm{dm}$. high, slightly angled; basal leaves spatulate, 1-1.5 $\mathrm{cm}$. long; stem-leaves lanceolate to oblong-ovate, about $3 \mathrm{~cm}$. long; calyx nearly $2 \mathrm{~cm}$. long, ventricose, wing-angled; outer sepals lanceolate, long-acuminate, the inner broader, acute; corolla-lobes elliptic, serrate-fimbriate. Gentiana ventricosa Griseb. Wet places: Hudson Bay-Sask. Boreal.

2. A. Macounii (Holm.) Rydb. Stem strict, angular, 0.5-3 dm. high, branched near the base; basal leaves spatulate or oblanceolate, 1-2 $\mathrm{cm}$. long, obtuse; stem-leaves acute, $2-3 \mathrm{~cm}$. long; calyx purplish green; tube about $1 \mathrm{~cm}$. long; lobes acuminate, the outer about $10 \mathrm{~mm}$. long; corolla deep bluish, 1.5-3 $\mathrm{cm}$. long; lobes broadly obovate, toothed at the summit and fringed on the sides, veiny. G. Macounii Holm. Prairies, gravelly soil, and edges of marshes: James Bay-Alta.-Mont.-B.C. Boreal-Submont. J-S.

3. A. tonsus (Lunell) Rydb. Stem branched above, 3-4 dm. high, slightly angled; basal leaves oblanceolate or spatulate-obtuse, 1-2 cm. long; stem-leaves 4-7 $\mathrm{cm}$. long; calyx-tube about $1 \mathrm{~cm}$. long; outer lobes 10-14 mm. long; inner, 8-12 mm. long, 3-4 times as broad as the outer; corolla blue or purple, 3-4 cm. long; lobes oblong to obovate, fimbriate-toothed around the summit. Gentiana detonsa tonsa Lunell. Wet meadows: Sask,-Minn,-Alta. Plain. Jl-S.

4. A. thermalis (O. Kuntze) Rydb. Stem 2-3 dm. high, angled, usually branched near the base; basal leaves spatulate, obovate or oblanceolate, $1-3 \mathrm{~cm}$. long, obtuse, tapering below; stem-leaves sessile, 2-4 cm. long; calyx angled, green, with purple spots; tube $10-15 \mathrm{~mm}$. long; lobes $8-15 \mathrm{~mm}$. long, acuminate; corolla 3-5 $\mathrm{cm}$. long, bluish to purple, veined; lobes obovate-oblong, dentate around the apex, usually fimbriate on the sides; filaments broadly winged, naked. $G$. elegans A. Nels. $G$. lineata Greene. $G$, thermalis Kuntze, based on depauperate specimens. Wet mountain meadows: Mack.-Colo.-Áriz.-Ida. Submont.-Subalp. JI-Au.

5. A. simplex (A. Gray) Rydb. Stem 1-2 dm. high, 1-flowered; leaves linear-oblong to lanceolate, about $1 \mathrm{~cm}$. long; calyx scarcely angled; lobes almost equal; corolla 1.5-2 cm. long; lobes oblong-spatulate, erose-dentate on the sides below. Mountain meadows: Calif.-Ida.-Ore. Submont.-Subalp. J1-Au.

6. A. barbellatus (Engelm.) Rydb. Stem angled, $5-15 \mathrm{~cm}$. high, branched at the base; basal leaves thick and fleshy, oblanceolate or spatulate, $3-5 \mathrm{~cm}$. long; stem-leaves linear or linear-oblanceolate, 3-4 cm. long; bracts linear, 2-3 cm. long; calyx-tube about $1 \mathrm{~cm}$. long; outer lobes linear-lanceolate, $10-15 \mathrm{~mm}$. long; inner ones ovate-lanceolate, shorter; corolla bright blue, 3-4 cm. long; lobes oblong, erose-dentate above, conspicuously fimbriate on the sides. G. barbellata Engelm. G. Moseleyi A. Nels. High mountains: Colo-Wyo. Mont.-Alp. $\mathrm{Au}-\mathrm{S}$.

\section{4. amarÉlla Gilib. Gentian.}

Annual, biennial or perennial herbs. Leaves opposite, entire, sessile. Flowers perfect, solitary or cymose, 4-merous or 5-merous. Calyx-lobes imbricate, the outer two often somewhat larger, without a membrane within the lobes. Corolla funnelform or salverform; lobes entire or sparingly toothed, but without plaits in the sinuses. Ovary 1-celled; ovules numerous.

Corolla with a fringed crown in the throat; glands at the base of the corolla obsolete or wanting.

Flowers solitary on 2-10 cm. long peduncles; stems depressed, cespitose.

1. A. monantha. 
Flowers numerous, short-peduncled; stem erect, more leafy, simple at the base.

Calyx-lobes very unequal, the outer two large, foliaceous, ovate or oval, much broader than the rest.

Calyx-lobes somewhat unequal, but all oblong, lanceolate, or linear. Stem-leaves lanceolate or broader.

Flowers numerous, crowded, very short-pedicelled, the whole inflorescence dense and spike-like; leaves usually equalling or exceeding the internodes. 3. A. strictiflora.

Flowers comparatively few, distinctly pedicelled; middle internodes elongate and usually longer than the leaves.

At least the outer calyx-lobes lance-oblong; stem-leaves, except the uppermost, oblong or oval, obtuse. 4 . A. anisosepala.

Calyx-lobes linear or linear-lanceolate; stem-leaves lanceolate or ovatelanceolate, acute.

Larger calyx-lobes usually half as long as the corolla or longer; plant stout, 2-4 dm. high; stem-leaves lanceolate. 5. A. scopulorum. Calyx-lobes less than half as long as the corolla; plant slender, 1-2 dm., seldom $3 \mathrm{dm}$. high; stem-leaves usually ovate-lanceolate.

Stem-leaves linear or linear-lanceolate.

6. A. plebeia.

7. A. tortuosa.

Corolla without a crown; glands at the base of the corolla evident.

Corolla-lobes obtuse or merely acute, not cuspidate; leaves narrowly linear-lanceolate.

Corolla-lobes cuspidate-tipped.

8. A. ventorum.

Stem-leaves lanceolate, rarely ovate-lanceolate; corolla-lobes lanceolate to ovate.

Stem-leaves ovate; corolla-lobes broadly ovate.

9. A. propinqua.

10. A. arctophila.

1. A. monantha (A. Nels.) Rydb. Low annual, less than $1 \mathrm{dm}$. high, usually with a few decumbent branches at the base; leaves oblong to spatulate, 5-10 mm. long; calyx-lobes only slightly unequal, oblong-lanceolate, acutish; corolla about $12 \mathrm{~mm}$. long; lobes lanceolate, acute. Gentiana monantha A. Nels. High mountains: Colo.-Utah-Ida. Mont.-Subalp. Jl-S.

2. A. heterosepala (Engelm.) Greene. Strict annual, 2-3 dm. high; basal leaves and lower stem-leaves spatulate, $1-3 \mathrm{~cm}$. long, rounded or obtuse at the apex; upper leaves lanceolate, strongly 3 -ribbed, acute or obtusish at the apex, $2.5-4 \mathrm{~cm}$. long; flowers $1-3$ in the axils of the leaves; corolla $10-15 \mathrm{~mm}$. long; bristles of the crown numerous. Gentiana heterosepala Engelm. A. distegia Greene. ? G. polyantha A. Nels., a many-flowered form. Mountains: UtahColo.-N.M. Submont.-Mont. J-Au.

3. A. strictiflora (Rydb.) Greene. Strict annual; stem 2-4 dm. high, simple or with erect branches; basal leaves spatulate, $2-3 \mathrm{~cm}$. long; upper stemleaves lanceolate, 3-5-ribbed, $2-5 \mathrm{~cm}$. long, acute or acuminate; calyx-lobes moderately unequal, linear or lanceolate, acute, $5-8 \mathrm{~mm}$. long; corolla 8-12 (rarely 14) $\mathrm{mm}$. long, varying from greenish yellow to azure or white, with blue lobes; crown well developed, but setae often rather few. G. strictiflora (Rydb.) A. Nels. A. conferta Greene. Wet meadows and open woods: Alaska-Calif.Colo.-Sask. Submont.-Subalp. Jl-S.

4. A. anisosepala Greene. Strict annual; stem simple, or with a few ascending branches, 1-3 dm. high; basal leaves obovate or spatulate, $1-3 \mathrm{~cm}$. long; middle stem-leaves oblong to oval, $1.5-3 \mathrm{~cm}$. long, rounded at the apex; uppermost leaves lanceolate or ovate, acutish or obtuse; flowers mostly 1-3 in the axils, on naked pedicels; the longer calyx-lobes $6-10 \mathrm{~mm}$. long, the smaller 4-6 $\mathrm{mm}$; corolla 8-10 $\mathrm{mm}$. long, blue; lobes usually obtuse; crown well developed. G. anisosepala Greene. Wet woods: B.C.-Wash.-Wyo.-Mont. Submont.-Mont. Je-Au.

5. A. scopulorum Greene. Annual; stem 2-4 dm. high, simple or with ascending branches; basal leaves spatulate, 1-3 cm. long, obtuse; stem-leaves lanceolate, often acuminate at the apex, 2-6 cm. long; flowers 1-4 in the axils of the leaves, usually on naked pedicels; calyx-lobes linear, acute, the longer 10-12 $\mathrm{mm}$. long; corolla $15-18 \mathrm{~mm}$. long, blue or rarely greenish yellow; lobes ovate-lanceolate, acute; crown well developed. Gentianella Clementis Rydb. Mountains: Mont.-Ariz.-N.M.-N.D. Submont.-Subalp. J1-Au.

6. A. plebeia (Cham.) Greene. Strict annual; stem simple or with a few branches, 1-3 dm. high; basal leaves spatulate, 1-3 cm. long, obtuse; stemleaves oblong, elliptic, or lanceolate, 1-3 cm. (usually about $2 \mathrm{~cm}$.) long, obtuse 
or the uppermost acute; flowers $1-3$ in each axil; calyx-lobes linear, slightly unequal, 3-7 mm. long; corolla blue or bluish, 10-15 mm. long; lobes acute or obtuse; setae of crown numerous. Gentiana plebeia Cham. Mountains: Alaska - (? Calif.)-Colo.-Sask.-Mack.; e Asia. Mont.-Subalp. J1-Au.

7. A. tortuosa (M. E. Jones) Rydb. Low annual, with spreading branches, about $1 \mathrm{dm}$. high or less; leaves all linear or linear-lanceolate, $1-3 \mathrm{~cm}$. long; flowers numerous, fascicled in the axils; calyx-lobes subequal, about $6 \mathrm{~mm}$. long; corolla yellowish, 8-10 mm. long; crown in the throat well developed. Gentiana tortuosa M. E. Jones. In meadows: South-central Utah. Mont. S.

8. A. ventorum Rydb. Low annual or biennial, branched near the base; stems 5-10 cm. long, branched; basal leaves oblanceolate; stem-leaves linear or linear-lanceolate, about $2 \mathrm{~cm}$. long; flowers $1-3$ in the axils; calyx-lobes linearlanceolate, 3-5 mm. long, acute, scabrous on the margins; corolla about $5 \mathrm{~mm}$. long; lobes ovate, obtuse or acute. Mountains: Wind River Mountains, Wyo. $\mathrm{Au}$.

9. A. propinqua (Richards.) Greene. Annual, often branched near the base; stems $0.5-3 \mathrm{dm}$. high, often purplish; basal leaves spatulate or oblanceolate, 1-2 cm. long; stem-leaves lanceolate, 1-2 cm. long, acute; flowers 1-3 in the axils, on naked pedicels; calyx-lobes very unequal, the two outer ovate or oblong, acute, 5-7 mm. long, the rest linear, 3-5 mm. long; corolla blue, $10-17 \mathrm{~mm}$. long. G. propinqua Richards. Moist slopes and glades: Alaska-B.C.-Alta.-Mack.; e Asia. Subalp.-Alp. Jl-Au.

10. A. arctophila (Griseb) Greene. Low annual, branching at the base; branches $2-10 \mathrm{~cm}$. high, decumbent; basal leaves spatulate or obovate, about 1 $\mathrm{em}$. long; stem-leaves $1 \mathrm{~cm}$. or less long, acute; flowers $1-2$ in the axils; calyxlobes ovate, $5-8 \mathrm{~mm}$. long; corolla $15-18 \mathrm{~mm}$. long. G. arctophila Griseb. Arctic coast: Alta.-B.C. Alp. Au-S.

\section{ChONdROPHÝlla A. Nels. Moss Gentian.}

Small annuals or biennials. Leaves numerous, small, opposite, imbricate, with white scarious or cartilaginous margins. Flowers solitary and terminal. Calyx narrow, 4- or 5-lobed. Corolla salverform, plicate, with broad emarginate plaits in the sinuses. Ovary 1-celled. Anthers versatile. Capsule more or less stipitate. Seeds oblong, with close coat.

Leaves and calyx-lobes with broad scarious margins; capsule long-stipitate, at last exserted from the corolla.

1. C. Fremontii.

1. C. Fremontii (Torr.) A. Nels. Low biennial, branched at the base, $1-10 \mathrm{~cm}$. high; leaves glaucous and with broad white margins, the basal ones orbicular or obovate or ovate, about $5 \mathrm{~mm}$. long; stem-leaves oblong to linearlanceolate, acute, appressed, 3-5 mm. long; calyx-tube 5-7 mm. long; corolla 10-15 mm. long, light greenish purple. Gentiana humilis A. Gray, not Stev. Grassy banks in the mountains: Wyo.-Colo.-Alta. Subalp,-Alp. Je-Jl.

2. C. americana (Engelm.) A. Nels. Low biennial, branched at the base, 1-12 cm. high; leaves green, slightly if at all white-margined; basal ones orbicular or obovate, 2-5 $\mathrm{mm}$. long; stem-leaves ovate, about $5 \mathrm{~mm}$. long, scarcely appressed; calyx-tube 5-8 mm. long; corolla $10-20 \mathrm{~mm}$. long, azure-blue; lobes ovate. Gentiana prostrata americana Engelm. Alpine-aretic regions: Alaska-Colo.Alta. Subalp.-Alp. Je-Au.

\section{DASYSTÉphana Adans. Gentian.}

Mostly perennial, rarely annual, caulescent herbs. Leaves opposite, entire or merely erose-ciliolate. Flowers perfect, cymose, sessile or nearly so, rarely solitary and pedicelled. Calyx with a membrane inside the calyx-lobes, which vary from obsolete to foliaceous. Corolla salverform, funnelform, or clavate, without glands and crowns, but with cleft plaits between the convolute lobes. Stamens with converging or cohering anthers. Ovary 1-celled; ovules numerous. Capsule stipitate. 
Seed-coats lamellose-rugose, the lamellae white, forming hexagonal areas; basal rosettes of leaves remaining at flowering time; perennials with short rootstocks.

Corolla $12-18 \mathrm{~mm}$. long; leaves ovate or oval.

Corolla 30-40 $\mathrm{mm}$. long; leaves linear or linear-oblanceolate.

1. D. glauca.

2. D. Romanzovii,

Seed-coats smooth, but often produced into wings; basal rosettes none at flowering time; cespitose perennials.

Corolla closed; lobes in ours obsolete or nearly so; limb as well as the plaits incurved.

Corolla open, campanulate; lobes spreading or ascending.

3. D. Andrewsii.

Calyx-lobes broadly ovate or oval; seeds wingless.

Corolla-lobes rounded at the apex; calyx-tube 5-6 mm. long. 4. D. obtusiloba.

Corolla-lobes acute; calyx-tube 7-10 $\mathrm{mm}$. Iong.

Leaves broadly ovate, usually obtuse at the apex and subcordate at the base; calyx-lobes obtuse.

Leaves ovate or lance-ovate, acute at both ends; calyx-lobes acute.

Calyx-lobes linear, lanceolate, or none.

Floral leaves more or less broadened and more or less scarious; seeds usually wingless.

Floral leaves narrow, not scarious; seeds winged.

Calyx-lobes erect or none; corolla-lobes ascending or nearly erect, not toothed; plaits equally lobed.

Flower-cluster dense, its branches, peduncles, and internodes very short.

Leaves all except the floral ones ovate, oblong, or lanceolate. Calyx-lobes well developed; calyx-tube truncate at the apex.

Leaves ovate or rarely lanceolate; calyx-lobes oblong or oblong-lanceolate; corolla open-funnelform.

8. D. oregana.

Leaves oblong or lanceolate; calyx-lobes linear or linearlanceolate; corolla narrowly funnelform.

9. D. affinis.

Calyx-lobes none or minute; calyx-tube irregular, more or less lobed or cleft.
10. D. Forwoodii.

Upper stem-leaves linear or lance-linear.

Plant erect, many-flowered; corolla nearly cylindraceous, 2-2.5 cm. long. 11. D. Bigelovii.

Plant decumbent, few-flowered; corolla funnelform, $2.5-3 \mathrm{~cm}$. long, or more. 9 . D. affinis.

Flower-cluster lax, its branches, lower peduncles, and internodes elongate.

Calyx-lobes widely spreading, linear-lanceolate; corolla-lobes in anthesis strongly spreading, more or less denticulate; plaits unequally 2-lobed.

$$
\text { Burvalh } 1796 \text { ! }
$$

13. D. puberula.

1. D. glauca (Pallas) Rydb. Stem simple, 2-10 cm. high; basal leaves rosulate, oval or obovate, $0.5-1.5 \mathrm{~cm}$. long, rather fleshy; stem-leaves $2-3$ pairs, oval or obovate, about $1 \mathrm{~cm}$. long; calyx-tube $5-6 \mathrm{~mm}$. long; lobes lanceolate, about $1.5 \mathrm{~mm}$. long; corolla blue; lobes ovate, obtuse; lobes of the plaits ovate, entire. Gentiana glauca Pallas. Aretic-alpine situations: Alaska-B.C.-Mont.; e Asia. Subalp.-Alp. Jl-Au.

2. D. Romanzovii (Ledeb.) Rydb. Basal leaves many, linear-oblanceolate to narrowly linear, 3-10 cm. long; stem-leaves linear or linear-oblong, $2.5-5 \mathrm{~cm}$. long; stem 5-10 cm. long; calyx-tube 12-15 mm. long; lobes linear-oblong, obtuse, 5-10 mm. long; corolla yellowish white, tinged with blue and purple-dotted; lobes triangular, acute; plaits entire, with a very broadly triangular summit. $G$. frigida A. Gray, not Haenke. G. Romanzovii Ledeb. Aretic-alpine situations: Alaska-Utah-Colo-Mont. Mont.-Alp. J-Au.

3. D. Andrewsii (Griseb.) Small. Stem glabrous, simple, 3-6 dm. high, leafy; leaves lanceolate or ovate-lanceolate, 7-15 cm. long, 3-7-ribbed; flowers in terminal clusters and in the axils of the uppermost leaves; calyx-tube $8-12 \mathrm{~mm}$. long; lobes lanceolate or ovate, ciliolate, spreading; corolla broadly clavate, bluish or white, closed; lobes obsolete, rounded; lobes of the plaits rounded, erose, yellowish. G. Andrewsii Griseb. Wet meadows and among bushes: Que.-Ga. -Nev.-Neb.-S.D. Plain. Au-O.

4. D. obtusiloba Rydb. Stems erect or ascending, about $1 \mathrm{dm}$. high; internodes short, equalling or a little longer than the leaves; leaves very broadly ovate, 3-5-ribbed, usually acute at the apex and subcordate at the base; calyxtube 5-6 mm. long; lobes broadly oval, rounded at the apex, often overlapping, about $8 \mathrm{~mm}$. long; corolla dark blue, about $3.5 \mathrm{~cm}$. long; lobes of the plaits about half as long as the corolla-lobes. High mountains: Mont. Submont. J1-Au. 
5. D. calycosa (Griseb.) Rydb. Stems 1-3 dm. high, ascending, erect or decumbent; internodes short, about equalling the leaves; leaves $2-3 \mathrm{~cm}$. long, 3-5-ribbed; flowers usually solitary, sessile, and subtended by the upper broad leaves; calyx-lobes ovate, foliaceous, $7-10 \mathrm{~mm}$. long, obtuse; corolla dark blue, or (in var. xantha A. Nels.) yellow, green-spotted, 3-4 cm. long; lobes ovate, triangular-acute at the apex; plaits with a lanceolate, more or less laciniate, acuminate prolongation, half as long as the corolla-lobes or longer. $G$. calycosa Griseb. High mountains: Wash.-Calif.-w Wyo. Mont.-Subalp. J-S.

6. D. monticola Rydb. Stem about $1 \mathrm{dm}$. high, erect; internodes usually shorter than the leaves; leaves 3-ribbed; flowers solitary and sessile, subtended by the broad upper leaves; calyx-tube 7-9 mm. long; lobes lance-ovate, 8-10 $\mathrm{mm}$. long; corolla dark blue, about $3 \mathrm{~cm}$. long; lobes of the plaits lanceolate, acuminate, laciniate or toothed, half as long as the corolla-lobes or longer. High mountains: Wash.-Mont.-nw Wyo. Mont.-Subalp. Au.

7. D. Parryi (Engelm.) Rydb. Stems erect or ascending, many-leaved, 1-4 dm. high; leaves from linear-lanceolate to ovate, fleshy and somewhat glaucous, $1.5-4 \mathrm{~cm}$. long; flowers $1-6$ at the summit of the stem; calyx-tube $10-15$ $\mathrm{mm}$. long, white and scarious; lobes linear or lanceolate, 4-8 mm. long; corolla bright blue, about $4 \mathrm{~cm}$. long; lobes obovate, acute; lobes of the plaits ovate, usually 2-cleft, toothed, two-thirds as long as the corolla-lobes. G. Parryi Engelm. G. bracteosa Greene. High mountains: Wyo.-Colo.-Utah. Mont. -Subalp. Jl-S.

8. D. oregana (Engelm.) Rydb. Stems erect, 3-4 dm. high, leafy; leaves 2-4 cm. long, 3-5-ribbed, acutish or obtuse, rounded to acute at the base; flowers short-pedicelled in the upper axils; calyx-tube about $1 \mathrm{~cm}$. long; lobes $5-8 \mathrm{~mm}$. long; corolla purple, 3-3.5 $\mathrm{cm}$. long; lobes ovate, acute; lobes of the plaits triangular, with 2 acuminate lobes. $G$. oregana Engelm. Meadows: Wash.Calif.-Mont. Submont. J1-S.

9. D. afflnis (Griseb.) Rydb. Stems 1-3 dm. high, leafy; leaves $1.5-3 \mathrm{~cm}$. long; calyx-tube 5-7 mm. long; lobes 2-10 $\mathrm{mm}$. long, acute; corolla blue or purple, $2.5-3 \mathrm{~cm}$. long; lobes ovate, acute; lobes of the plaits ovate, 2-cleft, acuminate, laciniate, two-thirds as long as the corolla-lobe. G. affinis Griseb. Mountains and hills: B.C.-(? Calif.)-Colo.-Sask. Mont.-Subalp. Au-S.

10. D. Forwoodii (A. Gray) Rydb. Closely related to D. affinis; stem 1-3 dm. high, leafy; leaves $1.5-3 \mathrm{~cm}$. long, rather thick; flowers short-pedicelled in the upper axils, forming a dense spike-like inflorescence; calyx-tube $5-8 \mathrm{~mm}$. long, usually purplish; corolla blue or purple, about $3 \mathrm{~cm}$. long; lobes obovate, acute; lobes of the plaits 2-cleft, lanceolate, acuminate, a little shorter than the corolla-lobes. G. Forwoodii A. Gray. Hills and mountains: Alta.-Colo.-Ida. Submont.-Mont. Jl-Au.

11. D. Bigelovii (A. Gray) Rydb. Stem 2-3 dm. high, erect; lower leaves oblong, the upper linear or lance-linear; floral leaves and calyx-lobes glandularciliolate; flowers short-pedicelled in the upper axils, forming a many-flowered spike; calyx-tube 5-6 $\mathrm{mm}$. long; lobes linear-subulate, $5-7 \mathrm{~mm}$. long; corolla cylindro-funnelform, 2-2.5 $\mathrm{cm}$. long; lobes acute; lobes of the plaits triangular, 2-eleft, acute, half as long as the corolla-lobes. G. Bigelovii A. Gray. Mountains: Colo.-N.M.-Ariz. Submont. Au-O.

12. D. interrupta (Greene) Rydb. Stem 3-4 dm. high; lower leaves ovate or oblong, 1-2 cm. long, the upper narrowly linear, 2-4 cm. long; lower flowers on peduncles 1-2 cm. long; calyx-tube 5-6 mm. long; lobes linear or subulate, 2.5-4 mm. long; corolla open-funnelform, 2.5-3 cm. long; lobes obovate; lobes of the plaits 2-cleft; divisions lanceolate, acute, two-thirds as long as the corollalobes. G. interrupta Greene. Mountains: Wash.-Ore.-Colo.-Sask. Submont. Au-S.

13. D. puberula (Michx.) Small. Stem strict, erect, $3-5 \mathrm{dm}$. high, more or less scabrous, leafy; leaves lanceolate, firm, scabrous-puberulent on the margins and midrib, paler beneath, $3-5 \mathrm{~cm}$. long; flowers subsessile, forming a dense spike; calyx-tube not scarious, about $1 \mathrm{~cm}$. long; lobes subulate, 8-12 mm. long, 
spreading; corolla blue, about $4 \mathrm{~cm}$. long, open-funnelform; lobes obovate, obtuse or acute; lobes of the plaits 2-cleft, often laciniate, half as long as the corolla-lobes. G. puberula Michx. Prairies: Ohio-Ga.-Kans.-Sask. Plain.

\section{PLeURÓGYNe Eschsch. Marsh Felwort.}

Low slender annuals. Leaves opposite, entire. Flowers perfect. Calyx deeply 4- or 5-cleft. Corolla rotate, 4- or 5-cleft, its divisions acute, with a pair of scale-like appendages on their base. Stamens inserted on the base of the corolla; anthers introrse, versatile. Style none; stigmas decurrent on the sutures; ovary 1-celled. Capsule lanceolate or oblong, not stipitate. Seeds numerous.

1. P. fontana A. Nels. Glabrous annual, 1-4 dm. high, with erect branches; leaves linear, thin, with strong midrib and faint lateral ribs, $2-2.5 \mathrm{~cm}$. long; flowers in narrow racemes or panicles, pentamerous; sepals linear, 3-nerved; corolla whitish, about $12 \mathrm{~mm}$. long, often slightly shorter than the sepals; lobes oblong, acute. P. rotata tenuifolia Griseb. Bogs in the mountains: Alta.Colo. Mont.-Subalp. Jl-Au.

\section{SWÉRTIA L.}

Simple-stemmed, caulescent perennials. Leaves opposite or some alternate. Flowers perfect, blue or rarely white, in a thyrsoid inflorescence. Calyx 4- or 5 -parted. Corolla rotate, usually 5-parted, each division bearing a pair of nectariferous pits; lobes convolute in the buds. Stamens inserted on the base of the corolla. Style very short or none; stigma 2-lobed; ovary 1-celled; capsule ovate; placentae not intruded. Seeds large, flat, commonly margined.

Inflorescence elongate; corolla-lobes linear or oblong.

Leaves with 3-5 parallel ribs from the base.

Leaves not parallel-ribbed.

1. S. parallela.

Petals not spotted; basal leaf-blades much longer than the petioles.

Petals spotted; basal leaf-blades not longer than the petioles. Inflorescence congested; corolla-lobes oval-elliptic.

2. S. scopulina.

3. S. Fritillaria.

4. S. congesta.

1. S. parallela Greene. Stem about $3 \mathrm{dm}$. high; lower leaves 10-15 $\mathrm{cm}$. long, oblong-oblanceolate or oblong-elliptic; upper stem-leaves oblong, sessile, opposite; inflorescence narrow; corolla lurid-purple; lobes lance-oblong, obtuse, about $1 \mathrm{~cm}$. long; glands with rather long fringe. Mountains: Mont.-Ida. Mont. Jl.

2. S. scopulina Greene. Stem 1-3 dm. high; basal leaves and lower stemleaves alternate, $10-15 \mathrm{~cm}$. long, thin, oblong or elliptic to oblanceolate, obtuse, pinnately-veined; upper stem-leaves opposite, elliptic or lanceolate, sessile; corolla dark blue or purple; lobes linear to oblong, obtuse, about $1 \mathrm{~cm}$. long; glands orbicular with short, subulate appendages. S, palustris A. Nels. Mountains, in wet places: Mont.-Colo.-Utah. Mont.-Subalp. JI-Au.

3. S. Fritillaria Rydb. Stem 1.5-3 dm. high; basal leaves and lower stemleaves alternate, $6-10 \mathrm{~cm}$. long, thin, obovate-spatulate, rounded at the apex; middle and upper stem-leaves all alternate or a single pair of opposite ones, oblanceolate or oblong; corolla-lobes lanceolate, mostly acute, greenish white along the midrib and azure along the margins, all over dotted with dark blue spots; glands inconspicuous, with rather long blue fringes. Wet places in cañons: Utah. Mont. Au.

4. S. congesta A. Nels. Stem about $1 \mathrm{dm}$. high; basal leaves and lower stem-leaves alternate, $5-10 \mathrm{~cm}$. long, elliptic to oblanceolate, feather-veined, obtuse; upper stem-leaves usually a single pair, opposite, oblong, sessile; corolla dark bluish purple; lobes obtuse or emarginate, 8-10 mm. long; glands cupshaped, with long appendages; stamens surrounded by a ring of setae. Swales: Wyo.-Utah-Ida.-Mont. Mont.-Alp. Au.

\section{FrÃsera Walt. American Columbo.}

Perennial herbs, with hollow stems and taproots. Leaves opposite or more often whorled, entire, thickish. Flowers perfect, in terminal paniculate cymes. 
Sepals 4, nearly distinct, narrow. Corolla rotate, deeply 4-cleft; lobes convolute in bud, each with a single round gland, without a crown. Stamens 4 , inserted at the base of the corolla; filaments subulate; anthers versatile. Ovary 1-celled; stigma 2-lobed. Capsule flattened parallelly to the valves. Seeds orbicular, wing-margined.

1. F. fastigiata (Pursh) Heller. Stem 6-10 dm. high, glabrous; basal leaves $2-4 \mathrm{dm}$. long, glabrous, oblanceolate to broadly spatulate, obtuse or acute, $5-8 \mathrm{~cm}$. wide, thin, feather-veined; stem-leaves verticillate, usually in 3 's, oblong or lanceolate, sessile, acute; inflorescence an interrupted, much compound panicle or thyrsus; corolla pale blue; lobes lance-oblong or elliptic, acute, thin. Hillsides and open woods: Ida.-Wash.-Ore. Submont. My-Jl.

\section{LEUCOCRÁSPEDUM Rydb.}

Perennials with taproots. Leaves opposite or whorled, narrow, firm, with white margins. Flowers perfect, thyrsoid or paniculate. Sepals 4, almost distinct, persistent. Corolla rotate, deeply 4-parted, marcescent; lobes each with a single gland usually contiguous with a decurrent crown, saccate at the base. Stamens inserted on the base of the corolla; filaments subulate to ovate. Style slender; ovary 1-celled. Capsule usually flattened parallelly to the flattish valves. Seeds mostly flat and margined.

Scales between the stamens wanting (represented by merely hairs); corolla greenish yellow. Basal leaves oblanceolate; lower stem-leaves linear.

Basal leaves lanceolate; lower stem-leaves long-acuminate from an ovate base.

Scales between the stamens present, fringed or cleft.

Flowers creamy white; plant glabrous.

Flowers blue.

2. L. utahense.

Plant puberulent; inflorescence dense; interstaminal scales lanceolate.

4. L. albicaule.

Plant glabrous; inflorescence more open; interstaminal scales obovate or orbicular.

5. $L$. coeruleum.

1. L. albomarginatum (S. Wats.) Rydb. Stem 3-10 dm. high, glabrous; basal leaves about $1 \mathrm{dm}$. long, glabrous; stem-leaves linear or the floral ones reduced to subulate bracts, verticillate in 3's or 4's, rarely opposite; inflorescence open, often flat-topped; sepals lanceolate, $4-5 \mathrm{~mm}$. long; corolla greenish yellow; lobes ovate, cuspidate-acuminate, $6-8 \mathrm{~mm}$. long; gland elongate, extending from the base to above the middle of the corolla-lobe, obcordate at the summit. Frasera albomarginata $\mathrm{S}$. Wats. Dry regions: s Utah-Nev.-Ariz. Son.

2. L. utahense (M. E. Jones) Rydb. Stem glabrous, 1-2 m. high, erect; basal leaves lanceolate, long-acuminate, $2-4 \mathrm{~cm}$. wide, strongly 3 -ribbed and with intermediate ribs; lower stem-leaves opposite, $7-10 \mathrm{~cm}$. long, about $2 \mathrm{~cm}$. wide, gradually tapering to a slender point, the upper bract-like; inflorescence open, its branches divaricate; sepals broadly ovate, acute or abruptly acuminate, about $4 \mathrm{~mm}$. long; corolla yellowish green, with purple spots; lobes oblongobovate, obtuse. F. utahensis M. E. Jones. Mountains: s Utah. Son. Je.

3. L. montanum (Mulford) Rydb. Stem glabrous, 3-9 dm. high; basal leaves narrowly oblanceolate, glabrous, $1.5-2 \mathrm{dm}$. long; stem-leaves opposite, linear, the upper spreading or reflexed; inflorescence many-flowered, dense; sepals linear-subulate, about $6 \mathrm{~mm}$. long; corolla creamy white; lobes $6-8 \mathrm{~mm}$. Iong, oblong, acute; glands oblong-obovate, near the base of the corolla-lobes and of scarcely one-third their length, short-fringed on the margins. $F$. montana Mulford. Mountains: Ida. Submont. Л.

4. L. albicaule (Dougl.) Rydb. Stems about $3 \mathrm{dm}$. high, erect, strict, finely puberulent; basal leaves narrowly linear-oblanceolate, about $1 \mathrm{dm}$. long, 4-15 $\mathrm{mm}$. wide, 3-ribbed; white margins very narrow; stem-leaves opposite, narrowly linear, 6-10 $\mathrm{cm}$. long, the upper spreading or reflexed; sepals linearlanceolate or linear-subulate, 6-8 $\mathrm{mm}$. long; corolla blue; lobes ovate-lanceolate, acuminate, thin, 8-10 $\mathrm{mm}$. long; gland linear, extending from the base of the corolla-lobes to their middle, fringed at the margin. F albicaulis Dougl. Hillsides and meadows: Wash.-Ore.-Ida. Submont. My-Je. 
5. L. coeruleum (Mulford) Rydb. Stems erect, 1.5-4 dm. high, glabrous; basal leaves linear-oblanceolate, glabrous, $1-1.5 \mathrm{dm}$. long; stem-leaves narrowly linear, opposite, 4-8 cm. long; floral ones bract-like; sepals lanceolate, whitemargined, about $6 \mathrm{~mm}$. long; corolla blue; lobes ovate, acute, $6-8 \mathrm{~mm}$. long; gland linear, green, extending from the base to near the middle of the corollalobes, fringed on the margin. $F$. coerulea Mulford. Mountains: Ida.-Ore. Submont.-Mont.

\section{TESSARÁNTHIUM Kellogg. Deer's Tongue.}

Stout perennials with taproots. Leaves in whorls of 4 , entire, strongly parallel-veined, rather firm. Flowers perfect, in an elongate many-flowered thyrsus. Sepals nearly distinct, narrowly linear, at least equalling the corolla. Corolla rotate, deeply 4-cleft; each division with a pair of oblong glands, and a separate crown below them, dull white or greenish white, dark spotted. Stamens inserted on the base of the corolla; filaments subulate. Capsule compressed contrary to the deeply boat-shaped valves. Seed oblong, flat, margined.

Corolla-lobes 18-22 mm. long, usually exceeded by the long sepals.

Plant glabrous; inflorescence simple with verticillate pedicels; basal leaves over $1 \mathrm{dm}$.

wide.
Plant puberulent; inflorescence compound; some branches simple, others again branched; basal leaves about $5 \mathrm{~cm}$. wide. $\quad 2 . T$. scabrum.

Corolla-lobes about $15 \mathrm{~mm}$. long or less; inflorescence compound.

Sepals narrowly linear, usually much exceeding the petals. 3 .
Sepals linear-lanceolate or subulate, scarcely equalling the petals.
Stem-leaves oblanceolate. Stem-leaves linear-lanceolate.

3. T. stenosepalum.

4. T. speciosum.

5. T. angustifolium.

1. T. macrophyllum (Greene) Rydb. Stem $1-2 \mathrm{~m}$. high, very leafy; basal leaves oblanceolate, $3-5 \mathrm{dm}$. long, $6-13 \mathrm{~cm}$. wide, rather thin, glabrous, 9-15-ribbed; stem-leaves lanceolate, verticillate; pedicels of various length, $3-15 \mathrm{~cm}$. long, usually simple; sepals linear-subulate, $2-3.5 \mathrm{~cm}$. long; corollalobes obovate, $18-22 \mathrm{~mm}$. long; fringes of the crown long, almost equalling the narrowly oblong glands. Frasera macrophylla Greene. Rich hillsides: Wyo.N.M. Submont.-Mont. J-Au.

2. T. scabrum (M. \&. Jones) Rydb. Stem $1 \mathrm{~m}$. or less high, leafy; basal leaves 1-3 dm. long, 3.5-6 $\mathrm{cm}$. wide, oblanceolate, acute, with 7-9 strong ribs, scabrous-puberulent; stem-leaves linear-lanceolate; peduncles axillary, some simple, one-flowered, others branched and 2-5-flowered; sepals linear-subulate, 12-30 $\mathrm{mm}$. long; corolla-lobes $18-20 \mathrm{~mm}$. long, oblong-obovate, obtuse; fringes of the crown equalling the oblanceolate glands. F. speciosa scabra M. E. Jones. Hills and mesas: Ariz.-Utah-Colo--N.M. Submont.-Mont. Je-Jl.

3. T. stenosepalum Rydb. Stem $1 \mathrm{~m}$. high or less; basal leaves oblanceolate, 1.5-3 dm. long, 3-5 cm. wide, scabrous-puberulent, thick, 11-13-ribbed, very acute; stem-leaves lanceolate; flowers numerous, on axillary, simple or rarely branched peduncles; sepals 1-2 cm. long; corolla-lobes elliptic, about $15 \mathrm{~mm}$. long, acute; fringes of the crown equalling the oblong glands. F. speciosa stenosepala Rydb. Foot-hills and mountain-sides: Wyo.-N.M. Submont.-Mont. Je-Au.

4. T. speciosum (Dougl.) Rydb. Stem 3-15 dm. high; basal leaves oblanceolate, acute, 1-3 dm. long, 3-5 cm. wide, more or less scabrous-puberulent; sepals $10-15 \mathrm{~mm}$. long; corolla-lobes oval, acutish, $12-15 \mathrm{~mm}$. long; fringes of the crown usually shorter than the oblong glands. F. speciosa Dougl. Hills and mountains: Ore.-Calif.-Colo.-S.D.-Mont. Plain-Mont. Je-Au.

5. T. angustifolium Rydb. Stem $3-6 \mathrm{dm}$. high, puberulent; basal leaves mostly reduced and scale-like or a few linear or linear-lanceolate, $5-8 \mathrm{~cm}$. long, $0.5-1.5 \mathrm{~cm}$. wide; peduncles usually simple and 1-flowered; sepals linear-subulate, $8-10 \mathrm{~mm}$. long; corolla-lobes about $12 \mathrm{~mm}$. long, oval, acute; fringes of the crown scarcely equalling the oblong glands. $F$, speciosa angustifolia Rydb. Hills: Mont.-Colo. Submont.-Mont.

\section{2. tetragonánthus J. F. Gmel. Spurred Gentian.}

Annual or perennial caulescent herbs. Leaves opposite, entire. Flowers perfect, in terminal or axillary eymes or panicles. Calyx deeply 4-cleft. Cor- 
olla white, yellow, blue, or purple, with a short tube, 4-lobed; each lobe produced into a spur or sack at the base. Stamens 4, inserted on the lower part of the corolla-tube; filaments filiform or dilated at the base; anthers versatile. Ovary 1-celled; placentae intruded; style short or wanting; stigma 2-lobed. Capsule ovoid or oblong. Seeds slightly flattened, smooth. [Halenia Borkh.]

1. T. deflexus (Smith) Kuntze. An annual, usually simple, 1.5-4.5 dm. high; basal leaves obovate or spatulate, petioled; stem-leaves oblong or the upper ovate, acute, 3-5-ribbed, 2-4 cm. long; sepals lanceolate, acuminate; corolla yellowish or greenish white, or purplish, 6-8 mm. long; lobes triangular-ovate, ac te; spurs slightly spreading, rather slender. $H$. deflexa (Smith) Griseb. Damp woods: N.S.-N.Y.-S.D.-B.C. Boreal-Submont. JI-Au.

\section{Family 104. MENYANTHACEAE. Buckbean Famtly.}

Perennial aquatic or bog plants with horizontal rootstocks. Leaves alternate, but often all basal, simple or trifoliolate. Flowers perfect, solitary or in terminal clusters or racemes. Calyx of 5 partially united sepals. Corolla from rotate to funnelform; lobes induplicate-valvate. Stamens 5; filaments adnate to the corolla-tube. Gynoecium of 2 united carpels; ovary 1-celled with two parietal placentae; stigmas 2. Fruit a capsule, indehiscent, irregularly bursting, or valvate.

\section{MENyánthes (Tourn.) L. Buckbean, Marsh Trefoil, BOG-BEAN.}

Perennial bog plant. Leaves long-petioled, trifoliolate, basal. Flowers perfect, racemose or paniculate, on a long scape. Calyx 5-parted. Corolla short funnelform, 5-cleft, its lobes fimbrate or bearded within, white, spreading. Stamens inserted on the tube of the corolla; filaments filiform; anthers sagittate. Capsule ovoid, indehiscent or at last ruptured. Seeds few, subglobose, shining.

1. M. trifoliata L. Perennial, with a stout rootstock; scape 1-3 dm. high; leaflets oval or elliptic, thick, glabrous, $5-10 \mathrm{~cm}$. long; corolla white, tinged with rose, campanulate-funnelform, about $15 \mathrm{~mm}$. long; lobes copiously fimbriate within. In water and bogs: Lab.-Newf.-Pa.-Colo.-Calif.-Alaska. Plain -Mont. My-Jl.

\section{Family 105. APOCYNACEAE. Dogbane Family.}

Perennial herbs (all ours), vines, shrubs, or trees, with milky juice. Leaves opposite or alternate, without stipules, simple. Flowers perfect, regular. Calyx of 5 persistent sepals, imbricate in the bud. Corolla of 5 partially united petals, with convolute lobes. Stamens 5, alternating with the corollalobes; anthers 2-celled. Gynoecium of two, distinct (in ours) or united carpels; if united, the ovary either 2-celled, or 1-celled, with two parietal placentae; styles united. Fruit in ours of two follicles.

Anthers unappendaged at the base, not connected with the stigma; flowers without a disk; leaves alternate.

Anthers appendaged at the base, converging around and coherent to the stigma; calyxtube partly attached to the gynoecium by means of a thick disk; leaves opposite.

2. APOCYNUM.

\section{AMSÒNIA (Clayt.) Walt.}

Perennial herbs. Leaves alternate, entire. Flowers in terminal corymbiform cymes. Calyx-lobes 5. Corolla salverform; tube slightly enlarging upwards, villous within; lobes narrow. Disk wanting. Stamens included; anthers unappendaged Carpels 2, united by the styles. Stigmas appendaged by a reflexed membrane. Follicles 2, ereet, several-seeded Seeds unappendaged. 
Sepals subulate, long-attenuate, 2-4 mm. long; pod more or less torulose or constricted around the seeds.

Leaves ovate or those of the branches lanceolate. Plant densely villous.

Leaves narrowly lanceolate, those of the branches linear.

1. A. latifolia M. E. Jones. Perennial, with a woody base; stems several, $2-5 \mathrm{dm}$. high, glabrous; leaves ovate to lanceolate, acute or acuminate, $3-5 \mathrm{~cm}$. long, sessile; corolla lead-purple, about $15 \mathrm{~mm}$. long; lobes oblong, two-thirds as long as the tube; follicles about $4 \mathrm{~cm}$. long, 3-4 mm. thick, not torulose. $A$. texana Rydb. (Fl. Colo.). Clayey or alkaline soil: w Colo.-Utah-Ariz. Son.

2. A. brevifolia A. Gray. Perennial, often with a woody base; stem glabrous, 3-5 dm. high; leaves thick; corolla about $1.5 \mathrm{~cm}$. long, constrieted at the mouth, and bearded within the throat; lobes ovate or oblong, half as long as the tube; follicles 5-7 cm. long, thickish. Arid regions: Utah-Ariz.-Calif. Son. $\mathrm{My}-\mathrm{Je}$.

3. A. Eastwoodiana Rydb. Perennial, with a short woody base; stem 3-5 $\mathrm{dm}$. high; leaves $3-5 \mathrm{~cm}$. long; corolla $16-20 \mathrm{~mm}$. long; tube narrowly trumpetshaped; lobes nearly $4 \mathrm{~mm}$. long; follicles $5-8 \mathrm{~cm}$. long, about $8 \mathrm{~mm}$. thick, often breaking off between the seeds. In eañons of desert regions: Utah-Ariz. Son. Je-Jl.

4. A. tomentosa Torr. Perennial, with a woody base; stems $2-4 \mathrm{dm}$. high, villous; leaves cinereous-villous, lanceolate to linear, sessile, $3-5 \mathrm{~cm}$. long; calyx-lobes subulate, about $3 \mathrm{~mm}$. long; corolla about $15 \mathrm{~mm}$. long, contracted at the throat, which is bearded within; lobes oblong, half as long as the tube; follicles 7-8 cm. long, not torulose. Sandy plains: Tex. $-\mathrm{s}$ Utah-Ariz. L. Son.

\section{APÓCYNum (Tourn.) L. Dogbane, Indian Hemp.}

Perennial herbs with branched stems. Leaves opposite, entire. Flowers in corymbose cymes. Sepals 5. Corolla campanulate; tube with five small appendages, alternating with the stamens; lobes 5 . Stamens adnate to the base of the corolla-tube; anthers sagittate, at least coherent to the stigma. Follicles 2 , slender. Seeds numerous, tipped with a long coma.

Corolla fully twice as long as the calyx; its lobes spreading in anthesis.

Leaves more or less pubescent beneath.

Sepals broadly lanceolate; corolla open campanulate; leaves thick, dark green, decidedly pubescent beneath.

Leaves oval, acute at both ends; plant usually tall. 1. A. androsemaefolium.

Leaves more or less ovate, rounded, truncate, or cordate at the base; plant low, diffuse.

Leaves rounded, rarely truncate at the base; stem and branches glabrous.

2. A. scopulorum.

Leaves subcordate or at least truncate at the base; stem and branches mostly pubescent.

3. A. pumilum.

Sepals narrowly lanceolate; corolla narrower, almost cylindro-campanulate; leaves pale green, pubescent merely on the petioles and the veins beneath, the lower truncate, the upper acute at the base. 4 . A. lividum.

Leaves perfectly glabrous.

Leaf-blades lanceolate or rarely ovate, pale; corolla almost white, narrowly campanulate.

Leaves broadly or rounded ovate, thicker and dark green; corolla rose-colored. open campanulate.

Sepals acute; corolla $5-6 \mathrm{~mm}$. long.

Sepals acuminate; corolla $7-9 \mathrm{~mm}$. long.
Corolla less than twice as long as the calyx; its lobes erect or nearly so.
Leaves acute at the base, petioled.

Leaves acute at the base, petioled.

Leaves, at least those of the main stem, truncate or subcordate at the base and subsessile.

9. A. sibiricum.

1. A. androsaemifolium L. Stem erect, $3-15 \mathrm{dm}$. high, glabrous; leafblades 4-10 cm. long, pale beneath; calyx-lobes ovate, acuminate, searcely 1 $\mathrm{mm}$. long; corolla pink; tube 4-5 mm. long; lobes ovate, obtuse. Thickets and fields: Anticosti-Ga.-Ariz.-Ida.-B.C. Plain-Mont. Je-Jl.

2. A. scopulorum Greene. Stem 3-6 dm. high, glabrous; leaf-blades ovate, rounded or truneate at the base, $3-6 \mathrm{~cm}$. long, thick, dark green above, pale beneath; calyx-lobes lanceolate, acute or somewhat acuminate, $1.5-2 \mathrm{~mm}$. long; 
corolla pink; tube about $4 \mathrm{~mm}$. long; lobes reflexed, ovate, obtuse. Hillsides and open woods: Sask.-Cola.-Ida.-Yukon. Plain-Mont.

3. A. pumilum (A. Gray) Greene. Stem 1-5 dm. high, more or less pubescent; leaf-blades rounded-ovate, $2-6 \mathrm{~cm}$. long, dark green above, pale and finely pubescent beneath, rounded at the apex, the lower usually truncate or cordate at the base; calyx-lobes lanceolate, acuminate, $2-3 \mathrm{~mm}$. long; corolla rose-colored; tube 4-5 mm. long; lobes oblong, reflexed, obtuse. A. polycardium and A. griseum Greene. Mountain sides and open woods: Wash.-Mont.-Utah-Calif. Son. -Mont. Je-Au.

4. A. lividum Greene. Stem $1 \mathrm{~m}$. or more high, glabrous, with ascending branches; leaf-blades elliptic-lanceolate or oblong-ovate, 7-10 $\mathrm{cm}$. long, pale green above, glaucous beneath; calyx-lobes lanceolate, acute, $2-2.5 \mathrm{~mm}$. long, whitish, thin; corolla pale flesh-colored or white; tube about $3.5 \mathrm{~mm}$. long; lobes fully $2 \mathrm{~mm}$. long, oblong, obtuse, spreading or reflexed. Mountains: UtahColo. Submont. Jl.

5. A. convallarium Greene. Stem tall, $1 \mathrm{~m}$. high or more, glabrous, with ascending branches; leaf-blades glaucous beneath, acute and mucronate at the apex, the lower rounded or subcordate at the base; calyx-lobes lanceolate, pale, acute, about $2 \mathrm{~mm}$. long, corolla white or nearly so; lobes $2 \mathrm{~mm}$. long, oblong, obtuse, spreading. A. vacillans Greene. A. Elmeri Greene. A. occidentale Rydb. Plains and rocky hills: Mont.-Wyo.-Ariz.-Wash. Plain-Submont. Je-Jl.

6. A. ambigens Greene. Stem 3-6 dm. high, glabrous, often tinged with purple above, with ascending branches; leaf-blades thick, dark green above, paler beneath, rounded or sometimes subcordate at the base, $3-6 \mathrm{~cm}$. long; calyxlobes lanceolate, acute, $2 \mathrm{~mm}$. long, usually purple-tinged; corolla flesh-colored or rose, 4-4.5 mm. long; lobes $2 \mathrm{~mm}$. long, oblong, obtuse, reflexed. River bottoms and hillsides: Mont.-S.D.-Colo.-Utah-Wash. Submont.-Mont. Je$\mathrm{Au}$.

7. A. macranthum Rydb. Stem 3-4 dm. high, glabrous, with rather spreading branches; leaf-blades thick, dark green above, paler beneath, roundedovate, 4-5 cm. long, rounded at the base; calyx-lobes lanceolate, acuminate, 3 $\mathrm{mm}$. long, tinged with purple; corolla pink; lobes oblong, reflexed, 3-3.5 mm. long. Copses: Ida. Submont. Jl.

8. A. cannabinum L. Stem $5-15 \mathrm{dm}$. high, glabrous, with ereet or ascending branches; leaf-blades oblong, lanceolate-oblong or ovate-oblong, light green above, glaucous beneath, usually perfectly glabrous; calyx-lobes lanceolate, acute or acuminate, about $2.5 \mathrm{~mm}$. long; corolla greenish white; lobes ovate, about $1.5 \mathrm{~mm}$. long. Thickets and fields: Anticosti-Fla.-L. Calif.-B.C. Plain-Submont. Je-Au.

9. A. sibiricum Jacq. Stem 3-6 dm. high, glabrous, with ascending branches; leaves oblong, oblong-lanceolate, or oval, $2-8 \mathrm{~cm}$. long, cordate-clasping, rounded or truncate at the base, obtuse or acute and mucronate at the apex, pale green and glabrous; calyx-lobes lanceolate, acute, $2.5 \mathrm{~mm}$. long; corolla greenish white, campanulate; lobes lance-oblong, erect; follicles 5-9 $\mathrm{cm}$. long. A. hypericifolium Ait. A. cervinum Greene. River valleys and hillsides: Ont.Ohio-N.M.-B.C. Plain-Submont. Je-Au.

\section{Family 106. ASClepiadaCeat. Milkweed Family.}

Perennial herbs or vines, or in warmer climates shrubs, with milky juice. Leaves opposite, whorled, or alternate, without stipules. Flowers perfect, regular, mostly umbellate. Sepals distinct or nearly so, imbricate in bud. Corolla campanulate, urceolate, funnelform or rotate, 5-lobed, the lobes usually reflexed. A 5-lobed crown is usually present between the corolla and the stamens, adnate to either or both. Stamens 5 , adnate to the base of the corolla; filaments monadelphous; anthers attached by the base, in- 
trorse. Gynoecium of 2 earpels. Styles 2, connected at the summit by the stigmas. Ovules numerous, anatropous, pendulous. Fruit of two carpels. Seeds many, compressed, appendaged by a long coma.

\section{Crowns wanting; corolla urceolate or campanulate; stem twining. 1. AstepHanus.} Crowns present; corolla rotate or open-campanulate.

Crowns double, the outer of a shallow undulate ring; plants twining.

Crowns simple; plants erect or decumbent, not twining.

2. Philibertella.

Corolla-lobes reflexed during anthesis

Hoods of the crown crestless or with an obscure crest within.

Hoods of the crown with a horn-like or tooth-like crest within ACERATES.

Corolla-lobes erect-spreading during anthesis.

4. ASCLEPIAS.

\section{ASTÉPHANUS R. Br.}

Perennial herbs or suffruticose plants, ours twining. Flowers perfect, regular, umbellate. Calyx 5-lobed, destitute of glands. Corolla urceolate or campanulate, 5-cleft; lobes slightly convolute. Crown wanting. Stamens inserted on the base of the corolla-tube. Follicles long-acuminate, smooth.

1. A. utahensis Engelm. Perennial from a thick root; stem slender, filiform; leaves linear-filiform; umbels short-peduncled, 3-5-flowered; corolla dull yellow, campanulate, $2 \mathrm{~mm}$. wide; lobes ovate, somewhat hooded, papillosepuberulent within. Dry sandhills: s Utah-Ariz. L. Son.

\section{PHILIBERTÉLLA Vail.}

Twining perennial herbs, or partly shrubby, Leaves opposite, linear, cordate, or hastate. Flowers perfect, regular, umbellate. Calyx small, 5-lobed. Corolla campanulate or rotate, with a double crown; outer crown in the throat ring-like, undulate; lobes 5, longer than the tube. Staminal crown represented by 5 turgid fleshy or hard scales or flat appendages at the base of the subsessile column. Follicles slender, naked. [Philibertia Benth. \& Hook., not H.B.K.]
Crowns separate by a short column; stem glabrous.
Crowns contiguous; stem puberulent or pubescent.
1. P. cynanchoides.
2. $P$, heterophylla.

1. P. cynanchoides (Dec.) Vail. Stem 2-12 m. high; leaves $1.5-6 \mathrm{~cm}$. long, deeply cordate, sagittate, or hastate, cuspidate; corolla white or creamcolored, purple-tinged at the apex; outer erown shallow; scales of staminal crown broadly oval, obtuse or acutish; follicles 3-7 cm. long, long-attenuate. Philibertia cynachoides A. Gray. Along rivers: Tex.-s Utah-Ariz.; Mex. and C.Am. L. Son. Je-S.

2. P. heterophylla (Engelm.) Cockerell. Twining perennial; leaves $3-5$ $\mathrm{cm}$. long, 2-4 mm. wide, some acute, some rounded or cordate-aurieulate or truncate at the base; corolla yellowish, purplish, or whitish; lobes ovate, smooth; follicles 6-8 $\mathrm{cm}$. long, attenuate at the apex, 6-7 mm. thick, puberulent. Philibertia linearis heterophylla A. Gray. Dry ground: Ariz, - s Utah-s Calif.; Mex. L. Son. Ja-D.

\section{ACeràtes ell. Green Milkweed.}

Perennial caulescent herbs. Leaves opposite or alternate. Flowers perfect, regular, umbellate. Calyx small, usually with 2 glands in the sinuses of the 5 acute lobes. Corolla rotate; lobes 5 , reflexed in anthesis. Hoods mostly attached over the short or obsolete column, erect, involute-concave, saceate at the base, entire, emarginate, or 2- or 3-toothed at the apex, with broad auricles at the base, without horns or crests within. Follicles fusiform. Seeds with a coma.

Auricles of the hoods when present, concealed within; leaves oval to linear.

Umbel solitary, terminal; plant hirsute.

Umbels several, lateral; plant glabrate or tomentose when young. 2. A. viridiflora.

Auricles of the hoods conspicuously spreading; umbels lateral; leaves narrowly linear.

Hoods emarginate or truncate at the summit, crestless within; umbels distinctly peduncled.

Hoods trilobed at the summit, with an internal crest-like midrib terminating in the middle lobe; umbels subsessile or on very short peduncles. 4 . A. angustifolia. 
1. A. lanuginosa (Nutt.) DC. Stem ereet, $1-4 \mathrm{dm}$. high; leaves oblong or elliptic, short-petioled, $3-10 \mathrm{~cm}$. long; corolla greenish; lobes oblong, about 5 $\mathrm{mm}$. long; hood purplish, oblong, with an auricle or fold on the ventral margins. Prairies: Ill,-Minn.-Mont.-Wyo, Je-Au.

2. A. viridiflora (Raf.) Eat. Stem $2-6 \mathrm{dm}$. high, often decumbent; leaves oval or oblong and obtuse or retuse or acute, or elongated lanceolate and acuminate (var. Ivesii Britton), or narrowly linear (var. linearis A. Gray), becoming leathery, with undulate margins; umbels sessile or nearly so, many-flowered; corolla-lobes oblong-lanceolate, about $5 \mathrm{~mm}$. long; hood dull purple or at least tinged with purple, lance-oblong, entire except for the small infolded auricles at the base. Dry or sandy soil: Mass.-Fla.-N.M.-Mont. Plain-Submont. $\mathrm{Je}-\mathrm{Jl}$.

3. A. auriculata Engelm. Stem 2-8 dm. high, mostly solitary; leaves alternate, scattered, narrowly linear, $5-15 \mathrm{~cm}$. long, with scabrous, often revolute margins; corolla-lobes greenish, about $4 \mathrm{~mm}$. long; hood yellowish, with purplish keel, erect, emarginate or truncate, the involute sides with broad auricles at the base. Plains and prairies: Neb.-Utah-N.M.-Tex. Plain-Submont. Je$\mathrm{Au}$.

4. A. angustifolia (Nutt.) Dec. Stem several from a thick rootstock, 3-6 $\mathrm{dm}$. high, puberulent or glabrate in age; leaves narrowly linear, 5-12 $\mathrm{cm}$. long, revolute-margined; umbels subsessile; corolla-lobes $5 \mathrm{~mm}$. long, oblong, greenish; hood white, erect, as high as the anthers, laterally compressed, 3-dentate at the apex, the inner margins with an erose truncate lobe. Asclepias stenophylla A. Gray. Dry plains: S.D.-Colo.-Tex.-Mo. Plain. Je-Au.

\section{4. asclèpias (Tourn.) L. Milkweed, Silkweed, Butterfly-weed.}

Perennial herbs, with deep taproots, sometimes woody at the base. Leaves opposite, alternate, or whorled. Flowers perfect, regular, in axillary or terminal umbels. Calyx small, usually with small glands at the base of the 5 lobes. Corolla rotate, deeply 5-cleft; lobes valvate-convolute in bud, reflexed in anthesis. Hoods of the crown involute, arising from the base of the corolla-lobes or on a short column, concave, hooded, bearing within a horn- or tooth-like projection, and sometimes additional processes between the anthers. Follicles fusiform, naked or with soft processes or warty. Seeds mostly with a coma.

Plant more or less hirsute; hoods orange; leaves mostly alternate; juice not milky.

Plant not hirsute; hoods greenish, purplish, yellowish, or white; leaves mostly opposite or verticillate; juice milky.

Leaves orbicular to linear-lanceolate, opposite (except No. 14).

Follicles with soft spinulose processes, tomentose; leaves large and broad, tomentose, transversely veined, oval or ovate.

Hoods oblong-ovate, obtuse, slightly exceeding the stamens.

2. A. syriaca.

Hoods lanceolate, produced, about three times as long as the stamens.

Follicles without processes.

Flowers very large; petals over $1 \mathrm{~cm}$. long; column none; corolla sphb-cordate outline; horns included in the hoods; leaves almost or. A. cryptoceras.

at the base.

Flowers middle-sized or small; petals

present andy oval or rectangular-oval or nearly orbicular, obtuse or Leaves broady ove at both is; umbels sessile.

Plant puberulent when young, glabrate in age; column very short.

Plant tomentulose; column half as long as the anthers.

5. A. latifolia.

6. A. arenaria.

Leaves ovate or lanceolate, or rarely oval, acute.

Leaves ovate or ovate-lanceolate, more or less tomentose, at least when young.

Hoods truncate, slightly longer than the anthers; leaves sessile, with rounded or subcordate bases. 7 . A. erosa.

Hoods ovate-oblong to lanceolate, much exceeding the stamens; leaves petioled.

Corolla yellowish; hoods with a tooth on each margin, not auricled or gibbous at the base; peduncles shorter than the pedicels.

8. A. ovalifolia. 
Corolla purple; hoods without teeth; peduncles longer than the pedicels.

Hoods not auricled or gibbous at the base; leaves permanently tomentose, at least beneath. 9. A. curvipes.

Hoods with two gibbosities at the base; leaves puberulent when young, glabrous in age. 10. A. Hallii.

Leaves linear-lanceolate; hoods truncate, little if at all longer than the anthers.

Column short; leaves pale.

Plant more or less tomentose or puberulent, at least when young.

Hoods shorter than the anthers; corolla purple; leaves in age glabrate or nearly so.

Hoods about half as long as the anthers; umbels peduncled.

11. A. brachystephana.

Hoods only slightly shorter than the anthers; umbel subsessile. 12. A. uncinalis.

Hoods longer than the anthers; corolla purplish outside, green within; leaves permanently tomentose.

13. A. macrosperma.

Plant glabrous; corolla greenish white; hoods white.

14. A. labriformis.

Column more than half as long as the anthers; corolla purple.

Leaves narrowly linear, verticillate or scattered.

Corolla usually ash-colored; leaves $4-8 \mathrm{~mm}$. wide.

Corolla greenish and white; leaves $1-3 \mathrm{~mm}$. wide.

15. A. incarnata.

Plant tall, 4-6 dm. high, from a rootstock; leaves verticillate. Hoods entire.

Hoods dorsally hastate-sagittate.

17. A. verticillata.

18. A. galioides.

Plant low, 1-2 dm. high, bushy, from a ligneous base; leaves scattered, crowded.

19. A. pumila.

1. A. tuberosa L. Stem 3-6 dm. high, coarsely hirsute, very leafy; leaves usually alternate, short-petioled or subsessile, lance-linear or lance-oblong, subcordate to acute at the base, $5-10 \mathrm{~cm}$. long, with revolute margins; corolla-lobes linear-oblong, obtuse, 6-8 mm. long, greenish or reddish orange; column about 1 $\mathrm{mm}$. long; hoods linear-oblong or linear-lanceolate, bright orange or yellow, 5-6 $\mathrm{mm}$. long; follicles $7-10 \mathrm{~cm}$. long, minutely pubescent. Dry fields and meadows: Ont.-Fla.-Tex.-Ariz.-Minn. Plain. Je-S.

2. A. syriaca L. Stem 5-15 dm. high, canescent or in age glabrate; leafblades elliptic to lance-oblong, 1-1.5 dm. long, 4-11 $\mathrm{cm}$. wide, rounded, truncate or acute at the base, obtuse or mucronate at the apex, green and glabrous or nearly so above, tomentulose beneath; corolla-lobes dull greenish purple, $8 \mathrm{~mm}$. long, more or less pubescent; column less than $1 \mathrm{~mm}$. long; hoods whitish or greenish purple; follicles 7-9 cm. long, lance-ovate, tomentose. A. Cornuti Dec. Fields and waste places: N.B.-Ga.-Kans.-Sask. Plain. Je-S.

3. A. speciosa Torr. Stem tall, 1-2 m. high, finely canescent-tomentose; leaves oval, subcordate at the base, thick; corolla greenish purple; lobes oblong or ovate-oblong, 9-13 mm. long; column short or none; hoods lanceolate, 11-15 $\mathrm{mm}$. long, with two blunt teeth below; follicles 7-10 $\mathrm{cm}$. long, with numerous processes. Valleys: Sask.-Minn.-Kans.-Calif.-B.C. Plain-Submont. My-Jl.

4. A. cryptoceras S. Wats. Stems several from a woody thick root, decumbent, 1-2 dm. high, glabrous; leaves very short-petioled or subsessile; blades ovate-orbicular, 4-6 cm. long, glabrous and glaucous, strongly veined, subcordate at the base; corolla-lobes greenish yellow, ovate, acute, about $1 \mathrm{em}$. long; column none; hoods flesh-colored, saccate-ovate, about $7 \mathrm{~mm}$. long, rounded on the sides; follicles ovate. Sandy plains, rocky hills, and clay benches: Wyo.-Colo.Calif.-Ore. Plain-Submont. My-Je.

5. A. latifolia (Torr.) Raf. Stem simple, stout, 3-8 dm. high, minutely puberulent when young; leaves sessile or short-petioled; blades rounded-oval, mucronate and often emarginate at the apex, cordate or subcordate at the base, $7-15 \mathrm{~cm}$. long, minutely puberulent; corolla-lobes ovate, $7-10 \mathrm{~mm}$. long, greenish; column thick, very short; hood truncate; follicles ovoid, $6 \mathrm{~cm}$. long, glabrate. A. Jamesii Torr. Dry plains: Neb.-Tex,-Ariz.-Utah. Plain. J1-Au.

6. A. arenaria Torr. Stem decumbent or ascending, tomentose, 3-6 dm. long; leaf-blades rectangular-oval or obovate, truncate or retuse and often muc- 
ronate at the apex, subcordate or truncate at the base, 5-10 $\mathrm{cm}$. long, tomentose; corolla-lobes oval-oblong, greenish white; hoods oblong, truncate, with a triangular tooth on each margin; follicles puberulent, 5-10 $\mathrm{cm}$. long. In sandy soil: Neb.-Tex.-Colo, $\mathrm{n}$ Mex. Son.-Plain. Je-S.

7. A. erosa Torr. Stem 5-10 dm. high, puberulent when young; leaves canescent with white wool when young, glabrate in age, sessile, ovate or ovatelanceolate, $10-15 \mathrm{~cm}$. long, thick, rounded or subcordate at the base; corollalobes oval, 6-7 mm. long, greenish white; column fully $1 \mathrm{~mm}$. long; hoods yellowish, obovate, truncate; follicles about $7 \mathrm{~cm}$. long, lance-ovoid, curved, canescentpuberulent when young. River valleys: s Utah-Ariz.-Calif.; Sonora. Son. My-Jl.

8. A. ovalifolia Dec. Stem simple, erect, 3-6 dm. high, finely tomentose; leaf-blades oval, ovate, or ovate-lanceolate, $5-8 \mathrm{~cm}$. long, acute at both ends, finely tomentose or the upper surface glabrate in age; lobes of the corolla greenish white or purplish, ovate-oblong, obtuse, about $5 \mathrm{~mm}$. long; hoods orange or yellow, oval-oblong, with a large tooth on each margin; follicles pubescent. Woods and prairies: Man.-Ill.-Neb.-Alta. Plain-Submont. Je-Jl.

9. A. curvipes A. Nels. Stems usually several, ascending or erect, 4-8 dm. high, obscurely puberulent, in age glabrous; leaves short-petioled; blades ovatelanceolate, rounded or acute at the base, minutely pubescent beneath, glabrate above, $7-15 \mathrm{~cm}$. long; corolla purple; its lobes ovate-elliptic, obtuse or emarginate, 6-7 mm. long; hoods yellowish, with purplish middle, ovate, obtuse, roundlobed on the sides; follicles lanceolate, acuminate, 7-10 cm. long, densely whitetomentose. Sandy banks: Wyo. Jl.

10. A. Hallii A. Gray. Stem stout, 3-4 dm. high, finely puberulent; leafblades lanceolate or ovate-lanceolate, acute at the apex, rounded or acute at the base, 5-12 cm. long, puberulent or in age glabrate; corolla greenish, tinged with purple; its lobes oblong, about $6 \mathrm{~mm}$. long; hood oblong, hastately 2-gibbous at the base, entire, obtuse; follicles about $8 \mathrm{~cm}$. long, lanceolate, tomentulose, in age glabrate. Gravelly soil in the mountains: Colo. Submont,-Mont. Jl.

11. A. brachystephana Engelm. Stems several, usually branched, ascending or spreading, $1.5-2.5 \mathrm{dm}$. high, minutely puberulent; leaf-blades narrowly linear-lanceolate, long-attenuate, $5-8 \mathrm{~cm}$. long, puberulent or in age glabrate; corolla greenish purple; its lobes about $4 \mathrm{~mm}$. long, oblong, acute; column almost none; hood ovate, obtuse, with large triangular lobes on the margins; follicles lance-ovoid, acuminate, 5-7 cm. long, tomentose. Dry soil: Kans.-Tex.Ariz.-Wyo.; n Mex. Son. Ap-Au.

12. A. uncinalis Greene. Stems usually several, less than $1 \mathrm{dm}$. high, puberulent; leaf-blades lanceolate to narrowly linear-lanceolate, acuminate, 3-5 $\mathrm{cm}$. long, sparingly puberulent or soon glabrate; corolla dull greenish purple; column very short; hood orbicular, obtuse, with large triangular-ovate lobes. Dry places: N.M.-Wyo. Submont. Ap.

13. A. macrosperma Eastw. Stems several from a woody rootstock, decumbent, 0.5-3 dm. high, tomentulose; leaves alternate; blades lanceolate or ovate-lanceolate, acuminate at the apex, obtuse, truncate or subcordate at the base, 3-7 cm. long, glabrous or nearly so above, tomentulose beneath; corollalobes 4-8 $\mathrm{mm}$. long, purplish beneath, greenish and puberulent above, membranous-margined and notched; column short; hoods rounded at the summit; follicles $6 \mathrm{~cm}$. long, lance-ovate, acuminate, tomentulose. Sandy soil: se Utah. L. Son. Au.

14. A. labriformis M. E. Jones. Stems erect, glabrous; leaves all but the lower alternate; blades glabrous, linear-lanceolate or lanceolate, $7-12 \mathrm{~cm}$. long, glabrous, acute at both ends; corolla-lobes oval, white, $5 \mathrm{~mm}$. long; column nearly $1 \mathrm{~mm}$. long; hood oblong, truncate, greenish white; follicles glabrous, ovate-oblong, acuminate, $3-4 \mathrm{~cm}$. long. Sandy gulches: s Utah. L. Son. J.

15. A. incarnata L. Stem glabrous or minutely puberulent, $6-20 \mathrm{dm}$. high, very leafy; leaves opposite; leaf-blades 4-17 $\mathrm{cm}$. long, oblong-lanceolate to linearlanceolate, acute to subcordate at the base; corolla deep rose-purple to pink or 
white; lobes oblong, 4-6 mm. long; column 1-1.5 mm. long, slender; hoods oblong, obtuse at the apex, the rounded margins overlapping; follicles $5-7 \mathrm{~cm}$. long, lance-ovoid, acuminate, glabrous or minutely puberulent. The southwestern plant is usually tall, over $1 \mathrm{~m}$. high and with long, narrow leaves (var. longifolia A. Gray). In swamps: N.B.-Fla.-N.M.-Wyo.-Man. Plain-Submont. $\mathrm{Je}-\mathrm{Au}$.

16. A. mexicana Cav. Stem 1-2 m. high, branched and woody at the base; leaves verticillate in 3's to 6's, rarely opposite, short-petioled or subsessile; blades linear or linear-lanceolate, 6-15 cm. long, glabrous; corolla ash-colored or rarely greenish, tinged with purple; lobes oblong, $4 \mathrm{~mm}$. long; column about $1 \mathrm{~mm}$. long; hood white, broadly ovate, without lobes; follicles linear-lanceolate, 6-8 $\mathrm{cm}$. long, puberulent. Grassy slopes and valleys: Calif.-Wash.-Ida.-Ariz.; Mex. Son. Ap-Au.

17. A. verticillata L. Stem angled, glabrous or pubescent in lines, 4-10 $\mathrm{dm}$. high; leaves narrowly linear to almost filiform, $5-10 \mathrm{~cm}$. long, verticillate in whorls of 2's to 4's; corolla greenish, sometimes tinged with purple; lobes oblong, $4 \mathrm{~mm}$. long; column about $1 \mathrm{~mm}$. long; hood white, broadly ovate, truncate at the apex, lobed on the sides near the base; follicles linear-lanceolate, $7-10 \mathrm{~cm}$. long, glabrous or minutely puberulent. Dry and sterile soil: Me.-Fla.-Tex. -Mex.-Ariz.-N.D. Plain-Son. Ap-Au.

18. A. galioides H.B.K. Stem erect, solitary, glabrous or minutely puberulent in lines, 4-10 dm. high; leaves in whorls of 3's to 6's, narrowly linear, 6-8 $\mathrm{cm}$. long; corolla-lobes greenish white, oblong, obtuse, $4 \mathrm{~mm}$. long; column nearly $1 \mathrm{~mm}$. long; hoods erect-spreading, broadly rounded at the apex, entiremargined, hastate-sagittate on the back; follicles $5-7 \mathrm{~cm}$. long, glabrous or minutely puberulent, lanceolate. Dry plains: Tex.-Kans.-Colo.-Calif.; Mex. Son. Je-Au.

19. A. pumila (A. Gray) Vail. Stems tufted, glabrous or nearly so, 1-2.5 $\mathrm{dm}$. high, simple; leaves very numerous, crowded, irregularly scattered on the stem, about $3.5 \mathrm{~cm}$. long, linear-filiform, revolute, glabrous or minutely scabrouspuberulent; corolla greenish white; lobes oblong, 4-5 mm. long; column about $0.5 \mathrm{~mm}$. long; hoods oblong, erect, entire; follicles narrowly lanceolate, $3-5 \mathrm{~cm}$. long, minutely puberulent. Dry plains: S.D.-Ark.-N.M.-Colo.-Mont. Plain-Submont. Jl-S.

\section{ASClepiódora A. Gray. Spider Milkweed.}

Perennial herbs. Leaves opposite or alternate. Flowers perfect, regular, purplish, greenish, or white, in terminal, solitary or corymbose umbels. Calyxlobes narrow, acute. Corolla rotate, 5-lobed, the lobes acute, spreading or erect. Hoods inserted over the whole short column, arising from the base of the corolla-lobes, saccate at the base, obtuse at the apex, crested within, with 1 or 2 small appendages between the hoods, simulating an inner crown. Follicles fusiform, often soft-spinulose.

1. A. decumbens (Nutt.) A. Gray. Perennial, with a woody rootstock; stems usually several, $2-4 \mathrm{dm}$. high, angled; leaves $4-15 \mathrm{~cm}$. long, lanceolate to linear, attenuate, thick, alternate or whorled in 3 's; corolla globose in bud; lobes greenish; hood purplish, incurved, obtuse, 2-lobed on the ventral margin; follicles about $8 \mathrm{~cm}$. long, pubescent, smooth, or with a few soft processes. Dry sandy soil: Kans.-Ark.-Tex.-Ariz.-Nev.; Mex. Son.-Submont. Je-S.

\section{Family 107. CONVOlvUlaceae. Morning-glory Family.}

Annual or perennial, twining or trailing herbs or vines, or rarely trees or shrubs. Leaves alternate, without stipules. Flowers perfect, regular, either solitary, axillary, or in cymes. Sepals 5, rarely 4 , more or less united. Corolla gamopetalous, usually funnelform, either plicate and the plaits convolute, or induplicate-valvate, rarely imbricate in the bud, 5-lobed, or 
rarely 4-lobed. Stamens 5, alternate with the corolla-lobes, partially adnate to the corolla-tube; anthers 2-celled, erect or incumbent. Gynoecium of 2 or 3 united carpels; ovary 2 - or 3-celled, or by false partitions 4- or 6-celled; styles usually united; ovules 1 or 2 in each cavity. Fruit a capsule, 2-6celled, or by breaking down of the septum 1-celled. Seeds large; endosperm mucilaginous; embryo curved with large plaited or crumpled cotyledons.

Styles distinct or partly so.

Corolla not plaited; styles simple.

Corolla plaited; styles 2-cleft.

Styles united up to the stigmas.

Stigmas subglobose.

Stigmas linear to oblong-cylindric.

1. Cressa.

2. Evolvulus.

3. IPOMOEA.

4. Convolvulus.

1. CRÉSSA L.

Perennial plants, branched, and somewhat suffrutescent at the base. Leaves small or reduced to scales, alternate. Flowers perfect, regular, solitary in the upper axils. Sepals 5, equal, distinet, imbricate. Corolla funnelform, persistent, 5-lobed. Stamens 5, exserted. Ovary more or less perfectly 2-celled; styles distinct; ovules 2 in each cavity.

Stem erect; pedicels longer than the leaves.

Stem decumbent; pedicels shorter than the leaves.

1. C. erecta.

2. C. depressa.

1. C. erecta Rydb. Stem 2-3 dm. high, with erect branches, silvery-canescent; leaves elliptic, 5-7 mm. long, acute at both ends, sessile, silvery-canescent; bracts elliptic, $3 \mathrm{~mm}$. long; sepals 4-5 $\mathrm{mm}$. long, oval, equalling the corolla-tube; corolla white; lobes elliptic, acutish, rarely spreading; filaments filiform, slightly pubescent; ovary densely pubescent. Saline places near hot springs: Utah. Son. Jl.

2. C. depressa Goodding. Stem many-branched, depressed, spreading, 1-2 $\mathrm{dm}$. long, loosely canescent; leaves loosely canescent, oblong to oval, subacute, 5-10 mm. long, 3-4 mm. wide; sepals 4 or 5 , elliptic or oval, $5 \mathrm{~mm}$. long, subtended by two bracts; corolla campanulate; lobes oval, subacute, reflexed, silky pubescent; filaments broadly subulate; ovary silky-lanate at the summit. Saline ground: Utah-Nev.-s Calif. Son. My-O.

\section{EVÓLVULUS L.}

Annual or perennial pubescent herbs. Leaves alternate, entire. Flowers perfect, regular, solitary in the axils, or in terminal racemes or panieles. Sepals 5 , nearly equal. Corolla funnelform, campanulate or rotate, white, pink, or blue, with 5-angled or 5-lobed limb. Stamens 5, with filiform filaments. Styles 2, distinet, each 2-cleft; stigmas slender. Capsule short, 2-4-valved; seeds 1-4, glabrous.

1. E. Nuttallianus R. \& S. Perennial, with a more or less woody base; stems branched below, ascending or spreading, 1.5-2.5 dm. high, silky-hirsute; leaves subsessile, silky-hirsute on both sides, oblong or oblanceolate, 1-1.5 $\mathrm{cm}$. long, aeute; sepals silky, linear-lanceolate, acuminate; corolla about $1 \mathrm{~cm}$. broad. $E$. argenteus Pursh., not R. Br. E. pilosus Nutt., not Lam. Sandy soil: S.D. -Mo.-Tex.-Ariz.-Colo. Plain-Submont. My-Jl.

\section{IPOMOÈA L. MORNING-GLORY.}

Annual or perennial, usually elimbing or trailing vines, or rarely erect. Leaves alternate, entire or lobed. Flowers perfect, regular, solitary and axillary, or cymose. Sepals 5, closely imbricate. Corolla funnelform, of various colors, with a spreading limb. Stamens 5, included. Ovary 2- or 4-celled; styles united. Capsule septicidal, 2- or 4-valved. Seeds often pubescent.

Plant bushy, not climbing; leaves linear.

1. I. leptophylla. Plant climbing; leaf-blades cordate.

2. I. purpurea.

1. I. leptophylla Torr. Perennial, with a deep-seated enormous fleshy root; stems several, erect or ascending, 3-12 dm. high, glabrous; leaves linear, 
5-15 cm. long, acute, entire; sepals ovate or orbicular-ovate, 5-10 mm. long, the inner larger than the outer; corolla pink-purple, 5-7 $\mathrm{cm}$. long. BUSH MorNING Glory, Big Root. Plains and prairies: S.D.-Tex.-N.M.-Mont. Plain. $\mathrm{Je}-\mathrm{Au}$.

2. I. purpurea (L.) Roth. Annual; stem high, climbing, twining, retrorselyhirsute; leaf-blades cordate, short-acuminate; flowers umbellate on long peduncles; calyx bristly-hairy; corolla purple or rarely pink or white, $4.5-7 \mathrm{~cm}$. long. ComMON MoRNING-GLORY. Cultivated ground, waste places, etc.: N.S.-Fla.-Tex. -Colo.; escaped from cultivation; native of trop. Am.

\section{CONvólvulus (Tourn.) L. Bindweed, Morning Glory.}

Annual or perennial, trailing or twining herbaceous vines, rarely shrubs. Leaves alternate, usually sagittate or cordate at the base. Flowers perfect, regular, solitary or clustered, on axillary peduncles. Sepals 5 , rarely equal, or the outer larger. Corolla funnelform or campanulate, with plaited, entire, 5-angled or 5-lobed limb. Stamens 5, included; filaments filiform or dilated at the base. Ovary 1-2-celled; styles united; stigmas linear to oblong; ovules 4. Capsule subglobose, 2-4-valved. Seeds glabrous.

Calyx not closely subtended by the bracts.

Plant not canescent; leaf-blades hastate, but otherwise entire.

Whole plant glabrous or nearly so.

Stem and lower surface of the leaves with scattered long hairs.

Plant more or less canescent; leaves usually lobed or dissected.

1. C. arvensis.

2. C. ambigens.

Main divisions of the leaf-blades ovate or oblong, obtuse, lobed; sepals auricled

at the base.
Main divisions of the leaf-blades linear, entire, the basal lobes usually deeply cleft; sepals not auricled.
$4, C$. incanus.

Calyx closely subtended and enclosed by the large bracts.

Plants climbing or trailing; bracts cordate.

Leaf-blades hastate; the basal lobes often sinuate-dentate, acute; stem and leaves

glabrous or slightly hairy.
Leaf-blades more sagittate; basal lobes rounded, entire; stem and leaves densely

$5 . C$. americanus.
Leaf-blades more sagittate; basal lobes rounded, entire; stem and leaves densely pubescent.
6 . C. interior.

Plants erect or decumbent: bracts oval or oblong. $\quad 7$. C. Macounii.

1. C. arvensis L. Stem branched at the base, prostrate or low-twining, 2-8 dm. long, glabrous; leaf-blades oblong or ovate-sagittate to linear-hastate, $1-5 \mathrm{~cm}$. long, obtuse or acutish; basal lobes more or less spreading, acute; bracts subulate; corolla white or rose-tinged, $1.5-2 \mathrm{~cm}$. long and broad. Waste places and fields: N.S.-N.J.-Nev.-Wash.-B.C. Plain-Submont. Je-Au.

2. C. ambigens House. Stem prostrate or trailing, 2-10 dm. long, finely cinereous, or glabrate in age; leaf-blades ovate-oblong or triangular-oblong, $1.5-$ $4 \mathrm{~cm}$. long, abruptly acute, truncate or nearly so at the base; basal lobes spreading, acute, often subtoothed below; flowers axillary, solitary; corolla $1.5-2 \mathrm{~cm}$. long and about as broad, white or with pink stripes. River valleys and loose soil: Mont.-N.M.-Calif.-Ore. Plain-Submont. Je-Au.

3. C. hermannioides A. Gray. Stem branched at the base, spreading or procumbent, 3-15 dm. long, silky-tomentose; leaf-blades ovate, oblong or oblonglanceolate, $1.5-7 \mathrm{~cm}$. long, sinuately-toothed, eordate or sagittate at the base; corolla white, $2-2.5 \mathrm{~cm}$. long, $1.5-2 \mathrm{~cm}$. wide, angulate. Dry plains: Tex. $\rightarrow$ Colo. Son. Ap-S.

4. C. incanus Vahl. Stem branched at the base, procumbent, 3-10 dm. long, cinereous; leaf-blades variable, linear-sagittate to lanceolate-hastate, with the basal lobes spreading, more or less lobed, or pedately cleft, $2.5-5 \mathrm{~cm}$. long, often mucronate; sepals becoming 6-8 mm. long; corolla white or pink, about $12 \mathrm{~mm}$. long, $15 \mathrm{~mm}$. broad; lobes acuminate. Dry hills and plains: Neb.Ark.-Tex.-Ariz. Son. Je-Au.

5. C. americanus (Sims) Greene. Stem twining, 1-3 m. high, glabrate; leaf-blades glabrous, broadly hastate or ovate-hastate, $5-12 \mathrm{~cm}$. long, acuminate or apiculate; basal lobes more or less spreading, broadly triangular, with a smaller lobe below; bracts broadly ovate-cordate, obtuse or acutish; corolla $4-5 \mathrm{~cm}$. long, 5-7 cm. broad, pink or rose-purple. Closely related to C. sepium L., of Europe. 
Thickets and fence-rows: N.S.-N.C.-N.M.-Wash.-B.C. Plain-Submont. $\mathrm{My}-\mathrm{Au}$.

6. C. interior House. Stems prostrate or somewhat climbing, 2-8 dm. long, densely and softly pubescent; leaf-blades deltoid or hastate-ovate, $2.5-4$ $\mathrm{cm}$. long, glabrous above, pubescent beneath; base shallowly cordate or truncate; bracts broadly ovate, obtuse, closely investing the calyx; corolla white, $3.5-4 \mathrm{~cm}$. long, the limb entire, $3-4 \mathrm{~cm}$. broad. Sandy soil: N.D.-Okla--Ariz.-Colo. Plain. My-Jl.

7. C. Macounii Greene. Stem erect, $7-15 \mathrm{~cm}$. high, glabrous; leaves broadly sagittate, about $5 \mathrm{~cm}$. long, glabrous; bracts broad, oval, obtuse, 2-2.5 em. long, auricled at the base; corolla white, fully $5 \mathrm{~cm}$. long. Sandy soil: Sask.-B.C. Plain. Au.

\section{Family 108. CUSCUtACEAe. Dodder Family.}

Herbaceous parasites, with twining stems, at first germinating in the ground, but soon attaching themselves to some other plant by means of aerial rootlets, and taking their nourishment from these, the lower part of the stem having decayed early. Leaves reduced to minute alternate scales. Flowers perfect, regular, in compact or open eymes. Calyx inferior; sepals 5 , or rarely 4, distinct or more or less united. Corolla campanulate or subglobose, 5-lobed, or rarely 4-lobed, the lobes being imbricate, usually with crenulate or fringed scales in the throat, alternating with the lobes. Stamens 5, rarely 4, partly adnate to the corolla; anthers 2-celled. Styles 2, mostly distinct; stigmas capitate or elongate. Capsule subglobose or ovoid, 2-celled, circumscissile or bursting irregularly. Embryo curved or spiral, in a fleshy endosperm.

\section{CÚSCUTA (Tourn.) L. Dodder, Love-vine, Coral-vine.}

Characters of the family.

Stigmas elongate, linear; styles equal; capsule circumscissile.

Corolla globose-urceolate; scales inside the corolla crenate. 1. Calyx-lobes obtuse.

Calyx-lobes acute.
mas capitate; styles usually unequal.

1. C. gracilis.

2. C. planiflora.

Stigmas capitate; styles usually unequal.

3. C. Anthemi.

Capsule circumscissile; calyx and corolla-lobes acuminate; inflorescence umbel-like.

Capsule indehiscent or bursting irregularly.

4. C. umbellata.

Calyx gamosepalous, usually not bracted.

Capsule depressed-globose.

Lobes of the corolla triangular or lanceolate, acuminate or acute,

Calyx-lobes acute or acuminate; corolla-lobes erect or somewhat spreading, in fruit connivent; flowers pedicelled. 5 . C. californica.

Calyx-lobes rounded; corolla-lobes strongly spreading with inflexed tips; flowers subsessile. 6 6. C. arvensis.

Lobes of the corolla oblong, very obtuse.

Corolla deeply campanulate, 4 -merous, about $2 \mathrm{~mm}$. wide; tube longer than the calyx.

7. C. cephalanthi.

Corolla open-campanulate, about $4 \mathrm{~mm}$. wide; tube shorter than the calyx. 8 . C. plattensis.

Capsule ovoid-globose, acute.

Corolla-lobes not incurved.

Lobes of the corolla and the calyx obtuse.

Flowers less than $2 \mathrm{~mm}$. long; calyx-lobes very short, rounded and denticulate. 9. C. denticulata.

Flowers $2.5-3 \mathrm{~mm}$. Iong; calyx-lobes ovate, not denticulate. Scales incurved over the ovary; styles about half as long as the ovary or longer.

10. C. Gronovii.

Scales appressed to the corolla-tube; styles one-third to onefourth as long as the ovary. $\quad 11$. C. curta.

Lobes of the corolla and calyx acute. 12 . C. salina.

Corolla-lobes incurved at the apex.

Capsule $4 \mathrm{~mm}$. or less broad; inflorescence rather open.

13. C. indecora. 
Capsule 5-6 mm. broad; inflorescence globular clusters.

14. C. megalocarpa.

Calyx of 5 almost distinct and overlapping sepals, subtended by 2 or more similar bracts.

15. C. cuspidata.

1. C. gra cilis Rydb. Stem filiform, about $0.25 \mathrm{~mm}$. in diameter; flowers in dense globular clusters; calyx gamosepalous but cleft to near the base; lobes ovate; corolla less than $2 \mathrm{~mm}$. high; lobes ovate, widely spreading, acute; scales ovate, crenate, almost half as long as the corolla-tube; capsule about $2 \mathrm{~mm}$. high, acute-globose, circumscissile near the base. Parasitic on Eriogonum, Chrysothamnus, Solanum, etc.: Wyo. Plain-Submont. Je.

2. C. planiflora Tenore. Stem filiform, reddish; flowers in dense glomerules, $5-10 \mathrm{~mm}$. in diameter; calyx obconic; lobes round, short, obtuse, carinate beneath; corolla-tube very short; lobes 5, always reflexed, ovate, apiculate. C. epilinum and C. epithymum of western reports. Parasitic on alfalfa and other herbs: Colo.-Wyo.-Utah-Mont.; introduced in alfalfa from $\mathrm{s} \mathrm{Eu.} \mathrm{Je-Au.}$

3. C. Anthemi A. Nels. Stem filiform, $2-3 \mathrm{dm}$. long; flowers sessile in small capitate clusters; calyx-lobes broadly ovate, acute; corolla less than $2 \mathrm{~mm}$. long, broadly campanulate; lobes ovate, acute, equalling or exceeding the tube; scales oval, fringed; capsule globose, $1 \mathrm{~mm}$. thick. Parasitic on Artemisia: Wyo.

4. C. umbellata H.B.K. Stem capillary, low; flowers few, umbellate; calyxlobes lanceolate, acute; corolla 3-4 $\mathrm{mm}$. long, campanulate; lobes lanceolatesubulate; scales deeply fringed, exceeding the tube; capsule capped by the remains of the corolla. On Amaranthaceae, Portulacaceae, Zygophyllaceae, Nyctaginaceae, and rarely Compositae: Tex.-Colo.-Ariz.; Mex. and W. Ind. Son.

5. C. californica Choisy. Stems very slender, filiform; flower-elusters rather open; pedicels slender but short; calyx turbinate, the lobes triangular or lanceolate; corolla-lobes lance-linear, in fruit mostly erect and connivent; scales wanting; eapsule enveloped by the corolla. On herbs of arid regions, Eriogonum, etc.: Calif.-Utah-Ariz, Son. My-Au.

6. C. arvensis Beyr. Stems slender; flowers in head-like clusters, sessile, less than $2 \mathrm{~mm}$. long; calyx-lobes rounded, obtuse; corolla-lobes longer than the tube, acute or acuminate, triangular; scales large and deeply laciniate. On various herbs: Mass.-Fla.-Calif.-B.C.; Mex, and W. Ind. Plain-Submont.

7. C. cephalanthi Engelm. Stem filiform; flowers cymose-paniculate, about $2 \mathrm{~mm}$. long, 4-merous, or even 3-merous; corolla deeply campanulate; scales ovate or spatulate; capsule $2-2.5 \mathrm{~mm}$. in diameter. C. tenuiflora Engelm. On coarse herbs and shrubs: Pa.-Tex.-Sask. Plain. Je-S.

8. C. plattensis A. Nels. Stem yellowish green; flowers densely or loosely cymose, short-pedicelled; calyx-lobes suborbicular, obtuse, fully $1 \mathrm{~mm}$. long; corolla marcescent at the base of the eapsule; lobes at first erect, at last reflexed; scales broadest at the truncate fringed summit; capsule $5 \mathrm{~mm}$. at maturity, indehiscent. On Grindelia, Solidago, Helianthus and other Composites: Wyo. J1-Au.

9. C. denticulata Engelm. Stem capillary-filiform; flowers few in small clusters; corolla-tube included in the calyx; lobes rounded-ovate, less than $1 \mathrm{~mm}$. long; scales reaching to the base of the stamens, denticulate at the rounded apex; capsule covered by the marcescent corolla, ovoid. On herbs and low shrubs: Utah-Nev.

10. C. Gronovii Willd. Stem rather coarse, high-climbing; flowers paniculate-cymose; calyx-lobes elliptic; corolla deeply campanulate; lobes elliptic, obtuse, spreading, flat; scales ovate, fringed, spreading; capsule broadly ovoid, 4-5 mm. in diameter. On coarse herbs or shrubs: N.S.-Fla.-Tex.-Colo.N.D.-Man. Plain. J-O.

11. C. curta (Engelm.) Rydb. Stems rather slender; flowers in small cymes; calyx short; lobes rounded, obtuse; corolla deeply campanulate, $3 \mathrm{~mm}$. long; lobes short, broadly oval; scales short, bifid or truncate, appressed to the tube; capsule ovoid, the marcescent corolla surrounding or covering the upper portion. On coarse herbs: Colo,-Utah-Nev. Au. 
12. C. salina Engelm. Stem filiform, low; flowers in small clusters; calyxlobes ovate-lanceolate, as long as the tube of the corolla; corolla $3-5 \mathrm{~mm}$. long; lobes lanceolate; scales fringed, small or reduced; capsule rounded but acute, surrounded but not covered by the marcescent corolla. On Salicornia and other salt plants: B.C.-Utah-Ariz,-Calif. Son. Ap-S.

13. C. indecora Choisy. Stem filiform, high twining; flowers loosely paniculate-cymose; calyx-lobes ovate or lanceolate, acute; corolla campanulate, 3-5 mm. long; lobes ovate-lanceolate, erect or more commonly spreading; scales large, broadly oval, fringed; capsule enveloped by the corolla, rounded-ovoid. On herbs and low shrubs, mostly Compositae and Leguminosae: Fla.-Ill.-Utah -Calif.; Mex., C. Am., W. Ind. and S. Am. Jl-S, or in the south Ja-D.

14. C. megalocarpa Rydb. Stem stout, usually over $1 \mathrm{~mm}$. in diameter; flowers in dense globular clusters; calyx-lobes rounded, scarcely $1 \mathrm{~mm}$. long; corolla about $3 \mathrm{~mm}$. high and broad; lobes broadly triangular, acutish, about 1 $\mathrm{mm}$. long, with incurved tip; scales deeply 2-lobed, and fringed only in the open sinuses. On willows: Mont,-Colo. Submont. Л-S.

15. C. cuspidata Engelm. Stem filiform; flowers in loose panicles, with bracted pedicels; bracts and sepals ovate-orbicular; corolla $3-5 \mathrm{~mm}$. long, eampanulate; lobes oblong, cuspidate or mucronate, rarely obtuse; scales large, deeply fringed; capsule capped by the marcescent corolla. On Ambrosiaceae and rarely Leguminosae: Mo.-Tex.-Utah. Son. Au-S.

\section{Family 109. POlemoniaceae. Phlox Family.}

Annual or perennial herbs, or rarely shrubby plants. Leaves alternate or opposite, entire, pinnatifid, or pinnately compound. Flowers perfect, regular or nearly so. Sepals 5, partly united. Corolla of 5 united petals, regular or nearly so, 5- or rarely 4-lobed, from rotate to salver- or trumpet-shaped; lobes convolute in aestivation. Stamens 5, rarely 4 , often unequal; filaments adnate to the corolla-tube, often inserted at different heights. Gynoecium of 3 united carpels; ovary 3-celled; styles wholly united; stigmas 3. Fruit a 3-celled, loculicidal capsule. Seeds often with a mucilaginous coat.

Calyx wholly herbaceous; leaves pinnately compound.

1. Polemontum.

Calyx more or less scarious between the lobes, or the lobes spinulose-tipped and pungent; leaves simple or pinnatifid, but not compound.

Calyx distinctly enlarging in fruit, not ruptured by the capsule. 2. Coliomi.

Calyx soon ruptured by the fruit, or if not ruptured, slightly if at all enlarged in fruit and calyx-teeth spinescent.

Corolla strictly salver-shaped with a narrow throat.

Perennials, with leaves opposite; seeds not mucilaginous when wetted.

Annuals, with the floral leaves alternate; seeds mucilaginous when wetted. 4. MICROSTERIS.

Corolla campanulate, funnelform, trumpet-shaped, or if somewhat salver-shaped,

the throat open.
Anthers sagittate at the base; calyx-lobes and 3-5-cleft bracts densely woolly,
pungent.

Anthers not sagittate; calyx-teeth and bracts usually not woolly, but if somewhat so, not pungent.

Corolla elongate, with a narrow tube and funnelform or spreading throat. Calyx-teeth either unequal in size or spinulose-laciniate, or both; pungent-leaved annuals.

6. NAVARRETIA.

Calyx-teeth neither unequal nor spinulose-laciniate; perennials or non-pungent annuals.

Calyx not at all scarious in the sinuses; mostly undershrubs, with pungent leaves.

Calyx decidedly scarious in the sinuses. Stem leafy; bracts not connate.

Leaves alternate; seeds mostly with spiracles; corolla with a long tube and a funnelform throat.

Lower segments of the leaves not changed into bristles: calyx-lobes not long-setose. $\quad 8$. GILIA.

Lower segments of the leaves changed into bristles; calyx-lobes long-setose. 9 . LANGLOISIA.

Leaves opposite; seeds without spiracles; corolla short salvershaped or short funnelform. 10. LINANTHUS. 
Stem without proper leaves, but with persistent connate cotyledons and connate bracts subtending the head-like flowerclusters.

11. GYMNOSTERIS.

Corolla rotate, or campanulate, with very short proper tube, and rather open.

Corolla campanulate or short-funnelform.

Leaves mostly opposite; flowers medium sized; corolla funnelform.

Leaves alternate; corolla very small, campanulate. 10. LINANTHUS.

Corolla rotate.

12. TINTINABULUM.

13. Gillastrum.

\section{POLEMÒNIUM (Tourn.) L. JACOB's Ladder, Skunk-weed.}

More or less caulescent perennial or annual herbs, with pinnate leaves. Flowers perfect, solitary or clustered. Calyx wholly foliaceous, campanulate, more or less glandular, 5-cleft, not ruptured by the fruit. Corolla campanulate or rotate-funnelform to almost tubular. Stamens 5; filaments adnate mostly to the lower part of the corolla-tube, rarely unequally adnate to the upper part. Style elongate. Ovules three to many (rarely 1 or 2) in each cell. Seeds remaining unchanged when wetted.

Annuals; corolla almost rotate, shorter than the calyx.

I. MicRantha.

Perennials; corolla longer than the calyx.

Corolla campanulate; filaments with pilose appendages at the base; inflorescence usually open; leaflets never verticillate.

Low, 1-3 dm. high, cespitose; basal leaves numerous and stem-leaves few.

Stem tall, leafy, usually solitary from the rootstock, 4-10 dm. high.

II. PUlchella.

III. CAERULEA.

Corolla funnelform to trumpet-shaped; fllaments without appendages at the base; inflorescence dense, spiciform; leaflets (except in the first species) verticillate.

IV. VIscosA.

One species.

I. Micrantha.

II. Pulchella.

1. P. micranthum.

Stem and leaves viscid-pubescent, with long flat hairs; leaflets inclined to be ovate or ovate-lanceolate.

Corolla over $1 \mathrm{~cm}$. Iong; plants light green; leaflets $1.5-2 \mathrm{~cm}$. long.

Corolla less than $1 \mathrm{~cm}$. long; plant dark green; leaflets $5-15 \mathrm{~mm}$. Iong. $P$. columbianum.

Stem and leaves viscid-puberulent, the latter often glabrate.

3. P. delicatum.

Inflorescence and leaflets crowded; sepals obtuse or rounded at the apex.

Inflorescence and leaflets scarcely crowded; sepals acutish.

Stem-leaves $1-3$; inflorescence open.

Stem-leaves $3-5$; inflorescence narrow.

4. P. parvifolium.

5. P. pulcherrimum.

6. P. Haydeni.

III. Caerulea.

Upper leaflets decurrent and confluent; plants with a woody base.

Corolla straw-colored or white.

Corolla purple.

Corolla $2 \mathrm{~cm}$. high, or nearly so; leaves glabrous,

Corolla 8-15 mm. high; leaves pubescent.

Stem and inflorescence long-villous, scarcely at all viscid.

Stem and inflorescence short-hairy; the latter at least distinctly viscid.

7. P. albiflorum.

8. P. Archibaldae.

Corolla over $12 \mathrm{~mm}$. long: inflorescence conical or ovoid in outline: main

peduncle usually exceeding the branches. 10. $P$. robustum.
Coroula less than $12 \mathrm{~mm}$. long; inflorescence flat-topped; main peduncle exceeded in length by the branches.

Upper leaflets not confluent; plant with a creeping rootstock.

11. $P$. foliosissimum.

Flowers in a narrow thyrsus; leaflets usually less than $3 \mathrm{~cm}$. long.

Flowers in an open corymbiform or paniculate inflorescence; leaflets $3-5 \mathrm{~cm}$. long.

13. P. intermedium.

Corolla purple.

IV. VIScosA.

Leaflets not verticillate.

Leaflets more or less verticillate.

14. P. speciosum.

Corolla $2 \mathrm{~cm}$. long or less, campanulate-funnelform, with a rather broad tube. Calyx densely viscid, but not conspieuously long-hairy.

Calyx conspicuously villous with long white viscid hairs.

Corolla $2-3 \mathrm{~cm}$. long, funnelform, with a narrow tube.

15. P. viscosum.

16. $P$. Grayanum.

17. P. confertum. 
Corolla yellow, ochroleucous, or greenish.

Corolla funnelform; stamens adnate to the middle of the corolla-tube.

Corolla almost tubular; stamens almost wholly adnate to the corolla-tube.

19. P. Brandegei.

1. P. micranthum Benth. Annual; stem branched from the base, glandular-puberulent, erect or ascending, $0.5-2.5 \mathrm{dm}$. high, leafy; leaves viscid-villous; leaflets 11-13, rounded, 3-6 mm. long; flowers axillary, solitary, pedicelled; corolla whitish; filaments dilated at the base; ovules $2-3$ in each cell. Sandy places: B.C.-Mont.-Utah-Calif. Submont. Ap-My.

2. P. columbianum Rydb. Stems several, $2-3 \mathrm{dm}$. high, distinctly glandular in the inflorescence; leaves $5-15 \mathrm{~cm}$. long, sparingly viscid, pubescent; leaflets $9-19$, elliptic or lance-elliptic, acute, $1.5-3 \mathrm{~cm}$. long; calyx about $6 \mathrm{~mm}$. long; lobes lanceolate, acute, fully equalling the tube; corolla violet, with yellowish base; lobes rounded-truncate at the apex; stamens slightly longer than the corolla. Woods: Ida.-Wash.-Ore. Submont. Je-Au.

3. P. delicatum Rydb. Stem very slender, about $1 \mathrm{dm}$. high; leaves $3-8$ cm. long; leaflets 11-23, ovate, ovate-lanceolate, or oblong, mostly acute, 3-10 $\mathrm{mm}$. long; calyx glandular, 4-5 mm. long; lobes lanceolate, acute; corolla violet, about $7 \mathrm{~mm}$. high and $8 \mathrm{~mm}$. broad; stamens nearly equalling the corolla. $P$. humile pulchellum A. Gray, not $P$. pulchellum Burge. $P$. scopulinum Greene. Mountains: Colo.-Utah-Ariz.-N.M. Mont.-Alp. J1-Au.

4. P. parvifolium Nutt. Stems rarely more than $1 \mathrm{~cm}$. high, glandularpuberulent, almost scapose; leaflets $11-25$, oval or suborbicular, rounded, $2-4$ $\mathrm{mm}$. long; inflorescence dense; calyx about $4 \mathrm{~mm}$. long; lobes oval or elliptic; corolla dark violet, 7-9 $\mathrm{mm}$. long; lobes rounded; stamens nearly equalling the corolla. P. mexicanum Nutt. Mountains: Mont. Je-Jl.

5. P. pulcherrimum Hook. Stems 1-3 dm. high, glandular-puberulent; leaflets 15-27, oval, mostly obtuse, $5-10 \mathrm{~mm}$. long; calyx about $5 \mathrm{~mm}$. long; lobes lanceolate; corolla $8-10 \mathrm{~mm}$. long, violet or rose-colored, with a yellowish base; lobes rounded; stamens shorter than the corolla. Mountains: Alta.-Wyo. -B.C. Mont.-Subalp. Je-Au.

6. P. Haydeni A. Nels. Stems several, 2-3 dm. high, glandular-puberulent, especially above; leaflets 15-25, oval, oblong, or oblanceolate, 5-10 $\mathrm{mm}$. long; calyx narrowly campanulate, 5-6 mm. long, glandular-puberulent; corolla blue, campanulate, $10-15 \mathrm{~mm}$. long; stamens often equalling the corolla. Mountainsides: Wyo.-Mont.-Ida. Je-Jl.

7. P. albiflorum Eastw. Stems solitary or few, $3-6 \mathrm{dm}$. high, glandularpuberulent or pubescent; leaflets $11-15$, lanceolate, acuminate, $1-3 \mathrm{~cm}$. long; calyx $7 \mathrm{~mm}$. long, densely glandular; lobes lanceolate, acute or obtuse; corolla cream-colored or white, about $15 \mathrm{~mm}$. long; stamens usually longer than the corolla. Mountains: Utah-Nev. Submont.-Mont. Je-Jl.

8. P. Archibaldae A. Nels. Stem 4-7 dm. high, glabrous below, glandular above; inflorescence openly cymose-corymbose, minutely glandular; leaflets 1319, oblong-lanceolate, 2-4 cm. long; calyx 6-8 mm. long; lobes lanceolate, acute; corolla-lobes orbicular; stamens much shorter than the corolla; filaments pubescent at the base. P. grande Greene. Mountains: Colo,-Utah. Mont. J-Au.

9. P. molle Greene. Stem $3-6 \mathrm{dm}$. high, densely villous; leaflets $13-21$, oblong or lanceolate, $1.5-2.5 \mathrm{~cm}$. long; flowers openly paniculate; calyx about 8 $\mathrm{mm}$. long; lobes lanceolate, acute; corolla campanulate, 10-12 $\mathrm{mm}$. long; stamens shorter than the corolla. Mountains: Colo.-N.M. Mont. Je-J.

10. P. robustum Rydb. Stem 4-10 dm. high; leaflets $11-17$, lanceolate or lance-oblong, acute, $1.5-2.5 \mathrm{~cm}$. long; inflorescence much branched; calyx glandular-villous, $7-8 \mathrm{~mm}$. long; lobes lanceolate; corolla rose or purplish, $12-15 \mathrm{~mm}$. high; stamens shorter than the corolla. Mountains: Colo. Mont. Jl.

11. P. foliosissimum A. Gray. Stems solitary or few, short-pilose throughout, glandular above, 3-9 dm. high; leaflets 11-21, oval or lanceolate; calyx about $7 \mathrm{~mm}$. long, densely glandular; corolla $9-12 \mathrm{~mm}$. long, funnelform-campanulate, 
blue or rose-colored, rarely white; stamens usually shorter than the corolla. Mountains: Colo.-N.M.-Utah. Submont.-Subalp. Je-Au.

12. P. occidentale Greene. Stems leafy, solitary and rather simple, glabrous below, glandular-puberulent above, 3-9 dm. high; leaves glabrous or sparingly pubescent; leaflets 15-27, ovate-oblong or lanceolate, rounded, oblique at the base, acute at the apex, 1-4 cm. long; calyx glandular-puberulent, 7-8 $\mathrm{mm}$. long; lobes oval, obtusish; corolla blue or violet, 10-12 mm. long, campanulate; stamens about as long as or longer than the corolla. Valleys and open woods: Sask.-Colo.-Calif.-Alaska. Submont,-Mont. Je-Au.

13. P. intermedium (A. Brand) Rydb. Stem solitary, 5-7 dm. high, puberulent throughout and glandular above; leaflets 11-27, ovate-lanceolate to linearlanceolate, often somewhat falcate, 3-5 $\mathrm{cm}$. long; calyx $6-7 \mathrm{~mm}$. long; lobes lanceolate; corolla blue, campanulate, $12-14 \mathrm{~mm}$. long; lobes acutish; stamens shorter than the corolla. P. occidentale intermedium A. Brand. Along streams: Ida.-Wash.-B.C. Л-Au.

14. P. speciosum Rydb. Stem 1-2 dm. high, with 2-3 leaves; basal leaves numerous, 8-15 $\mathrm{cm}$. long, with wing-margined rachis; leaflets $13-25$, ovate, $6-12$ $\mathrm{mm}$. long, acute; inflorescence capitate; calyx viscid-villous and glandular, 15-20 $\mathrm{mm}$. long; lobes lanceolate, acute; corolla pale blue, deeply campanulate-funnelform, 2-2.5 $\mathrm{cm}$. long; limb about $1.5 \mathrm{~cm}$. broad. Mountains: Colo. Alp. J1$\mathrm{Au}$.

15. P. viscosum Nutt. Stems several, viscid-pubescent, $5-10 \mathrm{~cm}$. high, erect; leaflets verticillate, $30-41$, orbicular or nearly so, 1-4 $\mathrm{mm}$. long; flowers subcapitate; calyx campanulate, densely glandular, 8-10 $\mathrm{mm}$. long; lobes lanceolate; corolla blue or violet, $15-20 \mathrm{~mm}$. long; lobes rounded; filaments sparingly barbed. Skunk-Weed. Mountains: Alta.-Wyo.-Utah-Ida. Mont.-Subalp. $\mathrm{Je}-\mathrm{Au}$.

16. P. Grayanum Rydb. Stems about $1 \mathrm{dm}$. high, glandular-villous; leaflets verticillate, obovate or spatulate, $2-6 \mathrm{~mm}$. long, obtuse; calyx about 18 $\mathrm{mm}$. long, villous with white hairs; lobes linear-lanceolate; corolla about $2 \mathrm{~cm}$. long, campanulate-funnelform, with a wide tube; lobes rounded. High mountains: Colo. Mont.-Alp. Jl-Au.

17. P. confertum A. Gray. Stems erect, 1-2 dm. high; leaflets verticillate, $30-40$, orbicular to oblong, more or less viscid, $3-10 \mathrm{~mm}$. long; flowers capitate or spicate; calyx oblong-campanulate, fully $1 \mathrm{~cm}$. long, densely glandular; lobes lanceolate, acute; corolla blue or violet, $2-3 \mathrm{~cm}$. long, funnelform. SKUNK-WEED. Mountains: Wyo.-N.M. - Utah. Mont.-Alp. J-Au.

18. P. mellitum (A. Gray) A. Nels. Stem 1-2.5 dm. high, leafy; leaflets verticillate, 30-60, oval to almost linear, 5-10 $\mathrm{mm}$. long; flowers racemose or spicate; calyx glandular-puberulent, about $12 \mathrm{~mm}$. long; lobes linear-lanceolate; corolla white or cream-colored, about $3 \mathrm{~cm}$. long. P. confertum mellitum A. Gray. Mountains: Wyo-Colo. Mont.-Subalp. Je-Au.

19. P. Brandegei (A. Gray) Greene. Stem 1-3 dm. high, sparingly leafy, glandular-puberulent; leaflets verticillate, $30-40$, elliptic, $5-8 \mathrm{~mm}$. long; flowers racemose or spicate; calyx about $1 \mathrm{~cm}$. long, glandular-puberulent; lobes linearlanceolate; corolla $2.5-3 \mathrm{~cm}$. long, yellow or greenish yellow. Gilia Brandegei A. Gray. Mountains: Colo,-Utah. Mont,-Subalp. Je-Au.

\section{COLLÒMIA Nutt.}

Simple or branched, caulescent annuals, Leaves alternate, entire or pinnatifid. Flowers perfect, in subcapitate clusters, at the end of the stem or axillary. Calyx obpyramidal, 5-cleft, scarious in the sinuses, not ruptured by the capsule. Corolla funnelform or salverform, 5-lobed. Stamens 5, unequally adnate to the tube of the corolla. Ovules solitary or rarely few in each cell. Seeds developing both mucilage and spiracles when wetted.

Annuals.

Leaves entire, rarely denticulate.

Floral leaves dilated, much broader than the rest; stamens inserted at different heights. 
Corolla $2 \mathrm{~cm}$. or more long; calyx-lobes broadly triangular-lanceolate, obtusish.

Corolla about $1 \mathrm{~cm}$. long; calyx-lobes lanceolate, acute. $\quad 2$. C. linearis.

Floral leaves like the stem-leaves, linear; stamens inserted at the same height.

Calyx-lobes triangular, merely acute. 3 . C. tenella.

Calyx-lobes lanceolate, aristate-tipped.

Leaves, at least the lower, pinnately divided; divisions again toothed.

4. C. aristella.

Perennials with a cespitose rootstock.

5. C. heterophylla.

6. C. debilis.

1. C. grandiflora Dougl. Stem at first simple, later on decidedly branched, 1.5-7 dm. high, hirsute above; leaves linear-lanceolate, 4-10 $\mathrm{cm}$. long, 5-15 mm. broad, puberulent, those of the inflorescence ovate and shorter, decidedly viscid; flowers in dense head-like leafy spikes ending the stem and its branches, those of the branches often smaller and with smaller flowers; corolla trumpetshaped, yellowish, turning reddish, $2-3 \mathrm{~cm}$. long; limb $12-15 \mathrm{~mm}$. broad; lobes oblong. Gilia grandiftora A. Gray. In sandy or gravelly soil: B.C.-Mont.Utah-Calif. Son.-Submont. My-Au.

2. C. linearis Nutt. Stems simple or in age sometimes branched, 1-4 dm. high, hirsutulous; leaves linear-lanceolate, $1.5-5 \mathrm{~cm}$. long, $2-8 \mathrm{~mm}$. wide, puberulent, the floral ones ovate or lance-ovate, often paler at the base and sometimes tinged with red; flowers in terminal head-like spike; corolla trumpet-shaped, 10-15 $\mathrm{mm}$. long; lobes oval; limb 4-5 $\mathrm{mm}$. broad. C. lanceolata Greene. Dry and sandy soil: Minn.-Neb.-Colo-Calif-B.C.; adv. in Que., N. B., and N. Y. Plain-Mont. $\mathrm{My}-\mathrm{Au}$.

3. C. tenella A. Gray. Stem slender, $1 \mathrm{dm}$. high or less, dichotomously branched, glandular-puberulent; leaves narrowly linear-obtuse, $2-5 \mathrm{~cm}$. long, $1-3 \mathrm{~mm}$. wide; flowers axillary, subsessile; calyx in fruit $5 \mathrm{~mm}$. long; corolla purplish, trumpet-shaped, $7-8 \mathrm{~mm}$. long; limb about $3 \mathrm{~mm}$. wide; lobesnarrowly ovate. Gilia leptotes A. Gray. Dry hills: B.C..-Wyo.-Utah-Calif. Submont. Je-Jl.

4. C. aristella (A. Gray) Rydb. Stem mostly simple, about $1 \mathrm{dm}$. high, filiform, glandular above; leaves lance-linear, 1-3 cm. long, 1-3 mm. wide, tapering at both ends; flowers in the upper axils; calyx in fruit $5 \mathrm{~mm}$. long; corolla trumpet-shaped, about $1 \mathrm{~cm}$. long; limb about $2 \mathrm{~mm}$. wide. Gilia aristella A. Gray. Bare hillsides: Wash.-Mont.-n Calif. Son.-Submont. Je.

5. C. heterophylla Hook. Stem at first simple, soon branched from the base, puberulent, 1-4 dm. high; leaves hirsute, the lower pinnatifid or bipinnatifid, with lanceolate, acuminate or acute divisions, the upper lanceolate or oblanceolate, toothed or entire, the floral ones ovate and about $1 \mathrm{~cm}$. long; flowers in head-like clusters at the end of the branches; calyx in fruit 7-8 mm. long; teeth ovate-lanceolate, acuminate; corolla rose-eolored, $12-15 \mathrm{~mm}$. long; limb 5-6 mm. broad. G. heterophylla Dougl. Open ground: B.C.-Ida.-Calif. Submont. $\mathrm{Ap}-\mathrm{Au}$.

6. C. debilis (S. Wats.) Greene. Stems 5-15 cm. high, decumbent, viscidpubescent above; leaves thick, petioled, puberulent, obovate-spatulate to oblanceolate in outline, the earlier entire, the later often 3-5-lobed at the apex; floral leaves like the others, but sessile and crowded; ealyx-lobes lance-subulate; corolla violet, $15 \mathrm{~mm}$. long, funnelform; lobes oblong; stamens exserted. Gilia debilis S. Wats. G. Howardii M. E. Jones. Among loose rocks: Wash.-Mont. -Wyo--Utah-Ore. Mont.-Alp. J-Au.

\section{PHLÓx L. Phlox.}

Perennial (all ours), or annual herbs, often shrubby at.the base. Leaves opposite or sometimes alternate above, entire. Flowers in terminal corymbiform or paniculate cymes. Calyx of 5 sepals, united into a 5-ribbed tube; lobes often pungent. Corolla salverform, white, blue, purple, or red, with a slender tube; lobes spreading, obovate, orbicular, or obcordate. Stamens 5, included; filaments equally adnate to the tube of the corolla. Capsule included in the tube of the calyx, which is ruptured at maturity. Seeds not emitting spiral threads when wetted. 
Intercostal portion of the calyx not replicate.

Plants conspicuously cespitose, less than $1.5 \mathrm{dm}$. high.

Leaves beset with cobwebby hairs; plants densely pulvinate-cespitose.

Leaves not cobwebby, except sometimes slightly so at the base CANESCENTES. Leaves glabrous, or merely cobwebby at the base, not glandular.

Leaves hispid-ciliate on the margin, usually with more II. MCLTIFLORAE. Leaves linear to subulate, not with thickened margins.

Leaves oblong or broadly linear, with more or less III. CAESPITOSAE. inous margins.

Plants suffrutescent at the base, 3-10 dm. high.

Intercostal portion of the calyx replicate.

thickened and cartilag-

IV. Albomarginatae.

VI. SPECIOSAE.

V. LONGIFLORAE.

\section{CANESCENTES.} Leaves ovate to lanceolate, densely arachnoid-lanate, mucronate-tipped, but scarcely
acerose.

Leaves ovate, distinctly 4-ranked, imbricate; corolla-tube twice as long as the calyx.

Leaves appressed, not conspicuously $4-$ bryoides. the calyx.

Leaves subulate, acerose, sparsely arachnoid.

Corolla small; its limb 8-10 mm. wide.

Corolla-tube about twice as long as the calyx.

Corolla-tube slightly if at all exceeding the calyx.

Corolla middle-sized, its limb $10-15 \mathrm{~mm}$, wide.

3. P. canescens.

4. P. Hoodii.

5. $P$. andicola.

\section{Multiflorae.}

\section{Plant not glandular.}

Calyx more than $8 \mathrm{~mm}$. long, its teeth longer than the tube.

Calyx and the bases of the leaves arachnoid-hairy. 5 .

Calyx more than $1 \mathrm{~cm}$. long; leaves flat, the margins not revolute; stem 5-10 $\mathrm{cm}$. high.

Calyx less than $1 \mathrm{~cm}$. long; leaves very narrow, with revolite. multiflora. Stem and calyx glabrous or nearly so. $\quad 7$. P. depressa.

Stem and calyx decidedly villous.
Calyx less than $8 \mathrm{~mm}$. Iong, its lobes much shorter than the tube.

8. P. costata.

Corolla-lobes 6-8 $\mathrm{mm}$. long.

$\begin{array}{ll}\text { Leaves all subulate-filiform. } & 9 . P \text {. scleranthifolia. }\end{array}$

Leaves of the stem broader, inclined to be linear-oblanceolate, those of the $\begin{array}{ll}\text { fascicles or branches subulate. } & 10 . P \text {. diffusa. }\end{array}$

Corolla-lobes 4-5 mm. long.

Plant more or less glandular.

\section{Caespitosae.}

11. $P$. glahrata.

12. P. Douglasii.

Leaves less than $1 \mathrm{~cm}$. long; plant densely pulvinate-cespitose; limb of corolla seldom over $1 \mathrm{~cm}$. broad.

Leaves almost erect, appressed; corolla-limb about $8 \mathrm{~mm}$. wide.

Leaves ascending-spreading; corolla-limb about $10 \mathrm{~mm}$. wide. Leaves linear, flat; margins only slightly revolute.

Leaves more acerose-subulate; margins strongly revolute.

13. P. condensata.

more than

Leaves acerose-subulate; margins strongly revolute; corolla white. Leaves linear; margins scarcely revolute; corolla usually pinkish or purplish.

\section{Albomarginatae.}

14. $P$. caespitosa.

15. $P$, rigida.

Plant cespitose, but not densely pulvinate, more than $3 \mathrm{~cm}$. high; leaves obıong to broadly linear, $7-20 \mathrm{~mm}$. long.

Leaves linear, $1-2 \mathrm{~cm}$. long; margins not very thick; corolla-tube twice as long as

the calyx; young stems white-angled.
Leaves oblong with very thick margins, $7-12 \mathrm{~mm}$. 16. . Kelseyi. long as the calyx; young stemsargins, 7-12 mm. long; corolla-tube not twice as Plants densely pulvinate, less than 3 white-angled. 17 . $P$, alyssifolia. long, with very thick margin $3 \mathrm{~cm}$. high; leaves ovate-oblong, less than $5 \mathrm{~mm}$.

Flowers peduncled. corollargins. densely glandular calyx.

Flowers subsessile; corolla-tube less than 18 . P, albomarginata.

\section{LONGIFoliAe.}

as long as the calyx.

Plant glabrous or only the upper portion, peduncles, and calyces pubescent.

Plant glabrous throughout, or rarely with a few scattered hairs on the calyces and peduncles; calyx-teeth longer than the tube; leaves less than $2 \mathrm{~mm}$. wide. Plant usually pubescent above, in one variety even glandular; calyx-teeth shorter $\begin{array}{ll}\text { than the tube; leaves over } 2 \mathrm{~mm} \text {. wide. } & \text { 21. P. longifolia. }\end{array}$ 
Plant pubescent throughout.

Plant densely grayish pubescent, not at all glandular, densely cespitose, with a thick woody caudex.

Plant glandular or viscid.

Corolla-tube glabrous.

Leaves 2-4 mm. wide.

Leaves long-attenuate, not thick; only upper portion glandular; corolla scarcely twice as long as the calyx. $21 . P$. longifolia.

Leaves obtusish or abruptly acute, thick and firm; corolla-tube fully twice as long as the calyx.

Leaves $1 \mathrm{~mm}$. wide; corolla not twice as long as the calyx.

23. P. Stansburyi.

Corolla-tube pubescent.

24. P. viridis.

25. P. gladiformis.

\section{SPECIOSAE.}

One species.

26. P. speciosa.

1. P. bryoides Nutt. Plant less than $1 \mathrm{dm}$. high; leaves densely imbricate, ovate or triangular-lanceolate, $2-3 \mathrm{~mm}$. long, densely cobwebby, with inflexed margins; flowers solitary at the end of the branches, sessile; calyx-teeth subulate. shorter than the tube; corolla about $1 \mathrm{~cm}$. long; lobes obovate, about $3 \mathrm{~mm}$. long, Dry hills: Neb.-Colo.-Utah-Wyo. Plain-Submont. My-Je.

2. P. muscoides Nutt. Plant rarely more than $5 \mathrm{~cm}$. high; leaves imbricate, but not 4-ranked, subulate, with revolute margins, 5-8 mm. long, decidedly cobwebby; flowers sessile and solitary at the ends of the branches; calyx-teeth subulate, equalling the tube; corolla $6-8 \mathrm{~mm}$. long; lobes obovate, $3 \mathrm{~mm}$. long. Dry hills: Mont. Submont. My-Jl.

3. P. canescens T. \& G. Leaves subulate, pungent, at length spreading, 6-10 mm. long, lanate-canescent, at least when young; flowers sessile, solitary at the ends of the branches; calyx arachnoid-hairy; teeth subulate; corolla white, about $1 \mathrm{~cm}$. long; lobes broadly obovate, 4-5 mm. long. Dry hills: w Colo.N.M.-Calif.-Ida. Submont. My.

4. P. Hoodii Richards. Leaves subulate, sparingly lanate, 4-10 $\mathrm{mm}$. long, apiculate; flowers sessile, solitary at the ends of the branches; calyx $5-7 \mathrm{~mm}$. long, arachnoid; teeth similar to the leaves; corolla white, $8-10 \mathrm{~mm}$. long; lobes obovate, entire or mucronate, $5 \mathrm{~mm}$. long. Moss Pink, Moss Phlox. Hills and plains: Mack.-Neb.-Wyo.-Ida.-Yukon. Plain. Ap-My.

5. P. andicola (Britton) E. Nels. Stem erect, branched at the ground, white, $5-10 \mathrm{~cm}$. high, sparingly arachnoid at the nodes; leaves subulate, $1-2 \mathrm{~cm}$. long, with strong midrib; flowers on short pedicels; calyx-teeth as long as the tube, subulate, pungent; corolla white, half longer than the calyx; lobes obovate, 5-7 mm. long. Plains and hills and sandy soil: S.D.-Colo,-Ida. Plain. Je-Jl.

6. P. multiflora A. Nels. Cespitose perennial, with a suffruticose base; branches erect, finely pubescent, not arachnoid; leaves broadly linear, glabrous, apiculate, 1-2 cm. long; flowers solitary; peduncles $1-3 \mathrm{~cm}$. long; calyx glabrous or nearly so, about $1 \mathrm{~cm}$. long; lobes linear, with a strong midrib; corolla light blue or white, nearly $2 \mathrm{~cm}$. long; tube longer than the calyx; lobes obovate, about $1 \mathrm{~cm}$. long. P. dasyphylla A. Brand, a small-flowered and narrow-leaved form. Mountains and hills: Mont.-Colo. Submont.-Mont. My-Jl.

7. P. depressa (E. Nels.) Rydb. Densely cespitose perennial, less than 1 $\mathrm{dm}$. high; leaves narrowly linear, $1 \mathrm{~cm}$., rarely $2 \mathrm{~cm}$. long, with strong midrib; flowers subsessile or with very short pedicels; calyx about $8 \mathrm{~mm}$. long, glabrous; teeth subulate; corolla mostly white, $15-18 \mathrm{~mm}$. long; lobes broadly obovate, 6-7 mm. long. Open hills: Mont.-Colo.-Utah-Ida. Submont.-Mont. JeAu.

8. P. costata Rydb. Stems less than $5 \mathrm{~cm}$. high; leaves about $1 \mathrm{~cm}$. long, linear-subulate, acerose; midrib prominent and margins slightly revolute; flowers solitary; pedicels less than $1 \mathrm{~cm}$. long; calyx strongly ribbed, villous between the ribs; teeth subulate, equalling the tube, more or less spreading; corolla bluish, turning white; tube twice as long as the ealyx; lobes almost orbicular, 7-8 mm. long. Dry ridges: Mont.-(? Utah). Mont. Jl.

9. P. scleranthifolia Rydb. Branches depressed, glabrous or nearly so; leaves very narrow, about $1 \mathrm{~cm}$. long, less than $0.5 \mathrm{~mm}$. wide, spinulose-tipped, 
s omewhat divergent, with prominent midrib; flowers sessile or nearly so; calyx about $5 \mathrm{~mm}$. long; teeth lanceolate, bristle-pointed; corolla white; tube exceeding the calyx; lobes oblong. Dry hills: Black Hills, S.D. Submont. Je.

10. $\mathbf{P}$. diffusa Benth. Loosely cespitose-spreading perennial; branches $2-3$ $\mathrm{cm}$. long, glabrous; leaves 6-12 mm. long, oblong-linear, 1-2 mm. wide, spreading, apiculate, with strong midrib; flowers sessile or subsessile; calyx sparsely lanate-ciliate, 5-7 mm. long; teeth lance-subulate, somewhat spreading; corolla white, about $15 \mathrm{~mm}$. long; lobes entire, obovate. Hills and mountains: B.C.Wyo.-Calif. Submont. Je-Au.

11. P. glabrata (E. Nels.) A. Brand. Branches numerous, $5 \mathrm{~cm}$. long or less; leaves glabrous or slightly arachnoid at the nodes, densely imbricate, appressed, linear, flat, 5-10 mm. long; flowers sessile, solitary; calyx 4-5 mm. long, glabrous or slightly arachnoid between the ribs; teeth subulate; corolla 8-10 mm. long; lobes broadly ovate. Open plains and hills: Wyo. Submont. My.

12. P. Douglasii Hook. Stem much branched from a woody root; leaves acerose, pungent, 5-15 mm. long, ciliate and usually conspicuously glandular, rarely glabrate; flowers sessile; calyx ciliate and glandular; teeth subulate; corolla 18-20 mm. long, white; tube exserted; lobes obovate or rounded, 6-7 mm. long. Hills and mountains: Wash.-Mont.-Nev.-n Calif. Submont.-Mont. My-Jl.

13. P. condensata (A. Gray) E. Nels. Leaves imbricate, rigid, linear, apiculate, 5-6 mm. long, strongly ascending, straight, with a strong midrib, hispid-ciliate on the margins; calyx glandular and ciliate; lobes similar to the leaves; corolla white, 8-10 mm. long; tube much exceeding the calyx; lobes rounded, about $4 \mathrm{~mm}$. long. P. caespitosa condensata A. Gray. High mountain ridges: Colo. Subalp.-Alp. Je-Jl.

14. P. caespitosa Nutt. Leaves linear or oblong-linear, apiculate, 8-14 $\mathrm{mm}$. long, 1-2 $\mathrm{mm}$. wide, usually flat, hispid-ciliate on the margins; flowers sessile or subsessile, solitary at the ends of the branches; calyx hispid-ciliate and glandular; lobes as long as the tube, lanceolate, pungent; corolla white or light blue, fully twice as long as the calyx; lobes obovate, 5-7 mm. long. Mountains: Mont.-N.M.-Utah-Ore.-B.C. Submont.-Subalp. Je-Au.

15. P. rigida Benth. Leaves subulate-acerose, at last recurved-spreading, 5-10 mm. long, hispid-ciliate and somewhat glandular; flowers solitary, subsessile; calyx hispid-ciliate, more or less glandular; lobes acerose; corolla 10-12 $\mathrm{mm}$. long; tube much longer than the calyx; lobes obovate, about $5 \mathrm{~mm}$. long. Dry hills and mountains: Mont.-Utah-Ore.-Wash. Submont. My-Jl.

16. P. Kelseyi Britton. Branches 1-2 dm. long; leaves flat, lanceolate or linear, 1-1.5 cm. long, narrowly white-margined, usually ciliate, sometimes glandular, sometimes glabrate; flowers solitary, short-pedicelled; calyx nearly 1 $\mathrm{cm}$. long, eiliate and often glandular; teeth subulate; corolla blue, lilac, or pink, rarely white, fully $2 \mathrm{~cm}$. long; lobes broadly obovate, $7-8 \mathrm{~mm}$. long. Valleys: N.D.-Colo.-Mont. Plain-Subalp.

17. P. alyssifolia Greene. Branches short, with white shreddy bark; leaves oblong or linear, or the earlier ones ovate, $5-15 \mathrm{~mm}$. long, $2-4 \mathrm{~mm}$. wide, usually ciliate on the margins and sometimes a little glandular, cuspidate; flowers sessile or nearly so; calyx ciliate, strongly ribbed, often considerably glandular; calyx 7-8 mm. long; teeth oblong, acerose-cuspidate, rather shorter than the tube; corolla bluish, rarely white, $15-18 \mathrm{~mm}$. long; lobes obovate, $7-8 \mathrm{~mm}$. long. $P$. collina Rydb. P. variabilis A. Brand. Mountains and dry benches: Sask. S.D.-Colo.-Utah-Mont. Submont.-Mont. My-Au.

18. P. albomarginata M. E. Jones. Floral stems $2-7 \mathrm{~cm}$. high, 1-3flowered; leaves 4-6 mm. long, 2-3 mm. wide, spreading, ovate or lanceolate, hispid-ciliate at the base, and pubescent beneath; pedicels $2-8 \mathrm{~mm}$. long; calyx 7-8 mm. long; teeth 2-3 mm. long, subulate, acerose, scarcely spreading; corolla purplish or lilac, $12-15 \mathrm{~mm}$. long; lobes about $4 \mathrm{~mm}$. long, obovate. Mountain sides and hills: Mont. Submont. My-Je.

19. P. diapensioides Rydb. Branches about $2 \mathrm{~cm}$. high; leaves crowded, numerous, 4-5 $\mathrm{mm}$. long, ovate, sharply acerose-cuspidate, thick, with a strong 
midrib, ciliate and more or less glandular beneath; calyx about $5 \mathrm{~mm}$. long, somewhat glandular; lobes lanceolate, in fruit divergent; corolla pink-purple; lobes obovate, 4-5 mm. long. P. albomarginata minor M. E. Jones. Dry hills: Mont. -Utah. Submont. Jl-S.

20. P. linearifolia (Hook.) A. Gray. Suffruticose perennial; herbaceous branches 1.5-3 dm. long, with straw-colored bark; leaves narrowly linear, about 2-5 cm. long, 1-2 mm. wide; flowers long-pedicelled; calyx glabrous, about 1 $\mathrm{cm}$. long; corolla $2-2.5 \mathrm{~cm}$. long; lobes obovate or oblanceolate, 7-12 $\mathrm{mm}$. long. Plains: B.C.-Wyo.-Utah-Ore. Plain-Submont. Ap-Jl.

21. P. longifolia Nutt. Perennial, with a woody base; stems 1-2 dm. high, erect, glabrous below, usually puberulent above or more puberulent throughout (var. puberula E. Nels.); leaves linear, with strong midrib, 3-7 cm. long, 2-3 mm. wide; calyx usually more or less pubescent, sometimes glandular, about $1 \mathrm{~cm}$. long; corolla $18-20 \mathrm{~mm}$. long; lobes obovate, $8-10 \mathrm{~mm}$. long. P. cernua E. Nels., a young form with nodding flowers. Sweet Wrlliam. Plains and hills: Mont. -N.M.-Utah-Ore.-B.C. Plain-Submont. My-Au.

22. P. austromontana Coville. Stems $5-10 \mathrm{~cm}$. high, woody at the base, minutely canescent, not glandular; leaves linear-subulate, acerose, $1-1.5 \mathrm{~cm}$. long (rarely $2-2.5 \mathrm{~cm}$. in var. prostrata), arcuate-spreading in age, minutely canescent; flowers subsessile; calyx 6-9 mm. long, glabrous or slightly puberulent; teeth acerose; corolla white or rarely purplish, 15-20 mm. long; tube exceeding the calyx; lobes obovate, 5-7 mm. long. P. densa A. Brand, a denser more compact form. Dry mountains: se Colo.-Ariz.-Calif.; L. Calif. Son.-Submont.

23. P. Stansburyi (Torr.) Heller. Stems with a ligneous branched base, 1-2 dm. high, pubescent and more or less glandular throughout; leaves thick, spreading, linear or linear-lanceolate, $2-2.5 \mathrm{~cm}$. long, 2-3 $\mathrm{mm}$. wide, or in the var. brevifolia ovate-lanceolate or oblong, 0.5-2 $\mathrm{cm}$. long, 3-4 mm, wide; calyx $1 \mathrm{~cm}$. long, glandular; teeth subulate-acerose, as long as the tube; corolla pink or rose-colored; lobes cuneate-obovate, erose or emarginate, $7-8 \mathrm{~mm}$. long. $P$. viscida E. Nels., a low, more viscid form. Sweet William. Dry regions: Colo. -N.M.-Calif.-Wash. Son.-Submont. Ap-Je.

24. P. viridis E. Nels. Stems several from a ligneous base, $0.5-1.5 \mathrm{dm}$. high, glabrous below, glandular-pubescent above; leaves linear-acerose, $2-3 \mathrm{~cm}$. long, $1 \mathrm{~mm}$. wide; pedicels short, glandular-pubescent; calyx glandular-pubescent, about $1 \mathrm{~cm}$. long; teeth acerose, as long as the tube; corolla light blue; lobes 6-7 mm. long, obovate-cuneate, emarginate. P.aculeata A. Nels. Tablelands: Wash.-Ida. My-Je.

25. P. gladiformis (M. E. Jones) E. Nels. Stems softly pubescent and slightly glandular throughout, prostrate at the base; leaves thick, with prominent midrib, narrowly lance-linear, $1.5-2 \mathrm{~cm}$. long, about $2 \mathrm{~mm}$. wide; flowers subsessile; calyx nearly $1 \mathrm{~cm}$. long, sparingly glandular, ciliate; teeth acerose, slightly longer than the tube; corolla white; tube twice as long as the calyx; lobes cuneateobovate, entire, $7 \mathrm{~mm}$. long. P. longifolia gladiformis M. E. Jones. Dry regions: Utah. Submont. My.

26. P. speciosa Pursh. Shrubby perennial, 5-10 dm. high; annual branches 2-3 dm. long, glandular-viscid above; leaves linear or the upper lance-linear, 4-7 cm. long, $2-4 \mathrm{~mm}$. wide, more or less pubescent; flowers in lax corymbiform cymes; calyx fully $1 \mathrm{~cm}$. long, glandular-pubescent; lobes subulate; corolla 2-2.5 $\mathrm{cm}$. long; lobes 8-14 $\mathrm{mm}$. long, obcordate or obovate, from deeply emarginate to entire. P. Sabini Dougl. Copses and hillsides: Wash.-Wyo,-Calif. Son.Submont. My-Je.

\section{MICRÓSTERIS Greene.}

Small branched annuals. Leaves all except the floral ones opposite, narrow and entire. Flowers small, perfect, axillary. Calyx tubular, 5-cleft, ruptured by the fruit; lobes scarious-margined. Corolla salver-shaped, with a narrow tube; throat funnelform. Stamens unequally adnate to the corolla-tube. Capsule 3-celled; seeds few, large, the coat, when wetted, mucilaginous but without sp iracles. 
Calyx-lobes much exceeding the tube in length; plant usually erect, simple below; corolla tube $1 \mathrm{~mm}$. wide or more; limb 3-4 mm. wide. 1 . M. gracilis.

Calyx-lobes not longer than the tube; plant low, diffusely branched from near the base; corolla-tube less than $1 \mathrm{~mm}$. wide; limb $1-2.5 \mathrm{~mm}$. wide.

Plant 1.5-2 dm. high; leaves except the lower ones lanceolate or linear-lanceolate,

mostly acute; corolla-tube longer than the ealyx.
Plant less than $1 \mathrm{dm}$. high; leaves, except the basal ones, humilis. the basal ones spatulate; corolla-tube scarcely exceeding the calyx.

3. M. micrantha.

1. M. gracilis (Dougl.) Greene. Stem erect or rarely decumbent (M. diffusa Heller), puberulent and glandular above, 1-4 dm. high; basal leaves spatulate, the upper stem-leaves linear or linear-lanceolate, acute, $2-6 \mathrm{~cm}$. long; calyx tubular, glandular-pubescent, 7-10 $\mathrm{mm}$. long; corolla 10-14 $\mathrm{mm}$. long; tube yellowish; limb purplish or violet. G. gracilis Hook. Hills and valleys: B.C.Mont.-Wyo.-Calif. Plain-Submont. My-Jl.

2. M. humilis (Dougl.) Greene. Stem puberulent and more or less glandular; lower leaves oblanceolate or spatulate; calyx tubular, 7-9 $\mathrm{mm}$. long; lobes subulate; corolla 8-10 mm. long; tube white; limb purplish or violet, sometimes white. Collomia humilis Dougl. Dry plains and sandy soil: B.C.-Mont.Colo.-Calif. Plain-Submont. My-Jl.

3. M. micrantha (Kellogg) Greene. Stem glandular and puberulent; lower leaves 1-2 cm. long, puberulent; calyx tubular, 4-5 mm. long, puberulent; teeth subulate; corolla 5-7 mm. long; tube white; limb white, rose-colored, or violet. Collomia micrantha Kellogg. 'Dry or sandy soil: Neb.-Colo.-Ariz.c Calif. Son.-Mont. Ap-Je.

\section{WELWÍtSCHIA Reichenb.}

Annual herbs, with alternate entire or pinnatifid floccose leaves. Flowers perfect in dense heads; bracts conspicuously long-villous. Calyx densely woolly; lobes acerose-tipped; tube ruptured by the fruit. Corolla salver-shaped, with a funnelform open throat. Stamens 5; filaments adnate to the whole tube of the corolla, exserted; anthers deeply sagittate. Seed usually mucilaginous and with spiracles when wetted. [Huegelia Benth., not Reichenb.]

Corolla-lobes much shorter than the tube.

Plant erect; heads acute at the base; bracts ascending.

Bracts not dilated at the base.

Bracts somewhat dilated at the base.

Plant diffuse; heads rounded at the base; bracts spreading. Corolla-lobes scarcely shorter than the tube.
1. W. Wilcoxii.
2. W. filifolia.
3. W. diffusa.
4. $W$, floccosa.

1. W. Wilcoxii (A. Nels.) Rydb. Stem erect, with erect or ascending branches, lanate, 1-2 dm. high; leaves 3-parted with linear, pungently-tipped lobes, floccose; bracts 5 -parted; calyx-lobes unequal, subulate; corolla about 1 $\mathrm{cm}$. long, tubular-funnelform, white; tube scarcely exceeding the calyx. Gilia Wilcoxii A. Nels. Dry soil: Ida.-Ore. Son. JI.

2. W. filifolia (Nutt.) Rydb: Stem 1-2 dm. high, sparingly floceose; leaves filiform, simple, or 3-parted into filiform divisions, cuspidate; bracts 2-5-cleft, with a hyaline base, somewhat areuate; calyx-lobes subulate, unequal, shorter than the tube; corolla light blue, scarcely longer than the calyx. $G$, filifolia Nutt. Plains: Wash.-Utah-N.M.-Calif. Ap-Jl.

3. W. diffusa (A. Gray) Rydb. Stem 1-10 cm. high, diffusely branched near the base, sparingly floccose; leaves spreading, 3-parted into spreading filiform lobes, or some entire; bracts 5-parted;-calyx-lobes subulate, unequal; corolla about $12 \mathrm{~mm}$. Iong; lobes about half as long as the tube. G. filifolia diffusa A. Gray. Plains and dry places: Tex.-s Utah-Calif. Son. Ap-Je.

4. W. floccosa (A. Gray) Rydb. Stem 1-3 dm. high, branched, more or less floccose or glabrate in age; leaves 3 -parted or entire, filiform or with filiform lobes, floccose; bracts much longer than the heads, divergent; calyx-teeth subulate; corolla violet blue to white, about $15 \mathrm{~mm}$. long; limb nearly $1 \mathrm{~cm}$. wide. $G$. floccosa A. Gray. Plains: Wash.-Utah-Ariz.-Calif. Son. My-Au. 


\section{NAVARRETTIA R. \& P.}

Glabrous or viscid-puberulent, branched annuals. Leaves all alternate, setaceously or spinulosely pinnatifid, or the lowest subentire. Flowers perfect, in crowded, bracted, head-like clusters at the ends of the branches. Calyx-tube short, scarious in the sinuses; lobes unequal, costate, pungently tipped, some of them at least spinulosely toothed or cleft. Corolla salverform, with a funnelform throat. Stamens adnate up to or nearly to the throat of the corolla. Seeds one to many in each cell, commonly mucilaginous and producing spiracles, when wetted. Capsule 1-3-celled,, partially dehiscent or indehiscent.

Corolla white; pericarp hyaline and indehiscent or irregularly bursting, closely adherent to the mucilaginous seeds.

Calyx and the bases of the floral leaves long-hairy; flowers nearly $1 \mathrm{~cm}$. long.

Glabrate or strigose, long-hairy only in the sinuses of the calyx; flowers 1 . intertexta. long.

Corolla yellow; pericarp of the capsule firm, dehiscent.

2. N. minima.

1. N. intertexta (Benth.) Hook. Stems erect, 1-2 dm. high, simple or widely branched, reflexed-strigose; leaves glabrate or sparingly hairy, pinnatifid or bipinnatifid, with filiform, spinescent divisions; bases of bracts and calyx densely arachnoid-villous with white hairs; some of the calyx-teeth dentate; corolla white, 9-10 mm. long; limb $2.5-3 \mathrm{~mm}$. broad; stamens equally inserted, exserted. Gilia intertexta Steud. Plains and sandy places: Wash.-Mont.-Ida.Calif. Submont. My-Au.

2. N. minima Nutt. Stem erect, simple, or branched near the base, 1-5 $\mathrm{cm}$. high, glabrate or nearly so; leaves glabrous, pinnatifid, with filiform-subulate, acerose divisions; bracts glabrous; calyx slightly hairy in the sinuses; corolla white, about $7 \mathrm{~mm}$. long; limb 1-1.5 mm. broad; tube shorter than the calyx; stamens equally inserted in the throat. G. minima A. Gray. Bottom lands and sandy places: Wash.-Sask.-Neb.-Ariz.-Calif. Plain-Submont. My-J1.

3. N. Breweri (A. Gray) Greene. Stem simple or branched below, 1-10 cm. high, glandular-puberulent; leaves pinnatifid, glandular-puberulent, with subulate-acerose divisions; bracts and calyx not villous, merely puberulent; corolla 6-7 mm. long, shorter than the calyx; limb $1.5 \mathrm{~mm}$. wide; stamens equally inserted in the throat, exserted. G. Breweri A. Gray. Foot-hills and sandy places: Wash.-Wyo.-Colo.-Calif. My-Au.

\section{LEPTODÁCTYLON Nutt.}

Much branched undershrubs or some species herbaceous except the base. Leaves alternate, or rarely opposite, with smaller ones fascicled in the axils, numerous, palmately 3-5-parted, usually acerose-subulate, pungent. Flowers showy, solitary or in small clusters, sessile. Calyx tubular or campanulate, with subulate teeth, ruptured by the fruit. Corolla trumpet-shaped, with a funnelform throat, yellow or reddish or lilac. Filaments equally adnate to the throat of the corolla; anthers included in the throat of the corolla. Capsule many- or few-seeded. Seeds neither mucilaginous, nor with spiracles.

Leaves alternate; stem woody throughout.

Plant pulvinate-cespitose; corolla 4-merous.

Plant suffruticose, with erect branches; corolla 5-merous. Leaves and their divisions ascending, straight.

Leaves $6-15 \mathrm{~mm}$. long.

Leaves thick, $2-5 \mathrm{~mm}$. long.

Leaves and their divisions spreading-recurved, stout.

Leaves opposite; stem woody only at the base.

Leaves decidedly pungent; ovules numerous.

Leaves scarcely pungent; ovules $2-3$ in each cell.

1. L. caespitosum.

2. L. pungens.

3. L. brevifolium.

4. L. patens.

5. L. Watsonii.

6. L. Nuttallii.

1. L. caespitosum Nutt. Densely pulvinate-cespitose perennial, with woody caudex; leaves densely crowded, slightly ciliate below, about $5 \mathrm{~mm}$. long, usually 3-parted, with subulate straight pungent divisions; calyx 6-8 mm. long; teeth subulate; corolla light yellow, trumpet-shaped, $12-15 \mathrm{~mm}$. long; lobes 4 $\mathrm{mm}$. long. Gilia pungens caespitosa A. Gray. Dry hills: w Neb.-Wyo.-Utah. Plain-Submont. My-Jl. 
2. L. pungens (Torr.) Nutt. Suffruticose perennial, 1-3 dm. high; leaves 5-8 mm. long, puberulent, but not glandular, or glabrate, digitately 3-7-divided, with linear-subulate, straight, ascending divisions; flowers axillary, solitary; calyx tubular, 5-ridged, about $1 \mathrm{~cm}$. long, glabrate; teeth subulate, pungent, much shorter than the tube; corolla yellow or yellowish, 15-20 $\mathrm{mm}$. long; lobes about $5 \mathrm{~mm}$. long, oblong. Gilia pungens (Torr.) Benth. Sandy valleys and hillsides: Mont.-Colo.-Calif.-B.C. Plain-Mont. Je-Jl.

3. L. brevifolium Rydb. Suffruticose, branched perennial, 1-2 dm. high; stems puberulent and slightly glandular above; leaves $3-5 \mathrm{~mm}$. long, glandularpuberulent or glabrate, 3-5-divided into subulate, acerose ascending divisions; calyx about $8 \mathrm{~mm}$. long, glandular-puberulent; teeth subulate-acerose, much shorter than the tube; corolla about $15 \mathrm{~mm}$. long. Dry hills: Utah-Wash.(? Colo.). Son. Je.

4. L. patens Heller. Suffruticose perennial, 1-3 dm. high; branches puberulent; leaves 5-7 mm. long, curved, 3-7-divided into subulate divisions, puberulent or glabrate, somewhat glandular; calyx 7-8 mm. long, glandular-puberulent; teeth subulate, erect, shorter than the tube; corolla about $15 \mathrm{~mm}$. long, trumpetshaped; lobes oblong, about $6 \mathrm{~mm}$. long; stamens inserted in the throat. Gilia pungens squarrosa A. Gray. Arid regions: Utah-Ariz.-Nev. Son. Je-Jl.

5. L. Watsonii (A. Gray) Rydb. Suffruticose perennial; stems erect, 5-15 cm. high; branches glandular-pubescent; leaves opposite, palmately 3-7-divided, with narrowly linear acerose divisions, glandular-pubescent; calyx tubular, glandular-ciliate; teeth subulate, much shorter than the tube; corolla white, with a purplish throat, $18-25 \mathrm{~mm}$. long; lobes oval, nearly as long as the tube. $G$. Watsonii A. Gray. Cliffs and rocky hills: Utah-Colo. Son.-Submont. My-Л.

6. L. Nuttallii (A. Gray) Rydb. Perennial, with a woody base; stems numerous, erect, 1-3 dm. high, erisp-puberulent; leaves palmately 3-7-divided into linear or linear-filiform divisions, or the lower ones entire; flowers axillary, clustered at the ends of the stems; calyx tubular, villous; teeth lance-subulate; corolla 1-2 cm. long, salver-shaped, white with a yellow throat; lobes oval. Gilia Nuttallii A. Gray. Mountains: Wash.-Wyo.-N.M.-Calif. Mont.-Subalp. $\mathrm{My}-\mathrm{Au}$.

\section{GÍlIA R. \& P.}

Annual, biennial, or perennial herbs. Leaves all or at least the upper ones alternate, entire to pinnatifid. Flowers perfect, mostly cymose. Calyx campanulate; tube more or less hyaline in the sinuses and bursted by the fruit; lobes subequal. Corolla trumpet-shaped or salverform, with an open salverform throat. Stamens 5, usually equally high inserted. Capsule usually many seeded; seeds changed when wetted, mucilaginous and usually spirilliferous.

Flowers capitately or spicately glomerate.

Plant strigose or short-villous (nearly glabrous in G. nuda); flowers leafy-bracted. Perennials; flowers in dense heads or spikes. I. CONGESTAE.

Annuals, repeatedly branched, with small clusters of flowers in the axils of the leaves, more capitate at the ends of the branches. II. PUMrLAE.

Plants glabrous; flowers in long-peduncled heads, not leafy-bracted.

Flowers openly paniculate or thyrsoid-paniculate.

\section{Capitatae.}

Leaves pinnately divided.

Corolla-tube over $1 \mathrm{~cm}$. long; calyx-lobes lanceolate, attenuate and spine-tipped; biennials.

Inflorescence thyrsoid, narrow.

Inflorescence open and inclined to be flat-topped.

Corolla-tube less than $1 \mathrm{~cm}$. long.

Stamens conspicuously exserted; corolla nearly salverform; biennials.

Stamens not exserted, or PINNATIFIDAE. throat; annuals.
VII. INCONSPICUAE.

Leaves entire or the lower ones toothed or lobed. Leaves not filiform.

Leaves or their divisions flliform; annuals.

VIII. LEPTOMERIAE.

IX. MINUTIFLORAE. 
Plant 1-2 dm. high, cespitose.

Leaves filiform, not very fleshy; flowering stems slender, sparingly leafy.

Leaves short, fleshy, faleate; flowering stems very short and very leafy.

Leaves, at least some of them, pinnatifid.

3. G. crebrifolia. Plant branched only at the base, or simple; stem or branches strict, with a single
head-like or spike-like inflorescence.

Stamens inserted in the throat of the corolla.

Inflorescence spike-like, more or less interrupted; corolla greenish white, its lobes acute.

Inflorescence head-like; corolla white, its lobes obtuse.

Corollarlobes $3-4 \mathrm{~mm}$. long.

Corolla-tube scarcely exserted. 5 . G. globularis.

4. G. spicata.

Corolla-lobes 2-2.5 mm. long.

Stamens inserted in the middle of the corolla-tube.

than the calyx.

6. G. cephaloidea.

7. G. congesta.

8. G. tridactyla.

Plant branched above as well as at the base; inflorescence of several heads more or Leaves glabrous; inflorescence glandular.

Leaves and inflorescence crisp-hairy.

9. G. nuda.

Corolla-lobes about $2 \mathrm{~mm}$. long; calyx-teeth and bracts green, with very short spine-tips; branches straw-colored.

Segments of the leaves short, oblong, crowded, the leaves therefore apparently subdigitate.

10. G. montana.

Segments of the leaves linear, not crowded, the leaves therefore distinctly pinnatifid.

Branches erect, $1.5-3 \mathrm{dm}$. high; plant sparingly pubescent.

Branches ascending, 0.5-1.5 dm. high; plant densely pubescent.

Corolla-lobes 4-5 mm. long; calyx-teeth and bract rose-tinged, with long spinetips; stem tinged with purple.

13. G. roseata.

Leaves entire or merely toothed.

II. Pumila E.

Leaves linear-filiform, entire.

Leaves oblanceolate, some of them toothed.

Leaves pinnatifid.

Divisions of the leaves linear-filiform; floral leaves similar; corolla twice as long as the calyx.

16. G. pumila.

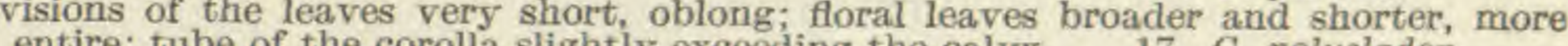
entire; tube of the corolla slightly exceeding the calyx. 17. G. polycladon.

One species.

\section{Capitatae.}

IV. AgGregatae.

18. G. capitata.

Corolla-lobes acute or acuminate; corolla usually scarlet or pink,

Calyx only slightly scarious at the angles; its lobes lanceolate-attenuate, longer than the tube.

Calyx and inflorescence glandular-puberulent, not long-hairy.

Stamens included.

Corolla-lobes ovate-lanceolate, acute; tube about $2 \mathrm{~cm}$. long.

Corolla-lobes narrowly lanceolate, attenuate; tube nearly. arizonica.

20. G. tenuituba.

Stamens exserted; corolla-lobes attenuate.

20. G. tenuituba.

Calyx and usually also the inflorescence with long white flat hairs, as well as glandular-puberulent.

22. G. pulchella.

Calyx very scarious at the angles; its teeth shorter than the tube; corolla-lobes acute.

Corolla-lobes rounded or obtuse at the apex; corolla white.

23. G. scariosa.

\section{LONGLFLORAE.}

Corolla-tube $3-4 \mathrm{~cm}$. Iong; its lobes obtuse.

Corolla-tube $1.5-2.5 \mathrm{~cm}$. long; its lobes acute.

25. G. longiflora.

26. G. laxiflora.

\section{Vi. Pinnatifinae.}

Divisions of the leaves all linear-filiform, not wider than the rachis; corolla about $1 \mathrm{~cm}$. long.

27. G. polyantha.

Divisions, at least of the lower leaves, obovate or oblong, much broader than the rachis. Corolla-tube 4-6 mm. long; calyx-lobes acuminate. Corolla-tube 8-10 mm. long; calyx-lobes acute.

28. G. calcarea.

29. G. MacVickerae.

\section{INCONSPICUAE.}

Corolla 7-14 mm. long.

Calyx about one-fourth as long as the corolla.

Calyx one-third to two-thirds as long as the corolla.

30. G. scopulorum. 

Corolla-tube distinctly exserted from the calyx; leaves mostly basal or the stem-
leaves reduced.

Plants branched near the base; the few stem-leaves pinnatifid. Limb of the corolla 5-6 mm. wide; calyx glandular-puberulent.

Limb of the corolla $3-4 \mathrm{~mm}$. wide; calyx glabrous 31 . G. hutchinsifolia.

Plants simple below, brancinuata.
32 . sinu.

toothed or rarely entire.

toothed or rarely entire.
Corolla-tube scarcely exserted from the calyx; plant more leafy. . straminea.

Corolla 4-6 mm. long.

34. G. inconspicua.

Plant leafy only at the base; divisions short and broad; corolla about twice as long as the calyx.

35. G. subacaulis. Plants leafy throughout; divisions of the leaves narrow; corolla only slightly exceeding
the calyx.

Leaves pinnatifid, with linear or oblong divisions. 36 . G. Tweedyi.

Lower leaves sometimes pinnatifid, with filiform divisions, otherwise the leaves
filiform and entire. filiform and entire.
47. G. minutiflora.

VIII. LEPTOMERIAE.

Stamens exserted; inflorescence narrow and spike-like; leaves pinnately lobed.

Stamens not exserted; inflorescence an open panicle.

37. G. stenothyrsa.

Basal leaves toothed or lobed; annuals, bienniais, or short-lived perennials.

Flowers $1 \mathrm{~cm}$. long or more.

Plant densely glandular; stem-leaves oblanceolate, usually toothed; corolla scarlet or orange.

38 . G. subnuda.
Plant nearly glabrous; upper stem-leaves lanceolate-subulate, entire; corolla rose-colored.

Calyx $5 \mathrm{~mm}$. long; corolla $15 \mathrm{~mm}$. long.

Calyx $3 \mathrm{~mm}$. long; corolla $10 \mathrm{~mm}$. long.

Flowers less than $1 \mathrm{~cm}$. long: annuals.

39. G. Crandallii.

40. G. Haydeni.

Leaf-blades lanceolate, sinuately lobed; lobes scarcely spinulose-tipped.

Leaf-blades orbicular or obovate, spinescent-toothed. 42. G. leptomeria.
Gatifolia.

Basal leaves oblanceolate, entire; perennials.

Basal leaves 4-5 cm. long.

Basal leaves $1 \mathrm{~cm}$. long.

Corolla about $5 \mathrm{~mm}$. long; plant simple.

Corolla about $10 \mathrm{~mm}$. long; plant cespitose.

43. G. pentstemonoides.

44. G. sedifolia.

45. G. caespitosa.

IX. Minutiflorae.

Tall plants with strict branches and erect pedicels.

Pedicels longer than the fruiting calyces; branches ascending; capsule with 2 seeds

in each cell; corolla $5 \mathrm{~mm}$. long. 46. G. Sinistra.
Pedicels usually shorter than the fruiting calyces; branches nearly erect; capsule Low delicate plants with spreading branches; pedicels in fruit reflexed.
L.

47. G. minutiflora.

48. $G$. tenerrima.

1. G. frutescens Rydb. Stems woody below, branched above, $3-5 \mathrm{dm}$. high; leaves linear, glabrous or nearly so, simple, $2-5 \mathrm{~cm}$. long, $1-2 \mathrm{~mm}$. wide, callous-tipped; flowers capitate at the ends of the branches; calyx-teeth lanceolate, cuspidate, shorter than the tube; corolla white, $5-6 \mathrm{~mm}$. long; tube barely exserted; lobes about $2.5 \mathrm{~mm}$. long, oval, acute. Utah. Son. My.

2. G. spergulifolia Rydb. Stem low, more or less woody at the base, 5-10 $\mathrm{cm}$. high, more or less pubescent with white crisp hairs, or puberulent; leaves linear-filiform, entire, or the upper rarely with 1-2 similar lobes, tipped with a pungent point; flowers in capitate clusters; calyx villous, with short subulate pungent teeth; corolla 4-5 mm. long, white; tube not exserted; lobes oblong, Sotuse, a little over $1 \mathrm{~mm}$. long. Stony slopes: Colo.-Wyo.-Mont.-Utah.

3. G. crebrifolia Nutt. Stems several, from a branched woody caudex, erect or ascending, sparingly villous, $5-15 \mathrm{~cm}$. long; leaves simple, fleshy, crowded, glabrous or nearly so, cuspidate, $1-2 \mathrm{~cm}$. long; flowers capitate; calyx sparingly villous; teeth subulate, shorter than the tube; corolla 4-6 mm. long, exserted; lobes oval, about $2 \mathrm{~mm}$. long. G. Merrillii A. Nels. Dry soil: Wyo. Submont.
Je.

4. G. spicata Nutt. Biennial or perennial, with a taproot; stem simple, erect, or branched at the base, arachnoid-villous, $1-3.5 \mathrm{dm}$. high; leaves linear, entire, or with few linear lobes, $2-5 \mathrm{~cm}$. long, $1-2 \mathrm{~mm}$. wide, sparingly arachnoid; 
calyx-lobes lanceolate, cuspidate; corolla 9-11 mm. long, greenish white; tube one-third longer than the calyx; lobes 3-4 mm. long, oval. Dry hills: Neb.Colo.-Utah-Wyo. Plain-Mont. My-Je.

5. G. globularis A. Brand. Perennial, with a taproot, simple or with a branched caudex; stems 1-1.5 dm. high, densely arachnoid-lanate; leaves numerous, 3-6 $\mathrm{cm}$. long, the basal ones usually entire, linear, the cauline ones often pinnately divided; calyx densely lanate-villous; lobes lanceolate, shorter than the tube, cuspidate; corolla about $9 \mathrm{~mm}$. long; lobes broadly oval. G. congesta capitata A. Gray. High mountains: Colo. Subalp. Jl.

6. G. cephaloidea Rydb. Biennial or perennial, with a taproot; stems 1-3 $\mathrm{dm}$. high; leaves pinnatifid into few linear lobes, or some entire, $2-6 \mathrm{~cm}$. long, floccose; calyx densely arachnoid; teeth lanceolate, subulate-tipped, shorter than the tube; corolla about $12 \mathrm{~mm}$. long; lobes oval. Hills and mountains: Mont.Wyo. Mont.-Subalp. Je-Au.

7. G. congesta Hook. Perennial, with a branched caudex; stems simple, 1-1.5 dm. high, arachnoid-villous; basal leaves simple, linear, or 3-cleft, 2-4 cm. long; stem-leaves pinnately 3-5-cleft; calyx densely arachnoid; teeth lanceolate, cuspidate, shorter than the tube; corolla white, $7-8 \mathrm{~mm}$. long. $G$. cephaloidea A. Brand, not Rydb. Hills and sandy plains: Sask. S.D.-Wyo.-(? B.C.) JeЛ.

8. G. tridactyla Rydb. Perennial, with a branched caudex; stems several, arachnoid-lanate, $1-1.5 \mathrm{dm}$. high; leaves $1-2 \mathrm{~cm}$. long, lanate, 3-cleft at the apex or the lower entire; flowers in a short spiciform inflorescence; calyx moderately pubescent; teeth lanceolate, shorter than the tube; corolla about $1 \mathrm{~cm}$. long; tube longer than the calyx-lobes, elliptic, $3 \mathrm{~mm}$. long. G. trifida A. Brand, not Nutt. Mountains: Utah. Subalp. Au.

9. G. nuda (Eastw.) Rydb. Perennial, suffruticose at the base, with ascending branches, glabrous; leaves simple, linear, or 3-cleft, with linear lobes, pungentpointed, 2-3 cm. long; flowers capitate at the ends of the branches; calyx glandular, 6-7 mm. long; teeth subulate, acerose; corolla white, about $1 \mathrm{~cm}$. long; lobes about $3 \mathrm{~mm}$. long. Cañons: se Utah. Son. Au.

10. G. montana Nels. \& Kenn. Suffruticose perennial, branched at the base; stem erect or ascending, 1-2 dm. high, arachnoid-villous; leaves almost palmately divided into short divisions, arachnoid-villous; calyx turbinate, arachnoid; lobes lance-subulate, cuspidate; corolla white, 5-7 mm. long; tube barely exserted; lobes $2 \mathrm{~mm}$. long, elliptic. G. palmifrons (A. Brand) Rydb. Sand hills and mountains: Ore--Ida.-Utah-Calif. Son. Je-Au.

11. G. Burleyana A. Nels. Perennial, with a suffruticose branched caudex; branches erect, $15-30 \mathrm{~cm}$. high; pubescence crisp, but scant, except in the inflorescence; leaves alternate, some entire and linear, others pinnatifid, with linear divisions, cuspidate-tipped; corolla white; tube less than 5. $\mathrm{mm}$. Iong; Iobes oblong, reflexed, about $2 \mathrm{~mm}$. long. Clay banks: Ida. Son. Jl.

12. G. iberidifolia Benth. Suffruticose perennial; stems several from the woody caudex, erect or ascending, floccose, 1-2 dm. high, branched above; leaves pinnately divided into $3-7$ linear lobes, $2-5 \mathrm{~cm}$. long, or the lower entire; calyxteeth lance-subulate, cuspidate, shorter than the tube; corolla white; tube a little exserted; lobes oval, $2 \mathrm{~mm}$. long or less, obtuse. Dry hills, plains, and badlands: S.D.-Neb.-Colo.-Utah. Plain-Submont, Je-Au.

13. G. roseata Rydb. Perennial, with a woody base, cespitose; flowering branches about $1 \mathrm{dm}$. high, purple-tinged, more or less villous or crisp-hairy; leaves pinnatifid, with linear pungent-pointed lobes, about $2 \mathrm{~cm}$. long; calyx also very pubescent and rose-tinged; lobes subulate and spinulose-pointed; corolla about $8 \mathrm{~mm}$. long; its lobes $4-5 \mathrm{~mm}$. long, elliptic, obtuse. Dry hills: Colo.(? Ida.). Submont. My.

14. G. Gunnisonii Torr. Stem erect, divaricately branched, 1-2.5 dm. high; leaves glabrous, 1-4 cm. long; flowers in small terminal heads; calyx campanulate, crisp-hairy and somewhat glandular; teeth lanceolate, shorter than 
the tube; corolla $5-6 \mathrm{~mm}$. long, white; lobes oval, $2 \mathrm{~mm}$. long. Sandy places: e Colo-Utah-Ariz. Son. My-Je.

15. G. depressa M. E. Jones. Stem erect, divaricately branched, $5-10 \mathrm{~cm}$. high, crisp-pubescent; leaves entire or with a few teeth above the middle; flowers cymose, more or less clustered towards the ends; bracts oblanceolate, acute; calyx campanulate; teeth subulate, equalling the tube; corolla $6 \mathrm{~mm}$. long, white; lobes $1.5 \mathrm{~mm}$. long, oval, acute. Desert regions: Utah-Ariz.-Calif. Son. My-Je.

16. G. pumila Nutt. Stem erect, branched, 1-2 dm. high, erisp-hairy; leaves pinnatifid, with few linear divisions, cuspidate, sparingly crisp-hairy; flowers in small terminal heads; calyx-lobes subulate, shorter than the tube, cuspidate; corolla 9-10 $\mathrm{mm}$. long; tube twice as long as the calyx; lobes oval, 2 mm. long. Dry hills: w Tex.-Wyo.-Utah-Ariz. Son.-Submont. My-Au.

17. G. polycladon Torr. Stems ascending or erect, branched at the base, $5-10 \mathrm{~cm}$. high; leaves mostly basal, rosulate, pinnatifid, crisp-hairy, with oblong divisions, cuspidate; stem-leaves few or none; flowers in small terminal heads; bracts 3-cleft at the apex; calyx glandular-puberulent; sepals lanceolate, cuspidate, shorter than the tube; corolla white, $4-5 \mathrm{~mm}$. long, exserted; lobes scarcely $1 \mathrm{~mm}$. long. Desert regions: w Tex.-Colo.-Nev.-Ariz. Son. Ap-Je.

18. G. capitata Dougl. Stem erect, simple, or virgately branched, glabrate or nearly so, $1.5-6 \mathrm{dm}$. high; leaves glabrous or arachnoid at their bases, bi- or tri-pinnatifid, with linear segments; flowers capitate at the ends of the branches; calyx glabrous or slightly puberulent; teeth subulate, equalling the tube; corolla light blue or white, short-trumpet-shaped, nearly funnelform; lobes linear or oblong, equalling the tube. Hills and plains: Alaska-Ida.-Calif. Son.-Submont. My-J.

19. G. arizonica (Greene) Rydb. Stem 2-4 dm. high, more or less crisphairy and glandular-puberulent; leaves erisp-hairy, pinnatifid, with rather approximate linear lobes, obovate in outline; calyx-teeth deltoid-lanceolate, gradually cuspidate; corolla $2.5-3 \mathrm{~cm}$. long. Callisteris arizonica Greene. Dry regions: Ariz. - S Utah. Son. Je.

20. G. tenuituba Rydb. Stem about $3 \mathrm{dm}$. high, glandular-puberulent; leaves pinnatifid into linear, puberulent, cuspidate divisions; calyx glandularpuberulent, searious in the sinuses; corolla flesh-colored, $4 \mathrm{~cm}$. long; tube $1 \mathrm{~mm}$. thick below, $2 \mathrm{~mm}$. at the throat; lobes $1 \mathrm{~cm}$. long. Dry soil: $\mathrm{s}$ Utah. Son.

21. G. aggregata (Pursh) Spreng. Stem erect, $3-5 \mathrm{dm}$. high, more or less puberulent, simple up to the inflorescence; leaves pinnatifid into narrowly linear divisions, more or less crisp-hairy; calyx-lobes lanceolate, attenuate, spinulosetipped; corolla $3-4 \mathrm{~cm}$. long, crimson to white; lobes 7-9 mm. long, lanceolate. Callisteris aggregata and C. flavida Greene. SKYrockeт. Hills, glades, and meadows: Mont.-N.M.-Calif.-B.C. Submont.-Mont. My-Au.

22. G. pulchella Dougl. Stem erect, simple up to the inflorescence, more or less crisp-hairy as well as glandular-puberulent, $3-6 \mathrm{dm}$. high; leaves pinnatifid into linear divisions, erisp-hairy; calyx-lobes narrowly lanceolate, attenuate, with spinulose spreading tips; corolla erimson to white, $3-4 \mathrm{~cm}$. long; lobes lanceolate, attenuate-acuminate. G. aggregata attenuata A. Gray. G. altenuata A. Nels. and Callisteris attenuata Greene, the white-flowered form. S. altenuata Open hills and plains: Mont.-Colo.-Nev.-Wash. Submont.-Mont. My-
$\mathrm{Au}$.

23. G. scariosa Rydb. Stems simple, strict, 3-6 dm. high, glandularpuberulent throughout; leaves pinnatifid into linear-filiform spinulose-tipped divisions, more or less white-villous when young, glandular-puberulent; calyxtube about $6 \mathrm{~mm}$. long, puberulent; teeth short, broadly rounded-ovate, abruptly subulate-acuminate; corolla pink, 3-4 cm. long; lobes acute, about $8 \mathrm{~mm}$. long. Callisteris collina Greene. Open hills: Colo.-Utah. Submont.-Mont. JI-S.

24. G. candida Rydb. Biennial or perennial; stems ascending or erect, simple, 4-6 dm. high, leafy; leaves rather fleshy, divided into linear-filiform, spinulose-tipped segments; calyx glandular-pubescent, about $8 \mathrm{~mm}$. long; lobes 
lanceolate, bristle-tipped; corolla white, or rarely pale pink, $2-3 \mathrm{~cm}$. long, its lobes oval or obovate, obtuse. Callisteris leucantha Greene. Open valleys: Colo. Mont. Je-Au.

25. G. longiflora (Torr.) G. Don. Stem erect, glabrous, branched above, 2-5 dm. high; leaves deeply pinnatifid, with few filiform divisions, or often entire and filiform; calyx glabrous; teeth subulate, much shorter than the tube; corolla white; lobes about $1 \mathrm{~cm}$. long. Sandy plains: Neb.-Tex.-Ariz.-Utah. Plain - Submont. Je-Au.

26. G. laxiflora (Coult.) Osterhout. Stem glabrous or glandular-puberulent above, about $3 \mathrm{dm}$. high; leaves pinnatifid, with filiform divisions, the upper few-lobed or entire; calyx-teeth subulate; corolla white or tinged with blue; lobes 4-5 mm. long. Gilia Macombii laxiflora Coult. Plains and table lands: Colo.-Tex.-N.M.-Utah. Plain-Submont. Je-S.

27. G. polyantha Rydb. Stems several, 3-4 dm. high, simple up to the inflorescence, glandular-puberulent; leaves $3-4 \mathrm{~cm}$. long, pinnatifid; lobes linearfiliform, pungent-pointed; flowers numerous in a narrow thyrsus; calyx about 5 $\mathrm{mm}$. long; lobes broadly ovate-triangular, abruptly cuspidate-pungent; corolla white, about $1 \mathrm{~cm}$. long; lobes about $5 \mathrm{~mm}$. long, lance-oblong, obtusish. $G$. exserta A. Nels. Dry places: Colo. Submont. Jí.

28. G. calcarea M. E. Jones. Stem erect, usually branched, glandularpilose, $0.5-5 \mathrm{dm}$. high; leaves pinnatifid, glandular; flowers paniculate; calyx densely glandular; teeth triangular-lanceolate, acuminate; corolla-tube yellowish, twice as long as the calyx; lobes violet, rounded-ovate. G. pinnatifida Nutt., not Moc. \& Sess. G. viscida Woot. \& Standl. Sandy soil: Neb.-N.M.-Wyo. Plain-Mont. Je-S.

29. G. MacVickerae M. E. Jones. Stem erect, glabrous, branched, 3-4.5 dm. high; basal leaves rosulate, as well as the lower stem-leaves pinnatifid, with obovate-mucronate divisions; leaves of the upper stem and branches linear, entire; calyx glandular-puberulent; teeth triangular, acute; corolla $12-14 \mathrm{~mm}$. long; lobes oval. Sandy soil: Utah. Submont. My.

30. G. scopulorum M. E. Jones. Stem 1-2 dm. high, glandular-pubescent; lower leaves oblanceolate in outline, pinnatifid, $1-2.5 \mathrm{~cm}$. long, glandular-pubescent; lobes obovate or oblong, aristate-tipped, the upper stem-leaves comparatively broader and shorter, the uppermost much reduced and few-toothed; calyxtube about $2 \mathrm{~mm}$. long, glandular; teeth subulate, $1 \mathrm{~mm}$. long; corolla $10-14 \mathrm{~mm}$. long, purple, with a yellow throat. Dry regions: s Utah-Nev.-s Calif. $L$. Son. Ap-My.

31. G. hutchinsifolia Rydb. Stem 1-2.5 dm. high, glandular-pubescent; leaves mostly crowded near the base, pinnatifid, with oblong, more or less lobed divisions, glandular-pubescent; leaves of the inflorescence often linear; calyx-tube glandular, 1.5-2 mm. long; lobes subulate; corolla 10-14 mm. long; lobes broadly ovate, acute. G. arenaria rubella Brand. Dry regions: s Utah-Ariz. L. Son. Ap-My.

32. G. sinuata Benth. Stem 1-3 dm. high, usually branched, glabrate or more or less glandular-puberulent; leaves oblanceolate in outline, pinnatifid, somewhat floccose when young, in age glabrate; lobes oblong to ovate, usually short; leaves of the branches lanceolate, entire or toothed; calyx-tube $2 \mathrm{~mm}$. long; teeth subulate, about $1 \mathrm{~mm}$. long; corolla $8-10 \mathrm{~mm}$. long, purple, with yellowish tube. Sandy soil: N.M.-Colo.-Nev.-Calif. Son.-Submont. Ap-J.

33. G. straminea Rydb. Stem 2-3 dm. high, glabrous, or rarely slightly glandular-puberulent above, straw-colored; basal leaves glabrous, firm, 1-2 cm. long, pinnately lobed, with lanceolate cuspidate-tipped lobes; stem-leaves sessile and partly clasping, lanceolate, sharply dentate with cuspidate teeth, or entire; calyx-tube $2 \mathrm{~mm}$. long; teeth subulate, $1 \mathrm{~mm}$. long; corolla 7-8 $\mathrm{mm}$. long. Dry regions: s Utah. L. Son.

34. G. inconspicua (Smith) Dougl. Stem 2-4 dm. high, glandular-puberulent; leaves mostly near the base, pinnatifid, more or less crisp-pubescent or glabrate; lobes mostly oblong, cuspidate; calyx-tube about $2 \mathrm{~mm}$. long, glabrous 
or glandular-puberulent; teeth subulate, about $1.5 \mathrm{~mm}$. long; corolla 7-8 $\mathrm{mm}$. long; limb purplish; lobes oval, $2 \mathrm{~mm}$. long, obtuse. Hillsides: N.M.-Wyo.Wash.-Calif. Submont.-Mont. F-Au.

35. G. subacaulis Rydb. Stem less than $1 \mathrm{dm}$. high, glandular-puberulent; leaves $1.5-3 \mathrm{~cm}$. long, pinnatifid, with triangular to oblong divisions, glandular-puberulent, or slightly white-villous when young; ealyx $2-2.5 \mathrm{~mm}$. long, puberulent; lobes lanceolate, about half as long as the tube, acute. Sandy valleys and cañons: Wyo.-N.M.-Ariz.-Ida. Son.-Submont. My-Jl.

36. G. Tweedyi Rydb. Stem $2-4 \mathrm{dm}$. high, glandular-puberulent, especially the upper part; leaves $2-3 \mathrm{~cm}$. long, pinnatifid, with lanceolate cuspidate lobes; calyx about $3 \mathrm{~mm}$. long; lobes lanceolate; corolla about $4 \mathrm{~mm}$. long, bluish. River bottoms and sandy plains: Wyo.-Ida.-Colo. Plain-Submont. MyJe.

37. G. stenothyrsa A. Gray. Biennial; stem erect, strict, about $3 \mathrm{dm}$. high, glandular-puberulent; basal leaves merely toothed, 1-2 cm. long, thick, obovate, puberulent; stem-leaves pinnately lobed, with oblong divisions; calyx campanulate; teeth triangular, shorter than the tube; corolla white, about 12 $\mathrm{mm}$. long. Among cedars: Utah. Son. Je.

38. G. subnuda Torr. Stem 1-5 dm. high, glandular-puberulent; leaves mostly basal, thick, spatulate or elliptic, 1-4 cm. long, dentate, densely glandularpuberulent; stem-leaves smaller, dentate or entire, glandular-pubescent, $4 \mathrm{~mm}$. long; teeth subulate, equalling the tube; corolla 12-15 mm. long, glandularpuberulent; lobes ovate, acute. G. superba Eastw. Cañons: Ariz.-Nev.Utah-N.M. Son.-Submont. My-Au.

39. G. Crandallii Rydb. Stem 3-5 dm. high, sparingly puberulent, glandular above, rather stout, much branched; basal leaves 3-10 $\mathrm{cm}$. long, spatulate or oblanceolate, serrate or pinnately lobed; calyx glandular; teeth lanceolate; corolla-lobes oblong-spatulate. Sage plains: Colo.-N.M. Submont.

40. G. Haydeni A. Gray. Stem 1-3 dm. high; basal leaves pinnately lobed or toothed, slightly pubescent, 2-3 cm. long, spatulate; calyx-tube $2 \mathrm{~mm}$. long; teeth triangular-subulate, scarcely $1 \mathrm{~mm}$. long; corolla-lobes obovate. Plains: sw Colo, Plain. Jl.

41. G. leptomeria A. Gray. Stem 1-2 dm. high, branched, glandularpubescent; leaves mostly basal, oblong to linear in outline, 1-5 cm. long, pinnately lobed or toothed, with mucronate teeth or lobes; calyx sparingly glandular or glabrous; teeth triangular-subulate, slightly shorter than the tube; corolla white or pale rose-colored, 4-5 $\mathrm{mm}$. long; lobes 1-1.5 $\mathrm{mm}$. long, acute or apiculate. G. triodon Eastw., Aliciella triodon A. Brand, a form with 3-cleft corollalobes. Dry soil: N.M.-Colo.-Ore.-Calif. Son.-Submont. My-Je.

42. G. latifolia S. Wats. Stem 1-2.5 dm. high, viscid-villous, with crisp hairs and glandular on the upper portion; leaves petioled or the upper sessile; blades coarsely dentate, with cuspidate triangular teeth; calyx sparingly glandular; tube about $2.5 \mathrm{~mm}$. long teeth lance-subulate, spinulose-cuspidate, $3 \mathrm{~mm}$. long; corolla light rose, $6-8 \mathrm{~mm}$. long, the broad tube equalling the calyx; lobes oval, acute. Desert regions: s Utah-Ariz.-se Calif. L. Som. Ap-My.

43. G. pentstemonoides M. E. Jones. Cespitose perennial, glandular above, about $1 \mathrm{dm}$. high; basal leaves densely crowded, linear-oblanceolate, $4-5 \mathrm{~cm}$. long, petioled, entire, thick, glabrous; stem-leaves 3-4, smaller; flowers in axillary racemes; calyx-teeth subulate, equalling the tube; corolla blue, $1 \mathrm{~cm}$. long, fully twice as long as the calyx; lobes ovate or oval. Rocks: Colo. S.

44. G sedifolia A. Brand. Perennial; stem simple, fleshy, $2-4 \mathrm{~cm}$. high; leaves basal, imbricate, fleshy, obovate-spatulate, obtuse, $5 \mathrm{~mm}$. long; cauline leaves linear-spatulate, $1 \mathrm{~cm}$. long or less; flowers congested in a short inflorescence; calyx campanulate; lobes ovate, obtuse; corolla violet, $5 \mathrm{~mm}$. long; a little longer than the calyx. Cliffs: Colo. Alp. Jl.

45. G. caespitosa A. Gray. Perennial, with a cespitose woody caudex; leaves basal, crowded, spatulate, thick, entire, viscid-puberulent, $8-12 \mathrm{~mm}$. long; 
flowering stems 3-7 $\mathrm{cm}$. long, 1-5-flowered; leaves much reduced; calyx about 4 mm. long; lobes subulate; corolla trumpet-shaped, fully $1 \mathrm{~cm}$. long. G. Grayi A. Nels. Valleys: Utah. Submont.

46. G. sinistra M. E. Jones. Stem with ascending branches, $2-3 \mathrm{dm}$. high, glandular-puberulent; leaves entire, linear or lance-linear, $1-3 \mathrm{~cm}$. long, $2-4 \mathrm{~mm}$. wide; calyx in flower, about $2 \mathrm{~mm}$. long, somewhat enlarging in fruit, at last bursted by the capsule; lobes subulate; corolla light blue, $5 \mathrm{~mm}$. long. Collomia sinistra Brand. Gumbo soil: Ida. Son. Jl.

47. G. minutiflora Benth. Stem much branched and leafy, 2-5 dm. high, minutely glandular-puberulent or glabrate; leaves linear-filiform, entire or some of the lower 3-cleft, those of the inflorescence reduced and subulate; calyx 1.5-2 $\mathrm{mm}$. long; teeth subulate, about $1 \mathrm{~mm}$. long; corolla white. $C$. linoides Nutt. Plains and sandy places: B.C.-Mont.-Colo.-Ore. Plain-Submont. Ji-Au.

48. G. tenerrima A. Gray. Stem erect, filiform, diffusely branched, glandular-puberulent, 5-15 cm. high; leaves linear, 1-5 cm. long, entire, the upper bract-like; flowers axillary; calyx short-campanulate; tube about $1 \mathrm{~mm}$. long; teeth triangular, shorter; corolla white, about $3 \mathrm{~mm}$. long; lobes oblong, equalling the tube; ovules solitary in each cell. Sandy soil: Mont.-Wyo.Utah-Ore. Plain-Submont. My-Jl.

\section{LANGLOİSIA Greene.}

Low annuals. Leaves alternate, pinnatifid, the lower segments modified into bristles, the upper bristle-tipped. Flowers perfect, in terminal involuerate heads; bracts with bristle-tipped lobes. Calyx campanulate or tubular, 5-cleft; lobes equal, bristle-tipped; tube in fruit cleft to the base. Corolla with a cylindric tube and funnelform limb, regularly 5-lobed or more or less 2-lipped. Stamens inserted in the throat, often more or less declined. Ovary 3-celled, with 3-8 ovules in each cell. Capsule loculicidal; seed submucilaginous when wetted.

Corolla almost regular and stamens nearly straight. Corolla bilabiate and the stamens declined, curved.

1. L. setosissima (A. Gray) Greene. Annual; stem branched from the base, 3-8 $\mathrm{cm}$. high, erisp-hairy; leaves glabrous, pinnatifid, the upper divisions deltoid, setaceously tipped; calyx-teeth terminated by a long bristle; corolla white, about $15 \mathrm{~mm}$. long; lobes oval. Gitia setosissima A. Gray. Desert regions: Ariz.-Ida.-Nev.-Calif. Son. Mr-My.

2. L. Schottii (Torr.) Greene. Annual; stem branched from the base, villous or glabrate, $2-10 \mathrm{~cm}$. high; leaves pinnatifid; upper lobes lanceolate, bristletipped; calyx tubular; teeth subulate, villous, longer than the tube, with long bristle-points; corolla white, half longer than the ealyx; lobes oblong. $G$. Schottii S. Wats. Desert regions: Ariz. $\rightarrow$ s Utah-Calif.-Sonora. L. Son. Ap-Je.

\section{LINÄNTHUS Benth.}

Erect, glabrous slender annuals. Leaves all opposite, 3-5-divided into filiform divisions or the lower entire and filiform. Flowers regular, axillary. Calyx-tube white-scarious, ruptured by the fruit; lobes acerose. Corolla shortsalver-shaped or with a short tube and a funnelform throat; lobes broadly cuneate, minutely erose or denticulate, convolute in bud. Stamens included in the tube of the corolla. Capsule cylindric or oblong. Seed-coat not producing spiracles when wetted.

Corolla short salver-shaped or campanulate.

Calyx 7-8 mm. long; corolla 10-15 mm. long; stamens inserted in the middle of the

tube.
Calyx $4 \mathrm{~mm}$. Iong; corolla $6-7 \mathrm{~mm}$. long; stamens inserted near the base of the tube.

1. L. Bigelovit.

Corolla with a funnelform throat and short tube.

2. L. Dactylophyllum.

Corolla more than twice as long as the hirsute or strigose calyx.

Corolla about half longer than the glabrous calyx.

3. L. pharnaceoides.

4. L. Harknessii. 
1. L. Bigelovii (A. Gray) Greene. Annual; stem glabrous, 1-3 dm. high, dichotomously branched; lower leaves entire, narrowly linear, the upper 3-divided into similar divisions, glabrous; flowers sessile; calyx glabrous, tubular, 7-8 mm. long, scarious except the ribs; teeth subulate, somewhat recurved-spreading; corolla 10-15 mm. long, white; lobes convolute, obovate. Gilia Bigelovii A. Gray. Desert regions: Tex.-s Utah-Ariz. L. Son. Ap-My.

2. L. Dactylophyllum (Torr.) Rydb. Low annual; stem hirsutulous, 2-6 $\mathrm{cm}$. long, branched; leaves 3-cleft, with linear divisions, or some entire, acerosecuspidate, alternate or the upper sub-opposite; flowers short-pedicelled or subsessile; calyx about $4 \mathrm{~mm}$. long, puberulent; sepals distinct to near the base, scarious-margined; corolla white, 6-7 mm. long; lobes ovate. G. Dactylophyllum Torr. G. demissa A. Gray. Linanthus demissus Greene. Desert regions: Ariz. -s Utah-Calif. L. Son. Ap-My.

3. L. pharnaceoides (Benth.) Greene. Annual; stem 1.5-4.5 dm. high, often diffusely branched, dichotomous, glabrous or minutely puberulent above; leaves 3-7-cleft, with filiform, acerose divisions; flowers with filiform pedicels; calyx $3 \mathrm{~mm}$. long; teeth lance-subulate; corolla white or rose-colored, $7-8 \mathrm{~mm}$. long; filaments bearded at the base. G. pharnaceoides Benth. Prairies and plains: Wash.-Ida.-Utah-Calif. Son. Ap-Jl.

4. L. Harknessii (Curran) Greene. Annual; stem glabrous, 0.5-3 dm. high, dichotomously branched; leaves opposite, 3-5-cleft into filiform divisions, or the upper simple; flowers with filiform pedicels; calyx $2-2.5 \mathrm{~mm}$. long; teeth lanceolate; corolla white, 3-4 mm. long. G. Harknessii Curran. Sandy and waste places: Mont.-Colo.-Calif.-B.C. Son.-Mont. Je-Au.

\section{GYMNÓSTERIS Greene.}

Diminutive annuals, with simple stems. Leaves proper wanting, the foliage represented by the persistent cotyledons, and the bracts, which are scarious at the base and herbaceous above. Flowers subumbellate. Calyx of 5 united sepals; tube campanulate, scarious, ruptured by the fruiting capsule; lobes unequal, partly herbaceous. Corolla salverform, with slender tube. Stamens 5; filaments adnate to the corolla-tube; anthers borne in the throat of the corolla. Seeds membranous-margined or winged; testa thin, mucilaginous when wetted, but not developing spiracles.

Lobes of the corolla $3-4 \mathrm{~mm}$. long, truncate, undulate at the apex. Lobes of the corolla 1-1.5 mm. long, acutish.

1. G. nudicaulis.

2. G. parvula.

1. G. nudicaulis (H. \& A.) Greene. Annual, glabrous; stem 5-10 cm. high; bracts lanceolate, $8-20 \mathrm{~mm}$. long; calyx about $3 \mathrm{~mm}$. long; teeth subulate; corolla $10-15 \mathrm{~mm}$. long, white or yellowish; lobes obovate; capsule $4 \mathrm{~mm}$. long or more. Gitia nudicaulis A. Gray. G. pulchella Greene. Sandy places: Ore.-Ida.-Nev. Son. Ap-My.

2. G. parvula (Rydb.) Heller. Annual; stem $2-3 \mathrm{~cm}$. high, glabrous; flowers capitate; bracts ovate-lanceolate, $5-15 \mathrm{~mm}$. long, often tinged with red; calyx $3 \mathrm{~mm}$. long; teeth ovate, acute; corolla white or pinkish, 6-8 mm. long; capsule 3-4 mm. long, ovoid. G. nudicaulis Greene, in part, and Rydb. (Fl. Colo.) Sandy places: Wyo.-Colo.-Utah-Ida. Submont.-Mont. Je-Jl.

\section{TINTINÂBULUM Rydb.}

Low slender annuals. Leaves alternate, narrow. Flowers perfect, solitary in the axils, on long reflexed pedicels. Calyx campanulate; lobes subulate, hyaline-margined. Corolla campanulate, deeply cleft. Ovary 3-celled. Seeds few, often mucilaginous when wetted, but not spirilliferous.

1. T. filiforme (Parry) Rydb. Stem filiform, $5-20 \mathrm{~cm}$. long, glabrous, branched; leaves all filiform, entire, $2-4 \mathrm{~cm}$. long; pedicels $0.5-2 \mathrm{~cm}$. long; calyx glabrous, $2 \mathrm{~mm}$. long; corolla white, whitish, or yellowish, 4-5 mm. long, cleft nearly to the base; lobes oblong. Gilia filiformis Parry. Arid regions: Ariz.s Utah-Calif. Ap-My. 


\section{GILIÁSTRUM (A. Brand) Rydb.}

Perennial or annual herbs. Leaves alternate, from toothed to pinnatifid. Flowers perfect, cymose. Calyx campanulate, 5-lobed or 5-cleft; tube scarious in the sinuses and bursted by the fruit; corolla rotate-funnelform, deeply 5-cleft. Stamens inserted near the base of the corolla. Seeds several in each cell, mucilaginous when wetted. [Gilia \& Giliastrum A. Brand.]

1. G. acerosum (A. Gray) Rydb. Suffruticose perennial, 1-3 dm. high, very leafy, glandular-puberulent; leaves pinnatifid, with linear-subulate, acerose divisions, glandular-puberulent; calyx glandular-puberulent, $5-6 \mathrm{~mm}$. long; teeth lanceolate, acuminate; corolla blue, nearly rotate, about $1 \mathrm{~cm}$. long; lobes broadly ovate, much longer than the united portion. Gilia rigidula acerosa A. Gray. G. acerosa Britton. Sandy plains and hills: Tex.-Kans.-Colo.-Ariz. Son. ApJl.

\section{FAMily 110. HYDROPHYLlaCEAE. WATERLeaf Family.}

Perennial or annual, mostly caulescent herbs, with watery sap. Leaves alternate, or rarely opposite or in basal rosettes, without stipules. Flowers perfect, regular or nearly so, in scorpioid racemes or cymes, or solitary and axillary. Calyx of 5 more or less united sepals, often appendaged in the sinuses. Corolla 5-lobed, mostly campanulate or funnelform, often appendaged inside, the lobes convolute or imbricate in aestivation. Stamens 5 , alternate with the corolla-lobes; filaments adnate to the base of the corolla, distinct, of ten bearded; anthers introrse, versatile. Ovary of 2 united carpels, 1-celled or 2-celled, with parietal placentae; styles more or less united; stigmas often capitate; ovules numerous, or few. Fruit a capsule. Seeds amphitropous; endosperm cartilaginous. [Hydroleaceae.]

Corolla-lobes convolute in bud; placentae dilated.

Stamens exserted; calyx without appendages; leaves alternate.

Stamens included.

Calyx without appendages; leaves opposite.

Seeds inserted only on the inner face of the placentae, globose, alveolate; ealyx enlarged in fruit. 2 . MACROCALYX.

Seeds inserted on both faces of the placentae, oblong or vermiform, rugose calyx not enlarged in fruit.

3. EUCRYPTA.

Calyx with appendages in the sinuses, not much enlarged in fruit; leaves alternate or opposite.

Corolla-lobes imbricate in bud; placentae not dilated.

Styles more or less united; stamens mostly equal.

Styles free at the apex.

Flowers in circinate racemes, or solitary in the axils of the stem-leaves. Calyx-lobes in two series, the outer 3 large and cordate.

Calyx-lobes in one series, similar or nearly so.

13. TRICARDIA.

Corolla deciduous, mostly purplish, bluish, or white. Flowers in circinate racemes.

5. Phacelia. FIowers solitary in the axils of stem-leaves. 12. CONANTHUS. Corolla persistent, marcescent, yellowish. Capsule ovoid, turgid; flowers not drooping. Capsule compressed; flowers drooping.

Flowers solitary, from the axils of basal leaves. Styles united to the apex; flowers racemose, but hardly circinate.

6. Miltitzla.

7. EMMENANTHE.

8. CAPNOREA.

9. ROMANZOFFIA.

Styles free to the base; stamens unequal.

Capsule coriaceous; shrubs.

Capsule membranous; herbs.

10. ERIODICTYON.

11. MARTLAUNIDIUM.

\section{HYDROPHÝLLUM (Tourn.) L. WATER-LEAF.}

Perennial (all ours) or biennial, caulescent herbs. Leaves alternate, pubescent, lobed, or (in all ours) pinnately divided. Flowers in more or less scorpioid cymes. Calyx-tube short; lobes 5, narrow, with naked sinuses. Corolla white, blue, or purple; tube short; lobes 5 , convolute, each with a linear appendage within. Stamens 5, exserted; filaments partly pubescent. Ovary 1-celled, pubescent; styles 2-cleft; ovules 4 , enclosed by the fleshy placentae, which is attached at the bottom and top of the ovary. Capsule 2-valved; seeds 1-4, thick. 

Peduncles shorter than the petioles and mostly shorter than the flower-cluster; anthers
oblong.

Flowers capitate-cymose; corolla 7-8 mm. high.

Flowers distinctly pediceled; corolla $5-6 \mathrm{~mm}$. high.

Peduncles longer than the petioles; anthers oblong-linear.

Leaf-segments $7-19$.

Divisions of the leaves acuminate.

Stem and leaves sparingly hirsute or glabrous; sepals about equalling the corolla.

3. H. Fendleri.

Upper part of the stem and lower surface of the leaves densely pubescent; sepals

much shorter than the corolla. $\quad 4 . \mathrm{H}$. albifrons.

Divisions of the leaves acute, mucronate.

Leaves hispid beneath; inflorescence dense, subcapitate.

Leaf-segments $3-5$.

1. H. capitatum.

2. $H$. alpestre.

5. H. occidentale.

6. H. Watsoni.

7. H. virginianum.

1. H. capitatum Dougl. Stem 1-2 dm. (rarely $3 \mathrm{dm}$.) high, more or less grayish puberulent; leaves pinnately aivided into $5-7$ obovate divisions, which are 2-5 cm. long, 2- or 3-cleft and sometimes again lobed, grayish strigose or softly hirsute, paler beneath; lobes ovate; calyx very hispid, its lobes linearlanceolate. Hillsides: Mont.-Colo-Calif.-B.C. Submont.-Mont. Ap-Jl.

2. H. alpestre Nels. \& Kenn. Stem 1-2 dm. high, sometimes nearly acaulescent; leaves pinnately divided, grayish, short-hirsute, paler beneath; divisions 5-7, obovate, cleft and lobed, with oblong mucronate lobes; calyx short-hispid; stamens long-exserted. H. capitatum alpinum S. Wats. Mountains: (? Utah)Nev.-Calif. Submont.-Mont, My-Je.

3. H. Fendleri (A. Gray) Heller. Stem 3-7 dm. high, sparingly hirsute, leafy; leaves $2-3 \mathrm{dm}$. long, sparingly short-hairy or glabrate, paler beneath; segments 9-19, lanceolate or ovate-lanceolate, $2-10 \mathrm{~cm}$. long, coarsely serrate, the upper 3-cleft; teeth ovate-lanceolate; cyme small; sepals linear, hispid; corolla about $8 \mathrm{~mm}$. long. H. occidentale Fendleri A. Gray. Along streams and among bushes: Wyo.-N.M.-Utah. Submont.-Mont. My-Jl.

4. H. albifrons Heller. Stem 4-6 dm. high, usually very hirsute; leaves rather densely short-hairy on both sides, paler beneath; segments ovate to lanceolate, coarsely serrate, $2-10 \mathrm{~cm}$. long; sepals linear-lanceolate; corolla creamcolored, or tinged with purple, nearly $1 \mathrm{~cm}$. long. Near streams: Ida.-Wash. -B.C. My-Jl.

5. H. occidentale A. Gray. Stem 2-4 dm. high, more or less hirsute; leaves densely hirsute on both sides; segments $7-13$, the upper more or less confluent, broadly ovate, more or less lobed, the lobes ovate; sepals linear-lanceolate, scarcely half as long as the corolla, hirsute on the back and hispid-ciliate; corolla nearly $1 \mathrm{~cm}$. high. Mountains: s Utah-Calif-Ore. Submont. Ap-Jl.

6. H. Watsoni (A. Gray) Rydb. Stem 1-3 dm. high, canescent-pilose; leaf-segments $7-13,1-6 \mathrm{~cm}$. long, ovate, acute, usually deeply cleft into ovate or lance-oblong divisions; sepals hirsute and hispid-ciliate, lanceolate, fully half as long as the corolla, which is 7-8 mm. long. Mountains: Utah-Calif. Son.Submont. My-Au.

7. H. virginianum L. Stem 1-6 dm. high, glabrous or sparingly pilose; leaves oval in outline, 1-3 dm. long; segments 3-5, the lateral one 2-cleft, the terminal 3-cleft, sharply and deeply serrate; cyme short-peduncled; sepals linearlanceolate, hispid; corolla fully $1 \mathrm{~cm}$. long. Damp woods: Que.-Ga.-Ark.Minn.; Colo. (fide Osterhout). Boreal.-Submont. My-Au.

\section{MACROCÀLYX Trew.}

Annual caulescent herbs. Leaves alternate or opposite, pubescent, from once to thrice pinnatifid. Flowers perfect, solitary in the axils. Calyx enlarging in fruit, 5-lobed, appendaged in the sinuses. Corolla campanulate, usually with 5 appendages within; lobes convolute. Stamens 5 , included. Ovary 1celled; styles 2-cleft; ovules 2-4 on each fleshy placenta, which is attached to the top and bottom of the ovary. Seeds pitted. [Ellisia L.]

1. M. Nyctelea (L.) Kuntze. Stem erect, $0.5-3 \mathrm{dm}$. high, diffusely branched; leaf-segments spreading, entire, toothed or incised; calyx-lobes triangular-lance- 
olate, becoming 7-8 mm. long, acute, pubescent; corolla bluish white, 7-8 mm. broad. Ellisia Nyc'elea L. Alluvial soil and shady places: N.J.-N.C.-Colo. -Ida,-Alta. Plain-Mont.

\section{EUCRÝPTA Nutt.}

Low annual herbs. Leaves membranous, pinnately parted. Flowers perfect, regular, in geminate or panicled racemes. Calyx deeply 5-cleft. Corolla almost rotate, bright blue with yellow center, with two plicate, transverse appendages, much higher up than the stamens. Capsule globose, loculicidal. Seeds few or many, cylindraceous or oblong, incurved, transversely rugose and tuberculate, or deeply flavose.

Seeds cylindric, transversely rugose and tubercled. Seeds oblong or oval, deeply favose.

1. E. micrantha.

2. E. pinetorum.

1. E. micrantha (Torr.) Heller. Weak annual; stem branched, 1-2 dm. long, minutely glandular-pilose; leaves thin, pinnately parted into 5-9 obovate or oblong, obtuse lobes; racemes loose; calyx-lobes obovate or broadly spatulate, 2.5-3 mm. long; corolla bright blue, with yellowish tube, according to Heller creamy, a little exceeding the sepals; capsule globular, 20-24-seeded. Phacelia micrantha Torr. Dry places: N.M.-Utah-Calif. Son. Mr-My.

2. E. pinetorum (M. E. Jones) Rydb. Weak annual; stem erect, branched, 5-20 cm. high, glandular-puberulent; lower leaves pinnatifid, with oblong divisions, the upper entire or 3-lobed; racemes few-flowered; calyx-lobes lanceolate or ovate, acutish, longer than the white or blue corolla. Phacelia pinetorum M. E. Jones. Pine woods: Utah. Submont. Je.

\section{NEMÓPHILA Nutt. BABY-BLUE-EYES.}

Diffuse annual herbs. Leaves alternate or opposite, pinnately lobed or pinnatifid. Flowers perfect, solitary on axillary or terminal pedicels. Calyx not accrescent, 5-lobed, with a spreading or reflexed linear appendage in each sinus. Corolla campanulate to nearly rotate, with 10 appendages within; lobes convolute. Stamens 5, included, with short filaments. Ovary 1-celled; styles 2-cleft; ovules 2-12 on each fleshy placenta, which is attached to the top and bottom of the ovary. Capsule two-valved. Seeds usually 1-4.

Corolla 12-18 $\mathrm{mm}$. long.

1. N. Kirtleyi.

Corolla 2-3 $\mathrm{mm}$. long.

Appendages of the corolla present.

Appendages of the corolla narrow, acuminate; seeds deeply pitted.

Appendages of the corolla broad, cuneate; seeds smooth.

Appendages of the corolla wanting.

2. N. inconspicua.

3. N. breviflora.

4. N. explicata.

1. N. Kirtleyi Henders. Stem 5-20 cm. high, short-hispid; lower leaves opposite, the upper alternate; blades ovate in outline, irregularly 5-parted; lobes oblong, 3-lobed or strongly dentate; appendages of the calyx ovate, less than onethird the length of the lobes; calyx-lobes lanceolate, in fruit nearly as long as the corolla; corolla with violet border and white center, greenish-spotted; internal appendages half fan-shaped, lobed and fimbriate; seeds deeply pitted. Loose soil: Ida.-Ore. Son. JI.

2. N. inconspicua Henders. Leaves pinnately 5-lobed or 5-parted; blades rounded to ovate in outline; lobes rounded or obtusely triangular; appendages of the calyx ovate, one-fourth as long as the sepals; corolla equalling the calyx or slightly shorter, white, $2.5 \mathrm{~mm}$. long; appendages narrow, acuminate or laciniate. Loose moist soil: Ida. Son. J.

3. N. breviflora A. Gray. Stem branched, diffuse, 1-3 dm. high; leaves often all alternate, pinnately 3-5-parted; divisions oblong-lanceolate, acute, entire, 6-18 mm. long; appendages of the calyx nearly half as long as the sepals; corolla whitish or tinged with violet, shorter than the calyx; internal appendages cuneate, broad, fimbriate. Rich soil, hillsides, and cañons: Mont.-Colo.-Ore. -B.C. Submont. My-Jl.

4. N. explicata Nels. \& Macbr. Stem branching from the base, 7-15 $\mathrm{cm}$. long, spreading; leaves obovate or orbicular in outline, crenately 3-5-lobed, 1-2 
cm. long; appendages of the calyx small, oblong; lobes ovate, short-ciliate; corolla barely exceeding the calyx; lobes oval; seeds obscurely pitted. Perhaps the same as N. Austinae Eastw. Cañons: Ida. Son. Jl.

\section{Phacèlia Juss. Scorpion Weed.}

Perennial or annual caulescent herbs. Leaves alternate or opposite below. Flowers perfect, in scorpioid racemes or cymes. Calyx slightly enlarging in fruit, 5-lobed, without appendages. Corolla white, purple, or blue; tube appendaged within; lobes 5 , imbricate. Stamens 5; filaments adnate to the tube of the corolla. Ovary 1-celled, with two narrow placentae attached to the walls of the ovary; styles 2-cleft; ovules two to many on each placenta. Capsule 1 -celled or falsely 2 -celled, 2 -valved. Seeds reticulate or roughened.

Stamens equalling or usually much exceeding the corolla.

Leaves all simple and entire, or some of the lower pinnately 3-5-divided, with entire divisions; capsule acute; ovules 4 .

Leaves from sinuate-crenate to twice pinnatifid.

Plant annual or in one species perhaps perennial, but not cespitose.

Capsule globular-ovoid, obtuse; ovules 4 ; stamens in most species long-exserted. Calyx-lobes oblong-spatulate to linear-oblanceolate, scarcely exceeding the

Calyx-lobes linear to linear-oblanceolate, much exceeding the capsule.
II. GLANDULSA

Calyx-lobes linear to linear-oblanceolate, much exceeding the capsule.

Capsules ovoid, acute; ovules $12-40$; stamens slightly if at all exceeding the

Plant perennial, cespitose; inflorescence spicate-thyrsiform V. LINEARES.

Stamens shorter than thespitose; inflorescence spicate-thyrsiform. V. SERICEAE.

Seeds reticulate or favose-pit; plant low and diffuse; annuals.

or crenately lobed.

seeds strongly corrugated transversely: VI. PULCHELLAE.

V. ingersely; leaves pinnately divided.

\section{$\begin{array}{ll}\text { I. HETEROPHYLIAE } & \text { VII. BICOLORES. }\end{array}$}

Plant perennial, or at least biennial.

Plant densely canescent.

Calyx-lobes linear or linear-oblong; midveins inconspicuous; corolla pink or pale lilac, about $6 \mathrm{~mm}$. long. Calyx-lobes narrowly linear; midveins, at least in fruit, very strong; corolla white,
4-5 mm. long.

Plant not densely canescent.

2. P. Burkei.

Pubescence of the leaves of two kinds, long hirsute hairs and a fine pilose or tomentose pubescence.

Calyx almost as long as the white corolla, its lobes narrowly linear, acute, with a strong midrib.

Calyx much shorter than the corolla; midveins faint.

3. P. nervosa.

Stem erect; calyx from two-thirds to three-fourths as long as the corolla.

Plant biennial or short-lived perennial; corolla pink or lilac.

Plant a cespitose perennial; corolla usually white.

4. P. biennis.

Stem ascending, slender; inflorescence open; calyx
the pilose purplish corolla.

5. $P$. heterophylla.

the pilose purplish corolla.
. P. P. alpina.

bout half as long as

ubescence of the leaves hirsute only; calyx-lobes narrowly linear; midrib weak;

Plant annual.

Corolla 5-6 mm. long; ovules 4.

Corolla 8-10 mm. long; ovules 12-16.

7. P. leptosepala.

8. P. humilis.

24. P. linearis.

\section{Glandulosae.}

Corolla-lobes entire or merely sinuate-crenate.

Leaves sinuate-crenate to lobed halfways to the midrib.

Corolla narrowly campanulate; plant simple, strict, densely hirsute.

Corolla open-campanulate; plant branched 9 , P. Palmeri.

Stem-leaves suborbicular, plant branched, scarcely at all hirsute, very glandular.

Stem-leaves not suborbicular.

10. $P$. orbicularis.

Stem-leaves ovate, oval, or elliptic in outline.

Leaves pinnately divided to the midrib.

11. $P$. integrifolia.

12. P. corrugata.

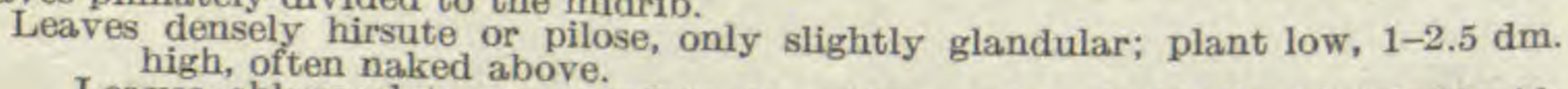

Leaves oblanceolate or spatulate in outline; calyx decidedly hirsute-hispid; stem and petioles glandular.

Leaves oblong or linear in outline; calyx scarcely hispid, but densely glandular; stem and petioles white-villous. Leaves hirsute only on the veins, short-pubescent and very viscid; plant stouter,
$2-4 \mathrm{dm}$. high, branched. 
Terminal divisions of the leaves large and obovate in outline.

15. P. splendens.

Terminal divisions of the leaves not much enlarged, ovate, lanceolate or oblong in outline.

Corolla-lobes distinctly dentate or erose.

Corolla white; stamens about twice as long as the corolla, 17. $P$, alba.

Corolla purplish or pink.

Stamens slightly exceeding the corolla; corolla-lobes erose. 18. $P$, neomexicana.

Stamens included; corolla-lobes dentate.

19. P. denticulata.

\section{RAMOSISSTMAE.}

Leaves pinnatifid or bipinnatifid.

Calyx-lobes oblanceolate; segments of the leaves broad, obovate or oblong; plant

diffusely branched.
Calyx-lobes linear; segments of the leaves small, oblong; plant simple.

Leaves round-lobed and coarsely crenate.

21. P. hispida.

22. P. Rattani.

\section{LINEARES.}

Leaves pinnately divided with numerous divisions, which are often toothed,

Leaves entire or with 3-5 entire divisions.

23. P. Franklinii.

24. P. linearis.

\section{SERICEAE.}

Stamens only slightly exceeding the corolla.

Stamens at least twice as long as the corolla.

Leaves divided halfways to the midrib; stamens twice as long as the corolla.

26. $P$. Lyallit.

Leaves divided to near the midrib; stamens about three times as long as the corolla. Plant equally sericeous throughout; segments of the leaves narrowly linear.

27. $P$. sericea.

Plant finely pubescent, hirsute-ciliate on the petioles; segments of the leaves oblong.

\section{Pulchellae.}

28. P. ciliosa.

Flowers almost sessile in small dense sessile spikes; calyx equalling the corolla, or slightly shorter.

Leaves pinnatifld; calyx enlarging in fruit and strongly reticulate.

29. $P$. firmomarginata.

Leaves merely toothed or lobed; calyx neither much accrescent nor reticulate.

Leaf-blades spatulate.

Calyx-lobes subequal. 30 . P. cephalotes.

Oalyx-lobes unequal, the longer twice as long as the shorter.

Leaf-blades orbicular or rounded ovate. $\quad 32$. P. Knightii.

Flowers pediceled in peduncled racemes; calyx much shorter than the corolla.

Leaf-blades entire or nearly so.

Leaf-blades orbicular or subreniform.

Leaf-blades ovate, obovate, oval, or oblong.

Corolla about $1 \mathrm{~cm}$. long; plant diffuse.

Corolla about $6 \mathrm{~mm}$. long; plant erect.

Filaments sparsely pilose.

Filaments glabrous.

Leaf-blades round, simuately toothed or crenate.

Corolla 8-10 mm. long: leaves glandular-puberulent.

Corolla 3-5 mm. Iong; leaves hirsutulous.

33. P. demissa.

34. P. pulchella.

35. P. curvipes.

36. $P$. incana.

37. $P$. glechomaefolia.

38. P. rotundifolia.

\section{BICOLORES.}

Corolla white or pale purple, not much, if at all, exceeding the calyx.

Plant not glandular or scarcely so; leaves pinnatifid.

Corolla shorter than the calyx.
Corolla usually slightly exceeding the calyx.

Plant decidedly glandular; leaves more or less bipinnatifid.

Calyx-lobes linear or nearly so, twice as long as the capsule.

Calyx-lobes spatulate, scarcely half longer than the capsule.

39. P. campestris.

40. P. Ivesiana.

41. P. glandulifera.

42. P. affinis.

Corolla about twice as long as the calyx; throat yellow; limb purple.

Corolla broadly funnelform; leaves once pinnate. $43 . P$. Fremontii.

44. P. bicolor.

1. P. leucophylla Torr. Stem 1-3 dm. high, densely canescent and only slightly hirsute; basal leaves petioled, $5-15 \mathrm{~cm}$. long, oblanceolate or elliptic; calyx-lobes linear or linear-oblong, obtuse, about two-thirds as long as the corolla; filaments villous-bearded. Dry hills: Neb.-Colo.-Ida.-B.C. Plain-Submont. Je-Au. 
2. P. Burkei Rydb. Stems $2-3 \mathrm{dm}$. high, canescent; basal leaves $3-10 \mathrm{~cm}$. long, petioled, lanceolate, entire, strongly veined, densely white-canescent on both sides; calyx canescent and hispid-ciliate; lobes obtuse, two-thirds as long as the corolla; corolla pubescent; stamens about twice as long as the corolla, villous-bearded. Dry hills: Ida.-Wash. Submont.

3. P. nervosa Rydb. Stems decumbent at the base, 1-3 dm. high, more or less hirsute; lower leaves $2-7 \mathrm{~cm}$. long, simple or with a pair of smaller lobes on the petioles, lanceolate, $2-5 \mathrm{~cm}$. long, acute, hirsute on both sides; inflorescence soon open; calyx more or less tinged with purple, about as long as the corolla; corolla white or nearly so, pubescent, about $5 \mathrm{~mm}$. long; filaments about twice as long as the corolla, slightly bearded. P. alpina Rydb. (Fl. Colo.) Mountains: Colo. Subalp.-Alp. Je-Au.

4. P. biennis A. Nels. Stem strict, usually purplish, 3-4 dm. long, sparingly and closely canescent and slightly hirsute; basal leaves simple or often with a pair of divergent lobes on the petioles, appressed-hirsute and with finer pubescence intermixed, oblong, acute, $5-10 \mathrm{~cm}$. long; calyx-lobes oblong-linear or linear, about three-fourths as long as the corolla, obtuse; corolla $5 \mathrm{~mm}$. long; filaments distinctly villous-bearded. Mountain valleys: Mont.-Colo.-Ida. Submont. My-Jl.

5. P. heterophylla Pursh. Stem $3-6 \mathrm{dm}$. high, strict, hirsute and tomentulose; leaves entire, or with one or two pairs of lanceolate segments or lobes below; blade or terminal segment lanceolate, 5-10 cm. long; calyx hirsute, ciliate and tomentose, three-fourths as long as the corolla or nearly equalling it; lobes narrowly linear, usually acute; corolla $5-6 \mathrm{~mm}$. long; filaments villous-bearded. $P$. hastata Dougl. Hills and mountains: Alta.-Colo.-Utah-Wash.-B.C. Submont. My-Jl.

6. P. alpina Rydb. Stem about $2 \mathrm{dm}$. high, sparingly grayish strigose and hirsute; basal leaves short-petioled, about $5 \mathrm{~cm}$. long, oblong-lanceolate or oblanceolate, entire, grayish strigose; calyx hispid; lobes linear, obtuse or acutish; corolla $5-6 \mathrm{~mm}$. long, lilac; filaments bearded. Mountains: Mont.-Wyo.Utah-B.C. Mont. Je-J.'

7. P. leptosepala Rydb. Stems ascending, hirsute, $1-3 \mathrm{dm}$. high; leaves usually simple, hirsute on both sides, $5-10 \mathrm{~cm}$. long, oblanceolate or elliptic; calyx hirsute; lobes narrowly linear, hirsute, nearly as long as the corolla, acute; corolla glabrous or nearly so, $5 \mathrm{~mm}$. long; filaments about twice as long, sparingly villous-bearded. Mountains: B.C.-Mont. Submont. Je-Au.

8. P. humilis T. \& G. Diffusely branched annual; stem 1-2 dm. high, pilose or somewhat hirsute; leaves elliptic, spatulate, or oblanceolate, more or less hirsute, $2-5 \mathrm{~cm}$. long, usually simple; calyx-lobes narrowly linear, hirsute, nearly two-thirds as long as the blue or purple corolla, which is 5-6 mm. long; filaments slightly exserted, glabrous or nearly so. Dry gravelly soil: Calif.Utah. Son. My-Jl.

9. P. Palmeri Torr. Stem simple, $2-4 \mathrm{dm}$. high, usually decidedly viscidglandular; leaves short-petioled or subsessile, numerous and crowded, $2-8 \mathrm{~cm}$. long, coarsely dentate, or more or less lobed, lanceolate or oblong; inflorescence dense and spike-like; calyx-lobes narrowly linear-oblanceolate, hirsute-glandular; corolla $6-7 \mathrm{~mm}$. long; filaments glabrous. $P$. foetida Goodding. Arid soil: $\mathrm{s}$ Utah. Son.

10. P. orbicularis Rydb. Stem 1-2 dm. high, glandular-villous, often tinged with red, branched; leaf-blades petioled, suborbicular in outline, crenately lobed, $1.5-2.5 \mathrm{~cm}$. long, hirsute as well as glandular; calyx-lobes oblong or oblanceolate, obtuse, $3 \mathrm{~mm}$. long; corolla purplish, $6 \mathrm{~mm}$. long; lobes crenulate; filaments about twice as long as the corolla. Arid places: Utah. Son.

11. P. integrifolia Torr. Stem $2-6 \mathrm{dm}$. high, branched, glandular-puberulent, only slightly hirsute; leaves short-petioled or the upper sessile; blades 2-10 $\mathrm{cm}$. long, round-lobed and crenate; inflorescence open, $5-10 \mathrm{~cm}$. long; calyx-lobes elliptic or oblong; corolla bluish or whitish, $5-6 \mathrm{~mm}$. long; filaments glabrous. In gypsum soil: Kans.-w Tex.-Ariz.-Utah; n Mex. Son. Ap-Jl. 
12. P. corrugata A. Nels. Stem 3-5 dm. high, glandular-puberulent, more or less branched; leaves short-petioled or the upper sessile; blades sinuately round-lobed and crenate; branches of the inflorescence long, dense, $5-15 \mathrm{~cm}$. long; sepals linear-oblanceolate, sparingly hirsute; corolla blue or purple, about $1 \mathrm{~cm}$. long; filaments glabrous; twice as long as the corolla. Dry soil: Colo.-Tex.N.M.-Utah. Son. Ap-Je.

13. P. crenulata Torr. Stem erect, branched, $2-4 \mathrm{dm}$. high, hispid and somewhat glandular; leaves distinetly petioled, pinnatifid; segments 8-12, oblong to orbicular, the upper confluent, coarsely crenate, densely hirsute; calyxlobes linear-oblanceolate, obtuse; corolla deep violet, $6-8 \mathrm{~mm}$. long, its lobes crenulate; filaments glabrous, nearly twice as long as the corolla. Mountains: Ariz.-Utah-Calif.-L. Calif. Son.-Submont. Ap-Je.

14. P. deserta A. Nels. Stem simple, erect, 1-2 dm. high, densely leafy, white-villous with short hairs; leaves petioled, pinnatifid, densely pilose; segments oval, crenate; inflorescence short and dense; sepals lanceolate-oblong; corolla blue, $7 \mathrm{~mm}$. long, with rounded entire lobes; filaments glabrous, about twice as long as the corolla. Dry bluffs: Wyo. Submont. My.

15. P. splendens Eastw. Stem erect, 2-4 dm. high, branched, purplish, glandular-puberulent or glabrous; leaves petioled, pinnatifid; divisions often alternate, 7-9, obovate or orbicular, oblique at the base, crenate or round-lobed, glandular-puberulent or nearly glabrous; infloreseence dense, on a long peduncle; calyx white-hirsute and somewhat glandular; lobes linear-lanceolate; corolla bright blue, rarely white, about $1 \mathrm{~cm}$. long; filaments glabrous. Desert or dry soil: Colo.-Utah. Submont. My-S.

16. P. glandulosa Nutt. Stem stout, $3-6 \mathrm{dm}$. high, leafy, glandularpuberulent; leaves densely glandular-puberulent, pinnatifid, with many oblong to oval divisions, which are coarsely crenate, lobed, or incised; inflorescence compound, of many short branches; sepals glandular, linear or oblanceolate; corolla deep blue or violet, $6-8 \mathrm{~mm}$. long; filaments glabrous. P. Bakeri F. Macbr., in part. Gravelly soil: Mont.-w Tex.-Ariz. Son.-Mont. Je-S.

17. P. alba Rydb. Stem leafy, 2-4 dm. high, strict and simple, viscid-villous and glandular above; leaves twice interruptedly pinnatifid, about $1 \mathrm{dm}$. long, glandular-puberulent; ultimate segments ovate or oblong, $3-6 \mathrm{~mm}$. long; inflorescence branched, dense; calyx glandular, cleft to near the base; lobes broadly linear, obtuse; stamens and style much exserted. Valleys: Wyo.-N.M. -Ariz.-Utah. Submont.-Mont. J1-Au.

18. P. neomexicana Thurb. Stem $2-6 \mathrm{dm}$. high, strict, leafy, glandularpubescent; leaves interruptedly twice pinnatifid; lobes ovate, short; inflorescence dense; calyx-lobes oblong or oblanceolate, glandular-puberulent and hirsuteciliate; corolla bluish or purplish; stamens slightly exserted. Plains: Colo.N.M. Son.-Submont. Je-O.

19. P. denticulata @sterhout. Stem 1-3 dm. high, pubescent and glandular-viscid; leaves 5-6 cm. long, petioled, oblong in outline, hispid-pubescent on both sides, pinnatifid; inflorescence branched; calyx-lobes linear, obtuse; corolla blue or bluish, $5 \mathrm{~mm}$. long. Glades: Colo. Submont. Je.

20. P. ramosissima Dougl. Stem often decumbent at the base, $3-6 \mathrm{dm}$. high, diffusely branched, glandular-puberulent, slightly hirsute above; leaves pinnatifid, densely puberulent; segments 5-9, ovate to oblong, dentate or incised; ealyx-lobes spatulate, obovate. or oblong, at least twice as long as the capsule, densely pilose and hispid-ciliate; corolla $6-8 \mathrm{~mm}$. long; filaments glabrous. Hills and dry places: Wash.-Ida.-Ariz.-Calif. Son. Je-Jl.

21. P. hispida A. Gray. Stem at last diffusely branched, $3-6 \mathrm{dm}$. high, hispid with long white hairs; leaves pinnatifid, conspicuously hispid; segments $7-11$, lanceolate or oblong, sharply serrate to incised; calyx-lobes about $5 \mathrm{~mm}$. long, in fruit often $10 \mathrm{~mm}$. long, narrowly linear, hispid-ciliate; corolla 7-10 mm. long, open-campanulate; filaments glabrous. Hills and rocky places: Calif.Utah-Ariz. Son. Ap-Je. 
22. P. Rattani A. Gray. Stem 1-4 dm. high; leaves oval or ovate in outline, thin, hirsute; inflorescence lax and few-flowered; sepals spatulate, long-hispid, twice as long as the fruit; corolla sky-blue or white, campanulate; lobes short. Shady places: Ore.-Ida.-n Calif. Je-Jl.

23. P. Franklinii R. Br. Stem 2-4 dm. high, softly hirsute, erect, rather simple; leaves pinnatifid, densely pilose or hirsute; divisions many, oblanceolate or oblong, deeply cleft or pinnatifid into lanceolate divisions; inflorescence dense; calyx-lobes linear, about $5 \mathrm{~mm}$. long; corolla pale blue or almost white, about 8 mm. long; stamens slightly exserted. Hillsides and banks: Hudson Bay-Mich. -Wyo.-Ida.-Mack. Submont.-Boreal. My-Jl.

24. P. linearis (Pursh) Holz. Stem 1-4 dm. high, at last branched, grayish puberulent; leaves $2-5 \mathrm{~cm}$. long, simple, linear, or cleft into $3-7$ linear divisions; inflorescence thyrsoid-paniculate; sepals narrowly linear, hispid-ciliate; corolla bright blue, rarely white, about $1 \mathrm{~cm}$. long; filaments glabrous, scarcely exserted. P. Menziesii (R. Br.) S. Wats. Valleys and hillsides, especially in sandy soil:

25. P. idahoensis Henders. Stem simple, $3-6 \mathrm{dm}$. high, glabrous below, somewhat hirsute above; leaves pinnatifid, the lower petioled, 1-2 dm. long, sparingly pilose; divisions oblong or lanceolate, entire or cleft, pale beneath; inflorescence an elongate spike-like thyrsus; calyx-lobes narrowly linear, ciliate; corolla light blue, puberulent, $5 \mathrm{~mm}$. long. Moist meadows: Ida. Submont. Je.

26. P. Lyallii (A. Gray) Rydb. Stem 1-2 dm. high, sparingly hirsute; leaves oblanceolate in outline, $5-10 \mathrm{~cm}$. long, green, sparingly strigose; lobes broadly oblong; inflorescence short and dense; calyx-lobes linear, hirsute, $5 \mathrm{~mm}$. Subalp. - Alp dark blue, $8 \mathrm{~mm}$. long. High mountains: Mont.-Ida.-B.C.

27. P. sericea (Graham) A. Gray. Stem 1-3 dm. high, strigose-canescent; leaves 3-10 cm. long, silvery-silky; divisions eleft into linear or linear-oblong divisions; inflorescence spike-like; calyx-lobes linear, silky-villous; corolla violetblue, open-campanulate, $5-6 \mathrm{~mm}$. long. High mountains: Alta.-Colo.-Nev. -Wash.-B.C. Mont.-Alp. Je-Au.

28. P. ciliosa Rydb. Stem 2-5 dm. high, more or less strigose; leaves 5-15 $\mathrm{cm}$. long; segments entire or 2- or 3-cleft, with oblong divisions, green, but more or less strigose; petioles and rachis often hispid-ciliate; inflorescence spike-like, 1-2 dm. long; sepals linear, hirsute; corolla violet-blue, $5-6 \mathrm{~mm}$. long; filaments glabrous. Mountains: Alta.-Colo.-Nev.-B.C. Submont.-Subalp. Je-Au.

29. P. firmomarginata A. Nels. Stem branched from the base, $1-2 \mathrm{dm}$. high, puberulent and slightly glandular and hispid; leaves alternate, $1-4 \mathrm{~cm}$. long, pinnatifid, with oblong or obovate crenulate divisions, puberulent and hispidulous; inflorescence spike-like, in fruit $3-6 \mathrm{~cm}$. long; corolla pale or white, shorter than the calyx; folds obsolete. Desert regions: Ida. Son. Je.

30. P. cephalotes A. Gray. Stem divaricately branched, nearly prostrate, less than $1 \mathrm{dm}$. long, glandular-hirsute; leaves petioled; blades somewhat fleshy, oblong or spatulate, $1-2 \mathrm{~cm}$. long; calyx-lobes linear-spatulate or linear, hispid; corolla white or yellowish, with blue or purplish limb, $4 \mathrm{~mm}$. long, almost cylindric. River banks and cañons: s Utah. L. Son. Ap-Je.

31. P. minutissima Henders. Stem branched at the base, $2.5-6.5 \mathrm{~cm}$. high; leaves lanceolate or linear, $7-9 \mathrm{~mm}$. long; inflorescence few-flowered; flowers subsessile; sepals oblong-spatulate, $2-4 \mathrm{~mm}$. long; corolla subcylindric, $2 \mathrm{~mm}$. long. P. foliosepala A. Nels. Rocky places: Ida, Mont.

32. P. Knightii A. Nels. Stem $2-5 \mathrm{~cm}$. high, minutely puberulent, simple or branched; leaves few, petioled; blades somewhat fleshy, orbicular to ovate, entire or nearly so, 5-10 mm. long; calyx-lobes linear-spatulate, shorter than the corolla; corolla narrowly eampanulate, about $5 \mathrm{~mm}$. long, with a yellowish tube and purple limb. Barren clayey slopes: Wyo. Submont. Je.

33. P. demissa A. Gray. Stem diffusely branched, less than $1 \mathrm{dm}$. high, viscid-puberulent; leaves petioled; blades orbicular or sub-reniform, entire or 
rarely somewhat repand, 1-2 $\mathrm{cm}$. broad, glandular-puberulent; calyx-lobes linear, glandular-puberulent; corolla white, 4-6 mm. long. $P$. nudicaulis Eastw. Arid places: N.M. - Utah-Nev. Son.

34. P. pulchella A. Gray. Stem diffusely branched, glandular-puberulent, 5-20 cm. high; leaves petioled, puberulent; blades $1-3 \mathrm{~cm}$. long, ovate, oval, or obovate, obtuse, entire or somewhat repand; pedicels shorter than the calyx; calyx-lobes linear-spatulate, 4-5 mm. long; corolla deep purple, with a yellowish base, about $1 \mathrm{~cm}$. long. Gypsum hills: s Utah. Son.

35. P. curvipes Torr. Low annual; stem pubescent, branched at the base; leaves lanceolate or oblong, entire; sepals oblanceolate, 6-7 mm. long, hirsute; corolla light blue or white; stamens sparsely bearded. Arid regions: Calif.-s Utah-Ariz. Son.

36. P. incana A. Brand. Stem branched, with erect branches, $8-15 \mathrm{~cm}$. high, glandular-pilose; leaves petioled, densely pilose; blades oval or oblong, entire, obtuse, $0.5-2 \mathrm{~cm}$. long; sepals linear or linear-spatulate, $3-4 \mathrm{~mm}$. long; corolla white, about $4 \mathrm{~mm}$. long. Dry places, sage plains, \&c.: Utah. Son. My.

37. P. glechomaefolia A. Gray. Stem 1-3 dm. high, paniculately branched, glandular-puberulent; leaves petioled, glandular-puberulent; blades orbicular or cordate-orbicular, $1.5-3 \mathrm{~cm}$. broad, coarsely crenate; calyx-lobes spatulate or oblong, 4-5 mm. long; corolla lilac-purple. Arid regions: Ariz. $\rightarrow \mathrm{s}$ Utah. L. Son. My-Je.

38. P. rotundifolia Torr. Stem diffusely branched, $0.5-2 \mathrm{dm}$. long, glandular-hirsute; leaves petioled, densely hirsutulous; blades orbicular, with a cordate base, crenate, $0.5-2 \mathrm{~cm}$. broad; sepals linear-spatulate, $2-3 \mathrm{~mm}$. long; corolla white. Arid regions: s Utah-Ariz. - S Calif. L. Son.

39. P. campestris A. Nels. Stem minutely puberulent, branched from the base, $8-12 \mathrm{~cm}$. high; leaves petioled, oblong in outline, $1.5-3 \mathrm{~cm}$. long, deeply pinnatifid, with oblong obtuse divisions; sepals oblong or linear-spatulate, hirsute-ciliate, 3-4 mm. long; corolla 2-3 mm. long, white, short-cylindric. Sandy sage-plains and rocky hills: Wyo. My-Je.

40. P. Ivesiana Torr. Stem diffusely branched, 5-15 cm. long; leaves petioled, pinnatifid, finely pilose, $1-4 \mathrm{~cm}$. long; divisions oblong or linear, entire or few-toothed; calyx-lobes linear-spatulate, 2-3 mm. long; corolla white, 3-4 $\mathrm{mm}$. long. Arid places: Utah-Ariz.-Calif.-Wash. Son--Submont. Ap-Je.

41. P. glandulifera Piper. Stem branched from the base, $5-30 \mathrm{~cm}$. high, glandular-hispid; leaves mostly bipinnatifid, with oblong lobes; calyx-Iobes spatulate or oblanceolate, hispid-glandular, $5-6 \mathrm{~mm}$. long; corolla pale violet or yellowish, with purplish limb, about $6 \mathrm{~mm}$. long, barely exceeding the calyx. P. luteopurpurea A. Nels. Sage plains and dry places: Wash.-Ida.-Ore. Son. My-Je.

42. P. afflnis A. Gray, Stem branched from the base, 1-2 dm. high, glandular-hispid; leaves pinnatifid; divisions oblong, more or less lobed or toothed, hirsute and glandular-pubescent; calyx hirsute and glandular; corolla light blue or yellowish, about equalling the calyx. Arid regions: L. Calif.-s Calif.-Utah. Son. My-Jl.

43. P. Fremontii Torr. Stem 1-3 dm. high, branched at the base, puberulent; leaves pinnatifid, with 7-15 oblong or obovate, entire or rarely 2-3-lobed divisions; calyx-lobes spatulate, $4 \mathrm{~mm}$. long; corolla open-funnelform, 8-12 mm. long; capsule oblong; seeds 20-30, strongly corrugated. Dry regions: s UtahAriz.-Calif. Son.-Submont. Mr-Je.

44. P. bicolor Torr. Stem diffuse, 1-2 dm. high, puberulent; leaves pinnatifid and the divisions again parted into linear or oblong divisions; calyx-lobes linear or linear-spatulate, $3 \mathrm{~mm}$. long; corolla narrowly funnelform, fully $1 \mathrm{~cm}$. long. Hills and desert slopes: Utah-Calif. Son.-Submont. My-Jl.

\section{MILTítziA A.DC.}

Diffuse or depressed annuals. Leaves alternate, pinnatifid. Flowers perfect, regular or nearly so, in more or less leaf $y$-bracted scorpioid racemes. Calyx 
5-cleft; lobes similar or nearly so. Corolla yellow or yellowish, campanulate or funnelform. Stamens equally inserted low down in the corolla-tube. Ovary more or less 2-celled by the intrusion of the placentae; style 2-cleft at the apex. Capsule loculicidal; seeds minutely reticulate.

Leaf-blades lanceolate to oblong, obtuse, laciniate-dentate.

Leaf-blades obovate, spatulate or oval, coarsely round-toothed.

1. M. foliosa.

Peduncles usually longer than the leaves; corolla and capsule equalling the calyx.

Peduncles shorter than the leaves; corolla and capsule shorter than 2 . M. scopulina.

3. M. salina.

1. M. foliosa (M. E. Jones) A. Brand. Stem minutely glandular-puberulent, branched, 2-5 cm. high; leaf-blades 1-2 cm. long; calyx $2 \mathrm{~mm}$. long in flower, 4 $\mathrm{mm}$. in fruit; lobes linear or linear-spatulate; corolla almost equalling the calyx, barely lobed. Emmenanthe foliosa M. E. Jones. Alkaline soil: Utah. Submont. Je.

2. M. scopulina (A. Nels.) Rydb. Stem branched near the base, ascending, 1-3 cm. long, pilose; leaf-blades crenately lobed to entire, 5-12 $\mathrm{mm}$. long; sepals linear, obtuse, less than $3 \mathrm{~mm}$. long in flower, $4 \mathrm{~mm}$. in fruit. Emmenanthe scopulina A. Nels. Dry sandy shales: Colo.-Mont. Submont. My.

3. M. salina (A. Nels.) Rydb. Stem short and thick, $2 \mathrm{~cm}$. high or less; leaf-blades entire, dentate, or round-lobed, 7-15 $\mathrm{mm}$. long; ealyx about $3 \mathrm{~mm}$. long; lobes linear. Emmenanthe salina A. Nels. E. dispar M. E. Jones. River flats: Wyo. Je.

\section{EMMENÁNTHE Benth. WHISPERING BeLLS.}

Erect caulescent annuals. Leaves alternate, pinnatifid, with toothed segments. Flowers perfect, regular, in short paniculate leafy-bracted racemes, on drooping pedicels. Calyx 5-cleft, with broad ovate lobes. Corolla broadly campanulate, cream-colored, persistent. Stamens slightly adnate to the base of the corolla. Style 2-cleft above, deciduous; placenta conspicuously dilated in the axis. Capsule loculicidal; seeds somewhat rugosely alveolate-reticulate.

1. E. pendulaeflora Benth. Erect annual; stem 1-3 dm. high, villousglandular; leaves pinnately parted or divided, with numerous oblong, sometimes toothed lobes; calyx-lobes ovate-lanceolate, acute, 6-7 mm. long; corolla nearly $1 \mathrm{~cm}$. long; seeds oblong-oval, rugosely alveolate-reticulate. Dry sandy soil: Calif.-s Utah-Ariz.-L. Calif. L. Son. Mr-Au.

\section{CAPNÒREA Raf.}

Dwarf stemless perennials. Leaves basal, oblong or spatulate, entire. Flowers singly on elongated pedicels from the axils of the leaves. Calyx 5-7-parted; lobes linear-lanceolate, often unequal. Corolla from eampanulate or funnelform to saucer-shaped, deciduous, without appendages within. Stamens inserted in the base of the corolla, more or less hairy at the base. Ovary 1-celled, with 2 more or less intruding placentae; ovules 20 or more on each placenta; style 2cleft at the apex. Capsule loculicidal, many-seeded. Seeds minutely reticulate.
[Hesperochiron S. Wats.]

Corolla saucer-shaped or rotate.

Calyx almost glabrous, except the ciliate margins; leaves not distinctly venulose.

Calyx long-villous at the base; leaves distinctly vento

Corolla campanulate or funnelform. $\quad 2$. C, nervosa.

Calyx-lobes oblong or Ianceolate, obtuse.

Corolla $12-15 \mathrm{~mm}$. long; pubescence of the plant short.

Corolla 7-10 mm. long; pubescence longer plant short. $\quad 3$. C. Watsoniana.

Calyx-lobes linear or linear-lanceolate, acute.

5. C. nana.

1. C. pumila (Dougl.) Greene. Leaves oblanceolate or elliptic, tapering into short petioles, 4-7 cm. long, glabrous except on the margins; scape $3-7 \mathrm{~cm}$.
long; calyx-lobes equal, lanceolate, $5-7 \mathrm{~mm}$. long; corolla $10-15 \mathrm{~mm}$. high. Hillsides: Wash.-Ida.-Utah-n Calif. Submont, Je-Jl. 
2. C. nervosa Greene. Leaves thin, petioled; blades elliptic, glabrous on both sides, sparingly silky-ciliate on the margin; ealyx-tube densely villous; lobes lanceolate, long-ciliate on the margins; corolla fully $1 \mathrm{~cm}$. high. Wet meadows: Ida. Submont. My.

3. C. Watsoniana Greene. Leaf-blades oblong or oblanceolate, obtuse, $3-7 \mathrm{~cm}$. long, grayish pubescent, with short hairs; scape $2-5 \mathrm{~cm}$. long; sepals oblong or elliptic, short-hairy; corolla lilac-purple, $12-15 \mathrm{~mm}$. Iong. Gravelly soil: e Calif.-w Wyo. Submont. Ap-Je.

4. C. incana Greene. Leaf-blades elliptic or spatulate, 1-3 cm. long, canescent on both sides; scape 1-3 cm. long; calyx-lobes oblong or lanceolate, obtuse; corolla 7-10 mm. long; lobes rounded. Wet benches and flats: Mont.Ida.-Wash. Submont. My-Je.

5. C. nana (Lindl.) Raf. Leaf-blades ovate-oblong or oval, strigose-pubescent, 2-5 $\mathrm{cm}$. long; scape 4-7 $\mathrm{em}$. long; calyx-lobes 5-8 mm. long; corolla 10-17 $\mathrm{mm}$. long; lobes ovate, acute. C. lasiantha Greene. C. macilenta Greene. Wet places and creek banks: .Wash.-Ida.-Ore. Submont. Ap-Au.

\section{ROMANZÓFFIA Cham.}

Low, delicate, scapose perennial herbs, with bulbiferous rootstocks, resembling some saxifrages in habit. Leaves mainly basal, but alternate, with long petioles and reniform lobed blades. Flowers perfect, regular, racemose or paniculate. Calyx-lobes 5, oblong-linear or lanceolate. Corolla pink or purple, funnelform or nearly campanulate. Stamens inserted in the base of the corolla-tube, unequal. Ovary 2-celled or nearly so by the intrusion of the placentae; style entire, filiform; stigma simple, small; ovules many. Capsule loculicidal. Seeds alveolate-reticulate.

Leaves 1.5-4.5 cm. broad.

Leaves 5-9-lobed; capsule longer than the calyx.

Leaves 3-5-lobed; capsule not exceeding the calyx. Leaves less than $0.5 \mathrm{~cm}$. broad.

1. $R$, sitchensis.

2. R. Leibergii.

3. R. minima.

1. R. sitchensis Bong. Stem slender, 1-3 dm. high, glabrous or nearly so; leaf-blades thin, glabrous or nearly so, reniform, $1-3 \mathrm{~cm}$, broad, with roundedovate, mucronate lobes; calvx-lobes linear-lanceolate, $3-5 \mathrm{~mm}$. long; corolla 7-10 mm. long. Wet rocks: Alaska-Alta,-Mont.-n Calif. Ap-Au.

2. R. Leibergii Greene. Stem 7-12 cm. high, glabrous; leaf-blades light green, glabrous; lobes extending to the middle, broadly ovate, acute; calyx-lobes oblong-linear; corolla small, open-funnelform. Ledges of slate: n Ida. Mont. Au.

3. R. minima A. Brand. Stem scarcely exceeding the leaves, rarely more than $2.5 \mathrm{~cm}$. long; leaf-blades 3-5-lobed; calyx-lobes $2-2.5 \mathrm{~mm}$. long, oblong; corolla campanulate, $6 \mathrm{~mm}$. long. High mountains: B.C. Alp. Л.

\section{ERIOdîtCtyon Benth. Mountain Balm, Yerba Santa.}

Low shrubs or undershrubs. Leaves alternate, pinnately veined and reticulate, more or less coriaceous and rigidly toothed. Flowers perfect, regular, scorpioid-cymose. Sepals nearly distinct, 5, narrow. Corolla violet or purple, rarely white, funnelform or campanulate, without appendages; its lobes imbricate in the bud. Stamens included; filaments variously adnate to the corollatube, more or less hairy. Ovary more or less completely 2-celled. Styles distinct to the base; stigmas eapitate. Capsule 4-valved, first loculicidal, then septicidal; placentae very broad. Seeds few, pendulous.

1. E. angustifolium Nutt. Low shrub; stem glabrous, glandular-pruinose above; leaves 3-10 $\mathrm{cm}$. long, 2-6 mm. wide, linear or narrowly linear-lanceolate, green above, white beneath, strongly reticulate; margin sinuate-denticulate, revolute; calyx-lobes hirsute-ciliate, $3 \mathrm{~mm}$. long, linear; corolla funnelform, 6-7 mm. long. Dry hills: N.M. - S Utah-Nev.-Calif. L. Son. Ap-Je.

\section{MARILAUNÍDIUM Kuntze.}

Annual or perennial herbs. Leaves alternate, entire, sometimes decurrent. Flowers perfect, regular, solitary, axillary. Calyx with 5 narrow lobes. Corolla 
funnelform or salver-shaped, blue; lobes 5, imbricate. Stamens 5, included; filaments irregularly inserted in the corolla-tube. Ovary 1-celled, or sometimes imperfectly 2-celled; styles distinct; ovules numerous on each placenta. Capsule subglobose or oblong, 2-valved. Seeds rugose. [Nama L., in part.]

Diffuse; corolla more than twice as long as the calyx.

Erect; corolla shorter than the calyx.

1. M. demissum.

2. $M$. angustifolium.

1. M. demissum (A. Gray) Kuntze. Diffuse annual; stem branched at the base, 5-10 cm. high, hirsutulous; leaf-blades linear-spatulate, more or less tapering into a petiole; flowers subsessile in the axils; sepals narrowly linear, 5-7 $\mathrm{mm}$. long; corolla 8-10 mm. long, purple. Nama demissum A. Gray. Desert regions: Wash.-Utah-Ariz.-Calif. Son. Ap-Jl.

2. M. angustifolium (A. Gray) Kuntze. Annual; stem erect, minutely glandular-puberulent, 1-3 dm. high; leaves narrow, lineat or nearly so, 1-3 cm. long; flowers subsessile in the forks; calyx-lobes narrowly linear or linear-spatulate, 4-5 mm. long, in fruit even $10 \mathrm{~mm}$. long; corolla about $2 \mathrm{~mm}$. long. Nama dichotomum angustifolium A. Gray. Plains and praixies: Tex.-Colo.-N.M.; Mex. Son. Je-O.

\section{CONÂNTHUS S. Wats.}

Small dichotomously branched winter annuals. Leaves alternate, linearspatulate, entire. Flowers solitary in the forks. Calyx-lobes 5, narrow, similar. Corolla funnelform, deciduous, not appendaged. Stamens unequally inserted in the tube of the corolla. Styles united to near the apex; stigmas capitellate; ovules about 10 on each placenta. Capsule loculicidal. Seeds smooth.

1. C. aretioides (Hook.) S. Wats. Depressed winter annual; stem 5-10 $\mathrm{cm}$. long, repeatedly forked, hirsute-hispid; leaves spatulate-linear; flowers sessile in the forks; calyx-lobes filiform-linear, hispid with long white hairs; corolla $10-15 \mathrm{~mm}$. long, purple, funnelform. Sandy or dry plains: Ore.-Wyo.-N.M. -Calif. Son. My-Je.

\section{TRICÃRDIA Torr.}

Perennial caulescent herbs, branched from the base. Leaves alternate, entire. Flowers perfect, regular, racemose. Sepals only slightly united, very dissimilar; the three outer much larger, and cordate, becoming scarious and finely reticulate-veiny, the inner two linear. Corolla broadly campanulate, deciduous, the 10 internal appendages free and rather distant from the filaments. Stamens equally inserted on the base of the corolla. Ovary 2-celled by the intrusion of the placentae. Style 2-cleft; ovules 4 on each placenta. Capsule loculicidal. Seeds roughened.

1. T. Watsoni Torr. Perennial; stem branched from the base, $1-2 \mathrm{dm}$. high, villous with long hairs or more glabrate in age; leaf-blades spatulate or oblanceolate, $3-5 \mathrm{~cm}$. long; larger sepals cordate in fruit, becoming $1.5 \mathrm{~cm}$. or more broad and long; corolla purplish, about $6 \mathrm{~mm}$. wide, moderately 5 -lobed; stamens included. Arid regions: Nev. $-\mathrm{s}$ Utah-Calif. Ap-Je.

\section{Family 111. ehretiaceae. Ehretia Family.}

Undershrubs, shrubs, or trees, rarely herbs. Leaves mainly alternate, without stipules; blades simple and entire. Flowers perfect, regular, in compound cymes. Calyx of 5 or fewer, partially united sepals. Corolla of 5 , rarely 4 or 6 , more or less united petals, deciduous, with spreading lobes. Stamens 4-6, adnate to the base of the corolla-tube; filaments often united at the base; anthers introrse. Gynoecium of 2-4 united carpels; ovary 2-4celled, or 1-celled, some of the partitions being imperfect; styles 2, distinct or partially united, or 4 , united in pairs; ovules 1 or 2 in each cavity. Fruit drupaceous, with a 4 -celled, but 1-seeded stone, or 2 two-seeded or 4 oneseeded stones. 
Corolla not appendaged; stamens unequally inserted; nutlets rough-granulate, ventrally united.

1. EDDYA.

Corolla appendaged; stamens equally inserted; nutlets smooth and shining, united only at the center.

2. Triquiliopsis.

\section{EDDYA Torr.}

Low suffruticose plants. Leaves alternate, fascicled, rigid, in age strongly revolute. Flowers perfect, regular, solitary in the forks. Calyx-lobes narrow, linear. Corolla not appendaged. Stamens unequally inserted. Fruit deeply 4-lobed, the mature nutlets rounded, ventrally united, thin-walled, rough-granulate. Embryo straight.

1. E. hispidissima Torr. Stem diffusely branched, procumbent, 1-3 dm. high; leaves fascicled, rigid, lanceolate or linear, hispid, 5-10 mm. long, margins at last strongly revolute; flowers scattered; calyx-lobes linear, resembling the leaves; corolla 5-6 mm. long. Coldenia hispidissima A. Gray. Dry hills: w Tex.-s Utah-Nev.-Ariz. Son. Je-Jl.

\section{TRIQUILIOPSIS (A. Gray) Heller.}

Annual or perennial herbs, dichotomously branched. Leaves alternate, petioled, veiny. Flowers perfect, regular, clustered in the forks. Calyx-lobes linear, hispid. Corolla salver-shaped, appendaged within; stamens equally inserted. Fruit deeply 4-lobed; nutlets rounded, smooth and shining, united only at the center. Cotyledons 4-parted around the cotyledons.

Annual, canescent and hirsute; leaf-blades rhombic or rotund; corolla pink or white.

1. T. Nuttallii.

Perennial, often suffruticose at the base, merely canescent; leaf-blades obovate or ovate; corolla bluish.

2. T. Palmeri.

1. T. Nuttallii (Hook.) Heller. Prostrate annual; stem divergently dichotomously branched, canescent; leaves petioled; blades rhombic or rounded, 4-8 $\mathrm{mm}$. long, with 5-7 strong veins below, canescent on both sides, revolute-margined; flowers clustered in the axils; corolla white or pink, 3-4 mm. long. Coldenia Nuttallii Hook. Arid plains: Wash.-Wyo.-Ariz.-Calif. My-Au.

2. T. Palmeri (A. Gray) Rydb. Perennial, suffruticose at the base, 1-3 dm. high, diffusely branched; leaf-blades obovate or ovate, with 6 pairs of strong veins, impressed on the upper surface, canescent, about $5 \mathrm{~mm}$. long; calyx-lobes lanceolate, half as long as the bluish corolla; nutlets globose, only one or two maturing. Coldenia Palmeri A. Gray. Sandhills: Ariz. $\rightarrow$ s Utah-s Calif, $L$. Son. Ja-My.

\section{FAMII 112. HELIOTROPACEAE. HeLIOTROPE FAMILY.}

Herbs, shrubs, or vines. Leaves alternate, without stipules, usually entire-margined. Flowers perfect, regular, mainly in scorpioid racemes or spikes, rarely axillary. Calyx of 5 slightly united sepals. Corolla of 5 united petals, funnelform, salver-shaped, or campanulate. Stamens 5, wholly adnate or nearly so to the corolla-tube. Gynoecium of 2-4 united carpels; ovary 2-4-celled, often 4-lobed; styles united; stigmas annular, surpassed by a 2 -lobed appendage; oviles pendulous. Fruit dry, separating into 2 or 4 one-seeded nutlets, drupaceous.

Cone of the stigma not setose; flowers in terminal scorpioid spikes or racemes.

1. HELIOTROPIUM. Cone of the stigma penicillate-setose; flowers axillary to leaf-like bracts.

2. Euploca.

\section{HELIOTRÒPIUM L. Heliotrope.}

Annual or perennial herbs, or in warmer climates shrubs. Leaves alternate, or rarely opposite, pubescent. Flowers perfect, regular, usually in terminal scorpioid racemes or spikes. Calyx-lobes 5, narrow. Corolla salver-shaped; tube cylindric, usually naked in the throat; lobes 5, induplicate or imbricate. Stamens 5, included; filaments short; anther-sacs sometimes appendaged at the 
tip. Ovary 4-celled or 2-celled, with 2 more or less intruding placentae; ovules pendulous. Fruit 4-lobed or 4-grooved, sometimes didymous, but separating into 4 nutlets.

1. H. spathulatum Rydb. A glabrous, more or less glaucous, fleshy perennial, 3-5 dm. high; leaves spatulate, fleshy, indistinctly nerved, $2-5 \mathrm{~cm}$. long, obtuse or rounded at the apex; inflorescence branched into $2-5$ racemes, these often starting from one point at the end of the common peduncle; corolla white or slightly tinged with blue, $6-8 \mathrm{~mm}$. long; nutlets $2.5-3 \mathrm{~mm}$. long, scarcely rugose. $H$. curassavicum Hook., not L. $H$. curassavicum obovatum DC., not $H$. obovatum. D. Don. River valleys: Sask,-N.M.-Calif.-Wash. Plain.

\section{EÙPLOCA Nutt.}

Annual caulescent herbs. Leaves alternate, broad, entire, petioled, pubescent. Flowers perfect, regular, solitary in the axils of leaf-like bracts. Calyxlobes 5, narrow. Corolla salver-shaped; tube eylindric, naked in the throat; limb 5-angled, strongly plicate in aestivation. Stamens 5, included; anthers subsessile, with a beard at their base; ovary 4-celled; style elongate; cone of stigma penicillate-setose; ovules pendulous. Fruit didymous, the two halves separating into 2 hemispheric, 1 -seeded nutlets.

1. E. convolvulacea Nutt. Diffusely branched annual; stem 1-4 dm. high, hispid-strigose; leaf-blades lanceolate or ovate, $2-4 \mathrm{~cm}$. long, hirsute-strigose; flowers usually supra-axillary; calyx-lobes linear-subulate; corolla white, salver-shaped to funnelform, 10-15 mm. long; nutlets almost hemispheric, 3 $\mathrm{mm}$. broad, more or less strigose. Heliotropium convolvulaceum A. Gray. Sandy plains: Tex.-Neb.-Wyo.-Calif.; Mex. Plain-Son. My-Au.

\section{Family 113. BORAginaCeae. Borage Family.}

Herbs (all ours), or shrubby plants. Leaves alternate, without stipules, simple, entire, bristly. Flowers perfect, regular, or sometimes irregular, in scorpioid racemes or spikes. Calyx of 5 , rarely 4 , more or less united sepals, persistent. Corolla salver-shaped or campanulate, rarely nearly rotate, deciduous; throat often with a crown of 5 small scales (fornices); lobes 5 , convolute, plicate or induplicate, usually equal. Stamens 5, adnate to the corolla-tube; filaments often appendaged; anthers introrse. Gynoecium of 2 united carpels; styles united, rising between the four lobes of the ovary; stigma simple or 2-lobed; ovules anatropous, solitary in each cell of the ovary. Fruit usually of 4 nutlets.

Nutlets with hooked prickles, at least on the margins.

Nutlets spreading or divergent on the low receptacle.

Nutlets elongate, flat, wing-margined, attached underneath the edge of the receptacle; prickles only on the margins; slender annuals.

Nutlets divergent in pairs; margin laciniate or undulate.

Nutlets equally radiately divergent, entire-margined.
Nutlets short, not wing-margined, prickly all over, attached horizontally or

Nutlets erect on the elevated receptacle, prickly on the margin, rarely along the back.

Nutlets unarmed, or if prickly the prickles not hooked.

Receptacle conic or elongate; nutlets attached laterally.

Calyx in fruit much enlarged, veiny-reticulate and folded.

Corolla blue or white (yellowish only in a few species of Oreocarya), with fornicles in the throat (except in Greeneocharis, and obscurely so in Eremocarya); cotyledons entire.

Nutlets attached below the middle, with an oblique truncate back, which is surrounded by an entire or toothed margin; low pulvinate-cespitose

perennials,
Nutlets attached at the middle or with an elongated scar reaching from the base to above the middle, not with a truncate, margined back; plants rarely pulvinate-cespitose.

Pedicels and calyx persistent in fruit.

Calyx circumscissile; plants dichotomously branched.

7. GREENEOCHARIS. 
Calyx not circumscissile.

Nutlets oblique or incurved, attached by a median false caruncle.

Nutlets erect, the groove or scar of attachment naked.

Plants dichotomously branched; racemes biserial; calyx cleft to the base.

Plants not dichotomously branched; inflorescence racemiform or thyrsoid; its branches uniserial; calyx not cleft to the base.

Calyx-lobes spreading in fruit; leaves alternate.

Perennials, with bracted racemose or thyrsoid inflorescence.

10. OREOCARYA.

Annuals, mostly with bractless racemose inflorescence.

12. CRYPTANTHA.

Calyx nearly closed in fruit; leaves proper opposite, with connate bases; annuals. 11. ALLOCARYA.

Pedicels in fruit falling off with the calyx; the latter closed; branched but not dichotomous annuals.

12. CRYPTANTHA.

Corolla yellow or orange, often with naked throat; cotyledons 2-cleft.

13. AMSINCEIA.

Receptacle flat or merely convex.

Scar of the nutlets small and marginless.

Nutlets obliquely attached; flowers mostly bractless; corolla blue or white, with funnelform throat.

14. Mertensia.

Nutlets attached by the very base.

Corolla salverform or funnelform, its lobes rounded and spreading.

Racemes not bracted; corolla in ours blue, its lobes convolute in the bud. 15. Myosotis.

Racemes bracted; corolla yellow or yellowish, its lobes imbricated in the bud.

16. LITHOSPERMUM.

Corolla tubular, its lobes erect, acute, otherwise as in Lithospermum.

17. ONOSMODIUM.

Scar of the nutlets large and excavated, bordered by a prominent margin.

Fornices in the throat of the corolla short, blunt. 18. ANCHUSA.

Fornices long, linear or lanceolate.

19. SYMPHYTUM.

\section{PECTOCÃRYA DC.}

Small dichotomously branched annuals. Leaves alternate, narrowly linear. Flowers perfect, regular, minute, scattered. Calyx deeply 5-cleft; lobes spreading or reflexed in fruit. Corolla salverform, with a crown nearly closing the throat. Stamens included. Style short; stigma capitate. Nutlets spreading, in pairs, thin, with laciniate or at least undulate wings, attached at the inner end to the depressed receptacle.

Nutlets linear or linear-oblong, their wings pectinately or laciniately toothed, each tooth ending in an uncinate prickle.

1. P. linearis.

Nutlets oblong, their wings not laciniate, sinuately lobed, uncinate-prickly usually only at the apex, sometimes with a few prickles on the sides.

2. P. penicillata.

1. P. linearis (R. \& P.) DC. Stem strigose, branched at the base, $5-20$ $\mathrm{cm}$. high; leaves narrowly linear, $1-4 \mathrm{~cm}$. long; corolla nearly $2 \mathrm{~mm}$. long, longer than the linear calyx-lobes; nutlets $3-4 \mathrm{~mm}$. long. Gravelly soil: Calif.-s Utah -Ariz.; Mex. and S. Am. L. Son. F-My.

2. P. penicillata (H. \& A.) A. DC. Stem branched at the base, strigose, 3-20 cm. long; leaves linear, $0.5-2 \mathrm{~cm}$. long, strigose; corolla white, $1-1.5 \mathrm{~mm}$. long; nutlets oblong or somewhat fiddle-shaped, $2-2.5 \mathrm{~mm}$. long. $P$. miser A. Nels. Sandy soil: B.C.-Wyo.-Ariz.-Calif.; L. Calif. Son. Mr-Je.

\section{GRUVÈLIA A. DC.}

Small branched annuals. Leaves alternate, narrowly linear. Flowers perfect, regular, minute, scattered, irregularly opposite the leaves. Calyx deeply 5-cleft; lobes reflexed in fruit. Corolla salverform, with a crown of small fornices, nearly closing the throat. Stamens included. Nutlets radiately divergent, flat, depressed, thin, attached at the inner end to the depressed receptacle, prickly on the back, the rim or wing-margin entire.

1. G. setosa (A. Gray) Rydb. Diffusely branched annual; stem more or less hirsute as well as strigose; leaves linear-oblanceolate or linear, 1-3 cm. long; corolla white, not exceeding the linear-oblanceolate obtuse sepals; nutlets broadly obovate, $2-2.5 \mathrm{~mm}$. long, surrounded by a thin wing-margin, prickly on the back 
as well as on the margins. Pectocarya setosa A. Gray. Sandy hills and cañons: Ore.-Ida.-Ariz.-Calif. Son. My-Je.

\section{CYNOGLÓSSUM (Tourn.) L. Hound's Tongue.}

Annual, biennial, or perennial caulescent herbs. Leaves alternate, entire, mostly decurrent, pubescent. Flowers perfect, regular, in scorpioid racemes. Calyx with 5 spreading or reflexed lobes, slightly accrescent in age. Corolla white, blue, or purple, salverform or funnelform; tube short; throat closed by 5 scales; lobes 5, imbricate. Stamens 5, included. Nutlets 4, flat, distinct, equally divergent, armed with short barbed prickles, attached by an oval or rounded scar at the upper end to a flat or low-pyramidal receptacle.

Soft pubescent; lower leaf-blades oblong or spatulate; stem-leaves lanceolate; inflorescence many-flowered and leafy. Hispidulous; lower leaf-blades oval; stem-leaves oblong-ovate, clasping; inflorescence few-flowered and naked.

2. C. boreale.

1. C. offlcinale L. Biennial; stem 6-8 dm. long, softly pilose, somewhat canescent; basal leaves petioled; blades $1-3 \mathrm{dm}$. long, velvety-pilose; racemes panicled; calyx-lobes oval or oblong; corolla dull red, rarely white, 7-10 $\mathrm{mm}$. broad; nutlets depressed on the back, margined, about $7 \mathrm{~mm}$. long; prickles in 4-5 rows on the margins and scattered on the back. Pastures and waste places: Que.-N.C.-Kans.-Utah-Mont.; nat. from Eu. My-Jl.

2. C. boreale Fernald. Perennial; stem 4-8 dm. high, hirsute and the inflorescence strigose; basal leaves long-petioled; blades 1-3 dm. long, hispid; racemes geminate; fruiting pedicels spreading, recurved; calyx strigose, $2-2.5 \mathrm{~mm}$. long; lobes ovate; corolla blue, 6-8 mm. wide; nutlets ovoid-pyriform, 4-5 mm. long, glochidiate-prickly all over. Woods: N.B.-Mass.-n Mich.-B.C. Je-Jl.

\section{LĀPpUla (Riv.) Moench. Stickseed, Burseed, Stick-tights, BEgGar Ticks.}

Annual, biennial, or perennial caulescent herbs. Leaves alternate, entire, narrow, pubescent. Flowers perfect, regular, in terminal scorpioid racemes. Calyx with 5 narrow lobes, slightly if at all accrescent. Corolla salverform, blue or white; tube very short; throat closed by 5 scales; lobes 5 , imbricate, obtuse. Stamens 5, included; filaments very short. Fruit of 4 , finally distinct nutlets, these with barbed prickles along the edge, and sometimes with smaller ones on the dorsal faces, muricate on the sides, obliquely attached by the inner angle to a conical receptacle. [Echinospermum Sw.]

Inflorescence leafy-bracted only at the base; bracts minute above; gynobase shortpyramidal; scar of the nutlets ovate or triangular; perennials or biennials.

Marginal prickles free to the base or nearly so.

Corolla $1.5-3 \mathrm{~mm}$. wide.

Leaves thin; stem-leaves lanceolate.

Fruit about $3 \mathrm{~mm}$. wide; nutlets usually with a few prickles on the back.

1. L. americana.

Fruit about $5 \mathrm{~mm}$. wide; nutlets merely muricate on the back.

Leaves firmer; stem-leaves oblanceolate to linear; fruit about $3 \mathrm{~mm}$. wide. not prickly on the back.

Corolla 4-12 mm. wide; leaves firmer.

Fornices of the corolla glabrous or papillose.

Fornices broader than long; corolla blue.

Foliage rather softly pubescent; stem leafy throughout.

Corolla 4-6 mm. broad; nutlets without prickles on the back.

Corolla 8-10 mm brond; mutlets with a. L. floribunda.

3. L. Besseyi.

Corolla 8-10 mm. broad; nutlets with a few prickles on the bac
5. L. diffusa.

Foliage hirsute; hairs with pustulate bases; stem very leafy at the base.

few-leaved above.
Fornices as long as broad; corolla white; foliage harshly papillose-scabrous.

Fornices of the corolla pubescent; nutlets with about 10 prickles on the back.

Corolla tinged with blue; appendages long-hirsute, 8 . L. coerulescens.

Corolla white; appendages pilose.

Marginal prickles united for one-third to one-half their length into a distinct wing.

Back of the nutlets strongly muricate and with prickles.

Corolla blue; pubescence fine, appressed.

Corolla white; pubescence hirsute.

11. L cinerea. 
Back of the nutlets without prickles, almost smooth. Stem-leaves lineat-lanceolate, densely strigose. Stem-leaves oblong-lanceolate, hispidulous, the hairs with papillose bases.

Inflorescence leafy, the floral leaves, although smaller, resembling those of the stem; annuals.

The annular margin connecting the bases of the prickles inconspicuous in all four nutlets.

Marginal prickles in two rows.

Corolla almost $3 \mathrm{~mm}$. wide; prickles shorter than the length of the fruit.

14. L. erecta.

Corolla less than $2 \mathrm{~mm}$. wide; prickles nearly as long as the fruit.

Fruit 4-5 mm. long; sepals ovate-lanceolate, obtuse; floral leaves ample, ovate or oblong.

15. L. cenchrusoides.

Fruit 3-4 mm. long; sepals lanceolate or linear-lanceolate, acute; floral leaves much reduced, lanceolate. 16. L. Fremontii.

Marginal prickles in one row.

Calyx-lobes more than twice as long as the fruit, reflexed-spreading; floral leaves broadly lanceolate.

Calyx-lobes less than twice as long as the fruit; floral leaves linear or linearlanceolate.

Dorsal faces of the nutlets inside the annular margin small; lower prickles inserted about one-third the distance from the base; stem strigose.

18. L. montana.

Dorsal faces of the nutlets inside the ring large; lower priekles inserted near the base of the nutlets; stem hirsute.

Prickles terete; plant green; corolla blue.

19. L. occidentalis.

Prickles flattened and dilated at the base; plant whitish long-hairy below; corolla white.

20. L. Leucatricha.

The annular margin connecting the bases of the prickles at least in three of the nutlets broadened and forming a cup.

Plant at flowering time with a large basal rosette of spatulate leaves; stems simple up to the inflorescence, softly pilose.

Stems several from the rosette, low, 1-2 dm. high; cup deep and much inflated. 21. L. collina.

Stems solitary, 3-4 dm. high; cup rather shallow and slightly gibbous.

22. L. cupulata.

Plant at flowering time without a basal rosette, diffusely branched, hirsute, green. Cup deep, more or less saccate.

Cup shallow, with revolute margins.

23. L. heterosperma.

24. L. foliosa.

1. L. americana (A. Gray) Rydb. Biennial; stem 3-10 dm, high, retrorsely hirsute; lower leaves petioled; blades oblanceolate, acute, $5-10 \mathrm{~cm}$. long, sparingly hirsute, thin; upper leaves sessile, lanceolate, acute or acuminate; corolla pale blue, $1.5-2 \mathrm{~mm}$. wide; back of the fruit convexed, but not keeled, murieate. E. deflexum americanum A. Gray. Copses: Man,-Neb.-Ida.-B.C. PlainSubmont. Je-Jl.

2. L. leptophylla Rydb. Biennial or perhaps perennial; stem 6-8 dm. high, finely retrorsely hirsutulous; basal leaf-blades oblanceolate, very thin, finely pubescent, somewhat scabrous; corolla blue, $2-3 \mathrm{~mm}$. in diameter; back of the fruit finely puberulent, slightly muricate, not prickly. Shaded lowlands: Mont. -Wyo. Submont.

3. L. Besseyi Rydb. Biennial; stem 5-10 dm. high, hirsute, branched above; lower leaf-blades spatulate or oblanceolate, obtuse, hispidulous and hirsute on the veins; corolla dark blue, scarcely over $1.5 \mathrm{~mm}$. wide; back of the fruit flat, prickleless, but minutely hispidulous. Cañons: Colo, Submont.-Mont.

4. L. floribunda (Lehm.) Greene. Biennial or perhaps perennial; stem 3-15 $\mathrm{dm}$. high, strigose or pilose; lower leaf-blades narrowly oblanceolate, $5-15 \mathrm{~cm}$. long, strigose; upper leaves linear or linear-lanceolate, sessile; nutlets $5-6 \mathrm{~mm}$. broad; back slightly ridged, glabrous or scabrous, muricate. $E$. floribundum Lehm. Hillsides and among bushes: Man.-N.M.-Calif.-B.C. Plain-Mont. $\mathrm{Je}-\mathrm{Au}$.

5. I. diffusa (Lehm.) Greene. Perennial; stem erect, pilose or softly hirsute, 5-10 dm. high; basal leaf-blades narrowly oblanceolate, 5-15 cm. long, pilose; fruit 6-7 mm. wide; back flat, hispidulous, somewhat muricate and with a few central prickles. Echinospermum diffusum Lehm. Brook banks: Alta.-Wyo. -Utah-Calif.-B.C. Submont.-Mont. My-JI.

6. L. gracilenta Eastw. Biennial; stem 4-6 dm. high, hispid throughout; basal leaf-blades spatulate or oblanceolate, $2-8 \mathrm{~cm}$. long, hirsute; stem-leaves 
lanceolate, $6 \mathrm{~cm}$. long; corolla blue, 6-8 $\mathrm{mm}$. wide; fornices each of 3 wart-like crests; fruit 4-5 mm. wide; backs pubescent. Cañons: s Colo. Son. Je.

7. L. trachyphylla Piper. Perennial; stem about $6 \mathrm{dm}$. high, hispid; upper leaves lanceolate, attenuate-acuminate, 4-5 cm. long, harshly scabroushispid on both sides; hairs with pustulate bases; corolla white, 10-12 $\mathrm{mm}$. broad; fornicles as broad as long, papillose; fruit about $6 \mathrm{~mm}$. wide; back plane, muriculate, bearing several prickles. Dry places: Mont. Submont.

8. L. coerulescens Rydb. Perennial; stems several, ascending, 4-6 dm. high, grayish strigose; basal leaf-blades oblanceolate or spatulate, obtuse, grayish strigose, ciliate-margined; stem-leaves linear-oblong, sessile; corolla 6-10 $\mathrm{mm}$. broad, sky-blue, veined with blue; fruit about $7 \mathrm{~mm}$. broad; back keeled, finely muricate, with a few prickles. Hillsides: Alta.-Wyo.-Utah-Nev. Sub-
mont.

9. L. subdecumbens (Parry) A. Nels. Perennial; stem diffusely softhirsute, spreading at the base, 3-7 dm. high; lower leaf-blades oblanceolate, 7-15 cm. long, soft hirsute, the upper ones oblong, sessile; corolla white, 8-12 $\mathrm{mm}$. broad; back of the fruit with few short prickles. E. subdecumbens Parry. Dry hillsides: Utah-Ida. Submont.

10. L. ciliata (Dougl.) Greene. Perennial; stem 3-7 dm. high, cinereousstrigose, with some hispid hairs; lower leaf-blades narrowly linear-oblanceolate, acute, cinereous-strigose and hispid-ciliate; upper leaves sessile, linear; corolla blue, 7-9 mm. broad; fruit 7-8 mm. broad; back flat, with a faint dorsal keel, roughly muricate and with a few short prickles. E. ciliatum A. Gray. Dry hillsides: Wash.-Ida. Submont. My-Jl.

11. L. cinerea Piper. Perennial; stem 4-6 dm. high, cinereous-strigose, and somewhat hispid; basal leaf-blades linear or linear-oblanceolate, $6-10 \mathrm{~cm}$. long; the upper linear, sessile, densely hispid, the hairs with pustulate bases; corolla white, $8-10 \mathrm{~mm}$. broad; fornicles short-pilose; fruit $7-8 \mathrm{~mm}$. broad; back with a faint dorsal ridge, muricate and with a few prickles. Mountains:

12. L. angustata Rydb. Short-lived perennial; stem strict, hirsute, 6-8 $\mathrm{dm}$. high; lower leaves petioled, 9-15 $\mathrm{cm}$. long, strigose or hirsute on the petioles; blades narrow, linear-oblanceolate, mostly acute; corolla blue, about $4 \mathrm{~mm}$. wide; fruit 4-5 mm. wide; back slightly keeled, minutely hispidulous or glabrous. Mountain valleys: Black Hills, S.D.-Colo, Submont. Je-Jl.

13. L. scaberrima Piper. Perennial; stem softly hirsute below; basal leafblades spatulate, obtuse, harshly hispid-strigose; stem-leaves oblong-lanceolate; corolla blue, $5 \mathrm{~mm}$. broad; fornicles broader than long, papillose; fruit $6 \mathrm{~mm}$. wide; back smooth, with prominent keel. Hills and mountains: w Neb.-Colo. Plain-Submont. Jl.

14. L. erecta A. Nels. Stem $2-4 \mathrm{dm}$. high, strigose; basal leaves numerous, rosulate, oblanceolate, 1-3 cm. long; stem-leaves linear or linear-oblong, sessile, $1-4 \mathrm{~cm}$. long, strigose; corolla blue; fruit about $5 \mathrm{~mm}$. broad; back muricate. Foot-hills and sandy places: Alta.-Wyo.-Yukon. Submont.-Mont. Je-S.

15. L. cenchrusoides A. Nels. Stem intricately branched, $2-4 \mathrm{dm}$. high, strigose; leaves and bracts numerous, small, oblong or ovate, obtuse, 1-2 cm. long, strigose above, hispid below; back of fruit papillose-tuberculate. Hills:
Wyo. Submont. S.

16. L. Fremontii (Torr.) Greene. Stem erect, strigose, with erect or ascending branches, $2-4 \mathrm{dm}$. high; leaves $1-3 \mathrm{~cm}$. long, oblong or oblanceolate,
strigose above, hispid beneath; bracts smaller, lanceolate, acute; back of the fruit
strongly muricate. E. Fremontii strongly muricate. E. Fremontii Torr. Cañons and river banks: Sask.-Wyo. - Calif. Submont. Ap-S.

17. L. calycosa Rydb. Stem hirsute, 3-4 dm. high, simple below, branched above, with long virgate branches; leaves oblong, obtuse, $3-4 \mathrm{~cm}$. long, $7-8 \mathrm{~mm}$. wide; corolla pale blue, about $1 \mathrm{~mm}$. broad; calyx-lobes enlarged in fruit, foliDeserted fields and waste places: Colo. Submont. Je-Jl. 
18. L. montana Greene. Stem slender, 2-4 dm. high, branched above, strigose; branches ascending; basal leaves spatulate, 1-2 cm. long; stem-leaves oblanceolate, $2-4 \mathrm{~cm}$. long, cinereous-strigose; corolla about $2 \mathrm{~mm}$. broad; fruit about $3 \mathrm{~mm}$. wide. Dry hills: Mont.-Wyo.-Wash.-B.C. Submont. Je-JI.

19. L. occidentalis (S. Wats.) Greene. Stem $2-6 \mathrm{dm}$. high, usually branched above, with ascending branches, more or less hirsute, with spreading hairs; basal leaves spatulate, 2-4 cm. long; stem-leaves linear or oblong, more or less hirsute; corolla blue, $1.5-2 \mathrm{~mm}$. wide; fruit about $3 \mathrm{~mm}$. wide. $E$. Redowskii occidentalis S. Wats. Sandy places and dry plains: Sask.-Mo.-N.M.-Wash. My-Au.

20. L. leucatricha Rydb. Stem 2-4 dm. high, slender, branched above, densely pilose; basal leaves oblanceolate, $2-4 \mathrm{~cm}$. long, softly pilose on both sides; stem-leaves linear or oblong, numerous; corolla $3 \mathrm{~mm}$. broad; fruit about $5 \mathrm{~mm}$. wide; nutlets about $2.5 \mathrm{~mm}$. long, light, almost straw-colored; back strongly muricate. Dry regions: Ariz. $-\mathrm{s}$ Colo. $-\mathrm{s}$ Utah. Son. Ap-Jl.

21. L. collina Greene. Stem usually branched at the base, 1-2 dm. high, rather simple, canescent-pilose; basal leaves numerous, spatulate, 1-3 cm. long, canescent-pilose; stem-leaves oblong or linear; corolla usually whitish; back of the nutlets white-tubercled. Dry places: w Tex. $\rightarrow$ Colo.-Utah-Ariz. Son. My-Je.

22. L. cupulata (A. Gray) Rydb. Stem simple below, branched above, 3-5 dm. high, softly pilose; basal leaves numerous, short-petioled; blades spatulate, 1-3 cm. long, softly pilose; stem-leaves linear, obtuse; corolla light blue or whitish, about $3 \mathrm{~mm}$. wide; fruit $5-6 \mathrm{~mm}$. broad; nutlets $2.5 \mathrm{~mm}$. long; back muricate, with about 3 rows of tubercles along the mid-ridge. E. Redowskii cupulata A. Gray. L. columbiana A. Nels. River bottoms and sandy soil: Nev. -Ida.-Wash.-Ore. Submont. Ap-My.

23. L. heterosperma Greene. Stem much branched, 1-3 dm. high, hirsute, green; basal leaves 1-2 cm. long, oblanceolate; stem-leaves lanceolate or oblong, hirsute on both sides; bracts lanceolate, longer than the fruit; corolla blue, 1.5-2 $\mathrm{mm}$. wide; fruit about $5 \mathrm{~mm}$. wide. $L$. heterosperma homosperma A. Nels., a form with all four nutlets cupulate. River valleys: S.D.-Kans.-Tex.-Ariz.Mont. Submont. My-Au.

24. L. foliosa A. Nels. Stem diffusely and profusely branched from the base, 1-2 dm. high; leaves broadly linear, 1-3 cm. long; bracts oblong-lanceolate, longer than the fruit; corolla blue; nutlets nearly alike, papillose-scabrous and distinctly ridged on the face. $L$. desertorum foliosa A. Nels. Gravelly slopes: Wyo.-Colo. Je-Jl.

\section{5. asperùgo (Tourn.) L. Catchweed, German Madwort.}

Low annuals, with hispid foliage and few axillary flowers on recurved pedicels. Calyx foliaceous, strongly reticulate-veiny, enlarged in fruit; lobes 5, flat, with 5 smaller ones intervening. Corolla with a short tube, enlarged throat, and spreading 5-lobed limb. Stamens 5, included. Nutlets ovoid, granular-tubercled, keeled, laterally attached above the middle to an elongate-conic receptacle.

1. A. procumbens L. Stem slender, $2-4.5 \mathrm{dm}$. long; leaves oblong or the lower spatulate, $1-4 \mathrm{~cm}$. long; corolla about $2 \mathrm{~mm}$. broad; fruiting calyx 8-12 mm. broad. Waste places: N.Y.-D.C.-Utah-Alta.; adv. from Eu. My$\mathrm{Au}$.

\section{ERITRICHIUM Schrader.}

Depressed pulvinate-cespitose perennials. Leaves short, entire, clustered on the short branches. Flowers perfect, regular, in few-flowered racemes, or subsolitary. Calyx 5-parted; lobes ascending in fruit. Corolla blue, rarely white, funnelform; tube short. Nutlets 4, obliquely attached by their inner angle to a conic receptacle, smooth, but with an obliquely truncate apex, the truncate portion surrounded by an entire or toothed margin. [Omphalodes A. Gray, in part, not Tourn.]

Dorsal surface of the nutlets margined with a ridge-like ring, but not toothed.

Plant strigose; dorsal surface of the nutlets papillose-hispid; corolla $7-9 \mathrm{~mm}$. wide.

1. E. Howardii. 

Basal leaves with long loose pubescence; dorsal surface of the nutlets smooth; corolla
5-6 mm. wide. Dorsal surface of the nutlets with a toothed border; corolla 4-6 mm. wide. . E. elongatum.

3. E. argenteum.

1. E. Howardi (A. Gray) Rydb. Floral branches 1-10 cm. long, canescentstrigose; leaves linear-oblanceolate, canescent or yellowish strigose; corolla dark blue; nutlets broadly obconic, oblique, $2 \mathrm{~mm}$. long and broad; dorsal surface oval, almost flat. Cynoglossum and Omphalodes Howardii A. Gray. Dry hills: Mont.-Wyo.-Wash. Submont. My-J.

2. E. elongatum (Rydb.) Wight. Floral branches $1-10 \mathrm{~cm}$. long; leaves of the caudex closely overlapping, $5-8 \mathrm{~mm}$. long, oblong or oblanceolate, those of the flowering branches linear or linear-oblong, loosely silky-villous; corolla light blue; nutlets about $2 \mathrm{~mm}$. long, oblique; dorsal surface ovate, smooth and shining. E. aretioides elongatum Rydb. Hills and mountains: Mont.-N.M. -Ore. Mont.-Alp. Je-Jl.

3. E. argenteum Wight. Floral branches 1-5 cm. high, loosely silky; leaves of the caudex elosely overlapping, oblanceolate or oblong, 5-10 mm. long; those of the flowering branches linear-lanceolate, silky villous; corolla bright blue, rarely white, $4-6 \mathrm{~mm}$. broad; nutlets about $2 \mathrm{~mm}$. long. Eritrichium nanum aretioides A. Gray, not Herder. Omphalodes nana aretioides A. Gray. Oreocarya pulvinata A. Nels., white-flowered form. High mountains: Colo.-Utah -(? Wyo.) J-Au.

\section{GREENEÓCHARIS Guerke \& Harms.}

Depressed, spreading annuals. Leaves alternate, linear, hirsute. Flowers perfect, regular, sessile, leafy-bracted. Calyx 5-cleft, the upper portion deciduous, the lower persistent around the fruit. Corolla salver-shaped; tube short; throat open, naked; limb 5-lobed. Nutlets oblong-ovate, attached by a narrow groove bifurcate at the base for nearly their whole length to a pyramidal-subulate receptacle. [Piptocalyx Torr.]

1. G. circumscissa (H. \& A.) Rydb. Stem depressed, divaricately branched and spreading, 3-10 cm. high, hispid; leaves linear, 5-15 $\mathrm{mm}$. long, hispid; flowers crowded at the ends of the branches, leafy-bracted; corolla white, $1 \mathrm{~mm}$. long; nutlets oblong-ovate, smooth or minutely scabrous. P. circumscissus Torr. Desert plains: Wash.-Wyo.-Ariz.-Calif. Son.-Plain. My.

\section{PLAgIobóthrys Fisch. \& Mey. Popcorn Flower.}

Low, commonly diffuse annuals. Leaves alternate, narrow, entire. Flowers perfect, regular, in scorpioid racemes. Calyx 5-lobed, persistent. Corolla salverform, white; tube very short. Nutlets attached at or near the middle, to a globular or depressed receptacle, ventrally carinate above the insertion, rugose or rough, rar ely smooth, only one or two maturing, succumbent horizontally and tardily detached, leaving a caruncle at the insertion. Receptacle subglobose or depressed, not 4-sulcate; nutlets only 1 or 2 maturing, hori-
zontally incumbent; plants with tufted basal leaves.

Nutlets cruciform; basal leaves rosulate; cauline few and small.

Receptacle deeply 4-sulcate, after thy throughout.

curved.

1. P. tenellus A. Gray. Stem branched at the base, hirsute; basal leaves numerous, rosulate, oblanceolate, $1-2 \mathrm{~cm}$. long, hirsute; stem-leaves few and small, linear-lanceolate; calyx hirsute, with yellowish or brownish hairs; corolla white, $1.5 \mathrm{~mm}$. broad; nutlets contracted both at the base and the apex, with transverse wrinkles. Sandy soil: B.C.-Ida.-Calif. Son. Ap-Je.

2. P. arizonicus (A. Gray) Greene. Stem branched from the base, hirsute; branches ascending or decumbent at the base, 2-3 dm. high; basal leaves oblanceolate to linear, 2-5 cm. long, hirsute; stem-leaves lanceolate or linear-lanceolate; calyx hispid; corolla white, nearly $2 \mathrm{~mm}$. wide; nutlets ovate, somewhat crosswrinkled and with a few tubercles on the ridges. Sandy soil: Ariz. - s Utah-
s Calif. L. Son. Ap-My. 
3. P. Kingii A. Gray. Stem 2-3 dm. high, canescent-hirsute; basal leaves spatulate, densely hirsute, the cauline oblong or lanceolate; inflorescence branched; corolla white, 6-8 mm. broad; fruiting calyx 4-6 mm. long; lobes lance-linear; nutlets roughened with scattered acute papillae. Sonnea Kingii Greene. Arid valleys: Nev.-Ida.-(? Utah). Son.

\section{EREMOCÃRYA Greene.}

Dichotomously branched annuals. Leaves alternate, linear, entire, hirsutecanescent. Flowers perfect, regular, biserial in dense leafy, racemes. Calyx wholly persistent, 5-cleft; lobes linear-oblong, obtuse, short-hirsute, not hispid. Corolla minute, salver-shaped, white; throat obseurely appendaged. Style thickened. Nutlets attached by a simple groove for their whole length to the columnar receptacle.

Nutlets smooth and shining.

Nutlets finely muricate, dull.

1. E. micrantha.

2. E. muricata.

1. E. micrantha (Torr.) Greene. Stem slender, branched from the base, diffuse, 5-15 $\mathrm{cm}$. high, strigose; leaves linear, 4-8 mm. long, hispid; corolla white, barely $2 \mathrm{~mm}$. long; nutlets oblong-ovate, acute. Eritrichium micranthum Torr. Dry plains: w Tex. $-\mathrm{s}$ Utah-s Calif. L. Son. Je.

2. E. muricata Rydb. Stem slender, branched throughout, with ascending branches, strigose; leaves linear, $2-5 \mathrm{~mm}$. long, hispidulous; corolla white, $1 \mathrm{~mm}$. long; limb scarcely $0.5 \mathrm{~mm}$. wide; nutlets lanceolate in outline. Dry plains and hills: s Utah-Ariz. L. Son. Ap-My.

\section{OREOCÃRYA Greene.}

Perennial or at least biennials, with taproots or short rootstocks. Leaves alternate, the earlier in basal rosettes, more or less hispid. Calyx wholly persistent, 5-cleft; the lobes ascending or spreading in fruit. Corolla salverform, white or yellowish; tube often elongate, annulate within near the base; throat elosed by conspicuous fornices; limb 5-lobed. Inflorescence thyrsoid or paniculate, leafy-bracted. Nutlets triangular, sometimes somewhat wing-margined, attached for the larger part of their length by a slender scar on the inner angle to a subulate or columnar receptacle.

Corolla-tube not exserted.

Fruit depressed; nutlets smooth, at the margins separated by an open space; caulescent cespitose perennials.

Leaves canescent.

Nutlets all maturing.

Leaves appressed-canescent, not hispid; corolla 5-7 mm. wide.

Leaves with the fine pubescence intermixed with hispid hairs on the lower surface; corolla less than $5 \mathrm{~mm}$. wide.

Plant low, grayish, not yellowish hispid above; racemes short, 2-ranked.

2. O. suffruticosa.

Plant tall, yellowish hispid above; racemes in fruit elongate, 1-ranked.

3. O. multicaulis.

Nutlets only one maturing, three abortive.

4. O. disticha.

Leaves green, having scattered short hairs with pustulate bases above, glabro
5 . O. pustulosa.

beneath.
Fruit conical or ovoid; nutlets touching each other.

Floral leaves long, many times longer than the

Nutlets transversely rugose.

6. O. virgata.

Floral leaves comparatively short, little if at all surpassing the flower-clusters.

Nutlets rough.

Nutlets decidedly wing-margined.

Branches of the inflorescence appressed, erect, in fruit elongate; nutlets merely muricate on the back. 8. O. setosissima. Branches of the inflorescence spreading; nutlets rugose as well as m
cate on the back.
11 . O. virginensis.

Nutlets acute-margined, not winged.

Calyx-lobes ovate-lanceolate, only slightly exceeding the mature nutlets; inflorescence paniculate, with rather few branches; caulescent perennials, of ten cespitose.

Corolla $7-8 \mathrm{~mm}$. broad; nutlets muricate and cross-ribbed, but not honeycomb-crested.

9. O. elata. 
Corolla 4-5 mm. broad; nutlets honeycomb-crested.

10. O. Bakeri.

Calyx-lobes lanceloate to linear, much exceeding the nutlets; inflorescence thyrsoid.

Inflorescence a broad, open, round-topped thyrsus; branches usually

again branched.
Plant tall, $2 \mathrm{dm}$. high or more; nutlets with acute backs and sharply acute margins; tubercles united into more or less distinct cross-ridges; biennials, with taproots.

Nutlets wing-margined, with the strong, rather regular crossridges uniting on the back. 11 . O. virginensis.

Nutlets merely acute-angled, weakly irregularly cross-ridged.

12. O. thyrsiflora.

Plant low, cespitose perennials, 1-2 dm. high; nutlets with rounded backs; murications united into star-shaped tubercles.

13. O. aperta.

Inflorescence, at least in flowers, narrow, almost spike-like, if more open, the branches simple.

Plants green, very hispid, only the basal leaves canescent; bristles with conspicuous pustulate bases, much longer than the short strigose or tomentose pubescence.

Leaves linear or narrowly linear-lanceolate; plant 1-2 dm. high, very slender.

14. O. Macounii.

Leaves, at least the basal ones, broadly oblanceolate or

spatulate.
Corolla $7-10 \mathrm{~mm}$. broad; nutlets ovate, more than half as broad as long.

Leaves obtuse; inflorescence dense.

Basal leaves broadly spatulate, usually canescent; stem 1-3 dm. high. 15. O. glomerata.

Basal leaves oblanceolate, greener; stem usually 3-4 dm. high. 16 . O. affinis.

Leaves acute, strongly hirsute-ciliate; inflorescence not very dense. 17 . O. spiculifera.

Corolla 5-7 mm. broad; nutlets lanceolate, less than half as broad as long; basal leaves oblanceolate, somewhat canescent; plant 1-3 dm. high.

18. o. perennis.

Plant canescent; at least the basal leaves with inconspicuous bristles scarcely longer than the other pubescence.

Plant stout, 2-4 dm. high, rather simple; corolla 7-10 mm. broad.

19. O. argentea.

Plant low, less than $2 \mathrm{dm}$. high, densely cespitose.

Basal leaves narrowly linear-oblanceolate, glossy, closely appressed-canescent; nutlets mammillate-papillose.

Basal leaves spatulate, white or yellow, scarcely glossy, at least when mature.

Nutlets 1 or 2 , acuminate with a blunt apex; calyxlobes linear-subulate. $21 . O$. nana.

Nutlets 4, merely acute; calyx-lobes lanceolate.

Nutlets more or less rugulose; tubercles more or less confluent.

Inflorescence in fruit rather open: corolla-tube slightly exserted. 22 . O. echinoides.

Inflorescence congested; corolla-tube not exserted.

Corolla 7-9 mm. broad.

Corolla 4-6 mm. broad.

Leaves tomentose and hispid; nutlets tuberculose-rugulose.

Leaves strigillose and hispid; nutlets sinuately and finely rugulose.

25. O. caespitosa.

Nutlets muricate.

Inflorescence narrow; plant not more than 1 dm. high.

Leaves strigillose and hispid.

Leaves subtomentose and hispid.

Shantzii.

27. O. dolosa.

Inflorescence open; plant 1-2 dm. high.

Nutlets smooth.

28. O. commixta.

Corolla-tube long-exserted; cespitose perennial, rarely biennial.

Corolla white.

Nutlets rough.

Nutlets more or less distinctly rugose, with irregular cross-ridges, as well as muricate. 
Fruit depressed-globose; nutlets incurved on the margins and separated by open spaces.

30. O. paradora.

Fruit ovoid-conic; nutlets touching.

Ridges of the nutlets honeycomb-crested; inflorescence narrow; leaves canescent and hispid.

31. O. eulophus.

Ridges of the nutlets neither much interlacing nor crested.

Inflorescence, at least in fruit, open, with elongate branches.

Corolla 15-18 mm. long; calyx enlarging and becoming 15-18 $\mathrm{mm}$. long in fruit.

32. $O$. longiflora.

Corolla 12-15 mm. long; calyx scarcely enlarging, in fruit less than $1 \mathrm{~cm}$. long.

Inflorescence narrow; stem slender.

Basal leaves spatulate. Corolla $12-14 \mathrm{~mm}$. Iong, much exceeding the calyx.

$\begin{array}{ll}\text { Corolla slightly exceeding the calyx. } & \text { 22. O. cristata. } \\ & \text { O. echinoides. }\end{array}$

Basal leaves linear-oblanceolate; corolla slightly exceeding the calyx.

35. O. tenuis.

Nutlets finely muricate; at least the inflorescence with yellowish hairs.

Plant low, 1-2 dm. high; basal leaves 2-3 cm. long, 3-7 mm. wide.

Corolla about $1 \mathrm{~cm}$. long, pure white; nutlets muricate on the back.

36. O. fulvocanescens.

Corolla 12-15 mm. long, often with a yellow eye; nutlets roughly papillose. 38 . O. flavoculata.

Plant 2-3 dm. high; basal leaves 4-10 cm. long, 7-15 mm. wide.

37. O. nitida.

Nutlets smooth.

Fruit not depressed; stem-leaves linear or linear-lanceolate.

Stem-leaves linear; nutlets brownish, obtuse, slightly ridged on the back. 39. O. flava.

Stem-leaves linear-lanceolate; nutlets ivory-white, acute, flat on the back.

Fruit depressed, acutely margined.

40. O. leucophaea.

Fruit depressed, acutely margined.
a yellow, or with a yellow throat.

41. O. alata.

Corolla yellow, or with a yellow throat.
Basal leaves spatulate or oblanceolate

nutlets papillose.
Basal leaves narrowly linear-oblanceolate; corolla yellow; nutlets smooth.
39. O. flava.

1. O. cinerea Greene. Stems 1-3 dm. high, einereous-strigose; leaves elongate, linear-oblanceolate or linear, silvery-cinereous, with appressed hairs; calyx-lobes broadly lanceolate; corolla $8-9 \mathrm{~mm}$. long, 5-7 $\mathrm{mm}$. broad; nutlets light gray, smooth. Arid plains: Colo.-N.M. Submont. My-Jl.

2. O. suffruticosa (Torr.) Greene. Stems 1-3 dm. high, decumbent or ascending at the base, cinereous and hirsute; leaves linear-oblanceolate or linear, 3-10 $\mathrm{cm}$. long; calyx-lobes ovate-lanceolate; corolla 5-6 mm. long; nutlets more or less tubercled and white-spotted. E. Jamesii Torr. Krynitzkia Jamesii A. Gray. Plains and foot-hills: S.D.-Tex.-N.M.-Utah-Wyo. Plain-Submont. $\mathrm{My}-\mathrm{Jl}$.

3. O. multicaulis (Torr.) Greene. Stems stout, 2-4 dm. high; leaves linear-oblanceolate or oblanceolate, $3-10 \mathrm{~cm}$. long; corolla $5-6 \mathrm{~mm}$. long; nutlets smooth and shining. Eritrichum multicaulis Torr. Dry plains: Tex. $-\mathrm{s}$ Colo. -Ariz. Son.-Submont. My-Au.

4. O. disticha Eastw. Stems about $3 \mathrm{dm}$. high, eanescent as well as hispid; leaves oblanceolate, $2-4 \mathrm{~cm}$. long, finely canescent-strigose above, appressedhirsute beneath; racemes few, distichous; calyx-lobes ovate-lanceolate, obtuse, $4 \mathrm{~mm}$. long; corolla white, $5 \mathrm{~mm}$. long, and about as wide; nutlets solitary, rounded and arched on the dorsal side, mottled with brown, and slightly papillose. Mesas: Utah. Son. Jl.

5. O. pustulosa Rydb. Stems 3-5 dm. high, glabrous or nearly so throughout; lower leaves linear-oblanceolate, the upper linear or linear-lanceolate, 3-10 cm. long, green; flowers paniculate; sepals triangular-lanceolate, acute; corolla white; tube not exceeding the calyx; limb 5-6 mm. broad; lobes orbicular; fruit depressed-globose; nutlets mottled with light brown. Cañons: se Utah. Son. J-Au.

6. O. virgata (Porter) Greene. Stem 3-6 dm. high, hispid with yellowish hairs; basal leaves oblanceolate, hirsute and hispid, $3-8 \mathrm{~cm}$. long; stem-leaves linear; corolla 6-7 mm. long and fully as broad; nutlets in age brown or gray; 
margins sharp, almost winged. $K$. virgata A. Gray. Dry hills and mountains: Colo.-Wyo. Submont.-Mont. My-Jl.

7. O. spicata Rydb. Stem solitary and simple, virgate, hispid throughout; basal leaves numerous, spatulate, $2-5 \mathrm{~cm}$. long, hispid on both sides; stem-leaves linear-oblanceolate or linear, 4-9 cm. long; corolla $6 \mathrm{~mm}$. long, $4 \mathrm{~mm}$. broad; nutlets $4 \mathrm{~mm}$. long, ovate in outline, scarcely keeled on the back, white and shining, the margins merely acute. Hills: Colo. Submont. J1-Au.

8. O. setosissima (A. Gray) Greene. Biennial or perennial, with a taproot; stem 6-8 dm. high, very hispid; basal leaves oblanceolate or linear-oblanceolate, 1-2 dm. long, hirsute; corolla about $5 \mathrm{~mm}$. long, $4 \mathrm{~mm}$. wide; nutlets nearly 6 $\mathrm{mm}$. long, broadly ovate, dull, scabrous-muricate on the back, distinctly winged. Dry hills: Utah-Ariz. Son. Je-Au.

9. O. elata Eastw. Stems 3-4 dm. high, virgate, white-strigose and somewhat hirsute; basal leaves clustered, spatulate, $2-3 \mathrm{~cm}$. long, densely whitestrigose; upper stem-leaves linear, more hirsute; inflorescence with very short branches; corolla white, $6-7 \mathrm{~mm}$. long; nutlets ovate, acutely margined. Dry clay-hills: w Colo. Submont. My-Je.

10. O. Bakeri Greene. Stem 1-2 dm. high, hirsute; leaves oblanceolate, strigose-hispid; inflorescence with few short branches; calyxhispid; corolla white, 4-5 mm. long; nutlets ovate. Sage plains: s Colo. Je-Jl.

11. O. virginensis (M. E. Jones) F. Macbr. Stem 2-3 dm. high, hirsute; basal leaves oblanceolate, $6-10 \mathrm{~cm}$. long, canescent and hispid; inflorescence rather open-paniculate, 1-2 dm. long, yellowish hispid; corolla white, $4 \mathrm{~mm}$. long; nutlets broadly ovate, narrowly winged and strongly ridged. $K$. glomerata viginensis M. E. Jones. Hillsides: s Utah. Son. My-Je.

12. O. thyrsiflora Greene. Stem branched above, very hispid, $2-4 \mathrm{dm}$. high; basal leaves numerous, spatulate or oblanceolate, very hispid, 4-10 cm. long; inflorescence 1-2 dm. long, 5-8 cm. wide, often yellowish hispid; corolla about 5 $\mathrm{mm}$. long, $3 \mathrm{~mm}$. wide; nutlets $3 \mathrm{~mm}$. long. O. hispidissima (Torr.) Rydb. Hillsides and river valleys: Neb.-N.M.-Utah. Plain-Mont. Je-Au.

13. O. aperta Eastw. Stem 1-2 dm. high, branching, hirsute; basal leaves spatulate or oblanceolate, $2-4 \mathrm{~cm}$. long, strigose as well as hirsute; stem-leaves oblanceolate; inflorescence a closely branched thyrsus; corolla white, $6 \mathrm{~mm}$. long; nutlets $2.5 \mathrm{~mm}$. long. Dry hills: Colo.-Mont. Submont. Je-S.

14. O. Macounii Eastw. Biennial or perennial, with a slender taproot; stem sparingly hirsute; leaves sparingly hirsute; corolla white, $5 \mathrm{~mm}$. long, $4 \mathrm{~mm}$. wide; nutlets ovate, obtuse, $2 \mathrm{~mm}$. long, acutely margined, rounded on the back and coarsely muricate. Plains: Sask. Plain. Jl.

15. O. glomerata (Pursh.) Greene. Perennial or biennial; stem erect, 1-3 $\mathrm{dm}$. high; basal leaf-blades $2-6 \mathrm{~cm}$; ; stem-leaves oblanceolate; corolla white, 7-8 $\mathrm{mm}$. long, $7-10 \mathrm{~mm}$. wide; nutlets ovate, $3 \mathrm{~mm}$. long, acute-margined, obtuse, transversely rugose and muricate on the back. K. glomerata A. Gray. Dry hills: Sask.-Neb.-(? Colo.)-Utah.-B.C. Plain-Submont. My-Jl.

16. O. affinis Greene. Biennial; stems $2-4 \mathrm{dm}$. high, hispid; leaves oblanceolate, somewhat grayish strigose and hirsute, 3-10 $\mathrm{cm}$. long; stem-leaves linear or linear-oblanceolate, greener and more hirsute; corolla $7-9 \mathrm{~mm}$. long, 7-10 $\mathrm{mm}$. wide; nutlets ovate, rounded on the back, coarsely tuberculate on the back (rarely somewhat rugose), finely so towards the margin. Krynitzkia pustulata Blankinship. Dry hills: S.D.-Colo--Ida.-Mont. Plain-Submont. Je-J1.

17. O. spiculifera Piper. Perennial, with a tufted caudex; stem erect, $2-3$ $\mathrm{dm}$. high, finely strigose and hispid; basal leaves spatulate-oblanceolate, densely strigose and sparingly hispid; blades $1.5-2 \mathrm{~cm}$. long; inflorescence of 8-12 false racemes; corolla white; tube $5 \mathrm{~mm}$. long; limb $8 \mathrm{~mm}$. broad; nutlets ovate, obtuse, $3 \mathrm{~mm}$. long, the back bluntly tuberculate. O. ciliohirsuta Nels. \& Macbr. Hills: Wash.-Ida. Submont. Je.

18. O. perennis (A. Nels.) Rydb. - Perennial, with a taproot; stem hispid; basal leaves grayish strigose and hirsute; corolla $5-7 \mathrm{~mm}$. long; nutlets about 3 
$\mathrm{mm}$. long, rounded and muricate on the back, not at all cross-ridged. perennis A. Nels. Dry hills: N.D.-Colo.-Ida. Submont. Je-Jl.

19. O. argentea Rydb. Cespitose perennial; stems 3-4 dm. high, hispid; basal leaves spatulate or oblanceolate, obtuse, $5-6 \mathrm{~cm}$. long, densely white or yellowish pubescent; stem-leaves oblanceolate, with the bristles more spreading; corolla white, less than $5 \mathrm{~mm}$. long; nutlets about $3.5 \mathrm{~mm}$. long, papillose and with more or less distinct cross-ridges. Hills: Colo.-Utah. Son. Je.

20. O. cana A. Nels. Stem $1 \mathrm{dm}$. high or less, silvery-strigose; leaves 1-3 $\mathrm{cm}$. long; corolla about $4 \mathrm{~mm}$. long and $3 \mathrm{~mm}$. wide; nutlets broadly ovate, $2 \mathrm{~mm}$. long. Krynitzkia sericea Nutt.; A. Gray, in part. Dry hills: w Neb. Submont. $\mathrm{Je}-\mathrm{Au}$.

21. O. nana Eastw. Densely cespitose perennial; stems $5-10 \mathrm{~cm}$. high, hispid; basal leaves crowded on the caudex, densely white-strigose, oblanceolate, 1-2 cm. long; corolla white, 6-7 mm. long; nutlets 1 or 2, ovate, muriculate and somewhat rugose. Mesas: Colo. Son. My.

22. O. echinoides (M. E. Jones) F. Macbr. Cespitose perennial; stems about $1.5 \mathrm{dm}$. high, fulvous-hispid; basal leaves spatulate, 4-5 cm. long, densely canescent and strigose; stem-leaves narrowly oblanceolate; corolla nearly $1 \mathrm{~cm}$. long, 5-6 mm. wide; nutlets sharply angled, muricate-papillose and short-setose on the sides. Eritrichum glomeratum humile A. Gray. Krynitzkia echinoides M. E. Jones. O. humile Greene. O. hispida Nels. \& Kenn. Dry hills: UtahCalif. Submont. Ap-Je.

23. O. sericea (A. Gray) Greene. Cespitose perennial; stem 1-2.5 dm. high, hirsute above with yellow hairs; basal leaves spatulate, $3-5 \mathrm{~cm}$. long, with long petioles, silky canescent; stem-leaves linear or linear-oblanceolate; corolla 7-8 mm. long; nutlets ovate, ridged on the back, rugose. O. humilis Greene. K. sericea A. Gray. Dry arid hills: Utah-w Wyo.-Mont. My-Jl.

24. O. depressa (M. E. Jones) F. Macbr. Densely cespitose perennial; basal leaves many, tomentose and strigose, spatulate, $2-5 \mathrm{~cm}$. long; petioles long-hairy; spike barely surpassing the leaves; calyx about $4 \mathrm{~mm}$. long, densely pubescent; lobes triangular; corolla $4 \mathrm{~mm}$. long and as broad, white; nutlets deltoid-ovate, with sharp edges, closely tuberculate on the back. $K$. depressa M. E. Jones. Dry slopes: Nev.-Utah. Submont.-Mont. Je.

25. O. caespitosa A. Nels. Densely cespitose perennial; stems $5-10 \mathrm{~cm}$. high, numerous, densely hirsute below; basal leaves crowded, very numerous, spatulate or oblanceolate, 1-3 cm. long, densely silky-canescent or sometimes yellowish; corolla white, 4-5 mm. long; nutlets narrowly ovate. Dry arid hills: Wyo. Submont. My-Je.

26. O. Shantzii Tidestr. Cespitose perennial; stems about $1 \mathrm{dm}$. high, strigose and white-hispid; leaves linear-spatulate, $2 \mathrm{~cm}$. long, $4 \mathrm{~mm}$. broad, densely strigose; calyx densely hirsute; lobes $4 \mathrm{~mm}$. long; corolla-tube slightly longer than the calyx; nutlets elongate-ovate, obtuse, white-punctate on the back. Dry saline soil: Utah. Son. Je-Au.

27. O. dolosa F. Macbr. Cespitose perennial; stem 7-10 cm. high, strigose and softly hirsute; basal leaves about $3 \mathrm{~cm}$. long and $4 \mathrm{~mm}$. wide, canescent and strigose-hispid; inflorescence spike-like, $3-5 \mathrm{~cm}$. long; calyx hispid; lobes in fruit $6 \mathrm{~mm}$. long; corolla $5 \mathrm{~mm}$. long, not exserted; nutlets ovate, $3 \mathrm{~mm}$. long, densely muricate. Bench lands: Utah. Son. My-Je.

28. O. commixta F. Macbr. Stem $1.5-2 \mathrm{dm}$. high, strigillose and softly hirsute; basal leaves spatulate, 4-5 cm. long, 5-8 mm. wide, appressed strigillose and hispid; stem-leaves few, oblanceolate; inflorescence 1-1.5 dm. long, yellowish hispid; corolla $5 \mathrm{~mm}$. long; tube not exserted; nutlets ovate, about $3 \mathrm{~mm}$. long; tube not exserted; nutlets ovate, about $3 \mathrm{~mm}$. long, densely muricate. Sandy slides and stony benches: Utah-Nev. Je-J.

29. O, salmonensis Nels. \& Macbr. Stem 1.5-2 dm. high, white-hispid and finely strigose; stem-leaves $3-8 \mathrm{~cm}$. long, oblanceolate or spatulate, hispidciliate, canescent and pustulate-hispid; inflorescence thyrsoid-glomerate, dense; 
calyx-lobes linear-lanceolate, 5-7 $\mathrm{mm}$. long in fruit; corolla white; tube shorter than the calyx; nutlet $3 \mathrm{~mm}$. long, ovate, acutely margined, gray, with a lighter indistinct keel. Loose soil: Ida. Plain. Je.

30. O. paradoxa A. Nels. Stems $8-15 \mathrm{dm}$. high, decumbent at the base, hirsute; leaves spatulate-oblanceolate, $1.5-3 \mathrm{~cm}$. long, hispid-strigose; inflorescence subcapitate at first; calyx-lobes linear-lanceolate, 4-5 mm. long; corollatube nearly three times as long as the calyx; nutlets ovoid, transversely rugose and muricate. O. gypsophila Payson. Gypsum hills: w Colo. Submont. Je.

31. O. eulophus Rydb. Stem about $2 \mathrm{dm}$. high, hispid with yellowish hairs; basal leaves numerous, spatulate, 4-5 cm. long, finely cinereous and appressed-hispid; stem-leaves oblanceolate, often yellowish; corolla white, 10-12 $\mathrm{mm}$. long; limb about $5 \mathrm{~mm}$. wide; nutlets $4-5 \mathrm{~mm}$. long. Gravelly hills: Colo. -Utah. Submont. Je-Jl.

32. O. longiflora A. Nels. Stem 1-2 dm. high, hispid; basal leaves crowded, spatulate, 3-7 cm. long, cinereous-strigose and more or less hispid; stem-leaves few, linear; inflorescence thyrsoid, yellowish hispid; corolla $7-8 \mathrm{~mm}$. wide; nutlets ovate, 3-4 mm. long, acutely margined, obscurely transversely rugose on the back and papillose towards the margins. Table-lands and plains: Colo.-Utah. Son.-Submont. My-Je.

33. O. Wetherillii Eastw. Biennial, with a taproot; stems 1-3 dm. high, hirsute; leaves mostly basal, spatulate, 1-3 cm. long; inflorescence of numerous unilateral or distichous spikes; corolla $8-9 \mathrm{~mm}$. wide; nutlets ovate-oblong, $3-5$ $\mathrm{mm}$. long, acute-margined, densely and irregularly rugose on the back. Cañons: Utah. Son. My.

34. O. cristata Eastw. Stems slender, about $2 \mathrm{dm}$. high, pubescent and hispid; leaves oblanceolate, $1.5-5 \mathrm{~cm}$. long, cinereous-strigose and hispid; inflorescence grayish or tawny hispid; calyx-lobes lanceolate, $6 \mathrm{~mm}$. long; corollalimb $7 \mathrm{~mm}$. broad; nutlets ovate, acute-margined, transversely rugose and papillose. Arid hills: w Colo.-N.M. Submont. My.

35. O. tenuis Eastw. Stem branched at the base, 1-2 dm. high, brown, strigose and hispid; leaves oblanceolate or linear-spatulate, $1-3 \mathrm{~cm}$. long, acute, strigose on both sides, and hispid beneath and on the margins; calyx-lobes in fruit $6 \mathrm{~mm}$. long, linear, white-hispid; corolla white, about $1 \mathrm{~cm}$. long; limb 8 $\mathrm{mm}$. wide; nutlets ovate, $3 \mathrm{~mm}$. long, acute-margined, keeled and corrugatedrugose on the back. Cañons: Utah. Son. My.

36. O. fulvocanescens (A. Gray) Greene. Stems $5-15 \mathrm{~cm}$. high, densely silvery-strigose; basal leaves linear-spatulate or oblanceolate, $2-3 \mathrm{~cm}$. long, thick, densely silvery-canescent, sometimes yellowish; stem-leaves yellow and more or less hispid; inflorescence narrow, yellow-hispid; corolla white, about 1 $\mathrm{cm}$. long; limb $6-7 \mathrm{~mm}$. wide; nutlets broadly ovate. $K$. fulvocanescens A. Gray. Hills: Wyo.-N.M. Submont. My-Au.

37. O. nitida Greene. Stem cinereous-strigose; basal leaves numerous, broadly oblanceolate, silvery silky-strigose; inflorescence an open thyrsus, yellowish hispid; corolla white, about $15 \mathrm{~mm}$. long; limb $6 \mathrm{~mm}$. wide; nutlets mostly solitary, finely muriculate. Dry hills and stony ground: Colo.-Utah. Son.Submont. My-Je.

38. O. flavoculata A. Nels. Stems 1-2 dm. high, strigose and hispid-ciliate; basal leaves numerous, spatulate or oblanceolate, canescent-strigose and somewhat hirsute; inflorescence narrow, yellowish hispid; corolla $12-15 \mathrm{~mm}$. long; limb 7-8 mm. wide; nutlets ovate. Dry hills: Wyo.-w Colo.-Utah. Submont. $\mathrm{My}-\mathrm{Je}$.

39. O. flava A. Nels. Stems 1-3 dm. high, white-strigose below, yellowish hirsute above; leaves numerous, linear or linear-oblanceolate, silky-strigose, 1-5 $\mathrm{cm}$. long; inflorescence narrow, yellow-hispid; corolla yellow, about $15 \mathrm{~mm}$. long; limb 7-8 mm. wide; nutlets broadly ovate, obtuse. O. lutescens Greene. Hills: Wyo.-N.M.-Ariz. Submont. My-Jl.

40. O. leucophaea (Dougl.) Greene. Stems $2-5 \mathrm{dm}$. high, silky-strigose; leaves silky-strigose and silvery, linear or linear-lanceolate, $5-10 \mathrm{~cm}$. long; 
corolla cream-colored, about $12 \mathrm{~mm}$. long. $K$. leucophaea A. Gray. Dry plains: B.C.-Calif.-Ida. Son. My-Jl.

41. O. alata (Jones) A. Nels. Stems 3-4 dm. high; basal leaves oblanceolate, 5-10 cm. long, silky-strigose, canescent; upper leaves linear-lanceolate; inflorescence narrow; corolla white, $15-18 \mathrm{~mm}$. long; limb 7-8 mm. wide; nutlets sharply ovate-trigonous. $K$. leucophaea alata M. E. Jones. Mountain sides and dry hills: s Utah. Submont. Je.

\section{ALLOCÃRYA Greene.}

Diffusely branched annuals. Lower leaves opposite, the upper alternate, narrow, more or less hirsute. Flowers in scorpioid racemes, some leafy-bracted, others not, perfect, regular. Calyx wholly persistent, 5-parted; lobes connivent and enclosing the fruit. Corolla salver-shaped, white; tube usually short; throat furnished with more or less conspicuous scales (fornices); limb 5-cleft. Nutlets ovoid or oblong, or somewhat trigonous, obliquely attached by an oblong or rounded scar to the low-conical receptacle. Seeds amphitropous, ascending.

Racemes loose and leafy-bracted; corolla small, less than $2 \mathrm{~mm}$. wide; nutlets more or less rugose.

Plant glabrous or nearly so.

Plant decidedly hairy.

Plant hirsute.

Plant strigose.

Calyx erect in fruit.

Bracts oblong, scarcely more than twice as long as the flowers; nutlets uncinate-bristly on the back.

3. A. Nelsonii.

Bracts (often lacking under some of the flowers) linear and resembling the leaves; nutlets merely rugose on the back.

Calyx spreading in fruit; nutlets irregularly wrinkled on the back.

1. A. orthocarpa.

2. A. hispidula.

5. A. cognata.

Racemes bractless; flowers $7-8 \mathrm{~mm}$. broad; nutlets not rugose.

6. A. Hendersoni.

1. A. orthocarpa Greene. Stem somewhat succulent, 7-20 $\mathrm{cm}$. high; leaves elongate-linear, 2-5 cm. long; spike long, strict; sepals erect, linear, twice as long as the fruit; nutlets lanceolate in outline, transversely rugose and minutely tuberculate. Wet places: Utah-Wyo. Son.-Submont. My-Je.

2. A. hispidula Greene. Stem diffusely branched, 1-2 dm. high, hispid with ascending hairs; leaves linear or narrowly linear-oblanceolate, hispid; bracts small, scarcely exceeding the densely hispid ealyces; nutlets $1.2 \mathrm{~mm}$. long, muriculate and rugose, with few transverse ridges. Valleys: Wash.-Ida.Nev. - s Calif. Son. Je-Jl.

3. A. Nelsonii Greene. Stem diffuse, branched, strigose, 1-2 dm. high; leaves linear or linear-oblanceolate, obtuse, strigose, $1-3 \mathrm{~cm}$. long; nutlets 1.5 $\mathrm{mm}$. long, transversely rugose, somewhat muriculate. Saline flats and river banks: S.D.-Wyo.-Ida. J-Au.

4. A. scopulorum Greene. Stem ascending or spreading, branched, strigose, 5-20 cm. high; leaves linear, strigose, 3-5 cm. long; nutlets ovate-lanceolate in outline, muricate and transversely rugose. Sandy soil: Sask,-Neb.-Colo. - Utah-Nev.-Wash. Son.-Mont. Je-Au.

5. A. cognata Greene. Annual; stem slender, reclining, strigose-pubescent, especially above; leaves linear; raceme loose; fruiting calyces spreading; nutlets minute, broadly ovate, acuminate. Wet places: Utah. Son. Je.

6. A. Hendersoni A. Nels. Stem simple at the base, but soon branched, erect, 2-4 dm. high, sparsely hirsute; leaves broadly linear, 4-6 cm. long, 3-6 mm. wide, hirsute; racemes elongate, the terminal ones geminate; nutlets ovate, $2-3$ $\mathrm{mm}$. long, finely muricate, with a few larger papillae intermixed. Sandy soil: Ida.-Wash. Son. Ap-Je.

\section{CRYPTÁNTHA Lehm.}

Annual caulescent, branched herbs. Leaves alternate, narrow, entire. Flowers perfect, regular, in scorpioid spikes or racemes. Calyx usually deciduous with the fruit, 5-cleft; the lobes in fruit connivent around the nutlets. Cor- 
olla salver-shaped or funnelform, white; tube short; throat closed by 5 scales (fornices); lobes 5, imbricate. Stamens 5, included; filaments short. Nutlets ovoid, attached for at least the lower half by a narrow, simple or bifurcate groove to the pyramidal receptacle. Seeds more or less amphitropous, pendulous. [Krynitzkia Fisch. \& Mey.]

Nutlets not winged.

Nutlets all or some of them tuberculate or muricate.

Nutlets usually solitary.

Nutlets usually 4

Nutlets dissimilar, 3 of them tubercled or muricate, the fourth smooth or nearly so.

Nutlets all alike and tubercled.

Nutlets all smooth.

Groove of the nutlets simple, continuous to the base.

Groove two-forked at the base.

No open areola between the forks of the groove; nutlets acute.

TII. HETEROCARYAE.

III. MURICUlatae.

V. TORREYANAE.

Nutlets winged.

A distinct open areola between the forks of the groove; nutlets lanceolate, acuminate.

Calyx-lobes recurved.

VI. RAMULOSISSIMAE.

Calyx-lobes not recurved.

\section{Recurvatae.}

VII. Pterocaryae,

\section{Heterocaryae.}

Sepals in fruit strongly thickened on the back.

Sepals in fruit not strongly thickened on the back.

Plant 1-2 dm. high; calyx in fruit $6-8 \mathrm{~mm}$. long.

Plant a few $\mathrm{cm}$, high; calyx in fruit less than $5 \mathrm{~mm}$. long.

1. C. recurvata.

5. C. barbigera.

\section{Muriculatae.}

Pubescence of the stem at least in part consisting of spreading hairs.

Leaves broadly linear or oblanceolate; calyx in fruit over $5 \mathrm{~mm}$. long.

Calyx densely pubescent with long white silky hairs and bristly on the midribs; nutlets tubercled even on the ventral side; groove open. 5. C. barbigera.

Calyx with appressed or ascending yellowish hairs, and with spreading bristles on the veins.

Nutlets smooth on the ventral side; groove closed.
Nutlets narrowly conical with an open narrow groove, finely spinilicautise-muri-
cate. cate.

Leaves narrowly linear; calyx in fruit about $4 \mathrm{~mm}$. long.

6. C. multicaulis.

2. C. crassisepala.

3. C. Kelseyana.

4. C. minima.

Leaves narrowly linear; calyx in fruit about $4 \mathrm{~mm}$. long.
Pubescence on the stem appressed; leaves very narrowly linear; calyx white-silky.
9 . C. leptophyila.

\section{LEIOCARPAE.} Mature nutlets solitary, subterete; stem strigose; leaves narrowly linear, almost filiform.
10 . C. flaccida.

Mature nutlets usually 4, angled on the ventral side; plants more or less hispid; leaves linear to oblanceolate.

Leaves narrowly linear or linear-lanceolate.

Fruiting calyx about $6 \mathrm{~mm}$. long; nutlets attached only to the middle.

Fruiting calyx 3-4 mm. long; nutlets attached their whole length.

11. C. affinis.

Leaves wider, oblanceolate or oblong.

12. C. leiocarpa.

13. C. confusa.

Mature nutlet solitary.

V. TORREYANA.

14. C. gracilis.

Mature nutlets usually 4. Nutlets broadly ovoid, attached by their lower half; fruiting calyx $4-7 \mathrm{~mm}$. Iong.
Corolla-limb $5-6 \mathrm{~mm}$. wide.
15. C. grandiflora.

Corolla-limb less than $2 \mathrm{~mm}$. wide.

Calyx 4-5 mm. long; lobes not much thickened on the back.

Calyx 6-7 mm. long; lobes much thickened on the back, usually spreading.

17. C. calycosa.

Nutlets lanceolate in outline, attached by their whole length.

18. C. Watsoni.

\section{Ramulosissimae.}

Leaves spatulate or oblanceolate, or the upper sometimes linear.
Leaves narrowly linear.

Branches ascending; flowers not conspicuously unilateral.

Branches divaricate, arcuate, and flowers conspicuously unilaterai.

19. C. Pattersoni.

20. C. Fendleri.

VII. Pterocaryae.

Fruiting calyx 4-5 mm. long; nutlets broadly ovate, with a broad erose or toothed wing.

Fruiting calyx, 2-3 mm. long; nutlets lance-ovate, with a narrow, entire wing.

23. C. utahensis. 
1. C. recurvata Coville. Stem $5-15 \mathrm{~cm}$. high, erect, branching, strigose, or in age hirsute; leaves linear-lanceolate or linear, 8-15 mm. long; racemes secund; sepals linear-filiform, $2 \mathrm{~mm}$. long, in fruit 3-4 mm., recurved; corolla $2 \mathrm{~mm}$. Iong; nutlet single, $1.5-1.8 \mathrm{~mm}$. long, muricate, ovate-lanceolate, acuminate; groove 2 -forked at the base. Bluffs and mountains: s Calif. $-N e v .-w$ Colo. $\longrightarrow$ S Utah. Son.-Submont. Ap-Je.

2. C. crassisepala (T. \& G.) Greene. Stem diffusely branched, 1-2 dm. high, hispid; leaves oblanceolate or linear-spatulate, $1-3 \mathrm{~cm}$. long; calyx-lobes linear, $5 \mathrm{~mm}$. long, in fruit $8-10 \mathrm{~mm}$. long; corolla $5 \mathrm{~mm}$. long; limb $1 \mathrm{~mm}$. wide; groove of the nutlets open, forming an open lance-ovate areola below. Krynitzkia crassisepala A. Gray. Loose soil, "prairie-dog towns," and waste places: Sask. -Tex.-Utah-Alta.; n Mex. Plain-Submont. My-Jl.

3. C. Kelseyana Greene. Stem branched, 1-2 dm. high, hispid; leaves linear-oblanceolate, obtuse, $3-5 \mathrm{~cm}$. long, hispid; calyx-lobes subulate, $3-4 \mathrm{~mm}$. long, in fruit 6-8 mm.; corolla $4 \mathrm{~mm}$. long; limb scarcely $1 \mathrm{~mm}$. wide; nutlets lanceolate; groove narrow, opening only at the base into a small areola. Dry sandy soil: Sask.-Colo.-Mont. Plain-Submont. Je-JI.

4. C. minima Rydb. Dwarf, beginning to bloom when only $1 \mathrm{~cm}$. high; stems several, erect; leaves spatulate or oblanceolate, obtuse, hirsute on both sides, 5-15 mm. long and 2-3 mm. wide; corolla $2.5-3 \mathrm{~mm}$. long; limb a little over $1 \mathrm{~mm}$. broad; nutlets whitish, about $1 \mathrm{~mm}$. long; groove triangular-dilated at the base. River valleys: Colo. Submont. My-Je.

5. C. barbigera (A. Gray) Greene. Stem hispid, branched, 1-3 dm. high; leaves broadly linear, hispid, 3-8 cm. long; calyx-lobes linear, in fruit $6-8 \mathrm{~mm}$. long, bristly; corolla $5 \mathrm{~mm}$. long, limb $1-3 \mathrm{~mm}$. wide; nutlet $2 \mathrm{~mm}$. long or more, ovate, acuminate, strongly muricate-papillose; groove narrow, widening into a small areola at the base. Krynitzkia barbigera A. Gray. K. mixta M. E. Jones. Arid hills and mountains: s Utah-Ariz.-Calif. Son. Ap-My.

6. C. multicaulis A. Nels. Stem branched at the base, $1.5-3 \mathrm{dm}$. high, hirsute; leaves numerous, $2-3 \mathrm{~cm}$. long, white-hispid; sepals about $5 \mathrm{~mm}$. long; nutlets ovate, less than $2 \mathrm{~mm}$. long, sparingly and minutely muricate; groove narrow, forked at the base, but without open areola. Dry and sandy places: Nev.Colo.-Mont.-Wash. Plain-Submont. Je-Au.

7. C. scoparia A. Nels. Stem about $1.5 \mathrm{dm}$. high, fastigiately branched from the base, with erect branches, sparingly hispid; leaves linear, hispid, the hairs with pustulate bases; racemes numerous; ealyx-lobes very narrow, thick, 4-5 $\mathrm{mm}$. long in fruit; nutlets 4 , about $2 \mathrm{~mm}$. long, muricate, brown, with the murications silvery-gray; groove scarcely forked at the base. Sage-brush plains: Ida. Plain. JI.

8. C. ambigua (A. Gray) Greene. Stem slender, branched, 2-4 dm. high, more or less hirsute; leaves $1-4 \mathrm{~cm}$. long, hirsute; nutlets muricate; groove barely open at the two-forked base. C. muriculata montana A. Nels. (?) C. depressa A. Nels. K. ambigua A. Gray. River banks and dry places: B.C.-Mont.-Wyo.-Utah-Calif. Son.-Submont. Je-J.

9. C. leptophylla Rydb. Stem 1.5-3 dm. high; leaves narrowly linear, 1-3 em. long, strigose; inflorescence cymose, short; calyx-lobes linear-filiform, $3-4$ $\mathrm{mm}$. long, white-silky, with long spreading hairs; corolla minute, shorter than the calyx; limb hardly $0.5 \mathrm{~mm}$. wide; nutlets $3 \mathrm{~mm}$. long, narrowly lanceolate, long-acuminate, strongly muricate; groove elosed, 2 -forked at the base. Arid regions: s Utah. Son.

10. C. flaccida (A. Gray) Greene. Stem with ascending branches, $1-5 \mathrm{dm}$. high; leaves 2-5 cm. long, grayish strigose; spikes many-flowered, in age slender; calyx-lobes about $3 \mathrm{~mm}$. long, in fruit only slightly elongate, hispidulous; corolla $4 \mathrm{~mm}$. long; limb about $2 \mathrm{~mm}$. wide; nutlet ovate-lanceolate, long-acuminate, 3 $\mathrm{mm}$. long. K. oxycarpa A. Gray. Banks, hills, and dry prairies: Wash.-Ida. - Calif. Son.-Plain. Ap-Je.

11. C. affinis (A. Gray) Greene. Stem 2-3 dm. high, strict, with erect branches, pilose; leaves $2-3 \mathrm{dm}$. long, grayish hirsute; flower-clusters at first 
almost sub-capitate; calyx-lobes subulate, pilose-hirsute with yellowish hairs; corolla $4 \mathrm{~mm}$. long, about $1 \mathrm{~mm}$. wide; nutlets ovate, thin-walled, whitish. $K$. affinis A. Gray. Dry places: Wash.-Mont.-Wyo.-Utah-Calif. Son.Submont. My-Jl.

12. C. leiocarpa (Fisch. \& Mey.) Greene. Annual; stem branched, hispid with ascending hairs, $2-4 \mathrm{dm}$. high; leaves $2-5 \mathrm{~cm}$. long, hirsute; flower-clusters short and dense; corolla $3 \mathrm{~mm}$. long, about $1 \mathrm{~mm}$. wide; nutlets ovate, glossy, brown, $2 \mathrm{~mm}$. long. K. leiocarpa Fisch. \& Mey. Hills and sandy places: B.C. - Sask.-Utah-Calif. Mr-Au.

13. C. confusa Rydb. Stem rather stout, hispid, branched; leaves $2-5 \mathrm{~cm}$. long, 3-8 mm. wide, coarsely hirsute; calyx-lobes $2 \mathrm{~mm}$. long, lance-subulate, hispid, in fruit 3-4 mm. long; corolla about $3 \mathrm{~mm}$. long; limb searcely $1 \mathrm{~mm}$. wide; nutlets ovate, $2 \mathrm{~mm}$. long, light-colored, thin-walled, attached by the lower half or two-thirds. River valleys and open woods: B.C.-Mont.-Wyo. -Utah. Plain-Submont. Je-Au.

14. C. gracilis Osterh. Stem slender, erect, branched, 1-1.5 dm. high, hirsute; leaves few, remote, linear-oblanceolate, obtuse, $1-2 \mathrm{~cm}$. long, hispid on both sides; spikes rather slender; calyx-lobes $2 \mathrm{~mm}$. long, in fruit $3 \mathrm{~mm}$., hispid with whitish or yellowish hairs; corolla white, $3 \mathrm{~mm}$. long; limb less than $1 \mathrm{~mm}$. wide; nutlet lance-ovate, acuminate, smooth, $2 \mathrm{~mm}$. long. C. Hilmanii Nels. \& Kenn. Dry places: Colo.-Utah-Ida. Submont. Je.

15. C. grandiflora Rydb. Stem branched, $2-4 \mathrm{dm}$. high, hirsute with white hairs; leaves broadly linear, lanceolate or oblong, 3-5 cm. long, 5-10 mm. wide, hirsute; calyx-lobes $3 \mathrm{~mm}$. long, in fruit $5 \mathrm{~mm}$.; corolla $4-5 \mathrm{~mm}$. long; nutlets $2.5 \mathrm{~mm}$. long, shining, smooth, rather thin-walled. River valleys: Wash.-Ida. -Ore. Son. Ap-JI.

16. C. Torreyana (A. Gray) Greene. Stem with ascending branches, hirsute; leaves linear, $2-4 \mathrm{~cm}$. long, $2-5 \mathrm{~mm}$. wide, hirsute; calyx $3 \mathrm{~mm}$. long, in fruit $4-5 \mathrm{~mm}$. long, hispid; corolla $4 \mathrm{~mm}$. long; limb 1-2 $\mathrm{mm}$. wide; nutlets about $2 \mathrm{~mm}$. long. Krynitzkia Torreyana A. Gray. Dry places: B.C.-Alta. -Colo.-Utah-Calif. Plain-Mont. Je-Au.

17. C. calycosa (Torr.) Rydb. Stem branched, 2-4 dm. high, hispid; leaves oblong or oblanceolate, $2-4 \mathrm{~cm}$. long, 4-8 mm. wide, hispid; racemes short, but elongating in fruit; calyx-lobes about $3 \mathrm{~mm}$. long, in fruit $6-7 \mathrm{~mm}$., subulate, hispid; corolla 3-4 mm. long, about $1 \mathrm{~mm}$. broad; nutlets $2.5 \mathrm{~mm}$. long. $C$. flexuosa A. Nels. $K$. Torreyana calycosa A. Gray. Stony and sandy places: Mont.-Wyo.-Nev.-Wash. Submont. Jl-Au.

18. C. Watsoni (A. Gray) Greene. Stem hispidulous, $2-3 \mathrm{dm}$. high; leaves linear, $2-5 \mathrm{~cm}$. long, hispid; calyx-lobes linear, hispid, $3 \mathrm{~mm}$. long; corolla white, about $4 \mathrm{~mm}$. long; limb $1.5 \mathrm{~mm}$. wide. $K$. Watsoni A. Gray. Hills and mountain slopes: Utah-Wyo.-Colo. Submont. Je-Au.

19. C. Pattersoni (A. Gray) Greene. Stem branched at the base, 1-2 dm. high, hirsute; leaves $2-5 \mathrm{~cm}$. long, 3-5 $\mathrm{mm}$. wide, hispid; calyx-lobes $2.5 \mathrm{~mm}$. long, in age $4 \mathrm{~mm}$. long; corolla $4 \mathrm{~mm}$. long, $1-1.5 \mathrm{~mm}$. wide; nutlets lanceolate, more or less mottled, attached by its lower half, K. Pattersoni A. Gray. Hillsides and dry places: S.D.-Colo.-Wyo.-Ida, Submont.-Mont. My-Jl.

20. C. Fendleri (A. Gray) Greene. Stem erect, hirsute with ascending hairs; calyx-lobes linear, $2-3 \mathrm{~mm}$. long, very hispid; corolla $3 \mathrm{~mm}$. long; limb scarcely $1 \mathrm{~mm}$. wide; nutlets ovate, acuminate, mottled, attached by their whole length. K. Fendleri A. Gray. River valleys and sandy places: Sask.-Neb.N.M.-Ariz.-Mont. Plain-Submont. Je-Au.

21. C. ramulosissima A. Nels. Stem densely and intricately branched, $2-3 \mathrm{dm}$. high, densely hispid; leaves small, 1-3 cm. long; sepals linear-subulate, $2-2.5 \mathrm{~mm}$. long, in fruit 5-6 mm. long, densely hispid; corolla minute; nutlets lanceolate, acuminate, $2 \mathrm{~mm}$. long. Sandy plains: Wyo. Plain. Jl-S.

22. C. pterocarya (Torr.) Greene. Stem slender, branched, hirsute, 2-3 $\mathrm{dm}$. high; leaves linear or the lower linear-spatulate, hispid; corolla $4 \mathrm{~mm}$. 
long; limb about $1 \mathrm{~mm}$. wide; nutlets ovate, granulate-tubercled on the back, affixed by nearly their whole length; groove narrow, forked at the base with an open areola. K. pterocarya A. Gray. Plains and dry places: Wash.-Ida.-W Colo.-N.M.-Calif. Son. My-JI.

23. C. utahensis (A. Gray) Greene. Stem branched, 2-3 dm. high, strigose or hirsute below; leaves linear, hispidulous; corolla $3 \mathrm{~mm}$. long; limb 1.5-2 mm. wide; nutlets lance-ovate, minutely papillate on the back; groove gradually opening below into an open areola. K. utahensis A. Gray. Eritrichium holopterum submolle A. Gray. Dry places: s Utah—s Calif. Son. My.

\section{AMSÍNCKIA Lehm. Fiddle Neck, Buckthorn-weed.}

Rough-hispid biennials. Leaves alternate, linear or oblong to ovate, entire. Flowers perfect, regular, in scorpioid spikes, leafy-bracted. Calyx persistent, 5-lobed, or some of the lobes united to near the apex. Corolla salver-shaped, yellow; tube mostly rather elongate; throat in scme flowers with and in others without fornices, in the latter the stamens inserted high up, in the former low down in the tube; limb often plicate in the sinuses. Nutlets bony, more or less triangular, attached below the middle to the pyramidal receptacle.

Leaves all narrowly linear.

Stem-leaves at least lanceolate to ovate.

Corolla about $5 \mathrm{~mm}$. long.

Corolla 8-10 mm. long.

Nutlets with tubercles in more or less distinct rows, but not with tessellate ridges. Fruiting calyx about $12 \mathrm{~mm}$. long.

Fruiting calyx about $8 \mathrm{~mm}$. long.

Stem-leaves narrowly lanceolate; tubercles distinctly in rows.

Stem-leaves broadly lanceolate; tubercles scarcely arranged in rows.

5. A. Menziesii.

Nutlets rugose, with tesselate ridges, interposed with smaller tubercles.

Stem-leaves narrowly lanceolate; inflorescence not leafy; sepals linear-lanceolate, free.

Stem-leaves broadly lanceolate or oblong; inflorescence leafy; sepals lanceolate, some often united.

1. A. retrorsa Suksd. Stem strict, $3-6 \mathrm{dm}$. high, hispid with spreading or retrorse hairs; leaves linear, 5-10 em. long, densely hirsute; sepals linear, $5 \mathrm{~mm}$. long, in fruit $8 \mathrm{~mm}$. long, not eovering the nutlets; corolla with indistinct orange spots, 7-8 mm. long; nutlets transversely rugose and with intermediate small tubercles. Dry ground and river valleys: Wash.-Ida. Son. Ap-My.

2. A. micrantha Suksd. Stem $3-4 \mathrm{dm}$. high, sparingly and finely hispid; basal leaves oblanceolate or oblong, 3-6 dm. long, sparingly hispid; upper stemleaves lanceolate; calyx-lobes linear, $4 \mathrm{~mm}$. long, in fruit 4-8 mm. long; corolla light yellow, unspotted; nutlets only faintly rugose, but rather strongly tubercled. Waste places and among bushes: Wash.-Ida.-B.C. My-Je.

3. A. idahoensis M. E. Jones. Stem about $6 \mathrm{dm}$. high, sparsely setosehispid; basal leaves oblanceolate, very hispid; stem-leaves ovate-oblong, $3-5 \mathrm{~cm}$. long; inflorescence broad and short; bracts leafy, 12-15 $\mathrm{mm}$. long; nutlets obliquely ovoid, $3 \mathrm{~mm}$. long, sharply tubercled, distinctly keeled on the back. Dry ground: Ida.-Mont. Son.

4. A. hispidissima Suksd. Stem very densely hispid, especially below, 3-7 dm. high; basal leaves oblanceolate, $5-8 \mathrm{~cm}$. long, densely hispid; stem-leaves linear-lanceolate; sepals linear-subulate, densely hispid; corolla $8 \mathrm{~mm}$. long, with orange spots in the throat. Dry and waste places: Ore--Ida.-Utah. Son.Submont. My-Je.

5. A. Menziesii (Lehm.) Nels. \& Macbr. Stem hispid, 4-7 dm. high; basal leaves oblanceolate; stem-leaves broadly lanceolate, hispid; calyx-lobes linear; corolla light yellow, spotless, $8 \mathrm{~mm}$. long; nutlets not at all rugose, densely covered with small tubercles not arranged in rows. A. intermedia A. Gray, in part. Hills: Ida.-B.C. Son. My-Jl.

6. A. rugosa Rydb. Stem 3-5 dm. high, densely hispid; basal leaves linearoblanceolate, $5-8 \mathrm{~cm}$. long, hispid; stem-leaves narrowly lanceolate; racemes 
elongate, not leafy-bracted; sepals linear-lanceolate; corolla about $8 \mathrm{~mm}$. long. A. parviflora Macbr., in part, not Bernh., nor Heller. Dry places: Ida.-Wash.Nev. Son. Ap-My.

7. A. tessellata A. Gray. Stem branched, 3-8 dm. high, sparingly hispid; basal leaves oblanceolate, 8-15 cm. long, strongly but rather sparingly hirsute; stem-leaves lanceolate, often somewhat clasping; calyx-lobes broadly lanceolate, $5-6 \mathrm{~mm}$. long, in fruit often $1 \mathrm{~cm}$. long; corolla orange, about $1 \mathrm{~cm}$. long. Dry and waste places: Wash.-Ida.-Utah-Calif. Son.-Submont. My-Jl.

\section{MERTÉnSIA Roth. Lungwort, Bluebells, Languid Lady.}

Perennial caulescent herbs. Leaves alternate, entire. Flowers perfect, regular, in racemes or panicles. Calyx deeply 5-cleft, persistent, essentially unchanged in age. Corolla tubular-funnelform or trumpet-shaped, blue or purple, rarely white; throat rarely appendaged; lobes 5 , imbricate. Stamens included or barely exserted; filaments often flattened. Nutlets obliquely attached by a small scar near the base to the convex receptacle, wrinkled at maturity. Style filiform; stigma entire.

Filaments equalling or exceeding, and usually broader than the anthers.

Calyx-lobes longer than the short tube, rarely slightly shorter.

Calyx-lobes linear or oblong, obtuse.

Stem 3-10 dm. high.

Stem 2-3 dm. high.

Calyx-lobes triangular-lanceolate to linear-lanceolate, acute.

Tube of the corolla at least twice as long as the throat and limb.

II. LONGIFLORAE.

Tube of the corolla only slightly if at all longer than the throat and limb.

Plant tall, usually more than $4 \mathrm{dm}$. high: leaves distinctly veined, in most feather-veined, but in a few triple-veined with anastomosing veins. Stem, calyx-tube and lower surface of the leaves long-hairy.

III. Paniculatae. Stem glabrous; calyx strigose or merely ciliate on the margins.

IV. MEMBRANACEAE.

Plant low, usually less than $4 \mathrm{dm}$. high; leaves with a strong midrib, without distinct lateral veins (except sometimes the basal leaves, which then however are thick and firm).

Calyx-lobes rounded-ovate, much shorter than the ample, campanulate tube.

Anthers subsessile or on very short narrow fllaments inserted in the tube or the throat of the corolla; low plants, 1-3 dm. high, of the habit of the LANCEOLATAE group. VII. ALPINAE.

\section{Ciliatae.}

Lower surface of the leaves decidedly pubescent.

Lower surface of the leaves glabrous, except the eiliate margins.

Calyx-lobes oblong, $1.5-2 \mathrm{~mm}$. long.

Stem-leaves, at least the upper ones, narrowly lanceolate; plant very pale; pedicels usually strigillose.

2. M. pallida.

Stem-leaves all ovate or broadly lanceolate; pedicels usually pustulate-muricate.

Calyx-lobes linear, $3 \mathrm{~mm}$. long, ciliate.

3. M. ciliata.

4. M. platensis.

\section{LONGIFLORAE.}

Plant with a tuberous-thickened root and mostly a single stem.

Leaves densely pubescent on both sides.

Leaves glabrous at least beneath.

Calyx-lobes linear-lanceolate, long-ciliate; pedicels strigose; leaves linear-oblong to oblong-lanceolate.

6. $M$. oblongifolia.

Calyx-lobes short-ciliate; pedicels glabrous or muriculate; leaves broader.

Corolla-tube twice as long as the limb and throat; leaves setulous-scabrous above. 7. $M$. longiflora.

Corolla-tube almost three times as long as the limb and throat; leaves merely papillose above.

Plant not tuberous-rooted, more or less cespitose.

Floral leaves oblong.

Floral leaves ovate.

8. M. pulchella.

Pedicels scabrous-muricate; corolla-tube about three times as long as the limb and throat.

9. M. nutans.

Pedicels glabrous or minutely pustulate; corolla-tube about twice as long as the limb and throat.

11. M. foliosa.

\section{Paniculatae.}

Corolla about $1.5 \mathrm{~cm}$. long; stem densely pubescent.

Corolla about $1 \mathrm{~cm}$. long; stem sparingly pubescent.

Calyx-lobes lance-linear to lanceolate, acuminate.

Calyx-lobes oblong-lanceolate, acutish.

12. M. pilosa.

13. M. paniculata.

14. M. toyabensis. 
Pedicels hairy.

\section{MEMBRANACEAE.}

Corolla $1 \mathrm{~cm}$. or less long.

Fruiting pedicels strongly reflexed.

Fruiting pedicels ascending or nodding.

Corolla-tube over $4 \mathrm{~mm}$. wide; calyx bristly-ciliate.

Corolla-tube $2-3 \mathrm{~mm}$. wide.

Calyx strigose; stem-leaves ovate.

5. M. refracta.

Calyx only ciliate on the margins; leaves oblong-lanceolate or only the uppermost ovate.

Hairs of the pedicels not with pustulate bases.

Plant stout; pedicels bristly-hispid with spreading hairs.

Plant slender; pedicels strigose.

18. M. muriculata.

32. $M$. viridis.

Hairs of the pedicels very short, and with pustulate bases.

Corolla about $1.5 \mathrm{~cm}$. long.

35. M. coronata.

19. M. pratensis.

Pedicels muricate-scabrous or smooth.

Calyx-lobes not longer than the fruit; leaves broadly ovate. 20. M. brachycalyx.

Calyx much exceeding the fruit; leaves oblong or lanceolate, or ovate in no. 23.

Calyx-lobes shorter than the calyx-tube, bristly ciliate. 21. M. arizonica.

Calyx-lobes longer than the calyx-tube.

Corolla about $15 \mathrm{~mm}$. long; pedicels smooth or sparingly callous-pustulate. Corolla-tube not shorter than the limb and throat.

Upper leaves at least three times as long as wide. 22. M. intermedia.

Upper leaves not more than twice as long as wide. 23. M. praecox. Corolla-tube shorter than the limb and throat. 24. M. Leonardi.

Corolla $10 \mathrm{~mm}$, long; pedicels with small hispidulous hairs with pustulate bases.

35. M. coronata.

\section{LANCEOLATAE,}

Pedicels decidedly strigose or hirsute.

Stem from a fusiform root; leaves glabrous beneath.

Stem from a more or less woody caudex or rootstock.

Leaves pubescent on both sides; calyx usually densely pubescent all over.

Leaves linear or only the uppermost lanceolate.

Blades of the lower leaves ovate or spatulate.

Plant more or less grayish and densely strigose throughout.

27. M. Bakeri.

Plant green.

Pubescence short, on the stem sparse.

Calyx conspicuously pubescent.

28. M. nivalis.

Calyx glabrous except the ciliate margins. 29. M. media.

Pubescence longer and loose.

Calyx less than half as long as the corolla-tube.

Calyx fully half as long as the corolla-tube. $31 . M$. amoena.

Leaves glabrous beneath; calyx usually glabrous, except the ciliate margins and sometimes the midrib.

Calyx-lobes ovate-lanceolate; inflorescence open.

Calyx-lobes narrowly lanceolate; inflorescence dense.

Leaves narrowly linear.

Leaves oblong-lanceolate to ovate.

32. $M$. viridis.

Stem-leaves ovate to lance-ovate, finely strigose above; corolla-limb and throat decidedly shorter than the tube. 34, M. ovata.

Stem-leaves oblong-lanceolate; corolla-limb and throat nearly equalling the tube.

Leaf-blades scabrous-hispidulous or merely pustulate above: stem $2-4 \mathrm{dm}$. high. $35 . M$. coronata.

Leaf-blades hispidulous-strigose above; stem rarely more than 2 dm. high.

Pedicels and calyx glabrous, except the ciliate lobes of the latter.

Calyx-Iobes ovate-lanceolate; upper stem-leaves ovate.

Calyx-lobes narrowly lanceolate; stem-leaves linear or oblong.

Upper surface of the leaves short-pubescent.

Upper surface of the leaves not hairy.

36. M. Parryi.

37. M. Drummondii.

38. $M$. linearis.

39. $M$. lanceolata.

\section{BRACHYLOBAE.}

Calyx-lobes ciliate on the margins.

Calyx-lobes not ciliate on the margins.

40. $M$. brachyloba.

41. $M$. campanulata.

VII. ALPINAE.

Calyx ciliate on the margins; inflorescence narrow.

Leaves short-strigose above, glabrous beneath.

Corolla 7-9 mm. long; plant depressed, decumbent or ascending, 1-2 dm, high.

Calyx-lobes obtuse.

Calyx-lobes acute.

Corolla more than $10 \mathrm{~mm}$. long; stem about $3 \mathrm{dm}$. high.

Leaves merely pustulate-punctate above.

42. M. alpina.

43. M. Tweedyi.

44. $M$. perplexa.

45. M. humilis. 
Calyx villous all over.

Leaves oblong or oblanceolate, glabrous beneath; inflorescence open. Leaves linear, densely hairy on both sides; inflorescence narrow. 46. . brevistyla. 47. M. cana.

One species.

VIII. INCONGRUENTES.

1. M. subpubescens Rydb. Stem simple, stout, 6-10 dm. high, glabrous throughout; leaf-blades broadly lanceolate, $5-10 \mathrm{~cm}$. long, tapering at both ends, thin, glabrous or nearly so above, short-pubescent beneath, and ciliate on the margins; pedicels slightly strigose; calyx-lobes ciliate on the margins, $2-2.5 \mathrm{~mm}$. long; corolla about $12 \mathrm{~mm}$. long, the tube only slightly longer than the limb and throat. Along streams: Mont. Mont. Je-Jl.

2. M. pallida Rydb. Stem glabrous, very pale, 5-8 dm. high, leafy; lower leaves oblanceolate, the upper narrow-lanceolate, $5-8 \mathrm{~cm}$. long, glabrous or minutely muriculate; calyx-lobes about $1 \mathrm{~mm}$. long, obtuse, ciliate on the margins; corolla about $1 \mathrm{~cm}$. long. River banks: Mont. Submont.-Mont. Je-Jl.

3. M. ciliata (Torr.) Don. Stem $3-5 \mathrm{dm}$. high, pale and somewhat bluish below; lower leaves petioled; blades oval or elliptic-ovate, $5-9 \mathrm{~cm}$. long, obtuse or acutish, sometimes finely pustulate; upper leaves lanceolate or ovate-lanceolate and subsessile; pedicels and calyx more or less pustulate; calyx-lobes in fruit nearly $2 \mathrm{~mm}$. long; corolla blue, $12-15 \mathrm{~cm}$. long. M. picta Rydb. M. polyphylla Greene. M. punctata Greene. Along streams: Wyo.-Colo.-UtahNev. Submont.-Mont. Je-Au.

4. M. platensis Rydb. Stem 3-4 dm. high, simple, pale; basal leaf-blades ovate or subcordate; stem-leaves lanceolate, pale and somewhat glaucous beneath, $5-6 \mathrm{~cm}$. long, glabrous on both sides or somewhat pustulate beneath, ciliate on the margins; pedicels pustulate-muricate, about $12 \mathrm{~mm}$. long; tube shorter than the throat and limb. Along streams: Colo. Mont.-Subalp. Je.

5. M. eplicata F. Macbr. Stem 2-3 dm. high, pubescent; leaves subvillous on both sides; basal leaves 1.5-2.5 dm. long; blades ovate; stem-leaves oblong or oblong-lancelate; calyx villous; lobes lanceolate, 4-5 mm. long; corolla-tube $10 \mathrm{~mm}$. long, not plicate; throat and limb 4-5 $\mathrm{mm}$. long. Open moist slopes: Ida. Submont. My.

6. M. oblongifolia (Nutt.) Don. Stems 1-2 dm. high, glabrous; basal leaves oblanceolate or spatulate; stem-leaves linear or linear-oblong, $2-5 \mathrm{~cm}$. long, glabrous or nearly so below, strigillose above; calyx-lobes $4 \mathrm{~mm}$. long; corolla-tube 10-14 mm. long; limb* 4.5-5 mm. long. Hills: Wash.-Nev.-Mont. -B.C. Submont. Je-J.

7. M. longiflora Greene. Stem 1-2 dm. high, glabrous; lowest leaves petioled; blades elliptic-spatulate or obovate; cauline leaves sessile, obovate or oval, 3-6 cm. long; calyx-lobes lanceolate, 4-5 $\mathrm{mm}$. long; tube of corolla $12-15 \mathrm{~mm}$. long; limb 7-8 mm. Mountains: Mont.-Ida.-Wash.-B.C. Submont.Mont. $\mathrm{My}-\mathrm{Jl}$.

8. M. pulchella Piper. Stems erect, 1-2 cm. high; lower leaves obovate, petioled, $2-6 \mathrm{~cm}$. long, the upper ovate and sessile; calyx-lobes broadly lanceolate, ciliolate-denticulate on the margins; corolla-tube about $15 \mathrm{~mm}$. long; limb $6 \mathrm{~mm}$. long. Slopes: Ida. Submont. Mr-Je.

9. M. nutans Howell. Stem 1-2 dm. high, glabrous; lower leaves oblanceolate or spatulate, the upper oblong or lanceolate, $3-6 \mathrm{~cm}$. long, glabrous below, pustulate-papillose above; pedicels short, glabrous; calyx-lobes $4 \mathrm{~mm}$. long, obscurely ciliolate; corolla-tube about $1 \mathrm{~cm}$. long; limb $5 \mathrm{~mm}$. long. Hills: Wash. -Ore.-Nev.-Mont. Submont. Ap-My.

10. M. tubiflora Rydb. Stem $2-3 \mathrm{dm}$. high, glabrous; basal leaves oblanceolate, short-petioled; stem-leaves sessile, lanceolate to ovate, about $4 \mathrm{~cm}$. long, glabrous beneath, pustulate above, ciliolate on the margins; calyx slightly

* In this species as in many of the following the throat is included with the limb, even if not specially mentioned. 
strigillose; Iobes lanceolate; corolla 13-15 mm. Iong. Mountains: Wyo. Mont. Jl.

11. M. foliosa A. Nels. Stem erect, glabrous, $2-4 \mathrm{dm}$. high; leaves thick, glabrous or slightly pustulate above, the lower ones oblong or spatulate, 4-7 cm. long, petioled; stem-leaves lanceolate or the upper ones ovate; calyx-lobes lanceolate, ciliolate; corolla $15-18 \mathrm{~mm}$. long. Hills and cañons: Wyo.-Utah. Submont. My-Je.

12. M. pilosa (Cham.) DC. Stem simple, 3-4 dm. high, villous; leaves lanceolate, 5-8 cm. long, acuminate at each end, villous-hirsute beneath, strigose above; pedicels and calyx canescent-strigose; lobes linear-lanceolate, $5 \mathrm{~mm}$. long, strigose; corolla-tube equalling the limb. Pulmonaria pilosa Cham. Lithospermum corymbosum Hook. Wet places: Hudson Bay-Canadian RockiesAlaska. Boreal.

13. M. paniculata (Ait.) Don. Stem moie or less hirsute, $3-6 \mathrm{dm}$. high; leaves lanceolate, acuminate at each end, $5-10 \mathrm{~cm}$. long, hirsute on both sides; pedicels and calyx strigose; lobes of the latter $4 \mathrm{~mm}$. long; corolla-tube 4-5 mm. long, about equalling the throat and limb. Pulmonaria paniculata Ait. Along streams and shady banks: Hudson Bay-w Ont.-Ia.-Ida.-Wash.-Alaska. Boreal-Mont. My-JI.

14. M. toyabensis F. Macbr. Stem 4-5 dm. high, subvillous; basal leaves oblong-lanceolate, $10-15 \mathrm{~cm}$. long; stem-leaves lanceolate or ovate-lanceolate, $10 \mathrm{~cm}$. long; pedicels hirsute; calyx-lobes hirsute, $3-4 \mathrm{~mm}$. long, in fruit $5-6 \mathrm{~mm}$. long; corolla-tube $6 \mathrm{~mm}$. long, equalling the throat and limb. Mountains: Nev.-Utah. Mont. Jl.

15. M. refracta A. Nels. Stems tufted, $2-4 \mathrm{dm}$. high; stem-leaves oblong to ovate, $3-5 \mathrm{~cm}$. long, minutely strigose; pedicels minutely strigose, in fruit reflexed; calyx-lobes linear, softly hirsute, $2-3 \mathrm{~mm}$. long; corolla $1 \mathrm{~cm}$. long; tube equalling the throat and limb. Mountains: Colo. Mont. Jl.

16. M. cynoglossoides Greene. Stem 4-6 dm. high, glabrous; basal leaves long-petioled; blades elliptic, 1-1.5 dm. long; stem-leaves ovate, acutish, somewhat cordate-clasping, 7-10 cm. long, thin, glabrous beneath, scabrous-hispidulous above and on the margins; pedicels sparingly hispidulous; calyx-lobes lanceolate, $4 \mathrm{~mm}$.; corolla-tube about $6 \mathrm{~mm}$. long, $4 \mathrm{~mm}$. thick, about equalling the throat and limb. Cañons, along streams: Colo. Submont. Je.

17. M. membranacea Rydb. Stem glabrous or sparingly hirsute above, 6-8 dm. high; leaf-blades ovate, acute or more often short acuminate, 4-8 cm. long, very thin, hispid-strigillose on both sides; pedicels hispidulous; calyx-Iobes $2-3 \mathrm{~mm}$. long, hispidulous, lanceolate; corolla about $1 \mathrm{~cm}$. long; tube longer than the dark blue limb and throat. Wet places: Mont.-Utah.-Wash. Submont. $\mathrm{Je}-\mathrm{Au}$.

18. M. muriculata Greene. Stem decumbent at the base, $3-5 \mathrm{dm}$. high; leaves thin, glabrous beneath, pustulate-seabrous above; basal leaf-blades elliptic-lanceolate, $7-10 \mathrm{~cm}$. long; stem-le aves lanceolate or ovate, sessile or clasping; calyx-lobes lance-ovate, hispid-ciliate; corolla $5 \mathrm{~mm}$. long, about equalling the throat and limb. Along streams: Colo. Submont. Je.

19. M. pratensis Heller. Stem pale, 6-8 dm. high; lower leaves petioled, upper sessile; basal leaf-blades oval-lanceolate or elliptic-lanceolate, glabrous beneath, hispidulous-strigcse above and on the margins; pedicels and calyx strigose; lobes linear-lanceolate, acute; corolla-tube about $8 \mathrm{~mm}$. long, and 4 $\mathrm{mm}$. wide; limb of about the same length, 8-10 mm. wide. M. alba Rydb., an albino form. Wet meadows and along streams: Colo.-N.M.-Ariz. Submont. -Subalp.

20. M. brachycalyx Piper. Stem glabrous, erect, 5-10 dm. high, leafy; leaves bright green, lance-ovate, acuminate, smooth beneath, minutely pustulate above, 5-10 $\mathrm{cm}$. long; pedicels smooth or nearly so; calyx-lobes triangular-ovate, acute, glabrous, minutely ciliate on the margins; corolla $10-12 \mathrm{~mm}$. long, the tube about as long as the throat and limb. Creek banks: Wash.-Ida. Submont. Jl-Au. 
21. M. arizonica Greene. Stem $3-5 \mathrm{dm}$. high; leaves thin, glabrous, smooth or minutely pustulate above, ciliolate on the margins, the lower petioled, with oblanceolate blades, the upper sessile, lanceolate or ovate, $5-10 \mathrm{~cm}$. long; calyx-lobes ovate, ciliate-margined, 3-4 mm. long; corolla $12-15 \mathrm{~mm}$. long. Cañons: Utah-Ariz. Submont. Je-J.

22. M. intermedia Rydb. Stem 3-4 dm. high, glabrous, strict; lower leaves about $1 \mathrm{dm}$. long; blades oblanceolate, obtuse, minutely pustulate and scabrous-ciliolate on the margins; upper leaves sessile, oblong or lanceolate; sepals lanceolate, hispid-ciliate, 3-4 mm., in fruit often $8 \mathrm{~mm}$. long; corolla-tube 8-10 $\mathrm{mm}$. long; limb 5-7 $\mathrm{mm}$. long. (?) $M$. umbratilis Greenm. $M$. stenoloba. Greene. Hills and banks: Mont.-Wyo.-Ida. Submont.-Mont. My-Jl.

23. M. praecox Smiley. Stem 4-5 dm. high, glabrous; cauline leaves ovateelliptic to suborbicular, 6-9 $\mathrm{cm}$. long, 3-4.5 $\mathrm{cm}$. wide; calyx-lobes glabrous or slightly ciliate, 2-4 $\mathrm{mm}$. long; corolla-tube slender, $2.5 \mathrm{~mm}$. thick; throat and limb. $5 \mathrm{~mm}$. long. Cañons: Utah. My.

24. M. Leonardi Rydb. Stem erect, glabrous, 5-10 dm. high; leaves thin, glabrous and smooth beneath, more or less pustulate-muricate above, and ciliolate on the margins, the lower short-petioled; blades oblanceolate, 4-7 cm. long; stem-leaves lanceolate or ovate, $5-15 \mathrm{~cm}$. long; pedicels sparingly pustulate; calyx-lobes lanceolate, $4 \mathrm{~mm}$. long, ciliolate; corolla-tube 6-7 mm. long; limb 8-10 $\mathrm{mm}$. long, 7-8 mm. wide. Cañons: Utah. Submont.-Mont. J.

25. M. fusiformis Greene. Stem 1-3 dm. high, glabrous; leaves thick, strigose above, glabrous beneath, the lower petioled, $5-8 \mathrm{~cm}$. long, with spatulate blades; stem-leaves oblong or lanceolate; pedicels strigose; calyx villousciliate on the margins and often with a few scattered hairs on the back; corolla 8-10 mm. long; tube equalling the limb. $M$. congesta Greene. Hillsides: Colo. Submont.-Mont. My-Je.

26. M. lateriflora Greene. Stems $2-3 \mathrm{dm}$. high, canescent-strigose; leaves crowded, linear or lance-linear, 3-5 cm. long, canescent-strigose on both sides; inflorescence leafy; pedicels and calyx strigose; calyx-lobes lanceolate, more villous; corolla 6-8 mm. long; throat and limb only slightly shorter than the tube. M. secundorum Cockerell. Mountains and hillsides: Colo. Submont.-Subalp. My-Jl.

27. M. Bakeri Greene. Stems 1-3 dm. high, densely strigose-canescent; lower leaves spatulate or oblanceolate, the upper oblong or lanceolate, $3-5 \mathrm{~cm}$. long, canescent; pedicels densely strigose; calyx pilose; lobes linear; tube of the corolla 6-7 mm. long; throat and limb 5-6 mm. long. Mountains: Colo. Mont. - Alp. Je-J.

28. M. nivalis (S. Wats.) Rydb. Stem 1-2 dm. high, sparingly strigose or almost glabrous; basal leaves petioled, $3-5 \mathrm{~cm}$. long; blades spatulate or oblanceolate; stem-leaves lanceolate or ovate, 1-3 cm. long, sparingly strigose on both sides; pedicels short, strigose; calyx-lobes lanceolate, $2 \mathrm{~mm}$. long, silky-strigose; corolla $10-12 \mathrm{~mm}$. long, tube about equalling the limb. M. paniculata nivalis $\mathrm{S}$. Wats. High mountains: Utah. Subalp. Au.

29. M. media Osterhout. Stem slender, 2-3 dm. high, glabrous or sparingly pubescent; leaves all linear, $3-6 \mathrm{~cm}$. long, the upper shorter, appressed shorthirsute on both sides, the upper often with pustulate-based hairs; pedicels hirsute; calyx 3-3.5 mm. long; lobes narrowly linear; corolla about $1 \mathrm{~cm}$. long, the tube equalling the throat and limb. Hills: Colo. Submont. My.

30. M. myosotifolia Heller. Stem 1-2 dm. high, densely pilose; leaves rather thick, densely pilose on both sides, the lower petioled, $5-8 \mathrm{~cm}$. long, with ovate or lance-elliptic blades; stem-leaves sessile, lanceolate or ovate, $3-5 \mathrm{~cm}$. long; pedicels and calyx pilose, the latter $3 \mathrm{~mm}$. long, with lance-ovate lobes; corolla-tube 5-7 mm. long, throat and limb 4-6 mm. long. M. micrantha A. Nels. Mountains: Colo. Mont. Je.

31. M. amoena A. Nels. Stem 1-3 dm. high, pilose with short spreading hairs; leaves pilose, the lower $4-7 \mathrm{~cm}$. long, petioled, with oblong-oblanceolate to 
oval blades, the upper broadly linear or narrowly oblanceolate, $3-6 \mathrm{~cm}$. long; pedicels pilose-strigose; calyx-lobes lanceolate, ciliate-hirsute on the margins and sometimes on the back; corolla $10-15 \mathrm{~mm}$. long; tube searcely longer than the limb. Hills and mountains: Mont.-Wyo.-Colo.-Ida. Submont.-Mont. Je.

32. M. viridis A. Nels. Stems slender, 2-4 dm. high, glabrous; leaves glabrous beneath, hispid-strigose above, the lower petioled, the upper sessile; blades of the basal ones spatulate, obtuse, those of the stem-leaves acute, elliptic, or lanceolate; pedicels strigose; calyx glabrous, except the base and the margins of the lobes; tube about $4 \mathrm{~mm}$. long; limb of about the same length. $M$. viridula Rydb. Mountains: Colo.-Wyo. Mont.-Alp. My-Jl.

33. M. lineariloba Rydb. Stem glabrous, simple, 2-3 dm. high; basal leaves 5-15 cm. long, long-petioled; blades oblanceolate, obtuse; stem-leaves subsessile, linear or linear-lanceolate, acute, $3-6 \mathrm{~cm}$. long, 4-9 mm. wide, strigose above; pedicels very slender, strigose; calyx-lobes linear, acute, $3-4 \mathrm{~mm}$. long, almost equalling the tube of the corolla, glabrous on the back, but hispid-ciliate on the margins; corolla blue, 7-8 mm. Iong; tube nearly of the same length as the throat and limb. Hillsides: Colo. Mont. Je-Jl.

34. M. ovata Rydb. Stem 1-1.5 dm. high, glabrous; leaves $2-5 \mathrm{~cm}$. long, minutely strigose above, glabrous beneath, the lower obovate and short-petioled, the upper broadly ovate and sessile; pedicels very short; calyx-lobes lanceolate, ciliate on the margin, about $4 \mathrm{~mm}$. long; corolla $10-12 \mathrm{~mm}$. long. High mountains among rocks: Colo.- e Utah. Mont. Jl.

35. M. coronata A. Nels. Stem glabrous, shining, adsurgent, 2-4 dm. high; leaves scabrous-hispidulous, or merely pustulate above, the basal ones petioled; blades oblong, obtuse, $5-10 \mathrm{~cm}$. long; upper stem-leaves ovate-lanceolate; calyx-lobes lanceolate, ciliate-margined; corolla-tube $5 \mathrm{~mm}$. long, a little longer than the limb. Rocky hills: Ida.-Wyo.-(Black Hills) S.D. Submont. Je.

36. M. Parryi Rydb. Stem about $2 \mathrm{dm}$. high, glabrous; leaves hispidulousstrigose above, only the basal ones petioled and spatulate; stem-leaves sessile, lanceolate or oblanceolate, about $5 \mathrm{~cm}$. long; pedicels strigose; calyx glabrous except the very base and the eiliate margins of the lobes, these narrowly linearlanceolate, about $3 \mathrm{~mm}$. long; tube of the blue corolla about $5 \mathrm{~mm}$. long and about equalling the length of the throat and limb. Alpine ridges: Colo. Subalp. - Alp. Jl.

37. M. Drummondii (Lehm.) Don. Stem 1-2 dm. high, decumbent at the base, glabrous; leaves hispidulous above, oblong or lance-oblong, or the upper ovate, $3-4 \mathrm{~cm}$. long; pedicels very short, pustulate; calyx-lobes ovate-lanceolate, ciliolate on the margins; corolla about $1 \mathrm{~cm}$. long, the tube equalling the throat and limb. Aretic seacoast-Canadian Rockies, Subarctic.

38. M. linearis Greene. Stems $2-4 \mathrm{dm}$. high, leafy, glabrous; leaves narrowly linear, $2-7 \mathrm{~cm}$. long, roughly strigillose above, glabrous beneath; pedicels glabrous or pustulate; calyx-lobes lanceolate, ciliolate on the margins, otherwise glabrous; corolla about $1 \mathrm{~cm}$. long; tube about equalling the throat and limb. Dry hillsides: Sask.-Neb.-Colo.-Alta. Plain-Mont. My-Jl.

39. M. lanceolata (Pursh) DC. Stem 2-4 dm. high, glabrous; leaves glabrous on both sides or merely pustulate above, the lower petioled, $3-10 \mathrm{~cm}$. long; stem-leaves oblong or lanceolate; pedicels pustulate-muricate; calyx-lobes lanceolate, ciliolate on the margins, otherwise glabrous; corolla about $1 \mathrm{~cm}$. long; tube equalling the limb. $M$. coriacea A. Nels. M. papillosa Greene. Hills: Sask.-N.D.-Colo.-B.C. Submont.-Subalp. Ap-Au.

40. M. brachyloba Greene. Stem 3-4 dm. high, glabrous and glaucous; lower leaves oblanceolate, the upper lanceolate or oblong-ovate, 4-6 cm. long, glabrous or slightly papillose; calyx-lobes ciliolate on the margins; corolla-tube 6-7 mm. long, slightly shorter than the limb and throat. Foot-hills: Colo. Submont. My-Je. 
41. M. campanulata A. Nels. Stem pale, $3 \mathrm{dm}$. high or more, glabrous; basal leaves long-petioled; blades glabrous, $8-12 \mathrm{~cm}$. long, oblong, tapering at both ends; stem-leaves oblanceolate; pedicels and calyx glabrous; calyx-lobes broadly triangular, one-fourth as long as the tube; corolla $18-20 \mathrm{~mm}$. long; tube equalling the throat and limb. Meadows: Ida. Лl.

42. M. alpina (Torr.) Don. Stems ascending, glabrous, 1-2 dm. high; lower leaves spatulate or oblanceolate, obtuse, tapering into a winged petiole, dark green, 3-5 cm. long, the upper broadly lanceolate, sessile; pedicels very short, often sparingly strigillose; calyx-lobes oblong, obtuse, $2-3 \mathrm{~mm}$. long; corolla dark blue, about $7 \mathrm{~mm}$. long; tube nearly equalling the throat and limb. M. obtusiloba Rydb. High mountains: Colo,-N.M. Subalp.-Alp.

43. M. Tweedyi Rydb. Stems decumbent or rarely ascending, often less than $1 \mathrm{dm}$. high; basal leaves petioled, somewhat fleshy, 2-5 $\mathrm{cm}$. long, with oblanceolate blades; stem-leaves 1-2 $\mathrm{cm}$. long, oblong-lanceolate; calyx-lobes linear-lanceolate, eiliate on the margins; corolla $8-10 \mathrm{~mm}$. long; limb and throat fully as long as the tube. High mountains: Colo.-Wyo. Mont.-Alp. $\mathrm{My}-\mathrm{Au}$.

44. M. perplexa Rydb. Stem about $3 \mathrm{dm}$. high, glabrous; basal leaves spatulate, 4-10 $\mathrm{cm}$. long, petioled; stem-leaves sessile, the lower oblanceolate, the upper ovate; pedicels minutely hispid-strigose, the hairs with pustulate bases; corolla blue, about $12 \mathrm{~mm}$. long; tube equalling the throat and limb, the latter 7-8 mm. wide. High mountains: Colo. Alp. Jl.

45. M. humilis Rydb. Stem 1-2 dm. high, ascending or decumbent, glabrous; basal leaves petioled, $3-8 \mathrm{~cm}$. long; blades thick, elliptic to ovate; stemleaves sessile, elliptic or ovate, rarely oblong, $2-4 \mathrm{~cm}$. long; pedicels with seattered large pustules; corolla $7-8 \mathrm{~mm}$. long; tube slightly shorter than the limb and throat. Stony slopes: Wyo. Subalp. My-Je.

46. M. brevistyla S. Wats. Stem 1-3 dm. high, glabrous or slightly strigose; leaves firm, strigose above, oblong, or the lower oblanceolate; pedicels strigose; calyx-lobes lanceolate, hirsute; corolla 7-8 mm. long; tube shorter than the limb and throat. High mountains: Utah. Submont.-Subalp. Ap-Je.

47. M. cana Rydb. Stems about $1 \mathrm{dm}$, high, strigose; leaves linear or linear-oblanceolate, grayish strigose on both sides; pedicels and calyx strigose; calyx-lobes linear-lanceolate, acute, about $2 \mathrm{~mm}$. long, ciliate on the margins; corolla blue, about $8 \mathrm{~mm}$. long; tube as long as the throat and the limb, the latter about $3 \mathrm{~mm}$. wide. M. canescens Rydb., not Kaulf. High mountains: Colo. Subalp.-Alp. Jl.

\section{MYOSÒTIS (Rupp.) L. FoRget-ME-Not.}

Annual, biennial, or perennial caulescent herbs. Leaves alternate, entire, narrow. Flowers perfect, regular, in 1-sided racemes. Calyx persistent, 5lobed; lobes erect or spreading. Corolla salverform, blue, pink, or white, often with an eye; tube short; throat with transverse crests; lobes rounded, convolute. Stamens included. Nutlets small, ovoid, smooth, attached by the very base to the flat receptacle.

Perennials, tufted; corolla $4-6 \mathrm{~mm}$. wide.

1. M. alpestris.

Annuals; corolla less than $2 \mathrm{~mm}$. wide.

Stem tall, 3-5 dm. high; calyx nodding in fruit, 5-7 mm. long; nutlets about $2 \mathrm{~mm}$.

long.
Stem lower, $1.5-3 \mathrm{dm}$. high; calyx not nodding in fruiting, less than 5 mm. long; nutlets about $1.5 \mathrm{~mm}$, long.

3. M. virginica.

1. M. alpestris Schmidt. Stem 1-3 dm. high, hirsute; basal leaves spatulate or oblanceolate, $3-7 \mathrm{~cm}$. long, hirsute; stem-leaves linear-lanceolate; calyx lobes lanceolate, ereet in fruit; corolla bright blue, $4-6 \mathrm{~mm}$. wide. Wet places in the mountains: Alta.-Colo.-Alaska; Eurasia. Mont.-Subalp. My-Au.

2. M. macrosperma Engelm. Stem 3-5 dm. high, hirsute with ascending hairs, leafy; basal leaves oblanceolate, $2-8 \mathrm{~cm}$. long, sparingly hirsute; stemleaves lanceolate or oblong; racemes 1-2 dm. long; calyx-lobes $2.5 \mathrm{~mm}$., in fruit 6-7 mm. long; corolla light blue or white, $3 \mathrm{~mm}$. long. River banks and open woods: D.C.-Fla.-Tex.-Calif.-B.C.-Ida. Plain-Submont. Ap-Je. 
3. M. virginica (L.) B.S.P. Stem branched from the base, $0.5-3 \mathrm{dm}$. high, hirsute; basal leaves spatulate, 1-3 cm. long; stem-leaves linear-oblong; corolla white, very small. Dry banks and rocky woods: Me.-Ga.-Tex.-Ore.-B.C. Ap-Je.

\section{LITHOSPÉRMUM (Tourn.) L. Gromwell, Puccoon, IndLAN PaINT.}

Annual or perennial caulescent herbs. Leaves alternate, entire, narrow, hirsute. Flowers perfect, regular, in bracted spikes or racemes. Calyx persistent, 5-lobed. Corolla salverform or funnelform, white or yellow; tube often elongate; throat either appendaged or pubescent; lobes 5, entire, erose, or toothed. Stamens included. Stigma capitate or 2-lobed. Nutlets white, shining and smooth, or brown and wrinkled, attached by their very bases to the flat receptacle.

Annuals; nutlets dull, brownish, coarsely wrinkled and pitted.

Perennials, with thick taproots; nutlets white and shining.

Corolla-lobes neither fimbriate nor toothed; flowers all well developed.

Corolla greenish or pale yellow, $1 \mathrm{~cm}$. or less long; crest in the throat obsolete; plant very leafy, with the flowers mostly on the short branches.

Corolla-limb 3-5 mm wide; tube not longer than the ealyx; stem grayish strigose, but scarcely hispid.

Corolla-limb $5-8 \mathrm{~mm}$. wide; tube longer than the calyx.

Leaves linear or narrowiy linear-lanceolate; stem very hispid; plant canescent.

3. L. ruderale.

Leaves lanceolate, long-attenuate; stem scarcely hispid; plant green.

4. L. lanceolatum.

Corolla bright yellow or orange, more than $1 \mathrm{~cm}$. long; crest in the throat prominent.

Floral leaves of the later flowers small, shorter than the flowers; limb of the corolla $6-8 \mathrm{~mm}$. wide.

5. L. multiflorum.

Floral leaves of the later flowers not reduced; limb of the corolla 8-20 $\mathrm{mm}$. wide.

Hispid-pubescent; corolla-tube bearded at the base within.

Canescent; corolla-tube not bearded at the base within.

6. L. Gmelini.

7. L. canescens.

Corolla-lobes of the early flowers fimbriate or dentate; later flowers cleistogamous.

Corolla of the early flowers $2.5-3 \mathrm{~cm}$. (rarely only $2 \mathrm{~cm}$.) long; lobes distinctly fimbriate.

Plant hirsute.

Plant appressed-canescent. Leaves narrowly linear. Leaves spatulate to linear-oblong.

Corolla of the early flowers $2 \mathrm{~cm}$. or less long; lobes dentate.

Corolla 15-20 mm. long; limb 8-10 mm. wide; stem low, ascending or decumbent.

8. L. asperum.

9. L. linearifolium. 10. L. oblongum.

Coroll $10 \mathrm{~mm}$ or less long; limb 6-8 mm. wide; stem strict, $2-4 \mathrm{dm}$, high, mostly simple, or with erect branches.

12. L. breviflorum.

1. I. arvense L. Stem 2-5 dm. high, strigose, simple or branched at the base; leaves lanceolate, linear, or oblong, sessile or the lower short-petioled, canescent-strigose; corolla white, about $6 \mathrm{~mm}$. long; calyx equalling or exceeding the corolla-tube; nutlets $2 \mathrm{~mm}$. long. Waste places and fields: Que.-Ga.-Kans. -Minn.; Utah; Mont.; nat. from Eu. Plain-Son. My-Au.

2. L. Torreyi Nutt. Stem erect, $2-4 \mathrm{dm}$. high; leaves linear or linearlanceolate, $3-8 \mathrm{~cm}$. long, strigose; corolla 6-8 $\mathrm{mm}$. long; nutlets $5 \mathrm{~mm}$. long, ovoid. Hills and cañons: Mont.-Colo.-Utah-Ida. Plain-Submont. Je$\mathrm{Au}$.

3. L. ruderale Lehm. Stem 3-5 dm. high; leaves $3-8 \mathrm{~cm}$. long, canescent, pilose, or strigose; corolla $10-12 \mathrm{~mm}$. long; nutlets slightly wrinkled, $5 \mathrm{~mm}$. long. L. pilosum Nutt. Hills: Alta.-Colo.-Nev.-B.C. Plain-Submont. Ap-J1.

4. L. lanceolatum Rydb. Stem 3-6 dm. high, strigose; lower leaves linearlanceolate, the upper lanceolate, 4-10 cm. long, finely strigose; corolla yellowish, 8-10 mm. long; nutlets 5-6 mm. long. Hills, cañons, and plains: Mont.-Utah -Calif.-Wash. Plain-Submont. My-Jl.

5. I. multiflorum Torr. Stem strigose or somewhat hirsute, $3-6 \mathrm{dm}$. high, virgately branched above; leaves linear or linear-lanceolate, appressed-strigose 
above, more hirsute beneath; corolla $10-12 \mathrm{~mm}$. long; nutlets $3 \mathrm{~mm}$. long. Hills, mountain sides, cañons: Wyo.-N.M.-Ariz.-Utah; Mex. Submont.-Mont. $\mathrm{My}-\mathrm{Jl}$.

6. L. Gmelini (Michx.) Hitchc. Stem hispid, 3-6 dm. high; leaves lanceolate, or oblong, hispid, 4-8 $\mathrm{cm}$. long; corolla $15-20 \mathrm{~mm}$. long; limb $15-20 \mathrm{~mm}$. wide; nutlets $4 \mathrm{~mm}$. long. L. hirtum Lehm. Sandy places, dry plains, and open woods: N.Y.-Fla.-N.M.-Mont. Plain-Submont. Ap-Jl.

7. L. canescens (Michx.) Lehm. Stem 2-4 dm. high, hirsute or pilose; leaves oblong to linear, 1-4 cm. long, canescent-strigose; corolla 10-12 $\mathrm{mm}$. long; limb about $1 \mathrm{~cm}$. wide; nutlets $3 \mathrm{~mm}$. long. Plains and prairies: Ont.-Ala.Tex.-Colo.-Sask. Plain. Ap-Jl.

8. L. asperum A. Nels. Stems $1.5-3 \mathrm{dm}$. high, hirsute, with white divaricate hairs; leaves oblong to linear, $2-4 \mathrm{~cm}$. long, rough-hirsute; corolla $2-3 \mathrm{~cm}$. long; limb $1-1.5 \mathrm{~cm}$. broad; lobes crenulate-erose. L. ciliolatum Greene. Sandstone slopes: Wyo. Submont. Je.

9. L. linearifolium Goldie. Stems strict, 1-5 dm. high, canescent-strigose; leaves all linear, $1-5 \mathrm{~cm}$. long, strigose; corolla of the earlier flowers $2.5-3 \mathrm{~cm}$. long; limb 10-18 mm. wide, erose-fimbriate; cleistogamous flowers $1 \mathrm{~cm}$. long or less; nutlets more or less pitted. L. angustifolium Michx. Dry soil: Man.Ill.-Tex.-Ariz.-B.C. Plain-Submont. Ap-Jl.

10. L. oblongum Greene. Stems numerous, 1-2 dm. high, strigose; leaves short, $2-3 \mathrm{~cm}$. long, strigose; corolla of the early flowers about $3 \mathrm{~cm}$. long; limb about $1 \mathrm{~cm}$. wide; nutlets pitted along the margins. Dry plains: N.M.-Wyo. Son.-Plain. Ap-Je.

11. L. mandanese Spreng. Stems many, 1-2 dm. high; leaves linear, 3-4 $\mathrm{cm}$. long, mostly strigose; corolla of the early flowers $1.5-2 \mathrm{~cm}$. long; nutlets sparingly pitted. Dry plains: N.D.-Tex-Ariz.-Alta. Plain-Submont. Ap-Je.

12. L. breviflorum Engelm. \& Gray. Stems several, erect, 2-4 dm. high, finely strigose; leaves narrowly linear, $3-5 \mathrm{~cm}$. long, ascending; corollas of the early flowers $1 \mathrm{~cm}$. long or less, deep yellow; nutlets scarcely pitted except near the margins. L. albicans Greene. Dry plains: Ark.-Tex.-N.M.-Colo. Son. My-Je.

\section{ONOSMÒdIUM Michx. False Gromwell.}

Coarse perennial caulescent herbs. Leaves alternate, entire, usually broad, strongly nerved, pubescent. Flowers perfect, regular, in terminal scorpioid racemes or spikes. Calyx persistent, with 5 narrow lobes. Corolla tubular, yellow, white, or greenish; tube elongate; throat without appendages; lobes erect. Stamens included; anthers often sessile. Nutlets white, shiny, smooth or sparingly pitted, attached by their very base to the flat receptacle, often only one or two maturing.

1. O. occidentale Mackenzie. Stem 3-6 dm. (rarely 6-12 dm.) high, branched above, white-hispid; leaves about $5 \mathrm{~cm}$. long, prominently 5-7-ribbed, coarsely hirsute-strigose; corolla $12-20 \mathrm{~mm}$. long, canescent, its lobes broadly triangular, acute, $3-4 \mathrm{~mm}$. long; nutlets $3.5-4 \mathrm{~mm}$. long, ovoid, not constricted at the base, dull, little if at all pitted. Plains and prairies: Man.-Ill.-Mo.-Tex.-N.M. -Utah-Alta. Plain-Submont.

\section{ANCHÛSA L. AlKanet.}

Annual or perennial herbs, with hispid or villous foliage. Flowers bracteate, in scorpioid cymes. Calyx 5-cleft. Corolla blue or purple; tube straight; throat closed by fornices or hairs. Nutlets rugose or granulate, inserted by a broad concave base on the flat receptacle.

1. A. officinalis L. Perennial, with a taproot; stem hispid, 3-8 dm. high; basal leaves oblanceolate, 1-2 dm. long, very hispid; stem-leaves lanceolate; corolla dark blue, fully $1 \mathrm{~cm}$. long. Waste places and roadsides: N.Y.-Utah; sparingly introduced from Eu. Plain-Submont. Jl-S. 


\section{SYMPHYेTUM (Tourn.) L. COMFreY.}

Large hairy perennials. Leaves alternate, entire, or the uppermost opposite; the lower long-petioled. Flowers in terminal scorpioid racemes. Calyx deeply 5-cleft. Corolla blue, purple, or yellow, campanulate, with short lobes; fornices in the throat lanceolate or linear, papillose-margined. Nutlets obliquely ovoid; scar large, concave, bordered by a prominent denticulate ring-margin.

1. S. offlcinale L. Stem 6-10 dm. high; leaves lanceolate to ovate, the lower petioled, the upper decurrent on the stem; calyx-lobes lance-linear; corolla purplish or yellowish, 1-2 $\mathrm{cm}$. long. Waste places: Newf.-Md.-Mont,; adv. or escaped from cultivation; native of Eu. Je-Au.

\section{Family 114. Verbenaceae. Vervain Family.}

Annual or perennial herbs, or in warmer climates sometimes shrubs or trees. Leaves usually alternate, rarely opposite or whorled, usually simple. Flowers perfect, more or less irregular, zygomorphic, in ours spicate. Calyx of 4 or 5 , more or less united sepals, usually bracteolate. Corolla of 4 or 5 , partially united petals, usually 2-lipped. Stamens 2 , or 4 , and then didynamous; filaments more or less adnate to the corolla; anthers erect or incumbent. Gynoecium of 2 or 4 carpels; styles united; stigma entire or 2or 4-lobed; ovules 1 or 2 in each cavity, anatropous. Fruit separating into 2 or 4 nutlets, or drupes, or berry-like. Seeds commonly solitary in each cavity; endosperm scant or wanting; embryo straight.

Corolla-limb 5-lobed; nutlets 4; flowers in terminal spikes.

Corolla 4-lobed; nutlets 2 ; flowers in short dense axillary spikes.

1. VERBENA.

2. Phrla.

\section{VERBENA (Tourn.) L. Vervain, Verbena.}

Annual or perennial herbs. Leaves opposite, entire, toothed, or dissected. Flowers in terminal spikes. Calyx-tube funnelform. Corolla more or less bilabiate; tube narrow, straight or curved. Limb 5-lobed. Stamens 4, didynamous, rarely only 2 ; connective of the anthers often bearing a gland. Ovary 4-celled; stigma 2-lobed, only one lobe stigmatose; ovules solitary in each cell. Fruit of 4 nutlets, enclosed in the calyx.

Anthers not appendaged; flowers in elongate spikes, less than $8 \mathrm{~mm}$. long.

Leaves not pinnatifid, sometimes merely lobed at the base in the first species; plant tall, erect, strict.

Bracts shorter than the calyx, or barely equalling it.

Spike peduncled; corolla-limb 3-6 mm. broad; pubescence sparse, coarse.

Spike sessile; corolla-limb 8-9 mm. broad; pubescence dense, soft.

Bracts one-third longer than the calyx; pubescence dense, soft.

2. V. stricta.

3. V. MacDougalii.

Leaves more or less pinnatifid, at least incised; bracts much longer than the calyx. Spike dense; nutlets muriculate on the commissural faces. 4 . V. bracteosa. Spike lax; nutlets nearly smooth on the commissural faces. 5. V. remota.

Anthers of the longer stamens appendaged by a gland on the connective; corolla $8 \mathrm{~mm}$. long or more.

Calyx-lobes subulate or lance-subulate. Leaves twice 3-parted into linear-oblong or lanceolate divisions.

6. V. ciliata.

Leaves once 3-parted, with toothed or slightly lobed divisions. 7 . V. Gooddingii.

Calyx-lobes setaceous.

7. V. Gooddingit.

Bracts narrowly lanceolate, shorter than the calyx; leaf-segments oblauceolate.
8. V. ambrosifolia.

Bracts setaceous, longer than the calyx; leaf-segments linear.

9. V. bipinnatifida.

1. V. hastata L. Perennial; stem 4-15 dm. high, hispidulous, branched above, 4-angled; leaf-blades scabrous-hispidulous, lanceolate or ovate-lanceolate, 4-12 cm. long, sharply and doubly serrate, often hastate at the base; spikes erect, narrow, 5-15 cm. long; calyx $2.5 \mathrm{~mm}$. long, pubescent; corolla purplish 
blue; nutlets smooth. River valleys, thickets and waste places: N.S.-Fla.N.M.-Calif.-B.C. Plain-Submont. My-Au.

v. hastata $\times$ stricta. In habit resembling $V$. hastata, but the leaves more veinyreticulate and softer pubescent and the corolla larger. Mo.-Colo.

2. V. stricta Vent. Perennial; stem stout, $3-12 \mathrm{dm}$. high, simple or branched above, densely pilose, almost velutinous, terete or nearly so; leaf-blades oblong, oval, 3-10 $\mathrm{cm}$. long, doubly serrate or incised, rugose, nearly sessile, densely soft-pubescent; spike stout, strict; calyx hirsute, $5 \mathrm{~mm}$. long; corolla dark blue; nutlets strongly reticulate. Dry soils, pastures, and river valleys: Minn.-Ky. -Tex.-N.M.-Wash.; introduced eastward to Conn. Je-Au.

3. V. MacDougalii Heller. Perennial; stem stout, simple, obtusely 4angled, 3-7 dm. high, densely pilose; leaf-blades oblong-lanceolate, densely softpubescent, short-petioled, thick, rugose and reticulate beneath, incised-serrate, 7-9 cm. long; spikes often solitary or few, stout, dense; corolla blue; limb $4 \mathrm{~mm}$. broad; nutlets striate, with a few cross-reticulations above. River valleys: N.M. -Colo.-Ariz. Plain-Submont. J-Au.

4. V. bracteosa Michx. Annual or perennial; stem branched at the base, prostrate or procumbent, 1-5 dm. long, diffusely branched, angled, more or less hirsute; leaf-blades spatulate in outline, pinnately lobed and incised or doublytoothed, 1-6 cm. long, prominently veined beneath, hirsute; bracts lanceolate or linear-lanceolate; calyx bristly, $3 \mathrm{~mm}$. long; corolla purple or bluish; limb $2 \mathrm{~mm}$. broad; nutlets strongly reticulate on the back. V. rudis Greene. Waste places, prairies and plains: Man.-Ill.-Fla.-Tex.-Calif.-B.C. Plain-Submont.

V. bracteosa $\times$ hastata. Resembling most $V$. bracteosa in habit, but stouter, more erect, with broad, laciniate rather than dissected leaves and shorter bracts. Neb.- Colo.

$\nabla$. bracteosa $\times$ stricta. Resembling $V$. bracteosa in habit, but stouter, with broad, laciniate, strongly reticulate leaves and larger flowers. Mo.-Kans.-Neb.

5. V. remota Benth. Annual or perennial; stem mostly erect, sparingly branched, 2-4 dm. high, round-angled, hirsute; leaf-blades obovate in outline, mostly bipinnatifid, with lanceolate divisions, $2-8 \mathrm{~cm}$. long, hirsute; bracts linear or linear-subulate; calyx $2-2.5 \mathrm{~mm}$. long, hirsute; teeth subulate, short; corolla lilac, 4-5 mm. long; nutlets reticulate on the back. Plains and waste places: Utah-c Mex. Son. Ap-N.

6. V. ciliata Benth. Perennial; stem branched at the base, $0.5-2 \mathrm{dm}$. high, decumbent, hirsute, leafy; leaf-blades $2-4 \mathrm{~cm}$. long, obovate in outline; calyx becoming 7-8 mm. long; corolla $1-1.5 \mathrm{~cm}$. long; limb 7-8 $\mathrm{mm}$. wide; nutlets strongly wrinkled. Dry plains and hills: Tex.-Colo.-Ariz.; Mex. Son.Submont. Ap-Au.

7. V. Gooddingii Briq. Perennial; stem 2-5 dm. high, robust, hirsute, branched; leaves spatulate or obovate in outline, densely hirsute; spikes very short; bracts lanceolate, acuminate, shorter than the calyx; corolla $12-15 \mathrm{~mm}$. long; limb $8 \mathrm{~mm}$. broad. Sandy bottom lands: Nev. - S Utah-Ariz. Son. Mr-My.

8. V. ambrosifolia Rydb. Perennial; stem branched and decumbent at the base, sparingly hirsute, $2-4 \mathrm{dm}$. long; leaf-blades obovate in outline, bipinnatifid or biternately divided, with oblanceolate divisions, sparingly hirsute; calyx becoming $8-9 \mathrm{~mm}$. long; corolla-limb $6-8 \mathrm{~mm}$. wide; nutlets coarsely wrinkled all over the back. Plains and stony soil: S.D.-Tex.-Ariz. Son.-PlainSubmont. Je-Au.

9. V. bipinnatifida Nutt. Perennial; stems often branched at the base, 1-4 dm. high, decumbent at the base; leaf-blades $2-5 \mathrm{~cm}$. long, bipinnatifid; segments linear; calyx becoming $9-10 \mathrm{~mm}$. long; corolla-limb 7-9 mm. wide; nutlets $3 \mathrm{~mm}$. long, prominently wrinkled above. Plains and dry ground: S.D.-La.-Tex. Son.-Plain. My-Jl.

\section{PHỲLA Lour.}

Perennial, caulescent, prostrate or creeping herbs. Leaves opposite, petioled, toothed or lobed. Flowers perfect, in dense, sometimes head-like, peduncled axillary spikes, conspicuously bracted. Calyx-tube flattened and 2- 
keeled. Corolla 2-lipped; tube curved; limb 4-lobed, oblique. Stamens 4, didymous; connective of the anthers not appendaged. Ovary 2-celled; stigma oblique; ovules solitary in each cell. Fruit tardily separating into two nutlets. [Lippia in part.]

Leaves from linear-oblanceolate to cuneate, 2-8-toothed above; peduncles slightly if any exceeding the leaves.

1. $P$. cuneifolia. Leaves lanceolate, oblong, or oval, sharply serrate; peduncles much exceeding the leaves.

1. P. cuneifolia (Torr.) Greene. Stems branched at the base, procumbent or creeping, 2-10 dm. long; leaves opposite and more or less fascicled in the axils; blades 1-3 cm. long; midvein prominent, the lateral ones obsolete; corolla purplish or whitish, $4 \mathrm{~mm}$. long. Lippia cuneifolia (Torr.) Steud. Plains and prairies: S.D.-Tex.-Ariz.-Wyo. Plain-Submont. Je-Au.

2. P. lanceolata (Michx.) Greene. Stem branched from the base, procumbent, 1-4 dm. long; leaves opposite, rarely fasciculate; blades elliptic-lanceolate, $1.5-5 \mathrm{~cm}$. long, acute, with about 4 pairs of lateral veins; corolla pale blue, 2-2.5 mm, long. Valleys: Ont.-Fla.-Tex.-Neb. Plain-Son. Je-O.

\section{Family 115. LAMiaCeae. Mint Family.}

Aromatic herbs or shrubs, with 4-angled stems. Leaves opposite or whorled, simple, usually toothed or lobed, glandular-punctate. Flowers perfect, irregular, zygomorphic, or nearly regular, pseudo-verticillate, i.e., in congested axillary reduced cymes. Calyx of 5 united sepals, sometimes regular, sometimes irregular, and then usually 2-lipped. Corolla bilabiate, or nearly regular. Stamens 4, didynamous, or one of the pairs abortive; anthers 2-celled. Gynoecium of united earpels; ovary 4-lobed and 4-celled; styles united, arising between the lobes; stigma terminal; ovules solitary in each cell. Fruit of 4 nutlets, included in the persistent calyx. Endosperm fleshy or wanting.

Ovary of 4 united nutlets; style not basal; nutlets laterally attached.

Corolla strongly bilateral, the upper lip very small, the lower large.

Flowers in small congested cymes, axillary to small bracts, and forming a racemelike panicle; calyx-lobes shorter than the tube; leaves toothed.

Flowers solitary in the axils of bracts similar to the leaves; calyx-lobes longer than the tube: leaves laciniate. 2. MELOSMON.

Corolla almost regularly 5-lobed, but lobes declined; stamens long-exserted and

Ovary of 4 distinct or nearly distinct nutlets; styles basal; nutlets basally attached.

Corolla bilabiate.

Calyx 2-lipped; both lips entire; stamens 4. Calyx not inflated, the upper lip with a crest on the upper side.

Calyx inflated, without a crest.

4. SCUTELLARIA.

5. SALAZARIA

Calyx either 2-lipped and at least one of the lips toothed, or regularly 4-5-toothed. Stamens included in the corolla-tube.

Stamens exserted from the tube.

Upper lip of the corolla concave.

Anther-bearing stamens 4 .

Upper stamens longer than the lower.

Calyx 5-toothed.

Anther-sacs parallel or nearly so; stamens divergent.

7. AGASTACHE.

Anther-sacs divaricate; anther approximate in pairs.

Flowers in terminal spikes; floral leaves reduced; plant

Flowers in axillary verticils; floral leaves like the rest;

8. NEPETA. plant spreading.

Calyx distinctly 2-lipped.

9. GLECOMA.

10. MOLDAVICA.

Upper stamens shorter than the lower.

Calyx distinctly 2-lipped, closed in fruit. 11. Prunella.

Calyx 5-toothed, not 2-lipped, open in fruit.

Calyx membranous, inflated in fruit, faintly nerved.

Calyx not membranous, not inflated in fruit, strongly 5-10. nerved. 
Anther-sacs not transversely 2-valved.

Nutlets 3-sided, truncate above.

Calyx-teeth awn-pointed, spreading.

Calyx-teeth not awn-pointed.

13. LEONURUS.

14. LAMIUM.

Nutlets ovoid, nearly terete, rounded above.

15. STACHYS.

Anther-sacs transversely 2-valved. 16. GALEOPSIS.

Anther-bearing stamens 2.

Connective of the anthers very long, articulated to the filaments, bearing a perfect anther at the ascending end and areduced one or none at the other; calyx 2-lipped.

Upper lip of the corolla erect, entire or emarginate; lower portion of the connective either dilated and naked or with a small anther.

Inflorescence head-like; calyx-teeth aristate; lower portion of the connective anther-bearing. 17. PYCNOSPHACE.

Inflorescence raceme or spike-like; calyx-teeth not aristate; lower portion of the connective not anther-bearing.

18. SALVIA.

Upper lip of the corolla spreading, 2-lobed; lower portion of the connective a mere tooth or lacking; flowers verticillateglomerate.

19. AUDIBERTELLA

Connective of the anther short; anther-cells confluent; calyx equally

5-toothed.

Upper lip of the corolla flat.

Stamens curved, often converging.

Calyx regularly 5-toothed.

Anther-bearing stamens 2. 21. Poliomintha.

Anther-bearing stamens $4 . \quad 25$. Micromeria.

Calyx 2-lipped or irregularly 5-toothed.

Anther-bearing stamens 2.

Anther-bearing stamens 4.

22. HEDEOMA.

23. ClinOPODIUM.

Stamens straight, distant and diverging; calyx almost regularly 5toothed; anther-bearing stamens $4 . \quad 24$. MADRONELLA.

Corolla nearly regular, 4-5-toothed.

Anther-bearing stamens 2.

Anther-bearing stamens 4 .

26. LYCOPUS.

27. MEnTHA.

\section{TEÙCRIUM (Tourn.) L. Germander, Wood Sage.}

Perennial caulescent herbs, rarely shrubs. Leaves toothed. Flowers perfect, in raceme-like inflorescence. Calyx campanulate, 10-ribbed; lobes 5, unequal. Corolla purplish, pink, or white; upper lip very short; lower lip 3-lobed, the middle lobe elongate. Stamens 4 , inserted between the lobes of the upper lip, the anterior pair the longer; anther-sacs divergent, confluent at the base.

1. T. occidentale A. Gray. Perennial, with a rootstock; stem $3-8 \mathrm{dm}$. high, villous-hirsute; leaf-blades ovate-oblong, oblong, or lanceolate, 4-9 cm. long, sharply serrate, strigose above, paler and softly villous beneath; calyx $5-6 \mathrm{~mm}$. long, viscid-villous, often purplish; corolla purplish, $8-10 \mathrm{~mm}$. long. Thickets and wet grounds: Ont.-Pa.-N.M.-Calif.-B.C. Plain-Submont. Je-Au.

\section{MELÓSMON Raf.}

Perennial or annual herbs. Leaves opposite, incised or parted. Flowers solitary in the axils of the leaves. Calyx-tube very short, 10-ribbed; lobes 5, equal or nearly so. Corolla blue, lilac, or white; upper lip small; lower lip 3lobed, with the middle lobe the longer. Stamens 4, as in Teucrium.

1. M. laciniatum (Torr.) Small. Perennial, with a woody root and short cespitose eaudex; stems 1-2 dm. high, glabrous or nearly so; leaf-blades pinnately 3-7-parted, into linear divisions, which are sometimes again lobed; calyx 10-12 mm. long; lobes linear-subulate, acuminate; corolla pale blue or lilac, 1.5-2 em. long. Plains: Kans.-Tex.-Ariz.-Colo. Son. My-Au.

\section{TRIChOSTEMA L. Blue Curls.}

Annual or perennial berbs, rarely shrubby. Leaves rather narrow, entire or merely repand. Flowers perfect, in axillary cymes or panicles. Calyx campanulate, with short tube; lobes 5, unequal. Corolla blue, purple, pink, or white, slightly irregular. Stamens 4, didymous, conspicuously exserted; filaments curved, the anterior pair the longer and spirally curled in bud; anthersacs divergent. Nutlets reticulate. 
1. T. oblongum Benth. Annual; stem branched, 1-3 dm. high, soft-villous; leaves short-petioled; blades oblong to oval, membranous, $1-4 \mathrm{~cm}$. long, softpubescent on both sides; flower-clusters axillary, much shorter than the leaves; calyx-lobes subulate, longer than the tube and nearly equalling the corolla; corolla about $6 \mathrm{~mm}$. long; filaments $8-10 \mathrm{~mm}$. long. Moist places: Wash.-Ida. -Calif. Submont. Je-Jl.

\section{SCUTELI.ÀRIA L. SkULlCAP.}

Annual or perennial herbs, sometimes shrubby. Leaves opposite, entire or toothed. Flowers perfect, in terminal racemes or panicles, often leafy-bracted. Calyx campanulate, 2-lipped; lips entire, the upper with a erest. Corolla blue, violet, or white; throat dilated; limb 2-lipped, the upper lip arched, the lower 3-lobed; lateral lobes small, the middle one large and spreading. Stamens 4, didymous; anthers ciliate, those of the upper pair 2-celled, those of the lower 1-celled. Nutlets papillose or tubercled.

Flowers in axillary and terminal racemes.

Flowers solitary in the axils of the leaves.

\section{S. lateriflora.}

Perennials, with horizontal rootstock.

Leaf-blades lanceolate or ovate, more or less distinctly toothed, at least the lower ones.

Leaf-blades lanceolate, acute.

Leaf-blades ovate, obtuse.

Leaf-blades entire or nearly so, ovate, oblong or linear.

Corolla blue or violet; nutlets not raised on a gynobase.

Pedicels shorter than the calyx; calyx and corolla villous outside; lower lip of the latter glabrous within.

3. S. Brittoni.

Pedicels not shorter than the calyx; calyx and corolla densely short-pubescent; lower lip of the latter bearded within.

Corolla 12-18 mm. long; leaves elliptic, usually entire.

Corolla $18-30 \mathrm{~mm}$. long.

4. S. antirrhinoides.

Leaves linear or oblong, entire; corolla-tube slender, gradually widening upward.

Lower leaves ovate, usually toothed; corolla-tube ample, abruptly widening upwards. 6 . S. veronicifolia.

Corolla yellow; nutlets raised on a gynobase. $\quad 7$. S. Footeana.

Perennials, with a woody caudex.

8. S. resinosa.

1. S. lateriflora L. Perennial, with a creeping rootstock; stem 2-10 dm. high, glabrous or sparingly puberulent above, branched; leaves slender-petioled; leaf-blades thin, ovate or ovate-lanceolate, $2-6 \mathrm{~cm}$. long, coarsely serrate, rounded or cordate at the base; calyx 2-4 mm. long; corolla blue, 6-7 mm. long. Along streams and swamps: Newf.-Fla.-Ida.-B.C. Plain-Submont. Je-S.

2. S. galericulata L. Stem strigose, at least on the angles, $2-9 \mathrm{dm}$. high; leaf-blades oblong or oblong-lanceolate, acute, crenate, truncate or cordate at the base, more or less densely strigose and often glandular-granuliferous beneath; calyx $3.5-5 \mathrm{~mm}$. long, minutely pubescent; corolla blue, or rarely pink or white, 15-18 mm. long, pubescent. River banks and swamps: Newf.-N.C.-Ariz.Alaska; Eurasia. Plain-Submont. Je-Au.

3. S. Brittoni Porter. Stem puberulent, 1-3 dm. high; leaves entire, nervose, finely puberulent, oblong to oval, $1-3 \mathrm{~cm}$. long; calyx puberulent, $5-6$ $\mathrm{mm}$. long; corolla about $2 \mathrm{~cm}$. Iong, gradually dilated upwards. $S$. resinosa A. Gray, not Torr. S. virgulata Nels. Hillsides and valleys: Wyo.-Colo. Submont.-Mont. My-Jl.

4. S. antirrhinoides Benth. Stem branched, diffuse or ascending, 1-3 $\mathrm{dm}$. high, puberulent; leaves elliptic, grayish puberulent, 1-2 cm. long, obtuse; calyx $4 \mathrm{~mm}$. long, finely puberulent. Moist shady places: Ore.-Ida.-Nev.Calif. Submont. Je-Jl.

5. S. angustifolia Pursh. Stem 1-3 dm. high, minutely puberulent; lower leaves oblong or oval, the upper linear to oblong, usually entire, $1-2.5 \mathrm{~cm}$. long, the radical ones often orbicular or cordate; calyx about $4 \mathrm{~mm}$. long, puberulent. Moist ground: B.C.-Mont.-Utah-Calif. Submont. My-Jl.

6. S. veronicifolia Rydb. Stem 2-4 dm. high, finely puberulent, more or less purplish; leaves ovate, obtuse, coarsely crenate, 1-4 cm. long, minutely 
puberulent or glabrate, short-petioled; those of the inflorescence and branches oblong and entire or nearly so; calyx finely pubescent, $6 \mathrm{~mm}$. long. Hillsides: Ida.-Calif. Submont. My-Je.

7. S. Footeana Mulford. Stem 6-10 cm. high, much branched and spreading, purplish, puberulent; leaves $1.5-2.5 \mathrm{~cm}$. long, entire, oblanceolate or obovate, finely and densely pubescent; calyx about $6 \mathrm{~mm}$. long; corolla $12-18 \mathrm{~mm}$. long, ampliate-dilated, lemon-yellow to dull brownish yellow at the base, somewhat hairy within. Cañons: Ida. Je.

8. S. resinosa Torr. Stems many, diffusely branched, 1-3 dm. high, grayish puberulent; leaf-blades ovate, oval, elliptic, or oblong-spatulate, 1-1.5 $\mathrm{cm}$. long, grayish puberulent, strongly veined beneath; calyx $3-5 \mathrm{~mm}$. long, merely resinous; corolla blue or purplish, minutely pilose, $1 \mathrm{~cm}$. long. S. Wrightii A. Gray. Plains and hills: Kans.-Tex.-Ariz.-Colo. Son.

\section{SAlazària Torr. Bladder Skullcap, Bladder Bush.}

Scraggly desert shrubs. Leaves small, entire. Flowers perfect, racemose. Calyx at first oblong, in age enlarging, becoming inflated and globular, barely repand-bilabiate. Corolla bilabiate; upper lip arched; lower lip 3-lobed, but the lateral lobes small. Stamens 4, didymous, parallel; anthers eiliate, those of the upper pair 2-celled, those of the lower 1-celled. Nutlets tubercled.

1. S. mexicana Torr. Shrub 6-10 dm. high; branches divaricate, often recurving, finely canescent-strigose; leaves glabrate, oblong or broadly lanceolate, about $1 \mathrm{~cm}$. long; racemes terminal, short; calyx about $5 \mathrm{~mm}$. long, in fruit inflated and $2 \mathrm{~cm}$. in diameter; corolla about $2 \mathrm{~cm}$. long. Ravines: s Utah-Ariz. -s Calif.-Nev. L. Son. My-Je.

\section{MARRÙBIUM (Tourn.) L. HOREHOUND.}

Perennial caulescent herbs. Leaves toothed, woolly. Flowers perfect, in axillary clusters. Calyx tubular, 5-10-ribbed; lobes 10, equal, or alternately longer and shorter, recurved at maturity. Corolla white or purplish, 2-lipped; upper lip erect, entire or notched; lower lip 3-lobed, the lateral lobes small, the middle one large and broad. Stamens 4 , included, didymous, the anterior pair the longer; anthers 2-celled, with divergent sacs. Nutlets smooth or granular.

1. M. vulgare L. Stem white-woolly, $2-10 \mathrm{dm}$. high, usually strict; leafblades suborbicular, oval or ovate, $1-4 \mathrm{~cm}$. long, erenate, strongly rugose; bracts subulate, with hooked ends; calyx 4-5 mm. long, 10-ribbed; lobes ridged, hooked; corolla white, $5-6 \mathrm{~mm}$. long, puberulent. Waste places: Me.-N.C.-Calif.B.C. Plain-Son.

\section{AGĀstACHE Clayton. Giant Hyssop.}

Tall perennial herbs, with rootstocks. Leaves petioled, broad, toothed. Flowers perfect, in dense terminal spike-like panicles. Calyx narrowly campanulate or tubular, slightly 2-lipped; lobes nearly equal or the upper somewhat longer. Corolla purplish, rose, or yellowish, 2-lipped; upper lip erect, notched; lower lip 3-lobed, the middle lobe toothed or undulate. Stamens 4, exserted, didymous; anthers 2-celled, sacs almost parallel. Nutlets smooth. [Lopanthus Benth. Vleckia Raf.]

Calyx-lobes ovate-lanceolate, acute.

Leaves glaucous beneath; calyx tinged with blue; stem glabrous. 1. A. anethiodora.

Leaves not glaucous beneath; calyx green, yellowish, or rarely pinkish; stem puberulent.
2. A. pallidiflora.

Calyx-lobes elongate-lanceolate, acuminate, rose-tinged.

3. A. urticifolia.

1. A. anethiodora (Nutt.) Britton. Stem glabrous or nearly so, 6-15 dm. high; leaf-blades ovate or deltoid-ovate, acute or acuminate, serrate, green above, pale beneath, 5-8 cm. long, anise-scented; spike dense, 4-10 cm. long, scarcely $2 \mathrm{~cm}$. thick; corolla blue, $8-10 \mathrm{~mm}$. long. L. anisatus Benth. A. Foeniculum (Pursh) Kuntze. Among bushes: Ont.-Ill.-Colo.-Alta.-Mack. PlainSubmont. J1-S. 
2. A. pallidiflora Heller. Stem 6-10 dm. high, einereous-puberulent; leafblades ovate or cordate, crenate, puberulent, 3-5 cm. long, acute; spikes 4-8 $\mathrm{cm}$. long, about $2 \mathrm{~cm}$. thick; corolla about $14 \mathrm{~mm}$. long, pale pink. Brittonastrum pallidiflorum Heller. A, montana Greene. Mountains: Colo.-N.M.-Ariz. Submont.-Mont. Jl-S.

3. A. urticifolia (Benth.) Rydb. Stem stout, 5-10 dm. high, glabrous or minutely puberulent; leaf-blades cordate, coarsely dentate, $3-10 \mathrm{~cm}$. long; spike very dense, $2-10 \mathrm{~cm}$. long, $2.5-3 \mathrm{~cm}$. thick; corolla rose or violet, about $15 \mathrm{~mm}$. long. L. urticifolius Benth. Hillsides and valleys: Mont.-Colo.-Calif.B.C. Submont.-Mont. My-Au.

\section{NËPETA L. CATnip, Cat Mint.}

Perennial or annual caulescent herbs. Leaves broad, toothed or incised, pubescent. Flowers perfect, in axillary cymes, clustered. Calyx inflated in age, 15-ribbed, incurved; lobes 5, the upper slightly longer than the lower. Corolla white or blue; throat enlarged; upper lip erect, entire or notched; lower lip 3-lobed, with large middle lobe. Stamens 4, didymous, exserted; anthers with 2 diverging sacs. Nutlets flattened, smooth.

1. N. Cataria L. Perennial; stem densely tomentulose, $6-10 \mathrm{dm}$. high; leafblades ovate or cordate, coarsely crenate, $2-8 \mathrm{~cm}$. long, green above, densely white-tomentose beneath; flower-clusters spicate at the end of the branches; calyx densely puberulent, its lobes subulate; corolla white or pale purple, darkdotted, 10-12 mm. long. Waste places and around dwellings: N.B.-Va.Utah-Ore,; nat. from Eu. Plain-Submont. Jl-N.

\section{GLeCòma L. Ground Ivy, Gill-over-the-Ground.}

Low creeping perennial herbs. Leaves opposite, long-petioled. Flowers perfect, in axillary verticils. Calyx-tube short-tubular, 15-nerved, oblique, unequally 5-toothed. Corolla 2-lipped; tube exserted, enlarged above; upper lip erect, 2-lobed or emarginate; lower lip spreading, 3-lobed, the middle lobe broad, emarginate. Stamens 4; anther-sacs divergent. Nutlets ovoid, smooth.

1. G. hederacea L. Stem pubescent, 3-5 dm. Iong; leaf-blades orbicular or reniform, crenate, 1-4 cm. broad; calyx-teeth lanceolate, acuminate; corolla $1.5-2$ $\mathrm{cm}$. long, light blue, three times as long as the calyx. Waste places, roadsides, and thickets: Newf.-Ga.-Colo.-Mont.; nat. from Eurasia. Plain-Submont. $\mathrm{Mr}-\mathrm{My}$.

\section{MOLdàvica (Tourn.) Adans. Dragon's Head.}

Herbs, with blue or purple flowers, in axillary and terminal bracted clusters. Leaves mostly toothed or dissected. Calyx tubular, 15-nerved, 5-toothed, or 2-lipped, with the upper 3 teeth more or less united. Corolla enlarged above, 2-lipped; upper lip erect, emarginate; lower lip spreading, 3-lobed. Stamens 4, the upper the longer, all fertile; anthers more or less approximate in pairs; sacs divergent. Nutlets ovoid, smooth. [Dracocephalum L., in part.]

1. M. parviflora (Nutt.) Britton. Annual or biennial; stem finely puberulent, 2-6 dm. high; leaf-blades lanceolate, ovate, or oblong, coarsely serrate, the upper with spinulose-tipped teeth; bracts pectinate, with awn-pointed teeth; upper tooth of the calyx longer than the rest; corolla light blue, scarcely longer than the calyx. D. parviflorum Nutt. Hillsides and valleys: N.Y.-Neb.N.M.-Ariz.-Alaska. Submont.-Mont. Je-Au.

\section{1. prunêlla l. Self-heal, Heal-all, Carpenter Weed.}

Perennial caulescent herbs, with rootstocks. Leaves opposite, petioled, toothed, pubescent. Flowers perfect, irregular, in axillary clusters, toward the end of the stem forming a leafy spike-like inflorescence. Calyx 2-lipped, elosed at maturity; tube 10-ribbed; upper lip truncate, slightly 2-lobed, the lower with 3 narrow lobes. Corolla purple or white, 2-lipped; upper lip arched; lower lip 
3-lobed, with broad middle lobe. Stamens 4, but 2 sterile; fertile stamens with forked filaments, one prong bearing the 2-celled anthers. Nutlets smooth.

1. P. vulgaris L. Stem procumbent or ascending or erect, $0.5-5 \mathrm{dm}$. high; leaf-blades ovate, oblong, or lanceolate, entire or erenate, 2-10 cm. long; spike terminal, very dense, $1-3 \mathrm{~cm}$. long in flower, or $5-10 \mathrm{~cm}$. in fruit; bracts broadly ovate-orbicular, cuspidate; corolla violet or purple, 8-12 $\mathrm{mm}$. long. Woods and wet places among bushes: Newf.-Fla.-Calif.-B.C.; nat. from Eurasia. Plain-Mont. My-O.

\section{DRacocéphalum (Tourn.) L. False Dragon-head.}

Perennial herbs, with mostly simple stems. Leaves opposite, glabrous, rather narrow, usually toothed. Calyx campanulate, 5-ribbed, more or less inflated; lobes 5, nearly equal. Corolla purple, pink, or white, 2-lipped; tube dilated upwards; upper lip entire; lower lip 3-lobed, with the middle lobe emarginate. Stamens 4, all fertile; anthers 2-celled; sacs parallel. Nutlets smo th, 3-angled. [Physostegia Benth.]

1. D. Nuttallii Britton. Stem simple, 3-10 dm. high, glabrous; leaves lanceolate, oblong, or linear, dentate, the upper sessile, 7-10 cm. long; spike 2-10 $\mathrm{cm}$. long; calyx campanulate, with ovate, obtuse teeth; corolla purple, about 1 cm. long. Physostegia parviflora Nutt. Banks of streams and among bushes: Sask.-Minn.-Colo.-Ore.-B.C. Plain-Submont. J1-Au.

\section{LEONÙRUS L. MOTHERWORT.}

Annual or perennial caulescent herbs. Leaves opposite, toothed, or palmately cleft or parted. Flowers perfect, irregular, in dense axillary clusters. Calyx tubular-campanulate, 5-ribbed; lobes 5, nearly equal, subulate or awntipped. Corolla white or pink, 2-lipped; upper lip erect, nearly flat; lower lip spreading, 3-lobed; middle lobe broad, truncate, or notched. Stamens 4, all fertile; anthers 2-celled; sacs mostly parallel. Nutlets smooth, 3-angled.

1. L. Cardiaca L. Perennial; stem erect, 3-10 dm. high, strigose-puberulent; leaf-blades 2-10 cm. long, palmately 3-5-cleft, with lanceolate, more or less acuminate, entire or toothed lobes; calyx 5-angled; lobes spinulose; corolla pale purple or white, villous without, $9-10 \mathrm{~mm}$. long. Waste places: N.S.-N.C. -Tex.-Utah.-Mont. Plain-Submont. Je-Au.

\section{LÀmium L. Dead Nettrle, Henbit.}

Annual or perennial caulescent herbs, with branched stems. Leaves opposite, petioled, usually broad, toothed or incised. Flowers perfect, irregular, in remote axillary clusters. Calyx campanulate, 5-nerved; lobes 5, equal or the upper somewhat longer. Corolla purple, blue, or white, 2-lipped; upper lip erect, concave, entire; lower lip 3-lobed; lateral lobes narrow, the middle one dilated and notched. Stamens 4, all fertile; anthers 2-celled; sacs divergent. Nutlets smooth or tuberculate.

1. L. amplexicaule L. Annual or biennial; stem slender, weak, branched from the base and lower axils, usually decumbent, 1-5 dm. long, glabrous; leafblades orbicular, cordate, or reniform, $1-4 \mathrm{~cm}$. broad, crenate, the upper sessile and more or less clasping; flowers axillary; corolla purplish or red, $12-16 \mathrm{~mm}$. long; middle lobe of the lower lip spotted. Waste places and eultivated ground: N.B.-Fla.-Utah-Calif.-B.C.; adv. from Eu.

\section{Stàchys (Tourn.) L. Hedge Nettle.}

Annual or perennial herbs, ours with rootstocks. Leaves opposite, in ours petioled and toothed. Flowers perfect, in axillary clusters, sometimes approximate, forming leafy spikes. Calyx mostly campanulate, 5-10-ribbed, 5-lobed. lip spreading, 3-lobed; middle lobe largest, often 2-lobed. Stamens 4; anthers all fertile, 2-celled; anther-sacs divergent or parallel; filaments naked. Nutlets obtuse, not truncate at the apex, smooth. 
Leaves and the angles of the stem coarsely hispid.

1. S, asperrima.

Leaves and stem softly pubescent.

Lateral lobes of the lower corolla-lip large, half as broad and three-fourths as long as the middle one.

2. S. ampla.

Lateral lobes of the lower corolla-lip small, scarcely half as long as the middle one. Stem glabrous below; leaves short-pubescent or glabrate. Stem pubescent throughout; leaves loosely villous.

Leaves oblong-ovate or cordate; corolla $12-15 \mathrm{~mm}$. long; ealyx lobes almost

4. S. teucriformis.
equalling the calyx-tube. shorter than the calyx-tube.

1. S. asperrima Rydb. Stem stout, 4-6 dm. high, coarsely hispid on the angles, with spreading or reflexed hairs; leaves nearly sessile, oblong, elliptic, or oblong-lanceolate, 5-8 $\mathrm{cm}$. long, coarsely erenate, hispid above, hispid on the veins and also puberulent beneath; corolla purplish, 10-12 $\mathrm{mm}$. long, puberulent, and more or less hirsute on the lips outside. Valleys: Utah. Son. Jl.

2. S. ampla Rydb. Stem 5-7 dm. high, softly hirsute and more or less viscid; leaves ovate to lanceolate, $5-10 \mathrm{~cm}$. long, sessile or nearly so, erenateserrate, softly pubescent on both sides; corolla rose-colored or pink, about 15 mm. long, somewhat puberulent without. Meadows: Black Hills, S.D. Submont. Au.

3. S. Leibergii Rydb. Stem 3-6 dm. high, sharply angled, glabrous below, softly hirsute above; leaves sessile, lanceolate, 4-8 cm. long, crenate-dentate, pubescent on both sides with short appressed hairs or in age glabrate; corolla about $12 \mathrm{~mm}$. long, rose-colored, glabrous. Low meadows: Ida.-B.C. Submont. Jl-Au.

4. S. teucriformis Rydb. Stem 4-6 dm. high, glandular-villous; lower leaves short-petioled, the upper sessile; blades 5-10 $\mathrm{cm}$. long, crenate, pubescent on both sides; corolla light rose, with reddish-purple veins and blotches. Wet meadows: Colo.-Wyo. Submont. J1-Au.

5. S. scopulorum Greene. Stem 3-6 dm. high, softly hirsute with spreading hairs and more or less glandular; leaf-blades serrate, $5-10 \mathrm{~cm}$. long, softly pubescent on both sides; corolla rose, lilae, or purplish, blotched. Wet meadows: Minn.-N.M.-Utah-Wash.-Mack. Plain-Submont. J-S.

\section{Galeópsis L. Hemp Nettle.}

Annual herbs. Leaves opposite, petioled. Flowers perfect, in several axillary verticils. Calyx 5-ribbed, with 5 subequal lobes. Corolla dilated at the throat; upper lip ovate, arehed, entire; lower lip 3-cleft, with an obcordate middle lobe; palate with 2 teeth at the sinuses. Stamens 4 ; anthers all 2-celled. Nutlets ovoid, slightly flattened, smooth.

1. G. Tetrahit L. Stem 3-10 dm. high, swollen below the nodes; leaf-blades ovate, coarsely serrate, 5-15 $\mathrm{cm}$. long; corolla purple or pink, variegated with white, $15-25 \mathrm{~mm}$. long, twice as long as the ealyx. Waste places: Newf.-N.C. -(Black Hills) S.D.-Alaska; nat. or adv. from Eu. Je-S.

\section{PyCNOSPhàCE (Benth.) Rydb. Thistle Sage, Chia.}

Annual herbs. Leaves opposite, mainly basal, pinnately lobed. Flowers perfect, capitate-verticillate, with persistent, spinulose-toothed bract-like floral leaves. Calyx 2-lipped; upper lip incurved, 3-toothed; lower lip 2-parted; teeth spinulose-aristate. Corolla open; tube pilose-annulate inside; limb 2-lipped; upper lip 2-lobed. Stamens separate, remote from the upper lip; lower branch of the long filiform appendaged connective carrying a pollen-bearing anther-cell. Nutlets smooth.

1. P. Columbariae (Benth.) Rydb. Winter annual; stem 1-5 dm. high, retrorsely strigose or hispidulous, leafy below; leaves petioled, deeply once or twice pinnatifid into oblong crenate obtuse divisions, rugose, strongly veined beneath, eanescent-hirsutulous; floral leaves and bracts broadly ovate, entire, abruptly acuminate, spinulose, puberulent, often purplish; corolla blue, 8-10 $\mathrm{mm}$. long, slightly exceeding the calyx. Salvia Columbariae Benth. Hillsides and sandy plains: Calif.-Utah-Ariz. Son. Mr-Jl. 


\section{SÁLVIA (Tourn.) L. SAgE.}

Annual or perennial herbs (ours), or rarely shrubby plants. Leaves opposite, sometimes mostly basal, entire, toothed, or lobed. Flowers perfect, in axillary clusters, disposed in spikes, racemes, or panicles. Calyx 2-lipped; upper lip 3-toothed; lower lip with 2 longer and narrower lobes. Corolla strongly 2-lipped, upper lip arched; lower lip longer, spreading, with 3 lobes. Stamens 4 , but only 2 anther-bearing, or sometimes only 2 ; lower branch of the connective deflexed, destitute of an anther-cell. Nutlets smooth.

Corolla 15-30 mm. long; tube exserted.

Corolla 8-12 mm. long; tube included in the calyx.

1. S. Pitcheri.

2. S. lanceolata.

1. S. Pitcheri Torr. Stem 4-12 dm. high, finely retrorsely strigose; leaves short-petioled, linear-lanceolate or linear, 3-12 cm. long, toothed or entire, strigillose; calyx densely canescent, $6-8 \mathrm{~mm}$. long; upper lip barely pointed; corolla blue or white; upper lip densely bearded on the back. Dry plains and prairies: Neb.-Mo.-Tex.-Colo. Plain. Jl-S.

2. S. lanceolata Willd. Perennial; stem puberulent, erect, branched, 1-4 $\mathrm{dm}$. high; leaf-blades oblong-lanceolate to oblong or linear, $2-8 \mathrm{~cm}$. long, remotely serrate or undulate or entire, puberulent or glabrate; calyx 7-8 mm. long, puberulent; upper lip abruptly pointed; corolla purplish; upper lip minutely puberulent. Prairies, plains, and hillsides: S.D.-Tex.-N.M.-Mont.; Mex. Plain-Submont. My-S.

\section{AUDibertî́lLa Briq. Ball Sage.}

Perennial, mostly suffruticose herbs, usually more or less canescent. Leaves opposite, short-petioled, crenate or crenulate. Flowers perfect, in bracteate axillary verticils. Calyx 2-lipped, deeply cleft in front, sometimes oblique. Corolla 2-lipped; upper lip spreading, 2-lobed or emarginate; lower lip spreading, 3-lobed. Fertile stamens 2; filaments slender, either simple or articulate above, but bearing a single anther-cell. Nutlets smooth. [A udibertia Benth.]

Leaf-blades oblong-spatulate; lower lip of the corolla much longer than the upper.

Leaf-blades rounded obovate-spatulate; lo 1 . A. incana.

upper.
2. A. argentea.

1. A. incana (Benth.) Briq. Branches grayish puberulent; leaves shortpetioled, $2-4 \mathrm{~cm}$. long; blades oblong-spatulate, scurfy-canescent, obtuse, entire; bracts obovate or oval, canescent and ciliate, about $1 \mathrm{~cm}$. long; corolla about 15 $\mathrm{mm}$. long. Audibertia incana Benth. Hillsides: Wash.-Ida.-Ore. Submont.

2. A. argentea Rydb. Branches cinereous-puberulent; leaves petioled, 1-2 $\mathrm{cm}$. long; blades rounded, obovate-spatulate, scurfy-cinereous, at first silvery white; bracts broadly obovate, membranous, strongly veined, puberulent and ciliate; corolla blue, about $1 \mathrm{~cm}$. long. Dry hills: Utah-Ariz.-Calif.-Nev. Șon. Ap-Je.

\section{0. monárda L. Horse Mint, Wild Bergamot, Lemon Mint.}

Perennial or annual, caulescent herbs. Leaves opposite, petioled, with broad usually toothed blades. Flowers perfect, in dense, remote or contiguous, axillary clusters. Calyx tubular or nearly so, mostly pubescent in the throat, 15-ribbed, nearly regularly 5-lobed. Corolla 2-lipped; throat dilated; upper lip narrow, erect or arched, entire or notched; lower lip spreading, 3-lobed, the middle lobe much the larger. Anther-bearing stamens 2, and with 2 or no rudimentary filaments; anthers narrow, 2-celled, versatile; sacs divergent. Nutlets smooth. Heads solitary at the ends of the stem and branches; stamens conspicuously exceeding
the acute upper lip of the corolla.

Petioles and stem more or less hirsute-villous, the latter especially so under the nodes. Leaves sparingly pilose; stem and petioles hirsute-ciliate. $\quad$ 1. $M$. comata. Leaves softly pubescent, especially below; stem, petioles, and the veins of the leaves lanate.
$2 . \mathrm{M}$. Ramaleyi.

Whole plant finely strigose or puberulent.

Petioles seldom over $5 \mathrm{~mm}$. long. 
Leaf-blades ovate-cordate; plant pale, more or less cinereous.

Leaf-blades lanceolate, with rounded or truncate base; plant green

3. $M$. menthaefolia.

Petioles $1-3 \mathrm{~cm}$. long.

4. M, stricta.

5. M. mollis.

Heads or verticillate glomerules several in the upper axils of the leaves; stamens scarcely exceeding the emarginate or cleft upper lip of the corolla.

6. M. pectinata.

1. M. comata Rydb. Stem 4-6 dm. high, simple; lower leaves with petioles, which are about $1 \mathrm{~cm}$. long, the upper subsessile; blades ovate or lance-ovate, more or less cordate at the base, serrate, 4-6 cm. long, sparingly silky-pilose on both sides; corolla red-purple, almost wine-color, densely villose-puberulent. Hillsides: Colo. Submont. J-Au.

2. M. Ramaleyi A. Nels. Stem $3-6 \mathrm{dm}$. high, glabrate below, softly lanately white-pubescent upwards; leaf-blades lanceolate or ovate-lanceolate, rounded or truncate at the base, sharply serrate; corolla lilac-purple, softly pubescent. Sandy soil: Colo. Submont. Je.

3. M. menthaefolia Benth. Stem 3-10 dm. high, finely puberulent; leafblades short-petioled or the upper subsessile, ovate or ovate-lanceolate, at least the lower cordate at the base, more or less cinereous, with short pubescence; corolla rose or lilac, $2-2.5 \mathrm{~cm}$. long. Hillsides and valleys: Sask.-Man.-Ill.Tex.-Utah-Ida.-Alta. Plain-Mont. Je-Au.

4. M. stricta Wooton. Stem $3-6 \mathrm{dm}$. high, slender, minutely pubescent; leaf-blades ovate or deltoid-lanceolate, 4-6 cm. long, acuminate, sharply serrate, minutely pubescent on both sides or glabrate above; corolla bright purple. Hillsides: Wyo.-N.M.-Ariz. Submont. Jl-S.

5. M. mollis L. Stem $3-10 \mathrm{dm}$. high, finely pubescent; leaf-blades elongate deltoid-lanceolate, sharply serrate, $2-5 \mathrm{~cm}$. long, finely puberulent, often paler beneath; corolla lilac, about $2.5 \mathrm{~cm}$. long. Prairies and among bushes: Me.Ga.-Tex.-B.C. Plain-Submont. Je-Au.

6. M. pectinata Nutt. Annual or perennial (?), with a taproot; stems simple or branched at the base, $2-4 \mathrm{dm}$. high, canescent-strigose; leaf-blades lanceolate or oblanceolate, distantly serrulate, minutely strigillose or glabrate, ciliate on the margins, densely punetate, $2-4 \mathrm{~cm}$. long; bracts $12-16 \mathrm{~mm}$. long, green or purplish, lanceolate or oblong, spinulose-cuspidate; corolla yellowish white, $15-18 \mathrm{~mm}$. long, puberulent. M. citriodora Coult. M. Nuttallii A. Nels. Plains, especially in sandy soil: Neb.-Tex.-Ariz.-Utah. Plain-Submont.

\section{Poliomíntha A. Gray.}

Low suffruticose canescent plants. Leaves opposite, entire. Flowers perfect, in small axillary cymes or glomerules, the floral leaves often reduced and bract-like. Calyx cylindric, 13-15 striate, bearded in the throat, equally 5toothed. Corolla 2-lipped, with two hairy rings in the throat; upper lip erect, emarginate; lower lip spreading, 3-cleft, the middle broad lobe emarginate. Anther-bearing stamens 2; posterior filaments rudimentary, subulate.

1. P. incana (Torr.) A. Gray. Low shrub, 3-6 dm. high; branches silvery white, with fine tomentum, erect; leaves linear or oblong, 5-20 mm. long, sessile, white-tomentulose; calyx 15-nerved, white-villous, $6 \mathrm{~mm}$. long; corolla about 1 $\mathrm{cm}$. long, rose or purplish. Sand hills: w Tex, $\rightarrow \mathrm{s}$ Colo. $\rightarrow \mathrm{s}$ Utah-Ariz; Mex. Son. Ap-Au.

\section{2. hedeòma Pers. Mock Pennyroyal.}

Annual or perennial herbs, usually aromatic. Leaves opposite, small, entire or sparingly toothed. Flowers perfect, in remote or contiguous axillary clusters. Calyx 13-ribbed, commonly gibbous at the base, pubescent in the more or less constricted throat, somewhat 2-lipped, the 2 lower calyx-lobes being different and usually longer than the 3 upper ones. Corolla blue or purple, 2-lipped; throat but little enlarged; upper lip erect, entire or 2-lobed; lower lip 3-lobed and spreading. Stamens 4, or usually only 2 fertile, the other with much reduced filaments or wanting. Nutlets smooth. 
Calyx-teeth about equal in length; bracts spreading or reflexed, hispid-ciliate.

1. H. hispida.

Calyx-teeth of the iower lip much longer than those of the upper; bracts mostly erect, cinereous-hispidulous.

Corolla 10-12 $\mathrm{mm}$. long, more than half longer than the calyx.

2. H. camporum.

Corolla 6-8 $\mathrm{mm}$. long, slightly exceeding the calyx.

Floral leaves longer than the subtended calyces; plant $1.5-4 \mathrm{dm}$. high.

3. H. sancta.

Floral leaves scarcely exceeding the subtended calyces; plant $1-1.5 \mathrm{dm}$. high. Leaf-blades oval or elliptic, distinctly petioled. $4 . H$. thymoides. Blades of the floral leaves oblong to linear.

5. H. ovata.

1. H. hispida Pursh. Annual; stem 1-2 dm. high, hispidulous; leaves linear, entire, thickish, hispid-ciliate; upper calyx-teeth subulate, the lower more aristiform, equalling the bluish corolla, $6 \mathrm{~mm}$. long. Sandy soil: Sask.-Wis.Ky.-Colo.-Alta. Plain. My-Jl.

2. H. camporum Rydb. Perennial, with a slender taproot; stems branched at the base, decumbent or ascending, finely. puberulent; leaves spreading, linearlanceolate, lanceolate, or oblong, 1-2 cm. long, grayish-puberulent, subsessile; calyx 7-8 mm. long, somewhat saccate below; teeth subulate, the lower $2 \mathrm{~mm}$., the upper $1 \mathrm{~mm}$. long; corolla puberulent, with an ample limb. H. longiflora Rydb., not Briq. Cañons: S.D.-Kans. Plain.

3. H. sancta Small, Annual or perennial; stem erect, branched, cinereouspuberulent; leaf-blades oval, oblong, or linear-oblong, 1-1.5 cm. long, entire, slightly revolute, short-petioled; calyx $5-6 \mathrm{~mm}$. long, hispidulous; tube somewhat saccate; lobes subulate, the lower about twice as long as the upper; corolla puberulent. Dry plains: Tex.-Colo--N.M. Plain-Submont. Ap-Jl.

4. H. thymoides A. Gray. Perennial, with a taproot; stem branched at the base, finely puberulent; leaf-blades ovate or elliptic, $6-10 \mathrm{~mm}$. long, shortpetioled, canescent-puberulent; calyx about $5 \mathrm{~mm}$. long, hispidulous; teeth subulate, the lower slightly longer than the upper; corolla $6-7 \mathrm{~mm}$. long. $H$. nana Rydb., in part. Mountain sides: N.M.-Colo.-Utah-Ariz. Son.Submont. Ap.

5. H. ovata A. Nels. Perennial, with a taproot; stem branched at the base, divaricate, puberulent, 1-2 dm. high; blades of lower leaves oval or elliptic, $7-15 \mathrm{~mm}$. long; floral leaves linear; calyx about $5 \mathrm{~mm}$. long; lower teeth a little longer than the upper; corolla barely exceeding the calyx. H. Drummondii Coult., in part. H. nana Rydb., in part. Hills: Mont.-Colo.-Utah. Submont. Je-Jl.

\section{CLINOPÒDIUM L. BASIL.}

Annual or perennial herbs or rarely shrubs. Leaves opposite, entire or toothed, narrow or broad. Flowers in ours in dense axillary clusters subtended by linear-filiform bracts. Calyx 13-ribbed, often swollen at the base; upper lip with 3 short lobes; lower lip with 2 longer lobes. Corolla 2-lipped, abruptly ailated at the throat; upper lip erect; lower lip spreading, 3-lobed. Stamens 4, all anther-bearing; anther 2-celled, awnless. Nutlets smooth.

1. C. vulgare L. Perennial, with a rootstock; stem 1-5 dm. high, simple or nearly so, sparingly hairy; leaf-blades oval or ovate, $1-4 \mathrm{~cm}$. long, obtuse, undulate or erenate; calyx 8-9 mm. long, villous-hirsute, ribbed; lobes subulate-aristate; corolla white or purple, $10-12 \mathrm{~mm}$. long. Thickets and waste places: N.S. -N.C.-Colo.-Man.; nat. or adv. from Eu. Plain-Mont. Je-Au.

\section{4. madronÉlla Greene. False Horse-mint, Western Pennyroyal, Mustang Mint.}

Aromatic caulescent perennials. Leaves mostly short-petioled, opposite, entire or dentate. Flowers perfect, in dense terminal or axillary verticillate heads, subtended by broad membranous or colored bracts. Calyx tubular, narrow, 15-nerved, with 5 equal teeth. Corolla 2-lipped; upper lip entire, flat, linear or oblong; lower lip 3-cleft, with linear divisions. Stamens 4, antherbearing, unequal, exserted; anther-sacs 2, divergent. [Monardella Benth., in part.] 
Bracts thin and pale, oval to orbicular; leaves usually entire.

Leaves tomentulose, especially beneath.

Leaves sparingly and minutely puberulent or glabrous.

Calyces and bracts $8-12 \mathrm{~mm}$. long.

Stem stout; leaves subsessile, ovate.

Stems slender; leaves distinctly petioled, oblong.

Calyces and bracts about $6 \mathrm{~mm}$. long.

\section{M. odoratissima.}
4. M. parvifolia.

Bracts thick, resembling the leaves, lanceolate or ovate-lanceolate, obtuse; leaves usually

Bracts thick, resembling the leaves, lanceolate or ovate-lanceolate, obtuse; leaves usually
dentate.

2. M. sessilifolia.

3. M. oblongifolia. 5. M. dentata.

1. M. odoratissima (Benth.) Greene. Stems decumbent at the base, more or less grayish pilose, with short hairs; leaves oblong or lance-oblong, subsessile or the lower short-petioled, 2-3 cm. long; bracts oval, densely pilose and ciliate on the margins, 8-10 $\mathrm{mm}$. long; calyx-lobes narrowly lanceolate, strongly ciliate; corolla about $12 \mathrm{~mm}$. long. Monardella odoratissima Benth. Mountains: Ore. -Wash.-Ida. Submont. J-Au.

2. M. sessilifolia Rydb. Stems stout, about $3 \mathrm{dm}$. high, finely puberulent; leaves entire, obtuse, rather pale; bracts oval, 10-12 mm. long, puberulent on the back, ciliate on the margins; calyx-lobes lanceolate, about $1 \mathrm{~mm}$. long; corolla 12-13 mm. long, pubescent. Dry hills: s Utah. Son.

3. M. oblongifolia Rydb. Stems 1-3 dm. high; leaf-blades oblong, 1-3 cm. long, entire, obtuse; braets pale or tinged with rose, finely puberulent, ciliate on the margins, oval; calyx-teeth lanceolate, and strongly ciliate; corolla white to rose-colored, 12-14 mm. long, puberulent. M. purpurea A. Nels., in part. Dry mountain sides: Utah-Nev.-Ida. Submont.-Mont. J-Au.

4. M. parvifolia (Greene) Rydb. Stems many, decumbent at the base, puberulent; leaf-blades ovate-lanceolate or oblong-lanceolate, obtuse, entire, 1-1.5 cm. long; bracts slightly rose-tinged, puberulent, ciliate-margined; calyxlobes lanceolate, not conspicuously ciliate; corolla lilac-purple, scarcely $1 \mathrm{~cm}$. long. Monardella parvifolia Greene. Cañons: Colo. Submont. J1-Au.

5. M. dentata Rydb. Stems slender, light brown, about $3 \mathrm{dm}$. high; leaves short-petioled; blades ovate, $1.5-2 \mathrm{~cm}$. long, serrate-dentate, finely pubescent and strongly punctate, obtuse, strongly veined beneath; calyx about $8 \mathrm{~mm}$. long, grayish pubescent; lobes lanceolate; corolla about $12 \mathrm{~mm}$. long. Mountains: Colo. Submont.

\section{MiCromèria Benth. Tea-vine, Yerba Buena.}

Perennial herbs or somewhat shrubby plants, often with creeping stems. Leaves opposite, entire or sparingly toothed, petioled. Flowers perfect, either solitary or in small clusters in the axils. Calyx nearly tubular, 13-ribbed, slightly 2-lipped, but the 5 teeth nearly equal. Corolla small, 2-lipped; upper lip erect, usually very small; lower lip 3 -lobed, with the middle lobe often notehed. Stamens 4, anther-bearing; anthers 2-celled, with divergent sacs. Nutlets smooth.

1. M. Chamissonis (Benth.) Greene. Stem decumbent, trailing or creeping, $2-5 \mathrm{dm}$. long, finely puberulent; leaf-blades broadly ovate or rounded, crenate or entire, 1-3 cm. long, slightly puberulent or glabrate; calyx naked in the throat, $4 \mathrm{~mm}$. long; corolla about $1 \mathrm{~cm}$. long. M. Douglasii Benth. Woods: B.C.-Ida.-Calif, Submont. My-Au.

\section{LỶCopUS (Tourn.) L. Water Horehound, Bugle Weed.}

Perennial caulescent herbs, mostly odorless, often stoloniferous. Leaves op posite, entire, toothed, or pinnatifid. Flowers perfect, in remote axillary vertieils. Calyx regular or nearly so, 4- or 5-toothed. Corolla funnelform or campanulate; lobes 4, nearly equal, or one of them broader. Anther-bearing stamens 2 , with or without 2 additional rudimentary filaments. Anther-saes 2, parallel. Nutlets 3-angled, truncate, smooth. 
Stem sparingly and coarsely pubescent or glabrous; leaves glabrous or nearly so.

Leaves merely coarsely serrate.

Leaves tapering at the base, rather thin.

Leaves rounded at the base, thicker.

Leaves sinuately pinnatifid.

3. L. lucidus.

4. L. asper.

5. L. americanus.

1. L. communis Bickn. Rootstock tuberous-thickened at the base of the stem; stem 1-8 dm. high, acutely angled; leaves $2.5-8 \mathrm{~cm}$. long, lanceolate or oblong-lanceolate, sharply serrate; calyx campanulate; corolla 2-3 mm. long; lobes spreading. Wet places: Newf.-Va.-Neb.-Ore.-B.C. Plain-Submont. Au-S.

2. L. velutinus Rydb. Stem 3-5 dm. high; leaf-blades lance-elliptic, coarsely toothed, 4-10 cm. long, short-petioled; calyx campanulate, copiously pubescent, $2.5 \mathrm{~mm}$. long; lobes lanceolate, acuminate, the upper two recurved; corolla $3.5 \mathrm{~mm}$. long, glandular-punctate. Low ground and swamps: Colo.Tex.-Miss.-Ark. Son. Au.

3. L. lucidus Turez. Stem stout, strict, 3-9 dm. high, sparingly pubescent on the angles; leaves oblong-lanceolate, sessile or short-petioled, 5-15 cm. long, sharply serrate; calyx-teeth subulate-lanceolate, nearly as long as the tube; corolla little longer than the calyx. Wet soil, especially in thickets: Neb.-Kans. -Ariz.-Calif.-B.C.; Asia. Plain-Submont. JI-S.

4. L. asper Greene. Stem 3-6 dm. high, obtusely angled; leaves firm, narrowly lanceolate, acute, sessile, strongly serrate, $4-6 \mathrm{~cm}$. long, very veiny, rough on both sides; calyx-teeth ovate-lanceolate, acuminate. Wet places: w Ont.-Neb.-B.C. Plain. Jl-Au.

5. L. americanus Muhl. Stem sharply angled, puberulent or glabrous, 1-10 dm. high; leaves lanceolate in outline, petioled, acuminate, pinnatifid or incised, 3-10 em. long; ealyx-teeth triangular-subulate, cuspidate, rigid; corolla little exceeding the calyx. $L$. sinuatus Ell. Swamps and wet meadows: Newf. -Fla.-Calif.-B.C. Plain-Submont. Je-O.

\section{MÉntha (Tourn.) L. Mint, Spearmint, Peppermint.}

Aromatic caulescent perennial herbs, with rootstocks. Leaves opposite, punctate, toothed, usually petioled. Flowers perfect, in dense, axillary clusters. Calyx campanulate, 10 -ribbed, regular or nearly so, 5-lobed. Corolla funnelform or campanulate, nearly regular; lobes 4 , the upper larger than the rest. Stamens 4, anther-bearing, erect; anther-sacs 2, parallel. Nutlets smooth.

Whorls of flowers forming terminal spikes.

1. M. spicata.

Whorls of flowers all axillary.

Stem and petioles densely pubescent with long villous hairs; leaves decidedly pubescent.

Stem and petioles retrorsely strigose or crisp-hairy with short hairs, or glabrous below; leaves sparingly puberulent or glabrous.

Corolla 5-6 mm. long, open-funnelform; bracts lanceolate or linear-lanceolate, usually exceeding the flower-clusters; leaves dark green, not strongly veined.

3. M. occidentalis.

Corolla 4-5 mm. long, salver-shaped-funnelform; bracts linear or subulate, shorter than the flower-clusters.

Leaf-blades thin, dark green, not strongly veined, tapering gradually into slender petioles, which equal or exceed the flower-clusters.

4. M. glabrior.

Leaf-blades thick, strongly veined, abruptly contracted into short petioles, which are much shorter than the flower-clusters.

Plant pale green, stout, 4-8 dm. high; calyx-teeth much longer than broad.

5. M. Penardi.

Plant usually purplish, low, 2-4 dm. high; calyx-teeth scarcely longer than broad.

6. M. rubella.

1. M. spicata L. Stem erect, 3-5 dm. high, glabrous; leaves lanceolate, sessile or nearly so, sharply serrate, $3-7 \mathrm{~cm}$. long; spikes $5-10 \mathrm{~cm}$. long; bracts subulate-lanceolate, ciliate; calyx-teeth subulate; corolla glabrous. SPEARMINT. Fields and waste places: N.S.-Fla.-Kans.-Minn.; Calif.-Utah-B.C.; nat. from Eu. Plain-Submont. JI-S.

2. M. lanata (Piper) Rydb. Stem 3-6 dm. high; leaves short-petioled, lanceolate or ovate, serrate, $2-7 \mathrm{~cm}$. long, more or less pilose above, villous beneath; bracts subulate, about equalling the flowers; calyx $2.5-3 \mathrm{~mm}$. long, 
villous; teeth lanceolate; corolla pink or rose-colored, rarely white, pubescent. Wet places: B.C.-Ida.-Calif. Submont. Je-Au.

3. M. occidentalis Rydb. Stem $3-6 \mathrm{dm}$. high; leaf-blades ovate or ovatelanceolate, short-acuminate, strongly serrate, 4-8 cm. long, minutely pubescent on both sides or in age glabrate; calyx about $3 \mathrm{~mm}$. long, pilose; teeth lanceolate, acute or acuminate, longer than broad; corolla white or pink, its lobes oblong, obtuse. Wet places: Wash.-Alta.-Ida. Submont. J1-Au.

4. M. glabrior (Hook.) Rydb. Stem 3-6 dm. high, glabrate or minutely puberulent on the angles; leaf-blades ovate, elliptic or lanceolate, acute, serrate, glabrous or nearly so; calyx $3 \mathrm{~mm}$. long, finely pubescent; lobes triangularlanceolate, acuminate, slightly longer than broad; corolla narrowly campanulate, $4 \mathrm{~mm}$. long. M. canadensis glabrata Benth. Wet places: Me.-Pa.-Colo.Mont. Plain-Submont. J1-Au.

5. M. Penardi (Briq.) Rydb. Stem 2-4 dm. high, short-pubescent especially on the angles; leaf-blades ovate-elliptic or ovate-lanceolate, $2-5 \mathrm{~cm}$. long, serrate, acute; calyx about $3 \mathrm{~mm}$. long, softly pilose; teeth lanceolate, acute; corolla usually pink, $4 \mathrm{~mm}$. long. Wet places, among bushes: Neb.-N.M.-UtahB.C.-Mack. Submont. Je-Au.

6. M. rubella Rydb. Stem 1-2 dm. high, more or less purple, finely puberulent, with short retrorse hairs; leaf-blades ovate, $1-3 \mathrm{~cm}$. long, finely puberulent and glandular-punctate, finely serrate; calyx $2-2.5 \mathrm{~mm}$. long, puberulent; teeth triangular-lanceolate, acuminate; corolla 4-5 mm. long, light rose. Wet places, especially around hot springs: B.C.-Alta.-n Wyo. Submont.-Mont. JI-Au.

\section{Family 116. SOlanaCeae. Potato Family.}

Herbaceous plants or rarely shrubs, with nareotic or stimulant properties. Leaves alternate, without stipules. Flowers perfect, usually regular. Calyx of 5 (rarely 4 or 6 ) more or less united sepals, mostly persistent. Corolla hypogynous, rotate, campanulate, funnelform, or salverform; limb mostly lobed. Stamens 5, rarely 4 or 6 , fertile; filaments adnate to the tube of the corolla and alternate with its lobes; anthers introrse, opening lengthwise or by pores. Gynoecium usually of 2 , rarely $3-5$, united carpels; ovary 2- (rarely 3-5-) celled; style terminal; stigma entire. Ovules and seeds numerous, amphitropous. Fruit a berry or capsule. Seeds crustaceous, often tuberculate, flattened; endosperm copious, fleshy.

Fruit a berry.

Corolla plicate; lobes usually induplicate; all our species herbs or vines.

Calyx inflated and bladder-like in fruit.

Corolla open-campanulate, yellow or whitish, often with a darker center; seeds finely pitted; flowers nodding in anthesis. 1. PHYsalis,

Corolla rotate, violet or purple; seeds rugose-tuberculate; flowers erect in anthesis.

Calyx not bladder-like inflated in fruit.

Calyx closely investing the berry.

stamens alike, not inclined; low unarmed perennials. 3. ChamaEsaracha. Stamens dissimilar, declined; prickly annuals. 4. ANDROCERA.

Calyx not inclosing the berry.

Anthers short, opening by a terminal pore or short slit. 5. SOLANUM.

Anthers long, tapering to the summit, opening longitudinally.

Corolla little if at all plicate; its lobes valvate; shrubs.

6. LYCOPERSICON.

7. LYCIUM.

Fruit a capsule.

Capsule circumscissile near the top, which separates as a lid; corolla irregular.

Capsule opening by valves; corolla regular.

Capsule prickly; seeds flat.
Capsule not prickly; seeds scarcely flattened.

8. Hyoscyamus.

9. DATURA.

10. Nicotiana.

1. Physális L. Ground Cherry, Strawberry Tomato, Tomatillo.

Annual or perennial herbs. Leaves alternate, entire or sinuately toothed. Pedicels usually solitary from the axils of the leaves. Calyx campanulate, 5lobed, accrescent and becoming bladder-like in fruit, 5-angled or prominently 
10-ribbed. Corolla yellow or whitish, campanulate or funnelform, often with a darker, brownish or purplish center, plicate in the bud. Stamens adnate to the base of the corolla; anther-sacs opening by longitudinal slits. Stigma minute. Seeds numerous, kidney-shaped, flattened, finely pitted.

Annuals, with branching roots; fruiting calyx cordate-ovoid, acuminate, strongly 5-angled.

Leaves very oblique, cordate, sinuate-dentate; fruiting calyx ovoid.

Leaves orbicular or broadly ovate, sinuately crenate, 1 . Pruinosa. oblique at the base.

2. P. neomexicana.

Pubescence if any not stellate, although in $P$, pumila with some branched hairs.

Leaves and stem glabrous or the veins of the former and the upper part of the latter with scattered appressed hairs.

Leaves ovate, ovate-lanceolate, or oval.

Leaves lanceolate, oblanceolate, or linear.

Leaves and stem more or less pubescent with spreading hairs.

3. P. subglabrata.

Pubescence sparse, consisting of flat, sometimes jointed hairs, scarcely viscid. Fruiting calyx ovoid, scarcely angled and scarcely sunken at the base; leaves thick, oblanceolate or spatulate to rhombic, subentire.

Leaves oblanceolate or spatulate; hairs all simple. Pubescence very short; leaves narrowly oblanceolate.

5. P. polyphylla.

Leaves broader, often rhombic: hairs on the lower surface branched.

7. P. pumila.

Fruiting calyx pyramidal-ovoid, obtusely 5-angled and deeply sunken at the base; leaves ovate to lanceolate, generally more or less toothed.

8. P. virginiana.

Pubescence dense, viscid, partly of fine and short, partly of long flat, jointed hairs.

Leaves large; blades over $5 \mathrm{~cm}$. long, more or less cordate; long flat hairs numerous. $9 . P$, helerophylla.

Leaves smaler; blades less than $5 \mathrm{~cm}$. long; long flat hairs few, mostly confined to the calyx.

Plant erect or ascending.

Leaf-blades reniform or rounded-cordate, coarsely-sinuately toothed.

Leaf-blades rounded-ovate or rhombic.

10. P. hederaefolia.

Plant prostrate, diffuse; leaf-blades nearly orbicular. 12 . $P$. rotundata.

13. P. Fendleri.

1. P. pruinosa L. Stem stout, finely villous and somewhat viscid, erect or spreading, 3-6 dm. high; leaf-blades $3-10 \mathrm{~cm}$. long, finely pubescent, sinuately toothed; calyx viscid, in fruit $2-3 \mathrm{~cm}$. long, sunken at the base; corolla $3-8 \mathrm{~mm}$. in diameter; berry yellow or green. Cultivated ground and waste places: Mass. -Fla.-Tenn.-Ia.; adv. in Colo. Plain. Jl-S.

2. P. neomexicana Rydb. Stem stout, obtusely angled, finely pubescent and slightly viscid, 3-6 dm. high, erect; leaf-blades $3-5 \mathrm{~cm}$. long, rounded or truncate, finely pubescent; calyx finely pubescent, sharply angled, deeply sunken at the base; teeth lanceolate, acuminate. Loose soil: N.M.-Colo.-L. Calif. Son. Je-Au.

3. P. subglabrata Mack. \& Bush. Stem 3-9 dm. high; leaf-blades 3-7 cm. long, entire or undulate, glabrous or very sparingly strigose; calyx strigose, in fruit ovoid, reticulate, $2.5-3 \mathrm{~cm}$. long; corolla yellow, with darker center, 1-1.5 $\mathrm{cm}$. broad. River valleys, sandy or cultivated ground: Ont.-Pa.-Ark.-Colo. -Ida. Plain-Submont. Je-S.

4. P. longifolia Nutt. Stem tall, 5-10 dm. high; leaf-blades entire-margined or somewhat repand; calyx glabrous or nearly so, in fruit ovoid, about $3 \mathrm{~cm}$. long; corolla 1-2 cm. broad, yellow, with brownish center; berry yellow, the lower portion and the stipe glutinous. River valleys and rich soil: Ia.-Ark,-Ariz.Mont.; Mex. Plain-Submont. My-Au.

5. P. polyphylla Greene. Stem ereet, branched, $1.5-2.5 \mathrm{dm}$. high, angular, scabrous-puberulent; leaf-blades $2-4 \mathrm{~cm}$. long, entire, scabrous-puberulent on the margins and veins; calyx sparingly puberulent, in fruit $2 \mathrm{~cm}$. thick; corolla greenish yellow, with greenish center. Plains: Colo. Plain-Submont. Jl.

6. P. lanceolata Michx. Stem $3-6 \mathrm{dm}$. high, erect or spreading, sparingly hirsute; leaf-blades acute or obtuse, entire or rarely wavy, thickish, sparingly short-hirsute; calyx hirsute or strigose; corolla dull-yellow, with brownish center, 
about $1.5 \mathrm{~cm}$. broad; berry yellow or greenish. Prairies and plains: Ill.-S.C.Ariz.-S.D. Plain-Submont. Jl-S.

7. P. pumila Nutt. Stem $3-10 \mathrm{dm}$. high, obscurely angled, hirsute; leafblades thick, acute at both ends, $5-10 \mathrm{~cm}$. long, entire or sinuate; calyx densely hirsute, 4-5 cm. long; corolla yellow, with brown center, $1.5-2 \mathrm{~cm}$. broad. Prairies and river valleys: Ill.-Ark.-Tex.-Colo. Plain-Submont. My-Jl.

8. P. virginiana Mill. Stem $3-10 \mathrm{dm}$. high, erect, angular, more or less hirsute; leaf-blades 3-6 cm. long, hirsutulous; calyx hirsute or puberulent; corolla $1.5-2.5 \mathrm{~cm}$. broad, sulphur-yellow, with purplish center; berry reddish. Prairies, river valleys, and cultivated ground: N.Y.-Fla.-Tex.-Mont. Plain-Submont. Ap-O.

9. P. heterophylla Nees. Stem 3-10 dm. high, erect or decumbent and spreading, puberulent and villous, viscid; leaf-blades $5-10 \mathrm{~cm}$. long, usually broadly cordate, acute or acuminate, thick, more or less sinuately toothed, densely pubescent and very viscid; calyx viseid-villous, in fruit ovoid, somewhat angled and sunken at the base; corolla 1.5-2 $\mathrm{cm}$. wide, yellow, with purple center; berry yellow. Cultivated ground, sandy or loose soil, etc.: N.B.-Fla.Tex.-Utah-Sask. Plain-Submont. My-S.

10. P. hederaefolia A. Gray. Stem erect, rarely decumbent, 3-5 dm. high, finely viscid-pubescent; leaf-blades $3-5$-ribbed, $3-5 \mathrm{~cm}$. broad; calyx finely viscid-pubescent, in fruit ovoid, 5-10-angled, $2-3 \mathrm{~cm}$. long, slightly sunken at the base; corolla about $1.5 \mathrm{~cm}$. wide. Rocky hills and dry plains: Tex.-Colo. -Utah-s Calif.; Mex. Son. Ap-Au.

11. P. comata Rydb. Stem about $5 \mathrm{dm}$. high, finely short-pubescent and viscid, with a few scattered long hairs on the upper part; leaf-blades $3-5 \mathrm{~cm}$. long, somewhat repand or entire, finely pubescent; calyx finely pubescent and villous, in fruit 3-4 cm. long, rounded-ovoid, scarcely sunken at the base; corolla greenish yellow, with brown center. Hillsides, eliffs, and dry plains: Neb.-Colo.-Tex. Plain-Submont. J1-Au.

12. P. rotundata Rydb. Stem diffuse or spreading, dichotomously zigzagbranched, densely and finely viscid-pubescent; leaf-blades with truncate or subcordate base, $2-4 \mathrm{~cm}$. broad, sinuate-dentate; fruiting ealyx ovoid, scarcely angled, not sunken at the base; corolla $1.5 \mathrm{~cm}$. broad, greenish yellow, with brownish center. Plains: S.D.-Tex.-N.M.-Colo. Plain. Jl-S.

13. P. Fendleri A. Gray. Stem $3-6 \mathrm{dm}$. high, finely puberulent, somewhat stellate, much branched; leaf-blades small, 1-4 $\mathrm{cm}$. long, deltoid, lanceolate, ovate or somewhat cordate, sinuately toothed; calyx somewhat stellate and puberulent, in fruit rounded-ovoid, $2-3 \mathrm{~cm}$. thick; corolla yellow, with brown center; berry yellow. Dry plains and rocky places: N.M.-Colo.-Utah-Ariz.; Mex. Submont. My-Au.

\section{QUínCULA Raf.}

Perennial scurfy-granuliferous perennials, with diffuse stems. Leaves alternate, sinuately lobed or pinnatifid, somewhat fleshy. Peduncles commonly in pairs from the axils of the leaves. Flowers perfect, regular, erect during anthesis. Calyx campanulate, accrescent and becoming bladder-like in fruit, 5 -angled, reticulate, with 5 converging lobes. Corolla flat, rotate, pentagonal in outline, violet or purple. Anthers opening by longitudinal slits. Seeds comparatively few, flattened, kidney-shaped, rugose-tuberculate.

1. Q. lobata (Torr.) Raf. Stem low, spreading or prostrate; leaf-blades oblanceolate or spatulate to oblong, sinuately lobed or more or less pinnatifid, with rounded lobes; calyx in fruit sharply 5 -angled, ovoid, sunken at the base; corolla purplish, $2-3 \mathrm{~cm}$. broad. Physalis lobata Torr. High plains and bluffs: Kans.-Tex.-Ariz.; Mex. Son.-Submont. Ap-Au.

\section{ChamAesàraCha A. Gray.}

Scurfy perennial herbs. Leaves alternate, entire or pinnatifid, with winged petioles. Peduncles solitary or 2 or 3 in the axils of the leaves. Calyx campanulate, 5-lobed, only slightly accrescent, not becoming bladder-like in fruit, 
close-fitting to the berry. Corolla rotate, white or ochroleucous, often tinged with purple, plicate. Stamens 5; filaments adnate to the base of the corolla; anther opening by longitudinal slits. Seeds reniform, flattened, rugose-favose.

Pubescence dense, hirsute as well as puberulent.

Pubescence sparse, puberulent or stellate, hirsute if at all only on the calyx.

1. C. conioides.

2. C. Coronopus.

1. C. conioides (Moric.) Britton. Stems erect, decumbent, or prostrate, viscid; leaf-blades oblanceolate to obovate-rhombic, acute and tapering into short petioles, usually deeply lobed, varying from subentire to pinnatifid; calyxlobes triangular, acutish; corolla about $1 \mathrm{~cm}$. broad, white or ochroleucous. $C$. sordida (Dunal) A. Gray. Dry clayey soil: Kans.-Colo.-Ariz.-Tex.; Mex. Son. My-Jl.

2. C. Coronopus (Dunal) A. Gray. Stem obtusely angled; leaf-blades linear or lanceolate, sinuately lobed to pinnatifid, pruinose; calyx-lobes triangular, acute; corolla white or ochroleucous, Dry clayey soil: Kans.-Colo.-Ariz.Tex. Son.-Submont. My-D.

\section{ANDRÓsera Nutt. Buffalo Bur.}

Annual prickly herbs. Leaves alternate, pinnatifid. Flowers perfect, cymose. Calyx campanulate, prickly, somewhat accrescent and enclosing the berry in fruit, 5-lobed. Corolla yellow or purple, 5-lobed, plaited. Stamens 5, dissimilar, declined, adnate to near the throat of the corolla; anthers narrow, opening by terminal pores. Ovary 2-celled. Fruit a berry, enclosed in the prickly calyx. Seeds flattened.

1. A. rostrata (Dunal) Rydb. Stem yellowish-hirsute and prickly, 2-7 $\mathrm{dm}$. high, widely branching; leaf-blades 5-12 $\mathrm{em}$. long, once or twice pinnatifid; segments oval to oblong, obtuse, entire or undulate, yellowish hirsute; calyx bristly; corolla yellow, about $2.5 \mathrm{~cm}$. broad. Solanum rostratum Dunal. Waste places, prairies, and river valleys: N.D.-Tex.-N.M.-Wyo.; Mex.; adv. eastward to N.H. and Fla. Plain-Submont. Mr-S.

\section{SOlànUm (Tourn.) L. Nightshade, Bittersweet, Potato, Horse NetTle.}

Annual or perennial, often prickly, or most of ours unarmed herbs, rarely vines. Leaves alternate, entire, toothed or pinnatifid. Flowers perfect, regular, in cymes, racemes, umbels, or panicles. Calyx from campanulate to rotate; lobes 5 . Corolla variously colored, rotate, 5-angled or 5-lobed, plicate. Stamens 5 , adnate to near the throat of the corolla. Anthers narrow, converging or united into a cone; sacs opening by terminal pores, rarely lengthwise. Ovary mostly 2-celled. Fruit a berry, seated in the calyx. Seeds flattened.

Annuals.

Leaves pinnatifid.

1. S. triflorum.

Leaves sinuately dentate or entire.

Plant strigose or glabrous; berry black.

Leaves glabrous or nearly so; sepals very obtuse. 2. S. nigrum.

Leaves decidedly strigose beneath; sepals abruptly acutish. Corolla-lobes $3-4 \mathrm{~mm}$, long. Corolla-lobes 6-8 mm. long.

3. S. interius.

4. S. Douglasii.

Plant more or less viscid-villous; berry greenish or yellowish. 5 . S. villosum. Perennials.

Plant green, glabrous or pubescent, but not stellate, never prickly.

Low plants with tuber-bearing rootstocks; leaves pinnately divided into $5-7$ divisions. 6 . S. Jamesii.

Tall piants, more or less woody below, not tuberiferous; leaves simple or pinnately 3-lobed.

Plant climbing; berry ellipsoid.

Plant not climbing; berry giobose.

Plant with stellate hairs; stem of ten prickly.

Leaves silvery-white, oblong to linear.

Leaves green, ovate, sinuately toothed.

7. S. Dulcamara.

4. S. Douglasii.

8. S. elaeagnifolium.

9. S. carolinense.

1. S. triflorum Nutt. Stem branched at the base, spreading, 2-9 dm. long, sparingly hirsute; leaf-blades oblong or ovate in outline, pinnatifid, $3-9 \mathrm{~cm}$. long; lobes acute, entire or toothed; calyx-lobes oblong or oblong-lanceolate; 
corolla white, 8-10 mm. broad; berry globose, 10-15 mm. thick. Prairies, cultivated ground, waste places, "prairie-dog towns": w Ont.-Kans.-N.M.-Ariz. -B.C. Plain-Mont. Je-S.

2. S. nigrum L. Stem ereet, branched, 1-12 dm. high; leaf-blades ovate or oblong-ovate, $2-8 \mathrm{~cm}$. long, undulate to sinuately lobed; inflorescence umbelliform; calyx-lobes ovate or oblong-ovate; corolla white or bluish, about $1 \mathrm{~cm}$. broad; lobes oblong or linear; berries subglobose, $5-8 \mathrm{~mm}$. thick, black. Sandy soil, waste places: N.S.-Fla.-Tex.-Wash.; nat. or adv, from Eu. Plain. Mr-D.

3. S. interius Rydb. Stem 3-6 dm. high, usually with narrow denticulate margins or wings; leaf-blades deltoid or rhombic, 3-7 $\mathrm{cm}$. long, acuminate, usually sinuately lobed or dentate, with acute or acuminate lobes or teeth; inflorescence corymbiform; calyx-lobes ovate, $2 \mathrm{~mm}$. long; corolla yellowish white; lobes ovate, acute, 3-4 mm. long; berry greenish black, nearly $1 \mathrm{~cm}$. in diameter. River valleys among bushes: Neb.-Kans.-N.M.-Ariz.-Utah. Plain-Submont. Je-Au.

4. S. Douglasii Dunal. Annual or perennial, and then more or less shrubby at the base; stem 1-3 m. high, denticulate on the angles, glabrous or strigose; leaf-blades ovate or somewhat hastate, $3-6 \mathrm{~cm}$. long, sinuate-dentate, grayish strigose beneath; inflorescence corymbiform; calyx-lobes oblong, acute, erect in fruit; corolla white or often tinged with blue, puberulent, its lobes 6-8 $\mathrm{mm}$. long; berry globose, black. Valleys: Calif.-Ore.-(? Colo.)-Ariz. Mr-S.

5. S. villosum Mill. Stem 3-10 dm. high, viscid-villous; leaves ovate or ovate-rhombic, coarsely sinuate-dentate, villous-hirsute, $2-5 \mathrm{~cm}$. long; calyxlobes triangular, acute; corolla white or greenish ochroleucous; lobes $2-3 \mathrm{~mm}$. long; berry globose, yellow or greenish. Waste places and sandy soil: Wyo.Colo.-L. Calif.-B.C.; adv, from the Old World. Plain-Submont. Jl-S.

6. S. Jamesii Torr. Stem 1-3 dm. high, erect, sparingly hairy or glabrous; leaves pinnately divided; divisions $5-7$, lanceolate, subentire, $2-4 \mathrm{~mm}$. long, glabrate, or with scattered hairs; inflorescence cymose; corolla white; lobes lanceolate, 7-8 mm. long. WILD Potato. Mountains: Tex.-Colo.-UtahAriz.; Mex. Son.-Submont. Je-S.

7. S. Dulcamara L. Stem climbing or twining, 4-15 dm. long; leaf-blades ovate, 3-10 cm. long, acute or acuminate, undulate, entire or with a lobe or two on one or both sides at the base; calyx glabrous, its lobes triangular; corolla blue or white, about $1.5 \mathrm{~cm}$. wide; lobes oblong-lanceolate, pubescent near the tips. BITTERsweET. Thickets: N.B.-Fla.-Kans.-Ida.; adv. or nat. from Eu. Je$\mathrm{Au}$.

8. S. elaeagnifolium Cav. Perennial, with a cespitose caudex or rootstock; stem 3-11 dm. high, silvery stellate-canescent, often more or less prickly; leafblades oblong to linear, $5-15 \mathrm{~cm}$. long, usually obtuse, undulate to deeply sinuate, silvery-stellate; calyx 5-ribbed; corolla violet or white, $2-2.5 \mathrm{~cm}$. broad; berries globose, $1-1.5 \mathrm{~cm}$. thick, yellow or black. Dry soil: Mo.-Tex.-Calif.; Mex. Sor. My-0.

9. S. carolinense L. Stem erect, 3-6 dm. high, hirsute and prickly; leafblades mostly ovate, sinuately toothed or lobed, 1-2 dm. long, green, but rather densely stellate-pubescent, prickly on the petioles, midribs, and the stronger veins beneath; corolla blue, about $2 \mathrm{~cm}$. in diameter; berry $1-1.5 \mathrm{~cm}$. in diameter, globose. Horse NetTLE. Sandy soil and waste places: Mass.-Fla.-Tex.Neb,; adv. in Utah and Idaho. Je-S.

\section{LYCOPÉRsicon Mill. Tomato, Love Apple.}

Annual herbs, with once or twice pinnately divided leaves. Flowers perfect, in small racemes, opposite the leaves. Calyx mostly 5-parted. Corolla rotate, 5-lobed, plicate. Stamens usually 5 ; filaments short; anthers elongate, connate or connivent, introrsely longitudinally dehiscent. Ovary 2-3-celled, manyseeded. Fruit a berry. 
1. L. Lycopersicum (L.) Karst. Viscid-pubescent, much branched; stem 3-10 dm. high; leaves 2-pinnatifid, lobed and dentate; corolla yellow, 10-15 $\mathrm{mm}$. broad; fruit through cultivation very variable, subglobose, ellipsoid, or pearshaped, red or yellow. L. esculentum Mill. Waste places and around dwellings: N.Y.-Fla.-Tex.-Colo.; Calif.; escaped from cultivation.

\section{LÝCiUM L. Matrimony Vine.}

Shrubs or woody vines, often spiny. Leaves alternate, thick, entire, often with smaller ones clustered in their axils. Flowers perfect, regular, solitary or clustered in the axils. Calyx enlarged and persistent under the fruit, deeply 5-cleft. Corolla whitish, yellowish, or purplish, funnelform, salverform, or campanulate; lobes 5 or rarely 4 , imbricate, obtuse. Stamens 5 or 4 ; filaments adnate up to the mouth of the corolla-tube; anthers opening lengthwise. Ovary 2celled. Berry rather dry.

Fruit red, globose; corolla narrowly funnelform, yellow or greenish.

Flowers $2 \mathrm{~cm}$. long.

Flowers about $1 \mathrm{~cm}$. long.

\section{L. pallidum.}

Leaves and calyces puberulent, the latter about half as long as the corollas.

Leaves and calyces glabrous (except the margin), the latter less than one-third as long as the corollas.

Calyx nearly one-third as long as the corolla, its lobes lanceolate or ovatelanceolate; leaves $1-4 \mathrm{~cm}$. long.

Calyx less than one-fourth as long as the corolla, its lobes broadly triangular; leaves usually less than $1 \mathrm{~cm}$. long.

Fruit orange-red, oval; corolla short-funnelform, greenish purple.

5. L. vulgare.

1. L. pallidum Miers. Shrub 6-12 dm. high, more or less spiny; leaves pale, spatulate or oblanceolate, $2-4 \mathrm{~cm}$. long, fascicled, glabrous or pruinose; corolla narrowly funnelform, greenish, tinged with purple; filaments exserted, glabrous. Arid hills: w Tex.-Colo.-Utah-Ariz.; Mex. Son. Ap-My.

2. L. Cooperi A. Gray. Shrub 5-10 dm. high, with very short spines and stout branches; leaves spatulate, minutely viscid-pubescent or puberulent, 1-2.5 $\mathrm{cm}$. long; corolla narrowly funnelform, $10-12 \mathrm{~mm}$. long, white; lobes oblong, obtuse; filaments hairy at the base. Arid hills: s Calif.-s Utah-Ariz. $L$. Son. Ap-Je.

3. L. Torreyi A. Gray. Shrub 1-2.5 m. high, more or less spiny; leaves spatulate or oblanceolate, 1-4 cm. long, glabrous; corolla $10-12 \mathrm{~mm}$. long, narrowly funnelform; limb about $8 \mathrm{~mm}$. wide; lobes tomentulose on the margins; filaments very woolly at the base; berry red. Arid hills: w Tex. $-\mathrm{s}$ Utah $-\mathrm{s}$ Calif. L. Son. Mr-Je.

4. L. Andersonii A. Gray. Shrub 5-10 dm. high, much branched, with short spines, glabrous; leaves linear-spatulate or oblanceolate, $3-10 \mathrm{~mm}$. long, glabrous; corolla tubular-funnelform, about $1 \mathrm{~cm}$. long; limb 4-5 mm. wide; lobes rounded; filaments slightly hairy at the base; berry bright red. Arid hills: Nev.-Utah-Ariz. Son. Ap-Je.

5. L. vulgare Dunal. Tall shrub, often climbing or trailing; stems $2-8 \mathrm{~m}$. long, sometimes spiny; leaves lanceolate, oblong, or spatulate, $1-4 \mathrm{~cm}$. long; corolla purplish, changing to greenish, $8-12 \mathrm{~mm}$. wide. Thickets and waste places: Ont.-Conn.-Utah-Alta.; escaped from cultivation, native of Eurasia and $\mathrm{n}$ Africa.

\section{HYOSCỲAMUS (Tourn.) L. Henbane.}

Viscid-pubescent herbs. Leaves alternate, lobed or pinnatifid. Flowers perfect, regular, solitary in the upper axils and in terminal racemes. Calyx urnshaped, 5-cleft, striate. Corolla funnelform, with slightly oblique 5-lobed limb. Stamens declined, mostly exserted; anthers opening longitudinally, Ovary 2-celled; stigma capitate. Capsule 2-celled, circumscissile above the middle.

1. H. niger L. Biennial, with a fusiform root; stem viscid-villous, $3-10 \mathrm{dm}$. high; leaves oblong to ovate, sinuately toothed or lobed, the upper clasping, viscid-villous; calyx campanulate, strongly veined, in fruit $2-2.5 \mathrm{~cm}$. long; corolla 
campanulate, lurid-yellowish, purple-veined, $2 \mathrm{~cm}$. long. Waste places and around dwellings: N.S.-N.Y.-Colo.-Mont.; nat. from Eu. My-S.

\section{Datùra L. Thorn Apple, Jimson Weed, Jamestown Weed, STRAMONIUM.}

Annual or perennial herbs, or in the tropies shrubs or trees, narcotic. Leaves alternate, mostly lobed. Flowers perfect, regular, solitary in the axils. Calyx prismatic-funnelform, 5-lobed. Corolla funnelform, plaited, 5-lobed; lobes acuminate. Stamens 5, included, adnate to near the middle of the corolla-tube. Ovary 2-celled or falsely 4-celled; stigma 2-lobed. Capsule more or less prickly, 4-valved or splitting irregularly.

Corolla 1.5-2 dm. long; capsule more or less fleshy, bursting irregularly.

Corolla about $1 \mathrm{dm}$. long; capsule dry, 4-valved.

1. D. meteloides.

Capsule erect; plant glabrous.

Corolla white; lower prickles of the capsule shorter.

Corolla violet; prickles all alike.

Capsule nodding; plant more or less cinereous.

2. D. Stramonium.

3. D. Tatula.

4. D. discolor.

1. D. meteloides DC. Annual or perennial; stem erect, 3-10 dm. high, finely grayish puberulent; leaves obliquely ovate, grayish puberulent, repand or nearly entire, 10-15 cm. long; calyx 10-12 cm. long; lobes lanceolate, acuminate; corolla white, often tinged with violet, $15-20 \mathrm{~cm}$. long; lobes with slender tips; eapsules subglobose, 4-5 cm., densely short-prickly, reflexed in fruit. Along streams: w Tex.-Colo.-Calif.; Mex. Son.-Submont. Mr-O.

2. D. Stramonium L. Annual; stems glabrous, 5-15 dm. high, widely branching; leaf-blades ovate to oblong, glabrous, 1-2 dm. long, acute, sinuately or laciniately toothed; calyx $3-5 \mathrm{~cm}$. long; lobes triangular or triangular-lanceolate, 5-7 mm. long; corolla white, 6-10 cm. long; lobes with slender tips; capsule 4-6 cm. long, densely prickly. Waste places and cultivated ground: N.S.-Fla. -Tex.-Colo.-Minn.; W. Ind. and S. Am.; nat. from Asia. My-D.

3. D. Tatula L. Annual; stem 5-15 dm. high, glabrous, purplish, branched; leaf-blades ovate to oblong, sinuately or angulately toothed, glabrous; calyx $3-6$ $\mathrm{cm}$. long; lobes triangular-lanceolate, 4-7 mm. long; corolla violet or lavender, 8-11 cm. long; lobes with slender tips; capsule oval or ovoid, $4-6 \mathrm{~cm}$. long, densely prickly. Waste places and fields: Conn.-Fla.-Tex.-Colo.-Calif.-Wash.; W. Ind. and Mex.; nat. from S. Am. Je-O.

4. D. discolor Bernh. Annual; stem puberulent, 3-6. dm. high; leaves sinuately or laciniately toothed, $5-15 \mathrm{~cm}$. long, more or less puberulent; ealyx about $5 \mathrm{~cm}$. long; teeth lanceolate; corolla white, tinged with purple, $5-7 \mathrm{~cm}$. long; capsule globose, with rather few, very stout prickles, pubescent. Valleys: N.M.-Colo. - s Calif.; Mex. Son. Ja-S.

\section{NICOTIÀNA (Tourn.) L. Toвacco.}

Annual or perennial, viscid-pubescent, narcotic herbs. Leaves alternate, entire or repand. Flowers perfect, regular, in terminal racemes or panicles. Calyx campanulate or tubular-ovoid, 5-lobed. Corolla funnelform, salverform, or nearly tubular; lobes 5 , spreading. Stamens 5 , included; filaments adnate to the base of the corolla-tube or free; anthers opening lengthwise. Ovary 2-celled, rarely 4-celled; stigma capitate. Fruit a 2- or rarely 4-valved capsule. Seeds numerous.

Corolla salverform; capsule 2-celled.

Leaves clasping at the base; flowers diurnal.

Leaves petioled, not clasping at the base; flowers nocturnal. Corolla funnelform; capsule 4-celled; leaves acute at both ends.

1. N. trigonophylla.

2. $N$. attenuata.

3. N. quadrivalois.

1. N. trigonophylla Dunal. Annuals; stem $3-10 \mathrm{dm}$. high, viscid-pubescent; leaves all sessile or the lower with winged petioles, obovate-oblong, 5-15 $\mathrm{cm}$. long, entire, the upper lanceolate, cordately half-clasping; inflorescence paniculate; calyx-lobes subulate-lanceolate; corolla greenish white or yellowish, 2-2.5 cm. long, somewhat pubescent. Valleys: Tex. $\rightarrow$ s Colo. $\rightarrow$ s Utah-Calif.; Mex. Son. Ap-S. 
2. N. attenuata Torr. Annual; stem 3-6 dm. viscid-puberulent; leaves petioled; blades ovate to lanceolate, long-acuminate, $5-10 \mathrm{~cm}$. long; inflorescence paniculate; calyx-teeth triangular-lanceolate; corolla dull white or greenish, glabrous, $2-2.5 \mathrm{~cm}$. long. N. Torreyana Nels. \& Macbr. Dry or sandy ground: Mont.-N.M.-Calif.-B.C.; Mex. Son.-Submont. Je-S,

3. N. quadrivalvis Pursh. Annual; stem 3-6 dm. high, viscid-pubescent, branched; lower leaves petioled, the upper sessile; blades ovate-lanceolate, lanceolate, or oblong, acute at both ends, viscid-pubescent; flowers few; corolla about $2 \mathrm{~cm}$. long, funnelform. Valleys and cultivated ground: Wash.-Mont.Ore.

\section{Family 117. SCROPHULARIACEAE. Figwort Family.}

Annual or perennial herbs, rarely shrubs or trees, with mostly round stems. Leaves usually opposite, sometimes whorled, or alternate, without stipules. Flowers perfect, more or less irregular. Calyx of 5 or 4 , more or less imbricate and united sepals. Corolla usually 2-lipped, sometimes almost regular. Stamens usually 4 , rarely 5 , or only 2 fertile, one pair longer than the rest, the fifth stamen sometimes represented by a sterile filament, all partly adnate to the tube of the corolla. Gynoecium of 2 united carpels; ovary 2-celled; styles usually united, rarely distinct. Fruit a 2-celled, 2-valved capsule, rarely baccate. Seeds numerous; endosperm present, surrounding the embryo, fleshy or cartilaginous. [RHINANTHACEAE.]

Anther-bearing stamens 5.

Corolla rotate.

Corolla funnelform, 2-lipped. (Occasional forms of)

1. VERBASCUM.

7. Pentstemon.

Anther-bearing stamens 4 or 2 .

Corolla spurred, saccate or gibbous at the base on the lower side. Corolla distinctly spurred at the base.

Corolla merely saccate or gibbous at the base.
Corolla neither spurred, nor saccate, nor gibbous on the lower side.

2. LINARIA.

3. ANTIRRHINUM.

Stamens 5, 4 anther-bearing; the fifth sterile and often rudimentary.

Sterile stamen rudimentary, represented by a scale or gland on the upper inside of the corolla-tube or throat; corolla short.

Corolla gibbous at the base on the upper side; ovules and seeds few or solitary; annuals.

Corolla deeply bilabiate, the middle lobe of the lower lip conduplicate and enclosing the stamens. 4 . Collinsia.

Corolla obscurely bilabiate, its five lobes rotately spreading, the lowest not enclosing the stamens. 5 . TONELLA.

Corolla not gibbous at the base, but more or less ventricose especially on the lower side; ovules and seeds numerous; 4 upper lobes of the corolla erect, the lower spreading; perennials.

6. SCROPHULARIA.

Sterile stamen elongate, flliform to spatulate; corolla-tube elongate, tubular or funnelform.

Inflorescence thyrsoid-paniculate; seeds not with an ariliform cellular-reticulate outer coat; corolla not gibbous at the base above; calyx deeply cleft.

7. Pentstemon.

Inflorescence racemose or spiciform; seeds with an ariliform cellular-re-

ticulate outer coat.
Corolla gibbous at the base above; calyx divided to near the base; inflorescence racemose.

8. PENTSTEMONOPSIS.

Corolla not gibbous at the base above; calyx deeply tubular-funnelform, Stamens 4 or 2 . obtusely 5-lobed; inflorescence spicate. 9. CHIONOPHILA.

Upper lip or lobes external in the bud.

Anther-bearing stamens 4.

Corolla more or less bilabiate; sepals united into an angled tube; plants leafy-stemmed.

Style glabrous; stigma divided into 2 oval lobes; placentae remaining united in the middle, rarely separating. 10. MrMULUS.

Style glandular above; stigma peltate-funnelform; placentae separating and remaining attached to the valves.

Corolla nearly regular.

11. Eunanus.

Calyx unequally 5-parted; flowers solitary in the axils of the leaves; plant caulescent.

12. MONIERA.

Calyx regularly 5-lobed; flowers solitary on scape-like peduncles from the basal rosette of leaves; plant acaulescent. 
Anther-bearing stamens 2; calyx of 5 almost distinct sepals; sterile flaments short or wanting.

14. Gratiola.

Upper lip or lobes internal in the bud.

Stamens 2.

Corolla almost regularly 4-lobed.

Corolla rotate; leaves opposite or verticillate.

Corolla campanulate or short-tubular; leaves alternate, mostly basal.

16. SYNTHYRIS.

Corolla none, or $\mid 2$-lipped, cleft to near the base; upper lip entire, the lower irregularly cleft or toothed; basal leaves ample; stem-leaves bract-like, reduced and alternate. 17. BESSEYA. Stamens 4

Corolla slightly 2-lipped; stamens not ascending under the upper lip.

18. AgALINIS.

Corolla distinctly 2-lipped; stamens ascending under the upper lip.

Anther-sacs dissimilar, the inner one pendulous by its apex; leaves mostly alternate.

Calyx gamosepalous.

Calyx deeply cleft in front and behind, less deeply so on the sides; upper lip of the corolla much longer than the 3-lobed lower one. 19. CASTILLFJA

Calyx almost equally 4-cleft; upper lip of the corolla slightly if at all longer than the 1-3-saccate lower one, which is minutely or obsoletely toothed.

Lip 1-saccate.

Lip 3-saccate.

20. ORTHOCARPUS.

21. TRIPHYSARIA.

Calyx 2-phyllous, $i$. e., cleft to the base on the sides or, by the absence of the lower leaf, 1-phyllous. 22. ADENOSTEGIA. Anther-sacs alike, parallel; leaves mostly opposite.

Margins of the 2-lobed upper lip of the corolla recurved; calyx 4-cleft. 23. EUPHRASIA.

Margins of the upper lip of the corolla not recurved.

Ovules several or numerous; capsule several or many-seeded. Calyx split below, or below and above, not inflated; capsule ovoid or oblong, oblique.

Galea prolonged into a filiform recurved beak; throat with a tooth on each side. 24, ELEPHANTELLA.

Galea if prolonged into a beak, the latter not filiform, straight or incurved; throat without teeth.

Calyx 4-toothed, inflated and veiny in fruit.

25. PEDICULARIS.

Ovules 2 in each cell; fruit 1-4-seeded.

26. RHINANTHUS.

27. MEI AMPYRUM.

\section{VERBÁSCUM (Tourn.) L. Mullen.}

Annual, biennial, or rarely perennial, caulescent herbs, more or less glandular or densely pubescent with branched hairs. Leaves alternate, entire, toothed, or pinnatifid, sometimes decurrent. Flowers perfect, in terminal spikes, racemes, or panicles. Sepals 5, partly united. Corolla rotate, 5-lobed, slightly irregular, the upper lobe exterior in the bud. Stamens 5, all fertile, exserted, the upper 3, or all of the filaments pubescent. Ovary 2-celled; styles dilated or flattened at the apex. Capsule oblong to subglobose, 2-valved, septicidal. Seeds rugose, wingless.

Plant densely woolly; flowers in a dense spike.

Plant glabrous or glandular; flowers racemose.

Pedicels longer than the fruit; plant glabrous or sparingly glandular.

Pedicels shorter than the fruit; plant densely glandular.

1. V. Thapsus.

2. V. Blattaria.

3. V. virgatum.

1. V. Thapsus L. Biennial; stem stout, $3-20 \mathrm{dm}$. high, woolly with densely matted branched hairs, winged; lower leaves spatulate or elliptic, 1-4 cm. long; upper stem-leaves oblanceolate, densely woolly; raceme dense and spike-like, continuous, 1-10 dm. long; calyx-lobes triangular-lanceolate; corolla deep yellow, rarely white, $1-2.5 \mathrm{~cm}$. wide, pubescent without. Waste places, fields, and roadsides: N.S.-Fla.-Calif.-B.C.; nat. from Eu. Plain-Submont. Je-Au.

2. V. Blattaria L. Biennial; stem rather slender, 4-12 dm. high, glabrous below, glandular above; basal leaves obovate or spatulate; stem-leaves oblong or ovate, the upper clasping, 2-12 cm. long, dentate, incised or lobed, glabrous; raceme slender, interrupted, 1-5 dm. long; calyx-lobes linear or oblong, recurved; corolla white or yellow, 3-4 cm. broad; filaments magenta. Fields and waste places: Que.-Fla.-Calif.-B.C.; nat. from Eu. Plain-Submont. My-S. 
3. V. virgatum With. Biennial; stem 5-10 dm. high, glandular-puberulent, purplish; basal leaves oblanceolate or spatulate, 1-3 dm. long, sinuate-dentate, somewhat pubescent; stem-leaves lanceolate, sessile or the upper clasping; calyxlobes lanceolate, spreading; corolla yellow. Waste places and roadsides: Calif. -Ariz.-Utah; N.S.-Ont.; adv. from Eu. My-J.

\section{LINÀRIA (Tourn.) L. BUTter-AND-EgGS, TOAD-FLAX.}

Annual or perennial herbs, with erect stems. Leaves alternate or opposite, or whorled on the shoots. Flowers in terminal racemes, spikes, or panicles; Sepals 5, partially united. Corolla irregular, 2-lipped; tube spurred at the base; throat partly closed by a convex fold. Stamens 4, didynamous, included. Capsule short, opening by 3 -toothed pores below the apex. Seeds angled and wrinkled, sometimes winged.

Corolla yellow, with an orange throat, $2-3 \mathrm{~cm}$. long.

Corolla blue or white, $12 \mathrm{~mm}$. or less long.

1. L. Linaria.

2. L. texana.

1. L. Linaria (L.) Karst. Perennial; stem glabrous or puberulent above, $1-10 \mathrm{dm}$. high; leaves linear or nearly so, $2-7 \mathrm{~cm}$. long; racemes dense; calyxlobes ovate, acute or acuminate. $L$. vulgaris Mill. Waste places and fields: Newf.-Ga.-N.M.-Man.; nat. from Eu. Plain-Submont. My-O.

2. I. texana Scheele. Annual or biennial; stem 2-8 dm. high, glabrous; leaves linear-spatulate, $1-2.5 \mathrm{~cm}$. long; racemes slender, 5-30 cm. long; calyx-lobes linear-lanceolate; corolla blue or white, $10-12 \mathrm{~mm}$. long. L. canadensis Coult. \& Nels., not Dum. Sandy soil: Okla.-Fla.-Tex.-Calif.-Ore.-Mex. Son. $\mathrm{Mr}-\mathrm{Je}$.

\section{ANTIRRHÎNUM (Tourn.) L. SNapdragon.}

Annual or perennial caulescent herbs. Leaves alternate, or the lower opposite, entire. Flowers solitary in the upper axils, or in terminal racemes or panicles. Sepals 5, partially united. Corolla irregular, 2-lipped; tube more or less saccate below; throat closed by a convex fold. Stamens 4, included; filaments sometimes dilated above. Styles united. Ovules numerous. Capsule opening by 2 or 3 pores below the apex. Seeds wingless, smooth or wrinkled.

Stem erect, 1-4 dm. high, with very short straight pedicels. $\quad 1$. A. Kingii. Stem 6-12 dm. high, climbing by means of long filiform curved pedicels. 2. A. Cooperi.

1. A. Kingii S. Wats. Annual; stem slender, somewhat hairy at the base; leaves narrowly lanceolate to linear, $1-3 \mathrm{~cm}$. long, the upper minute; calyx very oblique, glandular-hirsute; corolla 4-6 mm. long; capsule oblique, subglobose. Gravelly soil: Utah-Calif. Son. My-Jl.

2. A. Cooperi A. Gray. Annual; lower leaves ovate or oblong, the upper linear, the floral ones minute; corolla bright yellow, about $1 \mathrm{~cm}$. long, conspicuously saccate at the base; palate hairy; capsule globose. Ravines: s Calif.-s Utah. L. Son.

\section{Collínsia Nutt. Blue-eyed Mary, Blue-lips.}

Annual caulescent herbs. Leaves opposite or whorled, narrow, entire or toothed. Flowers solitary or elustered in the upper axils, perfect, irregular. Calyx-lobes 5. Corolla 2-lipped, violet, pink or white, open; tube short; lower lip 3-lobed, the middle lobe involute. Stamens 4, didynamous, declined, enclosed in the middle lobe of the lower lip of the corolla; staminodium present, but glandlike, near the base of the corolla. Styles united. Capsule ovoid or globose, 2-valved, the valves 2-cleft.

1. C. parviflora Dougl. Annual; stem 1-3 dm. high, at last diffuse and spreading, minutely puberulent; leaves oblong, lanceolate, oblanceolate, or linear, entire or nearly so, the floral ones often in whorls of 3-5; corolla blue, 4-6 mm. long. C. tenella Piper, in part. Shaded hillsides: Ont.-Ariz.-Calif.-B.C. Submont.-Mont. Ap.-Jl.

\section{TONÉLLA Nutt.}

Annual caulescent herbs. Leaves opposite, ternately divided. Flowers axillary, perfect, slightly irregular. Calyx deeply 5-cleft. Corolla obscurely 
2-lipped; lobes 5, unequal, rotately spreading; tube slightly gibbous above. Stamens 4, soon ascending, not inclosed; staminodium rudimentary. Capsule ovoid, 2 -valved. Seeds $1-4$ in each cell, oval.

1. T. floribunda A. Gray. Annual; stem 2-5 dm. high, glabrous; stemleaves mostly 3-5-foliolate, with linear or oblong leaflets, $1-5 \mathrm{~cm}$. long; floral leaves verticillate; corolla blue or purple; lobes broadly obovate. Banks and basaltic rocks: Ida.-Wash.-Ore. Son. Ap.-My.

\section{SCROPHULÀRIA (Tourn.) L. FigWORT.}

Perennial, caulescent herbs. Leaves opposite, usually petioled, with broad, toothed or incised blades. Flowers perfect, in terminal, paniculate eymes. Calyx with 5 short broad lobes. Corolla 2-lipped, purple, yellowish, or green; tube usually short; upper lip erect; lower lip with a spreading or reflexed middle lobe. Stamens 4, short; staminodium scale-like, in ours spatulate. Styles united. Capsule ovoid, 2-valved. Seeds numerous, marginless, rugose.

Leaves simply serrate, none lobed at the base; corolla-tube barely twice as long as the calyx.

Leaves incised or doubly serrate with sharp teeth, the lower inclined to be incised-lob.

at the base; corolla-tube more than twice as long as the calyx.

1. S. serrata Rydb. Stem 1-2 m. high, angled, sparingly puberulent or glabrous, slightly glandular in the inflorescence; leaf-blades ovate or cordate, 5-15 $\mathrm{cm}$. long; corolla-tube short, 6-7 mm. long; upper lip 4-5 mm. long; sterile stamen obovate-spatulate, purple. Wet places: Ida. Submont. J.

2. S. occidentalis (Rydb.) Bickn. Stem 1-2 m. high, more or less puberulent, or glabrate below, glandular in the inflorescence; leaves ovate; corolla lurid'greenish; tube gibbous below, $5 \mathrm{~mm}$. long; upper lip about $3 \mathrm{~mm}$. long; sterile stamen greenish yellow, very broad, kidney-shaped, on a distinct claw; capsule ovoid, $8-10 \mathrm{~mm}$. long. Low ground in thickets and woods: N.D.-Okla.-N.M. -Calif.-Wash. Submont.-Mont.

\section{PENTStÈmon (Mitchell) Schmidel. Beard-tongue, Mayflower, PRIDE-OF-THE-MOUNTAIN.}

Perennial, caulescent herbs. Leaves opposite, from petioled to sessile and clasping, entire or toothed, or rarely pinnatifid. Flowers irregular, in terminal racemes or panicles. Calyx deeply 5-cleft. Corolla 2-lipped, elongate, open; the tube often somewhat ventricose above, but not gibbous at the base; upper lip mostly erect, with 2 spreading lobes. Stamens 4; filaments nearly equal; staminodium well developed, spatulate, usually bearded. Styles united; stigma capitate. Capsule usually ovoid, 2-valved. Seeds numerous, wingless. Anthercells either united or confluent.

Corolla blue, purple, white, or yellowish, more or less funnelform or salverform.

Anthers bearded.

Plants suffrutescent; leaves leathery; anthers densely villous; sterile stamens

usually glabrous.
Plants not fruticose; leaves not leathery.

Plant more or less glandular at least in the rather few-flowered inflorescence; anthers densely villous; sterile stamen glabrous. II. Montani.

Plants glabrous or puberulent, not at all glandular; inflorescence dense and many-flowered; anthers and sterile stamens sparingly bearded.

Anthers glabrous or merely hirtello-ciliate along the line of dehiscence.

III. GLABRI.

Anthers dehiscent for nearly their whole length or at least at their distal end. Plants not suffruticose at the base. Leaves no, linear-filiform.

Corolla decidedly funnelform, $i$. e., throat much wider than the tube. Sterile stamen glabrous; plant tall. Sterile stamen bearded.

Corolla over $3 \mathrm{~cm}$. long, strongly ventricose; stem-leaves clasping.

Leaves strongly serrate.

Leaves with entire margins.

Corolla about $2 \mathrm{~cm}$ long or less; leaves linear. GRANDHLORI. not clasping; plant low.

Plants perfectly glabrous. 
Corolla strongly ventricose-gibbous; tube proper very short.

VI. HaLliani.

Corolla not ventricose-gibbous; tube gradually dilated into a funnelform throat. VII. ACUMINATI.

Plants glandular at least on the inflorescence.

Stem-leaves distinctly petioled; blades broadly ovate or suborbicular, coarsely dentate. VIII. PETIOLATI.

Stem-leaves sessile or nearly so; blades linear to lanceolate or oblong.

Stem glabrous below.

Stem glandular or puberulent. X. CRISTATI.
Corolla-tube almost cylindrical or

IX. WIPPLEANI.

$\mathrm{X}$. CRISTATI. less than $2 \mathrm{~cm}$. long.

Stems several from a branching rootstock, low and weak.

Stems solitary or a few from a taproot or short caudex.

Leaves linear-filiform.

XII. CONFERTI.

Corolla-limb not strongly oblique; sterile stamen bearded.

Corolla-limb strongly oblique; sterile stamen glabrous.

XIII. LARICIFOLII.

XIV. AMBIGUI.

Plant suffruticose at the base.

$\mathrm{XV}$. CaEspitosi.

Anthers dehiscent only on their proximate half, the distal half of the cells saccate, remaining unopened.

Plants densely glandular-pubescent throughout.

XVI. GLandULOSI.

Plant glabrous or puberulent; if at all glandular only in the inflorescence.

Corolla red, almost tubular.

XVII. AZUREI.

Anthers opening nearly their whole length.

Corolla scarcely bilabiate; lower lip not reflexed.

Corolla strongly bilabiate; lower iip reflexed.

Anthers opening only on their proximal part.

XVIII. PUNICEI.

XIX. BARBATI.

$\mathrm{XX}$. BRIDGESIANI.

\section{Fruticosi.} Leaves more or less distinctly petioled, broadest at or above the middle, not long-acumin-
ate.

Leaf-blades obovate or oval, obtuse or the upper acutish.

Plant $2-5 \mathrm{dm}$. high, erect.

Plant depressed, less than $2 \mathrm{~cm}$. high.

Corolla $3.5 \mathrm{~cm}$. long; leaf-blades $1-3 \mathrm{~cm}$. long.

Corolla $2.5-3 \mathrm{~cm}$. long; leaf-blades $1 \mathrm{~cm}$. long or less.

Leaf-blades oblanceolate, all acute.

Leaf-blades oblanceolate, entire or some rarely slightly denticulate; calyx-lobes

lanceolate, $5-10 \mathrm{~mm}$. long.
Leaf-blades very narrowly oblanceolate, sharply dentate; calyx-lobes lance-subu-

1. P. fruticosus.

2. P. ellipticus.

3. P. Menziesii. late, $10-15 \mathrm{~mm}$. long.

Leaves sessile, long-attenuate, broadest at the base.

Leaves glabrous; calyx 10-12 mm. long; corolla $3.5-4 \mathrm{~cm}$. long. 6. P. Lyallii.

Leaves grayish-pilose; calyx 12-15 mm. long; corolla $2.5-3.5 \mathrm{~cm}$, long.

\section{P. linearifolius.}

\section{Montani.}

Leaves narrowly lanceolate; corolla $3.5-4 \mathrm{~cm}$. long.
Leaf-blades ovate or cordate to broadly oblong; corolla about $3 \mathrm{~cm}$. long.

6. P. Lyallii.

8. P. montanus.

III. Glabri.

Anthers bearded, with long villous hairs; inflorescence secund.

Corolla-tube decidedly shorter than the throat; corolla deep blue.

Calyx-lobes oval or ovate, acute or obtuse, glabrous.

Corolla-tube nearly as long as the throat; corolla pale blue.

9. $P$. strictus.

10. P. strictiformis.

11. P. comarrhenus.

Anthers not long-villous.

Anthers sparingly short-hirsute.

Calyx-lobes ovate or lanceolate, acuminate.

Stem-leaves all lanceolate.

Calyx-lobes with narrow scarious margins, not auriculate.

Corolla about $1.5 \mathrm{~cm}$. long; limb almost regular; tube slightly ventricose; plant usually puberulent.

12. P. Fremontii.

Corolla $2 \mathrm{~cm}$. long or longer; limb distinctly 2-lipped; plant glabrous.

Corolla about $2.5 \mathrm{~cm}$. long; upper stem-leaves linear-lanceolate. Corolla about $2 \mathrm{~cm}$. long; upper stem-leaves broadily lanceolate to
ovate.

Calyx-lobes with very broad scarious margins, forming erose basal au
15 . $P$. alpinus.

Stem-leaves broadly ovate or subcordate.

Calyx-lobes with narrow or no searious margins, not auriculate. 
Leaves shorter than the internodes; anthers opening at the distal end. 16. P. cyananthus.

Leaves longer than the internodes; anthers opening their whole length. 14. $P$. cyanocaulis.

Calyx-lobes with very broad scarious margins, forming basal auricles; anther-sacs opening their whole length. 17. P. Brandegei.

Calyx-lobes orbicular or broadly ovate, abruptly short-acuminate, very scarious and erose.

Anthers perfectly glabrous.

18. P. glaber.

Sterile filament glabrous or nearly so.

Plant glabrate.

Calyx-lobes obovate or ovate, abruptly acuminate, decidedly scariousmargined.

19. P. speciosus.

Calyx-lobes acute or obtuse, scarcely scarious-margined.

Plant densely puberulent.

Sterile filament strongly bearded.
20. $P$. unilateralis.

21. P. Wardii.

22. P. perpulcher.
One species.

One species.

One species.

\section{ACUMINATI.}

\section{GRANDIFLORI.}

\section{HALLiani.}

23. P. Palmeri.

24. P. grandiflorus.

25. P. Hallii.

Inflorescence interrupted; bracts except the lowermost shorter than the flowers; basal leaves spatulate or oblanceolate.

Stamens exserted; bracts rounded-cordate, abruptly short-acuminate; sepais ovate, scarious-margined.

Stamens included.

Bracts ovate or cordate.

Calyx-lobes ovate, with scarious toothed margins, abruptly acuminate; bracts ovate, acute.

Calyx-lobes narrowly lanceolate, not scarious-margined.

Corolla-limb 15-18 mm. broad, glabrous within; tongue of the sterile filament strongly incurved, short yellow-bearded at the apex.

28. P. acuminatus.

Corolla-limb about $1 \mathrm{~cm}$. broad, usually slightly bearded within; tongue of the sterile filament less strongly incurved, yellow-bearded its whole length.

29. P. nitidus.

Bracts lanceolate to linear-lanceolate.

Stem-leaves except the uppermost obtuse, oblong or oblanceolate, tapering into a winged petiole.

30. $P$. arenicola.

Stem-leaves acute, sessile or the lowermost petioled, but the petiole not winged. Calyx-lobes broadly obovate, scarious, erose, abruptly contracted into a very short acumination.

Calyx-lobes ovate or lanceolate, acute or gradually acuminate.

Calyx-lobes lanceolate; plant 2.5-4 dm. high. 31. P. secundiflorus.

Calyx-lobes ovate, decidedly scarious-margined; plant $2 \mathrm{dm}$. or less high.

32. P. Fendleri.

Inflorescence dense; bracts large, long-acuminate, most of them exceeding the flowers; basal leaves linear or nearly so, narrower than the stem-leaves.

Bracts broadly lanceolate, or the upper ovate.

Bracts strongly veined; corolla $2.5-3 \mathrm{~cm}$. long, ventricose; basal leaves linear.

33. P. Haydenii.

Bracts not strongly veined; corolla about $2 \mathrm{~cm}$. long, scarcely ventricose; basal leaves linear-oblanceolate.

Bracts narrow, linear-lanceolate, not strongly veined.

34. $P$. caudatus.

35. P. angustifolius.

\section{Petiolati.}

One species.

\section{WIPPLEANI.}

One species.

X. Cristati.

36. P. petiolotus.

37. P. stenosepalus.

Corolla-tube decidedly gibbous-ventricose; sterile stamen densely yellow-villous; corolla purplish.

Stem viscid-villous as well as puberulent, especially the upper part.

Inflorescence densely glandular-villous; corolla $2.5-3.5 \mathrm{~cm}$. long; leaves entire or slightly denticulate.

Inflorescence sparingly glandular-villous; corolla $2-2.5 \mathrm{~cm}$. long; leaves sharply dentate.

Stem merely puberulent.

Basal leaf-blades obovate, spatulate, or ovate, broader than the cauline leaves. Corolla $2-2.5 \mathrm{~cm}$. long.

Corolla 15-18 cm. long. $\quad 41$. P. Moffattii.

Basal leaf-blades linear to linear-oblanceolate, usually narrower than the upper

cauline leaves.
Corolla over $2 \mathrm{~cm}$. long; calyx-lobes linear-lanceolate, about $8 \mathrm{~mm}$. long.

42. P. Jamesii. 
Corolla glabrous within, less than $2 \mathrm{~cm}$. long; calyx-lobes lanceolate, 4-5 mm. long.

Corolla-tube funnelform, scarcely gibbous; sterile stamen 43 . P. pumilus. corolla white.

One species.

\section{HARBOURIANI.}

\section{CONFERTI.}

Sterile filament usually naked; leaves sharply dentate.

Sterile filament bearded; leaves entire or denticulate.

Calyx glabrous or puberulent but not glandular.

Corolla sulphur-yellow.

Corolla purple.

Calyx 2-3 mm. long; lobes rounded-ovate, acute, denticulate; leaves thin, the upper acuminate. obes ovate, abruptly acuminate or obtuse; leaves firm, not acuminate.

Corolla more than $1 \mathrm{~cm}$. long; upper stem-leaves broadly lanceolate, often rounded at the base; plants $3 \mathrm{dm}$. high or more.

Calyx-lobes ovate, acuminate.

49. P. Rydbergii.

50. P. laxus.
. laxumin

Corolla less than $1 \mathrm{~cm}$. long; limb small; upper stem-leaves linear-lanceolate; plant seldom more than $3 \mathrm{dm}$. high. $51 . P$. procerus.

Calyx and inflorescence more or less glandular.

Leaves more or less denticulate.

Upper stem-leaves broad, ovate-cordate, acuminate, clasping.

Stem pubescent; calyx-lobes not scarious. $\quad 52$. P. ovatus.

Stem glabrous or sparingly puberulent up to the inflorescence; calyx-lobes margined.

Leaves firm; inflorescence rather dense; calyx-lobes narrowly scariousmargined.

Leaves thin; inflorescence open; calyx-Iobes not scarious-margined.

Upper stem-leaves lanceolate or linear.

Calyx-lobes elongate-lanceolate, not scarious; flowers ascending; stem-

leaves linear-lanceolate or linear. 62. P. gracilis.

Calyx-lobes ovate-lanceolate, scarious-margined below and usually toothed; stem-leaves oblong-lanceolate or lanceolate.

Tall, $3-5 \mathrm{dm}$. high; calyx-lobes acute.
Low, less than $3 \mathrm{dm}$. high; calyx-lobes abruptly acuminate.

Leaves entire or essentially so.

60. P. virens.

Plant depressed, decumbent; stems less than $2 \mathrm{dm}$. high; basal leaves usually less than $3 \mathrm{~cm}$. long, with rhombic-ovate or rounded-spatulate blades. Corolla about $1.5 \mathrm{~cm}$. long; stem-leaves more or less denticulate.

Corolla $1 \mathrm{~cm}$. long or less; stem-leaves entire. $\quad 56$. P. albertinus.

56. $P$. albertinus.

Plant not depressed, 2-7 dm. high; basal leaves more than $3 \mathrm{~cm}$. long, with oblanceolate blades; eorolla $1.5 \mathrm{~cm}$. long or more.

Calyx-lobes ovate, broadly scarious-margined.

Corolla sulphur-yellow.

Corolla purplish.

Stem-leaves ample, lanceolate or oblong.

Stem and leaves glabrous or nearly so.

Leaves thick, darkening in drying; stem-leaves always entire; inflorescence interrupted, congested.

Leaves thin, not darkening in drying. ste. P. pseudoprocerus. ticulate; inflorescence not congested, a more or less continuous panicle.

60. $P$, virens.

Stem and leaves decidedly puberulent. $\quad 68 . P$. humilis.

Stem-leaves linear or linear-lanceolate, reduced; basal leaves numer-

ous, oblanceolate to almost linear. 61 . $P$. a

61. $P$, aridus.

Leaves thick and darkening in drying; inflorescence congested and interrupted; corolla dark blue-purple.

Plant 2-3 dm. high; upper stem-leaves linear-lanceolate or oblong.

Plant 5-7 dm. high: 62 . P. pseudohumilis. half as long as the internodes.

Leaves thin, light green, not darkening in drying; inflorescence a continuous panicle; corolla white, light blue, or pink; leaves linear or linear-lanceolate.

Stem glabrous or nearly so.

Inflorescence narrow; pedicels short; stem-leaves linear-lanceolate.

63. $P$, gracilis.

Inflorescence open; pedicels long; stem-leaves narrowly linear.

Stem densely puberulent. 
Basal leaf-blades linear-oblanceolate.

Throat of the corolla funnelform, glandular-puberulent within; limb ample; lower lip almost equalling the upper; sterile stamen bearded at the end. 65. P. puberulentus.

Throat of the corolla almost cylindric; limb small; lower lip shorter than the upper, pubescent within; sterile fllament bearded at least half its length.

Stem-leaves narrowly linear; calyx-lobes not scariousmargined.

66. P. oreganus.

Stem-leaves narrowly lanceolate; calyx-lobes usually

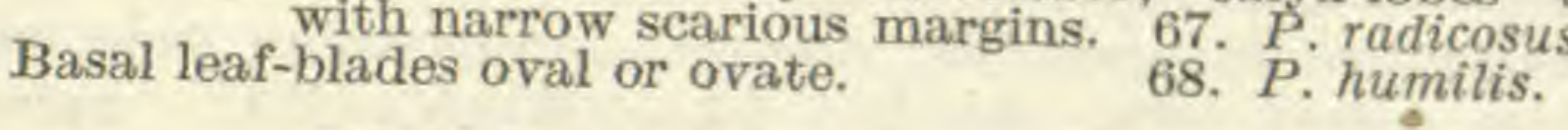

XIII, LARICIFOLII.

Calyx-lobes distinctly scarious-margined; lower lip of the corolla slightly hairy within

or glabrous.
Calyx-lobes not scarious-margined; lower lip of the corolla densely bearded within.

70. P. laricifolius.

Corolla-tube over $1 \mathrm{~cm}$. long.

Corolla-tube about $5 \mathrm{~mm}$. long.

\section{P. ambiguus.}

72. $P$. Thurberi.

\section{CAESPTTOSI.}

Leaf-blades obovate, spatulate, or broadly oblanceolate.

Leaves green and glabrous or slightly puberulent; calyx-lobes oblong-lanceolate.

Leaves densely grayish or whitish puberulent. calyx-lobes 73 . P. suffrutescens, Calyx-lobes linear-lanceolate, over 5 ment; calyx-lobes lanceolate.

Calyx-lobes linear-lanceolate, over $5 \mathrm{~mm}$. long; plant grayish puberulent.

Calyx-lobes broadly lanceolate, searcely $5 \mathrm{~mm}$. 74 . caespitosus,

almost white.

Leaf-blades narrowly oblanceolate to linear or filiform.

75. P. Thompsoniae. Calyx-lobes scarcely scarious-margined, entire; inflorescence few-flowered; floral
leaves like the rest.

Leaves green and glabrate.

Corolla 20-25 mm. long, deeply 2-lipped, with relatively broad tube.

Corola 15-20 mm 76. P. Crandallii.

Leaves densely canescent-puberulent.

Calyx-teeth scarious-margined, dentate or erose; inflorescence 78. P. teucrioides. form; floral leaves reduced.

One species.

\section{GLANDULOSI.}

.

79. P. coloradensis.

Leaves dentate, incised, or pinnatifid.

\section{AZUREI.}

80. P. glandulosus.

Corolla about $3 \mathrm{~cm}$. long; flowers in a dense terminal panicle; anthers villous.

Corolla $1-3 \mathrm{~cm}$. long; flowers in an open more or less leafy panicle venustus. branches; anthers glabrous.

Leaves opposite.

Leaves incised or pinnatifid.

Leaves merely dentate or serrate.

Leaves serrate; corolla $15-20 \mathrm{~mm}$. long.

Leaves saliently dent:
Leaves in whorls of three.

Leaves entire.

Leaves serrate; corolla $15-20$ mm. long. $\quad 83 . P$. diffusus.

82. P, Richardsonii.

85. P. triphyllus.

Calyx and inflorescence more or less glandular; leaves puberulent.

Calyx and inflorescence glabrous or the latter somewhat puberulent $P$. Kingii.

Calyx-lobes lanceolate, acute or acuminate.

Stem-leaves lanceolate, oblong or oblanceolate to linear, glabrous.

Plant low and decumbent at the base; lower stem-leaves oblanceolate, the upper oblong; calyx-lobes narrowly lanceolate. 87. P. Leonardi.

Plant tall; stem-leaves lanceolate or oblong-lanceolate; calyx-lobes ovateIanceolate, acuminate. Stem-leaves linear, puberulent.

88. P. platyphyllus.

89. P. Cusickii.

Calyx-lobes broadly ovate or obovate, mucronate, scarious-margined; leaves linear to lanceolate.

XVIII. PUNICEI.

90. $P$. sepalulus.

Stem and leaves puberulent; upper stem-leaves more or less acuminate.

Stem and leaves glabrous or nearly so; stem-leaves obtuse of acute.

Stem-leaves ovate to lanceolate; corolla $2-3 \mathrm{~cm}$. long.

Stem-leaves linear-lanceolate; corolla $1.5-2 \mathrm{~cm}$. long.

92. P. Eatonii.

93. P. utahensis. 
Anthers glabrous; leaves usually glabrous.

Anthers long-bearded; leaves usually somewhat puberulent.
95. P. Torreyi.

96. P. trichander.

One species.

XX. BRIDGesLant.

97. P. Bridgesii.

1. P. fruticosus (Pursh) Greene. Suffruticose, 2-10 dm. high; leaves spatulate, mostly obtuse, usually serrulate, $2-3 \mathrm{~cm}$. long, the upper ones of the flowering branches smaller, ovate, sessile; calyx about $1 \mathrm{~cm}$. long, densely glandular-hirsute; sepals lanceolate, acutish; corolla about $3 \mathrm{~cm}$. long, purple. Hills and mountain sides: Alta.-Mont.-Ida.-Wash.-B.C. Submont.-Mont. Jl-Au.

2. P. ellipticus Coult. \& Fisher. Perennial, with a procumbent subterranean woody stem; branches erect, minutely puberulent, 7-20 cm. high; leaves firm, broadly elliptic or rotund, the lower short-petioled, distantly serrulate or entire; calyx densely viscid-pubescent, 10-12 mm. long; lobes lanceolate, attenuate; corolla violet-purple, $3-3.5 \mathrm{~cm}$. long, strongly ventricose; anthers whitehairy. Mountains: Ida.-Mont.-Alta. Mont.-Subalp. Au.

3. P. Menziesii Hook. Densely matted suffrutescent perennial; branches 1-1.5 dm. high, ascending, puberulent; leaves short-petioled, obovate or broadly spatulate, more or less dentate, thick and leathery; calyx about $8 \mathrm{~mm}$. long, sparingly viscid; lobes lanceolate, acutish or obtuse; corolla purple, $2.5 \mathrm{~cm}$., rarely $3 \mathrm{~cm}$. long. High mountains: B.C.-Wash.-Alta. Subalp.-Alp. Je-Au.

4. P. crassifolius Lindl. Low shrub, 5-15 dm. high; leaves petioled, glabrous, $2-5 \mathrm{~cm}$. long, the upper floral ones much reduced, lanceolate or linear; calyx fully $1 \mathrm{~cm}$. long, densely glandular-hirsute; corolla lilac-purple, pinkish at the base, about $3 \mathrm{~cm}$. long, very slightly ventricose. Mountains: Wash.Wyo.-Mont. Submont.-Mont. Je-Au.

5. P. Scouleri Dougl. Low shrub, 2-5 dm. high; leaves short-petioled, $2-3 \mathrm{~cm}$. long, the upper lanceolate and somewhat reduced; calyx sparingly glandular; corolla lilac-purple, $3.5-4 \mathrm{~cm}$. long. Mountains: B.C.-Ida.-n Calif. Submont. Je-Au.

6. P. Lyallii A. Gray. Perennial, with a woody caudex; stems about $3 \mathrm{dm}$. high, glabrous or nearly so; leaves sessile, lanceolate to narrowly linear-lanceolate, sparingly denticulate, $5-10 \mathrm{~cm}$. long; calyx glandular-hirsute; lobes lanceolate, acute to attenuate. Mountains: B.C.-Ida.-Mont.-Alta. Submont.Mont. Je-Jl.

7. P. linearifolius Coult. \& Fisher. Perennial, with a woody caudex; stems $2-3 \mathrm{dm}$. high, grayish pubescent; leaves linear or linear-lanceloate, attenuate, $2-7 \mathrm{~cm}$. long, entire or minutely denticulate; calyx glandular; lobes linearlanceolate, attenuate; corolla light purple. Granite ledges: Ida.-Mont. Submont. Jl.

8. P. montanus Greene. Perennial, with a cespitose caudex; stems about $3 \mathrm{dm}$. high, cinereous-puberulent; leaves cinereous-puberulent, sessile, saliently dentate, $1-4 \mathrm{~cm}$. long; calyx about $1 \mathrm{~cm}$. long, densely glandular; lobes lanceolate, acute; corolla about $3 \mathrm{~cm}$. long, pink-purple, only slightly ventricose. (?) $P$. Woodsii A. Nels. Mountains: Ida.-Mont.-Wyo. Mont.-Subalp. Jl-Au.

9. P. strictus Benth. Stem strict, glabrous or nearly so, 2-5 dm. high; basal leaves spatulate or oblanceolate, $5-10 \mathrm{~cm}$. long; cauline leaves narrowly linear-lanceolate or linear, glabrous; calyx 4-5 mm. long; corolla $3 \mathrm{~cm}$. long. Hills: Wyo.-N.M.-Utah. Submont.-Mont. Je-Au.

10. P. strictiformis Rydb. Stems $3-5 \mathrm{dm}$. high, glabrous and strict, simple; basal leaves petioled, $5-10 \mathrm{~cm}$. long, oblanceolate, obtuse, glabrous and slightly glaucous; stem-leaves sessile, lanceolate, acuminate, 4-8 cm. long; corolla about $2.5 \mathrm{~cm}$. long. Hills and plains: Colo. Submont.-Mont. Je-S.

11. P. comarrhenus A. Gray. Stem 2-4 dm. high, glabrous or puberulent below; basal leaves petioled; blades oval, spatulate or oblanceolate, $5-10 \mathrm{~cm}$. long, finely puberulent; stem-leaves oblanceolate or linear; calyx-lobes ovate, 4-5 mm. long, short-acuminate; corolla $2.5-3 \mathrm{~cm}$. long, ventricose, but less so than in P. strictus. Dry hills: Utah-Colo. Submont.-Mont. Je-Jl. 
12. P. Fremontii T. \& G. Stems $2-3 \mathrm{dm}$. high; lower leaves spatulate or oblanceolate, 3-6 cm. long, finely puberulent; upper leaves lanceolate or linear; inflorescence dense, not secund; calyx $5 \mathrm{~mm}$. long, slightly puberulent; lobes lanceolate, acute or acuminate; corolla about $15 \mathrm{~mm}$. long; sterile stamen with dilated hirsute tip. Dry hills: Wyo,-Colo.-Utah. Submont. Je.

13. P. subglaber Rydb. Stem strict, 3-5 dm. high; basal leaves oblanceolate, 5-10 cm. long; stem-leaves narrowly lanceolate to nearly linear; calyx about $6 \mathrm{~mm}$. long; lobes lanceolate, acute or acuminate; corolla slightly ventricose; sterile stamen short-hirsute. P. glaber utahensis S. Wats. P. utahensis A. Nels., not Eastw. Mountains: Wyo.-Colo.-Utah-Ida. Submont.-Mont. Je-Au.

14. P. cyanocaulis Payson. Stem 3-6 dm. high, erect, glabrous; basal leaves spatulate, 4-7 cm. long; stem-leaves oblong-spatulate to lanceolate, sessile; calyx-lobes lanceolate, acute or acuminate, 4-5 mm. long, scarious-margined; corolla blue, 17-20 mm. long; sterile stamen sparsely hirsute, more than half its length. Dry mesas: w Colo. Submont. My-Je.

15. P. alpinus Torr. Stem 2-4 dm. high; basal leaves oblanceolate, obtuse, short-petioled; stem-leaves lanceolate and sessile, 5-10 cm. long, acute or acuminate; inflorescence dense and usually one-sided; calyx 8-10 mm. long; corolla funnelform, more or less ventricose, bluish purple; sterile stamen with yellow beard at the end. P. oreophilus Rydb. P. riparius A. Nels. Mountains: Colo. -s Wyo. Submont.-Mont. Je-Au.

16. P. cyananthus Benth. Stems $3-10 \mathrm{dm}$. high, glabrous and glaucous; lower leaves oblanceolate or spatulate, the upper ovate or subcordate; calyx 7-10 mm. long; lobes lanceolate; corolla $2-2.5 \mathrm{~cm}$. long, slightly ventricose; sterile stamen narrow, hirsute. Hills and mountains: Utah-Ida.-Wyo. Submont.-Mont. My-Au.

17. P. Brandegei Porter. Stems $3-6 \mathrm{dm}$. high, stout, glabrous or minutely puberulent; basal leaves $5-8 \mathrm{~cm}$. long, petioled, oblong to spatulate, glabrous or nearly so, glaucous; upper stem-leaves sessile, ovate or subcordate, $3-7 \mathrm{~cm}$. long; calyx 4-5 mm. long; sterile stamen club-shaped, almost glabrous. $P$. cyananthus Brandegei Porter. Mountains: Colo. Submont.-Mont. Jl-S.

18. P. glaber Pursh. Stems stout, glabrous and glaucescent, $3-6 \mathrm{dm}$. high; lower leaves oblanceolate, $5-15 \mathrm{~cm}$. long, glabrous, the upper oblong or lanceolate; calyx glabrous, about $5 \mathrm{~mm}$. long; corolla bluish purple, about $3 \mathrm{~cm}$. long, somewhat ventricose; sterile stamen sparingly hirsute. $P$, eriantherus Nutt. $P$. Gordoni Hook. Plains and hills: N.D.-Neb.-Ida. Plain-Submont. Je-JI.

19. P. speciosus Dougl. Stem $2-6 \mathrm{dm}$. high, glabrous; basal leaves oblanceolate, glabrous, 5-10 cm. long; upper stem-leaves narrowly linear-lanceolate, acuminate; calyx $5-6 \mathrm{~mm}$. long; corolla $2-2.5 \mathrm{~cm}$. long, narrower below and more ventricose above than in P. glaber. P. Rex A. Nels. Plains: Wash.-Calif.Nev.-Mont. My-Jl.

20. P. unilateralis Rydb. Stems 3-6 dm. high, glabrous, strict; lower leaves narrowly oblanceolate, $5-10 \mathrm{~cm}$. long, the upper linear-lanceolate; inflorescence decidedly secund; calyx glabrous, about $5 \mathrm{~mm}$. long; lobes round-oval or ovate, acute or obtuse; corolla narrow below, abruptly ventricose, $2 \mathrm{~cm}$. long. $P$. secundiflorus A. Gray, not Benth. Mountains: Wyo.-N.M.-Utah. Submont.-Mont.

21. P. Wardii A. Gray. Stem 1-3 dm. high, densely minutely cinereouspubescent; leaves thick, oblong or the upper oblong-lanceolate, puberulent; corolla pale and sparsely puberulent. P.glaber Wardii M. E. Jones. Mountains: Utah. Submont.

22. P. perpulcher A. Nels. Stem 4-8 dm. high, erect, puberulent below; leaves narrowly oblanceolate, $3-10 \mathrm{~cm}$. long; stem-leaves linear-lanceolate to linear; calyx-lobes glabrous, ovate, subscarious and denticulate on the margins; corolla blue, less than $2 \mathrm{~cm}$. long, glabrous within; anthers glabrous; sterile filament stiffly bearded, not dilated at the tip. P. minidocanus and (?) P. payetensis Nels. \& Macbr. Dry banks: Ida. Son. 
23. P. Palmeri A. Gray. Stem 6-10 dm. high, glabrous; lower leaves spatulate, petioled, the upper ovate, lanceolate, or oblong, sessile or perfoliate, sharply dentate; calyx glandular-pubescent; lobes broadly ovate, cuspidate, scarious-margined; corolla cream-colored, tinged with pink, from a narrow, short tube, strongly ventricose, about $2 \mathrm{~cm}$. long; sterile stamen densely yellow-bearded. Dry regions: s Utah-Nev.-Calif. Submont. Je-Jl.

24. P. grandiflorus Nutt. Stem 6-12 dm. high, glabrous; basal leaves glaucous, glabrous, obovate, entire; upper stem-leaves broadly ovate, oval, or rounded; calyx about $5 \mathrm{~mm}$. long, glabrous; lobes ovate, acute; corolla about 4 $\mathrm{cm}$. long, pink, strongly ventricose, with a narrow tube; sterile stamen hooked and minutely pubescent at the apex. P. Bradburyi Pursh. Prairies and plains: Wis.-Mo.-Okla.-Colo.-Wyo. Plain. My-Jl.

25. P. Hallii A. Gray. Caudex cespitose; stem glabrous, 1-2 dm. high; basal leaves linear-oblanceolate, obtuse, thick, glabrous; stem-leaves narrowly linear-lanceolate or linear; inflorescence short; ealyx $4 \mathrm{~mm}$. long; lobes broadly obovate, abruptly acuminate, with scarious erose margins; corolla $15-20 \mathrm{~mm}$. long, ventricose, without distinct tube; sterile filament short-bearded. High mountains: Colo.-Utah. Subalp. -Alp. J1-Au.

26. P. cyathophorus Rydb. Stem very strict, 3-4 dm. high; basal leaves and lower stem-leaves spatulate, petioled, $3-6 \mathrm{~cm}$. long, the others ovate or orbicular, often abruptly acuminate or mucronate; ealyx 6-8 $\mathrm{mm}$. long; lobes lanceolate, scarious-margined and more or less erose-dentate; corolla pink-purple, 12$15 \mathrm{~mm}$. long, little oblique and scarcely ventricose; sterile stamen with a yellow beard. Mountains: n Colo.-s Wyo. Submont.-Mont. Jl.

27. P. pachyphyllus A. Gray. Stem 3-6 dm. high, stout, glabrous and glaucous; basal leaves petioled, 6-10 cm. long, glabrous and glaucous; blades thick, oval, rounded at the apex; lower stem-leaves oblong or elliptic, the upper ones and the bracts oval, the latter usually scarious-margined; calyx glabrous, $5 \mathrm{~mm}$. long; corolla $15-20 \mathrm{~mm}$. long; sterile stamen spatulate, densely bearded. $P$. acuminatus major Benth. $P$. acuminatus congestus M. E. Jones. Plains: Utah.-Ariz. Son. Je.

28. P. acuminatus Dougl. Stem glabrous and glaucous, strict, 2-4 dm. high; lower leaves oblanceolate, glabrous, glaucous, 2-6 cm. long; upper leaves and bracts broadly ovate or cordate, abruptly acuminate, strongly veined; calyx glabrous, 8-10 mm. long; corolla blue or purple, about $2 \mathrm{~cm}$. long, funnelform. Plains: Wash.-Alta.-Ida.-Nev. Son. My-Jl.

29. P. nitidus Dougl. Stem $2-3 \mathrm{dm}$. high, glabrous, glaucous; lower leaves oblanceolate, 3-5 cm. long, glabrous, entire; upper leaves and bracts lanceolate or ovate, acute or abruptly acuminate; calyx glabrous, 4-6 $\mathrm{mm}$. long; corolla blue, 15-18 mm. long, obliquely funnelform. Plains: Man.-S.D.-Wyo.Wash.-Alta. Plain. My-Jl.

30. P. arenicola A. Nels. Stems 2-3 dm. high, glabrous and glaucous; lower leaves petioled, oblanceolate or spatulate, the middle ones oblong and the uppermost lanceolate; calyx glabrous, $4 \mathrm{~mm}$. long; sepals lanceolate, acute, slightly scarious; corolla $12-15 \mathrm{~mm}$. long; sterile stamen obliquely spatulate, bearded. Sand-dunes: Wyo. Plain. Je.

31. P. secundiflorus Benth. Stem glabrous and glaucous; basal leaves oblanceolate, 3-7 cm. long, glaucous and glabrous; stem-leaves lanceolate to ovate-lanceolate, more or less acuminate; inflorescence secund; calyx 5-6 mm. long, glabrous, often somewhat bluish; corolla about $2 \mathrm{~cm}$. long, funnelform, bluish purple; sterile stamen club-shaped, curved, densely bearded. Dry plains or hills: Wyo.-N.M.-Utah. Submont.-Mont.

32. P. Fendleri A. Gray. Stem glabrous and glaucous, 1-2 dm. high; basal leaves petioled, $3-6 \mathrm{~cm}$. long; blades oval or ovate; stem-leaves ovate to lanceolate; bracts small, lanceolate; calyx $4 \mathrm{~mm}$. long; corolla $15-18 \mathrm{~mm}$. long, almost salverform; sterile stamen club-shaped, densely yellow-bearded. Dry plains: Colo.-w Tex.-N.M.-(? Calif.). My-Jl. 
33. P. Haydenii S. Wats. Stem $2-5 \mathrm{dm}$. high, stout, leafy, glabrous; lower leaves, especially those of the shoots, narrowly linear, the upper stem-leaves linear-lanceolate; calyx glabrous, about $8 \mathrm{~mm}$. long; lobes lanceolate, acuminate; corolla blue, funnelform; sterile stamen bearded at the apex. Sand hills: Neb.Wyo. Plain. Je-Jl.

34. P. caudatus Heller. Stem glabrous, 2-4 dm. high, leafy; lower leaves 4-7 cm. long; stem-leaves lanceolate, linear-lanceolate or the upper ovate-lanceolate, acuminate; calyx about $5 \mathrm{~mm}$. long; lobes lanceolate, scarious-margined, long-acuminate; corolla violet, about $2 \mathrm{~cm}$. long, funnelform; sterile stamen bearded on the upper half. P. angustifolius caudatus Rydb. Hills: N.M.Colo. Submont. My-Je.

35. P. angustifolius Pursh. Stems 1-3 dm. high, glabrous; leaves linear or the upper linear-lanceolate, $5-10 \mathrm{~cm}$. long, glabrous; calyx glabrous, about $5 \mathrm{~mm}$. long; lobes lanceolate, acuminate, often with narrow scarious margins; corolla about $15 \mathrm{~mm}$. long, blue, lilac, or white, funnelform, scarcely ventricose; sterile stamen bearded above. P. coeruleus Nutt. Plains: S.D.-Colo.-Mont. Plain. My-Jl.

36. P. petiolatus Brand. Stem about $1 \mathrm{dm}$. high, cespitose from a woody root, puberulent, glandular in the inflorescence; petioles $1-1.5 \mathrm{~cm}$. long; leafblades 1-2 cm. long, cinereous-puberulent, sharply serrate, abruptly acuminate; bracts ovate, acuminate, 1-3 mm. long; calyx-lobes ovate, $6 \mathrm{~mm}$. long; corolla 15 $\mathrm{mm}$. long, broadly funnelform; lower lip bearded within; sterile stamen bearded. Hills: Nev.-s Utah. Submont.

37. P. stenosepalus (A. Gray) Howell. Stem 1-5 dm. high, glabrous up to the inflorescence; basal leaves petioled, 3-7 $\mathrm{cm}$. long, glabrous; blades spatulate or elliptic; stem-leaves sessile, lanceolate or linear-lanceolate, acuminate; calyx glandular-hirsute, 7-10 mm. long; lobes lance-subulate, attenuate; corolla 18-20 $\mathrm{mm}$. long, funnelform, slightly ventricose, dull-white, rose, or purplish; sterile stamen club-shaped, bearded above. P. glaucus stenosepalus A. Gray. Mountains: Wyo.-N.M.-Ariz.-Utah. Mont.-Subalp.

38. P. Erianthera Pursh. Stem stout, 1-4 dm. high, leafy, eanescent and more or less villous, especially above; basal leaves spatulate or oblanceolate, petioled, 5-10 cm. long; stem-leaves oblong or linear, entire or nearly so, grayish puberulent and sometimes villous on the veins; calyx fully $1 \mathrm{~cm}$. long; lobes lance-subulate; sterile stamen with very long yellow hairs, two-thirds its length; throat long-bearded within. P. cristatus Nutt. Plains: N.D. -Neb.-Nev.Wash. Plain. My-J.

39. P. saliens Rydb. Stems 2-3 dm. high, finely puberulent; basal leaves petioled, about $5 \mathrm{~cm}$. long; blades obovate or oblanceolate, finely puberulent; stem-leaves oblanceolate to linear-lanceolate; calyx about $1 \mathrm{~cm}$. long, villousglandular; lobes linear-lanceolate, acuminate; throat and sterile stamen longbearded. Plains: Mont. Plain. Je.

40. P. Cleburnei A. Nels. Stem low, densely puberulent, 1-2 dm. high; basal leaves entire or nearly so, petioled, ovate or elliptic, $2-4 \mathrm{~cm}$. long; stemleaves narrowly oblong; calyx minutely glandular, about $8 \mathrm{~mm}$. long; lobes lanceolate; corolla-throat short-villous within; sterile stamen long-villous at the apex. P. Jamesii A. Nels., not Benth. P. auricomus A. Nels. Dry plains and hills: Wyo.-S.D.-Mont. Plain. My-Je.

41. P. Moffattii Eastw. Stems $1-3 \mathrm{dm}$. high, densely grayish puberulent; basal leaves petioled, ovate-spatulate, entire, grayish-puberulent; upper leaves lanceolate; calyx glandular-hirsute; lobes linear-oblong or linear-lanceolate; corolla purplish blue; sterile stamen moderately bearded towards the apex. $P$. pseudo-humilis M. E. Jones, not Rydb. Dry table-lands: Utah-Colo. Submont. $\mathrm{My}-\mathrm{Je}$.

42. P. Jamesii Benth. Stems 1-3 dm. high, grayish puberulent, glandular in the inflorescence; lower leaves narrowly linear-lanceolate, 3-10 cm. long; upper stem-leaves linear or linear-lanceolate; calyx glandular-villous, $8-10 \mathrm{~mm}$. long; corolla glandular-villous; sterile stamen yellow-bearded at least half its length; 
lower lip white-hairy in the throat. Plains and dry valleys: Colo. Submont.Mont. My-Jl.

43. P. pumilus Nutt. Stems less than $1 \mathrm{dm}$. high, grayish-puberulent; basal leaves linear-oblanceolate to spatulate, 1-3 cm. long, grayish-puberulent; stem-leaves linear; calyx $4.5 \mathrm{~mm}$. long, viscid-puberulent; corolla about $18 \mathrm{~mm}$. long, slightly viscid-puberulent; sterile stamen yellow-bearded half its length. Hills: Mont.-Ida. Submont.

44. P. albidus Nutt. Stems $1.5-4 \mathrm{dm}$. high, puberulent, viscid-villous above; lower leaves petioled, lanceolate or oblanceolate, $3-8 \mathrm{~cm}$. long, densely puberulent; upper leaves linear or linear-lanceolate, entire or dentate; calyx viscid-villous, 5-7 mm. long; lobes lanceolate; corolla about $2 \mathrm{~cm}$. long, viscidpuberulent. Prairies and plains: Man.-Kans.-Colo.-Ida.-Alta. Plain. $\mathrm{My}-\mathrm{Jl}$.

45. P. Harbourii A. Gray. Stems 5-15 cm. long, decumbent at the base, puberulent; leaves thick, oval or obovate, the lower petioled, the upper sessile, green and puberulent or glabrate; flowers few, crowded; calyx viscid-villous, 6-8 mm. long; lobes lanceolate; corolla purple, $2 \mathrm{~cm}$. long; lower lip pubescent in the throat; sterile stamen spatulate, yellow-bearded half its length. P.Bakeri Greene. Rock-slides, on the higher peaks: Colo. Mont.-Alp. J1-Au.

46. P. deustus Dougl. Perennial, with a woody base; stem glabrous, 1-4 $\mathrm{dm}$. high; leaves firm, ovate, oblong or lanceolate, 1-3 cm.long; thelower petioled, the upper sessile; calyx glabrous or glandular-puberulent, $4 \mathrm{~mm}$. long; lobes ovate or lanceolate, acute; corolla ochroleucous or dull-white, 10-12 mm. long; sterile stamen glabrous, occasionally anther-bearing. Dry regions: Mont.Wyo.-Nev.-Calif.-B.C. Son.-Submont. My-Jl.

47. P. confertus Dougl. Stem slender, 1-5 dm. high, glabrous; lower leaves oblanceolate, $5-15 \mathrm{~cm}$. long, glabrous, thin, entire; stem-leaves linear to lanceolate, acute; inflorescence interrupted; calyx $5 \mathrm{~mm}$. long; lobes lanceolate to broadly ovate, abruptly acuminate, scarious-margined, erose; corolla $1 \mathrm{~cm}$. long; lower lip bearded within. Dry banks and hills: B.C.-Calif.-Wyo.Alta. Submont. My-Jl.

48. P. Watsonii A. Gray. Stem glabrous or glaucous, 3-5 dm. high; stemleaves lanceolate, glabrous, sessile, acute or acuminate, $3-5 \mathrm{~cm}$. long; calyx-lobes searious-margined; corolla $12-15 \mathrm{~mm}$. long, violet-purple; sterile stamen clubshaped, yellow-bearded. $P$. phlogifolius Greene. Dry plains: Nev.-Ida.Utah-Ariz. Jl.

49. P. Rydbergii A. Nels. Stem 2-4 dm. high; basal leaves oblanceolate, petioled, 3-5 cm. long, entire, mostly acute or obtuse; stem-leaves sessile, oblong or lanceolate, entire, acute or the uppermost acuminate; calyx-lobes tinged with dark purple and white, with an erose-dentate margin; corolla purple, with very dark limb, 10-15 mm. long; lower lip bearded on the inside; sterile stamen narrowly clavate, short-bearded. $P$. erosus Rydb. $P$. latiusculus Greene. $P$. lacerellus Greene. Mountains: Wyo.-Colo.-Nev.-Ida. Submont.-Mont.

50. P. laxus A. Nels. Stem slender, $5-8 \mathrm{dm}$. high, minutely puberulent; lower leaves linear-oblanceolate, the upper lanceolate or linear-lanceolate, minutely puberulent; flowers in a short thyrsus; corolla vivid-blue, about $12 \mathrm{~mm}$. long, densely bearded inside the lower lip; sterile stamen not dilated, blue at the tip, eurved at the apex, sparingly hairy or glabrate. Sage-brush lands: Ida. Jl.

51. P. procerus Dougl. Stem decumbent at the base, 1-3 dm. high, glabrous or puberulent; basal leaves petioled, oblanceolate or linear-oblanceolate, glabrous, 4-8 cm. long; inflorescence usually compact, but in large specimens interrupted below; calyx glabrous, $5 \mathrm{~mm}$. long; lobes obovate or cuneate, abruptly cuspidate, scarious-margined and erose; corolla dark purplish blue; lower lip bearded within. P. micranthus Nutt. P. confertus coeruleo-purpureus A. Gray. Hills and mountains: Sask.-Colo.-Calif.-B.C.-Yukon. Plain-Subalp. JeAu. 
52. P. ovatus Dougl. Stem 5-10 dm. high, more or less viscid above; basal leaves petioled; blades ovate, 4-8 cm. long, dentate, sparingly pilose; inflorescence a loose thyrsus; calyx somewhat viscid, 3-4 $\mathrm{mm}$. long; lobes lance-ovate, acute; corolla nearly $2 \mathrm{~cm}$. long; lower lip bearded in the throat; sterile stamen yellowbearded above. Woods and banks: B.C.-Mont.-Ida. Submont.-Mont. My-Jl.

53. P. pinetorum Piper. Stem 6-10 dm. high, glabrous or nearly so; basal leaves petioled; blades ovate or elliptic, mostly entire, glabrous, thickish, 1-7 $\mathrm{cm}$. long; calyx viscid-pubescent, $4 \mathrm{~mm}$. long; lobes ovate, short-acuminate; corolla bright blue, varying to pink, $15-20 \mathrm{~mm}$. long; lower lip bearded in the throat; sterile stamen bearded on the spatulate apex. P. veronicaefolius Greene. Woods and mountain sides: Mont.-Ida. $-\mathrm{n}$ Wash.-B.C. Submont. My-Jl.

54. P. leptophyllus Rydb. Stem 3-5 dm. high, glabrous or sparingly puberulent; lower leaves spatulate, petioled; upper stem-leaves ovate, $3-5 \mathrm{~cm}$. long, sharply serrate, thin, subcordate at the base; calyx sparingly viscid-pubescent, 3-4 mm. long; lobes ovate, short-acuminate; corolla light blue, elongatefunnelform, 20-22 mm. long; lower lip sparingly bearded within; sterile stamen sparsely hairy. Mountains: Ida. Submont. Jl.

55. P. Wilcoxii Rydb. Stems glabrous or slightly puberulent above, simple; leaves glabrous and somewhat glaucous, dentate with small sharp callous teeth, acute, the basal ones petioled, lanceolate, the upper stem-leaves lanceolate and slightly clasping; calyx-lobes lanceolate, acute, slightly margined and sinuately toothed below; corolla purple, about $15 \mathrm{~mm}$. long; lower lip longer than the upper, slightly bearded within; sterile stamen club-shaped, with a short dense brown beard. Plains: Mont.-Ida. Plain. My-Jl.

56. P. albertinus Greene. Stems about $2 \mathrm{dm}$. high, glabrous, only slightly glandular in the inflorescence; stem-leaves elliptic-ovate or -lanceolate, subsessile; calyx sparingly glandular, 3-4 mm. long; lobes ovate, acute, entire, only slightly scarious-margined below; corolla light blue, scarcely ventricose. Mountains: Alta.-B.C. Mont. Jl.

57. P. brevifolius (A. Gray) A. Nels. Perennial, with a cespitose caudex; stems ascending or decumbent at the base, 1-2 dm. high, glabrous; stem-leaves obovate or elliptic, entire; calyx densely viscid, $3 \mathrm{~mm}$. long; lobes ovate, acuminate, slightly scarious-margined; corolla light blue, $1 \mathrm{~cm}$. long, cylindric-funnelform, scarcely ventricose. $P$. humilis brevifolius A. Gray. P. brevis A. Nels. High mountains: Utah-Nev.-Ida. Mont.-Subalp.

58. P. attenuatus Dougl. Stem $3-5 \mathrm{dm}$. high, glabrous up to the inflorescence; basal leaves petioled, glabrous; blades spatulate or elliptic; stem-leaves oblong or lanceolate or the uppermost ovate-lanceolate; calyx $6 \mathrm{~mm}$. long; corolla narrowly funnelform, $15-18 \mathrm{~mm}$. long, bearded in the throat. Plains: Wash.Ida.-Ore. Submont. My-J.

59. P. pseudoprocerus $R y d b$. Stem glabrous up to the inflorescence, $1.5-3$ $\mathrm{dm}$. high; basal leaves petioled, 3-5 cm. long, thick, glabrous; upper stem-leaves lanceolate or linear; calyx about $5 \mathrm{~mm}$. long; corolla fully $15 \mathrm{~mm}$. long, dark purplish blue, cylindric-funnelform, puberulent; lower lip sparingly bearded; sterile stamen densely yellow-bearded at the spatulate end. Mountains: Mont.Wyo.-Ida. Submont. Je-Jl.

60. P. virens Pennell. Stem 1-3 dm. high, glabrous up to the inflorescence; leaves glabrous, glaucescent, the lower petioled; blades $2-4 \mathrm{~cm}$. long; upper stemleaves lanceolate or oblong, usually denticulate; calyx $4 \mathrm{~mm}$. long; corolla deepblue, $15 \mathrm{~mm}$. long, funnelform; lower lip slightly bearded; sterile stamen yellowbearded on the spatulate tip. P. humilis A. Gray, mainly, not Nutt. Plains and hills: Alta.-Colo.-Nev. Plain-Mont. Je-Au.

61. P. aridus Rydb. Stems puberulent or glabrate up to the inflorescence, 1-2 dm. high; basal leaves 2-4 cm. long, thick; calyx $5 \mathrm{~mm}$. long; corolla about $12 \mathrm{~mm}$. long, tubular-funnelform; sterile stamen slightly bearded at the end. Dry hillsides: Mont. Submont.-Mont. Je-Jl. 
62. P. pseudohumilis Rydb. Stem glabrous, $2-3 \mathrm{dm}$. high, simple; basal leaves petioled; blades elliptic or spatulate, thin; calyx 5-6 mm. long; corolla bluish purple, about $15 \mathrm{~mm}$. long, funnelform; sterile stamen with spatulate yellow-bearded end. P. Oweni A. Nels. Wooded mountain sides: Alta.-Wyo. -Ida.-B.C. Submont.-Mont. Je-Au.

63. P. gracilis Nutt. Stem 2-4 dm. high, viscid in the inflorescence; basal leaves short-petioled; blades oblanceolate or elliptic, entire; stem-leaves mostly linear-lanceolate, usually denticulate; corolla almost cylindric, lilac or whitish, 18-20 $\mathrm{mm}$. long, slightly bearded within; sterile stamen bearded three-fourths its length. Plains and prairies: Man.-Tex.-Colo.-Alta. Plain-Submont. $\mathrm{Je}-\mathrm{Jl}$.

64. P. oliganthus Woot. \& Standl. Stem slender, $2-3 \mathrm{dm}$, high, glabrous below, glandular above; basal leaf-blades oblong or oval, $2 \mathrm{~cm}$. long; stem-leaves linear-lanceolate or linear; calyx $4 \mathrm{~mm}$. long, glandular-villous; corolla 20-25 $\mathrm{mm}$. long, bearded in the throat; sterile stamen densely yellow-bearded. $P$. Griffini A. Nels. Mountains: N.M.-Colo. Submont. J1-Au.

65. P. puberulentus Rydb. Perennial, suffruticose and branched at the base; stems 3-4 dm. high, finely puberulent; leaves narrowly linear-lanceolate or linear-oblanceolate, $2-5 \mathrm{~cm}$. long, entire, acute, with strong midrib and somewhat revolute margins, finely puberulent on both sides; inflorescence elongate, racemiform, glandular-puberulent; calyx about $5 \mathrm{~mm}$. long, glandular-puberulent; sepals ovate-lanceolate, acute; corolla about $18 \mathrm{~mm}$. long, glandular-puberulent without and within; throat funnelform; limb ample, about $1 \mathrm{~cm}$. wide, slightly bilabiate; sterile filament with yellow beard towards the end. Valleys: Ida.Ore. Submont.-Son. Jl.

66. P. oreganus (A. Gray) Howell. Perennial, suffruticose at the base; stems strict, finely puberulent, 2-4 dm. high; basal leaves small, linear-oblanceolate; stem-leaves 2-4 cm. long, $1-3 \mathrm{~mm}$. wide, densely and finely puberulent; calyx-lobes lanceolate; corolla purple, $18-20 \mathrm{~mm}$. long, puberulent without; sterile filament bearded at least two-thirds its length. 'P. Gairdneri oreganus A. Gray. P. linarioides seorsa A. Nels. Lava fields: Ida.-Ore. Submont. Je.

67. P. radicosus A. Nels. Stems strict, erect, 2-3 dm. high, puberulent; basal leaves small or none; stem-leaves $2-4 \mathrm{~cm}$. long; calyx viscid, $5 \mathrm{~mm}$. long; corolla nearly tubular, dark blue, 14-18 mm. long, sparsely bearded within; sterile stamen bearded half its length. Dry plains: Mont.-Colo.-Utah-Ida. Plain-Submont. My-Jl.

68. P. humilis Nutt. Stems erect, 2-3 dm. high, puberulent throughout and viscid in the inflorescence; basal leaf-blades elliptic, acute, $2-3 \mathrm{~cm}$. long, finely puberulent; stem-leaves sessile, oblong or linear; calyx 4-5 mm. long; corolla deep-blue, tubular-funnelform, sparsely bearded in the throat; sterile stamen bearded at the apex. P. collinus A. Nels. Hills: Wyo.-Ore.-B.C. Plain-Submont. Je-Jl.

69. P. exilifolius A. Nels. Stems glabrous, 1-2 dm. high; leaves numerous, narrowly linear, channelled or convolute, $1.5-2.5 \mathrm{~cm}$. long; calyx glabrous, $5 \mathrm{~mm}$. long; sepals ovate, acuminate; corolla white, tubular-funnelform, $12-15 \mathrm{~mm}$. long; sterile stamen almost filiform, short-bearded. Dry plains and hilltops: Wyo.-Colo. Plain-Submont. Je-J.

70. P. laricifolius H. \&.A. Stems 1-2 dm. long, glabrous; leaves numerous, almost filiform, 1-2 cm. long, glabrous; calyx $5 \mathrm{~mm}$. long, glabrous; lobes lance-subulate; corolla 12-15 mm. long, funnelform; sterile stamen club-shaped, bearded half its length. Plains and hills: Ida.-Wyo. Submont.-Mont. JI.

71. P. ambiguus Torr. Stem glabrous, $3-6 \mathrm{dm}$. high, diffusely branched; bracts subulate; peduncles opposite, 1-3-flowered; calyx glabrous, $3 \mathrm{~mm}$. long; lobes ovate, short-acuminate; corolla $2 \mathrm{~cm}$. long, rose-colored or white; fifth stamen often anther-bearing. Plains: Tex.-Okla.-Colo.-Utah-Ariz.; Mex. Son. $\mathrm{My}-\mathrm{S}$.

72. P. Thurberi Torr. Stem $3-4 \mathrm{dm}$. high, glabrous; leaves $1-3 \mathrm{~cm}$. long; calyx 2-3 mm. long, glabrous; lobes ovate; corolla scarcely $1 \mathrm{~cm}$. long, more 
funnelform; stamens more equal in length, the fifth sometimes anther-bearing. Arid places: s Utah-Ariz.-N.M.; Mex. Son. Jl-Au.

73. P. suffrutescens Rydb. Stems decumbent or prostrate, often rooting, retrorsely puberulent, $1-2 \mathrm{dm}$. long; leaves thick, spatulate, about $1 \mathrm{~cm}$. long; inflorescence few-flowered; calyx 4-5 mm. long, puberulent; corolla 10-15 mm. long, tubular-funnelform, ventricose, glabrous within; sterile stamen bearded fully half its length. P. caespitosus suffruticosus A. Gray. P. procumbens Greene. High mountains: Colo.-Utah. Mont. Je-Jl.

74. P. caespitosus Nutt. Stems cinereous-puberulent, decumbent, 0.5-2 $\mathrm{dm}$. long; leaves 5-15 $\mathrm{mm}$. long, spatulate or oblanceolate, grayish puberulent; flower-clusters few-flowered; calyx puberulent, $6-8 \mathrm{~mm}$. long; corolla $15-20 \mathrm{~mm}$. long, tubular-funnelform, somewhat ventricose, sparingly villous within; sterile stamen strongly bearded. Dry hills: Wyo.-Colo.-Utah. Submont.-Subalp. Je-Jl.

75. P. Thompsoniae (A. Gray) Rydb. Stems ascending or decumbent, about $1 \mathrm{dm}$. high, densely puberulent; leaves spatulate or oblanceolate, 5-18 $\mathrm{mm}$. long, densely puberulent; calyx white-puberulent, $5 \mathrm{~mm}$. long or less; corolla about $15 \mathrm{~mm}$. long, tubular-funnelform, sparingly bearded within; sterile stamen strongly bearded half its length. P. pumilus Thompsoniae A. Gray. Dry hills: s Utah-Ariz.-Nev. Son. Jl-Au.

76. P. Crandallii A. Nels. Stems prostrate or ascending, finely puberulent, 1-2 dm. high, leafy; leaves linear-oblanceolate, 1-2 cm. long, puberulent; calyx glandular-pubescent, $4 \mathrm{~mm}$. long; lobes lanceolate, slightly scarious at the base; corolla elongate-funnelform, sparsely glandular-puberulent, sparingly villous in the throat; sterile stamen moderately bearded to near its base. Mountains: Colo. Submont.-Mont. Je-Au.

77. P. xylus A. Nels. Stems ascending, finely puberulent, 1-2 dm. high; leaves linear-spatulate, glabrous or nearly so, 1-2 cm. long; calyx glandularpuberulent; lobes linear-lanceolate, not scarious; corolla blue, sparingly puberulent, sparingly bearded in the throat; sterile stamen bearded half its length. Mountains: Colo. Submont.-Mont. My-Jl.

78. P. teucrioides Greene. Stems usually less than $1.5 \mathrm{dm}$., ascending, cinereous-puberulent; leaves spatulate-linear, entire, cinereous, about $1 \mathrm{~cm}$. long; calyx $4 \mathrm{~mm}$. long; lobes lance-subulate, not scarious-margined; corolla deep-purple, about $12 \mathrm{~mm}$. long, cylindro-funnelform, scarcely gibbous; sterile stamen bearded to near the base. Dry hills: Colo.-Utah. Submont. My-Je.

79. P. coloradensis A. Nels. Stems cinereous-puberulent, 1-3 dm. high; leaves 1-2.5 cm. long, oblanceolate-linear, puberulent; inflorescence elongate; calyx puberulent, $4 \mathrm{~mm}$. long; lobes ovate, short-acuminate; corolla lilac or purple, about $15 \mathrm{~mm}$. long, funnelform, ventricose; lower lip bearded within; sterile stamen bearded half its length. P. linarioides Rydb. (Fl. Colo.), not A. Gray. Dry hills and plains: Tex.-Colo.-Utah-Ariz.; Mex. Submont. Ap-Au.

80. P. glandulosus Lindl. Stem 6-10 dm. high, viscid-pilose or puberulent; lower leaves petioled; blades 5-15 cm. long, ovate, lanceolate, or oblong, dentate, acuminate; upper stem-leaves ovate-lanceolate to cordate, often clasping, saliently dentate, pubescent; calyx viscid-pilose, $10-15 \mathrm{~mm}$. long; lobes lanceolate, attenuate; corolla lilac, 3-4 cm. long, puberulent, funnelform, ventricose; sterile stamen glabrous. Mountain woods and along streams: Ore.-Ida.-Wash. Son.Submont. My-Jl.

81. P. venustus Dougl. Stem 3-6 dm. high, glabrous or somewhat puberulent; leaves lanceolate to oblong- or oval-lanceolate, closely and sharply serrate, glabrous, 2-4 cm. long; calyx $3 \mathrm{~mm}$. long, glabrous; sepals ovate, short-acuminate; corolla funnelform, somewhat ventricose; sterile stamen sparingly longbearded half or three-fourths its length. Dry plains and hills: Ore.-Ida.Wash. Submont. Je.

82. P. Richardsonii Dougl. Stem loosely branched, more or less puberulent; leaves ovate or lanceolate in outline, incised to laciniate-pinnatifid, 2-5 $\mathrm{cm}$. long, puberulent; calyx $6 \mathrm{~mm}$. long, viscid-puberulent; sepals ovate, apicu- 
late; corolla reddish, $2-2.5 \mathrm{~cm}$. long, funnelform, ventricose; sterile stamen sparingly villous-bearded at the apex. Rocky places: Alta.-Ida.-Ore.-B.C. Son.-Submont. Je-Au.

83. P. diffusus Dougl. Stem 3-6 dm. high, somewhat puberulent; leaves ovate or lanceolate, the upper subcordate, serrate, glabrate; inflorescence interrupted; calyx more or less pubescent, 6-8 $\mathrm{mm}$. long; lobes ovate or lanceolate, acuminate; corolla blue or purple; sterile stamen sparingly bearded above. Wooded or rocky banks: B.C.-Ore. Mont. Je-Jl.

84. P. diphyllus Rydb. Stem much branched, minutely puberulent, 2-3 $\mathrm{dm}$. high; leaves $3-5 \mathrm{~cm}$. long, the lower petioled, the upper sessile, lanceolate, acute; calyx glandular-pubescent, $5 \mathrm{~mm}$. long; lobes lanceolate, unequal; corolla funnelform, scarcely ventricose; sterile stamen filiform-clavate, sparingly bearded. Rocky woods: Mont.-B.C. Submont. Jl-Au.

85. P. triphyllus Dougl. Stem slender, $3-8 \mathrm{dm}$., puberulent or glabrate; leaves lanceolate or linear, $2-4 \mathrm{~cm}$. long, denticulate to incised; calyx $6 \mathrm{~mm}$. long, viscid-puberulent; lobes lanceolate, acuminate; corolla purple, $12-15 \mathrm{~mm}$. long, tubular-funnelform; sterile stamen bearded at the apex. Dry soil: B.C.-Ida.Ore. Son.-Submont. My-Je.

86. P. Kingii S. Wats. Stems branched, $2-4 \mathrm{dm}$. high, glabrous or pruinose; leaves oblanceolate, glabrous or puberulent, not glaucous, $2-3 \mathrm{~cm}$. long; inflorescence strict; calyx sparingly viscid-puberulent; lobes ovate, acuminate; corolla 15-25 mm. long, cylindro-funnelform. Mountains: (? Utah)-Nev. Submont. $\mathrm{Je}-\mathrm{Jl}$.

87. P. Leonardi Rydb. Stem 1-2 dm. high, minutely puberulent; leaves glabrous and somewhat glaucous, $1-3 \mathrm{~cm}$. long; inflorescence few-flowered; calyx glabrous, $5-6 \mathrm{~mm}$. long; sepals narrowly lanceolate, attenuate; corolla $15-18 \mathrm{~mm}$. long, narrowly funnelform; stamens included; sterile stamen long, glabrous. P. Kingii Coult. \& Nels., mainly. Mountains: Utah. Mont. Jl-Au.

88. P. platyphyllus Rydb. Stems glabrous or minutely puberulent, 3-4 $\mathrm{dm}$. high; leaves oval to broadly lanceolate, acute at each end, glabrous; calyx glabrous, $6-8 \mathrm{~mm}$. long; corolla about $2.5 \mathrm{~cm}$. long, funnelform, glabrous; stamens slightly exserted; anthers papillose-hispid on the margins; sterile stamen glabrous, gradually widened upwards. $P$. heterophyllus latifolius S. Wats. P. latifolius Krautter, not Hoffmgg. Cañons: Utah. Submont. Je-Au.

89. P. Cusickii A. Gray. Stems $2-4 \mathrm{dm}$. high, pruinose-puberulent; leaves narrowly linear, $2-4 \mathrm{~cm}$. long, puberulent; thyrsus loose; calyx $5 \mathrm{~mm}$. long, glabrous or puberulent, but not viscid; lobes ovate, acuminate; corolla 18-20 $\mathrm{mm}$. long, ventricose, funnelform; sterile stamen spatulate-dilated at the tip, glabrous. P. Macbridei A. Nels. Slopes: Ore.-Ida. Submont. Je.

90. P. sepalulus A. Nels. Stems glabrous and glaucous, $3-6 \mathrm{dm}$. high; leaves narrowly lanceolate or linear, glabrous and glaucous; inflorescence open; calyx glabrous, $3 \mathrm{~mm}$. long; corolla violet, funnelform, ventricose, $2.5 \mathrm{~cm}$. long; anthers minutely papillose on the margin; sterile stamen glabrous, graduately dilated to the truncate apex. P. azureus ambiguus A. Gray. Cañons: Utah. Submont. Je-Лl.

91. P. coccinatus Rydb. Stem erect, $3-6 \mathrm{dm}$. high; basal leaf-blades ovate or elliptic, acute at both ends, 3-7 cm. long, densely puberulent; upper stemleaves ovate or ovate-lanceolate, acuminate; calyx about $5 \mathrm{~mm}$. long, puberulent; lobes broadly ovate, short-acuminate, scarious-margined and denticulate; corolla red, about $2.5 \mathrm{~cm}$. long, nearly tubular; anthers papillose on the margin, glabrous; sterile stamen glabrous, club-shaped, truncate. $P$. Ealonii undosus M. E. Jones. Arid places: s Utah-Ariz.-se Colo. Son. My-Je.

92. P. Eatonii A. Gray. Stem 3-6 dm. high, glabrous; basal leaves 5-10 $\mathrm{cm}$. long; blades spatulate or oblanceolate; calyx glabrous, $5 \mathrm{~mm}$. long; lobes ovate or ovate-lanceolate, acute or somewhat acuminate, slightly scariousmargined; corolla carmine, tubular; sterile stamen usually slightly puberulent at the apex. Dry banks: Utah-Ariz.-Nev. Submont.-Mont. Je-Jl. 
93. P. utahensis Eastw. Stem 3-6 dm. high, glabrous; basal leaves oblanceolate, thick, $5-8 \mathrm{~cm}$. long, glabrous; calyx glabrous, $4 \mathrm{~mm}$. long; lobes ovate or lance-ovate, acute; corolla earmine, $15-20 \mathrm{~mm}$. long, slightly bilabiate, tubular-funnelform; sterile stamen dilated and hooked at the tip, glabrous. P. confusus M. E. Jones. P. Eastwoodiae Heller. Arid regions: Ariz.-s Utah. Son.

94. P. barbatus (Cav.) Nutt. Stem 3-18 dm. high, glabrous; lower leaves petioled, oblong or ovate, glabrous; stem-leaves lanceolate to linear; calyx $5 \mathrm{~mm}$. long, glabrous; lobes ovate; corolla $2.5-3 \mathrm{~cm}$. long, tubular, strongly 2-lipped; anthers and sterile stamen glabrous. Mountains: N.M.-s Utah-Ariz.; also Mex. Submont.-Mont. Je S.

95. P. Torreyi Benth. Stem glabrous, 3-6 dm. high, glabrous; basal leaves spatulate or oblanceolate; stem-leaves linear, glabrous; calyx glabrous, $4 \mathrm{~mm}$. long; lobes ovate, acute; corolla scarlet, 3-3.5 $\mathrm{cm}$. long; sterile stamen glabrous. Hills and mountain sides: N.M.-Colo.- Utah-Ariz.; Mex. Submont.-Mont. $\mathrm{Jl}-\mathrm{O}$.

96. P. trichander (A. Gray) Rydb. Stem glabrous or slightly puberulent and glaucous, 3-7 dm. high; basal leaves spatulate or oblanceolate, $4-8 \mathrm{~cm}$. long; stem-leaves linear; calyx glabrous, 5-6 mm. long; lobes ovate, more or less acuminate; corolla scarlet, about $3 \mathrm{~cm}$. long; sterile stamen filiform, glabrous. Mountains: Colo.-Utah. Submont.-Mont. Je-Jl.

97. P. Bridgesii A. Gray. Stem glabrous up to the inflorescence, or pruinose-puberulent; lower leaves spatulate or oblanceolate, the upper linear, mostly glabrous; calyx $5 \mathrm{~mm}$. long, viscid; lobes ovate or lanceolate, acuminate; corolla scarlet, tubular-funnelform, $2.5 \mathrm{~cm}$. long, strongly bilabiate, not ventricose, glabrous within; anthers strongly sagittate, glabrous; sterile stamen glabrous. Rocky banks: Calif.-Ariz.-(? s Colo.)-Utah. Submont. Jl-Au.

\section{PENTSTEMONÓPSIS Rydb.}

Pererennial caulescent herbs. Leaves opposite, but mostly basal, oblanceolate or spatulate, the stem-leaves bract-like. Flowers perfect, racemose. Calyx 5 -cleft to near the base. Corolla 2-lipped; tube gibbous at the base on the upper side. Stamens 4, nearly equal. Staminodium or sterile stamen glabrous. Capsule ovoid, 2-valved. Seeds numerous, with an arilliform reticulate coat.

1. P. Tweedyi (Canby \& Rose) Rydb. Stem 1-1.5 dm. high, glabrous; leaves mostly basal, $2-3 \mathrm{~cm}$. long, oblanceolate or spatulate, glabrous; stemleaves small and bract-like; inflorescence secund; calyx $3 \mathrm{~mm}$. long, glandularpuberulent; lobes ovate, acute; corolla white or tinged with purple, $8-10 \mathrm{~mm}$. long, tubular; anthers and sterile stamen glabrous. Pentstemon Tweedyi Canby \& Rose. Chionophila Tweedyi Henders. Rich soil: Mont.-Ida. Submont.Mont. Je-Jl.

\section{CHIONÓPHILA Benth.}

Perennial caulescent herbs. Leaves opposite, entire. Flowers perfect, racemose. Calyx funnelform, membranous, obscurely 5-lobed. Corolla 2-lipped; throat slightly dilate; upper lip erect, retuse; lower lip 3-lobed, bearded in the throat. Stamens 4, as in Pentstemon; staminodium small and short, glabrous. Styles united; stigma minute. Capsule oblong, 2-valved, loculicidal, the valves 2-parted. Seeds with a loose arilliform cellular-reticulate coat.

1. C. Jamesii Benth. Stem $1 \mathrm{dm}$. high or less, glabrous or minutely puberulent; basal leaves thick, entire, spatulate or oblanceolate, glabrous; stem-leaves small, linear; spike dense, secund, imbricate-bracteate; calyx tubular, 7-8 mm. long; corolla about $12 \mathrm{~mm}$. long, cream-colored, glabrous, tubular. Higher mountains: Colo. $\rightarrow$ S Wyo. Subalp. $-A l p$. J-Au.

\section{Mímulus L. Monkey-Flower.}

Annual or perennial herbs. Leaves opposite, mostly toothed. Flowers perfect, axillary, solitary, sometimes disposed in leafy racemes or panicles. Calyx angled; tube longer than the unequal 5 lobes. Corolla 2-lipped, yellow or red; tube with two ridges within on the lower side; upper lip spreading or re- 
flexed; lower lip erect. Stamens 4; filaments partly adnate to the corolla-tube. Styles glabrous, united up to the 2-lobed stigma. Capsule loculicidal; placentae separating from the valves, remaining united in the middle, seldom separating.

Calyx oblique, decidedly inflated in fruit; upper tooth much larger than the rest; corolla yellow.

Calyx-teeth acute; stem neither rooting at the nodes, nor floating.

Perennials, usually tall and erect, 3-6 dm. high; corolla 2-3.5 cm. long; upper calyx-tooth half longer than the rest.

Leaves glabrous; stem pubescent only above. $\quad$ 1. M. Langsiorfi.

Leaves and stem pubescent throughout.

Annuals, slender or low; corolla $2 \mathrm{~cm}$. or less long.

Corolla $1.5-2 \mathrm{~cm}$. long, at least twice as long as the calyx.

Stem long, usually slender; upper calyx-lobe about twice as long as the rest; calyx red-spotted. $3 . M$. nasutus.

Stem less than $1 \mathrm{dm}$. high; upper calyx-lobe only slightly longer than the rest; calyx not spotted. 4 . M. thermalis.

Corolla 5-10 mm. long, about half longer than the calyx. Plant perfectly glabrous.

Inflorescence and calyx villous-puberulent.
Calyx-teeth obtuse; stem decumbent or floating, rooting at the nodes.

5. M. Hallii.

6. M. microphyllus.

7. M. Geyeri.

Calyx neither oblique, nor inflated; its lobes nearly equal.

Perennials; flowers $1.5-4 \mathrm{~cm}$. long; sepals linear-lanceolate.

Corolla crimson or rose.

Tall, with erect stem, 3-10 dm. high, not stoloniferous.

Stem 1-2 dm. high, stoloniferous.

Corolla yellow; plant low or slender, weak.

Stem leafy throughout.

Stem leafy only at the base. 15. M. primuloides
15.

Annuals; flowers $0.5-2 \mathrm{~cm}$. long; sepals ovate, triangular, or broadly lanceolate.

Leaves petioled; blades cordate to ovate-lanceolate.

Leaf-blades cordate or broadly ovate, indistinctly 5-ribbed. Corolla $1.5-2 \mathrm{~cm}$. long.

Corolla $1 \mathrm{~cm}$. or less long.

Leaves not very thin, dark green, decidedly pubescent; stem often purple and villous.

Leaves very thin, membranous, light green, glabrous or nearly so; stem very delicate, white.

Leaf-blades ovate-lanceolate, tapering at the base, distinctly 3-ribbed.

Leaves sessile, oval, oblong, lanceolate or linear.

Corolla yellow; lower lip lobed.

Leaves basal or nearly so; peduncle solitary, scape-like, many times longer than the leaves.

15. $M$. primuloides.

Leaves scattered; peduncles axillary, scarcely exceeding the leaves.

Plant villous, 1-4 dm. high; lower lip of the corolla with 2 brown spots.

16. M. pilosus.

Plant $1 \mathrm{dm}$. high or less, glabrous or glandular-puberulent; corolla spotless.

Leaves thick, indistinctly veined; corolla 4-6 mm. long.

17. M. Suksdorfii.

Leaves thin, more or less distinctly 3 -ribbed; corolla about $8 \mathrm{~mm}$. long.

Corolla rose-colored; lower lip entire.

Plant glandular-puberulent.

Plant glandular-villous.

18. $M$. gratioloides.

19. M. rubellus.

20. M. Breweri.

1. M. Langsdorfii Donn. Stems erect or ascending, 1-10 dm. high, glabrous; lower leaves petioled, the upper sessile or clasping; blades ovate, rounded, or subreniform, sinuately dentate or denticulate, $2-7 \mathrm{~cm}$. long, glabrous; calyx 10-15 $\mathrm{mm}$. long, puberulent; teeth broadly triangular-ovate, acutish; corolla $2-3.5 \mathrm{~cm}$. long, yellow, rarely spotted, bearded inside. M. luteus A. Gray, not L. M. minor A. Nels. Swamps and along streams: Sask.-N.M.-Calif.-Alaska; Mex. Submont.-Subalp. Ap-Au.

2. M. puberulus Greene. Stem 2-3 dm. high, viscid-hirtellous; lower leaves petioled, obovate or spatulate, somewhat puberulent; upper stem-leaves sessile, ovate, coarsely dentate; calyx viscid-puberulent, about $1 \mathrm{~cm}$. long; teeth triangular, acute; corolla yellow, $2-2.5 \mathrm{~cm}$. long, funnelform. Mountains: Colo. Mont. Je-Jl.

3. M. nasutus Greene. Stem glabrous or minutely puberulent, $1-5 \mathrm{dm}$. high, 4-angled; lower leaves spatulate, petioled, the upper rounded or reniform, clasping; calyx 6-8 mm. long, puberulent; teeth triangular, very acute; corolla 
yellow, funnelform, 15-18 mm. long. Mountains: Ida.-(? Colo.)-Calif,-B.C. Submont.-Mont. Ap-Je.

4. M. thermalis A. Nels. Stem erect, $3-15 \mathrm{~cm}$. high, glabrous below, puberulent above; leaf-blades nearly orbicular, obscurely dentate, 3-9 $\mathrm{mm}$. long, the upper sessile, the lower short-petioled; calyx $5 \mathrm{~mm}$. long, in fruit $1 \mathrm{~cm}$. long; teeth broadly triangular-ovate, acute; corolla about $15 \mathrm{~mm}$. long, funnelform, yellow, short-pubescent on the lower lip. Geyser formations: Yellowstone Park, Wyo. Mont. Au.

5. M. Hallii Greene. Stem angled, glabrous, 1-3 dm. high; leaves broadly ovate, sparingly dentate or entire, 1-2 cm. long, the lower petioled, glabrous; calyx $5 \mathrm{~mm}$. long, in fruit nearly $1 \mathrm{~cm}$. and subglobose-inflated, with a few spots; teeth triangular, acute, the upper tooth about twice as long as the others; corolla 5-8 mm. long, light yellow. Wet places in the mountains: Colo.-(? Mont.)(? Ida.), Submont. My-Jl.

6. M. microphyllus Benth. Stem 1-2, rarely $3 \mathrm{dm}$. high, simple, erect, glabrous; leaves nearly all petioled; blades orbicular, sinuate-dentate, at the base cordate and more coarsely toothed, 1-2 cm. broad; those of the inflorescence similar, subsessile and usually villous-puberulent; calyx 8-10 mm. long; corolla yellow, about $1 \mathrm{~cm}$. long; tube scarcely exserted from the calyx. Wet places: Wash.-Ore--Ida. Submont. Ap-Je.

7. M. Geyeri Torr. Perennial; stem 1-4 dm. long, glabrous; leaves rounded or reniform, denticulate to entire, 8-25 $\mathrm{mm}$. long, all except the uppermost with margined petioles; calyx glabrous or slightly puberulent, $5-8 \mathrm{~mm}$. long; upper lobe broadly ovate, twice as long as the very short rounded other lobes; corolla yellow, 8-12 mm. long. M. Jamesii T. \& G. In water: Mich,-Ill.-Colo-Wyo.-N.D. Plain-Submont. Je-Au.

8. M. Lewisii Pursh. Stem 3-10 dm. high, more or less viscid-pilose; leaves lanceolate, oblong or ovate, dentate, $4-8 \mathrm{~cm}$. long, viscid-pubescent; calyx glandular-pubescent, about $2 \mathrm{~cm}$. long; teeth broadly-triangular, subulate-acuminate; corolla crimson, rose-red, or paler, $3.5-5 \mathrm{~cm}$. long, bearded within. Along streams: Minn.-Colo.-Ariz.-Calif.-B.C. Plain-Mont. Je-Au.

9. P. Eastwoodiae Rydb. Perennial, with a rootstock and stolons; stems 1-2 $\mathrm{dm}$. high, viscid-villous; leaves sessile, coarsely dentate, viscid, $3-5$-ribbed, $2-5$ $\mathrm{cm}$. long, the lower cuneate, the upper obovate or oblanceolate; stolons 1-3 $\mathrm{cm}$. long, rooting at the end; calyx narrowly funnelform; lobes lanceolate, subequal; corolla crimson, $3-4 \mathrm{~cm}$. long; anthers sparingly bearded. In crevices of overhanging eliffs: se Utah. Son. Au.

10. M. moschatus Dougl, Stem 1-4 dm., decumbent or creeping; leafblades petioled, ovate or oblong-ovate, villous and viseid; calyx prismatic, 7-10 $\mathrm{mm}$. Fong; teeth broadly lanceolate, acuminate, somewhat unequal; corolla 15-20 mm. long, yellow, funnelform. Musk Flower. Wet places: Ont.-Colo.Calif.-B.C. Submont.-Mont. My-Au.

11. M. peduncularis Dougl. Stem erect, viscid-puberulent, 1-6 dm. high; leaf-blades $0.5-2 \mathrm{~cm}$. long, ovate, dentate; peduncles slender, surpassing the leaves; calyx nearly glabrous, $6 \mathrm{~mm}$. long; teeth short, ovate; corolla funnelform, yellow, $1.5-2 \mathrm{~cm}$. long. Sandy banks: Wash.-Ida.-Ore. Son. My-O.

12. M. floribundus Dougl. Stem 1-3 dm. high, erect or diffuse, villous and viscid; leaf-blades ovate or subcordate, viscid-villous; calyx short-campanulate, 4-5 $\mathrm{mm}$. long; teeth triangular; corolla yellow, 6-10 $\mathrm{mm}$. long, tubularfunnelform. Wet places, sandy soil: Mont.-Colo.-Ariz.-Calif.-B.C. Submont. $\mathrm{My}-\mathrm{Au}$.

13. M. membranaceus A. Nels. Stem weak, diffusely spreading, glabrous or slightly viscid, $2-20 \mathrm{~cm}$. high; leaf-blades very thin, elliptic to ovate, entire or denticulate; calyx obscurely viscid-puberulent, 2-3 mm. long; teeth triangularlanceolate; corolla yellow, nearly tubular, 5-8 $\mathrm{mm}$. long. Wet shaded places in the mountains: Wyo.-Utah. Mont. Jl-Au.

14. M. breviflorus Piper. Stem slender, erect, $4-20 \mathrm{~cm}$. high, minutely puberulent; leaves short-petioled; blades lanceolate to ovate, acute, minutely 
few-toothed, about $1 \mathrm{~cm}$. long; calyx narrowly campanulate, $2-3 \mathrm{~mm}$. long, in fruit 6-8 mm. long; teeth triangular; corolla pale yellow, tubular, 4-5 $\mathrm{mm}$. long; lobes rounded. Wet places: Wash.-Ida.-Ore. Son.-Submont. My-Je.

15. M. primuloides Benth. Perennial by filiform stolons; stems very short, with crowded, elliptic, soft-villous or in age glabrate, dentate leaves 1-2 cm. long; peduncles 5-10 $\mathrm{cm}$. long, erect; calyx 5-7 mm. long, angled, oblong-cylindric; lobes ovate, acute, $1 \mathrm{~mm}$. long; corolla yellow, $15-20 \mathrm{~mm}$. long, with a narrow tube. Wet soil: Calif.-Nev.-Ida.-Wash. Submont.-Mont. Je-Au.

16. M. pilosus Benth. Stem 1-4 dm. high, softly villous; leaves lanceolate or oblong-lanceolate, sessile, entire, villous, obscurely 3-nerved at the base; calyxteeth ovate or oblong, the upper slightly longer; corolla bright, slightly 2-lipped, nearly $1 \mathrm{~cm}$. long; capsule oblong, ovate. Gravelly soil along streams: Ida.Ariz.-Calif,-Ore. Son. Jl.

17. M. Suksdorfii A. Gray. Stem $2-10 \mathrm{~cm}$. high, branched at the base, viscid-puberulent, reddish; leaves sessile, oblong or linear, 1-2 cm. long, thick, reddish; calyx $3 \mathrm{~mm}$. long, in fruit $5 \mathrm{~mm}$. long; teeth short; corolla 4-6 mm. long, yellow; lobes obcordate. Wet places: Colo.-Ariz.-Calif.-B.C. Submont. Je-Jl.

18. M. gratioloides Rydb. Stem branched, more or less reddish, generally less than $1 \mathrm{dm}$. high, somewhat viseid-puberulent above; leaves oblong-lanceoolate, sessile, about $1 \mathrm{~cm}$. long, sinuate-dentate; calyx 7-8 mm. long, cylindraceous in fruit; lobes short, broadly ovate, acute; corolla only slightly bilabiate. Hillsides: Colo.-Ariz. Submont. My-Je.

19. M. rubellus A. Gray. Stem viscid-puberulent, $2-10 \mathrm{~cm}$. long; leaves sessile, lanceolate, $1-3 \mathrm{~cm}$. long, entire or denticulate, usually reddish; calyx 4-5 mm. long, tubular; teeth rounded-ovate; corolla rose-colored or purpletinged, 7-8 mm. long; lower lip entire. Cliffs and sand: s Utah-N.M.-Calif. -Wash. Son. Ap-Jl.

20. M. Breweri (Greene) Coville. Stem $5-10 \mathrm{~cm}$. high, glandular-villous; leaves linear, entire, $2-3 \mathrm{~cm}$. long, sessile; calyx glandular-villous, $4 \mathrm{~mm}$. long; teeth short-triangular; corolla light purple, $8-10 \mathrm{~mm}$. long; lobes subequal, emarginate. Damp rocky places: Calif.-B.C. Mont. Je-Jl.

\section{EUNÃNUS Benth.}

Low annual herbs. Leaves opposite, usually dentate. Flowers perfect, on solitary peduncles in the upper axils. Calyx tubular, 5-angled and 5-toothed. Corolla more or less bilabiate, salver-shaped; lobes more or less spreading. Stamens 4, didynamous. Styles glandular above, united up to the peltatefunnelform stigma. Capsule shorter than the calyx, loculicidal, with the placentae separating in the middle and remaining attached to the valves. Seeds numerous, often muricate.

Calyx hardly at all oblique; teeth almost equal in length; stem glandular-pubescent.

Calyx-lobes lanceolate-subulate; upper stem-leaves somewhat acuminate; corolla

more than $2 \mathrm{~cm}$. long.
Calyx-lobes oblong-lanceolate, merely acute; leaves obtuse or acute; corolla $1.5-2$ $\mathrm{cm}$. long.

Calyx decidedly oblique; upper tooth twice as long as the lower; plant glandular-puberulent.
3. E. Parryi.

1. E. Bigelovii A. Gray, Stem glandular-pilose, 5-20 cm. high, branched; leaves oblong or elliptic, or the upper ovate; calyx $10-12 \mathrm{~mm}$. long, glandular; corolla salverform, about $2 \mathrm{~cm}$. long or more, $1-2 \mathrm{~cm}$. broad, crimson, with a yellow center. Sandy and stony places: Wash. $\rightarrow$ S Calif. $\rightarrow$ Utah. L. Son. My-S.

2. E. Tolmiei Benth. Stem $2-15 \mathrm{~cm}$. high, glandular-pubescent throughout, simple or branched from the base; leaves oblong-ovate to oblanceolate, $0.5-2$ $\mathrm{cm}$. long, 3-nerved, entire or somewhat toothed; calyx 6-10 $\mathrm{mm}$. long; corolla pale purple or rarely yellowish, often spotted, narrowly funnelform. M. clivicola Greenm. (?) Mimulus nanus H. \& A. M. Tolmiei Rydb. E. clivicola (Greenm.) Heller. Sandy places: Mont.-Wyo.-Ore. Je-Au. 
3. E. Parryi (A. Gray) Greene. Stem glandular-puberulent or glabrate, $5-10 \mathrm{~cm}$. high; leaves oblong or oblanceolate, $1-2 \mathrm{~cm}$. long; calyx about $8 \mathrm{~mm}$. long; teeth acute, the upper larger, ovate, the rest lanceolate; corolla yellow or pink, $1.5-2 \mathrm{~cm}$. long, narrowly funnelform. Gravelly hills: s Utah-Ariz. $L$. Son. Ap-Je.

\section{MONNitra (B. Juss.) P. Br. Water Hyssop.}

Perennial succulent herbs, with creeping or floating stems. Leaves opposite, entire or somewhat toothed, broadest above the middle, palmately veined, sessile. Flowers perfect, axillary, solitary, peduncled. Calyx subtended by 2 small bractlets; sepals nearly distinct, unequal, the uppermost the broadest. Corolla blue or white, nearly regular, 5-lobed; lobes spreading. Stamens 4, slightly didynamous, included; filaments adnate to the tube of the corolla. Capsule ovoid or oval, septicidal, the valves 2-cleft. Seeds numerous. [Herpestes Gaertn.]

1. M. rotundifolia Michx. Stem more or less densely pilose, ereeping or floating, rooting at the nodes; leaves sessile, rounded-obovate or suborbicular, 1-2 $\mathrm{cm}$. long; calyx glabrous, $4 \mathrm{~mm}$. long; lobes elliptic, obtuse, the upper larger; corolla white or yellowish, 5-6 mm. long, campanulate; lobes rounded-oval. Herpestes rotundifolia Pursh. Bacopa rotundifolia Wettst. Water: Ill.-Va.Tex.-Mont. Plain. J-S.

\section{Limosílla L. Mudwort.}

Low stemless, somewhat suceulent annuals, or perennials by means of stolons. Leaves rosulate at the base, narrow, entire. Flowers perfect, solitary on scapelike peduncles. Calyx campanulate, 5-lobed. Corolla nearly regular, openeampanulate, 5-cleft. Stamens 4, with the short filaments adnate to the corollatube; anthers confluently 1-celled. Style short; stigma capitate. Capsule 2-celled at the base, 1-celled above, many-seeded. Seeds ovoid, rugulose.

Leaves petioled, with spatulate or oblanceolate blades.

Leaves linear-filiform, or subulate.

1. L. aquatica.

2. L. tenuifolia.

1. L. aquatica L. Small annual, with runners; leaf-blades $0.5-3 \mathrm{~cm}$. long; glabrous; pedicels $0.5-3 \mathrm{~cm}$. long; calyx $1-1.5 \mathrm{~mm}$. long; teeth triangular, acute; corolla $2-2.5 \mathrm{~mm}$. long, exserted, white or purplish. Water and mud: Lab.Colo-Calif.-B.C.; Eurasia. Plain-Mont. Je-O.

2. L. tenuifolia Wolf. Minute annual, with runners; leaves $1-3 \mathrm{~cm}$. long; pedicels 1-2 cm. long; calyx 1-2 mm. long; lobes ovate, acute, corolla $2.5-3 \mathrm{~mm}$. long. Mud and shallow water: Lab.-N.J.-N.M.-Calif.-B.C.; Eurasia and S. Am. Plain-Mont. Je-N.

\section{GRATİola L. Hedge Hrssop.}

Annual or perennial, somewhat succulent herbs. Leaves opposite, entire or toothed. Flowers solitary on axillary peduncles. Calyx usually subtended by 2 bractlets; sepals 5, nearly distinct. Corolla white, yellow, or purplish, 2-lipped. Stamens 2, included; staminodia 2, scale-like or filiform, or wanting; anthersacs transverse, separated by a dilated membranous connective. Capsule globose or ovoid. Seeds striate.

Flowers without bracts.

Flowers subtended by a pair of bracts similar to the calyx-lobes.

1. G. ebracteata

2. G. virginiana.

1. G. ebracteata Benth. Stem $0.5-2 \mathrm{dm}$. high, leafy, glabrous or nearly so; leaves sessile, linear or lanceolate, 1-3 cm. long, entire or sparingly denticulate; sepals foliaceous, $6-8 \mathrm{~mm}$. long, lanceolate; corolla yellowish, equalling the calyx. Wet places: B.C.-Mont.-n Calif. Submont. Ap-Au.

2. G. virginiana L. Stem 1-2 dm. high, viscid-puberulent or glabrate below; leaves usually glabrous, oblong-lanceolate to linear, 1-5 $\mathrm{cm}$. long, entire or denticulate, sessile; bractlets 2, linear, 5-6 mm. long; calyx about $5 \mathrm{~mm}$. long; sepals lanceolate; corolla light yellow or nearly white, $8-10 \mathrm{~mm}$. long. Mud and shallow water: Me.-Fla.-Calif.-B.C. Plain-Submont. My-O. 


\section{Verónica (Tourn.) L. SPeedwell, Brooklime.}

Annual or perennial, eaulescent herbs. Leaves opposite or rarely alternate or whorled, entire or toothed. Flowers perfect, axillary, racemose, spicate, or solitary. Calyx of 4 , rarely 5 , slightly united sepals. Corolla rotate, only slightly irregular, 4-lobed, the lower lobe usually narrower than the rest. Stamens 2, one on each side of the upper corolla-lobe. Styles wholly united. Stigmas capitate. Capsule flat, usually notched or 2-lobed at the apex, loculicidal. Seeds flattened or concave on the sides.

Flowers in axillary racemes.

Leaves all short-petioled; leaf-blades ovate, oblong or oval. 1. V. americana.

Leaves of the flowering shoots at least sessile, lanceolate to linear.

Pedicels less than twice as long as the fruit, the latter not strongly flattened; leaves broadly lanceolate.

2. V. Anagallis-aquatica.

Pedicels several times as long as the fruit, the latter strongly flattened; leaves linear-lanceolate or linear.

3. V. scutellata.

Flowers in terminal spikes or racemes, or solitary in the axils of the leaves.

Perennials; flowers in terminal spikes or racemes; bracts reduced and unlike the leaves.

All leaves sessile, ovate or oval to oblong. Corolla 4-5 mm. wide, campanulate, blue; capsules obovate or oval, merely
emarginate. 4 . V. Wormskjoldit.

4. V. Wormskjoldii.

Corolla 8-9 mm. wide, broadly funnelform, violet; capsule obcordate.

5. V. Cusickii.

Lower leaves petioled; blades rounded oval or the upper oblong; capsule obcordate.

6. V. serpyllifolia.

Annuals; flowers solitary in the axils of the leaves, $i$. e., bracts resembling the other leaves and only slightly reduced.

Peduncles shorter than the leaves.

Leaf-blades spatulate, oblong, or linear; capsule emarginate.

Leaf-blades oval or ovate, or the upper lanceolate; capsule obcordate.

Peduncles as long as the leaves or usually longer.

8. V. arvensis.

Leaf-blades ovate, or oblong, crenate.

Corolla less than $6 \mathrm{~mm}$. wide.

Capsule narrowly emarginate.

Capsule deeply cleft to near the base.

Corolla 9-11 mm. broad; capsule with an open shallow apical sinus.

Leaf-blades orbicular or reniform, 3-5-lobed.

9. V. agrestis.

10. V. campylopoda.

11. V. Buxbaumit.

12. V. hederaefolia.

1. V. americana Sohwein. Stem erect or decumbent, $1-6 \mathrm{dm}$. high, sometimes branched; leaves petioled; blades ovate to oblong-lanceolate crenate or serrate or sometimes entire, rounded or truncate at the base; racemes loosely-flowered; corolla blue or nearly white, 4-5 mm. broad; capsule thick, slightly notched, broader than long. V. oxylobula Greene. $V$. crenatifolia Greene, a reduced form. In water: Newf.-Va.-N.M.-Calif.-Alaska. Plain-Subalp. My-Au.

2. V. Anagallis-aquatica L. Stem glabrous or glandular pubescent above, 2-9 dm. high, branched; leaves sessile, lanceolate or oblong, 2-12 $\mathrm{cm}$. long, acute, finely serrate or entire, often clasping; racemes spreading, many-flowered; corolla blue, 4-5 mm. broad; eapsule minutely notehed, suborbicular. Wet places and shallow water: N.S.-N.C.-Ariz.-B.C.; Eurasia and S. Am. Plain -Submont. My-S.

3. V. scutellata L. Stem ascending or decumbent at the base, 1-5 dm. high; leaves sessile, linear or lance-linear, acute, entire or remotely denticulate; racemes slender, divergent, zigzag; corolla $8-10 \mathrm{~mm}$. wide; capsule flat, deeply emarginate. Swamps and wet places: Newf.-N.Y.-Colo.-Calif.-B.C.Yukon. Plain-Submont. Je-Au.

4. V. Wormskjoldii R. \& S. Stem 1-3 dm. high, glandular-villous above, glabrate below, strict; leaves ovate, oval, or elliptic, 1-3 cm. long, sessile, entire or crenulate, drying black; corolla dark blue, campanulate, 4-5 mm. broad; capsule elliptic-obovate, emarginate. V. alpina unalaschkensis C. \& S. Wet meadows: Greenl.-N.H.-S.D.-N.M.-Ariz.-Alaska. Mont.-Subalp. Je-S.

5. V. Cusickii A. Gray. Stem 1-2 dm. high, glabrous or puberulent, glandular in the inflorescence; leaves oval to oblong, entire, 1-3 cm. long, darkening in drying; corolla open, with rounded lobes; capsule $6-7 \mathrm{~mm}$. long. Along brooks: Ore.-Ida.-Wash. Submont.-Subalp. J-Au. 
6. V. serpyllifolia L. Stems decumbent or creeping, 0.5-3 dm. high; leaves short-petioled or sessile; blades oblong, oval or suborbicular, 5-15 mm. long, entire or crenulate, obtuse; corolla white or purplish, 3-4 mm. broad; capsule retuse at the apex, obreniform, ciliate and puberulent. Open woods, fields, and thickets: Lab.-Ga.-Colo.-Calif.-Alaska; Eurasia. Submont.-Subalp. My$\mathrm{Au}$.

7. V. xalapensis H.B.K. Stem 1-3 dm. high, branched, with ascending branches, glandular-pubescent throughout; leaves thick, the lower ones petioled, spatulate, crenate, the upper linear or oblong; racemes spike-like; corolla whitish, 2-3 mm. wide; capsule orbicular, slightly notched, glandular. $V$. peregrina Coult., not L. Sandy soils: Sask.-Tex.-Calif.-B.C.; Mex. Plain-Submont. Je-S.

8. V. arvensis L. Stem pubescent, $0.5-3 \mathrm{dm}$. high, at first simple, later branched; lower leaves ovate or oval, crenate, 5-15 mm. long, petioled and opposite, the upper sessile, alternate and often entire; corolla blue or nearly white, $2 \mathrm{~mm}$. broad; capsule broadly obcordate, $2 \mathrm{~mm}$. high. Fields and waste places: N.S.-Fla.-Tex.-Minn.; B.C.-Ida.-Calif.; nat. from Eu. Mr-S.

9. V. agrestis L. Stem decumbent or creeping, 5-20 cm. long; leaf-blades broadly ovate or oval, obtuse at the apex, rounded or subcordate at the base; corolla small, blue, not longer than the ealyx; capsule broader than high, $4 \mathrm{~mm}$. broad. Fields and waste places: N.S.-N.J.-La.; Utah; nat. or adv. from Eu. $\mathrm{My}-\mathrm{S}$.

10. V. campylopoda Boiss. Stem 1-2 dm. high, erect or ascending, pubescent; leaves opposite or alternate, oblong or elliptic, entire or toothed, thick; sepals linear-lanceolate; fruit $3-4 \mathrm{~mm}$. high, $5-6 \mathrm{~mm}$. broad, cleft to near the base. Alfalfa fields: Utah; adv. from Asia Minor.

11. V. Buxbaumii Tenore. Stem finely pubescent, 1-4 dm. high, usually branched at the base; leaves opposite or alternate, short-petioled; blades ovate, oval, or suborbicular, 8-15 mm. long, coarsely serrate; sepals pubescent, elliptic or lanceolate; corolla blue, 9-11 mm. broad; capsule obreniform, 7-8 $\mathrm{mm}$. broad, pubescent. Fields and waste places: N.Y.-Ga.-Colo.-Utah; nat. from Eu. $\mathrm{Ap}-\mathrm{N}$.

12. V. hederaefolia L. Stem diffusely branched, $0.5-4.5 \mathrm{dm}$. long; leafblades $5-25 \mathrm{~mm}$. broad, pubescent; corolla $4 \mathrm{~mm}$. broad, searcely longer than the calyx; capsule broader than long, 2-lobed. Fields and waste places: N.Y.N.J. -S.C.; Utah; adv. or nat. from Eu. Ap-O.

\section{SŶNTHYRIS Benth.}

Perennial herbs, with rootstocks. Leaves mainly basal, petioled, digitately veined, the blades reniform, orbieular, or ovate in outline, toothed or variously cleft; stem-leaves alternate, reduced and bract-like. Flowers perfect, in terminal racemes. Calyx of 4 oblong, slightly united sepals. Corolla campanulate, nearly regular in the manner of Veronica. Stamens 2; filaments adnate to the corolla-tube, one on each side of the upper corolla-lobe, slender; anther-sacs parallel or somewhat divergent. Styles wholly united, filiform; stigma capitate. Capsule compressed, usually emarginate, loculicidal. Seeds few or several, flat or concave on the sides.

Leaves twice or thrice pinnately divided.

Calyx and capsule glabrous; corolla $3-4 \mathrm{~mm}$. long.

Calyx and capsule villous; corolla about $6 \mathrm{~mm}$. long.

Leaves not pinnate; blades reniform or rounded, with cordate base.

Leaf-blades deeply cleft and laciniate.

Leaf-blades lobed and dentate or crenate.

1. S. pinnatifida.

2. S. dissecta.

3. S. laciniata.

4. S. major.

1. S. pinnatifida S. Wats. Leaves $1 \mathrm{dm}$. long or less, twice or thrice pinnately divided, with linear or lanceolate divisions, somewhat villous-tomentose, or glabrate; scape 5-15 cm. long, villous-tomentose; corolla whitish or pink, 3-4 $\mathrm{mm}$. long; lobes oblong or elliptic; capsule $4 \mathrm{~mm}$. long. High mountains: Utah -Ida. Mont. Jl-Au. 
2. S. dissecta Rydb. Leaves $5-10 \mathrm{~cm}$. long, petioled, villous-tomentose; blades oval in outline, twice or thrice pinnatifid; scape villous-tomentose, 5-20 $\mathrm{em}$. high; corolla about $6 \mathrm{~mm}$. long, dark blue or purple, or in age paler; capsule obovate, $6 \mathrm{~mm}$. long. High mountains: Mont.-nw Wyo. Mont. Je-Au.

3. S. laciniata (A. Gray) Rydb. Leaves glabrous, or at first slightly villous, with petioles 3-8 $\mathrm{cm}$. long; leaf-blades cordate or reniform in outline, 1-3 $\mathrm{cm}$. long, 9-13 cleft, with laciniate and cleft divisions; scape 5-15 $\mathrm{cm}$. high, glabrous; corolla violet, light blue, or whitish, 4-5 mm. long; lobes oblong; capsule obovate, $5 \mathrm{~mm}$. long, glabrous. S. pinnatifida laciniata A. Gray. Mountains: UtahMont. Mont. Je-Jl.

4. S. major (Hook.) Heller. Leaf-blades reniform, glabrous, firm, shining, 3-7 $\mathrm{cm}$. broad, palmately many-lobed; the lobes dentate with triangular teeth; petioles 5-15 cm. long; scape 1-4 dm. high, glabrous; corolla purple, $6-7 \mathrm{~mm}$. long; lobes elliptic. S. reniformis major Hook. Wet places: Wash.-Ida.-Ore. $\mathrm{My}-$ Л.

\section{BeSSÈYA Rydb. Kitten-tails.}

Perennial herbs with rootstocks. Leaves mostly basal, with oblong or ovate, crenate blades and short petioles; stem-leaves reduced, alternate, sessile. Flowers perfect, in terminal spikes. Sepals 4 , or sometimes 1-3, almost distinct. Corolla irregular, 2-lipped, cleft nearly to the base or wanting; upper lip broad, entire, concave; lower lip irregularly 3-cleft. Stamens 2; filaments exserted, adnate to the tube of the corolla, or, if the latter is lacking, inserted on the outside of a hypogynous disk; anther-sacs parallel or nearly so. Capsule rather turgid, short, emarginate. Seeds several, flat.

Corolla present.

Flowers not reflexed; calyx-lobes 3-4.

Upper lip of the purple corolla twice as long as the calyx; plant 1-1.5 dm. high.

Upper lip of the corolla only slightly longer than the calyx; plant $1.5-3 \mathrm{dm}$. high. Corolla purple or pink, not ciliate; divisions of the lower lip obtuse.

Corolla white or yellowish, ciliate on the margin; divisions of the lower lip acute.

Flowers reflexed; cal yx-lobes 2 ; corolla greenish white.

3. B. Ritteriana. Corolla lacking.

Calyx almost regularly 4-cleft.

Calyx split to the base on the upper side, below irregularly divided or cleft into 2 (rarely 3 ) entire or toothed lobes.

Calyx cleft on the lower side to near the base or at least below the middle.

Calyx cleft only slightly below.

6. B. gymnocarpa.

7. B. wyomingensis.

1. B. alpina (A. Gray) Rydb. Petioles $2-6 \mathrm{~cm}$. long; leaf-blades ovate, oval, or elliptic, sometimes subcordate at the base, $2-5 \mathrm{~cm}$. long, crenate, soon glabrous; seape $1-1.5 \mathrm{dm}$. high; calyx densely white-villous; corolla $7-8 \mathrm{~mm}$. long; stamens exserted. Synthyris alpina A. Gray. Higher mountains: Colo.Wyo. Mont.-Alp.

2. B. plantaginea (Benth.) Rydb. Leaves more or less persistently tomentose; petioles $2-5 \mathrm{~cm}$. long; leaf-blades oblong, lance-oblong or lance-elliptic, crenate, 5-15 $\mathrm{cm}$. long; scape 1-3 dm. high; sepals oblong, villous-ciliate; upper lip of the corolla twice as long as the lower one. S. plantaginea Benth. Hillsides and mountains: Wyo.-N.M.-Ariz. Submont.-Alp. My-Au.

3. B. Ritteriana (Eastw.) Rydb. Leaf-blades elliptic or oblong, obtuse, cuneate at the base, crenate, $5-10 \mathrm{~cm}$. long, sparingly pubescent; scape $2-3 \mathrm{dm}$. high, sparingly villous; sepals 3-4, orbicular or obovate, villous-ciliate; corolla about $6 \mathrm{~mm}$. long; stamens exserted. S. Ritteriana Eastw. S. flavescens A. Nels. Higher mountains: Colo. Submont.-Subalp. My-Jl.

4. B. reflexa (Eastw.) Rydb. Leaf-blades $7 \mathrm{~cm}$. long, elliptic-oblong, obtuse, truncate or cuneate at the base, finely crenate, thin and glaucous; scape 1-2 dm. high; calyx $5 \mathrm{~mm}$. long; lobes only 2 , orbicular, villous-ciliate; corolla $8 \mathrm{~mm}$. long, sparingly fringed; filaments long-exserted. S. reflexa Eastw. High mountains: Colo. Mont. Au. 
5. B. rubra (Dougl.) Rydb. Leaf-blades ovate, rounded at the apex, cordate or rounded at the base, crenate, $3-8 \mathrm{~cm}$. long, more or less villous, or glabrate in age; scape 2-4 dm. high, villous, sometimes leafy below; calyx villous, $5 \mathrm{~mm}$. long; stamens about twice as long as the calyx. S. rubra Benth. Hills: B.C.Alta.-Ida.-Ore. Ap-Jl.

6. B. gymnocarpa (A. Nels.) Rydb. Leaf-blades oblong, elliptic, or ovate, crenate, sparingly villous or glabrate; stamens slightly exserted. Wulfenia gymnocarpa A. Nels. Hills: S.D.-Neb.-Colo.-Utah-Alta. Submont.Subalp. Je-Au.

7. B. wyomingensis (A. Nels.) Rydb. Leaf-blades ovate to oblong, erenate, rounded or subcordate at base, $3-5 \mathrm{~cm}$. long, obscurely puberulent; filaments twice as long as the calyx. W. wyomingensis A. Nels. S. wyomingensis Heller. Hills and mountains: S.D.-Colo--Ida.-Mont. Mont. My-Je.

\section{AGalìnis Raf. Gerardia.}

Annual or perennial, eaulescent herbs. with slender stems. Leaves mainly opposite, narrow or scale-like, entire. Flowers perfect, solitary in the axils of the leaves. Calyx 5-toothed to the middle. Corolla in ours rose-purple, 2-lipped; lower lip exterior in the bud, 5-lobed. Stamens 4, didynamous, included; filaments pubescent; anthers all alike. Styles wholly united, filiform. Capsule ovoid, rounded at the apex, loculicidal. Seeds angled. [Gerardia L., in part.]

Pedicels slightly if at all longer than the calyx.

Corolla $2-2.5 \mathrm{~cm}$. long.

Corolla $1-1.5 \mathrm{~cm}$. long.

Pedicels $2-6$ times as long as the calyx.

1. A. aspera.

2. A. paupercula.

3. A. Besseyana.

1. A. aspera (Dougl.) Britton. Annual; stem 1-6 dm. high, more or less scabrous; leaves linear, $1.5 \mathrm{~mm}$. wide or less, $1-3 \mathrm{~cm}$. long; calyx-tube 5-7 mm. long; lobes deltoid; corolla rose-purple; capsule elliptic or ovoid, 8-10 mm. long. G. aspera Dougl. Plains and prairies: Wis.-Ill.-Ark.-Kans.-Sask. Plain. $\mathrm{Au}-\mathrm{O}$.

2. A. paupercula (A. Gray) Britton. Annual; stem stout, 1-5 dm. high, smooth; leaves thickish, 1-3 cm. long, scabrous, often fascicled; calyx-tube eampanulate, 3-4 mm. long; corolla rose-purple; capsule globose, 5-7 mm. long. $G$. purpurea paupercula A. Gray. Bogs and wet meadows: Que.-Ga.-Okla.Sask. Plain. JI-S.

3. A. Besseyana Britton. Annual; stem 2-6 dm. high, somewhat scabrous, branching above; leaves linear or narrowly lance-linear, 1-5 cm. long, acute, scabrous; calyx-tube campanulate, 4-5 mm. long; corolla rose-purple, fully 1 $\mathrm{cm}$. long; capsule globose, 5-6 mm. long. G. Besseyana Britton. River bottoms and prairies: Ia.-La.-Colo.-Wyo. Plain. J-S.

\section{Castillèja Mutis. Painted Cup, Indian Paint-brush, Painter's} Brush, Squaw Feather.

Annual or perennial caulescent herbs, often partly root-parasites. Leaves alternate, sessile, entire, or toothed, or pectinately lobed, those subtending the flowers partly or wholly brightly colored. Flowers perfect, in terminal leafy spikes. Calyx laterally flattened, 4-lobed, more deeply cleft above and below than on the sides. Corolla highly. colored, laterally flattened, strongly 2-lipped; upper lip arched; lower lip much shorter, 3-lobed, only slightly saccate; lobes most commonly lanceolate. Stamens 4 , didynamous, surrounded by the upper lip of the corolla; anther-sacs unequal; the outer attached by the middle, the inner by its apex, pendulous. Styles wholly united, slender; stigmas 2-lobed or entire. Capsule loculicidal. Seeds reticulate.

Annuals or biennial.

Leaves and bracts linear to Ianceolate, entire.

Leaves pinnatifid; bracts dilated and lobed.

I. STENANTHAE.

Perennials.

Galea several times longer than the very short lip, usually at least two-thirds as long as the corolla-tube: bracts in most species tinged with scarlet, crimson or rose. Calyx cleft much deeper in front than behind. III. LINARIAEFOLIAE. 
Calyx about equally cleft in front and behind.

Stem canescent.

Stem tomentose-canescent; bracts entire, or trilobed, with broad rounded middle lobe.

IV. INTEGRAE.

Stem strigose or hirsutulous-canescent; bracts 3-cleft, with linear lobes.

Stem glabrous or pubescent, but not canescent.

V. SUBCINEREAE.

Leaves entire, rarely the uppermost slightly 3-lobed; corolla-lip very short and callous.

Bracts usually entire and obtuse, oblong to obovate, broad, if 3-lobed with a broad middle lobe.

Bracts tinged with crimson or rose.

Bracts yellow with the very tips brown or red.

VI. RHEXIFOLIAE.

VII. LUTESCENTES.

Bracts usually 3-cleft with lanceolate lobes, if entire very acute.

VIII. LANCIFOLIAE.

Leaves, at least the upper, pinnately cleft; bracts also cleft; lower corolla-

lip not callous, larger.
Galea less than 3 times as long as the lip, rarely half as long as the corolla-tube; bracts

lip not callous, larger.
Galea less than 3 times as long as the lip, rarely half as long as the corolla-tube; bracts in most species tinged with yellow or brown.

Leaves entire: bracts also entire or slightly 3 -lobed.

Leaves pinnately divided, at least the upper ones.

$\mathrm{X}$. Pallidae.

Bracts slightly 3-lobed or entire; lobes truncate or rounded at the apex.

Bracts deeply divided into lanceolate or linear-lanceolate lobes.

XI. LUTEAE.

Whole plant white-woolly.

Plant not white-woolly.

XII. LINEATAE.

Calyx about equally cleft in front and behind or deeper cleft behind.
Lip of the corolla scarcely more than half as long as the galea, not decidedly saccate.

Lip at least two-thirds as long as the galea, decidedly saccate.

Calyx much deeper cleft in front than behind.

Corolla $1.5-3 \mathrm{~cm}$. long, slightly exceeding the calyx.

Corolla 4-5 cm. long, almost twice as long as the calyx.

decidedly saccate.
XIV. PALlescentes.

XV. BRACHYANTHAE.

XVI. SESSILTFLORAE.

One species.

I. Stenanthat.

One species.

\section{Coccineae.}

1. C, exilis.

Bracts crimson or pink.

\section{Linariaefoliae.}

2. C. coccinea.

Plant low, cespitose, with several stems, about $2-3 \mathrm{dm}$. high; leaves and bracts pin-

nately divided; inflorescence short and head-like. 3 . C. collina.
Plant tall, 4-10 dm. high, with a single or sometimes $2-3$ stems; leaves entire or the upper with 2-3 lobes; inflorescence elongate.

Leaves all narrowly linear.

Upper leaves lanceolate.

4. C. linariaefolia.

Bracts yellowish or brownish.

5. C. Crista-galli.

Bracts cream-color; inflorescence villous-hirsute, with yellowish hairs.

Bracts brownish; inflorescence villous, with short white hairs.

6. C. cognata.

7. C. arcuata.

Leaves entire.

IV. INTEGRAE.

Bracts oblong.

Bracts obovate.

Leaves pinnatifid.

One species.

\section{SUBCINEREAE.}

\section{RHexifoline.}

Corolla 4-5 cm. long, nearly twice as long as the bracts.

Corolla $1.5-3.5 \mathrm{~cm}$. long, little if at all surpassing the bracts.

Bracts scarlet or crimson, rarely pink.

Corolla about $3 \mathrm{~cm}$. long; stem 3-5 dm. high.

Leaves narrowly lanceolate; bracts acute and usually deeply cleft.

13. C. confusa.

Leaves, at least the upper ones, broadly lanceolate or oblong-ovate; bracts rounded at the apex, entire or with a very broad middle lobe and small lateral ones.

Corolla $1.5-2 \mathrm{~cm}$., rarely $2.5 \mathrm{~cm}$. long; plant $2-3 \mathrm{dm}$. high.
Leaves lanceolate to linear. Stem and leaves glabrous or puberulent. Stem and leaves viscid-pubescent.

14. C. rhexifolia.

8. C. integra.

10. C. Lindheimeri,

11. C. subcinerea.

12. C. magna.

Leaves oblong, elliptic, or ovate-lanceolate. Stem and leaves densely pubescent.

15. C. lauta.

16. C. pinetorum.

17. C. Leonardi. 
Stem glabrous or puberulent; leaves finely puberulent.
Bracts brownish or yellowish.
18. C. humilis.
19. C. brunnescens.

\section{LUTESCENTES.}

Leaves linear; corolla $2-3 \mathrm{~cm}$. long.

Stem 2-3 dm. high; corolla scarcely longer than the calyx. 20. C. dubia.

Stem 3-5 dm. high; corolla decidedly longer than the calyx. Calyx-lobes obtuse.

Calyx-lobes acute or acuminate.

21. C. desertorum.

22. C. lutescens.

Leaves lanceolate; corolla nearly $4 \mathrm{~cm}$. long; calyx-lobes acute. 23. C. variabilis.

\section{LANCIFOLIAE.}

Corolla 3.5-4 cm. long; galea 1.5-2 cm. long; leaves lanceolate. Bracts brick-red or yellowish; leaves usually more or less pubescent.
Bracts crimson; leaves glabrous or neariy so.
24. C. Vreelandii.

23. C, variabilis.

Bracts crimson; leaves
Orolla $3 \mathrm{~cm}$. long or less

Calyx and upper part of the stem densely white-villous.

Calyx and upper part of the stem sparingly hirsute-villous.

25. C. trinervis.

Plants growing more or less in clumps, with a short caudex.

Corolla $2-3 \mathrm{~cm}$. long; bracts usually more or less crimson.

Plant tall, 4-6 cm. high; calyz-lobes acute or acuminate.
Galea 15-18 $\mathrm{mm}$. long.
Galea about $10 \mathrm{~mm}$. long.
13. C. confusa.
26. C. Tweedyi.
Plant low, 1-3 dm. high; calyx-lobes obtuse. 27. C. subpurpurascens.
Corolla less than $2 \mathrm{~cm}$. long; bracts brick-red.
28. C. mineata.

Plants with solitary stems from horizontal or ascending rootstocks,

\section{HISPIDAE.}

29. C. lancifolia.

Calyx-lobes rounded at the apex; bracts purplish, much exceeding the flowers.

30. C. obtusiloba.

Calyx-lobes acute or rarely obtuse at the apex; bracts if at all only slightly exceeding the flowers.

Corolla about $4 \mathrm{~cm}$. long.

Plant simple, with a horizontal rootstock; galea longer than the corolla-tube.

31. C. Suksdorfii.

Plant cespitose, with a short caudex; galea not longer than the corolla-tube.

13. C. confusa.

Corolla $1.5-3 \mathrm{~cm}$. long; plant more or less cespitose, with a short caudex.

Stem more or less pubescent, 3-6 dm. high.

Lobes of the calyces and bracts lanceolate or oblong; bracts usually crimson.

Body of the leaves lanceolate; lobes directed forward.

Plant decidedly glandular-or viscid-pubescent. 32. C. viscida.

Plant scarcely viscid, but puberulent and hirsute.

Corolla much exceeding the bracts; galea equalling or exceeding the tube.

33. C. amplifolia.

Corolla slightly if at all exceeding the bracts; galea shorter than the tube.

Bracts with very short lobes or merely toothed; stem sparingly hirsute or merely puberulent. 34 . C. Bradburyi.

Bracts with long narrow lobes; stem copiously hirsute.

Body of the leaves linear, the lobes linear, divergent.

35. C. hispida.

Galea shorter than the corolla-tube.

Galea longer than the corolla-tube.

36. C. angustifolia.

37. C. chromosa.

Lobes of the calyces and bracts narrowly linear; bracts brick-red.

Stem glabrous up to the inflorescence, 1-2 dm. high. 39 . C. Haydeni.

\section{Pallidae.}

Upper leaves long-acuminate, caudate-falcate.

Stem up to the inflorescence and leaves puberulent or glabrate.

Stem and leaves pilose.

40. C. pallida.

41. C. Cusickit.

Upper leaves neither caudate, nor falcate.

Bracts not pale-yellow; corolla usually Jess than $2 \mathrm{~cm}$. long.

Stem slender, 2-4 dm. high; bracts rose or brownish.

Stems from a rootstock, sparingly villous.
Stems from a caudex, hirsutulous, or villous in the inflorescence.

Stem 0.5-2 dm. high, from a cespitose caudex.

Braets puberulent, dark brownish scarlet.

Bracts villous, varying from light brownish crimson

43. C. Bennittii.

44. C. parvula.

to greenish yellow.

45. C. occidentalis.

Bracts pale yellow; corolla usually over $2 \mathrm{~cm}$. lon

Plant $0.5-2 \mathrm{dm}$. high, densely villous above.
Plant $2-4 \mathrm{dm}$. high, slightly if at all villous in the inflorescence.

45. C. occidentalis. 
Stems solitary from a creeping rootstock; corolla usually margined with yellow; plant darkening in drying.

46. C. luteovirens.

Stems growing in clumps, with a short caudex; plant rarely darkening in drying.

Upper leaves broadly lanceolate or ovate; all leaves 3-ribbed.

47. C. sulphurea.

Leaves all linear, 1-ribbed, or the uppermost linear-lanceolate and indistinctly 3-ribbed.

48. C. wyomingensis.

XI. LUTEAE.

Plant seldom over $1 \mathrm{dm}$. high; bracts green or tinged with brownish rose; calyx with short obtuse lobes.

Stem less than $2 \mathrm{dm}$. high, sparingly villous; bracts tinged with brown.

Stem 2-3 dm. high, hirsutulous; bracts tinged with rose.

49. C. pulchella.

43. C. Bennittii.

Plant 2-4 dm. high; bracts pale yellow.

Stems villous; leaves lanceolate.

Stems pilose; leaves linear or lance-linear.

50. C. lutea.

XII. LINEATAE.

One species.

41. C. Cusickii.

51. C. lineata.

XIII. Fasciculatae.

Bracts rhombic-obovate or broadly cuneate in outline, almost pectinately divided.

52. C. Pecten.

Bracts ovate or lanceolate in outline, pinnatifid.

Upper leaves and bracts, only 3 -fid at or above the middle. 48. C. wyomingensis.

Leaves and bracts deeply divided into linear divisions.

53. C. fasciculata.

\section{Pallescentes.}

Plant low, less than $2 \mathrm{dm}$. high, finely puberulent.

Plant 1.5-3 dm. high, hirsute or villous as well as puberulent.

Lateral divisions of the calyx deeply cleft into two subulate lobes; corolla $12-15 \mathrm{~mm}$. long.

Lateral divisions of the calyx merely 2-toothed.

55. C. longispica.

Lower lip two-thirds as long as the galea; corolla about $2.5 \mathrm{~cm}$. long.

Lower lip almost equalling the galea; corolla about $2 \mathrm{~cm}$. long.

50. C. lutea.

56. C. pilifera.

\section{BRACHYanthaE.}

Corolla $2-3 \mathrm{~cm}$. long; stem glabrous or nearly so.

6. C. cognata.

Corolla $1.5-2.5 \mathrm{~cm}$. long; stem pubescent.

Lower lip of the corolla fully half as long as the galea; plant less than $1 \mathrm{dm}$. high.

57. C. puberula.

Lower lip one-fifth to one-third as long as the galea; plant 3-4 $\mathrm{dm}$. high.

Lower lip about one-third as long as the galea, its lobes lanceolate, acuminate.

Stem 5-6 dm, high, finely puberulent; bracts minutely puberulent. 58. C. cervina.

Stem 2-4 dm. high, more or less hirsute-villous; bracts shortly villous-hirsute. 59. C. brachyantha.

Lower lip one-fifth to one-fourth as long as the galea, its lobes ovate, acute.

60. C. flava.

One species.

\section{SESSILIFLORAE,}

1. C. exilis A. Nels. Stem strict, 3-8 dm. high, 'more or less glandularhirsute or villous; leaves linear-lanceolate or lanceolate, long-attenuate, $3-10 \mathrm{~cm}$. long, 3-nerved, more or less glandular-hirsute; inflorescence long, spike-like; bracts linear-lanceolate, attenuate, only the uppermost tipped with scarlet or crimson; calyx more deeply cleft above than below, about equalling the corolla; lobes linear-lanceolate; corolla about $2 \mathrm{~cm}$. long, yellowish or tinged with pink on the margins; galea about $7 \mathrm{~mm}$. long, obtuse; lip less than $2 \mathrm{~mm}$., 3-cleft, with obtuse lobes. C. stricta Rydb., not DC. In swampy places, especially in saline soil: Wash.-Nev.-Colo.-Mont. Plain-Mont. Jl-Au.

2. C. coccinea (L.) Spreng. Stem usually simple, $3-6 \mathrm{dm}$. high, more or less short-villous; leaves of the basal rosette, oblong or obovate, entire, $2-5 \mathrm{~cm}$. long; stem-leaves 3-8 $\mathrm{cm}$. long, with 3-7 linear, obtuse divisions; bracts 3-5-cleft, tipped with crimson; lateral lobes usually lanceolate, acute, or obtuse, the middle one broadly oblong, rounded at the apex; calyx $1.5-2 \mathrm{~cm}$. long, almost equally deeply cleft above and below, into two oblong, truncate or retuse divisions; corolla greenish yellow, about $2 \mathrm{~cm}$. long; galea about $8 \mathrm{~mm}$. long, rounded at the apex; lower lip about $3 \mathrm{~mm}$. long. Meadows and thickets: Me.-N.C.Tex.-Sask. Plain. My-Jl. 
3. C. collina A. Nels. Stems many, puberulent and with scattered white villous hairs; leaves 2-4 $\mathrm{cm}$. long, dark green, divided into linear divisions, puberulent; bracts green below, scarlet above the middle, usually twice cleft into linear or oblong divisions; calyx sparsely soft-pubescent, about $2 \mathrm{~cm}$. long; corolla greenish, with erimson margins, nearly $3 \mathrm{~cm}$. long; galea about $1.5 \mathrm{~cm}$. long; lip about $2 \mathrm{~mm}$. long. Gravelly ridges and among sage-brush: Wyo.Colo. Plain-Submont. My-Je.

4. C. linariaefolia Benth. Stems glabrous or somewhat villous in the inflorescence; leaves narrowly linear or dissected into narrow, linear divisions, dark green, glabrous or nearly so, 5-10 $\mathrm{cm}$. long; bracts 3-5-parted into linearlanceolate or almost subulate divisions, more or less crimson and villous; calyx $3-4 \mathrm{~cm}$. long, more or less villous; corolla $4-5 \mathrm{~cm}$. long, greenish yellow, tinged with scarlet; galea about $2 \mathrm{~cm}$; lip saccate, about $4 \mathrm{~mm}$. long. Hills and rocky places: Wyo.-N.M.-Ariz.-Calif.-B.C. Submont.-Mont. Jl-S.

5. C. Crista-galli Rydb. Stems about $4 \mathrm{dm}$. high, finely pilose throughout or more or less villous above; lower leaves linear or linear-lanceolate, $5-8 \mathrm{~cm}$. long, 3-nerved, finely pubescent, the upper often divided into 3-5 oblong-linear divisions; bracts coccineous, 3-5-cleft, the middle lobe broad, oblong, acutish; calyx 2-2.5 cm. long, coccineous above; corolla about $3.5 \mathrm{~cm}$. long, green and tinged with red; galea $13-15 \mathrm{~mm}$. long; lip saceate, $2 \mathrm{~mm}$. long. Mountain sides: Mont.-Colo. Submont.-Mont. Je.

6. C. cognata Greene. Stem strict, about $1 \mathrm{~m}$. high, glabrous below, villous in the inflorescence; leaves nearly all entire, linear, $3-5 \mathrm{~cm}$. long, glabrous or nearly so; bracts 3-cleft, with linear-lanceolate divisions, tinged with creamcolor; calyx about $2 \mathrm{~cm}$. long, villous; corolla $2.5 \mathrm{~cm}$. long, greenish yellow; galea about $12 \mathrm{~mm}$. long; lip saccate, $2 \mathrm{~mm}$. long. Mountains of Colo. Submont.-Mont. Jl.

7. C. arcuata Rydb. Stems erect, strict, usually simple, 2-4 dm. high, shining, glabrous or short-villous in the inflorescence; leaves narrowly linear, 2-6 $\mathrm{cm}$. long, 1-3 mm. wide, glabrous or the lower sparingly white-villous; bracts 3-cleft with lanceolate lobes; calyx $12-15 \mathrm{~mm}$. long; corolla $2.5-3 \mathrm{~cm}$. long, at last strongly curved, greenish, with yellow margins; galea $12-15 \mathrm{~mm}$. long; lip about $3 \mathrm{~mm}$. long. Mountain sides: e Utah. Mont.-Subalp.

8. C. integra A. Gray. Stems several, simple, tomentose-canescent, 2-4 $\mathrm{dm}$. high; leaves entire, narrowly linear, more or less tomentulose-canescent, thick; inflorescence short and dense, bracts tomentose, crimson, rose-colored, pink, or even yellowish; calyx tomentulose, $2.5 \mathrm{~cm}$. long; corolla green, with erimson margins, about $3 \mathrm{~cm}$. long; galea $10-15 \mathrm{~mm}$. long; lip $2 \mathrm{~mm}$. long; lobes minute. Dry plains and table-lands: Colo.-N.M.-Ariz.-n Mex. PlainMont. My-S.

9. C. gloriosa Britton. Stems tomentose-canescent, 2-3 dm. high; leaves narrowly linear, canescent, 3-6 cm. long; inflorescence short and dense; bracts obovate, 4-5 cm. long, $2-2.5 \mathrm{~cm}$. wide, rounded at the apex, crimson, somewhat canescent, entire, or 3-cleft with a broad middle lobe; calyx $3-4 \mathrm{~cm}$. long, somewhat canescent; corolla about $4 \mathrm{~cm}$. long, green, with crimson margins; galea about $2 \mathrm{~cm}$. long; lip about $2 \mathrm{~mm}$. long; lobes very short. Dry places: Ariz.—s Colo.-N.M.; n Mex. Mr-Jl.

10. C. Lindheimeri A. Gray. Stems several, 1-3 dm. high, hirsute or villous-canescent; leaves dissected into $3-5$ linear divisions, canescent, $3-5 \mathrm{~cm}$. long; inflorescence dense; bracts rose-colored or brick-red, 3-5-cleft, with oblong, obtuse divisions; calyx about $1.5 \mathrm{~cm}$. long; corolla about $3 \mathrm{~cm}$. long, green, with pink margins; galea about $1.5 \mathrm{~cm}$. long; lip 3-4 mm. long. (?) C. scabrida Eastw. Dry places: w Tex.-s Colo. Plain-Submont. Ap-Jl.

11. C. subcinerea Rydb. Stem 3-5 dm. high, canescent-strigose; leaves eanescent, 3-ribbed, 5-7 cm. long, the lower entire and linear, the upper 3-cleft; bracts broadly cuneate, 5-7-cleft, the upper tinged with yellow and brown-tipped; calyx $2.5 \mathrm{~cm}$. long; corolla greenish yellow; galea $9 \mathrm{~mm}$. long; lip $3.5 \mathrm{~mm}$. long, slightly saceate. Dry mountain sides: Ida.-Mont. Submont.-Mont. 
12. C. magna Rydb. Stem a meter or so high, glabrous and shining, angled; leaves lanceolate, 4-6 cm. long, glabrous, 5-ribbed and reticulate, more or less acuminate; inflorescence short and dense; bracts ovate, entire, tipped with crimson; calyx about $2.5 \mathrm{~cm}$. long; corolla 4-5 cm. long, greenish, tinged with crimson and with crimson margins; galea fully $2 \mathrm{~cm}$. long; lip about $3 \mathrm{~mm}$. long. Woods: B.C. Mont.

13. C. confusa Greene. Stems glabrous below, villous above, 4-6 dm. high; leaves lanceolate or linear-lanceolate, 4-7 cm. long, acute or acuminate, 3-ribbed, glabrous or puberulent, entire or the uppermost 3-lobed; bracts ovate, entire to 5 -lobed; calyx about $2 \mathrm{~cm}$. long; corolla about $3 \mathrm{~cm}$. long; galea $13-14 \mathrm{~mm}$. long; lip about $4 \mathrm{~mm}$. Mountains: Colo.-N.M. Submont. -Subalp. Je-Jl.

14. C. rhexifolia Rydb. Stem $3-6 \mathrm{dm}$. high, usually glabrous below, more or less villous above; leaves oblong-lanceolate to ovate, $3-5$-nerved, about $5 \mathrm{~cm}$. long, from glabrous to densely puberulent; bracts crimson, scarlet or rose; calyx about $2.5 \mathrm{~cm}$. long, green below, colored above; corolla about $3 \mathrm{~cm}$. long, puberulent, green and tinged and bordered with crimson or scarlet; galea about $1 \mathrm{~cm}$. long, lip about $4 \mathrm{~mm}$. long. Open woods and mountain sides: Alaska-UtahColo.-Sask. Submont.-Subalp. Je-Au.

15. C. lauta A. Nels. Stems several, glabrous or puberulent; leaves 2-5 $\mathrm{cm}$. long, the lower linear-lanceolate, acuminate, the upper lanceolate; inflorescence short and dense; bracts ovate or obovate, entire or 3-cleft, with a broad middle lobe, villous-ciliate, tipped with crimson; corolla yellowish green, margined with crimson, $18-22 \mathrm{~mm}$. long; galea $7-8 \mathrm{~mm}$. long; lip about $2 \mathrm{~mm}$. long. $C$. oreopala subintegra Fern. Moist mountain slopes: Ore.-Utah-Colo.-Mont. Submont.-Subalp. Je-Au.

16. C. pinetorum Fern. Stem slender, 3-4 dm. high, viscid-pilose; leaves linear-lanceolate, 3-5 cm. long, minutely pilose; inflorescence narrow; lower bracts entire, the upper 3-5-cleft, roseate or bright red above; calyx about 18 $\mathrm{mm}$. long; corolla about $2.5 \mathrm{~cm}$. long; galea about equalling the tube; lip $2 \mathrm{~mm}$. long; lateral lobes longer than the middle one. Pine woods: Ore.-Ida.-Nev. -Calif. Mont. JI-Au.

17. C. Leonardi Rydb. Stems several, 2-3 dm. long, more or less viscidvillous; leaves ovate-lanceolate or oblong-lanceolate, $1.5-3 \mathrm{~cm}$. long, densely puberulent, 3-ribbed; bracts broadly ovate or obovate, rounded at the apex, densely pubescent, entire, tipped with crimson; ealyx $1.5 \mathrm{~cm}$. long, densely puberulent; corolla $2 \mathrm{~cm}$. long or less, densely puberulent; galea about $1 \mathrm{~cm}$. long; lower lip about $2 \mathrm{~mm}$. long. Mountains: Utah. Mont. Jl-Au.

18. C. humilis Rydb. Stems several, about $2 \mathrm{dm}$. high, glabrous below, somewhat viscid-pubescent above; leaves oblong to elliptic-lanceolate or the uppermost ovate, $2-3 \mathrm{~cm}$. long, obtuse or acute, finely puberulent; bracts entire, obovate, tipped with dark crimson; inflorescence short and dense; calyx densely puberulent, $10-12 \mathrm{~mm}$. long; corolla about $15 \mathrm{~mm}$. long, densely puberulent, greenish, with purple margins; galea $7-8 \mathrm{~mm}$. long; lip $2 \mathrm{~mm}$. long. Moist subalpine woods: Wyo.-Utah. Mont.-Subalp.

19. C. brunnescens Rydb. Stems 3-5 dm. high, more or less pubescent and purplish; leaves narrowly linear-lanceolate, more or less distinctly 3 -nerved, 4-5 cm. long, finely pubescent; bracts ovate to oblong-lanceolate, obtuse or rounded at the apex, entire or with a short tooth on each side; calyx about $2 \mathrm{~cm}$. long; corolla about $3 \mathrm{~cm}$. long; galea about $1 \mathrm{~cm}$. long; lip about $3 \mathrm{~mm}$. Mountains, along streams: Colo.-Wyo.-Utah. Submont.-Subalp. JI-S.

20. C. dubia A. Nels. Stems several, $2-3 \mathrm{dm}$. high, finely puberulent and with some white soft hairs; leaves linear, $3-5 \mathrm{~cm}$. long, usually with one or two pairs of divergent linear lobes; bracts with three relatively broad lobes, decidedly yellowish, or at tips bright yellow; calyx about $2 \mathrm{~cm}$. long; corolla scarcely longer; galea equalling the tube; lip very short, minutely toothed. C. angustifolia dubia A. Nels. Denuded slopes: Wyo. Son.

21. C. desertorum Geyer. Stems several, 3-5 dm. high, retrorsely pubescent, yellowish hirsute above; leaves linear-acuminate, hirsute, 3-ribbed, 4-5 
em. long, the upper usually 3-cleft; inflorescence dense and short; bracts lanceolate or ovate, usually 3 -cleft; calyx $2-2.5 \mathrm{~cm}$. long; corolla $3 \mathrm{~cm}$. or nearly so, pubescent; galea $12 \mathrm{~mm}$. long; lip $3 \mathrm{~mm}$. long. Meadows: Mont.-Ida.-Wash. Submont. My.

22. C. lutescens (Greenm.) Rydb. Stems 3-5, $5 \mathrm{dm}$. high, more or less hirsute and puberulent; lower leaves linear or linear-lanceolate, entire, scabrouspuberulent and somewhat hirsute, 3-ribbed, the upper broader, 3-cleft and 5ribbed; bracts ovate, 3-cleft, upper portion yellow and the tips often brown or red; calyx about $15 \mathrm{~mm}$. long; corolla $2-2.5 \mathrm{~cm}$. long; galea about $1 \mathrm{~cm}$. long; lip $2 \mathrm{~mm}$. long. C. pallida lutescens Greenm. Hills: Wash.-Ida.-Mont. Submont. My-Je.

23. C. variabilis Rydb. Stems pubescent, 4-8 dm. high; leaves linearlanceolate or lanceolate, 4-6 cm. long, 3-ribbed, puberulent and more or less short-hirsute; bracts lanceolate, deeply 3-cleft, yellow above, with scarlet or brickred tips or sometimes almost wholly brick-red; calyx viscid-villous, about $2.5 \mathrm{~cm}$. long, tinged with yellow; corolla yellowish-green, with scarlet or yellow margins, about $4 \mathrm{~cm}$. long; galea nearly $2 \mathrm{~cm}$. long; lip dark green, $3 \mathrm{~mm}$. long. Mountains: Utah. Mont.-Subalp. Л-Au.

24. C. Vreelandii Rydb. Stem usually single, 6-8 dm. high, glabrous or nearly so, shining; leaves lanceolate, 3-5-ribbed, glabrous or nearly so, 4-6 cm. long, somewhat acuminate; bracts lanceolate, usually 3 -lobed, with acute lobes, tipped with crimson; calyx 2-2.5 cm. long, tinged with crimson; corolla dark green, with purplish margins; galea about $2 \mathrm{~cm}$. long; lower lip $2 \mathrm{~mm}$. long. Banks, open woods, and meadows: Mont.-Wyo.-Utah-Wash. Submont. Je-Jl.

25. C. trinervis Rydb. Stem more or less villous, 3-6 dm. high; leaves dark green, finely puberulent, entire, acute, usually 3-ribbed, the lower linear, 5-8 $\mathrm{cm}$. long and about $0.5 \mathrm{~cm}$. wide, the upper lanceolate and often $15 \mathrm{~mm}$. wide; bracts 3-5-lobed, the upper with almost crimson tips; calyx densely white villous, about $3 \mathrm{~cm}$. long; corolla about $4 \mathrm{~cm}$. long, green, but the galea with crimson margins; galea about $15 \mathrm{~mm}$. long; lip 4-5 $\mathrm{mm}$. long, dark green, with three narrow lobes. Open woods: Colo. Mont. Je-Jl.

26. C. Tweedyi Rydb. Stems $2-5 \mathrm{dm}$. high, finely puberulent or sometimes glabrate; leaves linear-lanceolate, 3-nerved, 3-6 $\mathrm{cm}$. long, the upper somewhat broader and sometimes lobed; bracts light green, tipped with scarlet or brickred; calyx about $2 \mathrm{~cm}$. long; corolla about $2.5 \mathrm{~cm}$. long, greenish, margined with red; galea $1 \mathrm{~cm}$. long or less; lip $3 \mathrm{~mm}$. long. Valleys and hillsides: B.C.-Wash. -Utah-Wyo.-Mont. Submont.-Mont. Je-Au.

27. C. subpurpurascens Rydb. Stems several, 1-3 dm. high, glabrous or slightly puberulent, villous above; leaves narrowly linear, finely puberulent, $3-5$ $\mathrm{cm}$. long, 2-3 mm. wide; inflorescence short and dense; bracts lanceolate, acute or obtuse, the lower usually entire, the upper more or less cleft, tipped with crimson; calyx 15-20 mm. long, especially towards the base; corolla $2.5-3 \mathrm{~cm}$. long, green, with crimson margins; galea about $1 \mathrm{~cm}$. long; lower lip $3 \mathrm{~mm}$. long. C. purpurascens Rydb., not Greenm. Hillsides: Alta.-Mont. Submont.-Mont.

28. C. minetta Benth. Stems many, 4-6 dm. high, sparingly pubescent; leaves linear-lanceolate or linear, aeuminate, 5-7 cm. long, sparingly pubescent; bracts lanceolate, 3-cleft, tipped with scarlet or brick-red; calyx about $15 \mathrm{~mm}$. long, more or less hirsute; corolla about $2 \mathrm{~cm}$. long, green, margined with red; galea about $1 \mathrm{~cm}$. long; lip dark green, $2.5 \mathrm{~mm}$. long. Meadows: Wash.-Ida.Mont.-Sask. Submont. Jl-Au.

29. C. lancifolia Rydb. Stems solitary, 4-6 dm. high, sparingly villous or glabrate; leaves lanceolate, often acuminate, $3-5 \mathrm{~cm}$. long, 3-ribbed, usually all entire, usually glabrous, but sometimes finely puberulent; bracts lanceolate, acute or acuminate, often more or less cleft, crimson; calyx hirsute and puberulent, equally cleft, $2.5 \mathrm{~cm}$. long; lobes lanceolate, $5 \mathrm{~mm}$. long; corolla about 3 $\mathrm{cm}$. long, puberulent, green, with crimson margins; galea 12-15 mm. long; lower lip $3 \mathrm{~mm}$. long. Valleys and hillsides: Alaska-Ore-Utah-Colo.-Alta. Submont. -Subalp. Je-Au. 
30. C. obtusiloba Rydb. Stem very sparingly hairy, 3-4 dm. high; lower leaves oblong-lanceolate, 3 -nerved, minutely pubescent, $3-4 \mathrm{~cm}$. long, entire, the upper broader, 3-cleft; bracts similar, but broader, purple; middle lobe elliptic, rounded at the apex; calyx about $2.5 \mathrm{~cm}$. long; corolla yellowish and purpletinged; upper lip nearly $1 \mathrm{~cm}$. long; lower nearly $3 \mathrm{~mm}$. Mountain parks: Colo. Mont. Jl.

31. C. Suksdorfii A. Gray. Stems simple, 3-6 dm. high, sparingly pubescent; lower leaves often entire, lanceolate, sparingly villous, $4-5 \mathrm{~cm}$. long, the upper 3-cleft, with ascending lobes; bract 3-5-lobed, with lanceolate lobes; corolla nearly $4 \mathrm{~cm}$. long; galea fully $2 \mathrm{~cm}$. long; lip about $4 \mathrm{~mm}$. long. Mountains: Wash.-Mont.-B.C. Mont. Au.

32. C. viscida Rydb. Stems 1-3 dm. high; leaves $1.5-3 \mathrm{~cm}$. long, 3-5-cleft at the middle, densely glandular-puberulent, the body lanceolate, 3-ribbed, the lobes narrowly lanceolate and directed forward; bract similar to the leaves, tipped with crimson or scarlet; calyx 18-20 mm. long; corolla about $2.5 \mathrm{~cm}$. long, dark green, with crimson margins; galea about $1 \mathrm{~cm}$. long; lip $3 \mathrm{~mm}$. long. Mountains: Utah. Submont. - Subalp. Je-Au.

33. C. ampliflora Rydb. Stems $3-4 \mathrm{dm}$. high, puberulent and somewhat villous; most of the leaves entire, lanceolate, $2-3 \mathrm{~cm}$. long, with a short and rather dense pubescence, the upper 3-5-lobed; bracts 3-lobed, with a broad rounded middle lobe, erimson, $1-1.5 \mathrm{~cm}$. long; calyx $1.5-2 \mathrm{~cm}$. long, villous; corolla nearly $3 \mathrm{~cm}$. long, more than usually turgid; galea fully $1.5 \mathrm{~cm}$. long; lip 3 $\mathrm{mm}$. long. Open woods: Mont. Submont. Jl.

34. C. Bradburyi (Nutt.) G. Don. Stem 3-4 dm. high; leaves 3-4 cm. long, puberulent and slightly hirsute, 3-ribbed, 3-5-cleft above the middle; body lanceolate; lobes linear or lanceolate, directed forward; bracts obovate, usually 3-5lobed or toothed at the apex, the middle lobe usually rather broad and rounded, tipped with scarlet; calyx about $2 \mathrm{~cm}$. long; corolla about $2.5 \mathrm{~cm}$. long, green, with crimson margins; galea $10-12 \mathrm{~mm}$. long; lip $2 \mathrm{~mm}$. Hillsides: B.C.-Ore.Mont.-Wyo. Submont. My-Jl.

35. C. hispida Benth. Stems 3-5 dm. high, hirsute-villous as well as puberulent; leaves $2.5-5 \mathrm{~cm}$. long, hirsute-villous, $3-5$-cleft above the middle; body lanceolate or ovate-lanceolate; lobes lanceolate, directed forward; bracts similar, tipped with crimson; calyx $2.5 \mathrm{~cm}$. long, villous; corolla $2-3 \mathrm{~cm}$. long; galea about $12 \mathrm{~mm}$. long; lip $2.5 \mathrm{~mm}$. long. Hillsides: B.C.-Wash.-Utah-Colo.-Alta. Submont.-Mont. Ap-Л.

36. C. angustifolia (Nutt.) G. Don. Stems 1-4 dm. high, usually rather copiously hirsute and puberulent; leaves 3-6 cm. long, 3-7 cleft, the lower lobes usually arising below the middle, hirsute and puberulent; bracts deeply 3-5-cleft, crimson-tipped; calyx $1.5-2 \mathrm{~cm}$. long; corolla $2-2.5 \mathrm{~cm}$. long, yellowish green, with crimson margins; galea about $1 \mathrm{~cm}$. long; lip $3 \mathrm{~mm}$. long. (?) C. multisecta A. Nels. C. Buffumii A. Nels. Dry places: B.C.-Nev.-Colo.-Alta. Submont.-Mont. Ap-Jl.

37. C. chromosa A. Nels. Stems erect or ascending, $2-4 \mathrm{dm}$. high, usually simple, puberulent and hirsute with white crisp hairs; lower leaves usually entire, lanceolate to linear, 3-7 cm. long, the upper pinnatifid, $3-5 \mathrm{~cm}$. long, with $2-4$ linear or lanceolate divaricate lobes; bracts similar to the upper leaves, but with shorter, blunter lobes, tipped with scarlet or crimson; calyx densely white-villous, about $2 \mathrm{~cm}$. long; corolla about $2 \mathrm{~cm}$. long; galea fully $1 \mathrm{~cm}$.; lip about 3 $\mathrm{mm}$. long. Plains and hillsides: Wyo.-Colo.-Utah. Submont. My-Je.

38. C. linearis Rydb. Stem simple, $3-4 \mathrm{dm}$. high, finely villous-pubescent; leaves narrowly linear, about $5 \mathrm{~cm}$. long and $2 \mathrm{~mm}$. wide, pubescent, entire or the upper with a pair of narrowly linear lobes; bracts broader, deeply cleft into three linear lobes, tipped with brick-red; calyx villous, $2-2.5 \mathrm{~cm}$. long; corolla $2.5-3 \mathrm{~cm}$. long, greenish yellow; galea about $12 \mathrm{~mm}$. long, with red margins; lower lip dark green, about $3 \mathrm{~mm}$. long, 3-lobed. Meadows: Colo. Mont. Jl.

39. C. Haydeni (A. Gray) Cockerell. Stems glabrous up to the inflorescence; leaves linear or linear-lanceolate, entire or the upper broader and 3-5- 
cleft, glabrous or nearly so; bracts deeply 3-7-cleft, dark crimson, villous especially on the veins; calyx nearly $2 \mathrm{~cm}$. long; corolla $2-2.5 \mathrm{~cm}$. long, green, margined with dark crimson; galea about $8 \mathrm{~mm}$. long; lip nearly $3 \mathrm{~mm}$. long. C. pallida Haydeni A. Gray. High mountains: Colo. Alp. Jl.

40. C. pallida (L.) Kunth. Stems $2-4 \mathrm{dm}$. high, glabrous or puberulent below, sparingly villous in the inflorescence with long white hairs; leaves narrowly linear or the upper linear-lanceolate, 5-7 cm. long, puberulent; bracts ovate, entire or toothed, tipped with yellow or white; calyx nearly $2 \mathrm{~cm}$. long; corolla a little over $2 \mathrm{~cm}$. long, somewhat silky-villous; galea about $8 \mathrm{~mm}$. long; lip $4 \mathrm{~mm}$., saccate. Arctic and subarctic regions: Alaska-B.C.-Alta.-Mack. Subalp.-Alp. Je-Jl.

41. C. Cusickii Greenm. Stems several, 3-4.5 dm. high, short-pilose, somewhat cinereous; leaves 3-nerved, hirtellous, linear or linear-lanceolate, 2-4 cm. long, entire or the upper with one or two pairs of lobes on each side; raceme dense, bracts oblong, obtuse or rounded at the apex, usually entire; calyx pubescent; corolla $2-2.5 \mathrm{~cm}$. long, pale yellow, tinged with red; galea $6-7 \mathrm{~mm}$. long; lip 3 $\mathrm{mm}$. long, 3-cleft. Meadows: Ore--Ida. Jl.

42. C. gracillima Rydb. Stems usually solitary, slender, purplish, 2-4 $\mathrm{dm}$. high, sparingly villous; leaves linear-lanceolate, $2-4 \mathrm{~cm}$. long, 3-ribbed, sparingly short-villous; bracts ovate, entire, toothed or 3-cleft, puberulent, villous-ciliate; calyx about $15 \mathrm{~mm}$. long; corolla purplish, slightly longer than the calyx; galea $8 \mathrm{~mm}$. long; lip about $3 \mathrm{~mm}$. long, its lobes ovate. Meadows, especially near hot springs: Alta.-Wyo: Mont. Jl-Au.

43. C. Bennittii Nels. \& Macbr. Stems 2-3 dm. high, hirsutulous; leaves linear, entire or sometimes irregularly narrowly lobed; inflorescence dense; bracts 3-cleft, with blunt lobes, the middle broader; calyx $1.5-2 \mathrm{~cm}$. long, the divisions shallowly round-lobed; corolla $1.5-2 \mathrm{~cm}$. long; galea 6-7 mm. long; lip half as long, with short teeth. Sage-brush plains: Ida. Plain. Je.

44. C. parvula Rydb. Stems many, puberulent; leaves lanceolate, $1-2 \mathrm{~cm}$. long, puberulent; bracts ovate, dark brownish-crimson, finely puberulent, entire or with short lobes; calyx 12-14 mm. long, puberulent; corolla 17-18 $\mathrm{mm}$. long, greenish, with purple margins; galea about $7 \mathrm{~mm}$. long; lip 2.5-3 mm. long. High mountains: c Utah. Mont. -Subalp. Jl.

45. C. occidentalis Torr. Stems puberulent below, villous above; leaves linear or linear-lanceolate, $1.5-4 \mathrm{~cm}$. long, puberulent or somewhat villous; bracts ovate, entire or toothed, varying from brownish crimson to greenish yellow, villous with white or yellowish hairs; calyx about $1.5 \mathrm{~cm}$. long, villous; corolla about $18 \mathrm{~mm}$. long, usually dark brownish or greenish purple; galea 8 $\mathrm{mm}$. long; lip about $4 \mathrm{~mm}$. (?) C. arapahoensis Daniels. Alpine peaks: B.C.Utah-Colo.-Alta. Subalp.-Alp. JI-S.

46. C. luteovirens Rydb. Stem $3-4 \mathrm{dm}$. high, leafy, slightly pubescent when young, soon glabrate; leaves lanceolate to almost linear, $3-4 \mathrm{~cm}$. long, 3-9 $\mathrm{mm}$. wide, finely puberulent, 3-ribbed, acute, entire, or rarely the upper 3-lobed; lower bracts ovate, obtuse, entire, tipped with light greenish yellow or greenish white, the upper ones 3-toothed at the apex and greenish yellow throughout; calyx villous, $15-17 \mathrm{~mm}$. long; corolla 22-24 mm. long, greenish; galea 6-7 mm. long, with yellow margins; lower lip 2.5-3 mm. long, bluntly 3-lobed. Mountain meadows: Colo.-Utah-Wyo. Submont.-Mont.

47. C. sulphurea Rydb. Stems several, $3-5 \mathrm{dm}$. high, glabrous or finely puberulent; leaves lanceolate or the upper ovate, 3 -ribbed, $4-5 \mathrm{~cm}$. long, finely puberulent; bracts broadly ovate, obtuse, entire or with small teeth, puberulent, light yellow; calyx about $1.5 \mathrm{~cm}$. long; corolla greenish, 22-25 mm. long; galea about $1 \mathrm{~cm}$. long; lip 3-4 mm. long. Mountains: (? B.C.)-Mont.-UtahColo.-S.D. Submont.-Mont. Je-Au.

48. C. wyomingensis Rydb. Stems $3-4$ dm. high, striate, sparingly puberulent; leaves linear, 4-5 cm. long, minutely puberulent, not or less distinetly 3 -nerved, entire, or the upper 3 -lobed; bracts lanceolate to ovate, tinged with sulphur-yellow, 3-lobed at the apex or the lower entire; calyx villous, nearly $2 \mathrm{~cm}$. 
long, sulphur-yellow; corolla greenish, tinged and bordered with sulphur-yellow; galea about $6 \mathrm{~mm}$. long; lip about $2 \mathrm{~mm}$. long. Mountains: Mont.-Colo.Utah. Submont.-Mont. J1-Au.

49. C. pulchella Rydb. Stems 5-15 $\mathrm{cm}$. high, ascending, more or less villous especially above; leaves $1-4 \mathrm{~cm}$. long, the lower entire and linear-lanceolate, the upper broader and 3-cleft, puberulent and slightly villous; bracts elliptic, usually 3 -cleft, the middle lobe broad and rounded, villous; calyx yellowish, about $18 \mathrm{~mm}$. long; corolla slightly exserted; galea $7 \mathrm{~mm}$. long; lip $5 \mathrm{~mm}$. long. Mountains: Mont.-Wyo. Mont. J1-Au.

50. C. lutea Heller. Stems $2-3 \mathrm{dm}$. high, villous throughout, densely leafy; lower leaves lanceolate and entire, the rest broader, 2-4 cm. long, 3-5-ribbed, villous, 3-7-cleft at the apex; bract similar but broader, lobes rounded or obtuse at the apex, sulphur-yellow; calyx $2.5-3 \mathrm{~cm}$. long; corolla rarely exserted; galea about $8 \mathrm{~mm}$. long; lip $5 \mathrm{~mm}$.; lobes oblong, obtuse. C. pallida camporum Greenm. C. comporum Howell. C. villosa Rydb. Hillsides: Wash.-Ida.-Wyo.-Mont. Submont.-Mont. Ap-Au.

51. C. lineata Greene. Stems about $3 \mathrm{dm}$. high, densely white-floccose; leaves ascending, densely floccose, linear, about $5 \mathrm{~cm}$. long, entire or with narrow linear spreading lobes; bracts 3-cleft, with linear lobes; calyx densely villous, about $18 \mathrm{~mm}$. long; corolla greenish, $2 \mathrm{~cm}$. long; galea $8-9 \mathrm{~mm}$. long; lip about $5 \mathrm{~mm}$. Mountain slopes: Colo. Mont. Jl.

52. C. Pecten Rydb. Stem stout, 4-5 dm. high, puberulent throughout; lower leaves linear, entire, $5-6 \mathrm{~cm}$. long, puberulent, the upper $3-5$-cleft with linear divisions; bracts rhombic-obovate or broadly cuneate in outline, almost pectinately cleft into linear divisions, puberulent, upper portion yellowish or the tips brownish; calyx about $2 \mathrm{~cm}$. long, puberulent; corolla a little over $2 \mathrm{~cm}$. long; galea 8-9 mm. long; lip about $4 \mathrm{~mm}$. long, its lobes oblong. Valleys: Ida. Submont.

53. C. fasciculata A. Nels. Stems $2-3 \mathrm{dm}$. high, cinereous-puberulent and villous-hirsute; leaves $3-6 \mathrm{~cm}$. long, more or less divided into linear divergent lobes or entire and linear, cinereous-puberulent; bracts tipped with yellow or brick-red, 3-cleft below the middle; calyx puberulent, yellowish, $15 \mathrm{~mm}$. long; corolla $17-20 \mathrm{~mm}$. long, yellow; galea $6-7 \mathrm{~mm}$. long; lip about $3 \mathrm{~mm}$. Foot-hills and mountain slopes: Wyo.-Mont.-Ida. Submont. Je-Au.

54. C. pallescens (A. Gray) Greenm. Stems usually ascending, 1-1.5 dm. high, finely grayish puberulent; leaves entire, narrowly linear, or with narrowly linear lobes, $2-3 \mathrm{~cm}$. long, grayish puberulent; bracts 3-5-cleft, tinged with yellow or brownish; calyx puberulent, $18-20 \mathrm{~mm}$. long; corolla slightly longer than the calyx; galea 4-5 mm. long; lip 3-4 mm. Orthocarpus pallescens A. Gray. Hills and mountain sides: B.C.-Wash.-Wyo.-Mont. Submont.-Mont. Je-Au.

55. C. longispica A. Nels. Stems $2-3 \mathrm{dm}$. high, both finely puberulent and villous-hirsute; leaves $2-5 \mathrm{~cm}$. long, 3 -cleft to the middle into linear lobes, more or less villous; bracts 3-eleft; corolla $12-15 \mathrm{~mm}$. long; galea $5-6 \mathrm{~mm}$. long; lip 4-5 mm. long. Dry ground: Wyo.-Ida. ת-Au.

56. C. pilifera A. Nels. Stems several, erect, 1.5-2.5 dm. high; leaves nearly linear, entire, or with a few linear lobes, $3-6 \mathrm{~cm}$. long; corolla yellowish, about $2 \mathrm{~cm}$. long; galea $6 \mathrm{~mm}$. long; lip nearly as long; lobes linear, about as long as the undivided portion. Mountain valleys: $n$ Wyo. Mont. Jl.

57. C. puberula Rydb. Stems less than $1 \mathrm{dm}$. high, finely puberulent; leaves $2-3 \mathrm{~cm}$. long, pinnately divided into linear lobes or entire and linear, finely puberulent; bracts similar, but shorter and broader, tinged with yellowish, often more villous; calyx more or less villous, $1-1.5 \mathrm{~cm}$. long; corolla yellowish, 18-20 $\mathrm{mm}$. long; galea 6-8 mm. long; lower lip 3-4 mm. long, gibbous. High mountains: Colo. Mont.-Alp.

58. C. cervina Greenm. Stems $5-7 \mathrm{dm}$. high, finely puberulent; leaves entire, narrowly linear or more often 3-5-parted, with narrowly spreading linear divisions, puberulent; bracts laciniately $3-5$-lobed, tipped with yellow; calyx $1.5-$ 
$2 \mathrm{~cm}$. long; corolla $2-2.5 \mathrm{~cm}$. long; galea about $6 \mathrm{~mm}$. long; lip nearly half as long. Dry ground: B.C.-Wash. Submont. Je-Au.

59. C. brachyantha Rydb. Stems 2-4 dm. high, puberulent and more or less villous-hirsute especially below; leaves narrowly linear or cleft, with linear divisions, $2-5 \mathrm{~cm}$. long, puberulent; bracts 3-5-cleft into linear divisions, tipped with yellowish; calyx more or less villous; corolla $15-20 \mathrm{~mm}$. long; galea 7-8 $\mathrm{mm}$. long; lip about $3 \mathrm{~mm}$., gibbous. C. breviflora A. Gray. Mountains: Colo.-Wyo. Plain-Mont. Je-Au.

60. C. flava S. Wats. Stems puberulent and more or less villous-hirsute, especially below, $3-5 \mathrm{dm}$. high; leaves narrowly linear, entire or dissected into a few linear lobes, finely puberulent; bracts 3-cleft, with linear divisions, puberulent and villous-ciliate; calyx about $15 \mathrm{~cm}$. long; corolla $2-2.5 \mathrm{~mm}$. long, yellow; galea 8-10 mm. long; lower lip scarcely $2 \mathrm{~mm}$. long, greenish. Dry soil, especially among sage-brush: B.C.-Ida.-Utah-Colo.-Mont. Submont.-Mont. $\mathrm{Je}-\mathrm{Au}$.

61. C. sessiliflora Pursh. Stems 1-3 dm. high, more or less densely villous; leaves entire, linear or dissected into linear lobes, $3-5 \mathrm{~cm}$. long, puberulent; bracts broader, 3-cleft, with lanceolate or linear-lanceolate divisions, finely canescent; calyx 3-4 cm. long; corolla 4-5 cm. long, yellow, puberulent; galea 10-15 mm.; lip about $5 \mathrm{~mm}$. long. Dry plains and hills: Ill.-Mo.-Tex.Ariz.-Sask. Plain. Je-Au.

\section{ORTHOCÁRPUS Nutt. OwL's Clover.}

Annual caulescent herbs. Leaves alternate, sessile, pectinately cleft or entire, those subtending the flowers usually highly colored. Flowers perfect in terminal leafy spikes. Calyx tubular or deeply campanulate, nearly equally 4cleft. Corolla very irregular, 2-lipped; upper lip erect, slightly arched, equalling or slightly shorter than the more or less 3-lobed saccate lower lip. Stamens 4, didynamous, ascending under the upper lip; anther-sacs dissimilar, the outer one attached by its middle, the inner pendulous by its apex. Styles wholly united, slender; stigmas entire. Capsule oblong, loculicidal. Seeds many, reticulate.

Bracts dilated, entire or with a broad middle lobe and narrow lateral ones, somewhat petaloid.

Bracts herbaceous, resembling the leaves, 3- (rarely 5-) cleft, with lanceolate lobes.

Corolla yellow; spike dense; seeds ridged.

Plant hirsute; corolla not three times as long as the calyx. 2. O. luteus.

Plant puberulent; corolla $3-4$ times as long as the calyx.

Corolla white, turning rose-purple; spike lax; seeds loosely reticulate.

4. O. purpureo-albus.

1. O. tenuifolius Benth. Stem 1-2 dm. high, simple or branched above, somewhat hirsute, purplish; leaves usually dissected, with linear-filiform or subulate divisions, puberulent and sparingly hirsute; lower bracts leaf-like, usually 5-cleft, hirsute-ciliate; middle lobe lanceolate and the lateral ones subulate; upper bracts with an oblong to oval purple-tipped and rounded middle lobe; calyx about $1 \mathrm{~cm}$. long, its lobes subulate; corolla about $2 \mathrm{~cm}$. long, wholly yellow or purplish at the apex; galea about $5 \mathrm{~mm}$. long; lip $4 \mathrm{~mm}$., only slightly gibbous. Plains and bench lands: B.C.-Wash.-Ida. Plain-Submont. Je-Au.

2. O. luteus Nutt. Stem 1-4 dm. high, more or less hirsute, strict; leaves narrowly linear-lanceolate to almost subulate, entire, or rarely 3-cleft, attenuate, $1.5-5 \mathrm{~cm}$. long; bracts $3-5$-cleft, with lanceolate acute divisions, puberulent;
calyx $5-6 \mathrm{~mm}$. long, hirsute; its lobes lanceolate, about $1 \mathrm{~mm}$. long; corolla yellow, $10-15 \mathrm{~mm}$. long; galea and lip nearly $5 \mathrm{~mm}$. long, lip slightly gibbous. Sandy soil: B.C.-Wash.-Ariz.-N.M.-Neb.-Sask. Submont.-Mont. Je-Au.

3. O. Tolmiei H. \& A. Stem 2-4 dm. high, puberulent; leaves narrowly linear-lanceolate, usually entire, $2-5 \mathrm{~cm}$. long; bracts usually 3 -cleft, puberulent, with linear-lanceolate or subulate divisions; calyx 4-5 mm. long, its lobes lanceolate; corolla $15-18 \mathrm{~mm}$. long, yellow or tipped with brownish or purplish; galea about $5 \mathrm{~mm}$. long; lip slightly shorter, deeply gibbous. Pastures and mountain valleys: Ida.-Utah-Wyo. Submont.-Mont. JI-S. 
4. O. purpureo-albus A. Gray. Stem strict, somewhat viscid, puberulent, 3-5 dm. high; leaves narrowly lance-linear to almost filiform, usually entire; bracts 3-cleft to near the base into linear-lanceolate attenuate divisions; calyx about $6 \mathrm{~mm}$. long; its lobes linear-lanceolate, acuminate; corolla about $15 \mathrm{~mm}$. long; galea about $6 \mathrm{~mm}$. long; lip $5 \mathrm{~mm}$. long, only slightly gibbous. Mountains and table lands: Ida.-Ariz.-N.M.-Colo,-Submont.-Mont. JI-Au.

\section{TRIPhysària (Benth.) Rydb. Pelican Flower, Johnny-Tuck.}

Annual caulescent herbs. Leaves alternate, often pectinate, or else entire, those subtending the flowers usually colored. Flowers perfect, in terminal leafy spikes. Calyx deeply 4-cleft. Corolla irregular, 2-lipped; upper lip erect, straight, narrow, much shorter than the lower, which is 3-lobed and strongly 3-saccate. Stamens 4, didynamous, ascending under the upper corolla-lobe; anther-saes solitary or two and then dissimilar in the manner of the two preceding genera. Stigma capitate or sometimes 2-lobed. Capsule oblong, loculicidal; seeds many, reticulate.

1. T. hispida (Benth.) Rydb. Stem $2-3 \mathrm{dm}$. high, soft-hirsute, striet, simple; leaves with linear-lanceolate, attenuate divisions, or the lower entire, softhirsute; spike leafy; bracts similar to the leaves; calyx-lobes subulate; corolla white, 15-18 mm. long, viscid-puberulent; lip saccate, 2-3 mm. deep; galea subulate. Low ground: Wash.-Ida.-Nev.-n Calif. Submont. My-Jl.

\section{ADENOSTÈGIA Benth.}

Branching annuals. Leaves narrow, alternate. Flowers perfect, in leafy spikes at the ends of the branches. Calyx cleft to the base on the sides and therefore 2-leaved, or sometimes 1-leaved by the want of the lower division. Corolla tubular, with a funnelform throat, slightly 2-lipped; the upper lip narrow, entire; the lower round, slightly 3-toothed or entire. Stamens 4, didynamous, or sometimes the shorter pair wanting. Styles wholly united, with an inflexed apex; stigma entire. Capsule compressed, loculicidal. Seeds few. [Cordylanthus Nutt.]

Calyx diphyllous; flowers short-pedicelled, with 2-4 bractlets; flowers in head-like spikes. Stamens 4 ; anthers 2-celled; both divisions of the calyx 5-6-ribbed; leaves 3-7-
parted.

Bracts as well as the whole plant puberulent.

Corolla $2.5 \mathrm{~cm}$. long, more purplish.

Bracts ciliate with long white, more or less curled, hairs.

1. A. Wrightii.

2. A. ramosa.

Stamens 2; anthers 1-celled; posterior division of the calyx only 2-ribbed; leaves narrowly linear, entire, except those subtending the heads.

Calyx monophyllous, $i$. e., the anterior division 4 4. A. bicolor. flowers in more elongate spikes. division lacking; flowers sessile without bractlets;

Leaves and bracts all entire; spikes. lower sacs.

Leaves 3-5-parted; anthers of all the stamens 2-celled 5. A. canescens.

1. A. Wrightii (A. Gray) Greene. Stems puberulent, or almost glabrous, 3-6 dm. high; leaves 3-5-parted into filiform divirions, sparingly puberulent; bracts similar to the leaves; calyx about $2 \mathrm{~cm}$. long or more; corolla usually exserted; galea nearly $1 \mathrm{~cm}$. long; lips slightly shorter. Cordylanthus Wrightiz A. Gray. Dry places and sandhills: w Tex.- Colo-Utah-Ariz. Son. J-O.

2. A. ramosa (Nutt.) Greene. Stem much branched, finely puberulent, 1-4 dm. high; leaves dissected into filiform divisions, grayish puberulent; bracts similar; calyx 12-20 mm. long; galea 6-8 $\mathrm{mm}$. long; lip about 5-6 $\mathrm{mm}$. long. $C$. ramosus Nutt. In dry places: Ore. $-\mathrm{Nev} .-\mathrm{n}$ Colo.-Wyo. Submont.-
Mont. Je-Au.

3. A. ciliosa Rydb. Stem puberulent, purplish, 1.5-2 dm. high; leaves 2-3 cm. long, finely puberulent, 3-5-cleft into filiform divisions; bracts similar to the leaves but with broader bases; calyx nearly $1.5 \mathrm{~cm}$. long, more or less ciliate; corolla about $15 \mathrm{~mm}$. long; galea 5-6 mm. long; lip nearly as long, pubescent without. Slopes and plains: Wyo.-Ida. Submont. Jl-Äu. 
4. A. bicolor (A. Nels.) Rydb. Stem 2-5 dm. high, softly pilose and glandular-viscid; leaves usually entire, narrowly linear or 3-5-divided, softly pilose and viscid; bracts usually 3-cleft with linear divisions; calyx usually more or less scarious, purplish, villous; upper division about $1 \mathrm{~cm}$. long, 2-ribbed and 2-lobed at the apex; lower division oblong, 3-ribbed; corolla purplish, nearly $15 \mathrm{~mm}$. long; galea about $4 \mathrm{~mm}$. long; lip about $3 \mathrm{~mm}$. long. Cordylanthus bicolor A. Nels. Low grounds and hillsides: Nev.-Ida. Submont. J-S.

5. A. canescens (A. Gray) Greene. Stem strict, branched, villous or glabrous below, densely villous above; leaves entire, linear-lanceolate, $1-3 \mathrm{~cm}$. long, more or less villous; bracts lanceolate, $1.5-2 \mathrm{~cm}$. long, softly-villous, 1-3-ribbed; upper division of the calyx $15-20 \mathrm{~mm}$. long, softly villous, with 2 principal ribs; corolla nearly $2 \mathrm{~cm}$. long, puberulent; galea about $7 \mathrm{~mm}$. long; lip nearly as long. Saline soil: Calif.-Utah. Son. Jl-Au.

6. A. Kingii (S. Wats.) Greene. Stem erect, branched, 1-3 dm. high, more or less glandular-pubescent; leaves 3-cleft, 3-4 cm. long, with narrowly linear divisions; bracts 3-5-cleft, clasping; upper division of the calyx lanceolate, 2-3-toothed at the apex, about $2 \mathrm{~cm}$. long; corolla $1.5-2 \mathrm{~cm}$. long, purple, pubescent; galea 8-10 mm. long, little exceeding the 3-toothed lip. C. Kingii S. Wats. Limestone ridges: Nev.-sw Colo. Son.-Submont. Jl.

\section{EUPHRÃSIA (Tourn.) L. EYEBRIGHT.}

Low herbs, parasitic on other plants. Leaves opposite, dentate or incised. Flowers perfect, small, in terminal leafy spikes. Calyx 4-cleft, or rarely 5-cleft and with one lobe smaller than the other 4 . Corolla very irregular, 2-lipped; upper lip 2-lobed, the margins recurved; lower lip much larger, 3-lobed, spreading. Stamens 4, didynamous, ascending under the upper lip; anther-sacs equal, parallel. Capsule oblong, loculicidal. Seeds many, oblong, longitudinally ribbed.

\section{Bracts with acute or obtuse teeth.}

Teeth of the bracts obtuse; corolla $5-6 \mathrm{~mm}$. long; inflorescence capitate.

Teeth of the bracts a mollis.

Bracts with subulate or bristle-tipped teeth.

.

1. E. mollis (Ledeb.) Wettstein. Stem 4-10 cm. high, mostly simple; leaves 8-15 mm. long, ovate, coarsely crenate-dentate, densely pubescent; spike headlike when young, at last with 1-3 lower bracts remote; calyx densely pilose; corolla 5-6 $\mathrm{mm}$. long, like that of the next species but deeper purple. Grassy banks: Alaska-Yukon-Mont.-B.C.; e Siberia. Subarctic. Au.

2. E. disjuncta Fern. \& Wieg. Stem slender, 6-30 cm. high, branched below, puberulent; leaves ovate or orbicular, 8-18 $\mathrm{mm}$. long, crenate-dentate; spike interrupted, at last 5-25 $\mathrm{cm}$. long; bracts large, coarsely dentate; corolla 4-5.5 mm. long, with a yellow eye; upper lip purple, the lower white, with purple lines. Open places: Lab.-Me.-Alta.-Alaska. Subarctic. Je-S.

3. E. hudsonica Fern. \& Wieg. Stem $5-20 \mathrm{~cm}$. high, pubescent, simple or branched below; leaves oblong, 10-15 $\mathrm{mm}$. long, sparingly pubescent, with few acute teeth; spike elongate, at last 5-15 cm. long; bracts oblong, $7-15 \mathrm{~mm}$. long; corolla $5.5-6 \mathrm{~mm}$. long, whitish, with pale violet lines. Grassy places: Hudson Bay-Alta.-Mack. Subarctic. Au.

\section{4. elegphantéllia Rydb. Little Red Elephant, Elephant's Head, Elephant Flower.}

Perennial herbs, with rootstocks, blackening in drying. Leaves alternate, pinnately divided, with toothed segments. Flowers perfect, in terminal spikes. Calyx obliquely campanulate, 5-toothed. Corolla 2-lipped; upper lip strongly arcuate, produced into a long filiform upcurved beak, enclosing the long style; lower lip 3-lobed, the lateral lobes reflexed. Stamens 4, didynamous, ascending under the upper lip; anthers approximate in pairs; sacs transverse, parallel. Capsule compressed, beaked, loculicidal. 
1. F. groenlandica (Retz.) Rydb. Stem 2-6 dm. high, glabrous; leaves petioled, or the upper sessile, lanceolate in outline, pinnatifid, 5-20 cm. long; lobes linear or lanceolate, doubly dentate; spike dense, 1-3 dm. long; calyx glabrous, 5-7 mm. long; teeth triangular-ovate; corolla proper reddish-purple or claret-colored, about $1 \mathrm{~cm}$. long, the long curved beak $12-15 \mathrm{~mm}$. long. Swamps and wet meadows: Greenl--Lab.-N.M.-Calif.-Alaska. Mont.-Subalp. $\mathrm{Je}-\mathrm{Au}$.

\section{PEDICULÃRIS (Tourn.) L. Lousewort, Indian Warrior, DUCK-BILL.}

Perennial (all ours) or annual herbs. Leaves alternate, opposite or whorled, pinnately veined, pinnatifid, lobed, or merely crenate. Flowers perfect, in terminal spikes or racemes. Calyx cleft on the lower side, 2-5-lobed. Corolla strongly 2-lipped; upper lip laterally compressed, sometimes short-beaked, toothed, or blunt; lower lip erect or ascending, 3-lobed, the lobes mostly spreading. Stamens 4, didynamous, ascending under the upper lip; anther approximate in pairs; anther-sacs transverse, parallel. Capsule compressed, curved, beaked, loculicidal. Seeds many, pitted, striate, or ribbed.

Galea produced into a distinct beak.

Beak long, strongly incurved; lip very broad, meeting or enclosing the tip of the beak.

Leaves undivided, minutely doubly crenate.

Leaves pinnately divided into linear dentate divisions.

Corolla-tube not exserted; beak more or less spirally, incurved: calsx deeply cleft in front.

Corolla white; caly $\mathrm{x}$ greenish-striate and glabrous, 2. P. contorta.

Corolla purplish or rose; caly $\mathrm{x}$ purple-striate and villous at the base. Corolla-tube distinctly exserted; beak crescent-shaped, arcuate; calyx not
deeply cleft in front.
hort and straight; lip narrower and not meeting the tip of the galea.

Beak short and straight; lip narrower and not meeting the tip of the galea.
Beak about as long as the widtb of the galea; lip reflexed; primary divisions of the leaves short ( $8 \mathrm{~mm}$. or less long), not narrowed at the base.

Corolla yellow or ochroleucous.

$\begin{array}{ll}\text { Corolla purple. } & \text { 6. P. Hallii. }\end{array}$

Beak much shorter than the width of the galea; lip ascending; lower primary divisions of the leaves $8-30 \mathrm{~mm}$. long, usually narrowed at the base.

Plant 1-2 dm. high; bracts ovate, all shorter than the flowers.

Plant 3-6 dm. high; bracts linear, oblong, 7 . Panbyi. exceeding the flowers.
8. P. siifolia.

Galea not produced into a distinct beak, but often with two lateral teeth near the apex. Leaves pinnately divided or lobed.

Leaves divided to the midrib or nearly so into narrow, acute, dentate or serrate or incised divisions.

Galea distinctly arcuate; stems 2-15 dm. high (except in $P$, scopulorum, which often is only $1-2 \mathrm{dm}$. high).

Galea toothless; plant 4-10 dm. high; lip not reaching the tip of the galea. Corolla pale yellow; spike elongate, 6-30 cm. long; bracts lanceolate, usually produced and exceeding the flowers. 9. P. bracteosa.

Corolla tinged with purple: spike $3-10 \mathrm{~cm}$. long; bracts ovate, shortacuminate and about half as long as the flowers.

Galea with two lateral teeth.

10. P. montanensis.

Plant tall, 3-15 dm. high; corolla sordid yellow, $3-3.5 \mathrm{~cm}$. long; lip almost reaching the tip of the galea. $11 . P$. Grayi.

Plant lower, 1-4 dm. high; corolla purple, $2-2.5 \mathrm{~cm}$. long; lip not reaching the tip of the galea.

Leaves divided to the midrib, $i$, e., rachis not winged; divisions incised.

Leaves not quite divided to the midrib, $i$. e., rachis winged; divisions

merely dentate.
Galea scarcely arcuate, nearly straight, except the hood-like rounded apex, usually toothless; plant less than $1 \mathrm{dm}$. high.

Spike very dense, densely lanate; lower lip almost equalling the galea. Spike laxer, sparingly if at all lanate; lower lip of the corolla much shorter
than the upper.

Corolla 18-22 mm. long; lower lip $5 \mathrm{~mm}$. Iong; galea merely tinged

with purple. upper portion of the galea dark purple or crimson. Leaves pinnately lobed two-thirds to the midrib or less, with broadly oblong or
rounded, obtuse and crenate lobes. 
Plants caulescent; stamens merely acute.

Stem 1-3 dm. high; lower lip of the corolla mueh shorter than the upper.

Stem 3-10 dm. high; lower lip of the corolla reaching. $P$, canadensis.

Plants the galea. 18 . P. lanceolata.

18. almost to the tip of

(he base.

Leaves merely crenate.

19. $P$. centranthera.

20. P. crenulata.

1. P. racemosa Dougl. Stems cespitose, 3-5 dm. high, glabrous; leaves lanceolate or linear, doubly crenate, $3-8 \mathrm{~cm}$. long; spike leafy-bracted; calyx $5-6$ $\mathrm{mm}$. long, very oblique; lateral calyx-lobes lanceolate to triangular, the lower rounded, the upper obsolete; corolla white, $12-15 \mathrm{~mm}$. long; lip broadly reniform, 6-7 mm. long, about $12 \mathrm{~mm}$. wide. Mountain sides: B.C.-Calif.-N.M. -Alta. Submont.-Subalp. Je-Au.

2. P. contorta Benth. Stems 2-4 dm. high, glabrous; leaves glabrous, the lower $8-15 \mathrm{~cm}$. long; divisions linear, dentate; raceme 1-2 dm. long; bracts pectinately divided into linear divisions; calyx about $7 \mathrm{~mm}$. long; lobes linear, the lower and lateral ones subequal, the upper much smaller; corolla strongly curved; lip reniform, about $8 \mathrm{~mm}$. long and $12 \mathrm{~mm}$. broad. Mountains: B.C.Calif.-Ida.-Alta. Submont.-Mont. Je-Au.

3. P. ctenophora Rydb. Resembling the preceding species; stem about $3 \mathrm{dm}$. high, glabrous or slightly arachnoid-hairy in the inflorescence; bracts broader than in the preceding, more or less arachnoid. Mountains: Mont.-Wyo. Mont. Je-Au.

4. P. lunata Rydb. Stem about $4 \mathrm{dm}$. high, slightly striate and purplish; leaves alternate, glabrous, dark green, 5-12 cm. long; segments linear or linearoblong, crenate; spike $15-20 \mathrm{~cm}$. long; bracts pectinately divided, with prolonged endlobes, slightly arachnoid-villous; calyx about $9 \mathrm{~mm}$. long, its teeth broadly lanceolate, about $3 \mathrm{~mm}$. long; corolla pinkish, over $2 \mathrm{~cm}$. long; lower lip very broad, indistinetly 3 -lobed with large rounded lateral lobes. Mountains: Wyo. -Ida. Mont. Äu.

5. P. Parryi A. Gray. Stem 1-4 dm. high, glabrous; leaves glabrous, 5-12 $\mathrm{cm}$. long, pinnately divided to near the midrib; divisions lanceolate, $3-6 \mathrm{~mm}$. long, crenate; stem-leaves usually much reduced; raceme 3-13 cm. long; bracts shorter than the flowers, divided into lance-linear divisions; calyx about $7 \mathrm{~mm}$. long, usually glabrous; corolla $12-15 \mathrm{~mm}$. long; galea about $8 \mathrm{~mm}$. long; beak subconic at right angles to the galea; lip rather deeply 3-lobed, $4 \mathrm{~mm}$. long. Mountains: Wyo.-N.M.-Utah-Mont. Mont.-Subalp. J1-Au.

6. P. Hallii Rydb. Stem glabrous up to the inflorescence, 1-2 dm. high; leaves $5-8 \mathrm{~cm}$. long, mostly basal, deeply pinnately divided to near the midrib into lance-oblong crenate divisions 4-5 $\mathrm{mm}$. long; bracts deeply dissected into linear divisions; calyx more or less arachnoid-villous, 7-9 mm. long; lobes lanceolate; corolla purple, resembling that of the next preceding species, but the beak slightly shorter. Mountains: n Wyo. Subalp. Je-Au.

7. P. Canbyi A. Gray. Stem usually less than $1.5 \mathrm{dm}$. high, but leafy, glabrous; leaves pinnately divided to the midrib, $3-6 \mathrm{~cm}$. long; divisions lanceolate, usually more or less doubly serrate, $5-15 \mathrm{~mm}$. long; spike short and dense; bracts ovate, slightly villous; ealyx $8 \mathrm{~mm}$. long, villous, its lobes lanceolate; corolla 15-18 $\mathrm{mm}$. long, light yellow; galea about $8 \mathrm{~mm}$. long, helmet-shaped, with a short usually slightly porrect beak; lip about $4 \mathrm{~mm}$. long, with rounded lobes. Mountains: n Mont. Subalp. Jl.

8. P. siifolia Rydb. Stem glabrous, $3-6 \mathrm{dm}$. high, leafy; leaves pinnately divided to the midrib, glabrous, $5-15 \mathrm{~cm}$. long; divisions lanceolate, $1-4 \mathrm{~cm}$. long, more or less doubly serrate-dentate; spike short, $3-8 \mathrm{~cm}$. long; calyx glabrous, 8-9 mm. long, its lobes lanceolate; corolla yellowish, nearly $2 \mathrm{~cm}$. long; galea about $8 \mathrm{~mm}$. long, curved, helmet-shaped, with a short conical beak; lip $4 \mathrm{~mm}$. long, rather deeply 3-cleft, with rounded lobes. Meadows: Ida.-Mont. Mont.

9. P. bracteosa Benth. Stem 3-10 dm. high, glabrous; leaves glabrous, 6-30 $\mathrm{cm}$. long; divisions lanceolate, 2-6 $\mathrm{cm}$. long, laciniately double-serrate; spike elongate, $6-30 \mathrm{~cm}$. long; calyx 8-10 mm. long, villous, its lobes lanceolate; corolla 
yellowish, about $2 \mathrm{~cm}$. long; galea 11-12 $\mathrm{mm}$. long; lip erect, $5 \mathrm{~mm}$. long, with rounded crenulate teeth. In lowland, among bushes: B.C.-Calif.-UtahColo.-Alta. Submont.-Subalp. Je-Au.

10. P. montanensis Rydb. Stem 3-6 dm. high, glabrous; leaves similar to those of the preceding, glabrous; calyx about $8 \mathrm{~mm}$. long, its lobes subulate; corolla 15-18 mm. long, purplish, except a yellow spot on the lip; galea $8 \mathrm{~mm}$. long; lip $4 \mathrm{~mm}$. long, 3-lobed. Mountains: B.C.-Wash.-Wyo.-Alta. Submont.-Mont. Je-Au.

11. P. Grayi A. Nels. Stem 5-20 dm. high, glabrous or pubescent above; leaves 2-6 dm. long, somewhat pubescent, especially when young; divisions lanceolate, often 5-7 cm. long, with triangular dentate lobes; spike 2-4 dm. long; bracts lance-linear, about equalling the flowers; calyx about $1 \mathrm{~cm}$. long, villouspuberulent, its lobes lance-linear; corolla nearly $3 \mathrm{~cm}$. long; galea $12-15 \mathrm{~mm}$. long, cucullate; lip $1 \mathrm{~cm}$. long with broad rounded lobes. P. procera A. Gray, not Adams. Mountain woods: N.M.-Wyo.-e Utah. Mont.-Subalp. J1-Au.

12. P. cystopteridifolia Rydb. Stem 2-4 dm. high, purple-tinged; leaves 5-15 $\mathrm{cm}$. long, glabrous; divisions lanceolate, about $1 \mathrm{~cm}$. long, incised and serrate; bracts lanceolate, long-acuminate; calyx densely villous, nearly $1 \mathrm{~cm}$. long, its lobes lanceolate; corolla over $2 \mathrm{~cm}$. long, dark reddish purple; galea nearly $1 \mathrm{~cm}$. long, arcuate, cucullate; lip about $7 \mathrm{~mm}$. long, with rounded lobes. $P$. elata Pursh, not Willd. P.cystopterides Clements. Mountains: Mont.-Wyo. Mont. -Subalp. Jl-Au.

13. P. scopulorum A. Gray. Stem 1-2 dm. high, glabrous or villous above; leaves $4-8 \mathrm{~cm}$. long, divisions lanceolate $3-5 \mathrm{~mm}$. long, dentate; spike short, $3-5 \mathrm{~cm}$. long; bracts lanceolate, arachnoid-villous; calyx $8 \mathrm{~mm}$. long, arachnoidvillous, its lobes subulate-triangular; corolla purple, $15-18 \mathrm{~mm}$. long; galea over $1 \mathrm{~cm}$. long, arcuate and cucullate at the apex. Mountains: Colo. Subalp.-Alp. Jl.

14. P. lanata Willd. Stem densely lanate; leaves $2-3 \mathrm{~cm}$. long, glabrous, blackening in drying; divisions oblong, crenate, 1-2 mm. long; spike dense, 3-5 $\mathrm{cm}$. long; calyx about $7 \mathrm{~mm}$. long; lobes oblong; corolla reddish purple or rosecolored, about $2 \mathrm{~cm}$. long; galea about $7 \mathrm{~mm}$. long; lip almost as long, deeply 3-lobed, with rounded lobes. Aretic-alpine situations: Greenl.-Lab.-Canadian Rockies-Alaska; Eurasia. Alp. Je-Jl.

15. P. Oederi Vahl, Stem 1-1.5 dm. high, glabrous; leaves glabrous, 3-6 $\mathrm{cm}$. long; divisions broadly oblong to oval, dentate, $3-5 \mathrm{~mm}$. long; spike more lax, 3-10 cm. long; calyx 8-12 mm. long, slightly more deeply cleft in front; lobes lanceolate; corolla 18-22 mm. long, yellowish, with purple-tinged galea, which is about $8 \mathrm{~mm}$. long; lip deeply 3-eleft, with rounded lobes. $P$. versicolor Wahl. Aretic-alpine situations: Alaska-Mont.; Eurasia. Alp. J1-Au.

16. P. flammea L. Stem glabrous, $3-10 \mathrm{~cm}$. high; leaves darkening in drying, $2-6 \mathrm{~cm}$. long; divisions oblong or oval, crenate, $3-5 \mathrm{~mm}$. long; spike $2-5$ $\mathrm{cm}$. long, with almost erect flowers; calyx about $8 \mathrm{~mm}$. long; lobes lanceolate; corolla about $15 \mathrm{~mm}$. long, citron-yellow, with dark purple or crimson galea, which is about $6 \mathrm{~mm}$. long. Arctic-alpine situations: Greenl.-Lab.-Canadian Rockies-Alaska; Eu. Alp. Je-Au.

17. P. canadensis L. Stems $1.5-4.5 \mathrm{dm}$. high, more or less pubescent, or glabrate below; leaves $7-13 \mathrm{~cm}$. long, more or less pubescent; lobes oblong, obtuse, incised and dentate; spike 1-2 dm. high; the lower bracts foliaceous; calyx oblique, deeply cleft on the lower side; lobes minute, triangular; corolla yellow or reddish, 2-2.5 $\mathrm{cm}$. long; galea nearly $1.5 \mathrm{~cm}$. long, arcuate, beakless, but with 2 teeth near the apex; lip about $8 \mathrm{~mm}$. long, 3-lobed. Woods and thickets: N.S. -Fla.-N.M.-Colo-Man.; Mex. Submont.-Mont. My-Jl.

18. P. lanceolata Michx. Stem glabrous or nearly so, 3-10 dm. high; leaves often opposite, lanceolate, 5-13 cm. long; lobes oblong or ovate, obtuse, crenatedentate; spikes $5-10 \mathrm{~cm}$. long; calyx about $1 \mathrm{~cm}$. long, cleft above and below, the two lobes somewhat foliaceous and crenate; corolla $2-2.5 \mathrm{~cm}$. long, yellow, sometimes ringed with rose; galea $12-14 \mathrm{~mm}$. long, arcuate, truncate at the 
apex; lower lip 10-12 mm. long; lobes rounded. In swamps: Ont.-Conn.-Va. -Neb.-Sask. Plain. Jl-O.

19. P. centranthera A. Gray. Stem short, glabrous, with the spike 1.5 dm. or less; leaves $5-15 \mathrm{~cm}$. long, glabrous; divisions oval or ovate, doubly dentate, about $1 \mathrm{~cm}$. long, with callous mucronate teeth; bracts linear or nearly so, ciliate and often toothed towards the apex; calyx about $2 \mathrm{~cm}$. long, its lobes linear to linear-lanceolate; corolla $3-3.5 \mathrm{~cm}$. long, purple or yellowish; galea slightly curved, about $1 \mathrm{em}$. long; lip about $8 \mathrm{~mm}$. long with short rounded crenate lobes. Mountains: N.M.-Colo.-Utah-Calif. Submont. Ap-Je.

20. P. crenulata Benth. Stem more or less villous-puberulent, 2-4 dm. high; leaves linear, obtuse, $3-7 \mathrm{~cm}$. long, doubly crenate; spike $3-10 \mathrm{~cm}$. long; bracts similar to the leaves; calyx cleft in front, 2-3-lobed; lobes ovate-lanceolate; corolla $2-2.5 \mathrm{~cm}$. long, purplish or white; galea about $1 \mathrm{~cm}$. long, curved, not beaked, but with two small triangular teeth; lip 7-8 $\mathrm{mm}$. long, rather deeply 3-lobed; lobes rounded. Mountains: Wyo.-Colo.-Nev. Submont.-Mont. $\mathrm{Je}-\mathrm{Au}$.

\section{Rhinánthús L. Rattle-box, Yellow Rattle.}

Annual, erect, caulescent herbs, blackening in drying. Leaves opposite, toothed or lobed. Flowers perfect, in terminal, leafy, one-sided spikes or solitary in the upper leaf-axils. Calyx compressed, 4-toothed, much inflated in age and reticulate. Corolla irregular, 2-lipped; upper lip compressed, arched, minutely 2-toothed below the apex; lower lip shorter, with 3 spreading lobes. Stamens 4, didynamous, ascending under the upper lip; anthers pilose; sacs transverse. Capsule orbicular, flat, loculicidal. Seeds several, orbicular, winged. Corolla-tube exserted; teeth of the upper corolla-lip triangular, $1 \mathrm{~mm}$. long.

Corolla-tube included; teeth of the upper lip rounded.

1. R. Kyrollae. 2. $R$. rigidus.

1. R. Kyrollae Chab. Stem 3-7 dm. high, usually without black lines, glabrous, or pilose at the nodes and in decurrent lines, often branched at flowering time, yellowish; leaves elongate, lanceolate, oblong, or linear, dentate, with acute teeth, scabrous; calyx short-hairy, ciliate on the margins; corolla 8-9 $\mathrm{mm}$. long; tube yellow. R. Crista-Galli Rydb.(Fl. Colo.) Thickets and meadows: N.S.-Md.-Colo.-Wash.-Alta. Submont. Jl-Au.

2. R. rigidus Chab. Stem $2-6 \mathrm{dm}$. high, rigid, pilose in decurrent lines, at first simple, later branched, with strongly ascending branches; leaves glabrous or scabrous above and puberulent beneath, lanceolate or linear-lanceolate, dentate and bispidulous-ciliate on the margins; calyx glabrous or puberulent; corolla 7-8 mm. long. Meadows: Alta.-Colo.-Wash.-Alaska. Submont.-Mont. Je-Au.

\section{MELÁMPYRUM (Tourn.) L. Cow-Wheat.}

Annual herbs, often blackening in drying. Leaves opposite, entire or fewtoothed. Flowers perfect, solitary in the upper leaf-axils, or in leafy-bracted spikes. Calyx 4 -toothed, the upper 2 teeth somewhat longer. Corolla irregular, 2-lipped; tube gradually enlarged upwards; upper lip compressed, obtuse or
retuse; lower lip 3-lobed, 2-grooved beneath. Stamens 4, didynamous, ascending under the upper lip. Anther-sacs parallel. Capsule flat, oblique, loculicidal. Seeds $2-4$, smooth, strophiolate.

1. M. lineare Lam. Stem 1-5 dm. high, 4-angled, with puberulent lines; leaves lanceolate or linear-lanceolate, acuminate, short-petioled, $2-7 \mathrm{~cm}$. long, entire; bracts broader, often ovate-hastate, or with salient bristle-pointed teeth; calyx-teeth subulate; corolla $8-12 \mathrm{~mm}$. long, white or whitish, turning purplish. Dry woods: N.S.-N.C.-Ida.-B.C. Mont. My-Au.

\section{Family 118. LENTIBUlariaCeaE. Bladderwort Family.}

Small scapose or caulescent herbs, growing in water or wet places. Leaves when submerged dissected into linear or filiform segments, often bladderbearing, or when aerial basal and entire, or rarely wanting. Seapes naked 
or with minute scales, 1-many-flowered. Flowers perfect, irregular. Calyx of 2 or 5 herbaceous sepals. Corolla more or less 2-lipped; tube spurred or saccate. Stamens 2, the filaments adnate to the base of the corolla-tube on the upper side, flattened, twisted. Anthers 1-celled. Pistil solitary, with free central placenta; style thick and short; stigma 2-lobed, with unequal lobes. Fruit a 2-valved or irregularly dehiscent capsule. Seeds numerous, anatropous, rugose; endosperm wanting.

Calyx of 2 sepals; corolla-tube closed by a palate; plants submerged, with dissected leaves.

Calyx of 5 sepals; corolla with an open throat; plants aerial, with basal entire leaves. 2. Pinguícula.

\section{UTRICULÃRIA L. BLADDERWORT.}

Aquatic plants. Stems horizontal, mostly submerged. Leaves finely dissected and in ours bladder-bearing; bladders urn-shaped, the mouth closed by a lid. Flowers perfect, racemose. Sepals 2, slightly united. Corolla 2-lipped, in ours yellow, with the throat closed by a palate; upper lip 2-lobed or entire; lower lip 3-lobed or entire, with a spur at the base. Capsule irregularly dehiscent, many-seeded.

Leaves 2-3 times pinnately divided, with Iong divisions; corolla about $12 \mathrm{~mm}$. broad; spur prominent, elongate-conic, curved.

Leaves dichotomously divided, with very short divisions; corolla 4-6 mm. wide; spur a mere protuberance.

1. U. vulgaris $L$. Stem submerged, leafy, 3-12 dm. long; bladders $3-5 \mathrm{~mm}$. long; scape 1-3 dm. long; racemes 5-10-flowered; corolla yellow, 12-15 mm. broad; upper lip entire, erect; lower lip 3-lobed, spreading; spur not appressed, horn-like, slightly curved, shorter than the lower lip. Shallow water: Newf.Fla.-Calif.-B.C. Plain-Subalp. Je-Au.

2. U. minor L. Stem leafy, submerged, short; bladders few, $2 \mathrm{~mm}$. long or less; scape $0.5-1.5 \mathrm{dm}$. high; corolla pale yellow, $4-6 \mathrm{~mm}$. broad; spur much shorter than the lower lip. Shallow water: Greenl.-N.J.-Calif.-B.C. Submont.-Mont. J-Au.

\section{PINGUÎ́CULA (Tourn.) L. ButTerwort.}

Terrestrial scapose herbs of wet places. Leaves in basal rosettes, flat, entire, producing above a mucilaginous secretion. Scapes 1-flowered. Sepals 5, often more or less united. Corolla yellow, violet, or in ours purple, more or less 2-lipped, with an open throat; lobes entire or cleft; tube produced below into a nectariferous spur. Stamens 2. Capsule 2-valved. Seeds many.

Lower lip of the corolla about $15 \mathrm{~mm}$. long; base of the corolla conic, ending in a straight filiform cylindric spur.

Lower lip of the corolla $10-12 \mathrm{~mm}$. Iong; base of the corolla ovoid-conic, ending in a tapering, slightly recurved spur.

1. P. macroceras Willd. Leaves oval or obovate, $2-4.5 \mathrm{~cm}$. long, $1-1.5 \mathrm{~cm}$. wide; scape 5-10 $\mathrm{cm}$. high; calyx about $4 \mathrm{~mm}$. long; upper lip 2-cleft fully half its length into deltoid lobes; lower lip still deeper cleft, with lanceolate lobes; corolla dark purple, $10-15 \mathrm{~mm}$. broad; spur about $1 \mathrm{~cm}$. long. Bogs: AlaskaAlta.-Mont.-Wash.; e Asia. Subalp. My-Au.

2. P. vulgaris $\mathrm{L}$. Leaves elliptic or oval, $2-5 \mathrm{~cm}$. long, 1-2 cm. wide; scape $3-12 \mathrm{~cm}$. high; calyx about $3 \mathrm{~mm}$. long; upper lip not cleft to the middle, with triangular lobes; corolla paler, less than $1 \mathrm{~cm}$. wide; spur $6-8 \mathrm{~mm}$. long. Bogs: Greenl,-Newf.-Vt. - Mont.-Alta.-Yukon; Eurasia. Subalp.-Subarctic. $\mathrm{My}-\mathrm{Jl}$.

\section{Family 119. OROBANCHACEAE. Broom-Rape Family.}

Root-parasites, destitute of green foliage. Leaves scale-like. Flowers perfect or rarely dioecious. Calyx of 4 or 5 , more or less united sepals. Corolla more or less bilabiate, persistent and withering. Stamens 4, didyna- 
mous, mostly included; filaments terete, adnate to the tube of the corolla; anthers 2-celled or rarely 1-celled. Styles wholly united; stigma capitate or 2-lobed. Fruit a capsule, enclosed in the withering corolla. Seeds very many, anatropous, furrowed or tuberculate; endosperm transparent.

Flowers subtended by bractlets.

Flowers without bractlets.

1. MYZORRHIZA.

2. THALESIA.

\section{MYZORRhìzA Philippi. Broom-rape.}

Whitish or pinkish herbs, parasitic on the roots of other plants. Leaves scalelike, usually pubescent. Flowers spicate, racemose or corymbose, subtended by bractlets. Calyx of 5, nearly equal, narrow lobes. Corolla 2-lipped; tube more or less curved; throat open; lips erect. Capsule 1-celled, 2-valved. [Aphyllon A. Gray, in part.]

Flowers all manifestly pedicelled; inflorescence corymbose; anthers woolly.

Flowers sessile or nearly so; only the lowest sometimes short-pedicelled; flowers spicate or paniculate.

Inflorescence spicate, though sometimes branched; corolla usually purple; stem not bulbose at the base.

Corolla 20-25 mm. long; anthers woolly.

Corolla 15-20 mm. long; anthers glabrous.

2. M. multiflora.

3. M. ludoviciana.

Inflorescence usually a loose elongated panicle; corolla yellow, about $12 \mathrm{~mm}$. Iong: stem bulbose at the base.

4. M. pinorum.

1. M. corymbosa Rydb. Stem 5-10 cm. high, glandular-puberulent; scales about $1 \mathrm{~cm}$. long, lance-ovate, acute; bracts linear, about $1 \mathrm{~cm}$. long; bractlets linear-subulate; calyx-tube $4 \mathrm{~mm}$. long; lobes lance-subulate; corolla dark purple, about $2.5 \mathrm{~cm}$. long; anthers woolly. Parasitic on composites, \&e.: Mont. -Wyo.-Ida.-B.C. Submont.-Mont. J1.

2. M. multiflora (Nutt.) Rydb. Stem 1-2 dm. high, glandular-puberulent; scales ovate, acute, $1 \mathrm{~cm}$. long; calyx-tube about $4 \mathrm{~mm}$. long; lobes linear-lanceolate, attenuate, 8-10 mm. long; corolla dark purple; lobes oblong, acutish. Orobanche multiflora Nutt. A Apyllon multiflorum A. Gray. Parasitic on Covillea and other shrubs: Tex.-s Colo.-Utah-Calif.; Mex. Son. My-Jl.

3. M. ludoviciana (Nutt.) Rydb. Stem $0.5-2 \mathrm{dm}$. high, glandular-puberulent, simple or branched; scales ovate, scarcely $1 \mathrm{~cm}$. long; calyx-tube $3-4 \mathrm{~mm}$. long; lobes lanceolate, attenuate, $7-8 \mathrm{~mm}$. long; corolla usually purple, rarely yellowish; upper lip often only slightly cleft; lobes oblong, acute. O. ludoviciana Nutt. Parasitic on Artemisia and other Composites, \&c., in sandy soil: Sask.Ill.-Tex.-Calif.-Wash.-B.C. Plain-Submont. Je-Au.

4. M. pinorum (Geyer) Rydb. Stem 2-3 dm. high, glandular- and crisphairy; scales lanceolate, acute; calyx-tube $3 \mathrm{~mm}$. long; lobes lance-subulate, 4 $\mathrm{mm}$. long; corolla-lips 3-4 mm. long, the upper 2-cleft, the lower 3-divided to the base into lanceolate acute lobes. O. pinorum Geyer. A. pinetorum A. Gray. Parasitic on conifers: Ida.-Wash. Submont. Je-Au.

\section{THALÈSIA Raf. CANCER-ROOT.}

Pale or pink root-parasites. Stem simple or branched. Leaves scale-like. Calyx 5-cleft, with nearly equal lobes. Corolla slightly bilabiate; tube more or less curved; upper lip 2-lobed; lower lip 3-lobed. Stamens included. Stigma peltate. Capsule 1-celled, 2-valved, with 4 placentae. [A phyllon Mitchell.]

Calyx-lobes subulate, much longer than the tube; stem very short, 1-3-flowered.

Corolla lilac or pink, $2 \mathrm{~cm}$. or less long; tube 4-5 mm. wide at the throat; lobes oblong. acutish or obtuse.

acutish or obtuse. Corolla 15-18 mm. Iong; tube strongly curved, 4-5 mm. wide at the throat.
$2 . T$. minuta. Corolla 20-30 $\mathrm{mm}$. long; tube not so strongly curved, 5-8 mm. wide at the throat.
$3 . T$. purpurea.

Calyx-lobes lanceolate or triangular, about equalling the tube; stem evident, several-

flowered.
Corolla purplish, its lobes rounded or merely mucronate; sepals more or less acumin-
4 . T. fasciculata.

Corolla sulphur-yellow, its lobes acute; sepals acute.

5. T. lutea. 
1. T. sedi (Suksd.) Rydb. Peduncles $1-3$, slender, $5-10 \mathrm{~cm}$. long, yellow or straw-colored; scales $1 \mathrm{~cm}$. long or less, ovate, usually short-acuminate; calyxtube conic-campanulate, $2 \mathrm{~mm}$. long, glandular-puberulent; lobes subulate from a broad base, 4-5 mm. long, attenuate; corolla not strongly curved; lobes oblong, acutish or obtuse. Aphyllon sedi Suksd. Parasitic on Sedum: Ore--Mont.B.C. Submont. My-Je.

2. T. minuta (Suksd.) Rydb. Peduncles $1-4$, slender, $2-8 \mathrm{~cm}$. long; scales $1 \mathrm{~cm}$. long or less, acute; calyx-tube campanulate, $2 \mathrm{~mm}$. long; lobes subulate, from a broad base, $4 \mathrm{~mm}$. long; corolla hairy inside on the yellow folds; lobes broadly oval, rounded at the apex, not spreading. A. minutum Suksd. Parasitic on Lithophragma, etc.: Ore.-Mont.-B.C. Submont. Ap-Jl.

3. T. purpurea Heller. Peduncles $1-3$, stout, $8-15 \mathrm{~cm}$. high; scales broadly ovate, obtuse, glabrous; calyx-tube campanulate, $3-4 \mathrm{~mm}$. long; lobes lance-subulate from a broad base, 6-8 $\mathrm{mm}$. long; corolla-lobes obovate or semiorbicular, rounded or retuse at the apex, the lower ones usually more or less spreading. Parasitic on bushes: Ore.-Mont.-Wash. Submont. My-Jl.

4. T. fasciculata (Nutt.) Britton. Stem 2-10 cm. long; pedicels $3-12,2-8 \mathrm{~cm}$. long; scales brownish, ovate, obtuse; calyx-tube $3-4 \mathrm{~mm}$. long, eampanulate; lobes triangular-lanceolate, acuminate, $3-4 \mathrm{~mm}$. long; corolla $2-3 \mathrm{~cm}$. long. 0 . fasciculata Nutt. A. fasciculatum A. Gray. Parasitic on Artemisiu, other Composites, Eriogonum, Phacelia, \&c.: Sask.-Ind.-N.M.-Calif.-Yukon; Mex. Plain-Subalp. My-Au.

5. T. lutea (Parry) Rydb. Stem 5-10 cm. long, rather slender; scales ovate, acute, glandular-puberulent; pedicels $2-5 \mathrm{~cm}$. long; calyx-tube broadly campanulate, $3 \mathrm{~mm}$. long; lobes triangular or lance-triangular; corolla about $2 \mathrm{~cm}$. long; lobes elliptic. A. fasciculatum luteum A. Gray. Parasitic on grasses: Neb.Wyo.-Ariz. Plain. Ap-Jl.

\section{Family 120. MARTYNIACEAE. UnICORN-PLANT FAMILY.}

Annual or perennial herbs, with branching stem. Leaves opposite, rarely alternate, with broad blades. Flowers perfect, irregular. Calyx 4or 5-lobed. Corolla gamopetalous, bilabiate; tube more or less curved; upper lip 2-lobed, exterior in the bud; lower lip 3-lobed. Stamens 4, didynamous, all anther-bearing, or the posterior two without anthers: filaments elongate. Gynoecium of 2 united carpels; ovary 1-celled, with 2 parietal placentae; style slender; stigmas 2. Fruit a beaked capsule. Seeds flattened; endosperm wanting.

\section{MARTÝNIA L. UNICORN-PLANT.}

\section{Characters of the family.}

1. M. Louisiana Mill. A densely viscid annual; stem with spreading branches, 2-9 dm. long; leaves petioled; blades suborbicular or rounded-ovate, $5-30 \mathrm{~cm}$. broad, sinuate, cordate at the base; calyx cleft on the lower side; corolla white or pink, spotted with yellow and purple within; pod 8-15 cm. long, strongly curved, separating into two elastically spreading valves; the beak longer than the body. M. proboscidea Glox. Waste places and banks: Me.-Ga.-Tex.-

\section{Family 121. Plantaginaceae. Plantain Family.}

Annual or perennial herbs. Leaves basal or alternate. Flowers perfect, monoecious, or dioecious, bracteate. Sepals 4, persistent, often scariousmargined, slightly united. Corolla campanulate or tubular, with 4, erect or spreading lobes, scarious, nerveless, persistent. Pistil solitary; ovary superior, 1-4-celled; stigma single, filiform. Stamens 2 or 4 ; filaments adnate to 
the tube of the corolla; anthers 2-celled, versatile, opening lengthwise. Fruit a circumscissile capsule; seeds one to several in each cell, amphitropous; endosperm fleshy.

\section{Plantàgo (Tourn.) L. Plantain, Ribgrass.}

Annual or perennial herbs, in ours acaulescent and with basal leaves only. Blades often broad, prominently ribbed. Flowers spicate, in an elongate spike, sometimes conspicuously bracted. Calyx-lobes equal, or 2 longer. Corolla mostly salver-shaped, constricted at the throat. Capsule more or less membranous. Seeds with flattened or concave faces.

Flowers all perfect; corolla not closed over the fruit; stamens 4 .

Leaves lanceolate to ovate; neither leaves nor spike silky pubescent or lanate; stamens in all the flowers long-exserted.

Spike cylindrical; seeds not concave on the faces.

Leaves ovate, abruptly contracted at the base; seeds more than 2 in each cell.

Pyxis dehiscent at the middle, round-ovoid, obtusish; leaves usually thick and the dense spike obtuse. $\quad 1$. $P$. major.

Pyxis dehiscent far below the middle, elongate-ovoid, very acute; leaves thin and the lax spike acute. 2 . P. asiatica.

Leaves lanceolate, gradually tapering into the petioles; seeds not more than 2 in each cell.

Leaves thin; plant not woolly at the base.

Leaves thick.

3. P. Tweedyi.

Plant sparingly pubescent, with red or brown wool at the base.

4. $P$. eriopoda.

Plant copiously villous with jointed hairs, not woolly at the base.

5. P. septata.

Spike short, oblong, 1-3 cm. long; seeds concave on the faces; leaves narrowly

lanceolate.
Leaves linear; leaves or peduncles or both more or less pubescent with long silky hairs; anther in the more fertile flowers included; seeds solitary in each cell, concave on the faces.

Bracts atistate or herbaceous, at least the lower ones 2-many times as long as the flowers.

Bracts all much exceeding the flowers.

Plant dark green; spike compact. $\quad$ 7. P. aristata.

Plant light green; spike more slender. $\quad 8 . P$. spinulosa.

Upper bracts scarcely exceeding the flowers.

Bracts neither aristate nor foliaceous, slightly if at all exceeding the flowers.

Bracts linear-subulate; spike long-cylindric.

Bracts ovate, obtuse; spike globose to oblong.

Flowers subdioecious or polygamo-dioecious; corolla in the fertile plant remaining closed

or early closing over the capsule; stamens 2 ; leaves filiform.

1. P. major L. Perennial; leaves petioled; blades oval or ovate, sparingly pubescent or glabrous, $5-35 \mathrm{~cm}$. long, 5-7-ribbed, entire or coarsely toothed; scape 8-15 cm. long; spike dense, 4-20 cm. long; sepals ovate, acute, not keeled; corolla-lobes spreading or reflexed; pyxis ovoid, $3 \mathrm{~mm}$. long; seeds 6-18. Waste places: Newf.-B.C.-Calif.-Fla.; nat. from Eu. Plain-Mont. My-S.

2. P. asiatica L. Perennial; leaves petioled; blades oval or ovate, sparingly pubescent or glabrate, thin, 1-2 dm. long, 5-7-ribbed, dentate or subentire; scape 1-2.5 dm. high; spike laxer than in the preceding; bracts ovate, scariousmargined, round-keeled; sepals suborbicular, scarious, with green midrib, not keeled; corolla-lobes spreading; pyxis ovate, $3-4 \mathrm{~mm}$. long; seeds 14-20. $P$. nitrophila A. Nels. Alkaline ground and waste places: Sask.-Neb.-Colo.B.C. Plain-Submont. My-S.

3. P. Tweedyi A. Gray. Perennial; leaves short-petioled; blades narrowly lanceolate or oblanceolate, glabrous, 3-5-ribbed, thin, 3-7 cm. long; scape 1-2 dm. high; spike $2-5 \mathrm{~cm}$. long, dense; bracts and sepals broadly oval, with green midrib, $2 \mathrm{~mm}$. long; pyxis ovoid, acute, $4 \mathrm{~mm}$. long, circumscissile near the base. Grassy slopes: Mont.-N.M.-Uitah. Submont.-Subalp. Je-Au.

4. P. eriopoda Torr. Perennial; leaves petioled; blades oblanceolate, lanceoblong or elliptic, entire, 3-9-ribbed, pubescent, $0.5-2 \mathrm{dm}$. long; scape $1.5-4 \mathrm{dm}$. high; spike 2-10 cm. long, dense above; sepals oblong-obovate, scarious-margined; pyxis ovoid-oblong, obtuse, circumscissile below the middle. P retrorsa Greene. Alkaline or saline soil: N.S.-Que.-Minn.-N.M.-Nev.-Alta. Plain-Submont. Je-S. 
5. P. septata Morris. Perennial; leaves short-petioled; blades narrowly lanceolate, entire, about $1.5 \mathrm{dm}$. long, $1.5 \mathrm{~cm}$. wide, 5-ribbed, woolly; scape about $15 \mathrm{~cm}$. high, woolly, especially below; spike about $5 \mathrm{~cm}$. long, in fruit rather loose; bracts and sepals rounded-ovate, scarious-margined, obtuse, $2 \mathrm{~mm}$. long, glabrous; pyxis finely reticulate, circumscissile one-third from the base, oblong, rounded at the apex. Plains and gulches: Alaska-Mont.-Mack. Plain-Subarctic. Je-Au.

6. P. lanceolata L. A biennial or perennial; leaves 4-30 cm. long, linearelliptic to elliptic, acute, 3-7-ribbed, entire or denticulate, hairy at the base; scapes 1-7 dm. long; spike dense, $1-8 \mathrm{~cm}$. long; calyx-lobes $2-3 \mathrm{~mm}$. long, broadly oblong, obtuse; capsule oblong, circumscissile at the middle, 2 -seeded. Lawns and waste places: N.B.-Alaska-Colo.-Fla.; nat. from Eu. Plain. Ap-N.

7. P. aristata Michx. Annual; leaves linear, acuminate, pubescent, 3ribbed, $1-5 \mathrm{~mm}$. wide; scape stout, erect, $7-30 \mathrm{~cm}$. long; spike $3-12 \mathrm{~cm}$. long, pubescent; bracts $1-3 \mathrm{~cm}$. long; sepals spatulate-oblong, obtuse; corolla-lobes ovate, spreading; pyxis $2.5-3 \mathrm{~mm}$. long, circumscissile at the middle; seeds 2 . Dry soil: Me.-B.C.-N.M.-Fla. Plain. My-O.

8. P. spinulosa Decne. Annual; leaves linear, acuminate, 3-ribbed, 3-6 $\mathrm{mm}$. wide, villous; scape 5-10 $\mathrm{cm}$. long; spike interrupted, $3-7 \mathrm{~cm}$. long, villous; bracts 7-15 mm. long, spreading; sepals spatulate-oblong, obtuse; corolla-lobes ovate, spreading; capsule $2.5 \mathrm{~mm}$. long, obtuse, circumscissile at the middle, 2-seeded. Sask.-Alta.-Tex. Plain. My-O.

9. P. xerodea Morris. Annual; leaves linear, 3-20 cm. long, 2-4 mm. wide, glabrate or villous; scape $1-20 \mathrm{~cm}$. high, pubescent; spike $1-6.5 \mathrm{~cm}$. long; bracts herbaceous, linear, attenuate, the lower three times as long as, the upper merely equalling the flowers, scarious-margined at the base; sepals oblong, scarious, with green rib; pyxis round-ovate, eireumscissile just below the middle. $P$. picta Morris. Arid regions: Ariz. $-\mathrm{S}$ Utah - s Calif. L. Son.

10. P. Purshii R. \& S. Annual; leaves ascending, linear, or nearly so, acute, short-petioled, 3-ribbed, $3-8 \mathrm{~cm}$. long, entire, woolly; scape 5-35 cm. long; spike dense, cylindric, $2-12 \mathrm{~cm}$. long, very villous; sepals oblong, obtuse, scariousmargined; corolla-lobes ovate, spreading; pod oblong, circumscissile about the middle, 2-seeded. P. graphalioides Nutt. Plains and river valleys, in sandy soil: Ont.-Sask.-B.C.-Ariz.-Tex.-Mo. Plain-Mont. My-Au.

11. P. scariosa Morris. Annual; leaves linear or lance-linear, $2-4 \mathrm{~cm}$. long, 2-4 mm. wide, obscurely 3-ribbed, white-villous; scape $3-12 \mathrm{~cm}$. long, villous; spike 6-20-flowered, globose to oblong, 5-18 mm. long, densely villous; bracts scarious, with green rib, ovate, obtuse; sepals similar, with green or purple rib; pyxis twice as long as the sepals, circumscissile just below the middle. Arid places: Calif.-Utah-Ariz. Son.

12. P. elongata Pursh. Annual; leaves cinereous-pubescent, linear, entire or nearly so, 1-ribbed, $3-10 \mathrm{~cm}$. long, $0.5-2 \mathrm{~mm}$. wide; scape $3-8 \mathrm{~cm}$. high; spike $1-10 \mathrm{~cm}$. long; bracts triangular-ovate, scarious-margined, $2 \mathrm{~mm}$. long; corollalobes triangular, $0.5 \mathrm{~mm}$. long; pyxis oblong-ovate, rounded at the apex, circumscissile just below the middle. P. myosuroides Rydb. Wet places: Sask.Okla.-Utah.-Alta.

\section{Family 122. RUBIACEAe. Madder Family.}

Herbaceous or woody plants, with opposite or apparently verticillate leaves and usually perfect, but often dimorphous or trimorphous, regular and symmetrical flowers. Ovary inferior, sunken into and adnate to the hypanthium. Corolla in ours funnelform or rotate, gamopetalous and 3-5lobed. Stamens as many as the lobes of the corolla and alternate with them; filaments adnate to the corolla; anthers mostly linear-oblong. Ovary in ours 2-celled, ripening into a didymous indehiscent, dry or fleshy fruit. Ovules solitary in each cell. Endosperm in our genera fleshy or horny. 
Leaves opposite; conolla funnelform.

Leaves apparently verticillate; corolla rotate.

Flowers 3-4-merous, usually white; fruit dry.

Flowers 5-merous, yellow; fruit baccate.

\section{KELLÓGGIA Torr.}

2. GALTUM.

3. RUBIA.

Perennials, with opposite leaves, small interposed stipules and small white or pinkish flowers in paniculate cymes. Flowers perfect, 3-5-(mostly 4-) merous, Hypanthium obovoid. Calyx-teeth minute, persistent. Corolla funnel-salverform; lobes valvate in the bud. Stamens adnate to the corolla up to the throat, exserted; filaments flat; anthers fixed above the base. Ovary 2-celled; style filiform, exserted; stigmas 2, linear-clavate. Ovules solitary, erect, anatropous. Fruit dry, coriaceous, beset with uncinate bristles, separating into 2 carpels. Albumen fleshy.

1. K. galioides Torr. Stem slender, glabrous or puberulent, 1-3 dm. high; leaves narrowly lanceolate, $1.5-5 \mathrm{~cm}$. long, sessile, 1-3-nerved, acute at the apex; corolla 5-7 mm. long and as wide; fruit 3-4 mm. long and, with the bristles, 3-4 $\mathrm{mm}$. in diameter. Mountain woods: Wyo.-Wash.-Ariz.-Calif. Submont.Mont. Je-Jl.

\section{Gàlium L. Bedstraw, Cheavers.}

Annual or perennial herbs, some somewhat woody at the base, with 4-angled stems and branches, apparently verticillate leaves* and small, mostly white flowers in cymes or panicles. Flowers perfect or in some species dioecious. Hypanthium globose or ovoid. Calyx obsolete. Corolla wheel-shaped, 4parted, or rarely 3-parted. Stamens 4, rarely 3; filaments short. Styles 2; stigmas capitellate; ovary 2-celled, with one ovule in each cell. Fruit didymous, of two indehiscent carpels, often bristle-hairy, dry.

Flowers perfect; fruit birsute with uncinnate hairs, or glabrous.

Annuals.

Stem coarse, reclining; leaves $6-8$ in the whorls.

Leaves linear or oblanceolate.

Leaves $2-7 \mathrm{~cm}$. long; nutlets when ripe $3-5 \mathrm{~mm}$. in diameter; flowers white.

1. G. Aparine.

Leaves $0.5-2 \mathrm{~cm}$. Iong; nutlet when ripe 2-3 $\mathrm{mm}$. in diameter; flowers ochroleucous.

2. G. Vaillantit. Leaves elliptic.

10. G. flaviflorum.

Stem slender, erect or ascending; leaves $2-4$ in the whorls.

Leaves ovate or oblong, 5-7 $\mathrm{mm}$. long; fruit nearly sessile.

Leaves linear-oblong or linear, often $10-20 \mathrm{~mm}$. long; fruit distinctly peduncled.

Perennials.

Leaves not cuspidate-pointed.

Stem stout; leaves thick, 3-nerved.

Stem very slender; leaves 1-nerved.

Leaves mostly 4 in the whorls, $5-15 \mathrm{~mm}$. long.

Leaves obovate to broadly oblong-lanceolate, somewhat fleshy. Corolla-lobes almost $1 \mathrm{~mm}$. long; pedicels and generally also the stem glabrous.

6. G. Brandegei.

Corolla-lobes about $0.5 \mathrm{~mm}$. Iong; pedicels and stem more or less scabrous.

7. G. subbiflorum.

Leaves linear-oblong or linear-oblanceolate.

8. G. trifidum.

Leaves of the stem mostly $5-6$ in the whorls, $15-30 \mathrm{~mm}$. long.

9. G. columbianum.

Leaves cuspidate-pointed.

Fruit uncinate long-hispid; stem glabrous or sparingly hirsute or bristly; inflorescence axillary, mostly simple.

Stem retrorse-bristly; pedicels scarcely exceeding the bracts.

10. G. flaviflorum.

Stem glabrous or sparingly hirsute; pedicels much exceeding the small bracts.

11. G. triflorum.

Fruit minutely hispidulous or granular-scabrous; stem scabrous on the angles; inflorescence panicled.

Leaves firm, with strong midrib, lanceolate or oblanceolate; pedicels in fruit somewhat spreading.

12. G. asperulum.

Leaves thin, oblong, rounded and mucronate at the apex; pedicels very fine, in fruit spreading at right angles.

13. G. filipes.

* The leaves are really opposite; but the interposed stipules are large and leaf-like. 
Flowers dioecious, in small cymes; fruit with long, not uncinate hairs; perennials.

Leaves linear.

Leaves ovate or lanceolate.

Plant glabrous or nearly so.

Leaves of the stem lanceolate to ovate, 8-15 mm. long. 15. G. Watsoni. Leaves broadly ovate, 5-8 mm. long.

Plant decidedly puberulent.

Plant pruinose-puberulent; leaves broadly ovate, not cuspidate.

Plant hispidulous-puberulent; leaves lanceolate, cuspidate.

17. G. multiflorum.

18. G. stellatum.

1. G. Aparine L. Stem weak, prostrate or scrambling over bushes, 3-15 $\mathrm{dm}$. long, retrorsely hispid on the angles; leaves $6-8$ in the whorls, oblanceolate, sometimes almost linear, 2-7 $\mathrm{cm}$. long, 4-10 $\mathrm{mm}$. wide, cuspidate, the margins and midribs retrorsely hispid; flowers white in 1-3-flowered cymes in the upper axils. Copses: N.B.-Fla.-Mo.-Tex.-Calif.-B.C.; nat. from Eu. PlainSubmont. My-S.

2. G. Vaillantii DC. Stem prostrate, retrorsely hispid as the preceding, but the internodes shorter, and the whole plant smaller; leaves 6-8 in the whorls, usually oblong-linear, sometimes slightly oblanceolate, cuspidate-pointed; flowers in 2-9-flowered cymes. Low ground among bushes: Ont.-Fla.-Tex.-Calif. -B.C.; Eurasia. Plain-Submont. My-Au.

3. G. proliferum A. Gray. Stem hispidulous, branching, $3 \mathrm{dm}$. high; leaves $5-8 \mathrm{~mm}$. long, acute, with a strong midrib, mostly 4 in the whorls, the alternate ones often smaller; flowers solitary on axillary peduncles which are about twice as long as the leaves, almost sessile in the axil of two leaf-like bracts; peduncles sometimes with one or two prolifications from the axils of the bracts; carpels about $2 \mathrm{~mm}$. in diameter. On stony hills: Tex.-s Utah-Ariz.; Mex. L. Son. Ap-Je.

4. G. bifolium S. Wats. Stem slender, erect, glabrous, 1-1.5 dm. high; leaves $2-4$ in the whorls, often very unequal, thin, acutish, 1-nerved; flowers solitary on axillary peduncles, horizontal and curved under the fruit; carpels about $2 \mathrm{~mm}$. in diameter. In mountain meadows and around springs: B.C.Mont.-Colo.-Calif. Submont. My-Jl.

5. G. boreale L. Stem erect, glabrous, $2-7 \mathrm{dm}$. high; leaves 4 in the whorls, from linear to broadly lanceolate, obtuse or acutish, $3-5 \mathrm{~cm}$. long, the margins sometimes ciliate and slightly revolute, often with fascicles of smaller leaves in the axils; flowers white or ochroleucous (var. linearifolium) in terminal, densely many-flowered compound cymes; carpels about $2 \mathrm{~mm}$. in diameter. Rocky places, hillsides, and along streams: Que.-N.J.-Neb.-N.M.-Calif.-Alaska; Eurasia. Plain-Mont. My-Au.

6. G. Brandegei A. Gray. Stem loosely branched, glabrous, slender, 5-15 $\mathrm{cm}$. high, generally depressed; leaves unequal, 4-12 $\mathrm{mm}$. long, somewhat fleshy, obtuse; midrib faint; flowers usually solitary or geminate, on axillary peduncles; corolla white; fruit glabrous, its carpels about $1.5 \mathrm{~mm}$. in diameter. Around springs: Wyo.-N.M.-Ariz.-Calif. Submont.-Mont. Je-Au.

7. G. subbiflorum (Wiegand) Rydb. Stem slender, prostrate, 1-3 dm. long, somewhat scabrous on the angles; leaves mostly obtuse, slightly fleshy and with a faint midrib, 5-15 $\mathrm{mm}$. long; peduncles axillary, usually solitary, or more rarely geminate, 1-flowered, or less commonly 2-3-flowered; corolla white, 3lobed; fruit glabrous, its carpels $1-1.5 \mathrm{~mm}$. in diameter. G. trifidum subbiflorum Wiegand. Wet places: Minn.-N.M.—s Calif.-Wash. Plain-Mont. Je-Au.

8. G. trifidum L. Stem slender, ascending or depressed, 2-4 dm. long, branched, scabrous on the angles; leaves $5-15 \mathrm{~mm}$. long, obtuse, 1-nerved, thin, dark green and dull on both sides; midrib and margins scabrous; flowers on slender 1-3-flowered axillary peduncles; corolla white, 3-lobed, its lobes about $0.5 \mathrm{~mm}$. long; fruit glabrous, its carpels about $1.5 \mathrm{~mm}$. in diameter. Wet meadows and swamps: Lab.-Newf.-N.Y.-Colo.-Alaska. Plain-Submont. $\mathrm{Je}-\mathrm{Au}$.

9. G. columbianum Rydb. Stem slender, $3-10 \mathrm{dm}$. long, branched, somewhat scabrous on the angles; leaves of the stem generally linear-oblong or 
oblanceolate, obtuse, 1-nerved, scabrous on the midrib and margins; leaves of the branches generally 4 in the whorls, smaller; flowers axillary or in small terminal cymes, white; peduncles slender, 5-20 mm. long, solitary or geminate, 1-3-flowered, often curved; corolla white, 3-lobed; fruit glabrous; earpels about $1.5 \mathrm{~mm}$. in diameter. Damp woods and on grassy banks: Mont.-Wash.Alaska. Submont, Je-Au.

10. G. flaviflorum Heller. Stem diffuse, 3-10 dm. long; leaves mostly 6 in the whorls, elliptic or lance-oblong, retrorsely hispidulous on the midrib and margins, 2-5 cm. long; peduncles axillary, 2-4-flowered, about equalling the leaves; bracts lanceolate; corolla pale greenish yellow, 4-lobed; fruit hispid with uncinate hairs; carpels $2-3 \mathrm{~mm}$. in diameter. Hills: N.M.-s Colo. Submont. -Mont. Jl-Au.

11. G. triflorum Michx. Stem diffuse, 3-10 dm. long, glabrous or very sparingly hirsute, shining; leaves mostly 6 in the whorls, narrowly oval or slightly oblanceolate, 1-ribbed, narrowed at both ends, 3-7 cm. long; peduncles axillary or terminal, often exceeding the leaves, mostly 3 -flowered; corolla greenish white, 4-lobed; fruit long-hispid with uncinate hairs; earpels $3-4 \mathrm{~mm}$. in diameter. Damp open woods: Newf.-Ala.-Colo.-Calif.-Alaska. Plain-Mont. Je-Au.

12. G. asperulum (A. Gray) Rydb. Stem erect or ascending, but weak, 3-6 dm. long, retrorse-hispidulous on the angles; leaves thin, 2-4 cm. long, linear-oblanceolate, 1-ribbed, cuspidate at the apex, hispidulous on the ribs and margins; flowers in axillary and terminal, more or less compound cymes; branches merely ascending-spreading in fruit, 1-1.5 $\mathrm{cm}$. long; corolla purplish, its lobes acute; fruit very short uncinate-hispid or granular-scabrous; carpels $1-1.5 \mathrm{~mm}$. in diameter. G. asperrimum asperulum A. Gray. In copses and rocky places: Wash.-Ida.-Utah-Calif. Submont.

13. G. filipes Rydb. Stem ascending, about $5 \mathrm{dm}$. long, minutely, retrorsely hispidulous; leaves broadly oblanceolate, obtuse and cuspidate at the apex, thin, 2-4 cm. long, retrorsely hispidulous on the veins and margins; flowers in axillary or terminal cymes, the latter more compound; pedicels divaricate, very slender, in fruit often $1 \mathrm{~cm}$. long; corolla purplish, 4-lobed; lobes acuminate; fruit minutely hispidulous; carpels $1.5 \mathrm{~mm}$. thick, fully $2 \mathrm{~mm}$. long. Among bushes: Utah-Nev. Submont. Jl.

14. G. coloradense W. Wight. Stem erect, perfectly glabrous, with upright branches, about $3 \mathrm{dm}$. high, slightly woody at the base; leaves rather thick and firm, linear, acute, 1-ribbed, 1-2.5 cm. long and 2-3 mm. wide, 4 in the whorls; cymes of the sterile plant 8-15-flowered, those of the fertile plant 1-5-flowered; corolla apparently yellowish, $2 \mathrm{~mm}$. wide; hypanthium of the sterile flowers glabrous; carpels, including the hairs, 3-4 mm. in diameter. Dry regions: sw Colo.- - se Utah. Submont. Je-Jl.

15. G. Watsoni (A. Gray) Heller. Stem branched, with a somewhat woody base, $0.5-4 \mathrm{dm}$. high, glabrous or nearly so; cymes of the sterile plant 3-9-flowered, those of the fertile plant 1-5-flowered; leaves 4 in the whorls, generally unequal in size, $8-15 \mathrm{~mm}$. long, rather firm, more or less distinctly 3-ribbed, acute or acuminate; corolla yellowish, about $3 \mathrm{~mm}$. in diameter; hypanthium of sterile flowers sparingly short-hispid; carpels, with hairs, 5-6 mm. in diameter. On dry mountains: Ida.-Ore,-Ariz. Submont. Je-Au.

16. G. Bloomeri A. Gray. Stem glabrous, branched, somewhat woody at the base, 1-3 dm. high; leaves 4 in the whorls, firm, 5-8 mm. long, 3-ribbed, acute or more commonly abruptly short-acuminate; cymes of the sterile plant 3-9-flowered, those of the fertile plant 1-5-flowered; corolla yellowish, about $2 \mathrm{~mm}$. in diameter; hypanthium of the sterile flower glabrous or puberulent, or with a few long hairs at the base; carpels, with hairs, 3-4 mm. in diameter. Dry mountains: Utah-Ida.-Nev.-Calif. Submont. Je-Au.

17. G. multiflorum Kellogg. Stem branched, very similar to the preceding in habit; leaves 4 in the whorls, acute, more or less distinctly 3-ribbed, 5-12 mm. long; cymes of the sterile plant 3-7-flowered, those of the fertile plant 1-3-flowered, with very short pedicels; corolla light yellow, about $3 \mathrm{~mm}$. broad; hypan- 
thium of the sterile flowers puberulent or with a few long hairs; carpels, with hairs, 4-7 mm. in diameter. Barren hills and mountains: Utah-Wash.-Calif. Submont.

18. G. stellatum Kellogg. Stem intricately branched, woody at the base, 1-4 dm. high; leaves 1-ribbed, 4-10 mm. long, very firm; cymes of the sterile plants 3-5-flowered, those of the fertile ones 1-3-flowered, with very short pedicels; corolla white, $1.5 \mathrm{~mm}$. in diameter; hypanthium in both kinds of flowers hairy, but longer so in the fertile ones; carpels in fruit, with hairs, $3-4 \mathrm{~mm}$. in diameter. Arid regions: Utah-Ariz.-Calif.-L. Calif. Son.

\section{RUBİA L. MADDER.}

Perennial herbs, often woody below. Leaves apparently verticillate as in Galium. Flowers in axillary and terminal cymes. Corolla rotate or campanulate, 5-lobed. Styles 2, connate at the base; stigmas capitate. Fruit didymous or globose, succulent.

1. R. tinctorum L. Stem about $1 \mathrm{~m}$. high, armed with small hooked prickles on the angles; leaves lanceolate, retrorse-prickly on the ribs and margins; flowers bright yellow; lobes ovate-lanceolate, acute; berry subglobose, black, the size of a pea. Waste places: Utah; adv. from the Mediterranean region. Je-Au.

\section{Family 123. CAPRIfoliaceae. Honeysuckle Family.}

Shrubs, trees, vines, or perennial herbs, with opposite leaves and perfect, regular or irregular flowers, mostly in cymes. Stipules generally none. Calyx 3-5-lobed or 3-5-toothed. Corolla gamopetalous, from rotate to tubular, often gibbous at the base; limb 5-lobed and sometimes 2-lipped. Stamens 5, in Linnaea only 4, adnate to the corolla and alternate with its lobes; anthers versatile. Ovary inferior, enclosed in the hypanthium, 1-6celled. Fruit a 1-6-celled berry, drupe, or capsule. Ovules anatropous. Seed with a fleshy albumen; embryo small. Style deeply 3 -5-cleft; shrubs or trees with compound cymose inflorescence and drupace-
ous fruit.

Leaves pinnate; ovary 3-5-celled, each cell with one ovule.

Leaves simple; ovary 1-celled and 1-ovuled.

1. Sambucus.

Style slender, undivided; stigma capitate.

Trailing evergreen herb; flowers long-peduncled, geminate; stamens 4, didynamous.

Shrubs; stamens generally 5.

Fruit a few-seeded berry.

Corolla rarely gibbous at the base, regular or nearly so; fruit 2-seeded.

Corolla gibbous at the base, mostly irreguar and bilabiate; 4. SYMPHORICARPOS. Flowers in heads at the ends of the branches or in verticils in the upper axils; upper leaves connate; vines.

5. LONICERA.

Flowers in pairs on axillary peduncles; leaves not connate; erect shrubs.

Bracts and bractlets minute, not foliaceous; berries of the two flowers more or less united.

6. XYLOSTEON.

Bracts and bractlets foliaceous; berries of the two flowers distinct.

Fruit a 2-celled capsule; corolla slightly gibbous and somewhat irregular.

8. Diervilla.

\section{SAMBÙCUS (Tourn.) L. ELDER.}

Shrubs or trees with opposite, odd-pinnate leaves, large pith in the young branches, small whitish flowers in compound cymes. Hypanthium ovoid or turbinate. Calyx-lobes minute, generally 5 . Corolla rotate or saucer-shaped, regular, 5-lobed. Stamens 5, inserted at the base of the corolla; anthers oblong. Style short, 3-5-cleft; ovary and berry-like drupe 3-5-celled, each cell containing 1 ovule or seed.

Cyme not flat-topped, thyrsoid-paniculate, the axis continuous.

Fruit red or rarely yellow.

Young branches, inflorescence and the lower surfaces of the leaves pubescent.

1. S. pubens. 
Whole plant glabrous.

2. S. microbotrys.

Fruit black.

3. S. melanocarpa.

Cyme flat-topped, umbelliform, 4-5-rayed, the rays again variously compound; fruit blackish.

Fruit without bloom or nearly so, generally less than $5 \mathrm{~mm}$. broad. Leaflets ovate, ovate-lanceolate, to obovate, dark green. Leaflets lanceolate, pale green.

Fruit with copious bloom, generally over $5 \mathrm{~mm}$. broad.

4. S. canadensis.

5. S. neomexicana.

6. S. coerulea.

1. S. pubens Michx. Shrub, 6-35 dm. high; leaflets 5-7, dark green, ovatelanceolate or oval, long-acuminate, generally narrowed and slightly oblique at the base, 5-12 $\mathrm{cm}$. long, sharply serrate; cyme about 5-6 $\mathrm{cm}$. high and 4-5 $\mathrm{cm}$. broad; corolla white, turning brownish in drying; drupe scarlet or red or occasionally amber yellow, 4-6 mm. in diameter. S. racemosa Hook., not L. Damp rocky places: N.S.-Ga.-Colo.-B.C.-Alaska. Submont. Ap-My.

2. S. microbotrys Rydb. Shrub low, 5-20 dm. high, with pale green foliage; leaflets ovate or rarely ovate-lanceolate, acute or short-acuminate, $3-9 \mathrm{~cm}$. long, mostly rounded and oblique at the base, coarsely serrate; cyme small, about as long as broad, about $3 \mathrm{~cm}$. in diameter; flowers whitish; fruit bright red, 4-5 mm. in diameter. Damp places in mountains: S.D.-Colo.-Ariz.-Utah. Submont.-Subalp. My-Je.

3. S. melanocarpa A. Gray. Shrub 1-2 m. high, glabrous, or the young leaves pubescent, with dark green foliage; leaflets $5-7$, oval or ovate to ovate-lanceolate, coarsely serrate, abruptly acuminate, often obtuse or rounded and decidedly oblique at the base, $4-15 \mathrm{~cm}$. long; cyme convex, fully as broad as high, $4-7 \mathrm{~cm}$. in diameter; corolla white, but turning somewhat brownish in drying; fruit black, without bloom, 5-6 mm. in diameter. Along streams: Alta.-N.M.-UtahB.C. $\mathrm{My}-\mathrm{Je}$.

4. S. canadensis L. A shrub, 1-3 meters high, glabrous or nearly so, with dark green foliage; leaflets $5-11$, mostly 7 , ovate or oval, sharply serrate, mostly short-acuminate at the apex, acute or obtuse at the base, sometimes pubescent on the veins beneath, 5-12 cm. long, often with linear stipels; cyme flat-topped, 5-15 cm. high and 1-2 dm. broad; flowers white; fruit purplish black, 4-5 mm. in diameter. In wet soil: N.S.-Fla.-Tex.-Colo.-Mont.-Sask. Plain-Submont. Je-Jl.

5. S. neomexicana Wooton. Shrub 2 meters high, almost perfectly glabrous, with pale green foliage; leaflets $5-7$, lanceolate, coarsely serrate, long acuminate at the apex, acute and generally very oblique at the base, 4-12 $\mathrm{cm}$. long; cyme 4-8 $\mathrm{cm}$. high and 6-15 $\mathrm{cm}$. broad; flowers white; fruit bluish black, 4-5 mm. in diameter. Wet places in the mountains: N.M.-Colo. Submont.Mont.

6. $\mathrm{S}$. coerulea Raf. Shrub in clumps, $2-4 \mathrm{~m}$. high, glabrous throughout and with pale green foliage; leaflets $5-9$, thickish, oblong, acute or acuminate, coarsely serrate, generally rounded and very oblique at the base, $5-15 \mathrm{~cm}$. long, rarely with minute stipels; cyme 5-7-rayed, 4-6 cm. high and 8-15 cm. broad; flowers pure white; fruit black, but covered with a dense white bloom, $5-6 \mathrm{~mm}$. in diameter. S. glauca Auth. S. decipiens M. E. Jones. S. ferax A. Nels. Along creeks: B.C.-Alta.-Utah-Ariz.-Calif. Submont.

\section{VibÙRNUM (Tourn.) L. ARrow-Wood, Cranberry Tree, SNOW-BaLls.}

Shrubs or small trees with simple, often stipulate leaves. Flowers in compound cymes. Hypanthium ovoid, hemispherical, or turbinate. Calyx-teeth 5. Corolla rotate to short-campanulate, regular, 5-lobed. Stamens 5; anthers oblong. Style short, 3-cleft; ovary 1-3-celled; each cell with a single ovule. Drupe 1-seeded; seed compressed.

Leaves palmately veined, usually 3-lobed; fruit red.

Outer flowers of the cyme large, neutral and radiant.

None of the flowers radiant.

Leaves pinnately veined, not lobed; fruit blue or black.

Leaves coarsely dentate, pubescent.

Leaves sharply but finely serrulate, glabrous or nearly so.

1. V. Opulus.

2. V. pauciflorum.

3. V. pubescens.

4. V. Lentago. 
1. V. Opulus L. Shrub sometimes $3.5 \mathrm{~m}$. high; leaves glabrous or nearly so above, more or less pubescent on the veins beneath, deeply 3 -lobed, rounded or truncate at the base, the lobes divergent, long-acuminate, coarsely toothed; cyme peduncled, flat-topped, the exterior neutral flowers $1-2 \mathrm{~cm}$. broad; fruit globose, red, very acid, $8-10 \mathrm{~mm}$. in diameter; stone flat, orbicular, not grooved. Low places: N.B.-N.J.-Ore.-B.C.; Eurasia. Submont. Je-Jl.

2. V. pauciflorum Pylaie. Shrub $1-2 \mathrm{~m}$. high; leaves 3-5-ribbed, truncate or cordate at the base, more or less pubescent, $4-10 \mathrm{~cm}$. broad, generally with 3 shallow lobes, these acute or short-acuminate, coarsely dentate; cyme rather few-flowered, short-rayed, 1-3 $\mathrm{cm}$. broad; drupe round or ovoid, $8-10 \mathrm{~mm}$. long; stone flat, orbicular, scarcely grooved. Woods: Newf.-Pa.-Colo.-Alaska. Submont. Je-Jl.

3. V. pubescens (Ait.) Pursh. Shrub 5-15 dm. high, with gray branches; leaves ovate, acute or acuminate, rounded or subcordate at the base, $3-8 \mathrm{~cm}$. long, velvety pubescent beneath; cymes $3-7 \mathrm{~cm}$. broad; drupe nearly black, 8 $\mathrm{mm}$. long; stone 2-grooved on the faces. Rocky woods: N.B.-Ga.-Ia.(? Wyo.)-Man. Je-J.

4. v. Lentago L. Bush or small tree, sometimes $10 \mathrm{~m}$. high; leaf-blades ovate, 4-10 $\mathrm{cm}$. long, glabrous or slightly pubescent beneath, sharply serrulate, mostly rounded at the base and acuminate at the apex; cyme broad, sessile, 5-12 $\mathrm{cm}$. in diameter; drupe oval, sweet, bluish black, with a bloom, 10-14 mm. long; stone flat, circular or oval. NANNY-BERRY, In rich soil, in woods and along streams: Me.-Ga.-Colo.-Man. Submont. My.

\section{LINNAÈA (Gronov.) L. TwiN-FLower.}

Trailing or creeping evergreen, with slender branches, and opposite petioled leaves. Flowers pink or purplish, borne in pairs at the end of long terminal peduncles. Hypanthium ovoid. Calyx-teeth 5, subulate-lanceolate, deciduous in fruit. Corolla funnelform, almost regular, not gibbous at the base; limb 5-lobed. Stamens 4, didynamous, included. Ovary 3-celled; two of the cells with several abortive ovules, the third with a single perfect ovule; style slender, exserted; stigma capitate. Fruit coriaceous, 3 -celled, but 1-seeded.

Calyx-lobes about $2 \mathrm{~mm}$. long; leaves round, oval, or orbicular.

1. L. americana. Calyx-lobes about $4 \mathrm{~mm}$. long; leaves of the fertile shoots mostly broadly obovate-spatulate.

1. L. americana Forbes. Stem trailing, with pubescent branches; leaves somewhat coriaceous; blade round, oval, or orbicular, $8-15 \mathrm{~mm}$. in diameter, generally crenate above the middle; peduncles slender, often $1 \mathrm{dm}$. long; bracts and bractlets linear-subulate; calyx-lobes lance-linear, not longer than the ovary; corolla rose-colored, fragrant, about $1 \mathrm{~cm}$. long, funnelform. L. borealis Am. auth., not L. In cold woods: Greenl.-N.J.-Mich.-Colo.-Alaska. Submont.-Subalp. Je-Au.

2. L. longiflora (Torr.) Howell. Stem 3-6 dm. long; leaves of the flowering shoots generally more elongate, broadly ovate or spatulate, $1-2.5 \mathrm{~cm}$. long and

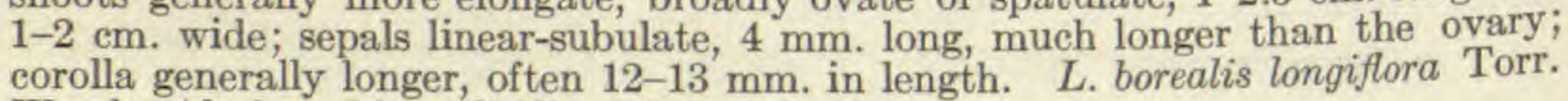
Woods: Alaska-Ida.-Calif.; e Asia.

\section{SYMPHORICÃRPOS (Dill.) Ludw. CORAL-BERRY, SNOW-BERRY, WOLF-BERry, StAa-BERry.}

Shrubs, with opposite short-petioled leaves and white or pink flowers in small terminal or axillary clusters. Hypanthium globose or ellipsoid. Calyxteeth 4-5. Corolla from open-campanulate to salverform, regular, rarely slightly gibbous at the base, 4-5-lobed. Stamens 4-5, adnate to the corolla. Ovary 4-celled; two of the cells with several abortive ovules, the other two each with a single pendulous ovule; style filiform; stigma capitate. Fruit a globose or ovoid 4-celled, but only 2 -seeded berry. 
Corolla short, open-campanulate.

Fruit red; style bearded.

Fruit white; style glabrous.

Style and stamens somewhat exserted; leaves thick.

Style and stamens not exserted; leaves rather thin.

Erect shrub; leaves $2-5 \mathrm{~cm}$. long; clusters several-flowered.

Diffuse shrub; leaves $1-2.5 \mathrm{~cm}$. Iong; elusters 1-2-flowered.

1. S. Symphoricarpos.

2. S. occidentalis.

3. S. racemosus.

4. S. pauciflorus.

Corolla elongate, oblong-campanulate to salverform.

Style glabrous; corolla with short, slightly spreading lobes.

Corolla oblong-campanulate, $6-8 \mathrm{~mm}$. long.

Leaves decidedly pubescent; stem puberulent; leaves rounded-oval, obtuse or rounded at the apex.

Leaves glabrate or slightly pubescent.

5. S, rotundifolius.

Leaves rounded-ovate or rounded-oval, $3-4 \mathrm{~cm}$. long.

Leaves oval, acute, $1-2 \mathrm{~cm}$. long.

Corolla tubular-funnelform, 8-12 mm. long.

style bearded; corolla salverform, with long divaricate lobes.

6. S. utahensis.

7. S. vaccinioides.

8. S. oreophilus.

9. S. longiflorus.

1. S. Symphoricarpos (L.) MacMill. Shrub 5-15 dm. high, with pubescent purplish branches; leaf-blades oval or ovate, entire or wavy, soft pubescent beneath, 2-4 cm. long; flower-clusters shorter than the leaves; corolla campanulate, pinkish, $4 \mathrm{~mm}$. long; berry ovoid-globose, 3-4 mm. long. S. vulgaris Michx. S. orbiculatus Moench. Coral-Berry. River banks: N.Y.-Ga.-Tex.-Colo. -Mont. Plain. Jl.

2. S. occidentalis Hook. Shrub 1-1.5 m. high, with slender, light-colored branches; leaves rounded-oval, broadly ovate or almost orbicular, $3-7 \mathrm{~cm}$. long, obtuse or rounded at the apex, more or less pubescent beneath, rather thick and firm, the margins entire or on vigorous shoots deeply sinuately toothed; flowerclusters spicate, $10-25 \mathrm{~mm}$. long; corolla $6 \mathrm{~mm}$. long; fruit globular, white, $8-10$ $\mathrm{mm}$. in diameter. Hillsides, open woods, and river banks: Mich.-Mo.-Colo. -B.C. Plain-Submont. Je-Jl.

3. S. albus (L.) Blake. Shrub erect, 5-15 dm. high, with slender glabrous branches; leaves rather thin, oval, obtuse at both ends, sometimes slightly pubescent beneath, sub-entire or on young shoots sinuate dentate; terminal flowerclusters often interrupted spicate, the axillary few-flowered; corolla thin, slightly gibbous, $6 \mathrm{~mm}$. long, bearded within; fruit white, globose, 6-10 $\mathrm{mm}$. in diameter. S. racemosus Michx. Rocky places and on river banks: N.S.-Va.-Wyo.Colo.-Calif.--B.C. Submont. Je-Au.

4. S. pauciflorus (Robbins) Britton. Shrub low, diffusely branched, 15-25 $\mathrm{dm}$. high; leaves broadly oval or orbicular, softly pubescent beneath, $12-25 \mathrm{~mm}$. long, entire; flowers $2-3$ in terminal spikes and solitary in the upper axils; corolla open-campanulate, 4-6 mm. long, bearded within; fruit oval to globose, 4-6 mm. in diameter. Rocky places: Vt.-Pa.-Neb.-N.M.-B.C. Submont. Je-Jl.

5. S. rotundifolius A. Gray. Shrub low, less than $5 \mathrm{dm}$. high, with spreading pubescent branches; leaves thick, $1-2 \mathrm{~cm}$. long, orbieular to broadly oval, generally entire; flowers in small axillary clusters; corolla elongate-campanulate, 6-8 mm. long, pubescent within, below the stamens; fruit white, ovoid, $10 \mathrm{~mm}$. long and $7 \mathrm{~mm}$. broad; stones oval, obtuse at both ends. Mountains: w Tex.Colo.-Nev.-Calif. Submont.

6. S. utahensis Rydb. Shrub $1 \mathrm{~m}$. or more high, with brownish bark; leaves broadly ovate, more or less rounded at both ends, obtuse or often mucronate, often coarsely sinuately toothed, pubescent when young, 3-4 cm. long and 2-3 cm. wide; flowers in terminal one-sided, drooping, short spikes, or with smaller clusters in the upper axils; corolla elongate-campanulate, about $8 \mathrm{~mm}$. long. Dry mountain-sides: n Utah-Colo. Submont.

7. S. vaccinioides Rydb. Shrub intricately branched, with dark grayish brown shreddy bark on the old branches and yellowish brown on the young ones; leaves about $2 \mathrm{~cm}$. long, oval, acute at both ends, dark green above, more or less glaucous beneath, puberulent or glabrate; corolla $6-8 \mathrm{~mm}$. long; fruit white, about $1 \mathrm{~cm}$. long and $7 \mathrm{~mm}$. in diameter. S. tetonensis A. Nels, Dry hillsides: Alta.-Wash.-Nev.-Wyo. Submont. 
8. S. oreophilus A. Gray. Shrub glabrous or somewhat pubescent, often $1 \mathrm{~m}$. high; leaves rather thin, oblong to broadly oval, mostly acute, about $2 \mathrm{~cm}$. long; corolla-tube glabrous within, 4-5 times as long as the rounded, slightly spreading lobes; fruit white, about $1 \mathrm{~cm}$. long, ovoid. $S$, glabratus Eastw. Hillsides and river banks: Colo.-Ida.--Calif.-Ariz.-N.M. Submont.

9. S. longiflorus A. Gray. Shrub glabrous or minutely pubescent, less than $1 \mathrm{~m}$. high; leaves spatulate-oblong to oval, thick and somewhat glaucous, 6-12 $\mathrm{mm}$. long; corolla salverform, slender, $10-15 \mathrm{~mm}$. long; tube glabrous within, 3-5 times as long as the oblong widely spreading lobes; fruit white, oblong; stones oblong. Mountains: Utah-Nev. Submont.

\section{XYLÓsteon Adans. Bush or Fly Honeysuckle, Twinberry.}

Erect branching shrubs, with opposite simple leaves. Flowers axillary in pairs, the common peduncle bibracteate at the summit. Bracts and bractlets if present small, lanceolate or subulate. Hypanthium ovoid or globose. Calyxteeth 5 , minute. Corolla funnelform-campanulate, more or less gibbous at the base and more or less irregular; limb 5-lobed, more or less 2-lipped. Stamens adnate to the corolla-tube; anthers linear or oblong. Ovaries 2-3-celled, those of the two flowers often more or less united; ovules numerous in each cell, pendulous, style slender; stigma capitate. Berry fleshy, 2-3-celled, few-seeded.

Leaves pale or glaucous, thick, narrow, oblong; fruit black or black-blue with a bloom.

Leaves bright green, thin, usually broad; fruit red.

Leaves glabrous, oval or broadly oblong.
Leaves pubescent and ciliate, ovate or broadly oval, often subcordate at the base. Leaves rounded at the apex; bracts $1 \mathrm{~mm}$, about one-third as long as the ovaries. 3. X. ebractulatum.

Leaves acute or obtuse; bracts one-half as long as the ovaries or more.

4. $X$. ciliatum.

1. X. coeruleum (L.) Dum-Cours. Shrub erect, 5-10 dm. high; leaves $2-4$ $\mathrm{cm}$. long, rounded at the apex, pale and more or less pubescent beneath, glabrate above; flowers short-peduncled; bracts linear-subulate, longer than the ovaries; corolla yellow, $12-15 \mathrm{~mm}$. long, often pubescent; ovaries of the two flowers wholly united, forming in fruit an oblong, bluish-black berry. Lonicera coerulea L. Low grounds: Lab.-Pa.-Wis.-Wyo.-Calif.-Alaska; Eurasia. Submont.-Mont. Je.

2. X. utahense (Wats.) Howell. Shrub low and rather simple, perfectly glabrous and with light bark; leaves usually broadly oval, obtuse at both ends, glabrous, thin, 3-5 $\mathrm{cm}$. long; bracts subulate, about half as long as the slightly united, divergent ovaries; corolla light yellow, funnelform, nearly $2 \mathrm{~cm}$. long; fruit almost globular, red, 6-8 mm. in diameter. L. utahensis S. Wats. Mountain woods: B.C.-Utah-Wyo.-Mont. Submont.

3. X. ebractulatum Rydb. Shrub divaricately branched, $1-2 \mathrm{~m}$. high, with gray bark; leaves short-petioled, thin, light green, somewhat glaucous and hairy beneath, ciliate on the margins, elliptic to broadly ovate, obtuse, rounded or cordate at the base, $2-6 \mathrm{~cm}$. long; bracts small, $1 \mathrm{~mm}$. long and scarcely onethird as long as the divergent ovaries; bractlets none; corolla funnelform, about $2 \mathrm{~cm}$. long, hairy within; ovaries almost distinct; fruit red, 6-8 mm. in diameter. L. ebractulata Rydb. In cañons and open woods: B.C.-Mont.-Wyo.-Ida. Submont.

4. X. ciliatum (Muhl.) Pursh. Shrub, 1-2 m. high, with glabrous branches; leaves thin, bright green, ovate, rounded or cordate at the base, pubescent beneath when young, more glabrate in age, strongly ciliate on the margins; bracts about half as long as the divergent, almost distinct ovaries; bractlets minute, rounded; corolla light yellow, almost regular, about $16 \mathrm{~mm}$. long; fruit ovoid, red, about Boreal.

\section{Distègia Raf. Swamp Honeysuckle, Bearberry.}

Erect shrubs, with opposite leaves and 2-3-flowered axillary peduncled clusters. Bracts and bractlets close under the flowers, broad oval or ovate, often 
cordate at the base, much enlarged in fruit. Corolla cylindric-campanulate, strongly gibbous at the base; limb almost regular, with 5 short rounded almost erect lobes. Fruit of the flowers distinct and surrounded by the bractlets and the bracts. Otherwise as in Xylosteon.

1. D. involucrata (Richardson) Cockerell. Shrub 1-3 m. high; leaves short-petioled, ovate, oval, or obovate, 5-15 $\mathrm{cm}$. long, acute or acuminate at the apex, rounded or acute at the base, glandular-dotted and more or less pubescent; bracts and bractlets foliaceous, and enlarged and reddish in fruit; bracts ovate or cordate, obtuse or acute; corolla yellow, pubescent; stamens and style slightly exserted; fruit globose or oval, dark purple or black, about $8 \mathrm{~mm}$. in diameter. Lonicera involucrata (Richards.) Banks. On wooded river banks: Que.-Mich. -Colo.-Calif.-Alaska. Submont.-Subalp.

\section{LONICÈRA L. HONEYSUCKLE.}

Mostly climbing shrubs, with opposite simple leaves, the uppermost in ours connate. Flowers usually irregular, in interrupted spikes or heads in the axils of the leaves. Hypanthium ovoid or globose. Calyx-lobes 5, small. Corolla in ours funnelform or trumpet-shaped, more or less gibbose at the base and more or less irregular; limb 5-lobed and more or less 2-lipped. Stamens adnate to the tube of the corolla; filaments slender; anthers linear or oblong. Ovary 2-3-celled; ovules numerous in each cell, pendulous; style slender; stigma capitate. Berry fleshy, 2-3-celled, few-seeded.

Corolla $3 \mathrm{~cm}$. long, its limb slightly bilabiate; lobes short; leaves glabrous except the ciliate margins.

Corolla $2 \mathrm{~cm}$. long, decidedly bilabiate; leaves hairy beneath.

1. L. ciliosa.

2. L. glaucescens.

1. L. ciliosa (Pursh) Poir. High twining shrub, with glabrous stem and light colored sheddy bark; leaves broadly oval or obovate, subsessile, obtuse, glaucous beneath, perfectly glabrous except the ciliate margins, the upper one or two pairs connate; flowers in a terminal interrupted spike of 1-3 verticils, also often in short-peduncled clusters in the axils of the upper leaves; corolla trumpet-shaped, 25-35 $\mathrm{mm}$. long, yellow to red, glabrous or nearly so, gibbous at the base; limb only slightly bilabiate; style and stamens exserted; fruit red. Copses and hillsides: Calif.-Ariz.-Mont.-B.C. Submont.

2. L. glaucescens Rydb. Shrub more or less twining, with light colored shreddy bark; leaves obovate or oval, mostly subsessile, glabrous above, glaucous and more or less hairy beneath, the margins chartaceous, not eiliate; flowers in a short terminal interrupted spike; corolla yellow, changing into reddish, $2-2.5$ $\mathrm{em}$. long, slightly hairy or puberulent without, pubescent within, funnelform, strongly gibbous at the base; style and stamens more or less hairy, and exserted; fruit red. Hillsides and among bushes: Ont.-Pa.-Okla.-(Black Hills) S.D.Mack. Plain-Submont.

\section{DieRvílla (Tourn.) Mill. Bush Honeysuckle.}

Shrubs, with simple opposite leaves and yellow flowers in small terminal or axillary cymes, or solitary. Hypanthium slender. Calyx-lobes 5, linear. Corolla narrowly funnelform, slightly gibbous at the base; limb 5-lobed, nearly regular. Stamens 5, adnate to the tube of the corolla; anthers linear. Ovary 2-celled; ovules numerous; style filiform; stigma capitate. Fruit a linear-oblong septicidal, 2-valved, many-seeded capsule.

1. D. Diervilla (L.) MacMill. Shrub 1-1.5 m. high, generally glabrous; leaves ovate, or oval, acuminate, generally rounded at the base, serrulate, 5-12 $\mathrm{em}$. long; flower-clusters 1-5-flowered, terminal or in the upper axils; corolla yellow, pubescent without and within, about $18 \mathrm{~mm}$. long, three of its lobes somewhat united; capsule slender, beaked and crowned with the persistent sepals. Diervilla trifida Moench. D. Lonicera Mill. Dry or rocky woods: Newf. -N.C.-Ky.-Sask. 


\section{Family 124. ADOXaCeae. Moschatel Family.}

Herbs with scaly or tuberiferous rootstocks. Leaves basal and opposite cauline, ternately compound. Flowers small, greenish, in terminal head-like clusters. Hypanthium hemispheric, adnate to the ovary. Calyx-lobes 2 or 3 . Corolla rotate, regular, 4-6-lobed. Stamens twice as many, inserted in pairs in the tube; anthers 1-celled. Ovary 3-5-celled; styles 3-5-parted; ovules 1 in each cell. Fruit a small drupe, with $3-5$ nutlets.

\section{1. adoxa L. Moschatel, Musk-Root.}

Characters of the family.

1. A. Moschatellina L. Stem erect, $5-15 \mathrm{~cm}$. high; basal leaves $1-4$, longpetioled, ternately compound; divisions broadly ovate or orbicular, thin, glabrous, 3-cleft; stem-leaves a single pair, ternate; flowers 3-6; corolla of the terminal flower 4- or 5-lobed, that of the others 5- or 6-lobed; drupe green. Mossy woods: Hudson Bay-Wis.-Ia.-Colo.-Utah-Mack. Submont.-Subalp. Je31 .

\section{Family 125. LORANTHACEAE. Mistletoe Family.}

Mostly shrubby parasites, with green tissue and jointed branches, growing on woody plants. Leaves mostly opposite, sometimes reduced to green scales. Flowers dioecious or monoecious, regular. Calyx entire-margined or lobed. Corolla of 2-6 more or less united petals, often green and calyxlike, or wanting. Stamens 2-6; anthers 2-celled or confluently 1-celled. Gynoecium of a compound pistil, but 1-celled. Fruit a berry; seed solitary.

Anthers 2-celled, opening by an apical pore or slit; berry globose; both staminate and

pistillate flowers usually 3 -merous.
Anthers 1-celled, PHORADENDRON. flowers 3-merous, the pistillate ones 2 -merous.

2. RAZOUMOFSKYA.

\section{PhORAdÉndRON Nutt. American Mistletoe.}

More or less fleshy shrubby dioecious or monoecious parasites. Leaves opposite, either petioled, with well developed blades or sometimes scale-like. Inflorescence axillary of several-jointed spikes. Flowers sessile, sunken in the rachis; hypanthium enclosing the ovary. Calyx usually 3 -lobed; lobes in the pistillate flowers persistent on the fruit. Corolla wanting. Stamens 3 , inserted at the base of the calyx-lobes; anthers 2-celled, opening by an apical pore or slit. Ovary 1-celled, 1-ovuled; style short; stigma obtuse. Fruit a globose berry, with a viscid mesocarp.

Leaves reduced to scales; pistillate flowers 2 on each internode.

Canescent; twigs terete; spike several-jointed.

Glabrous; twigs bluntly 4-angled; spike 1-jointed.
Leaves with well developed blades; pistillate flowers 6 or more on each internode.
3 . Cockerellii.

1. P. californicum Nutt. Plant dioecious; internodes 1-2 cm. long, softly canescent, becoming glabrate; scales spreading, $2 \mathrm{~mm}$. long; spikes mostly solitary, usually with about 4 joints, each with 2 pistillate or 4-6 staminate flowers; bracts acute; fruit red, $3 \mathrm{~mm}$. thick. Parasitic ehiefly on leguminous trees and shrubs, also on Covillea, Zizyphus, \&c.: Calif.-s Utah-Ariz.; Sonora and L. Calif. L. Son.

2. P. juniperinum Engelm. Plant dioecious; internodes $0.5-1 \mathrm{~cm}$, long, glabrous; seales spreading, deltoid, 1-2 mm. long; spike solitary, $3 \mathrm{~mm}$. long of a single joint, with either 2 pistillate or 6 or 8 staminate flowers; bracts blunt; fruit straw- or wine-colored, $3 \mathrm{~mm}$. thick. Parasitic on species of Sabina: w Tex. -s Colo.-Utah-Ariz.; Chihuahua. Son.

3. P. Cockerellii Trelease. Plant dioecious; internodes $2-4 \mathrm{~cm}$. long, glabrate; leaf-blades elliptic to oblanceolate, obtuse, $3.5-5.5 \mathrm{~cm}$. long, $1.5-2 \mathrm{~cm}$. 
wide; spikes mostly solitary, $1.5-3 \mathrm{~cm}$. in flower, becoming 4-5 cm. long, glabrous, 4-jointed, each joint bearing near the top 6 pistillate or 20-30 staminate flowers; bracts eiliate; berry white, glabrous, $4 \mathrm{~mm}$. thick. Parasitic on poplars, willows and ashes: Tex.-s Colo.-N.M.; Chihuahua. Son.

\section{RAZOUMÓFSKYA Hoffm.}

Small shrubby fleshy parasites, mostly dioecious. Leaves opposite, reduced to scales. Flowers solitary in the axils of the upper scales. Calyx of the staminate flowers 2-5-lobed, usually 3-lobed. Stamens as many as and adnate to the lobes; anthers sessile, 1-celled, opening by a transverse circular slit. Hypanthium of the pistillate flowers enlosing the ovary. Calyx-lobes 2, persistent on the fruit. Berry ovoid, more or less flattened. [Arceuthobium Bieb.]

Staminate flowers all or nearly all at the ends of the branches, on distinct pedicels, dichotomously paniculate.

Staminate flowers nearly all axillary, forming simple or compound spikes.

Branches 1-2 $\mathrm{mm}$. in diameter.

Plant yellowish green; accessory branchlets of fruiting specimens flower-bearing. Spikes short, 3-5-flowered; stems bluntly angled.

Rather simple, $1-3 \mathrm{~cm}$. high; leaves and sepals obtusish, not distinctly keeled.

Stout, $3-5 \mathrm{~cm}$. high, branched; leaves and sepals decidedly acute and keeled.

Spikes many-flowered; stems sharply angled.

Plant greenish brown; accessory branches merely leaf-bearing.

Branches 3-4 mm. in diameter.

1. R. americama (Nutt.) Kuntre. 1. R. americana (Nutt. Kuntze. Stems dich the base; pistillate plant $2-5 \mathrm{~cm}$. high; staminate flowers $2 \mathrm{~mm}$. wide; lobes round-ovate; pistillate flowers somewhat smaller; fruit $2 \mathrm{~mm}$. long, bluish. $A$. americanum Nutt. Parasitic on Pinus Murrayana, contorta, and divaricata: Sask. -Colo.-Ore.-B.C. Mont. Au-O.

2. R. Douglasii (Engelm.) Kuntze. Plant slender, 1-3 cm. high, greenish yellow, dichotomously branched; branches simple or with accessory branches behind the first; flowers in short usually 5 -flowered spikes, less than $2 \mathrm{~mm}$. wide, the staminate ones with round-ovate calyx-lobes; fruit $5 \mathrm{~mm}$. long. A. Douglasii Engelm. On Pseudotsuga mucronata: Mont.-N.M.-Ariz.-Ore.-B.C. Mont.

3. R. laricis Piper. Divaricately branched, $3-5 \mathrm{~cm}$. high, greenish yellow; branches angled; flowers in short 3-7-flowered spikes, the staminate ones fully $2 \mathrm{~mm}$. wide, 3-merous; lobes ovate, abruptly acute; scales (reduced leaves) decidedly acute; fruit unknown. A. Douglasii Laricis (Piper) M. E. Jones. On Larix occidentalis: Wash.-Mont.-Ida.-Ore. Mont.

4. R. cyanocarpa A. Nels. Stems simple or branched below, the staminate ones $2-3 \mathrm{~cm}$. high, sharply 4-angled, yellowish green, the pistillate ones olivegreen; staminate flowers 5-20 on the spikes; calyx-lobes usually 3 , ovate, keeled; berry obovate, bluish green. On A pinus flexilis: Wyo,-Colo. Mont. Jl-S.

5. R. divaricata (Engelm.) Kuntze. Stem $5-10 \mathrm{~cm}$. high and $2 \mathrm{~mm}$. thick, olive-green to pale brownish; branches often spreading and recurved, only leafbearing; staminate flowers in 1-7-flowered spikes, $2 \mathrm{~mm}$. wide; lobes ovate, acute; fruit 3-4 mm. long. A. divaricatum Engelm. On Caryopitys edulis and monophylla: N.M.-Colo.-Utah-Ariz. Son. Au-S.

6. R. cryptopoda (Engelm.) Coville. Stout, 5-10 cm. high, 4-6 mm. thick, paniculate, much branched, brownish-yellow to olive-brown; staminate plant smaller than the pistillate one; staminate spikes compressed; flowers mostly 3-merous, $2.5-3 \mathrm{~mm}$. wide; lobes ovate, acute; fruit $5 \mathrm{~mm}$. long. A. cryptopodum and robustum Engelm. On Pinus scopulorum, ponderosa, arizonica, Jeffreyi, \&c.: N.M.-Colo.-Ariz. Son.-Mont.

\section{Family 126. SantalaCeae. Sandalwood Family.}

Herbs, shrubs, or trees, mostly root-parasites or saprophytes. Leaves without stipules, simple. Flowers perfect, monoecious, or dioecious, mostly greenish. Hypanthium well developed and enclosing the ovary, adnate at 
least to the base. Calyx 3-6-lobed; lobes valvate. Corolla wanting. Stamens as many as the calyx-lobes, opposite and adnate at the base. Ovary 1-celled, 2-4-ovuled. Fruit a drupe or nut.

\section{COMĀndra Nutt. Bastard Toadflax.}

Smooth sometimes parasitic perennials. Leaves alternate, mostly sessile. Flowers perfect, greenish, cymose. Hypanthium campanulate or urn-shaped, enclosing and adnate to the ovary. Calyx 5-lobed. Corolla wanting. Stamens 5, inserted at the base of the calyx-lobes; anthers 2-celled, connected to the lobes by a tuft of hairs. Fruit drupe-like or nut-like.

Flowers in corymbose cymes at the end of the stem; leaves sessile; style slender.

Leaves all linear, spreading or reflexed; hypanthium in anthesis cylindrical, constricted above.

1. C. linearis.

Leaves at least those of the stem lanceolate, those of the branches narrower; hypanthium in anthesis turbinate, becoming constricted later.

Cymes 1-3-flowered on lateral peduncles; leaves short-petioled; style short. 3 . C. livida.

1. C. linearis Rydb. Stem simple, 3-4 dm. high, angled; leaves all linear, spreading, pale, glaucous, $3-5 \mathrm{~cm}$. long, $3-5 \mathrm{~mm}$. (rarely $7 \mathrm{~mm}$.) wide; hypanthium in flower $5-6 \mathrm{~mm}$. long, $2.5-3 \mathrm{~mm}$. thick; calyx-lobes linear-lanceolate, 3 $\mathrm{mm}$. long; fruit ellipsoid, green. Dry soil: Utah. Son. Au.

2. C. pallida A.DC. Stems $2-4 \mathrm{dm}$. high, branched above, from a stout rootstock; leaves ascending, pale and glaucous, those of the stem 1-5 cm. long, 2-8 $\mathrm{mm}$. wide, those of the branches much narrower; hypanthium in flower 4 $\mathrm{cm}$. long; calyx-lobes lanceolate, $3 \mathrm{~mm}$. long; fruit about $8 \mathrm{~mm}$. long, 5-6 $\mathrm{mm}$. thick, green. Sandy soil: Man.-Tex.-Ariz.-Wash.-B.C. Son.-PlainSubmont. Je-Au.

3. C. livida Richards. Stem slender, 1-3 dm. high; leaf-blades oval, thin, bright green, 1-2.5 cm. long, 6-12 $\mathrm{mm}$. wide; hypanthium in flower $1.5-2 \mathrm{~mm}$. long; calyx-lobes deltoid, $1 \mathrm{~mm}$. long; fruit sub-globose, $6 \mathrm{~mm}$. long, red. Bogs and wet places: Lab.-Vt.-Mich.-B.C.-Yukon. Boreal. Je-Jl.

\section{Family 127. VALERIANACEAE. Valerian Family.}

Annual or perennial herbs, usually heavy-scented, usually with dichotomously branched stems. Leaves opposite, entire or pinnately divided. Flowers perfect, monoecious or dioecious, in cymes. Hypanthium well developed, enclosing the ovary. Calyx of $3-5$ sepals, sometimes elongating in fruit and pappus-like. Corolla tubular, funnelform, or salver-shaped; lobes 3-5, imbricate. Stamens distinct; anthers introrse. Gýnoecium of 3 united carpels, 1-3-celled, but only one cell perfect; styles and sometimes also stigmas united. Fruit achene-like. Seed solitary, pendulous; endosperm usually wanting; embryo straight.

Sepals minute or wanting; fruit 3-celled, but only one seed-bearing.

Fruit laterally winged; stem not dichotomous.

Fruit wingless; stem dichotomous.

1. Plectritis.

Calyx-lobes inrolled in flower, in fruit expanding and

\section{PLeCtrìtis DC. Corn Salad.}

3. VALERIANA.

Annual herbs, with simple leaves. Flowers thyrsoid-glomerate, the clusters both terminal and sessile in the upper axils. Calyx-teeth wanting. Corolla with a short tube, funnelform throat, usually bearing a descending spur, and a more or less 2-lipped limb. Ovary 3-celled, but two cells empty. Fruit 3angular, with one angle dorsal and the other two lateral and winged.

1. P. macroptera (Suksd.) Rydb. Stem glabrous, 1-3 dm. high; basal leaves spatulate, 1-4 cm. long; upper leaves oblong or lanceolate; corolla pinkish, 2-3 mm. long, 2-lipped; upper lip erect, the lower one spreading; fruit pubescent, rounded on the back; wings incurved on the margins, their terminal lobes 
fully as long as the beak. Aligera macroptera Sucksd. Sandy places: Wash. -Ida.-Utah-Ore. Son. Ap-Je.

\section{2. valerianélla (Tourn.) Hill. Corn Salad, Lamb's lettuce.}

Annual herbs, with dichotomously branched stem. Leaves opposite, simple, entire or toothed, or rarely pinnatifid. Flowers perfect in head-like or corymbiform cymes. Calyx-teeth small or obsolete. Corolla funnelform; tube usually gibbous below; limb 5-toothed. Stamens 3. Ovary 3-celled, but only one ovule-bearing, the other two empty and more or less enlarged in the wingless fruit.

1. v. Locusta (L.) Betcke. Stem glabrous or pubescent, 2-3 dm. high; basal leaves spatulate or oblanceolate, $3-5 \mathrm{~cm}$. long, entire; upper leaves oblong, sometimes denticulate; corolla blue, about $2 \mathrm{~mm}$. long; fruit flattened, somewhat oval in cross-section, the two empty cells together about equalling the fertile one, the latter corky on the back. V. olitoria (L.) Poll. Waste places: N.Y.Pa.-La.-Va.; Ida.; nat. from Eu. Ap-Jl.

\section{VALERIÀna (Tourn.) L. Valerian, Tobacco-Root.}

Perennial herbs, heavy-scented. Leaves opposite, entire to pinnately divided. Flowers perfect or polygamous or polygamo-dioecious. Calyx-limb at first inrolled, at last spreading, developing into 5-15 plumose bristles. Corolla funnelform or salver-shaped, 5-lobed; tube often gibbous or saccate at the base. Stamens usually 3 . Ovary 1 -celled; style slightly $2-3$-cleft at the apex. Fruit achene-like, flattened, 1-nerved on one side and 3-nerved on the other.

Leaves thick, the lower entire or with linear entire divisions, the veining almost parallel; plants with thick fleshy taproots.

Fruit and ovaries pubescent; bracts in the staminate plant linear-lanceolate.

Fruit glabrous.

Fruit scurfy, muricate or rugose.

Basal leaves oblanceolate; fruit broadly ovate; corolla of the staminate plant 2.5-3 mm. wide; root thick. 2 . V. trachycarpa.

Basal leaves narrowly linear-oblanceolate; fruit narrowly ovate; corolla of staminate flowers less than $2 \mathrm{~mm}$. wide; root rather slender.

3. V. furfurescens.

Fruit smooth, narrowly ovate; inflorescence of staminate plant rather dense, with

short branches; corolla $3-4 \mathrm{~mm}$. wide. $\quad$. ceratophylla.
Leaves thin, the cauline ones pinnate; veining distinctly pinnate; plants with rootstocks. Bases of the stem-leaves and
pruinose-puberulent.

Fruit pilose; flowers perfect.

$\begin{array}{ll}\text { Fruit glabrous; plant polygamo-dioecious. } & \text { 6. V. puberulenta. }\end{array}$

Bases of the stem-leaves and the nodes of the stem ciliate or bearded; stem otherwise glabrous or slightly pubescent.

Ovary and fruit at least when young pubescent.

Ovary and fruit glabrous.

Basal leaf-blades ovate-cordate.

B. V. ovata.

Corolla of the pistillate plants $2-3 \mathrm{~mm}$. long and slightly wider: inflorescence in fruit elongate and narrow. $9 . V$. septentrionalis. Corolla of the pistillate plants $3 \mathrm{~mm}$. or more long; inflorescence even in fruit short, corymbiform or subcapitate.

Lateral leaflets or lobes of the stem-leaves small, linear-lanceolate, acuminate. 10. V. acutiloba.

Lateral leaflets of the stem-leaves ample, ovate to lanceolate, acute. Corolla 3-4 mm. long; leaflets from entire to slightly sinuate. 11. $V$. occidentalis.

Corolla 5-8 mm. long; leaflets from sinuate to coarsely toothed. Leaflets sinuate or sinuate-denticulate; corolla 5-6 mm. long; tube attenuate at the base. 12 . V. Scouleri.

Leaflets coarsely sinuate-dentate; corolla 6-8 mm. long, not conspicuously narrowed below. 13. V. sitchensis.

1. $\boldsymbol{\nabla}$. edulis Nutt. Stem glabrous, 4-10 dm. high; basal leaves thick, oblanceolate, 1-2 dm. long, puberulent at least on the veins and margins; upper stem-leaves usually pinnatifid with linear approximate divisions, the upper bracts and the bractlets lanceolate, somewhat scarious, puberulent; corolla of the staminate flowers yellowish, $3 \mathrm{~mm}$. broad; its tube obpyramidal, $1 \mathrm{~mm}$. high, slightly hairy; corolla of the pistillate flowers less than $1 \mathrm{~mm}$. high and broad; 
fruit ovate, 4-5 mm. long. Hillsides and dry meadows: Mont.-Colo.-UtahIda. Submont.-Subalp. Je-Au.

2. V. trachycarpa Rydb. Stem glabrous or nearly so, 5-7 dm. high; basal leaves $7-18 \mathrm{~cm}$. long, finely puberulent; stem-leaves $1-2$ pairs, pinnatifid with linear lobes; corolla of the essentially pistillate plant $1-1.5 \mathrm{~mm}$. wide; fruit not hairy, $5 \mathrm{~mm}$. long, $2.5 \mathrm{~mm}$. wide. Mountains: Wyo,-N.M.-Utah. Submont.-Mont. Jl-S.

3. V. furfurescens A. Nels. Stem glabrous, 5-10 dm. high; basal leaves 1-2 dm. long; stem-leaves few, entire or with a few approximate divisions; bracts linear; bractlets lanceolate; corolla of staminate flowers light yellow; stamens scarcely exserted; corolla of pistillate flowers about $0.5 \mathrm{~mm}$. high and broad; fruit 3-4 mm. long, $1.5 \mathrm{~mm}$. wide. Hillsides and mountains: Wyo.Colo. Submont.-Mont. Jl.

4. V. ceratophylla (Hook.) Piper. Stem 4-8 dm. high, glabrous; basal leaves oblanceolate, puberulent on the veins and margins, 1-2 dm. long; bracts and bractlets linear or linear-lanceolate; pistillate corolla 1-1.5 mm. wide; fruit 4-5 mm. long, scarcely $2 \mathrm{~mm}$. wide. Patrinia ceratophylla Hook. Grassy slopes and meadows: Mont.-Wyo.-Ore.-B.C. Submont.-Mont. My-Jl.

5. V. pubicarpa Rydb. Stem 2-4 dm. high; basal leaves spatulate or oblanceolate, $2-6 \mathrm{~cm}$. long, glabrous or nearly so; stem-leaves $2-4$ pairs, the lowest pair similar to the basal ones, the rest 3-5-foliate, or the uppermost simple, minute; leaflets oblong or lanceolate, $2-5 \mathrm{~cm}$. long, entire; inflorescence short and dense; corolla 4-6 mm. long, $4 \mathrm{~mm}$. wide, pubescent; fruit $5 \mathrm{~mm}$. long. Mountains: Mont.-Utah-Ida. Submont.-Mont. Je-Au.

6. V. puberulenta Rydb. Stem 1.5-3 dm. high; basal leaves spatulate, 2-5 cm. long; stem-leaves $1-3$ pairs, usually 3 -foliolate; terminal leaflet elliptic or oblong to lanceolate, $1-3 \mathrm{~cm}$. long, the lateral ones about half as long; inflorescence of the pistillate plants corymbiform, that of the smaller staminate ones subeapitate; corolla 4-5 mm. long, $2.5-3 \mathrm{~mm}$. wide; fruit nearly $5 \mathrm{~mm}$. long and $2 \mathrm{~mm}$. wide. Mountains: Utah. Submont.-Mont. Je-Au.

7. v. micrantha E. Nels. Stem glabrous or nearly so; basal leaves entire or with 1-2 pairs of small rounded or oblong lobes on the petioles; blades or terminal leaflets ovate or elliptic, 3-7 cm. long; cauline leaves with 5-7 elliptic to lanceolate leaflets; cyme as broad as high or broader; corolla white, the staminate ones $2-3 \mathrm{~mm}$. broad and high, the pistillate barely $2 \mathrm{~mm}$.; achenes narrowly ovate, $3-4 \mathrm{~mm}$. long, pubescent, at least when young. Mountains: Mont.-Colo.-Utah-Ida. Submont.-Mont. J1-Au.

8. V. ovata Rydb. Stem about $3 \mathrm{dm}$. high, glabrous; basal leaves entire, petioled, glabrous; blades ovate, usually truncate or slightly cordate at the base; stem-leaves 2-3 pairs; lateral lobes oblong to linear-lanceolate, the terminal one lanceolate or of the lower leaves elliptie; inflorescence small and corymbiform; corolla funnelform-salvershaped, about $8 \mathrm{~mm}$. long; limb of the fertile flowers about $4 \mathrm{~mm}$. wide, that of the staminate ones about $6 \mathrm{~mm}$. wide; fruit ovate, glabrous, $4 \mathrm{~mm}$. long. Wooded hillsides: Colo--N.M. Mont. My-Jl.

9. V. septentrionalis Rydb. Stem weak and slender, 2-5 dm. high, glabrous or nearly so; basal leaves usually entire; blades spatulate or elliptic, $2-5$ $\mathrm{cm}$. long; stem-leaves usually 2 pairs, with $3-7$ leaflets; terminal leaflet usually elliptic, twice as large as the lanceolate lateral ones; fruit $4 \mathrm{~mm}$. long, $1.5 \mathrm{~mm}$. wide. V. wyomingensis E. Nels. Hillsides and meadows: Lab.-Que.-Nev.B.C. Submont.-Mont. My-Jl.

10. V. acutiloba Rydb. Stem of fertile plant 4-5 dm. high; basal leaves entire, $5-7 \mathrm{~cm}$. long; blade spatulate or obovate, acute; stem-leaves usually 3 pairs, pinnately divided; lateral divisions lanceolate to linear, long-acuminate, the terminal one large, oblanceolate or of the upper leaves linear-lanceolate, entire or saliently toothed; cyme dense, contracted; corolla about $4.5 \mathrm{~mm}$. long; fruit broadly ovate, about $4 \mathrm{~mm}$. long; staminate plant lower, $3-4 \mathrm{dm}$. high, with more sterile shoots; stem-leaves usually only 2 pairs, less divided, with only 1-2 pairs of lateral divisions; cymes denser; corolla 5-6 mm. long, more 
oblique, about $5 \mathrm{~mm}$. wide. Mountains: Wyo.-N.M.-Utah. Mont.-Alp. $\mathrm{Je}-\mathrm{Au}$.

11. V. occidentalis Heller. Stem 5-8 dm. high, glabrous or sparingly puberulent; basal leaves petioled, thin, simple, elliptic or spatulate, entire, 2-8 $\mathrm{mm}$. long; stem-leaves 2-4 pairs, pinnate, with 3-9 leaflets, those of the lower leaves elliptic, those of the upper narrowly lanceolate; inflorescence open; corolla white, of the pistillate flowers, $3-3.5 \mathrm{~mm}$. long, 3-4 mm. broad; fruit glabrous, $5 \mathrm{~mm}$. long, $2 \mathrm{~mm}$. wide. Wet places in the mountains: Mont.-Colo. -Utah-Wash.-B.C. Submont,-Mont. Je-Au.

12. V. Scouleri Rydb. Stem glabrous; basal leaves simple or 3-5-foliolate; blade or terminal leaflet obovate or orbicular, the lateral ones elliptic; stem-leaves 3-7-foliolate; leaflets oval or elliptic or those of the upper leaves lanceolate; flowers usually perfect; corolla white; fruit glabrous, $6 \mathrm{~mm}$. long, $2 \mathrm{~mm}$. wide. Wet places: B.C.-Alta.-Mont.-Ore. Submont.-Mont. Je-Au.

13. V. sitchensis Bong. Stem 4-7 dm. high, glabrous or nearly so; stemleaves $3-5$-foliolate; leaflets of the lower ones broadly ovate, of the upper lanceolate, $5-8 \mathrm{~cm}$. long, sparingly pilose or nearly glabrous; basal leaves similar or simple, usually none at flowering time; cyme short and corymbiform; flowers mostly perfect; fruit glabrous, $6 \mathrm{~mm}$. long, $2 \mathrm{~mm}$. broad. Wet places: Alaska -Ore.-Ida.-Yukon. Submont.-Mont. J1-Au.

\section{Family 128. ARISTOLOChiaCEAE. Birthwort Family.}

Perennial herbs or vines. Leaves alternate, or basal, petioled. Flowers perfect, regular or irregular. Hypanthium usually well developed, often wholly enclosing the ovary. Calyx regular or irregular, mostly of 3 sepals, Corolla wanting. Stamens 6 to many; filaments either free or adnate to the style column. Styles united; ovary 4-6-celled; ovules many in each cavity. Fruit a capsule. Seeds numerous; endosperm fleshy.

\section{1. ẢSARUM (Tourn.) L. Wild Ginger.}

Perennial acaulescent herbs, with elongate rootstocks. Leaves 2, basal, petioled; blades cordate or reniform. Flowers perfect, regular, solitary, on a scape arising between the leaves. Hypanthium well developed, campanulate, enclosing the ovary, angled. Sepals 3 , inflexed in bud. Stamens 12, free. Ovary inferior, 6-celled; styles 6, united.

1. A. caudatum Lindl. Leaf-blades cordate-reniform, acutish at the apex, sparingly pubescent on the veins, $5-10 \mathrm{~cm}$. broad; peduncle $1-3 \mathrm{~cm}$. long; calyxlobes lanceolate, caudate-attenuate, $2.5-5 \mathrm{~cm}$. long. Woods and thickets: B.C. -Ida.-Calif. Submont.-Mont. Ap-Jl.

\section{Family 129, CUCURBitaCeae. Gourd Family.}

Annual or perennial succulent herbs, trailing or climbing by means of tendrils. Leaves alternate, palmately veined or lobed, usually rough-hairy. Flowers usually axillary, monoecious or dioecious. Calyx of 4-6, more or less united sepals, imbricate. Corolla of as many petals which are more or less united. Stamens 1-5, often 3 , two with 2-celled and one with 1-celled anthers; filaments distinct or united; anthers extrorse, often twisted. Gynoecium of a compound pistil; ovary 1-3-celled; styles terminal, united; stigma thick, dilated, or ringed. Fruit a pepo (large fleshy or dry berry with thick rind). Seeds usually numerous, flat and horizontal; endosperm wanting; embryo straight, with thick cotyledons.

Fruit large, with a tough rind, 1-celled, with 3-5 placentae and numerous seeds; corolla large, yellow, campanulate; flowers solitary in the axils.

large, yellow, campanulate; and spongiose, 2-3-celled; seeds few; corolla white, rotate;
Fruit spiny, becoming papery and
staminate flowers racemose or paniculate. staminate flowers racemose or paniculate. 


\section{CUCÚRbita (Tourn.) L. Gourd, Pumpkin, Seuash.}

Annual or perennial, rough-pubescent trailing vines. Leaves petioled, lobed or entire, often cordate. Tendrils more or less branched. Flowers large, solitary in the axils of the leaves, monoecious. Hypanthium in the staminate flowers campanulate, in the pistillate ones urn-shaped. Sepals 5. Corolla yellow, campanulate, 5-lobed, the lobes recurved at the ends. Stamens 3, in the staminate flowers with distinct filaments and linear, coherent, contorted anther, in the pistillate flowers reduced to staminodia. Pistil in the former wanting, in the latter with a single ovary and 3-5 stigmas, which are 2-branched or at least 2-lobed. Pepo 1-celled, with 3-5 placentae, many-seeded, usually large, fleshy, with a tough rind. Seeds flattened.

1. C. foetidissima H.B.K. Perennial, with a thick, long taproot; stem trailing, 1-8 m. long; leaves with stout petioles; blades ovate-triangular or ovate, thick, canescent-scabrous, truncate or cordate at the base, 1-4 dm. long, often sinuately-lobed, denticulate; hypanthium of the staminate flowers hemispheric, that of the pistillate flowers ellipsoid; corolla 6-15 cm. long, campanulate, greenish orange; fruit globose, $5-10 \mathrm{~cm}$. in diameter, smooth, bitter. C. perennis A. Gray, Dry plains and valleys: Tex.-Neb.-Colo.-Calif.-Mex. Plain -Son. $\mathrm{My}-\mathrm{S}$.

\section{MiCRÁmpelis Raf. Balsam Apple, Mock Apple.}

Annual or perennial herbaceous climbing vines. Leaves petioled, membranous, 5-7-lobed. Tendrils simple or compound. Flowers monoecious, small, the staminate ones racemose or paniculate, the pistillate ones solitary or clustered in the axils of the leaves. Hypanthium of the staminate ones broadly campanulate, that of the pistillate ones urn-shaped. Sepals 5 or 6 . Corolla white or greenish, rotate, 5- or 6-lobed. Stamens in the former 2 or 3 with united filaments and horizontalanthers, in the latter reduced to more or less prominent staminodia. Pistil in the former wanting, in the latter with an inferior ovary; stigmas 2- or 3-parted, or -lobed. Fruit covered with soft spines, becoming papery, spongy and fibrous within, 2- or 3-celled. Seeds few, 1-4 in each cavity, smooth, flattened, erect. [Echinocystis T. \& G.]

1. M. lobata (Michx.) Greene. Annual; stem angular, nearly glabrous, climbing, 4-8 m. high; leaf-blades thin, scabrous on both sides, 3-7-lobed, with triangular-lanceolate lobes, cordate at the base; staminate flowers 4-5 mm. long, numerous in compound racemes, light greenish yellow; pistillate flowers solitary or two together; fruit globose-ovoid, 4-5 cm. long, 3-4 cm. thick. Echinocystis lobata T. \& G. Alluvial soil among bushes: Me.-Va.-Tex.-Colo.Ida.-Sask. Jl-S.

\section{Family 130. Campanulaceat. Bellflower Family.}

Annual or perennial caulescent herbs (all ours) or rarely shrubs. Leaves without stipules, alternate, simple. Flowers perfect, racemose or spicate or solitary, terminal or axillary, regular. Hypanthium well developed, enclosing the ovary. Sepals 5, partially united, persistent. Corolla of 5 united petals, campanulate, tubular, or rotate. Stamens 5, inserted with the corolla; filaments distinct; anthers introrse. Gynoecium of $2-5$ united carpels; ovary inferior or nearly inferior, 2-5-celled; styles united; stigmas with 2-5 lobes or rarely capitate. Fruit a 2-5-celled capsule, opening loculicidally or by pores. Seeds numerous, angled or flattened; endosperm fleshy; embryo straight.

Capsule opening by $2-5$ lateral pores.

Corolla campanulate or funnelform; flowers all well developed; capsule turbinate.

Corolla rotate; earlier flowers cleistogamous; capsule linear.

1. CAMPANULA.

cleistogamous.

2. SPECULARIA.

dal; earlier flowers 


\section{1. campánula (Tourn.) L. Bellflower, Harebell, Bluebell.}

Perennial (all ours with rootstocks) or sometimes annual herbs. Leaves alternate, usually more or less toothed. Flowers perfect, all alike, in racemes or panicles, rarely solitary. Sepals 5, narrow, united only at the base. Corolla campanulate or funnelform, usually blue, with 5 lobes. Stamens 5 ; filaments dilated at the base; anther oblong. Ovary 3-5-celled; styles united; stigmas 3-5. Capsule turbinate, obconic, or obpyramidal, opening by pores, usually formed by the uplifting of small lids, either near the apex or near the base of the capsule. Seeds smooth.

Flowers more than $1 \mathrm{~cm}$. long; plant simple or with erect or ascending branches.

Style not exserted.

rapsule erect, opening by pores near the summit, just below the base of the sepals. Hypanthium and pod club-shaped, constricted just below the sepals, often hairy; leaves entire; sepals obtuse. 1. C. uniflora.

Hypanthium and pod turbinate, not constricted; sepals acuminate. Hypanthium villous; leaves saliently dentate. $2 . C$,

Hypanthium glabrous; leaves entire or minutely denticulate. Parryi.
3. C. Parta

Capsule nodding, opening by pores near the base.

Sepals erect; leaves thick.

Sepals spreading or reflexed; leaves thin.

Style exserted.
Flowers 5-8 mm. long; branches divaricate; stem retrorse-hispid.

4. C. petiolata.

5. C. heterodoxa.

6. C. MacDougalii.

7. C. aparinoides.

1. C. uniflora L. Stem $1 \mathrm{dm}$. high or less, glabrous; lower leaves spatulate, $2-3 \mathrm{~cm}$. long, entire or nearly so; upper leaves linear; hypanthium in fruit $1 \mathrm{~cm}$. long, often pubescent; sepals lance-linear, $3 \mathrm{~mm}$. long, erect, obtuse; corolla narrowly campanulate, $7-10 \mathrm{~mm}$. long. Arctic-alpine situations: Greenl.Lab.-Colo.-Utah-Alaska; Eurasia. Subalp.-Alp. J1-Au.

2. C. lasiocarpa Cham. Stem $1.5 \mathrm{dm}$. high or less, 1-flowered, glabrous or slightly ciliate; lower leaves petioled, $2-4 \mathrm{~cm}$. long; blades spatulate, oblanceolate, or obovate, sharply dentate, glabrous or sparingly ciliate; upper leaves linear or lance-linear; hypanthium turbinate-obconic, in fruit over $1 \mathrm{~cm}$. long, more or less villous; sepals subulate, acute, 6-10 mm. long, often toothed; corolla campanulate, $15-25 \mathrm{~mm}$. long. Arctic-alpine situations: Yukon-Alta.-B.C.Alaska; Siberia and Japan. Alp. Jl-Au.

3. C. Parryi A. Gray. Stem 1-3 dm. high, glabrous; lower leaves spatulate or oblanceolate, callous-denticulate or entire, $2-6 \mathrm{~cm}$. long, thin, ciliate on the margins, petioled; upper leaves linear or lance-linear; hypanthium turbinateobconic, in fruit 1-1.5 cm. long, glabrous; sepals subulate, erect, $15-18 \mathrm{~mm}$. long; corolla $15-20 \mathrm{~mm}$. long, funnelform, cleft to near the middle; lobes ovate, acute. Mountains: Wyo.-N.M.-Ariz.-Utah. Mont.-Subalp. Jl-S.

4. C. petiolata A. DC. Stem 1-4 dm. high, glabrous or retrorsely shorthirsute; basal leaves long-petioled; blades ovate or ovate-cordate, $1-3 \mathrm{~cm}$. long, usually longer than broad, rather thick, sinuate-dentate, with rounded or acute, but not sharp teeth; stem-leaves linear or linear-lanceolate or the upper almost filiform; hypanthium glabrous, turbinate; sepals subulate, 6-7 mm. long, ascending; corolla campanulate, $15-20 \mathrm{~mm}$. long; lobes broadly ovate, acutish. $C$. rotundifolia Western authors. Hills and mountains: Mack.-S.D.-N.M.Ariz.-w Calif.-B.C. Plain-Subalp. Je-S.

5. C. heterodoxa Vest. Stem 1-4 dm. high, decumbent at the base, glabrous; basal leaves long-petioled; blades small, rounded-cordate, 1-1.5 $\mathrm{cm}$. long and about as broad, thin, sinuate-dentate; lower stem-leaves petioled and usually lanceolate, often broadly so, often denticulate, the upper narrowly linear; hypanthium campanulate, in fruit $8 \mathrm{~mm}$. long; sepals subulate, $8-10 \mathrm{~mm}$. long; corolla 15-25 mm. long, campanulate; lobes broadly ovate, 4-5 mm. long. Cliffs: Alaska -B.C. Mont. Je-Au.

6. C. MacDougalii Rydb. Stem slender, glabrous, about $3 \mathrm{dm}$. high; leaves very thin, the basal ones and lower stem-leaves with slender petioles $2-4 \mathrm{~cm}$. long; blades broadly ovate, $2-3 \mathrm{~cm}$. long, coarsely sinuate-dentate; upper stemleaves lanceolate to linear, entire, the largest 5-6 cm. long; sepals linear-subulate, 
10-12 mm. long, at last reflexed; corolla $13-15 \mathrm{~mm}$. long, nearly of the same shape as that of $C$. petiolata; style exserted, straight. Woods: Ida. Mont. Jl.

7. C. aparinoides Pursh. Stem filiform, 2-6 dm. high, retrorsely scabrous on the angles; leaves lanceolate or linear-lanceolate, $2-5 \mathrm{~cm}$. long; hypanthium. hemispheric; sepals lanceolate, $1.5-2 \mathrm{~mm}$. long; corolla open-campanulate, white or tinged with blue, cleft beyond the middle, $5-8 \mathrm{~mm}$. long. Wet meadows: N.B.-Ga.-Colo.-Sask. Plain, Je-Au.

\section{SPECULÀRIA (Heist.) Fabricius. Venus's Looking-Glass.}

Annual or biennial herbs. Leaves alternate, sessile or clasping. Flowers of two kinds, the earlier ones cleistogamous, close-fertilized in the bud, with a calyx of 3-4 sepals and an undeveloped corolla, the latter ones with 5 sepals and a rotate or funnelform corolla. Stamens 5; filaments distinct, linear. Ovary 3-celled; stigmas 3. Capsule prismatic or cylindric, opening by pores near the top or the middle. [Legouzia Durande.]

Leaves cordate-clasping; capsule oblong.

Leaves linear or linear-lanceolate; capsule linear-cylindric.

1. S. perfoliata.

2. S. leptocarpa.

1. S. perfoliata (L.) A. DC. Stem 2-5 dm. high, retrorsely hispid on the angles, leafy; leaves round-cordate, crenate, $7-20 \mathrm{~mm}$. long, elasping or the lower merely sessile; sepals of the earlier flowers 3 or $4,2-3 \mathrm{~mm}$. long, longer than the rudimentary corolla, those of the later flowers 5, lanceolate-subulate, 4-5 mm. long; corolla $7-10 \mathrm{~mm}$. long, almost rotate; capsule opening at or below the middle. Hillsides and dry woods: Me.-Fla.-Ariz.-Ore--B.C.; Mex. Plain -Mont. My-S.

2. S. leptocarpa (Nutt.) A. Gray. Stem erect, 1-3 dm. high, retrorsely hispidulous; leaves lanceolate or linear-lanceolate, 1-3 cm. long; sepals of the earlier flowers 3 , subulate, $5 \mathrm{~mm}$. long; sepals of the later flowers 5 , subulate, 8-10 mm. long; corolla broadly funnelform, 6-8 $\mathrm{mm}$. long; capsules opening near the apex. Dry soil: Mo.-Ark.-Tex.-Colo.-Mont. My-Jl.

\section{HETEROCÒDON Nutt.}

Slender annuals. Leaves alternate, sessile. Flowers of two kinds, the earlier cleistogamous, with rudimentary corolla. Calyx with short tube and 5 large foliaceous lobes. Corolla of the later flowers blue, 5-lobed. Capsule obovoid, 3-angled, 3-celled, many-seeded, thin and membranous, bursting irregularly on the sides. Seeds oblong, obscurely triangular.

1. H. rariflorum Nutt. Annual; stem slender, delicate, diffusely spreading, 1-3 dm. high; leaves orbicular, cordate-clasping, coarsely dentate, 5-10 $\mathrm{mm}$. in diameter; hypanthium eampanulate, hispid; sepals ovate, $2 \mathrm{~mm}$. long, dentate and ciliate; corolla of the early flowers rudimentary, that of the later ones 3-6 $\mathrm{mm}$. long, eampanulate. Shady grassy places: B.C.-Ida.-Nev,-Calif. Son. $\mathrm{My}-\mathrm{S}$.

\section{Family 131. LOBEliaCeate. Lobelia Family.}

Annual or perennial herbs, or in warmer climates trees. Leaves alternate, without stipules, in ours simple. Flowers perfect, rarely dioecious, irregular. Hypanthium enclosing the ovary. Calyx of 5 almost distinct sepals. Corolla 2-lipped; upper lip 2-cleft, of ten to or nearly to the base of the corolla; lower lip longer, less deeply 3-lobed. Stamens 5, epigynous; filaments often coherent into a tube; anthers usually united or merely connate. Gynoecium of 2-5 united carpels. Ovary single, 2-5 celled; styles terminal, wholly united; stigmas fringed. Fruit a 1 -several-celled capsule or rarely a berry. Seeds numerous, smooth or furrowed; endosperm fleshy; embryo straight.

Anthers distinct, merely surrounding the pistil; stem-leaves reduced, subulate, bract-like.

Anthers united; stem-leaves developed.

1. NEMACladus.

Hypanthium cylindric or linear-clavate; pod at maturity 1-celled. 
Aquatic plants with two kinds of flowers, the submerged ones cleistogamous; pod splitting on one side.

splitting on one side.
Land plants of wet situations; flowers all alike; pod splitting lengthwise by $1-3$ slits, but the valves remaining united at the apex.

Hypanthium turbinate or oblong; pod 2-celled, 2-valved.

Corolla with a closed tube.

Corolla split to near the base on the upper side.

3. BOLELIA.

4. Porterella.

5. LOBELIA.

\section{NEMACLÀDUS Nutt.}

Small annuals. Leaves alternate, small, the basal ones obovate, the cauline ones reduced, subulate, bract-like. Flowers perfect, irregular. Sepals 5, nearly distinct. Corolla bilabiate; lower lip 3-lobed; upper lip 2-parted. Stamens 5; filaments monadelphous above the middle; anthers oval, free, merely surrounding the stigma; stigma 2-lobed. Capsule 2-celled, 2-valved from the top, 20-30seeded.

1. N. ramosissimus Nutt. Stem much branched, about $1 \mathrm{dm}$. high, glabrous or puberulent; basal leaves $1 \mathrm{~cm}$. long or less; stem-leaves 1-2 mm. long; hypanthium turbinate, or hemispheric in fruit; sepals lanceolate, $1 \mathrm{~mm}$. long; corolla $2 \mathrm{~mm}$. long. Arid places: s Calif.-s Utah-Ariz.-L. Calif. Son. Ap-J1.

\section{HOWÉLLIA A. Gray.}

Aquatic annual herbs. Leaves alternate, the submerged ones setaceous, the emersed ones narrow, entire. Flowers of two kind, the submerged ones cleistogamous. Hypanthium linear or linear-clavate. Sepals 5, nearly distinct, narrow and subequal. Corolla of the emersed flowers with its short tube split almost to the base on the upper side; lobes nearly equal. Stamens monadelphous; tube nearly free from the corolla; anthers oval, the two smaller with 3 bristles, the three larger naked. Ovary 1-celled, with 2 filiform parietal placentae. Capsule membranous, bursting irregularly on one side. Seeds few, smooth.

1. H. aquatilis A. Gray. Submerged aquatic, with only the end of the stem emersed; submerged leaves alternate or verticillate, flaccid, filiform, 1-5 $\mathrm{cm}$. long, less than $1 \mathrm{~mm}$. wide; emersed leaves lance-linear, often toothed; sepals linear-subulate, $2 \mathrm{~mm}$. long; corolla of the submersed flowers rudimentary, that of the emersed flowers $1.5-2 \mathrm{~mm}$. long; fruit $12-15 \mathrm{~mm}$. long. Lakes and ponds: Ore.-Ida. Submont. My-Jl.

\section{BOLìLIA Raf.}

Glabrous annuals. Leaves alternate, sessile, narrow, entire. Flowers perfect, axillary, sessile. Hypanthium linear-cylindric, usually twisted. Sepals foliaceous, 5, nearly distinct. Corolla with a short, entire tube, 2-lipped; upper lip with 2 narrow, spreading or reflexed lobes; lower lip very broad, 3-lobed, spreading. Filaments and anthers wholly united; two of the anthers bristletipped. Capsule long and slender, early becoming 1-celled, with 2 parietal placentae, opening by 1-3 long slits, but valves remaining united at the apex. Seeds numerous. [Downingia Torr.]

Corolla scarcely exceeding the obtuse sepals; stamens shorter than the sepals.

Corolla and stamens much exceeding the acute sepals.

1. B. brachyantha.

2. B. elegans.

1. B. brachyantha Rydb. Stem 1-3 dm. high, branched from the base; leaves oblong-lanceolate, $5-10 \mathrm{~mm}$. long, thick and somewhat fleshy; sepals linear or oblong-linear, about $5 \mathrm{~mm}$. long; corolla scarcely exceeding the calyx; stamens shorter than the sepals; fruit about $3 \mathrm{~cm}$. long. Downingia brachyantha Nels. \& Macbr. In water: Mont.-Ida.-Nev.-Ore. Submont. Je-Au.

2. B. elegans (Dougl.) Greene. Stem simple or branched below, $5-30 \mathrm{~cm}$. high, glabrous; leaves lanceolate, 1-3 cm. long, fleshy; sepals linear, 6-7 mm. long; corolla 8-10 $\mathrm{mm}$. long; fruit $3-4 \mathrm{~cm}$. long. D. elegans Torr. In water: B.C.-Ida.-Nev.-Calif. Submont. Je-Au.

\section{PORTERELLLA Torr.}

Small diffuse or creeping annuals or perennials (?). Leaves alternate, narrow, entire. Flowers perfect, axillary. Hypanthium oblong-clavate. Sepals 5, narrow, almost distinct. Corolla with a long closed tube, not split; upper lip 
erect, 2-cleft; lower lip larger, 3-cleft and widely spreading. Filaments and anthers completely united; two of the anthers with minute bristle-tufts. Capsule 2-celled, 2-valved. Seeds many, somewhat fusiform.

Pedicels longer than the floral leaves.

1. P. carnosula. Pedicels shorter than the floral leaves.

2. P. eximia.

1. P. carnosula (H. \& A.) Torr. Stem glabrous, branched, $2-25 \mathrm{~cm}$. high; leaves fleshy, lanceolate, entire, sessile, $5-15 \mathrm{~mm}$. long; pedicels 7-15 $\mathrm{mm}$. long; sepals linear, 3-5 mm. long; corolla 8-10 mm., blue, with yellow throat; fruit 8-10 mm. long. Laurentia carnosula H. \& A. Mud: Mont.-Wyo.-Calif. Je$\mathrm{Au}$.

2. P. eximia A. Nels. Perennial (?); stem about $1 \mathrm{dm}$. high, glabrous; leaves lanceolate or lance-linear, long-acuminate, $15-25 \mathrm{~mm}$. long; pedicels short, 4-7 mm. long; sepals linear, 3-6 $\mathrm{mm}$. long, obtusish; corolla deep blue with only the folds at the sinuses of the lip yellow, 8-12 mm. long. L. eximia A. Nels. Muddy shores: w Wyo. Mont. Au.

\section{5. lobèlia (Plum.) L. Lobelia, Cardinal-Flower.}

Terrestrial herbs with leafy stems, or aquatic ones with long scapes. Leaves alternate, or in the aquatic species mostly basal. Flowers perfect, in spikes, racemes, or panicles. Hypanthium short, oblong to turbinate. Sepals 5, practically distinct. Corolla split to or nearly to the base on the upper side; upper two lobes narrow, spreading or reflexed, the lower 3 lobes united to a broad spreading lip. Stamens 5; filaments monadelphous, free from the corolla; anthers united, two or all bearded at the apex. Ovary 2-celled; stigmas 2-lobed. Capsule 2-valved Seeds many.

Corolla red.

Leaves oblong-ovate to ovate-lanceolate.

Leaves narrowly lanceolate to linear.

Corolla blue or whitish.

Corolla $2-2.5 \mathrm{~cm}$. long.

Corolla less than $1 \mathrm{~cm}$. long.

Stem leafy.

Stem-leaves spatulate or oblanceolate; raceme many-flowered; plant puberulent.

1. L. cardinalis.

2. L. splendens.

Stem-leaves linear or linear-oblanceolate; racemes few-flowered; stem and leaves glabrous.

Stem scapiform; leaves all in a basal rosette, usually submerged

5. L. strictiflora.

6. L. Dortmanna.

1. L. cardinalis L. Perennial by means of slender offsets; stem 5-12 dm. high, glabrous or nearly so; leaves irregularly serrate or serrulate; hypanthium hemispheric, $3 \mathrm{~mm}$. long; sepals subulate, about $1 \mathrm{~cm}$. long; corolla red or crim. son, rarely rose-colored, $3-4 \mathrm{~cm}$. long. Wet ground: N.B.-Fla.-Tex.-Colo. - Sask. Plain. Jl-O.

2. L. splendens Willd. Perennial, with slender offsets; stem 3-10 dm. highglabrous or minutely puberulent; leaves denticulate; sepals subulate, about 8 $\mathrm{mm}$. long; corolla crimson, $2-2.5 \mathrm{~cm}$. long. Wet places: Tex.-Utah-Calif.; Mex. Son. JI-S.

3. L. syphilitica L. Perennial with offsets; stem glabrous or with scattered hairs, 5-10 dm. high; leaves thin, lanceolate or oblong, sinuate-dentate, $5-15 \mathrm{~cm}$. long, more or less puberulent; raceme spike-like; sepals subulate, about $1 \mathrm{~cm}$. long, ciliate, with auricles in the sinuses; corolla $2-2.5 \mathrm{~cm}$. long, with thick tube; hypanthium hemispheric. Wet places: Me.-Ga.-La.-Colo.-S.D. Plain. $\mathrm{Au}-\mathrm{O}$.

4. L. hirtella (A. Gray) Greene. Perennial, with offsets; stem simple, 2-4 dm. high, finely short-pilose; lower leaves spatulate or obovate, often sinuatedenticulate, 2-4 cm. long, puberulent; bracts, pedicels, hypanthium, and calyx hirsutulous; hypanthium turbinate, $2 \mathrm{~mm}$. long; sepals $4 \mathrm{~mm}$. long, subulate, minutely auricled at the sinuses; corolla light blue, 7-8 mm. long. L. spicata hirtella. Hills and prairies: Minn.-Ia.-Kans.-Sask. J1-Au. 
5. L. strictiflora (Rydb.) Lunell. Biennial; stem slender, glabrous or puberulent at the base, 1-3 dm. high, simple or with a few ereet branches; basal leaves petioled; blades spatulate or oblanceolate, puberulent or glabrate; pedicels erect, 5-8 mm. long, usually glabrous, sometimes glandular-pilose; hypanthium turbinate, $2-3 \mathrm{~mm}$. long; sepals subulate, $3 \mathrm{~mm}$. long; corolla $7-8 \mathrm{~mm}$. long. $L$. Kalmii strictiflora Rydb. Meadows and bogs: Man.-N.D.-Mont.-Wash.B.C. Submont. J1-Au.

6. L. Dortmanna L. Acaulescent perennial; leaves all basal, tufted, linear, fleshy, terete, fistulose, with two longitudinal tubes, $1-5 \mathrm{~cm}$. long; scape 1-4 dm. high, simple; hypanthium turbinate, in fruit clavate; sepals lanceolate, $2-3 \mathrm{~mm}$. long; corolla blue, 12-15 mm. long. In water: Lab.-N.J.-Wash.-B.C.; Eu. Subarctic. Jl-Au.

\section{Family 132. Dipsaceate. Teasel Family.}

Herbs, with opposite or rarely whorled leaves. Flowers perfect, in involucrate heads, each usually with an involucel. Calyx cup-like or of several bristles. Corolla gamopetalous, tubular-funnelform, with 2-5-lobed limb. Stamens 2-4, adnate to the upper part of the corolla-tube; filaments distinct; anthers versatile, opening lengthwise. Gynoecium of a single carpel; ovary inferior, 1-celled; style elongate, entire; stigma globose to elongate. Fruit an achene; embryo straight; endosperm fleshy.

\section{DIPSÃCUS L. Teasel.}

Coarse herbs. Leaves opposite, coarsely toothed or pinnatifid. Involucral bracts and paleae of the receptacle rigid. Involucel calyx-like, enclosing the ovary. Calyx cup-shaped or 4-lobed. Corolla 4-lobed, slightly irregular, blue or white. Stamens 4. Achenes 8-ribbed.

1. D. sylvestris Huds. Coarse biennial herb, armed with stout prickles; stem 1-2.5 m. high; basal leaves oblanceolate, crenate-serrate, $2-4 \mathrm{dm}$. long; stemleaves lanceolate, entire, sparingly spiny on the margins, clasping; heads ovoid, 5-6 cm. long; bracts linear-lanceolate; paleae with a long straight spine-point; corolla $10-13 \mathrm{~mm}$. long, white, with lilac lobes. Waste places and fields: Me.Va.-Mich.; Colo.-Utah; adv. or nat. from Eu. Jl-S.

\section{FAMILY 133. AMBROSIACEAE. RAgWeEd FAMILY.}

Annual or perennial herbs, rarely shrubs, monoecious or dioecious. Leaves alternate, or opposite on the lower part of the stem. Flowers in small heads, the staminate and pistillate ones in the same head or in different heads. Involucral bracts few, distinct or more or less united. Pistillate flowers, when in distinct heads usually enclosed in a bur-like or nut-like involucre. Staminate flowers with tubular, obconic, or funnelform corollas, 4-5-lobed; pistillate flowers corolla-less or with a small border or crown. Calyx none or rudimentary. Ovary inferior. Stamens 5, distinct. Stigmas 2, hairy at the top. Ovules and seeds solitary.

Staminate and pistillate flowers in the same heads, the latter few (rarely solitary or none), marginal.

Achenes turgid, obovoid or pear-shaped, marginless.

Involucres of 5 dilated-ovate, rigidly acuminate bracts; achenes with a large terminal areola, surrounded by a disk.

1. OXYTENLA.

Involucres not with dilated rigidly acuminate bracts; terminal areola minute. Heads paniculate; corolla of the pistillate flowers rudimentary or none.

2. CyclachaEna.

Heads spicately or racemosely disposed; corolla of the pistillate flowers evi-

dent.
Achenes flattened, wing-margined; involucres of 5 ovate or oblong herbaceous bracts and within them 1-2 large scarious ones subtending the pistillate flowers.

4. DICORIA. 
Staminate and pistillate flowers in different heads, the latter 1-1, without corolla and enclosed in a nut-like or bur-like involucre.

Involucres of the staminate heads with united bracts; receptacles low; rudimentary styles penicillate or fimbriate at the apex.

Involucres of the solitary pistillate flower with 9-12 dilated scarious wings; anthertips blunt.

5: HYMENOCLEA.

Involucres of the 1-4-flowered pistillate heads not winged, but usually armed with spines or tubercles; anther setiferous-acuminate.

Spines or tubercles of the 1-flowered pistillate heads in a single row.

Spines of the 1-4-flowered pistillate heads in more than one row.

6. AMBrosta.

7. FRANSERIA.

Involucres of the staminate heads with distinct bracts; receptacle cylindraceous; spines of the 2-flowered pistillate heads in several rows, uncinate. 8. XANTHIUM.

\section{OXYTĖNIA Nutt.}

Small shrubs. Heads small; involucres of 5 coriaceous-herbaceous, dilated, ovate, rigidly acuminate bracts. Receptacle convex. Staminate flowers 10-20, villous at the base, subtended by slender paleae, or these wanting in the central flowers; pistillate flowers 5, without a trace of corolla. Achenes obovate-turgid, very villous. Pappus none or of a single minute scale.

1. O. acerosa Nutt. Shrub 1-2 m. high, canescent; branches erect, often leafless and rush-like; leaves alternate, pinnately 3-7-parted, with filiform divisions, 3-12 cm. long, or the upper entire and filiform; heads numerous, in dense panicles, about $4 \mathrm{~mm}$. high; bracts ovate, mucronate, canescent. Dry plains and cañons: sw Colo.-N.M.-se Calif. Son. Au.

\section{2. cyclachaèna Fresen. Horseweed, Careless Weed.}

Annual herbs, with mostly opposite petioled leaves. Heads paniculate, not leafy-bracteate. Involucres of 5 obovate bracts. Receptacle chaffy, the paleae subtending the pistillate flowers broad, nearly as large as the bracts, partly embracing the achenes. Fertile flowers 5, marginal, their corollas none or rudimentary. Staminate flowers 10-15, with funnelform corollas. Filaments monadelphous. Achenes pyriform, without pappus.

1. C. xanthifolia (Nutt.) Fresen. Stem 1-2 m. high, puberulent above; leaf-blades ovate or ovate-lanceolate, cuneate to subcordate at the base, 5-10 $\mathrm{cm}$. long, canescent beneath, scabrous above; heads 4-5 $\mathrm{mm}$. broad, hemispheric; bracts ovate. Iva xanthifolia Nutt. Waste places and along streams: Sask.Mich.-Neb.-N.M.-Wash.-Alta. Plain-Submont. Jl-S.

\section{Iva L. Marsh Elder, Bozzleweed, Salt Sage, Poverty Weed.}

Annual or perennial herbs, or shrubs. Leaves opposite or alternate above, glabrous or coarsely pubescent. Heads axillary or in terminal bracteate spikes. Involucres campanulate or hemispheric, or turbinate; bracts 3-6, distinet or partially united. Pistillate flowers 1-8, marginal; corolla a short truncate tube. Disk-flowers perfect but sterile, with funnelform, 5-lobed corollas. Anthers entire at the base, mueronate above. Achenes broadest above the middle, without pappus.

1. I. axillaris Pursh. Perennial, suffrutescent at the base; stems much branched, 2-6 dm. high, sparingly hirsute or glabrate; leaves sessile, entire, obovate, oblong, or linear-oblong, 1-3 cm. long, fleshy, pubescent or glabrate, the upper alternate; heads axillary, 4-5 $\mathrm{mm}$. broad, hemispheric; bracts of the involucres $4-5$, connate at least at the base; pistillate flowers $4-5$; staminate flowers 12-15. Alkaline or saline meadows: Man.-Okla.-N.M.-Calif.-B.C. Plain-Submont. My-S.

\section{DICÒRIA T. \& G.}

Branched annuals. Lower leaves opposite, the upper alternate. Involucre of 5 , oval or oblong, herbaceous bracts; within these 1 or 2 large, broad, thinscarious paleae subtending the 1 or 2 pistillate flowers, or these lacking when the heads are wholly staminate. Staminate flowers $6-12$, with rudimentary pistils, subtended by a few narrow, hyaline paleae; corollas of the staminate flowers 
obconic. Filaments monadelphous. Corolla of the pistillate flowers wanting. Achenes oblong, flat on the inside, convex or angled on the outside, with thinscarious, pectinately dentate wings. Pappus rudimentary, of a few small bristlelike scales.

Upper leaf-blades broadly spatulate, ovate, or roundish.

Inner bracts $10-15 \mathrm{~mm}$. long; achenes with pectinate margins.

1. D. Wetherillii.

Inner bracts $6-8 \mathrm{~mm}$. long; achenes with continuous erose margins. 2 . D. canescens.

Leaves all oblong-lanceolate to linear.

Fertile flowers solitary in the heads; teeth of the achenes connected by a scarious margin.

Fertile flowers 2 in each head; achenes without scarious margins.

1. D. Wetherillii Eastw. Stems strigose; leaves spatulate, hirsutecanescent with appressed hairs; staminate flowers several, longer than the outer bracts; pistillate flowers usually 2 ; inner bracts hood-shaped, enclosing the achenes, 10-15 mm. long, $10 \mathrm{~mm}$. broad, intricately veined, pitted, glandularhairy; achenes oblong, mottled with brown, sparingly glandular. Sandy places: s Utah. L. Son.

2. D. canescens T. \& G. Stem intricately branched, $3-10 \mathrm{dm}$. high, hispidulous; lower leaves opposite, lanceolate or oblong, coarsely toothed, the upper alternate, round-ovate or orbicular, white with appressed pubescence, 1-3 cm. long, crenate; fertile flowers 2 ; inner bracts petaloid, orbicular, concave; staminate flowers many. Desert washes: se Calif.-Ariz.-s Utah. L. Son.

3. D. Brandegei A. Gray. Stem diffusely branched, 3-10 dm. high, canescent-hispid; leaves petioled; blades 1-5 cm. long, strigose-canescent, sinuatedenticulate; heads few, some wholly staminate; fertile flowers solitary; inner bracts dilated-cuneate, rather small. Sandy bottoms: s Colo.-s Utah-Ariz. Son. Au.

4. D. paniculata Eastw. Stem 3-5 dm. high, branched from the base, hispid-canescent; leaf-blades sparingly dentate or entire, $1-2 \mathrm{~cm}$. long; heads numerous, paniculate; inner bracts large, truncate or obcordate, suborbicular, glandular-ciliate; fertile flowers 2 ; achenes obovate, $6 \mathrm{~mm}$. long, dark brown, dentate with horny teeth; staminate flowers 9-10. Sandy flats: sw Colo.-se Utah. Son.

\section{HYMENOCLÈA T. \& G.}

Low shrubs. Heads unisexual, monoecious. Involucres of the staminate heads saucer-shaped, of 4-6 more or less united bracts; paleae of the receptacle subtending the outer flowers obovate or spatulate, those of the inner flowers filiform or none. Filaments distinct; anther-tips blunt; the abortive styles with dilated fimbriate or penicillate tips. Involucres of the 1-flowered pistillate heads ovoid or fusiform, beaked, with 9-12 dilated and silvery-scarious persistent transverse wings on the lower portion.

1. H. Salsola T. \& G. Low shrubs, much branched, puberulent; leaves alternate, linear-filiform, 1-5 cm. long; heads numerous, paniculate; staminate heads hemispheric, $5 \mathrm{~mm}$. broad, many-flowered; bracts of the pistillate involuere spirally arranged, imbricate, when dry spreading, suborbicular, 6-8 mm. broad, silvery-scarious. Saline soil: s Calif.-Nev.-s Utah-Ariz. L. Son.

\section{AMBRÒsIA (Tourn.) L. Ragweed, ROMan Wormwood, \\ BITTER-WEED.}

Annual or perennial, often more or less woody, caulescent herbs, mostly monoecious, rarely dioecious. Leaves opposite or alternate, usually much divided, or rarely merely toothed. Staminate heads in terminal spikes or racemes. Involucres saucer-shaped or hemispheric, with 5-12 partly united bracts; receptacle naked or with filiform paleae. Corollas funnelform, 5-lobed. Anthers mueronate at the apex; style rudimentary, brush-like at the apex. Pistillate involueres enclosing the single flower, turbinate or subglobose, with several tubercles or spines in a single series. Corolla wanting. Stigmas filiform. Achenes ovoid or obovoid; pappus wanting. 
Involucres of the staminate heads 3-ribbed; leaves palmately 3-5-cleft or entire.

Involucres of the rtaminate heads not ribbed; leaves once to thrice 1. A. trifida. Annual; fruit with acute teeth.

Leaves thin, not strongly veined, bipinnatifid.

Leaves thick, strongly veined, pinnate with broatior.

3. A. media.
A.

1. A. trifida L. Annual; stem 1-5 m. high, more or less hispid; leaves petioled; blades scabrous on both sides, ovate in outline, 3-5-cleft or entire, serrate, acute or acuminate; sterile racemes many; heads nodding; involucres 3ribbed on the back, slightly hispidulous or glabrous; fruit 6-7 mm. long, turbinate, 3-5-ribbed, with as many conical tubercles. Moist and waste places: Que. -Fla.-Colo.-B.C. Plain. Jl-O.

2. A. elatior L. Annual; stem 3-10 dm. high, strigose and ciliate; leaves with ciliate petioles, thin, hispidulous or glabrate above, more or less grayishstrigose beneath, bipinnatifid, with lanceolate, acute divisions; staminate heads nodding, oblique, about $3 \mathrm{~mm}$. broad, puberulent or in the western form more ciliate-pilose; fruit obovoid; body slightly pubescent or glabrate, $2.5-3 \mathrm{~mm}$. long, with 5-7 sharp spines about $0.5 \mathrm{~mm}$. long; beak 1-1.5 mm. A. artemisiaefolia A. Gray, not L. Waste places: N.S.-Va.-Colo.-Wash.-B.C. PlainSubmont. $\mathrm{Au}-\mathrm{O}$.

3. A. media Rydb. Annual; stem 4-6 dm. high, hispid and strigose; leaves pinnatifid, or the upper merely cleft, $5-10 \mathrm{~cm}$. long, scabrous above, hispidstrigose beneath; divisions lanceolate, the lower lobed or toothed; staminate heads numerous; involucre 5 -lobed and crenulate, 4-5 $\mathrm{mm}$. broad, hispid-strigose; fruit obovoid; body $3 \mathrm{~mm}$. long, puberulent; beak $1 \mathrm{~mm}$. long, pubescent; spines 5-7, sharp, subulate, $0.5 \mathrm{~mm}$. long. Dry places: S.D.-Kans.-N.M.-Nev.Wash. Plain-Submont. J-O.

4. A. psilostachya DC. Stem 3-8 dm. high, canescent-strigose; leaves sessile or the lower with short broadly-winged petioles, grayish-strigose on both sides, thick and strongly veined, pinnatifid; divisions entire, toothed or cleft, lanceolate, acute; staminate heads nodding, oblique, $3 \mathrm{~mm}$. wide; fruit roundelliptic; body pubescent, 3-3.5 mm. long, usually unarmed, sometimes with obtuse tubercles. A. coronopifolia T. \& G. Prairies and plains: Ill--Sask.La.-Calif.-Ida. Plain-Submont. J-O.

\section{FRANSÈRIA Cav.}

Annual or perennial herbs, rarely shrubby, resembling Ambrosia. Leaves mostly alternate, lobed or pinnatifid. Heads monoecious, the staminate ones in terminal racemes or spikes. Involucres hemispheric, open, with 5-12 more or less united bracts; receptacle chaffy. Corollas short, 5-lobed. Anthers scarcely coherent. Styles rudimentary, simple. Pistillate heads solitary or in small clusters below the staminate or rarely mixed with them. Involucres closed, globose or ovoid, beaked, enclosing 1-4 pistils, with several processes in more than one series, becoming bur-like at maturity. Stigmas 2. Achenes obovoid. [Gaertneria Medic.]

Fruit not villous.

Spines of the fruit flat, never hooked. Plant shrubby; leaves silvery white; pistillate heads mostly 2 -flowered and 2-
beaked.

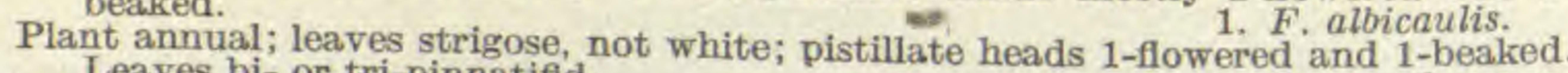
Leaves bi- or tri-pinnatifid.
Leaves pinnately 3-5-cleft.

Spines terete, usually more or less curved.

3. F. montana.

Bur 1-beaked, 1-2-flowered; leaves not tomentose beneath. Annual; divisions of the leaves oblong or linear-oblong, acute.

Perennial with a suffrutescent base; leaf-segments linear, obtuse. 4 . $\mathrm{Fuifolia.}$

Bur 2-beaked, 2-flowered; leaves tomentose beneath; plants perennial with a
rootstock. Leaves interruptedly pinnatifid, with lobed or coarsely toothed divisions.

6. $F$, discolor. 
Leaves pinnately 3-5-parted or entire; divisions or blades merely serrulate or entire.

Fruit villous; plant shrubby.

7. F. tomentosa.

8. $F$. eriocentra.

1. F. albicaulis Torr. Low shrub, often spinescent, divaricately branched, with white bark, 3-10 dm. high; leaves pinnate or bipinnate, silvery white; segments small, obovate, usually toothed; spike solitary; pistillate heads often mixed with the staminate ones, the latter about $4 \mathrm{~mm}$. broad; involucres canescent, lobed to the middle; fruit about $8 \mathrm{~mm}$. long; spines flattened, subulate, spreading or recurved in age. Desert regions: $\mathrm{s}$ Utah-Nev.-Calif.-Ariz.; n Mex. $L$. Son. Mr-My.

2. F. acanthocarpa (Hook.) Coville. Annual; stem erect, diffusely branched, 3-6 dm. high, hirsute or hispid, with white hairs; leaves petioled or the upper sessile, bi- or tri-pinnatifid; divisions or their lobes oblong, elliptic or linear, hispid-strigose on both sides or glabrate above; staminate heads nodding, about $3 \mathrm{~mm}$. broad; involueres dark brown with 3 blackish ribs, cleft beyond the middle into 6-7 oval lobes; fertile heads 1-flowered; fruit 12-20 $\mathrm{mm}$. long, with 7-12 flattened lance-subulate divergent spines. F. Hookeriana Nutt. Gaertneria acanthocarpa Britton. Plains and sandy valleys: Sask.-Mo.-Tex.-Calif.B.C. Son.-Submont. J1-O.

3. F. montana Nutt. Annual; stem 3-6 dm. high, strigose or hispidulous, angled, branched; leaves petioled, ovate in outline, pinnately 3-5-divided, hispidulous-strigose on both sides; divisions ovate or obovate, or the terminal one rhombic, often 2-3-cleft and round-lobed; staminate heads similar to those of the preceding, but the involucres scarcely cleft to the middle; fruit similar but $1 \mathrm{~cm}$. long or less, and spines more crowded. Sandy places: Utah-Ore.-se Calif. Son. Au-O.

4. F. tenuifolia Harv. \& Gray. Perennial; stem 3-15 dm. high, pubescent or nearly glabrous; leaves bi- or tri-pinnatifid into oblong or linear divisions, strigose; staminate heads about $4 \mathrm{~mm}$. broad; involucre pilose, lobed to near the middle; bur 1-2-flowered, but with a single beak, glandular-puberulent and with a depression above each hooked spine. Valleys: Tex.-Colo.-s Calif.; Mex. Son. My-N.

5. F. linearis Rydb. Perennial, shrubby at base; stems about $2 \mathrm{dm}$. high, sparingly hirsute, branched; leaves once or twice pinnate, $3-4 \mathrm{~cm}$. long, strigose above, minutely tomentulose beneath; lobes linear, obtuse, $3-5 \mathrm{~mm}$. long; staminate heads nodding, 3-4 mm. wide; involucre strigose, eleft scarcely half-ways into rounded-ovate lobes; pistillate involucre with few hooked slender spines. G. linearis Rydb. Dry plains: Colo. Submont. Jl.

6. F. discolor Nutt. Perennial with a rootstock; stem $2-4 \mathrm{dm}$. high, sparingly pubescent; leaves petioled, interruptedly pinnatifid, strigose above, whitetomentose beneath; larger division oblanceolate, cleft and with triangular teeth; staminate racemes usually solitary; heads about $5 \mathrm{~mm}$. wide; involucre finely pubescent, with 5-8 short, lobes; pistillate heads 2 -flowered; fruit ovoid, $4-5 \mathrm{~mm}$. long; spines short, with conic bases and usually slightly curved tips; beaks 2, short, hooked at the apex. Gaertneria tomentosa (Nutt.) Heller. Dry soil: S.D.Kans.-Ariz.-Wyo. Plain-Submont. Jl-Au.

7. F. tomentosa A. Gray. Perennial; stem 3-10 dm. high, strict, purplish, somewhat tomentose or glabrate below; leaves pinnately 3-5-parted or entire, white-tomentose on both sides or grayish above; blades or divisions lanceolateserrate; staminate racemes panieulate; heads about 4-5 $\mathrm{mm}$. broad; involucre tomentose, round-lobed; bur 6-8 mm. long, glandular-puberulent, 2-flowered, 2-beaked, with terete hooked spines. Gaertneria Grayi A. Nels. River bottoms: Neb.-Kans.-Colo. Plain. Au-S.

8. F. eriocentra A. Gray. Low shrub, with gray bark, minutely tomentose; leaves 2-4 cm. long, oblanceolate or cuneate-oblong, soon glabrate above, whitetomentulose beneath, coarsely sinuately toothed or lobed; staminate heads few, in short, terminal racemes, 6-7 mm. broad; involucre canescent, with triangular lobes; fruit about $1 \mathrm{~cm}$. long, the beak equalling the body; spines slender, slightly 
flattened, villous-pubescent. Desert regions: s Utah-Nev.-Ariz.-Calif. Son. Ap-Je.

\section{XÁNthium L. Cocklebur; Clotbur.}

Annual (all ours) or perennial herbs, monoecious. Leaves alternate, with toothed or lobed blades. Staminate heads in terminal spikes or racemes; involucres of several distinct bracts, in 1-3 series; receptacle chaffy; corolla tubular, 5-lobed; filaments monadelphous; anthers free, mucronate; styles rudimentary, simple. Pistillate heads axillary; involucres closed, 1-3-beaked, usually 2beaked, oblong or ovoid, with usually many spines; flowers $1-3$, mostly 2 ; corolla wanting; stigmas 2; pappus none.

Spines of the fruit about 20.

Spines of the fruit 50-200.

\section{1. $X$. oligocanthum.}

Bur and its spines merely puberulent or glandular, only slightly if at all hispid.

Bur and especially its numerous spines very hispid as well as glandular,

Prickles of the bur very numerous and dense, brownish-pubescent.

Prickles of the bur fewer, scattered, yellowish-pubescent.

3. X. echinatum.

Body of the bur oval or ovate, not twice as long as broad.

Body of the bur oblong, twice as long as thick, densely spiny.

Bur about $2 \mathrm{~cm}$. long; spines not longer than the width of the body.

5. $\boldsymbol{X}$. commune.

Bur 2.5-3 cm. long; spines much longer than the width of the body.

6. $\boldsymbol{X}$. speciosum.

1. X. oligocanthum Piper. Stem erect or spreading, 3-4 dm. long, sparsely hispid; leaf-blades reniform-orbicular to rounded-ovate, sinuately lobed, scabrous on both sides; fruit oblong; body glandular-hispid, 1.5-2.5 $\mathrm{cm}$. long, 6-8 $\mathrm{mm}$. thick; spines 15-25, hooked at the apex, glandular-hispid to the middle; beaks elongate-conic, curved only at the very apex. Fields and lake-banks: Wash.Colo. Plain-Submont. S.

2. X. pennsylvanicum Wallr. Stem 3-10 dm. high, glabrous below, rough above; leaf-blades thick, roughish, ovate, more or less distinctly $3-5$-lobed, with broad blunt teeth; fruit puberulent and glandular, oblong, 15-20 mm. long, 5-8 $\mathrm{mm}$. thick; spines 3-4 mm. long, puberulent below; beaks stout, incurved and hooked, 6-7 mm. long. X. canadense Mill., in part. Waste places: Que.-Mass. -Va.-Colo. Plain. Au-O.

3. X. echinatum Murr. Stem 3-6 dm. high, rough, purple-blotched; leaves sinuately-lobed, firm, scabrous; fruits usually clustered, ovoid or oval, 15-20 mm. long, 8-12 mm. thick, glandular; prickles about $5 \mathrm{~mm}$. long, about equalling the thick, conical, hispid beaks. Valleys and river banks: N.S.-N.C. -Colo.-N.D. Plain-Submont. Au-O.

4. X. glanduliferum Greene. Stem 3-6 dm. high, rough and angled, sometimes purplish; leaves very thick and very seabrous, sinuately lobed and dentate, with triangular teeth; fruit broadly ellipsoid, $10-15 \mathrm{~mm}$. long, $6-9 \mathrm{~mm}$. thick, yellow; prickles 3-4 mm. long; beak very stout, conic, 4-5 $\mathrm{mm}$. long. Valleys, especially in alkaline soil: Sask.-Mo.-Neb.-Calif.-B.C. Plain. $\mathrm{Au}-\mathrm{S}$.

5. X. commune Britton. Stem rather slender, 3-8 dm. high, roughish; leaf-blades broadly ovate, more or less sinuately lobed and dentate, scabrous, especially above; fruit oblong, $15-25 \mathrm{~mm}$. long, $7-12 \mathrm{~mm}$. thick; prickles 4-5 $\mathrm{mm}$. long; beaks slightly incurved and hooked, about $5 \mathrm{~mm}$. long. Waste places, valleys, and marshes: Que.-Va.-Tex.-Ariz.-Alta. Plain-Submont. $\mathrm{Au}-\mathrm{O}$.

6. X. speciosum Kearney. Stem stout, 8-15 dm. high, angled above, scabrous; leaf-blades usually distinctly $3-5$-lobed and dentate, very scabrous on both sides; fruit large, $25 \mathrm{~mm}$. long or more; prickles 8-10 mm. long; beaks 10-12 $\mathrm{mm}$. long, somewhat incurved, strongly hooked. Waste places and valleys: N.Y. (introduced ?)-Wis.-Mo.-Tex.-Ida.-Wash. Au-O. 


\section{Family 134. Carduaceae. Thistle Family.}

Herbs or shrubs, in the tropics sometimes trees. Leaves various, without stipules. Flowers aggregate in heads, inserted on a common receptacle and surrounded by an involucre of distinct or partly united bracts, in one or several series, the disk-flowers in the center, $(i$. e., all except those of the marginal series) or all flowers hermaphrodite or by the abortion of the pistil staminate, very rarely pistillate, the ray-flowers or marginal flowers pistillate or neutral. Plants sometimes dioecious or monoecious. Calyx reduced to a pappus consisting of bristles, awns, scales, or a cup-like crown, or wanting. Corolla of the disk flowers usually tubular or trumpet-shaped, 5- (rarely 4-) lobed or -toothed; that of the ray-flowers usually with a limb cleft on one side and drawn out into strap-shaped or oblong, usually $3-5-$ toothed ligule. When the ray-flowers are present, the head is said to be radiate, or when they are wanting, discoid. Androecium of 5 stamens; filaments more or less adnate to the corolla-tube; anthers more or less united into a ring (syngenecious); except in Kuhnia. Gynoecium 2-carpellary, but with a single ovule and seed; style single; branches in of the fertile flowers 2 , often appendaged. Fruit an achene. Endosperm wanting. [CомPositae.]

Anther-sacs not tailed at the base.

Stigmatic lines at the base of the style-branches or below the middle; heads always discoid, never yellow or brown.

Style-branches filiform or subulate, hispidulous. Tribe 1. VERNONIEAE.

Style-branches more or less clavate, papillose-puberulent.

Tribe 2. EUPATORIEAE.

Stigmatic lines extending to the tips of the style-branches or to the appendage thereof, if present; heads most commonly radiate and with yellow or brown disk-flowers.

Style-branches of the perfect flowers with more or less distinct appendages, these usually strongly hairy outside, glabrous inside, but never with a ring of longer hairs.

Style-branches of the perfect flowers without appendages, or if with appendages, these hairy on both sides and with a ring of longer hairs.

Pappus never capillary; style-branches rarely appendaged.

Bracts of the involucres herbaceous or foliaceous.

Receptacle with chaffy paleae subtending the flowers

Tribe 6. HELIANTHEAE.

Receptacle naked, or in Gaillardia and in some species of Chaenactis with bristles; but not chaffy bracted.

Plant-tissues without oil glands. Tribe 7. HELENIEAE.

Plant-tissues, especially the leaves and the bracts with oil-tubes; plants therefore heavy-scented. Tribe 8. TAGETEAE.

Bracts of the involucres dry and scarious. Tribe 9. ANTHEMIDEAE. Pappus capillary; style-branches often appendaged.

Tribe 10. SENECIONEAE.

Anther-sacs caudate at the base; heads never radiate and corollas yellow only in a few species of Cirsium.

Anthers not appendaged at the top; heads heterogamous or dioecious.

Pistillate flowers with filiform corollas. Tribe 4. GNAPHALIEAE.

Pistillate flowers with tubular-ampliate corollas. Tribe 5. ADENOCAULEAE.

Anther with elongated cartilaginous, mostly caudate appendages at the top; flowers all hermaphrodite or the marginal neutral; corolla not fliform.

Tribe 11. CYNAREAE.

One genus.

Tribe 1. VERNONIEAE.

Tribe 2. EUPATORIEAE.

1. VERNONIA.

Achenes 5-angled without intervening ribs.

Pappus double of 2-12 capillary bristles and as many or fewer outer short thin scales.

Pappus of wholly capillary bristles, mostly uniserial.

2. HOFFMEISTERIA.

Pappus of wholly capillary bristles
Achenes 8-20-ribbed or 8-20-striate.

3. EUPATORIUM.

Bracts of the involucre herbaceous or partly colored, not striate.

Bracts of the involucres not herbaceous, striate-nerved.

Pappus-bristles plumose; anthers distinct; bracts few.
Pappus-bristles scabrous or barbellate; anthers united; bracts usually many.

6. LACINIARIA.

4. Coleosanthus, 
Tribe 3. ASTEREAE.

A. Plants not dioecious.

I. Marginal pistillate flowers, if present, ligulate.

a. Ray-flowers yellow or none.

1. Pappus of scales or awns or lacking, never of numerous capillary bristles.

a. Bracts not conspicuously scarious-margined.

Heads small, not over $4 \mathrm{~mm}$. high, few-flowered; pappus more or less paleaceous.

Disk-flowers usually fertile; leaves linear to filiform.

Disk-flowers sterile; leaves short, 7 . GUTIERREZIA.

Heads large, many-flowered;
8. AMPHIPAPPUS.

Involucres hemispherical; pappus of a few deciduous awns.

Involucres turbinate; pappus of persistent linear, very acute paleae.

10. VANCLEVEA.

$b$. Bracts with conspicuous scarious fimbriate margins.

11. ACAMPTOPAPPUS.

2. Pappus at least in part of numerous capillary bristles.

a. Pappus double, the inner of capillary bristles, the outer of paleae or short bristles; involucres many-flowered, hemispherical with narrow imbricated bracts.

b. Pappus wholly of capillary bristles.

Heads discoid.

Leaves resinous-punctate.

Leaves not resinous-punctate.

12. ChRYSOPSIS.

Involucres narrowly turbinate, its bracts more or less chartaceous, keeled, arranged in definite (usually 5) vertical ranks; achenes elongate-linear; tips of style-branches subulate-filiform.

14. CHRYSOTHAMNUS.

Involucres broadly turbinate to hemispheric, its bracts more or less imbricate, but not in definite vertical ranks; achenes scarcely elongate-linear.

Style-tips obtuse; involucral bracts narrow and poorly imbricate. (Rayless species of) 45. ERIGERON.

Style-tips acute; bracts either broad or well imbricate or both.

Achenes truncate at the top, gradually tapering towards the base, usually cinereous-pubescent; bracts neither broad nor abruptly acuminate.

Appendages or tips of the style-branches filiform; undershrubs with white-tomentulose stems and glandular-hairy foliage; leaves entire-margined.

21. MACRONEMA.

Appendages or tips of the style-branches subulate to ovate.

Leaves with spinulose-tipped teeth; corolla-tube slender. (Rayless species of)

17. SIDERANTHUS.

Leaves not spinulose; corolla-tube dilated above. 15. IsocomA.

Achenes elongate-obovoid, $i$. e., tapering at both ends, but more so below, multi-striate, glabrous or slightly hairy; bracts of the involucres broad and abruptly acuminate; appendages of the style-branches ovate to

Heads radiate. short-subulate. 20 . OONOPSIS.

Rays scarcely longer than the disk-flower. 18. PYRROCOMA.

Rays conspicuous, much exceeding the disk.

Leaves pinnate or toothed; lobes or teeth spinulose-tipped.

Pappus of the fertile achenes deciduous in a ring; annuals, equally leafy throughout; bracts more or less foliaceous.

Pappus persistent. 16. PRIONOPSIS.

Bracts chartaceous, not foliaceous, merely with a green tip; plants annual, or perennial with a caudex, equally leafy throughout; pappus in age more or less spreading; achenes turbinate and densely silky.

17. SIDERANTHUS.

Bracts more or less foliaceous, at least above; plants perennial with taproots, large basal leaves, and few and rather smail stem-leaves; pappus not spreading; achenes oblong, glabrous or sparingly pubescent.

Leaves entire or toothed, but teeth not spinulose-tipped.

Bracts not longitudinally striate.

Shrubs with glandular-punctate leaves.

Heads large, solitary; involucral bracts in about 2 series; rays numerous. 19 . STENOTOPSIS. 
Heads small, paniculate or corymbose; bracts well imbricate, in several series; rays few or none.

13. ERICAMERIA.

Herbs or undershrubs; leaves not glandular-punctate.

Bracts abruptly acuminate; stems leafy up to the sessile heads.

20. OONOPSIS.

Bracts not abruptly acuminate.

Style-appendages filiform, much longer than the stigmatic portion; low shrubs with whitish bark and foliaceous outer bracts.

21. MACRONEMA.

Style-appendages of the stigmas ovate or triangular, not longer than the stigmatic portion.

Plants low, cespitose, with a woody caudex, more or less evergreen leaves, and solitary peduncled heads. 22 . STENOTUS.

Plants with wholly herbaceous stem, woody, if at all, only at the caudex; leaves not evergreen.

Bracts, at least the outer, foliaceous or with foliaceous tips.

Disk-flowers tubular; plants with a taproot.

18. PYRROCOMA.

Disk-flowers more or less widened upwards; plants with rootstocks or short caudices.

Heads solitary; rays numerous.

23. TONESTUS.

Heads corymbiform-cymose; rays small and narrow.

24. ORIOCHRYSUM.

Bracts not at all foliaceous or merely with green tips.

Bracts slightly if at all unequal and slightly imbricated; heads solitary or few, peduncled.

45. ERIGERON.

Bracts well imbricated and unequal in length.

Rays not more numerous than the disk-flowers; receptacle alveolate.

Inflorescence racemose or paniculate; bracts not in vertical rows. 25. SOLIDAGO.

Inflorescence corymbiform; bracts in distinct vertical rows.

26. PETRodoria.

Rays more numerous than the diskflowers; receptacle fimbriolate; heads corymbose.

27. EUTHAMUA.

Bracts of the involucres longitudinally striate; heads in congested corymbs.

28. OLIGONEURON.

b. Ray-flowers blue, pink, or white.

1. Pappus a mere crown or of few scales or awn-like bristles.

Prous of a cup-shaped crown and a single awn; dwarf annuals, branched at the base.

29. MONOPTILON.

Pappus of a series of long awns or that of the rays of short scales; annuals or perennials.

30. TOWNSENDIA.

2. Pappus of numerous capillary bristles.

a. Rays only slightly if at all exceeding the pappus; annuals.

Bracts in 2-3 series, the outer foliaceous; stigma-tips acute.

31. BRACHYACTIS.

Bracts in 1-2 series, narrow, not foliaceous; stigma-tips obtuse.

46. LEPTILON.

$b$. Rays conspicuous, longer than the pappus, usually equalling or exceeding the width of the disk.

Style-tips lanceolate or oblong to fliform.

Bracts in a single series, with hyaline-scarious erose-fimbriate margins; dwarf winter annuals.

32. ERfimastrum.

Bracts in at least 2 or usually in more than 2 series, Pappus simple, of similar bristles.

Plants rush-like, spiny.

33. LEUCOSYRIS.

Plants not spiny.

Perennials, with a rootstock or caudex.

Bracts acuminate, as well as the leaves tipped with callous points or spines; plants with solitary heads at the ends of the stems or branches, and cespitose caudices. 
Achenes pubescent; bracts all narrow, the outer not passing into the leaves; heads distinctly peduncled.

34. XYLORRHIZA.

Achenes glabrous; outer bracts broad, foliaceous, passing into the leaves; heads subsessile.

35. HERRICKIA.

Bracts not acuminate, or if long-attenuate with soft tips.

Pappus dilated at the apex; bracts narrow, more or less keeled. 36 . UNAMIA.

Pappus not dilated at the apex.

Bracts broad, with a distinct keel or mid-vein. not at all foliaceous. 37. EUCEPHALUS.

Bracts usually narrow, when broad neither keeled nor with a prominent midvein.

Bracts more or less foliaceous or foliaceoustipped, usually in several series; heads usually several, racemose or paniculate; stigma-tips lanceolate to subulate, shorter than the stigmatic portion.

38. ASTER.

Bracts not foliaceous, narrow and in 1-3 series.

Style-tips slender, usually twice as long as the stigmatic portions; achenes terete. 39. OREOSTEMMA.

Style-tips ovate or triangular and acuminate-subulate; achenes flat.

40. ASTERIGERON.

Annuals or biennials, or if short-lived perennials, with a taproot; bracts in many series, with herbaceous spreading or reflexed tips; stigma-tips linear to filiform.

44. MACHAERANTHERA.

Pappus double, the inner of capillary bristles, the outer of short bristles or scales.

Inner pappus-bristles more or less thickened above; bracts thin-coriaceous, without herbaceous tips, shorter than the disk.

41. DOELINGERIA.

Inner pappus-bristles filiform, not thickened above; bracts equalling the disk. 42. IONACTIS.

Style-tips triangular or ovate, obtuse or rarely acutish; bracts not foliaceous.

Involucres turbinate; bracts well imbricate, in several series, scariousmargined; disk-flowers white.

43. LEUCELENE.

Involucres hemispherical or broader; bracts not scarious-margined, in 1-3 series; disk-corollas yellow, rarely ochroleucous.

45. ERIGERON.

II. Marginal pistillate flowers not ligulate, reduced to a filiform or narrow short tube.

B. Heads unisexual, dioecious, discoid; pappus of the staminate flowers with clavate tips.

Tribe 4. GNAPHALIEAE.

48. BACCHARIS.

Shrubs; bracts coriaceous; receptacle naked; pistillate flowers numerous; corolla reduced to a short slender tube; hermaphrodite flowers few and sterile, their pappus with clavate tips.

Herbs, if at all shrubby only at the base; bracts more or less scarious.

Receptacle chaffy; style or style-branches of the hermaphrodite sterile flowers not truncate.

Pistillate flowers all subtended by paleae and without pappus.

Paleae in fruit enclosing the achenes and falling off with them, tipped with a hyaline appendage.

Heads ovoid; paleae subtending the pistillate flowers boat-shaped, with erect conspicuous hyaline tips, those of the 4-5 hermaphrodite flowers barely concave or plane.

Paleae subtending the central flowers hyaline and deciduous; bracts of the involucres in several series.

50. STYLOCLINE.

Paleae subtending the central flowers coriaceous-herbaceous, ending in a hooked spine, persistent; bracts of the involucres none beside the paleaceous ones enclosing the marginal flowers.

Heads globose; paleae subtending the pistillate 51. ANCISTROCARPHUS. and utricular, the apex introrse and the ovatewers cucullate-saccate appendage inflexed or porrect; paleae and pappus of the hermaphrodite flowers lacking. 52. PSILOCARPUS.

Paleae in fruit open and merely subtending the achenes, without a hyaline appendage. 53. DIAPERIA.

Pistillate flowers of two kinds, the outer with, the inner without pappus, the latter and the central fertile hermaphrodite flowers not subtended by individual paleae, but the cluster surrounded by a ring of open scarious paleae, the outer subtended by boat-shaped ones.

54. OGLIFA. 
Receptacle not chaffy; style or style-branches of the hermaphrodite flowers mostly truncate.

Plants dioecious, or the pistillate heads with a few hermaphrodite flowers in the center.

Pappus-bristles of the pistillate flowers falling off in a ring; central hermaphrodite flowers none.

55. ANTENNARIA.

Pappus-bristles of the pistillate flowers falling off separately; central hermaphrodite flowers present in the pistillate heads.

56. ANAPHALIS.

Plants not dioecious; flowers fertile throughout the heads, hermaphrodite in the middle, surrounded by pistillate ones.

57. GNAPHALIUM.

Tribe 5. ADENOCAULEAE.

Leaves cordate, white-woolly beneath.

58. ADENOCAULON.

Tribe 6. HELIANTHEAE.

A. Bracts (at least the outer series) not enclosing the achenes of the rays; plants not glandular-viscid.

I. Disk-flowers hermaphrodite but sterile.

Marginal pistillate flowers, with conspicuous rays.

Achenes not flattened; ligules in ours white; involucres of very dissimilar sets of bracts.

Achenes flattened; ligules in ours yellow.

59. MELAMPODIUM.

Ray-flowers in 2-3 series; achenes falling away free. with them. 61 . ENGELMANNIA.

paleae and falling away

Marginal pistillate flowers reduced to a truncate or obliquely-cleft tube; the ligules, if any, reduced to 2 or 3 small teeth.

Acaulescent cespitose perennials; pappus of a pair of lanceolate membranous scales.

Caulescent annuals; pappus none.

II. Disk-flowers fertile.

62. BOLOPHYTA.

63. Parthenice.

a. Ray-flowers fertile; the ligules with very short tube, persistent on the achenes and becoming papery in texture.

Achenes of the disk compressed; leaves entire. 64. Crassina.

Achenes obtusely 4-angled.

Leaves toothed; paleae pointless, partly enclosing the achenes.

65 . HeLIOPSIS.
Leaves entire; paleaelinear-lanceolate, not enclosing the achenes. (\$ Kalliactis, i. e., B. Careyana, of)

b. Ray-corollas deciduous from the achenes or wanting.

71. BALSAMORRHIZA.

1. Pappus a crown or none, or of a few squamellae on the angles of the achenes, and rarely minute ones between.

a. Achenes of the disk-flowers not obcompressed (except in Ratibida and Ximenesia): paleae usually more or less concave and clasping.

Receptacle conic, subulate or columnar. Achenes 4-angled.

Ray-flowers purplish or rarely whitish: disk-corollas almost without a tube; pappus coroniform. 66. BRAUNERIA.

Ray-flowers yellow or none; disk-corollas with a short but manifest tube.

Achenes quadrangular-compressed; apex of the achenes covered by the base of the corolla-tube.

67. GYMNOIOMIA.

Achenes nearly equally 4-angled; apex not covered by the base of the corolla.

Achenes 5-angled; ray-flowers white.

Achenes flattened, broad-margined or winged.

68. RUDBECKIA.

70. GaLinsoga.

Receptacle from flat to convex.

69. RATIBIDA.

Achenes of the disk neither sharp-angled, margined, nor winged.

Rays fertile, their achenes commonly 3-angled or obcompressed; plants with thick balsangiferous taproots.

Pappus none; stem scapiform or with reduced leaves.

71. BALSAMORRHIZA.

Pappus a lacerate chaffy crown or of distinct squamellae; stem low but leafy.

72. WYETHLA.

Rays sterile or wanting; plants not with fleshy taproot.

Pappus none or a minute ring. 67 . GYMNOLOMrA.

Pappus of 2 scarious awns. 73. HELIANTHUS.

Achenes of the disk thin-edged, margined or winged.

Ray-flowers neutral; achenes scarcely winged.

Pappus none or an awn to each angle of the achenes. 74. ENCELIA.

Pappus of small teeth between the 2 or more awns or scales over the angles of the achenes.

Plants scapose; achenes with a callous margin.

75. ENCELIOPSIS.

Plants caulescent; achenes not margined.

76. HeLIANTHELLA. 
Ray-flowers fertile; achenes winged; pappus-awns without inter-

mediate squamellae.
$b$. Achenes obcompressed; paleae flat or hardly concave; involucres dis-

mediate squamellae.
$b$. Achenes obcompressed; paleae flat or hardly concave; involucres distinetly double.

Bracts of the involucres distinct or nearly so. Pappus in ours of small teeth, a mere border, or wanting.

Pappus of 2-4 barbed or hispid awns. 78. COREOPSIS.

Bracts of the inner involucre united at least to near the middle.

2. Pappus of 5-many, linear to lanceolate squamellae with thickened axis and
(a) hyaline margins.

Rays fertile; paleae of the receptacle thin and scarious; pappus-squamellae

fimbriate.
Rays sterile; paleae of the receptacle bristle-form; pappus-squamellae not fimbriate.

B. Bracts of the involucres uniserial, partly or wholly enclosing the achenes of the fertile ray-flowers; plants glandular-viscid.

Achenes of the inconspicuous rays laterally compressed and enclosed in the conduplicately infolded involucral bracts. Disk-flowers several; corolla hairy; stout annuals with sessile or short-peduncled
heads.

Disk-flowers solitary; corolla glabrous; slender low ann. MADIA.

fisk-flowers solitary; corolla glabrous; slender low annuals with small heads on Achenes of the ray-flowers with broad and rounded backs, or 83. HARPAECARPUS. pressed.

Ligules of the ray-flowers minute; achenes completely invested by the whole involucral bract; disk-flowers solitary; heads small and short-peduncled.

Ligules of the ray-flowers conspicuous; achenes enclosed in the basal portion of the bracts, the dilated margins of which are abruptly infolded; disk-flowers several or many.

Ray-flowers about 5, with deeply 3-cleft ligules; disk-flowers sterile, without pappus.

85. LAGOPHYLLA. fertile with pappus of 5-20 bristles.

Tribe 7. HELENIAE. I. Ligules persistent and becoming papery on the striate achenes; plants more or less
woolly.

Pappus of scales; rays 3-4, very broad; involucres of 4-10 coriaceous woolly bracts.

Pappus none; rays 5-50; involucres of numerous thin herbaceous bracts.

II. Ligules deciduous or none.

88. BAILEYA.

A. Achenes flat with only marginal nerves; disk-corollas 4-toothed.

Pappus none or of a single bristle; bracts distinct; suffruticose plants.

Pappus of a lacerate-ciliate erown and 89. MONOTHRIX.

awns; bracts more or less connate; not suffruticose plants.

B. Achenes angled, not flat, nerved or striate.

90. PERICOME.

1. Receptacle naked.

a. Bracts of the involucres pale or colored, at least the margins and tips scarious.

Corollas of the disk-flowers with reflexed or spreading lobes; bracts of the broadly campanulate involucres obovate or broadly oblong. Heads discoid. 96. HYMENOPAPPUS. Heads radiate; ligules obscurely toothed, yellowish or white.

Corolla of the disk-flowers with linear, erect 97. LEUCAMPYX. involucres spatulate to linear-oblar, erect lobes; bracts of the turbinate

b. Bracts of the involucres neither colored nor scarious.

or. series; ligules if pres-

Pappus of numerous barbellulate white bristles, somewhat broadened and
united at the base into a ring.

Pappus of scales or wanting. Achenes either linear-prismatic or clavate-obpyramidal, $i . e$. , very
elongate.

Bracts more or less carinate-concave and partly enfolding the achenes; leaves more or less floccose woolly.

Low and diffuse winter annuals; anther-tips subulate; bracts herbaceous; tube of the disk-corollas equalling the throat.

Perennials; anther-tips obtuse; 103. ANTHEROPEAs.

Perennials; anther-tips obtuse; bracts firm; tube of the disk-

Bracts wholly herbaceous, broad throat. 102. ERIOPHYLLUM.

Bracts wholly herbaceous, broad and flat or merely concave, not embracing the achenes; plants not floccose-lanate.

Foliage impressed-punctate; leaves at least the lower opposite. Perennials, suffruticose at the base; leaf-segments oblong to linear.

91. PICRADENIOPSIS. 
Annuals; leaf-segments filiform or nearly so.

95. Cephalobemirix.

Foliage not impressed-punctate; leaves alternate.

Bracts obovate, cuneate or oblanceolate.

Perennials with a woody caudex; leaves entire; pappus of 10 squamellae. 93. PlatyschkuHria. Annuals; leaves dissected; pappus wanting.

Bracts linear. 92. AMAURIOPSIS.

Bracts in one row or two subequal rows; plant not fleshy; achenes linear.

Heads radiate, but ligules inconspicuous; pappus of opaque squameslae.

99. RIGIOPAPPUS.

Heads discoid; pappus of hyaline squamellae. Achenes angled; squamellae with strong midribs. 100. Chamaechenactis.

Achenes scarcely angled; squamellae not conspicuously ribbed.

Bracts in 2-3 rows; heads radiate; leaves more or less fleshy.

94. HuLseA.

Achenes obpyramidal, not 4 times as Iong as broad.

Bracts of the involucres erect, not spreading nor reflexed.

Involucres many-flowered; pappus present; achenes tapering below.

Bracts of the involucres nearly equal and similar, all distinct. Bracts few; corolla flesh-colored; rays wanting.

100. CHAMAECHAENACTIS.

Bracts numerous; corollas yellow; rays usually present.

Leaves entire; squamellae short, obtuse or abruptly contracted into a point. 105. TETRANEURIS.

Leaves pinnatifid; squamellae linear-lanceolate, attenuate but not awn-tipped.

106. RYDBERGLA.

Outer bracts united below; leaves usually pinnatifid with narrow divisions. 107. HYMENOXYs.

Involucres few-flowered; pappus wanting; achenes linear, 8-10striate.

Bracts of the involucres spreading or reflexed.

Leaves not decurrent on the stem; tubes of the disk-flowers moderately long.

109. DUGALDIA.

Leaves decurrent on the stem; tubes of the disk-corollas very

2. Receptacle with bristle-like chaffs.

short or reduced to a ring. 110. HELENIUM.

Involucral bracts spreading or reflexed.

Involucral bracts erect.

111. GaILLARDia.

101. Chafnactis.

Tribe 8. TAGETEAE.

Bracts of the involucres more or less united; style-branches of the disk-flowers elongate.

Bracts of the involucres united only at the base; style-branches with conical tips; squamellae of the pappus many-aristate.

Bracts of the involucres united into a cup; style-branches obtuse.

113. THYMOPHYLLA.

Bracts of the involucres distinct; style-branches very short, obtuse, without an appendage.

Tribe 9. ANTHEMIDEAE.

Receptacle chaffy.

114. PECTIS.

Achenes flattened; involucres campanulate or obovoid, small; ligules short and broad. 115. ACHILLEA.

Achenes terete, at least not flattened; involucres hemispherical, large; ligules elongate.

Ray-flowers fertile; paleae of the receptacle membranous, subtending all the flowers.

116. ANTHEMIS.

Ray-flowers neutral; paleae of the receptacle subulate, stiff, subtending only the inner disk-flowers.

Receptacle naked or merely pubescent.

117. Maruta.

Heads radiate: achenes 5-10-ribbed all around.

Ligules white, flat, spreading, longer than the disk-corollas.

Ligules yellow, concave, erect, not longer than the disk-flowers.

Heads in ours discoid; achenes 2-5-ribbed.

120. TANACETUM.

Anthers obtuse.

Heads solitary, peduncled; flowers in our species all alike (the ray-flowers found in other species lacking).

118. OHAMOMILLA.

Heads in contracted panicles or glomerules, or in one species solitary; flowers of two kinds, the marginal pistillate, but without ligules.

121. SPHAEROMERIA.

Anthers with pointed tips; heads racemose, rarely solitary; marginal pistillate flowers without ligules.

Plants spiny; achenes and corollas cobwebby.

Plants not spiny; achenes not cobwebby. 


\section{Tribe 10. SENECIONEAE.}

Plants scapiferous, dioecious or nearly so, with large basal leaves appearing after flowering; hermaphrodite flowers usually sterile. 124. PETASITES.

Plants not scapiferous; not dioecious; disk-flowers hermaphrodite, fertile.

Involucres of many or several bracts.

Involucres lax, of commonly much overlapping or unequal bracts. Low annual herbs, with alternate leaves.

Heads discoid; receptacle flat; corollas with very short tube.

126. Psatyrotes.

Heads radiate; receptacle conical; disk-flowers with long tube. 125. CROCIDIUM.

Suffrutescent perennial, with opposite leaves; heads radiate.

127. HAPLOESTES.

Involucres of connivent erect herbaceous equal bracts, with or without smaller calyculate ones below.

Leaves mostly opposite; pappus of a single series of rigid bristles.

128. ARNICA.

Leaves alternate; pappus of numerous soft bristles. 129. SENECIO.

Involucres of 4-6 firm concave erect and strongly overlapping bracts; shrubs with alternate leaves and discoid heads. 130. TETRADYMIA.

\section{Tribe 11. CYNAREAE.}

Achenes attached by the very base; flowers all alike or nearly so; hermaphrodite.

Leaves not prickly; filaments glabrous; style-branches slender, free.

Involucre globose; bracts subulate, spine- or awn-like, spreading, hooked at the

tip.
Involucre oblong or obovoid; bracts appressed, muèicous.

131. ARCTIUM.

132. SAUSSUREA.

Leaves more or less prickly; filaments bearded or papiılose, rarely glabrous; stylebranches more o. less united into a cylindrical body with a hair-ring below.

Receptacle densely bristly; pappus plumose.

Receptacle deeply honeycombed, scarcely bristly; pappus not plumose.

134. ONOPORDON.

Achenes obliquely attached by one side; marginal flowers usually neutral, with enlarged oblique corollas. 135. Centaurea.

\section{VERNÒNIA Schreb. IRON-WEED.}

Coarse erect perennial herbs, with alternate leaves and corymbose-paniculate, purple or rose-colored, or rarely white flowers. Involucre hemispherical to oblong-cylindric or turbinate; its bracts imbricate in several or many series, dry or partly herbaceous. Receptacle flat, naked. Ray-flowers none. Corollas regular, 5-cleft, with narrow lobes. Anthers sagittate at the base, but not caudate. Achenes 8-10-ribbed, truncate at the apex, callous at the base. Pappus in two series in our species, the outer of small squamellae or short stout bristles, the inner of capillary scabrous bristles.

Leaves ovate-lanceolate, pinnately veined; bracts obtuse or acute. Leaves linear or lance-linear; lateral veins indistinct; bracts short-acuminate.

1. V. corrmbosa Schwein Stem leaves sessile ovate-lanceote above, glabrous and pitted beneath 21-flowered; involucre campanulate or hemispheric; bracts purple, appressed achenes glabrous or nearly so. V. fasciculata Coult., not Michx. Valleys: Man. -Neb.-N.D. Plain. Au.

2. V. marginata (Torr.) Raf. Stem glabrous or nearly so, 4-8 dm. high; leaves linear or linear-lanceolate, $5-15 \mathrm{~cm}$. long, entire or minutely serrulate, punctate on both sides, puberulent above; heads in a flat-topped corymb, about $1 \mathrm{~cm}$. high; bracts purple, ovate or lance-ovate; achenes glabrous. V. Jamesii T. \& G. Plains: Neb.-Okla.-Tex.-Colo. Plain. Au.

\section{HOFMEISTËRIA Walp.}

Low suffrutescent plants, with incised leaves and long-peduncled heads with white flowers. Involucre campanulate or hemisphericad, its bracts imbricate in several series, striate-nerved. Receptacle naked. Ray-flowers none. Corollas of disk-flowers regular, 5-cleft. Anthers not caudate at the base. Style-branches clavate, stigmatose only at the base. Achenes 5 -angled, not caudate, but with 
a strong basal callus. Pappus double, the inner of 2-12 slender or capillary bristles equalling the slender corolla, the outer of alternating short thin paleae.

1. H. pluriseta A. Gray. Shrub 3-5 dm. high, with white bark; leaves long-petioled; blades lanceolate, deltoid or hastate, 5-10 $\mathrm{mm}$. long, dentate or entire; heads about 20-flowered, 8-10 mm. high; bracts with spreading tips, glandular-puberulent, the outer herbaceous, the inner chartaceous; pappus of 10-12 bristles and as many narrow acute chaff. Arid regions: s Calif.-Nev.s Utah-Ariz. L. Son. Ap-My.

\section{EUPATÕRIUM L. Joe-Pye Weed, Thoroughwort, Boneset, WHITE SNAKE-ROOT.}

Ours erect branching perennial herbs, with opposite or verticillate, often punctate leaves, cymose-paniculate heads, and white to purple flowers. Involucre oblong to hemispheric, its bracts imbricate in 2-several series. Receptacle from flat to conic, naked. Ray-flowers none. Corolla of the disk-flowers regular, with slender tube and 5-lobed limb. Anthers obtuse at the base, appendiculate at the tip. Style-branches elongate, flattened, or thickened above, stigmatic at the base. Achenes 5-angled, truncate at the apex. Pappus simple, of numerous capillary seabrous bristles.

Leaves verticillate in whorls of 3's; flowers pink or rose-colored.

Leaf-blades lanceolate, acuminate, strongly reticulate and rugose. 1. E. Bruneri.

Leaf-blades broadly ovate, acute, neither strongly reticulate nor rugose.

Leaves opposite; flowers white or slightly tinged with pink.

2. E. maculatum.

Achenes hispidulous on the angles.

Bracts unequal in length, distinctly ribbed only towards the base.

Bracts essentially equal in length, strongly ribbed to near the 3. E. texense.

the apex.

Achenes merely glandular-puberulent or glabrate. $\quad$ 4. E. arizonicum.

1. E. Bruneri A. Gray. Stem more or less canescent, 5-15 dm. high; leafblades serrate, scabrous above, velutinous beneath, 10-15 cm. long; bracts more or less purplish, the outer ovate, pubescent, the inner linear-oblong, glabrous, all rounded or obtuse at the apex; heads nearly $1 \mathrm{~cm}$. high. $E$. atromontanum A. Nels. E. Rydbergii Britton. Moist soil: Sask.-Ia.-Colo.-Utah-B.C. Plain-Submont. J1-S.

2. E. maculatum L. Stem scabrous or pubescent, at least above, 5-20 dm. high, striate, often spotted with purple; leaves ovate or the upper ovatelanceolate, acute, coarsely serrate, puberulent beneath and often pubescent on the veins above; bracts purplish, the outer ovate, rounded at the apex, the inner linear-oblong, acutish; heads about $1 \mathrm{~cm}$. high. Moist soil: N.Y.-Ky.-N.M. - Sask. Plain. Au-S.

3. E. texense (T. \& G.) Rydb. Shrubby at the base; stem $5-10 \mathrm{dm}$. high, puberulent; leaf-blades ovate, deltoid or cordate, coarsely dentate, triplenerved, more or less scabrous on both sides, 2-5 cm. long; inflorescence corymbiform-paniculate; heads $8 \mathrm{~mm}$. high; bracts in about 2 series, only slightly imbricate, lanceolate, acute, puberulent; flowers about 12. Rocky hills: Tex.-Colo. -Ariz. Son.-Submont. Jl-S.

4. E. arizonicum (A. Gray) Greene. Stems 3-7 dm. high, from a woody cespitose caudex, yellowish green, finely puberulent; leaf-blades ovate or cordate, $2-5 \mathrm{~cm}$. long, dentate, with small obtuse teeth, triple-nerved, minutely scabrous; inflorescence paniculate; heads about $7 \mathrm{~mm}$. high; bracts in 2 series, practically equal in length, scabrous-puberulent, lanceolate. $E$. occidentale arizonicum A. Gray. Cañons: s Utah-N.M.-s Calif. L. Son. Au-O.

5. E. occidentale Hook. Stems $2-5 \mathrm{dm}$, high, finely puberulent or glabrate; leaf-blades ovate, rounded or truncate at the base, 2-5 cm. long, triple-nerved, minutely scabrous-puberulent, more or less dentate; heads paniculate, $7-8 \mathrm{~mm}$. high; bracts in two series, equal, puberulent, faintly ribbed. Rocky places: Wash.-Ida.-n Utah-Calif. Son. Jl-S. 


\section{ColeosánthuS Cass.}

Herbs or shrubs, with opposite or alternate leaves. Heads discoid with white, ochroleucous or pink flowers, paniculate, cymose, or rarely solitary. Involucre campanulate or oblong, its bracts striate, imbricate in several series. Receptacle flat or convex, naked. Disk-corollas regular, slender, 5-lobed. Anthers. obtuse at the base. Style-branches elongate, obtuse, thickened upwards. Achenes 10-ribbed. Pappus simple, of numerous, long, scabrous or barbellate bristles. [Brickellia Ell.]

Leaf-blades ovate-cordate or deltoid.

Leaves subsessile or short-petioled, ovate, veiny, spinulose-toothed, acuminate; bracts firm-chartaceous, $3-6 \mathrm{~mm}$. wide.

1. C. atractyloides.

Leaves slender-petioled, not spinulose-toothed; bracts thin, $2 \mathrm{~mm}$. wide or less. Heads 30-50-flowered.

Leaves thin, minutely puberulent; their teeth usually broadly triangular, acute; peduncles usually longer than the heads.

2. C. grandiflorus.

Leaves thicker, densely scabrous-pubescent, veiny, their teeth rounded-ovate, obtuse or mucronate. $\quad 3$. C, umbellatus.

Heads 9-25-flowered.

Tips of the bracts not spreading; leaf-blades $2-5 \mathrm{~cm}$. long. Leaves distinctly petioled; blades subcordate, $2-5 \mathrm{~cm}$. long.

Leaves firm, crenate-dentate. $\quad 4$. C. albicaulis.

Leaves thin, crenate.

5. C. tener

Leaves short-petioled; blades lanceolate, $1-4 \mathrm{~cm}$. long. 6. C. brachyphyllus.

Tips of the bracts squarrose-spreading; leaf-blades less than $1 \mathrm{~cm}$. long.

Leaves on the peduncles many, passing into the bracts; inner bracts much longer than the outer ones; upper parts of the plant velutinous and glandular.

Stem and pedicels glandular-villous; head about $13 \mathrm{~mm}$. high, 20-24flowered; achenes 4-4.5 mm. long.

Stem lanulose; heads about $11 \mathrm{~mm}$. high, about 1-8-flowered; achenes about $3.5 \mathrm{~mm}$. long. 8 . C. Watsonii.

Leaves on the peduncles few; bracts gradually increasing in length up-
wards; plant scabrous-puberulent.
9. . scaber. Leaves linear or oblong, sessile.
wards; plant scabrous-puberulent.

Heads 30-40-flowered.

Achenes glandular; bracts comparatively firm.
Achenes hispidulous on the angles, not glandular; bracts thin.

Heads 3-5-flowered.

11. C. linifolius.

12. C. longifolius.

1. C. atractyloides (A. Gray) Kuntze. A shrub, 2-5 dm. high, divaricately branched; young branches straw-colored and shining; heads solitary, $1.5 \mathrm{~cm}$. high; involucre campanulate; bracts ovate, acuminate, puberulent. $C$. venulosus A. Nels. Brickellia atractyloides A. Gray. Rocky ravines: s Utah-Ariz.-Calif.Nev. L. Son. Ap-Je.

2. C. grandiflorus (Hook.) Kuntze. Stem 6-10 dm. high, paniculately branched, puberulent or glabrate, straw-colored; head paniculate-cymose, nodding, 12-15 mm. high; lower bracts ovate, abruptly acuminate, the inner linearoblong, obtuse or acutish; pappus-bristles scabrous. Brickellia grandiflora Nutt. Cañons, badlands, and draws: Alta.-Colo.-Utah-Ore.-Wash. Submont.Mont. Jl-S.

3. C. umbellatus Greene. Stems 3-6 dm. high, minutely puberulent; leafblades deltoid, 3-6 cm. long, seabrous-puberulent; heads nodding in congested, umbel-like clusters, 10-12 mm. high; outer bracts ovate, pubescent and ciliateacuminate, the innermost linear. C. congestus A. Nels. C. Garrettii A. Nels. C. minor (A. Gray) Daniels. Brickellia grandiflora minor A. Gray. Hillsides and eañons: N.M.-Ariz.-Wyo, Submont.-Mont. JI-S.

4. C. albicaulis Rydb. Shrubby at the base, 0.5-1 m. high; bark of the younger branches straw-colored or grayish, hirsute-puberulent; leaves shortpetioled; blades broadly cordate, strongly veined, thick, scabrous-puberulent, crenate-dentate; heads 2-6, in small axillary clusters on short peduncles, $10-20$ flowered; lower bracts short-ovate, the inner linear, all acutish or obtuse; corolla cream-colored; pappus white. Cañons and foothills: Colo--Utah-N.M. Submont.-Mont. Au-S.

5. C. tener (A. Gray) Kuntze. Shrubby at the base; leaves petioled; blades long-ovate, abruptly contracted at the base, $3.5-4.5 \mathrm{~cm}$. long, crenate; 
heads similar to those of the preceding, mostly clustered in the axils. B. tenera A. Gray. Cañons: N.M.-Utah-Nev.-Ariz.; Mex. Submont.

6. C. brachyphyllus (A. Gray) Kuntze. Stem slender, from a slightly woody caudex; leaves lanceolate, acute, slightly serrate or entire, 1-4 cm. long, 3 -nerved; inflorescence lax; heads about $1 \mathrm{~cm}$. high, $4 \mathrm{~mm}$. thick, about 9-flowered; bracts 16-17, acuminate, 5-7-striate, ciliolate; achenes hirsute; pappus-bristles short-plumose. B. brachyphylla A. Gray. Hills: N.M.-sw Colo.-Ariz. Son. -Submont.

7. C. microphyllus (Nutt.) Kuntze. A shrub, 3-6 dm. high, with ascending branches, densely short-pilose and glandular; leaves round-ovate, dentate, thick, 1-2 cm. long, densely glandular-puberulent; heads obconic, 12-14 mm. high; lower bracts ovate, thick; the inner two rows linear; achenes 4-4.5 $\mathrm{mm}$. long, hispidulous on the angles. B. microphylla (Nutt.) A. Gray. Dry soil: Ore.Ida.-Calif. Son.-Submont. Au.

8. C. Watsonii (B. L. Robins.) Rydb. Shrubby, 4-6 dm. high; stem and peduncles softly lanulate or crisp-puberulent; branches spreading; leaves as in preceding species; head about $11 \mathrm{~mm}$. high, 18-flowered; achenes about $3.5 \mathrm{~mm}$. long. B. Watsonii B. L. Robins. Mountains: Utah-Nev.-Calif. Submont.

9. C. scaber (A. Gray) Greene. A shrub 4-6 dm. high, with slender ascending branches, scabrous-puberulent and more or less viscid; leaves sessile, broadly ovate, coarsely dentate, $5-10 \mathrm{~cm}$. long, 3-ribbed, scabrous; heads obconic, $1 \mathrm{~cm}$. high; bracts thin, the lower lanceolate, the inner linear, erect, wholly chartaceous; flowers 10-12; achenes scabrous-hispidulous on the angles. B. microphylla scabra A. Gray. Mountains and dry soil: s Wyo.-N.M.-Ariz.-Nev. Submont.

10. C. oblongifolius (Nutt.) Kuntze. Perennial, with a cespitose woody caudex; stems 2-4 dm. high, straw-colored, puberulent; leaves elliptic, oblong, or linear, glandular-puberulent, firm, more or less triple-nerved; heads about 2 $\mathrm{cm}$. high, obconic-campanulate; bracts glandular-puberulent, acute, the outer ovate-lanceolate, the inner linear. B. oblongifolia Nutt. River banks: B.C.Mont,-Utah-n Calif. Je-Au.

11. C. linifolius (D. C. Eat.) Kuntze. Perennial, with a cespitose woody caudex; stems 2-4 dm. high, densely short-pubescent, subvelutinous; leaves linear-lanceolate or linear, densely puberulent; heads obconic-campanulate, about $15 \mathrm{~mm}$. 'high; bracts linear-lanceolate or linear, attenuate, thin. C, humilis Greene. Brickellia linifolia D. C. Eat. Dry places: Calif,-s Colo.-N.M. Son. -Submont. My-Jl.

12. C. longifolius (S. Wats.) Kuntze. Suffruticose perennial; branches leafy, straw-colored; leaves lance-linear, 3-nerved, 2-7 cm. long, 4-6 mm. wide; heads $5-6 \mathrm{~mm}$. long, obconic; bracts oblong to linear, obtuse; achenes glabrous or nearly so. B. longifolia S. Wats. Dry regions: Ariz. $-\mathrm{s}$ Utah $\rightarrow \mathrm{s}$ Nev.Calif. Son.

\section{KÜHnia L. False Boneset.}

Perennial herbs, with alternate resinous-dotted leaves. Heads discoid, cymose-corymbose with white or purplish flowers. Involuere narrow, turbinatecampanulate, its bracts striate, imbricate in several unequal series. Disk-corollas regular; tube slender; limb 5-cleft. Anthers obtuse and entire at the base, almost distinct. Receptacle flat, naked. Style-branches thickened upwards, obtuse, stigmatic only at the base. Achenes 10-20-costate. Pappus simple, of numerous plumose bristles.

Leaves oblong or lanceolate, 3-ribbed, more or less toothed.

Leaves densely puberulent beneath. Inner bracts abruptly acute or cuspidate.

Inner bracts gradually acuminate.

Leaves glabrous or nearly so beneath.

Leaves linear, 1-ribbed, entire.

1. K. glutinosa.

2. K. Hitchcockii.

3. K. reticulata.

4. K. leptophylla.

1. K. glutinosa Ell. Stem erect, 3-6 dm. high, puberulent and somewhat viscid; leaves sessile, lanceolate or ovate-lanceolate, puberulent on both sides, 
usually sharply dentate, veiny, $3-7 \mathrm{~cm}$. long; heads numerous, $12-16 \mathrm{~mm}$. high; outer bracts lanceolate, attenuate; pappus tawny. $K$. eupatorioides corymbulosa T. \& G. Dry prairies and plains: Ill--Ala,-Tex,-Colo--Mont. Plain. $\mathrm{Je}-\mathrm{O}$.

2. K. Hitchcockii A. Nels. Stem decumbent, divaricately branched, minutely puberulent; leaves lanee-linear or linear, puberulent, entire or with few sharp teeth, 3-4 cm. long; outer bracts linear-lanceolate, long-attenuate, or the inner narrowly linear; pappus tawny. Dry plains: Kans.-Colo. Plain. Au-S.

3. K. reticulata A. Nels. Stems $3-4 \mathrm{dm}$. high, finely puberulent; leaves puberulent on the upper side and on the veins beneath, punctate, strongly reticulate-veined beneath, oblong-lanceolate, $2-4 \mathrm{~cm}$. long, irregularly toothed or entire; bracts in 4-5 series, shorter than the disk, the outer short, lanceolate, the inner broadly linear, acute; pappus white. Cañons: Wyo. Submont. Au.

4. K. leptophylla Scheele. Stems 5-8 dm. high, striate and minutely puberulent; leaves numerous, minutely puberulent, linear or lance-linear, $2-4 \mathrm{~cm}$. long, entire or nearly so, revolute-margined; inflorescence paniculate; bracts in 5 series, the outer short, lanceolate, the inner linear, cuspidate; achenes strigose; pappus dingy white. $K$. Gooddingii A. Nels. Rocky hills: Colo.-Tex.-Ariz. Son.-Submont. Jl-S.

\section{Laciniària Hill. Blazing Star, Button Snake-root.}

Perennial herbs, with a globular corm or thickened rootstock. Leaves narrow, entire, alternate, more or less punctate. Heads discoid, racemose or spicate, with rose-purple or rarely white flowers. Involucre oblong to hemispheric; bracts more or less herbaceous, not striate, imbricate in several unequal series, Receptacle flat or nearly so, naked. Anthers obtuse at the base. Style-branches elongate, obtuse, flattened at the end, stigmatose only at the base. Achenes 10-ribbed, slender, tapering to the base. Pappus 1-2 series of equal, firm, plumose or barbellate bristles. [Liatris Schreber.]

Pappus plumose.

Heads 15-60-flowered; corolla-lobes hairy within.

Heads 4-6-flowered; corolla-lobes glabrous within. Pappus merely barbellate.

Heads few, hemispheric, 15-45-flowered.

Heads in a short raceme-like or corymbiform inflorescence; bracts obovate, with a dark rose-purple laciniate apex; leaves usually glabrous. 3 . L. ligulistylis.

Heads in a long spike-like inflorescence; bracts spatulate or obovate-oblanceolate, with a pale merely erose apex; leaves usually hispidulous or crisp-hairy.

Heads oblong, 3-15-flowered, numerous in a long spike. Bracts obtuse, appressed.

Bracts acute, their tips spreading.

1. L. squarrosa.

2. L. punctata.

1. L. squarrosa (L.) Hill, Stems often tufted, pubescent, 1-6 dm. high; leaves numerous, linear, $3-30 \mathrm{~cm}$. long, often with scattered hairs; heads solitary or few, subtended by bract-like leaves; involucres cylindric, $1.5-2 \mathrm{~cm}$. high; bracts lanceolate or oblong or linear-acuminate, squarrose-spreading. Liatris squarrosa (L.) Willd. Sandy soil: Ont.-Fla.-Tex,-Colo.-Minn. Plain. Jl-S.

2. L. punctata (Hook.) Kuntze. Stem glabrous or nearly so, 2-7.5 dm. high; leaves strongly punctate, 1-nerved, ciliate on the margins, otherwise glabrous, linear; spike dense, elongate, $5-15 \mathrm{~cm}$. long; heads $12-16 \mathrm{~mm}$. long, sessile; involucres narrowly campanulate; bracts cuspidate or acuminate, eiliate on the margins; flowers purple or rose. Liatris punctata Hook. Dry plains and hills: Sask.-Ia.-Tex.-Ariz.-Alta. Plain-Mont. Au-O.

3. L. ligulistylis A. Nels. Stem glabrate below, white-pubescent above, striate, $3-5 \mathrm{dm}$. high; leaves bright green, obscurely punctate, linear-oblanceolate, ciliolate on the margins, 5-12 $\mathrm{em}$. long; heads $15-20 \mathrm{~mm}$. high, broadly campanulate or hemispheric; bracts orbicular or oval; flowers $50-70$, purple. $L$. formosa Greene. Hills: Man.-S.D.-Colo-Alta. Plain-Submont. J-Au.

4. L. aspera (Michx.) Greene. Stem 3-10 dm, high, crisp-hairy especially above; leaves numerous, the lower linear-oblanceolate, the upper linear; heads globose-campanulate, $15-18 \mathrm{~mm}$. high; bracts orbicular or oval. Liatris aspera 
Michx. L. scariosa Auth., not L. Prairies: Wis.-Mo.-Kans,-N.D. Plain. $\mathrm{Au}-\mathrm{S}$.

5. L. spicata (L.) Kuntze. Stem 3-18 dm. high, glabrous or nearly so; leaves numerous, linear, obtuse, $5-30 \mathrm{~cm}$. long, obscurely punctate, glabrous: heads very numerous, campanulate, about $1 \mathrm{~cm}$. high; spike 2-4 dm. long; bracts oblong, scarious-margined at the apex; flowers purple, rarely white. L. kansana Britton. Liatris spicata (L.) Willd. Moist soil: Mass.-Fla.-La.-Colo. Plain. $\mathrm{Au}-\mathrm{O}$.

6. L. pycnostachya (Michx.) Kuntze. Stem more or less hirsute above, 6-15 dm. high, very leafy; leaves linear or lance-linear, attenuate at the apex, often $3 \mathrm{dm}$. long; heads 3-6-flowered, 8-12 $\mathrm{mm}$. long; bracts oblong, pubescent and ciliate, purple-tinged; flowers purple. Liatris pycnostachya Michx. Prairies: Wis.-Ky.-La.-Tex.-S.D. Plain. Au-S.

\section{GUTIERRÈZIA Lag. BRown-weEd.}

Annual or perennial herbs or shrubs, with glutinous foliage. Leaves alternate, narrow, entire. Heads radiate, usually many, clustered in terminal corymbs. Involucres campanulate, oblong, or clavate, few- or many-flowered, small; bracts leathery, imbricate in few series. Ray-flowers few, pistillate, fertile. Diskflowers hermaphrodite, perfect, or the central ones sometimes sterile; corollas yellow. Anthers obtuse at the base. Stigmas flattened; appendages narrow. Achenes obovate or oblong, terete or 5-angled; pappus of many short scales or that of the ray-flowers sometimes wanting.

Disk- and ray-flowers in the head 4-7 each.

Surface of the leaves marked with large dots, each bordered by a hyaline scale.

Surface of the leaves not lepidote, either puberulent or glabrous. Axils of the leaves with fasciculate branches.

Axils of the leaves without fasciculate branches.

1. G. lepidota.

Plant ligneous only at the short persistent caudex.

Leaves linear, usually $1.5-4 \mathrm{~mm}$. wide.

Involucres oblong-turbinate, over $5 \mathrm{~mm}$. high; outer bracts lanceolate; stems 3-4 dm. high.

3. G. scoparia.

Involucres campanulate, somewhat turbinate at the base, less than 5 $\mathrm{mm}$. high; bracts ovate; stems 1-2 dm. high. 4 . G. diversifolia.

Leaves linear-filiform, less than $1 \mathrm{~mm}$. wide.

Ligules of the rays nearly as long as the involucre. $\quad 5$. G. filifolia.

Ligules of the rays about half as long as the involucre.

Heads usually peduncled and solitary at the ends of the branches.

6. G. divaricata.

Heads usually subsessile in clusters of 3-4 at the ends of the branches. Plant low, 1-2 dm. high; branches green; leaves 1-2 cm. long.

7. G. juncea.

Plant shrubby.

Plants 2-5 dm. high; branches with straw-colored or gray bark; leaves $3-4 \mathrm{~cm}$. long.

8. G. Sarothrae.

Involucres elongate, clavate-turbinate, $2-3 \mathrm{~mm}$. wide; bracts oblong.

9. G. longifolia.

Involucres campanulate, only slightly turbinate at the base, $3-4 \mathrm{~mm}$. wide; outer bracts ovate or obovate.

Disk- and ray-flowers in the head only 1-2 each.

10. G. linearis.

11. G. glomerella.

1. G. lepidota Greene. Stem about $4.5 \mathrm{dm}$. high, glabrous; lower leaves narrowly oblanceolate, obtuse, the upper linear, all ascending, scabrous on the margins; heads corymbose-paniculate; involucres about $6 \mathrm{~mm}$. high, turbinate; bracts in 4 series, with thick blunt tips; ray- and disk-flowers each 6 or 7 , light yellow; pappus squamellae lanceolate, acute. Perhaps belonging to some other genus. Plains: Grand Junction, Colo. Son. Au.

2. G. fasciculata Greene. Stem shrubby below, 3-5 dm. high, sparingly scaberulous; leaves few, widely spreading, linear; axillary fascicled branches often bearing a single head; involucre oblong-clavate, $4 \mathrm{~mm}$. high; bracts in 4 series, the outer with stout green tips; disk- and ray-flowers each 5, pale yellow; achenes silky; pappus squamellae lanceolate. Valleys: Colo. Son. Au.

3. G. scoparia Rydb. Plant woody only at the base, about $3 \mathrm{dm}$. high; branches numerous, puberulent, mostly simple up to the inflorescence; leaves linear, $3-5 \mathrm{~cm}$. long, 1-2 $\mathrm{mm}$. wide, puberulent; inflorescence corymbiform; 
heads subsessile, $2-5$ together; disk- and ray-flowers each about 4 . Dry plains: Wyo.-Colo. Submont. S-O.

4. G. diversifolia Greene. Stems 1-2 dm. high, angled, scabrous; lower leaves often oblanceolate, the rest linear, $2-4 \mathrm{~cm}$. long, about $2 \mathrm{~mm}$. wide, scabrous; inflorescence corymbiform; heads subsessile, clustered; bracts oblong, with thick, obtuse or acutish tips; ray-flowers 5 or 6 , disk-flowers 8-10. (?) $G$. viridifolia Greene. Plains: Sask.-N.M.-Utah-Alta. Submont. J-S.

5. G. filifolia Greene. Stems 3-6 dm. high, puberulent; leaves 1-4 cm. long, scabrous-puberulent; involucres obovoid-turbinate, 3-4 mm. long; outer bracts ovate, acute, green-tipped, the inner obtuse, apiculate, scarcely at all green; ligules about $3 \mathrm{~mm}$. long; ray- and disk-flowers each 3 or 4 . Dry plains: Ida.N.M.-Ariz.-Nev. Plain-Submont. Au-O.

6. G. divaricata (Nutt.) T. \& G. Stem 2-4 dm, high, branched, glabrous or nearly so; leaves $1-2 \mathrm{~cm}$. long, about $0.5 \mathrm{~mm}$. wide, glabrous, spreading; involucre turbinate obconic, 4-5 mm. high; bracts lanceolate, acute, green-tipped; ray-flowers 5 or 6 ; ligules $2 \mathrm{~mm}$. long; disk-flowers 5-8. Plains: Wyo.-Tex.Utah. Plain-Submont. Au-S.

7. G. juncea Greene. Stems 1-2 dm. high; leaves $0.5 \mathrm{~mm}$. wide, puberulent, spreading, early deciduous; inflorescence corymbiform; involucre turbinate, $3 \mathrm{~mm}$. long; bracts ovate, acute, green-tipped except the innermost; ray- and disk-flowers each 4 or 5. Dry hills and plains: Okla.-Colo.-Ariz.-Tex. Plain-Mont. Jl-Au.

8. G. Sarothrae (Pursh) Britt. \& Rusby. Stems 1-3 dm. high; leaves puberulent; heads numerous in flat-topped cymes; involucres turbinate, $4 \mathrm{~mm}$. high; bracts oblong, acute, slightly green-tipped; ray-flowers 3-5; ligules 1.5-2 mm. long; disk-flowers 2-5. G. Euthamiae T. \& G. G. myriacephala A. Nels. Dry plains: Sask.-Kans.-Utah-Alta. Plain-Submont. J-S.

9. G. longifolia Greene. Shrub 5-10 dm. high; young branches scabrouspuberulent or nearly glabrous; leaves linear, $3-6 \mathrm{~cm}$. long, $1-2 \mathrm{~mm}$. wide, slightly scabrous; inflorescence ample, flat-topped; heads subsessile, often 2 or 3 together; involucre 4-6 mm. high; bracts with thick green obtuse or acutish tips; ray- and disk-flowers each 4 or 5 . Dry hills and plains: Colo.-Utah-N.M.-Tex. Plain-Submont. Au.

10. G. linearis Rydb. Shrubby and branched, $3-6 \mathrm{dm}$. high; leaves linear, about $3 \mathrm{~cm}$. long, 1-2 mm. wide, puberulent and viscid, punctate; heads $5-6$ $\mathrm{mm}$. high; bracts scarious-margined; inflorescence corymbiform; heads subsessile, 2 or 3 together; ray- and disk-flowers each 3-4. Plains: Neb.-Kans.-N.M.Colo. Plain-Submont. J-S.

11. G. glomerella Greene. Suffruticose, fastigiately branched, 4-6 dm. high; branches of the season striate, glabrous; leaves linear-filiform, $2-4 \mathrm{~cm}$. long, about $1 \mathrm{~mm}$. wide, scabrous-puberulent; inflorescence corymbiform; heads sessile, 2-5 together; involucres oblong, $2 \mathrm{~mm}$. high; bracts glutinous, oblong, obtuse. Dry plains: Tex.-Colo.-Ariz. Plain-Son. Au-S.

\section{AMPHIPÁPPUS T. \& G.}

Shrubs with glabrous foliage. Leaves alternate, small, entire. Heads numerous, conglomerate in small clusters forming a corymb, radiate; involucres campanulate, few-flowered; bracts leathery, imbricate in few series. Ray-flowers 1 or 2, short, pistillate and fertile. Disk-flowers hermaphrodite, but sterile, with rudimentary glabrous ovaries. Achenes of the ray-flowers pubescent; pappus of few and short bristles or scales, united at the base. Pappus of the diskflowers of about 20 flattish denticulate-hispidulous tortuose bristles, some of them branching or irregularly paleaceous-concreted at the base.

1. A. Fremontii T. \& G. A shrub $3-6 \mathrm{dm}$. high with rigid white branches; leaves obovate or spatulate, about $1 \mathrm{~cm}$. long; heads sessile and glomerate; involucres campanulate, $4 \mathrm{~mm}$. high; bracts $7-9$, thin, oval, without green tips; rayflowers 1 or 2, short; disk-flowers 3-6. Amphiachyris Fremontii A. Gray. Desert regions: s Calif.-Nev. - s Utah. L. Son. 


\section{GRINDÈLIA Willd. GUM-Plant, Resin-Weed.}

Coarse biennial or perennial herbs (some western species even shrubby), usually with glabrous and glutinous foliage. Leaves alternate, usually spinulose-toothed. Heads relatively large, radiate or rarely discoid, often corymbose, many-flowered. Involucres hemispheric or depressed; bracts imbricate, usually with subulate spreading or recurved tips and mostly gummy; receptacle pitted. Ray-flowers pistillate, fertile, with yellow ligules, or rarely wanting. Disk-flowers hermaphrodite, usually fertile; corolla yellow. Stigmas narrow, flattened, with linear or lanceolate appendages. Achenes 4-5-ribbed, sometimes flattened; pappus of $2-8$ awns or bristles, early deciduous.

\section{Involucres not viscid.}

Involucres more or less viscid.

\section{G. platylepis.}

Leaves all entire, the basal ones 3-4 dm. long; bracts narrowly linear-lanceolate, the outer nearly filiform, rather thin.

2. G. oregana.

Leaves, at least the basal ones, more or less dentate, the latter less than $2 \mathrm{dm}$. long; bracts lanceolate, with thick, rather fleshy tips.

Heads radiate.

Pappus-awns apparently smooth; barbules seen only under a compound microscope.

Tips of the outer bracts spreading, none reflexed.

Stem-leaves serrate. Stem-leaves laciniate.

3. G. decumbens.

Tips of the bracts squarrose, those of the outer ones strongly reflexed. Stem-leaves oval, ovate, or ovate-oblong with a broad base.

Leaves bluish green, spinulose-dentate; heads very broad and flat, its bracts broad and even the squarrose tips flattened.

Leaves yellowish green, merely dentate; heads hemispherical, its bracts narrow and with terete squarrose tips. 6. G. squarrosa. Stem-leaves oblanceolate, rarely oblong.

Pappus-awns scarcely longer than the achenes, curved and twisted. Squarrose tips of the bracts short; leaves subentire.

Squarrose tips of the bracts long and slender; leaves serrate, with spreading teeth.

Pappus-awns decidedly longer than the achenes, straight. Leaves all finely serrate, dentate or subentire.

Leaves finely and closely serrate.
Leaves rather remotely dentate or subentire.

10. G. perennis.

Leaves coarsely toothed, the basal-ones sublaciniate.

11. G. subincisa.

Pappus-bristles distinctly barbellate; barbules distinctly seen with a common pocket-lens.

Stems tall, 4-8 dm. high, usually solitary; stem-leaves broadly oblong or obovate; bracts broad, only the outer ones squarrose-reflexed.

12. G. erecta.

Stems low, about $3 \mathrm{dm}$. high, usually several from the base; stem-leaves Heads discoid. oblanceolate or oblong; all bracts squarrose. 13 . G. subalpina.

Stem-leaves oval or obovate.

Stem-leaves oblanceolate or oblong.

Outer bracts strongly recurved, the inner not squarrose, 15. G. fastigiata.

All bracts squarrose.

Bracts long and loose, but not strongly recurved.

Bracts short, strongly recurved-curled.

16. G. aphanactis.

17. G. columbiana.

1. G. platylepis Greene. Perennial; stem about $5 \mathrm{dm}$. high, glabrous; leaves oblanceolate or oblong; involueres hemispheric, subtended by one or two leafy bracts; bracts oblong, abruptly herbaceous-tipped, not viscid; ligules broad, oblong, obtuse; pappus-bristles subulate, barbulate. Hills: Wyo. Submont.

2. G. oregana A. Gray. Perennial; stem $3-10 \mathrm{dm}$. high, sparingly puberulent or glabrous; basal leaves narrowly oblanceolate, entire or slightly denticulate, 1-2 dm. long, glabrous; stem-leaves lanceolate, oblong or oblanceolate; involucre about $15 \mathrm{~mm}$. high and $15-20 \mathrm{~mm}$. broad; ligules numerous, $15-20 \mathrm{~mm}$. long; pappus-bristles 3-4 mm., smooth, curved. Dry grounds: B.C.-Ida.Ore. Submont. Л-Au.

3. G. decumbens Greene. Perennial, with a cespitose caudex; stem 2-5 $\mathrm{dm}$. high, more or less decumbent at the base; basal leaves oblanceolate, obtuse, serrate towards the summit; stem-leaves oblong, acute, entire or denticulate; 
involucres $8 \mathrm{~mm}$. high, $10-12 \mathrm{~mm}$. broad; bracts subulate; ligules $8 \mathrm{~mm}$. long; pappus-bristles straight, $4 \mathrm{~mm}$. long, barbellate above. Plains: Kans.-Colo.N.M. Plain-Submont. J1-Au,

4. G. laciniata Rydb. Low perennial; stems slender, several, $3-5 \mathrm{dm}$. high; lower leaves narrowly linear-oblanceolate, $1 \mathrm{~cm}$. long, $3-5 \mathrm{~mm}$. wide, sparingly dentate; stem-leaves irregularly pinnately lobed or laciniate, with narrow lanceolate divisions; involucre hemispheric, $10-12 \mathrm{~mm}$. broad; bracts lanceolate, with short subulate spreading tips; ligules $5-8 \mathrm{~mm}$. long, numerous; pappus-bristles curved, $3 \mathrm{~mm}$. long. Mesas: se Utah. Son.-Submont. Jl-Au.

5. G. texana Scheele. Perennial; stem stout, 4-10 dm. high, glabrous or nearly so, straw-colored; basal leaves oblanceolate; stem-leaves obovate or oval, $3-8 \mathrm{~cm}$. long; involucre $1 \mathrm{~cm}$. high, $2 \mathrm{~cm}$. wide; ligules $12-15 \mathrm{~mm}$. long; pappusbristles straight, slender, $5 \mathrm{~mm}$. long. G. squarrosa grandiflora A. Gray, in part. Plains: Colo.-Tex.-N.M. Plain-Submont. Au-O.

6. G. squarrosa (Pursh) Dunal. Biennial or perennial; stem 3-6 dm. high, corymbosely branched; basal leaves oblanceolate; stem-leaves oval, oblongovate, or ovate, broad at the base; involueres $8-10 \mathrm{~mm}$. high, $15-20 \mathrm{~mm}$. broad; ligules 8-10 mm. long. Prairies and plains: Sask.-Ia.-Kans.-Ariz.-Ida. Plain-Submont. Au-S.

7. G. integerrima Rydb. Perennial, with a cespitose base; stems about 3 dm. high, glabrous, somewhat angled; leaves narrowly oblanceolate, $2-4 \mathrm{~cm}$. long, acute, strongly resinous-dotted; heads numerous, corymbose; involucre about $7 \mathrm{~mm}$. high and $1 \mathrm{~cm}$. wide; ligules $6-7 \mathrm{~mm}$. long. Sandy soil: Ida. Jl.

8. G. Brownii Heller. Perennial, with a cespitose caudex; stems $3-6 \mathrm{dm}$. high, red or purplish, glabrous; leaves spatulate or oblanceolate, acute, $3-5 \mathrm{~cm}$. long; involucres $8 \mathrm{~mm}$. high, $10-12 \mathrm{~mm}$. broad; ligules $6 \mathrm{~mm}$. long. Plains: Ida. Ore. Plain. Jl-S.

9. G. serrulata Rydb. Biennial or perhaps short-lived perennial; stem glabrous, about $6 \mathrm{dm}$. high; leaves sessile, oblanceolate or oblong, acutish, very viscid, 3-5 cm. long; involucre very viscid, about $15 \mathrm{~mm}$. broad; ligules $7-8 \mathrm{~mm}$. long, 1-1.5 mm. wide. Plains and hills: N.M.-Wyo.-Utah. Plain-Submont. Jl-S.

10. G. perennis A. Nels. Perennial, sometimes cespitose at the base; stem paniculately branched, $3-5 \mathrm{dm}$. high, glabrous; leaves entire or remotely dentate, oblanceolate, 4-7 cm. long, the upper sessile and clasping; involucres nearly $1 \mathrm{~cm}$. high, $12-20 \mathrm{~mm}$. broad; ligules 8-10 mm. long. Plains and hills: Sask.Colo.-Ida.-Alta. Submont. Jl-S.

11. G. subincisa Greene. Perennial, with cespitose base; stems decumbent below, glabrous; basal leaves narrowly oblanceolate, $8-12 \mathrm{~cm}$. long, glabrous or nearly so, pinnately cleft or incised; stem-leaves oblong-lanceolate, sessile, coarsely toothed; heads few; involucres about $1 \mathrm{~cm}$. high and $2 \mathrm{~cm}$. broad; ligules 8-10 mm. long. Hills: Colo.-N.M.-Ariz. Submont. J-S.

12. G. erecta A. Nels. Biennial; stem glabrous throughout; leaves ample, serrate, the lower oblanceolate, $6-10 \mathrm{~cm}$. long; heads many; involucres about $1 \mathrm{~cm}$. high and $1.5 \mathrm{~cm}$. wide; bracts lanceolate, only the outer with squarrose, terete tips; ligules 14-18 mm. long. Mountains: Wyo.-Colo. Submont.Mont. Au-S.

13. G. subalpina Greene. Low perennial; stem 2-4 dm. high; basal leaves oblanceolate, coarsely and remotely toothed, scabrous-puberulent; involueres 8 $\mathrm{mm}$. high, $12-15 \mathrm{~mm}$. wide; rays many, 8-10 mm. long. (?) G. Eldorae Daniels. Mountains: Mont.-N.M.-Utah-B.C. Submont.-Mont. JI-S.

14. G. inornata Greene. Perennial; stems several from the woody root, low and stout; basal leaves oblanceolate, short-petioled, all saliently toothed all around; involucres hemispheric, large; bracts all squarrose; pappus-bristles barbellate below the very acute apex. Cañons: Colo.

15. G. fastigiata Greene. Perennial, sometimes suffruticose; stem 6-10 dm. high, glabrous; basal leaves oblanceolate, acute, remotely serrate; stem- 
leaves similar, but sometimes entire; heads small, rayless; involucres nearly 1 $\mathrm{cm}$. high and broad; pappus-bristles barbellate. Hills: w Colo.-N.M.-Utah. Son. Au-S.

16. G. aphanactis Rydb. Apparently perennial; stem 3-4 dm. high, glabrous and striate; leaves very viscid, oblanceolate, acute, 4-7 cm. long, sharply dentate and sessile, or the lower more or less pinnatifid and petioled; heads about $15 \mathrm{~mm}$. broad; bracts very viscid, subulate; awns of the pappus apparently smooth. Sandy soil: sw Colo.-se Utah-N.M. Son. Jl.

17. G. columbiana (Piper) Rydb. Perennial, cespitose at the base; stems about $3 \mathrm{dm}$. high, glabrous; leaves oblanceolate, denticulate, $3-6 \mathrm{~cm}$. long; heads numerous, rayless; involucres $8-10 \mathrm{~mm}$. high, 10-15 mm. broad; pappusbristles curved and twisted. G. discoidea Nutt., not H. \& A. Sandy places: Wash.-Ida.-Ore. Son. Au.

\section{VANCLÈVEA Greene.}

Low tufted desert shrubs, with white shreddy bark and entire leaves. Heads discoid. Involucre turbinate; bracts squarrose, acuminate, very gummy. Diskflowers hermaphrodite and fertile; corollas yellow, club-shaped, with 5 erect teeth. Style elongate; branches long, sub-terete, papillose-puberulent. Achenes prismatic, villous-hirsute. Pappus of about 12 narrowly linear acute squamellae, ciliate on the margins, persistent.

1. V. stylosa (Eastw.) Greene. Stems 6-10 dm. high, bushy; leaves 3nerved, linear-lanceolate, acuminate, $2-3 \mathrm{~cm}$. long, $2-3 \mathrm{~mm}$. wide, vertical by a twist at the base; heads corymbose, $15 \mathrm{~mm}$. high, $10 \mathrm{~mm}$. wide; pappus-scales $3 \mathrm{~mm}$. long, one-third $\mathrm{mm}$. broad. Grindelia stylosa Eastw. Sandy wastes: Utah. Son. Jl.

\section{ACAMPTOPÁPPUS A. Gray.}

Low shrubs, glabrous or obscurely puberulent, neither glandular nor resinous. Leaves small, linear, entire, without lateral veins. Heads terminal at the ends of the branches, discoid or radiate; involucres globose; bracts closely imbricate in 3 series, rounded-oval to oblong, scarious-margined, erose-fimbriate. Diskcorollas yellow, funnelform; style-branches with thickish subulate appendages. Aohenes round-turbinate, densely long-villous. Pappus equalling the corollas, of 15-18 flattened, rigid awns, slightly dilated at the end, and as many shorter setiform awns or bristles.

1. A. sphaerocephalus (Harv. \& Gray) A. Gray. Shrub 3-10 dm. high, with white striate bark; leaves oblanceolate, sessile, about $1 \mathrm{~cm}$. long, minutely puberulent; heads discoid, depressed-globose, $8-10 \mathrm{~mm}$. high; bracts strawcolored, with pale green spots, with scarious erose margins. Desert regions: Ariz. - s Utah-Calif. L. Son. My-Je.

\section{CHRYSÓPSIS Nutt. Golden Aster.}

Biennial or perennial (ours perennial with a cespitose caudex), caulescent herbs, usually conspicuously pubescent. Leaves alternate. Heads showy, golden yellow, radiate, or rarely discoid, mostly corymbose, many-flowered; bracts narrow, in several series, more or less imbricate; receptacle pitted. Rayflowers many, pistillate. Disk-flowers hermaphrodite and fertile. Stigmas with linear or subulate appendages. Achenes flattened. Pappus double, the outer series of small scales or bristles, the inner of numerous scabrous bristles.

\section{Heads radiate.}

Involucres strigose.

Heads sessile or subsessile, subtended by foliage-leaves. Leaves narrowly linear-oblanceolate, hirsute.

1. C. angustifolia.

Leaves oblanceolate, obovate, elliptic, or lanceolate, strigose at least when young, except in C. imbricata.

Plant about $1 \mathrm{dm}$. high or less; heads usually solitary. Involucres 5-8 $\mathrm{mm}$. broad; leaves less than $1 \mathrm{~cm}$. long.

Involucres 10-12 mm. broad; leaves $2-3 \mathrm{~cm}$. long. 2 . C. caespitosa. Plant 2-6 dm. high; heads corymbose. 
Leaves oblong or lanceolate, decidedly acute, those subtending the heads narrowly linear.

4. C. foliosa.

Leaves oblanceolate or obovate, those of the inflorescence elliptic or oval.

Disk of the heads about $15 \mathrm{~mm}$. broad; leaves strigose.

Inner bracts with subulate, usually brownish and spreading tips.

$\begin{array}{ll}\text { Inner bracts merely acute. } & \text { 5. C. caudata. } \\ \text { C. amplifolia }\end{array}$

Disk of the heads 10-12 $\mathrm{mm}$. broad; leaves hirsutulous.

7. C. imbricata.

Heads peduncled, naked or rarely subtended by one small leaf.

Plant less than $1 \mathrm{dm}$. high; heads solitary at the ends of the branches.

Plant 2-3 dm. high; heads more or less corymbose.

Heads long-peduncled; peduncles $2-7 \mathrm{~cm}$. long.

8. C. depressa.

Heads short-peduncled.

Plant finely silvery-canescent, scarcely at all hirsute.

10. C. mollis.

9. C. pedunculata.

Plant usually grayish-green, conspicuously hirsute on the stem; leaves hirsute-ciliate towards the base.

Most of the leaves sessile.

Leaves oblanceolate or obovate, obtuse or merely apiculate; disk of the heads $15-20 \mathrm{~mm}$. broad.

11. C. villosa.

Leaves narrowly oblanceolate, decidedly acute; disk $10-12 \mathrm{~mm}$. broad.

12. C. hirsutissima.

Most of the leaves distinctly petioled; disk $10-12 \mathrm{~mm}$. broad.

Involucre more than $1 \mathrm{~cm}$. high and broad; leaves oblanceolate. Involucre scarcely $1 \mathrm{~cm}$. high and broad; leaves linear-oblance-
olate.

Involucre hirsute or both hirsute and resinous-granuliferous.

14. C. floribunda.

Leaves lanceolate, acute or acuminate, sessile; plant densely hirsute with long white hairs.

15. C. barbata.

Leaves oblanceolate, oblong, obovate or oval; plant not conspicuously long-hairy.

Involucre densely hirsute, scarcely at all resinous-granuliferous.

Leaves short, 1-2 cm. long, obovate, nearly all sessile. 16. C. Butleri.

Leaves oblanceolate, the lower petioled.

Plant 1-2 dm. high; heads usually solitary and sessile.

Plant 2-3 dm. high; heads peduncled and corymbose.

17. C. pumila.

Disk of the heads 8-10 $\mathrm{mm}$. broad; leaves densely hirsute, not resinous, only the lower petioled. 18. C. columbiana.

Disk of the heads $12-18 \mathrm{~mm}$. wide; leaves distinctly resinous-granu-

liferous, nearly all petioled.
Involucre sparingly hirsute, copiously resinous-granuliferous.

19. C. grandis.

Upper leaves obovate, oval, only rarely oblong or broadly oblanceolate, sessile.

Heads sessile, subtended by oblong or obovate leaves.

Leaves numerous, ascending, $3-5 \mathrm{~cm}$. long; involucre about $1 \mathrm{~cm}$. high.

20. C. resinolens.

Leaves scattered, spreading, 1-2 cm. long; involucres $8-9 \mathrm{~mm}$. high.

Heads peduncled, naked or subtended by small linear leaves.

Leaves densely hispid, not conspicuously granuliferous.

Leaves conspicuously granuliferous, only sparingly hispidulous.

23. C. viscida.

Upper leaves as well as the lower oblanceolate, most of them petioled.

Leaves broadly oblanceolate; heads peduncled.

Leaves decidedly hairy, sparingly granuliferous.

Stem simple to near the top.

Stem profusely branched.

Leaves sparingly hairy, conspicuously granuliferous.

Leaves narrowly linea:-oblanceolate; heads subsessile.

24. C. asprella.

14. C. floribunda.

25. C. hispida.

26. C. stenophylla.

Heads discoid; leaves lanceolate, hispid-ciliate, otherwise glabrous, minutely granuliferous.

27. C. oregana.

1. C. angustifolia Rydb. Stems erect, $2-4 \mathrm{dm}$. high, canescent and more or less hirsute; leaves 2-5 cm. long, 2-5 mm. wide, acute, grayish-strigose, hispid-ciliate; involucres turbinate-campanulate, $8-10 \mathrm{~mm}$. high; bracts narrow and linear, acute; ligules about $1 \mathrm{~cm}$. long. C. stenophylla Britt. \& Brown, not Greene. Sandy places: Alta.-Kans. Plain. Au-S.

2. C. caespitosa M. E. Jones. Cespitose from a woody root, forming a mat; stems spreading, 5-8 cm. long, villous-hirsute; leaves spatulate, villouscanescent, apiculate; heads sessile; involueres $6 \mathrm{~mm}$. high; bracts ashy-strigose, 
the inner with purplish margins; ligules golden yellow, 5-6 $\mathrm{mm}$. long, 1-1.5 $\mathrm{mm}$. wide. Hills: s Utah. Son. My.

3. C. alpicola Rydb. Stems silky-villous, numerous; leaves oblanceolate, about $3 \mathrm{~cm}$. long, nearly all petioled, white-silky, strigose or the pubescence more spreading on the petioles; bracts linear-lanceolate, strigose or silky, acute; ligules about $8 \mathrm{~mm}$. long and $2 \mathrm{~mm}$. wide. C. Cooperi A. Nels. C. pumila Coult. \& Nels., not Greene. High peaks: Colo.-Wyo. Subalp.-Alp. J1-Au.

4. C. foliosa Nutt. Stem 3-6 dm. high, very leafy, canescent, strigose and hirsute; lower leaves oblanceolate, acute, $3-5 \mathrm{~cm}$. long, white silky-strigose on both sides, subsessile; heads subtended by linear bract-like leaves, about $1 \mathrm{~cm}$. high; bracts linear, acute, strigose. Sandy soil: Minn.-Kans.-Utah-Wash. Plain-Submont. Jl-Au.

5. C. caudata Rydb. Stems many, erect, hirsute with long white hairs; lower leaves oblanceolate, silky-strigose on both sides, $3-5 \mathrm{~cm}$. long; heads congested in small clusters at the end of the branches; bracts linear-lanceolate, hirsute-strigose; ligules bright yellow, about $12 \mathrm{~mm}$. long. Hills and mountains: Colo. Submont.-Mont. Jl-Au.

6. C. amplifolia Rydb. Stem 3-5 dm. high, often branched, pubescent and sparingly hirsute; lower leaves spatulate, strigose, obtuse or slightly mucronate, the uppermost cordate or truncate at the base, 3-4 cm. long, 12-15 mm. wide; inflorescence corymbiform; bracts hirsute-strigose, linear-lanceolate, acute; ligules about $12 \mathrm{~mm}$. long. Mountains: Colo.-Wyo. Submont. J1-Au.

7. C. imbricata A. Nels. Stems 3-4 dm. high, subcanescent and with some long hairs; leaves numerous, the lower oblanceolate or spatulate, petioled, the upper broadly oblong or oblong-oblanceolate, sessile and mostly obtuse or apiculate, grayish hirsutulous; involucres 8-10 mm. high; bracts lance-linear, hirsutestrigose. Mountains: Colo.-Utah-Mont. Submont. Jl.

8. C. depressa Rydb. Stems intricately branched; leaves seldom over 1 $\mathrm{cm}$. long, obovate or spatulate, the lower short-petioled, the upper sessile, densely silky-strigose canescent; involucres about $7 \mathrm{~mm}$. high and $1 \mathrm{~cm}$. broad; bracts linear, acute, puberulent-strigose. Geyser formations: Mont.-Wyo. Mont. $\mathrm{Au}$.

9. C. pedunculata Greene. Stems short, decumbent, about $2 \mathrm{dm}$. high, strigose-canescent; leaves oblanceolate, silvery canescent, 2-3 cm. long; heads solitary, on peduncles $2-8 \mathrm{~cm}$. long; involucres $8 \mathrm{~mm}$. high, $1-1.5 \mathrm{~cm}$, broad; bracts linear, acute, strigose-canescent. Dry hillsides: Colo. Submont. Jl.

10. C. mollis Nutt. Stems decumbent to erect, $2-4 \mathrm{dm}$. high, finely strigose-canescent; leaves spatulate or oblanceolate, obtuse or apiculate, or the upper oblong and more acutish, 2-4 cm. long; heads corymbose, peduncled; involucres about $8 \mathrm{~mm}$. high and as wide; bracts linear, acute. Sandy places: Wash.-Utah-Wyo.-Mont. Jl-Au.

11. C. villosa (Pursh.) Nutt. Stem 2-5 dm. high, strigose and more or less hirsute; leaves 2-4 cm. long, obovate, elliptic or oblong, appressed silky, hirsuteciliate, usually sessile; heads peduncled, sometimes subtended by a small leaf; involucres about $1 \mathrm{~cm}$. high. Dry hills: Sask.-Minn.-Tex.-N.M.-Ida. Plain-Mont. J1-S.

12. C. hirsutissima Greene. Stem 1-3 dm. high, densely long-hirsute as well as hirsutulous; leaves oblanceolate, somewhat spreading, the lower shortpetioled, the upper sessile, densely grayish-strigose; heads fastigiate-corymbose; involucres $8 \mathrm{~mm}$. high. Sandy soil: Sask.-N.D.-N.M.-Ariz. Plain-Submont. Je-Au.

13. C. Bakeri Greene. Stems $2-4 \mathrm{dm}$. high, often purplish, strigose and only sparingly hirsute; leaves mostly acute, strigose, only slightly resinousgranuliferous; heads few, peduncled; involucres about $8 \mathrm{~mm}$. high; bracts often purplish-margined. Hills: Wyo.-Ida.-N.M.-Utah. Submont.-Mont. J-Au.

14. C. floribunda Greene. Stem about $3 \mathrm{dm}$. high, sparingly strigose and with a few long spreading hairs; heads paniculate, small; involueres $7-8 \mathrm{~mm}$. 
high and about as broad; bracts linear, acute, rather sparingly hirsute. Sandy soil in cañons: Colo. Submont. Au.

15. C. barbata Rydb. Stems about $3 \mathrm{dm}$. high, more or less tinged with purplish or red, hirsute with long white hairs; leaves sessile, $3-5 \mathrm{~cm}$. long, longhirsute and somewhat resinous-granuliferous; heads subsessile; involucres $1 \mathrm{~cm}$, high and $12-15 \mathrm{~mm}$. broad; bracts linear, acute; ligules about $7 \mathrm{~mm}$. long. Sandy plains: Ida. Jl.

16. C. Butleri Rydb. Stem decumbent at the base or erect, grayish-hispidulous and slightly hirsute; leaves 1-3 $\mathrm{cm}$. long, obtuse or apiculate, grayish-hirsute with short hairs; heads peduncled; involucres $8 \mathrm{~mm}$. high, $10-15 \mathrm{~mm}$. broad; bracts linear, acute; ligules about $8 \mathrm{~mm}$. long. Plains and hills: Mont. -Utah. Plain. Au-O.

17. C. pumila Greene. Stems decumbent at the base; leaves oblanceolate, $1-3 \mathrm{~cm}$. long, mostly petioled, hirsute but not viscid; involucres about $8 \mathrm{~mm}$. high and $1 \mathrm{~cm}$. broad; bracts linear, hirsute but not viscid; ligules about $6 \mathrm{~mm}$. long. Cañons and mountain sides: Neb.-Colo.-Ida. Plain-Subalp. Je-S.

18. C. columbiana Greene. Stems ascending or decumbent at the base; leaves oblanceolate or the uppermost linear-lanceolate, $2-3 \mathrm{~cm}$. long, hispidulons on both sides, scarcely at all resinous; heads corymbose; involucres $8 \mathrm{~mm}$. high. Hills and sandy places: B.C.-Mont.-Ore. Je-S.

19. C. grandis Rydb. Stems about $3 \mathrm{dm}$. high; leaves spatulate or oblanceolate, 3-5 cm. long; involucres $8 \mathrm{~mm}$. high; ligules about $1 \mathrm{~cm}$. long. Sandy places: Mont.-Wyo. Plain-Submont. Je-Au.

20. C. resinolens A. Nels. Stems 2-4 dm. high, sparingly hirsute and resinous-granuliferous; leaves hirsute and resinous-granuliferous, hispid-ciliate, the lower oblanceolate, the upper oblong or oblong-oblanceolate, sessile, $3-5 \mathrm{~cm}$. long, obtuse or apiculate; heads crowded, corymbose; involucres $1 \mathrm{~cm}$. high, $1-1.5 \mathrm{~cm}$. broad. Sandy soil: Mont.-Colo.-Ariz,-Utah. Submont.-Mont. $\mathrm{Jl}-\mathrm{S}$.

21. C. fulcrata Greene. Stem 2-6 dm. high, hirsute, hispidulous and resinous-granuliferous; leaves oblong, elliptic or the lower oblanceolate, hirsute, hispidulous and granuliferous; heads corymbose, sessile; involucres $8-9 \mathrm{~mm}$. high. Mountains: N.M.-Tex,-Wyo. Submont.-Mont. J1-S.

22. C. horrida Rydb. Stems $2-3 \mathrm{dm}$. high, hirsutulous and hispid; leaves obovate, broadly oblaneeolate, or oblong; heads corymbose, peduncled, about $8 \mathrm{~mm}$. high; disk $1 \mathrm{~cm}$. or less wide; bracts sparingly strigose-hirsute. Hills: Neb.-Wyo.-N.M.-Tex. Plain-Son. J-S.

23. C. viscida (A. Gray) Greene. Stem 1-3 dm. high, resinous-granuliferous and hispidulous; lower leaves spatulate and petioled, the upper obovate, elliptic, or ovate, sessile, 1-2 $\mathrm{cm}$. long; heads few or solitary; involucres $8 \mathrm{~mm}$. high and $10 \mathrm{~mm}$. wide; bracts resinous-granuliferous and hispidulous. C. villosa viscida A. Gray. Mountains and dry ledges: Colo.-Tex.-Ariz. Plain-Mont. My-N.

24. C. asprella Greene. Stem erect, $2-4 \mathrm{dm}$. high, hispidulous and sparingly hirsute, simple up to the inflorescence; head corymbose; involueres $7-8 \mathrm{~mm}$. high and broad. C. compacta Greene. C. arida A. Nels. Dry hills and mountains: Mont.-N.M.-Ariz. Submont.-Subalp. J1-S.

25. C. hispida (Hook.) DC. Stems $2-3 \mathrm{dm}$. high, hirsute and resinousgranuliferous; lower leaves oblanceolate and petioled, the upper lanceolate, sessile, 1-3 cm. long; heads corymbose and peduncled; involucres 7-8 mm, high and 8-12 mm. wide. C. villosa hispida A. Gray. Sandy river valleys: Sask.N.M.-Ariz.-Calif.-B.C. Plain-Submont. Je-Au.

26. C. stenophylla (A. Gray) Greene. Perennial, with cespitose caudex; stem 2-4 dm. high, very hispid, stiff; leaves $2-3 \mathrm{~cm}$. long, spreading, early deciduous, hispid and resinous-granuliferous, the hairs with pustulate bases; heads subtended by a few narrow leaves; involucres $8 \mathrm{~mm}$. high and $1 \mathrm{~cm}$. broad; bracts granuliferous and sparingly hirsute. C. villosa stenophylla A. Gray. Dry plains: Tex.-Colo.-Ark. Plain. Au-S. 
27. C. oregana Nutt. Stem 3-6 dm. high, branched, sparingly hirsute; leaves lanceolate, 2-4 cm. long, sessile; heads corymbose, discoid, peduncled, 10-12 mm. high, 12-18 mm. wide; bracts lance-linear, scarious-margined, resinous-granuliferous and sparingly hirsute. Sandy banks: Wash.-W Ida.-n Calif. Son. Jl-Au.

\section{ERICAMÈRIA Nutt.}

Very leafy shrubs or undershrubs, with resinous-dotted heath-like foliage. Heads small, paniculate or corymbose; involucres oblong or campanulate; bracts well imbricate, chartaceous or thinner, appressed, wholly destitute of herbaceous tips or some of the outer looser, slightly foliaceous. Ligules yellow, few, sometimes solitary or wanting. Disk-corollas somewhat widening upwards, deeply 5-toothed, yellow. Appendages of the style-branches filiform or slender-subulate. Achenes slender, usually pubescent. Pappus of fine and soft bristles.

Heads radiate; bracts not in distinct ranks.

Leaves linear-filiform or linear-oblanceolate.

Leaves linear-oblanceolate, rarely $15 \mathrm{~mm}$. long, curved; flowers yellow.

I

2. $E$, resinosa.

Leaves oblong-oblanceolate, short-cuspidate. $\quad 3$. E. cervina.

Heads discoid; bracts distinctly 5-ranked. $\quad$ 4. E. paniculata.

1. E. nana Nutt. Low shrub, 1-3 dm. high, densely branched, somewhat glutinous, glabrous; leaves pointed, channelled; heads solitary or 1 or 2 together; involucres about $6 \mathrm{~mm}$. long; bracts linear-lanceolate, in 4 or 5 series; ray-flowers about 4; disk-flowers 8; achenes hirsute. A plopappus nanus D. C. Eat. Chrysoma nana Greene. Rocky hills: Wash.-Utah-Ore, Submont. Au-S.

2. E. resinosa Nutt. Shrub about $3 \mathrm{dm}$. high, branched, very glutinous; heads solitary at the ends of the short branches; involucres $6-7 \mathrm{~mm}$. high, subtended by numerous small leaves; bracts linear-lanceolate, in 4 or 5 series; rayflowers about 6 and disk-flowers about 12 ; achenes hirsute. A plopappus resinosus A. Gray. Rocky hills: Wash.-Ida.-Ore. Son. JI-S.

3. E. cervina (S. Wats.) Rydb. Low shrub about $1.5 \mathrm{dm}$. high; leaves 8-12 $\mathrm{mm}$. long, entire, 3-nerved; heads in corymbs of $3-5,6-8 \mathrm{~mm}$. high; outer bracts linear, acuminate, the inner chartaceous, acutish, with scarious margins; rays few. Aplopappus cervinus S. Wats. Cañons: Utah.

4. E. paniculata (A. Gray) Rydb. Shrub 3-6 dm. high; branches densely punctate; leaves numerous, involute-filiform, resinous-punctate and glabrous, 1-5 $\mathrm{cm}$. long; heads paniculate; involucres about $6 \mathrm{~mm}$. high, turbinate; bracts linear. Chrysoma paniculata Greene. A. paniculatus A. Gray. Desert regions: s Calif. - s Utah. Son.

\section{CHRYSOTHÁMNUS Nutt. RABBIT BRUSH.}

Shrubs or undershrubs, with narrow leaves. Inflorescence mostly paniculatecymose. Heads discoid; flowers all alike, 5-15; corollas yellow or in one species nearly white. Bract coriaceous or chartaceous, in distinct (usually 5) vertical rows, without herbaceous tips. Corollas 5-toothed, slender. Style-branches with exserted, subulate or setaceous-filiform appendages. Achenes slender, terete or slightly angled. Pappus of numerous slender bristles, white.

Bracts of the involucre acuminate.

Achenes glabrous.

Leaves oblanceolate or spatulate, scabrous-puberulent; plant less than $2 \mathrm{dm}$. high.

Leaves narrowly linear, slightly tomentulose or glabrous.

Bracts thick, strongly carinate, glabrous.

Bracts thin, not strongly carinate, arachnoid-ciliate.

Achenes pubescent, usually strigose.

Bracts 4-6 in each vertical row.

Bracts 2-3 in each vertical row.

1. C. depressus.

3. C. pulchellus.

2. C. Bigelovii.

3. C. pulchellus.

Outer bracts long-acuminate, produced and more or less foliaceous.

Leaves linear, more or less distinctly 3-nerved. 4 4. C. Parryi.

Leaves very narrowly linear, 1-nerved.

Leaves and branches green, or the latter slightly tomentulose.

5. C. attenuatus, 
Leaves and branches white-tomentose.

Leaves mostly erect, the upper reduced, not exceeding the heads.

Leaves arcuate-spreading, the upper longer than the heads.

7. C. Howardii.

Outer bracts short, neither produced nor foliaceous.

Heads 5-8 mm. high; bracts thin, glabrous.

Leaves $2-3 \mathrm{~cm}$. long, over $1 \mathrm{~mm}$. wide, light green.

Leaves 1-2 cm. long, less than $1 \mathrm{~mm}$. wide, dark green.

8. C. Greenei.

Heads about $1 \mathrm{~cm}$. long; bracts thicker.

Leaves less than $1 \mathrm{~mm}$. wide; bracts glabrous. 10. C. albidus.

Leaves $1 \mathrm{~mm}$. broad or broader; bracts arachnoid-ciliate.

Leaves 1-2 cm. long; involucre lanate as well as arachnoid.

11. C. collinus.

Leaves $3-6 \mathrm{~cm}$. long; involucre somewhat viscid, merely arachnoid-

Bracts not acuminate. ciliate on the margin. 12 . C. wyomingensis.

Bracts 6-7 in each vertical row.

Bracts 3-5 in each vertical row.

13. C. formosus.

Achenes pubescent; bracts acute or obtuse.

Branches, at least when young more or less whitened with a pannose tomentum; style-appendages longer than the stigmatic portion; corolla 7-12 $\mathrm{mm}$. long.

Bracts and mature leaves perfectly glabrous.

Bracts ovate, or the outer triangular; involucre about half as long as the flowers.

14. C. virens.

Bracts lanceolate to linear; involucre more than half as long as the flowers.

Leaves nearly erect or strongly ascending, straight, 1-2 mm. wide.

Leaves scarcely $1 \mathrm{~mm}$. wide.

15. C. graveolens,

Leaves spreading or reflexed, more or less falcate; lobes of the corollas lanceolate, mostly acute. 16. C. patens.

Leaves erect, about $0.5 \mathrm{~mm}$. wide; lobes of the corolla ovate, obtuse, about $0.5 \mathrm{~mm}$. long, erect in age.

Bracts erose-ciliate on the margin, or tomentose, or both. 17. C. pinifolius.

Inflorescence elongate-thyrsoid.

Inflorescence corymbiform, flat or round-topped.

Bracts lanceolate, acute; leaves less than $2.5 \mathrm{~mm}$. wide.

Bracts more or less erose-ciliate on the thin margins.

Mature leaves glabrous or nearly so, about $1 \mathrm{~mm}$. wide, erect. 19. C. oreophilus.

Mature leaves more or less densely white-tomentose; bracts lanceolate.

Leaves $1 \mathrm{~mm}$. wide or less, spreading.

Leaves 1-2.5 mm. wide.

20. C. plattensis.

Bracts narrow, linear-lanceolate, strongly carinate, almost glabrous, except the erose-ciliate margins, 21. C. pulcherrimus.

Bracts usually broader, more or less densely tomentose and viscid as well as ciliate.

Stems equally leafy throughout; leaves all alike, strongly ascending; bracts strongly carinate. 22. C. frigidus.

Stems more leafy towards the ends; upper leaves much shorter; bracts slightly carinate.

23. C. pallidus.

Bracts not at all ciliate on the thicker margin, but white-tomentose on the back.

Bracts scarcely carinate; older branches not densely and thickly woolly.

24. C. speciosus.

Bracts strongly carinate; older branches densely and thickly

woolly.
Bracts elliptical, nearly glabrous, the thinner ones obtuse: leaves 3-4 mm. wide.
26 . C. salicifolius. Branches without tomentum; style-appendages shorter than the stigmatic por-
tion; corolla $5-7 \mathrm{~mm}$. long.

Leaves and the white or straw-colored stem glabrous or nearly so, except the hispidulous-ciliate margins of the former.

Leaves narrowly linear, $2 \mathrm{~mm}$. wide or less.

Bracts neither strongly carinate nor with conspicuous green tips.

Leaves less than $1 \mathrm{~mm}$. wide, 1-nerved.

Bracts linear, the innermost rounded at the apex.

Bracts ovate-lanceolate, acute.

27. C. stenophyllus.

Leaves 1-2 mm. wide, 3-nerved; bracts lanceolate.

29. C. pumilus. 
Bracts strongly carinate and with conspicuous green tips. Bracts acute; upper leaves not much reduced.

Bracts obtuse; upper leaves much reduced.

30. C. elegans,

42. C. turbinatus.

Leaves linear to lance-linear or oblanceolate, 2-8 $\mathrm{mm}$. wide,

Bracts linear, oblong, or lanceolate.

Bracts at least the outer ones with thick green tips.

Bracts comparatively thin, not green-tipped.

31. C. linifolius.

Bracts linear-lanceolate, very acute. 32 . C. stenolepis.

Bracts oblong or lanceolate, the inner obtuse.

Involucre not viscid; leaves hispidulous ciliate-dentate. 33. C. glaucus.

Inflorescence densely viscid; leaves minutely denticulate.

34, C. viscidiflorus.

Bracts ovate, oval, or the inner broadly elliptic, abruptly short-cuspidate.

Leaves and stems decidedly puberulent.

Leaves 3-6 $\mathrm{mm}$. wide, rarely twisted.

Leaves $1-2.5 \mathrm{~mm}$. wide, usually twisted.

35. C. latifolius.

36. C. lanceolatus.

Leaves 3-nerved; inner bracts linear, acute; branches green or yellowish.

37. C. puberulus.

Achenes glabrous.

Leaves 1-nerved, thick; inner bracts spatulate-oblong, rounded at the apex; branches white.
$38 . C$. marianus.

Bracts acutish; leaves filiform.

Bracts rounded at the apex; leaves linear.

9. C. filifolius.

Branches white-tomentose when young; corolla 7-10 mm. long.

Leaves linear, more or less involute; corolla-lobes deltoid-lanceolate.

39. C. leiospermus.

Leaves linear-oblanceolate, not involute; corolla-lobes linear-lanceolate.

40. C. glareosus.

Branches not tomentose; corolla 5-6 mm. long.

Plant glabrous.

Leaves linear-oblanceolate.

Leaves filiform, the upper much reduced. Plant decidedly puberulent; leaves narrowly linear.

41. C. Vaseyi.

42. C. turbinatus.

38. C. marianus,

1. C. depressus Nutt. Undershrub, suffruticose at the base; stem 1-2 dm. high; leaves short, $0.5-1 \mathrm{~cm}$. long, thick; inflorescence short and corymbiform; heads few, about $1 \mathrm{~cm}$. high; bracts 5-ranked in 4-5 series, puberulent, lanceolate, gradually cuspidate. Bigelovia depressa A. Gray. Plains: Utah-Colo,N.M. Plain-Submont. J-S.

2. C. Bigelovii (A. Gray) Greene. A shrub, 3-10 dm. high; branches whitetomentose at first, soon glabrate; leaves linear-filiform, 1-3 cm. long, whitetomentulose when young, soon glabrate; involucres $10-12 \mathrm{~mm}$. high; bracts thin, lanceolate, tomentulose and arachnoid-ciliate, 5-ranked in 4 or 5 series. B. Bigelovii A. Gray. Dry plains: Colo.-Tex.-e Ariz,-Utah. Son.-Submont. $\mathrm{Au}-\mathrm{O}$.

3. C. pulchellus (A. Gray) Greene. A shrub 6-10 dm. high; branches glabrous, striate; leaves narrowly linear, 1-2 $\mathrm{cm}$. long, glabrous or ciliolate on the margins; involucres 10-15 mm. high; bracts 5-ranked in 5-6 series, lanceolate; achenes sparingly pubescent or glabrous. B. pulchella A. Gray. Dry hills: Kans.-Tex.-N.M.-Utah; n Mex. Son.-Submont. Au-S.

4. C. Parryi (A. Gray) Greene. Suffrutescent perennial; branches erect, 3-5 dm. high, white-tomentulous when young; leaves $3-7 \mathrm{~cm}$. long, minutely puberulent or glabrate; heads racemose-thyrsoid; involucres about $1 \mathrm{~cm}$. high; bracts linear-lanceolate, attenuate. C. affinis A. Nels. B. Parryi A. Gray. Hills and dry valleys: Wyo.-Colo. Submont.-Mont. Au-S.

5. C. attenuatus (M. E. Jones) Rvdb. Low shrub, 1-3 dm. high; leaves 2-3 $\mathrm{cm}$. long, erect, green; heads in small corymbs; involucres about $1 \mathrm{~cm}$. long; bracts narrowly lanceolate, gradually long-attenuate, arachnoid-ciliate on the margins; corollas 10-12 mm. long. B. Howardii attenuata M. E. Jones. C. affinis attenuatus A. Nels. Mountains: Utah. Submont.-Mont. Au-O.

6. C. Newberryi Rydb. Shrubby below, 2-4 dm. high; leaves slightly tomentulose when young, 2-3 cm. long; bracts narrowly lanceolate, attenuate into a long slender subulate spreading tip, carinate, slightly tomentulose and 
webby; corolla narrowly tubular-funnelform, about $15 \mathrm{~mm}$. long. Hills: N.M.Colo. Son.-Submont. Au-S.

7. C. Howardii (Parry) Greene. Low shrub, 1-3 dm. high; branches whitetomentose, ascending; leaves linear-filiform, 3-5 cm. long; involucres $10-12 \mathrm{~mm}$. high; bracts lanceolate-attenuate, tomentose as well as arachnoid; flowers scarcely $1 \mathrm{~cm}$. long. B. Howardii A. Gray. Dry hills: Neb.-Wyo.-Colo. PlainSubmont. Jl-S.

8. C. Greenei (A. Gray) Greene. Perennial, with a woody caudex and deep taproot; stems 1-3 dm. high, glabrous and shining, with a white bark; leaves narrowly linear, glabrous, scabrous on the margins, more or less twisted; cyme flat-topped; heads numerous, $6-8 \mathrm{~mm}$. high; bracts chartaceous, lanceolate. $B$. Greenei A. Gray. C. scoparius Rydb. Plains: Colo.-N.M.-Utah. Submont. S-O.

9. C. filifolius Rydb. Small shrub, about $3 \mathrm{dm}$. high, very bushy; leaves very narrow, linear-filiform, glabrous except the minutely scabrous-ciliolate margins; cyme large, flat-topped; heads very numerous, $5-6 \mathrm{~mm}$. high, turbinate; bracts lanceolate-acuminate, the outer with green tips. Plains: Colo.N.M. Submont.-Mont. J-Au.

10. C. albidus (M. E. Jones) Greene. Shrub, 3-8 dm. high; stem slightly tomentulose and viscid; leaves filiform, $2-4 \mathrm{~cm}$. long, about $1 \mathrm{~mm}$. wide, very numerous, slightly if at all tomentulose; heads fastigiate-corymbose; involucre 8-10 mm. high; bracts coriaceous, lanceolate, the outer subulate-acuminate, the inner merely acute; corollas straw-colored; achenes hirsutulous. B. albida M. E. Jones. Arid regions: Utah-Nev.-se Calif. Son. My-Au.

11. C. collinus Greene. Shrub, 2-4 dm. high, greenish, obscurely cinereous, tomentulose only when young; leaves linear-filiform, soon glabrate and gummy; heads few; bracts carinate, 3 or 4 in each series, the outer lanceolate, acuminate, the inner cuspidate-attenuate. B. collina A. Nels. Hills: Colo.-Wyo. Submont. Au.

12. C. wyomingensis A. Nels. Tufted shrub, 2-4 dm. high, bushy; branches yellowish green, slightly tomentulose when young; leaves narrowly linear, viscidulous; inflorescence thyrsoid, leafy; bracts somewhat indistinctly 5ranked, lanceolate gradually short-acuminate. Saline soil and dry plains: Colo. -Wyo. Submont. Jl-Au.

13. C. formosus Greene. Low shrub, branched from the base, about $3 \mathrm{dm}$. high; stem white-tomentose; leaves linear, spreading, white-tomentose; bracts 6 or 7 in each vertical rank, glabrous, the outer ovate, the inner longer, oblonglinear, obtuse or acutish. Hills: w Colo. Son. Au.

14. C. virens Greene. Shrub, 1-2 m. high; leaves 4-6 cm. long, linear; heads many in large corymb; involucres $6-7 \mathrm{~mm}$. long; bracts in 4 series; teeth of the corolla obtusish, one-fourth as long as the throat, not spreading. Plains: se Colo. Son. S.

15. C. graveolens (Nutt.) Greene. Shrub, 1-1.5 m. high, green, pannose only when young; leaves linear, 4-7 cm. long; heads numerous in a compound corymb; involucres about $8 \mathrm{~mm}$. long: bracts lanceolate, in 4 series; lobes of the corolla lanceolate, more than half as long as the throat, spreading. B. graveolens glabrata A. Gray. C. falcatus Greene. C. laetevirens Greene. Cañons, badlands, and dry hills: Neb.-N.M.-Utah-Mont. Plain-Submont. Au-O.

16. C. patens Rydb. Shrubby, half a meter or so high; leaves $6-8 \mathrm{~cm}$. long, about $1 \mathrm{~mm}$. broad; bracts lanceolate, acute, carinate, glabrous; corollalobes about $1 \mathrm{~mm}$. long. Dry plains and hills: Colo. Plain-Submont. Je-Jl.

17. C. pinifolius Greene. Shrub, 3-5 dm. high; branches erect, yellowish green and soon glabrous, slightly resinous; leaves $4-5 \mathrm{~cm}$. long, almost filiform; heads in small panicles; involucres about $8 \mathrm{~mm}$. high; bracts in 3 series, narrowly lanceolate. Dry hills and plains: Colo.-N.M.-Nev.-Ore. Son.-Submont.

18. C. concolor (A. Nels.) Rydb. Shrub, 3-4 dm. high, woody at the base; branches yellowish green, pannose only when young; leaves linear, somewhat 
spreading, 4-7 $\mathrm{cm}$. long, 1-2 mm. wide, slightly pannose-tomentose; involucres 8-9 mm. long; bracts lanceolate, acutish, scarious-margined, erose, ciliolate, the lower slightly tomentose. C. frigidus concolor A. Nels. Sandy alkaline soil: Wyo. Submont. S.

19. C. oreophilus A. Nels. Low shrub, 2-4 dm. high; branches grayish with a thin tomentum, yellowish green; leaves erect, linear-filiform, $3-5 \mathrm{~cm}$. long; involucres $8 \mathrm{~mm}$. long; bracts ovate-lanceolate or oblong-lanceolate, abruptly acute. Stony hills: Wyo.-Colo. Submont. Jl-O.

20. C. plattensis Greene. Low undershrub, 2-3 dm. high; branches more or less pannose-tomentose; leaves linear-filiform, tomentose, $3-5 \mathrm{~cm}$. long; bracts in about 3 series, lanceolate, acute, glabrous except the erose-ciliate margins; achenes hirsute-strigose. Plains and hills: Mont.-S.D.-Colo. Plain-Submont. Jl-O.

21. C. pulcherrimus A. Nels. Shrub, 5-15 dm. high; branches yellowish, minutely lanate; leaves narrowly linear, 5-8 cm. long, 1-2 mm. wide, whitetomentose to nearly glabrate; bracts in 2 or 3 series; linear-lanceolate, ciliate on the margins; achenes softly strigose. Plains: Mont.-Colo.-Utah-Ida. Plain. $\mathrm{Au}-\mathrm{O}$.

22. C. frigidus Greene. Undershrub, 2-6 dm. high; branches white-tomentose; leaves narrowly linear, $3-5 \mathrm{~cm}$. long, white-tomentose, rarely glabrate; bracts in 2 or 3 series, lanceolate, the outer acute, the inner obtuse. Plains: Sask.-Colo.-Utah-Alta. Plain-Submont. Jl-S.

23. C. pallidus A. Nels. Small tufted shrub, 2-5 dm. high; branches with close felted tomentum; leaves ascending or spreading, densely tomentose, the lower 4-5 cm. long; heads thyrsoid-paniculate; bracts ovate-lanceolate, subacute, ciliate on the margins and tomentose on the back. Alkaline flats: n Colo.-Wyo. Submont. Au-S.

24. C. speciosus Nutt. Shrub, 1-2 m. high; branches yellow, sparingly tomentose; leaves numerous, 3-4 cm. long, about $1 \mathrm{~mm}$. wide, white-tomentose; bracts in 3 or 4 series, tomentose, but not ciliate, lanceolate, acute; achenes strigose. B. graveolens A. Gray, mainly. Plains: Ore.-Ida.-Calif. Son. JI-S.

25. C. nauseosus (Pursh.) Britton. Shrub, 5-10 dm. high, permanently white-tomentose, almost cottony; leaves $3-6 \mathrm{~cm}$. long, about $1 \mathrm{~mm}$. wide, tomentose, often spreading; bracts lanceolate, acute, more or less tomentose, but not ciliate; achenes hirsute-strigose. B. graveolens albicaulis A. Gray. Hillsides: B.C.-Mont.-Wyo.-Utah-Ore. Son.-Submont. Je-Au.

26. C. salicifolius Rydb. Shrub, 3-10 dm. high; branches erect, finely pannose-tomentulose; leaves linear, 3-nerved, 4-6 cm. long, 3-6 mm. wide, minutely tomentulose; heads in a dense corymbiform cyme; involucres $7-8 \mathrm{~mm}$. long; corollas about $1 \mathrm{~cm}$. long; achenes coarsely strigose, angled. B. graveolens latisquamea A. Gray. Valleys: Utah. Son.-Submont. Au-S.

27. C. stenophyllus (A. Gray) Greene. Low shrub, 1-3 dm. high, much branched; bark white or straw-colored; leaves somewhat involute and twisted, spreading, 2-3 cm. long; bracts in three series, linear, thin, the outer acute, the innermost rounded at the apex; achenes strigose. C. pumilus varus A. Nels. $B$. Douglasii stenophylla A. Gray. Dry ridges and stony slopes: Nev.-Mont.Wyo.-Ariz. Submont. Au-S.

28. C. laricinus Greene. Low shrub, $2-3 \mathrm{dm}$. high, fastigiately branched; leaves filiform, 1-1.5 cm. long, scabrous-puberulent on the margins; heads few and corymbose; involucre about $5 \mathrm{~mm}$. high; bracts ovate-lanceolate, somewhat keeled, acute with the apex slightly spreading; achenes densely strigose. Valleys: c Utah-Ariz. Son. Au-S.

29. C. pumilus Nutt. Low shrub, 1-3 dm. high; branches glabrous, whitish, shining; leaves narrowly linear, 2-4 cm. long, sometimes involute, rarely somewhat twisted; involucres about $5 \mathrm{~mm}$. high; bracts mostly lanceolate, glabrous, acute or the inner obtuse; achenes sparingly strigose. B. Douglasii pumila A. Gray. Plains and foothills: Mont.-Colo--Utah.-Ore. Plain-Submont. $\mathrm{Jl}-\mathrm{S}$. 
30. C. elegans Greene. Low shrub, 1-3 dm. high, branched; branches glabrous, straw-colored; leaves narrowly linear, 1-3 cm. long, 1-2 $\mathrm{mm}$. wide, 3nerved, strongly twisted; involueres about $6 \mathrm{~mm}$. high; bracts lanceolate, acute, glabrous; achenes sparingly strigose. Plains and dry valleys: Colo.-N.M. Submont. Jl-Au.

31. C. linifolius Greene. Shrub, 6-10 dm. high, fastigiately branched; branches glabrous, white, striate; leaves ascending, linear-lanceolate, acute, 3nerved, 2-4 cm. long, 5-8 mm. wide; involucres about $7 \mathrm{~mm}$. high; bracts oblong, obtuse; achenes densely hirsute-strigose. B. linifolia A. Nels. Dry plains and river bottoms: Wyo.-Colo. Plain-Submont. Au-S.

32. C. stenolepis Rydb. Low shrub, 2-3 dm. high, somewhat spinescent; branches short, erect, glabrous or finely puberulent above; leaves narrowly lance-linear, 1-2 cm. long, 2-4 mm. wide, somewhat twisted; involucres about $8 \mathrm{~mm}$. long; achenes hirsute-strigose. Dry hills: Mont.-Wyo.-Utah-Ida. Plain-Submont. Au-S.

33. C. glaucus A. Nels. Shrub, 3-10 dm. high; leaves ascending, narrowly linear-lanceolate, acute, obscurely 3-nerved, 2-4 cm. long, usually somewhat twisted, bluish green; bracts subcarinate, membranous, glabrous; achenes silkystrigose. C. serrulatus (Torr.) Rydb. B. Douglasii serrulata A. Gray. C. leucocladus Greene. Dry plains and slopes: Wyo.-Colo.-Utah-Ariz. Submont.

34. C. viscidiflorus (Hook.) Nutt. Shrub, 6-12 dm. high; leaves linear, 3-5 $\mathrm{cm}$. long, 3-nerved, 2-4 $\mathrm{mm}$. wide; involueres about $7 \mathrm{~mm}$. high; bracts thin, oblong; achenes strigose. B. Douglasii A. Gray. Dry plains: Mont.-Wyo.Calif.-Wash. Plain-Son. JI-S.

35. C. latifolius (D. C. Eat.) Rydb. Low shrub; leaves oblanceolate or oblong, acute, 3-5-nerved, glabrous, 2-4 cm. long, 5-8 mm. broad; involucres 6 mm. high. Linosyris viscidiflora latifolia D. C. Eat. Mountains: Nev.-Ida.Utah. Submont. S.

36. C. lanceolatus Nutt. Undershrub, 1-3 dm. high; branches strawcolored or gray, finely puberulent; leaves linear-lanceolate, 2-4 cm. long; involucres 7-8 mm. long; outer bracts lanceolate, acute, the inner oblong, obtuse, glabrous, or the outer puberulent; achenes hispid-strigose. B. Douglasii lanceolata A. Gray. B. Douglasii spathulata M. E. Jones, a form with short lower leaves. Dry plains and hills: Mont.-Colo.-Nev.-Wash. Plain-Submont. Au-S.

37. C. puberulus (D. C. Eat.) Greene. Undershrub, 1-3 dm. high; branches finely puberulent; leaves narrowly linear, 2-4 cm. long, densely puberulent; involucres 6-7 mm. long; bracts glabrous, lanceolate or the inner linear, acute, somewhat viscid; achenes sparingly strigose. B. Douglasii puberula A. Gray. Dry plains and hills: B.C.-Mont.-Colo.-Calif. Son.-Mont. J1-S.

38. C. marianus Rydb. Undershrub, 1-2 dm. high, with a woody thick caudex; leaves linear or the lower linear-oblanceolate, acute, thick, $1-2 \mathrm{~cm}$. long, 1-15 mm. wide; bracts yellowish, glutinous, erose-ciliate on the margins, the outer ovate, acutish, the inner spatulate-oblong, rounded at the apex; achenes sparingly strigose. Valleys: Utah. Son. Jl.

39. C. leiospermus (A. Gray) Greene. Shrub, 3-6 dm. high; branches white-tomentose, or in age glabrate; leaves sparse, involute-filiform (in var. breviata about-1 $\mathrm{cm}$. long or less); bracts oblong, or the inner linear-oblong, rounded at the apex; achenes glabrous. B. leiosperma A. Gray. Desert regions: s Utah-Nev. L. Son.

40. C. glareosus (M. E. Jones) Rydb. Undershrub, growing in dense elumps, about $3 \mathrm{dm}$. high; leaves linear-oblanceolate, the upper reduced, oblong, and bract-like; inflorescence corymbiform; bracts about 4 in each vertical row, sparsely lacerate on the margins and white-tomentulose, obtuse or rounded at the apex, the lower small, ovate, the upper with conspicuous thickened tips, linear; corolla fully $1 \mathrm{~cm}$. long. B. glareosa M. E. Jones. Mesas: c Utah. Submont. O.

41. C. Vaseyi (A. Gray) Greene. Perennial, with a cespitose woody caudex, 1-2 dm. high, glabrous; leaves linear-oblanceolate, obtuse, thick, glabrous, 1-2.5 
$\mathrm{cm}$. long, 1-3 mm. wide; inflorescence fastigiate-cymose; bracts oblong, rounded at the apex, all but the innermost with a thickened greenish tip; achenes glabrous or slightly puberulent. C. Bakeri Greene. Mountains: Wyo.-Colo.-Utah. Submont. J1-S.

42. C. turbinatus (M. E. Jones) Rydb. Shrub, about $1 \mathrm{~m}$. high, bushy; leaves long and narrow, canaliculate, the uppermost much reduced, glabrous, or slightly viscid in the inflorescence; bracts 5 or 6 in each vertical row, the lowest minute, all obtuse, merely apiculate, with a darker center, the inner oblong to linear, $8 \mathrm{~mm}$. long. B. turbinata M. E. Jones. Gravel: Utah. Son. S.

\section{ISOCÒMA Greene:}

Herbaceous or shrubby plants, usually with viscid foliage. Leaves alternate, entire, toothed, or pinnately parted. Heads discoid. Involucres mostly campanulate, several- to many-flowered; bracts leathery, obtuse or acutish, well imbricate, with more or less thickened tips. Disk-flowers perfect; corolla yellow, the throat much inflated. Tips of the style-branches subulate, lanceolate or broader. Achenes short, broadened upwards, usually silky-strigose. Pappus of numerous barbellate bristles.

Bracts acute, linear-lanceolate.

Bracts obtuse or obtusish, linear, oblong, or oblanceolate.

Leaves 1-ribbed, the lower often toothed.

Plant herbaceous, except the suffruticose base; bracts comparatively thin.

Plant shrubby; bracts mucb thickened, especially at the apex. 3. I. Wrightii.

Leaves triple-nerved, entire.

4. I. scopulorum,

1. I. pluriflora (T. \& G.) Greene. Suffrutescent; stems angular, glabrous; leaves narrowly linear, obscurely 1 -nerved, $3-6 \mathrm{~cm}$. long; heads $8 \mathrm{~mm}$. high, 5 $\mathrm{mm}$. broad, 15-18-flowered, crowded at the ends of the branches in a fasciculate corymb; bracts smooth, shining, not thickened at the apex. Bigelovia pluriflora A. Gray. Plains: Colo. Son.

2. I. Wrightii (A. Gray) Rydb. Stems 3-6 dm. high, strict, glabrous; leaves thickish, narrowly linear, entire, or the lower toothed, somewhat scabrous; heads 5-6 mm. high, 4-5 mm. broad, 7-15-flowered, numerous in a large corymbiform cyme; bracts oblong or broadly lanceolate, obtuse. Linosyris Wrightii A. Gray. B. Wrightii A. Gray. Banks and saline soil: Tex.-Colo.-UtahAriz.; n Mex. Son. Au-S.

3. I. acradenia Greene. Low shrub, 3-6 dm. high, much branched, glabrous and glutinous; leaves narrowly oblanceolate, entire, 2-4 cm. long; heads 6-8 mm. high, 6-10-flowered, corymbose-clustered; bracts oblong, obtuse, with a conspicuous gland; achenes strigose. Desert regions: $\mathrm{s}$ Calif. $-\mathrm{s}$ Utah-Ariz. L. Son. S-O.

4. I. scopulorum (M. E. Jones) Rydb. Low shrub, about $5 \mathrm{dm}$. high, with straw-colored branches; leaves linear, 2-7 cm. long, acute, finely puberulent or glabrate, scabrous on the entire margins; heads few, corymbose; involucres turbinate, nearly $1 \mathrm{~cm}$. high; bracts well imbricate in 6-7 series, elliptic to oblong, yellowish, with a green spot on the back; achenes hispid. B. Menziesii scopulorum M. E. Jones. Hesperodoria scopulorum Greene. Cañons: s Utah. Son.-Submont. Au-S.

\section{PRIONÓPSIS Nutt.}

Annual or biennial, caulescent glabrous herbs. Leaves alternate, sessile, spinulose-toothed. Heads radiate, showy. Involueres broadly hemispheric; bracts well imbricate in several series, the outer spreading; receptacle naked. Ray-flowers numerous, pistillate; ligules yellow. Disk-flowers numerous, perfect; corolla yellow. Anthers obtuse at the base. Style-branches with linearlanceolate appendages. Achenes glabrous, those of the rays broader. Pappus of few firm, hair-like bristles, the outer often shorter; all deciduous.

1. P. ciliata Nutt. Stem $8-15 \mathrm{dm}$. high, sparingly branched, glabrous; leaves numerous, oval, ovate, or oblong, saliently dentate, with spinulose-tipped teeth; heads few, corymbose; involucres about $1 \mathrm{em}$. high, $2-2.5 \mathrm{~cm}$. broad; bracts 
linear-lanceolate, acuminate, squarrose; ligules numerous, 1-1.5 cm. long. Aplopappus ciliatus DC. River banks and hillsides: Mo.-Tex.-Colo. Plain.

\section{SIDERÁNTHUS Nutt. Iron Plant.}

Perennial or annual herbs, rarely suffruticose at the base. Leaves alternate, with spinulose-tipped lobes or teeth. Heads radiate, or in two species discoid. Involucres campanulate or hemispheric, many-flowered; bracts well imbricate, in 3-5 series, appressed or with loose tips, green; receptacle flat, naked, usually pitted. Ray-flowers pistillate, or in two species wanting; ligules yellow. Diskcorollas yellow; tube scarcely dilated into a distinct throat. Anthers obtuse at the base. Style-branches flattened, with lanceolate appendages. Achenes obtuse, pubescent, mostly 8-10-nerved. Pappus of many unequal hair-like bristles in 1-3 series, persistent.

Leaves spinescent-toothed, not pinnatifid.

Heads discoid; perennials, with woody caudex. Heads peduncled. Heads sessile.

Heads radiate; annuals.

1. S. grindelioides.

Leaves oblanceolate, spinulose-tipped; plant more or less viscid. 3. S. annuus.

Leaves linear-oblanceolate, bristle-tipped; plant strigose. 4. S. gracilis.

Leaves pinnatifid; perennials, with a short woody base; achenes somewhat flattened.

Stem more or less floccose or cinereous, especially when young.

Plant cinereous pubescent, more or less glandular.

Plant more or less floccose, not at all glandular.

Plant neither floccose nor cinereous.

Plant perfectly glabrous or sparingly glandular-puberulent.

Plant finely puberulent, or bispid.

Heads hemispheric; bracts slightly glandular.
Heads somewhat turbinate; bracts densely glandular-puberulent.

5. S. australis.

6. S. spinulosus.

7. S. glaberrimus.

8. S. puberulus.

9. S. turbinellus.

1. S. grindelioides (Nutt.) Rydb. Low cespitose perennial; stems erect, 1-3 dm. high, somewhat pubescent; leaves thick, obovate or oblanceolate, spinulose-serrate, 1-3 cm. long, more or less crisp-hirsute or strigose; involucres hemispheric, 6-7 mm. high, $1 \mathrm{~cm}$. broad; bracts lanceolate, puberulent; achenes somewhat flattened. Eriocarpum grindelioides Nutt. Aplopappus Nuttallii T. \& G. Dry plains and hills: Sask.-Neb.-N.M.-Ariz.-Nev.-Alta, Plain-Submont. Je-Au.

2. S. aberrans (A. Nels.) Rydb. Perennial, with a creeping rootstock; stems erect, 5-10 cm. long, glandular-pubescent; leaves obovate or oblong, glandularpuberulent, or the lower ovate, 1-3 cm. long, sparingly cuspidate-toothed on the margins; heads 1-4, subsessile, 9-14 mm. high; bracts broadly linear, acute, green and glandular-viseid at the apex; achenes cylindric-fusiform, $3 \mathrm{~mm}$. long. Macronema aberrans A. Nels. Mountains: Ida. Mont. Au.

3. S. annuus Rydb. Annual; stem simple below, branched above, more or less glandular-pubescent; leaves oblanceolate, spinulose-dentate, 3-6 cm. long; heads corymbose; involucres hemispheric, about $8 \mathrm{~mm}$. high, viscid-puberulent; bracts linear-lanceolate, acuminate; ligules light yellow, 5-6 mm. long; achenes obtusely 5-angled. Aplopappus rubiginosus A. Gray, in part. Sandy places:

4. S. gracilis (Nutt.) Rydb. Annual, branched, becoming woody at the base; stems 2-4 dm. high, hispid-strigose; leaves linear-oblanceolate to spatulate in outline, coarsely dentate or somewhat pinnatifid; teeth tipped with long bristles; involucres $6 \mathrm{~mm}$. high; bracts linear, spinulose-tipped, strigose; ligules 5-6 mm. long, light yellow. Dieteria gracilis Nutt. A. gracilis A. Gray. Dry hills: s Colo.-Tex.-Ariz.-Calif.; Mex. Son.-Submont. My-S.

5. S. australis (Greene) Rydb. Stem 2-4 dm. high; leaves pinnatifid, 2-7 $\mathrm{cm}$. long; segments linear or oblong, spinulose-tipped, entire or toothed; involucres $6 \mathrm{~mm}$. high; bracts linear, puberulent, spine-tipped; ligules 5-6 mm. long, yellow. Eriocarpum australe Greene. Dry soil: Colo.-Tex.-N.M.-Ariz.- e Utah; Mex.
Son.-Submont. Ap-Je.

6. S. spinulosus (Pursh) Sweet. Stem 1-4 dm. high, branched; leaves 1-3 $\mathrm{cm}$. long, pinnatifid; segments linear or oblong, usually toothed or pinnately 
parted; involucres 6-8 mm. high; bracts linear-lanceolate, spinulose-tipped, villous-canescent; ligules 6-7 mm. long, bright yellow. A. spinulosus DC. Plains and prairies: Sask.-Minn.-Tex.-Ariz.-Alta.; n Mex. Son.-Plain-Submont. $\mathrm{Je}-\mathrm{S}$.

7. S. glaberrimus Rydb. Stems several, 1-3 dm. high; leaves rather rigid, about $2 \mathrm{~cm}$. long, bluish green, glabrous, pinnatifid; segments oblong, spinulose-tipped; heads numerous, corymbose, depressed hemispherical, 8-15 $\mathrm{mm}$. broad; bracts acute or spinulose-tipped; ligules 4-5 mm. long. Dry plains: S.D.-Ia.-Tex.-N.M.-Wyo. Plain. Je-S.

8. S. puberulus Rydb. Stems less than $1.5 \mathrm{dm}$. high; leaves pinnatifid or bipinnatifid; segments 1-5 mm. long, spinulose-tipped; heads 8-9 mm. high, 10-12 $\mathrm{mm}$. broad; bracts narrowly linear-lanceolate, with small herbaceous tips, finely puberulent; ligules about 20,8-9 mm. long. Hills: Colo. Submont.-Mont.

9. S. turbinellus Rydb. A low and bushy puberulent perennial, 1.5-2 dm. high; leaves pinnatifid or the upper reduced and merely toothed; segments narrow; heads numerous, small, 7-8 mm. high; bracts linear-lanceolate, acute, appressed; ligules 10-15, 7-8 mm. long. Dry plains: Ida. Plain. Au.

\section{PYRROCÒMA Nutt.}

Perennial herbs, with thick taproots. Leaves alternate, sometimes with spinulose teeth. Heads terminal, or in the axils of the upper leaves, radiate. Involucres hemispheric; bracts more or less foliaceous; receptacle flat, alveolar. Ray-flowers numerous, fertile or sterile; ligules yellow, sometimes not longer than the disk. Disk-flowers yellow, perfect; corollas cylindric, slightly if at all dilated upwards, with short, erect teeth. Appendages of the style-branches subulatelinear, longer than the stigmatic portion. Achenes linear, 3-angled, striate, usually glabrous. Pappus reddish brown or yellow, of numerous rigid bristles.

Heads apparently discoid, the sterile rays being concealed in the pappus.

Inner bracts recurved cuspidate.

Bracts not recurved cuspidate.

1. P. subsquarrosa.

Bracts oblong or oval; heads hemispheric,

Leaves and bracts more or less spinulose-toothed, the latter with a narrow scarious margin.
$2 . P$. carthamoides.

Leaves and bracts not spinulose-toothed, the latter with a broad scarious erose margin.

Pappus sordid; plant almost glabrous.

Pappus brownish red; plant villous.

Bracts lanceolate; head campanulate-turbinate.

Heads distinctly radiate.

Bracts except the innermost obtuse, obovate or oblong.

Bracts mostly acute or acuminate.

Plant not glandular.

Heads large; disk $2 \mathrm{~cm}$. or more in diameter; bracts in about 3 series.

Bracts almost of the same length.

3. P. rigida.

4. $P$. erythropappa.

5. P. Cusickii.

6. P. crocea.

Outer bract decidedly shorter.

Involucre and upper part of stem decidedly villous; bracts wholly foliaceous.

Bracts oblanceolate, abruptly acute; achenes hirsute.

8. P. Clementis.

Bracts lanceolate, long-acute; achenes glabrous. 9. P. villosa,

Involucral bracts almost glabrous except the ciliate margins, chartaceous at the base with foliaceous tips.

Leaves and stem glabrous, or the latter slightly villous. Basal leaf-blades broadly lanceolate. 10. $P$. lapathifolia Basal leaf-blades narrowly oblanceolate. 11. P. integrifolia.

Leaves hirtellous; stem hirsute-villous. $12 . P$. scaberula.

Heads smaller; disk less than $2 \mathrm{~cm}$, in diameter.

Bracts in 2-3 unequal series.

Leaves 5-15 mm. wide; disk $1-2 \mathrm{~cm}$. wide.

Inflorescence corymbiform; bracts long-acute. 13. P. lanceolata.

Inflorescence racemiform; bracts abruptly acute.

Stem and bracts more or less white-woolly. 14. P. lagopus.

Stem and bracts glabrous or nearly so. 15. P. Vaseyi.

Leaves $2-4 \mathrm{~mm}$. wide; disk $1 \mathrm{~cm}$. or less wide. $16 . P$. tenuicaulis.

Bracts nearly of the same length.

Stem-leaves oblanceolate; bracts long-acuminate. 17. P. acuminata.

Stem-leaves lanceolate; bracts acute or short-acuminate.

Plant villous.

18. $P$. inuloides.

Plant, except the upper parts, glabrate in age. 19. P. uniflora.

Plant hirsute-villous, decidedly glandular.

20. P. hirta. 
1. P. subsquarrosa Greene. Stems several, more or less decumbent, 1-2.5 dm. high, canescent-tomentulose; leaves petioled; blades lanceolate, conspicuously spinulose-serrate; involueres about $2 \mathrm{~cm}$. high, narrowly campanulate; outer bracts linear-lanceolate, spinulose-serrate, the inner spatulate, subscarious-margined and with a recurved cusp. Mountains: Wyo. Mont.

2. P. carthamoides Hook. Stems $2-4 \mathrm{dm}$, high, strict, more or less villouspuberulent; leaf-blades oblanceolate, or the upper linear, mostly spinulose-dentate, puberulent; bracts in 3 or 4 series, of the same height or the outer longer, 18-20 mm. long, acute or acuminate; pappus tawny or reddish. A plopappus carthamoides A. Gray. Dry prairies: Alta.-Mont.-Ore--B.C. J1-S.

3. P. rigida Rydb. Stems 1-3, erect or ascending, finely pubescent when young, glabrate in age, 2-4 dm. high; leaves pale bluish green, firm, oblanceolate, acute, finely puberulent, or glabrate; heads $15-20 \mathrm{~mm}$. high; bracts very firm, imbricate in 3-4 series, acute or mucronate. Sandy places and meadows: Mont. -Ida.-Wash. Son.-Submont. J1-Au.

4. P. erythropappa Rydb. Stems 1.5-3 dm. high, with 1-4 heads; stemleaves $3-6 \mathrm{~cm}$. long, firm, subsessile, finely pubescent, or glabrate on the upper surface; heads very short peduncled, 10-15 mm. high; bracts imbricate in 4-5 series, pubescent, broadly oval or oblong, obtuse, mucronate, or the outer acute. Plains: Ida. Son.

5. P. Cusickii (A. Gray) Greene. Stem 1-2 dm. high, ascending or decumbent, puberulent; leaf-blades spatulate or oblanceolate, glaucous and puberulent, short-petioled, entire or sparingly spinulose-dentate; heads solitary, about $15 \mathrm{~mm}$. high, 10-15 mm. broad; bracts in about 3 series, of nearly the same length. A plopappus carthamoides Cusickii A. Gray. Stony places: Ore--Ida. Je-Jl.

6. P. crocea (A. Gray) Greene. Stems 3-6 dm. high, sparingly villous above; lower leaves petioled, 1-2 dm. long; blades spatulate, firm, glabrous; upper stem-leaves lanceolate and sessile; heads few; involucres $18-20 \mathrm{~mm}$. high; ligules $2 \mathrm{~cm}$. long, orange. A. croceus A. Gray. Mountains: Wyo.-N.M.-e Utah. Submont. Jl-Au.

7. P. insecticruris (Henders.) Heller. Stems 3-4 dm. high, more or less villous; basal leaves $8-10 \mathrm{~cm}$. long, almost glabrous or villous on the midrib, sinuately serrate, oblanceolate; upper stem-leaves lanceolate or oblong, saliently serrate; heads $2-3 \mathrm{~cm}$. wide; bracts loose, linear-lanceolate, acute or acuminate; ligules $1.5 \mathrm{~cm}$. long. Aplopappus insecticruris Henders. P. pratensis Greene. Stony ground: Ida. Son. Jl.

8. P. Clementis Rydb. Stems more or less villous, ascending or decumbent, 1-4 dm. high; lower stem-leaves linear-oblong, about $1 \mathrm{dm}$. long, glabrous except the ciliate margins, saliently dentate, the upper lanceolate or ovate-lanceolate; heads solitary; disk $2.5-3 \mathrm{~cm}$. broad; outer bracts almost equalling the inner; ligules $10-12 \mathrm{~mm}$. long, bright yellow. $P$. calendulacea and $P$. subcaesia Greene. (?) P. cheiranthifolia Greene, a depauperate form. Mountains: Wyo.-Colo.Utah. Submont.-Alp. Je-Au.

9. P. villosa Rydb. Stems 1-3, ascending, 1-1.5 dm. high; basal leaves oblanceolate, 7-10 $\mathrm{cm}$. long, somewhat glaucous and rigid, entire-margined or occasionally slightly spinulose-denticulate; stem-leaves linear-lanceolate, 2-4 cm. long; heads solitary; disk about $2 \mathrm{~cm}$. broad; outer bracts fully as long as the inner; ligules about $1 \mathrm{~cm}$. long. Mountains: Wyo. Mont. Au.

10. P. lapathifolia Greene. Stems several, 5-6 dm. high, reddish, somewhat villous above; basal leaves $1.5-2 \mathrm{dm}$. long, petioled; blades broadly lanceolate, often rounded, truncate or subcordate at base, light green and glabrous; cauline leaves lanceolate, sessile and dentate; heads rather numerous, corymbose; involuere $2-2.5 \mathrm{~cm}$. broad; bracts narrowly linear, slightly villous; ligules $6 \mathrm{~mm}$. long. Dry places: Utah.

11. P. integrifolia (Porter) Greene. Stems $1-4 \mathrm{dm}$. high, ascending or decumbent at the base; lower leaves oblanceolate, 1-2 dm. long; entire, glabrous, the upper linear or linear-lanceolate, sessile; heads solitary or few; involucres 15-18 mm. high; outer bracts often equalling or exceeding the inner; ligules 12- 
$15 \mathrm{~mm}$. long. A plopappus integrifolius Porter. Meadows: Sask,-Colo.-B.C. Plain-Submont. Jl-Au.

12. P. scaberula Greene. Stems erect, $3-6 \mathrm{dm}$. high, hirsute-villous; basal leaves 1-1.5 dm. long, lanceolate, entire, hirtellous, reticulate; stem-leaves lancelinear, sessile; involucres about $15 \mathrm{~mm}$. high; bracts lanceolate, acute, scabrousciliolate and sometimes slightly puberulent; ligules about $1 \mathrm{~cm}$. long. Hills: Ida. Submont. Jl.

13. P. Ianceolata (Hook.) Greene. Stems $2-4 \mathrm{dm}$. high, glabrous or nearly so; basal leaf-blades lanceolate, usually more or less dentate, glabrous; stemleaves narrowly lanceolate, sessile; heads several, corymbose; involucres 15-20 $\mathrm{mm}$. broad; bracts lanceolate, long-acute; ligules about $10 \mathrm{~mm}$. long. A. lanceolatus T. \& G. Meadows and flats: Sask.-Neb,-Wyo.-B.C. Plain. Jl-Au.

14. P. lagopus Rydb. Stems decumbent, 1-2 dm. long; basal leaves 6-10 $\mathrm{cm}$. long, lanceolate or linear-lanceolate, firm, distantly serrate with almost spinulose teeth; stem-leaves narrowly linear-lanceolate, sessile; involucre about $12 \mathrm{~mm}$. wide; bracts oblong, acute; ligules about $8 \mathrm{~mm}$. long. Dry plains and alkali flats: Wyo.-Colo. Plain-Submont. J1-Au.

15. P. Vaseyi (Parry) Rydb. Stems several, decumbent at the base, 1-3 dm. high, glabrous or nearly so; basal leaves $7-10 \mathrm{~cm}$. long, lanceolate, sinuatedentate or entire; stem-leaves linear or lance-linear, sessile, mostly entire; involucres about $1 \mathrm{~cm}$. broad; bracts lanceolate or oblong, abruptly acute; ligules about $8 \mathrm{~mm}$. long. A. lanceolatus Vaseyi Parry. Mountains: Sask.-Colo.Utah. Submont.-Mont. J1-S.

16. P. tenuicaulis (D. C. Eat.) Greene. Stems decumbent at the base, 1-3 dm. high, glabrous, but usually with a villous tuft at the base; leaves narrowly linear-lanceolate or linear, entire; inflorescence racemose; involucre somewhat turbinate, 6-7 mm. high; bracts acute; ligules 4-5 $\mathrm{mm}$. long. A. lanceolatus tenuicaulis A. Gray. Alkaline meadows: Ore.-Nev.-Utah-Wyo. Son. JIAu.

17. P. acuminata Rydb. Stems several, slender, about $1 \mathrm{dm}$. high, monocephalous; leaves narrowly linear-oblanceolate, with strong midrib, $2-4 \mathrm{~cm}$. long, entire-margined, finely villous on both sides; heads on naked peduncles, about $1 \mathrm{~cm}$. high and $12-15 \mathrm{~mm}$. broad; bracts broadly lanceolate; ligules about $1 \mathrm{~cm}$. long. Hills: Wyo.

18. P. inuloides (Nutt.) Greene. Stems 1-3 dm. high, ascending or decumbent, more or less white-villous; lower leaf-blades lanceolate, or oblanceolate, 1-1.5 dm. long, usually more or less dentate; stem-leaves lanceolate or linear, sessile; involucres $15-20 \mathrm{~mm}$. wide; bracts linear, acuminate. $P$. crepidinea, $P$. hololeuca, and P. sericea Greene. Plains and meadows: Mont.-Colo.-UtahIda. Submont.-Mont. Je-Au.

19. P. uniflora (Hook.) Greene. Stems ascending or decumbent at the base, 1-3 dm. high; basal leaf-blades lanceolate, usually sharply dentate; heads usually solitary; involucres $15-20 \mathrm{~mm}$. wide; bracts linear, acute, glabrous or slightly villous; ligules about $8 \mathrm{~mm}$. long. A. uniflorus T. \& G. P. tuberosa and P. plantaginea Greene. River valleys: Sask.-Colo.-Utah-Mont. Plain-Mont. Jl-S.

20. P. hirta (A. Gray) Greene. Stems ascending or decumbent at the base, 1-4 dm. high, hirsute-villous; basal leaves petioled, 1-2 dm. long, lanceolate, coarsely and saliently dentate; heads solitary or few; involucres $15-20 \mathrm{~mm}$. broad; bracts linear, acuminate, glandular-pubescent, imbricate, but nearly equal. A. hirtus A. Gray. P. foliosa Greene. Hills: Ore.-Ida.-Wash. Plain $\rightarrow$ Submont. Jl.

\section{STENOTÔPSIS Rydb.}

Low shrubs, with fastigiate branches, narrow fasciculate glandular-punctate leaves and large peduncled heads. Involucre broadly hemispherical; its bracts subequal, almost in a single series, linear-lanceolate, thin, scarious-margined, not at all herbaceous. Receptacle naked, alveolar. Ray-flowers about 12, pistillate and fertile; ligules yellow, large. Disk-flowers perfect; corollas tubular 
trumpet-shaped, deeply 5-lobed. Anthers obtuse at the base. Style-branches stigmatic their whole length, with ovate to lanceolate-subulate appendages. Achenes densely silvery-villous. Pappus of white capillary bristles, rather deciduous.

1. S. interior (Coville) Rydb. Shrub 3-10 dm. high; branches green, slightly puberulent; leaves linear, fleshy, glandular-punctate, 1-2 cm. long; involucres hemispheric, about $1 \mathrm{~cm}$. high; bracts linear, attenuate, glandular-granuliferous; ligules 9-11 mm. long, golden yellow. Aplopappus interior Coville. Hillsides in desert regions: s Calif.-s Utah-Ariz. Son. Ap-Jl.

\section{OONÓPSIS Greene.}

Perennial herbs with woody caudex or crown, and erect, leafy stems. Leaves linear or lanceolate, entire. Heads in terminal cymes or solitary. Involucres campanulate or hemispheric; bracts well imbricate, flat, cuspidate-acuminate. Ray-flowers pistillate or wanting; ligules yellow. Disk-corollas yellow, cylindric, with 5 short teeth. Tips of the style-branches ovate, shorter than the stigmatic part. Achenes glabrous or strigose, many-nerved. Pappus of rather few coarse bristles.

Dwarf; stem less than $1 \mathrm{dm}$. high; heads $6-10 \mathrm{~mm}$. high.

Plant more or less villous; leaves flat; heads radiate.

Heads 6-8 mm. high; leaves $1-3 \mathrm{~cm}$. long, not exceeding the stem.

Heads 8-10 mm. high; leaves $4-8 \mathrm{~cm}$. long, often overtopping the stem.

Plant glabrous; leaves involute; heads discoid. Plant robust, $1.5-3 \mathrm{dm}$. high; heads $15-20 \mathrm{~mm}$. high.
Heads discoid.

Heads clustered, 10-15 mm. bigh; achenes glabrous.

Heads solitary, $15 \mathrm{~mm}$. high or more; achenes glandular. Heads radiate.

2. O. argillacea.

3. O. Engelmannii.

4. O. Wardii.

5. O. monocephala.

6. O. foliosa.

1. O. multicaulis (Nutt.) Greene. Stems several, $1 \mathrm{dm}$. high or less, slightly villous; leaves narrowly linear, 1-3 cm. long, slightly villous, thick; heads corymbose; involucres turbinate; bracts ovate, lanceolate or oblong, cuspidate-acuminate; ligules 5-6, 4-5 mm. long. Aplopappus multicaulis A. Gray. Rocks: Wyo. Submont.

2. O. argillacea A. Nels. Stems numerous, $5-8 \mathrm{~cm}$. long, sparingly villous; leaves entire, narrowly-linear, acute; involucres slightly villous, turbinate; bracts oblong-ovate or lanceolate, acuminate; rays about 10 ; ligules 5-6 mm. long. Clayey slopes: Wyo. Submont. Je-Jl.

3. O. Engelmannii (A. Gray) Greene. Stems 1-2 dm. high, glabrous, leafy; leaves narrowly linear, $3-5 \mathrm{~cm}$. long, $2-3 \mathrm{~mm}$. wide, rigid; heads rather many, in a congested cyme, about $12 \mathrm{~mm}$. high; involucres turbinate-campanulate, shorter than the disk-flowers; bracts ovate or elliptic, short-cuspidate. Bigelovia Engelmannii A. Gray. Dry plains: Colo.-Kans. Plain. Au-O.

4. O. Wardii (A. Gray) Greene. Stems 1-2.5 dm. high, very leafy; leaves broadly linear or lanceolate, 1-nerved, or 3-nerved at the base, 6-12 cm. long; inflorescence dense, flat-topped; heads 15-25-flowered; bracts lanceolate, acuminate. A. Fremontii Wardii A. Gray. O. condensata A. Nels. Plains: Wyo.
Submont. J1-S.

5. O. monocephala A. Nels. Stems ereet or ascending, 1-2 dm. high, leafy to the summit; leaves glabrous, linear-oblong, sessile, acute, $5-8 \mathrm{~cm}$. long, about $1 \mathrm{~cm}$. broad; bracts oblong, abruptly acuminate, glabrous or eiliate on the margins. Plains: Colo. Plain.

6. O. foliosa (A. Gray) Greene. Stems 2-3 dm. high, very leafy, glabrous; leaves lanceolate or oblong-lanceolate, 3-5-nerved, $5-10 \mathrm{~cm}$. long; heads solitary or few together; involueres $15-20 \mathrm{~mm}$. high; bracts glabrous, broadly lanceolate, acuminate; rays $12-15 \mathrm{~mm}$. long; achenes glandular-puberulent. A plopappus Fremonti A. Gray. Plains and rocky hills: Kans.-Colo. Submont. Je-S. 


\section{MACRONÈMA Nutt.}

Undershrubs, never resinous-punctate, with short branches, leafy up to the heads. Involucre campanulate; its bracts imbricate, in a few series of more or less unequal length, linear or lanceolate, the inner thin, chartaceous or somewhat scarious, the outer more or less foliaceous and passing into the leaves. Receptacle naked, alveolar. Ray-flowers, when present, ligulate, pistillate and fertile; ligules yellow, conspicuous. Disk-flowers perfect; corollas tubular-trumpet shaped, 5-lobed. Anthers obtuse at the base. Branches of the style stigmatic their whole length, with very long and attenuate-filiform appendages. Achenes slender, compressed, 5-nerved, soft-pubescent. Pappus of numerous white soft bristles.

Heads radiate; branches glandular, not tomentose.

Heads smail, fastigiate-clustered; disk 5-8 $\mathrm{mm}$. in diameter. Leaves broadly obovate, mucronate-cuspidate. Leaves oblanceolate, acute or pointed.

Heads larger, solitary; disk $1 \mathrm{~cm}$. or more in diameter, Leaves oblanceolate, acute.

Leaves spatulate, obtuse or mucronate.

Heads discoid; branches white-tomentose.

Leaves oblong-oblanceolate.

Outer bracts linear to oblong, acute.

Outer bracts broadly oblong, obtuse or mucronate,

Leaves linear.

1. M. obovatum.

2. M. Watsoni.

3. M. suffruticosum.

4. $M$. grindelifolium.

5. M. discoideum.

6. M. obtusum.

7. $M$. lineare.

1. M. obovatum Rydb. Glandular-puberulent undershrub, 2-3 dm. high; leaves $1-2 \mathrm{~cm}$. long, 7-10 $\mathrm{mm}$. wide; heads usually $2-3$ together, about $10 \mathrm{~mm}$. high; bracts firm, oblong-linear, abruptly acute, unequal, imbricate in about 4 series; ligules about 10, short, 4-5 mm. long. Cañons and hillsides: Utah. Submont. Je-Au.

2. M. Watsoni (A. Gray) Greene. Glandular undershrub, 1-3 dm. high; leaves thin, 1-2 $\mathrm{cm}$. long; heads fastigiate-clustered, about $10 \mathrm{~mm}$. high; bracts linear-lanceolate, attenuate, the outer 1 or 2 , foliaceous; ligules $6-8 \mathrm{~mm}$. long. A plopappus Watsoni A. Gray. Mountains: Nev.-Utah-Ariz. Submont. Au-S.

3. M. suffruticosum Nutt. Undershrub, 1-2 dm. high; branches brown; leaves $2-3 \mathrm{~cm}$. long, glandular-hirsute; heads solitary, 10-12 mm. high; bracts linear-lanceolate, acuminate or the outer foliaceous and attenuate; ligules 8-10 $\mathrm{mm}$. long. A. suffruticosus A. Gray. Hills: Mont.-Wyo.-Ariz.-Calif. Submont.-Mont. Ji-S.

4. M. grindelifolium Rydb. Much branched undershrub, 1-2 dm. high; branches glandular-puberulent; leaves 1-2 $\mathrm{cm}$. long, glandular-pubescent; margins more or less crisped; heads $1.5 \mathrm{~cm}$. high; bracts few, linear-lanceolate or acute; ligules $6-12$, conspicuous, often $1 \mathrm{~cm}$. long. M. grindelioides Coult. \& Nels. High mountains: Mont.-Wyo.-Ida.-Ore. Submont.-Mont. J1-S.

5. M. discoideum Nutt. Low branched undershrub, 1-2 dm. high; leaves oblong to oblanceolate, 1-3 cm. long, glandular-puberulent; heads solitary, about $1.5 \mathrm{~cm}$. high and broad; inner bracts few, linear-lanceolate, attenuate. A. Macronema A. Gray. Mountains: Colo.-Calif-Ore. Submont.-Alp. J1-Au.

6. M. obtusum Rydb. Dense glandular-pubescent undershrub, 2-4 dm. high; leaves oblong-oblanceolate, about $3 \mathrm{~cm}$. long, obtuse or mucronate; heads about $18 \mathrm{~mm}$. high, $10-18 \mathrm{~mm}$. in diameter; inner bracts acute, scarcely more than half as long as the flowers. Mountains: Colo. Mont. Jl.

7. M. lineare Rydb. Low undershrub, woody only at the base, 1-2 dm. high; leaves numerous, linear, acute, glandular-puberulent, sometimes also more or less tomentose; heads 1-1.5 $\mathrm{cm}$. high; bracts few, linear, acuminate, the outer foliaceous. Sandy or gravelly places: Wyo. Submont. Au.

\section{STENÒTUS Nutt.}

Low perennials, with cespitose woody caudices and narrow, entire, more or less coriaceous and evergreen (except in the last species), mostly basal leaves. Involucre hemispherical or nearly so; its bracts imbricated in a few rows, ap- 
pressed, thin; lanceolate to oval, not herbaceous. Receptacle naked, alveolar. Ray-flowers ligulate, pistillate and fertile; ligules yellow, conspicuous. Diskflowers perfect; corollas tubular, somewhat enlarged upwards, deeply 5-toothed. Anthers obtuse at the base. Style-branches stigmatic their whole length, with subulate appendages. Achenes grayish or white villous. Pappus of numerous white soft capillary scabrous bristles.

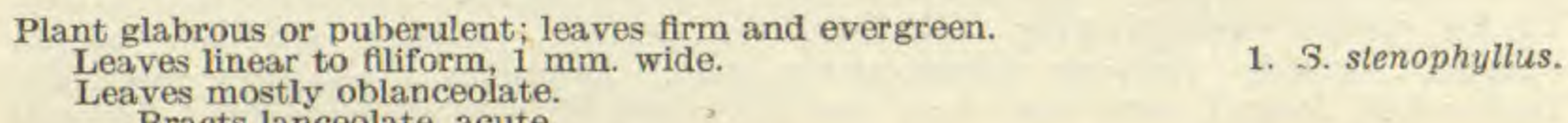
Bracts lanceolate, acute.

Plant puberuent.

Bracts in 3 series, broad, with broad scarious margins. 2. S. acaulis.

Brac is in 2 series, narrow, with narrow scarious margins.

Plant glabrous, except the scabrous leaf-margins.

3. S. Andersonii.

Bases of the basal leaves much enlarged, somewhat inflated and remaining for years on the short caudal branches; leaf-blades narrowly oblanceolate to linear.

Stem-leaves oblanceolate, $1-4 \mathrm{~cm}$. long. Stem-leaves linear, 4-7 cm. long.

4. S. caespitosus.

5. S. falcatus.

Bases of the basal leaves neither much enlarged nor persistent; leaf-blades broadly oblanceolate or spatulate. $\quad 6$. S. latifolius.

Bracts oval or oblong, very obtuse.

Plant floccose; leaves softer, not evergreen.

7. S. armerioides.

8. S. lanuginosus.

1. S. stenophyllus (A. Gray) Greene. Stems about $5 \mathrm{~cm}$. high; leaves 1-2 $\mathrm{cm}$. long, hirsutulous-scabrous; involucres 6-8 mm. high, puberulent; bracts linear, attenuate, with narrow scarious margins. Aplopappus stenophyllus A. Gray. Mountains and stony hills: Wash.-Ida.-Calif. Submont--Mont. Ap-Je.

2. S. acaulis Nutt. Plant 2-10 $\mathrm{cm}$. high; leaves oblanceolate or spatulate, 3-nerved; flowering stems scapiform; heads solitary, about $1 \mathrm{~cm}$. high; bracts lanceolate or ovate-lanceolate; ligules $8 \mathrm{~mm}$. long. A. acaulis A. Gray. Dry hills and bad lands: Sask.-Colo.-Calif.-Wash. Plain-Submont. My-Je.

3. S. Andersonii Rydb. Flowering stems about $1 \mathrm{dm}$. high, leafy at the base; leaves narrowly oblanceolate, not very rigid, distinctly 3 -ribbed, $3-5 \mathrm{~cm}$. long, 3-4 mm. wide; bracts narrowly lanceolate. Open dry hills: Mont. Plain. Jl.

4. S. caespitosus Nutt. Stems $5-15 \mathrm{~cm}$. high; basal leaves linear-oblanceolate, 3-nerved, glabrous except the scabrous-ciliolate margins, 3-5 cm. long; heads about $1 \mathrm{~cm}$. high; bracts lanceolate, acuminate; ligules $8 \mathrm{~mm}$. long. A. acaulis glabratus A. Gray. Dry hills: Sask.-Wyo.-Nev.-Mont. Plain-Submont. Je-Jl.

5. S. falcatus Rydb, Flowering stems $10-15 \mathrm{~cm}$. high, leafy; basal leaves oblanceolate, rigid, obtuse or acute, 4-5 cm. long, 3-ribbed; stem-leaves linear, more or less falcate; heads about $1 \mathrm{~cm}$. high; bracts lanceolate, acute, with scarious margin; ligules 6-7 mm. long. Dry hills: s Utah. Son. Je.

6. S. latifolius A. Nels. Flowering stems slender, leafy, 10-15 cm. high, striate; leaves spatulate or broadly lanceolate, $2-3 \mathrm{~cm}$. long, more distributed along the stem than in the other species; heads solitary, 10-12 $\mathrm{mm}$. high; bracts elliptic-lanceolate, abruptly short-acuminate; ligules $8 \mathrm{~mm}$. long, orange. Rockcrevices: Utah. Submont. Je.

7. S. armerioides Nutt. Flowering stems $5-15 \mathrm{~cm}$. high, glabrous or slightly scabrous-puberulent; leaves linear or linear-oblanceolate, 3-nerved, glabrous or nearly so, 3-7 cm. long; heads $10-13 \mathrm{~mm}$. high; ligules $10-12 \mathrm{~mm}$. long. $A$. armerioides A. Gray. Dry hills and badlands: Man.-Neb.-N.M.-Wyo.Sask. Plain-Submont. Je-Jl.

8. S. lanuginosus (A. Gray) Greene. Stem 1-2 dm. high, more or less floceose; leaves narrowly linear-oblanceolate, $3-6 \mathrm{~cm}$. long; heads solitary, $1 \mathrm{~cm}$. high; bracts linear-lanceolate, acute or acuminate, scarious-margined; ligules 8-10 mm. long. A. lanuginosus A. Gray. High ridges: Wash.-Mont.-Ore. Submont. $\mathrm{My}-\mathrm{Jl}$. 


\section{TONÉSTUS A. Nels.}

Dwarf herbaceous perennials, with woody taproots and short caudices. Leaves spatulate to linear, entire, alternate. Heads solitary, terminal, radiate. Involucres campanulate or hemispheric; bracts loosely imbricate, in 2-3 series, more or less foliaceous, the outer ones often leaf-like. Ray-flowers many, yellow, pistillate. Disk-corollas yellow, somewhat enlarged upwards, deeply 5-toothed. Appendages of the style-branches oblong to subulate. Pappus soft and white.

Basal leaves oblanceolate, spatulate, or oblong; bracts lanceolate or oblanceolate.

Bracts acute; plants glandular or viscid.

Bracts lacerate or ciliate; stem-leaves linear or linear-lanceolate, long-ciliate.

Bracts neither lacerate nor ciliate; stem-leaves oblanceolate, not ciliate. laceratus.

Bracts obtuse; plant soft-pubescent or glabrate, scarcely viscid.

Bracts obtuse; plant soft
Leaves and bracts linear.

2. T. Lyallii.

3. $T$, pygmaeus.

4. T. linearis.

1. T. laceratus (Henders.) A. Nels. Stem $1 \mathrm{dm}$. high or less, glandularpuberulent; basal leaves spatulate to narrowly oblanceolate; involucres $1 \mathrm{~cm}$. high and wide; bracts subequal in 2 or 3 series, lanceolate, hyaline-margined; achenes densely sericeous. Aplopappus laceratus Henders. Mountains, among rocks: Ida. Subalp.-Alp. Jl,

2. T. Lyallii (A. Gray) A. Nels. Stem $1 \mathrm{dm}$. high or less; leaves oblanceolate or spatulate, or the upper oblong; involucres about $1 \mathrm{~cm}$. high and broad; bracts lanceolate, glandular-puberulent; achenes glabrous or nearly so. $A$. Lyallii A. Gray. High mountains: Alta.-Colo.-Ida.-Wash.-B.C. Mont.Alp. J1-Au.

3. T. pygmaeus (T. \& G.) A. Nels. Stem 2-5 cm. high; leaves linearspatulate to spatulate-oblong, 2-4 cm. long; heads 8-10 $\mathrm{mm}$. high; bracts oblong to oval; achenes silky-strigose. Stenotus pygmaeus T. \& G. A. pygmaeus A Gray. High mountains: Wyo.-N.M. Alp.-Subalp. Je-Au.

4. T. linearis Nels. \& Macbr. Stem about $1 \mathrm{dm}$. long; leaves all narrowly linear, 3-nerved, minutely crisp-pubescent, 2-4 cm. long; bracts about $1 \mathrm{~cm}$. long, with narrow scarious margins, in 2 series; ligules broadly linear; achenes minutely pubescent. Mountains: Ida.

\section{OREOCHRỲSUM Rydb. MOUNTAIN GoLD.}

Plants with slender horizontal rootstock, leafy, viscid-puberulent above. Involucral bracts oblong, pale, rather obscurely 1-ribbed, chartaceous or the outer foliaceous, in about three moderately unequal ranks. Rays several, short. Disk-corollas narrowly trumpet-shaped, deeply 5-toothed. Style-appendages lanceolate, longer than the stigmatic portion. Achenes angled. Pappus white or slightly tawny, of soft scabrous bristles.

1. O. Parryi (A. Gray) Rydb. Stem 1-4 dm. high, puberulent or somewhat viscid above; basal leaves petioled, $5-15 \mathrm{~cm}$. long; blades spatulate or oblanceolate, glabrous; stem-leaves oval to oblong, sessile; heads 10-12 mm. high; ligules 5-6 mm. long, pale yellow, $1 \mathrm{~mm}$. wide; achenes glabrous. A plopappus Parryi A. Gray. Mountains: Wyo.-N.M.-Ariz.-Utah; Mex. Submont.-Subalp. J1-S.

\section{SOLIDĀGO L, GoldENROD.}

Perennial caulescent herbs, mostly with rootstocks (all ours), rarely shrubby at the base. Leaves alternate, often toothed. Heads small, several-flowered, paniculate or thyrsoid, radiate. Involucres campanulate, turbinate, or cylindric; bracts in several series, well imbricate, ribless; receptacle small, alveolate. Ray-flowers pistillate; ligules yellow, short. Disk-flowers hermaphrodite, fertile; corolla usually yellow, tubular to narrowly campanulate, 5-lobed. Anthers obtuse at the base. Style-branches flattened; appendages lanceolate. Achenes terete, usually ribbed. Pappus of many rough hair-like bristles, in 1-2 series.

Leaves glabrous or slightly pubescent along the veins and on the margins.

Leaves not triple-veined; branches of the inflorescence not recurved-spreading; heads not secund. 
Bracts of the inflorescence lanceolate or linear-lanceolate, acute or acuminate. Leaves ciliate at the base. Leaves not ciliate at the base.

Bracts of the inflorescence oblong or linear-oblong, obtuse. Leaves, at least the basal ones, toothed; stem-leaves few ;

Leaves all entire; stem very leafy, 4-8 dm. high.

I. VIRGA-AUREAE.

IV. GLABERRIMAE.

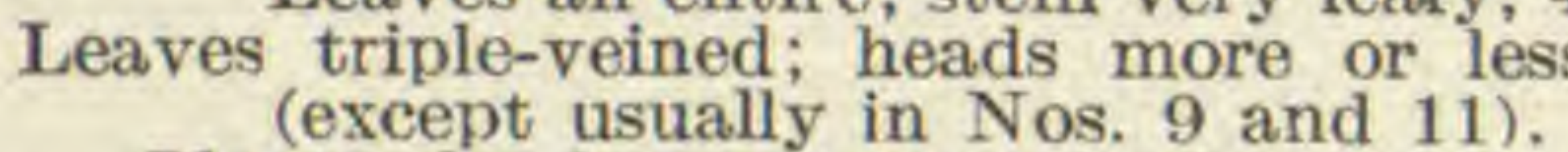

Plants slender, not very leafy, 2-4 dm. high; stem-leaves narrowly oblanceolate or linear.

Plant tall, leafy, 4-10 dm. high.

Stem-leaves lanceolate.

Stem-leaves obovate.

Leaves densely canescent.

Bracts not squarrose.

Leaves lanceolate; bracts narrowly linear-lanceolate.

Leaves, at least the lower ones, oblanceolate oi obovate.

Bracts squarrose; leaves numerous, entire, elliptic.

plants 1-4 dm. high.

II. HUMILES.

III. SPECIOSAE.

IV. GlaberrimaE.

V. SEROTINAE.

VI. RADULAE.

\section{VIRGA-AUREAE.}

Plants low and slender, 1-3 dm. high; inflorescence corymbiform; branches with a single or a few corymbose heads.

Heads 7-9 mm. high; inner bracts linear-lanceolate, of about the same length as the flowers and pappus; plant 2-3 dm. high.

1. S. scopulorum.

Heads 5-7 mm. high; bracts lanceolate, the inner shorter than the flowers and the pappus; plant usually less than $2 \mathrm{dm}$. high.

2. S. ciliosa.

Plants stout, 3-4 dm. high; inflorescence paniculate, but narrow; branches racemiform; heads $7-9 \mathrm{~mm}$. high.

Basal leaves broadly oblanceolate, acute; stem pubescent.

3. S. rubra.

Basal leaves narrowly oblanceolate, obtuse; stem glabrous up to the inflorescence.

\section{HuMILES.}

4. S. laevicaulis.

Plant low, 1-1.5 dm. high; inflorescence with few heads, short, congested.

Plant taller, 2-4 dm. high; inflorescence with many heads, elongate.

Leaves not ciliate; bracts oblong; inflorescence usually narrow.

Leaves ciliate at the base; bracts linear; inflorescence open.

5. S. decumbens.

6. S. oreophila.

7. S. dilatata.

One species.

III. SPECIOSAE.

\section{Glaberrimae.}

8. S. pallida.

Heads less than $5 \mathrm{~mm}$. high; stem slender.

Inflorescence decidedly viscid; leaves indistinctly triple-veined.

Inflorescence not viscid; leaves distinctly triple-veined.

Plant glaucous; bracts thick, oblong, obtuse.

Plant not glaucous; bracts not thick, linear-lanceolate to 10. S. glaucophylla. Inflorescence narrow, scarcely secund; bracts linear-lanceolate.

Inflorescence 11 . S. missouriensis.

11. S. missouriensis.

Heads 6-7 mm. high; stem stout.

12. S. glaberrima.

13. S. concinna.

\section{SEROTINAE.}

Inflorescence narrowly rhombic in outline; branches ascending, almost straight, scarcely secund.

Inflorescence broad; branches recurved-spreading, distinctly secund.

14. S. elongata.

Leaves green, sparingly pubescent or glabrous; pubescence scabrous, mostly confined to the margins and the veins.

Stem usually glabrous up to the inflorescence; leaves glabrous except on the margins and on the midveins.

Veins of the leaves glabrous; heads $5-6 \mathrm{~mm}$. high, in a short panicle with strongly curved branches.

15. S. serotina.

Veins of the leaves pubescent below; heads 4-5 mm. high; panicle with long branches.

Stem more or less pubescent.

Heads $5 \mathrm{~mm}$. or more high; leaves pubescent.

Heads about $4 \mathrm{~mm}$. high; plant comparatively slender.

Leaves pubescent, at least on the veins.

Leaves glabrous, except the scabrous-ciliolate margins.

16. S. salebrosa.

17. S. polyphylla.

18. S. canadensis.

19. S. serra.

Leaves densely eanescent, especially beneath.

Leaves usually broadly lanceolate.

Leaves scabrous above.

Leaves softly puberulent on both sides.

Leaves linear-lanceolate, finely and rather softly canescent on both sides, mor less yellowish gray.

20. S. dumetorum.

22. S. gilvocanescens. 
One species.

\section{RADULAE.}

VII. INCANAE.

Plant low, 1-2 dm. high; inflorescence corymbiform; branches not secund. Bracts oval to oblong, obtuse.

Bracts lanceolate, acute.

24. S. nana.

25. S. nivea.

Plants tall, 2-6 dm. high; inflorescence narrow, or if open with distinctly secund branches. Bracts oblong or linear, obtuse; stem-leaves scarcely triple-veined; inflorescence usually narrow.

Stem-leaves oblanceolate.

Stem-leaves spatulate or broadly oblanceolate.

26. S. pulcherrima.

Bracts lanceolate or ovate, acute; stem-leaves distinctly triple-veined; inflorescence usually more open.

Stem-leaves oblanceolate or elliptic; bracts lanceolate.

Stem-leaves obovate, thick; bracts ovate.

28. S. trinervata.

29. S. mollis.

VIII. WARDIANAE.

One species.

30. S. Wardii.

1. S. scopulorum (A. Gray) A. Nels. Stem glabrous below, pilose above; basal leaves $5-15 \mathrm{~cm}$. long; blades oblanceolate or spatulate, usually obtuse, crenate or serrate towards the apex; upper stem-leaves lanceolate or linearlanceolate, sessile; bracts acute, ciliolate; achenes strigose. S. corymbosa Nutt., not Ell. S. multiradiata scopulorum A. Gray. Hills and mountains: Alta.Colo.-Utah-B.C. Mont. Je-Au.

2. S. ciliosa Greene. Stem 1-2 dm. high, decumbent at the base, glabrous below, pilose above; basal leaves spatulate, serrate-crenate towards the apex, 2-5 cm. long, tapering into a short petiole; stem-leaves linear-lanceolate to linear-oblanceolate, entire, sessile, ciliolate; heads in a small dense thyrsus; achenes strigose. Higher mountains: Alta.-Colo.-Ariz.-B.C. Mont.-Alp. $\mathrm{Je}-\mathrm{S}$.

3. S. rubra Rydb. Stem about $3 \mathrm{dm}$. high, pubescent, reddish; basal and lower cauline leaves $6-12 \mathrm{~cm}$. long, firm, bluish green, glabrous, serrulate and minutely scabrous on the margins; upper stem-leaves sessile and lanceolate; bracts narrowly linear-lanceolate, ciliolate; achenes strigose. Mountains: Colo. Mont. S.

4. S. laevicaulis Rydb. Stem rather tall, 4-7 dm. high, light-colored and shining; basal leaves rather thin, obtuse, $5-10 \mathrm{~cm}$. long, entire or crenate, glabrous except the scabrous margin; upper stem-leaves narrowly lanceolate, sessile; branches nearly erect; bracts narrowly linear-lanceolate, acute, eiliolate on the margins; achenes sparingly strigose. Mountains: Colo.-Wyo. Jl-S.

5. S. decumbens Greene. Stem low, decumbent at the base, glabrous or nearly so; basal leaves spatulate or oblanceolate, obtuse or rounded at the apex, crenate-serrate towards the end; upper leaves narrower; bracts linear or oblong; heads $6-8 \mathrm{~mm}$. high; achenes strigose-hirsute. A. humilis nana A. Gray. Higher mountains: Wyo.-N.M. Subalp.-Alp. J-S.

6. S. oreophila Rydb. Stem glabrous or nearly so, often tinged with red; lower leaves spatulate, rounded and serrate or crenate at the apex, 3-10 cm. long, glabrous; stem-leaves oblanceolate, entire or nearly so; panicle narrow; heads about $8 \mathrm{~mm}$. high; bracts linear; achenes hirsute-strigose. $S$. humilis A. Gray, in part, not Nutt. Mountains: B.C.-Mack.-Colo. Mont-Subalp. J1-S.

7. S. dilatata A. Nels. Stem glabrous, 4-6 dm. high; basal leaves glabrous, scabrous-ciliolate, oblong-spatulate to elliptic, 1-1.5 dm. long, serrate; stem-leaves lanceolate, the upper sessile; heads numerous, in a rather open panicle, 6-8 mm. high; bracts linear, most of them obtuse; achenes slightly hirsute. Mountains: Mont.-Colo. Submont.-Mont. Jl-Au.

8. S. pallida (Porter) Rydb. Stem 4-8 dm. high, glabrous; leaves obovatespatulate to lanceolate, $5-15 \mathrm{~cm}$. long, acute, entire, pale; heads very numerous, in a dense, elongated-conic panicle; disk 5-6 $\mathrm{mm}$. high; bracts oblong or linearoblong, glabrous; achenes glabrous or nearly so. S. speciosa pallida Porter. Hills: S.D.-Neb.-Colo. Plain-Submont. Au-S. 
9. S. viscidula Rydb. Stem low, about $2 \mathrm{dm}$. high, finely pubescent, reddish; lower leaves narrowly linear-oblanceolate, finely puberulent and somewhat viscid, denticulate, obtuse or acutish; inflorescence paniculate but flattopped; branches scarcely secund; heads numerous, small, about $5 \mathrm{~mm}$. high; bracts linear, obtusish, viscid; achenes strigose. Mountains: Colo. Mont. Au.

10. S. glaucophylla Rydb. Stem slender, pale, glabrous; leaves glabrous, minutely ciliolate on the margins, rather thick, linear-oblanceolate or the upper linear, 6-10 $\mathrm{cm}$. long, entire, acute; inflorescence a round-topped panicle; heads about $5 \mathrm{~mm}$. high; achenes slightly strigose-hirsute. Valleys: Mont.-Wyo. Plain-Submont. J1-S.

11. S. missouriensis Nutt. Stem slender, 3-4 dm. high, glabrous; leaves linear-oblanceolate, glabrous, scabrous-ciliolate, $5-15 \mathrm{~cm}$. long, acute, the lower petioled and sometimes serrate, the upper sessile and entire; heads 4-5 mm. high; bracts acute, glabrous. S. Tolmieana A. Gray. Mountains: B.C.-Ore.-Colo. -S.D.-Alta. Submont. J1-Au.

12. S. glaberrima Martens. Stem 2-4 dm. high, glabrous up to the inflorescence; lower leaves narrowly oblanceolate, $3-15 \mathrm{~cm}$. long, often serrate or entire, glabrous, ciliolate; inflorescence flat-topped or round-topped; heads about $5 \mathrm{~mm}$. high; achenes sparingly hirsutulous. S. missouriensis A. Gray, not Nutt. Plains and hills: Mich.-Mo.-Tex.-Ariz.-Ida.-Alta. Plain-Mont. J1-S.

13. S. concinna A. Nels. Stem glabrous, 2-4 dm. high, densely leafy; basal leaves oblanceolate, $8 \mathbf{- 1 5} \mathrm{cm}$. long, serrate or entire; stem-leaves narrowly oblanceolate or linear-oblong; panicle round-topped, usually open; bracts oblong, acute, thin-margined; achenes pubescent. S. missouriensis extraria A. Gray. Mountains: Alta.-Colo.-B.C. -Submont.-Mont. Jl-S.

14. S. elongata Nutt. Stem 3-10 dm. high, glabrous below, finely puberulent above; leaves narrowly lanceolate, acuminate, 5-10 $\mathrm{cm}$. long, distantly serrate, with sharp teeth, more or less puberulent; heads about $5 \mathrm{~mm}$. high; bracts linear or linear-lanceolate, acute; achenes sparingly hirsutulous. Low ground: B.C.-Mont.-Nev.-Wyo.-Calif. Submont. Jl-S.

15. S. serotina Ait. Stem 5-20 dm. high; leaves lanceolate, $5-15 \mathrm{~cm}$. long, sessile, usually sharply serrate; inflorescence short-pyramidal, dense; bracts linear or linear-lanceolate, obtuse or acutish; achenes hirsutulous. S. Pitcheri Nutt., the western form, with shorter inflorescence. Meadows, valleys, and along streams: Newf.-Ga.-Ark,-Colo.-B.C. Plain-Submont. J1-S.

16. S. salebrosa (Piper) Rydb. Stem 5-20 dm. high; leaves narrowly lanceolate, sessile, sharply serrate, acuminate or the uppermost entire, 5-10 cm. long, thick; panicle large; bracts narrowly linear, acutish; achenes hirsutulous. S. serotina salebrosa Piper. Along streams: B.C.-Mont.-Ore. Submont. J1Au.

17. S. polyphylla Rydb. Stem tall, sometimes a meter high, striet, simple and puberulent up to the more hirsutulous inflorescence; leaves narrowly lanceolate, sessile, acuminate, serrate above the middle, thick and firm, green, scabrous above, more softly short-pubescent beneath; bracts linear, acute; achenes hispidulous. Perhaps not distinct from the eastern S. altissima L. Along streams: Wyo.-N.M. Submont. Au-S.

18. S. canadensis L. Stem 6-15 dm. high; leaves sessile, 5-10 dm. long, rarely $1.5 \mathrm{~cm}$. wide, narrowly lanceolate, acuminate, serrate, puberulent on both sides or glabrous above; panicle large, broadly conic; bracts narrowly linear or lance-linear, acute or obtusish; achenes sparingly hairy. Among bushes: Lab.W.Va.-Colo.-B.C. Plain-Submont. J1-O.

19. S. serra Rydb. Stem about $6 \mathrm{dm}$. high, more or less pubescent, especially above; leaves lanceolate, about $8 \mathrm{~cm}$. long, acuminate, sharply toothed, rather thin; heads numerous 3-4 mm. high; bracts linear or linear-lanceolate, acute; achenes hirsutulous. Along streams: Colo.-Wyo. Mont. Au.

20. S. dumetorum Lunell. Stem 5-10 dm. high, densely puberulent; leaves lanceolate, acute, thick, more or less serrate, strongly veined, revolute 
and scabrous-ciliolate on the margins, densely hispidulous-puberulent beneath; inflorescence short-conic; involucre about $3 \mathrm{~mm}$. high; bracts linear-acute; achenes sparingly hispidulous. S. scabriuscula Rydb., in part. Dry soil: Sask. -Mo.-Tex.-Mont. Plain. J1-S.

21. S. pruinosa Greene. Stem about $1 \mathrm{~m}$. high; leaves ascending, about 5 cm. long, elliptic-lanceolate, acute or acuminate, lightly but evenly serrate, 3 -ribbed, canescent on both sides, with a dense and soft pubescence; inflorescence short-pyramidal; outer bracts linear-subulate, the inner oblong, lance-obtuse. Plains: Sask. Plain. Au.

22. S. gilvocanescens (Rydb.) Smyth. Stem slender, 3-6 dm. high, puberulent; leaves 3-6 cm. long, sparingly serrate or entire, puberulent-canescent; inflorescence small and dense; heads $3-4 \mathrm{~mm}$. high; bracts narrowly linear, acute; achenes sparingly hairy. Sandy soil: Minn.-Kans.-Utah-Mont. Plain. $\mathrm{Jl}-\mathrm{Au}$.

23. S. Garrettii Rydb. Stem $2-3 \mathrm{dm}$. high, sparingly puberulent or glabrous; leaves obovate-spatulate or the upper oval, entire or the lower toothed towards the apex, rather thin, minutely and sparingly scabrous-puberulent, scabrous-ciliolate, 3-6 $\mathrm{cm}$. long; infloreseence more or less leafy, with a few secund branches; heads 5-6 mm. high; bracts lanceolate, acute, yellowish; achenes sparingly hirsute. Cañons: Utah-Wyo. Submont. Au.

24. S. nana Nutt. Stem finely canescent-puberulent, 1-2 dm. (rarely 3 $\mathrm{dm}$.) high; basal leaves $2-6 \mathrm{~cm}$. long, petioled, canescent-puberulent, spatulate, rounded at the apex, entire or crenulate; stem-leaves oblanceolate; heads 5-7 $\mathrm{mm}$. high; achenes strigose. High dry plains: Mont.-Colo.-Ariz. Submont. - Mont. Jl-S.

25. S. nivea Rydb. Stem 1-2 dm. high, canescent-puberulent; basal leaves 2-4 cm. long, short-petioled, obovate-spatulate, rounded at the apex, entire or nearly so, canescent-puberulent, almost velvety and almost white; stem-leaves oblanceolate; heads about $6 \mathrm{~mm}$. high; achenes hirsute-strigose. Dry hillsides: Mont. Submont. Jl-Au.

26. S. pulcherrima A. Nels. Stem 3-8 dm. high, striate, cinereous-puberulent; lower leaves narrowly oblanceolate, entire, 6-12 $\mathrm{cm}$. long; upper leaves oblong or linear; all cinereous-puberulent; heads about $6 \mathrm{~mm}$. high; achenes puberulent. S. diffusa A. Nels. Dry plains: Sask,-Minn,-Neb.-Colo.Ariz.-Alta. Plain-Mont. J1-S.

27. S. radulina Rydb. Stem 3-4 dm. high, grayish-puberulent; lower leaves obtuse, crenate at the apex, finely puberulent; heads about $4 \mathrm{~mm}$. high; bracts oblong, obtuse, or the inner linear; achenes hirsutulous. Mountains: Utah - Colo. Submont. Au.

28. S. trinervata Greene. Stem decumbent at the base, cinereous-puberulent, 3-6 dm. high; leaves oblanceolate, 5-10 cm. long, puberulent, seabrouseiliolate on the margins, entire or nearly so; heads about $6 \mathrm{~mm}$. high; achenes hispidulous. Plains and hills: S.D.-N.M.-Ariz.-Utah. Submont.-Mont. J1-S.

29. S. mollis Bartl. Stem 2-4 dm. high, cinereous-puberulent, strict, leafy; leaves obovate, oval, or broadly spatulate, or the upper elliptic, canescent, the lower more or less serrate; panicle usually dense and somewhat leafy; heads 5-7 $\mathrm{mm}$. high; achenes sparingly hirsutulous. S. nemoralis incana A. Gray. Dry plains: Sask.-Tex.-Colo.-Mont. Plain-Submont. Jl-S.

30. S. Wardii Britton. Stem 4-10 dm. high, puberulent; leaves lanceolate or ovate-lanceolate, entire or with a few teeth, firm, $5-9 \mathrm{~cm}$. long, pale, usually shining, scabrous-puberulent; panicle narrow, leafy; heads about $8 \mathrm{~mm}$. high; bracts lanceolate, acute, canescent, squarrose. Plains and prairies: Mo.-Ark. -Okla.-w Neb. Plain. Au-O.

\section{PETRADÒRIA Greene. Rock Goldenrod.}

Low tufted perennial herbs, with a short branched caudex. Leaves alternate, entire, 3-nerved and punctate. Heads small, several, corymbose. Involucres cylindraceous; bracts in more or less distinct rows, rigid, somewhat carinate, 
with green tips. Rays yellow, $1-3$, short. Disk-flowers few, yellow. Achenes flattish and broad, 5-nerved.

1. P. pumila (Nutt.) Greene. Stem strict, erect, $1-2 \mathrm{dm}$. high, glabrous; leaves rigid, linear-oblanceolate, 3-nerved, somewhat punctate, resiniferous, 5-10 $\mathrm{cm}$. long; cyme glomerate-fastigiate, flat-topped; heads 5-8-flowered, oblong, about $8 \mathrm{~mm}$. high; ligules 1-3, $2 \mathrm{~mm}$. long; achenes glabrous. Solidago pumila Nutt. Dry mountains: Wyo.-Tex.-Ariz.-Ore. Son.-Submont. Jl-Au.

\section{EUTHÀmia Nutt. Bushy or Fragrant Goldenrod.}

Perennial caulescent herbs with elongated rootstocks. Leaves alternate, narrow, more or less triple-ribbed. Heads numerous, in broad corymbs. Involucres oblong; bracts imbricate, narrow, glutinous; receptacle pubescent or fibrillate. Ray-flowers pistillate, usually more numerous than the disk-flowers, with inconspicuous ligules. Disk-flowers perfect; corollas yellow. Style-branches with lanceolate appendages. Achenes broadened upwards, pubescent. Pappus of long equal bristles.

Outer bracts broader than the inner, which are obtuse.

Outer bracts narrow, all acute; lateral ribs of the leaves rather prominent.

1. E. camporum.

2. E. occidentalis.

1. E. camporum Greene. Stem $3-5 \mathrm{dm}$. high, puberulent-scabrous on the angles above; leaves linear, triple-veined, but the lateral veins often glabrous or nearly so on both sides, scabrous-puberulent on the margins; outer bracts ovate, acutish, the inner oblong-linear, more or less green-tipped; achenes strigose. Closely related to $E$. graminifolia (L.) Nutt., of the East. Low ground: Man.Kans.-Colo.-Alta. Plain. J1-O.

2. E. occidentalis Nutt. Stem 5-20 dm. high, glabrous, striate; leaves linear, triple-veined, glabrous, obsoletely scabrous on the margins; bracts narrowly lanceolate, thin, ciliolate; achenes sparingly hairy. Solidago occidentalis Nutt. Moist ground: Alta.-N.M.-Calif.-B.C. Plain. Je-N.

\section{OLIGONEÙRON Small. Rough GOLDENROD.}

Perennial caulescent, usually balsamic herbs. Leaves alternate. Heads corymbose, radiate. Involucres several-flowered, campanulate; bracts imbricate in several series, thickish, longitudinally few-ribbed; receptacle pitted. Rayflowers pistillate; ligules yellow. Disk-flowers usually perfect; corollas yellow, the tube dilated into a short throat. Anthers obtuse at the base. Style-branches flat, with oblong appendages. Achenes several-nerved. Pappus of many capil-

1. O. canescens Rydb. Stem 5-7 dm. high; basal leaves long-petioled; blades oval, 7-12 cm. long, thick, yellowish canescent on both sides, crenulate; upper stem-leaves oval, sessile; inflorescence corymbiform but much congested; heads about $1 \mathrm{~cm}$. high; bracts oblong, canescent; achenes slightly hairy above, otherwise glabrous. S. rigida humilis Porter. Prairies and river valleys: Sask. -Neb.-Colo.-Mont. Plain-Submont. Au-O.

\section{MONÓPTILON T. \& G.}

Depressed dwarf annuals. Heads solitary, terminal. Involucres hemispheric; bracts narrow, numerous, in a single series, somewhat herbaceous. Rayflowers numerous, pistillate and fertile; ligules white or violet. Disk-flowers numerous, perfect; corollas yellow. Style-branches with triangular appendages. Achenes oblong-obovate, compressed. Pappus of a short, cup-shaped, denticulate crown and a single awn, which is barbellate or plumose towards the apex.

1. M. bellidiforme T. \& G. Stem branched at the base, $2-4 \mathrm{~cm}$. high, villous-hirsute; leaves spatulate or linear-spatulate, $5-10 \mathrm{~mm}$. long, hirsute; heads sessile; involucres $4 \mathrm{~mm}$. high, 6-8 $\mathrm{mm}$. wide; bracts linear, hirsute; ligules $3 \mathrm{~mm}$. long. Desert plains: s Utah-Ariz. - S Calif, L. Son. Ap-Je. 


\section{TOWNSÉNDIA Hook.}

Tufted scapose or caulescent plants, often with caudex-like stems or branches. Leaves alternate, entire, often crowded, usually broadest above the middle. Heads rather large, sessile or peduncled. Involucres hemispheric; bracts imbrieate, in several series, herbaceous, with more or less scarious margins; receptacle broad, flat, alveolate. Ray-flowers pistillate; ligules white, rose, or purplish. Disk-flowers mostly perfect. Anthers obtuse and entire at the base. Stylebranches flattened, with lanceolate appendages. Achenes various, those of the rays usually 3 -angled and those of the disk flattened. Pappus of a single series of scales or awns, or that of the ray-flowers sometimes reduced to a crown of small scales.

Bracts acuminate.

Caulescent biennials or short-lived perennials.

Stems spreading, with branches from the base, which surpass them in length.

Stems erect or nearly so, simple or with short branches above.

1. T. grandifiora.

Stems over $3 \mathrm{dm}$. high, generally branched; basal leaves oblanceolate.

Involucre $1.5-2 \mathrm{~cm}$. broad, naked, $\quad 2$. T. eximia.

Involucre $2-3 \mathrm{~cm}$, broad, generally subtended by leaves. 3. T. Vreelandii.

Stems 1-2 dm. high, generally simple and monocephalous, sometimes several from one root; basal leaves spatulate.

Acaulescent perennials, depressed, monocephalous.

Plant pilose or hirsute.

Plant arachnoid-lanuginose.

4. T. Parryi.

acute or obtuse.

Plant with evident leafy stems.

Stems $5-20 \mathrm{~cm}$. high; mostly annuals and biennials.

Pappus of disk- and ray-flowers elongate bristles.

Leaves linear or oblanceolate; pappus of the rays nearly as long as that of the disk-flowers.

5. T. alpina.

6. T. condensata.

Leaves spatulate; pappus of the ray-flowers much shorter than that of the disk-flowers.

Pappus of the rays reduced to a crown of short squamellae.

Bracts of the involucre in 3 series; pubescence of the stem appressed; leaves linear.

9. T. Fendleri.

Bracts in 2 series; pubescence of the stem not strictly appressed; earlier leaves spatulate. $10 . T$. strigosa.

Stem usually evident, but short, 1-5 cm. long; mostly cespitose perennials.

Leaves more or less cinereous.

Outer bracts rounded-obtuse at the apex; achenes almost glabrous.

Outer bracts acute; achenes pubescent.

11. T. montana.

Heads distinctly peduncled; hairs of the achenes not glochidiate-capitellate.

12. $T$. scapigera.

Heads subsessile; hairs of the achenes glochidiate-capitellate.

Stem-leaves oblanceolate or linear.

Pappus of the rays of bristles one-third to one-half as long as those of the disk-flowers; ray-flowers glandular-puberulent outside. 13. $T$. incana.

Pappus of the rays reduced to a crown of short squamellae; rayflowers glabrous.

10. T. strigosa.

Leaves all decidedly spatulate; pappus-bristles of ray-and disk-

flowers all alike. $\quad 14 . T$. arizonica.

Leaves glabrous or nearly so.

15. $T$, glabrella.

Plant acaulescent; heads sessile among the rosulate leaves.

Plant not lanate.

Plant glabrate, cinereous only when young; leaves oblanceolate or spatulate.

Bracts obtuse; ray-flowers with very short pappus. 16. T. Rothrockii.

Bracts acute; pappus of disk- and ray-flowers alike, of long bristles.

Leaves glabrous above.

Head 12-15 mm. high; pappus twice as long as the achenes; bracts lanceolate.

18. T. intermedia.

Head less than $1 \mathrm{~cm}$. high; pappus a little longer than the achenes; bracts linear.

19. T. leptotes.

Plant permanently cinereous; leaves linear or linear-oblanceolate.

Plant lanate.

20. T. exscapa.

21. T, spathulata.

1. T. grandiflora Nutt. Biennial, with a taproot; stem 2-10 $\mathrm{cm}$. high, densely strigose; leaves narrowly linear-oblanceolate, strigose; involucre 10-15 $\mathrm{mm}$. high, 15-20 mm. broad; bracts strigose, broadly lanceolate, acuminate, fimbriate; ligules rose-purple or pinkish, 15-20 mm. long; pappus of the ray-flowers reduced to a crown of short squamellae. Plains and hills: S.D.-Okla.-Colo. -Wyo. Plain-Subalp. Je-Au. 
2. T. eximia A. Gray. Biennial, with a taproot; stem $1.5-4 \mathrm{dm}$. high, strigose-hirsute; leaves linear-spatulate or linear-oblanceolate, strigose; bracts lanceolate, acuminate, the inner purplish, scarious and erose-ciliate on the margins; ligules bluish purple, $15-18 \mathrm{~mm}$. long; pappus of a coroniform ring of small squamellae and in the disk-flowers besides these two stout awns. Mountainsides: Colo.-N.M.-Ariz. Son. Je-S.

3. T. Vreelandii Rydb. A dark green biennial, branching near the base; stems 1.5-4 dm. high, sparingly villous; leaves numerous, all oblanceolate, glabrous, mucronate, 4-8 $\mathrm{cm}$. long, $5-8 \mathrm{~mm}$. wide; bracts lanceolate, acuminate, scarious, light green with dark green center; ligules bluish purple, 12-15 mm. long; pappus of 2 subulate bristles, with a few intermediate squamellae. Mountain-sides and valleys: Colo. Mont. Jl.

4. T. Parryi D. C. Eat. Biennial; stem simple or branched at the base, erect, 2-20 cm. high, strigose; leaves mostly basal, spatulate, thick, glabrous above, strigose beneath; stem-leaves few and small; involucre $2-3 \mathrm{~cm}$. broad; bracts narrowly lanceolate, acuminate, sparingly striate, scarious and erose on the margins; ligules $12-15 \mathrm{~mm}$. long, violet or bluish purple; pappus of long bristles. Mountains: Alta.-Wyo.-Ida. Mont.-Alp. My-J1.

5. T. alpina (A. Gray) Rydb. Apparently perennial, rosulate-tufted, with a taproot, acaulescent; leaves basal, spatulate, about $1 \mathrm{~cm}$. long, grayish strigose on both sides; involucre $12-18 \mathrm{~mm}$. broad; bracts lanceolate, acuminate, strigose, scarious and erose on the margins; ligules pink, puberulent outside, scarcely $1 \mathrm{~cm}$. long; pappus of long bristles. T. Parryi alpina A. Gray. High mountains: Wyo. Alp.

6. T. condensata Parry. Depressed stemless perennial; leaf-blades spatulate-obovate, 4-6 mm. long, petioled, lanuginous-arachnoid, rosulate, crowded; bracts linear, acuminate; rays 100 or more; ligules narrow; pappus of all flowers of many long bristles. High peak: Wyo. Alp. J1.

7. T. florifer (Hook.) A. Gray. Biennial; stem $1 \mathrm{dm}$. high or less, strigose, branched at the base; leaves strigose; involucre $12-15 \mathrm{~mm}$. wide; bracts linearlanceolate, acute, slightly imbricate and nearly of the same length, strigose, narrowly scarious-margined and ciliate; ligules pink or rose-colored, about $1 \mathrm{~cm}$. long; achenes hirsute. Stony hills and banks: Wash.-Mont.-Utah-Ore. My-Jl.

8. T. ambigua (A. Gray) Rydb. Stems several from the root, 8-10 $\mathrm{cm}$. high, strigose, leafy, from a slender root; leaves spatulate, strigose; involucres about $15 \mathrm{~cm}$. broad; oracts oblong-lanceolate, strigose on the back, with narrow scarious erose margins; ligules white, about $1 \mathrm{~cm}$. long; pappus of the ray-flowers about half as long as that of the disk. T. scapigera ambigua A. Gray. Dry valleys: Utah. Submont.

9. T. Fendleri A. Gray. Perennial, with a slender taproot; stem $2 \mathrm{dm}$. high or less, branched both at the base and above, strigose-canescent; leaves 2-4 cm. long, 1-2 mm. wide, strigose; involucres $8-12 \mathrm{~mm}$. broad; bracts ovate-lanceolate, acute, strigose, erose-ciliate; ligules rose-colored, 7-8 mm. long; pappus of the ray-flowers a short crown of squamellae and 1 or 2 short bristles. Gravelly hills: N.M.-Colo.-Ariz. Son. Ap-Au.

10. T. strigosa Nutt. Biennial or winter-annual; stems cespitose at the base, 2-10 $\mathrm{cm}$. high, strigose; lower leaves spatulate, the upper linear-oblanceolate, grayish-strigose; involucres 8-12 $\mathrm{mm}$. wide; bracts lanceolate, strigose on the back, broadly scarious and erose on the margins, acute. T. Watsoni A. Gray. Gravelly hills: Wyo.-Utah-N.M.-Ariz. Submont.-Mont. My-Jl.

11. T. montana M. E. Jones. Cespitose perennial; leaves clustered, 2-3 $\mathrm{cm}$. long, sparingly strigose, or glabrate, thick; peduncles $0.5-2 \mathrm{~cm}$. long; involucres 10-12 mm. broad; bracts oblong, purple-tinged, narrowly scarious-margined and erose, in 5 series; ligules $6-8 \mathrm{~mm}$. long, bluish purple, glabrous; achenes in age nearly glabrous; pappus of both ray- and disk-flowers of many bristles. T. dejecta A. Nels. High mountains: Utah. Mont.-Subalp. My-Jl. 
12. T. scapigera D. C. Eat. Cespitose, almost acaulescent perennial; leaves 2-4 cm. long, sparingly strigose; blades spatulate; stem 2-5 cm. high, scapiform; involucres about 10-15 mm. wide; bracts oblong-lanceolate, in 3 series, acute, strigose on the back, with rather narrow, pinkish, scarious, erose margins; ligules bluish purple, about $1 \mathrm{~cm}$. long; pappus of both ray- and disk-flowers of many bristles. High mountains: Mont.-Wyo.-Calif. Submont.-Mont. My-J1.

13. T. incana Nutt. Cespitose perennial; stems $1-10 \mathrm{~cm}$. high, canescenthirsute; leaves linear-oblanceolate, canescent-strigose, $2-3 \mathrm{~cm}$. long; heads sessile; involucres $8 \mathrm{~mm}$. high, about $1 \mathrm{~cm}$. wide; bracts lanceolate, acute, densely strigose, scarious and erose on the margins; ligules lilac, $8 \mathrm{~mm}$. long. Mountains and hills: Wyo.-N.M.-Ariz.-Utah. Son.-Subalp. My-Je.

14. T. arizonica A. Gray. Cespitose perennial, tufted; stems $3-8 \mathrm{~cm}$. long, sericeous-eanescent; leaves spatulate, 1-2 $\mathrm{cm}$. long, long-petioled; involucres 10-12 $\mathrm{mm}$. broad; bracts lanceolate, obtuse, strigose on the back, scarious and erose-ciliate on the margins; ligules 5-8 $\mathrm{mm}$. long; pappus of all the flowers of the same length, rather rigid, about as long as the achenes. Hills: Utah-Ariz. Son.

15. T. glabella A. Gray. Cespitose perennial; stems $2-5 \mathrm{~cm}$. high, sparingly strigose; leaves spatulate, $2-3 \mathrm{~cm}$. long; involucres $10-12 \mathrm{~mm}$. broad; bracts lanceolate, in 2 or 3 series, acute, green, only slightly scarious-margined, ciliate; pappus of the ray-flowers about one-fourth as long as that of the disk-flowers or less. T. Bakeri Greene. Mountains: Colo. Subalp.-Mont. My-J1.

16. T. Rothrockii A. Gray. Acaulescent pulvinate perennial; leaves spatulate, 2-3 mm. long, rosulate; involucres $8 \mathrm{~mm}$. high, $1-2 \mathrm{~cm}$. broad; bracts oblong, obtuse, glabrous, purple-tinged, scarcely scarious-margined, ciliate. High mountains: Colo. Submont.-Mont. J1.

17. T. Wilcoxiana Wood. Cespitose acaulescent perennial; leaves narrowly linear-oblanceolate, $3-7 \mathrm{~cm}$. long, glabrous above, sparingly pubescent beneath; involucres $1.5-3 \mathrm{~cm}$. broad; bracts acute, lanceolate, tinged with purple, scarcely scarious-margined; ligules $10-15 \mathrm{~mm}$. long. Plains and hills: Okla.-Colo. Plain. Ap-Je.

18. T. intermedia Rydb. Acaulescent cespitose perennial; leaves oblanceolate, mostly acute; involucres $1.5-3 \mathrm{~cm}$. broad; bracts narrowly lanceolate, in 4 or 5 series. Dry soil: Neb.-Kans.-Ariz.-Wyo. Plain. Ap-My.

19. T. leptotes (A. Gray) Osterh. Cespitose perennial, mostly acaulescent; leaves linear-oblanceolate, sparingly strigose; heads mostly sessile; involucres $1 \mathrm{~cm}$. broad; bracts linear, rounded on the back, ciliate on the margins, but not scarious. T. sericea leptotes A. Gray. Mountains: Colo. Je.

20. T. exscapa (Richards.) Porter. Cespitose acaulescent perennial; leaves sericeous-strigose, $2-5 \mathrm{~cm}$. long; involucres $1 \mathrm{~cm}$. high, $1-3 \mathrm{~cm}$. broad; bracts narrowly lanceolate, in 4 or 5 series; achenes hirsute; pappus-bristles of the diskflowers twice as long as the achenes, those of the ray-flowers often shorter, $T$. sericea Hook. T. mensana M. E. Jones. Plains: Sask.-Tex.-N.M.-Alta. Plain-Mont. Ap-Je.

21. T. spathulata Nutt. Cespitose, acaulescent, multicipital perennial; leaves crowded, spatulate, densely villous-lanate; heads sessile; involucres $8 \mathrm{~mm}$. high; bracts oblong-lanceolate, acute; rays short, pinkish; pappus of the ray- and disk-flowers similar, of many bristles. High mountains: Wyo.

\section{BRACHYÁCTIS Ledeb.}

Leafy-stemmed annuals, with entire leaves. Heads rather small, numerous, paniculate. Involucres campanulate; bracts in 2-3 series, linear or oblong, almost equal in length, the outer foliaceous and loose. Ray-flowers in several series, more numerous than the disk-flowers, white, shorter than the pappus, with short or no ligule. Disk-flowers perfect, with slender, 4-5-toothed corollas. Style-branches with lanceolate appendages. Achenes narrow, not compressed, 2-3-nerved, appressed-pubescent. 
Bracts oblong or oblong-linear, obtuse.

Bracts narrowly linear, acute.

1. B. frondosa.

2. B. angusta.

1. B. frondosa (Nutt.) A. Gray. Annual; stem 2-5 dm. high, glabrous or nearly so; leaves linear or lance-linear, $3-8 \mathrm{~cm}$. long, glabrous, ciliolate on the margins; involucre about $8 \mathrm{~mm}$. high, fully $1 \mathrm{~cm}$. broad; bracts in 3 distinct series; ligules about $2 \mathrm{~mm}$. long, pinkish. Aster frondosus T. \& G. Saline soil and along streams: Wyo.-Colo.-Calif.-Ore. Plain. Au-O.

2. B. angusta (Lindl.) Britton. Annual; stems erect, branched, glabrous, 2-6 dm. high; leaves narrowly linear, 3-10 cm. long, glabrous, slightly ciliolate on the margins; involucre $6-8 \mathrm{~mm}$. high, $8-10 \mathrm{~mm}$. broad; bracts in 2 series, almost equal; ray-flowers reduced to the tube or with rudimentary ligules. $A$. angustus T. \& G. Saline ground: Sask.-Wis.-Mo.-Utah-Alta. PlainSon. J1-S.

\section{EREMIÁSTRUM A. Gray.}

Dwarf, depressed winter annuals. Leaves entire. Heads solitary. Involucres hemispheric or broader; bracts numerous, linear, nearly in a single series, herbaceous, with hyaline-searious fimbriate margins; receptacle flat. Ray-flowers numerous, in a single series, pistillate; ligules white. Disk-flowers numerous, perfect and fertile. Achenes obovate-oblong, compressed, 2-nerved. Pappus of very unequal bristles, the outer setulose and scarcely longer than the pubescence of the achenes.

1. E. bellioides A. Gray. Winter annual; stem diffusely branched at the base; branches decumbent, 3-10 cm. long, hispid; leaves linear-spatulate, entire, $5-15 \mathrm{~mm}$. long, hispid; heads subtended by rosulate leaves; involucres $5-6 \mathrm{~mm}$. high, 8-10 mm. broad; bracts linear-lanceolate, hispid; ligules white or violet, about $5 \mathrm{~mm}$. long, dentate at the apex. Deserts: s Utah-Ariz.-Calif. L. Son. Ap-Je.

\section{LEUCOSỲris Greene. SPINY Aster.}

Rush-like spiny plants, often woody at the base, with small linear or subulate, often deciduous leaves. Involucres hemispheric; bracts well imbricate, in 3 series, subulate. Ray-flowers pistillate and fertile, with short white ligules. Disk-flowers perfect; corollas yellow. Style-branches with triangular-subulate appendages, much shorter than the stigmatic portion. Achenes glabrous.

1. L. spinosa (A. Gray) Greene. Perennial, usually shrubby at the base; stems 1-2.5 m. high, usually more or less spiny, striate, glabrous; cauline leaves linear or oblong, deciduous; involucre $5-6 \mathrm{~mm}$. high, about $8 \mathrm{~mm}$. broad; bracts subulate, in about 3 series, scarious-margined, shorter than the disk; ligules white, 3-4 mm. long; achenes glabrous. Aster spinosus A. Gray. Banks of streams: Tex, -s Utah-Calif.; Mex. L. Son. Je-S.

\section{XYLORRHìzA Nutt. HOLLY-Leaved Aster.}

Perennial caulescent herbs, with thick woody taproots and short caudices. Leaves many, spinulose-tipped, entire or spinulose-toothed. Heads large, solitary at the ends of the branches, radiate. Involucres hemispheric; bracts mostly in 2 or 3 series, acuminate, herbaceous, carinate below. Ray-flowers pistillate; ligules showy, white or pinkish. Disk-flowers perfect. Appendages of the stylebranches lanceolate, acute. Achenes oblong, compressed. Pappus fulvous, simple, of rather few coarse bristles.

Leaves not spinulose-toothed.

Glabrous or nearly so.

More or less villous.

Bracts only slightly unequal, linear-lanceolate.

Leaves linear-oblanceolate, acute.

Leaves spatulate, cuspidate.

Bracts very unequal, the outer ovate or ovate-lanceolate.

Leaves spinulose-toothed.

Plant $1 \mathrm{dm}$. or less high, with a short caudex.

Ligules 8-10 $\mathrm{mm}$. long.

Ligules $15-20 \mathrm{~mm}$. long.

Plant tall, shrubby.

1. $X$. glabriuscula.

2. X. villosa.

3. $X$. venusta.

4. X. Parryi.

5. $X$. coloradensis.

6. X. Brandegei.

7. $X$. lanceolata. 
1. X. glabriuscula Nutt. Stems 1-2 dm. high, glabrous; leaves linearoblanceolate, $2-5 \mathrm{~cm}$. long, glabrous; involucres $8-10 \mathrm{~mm}$, high, $10-15 \mathrm{~mm}$. wide; bracts linear-lanceolate, acuminate, glabrous, erose on the margins; ligule rosecolored, 10-12 mm. long. Alkali plains: Wyo. Je-Jl.

2. X. villosa Nutt. Stems $1-2 \mathrm{dm}$. high; leaves $2-5 \mathrm{~cm}$. long, or linearoblanceolate, villous, tipped with a callous point; involucres 8-10 mm. high, 10$15 \mathrm{~mm}$. broad; bracts linear-lanceolate, attenuate at.the apex, villous on the back, erose on the margins; ligules pale red, 8-12 mm. long. Aster Xylorrhiza T. \& G. Rocky places and clayey soil: Colo.-Wyo. My-Je.

3. X. venusta (M. E. Jones) Heller. Stems $2-5 \mathrm{dm}$. high; leaves entire, spatulate or oblanceolate, villous, 4-6 cm. long, spinulose-tipped; involucres about $1.5 \mathrm{~cm}$. high, $3 \mathrm{~cm}$. broad; bracts linear-lanceolate, attenuate, villous on the back, scarcely erose; ligules white or purple, $15-20 \mathrm{~mm}$. long. A. venustus M. E. Jones. Dry places: Colo.-Utah. Son. My-Je.

4. X. Parryi (A. Gray) Greene. Stems tomentose-villous, about 1 dm. high; leaves spatulate, obtuse with a callous point, $2-3 \mathrm{~cm}$. long, villous; involucres $8 \mathrm{~mm}$. high, 15-18 mm. broad; bracts well imbricate, villous on the back, erose on the margins; rays about $1 \mathrm{~cm}$. long, white. A. Parryi A. Gray. Flats: Wyo. Son.

5. $\mathbf{X}$. coloradensis (A. Gray) Rydb: Stems less than $1 \mathrm{dm}$. high, canescent; leaves spatulate or oblanceolate, 2-4 cm: long, spinulose-dentate, hirsute-canescent; involucres about $8 \mathrm{~mm}$. high, $15 \mathrm{~mm}$. broad; bracts lancesubulate, attenuate, eanescent; ligules $8-10 \mathrm{~mm}$. long, violet-purple. A. coloradensis A. Gray. Higher mountains: Colo. Alp.

6. X. Brandegei Rydb. Stem almost $1 \mathrm{dm}$. high; leaves spatulate or the upper oblanceolate, 3-4 cm. long, firm, closely and sharply serrate with bristletipped teeth; disk about $3 \mathrm{~cm}$. wide; bracts narrowly linear-lanceolate, attenuate; rays rose-purple. High mountains: s Colo. Subalp.-Alp. S.

7. X. lanceolata Rydb. Shrubby perennial, with white stems; branches more or less villous; leaves $4-6 \mathrm{~cm}$. long, more or less villous, reticulately veined, dentate with spinulose-subulate teeth; involucre fully $1 \mathrm{~cm}$. high, $15-20 \mathrm{~mm}$. broad; bracts lance-subulate, villous and slightly glandular, attenuate and spinulose-tipped; ligules purple, about $2 \mathrm{~cm}$. long. Arid places: s Utah. L. Son.

\section{HERRÍCKIA Woot. \& Standl.}

Perennial herbs, with thick rigid, spinulose-toothed, reticulate, sessile leaves. Heads solitary at the ends of the branches, subsessile. Involucre turbinatecampanulate; bracts in several series, conspicuously keeled, green and foliaceous above, with callous points, the outer more foliaceous and passing into the leaves; receptacle naked. Ligules purple. Disk-flowers perfect; corollas yellow, turning purplish, with short ovate lobes. Style-branches with lanceolate, acute tips. Achenes compressed, striate, glabrous. Pappus simple, of long barbellate bristles.

1. H. horrida Woot. \& Standl. Stems $3 \mathrm{dm}$. high or less, hirsute-glandular; leaves rigid, oblong to broadly ovate or oval, $2-4.5 \mathrm{~cm}$. long, sessile or somewhat cordate-clasping, reticulate, spinose-dentate, pubescent; ligules $8 \mathrm{~mm}$. long. Mountains: N.M. $\rightarrow$ s Colo. Au.

\section{UNÀmia Greene. Sneezewort Áster.}

Perennial, caulescent herbs with horizontal rootstocks. Leaves alternate, narrow, entire. Heads rather small, corymbose, radiate. Involucres turbinateeampanulate; bracts narrow, not foliaceous, more or less keeled. Ray-flowers pistillate; ligules white or ochroleucous. Disk-flowers yellow, perfect, numerous. Appendages of the style-branches lanceolate-subulate. Achenes 4-5-angled, not compressed, glabrous. Pappus of white rigid bristles, somewhat clavate at the ends.

Inner bracts ovate-lanceolate, acute, the outer lance-subulate; ligules white.

Inner bracts oblong or elliptic, obtuse or rounded at the apex; ligules yellowish, the outer lanceolate, obtusish. 
1. U. alba (Nutt.) Rydb. Stems $2-5 \mathrm{dm}$. high, smooth, scabrous, or hispidulous; lower leaves linear-oblanceolate, 3-5-ribbed, $5-15 \mathrm{~mm}$. long, firm, the upper linear; involucres about $5 \mathrm{~mm}$. high, $5-8 \mathrm{~mm}$. broad; ligules $5-6 \mathrm{~mm}$. long. Inula alba Nutt. Aster ptarmicoides T. \& G. Rocky banks and bluffs: Vt.N.Y.-Colo.-Sask. Plain-Submont. Jl-S.

2. U. lutescens (Lindl.) Rydb. Stem $2-4 \mathrm{dm}$. high, scabrous, at least above; leaves similar to those of the preceding species; involucres $5-6 \mathrm{~mm}$. high, 6-8 mm. broad; ligules about $8 \mathrm{~mm}$. long. Diplopappus lutescens Lindl. Aster ptarmicoides lutescens A. Gray. Banks and plains: Ill,-Wis.-Sask. Plain. $\mathrm{Au}-\mathrm{S}$.

\section{EUCÊPHALUS Nutt.}

Caulescent leafy perennials, with rootstocks. Leaves alternate, sessile, from ovate to linear. Heads corymbose, radiate, middle-sized. Involucres campanulate; bracts regularly imbricate in several series, ovate to lanceolate, not foliaceous or in one species with foliaceous tips, dry and chartaceous with a distinct keel or midrib. Ray-flowers pistillate; ligules violet or purplish. Diskflowers numerous, perfect; corollas yellow. Style appendages subulate, acute, or rarely oblong and obtuse. Achenes flat, hirsute or glabrate in age. Pappus of white capillary bristles.

Bracts all thin and acute, villous-ciliate on the margins; style-appendages subulate.

Leaves ovate-oblong or broadly lanceolate; heads $10-15 \mathrm{~mm}$. high. 1. E. Engelmannii.

Leaves lanceolate; heads 8-10 $\mathrm{mm}$. high.

Bracts firmer, merely ciliolate, the outer obtuse.

Bracts with more or less foliaceous tips; involucre and branches of inflorescence decidedly glandular, the leaves less so.

Bracts without foliaceous tips; plant not glandular or very rarely so. Inner bracts acute.

All bracts obtuse or rounded and mucronate at the apex.

3. E. wasatchensis.

4. E. glaucus.

1. E. Engelmannii (D. C. Eat.) Greene. Stem robust, 5-15 dm. high, glabrous or slightly puberulent; leaves thin, $5-10 \mathrm{~cm}$. long, loosely veined; involucres hemispheric; bracts ovate, acute or acuminate, purple-tinged, in 5 series, puberulent on the back and ciliate on the margins; ligules white, fully $1 \mathrm{~cm}$. long. Aster Engelmannii D. C. Eat. Mountains: Alta.-Colo.-Nev.-Wash.-B.C. Submont.-Mont. J1-S.

2. E. elegans Nutt. Stem 3-10 dm. high, leafy, puberulent; leaves pale, lanceolate, 3-5 cm. long, scabrous-puberulent; involucres campanulate; bracts ovate, acute, purple-tinged, puberulent on the back, villous-ciliate on the margins; ligules about $8 \mathrm{~mm}$. long, white. Aster elegans T. \& G. Woody mountain slopes: Mont.-Wyo.-Utah-Neb.-Ore. Submont.-Mont. Jl-S.

3. E. wasatchensis (M. E. Jones) Rydb. Perennial with a rootstock; stem glabrous up to the inflorescence; leaves lance-oblong, acute, sessile, 4-6 cm. long, rather pale, glandular-puberulent; involucres $10-12 \mathrm{~mm}$. broad; bracts lanceolate, acute; rays fully $1 \mathrm{~cm}$. long. A. glaucus wasatchensis M. E. Jones. Mountains: Utah. Mont. Au.

4. E. glaucus Nutt. Stem branched, glabrous, 3-5 dm. high; leaves glabrous, glaucous, lanceolate, linear or oblong, acute, $3-7 \mathrm{~cm}$. long, reticulatevenose; involucres about $6 \mathrm{~mm}$. high and $8 \mathrm{~mm}$. broad; bract ovate, glabrous, slightly ciliolate on the margins; ligules violet or white, $8-10 \mathrm{~mm}$. long. $A$, glaucus T. \& G. Mountains: Wyo.-Colo.-Utah. Submont.-Mont. J1-S.

5. E. formosus Greene. Stem glabrous, $3-5 \mathrm{dm}$. high; leaves linear, glaucous, glabrous, scabrous on the margins; involucres about $6 \mathrm{~mm}$. high and 8 $\mathrm{mm}$. broad; bracts ovate or oval, strongly purple-tinged, minutely ciliolate; ligules deep blue, about $1 \mathrm{~cm}$. long. Mountains: Colo. Mont. Au.

\section{8. ÄSTER (Tourn.) L. Aster.}

Perennial herbs, usually with a rootstock, rarely with a woody caudex. Leaves alternate, various. Heads corymbose, paniculate, racemose, or rarely solitary, radiate. Involucres hemispheric or campanulate, or turbinate; bracts imbricate in several series, herbaceous or with herbaceous tips; receptacle flat or 
convex, alveolate and often fimbrillate. Ray-flowers pistillate; ligules purple, pink, or white. Disk-flowers perfect; corollas tubular with a bell-shaped throat and short 5-lobed limb, yellow, changing into red, brown, or purplish. Anthers obtuse at the base. Style-branches flattened, their appendages subulate, lanceolate, or ovate, acute. Achenes more or less flattened, nerved, or ribbed, glabrous or pubescent. Pappus of numerous, slender, white bristles in a single series.

Involucres and peduncles glandular.

Leaves ovate, oval, or the lower obovate, sharply and coarsely serrate; bracts well imbricate, very unequal, broadly lanceolate, not thick.

I. CoNSPICUI.

Leaves lanceolate, oblong, or linear, entire or, if slightly toothed, bracts linear-lanceolate, almost equal in length.

Lower leaves petioled.

Stems stout, 3-5 dm. high, leafy; bracts lanceolate, firm, ascending. Stem-leaves lanceolate to ovate; disk of heads $1.5-2 \mathrm{~cm}$. broad.

Stem-leaves narrowly linear; disk of heads about $1 \mathrm{~cm}$. INTEad.

III. PAUCIFLORI.

Stem low, slender, few-leaved, 0.5-2 dm. high; bracts narrowly linear-lanceoLeaves all sessile.

Bracts narrowly linear, almost equal in length, attenuate.

Leaves broadly lanceolate or oblong.

Leaves linear.
Bracts thick, obla

IV. KINGIANI.

Involucres and peduncles not glandular.

V. MoDesti.

VI. CAMPESTRES.

g or lanceolate.

Outer bracts neither foliaceous nor equalling or surpassing the inner.

Bracts more or less pubescent on the back.

Bracts not bristle-pointed. Heads solitary; plant less than $3 \mathrm{dm}$. high; leaves oblanceolate or the upper
linear.
VIII. ALPINI.

Heads corymbose or paniculate; plant over $3 \mathrm{dm}$. high.

Upper leaves more or less clasping and auricled at the base.

Upper leaves neither auricled nor clasping.

IX. Molles.

Leaves obovate, broadly oblanceolate, oval or lanceolate, usually more or less toothed; bracts lanceolate, often tinged with purple.

Leaves narrowly oblanceolate or linear, entire; bracts linear or oblanceolate, green-tipped.

Pubescence villous.

Pubescence hirsute or strigose.

Bracts bristle-pointed, squarrose.

XI. ANDINI.

XII. GRISEI.

Bracts glabrous, except the ciliate margins.

XIII. MULTIFLORI.

Bracts linear, oblong or lanceolate, all acute or acutish,

Lower leaves long-petioled; blades cordate or ovate (rarely broadly lanceolate), usually more or less serrate.

Lower leaves oblanceolate, linear, or lanceolate.

Plants perfectly glabrous throughout.

Bracts whitish-coriaceous below and with a distinctly rhombic green tip above; upper leaves clasping. XV. LAEVES.

Bracts linear-subulate, green nearly throughout; leaves narrowly linear, not clasping.

XVI. PORTERTANI.

Upper part of the stem and peduncles with at least pubescent lines.

Heads usually numerous in a leafy panicle or compound corymb. Stem only with pubescent lines. Stem, at least above, pubescent on all sides.

Heads few in a naked small corymb. Bracts oblanceolate, the outer obtuse.

Outer bracts foliaceous, equalling or surpassing the inner.

Heads rather numerous in an open leafy panicle. XVII. SALICIFOLII.

XVIII. LONCHOPHYLT.

XIX. OCCIDENTALES.
XX. ADSCENDENTES. eads few, in a usually simple, racemose, or corymbose inflorescence with nearly erect branches.

One species.

\section{CONSPICUI.}

II. INTEGRIFOLII.

1. A. conspicuus.

Stem almost glabrous below; auricles of the thinnish leaves small; bracts narrowly linear, lanceolate. Stem hirsute-
lanceolate. 2. A integrifolius.

3. $A$, amplexifolius.

One species.

III. PAUCIFLORI.

One specise.

IV. KINGIANI.

4. A. pauciflorus.

5. A, Kingii. 


\section{Modesti.}

Stem not hispid; heads distinctly peduncled; leaves slightly if at all auricled at the base, thin.

Stem, especially upwards, with scattered long silky hairs; leaves not auricled, usually somewhat hairy.

Stem glandular-puberulent or glabrous below, not long-hairy.

Leaves and lower part of the stem glabrous, the former not auricled.

Leaves short-pubescent, somewhat scabrous above; 7 7. A. modestus. throughout; leaves with small auricles. $\quad$ 8. A. Sayianus.

Stem short-hispid; heads crowded, often subsessile, subtended by bract-like leaves; leaves thick, strongly auricled at the base. 9. A. Novae-Angliae.

One species.

VI. CAMPESTRES.

VII. OBLONGIFOLII.

Leaves scabrous-hirsutulous, mostly spreading or reflexed.

Leaves glabrous, except the bristly-ciliate margins, ascending.

One species.

One species.

VIII. ALPINI.

\section{Molles.}

X. RADULINI.

Upper part of the stem and the involucres long-villous.

Upper part of the stem and involucres short-pubescent.

\section{ANDINI.}

Stems decumbent or ascending, about $1 \mathrm{dm}$. high; leaves glabrate.

Stems erect, about $3 \mathrm{dm}$. high; leaves finely villous.

17. A. andinus.

18. A. Williamsii.

\section{GRISEI.}

Leaves rather copiously and permanently appressed-hirsutulous.

Inflorescence falsely racemose; lower leaves triple-nerved.

Inflorescence corymbiform or paniculate; leaves all 1-nerved.

Plant 3-4 dm. high; stem retrorse-hirsute below.

Plant 1-1.5 dm. high; hairs of the stem not retrorse.

40. A. subracemosus.

19. A. subgriseus.

20. A. griseolus.

Leaves sparingly strigose and glabrate in age, or perfectly glabrous, except the hispidulous-ciliate margins.

Bracts with a green tip and midvein.

Stem stout; leaves oblanceolate, the lower often triple-nerved.

Stem slender; leaves narrowly linear-oblanceolate or linear, 1-nerved. Underwoodii.

Outer bracts green almost throughout.

64. A. Nelsonii.

21. A. violaceus.

XIII. MULTIFLORI.

Inflorescence very leafy, not corymbiform.

Pubescence of the stem spreading or reflexed, hirsutulous.

Heads less than $5 \mathrm{~mm}$, high.

Heads 6-8 $\mathrm{mm}$. high.

Pubescence of the stem appressed or ascending.

Bracts very unlike in length, well imbricate, the outer much shorter; heads racemosely arranged, each at the end of a short leafy branch (except in no. 25).

Bracts narrowly oblanceolate, the inner especially acutish; heads less than 5 mm. high.

Stem much branched; heads racemosely disposed on the more or less diverging branches.

24. A. multiflorus. Stem simple below; heads few at the ends of the erect branches.

Bracts broadly oblanceolate or the outer spatulate, 25 . A. stricticaulis. $5 \mathrm{~mm}$. high. Bracts almost equal in length or the outer sometimes longer; heads few or solitary
at the ends of the main branches.

Bracts thick, very squarrose, the outer spatulate, rounded at the apex; leaves

thick, densely strigose.
Bracts thin, slightly squarrose, oblanceolate, acute; leammutatus.

in age often glabrate.

Inflorescence less leafy, corymbiform; leaves glabrous, merely hisp. A. falcatus. $\mathrm{mm}$. wide; stem slender.

Stem glabrous.

Stem puberulent.

XIV. SAGITTFOLII.

29. A. denudatus.

67. A. Hallit. Basal leaf-blades cordate or broadly ovate; upper stem-leaves lanceolate; achenes gla-
brous.

Petioles, midribs, and usually also the stem pubescent with long white hairs.

30. A. Wilsonii. 
Plant glabrous or sparingly short-pubescent.

31. A. Lindleyanus.

Basal leaf-blades lanceolate; upper stem-leaves narrowly lanceolate or those of the inflorescence lance-linear.

Heads few; involucres $8-9 \mathrm{~mm}$. high; rays about $15 \mathrm{~mm}$. long; achenes glabrous,

Heads numerous; involucres 5-6 mm. high; rays $8-10 \mathrm{~mm}$. 32 . A. MacCallae. strigose.

; achenes hispidulous-

XV. LAEves.

Bracts much shorter than the disk.

Bracts about equalling the disk or only slightly shorter.

Leaves merely scabrous-ciliate.

Green tips of the bracts broadly rhombic; leaves of the branches much reduced.

35. A. laevis.

Green tips of the bracts narrowly rhombic or rhombic-oblanceolate; leaves of the branches gradually but not conspicuously reduced.

Stem-leaves lanceolate or linear-lanceolate, auricled-clasping.

37. A. subsalignus.

38. A. Scribneri.

One species.

\section{Porteriani.}

XVII. SALICIFOLII.

39. A. Porteri.

Inflorescence falsely racemose; leaves linear to oblanceolate; leaves triple-nerved.

Inflorescence paniculate or corymbiform; leaves not triple-nerved.

40. A. subracemosus.

Inflorescence elongate, not flat-topped.

Heads numerous in a much branched panicle; involucre well imbricate.

Leaves distinctly toothed.

Disk of the head about $1 \mathrm{~cm}$. high and broad; leaves thickish.

Disk 6-8 mm. high and broad; leaves thin.

41. A. salicifolius.

42. A. paniculatus.

Leaves entire, rarely denticulate, with more or less clasping bases.

Disk of the head nearly $1 \mathrm{~cm}$. high and broad.

Bracts linear-filiform, more or less squarrose.

Bracts linear, erect.

Ligules purple.

Ligules white or sometimes pinkish.

43. A. hesperius.

44. A. fluviatilis,

Bracts not with white midrib; leaves narrowly linear.

45. A. Osterhoutii.

Bracts with white midrib; leaves lanceolate or oblong-lanceolate.

Disk of the head 6-8 $\mathrm{mm}$. high and broad.

46. A. laetivirens.

Bracts linear, nearly of the same length; leaves narrowly linear. 47. A. longulus.

Bracts oblong or linear-oblong, the outer shorter; leaves broadly linear. 48. A. roseolus.

Heads rather few, often solitary on the leafy branches; bracts narrowly linear, nearly of the same length, the outer green.

49. A. Franklinianus.

Inflorescence more or less flat-topped.

Leaves lanceolate to linear-lanceolate, firm; heads numerous.

Leaves narrowly linear, thin; heads few.

50. A. corymbiformis.

51. A. junciformis.

\section{LONCHOPHYLLI.}

Stem softly pubescent; leaves lanceolate, not pale.

Stem crisp-puberulent above; upper stem-leaves linear, sessile, but scarcely auricled.

52. A. lonchophyllus.

Stem villous above; upper stem-leaves oblong-Ianceolate, auriculate-clasping.

Stem hispidulous above; leaves linear, pale green.

53. A. eriocaulis.

54. A. leucopsis.

XIX. OCCIDENTaIES.

Bracts linear-subulate, acuminate, the inner almost caudate.

Leaves linear-oblanceolate, acuminate, or the upper linear-lanceolate.

Leaves linear.

55. A. subcaudatus.

49. A. Franklinianus.

Bracts linear, acute; lower leaves oblanceolate, the upper lanceolate, acute, usually auriculate-clasping.

Disk about $1 \mathrm{~cm}$. broad; stem-leaves linear or lance-linear; basal-leaves linear-oblanceolate; bracts distinctly imbricate in 3-4 series. 56 . A. occidentalis.

Disk $1.5 \mathrm{~cm}$, or more wide; leaves lanceolate or oblanceolate, entire; bracts in about 2 series.

Bracts, at least the outer ones, wholly green; plant $2-4 \mathrm{dm}$. high.

57. A. Fremontii.

Bracts with more or less distinct white margins below, green-tipped above.

Bracts with conspicuous rhombic-lanceolate green tips; dark green stemleaves oblanceolate, all except the uppermost crenate and petioled; rays dark blue.

58. A. Umbachii. 
Bracts with less conspicuous lanceolate green tips; stem-leaves usually entire, light green and glaucous; rays light purple. 59. A. ciliomarginatus.

\section{ADSCENDENTES.}

Heads few in a simple corymb.

Heads less than $1 \mathrm{~cm}$. high; upper leaves much reduced; stem 2-3 dm. high, slender.

Heads over $1 \mathrm{~cm}$. high; leaves all ample; stems stout, 3-6 dm. high. 60. A. armeriaefolius.

Heads many in a leafy panicle.

81. A. diabolicus.

Heads about $1 \mathrm{~cm}$. high; stem-leaves lanceolate or oblanceolate.

Stems 2-3 dm. high; bracts usually more or less pubescent on the backs.

Bracts with green midvein and tips, puberulent.

61. A. Underwoodii.

Outer bracts wholly green, densely pubescent.

21. A. violaceus.

Stems 4-6 dm, high; bracts glabrous on the backs; stem-leaves thick, oblanceolate; panicle elongate.

62. A. Tweedyi.

Heads less than $1 \mathrm{~cm}$. high; stem-leaves linear or narrowly linear-oblanceolate.

Bracts not spinulose-tipped.

Lower leaves oblanceolate; bracts glabrous, except the ciliate margins; plant 1-3 dm. high.

Lower leaves narrowly linear-oblanceolate.

Bracts more or less hairy on the back.

Bracts glabrous, except the ciliate margins.

63. A. adscendens.

Leaves of the floral branches elongate,

64. A. Nelsonii.

L 65. A. Nuttallii.

Leaves of the floral branches reduced, short, oblong, spreading.

66. A. halophilus.

Bracts with short spinulose or callous tips.

Stem decidedly puberulent.

Stem glabrous.

67. A. Hallii.

29. A. denudatus.

Outer bracts oblanceolate.

XXI. FULCRATI.

Leaves broadly lanceolate with auriculate-clasping bases.

Outer bracts very squarrose or reflexed; leaves entire.

Outer bracts appressed or slightly spreading; leaves distant Outer bracts obtuse.

Outer bracts acute.

Leaves linear or linear-lanceolate.

Outer bracts linear, or subulate, or linear-oblanceolate.

Leaves, at least the lower ones, toothed; bracts loose.

68. A. proximus.

Leaves entire; bracts close.

Outer bracts much exceeding the disk; some twice as long.

Leaves narrowly linear, not auricled.

Leaves linear to oblong-oblanceolate or lanceolate, auricled.

Outer bracts seldom exceeding the disk.

Leaves glabrous above; disk of the head 8-10 mm. high.

Leaves minutely scabrous-puberulent or pilosulous above.

74. A. Eatonii.

Bracts linear-subulate; stem short-villous abovie. 75. A. Hendersonii.

Bracts linear-oblanceolate; stem short-pubescent with stiff hairs above. Branches and leaves strongly ascending; disk $7-8 \mathrm{~mm}$. high and broad.

76. A. oreganus.

Branches ascending-spreading; leaves spreading; disk $8-10 \mathrm{~mm}$. high and over $1 \mathrm{~cm}$. broad.

77. A. microlonchus.

\section{Foliosi.}

Plant tall, 4-8 dm, high.

Bracts mainly linear or linear-lanceolate.

Bracts and stem villous:

Bracts glabrous, except the ciliate margins.

Stem-leaves thick, scabrous above; stem rough-hispid, red.

79. A. Forwoodii.

Stem-leaves thinner, lanceolate to linear, acute; stem glabrous, or sparingly pubescent, not hispid.

Disk about $2 \mathrm{~cm}$. wide; leaves sharply denticulate. 80 . A. amplus.

Disk 1-1.5 cm. wide; leaves usually entire.

Stem-leaves nearly all sessile, linear-lanceolate, only slightly auriculate; plant slender.

81. A. diabolicus.

Lower stem-leaves with winged petioles, the upper sessile, clasping, with usually conspicuous auricles.

Outer bracts broadly lanceolate or oblanceolate.

82. A. frondeus.

Outer bracts mostly acute.

Leaves firm, broadly lanceolate; auricles of the upper leaves small; branches of the inflorescence crisp-hirsute.

83. A. Canbyi.

Leaves thin, oblong-lanceolate; auricles of the stem-leaves large; branches of the inflorescence villous.

Outer bracts mostly obtuse.

84. A.Cusickii.

85. A. Burkei.

Plant low, 1-2 dm. high; heads usually solitary.

86. A. apricus. 
1. A. conspicuus Lindl. Stem 4-6 dm. high, scabrous-puberulent; leaves 1-1.5 cm. long, acute or short-acuminate, scabrous above, pubescent beneath; inflorescence corymbiform; involucre broadly campanulate, $1 \mathrm{~cm}$. high, $1-1.5$ em. broad; rays violet, $1 \mathrm{~cm}$. long. A. MacDougali Coult. \& Fisch. Hillsides, open woods: Sask.-S.D.-Wyo.-Ore.-B.C. Submont.-Mont. J1-S.

2. A. integrifolius Nutt. Stem $2-4 \mathrm{dm}$. high, puberulent below, glandular above; lower leaves 1-1.5 dm. long, tapering into a margined petiole, oblanceolate, entire; upper stem-leaves lanceolate, sessile, clasping; inflorescence racemiform; involucres hemispheric; bracts acute, often tinged with purple; ligules 1 $\mathrm{cm}$. long, bluish purple. Open moist woods: Mont.-Wyo.-Calif.-Wash. Submont.-Mont. J1-S.

3. A. amplexifolius Rydb. Stem stout, 3-4 dm. high; basal leaves oblanceolate, about $1.5 \mathrm{dm}$. long, tapering into a short winged petiole, entire, glabrate in age, ciliate on the margins; upper stem-leaves ovate or broadly lanceolate; inflorescence racemiform; involueres fully $1 \mathrm{~cm}$. high; bracts sometimes more or less leafy; ligules $1 \mathrm{~cm}$. long, bluish purple. Hills: Mont.-Wyo.-Utah. Mont. Au.

4. A. pauciflorus Nutt. Stem 1.5-5 dm. high, branched; leaves somewhat fleshy, entire, glabrous, the basal ones petioled, linear-oblanceolate, $3-10 \mathrm{~cm}$. long; inflorescence glandular-puberulent, flat-topped; heads few; involucres 7-8 $\mathrm{mm}$. high; bracts in 2 or 3 series, linear-lanceolate, acute; rays blue or whitish, $5 \mathrm{~mm}$. long. A.thermalis M. E. Jones. Erigeron paucipetalus Osterhout. Saline soil: Sask.-Tex.-Ariz.-Utah-Alta. Plain-Son. My-Au.

5. A. Kingii D. C. Eat. Cespitose perennial, with a short woody rootstock or caudex; stem glabrous below, glandular above; basal leaves petioled, $4-8 \mathrm{~cm}$. long, glabrous; blades spatulate or oblanceolate, entire; stem-leaves few and oblanceolate; involucres $1 \mathrm{~cm}$. high and $12-15 \mathrm{~mm}$. wide; bracts attenuate; ligules white, 8-10 mm. long. High mountains: Utah. Submont.-Mont. J1-Au.

6. A. major (Hook.) Porter. Perennial, with a horizontal rootstock; stem 5-10 dm. high; leaves 5-10 cm. long, lanceolate, acuminate or attenuate, thin, entire or minutely denticulate; inflorescence flat-topped, peduneled; involucres $1 \mathrm{~cm}$. high, 12-15 mm. broad; ligules fully $1 \mathrm{~cm}$. long, bluish purple. A. unalaschkensis major Hook. Moist woods: w Ont.-Ore.-Alaska. Mont. Au-S.

7. A. modestus Lindl. Stem 4-8 dm. high, often purplish; leaves lanceolate, 4-8 cm. long, glabrous or nearly so, distantly denticulate, acuminate, shining; heads few, in a corymbiform inflorescence; involucre $1 \mathrm{~cm}$. high, $12-15 \mathrm{~mm}$. wide; rays bluish purple, about $1 \mathrm{~cm}$. long. Moist woods: Alta.-Mont.-Ida.-Wash. -B.C. Mont. J1-S.

8. A. Sayianus Nutt. Stem 3-8 dm. high; leaves thin, lanceolate, $4-8 \mathrm{~cm}$, long, entire or distantly denticulate; heads few, in a flat-topped inflorescence; involucres $1 \mathrm{~cm}$. high and 10-15 mm. wide; rays bluish purple, nearly $1 \mathrm{~cm}$. long. Wet places: Alta.-Mont.-Ore.-B.C. Mont. Jl-S.

9. A. Novae-Angliae L. Stem 4-25 dm. high; leaves lanceolate or oblong. 3-12 cm. long, entire, acute, firm, hispidulous on both sides, hispidulous-ciliate on the margins; inflorescence leafy, much branched, flat-topped; involucres 8-10 $\mathrm{mm}$. high, about $15 \mathrm{~mm}$. wide; rays reddish purple or rose-colored, nearly $1 \mathrm{~cm}$. long. Low ground: Que.-S.C.-Colo.-Alta. Plain-Submont, Au-O.

10. A. campestris Nutt. Stem $2-4 \mathrm{dm}$. high, branched above or simple; leaves sessile, oblong or linear, $2-3 \mathrm{~cm}$. long or the lower linear-oblanceolate, glandular-puberulent, or glabrate, obscurely triple-nerved; involucres 6-7 mm. high, about $1 \mathrm{~cm}$. broad; ligules $8 \mathrm{~mm}$. long, light violet or purplish. $A . A n$ drewsii A. Nels. Valleys: Alta,-Colo.-Ore-B.C. Plain-Mont.

11. A. Kumleini Fries. Stem $2-5 \mathrm{dm}$. high, branched above, often yellowish or straw-colored, scabrous-puberulent; leaves rigid, sessile, oblong, $2-3 \mathrm{~cm}$. long, those of the branches reduced and more spreading; involucres $6-7 \mathrm{~mm}$. high, 8-10 $\mathrm{mm}$. wide; bracts in 3-4 series, imbricate, linear-oblanceolate, firm, squarrose; ligules bluish violet, $7-8 \mathrm{~mm}$. long. A. oblongifolius rigidulus A. Gray. Plains: Wis.-Mo.-Tex.-Colo.-S.D. Plain. Au-O. 
12. A. Fendleri A. Gray. Stem 1-3 dm. high, stiff, sparsely hispidulous; leaves linear, 1-nerved, $2-3 \mathrm{~cm}$. long; heads few; involucres turbinate, $7-8 \mathrm{~mm}$. high, fully $1 \mathrm{~cm}$. broad; bracts acute, unequal, in 3 or 4 series; ligules violet, $8 \mathrm{~mm}$. long. Plains and sand hills: Kans.-Tex,-N.M.-Colo. Plain-Submont. S.

13. A. alpinus L. Stem pilose throughout; basal leaves numerous, $2-5 \mathrm{~cm}$. long, rounded at the apex, pilose; involucres about $1 \mathrm{~cm}$. high, $2 \mathrm{~cm}$. wide; bracts oblong or linear, obtuse, pilose, in 2 or 3 series, but nearly of the same length; rays fully $1 \mathrm{~cm}$. long, violet. $A$. culminis A. Nels. Aretic-alpine situations: Mack.-Colo.-Alaska; Eurasia. Alp. Je-Jl.

14. A. Jessicae Piper. Stem densely villous, almost tomentose, 4-15 dm. high; leaves obovate to oblanceolate, 5-10 $\mathrm{cm}$. long, densely and softly grayishpubescent on both sides, sessile; involucre hemispheric, about $15 \mathrm{~mm}$. high and broad; bracts herbaceous, oblong, obtuse or acute, villous-pubescent; ligules numerous, bluish purple, about $1 \mathrm{~cm}$. long. A. latahensis Henders. A. mollis Rydb. River banks: Wyo.-Wash. Submont.-Mont. Au-S.

15. A. Richardsonii Spreng. Stem 1-3 dm. high; leaves sparingly shortvillous on both sides or glabrate above, $3-10 \mathrm{~cm}$. long; heads few; involucres about $1 \mathrm{~cm}$. high and $1.5 \mathrm{~cm}$. wide; ligules purplish, nearly $1 \mathrm{~cm}$. long. A. montanus Richards. A. giganteus (Hook.) Rydb. Aretic-alpine situations: Mack.Alta.-B.C.-Alaska. Alp. Jl-Au.

16. A. meritus A. Nels. Stem ascending, 2-4 dm. high; leaves somewhat crenate-serrate or some entire, glabrous above, puberulent beneath, 3-7 cm. long; inflorescence corymbiform; involucre turbinate-campanulate, $8 \mathrm{~mm}$. high, $1 \mathrm{~cm}$. broad; bracts in 3-4 series, acute; ligules purple or violet. Mountains: Mack.-S.D.-Wyo.-B.C. Submont.-Subalp. J1-Au.

17. A. andinus Nutt. Stem somewhat villous above; lower leaves ablanceolate or spatulate, 4-6 dm. long, ciliolate on the margins; upper stem-leaves linear, sessile; involucres about $10 \mathrm{~mm}$. broad; bracts linear, acute or the outer obtuse, few, in 3 series, but only slightly unequal. High mountains: Mont.Colo. Mont.-Subalp. Je-Au.

18. A. Williamsii Rydb. Stem erect, about $3 \mathrm{dm}$. high, more or less villous; leaves oblanceolate, $3-10 \mathrm{~cm}$. long, finely villous on both sides; heads few, corymbose; involucre about $1 \mathrm{~cm}$. broad; bracts linear or lance-linear, sparingly and finely villous on the back, imbricate in 3 series; ligules lilac, about $1 \mathrm{~cm}$. long. Mountains: Wyo. Mont. Jl-Au.

19. A. subgriseus Rydb. Stem decumbent or ascending at the base; lower leaves oblanceolate, pale, $7-10 \mathrm{~cm}$. long, the upper oblong or linear, sessile, entire, 1 -nerved; involucres about $8 \mathrm{~mm}$. high and $1 \mathrm{~cm}$. broad; bracts linear or oblong, the outer obtuse, the inner acutish; ligules $8 \mathrm{~mm}$. long, pale violet. A. griseus Greene, not Kuntze. Mountains: Wyo.-Colo.- e Utah. Mont. Jl.

20. A. griseolus Rydb. Stem 1-1.5 dm. high; leaves linear, $3-5 \mathrm{~cm}$. long, sessile, acute, entire; heads $1-4$ in a small corymb; involucres about $1 \mathrm{~cm}$. wide; bracts oblanceolate or linear, the outer obtuse, the inner acute, green or the inner white on the sides below; ligules purple, about $8 \mathrm{~mm}$. long. (?) A. spithamaeus Greene, not Kuntze. High mountains: Colo. Mont,-Subalp. Au.

21. A. violaceus Greene. Stem 3-4 dm. high, purple-tinged, strigose; lower leaves linear-oblanceolate, $10-12 \mathrm{~cm}$. long, petioled, the upper sessile, linear, entire; inflorescence corymbose; involucres $15 \mathrm{~mm}$. broad; bracts linear, the outer obtuse and wholly herbaceous; ligules violet, $1 \mathrm{~cm}$. long. Dry places in the mountains: Colo. Au-S.

22. A. exiguus (Fern.) Rydb. Stem erect, branched and very leafy above; branches divergent; leaves linear or oblong, sessile, $0.5-3 \mathrm{~cm}$. long, entire, densely hirsutulous; heads very numerous at the ends of short leafy branches; involucres about $4 \mathrm{~mm}$. high and broad; ligules white, $3-4 \mathrm{~mm}$. long. Prairies and plains: Vt.-Pa.-Tex.-Ariz.-Wash.; Mex. Plain-Submont. Au-O.

23. A. crassulus Rydb. Stem erect or ascending, branched above, 4-7 dm. high; stem-leaves linear, or oblong-linear, 3-6 cm. long, 2-3 mm. wide, sessile 
and slightly clasping, those of the branchlets only $3-5 \mathrm{~mm}$. long; heads numerous, borne at the end of leafy branchlets; involucre turbinate, $5-8 \mathrm{~mm}$. high, $8-10$ $\mathrm{mm}$. broad; ligules numerous, white, $5-7 \mathrm{~mm}$. long. A. hebecladus Coult \& Nels., not DC. A. multiflorus A. Gray, in part. Plains: Sask.-N.D.-Colo.-Calif. -Ida, Plain-Submont. J1-O.

24. A. multiflorus Ait. Stem much branched, 3-6 dm. high; branches mostly ascending-spreading; leaves linear, 1-5 cm. long, sparingly hirsute-strigillose, or above glabrate; involucre about $4 \mathrm{~mm}$. high and broad; ligules white, 3-4 mm. long. Prairies and dry ground: Me.-Ga.-Mex,-Colo.-B.C. Plain. $\mathrm{Au}-\mathrm{O}$.

25. A. stricticaulis (T. \& G.) Rydb. Stem 3-6 dm. high, slender; leaves narrowly linear, $1-5 \mathrm{~cm}$. long, $1-2 \mathrm{~mm}$. wide, sparingly strigose or glabrate; involucres $3-4 \mathrm{~mm}$. high and nearly as broad; bracts in 3 series, narrowly oblanceolate, almost glabrous, rather thin; ligules white, $3 \mathrm{~mm}$. long. Meadows and river valleys: Sask.-Neb.-Wash.-Alta. Plain. Au-S.

26. A. polycephalus Rydb. Stem with many ascending branches, $3-8 \mathrm{dm}$. high; leaves linear, $2-5 \mathrm{~cm}$. long, hispidulous-strigose or in age glabrate; involucres 5-7 mm. high and as broad; ligules white, 4-6 mm. long. Plains and hills: Alta. -Neb.-Tex.-Ariz. Plain-Submont. J1-S.

27. A. commutatus T. \& G. Stem branched above, with usually spreading branches, coarsely strigose; leaves linear, 1-4 cm. long, densely hispid-strigose; involucres 6-8 $\mathrm{mm}$. high and fully as wide; ligules white, 4-5 mm. long. A. adsurgens Greene. A. incanopilosus Sheld. Plains and river banks: Sask.Minn.-Kans.-N.M.-Ariz.-B.C. Plain-Submont. Au.

28. A. falcatus Lindl. Stem 3-4 dm. high, sparingly strigose; leaves linear, often falcate, 2-4 cm. long; heads more racemosely arranged than in the preceding; involucres 5-6 mm. high and as broad; ligules white or pinkish, 4-5 mm. long. A. Cordineri A. Nels. Valleys: Mack.-Colo.-Alaska. Plain-Mont. $\mathrm{J} 1-\mathrm{O}$.

29. A. denudatus Nutt. Stem 2-4 dm. high, glabrous or nearly so throughout, slender; leaves narrowly linear, 1-5 cm. long, the upper much reduced, rather firm; involucres $5-6 \mathrm{~mm}$. high; outer bracts oblanceolate, rounded at the apex, the inner linear and more acute, all glabrous; ligules $5-8 \mathrm{~mm}$. long. Dry plains: Utah $\rightarrow$ S Ida. Son. Jl-Au.

30. A. Wilsonii Rydb. Stem 3-6 dm. high, often purplish, more or less pubescent with long white hairs; lower leaf-blades $5-10 \mathrm{~cm}$. long, usually more or less hirsute on both sides, but in age glabrate, serrate, acuminate, the upper lanceolate, sessile, sub-entire; involucre 7-8 mm. high, scarcely $1 \mathrm{~cm}$. wide; bracts subulate, attenuate, with green oblanceolate midrib; ligules 8-10 $\mathrm{mm}$. long, bluish purple. River valleys: Mack,-B.C.-w Ont. Boreal. Au-S.

31. A. Lindleyanus T. \& G. Stem 3-10 dm, high, with crisp hairy lines above; lower leaf-blades cordate to ovate, serrate, $5-15 \mathrm{~cm}$. long, rather firm; middle leaves with winged ciliate petioles with clasping bases; the uppermost leaves lanceolate, sessile; involucres $7-8 \mathrm{~mm}$. high, about $1 \mathrm{~cm}$. broad; bracts linear-subulate, with a green oblanceolate midrib; disk-flowers reddish purple; ligules bluish purple, 10-12 mm. long. River banks: Lab.-N.H.-Ohio-Wyo. -B.C.-Yukon. Plain-Subalp.

32. A. MacCallae Rydb. Stems 3-6 dm. high, often purplish, glabrous up to the inflorescence, then slightly pubescent in lines; lower leaves with winged petioles; blades $8-15 \mathrm{~cm}$. long, usually serrate, acute, glabrous or essentially so; involucres $8-9 \mathrm{~mm}$. high, $1 \mathrm{~cm}$. broad; bracts subulate, glabrous, with linearlanceolate green tips; ligules blue or bluish purple, about $15 \mathrm{~mm}$. long; diskflowers red-purple. Along streams: Alta.-B.C. Mont. Au-S.

33. A. Butleri Rydb. Stem 4-10 dm. high, slender; lower leaf-blades about $1 \mathrm{dm}$. long, distantly serrate; involucres $5-6 \mathrm{~mm}$. high, about $8 \mathrm{~mm}$. wide; bracts subulate, with narrowly lanceolate green tips, attenuate, glabrous; ligules bluish purple, 8-10 mm. long. Along streams: Alta.-Mont.-B.C. Mont. Au-S. 
34. A. brevibracteatus Rydb. Stem 5-6 dm. high, glabrous, tinged with purple; basal leaves about $1 \mathrm{dm}$. long, with short winged petioles; blades spatulate or oblanceolate, crenate-serrate, glabrous; upper stem-leaves lanceolate, half elasping; involucre $5-7 \mathrm{~mm}$. high, nearly $1 \mathrm{~cm}$. broad; bracts linear-lanceolate, firm, with a narrowly rhomboid green tip; ligules blue, $8 \mathrm{~mm}$. long. Low ground: Wash.-Mont. Submont. Au-S.

35. A. laevis L. Stem 3-12 dm. high, rigid, glabrous, glaucous; basal leaves with winged petioles; blades ovate or lanceolate, more or less serrate, glabrous and glaucous; upper stem-leaves ovate, subcordate or auriculate-clasping; involucres $8-9 \mathrm{~mm}$. high, about $1 \mathrm{~cm}$. broad; ligules blue. Open woodlands: Ont.La.-N.M.-B.C. Plain-Mont. Au-O.

36. A. Geyeri (A. Gray) Howell. Stem 5-10 dm. high, glabrous; lower leaves 1-2 dm, long, with winged petioles; blades oblanceolate, entire or sparingly serrate, glabrous, glaucous; involueres about $8 \mathrm{~mm}$. high and $1 \mathrm{~cm}$. wide; ligules blue, 8-10 mm. long; achenes glabrous. Valleys: Alta.-S.D.-Colo.-Wash. Submont.-Mont. Ji-S.

37. A. subsalignus Rydb. Stem 6-10 dm. high; leaves nearly erect, glabrous, glaucous, entire, clasping, $5-10 \mathrm{~cm}$. long, $6-7 \mathrm{~mm}$. wide; involucres about $7 \mathrm{~mm}$. high and $8 \mathrm{~mm}$. wide; ligules bluish or bluish purple, about $8 \mathrm{~mm}$. long; disk-flowers dark, red-purple. Valleys: Colo. Submont. Au.

38. A. Scribneri Rydb. Stem 3-6 dm. high, glabrous; basal leaves 1-2 dm. long, with wing-margined petioles; blades thin, ovate, acute, sharply serratedentate, glaucous, glabrous; stem-leaves ovate or ovate-lanceolate, sessile and clasping; panicle small, with 5-10 heads; bracts glabrous; ligules about $8 \mathrm{~mm}$. long. Valleys: Mont. Submont. Au.

39. A. Porteri A. Gray. Stems 2-4 dm. high, glabrous, simple or branched above; leaves linear, or the lower oblanceolate, 5-10 cm. long, divergent, glabrous, or the lower hirsute-ciliate; heads numerous; involucres 4-5 mm. high, 6-7 mm. broad; ligules white, $5-6 \mathrm{~mm}$. long. Mountains: Colo. Submont.-Mont. J1-O.

40. A. subracemosus Rydb. Stem 5-6 dm. high, simple, strict, sparingly strigose; leaves oblanceolate or the upper linear, sessile, 4-8 $\mathrm{cm}$. long, more or less scabrous, scabrous-ciliate on the margins, entire; involucres about $8 \mathrm{~mm}$. high and $1 \mathrm{~cm}$. broad; bracts in 3-4 series, with oblanceolate green tips. Rocky
hillsides: Mont. Submont. S.

41. A. salicifolius Lam. Stem 5-20 dm. high, paniculately branched; leaves lanceolate, firm, glabrous or scabrous, $6-10 \mathrm{~cm}$. long, the lower more or less dentate; involucres $6-8 \mathrm{~mm}$. high, $8-10 \mathrm{~mm}$. broad; bracts with narrowly oblanceolate green tips or the outer nearly wholly green; ligules purple or violet, rarely white, 6-8 mm. long. Wooded banks: Me.-Fla.-Tex.-Colo.-B.C. Plain-Submont. Au-O.

42. A. paniculatus Lam. Stem 5-20 dm. high, paniculately branched; leaves oblong-lanceolate to narrowly linear-lanceolate, mostly attenuate, thin, glabrous, sharply denticulate or the upper entire; involucres $5-6 \mathrm{~mm}$. high, 8-10 $\mathrm{mm}$. wide; bracts with narrowly linear-lanceolate green tips; ligules white or rarely pink or pale lilac, 7-8 mm. long. Wooded banks: N.B.-Va.-Colo.Sask. Plain-Submont. Au-O.

43. A. hesperius A. Gray. Stem 4-10 dm. high, paniculately branched; leaves lance-linear, entire or rarely denticulate, $5-15 \mathrm{~cm}$. long, thin, glabrous or nearly so, hispid-ciliolate on the margins; involucres $7-8 \mathrm{~mm}$. high, nearly $1 \mathrm{~cm}$. broad; outer bracts green, the inner ones with narrowly lanceolate green tips, of the same length or the outer slightly shorter; ligules violet or white, $7-8 \mathrm{~mm}$. long. Along streams: N.M.-Colo.-Calif,; n Mex, Son. Au-O.

44. A. fluviatilis Osterh. Stem slender, 6-10 dm. high, leafy and branched; leaves lance-linear, sessile, somewhat clasping, the larger $1 \mathrm{dm}$. long, entire or nearly so; inflorescence paniculate; involucres $6-7 \mathrm{~mm}$. high, nearly $1 \mathrm{~cm}$. broad; bracts in 4 series, oblanceolate, acute, with oblanceolate green tips; ligules lilac to purple. A. coerulescens Rydb. (Fl. Colo.), not DC. Along streams: Wyo.- 
45. A. Osterhoutii Rydb. Stem branched and leafy, 5-10 dm. high; leaves $5-12 \mathrm{~cm}$. long, $8 \mathrm{~mm}$. wide or less, those of the branches much smaller; involucres 7-8 mm; bracts linear to oblanceolate, apiculate; ligules white or rarely pinkish, nearly $1 \mathrm{~cm}$. long. Along ditches and streams: Colo.-Sask.-Alta. Plain. $\mathrm{Au}-\mathrm{S}$.

46. A. laetivirens Greene. Stem erect, 3-6 dm. high, red or purplish; leaves lanceolate or oblong-lanceolate, thin, light green, somewhat glaucescent; involucres $8 \mathrm{~mm}$. high and about $1 \mathrm{~cm}$. wide; ligules $8-10 \mathrm{~mm}$. long, white or pinkish. Along streams: Colo.-Wyo.-Ida. Submont. Au-S.

47. A. longulus Sheld. Stem strict, branched above, 6-15 dm. high, hispid in lines; leaves narrowly linear, $3-10 \mathrm{~cm}$. long, sessile, glabrous on both sides or scabrous above; inflorescence paniculate; involucres 4-5 $\mathrm{mm}$. high, 6-7 $\mathrm{mm}$. broad; bracts acute, the outer often wholly green; ligules $6 \mathrm{~mm}$. long, white or lilac. Swampy ground: Sask,-Minn.-Neb.-Colo--B.C. Plain. J1-S.

48. A. roseolus Rydb. Stem 3-5 dm. high, often purple-tinged; leaves linear, glabrous or nearly so, $5-10 \mathrm{~cm}$. long, $5-12 \mathrm{~mm}$. wide; involucres about 5 $\mathrm{mm}$. high, $8-9 \mathrm{~mm}$. broad; bracts often wholly green, with broadly lanceolate tips; rays rose-colored, $5-6 \mathrm{~mm}$. long. Meadows: Mont. Submont. Au.

49. A. Franklinianus Rydb. A perennial, with a horizontal rootstock; stems 4-10 dm. high, simple; leaves narrowly linear, entire, scarcely clasping, rather firm, dark green, glabrous, $7-15 \mathrm{~cm}$. long, less than $1 \mathrm{~cm}$. wide; involucres $8 \mathrm{~mm}$. high, fully $1 \mathrm{~cm}$. broad; bracts linear, attenuate; ligules purple, $8-10 \mathrm{~mm}$. long. A. salicifolius Richards., not Lam. Wet meadows: Sask.-Mont,-Ida. -Mack. Boreal-Mont.

50. A. corymbiformis Rydb. Stem strict, about $3 \mathrm{dm}$. high, branched above; leaves linear, $5-8 \mathrm{~mm}$. long, half-clasping; inflorescence leafy, corymbiform; involucres $6 \mathrm{~mm}$. high, $8 \mathrm{~mm}$. broad; bracts linear-lanceolate, with an oblanceolate green tip; ligules white or purplish, about $7 \mathrm{~mm}$. long. Meadows: Colo. Submont. Au.

51. A. junciformis Rydb. Stem slender, 3-5 dm. high, simple below; leaves narrowly linear, 4-8 $\mathrm{cm}$. long, $2-4 \mathrm{~mm}$. wide; involucres about $6 \mathrm{~mm}$. high, about $1 \mathrm{~cm}$. broad; the inner bracts linear, acute, with green lanceolate tips, the outer oblong or oblanceolate, obtuse, often almost wholly green; ligules white, 6-8 mm. long. Meadows and swamps: Sask.-Wis.-Colo.-Wash.-B.C. Plain.

52. A. lonchophyllus Greene. Stem erect, $4-6 \mathrm{dm}$. high, reddish-purple; leaves 5-10 cm. long, narrowly lanceolate, acute, entire, sessile, firm, green and glabrous, 1-nerved; inflorescence paniculate; involucres about $7 \mathrm{~mm}$. high and $1 \mathrm{~cm}$. broad; bracts linear, acute, more or less tinged with purple; ligules rosepurple. Mountains: Colo. Mont. Au.

53. A. eriocaulis Rydb. Stem about $8 \mathrm{dm}$. high, leafy, purplish; stemleaves 3-7 cm. long, more or less auriculate-clasping; inflorescence a round-topped panicle; involucres $8 \mathrm{~mm}$. high, 10-12 $\mathrm{mm}$. broad; bracts linear, acute, more or less ciliate, the outermost almost wholly green; ligules purple, 8-10 mm. long. Mountain meadows: Ida. Submont. Au.

54. A. leucopsis Greene. Stem 3-6 dm. high, straw-colored, racemosely paniculate above, hispidulous in the inflorescence, linear, 5-10 cm. long, 5-10 mm. wide, thick, pale green, strongly scabrous-ciliolate on the margins; heads mostly solitary at the ends of the many short branches; involucres turbinate, about 8 $\mathrm{mm}$. high and broad; bracts well imbricate, oblanceolate, with a narrowly rhombic green lip; ligules $8 \mathrm{~mm}$. long, white or pale violet. Along ditches: Utah. Son. S.

55. A. subcaudatus Rydb. A perennial, with a creeping rootstock; stem 3-6 dm. high, more or less purple; lower leaves 1-2 dm. long, 4-10 cm. wide, often sparingly dentate with ascending sharp teeth, dark green; upper leaves sessile; panicle open, with rather few heads; involucres 7-8 mm. high, about 12 $\mathrm{mm}$. broad; bracts only slightly white-margined below; rays purple, about $1 \mathrm{~cm}$. long. Mountain meadows: Alta.-Wyo.-Ida.-B.C. Submont.-Mont. JeAu. 
56. A. occidentalis Nutt. Stem strict, $2-10 \mathrm{dm}$. high; lower leaves $1-2 \mathrm{dm}$. long, linear-lanceolate, entire or few-toothed, dark green; upper leaves lancelinear or linear, those of the corymbiform inflorescence much reduced; involucres 5-7 mm. high, 10-12 mm. broad; ligules 6-8 $\mathrm{mm}$. long. Mountain meadows and plains: Ida.-Colo.-Calif.-B.C.-Yukon. Plain-Mont. JI-S.

57. A. Fremontii (T. \& G.) A. Gray. Stem 2-4 dm. high; lower leaves petioled, 3-10 cm. long, dark green, oblanceolate or spatulate, entire; upper leaves oblonglanceolate or nearly linear, sessile and somewhat clasping; involucre $7-8 \mathrm{~mm}$. high, about $1 \mathrm{~cm}$. broad; bracts linear, acute or obtusish, the outer wholly green; ligules purple, 7-10 mm. long. Mountain valleys: Alta.-Colo.-Utah-B.C. Mont.-Subalp. J1-Au.

58. A. Umbachii Rydb. Stem slender, erect, simple, 3-5 dm. high; lower leaves about $1 \mathrm{dm}$. long, petioled, broadly oblanceolate or lanceolate, dark green, more or less crenate, acute; middle stem-leaves similar but the petioles with dilated, clasping bases; upper stem-leaves lanceolate, sessile; involucres 8-9 mm. high, 12-15 mm. broad; bracts oblong-oblanceolate, acute; ligules dark bluish purple, fully $1 \mathrm{~cm}$. long. River banks: Mont. Mont. Au.

59. A. ciliomarginatus Rydb. Stem 3-6 dm. high; lower leaves with wingmargined petioles, 1-2 dm. long, oblanceolate, acute; upper leaves lanceolate, sessile, more or less clasping; involucres $8-9 \mathrm{~mm}$. high, $12-15 \mathrm{~mm}$. broad; bracts linear or lance-linear, the outer rarely nearly wholly green; ligules light blue, 10 $12 \mathrm{~mm}$. long. A. glastifolius Greene. Along streams: Mont.-Colo.-UtahB.C. Submont.-Mont. J1-Au.

60. A. armeriaefolius Greene. Stem 2-3 dm. high, pubescent in lines above; lower leaves petioled, 5-10 cm. long, oblanceolate, entire, acute, deep green, glabrous, reticulate-venose; involueres $6-7 \mathrm{~mm}$. high, about $1 \mathrm{~cm}$. broad; bracts linear or linear-oblong, green or narrowly white-margined below; ligules violet or bluish purple, about $8 \mathrm{~mm}$. long. Mountains: Colo.-Wyo.-Utah. Mont. J1-Au.

61. A. Underwoodii Rydb. Stem 2-3 dm. high, often purplish, more or less hirsute-strigose; lower leaves spatulate or oblanceolate, tapering into a winged petiole; the other stem-leaves sessile and the uppermost linear-lanceolate; involucres about $8 \mathrm{~mm}$. high and $1 \mathrm{~cm}$. broad; bracts oblanceolate; ligules purple or bluish, about $1 \mathrm{~cm}$. long. High mountains: Colo.-Wyo. Mont. Je-S.

62. A. Tweedyi Rydb. Stem simple, usually purplish, about $4 \mathrm{dm}$. high; leaves oblanceolate, acute, rather firm, often $1 \mathrm{dm}$. long, the lower with a winged petiole, the upper sessile and half clasping; heads about $1 \mathrm{~cm}$. high; bracts linear or oblanceolate, not very unequal in length; ligules rose or purple, 8-10 mm. long. Valleys: Colo.-Alta. Submont. Jl-Au.

63. A. adscendens Lindl. Stem ascending or decumbent at the base, 2-8 dm. high, glabrous, slightly pubescent above; leaves firm and thick, the lower petioled, 6-12 cm. long, the upper linear, sessile; inflorescence paniculate; involucres $5-6 \mathrm{~mm}$. high, nearly $1 \mathrm{~cm}$. broad; bracts oblanceolate, with green tips; ligules bluish purple, 5-8 mm. long. A. pratincola Greene. (?) A. oxyphyllus Greene. Valleys: Sask,-Colo.-Nev.-Alta. Submont.-Mont. J1-S.

64. A. Nelsonii Greene. Stem 3-6 dm. high, leafy, sparingly strigose; leaves linear, 5-7 cm. long, firm, entire, acute, 1-nerved; involucres about $8 \mathrm{~mm}$. high, $10 \mathrm{~mm}$. broad; bracts oblong or linear; ligules violet or lilac, $8 \mathrm{~mm}$. long. A. vallicola Greene, a narrow-leaved form. Mountains: Colo.-Mont.-Wash.Ore. Submont. J1-S.

65. A. Nuttallii T. \& G. Stem $2-6 \mathrm{dm}$. high, glabrous or sparingly pubescent, especially above; basal leaves linear-oblanceolate, somewhat glaucous, glabrous; stem-leaves narrowly linear; inflorescence paniculate; involucres $5-6 \mathrm{~mm}$. high, less than $1 \mathrm{~cm}$. broad; bracts oblanceolate, green-tipped; ligules bluish purple, 6-8 mm. long. A. orthophyllus Greene. Mountains: Neb.-Colo.Utah. Submont. J1-Au.

66. A. halophilus Greene. Stem about $3 \mathrm{dm}$. high, sparingly hirsutulousstrigose, especially above; stem-leaves linear, $5-8 \mathrm{~cm}$. long, glabrous, except the 
hispidulous-ciliolate margins, deflexed, firm; leaves of the floral branches less than $1 \mathrm{~cm}$. long, spreading and becoming bract-like above; involucre turbinate, $7-8$ $\mathrm{mm}$. wide; bracts imbricate, coriaceous below, with green obovate or spatulate green tips, the outer rounded at the apex; ligules pale, $5 \mathrm{~mm}$. long. Salt marshes: Utah. Son. S.

67. A. Hallii A. Gray. Stem strict, 2-5 dm. high; lower leaves linear, the upper linear-oblong, $2-5 \mathrm{~cm}$. long, those of the branches much smaller, all entire; involucres 3-4 mm. high, 4-7 $\mathrm{mm}$. broad; bracts imbricate, rather thick, spatulate or oblanceolate, rounded and callous, mucronate at the apex; ligules $4-6 \mathrm{~mm}$. long, white or whitish. Dry places: Wash.-Mont.-Ore. Submont.-Mont. S.

68. A. proximus Greene. Stem 4-6 dm. high, glabrous below, sparingly pubescent above; leaves linear-lanceolate or lanceolate, entire, sessile, $5-10 \mathrm{~cm}$. long, smooth beneath, scabrous above, light green, spreading; disk about $9 \mathrm{~mm}$. high, $10-15 \mathrm{~mm}$. broad; outer bracts obtuse, mucronate; ligules flesh-colored or rose, 8-10 mm. long. River banks: Wyo.-Mont. Submont.-Mont. Au-S.

69. A. phyllodes Rydb. Stem 5-10 dm. high, leafy, glabrous below, pubescent in lines above; leaves thin, the lower usually more or less serrate, with small distant teeth, all glabrous on both sides, auriculate-clasping; disk $8 \mathrm{~mm}$. high, about $12 \mathrm{~mm}$. broad; outer bracts oblanceolate, acute, foliaceous, usually slightly exceeding the disk; rays violet, $8-10 \mathrm{~mm}$. long. Meadows: w Neb.- Colo. Plain. Au.

70. A. Mearnsii Rydb. Stem 3-10 dm. high, leafy, branched, glabrous below, sparingly pubescent above; leaves $5-10 \mathrm{~cm}$. long, ascending-spreading, sessile, entire, glabrous beneath, scabrous or glabrate above; disk about $8 \mathrm{~mm}$. high and barely $1 \mathrm{~cm}$. broad; bracts oblanceolate, acute, some longer than the disk; ligules about $8 \mathrm{~mm}$. long, white or pinkish. River banks: Sask.-Wyo.Ida.-B.C. Submont.-Mont. Jl-O.

71. A. Douglasii Lindl. Stem 4-10 dm. high, glabrous and shining below, pilose above; leaves linear-lanceolate or linear, 5-15 cm. long, glabrous or nearly so; involucres $8-10 \mathrm{~mm}$. high, about $15 \mathrm{~mm}$. wide; bracts linear, acute or acuminate, with often squarrose tips, the outer scarcely longer than the inner; ligules light blue, 10-12 mm. long. Moist places: Mont.-Wyo.-n Calif.-B.C. Submont. Au-S.

72. A. fulcratus Greene. Stem decumbent at the base, red-purple, more or less puberulent, 3-4 dm. high; leaves linear, 5-10 cm. long, entire, glabrous, scabrous-ciliolate; disk about $1 \mathrm{~cm}$. high and broad; bracts in about 2 series, mostly green, the outer foliaceous, linear, 1-2 cm. long; ligules about $1 \mathrm{~cm}$. long, rosepurple or rose-lilac. Valleys: Colo. Mont. Jl.

73. A. cordalenus Henders. Stem erect, $2-3 \mathrm{dm}$. high, pubescent above; leaves $5-8 \mathrm{~cm}$. long, 5-10 $\mathrm{mm}$. wide, entire or with a few distant serratures, strongly ciliate; disk $5-7 \mathrm{~mm}$. high and $7-10 \mathrm{~mm}$. broad; outer bracts linear, 1-2 $\mathrm{cm}$. long, green, the inner with white margins and foliaceous tips; ligules blue or violet, 8-10 $\mathrm{mm}$. long. Moist river bars: Ida. Submont. Au.

74. A. Eatonii (A. Gray) Howell. Stem 3-10 dm. high, glabrous; leaves narrowly linear or lance-linear, sessile, thin, entire; involucre about $7 \mathrm{~mm}$. high, 7-10 mm. broad; bracts glabrous, linear or lance-linear, acute; ligules 7-10 mm. long, lavender, rose, or whitish. Brachyactis hybrida Greene. Mountains: Mont. -Colo.-Nev.-B.C. Submont.

75. A. Hendersonii Fernald. Stem 5-10 dm. high, villous especially above, branched above; leaves thin, ciliate on the margins, more or less short-hairy or in age glabrate; stem-leaves linear-lanceolate, $5-8 \mathrm{~cm}$. long, the lower ones 1-1.5 $\mathrm{cm}$. long, narrowed below, with clasping bases; involucres turbinate, $10-15 \mathrm{~mm}$. broad; bracts linear, subulate, foliaceous, ciliate on the margins; ligules blue, 12-16 mm. long. Rich meadows: Ida. Submont. J-Au.

76. A. oreganus Nutt. Stem slender, branched, $3-6 \mathrm{dm}$. high, more or less pubescent; branches strongly ascending; leaves linear or lance-linear, $5-8 \mathrm{~cm}$. long, entire, $6-8 \mathrm{~mm}$. high, $7-8 \mathrm{~mm}$. broad; bracts lanceolate or lance-linear, the outer about equalling the inner ones; ligules purplish or white, 7-8 mm. long. 
Banks of streams and wet meadows: Mont.-Utah-Nev.-Ore.-B.C. Submont.-Mont. Jl-S.

77. A. microlonchus Greene. Stem $5-8 \mathrm{dm}$. high, glabrous, or pubescent in lines, branched; leaves narrowly lance-linear, $5-8 \mathrm{~cm}$. long, entire, sessile, thin, spreading and sometimes reflexed; involucres $7-8 \mathrm{~mm}$. high, $10-15 \mathrm{~mm}$. broad; bracts linear, acute, glabrous, the outer slightly longer than the inner; ligules pale violet or lilac, 7-8 mm. long. Valleys: B.C.-Mont. Submont. Au.

78. A. Kootenayi Nels. \& Macbr. Stem villous, 8-10 dm. high, branched above; leaves oblanceolate, acuminate, often sharply serrate, clasping with auricled bases, $5-15 \mathrm{~cm}$. long; disk fully $1 \mathrm{~cm}$. high, $15-20 \mathrm{~mm}$. broad; bracts numerous, linear-subulate, attenuate, green, sparingly villous, longer than the disk; ligules 10-12 mm. long, bluish purple. A. foliaceus Lyallii A. Gray. River valleys: Ida.-Wash. Jl.

79. A. Forwoodii S. Wats. Stem $4-6 \mathrm{dm}$. high, rough-hispid, strict; leaves sessile, obovate, oblanceolate or lanceolate, narrowed to a broad auriculate base, hirsute on the veins beneath, $5-10 \mathrm{~cm}$. long, serrate, or the upper entire; inflorescence corymbose-paniculate; disk 10-12 mm. high, 12-15 mm. broad; bracts linear, short-acuminate, equalling the disk; ligules $10-12 \mathrm{~mm}$. long. Mountains: S.D.-N.D. Submont. Au.

80. A. amplus Lindl. Stem stout, about $1 \mathrm{~m}$. high; leaves thin, the lower oblanceolate, 1-1.5 dm. long; blades tapering below into a winged petiole, the upper sessile, lanceolate, clasping; bracts glabrous, linear or narrowly linear-oblanceolate, about equalling the disk; ligules $12-13 \mathrm{~mm}$. long. Mountains: [Canadian] "Rocky Mountains." Mont.

81. A. diabolicus Piper. Stem erect, $5-10 \mathrm{dm}$. high, leafy; leaves thin, narrowly oblanceolate, or the upper linear-lanceolate, entire or nearly so, the basal 10-15 cm. long, with winged petiole; stem-leaves $3-10 \mathrm{~cm}$. long, sessile, somewhat clasping; disk about $1 \mathrm{~cm}$. high, 10-12 mm. wide; bracts green, linear or linear-lanceolate, barely equalling the disk; ligules violet, $10-14 \mathrm{~mm}$. long. $A$. foliaceous Coult., in part. Wet places: Ore.-Mont.-Alta.-B.C. Mont. Ji-Au.

82. A. frondeus (A. Gray) Greene. Stem $3-10 \mathrm{dm}$. high; leaves thin, the lower 1-2 dm. long, oblanceolate, entire, glabrous; middle stem-leaves oblanceolate, with clasping auriculate bases, the upper lanceolate and also clasping; disk about $1 \mathrm{~cm}$. high, $15-20 \mathrm{~mm}$. broad; bracts foliaceous, narrowly oblanceolate, equalling or sometimes exceeding the disk; ligules about $1 \mathrm{~cm}$. long, broad. Mountains: Alta.-Colo.-Utah-B.C. Submont.-Subalp. J1-S.

83. A. Canbyi Vasey. Stem 3-6 dm. high; lower leaves petioled, 1-2 dm. long; blades broadly oblanceolate; upper stem-leaves oblanceolate, sessile; disk about $1 \mathrm{~cm}$. high, $15-20 \mathrm{~mm}$. broad; outer bracts scarcely equalling the disk; ligules red-purple or rose-colored. Mountains: N.M.-Wyo.-Ida. Mont.Subalp. J1-Au.

84. A. Cusickii A. Gray. Stem 3-6 dm. high; lower leaves with winged petioles, $1-1.5 \mathrm{dm}$. long; blades oblanceolate, thin, entire or sparingly dentate; upper stem-leaves lance-oblong, with auriculate-clasping bases; disk about $1 \mathrm{~cm}$. high and nearly $2 \mathrm{~cm}$. broad; outer bracts exceeding the disk; ligules 10-14 $\mathrm{mm}$. long. Mountain meadows and along streams: Ore.-Ida.-B.C. J1-S.

85. A. Burkei (A. Gray) Howell. Stem 3-6 dm. high, glabrous below, villous above; lower leaves petioled; blades oblanceolate, glabrous, scabrous on the margins; upper leaves elliptic or lanceolate, broadly clasping at the base; heads few; disk $10-12 \mathrm{~mm}$. high, $2-2.5 \mathrm{~cm}$. broad; ligules $10-12 \mathrm{~mm}$. long. A. foliaceus Burkei A. Gray. A. majusculus Greene, a luxuriant form with several heads. Mountains: Wyo.-N.M.-Ariz.-Wash.-B.C. Mont. J.

86. A. apricus (A. Gray) Rydb. Stem 1-2 dm. high, sparingly cinereouspubescent; leaves oblong or oblanceolate, $2-5 \mathrm{~cm}$. long, glabrous, scabrous on the margins; the uppermost clasping; disk about $1 \mathrm{~cm}$. high, 12-15 mm. broad; bracts spatulate or oblanceolate, acutish, glabrous, softly ciliate on the margins; ligules purple. A. foliaceus apricus A. Gray. A. incerius A. Nels. (?) A. dis- 
tichophyllus Greene. Alpine peaks: Mont.-Colo--Ore.-B.C. Mont.-Subalp. J-Au.

\section{OREOSTÉMMA Greene.}

Subacaulescent perennials. Leaves narrow, entire, subcoriaceous. Heads solitary, terminating the scapiform stems. Involucre hemispheric; bracts subequal, in 2-3 series, herbaceous. Rays pistillate, numerous; ligules purple. Diskflowers perfect, fertile. Style-branches with subulate or lanceolate acute appendages. Achenes narrow, cylindric. Pappus of brittle, barbellate deciduous bristles. [Oreastrum Greene.]

1. O. Haydeni (Porter) Greene. Low perennial, with thick woody root and caudex; stem $1 \mathrm{dm}$. high or less, glabrous; basal leaves many, linear, 5-10 $\mathrm{em}$. long, 2-3 mm. wide, glabrous; stem-leaves shorter; head solitary; involucres about $1 \mathrm{~cm}$. high, 10-12 $\mathrm{mm}$. broad; bracts linear, glabrous, slightly tinged with purple, with narrow scarious, ciliolate margins; ligules blue, about $1 \mathrm{~cm}$. long. Aster pulchollus A. Gray, in part, not Willd. A. Haydeni Porter. Mountain slopes: Mont.-Wyo.-Nev. Mont.-Subalp. J1-S.

\section{ASTERİGERON Rydb.}

Low perennials, with cespitose rootstocks. Leaves alternate, the basal ones numerous, the cauline ones much reduced. Heads solitary, terminal, radiate. Involucres hemispheric; bracts imbricate in 3 series, those of the inner series broad, lanceolate, with reddish purple-tinged scarious margins, the rest linear. Ray-flowers pistillate; ligules purplish. Disk-flowers perfect, fertile. Stylebranches with ovate or triangular, subulate-acuminate appendages. Achenes flat, appressed pubescent. Pappus of many hispidulous bristles. In general habit, involucre and fruit agreeing with Erigeron, but the style-tips more like those of Aster.

1. A. Watsoni (A. Gray) Rydb. Perennial, with a cespitose rootstock; stems slender, decumbent, $1 \mathrm{dm}$. long or less, glabrous or nearly so; basal leaves $2-3 \mathrm{~cm}$. long, petioled, linear-spatulate, glabrous; stem-leaves very small, 4-10 $\mathrm{mm}$. long; heads solitary, peduncled; involucre about $5 \mathrm{~mm}$. high and $8 \mathrm{~mm}$. broad; bracts oblong-lanceolate, acute, pruinose, and with some seattered hairs, with purplish membranous margins; ligules about $4 \mathrm{~mm}$. long, white or purplish. Aster Watsoni A. Gray. Mountains: Nev.-Utah. Mont. Au.

\section{DOELlingËRia Nees. White Aster.}

Perennial caulescent herbs, with rootstocks. Leaves alternate, ciliate, entire. Heads in corymbiform cymes, radiate. Involucres campanulate; bracts imbricate in 2-4 series, narrow, appressed, not herbaceous at the tips; receptacle pitted. Ray-flowers few or several, pistillate; ligules white. Disk-flowers perfect; corollas slender, expanded into a 5-lobed limb. Anthers obtuse at the base. Appendages of the style-branches subulate to ovate. Achenes slightly broader above. Pappus double, the outer of short bristles or squamellae, the inner of capillary bristles, usually clavellate at the apex, tawny.

1. D. pubens (A. Gray) Rydb. Stem 5-10 dm. high, finely puberulent; leaves lanceolate or ovate-lanceolate, $5-15 \mathrm{~cm}$. long, entire, acute, green and scabrous above, pale and tomentulose beneath; involucres about $5 \mathrm{~mm}$. high; bracts linear-lanceolate, slightly tomentulose; ligules white, $4 \mathrm{~mm}$. long. Aster umbellatus pubens A. Gray. Meadows and open woods: Upper Mich.-Wis.Neb.-Sask. Plain. Jl-S.

\section{IONÄCTIS Greene.}

Perennial caulescent plants, often ligneous at the base. Leaves alternate, narrow, entire. Heads radiate, solitary or corymbose. Involucres turbinate; bracts narrow, well imbricate, appressed, firm. Ray-flowers numerous; ligules violet. Disk-flowers perfect; corollas with campanulate throats. Style-branches with subulate appendages. Achenes pubescent, flat, with strong marginal nerves. Pappus double, the inner series of capillary bristles, the outer short, setulose. 
Plant 2-3 dm. high; leaves linear, 1-2 cm. long.

Plant less than $2 \mathrm{dm}$. high; leaves oblong or lanceolate, $5-10 \mathrm{~mm}$. long.

1. I. stenomeres.

2. I. alpina.

1. I. stenomeres (A. Gray) Greene. Stems erect, canescent or glabrate; leaves acute, mucronate, scabrous-puberulent; involucres hemispheric, 10-12 $\mathrm{mm}$. high, $15-20 \mathrm{~mm}$. broad; bracts linear, acute or acuminate, puberulent in 2 series, slightly unequal; ligules pale violet, $10-12 \mathrm{~mm}$. long; outer pappus setulose. Aster stenomeres A. Gray. Mountain slopes: Mont.-Ida.-Wash.-B.C. Submont. Je-Jl.

2. I. alpina (Nutt.) Greene. Stems $1-2 \mathrm{dm}$. high, canescent, simple; leaves 5-12 mm. long, rigid, scabrous-puberulent; involueres hemispheric, 8-10 $\mathrm{mm}$. high, 12-15 mm. broad; bracts in 3 series, linear-lanceolate, puberulent, acuminate; ligules about $1 \mathrm{~cm}$. long, light violet; outer pappus sometimes distinctly squamellate. Chrysopsis alpina Nutt. Aster scopulorum A. Gray. Mountains: Mont.-Wyo.-Nev.-Ore. Submont. My-J1.

\section{Leucelìne Greene. Heath Aster.}

Suffruticose perennials, diffusely branched. Leaves oblanceolate, linear, or subulate. Heads solitary at the ends of the branches. Involucres turbinate; bracts imbricate in several series, herbaceous with narrow scarious margins. Ray-flowers pistillate and fertile; ligules white, turning reddish. Disk-flowers perfect, white; corollas tubular-funnelform. Style-branches with ovate obtuse appendages. Achenes long and slender. Pappus of long slender white bristles.

Upper leaves strigose, slightly glandular and not conspicuously hispid-ciliate.

Lower leaves broadly spatulate, upper linear-subulate; branches long and slender.

Leves all linear $\quad$ 1. L. arenosa.

Upper leaves conspicuously hispid-ciliate, copiously glandular.

Upper leaves linear-oblanceolate, the lower spatulate.

Upper leaves linear-subulate, the lower linear or linear-oblanceolate. Leaves of the branches 6-12 $\mathrm{mm}$. long.

Leaves of the branches $2-5 \mathrm{~mm}$. long.

2. L. serotina.

3. L. hirtella.

4. L. alsinoides.

5. L. ericoides.

1. L. arenosa Heller. Stems 1-3 dm. high, strigose, branched; lower leaves petioled, hispid, 1-1.5 $\mathrm{cm}$. long; upper leaves 5-8 $\mathrm{mm}$. long; involucres $6-7 \mathrm{~mm}$. high and broad; bracts linear-lanceolate, hirsute, scarious-margined; ligules 3 mm. long. Dry hills: Tex.-Colo.-Ariz.; Mex. Son.-Submont.

2. L. serotina (Greene) Rydb. Stems erect, $1 \mathrm{dm}$. high or less; leaves $5-10$ $\mathrm{mm}$. long, strigose, or the lower hirsute-ciliate, scarcely glandular; involucres 5-6 mm. high; ligules about $3 \mathrm{~mm}$. long. L. ericoides serotina Greene. Arid hills: Tex.-Colo.-Utah-Ariz. Son. Je-Au.

3. L. hirtella (A. Gray) Rydb. Stems $1 \mathrm{dm}$. high or less, decidedly glandular-puberulent; lower leaves about $1 \mathrm{~cm}$. long; all leaves hispid-ciliate; involucres $5-6 \mathrm{~mm}$. high and fully as broad; bracts linear-lanceolate, more or less glandularpuberulent, acute, scarious-margined; ligules 3-5 mm. long. Diplopappus ericoides hirtella A. Gray. Dry hills: Tex.-Wyo.-Utah-Ariz. Son.-Submont. Ap-Jl.

4. L. alsinoides Greene. Stems about $1 \mathrm{dm}$. high, strigose; lower leaves about $1 \mathrm{~cm}$. long, the upper bristle-tipped and appressed; involucres 5-6 $\mathrm{mm}$. high and broad; bracts strigose, slightly glandular-puberulent; ligules $5 \mathrm{~mm}$. long. Dry hills: Tex.-Kans,-Colo.-N.M. Plain-Submont. Ap-Je.

5. L. ericoides (Torr.) Greene. Stems 1-1.5 dm. high; lower leaves about $1 \mathrm{~cm}$. long; involucres barely $5 \mathrm{~mm}$. high and broad; bracts less imbricate than in the other species, strigose; ligules white, $5 \mathrm{~mm}$. long. Inula ericoides Torr. A. ericaefolius Rothrock. Plains: Kans.-Tex.-Colo. Plain. S.

\section{4. machaeranthìra Nees. Tansy Aster, Viscid Aster.}

Annual, biennial, or short-lived perennial, leafy, caulescent herbs, with taproots, never with rootstocks. Leaves alternate, bristle-tipped, pinnatifid, serrate, or rarely entire, the teeth or lobes bristle-tipped. Heads corymbose or paniculate, radiate. Involucres hemispheric or turbinate; bracts with narrow 
herbaceous tips, imbricate in several series; receptacle pitted, the pits with toothed or lacerate edges. Ray-flowers numerous, pistillate; ligules violet or purple. Disk-flowers perfect; corollas yellow, turning red or brown. Anthers rounded at the base. Style-branches with subulate or lanceolate, acute appendages. Achenes turbinate, pubescent or glabrate. Pappus of numerous firm rough bristles.

Leaves once or twice pinnatifid; root annual; achenes terete.

Green tips of the bracts short, not squarrose.

Heads 6-7 mm. high; plant 3-5 dm. high.

Heads about $1 \mathrm{~cm}$. high; plant low, 1-2 dm. high.

Green tips of the bracts long, reflexed-squarrose.
Leaves spinulose-toothed; plant perennial or biennial; achenes compressed.

Bracts linear-subulate; green tips in most longer than the straw-colored lower portion, squarrose reflexed.

Stem and inflorescence distinctly viscid.

Stem-leaves lanceolate or oblong, usually distinctly triple-veined.

Leaves thin, coarsely but not saliently dentate; bracts over $1 \mathrm{~mm}$. wide.

4. M. Bigelovii.

Leaves thick with salient teeth; plant very glandular; bracts less than 1 mm. wide.

Achenes glabrous or minutely pubescent; stem glabrous below.

5. M. varians.
. varior.

Achenes strigose; stem glandular-hispid throughout. 6. M. aspera.

Stem-leaves linear or oblanceolate, 1-nerved.

Plant 3-5 dm. high; heads numerous in a panicle or raceme.

7. M. viscosula.

Plant 1-2 (seldom 3) dm. high; heads solitary or few. 8. M. Pattersonii.

Stem strigose-puberulent; involucre slightly if at all viscid.

Leaves all saliently toothed; inflorescence narrow, racemiform; heads subsessile.

Leaves except the lowest entire or denticulate; inflorescence open; heads peduncled.

Stem-leaves narrowly linear.

Stem-leaves oblanceolate.

10. M. rubricaulis.

11. M. latifolia.

Bracts linear, with a lanceolate or rhombic green tip, which is usually much shorter than the straw-colored lower portion.

Leaves cinereous.

Bracts canescent, scarcely at all viscid or glandular.

Stem-leaves linear; plant erect.

Stem-leaves narrowly oblanceolate; plant diffuse.

Bracts densely viscid or glandular, especially the tips.

12. $M$. canescens.

13. M. superba.

Bracts in but 3 series, not at all squarrose; the outer wholly greenish.

Bracts in 4-7 series with squarrose tips.

14. M. angustifolia.

Stem 1-2 dm. high; upper stem-leaves ample, almost as large and broad as the lower ones.

15. $M$. commixta.

Stem 2-4 dm. high; upper stem-leaves smaller and narrower than the lower ones.

Heads distinctly peduncled.

Leaves very thin; stem-leaves entire or nearly so.

Leaves thick.

16. M. leptophylla.

Stem erect, rather simple; stem-leaves linear-oblanceolate or oblanceolate, spinulose-toothed. 17. $M$. viscosa.

Stem divaricately branched, low; upper leaves small, linear or some linear-oblanceolate.

18. M. pulverulenta.

Heads subsessile, racemosely disposed; stem-leaves linear oblanceo-

late, coarsely toothed.

19. $M$. divaricata.

Leaves glabrous, or glandular-hispid or scabrous, not cinereous.

Stem puberulent or glabrate, glandular only on the inflorescence.

Bracts slightly if at all squarrose.

Stem slender, with strongly ascending branches; leaves subentire.

Stem divaricately branched; lower leaves sharply toothed.

21. M. ramosa.

Bracts strongly reflexed-squarrose.

Leaves all, except those of the smaller branches, toothed; achenes strigose.

Leaves all entire; achenes glabrous.

22. M. Selbyi.

23. $M$. spectabilis.

Stem densely glandular-hispid.

Bracts more or less glandular-pubescent and with squarrose tips.

Bracts grayish puberulent; tips short, lanceolate, not squarrose.

25. M. Fremontii.

1. M. parviflora A. Gray. Annual; stem 3-5 dm. high, branched, glabrous

nearly so; leaves sparingly glandular, simply pinnatifid; lobes short, linear, 
barely mucronate; involucres $8-10 \mathrm{~mm}$. broad; bracts with lanceolate, acute, scarcely spreading tips; ligules about $6 \mathrm{~mm}$. long. Aster parviflorus A. Gray. Cañons and arid places: N.M. - S Utah-Ariz. Son. Jl-Au.

2. M. humilis (A. Gray) Standl. Annual; stem erect, 1-3 dm. high, branched, glandular-puberulent; leaves once pinnatifid, glandular-puberulent; divisions oblanceolate or oblong, entire or toothed, spinulose-tipped; involucres 10-15 mm. broad; bracts linear, acute, glandular-puberulent; ligules rarely $1 \mathrm{~cm}$. long. A. canescens humilis A. Gray. Plains: N.M.-Utah-Ariz. Son. My-O.

3. M. tanacetifolia (H.B.K.) Nees. Annual; stem branched, 1-4 dm. high, green, glandular-puberulent and somewhat villous; leaves once or twice pinnatifid, 1-4 cm. long, glandular-puberulent; divisions oblanceolate or linear, entire or toothed; involucres hemispheric, fully $1 \mathrm{~cm}$. high, $15-20 \mathrm{~mm}$. broad; bracts linear, attenuate, numerous; ligules $12-20 \mathrm{~mm}$. long, blue-purple. $A$. tanacetifolius H.B.K. M. coronopifolia (Nutt.) A. Nels. Sandy soil, plains, and hills: Tex.-S.D.-Alta.-Ariz.; Mex. Plain-Submont. Je-O.

4. M. Bigelovii (A. Gray) Greene. Biennial; stem glandular-hirsute, 3-10 $\mathrm{dm}$. high, robust; leaves oblong or lanceolate, thin, coarsely dentate, glandularpuberulent, the upper more or less clasping, the basal ones oblanceolate, petioled; involueres about $15 \mathrm{~mm}$. high, $2-3 \mathrm{~cm}$. broad; bracts glandular-puberulent; ligules about $1 \mathrm{~cm}$. long. A. Bigelovii A. Gray. Plains and foothills: Colo.N.M.-Ariz. Submont. S-O.

5. M. varians Greene. Biennial; stem erect, 6-10 dm. high, glandular-puberulent above; leaves lanceolate, 7-10 cm. long, sessile, more or less spinuloseserrate, glabrous or minutely puberulent; involucres hemispheric, $1 \mathrm{~cm}$. high, $1.5-2 \mathrm{~cm}$. broad; ligules $12-15 \mathrm{~mm}$. long, purple. Plains and mountains: Colo. -N.M. Submont. Jl-S.

6. M. aspera Greene. Biennial; stem stout, 6-10 dm. high, glandular-hispid; lower leaves oblanceolate, petioled, the upper oblong-lanceolate, sessile, more or less clasping, spinulose-serrate, scabrous and glandular-pruinose; involucres about $1 \mathrm{~cm}$. high, $1.5 \mathrm{~cm}$. broad; ligules 8-10 mm. long, purple. Mountains: Colo. Submont.-Mont. Je-Au.

7. M. viscosula Rydb. Biennial, with a rosette of basal leaves; stems few, about $2 \mathrm{dm}$. high, viscid-puberulent; basal leaves oblanceolate, petioled, the upper similar or linear, but sessile, all saliently and coarsely toothed to nearly entire; heads about $1 \mathrm{~cm}$. high; ligules reddish purple, $8-10 \mathrm{~mm}$. long and fully $1 \mathrm{~mm}$. wide. M. viscosa Greene, not Dieteria viscosa Nutt. Plains and mountains: Colo. Submont.-Mont. J1-Au.

8. M. Pattersonii (A. Gray) Greene. Biennial, with a stout taproot; stem 1-2 dm. high, villous and glandular; basal leaves numerous, $4-6 \mathrm{~cm}$. long, petioled, spatulate, toothed above, glabrous or nearly so; involucres fully $1 \mathrm{~cm}$. high and nearly $2 \mathrm{~cm}$. broad; bracts linear-attenuate, green except at the base, glandular-hispidulous; ligules 10-15 mm. long, purple. A. Pattersonii A. Gray. High mountains: Colo. Mont.-Alp. Jl-Au.

9. M. Sessiliflora (Nutt.) Greene. Biennial, leafy, 3-5 dm. high; leaves linear, saliently toothed, $3-6 \mathrm{~cm}$. long, scabrous-puberulent or nearly glabrous; involucres about $1 \mathrm{~cm}$. high and $1.5 \mathrm{~cm}$. broad; bracts subulate, canescent; ligules rose-purple. Hills and plains: Neb.-Wyo. Plain. Au-S.

10. M. rubricaulis Rydb. Biennial or perhaps perennial; stem erect or nearly so, simple below, branched above, 4-6 dm. high, usually tinged with red or purple; leaves entire or sparingly dentate, scabrous-ciliolate on the margins, the largest $8 \mathrm{~cm}$. long, and $8 \mathrm{~mm}$. wide; involucre $10-12 \mathrm{~mm}$. high, $12-15 \mathrm{~mm}$. in diameter; ligules numerous, dark blue, about $12 \mathrm{~mm}$. long and $1 \mathrm{~mm}$. wide. Table-lands and hills: Colo,- e Utah. Submont. Au-S.

11. M. latifolia A. Nels. Biennial or perhaps perennial; stem erect, 1.5-2.5 $\mathrm{dm}$. high; lower leaves petioled, the upper sessile; blades spatulate or oblanceolate, mostly 3-nerved, puberulent, or nearly glabrous above; inflorescence corymbiform; involucres hemispheric, about $8 \mathrm{~mm}$. high and $12 \mathrm{~mm}$. broad; bracts 
glandular-puberulent; ligules blue or bluish violet. $M$. paniculata A. Nels., a large form. Mountains: Utah. Mont. Au.

12. M. canescens (Pursh) A. Gray. Biennial; stem profusely branched, 1-4 dm. high; lower leaves spatulate or oblanceolate, slightly toothed; stemleaves linear, rarely narrowly oblanceolate, usually entire; heads numerous in an open panicle; involucres $7-8 \mathrm{~mm}$. high, about $1 \mathrm{~cm}$. broad; ligules $8 \mathrm{~mm}$. long, dark bluish purple. A. canescens Pursh. M. magna A. Nels., a robust form. Sterile ground and sandy banks: Sask.-Colo.-Calif.-B.C. PlainSon. J1-S.

13. M. superba A. Nels. Biennial; stem branched at the base; branches ascending or decumbent, 8-15 $\mathrm{cm}$. long; lower leaves oblong-oblanceolate, 4-6 $\mathrm{cm}$. Iong, petioled; stem-leaves entire or remotely denticulate; involucres about $8 \mathrm{~mm}$. high, $1 \mathrm{~cm}$. broad; ligules deep blue or purple, $8-10 \mathrm{~mm}$. long. Sandy hillsides: Wyo. Mont. Au.

14. M. angustifolia Rydb. Biennial or perhaps perennial; stem about 1.5 $\mathrm{dm}$. high, more or less tinged with purple; leaves linear, $2-5 \mathrm{~cm}$. long and about $2 \mathrm{~mm}$. wide, finely strigose-puberulent, sinuose-denticulate; involucres 7-9 $\mathrm{mm}$. high and broad; bracts oblong-lanceolate, acute, tinged with red or purple, comparatively thin; ligules $5-7 \mathrm{~mm}$. long, rose or light purple. $M$. linearis Rydb., not Greene. Sandy places: Wyo. Mont. Au.

15. M. commixta Greene. Biennial; stem branched at the base; leaves all spatulate, 3-6 $\mathrm{cm}$. long, serrate, at least above the middle, 3-ribbed; heads corymbose, large, about $1 \mathrm{~cm}$. high and 12-15 mm. broad; ligules purple, about $9 \mathrm{~mm}$. long. Mountains: Utah. Submont.-Mont. J1-Au.

16. M. leptophylla Rydb. Biennial, cespitose at the base; stem slender, simple, 3-5 dm. high; lower leaves petioled, $2-5 \mathrm{~cm}$. long, finely cinereous-puberulent, in age sparingly so; blades spatulate or oblanceolate, thin; upper leaves linear-oblanceolate or linear; involucre turbinate, $8 \mathrm{~mm}$. high, 8-10 mm. broad; ligules rose-purple, about $8 \mathrm{~mm}$. long. Hills: Utah. Submont. Au.

17. M. viscosa (Nutt.) Greene. Biennial; stem 3-5 dm. high; lower leaves petioled, 4-7 cm. long, entire or somewhat toothed, oblanceolate; middle leaves narrower and sharply serrate; involucres $8 \mathrm{~mm}$. high, $10-12 \mathrm{~mm}$. broad; ligules purple, $8 \mathrm{~mm}$. long. Hills, slopes, and plains: Mont.-Wyo,-Utah. PlainMont. Je-S.

18. M. pulverulenta (Nutt.) Greene. Biennial; stem erect, $2-4 \mathrm{dm}$. high; leaves narrowly oblanceolate, or the upper linear, $2-5 \mathrm{~cm}$. long, entire or sparingly denticulate; involucres $6-7 \mathrm{~mm}$. high, $8-10 \mathrm{~mm}$. broad, only slightly squarrose; ligules purple, $7-8 \mathrm{~mm}$. long. (?) M. subalpina Greene. Dry plains: Mont.Colo.-Utah-Ida. Au-O.

19. M. divaricata (Nutt.) Greene. Biennial; stem stout, about $3 \mathrm{dm}$. high; branches numerous, more or less spreading; involucres turbinate, about $8 \mathrm{~mm}$. high, $10-12 \mathrm{~mm}$. broad; ligules purple, nearly $1 \mathrm{~cm}$. long. Hills and plains: Mont.-Wyo. Plain-Submont. Au-O.

20. M. glabella Greene. Biennial; stem 3-4 dm. high, glabrous; lower leaves petioled, narrowly oblanceolate, glabrous, entire or slightly denticulate; upper leaves narrowly linear; involucres turbinate, about $7 \mathrm{~mm}$. high, 7-8 mm. wide; ligules bluish purple, about $8 \mathrm{~mm}$. long. $M$. pulverulenta vacans A. Nels. Mountains: Colo. Submont.-Mont. JI-S.

21. M. ramosa A. Nels. Biennial, branched at the base; stem ascending or spreading, 2-4 dm. high; leaves green, nearly glabrous, linear-oblanceolate or linear, the earlier sharply dentate; involucres hemispheric, about $7 \mathrm{~mm}$. high and $1 \mathrm{~cm}$. wide; bracts linear, acute or short-acuminate, glandular-puberulent; ligules purple, $8 \mathrm{~mm}$. long. Mountains and plains: Wyo.-Colo. Submont.Mont. JI-S.

22. M. Selbyi Rydb. Biennial; stem often reddish, branched above; lower leaves linear-oblanceolate to oblanceolate, petioled, glabrous or rarely slightly puberulent, dentate; upper leaves linear; involucres hemispheric, 7-8 mm. high 
and $1 \mathrm{~cm}$. broad; bracts well imbricate; glandular green tips small, lanceolate. Cañons and meadows: Colo. Submont.-Mont. S.

23. M. spectabilis Greene. Biennial; stems several, 2-3 dm. high, glabrous or nearly so; lower leaves oblanceolate, petioled, the upper linear and sessile; involucres turbinate, about $1 \mathrm{~cm}$. high and $12 \mathrm{~mm}$. broad; bracts linear, acuminate; tips almost as long as the chartaceous portion, glandular-puberulent; ligules violet, $1 \mathrm{~cm}$. long. Mountains: Colo. Mont. Au.

24. M. cichoriacea Greene. Biennial; stem stout, 3-6 dm. high; leaves pale green, glabrous, lanceolate, sessile, $3-5 \mathrm{~cm}$. long, runcinate-dentate; involucres turbinate, about $7 \mathrm{~mm}$. high and broad; bracts linear, acute; tips short, glandular-puberulent; ligules about $6 \mathrm{~mm}$. long, violet. Hills and mountains: Colo.-e Utah-N.M.-Ariz. Son.-Submont. Au.

25. M. Fremontii Rydb. Biennial, with thick taproot; stems several, 4-5 dm. high; basal leaves oblanceolate, petioled, glandular-hispid and scabrous, sharply dentate; upper leaves sessile, linear or lanceolate; heads over $1 \mathrm{~cm}$. high; bracts linear-lanceolate, cinereous; ligules purple, $8-10 \mathrm{~mm}$. long. River bottoms: Colo. J1.

\section{ERÍGERoN L. Fleabane.}

Annual, biennial, or perennial herbs, caulescent or almost scapose. Leaves alternate, entire, toothed, or lobed. Heads solitary, corymbose, or paniculate, radiate or rarely discoid. Involucres hemispheric or saucer-shaped; bracts in $1-2$, rarely 3 series, sub-equal or slightly imbricate; receptacle flat, naked. Rayflowers pistillate, white, pink, or purple, rarely ochroleucous or yellow, or wanting. Disk-flowers perfect with yellow corollas. Anthers entire and obtuse at the base. Stigmas flattened, with mostly obtuse appendages. Achenes usually flattened, 2-nerved, in a few species subterete and several-nerved. Pappus in a single series of capillary scabrous bristles, or sometimes with a series of shorter bristles outside. [Wyomingia A. Nels.]

Bracts of the involucre in 1-2 series of almost equal length, not thickened on the back.

Rays inconspicuous, erect or ascending, usually involute and incurved, numerous; often inside them a series of rayless pistillate flowers; leaves entire.

Rays conspicuous, spreading, flat; no rayless pistillate flowers inside. ACRES. Plant without runners.

Perennials with rootstocks or woody caudices.

Leaves dissected or deeply eleft.

Leaves entire or merely toothed.

\section{Compositi.}

Stems low, less than $2 \mathrm{dm}$. high, scapiform, usually bearing only one head; stem-leaves usually reduced.

Involucre and peduncles villous with many-celled hairs; bracts comparatively broad.

Involucre and peduncles hirsute to II. UNIFLORI. not long-villous.
IV. RADICATI.

Stem leafy, 2-10 dm. high, if lower bearing several heads; stem-leaves ample.

Stems densely cespitose from a thick taproot; heads small, the disk rarely more than $1 \mathrm{~cm}$. wide.

Pappus double; stem hirsute.

Pappus simple; stems strigose.

V. PUMTLI.

Stems usually solitary from the VI. DECUMBENTES. rootstocks;

large, the disk more than $1 \mathrm{~cm}$. wide.

Bracts with loose tips; rays broad; pappus simple; lower leaves broadly oblanceolate, the upper often reduced.

Bracts villous.

Bracts glandular-puberulent or glabrous.

VII. ELATIORES.

Bracts appressed, except the very tips; VIII. SALsUGINOSI. double; double; perennials with short rootstocks.

Upper stem-leaves ample, ovate to lanceolate, not much smaller than the lower, which are more or less distinctly 3-nerved; peduncles usually short, ascending.

Upper stem-leaves reduced, linear-laneelate; MACRANTHI. leaves 3-nerved; leaves 3-nerved; peduncles long and erect.

X. Glabelli.

Annuals or biennials, or perennials by means of stolons and offsets.

Stem-leaves broad, cordate-clasping; perennials with offsets. 
Stem-leaves not cordate-clasping.

Stems rather simple, with a few large heads; disks about $1 \mathrm{~cm}$. broad or more.

XII. ASPERI.

Stems much branched, leafy, with numerous small heads; disk 6-9 mm. wide.

Stems strigose or sparingly hirsute except at the base, or glabrous: pappus-bristles of the ray-flowers usually lacking; annuals.

XIII. RAMOSI.

Stems and leaves densely short-pubescent with spreading hairs; pappus-bristles of the ray-flowers present.

Annuals; pappus scant and simple. XIV. BELLIDIASTRA.

Biennials (rarely perennials); pappus double, the outer of short subulate squamellae. $\mathrm{XV}$. DIVERGENTES.

Plants at first with a scapiform naked peduncle, later producing runner-like branches.

Bracts of the involucre in 3-4 series, more or less imbricate, thickened on the back, the outer usually successively shorter; perennials with cespitose caudices.

Rays bluish, purplish, or white.

Achenes terete or nearly so, several-nerved.

Achenes flattened or quadrangular, 2-4-nerved.

Leaves more or less distinctly triple-nerved.

XVII. CANI.

Leaves not triple-nerved.

XVIII. CAEspitosi.

Plants low, $2 \mathrm{dm}$. or less high; basal leaf-blades from broadly oval to narrowly linear-oblanceolate; heads solitary to few.

Basal leaf-blades broadly oval or obovate.

Leaves narrowly linear-oblanceolate. Involucres glandular.

Involucres hirsute or strigose.

XIX. ASPERUGINEI.

Plant taller, 3-4 dm. high; leaves filiform or narrowly linear.

Leaves narrowly linear or linear-oblanceolate; achenes quadrangular, 4-nerved.

Leaves filiform; achenes flat, 2-nerved.

Rays yellow or ochroleueous.

XETRAPLEURI.

XXIII. FILIFOLII.

XXIV. LUTEI,

\section{ACRES.}

Bracts of the involucre linear, abruptly acute, never glandular; inner rayless pistillate flowers rare; inflorescence strictly racemiform, with almost erect branches,

Low, 1-2 dm. high, usually branched at the base; stem-leaves sessile; peduncles short, not exceeding the subtending leaves.

1. E. minor.

Taller, 3-6 dm. high, simple; lower stem-leaves petioled; basal leaves oblanceolate; peduncles elongate.

2. E. lonchophyllus.

Bracts of the involucre linear-subulate, long-attenuate, and except in $E$. elatus more or less glandular-puberulent; inflorescence inclined to be corymbiform or paniculate, branches ascending.

Plant tall, 3-8 dm. high, apparently only biennial; heads numerous, corymbose. Bracts glandular-puberulent, rarely with a few hairs.

Base of the involucre merely glandular-puberulent; whole plant glabrous or the margins of the leaves sparingly ciliate; stem-leaves lanceolate.

3. E. politus.

Base of the involucre sparingly hirsute; leaves hairy, at least on the margins and veins beneath; stem-leaves linear or linear-oblanceolate.

Bracts hirsute or both hirsute and glandular-puberulent.

Bracts both glandular-puberulent and hirsute; leaves more or less hairy.

Bracts not glandular; leaves glabrous except the ciliate margins.

5. yellowstonensis.

6. E. elatus.

Plant low, 1-3 dm. high, perennial; heads few or solitary.

Involucres not black-hairy.

Involucres glandular and hirsute.

Involucres villous, not glandular.

7. E. jucundus.

8. E. alpinus.

Involucre black-hairy.

9. E. unalaschkensis.

\section{UNIFLORI.}

Ligules purple or white.

Ligules $0.5 \mathrm{~mm}$. or less wide, erect; plant usually less than $1 \mathrm{dm}$. high; leaves and stem decidedly villous.

9. E. unalaschkensis.

Ligules 1-1.5 mm. wide, spreading; plant about $1 \mathrm{dm}$. high; basal leaves glabrate; lower part of the stem strigose or glabrate.

Involucres and peduncles with black-purple hairs.

Involucres and peduncles white-hairy.

Basal leaves sparingly hairy or glabrate.

Basal leaves spatulate, obtuse.

Basal leaves narrowly linear-lanceolate.

10. E. melanocephalus.

Basal leaves densely villous.

Stem 1-2 dm. high, leafy; basal leaves oblanceolate, often acutish.

Stem 5-6 cm. high, scapiform; basal leaves cuneate-spatulate, often 3-

toothed. 13. E. lanatus.

Ligules yellow.

14. E. aureus. 


\section{CoMPositi.}

Leaves divided into linear or spatulate divisions; plant with a cespitose caudex. Leaves pinnately divided.

Heads radiate; leaf segments rather distant; peduncles 5-20 cm. long.

Heads discoid; leaf segments crowded; peduncles $2-5 \mathrm{~cm}$. long.

15. E. pinnatisectus.

16. E. mancus.

Leaves once to thrice ternately divided.

Leaf-blades twice or thrice ternate.

17. E. compositus.

Leaf-blades cuneate, ternately or pedate-quinnately cleft at the apex; divisions spatulate.

Disk $10-15 \mathrm{~mm}$. broad; bracts linear-subulate, scarcely scarious-margined; lobes of the leaves spatulate.

18. E. trifidus.

Disk 7-10 $\mathrm{mm}$. broad; bracts linear-lanceolate, scarious-margined; lobes of the leaves linear.

Leaves flabelliform, lobed or twice 3-cleft at the apex; plant with a creeping rootstock.

20. E. flabellifolius.

\section{RADICATI.}

Head radiate.

Involucre glandular-puberulent or glabrate, not hirsute.

Stem and leaves glabrous or nearly so; involucres less than $12 \mathrm{~mm}$. broad.

Basal leaves linear-oblanceolate.

Basal leaves spatulate.

Stem and leaves pubescent; involucres $12-15 \mathrm{~mm}$. wide.

Stem and leaves hirsute.

Stem strigose; leaves puberulent, especially on the margins.

21. E. leiomerus.

22. $E$, spathulifolius.

63. E. viscidus.

23. E. controversus.

Involucre more or less hirsute or strigose, in some also slightly glandular-puberulent.

Leaves and stem glandular scabrous as well as hirsute. 24. E. glandulosus.

Leaves and stem hirsute or strigose, rarely glandular.

Stem $1 \mathrm{dm}$. or more high, appressed-pubescent; disk over $1 \mathrm{dm}$. high; branches of the caudex or rootstock rather slender, often purplish.

Leaves narrowly linear-oblanceolate, $1-3 \mathrm{~mm}$. wide, strigose.

Involucral bracts with appressed pubescence; rays purple.

Involucral bracts with spreading pubescence.

Rays white; bracts narrowly linear.

Rays usually purplish; bracts lance-linear.

Leaves oblanceolate to linear-oblanceolate, $3-8 \mathrm{~mm}$. wide, glabrous above,

except the margins. 27. E. ursinus.

25. E. gracilis.

26. E. Engelmannii.

Stem 4-7 cm. high; disk less than $1 \mathrm{~cm}$. wide; caudex and its branches stout and short, not purplish.

Leaves linear-oblanceolate to spatulate.

Stem with appressed hairs, or glabrate.

Leaves and stem glabrous or nearly so; stem almost leafless.

Leaves and stem distinctly strigose, 28 . E. Evermannii.

Leaves and stem distinctly strigose, the latter with several leaves.

Stem with more or less spreading hairs.

29. E. Peasei.

Stems decumbent or ascending; leaves spreading, either softly hairy or glabrate in age.

Pappus double; inner pappus of $10-12$ bristles, $2 \mathrm{~mm}$. long; outer pappus of small squamellae; rays white.

Pappus simple or nearly so, consisting of many bristles, $3 \mathrm{~mm}$.

long; rays purple.
Stems and leaves almost erect; the latter coarsely hirsute.

Basal leaves narrowly linear-oblanceolate; stem-leaves linear.

32. E. nanus.

Basal leaves narrowly spatulate; stem-leaves oblanceolate.

Leaves linear-filiform.

Heads discoid; leaves narrowly linear.

38. E. condensatus.

V. PUMrLi.

33. E. nematophyllus.

34. E. Bloomeri.

Pubescence of rather long hairs; branches of the stem almost erect.

Heads radiate.

Stems over $1 \mathrm{dm}$. high, when well developed, with more than one head each.

Ray-flowers white.

Outer pappus of small inconspicuous bristles; plant copiously hairy.

Outer pappus of broad squamellae; plant sparingly 35 . E. pumilus.

Ray-flowers blue or purplish; outer pappus conspicuous and squamellate.

Stems usually less than $1 \mathrm{dm}$. high and usually monocephalous.

Heads discoid.

Leaves spatulate.

Pubescence very short; branches of the stems spreading.

38. E. condensatus.

32. E. nanus.

39. E. aphanactis.

72. E. Wootonii. 


\section{Decumbentes.}

Leaves 1-nerved, linear-oblanceolate; the lower usually obtusish. 26. E. Engelmannii, Leaves 3-nerved, at least at the base, equally long-acuminate at both ends. Pubescence of the leaves loose, hirsute and somewhat glandular-puberulent.

Pubescence of the leaves appressed-strigose.

40. $E$. decumbens.

41. E. microlonchus.

VII. Elatiores.

Bracts very densely villous, squarrose; leaves entire.

Bracts sparingly villous; leaves usually dentate.

42. E. elatior.

Ligules white; bracts scarcely squarrose; stem sparingly pubescent.

Ligules blue or purple; bracts squarrose; stem densely pubescent above.

\section{SALSUGINOSI.}

44. E. peregrinus.

Rootstock thick; leaves thickish, acute; bracts narrowly linear-lanceolate, with strongly spreading tips.

Peduncles mostly solitary, finely strigose; stem single from the rootstock.

Peduncles usually more than one, scabrous; stems several from. E. salsuginosus.

49. E. eucephaloides.

Rootstock slender; leaves thin, with long mucronate tips; bracts narrowly linear-subu-
late, only slightly spreading.
46. . Howellii. late, only slightly spreading.

\section{Macranthi,}

Basal leaf-blades broadly obovate-spatulate, often denticulate; stem-leaves distant, shorter than the internodes, not ciliate on the margins; bracts glandular-puberulent, seldom with a few hairs. 47. E. superbus.

Basal leaf-blades oblanceolate, entire; stem-leaves usually longer than the internodes, usually ciliate on the margins.

Bracts linear-subulate, glandular-puberulent, not at all hirsute; leaves glabrous.

Leaves linear-lanceolate, minutely ciliolate.

Leaves dark green; bracts not with Ioose tips.

Leaves light green; bract with spreading tips.

Leaves not dark green, dull, strongly hirsute-ciliate.

Bracts linear, more or less hirsute.

Stem and leaves glabrous or nearly so; the latter ciliate only on the margin and the veins below; bracts glandular-puberulent and with scattered hairs. Stem and leaves hairy; bracts hirsute or both hirsute and glandular.
Leaves hirsute.

48. E. salicinus

49. E. eucephaloides.

50. E. macranthus.

Pubescence scant, that of the stem long; leaves linear-lanceolate.

52. E. conspicuus.

Pubescence of the leaves and the involucres dense, that of the stem short. Plant tall, green; upper stem-leaves ovate or ovate-lanceolate, distinctly triple-nerved. 52. E. subtrinervis.

Plant low, canescent; upper stem-Ieaves lanceolate, scarcely triple$\begin{array}{ll}\text { nerved, } & \text { 54. E. incanescens. } \\ \text { andular-puberulent. } & \text { 55. E. Vreelandit. }\end{array}$

Leaves glandular-puberulent.

\section{Glabelli.}

Involucre hirsute or strigose, not at all glandular.

Leaves glabrous, except the ciliate margins.

Leaves more or less pubescent.

Pubescence loose and spreading.

Pubescence appressed.

Involucres more or less glandular, sometimes also hirsute.

Leaves glabrous, except the ciliate margins.

Stem pubescent, especially above, only slightly glandular.

Bracts narrowly linear-subulate; ligules usually bluish or pink.

Involucre conspicuously hirsute as well as glandular; stem low, usually with a single head.

56. E. glabellus.

57. E. fruticetorum.

58. E. Earlei.

Involucre slightly if at all hirsute; stem $3 \mathrm{dm}$. high or more, usually with more than one head.

Bracts lance-subulate; ligules white.

Stem scarcely hairy, decidedly glandular above.

Leaves and stem more or less pubescent.

Involucres about $18 \mathrm{~mm}$. broad; plant conspicuously long-hairy.

Involucres about $15 \mathrm{~mm}$. broad; plant less conspicuously hairy, more glandular.

XI. PhiladelphicI.

60. E. eximius.

43. E. Coulteri.

61. E. Smithii.

63. E, viscidus.

Basal leaves crenate or dentate, with broad rounded or ovate teeth; upper leaves lanceolate, acute; rays white or pink.

64. E. philadelphicus.

Basal leaves dentate, with sharp, triangular, salient teeth; upper stem-leaves triangularIanceolate, acuminate; rays rose-colored or purple.

65. E. purpureus.

Pubescence short, usually not dense.

$$
\text { XII. ASPERI. }
$$

Pubescence appressed or rarely spreading; hairs not with pustulate bases. 
Heads small; disk $1 \mathrm{~cm}$. or less wide; ligules white; basal leaves linear-oblanceolate, entire.

66. E. asper.

Heads larger; disk 1-1.5 cm. wide; ligules blue or purple; basal leaves usually more or less toothed, oblanceolate.

67. E. oblanceolatus.

Pubescence spreading; hairs with pustulate bases; basal leaves narrowly oblanceolate; ligules white or rarely pale rose.

Pubescence long, dense, spreading or reflexed.

68. E. consobrinus.

69. E. Drummondii.

XIII. Ramosi.

One species.

\section{BELI.IDIASTRA.}

One species.

\section{DIVERGENTES.}

Stem simple below; rays usually white.

Stem branched at the base; rays usually purplish.

XVI. Flagellares.

Leaves and stems appressed-hairy.

Leaves and stem densely short-pubescent with spreading hairs.

Basal leaves oblanceolate, entire, or 3-lobed at the apex; leav plant gray. Basal leaves obovate-spatulate, entire, or with several lateral lobes or teeth; leaves
of the stolons oblanceolate; plant greener.

XVII. CANI.

Disk of the heads fully $1 \mathrm{~cm}$. high and about $1.5 \mathrm{~cm}$. wide; basal leaves spatulate, obtuse.

Leaves canescent.

Leaves silvery white.

77. E. Wyomingia.

78. E. argentatus.

Disk of the heads $7-8 \mathrm{~mm}$. high and about $1 \mathrm{~cm}$. wide; basal leaves oblanceolate, mostly acutish.

XVIII. Caespitosi.

Stem leafy; stem-leaves almost as broad as the basal ones.

Lower leaves narrowly linear-oblanceolate; upper leaves narrowly linear; all acute and coarsely hairy; rays usually lilac or purplish.

80. E. corymbosus.

Lower leaves oblanceolate or linear-spatulate, usually obtusish; stem-leaves linear or oblong; all densely canescent; rays usually white.

Stem erect, about $3 \mathrm{dm}$. high, usually with several heads; stem-leaves linear.

81. E. subcanescens.

Stem decumbent at the base, 1-2 dm. high, with 1-3 (seldom more) heads; stemleaves oblong.

Plant not conspicuously glandular.

Plant conspicuously glandular.

82. E. caespitosus.

83. E. nauseosus.

Stem more or less naked above, decumbent at the base; stem-leaves at least the upper ones reduced.

Stems about $2 \mathrm{dm}$. high; disk 10-12 mm. high and about $15 \mathrm{~mm}$. wide.

84. E. nevadensis.

Stems about $1 \mathrm{dm}$. high; disks about $6 \mathrm{~mm}$. high and less than $1 \mathrm{~cm}$. wide.

\section{AsPERUGINEI.}

Leaves with a spreading rough pubescence.

85. E. Eatonii.

Leaves strictly appressed-cinereous.

86. E. asperugineus.

Disk 10-15 mm. wide; leaves finely and densely hairy; involucral bracts strigose.

87. E. Tweedyi,

Disk 5-10 mm. wide; leaves sparingly and coarsely hairy; involucral bracts hirsute and glandular-puberulent.

One species.

XX. ARENARIOIDES.

88. E, tener.

89. E. arenarioides.

XXI. LAETEVIRENTES.

Stems 1.5-2 dm. high, leafy.

Ligules blue or purple, scarcely more than $1 \mathrm{~mm}$, wide.

Ligules white, $1.5-2 \mathrm{~mm}$. wide.

Stem 3-8 cm. high, scapiform, leafless or few-leaved.

Pubescence of the stem appressed or ascending; stems decumbent at the base.

Leaves grayish strigose, in age glabrate; bracts hirsute. Bracts linear, acuminate; ligules mostly purple, 7-8 mm. long.

Bracts lance-linear, acute; ligules mostly white. Leaves and bracts silvery strigose.

92. E. Scribneri.

30. $E$, radicatus.

101. E. pulvinatus.

Pubescence of the stem spreading; stems erect; leaves densely hirsute; ligules white.

93. E. Parryi.

\section{TETRAPLEURI.}

Ligules fully $1 \mathrm{~cm}$. long, white; involucres about $1 \mathrm{~cm}$. broad.

Ligules 5-6 mm. long, sky-blue or pinkish; involucres $6-8 \mathrm{~mm}$. broad. 
XXIV. LUTEI,

Bracts strigose or hirsute; plant cespitose; leaves narrowly linear. Stems scapiform, naked or with a few small leaves; bracts strigose.

Stems more or less leafy; bracts hirsute.

Petioles of the leaves hirsute-ciliate.

Petioles as well as the blades finely cinereous-strigose. Bracts long-villous; leaves spatulate.
98. E. luteus.

99. E. ochroleucus.

100. E. peucephyllus.

14. E. aureus.

1. E. minor (Hook.) Rydb. Biennial; stem more or less hirsute; basal leaves spatulate or oblanceolate, petioled, 3-6 cm. long, ciliate or glabrate; stem-leaves linear, 3-10 $\mathrm{cm}$. long, acute; peduncles erect, 1-5 cm. long; involucres $6-8 \mathrm{~mm}$. high, $10-15 \mathrm{~mm}$. wide; bracts hirsute; ligules about $2 \mathrm{~mm}$. long, erect, rose-colored or whitish. E. glabratus minor Hook. E. armeraefolius A. Gray, not Turez. Damp places: Sask.-Colo.-Utah-B.C. Submont.-Mont. Jl-S.

2. E. lonchophyllus Hook. Biennial; stem more or less hirsute; lower leaves petioled, narrowly oblanceolate, $6-15 \mathrm{~cm}$. long, hirsute-ciliate or glabrate; peduncles usually elongate, $2-8 \mathrm{~cm}$. long; involucres about $8 \mathrm{~mm}$. high and 15 $\mathrm{mm}$. broad; bracts hirsute; ligules $2-3 \mathrm{~mm}$. long, erect. $E$. racemosus Nutt. Wet places: Sask.-Colo.-Nev.-Ida. Submont.-Mont. Jl-Au.

3. E. politus Fries. Stem simple, erect, 4-8 dm. high, glabrous or nearly so; basal leaves oblanceolate, 5-10 cm. long, glabrous; stem-leaves lanceolate or linear-lanceolate, sessile; involucres 7-8 mm. high, 10-12 mm. broad; ligules 3-4 $\mathrm{mm}$. long, erect, convolute-filiform. E. glabratus Hook., not Hoppe. Rocky mountains: Alta.-Ida.-B.C.; n Scandinavia. Subalp. J1-Au.

4. E. droebachensis Muell. Stem simple, glabrous or sparingly hirsute; basal leaves $5-10 \mathrm{~cm}$. long, ciliate; stem-leaves narrowly oblanceolate to linearlanceolate; involucres about $6 \mathrm{~mm}$. high and $1 \mathrm{~cm}$. broad; ligules about $3 \mathrm{~mm}$. long, white. E. acris droebachensis Blytt. Woods: N.B.-Sask.-Colo.-Alaska; n Eu. Submont.-Mont. J1-Au.

5. E. yellowstonensis A. Nels. Stem mostly simple, stout, often purplish, hirsute and puberulent; lower leaves oblanceolate, petioled, 3-8 cm. long, hirsute; upper stem-leaves sessile, linear or linear-lanceolate; involucres $8 \mathrm{~mm}$. high, $10-12 \mathrm{~mm}$. broad; rays filiform, convolute, scarcely $2 \mathrm{~mm}$. long. $E$. lapiluteus A. Nels. Mountains: Alta,-Colo.-B.C. Submont.-Mont. Ji-Au.

6. E. elatus (Hook.) Greene. Stem mostly simple, 3-4 dm. high, sparingly hirsute; basal leaves spatulate, $2-7 \mathrm{~cm}$. long; stem-leaves lanceolate to nearly linear; involucres hemispherie, 7-8 mm. high, 10-15 mm. broad; ligules about $3 \mathrm{~mm}$. long, erect, convolute. E. alpinus elatus Hook. High mountains: Canadian Rockies. Subalp. Jl-Au.

7. E. jucundus Greene. Stems often several, puberulent and sparingly hirsute; basal leaves spatulate or oblanceolate, petioled, 3-5 $\mathrm{cm}$. long, sparingly hirsute-pilose; stem-leaves linear-lanceolate or oblong; heads solitary or few; involucres $6 \mathrm{~mm}$. high, 8-10 mm. broad; bracts often purple-tinged; ligules erect, pink, 2-2.5 mm. long. E. acris debilis A. Gray. E. debilis Rydb. Wet places: Que.-Hudson Bay-Colo.-Utah-B.C. Submont.-Subalp. Jl-Au.

8. E. alpinus L. Stem 1-3 dm. high, sparingly pubescent; basal leaves spatulate, petioled, $2-5 \mathrm{~cm}$. long, hirsute; stem-leaves sessile, linear-lanceolate; heads usually solitary; involucres $8-10 \mathrm{~mm}$. high, $1-2 \mathrm{~cm}$. broad; ligules white, rose, or lilac, about $4 \mathrm{~mm}$. long, erect, involute. High mountains: Canadian Rockies; subarctic Eurasia. Alp.

9. E. unalaschkensis (DC.) Rydb. Low perennial, with a short, somewhat cespitose rootstock; stem 3-20 cm. high, villous with blackish hairs, somewhat thickened under the involucres; leaves mostly basal, 1-4 cm. long, spatulate, obtuse, hirsute; involucres 8-10 mm. high, 10-15 mm. broad; bracts black-purple; ligules $2-3 \mathrm{~mm}$. long, $0.5 \mathrm{~mm}$, wide, ereet or ascending, often becoming involute. E. uniflorus pulchellus Fries. E. pulchellus unalaschensis DC. Aretic-alpine situations: Greenl.-Lab.-Mont.-Alaska. Alp. J-Au.

10. E. melanocephalus A. Nels. Stem erect, $5-15 \mathrm{~cm}$. high, monocephalous, villous with black-purplish hairs, especially above; leaves spatulate or 
oblong-spatulate, 2-7 cm. long, glabrous or nearly so; stem-leaves linear; involucres $8-10 \mathrm{~mm}$. high, $12-18 \mathrm{~mm}$. wide; bracts linear-subulate; ligules white or pinkish, about $8 \mathrm{~mm}$. long. High mountains: N.M.-Wyo. Subalp.-Alp. $\mathrm{Jl}-\mathrm{Au}$.

11. E. simplex Greene. Stem 5-20 cm. high, villous; basal leaves oblanceolate or spatulate, $3-5 \mathrm{~cm}$. long; stem-leaves oblanceolate to linear, 1-2 cm. long; head solitary; involucre $8-10 \mathrm{~mm}$. high, 10-15 mm. broad; bracts lanceolate, acuminate; ligules very numerous, about $6 \mathrm{~mm}$. long, light purplish pink or white. E. leucotrichus Rydb. E. uniflorus Am. auth., not L. High mountains: Mont. -Colo.-Calif. Mont.-Alp. Jl-S.

12. E. grandiflorus Hook. Stem about $1 \mathrm{dm}$. high, white-villous; basal leaves $2-4 \mathrm{~cm}$. long; stem-leaves lanceolate, acute, rather many; involucres fully $1 \mathrm{~cm}$. high and $2 \mathrm{~cm}$. wide, densely white-woolly; bracts linear, acuminate; ligules reddish purple or white, $8-10 \mathrm{~mm}$. long. High mountains: Canadian Rockies. Alp. Au.

13. E. lanatus Hook. Leaves 1-2 $\mathrm{cm}$. long, spatulate, some of them usually 3 -toothed at the rounded apex; involucres $10-12 \mathrm{~mm}$. high, $15-25 \mathrm{~mm}$. broad, densely woolly, with long white hairs; bracts linear-subulate, attenuate; ligules $1 \mathrm{~cm}$. long, reddish purple or white. High mountains: Alta.-Mont.-B.C. Alp. Jl.

14. E. aureus Greene. Stem scapiform, 3-10 cm. high, hirsute-villous; leaves mostly radical, spatulate, $2-4 \mathrm{~cm}$. long, densely hirsute; stem-leaves few and small; heads solitary; involucres $5-6 \mathrm{~mm}$. high, about $1 \mathrm{~cm}$. broad, densely villous; bracts linear-lanceolate, acuminate, dark purple, loose and spreading, in 3 or 4 series, but nearly equal; achenes somewhat flattened, hirsute; pappus simple, scanty. Aplopappus Brandegei A. Gray. Mountain summits: B.C.Alta. Subalp.-Alp. Ji-Au.

15. E. pinnatisectus (A. Gray) A. Nels. Leaves mostly basal, once or twice pinnatifid, with linear divisions, glandular-puberulent; stem-leaves linear and mostly simple; involucres $7-8 \mathrm{~mm}$. high, $10-15 \mathrm{~mm}$. broad; bracts linearsubulate, glandular-puberulent, often purplish; ligules 8-14 mm. long, bluish purple or violet. E. compositus pinnatisectus A. Gray. Higher peaks: Wyo.Colo. Subalp. - Alp.

16. E. mancus Rydb. Perennial, with a cespitose caudex; leaves basal, 1-4 $\mathrm{cm}$. long, pinnatifid, with linear-oblanceolate crowded segments, glabrous or nearly so; stem scapiform, with few small stem-leaves, decumbent at the base, $2-5 \mathrm{~cm}$. high, glabrous; heads solitary; involucres hemispheric, $10-12 \mathrm{~mm}$. broad; bracts in 2-3 series, linear-subulate, sparingly hirsute and glandular-puberulent; ligules wanting; achenes strigose. E. pinnatisectus insolens Macbr. \& Payson. Mountain tops: se Utah. Alp. Jl.

17. E. compositus Pursh. Stem 3-20 cm. high, scapiform; leaves basal, crowded, usually twice ternate (or the earlier simply ternate), $2-8 \mathrm{~cm}$. long, with linear or spatulate divisions, more or less hirsute and glandular-puberulent or almost glabrous (v. nudus Rydb.); head solitary; involucres about $7 \mathrm{~mm}$. high, 10-18 mm. broad; bracts linear-subulate, hirsute and glandular-puberulent; ligules $5-8 \mathrm{~mm}$. long, white or purplish or lacking [v. discoidens]. E. multifidus Rydb., a form with shorter leaf-segments. Mountains and rocky places: Greenl. -Sask.-Colo.-Calif.-Alaska. Mont.-Alp. Je-Au.

18. E. trifidus Hook. Peduncles $5-10 \mathrm{~cm}$. long; leaves basal, 2-5 cm. long, more or less hirsute and glandular-puberulent, the earlier 3-cleft, the later often with the lateral divisions again 2-3-cleft; lobes oblanceolate or spatulate; involucres $6-7 \mathrm{~mm}$. high, $10-15 \mathrm{~mm}$. broad; bracts linear-subulate, often purpletinged, more or less hirsute and glandular-puberulent; ligules about $5 \mathrm{~mm}$. long, white or pinkish. E. Gormani Greene. Stony crests: Alta.-Colo.-Yukon. Alp. My-Jl.

19. E. pedatus Nutt. Leaves crowded at the base, $1-3 \mathrm{~cm}$. long, glabrous except the ciliate petioles, 3 -cleft or pedately 5 -cleft, with linear divisions; involucres 4-5 mm. high, 7-10 $\mathrm{mm}$. broad; bracts slightly puberulent; linear-lanceo- 
late; ligules $4 \mathrm{~mm}$. long, pale rose or white. Stony hills: Wash.-Mont. Submont. $\mathrm{Jl}-\mathrm{Au}$.

20. E. flabellifolius Rydb. Stem 1-2 dm. high, glandular-puberulent above; basal leaves petioled, about $3 \mathrm{~cm}$. long, slightly glandular-puberulent; stem-leaves cuneate or obovate, less divided; heads about $10 \mathrm{~mm}$. high and 10-15 $\mathrm{mm}$. in diameter; bracts linear, acuminate, glandular-puberulent; ligules 7-8 mm. long, light pink or white. Rocky slides: Wyo. Alp. Au.

21. E. leiomerus A. Gray. Stem 5-15 cm. high, often decumbent at the base; basal leaves spatulate, obtuse, $3-8 \mathrm{~cm}$. long, glabrous or nearly so; stemleaves few and small, linear or oblong; heads solitary; involucres $5-6 \mathrm{~mm}$. high, 10-15 $\mathrm{mm}$. broad; bracts linear, acute, purplish; ligules about 40, violet, $6-8 \mathrm{~mm}$. long. E. minusculus Greene. E. Garrettii A. Nels. Alpine peaks: Wyo.-N.M. -Utah-Alta. Submont.-Alp. J-Au.

22. E. spathulifolius Rydb. Stem 5-8 cm. high, glabrous or slightly puberulent above; basal leaves $2-3 \mathrm{~cm}$. long, glabrous, broadly spatulate; stemleaves linear-oblong, obtuse; involucres about $1 \mathrm{~cm}$. broad; bracts linear-lanceolate, acute, slightly glandular-puberulent; ligules light blue, in age white, about $8 \mathrm{~mm}$. long. High mountains: Wyo. Alp. Jl-Au.

23. E. controversus Greene. Stem 5-15 cm. long, scapiform, strigose, especially above, monocephalous; basal leaves oblanceolate or oblong-spatulate, $3-6 \mathrm{~cm}$. long, minutely puberulent or glabrate except the margins; stem-leaves few, linear, near the base; bracts linear, acute, glandular-puberulent, as well as sparingly strigose, purplish; ligules pale purple or white, $5-8 \mathrm{~mm}$. long. Mountains: Utah. Submont.-Subalp. Je-Au.

24. E. glandulosus Porter. Stem 5-15 cm. high, glandular-scabrous; basal leaves numerous, $3-8 \mathrm{~cm}$. long, oblanceolate or linear-oblanceolate, glandularscabrous; stem-leaves small and linear; heads solitary; involucres $6-8 \mathrm{~mm}$. high, 10-15 mm. broad; bracts linear, acute, glandular-puberulent and hírsute; ligules purple or blue, $8-10 \mathrm{~mm}$. long. Hills and mountains: Wyo.-Colo. Submont. -Alp.

25. E. gracilis Rydb. Stem ascending, strigose, about $15 \mathrm{~cm}$. high, monocephalous; basal leaves oblanceolate or linear-oblanceolate, $2-5 \mathrm{~cm}$. long; stemleaves narrowly linear, acuminate; involueres about $6 \mathrm{~mm}$. high, 10-12 $\mathrm{mm}$. broad; bracts narrowly linear, tinged with purple, strigose; ligules about 50, light purple, 7-10 mm. long. Meadows and hillsides: Wyo. Submont. J1-Au.

26. E. Engelmannii A. Nels. Stem decumbent at the base, $3-20 \mathrm{~cm}$. long; basal leaves numerous, linear or linear-oblanceolate, grayish-strigose, 3-10 $\mathrm{cm}$. long; stem-leaves smaller; heads usually solitary; involucres about $5 \mathrm{~mm}$. high and $1 \mathrm{~cm}$. broad; ligules white or rarely lilac, about 40, 5-7 mm. long. $E$. simulans Greene. Stony slopes: Mont.-Colo.-Utah-Ida, Submont. Je-Jl.

27. E. ursinus D. C. Eat. Stem 1-2 dm. high, ascending, sparingly hairy or glabrous; basal leaves numerous, oblanceolate or linear-oblanceolate, 3-8 em. long; stem-leaves linear or linear-lanceolate, acute; involucres 5-7 mm. high, $10-15 \mathrm{~mm}$. wide; bracts hirsute and glandular-puberulent, linear, acute; ligules purple or violet, $8-10 \mathrm{~mm}$. long. Mountains: Mont.-Colo.-Utah-Ida. Submont.-Subalp. J1-Au.

28. E. Evermannii Rydb. Scapose perennial with a cespitose rootstock; leaves basal, narrowly spatulate, $2-4 \mathrm{~cm}$. long, glabrous, obtuse; stem-leaves if present less than $5 \mathrm{~mm}$. long; stem scapiform, $3-5 \mathrm{~cm}$. long, slightly strigose above, otherwise glabrous; involueres hemispheric, about $1 \mathrm{~cm}$. broad; bracts linear, abruptly acute, purple-tinged, sparingly hirsute-villous; ligules about 20 , apparently white, $8 \mathrm{~mm}$. long. Mountain tops: Ida. Alp. Au.

29. E. Peasei Rydb. Stem 5-8 cm. high, with 1-4 leaves; basal leaves about $2 \mathrm{~cm}$. long, petioled, oblanceolate, acute, strigose; stem-leaves linear, sessile; heads solitary; involucre 4-5 $\mathrm{mm}$. high, about $1 \mathrm{~cm}$. wide; bracts linear-subulate, sparingly hirsute; ligules numerous, about $7 \mathrm{~mm}$. long, pinkish. Mountains: Colo.- U Utah. Je.

30. E. radicatus Hook. Stem 3-6 $\mathrm{cm}$. high, scapiform, hirsute-strigose; basal leaves oblanceolate to nearly linear, 1-4 cm. long, sparingly hirsute or gla- 
brate; stem-leaves very few, linear; heads solitary; involucres about $5 \mathrm{~mm}$. high and $10 \mathrm{~mm}$. wide; bracts lance-linear, acute, hirsute; ligules white, $4-6 \mathrm{~mm}$. long. Mountains and hills: Sask.-Wyo.-B.C. Mont.-Alp. My-Je.

31. E. vetensis Rydb. Stem 3-8 cm. high, hirsute, few-leaved; leaves linear or linear-oblanceolate, hirsute, $2-4 \mathrm{~cm}$. long; heads solitary; involucres 4-5 mm. high, about $10 \mathrm{~mm}$. broad; bracts linear, acuminate, hirsute; ligules purple, $8-10 \mathrm{~mm}$. long. E. radicatus Gray, not Hook. High mountains: Mont. -Colo.-Utah. Submont.-Mont. Je-Au.

32. E. nanus Nutt. Stem $5-10 \mathrm{~cm}$. high, hirsute; leaves crowded, densely hirsute, linear-oblanceolate, $3-5 \mathrm{~cm}$. long; heads solitary; involucres about $5 \mathrm{~mm}$. high and $10 \mathrm{~mm}$. broad, hirsute; bracts linear; ligules 20-50, purple, violet or white, about $6 \mathrm{~mm}$. long. E. poliospermus A. Gray. E. inamoenus A. Nels. E. wyomingensis A. Nels. Hills: Mont.-Colo.-Utah. Submont. Je-Au.

33. E. nematophyllus Rydb. Stems several, strigose, about $5 \mathrm{~cm}$. high, few-leaved; leaves linear-filiform; $2-4 \mathrm{~cm}$. long, less than $1 \mathrm{~mm}$. wide, strigose; heads solitary; involucres 4-5 $\mathrm{mm}$. high, 8-10 $\mathrm{mm}$. broad; bracts linear, acute, hirsute-strigose; ligules pinkish or white, 4-5 mm. long; outer pappus of short bristles. E. Eatonii Coult. \& Nels., in part, not A. Gray. Rocky hills: Colo.Wyo. Submont. My-Jl.

34. E. Bloomeri A. Gray. Stem scapiform, 5-15 cm. high, finely strigose; basal leaves numerous, $2-10 \mathrm{~cm}$. long, $2-3 \mathrm{~mm}$. wide, cinereous-strigose; involucres 7-8 mm. high, 10-12 mm. broad, softly villous; bracts linear; ligules wanting. Stony ground: Ore.-Ida.-Nev.-Calif. My-Je.

35. E. pumilus Nutt. Perennial, with a cespitose short caudex; stem erect, 1-3 dm. high, hirsute, leafy; lower leaves narrowly oblanceolate, $2-10 \mathrm{~cm}$. long, hirsute, the upper linear; heads several; involucres 7-8 mm. high, 12-15 $\mathrm{mm}$. broad; bracts narrowly linear, acute, hirsute; ligules 50-80, white, 7-10 $\mathrm{mm}$. long, at length reflexed. Dry plains: Sask.-N.D.-Kans.-Utah-B.C. Plain-Submont. My-Jl.

36. E. Brandegei A. Gray. Stem $2-3 \mathrm{dm}$. high, sparingly hispidulous-hirsute; basal leaves linear-spatulate, sparingly hirsute; stem-leaves linear, the upper minute; bracts of the involuere linear, short, almost glabrous; ligules 30 or more; inner pappus rather scanty. Adobe plains: sw Utah. Son.

37. E. concinnus T. \& G. Perennial, with a taproot and short cespitose caudex; stem erect, 1-3 dm. high, hirsute with long white hairs, lower leaves linear-oblanceolate, the upper linear, densely hirsute; heads corymbose; involucres. 6-7 mm. high, 10-15 mm. broad; bracts narrowly linear, acute, densely hirsute; ligules $7-9 \mathrm{~mm}$. long. $E$. hispidissimum Piper. Plains and hills: Mont.-N.M. -Calif.-B.C. Plain-Submont.

38. E. condensatus (D. C. Eat.) Greene. Perennial, with a cespitose caudex; stem usually less than $1 \mathrm{dm}$. high and monocephalous, hirsute; leaves narrowly spatulate, hirsute, $2-3 \mathrm{~cm}$. long; involucres $5-6 \mathrm{~mm}$. high, about $1 \mathrm{~cm}$. broad; bracts linear, acute, hirsute; ligules white, rarely pinkish, $6 \mathrm{~mm}$. long; pappus double, the outer of broad scales. E. concinnus condensatus D. C. Eat. Dry hills: Mont.-Ariz.-Nev. My-Jl.

39. F. aphanactis (A. Gray) Greene. Perennial, with a cespitose caudex; stem 1-2 dm. high, branched, short-hirsute; lower leaves spatulate, 3-5 cm. long, hirsute, the upper linear-oblanceolate; heads several, corymbose; involucres about $5 \mathrm{~mm}$. high and $1 \mathrm{~cm}$. broad, hirsute; bracts linear, acute, hirsute; rays wanting; pappus double, the outer squamellate. Arid regions: Utah-Nev.Calif. Son. My-Jl.

40. E. decumbens Nutt. Perennial, with a taproot and short caudex; stems several, 15-30 cm. high, hirsute; basal leaves linear-oblanceolate, 6-10 $\mathrm{cm}$. long, 3-nerved, hirsute as well as glandular-scabrous; stem-leaves narrowly linear; heads solitary or few; involucres $6-7 \mathrm{~mm}$. high, 12-15 $\mathrm{mm}$. broad, hirsute; bracts linear, in about 2 series; ligules $30-40$, purplish or white, $7-8 \mathrm{~mm}$. long. Plains and hills: Mont.-Wyo.-Calif.-Wash. Plain-Submont. Je-Au. 
41. E. microlonchus Greene. Perennial, with a deep taproot, slightly cespitose; stems few, 1-3 dm. high, strigose; basal leaves 7-12 $\mathrm{cm}$. long, linear-oblanceolate, 3-nerved, strigose; stem-leaves narrowly linear; heads usually solitary; involucres 6-7 $\mathrm{mm}$. high, 10-15 $\mathrm{mm}$. wide; bracts narrowly linear, acute; ligules 30-40, light purplish, 5-7 mm. long. Grassy plains: Wyo.-Colo.-Ariz. -Ida. Submont. Je-Au.

42. E. elatior (A. Gray) Greene. Perennial, with a short woody rootstock; stem simple, leafy, 2-6 dm. high, hirsute-villous; leaves ovate-lanceolate, or lanceolate, acute or acuminate, entire, the lower oblanceolate, 3-6 cm. long, hirsute-villous; heads 1-3; involucres 10-13 mm. high, 15-25 mm. broad; bracts linear, attenuate; ligules lilac or purple, $12-15 \mathrm{~mm}$. long. E. grandiflorus elatior A. Gray. Wet places: Colo.-Wyo. Mont.-Subalp. Jl-Au.

43. E. Coulteri Porter. Perennial, with a rather slender rootstock; stem $1.5-4 \mathrm{dm}$. high, sparingly hirsute or glabrate; basal leaves $5-15 \mathrm{~cm}$. long, slenderpetioled, lanceolate or ovate-lanceolate; lower stem-leaves with winged petioles, the upper ovate-lanceolate, sessile or somewhat clasping; heads usually solitary; involucres about $1 \mathrm{~cm}$. high and $1.5 \mathrm{~cm}$. broad; ligules numerous, white, about $15 \mathrm{~mm}$. long. E. leptophyllus Greene. E. leucanthemoides Greene. E. lucidus Greene, an entire-leaved form. Mountains: Colo.-N.M.-Utah-Calif.-Wash. Mont.-Subalp. Jl-S.

44. E. peregrinus (Pursh) Greene. Perennial, with a rootstock; stem 2-5 $\mathrm{dm}$, high, villous, densely so on the upper part; lower leaves oblanceolate, obtuse, 7-10 cm. long, petioled, the upper lanceolate or ovate-lanceolate, acuminate, more or less sharply few-toothed, sparingly villous, thin; heads solitary; involucres about $15 \mathrm{~mm}$. broad or more; bracts linear-subulate, attenuate, villous, squarrose; ligules numerous, about $1 \mathrm{~cm}$. long. Meadows: Alaska-B.C.-Alta. Subalp. J1-Au.

45. E. salsuginosus (Richards.) A. Gray. Perennial, with a short thick rootstock; stem simple, erect, 1-5 dm. high; basal leaves spatulate or obovate, 5-10 cm. long, glabrous or nearly so, entire; upper stem-leaves ovate or lanceolate, sessile or partly clasping; involucre about $1 \mathrm{~cm}$. high, $1.5-2 \mathrm{~cm}$. broad; bracts linear, acuminate, glandular-puberulent; ligules $50-70$, purple or violet, 10-15 mm. long. E. callianthemum Greene. E. hesperocallis Greene. (?) $E$. membranaceus Greene. E. salsuginosus glacialis (Nutt.) A. Gray, is a depauperate alpine form. Wet places: Sask.-N.M.-Calif.-Alaska. Submont.-Subalp.

46. E. Howellii A. Gray. Stem 3-5 dm. high, glabrous; peduncle puberulent; basal leaves membranous, glabrous, obovate, petioled; stem-leaves ovate, with broad clasping base; heads solitary; involucres 8-10 mm. high, 15-18 mm. broad, glandular-puberulent; ligules $30-35$, about $15 \mathrm{~mm}$. long, white or rosecolored. Wet places: Mont.-Ore.-Wash. Submont. Ap-Au.

47. E. superbus Greene. Stem $3-6 \mathrm{dm}$. high, nearly glabrous throughout; basal leaves and lower stem-leaves obovate or oblanceolate, petioled, $3-8 \mathrm{~cm}$. long; upper stem-leaves sessile, ovate, acute; heads few, corymbose; involucres 7-8 $\mathrm{mm}$. long and 12-18 mm. wide; bracts linear, acuminate; ligules 40-60, narrow, white, or rose-colored, 12-18 mm. long. Mountains: Colo.-Utah-Wyo. Submont. $\rightarrow$ Subalp. J1-Au.

48. E. salicinus Rydb. Stem simple, 4-7 dm. high, glabrous; lower leaves petioled, about $1 \mathrm{dm}$. long, narrowly oblanceolate, dark bluish green, 3-nerved; upper leaves linear or linear-lanceolate, sessile and half-clasping; inflorescence corymbiform, leafy; involucres 6-7 mm. high, $12-15 \mathrm{~mm}$. broad; bracts linearsubulate, acuminate; ligules numerous, fully $1 \mathrm{~cm}$. long, purple. Mountains: Colo. Mont. Jl-Au.

49. E. eucephaloides Greene. Perennial, with a woody caudex; stem about $3 \mathrm{dm}$. high, glabrous; peduncles scabrous; leaves glabrous, scabrous-ciliate on the margins, the lower narrowly oblanceolate, 7-10 cm. long, the upper lanceolate and clasping; heads $1-3$; bracts subulate, with spreading tips, glandularor scabrous-puberulent; ligules bluish purple, $1 \mathrm{~cm}$. long. Morains: Ida. Mont. $\mathrm{Au}$. 
50. E. macranthus Nutt. Stem 4-8 dm. high; basal leaves oblanceolate, petioled, 5-10 cm. long; upper stem-leaves sessile, ovate to linear-lanceolate, acuminate; inflorescence corymbiform; involucres 7-8 mm. high, 12-18 mm. broad; ligules very numerous, $10-12 \mathrm{~mm}$. long, lilac or bluish purple. E. leiophyllus Greene, a broad-leaved form. Mountains: Alta.-N.M.-Ariz.-Ore.B.C. Submont.-Mont. Je-Au.

51. E. speciosus DC. Stem 3-5 dm. high; basal leaves linear-oblanceolate, ciliate, 5-10 cm. long, petioled; upper leaves sessile, narrowly lanceolate; heads corymbose; involucres $7-8 \mathrm{~mm}$. high, $12-18 \mathrm{~mm}$. broad; ligules blue or violet, numerous, 12-18 mm. long. Mountains: Alta.-Colo.-Utah-Ore.-B.C. Submont.-Mont. J1-S.

52. E. conspicuus Rydb. Stem 3-5 dm. high, hirsute with long hairs, very leafy; lower leaves oblanceolate, $5-10 \mathrm{~cm}$. long, petioled; upper leaves lanceolate, sessile; heads corymbose; involucres $7-8 \mathrm{~mm}$. high, 15-20 mm. broad; ligules bluish purple, very numerous, narrow, 10-12 mm. long. Mountains: Mont.Colo.-Wash. Mont. Jl-S.

53. E. subtrinervis Rydb. Stem 3-6 dm. high, hirsute with short hairs; lower leaves oblanceolate, $5-10 \mathrm{~cm}$. long, hirsutulous on both sides; inflorescence corymbiform; involueres 7-8 mm. high, 12-20 mm. broad; ligules numerous, violet, rose-colored or purplish, rarely white, about $1 \mathrm{~cm}$. long. Wooded mountain sides: S.D.-N.M.-Utah-Wash. Submont.-Mont. JI-Au.

54. E. incanescens Rydb. Stem simple, $1.5-3 \mathrm{dm}$. high, mostly ascending, densely pubescent, leafy; basal leaves oblanceolate or spatulate; stem-leaves about $5 \mathrm{~cm}$. long and $1 \mathrm{~cm}$. wide, oblong to lanceolate, sessile, and somewhat clasping; heads 1-4; involucres about $7 \mathrm{~mm}$. high and $15 \mathrm{~mm}$. broad; bracts Mont. J1-Au.

55. E. Vreelandii Rydb. Stem 6-7 dm. high, simple, sparingly pubescent and puberulent; lower leaves petioled, oblanceolate, the rest sessile, lanceolate, somewhat clasping; inflorescence leafy, corymbiform; involucres $7-8 \mathrm{~mm}$. high, $15-18 \mathrm{~mm}$. broad; ligules fully $1 \mathrm{~cm}$. long, very numerous, dark purple. Mountains: Colo. Submont. J1.

56. E. glabellus Nutt. Stem decumbent at the base, $1.5-4 \mathrm{dm}$. high, glabrous or sparingly hirsute above; basal leaves oblanceolate, 5-10 cm. long, glabrous; stem-leaves narrowly linear-lanceolate, the upper often much reduced; heads 1-3; involucres $6-7 \mathrm{~mm}$. high, $1-1.5 \mathrm{~cm}$. broad; bracts linear, acuminate; ligules purple. Hills and mountains: Sask.-Wis.-N.M.-Mack. Submont.-

57. E. fruticetorum Rydb. Perennial, with a cespitose rootstock; stem decumbent at the base, 2-4 dm. high, rather densely and finely hirsute; basal leaves narrowly oblanceolate, 4-10 cm. long, petioled, finely hirsute on both sides; stem-leaves sessile, lanceolate to linear; heads 1-4, long-peduncled; involucres $12-15 \mathrm{~mm}$. broad; bracts linear, acute, softly hirsute, not glandular; ligules numerous, narrow, lilac or white, about $8 \mathrm{~mm}$. long. Mountains among bushes: se
Utah. Mont. Jl-Au.

58. E. Earlei Rydb. Stems several, simple, 3-4 dm. high; basal leaves 5-6 sessile; heads about $3,6 \mathrm{~mm}$. high; ligules numerous and and very narrow, white, about $8 \mathrm{~mm}$. long. E. strigulosus Rydb. (F1. Colo.). Meadows: Colo. Jl.

59. E. rubicundus Greene. Stem decumbent and reddish at the base, rarely $2 \mathrm{dm}$. high, usually monocephalous, hirsute throughout and glandular above; basal leaves spatulate or oblanceolate, $3-5 \mathrm{~cm}$. long, glabrous except the ciliate margins and the midrib beneath; stem-leaves oblong or lance-oblong, sessile; involucre about $18 \mathrm{~mm}$. broad; bracts linear, sparingly hirsute as well as glandular-puberulent; ligules pink, very numerous, 8-10 mm. long. Mountains:
Colo. Subalp. -Alp. J1-Au.

60. E. eximius Greene. Stem $2.5-5 \mathrm{dm}$. high, sparingly hirsute throughout, decumbent at the base; basal leaves petioled, linear-oblanceolate to spatulate, 
glabrous except the ciliate margins, 3-10 cm. long; stem-leaves linear-lanceolate, sessile; heads 1-9; involucre about $15 \mathrm{~mm}$. wide, glandular-puberulent, only with a few hirsute hairs below; bracts linear-subulate; ligules usually light purple, numerous, about $8 \mathrm{~mm}$. long. Meadows: Wyo.-Colo.-e Utah. Submont.Subalp. J1-Au.

61. E. Smithii Rydb. Stem simple, glabrous or nearly so below, glandularpuberulent above; basal leaves $6-10 \mathrm{~cm}$. long, petioled, oblanceolate or spatulate; upper stem-leaves lanceolate, sessile, more or less clasping; heads 1-5; involucre about $6 \mathrm{~mm}$. high; ligules purplish, 10-12 mm. long. Mountains: Colo.Utah. Submont.-Mont.

62. E. formosissimus Greene. Stem stout, about $3 \mathrm{dm}$. high, rather densely long-hirsute; basal leaves oblanceolate, 5-10 $\mathrm{cm}$. long, sparingly hirsute on both sides; stem-leaves lanceolate, sessile; heads 1-3; involucre about $18 \mathrm{~mm}$. broad; bracts linear, usually copiously hirsute as well as glandular-puberulent; ligules lilac or rose-colored, fully $1 \mathrm{~cm}$. long. Mountains: Colo.-N.M. Submont. J1-Au.

63. E. viscidus Rydb. Stem ascending, 1-5 dm. high, more or less hirsute and glandular-puberulent; basal leaves 3-5 $\mathrm{cm}$. long, oblanceolate, dark green, sparingly hirsute and ciliate on the entire margins; stem-leaves lanceolate, sessile; heads few; involucres about $8 \mathrm{~mm}$. high and $15 \mathrm{~mm}$. broad; bracts very numerous, narrowly linear, acuminate; ligules very numerous, pale blue or rosecolored, about $8 \mathrm{~mm}$. long and $5 \mathrm{~mm}$. wide. E. iodanthus Greene. E. hirtuosus Greene, a less glandular form. Mountains: Colo.-N.M.-Utah-Ariz. Mont. -Subalp. Je-Au.

64. E. philadelphicus L. Stem 3-10 dm. high, branched above, soft-hirsute; basal leaves oblanceolate, $5-15 \mathrm{~cm}$. long, scarcely petioled, softly pubescent; lower stem-leaves oblong, the upper lanceolate, acute, half clasping; involucres 4-5 mm. high, 8-12 mm. broad, sparingly hirsute; bracts broadly linear, acute; ligules white or pinkish, 5-6 mm. long. Wet fields, meadows, and woodlands: Lab.-Fla.-Calif.-B.C. My-Au.

65. E. purpureus Ait. Stem 3-10 dm. high, sparingly hirsute or glabrate above; basal leaves $8-15 \mathrm{~cm}$. long, oblanceolate, acute, sparingly pubescent; upper leaves triangular-lanceolate or ovate, with a broad cordate base, acuminate; involucres $5 \mathrm{~mm}$. high, 10-12 $\mathrm{mm}$. broad; bracts broadly linear; ligules rose or reddish purple, 8-10 mm. long. Wet meadows: Hudson Bay-Mont.-Wash. -Mack. Je-J1.

66. E. asper Nutt. Stem strict, erect, $2-3 \mathrm{dm}$. high, shortly hirsute-strigose; lower leaves linear-oblanceolate, $3-6 \mathrm{~cm}$. long, entire or rarely minutely denticulate, short-pubescent; upper stem-leaves linear-lanceolate, acuminate; heads 1-4; involucres 5-6 mm. high, about $1 \mathrm{~cm}$. wide, hirsute; ligules white, 7-8 mm. long. E. anicularum Greene. Prairies and hills: Man.-N.D.-Alta. Plain -Submont. Je-Jl.

67. E. oblanceolatus Rydb. Stem 3-5 dm. high, strigose; lower leaves oblanceolate, winged-petioled, 5-10 cm. long; upper leaves lanceolate or linearlanceolate; heads 1-4; involucres 7-9 mm. high, 15-20 mm. broad; ligules numerous, pink or purple, 10-12 mm. long. Plains and meadows: Mont.-Wyo.Utah-Ida. Plain-Submont. Je-Au.

68. E. consobrinus Greene. Stem strict, 3-6 dm. high, hirsute with short spreading hairs; lower leaves oblanceolate, $5-8 \mathrm{~cm}$. long, entire or denticulate, short-hirsute; stem-leaves linear-lanceolate, sessile; involucres 6-8 mm. high, $12-$ $18 \mathrm{~mm}$. broad; ligules numerous, white, turning pinkish, about $1 \mathrm{~cm}$. long. $E$. fraternus Greene. Mountain valleys: Colo. Submont.-Mont. Je-Au.

69. E. Drummondii Greene. Stem 2-4 dm. high, strict; lower leaves oblanceolate, short-petioled, densely hirsute, entire or denticulate; upper leaves lance-linear; heads 1-4, with long peduncles; involucres 6-7 mm. high, 10-15 mm. broad; ligules numerous, very narrow, about $1 \mathrm{~cm}$. long, pink or lilac. $E$. glabellus pubescens Hook. Hillsides and mountains: Alta.-Mont.-B.C.-Yukon. Plain. Je-Au. 
70. E. ramosus (Walt.) B.S.P. Annual; stem erect, 3-6 dm. high, corymbosely branched, strigose; basal leaves petioled, 5-10 $\mathrm{cm}$. long, spatulate or oblanceolate, often sparingly serrulate; stem-leaves linear, or nearly so; heads numerous; involucres hirsute, $3-4 \mathrm{~mm}$. high, 6-8 $\mathrm{mm}$. broad; bracts linear, acute; ligules white, numerous, about $5 \mathrm{~mm}$. long; inner pappus of few bristles or in the rays lacking. $E$. strigosus Muhl. Dry places: N.S.-Fla.-Calif.-B.C.; the more hairy western form west of Minn, and Kans. Je-S.

71. E. Bellidiastrum Nutt. Stem corymbosely branched above, grayishhirsutulous; leaves linear-spatulate or linear-oblanceolate, obtuse, entire, densely hirsutulous; heads numerous; involucres 3-4 mm. high, 7-8 mm. broad; bracts linear, acute, hirsute; ligules light purple or white, 5-6 $\mathrm{mm}$. long. Low ground: S.D.-Tex.-Ariz.-Wyo.-(? B.C.). Plain-Mont. J1-O.

72. E. Wootoni Rydb. Biennial, with a taproot; stem $3-6 \mathrm{dm}$. high, finely and densely hirsutulous; basal leaves oblanceolate, petioled, 3-10 cm. long, hirsutulous; stem-leaves linear, sessile; heads numerous, corymbose; involucres hirsute, about $4 \mathrm{~mm}$. high and $8 \mathrm{~mm}$. broad; bracts linear, acute; ligules white, 6-7 mm. long. E. cinereus A. Gray. Sandy soil: Mont.-N.M.-Ariz. Son. -Submont. Je-Au.

73. E. divergens T. \& G. Biennial or perennial, with a taproot, branched at the base; stems several, 2-4 dm. high, densely hirsute with short hairs; basal leaves spatulate or oblanceolate, petioled, $2-6 \mathrm{~cm}$. long, entire or rarely somewhat lobed, hirsutulous; stem-leaves linear, sessile; heads numerous; involucres 4-5 $\mathrm{mm}$. high, 8-10 $\mathrm{mm}$. broad, hirsute; bracts linear, acute; ligules numerous, bluish purple or lilac, about $5 \mathrm{~mm}$. long. Low plains and river banks: Mont.Tex.-Calif.-B.C. Son.-Submont. My-Au.

74. E. flagellaris A. Gray. Branched at the base; stem decumbent, usually rooting at the ends and producing new plantlets, strigose; basal leaves spatulate or oblanceolate, 2-4 cm. long, strigose; stem-leaves linear; peduncles naked, 4-10 $\mathrm{cm}$. long; involucre $4 \mathrm{~mm}$. high and $8 \mathrm{~mm}$. broad, hirsute; bracts linear, acute; ligules $5 \mathrm{~mm}$. long, white or purplish. E. stolonifer Greene. E. MacDougalii Heller. Banks of streams and valleys: S.D.-N.M.-Ariz.-B.C.; Mex. Submont.-Subalp. Ap-Au.

75. E. commixtus Greene. Biennial; stem branched at the base, decumbent, hirsutulous, 1-3 dm. long; basal leaves narrowly oblanceolate, entire, or more or less lobed at the apex, densely canescent, 2-4 cm. long; stem-leaves narrowly linear; peduncles 5-10 $\mathrm{cm}$. long; involucres hirsute, $4 \mathrm{~mm}$. high and about $8 \mathrm{~mm}$. broad; ligules about $5 \mathrm{~mm}$. long, white or pink. $E$. cinereus A. Gray, not H. \& A. E. colo-mexicanus A. Nels. River bluffs: Colo.-Tex.-Ariz. -Utah; Mex. Son.-Submont. Ap-Je.

76. E. nudiflorus Buckley. Biennial; stem at first erect, 1-2 dm. high, later producing spreading or decumbent branches, 1-3 dm. long, hirsutulous; basal leaves spatulate, 4-8 cm. long, petioled, hirsutulous; stem-leaves oblanceolate; heads solitary at the ends of peduncles often $1 \mathrm{dm}$. long; involueres hirsute, about $4 \mathrm{~mm}$. high, 8-10 mm. broad; ligules numerous, white or pinkish, 7-8 mm. long. E. divergens nudiflorus A. Nels. Hills and river bluffs: Colo.Tex.-Ariz.-Nev.; Mex. Son.-Submont. Mr-Au.

77. E. Wyomingia Rydb. Stem numerous, erect, 1-2 dm. high, striate, strigose-canescent; basal leaves linear-spatulate, 2-5 cm. long, strigose-cinereous; stem-leaves linear; heads solitary; involucres about $6 \mathrm{~mm}$. high, $12-15 \mathrm{~mm}$. broad; bracts linear, acute, pubescent; ligules about 30 , white or pinkish, about 1 cm. long; achenes 3-5-angled. Wyomingia cinerea A. Nels. ${ }^{*}$ Dry hillsides: Wyo.

78. E. argentatus A. Gray. Stem 1-3 dm. high; basal leaves linear-oblanceolate, 2-4 cm. long, 2-4 mm. wide, silvery white; stem-leaves scattered and

*The genus Wyomingia seem to be well differentiated as far as the group CANI is concerned, but both the LAETEVIRENTES and TETRAPLEURI connect it with CAESPITOSI and 
small, linear; heads solitary; involucres $8-10 \mathrm{~mm}$. high, $15-20 \mathrm{~mm}$. broad, strigose; rays white, $8-10 \mathrm{~mm}$. long. $W$. argentata A. Nels. Arid regions: Mont.w Colo.-Utah-Nev. Plain-Son. Je-Jl.

79. E. canus A. Gray. Stem decumbent at the base, 1-2 dm. high, strigose-canescent; basal leaves narrowly linear-oblanceolate, 1-4 cm. long, canescentstrigose; stem-leaves narrowly linear; heads solitary; involucres 5-6 mm. high, 10-12 mm. broad; bracts lanceolate-linear, acute; ligules purplish or white, 6 mm. long. W. cana A. Nels. Dry plains and ridges: S.D.-Neb.-N.M.-Wyo. Plain-Mont. J1-Au.

80. E. corymbosus Nutt. Stem 1-4 dm. high, corymbosely branched above, short-hirsutulous; basal leaves narrowly linear-oblanceolate, 3-nerved, 5-15 cm. long, densely hirsutulous; stem-leaves linear; involucres $5 \mathrm{~mm}$. high, $8-12 \mathrm{~mm}$. broad; bracts hirsute; ligules lilac or purplish, rarely white, $30-50$, about $8 \mathrm{~mm}$. long. E. Nelsonii Greene. Plains: Mont.-Wyo.-Calif.-B.C. Plain. JeAu.

81. E. subcanescens Rydb. Stem erect, canescent-hirsutulous; basal leaves linear-oblanceolate, mostly obtuse, 6-10 cm. long, triple-nerved, densely canescent; involucres $5 \mathrm{~mm}$. high, 10-12 $\mathrm{mm}$. broad; bracts linear, acute, canescent-hirsutulous; ligules white or rarely pinkish, about $8 \mathrm{~mm}$. long. E. caespitosus laccolilicus M. E. Jones. Stony slopes and plains: Sask.-Colo.-UtahB.C. Plain. J1-Au.

82. E. caespitosus Nutt. Stem 1-1.5 dm. high, canescent; basal leaves oblanceolate, 5-10 cm. long, less distinctly 3-nerved, obtuse, densely hirsutulouscanescent; involucre 6-7 mm. high, $10-15 \mathrm{~mm}$. wide; bracts linear, hirsute-canescent, acute; ligules 40-50, white, $7-10 \mathrm{~mm}$. long. Dry hills and plains: Sask.Colo.-Utah-Yukon. Plain-Mont. Jl-Au.

83. E. nauseosus (M. E. Jones) A. Nels. Stem $1-1.5 \mathrm{dm}$. high, glandularpuberulent; basal leaves with winged petioles, $3-5 \mathrm{~cm}$. long, spatulate, 3-nerved, glandular-puberulent and ciliate on the margins; stem-leaves spatulate or elliptic, sessile; heads solitary; involucres about $6 \mathrm{~mm}$. high, $12-15 \mathrm{~mm}$. wide; ligules white, 8-10 mm. long, $1 \mathrm{~mm}$. wide. E. caespitosus nauseosus Jones. Hillsides: Utah. Submont. Je.

84. E. nevadensis A. Gray. Stem 1-3 dm. high, strigose-canescent; basal leaves narrowly linear-oblanceolate, 3-nerved, canescent, 5-10 $\mathrm{mm}$. long; stemleaves linear; heads solitary; involucres about $7 \mathrm{~mm}$. high, 12-18 mm. broad, much shorter than the flowers; ligules white or pale blue, 8-12 mm. long. Dry hills and mountains: Utah-Nev.-Calif. Submont. My-Jl.

85. E. Eatonii A. Gray. Stem $1 \mathrm{dm}$. high or less, strigose; basal leaves narrowly linear-oblanceolate or linear, 3-nerved, strigose, 5-10 cm. long, 1-4 $\mathrm{mm}$. broad; stem-leaves narrowly linear, often falcate; heads usually solitary; involucres 5-6 mm. high, $7-10 \mathrm{~mm}$. broad; bracts rather few, linear, in about 3 series, but only slightly imbricate; ligules about 20, purplish or white, 6-7 mm. long. Mountains: Utah-Wyo.-Ore. Submont.-Mont. J1-Au.

86. E. asperugineus (D. C. Eat.) A. Gray. Perennial, with a cespitose woody caudex; stem monocephalous, less than $1 \mathrm{dm}$. high, hirsutulous-canescent; basal leaves thick, spatulate, petioled, 1-3 cm. long, densely hirsutulous-canescent; stem-leaves small, oblong or oblanceolate; involucres 5-6 mm. high, 10-12 mm. broad, hirsute; bracts linear, slightly imbricate; ligules about 20 , bluish or purple, about $8 \mathrm{~mm}$. long. $E$, elkoensis Nels. \& Macbr. Dry hills and mountains: Mont.-Wyo.-Nev. Submont.-Mont. J1-Au.

87. E. Tweedyi Canby. Stem scapiform, 5-15 cm. long, canescent-strigose; basal leaves $2-5 \mathrm{~cm}$. long, oval or obovate-spatulate, thick, silvery-canescent; stem-leaves few and small, linear-oblanceolate; heads solitary, or rarely 2 or 3 ; involucres $5-6 \mathrm{~mm}$. high, 12-15 mm. broad; ligules purple, 5-7 mm. long. Dry mountains and hillsides: Mont.-Wyo. Mont.-Subalp. Je-Au.

88. E. tener A. Gray. Stem scapiform, 5-10 cm. long, strigose; basal leaves oblanceolate or spatulate, petioled, $2-4 \mathrm{~cm}$. long, rather sparingly strigose; stem-leaves small and linear; heads solitary or rarely 2 or 3 ; involucres $4-5 \mathrm{~mm}$. 
high, 5-10 mm. broad; ligules purplish, 4-5 mm. long. Mountains: Ida.-Mont. -Nev.-Utah. Submont.-Mont. Au-S.

89. E. arenarioides A. Gray. Stem 1-2 dm, high, glabrous, filiform; basal leaves narrowly linear-oblanceolate to almost filiform, 2-4 mm. long, glabrous; stem-leaves linear-filiform, diminishing upwards; heads usually solitary; involucres $4-5 \mathrm{~mm}$. high and nearly $1 \mathrm{~cm}$. wide; bracts linear-subulate, acuminate, glandular-puberulent, slightly purplish; rays bluish purple or white, $5 \mathrm{~mm}$. long; achenes flattened, hirsute; pappus simple. Aster arenarioides A. Gray. Mountains: Utah. Mont. Jl-Au.

90. E. laetevirens Rydb. Stems several, 1.5-2 dm, high, slender, erect or ascending, silky-strigose; basal leaves very narrowly linear-oblanceolate, acute, 5-10 cm. long, sparingly strigose; stem-leaves narrowly linear; heads solitary; involucre $6 \mathrm{~mm}$. high, $12-15 \mathrm{~mm}$. broad, grayish villous-hirsute; ligules numerous, blue or purple, 7-8 mm. long. Mountain slopes: Wyo. Submont.-Mont. Jl$\mathrm{Au}$.

91. E. montanensis Rydb. Stem 1-2 dm. high, softly strigose; basal leaves narrowly linear to linear-oblanceolate, sparingly strigose, $5-10 \mathrm{~cm}$. long; stem-leaves narrowly linear; heads solitary; involucres about $7 \mathrm{~mm}$. high and $12-15 \mathrm{~mm}$. broad; bracts linear, acuminate, densely hirsute-villous; ligules white or pinkish, 5-7 mm. long, $1.5-2 \mathrm{~mm}$. wide. E. Tweedyanus Canby \& Rose. Wyomingia Tweedyana A. Nels. Dry hills and plains: Mont.-Wyo. PlainMont. My-Au.

92. E. Scribneri Canby. Stem 3-8 cm. high, grayish-strigose; basal leaves linear or narrowly linear-oblanceolate, strigose, $3-5 \mathrm{~cm}$. long; heads solitary; involucres 5-6 mm. high, about $15 \mathrm{~mm}$. wide; ligules 7-8 mm. long. E. Macounii Greene. Mountains: Alta.-Wyo. Mont.-Subalp. J1-Au.

93. E. Parryi Canby \& Rose. Stem scapiform, 3-5 $\mathrm{cm}$. high, densely hirsutulous; leaves narrowly linear, 2-4 cm. long, densely hirsutulous; involucres densely hirsute, 5-6 mm. high, 10-12 $\mathrm{mm}$. broad; ligules 6-7 mm. long. Dry hills: Mont. Mont. Jl.

94. E. utahensis A. Gray. Perennial, with a branched woody caudex, often suffrutescent; stem 3-4 dm. high, silvery-strigose, branched; leaves all narrowly linear, 5-10 $\mathrm{cm}$. long, silvery strigose-canescent; heads solitary, on long peduncles; involucres 6-8 $\mathrm{mm}$. high, 10-12 $\mathrm{mm}$. broad; bracts lance-linear, acuminate, silky-strigose; ligules white, $12-15 \mathrm{~mm}$. long. E. tetrapleurus (A. Gray) Heller. Arid regions: s Utah-Ariz. My-Je.

95. E. sparsifolius Eastw. Suffruticose perennial; stem 3-4 dm. high, silvery strigose; lower leaves narrowly oblanceolate, $3-5 \mathrm{~cm}$. long, 4-5 $\mathrm{mm}$. wide, silvery-strigose, the upper narrowly linear or nearly so, the uppermost almost filiform and reduced; involucre hemispheric, $6-8 \mathrm{~mm}$. broad; bracts linear, silverystrigose; achenes quadrangular, strigose-hirsute. Wyomingia vivax A. Nels. Cañons: sè Utah-Ariz. Son. Je-Au.

96. E. filifolius (Hook.) Nutt. Perennial, with a branched woody caudex, often more or less suffruticose; stem 2-6 dm, high, cinereous-strigose; leaves linear-filiform or filiform, cinereous, $2-5 \mathrm{~cm}$. long; involucres about $5 \mathrm{~mm}$. high and $10 \mathrm{~mm}$. broad; ligules about $8 \mathrm{~mm}$. long, bluish, violet, or white. E. linearis Piper, in part. Rocky ground: Mont.-Ida.-Calif,-B.C. Son. Je-Au.

97. E. linearis (Hook.) Piper. Perennial, with a branched caudex; stem 1-3 dm. high, decumbent at the base, slender, cinereous-strigose; leaves all filiform, cinereous, 3-5 $\mathrm{cm}$. long; involucres $5 \mathrm{~mm}$. high, $10 \mathrm{~mm}$. broad; ligules $7-8$ $\mathrm{mm}$. long, white or bluish. Dry or sandy places: Wash.-Ida.-Ore. Son. My$\mathrm{Jl}$.

98. E. luteus A. Nels. Perennial, with a cespitose, multicipital caudex; stem $1 \mathrm{dm}$. high or less, einereous-strigose; leaves narrowly linear, cinereousstrigose, 3-5 cm. long; heads solitary; involucres about $5 \mathrm{~mm}$. high and $1 \mathrm{~cm}$. broad; ligules $30-40$, yellow, $3-4 \mathrm{~mm}$. long. Sandy hillsides and stream banks: Wyo. Plain. Jl. 
99. E. ochroleucus Nutt. Perennial, with a cespitose caudex; stem 1-2 dm. high, cinereous-strigose; leaves narrowly linear, 3-7 cm. long, strigose and hispidciliate below; heads usually solitary; involucres about $5 \mathrm{~cm}$. high, 10-12 mm. broad; ligules 40-60, ochroleucous or white. Gravelly hills: Ore--Ida.

100. E. peucephyllus A. Gray. Perennial, with a densely cespitose caudex; stems 1-2 dm. high, cinereous-strigose, erect; leaves filiform, cinereous, $2-5 \mathrm{~cm}$. long; heads usually solitary; involucres $4-5 \mathrm{~mm}$. high, $8-10 \mathrm{~mm}$. broad; bracts linear, acute, hirsute; ligules 5-6 mm. long. E. filifolius Piper, not Nutt. Dry hills: B.C.-Calif.-Ida.-Sask. Son.-Mont. My-Jl.

101. E. pulvinatus Rydb. Pulvinate cespitose perennial, with a very thick woody root and short caudex; leaves basal, densely clustered, linear, 1-2 cm. long, about $1 \mathrm{~mm}$. broad, silvery-strigose; peduncles naked or with a single diminutive leaf, about $3 \mathrm{~cm}$. high, silvery-strigose; involucres hemispheric, about $1 \mathrm{~cm}$. broad; bracts linear, in 3 series, slightly thickened on the back, silverystrigose, acute; ligules white, 6-7 mm. long; achenes (not mature) flat, hirsute on the margins; pappus of rather few scabrous bristles. Arid places: Utah. Jl.

\section{LÉptilon Raf. Horseweed, Canada Fleabane.}

Annual or biennial, caulescent herbs. Leaves alternate, narrow. Heads small, paniculate. Involucres campanulate; bracts in 2-3 series; receptacle naked. Ray-flowers few, pistillate, with short white or purplish ligules, not exceeding the disk. Disk-flowers several, perfect, with usually 4-lobed corollas. Anthers obtuse at the base. Stigmas flat, with short, obtuse appendages. Achenes flattened, often pubescent. Pappus of many capillary brittle bristles in one series.

1. L. canadense (L.) Britton. Annual; stem erect, 5-30 dm. high, hirsute -or glabrate; lower leaves spatulate or oblanceolate, petioled, $2-10 \mathrm{~cm}$. long, hirsute or at least ciliate on the margins, incised to entire; upper stem-leaves linear, entire, sessile; heads numerous in an elongate panicle; involucres $3-4 \mathrm{~mm}$. high and broad; ligules numerous, white. Erigeron canadensis L. Waste places and dry soil: Lab.-Fla.-Calif.-B.C.; Mex., W. Ind., and adv. or nat. in Eu. Plain-Submont. Je-N.

\section{ESCHENBÃCHIA Moench.}

Annual or perennial caulescent herbs. Heads paniculate or corymbose. Involucres campanulate or subcylindric; bracts narrow in 1-3 series. Marginal flowers pistillate, more numerous than the hermaphrodite central ones; corolla with a slender filiform tube, without any ligule; their styles truncate or toothed at the apex. Achenes compressed. Pappus in a single series of soft capillary bristles. [Conyza Less., not L.]

1. E. Coulteri (A. Gray) Rydb. Annual; stem erect, 3-6 dm. high, hirsutevillous and viscid; lower leaves spatulate or oblanceolate, dentate or laciniate, $2-5 \mathrm{~cm}$. long, hirsute and glandular-puberulent; upper leaves oblong or linearlanceolate; heads numerous in an elongated panicle; involucre about $3 \mathrm{~mm}$. high and broad; bracts linear-subulate, viscid-hirsute; flowers whitish; pistillate flowers numerous, with an entire corolla-tube; hermaphrodite flowers 5-7. River bottoms: Tex.-Colo.-Calif.; Mex. Son.

\section{BÁccharis L. Groundsel Tree.}

Perennial caulescent herbs or shrubs, usually with glabrous resinous foliage. Leaves alternate, often leathery, entire or toothed. Heads discoid, dioecious, corymbose or paniculate. Involucres campanulate; bracts imbricate in several series, those of the pistillate heads often more numerous; receptacle flat, pitted, naked. Corollas mostly yellow, those of the staminate plant tubular, those of the pistillate heads filiform. Anthers entire and obtuse at the base. Pappus of filiform bristles, those of the pistillate heads usually elongating in fruit, very fine, those of the staminate heads shorter, scabrous and often tortuose. 
Pappus copious, in fruit elongating and surpassing the styles.

Pappus-bristles in several series; plant 3-6 dm. high, herbaceous, with a woody base.

Pappus-bristles in one series; plants 1-5 mm. high, shrubby.

Fertile heads hemispherical, $5-10 \mathrm{~mm}$. broad; bracts all acute. 2. B. salicina.

Fertile heads deeply campanulate, 3-5 mm. broad; outer bracts obtuse.

Pappus scant, little if at all elongating, in fruit not exceeding the styles.

3. B. Emoryi.

Achenes 10-nerved; leaves less than $2 \mathrm{~cm}$. long, subentire.

Achenes 5-nerved; leaves 5-15 cm. long, serrate.

4. B. sergiloides.

5. B. glutinosa.

1. B. Wrightii A. Gray. Herbaceous, with a woody base; stems diffusely branched, 3-6 dm. high, glabrous and angled; lower leaves linear, $2-4 \mathrm{~cm}$. long, glabrous, the upper smaller and linear-subulate; involucres of the staminate heads about $7 \mathrm{~mm}$. high, 10-12 $\mathrm{mm}$. broad; bracts in 3 series, lanceolate, acute, erose-ciliate on the margins; involucres of the pistillate heads $8-10 \mathrm{~mm}$. high, 12-15 $\mathrm{mm}$. broad; bracts in 5-6 series, with more evident scarious margins; achenes oblong, 8-10-ribbed, scabrous, puberulent and cross-rugose; pappus brownish, 10-12 mm. long. Saline soil: Kans.-Colo.-Ariz.-Mex. Son. ApJe.

2. B. salicina T. \& G. Shrub 1-4 m. high; branches green and glabrous, angled; leaves oblong or oblong-lanceolate, denticulate or entire, $3-5 \mathrm{~cm}$. long; heads in small clusters; involucres of the staminate heads hemispheric, 4-5 $\mathrm{mm}$. high and slightly broader; bracts in 4-5 series, ovate, yellowish green, glabrous, erose-ciliate on the margins; involucres of the pistillate heads $6-8 \mathrm{~mm}$. high and broad, the inner bracts lanceolate; achenes 10-ribbed, glabrous; pappus white and soft, 10-12 mm. long. Saline soil: Kans.-Utah-N.M.-Tex. Son. Je-Jl.

3. B. Emoryi A. Gray. A shrub 1-5 m. high; branches very glutinous, glabrous, slightly angled; leaves linear-oblong, entire, $2-5 \mathrm{~cm}$. long, or the larger broader, somewhat 3-ribbed and somewhat lobed, glabrous; heads more or less glomeruled; involucres of the staminate heads campanulate, 5-6 $\mathrm{mm}$. high, 4 $\mathrm{mm}$. wide; bracts ovate, acute, thick, in 6-7 series; involucres of the pistillate heads $6-8 \mathrm{~mm}$. high, 4-5 mm. broad; bracts in 7-8 series; achenes glabrous, 10-ribbed; pappus tawny, nearly $1 \mathrm{~cm}$. long. Along rivers: Tex.-s Utah-Calif. Son.

4. B. sergiloides A. Gray. A shrub 1-2 m. high; branches glabrous, strongly angled, and broom-like; leaves few, oblanceolate, $5-15 \mathrm{~mm}$. long, soon caducous or wanting; heads paniculate; involucres of the staminate heads $3-4 \mathrm{~mm}$. high and as broad, those of the pistillate heads 4-5 mm. high; bracts ovate to lanceolate, acute, glabrous in about 5 series, thick; achenes glabrous, 10-nerved, 1.25 $\mathrm{mm}$. long; pappus tawny, $3-4 \mathrm{~mm}$. long. Arid regions: Ariz. $-\mathrm{s}$ Utah-s Calif. L. Son.

5. B. glutinosa (R. \& P.) Pers. Plant herbaceous above, woody below; stem 1-3 m. high; branches striate, glabrous; leaves elongate-lanceolate, $5-15$ $\mathrm{cm}$. long, 3-nerved, serrate, or the upper entire; heads numerous, corymbosely cymose; involucre both in the staminate and the pistillate heads 4-5 mm. high and broad, hemispheric; bracts ovate, acute, in 4-5 series, glabrous, erose-ciliate; achenes glabrous, 5 -nerved; pappus white, $4 \mathrm{~mm}$. long. Along streams: Tex.Colo.-Calif.; Mex. and S. Am. Son. Mr-N.

\section{BERTHELŌTIA DC.}

Very leafy silvery-canescent shrubs. Heads glomerate. Involucres campanulate; bracts imbricate, chartaceous, the innermost narrowly linear and falling off with the flowers. Receptacle flat, naked and glabrous. Marginal flowers pistillate, numerous, their corollas with a filiform truncate tube, without ligules; style-branches without appendages. Central flowers perfect, but sterile; their corollas tubular, regularly 5-lobed; styles with entire tips. Achenes 4-5-angled. Pappus of the marginal flowers of a series of eapillary bristles; pappus-bristles of the central flowers shorter and with clavellate tips.

1. B. sericea (Nutt.) Rydb. A shrub 2-3 m. high, much branched; branches silky tomentose; leaves entire, linear-lanceolate, sessile, acute at each end, 1-3 
cm. long, silvery-canescent; heads conglomerate; involucres about $5 \mathrm{~mm}$. high, 5-7 mm. broad; outer bracts broadly ovate, obtuse, the innermost linear, acute. Polypappus sericeus Nutt. Tessaria borealis T. \& G. Pluchea borealis A. Gray. Along streams: Tex.-s Utah-Calif.-Mex. L. Son. N-Je.

\section{STYLOCLİNE Nutt.}

Floccose woolly annuals, branched from the base, with alternate leaves. Heads glomerate, discoid. Involueres ovoid; bracts more or less scarious and imbricate; receptacle chaffy, the paleae subtending the pistillate flowers more or less boat-shaped, with at least hyaline tips, loosely enclosing the achenes and falling with them, those subtending the staminate flowers searious-hyaline, deciduous. Marginal flowers pistillate and fertile, numerous, with filiform corollas, without ligules. Central flowers hermaphrodite, but sterile, their corollas tubular, 4-5-toothed. Anthers sagittate at the base. Achenes slightly compressed. Pappus of the pistillate flowers wanting, that of the hermaphrodite flowers of very few capillary bristles.

1. S. micropoides A. Gray. Stem $2-10 \mathrm{~cm}$. high, branched from the base, white-tomentose; leaves linear or lance-linear, acute, 5-8 $\mathrm{mm}$. long; paleae of the receptacle with a narrow oblong-ovate hyaline tip, densely long-woolly. Arid plains: N.M. $-\mathrm{s}$ Utah $-\mathrm{s}$ Calif. L. Son. Ap-My.

\section{ANCISTROCÁRPHUS A. Gray.}

Floccose annuals, branched at the base, with alternate leaves. Heads discoid. Bracts of the involucre boat-shaped, enclosing each a marginal flower, firm, with a hyaline tip. Central flowers subtended by 5 open paleae, these being coriaceous-herbaceous, ovate-lanceolate, ending in incurved hooked spines, persistent, and in age spreading. Marginal flowers 5-9, pistillate and fertile, with filiform corollas. Central flowers few, hermaphrodite and sterile. Achenes obovatefusiform. Pappus wanting in all flowers.

1. A. filagineus A. Gray. Stem erect or diffuse, $2-5 \mathrm{~cm}$. high, appressed lanate; leaves linear to spatulate, $1 \mathrm{~cm}$. long or less, lanate; heads capitateglomerate; paleae with the hook in fruit $4 \mathrm{~mm}$. long. Styloclene filaginea A. Gray. Dry hillsides: Calif.-Ida.-Ore. Son. Ap-My.

\section{PSILOCÁRPHUS Nutt.}

Small diffuse, branched floccose annuals. Leaves mostly opposite. Heads small, solitary in the forks or ends of the branches. Involucres globose; bracts few; receptacle globose, chaffy; paleae or bractlets subtending the pistillate flowers cucullate-saccate, semi-ovate or semi-cordate in outline, rounded at the top, herbaceo-membranous, and with hyaline, porrect or erect appendages; paleae of the hermaphrodite flowers wanting. Marginal flowers pistillate and fertile, with filiform corollas, numerous. Central hermaphrodite and sterile flowers few, with tubular, 5-toothed corollas; achenes cylindrie. Pappus wanting in all flowers.

Involucres with long loose wool; upper leaves not narrowed at the base. Involucres with very short wool; leaves all narrowed at the base.
1. P. elatior.

2. $P$. oreganus.

1. P. elatior A. Gray. Stem erect or ascending, $5-15 \mathrm{~cm}$. high, with spreading branches, densely tomentose; leaves oblanceolate or linear-spatulate, $1-2 \mathrm{~cm}$ long, loosely white-tomentose, those subtending the heads elliptic; heads 6-8 $\mathrm{mm}$. broad; involucres densely woolly-tomentose. Banks: Ore.-Ida.-B.C. Submont. Je-Jl.

2. P. oreganus Nutt. Stem diffusely branched, $2-6 \mathrm{~cm}$. high; leaves linearspatulate, about $1 \mathrm{~cm}$. long, finely silky-tomentose; heads 4-6 mm. broad; involucres finely short woolly; bracts in fruit $2 \mathrm{~mm}$. long or less. Banks: Ore.-Ida. -Wash. Son. JI.

\section{DIAPÈRIA Nutt.}

Low caulescent annuals. Leaves alternate, floccose. Heads globose, glomerate, discoid. Involucres woolly; bracts few, more or less scarious, in several 
series. Receptacle convex, chaffy. Paleae of the pistillate flowers barely concave, scarious, deciduous, those of the central flowers similar or with woolly tips. Marginal flowers pistillate, fertile, with filiform corollas, and 2 stylebranches. Central flowers $2-5$, hermaphrodite and usually sterile, with undivided styles. Achenes obcompressed, smooth or very minutely papillose. Pappus wanting. [Evax DC., in part.]

1. D. prolifera Nutt. Stem erect, simple or with ascending branches from the base, loosely tomentose; leaves spatulate, $1 \mathrm{~cm}$. long or less, loosely tomentose; heads in terminal glomerules, subtended by a rosette of leaves, from which later develop 1-4 branches bearing similar terminal glomerules; involucres cylindraceous or oblong; paleae subtending the fertile flowers chartaceous-scarious, naked; those subtending the staminate flowers herbaceous and woolly-tipped. Evax prolifera Nutt. Filago prolifera (Nutt.) Britton. Dry ground: S.D.-Ark. -Tex.-Ariz.-Colo. Plain. My-Jl.

\section{4. ÓGLIFA Cass.}

Low tomentose erect annuals. Leaves alternate. Heads glomerate, discoid. Involucres oblong or campanulate; bracts scarious, in several series. Receptacle convex or conic, chaffy; paleae or bractlets of the marginal flowers boatshaped, rather few, enclosing the achenes and stellate-spreading at maturity. Marginal flowers pistillate, with filiform corollas, each subtended by a palea and without pappus. Middle flowers surrounded by a series of open paleae; a few of the central ones hermaphrodite, the others pistillate, all fertile and with a pappus of eapillary bristles. Anthers sagittate at the base. Achenes terete or slightly compressed, those of the marginal flowers oblique.

1. O. californica (Nutt.) Rydb. Annual; stem erect, 1-2 dm. high, more or less branched, with erect-ascending branches; leaves linear or linear-oblong, 1-2 cm. long; marginal flowers 8-10, their paleae ovate, very woolly; inner paleae oblong, concave, nearly glabrous; achenes oblong, subterete, minutely papillose-granular. Filago californica Nutt. Open dry grounds: Ariz. - s Utah - Calif. L. Son. Mr-My.

\section{ANTENNÀRIA Gaertn. Cats-Paws, Everlasting.}

Woolly perennial herbs, usually stoloniferous or soboliferous. Leaves alternate, the basal ones in the stoloniferous species forming rosettes. Heads discoid, usually corymbose, dioecious. * Involucres many-flowered; bracts imbricate, in several series, those of the staminate heads often broader; receptacle flat, not chaffy. Pistillate flowers fertile, their corollas filiform, truncate. Styles with 2 branches; pappus-bristles capillary, united at the base and falling off together. Staminate or rather hermaphrodite flower with tubular, 5-lobed corollas, rudimentary styles and ovaries, and usually with pappus-bristles somewhat clavate at the apex. Anthers caudate at the base. Achenes terete or nearly so.

Pappus-bristles of the staminate heads with clavate or scarious-dilated tips.

Plants surculose-proliferous with prostrate leafy stolons.

Plant caulescent.

Heads racemose or paniculate, long-peduncled; involucres almost glabrous.

Heads in cymose clusters or rarely solitary; involucres woolly at the base. Bracts of the involucres with green or brown upper portion.

Bracts of the involucres with white or pink upper portion.

II. Alpinaf.

Heads $5-8 \mathrm{~mm}$. high.

Bracts usually with bright pink upper portion.

Bracts with white upper portion.

III. ROSEAE.

Leaves of the stolons narrowly oblanceolate, $1.5-5 \mathrm{~cm}$. long; bracts with dark spots. IV. NARDINAE.

Heads 8-12 $\mathrm{mm}$. high.

* The staminate plants are usually much less common than the pistillate ones (except in no. 13) and unknown to the author in nos. $5,8,9,18$, and 20 . The pistillate flowers often produce seeds; without being fertilized by pollen. 
Leaves tomentose on both sides.

Leaves glabrous above.

VI. APRICAE,

VII. CAMPESTRES.

Plant acaulescent; heads subsessile among the rosettes of the basal leaves.

Plants not surculose-proliferous; stolons erect.

VIII. Rosulatae.

Heads 4-5 mm. high; bracts nearly glabrous, scarious throughout; leaves silkytomentose.

IX. Argentean.

Heads 6-10 mm. high; bracts tomentose at the base, only tips scarious; leaves villous-tomentose.

$X$. PUlcherrimae.

Pappus-bristles of the small staminate heads not clavate; achenes puberulent; hairs bifurcate at the apex; plant low and densely cespitose. XI. DIMORPHAE.

\section{RACEMOSAE.}

Leaves of the rosettes oval or spatulate; lower pedicels $2-5 \mathrm{~cm}$. long.

Leaves of the rosettes oblanceolate; lower pedicels $1 \mathrm{~cm}$. long or less.

1. A. racemosa.

\section{ALPINAE,}

2. A. oblancifolia.

Leaves glabrous above.

Leaves of the rosettes narrowly oblanceolate; heads usually several; bracts of the pistillate heads abruptly acuminate.

3. A. alpina.

Leaves of the rosettes broadly oblanceolate or spatulate; inner bracts acute or acuminate, the outer obtuse.

Heads usually solitary.

Heads 3-6 in a cluster.

Leaves tomentose on both sides; bracts acute or obtuse.

4. A. monocephala.

5. A. chlorantha.

Leaves of the rosettes broadly obovate-cuneate, subsessile.

Heads 7-8 mm. high; leaves 8-10 $\mathrm{mm}$. long; tips of bracts dark brown.

Heads 5-6 mm 6. A. pulvinata.

Leaves of the rosettes spatulate or oblanceolate, distinctly petioled. A. albescens.

Heads 6-8 mm. high.

Heads 5-6 mm. high.

8. A. fusca.

Bracts very dark, almost black at the base, but often with white tips.

Inner bracts of the pistillate heads acute.

Leaves narrowly oblanceolate, acute or short-acuminate; tomentum very fine and appressed.

9. A. acuta.

Leaves spatulate or broadly oblanceolate, obtuse; tomentum rather loose.

Bracts obtuse or rounded.

10. A. media.

11. A. mucronata.

Bracts moderately dark, umber-colored to light brown.

Inner bracts not rose-colored.

Leaves appressed-tomentose, shining and yellowish.

Bracts of the pistillate heads linear-lanceolate, acute.

Bracts of the heads oblong, obtuse.

Heads sessile; stolons decumbent.

12. A. Sansoni.

Heads peduncled; stolons ascending.

Leaves white-tomentose, very rarely yellowish.

13. A. flavescens.

14. A. confinis.

Heads 2 or 3 ; leaves broadly obovate-spatulate.

15. A. aizoides.

Heads severai; leaves spatulate or oblanceolate.

Bracts of the pistillate heads obtuse.

Involucres more or less viscid; bracts with whitish tips.

Involucres not viscid; bracts umber-colored.

Inner bracts rose-colored.

16. A. umbrinella.

18. A. concinna.

III. ROSEAE.

Leaves cuneate-spatulate, obtuse, without distinction between blade and petiole.

Leaves oblanceolate or spatulate, with distinct petioles.

Leaves narrowly oblanceolate, acute.

Leaves broadly spatulate, obtuse.

18. A. concinna.

19. A. rosea.

20. A. imbricata.

IV. NARDINAE.

One species.

V. ARIDAE.

Stem-leaves 6-8 mm. wide, oblong or the uppermost lanceolate.

21. A. corymbosa.

Stem-leaves $2-5 \mathrm{~mm}$. wide, linear or oblanceolate.

Bracts with a large brown or green spot, more or less viscid. 23. A. sedoides.

Bracts slightly if at all spotted, not viscid.

Bracts of the pistillate heads obtuse; plant 1-2 dm. high.

Bracts of the pistillate heads with oblong to linear upper portions.

24. A. arida.

Bracts of the pistillate heads with oval or obovate upper portions. 
Bracts of the pistillate heads acute, at least the inner ones.

Inflorescence and upper leaves glandular-hairy; leaves of the inflorescence large, scarcely smaller than the upper stem-leaves; bracts greenish.

Leaves of the stolons 5-15 mm. long, rhombic-spatulate; tomentum very fine, appressed and silky. 26. A. microphylla.

Leaves of the stolons spatulate, usually rounded at the apex, $15-30 \mathrm{~mm}$.

long, tomentum looser.
Inflorescence and upper leaves not glandular, the latter reduced; bracts brownish. 28. A. oxyphylla.

VI. APRICAE.

Plant tall, 2-3 dm. high; heads usually peduncled.

Leaves less than $2 \mathrm{~cm}$. long and 5-8 mm. wide, usually not triple-nerved; heads 7-9

mm. high.
Leaves over $2 \mathrm{~cm}$. long, $7-10 \mathrm{~mm}$. wide, triple-nerved; heads 28 . A. oxyphylla.

Plant low, usually less than $1 \mathrm{dm}$. high; heads subsessile. about $1 \mathrm{~cm}$. high. 29. A. obovata.

VII. CAMPESTRES.

Plant about $3 \mathrm{dm}$. high; basal leaves distinctly triple-nerved.

Plant $1 \mathrm{dm}$. or less; basal leaves not distinctly triple-nerved.

30. A. aprica.

Inflorescence not glandular; bracts of the pistillate heads lanceolate or linear-lanceo-

late, acute; those of the staminate heads oblong, obtuse. $32 . A$. campestris.
Inflorescence more or less glandular-hairy; bracts in both heads ovate to lanceolate, acute or acutish, in the staminate broader.

33. A. marginata.

\section{Rosulatae.}

Bracts with white upper portion; leaves white on both sides.

Bracts with brown upper portion; leaves glabrate above.

34. A. rosulata.

35. A. Sierrae-Blancae.

IX. Argenteat.

Basal leaves oblanceolate.

Basal leaves very narrowly linear-oblanceolate.

36. A. oblanceolata.

37. A. luzuloides.

\section{Pulcherrimae.}

Bracts with a large dark spot, those of the pistillate heads ovate to lanceolate, acute, those of the staminate heads ovate or oval, obtuse or acutish; pistillate heads 6-10 $\mathrm{mm}$. high, turbinate at the base.

Plants 1-2 dm. high; ribs of the leaves not conspicuous; outer bracts wholly fuscous.

Plants 3-5 dm. high; leaves with conspicuous ribs; tips of 38. A. lanata. white.

Bracts with small dark spots or none; bracts of both staminate 39. A. pulcherrima.

oblong or oval, obtuse tips, those of the staoth staminate and pistillate heads with

39. A. pulche

\section{DimorphaE.}

40. A. anaphaloides.

Plant without filiform stolons.

Fruiting heads not over $1.5 \mathrm{~cm}$. high; leaves oblanceolate; stem 1-3 cm. high.

Fruiting heads about $2 \mathrm{~cm}$. high; leaves spatuate 41 . A. dimorpha. high. Plants with fliform ascending stolons.

42. A. macrocephala.

43. A. flagellaris.

1. A. racemosa Hook. Stem of the pistillate plant $2-5 \mathrm{dm}$. high, glabrous or puberulent; leaves of the rosettes 3-ribbed, petioled, 3-7 cm. long, whitetomentose beneath, glabrate above; stem-leaves lanceolate or linear, sessile; heads many; involucres 6-8 mm. high and about as broad; bracts ovate to lanceolate, acute, light greenish yellow; stem of staminate plant 1-3 dm. high; involucres more hemispheric, $5 \mathrm{~mm}$. high; bracts elliptic, obtuse, the inner slightly white-tipped. Woods and hillsides: Alta.-Wyo.-Calif.-B.C. Submont.Mont. Je-Au.

2. A. oblancifolia E. Nels. Stem of the staminate plant 1-2 dm. high; basal leaves oblanceolate, $2-3 \mathrm{~cm}$. long, sparingly tomentose or glabrate above, appressed, white-tomentose beneath; stem-leaves narrowly oblanceolate or linear, acute or acuminate; heads 4-13; involucres 4-5 mm. high, sparsely woolly; bracts oval, obtuse, or rounded, light brownish green below, often with a purplish spot and white tips. Wooded slopes: w Wyo. Mont. J1.

3. A. alpina (L.) Gaertn. Stem $5-15 \mathrm{~cm}$. high, floccose; leaves of the stolons silky-tomentose, 8-20 mm. long, 2-4 mm. wide; heads usually $3-5$, conglomerate; involucres about $5 \mathrm{~mm}$. high and $8 \mathrm{~mm}$. broad; bracts of the very ish brown, lanceolate, long-acuminate. Arctic-alpine situations: Greenl.-Lab. -Alta.-B.C.; n Eur. Alp. J1-Au. 
4. A. monocephala DC. Stem 5-10 cm. high; leaves of the rosettes cuspidate-mucronate, 8-15 mm. long, silky-tomentose beneath; stem-leaves linear, 5-10 $\mathrm{mm}$. long; involucres about $5 \mathrm{~mm}$. high and $8 \mathrm{~mm}$. broad; bracts of the (rare) staminate heads broadly ovate, obtuse or acutish, those of the pistillate heads lanceolate, the outer obtuse, the inner acute or acuminate. Aretic-alpine situations: Alaska-B.C.-Alta. Alp. Jl.

5. A. chlorantha Greene. Stem $7-15 \mathrm{~cm}$. high; basal leaves and those of the rosettes mucronate or acutish, loosely floccose, densely and permanently so beneath, $1.5-2.5 \mathrm{~cm}$. long; stem-leaves oblong-linear; heads $3-6$, somewhat conglomerate; involucres about $7 \mathrm{~mm}$. high; bracts of the pistillate heads with dark olive-green tips, the outer obtuse, the inner acute or acuminate. Mountains: B.C. Mont. Jl-Au.

6. A. pulvinata Greene. Stem 5-10 cm. high, densely white-tomentose; leaves of the rosettes densely white-tomentose on both sides, with loose villous tomentum; stem-leaves oblanceolate or oblong, acute; heads 5-8, in a dense cluster; bracts of the staminate heads brown, oblong and obtuse, those of the pistillate heads similar, but the inner more lanceolate and acute. Mountains: Alta,-Mont.-B.C. Mont.-Alp. Je-Au.

7. A. albescens (E. Nels.) Rydb. Stem $1 \mathrm{dm}$. or less high, tomentose; leaves of the stolons 4-8 mm. long, densely and closely white-tomentose, obovate; stem-leaves oblanceolate; heads $3-5$ in a dense subcapitate cluster; bracts elliptic, obtuse, light brown or yellowish. A. pulvinata albescens E. Nels. Mountains: Alta.-Mont.-Ida. Submont.-Subalp. Je-Jl.

8. A. fusca E. Nels. Stem 1-1.5 dm. high, tomentose; leaves of the rosettes $15-22 \mathrm{~mm}$. long, white-tomentose, with a close silky pubescence; stemleaves linear or linear-oblanceolate; heads 3-13, pedicellate, corymbose; bracts of the pistillate heads elliptic or oblong, obtuse, greenish brown. Open woods: Wyo.-Ida. Mont. Au.

9. A. acuta Rydb. Stem slender, 5-12 $\mathrm{cm}$. high; leaves of the rosettes 15-25 mm. long, 2-4 mm. wide; stem-leaves narrowly linear or linear-oblanceolate; heads 3-5, conglomerate, sessile; bracts of the pistillate heads lanceolate to linear-lanceolate, dark greenish brown with slightly lighter tips, the inner acute. Mountains: Alta. Subalp.-Alp. Jl-Au.

10. A. media Greene. Stem 5-10 cm. high, loosely tomentose; leaves of the rosettes 1-2 cm. long; heads 4-7, densely conglomerate; bracts of the staminate head elliptic and obtuse, very dark green, or the innermost sometimes with whitish tips; outer bracts of the pistillate head oblong, obtuse, the inner lanceolate, acute. A. austromontana E. Nels. Higher peaks: Alta.-Colo.-Calif.B.C. Alp. $\rightarrow$ Subalp. J1-Au.

11. A. mucronata E. Nels. Stem 5-12 cm. high, tomentose; leaves of the rosettes oblanceolate or narrowly spatulate, 1-2 cm. long; stem-leaves oblonglinear, acute; heads 4-8, conglomerate; bracts in both the pistillate and the staminate heads oblong or elliptic, obtuse, dark brownish green, the inner bracts, especially in the staminate heads, often with whitish tips. Mountains and rocky slopes: Alta.-Wyo.-B.C. Alp.-Subalp.

12. A. Sansoni Greene. Stem 1-2.5 dm. high, slender; leaves of the rosettes linear-spatulate or oblanceolate, 1-2 cm. long; stem-leaves linear, acute or acuminate, erect; heads 8-10, cymose and peduncled; involucres 6-7 mm. high and nearly as wide; bracts of the pistillate heads oblong or lanceolate, the inner acute, brownish below, dirty white, yellowish or pinkish towards the apex, those of the staminate heads oblong, obtuse. Hills and mountains: Alta.-Mont.-B.C. Submont. Je-Jl.

13. A. flavescens Rydb. Stem about $1 \mathrm{dm}$. high; leaves of the stolons broadly spatulate, about $1 \mathrm{~cm}$. long, acute, densely tomentose on both sides; stem-leaves oblong or linear; heads 4-8, in a dense subcapitate cluster; involucres 4-5 mm. high, $5 \mathrm{~mm}$. broad; bracts isabel-colored or yellowish, in the staminate heads broadly elliptic, in the pistillate heads oblong, in both obtuse. A. reflexa E. Nels., in part. Dry hills: Mont.-Colo.-Wash. Submont.-Mont. My-Jl. 
14. A. confinis Greene. Cespitose, somewhat suffrutescent perennial; stem 1-2 dm. high, tomentose; leaves of the rosettes oblong-spatulate, about 1 $\mathrm{cm}$. long, tomentose on both sides; tomentum loose; heads usually peduncled, numerous, in a corymbiform inflorescence; involucres about $5 \mathrm{~mm}$. high; bracts of the pistillate ones oval to oblong, obtuse, brownish or yellowish, those of the staminate heads somewhat broader. Mountains: Ida.-Ariz.-Calif.-Ore. Mont. Je-Jl.

15. A. aizoides Greene. Stolons ascending; stem 3-8 $\mathrm{cm}$. high; leaves of the stolons thick, $10-15 \mathrm{~mm}$. long, with a very fine silvery-white shining tomentum; stem-leaves linear or linear-oblanceolate; heads 2 or 3 , sessile; involucres 4-5 $\mathrm{mm}$. high, densely tomentose at the base; bracts of the staminate heads ovate to obovate, dark brown, rounded at the apex. Barren hills and mountains: Sask.-B.C. Plain. Je-Au.

16. A. umbrinella Rydb. Stem about $1 \mathrm{dm}$. high; leaves of the rosettes spatulate, 1-1.5 cm. long, densely white-tomentose; stem-leaves linear-oblong; heads 3-8, conglomerate; involucres about $5 \mathrm{~mm}$. high; bracts of the staminate heads elliptic, obtuse, isabel-colored (dirty yellowish), those of the pistillate heads similar, but darker, usually light umber-colored, and the inner narrower. Higher mountains: Mont.-Colo.-B.C. Mont.-Alp.

17. A. Macounii Greene. Stem 5-15 dm. high; leaves of the stolons obovate or spatulate, $1-1.5 \mathrm{~cm}$. long, sometimes yellowish; heads $3-8$ in a close glomerate cluster; bracts of the staminate heads brown, elliptic or oval, very obtuse, more or less spreading; outer bracts of the pistillate heads oblong, obtuse, the inner ones linear-lanceolate, acute. A. reflexa E. Nels., mainly. Mountains: Alta.-Wyo.-B.C. My-Au.

18. A. concinna E. Nels. Stem slender, 10-15 $\mathrm{cm}$. high; leaves of the rosettes spatulate or obovate, scarcely petioled, abruptly acute, about $1 \mathrm{~cm}$. long, 2-4 mm. broad, white-tomentose with rather loose tomentum; stem-leaves linear-oblong or linear; heads $6-15$, conglomerate or in more open clusters; bracts of the pistillate heads elliptic, obtuse, the outer brownish, the inner pinkish. Hills: Wash.-Ore.-Colo.-Wyo. Submont.-Mont. Je-Ji.

19. A. rosea (D. C. Eat.) Greene. Stem $2-4 \mathrm{dm}$. high, slender, tomentose; leaves of the rosettes acute, $15-20 \mathrm{~mm}$. long, white-tomentose, with close tomentum; heads usually many; involucres about $5 \mathrm{~mm}$. high and broad; bracts of the rare staminate head broadly elliptic, pale pink, those of the pistillate heads elliptic to linear-oblong, obtuse, rose or rarely dull white. A. dioica rosea D. C. Eat. A. parvifolia [? Nutt., in part] Rydb. A. sordida Greene. Meadows: Alta. -S.D.-Colo.-Calif.-Yukon. Plain-Subalp. Je-Au.

20. A. imbricata E. Nels. Stem 1-3 dm. high; leaves of the rosettes mucronate, petioled, about $2 \mathrm{~cm}$. long, grayish-tomentose, with appressed tomentum; stem-leaves ample, oblong or oblanceolate; heads in a close cluster; involucres hemispheric, about $7 \mathrm{~mm}$. high and broad; bracts of the pistillate heads pinkish, elliptic, obtuse or the inner rarely acutish. A. rosea imbricata E. Nels. Hills: Alta.-Colo. Je-Jl.

21. A. corymbosa E. Nels. Stem 2-3 dm. high; leaves of the rosettes thin, sparsely tomentose, with appressed tomentum, $3-3.5 \mathrm{~cm}$. long; stem-leaves linear, acuminate; heads peduncled, corymbose; involucres 4-5 mm. high; bracts of the pistillate heads elliptic and obtuse or the innermost lanceolate and acute, those of the staminate plant broadly oval and rounded at the apex. A. nardina Greene. Meadows: Mont.-Colo.-Ida.-Ore. Submont.-Subalp.

22. A. foliacea Greene. Stem 3-4 dm. high; leaves of the rosettes cuneateobovate or broadly spatulate, $1-2 \mathrm{~cm}$. long, white-tomentose on both sides, with rather loose tomentum; stem-leaves ample, $2-3 \mathrm{~cm}$. long; heads many, pedicelled, corymbose; involucres about $6 \mathrm{~mm}$. high; bracts of the pistillate heads dirty white, the outer oblong or elliptic, obtuse, the inner linear-lanceolate, acute; staminate plant unknown. Mountains: Mont. Submont. Au.

23. A. sedoides Greene. Stem about $1 \mathrm{dm}$. high; leaves of the rosettes spatulate, less than $1 \mathrm{~cm}$. long, densely and finely white-tomentose on both sides; 
heads 4-6, conglomerate, sessile; involucres 5-6 $\mathrm{mm}$. high; lower portion of the pistillate bracts brownish or greenish; tips dirty white, oblong, obtuse or acutish. A. arida viscidula E. Nels. A. viscidula Rydb. High mountains: B.C.Colo.-Man. Mont.-Alp. Jl.

24. A. arida E. Nels. Stem 1-2 dm. high, slender; leaves of the rosettes spatulate, acutish, 8-12 $\mathrm{cm}$. long, densely and finely appressed-tomentose on both sides, often conduplicate; stem-leaves often twisted or curved; heads 6-10, sessile, conglomerate; involucres $5-6 \mathrm{~mm}$. high; bracts of the pistillate heads oblong, obtuse, milky-white, those of the staminate heads rounded oval. Dry plains and hills: Mont.-N.M.-Utah-Ida. Submont.-Mont. Je-Jl.

25. A. scariosa E. Nels. Stem $1 \mathrm{dm}$. high or less; basal leaves spatulate, obtuse or acutish, 1-1.5 cm. long, white-floccose on both sides; stem-leaves oblong or linear-oblong; heads several, somewhat congested; involucres $7-8 \mathrm{~mm}$. high; bracts of pistillate and staminate heads with obovate or oval, obtuse, white tips. Hills: Wyo. Submont. Je.

26. A. microphylla Rydb. Stem slender, strict, 2-3 dm. high; stem-leaves linear-oblong, small; heads 5-30, conglomerate, 5-6 mm. high and broad; bracts of the pistillate heads linear-oblong to lanceolate, greenish straw-colored, the inner acute, those of the staminate heads oval or elliptic, rounded at the apex. A. parvifolia Greene, not Nutt. A. formosa Greene, a large form. A. solstitialis Lunell., is the staminate plant, which is smaller. Dry hills and plains: Sask.Neb.-N.M.-B.C.-Yukon. Plain-Subalp. Je-Jl.

27. A. bracteosa Rydb. Stem 3-4 dm. high, strict; leaves of the rosettes spatulate, petioled, about $2 \mathrm{~cm}$. long, acutish or mucronate, white-tomentose, with a fine, silky tomentum; stem-leaves about $3 \mathrm{~cm}$. long, oblong or narrowly oblanceolate; heads corymbose; involucres 7-8 $\mathrm{mm}$. high, 5-6 mm. broad; bracts of the pistillate heads oblong or lanceolate, acute, or the inner acuminate, those of the staminate heads oval and obtuse or rounded at the apex. A. parvifolia bracteosa A. Nels. Mountain meadows: Mont.-Colo. Submont.-Subalp. JeJl.

28. A. oxyphylla Greene. Stem 2-4 dm, high; leaves of the rosettes spatulate-obovate or broadly oblanceolate, densely white-tomentose beneath, less so above; heads many in a rounded corymb; involucres $6-7 \mathrm{~mm}$. high; bracts of the pistillate heads with dull white tips, the outermost ovate, obtusish, the rest lanceolate to linear-lanceolate, acute; staminate plant unknown. Hills and mountains: Mont.-Ida.-Wyo.-Neb.-S.D. Plain-Submont. My-Jl.

29. A. obovata E. Nels. Stem 2-3 dm. high; leaves of the rosettes about $3 \mathrm{~cm}$. long, obovate-cuneate, permanently tomentose on both sides; stem-leaves small, oblong-linear; heads 3-7, corymbose; involucres about $8 \mathrm{~mm}$. high; bracts of the pistillate heads oblong to linear-lanceolate, with a purplish brown spot, acute or acuminate, or the outermost obtusish. Hills and mountains: Man.S.D.-Colo,-Alta. Plain-Submont. Je-Jl.

30. A. aprica Greene. Stem low, less than $1.5 \mathrm{dm}$. high; leaves of the rosettes spatulate or cuneate-oblanceolate, 1-2 cm. long, densely tomentose on both sides; stem-leaves linear, $1 \mathrm{~cm}$. long, acute; heads 3-6, sessile or nearly so, conglomerate; involueres of the pistillate head 7-9 mm. high; bracts numerous, usually with a brown spot and white or pinkish tips, oblong, obtuse, or acutish; involueres of the staminate heads 6-7 mm. high; bracts oval or elliptic-obtuse. (?) A. parvifolia Nutt. A. Holmii, A. obtusa, A. modesta, and A. pumila Greene. Plains, hills, and mountains: Man.-Neb.-N.M.-Utah-B.C. Plain-Subalp. $\mathrm{My}-\mathrm{Jl}$.

31. A. Howellii Greene. Stem 2-4 dm. high; leaves of the rosettes cuneateobovate, acute or acutish, 3-5 cm. Iong, glabrous above, closely silky-tomentose beneath, petioled; stem-leaves small and linear; heads several, corymbose; involucres of the pistillate heads $8-10 \mathrm{~mm}$. high and nearly as broad; outer bracts oblong, the inner linear-lanceolate, very acute, all more or less brownish below. Hillsides and open woods: Alta.-Mont.-Ida.-Wash.-B.C. Submont.-Mont. My-Jl. 
32. A. campestris Rydb. Stem low, about $1 \mathrm{dm}$. high or less; leaves of the rosettes obovate-cuneate, $2-4 \mathrm{~cm}$. long and about $1 \mathrm{~cm}$. wide, glabrate above, tomentose beneath; stem-leaves small, linear, acute; heads 3-6, sessile, conglomerate; involucres of the pistillate heads $8-9 \mathrm{~mm}$. high, outer bracts oblong, obtuse, the inner linear-lanceolate, acute or acuminate; staminate involucres $6-7$ $\mathrm{mm}$. high; bracts elliptic or obovate, rounded. A. Lunellii and A. athabascensis Greene. Prairies: Man.-Mich.-Mo.-Kans.-Sask.-(? B.C.). Plain. My-
Je.

33. A. marginata Greene. Stem 1-2 dm. high; leaves spatulate or oblanceolate, obtuse or mucronate, $1-2.5 \mathrm{~cm}$. long, glabrate above, densely but loosely white-tomentose beneath; heads 4-8, conglomerate, but short-pedicelled; involucres of the pistillate plant 8-10 mm. high; outer bracts oblong, obtuse, the inner linear-lanceolate, acute; involucres of staminate heads 6-7 mm. high; bracts obovate or rhombic-obovate, obtuse, acutish or abruptly short-acuminate. Hills and mountain sides: N.M.- $\mathrm{s}$ Colo.-Utah-Ariz. Submont.-Mont. Je-Jl.

34. A. rosulata Rydb. Plant almost acaulescent; stem $1 \mathrm{~cm}$. long or less; leaves of the rosettes 5-10 $\mathrm{mm}$. long, spatulate or spatulate-obovate, densely and closely silvery-tomentose; heads $1-3$ together, sessile; involucral bracts of the pistillate heads lanceolate, acute, milky white, those of the staminate ones Submont.-Mont. My-Jl. A. Bakeri Greene. Mountains: Colo.-Utah-Ariz.

35. A. Sierrae-Blancae Rydb. Rosulate, almost stemless; leaves broadly spatulate, less than $1 \mathrm{~cm}$. long, abruptly acute; heads subsessile in the rosettes, 6-7 mm. in diameter; bracts broadly oblong to almost obovate, with a searious brown upper portion. High mountains: s Colo. Alp.

36. A. oblanceolata Rydb. Stem 2-4 dm. high, slender; basal leaves 3-6 $\mathrm{cm}$. long, evidently 3 -ribbed, densely white-tomentose; upper stem-leaves linear; heads corymbose; involucres 4-5 mm. high; bracts brownish, with white or strawcolored tips, those of the pistillate heads oblong to linear, the outer obtuse, the inner acute, those of the staminate heads oval and rounded. Mountain sides: Mont.-Colo.-Calif.-B.C. Submant.-Mont. Je-Au.

37. A. luzuloides T. \& G. Stem 2-4 dm. high; leaves 5-7 cm. long, 1-4 $\mathrm{mm}$. Wide, densely silky white-tomentose; heads numerous, corymbose; involucres 4-5 mm. high, nearly glabrous throughout; bracts of the pistillate heads brownish and shining, the outer ovate, the inner linear-oblong, mostly obtuse; those of the staminate heads broader, rounded and white-tipped. Valleys and hillsides: Mont.-Wyo.-Ore.-B.C. My-Jl.

38. A. lanata (Hook.) Greene. Basal leaves narrowly oblanceolate, 4-8 cm. long, loosely white-tomentose; stem-leaves linear; heads several, conglomerate; involucres densely tomentose below, those of the pistillate heads $6-8 \mathrm{~mm}$. high, those of the staminate $5-6 \mathrm{~mm}$. high; bracts of the former in 5 or 6 series, dark brown or almost black with light brown tips. High mountains: Alta.-Mont. Ore.-B.C. Mont.-Alp. Je-Au.

39. A. pulcherrima (Hook.) Greene. Stem 3-5 dm. high; basal leaves oblanceolate, 8-12 $\mathrm{cm}$. long; stem-leaves narrower; heads several, corymbose; involucres of the pistillate heads nearly $1 \mathrm{~cm}$. high, more or less turbinate; bracts in 6 or 7 series, the outer broadly ovate, obtusish, the inner narrowly lanceolate, acuminate, all with dark brown bases and light brown or dirty white tips; staminate involucres 5-6 mm. high; bracts with rounded obovate tips. A. carpathica pulcherrima Hook. Hillsides and mountains: Sask.-Colo.-Wash.-Yukon, Submont.-Subalp.

40. A. anaphaloides Rydb. Stem 3-4 dm. high, stout; basal leaves narrowly oblanceolate, $10-15 \mathrm{~cm}$. long, acute; heads many in an open corymb; involucres of the staminate and pistillate heads much alike, $6-8 \mathrm{~mm}$. high; bracts in 3-4 series, with white tips, in the pistillate heads obtuse or acutish, in the staminate heads rounded or truncate at the apex. A. pulcherrima Coult. \& Nels., not Greene. Hillsides: Mont.-Colo.-Ore-_B.C. Submont.-Subalp.
My-Au. 
41. A. dimorpha (Nutt.) T. \& G. Pulvinate-cespitose perennial; stem 1-3 dm. high; leaves 1-2 cm. long; heads solitary; involucres of pistillate heads 1-1.5 $\mathrm{cm}$. high, turbinate, tomentose at the base only; outer bracts ovate, acute, the inner narrowly linear-lanceolate, attenuate; involucre of the staminate heads more hemispheric, 6-7 mm. high; bracts oblong, obtuse, darker brown. Dry plains: Mont.-Neb.-Colo.-Calif.-B.C. Plain-Submont. Ap-J.

42. A. macrocephala (D. C. Eat.) Rydb. Pulvinate-cespitose perennial; stem 2-5 cm. high; leaves $1.5-3 \mathrm{~cm}$. long; involucres of the pistillate heads turbinate, 18-20 mm. high; outer bracts ovate, the inner narrowly linear-lanceolate, scarious-margined, brownish on the back; involucres of the staminate heads about $8 \mathrm{~mm}$. high; bracts elliptic to ovate, often acutish. A. dimorpha macrocephala D. C. Eat. Bench-lands: Utah. Son,-Submont. Ap-My.

43. A. flagellaris (T. \& G.) A. Gray. Pulvinate perennial with a small caudex, producing filiform ascending stolons, $5-10 \mathrm{~cm}$. long, which bear at their apex a rosette of small leaves; basal leaves narrowly linear, grayish-tomentose; stem 1-2 cm. long, few-leaved; heads solitary; involucres of the staminate heads 6-7 mm. high, tomentose at the base; bracts dark brown, oblong-obtuse; involucre of the pistillate heads 8-10 $\mathrm{mm}$. long; bracts lanceolate to linear-lanceolate, acute. Mountains: n Wyo.-Wash.-Ore. Submont.-Subalp. Je-J.

\section{6. anÁPhalis DC. Pearly Everlasting.}

Tomentose, perennial, caulescent herbs with rootstocks. Leaves alternate, narrow, sessile. Heads discoid, polygamo-dioecious. Involucres hemispheric; bracts imbricate in several series, pearly-white; receptacle convex, not chaffy. Pistillate heads usually with a few hermaphrodite flowers in the center. Pistillate corollas filiform, their pistils with distinct style-branches. Hermaphrodite flowers with tubular, 5-toothed corollas, and undivided styles, sterile. Pappusbristles capillary, falling off separately. [Nacrea A. Nels., based on a staminate plant.]

Leaves narrowly linear, 1-nerved; heads about $5 \mathrm{~mm}$. high.

1. A. angustifolia. Leaves linear-lanceolate to oblong-lanceolate, 3-nerved; heads 6-7 mm. high.

Leaves comparatively thin, less tomentose above.
Leaves comparatively thick, almost equally white-tomentose on both sides.

Leaves comparatively thick, almost equally white-tomentose on both sides.
3. A. lanata.

1. A. angustifolia Rydb. Stem slender, strict, 3-6 dm. high; leaves 5-10 $\mathrm{cm}$. long, $2-5 \mathrm{~mm}$. wide, densely white-tomentose beneath, less so above, glabrate in age; inflorescence small, corymbose; bracts elliptic, obtuse or acutish. Wooded slopes: Mont.-B.C. Submont. Jl-Au.

2. A. subalpina (A. Gray) Rydb. Stem 3-4 dm. high; leaves $3-8 \mathrm{~cm}$. long, 5-15 mm. wide, densely white-tomentose beneath; inflorescence corymbiform; bracts pearly-white, broadly ovate, mostly acute. A. margaritacea subalpina A. Gray. Open mountain woods: Alta.-S.D.-Colo-Utah-B.C. Submont.Subalp. Je-Au.

3. A. Ianata (A. Nels.) Rydb. Stem strict, 2-4 dm. high; leaves densely lanate on both sides, ascending, sessile and clasping, oblong-lanceolate, 4-6 cm. long, $10-15 \mathrm{~mm}$. wide, mucronate; inflorescence corymbiform, high; bracts pearly white, ovate or obovate, obtuse or acutish. Nacrea lanata A. Nels. Mountains: Wyo. Mont. Jl-S.

\section{GNaphàlium L. Cudweed, Everlasting.}

Annual, biennial, or perennial caulescent herbs, with woolly or sometimes glandular foliage. Leaves alternate, entire, narrow. Heads discoid, glomerate or paniculate in our species. Involucres campanulate or hemispheric; bracts scarious, imbricate in several series; receptacle not chaffy, usually pitted. Marginal flowers pistillate, fertile, in several series, with filiform corollas. Central flowers hermaphrodite, few, with tubular corollas. Pistils in all the flowers with 2 distinet stigmas. Anther sagittate at the base. Achenes terete or slightly flattened. Pappus of capillary bristles, distinct or united at the base, deciduous. 
Bristles of the pappus not united at the base, falling off separately.

Heads not leafy-bracted; involucral bracts well imbricate, scarious, white or tinged with brownish, rose, or yellow; plants mostly tall.

Leaves tomentose on both sides; plants little if at all glandular; involucres tomentose at the base.

Stem-leaves narrowed at the base, neither decurrent nor clasping.

Perennial or biennial; stem 3-5 dm. high; inflorescence open; bracts white.

Annual; stem 1-2 dm. high; inflorescence dense; bracts yellowish

2. G. thermale.

Stem-leaves not narrowed at the base, more or less decurrent, or at least auricled-clasping.

Leaves with short broad adnate auricles at the base; bracts obtuse.

Heads 5-6 mm. high, numerous, in glomerules ending the short spreading branches; bracts slightly if at all yellowish; plant tall; stemleaves lanceolate or oblong, with rounded bases, cuspidate.

3. G. proximum.

Heads $4 \mathrm{~mm}$. high, few, in small glomerules, ending the stem or few erect branches; bracts decidedly yellowish when young; plant low; leaves oblong to linear, merely acute or obtuse. Stem erect, strict; lower stem-leaves oblong-oblanceolate.

Stem decumbent at the base; lower stem-leaves spatulate.

5. G. lagopodioides.

Leaves distinctly decurrent; bracts acutish; heads 4-5 mm. high.

Bracts broadly ovate; inflorescence corymbiform. 6. G. Williamsii.

Bracts lance-ovate; inflorescence narrow. $\quad$ 7. G. microcephalum.

Leaves on the upper surface green and decidedly glandular, decurrent; involucres glabrous.

8. G. Macounii.

Heads leafy-bracted; involucral bracts little imbricate, brown or greenish; plant low; involucre floccose at the base.

Plants loosely floccose; leaves broad, spatulate, oblong or oblanceolate. Plants appressed-tomentose; leaves except the lowest narrowly oblanceolate or
linear.

Stem diffusely branched; glomerules crowded, cymosely disposed.
Upper leaves narrowly oblanceolate.
G. uliginosum

Upper leaves narrowly linear.

Stem mostly simple, erect; glomerules spicately disposed.

11. G. exilifolium.

12. G. Grayi.

Bristles of the pappus united in a ring at the base and falling off together: leaves oblanceolate or spatulate.

13. G. ustulatum.

1. G. Wrightii A. Gray. Biennial or perennial, with a taproot; stem upright, much branched above, white-floccose throughout; leaves oblanceolate or spatulate, 2-4 cm. long, the uppermost linear; heads numerous in a rather open panicle; involucres $5-6 \mathrm{~mm}$. high; bracts white, oblong, abruptly pointed, pearly white. G. albatum Osterh. Dry grounds: Colo.-N.M.-Calif. Submont. Au-O.

2. G. thermale E. Nels. Annual; stem low, branched from the base, grayish-tomentose; basal leaves oblanceolate, about $3.5 \mathrm{~cm}$. long; stem-leaves narrowly oblanceolate to linear, $1-3 \mathrm{~cm}$. long; heads sessile in small glomerules, terminating the branches; involucres $4-5 \mathrm{~mm}$. high; bracts dull white or yellowish, the outer ovate, the innermost linear, abruptly apiculate. $G$. Wrightii Coult. \& Nels., not A. Gray. Hot-spring formations: n Wyo. Mont. Jl.

3. G. proximum Greene. Biennial or annual, with a taproot, branched at the base; stem 3-6 dm. high, very leafy; basal leaves spatulate or oblanceolate, 3-4 mm. long; inflorescence closely paniculate, leafy-bracted; involucres villous, 5-6 mm. high; bracts straw-colored or ochroleucous, obtuse. Perhaps scarcely distinct from G. Chilense Spreng. Wet places: Wyo.-Utah-Nev.-Wash. Submont.-Mont. JI-Au.

4. G. sulphurescens Rydb. Annual or biennial; stem usually simple, 2-4 dm. high, often yellowish above; basal leaves spatulate, $2-3 \mathrm{~cm}$. long, whitewoolly; stem-leaves linear or the lower oblong-spatulate, mostly erect; heads sessile in small glomerate cymes; involucres 4-5 mm. high; bracts elliptic or oval, very obtuse, yellow, glossy. G. luteo-album Hook,, not L. Wet sandy soil: Mont.-Tex.-N.M.-Wash. Jl-N.

5. G. lagopodioides Rydb. Biennial, usually branched at the base; stem about $1 \mathrm{dm}$. high, densely woolly-tomentose; basal leaves spatulate, $1-1.5 \mathrm{~cm}$. long, loosely woolly; stem-leaves oblong-spatulate or the lower obovate-spatulate; heads in small conglomerate cymes; involueres about $4 \mathrm{~mm}$. high; bracts oblong 
or elliptic, sulphur-yellow, glossy. Perhaps scarcely distinct from the preceding. Geyser formations: n Wyo. Mont. Au-S.

6. G. Williamsii Rydb. Probably biennial; stem 3-6 dm. high, branched above, loosely floccose; leaves linear or linear-lanceolate, decurrent, $5-10 \mathrm{~cm}$. long; inflorescence large, corymbosely paniculate; involucre $6 \mathrm{~mm}$. high, only slightly tomentose at the base; bracts broadly ovate, acute, light straw-colored or white. Woods: Mont. Mont. Au.

7. G. microcephalum Nutt. Perennial, with a taproot; stem slender, 3-5 $\mathrm{dm}$. high, simple below; leaves linear or the lower oblanceolate, densely floccose; inflorescence a narrow panicle; involucres campanulate, 4-5 $\mathrm{mm}$, high; bracts straw-colored to pearly-white, lance-ovate, acute. Along streams: Calif.-Ida. - B.C.

8. G. Macounii Greene. Biennial, with a taproot; stem 5-8 dm. high, corymbosely branched above, glandular-pubescent, loosely tomentose above; leaves numerous, lanceolate to linear, white-tomentose beneath, 5-10 $\mathrm{cm}$. long; heads numerous; involucres hemispheric, glabrous, about $5 \mathrm{~mm}$. high; bracts ovate or the inner lanceolate, all acute, white or straw-colored, turning rusty. G. decurrens Ives, not L. G. Ivesii Nels. \& Macbr. Open ground: N.S.-Pa.N.M.-Ariz.-B.C. Plain-Submont. J-S.

9. G. palustre Nutt. A low spreading annual; stem at first erect, later diffusely branched, with spreading branches, 5-20 $\mathrm{cm}$. high; leaves 1-2 $\mathrm{cm}$. long; involueres 3-4 $\mathrm{mm}$. high; bracts oblong to linear, brown, or the inner with white tips. Wet places: Alta.-Neb.-N.M.-Calif.-B.C. Plain-Submont. My$\mathrm{Au}$.

10. G. uliginosum L. Annual; stem at first simple, erect, later diffusely branched, with ascending or spreading branches, 5-20 cm. long; leaves 2-4 cm. long, 3-4 mm. wide; bracts oblong to linear, mostly acute, brown. Wet places: Newf.-Va.-Colo.-Utah-Ore.-B.C.; n Eu. Plain-Mont. J1-Au.

11. G. exilifolium A. Nels. Low annual; stem branching at the base; branches decumbent or adsurgent, $8-12 \mathrm{~cm}$. long, sparingly floccose; leaves 2-4 $\mathrm{cm}$. long; involucres about $3 \mathrm{~mm}$. high; bracts lanceolate, acute, brown below, white-tipped. G. angustifolium A. Nels., not Lam. Wet places: Colo.-Wyo. Submont.-Mont. Jl-S.

12. G. Grayi Nels. \& Macbr. Strict and simple annual; stem 1-3 dm. high, appressed-tomentose; leaves all linear, appressed-tomentose, 1-4 $\mathrm{cm}$. long; involucres about $3 \mathrm{~mm}$. long; bracts oblong to linear, wholly brown, or the innermost with lighter tips, obtuse. G. strictum A. Gray, not Moench. Wet places: Wyo. -N.M.-Ariz. Submont.-Mont. Au-S.

13. G. ustulatum Nutt. Perennial, with a short rootstock; stem 1-3 dm. high, loosely floccose; leaves $2-8 \mathrm{~cm}$. long, rather loosely floceose on both sides, white beneath, greener above; glomerules of the heads arranged in a narrow dense spike-like panicle; involucres about $5 \mathrm{~mm}$. long; bracts ovate, abruptly short-cuspidate, brown, shining. Closely related to G. purpureum of the Atlantic States. In saline soil: B.C.-Mont.-Calif. Ap-Jl.

\section{ADENOCAÙLON Hook.}

Perennial herbs, with rootstocks. Leaves alternate, with winged petioles and dilated blades. Inflorescence panieulate, the peduncles beset with stalked glands. Heads many-flowered, discoid. Involucres turbinate of few thin herbaceous bracts. Marginal flowers pistillate, 4-lobed or somewhat 2-lipped. Central flowers hermaphrodite, sterile, broadly funnelform, deeply 4-5-cleft, all white. Anther sagittate and the auricles minutely caudate. Achenes obovoid or clavate, very obtuse, with stipitate glands above. Pappus none.

1. A. bicolor Hook. Stem erect, 3-10 dm. high, more or less floceose; leafblades deltoid-cordate, $5-10 \mathrm{~cm}$. long, sinuate-dentate or somewhat lobed, soon green and glabrate above, densely white-tomentose beneath; involucres 2.5-3 $\mathrm{mm}$. high, turbinate; bracts 4 or 5, ovate, acute, reflexed in fruit; achenes 4-6, 
clavate, 7-8 mm. long. Damp woods: B.C.-Calif--Mont.-Lake Superior. Mont. Je-Au.

\section{MELAMPÓDIUM L.}

Annuals or perennial herbs or shrubs. Leaves opposite, often narrow, entire, toothed or pinnatifid. Heads radiate. Involueres double, the outer of 4-5, partially united flat bracts, the inner of a series of bracts, each embracing an achene, and deciduous with it. Receptacle convex or conic. Ray-flowers in one series, pistillate, white or yellow. Disk-flowers hermaphrodite, but sterile. Anthers entire at the base. Achenes broadened upwards, somewhat incurved. Pappus wanting.

1. M. leucanthum T. \& G. Perennial, with a taproot and short caudex; stems several, branched below, 1-3 dm. high, cinereous-strigose; leaves linear or the lower oblanceolate, 3-5 cm. long, entire or sinuately lobed; involucres about $5 \mathrm{~mm}$. high and fully $1 \mathrm{~cm}$. broad, cinereous; ligules white, about $1 \mathrm{~cm}$. long and $5 \mathrm{~mm}$. wide. Dry plains: Tex.-Colo-Ariz. Plain-Submont. $\mathrm{Mr}-\mathrm{O}$.

\section{Sílphium L. Rosinweed, Compass Plant.}

Large perennial herbs, often with resinous sap. Leaves alternate. Heads radiate. Involucres hemispheric or campanulate; bracts broad, in few series. Receptacle flat, with numerous paleae. Ray-flowers pistillate, in 2 or 3 series, fertile; ligules yellow, rarely white. Disk-flowers hermaphrodite but sterile; corollas yellow. Anthers 2-toothed at the base or entire. Achenes flat and broad, 2-winged, notched at the apex. Pappus wanting or of 2 small awns.

1. S. integrifolium Michx. Stem 8-15 dm. high, rough-pubescent, 4angled; leaves mostly sessile, ovate to lanceolate, entire or dentate, 7-12 cm. long, scabrous; involucre $1-1.5 \mathrm{~cm}$. high; bracts triangular-ovate to lanceolate, acute, or the inner obtuse; ligules $15-23$, yellow, 2-3 cm. long. RosinweED Prairies: Mich.-Miss.-Tex.-Colo.-Minn. Plain. Au-S.

\section{ENGELMĀNNIA T. \& G.}

Perennial herbs, with alternate pinnatifid leaves. Heads radiate. Involucres hemispheric, or campanulate; bracts of 2 or 3 series, the outer narrow, the inner broad. Receptacle flat, chaffy. Ray-flowers 8-10, pistillate, fertile; ligules yellow. Disk-flowers hermaphrodite, but sterile, partly embraced by the paleae. Anthers 2-toothed at the base. Achenes flat, broader upwards, 1-ribbed on each side. Pappus an irregular crown.

1. E. pinnatifida T. \& G. Stem 3-7 dm. high, hirsute or hispid; leaves 5-15 $\mathrm{cm}$. long, pinnatifid, the upper sessile; outer bracts linear, the middle ones suborbicular, with linear tips, and the inner oval or obovate, ciliate; ligules 8-10, golden yellow, $1 \mathrm{~cm}$. long. Plains and hillsides: La.-Kans.-Colo.-Ariz. Son.

\section{BOLŌPHYTA Nutt.}

Acaulescent cespitose herbs. Leaves all basal, crowded, entire. Heads solitary, subsessile among the leaves, discoid. Involucres hemispheric; bracts few, broad, in about 2 series, herbaceous. Marginal flowers pistillate, few, without ligules; corollas truncate at the apex. Central flowers hermaphrodite and sterile, their corollas tubular-funnelform; anthers entire at the base; styles dilated, truncate and pubescent at the summit. Pappus a pair of oblong-lanceolate membranous scales.

1. B. alpina Nutt. Tufted, subacaulescent perennial, with a cespitose caudex, 2-5 cm. high; leaves basal, crowded, silvery-canescent, spatulate-linear, 2-3 cm. long, entire; heads solitary, subsessile, $7-8 \mathrm{~mm}$. wide. Parthenium alpinum A. Gray. Among rocks: Wyo. Submont.

\section{PARTHËICE A, Gray.}

Annual herbs, with alternate leaves. Heads paniculate, discoid. Involucres hemispheric, double, the outer of 5 somewhat herbaceous broad bracts, the inner of 6-8 somewhat larger orbicular bracts more or less searious, and subtending the 
pistillate flowers. Receptacle convex, with a series of linear-oblong or spatulate paleae, subtending the outer series of the central flowers. Marginal flowers 6-8, pistillate and fertile, with an obliquely cleft corolla-tube. Central flowers hermaphrodite but sterile, 40-50, with funnelform corollas. Anthers entire at the base. Achenes oblong-obovate, glabrous, wingless, but acutely angled; with an incurved apiculation. Pappus wanting.

1. P. mollis A. Gray. Annual, with the odor of Artemisia; stem 1-2 m. high, paniculately branched; leaf-blades rhombic-ovate or the lower subcordate, 8-15 cm. long, acuminate, sinuately and often doubly dentate, cinereous-puberulent; involucres hemispheric, $3 \mathrm{~mm}$. high and 4-5 mm. broad; corollas greenish white. Hillsides along streams: s Colo.-N.M.-Ariz. Son. Au-S.

\section{CRASSÌNA Scepin.}

Annual or perennial herbs or shrubby plants. Leaves opposite, commonly narrow, entire or sparingly toothed. Heads radiate. Involucres campanulate to nearly cylindric; bracts in 3-5 series, firm, appressed, rather dry. Receptacle conic to nearly cylindric, chaffy. Ray-flowers pistillate, fertile; their ligules red, purple, or yellow, or variegated, in ours yellow, persistent and becoming papery. Disk-flowers hermaphrodite, fertile, enveloped in the paleae. Achenes various, those of the rays 3-angled, those of the disk-flowers flattened. Pappus of one to several teeth or awns, or lacking. [Zinnia L.]

Ligules large, much longer than the disk.

Ligules scarcely longer than the disk.

1. C. grandiflora.

2. C. anomala.

1. C. grandiflora (Nutt.) Kuntze. Perennial, with a woody root and short caudex; stem 1-2 dm. high, branched, puberulent; leaves linear, more or less distinctly 3-nerved, impressed-punctate, scabrous-hispidulous, $2-3 \mathrm{~cm}$. long; heads solitary, short-peduncled; involucres 6-9 mm. high; ligules yellow, turning whitish, 12-15 mm. long; disk-corollas dark brick-red. Zinnia grandiflora Nutt. Plains: Tex.-Kans.-Colo.-Ariz. Son.-Submont. My-S.

2. C. anomala (A. Gray) Kuntze. Perennial, with a woody rootstock and short caudex; stems numerous, 1-1.5 dm. high, puberulent; leaves linear, 2-3 $\mathrm{cm}$. long, one-nerved or 3-nerved at the base, punctate and hispidulous-scabrous; involucres fully $1 \mathrm{~cm}$. high, $5-7 \mathrm{~mm}$. broad; ligules short and rounded, $5 \mathrm{~mm}$. long or less, yellow or orange, often lacking; disk dark brick-red. Plains: Tex.Colo.-n Mex. Son. Ap-Au.

\section{HELIÓPSIS L. OX-EYE.}

Perennial or rarely annual, leafy-stemmed herbs. Leaves opposite, petioled, toothed. Heads radiate, corymbose or solitary. Involueres hemispheric or campanulate; bracts nearly equal, in 2-3 series, the outer herbaceous. Receptacle conic or convex, chaffy. Ray-flowers pistillate, fertile, with oblong yellow ligules, more or less persistent on the fruit. Disk-flowers numerous, hermaphrodite, fertile, enveloped by paleae. Stigmas with short conic hirsute appendages. Achenes 3-4-angled, truncate. Pappus none or reduced to a short, 1-4-toothed annular border.

1. H. scabra Dunal. Perennial, with a short crown and a fascicle of fibrous roots; stem 5-15 dm. high, more or less hispidulous-scabrous; leaf-blades ovate or subcordate, $5-10 \mathrm{~cm}$. long, scabrous-hispidulous, strongly veined, triplenerved, coarsely dentate; involucres $8-12 \mathrm{~mm}$. high, $15-25 \mathrm{~mm}$. broad, canescent; bracts oblong, obtuse, in 2 series, the outer usually longer; ligules $15-25$ $\mathrm{mm}$. long. Dry soil and river banks: Me.-N.Y.-N.M.-B.C. Plain-Submont.

\section{BRAUNËria Neck. Purple Cone-Flower.}

Perennial caulescent herbs. Leaves mostly alternate, entire or toothed. Heads radiate, solitary or few, mostly long-peduncled. Involucres rather flat; bracts in 2-4 series, narrow, herbaceous, squarrose. Receptacle hemispheric, chaffy. Ray-flowers several, neutral, with rudimentary styles; ligules spreading 
or drooping, purple or rose, seldom yellow or white. Disk-flowers hermaphrodite, fertile. Paleae awned, surpassing the flowers, persistent. Achenes acutely 4-angled. Styles with acute or obtuse, hispid appendages. Pappus a crown produced into a small tooth at each angle. [Echinacea Moench.]

1. B. angustifolia (DC.) Heller. Perennial, with a taproot; stem 3-6 dm. high, erect, hispid; lower leaves petioled, the upper subsessile; blades lanceolate to nearly linear, 3-ribbed, scabrous-hispidulous; involucres about $1 \mathrm{~cm}$. high, 2-3 $\mathrm{cm}$. wide; bracts lanceolate, hispid; ligules about $2-2.5 \mathrm{~cm}$. long, light purple, spreading. E. angustifolia DC. Prairies: Sask,-Minn.-Tex.-Colo.-Mont. Plain. Je-Au.

\section{GYMNOLÒMIA H.B.K.}

Annual or perennial, caulescent herbs, or rarely shrubby plants. Leaves alternate or opposite, narrow, entire or toothed. Heads radiate, corymbose or paniculate. Involucres hemispherical; bracts narrow, herbaceous, in 2-3 series. Receptacle more or less conic, chaffy; paleae strongly concave or conduplicate, enclosing the disk-flowers. Ray-flowers neutral; ligules yellow. Disk-flowers hermaphrodite, fertile; corollas yellow or brownish. Achenes 4-angled, sometimes somewhat flattened, truncate. Pappus a denticulate crown or wanting.

Perennials.

Leaves lanceolate; caudex thick, lignescent.

Leaves linear; caudex slender.

Annuals; leaves linear.

Plant finely strigose.

Plant hispid.

1. G. multiflora.

2. G. linearis.

1. G. multiflora (Nutt.) Benth. \& Hook. Perennial, with a taproot; stems several, 2-12 dm. high, striate and strigose; leaves lanceolate or linear-lanceolate, acutish, or some oblong and obtuse, 4-7 cm. long, 4-20 mm. wide, finely scabrouspuberulent; involucres $12-15 \mathrm{~mm}$. broad; bracts linear-lanceolate, hirsute; ligules golden yellow, 10-15 mm. long; achenes smooth. Prairies and banks of streams: Mont.-N.M.-Calif.-Ida. Plain-Mont. J-S.

2. G. linearis Rydb. Perennial, with a rootstock or slender caudex; stem 3-4 dm. high, terete, strigose; leaves narrowly linear, 3-4 cm. long, 2-4 mm. wide, entire, hirsutulous, sparingly hispid-ciliate at the base; involucres about $6 \mathrm{~mm}$. high, 12-15 mm. broad; bracts linear-lanceolate, canescent-strigose; ligules 10-12 $\mathrm{mm}$. long, 3-4 mm. wide. Sandy soil: sw Utah. L. Son.

3. G. annua (M. E. Jones) Robins. \& Greenm. Annual, with a taproot; stem branched from the base, 3-5 dm. high, copiously branched above; leaves linear, somewhat canescent, 4-7 cm. long, 2-3 mm. broad, those of the branches smaller; involucres $5 \mathrm{~mm}$. high, 7-10 mm. broad; ligules yellow, 4-8 mm. long. G. multiflora annua M. E. Jones. Dry regions: Tex.-se Utah-Ariz.; n Mex. L. Son. $\mathrm{S}-\mathrm{N}$.

4. G. ciliata (Robins. \& Greenm.) Rydb. Annual, with a slender taproot, usually branched from the base; stem 3-5 dm. high, sparingly hirsute; leaves linear, green, conspicuously hirsute-ciliate throughout; involucres about $5 \mathrm{~mm}$. high, 8-10 mm. broad; bracts linear-lanceolate, hirsute-ciliate on the margins and midvein; ligules golden yellow, about $8 \mathrm{~mm}$. long. G. hispida ciliata Robins. \& Greenm. Dry regions: N.M. $\rightarrow \mathrm{s}$ Utah $-\mathrm{s}$ Calif. L. Son.

\section{RUdBÉCKIA L. Cone-flower, Golden Glow, Nigger-heads.}

Perennial, or rarely annual or biennial, caulescent herbs. Leaves alternate, entire, toothed, or pinnatifid, petioled or sessile. Heads radiate or discoid, manyflowered. Involucres hemispheric; bracts imbricate in 2 or more series, more or less foliaceous, loose and spreading. Receptacle convex, conic, or in fruit cylindric, chaffy; paleae not spinescent. Ray-flowers neutral; ligules yellow, or partly or rarely wholly brown-purple or crimson, or none. Disk-flowers hermaphrodite, fertile; corollas with a short but manifest tube, 5-lobed. Style-branches with blunt or subulate pubescent tips. Achenes 4-angled, obtuse or truncate. Pappus a 4-toothed crown, a low border, or wanting. 
Heads radiate; disk in fruit spherical or oblong.

Leaves entire or merely toothed; plant hispid.

1. R. hirta.

Leaves except the uppermost 3-5-cleft or pinnatifid; plant glabrous or nearly so.

Heads discoid; disk in fruit cylindraceous.

Leaves pinnately parted.

Leaves undivided, toothed or entire.

2. R. ampla.

1. R. hirta L. Perennial; stem erect, usually straw-colored, $3-5 \mathrm{dm}$. high, usually purple-dotted, hirsute; lower leaves long-petioled; blades oblong-lanceolate or oblanceolate, $5-10 \mathrm{~cm}$. long, entire or remotely denticulate, obtuse, 3ribbed, hirsute; upper stem-leaves linear and subsessile; peduncles $5-15 \mathrm{~cm}$. long; involucres $15-18 \mathrm{~mm}$. high, 3-3.5 $\mathrm{cm}$. broad; bracts oblong-linear, hispid; ligules yellow, $1.5-3 \mathrm{~cm}$. long. R. flava T. V. Moore. Hillsides and plains: Que.-Fla.Neb.-Colo.-B.C. Plain-Mont. Jl-Au.

2. R. ampla A. Nels. Perennial, with a rootstock and thick crown; stem 1-2 m. high, glabrous, striate, branched above; basal leaves large, long-petioled, pinnately 3-7-divided; divisions ovate or lanceolate, 2-3-cleft, and coarsely serrate, glabrous and slightly paler beneath, somewhat hairy above; upper stemleaves 3-parted or entire, toothed, acuminate; involucre about $1 \mathrm{~cm}$. high and $3 \mathrm{~cm}$. wide; bracts very unequal, oblong or ovate-oblong, mostly obtuse, reflexed in age, 8-12 mm. long; ligules 3-5 cm. long, 8-15 mm. wide; disk ovoid in fruit; pappus coroniform, sometimes 4-toothed. Closely allied to the eastern R. laciniata L. Wet places: Sask.-N.M.-Ariz.-Ida. Plain-Mont. J1-Au.

3. R. montana A. Gray. Perennial; stem 1-2 m. high, glabrous; lower leaves 2-3 dm. long, petioled, pinnately parted into 3-9 oblong-lanceolate divisions, glabrous, ciliolate on the margins; upper stem-leaves ovate or lanceolate, acuminate, entire; peduncles $3 \mathrm{dm}$. long or more; involucral bracts linear, foliaceous, acute, 2-4 cm. long; disk cylindric, at length 5-6 cm. long, purplish black; pappus coroniform. Mountains: Colo. Mont. Jl.

4. R. occidentalis Nutt. Perennial; stem 5-20 dm. high, glabrous, striate; leaves ovate or ovate-lanceolate, acuminate, entire or dentate, the upper sessile with a cordate base, the lower with winged petioles, more or less hairy; peduncles 1-3 dm. long; bracts oblong or lanceolate, 1-2 cm. long; disk brownish black, oblong, becoming 3-5 cm. long; pappus coroniform. Shaded banks: Mont.Wyo.-Utah-e Calif.-Wash.' Nigger-Heads. Submont.-Mont. Jl-S.

\section{RATIBİDA Raf. CONE-FLOWER.}

Annual, biennial, or perennial caulescent herbs. Leaves alternate, pinnatifid with narrow divisions. Heads radiate, long-peduncled. Involucres manyflowered, rather flat. Ray-flowers neutral; ligules yellow, or partly brown at the base, rarely wholly brown-purple, spreading or drooping. Disk-flowers hermaphrodite, perfect, usually enveloped by the paleae; corollas gray or yellowish, almost without a tube. Style-branches with blunt or lanceolate tips. Achenes flattened, broad-margined or winged, deciduous with the scale. Pappus 1 or 2 teeth, or wanting. [Lepachys Raf.]

Disk in fruit oblong, about $1 \mathrm{~cm}$. long; pappus of 1-2 awn-like teeth, without intermediate squamellae.

Disk in fruit cylindraceous, $2-4 \mathrm{~cm}$. long; pappus with a series of squamellae.

2. R. columnifera.

1. R. Tagetes (James) Barnh. Perennial, with taproot; stems several, branched, 2-4 dm. high, grayish-strigose; leaves pinnately divided, with 3-7 linear divisions, hispidulous; heads rather short-peduncled; bracts reflexed, oblong, 3-5 mm. long; ligules $7-10 \mathrm{~mm}$. long; receptacle about $1 \mathrm{~cm}$. high in fruit. L. Tagetes A. Gray. Plains: Tex.-Kans.-Colo.-Ariz. Plain-Submont. J1$\mathrm{Au}$.

2. R. columnifera (Nutt.) Woot. \& Standl. Perennial, with a taproot; stems often several, 3-6 dm. high, hispidulous-strigose, angled; leaves pinnately divided, hispidulous; divisions of the stem-leaves 5-9, oblong to linear, entire or rarely 2-3-cleft; heads long-peduncled; involueral bracts oblong, 5-8 mm. long, soon spreading; ligules yellow or in the variety pulcherrima partly or wholly 
brown-purple, 1-3 cm. long; receptacle in fruit 2-4 $\mathrm{cm}$. long. $L$. columnaris (Sims) T. \& G. Plains: Sask.-Tenn,-Tex.-Ariz.-B.C. Plain-Submont. My-S.

\section{GALINSOGA R. \& P.}

Annual leafy-stemmed herbs. Leaves opposite, petioled, toothed. Heads radiate, small. Involucre campanulate or hemispheric; bracts imbricate in 2 series, thin. Receptacle conic, chaffy. Ray-flowers few, pistillate, fertile; ligules short, white. Disk-flowers hermaphrodite, fertile. Anthers sagittate at the base. Style-branches with acute appendages. Achenes 4-5-angled or those of the rays slightly flattened. Pappus of the ray-flowers of several bristles or wanting, that of the disk-flowers of lacerate or fimbriate squamellae.

1. G. parviflora Cav. Stem 1-7 dm. high, branched; leaf-blades hispidulous or glabrous, ovate or ovate-lanceolate, $2-5 \mathrm{~cm}$. long, dentate or undulate; involucre 2-2.5 $\mathrm{mm}$. high; bracts ciliate, ovate; ligules 4 or 5 , only $1-1.5 \mathrm{~mm}$. long; pappus-squamellae in the disk-flowers 8-15. Waste places: Mass.-Ga.-Mex. -Ore.; nat. from S. Am.

\section{BALSAMORRHİZA Hook. BALSAM-ROOT.}

Low perennials, with almost scapose stems, numerous petioled basal leaves, and a thick edible root, its bark exuding a terebinthine balsam. Involucre mostly hemispherical; bracts in several series, more or less foliaceous, especially the outer ones. Receptacle almost flat, beset with concave paleae, which loosely embrace the disk-flowers. Ray-flowers present, fertile; ligules yellow. Diskflowers hermaphrodite, fertile. Anthers not caudate. Style-branches with filiform or slender subulate hispid appendages. Achenes mostly glabrous, those of the disk-flowers quadrangular with intermediate nerves, those of the rayflowers flattened. Pappus none.

Leaves entire or bluntly toothed, never pinnatifid.

Plant white-tomentose.

Leaves with entire margins or slightly undulate, oblong-cordate to hastate.

1. B. sagittata.

Leaves more or less distinctly toothed, ovate-lanceolate, with subcordate base.

Plant hirsute-puberulent; basal leaves cordate.

Ligules linear, deciduous; achenes glabrous.

2. B. tomentosa.

Ligules oval, becoming papery, and more or less persistent; ache

Leaves mostly pinnatifid or at least incisedly toothed.

B. deltoidea.

Plant canescent or white-tomentose.

Plants loosely white-tomentose.

Stem 1-3 dm. high; segments of the leaves $1-3 \mathrm{~cm}$. long, ovate, entire or slightly toothed.

5. B. incana.

Stem $3 \mathrm{dm}$. or more high; segments of the leaves $3-5 \mathrm{~cm}$. long, lanceolate, coarsely toothed.

6. B. floccosa.

Plant finely canescent, tomentose only on the involucre; some of the leaves merely toothed.

Plants more or less hispid, neither canescent nor tomentose.

Disk 3-4 cm. broad; segments of the leaves mostly entire.

Disk 2-2.5 cm. broad; segments of the leaves mostly toothed. 9 . B. hirsuta.

1. B. sagittata (Pursh) Nutt. Leaves mostly basal, long-petioled; blades from cordate to hastate or sagittate, mostly entire, white-tomentose on both sides, 1-2 dm. long; peduncles 3-5 dm. high, tomentose; involucres floccose, about 2 $\mathrm{cm}$. high and $2.5 \mathrm{~cm}$. broad; bracts lanceolate or linear-lanceolate, usually all appressed; ligules 2-3 cm. long, 8-10 mm. broad, oblong. Hillsides: Sask.-S.D. -Colo.-Calif.-B.C. Submont.-Mont. Ap.

2. B. tomentosa Rydb. Basal leaves with long petioles; blades about 12 $\mathrm{dm}$. long, ovate-lanceolate, with subcordate bases, $15-20 \mathrm{~cm}$. long, acute, coarsely toothed; stem 3-4 dm. high; involucre densely floccose, over $2 \mathrm{~cm}$. broad; outer bracts usually half longer than the inner, and reflexed; ligules about $3 \mathrm{~cm}$. long and $1 \mathrm{~cm}$. wide. Hills: Wyo. Submont.-Mont. J-Au.

3. B. deltoidea Nutt. Basal leaves numerous, long-petioled; blades cordate, hastate or deltoid, green, more or less pubescent, but not tomentose, 8-15 $\mathrm{cm}$. long and almost as wide, coarsely dentate-crenate or sinuate or entire; heads 
1-3; involucres $1.5-3 \mathrm{~cm}$. high, slightly tomentose; bracts lanceolate, the outer foliaceous, exceeding the disk; ligules $2-4 \mathrm{~cm}$. long, 4-8 mm. wide. Hills: B.C.Ida.-Calif. Submont. Ap-Je.

4. B. Careyana A. Gray. Basal leaves long-petioled; blades cordate, entire, somewhat grayish scabrous-puberulent, subcoriaceous, reticulate, $1-1.5 \mathrm{dm}$. long; involucres 10-15 mm. high; bracts oblong-lanceolate or a few of the outer lanceolate and longer, all firm and puberulent; ligules broadly oval, $15-18 \mathrm{~mm}$. long, 8-9 mm. wide, becoming papery and persistent; style-branches of the diskflowers subulate and very hispid; achenes pubescent. Sandy plains: Ida.-Wash. Son. My.

5. B. incana Nutt. Leaves all basal, 1-1.5 dm. long, short-petioled, tomentose, pinnately divided into ovate, entire or slightly toothed divisions $1-3 \mathrm{~cm}$. long; scape 1-2 dm. high; involucre floccose, 15-20 mm. high, 20-25 mm. broad; bracts lanceolate, appressed or the outer with spreading tips; ligules $2-2.5 \mathrm{~cm}$. long, about $5 \mathrm{~mm}$. wide. Dry hills: Wash.-Mont.-Wyo.-Calif. PlainSubmont. My-Jl.

6. B. floccosa Rydb. Leaves mostly basal, floccose on both sides, 2-3 dm. long, regularly pinnately divided to near the midrib or some sometimes only coarsely toothed; segments lanceolate, acute, $3-5 \mathrm{~cm}$. long, coarsely toothed; stem scapiform, 3-5 dm. high, villous, the upper portion densely floccose; involucre about $3 \mathrm{~cm}$. broad; bracts numerous in several series, lanceolate, the outer often spreading with recurved tips; ligules $3-4 \mathrm{~cm}$. long, about $1 \mathrm{~cm}$. wide. Hillsides: Mont.-Wyo.-Ida. Plain-Mont. My-Jl.

7. B. terebinthacea (Hook.) Nutt. Leaves mostly all basal, short-petioled; blades 1-2 dm. long, lanceolate in outline, some of them only incised-toothed, others pinnately divided, hirsutulous-pubescent or glabrate; scape 1-3 dm. high; involucre $15-20 \mathrm{~mm}$. high; bracts lanceolate, almost equal. In stony grounds and open woods: Ida.-Wash.-Ore. Submont. My-Je.

8. B. macrophylla Nutt. Stem 4-6 dm. high, sparingly villous-hirsute; basal leaves $2-5 \mathrm{dm}$. long, petioled, most of them pinnately divided into lanceolate divisions, but some occasionally only toothed; involucre $25 \mathrm{~mm}$. high and 2.5-4 cm. broad; bracts linear-lanceolate, loose and the outer reflexed; ligules 3-5 $\mathrm{cm}$. long, about $1 \mathrm{~cm}$. wide. On dry hillsides: Utah-Wyo. Submont. My-Je.

9. B. hirsuta Nutt. Stem scapiform, sparingly villous-hirsute; leaves short-petioled, lanceolate in outline, pinnately divided; divisions ovate or lanceolate, coarsely toothed or again pinnatifid, strongly veined and rigid; involucre about $1.5 \mathrm{~cm}$. high and $2 \mathrm{~cm}$. broad; bracts linear-lanceolate, spreading, hirsute; ligules 15-20 mm. long, 4-6 mm. wide. On dry ground: Utah-B.C.-Calif. Submont. My-Je.

\section{WYËTHIA Nutt. Mule-ears.}

Stout and low perennial herbs, with thick taproot, balsamic juice, and alternate, commonly entire, pinnately veined leaves. Heads solitary or few. Involucres hemispheric or flat; bracts more or less imbricate, the outer often foliaceous. Ray-flowers pistillate and fertile; ligules yellow. Disk-flowers hermaphrodite and fertile; styles with slender, subulate hispid appendages. Paleae of the receptacle lanceolate, partly embracing the achenes. Achenes prismatic, 4-angled, somewhat flattened in the disk-flowers, or 3-angled in the ray-flowers. Pappus a lacerate chaffy crown or of almost distinct squamellae.

Involucral bracts nearly equal, in 2-3 series; stem not white.

Rays pale yellow or white; plant hispid.

Rays bright yellow.

Plant glabrous.

Plant pubescent.

Plant sparingly hirsute or scabrous.

Plant densely pubescent.

Involucral bracts unequal, the outer much shorter, in 5-6 series; stem white.

\section{W. helianthoides.}

2. W. amplexicaulis.

3. W. robusta.

4. W. arizonica

5. W. scabra.

1. W. helianthoides Nutt. Stem 2-4 dm. high, more or less hirsute; leaves with margined petioles, more or less hirsute; blades of the basal leaves oval or 
elliptic, 1-2 dm. long, those of the stem-leaves oblanceolate; heads solitary; involucre $2-2.5 \mathrm{~cm}$. high, $5-6 \mathrm{~cm}$. broad; bracts numerous, linear-lanceolate, acute or acuminate, hirsute-ciliate on the margins and back; ligules $2-4 \mathrm{~cm}$. long; pappus coroniform or cleft into several teeth. Hills: Mont.-n Wyo.-Ore.-Wash. Submont. Мy-Л.

2. W. amplexicaulis Nutt. Stem 3-6 dm. high, glabrous; basal leaves petioled, 3-4 dm. long; blades oblong, elliptic or lanceolate, denticulate or entire, glossy, reticulate, glabrous; upper stem-leaves lanceolate or ovate, sessile or somewhat clasping; involucres $2 \mathrm{~cm}$. high, 2-4 cm. wide; bracts rather few, broadly lanceolate, acute, glabrous, firm; ligules $3-4 \mathrm{~cm}$. long; pappus coroniform, but cleft into distinct teeth. Moist valleys: Mont.-Colo.-Utah-Ore. -B.C. Submont.-Mont. My-Au.

3. W. robusta Nutt. Stem decumbent at the base, 3-4 dm. high, sparingly hirsute; basal leaves 2-3 dm. long, short-petioled; blades oblanceolate, acute, sparingly hirsutulous or scabrous; stem-leaves lanceolate and sessile; involucres 1.5-2 cm. high, 3-4 cm. broad; bracts lanceolate, hirsute-ciliate on the margins and back; ligules 3-4 cm. long; pappus of a toothed crown and 1-4 stout awns. Valleys: Wash.-Ida.-Calif. Son. My-Jl.

4. W. arizonica A. Gray. Stem 3-5 dm. high, rather copiously hirsutevillous; basal leaves $2-4 \mathrm{dm}$. long, petioled; blades oblanceolate or oblong-oblanceolate, densely pubescent; upper stem-leaves sessile, ovate or lanceolate; involueres about $2 \mathrm{~cm}$. high, 3-4 cm. wide; bracts oblong-lanceolate, acute, hirsute and finely puberulent; ligules $3-5 \mathrm{~cm}$. long; crown of pappus with teeth, and 1 or 2 awns. Mountains, along streams: N.M.-Colo.-Utah-Ariz. Submont. $\mathrm{My}-\mathrm{Au}$.

5. W. scabra Hook. Stem leafy, hispidulous-scabrous, soon turning strawcolored or white; leaves linear, very scabrous, 5-8 cm. long, 6-12 $\mathrm{mm}$. wide; involucres about $2 \mathrm{~cm}$. high and $3 \mathrm{~cm}$. broad; bracts linear-subulate, attenuate, hispid-ciliate and hirsute; ligules $2.5-4 \mathrm{~cm}$. long; pappus of 3-4 blunt teeth. Dry plains: Wyo.-N.M.-Utah. Son.-Submont. Je-S.

\section{3. heliánthus L. Sun-Flower, Ground Artichoke.}

Erect, mostly branched annuals or perennials, with simple leaves and large, peduncled, corymbose or solitary heads. Involucre hemispherical or depressed; its bracts imbricated in several series. Receptacle flat or convex, rarely conic, with paleae subtending the disk-flowers. Ray-flowers neutral; ligules yellow, spreading, mostly entire. Disk-flowers perfect, fertile; their corollas tubular, yellow, brown or purple. Anthers entire or minutely 2-toothed at the base. Style-branches with hirsute appendages. Achenes more or less 4-angled and somewhat compressed. Pappus of 2 scales or awns, sometimes with a few additional smaller intermediate ones, deciduous.

Annuals; leaves broad, ovate or cordate or lanceolate; disk purple or dark brown.

Bracts ciliate, hispid, ovate or obovate, abruptly acuminate.

Lower leaves at least ovate or cordate, distinctly toothed.

Leaves lanceolate or narrowly deltoid, minutely toothed or entire.

Bracts not ciliate, canescent-strigose, lanceolate.

Perennials.
Disk dark brown or purple.

Disk dark brown
Leaves linear.

Leaves rhombic-ovate.

Disk yellow or light brownish.

Bracts broadly lanceolate, acute, appressed.

Bracts narrowly lanceolate, acuminate, 6 . pumilus. Leaves ovate. Leaves lanceolate.

Leaves rounded or obtuse at the base, subsessile.

Leaves tapering at the base, petioled. Stem more or less scabrous or hispid; upper leaves subsessile.

Leaves and stem very scabrous. 9. H. Maximiliani.

Leaves scabrous above, hirsute beneath; stem more or less hirsute. Upper leaves mostly alternate and indistinctly triple-nerved. 
Leaves usually all opposite, distinctly triple-nerved.

Leaves lanceolate, thick, often toothed, yellowish green, the lower distinctly petioled. 11. H. subtuberosus.

Leaves linear-lanceolate, dark green, entire, all subsessile.

12. H. Cusickii.

Stem, except the upper portion, glabrous and glaucous; leaves mostly all petioled.

Lower leaves coarsely toothed; bracts hirsute ciliate.

13. $H$. grosse-serratus.

All leaves distantly and minutely denticulate or subentire; bracts not ciliate or ciliate merely at the base.

Leaves lanceolate, often somewhat triple-ribbed. Leaves all opposite; bracts ciliate on the margins,

11. $H$. subtuberosus.

Leaves mostly alternate; bracts ciliate only below the middle. 14. H. fascicularis.

Leaves narrowly linear-lanceolate, not triple-ribbed.

15. H. Nuttallii.

1. H. lenticularis Dougl. Stem 1-2 m. high; leaves mostly alternate, the lower long-petioled; blades ovate, 1-2 dm. long, sometimes cordate at the base, dentate, hispidulous-scabrous, the upper more lanceolate, subentire; involucres 1.5-2 $\mathrm{cm}$. high, 4-5 $\mathrm{cm}$. broad; achenes grayish strigose, about $6 \mathrm{~mm}$. long. Closely related to the cultivated $H$. annuus, which has larger, more nodding heads, looser bracts, more salient teeth to the leaves and larger achenes, often $1 \mathrm{~cm}$. long. Plains and alluvial soil, also in waste places and cultivated ground: Sask.-Tex.-Calif.-Wash. Plain-Submont. Je-S.

2. H. aridus Rydb. Stem 3-8 dm. high, more or less hispid; leaves all petioled; blades lanceolate, $4-7 \mathrm{~cm}$. long, entire or crenate, acute, hispid-scabrous on both sides; disk 1.5-2 $\mathrm{cm}$. wide; ligules oblong to oval, $15-20 \mathrm{~mm}$. long, 6-8 $\mathrm{mm}$. wide; achenes cuneate, almost black, finely strigose, about $5 \mathrm{~mm}$. long. Arid soil: Sask.-Neb.-N.M.-Ariz.-B.C. Plain-Submont. Je-S.

3. H. petiolaris Nutt. Stem $3-10 \mathrm{dm}$. high, hirsute-strigose; leaves petioled; blades lanceolate or ovate-lanceolate, mostly cuneate at the base, $5-8 \mathrm{~cm}$. long, hispidulous-scabrous; involucres about $1 \mathrm{~cm}$. high, $2-3 \mathrm{~cm}$. broad; ligules golden yellow, $1.5-2 \mathrm{~cm}$. long; achenes about $5 \mathrm{~mm}$. long, strigose. Dry plains and waste places: Sask.-Mo.-Tex.-Calif.-B.C. Plain-Mont. Je-S.

4. H. orgyalis DC. Stem smooth and glabrous, 5-30 dm. high, very leafy; leaves mostly alternate, narrowly linear, 2-4 dm. long, 4-8 $\mathrm{mm}$. wide, seabrouspuberulent; involucres fully $1 \mathrm{~cm}$. high and about $2 \mathrm{~cm}$. wide; bracts linearsubulate, long-attenuate, eiliolate on the margins; rays $15-18 \mathrm{~mm}$. long. Dry plains: Mo.-Tex.-e Colo. Plain. Au-S.

5. H. subrhomboideus Rydb. Perennial, with a rootstock; stem 3-6 dm. high, terete, tinged with red, sparingly hirsute; leaves opposite; blades firm, very scabrous, triple-veined, serrate, the lower ovate or obovate-spatulate, the upper rhombic-ovate or rhombic-lanceolate, 5-10 $\mathrm{cm}$. long; heads solitary, rarely 2 or 3 ; involucres $10-12 \mathrm{~mm}$. high and $1.5-2 \mathrm{~cm}$. broad; bracts in 4 or 5 series, oblong, acutish, white-ciliolate; ligules about $1.5 \mathrm{~cm}$. long. Plains: Man.-Ark.-N.M. -Alta. Plain-Submont. J-S.

6. H. pumilus Nutt. Perennial, with a woody erown; stem 3-6 dm. high, hispid; leaves opposite, short-petioled; blades ovate or lanceolate, entire or nearly so, acute or obtuse, 3-10 $\mathrm{cm}$. long, very scabrous, hispid on the veins, 3-ribbed; involucres nearly $1 \mathrm{~cm}$. high and about $2 \mathrm{~cm}$. broad; ligules $15-20 \mathrm{~mm}$. long. Plains and mountains: Wyo.-Colo. Plain-Submont. Je-Au.

7. H. tuberosus L. Perennial, with tubers; stem 1-3 m. high, branching at the summit, more or less hirsute; lower leaves usually opposite, the upper alternate, petioled; blades ovate or subcordate, acuminate, firm, 3-ribbed, scabrous above, pubescent beneath, 5-30 $\mathrm{cm}$. long, usually dentate; involucres about $1.5 \mathrm{~cm}$. high, $2-3 \mathrm{~cm}$. broad; bracts lanceolate, attenuate, hirsute at least on the margins; ligules 12-20, 2.5-3.5 cm. long. Alluvial soil: N.S.-Ga.-Ark.Neb.-Sask. Plain. Au-O.

8. H. divaricatus L. Perennial, with a rootstock; stem 3-10 dm. high, simple, smooth below, hispidulous-scabrous above; leaves opposite, subsessile, 
divaricate, lanceolate or elongate-deltoid, $5-15 \mathrm{~cm}$. long, gradually attenuate above, rounded at the base, 3-ribbed, scabrous on both sides; involucres about 1 $\mathrm{cm}$. high and $2 \mathrm{~cm}$. broad; bracts narrowly lanceolate, acuminate, hirsute-ciliate on the margins, hirsutulous on the back; ligules $8-12$, about $2 \mathrm{~cm}$. long. Dry ground: Que.-Fla.-La.-Sask. Plain. Jl-S.

9. H. Maximiliani Schrad. Perennial, with a thick rootstock; stem 5-30 $\mathrm{dm}$. high, scabrous-hispidulous; leaves mostly alternate and subsessile, lanceolate to linear, entire or denticulate, 5-15 $\mathrm{cm}$. long, 1-ribbed, very scabrous on both sides; heads many in a narrow panicle; involucres about $1.5 \mathrm{~cm}$. high and $3 \mathrm{~cm}$. wide; bracts lanceolate-subulate, long-attenuate, strigose-canescent or somewhat hispidulous; ligules golden yellow, $15-30 \mathrm{~mm}$. long. Prairies, plains, and river banks: Man.-Mo.-Tex.-Wyo.-B.C. Plain-Submont.

10. H. giganteus L. Perennial, with a rootstock, some of the roots often becoming fusiform; stem 1-3 m. high, more or less hirsute; leaves lanceolate or oblong-lanceolate, $5-15 \mathrm{~cm}$. long, scabrous above, hirsutulous beneath, shortpetioled or subsessile, serrulate or denticulate, rarely entire; heads in an open panicle; involueres $12-15 \mathrm{~mm}$. high and about $3 \mathrm{~cm}$. broad; bracts linear-lanceolate, attenuate, hirsute-ciliate; ligules pale yellow, $1.5-2 \mathrm{~cm}$. long. Low ground: Me.-Fla.-La.-Colo.-B.C. Plain. Au-S.

11. H. subtuberosus Bourgeau. Perennial, with tubers; stem 3-6 dm. high, glabrous or nearly so; leaves short-petioled, opposite; blades narrowly lanceolate, acute at both ends, finely serrate, scabrous-hispidulous above, hirsutulous beneath, $5-8 \mathrm{~cm}$. long; involucres about $1.5 \mathrm{~cm}$. high, $2.5-3 \mathrm{~cm}$. wide; bracts linear-lanceolate or subulate, attenuate, hirsute, the outer spreading; ligules about $3 \mathrm{~cm}$. long; disk yellow. Valleys and plains: Sask.-Minn.-Wyo. -Mont. Plain. J1-Au.

12. H. Cusickii A. Gray. Perennial, with thick fleshy root; stem 3-6 dm. high, usually several; leaves subsessile, linear-lanceolate, hirsutulous, tripleveined; heads solitary; involucres $12-15 \mathrm{~mm}$. high; bracts linear-lanceolate, attenuate, rather loose, hirsute; ligules about $2.5 \mathrm{~cm}$. long. Dry sandy soil: Ore. -Wash.-Ida.-B.C. Son. My-J.

13. H. grosse-serratus Martens. Perennial; stem 1-3 m. high, glabrous and often purplish; leaves alternate, or some opposite, short-petioled; blades elongate-lanceolate, 1-2.5 dm. long, gradually acuminate, sharply serrate, slightly scabrous above, paler and short-pubescent beneath; heads in an open panicle; involucre about $1.5 \mathrm{~cm}$. high, $2.5-3 \mathrm{~cm}$. wide; bracts linear-subulate, attenuate; ligules golden yellow, $2-3 \mathrm{~cm}$. long. Plains and prairies: N.Y.-Pa. -Tex.-N.M.-Utah-Sask. Plain. Au-S.

14. H. fascicularis Greene. Perennial, with a rootstock and fusiform thickened roots; stem glabrous and somewhat glaucous, $5-10 \mathrm{dm}$. high; leaves alternate or the lower opposite, 7-15 cm. long, short-petioled; blades lanceolate or linear-lanceolate, scabrous on both sides; heads in an open panicle; involueres about $1.5 \mathrm{~cm}$. high and $3 \mathrm{~cm}$. broad; bracts linear-subulate, attenuate; ligules 14-18, deep yellow, $2.5-3 \mathrm{~cm}$. long; disk yellowish brown. H. giganteus utahensis D. C. Eat. $H$. utahensis A. Nels. (?) H. coloradensis Cockerell. Closely related to $H$. subtuberosus and Nuttallii. Mountain valleys: Sask.-N.M.Ariz.-Alta. Plain-Submont. Au-S.

15. H. Nuttallii T. \& G. Perennial; stem glabrous, strict, $3-8 \mathrm{dm}$. high; leaves alternate or opposite, linear or narrowly linear-lanceolate, $5-10 \mathrm{~cm}$. long, entire or denticulate, scabrous-hispidulous on both sides; branches of the panicle erect; involucres about $1.5 \mathrm{~cm}$. high, $2.5 \mathrm{~cm}$. wide; bracts narrowly linear-subulate, attenuate, grayish hirsutulous, sparingly, if at all, ciliate at the base; ligules 2-2.5 cm. long. Dry plains: Alta.-Wyo.-Utah-Ida. Plain. Jl-S.

\section{ENCÈLIA Adans.}

Annual or perennial herbs or shrubby plants, ours shrubs with white branches. Leaves alternate or opposite, mostly ovate. Heads radiate or rarely discoid, peduncled. Involucres hemispheric or flattened. Receptacle convex, chaffy. 
Ray-flowers neutral, yellow, or none. Disk-flowers hermaphrodite, fertile; corollas yellow or brown. Anthers slightly sagittate at the base. Style-branches with elongated pubescent appendages. Achenes flattened, wingless. Pappus wanting (in ours) or a small awn at each angle of the achenes.

Leaves densely white-tomentose.

Leaves hispidulous-canescent.

1. E. farinosa.

2. E. virginensis.

1. E. farinosa A. Gray. Shrub, 5-15 dm. high; leaves petioled; blades ovate, obtuse, $2-5 \mathrm{~cm}$. long, triple-nerved, entire; heads nodding; involueres about 8 $\mathrm{mm}$. high, 1-1.5 $\mathrm{cm}$. wide; bracts lanceolate or linear-lanceolate, sparingly pilose or nearly glabrous, the outer reflexed; ligules 6-10, yellow, 8-12 $\mathrm{mm}$. long; achenes obovoid, with a deep notch. Dry hills: Ariz. - s Utah - s Calif.; Mex. L. Son. N-My.

2. E. virginensis A. Nels. Shrub $3-10 \mathrm{dm}$. high; leaves alternate, shortpetioled; blades broadly rhombic- or deltoid-ovate, triple-nerved at the base, $1-3 \mathrm{~cm}$. long, hispidulous as well as canescent-puberulent; involucres $8 \mathrm{~mm}$. high, 10-15 mm. broad; bracts hirsute-canescent, lanceolate, acute or acuminate; ligules 12-20, deeply 2- or 4-toothed, 15-20 mm. long; achenes linear-cuneate, slightly depressed at the apex, eiliate on the margins. Dry hills: $\mathrm{s}$ Utah $-\mathrm{s}$ Calif. L. Son. Ap-My.

\section{ENCELIÓPSIS (A. Gray) A. Nels.}

Silvery or canescent, often acaulescent scapose perennials. Heads radiate or in an anomalous species discoid. Involucres flat; bracts imbricate in 2-3 series. Receptacle chaffy. Ray-flowers neutral or lacking. Disk-flowers numerous, hermaphrodite and fertile; corollas yellow. Achenes flat, oblongcuneate, villous, with narrow callous margins at the summit, bordered between the short subulate teeth by a short fringe of membranous confluent squamellae.

Plant white-tomentose; heads radiate.

Stem scapiform; leaf-blades orbicular or spatulate; ligules $1-2.5 \mathrm{~cm}$. long.

Stem leafy; leaf-blades rhombic-obovate; ligules $3.5-4 \mathrm{~cm}$. long. Plant hispid-scabrous; heads discoid.

1. E. nudicaulis.

2. E. argophylla.

3. E. nutans.

1. E. nudicaulis (A. Gray) A. Nels. Acaulescent perennial, with a thick caudex; leaves all basal, petioled; blades thick, orbicular or rounded, spatulate, 1-5 $\mathrm{cm}$. long and as broad, 3-5-ribbed; scape naked, 3-5 dm. high; involucre about $1.5 \mathrm{~cm}$. high and $3 \mathrm{~cm}$. wide; bracts lanceolate, white-tomentose; ligules 20 or more, $1-2.5 \mathrm{~cm}$. long; pappus-awns scarcely exceeding the hairs. Helianthella nudicaulis A. Gray. $E$. tuta A. Nels. Dry rocky ridges and alkaline soil: Ida.-Utah-Nev. Son. My-Je.

2. E. argophylla (S. Wats.) A. Nels. Perennial, with short leafy stem; leaves with winged petioles, $5-10 \mathrm{~cm}$. long; blades rhombic-obovate, thick, $3-5$-ribbed; involucres about $1.5 \mathrm{~cm}$. high, $2.5-3 \mathrm{~cm}$. wide; bracts tomentose, ovate-lanceolate, acuminate; ligules about $2.5 \mathrm{~cm}$. long, 3-4 $\mathrm{mm}$. wide; pappus-awns nearly as long as the corolla-tube. Tithonia argophylla S. Wats. Helianthella argophylla A. Gray. Alkaline soil: Nev.-s Utah. L. Son. Ap.

3. E. nutans (Eastw.) A. Nels. Subacaulescent perennial, with an erect woody caudex; leaves basal, petioled, clustered; blades oval or obovate, 3-5ribbed, 2-4 cm. long, hispid-scabrous; heads deflexed in fruit; involucres about 18 $\mathrm{mm}$. high, 2.5-3 cm. broad; bracts lanceolate, densely hispid; pappus none. Encelia nutans East. Verbesina scaposa M. E. Jones. Dry mesas: Colo.-Utah. Son. My.

\section{HELIANTHÉLLA T. \& G.}

Caulescent perennials, with taproots. Leaves alternate or opposite, more or less distinctly triple-ribbed. Involucres hemispheric or flat; bracts more or less imbricate, often foliaceous; receptacles chaffy. Ray-flowers neutral, showy; ligules yellow. Disk-flowers hermaphrodite and fertile; tube of the corollas half as long as the throat; lobes short, ovate, puberulent. Appendages of the stylebranches obtuse, short, spatulate or oblong. Achenes flat, cuneate-obovate, emarginate or obcordate. Pappus of "several squamellae between the awns or paleaceous teeth. 
Paleae of the receptacle soft and scarious.

Disk 2-3 cm. in diameter; leaves ovate to lanceolate, thin, not strongly reticulate.

1. H. quinquenervis.

Disk less than $2 \mathrm{~cm}$. wide; leaves oblanceolate to linear, strongly reticulate.

Disk about $1.5 \mathrm{~cm}$. wide, yellow; bracts linear-lanceolate, subequal, in about 2 series.

Disk about $1 \mathrm{~cm}$. broad, purple; bracts unequal, in 3-4 series.

Ligules 5-6 mm. long.

Ligules more than $1 \mathrm{~cm}$. long.

2. H. Parryi.

Paleae of the receptacle firm-chartaceous.
Stem more or less hirsute, rarely glabr

3. H. microcephala.

4. H. scabra.

Stem more or less scabrous-puberulent; leaves rather firm and reticulate.

6. H. uniflora.

1. H. quinquenervis (Hook.) A. Gray. Stem 5-15 dm. high, glabrous or sparingly hirsute; leaves mostly opposite; blades ovate-lanceolate or ellipticlanceolate, acuminate, $1-2.5 \mathrm{dm}$. long, usually with two pairs of the lateral veins prominent, sparingly hirsute; heads long-peduncled, nodding; involucres about $2 \mathrm{~cm}$. high and 4-5 $\mathrm{cm}$. broad; bracts lanceolate, acuminate, hirsute-ciliate; ligules 15-20, pale yellow, $2.5-3 \mathrm{~cm}$. long. Mountains, along streams: S.D.N.M.-Utah-Ida.-Mont. Submont.-Mont. J1-Au.

2. H. Parryi A. Gray. Stem slender, about $3 \mathrm{dm}$. high, hirsute; the lower leaves opposite, petioled, the upper subsessile, mostly alternate; blades oblanceolate or elliptic, 2-10 $\mathrm{cm}$. long, rigid, triple-veined; heads rather short-peduncled; involucres 10-12 $\mathrm{mm}$. high, 15-20 mm. broad; bracts linear-lanceolate, attenuate, hirsute-ciliate; ligules about $15 \mathrm{~mm}$. long. Mountains: Colo.-N.M.Ariz. Mont. Jl-Au.

3. H. microcephala A. Gray. Stem 2-4 dm. high, paniculately branched, scabrous-hispidulous; leaves ridged, all but the lower alternate; basal leaves petioled, spatulate, scabrous; stem-leaves linear or nearly so, sessile; involucres about $1 \mathrm{~cm}$. high and broad; bracts lanceolate, obtuse, hirsute; ligules 5-6 mm. long. Dry plains and cañons: sw Colo.-Utah-N.M. Son.

4. H. scabra Payson. Stems several, 6-8 dm. high, cymosely branched; leaves dark green, coriaceous, linear-lanceolate to linear, the lower 1.5-2.5 dm. long, petioled; bracts lanceolate, acute; paleae truncate, ciliate at the apex; ligules 8-10, orange, more than $1 \mathrm{~cm}$. long; pappus of two awns and several lacerate squamellae. Ravines: w Colo. Au.

5. H. Douglasii T. \& G. Stem 4-10 dm. high, more or less hirsute or glabrous below; leaves mostly opposite, the lower oblanceolate, petioled, tripleveined, hirsute, $8-12 \mathrm{~cm}$. long, the upper lanceolate, sessile; involucres about $15 \mathrm{~mm}$. high and $3 \mathrm{~cm}$. broad; bracts linear-lanceolate, attenuate, hirsute-ciliate; ligules 2.5-3 cm. long. Hillsides and pine-land: Mont. $-\mathrm{w}$ Wyo.-Ore.-B.C. Submont. Je-Jl.

6. H. uniflora (Nutt.) T. \& G. Stem 3-6 dm. high, puberulent; leaves mostly opposite, petioled or the uppermost sessile, oblong-lanceolate, 5-12 $\mathrm{em}$. long, seabrous, obtuse; involucres $12-15 \mathrm{~mm}$. high, $2.5-4 \mathrm{~mm}$. broad; bracts lanceolate, acute, hirsute-ciliate on the margins; ligules $2-3 \mathrm{~cm}$. long. $H$. multicaulis D. C. Eat. Hills and mountains: Mont.-N.M.-Nev.-Ida. Submont. -Mont.

\section{XIMENÈSIA Cav.}

Annual caulescent herbs, ours canescent. Leaves alternate or sometimes opposite, toothed or lobed. Heads solitary or few, radiate, peduncled. Involucres rather flat; bracts narrow, spreading, foliaceous, nearly equal. Rayflowers pistillate, fertile; ligules yellow. Disk-flowers numerous, hermaphrodite, fertile. Anthers somewhat sagittate at the base. Style-branches with slender pubescent appendages. Achenes flat, winged. Pappus of short awns, without intermediate scales.

1. X. exauriculata (Robins. \& Greenm.) Rydb. Annual, with a taproot; stem $3-6 \mathrm{dm}$. high, white-tomentose; leaf-blades ovate or rhombic-lanceolate, saliently dentate, minutely strigose but green above, densely white-strigose 
beneath, 3-7 cm. long; heads few, paniculate; involucres scarcely $1 \mathrm{~cm}$. high, $1.5 \mathrm{~cm}$. broad; ligules orange, $12-15 \mathrm{~mm}$. long. Verbesina encelioides exauriculata Robins. \& Greenm. Mountain valleys: Mont.-Tex.-Ariz. Son.-Mont. Je-O.

\section{COREÓPSIS L. TICKSEED.}

Annual or perennial herbs. Leaves various. Heads on long peduncles, radiate. Involucres campanulate, their bracts in two series, all more or lesp united at the base, the outer ones usually narrow and foliaceous, the inner broad, variously colored, in ours orange or brown, scarious or with scarious margins. Ray-flowers neutral; ligules yellow. Disk-flowers fertile. Receptacle flat or slightly convex. Achenes flat or more or less convex on the back. Pappus of two fimbriate squamellae, two awns or minute teeth, or none.

Leaves pinnatifid.

Achenes winged.

Achenes wingless.

Leaves simple.

1. C. Atkinsoniana.

2. C. tinctoria.

3. C. lanceolata.

1. C. Atkinsoniana Dougl. Annual or perennial (?), with a taproot; stem 4-10 dm. high, glabrous; leaves opposite, pinnately or bipinnately divided into linear divisions, glabrous; involucres about $6 \mathrm{~mm}$. high, $15 \mathrm{~mm}$. broad; outer bracts oblong, obtuse, the inner broadly ovate; ligules orange, $12-15 \mathrm{~mm}$. long. River banks: B.C.-N.D.-Ore. Plain. Jl-Au.

2. C. tinctoria Nutt. Annual, with a taproot; stem 4-10 dm. high, glabrous; lower leaves bipinnately, the upper ones pinnately divided into linear divisions, glabrous; involucres about $7 \mathrm{~mm}$. high, $10-15 \mathrm{~mm}$. wide; outer bracts oblong, in fruit reflexed; inner bracts ovate or lance-ovate, acute; ligules $8-12 \mathrm{~mm}$. long, orange, with or without purple base, Low ground: Man.-Va.-Tex.-Ariz.e B.C. Plain. Je-Au.

3. C. lanceolata L. Perennial, with a short rootstock; stem $2-5 \mathrm{dm}$. high, glabrous; leaves opposite, the lower spatulate or oblanceolate, petioled, the upper linear-lanceolate or linear, obtuse; involucres $8 \mathrm{~mm}$. high and $12-15 \mathrm{~mm}$. broad; outer bracts lanceolate, only slightly shorter than the ovate-lanceolate inner ones; ligules orange, $12-25 \mathrm{~mm}$. long, coarsely toothed; achenes broadly wingmargined; pappus obsolete. Rich soil: Ont.-Fla.-La.-N.M.-Colo. Plain. $\mathrm{My}-\mathrm{Au}$.

\section{BİdENS L. BEgGar-TICKS, BUR-MARIGOLd.}

Caulescent herbs, ours all annual. Leaves mostly opposite, simple or pinnatifid. Heads numerous, radiate or discoid. Involucres campanulate or turbinate, of two series of bracts, distinet or united only at the very base, the outer foliaceous, the inner scarious and appressed. Receptacle flat, chaffy. Rayflowers neutral; ligules yellow or white, or none. Disk-flowers hermaphrodite and fertile. Achenes flat, 4-angled, or rarely almost terete, beakless. Pappus of 2-4 (in ours retrorsely) barbed awns or teeth, rarely none.

Achenes flat, obovate or cuneate; leaves or segments broad.

Leaves pinnately $3-5$-foliolate.

Outer bracts 4-8; achenes nearly black.

Outer bracts 10-16; achenes brown.

1. B. frondosa.

aves simple.

Heads discoid, erect; corolla 4-toothed; achenes not tubercled. 3. B. comosa.

Heads usually radiate, nodding; corolla 5-toothed.

Outer bracts surpassing the rays; achenes with corky angles.

4. B. prionophylla.

5. B. glaucescens.

Achenes linear, tetragonal; leaf-segments small.

Divisions of the leaves oblong or lanceolate.

6. B. Bigelovii.

Divisions of the leaves linear.

7. B. tenuisecta.

1. B. frondosa L. Annual; stem 3-10 dm. high; leaves pinnately $3-5$-foliolate, glabrous or nearly so, scabrous on the margins; leaflets $3-8 \mathrm{~cm}$. long, lanceolate or oblong-lanceolate, sharply serrate, acuminate; involucres 10-15 mm. high and broad; outer bracts 4-8, spatulate-linear, entire, ciliate; ligules usually 
present, golden-yellow, equalling the disk; achenes black, tuberculate. Wet places: N.B.-Fla.-Utah-B.C. Plain. Jl-O.

2. B. vulgata Greene. Annual; stem 5-10 dm. high, glabrous; leaves pinnately 3-5-foliolate, glabrous or nearly so; leaflets lanceolate, acute, serrate, short-stalked; involucres 10-12 mm. high, 15-25 mm. broad; outer bracts 8-16, linear or linear-oblanceolate, ciliate, entire, rarely exceeding the disk; ligules usually present, equalling the disk; achenes brown or olivaceous, smooth or merely papillose. Wet ground: Ont.-N.C.-Calif.-B.C. Plain. Au-S.

3. B. comosa (A. Gray) Wiegand. Annual; stem 3-8 m. high, glabrous; leaves simple, $5-10 \mathrm{~cm}$. long, narrowly elliptic or lance-elliptic, acuminate, serrate; involucres about $12 \mathrm{~mm}$. high and $12-18 \mathrm{~mm}$. broad; outer bracts $6-8$, linear or linear-lanceolate, mucronate, entire, 2-5 times as long as the disk, nearly erect; achenes olive-green or brownish, smooth; awns 3. Wet ground: Mass.-Va.-Colo.-Neb. Plain. Au-O.

4. B. prionophylla Greene. Annual; stem slender, 3-5 dm. high, more or less pubescent; leaves linear or linear-lanceolate, sharply serrate, 5-10 cm. long, sessile; heads nodding, about $1 \mathrm{~cm}$. high, and $2 \mathrm{~cm}$. broad; achenes greenish; awns 3 or 4 , very unequal. Water and wet places: Ont.-N.Y.-S.D.-(? Colo.) -Mont. Plain. Au-S.

5. B. glaucescens Greene. Annual; stem 3-7 dm. high, glabrous or sparingly hairy; leaves linear-lanceolate, $5-15 \mathrm{~cm}$. long, serrate, sessile, somewhat paler beneath; heads nodding, $1 \mathrm{~cm}$. high, $2-3 \mathrm{~cm}$. wide; ligules often $1 \mathrm{~cm}$. long; awns 4. B. cernua of western reports. In water and wet grounds: Sask.Kans.-Utah-Ida.-Alta. Plain-Submont. J-S.

6. B. Bigelovii A. Gray. Annual; stem 4-6 dm. high, glabrous or sparingly pubescent; leaves bipinnate, 4-10 $\mathrm{cm}$. long; blades deltoid in outline, primary divisions broadly ovate, the secondary ones oblong or oblong-ovate, obtuse or acutish; involucres about $6 \mathrm{~mm}$. high and $1 \mathrm{~cm}$. broad; outer bracts linear, obtuse, shorter than the inner; outer achenes $5-6 \mathrm{~mm}$. long, terete, striate, their awns less than $2 \mathrm{~mm}$. long; central achenes $10-15 \mathrm{~mm}$. long, their awns over 3 $\mathrm{mm}$. long. Along streams: Tex.-Colo.-Ariz, Son.-Submont. Jl-S.

7. B. tenuisecta A. Gray. Annual; stem 3-6 dm. high, branched from the base, glabrous; leaves twice or thrice ternately or pinnately dissected into linear lobes; heads about $1 \mathrm{~cm}$. high and broad; bracts linear, hirsute, the outer usually slightly longer than the inner; achenes glabrous, the outer $6-8 \mathrm{~mm}$. long, the inner 10-12 mm. long; awns fully $3 \mathrm{~mm}$. long, those of the outer achenes shorter. Along streams: Tex.-Colo.-Ida.-Ariz.; Mex. Son.-Submont. Au-S.

\section{THELESPÉRMA LesS.}

Glabrous perennial, or annual, with finely dissected or rarely linear entire leaves and long-peduncled heads. Involucre hemispheric or eampanulate, of two distinct series of bracts, the outer narrow, short, often spreading, the inner broad, united to about the middle into a cup, their free lobes scarious-margined. Receptacle flat, with a broad, 2-nerved, white-scarious palea subtending each diskflower. Ray-flowers present, neutral, or none; ligules, if present, yellow, mostly toothed. Disk-flowers perfect, fertile; corolla-tube slender; limb 5-toothed. Anthers obtuse and entire at the base. Style-tips acute. Achenes oblong or linear, terete or slightly compressed. Pappus of 2 retrorsely hispid awns, or sometimes none.

Heads radiate.

Leaf-segments linear-filiform, $1 \mathrm{~mm}$, or less wide.

Annual or biennial; outer bracts subulate-linear, more than half as long as the inner.

1. T. trifidum.

Perennial from a rootstock; outer bracts linear-lanceolate, haif as long as the inner or less.

2. T. tenue.

Leaf-segments linear, over $1 \mathrm{~mm}$. wide; plant perennial or the first only biennial. Plant with a taproot, leafy throughout.

Plant with a creeping rootstock or woody caudex, leafy only near the base. Involucre not cleft below the middle; throat of the disk-flowers campanulate, shorter than the lobes.

4. T. ambiguum. 
Involucre cleft below the middle; throat of the disk-flowers cylindraceous, longer than the lobes.

Heads discoid; perennials, with a rootstock or woody caudex.

5. T. subnudum.

Plant less than $2 \mathrm{dm}$. high; involucre with very broad scarious margins.

Plants 3-6 dm. high; involucre with very narrow scarious margins. 7 . T. gracile.

1. T. trifidum (Poir.) Britton. A slender annual or biennial; stem branched, 3-9 dm. high, leafy; leaves bipinnately divided; inner bracts united not higher than the middle, with broad scarious margins; ligules $12-15 \mathrm{~mm}$. long; awns of the pappus rather short, not longer than the width of the achenes. In dry soil: Neb.-Tex.-N.M.-e Colo. Plain-Submont. Je-Au.

2. T. tenue Rydb. Stem 1-3, slender, less than $2 \mathrm{~mm}$. in diameter, mostly simple, 1.5-4 dm. high; leaves twice pinnately dissected; inner bracts united to the middle, broadly scarious-margined; ligules 8-12 $\mathrm{mm}$. long; awns of the pappus very short, about half as long as the width of the achenes. Plains and mountain valleys: Colo. Submont.-Mont.

3. T. intermedium Rydb. A glabrous bushy biennial or perhaps perennial; stems several, 2-6 dm. high; leaves once or twice pinnately divided; involucre about $1 \mathrm{~cm}$. broad; outer bracts very narrowly linear-lanceolate, about half as long as the inner, these united to about the middle, scarious-margined; ligules 10-12 mm. long; teeth of the pappus longer than the width of the achenes. On plains in dry or sandy soil: Neb.-Wyo.-Colo. Plain-Submont. Je-Au.

4. T. ambiguum A. Gray. Stem $2-4 \mathrm{dm}$. high; leaves once or twice pinnately divided; upper stem-leaves much reduced, often simple; outer bracts very short, ovate or elliptic, 1-2 mm. long, obtuse, the inner very broadly scarious-margined. In dry soil: N.M.-Colo. Son. Je-J.

5. T. subnudum A. Gray. Stem subscapose, 1-3 dm. high; leaves pinnately or bipinnately divided into linear or linear-lanceolate divisions; outer bracts short, oblong, about one-fourth as long as the inner, these broadly scariousmargined; pappus a minute 4-5-toothed crown or obsolete. In dry soil: N.M.Colo-Utah-Ariz. Son-Submont. My-Je.

6. T. marginatum Rydb. Stem 1-2 dm. high, leafy mostly at and near the base; leaves pinnately or bipinnately divided into linear divisions, $1-2 \mathrm{~mm}$. wide; peduncles mostly solitary, 7-10 $\mathrm{cm}$. long; heads about $1 \mathrm{~cm}$. broad; outer bracts oblong, about one-third as long as the inner, these united to the middle; teeth of the pappus minute. On dry plains: Sask.-Mont. Plain. My-S.

7. T. gracile (Torr.) A. Gray. Stem 3-9 dm. high, branched and leafy; leaves as in the preceding, the upper reduced and often simple; heads $12-15 \mathrm{~mm}$. broad; outer bracts oblong, obtuse, one-fourth as long as the inner, the latter united to the middle or beyond; awns of the pappus longer than the width of the achenes. On plains and prairies: Neb.-Tex.-Ariz.-Wyo. Plain-Mont. $\mathrm{My}-\mathrm{Au}$.

\section{PTILONÉLLA Nutt.}

Loosely branched annuals. Leaves alternate, narrowly linear, entire. Heads radiate. Bracts of the involucre narrow, subequal, in two series. Receptacle convex; paleae thin or searious, narrow. Ray-flowers 3-6, pistillate and fertile; ligules white, 3-cleft. Disk-flowers 7-12, hemaphrodite, fertile, or the central one sterile; corollas white, 5-cleft. Style of the fertile disk-flowers with two short branches, that of the infertile central one entire. Pappus of many narrow, linear or aristiform, fimbriate-lacerate squamellae, sometimes wanting. [Blepharipappus Hook., in part.]

1. P. scabra (Hook.) Nutt. Annual; stem 1-3 dm. high, branched, puberulent, sometimes also sparingly hispid, more or less glandular above; leaves alterlent, sometimes also spar, entire, scabrous; heads short-peduncled; involucres 6-7
nate, narrowly linear,
$\mathrm{mm}$. high, 7-10 mm. broad; bracts oblong, glandular-puberulent; ligules white, 6-7 mm. long; disk white. Blepharipappus scaber Hook. Dry plains and mountains: Wash.-Ida.-Nev.-Calif. Son.-Submont. Ap-Jl. 


\section{MÃdIA Molina.}

Glandular-viscid, heavy-scented annuals. Leaves alternate, entire, narrow. Heads radiate. Involucre campanulate; bracts in a single series, strongly inflexed on the margins enclosing the ray-achenes; paleae in a single series enclosing the disk-flowers as an inner involucre inside the rays. Ray-flowers pistillate, fertile; ligules inconspicuous, cuneate, 3-lobed. Disk-flowers hermaphrodite and fertile. Achenes angled, those of the ray-flowers laterally flattened, very oblique. Pappus wanting.

Ray-flowers 5-12; heads not glomerate.

Heads on short branches, racemosely disposed.

Heads on long branches, more corymbose.

Ray-flowers $2-5$, or none; heads glomerate.

1. M. racemosa.

2. M. dissitiflora.

3. M. glomerata.

1. M. racemosa T. \& G. Stem 3-6 dm. high, pilose, glandular above; leaves linear, 8-15 cm. long, pilose on both sides; branches of the inflorescence short; involucres 8-10 cm. high and broad; ligules 5-8; disk-achenes flat, indistinctly nerved. $M$. sativa racemosa A. Gray. Rocky or sandy places: B.C.-Ida. -Utah-Calif. Son. My-Jl.

2. M. dissitiflora (Nutt). T. \& G. Stem slender, pilose, 3-6 dm. high; leaves linear or lance-linear, finely pilose, entire; heads scattered, solitary at the ends of rather slender branches; involucres about $6 \mathrm{~mm}$. high and broad, glandular; ligules 5-8; achenes all flat, not at all angled. Hillsides and valleys: B.C.Mont.-Utah-Calif. Submont. Je-Au.

3. M. glomerata Hook. Stem 3-5 dm. high, leafy, hirsute, glandular in the inflorescence; leaves linear, pilose and hirsute-ciliate; heads more or less glomerate; involucres about $6 \mathrm{~mm}$. high and $4 \mathrm{~mm}$. wide; rays $2-5$, sometimes none; achenes of the rays somewhat curved, 1-nerved on each face, those of the disk 4- or 5-angled. Open places in the mountains: Sask.-Colo.-Calif.-B.C. Son.-Mont. J-S.

\section{HARPAECÁRPUS Nutt.}

Slender annuals, with narrowly linear leaves. Heads ligulate. Involucre campanulate; bracts $4-8$, in a single series, boat-shaped, each enclosing a rayachene; paleae of the receptacle united into a $3-5$-toothed cup, surrounding the single disk-flower. Ray-flowers 4-8, fertile; ligules inconspicuous, cuneate. Disk-flower single, hermaphrodite and fertile. Ray-achenes compressed laterally, lunate, but broader above; disk-achene obliquely obovate. Pappus want-

1. H. exiguus (Smith) A. Gray. Stem slender, 1-3 dm, high, hirsute as well as glandular-puberulent, paniculately branched; heads on filiform peduncles; involucres about $3 \mathrm{~mm}$. high and broad; bracts 4-8, hirsute-glandular. Madia filipes A. Gray. Open ground: B.C.-Ida.-L. Calif. Son. My-Jl.

\section{HEMIZONELLA A. Gray.}

Hirsute pubescent and glandular annuals, with linear, mostly opposite leaves. Heads radiate, small. Bracts of the involueres 4 or 5 , broad, infolded, enclosing each a ray-achene; paleae united into a 3-5-toothed cup, surrounding the diskflowers. Ray-flowers 4 or 5, pistillate and usually fertile; ligules minute. Diskflowers solitary or rarely 2-4, hermaphrodite and fertile. Achenes somewhat dorso-ventrally compressed, those of the disk-flowers straight, those of the rayflowers incurved.

1. H. minima A. Gray. Annual; stem 3-10 cm. high, pilose; leaves $1 \mathrm{~cm}$. long or less, linear, pilose; peduncles shorter than the heads; involucres about 3 mm. high and broad; ray-achenes obovate, slightly curved, strongly obcompressed. Dry sterile soil: B.C.-Ida.-Nev.-Calif. Son. Je-Jl.

\section{LAGOPHÝLLA Nutt.}

Slender herbs, with alternate entire leaves and small heads in leafy-bracted clusters. Heads radiate. Bracts of the involucres about 5, thin, herbaceous, with the margins at the base, infolded and each enclosing an achene, with which 
they fall; paleae in a single series surrounding the disk-flowers. Ray-flowers pistillate and sterile; ligules cuneate, 3 -cleft. Disk-flowers about 5, hermaphrodite and fertile. Ray-achenes obovate-oblong or clavate, obcompressed.

1. L. ramosissima Nutt. Stem $2-8 \mathrm{dm}$. high, at least diffusely branched, glabrate or slightly pilose when young; lower leaves spatulate, the upper linear or nearly so, softly silky-canescent; head about $6 \mathrm{~mm}$. high; bracts silky-ciliate; ligules short, purplish, clavate, carinate along the upper side, about $3 \mathrm{~mm}$. long. Dry ground: Wash.-Ida.-Nev.-Calif. Son. Je-S.

\section{BLEPHARIPÁPPUS Hook.}

Annuals, with mostly alternate leaves. Heads radiate. Bracts of the involucre broad, flattened on the back below, with thin, infolded margins, enclosing the ray-achenes; paleae in a series between the disk- and ray-flowers and occasionally some among the latter. Ray-flowers 8-20, pistillate and fertile; ligules conspicuous, various-colored. Disk-flowers hermaphrodite and mostly sterile; corollas yellow; lobes pubescent. Achenes of the ray-flowers obcompressed, without pappus. Pappus of the disk-flowers of 5-20 bristles or awns.

1. B. glandulosus Hook. Annual; stem 1-4 dm. high, diffusely branched, more or less hirsute, glandular at the summit; leaves lanceolate or linear, hirsute, the lower laciniate-pinnatifid or lobed, the upper entire; involucres $7-8 \mathrm{~mm}$. high, 12-15 mm. broad; bracts lance-linear, acute, hispidulous and with some black glands below; ligules 8-13, white, about $1 \mathrm{~cm}$. long, 3-lobed; pappus white, Layia glandulosa Hook. \& Arn. Sandy places: B.C.-Ida.-w N.M.-s Calif. Son. Mr-Je.

\section{PSILÓSTROPHE DC. PAPER Flower.}

Tomentose or woolly perennial (all ours) or rarely biennial herbs, or low shrubs. Leaves alternate, entire or lobed. Involucre cylindric or campanulate; bracts in a single series, equal, connivent, sometimes with 1-4 scarious ones within; receptacle naked. Ray-flowers few, pistillate and fertile; ligules broad, 3-lobed, yellow, becoming papery, persistent. Disk-flowers hermaphrodite and fertile; corollas yellow. Style-branches truncate at the apex. Achenes linear, striate. Pappus of lacerate or ciliate squamellae. [Riddellia Nutt.]

Stem merely sparingly villous or floccose, not densely white-pannose.

Squamellae of the pappus one-third as long as the disk-corollas, ovate, mostly obtuse; leaves broadly spatulate; ligules 8-12 mm. long, indistinctly nerved. 1. P. Bakert.
Squamellae of the pappus one-half as long as the disk-corollas, lanceolate, acute or
acuminate; ligules $5-8 \mathrm{~mm}$. long, distinctly veined.

Leaves oblanceolate, loosely villous; heads short-peduncled. $\quad 2 . P$. Tagetinae.

Upper leaves linear or linear-oblanceolate, glabrate; heads slender-peduncled.

3. P. sparsiflora.

Stem densely white-pannose.

4. P. Cooperi.

1. P. Bakeri Greene. Stem much branched, 1-2 dm. high, loosely floccose; basal leaves 5-10 $\mathrm{cm}$. long, petioled; blades spatulate, more or less distinetly 3-5-ribbed; involucres 7-10 $\mathrm{cm}$. high and nearly as broad; ligules 5, 10-15 mm. long; achenes glabrous, striate. P. pumila (M. E. Jones) A. Nels. Dry plains and hills: Colo.-Utah. Submont. My-Je.

2. P. Tagetinae (Nutt.) Greene. Stem 1-3 dm. high, diffusely branched, loosely villous; lower leaves spatulate, $2-5 \mathrm{~cm}$. long, entire or lobed; upper leaves narrowly oblanceolate; heads numerous, paniculate; involueres $6-8 \mathrm{~mm}$. high and a little less broad; ligules $3-5,5-8 \mathrm{~mm}$. long. Riddellia tagetina T. \& G. Dry plains: Tex.-Colo.-Ariz.; n Mex. Son. Je-S.

3. P. sparsiflora (A. Gray) A. Nels. Stem 1-3 dm. high, green, but sparingly hirsute; leaves linear, $5-8 \mathrm{~cm}$. long, usually entire, hirsute; heads corymbosepaniculate; involucres about $6 \mathrm{~mm}$. long, 4-5 $\mathrm{mm}$. wide; ligules usually $3,7-8$ $\mathrm{mm}$. long and still broader. R. tagetina sparsiflora A. Gray. Arid places: Ariz, -Utah. Son.

4. P. Cooperi (A. Gray) Greene. Undershrub, 2-5 dm. high; branches densely and finely white-pannose; leaves linear, $2-7 \mathrm{~cm}$. long, tomentose; heads 
paniculate; involucres 7-9 mm. high, 5-6 mm. broad; ligules mostly 5, 8-15 mm. long; pappus-squamellae oblong or lanceolate, erose at the summit, less than half as long as the disk-corollas. Gravelly plains: Ariz. - s Utah-s Calif.; L. Calif. L. Son. Ap-My.

\section{BAILÈya Harv. \& Gray. Wild Marigold.}

Annual or perennial floccose herbs. Leaves alternate, pinnatifid or the upper entire. Heads radiate. Involucre hemispheric; bracts equal, woolly, in two series; receptacle flat, naked, alveolate. Ray-flowers pistillate and fertile; ligules oval or oblong, yellow, 7-nerved, becoming papery, persistent. Disk-flowers hermaphrodite and fertile; corollas yellow. Anthers minutely sagittate at the base. Style-branches short, truncate. Achenes linear, truncate, many-ribbed. Pappus none.

Plant leafy throughout; annual.

Plant naked above, almost scapose; biennial.

1. B. pleniradiata.

2. B. multiradiata.

1. B. pleniradiata Harv. \& Gray. Stem $2-4 \mathrm{dm}$. high, floecose, leafy and branched; lower leaves incise-pinnatifid, with oblong or linear divisions, loosely floccose, the upper merely toothed or entire; heads solitary at the ends of the branches; peduncles $5-10 \mathrm{~cm}$. long; involucres about $6 \mathrm{~mm}$. high and $12 \mathrm{~mm}$. broad; ligules 25-40, about $1 \mathrm{~cm}$. long, $5 \mathrm{~mm}$. wide. B. multiradiata A. Gray, not Harv. \& Gray. Plains: Ariz.-Utah-s Calif; n Mex. Son. Ap-N.

2. B. multiradiata Harv, \& Gray. Stem decumbent at the base, and leafy only below, very floccose; leaves pinnately or ternately pinnatifid; divisions again cleft with obovate or elliptic divisions; peduncles 1-2 dm. long; involucres about $8 \mathrm{~mm}$. high, 15-20 mm. broad; ligules about 50, 12-15 mm. long, goldenyellow. B. multiradiata nudicaulis A. Gray. Dry plains: w Tex. $-\mathrm{s}$ Utah-Nev. -Ariz.;n Mex. Son. Ap-O.

\section{MONÓTHRIX Torr.}

Low scabrous undershrubs. Leaves mostly alternate, small, punctate, mostly ovate. Heads radiate or discoid. Involucre hemispheric; bracts in two equal series, boat-shaped, double-ribbed, partly enclosing the marginal achenes; receptacle flat, alveolate. Ray-flowers, if present, pistillate and fertile. Diskflowers many, hermaphrodite and fertile. Achenes flat, with a thick margin. Pappus of 1 barbellate awn or wanting.

1. M. Stansburii (A. Gray) Rydb. Stems 1-2 dm. high, diffusely branched; lower leaves opposite, the upper alternate, petioled; blades ovate or rhombicovate, dentate, $1 \mathrm{~cm}$. long or less, scabrous, triple-veined; involucres $5-6 \mathrm{~mm}$. high and fully as broad; bracts linear, acute; ligules 6-10, oblong, 3-4 mm. long; pappus-bristle present, shorter than the disk-corollas. Laphamia Stansburii A. Gray. Among rocks: Utah. Son. Je-Jl.

\section{PERICÒME A. Gray.}

Tall, strong-scented perennial herbs. Leaves opposite, petioled; blades hastate or triangular. Heads discoid in large cymes. Involucre turbinate-campanulate; bracts in a single series, more or less united below, hyaline-margined, with thick midrib. Flowers hermaphrodite and fertile; corollas pale yellow, 4-toothed. Anthers subsagittate at the base. Style-branches filiform, obtuse. Achenes linear-oblong, compressed, hispid-ciliate on the margins. Pappus a erown of fimbriate-lacerate squamellae, sometimes with two marginal awns.

1. P. caudata A. Gray. Widely branching perennial, $1 \mathrm{~m}$. high or more; leaf-blades thin, green, minutely resinous-granuliferous, triangular-hastate, 5-15 $\mathrm{cm}$. long, sparingly sinuate-dentate, caudately long-acuminate; involucres about $5 \mathrm{~mm}$. high and $6 \mathrm{~mm}$, wide. Rocky eañons: N.M.-Colo.-Calif.; $\mathrm{n}$ Mex. Submont. Л-O.

\section{PICRADENIÓPSIS Rydb.}

Low perennial canescent herbs, more or less woody at the base. Leaves opposite, pedately 3-5-divided, with linear divisions, or the upper entire. Heads radiate, corymbose. Involucre eampanulate; bracts subequal, in two series, 
3-nerved, the outer more or less keeled. Ray-flowers few, pistillate and fertile; ligules yellow, short. Disk-flowers many, hermaphrodite and fertile; corollas yellow. Achenes elongate-obpyramidal, glandular or hispidulous. Pappus of a crown of 8 ovate or lanceolate squamellae.

1. P. oppositifolia (Nutt.) Rydb. Stem 1-2 dm. high, branched below, strigose-puberulent; leaves 1-5 $\mathrm{cm}$. long, impressed-punctate and strigose-puberulent; involucres 5-7 mm. high and 7-10 $\mathrm{mm}$. broad; ligules $3-4 \mathrm{~mm}$. long; achenes glandular. Bahia oppositifolia A. Gray. Alkaline soil and dry plains: N.D.Tex.-Ariz.-Mont. Plain-Submont. Je-S.

\section{AMAURIÓPSIS Rydb.}

Glandular-pubescent annuals. Leaves alternate, twice or thrice ternately divided. Heads radiate, in leafy corymbs. Involucre hemispheric; bracts 16-20, herbaceous, in 3 series; receptacle flat, alveolate. Ray-flowers 16-20, pistillate, fertile; ligules cuneate, 3-cleft. Disk-flowers hermaphrodite and fertile; corollas yellow. Achenes elongate, narrowly obpyramidal, 4-angled, striate. Pappus wanting.

1. A. dissecta (A. Gray) Rydb. Stem 3-10 dm. high, puberulent or glabrate below, glandular above; leaves with oblong or linear obtuse divisions, more or less puberulent; involucres $6-7 \mathrm{~mm}$. high, about $1 \mathrm{~cm}$. broad, glandular-puberulent; bracts oblong-oblanceolate to obovate-oblong, abruptly acuminate. Bahia chrysanthemoides A. Gray. Villanova dissecta Rydb. Along streams: N.M.-Wyo.-Ariz,; n Mex. Son.-Mont. Jl-S.

\section{PLATYSChKÙRIA (A. Gray) Rydb.}

Perennial grayish puberulent herbs, woody at the base. Leaves alternate, petioled, entire. Heads radiate, corymbose. Involucre hemispheric; bracts herbaceous in 2 series, oblong; receptacle flat, glabrous. Ray-flowers pistillate and fertile; ligules yellow, oblong, slightly 3-toothed. Disk-flowers fertile; corollas glandular, yellow. Achenes elongate, 4-angled, tapering downward, sparingly hairy on the angles. Pappus of 10-16 lanceolate squamellae, with the distinct midrib extending beyond the apex.

Stem scapiform or nearly so; leaves firm, oval to lanceolate. Stem leafy; leaves thin, oblong.

1. P. integrifolia.

2. P. oblongifolia.

1. P. integrifolia (A. Gray) Rydb. Stem $1.5-4 \mathrm{dm}$. high, almost scapiform; basal leaf-blades cinereous-puberulent, oval to lanceolate, $2-7 \mathrm{~cm}$. long, 3-ribbed, thick; upper stem-leaves much reduced, linear-lanceolate; involucres $8-10 \mathrm{~mm}$. high, $12-20 \mathrm{~mm}$. broad; ligules $8-10 \mathrm{~mm}$. long; pappus-squamellae lanceolate, erose, $2 \mathrm{~mm}$. long. Bahia integrifolia A. Gray. B. nudicaulis A. Gray. B. desertorum M. E. Jones. Dry plains: Wyo.-Colo.-Utah. Son.-Submont. My-Je.

2. P. oblongifolia (A. Gray) Rydb. Stem leafy, 2-3 dm. high, strigosepuberulent; leaf-blades oblong or lanceolate, obtuse, 2-5 cm. long, 3-ribbed; involucres about $8 \mathrm{~mm}$. high and $12 \mathrm{~mm}$. wide; pappus-squamellae linear-lanceolate, entire, fully $4 \mathrm{~mm}$. long. Bahia oblongifolia A. Gray. Arid regions: N.M. -sw Colo.-se Utah-Ariz. Son. Jl-S.

\section{HÚLSEA T. \& G.}

More or less fleshy villous or viscid perennials, biennials, or annuals. Leaves alternate, sessile or with winged petioles. Heads radiate, large. Involucre hemispheric; bracts in 2 or 3 series, narrow; receptacle flat, alveolate-dentate with minute horny teeth. Ray-flowers pistillate and fertile; ligules elongate, yellow or purplish. Disk-flowers fertile; corollas yellow, glandular-viseid. Stylebranches obtuse. Achenes linear-cuneate, compressed, villous especially on the margins. Pappus of 4 hyaline nerveless squamellae.

1. H. carnosa Rydb. Perennial, with a thick root and creeping subterranean stems, cespitose; overground stems $1.5-3 \mathrm{dm}$. high, very leafy throughout, pubescent, more or less viscid; leaves very fleshy, linear, sinuately lobed, viscid-pubes- 
cent, 5-8 cm. long; head solitary, 1.5-2 cm. high; bracts linear-lanceolate, viscidpubescent and more or less villous; rays light yellow, less than $1 \mathrm{~cm}$. long. Among rocks: Mont.-Wyo.-Ida. Subalp.-Alp. J-Au.

\section{CEPHALOBÉMBIX Rydb.}

Slender glandular-hirsute annuals. Leaves impressed-punctate, pinnately dissected into linear-filiform divisions, the lower opposite, the upper alternate. Heads discoid, corymbose. Involucres turbinate or obconic; bracts 5-8, obovate, scarious and more or less colored around the margins. Flowers hermaphrodite and fertile; corollas light yellow, glandular on the tube. Style-branches with short acute appendages. Achenes elongate-obpyramidal, 4-angled, hispidulous on the angles below. Pappus of 8 scarious squamellae.

1. C. neomexicana (A. Gray) Rydb. Stem branched, 1-2 dm. high, sparingly strigose or glabrate; leaves pinnately divided into 3-5 linear divisions, which are entire or the lowest 2-3-cleft; involucres about $6 \mathrm{~mm}$. high and $8 \mathrm{~mm}$. broad; bracts about 10, striate. Bahia neomexicana A. Gray. Sandy soil: N.M. -Colo.-Ariz.; Mex. Son.-Submont. Au-O.

\section{HYMENOPÁPPUS L'Her.}

More or less tomentose-floceose perennials or biennials, with mostly 1-2-pinnately divided leaves. Heads eorymbose or rarely solitary, discoid. Involucre hemispheric, or nearly so; bracts 6-12, in 1-2 series, subequal, appressed, more or less colored and scarious-margined. Receptacle naked. Disk-flowers all perfect and fertile; corollas yellow. Styles with short conic appendages. Achenes mostly obpyramidal, 4-5-angled, the faces 1-3-nerved. Pappus of 10-20 hyaline obtuse scales without costa, or none.

Throat of the corolla campanulate, 1-2 mm. long, not over twice as long as the lobes.

Pappus over $1 \mathrm{~mm}$. long, equalling the corolla-tube or nearly so. Stem 3-6 dm. high, leafy throughout; heads numerous.

Plant sparingly and loosely floccose; leaves glabrate in age. Plant densely tomentose; leaves permanently tomentose.

Stem less than $3 \mathrm{dm}$. high.

Stem-leaves much reduced; stem white-tomentose or nearly so; heads few.

3. H. scaposus.

Stem-leaves not much reduced; stem sparingly grayish-tomentose.

5. H. cinereus.

Pappus $1 \mathrm{~mm}$. or less long, much shorter than the corolla-tube; stem-leaves and heads few.

Pappus not hidden by the hairs of the achenes.

Stem permanently densely white-tomentose; achenes silky. 4, H. arenosus.

Stem sparingly grayish-tomentose, glabrate in age; achenes loosely villous.

Pappus hidden by the hairs of the achenes, or sometimes none.

5. H. cinereus.

Leaflets glabrate in age, at least above; ultimate segment 5-30 mm. long.

Leaves permanently densely white-tomentose; ultimate segments short, $1-5$ $\mathrm{mm}$. long.

Throat of the corolla cylindro-campanulate, $1.5-4 \mathrm{~mm}$. long, 3-4 times as long as the lobes.

Pappus equalling the corolla-tube; plant dware.

Heads less than $1 \mathrm{~cm}$. high and broad; corolla-tube $1.5-2 \mathrm{~mm}$. long; stem not woolly at the base. 8 . H. parvulus.

Heads over $1 \mathrm{~cm}$. high and $1.5 \mathrm{~cm}$. broad; corolla-tube $3-4 \mathrm{~mm}$. long; stem woolly at the base.

Bracts more or less rose- or purple-tinged.

Bracts yellow-tinged.

9. H. lugens.

3. H. scaposus.

Pappus shorter than the corolla-tube; throat $3-4 \mathrm{~mm}$. long; plant $2-4$ dm. high. Stem leafy at least half its height, decidedly woolly at the base. 10. H. eriopodus.

Stem leafy only at the base, not conspicuously woolly.

11. H. macroglottis.

1. H. tenuifolius Pursh. Biennial or short-lived perennial, slightly tomentose, in age often glabrate, 3-6 dm. high, branched and leafy; leaves except the uppermost 1-3 pinnately divided into linear divisions, $5-30 \mathrm{~mm}$. long; heads numerous, 8-12 mm. broad; corollas dirty white or cream-colored; achenes densely pubescent. Plains and dry prairies: N.D.-Wyo.-N.M.-Tex.-Ark. Plain. Je-S. 
2. H. tomentosus Rydb. Biennial; stem 3-4 dm. high, leafy and branched above; leaves $5-7 \mathrm{~cm}$. long, bipinnately divided into linear segments, 4-10 $\mathrm{mm}$. long; involucre densely woolly, somewhat turbinate, $8 \mathrm{~mm}$. high and broad; flowers yellow; corolla throat a little over $1 \mathrm{~mm}$. long, broadly campanulate, of about the same length as the lobes. Dry plains: s Utah. Son.

3. H. scaposus Rydb. Perennial; stem almost naked, with 1-2 reduced leaves, more or less densely tomentose; leaves mostly basal, 5-7 cm. long, bipinnately divided into linear segments, 3-10 $\mathrm{mm}$. long, densely tomentose, especially at the base; heads about $1 \mathrm{~cm}$. high and broad; bracts obovate, with yellowish or purplish scarious margins; corollas yellow; throat nearly $2 \mathrm{~mm}$. long, campanulate and longer than the lobes; squamellae of the pappus fully $2 \mathrm{~mm}$. long, longer than the tube of the corolla. Dry hills: N.M.-Utah-Nev.-Ariz. Son. My-Jl.

4. H. arenosus Heller. A white-tomentose perennial, with branched woody caudex; stems several, $2-4 \mathrm{dm}$. high, densely tomentose, especially at the base, 2-4-leaved; leaves mostly basal, twice pinnately divided into linear-filiform divisions 3-15 $\mathrm{mm}$. long, $1 \mathrm{~mm}$. wide; heads about $8 \mathrm{~mm}$. high, $8-10 \mathrm{~mm}$. broad; bracts oblong, with narrow scarious margins, tomentose; corollas yellow; throat nearly $2 \mathrm{~mm}$. long; achenes long-silky; pappus rather short, about $1 \mathrm{~mm}$. long, but not hidden by the hairs. On dry hills: N.M.-Colo.-Ariz. Son.-Submont. $\mathrm{My}-\mathrm{Jl}$.

5. H. cinereus Rydb. Perennial, with a cespitose caudex; stems about 2 $\mathrm{dm}$. high, branched; leaves bipinnately divided into linear segments $1-2 \mathrm{~cm}$. long and about $1 \mathrm{~mm}$. wide, sparingly grayish tomentulose; heads $8-10 \mathrm{~mm}$. high, $10-12 \mathrm{~mm}$. broad; bracts oblong-obovate, with narrow scarious margins; corollas yellow; throat about $1.5 \mathrm{~mm}$. long, broadly campanulate, longer than the lobes; achenes loosely villous. H. ochroleucus Greene. Dry hills and plains: Colo.-Utah. Submont.-Subalp. My-Jl.

6. H. filifolius Hook. Perennial; stem $2-3.5 \mathrm{dm}$. high, sparingly branched; leaves similar to those of $H$. tenuifolius; heads few, $10-15 \mathrm{~mm}$. broad; bracts obovate-oblong, with broad scarious margins, tomentose; corollas bright yellow; throat about $1.5 \mathrm{~mm}$. long; achenes densely villous, the long hairs hiding the small pappus; squamellae less than $1 \mathrm{~mm}$. long. On plains and prairies: Alta.Sask.-Kans.-N.M.-Nev.-Wash. Plain-Submont. Je-S.

7. H. luteus Nutt. Perennial; stem 1-2 dm. high, with a few reduced leaves and few heads; basal leaves $2-7 \mathrm{~cm}$. long, twice pinnately divided into short lobes 1-5 mm. long; heads about $1 \mathrm{~cm}$. high, 10-15 mm. broad; bracts oblong, broadly scarious-margined; corolla yellow; throat about $1 \mathrm{~mm}$. long; achenes densely villous-hirsute; scales of the pappus short, about $0.5 \mathrm{~mm}$. long. Bad-lands and clay-hills: Wyo. Submont.-Mont. My-Jl.

8. H. parvulus Greene. Perennial; stem 1-2 dm. high, scapiform, slightly tomentose; basal leaves $5-8 \mathrm{~cm}$. long, bipinnatifid, with narrowly linear-filiform divisions, 5-12 mm. long, grayish-tomentose; stem-leaves few and small; involucres turbinate, 6-7 mm. high and broad; bracts oblong-obovate, greenish yellow, sparingly tomentulose; corollas brownish yellow; throat cylindro-campanulate, $1.5-2 \mathrm{~mm}$. long, about 3 times as long as the teeth; achenes short villous. Dry hills: Colo. Submont. Jl-Au.

9. H. lugens Greene. Perennial; stem scapiform, 2-3 dm. high, whitetomentulose; leaves bipinnatifid with filiform divisions, permanently whitetomentose, 5-10 $\mathrm{cm}$. long; stem-leaves small and few; involucres nearly $1 \mathrm{~cm}$. high, 12-15 mm. broad; bracts elliptic, the outer usually with purple-tinged margins; corolla-throat cylindraceous, 3-4 $\mathrm{mm}$. long, 3-4 times as long as the lobes; pappus-scales oblong-obovate, as long as the corolla-tube. Dry ridges: s Calif.-Utah-Ariz. Son.-Submont. My-Au.

10. H. eriopodus A. Nels. Perennial; stem $3-10 \mathrm{~cm}$. high, leafy; leaves numerous, bipinnately divided into filiform divisions, sparingly tomentulose or glabrate; involucres about $1 \mathrm{~cm}$. high and 12-15 mm. broad; bracts elliptic, scarious-margined, sometimes purplish; corolla-throat about $3 \mathrm{~mm}$. long, cylindro- 
campanulate, about 3 times as long as the lobes; pappus-scales linear-oblong, about half as long as the corolla-tube. Rocky places: Utah-Nev. Son. My.

11. H. macroglottis Rydb. Perennial; stems several, 3-4 dm. high; leaves mostly basal, about $1 \mathrm{dm}$. long, bipinnately divided into linear lobes $8-25 \mathrm{~mm}$. long; stem-leaves simply pinnate or simple; heads few, $12 \mathrm{~mm}$. high and 12-15 $\mathrm{mm}$. broad; bracts oblong, with very narrow yellowish scarious margins; corolla yellow; throat deeply campanulate, 3-4 mm. long, 3-4 times as long as the lobes; squamellae of the pappus about $1 \mathrm{~mm}$. long. Dry hills: Tex.-Colo.-UtahAriz. Son. Au-S.

\section{LEUCÁMPYX A. Gray. Wild Cosmos.}

More or less floccose perennials. Leaves alternate, bi- or tripinnatifid into linear divisions. Heads corymbose, radiate. Involucres hemispheric; bracts subequal, in 2-3 series, with scarious colored tips and margins; receptacle convex, with broad membranous paleae, half enclosing the achenes. Ray-flowers pistillate and fertile; ligules broad, 3-toothed, white or cream-colored. Diskflowers fertile; corollas yellow. Style branches penicillate, with short appendages. Achenes of the ray-flowers cuneate, 3 -angled, those of the disk-flowers 5-angled, all more or less curved, striate and muriculate. Pappus a minute crown.

1. L. Newberryi A. Gray. Stem stout, $3-6 \mathrm{dm}$. high; involucres about 8 $\mathrm{mm}$. high, $10-15 \mathrm{~mm}$. wide; bracts obovate, obtuse; ligules $10-15 \mathrm{~mm}$. long. Cañons: Colo.-N.M. Submont.-Mont. Je-Au.

\section{OTHĀKE Raf.}

Erect glandular annual herbs. Leaves alternate, mostly entire. Heads corymbose or paniculate, radiate or discoid. Inflorescence campanulate to obconic; bracts narrow, in 1-2 series, herbaceous, usually colored, at least at the tips. Receptacle small, flat, naked. Ray-flowers, when present, pistillate, fertile; ligules pink or rose-colored, broad, 3-cleft. Disk-flowers fertile; corollas pink or rose, 5 -divided almost to the tube. Style-branches filiform, pubescent throughout. Achenes linear to narrowly obpyramidal, 4-angled. Pappus of 6-12 lanceolate, strongly ribbed squamellae.

Heads radiate; leaves lanceolate to linear-lanceolate. Heads discoid; leaves narrowly linear.

1. O. sphacelata.

2. O. macrolepis.

1. O. sphacelata (Nutt.) Rydb. Stem stout, branched, hispid, glandularpubescent and viscid above, $2-6 \mathrm{dm}$. high; leaves petioled, lanceolate or linearlanceolate, scabrous on both sides, indistinctly 3-veined; involucre $10-15 \mathrm{~mm}$. high; ligules 8-10, rose-purple, 1-2 cm. long; pappus-scales of the disk-flowers 6-8, lanceolate, more than half as long as the achenes. Polypteris Hookeriana A. Gray, in part, not Palafoxia Hookeriana T. \& G. Sandy plains: Tex.-Neb. -Colo.-N.M.; n Mex. Son.-Submont.

2. O. macrolepis Rydb. Stem 3-4 dm. high, strigose-puberulent, and glandular on the upper parts; leaves strigose-puberulent on both sides, $3-5 \mathrm{~cm}$. long, 2-3 mm. wide; involucres 9-10 $\mathrm{mm}$. high and about as wide; bracts 8-12, linear-oblanceolate, abruptly acute; disk-corollas $14-15 \mathrm{~mm}$. long; pappus-squamellae 6-8, lanceolate, caudate-acuminate $5-6 \mathrm{~mm}$. long. Plains: Colo. Au.

\section{RIGIOPÁPPUS A. Gray.}

Slender puberulent annuals. Leaves alternate, linear, entire. Heads radiate. Involucre turbinate; bracts subequal, in 2 series, linear-subulate, concave, partly enclosing the ray-flowers; receptacle flat, naked. Ray-flowers 5-8, pistillate, fertile; ligules short, scarcely exceeding the disk. Disk-flowers fertile. Style-branches short, glabrous, with subulate hirtellous tips. Achenes slender, linear, hispid. Pappus of 4 or 5 rigid subulate awn-like squamellae.

1. R. leptocladus A. Gray. Stem slender, 1-3 dm. high, minutely hirsutulous; branches naked below and becoming longer than the main stem; leaves 
sessile, hirsutulous; heads solitary at the ends of the stem and branches; involucres $6 \mathrm{~mm}$. high; flowers yellow, turning purplish or whitish. Dry ground: Calif.-Ida.-Wahs. Son. Mr.

\section{ChamaechaenáCTIS Rydb.}

Cespitose scapiferous perennial, branching below the surface of the ground and with a woody root. Leaves all basal and simple, coriaceous, white-strigose below, sparingly hirsute and punctate above. Involucral bracts about twelve, in two series, the inner series longer and with scarious-margined, reddish tips. Corolla flesh-colored, with equal lobes. Stamens included. Style-tips broad. Achenes clavate, densely villous. Pappus of eight nearly equal squamellae, with prominent midrib and erose tips.

1. C. scaposa (Eastw.) Rydb. Leaves petioled; blades oblong or elliptic, to orbicular, 8-12 mm. long, coriaceous, entire or crenate, with revolute margins, strigose-canescent; scape $3-8 \mathrm{~cm}$. long; involueres about $15 \mathrm{~mm}$. high and broad; bracts oblong, obtuse, densely hirsute-villous. Chaenactis scaposa Eastw. Actinella carnosa A. Nels. Dry mesas and clayey soil: w Colo.- Utah. MyJe.

\section{Chaenáctis DC. Morning Brides.}

Annual, biennial, or perennial herbs. Leaves alternate, usually pinnately dissected. Heads discoid, but the marginal flowers often with enlarged corollas. Involucre campanulate or turbinate; bracts herbaceous in 2 series; receptacle alveolate, naked or in some species bristly. Flowers hermaphrodite and fertile; corollas yellow, white, or flesh-colored, the throat cylindric or in some species funnelform in the marginal flowers. Achenes linear, terete or oval in crosssection, or obscurely 4-angled, pubescent. Pappus of 4-16 hyaline squamellae.

Annuals.

Corollas yellow; pappus of minute callous squamellae.

Corollas white or flesh-colored; pappus of well developed squamellae.

Stamens partly exserted; bracts all appressed.

Involucral bracts acuminate; receptacle usually somewhat bristly.

Involucral bracts obtuse or merely acute; receptacle naked.
Leaves bipinnatifid.
Leaves simple, spatulate-linear.
3. C. stevioides.
4. C. Cusickii.

Stamens included; some of the outer bracts with spreading tips.

5. C. macrantha.

Perennials.

Leafy-stemmed plants.

Plant densely white-floccose.

Leaves mostly basal, broadly obovate in outline, with approximate divergent divisions; branches of the inflorescence usually divergent at the base and curved upwards.

6. C. brachiata.

Leaves scattered, ovate or lanceolate in outline; branches of the inflorescence ascending or erect, strict.

Plant 1-3 dm. high, not fruticulose; leaves regularly pinnatifid.

Plant $3-4 \mathrm{dm}$, high.

7. C. achilleaefolia.

Leaves narrow, mostly regularly pinnatifid; plant often fruticulose at the base.

8. C. imbricata.

Leaves broader, interruptedly pinnatifid, with smaller segments interposed between the larger ones; plant not fruticulose.

9. C. cheilanthoides.

Plant sparingly floccose, in age greener and glabrate.

Squamellae about half as long as the corolla; low perennials, 1-2 dm. high, branched at the caudex.

Squamellae at least two-thirds as long as the corollas.

Bracts shorter than the disk; stem 2-4 dm. high; biennials with a taproot. 11. C. Douglasii.

Bracts equalling the disk; stems 1-2 dm. high, from a cespitose rootstock.

12. C. peduncularia.

Subscapose perennials, with rosulate leaves and nearly naked peduncles.

Leaves oblanceolate, elliptic, or linear in outline; plants with a cespitose caudex. Inner bracts acuminate; leaf-blades narrowly lanceolate in outline.

13. C. minuscula.

Inner bracts merely acute; leaf-blades oblanceolate or oblong in outline.

14. C. alpina.

Leaf-blades obovate-cuneate or flabellate in outline; plant with a cespitose rootstock.

15. C. Evermannii. 
1. C. Nevii A. Gray. Stem 1-2 dm. high, puberulent, branched; leaves pinnate or bipinnate, with linear or oblong lobes, slightly puberulent; involucres about $8 \mathrm{~mm}$. high and $1 \mathrm{~cm}$. broad; corollas yellow, the marginal ones not conspicuously enlarged; pappus of minute teeth or obsolete. Clayey soil: Ore.Ida. Son. My-Je.

2. C. carphoclinia A. Gray. Stem diffusely branched, puberulent, not at all tomentose, 1-3 dm. high; leaves once or twice pinnatifid, with short filiform divisions, puberulent; heads numerous, 30-40-flowered; involucres about $8 \mathrm{~mm}$. high and $10 \mathrm{~mm}$. broad; bracts linear-subulate, puberulent; marginal corollas scarcely enlarged; pappus squamellae 4, ovate-lanceolate, acute or acuminate, those of the marginal flowers much shorter than those of the central ones. Arid regions: N.M.-s Utah-s Calif. Son.

3. C. stevioides H. \& A. Stem 1-3 dm. high, sparingly floccose when young, glabrate in age, and glandular-puberulent in the inflorescence; leaves once or twice pinnately divided into linear divisions, floccose when young; involucres 7-8 $\mathrm{mm}$. high, 10-12 $\mathrm{mm}$. broad; bracts narrowly linear, obtuse; the marginal corollas with enlarged throat and limb, oblique; pappus-squamellae oblong-lanceolate to oblong-ovate, in the marginal flowers broader than in the central ones and unequal. Arid places: Ida.-Wyo.-N.M.-Calif.-Nev. Son. -Submont. Ap-Je.

4. C. Cusickii A. Gray. Stem decumbent, $1 \mathrm{dm}$. high or less, sparingly floccose, soon glabrate; leaves fleshy, $2-3 \mathrm{~cm}$. long; involucres subtended by a linear leaf, $7-8 \mathrm{~mm}$. high; bracts broadly linear; corolla white, the marginal not enlarged; pappus-squamellae 10, linear-oblong, nearly equal and equalling the corolla-tube. Sandy hills: Ore--Ida. Submont.

5. C. macrantha D. C. Eat. Stem 1-2 dm. high, tomentose when young, glabrate in age, branched from the base; leaves pinnately or bipinnately divided into oblong or linear divisions, floccose when young, glabrate in age; involucres $12-15 \mathrm{~mm}$. high and about as wide; bracts linear, more or less tomentose; corollas externally puberulent, all alike, white or flesh-colored; pappus of 4 linear-oblong squamellae, $4 \mathrm{~mm}$. long, and sometimes some smaller ones. Hills in desert regions: Ariz.-Utah-Nev.-Calif. Son. My.

6. C. brachiata Greene. Stem 2-4 dm. high; leaves white-tomentose; involucres about $12 \mathrm{~mm}$. high, 12-15 $\mathrm{mm}$. broad; bracts linear, acute or obtuse; corollas dull white, 6-7 mm. long; pappus-squamellae 8, unequal, obtuse, 3-4 $\mathrm{mm}$. long. Dry places: Utah. Son.

7. C. achilleaefolia H. \& A. Stem 1-2 dm. high, densely white-tomentose; leaves twice pinnately cleft with very short crowded obtuse divisions, permanently white-tomentose; involucres 8-10 $\mathrm{mm}$. high and 10-12 $\mathrm{mm}$. wide, tomentose; bracts linear, obtuse; corollas flesh-colored, all alike; pappus-squamellae linear, acute, $5-6 \mathrm{~mm}$. long. C. angustifolia Greene. Dry soil and hot-spring formations: Wyo.-Utah-Nev.-Ore. Je-Au.

8. C. imbricata Greene. Stem branched at the base, about $3 \mathrm{dm}$. high, floccose; leaves 5-10 cm. long, with narrow divisions, yellowish; involucres 10-12 $\mathrm{mm}$. high, 12-15 mm. broad, viseid-pubescent; bracts linear, obtuse; corollas flesh-colored or white, 6-7 mm. long; squamellae 8, oblong, obtuse, 4-5 mm. long. Dry places: Wash.-Ida.-Ore. Son.

9. C. cheilanthoides Greene. Stem about $3 \mathrm{dm}$. high; leaves $4-8 \mathrm{~cm}$. long, white-tomentose; involueres $8 \mathrm{~mm}$. high, $10 \mathrm{~mm}$. broad, floceose and glandular; bracts linear or linear-spatulate, obtuse; corollas whitish, $6 \mathrm{~mm}$. long; squamellae 8 , linear, 5-6 mm. long, or those of the marginal flowers 2-4 mm. long. Dry places: Ore.-Ida.-Wash. Son.

10. C. humilis Rydb. Stems several from the crown; leaves $2-5 \mathrm{~cm}$. long, floccose, in age glabrate, oblanceolate in outline, with oblong round-lobed divisions; involucres $7-8 \mathrm{~mm}$. high, $5-10 \mathrm{~mm}$. broad; bracts narrowly linear, obtuse, glandular-puberulent; corollas whitish; squamellae 8 , oblong, obtuse, about 3 mm. long. Dry places: Wyo.-Ida. Plain. 
11. C. Douglasii (Hook.) H. \& A. Stem 2-5 dm. high, sparingly floceose, in age glabrate, glandular-puberulent in the inflorescence; leaves bipinnatifid with numerous short, crowded, obtuse lobes, more or less floccose; heads paniculate; involucres $10-13 \mathrm{~mm}$. high, $15-20 \mathrm{~mm}$. broad; bracts linear, obtuse, glandular-puberulent; pappus-squamellae oblong or linear, obtuse, about $5 \mathrm{~mm}$. long. Sandy and rocky places: Alta.-N.M.-Calif.-B.C. Plain-Mont. Je-Jl.

12. C. pedicularia Greene. Stem leafy, 1-2 dm. high, decumbent; leaves twice pinnatifid, with short obtuse lobes, sparingly tomentulose when young; peduncles 1-2 $\mathrm{cm}$. long; involucres about $15 \mathrm{~mm}$. high and broad; bracts tomentulose, scarcely at all glandular, acutish; pappus-squamellae linear-oblong to linear, obtuse. High mountains: Colo. Alp. Лl.

13. C. minuscula Greene. Scape $1-3 \mathrm{~cm}$. high; leaves crowded, $2-3 \mathrm{~cm}$. long, lanceolate in outline, with short entire or toothed divisions, nearly glabrous; involucres $1 \mathrm{~cm}$. high and broad; bracts linear, acute or the inner acuminate, finely glandular-puberulent; corollas white, $6 \mathrm{~mm}$. long; squamellae oblong, obtuse, $3 \mathrm{~mm}$. long. Mountain tops: Ida. Alp.

14. C. alpina (A. Gray) M. E. Jones. Stem $1 \mathrm{dm}$. high or less, subscapose; leaves mostly basal, twice pinnately dissected, with short obtuse lobes, somewhat tomentose when young; peduncles 2-7 cm.long, glandular-puberulent; involucres 8-12 $\mathrm{mm}$. high, 10-15 $\mathrm{mm}$. broad; bracts linear, obtuse, usually purple; corollas flesh-colored, all alike; pappus-squamellae linear-oblanceolate or linear-spatulate, obtuse, 4-5 mm. long. C. rubella Greene. High mountains-Colo.-Calif. -Ore. Mont.-Alp. J-Au.

15. C. Evermannii Greene. Scape 1-3 cm. long, floccose; leaves 1-2 cm. long, 3-5-toothed or 3-5-lobed above the middle, loosely floccose; involucres 6-8 $\mathrm{mm}$. high and broad, puberulent; bracts linear-spatulate, rounded at the apex; corollas flesh-colored or white, $5 \mathrm{~mm}$. long; squamellae 8, unequal, oblong, obtuse, the longer 4-5 mm. long. Mountain tops: Ida. Alp.

\section{ERIOPHÝllum Lag. WoOlly Yellow Daisy.}

Annual or perennial (in ours with a cespitose caudex), floccose or tomentose herbs or low shrubs. Leaves alternate, entire or pinnately lobed or dissected. Heads radiate, rarely discoid. Involucre hemispheric; bracts in a single series or in 2 equal series, somewhat overlapping, concave or somewhat boat-shaped, partly enveloping the marginal achenes; receptacle usually more or less convex, naked. Ray-flowers pistillate and fertile; ligules yellow, oblong. Disk-flowers usually numerous, hermaphrodite and fertile. Achenes 4-5-angled, narrowly elongate-obpyramidal, glabrous, hirsute, or glandular. Pappus of 4-12 hyaline, often erose squamellae, or rarely wanting.

Leaves entire or merely the earlier ones toothed at the apex.

Achenes glabrous or nearly so.

Achenes decidedly pubescent or glandular.

Leaves narrowly linear-oblanceolate or linear.

Leaves oblanceolate or obovate.

Leaves more or less lobed or dissected.

Achenes glabrous.

Bracts acuminate, surpassing the disk.

Bracts abruptly acute, not surpassing the disk.

Achenes hairy.

1. E. pedunculatum.

2. E. gracile.

3. E. integrifolium.

1. E. pedunculatum Heller. Stems several, simple, $3-5 \mathrm{dm}$. high, reddish below, sparingly tomentose; leaves oblong-lanceolate, subsessile, $3-5 \mathrm{~cm}$. long, $1 \mathrm{~cm}$. wide, entire, acute, floccose on both sides; peduncles $5-15 \mathrm{~cm}$. long; involucres about $1 \mathrm{~cm}$. high and broad, lanate; bracts 8 , lanceolate, short-acuminate; ligules oblong, orange, about $1 \mathrm{~cm}$. long. Dry open places: Ida. Plain. Jl.

2. E. gracile (H. \& A.) A. Gray. Stems several, 2-3 dm. high; leaves narrowly linear or narrowly linear-oblanceolate, $3-5 \mathrm{~cm}$. long, loosely floccose; involucres $7-8 \mathrm{~mm}$. high and about as broad; bracts about 10 , oblong, acutish; rays 7-8 mm. long; achenes densely glandular-granuliferous. Gravelly places: Wash. -Ida. Plain-Submont. Je-Jl. 
3. E. integrifolium (Hook.) Greene. Stems numerous, decumbent at the base, 1-3 dm. high, finely tomentose; leaves linear-oblanceolate, closely tomentose, 2-5 cm. long, entire or somewhat 3-lobed; involucres $6-8 \mathrm{~mm}$. high and broad; bracts 8-10, elliptic, mostly obtuse; ligules orange, 7-10 $\mathrm{mm}$. long; achenes hispidulous or slightly glandular above and on the margins. E. caespitosum integrifolium A. Gray. Hills and mountain sides: Mont.-Wyo.-Ore.Wash. Plain-Submont. Je-J.

4. E. multiflorum (Nutt.) Rydb. Stem rather stout, 3-4 dm. high, loosely floccose; leaves pinnatifid, with lanceolate acute divisions, floccose; involucres fully $1 \mathrm{~cm}$. high and $1.5 \mathrm{~cm}$. broad; bracts oblanceolate, acuminate; ligules about $1 \mathrm{~cm}$. long, glabrous. Dry places: Ore.-Mont.

5. E. lanatum (Pursh) Forbes. Stem $3-5 \mathrm{dm}$. high, loosely floccose; leaves more or less deeply pinnatifid, with oblong or linear, mostly obtuse divisions, loosely floccose; involucres fully $1 \mathrm{~cm}$. high, usually over $15 \mathrm{~mm}$. broad; bracts 10-14, oblong-lanceolate, acute or obtuse; ligules 10-15 mm. long, orange. Hillsides and gravelly soil: B.C.-Ida.-Calif. Submont. My-Jl.

6. E. Watsoni A. Gray. Stem 1-1.5 dm. high, white-tomentose, simple or slightly branched; lower leaves cuneate-oblanceolate, about $1 \mathrm{~cm}$. long, $3-5-$ toothed at the apex, white-tomentose beneath, floccose above; stem-leaves mostly pinnatifid, with linear divisions, $1-2 \mathrm{~cm}$. long, revolute-margined; involucre hemispheric, $6 \mathrm{~mm}$. high, $1 \mathrm{~cm}$. broad or less; bracts 9-10, acute; ligules bright yellow, 5-8 mm. long. Mountains: Ore.-Ida.-Nev. Submont.-Mont,

\section{ANTHERÓPEAS Rydb. DaIsy Dwarf.}

Low floccose annual herbs, branched at the base. Leaves alternate, spatulate to linear-spatulate, entire or 3-toothed. Heads radiate. Involucre campanulate; bracts 5-9, elliptic, distinct or nearly so, concave and slightly enfolding the ray-achenes; receptacle strongly convex or low-conic, obtuse, naked. Ray-flowers 5-9, pistillate and fertile; ligules yellow, white, or tinged with rose or purple. Disk-flowers hermaphrodite and fertile. Anthers with subulate tips. Style-branches obtuse or with conic tips. Achenes elongate, narrow, 5-angled, gradually tapering downward. Pappus of 6-12 opaque squamellae, either all elliptic and obtuse or those of the angles linear-lanceolate and produced into an awn-tip, or rarely wanting. Pappus squamellae all oval or obovate, obtuse; leaves broadly spatulate or obovate;
ligules yellow or reddish.
Pappus squamellae of the Pappus squamellae of the angles narrow, linear-lanceolate or linear; leaves linear or

\section{A. Wallacei \\ 2. A. lanosum.}

1. A. Wallacei (A. Gray) Rydb. Stem $2-10 \mathrm{~cm}$. high, diffusely branched, densely floccose; leaves occasionally $2-3$-toothed at the apex, $1 \mathrm{~cm}$. long or less; involucres about $4 \mathrm{~mm}$. high, hemispheric; bracts oblong, obtuse; ligules broadly obovate, $4 \mathrm{~mm}$. long. Eriophyllum Wallacei A. Gray. Dry plains: Ariz. - s Utah -s Calif. L. Son. Ap-Je.

2. A. lanosum (A. Gray) Rydb. Stem $2-8 \mathrm{~cm}$. high, floccose, or in age glabrate, branched; leaves floceose, $1 \mathrm{~cm}$. long or less; heads campanulate, about 5 long. E. lanosum A. Gray. Dry plains: Ariz. - s Utah-Calif. L. Son. MrMy.

\section{SYNTRICHOPÁPPUS A. Gray.}

Low branched floccose annuals. Leaves alternate, from linear to spatulate, entire or 3-lobed at the apex. Heads radiate, solitary at the ends of the branches. Involucre campanulate; bracts 5-8, oblong, concave and partly enfolding the ray-achenes; receptacle flat. Ray-flowers 5-8, pistillate and fertile; ligules yellow, or purplish, rose, and white, oval, mostly 3 -lobed at the summit. Disk-flowers about 20, fertile. Anther-tips linear-lanceolate. Style-tips elongate-lanceolate, flattened. Achenes linear, obpyramidal, 5-ribbed, hairy. Pappus-squamellae dissected into numerous barbellate bristles united at the base into a wing, falling off together, or wanting. 
1. S. Fremontii A. Gray. Stem $1 \mathrm{dm}$. high or less, branched from the base, slightly floccose; leaves spatulate or linear-cuneate, often 3-lobed at the summit, $8-15 \mathrm{~mm}$. long, floceose; involucres about $6 \mathrm{~mm}$. high; bracts 5 , broadly oblong; ligules 5, golden yellow, $4 \mathrm{~mm}$. long and fully half as wide. Desertplains: Ariz. -Utah-Nev.-Calif. L. Son. Ap-My.

\section{TETRANEÙRIS Greene.}

Perennial (all ours) or annual, caulescent or scapose, more or less villous or silky herbs. Leaves usually entire, rarely some of them lobed, alternate, either clustered at the base, or scattered along the stem, or both. Heads radiate, rarely discoid, on slender peduncles. Involucre hemispheric, or nearly so; bracts several in two subequal series; receptacle convex, naked. Ray-flowers 10-20, pistillate and fertile; ligules yellow, oblong, broad, 3- (rarely 4-) toothed; nerves 4. Disk-flowers many, hermaphrodite and fertile; corollas with 5 short pubescent teeth. Anther-tips broad, triangular or ovate. Style-branches dilated, truncate, somewhat penicillate at the tips. Achenes obpyramidal, 5-angled, about 3 times as long as broad, densely hirsute. Pappus of about 5 hyaline squamellae, with a strong midrib, which sometimes is produced into an awn.

\section{Heads sessile among the leaves.}

1. T. depressa.

Heads distinctly peduncled.

Stems scapiform, leafy only at the base.

Leaves appressed-silky.

Leaves not strongly 3-nerved on the broadened bases.

Leaves spatulate or oblanceolate, $2-4 \mathrm{~cm}$. long; scape stout, $5-10 \mathrm{~cm}$. high.

Leaves linear or linear-oblanceolate; scape $10-20 \mathrm{~cm}$. high.

Leaves silvery-silky; ligules $6-8 \mathrm{~mm}$. long. $3 . T$. acaulis.

Leaves greenish, sparingly silky; ligules 8-10 $\mathrm{mm}$. long.

4. $T$. simplex.

Leaves strongly 3-nerved on the broadened bases, narrowly linear-oblanceolate.

Leaves loosely villous or glabrate.

Leaves, scape, and involucre decidedly villous.

Involucre more than $1 \mathrm{~cm}$. broad; scape $3-8 \mathrm{~cm}$. long; plant densely cespitose-pulvinate; leaves not conspicuously broad-based.

6. T. lanigera.

Involucre less than $1 \mathrm{~cm}$. broad; scape $1-3 \mathrm{~cm}$. (rarely $3-5 \mathrm{~cm}$.) long; plant loosely cespitose; leaves conspicuously broad-based.

7. T. brevifolia.

Leaves glabrous or sparingly villous; scape finely pubescent or villous (longvillous only in $T$. Torreyana).

Branches of the caudex decidedly villous at the ends, with long, at first white, but later brownish hairs.

Pappus-scales lanceolate, acuminate, not awned; scape villous.

Pappus-scales oval, awned; scape silky.

Bracts oval.

Bracts linear-oblong.

8. T. Torreyana.

9. T. arizonica.

10. T. Crandallii.

Branches of the caudex not conspicuously villous.

Bases of the leaves not wider than the oblanceolate or almost linear blades; branches of the caudex short and stout.

Leaves glabrous, scarcely punctate; bracts slightly shorter than the disk; ligules not strongly nerved. 11 . T. epunctata.

Leaves long-hairy, distinctly punctate; bracts three-fourths as long as the disk; ligules strongly nerved. 12 . T. angustifolia.

Bases of the leaves 2-4 times as wide as the linear leaf-blades; branches of the caudex or rootstock elongate.

Stems 2-3 dm. high, with 2-6 stem-leaves.

Basal leaves oblanceolate to linear-oblanceolate, more than $5 \mathrm{~mm}$. wide; invo-

lucre hemispheric.
Basal leaves narrowly linear-oblanceolate, less than $5 \mathrm{~mm}$. wide; involucre narrower.

wide; involucre

1. T. depressa (T. \& G.) Greene. Pulvinate-cespitose perennial; leaves narrowly linear or nearly so, 1-2 cm. long, 1-2 mm. wide, glabrate, hairy-tufted at the base; heads sessile; involucres about $6 \mathrm{~mm}$. high and $8 \mathrm{~mm}$. broad; bracts oblong, obtuse; achenes silky-strigose; pappus-squamellae ovate, tapering into an awn. Actinella depressa T. \& G. Dry hills and mountains: Utah.

2. T. septentrionalis Rydb. Leaves mostly rounded at the apex, $5-8 \mathrm{~mm}$. wide, canescent-tomentose, subvelutinous; scape 5-10 dm. high, rather thick, 
appressed-tomentose; involucres 6-7 $\mathrm{mm}$. high, $12-15 \mathrm{~mm}$. broad, densely villous; bracts elliptic, rounded at the apex; ligules $8-10 \mathrm{~mm}$. long, very strongly veined; pappus-squamellae ovate, abruptly short-aristate. Dry hills: Sask.Wyo.-Ida. Plain. Je-Jl.

3. T. acaulis (Pursh) Greene. Leaves crowded, narrowly linear-oblanceolate, $2-8 \mathrm{~cm}$. long, 2-6 mm. wide, mostly acutish; involucres $7-8 \mathrm{~mm}$. high, 10-15 mm. broad, hemispheric, silky-villous; bracts linear to oblong, or spatulate, obtuse; ligules 6-8 mm. long, yellow with orange veins; pappus-squamellae ovate, abruptly aristate. Galardia acaulis Pursh. Actinella acaulis Nutt. T. incana A. Nels. T. eradiata A. Nels., a rayless form. Dry hills and plains: N.D.-Tex.-N.M.-Ida.-Mont. Plain-Submont.

4. T. simplex A. Nels. Leaves green, sparingly appressed-pubescent, glabrate in age, ascending or erect, $2-5 \mathrm{~mm}$. wide, acute; involucres $12-18 \mathrm{~mm}$. broad, 8-10 mm. high, silky-villous; ligules 8-10 $\mathrm{mm}$. long, 4-7 mm. wide, golden yellow, with orange veins; pappus-squamellae lance-ovate, abruptly aristate. A. simplex A. Nels. Dry hills: S.D.-Colo.-Wyo. Plain. Je-Jl.

5. T. trinervata Greene. Leaves 3-5 mm. long, 1-5 mm. broad, more or less appressed-silky, with tufts of brown hairs at the bases; scape $5-15 \mathrm{~cm}$. long, appressed-silky; involucres hemispheric, $5-6 \mathrm{~mm}$. high, about $1 \mathrm{~cm}$. broad, appressed-silky; bracts linear-oblong, obtuse; ligules about $8 \mathrm{~mm}$. long; pappussquamellae ovate, aristate. Dry hills: N.M.-Colo. Son.-Submont. Jl-O.

6. T. lanigera Daniels. Leaves numerous, linear-oblanceolate, $2-5 \mathrm{~cm}$. long, 2-5 mm. broad, somewhat silky when young, in age with loose brownish pubescence, with tufts at their bases; scape 3-6 $\mathrm{cm}$. long, loosely silky-villous; involucres 10-15 $\mathrm{cm}$. broad, 7-8 $\mathrm{mm}$. high, villous; bracts oblong, obtuse; ligules $8-10 \mathrm{~mm}$. long; pappus-squamellae lance-ovate, rather gradually aristate. A. lanata Nutt., not Pursh. Mountains: Colo.-Wyo. Submont.-Mont. Je-Jl.

7. T. brevifolia Greene. Branches of caudex densely covered with the scarious bases of old leaves; leaves narrowly oblanceolate, $1-2 \mathrm{~cm}$. (rarely 2.5 $\mathrm{cm}$.) long, 2-3 mm. wide, silky-villous, rather densely so; involucres about $7 \mathrm{~mm}$. high and $1 \mathrm{~cm}$. broad or less, densely silky-villous; ligules pale yellow, with orange veins, 5-7 mm. long; pappus-squamellae ovate, abruptly aristate, nearly as long as the corollas. T. acaulis caespitosa A. Nels. Actinea integrifolia Torr., not Kunth. Foothills and mountains: Colo.-Wyo. Submont.-Mont. My-Je.

8. T. Torreyana (Nutt.) Greene. Leaves narrowly oblanceolate or spatulate, 3-5 cm. long, 3-6 mm. broad, glabrous or with a few scattered hairs; scape more or less villous, $3-8 \mathrm{~cm}$. high; involueres 9-10 $\mathrm{mm}$. high and about $15 \mathrm{~mm}$. broad; bracts linear, slightly villous and scarious-margined; ligules $10-12 \mathrm{~mm}$. long, 3-6 $\mathrm{mm}$. broad; pappus-squamellae lanceolate or lance-ovate, acuminate. A. Torreyana Nutt. A. glabra A. Nels., not Nutt. Rocky hills: Wyo,-Colo. -Utah. Plain-Submont. My-Je.

9. T. arizonica Greene. Leaves linear-oblanceolate, $3-5 \mathrm{~cm}$. long, 3-6 $\mathrm{mm}$. wide, sparingly pilose; scapes 5-20 cm. long, appressed-pubescent or glabrate; involucres about $8 \mathrm{~mm}$. high and $15 \mathrm{~mm}$. broad; bracts oblong or oval, obtuse, villous, often with brownish margins; ligules $7-10 \mathrm{~mm}$. long; pappus-squamellae broadly ovate, abruptly aristate. $T$. pilosa Greene, a more glabrous plant. Dry regions: Ariz.-Nev.-s Colo.-N.M. Son.-Submont. My-J.

10. T. Crandallii Rydb. Leaves narrowly linear-oblanceolate, 4-6 $\mathrm{cm}$. long, 2-3 mm. wide, sparingly long-hairy, soon glabrate; scape 1-3 dm. long, sparingly strigose; involucre hemispheric; bracts about $8 \mathrm{~mm}$. long, linearoblong, silky; ligules about $15 \mathrm{~mm}$. long; pappus-squamellae ovate, aristate. Dry hills: Colo. Plain-Submont. My-Je.

11. T. epunctata A. Nels. Leaves glabrate or with few seattered hairs, indistinctly punctate, narrowly oblanceolate, $2-4 \mathrm{~cm}$. long; seape about $1 \mathrm{dm}$. high, sparsely silky-strigose; involucres about $8 \mathrm{~mm}$. high and $15 \mathrm{~mm}$. broad, silky-villous; bracts elliptic or oblong; ligules bright yellow, 10-12 $\mathrm{mm}$. long; pappus-squamellae obovate, abruptly aristate. T. glabra Greene, in part. T. 
glabriuscula Rydb. A. epunctata A. Nels, Dry hills: Colo.-N.M.-Utah. Submont.-Mont. Je-Jl.

12. T. angustifolia Rydb. Leaves narrowly linear-oblanceolate, 4-10 cm. long, 4-5 $\mathrm{mm}$. wide, loosely and sparingly long-villous, or glabrate in age; scape 2-3 dm. high, strigose; involuere hemispherical, 10-12 mm. wide; bracts oblong, obtuse, densely villous; ligules about $1 \mathrm{~cm}$. long; pappus-squamellae ovate, acuminate. Dry rocky hills: Colo.-Tex.-N.M. Plain-Submont. Mr-O.

13. T. fastigiata Greene. Leaves basal, very narrowly linear-oblanceolate, 2-4 cm. long, 1-2 mm. wide, strongly punctate, glabrous or with a few long hairs near the base; scape $5-10 \mathrm{~cm}$. long, striate, punctate and sparingly strigose; involucre about $5 \mathrm{~mm}$. high and $10 \mathrm{~mm}$. wide, hemispheric; bracts elliptic, obtuse; ligules light yellow, about $10 \mathrm{~mm}$. long and $5 \mathrm{~mm}$. wide; pappus-squamellae ovate, acuminate. $T$. stenophylla Rydb. A. fastigiata A. Nels. Dry plains: Kans.-Colo.-Tex. Plain. My-Jl.

14. T. leptoclada (A. Gray) Greene. Stem 1-3 dm. high, sparingly appressed-pubescent; basal leaves glabrate or slightly hairy, hairy-tufted at the base, 3-6 $\mathrm{cm}$. long, 4-6 mm. wide; stem-leaves linear, few; involucres 7-8 $\mathrm{mm}$. high, 12-15 $\mathrm{mm}$. broad, more or less villous; outer bracts oblong, lanceolate or linear, the inner elliptic, oval, or somewhat obovate, rounded; ligules 8-10 mm. long; pappus-squamellae ovate, gradually aristate. A. leptoclada A. Gray. $T$. mancosana A. Nels. $T$. intermedia Greene, a form with somewhat narrow bracts. Dry hills: Colo.-N,M.-Utah. Submont.-Mont. Ap-Jl.

15. T. Ivesiana Greene. Stem 1-3 dm. high, sparingly pubescent; leaves all narrowly linear or lance-linear, 5-10 $\mathrm{cm}$. long, 1-4 mm. wide, erect; involucre somewhat turbinate, 5-6 mm. high, 7-8 mm. broad, silky-villous; bracts elliptic, obtuse; ligules about $10 \mathrm{~mm}$. long, strongly veined; squamellae lanceolate, acuminate into an awn. Cañons and hillsides: Utah-Ariz.-N.M. Son.

\section{RYDBÉRGIA Greene.}

Stout caulescent perennials with taproots. Leaves alternate, once or twice ternately or quinately divided into linear divisions, or some of them entire. Heads radiate, solitary. Involucre depressed-hemispherie; bracts in about 3 series, linear, distinct, subequal or the inner shorter, densely woolly. Receptacle convex or hemispheric, naked. Ray-flowers 15-30, pistillate, fertile; ligules yellow, elongate, 3-toothed. Disk-flowers numerous, hermaphrodite and fertile. Style-tips truncate, penicillate. Achenes obpyramidal, silky-hirsute, 5 -angled. Pappus of 5 lance-subulate or linear-lanceolate attenuate squamellae with faint midrib.

Basal leaves all dissected; plant villous.

Basal leaves, at least some of them, simple; plant more glabrate.
1. $R$. grandiflora.

2. $R$. Brandegei.

1. R. grandiflora (T. \& G.) Greene. Stem 1-3 dm. high, stout, floccose, leafy; leaves once or twice pinnatifid with linear lobes, more or less floceose; involucres $2-4 \mathrm{~cm}$. broad, densely white-woolly; ligules $1.5-2 \mathrm{~cm}$. long, 4-5 mm. broad. Actinella grandiflora T. \& G. High mountain sides: Mont.-N.M.Utah. Mont.-Alp. J-Au.

2. R. Brandegei (A. Gray) Rydb. Stem short-villous above, glabrate below, almost scapiform, 1-2 dm. high; leaves pinnatifid, with a few linear lobes or entire and linear, glabrate; involuere $2-3 \mathrm{~cm}$. wide, dark, short villous; ligules $8-10 \mathrm{~cm}$. long and $4 \mathrm{~mm}$. wide. A. Brandegei A. Gray. R. glabrata (Porter) Greene. High mountains: Colo.-N.M. Mont.-Alp. Л-Au.

\section{7. hymenóxys Cass. Colorado Rubber Plant.}

Caulescent annuals, biennials, or perennials. Leaves alternate, commonly pinnatifid into narrowly linear divisions. Heads (in ours) radiate. Involucre of two series of bracts, 5-16 in each series, the outer usually narrower and more or less united at the base, rather firm, entire, acute, the inner broader, either similar, or else more or less erose on the margin and abruptly acuminate or 
mucronate. Ray-flowers 5-16, pistillate and perfect; ligules usually conspicuous, 3-lobed. Disk-flowers many, hermaphrodite, perfect. Style-branches obtuse or truncate, penicillate. Achenes obpyramidal, 5-angled, densely hirsute with ascending hairs. Pappus of 5 hyaline squamellae, with faint or indistinct midrib, usually acute or acuminate. [Picradenia Hook.]

Perennials or biennials; inner bracts fimbriate or erose, abruptly acute, acuminate, or mucronate, unlike the outer ones; disk-corollas not expanded at the mouth.

Plant low, perennial, usually with a multicipital caudex; outer bracts united at least one-third their length; plant long-hairy on the basal leaf-bases,

Outer bracts not strongly thickened on the back.

Outer bracts united to the middle; free portions ovate or ovate-lanceolate.

1. H. Richardsonii.

Outer bracts united about a third their length; free portions narrowly lanceolate.

Involucre 10-15 mm. broad; ligules 10-18 mm. long; plant 1-3 dm. high.

2. H. macrantha

Involucre $8-10 \mathrm{~mm}$. broad; ligules $5-8 \mathrm{~mm}$. long; plant less than $1 \mathrm{dm}$. high.

Outer bracts strongly thickened on the back, subcarinate.

Heads few, often solitary; ligules nearly rectangular-oblong.

Heads several; ligules decidedly cuneate.

Ligules light yellow, at least twice as long as wide; pappus-squamellae aristate-pointed.

Ligules orange, half longer than wide; pappus-squamellae acute or acum-

inate.
Plant tall, biennial or short-lived perennials; outer bracts united only at the base.

3. H. pumila.

\section{H. Macounir.}

5. H. floribunda.

Leaves all dissected into narrowly linear divisions.

Leaves of the stem very numerous, more or less lepidote-pubescent; segments narrow, rarely more than $1 \mathrm{~mm}$. wide.

Plant low, densely canescent; heads $1-3$; squamellae not more than half as long as the corolla, not subulate-tipped. $\quad 7$. H. canescens.

Plant tall, greener; heads several or many; squamellae about half as long

as the corolla, subulate-tipped.
Leaves of the stem not conspicuously numerous, glabrate and green; segments

$1-3 \mathrm{~mm}$. wide.
Leaves, at least the lower ones, entire or with broad lobes $3-8 \mathrm{~mm}$. Wide.

10. $\vec{H}$. helenioides.

Annuals, with numerous heads; inner bracts not very different from the outer, neither abruptly acute nor mucronate, nor evidently erose; throat of the disk-corollas somewhat funnelform.

11. H. odorata.

1. H. Richardsonii (Hook.) Cockerell. Stem 1-3 dm. high, glabrous or nearly so; leaves $5-10 \mathrm{~cm}$. long, pinnatifid, with narrowly linear divisions $2-4$ $\mathrm{cm}$. long and 1-2 $\mathrm{mm}$. wide; involucres about $8 \mathrm{~mm}$. high and $10-15 \mathrm{~mm}$. broad; ligules bright yellow, 7-10 mm. long. Picradenia Richardsonii Hook. Actinella Richardsonii Nutt. Hymenopappus ligulaeflorus A. Nels. P. ligulaeflora A. Nels. Dry plains: Sask.-Mont.-Alta. Plain. Je.

2. H. macrantha (A. Nels.) Rydb. Stem 1-2 dm. high, sparingly pubescent or glabrate, hairy-tufted at the base; leaves glabrate, pinnatifid, with narrowly linear divisions; involucres $10-15 \mathrm{~mm}$. broad and $8 \mathrm{~mm}$. high; inner bracts obovate, abruptly short-acuminate, tips often greenish; ligules 8-18 $\mathrm{mm}$. long, bright yellow. Picradenia macrantha A. Nels. Dry soil: Wyo.-Colo.-Utah. Plain-Mont. Je-Au.

3. H. pumila (Greene) Rydb. Stem $1 \mathrm{dm}$. high or less, glabrate or slightly hairy; leaves pinnatifid, with 3-5 linear-filiform divisions, or the lower entire and filiform; involueres $8-10 \mathrm{~mm}$. broad, $5-6 \mathrm{~mm}$. high; inner bracts ovate, with short but sharp acumination; ligules pale yellow, $5-6 \mathrm{~mm}$. long. $P$. pumila Greene. Dry hills: Wyo.-Colo.-Utah. Submont. Jl-Au.

4. H. Macounii (Cockerell) Rydb. Stem about $1 \mathrm{dm}$. high, sparingly pubescent or glabrous; leaves pinnately divided unto $3-5$ filiform divisions; involucres about $6 \mathrm{~mm}$. high and $8-10 \mathrm{~mm}$. broad, usually acute at the base; ligules bright yellow, 5-7 mm. long. Dry plains: Sask,-Mont. Plain. Je-Au.

5. H. floribunda (A. Gray) Cockerell. Stem 1-3 dm. high, corymbosely branched; leaves pinnatifid, with 3-5 narrowly linear divisions; involucres 4-6 $\mathrm{mm}$. high, $6-8 \mathrm{~mm}$. broad; outer bracts scarcely united to the middle, lanceolate; ligules 6-8 mm. long, bright yellow, cuneate. A. Richardsonii floribunda A. Gray. 
P. floribunda Greene. Dry and gravelly soil: Wyo.-Tex.-Ariz.-Utah. Plain - Mont. Je-Au.

6. H. Earlei Cockerell. Stem 2-3 dm. high, corymbosely branched above; leaves pinnatifid into 3-5 narrowly linear divisions, somewhat broader than in the preceding; involucres $5-6 \mathrm{~mm}$. high, $7-8 \mathrm{~mm}$. broad; outer bracts united about one-third their length, lanceolate; inner bracts barely mucronate. $P$. Earlei Cockerell. Foot-hills and cañons: s Colo. Submont. Л.

7. H. canescens (D. C. Eat.) Cockerell. Stem 1-2 dm. high, eanescent with flat scale-like hairs; leaves numerous, $2-4 \mathrm{~cm}$. long, divided into $3-5$ linearfiliform divisions, canescent like the stem, rather fleshy; involucre 5-6 mm. high, 10-15 mm. broad; outer bracts 12-15, lanceolate; ligules about $8 \mathrm{~mm}$. long, $3 \mathrm{~mm}$. wide. A. Richardsonii canescens D. C. Eat. Dry places: Nev,-Utah. Son.

8. H. biennis (A. Gray) H. Hall. Biennial; stem 3-5 dm. high, more or less grayish-puberulent; leaves numerous, pinnatifid, with narrowly linear divisions 1-1.5 $\mathrm{mm}$. broad, puberulent; involucres $6 \mathrm{~mm}$. high, 10-15 mm. broad; inner bracts obovate or oblanceolate, usually with one small tooth on each side; ligules fully $1 \mathrm{~cm}$. long, orange, cuneate. A. biennis A. Gray. Arid regions: $\mathrm{s}$ UtahAriz. L. Son.

9. H. Greenei (Cockerell) Rydb. Stem about $3 \mathrm{dm}$. high, with erect branches, leafy, glabrous; leaves pinnatifid; divisions linear, $2-4 \mathrm{~mm}$. broad; involucres about $6 \mathrm{~mm}$. high and $10-13 \mathrm{~mm}$. broad; inner bracts broadly obovate, more or less erose-dentate; pappus-scales lanceolate, gradually aristate. H. Lemmonii Greenei Cockerell. Arid regions: s Utah-Nev.-Ariz. Son.

10. $\mathbf{H}$. helenioides Rydb. Biennial; stem leafy, about $5 \mathrm{dm}$. high, with several to many erect branches; leaves rather firm, distinctly ribbed, finely pubescent; basal leaves entire, very narrowly linear-oblanceolate; middle stemleaves erect, fully $1 \mathrm{dm}$. long, parted into $3-5$ linear divisions; upper stem-leaves linear, entire; involucre $8-10 \mathrm{~mm}$. high and often $15 \mathrm{~mm}$. broad; outer bracts lanceolate, longer than the inner, 14-18 in number; ligules orange, about $1 \mathrm{~cm}$. long, 2-3 mm. wide. River valley: s Colo. Mont. Jl.

11. H. odorata DC. Stem branched near the base, 1-3 dm. high, sparingly pilose or glabrous; leaves pinnatifid, with linear-filiform divisions; involueres about $4 \mathrm{~mm}$. high, $6-8 \mathrm{~mm}$. broad; ligules cuneate, 3-5 mm. long; pappus-scales ovate, aristate. Philozera multiflora Buckley. Picradenia multiflora Greene. A. odorata A. Gray. Dry plains: Tex.-Kans.-Colo.-Ariz. Son. Je-Au.

\section{FLAVÈRIA Juss.}

Glabrous or puberulent herbs. Leaves opposite, narrow, entire or dentate, sessile, often more or less connate. Heads numerous, narrow, in dense cymes or glomerules. Involucre of 1-8 subequal bracts, and sometimes 1 or 2 smaller outer ones. Receptacle small, naked or setose. Ray-flowers solitary, pistillate and fertile, or wanting; ligules entire, emarginate, or 3-dentate, yellow, inconspicuous. Disk-flowers 1-15, hermaphrodite and fertile. Style of the hermaphrodite flowers 2-parted, reflexed, obtuse. Achenes oblong, somewhat compressed, 10-ribbed; pappus in ours wanting.

1. F. campestris J. R. Johnston. Annual; stem 2-6 dm. high, glabrous; leaves lanceolate to linear, serrulate to entire, more or less distinctly 3 -ribbed; heads in close, subsessile clusters at the ends of the branches, $2-5$-flowered; involueres cylindric, about $5 \mathrm{~mm}$. long; bracts mostly 3 , linear-oblong, glabrous; ligule elliptic, 1.5-2 mm. long, exceeding the disk. F. angustifolia A. Gray, not Pers. Alkali grounds: Tex.-Colo.-N.M.; Mex. Son. J-Au.

\section{DUGÁLDIA Cass.}

Perennial caulescent herbs, with rootstocks, more or less floccose or villous. Leaves linear, entire, not decurrent, with several nearly parallel nerves. Heads radiate, large. Involucre almost rotate; bracts lance-subulate, herbaceous, in 2 or 3 subequal series, spreading and tardily reflexed. Receptacle convex or nearly 
flat, naked or with some bracts between the ray and disk. Ray-flowers fertile, pistillate; ligules yellow, rather narrow. Disk-flowers numerous. Style-branches with truncate subcapitate tips. Achenes obpyramidal, densely pubescent. Pappus of 5-7 lanceolate or subulate, acuminate, aristate, scarious, and nerveless squamellae.

1. D. Hoopesii (A. Gray) Rydb. Stem 3-10 dm. high, tomentulose when young, leafy; basal leaves petioled, 1-3 dm. long, 2-7 cm. broad, oblanceolate, several-ribbed; upper leaves lanceolate, sessile; involucres 2-3 cm. broad; ligules golden, 1.5-3 cm. long. Helenium Hoopesii A. Gray. Mountain valleys: Ore. -Wyo.-N.M.-Calif. Submont.-Subalp. Je-Au.

\section{HELÈNIUM L. SNeEzeweed,}

Annual or perennial leafy herbs. Leaves alternate, narrow, impressed-punctate, more or less decurrent, producing wings on the stem. Heads usually radiate. Involucre rotate; bracts narrow, linear or subulate in 2 or 3 series, subequal or the inner shorter, at first spreading, usually soon reflexed. Receptacle from convex to ovoid or conic, naked or sometimes with a few bracts between the ray- and disk-flowers. Ray-flowers usually present, in most species pistillate and fertile, in the rest neutral and sterile; ligules large, conspicuous, 3-4toothed or -lobed, cuneate in outline. Disk-flowers numerous, hermaphrodite and fertile; corollas yellow, brown, or purplish. Achenes truncately obpyramidal, 4- or 5-angled, with as many intermediate ribs, pubescent on the angles and ribs. Pappus of 4-8 thin scarious squamellae, with or without midrib.

Plant scabrous-puberulent throughout; bracts about equalling the disk; ligules about 1 $\mathrm{cm}$. long or less. 1. H. montanum.

Plant glabrous or minutely puberulent; bracts much longer than the disk; ligules generally over $1 \mathrm{~cm}$. long.

2. H. macranthum.

1. H. montanum Nutt. Perennial; stem 3-10 dm. high, more or less puberulent; leaves lanceolate, decurrent, $5-10 \mathrm{~cm}$. long, denticulate or subentire; heads numerous, paniculate-cymose; involucres about $8 \mathrm{~mm}$. high, $10-15 \mathrm{~mm}$. broad; ray-flowers fertile; ligules $8-10 \mathrm{~mm}$. long, cuneate, puberulent beneath, golden yellow; pappus-scales lanceolate, acuminate. Meadows: Mont.-Kan.N.M.-Wash.-B.C. Plain-Submont. Jl-S.

2. H. macranthum Rydb. Perennial; stem 3-12 dm. high; leaves broadly lanceolate or ovate-lanceolate, dentate or entire, thinner than in the preceding; heads with longer naked peduncles; involucres over $1 \mathrm{~cm}$. high, $15-20 \mathrm{~mm}$. broad; ligules 12-20 mm. long, orange. $H$. grandiflorum Nutt., not Gilib. $H$. autumnale grandiflorum A. Gray. Wet places: Mack.-Sask,-Wyo.-Ore.B.C. Plain-Submont. J1-S.

\section{GAILLÃRdia Foug. Blanket-Flower.}

Annual, biennial, or perennial herbs, either scapose or caulescent. Leaves alternate or basal, entire, toothed, or pinnatifid, often in the same species. Heads radiate or discoid, peduncled. Involucre saucer-shaped or rotate; bracts in 2-3 series, ovate, oblong or lanceolate, at least the upper half strongly reflexed. Receptacle convex to subglobose, alveolate, usually more or less fimbrillate, the fimbrillae from soft and short-conic, to elongate-subulate, stiff and awn-like. Ray-flowers usually neutral, rarely pistillate and fertile, often wanting; ligules, if present, broad, cuneate or flabelliform, deeply 3-cleft, yellow, or purple, or both. Disk-flowers hermaphrodite and fertile. Anthers auricled at the base. Style-branches appendaged; appendages from glabrous and short to hispidulous and filiform. Achenes broadly obpyramidal, about twice as long as broad, wholly or partly covered by long, stiff, ascending hairs.

Lobes of the disk-corollas acuminate, covered with moniliform hairs.

Plant perennial; ligules usually wholly yellow.

Plant annual; ligules partly or wholly purple.

Lobes of the disk-corollas short and broad, acute or obtuse.

1. G. aristata.

2. G. pulchella.

Plant hirsute or villous; leaves neither coriaceous nor conspicuously punctate. Pappus-squamellae lanceolate, awn-pointed. Disk purple; leaf-segments more or less ascending. 
Leaves, except the earliest ones, pinnatifid with narrow divisions.

Leaves entire or with broad divisions.

Perennials with a thick root.

Annuals or biennials; root not thick.

Disk pale yellow; leaf-segments divaricate.

3. G. pinnatifida.

pus-squamellae elliptic, muticous, or with a very short awn-tip; disk yellow.
Squamellae with a distinct midrib, usually minutely awn-tipped.

Squamellae without midrib and awn-tip.

4. G. gracilis.

5. G. Mearnsii.

6. G. flava.

7. G. Pringlei.

8. G. arizonica.

Plant minutely and sparingly puberulent; caudex thick and woody; leaves coriaceous, conspicuously punctate.

Plant distinctly caulescent; leaf-blades spatulate to linear.

Plant acaulescent, scapose; basal leaf-blades broadly obovate.

9. G. spathulata.

10. G. Parryi.

1. G. aristata Pursh. Stem 2-6 dm. high, simple, leafy, more or less hirsute and puberulent; leaves oblanceolate in outline, the lower petioled, the upper sessile, grayish-puberulent, entire, dentate, lobed, or pinnatifid; involucres 2-3 $\mathrm{cm}$. broad; bracts lance-subulate, long-attenuate, surpassing the disk, hirsutevillous; disk-corollas purple; ligules wholly yellow, or purplish at the base, $1.5-3$ $\mathrm{cm}$. long; pappus-squamellae lanceolate, long-aristate. G. bracteos $a$ Standl. Hills and plains: Sask.-S.D.-Colo.-Ore--B.C. Submont. Je-S.

2. G. pulchella Foug. Stem branched, leafy, $2-4 \mathrm{dm}$. high, puberulent; lower leaves oblanceolate or spatulate in outline, petioled, puberulent, entire, dentate or sinuately pinnatifid, the upper leaves sessile, lanceolate, acute or acuminate; involucres $15-20 \mathrm{~mm}$. broad; bracts lanceolate, acuminate, hirsute; disk-flowers purple; ligules $10-18 \mathrm{~mm}$. long, purple below with yellow tips, or sometimes wholly purple; squamellae lanceolate, long-aristate. Plains: La.Mo.-Neb.-Colo.-Ariz.; n Mex. Son.-Plain. Ap-Au.

3. G. pinnatifida Torr. Perennial, often branched at the base; stem 1-3 $\mathrm{dm}$. high, leafy towards the base; leaves short-pubescent, pinnatifid, with linear or lanceolate divisions, or some of the earlier merely lobed; peduncles 1-2 dm. long; involucres $15-20 \mathrm{~mm}$. broad; bracts lance-subulate, attenuate, hirsute, often purplish; ligules yellow, 10-15 mm. long; squamellae lanceolate, longaristate. Dry plains: Tex.-Colo.-Utah-Ariz,; n Mex. Son.-Submont. MyAu.

4. G. gracilis A. Nels. Stems usually several, 3-5 dm. high, straw-colored, finely puberulent; leaves short-pubescent, oblanceolate in outline, $4-8 \mathrm{~cm}$. long, entire, lobed, rarely sinuate-pinnatifid with obtuse lobes; involueres $1.5-2 \mathrm{~cm}$. wide; bracts narrowly lanceolate, attenuate, pubescent; ligules yellow, about $15 \mathrm{~mm}$. long; squamellae lanceolate, abruptly acuminate. Dry valleys and canyons: Utah. Son. My.

5. G. Mearnsii Rydb. Stem 1-3 dm. high, leafy only towards the base, finely pubescent; leaves oblanceolate or spatulate, petioled, $5-10 \mathrm{~cm}$. long, puberulent, entire or round-lobed; peduncles 1-2 dm. high; involueres about 2 $\mathrm{cm}$. broad; bracts lanceolate, acute, grayish-pubescent; ligules yellow, 10-15 mm. long; squamellae lanceolate, each gradually attenuate into a slender awn equalling the corolla. Arid places: Ariz.-Utah. Son.

6. G. flava Rydb. Perennial, somewhat woody at the base; stem leafy, sparingly hirsutulous, about $3 \mathrm{dm}$. high; leaves obovate in outline, $3-5 \mathrm{~cm}$. long, pinnately parted with divergent oblong or lanceolate, often few-toothed divisions, hirsutulous and conspicuously punctate; involucral bracts lanceolate, longacuminate, hirsutulous; ligules pale yellow, about $8 \mathrm{~mm}$. long; squamellae 5-6 $\mathrm{mm}$. long, lanceolate, the midrib produced into an awn between the lobes of the 2-cleft apex. Cañons: Utah. Son. Jl.

7. G. Pringlei Rydb. A subscapose annual; leaves clustered at the base, 4-6 $\mathrm{cm}$. long, usually pinnately lobed or sometimes merely toothed, with ovate lobes or teeth, villous; scape 1-2 dm. high, short-pubescent; involucral bracts $8 \mathrm{~mm}$. long, villous; ligules yellow, $10-15 \mathrm{~mm}$. long; disk yellow, 15-18 mm. broad; squamellae 8-10, obovate, rounded or slightly retuse at the apex. Mesas: Ariz.-Utah. Son. 
8. G. arizonica A. Gray. Annual; stem 1-3 dm. high, branched and leafy at the base, puberulent; leaves pinnatifid or lobed, with obtuse divisions, puberulent or pilose; peduncles 1-2 dm. long; involucres about $15 \mathrm{~mm}$. broad; bracts lanceolate or linear, acute; disk yellow; ligules yellow, 10-15 mm. long. Dry regions: s Utah-Ariz.-Nev. L. Son. Mr-My.

9. G. spathulata A. Gray. Stem leafy, 1-3 dm. high, finely puberulent or glabrate; leaves spatulate, petioled, thick; peduncles short; involucres 15-20 $\mathrm{mm}$. broad; bracts ovate-lanceolate, acuminate; disk yellow; squamellae lanceolate, long-aristate, surpassing the disk. Dry valleys: Utah. Son. Je-Jl.

10. G. Parryi Greene. Leaves petioled, ovate or obovate, all basal, thick, glabrous or minutely puberulent; peduncles 1-3 dm. high; involucres about 2 $\mathrm{cm}$. wide; bracts ovate, abruptly acuminate; disk yellow; ligules yellow, 15-20 $\mathrm{mm}$. long; squamellae narrowly lanceolate, short-aristate. G. acaulis A. Gray, not Pursh. Arid regions: s Utah-Ariz. L. Son. Je-Jl.

\section{Bok̀Bera Willd. Fetid Marigold.}

Annual or perennial herbs. Leaves opposite or the upper alternate, pinnately or bipinnately dissected. Heads usually radiate. Involucre hemispheric, turbinate or broadly campanulate, with a distinct calyculum; principal bracts 8-10, broad, thin and somewhat scarious on the margins, with 3-7 conspicuous glands; receptacle puberulent. Ray-flowers pistillate and fertile; ligules oblong to rounded-oval, yellow or orange. Disk-flowers many. Stylebranches with a short conic or obtuse appendage. Achenes hirsute, more or less angled, somewhat compressed, cuneate-oblong. Pappus of 8-15 squamellae, each dissected into 5-10 bristles. [Dyssodia Cav., not Lour.]

1. B. papposa (Vent.) Rydb. Ill-scented annual; stem leafy, branched, 1-3 dm. high; leaves pinnately or bipinnately divided into linear lobes; involueres $6-8 \mathrm{~mm}$. high and as broad; outer bracts linear, green, the inner 8-10, oblong, scarious, tipped, brownish green or purplish-tinged, with conspicuous oblong glands; ligules few, inconspicuous. Dyssodia chrysanthemoides Lag. D. papposa (Vent.) Hitchc. Prairies, river valleys, roadsides, and waste places: Ohio-La.-Ariz.-Mont.; Mex. Son.-Submont. Jl-S.

\section{THYMOPHÝlLA Lag. Tiny Tim.}

Annual or perennial herbs. Leaves opposite or alternate, or both, pinnately dissected into narrow lobes. Heads usually radiate, peduncled. Involuere turbinate, campanulate, or hemispherie, with or without a few small accessory bracts below; principal bracts in one or two more or less distinct series, equal in length and more or less united, each with 1-5 glands towards the tip. Receptacle naked. Ray-flowers pistillate and fertile, rarely wanting. Diskflowers hermaphrodite, fertile. Style-tips obtuse or truncate. Achenes clavate, 4-5-angled. Pappus of normally 10 (rarely 11-20) squamellae most often in two series. [Hymenatherum Cass. Lowellia A. Gray.]

Annuals; pappus-squamellae muticous.

Perennials; pappus-squamellae awn-tipped.

1. T. aurea.

2. T, Thurberi.

1. T. aurea (A. Gray) Greene. Glabrous annual; stem branched from below, leafy, 1-1.5 dm. high; leaves alternate, pinnately parted into 7-9 linearfiliform divisions; involucres 4-5 mm. high, $5-6 \mathrm{~mm}$. broad; bracts oblanceolate, with conspicuous glands; ligules about 12 , oblong, $5-6 \mathrm{~mm}$. long; pappus of $6-8$ quadrate or oblong, erose-truncate scales. Lowellia aurea A. Gray. Hymenatherum aureum A. Gray. Dyssodia aurea A. Nels. Dry plains: Colo.-Tex.N.M. Je-O.

2. T. Thurberi (A. Gray) Woot. \& Standl. Suffruticose perennial; stems much branched, 1-2 dm. high, puberulent or glabrate; leaves pinnatifid, with filiform divisions, more or less finely short-pilose; involucres $4-6 \mathrm{~mm}$. high and broad; outer bracts 1-3, subulate, very small; inner bracts linear, with triangular tips and 3-5 glands; ligules oblong, about $3 \mathrm{~mm}$. long; outer pappus-squamellae 
10 , the inner 5 , usually 3 -awned, the outer 1 -awned. H. Thurberi A. Gray. D. cupulata A. Nels. D. Thurberi B. L. Robins. Dry hills: Tex. - S Utah-Ariz.; Mex. Mr-N.

\section{PÉCtis L. Lemon-Scent.}

Rather low, branching, mostly aromatic or strong-scented, annual or perennial herbs. Leaves opposite, glandular-dotted, mostly entire, usually with several pairs of marginal bristles near the base. Heads usually small, solitary or cymose, radiate. Involucre from cylindric or oblong to campanulate or turbinate; bracts 3-12, free, in a single series, without calyculum, glandular-dotted, roundedcarinate at least below; receptacle naked. Ray-flowers few, pistillate and fertile; ligules yellow or tinged with red or purple. Disk-flowers rather few, hermaphrodite and fertile; corollas yellow. Style hispidulous, the short branches obtuse and without appendages. Achenes linear, terete or somewhat angled, pubescent or glabrate. Pappus various, of few or many squamellae, awns, or bristles, or rarely reduced to a mere crown.

Flowers subsessile; pappus of a crown of 4 or 5 connate squamellae, sometimes with 1 or

Flowers distinctly peduncled; pappus at least of the disk-flowers of $12-18$ barbellate bristles.

2. P. papposa.

1. P. angustifolia Torr. Glabrous annual, lemon-scented; stem branched, 5-20 $\mathrm{cm}$. high; leaves narrowly linear; involucres 4-5 mm. high, $2-3 \mathrm{~mm}$. broad; bracts linear, about 8 ; ligules oblong, about $3 \mathrm{~mm}$. long. $P$. papposa sessilis M. E. Jones. "Sand-draws" and sandy hillsides: Tex.-Neb.-Colo.-Ariz.; Mex. Son.-Mont. Ap-O.

2. P. papposa A. Gray. Annual, glabrous; stem branched from the base, 5-30 $\mathrm{cm}$. high; leaves narrowly linear, 3-5 cm. long; involucres about $4 \mathrm{~mm}$. high and $3 \mathrm{~mm}$. broad; bracts $7-9$, linear; ligules $4-5 \mathrm{~mm}$. long. Sandy places: Calif. $\rightarrow$ Utah-N.M. Son. Au-O.

\section{ACHILLÈA (Vaillant) L. YARROW, MilfoIL.}

Perennial caulescent, usually villous, herbs. Leaves alternate, from serrate to tripinnatifid. Heads several, usually radiate. Involucre campanulate to hemispheric; bracts imbricate in 3-4 series, the outer usually much shorter. Receptacle conic or convex, chaffy; paleae membranous. Ray-flowers few, 5-12, pistillate and fertile; ligules short and broad, in most species white or sometimes pink or purple. Disk-flowers 15-75, hermaphrodite and fertile; corollas yellowish white or straw-colored. Anthers with ovate obtuse tips. Style-branches in the pistillate flowers oblong, obtuse, in the hermaphrodite ones with truncate, fimbriate tips. Achenes oblong or obovate, obcompressed, callous-margined, glabrous. Pappus wanting.

Leaves pinnatifid to tripinnatifid.

Bracts with dark brown, almost black margins.

Involucre 5-6 $\mathrm{mm}$. high, 4-5 $\mathrm{mm}$. broad.

Ultimate segments of the leaves long and linear, not thickened at the apex; bracts all acute.

1. A. borealis.

Ultimate segments of the leaves ovate, lanceolate, or oblanceolate, short, often thickened at the apex; bracts except the outermost obtuse.

tper leaves 1-2 cm. broad, with spreading not densely crowded divisions.

2. A. Palmeri.

Upper leaves 5-10 mm. broad, with short densely crowded divisions.

Involucre $3.5-4 \mathrm{~mm}$. high, about $3 \mathrm{~mm}$. broad.

3. A. fusca.

Bracts with light brown, yellowish, or straw-colored margins.
Involucre 5-8 $\mathrm{mm}$. high, $4 \mathrm{~mm}$. broad or more.

4. A. subalpina.

Ultimate divisions of the leaves linear, not thickened, spreading, not crowded bracts with light brown margins.

5. A. californica.

Ulimate divisions lanceolate or ovate, usually thickened towards the apex, ascending and crowded; bracts and their margins of the same color, light yellowish or straw-colored.

Involucre $4-4.5$, rarely $5 \mathrm{~mm}$. high, $2.5-4 \mathrm{~mm}$. broad.

6. A. pacifica.

Tlimate leaf-segments linear; rachis merely margined. Ligules 2.5-4 mm. long; leaf-segments ascending, crowded.

7. A. lanulosa. 
Ligules 1.5-2.5 mm. long; leaf-segments more or less spreading, not crowded. 8. A. occidentalis.

Ultimate leaf-segments ovate or lanceolate; rachis distinctly winged.

9. A. millefolium.

Leaves serrate or incised, not pinnatifid.

10. A. multiflora.

1. A. borealis Bong. Stem stout, $2-4 \mathrm{dm}$. high, villous with long silky hairs; leaves linear or lance-linear in outline, 5-30 cm. long, 1-5 cm. broad, bipinnatifid; segments linear-filiform and spreading; bracts ovate or elliptic, acute, with blackish or brown margins; ligules suborbicular, 3-4 mm. broad. Bench? lands and meadows: Mack.-(? Wyo.)-Alta.-B.C.-Alaska; e Siberia. Subarctic-Subalp. Je-Au.

2. A. Palmeri Rydb. Stem $3-6 \mathrm{dm}$. high, sparingly villous; leaves usually less than $1 \mathrm{dm}$. long, 1-2 $\mathrm{cm}$. wide; primary divisions ovate, spreading, the ultimate ones lanceolate, rather conspicuously punctate; heads in corymbiform panicles; bracts about 20 , the outer ovate and acutish, the inner elliptic and obtuse; margins narrow, dark brown; ray-flowers usually 5; ligules suborbicular, about $4 \mathrm{~mm}$. long. Mountains: Colo.-Calif.; Mex. Submont.

3. A. fusca Rydb. Stem 3-6 dm. high, long-villous; leaves 1-2 dm. long, 5-10 $\mathrm{mm}$. wide, bipinnatifid, linear or the lower linear-oblanceolate in outline, long-villous; primary divisions short ascending, the ultimate ones lanceolate or ovate; heads in a corymbiform panicle; bracts about 20 , the outer oval, the inner elliptic, all rounded or obtuse at the apex; margins dark brown, almost black; ray-flowers about 5; ligules white or pinkish, suborbicular, round-lobed, 3-4 mm. long. Hillsides: Alta.-Wash.-Yukon. Submont.-Mont.

4. A. subalpina Greene. Stem slender, 1-3 dm. high, villous with long hairs; leaves 3-10 $\mathrm{cm}$. long, linear in outline, more or less long-villous; segments short and narrow, linear, much crowded; heads in a dense crowded corymb; bracts elliptic, with dark brown or blackish margins, the innermost usually acute, the rest obtuse; ligules $2-3 \mathrm{~mm}$. long and broad. A. lanulosa alpicola Rydb. $A$. alpicola Rydb. High mountains: Alta.-N.M.-Nev.-B.C. Subalp.-Alp. $\mathrm{Jl}-\mathrm{Au}$.

5. A. californica Pollard. Stem 5-10 dm. high, usually branched above, villous, with long hairs; leaves numerous, bi- or tripinnatifid, sparingly villous, the lower 10-15 $\mathrm{cm}$. long, the upper sessile and clasping, lanceolate in outline; rachis merely margined; primary divisions ovate in outline, spreading, the ultimate ones linear or lance-linear, spinulose-tipped; heads in compound corymbiform panicles; bracts about 20 , all obtuse or rounded at the apex; margins brown; ray-flowers 5 or 6; ligules orbicular or rounded-oval, 3-4 mm. long. Sea coast, rarely inland: Calif,-Wash.-Ida. Son.

6. A. pacifica Rydb. Stem 3-7 dm. high, sulcate, usually decidedly longvillous; leaves 1-2 dm. long, 5-20 mm. wide, linear in outline, villous, bipinnatifid; primary divisions ovate in outline, short, crowded, the ultimate ones lanceolate or ovate, strongly punctate, callous-thickened towards the spinulose-mucronate tips; heads in round-topped corymbiform panicles; bracts about 20, yellowish or straw-colored, with margins of the same color, all obtuse or rounded at the apex; ray-flowers about 5; ligules 3-4 mm. long. Plains: Wash.-Ida.-Calif. Son.

7. A. lanulosa Nutt. Stem 3-6 dm. high, copiously villous with long silky hairs; leaves 5-10 dm. long, linear in outline, densely long-villous, bipinnatifid; segments (primary and secondary) short and directed forward, the secondary linear-lanceolate; bracts elliptic, obtuse, with green midrib and straw-colored (rarely brownish) margins. Plains and mountain valleys: Sask.-Kans.-N.M. -Calif.-B.C.; adv. eastward to Ont.; n Mex. Plain-Subalp. My-S.

8. A. occidentalis Raf. Stem $3-6 \mathrm{dm}$. high, usually rather copiously villous with long silky hairs; leaves lanceolate in outline, $5-10 \mathrm{~cm}$. long, twice or thrice pinnatifid; ultimate segments narrow, linear; involucres about $4 \mathrm{~mm}$. high and $3 \mathrm{~mm}$. broad; bracts elliptic, obtuse, with a green midrib and straw-colored margins. Roadsides and prairies: Pa.-S.C.-Ark.-Neb.; adv. in Colo. My-Au.

9. A. millefolium L. Stem $2-6$ dm. high, somewhat villous, with short hairs; leaves oblong in outline, $5-10 \mathrm{~cm}$. long, $8-20 \mathrm{~mm}$. broad, finely villous 
or glabrate, twice pinnatifid; primary segments more or less spreading, more or less decurrent into the wing-margins; secondary segments short, lanceolate, flat, spinulose-tipped; involucres 4-5 $\mathrm{mm}$. high, 3-4 mm. broad; bracts lance-elliptic or elliptic, obtuse, with brown (rarely nearly black) margins; ligules $2-3 \mathrm{~mm}$. long and broad. Shores, hillsides, and roadsides: Newf.-Va.-Colo.-B.C.; nat. or adv, from Eu. Je-S.

10. A. multiflora Hook. Stem $3-10 \mathrm{dm}$. high, villous; leaves linear, 5-10 $\mathrm{cm}$. long, 5-8 $\mathrm{mm}$. broad, somewhat pubescent or glabrate, pectinately cleft into lanceolate, serrulate lobes; involucres 4-5 mm. high, 4-6 mm. broad; bracts more or less villous, elliptic with brown margins; ligules 10-12, suborbicular, 1-1.5 mm. long. Valleys: Mack.-Sask.-Alaska. Boreal. Jl-Au.

\section{ANTHÈmis L. Corn Chamomile.}

Annual or perennial herbs. Leaves alternate, mostly pinnatifid or bipinnatifid. Heads solitary at the ends of the branches, usually radiate. Involucre saucer-shaped; bracts in about 3 series of nearly the same length, usually thin; receptacle conic to hemispheric, chaffy; paleae membranous with a distinct midrib. Ray-flowers pistillate and fertile; ligules white. Disk-flowers hermaphrodite and fertile; corollas yellow. Anthers with ovate obtuse tips. Stylebranches truncate and fimbriate at the apex. Achenes subcylindric or somewhat obovoid, not angled, with filiform ribs. Pappus wanting, or a minute crown.

1. A. arvensis L. A leafy annual; stem $2-5 \mathrm{dm}$. high, branched, hirsutevillous; leaves $3-5 \mathrm{~cm}$. long, bipinnatifid, with linear-lanceolate cuspidate lobes, hirsute-villous; involucre 4-5 mm. high, 7-12 mm. broad; bracts villous-hirsute; receptacle conic; paleae linear-lanceolate, abruptly cuspidate; ligules white, 7-12 $\mathrm{mm}$. long, 3-4 mm. wide; achenes subcylindric, 10-ribbed; pappus a minute border. Field and waste places: Me.-Ga.-Ore.-B.C.; adv. or nat. from Eu.

\section{7. marùta Cass. May Weed, Dog Fennel, Dog Chamomile.}

Leafy annuals. Leaves alternate, bipinnatifid, with narrow divisions. Heads radiate, solitary at the ends of the branches. Involucre saucer-shaped; bracts in 2 series, subequal. Receptacle conic, chaffy towards the apex; paleae subulate, stiff, rather persistent. Ray-flowers 10-15, neutral; ligules white. Disk-flowers hermaphrodite and fertile; corolla-tube cylindric, longer than the funnelform throat; lobes 5, ovate, spreading. Anthers with ovate obtuse tips. Style included, with short branches truncate and fimbriate at the apex. Achenes nearly cylindric, 10-ribbed, glandular-tubercled. Pappus wanting.

1. M. Cotula (L.) DC. Annual, with fetid odor; stem glabrous or slightly pubescent above, 3-6 dm. high; leaves $3-5 \mathrm{~cm}$. long, twice or thrice pinnatifid, with narrow linear-filiform divisions; glabrate or somewhat hairy; involucre 8-12 mm. broad; bracts oblong, obtuse, somewhat pubescent; ligules 10-18, white, about $1 \mathrm{~cm}$. long, at length reflexed. Anthemis Co'ula L. Fields and waste places: Newf.-Fla.-Calif.-B.C.-Yukon; nat. from Eu. Plain-Submont. J-S.

\section{Chamomílla (Hall.) Gilib. Chamomile, Pineapple-Weed, Green Dog-Fennel.}

Mostly annual glabrous herbs. Leaves alternate, once to thrice pinnatifid into narrow divisions. Heads solitary or corymbose, radiate or discoid. Involucre saucer-shaped to hemispheric; bracts in 2-4 series, somewhat imbricate, obtuse, scarious-margined; receptacle conic, hemispheric, or subglobose, naked. Ray-flowers, if present, pistillate and fertile; ligules white. Disk-flowers numerous, hermaphrodite and fertile; corollas yellow; anthers with ovate obtuse tips; style-branches short, with truncate tips. Achenes usually asymmetric, with 3-5 ribs on the inner half, the back being nerveless. Pappus of a more or less developed crown or margin. [Matricaria L., in part.]

1. C. suaveolens (Pursh) Rydb. Annual; stem glabrous, very leafy, much branched, 1-4 dm. high; leaves glabrous, 2 or 3 times pinnatifid, with linear acute 
lobes; involucres 7-10 $\mathrm{mm}$. broad; bracts glabrous, oval to oblong, with broad scarious margins; ligules none; disk-corollas yellow, 4-lobed; receptacle conic; achenes oblong, slightly angular; pappus an obscure crown. $M$. discoidea DC. M. matricarioides (Less.) Porter. Moist and sandy places, roadsides, and waste places: Alaska-Calif.-Ariz.-N.D.; adv. or nat. eastward to Newf.-N.J.N.Y., and in Eu. Plain-Submont. Mr-S.

\section{LeUCÁNTHEMUM (Tourn.) Mill. OX-eye Datsy.}

Perennial herbs with rootstocks. Leaves alternate, dentate or entire or in some exotic species pinnatifid. Heads radiate, rarely discoid, solitary, rather long-peduncled at the ends of the stems. Involucre saucer-shaped; bracts many, rather narrow, in 2-4 series, somewhat imbricate. Receptacle flat or convex, naked. Ray-flowers in a single series, pistillate and fertile; ligules usually welldeveloped, white. Disk-corollas yellow. Anthers with ovate tips. Style of the ray-flowers slightly exserted, with short oblong branches, that of the diskflowers included and with short branches, truncate and fimbriate at the apex. Achenes all cylindric, 10-ribbed or 10-angled. Pappus wanting.

1. L. Leucanthemum (L.) Rydb. Stem 3-10 dm. high, glabrous; basal leaves petioled, obovate or spatulate, coarsely dentate or incised; stem-leaves sessile, narrowly oblanceolate to nearly linear, dentate; involucres $12-15 \mathrm{~mm}$. broad; bracts lanceolate, margined by a narrow brown band and a scarious margin; ligules white, 12-15 mm. long. Chrysanthemum Leucanthemum L. L. vulgare Lam. Meadows, roadsides, and pastures: Lab.-Fla.-Utah-B.C.; nat. from Eu. Plain-Submont. My-N.

\section{TANACÈTUM (Tourn.) L. TANSY.}

Strongly aromatic, leafy, mostly perennial herbs, with rootstocks. Leaves alternate, once to thrice pinnatifid, conspicuously punctate. Heads corymbose, usually several or many, radiate, but the rays often inconspicuous and not exceeding the disk. Involucre hemispheric or broader; bracts in 2-3 series, usually narrow, not very unequal in length; receptacle convex, naked. Ray-flowers pistillate and fertile; ligules yellow, varying from erect, 3-lobed, concave and searcely exceeding the disk to spreading, flat, and well developed. Disk-flowers many, hermaphrodite and fertile; corollas yellow. Style in the ray-flowers slightly exserted, in the disk-flowers included. Anthers with obtuse tips. Achenes subcylindric, those of the ray-flowers mostly 3-angled, those of the disk-flowers 5-angled. Pappus-squamellae united into a short crown.

1. T. vulgare L. Stout perennial; stem $5-10 \mathrm{dm}$. high, glabrous or nearly so; leaves bipinnatifid, with oblong-acute serrate divisions, glabrous or nearly so; heads numerous in a corymbiform panicle; involuere $6-10 \mathrm{~mm}$. broad; flowers yellow; marginal flowers with short oblique 3-toothed limbs. Roadsides and waste places: N.S.-N.C.-Miss.; Calif.-Wash., escaped from cultivation; native of Eurasia. J1-S.

\section{SPHAEROMÈRIA Nutt.}

Low cespitose perennials, with a woody base, or small shrubs. Leaves alternate, often crowded at the base, pinnately or pedately divided or simple, usually silvery-canescent. Heads heterogamous but apparently discoid, few, corymbose, or in subcapitate clusters or solitary. Involucre hemispheric to broadly campanulate; bracts few, in 2 subequal series, usually broad; receptacle conic or convex, naked. Marginal flowers (functionally ray-flowers) few, pistillate and fertile, but without ligules; corollas cylindric to lance-ovoid, 3- or 4-lobed, slightly if at all oblique. Disk-flowers many, hermaphrodite and fertile; corollas with the short tube passing into the campanulate or cylindro-campanulate throat. Style of the ray-flowers short-exserted, that of the disk included; branches of the former oblong, obtuse, of the latter short, truncate and penicillate at the apex. Achenes subcylindric, tapering at the base, 5-10-ribbed. Pappus wanting. 
Plant shrubby, 2-4 dm. high, glabrous; heads several, corymbose.

1. S. diversifolia.

Plant with cespitose caudices, $1.5 \mathrm{dm}$. or less high, silvery-canescent; heads solitary or in a small cluster.

Heads few, clustered.

Heads more or less peduncled; basal leaves obovate-cuneate, with 3-5 round lobes at the apex.

2. S. argentea.

Heads sessile in a capitate cluster; basal leaves once or twice ternately divided into linear or oblong divisions.

3. S. capitata.

Heads solitary; basal leaves simple, linear, or ternately cleft at the apex into linear divisions,

4. S. simplex.

1. S. diversifolia (D. C. Eat.) Rydb. Undershrub 2-4 dm. high; stem glabrous, leafy; lower leaves pinnatifid, with linear divisions, glabrous, the upper narrowly linear and entire; involucres hemispheric, $5-6 \mathrm{~mm}$. broad, glabrous; bracts broadly ovate, with erose, white-scarious margins; marginal pistillate flowers 8-10. Tanacetum diversifolium D. C. Eat. Cañons: Utah. Submont. $\mathrm{Jl}-\mathrm{Au}$.

2. S. argentea Nutt. Stem $5-15 \mathrm{~cm}$. high, silvery-canescent; leaves cuneate or flabelliform, 5-12 mm. long, 3-6-toothed or -lobed at the apex, silvery-canescent, or the uppermost oblong or linear, entire; heads few, corymbose; involucres hemispheric or campanulate, $3-5 \mathrm{~mm}$. broad; bracts obovate, slightly tomentose when young, yellowish, with broad erose scarious margins; marginal pistillate flowers about 5. T. Nuttallii T. \& G. Barren hills: Mont.-Wyo. Submont. My-Je.

3. S. capitata Nutt. Stem $5-15 \mathrm{~cm}$. high, silvery-canescent; leaves mostly basal, ternately or bi-ternately divided into linear divisions, silvery-canescent; heads $8-15$; involucre $4-5 \mathrm{~mm}$. broad; bracts tomentose, yellowish, obovate, erose; marginal pistillate flowers about 5. T. capitatum T. \& G. Dry hills: Mont.-Wyo. Submont. My-Jl.

4. S. simplex (A. Nels.) Heller. Leaves mostly basal, silvery-canescent, simple and linear or 2-3-cleft, with linear divisions, only 2-3 cm. long; stem 5-12 $\mathrm{cm}$. high; heads solitary, 8-10 $\mathrm{mm}$. broad, hemispheric; bracts obovate, slightly canescent, yellowish; pistillate marginal flowers few. T. simplex A. Nels. Dry hills: Wyo. Submont. My-Je.

\section{PICROTHÁMNUS Nutt.}

Low spiny shrubs. Leaves alternate, pedately divided and again lobed, with narrow divisions. Heads solitary or in small racemes, apparently discoid, the marginal flowers without ligules. Involucre saucer-shaped; bracts obovatecuneate, scarious, in two more or less distinct subequal series; receptacle naked. Marginal flowers (functionally ray-flowers) few, pistillate, fertile; corolla short, deeply 2-cleft, villous; style long-exserted, with long linear obtuse branches. Disk-flowers hermaphrodite but sterile; corollas with a narrow obconic tube, a turbinate throat, and a 5-lobed limb, densely arachnoid-hairy; anthers oblong, with subulate tips and obtuse bases; style slender, with a peltate, erose stigma. Achenes ellipsoid, densely arachnoid-hairy.

1. P. desertorum Nutt. Spiny undershrub; stem villous-tomentose, 1-5 $\mathrm{dm}$. high; leaves pedately 5-parted and again 3-lobed, with spatulate divisions, villous. Artemisia spinescens D. C. Eat. Desert regions: Wyo.-N.M.- C Calif. -Ore. Plain-Submont.

\section{3. artemísia L. Wormwood, Mugwort, Cudweed, Sage Brush.}

Perennial or annual herbs, or shrubs, usually bitter-aromatic. Leaves alternate. Heads small, most commonly panicled and nodding when young, apparently discoid; the marginal flowers without ligules or wanting. Involuere campanulate to hemispheric; bracts in 2-4 series, at least the inner ones more or less scarious. Receptacle naked or hairy, convex or conic. Marginal flowers (functionally ray-flowers) pistillate and fertile or wanting; corollas cylindric or subcylindric and somewhat tapering upwards, 2-3-, rarely 4-toothed, often somewhat oblique; style more or less exserted, 2-cleft; style-branches linear-filiform and subterete to oblong and somewhat flattened. Disk-flowers hermaphrodite, 
fertile or sterile; corollas campanulate, funnelform, or trumpet-shaped, 5-toothed, regular; anthers with lanceolate or subulate tips; style either 2-cleft and the branches more or less recurved, truncate at the apex, with an erose or fimbriate apex, or else entire and surmounted by an erose or fimbriate cup; achenes ellipsoid, terete, usually glabrous, without pappus.

Disk-flowers sterile, their styles undivided or with short erect branches; receptacle naked. Annual or perennial herbs; style of the disk-flowers undivided, ending in a cupshaped penicillate appendix.

I. DRACUNCULOIDES.

Low shrubs or undershrubs; style of the disk-flowers usually more or less 2-cleft, each branch erect with truncate penicillate or erose apex.

Disk-flowers fertile, their styles 2-cleft; branches more or less recurved.

Marginal pistillate flowers present. Receptacle hairy.

Heads numerous, usually paniculate; plant more or less shrubby at the base.

III. FRIGIDAE.

high. Receptacle naked.

Annual or biennial herbs with bipinnatifid leaves. $\quad$ V. ANNUAE.

Perennials.

Leaves silvery or silky or glabrate, but not tomentose beneath.

Plants low, herbaceous perennial, with rootstocks; heads many-flowered. nodding in a simple racemose inflorescence; leaves divided into linear or oblong divisions.

VI. NORVEGICAE.

Plants more or less shrubby at the base; heads paniculate.

Leaves pinnately dissected into narrow divisions (glabrate forms of A. Abrotanum, A. graveolens and A. tenuis).

Leaves cuneate, 3-toothed at the apex or the upper entire.

Leaves more or less tomentose beneath.

XIII. BIgelovianaE.

Leaves not dissected into narrowly linear more or less divergent divisions; these, if narrow, very few, directed forward and entire.

Leaves greener and glabrate above, at least in age.

Heads 60-100-flowered; leaves twice pinnatifid with obtuse divisions, the lower long-petioled.

Heads 5-50-flowered; leaves simple or once pinnatifid, or if bipinnatifid, with acute lobes and sessile or short-petioled.

Leaves entire or with a few lobes, if dissected to near the midrib, the lobes rather broad [except in A. mexicana].

VIII. VULGareS.

Leaves deeply dissected to near the midrib; divisions linear or oblong, usually more or less cleft.

Leaves white-tomentose on both sides.

X. DisCOLORES.

IX. GNAPHALOIDES.

Leaves once or twice dissected into linear or fliform, more or less spreading divisions.

Leaf-segments broadly linear or linear-lanceolate, usually again

lobed or toothed.
Leaf-segments narrowly linear or flliform, mostly revolute.

Leaves once pinnatifid; plant herbaceous; style of the ray-flowers long-exserted.

XI. WRIGHTIANAE.

Leaves twice pinnatifid; plant suffruticose; style of the rayflowers short-exserted. XII. PONTICAE.

Marginal pistillate flowers wanting; receptacle naked.

Shrubs 1-50 dm. high; leaves canescent, not with raised midribs.

Heads in terminal panicles; leaves entire, 3-5-toothed to 3-5-divided at the apex.

Heads axillary; leaves pinnatifid into linear divisions. XV. RIGIDAE.

Dwarf undershrubs, scarcely more than $1 \mathrm{dm}$. high; leaves pinnatifid into linearspatulate divisions, green, with the ribs raised beneath.

XVI. Pygmaeae.

\section{Dracunculotdes.}

Leaves all entire or the lower 3-fid.

Leaves densely pubescent when young.
Leaves glabrous.

Involucre 3-4 mm. broad; lower stem-leaves 3-12 mm. wide; heads 30-100-flowered; outermost involucral bracts almost as long as the inner. Involucre $2-3 \mathrm{~mm}$. broad; leaves $1-3 \mathrm{~mm}$. wide; heads $20-40$-flowered; outer
bracts much shorter than the inner.

Leaves, at least the lower, pinnatifid or bipinnatifid.

Heads very small, $2-3 \mathrm{~mm}$. broad, numerous in large leafy panicles; plants mostly tall, 3-10 dm. high.

Biennials; heads mostly erect; outer bracts acute.

Plant glabrous or nearly so.

4. A. caudata. 
Plant decidedly pubescent.

5. A. Forwoodii.

Perennials, with a rootstock or caudex; heads nodding at least at first.

Plant 3-10 dm. high; stem leafy.

Stem tall, very leafy, 4-10 dm. high; bracts acute or acutish.

Stem lower, 3-5 dm. high; stem-leaves rather 6. A. pacifica. obtuse or rounded at the apex.
7. A. Aamporum.

Plant less than $1 \mathrm{dm}$. high; stem scapiform; stem-leaves minute.

18. A. minuta.

Heads larger, 4 $-5 \mathrm{~mm}$. broad, not very numerous (except in A. Bourgeauana), in narrow spike-like panicles; plants low, rarely $3 \mathrm{dm}$. high.

Involucral bracts glabrous or nearly so; disk-corollas glabrous.

8. A. MacCallae.

Involucral bracts more or less villous; disk-corollas usually with a few hairs on the lobes.

Plant 3-4 dm. high; heads very numerous, in a dense panicle.

Plant 1-3 dm. high; heads fewer, usually a spike-like panicle or racemose.

10. A. spithamaea.

\section{Filifollae.}

Taller shrubs, 3-10 dm. high, with numerous heads in leafy panicles; heads 3-7-flowered.

Low undershrubs, less than $1.5 \mathrm{dm}$. high, with racemose inflorescence; heads 10-15flowered.

Leaves ternate or biternate.

Leaves pinnatifid with 5-7 divisions.

12. A, pedatifida.

18. A. minuta.

III. FRIGIDAE.

Plant tall, 6-10 dm. high, erect; leaves twice or thrice pinnatifid. 13. A. Absinthium.

Plant lower, 2-4 dm. high, often decumbent at base; leaves twice ternate.

14. A. frigida.

IV. Lanatae.

Basal leaves twice pinnatifid into linear divisions; stem-leaves pinnate; heads 5-12.

15. A. scopulorum.

Basal leaves pinnatifid into $3-5$ linear-oblanceolate approximate divisions; stem-leaves ternately cleft or entire; heads $1-4$.

16. A. Pattersoni.

One species.

\section{ANNUAE.}

\section{NORVEGICAE.}

Heads 6-10 mm. broad, usually more than 40-flowered; corollas hairy or rarely glabrous; bracts with fuscous margins.

Plant more or less pubescent, at least on the leaves and peduncles.

Plant silvery-silky; basal leaves $6 \mathrm{~cm}$. long or less, pinnatifid or bipinnatifld with few divisions.

Plant less than $i \mathrm{dm}$. high; leaves 1-1.5 cm. long; involucral bracts with inconspicuous light brown margins, slightly tomentose, soon glabrous.

18. A. minuta.

Plant 1-3 dm. high; leaves 2-6 cm. long; involucral bracts with conspicuous dark brown or blackish scarious margins.

19. A. Tyrrellii.

Plant green; leaves twice pinnatifid, the basal ones more than $1 \mathrm{~cm}$. long.

Leaves and stem decidedly hairy; inner bracts ovate, acute, with narrowly Ianceolate green center. 20. A. saxicola.

Leaves sparingly pubescent or glabrate; stem glabrous or nearly so; inner bracts obovate, obtuse or rarely acutish, with broadly lanceolate green 21. A. arctica.
center. Plant glabrous.

22. A. laevigata.

Heads 5-6 mm. broad, 30-40-flowered; corolla glandular-granuliferous; plant glabrous; bracts with light brown margins.

23. A. Parryi.

\section{FranserioIDES.}

One species.

VIII. VULGARES.

\section{A. franserioides.}

Leaf-segments again divided or lobed.

Inflorescence much branched, pyramidal; heads very numerous; involucre campanulate, $4 \mathrm{~mm}$. high, 10-30-flowered; leaf-segments obovate in outline.

25. A. vulgaris.

Inflorescence narrow, cylindric; heads fewer; involucre hemispheric, $3 \mathrm{~mm}$. high, 2535-flowered; leaf-segments lanceolate, short, acute.

26. A. incompta.

Leaves or their segments entire or nearly so.

Heads not very numerous, comparatively large, 25-50-flowered; involucre hemis-

pheric.
Inflorescence spike-like; suffruticose with a woody base; leaves coarse-toothed.

Inflorescence open-paniculate.

28. A. Leibergii.

Leaves lanceolate, thin, deeply lobed; involucre glabrous or nearly so.

27. A. elatior. 
Leaves linear-lanceolate, entire or short-lobed, thicker, sparingly floccose above; involucre arachnoid.

29. A. arachnoidea.

Heads very numerous in dense compound panicles (except in A. Lindleyana), 5-25flowered; involucre campanulate or ellipsoid.

Upper leaves lanceolate or oblanceolate, usually more than $4 \mathrm{~mm}$. wide.

Involucre $4 \mathrm{~mm}$. high; leaves large, $5-15 \mathrm{~cm}$. long, lanceolate or ovate-lanceolate in outline, with very few divisions, directed forward.

Lower leaves deeply divided into more or less falcate divisions.

Lower leaves with shorter lobes or teeth directed forward.

Heads nodding in anthesis, 15-25-flowered; involucre rounded-campanulate.

31. A. Douglasiana.

Heads erect in anthesis, 5-15-flowered; involucre oblong or subcylindric.

32. A. Herriotii.

Involucre $3 \mathrm{~mm}$. high; leaves shorter; lobes of the lower leaves often spreading.

Leaves of a lanceolate type; involucre campanulate, usually less than 3 $\mathrm{mm}$. broad. 33. A. ludoviciana.

Leaves of a cuneate type; involucre hemispheric, 3-4 mm. broad.

Leaves with 3-5 ovate teeth at the apex, dark green.

Leaves with 3-7 lanceolate lobes, yellowish green.

34. A. cuneata.

49. A. rhizomata.

Upper leaves linear or narrowly linear-oblanceolate, less than $4 \mathrm{~mm}$. wide.

Heads numerous, paniculate; leaves usually more than $5 \mathrm{~cm}$. long; plant not suffruticose at the base.

Inflorescence loose; branches long and heads scattered.

Leaves entire, or the lower coarsely toothed or with short lanceolate lobes.

35. A. silvicola.

Leaves, at least some of them, with long narrow, alternate, salient, falcate lobes.

36. A. falcata.

Inflorescence dense and narrow; branches short; heads crowded; stemleaves mostly pinnatifid.

Bracts and upper surface of the leaves nearly glabrous; lower surface minutely tomentulose.

37. A. potens.

Bracts and upper surface of the leaves floccose; lower surface whitetomentose.

38. A. Underwoodii.

Heads less numerous, in narrow spikes or spike-like panicles; leaves narrow, usually less than $5 \mathrm{~cm}$. long, the lower toothed or rarely lobed towards the apex, the upper entire, linear or nearly so; plant suffruticose at the base,

\section{GNAPHaLOIDES,}

39. A. Lindleyana.

Leaves all entire or the basal ones merely toothed.

Involucre 3-4 mm. high, 2-3.5 mm. broad; heads less than 25-flowered.

Corollas dark brown or purplish; leaves usually less tomentose above, the lower serrate towards the apex. 40. A. gnaphaloides.

Corollas light brown or yellow; leaves equally white-tomentose on both sides.

Involuere $2-2.5 \mathrm{~mm}$. broad; leaves very narrow, linear or lance-linear, acute. 41. A. pabularis.

Involucre $2.5-3.5 \mathrm{~mm}$. broad; leaves broader, if lance-linear, more or less acuminate.

Upper leaves ovate to lanceolate, acute; heads densely crowded and usually erect.

42. A. Purshiana.

Upper leaves lanceolate to lance-linear, acuminate; heads less crowded, mostly spreading. (Entire-leaved forms of ) 46. A. diversifolia.

Involucre 4-5 mm. high, 4-7 mm. broad; heads 25-40-flowered (in A. longifolia sometimes 20-25-flowered).

Heads nodding or spreading; leaves equally floccose on both sides, not revolute, acute.

Heads nodding, rather long-peduncled on elongate racemiform branches: leaves linear. 43. A, pudica.

Heads spreading, subsessile or short-peduncled on shorter branches; stemleaves lanceolate.

Heads erect, peduncled; stem-leaves linear-lanceolate,

revolute-margined and greener above.
45. A. longifolia.

44. A. argophylla.

Leaves, at least the lower ones, more or less lobed or divided.

45. A. longifolia.

Lower leaves with simple divisions.

Lower leaves with long and narrow lobes.

Involucre 3-4 mm. high, 3-4 $\mathrm{mm}$. broad.

Involucre 4-5 mm. high, 5-7 $\mathrm{mm}$. broad.

Lower leaves with short and broad often salient lobes.

46. A. diversifolia.

44. A, argophylla.

Leaves $5-8 \mathrm{~cm}$. long; involucre $4-5 \mathrm{~mm}$. high and about as broad.

Leaves 1-5 cm. long; involucre $3-4 \mathrm{~mm}$. high, $2-3 \mathrm{~mm}$. broad.

47. A. platyphylla.

Stem simple up to the inflorescence.

Inflorescence dense and much branched; heads clustered.

48. A. Brittonii.

Inflorescence lax, narrow, spike-like, with short racemiform branches.

Stem conspicuously branched, the branches ending in small simple or branched racemes.

50. A. albula. 
Lower leaves and often the upper with narrow, again cleft or toothed, spreading divisions.

Heads 25-50-flowered; involucre 4-5 mm. high, 5-8 mm. broad.

Heads erect, borne singly on peduncles 1-12 $\mathrm{mm}$. long; leaves equally tomentose on both sides.

51. A. floccosa.

Heads borne in small glomerules, sessile, only the terminal one erect; leaves less tomentose above. 52. A. candicans.

Heads 20-30-flowered; involucre $3 \mathrm{~mm}$. high, $2.5-3.5 \mathrm{~mm}$. broad.

53. A. Flodmanii.

\section{Discolores.}

Leaves densely white-tomentose beneath, loosely floccose above, at least when young.

Heads very numerous in a branched leafy panicle; leaves not revolute-margined. 54. A. discolor.

Heads fewer, usually in a narrow spike-like or racemiform inflorescence; leaves revolute-margined.

Leaves minutely tomentulose beneath, glabrous above.

Heads hemispheric, nodding at least in anthesis.

Heads campanulate, erect in anthesis. 55. A. Michauxiana.

56. A. graveolens. 57. A. tenuis.

\section{Wrightianae.}

Leaves sparingly pubescent or glabrous, green above.

Heads erect; involucre about $2 \mathrm{~mm}$. broad.

Heads nodding; involucre about $3 \mathrm{~mm}$. broad.

Leaves white-tomentose on both sides.

58. A. Wrightii.

59. A. Bakeri.

60. A. Carruthiti.

One species.

\section{XiI. Ponticae.}

One species.

\section{Bigelovianae.}

61. A. Abrotanum.

62. A. Bigelovii.

XIV. Tridentatae.

Involucre 4-5 mm. high, 3-5 mm. broad; heads 7-15-flowered (rarely 5- or 6-flowered). Leaves mostly entire; heads numerous in a dense but not spike-like panicle.

63. A. cana.

Leaves, at least some of them, 3-5-toothed at the apex; heads fewer in a narrow spikelike panicle.

Plant 1-3 dm. high; branches decumbent or spreading at the base.

Plant about $5 \mathrm{dm}$. high, with erect strict branches.

64. A. arbuscula.

65. A. spiciformis.

Involucre $2-4 \mathrm{~mm}$. high, $2-2.5 \mathrm{~mm}$. broad; heads $1-8$-flowered.

Leaves, at least some of them, 3-toothed at the apex.

Shrubs 5-50 dm. high; heads numerous in ample panicles.

Leaves cuneate.

Leaves narrowly linear-cuneate or linear.

66. A. tridentata.

67. A. angusta.

Shrub 1-4 dm. high; heads fewer.

Heads glomerate in dense panicles; involucre turbinate. 62. A. Bigelovii.

Heads in simple, raceme-like panicles; involucre campanulate.

$\begin{array}{ll}\text { Heads 7-9-flowered; involucre densely canescent. } & 64 . \text { A. arbuscu } \\ \text { Heads 1-6-flowered; involucre nearly glabrous. } & 68 . \text { A. nova. }\end{array}$

Leaves 3-cleft into linear-filiform divisions.

69. A. tripartita.

XV. Rigidae.

One species.

70. A. rigida.

One species.

XVi. Pygmaeae.

71. A. pygmaea.

1. A. glauca Pallas. Perennial; stem 3-6 dm. high, silky-pubescent; leaves entire, linear, 2-5 dm. long, 2-5 $\mathrm{mm}$. wide, or with a few linear divisions, silkycanescent; heads small, numerous in a large panicle; involucres about $13 \mathrm{~mm}$. broad; bracts elliptic, pubescent, scarious-margined; flowers yellow. Prairies and banks: Man.-Neb.-Colo.-Alta.; Siberia. Plain. J1-O.

2. A. aromatica A. Nels. Perennial; stems mostly simple, 4-8 dm. high, glabrous; leaves mostly entire, some of the lower 3-cleft, linear, 2-7* $\mathrm{cm}$. long, 2-6 mm. wide; heads numerous, in a large leafy panicle, nodding; involucres 3-4 $\mathrm{mm}$. broad, glabrous; bracts elliptic, dark green with scarious margins; flowers brown, the fertile ones 10-20, the sterile more numerous. Mountain valleys: Alta.-Colo.-n Calif.-Wash.; n Mex. Submont.

3. A. dracunculoides Pursh. Perennial; stem 5-15 dm. high, glabrous; leaves narrowly linear, or some 3-cleft with similar divisions, glabrous, 3-7 dm. long, 1-3 mm. wide; heads very numerous, in a compound panicle, nodding; involucres broad, glabrous, yellowish green; bracts elliptic, obtuse; ray-flowers 10-20. Prairies and plains: Man.-Mo.-Tex.-Calif.-B.C. Plain-Submont. 
4. A. caudata Michx. Biennial; stem glabrous, 5-20 dm. high; leaves 1-3pinnately divided into linear-filiform divisions, glabrous or nearly so, the lower petioled, 7-15 $\mathrm{cm}$. long; heads very numerous in a narrow panicle, nodding; involucres $2-3 \mathrm{~mm}$. broad; bracts glabrous, elliptic, obtuse, yellowish green; flowers yellow. Sandy soil: N.B.-Fla.-Tex.-Colo,-Sask. Jl-S.

5. A. Forwoodii S. Wats. Biennial; stem 4-7 dm. high, somewhat pubescent when young; basal leaves 5-10 $\mathrm{cm}$. long, petioled, bi- or tripinnatifid into narrowly linear divisions, loosely silky-canescent at least when young; heads numerous in a dense panicle, mostly erect, heterogamous; involucre subglobose, 2-2.5 mm. high, 2.5-3 mm. broad; bracts in 3-4 series, the outermost lanceolate or ovate, acute, half as long as the innermost ones; ray-flowers 15-20. A. caudata calvens Lunell. Plains: Ont.-Mich.-Neb.-Sask. Plain.

6. A. pacifica Nutt. Perennial; stem 4-10 dm. high, glabrate or sparingly pubescent when young, often purplish; leaves $1-2 \mathrm{~cm}$. long, twice pinnatifid, with narrowly linear divisions; heads very numerous, in a leafy panicle, at first nodding, soon erect; involucre subglobose, about $2.5 \mathrm{~mm}$. high, $2.5-3 \mathrm{~mm}$. broad; bracts glabrous or sparingly short-hairy, scarious-margined; outermost bracts ovate, acute, about half as long as the inner ones; ray-flowers 8-12; corollas glabrous. A. desertorum Scouleriana Besser. A. Scouleriana Rydb. Plains: Alta. -B.C.-Ore.; (? Colo.).

7. A. camporum Rydb. Perennial; stem 3-5 dm. high, striate, often purplish; basal leaves clustered, 4-10 $\mathrm{cm}$. long, petioled, twice or thrice pinnatifid into linear or oblong divisions, more or less silky-canescent; upper stem-leaves sessile, pinnatifid, with narrowly linear divisions; heads numerous in a narrow leafy panicle, nodding; involucre hemispheric, $2.5-3 \mathrm{~mm}$. high and fully as broad; bracts in 3-4 series, scarious-margined, the outermost ovate, obtuse, a little more than half as long as the innermost ones; ray-flowers 15-20. A. canadensis Nutt., not Michx. A. Forwoodii Rydb. (Fl. Colo.), not S. Wats. Plains and hills: Ont.-Sask.-Neb.-Ariz.-Yukon. Plain-Submont.

8. A. MacCallae Rydb. Perennial; stem $2-3 \mathrm{dm}$. high, rather strict, more or less canescent, sometimes purplish; basal leaves $5-10 \mathrm{~cm}$. long, petioled; blades ovate in outline, twice pinnatifid, with rather few, linear or narrowly oblanceolate divisions, silky-canescent; upper stem-leaves less divided; heads rather numerous, in narrow panicles; involucre $3 \mathrm{~mm}$. high, $4-5 \mathrm{~mm}$. broad; bracts green with yellowish scarious margins, acutish, sparingly long-hairy or glabrous; outer bracts ovate, about half as long as the inner broadly oval ones; ray-flowers 10-15. Gravelly slopes: Alta.-Yukon-Wash.-Colo. Plain-Submont.

9. A. Bourgeauana Rydb. Perennial; stem 3-4 dm. high, rather densely silky-villous, more or less tinged with red; basal leaves clustered, 4-6 dm. long, petioled, sericeous-canescent on both sides, twice pinnatifid, with oblanceolate divisions; stem-leaves mostly sessile, rather small, with linear divisions, or 3-fid or entire; heads very numerous, in dense leafy panicles; involucre hemispheric, about $4 \mathrm{~mm}$. high and $5 \mathrm{~mm}$. broad; bracts yellowish, silky-villous, scariousmargined, the outermost about half as long as the innermost, ovate, acute; rayflowers about 20. Plains: Sask.-N.D. Plain.

10. A. spithamaea Pursh. Perennial; stem 1-3 dm. high, sericeous; basal leaves pinnately or bipinnately divided into oblanceolate lobes, silky-canescent on both sides; upper leaves reduced, linear or with linear lobes; heads comparatively few, in a spiciform inflorescence; involucres $4-5 \mathrm{~mm}$. broad; bracts oval, silky or glabrate, with brownish green centres, and searious margins; flowers brown or purplish. A. borealis Am. auth. A. groenlandica Wormsk. Subaretic, arctic, and alpine regions: Greenl,-Que.-Mont.-Colo.-Wash. Subalp.-Alp. Jl-Au.

11. A. filifolia Torr. Undershrub, 3-10 dm. high; branches erect, minutely tomentulose, leafy; leaves all slender, entire and filiform, or some 3-parted with filiform divisions, minutely tomentulose, more or less fascicled; heads very small and very numerous, in narrow leafy panicles; involucres $1-1.5 \mathrm{~mm}$. broad, to- 
mentulose, 3-5-flowered; sterile central flowers 1-3. A. plattensis Nutt. Plains: Neb.-Tex.-Ariz.-Nev.; Mex. Son.-Plain. Ap-O.

12. A. pedatifida Nutt. Perennial, with a thick woody cespitose caudex; stems 5-15 cm. high, finely canescent; leaves mostly basal, once or twice ternately divided into linear or narrowly spatulate divisions, finely white-tomentulose; heads few in a spicate or racemose inflorescence, 12-15-flowered; involucres 3-4 $\mathrm{mm}$. broad, tomentose; bracts elliptic; flowers brownish. Arid ground: Wyo.Mont.-Ida. Submont. Je-Au.

13. A. Absinthium L. Shrubby; stem $5-15 \mathrm{dm}$. high, finely canescent; leaves $5-12 \mathrm{~cm}$. long, once to thrice pinnately divided into oblong or lanceolate, obtuse divisions, finely canescent, especially beneath; heads numerous in a large panicle, with racemiform branches, nodding; involucres 4-5 $\mathrm{mm}$. broad, canescent; outer bracts linear, the inner oval, scarious-margined. Waste places and around dwellings: Newf.-N.C.-Mont.; escaped, native of Eu. Au-S.

14. A. frigida Willd. Perennial, with a cespitose, suffrutescent caudex; stem 2-5 dm. high, finely canescent; leaves twice pinnatifid, with linear-filiform divisions, silvery-white, in age often turning brownish; heads numerous, racemosely disposed, nodding; involucres $4-6 \mathrm{~mm}$. broad, canescent or tomentose; bracts oblong or lanceolate; corollas yellow, glabrous. Dry plains and hills: Hudson Bay-Tex.-Ariz.-Ida.-Alaska; Asia. Plain-Mont. J1-O.

15. A. scopulorum A. Gray. Perennial, with a cespitose caudex; stem simple, canescent, 1-2 dm. high; lower leaves petioled, 3-7 cm. long, bipinnatifid, with linear or oblong divisions, silky-canescent; upper stem-leaves small and less divided; heads 3-12, spicately or racemosely disposed, 18-30-flowered; involucres 6-8 mm. broad; bracts oval, tomentose, black-or brown-margined; corollas yellow, hirsute at the summit. High mountains: Mont.-N.M.-Utah. Subalp. -Alp. Jl-S.

16. A. Pattersoni A. Gray. Perennial, with a cespitose caudex; stem whitetomentose; lower leaves pinnatifid, with 3-5 linear divisions, sericeous; upper stem-leaves linear, entire or 2-3-cleft at the apex; heads 1-5, usually conglomerate, 8-12 mm. broad; bracts oblong or elliptic, white-tomentose with brown or black margins; flowers yellow, $40-50$, the central ones fertile; receptacle villous. Alpine peaks: Colo. Subalp. $-A l p$. J-Au.

17. A. biennis Willd. Biennial; stem $3-10 \mathrm{dm}$. high, glabrous; leaves pinnately or bipinnately parted into lanceolate, laciniate-dentate divisions, glabrous; heads small, numerous, in a dense leafy panicle; involucres $2-3 \mathrm{~mm}$. wide, glabrous; bracts elliptic, dark-green, scarious-margined; corollas yellow, glabrous. Wet places: N.S.-N.J.-Calif.-B.C.-Mack. Plain-Mont. Au-D.

18. A. minuta Rydb. A low undershrub, woody at the base; stems $1 \mathrm{dm}$. high or less, at first slightly tomentose, in age glabrate and reddish; leaves mostly basal, silvery-silky, about $1 \mathrm{~cm}$. long, pinnatifid, with 5-7 narrowly oblanceolate approximate divisions; stem-leaves smaller, with linear-filiform divisions; inflorescence simple, spike-like, $2-4 \mathrm{~cm}$. long; involucre hemispheric, $2.5 \mathrm{~mm}$. high; bracts about 10, light brown, slightly tomentose, in age glabrate, ovate, acutish, scarious-margined. Plains: Alta. Plain.

19. A. Tyrrellii Rydb. Tufted perennial; stems $2-3 \mathrm{dm}$. high, densely silky-canescent; leaves $1.5-3 \mathrm{~cm}$. long, white-silvery on both sides, the basal ones twice pinnatifid, with $3-5$ crowded primary divisions, which are $3-5$-cleft into oblanceolate or spatulate divisions; upper leaves ternate to entire and linear; heads racemose, nodding; involucre hemispheric, about $5 \mathrm{~mm}$. high and $7 \mathrm{~mm}$. broad; bracts 12-15, elliptic, densely canescent on the back, with conspicuous dark brown scarious margins; ray-flowers about 10; disk-flowers about 30 . Mountains: B.C. Subalp. S.

20. A. saxicola Rydb. Perennial, with a cespitose caudex; stem decumbent at the base, 1-3 dm. high, loosely villous; basal leaves petioled, $2-8 \mathrm{~cm}$. long, twice pinnately parted into lanceolate divisions, loosely villous; heads several, racemosely disposed, some of them, at least the lower, on long erect peduncles, nodding; involucres 8-10 mm. broad, villous; bracts elliptic with black or dark 
brown margins; corollas yellow, loosely pubescent. A. norvegica A. Gray, not Fries. Higher mountains: Colo.-Alta. Mont.-Alp. Jl-S.

21. A. arctica Less. Perennial, with a cespitose caudex; stem $2-4 \mathrm{dm}$. high, glabrous or sparingly pubescent above; lower leaves petioled, $5-15 \mathrm{~cm}$. long, twice pinnately parted, with lanceolate, acute or acuminate divisions, slightly pubescent or glabrate, the upper leaves less divided, smaller and sessile; heads several, in racemose inflorescence, nodding, the lower usually on elongated peduncles; involucres 8-10 mm. broad; bracts elliptic, sparingly hairy, with black or dark brown margins; corollas yellow, usually pilose. A. norvegica pacifica A. Gray. A. longepedunculata Rudolphi. Aretic, subarctic, and alpine situations: Yukon-B.C. (Selkirk Mts.)-Wash.-Alaska; Asia. Au-S.

22. A. laevigata Standl. A low perennial, with a rootstock; stems 2.5-3 $\mathrm{dm}$. high, glabrous, reddish, striate; basal leaves slender-petioled, twice pinnatifid into oblong-linear, acute divisions, glabrous, $2-6 \mathrm{~cm}$. long; stem-leaves mostly once pinnatifid into narrow acute divisions; heads 5-8, nodding, in a racemose inflorescence; involucre $8-10 \mathrm{~mm}$. broad; bracts glabrous, ovate, obtuse, green on the back, with broad dark brown erose margins; ray-flowers 5-10. Mountains: Alta. Subalp.

23. A. Parryi A. Gray. Perennial, with a cespitose caudex; stem glabrous, 2-4 dm. high; leaves twice to thrice pinnatifid, with linear divisions, glabrous; heads rather many, racemosely or paniculately disposed, nodding; involucres 5-7-mm. broad, glabrous; bracts elliptic or oval with light brown margins; corollas yellow, glabrous. Alpine peaks: Colo.-e Utah. Subalp. Au.

24. A. franserioides Greene. Perennial, with a rootstock; stem 3-10 dm. high, minutely puberulent or glabrous; leaves twice or thrice pinnatifid, with oblong, obtusish divisions, green and glabrous above, pale and usually minutely tomentulose beneath; heads numerous, in a narrow panicle, nodding; involucres about $6 \mathrm{~mm}$. broad, sparingly tomentose; outer bracts linear, green, the inner oblong, scarious-margined; corollas 40-90, glabrous; marginal flowers few. Mountains: Colo.-N.M.; Mex. Submont. Jl-S.

25. A. vulgaris L. A stout perennial, with a rootstock; stem 5-15 dm. high, sparingly tomentose when young; lower and middle leaves ovate in outline, pinnately or bipinnately divided to near the midrib, green and glabrate above, white-tomentose beneath, 5-10 cm. long; primary divisions 5-7, obovate, oblong, or oblanceolate, acute, the ultimate lanceolate, often few-toothed; upper leaves pinnatifid, with lanceolate or linear divisions, or simple; heads very numerous in a leafy panicle; involucre about $4 \mathrm{~mm}$. high, $3-4 \mathrm{~mm}$. broad, more or less tomentose; bracts ovate to oblong, obtuse; ray-flowers 6-12. Waste places: Newf.Man.-Wis.-Ala.-Ga.; B.C.; escaped from cultivation; native of the Old World.

26. A. incompta Nutt. Perennial, with a creeping rootstock; stem 3-6 dm. high, glabrate or at first slightly floccose; leaves soon glabrate above, tomentose beneath, the lower obovate or oblanceolate in outline, 3-10 cm. long, often bipinnatifid with lanceolate, acute divisions, the upper narrower and merely pinnately cleft; heads numerous, in a narrow panicle; involucres glabrous or nearly so, about $4 \mathrm{~mm}$. broad; bracts oval, scarious-margined; corollas brownish. $A$. discolor incompta A. Gray. Hillsides: Mont.-Colo-Calif.-B.C. J1-Au.

27. A. elatior (T. \& G.) Rydb. Perennial, with a creeping rootstock; stem 5-10 dm. high, glabrous or slightly floccose; leaves glabrous or nearly so above, tomentose beneath, acuminate, $5-10 \mathrm{~cm}$. long, the lower pinnatifid, with lanceolate, long-acuminate lobes, the upper trifid or entire; heads numerous, in a panicle, nodding; involucres about $5 \mathrm{~mm}$. broad, shining, nearly glabrous; bracts with yellowish or brownish scarious margins, oval; corollas yellow or brownish. A. Tilesii elatior T. \& G. Valleys: Mack.-Hudson Bay-Mont.-Wash.Alaska. Submont.-Subalp. Jl-S.

28. A. Leibergii Rydb. A suffrutescent perennial, 3-6 dm. high, with a woody caudex and short perennial stems; branches erect, simple, sparingly tomentulose or glabrate, striate; leaves $3-6 \mathrm{~cm}$. long, oblanceolate, coarsely 
toothed or lobed towards the apex, or the upper entire, glabrous and yellowish green above, finely floccose beneath; heads many in a dense spike-like panicle; involuere hemispheric, about $4 \mathrm{~mm}$. high, 4-5 mm. broad; bracts yellowish, only sparingly floccose, ovate, oval, acutish, broadly scarious-margined; ray-flowers 5-7. Plains: Wash.-n Ida. Son.-Submont.

29. A. arachnoidea Sheld. A perennial, with a branched rootstock or caudex; stem 5-10 dm. high, striate, arachnoid-floccose; leaves linear-lanceolate, acuminate or acute, sessile, sparingly floccose but soon glabrate above, permanently floccose beneath, 3-8 cm. long, the lower with a few lanceolate short lobes; heads many, in a lax panicle, often sub-secund and nodding; involucre hemispheric, about $4 \mathrm{~mm}$. high and $6 \mathrm{~mm}$. broad; bracts about 10 , sparingly floccose, yellowish green, ovate to elliptic, acute or obtuse, scarious-margined; ray-flowers 8-10. Banks: Ore.-Ida. Son.

30. A. Hookeriana Besser. Tall perennial, with a rootstock; stem 3-6 dm. high; leaves lanceolate or ovate in outline, glabrate above, densely white-tomentose beneath, the upper entire, the lower deeply cleft into 3-7 lanceolate often falcate divisions; heads numerous, in very dense elongate panicles, mostly erect; involucre about $4 \mathrm{~mm}$. high and $3 \mathrm{~mm}$. broad, more or less tomentose; bracts ovate to elliptic, obtuse, scarious-margined; ray-flowers 5 or 6 . Valleys: Sask.B.C.-Ore. Plain.

31. A. Douglasiana Besser. Stout perennial, with a rootstock; stem 6-10 $\mathrm{dm}$. high; leaves numerous, $5-15 \mathrm{~cm}$. long, lanceolate, acuminate, the lower more or less lobed or toothed, with few lanceolate lobes or teeth, the upper ones entire, all somewhat grayish-floccose above when young, permanently white-tomentose beneath; heads numerous, at first nodding, in a large dense narrow leafy panicle; involucre $4 \mathrm{~mm}$. high, $3-4 \mathrm{~mm}$. broad; bracts tomentose, at least when young; the outer lanceolate, acutish, the inner elliptic, obtuse, broadly scarious-margined above; ray-flowers 6-8. A. vulgaris californica Besser. A. Kennedyi A. Nels. Banks: Wash.-Ida.-s Calif. Son.-Submont.

32. A. Herriotii Rydb. Tall perennial, with a rootstock; stem simple, 6-10 $\mathrm{dm}$. high, finely tomentose; leaves entire or sparingly and sharply toothed, 5-20 $\mathrm{cm}$. long, glabrate and green above, densely white-tomentose beneath; heads very numerous, erect, in a narrow dense panicle; involucre 4-5 mm. high, 2.5-3 $\mathrm{mm}$. broad; bracts tomentose, the outer ovate-lanceolate, acute; inner bracts elliptic, mostly obtuse; ray-flowers 6-8. Banks: Alta.-Sask.-S.D. Plain.

33. A. ludoviciana Nutt. Perennial, with a cespitose rootstock; stem usually branched, more or less tomentose, $3-6 \mathrm{dm}$. high; lower leaves oblanceolate, 3-7-lobed above the middle, $3-8 \mathrm{~cm}$. long, soon glabrate and dark green above, densely white-tomentose beneath; lobes lanceolate and falcate; upper leaves lanceolate and entire; heads very numerous and small, in a compound open panicle; involucres $3-4 \mathrm{~mm}$. high, $2-3 \mathrm{~mm}$. broad, usually densely tomentose; bracts elliptic; corollas light brown. Prairies, cañons, and mountain sides: Mo.-Tex. -Ariz.-Utah. Plain-Submont. Au-S.

34. A. cuneata Rydb. Perennial, with a creeping rootstock; stem 5-10 dm. high, tomentose, branched; leaves sessile, $2-4 \mathrm{~cm}$. long, grayish floccose or coarsely toothed towards the apex, the lobes or teeth ovate, often mucronate; leaves of the inflorescence lanceolate and entire; heads numerous, hemispheric, about $3 \mathrm{~mm}$. broad; bracts oval, obtuse, tomentose, the inner scarious-margined; ray-flowers 6 or 7 . Banks: Colo.-Tex. Son.-Submont. Au-S.

35. A. silvicola Osterhout. Perennial, with a creeping rootstock; stem 4-6 $\mathrm{dm}$. high, slender, sparingly tomentose; leaves linear or linear-lanceolate, 4-6 cm. long, 3-8 dm. wide, entire or with a few sharp teeth, acuminate, glabrate above, densely silvery-tomentose beneath; inflorescence loosely paniculate, 2-3 dm. long; heads numerous, nodding; involucres about $5 \mathrm{~mm}$. broad, tomentose, but not very densely so; bracts oblong; ray-flowers 10-15. Mountains and prairies: Tex.-Colo.-Utah-Calif.; n Mex.-Ariz.-Ida. Son.-Submont. Au-S. 
36. A. falcata Rydb. Tall perennial, with a rootstock; stem $6-10 \mathrm{dm}$. high, loosely floccose; leaves linear or narrowly linear-lanceolate, $10-15 \mathrm{~cm}$. long, green and glabrate above, white-tomentose beneath, the upper simple, falcate, the lower usually with several alternate, spreading and strongly falcate, narrow lobes; panicle very large; involucre about $4 \mathrm{~mm}$. high and fully as broad, densely floccose; outer bracts ovate, acute, the inner oval and obtuse; ray-flowers 5-7. Banks: S.D.-Sask. Plain. Au-S.

37. A. potens A. Nels. Perennial, with a creeping rootstock; stem simple, pale green, 4-8 dm. high; leaves 3-6 $\mathrm{cm}$. long, sessile, pale and glabrate above, thinly tomentose beneath, with somewhat revolute margins, linear, simple or pinnatifid, with 2-4 divaricate lobes; heads numerous in a dense narrow panicle, crowded; involucre $3 \mathrm{~mm}$. high and as broad; bracts $8-10$, nearly glabrous, the outer ovate, acute; inner bracts oval, obtuse; ray-flowers 10-12. Banks: Calif. -Mont.-B.C.

38. A. Underwoodii Rydb. Perennial, with a horizontal much-branched rootstock; stem slender, $2-6 \mathrm{dm}$. high, somewhat floccose; leaves $3-5 \mathrm{~cm}$. long, pinnately parted, with 3-7 (usually 5) linear or linear-lanceolate acute lobes, densely white-floccose beneath, green and slightly tomentose above, in age glabrate; panicle narrow; heads crowded; involucre $3 \mathrm{~mm}$. high and $2.5 \mathrm{~mm}$. broad; bracts ovate, tomentose, slightly scarious on the margin. Hills and mountain sides: Nev.-Colo.-Ariz.-Calif.-B.C. Plain-Submont. Jl-S.

39. A. Lindleyana Besser. Perennial, with a cespitose rootstock; stem 1-4 dm. high, slender; leaves lanceolate to linear, 1-3 cm. long, entire or the lower with sharp teeth, floccose when young, soon glabrate above, more or less permanently tomentose beneath; inflorescence narrow, racemiform, or with short. erect branches; involucres 3-4 mm. high, 2-3 mm. broad, tomentose. Rocky banks: Wash.-w Mont.-Ariz.-n Calif. Son.-Submont. Jl-S.

40. A. gnaphaloides Nutt. Perennial, with a slender, horizontal, cespitose rootstock; stem 3-6 dm. high, white-tomentose; lower leaves oblanceolate, entire or serrate, $2-10 \mathrm{~cm}$. long, tomentose on both sides; upper leaves lanceolate or linear, entire; heads very numerous, in rather dense panicles; involucres about 4 $\mathrm{mm}$. high, $2-3 \mathrm{~mm}$. wide, about 20 -flowered. Prairies and river banks: Ont.Mo.-Tex.-Colo.-Alta.; adv. eastward to N.H. and N.Y. Plain-Submont.

41. A. pabularis (A. Nels.) Rydb. Perennial, with a creeping rootstock; stem 2-4 dm. high, slender, white-tomentose; leaves linear or narrowly linearlanceolate, the lower, often toothed, densely tomentose, inclined to become yellowish, $3-5 \mathrm{~cm}$. long; heads small, in a narrow spike-like inflorescence; involucres tomentose, about $3 \mathrm{~mm}$. high and $2 \mathrm{~mm}$. broad, about 15 -flowered. $A$. rhizomata pabularis A. Nels. Saline soil: S.D.-Neb.-Colo.-Ida. Plain. Ji-Au.

42. A. Purshiana Besser. Perennial, with a horizontal rootstock; stem 3-6 $\mathrm{dm}$, high, tomentose; leaves ovate to lanceolate, entire or the lower somewhat toothed, white-tomentose on both sides; heads small, in a dense, contracted panicle; involucres about $3 \mathrm{~mm}$. high, $2 \mathrm{~mm}$. broad, tomentose; flowers about 15 . Plains: Sask.-Neb.-Calif.-B.C.' Plain-Submont. Au-O.

43. A. pudica Rydb. Perennial, with a horizontal rootstock; stem 4-6 dm, high, simple up to the inflorescence, white-floccose; leaves linear or narrowly linear-lanceolate, $6-10 \mathrm{~cm}$. long, 6-8 mm. wide, entire, white-floccose on both sides; inflorescence a narrow panicle; involucres campanulate, about $5 \mathrm{~mm}$. high and $4 \mathrm{~mm}$. broad; bracts ovate, densely tomentose, with a darker midrib and slightly scarious margin; flowers about 20, yellow. Mountains: Colo. Submont. $\mathrm{Jl}-\mathrm{Au}$.

44. A. argophylla Rydb. Perennial, with a strong rootstock; stem 5-10 $\mathrm{dm}$. high, white-tomentose, angled; leaves many, lanceolate, entire, or the lower oblanceolate, sometimes coarsely toothed or with lanceolate lobes, $5-10 \mathrm{~cm}$. long, white-tomentose on both sides, acute; heads numerous in a leafy panicle; involucre hemispheric, 4-5 mm. high, 5-7 mm. broad, densely tomentose; bracts $12-$ 14, the outer lanceolate, acute; inner bracts elliptic or oval, obtusish; flowers 25-40; corollas yellow. Valleys: Colo.-Wyo.-Wash.-n Calif. 
45. A. longifolia Nutt. Perennial, with a suffruticose base or woody caudex; stem 3-12 dm. high, silvery-tomentose; leaves linear or lance-linear, tomentose on both sides, in age greener above, with revolute margins; heads erect, in a narrow raceme-like panicle; involucres $5-6 \mathrm{~mm}$. broad, tomentose; bracts ovate or oval; flowers about 20 , yellow. A. natronensis A. Nels., a broad-leaved form. Plains in alkaline soil: Man.-Colo.-Ida,-Wash. Plain. Jl-Au.

46. A. diversifolia Rydb. White-tomentose perennial, with horizontal rootstock; stem simple, leafy, 5-10 dm. high; leaves densely tomentose on both sides, subsessile, $5-10 \mathrm{~cm}$. long, the lower usually pinnately cleft into $3-5$ narrowly lanceolate-acuminate lobes, which are directed forward, the upper or all entire, linear-lanceolate, passing into the bracts of the inflorescence; inflorescence a narrow panicle, $1.5-3 \mathrm{dm}$. long; heads numerous; involucres $3-4 \mathrm{~mm}$. high and $3 \mathrm{~mm}$. broad; bracts oblong or ovate-oblong, scarious-margined, densely villoustomentose; flowers light yellow. Valleys: Hudson Bay-Neb.-Colo.-Calif.B.C. Plain-Submont. Jl-S.

47. A. platyphylla Rydb. Perennial, with a creeping rootstock; stem 4-6 $\mathrm{dm}$. high, finely tomentose, simple; lower leaves cuneate-obovate, $5-8 \mathrm{~cm}$. long, with rounded-ovate mucronate lobes above the middle, equally tomentose on both sides; middle leaves similar, but the lobes deeper, triangular or lanceolate; upper leaves ovate or lanceolate, with 3 lanceolate lobes or entire; heads many, in a narrow panicle; involucre hemispheric, $4-5 \mathrm{~mm}$. high and nearly as broad; bracts densely floccose, the outer ovate, acute, the inner oval, obtuse; flowers 15-25; corollas yellow. A. ludoviciana latiloba Nutt. Banks: Wash.-Ore.Mont.

48. A. Brittonii Rydb. Perennial, with a horizontal rootstock; stem rather stout, 3-6 dm. high, white-floccose; lower leaves thick, cuneate or oblong-oblanceolate, 3-5-lobed, mostly above the middle, densely white-tomentose on both sides, the lobes lanceolate; upper leaves ovate-lanceolate, entire; panicles narrow; involucres $3-4 \mathrm{~mm}$. high, about $2 \mathrm{~mm}$. broad; bracts ovate and densely floccose; flowers about 15 , light brown or yellow. Hills and plains: Wyo.-Ore. -Ariz.-N.M.; n Mex. Submont. Au-O.

49. A. rhizomata A. Nels. Perennial, with a cespitose rootstock; stem 4-6 $\mathrm{dm}$. high, white-tomentose; leaves white-tomentose on both sides, $2-4 \mathrm{~cm}$. long, the lower elliptic, oblanceolate, or oblong-cuneate, usually with 3-5 short ovate or lanceolate lobes, the upper lanceolate and entire; heads comparatively few, in a narrow, spike-like panicle; branches of the latter short, with 2-6 erect heads; involucre campanulate, about $3.5 \mathrm{~mm}$. high and $3 \mathrm{~mm}$. broad, densely tomentose; bracts ovate to elliptic, obtuse; ray-and disk-flowers each 7 or 8; corollas light brown. Hills: Wyo.-N.M. Submont.

50. A. albula Woot. Perennial, with a rootstock; stem tomentose, 4-10 $\mathrm{dm}$. high; lower leaves ovate in outline, 4-5 cm. long, 3-5-lobed, white-tomentose on both sides; upper leaves linear to narrowly oblong-lanceolate, 1-3 cm. long, $2-5 \mathrm{~mm}$. broad, usually entire; heads in an open leafy panicle, very numerous; involucres $3 \mathrm{~mm}$. high, $2 \mathrm{~mm}$. broad, tomentose; flowers 15-20, yellow. $A$. microcephala Woot, not Hildebr. Dry plains: Tex.-Colo.-s Calif,; n Mex. Son. $\mathrm{Au}-\mathrm{O}$.

51. A. floccosa Rydb. Perennial, with a creeping rootstock; stem stout, 5-8 dm. high, tomentose; leaves $3-5 \mathrm{~cm}$. long, pinnately divided into oblong, linear, or lanceolate divisions, loosely white-tomentose on both sides, the upper often entire; heads erect, short-peduncled, in a racemiform panicle; involucres 5-6 mm. broad, hemispheric; bracts oval, tomentose, scarious-margined; flowers 30-60, brownish. A. gracilenta A. Nels. A. paucicephala A. Nels., is a form with more entire leaves. Dry banks and mountains: Mont.-Wyo,-Ore. Plain-Mont. Au-S.

52. A. candicans Rydb. Perennial, with a creeping rootstock; stem stout, 5-10 dm. high, tomentose, branched; leaves pinnately or bipinnately divided into oblong divisions, or the upper entire, densely tomentose on both sides; heads numerous, sessile, in small clusters forming interrupted spikes or panicles; invo- 
lucres 5-8 $\mathrm{mm}$. broad, hemispheric, densely tomentose; bracts oval, scariousmargined; flowers 30-40, yellowish brown. Mountains: Mont.-Ore. Submont. Jl-Au.

53. A. Flodmanii Rydb. Perennial, with a branched rootstock; stem slender, 3-5 dm. high, tomentose, grooved, simple up to the inflorescence; leaves many, 3-7 cm. long, white-tomentose on both sides, usually twice pinnatifid into lanceolate or linear divisions, the upper less divided or simple; heads numerous, in a rather dense leafy panicle; involucre about $3 \mathrm{~mm}$. high, $2.5-3.5 \mathrm{~mm}$. broad; bracts floccose, the outer lance-ovate, acute, the inner bracts elliptic, obtuse; flowers 20-30. Hillsides: Mont.-Wyo.-Ore.-(? Utah). Submont.

54. A. discolor Dougl. Perennial, with a horizontal rootstock; stem 5-7 $\mathrm{dm}$. high, striate, slightly floccose when young, glabrate in age; leaves 4-7 cm. long, sessile, loosely floccose when young, but soon glabrous above, white-tomentose beneath, thin, pinnatifid, with linear or linear-lanceolate acute divisions; divisions of the larger leaves again cleft or toothed; involucre $3.5-4 \mathrm{~mm}$. high and as broad; bracts arachnoid-tomentose, yellowish, lanceolate to elliptic, acutish; flowers 35-50. Rocky situations: Mont.-Ida.-Wash.-B.C. Submont.

55. A. Michauxiana Besser. Perennial, more or less suffruticose at the base, with a much branched caudex; stem 2-4 dm. high; leaves $3-6 \mathrm{~cm}$. long, subsessile, pinnately or bipinnately divided or cleft into linear or lanceolate or rarely broader, often toothed divisions, white-tomentose beneath; involucre 3-4 $\mathrm{mm}$. high, 5-7 mm. broad; outer bracts linear-lanceolate, acute, the inner oval, obtuse; flowers 25-40. A. discolor A. Gray, mainly. Hills and mountain sides: Sask.-B.C.-Wash.-Utah-Colo. Plain-Mont.

56. A. graveolens Rydb. Perennial, with a cespitose slender caudex; stems numerous, branched, glabrous; leaves twice or thrice pinnatifid into linear or lance-linear divisions; margins more or less revolute; heads numerous, in a narrow panicle, with racemiform branches, nodding; involucres about $4 \mathrm{~mm}$. broad, glabrous; bracts ovate, with brownish searious margins; corollas brown, glabrous, 15-30. A. subglabra A. Nels. Banks and hillsides: Alta.-Wyo,Ore.-B.C. Submont. Jl-Au.

57. A. tenuis Rydb. Perennial, with a creeping cespitose rootstock; stem slender, glabrous or minutely puberulent, $3-4 \mathrm{dm}$. high; leaves $2-3 \mathrm{~cm}$. long, deeply pinnatifid into 5-7 linear, acute, divergent segments; inflorescence with raceme-like slender branches; involucres about $4 \mathrm{~mm}$. high, 2-3 mm. wide; bracts glabrous or minutely puberulent, with searious margins; corollas 10-20, brownish. Sandy gulches: Mont. $-\mathrm{n}$ Wyo. Submont. Jl-Au.

58. A. Wrightii A. Gray. Perennial, suffruticose at the base; stem 3-5 dm. high; leaves pinnatifid, with linear-filiform divisions, slightly pubescent when young, soon glabrate above, white-tomentulose beneath, with revolute margins; heads in narrow, dense panicle; involucres about $3 \mathrm{~mm}$. high, $1.5-2 \mathrm{~mm}$. broad, slightly tomentose; bracts oval; flowers $10-15$, yellowish. Dry hills and mountains: N.M. - s Colo.-Utah-Ariz. Son.-Submont. Au-S.

59. A. Bakeri Greene. Perennial, with a cespitose caudex; stem decumbent at the base, loosely branching, $3-7 \mathrm{dm}$. high; leaves green and glabrous above, white-tomentose beneath, with revolute margins, the lower pinnatifid, with narrowly linear segments, the upper entire and narrowly linear; heads in an open loose panicle; involucres $2.5-3 \mathrm{~mm}$. high; about $2 \mathrm{~mm}$. broad, only slightly tomentose; outer bracts linear, the inner oval, with broad scarious margins. Cañons and valleys: N.M.-Colo.-Ariz. Submont. Au-S.

60. A. Carruthii Wood. Perennial, with a short cespitose caudex; stem 3-5 dm. high, white-tomentose, very leafy; leaves pinnatifid, with narrowly linear divisions, with revolute margins, densely white-tomentose on both sides, the uppermost often entire, linear-filiform; heads very numerous in a dense panicle; involueres about $2.5 \mathrm{~mm}$. high, $2 \mathrm{~mm}$. broad, densely tomentose; outer bracts lanceolate, the inner oval, broadly scarious-margined. A. kansana Britton. A. coloradensis Osterhout, a form with broader segments. Dry plains and prairies: Mo.-Colo.-Utah-Tex. Son.-Mont. Au-S. 
61. A. Abrotanum L. A much branched shrub, 5-10 dm. high; lower leaves petioled, 4-6 cm. long, twice pinnately dissected into linear-filiform divisions, with revolute margins, slightly tomentose beneath; heads numerous, nodding in leafy panicles with racemiform branches; involucre hemispheric, about $3 \mathrm{~mm}$. high and $5 \mathrm{~mm}$. broad; bracts canescent, the outer linear-lanceolate, the rest broadly oval, scarious; ray-flowers about 10; disk-flowers 15-20. Around dwellings: N.B.-Mass.-N.C.-Colo.; escaped from cultivation, native of s Eu. and the Orient.

62. A. Bigelovii A. Gray. Perennial, with a suffruticose base; stems many, 2-3 dm. high, silvery-canescent; leaves linear-cuneate to oblong, mostly 3 -toothed at the apex, about $1 \mathrm{~cm}$. long, silvery-canescent; heads numerous in a thyrsiform panicle; involucres canescent, about $2 \mathrm{~mm}$. high and $1.5 \mathrm{~mm}$. broad, 2-4flowered; flowers yellow, one, or rarely two, of them pistillate. A. petrophila Woot. \& Standl. Rocky banks and cañons: Tex.-Colo.-Utah-Ariz. Son. $\mathrm{Au}-\mathrm{S}$.

63. A. cana Pursh. Shrub, 3-30 dm. high; branches strict, canescent; leaves linear or lance-linear, acute at both ends, 1-4 cm. long, silvery-canescent on both sides, or the lower with 2-3 acute teeth or lobes at the apex; heads glomerate, in a leafy panicle; involucres 5 -9-flowered; outer bracts linear or subulate, the inner oval, all more or less tomentose; flowers yellowish. A. columbiana Nutt. Plains and hills: Sask.-Colo.-Utah-Ore--Mont. Plain-Mont. Au-S.

64. A. arbuscula Nutt. Low shrub, 1-3 dm. high; branches slender, canescent; leaves short-cuneate or flabelliform, 3-lobed or 3-parted, 5-12 mm. long, silvery-canescent, or the uppermost entire; heads rather few, in a spike- or racemelike panicle; involucres about $4 \mathrm{~mm}$. high and $3 \mathrm{~mm}$. broad, $7-9$-flowered; bracts elliptic, at least the outer decidedly tomentose; flowers brownish. Dry mountains and high plains: Wyo.-Calif.-Wash. Submont.-Mont. Je-Au.

65. A. spiciformis Osterhout. Shrub, 3-10 dm. high; branches somewhat canescent; leaves oblanceolate or cuneate, $1-3.5 \mathrm{~cm}$. long, 3-toothed at the apex or the upper entire, silvery-canescent; heads comparatively few, in a spike- or raceme-like inflorescence; involucres about $6 \mathrm{~mm}$. high and $5 \mathrm{~mm}$. wide, about 12-flowered; bracts imbricate, ovate, at least the outer tomentose; flowers brownish. A. Rothrockii A. Gray, in part. Dry plains: Colo.-Utah. Son.-Mont. $\mathrm{Au}-\mathrm{S}$.

66. A. tridentata Nutt. Shrub, 1-4 m. high, much branched; bark of the old stems shreddy; branches erect, silvery-canescent; leaves cuneate, 1-2 cm. long, 3-toothed (rarely 4-7-toothed) at the apex, or the upper linear-cuneate and entire, silvery-canescent; heads paniculate, numerous; involucres well imbricate, about $4 \mathrm{~mm}$. long and $2 \mathrm{~mm}$. wide, 5 -8-flowered; bracts oval-elliptic; at least the outer densely tomentose; flowers yellow or brownish. Dry plains and hills: Neb.-Colo.-Calif.-B.C. Plain-Mont. Jl-O.

67. A. angusta Rydb. A shrub, 10-12 dm. high, with ereet branches; leaves canescent, 2-4 cm. long, 1-4 mm. wide, linear and entire or linear-cuneate and merely 3 -toothed at the apex; heads numerous, elustered in leafy panieles; involucre $3.5-4 \mathrm{~mm}$. high, $2 \mathrm{~mm}$. broad; the outer bracts thick, ovate, less than one-fourth as long as the innermost; inner bracts oblong, obtuse, scarious-margined; flowers 4-6. A. tridentata angustifolia A. Gray. Plains: Wash.-Ida. -Nev. - n Calif. Son.

68. A. nova A. Nels. Undershrub, 1-3 dm. high; branches slightly tomentose, strict; leaves narrowly cuneate, $0.5-2 \mathrm{~cm}$. long, 3 -toothed at the apex, finely silvery-canescent; heads numerous, in a narrow, racemiform panicle; involucres 3-4 mm. high, scarcely $2 \mathrm{~mm}$. broad, 2-4-flowered; bracts well imbricate, glabrate or slightly puberulent, elliptic; flowers light brown. Plains and tablelands: Mont.-N.M.-Ariz.-Ida. Submont.-Mont. Au-O.

69. A. tripartita Rydb. Shrub or undershrub, 2-6 dm. high; branches canescent; leaves 3-cleft or 3-parted or the upper entire, silvery-canescent; blades or lobes narrowly linear; heads numerous, in a leafy panicle; involueres about $4 \mathrm{~mm}$. high and $2 \mathrm{~mm}$. broad, 3-6-flowered; bracts well imbricate, the 
outer linear or oblong, densely canescent, the inner oval; flowers brownish. $A$. trifida Nutt. Plains: Mont.-Colo.-Nev.-Ore.-Wash. Plain-Mont. Au-S.

70. A. rigida (Nutt.) A. Gray. Undershrub, 2-4 dm. high; branches rigid, slightly canescent when young, soon glabrate, leafy to the top; leaves rigid, silvery-canescent, linear-filiform, 3-cleft, or the upper and those of the fascicles entire, 1-2 cm. long; heads solitary (rarely 2 or 3 ), sessile in the axils of the leaves; involucres $3 \mathrm{~mm}$. long, $1.5-2 \mathrm{~mm}$. wide, $5-12$-flowered; bracts oval, well imbricate, hyaline-margined; corollas tinged with purple. Rocky ridges: Ore.-Ida. -Wash. Son. Au-O.

71. A. pygmaea A. Gray. Perennial, with a woody, cespitose caudex; branches $1 \mathrm{dm}$. high or less, slightly canescent or glabrate; leaves $5-10 \mathrm{~mm}$. long, rigid, pinnatifid with 3-7, linear-subulate divisions, thick, glabrous above, slightly canescent beneath; heads few, in a short spike-like inflorescence; involucres $4-5 \mathrm{~mm}$. long, $2-3 \mathrm{~mm}$. broad, 3-4-flowered; bracts imbricate, the outer lanceolate, the inner elliptic. Desert regions: Nev.-Utah. Son. Au-S.

\section{Petasittes L. Sweet Coltsfoot, Butterbur.}

Perennial herbs, with thick creeping rootstocks. Leaves basal, long-petioled, with ample reniform, cordate, triangular, or sagittate blades, usually tomentose beneath, appearing later than the scaly-bracted flowering stems. Heads racemose or corymbose, subdioecious. Involucre campanulate; bracts in one series, herbaceous. Flowers of the fertile plants, all or most of them pistillate, fertile; corolla irregularly 2-5-toothed and cylindric, or else ligulate. Flowers of the substerile plant mostly hermaphrodite, but sterile, and a few pistillate ones at the margin; corolla of the sterile flowers tubular and 5-toothed; style 2-lobed, but ovary sterile. Achenes narrow, 5-10-ribbed. Pappus of soft white bristles.

Leaf-blades sagittate or cordate, pinnately veined (except in $P$. vitifolia).
Leaves not cleft.

Leaves repand-denticulate, with numerous teeth.

Leaves angulately and sinuately few-lobed.

Leaves cleft one-third to one-half to the midrib; lobes dentate.

1. P. sagittata.

Leaves not broader than long; only one pair of lateral veins rising from the base.

Leaves decidedly broa than the base.

Leaves round-reniform, pedately veined and lobed.

veins rising from

1. P. sagittata (Pursh) A. Gray. Leaf-blades cordate, ovate-cordate to deltoid-cordate, 1-3 dm. long, 1-2 dm. wide, with a deep basal sinus, glabrate above; white-tomentose beneath; scape $2-3 \mathrm{dm}$. high; heads corymbose; involucres obconic, 8-9 mm. high, glandular-pubescent as well as tomentose; ligules of the substerile heads 5-7 mm. long, 1-1.5 $\mathrm{mm}$. wide, those of the subfertile heads smaller, 3-5 mm. long, less than $1 \mathrm{~mm}$. wide. Tussilago sagittata Pursh. Petasites dentata Blankinship. Wet grounds: Lab.-Minn,-Colo.-Alaska. Plain-Mont. My-J.

2. P. frigida (L.) Fries. Leaf-blades deltoid or cordate, with an open basal sinus, 2-10 cm. long and as broad, sinuately few-lobed or coarsely dentate; lobes or teeth 11-20; heads racemose-corymbose; involucres about $1 \mathrm{~cm}$. high, tomentulose and glandular-pubescent; bracts oblong, obtuse, purplish; ligules of the substerile heads about $8 \mathrm{~mm}$. long and $1.5-2 \mathrm{~mm}$. wide, those of the subfertile heads about $2 \mathrm{~mm}$. long and $0.5 \mathrm{~mm}$. wide. Wet places: Mack.-B.C.-Alaska; n Eu. Alp. Je-J.

3. P. corymbosa (R. Br.) Rydb. Leaf-blades broadly deltoid or cordate in outline, $3-10 \mathrm{~cm}$. long and broad, deeply cleft, the lobing extending one-third to one-half the distance to the midrib; divisions again lobed or dentate, with triangular lobes or teeth; peduncles 2-3 dm. high; heads corymbose; involucres 8-10 mm. high, glandular-pubescent, scarcely tomentose; ligules of the substerile heads 5-7 mm. long, $1.5 \mathrm{~mm}$. broad, those of the subfertile heads $2 \mathrm{~mm}$. long, $0.5 \mathrm{~mm}$. wide. Nardosmia corymbosa R. Br. P. palmata frigida Macoun.

Wet places: Alta.-B.C.-Alaska. Subalp. Je-Au. 
4. P. vitifolia Greene. Leaf-blades broadly cordate or deltoid-reniform, $5-12 \mathrm{~cm}$. long, 8-20 $\mathrm{cm}$. broad, with two or more lateral veins rising from the base, usually 5 -lobed, the basal lobes usually deeply 2-cleft and the terminal one 3-5-lobed; lobes coarsely dentate; scape 2-3 dm. high; involucres over $1 \mathrm{~cm}$. high, glandular and floccose; ligules of the substerile heads about $7 \mathrm{~mm}$. long and 1.5 mm. wide. Wet places: Man.-Alta. Boreal. Je-Jl.

5. P. palmata (Ait.) A. Gray. Leaf-blades reniform in outline, $5-15 \mathrm{~cm}$. long, $10-30 \mathrm{~cm}$. wide, sparingly villous-tomentulose beneath, pedately veined and lobed; lobes oblanceolate, coarsely few-toothed, with broadly triangular, mucronate teeth; scape stout, 1.5-6 dm. high; heads corymbose; involucres about 1 $\mathrm{cm}$. high, somewhat glandular-pubescent, tomentulose at the base; ligules of the substerile heads about $5 \mathrm{~mm}$. long, $1 \mathrm{~mm}$. wide, those of the fertile heads 2.5-3 $\mathrm{mm}$. long, $0.5 \mathrm{~mm}$. wide. Boggy places: Newf,-N.Y.-Minn.-Alta. PlainBoreal. Je-Au.

\section{CROCÍDIUM Hook.}

Small winter annuals. Leaves alternate. Heads radiate. Involucre hemispheric; bracts 8-12, equal, oblong. Ray-flowers about 12, pistillate, fertile; ligules yellow. Disk-flowers hermaphrodite, fertile; corollas yellow, with slender tube, campanulate throat, and 5-toothed limb. Anthers with deltoid-ovate tips. Style-branches short and broad, with deltoid appendages. Achenes fusiform, obscurely 3-5-ribbed, papillate. Pappus of a single series of white barbellate bristles, or in the ray-flowers wanting.

1. C. multicaule Hook. Stems several from the base, $1-2 \mathrm{dm}$. high, slightly floceose when young; basal leaves tufted, obovate or spatulate, sessile or shortpetioled, few-toothed, 2-5 cm. long; stem-leaves linear, entire or the lower denticulate; involucres $7-8 \mathrm{~mm}$. broad, hemispheric; bracts lance-ovate, acute; flowers golden yellow; ligules 5-8 mm. long; achenes ovoid, angled, scurfy. Plains and hills: B.C.-Ida.-Calif. Son. Mr-My.

\section{PSATHYRÒthes A. Gray. Velvet-Rosettes.}

Low pubescent or scurfy, winter annuals. Leaves petioled, with broad blades. Heads discoid. Involucres hemispheric; bracts in 2 series, at least the outer herbaceous; receptacle flat. Flowers all hermaphrodite and fertile; corolla with a very short tube, cylindric throat and short obtuse teeth, woolly at the summit. Style-branches flat, obtuse or truncate, with obscure appendages. Achenes terete, turbinate-villous or hirsute. Pappus of numerous stiff, ferruginous bristles.

Leaves not beset with long hairs.

Outer bracts obovate, larger than the inner; spreading tomentum long-villous.

1. P. ramosissima.

Outer bracts oblong, not longer than the inner, erect; tomentum fine, furfuraceous.

Leaves with scattered long-jointed hairs.

2. $P$. annua.

3. P. pilifera.

1. P. ramosissima (Torr.) A. Gray. Stem branched from the base, scurfytomentose; branches decumbent, 8-12 $\mathrm{cm}$. high; leaf-blades rounded, subcordate or cuneate at the base, 1-2 cm. broad, scurfy-tomentose, crenate; head solitary, axillary; involucres $5-6 \mathrm{~mm}$. high; flowers yellow; achenes short-turbinate, densely long-villous. Gravelly hills: Ariz. $-\mathrm{s}$ Utah-Nev.-s Calif.; L. Calif, L. Son. Ap-My.

2. P. annua (Nutt.) A. Gray. Stem branched from the base, 5-12 $\mathrm{cm}$. high, scurfy-tomentose; leaf-blades orbicular or rounded-ovate, cuneate at the base, coarsely dentate, $1 \mathrm{~cm}$. broad or less; heads solitary, axillary, short-peduncled; involucres 5-7 mm. high; corollas pale yellow, sometimes changing into purplish; achenes oblong-turbinate, densely villous. Saline plains: Ariz. $\rightarrow \mathrm{s}$ Utah -Nev, - s Calif. Son. My-Au.

3. P. pilifera A. Gray. Stem branched from the base, scurfy-tomentose, 5-15 cm. high; leaf-blades rhombic-obovate or subrotund, with euneate base, entire, scurfy-tomentose and hirsute-ciliate on the margins and petioles; heads 
short-peduncled; involucres campanulate, about $1 \mathrm{~cm}$. high; outer bracts oblonglinear; achenes cylindric, short-hirsute. Arid places: s Utah. Son. Au-S.

\section{HAPLOF́STES A. Gray.}

Suffrutescent perennials. Leaves opposite, linear-filiform, somewhat fleshy. Heads cymose, radiate. Involucres campanulate; bracts 4 or 5 , broadly oval, strongly overlapping. Receptacle flat, naked. Ray-flowers few, pistillate and fertile. Disk-flowers hermaphrodite and fertile. Achenes linear, terete, glabrous, ribbed. Pappus of a single series of rigid, scabrous, white bristles.

1. H. Greggii A. Gray. Stem 3-6 dm. high, branched, glabrous, leafy; heads cymose; involucres hemispheric, about $4 \mathrm{~mm}$. high; bracts glabrous, obovate, shorter than the disk; flowers yellow; ligules $3-5$, oblong, about $3 \mathrm{~mm}$. long. Saline soil: Tex.-Kans.-Colo.-N.M.; n Mex. Son. Je-S.

\section{8. ÁRNICA L. ARNICA.}

Perennial caulescent herbs, ours with rootstocks. Leaves mostly opposite, entire or toothed. Heads usually radiate, rarely discoid, several or solitary. Involucre campanulate or turbinate; bracts equal, in 1 or 2 series. Receptacle flat, naked, pubescent, or fimbrillate. Ray-flowers pistillate and fertile; ligules yellow. Disk-flowers many, hermaphrodite and fertile; corolla tubular, yellow. Anthers sometimes sagittate. Achenes narrow, 5-10-ribbed, pubescent or glabrous. Pappus a single series of capillary, scabrous bristles.

Stem with several pairs of leaves, the upper not conspicuously reduced (except in $A$. Parryi); heads usually several.

Heads nodding in the bud, usually discoid.

Heads erect in bud, radiate.

Basal leaves cordate or ovate, long-petioled.

Pappus white, merely barbellate; involucre turbinate (except in A. granulifera). not conspicuously glandular-hirsute (except in $A$. paniculata).

Achenes densely hirsute; involucre densely villous at the base.

II. CORDifoliaE.

Achenes glabrous, glandular-puberulent, or with a few scattered hairs above. Involucre, peduncle, and achenes densely glandular-granuliferous. Involuere hemispheric; disk about $15 \mathrm{~mm}$. high.

Involucre turbinate; disk 10-12 mm. high. Involucre slightly villous at the base, scarcely gli
disk about $15 \mathrm{~mm}$. high.

Pappus tawny or brownish, distinctly plumose; involucre hirsute.

Basal leaves lanceolate or oblanceolate, short-petioled.

Pappus distinctly plumose, brownish.

Achenes glandular-granuliferous; involucre glandular-granuliferous and somewhat hirsute; leaves narrowly linear-lanceolate, entire or nearly so.

VII. LONGIFOLIAE.

Achenes pubescent, not glandular; involucre usually glandular-hirsute (villous in $A$. gracilenta and glandular-granuliferous in A. arcana).

Pappus merely barbellate, white or yellowish. VIII. MOLLES.

Leaves numerous, more or less grayish, the larger more than $7 \mathrm{~cm}$. long; pappus yellowish; heads many. IX. FOLIOSAE.

Leaves rather few, green, the larger not more than $7 \mathrm{~cm}$. long; pappus white; heads $1-3$.

Stem-leaves 1-3 pairs, the upper much reduced, linear or linear-lanceolate; heads 1-3. Heads erect.

Involucre hemispheric, glandular-hirsute; pappus brown, plumose.

XI. PEDUNCULATAE.

Involucres turbinate, villous at the base (glandular only in A. arnoglossa); pappus white, barbellate.

Heads nodding in bud.

X. AlPinaE.

XII. LESSINGIANAE.

\section{ERADIATAE.}

One species.

II. CORDifoliaE.

\section{A. Parryi.}

Heads numerous; involucre more or less glandular-hirsute; bracts linear.

Heads $1-3$, rarely 5 ; involucre villous, only with subsessile glands.

2. A. paniculata.

Plant 2-4 dm. high; leaves thin, usually coarsely toothed; bracts oblanceolate.

Lower leaves with a close sinus, their teeth salient.
Lower leaves with an open sinus, their teeth directed forward.

4. A. cordifolia. 
Plant 1-2 dm. (rarely $3 \mathrm{dm}$.) high; leaves thick, subentire, or with a few teeth: bracts linear-lanceolate.

One species.

\section{GranUliferae.}

IV. GRACILES.

Upper leaves not linear.

Bracts linear-lanceolate; leaves thin, usually more or less dentate.

Bracts oblanceolate; leaves thick, usually entire.

Upper stem-leaves linear, much reduced.

5. A. pumila.

6. A. granulifera.

7. A. gracilis.

8. A, puberula.

9. A. arnoglossa.

\section{- V. LatifoltaE.}

Leaves decidedly hairy, especially above.

10. A. Jonesii.

Leaves nearly glabrous.

Achenes slightly glandular-granuliferous, and with a few scattered hairs above.

Leaves not saliently toothed, merely denticulate. 11. A. ventorum.

Leaves saliently and coarsely toothed.

Achenes glabrous; leaves more or less toothed.

12. A. Menziesii.

13. A. latifolia.

\section{Diversifoliae.}

Leaves thin, nearly glabrous.

Leaves thick, densely glandular-puberulent, at least above.

14. A. silvatica.

15. A. diversifolia.

VII. LONGIFOLIAE.

Involucre merely puberulent or glandular-granuliferous; leaves not caudate-attenuate; stem usually over $3 \mathrm{dm}$. high. 16 . A. longifolia.

Involucre copiously hirsute, as well as puberulent; leaves caudate-acuminate.

17. A. caudata.

VIII. Molles.

Involucre villous, not at all glandular or viscid.

18. A. macilenta.

Involucre more or less glandular or viscid.

Involucre densely glandular-granuliferous, only with a few white hairs.

Involucre decidedly villous or hirsute, as well as glandular.

19. A. arcana.

Middle stem-leaves broadly ovate, less than $5 \mathrm{~cm}$. long; stem 2-3 dm. high.

Involuere less than $1 \mathrm{~cm}$. high, villous at the base, only slightly glandular; bracts broadly lanceolate.

bracts broadly lanceolate.
Involucre $12-15 \mathrm{~mm}$. high, densely glandular-hirsute; bracts narrowly oblanceolate.

lanceolate.
$\begin{aligned} & \text { Middle stem-leaves lanceolate, oblanceolate, or linear-lanceolate. } \\ & \text { Bracts oblanceolate, abruptly acuminate. }\end{aligned}$

Bracts linear or lanceolate.

Stem-leaves more or less sharply dentate, except at the base.

Leaves nearly glabrous, except the margins.

Stem-leaves ovate-lanceolate, broad at the base.

Stem-leaves oblanceolate or narrowly lanceolate, narrowed at the base. 24 . A. Macounii.

Leaves decidedly pubescent, both villous and glandular-granuliferous.
25 . A. rivularis.

Stem-leaves entire, sparingly denticulate, densely glandular-puberulent.
26 . A. subplumosa

\section{Foliosae.}

Pubescence of the leaves long and soft, villous.

Bracts obovate-oblanceolate, mostly obtuse.

27. A. tomentulosa.

Bracts oblong-lanceolate, acute.

Plant sparingly pubescent, with long flat hairs; leaves long-acute.

Plant densely pubescent with fine hairs; leaves acute or obtuse.

28. A. Chamissonis.

Leaves broadly oblanceolate or lanceolate.

29. A. rhizomata.

Leaves linear or lance-linear.

30. A. foliosa.

Pubescence of the leaves very short and fine.

Stem-leaves linear-lanceolate, usually entire or callous-denticulate; involucre rarely more than $1 \mathrm{~cm}$. high.

Pubescence of the involucre and peduncle very short and fine.

Pubescence of the involucre and peduncle longer and coarser.

Stem-leaves broadly lanceolate, more or less dentate; involucre $\mathrm{cm}$. high.

\section{Alpinae.}

31. A. ocreata.

32. A. celsa.

usually more than 1

33. A. rubricaulis.

20. A. coloradensis.

Stem-leaves ovate.

Stem-leaves linear to lanceolate.

Leaves glabrate in age, at least above.

Involucre and peduncle more or less glandular-puberulent; achenes hispidulous.

Involucre more or less villous, at least at the base; achenes canescent.

Leaves and lower part of the stem glabrous or nearly so; leaves mostly acute; bracts green.

Leaves strongly 3 -ribbed.

Leaves faintly 3-ribbed.

34. A. Rydbergii.

35. A tenuis. 
Leaves and stem villous when young; leaves mostly acuminate; bracts purpletinged.

Leaves densely villous-tomentose.

36. A. alpina.

37. A. tomentosa.

\section{Xi. Pedunculatae.}

Stem with tufts of brown wool at the base.

Stem without tufts of wool at the base.

38. A. pedunculata.

39. A. fulgens.

One species.

XII. LESSINGIANAE.

1. A. Parryi A. Gray. Stem 2-6 dm. high, somewhat hirsute-villous below, glandular above; lower leaves petioled; blades ovate or ovate-oblong, usually denticulate; upper leaves sessile, narrowly lanceolate, smaller and entire; heads 3-9; involucres broadly turbinate, 12-15 $\mathrm{mm}$. high, glandular-hirsute; bracts linear, attenuate; ligules usually none, but the marginal flowers sometimes ampliate; achenes hirsute or glabrate; pappus brownish, subplumose. A. eradiata (A. Gray) Heller. Mountains: Alta.-N.M.-Utah-Ore-B.C. Mont.-Alp. Jl-Au.

2. A. paniculata A. Nels. Stem 4-7 dm. high, glandular and viscid-villous; blades of the basal leaves broadly ovate, subcordate at the base, 6-10 cm. long, viscid-villous on both sides; stem-leaves 3-4 pairs, the lower petioled, the upper sessile; blades ovate, denticulate; heads paniculate-cymose; involucres nearly hemispheric, $12-15 \mathrm{~mm}$. high; bracts linear-lanceolate, acute or acuminate; achenes hirsutulous. Moist woods: Mont.-Wyo.-Utah. Au.

3. A. grandifolia Greene. Stem 3-4 dm. high, sparingly villous-ciliate or glabrous; basal leaf-blades ovate-cordate, 5-7 $\mathrm{cm}$. long, toothed; stem-leaves about 3 pairs, the lowest pair long-petioled; blades cordate, with a narrow sinus, 10-15 cm. long, saliently toothed with triangular teeth, puberulent above, glabrous or nearly so beneath; upper stem-leaves subsessile, oval or ovate; involucres nearly hemispheric, about $15 \mathrm{~mm}$. high; bracts oblanceolate, short-acuminate. Perhaps a large-leaved form of $A$. cordifolia. Mountain sides: Mont.-B.C. Mont. Jl.

4. A. cordifolia Hook. Stem 2-6 dm. high, somewhat viscid; basal leafblades broadly cordate, usually coarsely toothed, $3-10 \mathrm{~cm}$. long, puberulent, and viscid-villous on the veins; stem-leaves 2-4 pairs, all except the uppermost petioled and cordate or rarely ovate; involucres campanulate-turbinate, 15-18 $\mathrm{mm}$. high; bracts oblanceolate, acuminate. A. abortiva Greene, a small-leaved form. Wooded hills: Alta.-Colo.-Calif.-B.C. Submont.-Subalp. Je-Au.

5. A. pumila Rydb. Stem 1-2, rarely $3 \mathrm{dm}$. high, viscid-villous; basal leaf-blades firm, ovate, rarely subcordate, entire or few-toothed, $2-5 \mathrm{~cm}$. long, puberulent; stem-leaves 1-3 pairs, short-petioled or the upper sessile; involueres turbinate, $10-12 \mathrm{~mm}$. high, puberulent and slightly villous. A. parvifolia Greene. A. Evermannii Greene. Mountains: Alta.-Colo.-Utah-B.C. Mont.-Subalp. Je-Au.

6. A. granulifera Rydb. Stem about $3 \mathrm{dm}$. high, glandular-granuliferous; basal leaves petioled, with probably cordate blades, fallen at the time of flowering; lower stem-leaves obovate, dentate, about $5 \mathrm{~cm}$. long, glandular-granuliferous, thin, with strong ribs; upper stem-leaves ovate or cordate, sessile; heads 3-5; involucre about $12 \mathrm{~mm}$. high and $2 \mathrm{~cm}$. broad; bracts oblanceolate, abruptly acuminate, glandular-granuliferous and slightly ciliolate; ligules orange, about 1 $\mathrm{cm}$. broad; achenes glandular-puberulent, striate; pappus dirty white, barbellate. Mountains: Mont. Mont. Au.

7. A. gracilis Rydb. Stem slender, 1-3 dm. high, glabrous; inflorescence glandular-pruinose; basal leaf-blades broadly ovate, dentate, 3-ribbed, 2-4 cm. long, glabrous or nearly so; stem-leaves 2 or 3 pairs, the lower short-petioled, the upper sessile and smaller; heads usually 1-5; involucres turbinate, about $1 \mathrm{~cm}$. high; bracts oblanceolate, acuminate; achenes sparingly glandular-pruinose. $A$. lactucina Greene. A. columbiana A. Nels. A. multiflora Greene, with more numerous heads. (?) A. ovalifolia Greene. -Wash.-B.C. Submont.-Mont. Je-Au. 
8. A. puberula Rydb. Stem about $3 \mathrm{dm}$. high, glandular-puberulent; lower leaves short-petioled; blades ovate, $2-4 \mathrm{~cm}$. long, puberulent and glandularpruinose, entire or slightly dentate; upper stem-leaves sessile, ovate, mostly entire; heads 1-5; involucres turbinate, about $1 \mathrm{~cm}$. high and broad; bracts oblanceolate, glandular-puberulent, with deltoid tips; ligules $10-12 \mathrm{~mm}$. long; achenes glandular-puberulent, brown; pappus straw-colored, barbellate. Rocky places and hillsides: Alta.-Wyo.-B.C. Mont. Jl-Au.

9. A. arnoglossa Greene. Stem 3-5 dm. high, rather slender, glandularpuberulent and with scattered hairs; lower leaf-blades lanceolate, acute, wingpetioled, remotely serrate, strongly 5 -ribbed, firm, sparsely scabrous, pale beneath; upper stem-leaves lanceolate, sessile; heads $1-5$, usually 3 ; involucres turbinate, 9-10 $\mathrm{mm}$. high, glandular-puberulent; achenes slightly hirsute. Hills: (Black Hills) S.D.-Wyo.-Alta. Submont.-Mont. Je-Au.

10. A. Jonesii Rydb. Stems 3-4 dm. high, glandular-puberulent and slightly villous, especially on the peduncles; basal leaves long-petioled; blades ovate-cordate, 1-3 cm. long, sparingly villous and glandular-puberulent; stemleaves sessile, ovate-cordate, $2-5 \mathrm{~cm}$. long, dentate; heads 1-3; involucres turbinate, 10-12 $\mathrm{mm}$. high and as broad; bracts linear-lanceolate, acuminate, slightly villous, as well as glandular-puberulent; ligules about $1 \mathrm{~cm}$. long; achenes glandular-puberulent and with a few stiff hairs on the upper part; pappus straw-colored, barbellate. Mountains: Utah. Mont. Jl-Au.

11. A. ventorum Greene. Stem $2-4 \mathrm{dm}$. high, glabrous or nearly so; basal leaf-blades ovate to orbicular-cordate, thin, repand-dentieulate, $3-6 \mathrm{~cm}$. long, delicately ciliolate, otherwise glabrous; stem-leaves $2-3$ pairs, the lower shortpetioled, the upper sessile, oval or ovate, acute, minutely denticulate; heads 1-3; involucres turbinate, $12-15 \mathrm{~mm}$. high, puberulent; bracts narrowly oblanceolate, acuminate; achenes glandular-scabrellous. Wet places in the mountains: Wyo. -Utah. Mont. Au.

12. A. Menziesii Hook. Stem $3-6 \mathrm{dm}$. high, sparingly hairy or nearly glabrous below; basal leaf-blades cordate or broadly ovate, sinuately dentate, 4-8 $\mathrm{cm}$. long, minutely puberulent, thin; stem-leaves $2-4$ pairs, the lower shortpetioled, the rest sessile and usually more sharply toothed; heads 3-5; involucres broadly turbinate, $10-12 \mathrm{~mm}$. high; bracts narrowly oblanceolate, acuminate; rays bright yellow, 12-15 mm. long; achenes sparingly glandular-puberulent, or with a few short hairs towards the apex. A. platyphylla A. Nels., at least in part, more glabrous than the type. Meadows: Calif.-Mont.-Alaska. Mont. Je-Au.

13. A. latifolia Bong. Basal leaf-blades $4-6 \mathrm{~cm}$. long, ovate or cordate, toothed, minutely puberulent or glabrate, thin; lower stem-leaves short-petioled and more oval; upper stem-leaves sessile, oval; heads $1-5$; involueres turbinate, 12-15 $\mathrm{mm}$. high, sparingly villous-pilose; bracts narrowly oblanceolate, acuminate; achenes usually wholly glabrous. A. teucrifolia Greene. A. platyphylla Rydb. (Fl. Colo.). A. ventorum Coult. \& Nels., in part, not Greene. Wet places: Alta.-Colo.-Utah-Alaska. Je-Au.

14. A. silvatica Greene. Stem slightly villous, with scattered hairs and somewhat glandular-puberulent above; basal leaf-blades ovate, glabrous or slightly gland dlar-puberulent above, hirsutulous-ciliolate on the margins, coarsely dentate; stem-leaves 4-5 pairs, the lower wing-petioled, the uppermost sessile, very coarsely incisely dentate, all more or less connate-sheathing; heads 3-5; involucres hemispheric, $12-15 \mathrm{~mm}$. high; bracts linear-lanceolate, acute; achenes sparsely hirsute. Woods: Colo. Mont. J1-Au.

15. A. diversifolia Greene. Stem 3-6 dm. high, densely glandular-puberulent and with a few scattered hairs; basal leaf-blades broadly ovate or subcordate, saliently toothed, glandular-puberulent on both sides or nearly glabrate beneath; upper stem-leaves ovate and sessile, saliently toothed; heads $1-5$; involucres hemispheric; bracts lanceolate, acuminate; achenes hirsute on the angles. $A$. latifolia viscidula A. Gray. Mountains: Alta.-Calif.-B.C. Mont. J1-S.

16. A. longifolia D. C. Eat. Stem tufted, leafy, $3-6 \mathrm{dm}$. high, finely puberulent; leaves linear-lanceolate, $5-15 \mathrm{~cm}$. long, entire or denticulate, finely puberu- 
lent, sessile, the lower sheathing at the base; heads paniculate-cymose; involucres hemispheric, $8-10 \mathrm{~mm}$. high, densely puberulent; bracts linear, attenuate. $A$. polycephala A. Nels. Meadows: Mont.-Colo.-Calif.-Wash. Submont.Mont. Jl-Au.

17. A. caudata Rydb. Stem 2-3 dm. high, leafy, villous, and densely glandular-puberulent; leaves linear-lanceolate, mostly sheathing at the base, densely glandular-puberulent and with scattered villous hairs, 5-10 cm. long, with entire, somewhat revolute margins; heads mostly 3 , cymose; involucres turbinate, about $1 \mathrm{~cm}$. high; bracts linear-lanceolate, almost subulate, attenuate; ligules nearly $1 \mathrm{~cm}$. long. Wet places: Utah. Mont. Au.

18. A. macilenta Greene. Stem 4-7 dm. high, softly villous; leaves 5-6 pairs, the lower ones elliptic-oblanceolate, tapering below into winged petioles, often connate-sheathing, sparingly and softly short-pubescent on both sides, repand-denticulate or entire; upper leaves lanceolate, sessile; heads 1-3; involucres hemispheric, about $12 \mathrm{~mm}$. high; achenes sparingly hirsutulous; pappus tawny, barbellate. Mountains: Colo-Utah-Wyo.-(? Alta.). Mont.-Subalp. J1$\mathrm{Au}$.

19. A. arcana A. Nels. Stem about $3 \mathrm{dm}$. high, glandular-granuliferous; basal leaves petioled; blades oblong-oblanceolate, glandular-granuliferous, denticulate; upper leaves lanceolate, sessile, $3-5 \mathrm{~cm}$. long; heads usually 3 ; involucres turbinate, about $8 \mathrm{~mm}$. high; rays orange; achenes sparingly hispidulous; pappus whitish, barbellate. Rock crevices in the mountains: Wyo-Utah-Ida. Mont. $\mathrm{J}-\mathrm{Au}$.

20. A. coloradensis Rydb. Stem about $2 \mathrm{dm}$. high and with about 3 pairs of leaves, villous; lower leaves obovate, nearly sessile, sparingly pubescent, $4-5$ $\mathrm{cm}$. long; upper leaves sessile, ovate or ovate-lanceolate, 5-nerved; heads often solitary or few; involucre hemispheric; bracts broadly oblanceolate, acute or acuminate, often tinged with purple, 8-9 mm. long; ligules bright yellow, over $1 \mathrm{~cm}$. long; achenes finely strigose. Mountains: Colo. Mont.

21. A. ovata Greene. Stem 3-4 dm. high, glandular-puberulent and slightly villous; lower leaves obovate, with short winged petioles, finely pubescent on both sides, callous-denticulate or entire; upper stem-leaves ovate, sessile; heads 1-5; involucres hemispherie, $10-15 \mathrm{~mm}$. high; bracts lanceolate, acuminate; achenes hirsute, angled. Mountains: Utah-Wyo. Mont.-Subalp. Jl.

22. A. mollis Hook. Stem 3-6 dm. high, glandular-puberulent and more or less villous; lower leaves oblanceolate, short-petioled, 5-15 $\mathrm{cm}$. long, usually denticulate, more or less pubescent on both sides; upper leaves sessile, ovate to lanceolate; heads 1-3; involucres hemispheric, 12-15 mm. high; achenes hirsute. A. crocea and A. crocina Greene. Mountains: Alta.-Colo.-Utah-Wash.B.C. Submont.-Mont. Je-Au.

23. A. amplexifolia Rydb. Stem 3-6 dm. high, sparingly eiliate; stemleaves ovate-lanceolate, sharply and saliently dentate, $5-12 \mathrm{~cm}$. long, broad, rounded and sometimes half-clasping at the base; heads $3-9$; involucres hemispheric, about $12 \mathrm{~mm}$. high; bracts linear-lanceolate, acute or acuminate; achenes hirsutulous. A. amplexicaulis Nutt. (?) A. columbiana Greene. A. Greenei A. Nels. Mountains in damp places: B.C.-W Mont.-Wash. Submont. Je-J.

24. A. Macounii Greene. Stem 6-10 dm. high, glabrous or sparingly ciliate; lower stem-leaves oblanceolate, tapering below, $5-15 \mathrm{~cm}$. long, saliently dentate, hispidulous-ciliolate on the margins, sparingly pubescent above; upper stem-leaves elongate-lanceolate, long-attenuate, somewhat clasping; heads 1-7; involucres hemispheric, $10-12 \mathrm{~mm}$. high; bracts linear-lanceolate, acuminate; achenes hirsutulous. Valleys: B.C.-Alta.-Mont.-Wash. Submont.

25. A. rivularis Greene. Stem 3-6 dm. high, more or less glandular-granuliferous and sparingly hirsute; leaves $3-5$ pairs, the lowest short-petioled and oblanceolate, the rest sessile, lanceolate, denticulate; heads $3-5$; involucres hemispheric, about $12 \mathrm{~mm}$. high; bracts linear-lanceolate, acuminate; ligules 10-12, deep yellow, $12-15 \mathrm{~mm}$. long; achenes sparingly hirtellous and granulifer-
ous. Along mountain streams: Alta.-Ore.-B.C. Je-Au. 
26. A. subplumosa Greene. Stem 3-8 dm. high, more or less villous and somewhat glandular above; lower leaves oblanceolate, wing-petioled, 5-10 $\mathrm{cm}$. long, denticulate or entire; upper stem-leaves sessile, lanceolate or oblanceolate; heads 1-5; involucres hemispheric, 10-15 $\mathrm{mm}$. high; bracts linear-lanceolate, acute; achenes hirsute, rarely almost glabrous. A. Chamissonis longinodosa A. Nels. A. subplumosa silvatica A. Nels., in part, a low form. Mountain meadows: Mont.-Colo.-Utah. Mont.-Subalp. Je-Au.

27. A. tomentulosa Rydb. Stem villous, about $4 \mathrm{dm}$. high; leaves oblanceolate, obtuse, sessile or the lower with short-winged petioles, denticulate, finely villous-pubescent, almost tomentulose, with two pairs of stronger veins, the larger $13 \mathrm{~cm}$. long, somewhat yellowish; heads few, hemispherieal; involucres about $12 \mathrm{~mm}$. high and $2 \mathrm{~cm}$. broad; bracts ovate or ovate-oblong, villous; rays light yellow, over $1 \mathrm{~cm}$. long; achenes sparingly hispidulous. (?) A. stricta A. Nels. Mountains: Wyo.-Colo, Mont. Au.

28. A. Chamissonis Lessing. Stem 4-6 dm. high, softly villous, very leafy; lower leaf-blades oblanceolate, tapering into winged petioles, which are connate-clasping, usually with 5 stronger veins, $7-15 \mathrm{~cm}$. long, denticulate or entire; upper leaves lanceolate, sessile; heads cymose-paniculate; involucres hemispheric, about $1 \mathrm{~cm}$. high, hirsute-villous; bracts narrowly linear-lanceolate; achenes hirsutulous. Wet places: Sask.-Mont.-Ida.-B.C. Submont. J$\mathrm{Au}$.

29. A. rhizomata A. Nels. Stem 2-5 dm. high, densely short-tomentose; leaves 5-7 pairs, oblong-lanceolate, obtuse or acute, $6-9 \mathrm{~cm}$. long, denticulate or entire, densely tomentose, the lower tapering into winged petioles, which are sheathing at the base, the upper sessile; heads 1-5; involucres 10-12 $\mathrm{mm}$. high, more or less villous-tomentose; bracts oblong or oblong-lanceolate, obtuse or acute; achenes sparingly hirsutulous. A. lanulosa Greene. A. exigua A. Nels., a depauperate form. Valleys: Mont.-Colo.-Utah-Ida. Mont.-Subalp. JIAu.

30. A. foliosa Nutt. Stem 3-6 dm. high, tomentose, slightly glandularpuberulent in the inflorescence; leaves linear or linear-lanceolate, densely tomentulose, entire or rarely denticulate, $5-10 \mathrm{~cm}$. long, the lower petioled, the upper sessile; heads 1-7; involucres about $8 \mathrm{~mm}$. high, hemispheric, tomentose, at least at the base; bracts linear or lance-linear, acute; achenes hispidulous. Wet places: Mack.-Colo.-Utah-Alaska. Submont.-Mont. J1-Au.

31. A. ocreata A. Nels. Stem $2-4 \mathrm{dm}$. high, sparingly puberulent, somewhat glandular so above; leaves linear-lanceolate, entire, or sparingly denticulate, finely puberulent, but green, the lower tapering into petioles, more or less sheathing, the upper sessile; heads 3-5; involucres somewhat turbinate, $7-9 \mathrm{~mm}$. high, finely puberulent; achenes glabrous or sparingly hispidulous. Valleys: Mont,-Wyo.-Utah. Plain-Submont. Jl-Au.

32. A. celsa A. Nels. Stem 4-6 dm. high, sparingly villous, and glandularpuberulent in the inflorescence; leaves $6-8$ pairs, puberulent and glandulargranuliferous, green, linear-oblanceolate or linear-oblong, the lower petioled, with sheathing bases; upper leaves sessile, lanceolate; heads $3-5$, corymbosecymose; involucres hemispheric, nearly $1 \mathrm{~cm}$. high, villous as well as glandularpuberulent; bracts linear-lanceolate, acute; achenes sparingly hirsutulous. Perhaps not distinct from the preceding. Wet meadows: Mont.-Colo.-Ida. Submont.-Mont. J1-Au.

33. A. rubricaulis Greene. Stem 3-6 dm. high, villous, often tinged with reddish purple; leaves lanceolate, $8-15 \mathrm{~cm}$. long, the lower tapering into winged petioles, all thin, triple-ribbed, sinuate-dentate or -denticulate, short-pubescent on both sides; heads many, paniculate; involucres about $1 \mathrm{~cm}$. high, nearly $2 \mathrm{~cm}$. broad; bracts lanceolate, acutish, sparsely hirsute; ligules about $12 \mathrm{~mm}$. long; achenes hirsute; pappus brownish, plumose. Meadows: B.C.-Mont.-(? Alaska). Submont.-Mont. Je-Au.

34. A. Rydbergii Greene. Stem 2-4 dm. high, sparingly villous; basal leaves oblanceolate, entire, petioled; stem-leaves $3-4$ pairs, glabrate or sparingly 
puberulent, villous-ciliate on the margins, 3-8 $\mathrm{cm}$. long, remotely dentate, strongly 3-nerved, the lower short-petioled and spatulate or oblanceolate, the upper lanceolate and sessile; heads 1-3; involucres turbinate, 10-12 mm. high, villous; bracts lanceolate, acute; ligules usually orange; achenes densely silkypilose. A. caespitosa A. Nels. A. aurantiaca Greene. Hills and mountains: Alta.-Colo.-Wash. Mont.-Subalp.

35. A. tenuis Rydb. Stem sparingly villous-pubescent, about $2 \mathrm{dm}$. high, monocephalous; leaves usually 3 pairs, sparingly villous when young, entire, the lower two pairs oblanceolate or spatulate, the upper lanceolate; involucre turbinate-campanulate, villous, about $10 \mathrm{~mm}$. high; bracts linear, 1-1.5 mm. wide, green; ligules orange, $16-18 \mathrm{~mm}$. long; achenes sparingly pilose. (?) A. lasiosperma Greene. Mountains: Wyo.-Colo. Mont.-Subalp. JI-Au.

36. A. alpina (L.) Olin. Stem 1-3 dm. high, loosely villous; basal leaves with margined petioles, 4-10 cm. long; blades lanceolate, 3-nerved, acuminate; stem-leaves 1 or 2 pairs, sessile, lanceolate, with long acumination; heads usually solitary; involucre turbinate, about $1 \mathrm{~cm}$. high, loosely white-villous, densely so at the base; bracts lanceolate. A. angustifolia Vahl. Arctic-alpine situations: Greenl.-Lab.-B.C.-Alaska; Wyo.; n Eu. Alp. Au.

37. A. tomentosa J. M. Macoun. Stem rarely over $1 \mathrm{dm}$. high; basal leaves oblanceolate, 3-nerved, white villous-tomentose, $2-5 \mathrm{~cm}$. long, entire; stem-leaves 1 or 2 pairs, lanceolate, the upper pair diminutive, acute; heads usually solitary; involucres turbinate, $10-12 \mathrm{~mm}$. high, densely white-villous; bracts lanceolate, acute or obtusish; achenes densely silky villous. High mountains: Alta.-B.C. Alp. J-Au.

38. A. pedunculata Rydb. Stem $2-6 \mathrm{dm}$. high, finely villous, somewhat glandular above; leaves mostly basal, broadly oblong to nearly linear, 3-5-ribbed, 5-10 cm. long, densely short-pilose, entire, tapering into winged petioles; stemleaves usually 2 pairs, linear, sessile, the upper small; heads usually solitary; involucres hemispheric, $12-15 \mathrm{~mm}$. high, densely villous; bracts $18-20$, lanceolate or linear-lanceolate, acute; ligules orange, $1.5 \mathrm{~cm}$. long; achenes hirsute. $A$. monocephala Rydb., a low broad-leaved form. Hills and meadows: Sask.-N.D. -Colo.-Calif.-Wash. Submont.-Subalp. Je-Au.

39. A. fulgens Pursh. Stem 2-4 dm. high, glandular-pubescent; basal leaves petioled, 6-8 cm. long; blades oblanceolate, glandular-puberulent, somewhat hirsutulous on the veins, 3-ribbed, entire; stem-leaves 2 or 3 pairs, linearlanceolate or linear, small; heads usually solitary, sometimes 3 ; involucres hemispheric, $12-15 \mathrm{~cm}$. high; bracts linear, acute; ligules orange; achenes hirsute. $A$. stricta Greene, not A. Nels. A. sororia Greene. Hills: S.D.-Colo.-Calif.B.C. Plain-Submont. My-O.

40. A. Louiseana Farr. Stem 1-2 dm. high, glandular-puberulent and with scattered longer hairs; leaves glandular-puberulent and hispidulous-ciliate on the margins, about 3 pairs; lowest pair obovate, short-petioled, mostly entire; second pair oblong, 4-6 $\mathrm{cm}$. long, sparingly denticulate, sessile, the uppermost lanceolate; reduced; heads 1-3, nodding; involucres broadly turbinate, villousglandular at the base, about $1 \mathrm{~cm}$. high; bracts lanceolate, purplish, glandularpuberulent; flowers light yellow; achenes with scattered hairs; pappus white, barbellate. Rocky slopes: Alta. Subalp.-Alp. Jl-Au.

\section{Senècio L. Groundsel, Ragwort, Squaw-Weed.}

Annual or perennial caulescent herbs. Leaves alternate, entire, toothed, or pinnatifid. Heads several or many, rarely solitary, radiate or discoid. Involucre from hemispheric or campanulate to cylindric; bracts many, strictly in one series or with a few smaller, forming a calyculum at the base. Receptacle flat or slightly convex, naked, often pitted. Ray-flowers, if present, pistillate and fertile, ligulate. Disk-flowers more numerous, hermaphrodite and fertile; corollas yellow, tubular. Anthers obtuse or rarely slightly sagittate at the base. Stylebranches in the disk-flowers spreading and recurved. Achenes terete, or slightly flattened, 5-10-ribbed. Pappus copious, of capillary bristles. 
Perennials with a more or less developed rootstock or caudex; if the latter is less welldeveloped, it bears numerous fibrous-fleshy roots.

Heads more or less nodding.

Heads discoid; crown short, with fleshy-fibrous roots.

Heads radiate; rootstock well developed.

I. PUDICI,

II. AMPLECTENTES.

Heads not nodding.

Heads more than $15 \mathrm{~mm}$. high and $20 \mathrm{~mm}$. broad, solitary (seldom 2-3).

Plant low, less than $2 \mathrm{dm}$. high, with rootstocks; bractlets short.

II. AMPLECTENTES.

Plant tall, 3-5 dm. high, stout, with a short erown and a cluster of fleshyfibrous roots.

Bractlets linear-filiform, almost equalling the involucre; bracts not blacktipped.

Bractlets short; bracts usually tipped with black.

XIX. Megacephali.

Heads less than $15 \mathrm{~mm}$. high and broad.

XVIII. INTEGERRIMI.

Plants equally leafy throughout.

Leaves or their divisions not narrowly linear or filiform.

Leaves merely toothed or entire, not pinnatifid.

Leaf-blades oval, elliptic, or obovate, usually obtusish; heads few; plants cespitose.

III. OCCIDENTALES.

Leaf-blades triangular or ovate to linear-lanceolate, distinctly acute; heads usually many.

Leaf-blades, at least the lower ones, triangular or cordate; plants growing in clumps. with fleshy-fibrous roots.

IV. TRLANGULARES.

Leaf-blades neither triangular nor cordate.

Plant tall, 5-15 dm. high; heads numerous; plants with rootstocks.

Plant low, 2-4 dm. high; heads few. Heads radiate. Heads discoid.

Leaves pinnatifid.

V. 'SERRAE.

VI. EREMOPHUL.

Leaves or their divisions linear-filiform; plants usually suffruticose at the base.

VII. LONGIUOBI.

Plants with the stem-leaves more or less reduced upwards.

Rootstock well developed, horizontal or ascending, woody.

Stem leafy, more than $2 \mathrm{dm}$. bigh.

Heads campanulate, rarely solitary.

Stem stout; rootstock not cespitose; leaves callous-denticulate or saliently dentate.

Heads discoid; leaves saliently dentate.

Heads radiate; leaves callous-denticulate.

XVII. RAPIFOLII.

Leaves glabrous.

Leaves tomentose.

VIII. GLAUCESCENTES.

IX. Foliosi.

Stem slender; rootstock usually more or less cespitose; leaves neither callous-denticulate, nor saliently and closely dentate; stem-leaves in the larger forms usually pinnatifid.

Basal leaves entire, more or less white-tomentose. $\mathrm{X}$. CANI.

Basal leaves, at least most of them, toothed or pinnatifid.

Leaves and stem more or less floccose, tardily becoming

glabrate.
Leaves and stem glabrous or slightly floccose when young.

XII. AUREI.

XIII. SUBNUDI.

Heads turbinate, solitary.

XIV. ANDICOLAE

Stem subscapose, less than $2 \mathrm{dm}$. high.

Rootstock very short, erect, of short duration, with numerous fleshy-fibrous roots; leaves dentate or entire.

Tall bog-plants, 5-15 dm. high; basal leaves long-petioled.

Tall bog-plants, $5-15$ dm. XV. HYDROPHIL.

Meadow or wood-plants, 2-5 dm. high;-basal leaves comparatively short-petioled.

Leaves sharply and densely dentate.

XVI. Crassuli.

Leaves entire-margined or denticulate, seldom sinuate-dentate.

XVIII. INTEGERRIMI.

Annuals.
Plant branched, more or less viscid; heads discoid, or with minute rays.
$\mathrm{XX}$. VULGARES.

Plant simple, more or less floceose: heads radiate.

XXI. Palustres.

\section{PudicI.}

Heads 12-20 mm. high, broadly campanulate.

Auricles of the upper leaves small and entire; midvein of the leaves long-villous.

Auricles of the upper leaves large and usually toothed; midvein of the leaves not conspicuously villous.

Heads 8-10 mm. high, narrowly campanulate.

2. S. chloranthus.

3. S. pudicus. 


\section{AMPLECTENTES.}

Stem $2 \mathrm{dm}$. or more high, leafy; leaves acute.

Stem-leaves with clasping bases; stem high, slightly floccose when young.

Stem-leaves not clasping, usually short-petioled.

4. S. amplectens.

Stem less than $2 \mathrm{dm}$. high.

Rootstock hard, scaly at the top; upper stem-leaves sessile. 6. S. seridophyllus.

Rootstock fleshy, not scaly; stem-leaves usually petioled.

Basal leaves gradually tapering into the petioles.

Plant glabrous or nearly so; leaves dentate; bracts oblong.

7. S. Holmii.

Plant arachnoid-floccose; leaves pinnatifid; bracts narrowly lanceolate.

Basal leaves abruptly contracted into the petioles. $\quad$ 9. S. Saraxacoides. Soldanella.

\section{OCCIDENTALES.}

Plant 2-3 dm. high; stem-leaves obovate or oblong, clasping.

Plant very leafy; involucres $10-15 \mathrm{~mm}$. broad, short-peduncled or subsessile; achenes strigose.

10. S. carthamoides.

Plant less leafy; involucres about $10 \mathrm{~mm}$. broad, long-peduncled: achenes glabrous. 11. S. blitoides.

Plant about $1 \mathrm{dm}$. high; stem-leaves spatulate or obovate, scarcely clasping.

Leaves obovate-spatulate; plant glabrous; achenes puberulent.

12. S. Fremontii.

Leaves oval, spinulose-dentate; leaf-margins scaberulous; surfaces with a few hairs; achenes glabrous.

13. S. invenustus.

\section{TRIANGULARES.}

Heads few; involucres $10 \mathrm{~mm}$. high; lower leaf-blades cordate, the upper oval.

14. S. variifolius.

Heads usually many; involucres 6-8 mm. high; all leaves triangular, or the upper deltoidlanceolate.

Stem 3-4 dm. high; leaves fleshy.

Stem_4-10 dm. high; leaves thin.

15. S. saliens.

16. S. triangularis.

V. SERRAE.

Heads 12-15 mm. high; disk 8-15 mm. broad; whole plant dark green.

Heads 8-10 mm. high; disk 5-6 mm. wide; plant light green.

Leaves oval-deltoid to lanceolate; panicles elongate. 18. S. S
Leaves narrowly lanceolate to almost linear; panicles round-topped.

Leaves, at least the lower, closely dentate; involucre cylindro-campanulate.

Leaves entire; involucres turbinate-campanulate.

19. S. serra.

20. S. lanceolatus.

\section{EREMOPHILI.}

Blades of the leaves sinuately lobed, the upper eleft halfway to the midrib.

Bracts linear-subulate, not thickened on the back.

Bracts linear, carinate on the back.

21. S. glauciifolius.

Blades of the leaves pinnatifid or laciniate, cut usually to near the midrib.

Leaf-blades ovate in outline; divisions toothed or lobed.

Involucres 6-7 mm. high, 5-6 mm. broad; bracts black-tipped.

Involucres 7-10 $\mathrm{mm}$. high, 6-8 $\mathrm{mm}$. broad.

23. S. ambrosioides.

24. S. eremophilus.

Leaf-blades narrowly oblanceolate; divisions linear, entire. 25. S. Kuntzei.

Plant glabrous, at least in age.

\section{LONGHOBI.}

Leaves except those of the branches pinnately divided.

Leaves oblanceolate, with lanceolate or oblong lobes or teeth.

Leaves and their divisions linear-filiform.

25. S. Kuntzei.

Bractlets one-third to one-half as long as the bracts, filiform.

Bractlets very short, subulate.

Involucres campanulate: bracts 12-15.

Involucres almost cylindrical; bracts 8-10.
Leaves entire, linear-filiform, or some rarely with a pair of

Plant more or less permanently tomentose.

\section{GlaAucescentes.}

Basal leaves spatulate or oblanceolate.

26. S. filicifolius.

27. S. Riddellii.

28. S. multicapitatus.

tobes.

29. S. spartioides.

30. S. longilobus.

Bracts long-attenuate, slightly if at all black-tipped; lower leaves broadly spatulate.

Bracts short, acute, with conspicuous black tips.

Lower leaves broadly spatulate.

Lower leaves oblanceolate.

Basal leaves narrowly linear-oblanceolate.

31. S. anacletus.

32. S. glaucescens.

96. S. lapathifolius.

33. S. lugens. 


\section{FOLIOSI.}

Heads cylindro-campanulate; disk about $5 \mathrm{~mm}$. wide.

Bracts black-tipped.

Bracts broadly linear, abruptly acute.

Bracts narrowly linear, long-acute.

Bracts not black-tipped.

Heads openly campanulate; disk 8-10 mm. wide; upper stem-leaves much reduced.

34. S. atratus.

35. S. milliflorus.

36. S. foliosus.

37. S. sphaerocephalus.

\section{CANI.}

Heads $7-8 \mathrm{~mm}$. high.

Involucres as well as the whole plant densely white-tomentose.

38. S. Hallii.

Involucres glabrate or nearly so.

Plant densely tomentose; basal leaves short-petioled; petioles scarcely exceeding the blades.

Blades of the basal leaves obovate or spatulate,

Blades of the basal leaves linear or nearly so.

39. S. Purshianus.

40. S. larimiensis.

Plant finely tomentose, becoming more glabrate in age; basal leaves with slender petioles, much longer than the blades.

Heads $1 \mathrm{~cm}$. or more high.

41. S. Howellii.

Blades of the basal leaves narrowly oblanceolate: stem-leaves linear, entire,

Plant 3-6 dm. high; involucres campanulate; upper leaves much reduced.

42. S. spaluliformis.

Plant 1-2 dm. high; involucres turbinate-campanulate; upper leaves not much reduced.

43. S. Harbourii.

Blades of the basal leaves spatulate or broadly oblanceolate; stem-leaves lanceolate or oblong, usually more or less pinnatifid; heads hemispheric

44. S. canus.

\section{Tomentosi.}

Some of the basal leaves entire or dentate.

Basal leaves obovate or spatulate.

Plant conspicuously rosulate-stoloniferous; stem-leaves sinuately round-lobed.

50. S. Fendleri.

Plant not stoloniferous; stem-leaves pinnatifid with toothed lobes or dentate. Lower stem-leaves acute; plant dark green. 45 , S. plattensis.

Lower stem-leaves obtuse or rounded at the apex; plant yellowish green. Basal leaves dentate; achenes hispidulous on the angles.

Basal leaves crenate; achenes glabrous.

46. S. neomericanus.

47. S. Leonardi.

Basal leaves lanceolate or oblanceolate; achenes glabrous.

Basal leaves narrowly oblanceolate, serrate.

Basal leaves lanceolate, sinuate-dentate.

All leaves pinnatifid, with toothed segments.

Heads discoid; leaves crisp.

Heads radiate; leaves scarcely crisp.

Caudex subligneous; plant tomentose; bracts shorter than the disk; achenes glabrous.

Caudex not subligneous; plant glabrate in age.

Achenes glabrous.

Achenes hispidulous.

48. S. salicinus.

49. S, canovirens.

51. S. lanatifolius.

50. S, Fendleri.

52. S. uintahensis.

53. S. multilobatus.

XII. AUREI.

Heads radiate.

Leaves thick, more or less fleshy.

Basal leaves narrowly oblanceolate.

Plant low, less than $2 \mathrm{dm}$. high, often with several stems from the base; basal leaves short-petioled; achenes hispidulous on the angles; ligules yellow. Cyme dense; upper leaves usually pinnatifid with narrow lobes. 54. S. densus.

Cyme more open; stem-leaves entire or merely crenate.

Basal leaves subentire or 3-toothed at the apex.

Basal leaves crenate.

55. S. tridenticulatus.

56. S. oblanceolatus.

Plant about 4-6 dm. high, simple; achenes glabrous; ligules orange.

Leaves serrate or subentire; basal leaves $1 \mathrm{~cm}$. or more, slender-petioled.

57. S. longipetiolatus.

Stem-leaves with long, triangular lobes; basal leaves $5 \mathrm{~cm}$. long or less, 58. S. Rydbergii.

Basal leaves cuneate, spatulate, or broadly oblanceolate, subentire at the base. Lower stem-leaves spatulate, with broad-winged petioles; upper ones sessile and with much enlarged bases. 72. S, dimorphophyllus. Stem-leaves neither broad-winged nor with much enlarged bases.

Stem-leaves, like the basal ones, broadly obovate, coarsely toothed.

Stem-leaves reduced, either very narrow or else pinnatifid. 59. S. oodes.

Basal leaves angularly dentate or crenate all around, or more or less lyrate.

Achenes glabrous.

Basal leaves oval, crenate, or subentire. 60. S. laetiflorus. 
Leaves thin.

Basal leaves distinctly crenate or dentate.

Achenes glabrous.

Basal leaf-blades broad, from cordate to obovate or oval, not tapering at the base.

Stem-stout; heads 8-10 mm. high.

Basal leaves usually subcordate at the base; stem-leaves lyratepinnatifid, with the lower lobes narrow.

Basal leaf-blades obovate; stem-leaves pinnatifid, with broad divisions.

Stem slender; heads 6-7 mm. high.

67. S. platylobus.

Basal leaf-blades oblanceolate.

Plant subglaucous.

Plant not subglaucous.

Achenes hispidulous.

68. S. flavulus.

70. S. Willingii.

69. S. multnomensis.

71. S. Tweedyi.

Basal leaves sinuate or entire.

Stem-leaves pinnatifid with dilated-auricled bases.

Plant low, 1-2 dm., rarely $3 \mathrm{dm}$. high; ligules mostly yellow.

Plant tall, 3-7 dm. high; ligules deep orange to brick-red.

Stem-leaves not with dilated-auricled bases.

Stem-leaves entire or nearly so, not auricled. $\quad 74$. S. Tracyi.

Stem-leaves more or less lyrate-pinnatifid.

Basal leaf-blades suborbicular, sinuate.

Basal leaf-blades oval or ovate.

75. S. Pammelii.

Plant densely cespitose; bracts $5-6 \mathrm{~mm}$. long.

Plant not densely cespitose; bracts $7-8 \mathrm{~mm}$. long

$$
\text { 76. S. aquariensis. }
$$

Heads discoid

77. S. Farriae.

First basal leaves reniform.

78. S. nephrophyllus.

None of the leaves reniform.

Plant stout; stem-leaves with broad laciniate segments. 79. S. idahoensis.

Plant slender; stem-leaves with narrow segments.

Plant yellowish or light green; bracts not purple-tinged.

Plant dark green.

68. S. flavulus.

Basal leaves crenate; head 8-10 mm. high; bracts purple-tinged, linear.

80. S. pauciflorus.

Basal leaves wavy; heads about $6 \mathrm{~mm}$. high; bracts broadly lanceolate or oblong, not purple-tinged.

81. S. fedifolius.

One species.

XIII. SUBNUDI.

XIV. ANDICOLAE.

82. S. subnudus.

Blades of the basal leaves orbicular, rounded, subcordate, obovate or cuneate, toothed at least at the apex, obtuse.

Heads 7-8 mm, high, several in a dense cluster.

Heads 9-12 mm. high, solitary or a few in an open corymb.

Rays golden yellow.

Rays paler yellow.

Basal leaf-blades sub-reniform; plant subacaulescent. 85. S. Porteri.

Basal leaf-blades oval or obovate; plant with a short stem.

Involucre hemispherical to campanulate.

Flowering stems about $2 \mathrm{dm}$. high; heads 9-10 $\mathrm{mm}$. high; basal leaves crenate-serrate, except at the very base; achenes hispidulous on the angles. 86. S. cognatus.

Flowering stems less than $1.5 \mathrm{dm}$. high; heads $10-12 \mathrm{~mm}$. high; achenes glabrous.

Stem-leaves linear or linear-oblanceolate, if toothed, only at the apex.

87. S. pentodontus.

Stem-leaves lanceolate, the lower more or less pinnately lobed or toothed.

Involucre turbinate.

88. S. ovinus.

89. S. turbinatus.

Blades of the basal leaves elliptical to linear, entire or very rarely some of them 3-toothed at the apex, acute.

Plant in age nearly glabrous, monocephalous, $5-6 \mathrm{~cm}$. high. 90. S. alpicola.

Plant more or less permanently floccose, with usually several heads, over $1 \mathrm{dm}$. high. 91. S. werneriaefolius. 
XV. HYDROPHIT.

Leaves thick, entire or rarely minutely dentieulate; inflorescence dense.

Heads discoid; stem-leaves more or less clasping.

Heads radiate; stem-leaves narrowed at the base.

Leaves dentate; inflorescence open.

XVI. Crassuli.

92. S. pacificus.

93. S. hydrophilus.

94. S, hydrophiloides.

Stem-leaves linear or linear-lanceolate.

Stem naked above; disks $8-10 \mathrm{~mm}$. broad.

Stem leafy; disks $12-15 \mathrm{~mm}$. broad.

95. S. pereziifolius.

96. S. lapathifolius.

Stem-leaves ovate or ovate-lanceolate.

Leaves firm; bracts very thick and fleshy.

Leaves thin; bracts not very thick.

97. S. crassulus.

98. S. semiamplexicaulis.

One species.

XVII. RAPIFOLII.

Heads several.

XVIII. INTEGERRIMI.

99. S. rapifolius.

Bracts of the involucres narrowly linear-lanceolate, long-attenuate.

Bracts without black tips; leaves entire-margined. Plant low, 1-3 dm. high, simple, more or less villous.

Plant tall, 4-10 dm, high, branched, glabrous. 101. S. integerrimus.
Bracts usually black-tipped; leaves more or less dentate or denticulate.

Leaves thick, the basal ones obovate, dentate. 102. S. Hookeri.

Leaves thin, the basal ones oblanceolate or spatulate, merely denticulate.

103. S. dispar.

Bracts of the involucres linear or oblong, rather abruptly acute, with a lanceolate or triangular black tip.

Basal leaf-blades cordate to broadly oval, rather abruptly contracted into the petioles.

Rays ochroleucous or white.

104. S. Leibergii.

Rays deep yellow,

Leaves more or less dentate or denticulate; stem 3-10 dm. high.

Basal leaves entire: stem 2-3 dm. high. 105. S. Flintii.

Basal leaf-blades spatulate to linear-oblanceolote or rarely lanceolate, gradually tapering into the petioles.

Bracts about half as long as the fully developed disk.

Plant 6-8 dm. high; inflorescence open, broad, about $2 \mathrm{dm}$. wide.

107. S, latus.

Plant 3-6 dm. high, slender; inflorescence 5-8 $\mathrm{cm}$. broad, with a few heads. 33. S. lugens.

Bracts more than half as long as the disk; inflorescence usually congested.

Leaves crisp, as well as the stem, conspicuously arachnoid-hairy, especially when young; inflorescence dense; heads less than $1 \mathrm{~cm}$. high.

108. S. condensatus.

Leaves not crisp, only slightly villous when young; inflorescence more open; heads usually over $1 \mathrm{~cm}$. high.

Leaves more or less dentate; inflorescence even in age a flat-topped corymb.

109. S. columbianus.

Leaves merely callous-denticulate; inflorescence with a short-peduncled terminal head and the lateral ones usually very long-peduncled.

Heads solitary.

One species.

One species.

One species.

1. S. accidens Greene. Stem 4-10 dm. high, simple and leafy; basal leaves and lower stem-leaves tapering into rather long winged petioles, lanceolate or oblanceolate, 10-15 cm. long, dentate or denticulate; upper stem-leaves linearlanceolate, sessile and somewhat clasping; heads few or several on erect branches, nodding; involucre 2-2.5 $\mathrm{cm}$. broad; bracts glabrous, thin, oblong-linear, acute, S. Bigelovii Hallii A. Gray. S. scopulinum Greene. Mountains: Colo,-Utah -N.M.-Wyo. Mont. Jl-O.

2. S. chloranthus Greene. Stem 3-10 dm. high, leafy; basal leaves and lower stem-leaves oblanceolate, abruptly contracted into short, winged petioles, coarsely dentate, acute; uppermost leaves sessile, lanceolate; heads several, corymbose or racemose, the lower ones on elongate, erect peduncles, nodding; involucres openly campanulate, $12-15 \mathrm{~mm}$. high and $20-25 \mathrm{~mm}$. broad; bracts glabrous, thin, linear, oblong, or lanceolate, acute. S. Bigelovii A. Gray, in part. 
S. contristatus Greene, a glabrous form with purplish involucres. Mountains: Colo.-N.M. Mont.-Alp. J-Au.

3. S. pudicus Greene. Stem leafy, often much branched, $3-8 \mathrm{dm}$. high; basal leaves rather short-petioled, firm; blades about $1 \mathrm{dm}$. long, oblong or narrowly lanceolate, acute, denticulate or rarely dentate; upper leaves linear, sessile, entire, not clasping; inflorescence paniculate, with numerous heads; branches erect; bracts linear, acute, 7-8 $\mathrm{mm}$. long, about one-fourth shorter than the disk, with membranous margins. S. cernuus A. Gray. Mountain meadows and ereek-banks: Colo.-se Utah-N.M. Submont.-Subalp. J-Au.

4. S. amplectens A. Gray. Stem 3-6 dm. high, leafy; lower leaves with winged petioles, $7-15 \mathrm{~cm}$. long, slightly floccose when young; blade oblanceolate. very thin, sinuate-dentate or denticulate, acute or mucronate, tapering at the base into winged petioles, clasping at the base; upper leaves oblong, more entire, sessile, half-clasping; heads 1-4, nodding, about $2 \mathrm{~cm}$. broad; bracts linear, acuminate, about equalling the disk, purplish, the calyculate ones few; ligules almost $2 \mathrm{~cm}$. long. Wet subalpine places in open woods: Colo.-N.M. Mont. -Alp. Jl-Au.

5. S. pagosanus Heller. Stem $2-4 \mathrm{dm}$. high, glabrous; lower leaves petioled, 10-15 cm. long; blades oblanceolate, or elliptic, obtusish, deeply and sharply dentate, glabrous and somewhat glaucous; upper stem-leaves sessile, lanceolate, tapering at the base; heads 1-4, nodding, on erect long peduncles; involucres broadly campanulate, glabrous, $15-20 \mathrm{~mm}$. broad; bracts linear, scarious-margined; ligules 15-20 mm. long. S. lactucinus Greene (1900, not 1893). Alpine regions: Colo. Subalp.-Alp. Jl-Au.

6. S. seridophyllus Greene. Stem about $2 \mathrm{dm}$. high, 2-3-leaved, the lower short-petioled, oblanceolate, the upper oblong or lanceolate, sessile, and half clasping, thin, sinuate-dentate, 5-10 $\mathrm{cm}$. long, slightly glaucous; head solitary or 2 or 3 , nodding, about $2 \mathrm{~cm}$. in diameter; bracts very thin, light green, linear, acuminate, shorter than the disk, the calyculate ones very few, about half as long; ligules light yellow, about $15 \mathrm{~mm}$. long and 3-4 mm. wide. Alpine regions: Nev.-w Wyo.-Utah. Mont.-Subalp. Au-S.

7. S. Holmii Greene. Stem 1-2 dm. high, often almost seapiform, with 1, seldom 2-3, large heads; lower leaves obovate or oblanceolate, 5-10 $\mathrm{cm}$. long, thin, shining, sharply sinuate-dentate, tapering at the base, obtuse or acutish at the apex, the upper ones much reduced, linear-lanceolate; heads about 15-20 mm. broad, nodding; bracts linear or linear-lanceolate, acute, thin, with a membranous margin, light green or tinged with purple; ligules light yellow, about $1 \mathrm{~cm}$. long. High mountains: Colo.- e Utah. Mont.-Alp. J-Au.

8. S. taraxacoides (A. Gray) Greene. Stem subscapose or with a few leaves, 5-9 cm., seldom 10-12 cm. high; leaves 3-4 cm. long, oblanceolate or spatulate, or the stem-leaves, if any, lanceolate in outline, pinnatifid, with sharp triangular salient lobes; head solitary, openly' campanulate, $12-15 \mathrm{~mm}$. broad; bracts narrowly linear-lanceolate, acuminate, rather thick, about equalling the disk, the calyculate ones about half as long; ligules 8-14 mm. long. S. amplectans taraxacoides A. Gray. Alpine peaks: Colo.-N.M. Mont.-Alp. J-Au.

9. S. Soldanella A. Gray. Stem about $1 \mathrm{dm}$. high, 3-4-leaved, perfectly glabrous; leaves more or less petioled; blades orbicular, reniform, or obovatespatulate, rounded or somewhat cordate at the base, rounded or obtuse at the apex, callous-denticulate or subentire; head solitary, $15-18 \mathrm{~mm}$. high and 2-3 $\mathrm{cm}$. broad, erect or slightly nodding; bracts lanceolate, acute, often tinged with purple, almost equalling the disk, the calyculate ones of ten long; ligules 6-10 $\mathrm{mm}$. long. Rocky places: Colo. Mont.-Alp. Jl.

10. S. carthamoides Greene. Stem $2-5 \mathrm{dm}$. high, very leafy; leaves thickish and somewhat fleshy, obovate or spatulate, coarsely and sharply dentate or somewhat pinnatifid-dentate, obtuse or acutish, 2-6 $\mathrm{cm}$. long, sessile and clasping; inflorescence leafy-corymbose; peduncles rather short; bracts lanceolate, acuminate, about equalling the disk, thick and somewhat fleshy, the calyculate ones narrowly linear-lanceolate, about one-third as long; ligules light yellow, about $8 \mathrm{~mm}$. long. Alpine regions: N.M.-Wyo. Mont.-Alp. Л-Au. 
11. S. blitoides Greene. Stem $2-3 \mathrm{dm}$. high, leafy; leaves thinner than in the preceding, obovate or oval, tapering at the base, sharply dentate, $2-4 \mathrm{~cm}$. long; inflorescen ce leafy-corymbose, but the peduncles $3-10 \mathrm{em}$. long; bracts as in the preceding species; ligules 7-8 $\mathrm{mm}$. long. Mountains: Colo.-Utah-s Wyo. Subalp.-Alp. Au.

12. S. Fremontii T. \& G. Glabrous and fleshy perennial, branching below the surface of the ground; stem about $1 \mathrm{dm}$. high; leaves $2-3 \mathrm{~cm}$. long, roundedobovate or spatulate, fleshy, coarsely toothed or lobed, the lower with a winged petiole, the upper sessile; involucres campanulate, about $8 \mathrm{~mm}$. high and broad; bracts linear or linear-lanceolate, acute, glabrous, the calyculate ones very small; ligules bright yellow, about $8 \mathrm{~mm}$. long. $S$, ductoris Piper. $S$. occidentalis rotundatus Rydb. Alpine regions, among loose rocks: Mont.-Wyo.-Ore.-B.C. Subalp.-Alp. Jl-Au.

13. S. invenustus Greene. Stem 1-1.5 dm. high, very leafy, glabrous; leaves $2-4 \mathrm{~cm}$. long, spatulate or obovate, doubly laciniate-toothed, glabrate or nearly so, scaberulous on the margins; heads $2-5$, short-peduncled; involucres campanulate, about $1 \mathrm{~cm}$. high and $8 \mathrm{~mm}$. broad, glabrous; bracts linear, scariousmargined, the calyculate ones few and half as long; ligules orange, $6-7 \mathrm{~mm}$. long; achenes glabrous, striate. Higher peaks: Colo.- Utah. Mont.-Alp. Jl-Au.

14. S. variifolius Rydb. Stem 6-12 dm. high, angled or striate, branched above, leafy; basal leaves petioled; blades cordate, saliently dentate, acute, rather firm, about $1 \mathrm{dm}$. long; upper stem-leaves elliptical or lanceolate, shortpetioled or sessile, 5-10 $\mathrm{cm}$. long; cyme open; heads few; involucres 6-7 mm. broad; bracts linear, acute, with broad membranous margins, slightly shorter than the disk, the calyculate ones small, linear-subulate; ligules 5-10 mm. long; achenes glabrous, angled. Wet places in the mountain regions: Mont.-Ida. Submont. J1-Au.

15. S. saliens Rydb. Stem simple, 3-4 dm. high; leaves rather thick, petioled or the upper subsessile; blades 3-5 $\mathrm{cm}$. long, elongate-triangular or lanceolate, very sharply dentate; cyme corymbiform, dense; involucre $8 \mathrm{~mm}$. high and broad; bracts broadly linear, acute, rather thick; ligules bright yellow, 8-10 $\mathrm{mm}$. long; achenes glabrous. Wet subalpine stations, among rocks: Yukon-Mont.Wyo.-Wash.-B.C. Mont.-Subalp. J-Au.

16. $\mathbf{S}$. triangularis Hook. Stems several from the same clump, 5-15 dm. high; leaf-blades thin and shining, elongate-triangular or lanceolate, acute, 5-20 $\mathrm{cm}$. long, dentate, with triangular teeth; petiole narrowly winged, in the lower $1-3 \mathrm{~cm}$. long; heads numerous in an open, more or less leafy cyme; involueres campanulate, 6-8 $\mathrm{mm}$. high and broad; bracts broadly linear, very thin, the calyculate ones linear-subulate, short; ligules light yellow, about $1 \mathrm{~cm}$. long; achenes glabrous. Along brooks and in swamps, especially in the mountains: Sask.-N.M.-Calif.-Alaska. Submont.-Subalp. Je-Au.

17. S. admirabilis Greene. Stem simple or branched above, striate, 5-15 $\mathrm{dm}$. high; leaves linear-lanceolate, $10-15 \mathrm{~cm}$. long, sharply serrate with callous teeth, acute or acuminate at both ends, sessile or very short-petioled; cyme paniculate, with numerous heads and somewhat leafy; bracts lanceolate or ovatelanceolate, two-thirds as long as the disk, thick on the back, with broad scarious erose margins; tips abruptly spreading; ligules light yellow, about $1 \mathrm{~cm}$. long; achenes glabrous and shining, striate. Damp places in mountain valleys: Colo. -Wyo. Submont.-Mont. J1-Au.

18. S. Solidago Rydb. Stem about $1 \mathrm{~m}$. high, glabrous, very leafy and much branched; leaves 6-10 $\mathrm{cm}$. long, rather thin, coarsely dentate, with salient teeth, short-petioled or the upper subsessile; panicle very large and branched, elongate; heads small, about $8 \mathrm{~mm}$. high; involucres glabrous; bracts linear, yellowish, much shorter than the disk; ligules pale yellow; achenes glabrous. Wet places: Mont.-Ida.

19. S. serra Hook. Stem 6-15 dm. high; leaves lanceolate or linear-lanceolate, $5-15 \mathrm{~cm}$. long, sharply serrate or the upper entire, subsessile or the lower short-petioled; heads very numerous, in a leafy panicle; involuere almost cylin- 
drical, about 6-7 $\mathrm{mm}$. high and 5-6 $\mathrm{mm}$. wide; bracts narrowly lanceolate or linear, thick on the back; tips not spreading, very dark, glandular and puberulent; ligules light yellow, $6-8 \mathrm{~mm}$. long; achenes glabrous. $A$. andinus Nutt., a form with the upper leaves entire-margined. Mountain meadows: Mont.Colo.-Ore.-Wash. Plain-Mont. Jl-Au.

20. S. lanceolatus T. \& G. Stem 6-10 dm. high, glabrous; leaves lanceolate or linear-lanceolate, entire, shining, yellowish green, 1-2 dm. long; heads paniculate; involucres turbinate-campanulate, about $6 \mathrm{~mm}$. high and $5 \mathrm{~mm}$. broad, glabrous; bracts linear-lanceolate, scarious-margined, acute, the calyculate ones subulate; ligules light yellow, $5 \mathrm{~mm}$. long; achenes cylindric, glabrous, striate. S. serra integriusculus A. Gray, in part. Along streams: Wyo.-Nev. Submont. J1-Au.

21. S. glauciifolius Rydb. Perennial, with a rootstock, glabrous or slightly tomentose when young; stem $5-6 \mathrm{dm}$. high, leafy; lower leaves elliptic, coarsely sinuately lobed, generally with smaller lobes on the petioles, which are somewhat enlarged and clasping at the base; stem-leaves ovate or rounded-ovate in outline, sessile and half-clasping, deeply cleft into oblong divergent lobes; heads many, corymbose or panieulate, about $1 \mathrm{~cm}$. high; involucral bracts very narrowly linear, almost subulate; rays narrow, light yellow; achenes striate, glabrous. Meadows: Mont.

22. S. Kingii Rydb. Stem glabrous, $3-6 \mathrm{dm}$. high, rather stout, leafy; leaves obovate or oblanceolate in outline, 4-7 $\mathrm{cm}$. long, the lower petioled, all pinnately lobed one-third to one-half the distance to the midrib, with ovate or lanceolate, more or less toothed lobes; heads corymbose-paniculate; involucres glabrous, campanulate, $7-8 \mathrm{~mm}$. high, 6-7 mm. broad; ligules 5-7 $\mathrm{mm}$. long; achenes scabrous-papillose. Mountains: Utah. Submont.-Mont. J1-Au.

23. S. ambrosioides Rydb. Stem glabrous, leafy, 4-10 dm. high; leaves lanceolate or oblanceolate in outline, pinnatifid to near the midrib or the lower incised, mostly short-petioled, the lobes lanceolate, coarsely dentate or incised; heads corymbose-paniculate; bracts carinate, linear, acute, with black tips, the calyeulate ones subulate, 4-5 $\mathrm{mm}$. long; ligules light yellow, 5-6 mm. long; achenes minutely scabrous-puberulent on the angles. Mountains: Wyo.-Utah -N.M. Mont.-Subalp. J-Au.

24. S. eremophilus Richards. Stem stout, 5-10 dm. high; leaves deeply pinnatifid, 1-2 dm. long, the lower petioled, the upper sessile; lobes lanceolate, usually toothed or cleft; heads many, corymbose, 10-12 $\mathrm{mm}$. high; bracts linearlanceolate, costate, black-tipped; ligules 6-8 mm. long; achenes papillose-scabrous on the angles. Wet ground: Sask.-N.D.-Wyo.-Alta.-Mack. Au-S.

25. S. Kuntzei Rydb. Perennial, probably suffruticose below; stem $5 \mathrm{dm}$. high or more; stem-leaves oblanceolate in outline, 5-10 $\mathrm{cm}$. long, with a broad blade above, pinnately eleft into linear, oblong, or lanceolate lobes below the middle, the upper merely toothed, those of the branches linear and entire; heads numerous, cymose-paniculate; involucres eylindro-turbinate, nearly $1 \mathrm{~cm}$. high, $8 \mathrm{~mm}$. broad; bracts linear, acute; ligules about $1 \mathrm{~cm}$. long; achenes hispidulous. Mountains: Colo.-Wyo. Submont. J-S.

26. S. filicifolius DC. Stem $5-10 \mathrm{dm}$. high, slightly floceose when young, soon glabrate; leaves pinnatifid, with linear-filiform divisions; heads corymbose, 10-12 $\mathrm{mm}$. high; involucres campanulate, slightly floccose when young; bracts carinate, linear, abruptly acuminate, the calyculate ones linear-subulate, onehalf to two-thirds as long; ligules $10-15 \mathrm{~mm}$. long; achenes strigose-canescent. S. lathyroides M. E. Jones. Sandy plains: Ariz.-Utah-Calif. Ap-N.

27. S. Riddellii T. \& G. Stem $3-10 \mathrm{dm}$. high, gläbrous, leafy, branched; leaves pinnatifid, with linear or linear-filiform divisions, glabrous; heads corymbose, $10-12 \mathrm{~mm}$. high; involucres campanulate, glabrous; bracts linear, acute, somewhat carinate; ligules about 12 , light yellow, 9-12 $\mathrm{mm}$. long; achenes somewhat canescent. Plains: Tex.-Neb.-Wyo.-N.M. Plain-Submont. Je-O.

28. S. multicapitatus Greenm. Stem 4-10 dm. high, yellowish, glabrous, branched and broom-like, leafy; leaves irregularly pinnately dissected into 
linear-filiform lobes, 1-1.5 mm. wide, or the upper simple and linear-filiform, somewhat fleshy; heads in a corymbiform inflorescence, numerous; involueres almost cylindric, 6-7 mm. high, about $4 \mathrm{~mm}$. in diameter; bracts linear, gradually acute, the calyculate ones small, subulate; ligules pale yellow, 7-8 mm. long; achenes strigose-hispidulous. Mountain valleys and high plains: N.M.-Colo. -Ariz. Submont.-Subalp. Au-S.

29. S. spartioides T. \& G. Stem 3-6 dm, high, leafy throughout, often several from one root; leaves glabrous, narrowly linear, entire; heads corymbose; involucre nearly cylindric; bracts about 12 , carinate, linear, acute, the calyculate ones subulate, minute; ligules few, 8-10 mm. long; achenes silky-canescent. Banks and plains: Tex.-Neb,-Wyo.-Ariz. Plain-Mont. Jl-O.

30. S. longilobus Benth. Stem $3-10 \mathrm{dm}$. high, white-tomentose, at least when young, leafy; leaves white-tomentose, pinnately divided into linear-filiform divisions, or the upper entire and linear-filiform; heads corymbose, 12-15 mm. high; involucres campanulate, $10-12 \mathrm{~mm}$. broad, floccose at the base; bracts linear, carinate, short-acuminate; ligules $10-12 \mathrm{~mm}$. long; achenes finely strigosecanescent. S. filifolius Nutt., not Bergius. Plains and valleys: Tex.-Colo,Utah-Ariz.; Mex. Son.-Submont. Ap-Au.

31. S. anacletus Greene. Stems 1-3, few-leaved, terete and slightly striate; basal leaves obovate or broadly spatulate, obtuse or mucronate, copiously callousdenticulate, rather thick, $5-15 \mathrm{~cm}$. long, with a distinet winged petiole; stemleaves few and small, from spatulate to narrowly lanceolate, sessile and often subentire; eyme corymbiform; involucres campanulate, $10-12 \mathrm{~mm}$. high and $12-15 \mathrm{~mm}$. broad; bracts linear-lanceolate, acuminate, about two-thirds as long as the disk; ligules bright yellow, about $8 \mathrm{~mm}$. long; achenes glabrous. $S$. toluccanus microdonthes A. Gray. (?) S. Wootonii Greene. Damp places in the mountains: Ariz.-N.M.-Colo. Submont.-Subalp. My-Jl.

32. S. glaucescens Rydb. Stem 2-7 dm. high, striate, shining, glabrous or slightly hairy at first; lower leaves $5-10 \mathrm{~cm}$. long, with winged petioles; blades spatulate or oblanceolate, or even oval, callous-dentate or subentire, somewhat glaucous; upper stem-leaves reduced, lanceolate, sessile; cyme corymbose, dense; heads campanulate, about $1 \mathrm{~cm}$. high; bracts linear-lanceolate, acute, blacktipped, about two-thirds as long as the disk; ligules dark yellow, about $8 \mathrm{~mm}$. long; achenes glabrous. Wet places: Mont.-n Wyo.-Ida. Plain-Submont. $\mathrm{Au}$.

33. S. lugens Richards. Stem slender, terete, about $3 \mathrm{dm}$. high; basal leaves $5-10 \mathrm{~cm}$. long, narrowly oblanceolate, sinuate-dentate; upper stem-leaves much reduced, linear or linear-lanceolate; cyme corymbiform; heads 5-7, campanulate, about $1 \mathrm{~cm}$. high, 8-12 mm. broad; bracts rather thick, linear-oblong or lanceolate, acute, conspicuously black-tipped; rays about $8 \mathrm{~mm}$. long; achenes glabrous. Wet places: Subarctic America-Man.-Ida.-Alaska. Subalp. Je-J.

34. S. atratus Greene. Plant tomentose when young, tardily becoming more glabrate in age; stem 3-6 dm. high, terete; basal leaves distinctly petioled, 1-2 dm. Iong; blade spatulate or oblanceolate, callous-denticulate, tapering at the base; upper stem-leaves lanceolate and sessile; cyme compound, corymbiform; heads very numerous, small; involucre $6-10 \mathrm{~mm}$. high, almost eylindric; bracts broadly linear, acute; ligules light yellow, $6-8 \mathrm{~mm}$. long; achenes glabrous. $S$. lugens foliosus A. Gray, in part. Mountain sides: Colo.-Utah-N.M. Submont.-Subalp. Je-Au.

35. S. milliflorus Greene. Stem persistently tomentose, about $1 \mathrm{~m}$. high; basal leaves petioled, $2-3 \mathrm{dm}$. long, tomentose on both sides; blades oblanceolate, callous-dentate; stem-leaves lanceolate, sessile, acuminate; heads very numerous, in a compound flat-topped cyme; involucres narrow, eylindric, 6-7 mm. high, about 12-flowered; bracts about 8, narrowly linear; ligules 3 or 4, 3-4 $\mathrm{mm}$. long; achenes glabrous. Mountains: Colo. Mont. J1.

36. S. foliosus (A. Gray) Rydb. Stem floccose-tomentose when young, $2-3 \mathrm{dm}$. high, terete; lower leaves oblanceolate, $7-10 \mathrm{~cm}$. long, sinuate-denticulate, acute, tapering at the base and short-petioled; upper leaves lanceolate or 
linear, sessile; cyme compound, corymbiform; heads small; involucre about $8 \mathrm{~mm}$. long, almost cylindric; bracts broadly linear, acute, about two-thirds as long as the disk; ligules light yellow, 6-8 mm. long; achenes glabrous. A. lugens foliosus A. Gray, in part. Subalpine regions: Utah. Subalp. Л.

37. S. sphaerocephalus Greene. Stem 6-10 dm. high, striate, sparingly woolly when young, leafy below; lower leaves $2-3 \mathrm{dm}$. long, wing-petioled; blades firm, oblanceolate, sinuately callous-dentate, more or less tomentose on both sides; upper leaves linear-lanceolate; heads in a corymbiform cyme, about $1 \mathrm{~cm}$. high; bracts linear, rather thick, black-tipped, much shorter than the disk; ligules $8 \mathrm{~mm}$. long, orange or lemon; achenes hispidulous on the angles. S. altus Rydb. Wet meadows in the mountains: Mont.-Wyo.-Nev.-Ida. Mont.Subalp. J1-Au.

38. S. Hallii Britton. Plant densely white-tomentose; stems several, a little over $1 \mathrm{dm}$. high; basal leaves $2-3 \mathrm{~cm}$. long, distinetly petioled; blade spatulate, obtuse, thick, entire; stem-leaves linear, sessile; heads few, crowded, about $5 \mathrm{~mm}$. high and as broad; involucre turbinate-campanulate; bracts broadly linear, acute, densely tomentose; ligules light yellow, about $5 \mathrm{~mm}$. long; achenes glabrous. Geyser formations: Yellowstone Park, Wyo. Mont. J1-Au.

39. S. Purshianus Nutt. Stems 1-2 dm. high; basal leaves broadly spatulate, entire, $3-5 \mathrm{~cm}$. long, obtuse; cyme small, corymbiform; heads 2-10; involucre campanulate, $7-8 \mathrm{~mm}$. high; bracts linear-lanceolate, acute; ligules bright yellow, about $6 \mathrm{~mm}$. long; achenes glabrous. Dry hills and mountain sides: Sask.-Tex. -Utah-B.C. Plain-Alp. Je-Au.

40. S. larimiensis A. Nels. Stem 1-2 dm. high, floceose; basal leaves 4-5 $\mathrm{cm}$. long, short-petioled; blades linear or linear-oblanceolate, entire, white-tomentose; stem-leaves similar, but smaller and sessile; heads $10 \mathrm{~mm}$. high or less; bracts linear-lanceolate, acute, almost glabrous, calyculate ones few, small and subulate; ligules about $5 \mathrm{~mm}$. long; achenes glabrous. Searcely distinct from S. Purshianus. Dry hills: Wyo.-S.D. (Black Hills). Plain. My-J.

41. S. Howellii Greene. Stem 2-4 dm. high, finely white-tomentulose, in age sometimes more glabrate; lower leaves $5-15 \mathrm{~cm}$. long, with slender petioles longer than the blades, white-tomentulose; blades oblanceolate, entire, the upper sessile, more or less pinnatifid or toothed, lanceolate in outline; heads corymbose; involucres 7-8 mm. high, one-fourth shorter than the disk, glabrous or nearly so; bracts linear-lanceolate, acute; ligules 8-10, yellow, about $5 \mathrm{~mm}$. long; achenes glabrous. Hillsides and banks: Mont. -n Wyo.-Ore.-Wash. Submont.-Mont. My-Jl.

42. $\mathbf{S}$. spatuliformis Heller. Stem $3-6 \mathrm{dm}$. high; leaves mostly basal, 1-2 $\mathrm{dm}$. long, with long petioles; blades linear-oblanceolate, entire or undulate, floecose, sometimes glabrate above in age; upper stem-leaves small and seattered, subulate, sessile; heads in an open corymb, about $1 \mathrm{~cm}$. high; bracts linear, acute, almost glabrous, yellowish; ligules bright yellow, $1 \mathrm{~cm}$. long; achenes glabrous. S. fastigiatus Nutt., not Schwein. S. leucocrinus Greene. Wet ground, mostly near the coast: Ore.-Wash.-Ida. (acc. to Gray). Je-Ji.

43. S. Harbourii Rydb. Stem 1-2 dm. high, striate, white-floccose, leafy; basal leaves and most stem-leaves petioled, $3-10 \mathrm{~cm}$. long, densely white-floccose; blades oblanceolate or linear-spatulate, entire; uppermost stem-leaves sessile, lanceolate, more or less auricled at the base; inflorescence corymbiform; heads $2-7$, mostly 10-15 mm. high; bracts narrowly linear, long-attenuate, light yellowish green and slightly floccose, the calyculate ones minute, subulate; rays bright yellow, over $1 \mathrm{~cm}$. long; achenes brown, shining, glabrous, angled. Mountains:
Colo. Mont. - Alp. JI-Au.

44. S. canus Hook. Stem 3-5 dm. high; basal leaves petioled, entire, 4-15 em. long, obovate or spatulate, thick, obtuse; stem-leaves oblong or lanceolate in outline, more or less lyrate-pinnatifid or lobed, sessile, auricled; cyme compound, corymbose; heads generally many, $10-12 \mathrm{~mm}$. high; bracts narrowly linearSask.-Neb.-Colo.-Calif.-B.C. Plain-Submont. My-Aurous. Dry hills: 
45. S. plattensis Nutt. Stem $2-5 \mathrm{dm}$. high, loosely floceose, very tardily glabrate; basal leaves petioled, 3-10 $\mathrm{cm}$. long; blades ovate or elliptic, floccose when young, glabrate in age; lower stem-leaves petioled, lyrate-pinnatifid, with oblong lobes, the upper sessile, reduced, linear-lanceolate in outline, pinnatifid or toothed; heads corymbose; involucres campanulate, 6-7 mm. high, tomentose at the base; bracts lance-linear, acute, the calyculate ones minute, subulate; ligules about $8 \mathrm{~mm}$. long, orange; achenes hispidulous on the angles. $S$. pseudotomentosus Mack. \& Bush. Prairies and river valleys: w Ont.-Mo.-Tex.-Colo. e Mont.-Sask. Plain. My-Je.

46. S. neomexicanus A. Gray. Stem 2-4 dm. high, densely and loosely floceose when young; basal leaves $3-8 \mathrm{~cm}$. long, petioled; blades spatulate, coarsely dentate, tomentose on both sides, glabrous in age above; stem-leaves very small, linear-oblanceolate or linear, more or less dentate or pinnatifid; heads rather few, corymbose; involucres campanulate, about $8 \mathrm{~mm}$. high, shorter than the disk, tomentose at the base; bracts lance-linear, acute; ligules light yellow, $8 \mathrm{~mm}$. long. Mountains: N.M.-Ariz.-(? Colo.). Son. My-J.

47. S. Leonardi Rydb. Stem 4-5 dm. high, loosely floccose; lower leaves petioled; blades obovate or oval, $2-6 \mathrm{~cm}$. long, densely crenate, rather thick, loosely floccose, or in age glabrate, rounded at the apex, the middle ones more or less lyrate-pinnatifid at the base, the upper 1-3 cm. long, lanceolate in outline, pinnately lobed and somewhat auriculate-clasping; heads in a rather dense corymb; involueres somewhat turbinate and floccose at the base, $5-6 \mathrm{~mm}$. high, 6-7 mm. broad; bracts linear, acute, carinate; ligules orange, about $6 \mathrm{~mm}$. long, $2 \mathrm{~mm}$. wide. Valleys: Utah. Jl.

48. S. salicinus Rydb. Stems several, about $4 \mathrm{dm}$. high, simple below, striate and floccose; basal leaves $5-10 \mathrm{~cm}$. long, narrowly oblanceolate, the first ones subentire, but most of them serrate except at the tapering base, finely tomentose on both sides, in age more glabrate above; stem-leaves small, linear, sessile, dentate, slightly auricled at the base; heads subumbellate, $7-8 \mathrm{~mm}$. high, slightly floccose at the base; bracts yellowish, thin, lanceolate, shorter than the disk; ligules light yellow, short and broad, 3-4 mm. long; achenes glabrous. Mountains: Colo. Submont. Je-Jl.

49. S. canovirens Rydb. Stem 4-5 dm. high, loosely floccose; lower leaves $5-12 \mathrm{~cm}$. long, short-petioled; blades lanceolate or oblanceolate, sinuately toothed,
dark green, firmly floccose, in age almost glabrate above; upper leaves linear, sinuately dentate, with rather acute teeth; cyme with erect or ascending branches; involucre 7-8 $\mathrm{mm}$. high, turbinate-campanulate; bracts 12-14, oblong, linear, floccose at the base and more or less villose; ligules $5-6 \mathrm{~mm}$. long, at first orange, in age paler; achenes glabrous. Mountains: Colo.-N. M. Submont.-Mont. $\mathrm{Je}-\mathrm{Au}$.

50. S. Fendleri A. Gray. Stem 2-3 dm. high, floccose when young, but in age sometimes almost glabrate, floccose only at the axils of the leaves; leaves all deeply pinnatifid, or the lower oblanceolate, round-lobed or entire, more or less tomentose on both sides or glabrate above, 4-8 cm. long, the lower petioled, the upper sessile; divisions of the leaves toothed or cleft; heads corymbose; involucres campanulate, 4-5 mm. high, one-half to two-thirds as high as the disk, only slightly tomentose at the base; bracts lance-linear, abruptly acuminate; ligules yellow, $5 \mathrm{~mm}$. long; achenes glabrous. S. rosulatus Rydb., a form with subentire basal leaves. S. Nelsonii Rydb. Mountains: N.M.-Colo.-Utah. Submont.-Alp. Je-Au.

51. S. lanatifolius Osterhout. Stems several, 1-2 dm. high, usually branched, very leafy to the inflorescence; leaves linear, pectinate-pinnatifid, the divisions crenate-toothed with inrolled edges, especially those of the lower leaves; both stem and leaves pannose-canescent; heads numerous and crowded, about $8 \mathrm{~mm}$. high; involucres campanulate, glabrate; bracts about 7 , the calyculate ones minute; flowers 15; rays none; achenes glabrous. Hills and mountains: Colo.Neb. Plain-Mont.

52. S. uintahensis (A. Nels.) Greenm. Stems several, 2-4 dm. high, floccose when young, soon glabrous; leaves pinnatifid or the lower lyrate, tomentose 
when young, soon glabrate, $5-10 \mathrm{~cm}$. long; divisions obovate, usually toothed or cleft; heads in a dense corymb; involucres campanulate, somewhat turbinate at the base, $7-8 \mathrm{~mm}$. high, only slightly shorter than the disk; bracts linear, acuminate, the calyculate ones minute, subulate or wanting; ligules 5-6 mm. long, bright yellow or orange. S. Nelsonii uintahensis A. Nels. Hills and mountain sides: Wyo.-Colo.-Ariz.-Ida. Submont.-Mont. My-Jl.

53. S. multilobatus T. \& G. Stems several, $2-3 \mathrm{dm}$. high, glabrous, except at the leaf-axils where they are sometimes slightly floccose; leaves somewhat fleshy, pinnatifid or the lower merely lyrate, loosely floccose when young, soon glabrate, 4-10 $\mathrm{cm}$. long; divisions obovate or those of the stem-leaves oblong, toothed or cleft; heads corymbose; involucres glabrate, campanulate, 5-6 mm. high; bracts linear, abruptly acuminate; ligules about $6 \mathrm{~mm}$. long. Dry plains: Colo.-Utah-n Wyo. Son.-Submont. My-Jl.

54. S. densus Greene. Stem 1.5-3 dm. high, tomentose at the base and at the axils of the leaves; basal leaves petioled, $4-7 \mathrm{~cm}$. long; blades oblanceolate or linear-oblanceolate, serrate, thick, slightly floccose when young; lower stemleaves similar but laciniate or pinnately lobed; upper stem-leaves reduced, more or less pinnatifid; heads in a small dense corymb; involucres $6-7 \mathrm{~mm}$. high, hemispheric, glabrous; bracts linear or oblong, abruptly acuminate, scariousmargined; ligules 6-7 mm. long. S. aureus compactus A. Gray. S. compactus Rydb., not Kirk. S. condensatus Rydb., not Greene. Plains: Man.-Neb.e Colo. My-Je.

55. S. tridenticulatus Rydb. Stem very slender, 2-3 dm. high; basal leaves very narrowly linear-oblanceolate, thick, with a slender petiole, slightly 3 -toothed (rarely 5-toothed) at the apex or wholly entire, 4-8 $\mathrm{cm}$. long and 4-5 $\mathrm{mm}$. wide; stem-leaves linear and subentire; heads $7-8 \mathrm{~mm}$. high; bracts lanceolate, acute; ligules light yellow, about $8 \mathrm{~mm}$. long, 3-nerved. S. Metcalfei Greene. Plains: Tex.-N.M.-Colo. Son.-Submont. My-Jl.

56. S. oblanceolatus Rydb. Stem short and stout, about $2 \mathrm{dm}$. high, floccose at the base of the leaves; basal leaves oblanceolate, thick and fleshy, $4-6 \mathrm{~cm}$. long, obtuse, erenate, with entire long tapering bases, or the first subentire; stemleaves similar or reduced and linear in outline; heads about $8 \mathrm{~mm}$. high; bracts linear, acute, yellowish green, the calyculate ones minute and few; ligules 5-6 mm. long. Dry plains: Wyo.-Tex.-N.M.-Utah. Plain-Mont. My-Jl.

57. S. longipetiolatus Rydb. Stem strict, 3-6 dm. high, terete; lower leaves oblanceolate, $1-1.5 \mathrm{dm}$. long, with slender petioles, from serrate to subentire, the upper reduced, lanceolate, sessile, sharply serrate, or laciniate-dentate, often auricled at the base; heads $8-9 \mathrm{~mm}$. high; bracts about 20 , linear, acute; ligules dark orange, 4-7 mm. long. Valleys: Wyo.-Colo. Submont.Mont. Jl-Au.

58. S. Rydbergii A. Nels. Stem about $3 \mathrm{dm}$. high; basal leaves oblanceolate, thick and somewhat fleshy, dentate or subentire; lower stem-leaves spatulate, with a winged petiole, coarsely dentate; upper stem-leaves sessile with an auricled base; heads about $8 \mathrm{~mm}$. high; bracts about 15 , oblong, acute, with a broad membranous margin; ligules $4-5 \mathrm{~mm}$. long and $2 \mathrm{~mm}$. wide, dark orange. $S$. fulgens Rydb., not Nichols. Creek banks: Wyo.-Ida. Mont. Au.

59. S. oodes Rydb. Stem 3-4 dm. high, slightly floccose below, branched; lower leaves long-petioled, loosely villous-floccose when young, in age glabrous; blades thick, oval, $3-6 \mathrm{~cm}$. long, $1.5-4 \mathrm{~cm}$. wide, rounded or obtuse at the apex, abruptly contracted below, coarsely dentate-crenate, with triangular-ovate, obtuse teeth; lower stem-leaves with enlarged toothed or lobed stipule-like bases, the upper short-petioled and narrower; heads many, about $1 \mathrm{em}$. high; bracts linear, abruptly acute, $5-7 \mathrm{~mm}$. long, slightly villous; ligules bright yellow, $10-12$ $\mathrm{mm}$. long, about $2 \mathrm{~mm}$. wide; achenes glabrous. Mountains: Colo. Je-Au.

60. S. laetiflorus Greene. Stem $2-5 \mathrm{dm}$. high, slightly floccose, soon glabrous; lower leaves petioled, $1-6.5 \mathrm{~cm}$. long; blades broadly ovate, elliptic, or obovate, entire or crenate-dentate, cuneate at the base; stem-leaves lyrate or pinnately lobed, the upper semi-amplexicaul; heads $8-10 \mathrm{~mm}$. high; involucre 
campanulate; bracts thickish, at first slightly tomentulose; ligules pale yellow; achenes glabrous. Meadows and open slopes: Ore.-Ida.-Nev.-Calif. Submont. Je-Au.

61. S. rubricaulis Greene. Stem about $3 \mathrm{dm}$. high, slender, terete; basal leaves rounded-obovate, sinuately dentate, sometimes more or less lyrate, their petioles often tinged with red; stem-leaves oblanceolate in outline, pinnatifid, with oblong segments, generally short-petioled; heads about $8 \mathrm{~mm}$. high; bracts 12-15, lanceolate, acuminate, as long as the disk, membranous-margined; ligules about $5 \mathrm{~mm}$. long. S. Jonesii Rydb. Mountains: Utah-w Wyo.-Nev. Mont. -Subalp. J1-Au.

62. S. mutabile Greene. Stem striate, 4-5 dm. high; basal leaves spatulate or cuneate, dentate-serrate, about $5 \mathrm{~cm}$. long, with short petioles, soon glabrous; lower stem-leaves long-petioled, cuneate or spatulate, lyrately lobed, the upper narrowly oblanceolate and subsessile, slightly auricled at the base; heads about 8 $\mathrm{mm}$. high; bracts 12-16, glabrous, yellowish green, lanceolate, thin; ligules golden yellow, 5-6 mm. long. S. aurellus Rydb. Valleys: Colo.-N.M.-Utah. Submont.-Mont. Je.

63. S. subcuneatus Rydb. Stem 3-4 dm. high; basal leaves about $5 \mathrm{~cm}$. long, spatulate or cuneate, dentate or serrate above the middle, tapering into short petioles, rather thick; lower stem-leaves narrowly cuneate, short-petioled, dentate at the apex, the upper ones linear and sessile, often sharply dentate; heads about $8 \mathrm{~mm}$. high; bracts about 15 , lanceolate, acute, shorter than the disk; ligules 4-5 mm. long; achenes glabrous. In meadows: Colo.-Wyo. Submont. -Mont. Je-Jl.

64. S. acutidens Rydb. Stems several, about $2 \mathrm{dm}$. high, angled, more or less tinged with red; lower leaves about $5 \mathrm{~cm}$. long, thick, fleshy and somewhat glaucous, obovate or spatulate, sharply dentate above the middle, at the base abruptly contracted into slender petioles, the upper reduced, linear, laciniatedentate or somewhat pinnatifid; heads $8-10 \mathrm{~mm}$. high; bracts broadly linear, acute; ligules about $5 \mathrm{~mm}$. long; achenes glabrous. Mountains: Wyo.-N.M. Submont.-Mont. Au.

65. S. cymbalarioides Nutt. Stem 2-3 dm. high; basal leaves petioled; blades obovate or obovate-cuneate, $2-5 \mathrm{~cm}$. long, crenate above the middle; lower stem-leaves similar or lyrate-pinnatifid, the upper reduced, sessile, lobed or toothed; cyme corymbiform; heads 7-9 mm. high; involucres hemispheric, 6-7 $\mathrm{mm}$. high; bracts broadly linear, acutish; ligules 6-8 $\mathrm{mm}$. long, bright yellow; achenes glabrous. S. aureus borealis A. Gray. Mountain meadows: Mack.N.M.-Utah-B.C. Mont.-Alp. Je-Au.

66. S. pseudaureus Rydb. Stem 3-8 dm. high; basal leaves long-petioled; blades thin, broadly ovate or subcordate, serrate, 3-7 $\mathrm{cm}$. long; stem-leaves more or less laciniate or lyrate-pinnatifid, the upper clasping; heads 8-10 mm. high; involucres hemispheric; bracts lance-linear, acute; ligules bright yellow, about $8 \mathrm{~mm}$. long; achenes glabrous. S. Burkei Greenm. Wet meadows: Mack. -S.D. (Black Hills) - N.M.-Calif.-B.C. Submont.-Alp. Je-S.

67. S. platylobus Rydb. Stem about $4 \mathrm{dm}$. high, rather leafy, striate and somewhat angled; basal leaves 6-10 $\mathrm{cm}$. long, slender-petioled; blades obovate or broadly oval, sinuately crenate-dentate, thin; lower stem-leaves oblanceolate, petioled, deeply lobed or divided, with rounded lobes; upper stem-leaves broadly ovate in outline, sessile, pinnately divided into broadly oblong or cuneate divisions, which are more or less deeply sinuate-dentate; heads about $8 \mathrm{~mm}$. high; bracts broadly lanceolate, acute, membranous-margined; ligules 6-7 $\mathrm{mm}$, long; achenes glabrous. Wet banks: Wyo.-Utah-Ida.-Alta. Je-Au.

68. S. flavulus Greene. Stem 3-4 dm. high, striate, pale; basal leaves 3-8 $\mathrm{cm}$. long, obovate or broadly oval, gradually tapering into the petioles, but sometimes truncate at the bases, obtuse, crenate or sinuate, light green; lower stemleaves oblanceolate in outline and petioled, the upper lanceolate or linear and sessile, all deeply pinnatifid, with narrow, oblong or linear segments; heads 7-8 $\mathrm{mm}$. high; bracts linear, acute, yellowish green; ligules pale yellow, about $6 \mathrm{~mm}$. 
long or often lacking; achenes glabrous, striate. S. flavovirens Rydb. Wet meadows: Mont.-N.M.-Ida. Submont. Je-Jl.

69. S. multnomensis Greenm. Stem $3-7 \mathrm{dm}$. high, slightly floccose in the axils of the leaves; lower leaves $4-15 \mathrm{~cm}$. long, petioled; blades oblong-oblanceolate, obtuse or rounded at the apex, crenate-dentate, or somewhat lyrately lobed; upper stem-leaves pinnatisect, or the uppermost entire; heads 10-13 mm. high; involucres campanulate; bracts linear-lanceolate, pale green; ligules yellow; achenes glabrous. Meadows and open places: Sask.-Ore.-B.C.-Mack. Submont.-Mont. Je-Jl.

70. S. Willingii Greenm. Stem erect, $2.5-3 \mathrm{dm}$. high, glabrous; leaves oblong-lanceolate, $3-12 \mathrm{~cm}$. long, crenate-serrate to pinnatifid into oblong entire or subentire lobes, floccose-tomentulose along the veins when young; heads 8-10 $\mathrm{mm}$. high; involucre campanulate, sparingly floccose; bracts linear-lanceolate; ligules yellow; achenes glabrous. Gravelly soil: Man.-Alta. Plain.

71. S. Tweedyi Rydb. Stem glabrous, or slightly floceose at the leaf-axils, 4-6 dm. high, striate; basal leaves 3-15 cm. long, petioled; blades elliptic or oval to oblanceolate, crenate-dentate, often lyrate-pinnatifid, with a few lobes below the large terminal one; lower stem-leaves similar, but more pinnatifid; upper stem-leaves deeply pinnatifid, with oblong toothed divisions; involucres somewhat turbinate at the base, about $8 \mathrm{~mm}$. high and as broad; ligules narrow, bright yellow, 8-10 mm. long; achenes hispidulous on the margins. $S$. flavovirens Greenm., mainly, not Rydb. Wet meadows: Wyo.-Mont. Je-Au.

72. S. dimorphophyllus Greene. Stem $1.5-3 \mathrm{dm}$. high; basal leaves $2-3$ $\mathrm{cm}$. long, obovate or spatulate, crenate or subentire, with a winged petiole; lower stem-leaves with broader winged petioles somewhat auricled at the base, or else oblong without distinction between blade and petiole; upper stem-leaves ovate or triangular with very large and large-toothed auricles; heads 8-10 mm. high; bracts about 20 , linear; ligules $7-8 \mathrm{~mm}$. long and $1.5-2 \mathrm{~mm}$. wide, bright to pale yellow; achenes striate, glabrous. Senecio aureus croceus A. Gray, and S. crocatus Rydb., in part. S. heterodoxus Greene. Higher mountains: Wyo.-Colo. Mont.

73. S. crocatus Rydb. Stem 3-7 dm. high, glabrous, leafy; basal leaves long-petioled; blades thin, glabrous, broadly ovate, subcordate, or even subreniform, sinuate or subentire, $4-8 \mathrm{~cm}$. long; stem-leaves larger, lyrate pinnatifid or lobed, the lower 1-1.5 dm. long, with winged petioles and enlarged, laciniate bases, the uppermost sessile, with enlarged, clasping, and lobed bases; heads 8-9 $\mathrm{mm}$. high; involucres hemispheric, glabrous; bracts linear, acute; ligules orange or brick-red, about $7 \mathrm{~mm}$. long; achenes glabrous. S. aureus croceus A. Gray. S. pyrrochrous Greene. Wet meadows: Colo.-Wyo. Mont. J1-Au.

74. S. Tracyi Rydb. Stem about $4 \mathrm{dm}$. high, glabrous; basal leaves glabrous, long-petioled; blades round-oval or oval, thin, $1.5-5 \mathrm{~cm}$. long, $1-3 \mathrm{~cm}$. wide, entire or merely wavy, rounded at the apex, rounded, truncate or subcordate at the base; stem-leaves lanceolate, acuminate, $2-6 \mathrm{~cm}$. long, the uppermost still smaller, sinuate-crenate, auriculate-clasping; involucres broadly turbinate, 6-7 $\mathrm{mm}$. high; bracts linear, abruptly acute, glabrous; ligules yellow, $6-8 \mathrm{~mm}$. long,
about $2 \mathrm{~mm}$. wide; achenes glabrous. Mountains: Colo.- Utah. Mont. Subalp. J1-S.

75. S. Pammelii Greenm. Stem 2-4 dm. high, more or less purplish towards the base, slightly white-tomentose in the axils; lower leaves long-petioled, $1-2.5 \mathrm{~cm}$. long; blades rounded-ovate or suborbicular, subcordate or truncate at the base, sinuate-crenate or entire; stem-leaves lyrate to entire; heads $7-10 \mathrm{~mm}$. high; bracts linear-lanceolate, acute, glabrous; ligules bright yellow; achenes glabrous. Mountains: Utah-Nev. Mont. Jl-Au.

76. S. aquariensis Greenm. Stem erect, $2-3.5 \mathrm{dm}$. high; lower leaves petioled; blades ovate to oblong-lanceolate, $1-7 \mathrm{~cm}$. long; stem-leaves petioled and lyrate to sessile and pinnatisect; heads $8-10 \mathrm{~mm}$. high; involucre campanulate; bracts lanceolate; achenes glabrous. Table-lands: Utah. Mont. Au. 
77. S. Farriae Greenm. Stem 1-3 dm. high, branched near the base; lower leaves with winged petioles; blades ovate to obovate, $1-4 \mathrm{~cm}$. long, rounded at the apex, crenate to subentire; stem-leaves lyrate or irregularly pinnatifid, the upper bract-like; heads about $1 \mathrm{~cm}$. high; involueres campanulate, sparingly tomentose at the base; bracts often reddish tipped; ligules yellow; achenes glabrous. Mountains: Alta.-Wash. Mont. Je-Jl.

78. S. nephrophyllus Rydb. Stem $3-5 \mathrm{dm}$. high, branched above, glabrous; basal leaves long-petioled; blades of the earliest reniform or orbicular, slightly wavy or entire, those of the succeeding ones oval, sinuate; lower stemleaves petioled and lyrate, the upper sessile and pinnatifid, with obtuse segments and rounded sinuses; heads rayless; involucres campanulate, 7-9 mm. high; bracts linear, glabrous, 5-6 mm. long, greenish yellow or brownish; achenes glabrous. (?) S. debilis Nutt. Wet ground: Mont.-Colo.-Ida. J1-Au.

79. S. idahoensis Rydb. Stem 4-5 dm. high, branched, striate, tinged with purplish; basal leaves obovate, serrate; lower stem-leaves oblanceolate in outline, about $1 \mathrm{dm}$. long, petioled, the upper ovate or lanceolate in outline, sessile and auricled at the base, all bluish green, pinnately divided into oblong or oblique-cuneate incised segments; heads numerous, about $1 \mathrm{~cm}$. high; bracts very narrowly linear, equalling the disk; achenes glabrous. Wet places: Mont.Ida.-B.C. Plain-Submont. Je-JI.

80. S. pauciflorus Pursh. Stem glabrous, $3-5 \mathrm{dm}$. high, slender; basal leaves petioled; blades oval, ovate, or subcordate, crenate or rarely serrate, 1-3 $\mathrm{cm}$. long; stem-leaves lyrate or pinnatifid, the upper reduced; heads about $8 \mathrm{~mm}$. high; involucre campanulate; bracts narrowly linear, acute, usually purpletinged; achenes glabrous. S. discoideus (Hook.) Britton. Low ground: Lab.-Que. -Mich.-Wyo.-Calif.-B.C.-Alaska. Mont.-Subalp. Je-Au.

81. S. fedifolius Rydb. Stem slender, weak, about $1.5 \mathrm{dm}$. high; basal leaves $3-5 \mathrm{~cm}$. long, with slender petioles; blades 1-2 $\mathrm{cm}$. long, rounded-ovate or broadly oval, wavy or subentire; stem-leaves mostly small, pinnately divided into short oblong segments; heads $2-3$, about $6 \mathrm{~mm}$. high; involueres somewhat turbinate; bracts broadly lanceolate, conspicuously membranous-margined; achenes glabrous. High mountains: Colo. Subalp.

82. S. subnudus DC. Stem 1-3 dm. high; basal leaves petioled; blades broadly obovate or orbicular, coarsely crenate-dentate; stem-leaves pinnately lobed, with clasping bases, the uppermost minute; involucre decidedly turbinate, $8 \mathrm{~mm}$. high, with narrow linear-acuminate bracts; ligules orange, $7-8 \mathrm{~mm}$. long; achenes glabrous. Senecio aureus subnudus A. Gray. Marshy ground: Mont.Wyo.-n Calif.-B.C. Mont.-Subalp. J-Au.

83. S. Wardii Greene. Stem $5-15 \mathrm{~cm}$. high, glabrous; basal leaves petioled; blades thick, obovate, 1-2 cm. long, crenate above the middle or entire; stemleaves much reduced, sessile, crenate; heads several, in a dense head-like cluster; involucres campanulate, 7-8 mm. high; bracts glabrous, linear-lanceolate; ligules few, 4-5 mm. long; achenes glabrous. High mountains: Utah-Mont. Mont.

84. S. petrocallis Greene. Stem 2-10 cm. high; basal leaves numerous, petioled; blades rather thick, broadly obovate or orbicular, 1-2 cm. long, somewhat tomentose when young; stem-leaves $1-2$, the lower similar, with dilated petioles, the upper linear-lanceolate and bract-like; head 1 or 2 ; involucre turbinate-campanulate, $1 \mathrm{~cm}$. high, slightly floccose at the base; bracts linear, often tinged with purple; ligules golden yellow, $6-8 \mathrm{~mm}$. long; achenes glabrous. $S$. petraeus Klatt. S. petrophilus Greene. Alpine peaks: Colo.-Utah-Ida. Subalp.-Alp, Je-Au.

85. S. Porteri Greene. Stem scapiform, purplish; basal leaves numerous, petioled; blades subreniform, crenate or crenately lobed, 8-12 $\mathrm{mm}$. long, dark green above, glabrous; heads solitary, 9-12 mm. high; bracts shorter than the disk, $8 \mathrm{~mm}$. long, linear-lanceolate, purple, the inner slightly scarious-margined; ligules about $8 \mathrm{~mm}$. long, bright yellow; achenes glabrous. S. renifolius Porter, not Schultz-Bip. Alpine peaks: Colo. Alp. 
86. S. cognatus Greene. Stem nearly scapiform, 2-3 dm. high, slightly floccose; basal leaves slender-petioled; blades obovate, with cuneate bases, $2-4$ $\mathrm{cm}$. long, crenate, except at the base, grayish tomentulose; lower stem-leaves oblanceolatc, pinnately lobed, the rest very small and bract-like; heads 2-10; involucres campanulate, about $8 \mathrm{~mm}$. high, shorter than the disk; bracts linear, acute, scarious-margined; ligules light yellow, 6-8 $\mathrm{mm}$. long, over $2 \mathrm{~mm}$. broad; achenes slightly hispidulous on the angles. Dry lowlands and mountains: Colo.

87. S. pentodontus Greene. Stem scapiform, 5-20 cm. high, slightly floccose; basal leaves petioled; blades obovate, 1-4 cm. long, crenate or dentate above the middle, or entire, rather thick, loosely floccose when young; stem-leaves much reduced, the lower oblanceolate, the upper subulate; heads 1-5, slenderpeduncled; involucres campanulate, about $1 \mathrm{~cm}$. high; bracts linear-lanceolate, acute, slightly floccose bélow; ligules yellow, about $8 \mathrm{~mm}$. long; achenes striate, glabrous, Alpine mountain sides: Wyo.-N.M. Submont. Jl-Au.

88. S. ovinus Greene. Stem less than $1 \mathrm{dm}$. high, decumbent at the base; basal leaves short-petioled; blades orbicular, oval or obovate, some entire and some dentate; stem-leaves, at least the lower ones, lyrate-pinnatifid, floccose when young; heads mostly solitary, about $1 \mathrm{~cm}$. high; involucres hemispheric; bracts linear-lanceolate, acute, often purple-tinged; ligules 12-15, yellow, 7-8 $\mathrm{mm}$. long; achenes glabrous. S. Lyallii Klatt, not Hook. S. conterminus Greenm. High mountains: Alta.-Mont.-B.C. Alp.-Subalp. Je-Au.

89. S. turbinatus Rydb. Stem scapiform, about $1.5 \mathrm{dm}$. high, more or less floccose; basal leaf-blades cuneate-obovate, thick, 2-3 cm. long, $8-18 \mathrm{~mm}$. wide, loosely floccose when young, dentate above the middle, rounded at the apex, tapering below into the petioles; heads about 4 , about $12 \mathrm{~mm}$. high, turbinate, floccose at the base; bracts linear, gradually acute; ligules pale yellow, $8-9$
$\mathrm{~mm}$. long. Mountains: Colo.

90. S. alpicola Rydb. Stem less than $5 \mathrm{~cm}$. high, glabrous or tomentose when'young; basal leaves $1-3 \mathrm{~cm}$. long; blades thick, elliptic, entire or rarely sinuately 3 -toothed at the apex, with slightly winged petioles; stem-leaves reduced to small bracts; heads solitary, about $1 \mathrm{~cm}$. high; bracts linear-lanceolate, green or slightly purplish, equalling the disk; ligules lemon yellow, about $8 \mathrm{~mm}$. long; achenes glabrous. High mountains: Mont. Alp. Jl.

91. S. werneriaefolius A. Gray. Stem adsurgent at the base, $1-2 \mathrm{dm}$. high, floccose, tardily glabrate; basal leaves numerous, petioled; blades $1-5 \mathrm{~cm}$. long, from oval to linear-oblong, entire or some sinuately 3 -toothed at the apex, tomentose or in age glabrate, thick; stem-leaves bract-like, linear or subulate; heads $1-8$, corymbose, $9-12 \mathrm{~mm}$. high; involucres densely floccose at the base; bracts linear-lanceolate, slightly scarious-margined; ligules $5-9$, bright yellow, a $-7 \mathrm{~mm}$. long; achenes glabrous. S. scaposus A. Nels., and S. perennans A. Nels., 92. S. pacificus (Greene) Rydb. Stem glabrous, $6-10 \mathrm{dm}$. high, hollow;
basal leaves petioled, $2-3 \mathrm{dm}$. long; blades thick, oblanceolate, entire or sinuate-
dentate; stem-leaves dentate; stem-leaves narrowly lanceolate, half-clasping; inflorescence corymbosecymose; heads 8-10 mm. high; involucres campanulate, glabrous; bracts linear or oblong, scarious-margined; achenes glabrous. S. hydrophilus pacificus Greene.

93. S. hydrophilus Nutt. Stem $5-20 \mathrm{dm}$. high, striate, hollow, strict and simple; basal leaves generally long-petioled, 1-3 dm. long, thick, oblanceolate and entire; stem-leaves subsessile, lanceolate, oblong or linear, the upper much reduced and bract-like; heads numerous; involucres cylindric-campanulate, about $1 \mathrm{~cm}$. high and 5-8 mm. broad; bracts oblong, thin, membranous-margined, acute, more or less black-tipped, shorter than the disk; ligules few, light yellow, about $5 \mathrm{~mm}$. long; achenes glabrous. Swampy places: S.D.-Colo.-Calif.B.C. Plain-Submont. Je-Au.

94. S. hydrophiloides Rydb. Stem 6-8 dm. high; lower leaves with long winged petioles; blades rather thick, oblanceolate, sinuate-dentate, the upper 
much reduced, lanceolate, sessile; cyme corymbiform; heads cylindro-campanulate, about $1 \mathrm{~cm}$. high; bracts linear; ligules few, light yellow, about $7 \mathrm{~mm}$. long; achenes glabrous. Wet places: Mont.-Ida.-Wash.-B.C. Je-Jl.

95. S. pereziifolius Rydb. Stem 6-8 dm. high, glabrous, striate, somewhat branched above; basal leaves $2-2.5 \mathrm{dm}$. long, thin and glabrous, oblong or elliptic, with a short winged petiole, sinuately dentate, with small sharp salient teeth; lower stem-leaves similar, but sessile; the upper ones linear, with entire margins; cyme rather narrow; heads cylindric-campanulate, about $1 \mathrm{~cm}$. high; bracts linear, tipped with black, much shorter than the disk; ligules fully $1 \mathrm{~cm}$. long; achenes glabrous. Swampy ground: Mont. Submont. Jl.

96. S. lapathifolius Greene. Stem glabrous, about $3 \mathrm{dm}$. high; leaves 1-1.5 dm. long; lower leaves linear-oblanceolate, glabrous, denticulate, tapering below into broadly winged petioles; upper leaves linear-lanceolate, half-clasping; heads $5-10$; involucres campanulate, $10-15 \mathrm{~mm}$. high, with the peduncle gradually thickened under the head; bracts lanceolate, thickened on the back, the calyculate ones few, linear-subulate, almost as long; ligules about $1 \mathrm{~cm}$. long, narrow; achenes glabrous. Mountains: Colo.-Wyo. Mont.-Subalp. Jl-Au.

97. S. crassulus Gray. Stem 2-4 dm. high, glabrous; basal leaves $8-15 \mathrm{~cm}$. long; blades obovate or lanceolate, acutish or obtuse, dentate or denticulate, tapering into a winged petiole; upper stem-leaves oblong, ovate, or lanceolate, sessile and clasping at the base; heads corymbose; involuere campanulate, 12-15 $\mathrm{mm}$. high and 10-12 $\mathrm{mm}$. broad; bracts oblong, acute, very thick and fleshy, the inner with membranous margins, slightly shorter than the disk, the ealyeulate ones linear-subulate, about one-third as long; ligules bright yellow, about $1 \mathrm{~cm}$. long; achenes glabrous. Subalpine meadows: (Black Hills) S.D.-N.M.-Utah -Ida. Submont.-Alp. Je-Au.

98. S. semiamplexicaulis Rydb. Stem 4-6 dm. high, glabrous; lower leaves obovate, tapering into winged petioles, acute, the upper oblong, more or less clasping by a slightly auricled base, acute or acuminate, all very thin, sinuately dentate and often with salient teeth; heads few; disk $12-15 \mathrm{~mm}$. high; involucres campanulate; bracts oblong, tipped with black, much shorter than the disk; ligules narrow, about $8 \mathrm{~mm}$. long; achenes glabrous. Wet meadows: Mont. -Colo.-Utah-Ida. Submont.-Mont. Jl-Au.

99. S. rapifolius Nutt. Stem $2-5 \mathrm{dm}$. high, terete or slightly obtuseangled; leaves rather thin, sharply dentate or incised; blades of the lower leaves obovate or broadly oblanceolate, obtuse or acutish, 3-10 $\mathrm{cm}$. long, tapering into wing-margined and auricled petioles, half-clasping at the base; upper leaves subsessile, oval, oblong, or lanceolate, clasping and auricled at the base; heads numerous, panicled, $6-8 \mathrm{~mm}$. high and about $5 \mathrm{~mm}$. broad; bracts oblong, acute, thick on the back, membranous-margined, about two-thirds as long as the brownish yellow disk; ligules none; achenes glabrous. S. lactucinus Greene. Rocky wooded hillsides and mountains: Ida.-Colo.-S.D. (Black Hills), Submont. Jl-Au.

100. S. Scribneri Rydb. Stem stout, $2-3 \mathrm{dm}$. high, more or less villous; basal leaves oval or oblanceolate, with somewhat winged petioles, 3-4 em. long, fleshy; stem-leaves linear or linear-lanceolate, the upper sessile; heads 5-16, 10-15 $\mathrm{mm}$. high; involucre campanulate; bracts linear, slightly villous, long-attenuate; ligules 12-15 mm. long; achenes glabrous. Wet places: Sask.-Mont. Je-Jl.

101. S. integerrimus Nutt. Stem $3-10 \mathrm{dm}$. high, striate, leafy, branched above; basal leaves oblong-lanceolate, entire or sinuate-petioled, acute, somewhat fleshy; stem-leaves linear-lanceolate, sessile, sometimes auricled at the base; heads numerous, $12 \mathrm{~mm}$., or in fruit even $16 \mathrm{~mm}$. high and $10-15 \mathrm{~mm}$. broad; involucres campanulate; bracts narrowly lanceolate, long-acuminate, thick and fleshy, somewhat shorter than the disk; ligules dull yellow, about $1 \mathrm{~cm}$. long; achenes glabrous. Wet meadows: Minn.-Neb.-Colo.-Sask. Plain-Submont. Je-Au.

102. S. Hookeri T. \& G. Stem stout, arachnoid-villous when young, glabrate in age, simple, 2-3 dm. high; lower leaves 5-10 $\mathrm{cm}$. long, more or less dis- 
tinctly petioled, sinuate, obtuse, from oval-obovate to oblanceolate; upper stemleaves reduced, narrowly lanceolate and sessile; heads in a dense corymb, 10-12 $\mathrm{mm}$. high; bracts linear or linear-lanceolate, long-acuminate; ligules bright yellow, 8-10 mm. long; achenes glabrous. Wet meadows: Subarctic AmericaMont.-Ida. Submont.-Subalp. My-Au.

103. S. dispar A. Nels. Stem erect, 3-8 dm. high, sparingly crisp-hairy when young; leaves thin, entire, or rarely denticulate, the lower long-petioled, 8-10 cm. long; blades oblong-oblanceolate or sometimes oval; upper leaves sessile, lanceolate, the uppermost reduced; heads $5-20$, corymbose, the central one usually short-peduncled; bracts 7-9 mm. long, linear-subulate, long-attenuate, minutely black-tipped; ligules $12-15 \mathrm{~mm}$. long, $3 \mathrm{~mm}$. broad; achenes glabrous. Mountain valleys: Wyo.-Colo.-Utah. Plain-Mont. Je-J1.

104. S. Leibergii Greene. Stem 5-10 dm. high, sparingly arachnoid-tomentose when young, soon glabrate; lower leaves slender-petioled, 1-2 cm. long; blades oval or elliptic, $5-8 \mathrm{~cm}$. long, sinuate-dentate or nearly entire; middle stem-leaves lanceolate or lance-linear, sessile, denticulate, somewhat arachnoidhairy when young; inflorescence corymbiform; involucres 7-8 mm. high, about. half as high as the disk; achenes glabrous. S. exaltatus ochroleucus A. Gray. S. ochraceus Piper. Bluffs and open woods: Ore.-w Mont.-Wash.-B.C. Submont. My-Je.

105. S. exaltatus Nutt. Stem 3-10 dm. high, striate, simple; basal leaves with slender petioles; blades ovate, rarely subcordate, $5-8 \mathrm{~cm}$. long, sinuately dentate or denticulate, acute, rounded or truncate at the base; stem-leaves lanceolate, sessile. with more or less auricled bases, the upper ones much reduced; heads numerous; $10-12 \mathrm{~mm}$. high and as broad; involucre campanulate; bracts two-thirds as long as the disk; ligules bright yellow, 8-10 $\mathrm{mm}$. long; achenes glabrous. Wet places in the woods: B.C.-Sask.-n Wyo.-Calif, Submont. My-Лl.

106. S. Flintii Rydb. Stem about $3 \mathrm{dm}$. high, striate, sparingly arachnoidhairy; basal leaves about $8 \mathrm{~cm}$. long; blades orbicular or rounded-oval, abruptly contracted into short petioles, sparingly arachnoid when young, rather thick, entire-margined; stem-leaves lanceolate, sinuately-toothed, auricled and clasping at the base; heads $3-6$, about $1 \mathrm{~cm}$. high; bracts linear, $7-8 \mathrm{~mm}$. long; ligules light yellow, broad; achenes striate, glabrous. Mountains: Colo.

107. S. latus Rydb. Stem 6-8 dm. high, more or less densely crisp-hairy; lower leaves about $1 \mathrm{dm}$. long, broadly oblanceolate, sinuately toothed, tapering into short winged petioles, white-hairy above, glabrous beneath, except the veins and the margins; upper leaves lanceolate, more or less clasping at the broad base; inflorescence a large compound corymb; involucral bracts short, searcely more than half as long as the fully developed disk, rather fleshy, oblong; achenes glabrous. Wet places: Mont.

108. S. condensatus Greene. Stem copiously arachnoid-floccose when young, $3-4 \mathrm{dm}$. high; basal leaves $7-15 \mathrm{~cm}$. long, rather thick, with winged petioles; blades lanceolate, floccose, irregularly sinuate-dentate, usually erisp; stemleaves lanceolate, sessile and half-clasping, with auricled bases; heads in a dense cluster; involueres campanulate, $8-9 \mathrm{~mm}$. high; bracts linear; ligules light yellow, $8 \mathrm{~mm}$. long; achenes glabrous. S. arachnoideus Rydb. Wet places: Mont.Ida.-Wash. Plain-Submont. My-Je.

109. S. columbianus Greene. Stem $3-6 \mathrm{dm}$. high, floccose when young; leaves sinuate-dentate, the lower petioled, oblanceolate or spatulate, the uppermost linear-lanceolate, much reduced, sessile; inflorescence a short corymb; involucres campanulate, about $1 \mathrm{~cm}$. high; ligules $5-8 \mathrm{~mm}$. long; achenes glabrous. S. lugens A. Gray, in part. S. atriapiculatus Rydb. Valleys: Sask.-Colo.Ida.-Alaska. Plain-Submont. Je-Au.

110. S. perplexus A. Nels. Stem ereet, $3-6 \mathrm{dm}$. high, slightly and loosely arachnoid-floccose when young; lower leaves oblanceolate or obovate-oblanceolate, obtuse, $5-10 \mathrm{~cm}$. long, with short petioles; upper leaves lanceolate or linear, entire or rarely denticulate, slightly if at all clasping, the uppermost reduced; 
heads 8-15; involucres 8-10 $\mathrm{mm}$. high, campanulate; bracts shorter than the disk; achenes striate, glabrous. Perhaps not distinct from $S$. columbianus. Wet places: Wyo.-Colo.-Utah-Ida. Submont.-Subalp. Je-Au.

111. S. solitarius Rydb. Stem glabrous, 3-4 dm. high; lower leaves thin, glabrous, wing-petioled; blades oval, subentire, about $5 \mathrm{~cm}$. long; middle leaves lanceolate, clasping at the base, the uppermost reduced, linear-lanceolate or subulate; heads solitary, about $2 \mathrm{~cm}$. high; bracts narrowly linear, black-tipped; ligules light yellow, almost $1.5 \mathrm{~cm}$. long; achenes glabrous. Meadows: n Wyo.

112. S. megacephalus Nutt. Stout, more or less floccose perennial, with a thick rootstock; stem simple; leaves oblong, oblanceolate, or linear, 1-2 dm. long, rather thick, entire-margined or merely denticulate; heads solitary or seldom $2-3,15-20 \mathrm{~mm}$. high and about $1.5 \mathrm{~cm}$. broad; bracts linear, thick, acuminate, often surpassed by the subulate calyculate ones; disk light brownish yellow; ligules orange, $15-20 \mathrm{~mm}$. long; achenes glabrous. Mountain regions: Ida.Mont.-Alta.-B.C. Mont.-Subalp. Л-Au.

113. S. vulgaris L. Annual; stem erect, 1-4 dm. high, more or less pilose or glabrate; leaves sinuate-pinnatifid, glabrous or slightly arachnoid, with oblong to rounded incised divisions, the upper auriculate-clasping; heads cymose; involucres campanulate-cylindric, 7-9 mm. high, glabrous; bracts linear-subulate, black-tipped, the calyculate ones minute; rays none; achenes canescent-puberulent. Waste places: Lab.-Newf.-N.C.-Calif.-Alaska; nat. from Eu. F-Au.

114. S. palustris (L:) Hook. Stem arachnoid-villous when young, $1.5-5$ $\mathrm{dm}$. high, rather fleshy, strongly striate; lower leaves with winged petioles; blades lanceolate in outline, sinuately dentate to laciniate-pinnatifid, the upper linear, more or less clasping; cyme crowded, corymbiform; involucres hemispheric, about $8 \mathrm{~mm}$. high, not calyculate; bracts narrowly linear-lanceolate, acuminate; ligules broad and short, oblong, light yellow, 4-5 mm. long; achenes glabrous. Wet ground: Lab.-Ia.-Sask.-Alaska and the Aretic coast; Eu. Subboreal -Subarctic. My-Jl.

\section{TETRADỲMIA DC.}

Low and rigid shrubs; leaves or branches, or both covered with white permanent or deciduous tomentum. Leaves alternate, entire, with smaller secondary ones fascicled in their axils, or the primary leaves modified into spines. Heads discoid. Involucre cylindric or oblong; bracts 4-6, concave, overlapping. Receptacle small, flat, naked. Corolla with elongate cylindric tube and lanceolate, spreading lobes longer than the short campanulate throat. Anthers sagittate at the base, with triangular tips. Style-branches flat, with short obtusely conical tips. Achenes terete, 5-nerved, short. Pappus of numerous fine, white, minutely scabrous bristles.

Heads 4-flowered; bracts 4, lance-oblong; branches with scurvy-tomentose lines.

Primary leaves linear to oblanceolate, permanently tomentose, more or less spreading.

Primary leaves oblanceolate.

Primary leaves linear.

Primary leaves $2-3 \mathrm{~cm}$. long, straight,

Primary leaves 2-3 cm. long, straight. leaves fascicled.

Primary leaves linear-subulate. Primary leaves erect, slender; secondary leaves linear, or spatulate-linear, glabata.

in age.
Primary leaves spreading, stifr, spine-like; secondary leaves oblanceolate.
$5 . T$. Nuttallii.

Heads 5-9-flowered; bracts 5-6, at least the inner broadly oval; branches white-tomentose throughout; plant spiny.

Spines 5-12 mm. long, more or less curved.

Spines 15-30 mm. long, straight.

1. T. inermis Nutt. Shrub, 2-5 dm. high; branches canescent, short and 1. T. inermis Nutt. Shrub, leaves oblanceolate or linear-oblanceolate, white-
crowded, very leafy; primary lict
tomentose, $1-4 \mathrm{~mm}$. long; heads about $1 \mathrm{~cm}$. high; involucres cylindric; bracts 4, white-tomentose, linear-oblong, obtuse, somewhat carinate; achenes silkycanescent. T. multicaulis A. Nels, a dwarf form, merely suftruticose at the base. Alkaline flats and stony ridges: Mont.-Colo.-Utah-Nev. PlainMont. JI-S. 
2. T. canescens DC. A shrub, 3-10 dm. high; branches canescent, leafy; leaves not fascicled, narrowly linear, straight or nearly so, $2-3 \mathrm{~cm}$. long, $1-2 \mathrm{~mm}$. broad, white-tomentose; heads about $15 \mathrm{~mm}$. high; bracts 4 , linear-oblong, obtusish, canescent, slightly carinate; achenes densely silky-hirsute. Dry hillsides: Calif.-Utah-Ida.-B.C. Son. Je-S.

3. T. linearis Rydb. A low, unarmed shrub; bark of the older stems shining and flaky; leaves linear, white-tomentose, somewhat keeled; bracts of the involucre oblong, acute, white-tomentose, about $8 \mathrm{~mm}$. long; achenes hirsutevillous. Dry hills: Utah-Colo. Son. Jl-Au.

4. T. glabrata A. Gray. Shrub, 3-10 dm. high; primary leaves $6-15 \mathrm{~mm}$. long; secondary ones narrowly linear, spatulate, fleshy, 4-10 mm. long; heads about $12 \mathrm{~mm}$. high; involueres cylindric, $6-7 \mathrm{~mm}$. high, $4 \mathrm{~mm}$. broad, silkytomentose; achenes densely silky-hirsute. Dry hills: Ore.-Ida.-Utah-Calif. Son. Je-Au.

5. T. Nuttallii T. \& G. Shrub, 3-10 dm. high; primary leaves transformed into spreading subulate spines, $10-18 \mathrm{~mm}$. long; secondary leaves oblanceolate, 8-12 mm. long, loosely floceose; heads 10-14 mm. high, fascicled-corymbose; involucres 7-8 mm. high, tomentose; bracts 4, linear-oblong; achenes densely whitehoary. Barren hills: Wyo.-Utah. Son.-Submont. My-Au.

6. T. spinosa Hook. \& Arn. A divaricately branched shrub, 5-12 dm. high; branches white-tomentose; primary leaves transformed into spines, $5-12 \mathrm{~mm}$. long, usually more or less curved; secondary leaves 5-15 mm. long, linear-clavate, fleshy, glabrous or soon glabrate; heads from the axil of the leaves, $15-18 \mathrm{~mm}$. high; involucres tomentose, about $1 \mathrm{~cm}$. high; bracts oval, obtuse, or some of them acutish. Dry hills and plains: Mont.-Colo.-Nev.-Ore. Plain-Submont. $\mathrm{My}-\mathrm{Au}$.

7. T. longispina (M. E. Jones) Rydb. Shrub, 1-2 m. high; branches divaricate, tomentose; primary leaves transformed into slender, straight spines, $1.5-3 \mathrm{~cm}$. long; secondary leaves linear-clavate, $10-12 \mathrm{~mm}$. long, glabrate; heads solitary in the axils of the leaves, $12-15 \mathrm{~mm}$. high; involucres about $6 \mathrm{~mm}$. high, tomentose; bracts elliptic; achenes with long white hairs equalling the pappus. T. spinosa longispina M. E. Jones. Alkaline hills: Utah-Ariz.-Calif. Son. Ap-Jl.

\section{1. ÁRCTIUM L. BURDOCK.}

Coarse biennial herbs. Leaves alternate, petioled, with broad cordate or sagittate blades. Heads discoid. Involucres globular; bracts imbricate, in many series, subulate, with hooked tips. Receptacle flat, setose. Flowers hermaphrodite and fertile. Corolla purple or white; tube slender. Anthers sagittate at the base. Achenes oblong, somewhat compressed and 3-angled, truncate. Pappus of numerous short and rigid bristles, falling off separate.

Involucre less than $2 \mathrm{~cm}$. broad; inner bracts not exceeding the flowers. Involucre $2.5 \mathrm{~cm}$. broad or more; inner bracts at least equalling the flowers.

1. A. minus.

1. A. minus Schk. Stem stout, 5-20 dm. high, puberulent, branched; leaves petioled; blades 2-4 cm. long, cordate, repand, grayish tomentulose beneath; heads in a leafy panicle, often with racemiform branches; involucres $12-20 \mathrm{~mm}$. high, glabrous; the inner bracts purple-tipped; corollas rose-purple. Lappa minor DC. Waste places: N.S.-Ga,-Ala.-Colo.-Ida.-B.C.; nat.
from Eu. Au-S.

2. A. Lappa L. Stem 1-2 m. high; leaf-blades thin, broadly ovate-cordate, the lower 4-5 cm. long, grayish tomentose beneath; heads corymbose; involucre glabrous or nearly so; bracts longer and more spreading or reflexed; corollas rosepurple. Waste places: N.B.-N.Y.-Neb.-Minn.; Mont.; nat. or adv. from
Eu. J-O.

\section{SAUSSÙREA DC.}

Perennial herbs. Leaves not spiny, entire or dentate, often somewhat floccose. Heads discoid, many-flowered. Involucre usually narrow, turbinate; bracts imbricate in several series. Receptacle flat, fimbrillate or chaffy. Corollas 
purple or violet; tube slender; throat inflated, and limb 5-toothed. Flowers hermaphrodite and fertile. Anthers caudate at the base, with setiform ciliate or villous appendages. Pappus double, the outer of short rigid bristles, the inner of stout plumose bristles united at the base.

Leaves broadly ovate or the lower cordate; plant tall, 4-10 dm. high. 1. S. americana. Leaves lanceolate to linear.

Leaves lanceolate; stem 1-2 dm. high; heads crowded.

Leaves very narrowly linear-lanceolate; stem 3-4 dm. high; heads long-pedunlced.

3. S. remotiflora.

1. S. americana D. C. Eat. Stem 4-10 dm. high, glabrous or slightly arachnoid-hairy when young, leafy; lower leaves petioled, the uppermost sessile; blades cordate or ovate, thin, arachnoid when young, dentate, acute or acuminate; heads more or less paniculate; involucres cylindro-campanulate, about $12 \mathrm{~mm}$. high, 7-9 mm. broad, arachnoid-pubescent; bracts in 5-6 series, deltoid or deltoidovate, acute, the inner dark-margined; corollas blue or purple. Mountain meadows and slopes: Ore.-Ida.-Wash. Submont.-Mont. J1-Au.

2. S. densa (Hook.) Rydb. Stem short, 1-2 dm. high, leafy; leaves 5-10 $\mathrm{cm}$. long, the lower with winged petioles, the upper sessile; blades lanceolate, arachnoid-hairy when young, sinuate-dentate; involucres campanulate, about 1 $\mathrm{cm}$. high and broad, arachnoid-hairy; bracts in 4-5 series, but almost of the same length, lanceolate or ovate-lanceolate, acuminate; flowers purple. S. alpina densa Hook. High mountains: Canadian Rockies. Alp. Au.

3. S. remotiflora (Hook.) Rydb. Stem slender, 3-4 dm. high, glabrous or slightly arachnoid, sparingly leafy, often purple-tinged; lower leaves petioled, 5-10 cm. long, arachnoid when young; blades linear-lanceolate, remotely dentate; inflorescence corymbiform; involucres turbinate, about $12 \mathrm{~mm}$. high and $10 \mathrm{~mm}$. broad, slightly arachnoid; bracts lanceolate, acute, well-imbricate, the outer successively shorter; flowers purple. S. alpina remotiflora Hook. Valleys: Sask. -Yukon-Alaska. Alp. Jl-Au.

\section{CÍRsium (Tourn.) Hill. Thistle.}

Stout perennial or biennial herbs. Leaves alternate, with spinosely tipped lobes or teeth, often decurrent on the stem. Heads discoid. Involucres globose, campanulate, or urceolate, of many imbricate bracts in several series. Receptacle flat, bristly. Flowers hermaphrodite and fertile, or the plant rarely dioecious. Corollas all alike, tubular, deeply 5-cleft. Anthers sagittate at the base, the two lobes produced into longer or shorter tails. Styles filiform or sometimes thickened, or with a ring at the base of the stigmatic portion. Achenes obovate or oblong, somewhat flattened. Pappus of one series of slender plumose bristles, united at the base and falling off together.

Bracts of the involucre conspicuously arachnoid-pubescent,

Bracts not reflexed, only the tips sometimes spreading; stem arachnoid.

Inner bracts conspicuously dilated.

Inner bracts not dilated.

Leaves not conspicuously decurrent.

Leaves conspicuously decurrent, forming wings on the stem.

I. Parryana.

II. ERIOCEPHALA.

III. LANCEOLATA.

Bracts squarrose and the lower reflexed.

IV. NEOMEXICANA.

Bracts of the involucre not arachnoid-pubescent, or only slightly so on the margins.

Bracts all, except the outermost, with dilated fimbriate tips. V. CARIINOIDIA.

Bracts all, except sometimes the very innermost, without dilated fimbriate tips. Bracts neither with a dorsal glutinous ridge, nor a dark spot.

Bracts, at least some of them, spinulose-ciliate on the margins, not very unequal in length.

VI. LEIOCEPHALA.

Bracts not spinulose-ciliate, regularly imbricate, the inner much longer.

Innermost innocuous bracts not conspicuously elongate, their tips more or less spreading, usually crisp or twisted, sometimes erose.

VII. FOLIOSA.

Innermost innocuous bracts elongate and usually more or less reddish, straight, neither dilated, crisp or twisted. VIII. PULCHELLA.

Bracts with either a glutinous dorsal ridge or a black spot near the tip.

Bracts with a dark spot, but not glutinous; their spines erect.

Bracts with a glutinous dorsal ridge.

Flowers perfect.

Flowers dioecious.

IX. GrisEA.

X. UndUlata.

XI. ARVENSIA. 


\section{Parryana.}

Flowers light, not pinkish; leaves glabrate.

Flowers light greenish yellow; leaves arachnoid, but not tomentose beneath.

Flowers whitish; leaves somewhat tomentose beneath.

Flowers pinkish; leaves densely white-tomentose beneath.

1. C. Parryi.

2. C. araneosum.

3. C. scariosum.

Anthers glabrous.

\section{ERIOCEPHALA.}

Leaves densely tomentose on both sides.

Leaves not densely tomentose on both sides.

4. C. subniveum.

Flowers ochroleucous or white.

Leaves with very short or no lobes and numerous almost parallel spines along the margins, not crisp.

Leaves with deep divisions, often again lobed, crisp, and with the spines pointing in various directions.

Leaves white-tomentose beneath.

Involucre densely arachnoid; bracts all narrowly linear-lanceolate.

Heads not nodding, scattered on short branches in the axils of the leaves.

6. C. Hookerianum.

Heads in a terminal dense cluster, at first nodding.

7. C. scopulorum.

Involucres only slightly arachnoid; outer bracts lanceolate.

25. C. oreophilum.

Leaves glabrous on both sides; heads clustered in an elongate leafy spike.

Flowers purple or pink.

8. C. polyphyllum.

Involucre densely arachnoid; bracts rarely spinulose-ciliate.

Heads $3.5-4 \mathrm{~cm}$. high, $4-6 \mathrm{~cm}$. broad, not densely clustered; corolla redpurple.

Heads $2.5-3 \mathrm{~cm}$. high and about as broad.

9. C. edule.

Heads sessile at the end of the stem; bracts linear-subulate; corolla purple.

Heads scattered; bracts lance-subulate; corolla pink.

10. C. Macounii.

Involucres only slightly arachnoid if at all; bracts except the innermost spinuAnthers pubescent.

11. C. Eatonii.

One species.

\section{Lanceolata.}

12. C. hesperium.

13. C. lanceolatum.

IV. NeOMEXICANA.

Leaves densely white-tomentose; heads $3.5-6 \mathrm{~cm}$. high, $4-8 \mathrm{~cm}$. broad; bracts strongly squarrose, the outer reflexed.

Leaves loosely floccose; heads $3-3.5$ (rarely 4) $\mathrm{cm}$. high, $3.5-5 \mathrm{~cm}$. broad; bracts spreading only in age.

\section{OARLINOIDIA.}

15. C. nevadense.

Flowers ochroleucous or white; bracts without glutinous ridge,

Leaves pinnately divided,
Leaves merely sinuately lobed, the upper with broad clasping bases.

Flowers red.

17. C. laterifolium.

Bracts without glandular ridge; leaves deeply lobed, with lanceolate divisions.

Bracts with glandular ridge; leaves slightly Iobed, with broadly triangular lobes.

\section{LEIOCEPHALA.}

19. C. perplexans.

Leaves green on both sides, glabrous or arachnoid beneath.

Leaves crisp and very spiny; involucral bracts very spiny, the outer ones as long as

the inner; corollas rose or pink.
Leaves almost flat, with weak spines; involucral bracts well imbricate, the
ones short and with short spines. Leaves tomentose beneath; involucral bracts with strong flat spines.

outer

\section{FoliosA.}

39. C. griseum.

Plant acaulescent or nearly so; heads clustered.

Plant distinctly caulescent.

Inner bracts with scarcely dilated, not erose linear-lanceolate tips.

Heads 3.5-5 cm, high.

Leaves deeply pinnatifid, with strong spines.

Leaves nearly entire, spinulose-ciliate.

Heads 2-3.5 cm. high.

Leaves green, distinctly decurrent.

Lobes of the leaves lanceolate or triangular.

Lobes of the leaves semi-orbicular.
Leaves more or less tomentose beneath, scarcely decurrent

Bracts broad and short, with flat spines.

22, C, acaulescens.

23. C. coloradense.

24. C. Butleri.

33. C. calcareum.

34. C. lactucinum.

35. C. spathulatum. 
Bracts narrow, with weak or slender spines.

Bracts greenish, sometimes slightly arachnoid on the margins, but not floccose; lobes of the leaves obtuse. 25. C. oreophilum.

Bracts slightly floccose when young; lobes of the leaves acute.

Involucral spines more or less spreading; bracts yellowish; leaves slightly lobed. 15. C. nevadense.

Involucral spines ascending; bracts greenish; leaves deeply lobed. 26. C. olivescens.

Inner bracts with conspicuous dilated, ovate or lanceolate, erose and twisted tips. Leaves not at all tomentose; heads usually solitary; corollas rose-purple.

27. C. Drummondii.

Leaves more or less tomentose beneath; heads usually clustered; corollas white or pale rose.

Heads on short branches solitary in the axils of the leaves.

Heads subsessile and clustered at the end of the stem.

28. C. magnificum.

Plant more or less arachnoid as well as tomentose; leaves linear in outline.

Plant not arachnoid, dark green; leaves broader.

29. C. foliosum.

30. C. lacerum.

\section{PULChella.}

Leaves glabrous or at least glabrate in age.

Spines of the middle bracts fully $1 \mathrm{~cm}$. long and longer than the bracts.

Spines of the middle bracts 3-7 mm. long, shorter than the bracts.

31. C. diffusum.

Divisions of the leaves linear to triangular; involucre campanulate.

Divisions of the leaves linear or linear-lanceolate, often again pinnatifid; leaves scarcely decurrent.

32. C. bipinnatum.

Divisions of the leaves ovate or triangular; leaves conspicuously decurrent.

Divisions of the leaves semi-orbicular, rounded-ovate; involucre hemispheric.

34. C. lactucinum.

Leaves permanently tomentose, at least beneath.

Tips of the inner bracts chartaceous, yellow, spreading, and slightly erose.

Tips of the inner bracts soft, erect and usually purplish.

Spines of the middle bracts more than $1 \mathrm{~cm}$. long, stout.

Spines of the middle bracts $3-6 \mathrm{~mm}$. long, slender.

Divisions of the leaves narrow; corolla rose-purple; involucre narrow.

37. C. pulchellum.

Divisions of the leaves broad and short, ovate; corollas crimson; involucre broad.

IX. GRISEA.

Leaves green above, tomentose beneath; bracts not viscid.

Bracts, with short spines, the outer not spinulose-ciliate.

Bracts, with long spines.

Spines of the bracts stout; heads $2.5-3 \mathrm{~cm}$. broad.

Spines of the bracts slender; heads about $1.5 \mathrm{~cm}$. broad.

Leaves loosely floccose on both sides; bracts decidedly viscid.

35. C. spathulatum.

39. C. griseum.

40. C. modestum.

41. C. canovirens.

Leaves white-tomentose beneath.

\section{Undulata.}

Flowers ochroleucous.

Involucral bracts very viscid, with broad glutinous dorsal ridge; divisions of the leaves rather few; spines of the bracts short.

Tips of the inner bracts more or less dilate and crisp; involucre of the terminal

head 4-5 $\mathrm{cm}$. in diameter.
Tips of the inner bracts linear-lanceolate, neither dilated nor crisp: heads

42. C. plattense. usually less than $4 \mathrm{~cm}$. in diameter.

Bracts very numerous and small, with small spreading spines. Stem-leaves deeply pinnately lobed, with rather stout spines.

Lobes, at least of the lower leaves, oblong to rounded-ovate, obtuse,

43. C. Nelsonii.

Lobes of the leaves lanceolate or linear-lanceolate, acute. Heads more than $3 \mathrm{~cm}$. broad; bracts linear-lanceolate.

44. C. palousense.

Heads less than $3 \mathrm{~cm}$. broad; middle bracts ovate-lanceolate or ovate.

45. C. Tracyi.

Stem-leaves sinuate-dentate or sinuately lobed, merely spinulose; heads $2.5-3 \mathrm{~cm}$. broad.

Bracts comparatively few and broad, with erect spines; leaves sinuate-

dentate or slightly lobed.
Involucral bracts greenish or yellowish, scarcely viscid, with inconspicuous dorsal

47. C. brevifolium.

ridge; divisions of the leaves numerous; spines of the bracts long and sten.

Flowers rose or purple, rarely white; dorsal viscid ridge not so prominent.

Involucres less than $4 \mathrm{~cm}$. broad.

Spines of the middle bracts $5-10 \mathrm{~mm}$. long.

Spines of the middle bracts slender and spreading. 48, C. acuatum. 
Spines of the middle bracts stout and ascending.

Upper leaves entire or with shallow lobes; involucre less than $2 \mathrm{~cm}$. broad, very dark.

49. C. canescens.

Upper leaves deeply pinnatifid; involucres about $3 \mathrm{~cm}$. broad, light colored, except the viscid ridge.

Spines of the middle bracts $5 \mathrm{~mm}$. long or less, weak and spreading.

Leaves, at least the upper ones, entire or slightly lobed, tomentose on both sides.

Leaves pinnately divided or deeply lobed.

Leaves deeply pinnatifid, with narrow, linear-lanceolate lobes; plant yellowish.

Leaves with triangular or ovate-lanceolate lobes. Bracts with very inconspicuous glandular ridge, not at all viscid.

53. C. floccosum.

Bracts with a conspicuous glandular ridge, surrounded by a viscid area.

Leaves tomentose on both sides.

Leaves glabrate and dark green above.

Involucres 4-7 cm. in diameter.

54. C. undulatum.

55. C. Engelmannii.

Spines of the involucral bracts rarely more than $5 \mathrm{~mm}$. long; leaves not conspicuously decurrent.

56. C. megacephalum.

Spines of the middle bracts fully $1 \mathrm{~cm}$. long; leaves narrower, conspicuously decurrent.

57. C. ochocentrum.

Leaves greenish and sparingly floccose on both sides; bracts linear-lanceolate, very viscid, with stout erect or ascending spines.

41. C. canovirens.

One species.

XI. ARVENSIA.

58. $C$, arvense.

1. C. Parryi (A. Gray) Petrak. Stem 3-10 dm. high; lower leaves petioled, oblanceolate, 2-4 dm. long, stem-leaves lanceolate or linear in outline, sessile, with auriculate-clasping bases, more or less lobed with triangular teeth and weak spines; heads several, spicately-glomerate, leafy-bracted, $2-3 \mathrm{~cm}$. high; outer bracts with weak spines, the inner mostly with lanceolate-erose tips, spineless. Cnicus Parryi A. Gray. Carduus viridiflorus Greene. Mountains: Colo.Utah-N.M.-Ariz. Submont.-Subalp.

2. C. araneans Rydb. Stem slender, about $5 \mathrm{dm}$. high, slightly arachnoid; leaves linear in outline, $10-12 \mathrm{~cm}$. long, slightly arachnoid or glabrate and bright green above, grayish tomentose beneath, pinnatifid, with oblong, moderately strongly spine-tipped lobes; heads at the ends of the branches, $2.5-3 \mathrm{~cm}$. high; outer bracts tapering into a stout broad-keeled spine, the inner with narrow lanceolate erose tips. Perhaps of hybrid origin. Carduus araneosus Osterh., not Steud. Banks: Colo. Submont.-Mont. Je-Au.

3. C. scariosum Nutt. Stem slender; leaves densely white-tomentose beneath, pinnatifid with short lobes; heads about $3 \mathrm{~cm}$. high; bracts lanceolate to lance-subulate, the outer spinulose-ciliate, the inner with lanceolate-erose tips. Carduus scariosus Hook. C. Hookerianus Rydb. (Fl. Mont.), in part. Mountains: Wyo.-Mont. Submont. J-Au.

4. C. subniveum Rydb. Stem 6-10 dm. high, white-floccose, paniculately branched above; leaves $1-1.5 \mathrm{~cm}$. long, linear in outline, deeply pinnatifid, tomentose on both sides, densely so and white beneath, more loosely so above; lobes lanceolate or triangular, often toothed or lobed and armed with moderately strong yellow spines; involucres $2 \mathrm{~cm}$. high and nearly as broad, densely arachnoid, almost floceose; outer bracts with ascending spines, $5 \mathrm{~mm}$. long, the inner with subulate weak tips. Valleys: w Wyo. Au.

5. C. Kelseyi Rydb. Stem 5-20 dm. high, very leafy; leaves linear, at most sinuately short-lobed, green above, somewhat tomentose or glabrate beneath; heads 3-4 cm. high, erect, in a leafy spike-like inflorescence; bracts all linearlanceolate, attenuate into short spines or slender tips. Carduus Kelseyi Rydb. Mountains: Mont. Plain-Submont. Je-Au.

C. Butleri $\times$ Kelseyi. With the inflorescence of C. Kelseyi and the bracts of C, Butleri, but slightly arachnoid-hairy. Mont.

6. C. Hookerianum Nutt. Stem 3-6 dm. high; leảves scarcely decurrent, pinnatifid, with rather distant, oblong-lanceolate lobes and short spines, densely tomentose beneath, sparingly floccose above; heads $2.5-3 \mathrm{~cm}$. high; bracts linearsubulate, attenuate into short spines. Carduus Hookerianus (Nutt.) Heller . Mountains: Alta.-Mont.-B.C. JI-Au. 
7. C. scopulorum (Greene) Cockerell. Stem 3-6 dm. high, very leafy; leaves more or less decurrent, pinnatifid, with numerous triangular or ovate lobes, glabrate and green above, more or less tomentose beneath; heads 3-4 cm. high; bracts linear-subulate, attenuate into long yellowish spines. Cnicus eriocephalus A. Gray. Cirsium eriocephalum A. Gray, Carduus Hookerianus (Fl. Colo.) in part. Carduus scopulorum Greene. Mountains: Colo.-Wyo. Mont. -Subalp.

8. C. polyphyllum Rydb. Stem stout, 3-8 dm. high, very leafy; leaves 1-2 dm. long, deeply pinnatifid, with lanceolate divisions ending in yellow spreading spines; heads hemispheric, about $3 \mathrm{~cm}$. high and broad; bracts linear-subulate, the outer with rather long yellow spines often $1 \mathrm{~cm}$. long. Carduus polyphyllus Rydb. Mountains: Mont.-Alta. Subalp. J1-Au.

9. C. edule Nutt. Stem 1-2 m. high, sparingly arachnoid, moderately leafy; leaves pinnately cleft; divisions again 2-3-lobed, with broadly triangular lobes, sparingly arachnoid and green above, grayish floccose beneath, weakly spiny; heads solitary or 2 or 3 together, leafy-bracted; bracts conspicuously arachnoid, gradually tapering into short spines. Cnicus edulis A. Gray. Low ground: B.C.-Mont.-Calif. Son.-Submont. Je-Au.

10. C. Macounii (Greene) Rydb. Stem 3-10 dm. high; leaves pinnatifid, with broadly ovate lobes, toothed and with weak spines, arachnoid-hairy and somewhat tomentose beneath; involucres $2.5-3 \mathrm{~cm}$. high; bracts linear-subulate, the outer with weak dark brown or purplish spines, the inner almost innocuous. Carduus Macounii Greene. Valleys: Alta.-Mont.-Wash.-B.C. Submont.Mont.

11. C. Tweedyi Rydb. Stem stout, $3-5 \mathrm{dm}$. high, in age glabrate; leaves not decurrent, shining, somewhat glaucous, pinnatifid, with rounded-ovate lobes, with short yellow spines; heads about $3 \mathrm{~cm}$. high, somewhat leafy-bracted; bracts with short yellowish spines 5-8 mm. long. Carduus Tweedyi Rydb. Mountains: Mont.-n Wyo. Jl-Au.

12. C. hesperium (Eastw.) Rydb. Stem stout, leafy, almost glabrous, 3-4 $\mathrm{dm}$. high; leaves 10-15 $\mathrm{cm}$. long, pinnatifid with numerous rounded lobes, with yellow spines up to $5 \mathrm{~mm}$. long, glabrate above, tomentose beneath; heads terminal, sessile in an erect cluster; involucres $2 \mathrm{~cm}$. high; bracts with broad yellowish bases, tapering into long brownish spines; flowers light purple or pink. Cnicus hesperius Eastw. Carduus hesperius (Eastw.) Heller. Mountains above timberline: Colo. Alp. -Subalp. Au.

13. C. lanceolatum (L.) Hill. Stem 1-1.5 m. high, more or less villous when young; leaves deeply pinnatifid, with lanceolate lobes and long stout spines, grayish tomentose or glabrate beneath; heads scattered at the ends of the branches, 4-5 cm. high; bracts lanceolate, attenuate, with long yellowish spines; flowers rose-purple. Carduus lanceolatus L. Waste places and roadsides: N.S.-Ga.Calif.-B.C.; nat. from Eu. Jl-S.

14. C. neomexicanum A. Gray. Stem 6-12 dm. high, white-tomentose; leaves lanceolate or oblong-linear, sinuately pinnatifid, with short ovate or triangular lobes ending in weak yellow spines, tomentose on both sides; heads solitary or few, hemispheric; bracts linear-subulate, ending in rather stout yellow spines; corolla pink or white. Carduus neomexicanus Greene. Plains: N.M.Colo--Ariz. Son. Ap-Л.

15. C. humboldtense Rydb. Stem strict, rather slender, 5-10 dm. high, sparsely arachnoid-pubescent; leaves loosely floceose, pinnatifid, with short triangular lobes and rather short spines; heads few or solitary; bracts linear-lanceolate, without a dorsal glutinous ridge, in age more or less spreading, gradually tapering into yellow spines, $3-6 \mathrm{~mm}$. long; corollas white. Carduus nevadensis Greene. Mountains and hills: Nev, - sw Utah-nw Ariz. Son. My-Je.

16. C. Centaureae (Rydb.) K. Schum. Stem rather slender, 6-10 dm. high; leaves deeply pinnatifid to near the midrib, above light green, beneath more or less permanently grayish tomentose; lobes lanceolate or triangular, with weak spines, the upper sessile and clasping, lanceolate and undivided; heads $2-2.5 \mathrm{~cm}$. 
high; outer bracts narrowly lanceolate, yellowish, often with a darker center and a flat weak spine. Cnicus carlinoides americanus A. Gray. Cnicus americanus A. Gray. Carduus americanus Greene. Cirsium americanum Daniels, not K. Schum. Carduus Centaureae Rydb. Mountains: Colo.-Wyo. Submont.-Mont. Jl-Au.

C. Centaureae $\times$ spathulatum. Resembling $C$. americanum in habit and leaf-form; the bracts being somewhat erose on the margins as in that species, but scarcely at all dilated, and if so only the innermost, and tipped with the short and broad spines characteristic of C. spathulatum. Colo.

c. Centaureae $\times$ griseum. With the leaves of C. griseum, dark green above, grayish tomentose beneath, the strong and broad spines of the involucral bracts of that species; but most of the bracts are erose on the margins and the inner ones have dilated tips as in C. americanum. Colo.

C. acaulescens $\times$ Centaureae. Resembling $C$. americanum, but the stem lower, heads crowded, involucral bracts elongate and less dilated, leaf-segments more lanceolate, spines stronger, and stem somewhat arachnoid. Colo.

c. Centaureae $\times$ coloradense. Resembling $C$. americanum, but head larger, hemispheric, bracts broader, with less dilated tips, leaves more spiny, with more numerous, lanceolate lobes, and slightly arachnoid. Carduus erosus Rydb. Colo.

17. C. laterifolium (Osterhout) Rydb. Stem 6-8 dm. high; leaves broad, oblong, 1-1.5 dm. long, sessile, auriculate at the base, short-lobed, glabrous above, white-tomentose beneath, with short and slender spines; involucre $1.5 \mathrm{~cm}$. long and as broad; bracts glabrous, except the slightly tomentose edges, the outer with short spines, the inner spineless, with narrow, lanceolate tip. Carduus laterifolius Osterhout. Cañons: Colo. Au.

18. C. vernale (Osterhout) Cockerell. Stem $2-5 \mathrm{dm}$. high, slightly tomentose, grooved; leaves narrowly linear in outline, white-tomentose beneath, green and glabrate or slightly floccose above, up to $1 \mathrm{dm}$. long, distantly lobed, with triangular-lanceolate lobes; heads seattered, $1.5-2 \mathrm{~cm}$. wide and about as high; bracts all except the innermost with dilated fimbriate tips; flowers bright rosecolored. Cardur vernalis Osterhout. Hills: w Colo. Submont. My-Je.

19. C. perplexans Rydb. Stem slender, about $5 \mathrm{dm}$. high, striate, purplish, slightly tomentose; lower leaves oblanceolate, the upper lanceolate and clasping, all merely toothed, with weak yellowish spines, glabrous and somewhat glaucous above, rather thinly white-tomentose beneath; heads about $3 \mathrm{~cm}$. high and broad; outer bracts tipped with a short weak spine, the inner tipped with a dilated, deltoid, erose appendage; corolla rose or red-purple. Carduus perplexans Rydb. C. americanus perplexans A. Nels. Mountains: Colo. Submont. Je.

20. C. Eatoni (A. Gray) B. L. Robinson. Stem 3-6 dm. high, glabrous or slightly arachnoid, angled; leaves linear in outline, pinnatifid, with short ovate lobes ending in yellow spines, 5-15 cm. long, green on both sides, glabrous or slightly arachnoid on the veins; heads scattered, $3-3.5 \mathrm{~cm}$. high, leafy-bracted; outer bracts spinulose-ciliate and ending in rather stout spines; inner bracts sparingly if at all arachnoid, lance-subulate; corollas rose-purple. Cnicus Eatoni A. Gray. Carduus leiocephalus (D. C. Eat.) Heller. Mountains: Ida.-UtahColo. Mont.-Subalp. J1-S.

C. Eatoni $\times$ olivescens. Resembling $C$. Eatoni in habit, but leaves with fewer and deeper lobes and grayish tomentose beneath, and involucres with shorter and weaker spines; differing from $C$. olivescens in the broader leaf-segments, and narrower bracts, the outer of which are spinulose-ciliate. Utah.

21. C. clavatum (M. E. Jones) Rydb. Stem 3-7 dm. high, glabrous throughout or nearly so; leaves $2-3 \mathrm{dm}$. long, pinnatifid, with lanceolate or ovate divisions, ending in very short spines, glabrous and shining; heads solitary or few, hemispheric, $2.5-3 \mathrm{~cm}$. high; bracts glabrous, with a dark spot, all except the innermost with short spines 1-3 mm. long, the outer ones ovate and spinuloseciliate on the margins, the innermost lance-linear and attenuate into lanceolate or linear-lanceolate, spreading tips; corollas white. Cnicus clavatus M. E. Jones; Carduus clavatus Heller. Wet hillsides: Utah. Subalp. Au.

22. C. acaulescens (A. Gray) K. Schum. Biennial or perennial; leaves oblanceolate or linear in outline, green, but more or less arachnoid-hairy above, white-tomentose beneath, pinnatifid, with lanceolate lobes tipped with yellow 
spines; heads subsessile, clustered on the crown, $2.5-3 \mathrm{~cm}$. high; bracts glabrous, lanceolate, the outer successively shorter and tipped with usually short spines, the inner with lanceolate, slightly erose and twisted tips; corollas pinkish or white. Cnicus Drummondii acaulescens A. Gray. Carduus acaulescens Rydb: Carduus americanus Rydb., not Greene, Carduus longissimus Heller, and Cirsium americanum K. Schum. represent a form with long-spined involucral bracts. Mountains: Colo.-Utah-Wyo. Submont,-Mont. Je-Au.

23. C. coloradense (Rydb.) Cockerell. Stem rather stout, simple, 3-5 dm. high, striate, sparingly arachnoid; leaves $1.5-2 \mathrm{dm}$. long, pinnately lobed about half-way to the midrib, sparingly arachnoid or glabrous above, more or less white-tomentose beneath; lobes ovate, tipped with yellowish spines, $2-5 \mathrm{~mm}$. long; heads usually scattered, 3-4 cm. high and about as broad; bracts glabrous or nearly so, firm, the outer with weak spines, the inner unarmed; corolla white or slightly pinkish. Carduus coloradensis Rydb. Cnicus Drummondii A. Gray, in part. C. scariosus A. Gray, in part. Mountains: Colo.-Utah. Submont.Mont. Jl-Au.

C. acaulescens $\times$ coloradense. Intermediate between the two parents, usually short-stemmed with small heads, in a flat-topped terminal cluster. Colo.-U.tah.

C. coloradense $\times$ undulatum. Resembling C. undulatum in the red flowers, though paler, in the bracts which have a glandular ridge, though less distinct, and in the leafform; and approaching $C$. coloradense in the habit and the form of the bracts, the innermost of which have lanceolate twisted tips. Colo.

24. C. Butleri Rydb. Stem angled, purple, sparingly arachnoid-hairy, very leafy, 6-10 dm. high or more; leaves linear-oblanceolate or linear, almost entire or sinuately lobed, spinulose-ciliate, and if lobed the short lobes ending in slightly stronger spines, green and sparingly arachnoid above, grayish tomentose beneath; heads few, scattered, leafy-bracted, hemispheric, about $4 \mathrm{~cm}$. high, 4-5 $\mathrm{cm}$. wide; outer bracts lanceolate, brownish, glabrous or nearly so, ending in short weak spines 2-3 mm. long, the innermost linear-lanceolate, attenuate; corollas pinkish. Carduus Butleri Rydb. Valleys: Mont. J-Au.

25. C. oreophilum Rydb. Stem 4-8 dm. high, stout, angled; basal leaves about $2 \mathrm{dm}$. long, thin, light green and glabrate above, more or less grayish tomentose beneath, pinnately lobed; lobes triangular, usually $2-3$-lobed, with slender spines 3-10 $\mathrm{mm}$. long; heads hemispheric, 2-2.5 $\mathrm{cm}$. high; outer bracts tipped with flat spines, 3-6 mm. long. Carduus oreophilus Rydb. Cirsium eriophilum K. Schum. Wooded valleys: Colo._Utah. Submont.-Subalp. Л-Au.

C. oreophilum $\times$ scopulorum. Resembling $C$. scopulorum in the heads crowded at the ends of the stem, the arachnoid involucres, and general habit; but the leaves are broader, the involucral bracts broader at the base, and the flower-cluster not nodding; differing from $C$. oreophilum in its less deeply dissected leaves and more arachnoid inflorescence. Colo.

C. acaulescens $\times$ scopulorum. Resembling $C$. acaulescens in leaf-form and pubescence, in the small and clustered heads, but is usually leafy-stemmed and has arachnoid involucres. Colo.

C. foliosum $\times$ scopulorum. This has the habit and bracts of Cirsium foliosum, but the involucre is densely arachnoid as in $C$. scopulorum and the leaves have more numerous and crowded lobes. Wyo.

C. griseum $\times$ scopulorum. With the habit, leaf-form and long flat involucral spines of $C$. griseum, but inflorescence arachnoid-hairy and leaf-segments more numerous. Carduus Osterhoutii Rydb. Colo.

26. C. olivescens Rydb. Stem slender, somewhat tinged with purple, more or less floccose, 4-8 dm. high; leaves linear in outline, 1-2 dm. long, densely white-tomentose beneath, loosely floccose above, deeply pinnatifid, with numerous lanceolate, often 2- or 3-cleft lobes, ending in short yellow spines; heads few, peduncled, about $3 \mathrm{~cm}$. high, 3-3.5 $\mathrm{cm}$. wide; bracts slightly floccose on the margins, light olive-colored, ending in yellow spines 2-4 mm. long, or the innermost innocuous; corollas straw-colored. Carduus olivescens Rydb. Table lands: Utah. Mont, Au.

27. C. Drummondii T. \& G. Stem low, 1-3 dm. high, slightly arachnoidhairy; leaves oblanceolate in outline, green, somewhat arachnoid, but not at all 
tomentose, with triangular lobes and weak spines; heads 4-6 cm. high; bracts thin, brownish, the outer ovate, tipped with bristle-like spines; corollas rosepurple. Carduus Drummondii Coville. Hills and mountains: Sask.-(Black Hills) - S.D.-B.C. Submont.-Mont. Jl-Au.

28. C. magnificum (A. Nels.) Rydb. Stem tall, 1-2 m. high, purplish, slightly arachnoid, leafy; leaves glabrate above, tomentose beneath, $1-3 \mathrm{dm}$. long, deeply pinnatifid, with 2-3-cleft divisions with lanceolate lobes; heads racemosely disposed, each ending a short axillary branch, 4-6 $\mathrm{cm}$. high and broad, leafy-bracted; bracts glabrous except the margin, the outer ones with slender spines; flowers rose-purple. Carduus magnificus A. Nels. Saline flats: Ida. Je.

29. C. foliosum (Hook.) DC. Stem 2-6 dm. high, more or less arachnoidhairy; leaves light green, but more or less arachnoid above, tomentose beneath, from deeply pinnatifid, with oblong lobes, to nearly entire, with rather weak yellow spines; heads clustered at the end of the branches, leafy-bracted, $3-5 \mathrm{~cm}$. high; outer bracts ovate, glabrous, with short weak spines; corollas white or nearly so. Carduus foliosus Hook. C. scariosus Rydb. (Fl. Mont. \& Fl. Colo.) Mountain valleys: Sask.-S.D.-Colo.-Utah-B.C. Submont.-Mont.

30. C.' lacerum Rydb. Stem stout, 6-10 dm. high, sparingly arachnoid; lower leaves oblanceolate, 2-3 dm. long, pinnatifid, with rather broad, ovate or lanceolate divisions ending in weak spines, glabrous or slightly long-hairy and green above, grayish tomentose beneath; upper leaves lanceolate, sessile and clasping, with narrower lobes and stout spines; heads more or less clustered, about $4 \mathrm{~cm}$. high and broad; outer bracts ovate-lanceolate, glabrous, ending in short stout spreading spines $3-5 \mathrm{~mm}$. long; corollas rose-colored. Carduus lacerus Rydb. Valleys: Utah. Submont. JI-S.

31. C. diffusum (Eastw.) Rydb. Stems several, 6-9 dm. high, glabrous or slightly floccose when young; leaves pinnatifid, with triangular lobes and rather stout yellow spines, glabrous or slightly floccose beneath when young; stem-leaves somewhat decurrent; heads scattered, 3-4 cm. high, scarcely $2 \mathrm{~cm}$. broad; bracts lanceolate to linear-lanceolate, slightly tomentose on the margins, the outer and midale ones spine-tipped; spines in age spreading; inner bracts attenuate into slender, purple, straight tips; corollas rose-purple; pappus plumose except the slender tips. Cnicus Rothrockii diffusus and C. diffusus Eastw. Carduus diffusus Heller. Cañons: Ariz.-Utah. Jl-S.

32. C. bipinnatum (Eastw.) Rydb. Stem glabrous or slightly arachnoid, 5-8 dm. high, branching above; leaves pinnatifid, with numerous linear or linearlanceolate divisions, which are deeply parted at the base on one side, or sometimes pinnatifid-incised, with weak spines and spinulose-ciliate, glabrous or slightly deciduously floccose beneath; heads scattered, $3-4.5 \mathrm{~cm}$. high, 2-2.5 $\mathrm{cm}$. wide; outer bracts ovate-lanceolate, with short weak prickles, 3-5 mm. long, the inner purplish, soft; corollas purplish. Cnicus Drummondiibipinnatus and C. bipinnatus Eastw. Carduus bipinnatus Heller. Carduus truncatus Greene. Cañons and sage plains: Colo. Jl-S.

33. C. calcareum (M. E. Jones) Woot. \& Standl. Stem stout, 4-6 dm. high, slightly arachnoid, branched above; leaves 2-3 dm. long, distinctly decurrent, pinnatifid, with triangular or oblong lobes, with short and stout yellow spines, glabrous or nearly so on both sides, shining; head scattered, sessile, about 2.5 $\mathrm{cm}$. high; bracts glabrous, the outer ovate, with short spines, the inner subulateacuminate; corollas rose-colored. Cnicus calcareus M. E. Jones. Mountains: Utah. Submont.-Mont. Jl.

34. C. lactucinum Rydb. Stem 5-10 dm. high, glabrous, striate; leaves very thin, glabrous, dark green, pinnately lobed, the lower petioled, 3-4 cm. long, the upper clasping, with rounded auricles; lobes broadly ovate or semi-orbicular, angular, armed with yellow spines 3-10 mm. long; heads scattered, about $3 \mathrm{~cm}$. high and as broad; involucre glabrous, about $2 \mathrm{~cm}$. high; bracts ovate to lancelinear, well imbricate, brownish green, darker towards the end, the innermost not much elongate, with soft tips, the rest ending in weak spines, $2-6 \mathrm{~mm}$. long; corolla rose-colored. Under overhanging cliffs: se Utah. Son. 
35. C. spathulifolium Rydb. Stem 6-8 dm. high, slightly tomentose; lower leaves oblanceolate, 1-2 dm. long, remotely serrate; stern-leaves pinnately cleft, with oblong or ovate lobes and slender spines, glabrate above, densely tomentose beneath; heads several, about $3 \mathrm{~cm}$. high; bracts glabrous or slightly floccose on the edges, lanceolate, the outer with short slender spines, the inner acuminate; corollas rose-colored or whitish. Carduus spathulatus Osterhout, not Gaudin. Mountains: Colo. Mont. Au.

36. C. nidulum (M. E. Jones) Rydb. Stem 5-7 dm. high, floccose-tomentose; leaves tomentose on both sides, lanceolate in outline, pinnatifid, with triangular lobes, with stout yellow spines 1-2 cm. long; heads scattered, campanulate, $2.5-3 \mathrm{~cm}$. high; outer and middle bracts ovate to lanceolate, with stout spines, those of the middle ones fully $1 \mathrm{~cm}$. long; inner bracts linear-subulate, attenuate, red-tipped; corolla purplish (?). Cnicus nidulus M. E. Jones. Carduus nidulus Heller, Red sand: Utah-Ariz. Son.-Submont. My-Je.

37. C. pulchellum (Greene) Woot. \& Standl. Stem 3-10 dm. high, loosely floccose when young; leaves white-tomentose beneath and deciduously floccose above, pinnatifid, with linear-oblong or lanceolate divisions, armed with short weak spines; heads scattered, about $4 \mathrm{~cm}$. high and $3 \mathrm{~cm}$. broad; outer and middle bracts ovate to lanceolate, slightly floccose on the margins, with short and weak spines less than $5 \mathrm{~mm}$. long; inner bracts linear-lanceolate, attenuate, purplish; corollas rose or purplish. Carduus pulchellus Greene. Mountains and valleys: Colo.-Utah. Submont. J.

C. pulchellum $\times$ undulatum. Resembling $C$. pulchellum in habit, but the invoiucres more hemispheric, the bracts broader and with a narrow glutinous ridge, and the inner ones not so elongate as in that species; differing from C. undulatum in the narrower segments of the leaves, the glabrate upper surface, the somewhat purple-tipped inner bracts, and the inconspicuous dorsal ridge. Utah-Colo.

38. C. arizonicum (A. Gray) Petrak. Stem 5-10 dm. high, floccose; leaves white-tomentose beneath, loosely floccose above, pinnatifid, with lanceolate or triangular lobes and rather weak yellow spines; heads solitary or scattered, 4-4.5 $\mathrm{cm}$. high, 3-4 $\mathrm{cm}$. broad; outer and middle bracts ovate to lanceolate, with short yellow spines, slightly floccose on the margins, the innermost linear-lanceolate, attenuate, purple-tipped; corollas crimson. Cnicus arizonicus A. Gray. Carduus arizonicus Greene. Mountains: Ariz.-Utah-(? Wyo.) Son.-Submont. $\mathrm{My}-\mathrm{Au}$.

39. C. griseum (Rydb.) K. Schum. Stem stout, sparingly floccose when young; basal leaves oblanceolate in outline, thin, glabrate above, grayish tomentose beneath, deeply pinnately divided; segments $3-4 \mathrm{~cm}$. long, deeply $2-3$-lobed and toothed, with rather slender spines 3-5 $\mathrm{mm}$. long, the upper less deeply divided, sessile and half-clasping by the dilated rounded shortly decurrent base; heads about $3 \mathrm{~cm}$. high and broad; outer bracts narrowly lanceolate, with a longattenuate tip gradually changing into a flat spine, and somewhat laciniate or spinulose-dentate on the margin, the inner ones less rigid, their tips not spinose, long-attenuate, scarious and somewhat crisp; flowers ochroleucous. Carduus griseus Rydb. Mountains: Colo. Submont.-Subalp. Jl-Au.

40. C. modestum (Osterhout) Rydb. Stem 6-8 dm. high, slightly arachnoidpubescent; lower leaves oblanceolate in outline, 1-2 dm. long, pinnately parted into triangular divisions, white-tomentose beneath; spines small; upper leaves lanceolate and less divided; heads scattered, small, $1.5 \mathrm{~cm}$. high; bracts somewhat floccose, the middle ones with somewhat broadened spines, the inner unarmed; flowers whitish. Carduus modestus Osterh. Cañons: n Colo. Au.

C. Centaureae $\times$ modestum. Resembling $C$. Centaureae in habit, but the bracts scarcely dilated and with flat short spines. Colo.

41. C. canovirens Rydb. Stem 6-10 dm. high, more or less floceose, striate; leaves about $2 \mathrm{dm}$. long, grayish green, slightly floccose on both sides or glabrate in age above, the lower petioled, the upper more or less decurrent, deeply pinnately divided, with lanceolate or triangular lobes, tipped with moderately strong spines; heads seattered, usually many, $2-3 \mathrm{~cm}$. high; bracts more or less floceose on the margins, with broad glutinous ridges, the innermost attenuate into a 
slender tip, the rest lanceolate with yellow spines $3-5 \mathrm{~mm}$. long; corolla strawcolored. Carduus canovirens Rydb. Meadows and slopes: Mont.-n Wyo.Ida. Submont. J1-Au.

42. C. plattense (Rydb.) Cockerell. Stem 3-7 dm. high, white-tomentose; leaves deeply pinnatifid into oblong divisions, $3-5 \mathrm{~cm}$. long, tipped with slender short yellow spines, densely white-tomentose beneath, more sparingly floccose above; heads $4-5 \mathrm{~cm}$. high; bracts very numerous, yellow, with dark thick glutinous backs, all except the innermost broad, ovate, lanceolate, with short yellow spreading spines. Carduus plattensis Rydb. Sandy places: Neb.-Colo. Plain. Je-Jl.

C. plattense $\times$ undulatum. Resembling $C$. plattense in the heads and leaf-form, but the former smaller and with narrower and less viscid bracts. Colo.

43. C. Nelsonii (Pammel) Rydb. Stem 6-10 dm. high, tomentose; leaves deeply pinnatifid, densely white-tomentose beneath, loosely floccose above; lobes with yellow spines; heads scattered, hemispheric, 3-3.5 $\mathrm{cm}$. high, $3-4 \mathrm{~cm}$. wide; bracts very numerous, all except the innermost lanceolate and tipped with short, flattened, yellow, spreading spines. Cnicus Nelsonii Pammel. Plains: Wyo. Plain.

44. C. palousense Piper. Stem 3-10 dm. high, tomentose; leaves lanceoolate, pinnatifid, with entire or 2-cleft lobes, gradually tapering into short spines, white-tomentose beneath, loosely floccose or glabrate above; heads scattered, 3-4 cm. high, hemispheric; bracts very numerous, all but the innermost with short slender, terete spines. Carduus palousensis Piper. Meadows: Ore.-Ida. -Wash. Son. Je-Au.

45. C. Tracyi Rydb. Stem 3-7 dm. high, loosely floccose; leaves oblanceolate in outline, divided to near the base, green but slightly floccose above, more or less tomentose beneath; lobes lanceolate to linear-lanceolate, tipped with yellow spines 5-8 mm. long; heads 3-3.5 $\mathrm{cm}$. high and about $3 \mathrm{~cm}$. or less wide; bracts slightly floccose when young, yellowish, the outermost and inner narrowly lanceolate, the middle ovate-lanceolate, all except the innermost with short spreading spines; innermost bracts attenuate into a linear-lanceolate yellow tip. Carduus Tracyi Rydb. Dry fields: Colo.-Utah. Submont. Je-Jl.

46. C. nebraskense (Britton) Lunell. Stem 3-5 dm. high, tomentose; leaves linear-oblong or lanceolate, white-tomentose beneath, loosely floccose above, entire or irregularly toothed; heads solitary, $3-3.5 \mathrm{~cm}$. high, 3-4 cm. broad; bracts numerous, lanceolate, with short, slender, spreading spines; inner bracts linear-lanceolate, tapering into linear-lanceolate spreading tips. Carduus nebraskensis Britton. Magnesia cliffs: $\mathrm{w}$ Neb.-Wyo. Plain. Jl.

47. C. brevifolium Nutt. Stem tomentose, 3-5 dm. high; leaves oblanceolate or lanceolate, more or less lobed, with triangular lobes and weak yellow spines, white-tomentose beneath, more loosely floceose above; head solitary, about $3 \mathrm{~cm}$. high and $2.5 \mathrm{~cm}$. broad; bracts fewer than in the related species, ovate, with small erect yellow spines, the innermost lance-linear tapering into a slender yellow tip. Hills and ravines: Sask.-Mont.-Ida.

48. C. acuatum (Osterhout) Rydb. Stem 8-10 dm. high, striate, floccose; leaves numerous, linear in outline, divided halfway to the midrib, the divisions being again divided into 2 or 3 lanceolate, attenuate, strongly spiny lobes; lower surface densely tomentose, the upper loosely arachnoid, floccose; heads 15-20 $\mathrm{mm}$. wide; bracts somewhat floceose on the margins, with a narrow glandular dorsal ridge, all except the innermost armed with slender spreading spines, $5-6$ $\mathrm{mm}$. long. Carduus acuatus Osterhout. River banks: Colo. Submont. J.

49. C. canescens Nutt. Stem 3-5 dm. high, more or less tomentose; leaves oblong or lanceolate, entire or pinnatifid, with short rounded-oblong lobes, densely tered or sometimes conglomerate, $2-2.5 \mathrm{~cm}$. high, usually less than $2 \mathrm{~cm}$. broad; bracts lanceolate, with very broad, dark glutinous ridges, all except the innermost with stout ascending or erect spines $5-10 \mathrm{~mm}$. long; corollas rose or rosepurple. Hills and plains: Colo.-Wyo. Plain-Submont. Je-S. 
50. C. pulcherrimum (Rydb.) K. Schum. Stem about $4 \mathrm{dm}$. high, very leafy, grayish tomentose; lower leaves 1-1.5 dm. long, pinnately divided, bright green and glabrate above, densely white-tomentose beneath; segments lanceolate or triangular, lobed and toothed with slender spines $3-5 \mathrm{~mm}$. long, the upper sessile and half-clasping; heads $2.5-3 \mathrm{~cm}$. high, $2.5-4 \mathrm{~cm}$. broad; outer bracts lanceolate, slightly floccose, tipped with yellow spines about 5-7 mm. long; flowers rose-colored. Carduus pulcherrimus Rydb. Plains: Wyo.-Colo. Submont. Л-Au.

51. C. oblanceolatum (Rydb.) K. Schum. Stem rather slender, 3-6 dm. high, densely white-tomentose; lower leaves about $1 \mathrm{dm}$. long, thick, merely spinulose-dentate or rarely with a few triangular lobes, loosely floccose above, densely white-tomentose beneath; spines slender, $2-5 \mathrm{~mm}$. long; upper leaves lanceolate, sessile and half-clasping; heads $1-3$, campanulate, $3-3.5 \mathrm{~cm}$. high, $1.5-2.5 \mathrm{~cm}$. broad; bracts slightly floccose at first, with slender divergent spines 3-5 mm. long, the innermost unarmed; flowers rose-colored. Carduus oblanceolatus Rydb. Mountains: Colo.-Wyo.-Utah-Mont. Jl-S.

52. C. Flodmanii (Rydb.) Arthur. Stem comparatively slender, 5-10 dm. high, white-floccose; leaves deeply pinnatifid (or those of the seedlings entire), with narrowly lanceolate lobes, tipped with short prickles, densely tomentose beneath, floccose above; heads 3-4 $\mathrm{cm}$. high and nearly as broad; bracts more or less floccose when young, the outer ovate and with short ascending or spreading spines; the innermost linear-lanceolate, attenuate into a weak tip; corollas rose or rose-purple. Carduus canescens Pammel, mainly, not Cirsium canescens Nutt. Carduus Flodmanii Rydb. Carduus filipendulus A. Nels., not Rydb. Meadows and river valleys: Sask.-Minn.-Ia.-Colo.-Mont. Plain-Submont.

53. C. floccosum Rydb. Stem angled, loosely floccose; leaves about $2 \mathrm{dm}$. long, loosely floccose on both sides, divided two-thirds to the midrib; lobes 2cleft, each division lanceolate, $1.5-2 \mathrm{~cm}$. long, tipped with spines about $5 \mathrm{~mm}$. long; heads about $3 \mathrm{~cm}$. high, $1.5-2.5 \mathrm{~cm}$. wide; bracts slightly flocose on the margins, the outer lanceolate, with short and weak spines, the innermost attenuate into a purplish tip; corolla red-purple. Mountains: Colo. Submont. Jl.

54. C. undulatum (Nutt.) Spreng. Stem $3-6 \mathrm{dm}$. high, white-tomentose; leaves pinnately lobed or parted, with ovate or triangular lobes and moderately strong prickles, white-tomentose beneath, floceose or rarely in age glabrous above; heads solitary or few, scattered, $3-4 \mathrm{~cm}$. high and about as broad; bracts numerous, except the innermost ovate to ovate-lanceolate, with short divergent spines, the innermost lance-linear, attenuate into a weak point; corollas rose or rose-purple, rarely white. Carduus undulatus Nutt. Dry plains: Mich.-Tex.Ariz,-B.C. Plain-Submont, Jl-S.

55. C. Engelmannii Rydb. Perennial; stem 5-10 dm. high, loosely floccose; leaves lanceolate, more or less pinnatifid or the upper entire, with triangular lobes, white-tomentose beneath, loosely floccose above, in age glabrate and dark green, with short spines; heads long-peduncled, $3.5-4 \mathrm{~cm}$. high, $4-5 \mathrm{~cm}$. wide; bracts numerous, slightly tomentose on the margins, ovate, with conspicuous glutinous ridges and short slender, spreading spines, the innermost attenuate; corollas rose-purple. Cirsium virginianum filipendulum Engelm., not Cirsium filipendulum Lange. Carduus filipendulus Rydb. Plains and waste places: Colo.-Tex.; apparently also Ida. and Mont. Jl-Au.

C. Engelmannii Xochrocentrum. With the large heads and long spines of C. ochrocentrum, but the broad non-decurrent leaves, dark and glabrate above, of C. Engelmannii. Colo.

C. Engelmannii $\times$ megacephalum. Resembling C. Engelmannii, but the heads larger and with broader bracts, and the leaves broader and conspicuously auriculate-clasping. Colo.

56. C. megacephalum (A. Gray) Cockerell. Stem 3-7 dm. high, tomentose; leaves broadly oblanceolate or lanceolate, pinnatifid, with short triangular lobes, moderately stout-spined, densely tomentose beneath, floccose but in age becoming green above; heads peduncled, solitary or few, $5-7 \mathrm{~cm}$. high and as broad; bracts numerous, all except the innermost with short and slender diver- 
gent spines and conspicuous dorsal glutinous ridges, the inner tapering into slender tips; corollas rose or purple, rarely white. Cnicus undulatus megacephalus A. Gray. Prairies and plains: N.D.-Mo.-Tex.-Colo.-Ida. Plain-Submont. Je-S.

C. Flodmanii $\times$ megacephalum. Intermediate between the two parents, leaves much broader and with broader lobes, heads larger and bracts more glutinous than in C. Flodmanii. Colo.

C. megacephalum $\times$ ochrocentrum. Leaves broad, resembling those of C. ochrocentrum, but not decurrent and involucral bracts with short spines as in C. megacephalum. Neb. - Kans.

57. C. ochrocentrum A. Gray. Stem stout, 3-15 dm. high, tomentose; leaves pinnatifid, with crowded, triangular segments and long, yellow spines, the upper leaves usually conspicuously decurrent, white-tomentose beneath, floccose above, greener but scarcely glabrate in age; heads $4-6 \mathrm{~cm}$. high; bracts numerous, lanceolate, with conspicuous broad glutinous ridges; spines yellow, stout; inner bracts attenuate; corollas purple, rose, or rarely white. Carduus ochrocentrus Greene. Plains: Neb.-Tex.-Ariz. Son.-Plain. Je-Au.

58. C. arvense (L.) Seop. Perennial, with a horizontal rootstock, dioecous; stems striate, 3-10 dm. high, branched above, hirsutulous or glabrous; leaves sessile, slightly clasping, or the lower petioled, green on both sides, glabrous or slightly pubescent, pinnatifid, with oblong, lanceolate or triangular lobes; heads numerous, corymbose, about $2 \mathrm{~cm}$. high; involucres of the staminate heads hemispheric, those of the pistillate ones eampanulate; corollas purple or rarely white. Cnicus arvensis L. Carduus arvensis Robson. CANADA THISTLE. Fields, roadsides, and waste places: Newf.-Va.-Utah-B.C.; nat. from Eu. Je-S,

\section{ONOPÓRDON (Vaill.) L. Cotton Thistle, Scotch Thistle.}

Coarse biennial or perennial herbs. Leaves alternate, lobed, spinescent, conspicuously decurrent on the stem. Heads discoid. Involucre globose; bracts imbricate in many series, tipped with long spines. Receptacle flat, honey-combed, not bristly. Flowers all hermaphrodite and fertile. Corolla mostly purplish; tube slender; throat dilated, and limb 5-eleft. Filaments pilose; anthers sagittate at the base. Achenes 4-angled, oblong. Pappus of many plumose or barbellate bristles, in several series, united at the base.

1. O. Acantium L. Biennial; stem 1-3 m. high, white-tomentose, wingangled by the decurrent leaves; leaf-blades oblong, densely white-tomentose, with triangular lobes, very spiny, the lower often $3 \mathrm{dm}$. long; heads $3-5 \mathrm{~cm}$. broad; bracts floccose and arachnoid-hairy, ending in short spines; flowers pale purple. Waste places: N.S.-N.J.-Mich.; Utah-Colo.; native of Eurasia, cultivated and escaped. Jl-S.

\section{Centaurèa l. Blue Bottle, Cornflower, Bachelor's Buttons, Star Thistle.}

Perennial or annual herbs. Leaves alternate, entire or lobed. Heads discoid. Involucres ovoid or globose, or urn-shaped; bracts imbricate in several series, with appressed bases and spreading, lacerate, erose or spine-tipped appendages. Receptacle flat, densely bristly. Flowers all hermaphrodite and fertile, or the marginal ones usually neutral, and with funnelform-dilated corollas. Corolla of the fertile flowers purple, pink, yellow, or blue, with slender tube and 5-cleft limb. Anthers sagittate at the base. Style-branches short and obtuse. Achenes compressed or obtusely 4-angled, obliquely attached, and crowned by a disk or margin. Pappus of several series of bristles or palea, rarely wanting.

Involucral bracts with lacerate broad appendages; flowers blue. Involucral bracts with 3-5 spines; flowers yellow.

1. C. Cyanus.

2. C. solstitialis.

1. C. Cyanus L. Annual; stem 3-7 dm. high, with slender, ascending branches, more or less floceose; leaves linear or linear-lanceolate, floccose, entire or the lowest dentate or somewhat pinnatifid; heads long-peduncled; involueres round-urceolate, about $15 \mathrm{~mm}$. high; bracts greenish yellow, with dark brown fimbriate margins and tips; flowers blue, varying to rose or white. Waste places 
and around dwellings: Que.-Va.-Calif.-B.C.; native of Eu.; escaped from cultivation. Je-S.

2. C. solstitialis L. Annual; stem much branched, 3-6 dm. high, canescent; leaves decurrent on the margins of the stem, canescent, the lower pinnatifid with oblong or ovate divisions, the upper entire and linear; involucres round-urceolate, about $1 \mathrm{~cm}$. high; bracts yellowish, ending in 3-5 spines; the central one of the middle bracts very stout, 1-2 cm. long; corollas yellow. Waste places: Mass. -N.Y.-Ia.-Ont.; Calif.-Utah; adv. from the Mediterranean region. Jl-S.

\section{Family 137. CiChoriaCeaE. Chicory Family.}

Herbs with a bitter or milky sap. Leaves mostly alternate, sometimes all basal. Flowers all alike, hermaphrodite and fertile, in involucrate heads. Involucres of 1-several series of bracts, sometimes subtended by a series of smaller bracts (calyculum). Receptacle flat or nearly so. Corollas all gamopetalous, split on one side part way down, the upper portion modified into a strap-shaped ligule. Stamens 5; anthers united into a tube around the pistil; sacs auricled or sagittate at the base, appendaged at the apex. Style 2-eleft; branches filiform, naked, stigmatic only towards the base.

A. Pappus none; achenes with corky pericarp.

1. ATRIChoseris.

B. Pappus present.

I. Pappus of plumose bristles, often more or less paleaceous at the base.

Achenes truncate at the apex, not beaked.

Flowers yellow; simple plants with fusiform roots.

2. Ptilocalais.

Flowers pink, rose, or white; branched plants with rush-like stems.

Achenes with long beaks.

3. Ptiloria.

Receptacle not chaffy.

Involucres of 7-15 linear-acuminate equal bracts and smaller calyculate ones at the base; achenes obscurely ribbed; branched annuals with pinnatifid leaves.

4. NEMOSERIS.

Involucres of several lanceolate-attenuate herbaceous bracts; no calyculate ones at the base; achenes 5-10-ribbed; leaves grass-like and heads solitary.

Receptacle chaffy.

5. TRAGOPOGON.

6. HYPOCHERIS.

II. Pappus not plumose.

a. Pappus consisting, at least partly, of squamellae or these reduced and united into a crown.

1. Involucres simple and naked, $i$. e., without smaller calyculate ones below; pappus of both squamellae and bristles; flowers yellow.

7. ADOPOGON.

2. Involucres double, either imbricate or with smaller calyculate ones below. Flowers blue; pappus crown-like of small numerous blunt squamellae in 2 or more series; tall perennials.

8. CiCHORIUM.

Flowers yellow; pappus of large squamellae; low annuals, acaulescent or nearly so.

Squamellae of the pappus 5 , cleft at the apex with an awn in the notch; involucres calyculate.

9. UROPAPPUS.

Squamellae of the pappus 20-30, very narrow, linear-lanceolate, tapering into a bristle-like apex; bracts nearly equal, in two series.

10. NOTHOCALAIS.

b. Pappus of capillary bristles, not plumose, slightly if at all broadened below.

1. Achenes not flattened.

a. Pappus-bristles promptly deciduous, mainly together, only a few of the stouter ones in some species remaining.

Achenes more or less narrowed into a beak.

Achenes without a cup-shaped shoulder, not cancellate. Achenes 5-ribbed; main bracts scarious-margined; receptacle bristly.

11. CALYcoseris. Achenes 10-striate; bracts not scarious; receptacle not bristly,

12. YOUNGIA.

Achenes 5-ribbed, conspicuously cancellate-sculptured, with a cupulate shoulder, from which the slender, 5-ribbed hollow beak arises.

13. GLYPTOPLURA.

Achenes not beaked, columnar, 5-15-ribbed, truncate at the apex.

Involucres of broad silvery-scarious bracts, regularly imbricate; bristles of the receptacle persistent. 14. MALACOLEPIS.

Involucres of narrow acuminate or acute bracts, only slightly scarious-margined; bristles of the receptacle, if any, few and deciduous.

15. Malacothrix. 
$b$ Pappus persistent, tardily falling off, separately, or together only by the breaking off of the beak.

Beak of the achenes none or a mere attenuation.

Flowers rose or purplish.

Plants spiny and rush-like; leaves scale-like; achenes truncate at the summit.

16. Pleicanthus.

Plants not spiny.

Stems rush-like and striate; leaves narrowly linear-lanceolate or reduced; achenes tapering at the summit.

17. LYGODESMIA.

Stems not rush-like; leaves ample; achenes tapering to the base. Annuals; heads 4-5-flowered; achenes with 4-5 strong ribs.

18. Prenanthella.

Perennials; heads 8-30-flowered (rarely less); achenes Flowers yellow or white. terete or 4-5-angled.

Heads several, rarely solitary; stem leafy.

Achenes tapering upwards; pappus white.

Achenes not dilated into a pappiferous disk.

Bracts in fruit more or less thickened at the base or on the midrib. Bracts not thickened on the backs.

21. HETEROPLEURA

Achenes contracted into a more or less distinct beak, enlarged at the apex into a pappiferous disk.

12. YOUNGIA.

Achenes not tapering upwards; pappus in ours sordid or reddish; bracts not thickened.

Leaves simple and entire-margined or denticulate; inflorescence in ours more or less corymbiform; bracts narrow, green.

22. Hieractum.

Leaves divided or lobed; inflorescence thyrsoid-panieulate; bracts broad and colored. 19. NABALUS.

Heads solitary on a leafless scape. 10 . NotHocalais.

Beaks of the achenes distinct and slender; plants scapiferous.

Achenes 10-ribbed or 10-nerved, not spinose-muricate; involucres more or less imbricate.

23. Agoseris.

Achenes 4-5-ribbed, muricate-spinulose at least near the apex; involucres of a single series of principal bracts and several or numerous calyculate ones below.

24. LEONTODON.

2. Achenes flattened; leafy-stemmed plants with paniculate heads,

Achenes narrowed at the top or beaked; pappus-bristles falling separately: involucres cylindraceous. 25. LACTUCA.

Achene truncate at the top; pappus-bristles falling off more or less in connection; involucres hemispherical or campanulate. 26 . SONCHUS.

\section{ATRICHÓSERIS A. Gray.}

Glabrous winter annuals of desert regions, acaulescent, with cymosely branched scapes. Involucre of about 15 linear, acute bracts in a single series, and several small calyculate ones at the base. Receptacle scrobiculate. Flowers white or purplish; ligules 5-toothed at the truncate apex. Achenes oblong, with corky-thickened pericarp, 8-10-ribbed, the alternate ribs thicker. Pappus none.

1. A. platyphylla A. Gray. Leaves rosulate-tufted at the base, sessile, rounded-obovate, denticulate, with eallous or spinulose teeth, 4-10 cm. long; scape 3-6 dm. high, paniculately branched, with small bracts; involucres turbinate, 6-8 mm. high; corollas white, with a purple base; ligules 10-12 $\mathrm{mm}$. long. Gravelly deserts: s Calif. $-\mathrm{s}$ Utah-w Ariz. Ap-Je.

\section{PTILOCÃLAIS Greene.}

Perennial herbs, with fusiform roots. Heads solitary at the end of the branches. Involucres cylindric, of $8-12$ bracts, in 1 or 2 series, and a few small calyculate ones at the base. Receptacle with narrow scarious paleae. Corollas yellow. Achenes 8-10-ribbed, columnar, linear, truncate at the apex. Pappus of 15-20 white soft plumose bristles with paleaceous bases.

Pappus-squamellae oblanceolate or oblong, truncate or abruptly contracted into the awn.
Leaves entire or with short lobes.

Leaf-blades proper lanceolate or elliptic; heads about $2.5 \mathrm{~cm}$. high.

Leaf-blades proper linear or linear-lanceolate; heads less than $2 \mathrm{~cm}$. Pigh.

Leaves with long fliform lobes.

2. P. nutans,

3. P. graciloba. 
Pappus-squamellae linear-lanceolate, gradually tapering into the awn. Leaves linear-lanceolate or lanceolate; squamellae 4-5 $\mathrm{mm}$. long.

Leaves narrowly linear; squamellae $2 \mathrm{~mm}$. long or less.

4. P. macrolepis. 5. P. tenuifolia.

1. P. major (A. Gray) Greene. Stem 3-6 dm. high, glabrous; lower leaves petioled, the upper sessile and half-clasping, glabrous; blades lanceolate or elliptic, entire, laciniate-toothed or pinnatifid with lanceolate divisions; involucres 15-20 $\mathrm{mm}$. high, often finely puberulent; bracts proper 10-15, linear-lanceolate, attenuate; squamellae about $2 \mathrm{~mm}$. long, oblong, truncate or 3-toothed at the apex, the middle tooth ending in a plumose bristle about $5 \mathrm{~mm}$. long. Microseris major A. Gray. Hillsides and valleys: Mont.-Utah-Calif.-B.C. Son. Ap-Jl.

2. P. nutans (Geyer) Greene. Stem 2-5 dm. high, slender; lower leaves petioled, the upper sessile; blades linear or narrowly linear-lanceolate, entire or pinnatifid with rather short divergent lobes; involucres turbinate, $10-15 \mathrm{~mm}$. high; bracts 8-10, lanceolate, acuminate; squamellae $2 \mathrm{~mm}$. long, oblanceolate, truncate and slightly toothed at the apex; awns $4-5 \mathrm{~mm}$. long. $M$. nutans A. Gray. Hillsides and valleys: Mont.-Colo.-Calif.-B.C. Son.-Submont. My$\mathrm{Jl}$.

3. P. graciloba (Kellogg) Greene. Stem slender, 2-6 dm. high, glabrous or minutely puberulent; leaves pinnatifid, with elongate narrowly linear divisions, or the uppermost linear and entire; involucres turbinate, 10-15 mm. high; bracts 9-12, linear-lanceolate, attenuate; pappus-squamellae oblong, truncate, $2 \mathrm{~mm}$. long; bristles about $5 \mathrm{~mm}$. long. Calais graciloba Kellogg. M. major laciniata A. Gray. Hills and grasslands: Mont.-Utah-Calif.-B.C. Son. My-Jl.

4. P. macrolepis Rydb. Stem 2-5 dm. high; lower leaves petioled, the upper sessile; blades linear-lanceolate, entire or rarely pinnatifid with linearlanceolate divergent divisions; involucres turbinate, $2 \mathrm{~cm}$. high; bracts proper 12-15, linear-lanceolate, attenuate; pappus-squamellae lanceolate, 4-5 mm. long; bristles 6-7 mm. long. Benchlands: Utah. Son.-Submont. Ap-Je.

5. P. tenuifolia Osterhout. Stem very slender, 1-3 dm. high, often scapiform; leaves narrowly linear, entire or with a few distant linear lobes directed downwards; involucres turbinate, 12-15 mm. high; bracts 8-15, linear-lanceolate, attenuate; squamellae lanceolate; awns 5-6 mm. long. Hillsides and valleys: Colo.-Utah. Mont. Je-Au.

\section{Ptilòria Raf. Desert Pink, Flowering Straw.}

Rush-like slender plants, with the upper leaves reduced and mostly bract-like. Heads small, 3-20-flowered. Involucres cylindric, rarely campanulate. Bracts few, in a single series, with a few small calyculate ones at the base. Flowers pink or flesh-colored. Achenes prismatic, truncate at both ends, strongly angled, glabrous, often rugose, the base broad and hollowed. Pappus of 10-20 bristles, somewhat paleaceous at the base, plumose at least above the middle. [Stephanomeria Nutt.]

Perennials.

Heads 10-20-flowered; involucres over $1 \mathrm{~cm}$. high; leaves broad, runcinate, with short lobes.

Heads 3-9- (mostly 5-) flowered.

Pappus plumose to the base; involucres 7-10 $\mathrm{mm}$. high.

Leaves very narrow, almost filiform and usually entire. $2 . P$. tenuifolia.
Leaves, at least the lower ones, broad, oblanceolate in outline, and runcinate.

1. P. Parryi.

Pappus merely scabrous or hirsutulous at the base.

Leaves runcinate, but narrow; involucres $9-10 \mathrm{~mm}$, high.

Leaves linear-filiform; involucres $5-6 \mathrm{~mm}$. high.

3. P. ramosa.

Annuals or biennials.

4. P. pauciflora.

5. P. myrioclada.

Pappus-bristles not dilated at the base; heads usually subsessile on spike-like branches.

Pappus-bristles somewhat dilated at the base, often more or less unit $P$. virgata. late.

Pappus plumose to the base or nearly so; plant tall and slender. 7. P. paniculata.

Pappus plumose only above the middle; plant usually low and stout.

8. P. exigua.

1. P. Parryi (A. Gray) Coville. Stem rather stout, white, 1-3 dm. high, branched; leaves thickish, runcinate-pinnatifid; lobes reflexed, spinulose-tipped; 
heads 10-20-flowered, terminating leafy branches; involucres fully $1 \mathrm{~cm}$. high; bracts 8-10; achenes smooth; pappus-bristles naked at the base, sordid. Stephanomeria Parryi A. Gray. Desert regions: s Utah-Ariz.-Calif. Son. My-Je.

2. P. tenuifolia (Torr.) Raf. Stem slender, much branched, with ascending branches; leaves narrowly linear, usually entire; involucres about $7 \mathrm{~mm}$. high, about 5-flowered; bracts usually 5, linear, obtuse; achenes smooth or slightly rugose; pappus white; bristles plumose to the base. S. minor Nutt. Plains: Mont.-Colo.-Ariz.-Wash. Son.-Plain. Je-S.

3. P. ramosa Rydb. Stem branched at the base, with more or less spreading branches, striate, puberulent below, 2-3 dm. high; lower leaves lanceolate, runcinate-divided; upper leaves linear and entire; involucres 8-10 mm. high, usually 5 -flowered; bracts proper usually 5 , lance-linear, usually acutish; achenes strongly rugose; pappus white, plumose to the base. (?) S. runcinata Nutt. Dry hills: Neb.-Colo.-Mont. Plain-Submont. Je-S.

4. P. pauciflora (Torr.) Raf. Stem 2-4 dm. high, with stiff ascending branches; leaves linear or nearly so, the lower runcinate-pinnatifid with narrow divisions, the upper entire; involucres 9-10 $\mathrm{mm}$. high; bracts about 5 , linear, obtuse; achenes rugose; pappus tawny; bristles naked at the base. (?) S. runcinata Nutt. Dry plains: Kans.-Tex.-Ariz.-Nev. Son. Je-S.

5. P. myrioclada (D. C. Eat.) Greene. Stem 3-5 dm. high, slender, more or less flexuose, with numerous branches; leaves linear-filiform, 1-4 cm. long; heads on short lateral branches; bracts 3-5, narrow, 5-6 $\mathrm{mm}$. long; achenes striate; pappus white, merely hirsutulous at the base. S. myrioclada D. C. Eat. Dry hills and slopes: Nev.-Ida. Son. Je-S.

6. P. virgata (Benth.) Greene. Stem 3-10 dm. high, ridged; lower leaves oblong or spatulate, sinuate or pinnatifid, $2-4 \mathrm{~cm}$. long; upper leaves linear, very small, entire; heads $6-8 \mathrm{~mm}$. high, subsessile; bracts $5-7$, linear; flowers 4-10; achenes rugose-tuberculate; pappus-bristles moderately plumose. S. virgata Benth. Arid regions: Ore-Colo.-Calif. Son. Je-O.

7. P. paniculata (Nutt.) Greene. Stem ereet, 3-6 dm. high; lower leaves oblanceolate or spatulate, toothed, the upper linear, entire, much reduced; panicles with racemiform or spicate branches; bracts mostly 5 , linear, $5-7 \mathrm{~mm}$. long; achenes more or less rugose. S. paniculata Nutt. Plains: Wash.-Ida.-Calif. Son. J-O.

8. P. exigua (Nutt.) Greene. Annual; stem 3-6 dm. high, diffusely branched; lower leaves pinnatifid, with lanceolate or linear divisions, those of the branches diminutive and scale-like; heads paniculate, ending short scaly branches; calyculate bracts ovate, 1-1.5 mm. long; bracts proper mostly 5 , linear, obtuse, $6-7 \mathrm{~mm}$. long; flowers 3-8, mostly 5; achenes thick-ribbed, rugose-tubereulate. S. exigua Nutt. Dry places: Wyo.-N.M.-Calif.-Nev. Son.

\section{NEMóseris Greene. Desert Chicory.}

Stout branching winter annuals, with somewhat fistulose stems and toothed or pinnatifid leaves. Heads 15-30-flowered. Involucres turbinate-cylindric; bracts $7-15$, linear, acuminate, equal, in a single series, with a few small calyculate ones at the base. Flowers white or tinged with rose-color. Achenes terete, with obscure ribs, produced into a beak at the summit, callous at the base, with a hollowed insertion. Pappus of 10-15 capillary plumose bristles. [Rafinesquia Nutt.]

Ligules 10-15 mm. long; beak of the achenes much shorter than the body

Ligules about $5 \mathrm{~mm}$. long; beak of the achenes as long as the body. $2 . N$. Neomexicana.

1. N. neomexicana (A. Gray) Greene. Stem 2-5 dm. high; leaves lanceolate, runcinate-pinnatifid, with narrow divisions; heads few, paniculate; bracts 10-12, linear-lanceolate, $15-18 \mathrm{~mm}$. long; ligules white, tinged with flesh-color; achenes gradually tapering into the short beak. $R$. neomexicana A. Gray. Sandhills: N.M. $\rightarrow$ U Utah $\rightarrow$ se Calif. L. Son. Mr-My. 
2. N. californica (Nutt.) Greene. Stem glabrous, 5-10 dm. high, paniculately branched; leaves oblong, $5-15 \mathrm{~cm}$. long, lanceolate, runcinate-pinnatifid, the cauline ones somewhat clasping; bracts $12-15$, linear-lanceolate, acuminate, $12-15 \mathrm{~mm}$. long; ligules white; beak of the achenes slender. R. californica Nutt. Moist ground: Calif. -s Utah-Ariz. L. Son. Ap-Je.

\section{TRAGOPÒgON (Tourn.) L. SALSIFY, Oyster Plant.}

Tall perennial herbs, with fleshy taproots and long alternate grass-like leaves clasping at the base. Involucres nearly cylindric; bracts in a single series, united at the base. Flowers many, yellow or purplish; ligules truncate and 5-toothed at the apex. Achenes muricate, 5-10-ribbed, produced at the apex into a distinct beak. Pappus of plumose bristles connate at the base.

Flowers yellow.

Bracts 8-9; flowers chrome yellow; involucral bracts equalling or shorter than the

flowers.
Bracts $10-13$, rarely less; flowers lemon yellow; involucres longer than the flowsis. Flowers purple; involucral bracts much longer than the flowers.

2. T. dubius.

3. T. porrifolius.

1. T. pratensis L. Stem $3-6 \mathrm{dm}$. high, glabrous; leaves linear-lanceolate, long-attenuate; peduncles scarcely fistulose, little if at all thickened below the heads; bracts linear-lanceolate, attenuate, $2.5-3 \mathrm{~cm}$. long; outer achenes muricate. Fields and waste places: N.B.-N.J.-Utah-Mont.-Man.; adv. or nat. from Eu. Je-Au.

2. T. dubius Scop. Stem 5-10 dm. high, glabrous; leaves elasping, lanceolate, attenuate; peduncles fistulose, gradually thickening upwards; bracts green, linear-lanceolate; achenes strongly tuberculate. Waste places: Colo.; escaped from cultivation.

3. T. porrifolius L. Stem 6-10 dm. high, glabrous; leaves clasping, with lanceolate bases, long-attenuate; peduncles distinctly fistulose, gradually thickened below the head; bracts 8-10, linear-lanceolate, long-attenuate, $3-5 \mathrm{~cm}$. long; outermost achenes strongly muricate. Fields and waste places: Ont.-N.C. -N.M.-Utah; Calif.-B.C.; escaped from cultivation. Je-Au.

T. dubius $\times$ porrifolius. Corolla very pale purplish; involucral bracts $9-13$. With the parents. Colo.

T. porrifolius $\times$ pratensis. Corolla pale lilac; involucral bracts $8-10$, mostly 8 . With the parents. Ont.-N.J.-Colo.-Mont.

\section{HYPOCHAÈRIS L. Cat's-ear, Gosmore.}

Subscapose annuals or perennials. Leaves mostly in basal clusters or rosettes, often lyrate. Involucres campanulate; bracts rather few, but imbricate and the outer successively shorter. Receptacle chaffy; paleae thin and narrow. Flowers yellow. Achenes fusiform or oblong, 10-ribbed, tapering at the top into a more or less distinct beak. Pappus of capillary plumose bristles, or some of the outer bristles shorter and not plumose.

1. H. radiata L. Perennial; stem 5-20 dm. high, corymbosely branched, almost leafless; basal leaves lyrate-pinnatifid, with the lateral lobes oblong, obtuse, hirsute; involucre about $25 \mathrm{~mm}$. high; ligules 7-10 $\mathrm{mm}$. long. Waste places and fields: N.Y.-N.J.-Colo.; Calif.-B.C.; adv. or nat. from Eurasia. My-O.

\section{ADOPÒGON Neck.}

Perennial herbs with pale green foliage. Leaves mainly basal. Involucre campanulate; bracts in 1 or 2 subequal series, without calyculum. Receptacle naked. Flowers yellow. Achenes oblong or somewhat turbinate, 15-20-ribbed, beakless. Pappus of 10-15 outer short squamellae and 15-20 capillary inner bristles.

1. A. virginicus (L.) Kuntze. Stem glabrous, 3-6 dm. high, 1- or 2-leaved, branched above; basal leaves spatulate, wing-petioled, runcinately lobed, toothed, or entire, 5-10 cm. long; cauline leaves partly clasping, with a broad base; bracts 10-15, linear-lanceolate, acutish, glabrous, 8-10 $\mathrm{mm}$. long; flowers orange 
Krigia amplexicaulis Nutt. Moist woods: Ont.-Ga.-Colo.-Man. PlainSubmont.

\section{CICHÒRIUM (Tourn.) L. CHICORY.}

Herbs with stiff branching stems and mostly basal leaves, the stem-leaves reduced and bract-like. Involucres cylindraceous; bracts in 2 series, the outer somewhat spreading, the inner erect and partly enfolding the achenes at the base. Flowers blue, rose, or pink. Achenes 5-angled, truncate and beakless at the apex. Pappus of $1-3$ series of short blunt squamellae.

1. C. Intybus L. Perennial, with a taproot; stems slightly hispid, 3-10 dm. high; basal leaves spreading, runcinate-pinnatifid, spatulate in outline, $7-15 \mathrm{~cm}$. long; stem-leaves smaller, lanceolate or oblong, lobed or entire, clasping and auricled at the base; heads numerous, 1-4 together in sessile clusters; bracts proper about 8, glandular-ciliate. Roadsides, fields, and waste places: N.S.N.C.-Calif.-B.C.; nat. from Eu. Plain-Submont. JI-S.

\section{UROPÁPPUS Nutt.}

Acaulescent annuals. Leaves basal, narrow. Involucres narrowly turbinate; bracts nearly equal, subtended by a calyculum of small ones. Flowers yellow; ligules short. Achenes fusiform, produced into a beak. Pappus of 5 scarious squamellae, 2-cleft at the apex, with an awn between the lobes.

Awns 1-2 times as long as the short pappus-squamellae.

Awns scarcely half as long as the long pappus-squamellae.
1. U. macrochaetus.

2. U. linearifolius.

1. U. macrochaetus (A. Gray) Greene. Leaves mostly near the base, linear, entire, sinuately and saliently toothed or lobed; peduncles $2-4 \mathrm{dm}$. long; involucres narrowly turbinate, $15-20 \mathrm{~mm}$. high; squamellae lanceolate, about $2 \mathrm{~mm}$. long, cleft to the middle; awns 6-7 mm. long. Microseris macrochaeta A. Gray: Meadows: Ore.-Ida.-s Calif. Son. Ap-My.

2. U. linearifolius (DC.) Nutt. Leaves near the base, somewhat pubescent when young, narrowly linear, entire or with divaricate linear lobes; peduncles 1-3 dm. long, usually thickened obove; involucres turbinate, $18-25 \mathrm{~mm}$. high; bracts linear-lanceolate, acuminate, the outer about half as long as the inner; squamellae $7-9 \mathrm{~mm}$. long, linear-lanceolate, notched at the apex; awns 3-4 $\mathrm{mm}$. long. M. linearifolia A. Gray. Low ground: Ida.-N.M.-Calif.-Wash.
Son. Mr-Je.

\section{NOTHOCÀluIS (A. Gray) Greene.}

Acaulescent perennial, of the habit of Agoseris, with narrow, entire or pinnatifid leaves. Involucres oblong-campanulate; bracts in 2-3 series, nearly equal, without calyculum. Receptacle naked. Flowers yellow. Achenes attenuatefusiform, beaked. Pappus of 20-30 narrow linear-lanceolate, in one species nearly bristle-like, squamellae tapering into an awn.

Bracts linear-lanceolate, scarcely spotted.

Pappus distinctly paleaceous, of narrow squamellae gradually attenuate.

Pappus of bristles only slightly broader and flattered Bracts ovate or ovate-lanceolate, acuminate, conspicuously spotted. $2 . N$. cuspidata.

1. N. troximoides (A. Gray) Greene. Leaves narrowly linear-lanceolate, undulate, attenuate; scape puberulent when young, 1-3 dm. high; involucres about $2 \mathrm{~cm}$. high; bracts narrowly linear-lanceolate, somewhat purple-tinged on the midrib, gradually attenuate; pappus of 20-25, narrowly linear-lanceolate attenuate scales. Microseris troximoides A. Gray. Wooded hills and plains: Mont.-Utah-Calif.-Wash. Plain-Submont. Ap-Je.

2. N. cuspidata (Pursh) Greene. Leaves somewhat glaucescent, linearlanceolate, caudately attenuate, more or less wavy, villous-tomentulose on the margins when young; scape 6-30 cm. long; involucres turbinate, about $2 \mathrm{~cm}$. high; bracts lanceolate or linear-lanceolate, gradually acuminate, somewhat tinged with purple; pappus of $40-50$ bristles. Troximon cuspidatum Pursh. Prairies and plains: Wis.-Mo.-Colo.-S.D. Plain-Submont. Ap-Je. 
3. N. nigrescens (Henders.) Heller. Perennial, with a taproot and short caudex; leaves linear-oblanceolate, 3-24 cm. long, 3-10 $\mathrm{mm}$. wide, pale green, acute or acuminate, mucronate; scape 1-2 dm. high, slightly villous below the head; involucres campanulate; bracts in 3 series, abruptly acuminate, the outer ovate, the inner lanceolate, conspicuously scarious-margined and black-dotted; flowers purple on the outside; achenes blackish; pappus of very narrow scales gradually attenuate upwards into long bristles. Micoseris nigrescens Henders. Wet meadows: Mont.-n Wyo.-Ida. Plain-Submont. Je.

\section{CALYCÓSERIS A. Gray.}

Much branched winter annuals, glabrous below, glandular in the inflorescence. Involucre campanulate; bracts many, scarious-margined, equal, with 1-2 outer series of small calyculate ones. Receptacle with capillary bristles. Flowers yellow or rose-colored. Achenes 5-ribbed, narrowed above into a short beak, ending in a denticulate crown. Pappus of numerous capillary white bristles united at the base and falling away in a ring.

Flowers rose-colored; achenes with the short beak about $5 \mathrm{~mm}$. long. Flowers yellow; achenes with the long beak about $10 \mathrm{~mm}$. long.

1. C. Wrightii. 2. C. Parryi.

1. C. Wrightii A. Gray. Stem 2-4 dm. high, branched from the base; leaves mostly close to the base, pinnately or bipinnately dissected into narrow linear divisions; heads corymbose; involucre $12-15 \mathrm{~mm}$. high; bracts more or less glandular-ciliate; bracts proper linear or lance-linear; flowers tinged with rose; ligules 10-15 mm. long; achenes rugose on the thick ribs. Arid regions: N.M.s Utah-Ariz. L. Son. Mr-My.

2. C. Parryi A. Gray. Stem more leafy, 3-5 dm. high; leaves pinnatifid, with linear or lanceolate divisions; heads paniculate; involueres $12-15 \mathrm{~mm}$. high; bracts glandular-ciliate, in about 3 series, lanceolate, the outer squarrose; bracts proper lance-linear; flowers yellow, about $15 \mathrm{~mm}$. long; achenes more slender, not rugose; beak with a more distinct apical cup. Arid regions: Ariz. $\rightarrow \mathrm{s} U \mathrm{tah}-\mathrm{s}$ Calif. L. Son. My.

\section{YOÚNGIA Cass.}

Low or depressed perennials, with many basal leaves. Heads several, 8-15flowered. Involucres cylindric; bracts linear, obtuse, in single series, not thickened on the back, with 3 or 4 short calyculate ones at the base. Flowers yellow. Achenes narrow, 10-striate, tapering above and there enlarged into a disk, bearing the pappus. Pappus of numerous white capillary deciduous bristles.

Achenes conspicuously beaked; stem 1-2 dm. high.

1. Y. elegans. Achenes scarcely beaked, merely constricted below the disk; stem $5 \mathrm{~cm}$, or less high.

2. Y. nana.

1. Y. elegans (Hook.) Rydb. Perennial, with a taproot; stem branched, 1-2 dm. high; leaves petioled, 5-10 $\mathrm{cm}$. long; blades oblanceolate, entire to sinuately lyrate-pinnatifid, with triangular salient lobes; heads paniculate; involucres about $8 \mathrm{~mm}$. high; bracts proper narrowly linear; achenes $4 \mathrm{~mm}$. long. Crepis elegans Hook. Barkhausia elegans Nutt. High mountains: Mack.-Sask.Wyo.-B.C.-Yukon. Mont. J-Au.

2. Y. nana (Richards.) Rydb. Depressed perennial, with creeping rootstock; stem 1-5 cm. high; leaves mostly basal, petioled, $2-5 \mathrm{~cm}$. long; blades obovate or spatulate, entire, repand-dentate, or lyrate; involucres 8-10 mm. high; bracts proper linear, obtuse, with the backs thickened at the base; achenes cylindric, about $5 \mathrm{~mm}$. long, $0.5 \mathrm{~mm}$. thick. Crepis nana Richards. $Y$. pygmaea Ledeb. High mountains: Lab.-Alta.-Utah-Ida.-B.C.; Asia. Mont.-Subalp. $\mathrm{Jl}-\mathrm{Au}$.

\section{GLYPTOPLEÙRA D. C. Eat.}

Tufted annuals, with thick runcinate leaves. Involucres campanulate; bracts 7-12, linear-lanceolate, in one series, and a few loose and foliaceous ones at the base. Flowers white, pink, or yellow. Achenes obtusely 5-angled, oblong, each interval with two rows of tubercles, abruptly contracted above into a stout 
beak, the base of which is surrounded by a cup-shaped border. Pappus of capillary white bristles, in several series, the outer falling off separate.

Corollas white, turning pink; leaves with broad white scarious margins and short broad teeth.

Corollas yellow, turning pink; leaves with very narrow white scarious.margins and subulate, setiform teeth.

2. G. setulosa.

1. G. marginata D. C. Eat. Stems many, 1-5 cm. long; leaves numerous, with winged petioles, runcinate-pinnatifid; lobes rounded, scarious-margined, with triangular obtusish teeth; leaves subtending the heads pectinate-setiferous; involucres $10-12 \mathrm{~mm}$. high; bracts lance-linear; ligules 2-3 mm. long; achenes 4 $\mathrm{mm}$. long; beak $1 \mathrm{~mm}$. Desert regions: Nev.-s Utah-Ariz.-Calif,-Ore. $L$. Son. My-Je.

2. G. setulosa A. Gray. Stems 1-5 cm. long; leaves petioled, oblanceolate or obovate in outline, runcinate-pinnatifid; lobes rounded, with lance-linear or subulate, setiform teeth; ligules 1-2 $\mathrm{cm}$. long; achenes similar to those of the preceding. Desert regions: s Utah-Ariz. -s Calif. L. Son. My.

\section{Malacolèpis (A. Gray) Heller. Snake's Head.}

Leafy-stemmed annuals, with broad leaves. Involucre broadly campanulate; bracts imbricate in several series, silvery-scarious, with green midribs, the outer short and orbicular. Receptacle bearing slender persistent bristles. Corollas white, becoming purple-tinged in fading. Achenes 4- or 5-angled, 12-15ribbed, columnar, truncate and denticulate at the apex. Pappus of numerous white capillary bristles, united at the base and falling off together, and one or two stouter outer ones, more persistent.

1. M. Coulteri (A. Gray) Heller. Stem glabrous, 2-4 dm. high; lower leaves short-petioled, the upper sesșile and clasping, all sinuate-dentate to pinnatifid, with broad triangular lobes or teeth; heads paniculate; involucres 12-15 $\mathrm{mm}$. high. Malacothrix Coulteri A. Gray. Hillsides: s Calif.-s Utah-Ariz. L. Son. Mr-My.

\section{MALACóthrix DC. Desert Dandelion.}

Annual or perennial herbs, commonly with a basal cluster of leaves. Involucre campanulate or turbinate; bracts narrow, acute or acuminate, imbricate. Receptacle naked or with a few deciduous bristles. Flowers yellow, white, or pinkish. Achenes short, truncate at the apex, with a denticulate border, 10-15ribbed. Pappus of numerous, eapillary, white-scabrous bristles, more or less united at the base and falling off together or with 1-8 stronger outer ones more persistent.

Divisions of the leaves filiform; plant scapose or nearly so.

Divisions or lobes of the leaves not filiform; stem more or less leafy.

Leaves sinuately runcinate; lobes entire or nearly so; achenes not winged.

Leaves deeply pinnatifid; divisions toothed or lobed.

Achenes wing-margined on 5 of the ribs; outer persistent bristles of the pappus present.

Achenes not winged; outer persistent bristles of the pappus none.

3. M. Torreyi.

4. M. sonchioides.

1. M. glabrata (D. C. Eat.) A. Gray. Annual, branched at the base, subacaulescent; leaves mostly basal, pinnatifid, with narrowly linear divisions, glabrous; branches scapiform, bearing 1-3 heads; involucres about $1 \mathrm{~cm}$. high; bracts lance-linear, slightly tomentulose when young; flowers yellow; outer pappus of 2 persistent bristles; achenes narrow, slightly costate-striate. Dry regions: s Utah-Ariz.-e Calif.-Ida. Son. Ap-My.

2. M. runcinata A. Nels. Annual; stem branched at the base, $5-15 \mathrm{~cm}$. long, with decumbent branches, glabrous or nearly so; leaves $2-4 \mathrm{~cm}$. long, oblanceolate to linear in outline, dentate to runcinate-pinnatifid, with mostly entire lobes; involucres 10-12 mm. high, broadly campanulate; bracts linear-lanceolate, in about 3 series, scarious-margined; achenes linear-columnar, about $3 \mathrm{~mm}$. long, 
with 15 subequal ribs; outer persistent pappus-bristles often wanting, sometimes 1 or 2 . Dry sandy slopes: Wyo.-Colo. Son.-Submont. Je.

3. M. Torreyi A. Gray. Annual; stem branched at the base, 1-2 dm. high, with decumbent branches, glabrous or sparingly glandular in the inflorescence; leaves obovate in outline, runcinate-pinnatifid, with oblong or lanceolate, divergent toothed, lobes; heads paniculate; involucres about $1 \mathrm{~cm}$. high; achenes linear-cylindric, with 5 of the angles wing-margined; outer pappus of 2-5 persistent bristles. Low ground: Ore.-Utah-Calif. Son. Je.

4. M. sonchioides (Nutt.) T. \& G. Annual; stem branched at the base, with ascending branches; leaves oblanceolate or obovate in outline, lyrate-pinnatifid, with oblong, dentate lobes; heads paniculate; involucres $8-10 \mathrm{~mm}$. high; bracts in 3 series, the outer ovate-lanceolate, the inner linear-lanceolate; achenes cylindric, 15-ribbed, with 5 ribs, but slightly stronger, not winged; outer persistent bristles usually none. Plains: Neb.-Kans.-s Calif.-Nev.-Ida. Son. My-Je.

\section{PLEIACÁNTHUS (Nutt.) Rydb.}

Diffuse and spinescent perennials, suffruticose at the base, with flexuose branches. Lower leaves linear, entire, the upper reduced to scales. Involucre cylindric; bracts 3-5, linear, with 1-3 minute calyculate ones at the base. Flowers 3-5, rose-colored. Achenes prismatic, 4- or 5-ribbed, truncate at the apex. Pappus of rather few rigid, unequal bristles, falling off separate.

1. P. spinosus (Nutt.) Rydb. Lower leaves linear, the upper leaves scalelike, lanceolate, $2-5 \mathrm{~mm}$. long; heads lateral, short-peduncled; calyculate bracts ovate, more or less imbricate; bracts proper, ovate-lanceolate. Lygodesmia spinosa Nutt. Gravelly hills and plains: Mont.-Ar̂̃z.-Calif.-B.C. PlainSubmont. Au-S.

\section{7. lygodésmia D. Don. Wild Asparagus, Skeleton Weed, Prairie Pink.}

Rush-like herbs, with narrow alternate leaves. Involucre cylindric; bracts $5-12$, linear, equal, with a few calyculate ones at the base. Flowers 5-12, pink or rose-colored. Achenes slender, 4-8-ribbed, slightly tapering towards the summit. Pappus of numerous soft bristles, falling off separate.

Perennials, with deep-seated rootstocks.

Involucres $15-25 \mathrm{~mm}$. high, 6-10-flowered.

Involucres $10 \mathrm{~mm}$. high, usually 5-flowered; upper leaves reduced. Annuals; involucres 10-15 $\mathrm{mm}$. high.

1. L. grandiflora.

2. L. juncea.

3. L. rostrata.

1. L. grandiflora (Nutt.) T. \& G. Stem simple below, 1-4 dm. high, leafy; leaves narrowly linear, ascending, 5-10 $\mathrm{cm}$. long; calyculate bracts ovate, 2-3 $\mathrm{mm}$. long; bracts proper narrowly linear; achenes about $1 \mathrm{~cm}$. long; pappus sordid. Gravelly hills: Wyo.-Colo.-Ariz.-Ida. Son.-Submont. My-Jl.

2. L. juncea (Pursh) D. Don. Stem $2-4 \mathrm{dm}$. high, much branched from near the base; lower leaves linear, 2-10 $\mathrm{cm}$. long, those of the branches reduced and subulate; involucres $10-12 \mathrm{~mm}$. high; calyeulate bracts lanceolate, 1-2 mm. long; bracts proper 5 , narrowly linear; achenes $5-6 \mathrm{~mm}$. long; pappus sordid. Plains and prairies: Minn.-Mo.-N.M.-Nev.-Alta. Plain-Submont. Je$\mathrm{Au}$.

3. L. rostrata A. Gray. Stem erect, $3-10 \mathrm{dm}$. high, with strongly ascending branches; leaves narrowly linear, obscurely 3-nerved, 5-20 cm. long; heads numerous, ending short scaly branches; calyculate bracts lanceolate, $2-3 \mathrm{~mm}$. long; bracts proper 8-9, narrowly linear; flowers as many; achenes fusiform, 5-8-striate; pappus dull white. Cañons and sandy plains: Sask.-Kans.-Colo. Plain. Jl-S.

\section{PRENANTHÉLLA Rydb.}

Low diffusely branched annuals, with numerous small heads terminating the branches. Lower leaves ample, more or less runcinate, the upper reduced and bract-like. Involucres oblong, 4-5-flowered, with as many oblong bracts and 
1 or 2 small calyculate ones. Achenes gradually tapering downward from the truneate summit, 4-5-ridged. Pappus of white soft eapillary bristles.

1. P. exigua (A. Gray) Rydb. Stem 1-2 dm. high, divaricately branched; basal leaves spatulate or oblong in outline, $2-3 \mathrm{~cm}$. long; involueres $3-4 \mathrm{~mm}$. high; calyculate bracts small, ovate; bracts proper 4-5, oblong. Lygodesmia exigua A. Gray. Stony hills: Tex.-Colo.-Utah-se Calif. Ap-Je.

\section{NÁBalús Cass. Rattlesnake-root.}

Perennial caulescent herbs. Heads small, elustered, and usually nodding. Involucre narrow, cylindric to campanulate; bracts narrow, in 1 or 2 subequal series, subtended by a few small calyculate ones. Receptacle flat, naked. Flowers pale, cream-colored or purplish. Achenes oblong or columnar, terete or 5 -angled, often 10-ribbed, sometimes slightly tapering towards the- base. Pappus of numerous capillary, rather rigid, pale or brown bristles. [Prenanthes Vaill.]

Basal leaves oblanceolate or spatulate; inflorescence hirsute. 1. N. ract
Basal leaves cordate, sagittate, or hastate; inflorescence glabrous or puberulent.

Leaves variously lobed or cleft; heads nodding; calyculate bracts ovate, very

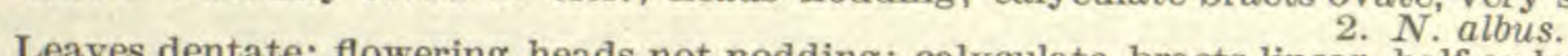
the bracts proper.

ear, half as long as

1. N. racemosus (Michx.) DC. Stem 5-10 dm. high, glabrous or pubescent above; basal leaves glabrous, entire or dentate, with winged petioles; stemleaves sessile, oblong or elliptic, partly clasping; heads in a long spike-like thyrsus; involucres campanulate, 12-14-flowered, $10-12 \mathrm{~mm}$. high; bracts narrowly linear, obtuse, hirsute; flowers rose or purplish; pappus fulvous. Moist ground: N.B.N.J.-Colo.-Mont.-Alta. Plain-Mont. Au-S.

2. N. albus (L.) Hook. Stem 5-15 dm. high, glabrous, often tinged with purple; leaves petioled; blades deltoid-hastate, denticulate, dentate, lobed, or divided, or the upper lanceolate and entire, thin, glabrous, paler beneath; heads numerous, paniculate, pendulous, about $12 \mathrm{~mm}$. high and $6 \mathrm{~mm}$. broad; principal bracts about 8 , purplish, linear; corollas greenish or white; pappus reddish brown. Open woods: Me.-Ga.-Ky.-Minn.-Sask. Boreal. Au-S.

3. N. sagittatus (A. Gray) Rydb. Stem glabrous, 3-7 dm. high; lower leaves petioled; blades sagittate, hastate or ovate, dentate or lobed, with lanceolate salient lobes, glabrous, thin; upper leaves sessile, lanceolate, acuminate; heads in a narrow panicle, at first erect, in fruit spreading or rarely somewhat deflexed; involucres about $12 \mathrm{~mm}$. high; bracts linear, green; flowers tinged with purple; pappus sordid. Along rivers: Mont.-Ida. Submont. Jl-S.

\section{CRÈPIS L.}

Annual, biennial, or perennial (all ours), mostly caulescent herbs. Involucre cylindric or campanulate; bracts in a single series, equal, with a more or less thickened midrib; a small outer calyculum present or absent. Flowers yellow. Achenes $10-30$-ribbed, narrowed towards the summit. Pappus of numerous,
white and soft bristles.

Plant neither canescent nor furfurascent; heads hemispherical to turbinate.

Involucres glabrous or tomentulose when young; neither hirsute nor glandular. Involucres and peduncles tomentulose, at least when young. 1 . C. tomentulosa.

Involucres and peduncles hirsute or glandular when young. Plant 3-10 dm. high; heads few or many.

Leaf-blades oblanceolate or oblong to linear-oblanceolate. Leaves long-petioled; petioles half as long to fully as long as the blades,
not winged.

Blades of the basal leaves broadly oblanceolate; stem usually with 1-2

leaves; involucres over $1 \mathrm{~cm}$. high.
Blades of the basal leaves narrowly linear-lanceolate or linear-oblanceolate; stem scapiform; involucres less than $1 \mathrm{~cm}$. high.

Leaves subsessile or with short winged petioles.

4. C. glaucella.

Leaves glabrous or nearly so; involucres with a few short hairs.

5. C. perplexans. 
Leaves hairy.

Involucres more sparingly and usually short-hirsute; peduncles and stem usually glabrous; involucres less than $1 \mathrm{~cm}$. high.

Involucres, peduncles, and usually also the stem, 6, C. runcinata. lar-hirsute; involucre over $1 \mathrm{~cm}$. high. Leaf-blades obovate to elliptic; involucres and peduncles densely glandularhispid with long hairs.

Involucres over $1 \mathrm{~cm}$. high; leaves hairy, 1.5-2 dm. long.

Involucres $1 \mathrm{~cm}$. or less high; leaves glabrous or nearly so.

8. C. riparia.

Plant 1-2 dm. high; heads solitary, rarely 2 or 3.
Plant more or less canescent or furfurascent, especially the leaves; heads mostly narro

9. C. denticulata. often almost cylindric.

Involucres glabrous, 5-7-flowered.

Leaves lanceolate in outline, pinnately lobed, with lanceolate to linear lobes.

Leaves more or less twice dissected, with linear-filiform divisions. 11. C. acuminata.

Involucres canescent.

Involucres cylindric; principal bracts of the involucres 5-8 (rarely 9-14); flowers of the same number; bracts not black-hairy, except sometimes in C. gracilis.

Leaves not divided to near the midrib; blade proper wider than the lobes. Blade proper broadly lanceolate; lobes usually directed downward.

Blade proper narrowly lanceolate to 13 . C. intermedia.

or spreading.
Leaves dissected to near the midrib into linear-filiform 14. C. angustata. pror or bisions, the blade

Involucres plant low.

Involucres and peduncles without black hairs; achenes nearly columnar.

Involucres and peduncles with some black hairs intermixed 16 . C. pumila. tum; achenes more or less fusiform.

Hairs glandular.

Hairs not glandular.

17. C. occidentalis.

Achenes ribbed, at maturity brown or almost black. Stem low, 1-2 dm. high, as well as the petioles usually hispid with yellow hairs; leaves not long-acuminate. 18. C, subacaulis. Stem tall, 4-5 dm. high, not hispid; leaves long-acuminate.

Achenes not ribbed at maturity, greenish or reddish. $\begin{aligned} & \text { 19. C. atribarba. } \\ & \text { C. scopulorum. }\end{aligned}$

1. C. tomentulosa Rydb. Stem scape-like, $4-5 \mathrm{dm}$. high; basal leaves glabrous and glaucous, 1-1.5 dm. long, oblanceolate in outline, acute, sessile, dentate, with sharp salient or reflexed teeth; stem-leaves, if any, linear-lanceolate, bract-like, entire; involucre turbinate, about $12 \mathrm{~mm}$. high; bracts linear-lanceolate, acuminate, with dark backs, and with a few calyculate ones at their base. Mountains: Colo. Submont.-Mont. J1.

2. C. glauca (Nutt.) T. \& G. Stem scape-like, 3-6 dm. high, glabrous; leaves oblanceolate in outline, tapering below into short petioles, more or less runcinate-pinnatifid, with triangular or lanceolate lobes or sometimes entire, glabrous and somewhat glaucous; involucres turbinate, about $1 \mathrm{~cm}$. high; bracts narrowly linear-lanceolate, acute, glabrous. C. lancifolia Greene. Valleys: Sask. -Colo.-Nev.-Alta. Plain-Mont. Je-Au.

3. C. petiolata Rydb. Stem with 1-3 leaves, glabrous and often purplish below, more or less glandular-hirsute above; basal leaf-blades usually obtuse, sinuate-dentate or entire, about $1 \mathrm{dm}$. long, glabrous and glaucous; stem-leaves oblanceolate and usually sessile; involucre about $12 \mathrm{~mm}$. high, turbinate-campanulate, with glandular black hairs; bracts linear-lanceolate, acuminate. Mountains: S.D.-Colo.-Utah-Wyo. Submont.-Mont. J1-Au.

4. C. glaucella Rydb. Stem slender, about $3 \mathrm{dm}$. high, glabrous and shining; basal leaves glabrous and shining, somewhat glaucous, thin, 5-10 cm. long; blades oblanceolate, acute at the apex, remotely sinuate-dentate, with divaricate or retrorse short teeth, or entire; stem-leaves 1-2, much reduced, 1-2 cm. long, linear or nearly so; involucre turbinate, sparingly hirsute; bracts linear-lanceolate, acuminate. Wet meadows: Sask.-Mont.-Colo. Submont.-Mont. J-S.

5. C. perplexans Rydb. Stem scape-like; leaves about $1 \mathrm{dm}$. long, glaucous and glabrous or rarely with a few hairs on the midrib below and on the margin, 
of the narrower base, oblanceolate, runcinate-toothed; involucres turbinate-campanulate, about $1 \mathrm{~cm}$. high, more or less glandular-hairy, with yellowish hairs; bracts linear-lanceolate, acuminate; calyculum about one-third as long. Valleys: Man.-Neb.-Colo.-Alta. Submont.-Mont. Je-Au.

6. C. runcinata (James) T. \& G. Stem scapiform, $3-5 \mathrm{dm}$. high, slightly pubescent or glabrous; leaves mostly basal, oblanceolate or spatulate, tapering below, dentate or entire or runcinate, rather densely glandular-hirsute; involucres turbinate, glandular-hirsute, with 'yellowish hairs; bracts narrowly lancelinear. Valleys: Sask.-N.D.-Colo.-Alta. Je-Au.

7. C. platyphylla Greene. Stem scape-like, 3-6 dm. high, glandular-hirsute in the inflorescence, otherwise glabrous; leaves basal, hirsute, oblanceolate, dentate or somewhat runcinate, $10-15 \mathrm{~cm}$. long; involucres broadly turbinate, 12-15 mm. high, densely glandular-hirsute; bracts lance-linear. $\check{C}$. runcinata hispidulosa Howell. (?) C, subcarnosa Greene. Meadows and bogs: Mont.Wyo.-Utah-Neb.-Ore. Plain-Submont. Je-Au.

8. C. riparia A. Nels. Stems $2-4 \mathrm{dm}$. high, subscapose, minutely and sparsely pubescent below, glandular-hirsute in the inflorescence; leaves mostly basal, usually rounded at the apex, coarsely and irregularly dentate or entire, somewhat runcinate towards the base, $10-18 \mathrm{~cm}$. long, sparingly hirsute on the veins; involueres broadly turbinate, $12-15 \mathrm{~mm}$. high, densely glandular, with dark hairs; principal bracts linear. (?) C. aculeolata Greene. River-banks: Neb. -Colo.-Utah-Wyo. Plain-Submont. Jl-Au.

9. C. denticulata Rydb. Stem scape-like; leaves basal, obovate or more rarely obovate-oblanceolate, glabrous or nearly so, obtuse, less than $1 \mathrm{dm}$. long, denticulate or with a few lobes towards the base. Mountains: Wyo.-Colo.Utah. Submont.-Mont. J1-Au.

10. C. alpicola (Rydb.) A. Nels. Stem scape-like, 1-2 dm. high, glandularhirsute above; leaves obovate or oblanceolate, sessile or nearly so, entire or dentate, glabrous, 3-6 cm. long; involucres 12-14 mm. high, glandular-hirsute; principal bracts lance-linear. High mountains: Mont.-Colo. Mont.-Alp. Au.

11. C. acuminata Nutt. Stem 4-8 dm. high, 1-3-leaved; basal leaves slender-petioled; blades 1-2 dm. long, broadly lanceolate in outline, long-acuminate at the apex, grayish canescent; lobes salient or reflexed; stem-leaves subsessile, the upper ones linear and entire; heads corymbose; involucres cylindric, glabrous, about $1 \mathrm{~cm}$. high, 4-5 mm. broad; principal bracts 5-7. Hillsides: Alta.-Colo. -Calif.-B.C. Submont. Je-Au.

12. C. sesilifolia Rydb. Stem 4-6 dm. high, slender, canescent-tomentose or glabrous above; basal leaves long-petioled; blades 1-2 dm. long, deeply twicepinnatifid, with linear-filiform divisions, canescent, caudate-acuminate; stemleaves subsessile, less divided, the uppermost entire and linear-filiform; involucre about $1 \mathrm{~cm}$. high; bracts proper 5-7, linear, yellowish green. Rocky hillsides: Ida. Submont. Je.

13. C. intermedia A. Gray. Stem 3-5 dm. high, canescent-tomentulose; basal leaves broadly lanceolate, acuminate, canescent-tomentulose, usually divided only halfway to the midrib into lanceolate acuminate lobes, which are usually directed downward; stem-leaves subsessile, the uppermost linear and entire; involucres subcylindric, tomentose, $12-14 \mathrm{~mm}$. high; bracts proper about 7 , linear-lanceolate, more or less scarious-margined. Hillsides: Sask. - Colo.Calif.-B.C. Submont. My-Au.

14. C. angustata Rydb. Stems $3-7 \mathrm{dm}$. high; basal leaves and lower stemleaves petioled, canescent-puberulent, runcinate; main body narrowly linearlanceolate, acuminate; upper stem-leaves entire and sessile; involucre cylindric, about $1 \mathrm{~cm}$. high and $5 \mathrm{~mm}$. broad; bracts $5-7$, linear-lanceolate, acute, canescent. Mountains: Mont.-Colo.-Ore.-B.C. Submont. Je-Au.

15. C. gracilis (D. C. Eat.) Rydb. Stem slender, $2-5 \mathrm{dm}$. high, canescenttomentulose; basal leaves petioled, the cauline ones sessile, all except the uppermost pinnatifid, with narrowly linear divisions; involueres tomentulose, cylindric, about $1 \mathrm{~cm}$. high; bracts proper, 7-14, narrowly linear-lanceolate, often with a 
few black hairs along the midvein. C. occidentalis gracilis D. C. Eat. C.exilis Osterhout. Hillsides and mountain slopes: Mont.-Colo.-Nev.-Ida. Son.Submont. Je-Au.

16. C. pumila Rydb. Stem rather low and stout, $1.5-2 \mathrm{dm}$., rarely $3 \mathrm{dm}$. high, canescent-tomentose, leafy; basal leaves petioled; blades 8-10 $\mathrm{cm}$. long, broadly lanceolate, acute, laciniate-pinnatifid about halfway to the midrib, with lanceolate-triangular lobes; the stem-leaves sessile; involucres canescent, campanulate, about $12 \mathrm{~mm}$. high; principal bracts about 10, linear or linear-lanceolate. $C$. occidentalis costata A. Gray. Dry hillsides: Mont.-Wyo.-UtahNev. Submont. My-Au.

17. C. occidentalis Nutt. Stem stout, 1-3 dm. high, canescent-tomentose, usually also glandular-hispid in the inflorescence; basal leaves petioled; -blades 1-2 dm. long, broadly lanceolate or oblanceolate, runcinate-lobed or cleft, usually about halfway to the midrib, canescent-tomentose, acute; lobes triangular or lanceolate, often toothed; involucres campanulate, $12-15 \mathrm{~mm}$. high; bracts proper 9-14, tomentose. Plains and hillsides: Sask.-Colo.-Ariz.-Calif.-B.C. Plain-Submont. My-Au.

18. C. subacaulis (Kellogg) Coville. Stem 1-2 dm. high, striate, canescenttomentose as well as hirsute but not glandular; basal leaves petioled; cauline leaves sessile, all pinnatifid or bipinnatifid, tomentose and somewhat hirsute on the rachis and ribs; involucres campanulate, $12-15 \mathrm{~mm}$. high; bracts proper 1117, lance-linear, tomentose and usually with scattered bristles. C. occidentalis subacaulis Kellogg. Dry hillsides: Calif.-Wyo. Son,-Submont. Je.

19. C. atribarba Heller. Stem 4-5 dm. high, tomentose or in age glabrate; basal leaves petioled; blades lanceolate, 1-1.5 dm. long, deeply pinnately lobed or runcinate, with lanceolate or lance-linear divisions, canescent-tomentulose, long-caudate; uppermost cauline leaves much reduced and entire; involucres campanulate, 12-14 mm. high, tomentose; bracts linear, somewhat scariousmargined, with seattered black bristles on the back. Hills: Mont.-Ida. Son. - Submont. Je.

20. C. scopulorum Coville. Stem 1-4 dm. high, seantily tomentose, usually glabrate in age, bearing scattered glandless bristles; basal leaves petioled, pinnatifid or bipinnatifid, with linear or linear-lanceolate divisions, tomentose and also hirsute on the veins; heads corymbose, long-peduncled; involueres campanulate, $10-12 \mathrm{~mm}$. high, sparingly tomentose, and sparingly greenish hispid; calyculate bracts lanceolate, $2 \mathrm{~mm}$. long; bracts proper 13-17, lance-linear. Mountains: Mont.-Colo.-Nev.-Ore. Submont. My-Jl.

\section{HETEROPLEÙRA Schultz-Bip.}

Perennial leafy-stemmed herbs, of the habit of Hieracium. Involucre campanulate; bracts in 1 or 2 series, subequal, narrow, with a few calyculate ones at the base, not thickened on the back. Flowers light yellow. Achenes tapering from the base to the summit, 10-ribbed, the alternating ribs much stronger. Pappus of numerous dirty white soft bristles.

1. H. Fendleri (Schultz-Bip.) Rydb. Stem scape-like, $2-3 \mathrm{dm}$. high, sparingly setose-hirsute; basal leaves spatulate or obovate, with short wing-margined petioles, setose-hirsute, the hairs long, with pustulate bases; stem-leaves few, the upper or all reduced, narrowly linear, and bract-like; heads rather few, racemiformpaniculate, long-peduncled, nodding in anthesis; involucres eampanulate, 12-14 $\mathrm{mm}$. high; bracts proper lance-linear, puberulent or glabrate, with or without a few long hairs; achenes reddish or blackish. Heteropleura ambigua (A. Gray) Schultz-Bip. Hieracium Fendleri Schultz-Bip. H. nigrocollinus S. Wats. Woods: (Black Hills) S.D.-N.M.-Ariz, Submont.-Mont. Je-Au.

\section{HIERÃCIUM (Tourn.) L. HawKWEed.}

Perennial, mostly caulescent herbs, with entire or dentate leaves and paniculate heads. Involucre cylindric or campanulate; bracts in 1-3 series, subequal or somewhat imbricate, not thickened on the back, with a few small calyculate 
ones at the base. Flowers yellow, seldom white or orange. Achenes cylindric, not tapering towards the apex, truncate, 10-15-ribbed. Pappus of 1 or 2 series of sordid or brownish, fragile capillary bristles.

Involucres of the rather large heads irregularly more or less imbricate.

Stem yellowish or whitish hirsute below.

Stem glabrous or puberulent.

1. H. columbianum.

2. H. scabriusculum.

Involucres of the rather small heads of an almost single series of principal bracts and small calyculate ones below.

Flowers yellow.

Plant 4-10 dm, high, leafy.

Involucres and peduncles densely hairy with long yellow hairs.

Involucres blackish and glandular, without or with a few scattered yellow hairs.

Involucres 8-10 mm. high, with scattered yellow hairs. 4. H. griseum.

Involucres 6-8 mm. high, without yellow hairs on the involucre or peduncles.

Plant low, 1-3 dm. high, with 1-3 stem-leaves and few heads. 5. H. cynoglossoides.

6. H. gracile.

7. H. albiflorum.

Flowers white or ochroleucous.

1. H. columbianum Rydb. Stem about $6 \mathrm{dm}$. high, terete, more or less tinged with purple; lower leaves oblanceolate, 8-10 $\mathrm{cm}$. long, light green and somewhat glaucous beneath, usually more or less silky-hirsute, sinuately dentate, acute; middle leaves lanceolate or ovate-lanceolate, with rounded or obtuse bases, sessile, the uppermost much reduced and bract-like; inflorescence corymbosecymose; heads 2-6; involucres $10-12 \mathrm{~mm}$. high; bracts lanceolate, dark, puberulent when young, glabrous in age. Marshy ground: Mont.-Ida.-Wash.-B.C. Submont. Jl-Au.

2. H. scabriusculus Schwein. Stem erect, rather simple and strict, leafy; lower leaves oblanceolate, the rest lanceolate, sessile, $3-8 \mathrm{~cm}$. long, distantly and acutely dentate, rather firm, paler beneath, scabrous-puberulent; heads corymbose; involucres rounded-campanulate, $10-12 \mathrm{~mm}$. high; bracts glabrous or nearly so, usually blackish. H. macranthum Nutt. Open woods, hills, and valleys: Man.-Minn.-Wis.-Ore.-B.C. Plain-Submont.

3. H. albertinum Farr. Stem $3-5 \mathrm{dm}$. high, villous with long white or yellowish hairs from black papillae, or black-hairy above; leaves $5-12 \mathrm{~cm}$. long, the lower oblanceolate with winged petioles, the upper lance-linear to oblonglanceolate, densely long-hairy; heads paniculate; involucres 10-12 mm. high; bracts long, narrowly lance-linear; pappus tawny. H. Scouleri A. Gray, not Hook. Hills and woods: Alta.-Utah-Ore.-Wash. Submont.-Mont. JI-Au.

4. H. griseum Rydb. Stem 6-10 dm. high, eovered with long white or yellowish hairs from evident papillae; lower leaves linear-oblanceolate, the upper oblong-linear or lance-linear, sessile, densely long-hairy; heads in a narrow panicle; involucres about $1 \mathrm{~cm}$. high; inner bracts linear-lanceolate, glandular, dark, and at least when young beset with a few long hairs; pappus yellowish or tawny. Hills, benchlands, and open woods: Alta.-Wyo.-Utah-B.C. Submont.Mont. Jl-Au.

5. H. cynoglossoides Arvet-Touvet. Stem 3-5 dm. high, several-leaved, hirsute throughout or glabrous above; lower leaves oblanceolate, rather sparingly hirsute; upper leaves lanceolate, sessile, often glabrate; heads corymbose-paniculate; involucres campanulate, $8-10 \mathrm{~mm}$. high, black; bracts proper narrowly linear, densely glandular, but without long hairs; pappus tawny-white. Hills: Mont.-Wyo.-Wash.-B.C. Submont. Je-Au.

6. H. gracile Hook. Stem 1-3 dm. high, often scape-like, puberulent or glabrate, sometimes with a few hispid hairs, especially in the inflorescence; basal leaves obovate to oblong-spatulate, $2-7 \mathrm{~cm}$. long, petioled, entire or repanddenticulate, glabrous or nearly so; upper stem-leaves all small and bract-like; heads usually few; involucres campanulate, $7-9 \mathrm{~mm}$. high, usually densely blackhirsute; pappus sordid or tawny. Mountains: Alta.-N.M.-Calif.-Alaska. Submont.-Subalp. Je-Au.

7. H. albiflorum Hook. Stem $3-6 \mathrm{dm}$. high, more or less leafy or in depauperate specimens scapiform, long-hirsute below, glabrate above; basal leaves 
petioled; blades oblanceolate or oblong, thin, long-hirsute, especially on the veins and petioles; stem-leaves sessile, lanceolate, less hairy; heads numerous, corymbose-paniculate; involucres campanulate, $8-10 \mathrm{~mm}$. high; bracts proper narrowly lance-linear, glabrous or minutely puberulent; pappus sordid. Woods: Sask.Colo.-Calif.-Yukon. Submont.-Mont. Je-Au.

\section{AGÓSERIS Raf. Goat Chicory.}

Perennial herbs, with strong taproots, or annuals, mostly acaulescent. Involucre campanulate to nearly cylindric; bracts imbricate in a few series, the outer broader and shorter. Flowers yellow, orange, or purplish. Achenes fusiform or oblong, 10-ribbed, narrowed above into a beak. Pappus of numerous capillary white bristles.

Perennials.

Beak short, scarcely more than half as long as the body of the achene, striate throughout.

I. GLAUCAE.

Beak long, about as long as or longer than the body of the achene, scarcely striate at the middle.

Body of the achenes tapering at the apex. Annuals.

Body of the achenes truncate at the apex.

II. AURANTIACAE.

III. RETRORSAE.

\section{GLAUCAE.}

Leaves decidedly pubescent, even in age.

Outer bracts linear-lanceolate to oblong, obtuse or acute.

Outer bracts linear-lanceolate.

Plant tall and stout, $3^{-5} \mathrm{dm}$. high; involucres broadly campanulate, about $2.5 \mathrm{~cm}$. high and $2.5-3 \mathrm{~cm}$. wide.

1. A. taraxacifolia.

Plant low, 1-2 dm. high; involucres less than $2 \mathrm{~cm}$. high and $1-2 \mathrm{~cm}$. wide. Leaves linear-oblanceolate, $6-10 \mathrm{~cm}$. long; peduncle slender, about $2 \mathrm{dm}$. high.

2. A. pubescens.

Leaves oblanceolate, 4-6 cm. long, often lobed or toothed; peduncles $1 \mathrm{dm}$. high or less.

Outer bracts oblong or oblong-ovate.

3. A. aspera.

Scape low and stout, about $2 \mathrm{dm}$. high; leaves oblanceolate, about $1 \mathrm{dm}$. long.

4. A. villosa.

Scape tall, about $6 \mathrm{dm}$. high; leaves 2-3 dm. long; flowers turning purple.

Outer bracts ovate or ovate-lanceolate, acuminate. $\quad 6$. A. maculata.

Leaves in age glabrate and glaucous.

Bracts villous-ciliate, at least on the margins.

Involucre turbinate; leaves narrowly linear; flowers light yellow, turning pink.

7. A. turbinata.

Involucres campanulate to hemispherical; leaves oblanceolate or lanceolate.

Inner bracts long-acuminate; plant less than $2 \mathrm{dm}$. high.

Inner bracts merely acute.

8. A. attenuata.

Leaves obtuse or acute, entire or rarely toothed.

Outer bracts much broader than the inner, often obtusish: plant generally low and leaves short, obtuse. 9. A. pumila.

Outer bracts usually not much broader than the inner; plant $3-5 \mathrm{dm}$. high; leaves long and acute. 10. A. scorzoneraefolia.

Leaves acuminate, more or less pinnatifid. 11. A. agrestis

Bracts glabrous; involucres if at all hairy, tomentose only at the very base.

Outer bracts oval or ovate, obtusish; leaves 2-3 dm. long, oblanceolate; flowers rose-colored.

12. A. roseata.

Bracts all linear-lanceolate, acute or acuminate; flowers yellow.

Leaves entire or toothed; fiowers yellow, turning pink. Leaves linear-oblanceolate.

Leaves narrowly linear.

13. A. glauca.

14. A. parviflora

Leaves pinnatifld, with narrow lobes; flowers yellow, turning purple. Bracts, with loose spreading tips; heads broadly campanulate.

Bracts appressed; heads more or less turbinate. 16. A. laciniata.

\section{Aurantiacae.}

Bracts all broad, ovate to elliptical, abruptly acuminate.

\section{A. montana.}

Bracts, at least the inner ones, linear or linear-lanceolate, acute.

Involucres more or less regularly imbricate; beak about equalling the body of the achenes.

Leaves densely pubescent. Plant low; flowers purple. Plant tall; flowers yellow.

Leaves glabrous or nearly so, somewhat hairy in No. 27. Flowers reddish brown or deep orange, changing into purplish Bracts with purplish blotches; leaves glaucous.

18. A. arachnoidea.

19. A. elata.

20. A. purpurea. 
Bracts not with purplish blotches, if at all purplish only along the midrib. Leaves narrowly linear, glaucous, usually pinnatifid with linear lobes. 21. A. graminifolia.

Leaves oblanceolate, usually entire, rarely with short broad lobes or teeth.

All bracts linear-lanceolate and acute.

Plant tall, slender, $3-5 \mathrm{dm}$. high; leaves erect; heads $2-3 \mathrm{~cm}$. high.

22. A. gracilens.

Plant low, 1-3 dm. high; leaves spreading; heads $1.5-2 \mathrm{~cm}$ high. 23. A. nana.

Outer bracts oblong or lanceolate, often obtuse.

Plant low, $1 \mathrm{dm}$, high or less; inner bracts only slightly longer. 24. A. carnea.

Plant taller, 3-5 dm. high; inner bracts much longer. 25. A. aurantiaca.

Flowers light yellow, but often turning pinkish; inner bracts elongate in age. Involucres $2-2.5 \mathrm{~cm}$. in diameter; plant tall and stout, scarcely glaucous. 19. A. elata.

Involucres less than $1 \mathrm{~cm}$. in diameter; plant slender, glaucous. Scapes tall, 2.5-4 dm. high, much exceeding the leaves.

26. A. arizonica.

Scapes low, about $1 \mathrm{dm}$. high, slightly if at all exceeding the leaves. 27. A. leptocarpa.

Involucres of two distinct sets of bracts, the inner narrowly linear, 2-3 times as long as the ovate or oval outer ones; beak $2-3$ times as long as the body of the achenes.

Leaves glabrous and glaucous, linear or oblanceolate, acuminate, with linear lobes, or entire.

Outer bracts oblong-obtuse; lobes of the leaves linear to lanceolate, acute.

28. A, rostrata.

Outer bracts acute or acuminate; lobes of the leaves narrowly linear.

29. A. tenuifolia.

Leaves more or less pubescent, oblanceolate in outline. Leaves obtuse and with oblong-obtuse lobes. Leaves attenuate and with lanceolate, acute lobes.

30. A. obtusifolia.

31. A. grandiflora.

One species.

III. RETRORSAE.

One species.

IV. HETEROPHYLLAE.

32. A. retrorsa.

33. A. heterophylla.

1. A. taraxacifolia (Nutt.) Dietr. Leaves oblanceolate or linear-oblanceolate in outline, usually more or less toothed or lobed, with lanceolate, salient teeth or lobes, permanently villous, 1-2 dm. long; scape more or less villous; involucres broadly campanulate, about $2.5 \mathrm{~cm}$. high, $2.5-3 \mathrm{~cm}$. broad, villous-tomentose at the base; bracts all linear-lanceolate, villous-ciliate on the margins, with a purplish midvein and sometimes with purple blotches, the inner attenuate; flowers yellow, turning pinkish; body of the achenes fusiform, about $1 \mathrm{~cm}$. long, gradually tapering into a striate beak $3 \mathrm{~mm}$. long. Troximon taraxacifolium Nutt. Meadows: Wash.-Ida.-Utah. Submont. Je-Jl.

2. A. pubescens Rydb. Leaves narrowly oblanceolate, about $1 \mathrm{dm}$. long, $0.5-1 \mathrm{~cm}$. wide, acuminate, slightly glaucous, but even in age villous-pubescent; seape 1.5-2 dm. high, sparingly villous; involuere about $2 \mathrm{~cm}$. high and $1.5 \mathrm{~cm}$. wide, villous and somewhat viscid; bracts with a dark median line and sometimes tinged with purple, the outer ones lanceolate to linear-lanceolate; flowers lemonyellow, the outer striate or tinged with purple. T. puhescens A. Nels. Moist meadows and hillsides: Man.-Colo.-B.C. Plain-Submont. Je-Au.

3. A. aspera Rydb. Leaves oblanceolate, 4-6 $\mathrm{cm}$. long, often lobed or toothed, permanently short-villous, with rather coarse hairs; scapes $3-10 \mathrm{~cm}$. high; involucres turbinate, 10-14 mm. high; bracts linear-lanceolate or the outer lanceolate, aeute, with a purplish midvein, villous throughout, with longer hairs on the margins; flowers light yellow, turning pink, purple-veined. A. Leontodon v. aspera and v. pygmaea Rydb. Mountains: Mont.-Ida.-B.C. Mont. -Subalp. Jl.

4. A. villosa Rydb. Leaves very villous, about $1 \mathrm{dm}$. long, broadly lanceolate or oblanceolate, entire or laciniately toothed, rather thick; scape stout, 1-3 $\mathrm{dm}$. high, densely villous when young; involucres broadly campanulate or hemispheric, $2 \mathrm{~cm}$. high and $2-2.5 \mathrm{~cm}$. broad; bracts densely villous, the outer oblong or oblong-ovate, obtuse or acutish, the inner lanceolate, acute, with dark mid- 
rib; flowers light yellow, turning pinkish. T. villosum A. Nels. Mountains and hills: Alta.-Mont.-Utah-B.C. Submont.-Mont. Je-Au.

5. A. altissima Rydb. Leaves linear-oblanceolate, entire, sparingly villous, especially on the margins; scapes sparingly villous; involucres broadly campanulate, $2 \mathrm{~cm}$. high and broad; bracts densely pilose, more or less brownish in color, the outer ovate-oblong, obtuse, or acute, the inner lanceolate, acute; flowers yellow, turning pinkish. Meadows: Alta.-Mont. Submont.

6. A. maculata Rydb. Leaves oblanceolate, more or less pubescent, especially on the margins and veins; scape 1-2 dm. high, often sparingly hairy and villous under the head; involucre campanulate, about $2 \mathrm{~cm}$. high; outer bracts dotted with blackish dots; inner bracts lanceolate, all abruptly acuminate; ligules yellow or the outer tinged with reddish. A. apiculata Greene. Mountains: Colo. Mont.-Alp. Jl-Au.

7. A. turbinata Rydb. Leaves narrowly linear, $7-15 \mathrm{~cm}$. long, $1-5 \mathrm{~mm}$. broad, glabrous, bluish green, the midvein and base often purplish, entire, attenuate; scape about $3 \mathrm{dm}$. high, slender, sparingly villous, more densely so under the head; involucres $17-20 \mathrm{~mm}$. high; bracts all narrowly lance-linear, villous on the back and the margins, with dark purple middle and yellowish green margins; ligules 15-18 mm. long, yellow, with purple veins, turning pinkish in age. Mountains: Alta. Mont.

8. A. attenuata $\mathrm{Rydb}$. Leaves narrow ly oblanceolate, $1-1.5 \mathrm{dm}$. long, glabrous and glaucous, usually denticulate, tapering into a short petiole; scape about $1.5 \mathrm{dm}$. high, villous near the head; involucre campanulate, about $2 \mathrm{~cm}$. high; outer bracts ovate-lanceolate, somewhat villous on the margins, purplish on the back. Mountains: Colo. Mont. Au.

9. A. pumila (Nutt.) Rydb. Leaves $5-15 \mathrm{~cm}$. long, usually broadly oblanceolate, entire or merely dentate, glabrous and somewhat glaucous; scape 1-2 dm. (rarely $3 \mathrm{dm}$.) high, stout, more or less villous under the heads; involucres campanulate, about $2 \mathrm{~cm}$. high, $2-2.5 \mathrm{~cm}$. broad; bracts villous-ciliate on the margins and usually also on the back; outer bracts ovate to oblong, often obtuse or rounded at the apex; flowers light yellow, with purplish veins, turning pinkish in age. T. pumilum Nutt. Hills: Mont.-Colo. Submont.-Alp. J-Au.

10. A. scorzoneraefolia (Schrad.) Greene. Leaves oblanceolate or linearoblanceolate, scarcely glaucous, glabrous, 1-3 dm. long, usually acute, entire, or rarely dentate; scape villous under the head; involucres $2-3 \mathrm{~cm}$. high, $2-3.5 \mathrm{~cm}$. wide; bracts lanceolate or the inner linear-lanceolate, acute, villous-ciliate at least on the margins; flowers light yellow, with purplish veins, turning pinkish in age. T. glaucum dasycephalum T. \& G. Hillsides: Alta.-S.D.-Colo.-Nev. -Ore.-B.C. Plain-Submont. J1-Au.

11. A. agrestis Osterhout. Leaves linear or oblong in outline, more or less pinnatifid or saliently toothed, with up-turned divisions, acuminate; scape 2-3 $\mathrm{dm}$. high, glabrous; involucres about $2 \mathrm{~cm}$. high and as broad; bracts acuminate, the outer ovate or ovate-lanceolate, the inner linear-lanceolate; flowers yellow, drying purplish. A. Leontodon Rydb. (Fl. Colo.), in part. Hills and mountains: Colo,-Mont. Submont.-Subalp. J-Au.

12. A. roseata Rydb. Leaves about $2 \mathrm{dm}$. long, long-petioled; blades oblanceolate, acute, denticulate or entire or pinnatifid, glabrous and glaucous; scape 5-6 dm. high, slightly villous above; involucre campanulate, 1.5-2 cm. high; bracts oblong-ovate, acute, nearly glabrous, often with a rose-colored spot in the middle; corolla rose-colored. Hills: Colo. Submont. Jl-Au.

13. A. glauca (Nutt.) Greene. Leaves 1-2 dm. long, glaucous, not tworanked, rarely pinnatifid; scape $2-4 \mathrm{dm}$. high, glabrous; involucres turbinate or turbinate-campanulate; bracts lanceolate or linear-lanceolate, acute; corollas light yellow, turning pinkish. (?) A. vicinalis Greene, T. glaucum Nutt. Prairies and meadows: Man.-S.D.-Colo.-Utah-Wash.-B.C. Plain-Mont. $\mathrm{Je}-\mathrm{Au}$.

14. A. parviflora (Nutt.) Greene. Leaves 1-1.5 dm. long, 2-5 mm. wide; more or less distinctly 2-ranked; scapes decumbent at the base, 1-2 dm. high, 
glabrous; involucres turbinate, about $15 \mathrm{~mm}$. high; bracts linear-lanceolate; corollas yellow, turning pink in drying. T. parviflorum Nutt. Meadows: Man.N.D.-Colo.-Utah-Wash. Plain-Submont. Je-Au.

15. A. rosea (Nutt.) Greene. Leaves $7-15 \mathrm{~cm}$. long, pinnatifid, with linear divisions, caudate-acuminate, glabrous; scape 1-1.5 dm. high, decumbent or ascending, glabrous; involucres about $15 \mathrm{~mm}$. high, slightly villous at the base; bracts lanceolate to linear-lanceolate; corollas yellow, turning rose-colored. $T$. roseum Nutt. Plains and table-lands: Colo.-Wyo. Submont. My-Jl.

16. A. laciniata (Nutt.) Greene. Leaves linear or lance-linear in outline, pinnatifid with narrow, lanceolate or linear divisions, glabrous or slightly villous, when young; scape 1-2 dm. high; involucres turbinate, slightly villous below, about $15 \mathrm{~mm}$. high; bracts linear-lanceolate or lanceolate; corollas light yellow, turning rose-colored. Stylopappus laciniatus Nutt. Troximon arachnoideum A, Nels., not A. arachnoidea Rydb. Meadows and valleys: Wyo.-Colo.-Calif.B.C. Submont.-Mont. Je-Au.

17. A. montana Osterhout. Leaves oblanceolate, 1-2 dm. long, glabrous or slightly villous when young, entire or dentate, dark green; scapes $1-3 \mathrm{dm}$. high, woolly beneath the head and at the base; involucres campanulate, about 3 cm. high, more or less villous; flowers yellow. Mountains: Colo.-Wyo. Mont.

18. A. arachnoidea Rydb. Leaves $1.5-2 \mathrm{dm}$. long, more or less runcinatelobed, oblanceolate in outline, long-attenuate at the apex, densely floccose when young; scape $1.5-4 \mathrm{dm}$. high, densely woolly above; head $2-2.5 \mathrm{~cm}$. high, $1.5-2$ $\mathrm{cm}$. broad; bracts in about 3 series, linear-lanceolate, long-attenuate; flowers at least in age rose-purple. Hills: Colo. Submont.-Mont. Je-Jl.

19. A. elata (Nutt.) Greene. Leaves thickish, oblanceolate in outline, dentate or pinnatifid, with lanceolate divisions, somewhat villous, especially when young, or glabrate; scapes usually several, robust, $3-5 \mathrm{dm}$. high, villous, especially under the heads; involucres campanulate, villous especially below; bracts linear-lanceolate or the outer lanceolate, all gradually acute; corollas yellow. T. Nuttallii Greene. T. elatum A. Nels., not Greene. Low ground: Mont.-Colo.-Calif.-B.C. Submont.-Mont. Je-Au.

20. A. purpurea (A. Gray) Greene. Leaves linear or linear-oblanceolate, glaucous and glabrous, at least in age, dentate or pinnatifid; scape 1-2 dm. (rarely $3 \mathrm{dm}$.) high, villous, especially under the heads; involucres turbinate, 1.5 $\mathrm{cm}$. high, or in fruit fully $2 \mathrm{~cm}$. high; outer bracts oblong and obtuse, the inner linear-lanceolate, acute; flowers orange, turning purple. T. aurantiacum purpureum A. Gray. Mountains: Colo.-N.M.-Ariz,-Utah. Submont.-Mont.
J-Au.

21. A. graminifolia Greene. Leaves glabrous, somewhat glaucous, narrowly linear, from entire to pinnatifid with linear lobes, long-attenuate; scape about 3

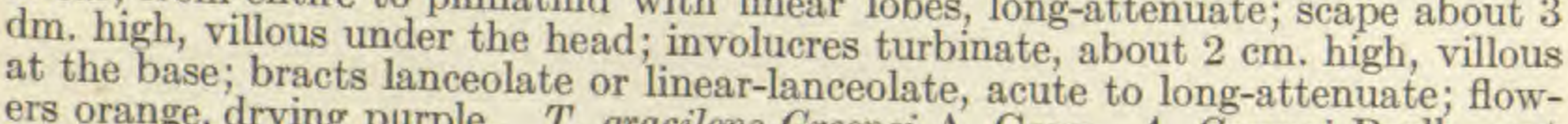
ers orange, drying purple. T. gracilens Greenei A. Gray. A. Greenei Rydb., not A. Greeneana O. Kuntze. Meadows: Alta.-Ariz.-Utah-B.C. Submont.-
Subalp.

22. A. gracilens (A. Gray) Kuntze. Leaves oblanceolate, rarely linear in outline, usually entire or some with a few short lobes, 1-2 dm. long; scape slender, 1-4 dm. high, villous below the head; involucres turbinate-campanulate, 18-20 mm. high; bracts linear-lanceolate, acute or acuminate; flowers orange, turning purple. T. gracilens A. Gray. A. gracilenta Greene. Meadows and hillsides: Alta.-Colo.-Utah-B.C. Plain-Subalp.

23. A. nana Rydb. Leaves spreading or ascending, oblanceolate or linearoblanceolate, 6-10 $\mathrm{cm}$. long, entire or denticulate, glabrous or slightly hairy on the short petioles; scape 1-1.5 (seldom 2) $\mathrm{cm}$. high, slightly villous below the côrolla rose-purple or at first orange. tains: Colo.-Wyo. Mont. 
24. A. carnea Rydb. Leaves oblanceolate, entire, or denticulate, $8-15 \mathrm{~cm}$. long, glabrous, dark green; scape 1-2 dm. high, villous under the head; involucres turbinate, about $15 \mathrm{~mm}$. high, villous; outer bracts oblong, obtuse, about equalling the inner linear-lanceolate, acute ones, somewhat purple-spotted; flowers orange, turning pink and purple. Wet places: Alta.-Mont.-B.C. Submont.

25. A. aurantiaca (Hook.) Greene. Leaves oblanceolate, entire or dentate or lobed with reflexed or salient lobes; scape 4-6 dm. high, villous under the head; involueres turbinate-campanulate, $15-20 \mathrm{~mm}$. high; inner bracts linear-lanceolate and acute; flowers orange, turning purplish. T. aurantiacum Hook. Meadows and banks: Alta.-Colo.-Utah-B.C. Submont.-Alp. Jl-Au.

26. A. arizonica Greene. Leaves linear or linear-oblanceolate, entire, runcinate-toothed, or somewhat lobed, 1-1.5 dm. long, somewhat glaucous; scape $2.5-4 \mathrm{dm}$. high, villous under the head; involueres turbinate, $2-2.5 \mathrm{~cm}$. high, about $1.5 \mathrm{~cm}$. broad; bracts rather few, in three series, lanceolate to narrowly linear-lanceolate, nearly glabrous and with a purple midvein; flowers light yellow, turning rose-colored. Mountains: N.M.-Colo.-Utah-Ariz. Submont--Mont.
Je-Au.

27. A. leptocarpa Osterhout. Leaves linear or linear-oblanceolate, entire to runcinate-pinnatifid, $5-8 \mathrm{~cm}$. long, glabrous or somewhat villous, somewhat glaucous; scape 1-1.5 cm. high, villoas under the heads; involucres turbinate, $15-20$ $\mathrm{mm}$. high; bracts in 3 series, with purple midribs, the outermost lanceolate, acute, the inner linear-lanceolate; flowers light yellow, turning pinkish. A. caudata Greene. Hills and plains: Wyo.-Colo.-Utah. Submont.-Mont. Je,

28. A. rostrata Rydb. Leaves narrowly linear-lanceolate, about $2 \mathrm{dm}$. long, usually more or less laciniate, with linear lobes, glabrous and glaucous; scape $2-6 \mathrm{dm}$. high, more or less villous under the head; involucre fully $3 \mathrm{~cm}$. high; inner bracts elongate-linear or linear-lanceolate; corolla orange or purple. Mountains: Colo. Submont.-Mont. Je-Au.

29. A. tenuifolia (A. Gray) Rydb. Leaves linear-oblanceolate or linear, laciniate-dentate or pinnatifid, with narrow divisions, slightly villous or glabrous, caudate-acuminate; scape slender, $3-5 \mathrm{dm}$. long, glabrous, slightly villous under the heads; involucres campanulate or nearly hemispheric, $15-25 \mathrm{~mm}$. high; bracts in about 4 series, those of the two outer ovate-acuminate; inner bracts linear or linear-lanceolate. T. grandiflorum tenuifolium A. Gray. T. lacinialum A. Gray, not Stylopappus laciniatus Nutt. Dry places: Ore-Ida.-B.C. Son. My-Jl.

30. A. obtusifolia (Suksd.) Rydb. Leaves pinnatifid, or rarely entire, more or less villous on the midrib and veins beneath; scape stout, $3-6 \mathrm{dm}$. high, villous under the heads; involucres campanulate, $3-4 \mathrm{~cm}$. high; bracts in 4 series, the outer two series short, ovate or oval, decidedly villous, acute or short-acuminate; inner bracts glabrous, narrowly linear-lanceolate. $T$. grandiflorum obtusifolium Suksd. Valleys: Wash.-Ida.-Calif. Son. My-Jl.

31. A. grandiflora (Nutt.) Greene. Leaves 1-2 dm. long, oblanceolate, attenuate at each end, sinuate-dentate to laciniate-pinnatifid, with acute divisions more or less pubescent, at least on the midrib; scape $2-5 \mathrm{dm}$. high; involucres $2.5-3 \mathrm{~cm}$. high and as wide; bracts very unequal, the outer ovate or lanceolate, lanate or tomentose, the inner linear and glabrate. Stylopappus grandiflorus Nutt. T. grandiflorum A. Gray. Plains and hillsides: B.C.-Ida.-Calif, Son. Ap-Au.

32. A. retrorsa (Benth.) Greene. Leaves pinnatifid, decidedly villous, with linear, salient or retrorse lobes, caudate-elongate; scape 3-8 dm. high, more or less villous; involucres campanulate, $3-4 \mathrm{~cm}$. high; bracts in about 4 series, more or less villous, the outer ovate, elliptic, or oval, acute; inner bracts narrowly linearlanceolate; flowers yellow. T. retrorsum A. Gray. Pine woods and grassy slopes: Calif.-sw Ida.-Ore. Son. -Submont. Ap-J.

33. A. heterophylla (Nutt.) Greene. Leaves linear-oblanceolate or linear, entire or dentate, or somewhat pinnatifid, with lanceolate divisions, more or less hirsute; scapes several, 1-2.5 dm. high, slender; involucres more or less hirsute, 
eampanulate, 12-18 mm. high; bracts in 3 series, the outermost bracts ovatelanceolate, the innermost linear-lanceolate, all acute; flowers light yellow; marginal achenes with broad wavy wings or wingless, the central ones merely costate; body about $5 \mathrm{~mm}$. long; beak filiform, about $1 \mathrm{~cm}$. long. Macrorhynchus heterophyllus Nutt. Hills and prairies: Calif.-Utah-Ida.-B.C. Son. My-Je.

\section{LEÓNTODON L. DANDELION.}

Acaulescent perennial herbs, with pinnatifid fleshy taproots, toothed or rarely entire leaves, and the heads solitary on naked hollow scapes. Involucre campanulate; bracts equal, subtended by a well-developed calyculum of shorter bracts, the calyculate bracts in several series. Receptacle naked. Flowers yellow. Achenes mostly fusiform, 4- or 5-angled, 8-10-ribbed, retrorsely spinulose above, contracted into a slender beak. Pappus of numerous persistent bristles spreading in fruit. [Taraxacum (Haller) Ludv.]

Outer bracts (calyculum) more or less squarrose.

Outer bracts reflexed from the base; leaves deeply runcinate, with triangular to lanceolate lobes.

Achenes bright red.

Achenes greenish or brownish.

1. L. erythrospermum.

Bracts numerous; leaves broad and the terminal lobe large.

2. L. Taraxacum.

Bracts few; leaves narrow and the terminal lobe small. 3. L. mexicanum.

Outer bracts or most of them appressed at the base and with spreading or reflexed tips; leaves with short lobes or sinuate.

Bracts conspicuously corniculate, the outer about two-thirds as long as the inner: scape usually much exceeding the erect leaves; achenes spinulose-toothed above and tuberculate on some of the ribs to near the base.

4. L. dumetorum.

Bracts, at least the outer ones, not corniculate, the outer about half as long as the inner; achenes merely tuberculate above, smooth below. 5. L. leiospermum.

Outer bracts wholly appressed, short, the mere tip rarely spreading.

Plant not dwarf; scape 5-20 cm. high; involucres $15 \mathrm{~mm}$. or more high.

Plant with a tuft of brown hairs at the base. 6. L. eriophorum.

Plant not with brown hairs at the base. Achenes brownish or greenish.

Calyculate bracts in 2-3 series; achenes muricate to near the base.

7. L. monticola.

Calyculate bracts in 1-2 series; achenes smooth below the middle. Achenes bright red.

8. L. angustifolium.

9. L. ammophilum.

Plant dwarf; scape 2-10 cm. high; involucres 6-12 mm. high, dark green.

Involucres campanulate, 10-12 $\mathrm{mm}$. high; lobes of the leaves oblong or lanceolate,

acutish.
Involucres cylindro-campanulate, $6-8 \mathrm{~mm}$. high, $5 \mathrm{~mm}$. broad; lobes of the leaves broadly triangular, obtuse.

11. L. scopulorum.

1. L. erythospermum (Andrz.) Eichw. Leaves 1-2 dm. long, oblanceolate in outline, deeply runcinate-pinnatifid to near the midrib; lobes with a triangular base, more or less eaudate-lanceolate; scape 1-3 dm. high; involucres about 15 $\mathrm{mm}$. high; inner bracts $12-20$, linear, with a lanceolate, slightly scarious-margined base; achenes $3 \mathrm{~mm}$. long, bright red; ridges spinulose above and muricate below to the very base. Taraxacum erythrospermum Andrz. Roadsides and around dwellings: Me.-W.Va.-Kans.-Wyo.-Alta.; nat. from Eu. My-Au.

2. L. Taraxacum L. Leaves 1-3 dm. long, oblanceolate in outline, usually deeply runcinate, with triangular, more or less cut-toothed lobes, the terminal division large, deltoid or deltoid-ovate; scape 1-3 dm. high; involucres about 15 $\mathrm{mm}$. high; inner bracts linear-lanceolate, $15-25$, with narrow scarious margins, rarely corniculate; achenes greenish or brownish yellow, the ridges spinulose above, then muricate and nearly smooth at the base. T. officinale Weber. $T$. Taraxacum Karst. Around dwellings, fields, and roadsides: Lab.-S.C.-Calif . Alaska; nat. from Eu. Plain-Mont. Mr-N.

3. L. mexicanum (DC.) Rydb. Leaves 1-1.5 dm. long, narrowly oblanceolate, deeply runcinate, with retrorsely obliquely triangular, often toothed lobes; terminal division small, deltoid; scape 5-15 cm. long; involucres about $15 \mathrm{~mm}$. high, green or slightly livid; inner bracts narrowly linear, lanceolate, scariousmargined towards the base, $12-20$ in number; achenes about $3 \mathrm{~mm}$. long; ridges strongly spinulose above and muricate usually to the very base. T. mexicanum 
DC. Meadows and hills: N.M.-Colo.-Utah-Ariz.; Mex. Submont.-Mont.
My-Au.

4. L. dumetorum (Greene) Rydb. Leaves 1-2 dm. long, oblanceolate, mostly erect, sinuately toothed or lobed, glabrous or slightly hairy on the veins; teeth or lobes usually triangular; scape $1-4 \mathrm{dm}$. high; involucres $2-3 \mathrm{~cm}$. high; inner bracts narrowly linear-lanceolate, dilated and bifid at the apex; achenes olive-green; ribs spinulose at the summit, muricate below. T. dumetorum Greene. Mountain valleys: Man.-N.M.-Utah-B.C. Submont.-Mont. My-Au.

5. L. leiospermum Rydb. Leaves spreading, broadly oblanceolate, less than $1 \mathrm{dm}$. long, dark green, obtuse or acutish, retrorse-dentate, rarely lobed; scape about $1 \mathrm{dm}$. high, slightly villous when young; outer bracts $7-10 \mathrm{~mm}$. long, lanceolate, with spreading tips, the inner linear, about twice as long, neither corniculate; achenes greenish. T. leiospermum Rydb. Mountains: Colo. Submont.-Mont. $\mathrm{Jl}-\mathrm{Au}$.

6. L. eriophorum Rydb. Leaves $2-3 \mathrm{~cm}$. long, oblanceolate to spatulate, slightly sinuately dentate or entire; scape $2-3 \mathrm{dm}$. high; involucres about $1.5 \mathrm{~cm}$. high, somewhat livid; calyculate bracts in a single series, ovate, erect, slightly corniculate. T. eriophorum Rydb. Hills: Mont. Submont.

7. L. monticola Rydb. Leaves oblanceolate in outline, $6-12 \mathrm{~cm}$. long, from dentate to sinuately lobed with triangular entire lobes, glabrous or nearly so; scape 1-2 dm. high; involucres campanulate, 15-18 mm. high; bracts proper linear-lanceolate, in 2 series, the inner ones with broad scarious margins; achenes greenish or brown; ribs strongly spinulose above. T. montanum Nutt., not DC. Mountains: Alta,-Colo. Submont.-Mont. Je-Au.

8. L. angustifolium (Greene) Rydb. Leaves oblong-linear, 4-10 cm. long, obtuse or mucronate, denticulate or dentate; scape decumbent, at last twice as long as the leaves; involucre narrowly campanulate; achenes brown, spinulose at the apex, smooth below the middle. T. angustifolium Greene. (?) T. fasciculatum A. Nels. Meadows: Wyo.-Colo. Mont.-Alp. Jl-Au.

9. L. ammophilum (A. Nels.) Rydb. Leaves decumbent, $1 \mathrm{dm}$. long or less, glabrous, oblong or oblanceolate, sinuate-dentate; scape decumbent, about as long as the leaves; involueres about $15 \mathrm{~mm}$. high; bracts proper narrowly linear-lanceolate, slightly scarious-margined; achenes dark red; ribs spinulose above, tuberculate below. T. ammophilum A. Nels. Grassy valleys: Wyo.Colo. Mont.-Subalp, Je-Au.

10. L. rupestre (Greene) Rydb. Leaves narrowly oblanceolate in outline, acute, runcinate-pinnatifid or runcinate-toothed, 3-8 cm. long; involucres narrowly campanulate, dark livid green, $10-12 \mathrm{~mm}$. high; proper bracts $10-15$, in 2 series, lance-linear, the inner series with broad scarious margins; ribs of the achenes spinulose at the summit, muricate below. T. rupestre Greene. (?) $T$. ovinum Greene. High mountains: Alta.-Mont.-B.C. Subalp.-Alp. Jl-Au.

11. L. scopulorum (A. Gray) Rydb. Leaves $2-6 \mathrm{~cm}$. long, sinuate-pinnatifid; scape 1-6 $\mathrm{cm}$. high; involucres $6-8 \mathrm{~mm}$. high, $5 \mathrm{~mm}$. wide, dark livid green; bracts proper 8-12, in 2 series, oblong-linear, scarious-margined, often obtuse. T. officinale scopulorum A. Gray. T. scopulorum Rydb. Alpine regions: Colo. -Ida. Mont.-Alp. Jl-Au.

\section{LACTÙCA (Tourn.) L. LetTuce.}

Tall leafy-stemmed herbs, with paniculate heads. Involucres cylindric, or in fruit conic; bracts imbricate, in 3 or more series. Achenes obcompressed, 1-5-nerved on the faces, contracted into a beak dilated at the apex. Pappus of numerous capillary bristles, which fall off separately.

Achenes with a slender beak; pappus white.

Outer bracts (calyculum) not more than half as long as the bracts proper; flowers yellow, rarely tinged with blue.

Heads 6-15-flowered; achenes several-nerved, not rugose; leaves spinulose on the ribs.

Leaves sinuate-dentate; achenes dark.

Leaves sinuately pinnatifid; achenes light colored.

1. L. virosa.

2. L. Scariola. 
Heads 12-20-flowered; achenes 1-3-nerved, transversely rugose.

Involucres about $1 \mathrm{~cm}$. high.

Leaves linear-lanceolate, perfectly entire.

Leaves pinnatifid or lobed, at least some of them.

3. L. polyphylla.

Involucres $1.2-2 \mathrm{~cm}$. high.

Leaves obovate or oblanceolate in outline, with broad lobes, often spinulose on the midribs beneath.

5. L. ludoviciana.

Leaves linear or linear-lanceolate in outline, entire or with narrow lobes, never spinulose.

6. L. graminifolia.

Bracts in 5-6 series, gradually increasing upwards, a distinct calyculum therefore not evident; flowers blue.

Achenes beakless; pappus tawny or brown.

Lobes of the leaves broadly triangular or ovate, sinuately and saliently dentate.

Lobes of the leaves lanceolate or linear, again 1-3-lobed.

8. L. spicata.

9. L. multifida.

1. L. virosa L. Biennial, with a branched root; stem erect, 5-20 dm. high, more or less hispid towards the base; leaves numerous, oblong or oblanceolate, obtuse or mucronate, horizontal, 1-3 dm. long, spinulose-denticulate, sessile and clasping; panicle loosely branched; involucres 10-12 mm. high, 4-6 mm. broad; bracts in about 4 series, lanceolate, thick; flowers light yellow, turning bluish; achenes with broader margins than those of the next. $L$. integrata A. Nels. Waste places and fields: Me.-Ga.-Calif.-B.C.; nat. or adv. from Eu. PlainSubmont. Je-S.

2. L. Scariola L. Biennial, with a branched root; stem 3-10 dm. high, sparingly prickly-bristly below; leaves pinnatifid or lobed, rarely merely sinuate, tending to turn edgewise into a vertical position; involucres ovoid-cylindric, about $10 \mathrm{~mm}$. high, $4 \mathrm{~mm}$. broad; bracts imbricate in about 4 series, lanceolate or the inner linear-lanceolate; flowers yellow, turning bluish; achenes ellipticoblanceolate, slightly margined, 5-nerved on each side. Fields and waste places: Mass.-Tenn.-Calif.-B.C.; nat. from Eu. Jl-Au.

3. L. polyphylla Rydb. Biennial; stem about $1 \mathrm{~m}$. high, glabrous; leaves sessile, slightly auriculate-clasping, very numerous, linear-lanceolate, entire, acuminate, 1-2 dm. long, glabrous; involucre about $1 \mathrm{~cm}$. high; outer bracts lanceolate, the inner linear-lanceolate; achenes nearly black, 3-4 mm. long, indistinctly 3-nerved, transversely rugose. Meadows: Ida. Submont. Au.

4. L. canadensis L. Biennial; stem 1-3 m. high, often mottled, glabrous or nearly so; basal leaves mostly spatulate or oblong, dentate or pinnatifid; stemleaves 1-3 dm. long, sinuately pinnatifid; involucres $10-12 \mathrm{~mm}$. high; outer bracts lanceolate, inner linear; flowers yellow; achenes oval-oblong, almost black, transversely rugose, 3-nerved. Moist places: N.S.-Fla.-Colo.-Sask.-Alta. Plain-Submont.

5. L. ludoviciana (Nutt.) DC. Biennial; stem 5-15 dm. high, glabrous; leaves oblong-oblanceolate in outline, sinuately lobed or pinnatifid, with rounded, ovate or lanceolate, spinulose-denticulate lobes; involucres $15-20 \mathrm{~mm}$. high; outer bracts ovate, the inner linear-lanceolate, scarious-margined; flowers yellow; achenes brown or black, $4 \mathrm{~mm}$. long, broadly oval or obovate, 3-ribbed, obscurely transversely rugose. River-banks and wet places: Minn.-Mo.-Tex.-Colo.Mont. Plain-Submont. J-S.

6. L. graminifolia Michx. Biennial or perhaps perennial; stem 5-15 dm. high, glabrous; leaves glaucescent, elongated linear or linear-oblanceolate, 1-4 dm. long, entire or sinuately lobed or pinnatifid with narrow, spreading or deflexed lobes; involucres $12-15 \mathrm{~mm}$. high; outer bracts lanceolate, the inner linearlanceolate, scarious-margined; flowers yellowish, white or purplish; achenes elliptic, 4-5 mm. long, 3-nerved, black. Rich soil: N.C.-Fla.-Ariz.-Colo. Son.-Submont. Ap-S.

7. L. pulchella (Pursh) DC. Perennial, with a deep rootstock; stem 3-10 $\mathrm{dm}$. high, glabrous; leaves linear-lanceolate, lanceolate, or oblong, acute, entire, dentate or even some of them pinnatifid, 5-20 cm. long, somewhat glaucous; panicle usually narrow; involucres $16-20 \mathrm{~mm}$. high; flowers blue; achenes oblonglanceolate, about $4 \mathrm{~mm}$. long, rather strongly 3-nerved on the faces, gradually tapering into the short beak. L. sylvatica A. Nels. Wet meadows: Sask.-Mo. -N.M.-Calif.-B.C. Plain-Submont. My-Au. 
8. L. spicata (Lam.) Hitchc. Annual or biennial; stem glabrous 5-35 dm. high; leaves deeply pinnatifid, more or less hispid on the veins beneath; lobes somewhat recurved; involucres campanulate, about $1 \mathrm{~cm}$. high; bracts imbricate in about 4 series, lanceolate; flowers blue to nearly white; achenes elliptic, 5nerved. L. leucophaea (Willd.) A. Gray. Moist ground: Newf.-N.C.-Colo. -Ida.-Man. Submont.-Mont. Jl-O.

9. L. multifida Rydb. Annual or biennial; stem 1-2 m. high, glabrous, somewhat glaucous; leaves deeply pinnatifid, glabrous and glaucous; involucres about $1 \mathrm{~cm}$. high, campanulate; bracts purplish, in 3-4 series, lanceolate to linearlanceolate, obtusish; flowers blue; achenes brown, 5-ribbed. Wet places: B.C.Mont.-Ida.-Ore. Submont. J1-Au.

\section{SÓNCHUS (Tourn.) L. Sow-THIStle.}

Leafy-stemmed, mostly glaucous herbs, with cymose or umbellate heads. Involucre campanulate; bracts few, thin, with many shorter ones at the base. Flowers yellow. Achenes obcompressed, ribbed, not beaked. Pappus of numerous white, soft, fine bristles, mainly falling off together.

Perennial; achenes slightly compressed; involucres usually glandular-pubescent; heads about $2 \mathrm{~cm}$. high

1. S. arvensis.

Annual; achenes strongly compressed; involucres usually glabrous; heads about $15 \mathrm{~mm}$. high.

Auricles of the leaves acute; achenes transversely wrinkled.

Auricles of the leaves rounded; achenes not transversely wrinkled.

2. S. oleraceus.

1. S. arvensis L. Stem 5-12 dm. high, leafy below; lower leaves runcinatepinnatifid, spinulose-dentate, with short petioles, glabrous; upper leaves lanceolate, sessile, clasping, undivided or pinnatifid; bracts linear-lanceolate, in about 3 series; achenes oblong, slightly flattened, with thick ribs, transversely rugose. Fields and roadsides: Newf.-N.J.-Utah-Ida.-B.C.; nat. from Eu. J-O.

2. S. oleraceus L. Stem 5-30 dm. high, glabrous; lower leaves petioled, lyrate-pinnatifid, 1-2.5 dm. long; lobes lanceolate, spinulose-dentate, or the terminal one large and triangular or triangular-hastate; upper leaves similar but auriculate-clasping; involucral bracts linear-lanceolate, imbricate in about 4 series; achenes $2.5 \mathrm{~mm}$. long, oblong, 3-ribbed. Fields and waste places: N.S.Fla.-Calif.-Wash.; Mex., C. Am., and S. Am.; nat. from Eu. Plain-Submont. $\mathrm{My}-\mathrm{N}$.

3. S. asper (L.) All. Stem 5-30 dm. high, glabrous; lower leaves obovate or spatulate, petioled, the upper oblong or lanceolate, auriculate-clasping, undivided to deeply runcinate-pinnatifid, with broad lobes, spinulose-denticulate; bracts linear-lanceolate, imbricate in about 4 series, the outer with the midribs more or less thickened in age; achenes oblong, 3-ribbed, about $3 \mathrm{~mm}$. long. Waste places and fields: N.S.-Fla.-Calif.-B.C.; W. Ind. and Mex.; nat. from Eu. Plain-Submont. $\mathrm{My}-\mathrm{N}$. 


\section{PTERIDOPHYTA*}

Fernworts.

Plants of two distinct generations, in one consisting of a plantbody (sporophyte), which has stems containing vascular tissue and produces spores asexually, in the next, developing from the spore, consisting of a thalloid-body (gametophyte or prothallium), which bears the sexual reproductive organs (archegones and antherids). The plant-body develops from the oosphere within the archegone, after being fertilized by spirally coiled motile bodies (spermatozoids), produced by the antherids.

\section{KEY TO THE FAMILIES.}

Leaves usually broad, entire or dissected, not scale-like; fern-like plants.

Spores of one kind, minute, borne in sporanges.

Vernation not spirally coiled; sporangia ringless, leathery, opening by a transverse slit, arranged in spikes or panicles. 1. OPHIOGLOSSACEAE. 1038

Vernation spirally coiled; sporangia membranous, provided with a ring, which opens elastically. 2 2. PoLYPODIACEAE. 1040 Spores of two kinds, minute microspores (male) and larger macrospores (female),
borne in sporocarps.

$\begin{array}{ll}\text { Plant rooting in the mud; leaves 4-foliolate, petioled. 3. MARSILIACEAE. } & 1050\end{array}$

Plant minute, floating; leaves entire or 2-lobed. 4. SALVINIACEAE. 1051

Leaves scale-like or awl-like; moss-like or rush-like plants. Sporanges in an apical cone, borne under peltate bracts; stem usually hollow, rush-
like.

Sporanges in the axils of small leaf-like bracts; stem solid.

Leaves awl-like, elongate, borne on a short thick corm-like caudex; water plants.

Leaves scale-like, flat, borne on a distinct stem; land 6. ISOETACEAE. 1053 Spores uniform, minute.

7. LYCOPODIACEAE. 1054 Spores of two kinds, microspores and macrospores. 8. SELAGINELLACEAE. 1056

\section{Family 1. OPhioglossaceae. Adder's Tongue Family.}

Leafy succulent plants with fleshy rhizomes and fibrous, of ten fleshy, roots. Leaves (fronds) erect to reflexed, but not coiled in vernation, consisting of a sterile simple or compound leaf-blade and one or more stalked spore-bearing spikes or panicles (sporophylls), all borne on a common stalk. Sporanges bivalvular, formed from the interior tissue of the sporophylls. Prothallia underground, not green, monoecious. Spores of one kind.

\section{BOTRÝCHIUM Sw. Moonwort.}

Terrestrial plants, with erect rhizomes and usually only one frond. Roots clustered, fleshy. Common stalk with more or less of its length below ground, the bud of the frond of the following year enclosed within its hollow base. Veins free, forking. Sporophyll single. Sporangia distinct, globose, arranged in two rows.

Frond-bud without hairs.

Sporophyll and sterile leaf-blade not completely bent down in the bud.

Sporophyll erect in the bud, the sterile leaf-blade erect or with the apex bent over; segments of the sterile leaf commonly cuneiform or fan-shaped.

1. B. simplex.

* Contributed by Miss Margaret Slosson, except the families Equisetaceae, Isoetaceae, and Selaginellaceae, and the key to the families. 
Sporophyll and sterile leaf-blade with the apex or upper part bent down in the bud. Sterile leaf-blade sessile or subsessile, once pinnately divided, the segments lunulate or fan-shaped.

2. B. Lunaria.

Sterile leaf-blade usually stalked, entire to twice pinnately divided, the segments mostly oblong or ovate. 3 . B. neglectum.

Sporophyll and sterile leaf-blade completely bent down in the bud; sterile leaf-blade deltoid.

Frond-bud hairy.

4. B. lanceolatum.

Common stalk open along one side at base, usually long; sterile leaf-blade sessile.

Common stalk completely closed at base, usually short; sterile leaf-blade virginianum. Sterile leaf-stalk 1-4 cm. long; plant very stout and fleshy. leaf-blade stalked.

Sterile leaf-stalk usually $5 \mathrm{~cm}$. long or more; plant not so fleshy, often slender.

7. B. silaifolium.

1. B. simplex Hitche. Frond $3.5-20 \mathrm{~cm}$. long; common stalk usually short; sterile leaf-blade with a stalk $0.2-0.5 \mathrm{~cm}$. long, oblong or deltoid or deltoid-ovate, rounded, entire to twice pinnately or sometimes subternately subdivided; segments cuneiform or fan-shaped or rarely lunulate, rounded at apex; sporophyll usually long-stalked. In grassy places and open woods: "N.S."-Me.- "Md."Wis.-Ont.; "Sask."-(?)"Alta."-Mont.-Colo.-Utah; Eu, Submont.-Mont.

2. B. Lunaria (L.) Sw. Frond $3-28 \mathrm{~cm}$. long; sterile leaf-blade with the apex bent down and clasping the sporophyll in the bud, oblong or rarely ovate or deltoid-ovate, rounded above, once pinnately divided; segments fan-shaped or lunulate or reniform, often imbricate, entire, or rarely radially incised or cleft into cuneiform lobes; sporophyll with the apex bent down in the bud, 1-3 times divided. Woods and grassy places: Greenl.-P.E.I.-"Vt."-N.Y.-n OhioMont.-Colo.-Utah-B.C.-Alaska; Calif., Old World. Mont.-Submont. The var. onondagense (B. onondagense Underw.), which is distinguished by its rather distant fan-shaped segments, is the form usually occurring in the United States.

3. B. neglectum Wood. Frond 5.5-32 $\mathrm{cm}$. long; common stalk usually long; sterile leaf with the upper part bent down in the bud, with a stalk $0.2-1.7$ $\mathrm{cm}$. long, oblong or sometimes deltoid, subacute, the primary divisions oblong or ovate, the segments usually oblong, rounded at apex, entire or incised; sporophyll with the upper part bent down in the bud, commonly diffusely branched. Wooded places: Que.-Md.-" "Ohio"-Wis.; (Black Hills) S.D.; Colo.; "B.C."; Eu. Mont.

4. B. lanceolatum (S. G. Gmel.) Ångstr. Frond 5-30 cm. long; common stalk long; sterile leaf-blade broadly deltoid, acute, 1-2 times pinnately or subternately divided, the primary divisions oblong to ovate or oblong-lanceolate, the segments ovate, ovate-lanceolate or suboval, entire or incised; stalk of sporophyll mostly shorter than the rather diffuse panicle; sporangia large, crowded, sessile or broadly short-pedicelled. Woods and damp hillsides: Alaska- "B.C." -Wash.-Wyo.; "Greenl."; Öld World.

5. B. virginianum (L.) Sw. Frond $6.5-60 \mathrm{~cm}$. long; sterile leaf-blade thin, 3-5 times divided, broadly deltoid, the subdivisions next to the last narrowly oblong or lanceolate to ovate or deltoid, pinnately divided, the segments oblong, blunt, incised; sporophyll mostly long-stalked. Wooded places: Que.-Fla.Tex.-Colo.-Ore.-B.C.; trop. Am. and the Old World. Plain-Mont.

6. B. Coulteri Underw. Frond $12-26 \mathrm{~cm}$. long; sterile leaf-blade broadly deltoid to pentagonal, obtuse, about 4 times pinnately or subternately divided, the primary divisions crowded and imbricate, oblong to deltoid, the subdivisions next to the last oblong, pinnately divided into $2-5$ pairs of oblique, broadly oblong or ovate, mostly acute or subacute lateral segments, and with ovate to rhomboid subacute tips, the segments entire or undulate; panicle of the sporophyll short and compact. Very close to the next and possibly only a form of it. Mostly geyser formations: Ore.-Mont.-Wyo. Mont.

7. B. silaifolium Presl, Frond $9.5-60 \mathrm{~cm}$. long; sterile leaf-blade broadly deltoid to pentagonal, acute or obtuse, 3-4 times pinnately or subternately divided, the primary divisions oblong or oblong-lanceolate to deltoid or pentagonal, the subdivisions next to the last oblong-lanceolate, pinnately divided into $2-5$ pairs of oblique, oblong, narrowly elliptic, or sometimes ovate, decurrent lateral 
segments, and with broader rhomboid tips, the segments crenulate; panicle of the sporophyll diffuse. Fields and open woods: Ont.-Que.-N.J.-Pa.-Wis.; Alaska-B.C.-Calif. Submont.-Mont.

\section{Family 2. POLYPodiaceae. Fern Family.}

Sporophytes consisting of a rhizome and leaves (fronds) coiled in the bud. Sterile fronds leaf-like, fertile fronds (sporophylls) either leaf-like or partially or completely non-foliaceous, bearing the sporanges on their lower surface or at their margins, commonly in clusters-(sori). Sori naked or furnished with a special covering (indusium). Sporanges stalked, furnished with an incomplete vertical ring of thickened cells (annulus), opening transversely. Prothallia green, above ground.

Fertile fronds, with contracted berry-like or necklace-like subdivisions, not foliaceous.

Veins of the sterile fronds netted.
Veins

$\begin{array}{ll}\text { Veins of the sterile fronds free. } & \text { 2. PTERETIS. }\end{array}$

Fertile and sterile fronds foliaceous, alike or differing; veins free,

Sori on the under surface of the fronds, each provided with a special indusium not connected with the margin of the frond.

Sori roundish.

Indusia inferior or attached at base at one side of the sorus.

Indusia inferior, stellate or split into spreading lobes, 3. WooDsiA.

Indusia attached at base at one side of the sorus, at first arched over it,

Indusia superior.

Indusia peltate.

Indusia orbicular-reniform, adherent at the sinus.

4. FIlLX.

5. Polystichum.

Midveins and midribs united at a wide angle; fronds usually provided with true hairs, consisting of a single cell or a single row of cells.

Midveins and midrib united at a very acute angle; 6 . THELYPTERIS. hairs.

hairs.
Sori oblong or linear, or shaped like a horseshoe or shepherd's crook.
Sori all straight or rarely slightly curveds.

列

8. AsPLENTUM.

Sori, at least in part, shaped like a horseshoe or shepherd s crook, crossing the fertile vein and more or less recurved upon it. 9. ATHYRIUM. Sori naked, or protected, at least at first, by the revolute or reflexed margins or por-
tions of the margins of the frond.

Margin of the frond flat or merely revolute, not modified.

Margin of the frond revolute; sori more or less confluent, forming a marginal

Margin of the frond flat; sori dot-like on the veins. 16 . NOTHOLAENA.

Stipes jointed to the rhizome.

Stipes not jointed to the rhizome.

Margin of the frond reflexed over the sori, more or less modified.

Sori borne on the under side of reflexed lobes of the frond. 10. ADIANTuM. Sori not borne on the under side of the reflexed portions of the margin of the
frond.

Sori borne on a continuous vein-like receptacle connecting the ends of the veinlets.

Sori borne on the veins at or near their tips.

11. PTERIS.

Sori extending down the veins; edges of the fertile fronds finally opening out flat; sterile and fertile fronds markedly dissimilar.

12. Cryptogramma.

Sori marginal or submarginal; sterile and fertile fronds alike or somewhat dissimilar.

Sori confluent, forming a submarginal band; segments of the fronds glabrous or nearly so.

Sori distinct or contiguous; segments usually pubescent, tomentose or scaly.

14. Cheilanthes.

\section{ONOCLÈa L. Sensitive Fern.}

Ferns, with coarse dimorphous fronds scattered on creeping rhizomes. Sterile fronds foliaceous. Fertile fronds with rigid, contracted ball-like subdivisions. Sori roundish, on elevated receptacles, partly covered by delicate hood-like indusia attached to the bases of the receptacles.

1. O. sensibilis L. Sterile fronds $3-13.5 \mathrm{dm}$. high, deltoid-ovate, pinnatifid; segments lanceolate-oblong, entire, undulate or sinuate-pinnatifid; rachis winged; veins anastomosing; fertile fronds 3-7.5 dm. high, bipinnate; pinnules 
rolled into closed balls, finally dehiscent; veins free; sporangia dorsal on the simple or forked veinlets. Damp places: Newf.-Fla.-Tex.—S.D. (Black Hills) -Sask. Plain-Submont.

\section{PTEREtTIS Raf. Ostrich Fern.}

Plants with coarse dimorphous fronds, growing in crowns from stoloniferous rhizomes. Sterile fronds foliaceous. Fertile fronds contracted, with revolute margins covering the sori. Sori roundish, on elevated cylindrical receptacles partly covered by delicate lacerate fugacious indusia inferiorly attached. [Struthiopteris Mett., Matteuccia Todaro.]

1. P. nodulosa (Michx.) Nieuwland. Seales of base of stipe pale brown to cinnamon-colored, thin, membranous; fronds abruptly acuminate at apex, gradually reduced towards base; sterile fronds $0.6-3 \mathrm{~m}$. long, broadly oblanceolate or spatulate, with lanceolate or linear, pinnatifid pinnae $5-18 \mathrm{~cm}$. long; segments oblong, obtuse or acute; fertile fronds shorter, with rigid, upcurved, commonly pinnatifid necklace-shaped pinnae; veins free, pinnate; veinlets simple. Onoclea nodulosa Michx. Related to but distinct from the European $P$. struthiopteris (L.) Nieuwland [Matteuccia struthiopteris (L.) Todaro.] Wet places: Newf.Va.-S.D.-B.C. Mont.-Submont.

\section{WOŌDSIA R. Br.}

Small plants with tufted pinnately compound fronds. Sori round, borne on the veins. Indusia placed under the sporangia, sometimes enclosing it at first, often variously divided. Veins free.

Stipe articulate near the base.

Stipe not articulate.

1. W. glabella.

Blades pulverulent, with flattened articulate hairs and stalked glands.

2. W. scopulina.

Blades without articulate hairs, unless at the ends of the indusia or segments, glabrous or minutely glandular.

Indusia very small, divided almost to the center into a few hair-like filaments.

Indusia large, cleft more or less deeply into several lobes.

3. W. oregana.

Lobes of the indusia divided at least halfway down into slender articulate flattened hairs. 4 . W. mexicana.

Lobes of indusia merely jagged, rarely with an occasional jointed extension, often glandular. 5 . W. obtusa.

1. W. glabella $\mathrm{R}$. Br. Fronds tufted, 2.5-15.5 cm. long; stipes usually straw-colored; blades linear or narrowly lanceolate, somewhat narrowed toward base, smooth, pinnate; pinnae deltoid to roundish-ovate, crenately lobed; indusia divided into narrow jointed hair-like curving divisions. Moist rocks: AlaskaGreenl.-Que.-Alta.; N.H., N.Y.; "Minn."; Eu. Boreal-Subarctic.

2. W. scopulina D. C. Eat. Fronds 5.5-35 cm. long; blades lanceolate, pinnate; pinnae mostly oblong-ovate, deeply pinnatifid; segments short, ovate or oblong, crenate-serrulate; indusia delicate, deeply cleft into laciniae which terminate in short hairs. On rocks: B.C.-Neb.-Ariz.-Calif.; (Gas pe Peninsula) Que. and (Great Craggy Mts.) N.C.; reported from Minn. and nw Ia. Submont.-Mont.

3. W. oregana D. C. Eat. Fronds $5-26.5 \mathrm{~cm}$. long; blades lanceolateoblong, pinnate; pinnae triangular-oblong, obtuse or subacute, pinnatifid; segments oblong or ovate, obtuse, toothed or crenate; teeth often reflexed over the sori; sori submarginal. On rocks: B.C.-Calif.-Ariz.-Colo.-(? S.D.)-Sask. -Que. Submont.-Subalp.

4. W. mexicana Fée. Fronds 5-30 cm. long; blades lanceolate, pinnate, minutely glandular; pinnae triangular-lanceolate or rarely suboblong, pinnately divided; segments finely toothed, the teeth ending in delicate semitransparent tips which are ciliated in young fronds; sori submarginal. (?) W. Cathcartiana B. L. Robins. Rocks: S.D.-Colo.-N.M.-Ariz.; Minn. and Mex. Son.Mont.

5. W. obtusa Torr. Fronds 6-62 cm. long; blades broadly lanceolate, slightly reduced at base, pinnate to bipinnate, minutely glandular; pinnae oblong 
or triangular-ovate, pinnately parted or pinnate below; segments oblong, obtuse, crenate-dentate or the lower pinnatifid with toothed lobes. "N.S."-N.H.-Ga. -N.M.-Wis.; Ariz. and (?) "B.C."

\section{FìllX Adans.}

Ferns, with pinnately compound fronds of rather thin texture. Sori roundish, indusiate, borne on the veins. Indusia delicate, hood-like or flattish, attached at one side of and partly under the sorus, at first arched over it, finally thrown back or withering. Veins free. [Cystopteris Bernh.]

Blades of the fronds deltoid-lanceolate or broadly lanceolate, twice or thrice pinnate.

Blades elongate deltoid-lanceolate, 3-12 dm. long; basal pair of pinnae the largest.

Blades broadly lanceolate, $2-4.5 \mathrm{dm}$. long: basal 1 . F. bulbifera. ened.

Blades of the fronds deltoid-ovate, three to four times pinnate.

slightly short-

1. F. bulbifera (L.) Underw. Rhizome short; fronds clustered; blades minutely more or less glandular beneath, especially on the rachises and midribs; pinnae oblong-ovate to lanceolate-oblong, pinnate; pinnules unequally oblongovate, obtuse, variously incised to deeply pinnatifid, more or less adnate or free; rachis and pinnae commonly bulbiferous beneath, the bulblets producing new plants after falling to the ground; indusia short, convex, truncate. C. bulbifera (L.) Bernh. Damp places, especially about rocks: "Newf."-N.S.- "Man."Wis.-Ark.-Ga.; Utah-Ariz. Boreal-Austr.-Son.

2. F. fragilis (L.) Gilib. Rhizome creeping; fronds clustered or slightly scattered, glabrous; stipe and primary rachis slender, brittle, stramineous or brownish below; secondary rachises usually winged; pinnae deltoid-lanceolate or deltoid-ovate; segments decurrent, variable, roundish-oval or ovate or rhomboidovate or ovate-lanceolate, dentate, with short obtuse teeth or deeply toothed or cleft, with narrower teeth, or cleft or sometimes pinnatifid, with toothed segments; indusia delicate, convex, roundish or commonly pointed, often toothed or laciniate at apex. Cystopteris fragilis (L.) Bernh. Rocky places: Greenl.-Ga.Okla.-Calif.-Alaska; trop. Am., and the Old World. Plain-Alp.

3. F. montana (Lam.) Underw. Rhizome slender, creeping; fronds scattered, 12-45 cm. long; stipes slender; blades often subternate; basal pair of pinnae much the largest, unequally deltoid-ovate; pinnules deeply divided; segments oblong, deeply toothed or divided; indusia convex, ovate, soon thrown back or evanescent. Lab.-Que.-Ont.; Colo.; B.C.-Alaska; Eurasia. Mont.-Subalp.

\section{POlÝstichum Roth. Holly Fern, Christmas Fern.}

Ferns of mostly rigid habit, with firm-textured pinnate to pinnately decompound fronds usually with sharply toothed or spinulose margins. Sori round, indusiate, borne on the veins. Indusium peltate. Veins free.

Blades normally simply pinnate; pinnae auricled or the upper side at base, obliquely truncate at the lower.

Fronds very short-stalked; pinnae broadly lanceolate, falcate, on the lower triangular.

Fronds rarely very 1 . lonchitis.

linear, acuminate.
$2 . P$, munitum. Blades normally more compound.

$\begin{array}{ll}\text { Blades proliferous below the apex. } & \text { 3. P. Andersoni. }\end{array}$

Blades not proliferous.

Pinnae serrate in the distal part, pinnately lobed at base. $\quad$ 4. P. scopulinum. Pinnae pinnately divided almost throughout the blade, commonly fully bipinnate.

5. P. Braunii.

1. P. Lonchitis (L.) Roth. Fronds growing in a crown, $8-22 \mathrm{~cm}$. long; stipes and rachises chaffy with light brown scales; blades linear-lanceolate, gradually tapering toward base; pinnae $1-4.5 \mathrm{~cm}$. long, densely spinulose-toothed, the teeth mostly spreading; sori medial or supramedial. Woods: Greenl.-N.S."Wis."-Alta.-Colo.-Calif.-Alaska. Boreal.

2. P. munitum (Kaulf.) Presl. Fronds growing in a crown, 22-152 cm. long; stipes densely chaffy at base, less so above; rachises chaffy; scales bright reddish 
brown; blades lanceolate; pinnae 2-14 cm. long, sharply and often doubly serrate, the serrations spinescent, often incurved; sori mostly supramedial. Woods: Alaska-Mont.-Ida.-Ore.-Calif.

3. P. Andersoni Hopkins. Fronds $32-74 \mathrm{~cm}$. long; stipes $2-21.5 \mathrm{~cm}$. long; stipe and rachis densely chaffy, with bright golden-brown scales; blades ellipticlanceolate, gradually narrowed both ways; pinnae lanceolate or the basal subdeltoid, acute or acuminate, the uppermost adnate-decurrent, those below sessile to short-stalked, obliquely pinnatifid, the basal segment, especially the upper, the largest; segments decurrent, suboval to oval-oblong, not auricled or only the basal auricled, long-spinescent, serrate-spinulose, with often incurved teeth, chaffy beneath, chaffy-fibrillose above; sori medial; indusia ciliate-erose. In thickets: Alaska-B.C.-Wash.

4. P. scopulinum Maxon. Fronds $6.5-43 \mathrm{~cm}$. long; stipes and rachis conspicuously chaffy, with light brown scales; blades lanceolate or linear, commonly somewhat narrowed toward base; pinnae ovate or ovate-oblong, mostly obtuse, serrate in the outer part, with pointed or aculeate, not spinescent teeth, pinnately lobed at base, the superior basal lobe the largest, parallel to the rachis, the inferior oblique to the rachis; sori near the midvein; indusia large, smooth, somewhat irregularly lobed, not ciliate. Doubtful if distinct from P. Lemmoni Underw. Rocks: B.C.-n Utah-Ore.; s Calif., and (Gaspe Peninsula) Que. Mont.

5. P. Braunii (Spenner) Fée. Fronds in a crown, 1.5-8.5 dm. long; stipe and rachis chaffy, with bright brown scales; blades lanceolate, gradually narrowed toward base; pinnae oblong-lanceolate from a slightly broader base; segments ovate-oblong, produced on the upper side, obliquely cut away on the lower, commonly acute, sharply toothed, scaly; indusia small, entire. Rocky woods: Newf.-Mass.-Pa.-Mich.; "B.C." Boreal.

\section{THELŸPTERIS Schmidel.}

Ferns with stipes not articulated to the rhizomes, and pinnatifid to bipinnatifid or rarely more compound fronds. Midveins and midribs united at a broad angle. Veins pinnate, the veinlets simple or occasionally forked, the lower ones ending above the sinus between segments of the blade or running to it, more or less connivent, or the basal pair uniting in the leaf-tissue and sending a common branch to the sinus. Sori borne on the veins, with or without indusia, round or, especially when nonindusiate, oblong or linear or rarely curved. Indusia reniform or rarely otherwise curved. Fronds usually hairy, often glandular, sometimes scaly also. Hairs whitish, one-celled or long, soft, thin, subulate, and consisting of a single row of cells (not reddish, short, articulated and cylindric), often hooked at the point, simple and single, or fascicled or branched and sessile (never branched at apex of a stalk). [Dryopteris, subgenera Lastrea, Glaphyropteris, Steiropteris, Cyclosorus, and Leptogramma C. Chr., Phegopteris Fée.]

Blades of the fronds bipinnatifid.

Blades broadest at base, or only the basal pair of pinnae slightly shortened.

Blades gradually much narrowed toward base.

Blades of the fronds ternate or subternate, once to twice pinnate.

Fronds glabrous, excepting a few scales on the stipe, or with only occasional microscopic trichomes resembling rudimentary glands.

Fronds distinctly glandular, especially the stipes and rachises; glands capitate.

1. T. Phegopteris,

2. T. Oreopteris.

4. T. Robertiana.

1. T. Phegopteris (L.) Slosson. Rhizome creeping; fronds scattered, 10-55 $\mathrm{cm}$. long; blades triangular or nearly so, mostly longer than broad, sparingly hairy on both surfaces, especially on the veins; hairs unicellular; pinnae mostly linear-lanceolate, the basal pair deflexed and advanced; segments oblong, obtuse, entire or slightly crenate, the basal decurrent and adnate to the main rachis; rachises scaly beneath; sori submarginal. Dryopteris Phegopteris (L.) C. Chr. Phegopteris polypodioides (L.) Fée. Wooded places: Greenl.-Newf.-Va.Minn.-Man.-Ore.-Alaska; Eu. Mont.-Subalp.

2. T. Oreopteris (Ehrh.) Slosson. Fronds in a erown; stipes rather short; stipe and rachis somewhat scaly; blades broadly lanceolate, tapering below, pin- 
nate, glandular; pinnae broadest at base, deeply pinnatifid, noticeably shorthairy below on the midribs or both midribs and midveins; veins simple or forked; sori submarginal; indusia toothed. Dryopteris Oreopteris (Ehrh.) Maxon. Polypodium montanum Vogler. Alaska; Eu. Represented in our range by the variety T. Oreopteris hesperia Slosson, which differs chiefly in having the stipe and rachis conspicuously powdered with small light brown scales, a few occurring also on the midribs of the pinnae beneath, the fronds otherwise glabrous or occasionally with only a few scattered microscopic hairs on or near the rachis or midribs, and (?) the fronds smaller. Near streams: B.C.-Wash.-Alaska. Mont,-Subalp.

3. T. Dryopteris (L.) Slosson. Rhizome slender, creeping; fronds scattered, 8-69 $\mathrm{cm}$. long; blades broadly triangular; the three primary divisions stalked, 1-2 pinnate; segments oblong, obtuse, entire or toothed; rachis not winged; sori submarginal. OAK FERN. Wood places: Greenl.-Newf.-Va.-Minn.-(Black Hills) S.D.-Mont.-Ida.-Ore.-Alaska; Colo., Ariz., and Eu.

4. T. Robertiana (Hoffm.) Slosson. Rhizome slender, creeping; fronds scattered, 13-62 $\mathrm{cm}$. long, somewhat rigid; blaaes triangular-ovate, the three primary divisions stalked, the lateral smaller in proportion than in the preceding species; sori submarginal. Woods: Alaska-Yukon Terr.-Que.-Ia.-Minn.(?) Ida.; Eu.

\section{DRYópteris Adans. Shreld Fern, Male Fern.}

Ferns with stipes not articulated to the rhizomes and mostly bipinnate to decompound fronds. Midribs and midveins of the pinnae's subdivisions attached at a very acute angle. Veins pinnate, free, the veinlets usually forked. Sori borne on the veins, round, usually indusiate. Indusia reniform or occasionally resembling that in Filix. Fronds furnished with scales, at least on the stipes and rachises, often glandular, without true hairs consisting of a single cell or row of cells. Scales thin, entire or fimbriate, always consisting of 2 or more rows of cells, which are mostly long and narrow, with flexuose walls. [Dryopteris, subgenus Eudryopteris C. Chr.]

Indusia comparatively large, not dot-like.

Sori not close to the margin.

Rachis usually conspicuously chaffy; fronds $4.5-40 \mathrm{~cm}$. long.

Rachis naked or not noticeably chaffy; fronds $16-110 \mathrm{~cm}$. long. Pinnae triangular-oblong, or the lowest nearly triangular-ovate.

Pinnae linear-lanceolate from a somewhat broader base. Sori close to the margin.

Indusia minute, dot-like; blades bipinnatifid to tripinnate.

Pinnules decurrent on the narrowly-winged midribs; indusia glabrous.

Larger pinnules not decurrent.

Indusia, and frond when young, conspicuously glandular.

Indusia glabrous or with only a few glands.

1. D. fragrans.

2. $I$

cristata.

D. Filix-mas.

3. D. marginalis.

1. D. fragrans (L.) Sehott. Fronds borne in a crown, 4.5-40 cm. long, aromatic; stipe and rachis chaffy with bright brown scales; blades lanceolate to narrowly oblanceolate, somewhat narrowed toward base, nearly or quite bipinnate; pinnae oblong-lanceolate to deltoid-lanceolate; segments oblong, obtuse, adnate-decurrent, subentire to deeply incised; indusia very large, ragged and somewhat glandular at margin. On rocks: Alaska-Ellesmereland-Me.-Minn.; Russia.

2. D. cristata (L.) A. Gray. Fronds crowded at apex of a short stout creeping rhizome, the fertile erect, 2.5-10 dm. long, 7-15 $\mathrm{cm}$. broad, much overtopping the sterile; scales of stipe and rhizome pale brown, one-colored; blades linear or lanceolate, bipinnatifid; segments rather broad, oblong or triangular-oblong, obtuse, finely, usually sharply, serrate or obscurely or more deeply cut into serrate lobes; sori about medial; indusia smooth. Swampy places and roadsides: "Mack."-n Ida.-Man.-Va.-Newf.; Neb.; Eu. Submont.-Subalp.

3. D. marginalis (L.) A. Gray. Rhizome with golden brown scales; fronds in a crown, 1.2-10 dm. long; blades evergreen, coriaceous, ovate-oblong or ovate-lanceolate, usually bipinnate or nearly so; lower pinnae unequally deltoid- 
lanceolate, those above lanceolate to broadly oblong-lanceolate; segments oblong or lanceolate, mostly obtuse or subacute, falcate or subfalcate, subentire to erenately lobed; indusia smooth. Rocky places and old wood in swamps: Que. -N.S.-Ga.-Okla.-Sask.

4. D. Filix-mas (L.) Sw. Fronds borne in a crown, 1.5-10 dm. long, 6-30 $\mathrm{em}$. broad; blades broadly oblong-lanceolate, somewhat narrowed toward the base, bipinnatifid or bipinnate; pinnules oblong, obtuse, serrate at apex and obscurely so on the sides, the larger incisely lobed; sori nearer the midvein than the margin; indusia glabrous or glandular, often some with one or more glands and others glabrous on the same frond. Damp woods: B.C.-Ore.-Ida.-Ariz.-N.M.(Black Hills) S.D.; Ont.-Que.-N.S.-Vt.; "Greenl.," Eu. Submont.—Subalp.

5. D. spinulosa (L.) Kuntze. Scale of stipe and rhizome light brown, onecolored; fronds 2-9.5 dm. long; blades ovate-lanceolate to oblong; pinnae oblique to the rachis, elongate-triangular, the lower broadly and unequally triangular; pinnules oblique to the midribs, connected by a very narrow wing, acute, incisely serrate or obliquely pinnatifid; segments incised; teeth mucronate, falcate, appressed; sori submarginal, terminal on the veinlets. Damp woods: Newf. Va.-"Ky."-Wis.; B.C., Ida., and Eu. According to Macoun, throughout Canada. Submont.-Mont.

6. D. intermedia (Muhl.) A. Gray. Fronds in a crown, 2-9.5 dm. long; scales of the stipe light brown, mostly with darker centers; blades usually dark, often bluish green, ovate-lanceolate to oblong; pinnae usually nearly or quite at right angles to the rachis, the lower unequally lanceolate to ovate-lanceolate, the lowest inferior segment in the basal pair commonly shorter than the next; upper pinnae lanceolate to oblong; pinnules pinnately divided, the largest not decurrent; segments dentate. Wooded places: Newf.-N.C.-Tenn.-Wis.Ont.; Tex. (? "Throughout Canada.")

7. D. dilatata (Hoffm.) Underw. Fronds about $1-11 \mathrm{~cm}$. or more long; blades triangular to ovate or broadly oblong, usually tripinnate; lower pinnae broadly and unequally ovate or triangular, the upper lanceolate to oblong or elliptic-lanceolate; pinnules lance-oblong; teeth mucronate, straight or falcate, usually not appressed; sori mostly subterminal on the veinlets; in the typical form with scales of the rhizome mostly heavily dark-striped, and indusia often somewhat glandular, often some glabrous and others with one or more glands on the same frond. Alaska-B.C.-Calif.; Eu. Intergrading with the form designated by Kunze as Aspidium compylopterum, having large light brown scales only somewhat or not darker at center, ample fronds with spreading pinnules, basal pinnae on the lower side much elongate, the upper pinnae often ellipticlanceolate, and indusia always glabrous. Greenl.-N.C.-n Ida.-(?) Wash.B.C.-Alaska; Calif. (rare); Eu.

\section{ASPLÈniUm L. SPleEnWort.}

Ferns varying in size, with simple or compound commonly pinnate fronds. Sori oblong or linear, single or rarely a few double, borne on the veins. Indusia superior, attached laterally to the vein, opening toward the midrib or midvein. Veins free or rarely a few uniting. Scales of rhizome with dark-walled cells.

Blade irregularly forking.

1. A, septentrionale.

Blade not forking.

Blade simply pinnate.

Stipe brown below; rachis green.

stipe and rachis chestnut-brown or blackish. Pinnae not auricled.

Pinnae auricled at base on the upper or both sides.

Blade bi- to tripinnatifid.

2. A. viride.

3. A. Trichomanes.

4. A. platyneuron.

5. A. Adiantum-nigrum.

1. A. septentrionale (L.) Hoffm.- Fronds tufted, $3.5-20 \mathrm{~cm}$. long; stipes brown below; segments $2-5$, oblique, linear, tapering both ways, entire or with a few oblique long narrow teeth; sori elongate, mostly $2-3$ to each segment, usually opposed in pairs; indusia entire or sparingly short-ciliate. Belvisia septentrionalis (L.) Mirb. On rocks: S.D.-N.M.-L. Calif,-Wyo.; Eurasia. Submont.-Mont. 
2. A. viride Huds. Fronds tufted; blades $2.7-20 \mathrm{~cm}$. long, $0.8-1.5 \mathrm{~cm}$. broad, linear-lanceolate; pinnae roundish ovate or rhombic, obtuse, broadly cuneate at base, the lower side obliquely truncate; margins, excepting the basal parts, deeply erenate; sori near the margins; indusia entire or denticulate. On rocks: Newf.-Vt.-Sask.-(Black Hills) S.D.-Wyo.-Wash.-Alaska. Mont.

3. A. Trichomanes L. Fronds tufted; blades 4-18 cm. long, linear; rachis faintly alate, not fibrillose; pinnae mostly oval or oval-oblong, inequilateral; margins, except the basal sides, slightly crenate; veins on both sides of the midveins usually forked; indusia commonly slightly crenulate. On rocks: Hudson Bay-Ala.-Ariz.-Alaska; Eu., the Azores, and Canary Islands. Submont.Mont.

4. A. platyneuron (L.) Oakes. Fronds tufted, the fertile erect, $20-50 \mathrm{~cm}$. long, $2.5-6.3 \mathrm{~cm}$. broad, the sterile rosulate much shorter; blades linear-oblanceolate, gradually reduced toward the base; pinnae auriculate-lanceolate, subfalcate, crenate, serrate, or incised, the lower oblong or deltoid; sori oblique, near the midveins. Among rocks or stones: s Ont.-Me.-Fla.-N.M.-Colo.; Africa. Submont,-Mont.

5. A. Adiantum-nigrum L. Fronds tufted; stipes and lower part of the rachis chestnut-brown, except in young plants; rachis winged; blades $3-33 \mathrm{~cm}$. long, ovate-deltoid to elongate-deltoid; lower pinnae deltoid, or nearly so, those above mostly lanceolate-deltoid, gradually passing into the pinnatifid apex of the blade; segments ovate to spatulate, euneate at base, sharply toothed or obliquely cleft into toothed lobes; veins very oblique; indusia entire or subentire. A. Andrewsii A. Nels. On rocks: Colo.; Eurasia, and Africa. Submont.

\section{ATHÝRIUM Roth. LADY FERn.}

Various sized ferns, with more or less compound fronds. Scales of the rhizome with thin-walled cells. Veins free. Sori borne on the veins, indusiate, mostly oblong or linear-oblong and curved at one end over the vein, or bent back upon itself along the other side of the vein, often horseshoe-shaped, occasionally roundish. Indusia following the shape of the sorus, attached along its length at the side next the vein, opening outwardly, rarely vestigial and hidden.

Pinnules commonly somewhat cuneate at base, sometimes appearing short-stalked; indusia rarely seen, very minute and evanescent. 1 . A. alpestre.

Pinnules more or less parallel at base down to the rachis, at least on the upper side; indusia evident.

Indusia straight or variously curved, often shaped like a shepherd's crook.

Indusia mostly curved so as to appear circular with a narrow sinus, $2 . A$. filix-foemina

1. A. alpestre (Hoppe) Rylands. Rhizome short, stout; fronds in a crown, 25-95 cm. long; blades oblong-lanceolate, slightly narrowed toward the base, bior tripinnate; pinnae deltoid-lanceolate, their rachises commonly very narrowly winged; pinnules ovate-oblong or oblong-lanceolate or deltoid-lanceolate, somewhat obliquely incised or pinnatifid or occasionally pinnate below; segments sharply toothed. Alaska-Mont.-Colo.-Calif.; Que.; Eu.

2. A. Filix-foemina (L.) Roth. Rhizome short, creeping; fronds closely clustered, 1.3-12.5 dm. long; stipes straw-colored, brownish or pinkish red; blades firmly herbaceous to herbaceous-membranous, rather deep green, often with a bluish tinge, except when growing in sun, broadly oblong-ovate to oblonglanceolate or broadly lanceolate, not or somewhat shortly narrowed at base; pinnae short-stalked or the upper sessile, lanceolate, acuminate, toward apex pinnatifid, below pinnate or nearly so; pinnules oblong-lanceolate or broadly elliptical, incised or serrate, the lobes or teeth often again toothed; sori oblong, linear or hamate or occasionally horseshoe-shaped; indusia subentire to ciliate, the cilia often jointed and occasionally gland-tipped; some at least of the sporangia with a flat, jointed gland-tipped hair on the pedicel. Woods and fields: Ont.-Newf.-Fla.-La.; Tex.-Ariz.; (Black Hills) S.D.; the Old World. Probably also extends farther north in Canada. 
3. A. cyclosorum Rupr. Rhizome erect or oblique; fronds in a crown, 2.8-15 dm. long; blades somewhat softly herbaceous, olive or yellowish green, elliptic-lanceolate, decidedly and rather gradually narrowed toward the base; pinnae lanceolate or oblong-lanceolate or elliptic-lanceolate, acuminate, pinnatifid toward tip, below pinnate or nearly so; pinnules oblong to lanceolate or ovatelanceolate, commonly broader than in A. filix-foemina, serrate or incised or deeply pinnatifid, the teeth or lobes often toothed, sometimes doubly so; indusia very short, usually curved so as to appear circular or irregular, nearly always fringed with long jointed cilia; sporangia without hairs on the pedicel. Woods and open places: Calif.-B.C.-Mont.-N.M.; Alaska and the Old World. Undoubtedly will be found more widely distributed in Canada.

\section{AdiÁntum (Tourn.) L. Matden-hair Fern, VenUs'-HAir Fern.}

Ferns with compound fronds having segments in the form of small leaflets, and slender, usually dark-colored shining stipes. Lobes of the leaflets reflexed, indusiform, bearing the sori on the under side at the ends of the veins. Veins free.

Stipes forked into two rachises, which bear on upper side pinnae interspersed with single leaflets.

Stipes not forked at apex; blades alternately bipinnate or tripinnate.

Rachises wavy-flexuose; leaflets very short-stalked.

Rachises strongly divaricate-flexuose; leaflets mostly conspicuously stalked.

1. A. pedatum.

2. A. modestum.

3. A. rimicola.

1. A. pedatum L. Stipes and rachises dark chestnut-brown; fronds $2-5$ $\mathrm{dm}$. high; principal leaflets dimidiate-triangular-oblong, lobed on the upper side with unilateral midveins; branches of midveins several times forked. Damp woods and in shade near water: Newf.-Ga.-Kans.-(Black Hills) S.D.; Utah; Calif.-Mont.-Alaska; China, Japan, India.

2. A. modestum Underw. Rhizome creeping, chaffy with lightbrown scales; stipes and rachises purplish brown to ebeneous; blades 8-29 $\mathrm{cm}$. long and 5-15 $\mathrm{cm}$. broad, deltoid-lanceolate to deltoid-ovate, commonly tripinnate; pinnae commonly arched; leaflets 6-15 mm. wide or the terminal wider, nearly as long as wide, truncate, roundish or broadly cuneate at base, equilateral or inequilateral, rounded above, 2-5-lobed, mostly 3-lobed, the incisions shallow, the margin in sterile leaflets, with rare exceptions, evenly and finely serrate-denticnlate, in fertile leaflets similarly toothed between the sori; stalks of pinnules and basal veins commonly greenish white or the stalks light brown; veins repeatedly forked; indusia largely oblong, entire to crenate. Wet places among rocks: Ariz. -s Utah-s Colo.-Tex.; (Black Hills) S.D.

3. A. rimicola Slosson. Stipes and rachises dark reddish brown; blades up to $17.5 \mathrm{~cm}$. long and $12 \mathrm{~cm}$. broad, ovate-oblong to ovate-deltoid, mostly broadest at base; leaflets up to $2 \mathrm{~cm}$. long and $2.5 \mathrm{~cm}$. broad, equilateral or inequilateral, narrowly cuneate below, above flabelliform and flaring, at base mostly edged by the first, usually dark brown, fork of the veins, cleft one-eighth to twothirds of the way down into 2 or 3 lobes; lobes often shallowly incised, when fertile completely recurved between the notches, when sterile sharply serrulate; veins repeatedly forking; indusia transversely elongate, up to $8 \mathrm{~mm}$. long, subentire or erose. Cliffs: Utah. L. Son.

\section{PtÈris L. Brake, Bracken.}

Large ferns, with coarse compound fronds and ereeping rhizomes. Margins of the frond's divisions reflexed, forming an indusium. Sporangia borne on a continuous vein-like receptacle connecting the ends of the veins, with an obseure inner inferior indusium attached to the receptacle. Veins pinnate.

1. P. aquilina L. Stipes up to $9 \mathrm{dm}$. long; fronds to $12 \mathrm{dm}$. long, deltoid to ovate-deltoid, subternately decompound, the larger tripinnate below; pinnules entire, lobed, auricled or pinnatifid, the entire ones mostly oblong or linear, commonly spaced, rarely abruptly dilated at base; costae, midribs, and reflexed 
margins slightly hairy; surfaces otherwise glabrous or with a few seattered hairs; hairs mostly pluricellular. Rare in the west, where it is replaced by the following variety, Woods: Newf.-Fla.-Colo. (?) -S.D.; Eu. Submont.-Mont.-Boreal. Pteris aquilina pubescens Kuntze. Pinnules more regularly pinnatifid, the entire ones often deltoid-oblong; midribs only slightly raised, not broad and conspicuously elevated; under surface pubescent or tomentose, the upper slightly hairy or glabrous; hairs slender, many, short, erect, setiform or hamate and unicellular, others longer, often tortuous and pluricellular. Pteridium aquilina pubescens Underw. Pteris Feei Schaffner. Woods: Alaska-Mont.-N.M.-Calif.; Mex., Guatemala, and (?) Eu.

\section{CRYPTOGRÀMmA R. Br. ROCK-BRAKE.}

Small ferns, with slightly dimorphous compound fronds. Margins of the blades' subdivisions reflexed over the sporangia, finally opening out flat. Sporangia without other indusia, on the upper part of the veins and extending down them. Veins free.

Fronds scattered; leaf-texture very delieate; stipes brown or brownish below or throughout.

Fronds tufted; leaf-texture firm.

Stipes straw-colored.

Stipes chestnut-colored.

1. C. Stelleri.

2. C. acrostichoides. 3. C. densa.

1. C. Stelleri (Gmel.) Prantl. Rhizome slender, ereeping; fertile fronds 5.5-22 cm. long, the sterile usually shorter; blades ovate, bi-tripinnatifid; ultimate segments cuneate and decurrent at base, the fertile linear-oblong to lancelinear, the sterile ovate to obovate-flabelliform, crenulate. Pellaea gracilis Hook. On shaded, damp, mostly limestone, rock: Que.-Ga.-Minn.-Sask.-Mont.B.C.; Colo.; India. Submont.-Mont.

2. C. acrostichoides R. Br. Fertile fronds 8-36 cm. long, long-stalked, commonly overtopping the sterile; blades ovate, the sterile tri-quadripinnatifid; sterile ultimate segments ovate-oblong or suboval, obtuse, serrulate, the fertile narrowly elliptical or linear, their reflexed margins scarcely altered. On rocks: Baffin Bay-Mont.-Sask.-Colo.-Calif.-Alaska. Submont.-Subalp.

3. C. densa (Brack.) Diels. Primary rachis, except in the upper part of the blade, and scales of rhizome chestnut-colored, like the stipe; fronds 6-29 $\mathrm{cm}$. long; blades ovate or oblong-deltoid, densely tripinnate; sterile ultimate segments lance-linear, incisely serrate, the fertile linear, nearly sessile, their reflexed margins delicately indusiform, erose-toothed. Pellaea densa Hook. On rocks: B.C.-Mont.-N.M.-Utah-Calif.; se Canada.

\section{PELLÀEA Link. Cliff-brake.}

Ferns, with compound fronds and usually dark-colored stipes, the fertile divisions usually narrower than the sterile. Sori borne on the upper part of the free veins, ususlly confluent in a submarginal line. Margins of the fertile segments reflexed over the sporangia, indusiform.

Segments of the blade obtuse or acute, rarely a few mucronate.
Blades once pinnate, the pinnae mostly two-parted; stipes repeatedly marked with
transverse crack-like depressions.
Blades once or twice pinnate; stipes not marked with transverse depressions.
Stipes and rachises reddish brown, entirely glabrous or with only few occeasional
long flaccid jointed hairs.
Stipe and rachises purplish black, rather thickly clothed with slender flaccid
jointed hairs.
Segments sharp-pointed or mucronate; blades once pinnate above, bipinnate below.
4. P. mucronata.

1. P. Breweri D. C. Eat. Scales of rhizome rust-colored; fronds tufted, 5-20 cm. long; stipes brittle, breaking off above the scales, reddish brown; rachis reddish brown except near apex; blades oblong; pinnae short-stalked, the superior segment the larger, segments obtuse or the fertile subacute; indusia pale, On rocks: Ida.-Calif. 
2. P. glabella Mett. Scales of rhizome rust-colored; fronds tufted, 2.5-16.7 cm. long; stipes slender; blades ovate to oblong or ovate-lanceolate; pinnae simple and 0.7-1.9 $\mathrm{cm}$. long, or commonly the lower pinnately trifoliate, those of the lowermost one or two pairs rarely with 4 or 5 segments; segments oblong to lanceolate or the smaller ovate-oblong or suboval, obtuse or abruptly acute; branches of midveins mostly once or twice forked; indusia entire or slightly erose. P. pumila Rydb. P. atropurpurea occidentalis A. Nels. P. atropurpurea Bushii Macoun. On dry rocks: Ariz.-Wyo.-Wash.-Minn.-Ark.-Kan.N.Y.-Vt.-B.C. Undoubtedly of wider range, especially in the north. PlainMont.

3. P. atropurpurea Link. Scales of rhizome fulvous rust-colored; fronds tufted, 2.5-41.7 cm. long; stipes wiry; blades lanceolate or ovate-lanceolate, pinnate or usually bipinnate below; sterile segments commonly suboval; fertile segments mostly linear or sublinear, sometimes auricled, obtuse or acute; branches of midveins mostly about twice forked; indusia entire or slightly erose. On dry rocks, particularly limestone: "N.H."-"R.I."-Ga.-nw Mex.-Ariz.-S.D.; "B.C."-"Athabasca."

4. P. mucronata D. C. Eat. Scales of rhizome black-striped at center, with light tawny margins; fronds tufted, 8-60 cm. long; stipes and rachises dark mahogany-colored or purplish black, smooth; segments sessile or subsessile, the sterile roundish oval, sometimes subcordate at base, the fertile linear-oblong, with strongly revolute margins. $P$. Wrightiana Hook. $P$. longimucronata Hook. P. truncata Goodding. On rocks: Tex.-Kans.-Calif.-L. Calif. Son.

\section{CHEILĀNTHESS SW. LIP-FERN.}

Small ferns with compound, usually chaffy or hairy fronds. Indusium formed of the reflexed margins of the subdivisions, roundish and distinct or continuous. Sori roundish and distinct or more or less confluent, borne on the thickened apices of free veins.

Blades scaly, not tomentose.

Blades tomentose beneath, with or without scales,

Blades without scales.

Blades having scales.

1. C. Fendleri.

Ultimate segments oblong-oval; upper surface at first scantily webby, soon glabrous.

Ultimate segments rounded, narrowed toward base; upper surface tomentose.

4. C. Eatoni.

1. C. Fendleri D. C. Eat. Rhizome creepy, chaffy with bright tawny scales without dark centers; fronds mostly scattered, $6-25 \mathrm{~cm}$. long; blades ovatelanceolate, tripinnate; stipes and primary rachises brown, chaffy with mostly slender scales; secondary and tertiary rachises chaffy, the scales imbricate, bright brown, usually white-margined, broadly ovate, entire or subentire, not ciliate or very sparingly ciliate at base; ultimate segments minute, subglobose, entire, or obovate and 2-3-lobed, smooth above, commonly with a single broad scale at the center beneath; indusia formed of the much recurved margins. Dry rocks: Colo.-"w Tex."-Ariz. Submont.-Mont.

2. C. Feei Moore. Scales of the rhizome cinnamon-brown, mostly blackstriped at center; fronds tufted, 5-16 $\mathrm{cm}$. long; stipes and rachises dark brown or blackish; blades ovate-lanceolate, tripinnate or tripinnatifid, rarely bipinnate; lower pinnae deltoid, those above oblong-ovate; ultimate segments minute, the apical one slightly the largest, their lower surfaces densely tomentose; hairs whitish brown, soft, matted, flattened, jointed; indusium subcontinuous around the segment, formed of its scarcely altered margin. C. lanuginosa Nutt. On or among rocks: B.C.-Minn.-Ill.-Ark.-Ariz.; Mex. Plain-Submont.

3. C. gracillima D. C. Eat. Scales of the rhizome dark rusty brown with darker, not black, centers; fronds tufted, 4-24 cm. long; stipes and primary rachises dark brown or blackish; blades narrowly ovate-lanceolate, bipinnate or sometimes subtripinnate; tomentum consisting of scale-like branching hairs; rachises chaffy, with slender scales ciliate at base; indusium continuous around the segment. 'On rocks: B.C.-Mont,-Ida.-Calif.; Mex. 
4. C. Eatoni Baker. Scales of the rhizome mostly with dark brown or blackish centers; fronds tufted, 6-38 cm. long; blades oblong-lanceolate, tripinnate; pinnae ovate-oblong; stipes and primary and secondary rachises chaffy, with white or pale rusty, imbricate, sub-appressed, lanceolate to linear scales; tomentum consisting of long slender ribbon-like hairs; ultimate segments about $1.5-2$ $\mathrm{cm}$. long, the terminal one often twice larger; indusium continuous around the pinnule, slightly membranous at margin. Rocky places: Utah-Ark.-Ariz.;
Mex.

\section{NOTHOLĀENA R. Br.}

Small ferns, with pinnately compound fronds lacking proper indusia and almost always farinose, hairy, or chaffy on the under surface. Margins of the blade sometimes inflexed at first over the sporangia. Sori roundish or oblong,

Blades tomentose, not farinose beneath.

Blades whitish-farinose beneath, not hairy.

Rachises divaricate-flexuose.

Rachises straight or nearly so, not divaricate-flexuose.

1. N. Parryi.

2. N. Fendleri,

3. N. nivea.

1. N. Parryi D. C. Eat. Scales of the rhizome dark reddish brown, mostly with narrow blackish midribs; fronds tufted, 4-26 $\mathrm{cm}$. long; stipe and rachises dark reddish or purplish brown; blades oblong-lanceolate, tripinnate; ultimate segments roundish obovate, $2 \mathrm{~mm}$. broad, crenately incised, densely coated on the upper surface with tangled, whitish or pale tomentum, and on the lower surface with light brown tomentum; tomentum consisting of slender articulated hairs. On rocks: Calif.-Utah-Ariz. Son.

2. N. Fendleri Kunze. Seales of the rhizome bright reddish brown, one-colored; fronds tufted, $7.5-23 \mathrm{~cm}$. long; stipes and rachises dark brown; blades broadly deltoid-ovate, 4-5 pinnate below, gradually simpler above; ultimate segments oval or elliptical, simple or 3-lobed. On rocks: Colo.-"Tex."- "Ariz."

3. N. nivea Desv. Scales of the rhizome reddish brown, one-colored, fronds tufted, 3-20 cm. long; stipes and rachises dark brown or black; blades ovate, lanceolate, triangular-ovate or deltoid, 3-pinnate; pinnules long-stalked; ultimate segments green and smooth on the upper surface, roundish, nearly as broad as long, the terminal ones larger, entire or 3-lobed; sori often descending the veins. On rocks: Utah-N.M.-Ariz.; Mex. and S. Am. Son.

\section{POLYPÒDIUM [Tourn.] L. POLYPODY.}

Ferns varying in size and habit. Fronds entire to pinnately compound. Sori borne on the backs of the fronds, round to elliptical, non-indusiate, dorsal or terminal on the free or anastomosing veins, the veins free in our species.

1. P. hesperium Maxon. Rhizomes hard, liquorice-like, chaffy; stipes stramineous; blades 7.6-20 cm. long, 2.5-4.4 cm. broad, linear-oblong, deeply pinnatifid or below pinnate; segments elliptical or somewhat spatulate, narrowest just above the often dilated base, broadly rounded at apex, obscurely or evidently crenate; under surface slightly glandular; veins 1-3 times forked; sori large, medial, on the ends of the veinlets. B.C.-S.D.-N.M.-Ariz.-Wash.

\section{Family 3. MaRsiliaceae. Marsilia Family.}

Perennial herbaceous plants rooting in mud, in ours with 2-4-foliolate stalked leaves borne on a creeping rhizome. Sporocarps containing both macrospores and microspores, borne on peduncles attached to the lower parts of petioles or to the rhizome close to them.

\section{MARSílea L.}

Marsh or aquatic plants commonly growing in shallow water, with their leaves floating on its surface. Leaves 4 -foliolate. Sporocarps crustaceous, ovoid 
or bean-shaped, usually with 2 teeth near the base, divided vertically into two cells, which are subdivided into transverse compartments (sori).

Sporocarps with two distinct acute teeth separated by a rounded sinus, the upper tooth the longer, straight or curved.

1. M. vestita.

Sporocarps with the lower tooth short and blunt, the upper a mere rounded papilla or wanting.

2. M. oligospora.

1. M. vestita Hook. \& Grev. Petioles 1-14 cm. long; leaflets broadly cuneate, usually hairy, entire; peduncles erect or ascending, distinct from the petioles, scarcely as long as the sporocarps; sporocarps solitary, hairy, with about 7-9 sori in each cell. B.C.-"Ia."-Ark.-Calif.

2. M. oligospora Goodding. Petioles $1-12 \mathrm{~cm}$. long; leaflets cuneate, spreading above, hairy or glabrescent; peduncles erect or ascending, each united at base with the base of a petiole, 0.4-1.7 cm. long; sporocarps solitary, somewhat deflexed, with 5-8 sori in each cell, clothed with lance-shaped, jointed, tuberculate hairs. Wyo.-Wash.; Calif.

\section{Family 4. SalviniaCeae. Salvinia Family.}

Aquatic, floating plants, bearing minute, apparently 2-ranked leaves on a more or less elongate, sometimes branching, axis. Sporocarps borne 2 or more on a common stalk, soft, one-celled, thin-walled, each containing a central often branched receptacle, which bears either macrosporangia containing solitary macrospores or microsporangia containing numerous microspores.

\section{AZÖLLA Lam.}

Small moss-like plants, with pinnately branched stems bearing rootlets on the under side. Leaves imbricate, 2-lobed. Sporocarps borne in pairs beneath the stem, some small, ovoid or acorn-shaped, containing at base a single macrospore with a few attached bodies of uncertain function above it, the others larger, globose, containing on a basal placenta numerous stalked microsporangia enclosing masses of microspores, which are usually furnished with anchor-shaped processes.

1. A. caroliniana Willd. Plants much branched, 6-25 mm. broad; lobes of leaves ovate, the lower reddish, the upper green, reddish margined; macrospores minutely granular, accompanied with three corpuscles; processes of the microspores rigid, septate. In still waters: "Ont."-"Fla."-Calif.-B.C.; trop. Am.

\section{Family 5. EQUISETACEAE. Horsetail Family.}

Rush-like, verticillately branched or unbranched plants, with rootstocks and mostly hollow, jointed stems, bearing sheaths at the nodes. Spores in a terminal cone formed of verticels of stalked peltate bracts bearing on the under side 6 or 7 sporanges, which open on the inner side. Prothallium in damp places, green, variously lobed.

\section{EQUISÈTUM. HoRsetail.}

Characters of the family.

Stem annual; spike rounded at the top; stomata scattered in the grooves of the stem.

Stems of two kinds, the fertile ones succulent, appearing earlier than the sterile ones.

Fertile stems simple, soon withering, branchless.

1. E. arvense.

Fertile stems, when older, producing branches, only the naked apex withering. Branches compound; ridges with 2 rows of hooked spinules.

Branches simple; ridges with 3 rows of broad spinules.

2. E. sylvaticum.

Stems of one kind; branches simple or none.

Teeth of the sheaths persistent; plant usually branched, at least in age.

Sheaths loose; teeth grooved, black with white margins; central cavity one. sixth of the diameter of the stem.

4. E. palustre. 
Sheath close; central cavity one-half of the diameter of the stem or more.

Sheaths 7-8 mm. long; stem stout, sparingly branched. 5. E. fluviatile.

Sheaths less than $5 \mathrm{~mm}$. long; stem slender, much branched. (Autumnal Teeth of the sheaths deciduous; plant unbranched or nearly so. 1. E. arvense.

Stem perennial, evergreen (except sometimes in E. laevigatum), mostly. kansanum. apiculate, with a rigid tip; stomata in regular rows.

Central cavity present; stem more than 6-angled, except sometimes in E. variegatum. Teeth of the sheaths deciduous; stem tall and stout, many-grooved.

Stem tubercled, rough.

Sheath close, usually with a black or dark ring near the base, then grayish and with a narrow dark border at the base of the teeth.

Stem 1-2 m. high, stout; sheaths as broad as long.

Stem 0.3-1 m. high, slender; sheath longer than broad.

Sheaths more ampliate above, green, with or without 8 . E. affine.

but no ring below.

9. E. intermedium. margin, but rarely with a ring below.

Teeth of the sheaths persistent, white-margined; stem low, slender, 10 - laevigatum.

Central cavity wanting; stem 6-angled.

11. E. variegatum

1. E. arvense L. Spore-bearing stems 1-2.5 dm. high, $3-5 \mathrm{~mm}$. in diameter, with loose 8-12-toothed sheaths, rarely with a few branches; cones peduncled, 2-4 cm. long, 5-10 mm. thick; sterile stems decumbent to erect, 1-3.5 dm. high, 2-3 mm. thick, 10-14-furrowed, branched; branches 3-4-angled, solid; teeth of the sheaths lanceolate, acuminate. In the fall the sterile stems sometimes bear small cones 4-10 mm. long, mostly with sterile spores (var. serotinum). Wet banks: Greenl.-S.C.-Calif.-Alaska; Eurasia. Plain-Alp.

2. F. sylvaticum L. Stems 1-4.5 dm. high, 8-14-riaged, 3-4 mm. thick; both the fertile and the sterile ones branched; central cavity constituting half the diameter; sheaths brown, loose, the teeth more or less coherent; primary branches 4-5-angled, the secondary ones 3-angled; cones peduncled, 1-3 cm. long, 5-8 mm. thick. Wet shady places: Newf.-Va.-Ia.-B.C.-Alaska;
Eurasia. Submont.-Mont. My-Je.

3. E. pratense Ehrh. Stems 2-4 dm. high, 3-5 mm. thick, 8-20-ridged, the fertile ones at first nearly unbranched, some developing short spreading branches, the sterile ones with long branches; central cavity one-third the diameter; sheaths green, loose; teeth lanceolate with dark middle; branches 3-ridged; teeth of the sheaths deltoid; cones peduncled, 1-2 cm. long, about $5 \mathrm{~mm}$. thick. Alluvial soil: N.S.-N.J.-Colo.-Alaska; Eurasia. Submont.-Subalp. Ap-
My.

4. E. palustre L. Stems 2-9 dm. high, 3-5 mm. thick, 5-10-angled; branches long, ascending, hollow, 4-7-angled; sheaths widened upwards; teeth lance-subulate; cones 1.5-2.5 $\mathrm{em}$. long, 5-6 mm. thick. Wet places: Newf,-Conn.-Wyo. -Wash.-Alaska; Eurasia. Submont.-Mont. Je-Au.

5. E. fluviatile L. Stems $3-15 \mathrm{dm}$, high, 4-8 mm. thick, 10-30-angled; central cavity four-fifths of the diameter; branches spreading or upeurved, long, 4-6-angled, hollow; sheaths appressed; teeth dark brown, distinct, narrow; cones short-peduncled, 1.5-2.5 $\mathrm{cm}$. long, 5-7 mm. thick. E. limosum L. Shallow water: Newf.-N.Y.-Wyo.-Wash.-B.C. Plain-Mont. Je-Jl.

6. E. kansanum J. H. Schaffner. Stems 3-5 dm. high, 15-30-grooved, light green; sheaths long, dilated above, green, with a narrow black band at the top, rarely with a faint one below; cones short-peduncled, ovate or ovate-oblong, $1.5-2.5 \mathrm{~cm}$. long, 7-8 mm. thick. Clay banks: Mo.-Utah-Mont. PlainSubmont.

7. E. robustum A. Br. Stems 1-3 m. high, 8-12 mm. thick, 16-48-angled, dark green; ridges rounded, rough, with 3 rows of tubercles; sheath tight, about as broad as long; teeth mostly persistent, lance-linear, sharply 3-angled, black, with white margins; spike sessile, $1.5-2.5 \mathrm{~cm}$. long, 6-7 mm. thick, strongly apiculate. N.Y.-Md.-La.-Tex.-Calif.-B.C. Plain-Submont. Je-Au.

8. E. affine Engelm. Stems 3-10 dm. nigh, 4-8 mm. thick, 16-40-angled, dark green; ridges rounded, rough with 2 rows of tubercles; sheaths longer than 
broad; teeth lance-linear, sharply 3-angled, persistent or coherent by their tips and torn off; cone $1-1.5 \mathrm{~cm}$. long, about $5 \mathrm{~mm}$. thick, sharply apiculate. $E$. robustum affine Engelm. E. hyemales Am. auth., not L. N.S.-N.Y.-Ariz.Sask. Plain-Submont. Je-Au.

9. E. intermedium (A. A. Eaton) Rydb. Stems 3-12 dm. high, 5-8 mm. thick, 20-30-angled; ridges rough, with 2 rows of tubercles; sheath longer than broad, green, except a narrow black and white border, sometimes with a dark band beneath; teeth thin, brown, hyaline-margined, deciduous or persistent; cones sessile, about $1 \mathrm{~cm}$. long and $5 \mathrm{~mm}$. thick, apiculate. E. laevigatum Milde, not A. Br. Moist sandy soil: Mich.-Mo.-Calif.-Wash. Plain-Submont.

10. E. laevigatum A. Br. Stems 1-10 dm. high, 4-6 mm. thick, simple or with erect branches, 20-30-grooved; sheaths widened upwards, green, with a black limb; teeth mostly deciduous, with black triangular bases; cones sessile or nearly so, $1-1.5 \mathrm{~cm}$. long, about $5 \mathrm{~mm}$. thick, rather bluntly apiculate. Alluvial soil: Ohio-Tex.-Calif.-B.C. Plain-Mont. Je-Au.

11. E. variegatum Schleich. Stems $1.5-3 \mathrm{dm}$. high, 2-4 mm. thick, 5-10grooved, tufted; central cavity one-third the diameter; sheaths loose, green below, with a dark ring above; teeth black, with broad white border, persistent, with a filiform deciduous tip; cones short-peduncled or sessile, 8-10 mm. long, about $3 \mathrm{~mm}$. thick. Wet grounds: Lab.-N.Y.-Colo.-Alaska. Plain-Mont.

12. E. scirpoides Michx. Stems tufted, filiform, less than $1.5 \mathrm{dm}$. bigh, 1-2 mm. thick, flexuose-curving; sheaths short, with 3 subulate, persistent teeth; cones 3-5 mm. long, $2 \mathrm{~mm}$. thick. Damp places: Lab.-Pa.-Mont.-Wash.B.C.; Eurasia. Submont.-Mont.

\section{Family 6. ISOETACEAE. Qulllwort Family.}

Small water or bog plants, with a corm-like short stem and numerous crowded subulate or nearly filiform leaves. Spores of two kinds, smaller microspores (male) and larger macrospores (female), in axillary sporangia covered by the enlarged bases of the leaves, the macrospores spherical, with an equitorial ring-like ridge and three other ridges meeting at the apex, the microspores obliquely oblong, triangular in eross-section.

\section{ISÒETES. QUILLWORT.}

Characters of the family.

Submerged species; leaves without peripheral bast-bundles.

Stomata absent; macrospores marked with confluent crests, more or less honeycombed.

Stomata present; macrospores spinulose or tubercled.

Macrospores spinulose.

Macrospores with low tubercles.

A mphibious or terrestrial species; leaves with peripheral bast-bundles and stolanderi.

Macrospores, with low blunt isolated or confluent crests; peripheral bast-bundles 4.

4. I. Howellii.

Macrospores, with numerous minute tubercles or almost smooth; peripheral bastbundles 3 .

5. I. Nutlallii.

1. I. occidentalis Henders. Leaves rigid, spreading, quadrangular, dark green, 5-20 cm. long; ligule narrowly triangular; velum covering about one-third of the sporangium; macrospores about $0.4 \mathrm{~mm}$., finely crested, with simple or confluent crests; microspores papillose to echinulate. I. lacustris paupercula Engelm., a depauperate form. In water: Ore--Wyo.-Colo.-Calif. PlainMont. Jl-O.

2. I. Braunii Durieu. Leaves erect or spreading, green or reddish green, tapering, 7-20 cm. long; velum covering one-half to three-fourths of the spotted sporangia; macrospores $0.4-0.5 \mathrm{~mm}$., with broad retuse spinules; microspores smooth. I. echinospora Braunii Engelm. In water: Greenl.-N.J.-Calif.B.C. 
3. I. Bolanderi Engelm. Leaves erect, soft, bright green, tapering to a fine point, 5-10 cm. long, thin-walled; stomata few; ligule triangular; velum narrow; sporangia unspotted; macrospores $0.3-0.45 \mathrm{~mm}$. thick; microspores deep brown, spinulose. In water and mud: Wash.-Wyo.-Colo.-Calif. Plain-Mont, $\mathrm{Au}-\mathrm{S}$.

4. I. Howellii Engelm. Leaves 5-20 cm. long; stomata numerous; bastbundles 4 ; velum narrow, densely spotted; ligule short triangular to $4 \mathrm{~mm}$. long; macrospores $0.48 \mathrm{~mm}$., with low blunt crests; microspores light brown, with low tubercles or spines. I. nuda Engelm. I. Underwoodii Henders. Borders of ponds: B.C.-Mont.-Ida.-Calif. Plain-Submont. Je-Au.

5. I. Nuttallii A. Br. Trunk almost globose, 3-lobed; leaves slender, bright green, 7-20 cm. long; stomata many; bast-bundles 3 ; velum broad, covering the sporangia; macrospores $0.25-0.5 \mathrm{~mm}$; microspores brown, papillose. I. opaca Nutt. I. Suksdorfii Baker. Mud: B.C.-Ida.-Calif. Son.-Plain. Mr-Jl.

\section{Family 7. Lycopodiaceae. Club-moss Family.}

Low, erect or trailing plants, somewhat resembling mosses, with leafy, usually branched, often elongate stems. Leaves small, lanceolate or subulate or sometimes oblong or roundish, some bearing on their axils or on their upper surfaces solitary 1-3-celled sporanges. Spores minute, of one kind.

\section{LyCopòdium L. Club-moss, Ground Pine.}

Perennial plants, with evergreen, usually stiff, commonly imbricate, onenerved, 4-16-ranked leaves. Main stems usually creeping, with aerial branches. Sporangia flattened, coriaceous, usually reniform, 1-celled, opening by a transverse slit around the margin, borne in the axils of ordinary or modified and bract-like leaves. Spores sulphur-colored.

Sporanges borne in the axils of ordinary leaves, which are not arranged in distinct spikes.

Leaves hollow at base, all or mostly all ascending, of nearly one length.

Leaves flattened, not hollow at base, spreading or deflexed, 1 . L. Selago. alternating zones.

Sporanges borne in the axils of bracts arranged in spikes on the aerial 2 . L. porophilum.

Spikes sessile, or with stalks not more than $1 \mathrm{~cm}$. Aerial branches all simple.

Aerial branches, at least in part, branched.

3. L. inundatum.

Leaves of the ultimate divisions of the aerial branches in 4 rows.

Leaves of the ultimate divisions of the aerial branches 4 . L. alpinum.

Aerial branches tree-like.

Aerial branches not tree-like, mostly loosely forling 5 . L. obscurum. tufts.

Leaves of the ultimate divisions of the aerial branches in 5 rows.

Leaves of the ultimate divisions of the aerial branch. L. sitchense.

Spikes borne on bracteate peduncles more than $2 \mathrm{~cm}$. long, Leaves of the divisions of the aerial branches in 4 rows.

Leaves of the divisions of the aerial branches in many rows,

.

7. L. annotinum.

9. L. clavatum.

1. L. Selago L. Main stems very short, dichotomously branching into upcurved or erect forking branches forming a tuft $2.5-24 \mathrm{~cm}$. high; leaves crowded, appressed or ascending or rarely a few reflexed, triangular to linear-acuminate or aciculate, acute, entire; sporophylls shorter than the leaves, triangular; plant often bearing gemmae. Rocks: Greenl.-Newf.-Me.-N.Y.-Ont.-AlaskaMont.-Wash.-Va.-N.C.-Tenn.; Mex.; Eu.

2. L. porophilum Lloyd \& Underw. Main stems short, upeurved, dichotomously branching into upeurved or erect forking branches forming a tuft 3-35 $\mathrm{cm}$. high; leaves crowded, spreading or reflexed, linear or nearly so, entire or rarely very minutely denticulate, those in the zones of the longer slightly broadened above the middle and similarly contracted toward the base, those in the zones of the shorter broadest at the base, but very gradually tapering; sporophylls entire or minutely denticulate above the middle, acuminate; plant often 
bearing gemmae.* On rocks, especially sandstone: "Newf."- "Que."-Pa.Ind.-Minn.-Ala.-B.C.-Wash. Probably of wider range.

3. L. inundatum L. Main stems very slender, simple or slightly forked, creeping above ground, oftenest arched, leafy; aerial branches 1 or 2 to each division of the main stem, erect, $1-8 \mathrm{~cm}$. high, the sterile portion commonly shorter or not longer than the spikes; leaves of the main stem linear-lanceolate, entire or rarely a few slightly toothed, upcurved, leaves of the aerial branches more slender, spreading, entire; spikes solitary; sporophylls spreading, lineardeltoid, entire or toothed just above the base. Sandy bogs: Ont.-Newf.-N J. -Pa.-Ida.-Wash.-Alaska; Old World.

4. L. alpinum L. Main stem creeping at or near the surface of the ground; aerial stems ascending, 2.5-11 $\mathrm{cm}$. high, repeatedly branched; fertile branches the longer, terete, with subulate leaves, sterile branches dorsiventral with 4ranked leaves, those of the upper row narrowly ovate, acute, those of the lateral rows thick, asymmetrical, falcate, acute, with decurved tips, those of the under row trowel-shaped; spikes sessile; sporophylls ovate, acute, erose. Woods: Alaska-B.C.; Que.-Lab.-Greenl.; Old World.

5. L. obscurum L. Main stems creeping, buried in the ground; aerial branches 9-42 $\mathrm{cm}$. long, the leaves of their divisions 8-ranked on the lower, 6ranked on the terminal, linear-lanceolate, spreading, upcurved, twisted, acute, or mucronate; spikes sessile; sporophylls broadly ovąte, papery and erose-margined, acuminate, with a subulate apex. Woods: "Lab."-Newf.-N.C.-Tenn. -Mich.-"Sask."-Mont.-B.C.-Alaska; Asia.

6. L. sitchense Rupr. Main stems creeping on or near the surface of the ground; aerial branches dichotomously branching, forming tufts, $2.5-25 \mathrm{~cm}$. high, their branches terete, the fertile the longer; leaves of the branchlets appressed or spreading and upcurved, linear, thick, entire, acute; spikes sessile or short-stalked, the peduncles with minute bracts; sporophylls broadly ovate, long-acuminate-subulate, erose. Cold woods: Lab.-Newf.-N.Y.-w Ont.; Alaska-B.C.-"Ida."-Wash.

7. L. annotinum L. Main stems ereeping above ground, leafy; aerial stems 2-39 $\mathrm{cm}$. high, simple or 1-3 times forked; leaves spreading or reflexed, upcurved at apex, lanceolate or linear-lanceolate, serrulate, tipped with a rigid point; spikes 1-several; sporophylls broadly ovate-serrulate, erose. Wooded places: Greenl.-W.Va.-Mich.-Alta.-Colo.-Wash.-Alaska.

8. L. complanatum L. Main stems creeping on or slightly below the surface of the ground; aerial branches yellowish green, 4-47 cm. high, irregularly forked, their branches few, glaucous, flattened, mostly making annual growths at their tips, with minute, decurrent leaves, the lateral leaves broad, little or not spreading at the tip, the upper narrow, incurved, the lower diminished, deltoidcuspidate; peduncles mostly 1-2 times forked at summit; sporophylls broadly ovate, acuminate. Wooded places: Lab.-Newf.-N.Y.-Minn.-B.C.-Mont. -Ida.-Wash.; Alaska; Eu.

9. L. clavatum L. Main stems creeping above ground, leafy; aerial branches ascending, 4-33 cm. high, simply or pinnately branched; leaves many-ranked, linear, mostly bristle-tipped, entire or denticulate, on the main stems denticulate; peduncles simple or forked at apex, their bracts whorled or scattered, mostly bristle-tipped; sporophylls deltoid-ovate, acuminate or bristle-tipped, with membranous erose margins. Woods: "Lab."-N.C.-Mich.-Wis.-Ont.-Sask.Ida.-Ore.-Alaska; trop. Am. and Old World.

\section{Family 8. Selaginellaceae. Little Clubmoss Family.}

Leafy terrestrial plants, with branching stems and 4-6-ranked leaves. Sporanges solitary in the axils of the leafy bracts, some containing macrospores, others microspores, the macrospores with a hemispheric base and a triangular-pyramidal apex.

* Closely related to $L$. lucidulum, which has leaves broadening and erose denticulate above the middle, and is apparently not found in the Rockies. 


\section{Selaginélla. Little Clubmoss, Selaginella.}

Characters of the family.

Stem rooting only at the base; bracts of the spike broad, thin, spreading; macrospores spinulose.

Stem rooting mostly their whole length; bracts of the spike narrower and thicker, appressed and closely imbricate.

Leaves without an apical bristle.

Leaves with a distinct apical bristle.

Macrospores smooth or nearly so.

Macrospores with a network of thickened ridges.

Leaves abruptly acute; plant dense and tufted.

Apical bristle yellowish green.

Apical bristle white.

Apical bristle $0.3-0.4 \mathrm{~mm}$. long.

A pical bristle $0.6-1.5 \mathrm{~mm}$. long.

Leaves gradually tapering towards the apex; stem long, loose and spreading; apical bristle $0.5-1 \mathrm{~mm}$. long.

2. S. mutica.

3. S. montanensis.

4. S. Watsonii.

5. S. Wallacei.

6. S. densa.

7. S. Underwoodii.

1. \$. selaginoides (L.) Link. Stems prostrate, creeping, slender; leaves lanceolate, acute, spreading, sparsely spinulose-ciliate; spikes thicker, ascending, 3-7 $\mathrm{cm}$. high; bracts lax, ascending, lanceolate or ovate-lanceolate, strongly ciliate. Mountains: Greenl.-N.H.-Colo.-B.C. Boreal-Mont.

2. S. mutica D. C. Eaton. Stems creeping, rigid, pinnately branched; leaves 6-ranked, closely imbricate, $1 \mathrm{~mm}$. long, oblong-ovate, obtuse, without terminal bristle; marginal cilia 8-15 on each side, spreading; spikes searcely thicker than the branches, quadrangular; bracts broader than the leaves, pointed. Mountains: N.M.-Colo--Ariz. Son.-Submont.

3. S. montanensis Hieron. Stems prostrate, creeping, $4 \mathrm{~cm}$. long; leaves sessile, imbricate, pale glaucous when young, yellowish cinerascent in age, linearoblong, slightly tapering at the apex, obtuse, cuspidate-setaceous; bristle $0.3-0.4$ $\mathrm{mm}$. long; marginal cilia 6-9 on each side, about $0.1 \mathrm{~mm}$. long; bracts ovate-triangular, pale glaucous, thick, obtusish; bristle 0.25-0.4 mm. long; marginal cilia 15-20, tooth-like. S. columbiana A. A. Eat. Mountains: Mont.-Wash.-B.C. $\mathrm{Au}-\mathrm{O}$.

4. S. Watsoni Underw. Stems short, 4-6 $\mathrm{cm}$. long, creeping, sparingly branched; leaves short, deeply channeled, abruptly contracted into the bristle; apical bristle $0.25-0.33 \mathrm{~mm}$. long; marginal cilia few or none; spikes $1.5-2.5 \mathrm{~cm}$. long, quadrangular; bracts lance-ovate to ovate, with shorter and stouter bristlés. Mountains: Colo.-Calif. Mont.-Alp. Jl-S.

5. S. Wallacei Hieron. Stems up to $3-10 \mathrm{~cm}$. long, sparsely rooting, pinnately branched; leaves imbricate, pale glaucous when young, yellowish cinerascent in age, thick, plane above, linear-oblong, contracted at the apex, $2.5 \mathrm{~mm}$. long or less; apical bristle $0.3-0.4 \mathrm{~mm}$. long; marginal eilia 7-12 on each side, nearly $0.1 \mathrm{~mm}$. long; spike up to $1.5 \mathrm{~cm}$. long; bracts ovate-triangular, acute, thick; apical bristle 0.3-0.4 mm. long; marginal eilia 15-20. Rock: B.C.-Ida.Calif. Submont.

6. S. densa Rydb. Stems densely cespitose, 4-12 cm. long, creeping, densely branched; leaves densely imbricate, pale glaucous when young, dark-cinerascent in age, linear-oblong, 2-3.5 mm. long; apical bristle $0.6-1.5 \mathrm{~mm}$. long; marginal cilia 2-12, nearly $0.1 \mathrm{~mm}$. long; spike $1-3 \mathrm{~cm}$. long; bracts ovate-triangular, 0.3 $\mathrm{mm}$. long or less; apical bristle nearly $1 \mathrm{~mm}$. long; eilia $10-20$ on each side, less than $0.1 \mathrm{~mm}$. long. S. Engelmannii, S. Bourgeauii, and S. Haydeni Hieron. Hills and mountains: Man.-N.M.-Utah-Wash.-B.C. Plain-Alta.

7. S. Underwoodii Hieron. Stem elongate, creeping, up to $15 \mathrm{~cm}$. long, sparsely pinnately branched; leaves densely imbricate, appressed, dark glaucous when young, reddish or cinerascent in age, elongate-triangular, up to $2 \mathrm{~mm}$. long; cilia 5-7 on each side, $0.05 \mathrm{~mm}$. long; spike 5-20 mm. long; bracts elongate-triangular; bristle $0.2-0.3 \mathrm{~mm}$. long; cilia $12-15$. S. Fendleri (Underw.) Hieron., not Baker. Mountains: N.M.-Colo.-Calif. Submont.-Mont. 


\section{SUMMARY}

Number of genera and species described in this book, compared with the number given in older floras of the Rocky Mountain region.*

Rydberg
1917

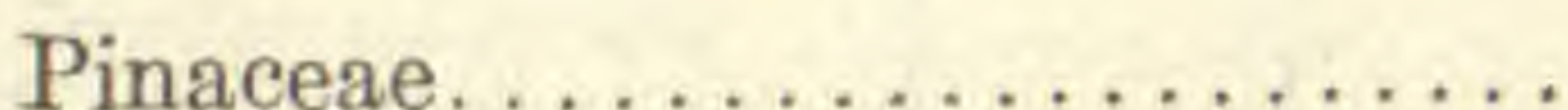

Juniperaceae ...............

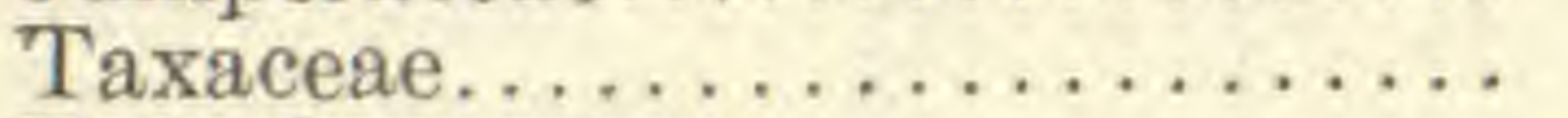

Ephedraceae..............

Gymnospermae......... $\frac{-14}{14}$

Typhaceae................

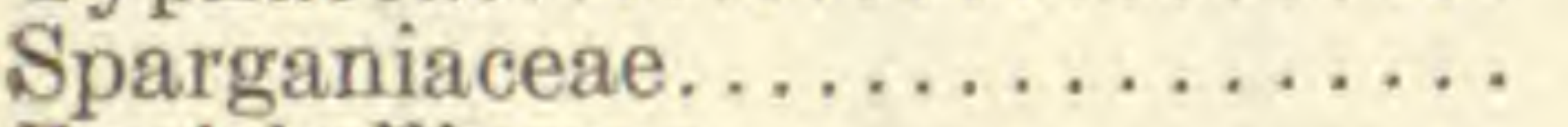

Zanichelliaceae...............

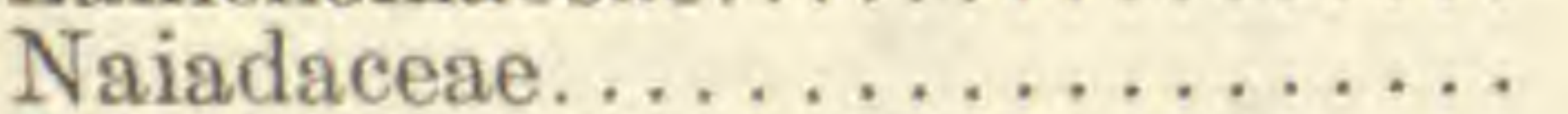

Scheuchzeriaceae............

Alismaceae. ................

Elodiaceae.................

Poaceae..................

Cyperaceae................ 13

Araceae..................

Lemnaceae. . . . . . . . . . . . . .

Commelinaceae.............

Pontederiaceae..............

Melanthaceae..............

Juncaceae.................

Alliaceae..................

Liliaceae..................

Convallariaceae.............

Dracaenaceae..............

Calochortaceae..............

Trilliaceae................

Smilacaceae................

Amaryllidaceae..............

Iridaceae..................

Orehidaceae

Monocotyledones..........
$9 \quad 19$

\begin{tabular}{rr}
3 & 8 \\
1 & 1 \\
1 & 15 \\
\hline 14 & - \\
- & -
\end{tabular}

1

1

1

2

2

1

78

13

2

2

2

2

24

3

451

215

6
2
5

3

7

2

2

6

2

21

47

40

16

17

7

10

2

1

2

13

45

749

Coult. \& Nels. 1909

Coulter 1885

$\begin{array}{ll}4 & 12 \\ 1 & 6 \\ 0 & 0 \\ 1 & 3 \\ -6 & 21 \\ - & \end{array}$

12

6

0

3

21

$\begin{array}{rrrr}1 & 2 & 1 & 1 \\ 1 & 5 & 1 & 3 \\ 4 & 16 & 2 & 12 \\ 1 & 2 & & \\ 1 & 2 & 2 & 3 \\ 2 & 5 & 2 & 2\end{array}$

65

206

$\begin{array}{rr}7 & 99 \\ 0 & 0\end{array}$

48

139

2

2

1

4

2

2

6

4

1

1

0

1

0

2

11

7

3

1

6
25

10

8

Salicaceae..................

$\begin{array}{rr}2 & 90 \\ 1 & 17 \\ 2 & 19 \\ 2 & 3 \\ 2 & 6 \\ 2 & 3 \\ 2 & 12\end{array}$

* The columns under the heading "Rydberg" give the number of genera and species admitted in this book: those under "Coult. \& Nels." give those in the New Manual of Botany of the Central Rocky Mountains, by Coulter and Nelson, 1909: and those under "Coulter," in Manual of Botany of the Rocky Mountain Region, by John M. Coulter, 1885. 'The geographical area covered by the present book is, however, about half larger than that of the old Coulter's Manual, and nearly twice as large as that of Coulter \& Nelson's. 
Rydberg

Polygonaceae................ $15 \quad 188$

Chenopodiaceae.............. $16 \quad 92$

Amaranthaceae............. $4 \quad 16$

Nyctaginaceae.............. 9934

Tetragoniaceae.............. 2

Portulacaceae.............. 11

Corrigiolaceae.............. 1

Alsinaceae................ 10

Silenaceae............... 5

Ceratophyllaceae............ 1

Nymphaeaceae.............

Ranunculaceae............. 23

Berberidaceae............... 2

Papaveraceae............... 6

Fumariaceae............... 3

Brassicaceae.............. 54

Capparidaceae............ 5

Droseraceae...............

Crassulaceae.................

Parnassiaceae.............. 1

Saxifragaceae.............. 24

Hydrangeaceae............. 4

Grossulariaceae............. 4

Rosaceae................ 36

Malaceae................ 4

Amygdalaceae ............. 2

Mimosaceae................

Caesalpiniaceae.............

Fabaceae.................

Geraniaceae...............

Oxalidaceae................

Linaceae.................

Balsaminaceae...............

Limnanthaceae..............

Zygophyllaceae...............

Rutaceae..................

Polygalaceae...............

Euphorbiaceae..............

Callitrichaceae..............

Celastraceae................

Anacardiaceae. . . . . . . . . . . .

Aceraceae.................

Rhamnaceae..............

Vitaceae..................

Malvaceae................

Hypericaceae. .............

Elatinaceae................

Frankeniaceae .............

Cistaceae...................

Violaceae..................

Loasaceae.................

Cactaceae..................

Elaeagnaceae. ..............

Lythraceae. . . . . . . . . . . . . .

Onagraceae.................

Haloragidaceae..............

Ammiaceae................

Araliaceae. .................

Cornaceae.................

Pyrolaceae.

325

14

3

8

6

81

12

30

232

27

13

2

45

45

473

20

3

12

5

1

5

5

34

2

8

8

15

4

Coult. \& Nels.

Coulter

$\begin{array}{rrrr}4 & 77 & 5 & 50 \\ 14 & 51 & 12 & 31 \\ 4 & 12 & 4 & 8 \\ 4 & 17 & 4 & 9 \\ 2 & 2 & 2 & 2 \\ 7 & 16 & 7 & 18 \\ 1 & 5 & 1 & 3 \\ 6 & 30 & 4 & 24 \\ 4 & 14 & 2 & 10 \\ 1 & 1 & 1 & 1 \\ 1 & 1 & 1 & 2 \\ 15 & 87 & 11 & 58 \\ 1 & 3 & 1 & 2 \\ 3 & 3 & 2 & 2 \\ 2 & 5 & 2 & 5\end{array}$

133

22

3

0

2

1

7

3

1

29

4

1
0

0

18

2

1

1

1 
Rydberg

Monotropaceae.............. 3

Ericaceae................ 10

Vacciniaceae............... 5

Primulaceae............... 13

Oleaceae................. 3

Loganiaceae............... 1

Gentianaceae............... 12

Menyanthaceae............ 1

Apocynaceae............... 2

Asclepiadaceae.............. 5

Convolvulaceae............. 4

Cuscutaceae................ 1

Polemoniaceae............. 13

Hydrophyllaceae........... 13

Ehretiaceae............... 2

Heliotropaceae.............. 2

Boraginaceae............. 19

Verbenaceae............... 2

Lamiaceae................ $\quad 27$

Solanaceae................ 10

Scrophulariaceae............ 27

Lentibulariaceae............... 2

Orobanchaceae.............. 2

Martyniaceae............... 1

Plantaginaceae..............

Rubiaceae................. 3

Caprifoliaceae............... 8

Adoxaceae................. 1

Loranthaceae................ 2

Santalaceae................ 1

Valerianaceae.............. 3

Aristolochiaceae............ 1

Cucurbitaceae............... 2

Campanulaceae............. 3

Lobeliaceae............... 5

Dipsaceae................ 1

Ambrosiaceae............. 8

Carduaceae............... 135

Cichoriaceae.............. 26

Dicotyledones............ 833

Ophioglossaceae............. 1

Polypodiaceae.................. 16

Marsiliaceae................ 1

Salviniaceae............... 1

Equisetaceae.............. 1

Isoetaceae................. 1

Lycopodiaceae............... 1

Selaginellaceae.............. 1

Pteridophyta........... $\overline{23}$

Spermatophyta

Gymnospermae.......... 14

Angiospermae

Monocotyledones......... 168

Dicotyledones ........... 833

Pteridophyta.............. 23
3

17

16

48

5

1

52

1

13

27

12

15

125

75

3

2

181

11

63

40

262

4

9

1

12

20

29

1

9

3

15

1

2

10

12

26

1068

130

$\overline{5019}$

7

53

2

12

5

9

7

96

33

749

5019

96

1038

Coult. \& Nels.

Coulter

3

7

1

3

23

5

922

2

0

7

1

2

3

3

1

6

0

22

1

4

15

10

12

56

22

1

1

67

7

28

$\begin{array}{rr}6 & 25\end{array}$

$17 \quad 121$

$\begin{array}{ll}1 & 2 \\ 2 & 4\end{array}$

1 


\section{NEW GENERA AND SPECIES AND NEW COMBINATIONS PUBLISHED IN THIS FLORA*}

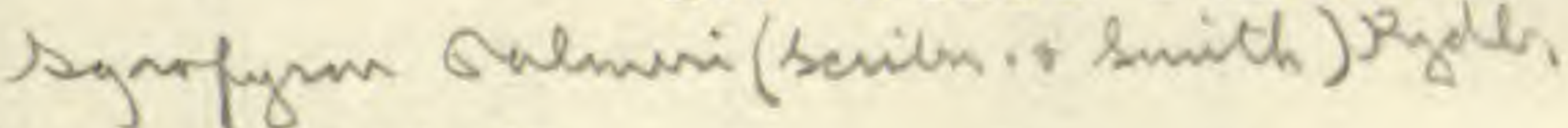

Strobus monticola.

Pinus monticola Dougl.; Lamb. Pinus 3: pl. 87. 1837.

Agrostis reptans.

A. exafrata stolonifera Vasey, Bull. Torrey Club 13: 54. 1886.

Calamagrostis luxurians.

C. Suksdorfi luxurians Kearney, Bull. U. S. Div. Agrost. 11: 24. 1898.

Calamagrostis elongata.

C. hyperborea elongata Kearney, Bull. U. S. Div. Agrost. 11: 40.1898.

Deschampsia ciliata.

D. elongata ciliata'Vasey; Beal, Grasses 2: 371. 1896.

Graphephorum Brandegei.

Trisetum Brandegei Scribn. Bull. Torr. Club 10: 64. 1883.

Poa pratensiformis.

P. pseudopratensis Scribn. \& Rydb. Contr. U. S. Nat. Herb. 3: 531. 1896, not P. pseudopratensis Beyer. 1891.

Panicularia rigida.

P. nervata rigida Nash, Mem. N. Y. Bot. Gard. 1: 54. 1900.

Bromus latior.

B. marginatus latior Shear, Bull. U. S. Div. Agrost. 23: 55. 1900.

Bromus paniculatus.

B. polyanthus paniculatus Shear, Bull. U. S. Div. Agrost. 23: 57. 1900.

Leucocoma alpina.

Eriophorum alpinum L. Sp. Pl. 53. 1753.

- Carex incurviformis Mackenzie, sp. nov.

Type: National Park, Banff, Alta., July 31, 1891, Macoun. (N.Y.)

Carex angustior (Carey) Mackenzie.

Carex stellulata angustata Carey; Gray, Manual 544. 1848.

Carex leptopoda Mackenzie, sp. nov.

Type: Elk Rock, near Oswego, Clackamas County, Oregon, Heller 10052. (Herb. K. K. Mackenzie.)

Carex Nelsonii Mackenzie, sp. nov.

Type: La Plata Mines, Wyoming, August $30,1898, A . \&$ E. Nelson 5264. (Herb. K. K. Mackenzie.)

Carex albo-nigra Mackenzie, sp. nov.

Type: Needle Mountain, Wyoming, July 11, 1910, Merritt Cary 613. (U. S., 858, 947.)

- Carex epapillosa Mackenzie.

Type: Marysvale, Utah, June 1, 1874, M. E. Jones 5845. (Herb. K.

K. Mackenzie.)

Carex substricta (Kukenthal) Mackenzie.

Carex aquatilis substricta Kukenthal, Pflanzenreich $4^{20}$ : 309.1909.

Juncus ater.

$J$. balticus montanus Engelm. Trans. Acad. Sci. St. Louis 2: 442.1866. Juncus vallicola.

J. balticus vallicola Rydb. Bull. Torrey Club 31: 399. 1904.

*In this list, after the citation of a type specimen, the words "(N.Y.)" mean that the type is preserved in the herbarium of the New York Botanical Garden, "(C.U.)" that it is in the herbarium of Columbia University, and "(U.S.)", the United States National Herbarium,

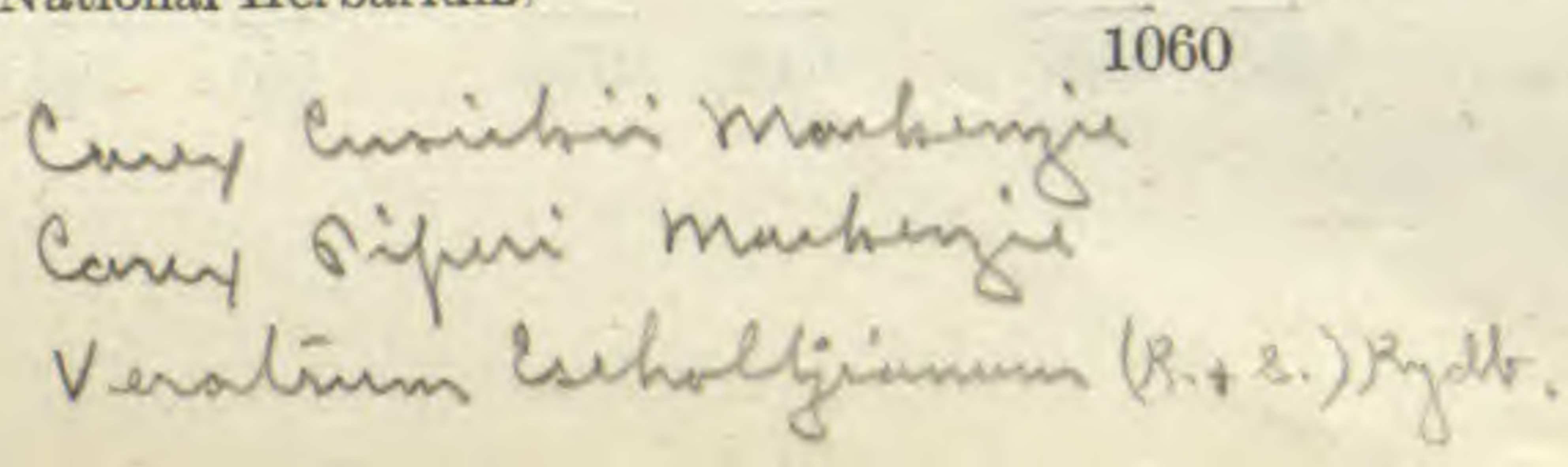


Juncus Jonesii, sp. nov.

Type: Alta, Wasatch Mountains, Utah, Au. 6, 1879, M. E. Jones (N.Y.).

Juncus Tracyi, sp. nov.

Type: Ogden, Utah, 1887, S. M. Tracy 389 (C.U.).

- Allium aridum, sp. nov.

Type: Green River, Wyoming, June 25, 1895, Rydberg 2605 (N.Y.).

Allium cuspidatum.

A. acuminatum cuspidatum Fernald, Zoe 4: 380. 1894.

OCHROCODON, gen. nov.

Type species:

Ochrocodon pudicus.

Lilium pudicum Pursh, Fl. Am. Sept. 228. 1814.

Fritillaria pudica Spreng, Syst. 2: 64. 1825.

- Erythronium utahense, sp. nov.

Type: Salt Lake, Utah, Captain Stansbury (N.C.)

- Erythronium leptopetalum sp. nov.

Type: Near Boise, Idaho, June, 1892, Isabel Mulford (C.U.).

Yucca Gilbertiana.

164

164

Yucca Gilbertiana.
Y. Harrimaniae Gilbertiana Trelease, Rep. Mo. Bot. Gard. 18: 225. 1917.
Clistoyucca brevifolia.

Yucca brevifolia Engelm.; S. Wats. Bot. King. Exp. 496. 1871.

Salix idahoensis.

S. Wolfii idahoensis Ball, Bot. Gaz. 40: 378. 1905.

Celtis rugulosa.

C. rugosa Rydb. Bull. Torrey Club 39: 304. 1912. Not Newberry.

Humulus neomexicanus.

H. Lupulus neomexicanus Nels. \& Cockerell, Proc. Biol. Soc. Wash. 16: 45. 1903.

- Eriogonum chrysops, sp. nov.

Type: Stony top of northern Stein's Mountains, June 10, 1901, Cusick 2558 (N.Y.).

- Eriogonum medium, sp. nov.

Type: Mount Nebo, Utah, Aug. 15, 1905, Rydberg \& Carlton 7594 (N.Y.).

- Eriogonum Brandegei, sp. nov.

Type: Southern Colorado, Sept. 1, 1873, T. S. Brandegee (N.Y.).

- Eriogonum mancum, sp. nov.

Type: Beaver Head County, Mont., July, 1888, F. Tweedyi 106 (C.U.).

Eriogonum lachnostegium.

E. strictum lachnostegium Benth. in DC. Prod. 14: 16. 1857.

Eriogonum lagopus, sp. nov.

Type: Dayton, Wyo., Sept., 1899, Tweedy 2624 (N.Y.).

Eriogonum nebraskense, sp. nov.

Type: Kimball County, Nebr., July 12, 1891, Rydberg 337 (N.Y. and C.U.).

Aconogonum phytolaccaefolium (Meisn.) Small.

165

165

197

207

208

Polygonum phytolaccaefolium Meisn.; Small, Bull. Torrey Club 19: 360. 1892.

Atriplex subconferta, sp. nov.

Type: Twin Falls and Shoshone Falls, July 27, 1911, Nelson \& Macbride 1379 (N.Y.).

Claytonia multiscapa.

C. multicaulis A. Nels. Bull. Torrey Club 27: 259. 1900. Not Kuntze. 1891.

MONTIASTRUM, gen. nov.

Claytonia \& Montiastrum A. Gray, Proc. Am. Acad. 22: 283. 1887.

Montiastrum lineare.

Claytonia linearis Dougl.; Hook. Fl. Bor. Am. 1: 224. 1832.

- Delphinium canmorense, sp. nov.

Type: Canmore, B.C., July 1, 1885, John Macoun (C.U.).

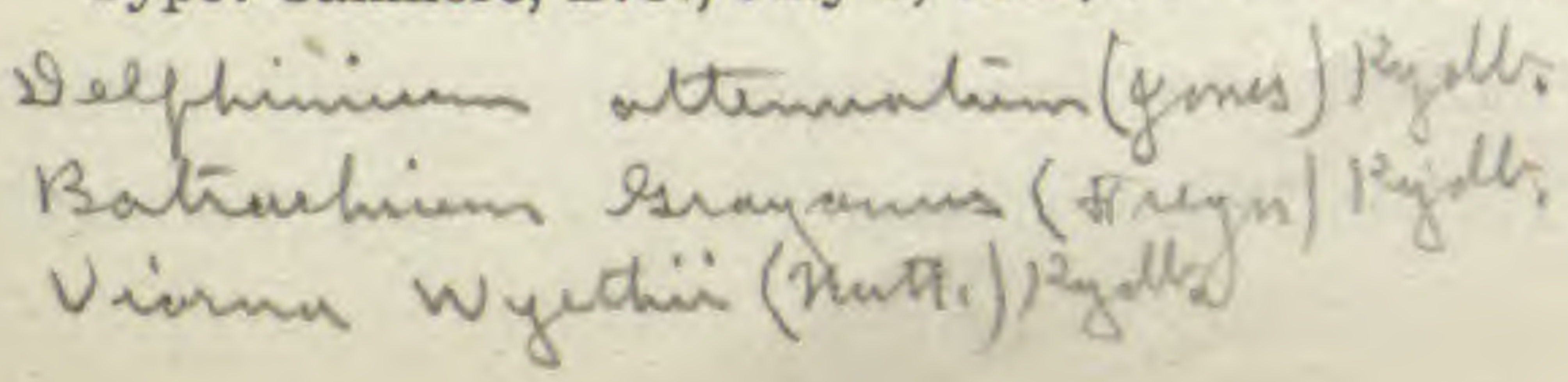




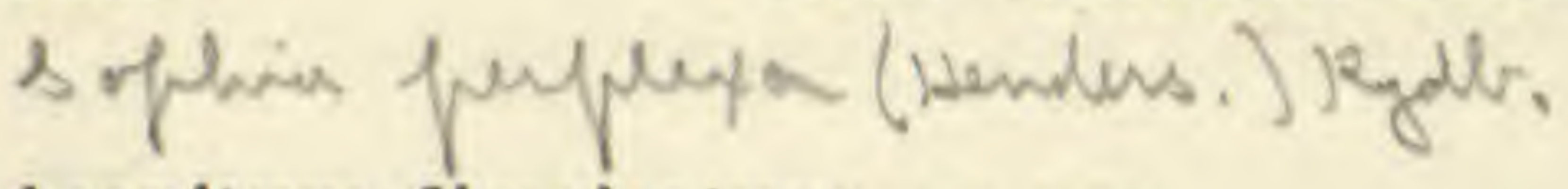

- Aconitum divaricatum, sp. nov.

Type: City Creek Cañon, Utah, Aug. 9, 1884, Leonard 204/182 (N.Y.)

- Aconitum patens, sp. nov.

Type: Latah County, Idaho, July 14, 1896, Elmer 18 (N.Y.),

Arabidopsis Richardsonii.

Pilosella Richardsonii Rydb. Torreya 7: 159. 1907.

Arabidopsis virgata.

Sisymbrium virgatum Nutt.; T. \& G. Fl. N. Am. 1: 93. 1838.

Arabidopsis stenocarpa.

Pilosella stenocarpa Rydb. Torreya 7: 161. 1907.

Arabidopsis glauca.

Sisymbrium glaucum Nutt.; T. \& G. Fl. N. Am. 1: 93. 1838.

Dentaria rupicola.

Cardamine californica rupicola O. E. Schulz, Bot. Jahrb. 32: 388. 1903.

- Arabis Egglestonii, sp. nov.

Type: Clover Mountain, Colo., July 31, 1910, Eggleston 6013 [fr.], 6016 [fl.] (N.Y.).

Arabis spatifolia, sp. nov.

Type: Estes Park, Colo., July 20, 1903, Osterhout 2808 (N.Y.).

- Arabis Stokesiae, sp. nov.

Type: Parley's Cañon, Utah, June 8, 1901, Miss S. G. Stokes (N.Y.).

Phoenicaulis Huddelliana.

Parrya Huddelliana A. Nels. Bot. Gaz. 54: 139. 1912.

STREPTANTHELLA, gen. nov.

Type species:

Streptanthella longirostris.

Arabis longirostris S. Wats. Bot. King Exp. 17. 1871.

Peritoma angustum.

Cleome integrifolia angusta M. E. Jones, Proc. Calif. Acad. II, 5: 625. 1895.

LIMNOBOTRYA, gen, nov.

Type species: Ribes lacustre (Pers.) Poir.

Limnobotrya lacustris.

Ribes oxyacanthoides lacustre Pers. Syn. Pl. 1: 252. 1805.

R. lacustre Poir. in Lam. Encycl. Suppl. 2: 856. 1812.

Limnobotrya echinata.

Ribes echinatum Dougl. Trans. Hort. Soc. London 7: 517. 1830.

Limnobotrya parvula.

Ribes lacustre parvulum A. Gray, Bot. Calif. 1: 206. 1876.

R. parvulum Rydb. Mem. N. Y. Bot. Gard. 1: 203. 1900.

Limnobotrya montigena.

Ribes montigenum McClatchie, Erythea 5: 38. 1897.

Chrysobotrya odorata.

Ribes odoratum Wendl. in Bartl. \& Wendl. Beitr. 2: 15. 1825.

Chrysobotrya aurea.

Ribes aureum Pursh, Fl. Am., Sept. 164. 1814.

Rosa collaris, sp. nov.

Type: Pinehurst, Idaho, August 17, 1911, J Francis Macbride 1676 (N.Y.)

Rosa puberulenta, sp. nov.

Type: Montezuma Canyon, east of Monticello, August 13, 1911, Rydberg \& Garrett 9705 (N.Y.)

Rosa pyrifera, sp. nov.

Type: Lake Pend d'Oreille, Idaho, August 7, 1892, Sandberg, MacDougal \& Heller 871 (N.Y.).

Sorbus angustifolia, sp. nov.

Type: Cedar Mountain, Ida., July, 1898, C. V. Piper (N. Y.).

Prunus valida.

Padus valida Woot. \& Standl. Contr. U. S. Nat. Herb. 16: 134. 1913.

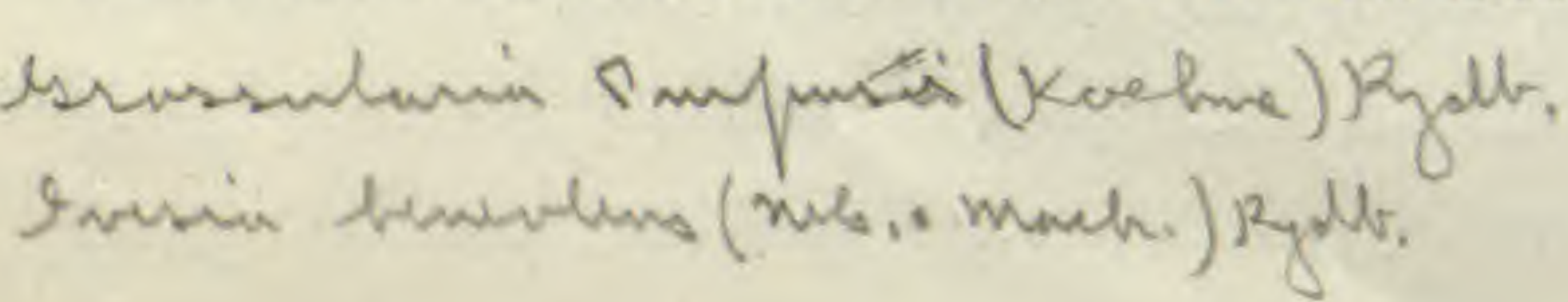


Lupinus glabratus.

Lupinus ornatus glabratus S. Wats. Proc. Am. Acad. 8: 528. 1873 (as to the type: Fremont 578).

Anisolatus longebracteatus.

Lotus longebracteatus Rydb. Bull. Torrey Club 30: 254. 1903.

Parosela alopecuroides.

Dalea alopecuroides Willd. Sp. Pl. 3: 1336. 1803.

Parosela carnescens.

Dalea nana elatior Port. \& Coult. Syn. Fl. Colo. 22. 1874. Not A. Gray. 1852.

Parosela rubescens Coult. \& Nels. Man. Rocky Mt. Reg. 298. 1909.

Not Dalea rubescens S. Wats. 1882.

Phaca allochroa.

Astragalus allochrous A. Gray, Proc. Am. Acad. 13: 366.1878.

Phaca lutosa.

A. lutosus M. E. Jones, Cont. W. Bot. 13: 7. 1910.

Cystium heliophilum, sp. nov.

Type: Lima, Mont., July 1, 1895, C. L. Shear 3480 (N.Y.).

Cystium salinum.

A. salinus Howell., Erythea 1: 111. 1893.

Hamosa amplexa.

A. amplexus Payson, Bot. Gaz. 60: 378. 1915.

Hamosa malaca.

A. malacus A. Gray, Proc. Am. Acad. 7: 336. 1868.

Tium obscurum.

A. obscurus S. Wats. Bot. King Exp. 69. 1871.

Tium Rusbyi.

A. Rusbyi Greene, Bull. Calif. Acad. I. 1: 8. 1884.

Tium owyheense.

A. owyheensis Nels. \& Macbr. Bot. Gaz. 55: 375. 1913.

Tium naturitense.

A. naturitensis Payson, Bot, Gaz. 60: 377. 1915.

Rydbergiella scaphoides.

A. arrectus scaphoides M. E. Jones, Proc. Calif. Acad. II. 5: 664. 1895.

Rydbergiella arcta.

A. Preussii arctus Sheld. Minn. Bot. Stud 1: 130.1894.

Rydbergiella Preussii.

A. Preussii A. Gray, Proc. Am. Acad. 7: 222. 1864.

Ctenophyllum adanum.

A. adanus A. Nels. Bot. Gaz. 53: 222. 1912.

Xylophacos stipularis.

A. aridtinuph stipularis M. E. Jones, Proc. Calif. Acad. II. 5: 654, 1895.

Xylophacos eurekensis.

A. eurekensis M. E. Jones, Cont. W. Bot. 8: 12. 1898.

Xylophacos glareosus.

A. glareosus Dougl.; Hook. Fl. Bor. Am. 1: 152. 1831.

PTEROPHACOS, gen, nov.

Type species:

Pterophacos tetrapterus.

Astragalus tetrapterus A. Gray, Proc. Am. Acad. 13: 369. 1878.

Homalobus detritalis.

Astragalus detritalis M. E. Jones, Cont. W. Bot. 13: 9. 1910.

Oraphaca argophylla.

Phaca argophylla Nutt.; T. \& G. Fl. N. Am. 1: 342. 1838.

Lathyrus tenuior.

L. parvifolius tenuior Pifer; Piper \& Beattie, Fl. Palouse Region 108. 1901.

Chamaesyche Greenei.

Euphorbia Greenei Millsp. Pittonia 2: 88, 1890.

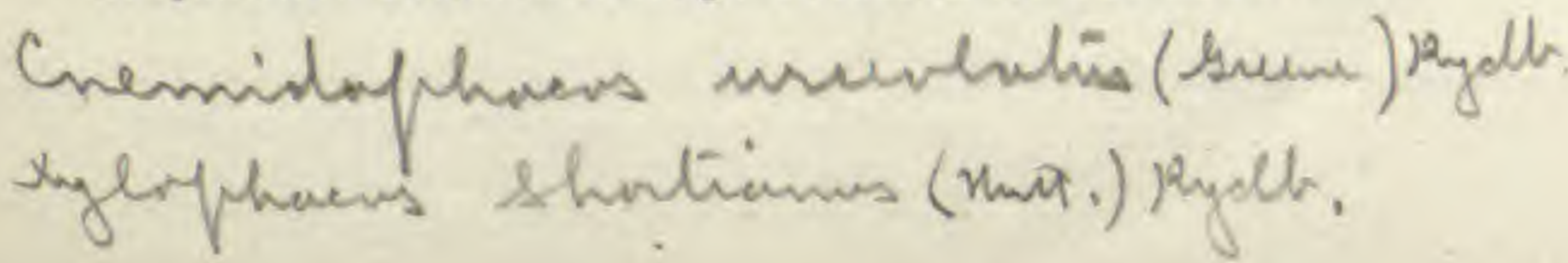


Chers

Rhus Osterhoutii.

Schmaltzia pubescens Osterh. Muhlenbergia 7: 11. 1911. Not Rhus pubescens Farw. 1900.

Rhus oxyacanthoides.

Schmaltzia oxyacanthoides Greene, Leaflets 1: 134. 1905.

Acrolasia dispersa.

Mentzelia dispersa S. Wats. Proc. Am. Acad. 11: 115, 137. 1876.

Echinocactus subglaucus. E. glaucus K. Schum. Gesamtb. Kakt. 1: 438, 1898. Not Karw. 1837.

Coryphantha Grahami. Mammillaria Grahami Engelm. Proc. Am. Acad, 3: 262. 1856.

Coryphantha radiosa. M. radiosa Engelm. Bost. Journ. Nat. Hist. 6: 196. 1850.

- Epilobium MacDougalii, sp. nov.

Type: Eastern shore of Flathead Lake, Mont., July 29, 1901, MacDougal 793 (N.Y.).

CORDYLOPHORUM, gen. nov.

Epilobium § Cordylophorum Nutt.; T. \& G. Fl. 1: 488. 1840. Type species:

Cordylophorum suffruticosum.

E. suffruticosum Nutt.; T. \& G., Fl. N. Am. 1: 488, 1840.

- Zauschneria crassifolia, sp. nov.

Type: D. A. Adams Raneh, Ariz., Oct. 8, 1900, D. Griffiths 1842 (N.Y.).

- Anogra perplexa, sp. nov.

Type: Near Dolores, Colo., 1901, Vreeland 880 (N.Y.).

Anogra Bradburiana.

Oenothera Bradburiana Nutt.; T. \& G. Fl. 1: 494. 1840.

Pachylophus Johnsoni.

O. Johnsoni Parry, Am. Natur. 9: 270. 1875.

Pachylophus crinitus.

Type: Rabbit Valley, Utah, Aug. 6, 1875, L.F. Ward 526 (U. S. 140110 , in part).

Chylisma parviflora.

O. brevipes parviflora Parry Am. Natur. 9: 271. 1875.

Orogenia Leibergi.

O. fusiformis Leibergi Coult. \& Rose, Rev. N. Am. Umbell. 92. 1888.

- Ligusticum brevilobum, sp. nov.

Type: Aquarius Plateau, Utah, Aug. 5, 1905, Rydberg \& Carlton 7473 (N.Y.).

Phellopterus Jonesii.

Rhysopterus Jonesii Coult. \& Rose, Cont. U. S. Nat. Herb. 7: 186. 1900.

Coriophyllus basalticus.

Cymopterus basalticus M. E. Jones, Contr. W. Bot. 12: 16. 1908.

Pteryxia Elrodi.

Cymopterus Elrodi M. E. Jones, Bull. Univ. Mont. Biol. Ser. 15: 41. 1910.

- Pseudocymopterus versicolor, sp. nov.

Type: Aquarius Plateau, at the head of Poison Creek, Utah, 1905, Rydberg \& Carlton 7426 (N.Y.).

Pseudopteryxia Hendersoni.

Pseudocymopterus Hendersoni Coult. \& Rose, Cont. U. S. Nat. Herb. 7: 190.1900.

Cogswellia lapidosa.

Peucedanum lapidosum M. E. Jones, Zoe. 2: 246. 1891.

Cymopterus lapidosus M. E. Jones, Cont. W. Bot. 8: 31. 1838.

Cynomarathrum megarrhizum.

Peucedanum megarrhiza A. Nels. Bull. Torrey Club 26: 130. 1899.

Cynomarathrum brecciarum.

Cogswellia brecciarum M. E. Jones, Cont. W. Bot, 12: 37. 1908.

- Angelica Piperi, sp. nov.

Type: Blue Mountains, Walla Walla County, Wash., 1896, Piper 2336 (N.Y.). 
Svida instolonea.

Cornus instolonea A. Nels. Bot. Gaz. 53: 224. 1912.

Chamaepericlymenum unalaschkense.

Cornus unalaschkensis Ledeb. Fl. Ross. 2: 378. 1844-6.

CYANOCOCCUS, gen. nov.

Vaccinium \& Cyanococcus A. Gray, Mem. Am. Acad. II. 3: 53. 1846.

Type species: Vaccinium pennsylvanicum Lam.

Cyanococcus canadensis.

Vaccinium canadense Kahm; Richards. in Franklin, Journ. ed. 2: 12. 1823.

Cyanococcus penpisylvanicus.

$V$. penpisylvanicum Lam. Encycl. 1: 74. 1783.

Oxycoccus intermedius.

V. oxycoccus intermedium A. Gray, Syn. Fl. ed. 2, 2 ${ }^{1}$ : 396. 1886.

Drosace albertina.

Androsace albertina Rydb. Bull. Torrey Club, 40: 462. 1913.

Anthéropogon thermalis. Gentiana thermalis Kuntze, Rev. Gen, 427. 1891.

LEUCOCRASPEDUM, gen. nov. Type species: Frasera albomarginata S. Wats.

Leucocraspedum albomarginatum.

Frasera albomarginata S. Wats. Bot. King. Exp. 280. 1871.

Leucocraspedum utahense.

F. utahensis M. E. Jones, Zoe 2: 13, 1891.

Leucocraspedum montanum.

F. montana Mulford, Bot. Gaz. 19: 119. 1894.

Leucocraspedum albicaule.

F. albicaulis Dougl.; Griseb. in Hook. Fl. Bor. Am. 2: 67. 1834.

Leucocraspedum coeruleum.

F. coerulea Mulford, Bot. Gaz. 19: 118. 1894.

Tessaranthium macrophyllum.

Frasera macrophylla Greene, Pittonia 4: 186. 1900.

Tessaranthium scabrum.

F. speciosa scabra M. E. Jones, Zoe 4: 277. 1893.

Tessaranthium stenosepalum.

F. speciosa stenosepala Rydb. Bull. Torrey Club 31: 632. 1905.

Tessaranthium speciosum.

F. speciosa Dougl.; Hook. Fl. Bor. Am. 2: 66. 1834.

Tessaranthium angustifolium.

F. speciosa angustifolia Rydb. Bull. Torrey Club 31: 632. 1905.

- Apocynum macranthum, sp. nov.

Type: Big Potlatch River, Idaho, July 9, 1892, Sandberg, MacDougal \& Heller 372 (N.Y.)

Welwitchia Wilcoxii.

G. Wilcoxii A. Nels. Bot. Gaz. 34: 27. 1902.

Welwitchia filifolia.

Gilia filifolia Nutt. Journ. Acad. Phila. II, 1: 156. 1848.

Welwitchia diffusa.

G. filifolia diffusa A. Gray,,Proc. Am. Acad. 8: 272. 1870.

Welwitchia floccosa.

G. floccosa A. Gray, Proc. Am. Acad. 8: 272. 1870.

Gilia tridactyla.

G. trifida A. Brand, Pflanzenreich $4^{250}: 120.1907 . \quad$ Not Nutt. 1848.

Linanthus Dactylophyllum.

G. Dactylophyllum Torr. in Ives Bot. Colo. Riv. 22. 1860.

G. demissa A. Gray, Proc. Am. Acad. 8: 263. 1870.

TINTINABULUM, gen. nov. 


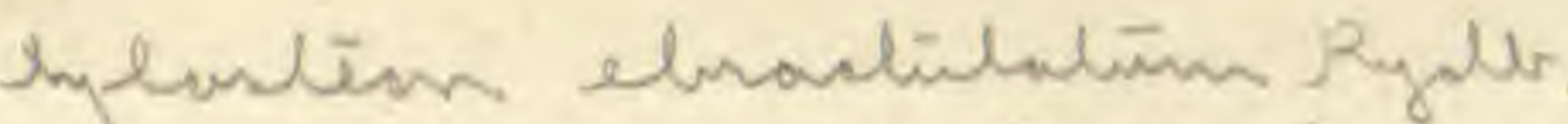

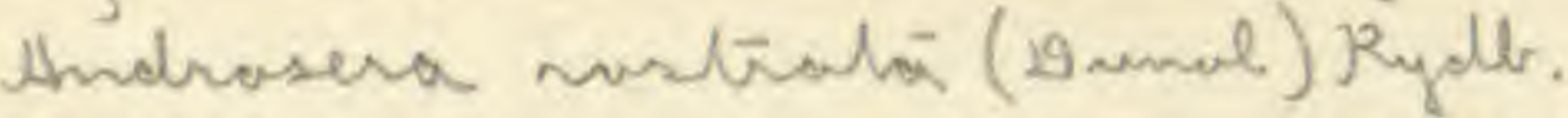

GILIASTRUM, gen. nov.

699

Gilia \& Giliastrum A. Brand. Pflanzenreich $4^{250}$ : 147. 1907.

Type species: Giliastrum rigidulum. Gilia rigidula Benth. in DC.

Prod. 9: 312. 1845.

Giliastrum acerosum.

Gilia rigidula acerosa A. Gray, Proc. Am. Acad. 8: 280. 1870.

Eucrypta pinetorum.

Phacelia pinetorum M. E. Jones, Zoe 4: 279. 1893.

Triquiliopsis Palmeri.

Coldenia Palmeri A. Gray, Proc. Am. Acad. 8: 292, 1870.

Amsinckia rugosa, sp. nov.

Type: Lewiston, Ida., April 27, 1896, A. A. \& E. G. Heller 2975 (C.U.).

PYCNOSPHACE, gen. nov.

Salvia \& Pycnosphace Benth. Lab. Gen. \& Sp. 302, 1833. Type species:

Pycnosphace Columbariae.

Salvia Columbariae Benth. Lab. Gen. \& Sp. 302. 1833.

Hedeoma camporum.

H. longiflora Rydb. Bull. Torrey Club 36: 685. 1909. Not Briq. 1896.

- Pentsternon puberulentus, sp. nov.

Type: Long Valley, Ida., July 6, 1895, Henderson 3169 (U. S. \& N.Y.).

Pentstemon pachyphyllus A. Gray, in herb.

P. nitidus major Benth. in DC. Prod. 10: 323. 1846.

- Pentstemon virens Pennell.

Type: Stony hillsides, foothills north of Morrison, Colo., 1915, Pennell 5821 (N.Y.).

P. humile A. Gray, Am. Jour. Sci. II, 34: 253. 1862. Not Nutt.

- Pentstemon leptophyllus, sp. nov.

Type: Rush Creek, Washington Co., Ida. 1899. M. E. Jones 6493 (N.Y.).

PENTSTEMONOPSIS, gen. nov.

Type species:

Pentstemonopsis Tweedyi.

Pentstemon Tweedyi Canby \& Rose, Bot. Gaz. 15: 66. 1890.

Castilleja subpurpurascens.

C. purpurascens Rydb. Bull. Torrey Club 34: 38. 1907. Not Greenm. 1906.

Adenostegia bicolor.

Cordylanthés bicolor Nels. Bot. Gaz. 54: 416. 1912.

699

701

711

729

747

747

750

774

770

773

773

777

777

791

797

Galium columbianum, sp. nov.

Type: Wood on St. Joseph River, Kootenai Co., Ida., July 8, 1892, Sandberg, MacDougal \& Heller 600 (N.Y.)

Galium asperulum.

G. asperrimum asperulum A. Gray, Bot. Calif. 1: 284. 1876.

- Galium filipes, sp. nov. Type: City Creek Cañon, Utah, 1883, Leonard 166/fi5 (N.Y.)

- Comandra linearis, sp. nov. Type: Green River, Utah, Aug. 19, 1887, S. M. Tracy 716 (N.Y.).

Plectritis macroptera. Aligera macroptea Suksd. Deuts. Bot. Monatsv 15: 146. 1897.

Coleosanthus Watsonii.

Brickellia Watsonii B. L. Robinson, Mem. Gray Herb. 1: 42. 1917.

Grindelia laciniata, sp. nov.

Type: Montezuma Cañon, east of Monticello, Utah, Aug. 13, 1911, Rydberg \& Garrett 9692 (N.Y.).

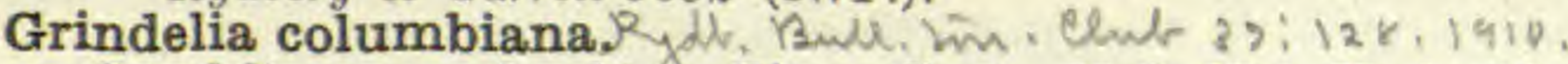

Grindelia nana columbiana Piper, Contr. U. S. Nat. Herb. 11: 556. 1906.

Ericameria paniculata.

Linosyris viscidiflora paniculata A. Gray in Torr. Bot. Mex. Bound. Surv. 80, 1859.

Bigelovia paniculata A. Gray, Proc. Am. Acad. 8: 644. 1873.

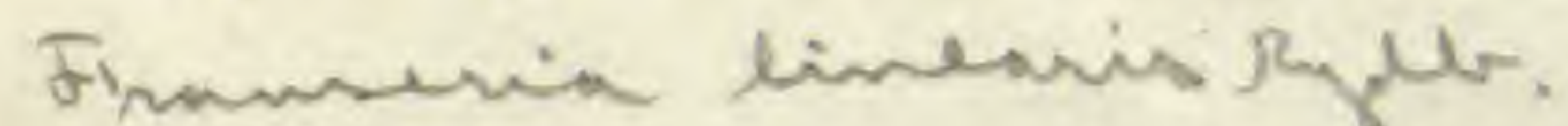


Ericameria cervina.

Chrysothamnus glareosus. Bigelovia glareosa M. E. Jones, Zoe 2: 247. 1891.

Chrysothamnus turbinatus.

Isocoma scopulorum.

Bigelovia Menziesii scopulorum M. E. Jones, Proc. Calif. Acad. II. 5: 692.

Sideranthus aberrans.

Macronema aberrans A. Nels. Bot. Gaz. 53: 226. 1912.

Solidago salebrosa.

S. serotina salebrosa Piper; Piper \& Beattie, Fl. Palouse Region 185. 1901.

Townsendia ambigua.

T. scapigera ambigua A. Gray, Proc. Am. Acad. 16: 84. 1880.

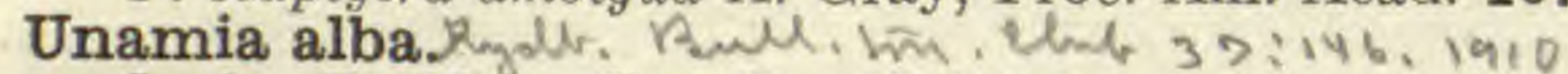
Inula alba Nutt. Gen. 2: 152. 1818.

- Aster ptarmicoides T. \& G., Fl. N. Am. 2: 160. 1841.

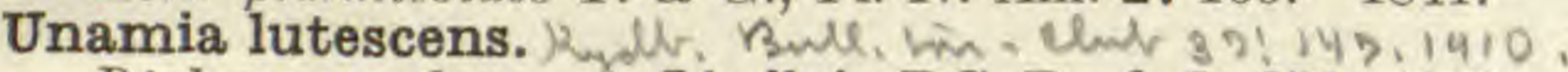

Diplopappus lutescens Lindl. in DC. Prod, 5: 278. 1836.

Aster ptarmicoides lutescens A. Gray, Syn. Fl. 12: 199. 1878.

Eucephalus wasatchensis.

Aster glaucus wasatchensis M. E. Jones, Proc. Calif. Acad. II. 5: 694 , 1895.

Aster subgriseus.

A. griseus Greene, Leaflets 1: 147. 1905. Not Kuntze. 1891.

Aster stricticaulis.

Aster multiflorus stricticaulis T. \& G. Fl. N. Am. 2: 125. 1841.

ASTERIGERON, gen. nov.

Type:

Asterigeron Watsonii.

Aster Watsoni A. Gray, Syn. Fl. 12: 201. 1878.

Doellingeria pubens. Aster umbellatus pubens A. Gray, Syn. Fl. 12: 197. 1878.

Erigeron mancus, sp. nov.

Type: La Sal Mountains, Utah, July 7, 1911, Rydberg \& Garrett 8671 (N.Y.).

Erigeron Evermannii, sp. nov.

Type: Top of Mount Parks, Idaho, 1895, Evermann 378 (U. S. Nat. Herb. 241347).

Erigeron fruticetorum, sp. nov.

Type: Ridges north of Brumley Creek, La Sal Mountains, Utah, July 14, 1911, Rydberg \& Garrett 8912 (N.Y.).

Erigeron Wyomingia.

Wyomingia cinerea A. Nels. Bull. Torrey Club 26: 250. 1899.

Erigeron arenarioides. Aster arenarioides D. C. Eat.; A. Gray, Proc. Am. Acad. 8: 647. 1873.

Erigeron pulvinatum, sp. nov.

Type: Deep Creek, Utah, 1891, M. E. Jones (U. S. Nat. Herb. 227851).

Oglifa californica.

Filago californica Nutt. Trans. Am. Phil. Soc. II. 7: 405. 1841.

Antennaria albescens.

A. pulvinata albescens E. Nels. Proc. U. S. Nat. Mus, 23; 702. 1901.

Antennaria macrocephala. A. dimorpha macrocephala D. C. Eat. Bot. King Exp. 186, 1871.

Anaphalis lanata.

Nacrea lanata A. Nels. Bull. Torrey Club 26: 357. 1899.

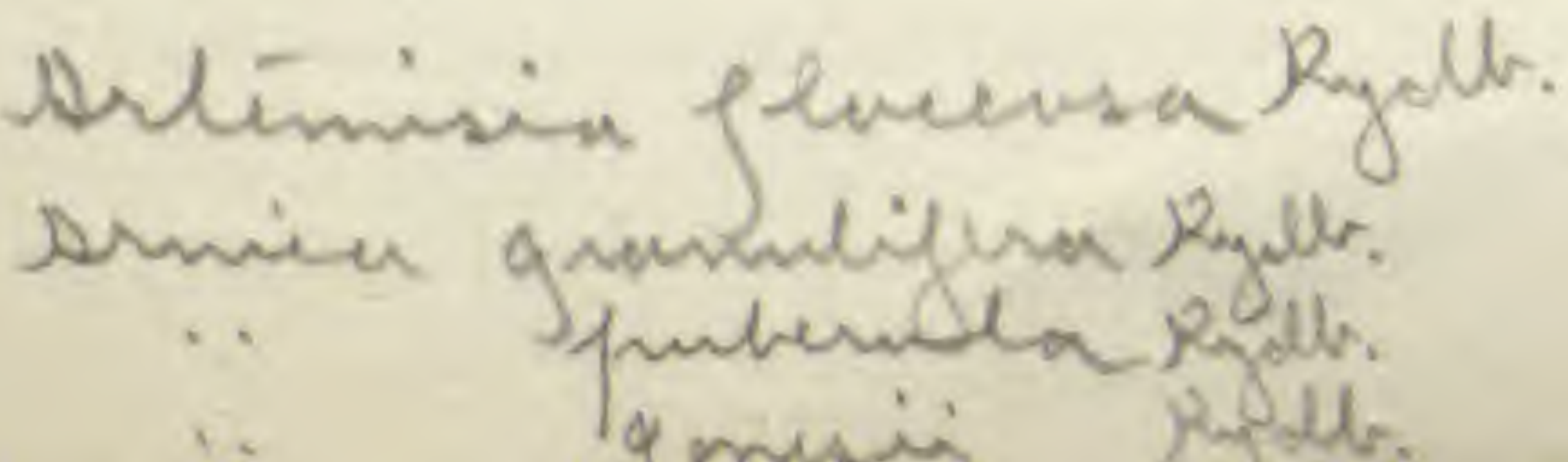


- Senecio Kuntzei, sp. nov.

S. Douglasii Riddellii Kuntze, Rev. Gen. 362, in part. 1891.

Type: Colorado, Sept., 1874, O. Kuntze 3033 (N.Y.).

Senecio pacificus.

S. hydrophilus pacificus Greene, Pittonia 1:220. 1888.

Cirsium araneans.

Carduus araneosus Osterh. Bull. Torrey Club 32: 612. 1905. Not Steud. 1841.

- Cirsium subniveum, sp. nov.

Type: Jackson's Hole, Wyo., Aug. 21, 1894, A. Nelson 1070 (U.S. Nat. Herb. 284473).

Cirsium Kelseyi.

Carduus Kelseyi Rydb. Mem. N. Ý. Bot. Gard. 1: 449. 1900.

Cirsium polyphyllum.

Carduus polyphyllus Rydb. Bull. Torrey Club 37: 542. 1910.

Cirsium Macounii.

Carduus Macornii Greene, Ottawa Nat. 16: 38. 1902.

Cirsium Tweedyi. Carduus Tweedyi Rydb. Mem. N. Y. Bot. Gard. 1: 449. 1900.

Cirsium hesperium.

998

1006

1006

Cnicus hesperius Eastw. Proc. Calif. Acad. III. 1: 122. 1898.

Cirsium humboldtense.

Carduus nevadensis Greene, Pittonia 3: 26. 1896. Not Cirsium nevadense Willk. 1859.

Cirsium laterifolium.

Carduus laterifolius Osterh. Muhlenbergia 1: 141. 1906.

Cirsium perplexans.

Carduus perplexans Rydb. Bull. Torrey Club 32: 132. 1905.

Cirsium clavatum.

Cnicus clavatus M. E. Jones, Proc. Calif. Acad. II. 5: 704. 1895.

Cirsium Butleri. Carduus Butleri Rydb. Bull. Torrey Club 37: 542. 1910.

Cirsium oreophilum. Carduus oreophilus Rydb. Bull. Torrey Club 28: 509. 1901.

Cirsium olivescens. Carduus olivescens Rydb., 37: 540. 1910.

Cirsium magnificum. Carduus magnificus A. Nels. Bot. Gaz. 53: 228. 1912.

Cirsium lacerum. Carduus lacerus Rydb. Bull. Torrey Club 37: 543. 1910.

Cirsium diffusum. Cnicus Rothrockii diffusus Eastw. Proc. Calif. Acad. II. 6: 303. 1896. Cnicus diffusis Eastw. loc. cit. III. 1: 121. 1898.

Cirsium bipinnatum. Cnicus Drummondii bipinnatus Eastw. Zoe 4: 8. 1893. Cnicus bipinnatus Eastw. Proc. Calif. Acad. III, 1: 121. 1898.

Cirsium lactucinum, sp. nov. Type: San Juan River, near Bluffs, Utah, Aug. 29, 1911. Rydberg 10001 (N.Y.)

Cirsium spathulifolium.

Carduus spathulatus Osterh. Bull. Torrey Club 32:612. 1905. Not Gaudin. 1829.

Cirsium nidulum.

Cnicus nidulus M. E. Jones, Proc. Calif. Acad. II. 5: 705. 1895.

Cirsium modestum. Carduus modestus Osterh. Muhlenbergia 9: 54. 1913.

Cirsium canovirens

Carduus canovirens Rydb. Mem. N. Y. Bot. Gard. 1: 450. 1900. 
Cirsium Nelsonii.

Cnicus Nelsonii Pammel, Proc. Iowa Acad. Sci. 8: 235. 1901.

Cirsium Tracyi.

Carduus Tracyi Rydb. Bull. Torrey Club 32: 133. 1905.

Circium acuatum.

Carduus acuatus Osterh. Muhlenbergia 9: 55. 1913.

Cirsium floccosum.

Carduus floccosus Rydb. Bull. Torrey Club 32: 133. 1905.

Cirsium Engelmannii.

Cirsium virginianum filipendulum Engelm.; A. Gray Man. ed. 2, 233.

1856. Not C. filipendulum Lange, 1861.

Youngia elegans.

1013

1013

Crepis elegans Hook. Fl. Bor. Am. 1: 297. 1833.

Youngia nana.

Crepis nana Richards. in Frankl. Journ, ed. 2, 29. 1823.

PLEIACANTHUS, gen. nov.

Lygodesmia \& Pleiacanthus Nutt. Trans. Am. Phil. Soc. II. 7: 444. 1841. Type:

Pleiacanthus spinosus.

Lygodesmia spinosa Nutt., loc. cit.

Agoseris aspera.

Agoseris Leontodon aspera Rydb. Mem. N. Y. Bot. Gard. 1: 457. 1900.

Agoseris nana.

A. humilis Rydb. Bull. Torrey Club 32: 137. 1905. Not Kuntze. 1891.

Leontodon mexicanum.

Taraxacum mexicanum DC. Prodr. 7: 146. 1838.

1021

1021

1023

Leontodon dumetorum.

T. dumetorum Greene, Pittonia 4: 230. 1901.

Leontodon leiospermum.

T. leiospermum Rydb. Bull. Torrey Club 32: 137. 1905.

Leontodon eriophorum.

T. eriophorum Rydb. Mem. N. Y. Bot. Gard. 1: 454. 1900.

1023

1030

1032

1034

1035

1035

1035

Leontodon monticola.

Taraxacum montanum Nutt. Trans. Am. Phil. Soc. II, 7: 430. 1841. Not DC. 1838.

Leontodon angustifolium.

T. angustifolium Greene, Pittonia 4: 232. 1901.

Leontodon ammophilum.

Taraxacum ammophilum Greene, Pittonia 4: 233. 1901.

Leontodon rupestre.

T. rupestre Greene, Pittonia 4: 229. 1901.

Leontodon scopulorum.

T. officinale scopulorum A. Gray, Syn. Fl. 12: 440, 1876.

Thelypteris Phegopteris (L.) Slosson.

Polypodium Phegopteris L. Sp. Pl. 1089. 1753.

Thelypteris Oreopteris (Ehrh.) Slosson. Polypodium Oreopteris Ehr.; Willd. Fl. Berol. Prod. 292. 1787.

Thelypteris Oreopteris hesperia Slosson, var. nov. Type: Attu Island, Alaska, August 29, 1891, J. M. Macoun 153 (N.Y.).

Thelypteris Dryopteris (L.) Slosson.

Polypodium Dryopteris L. Sp. Pl. 1093. 1753.

Thelypteris Robertiana (Hoffm.) Slosson.

Polypodium Robertianum Hoffm. Deuts. Fl, 2: 20. 1795.

Equisetum intermedium. 


\section{ABBREVIATIONS OF THE NAMES OF AUTHORS*}

Adams. Adams, Michael Friedrich, 17-1838 .

Adans.

Ag.

Ait.

Alef.

All.

Ames.

Anders.

André. Adanson, Michel, 1727-1806. Agardh, Carl Adolf, 1785-1859. Aiton, William, 1731-1793.

Alefeld, Friedrich, 1820-1872. Allioni, Carlo, 1725-1804.

Ames, Oakes, 1874-

Andersson, Nils Johan, 18211880.

André, Edouard François, 18401911.

Andrz. Andrzejowski, Anton Lukianowicz, 1784-1868.

Angstr. Angström, Johan, 1813-1879.

Arn. Arnott, George Arnott Walker, 1799-1868.

Arth. Arthur, Joseph Chal les, 1850-

Arv,-Touv. Arvet-Touvet, Jean Maurice Casimir, 1841-1913.

Aschers. \& Graebn.

Ascherson, Paul Friedrich August, 1834-1913; Graebner, Paul, 1871-

Aschers. \& Magnus.

Ascherson, Paul Friedrich August, 1834-1913; Magnus, Paul Wilhelm, 1844-1914.

Ashe. Ashe, William Willard, 1872-

Avé-Lall. Avé-Lallemant, Julius Leopold Eduard, 1803-1867.

B. S. P. Britton, Nathaniel Lord, 1859-; Sterns, Emerson Ellick, 18-; Poggenburg, Justus Ferdinand, 1840-1893.

Bab.

Babington, Charles Cardale, 1808-1895.

Bailey. Bailey, Liberty Hyde, 1858-

Baillon. Baillon, Henri Ernest, 18271895 .

Baker. Baker, John Gilbert, 1834-

Baker,E. G. Baker, Edmund Gilbert, 1864Baker \& Rydb.

Baker, Charles Fuller, 1872-; Rydberg, Per Axel, 1860-

Balbis. Balbis, Giovanni Battista, 1765 $-1831$.

Balf. Balfour, John Hutton, 18081884.

Ball. Ball, Carleton Roy, 1873-

Banks. $\quad$ Banks, Joseph, 1743-1820.

Barbey. Barbey, William, 1842-1914.

Barnh. Barnhart, John Hendley, 1871-

Barratt. Barratt, Joseph, 1797-1882.

Bartlett. Bartlett, Harley Harris, 1886-

Bartl. Bartling, Friedrich Gottlieb, 1798-1875.

Bauhin, C. Bauhin, Gaspard, 1560-1624.

Beal. Beal, William James, 1833-

Beauv. Palisot de Beauvois, Ambroise Marie François Joseph, $1752-1820$.

Bebb. Bebb, Michael Schuck, 18331895.

Benn., A. Bennett, Árthur, 1843-

Benth. Bentham, George, 1800-1884.
Benth, \& Hook.

Bentham, George, 1800-1884; Hooker, Joseph Dalton.

Berch. \& Presl. 1817-1911.

Berchtold, Friedrich von, 17811876; Presl, Jan Swatopluk, 1791-1849.

Berland. Berlandier, Jean Louis, 180-1851.

Bernh. Bernhardi, Johann Jacob, 1774-1850.

Bess. Besser, Wilibald Swibert Joseph Gottlieb, 1784-1842.

Betcke. Betcke, Ernst Friedrich, 18- 1865.

Beurl. Beurling, Pehr Johan, 18001866.

Beyer. Beyer, Rudolf, 18--

Beyr. Beyrich, Heinrich Karl, 17961834.

Bickn. Bicknell, Eugene Pintard,

Bieb. Marschall von Bieberstein, Friedrich August, 1768-1826.

Bigel. Bigelow, Jacob, 1787-1879.

Bigel. \& Engelm.

Bigelow, John Milton, 18041878; Engelmann, George. 1809-1884.

Bisch. Bischoff, Gottlieb Wilhelm, 1797-1854.

Björnstr, Björnström, Fredrik Johan, 1833-1889.

Blake. Blake, Sidney Fay, 18--

Blankinship.

Blankinship, Joseph William, 1862-

Blytt. Blytt, Mathias Numsen, 17891862.

Böck. Böckeler, Johann Otto, 18031899.

Boehm. Boehmer, Georg Rudolf, 17231803.

Boiss.

Boissier, Pierre Edmond, 1810 1885.

Bolander, Bolander, Henry Nicholas, 1831-1897.

Bong. Bongard, Heinrich Gustav, 1786-1839.

Booth. Booth, William Beattie, 18041874.

Boott. Boott, Francis, 1792-1863.

Boott, W. Boott, William, 1805-1887.

Borkh. Borkhausen, Moriz Balthasar. 1760-1806.

Bosc. Bosc, Louis Augustin Guillaume, 1759-1828.

Bosch. Bosch, Roelof Benjamin van den, 1810-1862.

Bouché. Bouché, Peter Carl, 17821856.

Bourgeau. Bourgeau, Eugène, 1813-1877, Boynton.

Br., P.

Boynton, Frank Ellis, 1859 Browne, Patrick, 1720-1790.

* Prepared by Dr. J. H. Barnhart. 
Br., R.

Brack.

Brown, Robert, 1773-1858.

Brand.

Brackenridge, William 1810-1893.

D., Brandegee, Townshend Stith, 1843-

Brand, A. Brand, August, 1863-

Brewer. Brewer, William Henry, 18281910.

Brewer \& Wats.

Brewer, William Henry, 18281910 ; Watson, Sereno, 18261892 .

Brign. Brignoli, Giovanni, 1774-1857. Briq. Briquet, John Isaac, 1870-

Britt, or Britton.

Britton, Nathaniel Lord, 1859-

Britton \& Rose.

Britton, Nathaniel Lord, 1859-; Rose, Joseph Nelson, 1862-

Britton \& Rusby.

Britton, Nathaniel Lord, 1859-;

Britton \& Rydb. Rusby, Henry Hurd, 1855-

Britton, Nathaniel Lord, 1859-; Rydberg, Per Axel, 1860-

Brongn. Brongniart, Adolphe Théodore, 1801-1876.

Brown, S. Brown, Stewardson, 1867-

Brown \& Schäffer.

Brown, Stewardson, 1867Schäffer, Mary Townsend (Sharples), 1861-

Buch. Buchenau, Franz Georg Philipp, 1831-1906.

Buckl. Buckley, Samuel Botsford, 1809-1884.

Bunge. Bunge, Alexander von, 18031890.

Burgsd. Burgsdorf, Friedrich August Ludwig von, 1747-1802.

Burm. Burman, Johan, 1706-1779.

Buse. $\quad$ Buse, L. H., 1819-1888.

Bush. Bush, Benjamin Franklin, 1858-

Butler. Butler, Bertram Theodore, $1872-$

Canby. Canby, William Marriott, 1831Canby \& Rose. 1904.

Canby, William Marriott, 18311904; Rose, Joseph Nelson, $1862-$

Carey. Carey, John, 1798-1880.

Carr. Carriềre, Elie Abel, 1818-1896.

Casp. Caspary, Johann Xaver Robert, 1818-1887.

Cass. Cassini, Alexandre Henri Gabriel, 1781-1832.

Cassidy. Cassidy, James, $18--1889$

Cav. Cavanilles, Antonio José, 17451804.

Celak. Celakovsky, Ladislav Josef, 1834-1902.

Cerv.

Chab.

Chaix. Chaix, Dominique, 1730-1799.
Cham.

Cervantes, Vicente, 1759-1829.

Chabert, Alfred, $1836-$ von, 1781-1838.

Cham. \& Schlecht. or C. \& $\mathrm{S}$.

Chamisso, Ludolf Adalbert von, 1781-1838; Schlechtendal, Diederich Franz Leonhard von, 1794-1866.

Chapm. Chapman, Alvan Wentworth, 1809-1899.

Chase.

Chase, Mary Agnes (Merrill), 1869

Chev.

Chevallier, François Fulgis, 1796-1840.

Choisy.
Chr., C.

Christ.

Clarke.

Clayton.

Clem.

Clements. Clements, Frederic Edward, 1874 -

Cockerell. Cockerell, Theodore Dru Alison, 1866-

Cohn.

Cohn, Ferdinand Julius, 18281898.

Cosson. Cosson, Ernest Saint-Charles, 1819-1889.

Coss. \& Germ.

Cosson, Ernest Saint-Charles, 1819-1889; Germain de Saint-Pierre, Jacques Nicolas Ernest, 1815-1882.

Coult. Coulter, John Merle, 1851-

Coult. \& Fisher.

Coulter, John Merle, 1851-

Coult. \& Nels. Fisher, Elmon McLean, 18

Coulter, John Merle, 1851Nelson, Aven, 1859

Coult. \& Rose.

Cou

Rose, Joseph Nelson, 1862-

Coville. Coville, Frederick Vernon, 1867-

Cov. \& Britt.

Coville, Frederick Vernon, 1867- ; Britton, Nathaniel Lord, 1859-

Cov. \& Rose.

Coville, Frederick Vernon, 1867- : Rose, Joseph Nelson, $1862-$

Crantz. Crantz, Heinrich Johann Nepomuk von, 1722-1797.

Crép. Crépin, Francois, 1830-1903.

Curran. Curran, Mary Katherine (Layne), 1844-

Cyrill. Cirillo, Domenico, 1734-1799.

DC. Candolle, Augustin Pyramus de, $1778-1841$.

DC., A. Candolle, Alphonse Louis Pierre Pyramus de, 1806-1893.

DC., C. Candolle, Anne Casimir Pyra-

Dalla Torre. mus de, 1836-

Dalla Torre, Karl Wilhelm von, $1850-$

Daniels. Daniels, Francis Potter, 1869

Dec. Decaisne, Joseph, 1809-1882.

Dec. \& Planch.

Decaisne, Joseph, 1809-1882; Planchon, Jules Emile, 18231888.

Deless. Delessert, Benjamin, 17731847.

Desf. Desfontaines, Rénê Louiche, 1750-1833.

Desr. Desrousseaux, Louis Auguste Joseph, $17--179$.

Desv. Desvaux, Nicaise Auguste, $1784-1856$.

De Vries. De Vries, Hugo, 1848-

Dewey. Dewey, Chester, 1784-1867.

Diels. Diels, Ludwig, 1874-

Dietr. Dietrich, Friedrich Gottlieb, 1768-1850.

Dietr., D. Dietrich, David Nathanael Friedrich, 1799-1888.

Dill. Dillenius, John James, 16871747.

Dode. Dode, Louis Albert, 1875-

Don. Don, George, 1798-1856. 
Don, D. Don, David, 1799-1841.

Donn. Donn, James, 1758-1813.

Dougl. Douglas, David, 1798-1834.

Drejer. Drejer, Salomon Thomas Nicolai, $1813-1842$.

Duby. Duby, Jean Etienne, 17981885.

Dulac. Dulac, Joseph, 18- -189-

Dum. Dumortier, Barthélemy Charles Dum.-Cours. Joseph, 1797-1878.

Dumont de Courset, Georges Louis Marie, 1746-1824.

Dunal. Dunal, Michel Félix, 17891856.

Durand. Durand, Elie Magloire, 17941873.

Durand \& Hilgard.

Durand, Elie Magloire, 17941873; Hilgard, Theodore Charles, 1828-1875.

Durande. Durande, Jean François, 17321794.

Durieu. Durieu de Maisonneuve, Michel Charles, 1797-1878.

Du Roi. Du Roi, Johann Philipp, 17411785.

Eastw. Fastwood, Alice, 1859-

Eat. Eaton, Amos, 1776-1842.

Eat., A. A.

Eaton, Alvah Augustus, 18651908.

Eaton, D. C.

Eaton, Daniel Cady, 1834-

Eat. \& Wright. 1895 .

Eaton, Amos, 1776-1842; Wright, John, 1811-1846.

Eggl. Eggleston, Willard Webster, 1863-

Ehrh. Ehrhart, Friedrich, 1742-1795.

Eichw. Eichwald, Karl Eduard von, 1795-1876.

Ell. Elliott, Stephen, 1771-1830.

Elmer. Elmer, Adolph Daniel Edward, $1870-$

Endl. Endlicher, Stephan Ladislaus, 1804-1849.

Engelm. Engelmann, George, 18091884.

Engelm. \& Bigel.

Bngelmann, George, 1809-1884; Bigelow John Milton, 18041878.

Engelm. \& Gray.

Engelmann, George, $1809-$ 1884; Gray, Asa, 1810-1888.

Engler. Engler, Heinrich Gustav Adolf, $1844-$

Eschsch. Eschscholtz, Johann Friedrich, 1793-1831.

Fabr.

Fabricius, Philipp Conrad, 1714-1774.

Farr. Farr, Edith May, 18--

Farwell. Farwell, Oliver Atkins, 1867-

Fedde. Fedde, Friedrich Karl Georg, 1873-

Fedde \& Sydow.

Fedde, Friedrich Karl Georg, 1873- ; Bydow, Paul, 1851-

Fée.

Fée, Antoine Laurent Apollinaire, $1798-1874$.

Fenzl. Fenzl, Eduard, 1808-1879.

Fern. $\quad$ Fernald, Merritt Lyndon, 1873-

Fern. \& Rydb.

Fern. \& Wieg.

ernald, Merr itt Lyndon, 1873-; Rydberg, Per Axel, 1860-

Fernald, Merritt Lyndon, 1873; Wiegand, Karl MeKay, 1873
Fisch. Fischer, Friedrich Ernst Ludwig von, $1782-1854$.

Fisch. \& Avê-Lall.

Fischer, Friedrich Ernst Ludwig von, 1782-1854: AvéLallemant, Julius Leopold Eduard, 1803-1867.

F. \& M. or Fisch. \& Mey.

Fischer, Friedrich Ernst Ludwig von, 1782-1854: Meyer, Carl Anton von, 1785-1855.

Fisch., Mey. \& Avé-Lall.

Fischer, Friedrich Ernst Ludwig von, 1782-1854; Meyer, Carl Anton von, 1785-1855; Avé-Lallemant, Julius Leopold Eduard, 1803-1867.

Fisch. \& Trautv.

Fischer, Friedrich Ernst Ludwig von, 1782-1854: Trautvetter, Ernst Rudolf von, 1808-1889.

Flügge. Flügge, Johann, 1775-1816.

Focke. $\quad$ Focke, Wilhelm Olbers, 1834-

Forbes. Forbes, James, 1773-1861.

Foug. Fougeroux, Auguste Denis, 1732-1789.

Fourn. Fournier, Eugène Pierre Nicolas, 1834-1884.

Fourr. Fourreau, Pierre Jules, 18441871.

Fraser. Fraser, John, 1750-1811.

Frém. Frémont, John Charles, 18131890.

Fresen. Fresenius, Johann BaptistGeorg Wolfgang, 1808-1866.

Freyn. Freyn, Josef Franz, 18451903.

Fries. Fries, Elias Magnus, 17941878 .

Fries, Th. Fries, Theodor Magnus, 1832 1913.

Gaertn. Gaertner, Joseph, 1732-1791.

Gand. Gandoger, Michel, 1850-

Garcke. Garcke, Friedrich August, $1819-1904$.

Garrett. Garrett, Albert Osbun, 1870 -

Gesn. Gesner, Conrad, 1516-1565.

Geyer. Geyer, Carl Andreas, 1809 1853.

Gilib.

Gilibert, Jean Emmanuel, 1741 1814.

Glatf. Glatfelter, Noah M., 18371911.

Glox. Gloxin, Benjamin Peter, 17-

$\underset{1755 \text {. }}{17-}$, Johann Georg, 1709-

Gmel.

Gmel.J. F. Gmelin, Johann Friedrich, 1748-1804.

Gmel., S. G.

Gmelin, Samuel Gottlieb, 1743-1774.

Godr. Godron, Dominique Alexandre, $1807-1880$.

Goldie. Goldie, John, 1793-1886.

Goodding. Goodding, Leslie Newton, 18

Gooden. Goodenough, Samuel, 17431827.

Gordon. Gordon, George, 1806-1879.

Gouan. Gouan, Antoine, 1733-1821.

Grah. Graham, Robert, 1786-1845.

Gray, A. Gray, Asa, 1810-1888.

Gray, S. F.

Gray, Samuel Frederick, 17801836.

Gray \& Engelm.

Gray, Asa, 1810-1888; Engelmann, George, 1809-1884.

Greene. Greene, Edward Lee, 18421915 . 
Greenman. Greenman, Jesse More, 1867Gren. \& Godr.

Grenier, Jean Charles Marie, 1808-1875; Godron, Dominique Alexandre, 1807-1880.

Griff., D. Griffiths, David, 1867-

Griseb. Grisebach, August Heinrich Rudolf, 1814-1879.

Gron.

Gronovius, Jan Fredrik, 1690 1762 .

Gürke \& Harms

Gürke, Robert Louis August Max, 1854-1911; Harms, Hermann, 1870

Gunn. Gunnerus, Johan Ernst, 17181773.

Guss. Gussone, Giovanni, 1787-1866.

H. \& A, or Hook. \& Arn.

Hooker, William Jackson, 1785-1865: Arnott, George Arnott Walker, 1799-1868.

H.B.K. Humboldt, Friedrich Wilhelm Heinrich Alexander von, 1769-1859; Bonpland, Aimé Jacques Alexandre, 17731858; Kunth, Carl Sigismund, 1788-1850.

Hack. Hackel, Eduard, 1850-

Haenke, Haenke, Thaddius, 1761-1817.

HaIl. Haller, Albert von, 1708-1777.

Hall, H. M. Hall, Harvey Monroe, 1874-

Hansen, G. Hansen, George, 1863-1908.

Hartm. Hartman, Carl Johan, 17901849.

Harv. " Harvey, William Henry, 1811-

Harv. \& Gray. 1866.

Harvey, William Henry, 18111866: Gray, Asa, 1810-1888.

Hausskn, Haussknecht, Heinrich Carl, 1838-1903.

Haw. Haworth, Adrian Hardy, 17681833.

Hegelm、 Hegelmaier, Christoph Friedrich, 1833-1906.

Heimerl. Heimerl, Anton, 1857-

Heist, Heister, Lorenz, 1683-1758.

Heller. Heller, Amos Arthur, 1867-

Hemsl. Hemsley, William Botting, $1843-$

Henders. Henderson, Louis Forniquet 1853-

Hieron. Hieronymus, Georg Hans Emmo Wolfgang, 1846 -

Hill. Hill, John, 1716-1775.

Hitche, Hitchcock, Albert Spear, 1865Hitche. \& Chase.

Hitchcock, Albert Spear, 1865-; Chase, Mary Agnes (Merrill), 1869-

Hoffm. Hoffmann, Georg Franz, 17611826.

Hoffmgg. Hoffmannsegg, Johann Centurius yon, 1766-1849.

Holm. Holm, Herman Theodor, 1854-

Holz. Holzinger, John Michael, 1853-

Hook. Hooker, William Jackson, $1785-1865$.

Hook. f. Hooker, Joseph Dalton, 18171911.

Hook, \& Grev.

Hooker, William Jackson, 1785-1865; Greville, Robert Kaye, 1794-1866.

Hopkins. Hopkins, Lewis 8ylvester, 1872Hoppe, Hoppe, David Heinrich, 17601846.

Hornem. Hornemann, Jens Wilken, $1770-1841$.

Host.

Host. Nicolaus Thomas, 17611834.
House, House, Homer Doliver, 1878-

Houst. Houstoun, William, 1695-1733.

Howe. Howe, Elliot Calvin, 18281899.

Howell. Howell, Thomas, 1842-1912.

Huds. Hudson, William, 1730-1793.

Humb. \& Bonpl.

Humboldt, Friedrich Wilhelm Heinrich Alexander von, 1769-1859; Bonpland, Aimé Jacques Alexandre, 17731858 .

Huth, Huth, Ernst, 1845-1897.

Ives. Ives, Eli, 1779-1861.

Jacq. Jacquin, Nicolaus Josef von, $1727-1817$

James, James, Edwin, 1797-1861.

Jeps. Jepson, Willis Linn, 1867-

Johnston, J. R.

Johnston, John Robert, 1880-

Jones, M. E.

Jones, Marcus Eugene, 1852-

Juss,

Jussieu, Antoine Laurent de, $1748-1836$

Juss, A. Jussieu, Adrien de, 1797-1853.

Juss, B. Jussieu, Bernard de, 16991777 .

Kalm. Kalm, Pehr, 1717-1779.

Karst. Karsten, Gustav Karl Wilhelm Hermann, 1817-1908.

Kaulf. Kaulfuss, Georg Friedrich, $17-1830$.

Kearney. Kearney, Thomas Henry, 1874-

Kellogg. Kellogg, Albert, 1813-1887.

Kennedy, Kennedy, Patrick Beveridge, 1874-

Kenn. \& McDerm.

Kennedy, Patrick Beveridge, 1874- ; McDermott, Laura Frances, 18

Ker.

Kit.

Ker, John Bellenden, 17651842.

Klatt. Klatt, Friedrich Wilhelm, $1825-1897$.

Klotzsch. Klotzsch, Johann Friedrich, 1805-1860.

KI. \& Garcke.

Klotzsch, Johann Friedrich, 1805-1860: Garcke, Friedrich August, 1819-1904.

Knerr. Knerr, Ellsworth Brownell, 1861-

Koch. Koch, Wilhelm Daniel Joseph, 1771-1849.

Koch, K. Koch, Karl Heinrich Emil, 1809-1879.

Koehne, Koehne, Bernhard Adalbert Emil, 1848-

Koel.

Koeler, Georg Ludwig, 17641807.

Konig. Konig, Charles Dietrich Eberhard, 1774-1851.

Kostel. Kosteletzky, Vincenz Franz, $1801-1887$

Krautter. Krautter, Louis, 1880-1909.

Kuikenth. Kuikenthal, Georg, 1864-

Kunth. Kunth, Carl Sigismund, 17881850.

Kunth \& Bouche.

Kunth, Carl Sigismund, 17881850; Bouchế, Oarl David. 1809-1881.

Kuntze. Kuntze, Oarl Ernst Otto, 18431907 .

Kunze. Kunze, Gustav, 1793-1851.

L.

L. $\mathrm{f}$.

Labill.

Linnaeus, Carl, 1707-1778.

Linné, Carl von, 1741-1783.

Labillardiére, Jacques Julien Houtton de, 1755-1834. 
Laest.

Laestadius, Lars Levi, 18001861.

Lag.

Lagasca y Segura, Mariano, $1776-1839$.

Lam.

Lamarck, Jean Baptiste Antoine Pierre Monnet de, 1744-1829.

Lamb. Lambert, Aylmer Bourke, 1761-1842.

Lang, O. F

Lang, Otto Friedrich, 18171847.

Lange.

Lange, Johan Martin Christian, 1818-1898.

Ledeb. Ledebour, Carl Friedrich von, 1785-1851.

Lehm. Lehmann, Johann Georg Christian, 1792-1860.

Leiberg. Leiberg, John Bernhard, 18531913.

Lem. Lemaire, Charles Antoine, 1801-1871.

Lemmon. Lemmon, John Gill, 18321908.

Less. Lessing, Christian Friedrich, $1809-1862$.

Lẻv. Léveillé, Augustin Abel Hector, 1863-

Leyss. Leysser, Friedrich Wilhelm von, 1731-1815.

L'Hêr.

L'Heritier de Brutelle, Charles Louis, 1746-1800.

Liebm. Liebmann, Frederik Michael, 1813-1856.

Lightf. Iightfoot, John, 1735-1788.

Lilja. Lilja, Nils, 1808-1870.

Liljebl. Liljeblad, Samuel, 1761-1815.

Lindb.

Lindberg, Sextus Otto, 18351889.

LindI. Lindley, John, 1799-1865.

Lindl. \& Gord.

Lindley, John, 1799-1865; Gordon, George, 1806-1879.

Link, Link, Johann Heinrich FriedLink \& Otto. rich, 1767-1851.

Link, Johann Heinrich Friedrich, 1767-1851; Otto, Christoph Friedrich, 1783-1856.

Lloyd. Iloyd, Francis Ernest, 1868-

Lloyd \& Underw.

Lloyd, Francis Ernest, 1868-; Ünderwood, Lucien Marcus, 1853-1907.

Lodd. Loddiges, Conrad, 1738-1826.

Loefli. Loefling, Pehr, 1729-1756.

Loisel. Loiseleur-Deslongchamps, Jean Louis Auguste, 1774-1849.

Loud. Ioudon, John Claudius, 1783 1843.

Lour. $\quad$ Loureiro, Joao de, 1715-1796.

Ludw. Ludwig, Christian Gottlieb. $1709-1773$

Lunell. Iunell, John, 1851-

Macbr., F. Macbride, J Francis, 1892-

Macbr. \& Payson.

Macbride, J Francis, 1892

McClatchie Payson, Edwin Blake, 1893-

McClatchie, Alfred James, 18 1906

Mackenzie.

Mackenzie, Kenneth Kent,

Mackenzie \& Bush.

Mackenzie, Kenneth Kent, 1877- ; Bush, Benjamin

MacM. or MacMill. Franklin, 1858-

MacMillan, Conway, 1867

Macoun, John, 1832
Macoun, J. M.

Macoun, James Melville, 1862Marshall, Humphry, 1722 1801.

Marsh.

Martens, Martens, Martín, 1797-1863.

Maxim. Maximowicz, Karl Johann, 1827-1891.

Maxon. Maxon, William Ralph, 1877-

Medic. Medicus, Friedrich Casimir. 1736-1808.

Meinsh. Meinshausen, Karl Friedrich, 1819-1899.

Meissn. Meissner, Carl Friedrich, 18001874.

Merr.

Merrill, Elmer Drew, 1876-

Merriam. Merriam, Clinton Hart, 1855-

Mert, \& Koch.

Mertens, Franz Carl, 17641831; Koch, Wilhelm Danie Joseph, 1771-1849.

Mett. Mettenius, Georg Heinrich, 1823-1866.

Meyer, O. A.

Meyer, Carl Anton von, 17951855.

Meyer, E. Meyer, Ernst Heinrich Friedrich, 1791-1858.

Mich, Micheli, Pier' Antonio, 16791737.

Michx. Michaux, André, 1746-1802.

Miers. Miers, John, 1789-1879

Mill. Miller, Philip, 1691-1771.

Mill. \& Standl.

Miller, Gerrit Smith, 1869Standley, Paul Carpenter, 1884 -

Millsp. Millspaugh, Charles Frederick, 1854-

Mitchell. Mitchell, John, 1680?-1772?

Moc. Mocino, José Mariano, 176 -

Moc. \& Sessể. 1819.

Mocino, José Mariano, 1761819; Sessé, Martin, 175 1809.

Moench. Moench, Conrad, 1744-1805.

Molina. Molina, Juan Ignacio, 1737 1829.

Moore. Moore, Thomas, 1821-1887.

Moore, T. V.

Moore, Thomas Verner, 1877-

Moguin-Tandon, Christian Horace Bénédict Alfred, 1804-1863.

Moric. Moricand, Moise Etienne, $1779-1854$.

Morong. Morong, Thomas, 1827-1894

Morris. Morris, Edward Lyman, 18701913.

Miull. Muller, Otto Fridrich, 17301784.

Muell.-Arg

Miller, Jean, 1828-1896. ("Mueller-Argoviensis,")

Mühlenpf. Múhlenpfordt, F., 18 -18

Muhl. Muhlenberg, Gotthilf Henry Ernest, 1753-1815.

Mulford. Mulford, A. Isabel, 18

Munro. Munro, William, 1818-1880.

Murr.

Murray, Johan Ảndreas, 1740 1791.

Mutis. Mutis, José Celestino, 17321808.

Nash.

Nash, George Valentine, 1864-

Neck.

Necker, Noel Joseph de, 1729 1793.

Nees, Nees von Esenbeck, Christian

Nees \& Meyen. Gottried Daniel, 1776-1858.

Nees von Esenbeck, Christian Gottfried Daniel, 1776-1858; 
Meyen, Franz Julius Ferdinand, $1804-1840$.

Nels., A. Nelson, Aven, 1859-

Nels., E. Nelson, Elias Emanuel, 1876Nels. \& Cockerell.

Nelson, Aven, 1859- ; Cockerell, Theodore Dru Alison, 1866 -

Nels. \& Kenn.

Nelson, Aven, 1859- ; Kennedy, Patrick Beveridge, $1874-$

Nels, \& Macbr.

Nelson, Aven, 1859- ; Macbride, J Francis, $1892-$

Niedzu. Niedenzu, Franz, 1857-

Nieuwl. Nieuwland, Julius Aloysius, $1878-$

Norton. Norton, John Bitting Smith, $1872-$

Nutt.

Nuttall, Thomas, 1786-1859.

Nym.

Nyman, Carl Fredrik, 18201893.

Oakes. Oakes, William, 1799-1848.

Oeder. Oeder, Georg Christian von, $1728-1791$.

Olin. Olin, Emil Hjalmar Fredrik. 1869-1914.

Olney. Olney, Stephen Thayer, 18121878.

Opiz.

Opiz, Philipp Maximilian, $1787-1858$.

Ort. Ortega, Casimiro Gomez, 1740 1818.

Osterh. Osterhout, Georgo Everett, 1858-

Pall. Pallas, Peter Simon, 17411811.

Pammel. Pammel, Louis Hermann, 1862Parish.

Parl.

Parry,

Patrin.

Pax.

Payson.

Pennell.

Pers.

Petrak.

Philippi. Philippi,
1808-1904.
Pickering. Pickering, Charles, 1805-1878.

Parish, Samuel Bonsall, 1838-

Parlatore, Filippo, 1816-1877.

Parry, Charles Christopher. $1823-1890$.

Patrin, Eugène Louís Melchior, $1742-1815$.

Pax, Ferdinand, 1858-

Payson, Edwin Blake, 1893-

Pennell, Francis Whittier, 1886-

Persoon, Christiaan Hendrik, 1755-1837.

Petrak, Franz, 18--

Piper. Piper, Charles Vancouver, $1867-$

Piper \& Brodie.

Piper, Charles Vancouver, 1867 - Brodie, David Arthur, 1868-

Planch. Planchon, Jules Emile, 18231888.

Plum, or Plumier.

Poir. Poiret, Jean Louis Marie,

Plumier, Charles, 1646-1704. 1755-1834.

Poll.

Pollard. Pollard, Charles Louis, 1872-

Porter. Porter, Thomas Conrad, 18221901.

Porter \& Coult.

Porter, Thomas Conrad, 18221901; Coulter, John Merle, $1851-$

Prantl. Pranti, Karl Anton Eugen, $1810-1893$.

Prescott. Prescott, John D., 17-1836.

Presl.
Presl, J. Presl, Jan Swatopluk, 17911849.

Presl, J. \& C.

Presl, Jan Swatopluk, 17911849: Presl, Karel Boriwog, 1794-1852.

Pritzel. Pritzel, Georg August, 18151874.

Prov.

Purdy.

Purpus.

Pursh.

Pylaie.

Provancher, Lếon, 1820-1892.

Purdy, Carl, 18--

Purpus, Joseph Anton, 1860-

Pursh, Frederick, 1774-1820.

La Pylaie, Auguste Jean Marie Bachelot de, 1786-1856.

R. \& P. Ruiz Lopez, Hipolito, 17541815; Pavon, José, 175--1844.

R. \& S. Roemer, Johann Jacob, 17631819; Schultes, Joseph August, $1773-1831$.

Raf.

Rafinesque, Constantine Samuel, 1783-1840.

Raim. Raimann, Rudolf, 1863-1896.

Ramaley. Ramaley, Francis, 1870-

Ray. Ray, John, 1627-1705.

Regel. Regel, Eduard August von,

Regel \& Tiling. $1815-1892$.

Regel, Eduard August von, 1815-1892; Tiling, Heinrich Sylvester'Theodor, 18--1871

Reich. Reichenbach, Heinrich Gottlieb Ludwig, 1793-1879.

Reichard. Reichard, Johann Jacob, 17431782.

Retz.

Retzius, Anders Johan, 17421821.

Rich. Richard, Louis Claude Marie, 1754-1821.

Richards, Richardson, John, 1787-1865.

Ricker. Ricker, Percy Leroy, 1878-

Riddell. Riddell, John Leonard, 18071865.

Riv.

Rivinus, Augustus Quirinus, $1652-1723$

Robbins. Robbins, James Watson, 18011879.

Robins. \& Greenm.

Robinson, Benjamin Lincoln, 1864- ; Greenman, Jesse More, 1867-

Robinson, B. I.

Robinson, Benjamin Lincoln, 1864-

Robson. Robson, Stephen, 1741-1779.

Roem. Roemer, Johann Jacob, 17631819.

Rose. Rose, Joseph Nelson, 1862-

Rostk. \& Schmidt.

Rostkovius, Friedrich WiIliam Theophil, 1770-1848; Schmidt, Wilhelm Ludwig Ewald, 1804-1843.

Roth. Roth, Albrecht Wilhelm, 17571834.

Rothr. Rothrock, Joseph Trimble, 1839-

Rottb. Rottböll, Christen Friis, 17271797.

Rowland. Rowland, Verner Hawsbrook, $18-$ willard Winfleld,

Rowlee.

Rowlee, 1861-

Royen.

Royle. Royle, John Forbes, 1800-1858

Royen, Adrian van, 1704-1779

Rudolphi. Rudolphi, Iriedrich Karl Ludwig, 1801-1849.

Ruimpl.

Rimpler, Theodor, 1817-1891.

Rupp.

Ruppius, Heinrich Bernhard, $1688-1719$

Rupr.
Ruprecht, Franz Josef, 18141870. 1852. 
Rydb. Rydberg, Per Axel, 1860-

Rylands. Rylands, Thomas Glazebrook, $1818-1900$.

Salisb. Salisbury, Richard Anthony, $1761-1829$.

Sarg. Sargent, Charles Sprague, $1841-$

Scepin. - Scepin, Constantin, 17--17-

Schaffn. Schaffner, Wilhelm, 181883.

Schaffn., J. H.

Schaffner, John Henry, 1866-

Scheele. Scheele, Adolf, 1808-1864.

Scheutz. Scheutz, Nils Johan Wilhelm, 1836-1889.

Schk. Schkuhr, Ohristian, 1741-1811.

Schlecht. Schlechtendal, Diederich Franz

Schlecht. \& Cham. Leonhard von, 1794-1866.

Schlechtendal, Diederich Franz Leonhard von, 1794-1866; Chamisso, Ludolf Adalbert von, 1781-1838.

Schleich. Schleicher, Johann Christoph, 1768-1834.

Schleiden. Schleiden, Matthias Jacob, 1804-1881.

Schmidel. Schmidel, Casimir Christoph, Schmidt, F. W. 1718-1792.

Schmidt, Franz,Wilibald, 17641796.

Schneid., C. K.

Schneider, Camillo Karl, 1876-

Schott. Schott, Heinrich Wilhelm, 1794-1865.

Schrad. Schrader, Heinrich Adolph, 1767-1836.

Schrank. Schrank, Franz von Paula von, 1747-1835.

Schreb. Schreber, Johann Christian Daniel von, 1739-1810.

Schult. Schultes, Joseph August, 17731831.

Schultz, F

Schultz, Friedrich Wilhelm, 1804-1876.

Schultz-Bip.

Schultz, Carl Heinrich, 1805-

Schulz, O. E.

1867.

Schum., K.

Schulz, Otto Eugen, 18- -

Schumann, Karl Moritz, 18511904.

Schur. Schur, Philipp Johann Ferdinand, 1799-1878.

Schw. or Schwein.

Schweinitz, Lewis David de, 1780-1834.

Schweinf. Schweinfurth, Georg August, 1836-

Scop.

Scopoli, Johann Anton, 17231788 .

Scribn. Scribner, Frank Lamson, 1851-; Scribn. \& Ball.

Scribner, Frank Lamson, 1851-; Scribn. \& Merr. Ball, Carleton Roy, 1873-

Scribner, Frank Lamson, 1851-; Scribn. \& Rydb. Merrill, Elmer Drew, 1876-

Scribner, Frank Lamson, 1851-; Seribn. \& Smith. Rydberg, Per Axel, 1860-

Scribn. \& Tweedy.

cribner, Frank Lamson, 1851-:

Scribner, Frank Lamson, 1851-; Tweedy, Frank, 1854-
Scribn. \& Williams.

Scribner, Frank Lamson, 1851-; Williams, Thomas Albert, 1865-1900.

Seem. Seemann, Berthold Carl, 18251871.

Seem., v. Seemen, Karl Otto von, 18381910.

Seringe. Seringe, Nicolas Charles, 17761858.

Shafer. Shafer, John Adolph, 1863-

Sharp, S. S.

Shear Sharp, Seymour Sereno, 18-

Shear, Cornelius Lott, 1865-

Sheld. or Sheldon.

Sheldon, Edmund Perry, 1869

Sibth. Sibthorp, John, 1758-1796.

Sims. Sims, John, 1749-1831.

Slosson. Slosson, Margaret, 18- -

Small. $\quad$ Small, John Kunkel, 1869-

Smiley. Smiley, Frank Jason, 18-

Smith. : Smith, James Edward, 17591828 .

Smith, J. G.

Smith \& Rydb.

Smith, Jared Gage, 1866-

Smith, Jared Gage, 1866Rydberg, Per Axel, 1860-

Smyth.

Smyth, Bernard Bryan, 18431913.

Soland. Solander, Daniel Carl, 17331782.

Sond.

Spach.

Sonder, Otto Wilhelm, 18121881.

Spach, Edouard, 1801-1879.

Spenner. Spenner, Fridolin Carl Leopold. 1798-1841.

Spreng. Sprengel, Kurt Polykarp Joachim, 1766-1833.

Standl. Standley, Paul Carpenter, 1884-

Sternb. Sternberg, Kaspar Maria von, 1761-1838.

Sternb. \& Hoppe.

Sternberg, Kaspar Maria von, 1761-1838; Hoppe, David Heinrich, 1760-1846.

Steud. Steudel, Ernst Gottlieb, 17831856.

Stev.

St. Hil.

Steven, Christian von, 17811863.

Stokes. Stokes, Jonathan, 1755-1831.

Sudw. Sudworth, George Bishop,

$1864-$
Suksdorf

Suksd.

Sw.

Sweet,

Swezey.

T. \& G.

Tausch.

Tenore.

Thal.

Thellung.

Saint-Hilaire, Auguste Francois César Prouvençal de, 1799-1853. $1850-$

Swartz, Olof, 1760-1818.

Sweet, Robert, 1783-1835.

Swezey, Goodwin Deloss, 1851-

Torrey, John, 1796-1873; Gray, Asa, 1810-1888.

Tausch, Ignaz Friedrich, 1793 -1848 .

Tenore, Michele, 1780-1861.

Thornber. Thornber, John James, 1872-

Thouars, Aubert du Petit-Thouars, Aubert, $1758-1831$.

Thuill.

Thuillier, Jean Louis, 17571822.

Thunb. Thunberg, Carl Peter, 17431828.

Thurb. Thurber, George, 1821-1890.

Tidest. Tidestrom, Ivar, 1865-

Tiling. Tiling, Heinrich'Sylvester Theodor, $18--1871$. 
Todaro. Todaro, Agostino, 1818-1892.

Torr. Torrey, John, 1796-1873.

Torr. \& Frém.

Torrey, John, 1796-1873; Frémont, John Charles, 18131890.

Tourn. Tournefort, Joseph Pitton de, 1656-1708.

Trautv, Trautvetter, Ernst Rudolf von, 1809-1889.

Trel. Trelease, William, 1857-

Trev. Treviranus, Ludolf Christian, 1779-1864.

Trew. Trew, Christoph Jakob, 16951769.

Trin. Trinius, Karl Bernhard von, Trin. \& Rupr. 1778-1844.

Trinius, Karl Bernhard von, 1778-1844; Ruprecht, Franz Josef, 1814-1870.

Tuckerm. Tuckerman, Edward, 18171886.

Turcz. Turczaninow, Nicolaus, 17961864.

Uline \& Bray.

Uline, Edwin Burton, 1867- ; Bray, William L, 1865- .

Underw. Underwood, Lucien Marcus, 1853-1907.

Urv. Dumont d'Ưrville, Jules Sébastien César, 1790-1842.

Vahl. Vahl, Martin, 1749-1804.

Vail. Vail, Anna Murray, 1863-

Vaill. Vaillant, Sébastien, 1669-1722.

Vasey. Vasey, George, 1822-1893.

Vasey \& Scribn.

Vasey, George, 1822-1893; Scribner, Frank Lamson, 1851 - .

Vent. Ventenat, Etienne Pierre, 17571808.

Vest. Vest, Lorenz Chrysanth von, 1776-1840.

Vill. Villars, Dominique, 1745-1814.

Vogel. Vogel, Julius Rudolph Theodor, 1812-1841.

Vogler. Vogler, Johann Andreas, 17-

Wahl. Wahlenberg, Göran, 17801851 .
Waldst. \& Kit.

Waldstein, Franz de Paula Adam von, 1759-1823; Kitaibel, Paul, 1757-1817.

Wallr. Wallroth, Carl Friedrich Wilhelm, 1792-1857.

Walp. Walpers, Wilhelm Gerhard, 1816-1853.

Walt. Walter, Thomas, 1740-1788.

Wats., S. Watson, Sereno, 1826-1892.

Wats. \& Coult.

Watson, Sereno, 1826-1892; Coulter, John Merle, 1851-

Weber. Weber, Georg Heinrich, 17521828.

Weinm. Weinmann, Johann Anton, $1782-1858$.

Wendl. Wendland, Heinrich Ludolph, 1792-1869.

Wettst. Wettstein, Richard von, 1862-

Wheelock. Wheelock, William Efner, $1852-$

White. White, Theodore Greely, 18721901.

Wieg. Wiegand, Karl McKay, 1873-

Wight, W. Wight, William Franklin, 1874-

Wikst. Wikström, Johan Emanuel, 1789-1856.

Willd. Willdenow, Carl Ludwig, 17651812.

Williams. Williams, Thomas Albert, 18651900.

With. Withering, William, 1741-1799.

Wolf. Wolf, Dr., 1738-1825.

Wood. Wood, Alphonso, 1810-1881.

Woot. Wooton, Elmer Ottis, 1865-

Woot. \& Standl.

Wooton, Elmer Ottis, 1865- ; Standley, Paul Carpenter, 1884-

Wormsk. Wormskjold, Morten, 17831845.

Wulfen. Wulfen, Franz Xaver von, 1728-1805.

Wylie. Wylie, Robert Bradford, 1870-

York. York, Harlan Harvey, 1875-

Zucc. Zuccarini, Joseph Gerhard, 1797-1848.

Zuccagni. Zuccagni, Attilio, 1754-1807. 


\section{GLOSSARY}

Abnormal. Differing from the usual structure.

Abortion. Imperfect development or nondevelopment of an organ.

Abortive. Imperfectly formed, rudimentary, or barren.

Abruptly pinnate. Pinnate without an odd leaflet at the end.

Acaulescent. Stemless or apparently so.

Accrescent. Growing larger after flowering.

Accumbent (cotyledon). Having the edges against the radicle or hypocotyl.

Acerose. Needle-shaped, as the leaves of pines.

Achene. A small, dry and hard, 1-celled, 1-seeded, indehiscent fruit.

Acicular. Slender needle-shaped.

Aculeate. Prickly; beset with prickles.

Acuminate. Tapering at the end.

Acute. Sharp-pointed, but less so than acuminate.

Adnate. An organ adhering to a different one; united, as the inferior ovary with the calyx-tube. Adnate anther, one attached for its whole length to the filament.

Adsurgent $=$ assurgent .

Adventitious. Out of the usual place.

Adventive. Not indigenous, but apparently becoming naturalized.

Aequilateral. Equal-sided.

Aerial. Growing in or pertaining to the air; hence above the ground or the water.

Aestivation. The arrangement of the parts in a flower bud.

Alate. Winged.

Albumen. See Endosperm.

Alliaceous. Onion-like, in aspect or odor, or taste.

Alternate. Not opposite to each other.

Alveolar. Containing sockets or pits.

Alveolate. Honeycombed; having angular depressions separated by thin partitions.

Ament. A catkin, or peculiar scaly unisexual spike.

Amentaceous. Catkin-like, or catkin-bearing.

Amphitropous (ovule or seed). Half-inverted and straight, with the hilum lateral.

Amplexicaul. Clasping the stem.

Anastomosing. Connecting so as to form a well-defined network.

Anatropous (ovule). Inverted and straight, with the micropyle next the hilum.

Androecium, The whole set of stamens.

Androgynous. Having both staminate and pistillate flowers in the same inflorescence, or in Carex in the same spikelet, the former above the latter.

-androus (in compounds). Having stamens.

Angiospermous. Having the seeds borne within a pericarp.

Annual. of only one year's duration. Winter annual, a plant from autumnsown seed which blooms and fruits in the following spring.
Annular. In the form of a ring.

Annulate. Furnished with a ring or annulus.

Annulus. A ring, like that of the sporecase of most ferns.

Anterior (in the flower). The side towards the bract (external).

Anther. The part of the stamen which contains the pollen.

Antherid, Antheridium (-a). Themaleorgan of reproduction in ferns and mosses.

Antheriferous. Anther-bearing.

Anthesis. The time of expansion of a flower.

Apetalous. Having no petals.

Aphyllopodic. Without leaves at the base.

Aphyllous. Destitute of leaves, at least of green leaves.

Apical. Situated at the apex or tip.

Apiculate. With a minute point.

Appressed. Lying close and flat against.

Approximate. Near together.

Arachnoid. Cobwebby; of slender entangled hairs.

Arborescent. Tree-like, in size or shape.

Archegone, or Archegonium (plural archegonia). The female organ in mosses and ferns.

Arcuate. Bent or curved like a bow.

Areola (-ae). A little, usually angular, space on the surface.

Areolate. Marked out into little areas; reticulate.

Aril. A fleshy organ growing about the hilum.

Ariliform. Resembling an aril.

Arillate. Having an aril.

Aristate. Tipped by an awn or bristle.

Aristulate. Diminutive of aristate.

Articulate. Jointed; having a node or joint.

Ascending. Growing obliquely upward, or upcurved,

Asexual. Without sex.

Assurgent. Ascending.

Attenuate. Slenderly tapering; becoming very narrow.

Auricle. An ear-shaped appendage.

Auriculate. Furnished with auricles.

Awl-shaped. Sharp-pointed from a broader base.

Awn. A slender bristle-like organ.

Axial $=$ Axile.

Axil. The upper angle formed by a leaf or branch with the stem.

Axile. In the axis of an organ.

Axillary. Borne at or pertaining to an axil.

Axis. The central line of any organ or support of a group of organs; a stem, etc.

Baccate. Berry-like.

Banner. Upper petal of the papilionaceous flower; vexillum or standard.

Barbed. Furnished with rigid points or short bristles, usually reflexed like the barb of a fish-hook.

Barbellate. Finely barbed.

Barbulate. Finely bearded. 
Basal, Basilar. At or pertaining to the base.

Basifixed. Attached by the base.

Bast. The fibrous portion of the inner bark.

Beaked. Ending in a beak or prolonged tip.

Bearded. With long or stiff hairs of any sort; awns of grasses are sometimes called beard.

Berry. A fruit with pericarp wholly pulpy.

Bi- or Bis-. A Latin prefix signifying two, twice, or doubly.

Biconvex. Convex on both sides; lensshaped.

Bidentate. Having two teeth.

Bidentulate. Diminutive of bidentate.

Biennial. Of two years' duration.

Bifid. Two-cleft.

Bilabiate. Two-lipped.

Bilocular. Two-celled.

Binate. Two together.

Bipinnate (leaf). Twice pinnate.

Bipinnatifid. Twice pinnatifid.

Biserial, Biseriate. Occupying two rows, one within the other.

Bisexual. Having both stamens and pistils.

Biternate. Twice ternate (principal divisions 3 , each with 3 leaflets).

Bivalvular. Two-valved.

Bladdery. Thin and inflated.

Blade. The flat expanded part of a leaf.

Bract. A leaf, usually small, subtending a flower or flower-cluster, or a sporange.

Bracteate. With bracts.

Bracteolate. Having bractlets.

Bracteose. With numerous or conspicuous bracts.

Bractlet. A secondary bract, borne on a pedicel, or immediately beneath a flower; sometimes applied to minute bracts.

Bristle. A stiff hair or any similar outgrowth.

Bulb. A subterranean leaf-bud with fleshy scales or coats.

Bulbiferous. Bearing bulbs.

Bulblet. A small bulb, especially one borne upon the stem.

Bulbose, Bulbous, Bulb-like in form.

Caducous. Dropping off very early.

Calcarate. Produced into or having a spur.

Callus, An extension of the inner scale of a grass spikelet; a protuberance.

Calyculate. Having bracts around the calyx imitating an outer calyx.

Calyptrate. Furnished with a calyptra, or coming off as a lid or extinguisher.

Calyx. The outer of two series of floral leaves.

Campanulate. Bell-shaped.

Campylotropous (ovule or seed). So curved as to bring the apex and base nearly together.

Canaliculate. Channelled; Iongitudinally grooved.

Cancellate. Reticulated, with the meshes sunken.

Canescent. With gray or hoary fine pubescence.

Capillary. Hair-like in form; as fine as hair or slender bristles.

Capitate. Shaped like a head; collected into a head or dense cluster.

Capitellate. Diminutive of capitate.

Capitulum. A little head.
Capsular. Belonging to or of the nature of a capsule.

Capsule. A dry dehiscent fruit, composed of more than one carpel.

Carinate. Keeled; with a longitudinal ridge.

Carpel. The modified leaf forming the ovary, or a part of a compound ovary.

Carpophore. The slender prolongation of the floral axis which in the Umbelliferae supports the pendulous ripe carpels.

Cartilaginous. Of the texture of cartilage; firm and tough.

Caruncle. An appendage to a seed at the hilum.

Carunculate. With a caruncle.

Caryopsis. The grain; fruit of grasses, with a thin pericarp adherent to the seed.

Catkin. A scaly deciduous spike of fluwers; an ament.

Caudate. With a slender tail-like appendage.

Caudex. The persistent base of an otherwise annual herbaceous stem.

Caudicle. Stalk of a pollen-mass in the Orchid and Milkweed families.

Caulescent. Having a manifest stem.

Cauline. Pertaining to the stem.

Cell. A cavity, of an anther or ovary.

Chaff. Thin dry scales.

Chaffy. Furnished with chaff, or of the texture of chaff.

Channelled. Deeply grooved longitudinally, like a gutter.

Chartaceous. Papery in texture.

Chlorophyll. Green coloring matter of plants.

Choripetalous. Applied to a corolla whose petals are distinct.

Chorisepalous. Applied to a calyx whose sepals are distinct.

Ciliate (foliar organs). Beset on the margin with a fringe.

Ciliolate. Minutely ciliate.

Cinereous. Ash-grayish; the color of ashes.

Circinate. Coiled downward from the apex.

Circumscissile. Transversely dehiscent, the top falling away as a lid.

Clavate. Club-shaped.

Claw. The narrow or stalk-like base of some petals.

Cleft. Cut about half-way to the midvein.

Cleistogamous. Fertilized in the bud, without the opening of the flower.

Coalescence. The union of parts or organs of the same kind.

Cochleate. Coiled or shaped like a snail shell.

Cohesion. The union of one organ with another.

Columella. A term applied to the persistent axis of the capsule.

Columnar. Like a column.

Coma. Tuft of hairs at the ends of some seeds.

Commissure. The surface by which one carpel joins another, as in the Umbelliferae.

Composite. A plant belonging to Carduaceae, Cichoriaceae, or Ambrosiaceae (constituting the old Compositae).

Concave, With the surface curved in.

Conduplicate. Folded lengthwise.

Conglomerate. Densely clustered.

Coniferous. Cone-bearing.

Connate. Similar organs more or less united. 
Connective. The end of the filament between the anther-sacs.

Connivent. Converging.

Convolute. Rolled up longitudinally.

Coralloid. Resembling coral.

Cordate. Heart-shaped with the point upward.

Coriaceous. Leathery in texture.

Corm. The enlarged fleshy base of a stem, bulb-like but solid.

Corniculate. Furnished with a small horn or spur.

Corolla. The inner of two series of floral leaves.

Coroniform. Shaped like a crown.

Corrugate. Wrinkled or in folds.

Corymb. A convex or flat-topped flowercluster of the racemose type, with pedicels or rays arising from different point on the axis.

Corymbose. Borne in corymbs; corymblike.

Costa. A rib; the midrib of a leaf, etc.

Costate. Ribbed.

Cotyledon. A rudimentary leaf of the embryo.

Crateriform. In the shape of a saucer or cup, hemispherical or more shallow.

Creeping (stems). Growing flat on or beneath the ground and rooting.

Crenate. With rounded teeth.

Crenulate. Diminutive of crenate.

Crested, Cristate. Bearing any elevated appendage like a crest.

Crinite. Bearded with long hairs, etc.

Crown. An inner appendage to a petal, or to the throat of a corolla.

Crucifer. A member of Brassicaceae, or Mustard Family, from the cross-like corolla.

Crustaceous. Hard and brittle in texture; crust-like.

Cucullate. Hooded, or resembling a hood.

Culm. The stem of grasses and seges.

Cuneate, Cuneiform. Wedge-shaped.

Cupulate. Cup-shaped.

Cusp. A sharp stiff point.

Cuspidate. Sharp-pointed; ending in a cusp.

Cyme. A convex or flat flower-cluster of the determinate type, the central flowers first unfolding.

Cymose. Arranged in cymes; cyme-like.

Cymule. A small cyme.

Deciduous. Falling away at the close of the growing period.

Decompound. More than once compound or divided.

Decumbent. Reclining, but with the summit ascending.

Decurrent (leaf), Extending down the stem below the insertion.

Decussate. Alternating in pairs at right angles, or in threes.

Deflexed. Turned abruptly downward.

Dehiscence. The opening of an ovary, anther-sac, or sporange to emit the contents.

Dehiscent. Opening to emit the contents.

Demidiate. Appearing as if cut in half.

Dentate. Toothed, especially with outwardly projecting teeth.

Denticulate. Diminutive of dentate.

Dentiform. Tooth-like.

Depressed. Somewhat flattened from above.

Dextrorse. Turned to the right.

$D i-$, as a prefix in compounds, means two or twice.
Diadelphous (stamens). United by filaments in two sets.

Diandrous. Having two stamens,

Dicarpellary. Composed of two carpels.

Dichotomous. Forking regularly by pairs.

Dicotyledonous. Having two cotyledons.

Didymous. Twin-like.

Didynamous. With two stamens longer than the other two.

Diffuse. Loosely spreading.

Digitate. Diverging, like the fingers spread.

Digynous (flower). Having two pistils.

Dimerous. In two parts. Referring to a flower constructed on the numerical plan of two.

Dimorphism (in flowers). Possessing two forms of flowers, one with short styles and long stamens, the other with long styles and short stamens.

Dimorphous. Of two forms.

Dioecious. Bearing staminate flowers or antherids on one plant, and pistillate flowers or archegones on another of the same species.

Disciform, Disk-shaped. Flat and circular, like a disk or quoit.

Discoid. Heads of Compositae composed only of tubularflowers; rayless; like a disk.

Disk. A development of the receptacle at or around the base of the pistil. In Compositae, the tubular flowers of the head as distinct from the ray.

Dissected. Cut or divided into numerous segments.

Dissepiment. A partition-wall of an ovary or fruit.

Distichous. In two vertical ranks.

Distinct. Separate; not united; evident.

Divaricate. Widely divergent.

Divided. Cleft to the base or to the midrib.

Dorsal. On the back, pertaining to the back.

Dorsiventral. In the plane, running through the axis from above to below; contrary to lateral.

Drupaceous, Drupe-like.

Drupe. A simple fruit, usually indehiscent, with fleshy exocarp and bony endocarp.

Drupelet. Diminutive of drupe.

$E$ - or $E x$-, as a prefix in compounds, means destitute of.

Echinate. Prickly.

Ellipsoid. A solid body, elliptic in section.

Elliptic. With the outline of an ellipse; usually narrowly oval.

Emarginate. Notched at the apex.

Embryo. A rudimentary plant in the seed.

Emersed. Raised out of water.

Endocarp. The inner layer of the pericarp.

Endogenous. Forming new tissue within.

Endogens. Monocotyledons.

Endosperm. The substance surrounding the embryo of a seed; albumen.

Ensiform. Sword-shaped, as the leaves of Iris.

Entire. Without divisions, lobes, or teeth.

Ephemeral. Continuing for only a day or less.

Epicarp. The outer layer of the pericarp.

Epigynous, Upon the ovary.

Epiphyte. A plant that grows upon another plant, but does not derive its sustenance from it. 
Epiphytic. Growing on other plants, but not parasitic.

Equitant. Astride, used of conduplicate leaves which enfold each other in two ranks, as in Iris.

Erose. Irregularly margined, as if gnawed.

Evanescent. Early disappearing.

Evergreen. Bearing green leaves throughout the year.

Excurrent. With a tip projecting beyond the main part of the organ.

Exfoliating. Peeling off in layers.

Exocarp. The outer layer of the pericarp.

Exogenous. Forming new tissue outside the older.

Exogens. Dicotyledons.

Exserted. Prolonged past surrounding organs.

Extravaginal innovalion. Where the new shoot breaks through the basal sheath and produces a horizontal stolon.

Extrorse. Facing outward.

Falcate. Scythe-shaped.

Farinaceous. Mealy in texture.

Farinose. Covered with a mealy powder.

Fascicle. A dense cluster.

Fastigiate. Stems or branches which are nearly erect and close together.

Faveolate, Favose. Honeycombed; same as alveolate.

Fenestrate. With window-like markings.

Fenestration. Transparent spots or openings.

-ferous (in composition). Bearing.

Ferruginous. Color of iron-rust.

Fertile. Bearing spores, or bearing seed.

Fetid. Ill-smelling.

Fibrillate, Fibrillose. Furnished with or abounding in fine fibres.

Fibro-vascular. Composed of woody fibres and ducts.

Filament. The stalk of a stamen; also any slender thread-shaped appendage.

Filamentose, Filamentous. Bearing or formed of slender threads.

Filiform. Thread-like.

Fimbriate. Fringed.

Fimbrillate. Minutely fringed.

Fistular, Fistulose. Cylindrical and hollow, as the leaves of an onion.

Flabellate, or Flabelliform. Fan-shaped; applied to leaves, etc.

Flaccid. Without rigidity; lax and weak.

Flagellate. Producing slender runners.

Flagelliferous, Bearing flagella.

Flagellum $(-a)$. A slender runner as in the strawberry plant.

Flexuous. Zigzag; bending alternately in opposite directions.

Floccose. With loose tufts of wool-like hairs.

Floret. A small flower, usually one of a dense cluster.

Foliaceous. Leaf-like in texture or appearance.

-foliate. Having leaves.

Foliolate, With separate leaflets.

-foliolate. Having leaflets.

Foliose. Leafy.

Follicle, A fruit consisting of a single carpel, dehiscing by the ventral suture.

Follicular. Like a follicle.

Fornicate. Arched over, as the corona of some Boraginaceae, closing the throat of the corolla.

Fornix (-ces). Small arching crest in the throat of the corolla.

Foveate, Foveolate. More or less pitted.

Free. Not adnate to other organs.
Frond. The leaf of ferns and some other cryptogams; in Lemnaceae, the thalluslike stem which functions as foliage.

Frutescent, Fruticose. More or less shrublike.

Fugacious. Soon falling off or perishing.

Funiculus, The stalk of an ovule or seed.

Funnelform, Funnel-shaped. Expanding gradually upwards, like a funnel.

Furfuraceous. Resembling bran; scurfy.

Fuscous. Grayish brown.

Fusiform. Spindle-shaped; swollen in the middle and narrowing toward each end.

Galea. A hood-like part of a perianth or corolla; upper lip of a two-lipped corolla.

Galeate. Helmet-shaped; having a galea. Gamopetalous. With united petals; same as monopetalous and sympetalous.

Gamosepalous. With united sepals; same as monosepalous.

Geminate. Iike twins.

Geniculate. Bent abruptly, like a knee, as many stems.

Gibbous. Enlarged or swollen on one side.

Glabrate. Becoming glabrous with age, or almost glabrous.

Glabrous. Devoid of hairs.

Gland. A secreting cell, or group of cells.

Glandular. With glands, or gland-like.

Glaucous. Covered or whitened with. a bloom.

Globose. Spherical or nearly so.

Glochidiate. Barbed at the tip.

Glomerate. In a compact cluster.

Glomerule. A dense capitate cyme.

Glumaceous, Resembling glumes.

Glume. The scaly bracts of the spikelets of grasses and sedges.

Glutinous. Covered with a sticky exudation.

Granuliferous. Bearing or covered with small granules.

Gregarious. Growing in groups or colonies.

Gymnospermous. Bearing naked seeds, without an ovary.

Gynaecandrous. Having staminate and pistillate flowers in the same spikelet, the latter above the former.

Gynandrous. Having the stamens and pistils more or less united.

Gynobase. A prolongation or enlargement of the receptacle supporting the ovary.

Gynaphore. An elongation of the receptacle bearing the pistil; a stalk of the pod made up from a part of the receptacle; compare stipe.

Gynoecium. The whole set of pistils.

Gynophore. A stalk raising a pistil above the insertion of the stamens.

Habit. The general aspect of a plant, or its mode of growth.

Habitat. The situation in which a plant grows in a wild state.

Halberd-shaped. The same as hastate.

Hamate, Crooked, hooked.

Hastate. Halberd-shaped; like sagittate; but with the basal lobes diverging.

Head. A dense cluster of sessile or nearly sessile flowers on a very short axis or receptacle.

Hemispheric. Shaped like half a globe.

Herb. A plant with no persistent woody stem above ground.

Herbaceous. Leaf-like in texture and color; pertaining to an_herb. 
Hermaphrodite (flower). Having both stamens and pistils; same as perfect.

Heterogamous. Producing more than one kind of flowers.

Heteromorphous. Having flowers of different forms as regards the size or relative position of the essential organs.

Hexa-, in compounds, means six.

Hexamerous. Consisting of six parts or members. Applied to a flower that is constructed on the numerical plan of six.

Hilum. The scar or area of attachment of a seed or ovule.

Hirsute. With rather coarse stiff hairs.

Hirtellous. Minutely hirsute.

Hispid. With bristly stiff hairs.

Hispidulous. Diminutive of hispid.

Hoary. Grayish white; see canescent.

Homogamous. A head or cluster with flowers all of one kind.

Hyaline. Thin and translucent.

Hybrid. A cross between two spećies.

Hydrophilous. Water-loving.

Hydrophyte. A water-plant.

Hypanthium. A calyx-like enlargement of the flower-axis or receptacle, often surrounding or enclosing the pistils and bearing the calyx and corolla and of ten the stamens on its margin.

Hypocotyl. The rudimentary stem of the embryo; also termed radicle.

Hypogynous. Inserted under the pistil.

Imbricate. Overlapping (as shingles on a roof).

Immersed. Growing wholly under water.

Imperfect flowers. Wanting either stamens or pistils.

Inaequilateral. Unequal-sided, as the leaf of Begonia.

Incised. Cut sharply and irregularly, more or less deeply.

Incision. A cut; a narrow opening between two lobes.

Included. Not at all protruded from the surrounding envelope.

Incumbent (embryo). Cotyledons with the back of one of them against the hypocotyl.

Indehiscent. Not splitting open.

Indigenous. Native to the country.

Induplicate. Valvate aestivation in which the margins of the leaves are inflexed or folded inward.

Indurated. Hardened.

Indusiate. With an indusium.

Indusium. The proper (often shieldshaped) covering of the sorus or fruitdot in Ferns.

Inequilateral. Unequal-sided.

Inferior. Lower or below; outer or anterior. Inferior ovary, one that is adnate to the hypanthium.

Inflated. Turgid and bladdery.

Inflexed. Bent inwards.

Inflorescence. The flowering part of plants; its mode of arrangement.

Infra- (in compound words). Below, being below.

Infra-axillary. Inserted some distance below the axils.

Innocuous. Harmless, hence unarmed or spineless.

Innovation. An offshoot from the stem.

Inserted. Attached to or growing out of.

Insertion. The place or the mode of attachment of an organ to its support.

Inter- or intra-. In composition, between.

Internerve. Space between the nerves.
Internode. Portion of a stem or branch between two nodes.

Interval. Space between ridges.

Intramarginal. Within and near the margin.

Intravaginal innovalion. Where the new shoot starts inside a basal sheath and continues to grow, remaining between it and the stem.

Introrse. Facing inward.

Involucel. A secondary involucre.

Involucrate. With an involucre, or like one.

Involucre. A whorl of bracts subtending a flower or flower-cluster.

Involute. Rolled inwardly.

Irregular. A flower in which one or more of the organs of the same series are unlike the rest.

Isabel-colored. Dirty yellowish white.

Keel. A projecting ridge on a surface, like the keel of a boat; the two anterior petals of a papilionaceous corolla.

Labellum. The odd (lower) petal of orchids.

Labiate. Lipped; belonging to the Labiatae or LAMLACEAE.

Lacerate. Irregularly cleft, as if torn.

Lacinia (-ae). Lobe.

Laciniate. Cut into narrow lobes or segments.

Lamina. A plate or blade; the blade of a leaf or a petal.

Lanate. Woolly; clothed with long and soft entangled hairs.

Lanceolate. Considerably longer than broad, tapering upward from the middle or below ; lance-shaped.

Lanose. Densely lanate.

Lanuginous. Cottony or woolly.

Lateral. Belonging to or borne on the side.

Latex. The milky sap of certain plants.

Lax. Loose and slender.

Leaflet. One of the divisions of a compound leaf.

Legume. A simple dry fruit, dehiscent along both sutures.

Leguminosae. Plants of the families Fabaceae, Caesalpiniaceae, and Mimosaceae.

Leguminous. Pertaining to a legums or to the Leguminosae.

Lenticels. Small oval dots which appeai upon the branches of cork-forming Dicotyledons during the first year's growth, and which, by further growth during the early part of the second year, rupture the epidermis.

Lenticular. Lens-shaped.

Lepidote. Beset with small scurfy scales.

Ligneous. Woody, or having a woody texture.

Ligulate. Provided with or resembling a ligule.

Ligule. A strap-shaped corolla, as in the ray-flowers of Compositae; a thin scarious projection from the summit of the sheath in grasses.

Limb. The expanded part of a petal, sepal, or gamopetalous corolla.

Linear. Long and narrow, with parallel margins.

Lip. The principal lobes of a bilabiate corolla or calyx; the odd and peculiar petal in the orchis family; the labellum.

-locular. In composition, having cells. 
Loculicidal (dehiscence), Splitting down through the middle of the back of each cell.

Lodicules. Minutè hyaline scales subtending the flower in grasses.

Loment. A jointed legume, usually constricted between the seeds.

Lunate. Crescent-shaped.

Lunulate. Diminutive of lunate.

Lurid. Dirty brown.

Lutescent. Yellowish, or becoming yellow.

Lyrate. Pinnatifid, with the terminal lobe or segment considerably larger than the others.

Macrosporange. Sporange containing macrospores.

Macrospore. The larger of two kinds of spores borne by a plant, usually giving rise to a female prothallium.

Magenta. A glaring red.

Mammillate. Furnished with nipple-shaped processes.

Marcescent. Withering, but remaining attached.

Medullary. Pertaining to the pith or medulla.

Membranaceous, Membranous. Thin and rather soft and more or less translucent.

-merous. In composition, having parts, as 2-merous, having two parts of each kind.

Mesa. Dry tableland.

Mesocarp. The middle layer of a pericarp.

Micropyle. Orifice of the ovule, and corresponding point on the seed.

Microsporange. Sporange containing microspores.

Microspore. The smaller of two kinds of spores borne by a plant, usually giving rise to a male prothallium; pollen-grain.

Midvein, Midrib. The central vein or rib of a leaf or other organ.

Monadelphous. Stamens united by their fllaments into one set.

Moniliform. Like a string of beads.

Monocephalous. Bearing only one head.

Monocotyledonous (embryo). Having only one cotyledon.

Monoecious. Bearing stamens and pistils on the same plant, but in different flowers.

Mucro. A short and small abrupt tip.

Mucronate. With a short sharp abrupt tip.

Mucronulate. Diminutive of mucronate.

Multicellular. Consisting of many cells.

Multifid. Cleft into many lobes or segments.

Multilocular. Possessing many loculi or cavities.

Muricate. Roughened with short hard processes.

Muriculate. Very finely muricate.

Muticous. Pointless, or blunt.

Napiform. Turnip-shaped.

Naturalized. Plants not indigenous to the region, but so firmly established as to have become part of the flora.

Nectariferous. Nectar-bearing; having a nectary.

Nectary. An organ which secretes nectar.

Nerve, A simple or unbranched vein or slender rib.

Nigrescent. Becoming black or blackish.

Node. The place upon a stem which normally bears a leaf or whorl of leaves.

Nodose. Furnished with knots or nodes.
Nodulose. Diminutive of nodose.

Nut. An indehiscent one-seeded fruit with a hard or bony pericarp.

Nutlet. Diminutive of nut.

$O b$-, as a prefix, signifies inversion, as follows:

Obcompressed. Flattened the opposite of the usual way.

Obconic. Conical, but with the point of attachment at the apex.

Obcordate. Inversely heart-shaped.

Oblanceolate. Inverse of lanceolate.

Oblong. Longer than broad, with the sides nearly parallel, or somewhat curving.

Obovate. Inversely ovate.

Obovoid. Inversely ovoid.

Obpyramidal. Inverted pyramidal, i. e., pyramidal with the base uppermost.

Obsolete. Imperfectly developed or rudimentary.

Obtuse. Blunt, or rounded.

Ochroleucous. Yellowish white.

Ocrea. A sheathing stipule.

Ocreate. Having sheathing stipules.

Offet. Short branch next the ground which takes root.

Opaque. Not transparent.

Operculate. With an operculum.

Operculum. A lid.

Orbicular. Approximately circular in outline.

Orthotropous (ovule or seed). Erect, with the orifice or micropyle at the apex.

Oval. Broadly elliptic.

Ovary. The part of the pistil that contains the ovules.

Ovate. In outline like a longitudinal section of a hen's egg.

Ovoid. Shaped like a hen's egg.

Ovule. The macrosporange of flowering plants, becoming the seed after fertilization.

Oauliferous. Bearing ovules.

Palate, A rounded projection of the lower lip of a personate corolla, closing the throat.

Palea (plural paleae). Chaff; the chaff or bracts on the receptacle of many Compositae.

Paleaceous. Chaffy.

Palet. The upper thin chaffy or hyaline bract which with the lemna encloses the flowers in Grasses.

Pallid. Pale.

Palmate. Diverging radiately like the fingers.

Palmately. In a palmate manner.

Panduriform. Same as fiddle-shaped.

Panicle. A compound flower-cluster of the racemose type.

Panicled, Paniculate. Borne in a panicle: resembling a panicle.

Pannose. Of the appearance or texture of felt.

Papilionaceous (corolla). Having a standard, wings, and keel, as in the peculiar corolla of the Pea Family.

Papilla. A little nipple-shaped protuberance.

Papillate, Papillose. Covered with papillae.

Pappiferous. Pappus-bearing.

Pappus. The modified calyx-limb in Compositae, forming a crown of very various character at the summit of the achene.

Papyraceous. Having a papery texture. 
Parasitic. Growing on and deriving nourishment from another plant.

Parietal. Borne on or pertaining to the wall or inner surface of a capsule.

Parted. Cleft nearly, but not quite to the base.

Pectinate. Pinnatifid with narrow, closely set segments; comb-like.

Pedate. Palmately divided or parted, with the lateral segments 2-cleft.

Pedicel. The stalk of a single flower in a flower-cluster.

Pedicellate, Pedicelled. Furnished with a pedicel.

Peduncle, A primary flower-stalk, supporting either a cluster or a solitary flower.

Peduncled, Pedunculate. Furnished with a peduncle.

Peltate. Shield-shaped; a flat organ, with a stalk on its lower surface.

Pendulous, More or less hanging or declined. Pendulous ovule, one that hangs from the side of the celi.

Penicillate. With a tuft of hairs or hairlike branches.

Penta-, in compounds, means five.

Pentagonal. Five-angled.

Perennial. Lasting from year to year.

Perfect (flower). Having both stamens and pistils.

Perforated. With holes.

Perianth. The floral envelopes of the flower, especially used when calyx and corolla cannot be distinguished.

Pericarp. The wall of the fruit, or seedvessel.

Perigynium $(-a)$. The more or less inflated sac-like organ surrounding the pistil in Carex.

Perigynous. Borne around the ovary.

Persistent. Long-continuous, as a calyx upon the fruit, leaves through winter, etc.

Personate. Masked; bilabiate, and the throat closed by a prominent palate.

Petal. One of the leaves of the corolla.

Petaloid. Petal-like; resembling or colored like petals.

Petiolale. Having a petiole.

Petiole. The leaf-stalk.

Petioled. Furnished with a petiole.

Petiolulate. With a petiolule (leaflet)

Petiolule. The stalk of a leaflet.

Phaenogamous, Having flowers with stamens and pistils and producing seeds.

Phyllode, Phyllodium (-a). A somewhat dilated petiole having the form of and serving as a leaf-blade.

Phyllopodic. With a leafy base

-phyllous (in composition). With leaves as gamophyllous, with united leaves, and diphyllous, with two leaves, etc.

Pilose. Hairy, with soft hairs.

Pinna (pl. Pinnae). One of the primary divisions of a pinnate or compoundly pinnate frond or leaf.

Pinnate (leaf). Compound, with the leaflets arranged on each side of a common petiole.

Pinnatifid. Pinnately cleft.

Pinnatisect. Pinnately dividẻd.

Pinnule. A division of a pinna.

Pistil. The central organ of a flower containing the macrosporanges (ovules).

Pistillate. Provided with pistils, and, in its more proper sense, without stamens.

Pitted. Marked with small depressions or pits.

Placenta. An ovule-bearing surface.
Plane. With a flat, not curved surface.

Planoconvex. Plane on one side and convex on the other.

Plicate. Folded into plaits, like a fan.

Plumose. Having fine hairs on each side, like the plume of a feather.

Plumule. The rudimentary terminal bud of the embryo.

Pod. Any dry and dehiscent fruit.

Pointed. Acuminate.

Pollen. Pollen grain. See Microspore.

Pollinia. The pollen-masses of the Orchid and Milkweed Families.

Polliniferous. Bearing pollen.

Poly-, in compounds, means many.

Polyadelphous. Applied to stamens which are united by their filaments into many sets.

Polygamous. Bearing both perfect and imperfect flowers.

Polymorphous. Of several forms.

Polypetalous. Possessing many petals. Applied by the older botanists to flowers having the petals distinct or ununited.

Polysepalous, When the sepals are distinct.

Pome. The fleshy fruit of the Apple Family.

Posterior. On the side towards the axis; see anterior.

Prickles. Sharp elevations of the bark, and coming off with it, as in the rose.

Prismatic. Of the shape of a prism, angular, with flat sides, and of nearly uniform size throughout.

Procumbent. Trailing on the ground.

Proliferous. Bearing offsprings; a shoot, a branch, a rosette, or a flower producing a shoot ending in a similar organ.

Prostrate. Lying flat upon the ground.

Prothallium. The sexual generation of Pteridophyta.

Pruinose. Frosted; covered with a powder like hoar-frost.

Pseudo (in combinations). Falsely.

Pteridophytes. Fern-plants; ferns and their allies.

Puberulent. Minutely pubescent.

Pubescent. Covered with hairs.

Pulverulent. Dusted; covered apparently with fine powder.

Pulvinate. Cushioned, or shaped like a cushion.

Punctate. Dotted with depressions or with translucent internal glands or colored dots

Puncticulate. Minutely punctate.

Pungent. Terminating in a rigid sharp point; acrid.

Pustular, Pustulate. With blister-like elevations.

Pustule. Blister or blister-like process.

Putamen. The bony part of a stone-fruit.

Pyriform. Pear-shaped.

Pyxis, A capsule whose dehiseence is circumscissile, or which opens by a circular, horizontal line, so that the upper part comes off like a lid.

Quadrate. Nearly square in form.

Raceme. An elongated indeterminate flower-cluster with each flower pedicelled.

Racemose. In racemes, or resembling a raceme.

Rachilla. The axis of the spikelet in grasses.

Rachis. The axis of a compound leaf, or of a spike or raceme.

Radially. Spreading from a common center. 
Radiant. With the marginal flowers enlarged and ray-like.

Radiate. Bearing ray-flowers; spreading from or arranged around a common center.

Radical. Belonging to the root, or apparently coming from the root.

Radicle. The rudimentary stem of the embryo; hypocotyl.

Rameal. Belonging to a branch.

Ramification. Branching.

Ray. One of the peduncles or branches of an umbel; the flat marginal flowers in Compositae.

Receptacle. The end of the flower stalk, bearing the floral organs; or, in Compositae, bearing the flowers; also in some ferns, an axis bearing sporanges.

Reclined. Turned or curved downwards.

Recurved. Curved backwards.

Reflexed. Bent backward abruptly.

Regular. Having the members of each part alike in size and shape.

Reniform. Kidney-shaped.

Repand. With a somewhat wavy margin.

Replicate. That form of vernation in which the apex of the leaf is bent backward toward the base.

Replum. The septum of certain pods that persists after the valves have fallen away.

Resiniferous. Producing resin.

Reticulate. In the form of network.

Retrorse. Directed back or downward.

Retuse. With a shallow notch at a rounded apex.

Revolute. Rolled backward.

Rhaceola. The prolongation of the secondary axis at the spikelets of sedges, within the perigynium; compare rachilla.

Rhachis. See Rachis.

Rhizome. See Rootstock.

Rhombic, Rhomboidal. Somewhat lozengeshaped; obliquely four-sided.

Rib. A primary or prominent vein of a leaf.

Ringent. Gaping, as the mouth of an open bilabiate corolla.

Rostellum. Beak of the style in Orchids.

Rosirate. Bearing a beak or a prolonged appendage.

Rosulate. In the form of a rosette.

Rosuliferous. Bearing rosettes.

Rotate (corolla). Wheel-shaped; flat and circular in outline.

Rotund. Rounded in outline.

Rudiment. A very partially developed organ; a vestige.

Rudimentary. Imperfectly developed, or in an early stage of development.

Rufous. Reddish brown.

Rugose. Wrinkled.

Runcinate. Sharply pinnatifid or incised, the lobes or segments turned backward.

Runner. A fliform or very slender stolon.

Sac. A pouch, especially the cavities of anthers.

Saccate. Like a sac or pouch; furnished with a sac.

Sagittate. Like an arrow-head, with the lobes turned downward.

Salver-shaped (corolla). Having a slender tube abruptly expanded into a flat limb.

Samara. An indehiscent winged fruit.

Saprophyte. A plant which grows on dead organic matter.

Scabrous. Rough to the touch.
Scale. A minute, rudimentary, or vestigial leaf.

Scape. A peduncle rising from the ground, naked or without proper foliage.

Scapose. Bearing or resembling a scape.

Scarious. Thin, dry, and translucent, not green.

Scorpioid. Coiled up in the bud, or in the beginning of growth, unrolling in expanding.

Scrobiculate. Possessing minute or shallow depressions.

Secund. Borne along one side of an axis.

Segment. One of the parts of a leaf or other like organ that is cleft or divided.

Semi- (in compounds) means half.

Sepal. One of the leaves of a calyx.

Septate. Divided in compartments by cross-partitions.

Septicidal (capsule). Dehiscing through the partitions and between the cells.

Septum (plural septa), A partition, as of a pod, etc.

Sericeous. Silky; clothed with satiny pubescence.

Serrate. Having teeth pointing forward.

Serrulate. Finely serrate.

Sessile. Without a stalk.

Seta $(-a e)$. A bristle, or a slender body resembling a bristle.

Setaceous. Bristle-like.

Setose. Bristly.

Setulose. Having minute bristles.

Sheath. A tubular envelope, as the lower part of the leaf in grasses.

Sheathing. Enclosing as by a sheath.

Silicle. A short silique.

Silique. The peculiar pod of Brassicaceae.

Sinuate. Strongly wavy.

Sinus. The cleft or recess between two lobes.

Smooth. Without roughness.

Sobol, Sobole. A creeping underground stem.

Soboliferous. Bearing underground mostly horizontal branches.

Sorus (pl. Sori). A heap or cluster, applied to the fruit-dots of ferns.

Spadiceous. Like or pertaining to a spadix.

Spadix. A fleshy spike of flowers.

Spathaceous. Resembling a spathe, furnished with a spathe.

Spathe. A bract, usually more or less concave, subtending a spadix.

Spatulate. Shaped like a spatula; spoonshaped.

Spermatozoid. A motile ciliated male reproductive cell.

Spicate. Arranged in or resembling a spike.

Spiciform. Spike-like.

Spike. An elongate flower-cluster, with sessile or nearly sessile flowers.

Spikelet. Diminutive of spike; especially applied to flower-clusters of grasses and sedges.

Spine. A sharp woody or rigid outgrowth from the stem.

Spinescent. Tipped by or degenerating into spines or thorns.

Spinose. Thorny; with spines or similar to spines.

Spiricle. Delicate coiled thread on the surface of seeds and achenes.

Spirilliferous. Bearing or having spiricles.

Spirillum $(-a)$. A little coil, spiricle.

Sporange, Sporangium (-a). A sac containing spores.

Spore. The reproductive organ in Cryptogams which corresponds to a seed. 
Sporocarp. The fruit-cases of certain Cryptogams containing sporangia or spores.

Sporophyll. A spore-bearing leaf.

Sporophyte. The asexual generation of plants.

Spreading. Diverging nearly at right angles; nearly prostrate.

Spur. A hollow projection.

Squamella (-ae) A scale-like member of the pappus of some composites.

Squamiform. Resembling a scale.

Squarrose. With spreading or projecting parts.

Stamen. The organ of a flower which bears the microspores (pollen-grains).

Staminate. Possessing stamens. Applied to flowers which have stamens but not pistils.

Stameniferous. Bearing stamens.

Staminodium. A sterile stamen, or other organ in the position of a stamen.

Standard. The upper, usually broad, petal of a papilionaceous corolla.

Stellate. Star-like.

Sterigmata. The projection from twigs, bearing the leaves, in some genera of Pinaceae.

Sterile. Without spores, or without seed.

Stigma. That part of a pistil through which fertilization by the pollen is effected.

Stigmatic. Belonging to or characteristic of the stigma.

Stipe. The stalk-like lower portion of a pistil; the leaf-stalk of a fern.

Stipitate. Provided with a stipe.

Stipular. Belonging to stipules.

Stipulate. Having stipules.

Stipules. The appendages on each side of the base of certain leaves.

Stolon. A basal branch rooting at the nodes.

Stoloniferous. Producing or bearing stolons.

Stoma (pl. Stomata). An orifice in the epidermis of a leaf communicating with internal air-cavities.

Stramineous. Straw-colored.

Striate. Marked with slender longitudinal grooves or channels.

Strict. Very straight and upright.

Strigillose. Diminutive of strigose.

Strigose. With appressed stiff hairs.

Strobilaceous. Like a pine-cone.

Strobile. An inflorescence marked by imbricated bracts or scales, as in the pinecone.

Strophiolate. With a strophiole.

Strophiole. An appendage to a seed at the hilum.

Style. The usually attenuated portion of the pistil connecting the stigma and ovary.

Stylopodium. A disk-like expansion at the base of a style, as in Umbelliferae.

Sub- (in compound words). Somewhat, almost, in a subordinate grade, of inferior rank, beneath.

Submarginal. Near the margin; situated under the margin.

Subulate. Awl-shaped.

Succulent. Soft and juicy.

Sucker. A shoot from subterranean branches.

Suffrutescent. Slightly or obscurely shrubby.

Suffruticose. Very low and woody; diminutively shrubby.

Sulcate. Grooved longitudinally. Supra- (in compound words). Above,
being above.
Supra-axillary. Inserted some distance above the axils.

Surculose. Producing shoots from the rootstock.

Superior (ovary). Free from the calyx or hypanthium.

Suspended (ovule), Hanging from the apex of the cell.

Suture. A line of splitting or opening.

Symmetrical. Applied to a flower with the different series of its parts of equal numbers.

Sympetalous. With united petals.

Syngenecious. With stamens united by their anthers.

Synonym. A superseded or unused name.

Taproot. A stout vertical root which continues the main axis of the plant.

Tawny. Dull yellowish, with a tinge of brown.

Tendril. A thread-shaped process used for climbing.

Terete. Circular in cross-section.

Ternary. Consisting of three.

Ternate. Divided into three segments, or arranged in threes.

Tesellate. Checkered.

Testa. The outer coat or covering of the seed.

Tetra- (in compounds) means four.

Tetradynamous. Applied to stamens when there are six in the flower, four of them longer than the other two.

Tetragonal. Four-angled.

Tetramerous. Applied to flowers constructed on the numerical plan of four.

Thalloid. Resembling a thallus.

Thallus. A usually flat vegetative organ.

Throat. The orifice of a gamopetalous corolla or calyx; the part between the proper tube and the limb.

Thyrsoid. Like a thyrsus,

Thyrsus. A congested cyme.

Tomentose. Covered with tomentum.

Tomentulose. Diminutive of tomentose.

Tomentum. Dense matted wool-like hairs.

Torose. Cylindrical with contractions at intervals.

Torsion. Twisting of an organ.

Tortuous. Twisted or bent.

Torulose. Diminutive of Torose.

Torus. The receptacle of a flower.

Transverse. Across; in a right and left direction.

Tri- (in composition) three or thrice.

Triandrous. Having three stamens.

Trichotomous. Three-forked.

Tridentate. Three-toothed.

Trifoliolate. Having three leaflets.

Trigonous. Three-angled.

Triquetrous. Having three salient angles, the sides concave or channelled.

Truncate. Ending abruptly, as if cut off transversely.

Tuber. A thickened and short subterranean branch, having numerous buds.

Tubercle. The persistent base of the style in some Cyperaceae; a small projection.

Tuberculate. With rounded projections.

Tuberiferous. Bearing tubers.

Tuberous. Resembling a tuber.

Tumid. Swollen.

Tunicate. Coated; invested with layers, as an onion.

Turbinate. Top-shaped.

Turion. A scaly shoot from a subterranean bud.

Turioniferous. Bearing turions or suckers like the shoots of Asparagus. 
Twining. Ascending by coiling round a support.

Umbel. A determinate, usually convex flower-cluster, with all the pedicels arising from the same point.

Umbellate. Borne in umbels; resembling an umbel.

Umbellet. A secondary umbel.

Umbellifer. A member of Ammiaceae, or Carrot Family.

Umbonate. Bearing a stout projection in the center; bossed.

Unarmed. Destitute of spines, prickles, and the like.

Ucinate. Hooked, or in form like a hook.

Undulate. With a wavy surface; repand.

Unguiculate. Contracted at base into a claw.

Uni- (in compounds) means one.

Unicellular. One-celled.

Unifoliolate. Applied to a compound leaf that has but one leaflet, as the leaves of the Orange and Lemon.

Unilocular. Possessing one locule or cell.

Uniserial. Arranged in one series. Applied to parts that are arranged in one horizontal whorl.

Unisexual. Having only one kind of sexorgans; applied also to flowers having only stamens or pistils.

Urceolate. Urn-shaped.

Utricle. A small, thin-walled, one-seeded fruit.

Utricular. Like a small bladder.

Vaginate. Surrounded by a sheath.

Valvate. Meeting by the margins in the bud, not overlapping; dehiscent by valves.

Valve. One of the pieces into which a dehiscent pod, or any similar body, splits.

Veinlet. The smaller ramifications of veins.

Veins. Threads of flbro-vascular tissue in a leaf or other organ, especially those which branch (as distinguished from nerves).

Velum. A fold of the inner side of the leaf-base in Isoetes.

Velutinous. Velvety; with dense fine pubescence.

Venation. The veining of leaves, etc.

Ventral, Ventrally. Being on the side next the axis.

Ventricose. Swelling unequally, or inflated on one side.

Venulose. Finely veiny.

Vernation. The arrangement of leaves in the bud.

Verrucose. Warty; covered with protuberances.

Versatile. An anther attached at or near its middle to the filament.

Verticil. A whorl.

Verticillaster. A pair of opposite cymes that occur in the axils of the leaves of Mints.

Verticillate. Whorled.

Vesicle. A small bladder or air-cavity.

Vespertine: Belonging to the evening; applied to flowers that open at nightfall.

Vexillum. The standard of a papilionaceous flower.

Villous. Bearing long and soft hairs.

Virgate. Wand-shaped; slender, straight and erect.

Viscid. Glutinous; sticky.

Whorl. A group of three similar organs or more, radiating from a node. Verticil.

Wing. Any membranous expansion.

Woolly. Clothed with long and entangled soft hairs.

Zoospore. Literally, an animal spore; a vegetable spore endowed with the power of locomotion, and therefore appearing like an animal.

Zygomorphous, Zygomorphic. Flowers which are divisible in only one plane into similar halves are called zygomorphous. 


\section{INDEX}

The Latin names of genera and species are printed in common type, the synonyms are indicated by italic, the common or English names are in SMALL CAPITALS and the family names in CAPITALS. The species of only the larger genera are indexed.

\section{Abies 14}

Abronia $256-7,258$

Abutilon 562-3

Acamptopappus 849

Acanthogonum 229

Acer 552,553

ACERACEAE 551

Acerates 670-1

Achillea 957-9

Achroanthes 183

Acmispon 477

Acnida 254-5

Acomastylis 433

ACONITE 313

Aconitum 313-15

Aconogonum 238

Acorus 143

Acrolasia 573-4

Actaea 304

Actinea 950

Actinella 949-53

Acuan 452

ADAM AND EVE, 183

ADDER'S MOUTH, 182

ADDER-TONGUE 164

ADDER'S TONGUE FAMILY, 1038

Adelia 656

Adenocaulon 923

Adenostegia 796-7

Adiantum, 1047

Adopogon 1019

Adoxa 816

ADOXACEAE 816

Agalinis 785

Agastache 744

Agave 173

Agoseris 1029

agrestis 1031

altissima 1031

apiculata 1031

arachnoidea 1032

arizonica 1033

aspera 1030

attenuata 1031

aurantiaca 1033

carnea 1033

caudata 1033

elata 1032

glauca 1031

gracilens 1032

gracilenta 1032

graminifolia 1032

grandiflora 1033

Greenei 1032

heterophylla 1033

humilis 1032

laciniata 1032

Leontodon 1031

leptocarpa 1033

maculata 1031

montana 1032

nana 1032

obtusifolia 1033

parviflora 1031

pubescens 1030

pumila 1031 purpurea 1032

retrorsa 1033

rosea 1032

roseata 1031

rostrata 1033

scorzoneraefolia 1031

taraxacoides 1030

tenuifolia 1033

turbinata 1031

vicinalis 1031

villosa 1030

Agrimonia 428-9

AGRIMONY 428

Agropyron 92-95, 98

Agrostemma 280

Agrostis 53-55

AlASKA ALDER, 205

ALBERTA SPRUCE 16

ALDER 204-5

Aletes 616, 617

ALEXANDERS 614

ALFALFA 476

ALFILARIA 533

Aliciella 696

Alsima 27

ALISMACEAE 27

ALKALI BLITE 242

ALKALI GRASS 72

ALKANET 738

Allenrolfia 251

ALLIACEAE 157

Allionella 259

Allionia 259-61

Allium 157

acuminatum 160

anceps 161

aridum 159

bisceptum 161

Brandegei 161

brevistylum 158

canadense 159

cernuum 159

collinum 160

cristatum 161

Cusickii 161

cuspidatum 160

deserticola 160

dictyotum 160

Diehlii 160

Douglassii 161

fibrillum 160

fibrosum 159

Geyeri 159

Hendersonii 161

incisum 160

macropetalum 159

minimum 160

neomexicanum 159

nevadense 161

Nivii 161

Nuttallii 159

Palmeri 161

Pikeanum 160

pleianthum 161

recurvatum 159

reticulatum, 159,160 rubrum 159

scillioides 160

sibiricum 158

simillimum 160

stellatum 161

textile 159

tribracteatum 160

Tolmiei 161

validum 158

Allocarya 725

ALMONDS, WILD 452

Alnus 204-5

ALOE, AMERICAN 173

Alopecurus 50

ALPINE BEARBERRY 643

ALPINE COTTONGRASS 108

ALP LILY 165

ALSINACEAE 268

Alsine 268-271, 274

Alsinopsis 274-5

ALUM-ROOT 380

Alyssum 347

ALYSSUM, HOARY 347 SWEET 347

WILD SWEET, 328

AMARANTH, 253

AMARAN'THACEAE, 253

AMARANTH FAMILY 253

Amaranthus 253-4

Amarella 650-1

AMARYLLIDACEAE 173

AMARYLLIS FAMILY, 173

Amauropsis 941

Ambrosia 829-30

A MBROSI ACEAE 827

Amelanchier 446

AMERICAN ALOE 173

AMERICAN COLUMBO 664

AMERICAN CowsLIP 652

AMERICAN ELM 206

AMERICAN IVY 556

AMERICAN MISTLETOE 816

AMERICAN LARCH 14

AMERICAN LAUREI 641

Ammannia 582

AMMIACEAE 606

Ammodenia 274

Amorpha 479-80

Amphiachyris 847

Amphilophis 33

Amphipappus 846

Amsinckia 729-730

Amsonia 667-8

AMY GDALACEAE 450

Amygdalus 452

\section{ANACARDIACE-}

AE 550

Anagallis 651

Anaphalis 921

Anchusa 738

Ancistrocarphus 913

Androcera 756

Andromeda 642

Andropogon 33-4

Androsace 649-50

Androstephium 162

Anemone 286-8, 302

Angelica 630-2

ANGIOSPERMAF 20

Anisolotus 478-9

Anogra 594-7

Antennaria 914

acuta 917

aizoides 918

albescens 917

alpina 916

anaphaloides 920

aprica 919

arida 919

athabascensis 920

austromontana 917

Bakeri 920

bracteosa 919

campestris 920

carpatica 920

chlorantha 917

concinna 918

confinis 918

corymbosa 918

dimorpha 921

dioica 918

flagellaris 921

flavescens 917

foliacea 918

formosa 919

fusca 917

Holmii 919

Howellii 919

imbricata 918

lanata 920

Lunellii 920

luzuloides 920

Macounii 918

macrocephala 921

marginata 920

media 917

microphylla 919

modesta 919

monocephala 917

mucronata 917

nardina 918

oblanceolata 920

oblancifolia 916

obovata 919

obtusa 919

oxyphylla 919

parvifolia 919

pulcherrima 920

pulvinata 917

pumila 919

racemosa 916 
Antennaria reflexa $917-8$ rosea 918 rosulata 920 Sansoni 917 sedoides 918 scariosa 919 Serrae-Blancae 920 solstitalis 919 sordida 918 umbrinella 918 viscidula 919

Anticlea 148-9

Antiphylla 391 Antirrhinum 762

Anthemis 959

Antheropeas 948

Anthopogon 658-9

APACHE PLUME 433

Aphyllon 803, 804

Apinus 13

Apios 529

Aplectrum 183-4

Aplopappus 860 acaulis 866 armerioides 866 Brandegei 902 carthamoides 862 cervinus 853 ciliatus 860 croceus 862 Fremonti 864 gracilis 860 hirtus 863 insecticruris 862 integrifolius 863 interior 864

laceratus 867

lanceolatus 863 lanuginosus 866

Lyallii 867

Macronema 865

multicaulis $864_{4}$

nanus 853

Nuttallii 860

paniculatus 853

Parryi 867

pygmaeus 867

resinosus 853

rubiginosus 860

stenophyllus 866 spinulosus 860 suffruticosus 865 uniflorus 863

Watsoni 865

APOCYNACEAE 667

Apocynum 668-9

APPLE FAMILY 445

Aquilegia $305-308$

Arabidopsis 341-2

Arabis 356

albertina 359

ambigua 358

aprica 361

arcoidea 360

arcuata 361

Bourgovii 361

bracteolata 360

brachycarpa 361

Brebneriana 342

brevisiliqua 362

Bridgeri 359

caduca 363

canescens 363

connexa 359

consanguinea 362

Crandallii 359

dacotica 361

demissa 362 densicaulis 362

Diehlii 361

divaricarpa 362

drepanoloba 360

Drummondii 359

Egglestonii 361

elegans 361

exilis 363

Fendleri 362,361

formosa 360

fructicosa 362

furcata 359

glabra 337

gracilenta 362

hirsuta 359

Holboellii 362

Kochii 362

Lemmonii 360

lignifera 362

lignipes 362

longirostris 364

Lyallii 359

yrata 358

MacDougaldii 360

Macounii 360

microphylla 359

Nuttallii 358

oblanceolata 359

oreocallis 3.59

oreophila 359

ovata 359

oxylobula 361

oxyphylla 359

pendulocarpa 363

perelegans 361

perennans 360

perfoliata 337

philonipha 359

puberula 363

pulchra 360

recondita 361

retrofracta 362

rhodantha 362

rugocarpa 361

rupestris 359

Selbyi 361

setulosa 361

spathulata 358

spatifolia, 361

stenoloba 360

Stokesiae 361

subpinnatifida 360

suffrutescens 360

Thaliana 341

ARACEAE 143

Aragallus 517

albertinus 521, 522

albiflorus 522

alpicola 522

angustatus 521

argophyllus 520

atropurpureus 520

Aven-Nelsonii 521

Besseyi 520

Bigelovii 521

Blankenshipii 519

caudatus 523

cervinus 522

collinus 519

deflexus 519

dispar 521

falcatus 521

foliolosus 519

formosus 521

galioides 522

gracilis 522

Hallii 520

invenustus 522

Lagopus 520

Lambertii 521
Macounii 522

majusculus 522

melanodontus 520

minor 519

monticola 521

multiceps 519

nanus 519

oreophilus 520

Parryi 520

patens 521

plattensis 521

podocarpus 520

Richardsonii 522

saximontanus 522

sericeus 521

spicatus 522

splendens 523

ventosus 520

villosus 522

viscidulus 522

viscidus 522

Aralia 633

ARALIACEAE 633

ARBOR VITAE 17

Arceuthobium 817

Arctium 1002

Arctomecon 317

Arctostaphylos 643

Arctous 643

Arenaria 275, 274

aculeata 278

aequicautis 275

Burkii 278

capillaris 277

cephaloidea 277

ciliata 277

compacta 277

confusa 277

congesta 277,278

cylindrocarpa 277

Eastwoodiae 278

Fendleri 278

formosa 277

Franklinii 278

glabrescens 278

Hookeri 278

Kingii 277

laricifolia 275

lateriflora 274

laxiflora 278

lithophila 277

macradenia 278

macrophylla 274

nardifolia 277

Norvegica 277

Nuttallii 275

obtusa 275

peploides 274

pinetorum 278

polycaulos 277

propinqua 275

pungens 275

quadrivalvis 27.5

Rossii 275

sajanensis 275

salmonensis 277

saxosa $27 z$

serpyllifolia 276

subcongesta 277,278

tenella 275

Tweedyi 278

uintahensis 277

verna 275

Argemone 317-8

Argentina 421-2

Aristida 40-1

ARISTOLOCHIACEAE 821

ARIZONA BALSAM 15

Armoracia 334

Arnica 976

alpina 982

abortiva 978

amplexicaulis 980

amplexifolia 908

angustifolia 982

arcana 980

arnoglossa 979

aurantiaca 982

caespitosa 982

caudata 980

Chamissonis 981

celsa 981

coloradensis 980

columbiana 978,980

cordifolia 978

crocea 980

crocina 980

diversifolia 979

eradiata 978

Evermannii 978

exigua 981

foliosa 981

fulgens 982

gracilis 978

grandifolia 978

granulifera 978

Greenei 980

Jonesii 979

lactucina 978

lanulosa 981

lasiosperma 982

latifolia 979

longifolia 979

Louisiana 982

macilenta 980

Macounii 980

Menziesii 979

mollis 980

monocephala 982

multiflora 978

ocreata 981

ovalifolia 978

ovata 980

paniculata 978

Parryi 978

parvifolia 978

pedunculata 982

platyphylla 979

polycephala 980 
Artemisia

aromatica 965

Bakeri 972

biennis 967

Bigelovii 973

borealis 966

Bourgeauana 966

Brittonii 971

camporum 966

cana 973

canadensis 966

candicans 971

Carruthii 972

caudata 966

columbiana 973

cuneata 969

desertorum 966

discolor 972,968 , 972

diversifolia 971

Douglasiana 969

dracunculoides 965

elatior 968

falcata 970

filifolia 966

floccosa 971

Flodmanii 972

Forwoodii 966

franserioides 968

frigida 967

glauca 965

gnaphalodes 970

gracilenta 971

graveolens 972

groenlandica 966

Herriotii 969

Hookeriana 969

incompta 968

kansana 972

Kennedyi 969

laevigata 968

Leibergii 968

Lindleyana 970

longifolia 971

ludoviciana 969-71

MacCallae 966

Michauxiana 972

microcephala 971

minuta 967

natronensis 971

norvegica 968

nova 973

pabularis 970

pacifica 966

Parryi 968

Pattersonii 967

paucicephala 971

pedatifida 967

petrophila 978

plattensis 967

platyphylla 971

potens 970

pudica 970

Purshiana 970

pygmaea 974

rigida 974

rhizomata 971

Rothrockii 97 .

saxicola 967

scopulorum 967

Scouleriana 966

silvicola 969

spiciformis 973

spinescens 961

spithamaea 966

subglabra 972

tenuis 972

Tilesii 968

tridentata 973

trifida 974

tripartita 973
Tyrellii 967

Underwoodii 970

vulgaris 968-9

Wrightii 972

ARTICHOKE, GROUND 930

ARUM FAMILY 143

Aruncus 405

Asarum 821

ASCLEPIADACEAE 669

Asclepias 671-4

Asclepiodora 674

AsH 655

AsH, MountaIN 448

ASH-LEAVED MAPLE 553

ASPARAGUS, WILD 1023

ASPEN 185

Asperugo 717

ASPHODEL, SCOTTISH 146

Asplenium 1045-6

Asprella 103

Astephanus 670

ASTER 678

GOLDEN 849

HEATH 892

HOLLY-LEAVED 876

SPINY 876

SNEEZEWORT 877

TANSY 892

VISCID 892

WHITE 891

Aster 878

adscendens 888

adsurgens 885

alpinus 884

amplexifolius 883

amplus 890

andinus 884

Andrewsii 884

angustus 876

apricus 890

arenarioides 910

armeriaefolius 888

Bigelovii 894

Brandegei 903

brevibracteatus 886

Burkei 890

Butleri 885

campestris 883

Canbyi 890

canescens 894-5

ciliomarginatus 888

coerulescens 886

coloradensis $87 \%$

commutatus 885

conspicuous 883

cordalenus 889

Cordineri 88.5

corymbiformis 887

crassulus 884

culminis 884

Cusickii 890

denudatus 885

diabolicus 890

distichophyllus 890

Douglasii 889

Eatonii 889

elegans 878

Engelmannii 878

ericaefolius 892

eriocaulis 887

exiguus 884

falcatus 885

Fendleri 884

fluviatilis 886

foliaceus 890

Forwoodii 890
Franklinianus 887

Fremontii 888

frondeus 890

frondosus 876

fulcratus 889

Geyeri 886

glastifolius 888

giganteus 884

glaucus 878

griseolus 884

griseus 884

Hallii 889

halophilus 888

Haydeni 891

hebecladus 88.5

Hendersonii 889

hesperius 887

incanopilosus 885

incertus 890

integrifolius 883

Jessicae 884

junciformis 887

Kingii 883

Kootenayi 890

Kumleinii 883

Iaetivirens 887

aevis 886

latahensis 884

leucopsis 887

Lindleyanus 885

lonchophyllus 887

ongulus 887

MacCallae 885

MacDougali 883

major 883

majusculus 890

Mearnsii 889

meritus 884

microlonchus 890

modestus 883

mollis 884

montanus 884

multiflorus 885

Nelsonii 888

Novae-Angliae 883

Nuttallii 888

oblongifolius 883

occidentalis 888

oreganus 889

orthophyllus 888

Osterhoutii 887

oxyphyllus 888

paniculatus 886

Parryi 877

parviflorus 894

Pattersonii 894

pauciflorus 883

phyllodes 889

polycephalus 885

Porteri 886

pratincola 888

proximus 889

ptarmicoides 878

pulchellus 891

Richardsonii 884

roseolus 887

salicifolius 886-7

salicifolius 888

Sayianus 883

Scribneri 886

scopulorum 852

spinosus 876

spithamaeus 884

stenomeres 892

stricticaulis 885

subcaudatus 887

subgriseus 884

subracemosus 886

subsalignus 886

tanacetifolius 894

thermalis 883

Tweedyi 888 unalaschkensis 883

Umbachii 888

umbellatus 891

Underwoodii 888

vallicola 882

venustus 877

violaceus 884

Watsoni 891

Williamsii 884

Wilsonii 884

Xylorrhiza 877

Asterigeron 891

Astragalus 493

aboriginorum 507

acerbus 512

aculeatus 516

adanus 502

adsurgens 495

agrestis 495

allochrous 488

alpinus 498

amphidoxus 511

amphioxys 504

amplexus 496

ampullarius 487

anisus 494

araneosus 492

argillosus 502

argophyllus 505

arietinus 504

arrectus 497, 498. 501

Arthuri 507

artipes 488

asclepiadoides 500

atropubescens 498

Beckwithii 490

Bigelovii 494

bisulcatus 500

Bodinii 489

boiseanus 497

Booneanus 506

Bourgovii 513

Brandegei 508

brevicaulis 496

caespitosus 511 
Astragalus

eriocarpus 505-6

eucomus 508

eurekensis 504

exilifolius 511

Fendleri 515

flavus 502

flexuosus 515

Forwoodii 508

frigidus 487

Geyeri 490

glabriusculus 508

glareosus 504, 506

goniotus 495

gracilis 506

grallator 511

Grayi 501

griseopubescens 513

Halli 515

Haydenianus 500

humillimus 490

humistratus 499

hyalinus 517

hypoglottis 495

ibapensis 508

ineptus 491

inflexus 506

jejunus 490

junceus 513

junciformis 513

Kelseyi 498

Kentrophyta 516

lancelarius 511

lentiginosus 492

leptaleus 489

leptocarpus 497

Liebergii 498

lingulatus 510

lonchocarpus 515

lotiflorus 490

Iutosus 488

macer 515

Macounii 508

malacus 496

megacarpus 488

microcystis 489

microlobus 507

minor 508

miser 511

missouriensis 505

mollissimus 493

Mortoni 494

Mulfordae 492

multiflorus 512

musinensis 50.5

naturitensis 499

Newberryi 505

nitidus 495

nudisiliquus 506

Nuttallianus 496

obfalcatus 496

obscurus 498

oreganus 495

oreophilus 494

oroboides 508

owyheensis 499

palans 495

Palliserí 514

palousiensis 498

panguicensis 505

Parryi 506

Pattersonii 501

pauciflorus 511

Peabodyanus 490

pectinatus 501

pictus 488

plattensis 492

platytropis 491

praelongus 501

Preussii 501 prunifer ${ }_{4} 93$

pubentissimus 490

puniceus 504

Purshii 506

racemosus 498

rasus 498

reventoides 502

reventus 502

Rusbyii 498

sabulonum 490

sabulosus 501

salinus 492

scaposus 496

scobinatulus 500

scopulorum 498

sericoleucus 517

serotinus 514

serpens 489

sesquiflorus 491

Shearii 508

Shortianus 504

Sileranus 489

simplicifolius 511

Spaldingii 495

sparsiflorus 499

spatulatus 511

speirocarpus 515

spicatus 494

straturensis 497

stenophyllus 514

striatus 494

strigosus 513

subcinereus 489

subcompressus 498

succulentus 493

sulphurescens 495

tegetarius 516

terminalis 494

tetrapterus 507

thermalis 504

Thompsonae 494

tridactylicus 517

triflorus 489

triphyllus 517

uintensis 505

urceolatus 503

ursinus 494

utahensis 506

ventorum 495

vespertinus 505

vexilliflexus 511

virgultulus 495

viridis 516

Wardij 489

Wetherillii 487

wingatanus 512

Zionis 504

Atenia 612

Atelophragma 507-8

Atheropogon 65

Athyrium 1046

Athysanus 346

Atragene 292-3

Atrichoseris 1016

Atriplex 245-50

aptera 249

argentea 247

buxifolia 249

canescens 249

Caput-Medusae 247

carnosa 246

collina 248

confertifolia 248

corrugata 248

cornuta 247

cuneata 249

Draconis 247

Endolepis 250

eremicola 248 expansa 247

falcata 249

fruticulosa 248

Gardneri 248

Garrettii 249

Gordoni 248

gracilliflora 248

Greenei 248

hastata 246

hortensis 246

hymenolytra 248

lapathifolia 246

lentiformis 248

Nelsonii 247

Nuttallii 249

oblanceolata 249

occidentalis 249

odontoptera 249

pabularis 248

philonitra 247

phyllostegia 246

Powellii 247

rosea 247

Rydbergii 247

saccaria 247

spatiosa 247

subconferta 248

subdecumbens 247

subspicata 246

Suckleyana 250

tenuissima 248

tetraptera 249

Torreyi 248

tridentata 248

truncata 247

volutans 247

Wolfii 247

Atropis 84

Audibertia 748

Audibertiella 748

Aulospermum 618, 620

AUTUMN WILLOW 191

Avena 61-2

AVENS 430

MOUNTAIN 429

AZALEA 640

Azaliastrum 640

Azolla 1051

BABY-BLUE-EYES 701

BABY's BREATH 590

Baccharis 911-2

Bachelor's Buttons 1014

Bacopa 781

Bahia 941-2

Baileya 940

BAKED-APPLE BERRY 437

BALL SAGE 748

BALM, MOUNTAIN 709

BALM OF GILEAD 187

BALSAM 14, 15

BALSAM APPLE 822

BALSAM FIR 14

BALSAM POPLAR 186-7

BALSAM-ROOT 928

BALSAM WILLOW 193

BALSAMINACEAE 536

Balsamorrhiza 928 -9

BANEBERRY 304

BANKSIAN PINE 12

Barbarea 344

BARBERRY 315

BARBERRY FAMILY 315

Barkhausia 1021

BARLEY 96

BARNYARD GRASS 38

BARREL CACTUS 579

BARREN-GROUND WrLLOW 197

BARREN STRAWBERRY 429

Bartonia 571-2

BASIL 750

BASTARD TOADFLAX 818

Batidaea 438-9

Batrachium 293-4

BAYONET, SPANISH 169

BEAKED HAZLENUT 206

BEAKED RUSH 105

BEAKED WILLOW 195

BEARBERRY 643, 814

BEARD-GRASS $32-3$, 52

BEARD-TONGUE 763

BEAR-GRASS 147

Beckmannia 64

Beckwithia 302

BEDSTRAW 807

BEECH FAMILY 199

BEE FLOWER 371

BEGGAR-TICKS 525 , 714,937

BEGONIA, WILD 231

BELLFLOWER 823

BELLFLOWER FAMILY 822

BELL RUE 292

Belvisia 1045

BENT-GRASS 53

BERBERIDACEAE 315

Berberis 315-6

BERGAMOT, WILD 748

Berteroa 347

Berthelotia 912

Berula 612

Besseya 784-5

Betula 202-4

BETULACEAE 202

Bicucuall 319

Bicuspidaria 570

Bidens 935 
BLACK BUNCH-GRASS 34

BLACK BUSH 429

BLACK-CAP 438

BLACK COTTONWOOD 187

BLACK GRAMA 65

BLACK HEMLOCK 16

BLACK MUSTARD 346

BLACK SALTWORT 652

BLACK SPRUCE 16

BLACK WHLOW 191

BLEEDING HEART 319

BLADDER BUSH 744

BLADDER CAMPION 282

BLADDER-POD 331 DOUBLE 330

BLADDER SKULLCAP 744

BLADDERWORT 802

BLADDERWORT FAMrLY 801

BLANKET-FLOWER 956

BLAZING STAR 570 , 844

Blepharidachne 67

Blepharoneuron 50-1

Blepharopappus 939, 937

Blite, Alkali 242 COAST 242

SEA 252

STRAWBERRY 242

Blitum 242-3

BLOW-OUT GRASS 49, 68

BLUEBELLS 730, 823

BLUEBERRY 645

BLUEBERRY WILLOW 194

BLUE BONNET 457

BLUE BOTTLE 1014

BLUE CAMAS 166

BLUE CURLS 742

BLUE-EYED MARY 762

BLUE-EYED GRASS 174

BLUE FLAG 176

BLUE FLAX 534

BLUE GRAMA 65

BLUE-GRASS 72

BLUE-JOINT 95

BLUE-LIPS 762

BLUE-STEM 33, 95

BLUE TULIP 288

BLUE WILLOW 197

Boebera 956

BOG-BEAN 667

BOG BIRCH 204

BOG ORCHID 179

BOG ROSEMARY 642

BOG WILLOW 193

Boisduvallia 592

Bolelia 825

Bolophyta 924

BONESET 841 FAISE 843

BORAGE FAMILY 712

BORAGINACEAE 712

Bossekia 436

Botrychium 1038-9

BOUNCING BET 284

Bouteloua 64-5

BOX-ELDER 553

Boykinia 384-5

BOZZLEWEED 828
Brachiaria 38

Brachyactis 875,889

BRACKEN 1047

BRAKE 1047

Brassica 346, 345

BRASSICACEAE 321

Brauneria 925

Braya 338

HES, DUTCH MAN's 319

Brickellia 842-3

BRIDES, MORNING 947

BRIER, SENSITIVE 452

BRIGHAM TEA 19

Bristle-cone PINE 12

Brittonastrum 745

Briza 72

Brodiaea 162

BRoMEgrass 88

Bromus 88

Brook-grass 70

BROOKLIME 782

BROOKWEED 655

BROOM CORN 34

BROOM-RAPE 803

BROOM-RAPE FAMILY 802

BROWN-WEED 845

BRUSH, DEER 554

BRUSH, PAINTER's 785

Buchloe 66

BUCKBEAN 667

BUCKBEAN FAMILY 667

BUCKTHORN 553

BUCKTHORN FAMILY 553

BUCKTHORN-WEED 729

BUCKWHEAT 238-9

BUCKWHEAT FAMILY 210

Buddleia 657

BUFFALO BEANS 492

BUFFALO-BERRY 582

BUFFALO BUR 756

BUFFALO CURRANTS 399

BUFFalo Grass 64, 66

FALSE 66

Buffalo Peas 492

BUFFALO RYE 99

BUGBANE, FALSE 290

BUGLE WEED 751

BUG-SEED 244

Bulbilis 66

BULL-BERRY 582

BULL PINE 12

BULRUSH 108, 110

BUNंCHBERRY 635

BUNCH-FLOWER FAMILY 146

BUNCH-GRASS 32, 93 BLACK 34

Bupleurum 614

Bur Clover 476

BURDOCK 1001

BUR-GRASS 39

BUR-MARIGOLD 937

BURNET 428

BURNING BUSH 548

BUR-NUT 539

BUR OAK 200

BUR-REED 21

BUR-REED FAMILY 20

BURRO WEED 251
Bursa 329

BURSEED 714

BUSH HONEYSUCKLE 814-5

BUSH MORNING GLORY 676

BUSHY GOLDENROD 872$$
762
$$

BUTTERBUR 974

BUTTERCUP 294

BUTTERFLY LILY 171

BUTTERFLY WEED 604,671

BUTTERWORT 802

BUTTON SNAKE-ROOT 844

CABBage 346

Cow 632

SKUNK 143,147

SQUAW 263

WILD 364

CACTACEAE 575

Cactus 581

CACTUS, BarRel 579 GRASS 169

HEDGEHOG 579

TREE 575,576

CACTUS FAMILY 575

Caesalpinia 453

CAESALPINICEAE 453

Calais 1018

Calamagrostis 55-8

Calamovilfa 58

CALAMUS-ROOT 143

Calandrinia 265-6

Calceolaria 569

CALIFORNIA POPPY 318

Callirrhoe 558

Callisteris $694-5$

CALLITRICHACEA E 547

Callitriche 548

CALOCHORTACEA E 171

Calochortus 171-2

Caltha 303

CALTROP 539

CALTROP FAMILY 538

Calycoseris 1021

CALYPSO 183, 183

Camas, Death 149 POISON 149

WHITE 148

Camash 166

BLUE 166

Camassia 166

Camelina 334

Campanula 823-4

CAMPANULACEAE 822

Campe 344-5

CAMPION 280

BLADDER 282 CORN 280

Moss 282

Canada Fleabane 911

CANARY-GRASS 40 , 324

CANCER-ROOT 803

CANDYTUFT, WILD 356

CANE-GRASS 66

CANNABINACEA E 207

Cannabis 208

CAPER FAMILY 370

CAPILLAIRE 644

Capnoides 319-21

Capnorea 708-9

CAPPARIDACEAE 370

CAPRIFOLIACEAE 810

Capsella 329

CARAWAY 612

Cardamine 348-50

Cardaria 323

CARDINAL FLOWER 826

CARDUACEAE 833

Carduus (See Cirsium) 1006-14

CAREless WEed 828

Carex 111

abbreviata 135

ablata 135

aboriginum 137

adusta 125

aenea 125

albicans 131

albo-nigra 137

alpina 137

alterna 121

amplifolia 135

angustior 124

aperta 138

aquatilis 139

arcta 128

aristata 140

assiniboinensis 134

atrata 138

atratiformis 137

atherodes 140

atrosquama 137

athrostachya 125

aurea 132

Backii 129

Bebbii 126

bella 137

Bigelovii 138

blanda 133

Bolanderi 125

brevior 126

brevisquama 12.2 
Carex

epapillosa 138

exsiccata 142

festiva 127

festivella 127

festucacea 126

filifolia 130

filiformis 140

fissuricola 135

flava 141

foenea 125

Franklinii 135

furva 127

Gayana 121

Geyeri 130

gravida 122

gynocrates 120

Halleri 137

Hassei 132

Haydeniana 127

Heleonastes 128

heliophila 131

Hepburnii 119

Holmiana 136

Hoodii 122

Hookeriana 122

Houghtonii 140

hystricina 141

idahoa 136

illota 124

incurva 120

incurviformis 120

interior 124

invisa 136

irrasa 121

Jonesii 123

Kelloggii 139

lacustris 140

Lachenalii 128

laeviconica 140

laeviculmis 124

lagopina 128

lanuginosa 140

lasiocarpa 140

lenticularis 139

leporina 126

leptalea 129

leptopoda 124

Liddonii 125

limosa 136

livida 133

longirostris 134

lupulina 142

luzulaefolia 135

luzulina 134

Macloviana 125

magellanica 136

marcida 121

Meadii 133

Mertensii 138

microglochin 141

microptera 127

miliaris 142

mirata 142

misandra 134

monile 142

montanensis 136

multimoda 127

nardina 119

nebraskensis 139

Nelsonii 137

nervina 123

nigella 136

nigricans 120

nova 137

nubicola 127

obtusata 129

occidentalis 122

Oederi 141

oligosperma 142 oreocharis 130

owyheensis 135

pachystachya 127

Parryana 136

pauciflora 141

paupercula 136

Peckii 131

pedunculata 131

pennsylvanica 131

perglobosa 120

petasata 125,126

petricosa 135

phaeocephala 126

physocarpa 142

pinguis 125

Piperi 127

podocarpa 136

polytrichoides 129

praegracilis 121

prairea 123

pratensis 12 ?

praticola 126

Preslii 127, 126

prionophylla 139

pseudoscirpoidea 130

pyrenaica 120

Raeana 142

retrorsa 142

Reynoldsii 137

rhomboidea 139

Richardsonii 132

rigida 138

Rossii 131

rostrata 142

rupestris 129

Sartwellii 121

saxatilis 142

saximontana 128

scirpiformis 130

scirpoidea 130

scoparia 126

scopulorum 138

Sheldonii 140

Shriveri 133

siccata 122

simulata 121

spectabilis 136

Sprengelii 134

stantonensis 119

stellulata 124

stenochlaena 130

stenophylla 121

stipata 123

straminea 126

straminiformis 126

substricta 139

supina 129

sychnocephala 125

tenella 128

tenera 126

tenuiflora 128

tenuirostris 125

teretiuscula 123

tetanica 133

tincta 126

Tolmiei 136

Torreyi 135

trisperma 128

umbellata 131

usta 121

utriculata 142

vaginata 133

vallicola 122

variabilis 139

venustula 136

vernacula 120

vesicaria 142

viridula 141

vulgaris 139 vulpinoidea 123

Watsoni 140

xerantica 126

CARPENTER WEED 745

CARPET-WEed 261; 542

CARPET-WEED FAMILY 261

CARRION FLOWER 173

CARROT 608

CARROT FAMILY 606

Cartiera 363-4

Carthartolinum 535-6

Carum 612

CARYOPHYLLACEAE 280

Caryopitys 12

Cassia 4.53

Cassiope 642

Castalia 285

Castilleja 785

amplifolia 792

angustifolia 792 , 790

arapahoensis 793

arcuata 789

Bennittii 793

brachyantha 795

Bradburyi 792

breviflora 795

brunnescens 790

Buffumii 792

camporum 794

cervina 794

chromosa 792

coccinea 788

cognata 789

collina 789

confusa 790

Crista-galli 789

Cusickii 793

desertorum 790

dubia 790

exilis 788

fasciculata 794

flava 795

gracillima 793

gloriosa 789

Haydeni 792

hispida 792

humilis 790

integra 789

lancifolia 791

lauta 790

Leonardi 790

linariaefolia 789

linearis 792

lineata 794

Lindheimeri 789

longispica 794

lutea 794

luteovirens 793

lutescens 791

magna 790

mineata 791

multisecta 792

obtusiloba 792

occidentalis 793

oreopala 790

pallescens 794

pallida 793,791 ,

793,794

parvula 793

Pecten 794

pilifera 794

pinetorum 790

puberula 794

pulchella 794

purpurascens 791

rhexifolia 790

scabrida 789

sessiliflora 795

stricta 788

subcinerea 789

subpurpurascens 791

Suksdorfii 792

sulphurea 793

trinervis 791

Tweedyi 791

variabilis 791

villosa 794

viscida 792

Vreelandii 791

wyomingensis 793

Catabrosa 70

CATCHFLY 280

NIGHT-BLOOMING 281

SLEEPY 281

CATCHWEED 717

CAT MINT 745

CATNIP 745

CAT'S-EAR 1019

CAT'S-PAWS 916

CAT-TAIL 20

CAT-TAIL FAMILY 20

CAT-TAIL FLAG 20

Caucalis 608

Caulanthus $[364,365$

Ceanothus 554-5

CEDAR, RED 17

WHITE 17

CELANDINE 317

CELASTRACEAE 548

Celastrus 548

Celome 371-2

Celtis 207

Cembra PINes 13

Cenchrus 39

Centaurea 1014

Centaurium 658

CENTAURY 658

Centrostegia 228-9

Centunculus 652

Century Plant 173

Cephalanthera 181

Cephalobembix 943 
Cheiranthus 343-4

Chelidonium 317

CHENOPODIACEAE 239

Chenopodium 239-42, 252

CHERRIES 450

CHERRY WILLOW 194

CHIA 747

CFICKWEED 268-9

MOUSE-EAR 271

INDIAN 261

CHICKWEED FAMILY 268

CHICO 251

CHICORY 1020 DESERT 1018 GOAT 1030

CHICORY FAMILY 1016

Chimaphila 636

Chiogenes 644

Chionophila 777

CHIVES 157

Chloraea 181

Chloris 64

Chlorocrambe 364-5

ChOLla 575

Chondrophylla 661

Chondrosea 387

Chorizanthe 229

CHRISTMAS FERN 1042

Chrysanthemum 960

Chrysobotrya 399

Chrysocoptis 304

Chrysopogon 34

Chrysopsis 849

Chrysosplenium 377

Chrysothamnus 853 afinis 855

albidus 856

attenuatus 855

Bakeri 859

Bigelovii 855

collinus 856

concolor 856

depressus 855

elegans 858

falcatus 856

formosus 856

filifolius 856

frigidus 857

Howardii 856

glareosus 858

glaucus 858

graveolens 856

Greenei 856

laetevirens 8.56

lanceolatus 858

larieinus 857

latifolius 858

leucocladus 858

leiospermus 858

linifolius 858

marianus 858

nauseosus 857

Newberryi 855

oreophilus 857

pallidus 857

Parryi 855

patens 856

plattensis 857

pinifolius 856

puberulus 858

pulchellus 855

pulcherrimus 857

pumilus 857

salicifolium 857

serrulatus 858

scoparius 856 speciosus 857

stenolepis 858

stenophyllus 857

turbinatus 859

Vaseyi 858

virens 856

viscidiflorus 858

wy omingensis 856

Chylisma 602-3

CICELY, SWEET 609

CICHORIACEAE 1015

Cichorium 1020

Cicuta 617-8

Cinna 52

CINQUEFOIL 408

MARSH 422

SHRUBBY 425

Circaea 605

Cirsium 1003

acaulescens 1008

acuatum 1012

americanum 1008-9

araneans 1006

arizonicum 1011

arvense 1014

bipinnatum 1010

brevifolius 1012

Butleri 1009

calcareum 1010

canescens 1012

canovirens 1011

Centaureae 1007

clavatum 1008

coloradense 1009

diffusum 1010

Drummondii 1009

Eatoni 1008

edule 1007

Engelmannii 1013

eriocephalum 1007

eriophilum 1009

filipendulum 1013

floccosus 1013

Flodmanii 1013

foliosum 1010

griseum 1011

hesperium 1007

Hookerianum 1006

humboldtense $\mathbf{1 0 0 7}$

Kelseyi 1006

lacerum 1010

lactucinum 1010

lanceolatum 1007

laterifolium 1008

Macounií 1007

magnificum 1010

megacephalum 1013

modestum 1011

nebrascense 1012

Nelsonii 1012

neomexicanum 1007

nevadense 1007

nidulum 1011

oblanceolatum

1013

ocrocentrum 1014

olivescens 1009

oreophilum 1009

palousiense 1012

Parryi 1006

perplexans 1008

plattense 1012

polyphyllum 1007

pulchellum 1011

pulcherrimum 1013

scopulorum 1007

scariosum 1006 spathulifolium 1011 subniveum 1006

Tracyi 1012

Tweedyi 1007

undulatum 1013

vernale 1008

virginianum 1013

CISTACEAE 565

Cladothrix 255

CLAMMY-WEED 370

Clarkia 592, 59.

Claytonia 262-3, 264 $-6$

Cleavers 807

Clematis 290-1, 291-3

Clamatis, White 290

Clementsia 373

Cleome 371

Cleomella 372

CLIFF-BRAKE 1048

CliffF Rose 434

Clinopodium 750

Clintonia 169

Clistoyucca 170

Clover 469 SWEET 477

CLOTBUR 832

ClOUdBERRY 436-7

CluB, DEVIL's 634

CluB-Moss 1054 LITTLE 1055

CluB-MOSS FAMTLY 1054

CLUB-RUSH 108

Cnemidophacos 502

Cnicus (See Cirsium) 1006-14

CoAst Blite 242

COCKLE, CORN 280

Cow 284

COCKLebUR 832

Coeloglossum 178

Cogswellia 624-28, 611,630

Coleogyne 429

Coleosanthus 842

Collinsia 762

Collomia $682-3,688$, 697

Coloptera 622

Colorado BLUE SPRUCE 17

COLORADO RUBBER PLANT 951

COLORAdo State FLOWER 307

Coloptera 62

ColTsFoot, SWFET 976

COLUMBINE 305

COLUMBO, AMERICAN 664

Comandra 818

Comarella 408

Comarum 422

Comfrey 739

Commelina 145

COMMELINACEAF 144

COMPASS PLANT 925

Conanthus 710

CONE-FLOWER 926-7 PURPLE 925

Conimitella 380

Conioselinum 632-3

Conringia 341

CONVALLARIACEAE 166

CONVOLVULACE-

AE 674

Convolvulus $676-7$

Conyza 91

Coptidium 302

Coptis 304

CORAL-BERRY 812-3

Corallorrhiza 184

CORAL-ROOT 184

CORAL-VINE 677

Cordylanthus 796-7

Cordylophorum 590

Coreopsis 935

Coriophyllus 620

Corispermum 244-5

CORN, BROOM 34 SUGAR 34

CORNACEAE 634

CORN CAMPION 280

CORN CHAMOMILE 959

CORN COCKLE 280

CORNEL 634

Cornella 635

CORNFLOWER 1014

CORN SALAD 818-9

CORN SPURRY 279

Cornus 634-5

CORRIGIOLACE-

AE 267

CORYDALIS 319-20

CORYLACEAE 205

Corylus 206

Coryphantha 580-1

Cosmos, WILD 944

COTTON-GRASS 107

ALPINE 108

COTTONTHISTLE 1014

COTTON-WEED 585

COTTONWOOD $185-7$

Cous 624

Covillea 538

Cowania 434

COW BANE 617

COWBERRY 422

COW CABBAGE 632

COW COCKLE 284

COW-HERB 284

COW PARSNIP 632

COWSLIP 647

AMERICAN 652

COW-WHEAT 801

CRAB, WILD 448 
Cristatella 370

Crocanthemum 565

Crocidium 975

Crocus, WILD 288

Crossostigma 589

Croton 541-2

CROWFOOT 294

CROWFOOT FAMILY 285

Cruciferae 321

Crunocallis 264

Cryptantha 725

Cryptogramma 1048

Ctenophyllum 501-2

Cucurbita 822

CUCURBITACEAE 821

CudWeEd 921, 961

CUP, PaINTEd 785

CURled DOCK 232

CURLS, BLUE 742

Currants 397-9

Cuscuta 677-9

CUSCUTACEAE 677

Cut-Grass, RICE 39

Cyanococcus 645

Cyclachaena 828

Cycloloma 243

Cyclosorus 1044

Cymopterus 621-2

acaulis 622

albiflorus 621

alpinus 617

asinatus 623

basalticus 620

bipinnatus 621

bulbosus 619

calcareus 621

decipiens 622

duchesnensis 620

Elrodi 621

Fendleri 622

foeniculaceus 621

glaucus 618

ibapense 618

Jonesii 620

lapidosus 627

Leibergii 622

longipes 618

lucidus 622

montanus 619

Newberryi 622

Parryi 622

petraeus 621

purpurascens 619

purpureus 620

utahensis 619

Cynoglossum 714, 718

Cynomarathrum 629 $-30,621$

OYPERACEAE 103

Cyperus 104-5

Cypripedium 177-8

Cyrtorhyncha 303

Cystium 491-2

Cystopteris 1042

Cytherea 183

Dactylis 71-2

Daisy Dwarf 948

DAISY, OX-EYE 962

WOOLLY YELLOW 947

Dalea 48:2-4

DAME'S ROCKET 344

DAME'S VIOLET 344

DANDELION 1034

DESERT 1022

Danthonia 62-3

DARNEL 91
Dasiphora 425

Dasyochloa 67

Dasystephana 661-3

Datura 759

Daucophyllum 615-6

Daucus 608

DAY-FLOWER 145

DEAD NETTLE 746

DEATH CAMAS 149

DEER BRUSH 554

DEER'S TONGUE 666

DEER-WEED 478

Delphinium 308

abietinum 312

Ajacis 313

albescens 310

alpestre 313

attenuatum 313

Barbeyi 313

bicolor 310

Brownii 312

Burkei 310

camporum 310

canmorense 312

coelestinum 311

cucullatum 312

cyanoreios 310

depauperatum 311

distichum 310

diversicolor 310

dumetorum 311

elongatum 312

geranifolium 311

Geyeri 312

glaucescens 313

Helleri 310

Leonardi 310

megacarpum 310

Menziesii 311

multiflorum 312

Nelsonii 311

Nuttallianum 311

occidentale 312

pauciflorum 311

Penardii 310

pinetorum 311

quercetorum 313

ramosuim 312

reticulatum 313

robustum 312

scaposum 311

simplex 310

strictum 310

subalpinum 313

virescens 310

viscidum 312

xylorhizum 311

Dentaria 347-8

Deschampsia 58-60

DESERT DANDELION 1022

DESERT CHICORY 1018

DESERT LILY 165

DESERT PINK 1017

Desmanthus 452

Desmodium 525

DEVIL's OLUB 634

DEVIL'S DARNINGNEEDLES 42

DEVIL'S WALKINGSTICK 634

DEW-FLOWER 145

DIAMOND WILLOW 193

Diaperia 913

Dicentra 319

Dicoria 828-9

DICOTYLEDONES 185

Dicrophyllum 545
Diervilla 815

Dieteria 860

Digitaria 35

Diholcos 499-500

Diplachne 68

Diplopappus 878,892

DIPSACEAE 827

Dipsacus 827

Dipterostemon 162

Disella 562

Disporum 168-9

Distegia 814-5

Distichlis 72

Ditaxis 542

Dithyrea 330

DOCK 230-232

DODDER 677

DODDER FAMILY 677

Dodecatheon 653-5

Doellingeria 891

DOGBANE 668

DOGBANE FAMILY 667

DOG CHAMOMILE 959

DOG FENNEL 959

DOG-TOOTH VIOLET 164

DOGWOOD 634

DOGWOOD FAMILY 634

Dondia 252-3

DOORWEED 232

DOUBLE BLADDERPOD 330

DOUGLAS FIR 15

DOUGLAS SPRUCE 15

Douglasia 648-9

DOUGLAS SPRUCE 15

Downingia 825

Draba 350

albertina 353

alpina 353

andina 354

argyrea 353

asprella 352

aurea 356

aureiformis 356

Bakeri 356

brachycarpa 352

brachystylis 356

cana 355

caroliniana 352

chrysantha 355

coloradensis 352

columbiana 355

crassa 355

crassifolia 353

cuneifolia 352

decumbens 356

deflexa 352

densifolia 353

dictyota 353

eurocarpa 353

fladnizensis 355

glacialis 353

glacialis 354

globosa 354

graminea 355

Helleriana 356

incerta 353

laevicapsula 353

laevipes 355

lapilutea 3.52

lapponica 354

lonchocarpa 355

lutea 352

luteola 356

MacCallae 355

Macouniana 353

micrantha 352

montana 352

Mulfordae 353

Nelsoni 354

nemorosa 352

nivalis $354-5$

nitida 353

oligosperma 354

oreibata 355

oxyloba 356

Parryi 353

pectinata 354

praealta 352

saximontana 354

sobolifera 354

spectabilis 355

sphaerocarpa 354

sphaerula 354

stenoloba 353

streptocarpa 355

surculifera 356

uber 356

uncinalis 354

valida 355

ventrosa 354

vestita 354

yellowstonensis 352

DRACAENACEAE 169

Dracocephalum 746, 745

DRAGON'S HEAD 745

FALSE 746

DROP-SEED 51

Drosace 648-9

Drosera 373

DROSERACEAE 372

DRYAD 429

Dryas 429-30

Drymocallis $425-7$

Dryopteris 1044-5, 1043-4

DUCK-BILL 798

DUCKWEED 143 LARGER 144

DUCKWEED FAMILY 143

Dugaldia 953

Dulichium 103

DURUMWHEAT 95 
Ellisia 700-1

ELM 206

ELM FAMILY 206

Elodea 29

ELODEACEAE 28

Elyna 111

Elymus 99

ambiguus 102

americanus 101

angustus 101

arenicola 102

brachystachys 101

Brownii 103

canadensis 100

cinereus 102

condensatus 102

curvatus 101

dasytachys 102

diversiglumis 100

flavescens 103

glaucus 101,102

Howellii 102

innovatus 103

jejunus 100

marginalis 101

Macounii 101

nitidus 101

Petersonii 101

robustus 100

salinus 102

Saundersii 101

simplex 102

striatus 101

strigosus 102

triticoides 102

villiflorus 102

virginicus 100,102

vulpinus 101

Emmenanthe 708

Emplectocladus 452

Encelia 932

Enceliopsis 933

ENCHANTER'S NIGHTSHADE 605

Endolepis 249-50

Engelmannia 924

ENGELMANN'S

SPRUCE 16

Ephedra 19

EPHEDR ACEAE 19

Epilobium 584-5, 590 adenocaulon 587 adenocladon 589 adscendens 589 alpinum 588 americanum 587 anagallidifolium 588

angustifolium 584 brevistylum 587

canadense 588

clavatum 588

davuricum 589

delicatum 588

Drummondii 588 , 587

glaberrimum 588 , 589

glandulosum 587

Hammondii 589

Hornemannii 588

laevicaule 589

lactiflorum 588

latifolium 585

latiusculum 587

lineare 589

luteum 590

MacDougalii 587

minutum 589

occidentale 587 oregonense 588

ovatifolium 587

Palmeri 586

palustre 589

paniculatum 589

platyphyllum 588

rubescens 587

Sandbergii 586

saximontanum 588

stramineum 587

subulatum 589

suffruticosum 590

Tracyi 589

Treleaseanum 587

ursinum 586

wyomingense 589

Epipactis 181

EQUISETACEAE 1051

Equisetum 1051

Eragrostis 68-9

Eremalche 562

Eremiastrum 876

Eremocarya 719

Eremochloa 67

Eremochloe 67

Eremocrinum 165

Eremosemium 250

ERICACEAE 639

Ericameria 853

Erigeron 896

acris 901

alpinus 901

anicularum $90 \%$

aphanactis 904

arenarioides 910

argentatus 908

armeriaefolius 902

asper 907

asperugineus 909

aureus 902

Bellidiastrum 908

Bloomeri 904

Brandegei 904

caespitosus 909

callianthemum 905

canus 909

canadensis 911

cinereus 908

colo-mexicanus 908

commixtus 908

compositus 902

concinnus 904

condensatus 904

consobrinus 907

controversus 903

conspicuus 906

corymbosus 909

Coulteri 905

debilis 901

decumbens 904

divergens 908

droebachiensis 901

Drummondii 907

Eatonii 909, 904

Earlei 906

elatior 905

elatus 901

elkoensis 909

Engelmannii 903

eucephaloides 905

Evermannii 903

eximius 906

filifolius 910

flabellifolius 903

flagellaris 908

formosissimum 907

fraternus 907

fruticetorum 906

Garrettii 903 glabellus 906-7

glabratus 901

glandulosus 903

gracilis 903

grandiflorus 902, 905

Gormani 902

hesperocallis 905

hirtuosus 907

hispidissimum 904

Howellii 905

iodanthus 907

inamoenus 904

incanescens 906

jucundus 901

laetivirens 910

lanatus 902

lapiluteus 901

leiomeris 903

leiophyllus 906

leptophyllus 905

leucatrichus 903

leucanthemoides 905

linearis 910

lonchophyllus 901

lucidus 905

luteus 910

MacDougalii 908

Macounii 910

macranthus 906

mancus 902

membranaceus 90.5

melanocephalus 901

microlonchus 905

minor 901

minusculus 903

montanensis 910

multifidus 902

nanus 904

nauseosus 909

Nelsonii 909

nematophyllus 904

nevadensis 909

nudiflorus 908

oblanceolatus 907

ochroleucus 911

Parryi 910

paucipetalus 883

Peasei 903

pedatus 902

peregeinus 905

peucephyllus 911

philadelphicus 907

pinnatisectus 902

poliospermus 904

politus 901

pulchellus 901

pulvinatus 911

pumilus 904

purpureus 907

racemosus 901

radicatus 903,904

ramosus 908

rubicundus 906

salsuginosus 905

salicinus 905

Scribneri 910

simulans 904

simplex 902

Smithii 907

sparsifolius 910

spathulifolius 903

speciosus 906

stolonifer 908

strigosus 908

strigulosus 906

subcanescens 909

subtrinervis 906

superbus 905

tener 909

tetrapleurus 910

trifidus 902

Tweedyanus 910

Tweedyi 909

unalaschensis 901

uniflorus 901

ursinus 903

utahensis 910

vetensis 904

viscidus 907

Vreelandii 906

Wootonii 908

wyomingensis 904

Wyomingia 908

yellowstonensis 901

Eriocarpum 860

Eriocoma 45-6

Eriodictyon 709

Eriogynia 40.5

Eriogonum 211

acaule 219

alatum 216

andinum 217

androsaceum 217

angulosum 228

annuum 225

arcuatum 216

aridum 218

aureum 221, 216

Baileyi 225

Bakeri 216

Batemani 225

bicolor 225

biumbellatum 218

Brandegei 220

brevicaule 222

caespitosum 217

campanulatum 222

cernuum 226

chloranthum 216

chrysocephalum 220

chrysops 220

clavellatum 225

coloradense 220

compositum 217

confertifolium 223

contortum 222

corymbosum 224 
Eriogonum

idahoense 222

inflatum 227

insigne 226

intricatum 224

Jamesii 216

Jonesii 224

Kearneyi 223

Kingii 220

lachnogynum 218

lachnostegium 221

lagopus 222

latifolium 220

latum 218

leptocladon 225

loganum 220

lonchophyllum 223

longilobum 219

mancum 220

marginale 218

Mearnsii 224

medium 220

micranthum 222

microthecum 224, 223

multiceps 221

myrianthum 224

nebraskense 224

neglectum 218

nidularium 226

niveum 221

nudicaule 223

nummulare 226

nutans 227

ochroleucum 219

Ordii 227

orendense 222

orthocaulon 219

Ostlundi 223

ovalifolium 219

Parryi 227

pauciflorum 220

pharnaceoides 228

Piperi 216

Plumatella 226

polifolium 221

polyphyllum 216

Porteri 218

proliferus 219

puberulum 228

pulvinatum 219

pusillum 226

pyrolaefolium 217

racemosum 225

ramosissimum 225

rhomboideum 218

rotundifolium 226

rubidum 219

rubiflorum 2.27

Rydbergii 218

sabulosum 222

salicinum 223

salinum 224

salsuginosum 228

sarothriforme 224

scoparium 223

sericeus 216

Shockleyi 219

shoshonense 225

Simpsoni 224

spathulatum 222

spathuliforme 223

spergulinum 228

sphaerocephalum 217

stellatum 218

strictum 221

subalpinum 218

subreniforme 227

sulcatum 225 tenellum 226

Tetraneuris 219

Thomasii 227

Thompsonae 222

thymoides 217

trichopodum 227

triste 216

tristichum 223

trinervatum 227

turbinatum 226

umbellatum 218

umbelliferum 218

vegetius 216

villiflorum 221

vimmineum 225

Visheri 227

wasatchense 223

Wetherillii 226

Wrightii 225

xanthum 217

Erioneuron 67

Eriophorum 107-8

Eriophyllum 947, 948

Eritrichium 717-8, $719,721,723$

Erocallis 266

Erodium 533

Eruca 345

Erxlebenia 638

ERYNGO 609

Eryngium 609

Erysimum 337, 342-4

Erythraea 658

Erythrocoma 432-3

Erythronium 164-5

Eschenbechia 911

Eschscholtzia 318-9

Eucephalus 878

Eucnide 574

Eucrypta 701

Eulophus 611

Eunanus 780-1

Euonymus 548-9

Eupatorium 841

Euphorbia 543-547

EUPHORBIACEAE 541

Euphrasia 797

Euploca 712

Eurotia 250-1

Eustoma 658

Euthamia 872

Evax 914

Eventng PRIMROSE 593

WHITE 594

EVENING PRIMROSE FAMILY 583

EVERLASTING 914. 921

PEARLY 921

Evolvulus 675

EYEBRIGHT 797

FABACEAE 454

FAGACEAE 199

Fagonia 538

Fagopyrum 238

Fallugia 433

FALSE BONESET 843

FaIse BUfFalo GRASS 66

FALSE BUCKWHEAT 238-9

FALSE BUGBANE 290

FALSE DRAgON HEAD 746

FALSE Flax 334

FALSE GROMWELL 738
FALse Hellebore 147

FALSE HORSE-MINT 750

FALSE INDIGO 479

FaLse Mallow 558

FALSE MERMAID 537

FALSE MERMaid

FAMILY 537

FALSE MITERWORT 383

FALSE OATS 60

FALSE PIMPERNEL 652

FALSE SOLOMON'S SEAL 166

FALSE SPRUCE 15

FAME-FLOWER 262

Fatsia 634

FEATHER, SQUAW 785

FEATHER GRASS 42

FELWORT, MARSH 664

Fendlera 394

Fendlerella 393-4

FERN, CHRISTMAS 1042

HOLLY 1042

LADY 1046

MAIDEN-HAIR 1047

MALE 1044

OAK 1044

OSTRICH 1041

SENSITIVE 1040

SHIELD 1044

VENUS'-HAIR 1047

FERN-BUSH 405

FERN FAMILY 1041

FERNWORTS 1038

FESCUE-GRASS 84

Festuca $84-87,88$

altaica 86

arizonica 86

brachyphylla 86

brevifolia 86

calligera 86

campestris 87

confinis 88

dasyclada 87

Earlei 85

elatior 87

fratercula 87

Hallii 87

idahoensis 86

ingrata 86

Jonesii 87

Kitaibeliana 85

megalura 87

minutiflora 86

occidentalis 86

octoflora 87

ovina 86

pacifica 87

pseudovina 86

reflexa 88

rubra 85

saximontana 86

scabrella 87

sororia 87

subulata 87

supina 86

tenella 87

Thurberi 87

vallicola 85

Vaseyana 86

viridula 86

Fetid Marigold 956

FIDDLE NECK 729

FIG, INDIAN 575

FIGWORT 763

FigWORT FAMTLY 760

Filago 914

FILAREe 533

Filix 1042

Fimbristylis 107

FIR 14

BALSAM 14

DOUGIAA 15

GRAND 15

JOINT 19

RED 15

SÜBALPINE 15

WHITE 15

FIRE-WEED 584

FISH-WEED 22

FIVE-FINGER 408

FlaG, BLUE 176

CAT-TAIL 20

SWEET 143

FLAT-POD 347

Flaveria 953

FLAX 534

BLUE 534

FALSE 334

YELLOW 535

FLAX FAMILY 534

FLEABANE 896

CANADA 911

FLEUR-DE-LIS 176

Floerkea 537

FLOWERING CuRRANTS 399

FLOWERING RASPBERRY 435

FLOWERING STRAW 1017

FLY HONEYSUCKLE 814

Forestiera 656

Forsellesia 549-50

FORGET-ME-NOT 736

FOUR-O'CLOCK 258

FOUR-O'CLOCK FAMILY 255

FOXTAIL 50, 96

FoxtaIl Grass 38

Fragaria 423-4

FRAGRANT GOLDENROD 872

Frankenia 564

FRANKENIACEA E 564 
GARLIC 157

GARDEN ROCKET 345 Garrya 634

Gaultheria 642

Gaura 601, 604-5

Gaurella 599

Gayophytum 590-1

GENTIAN 659, 661

FRINGED 658

Moss 661

SPURRED 666

Gentiana 659-64

affinis 663

Andrewsii 66.

anisosepala 660

arctophila 661

barbellata 659

Bigelovii 663

bracteosa 663

calycosa 663

detonsa 6.59

elegans 659

Forwoodii 663

frigida 66.

glauca 662

helerosepala 660

humilis 661

interrupta 663

lineata 659

Macounii 659

monantha 660

Moseleyi 659

oregana 663

Parryi 663

plebria 661

polyantha 660

propinqua 661

prostrata 661

puberula 664

Romanzovii 662

strictiflora 660

thermalis 659

tortuosa 661

ventricosa 65.9

GENTIANACEAE 657

Gentianella 660

GENTLAN FAMILY 657

Geoprumnon 492-3

Geraea 934

GERANIACEAE 530

Geranium 530-3

GERANIUM, WILD 530

GERANIUM FAMILY 530

Gerardia 785

GERMANDER 742

GERMAN MADWORT 717

Geum 430-3

GIANT BIRD'S-NEST 638

GLANT HYsSOP 744

Gilia 690

acerosa 699

aggregata 694

arenaria 695

aristella 683

arizonica 694

atlenuata 694

Bigelorii 698

Brandegei 682

Breweri 689

Burleyana 693

crespitosa 696

calcarea 695

candida 694

capitata 694

cephaloidea 693 congesta 693

Crandallii 696

crebrifolia 692

Dactylophyllum 698

debilis 683

demissa 698

depressa 694

exserta 695

filifolia 688

filiformis 698

floccosa 688

frutescens 692

globularis 693

gracilis 688

grandiflora 683

Grayi 697

Gunnisonii 693

Harknessii 698

Haydeni 696

heterophulla 683

Howardii 683

hutchinsifolia 695

iberidifolia 693

inconspicua 695

intertexta 689

latifolia 696

laxiflora 695

leptomeria 696

leptotes 683

longiflora 695

Macombii 695

MacVickerae 695

Merrillii 692

minima 689

minutiflora 697

montana 693

nuda 693

nudicaulis 698

Nuttallit 690

palmifrons 693

pentstemonoides 696

pharnaceoides 698

pinnatifida 695

polyantha 695

polycladon 694

pulchella 694,698

pumila 694

pungens 689-90

rigidula 699

roseata 693

scariosa 694

scopulorum 695

Schottii 697

sedifolia 696

setosissima 697

sinistra 697

sinuata 695

spergulifolia 692

spicata 692

stenothyrsa 696

straminea 695

subacaulis 696

subnuda 696

superba 696

tenerrima 697

tenuituba 694

tridactyla 692

trifida 693

triodon 696

Tweedyi 696

viscida 695

Watsonii 690

Wilcoxii 688

Giliastrum 699

GILL-OVER-THE

GROUND $\mathbf{7 4 5}$

GINGER, WILD 821

GINSENG FAMILY 633
GINSENG, WILD 633

Glaphyropteris 1043

GLAssWORT 251

Glaux 652

Glecoma 745

GLOBE-FLOWER 304

GLOBE MaLLOW 559

Glossopetalon 550

GLOW, GOLDEN 926

Glyceria 82-4

Glycosma 610-1

Glycyrrhiza 523

Glyptopleura 1021-2

Gnaphalium 921-3

GOAT'S BEARD 405

GOAT CHICORY 1029

GOLDEN ASTER 849

GOLDEN CURRANTS 399

GOLDEN DOCK 232

GOLDEN GLOW 926

GOLDEN PEA 456

GOLDENROD 867

BUSHY 872

FRAGRANT 872

ROCK 871

ROUGH 872

GOIDEN SAXIFRAGE 377

GOLD-THREAD 304

Goodyera 182

GoOSEBERRIES 394

GOOSEBERRY FAMILY 394

GOOSEFOOT 239

GOOSEFOOT FAMILX 239

GoOsE TANSY 421

Gormania 373-4

GOSMORE 1019

GOURD 822

GOURD FAMILY 821

GRAMA 64-5

Grama Grass 64

GRAND FIR 15

GRAPE 556

GRAPE FAMILY 556

GRAPES, OREGON 316

Graphephorum 61

GRASS CACTUS 169

GRASS FAMILY 29

Grass of Parnassus 375

Grass of Parnassus FAMILY 375

Gratiola 781

Grayia 250

GRAY SCRUB PINE 12

GREASEWOOD 251

GREEN DOG-FENNEL 959

Greeneocharis 718

GREEN MILKWEED 670

GREEN VIOLET 569

Grindelia 847-9

GROMWELL 737

FAISE 738

Grossularia 394-6

GROSSULARIA-

CEAE 394

GROUND ARTICHOKE 930

GROUND CHERRY 753

GROUND IVY 745

GROUND-NUT 262, 529

GroUND PINE 1054

GROUND PLUMS 492

GROUNDSEL 982

GROUNDSEL TREE 911

Gruvelia 713

GUM-PLANT 847

Gutierrezia 845-6

Gymnolomia 926

GYMNOSPERMAE 11

Gymnosteris 698

Gyrostachys 181

Habenaria 178-80

HACKBERRY 207

HAIR-GRASS 58

PURPLE 49

HAIRY CHEAT 90

HAIRY GRAMA 65

Halenia 667

Halerpestes 302

HALORAGIDACE-

AE 605

Hamosa 495-7

Haploestes 976

Harbouria 617

HARD PINES 11

HAREBELL 823

HARE'S-EAR 341

Harpaecarpus 938

HAW 448

HAWKWEED 1027

HAWTHORN 448

HAZLENUT 206

HAZLLENUT FAMILY 205

HEAL-ALL 745

HEART-LEAVED WILLOW 193

HEARTS-EASE 565

HEATH ASTER 892

HEATH FAMTLY 639

HEATH 640

HEATHER 641-2

Hedeoma 749-50

HEDGEHOG CACTUS 579

Hedgehog Cereus 577

HEDGE HYSSOP 781

HEDGE MUSTARD 337

HEDGE NETTLE 746

HEDIONDILLA 538

Hedysarum 523-4

Helenium 954 
Hermidium 258

Herpestes 781

Herrickia 877

Hesperidanthus 366

Hesperis 344

Hesperaster 570-2

Hesperochiron 708

Hesperochloa 88

Hesperodoria 859

Hesperonia 258-9

Hesperopeuce 16

Hesperoscordum 162

Heteranthera 146

Heterisia 391

Heterocodon 824

Heterothrix 366

Heteropleura 1027

Heuchera 380-3, 384

Hieracium 1027-9

Hierochloa 40

Hilaria 34-5

Hippuris 606

HOARY ALYSSUM 347

HOARY WILLOW 196

Hoffmanseggia 453

Hofmeisteria 840

Holcus 34

HOLLY FERN 1042

HOLLYHOCK, WILD 558,561

HOLLY-LEAVED ASTFR 876

HOLLY OAK 201

Holodiscus 406

HOLY GRAsS 40

Homalobus 508

acerbus 512

Bourgovii 512

brachycarpus 511

caespitosus 511

campestris 513

camporum 513-4

Clementis 512

collinus 515

curvicarpus 515

debilis 512

decumbens 513

decurrens 514

detritalis 511

dispar 512

divergens 513

Dodgeanus 512

Episcopus 514

exilifolius 510

Fendleri 515

flexuosus 515

grallator 511

Hallii 515

humilis 514

hylophilus 514

junceus 513

junciformis 513

lancearius 511

ligulatus 510

macrocarpus 515

microearpus 514

miser 511

oblongifolius 514

Palliseri 514

paucijugus 514

ploximus 515

Salidae 515

serotinus 513

simplicifolius 511

stenophyllus 514

strigosus 513

strigulosus 512

stipitatus 512

tenellus 512

tenuifolius 513 uniflorus 511

vexiliflexus 511

wingatanus 512

Homalocenchrus 39

HONEY CLOVER 477

HONEYSUCKLE 815

BUSH 814-5

FLY 814

SWAMP 814

HONEYSUCKLE FAMILY 810

Honkneya 27/

HOP-HORNBEAM 205

HoPs 208

HOP SAGE 250

HOP-TREE 540

Hordeum 96-7

HOREHOUND 744 WATER 751

Horkelia 406-7, 408

HORNWORT 284

HORNWORT FAMILY 284

HORSE MINT 748

FALSE 750

HORSE NETTLE 756-7

HORSE-RADISH 334

HORSEWEED 828, 911

HORSFTAIL 1051

HORSETAIL FAMILY 1051

Hosackia 478, 477-9

HOUND's TONGUE 714

Howellia, 825 .

HUCKLEBERRY 644

HUCKLEBERRY FAMILY 643

Huegelia 688

Hulsea 941

Humulus 208

Hutchinsia 329

HYACINTH, WILD 162, 166

Hybanthus 569

HYDRANGEA, WILD 231

HYDRANGEACEAE 392

HYDRANGEA FAMILY 392

Hydroleaceae 699

HYDROPHYLLACEAE 699

Hydrophyllum 699, 400

Hymenatherum 956

Hymenoclea 829

Hymenopappus 9424

Hymenoxys 951

Hyoscyamus 758

HYPERICACEAE 563

Hypericum 563

Hypochaeris 1019

Hypopitys 639

Hypoxis 173

HYSSOP, GIANT 744 HEDGE 781

WATER 781

Hystrix 103

Ibidium 181

Idahoa 347

Iliamna 561-2

Impatiens 536-7

INDIAN CHICKWEED 261

INDIAN FIG 575

INDIAN GRASS 34
INDIAN HEMP 668

INDLAN MALLOW 562

INDIAN MILLET 45

INDIAN PAINT 737

INDIAN PAINT-BRUSH 785

INDIAN PARSNIP 620

INDIAN PINK 371

INDIAN PIPE 639

INDIAN PIPE FAMILY 638

INDIAN TURNIP 480

INDLAN WARRIOR 798

INDIGO, FALSE 479

Inula 878, 894

Ionactis 891

Ionidium 569

Ionoxalis 533

Ipomoea $675-6$

IRIDACEAE 173

IRIS 176

IRIS FAMILY 173

IroN PLANT 860

IRONWEED 840

IRONWOOD 205

Isatis 323

Isnardia 592

Isocoma 859

ISOETACEAE 1053

Isoetes 1053

Iva 828,828

Ivesia $407-8$

IVY, AMERICAN 556

GROUND 745

POISON 551

Jacksonia 370

JACOB'S LADDER 680

Jamesia 393

JAMESTOWN WEED 759

JERUSALEM OAK 242

JEWEL-WEED 536

JEWEL-WEED FAMILY 536

JIMSON WEED 759

JOE-PYE WEED 841

JOHNNY-TUCK 796

JOHNSON GRASS 34

JOINT FIR 19

JOINT FIR FAMILY 19

Jonesiella 500

JOSHUA TREE 170

JUNCACEAE 149

Juncoides 155-6

Juncus 150

alpinus 154

arizonicus 152

ater 151

badius 154

balticus 159

biglumis 153

brachyphyllus 152

brunnescens 155

bufolius 153

canadensis 155

castaneus 153

columbianus 154

confusus 152

compressus 152

Drummondii 152

Dudleyi 153

ensifolius 155

fliformis 151

Hallii 152

interior 152

Jonesii 153

longistylis 153,154

Mertensianus 154

mexicanus 152

nevadensis 154

nodosus 154

orthophyllus 154

parous 155

Parryi 152

phaeocephalus 154

Regelii 153

Richardsonianus 154

saximontanus $\mathbf{1 5 5}$

sphaerocarpus 153

subtriflorus 152

tenuis 153,152

Torreyi 154

Tracyi 155

triformis 154

triglumis 153

truncatus 154

Tweedyi 154

uncialis 154

vallicola 152

Vaseyi 152

xiphioides 155

JUNE-BERRY 446

JUNE GRASS 68

JUNGLE RICE 38

JUNIPER 17

JUNIPERACEAE 17

JUNIPER FAMILY 17

Juniperus 17,18

KALISPELL 380

Kallstroemia 539

Kalmia 641

Kelloggia 807

Kelseya 404

Kentrophyta 515-6

KINNIKINNIK 634,643

KITTEN-TAILS 784

KNOTGRASS 232

KNOTWEED 232

Kobresia 111

Kochia 244, 250

Koeleria 68

Krigia 1020

Kruhsea 168

Krynitzkia 721-9

affinis 728

ambigun 727

barbigera 727

crassisepala 727

depressa 723 
LADY'S THUMB 235, 237

Lagophylla 938

LAMB'S LETTUCE 819

LAMB'S QUARTER 239

LAMIACEAE 741

Lamium 746

Langloisia 697

LANGUID LADY 730

Laphamia $94_{4} 0$

Lappa 1002

Lappula 714-7

LARCH 13-4

LARGER DUCKWEED 144

Larix 13

LARKSPUR 308

Larrea 538

Lastrea 1043

Lathyrus 526-9, 526

LAUREL, AMERICAN 641

MOUNTAIN 554

SWAMP 641

Laurentia 826

Lavauxia 598-9

Laya 939

LEATHER-FLOWER 291

Ledum 640

LEFK 157

Leersia $39-40$

Legouzia 824

Leibergia 611

Lemna 143-4

LEMNACEAE 143

LEMON MINT 748

LEMON-SCENT 957

LENTIBULARIACEAE 801

Leontodon 1034

Leonurus 746

LEOPARD LILY 164

Lepachys 927

Lepadenia 545

Lepargyrea 582

Lepidium 324,323

alyssoides 326

apetalum 327

Bourgeauanum 327

brachybotryum 326

Crandallii 325

crenatum 325

densiflorum 327

dictyotum 328

divergens 327

Draba 323

Eastwoodiae 326

elongatum 327

Fletcheri 327

Fremontii 326

Georginum 327

hirsutum 326

integrifolium 325

idahoense 326

intermedium 326

Jonesii 326

lasiocarpum 327

medium 326

montanum 325, 326

papilliferum 326

perfoliatum 325

philonitrum 325

pubecarpum 327

ramossissimum 327

ramosum 327

sativum 325

scopulorum 325

simile 327 spathulatum 325

texanum 326

utahense 325

Vaseyianum 325

virginicum 326

Wrightii 327

Zionis 325

Leptarrhenia 390

Leptasea 390-1

Leptilon 911

Leptochloa 65

Leptodactylum 68990

Leptogramma 1043

Leptorchis 183

Leptotaenia 628-9

Lesquerella 331-3

LETTUCE 1037

LAMB'S 819

MINERS' 263

SPANISH 263

SQUAW 263

Leucampyx 944

Leucanthemum 960

Leucelene 892

Leucocraspedum 665-6

Leucocoma 108

Leucocrinum 163

Leucosyris 876

Lewisia 265, 266

Liatris $844-5$

Iigusticella 614

Ligusticum 612-4

LILIACEAE 163

Lilium 163-4

LILY 163

ALP 165

BUTTERFLY 171

DESERT 165

LEOPARD 164

MARIPOSA 171

MOUNTAIN 163

POND 285

SAND 570

SEGO 171

TIGER 164

WATER 285

Y ELLOW POND 285

LILY FAMILY 163

LILY-OF-THE-VALLEY FAMILY 166

LILY-OF-THE-VALLEY, WILD 166

LTMBER PINE 13

LIMNANTHACEAE 537

Limnia 263-4

Limnobotrya 396-7

Limnorchis 179-80

Limosella 781

LINACEAE 534

Linanthus 697-8

Linnaea 812

Linaria 762

Linosyris 8.58-9

Linum 534, 535-6

LION'S BEARD, 288 , 291

Liparis 183

LIP-FERN 1049

Lippia 741

LIQUORICE 523

Listera 181-2

Lithophragma 3778, 380

Lithospermum 737, 733

LitThe Clubmoss 1056
LITTLE CLUBMOSS FAMILY 1055

LITTLE RED ELEPHANT 797

LIVE OAK 201

Lloydia 165

LOASACEAE 569

LOASA FAMILY 569

Lobelia 826-7

LOBELIA CEAE 824

LOBELIA FAMILY 824

LOCO WEED 493, 517

LOCUST-TREE 485

LODGE-POLE PINE 12

Loeflingia 279-80

LOGANIACEAE 657

LOGANIA FAMILY 657

Lolium 91-2

Lonicera 815, 814

LOOKING-GLASS, VENUS's 824

LOOSESTRIFE 583, 651 FRINGED 651 TUFTED 651

LOOSESTRIFE FAMILY 582

Lophanthus 74,-5

LORAN'THACEAE 816

Lotus $477,477-9$

LOUTSA, RED-HEAD 265

LOUSEWORT 798

LOVE APPLE 757

LOVE-VINE 677

Lowellia 958

LUCERNE 476

Luetkea 405

LUNGWORT 730

LUPINE 457

Lupinus 457

adscendens 463

aduncus 462

albicaulis 463

alpestris 461

alsophilus 462

ammophilus 465

amplus 465

aphronosus 466

arceutinus 466

argenteus 461

argentinus 462

argophyllus 462

aridus 467

axillaris 464

Bakeri 466

barbiger 467

Blankinship pii 461

brevicaulis 469

Burkei 465

caespitosus 468

calcaratus 462

candicans 468

capitatus 469

comatus 466

crassus 461

Cusiekii 469

cyaneus 466

cytisoides 465

decumbens 461-2

depressus 467

dichrous 466

erectus 468

Evermannii 468

flavescens 463

flavicaulis 466

flexuosus 464

floribundus 462

foliosus 463

fulvomaculatus 462

glabratus 465

Greenei 464

habrocomus 466

Hellerae 464

Helleri 462

holosericeus 462

humicola 464

ingratus 463

Jonesii 467,461

Kingii 469

laxiflorus 462

laxispicatus 461

laxus 463

lepidus 468

leptostachys 461

leptostachyus 462

leucanthus 461

leucophyllus 467

leucopsis 464

lucidulus 463

lupinus 462

Macounii 463

macrostachys 466

maculatus 462

marianus 465

micensis 469

minimus 467

monticola 468

multitinctus 462

myrianthus 462

nootkatensis 465

oreophilus 464

ornatus 464, 465

ovinus 468

parviflorus 462

plattensis 460

plumosus 467

polyphyllus 465

pseudoparviflorus 461

psoraleoides 468

pulcherrimus 464

pusillus 469

ramosus 467

retrorsus 467

rivularis 465

roseolus 468

rubens 469

rubricaulis 461

Rydbergii 464 
Macaroni WhEAT 95

Machaeranthera 892 angustifolia 895 aspera 894 Bigelovii 894 canescens 895 cichoriacea 896 commixta 895 coronopifolia 894 divaricata 895 Fremontii 896 glabella 895 humilis 894 latifolia 894 leptophylla 895 linearis 895 magna 895 paniculata 895 parviflora 893 Pattersonii 894 pulverulenta 895 ramosa 895 rubricaulis 894 Selbyi 895 sessiliflora 894 spectabilis 896 subalpina 895 superba 895 tanacetifolia 894 varians 894 viscosa 895,894 viscosula 894

Macrocalvx 700

Macronema 865-6. 860

Macrorhynchus 1034

Madia 938

MADDER 810

MADDER FAMILY 806

Madronella 750-1

MADWORT, GERMAN 717

MAHOGANY, MOUNTAIN 434

Mahonia 316

Maianthemum 167-8

MAIDEN-HAIR FERN 1047

MAID-OF-THE-MIST 288

Mairania 643

MALACEAE 445

Malacolepis 1022

Malacothrix 1022

Malaxis 182-3

Malcolmia 341

MALE FeRN 1044

MALLOW 557

FALSE 558

GLOBE 559

INDIAN 562

MAPLE-LEAVED 561

POPPY 558

ROSE 558

SCARLET 559

MALIOW FAMILY 556

Malva 557

MALVACEAE 556

Malvastrum 559, 562

Mamillaria 580-1

MANNA-GRASS 82

MANZANITA 643

MAPLE 552 ASH-LEAVEN 553

MAPLE FAMILY 551

MAPLE-LEAVED MaLLow 561

MARE'S-TAIL 606

MARigold, Fetid 956 WIIJ 940
Marilaunidium 70910

MARIPOSA LILY 171

MARIPOSA LILY FAMILY 171

Marrubium 744

Marsilea 1050

MARSILEACEAE 1050

MARSILEA FAMILY 1050

Marsh CINQUEFOIL 422

MARSH-CRESS 334

MARSH ELDER 828

MARSH FELWORT 664

MARSH-GRASS 63

MARSH-MARIGOLD 303

Marshlocks, PURPLE 422

Marsh PURSLANE 592

MARSH TREFOIL 667

Martynia 804

MARTYNIACEAE 804

Maruta 959

MARY, BLUE-EYED 762

Matricaria 959

MATRIMONY VINE 758

Matteuccia 1041 .

MAYFLOWER 763

MAY WEED 959

MEADOW-GOWAN 303

MEADOW-GRASS 72 , 84

Meadow Parsnip 614

MeAdOW RuE 288

MEADOW SWEET 403

Medicago 476

MEDICK 476

Meibomia 525

Melampodium 924

Melampyrum 801

MELANTHACEAE 146

Melica 70-1

Melic-Grass 70

Melilotus 477

Melosmon 742

Menodora 656

Mentha 752-3

Mentzelia 574, 570-4

MENYANTHACEAE 667

Menyanthes 667

Menziesia 641

Meriolix 599-600

MERMAID, FAISE 537

Mertensia 730 amoena 734 alba 733

alpina 736 arizonica 734

Bakeri 734 brachycalyx 733

brachyloba 735

brevistyla 736

campanulata 736

cana 736

canescens 736

ciliata 732

congesta 734

coriacen 735

coronata 735

cynoglossoides 733

Drummondii 735 eplicata 732

foliosa 733

fusiformis 734

humilis 736

intermedia 734

lanceolata 735

lateriflora 734

Leonardi 734

lineariloba 735

linearis 735

longiflora 732

media 734

membranacea 733

micrantha 73 s

muriculata 733

myosotifolia 734

nivalis 734

nutans 732

oblongifolia 732

obtusiloba 736

ovata 735

pallida 732

paniculata 733,734

papillosa 735

Parryi 735

perplexa 736

picta 732

pilosa 733

platensis 732

polyphylla 732

praecox 734

pratensis 733

pulchella 732

punctata 73.2

refracta 733

stenoloba 734

subpubescens 732

toyabensis 733

tubiflora 732

Tweedyi 736

umbractilis 734

viridis 735

viridula 7.3 .5

Mesquite Grass 49 , 64

Micrampelis 822

Micranthes $387-9$

Micromeria 751

Microphacos 506

Microseris 1017, 1020-1

Microsteris 687-8

Microstylis 183

MILFOIL 957 WATER 605

MILK MAIDS 347

MILKWEED 671

GREEN 670

SPIDER 674

MILKWEED FAMILY 669

MuL VETch 493

MILKWORT 540 SEA 652

MILKWORT FAMILY 540

MILUET, INDIAN 45

Miltitzia 707-8

MIMOSACEAE 452

MIMOSA FAMILY 452

MimosA, PRAIRIE 452

Mimulus 777-780

MINER' LETT LCE 263

MINT 752

CAT 745

HORSE 748

LEMON 748

MUSTANG 750

MINT FAMILY 741

Missouri CURRants 399

Mistletoe, AMERICAN 816

MISTLETOE FAMILY 816

Mitella 378, 379-80

Mitellastra 379

MITERWORT 378-9 FALSE 383

MOCK APPLE 822

MOCK ORANGE 392

MOCK PENNYRoYAL 749

Moehringia 274

Moldavica 745

Mollugo 261

Monarda 748-9

Monardella 750-1

Moneses 636

MONKEY-FLOWER 777

MONKSHOOD 313

Monniera 781

MONOCOTYLEDONES 20

Monolepis 243

Monoptilon 872

Monothrix 940

Monotropa 639

MONOTROPACEAE 638

Montia 264-5

Montiastrum 265

MOONWORT 1038

MoOSE-GRASS 147

MORNING BRIDES 945

MORNING-GLORY 675-6

MORNING-GLORY FAMILY 674

Morongia 452-3

Mortonia 549

Moschatel 816

MOSCHATEL FAMILY 816

Moss Campion 282

Moss GeNTIAN 661

Moss PINK 685

Moss PHLOX 685 
MOUNTAIN SORREL 232

MOUNTAIN SPRAY 405

MOUSE-EAR CRESS 341

MOUSE-EAR CHICKWEED 271

MOUSE-TAIL 293

MoXIE PLUM 644

MUd-PLANTAIN 146

MUD-PURSLANE 564

MUDWORT 781

MUGWORT 961

Muhlenbergia 46-9

MULE-FARS 929

MULLen 761

Munroa 66

Muscaria 386

Musenium 615-6

Musineon 615

MUSK-FLOWER 779

MUSK-ROOT 816

MUSTARD 345

BLACK 346

HEDGE 337

TANSY 338

TOWFR 337

TUMBLE 337

WORM-SEED 343

MUSTARD FAMILY 321

MUstang Mint 750

Myosotis 736

Myosurus 293

Myriophyllum 605-6

Myzorrhiza 803

Nabalus 1024

Nacrea 922

Naiocrene 265

NAJADACEAE 26

Najas 26

NAJAS FAMILY 26

NAKED-SEEDED PLANTS 11

Nama 710

NANNY-BERRY 812

Nardosmia 974

NARROW-LEAVED COTTONWOOD 187

Nasturtium $33 y_{5}-7$

Naumburgia 651

Navarretia 689

NECK, FIDDLE 729

Negundo 553

Nemacladus 825

Nemexia 173

Nemophila 701

Nemoseris 1018

Nepeta 745

Neslia 334

NetTle 208

DEAN 746

HEDGE 746

HEMPP 747

HORSE 756-7

NeTtLe FAMILY 208

NET-VEINED WILLOW 198

NEW JERSEY TEA 554

Nicotiana $760-1$

Niellia 403

NIGGER-BABIES 609

NIGGER-HEADS 926

NIGHT-BLOOMING CATCHFLY 281

NIGHTSHADE 756 ENCHANGER'S 605

NINE-BARK 401

Nolina $170-1$

NoNESUCH 476
Norta 337-8

NORTHERN SCRUB PINE 12

Nothocalais 1020

Notholaena 1050

Nuphar 285

NUT-GRASS 104

NUT-PINE 12-3

Nuttallia 570-2

Nymphaea 285

NYMPHAEACEAE 284

NYCTAGINACEAE 255

OAK 199-200

JERUSALEM 242

PoIsON 551

OAK FERN 1045

OAT-GRASS 62

OATS 61-2

FALSE 60

Obione 247, 250

OCEAN SPRAY 405

Ochrocodon 164

Odostemon 316

Oenothera 593

albicaulis $596-7$

andina 601

biennis 593-4

Boothii 601

brachycarpa 599

Bradburiana 596

breviflora 600

brevipes 603

caespitosa 597

canescens 599

Cockerellii 594

coronopifolia 597

cruciformis 603

densiflora 592

depressa 594

eximia 598

gauriflora 601

guttulata 599

heterantha 600

hirsutissima 593

Hookeri 593

Howardii 599

idahoensis 598

Jamesii 594

Johnsoni 5.98

lavandulaefolia 599

longissima 594

marginata 5.98

montana 598

multijuga 604

muricata 594

Nuttallii 600

ornata 594

parvula 601

pinnatifida 596

pterosperma 603

refracta 601

salicina 592

scapoidea 603

serrulata 600

strigosa 594

strigulosa 601

subulifera 593

tenuissima 603

trichocalyx 596

triloba 599

Oglifa 914

OLD MAN'S WHISKERS 291,432

OLEACEAE 655

OLEASTER FAMILY 581
Oligoneuron 872

OLIVE FAMILY 655

Olsynium 175

Onagra 593-4

ONAGRACEAE 583

ONE-FLOWERED WINTERGREEN 636

ONE-LEAVED PINYON 13

ONION 157

ONION FAMILY 157

Onix 492

Onobrychis 524-5

Onoclea 1040,1041

Onopordon 1014

Onosmodium 738

Omphalodes $717-8$

Oonopsis 864-5

OPHIOGLOSSACEAE 1038

Ophrys 181-2

Opulaster 401-3

Opuntia 575

ORACHE 245

ORANGE, MOCK 392

ORCHARD-GRASS 71

ORCHID, BOG 179

WOOD 180

ORCHIDACEAE 176

Orchis 178

ORCHIS FAMILY 176

Oreastrum 891

OREGON GRAPES 316

Oreobatus 436

Oreobroma 265-6

Oreocarya 719 ,

affinis $722-3$

alata 725

aperta 722

argentea 723

Bakeri 722

caespitosa 723

cana 723

ciliohirsuta 722

cinerea 721

commixta 723

cristata 724

depressa 723

disticha 721

dolosa 723

echinoides 723

elata 722

eulophus 724

flava 724

flavoculata 724

fulvocanescens 724

glomerata 722

gypsaphila 724

hispida 723

hispidissima 722

humilis 723

leucophaea 724

longiflora 724

lutescens 724

Macounii 722

multicaulis 721

nana 723

nitida 724

paradoxa 724

Paysonii

perennis 722

pulvinata 718

pustulosa 721

salmonensis 723

sericea 723

setosissima 722

Shatzii 723

spicata 722

spiculifera 722

suffruticosa 721

tenuis 724

thyrsiflora 722

virgata 721

virginensis 722

Wetherillii 724

Oreochrysum 867

Oreostemma 891

Oreoxis 616-7

OROBANCHACE-

AE 802

Orobanche 803-4

Orogenia 611

Orophaca 516-7

ORPINE 374

RED 373

Orthocarpus 795-6, 794

Oryzopis 45

Osmorrhiza 609-10. 611

Ospianthes 593

OSTRICH FERN 1041

Ostrya 205-6

OTHAKE 944

OWL's ClOVER 795

OXALIDACEAE 533

Oxalis 533-t

OX-EYE 925

OX-EYE DAISY 960

Oxybaphus 259-60

Oxycoccus 646

Oxypolis 633

Oxyria 232

Oxytenia 828

Oxytheca 228

Oxytropis 517

OYsTer PLANT 1019

Ozomelis 380-1

Pachylophus 597-8

Pachystima 549

Padus 451

Paeonia 315

PAEONY 315

PAINT-BRUSH, INDIAN 785

PAINTER'S BRUSH 785

PAINTED CUP 785

PANIC-GRASS 36

Panicularia 82-3

Panicum 36-8, 35 , 
Paspalum 35

PASQUE-FLOWER 288

Pastinaca 632

PATIENCE 232

Patrinia 820

PEA, GOLDEN 456

PARTRIDGE 453

SENSITIVE 453

YELLOW 456

WILD 525

PEA FAMILY 454

Peas, Buffalo 492 TURKEY 611

Peach-Leaved WILLOW 191

PEAR, PRICKLY 575

PEARL BARLEY 96

PEARLWORT 278

PEARLY EVERLASTING 921

Pectianthia 379

Pectis 958

Pectocarya 713

Pedicularis 798-801

Pediocactus 580

PELICAN FLOWER 796

Pellaea 1048

PELI.ITORY 210

PFNNY CRESS 328

PENNY-GRASS 328

PENNYROYAL, MOCK 749

WESTERN 750

Pentstemon 763

acuminatus 770

albertinus 773

albidus 772

alpinus 769

ambiguus 774

angustifolius 771

arenicola 770

aridus 773

attenuatus 773

auricomus 771

azureus 776

Bakeri 772

barbatus 777

Bradburyi 770

Brandegei 769

brevifolius 773

Bridgesii 777

caespitosus 775

caudatus 771

Cleburnei 771

coccinatus 776

coeruleus $77_{1}$

collinus 774

coloradensis 775

comarrhenus 768

confertus 772

confusus 777

Crandallii 775

crassifolius 768

cristatus 771

Cusickii 776

cyananthus 769

cyanocaulis 769

cyathophorus 770

deustus 772

diffusus 776

diphyllus 776

Eastwoodiae 777

Eatonii 776

ellipticus 768

Erianthera 771

eriantherus 769

erosus 779

exilifolius 774

Fendleri 770

Fremontii 769 fruticosus 768

Gairdneri 774

glaber 769

glandulosus 775

glaucus 771

Gordoni 769

gracilis 774

grandiflorus 770

Griffini 774

Hallii 770

Harbourii 772

Haydenii 771

heterophyllus 776

humilis 774

humilis 773

Jamesii 771

Kingii 776

lacerellus 772

laricifolius 774

latifolius 776

latiusculus 772

laxus 772

Leonardii 776

leptophyllus 773

linearifolius 768

linarioides $774-5$

Lyallii 768

Macbridei 776

Menziesii 768

micranthus 77\%

minidocanus 769

Moffattii 771

montanus 768

nitidus 770

oliganthus 774

oregonus 774

oreophilus 769

ovatus 773

Oweni 774

pachyphyllus 770

Palmeri 770

payetensis 769

perpulcher 769

petiolatus 777

pinetorum 773

phlogifolius 772

platyphyllus 776

procerus 772

procumbens 775

puberulentus 774

pumilus 772,775

pseudohumilis 774 , 771

pseudoprocerus 773

radicosus 774

Rex 769

Richardsonii 775

riparius 769

Rydbergii 772

saliens 771

Scouleri 768

secundiflorus 770 . 769

sepalulus 776

speciosus 769

stenosepalus 771

strictiformis 768

strictus 768

subglaber 769

suffrutescens 775

teucrioides 775

Thompsoniae 775

Thurberi 774

Torreyi 777

trichander 777

triphyllus 776

Tweedyi 777

unilateralis 769

utahensis 777,769

venustus 775 veronicaefolius 773

virens 773

Wardii 769

Watsonii 772

Wilcoxii 773

xylus 775

Pentstemonopsis 777

PEPPER, WATER 235. 237

PEPPERMINT 752

PEPPERGRASS 324

Peramium 182

Peraphyllum 448

Pericome 940

Peritoma 371

Persicaria 235-7

Petalonyx 574

Petalostemon 484-5

Petasites 974

Peteria 485-6

Petradoria 871

Petrophy tum 404

Peucedanum 62 $4_{4}-9$

Phaeostoma 593

Phaca 486

allochroa 487

americana 487

ampularia 487

annua 490

argophylla

artemisiarum 490

artipes 488

Beckwithii 490

Bodinii 489

caespitosa 517

Candolleana 489

cerussata 489

Cusickii 488

Eastwoodiae 488

elatiocarpa 490

elegans 508

elongata 515

Fendleri 515

glabriuscula 508

Hookeriana 488

humillima 490

inepta 491

jejuna 490

leptalea 489

longifolia 488

lotiflora 490

lutosa 488

megacarpa 488

microcystis 489

pauciflora 489

picta 488

pubentissima 490

pygmaea 505

sabulonum 490

sesquiflora 491

sericea 517

serpens 489

Silerana 489

subcinerea 489

Wardii 488

Wetherillii 487

Phacopsis 500

Phacelia 702

affinis 707

alba 705

alpina 704

bicolor 707

biennis 704

Burkei 704

campestris 707

cephalotes 706

ciliosa 706

corrugata 705

crenulata 705

curvipes 707

demissa 706

denticulata 705

deserta 705

firmomarginata 706

foetida 704

foliosenala 706

Franklinii 706

Fremontii 707

glandulifera 707

glandulosa 705

glechomaefolia 707

hastata 704

heterophylla 704

hispida 705

humilis 704

idahoensis 706

incana 707

integrifolia 704

Ivesiana 707

Knightii 706

leptosepala 704

leucophylla 703

linearis 706

luteopurpurea 707

Lyallii 706

Menziesii 706

minutissima 706

neomexicana 705

nervosa 704

nudicaulis 707

orbicularis 704

Palmeri 704

pulchella 707

ramosissima 705

Rattani 706

rotundifolia 707

sericea 706

splendens 705

Phalaris 40

Phaseolus 529

Phegopteris 1043

Phellopterus 619

Philadelphus 392-3

PhildBertella 670

Philibertia 670

Philotria 29

Philozera 955

Phippsia 50

Phleum 49 
Pine Family 11

Pine-grass 147

PInes, Cembra 13

HARD 11

PrTCH 11

WHITE 13

Pinesap 639

Pinguicula 802

PINK, DESERT 1017 INDIAN 371

Moss 685

MoUnTAIN 648

PRAIRIE 1023

PINK FAIRIES 592

PINK FAMILY 280

PINK LADY-FINGERS 506

Pinyon, ONE-LEAVEd 13

PINYONS 12

Pinus 11, 12, 13

PIPE, INDIAN 639

Piperia 180

PIPE-STEM 290

PIPSIsSEWA 636

Piptocalyx 718

Pirus 448

PITCH PINEs 11

Plagiobotrys 718

PLANTAGINACEAE 804

Plantago 805-6

PLANTAIN 805

RATTLESNAKE 182

Plantain Family 804

Platanthera 178-9

Platyschkuria 941

Platyspermum 347

Platystemon 317

Plectritis 818

Pleiacanthus 1023

Pleuraphis 34-5

Pleurogyne 664

Pleurophragma 368

Pluchea 913

PLUM FAMILY 450

Plum, MoXIE 644

Plume, Apache, 433 PRINCE's 368

Plums 450

Plums, Ground 492

Poa 72

alpicola 77

alpina 78

ampla 82

andina 79

annua 75

aperta 77

aretica 76

arida 79

Bigelovii 76

brachyglossa 82

Brandegei 79

brevipaniculata 81

Buckleyana 81

callichroa 76

callida 76

Canbyi 81

cenisia 76

compressa 77

confusa 82

crocata 78

curta 78

Cusickii 79

Eatoni 81

epilis 80

Fendleriana 81

festucoides 87

filifolia 80 flava 77

glaucifolia 79

gracillima 80

Grayiana 78, 79

Helleri 81

idahoensis 80

incurva 82

interior 78

juncifolia 82

Keibensis 87

Kingii 88

laeviculmis 82

laevigata 81

laevis 81

lanata 76

laxa 77

leptocoma 77

Lettermanni 79

longiligula 80

longipedunculata 80

longipila 76

lucida 81

macroclada 77

Multnomae 79

nematophylla 80

nemoralis 78

nervosa 77

nevadensis 81

occidentalis 76,78

Olneyae 78

paddensis 79

Pattersonii 79

phoenicia 79

platyphylla 76

pratensis 76

pratensiformis 79

pratericola 79

pseudopratensis 79

pudica 77

pulchella 80

purpurascens 79

reflexa 77

rhizomata 76

rupestris 79

rupicola 79

Sandbergii 81

scaberrima 80

scabrifolia 80

scabriuscula 80

serotina 77

Sheldoni 79

subaristata 80

subpurpurea 79

subreflexa 78

subtrivialis 78

tenuifolia 81,82

Tracyi 78

tricholepis 78

triflora 77

truncata 82

Vaseochloa 80

Vaseyana 78

Wheeleri 78

wyominaensis 81

POACEAE 29

Poinsettia 547

PoIson Camas 149

POISON HEMLOCK 617

POISON IVY 5.51

POISON OAK 551

POISON SUMACH 551

Polanisia 371

POLEMONIACEAE 679

Polemonium 680-2

Poliomintha 749

Polygala 540-1

POLYYGALACEAE 540
POLYGONACEAE 210

Polygonatum 169

Polygonum 232

alpinum 238

amphibium 236

aviculare 234

Austinae 235

Bistorta 238

bistortoides 237

buxiforme 234

coarctatum 235

commixtum 235

confertiflorum 234

consimile 235

Convolvulus 239

Douglasii 235

emaciatum 235

emersum 236

Engelmannii 235

erectum 233

flexile 234

Hartwrightii 236

Hydropiper 237

imbricatum 234

incarnatum 236

incanum $23 \%$

Kelloggii 224

lapathifolium 237

majus 235

minimum 233

montanum 235

Muhlenbergii 236

neglectum 234

omissum 236

paronychioides 224

pannosum 235

Persicaria 237

polygaloides 235

polymorphum 238

prolificum 224

punctatum 237

ramosissimum 224

rubescens 224

sagitatum 238

sawatchense 224

scandens 239

spergulariforme 235

tenue 235

viviparum 238

Torreyi 233

unifolium 224

Watsonii 224

Polypappus 913

Polypteris 944

POLYPODIACEAE 1040

Polypodium 1050

POLYPODY 1050

Polypogon 52

Polystichum 1042

POMME BLANCHE 480

PoMme de Pratrie 480

POND LILY 285

Y ELLOW 285

PONDWEED 22

PONDWEED FAMILY 21

PONTEDERIACEAE 145

POOR MAN's WEATHERGLASS 651

POPCORN FLOWER 718

POPLAR 185-7

POPPY 318

CALIFORNIA 318

PRICKIY 317

THISTLE 317

POPPY FAMILY 316

POPPY-MALIOW 558

Populus 185-7

PORCUPINE GRASS 42

Porterella 825-6

Portulaca 266

PORTULACACEAE 262

Potamogeton 22-5

POTATO 756

SWAMP 27

SWAN 27

WILD 757

Potato Family 753

Potentilla 408, 426, 433

ambigens 419

arachnoidea 421

arguta 426

argyrea 419

atrovirens 421

Bakeri 414

bicrenata 416

biennis 413

bipinnatifida 420

Blaschkeana 414

brevifolia 417

brunnescens 413

camporum 415

candida 414

coloradensis 418

concinna 416

concinnaeformis 416

crinita 420

ctenophora $41 y_{4}$

dascia 414

decurrens 420

dichroa 415

diffusa 419

dissecta 416,420

divisa 416

diversifolia $\mathbf{4 1 6}$, 420

Drummondii 420

effusa 418

emarginata 417

fastigiata 416

filicaulis 418

filipes 415 
Potentilla

paucijuga 420

Pecten 414

pectinisecta 414 , 419

pennsylvanica 421

pentandra 413

perdissecta 416

pinnatisecta 419

plattensis 419

platyloba 421

propinqua 419

proxima 418

pseudosericea 420

pulcherrima 419

quinquefolia 417

rectiformis 413

rivalis 412

rubricaulis 418

rubripes 418

rupincola 418

sabulosa 408

saximontana 418

strigosa 421

subjuga 415

subquinata 417

tenerrima 417

uniflora 417

virgulata 420

viridescens 415

viridior 419

Vreelandii 415

Wardii 419

wyomingensis 420

Poteridium 428

Poterium 428

POVERTy GRass 40

Poverty WeED 243 , 828

PRAIrie A pPLES 492

Pratrie Bean 456

Pratrie Clover 484

PraIRIE MIMosA 452

PRATRIE PINK 1023

PRAIRIE-ROCKET 342

PRAIRIE STAR 377

Prenantella 1023

Prenanthes 1024

PRICKLY POPPY 317

PRICKI.Y PEAR 575

PRIDE-OF-THEMOUNTAN 763

Primrose 647

EVENING 593

MOUNTAIN 597

SPOTTED 599

WHITE EVENING 594

PrImRose FAMILY 646

Primula 647-8

PRIMULACEAE 646

Prince's Plume 368

PRInce's PIne 636

Prionopsis 859

Prosartes 168-9

Prunella 745-6

Prunus 450-2, 452

Psathyrotes 975

Pscdera 5.56

Pseudocymopterus $622-3,621,623,624$

Pseudoreoxis 621

Pseudopter yxia 623-4

Pseudotsuga 15

Psilocarphus 913

Psilostrophe 939

Psoralea 480-2

Ptelea 540
PTERIDOPHY'TA 1038

Pteretis 1041

Pteridium 1048

Pteris 1047, 1048

Pterophacos 507

Pterospora 638-9

Pterostegia 229

Pteryxia 620-1

Ptilocalais 1016

Ptilonella 937

Ptiloria 1017

Puccinellia 84

PUCCOON 737

Pulmonaria 733

Pulsatilla 288

PUMPKIN 822

Purple ConeFLOWER 925

PURPle HaIr-grass 49

PURple Heather 641

PURPLE MARSHLOCKS 422

PURPLE RASPBERRY 438

PURPI.E SAXIFRAGE 391

PURPLE VIRGIN'S BOWER 292

Purshia 434

Purslane 266 MARSH 592 SEA 261

PURSLANE FAMILY 262

PUSSLEY 266

PUSSY-PAWs 266

PUSSY WILlow 195

PUTTY-ROOT 183

Pycynosphace 747

Pyrola 636-7, 638

PYROLACEAE 635

Pyrrocoma 861-3

Pyrus 448

QUAKE-GRASS 72

QUAKER BONNET 457

QUAKING ASPEN 186

QUAKING GRASS 72

Quamasia 166

Quamoclidion 258

Quercus 199-202

QUICK-GRASS 92

QUILLWORT 1053

QUILLWORT FAMILY 1053

Quincula 755

QUITCH-GRASS 92

RABBIT BRUSH 853

Radicula 334-6

RADISH 345

Rafinesquia 1018

RAGWEED 829

RAGWEED FAMILY 827

RAGWORT 982

Ramischia 638

RAM'S-HEAD 177

RAM'S-HEAD LADIES' SLIPPER 177

RANUNCULACEAE 28.5

Ranunculus 294 abortivus 299,300

acriformis 300

acris 301

adoneus 299 affinis 298

alismaefolius 297

alismellus 297

alpeophilus 298

Andersonii 302

apetalus 299

aquatilis 294

arcuatus 300

arvensis 302

Bolanderi 297

Bongardi 300

brevicaulis 299

calthaefolius 297

cardiophyllus 298

circinatus 294

Cusickii 297

Cymbalaria 303

delphinifolius 301

digitatus 299

Douglasii 300

Drummondii 299

Earlei 300

ellipticus 298

eremogenes 300

Eschscholtzii 299

eximius 298

Flammula 297

glaberrimus 298

Grayanus 294

Grayi 299

Greenei 300

Helleri 299

Hookeri 299

hyperboreus 302

inamoenus 298

intertextus 301

Jovis 299

lapponicus 30\%

limosus 301

Lyallii 300

MacCallae 300

Macaulevi 297

Macounii 301

micranthus 300

microlonchus 297

micropetalus 298

montanensis 300

multifidus 301

natans 302

Nelsonii 300

nivalis 297

Nuttallii 303

occidentalis 300

ocreatus 299

oreganus 300

oreogenes 298

orthorhynchus 301

ovalis 299

pedatifidus 299

pennsylvanicus 300

platyphyllus 301

Populago 297

Purshii 301

pygmaeus 299

reptans 297

repens 301

rivularis 301

rhomboideus 299

Sabini 299

saxicola 298

sceleratus 300

stenolobus 299

Suksdorfii 298

tenellus 300

unalaschensis 297

unguiculatus 297

utahensis 298

vericundus 299

RAPE 346

Raphanus 345

RASPBERRY 435-8

Ratibida 927

RATTLE, YELLOW 801

RATTLE-BOX 801

RATTLE-POD 486

RATTLESNAKE-MASTER 609

RATTlesnake PlaANTAIN 182

RATTLESNAKE-ROOT 1024

RATTLE-WEED 486

Razoumofskya 817

RED OEDAR 17

Redfieldia 68

RED FIR 15

RED-HEAD LOUISA 265

RED HEATHER 641

RED ORPINE 373

RED RASPBERRY 439

RED-TOP 53

REED 66

REED-GRASS 52，55, 58

RESIN-WEED 847

RHAMNACEAE 553

Rhamnus 553-4

Rhinanthus 801

Rhodiola 374

RHODODENDRON, WHITE 640

Rhus 550

Rhysopterus 619

Ribes 397-9, 395-9

RIBGRASS 805

RICE, JUNGLE 38

MOUNTAIN 45

WILD 45

RICE CUT-GRass 39

Riddellia 939

Rigiopappus 944

RING GRASS 49

RIVER AI.DER 205

RIVER COTTONWOOD 186

Robinia 485

ROCK-BRAKE 1048

ROCK CRESS 356

ROCK GOLDENROD 872 
grosseserrata 445

gymnocarpa 445

heliophila 441

leucopsis 445

Lunellii 441

MacDougali 442

Macounii 445,444

manca 443

Maximiliani 445

melina 443

muriculata 442

neomexicana 443

nutkana 442

oreophila 443

pandorana 443

praetincta 444

pratincola 441

puberulenta 443

pyrifera 445

salictorum 444

Sandbergii 444

Sayi 442

Spaldingii 442

suffulta 441

ultramontana 444

Underwoodii 442

Woodsii 444,445

ROSACEAE 399

ROSE 439

CliffF 434

ROCK 597

YELLOW 425

ROSE FAMILY 399

ROSE MALLOW 558

ROSEMARY, BOG 642

ROSE-ROOT 374

ROSE-WORT 374

ROSINWEED 924

Rotala 583

ROUGH GOLDENROD 872

Rubacer 435

RUBBER PLANT, COLORADO 951

Rubia 810

RUBIACEAE 806

Rubus 436-9, 436

Rudbeckia 926

RUE, BFLL 292

MEADOW 288

RUE FAMILY 539

Rulac 553

Rumex 230-2

Ruppia 25

RUSH 150

BEAKED 105

RUSH FAMILY 149

RUSH-GRASS 51

RUSSIAN THISTLE 252

RUTABAGA 346

RUTACEAE 539

Rutosma 540

Rydbergia 951

Rydbergiella 500-1

RYDBERG'S COTTONWOOD 186

RYE 95

BUFFALO 99

Wrid 99

RYE-GRASS 91, 99

Rynchospora 105

Sabina 17

SAGE 748

BALL 748

HOP 250

SALT 828

THISTLE 747

WHITE 250

WINTER 250

WOOD 742
SAGE BRUSH 963

Sagina 278-9

Sagittaria 27

ST. JOHN's-WORT 563

ST. JOHN'S-WORT FAMILY 563

SALAD, CORN 818-9

Salazaria 744

SALICACEAE 185

Salicornia 251

Salix 187

aemulans 199

alaxensis 196

alba 191

albertana 196

amygdaloides 191

arbusculoides 196

arctica 198

argophylla 192

arguta 191

argyrocarpa 196

Austinae 198

balsamifera 193

Barkleyi 193

Barrattiana 196

Bebbiana 195

bella 196

boiseana 19.

brachycarpa 196

candida 196

cascadensis 198

chlorophylla 198

Columbiae 193

commutata 194

conjuncta 194

cordata 193

curtiflora 194

desertorum 197

Drummondiana 196

discolor 195

Dodgeana 195

erythrocoma 191

exigua 192

Fendleriana 191

Fernaldii 198

flava 193

flavescens 195

Geyeriana 195

glaucops 196,198

gracilis 195

Hookeriana 193

idahoensis 196

interior 192

irrorata 194

laevigata 191

lasiandra 191

lasiolepis 193

Lemmonii 196

linearifolia 192

longifolia 19\%

lucida 191

Iutea 193

luteosericea 199

Lyallii 191

MacCalliana 198

Mackenziana 193

macrocarpa 195

macrostachya 192

melanopsis 192

monticola 194

myrtillifolia 194

myrtilloides 193

Nelsonii 198

nigra 191

nivalis 199

Nuttallii 195

orbicularis 198

pachnophora 196

padifolia 194

padophylla 194 pallescens 191

pedicellaris 193

pellita 196

perrostrata 195

petiolaris 195

petrophila 198

pseudocordata 194

pseudolapponum 196

pseudomyrsinites 194

pyrifolia 193

reticulata 198-9

rosmarinifolia 19.5

rostrata 195

rubra 192

Sandbergii 192

saskatchewana 198

saximontana 199

Scouleriana 195

Seemanii 197

serissima 191

sessilifolia 192

sitchensis 196

speciosa 196

stenophylla 192

stricta 197

subcoerulea 196

subcordata 197

tenera 198

tenerrima 192

Tweedyi 194

vestita 198

Watsonii 193

Wolfii 194,197

Wrightii 191

SALMON-BERRY 435

Salmonia 169

SALSIFY 1019

Salsola 252

SALT-BUSH 245

SALT-GRASS 72

SALT SAGE 828

SALTWORT 252

BLACK 652

Salvia 748,747

SALVINIACEAE 1051

SALVINIA FAMILY

1051

Sambucus 810-1

Samolus 655

SAMPHIRE 251

SANDALWOOD FAMILY 817

SANDBAR WILI.OW 192

SANDBUR 39

SAND-FOIN 524

SAND-GRASS 58, 67-8

SAND LILY 570

SAND PUFFS 256-7

SANDSPUR 39

SAND SPURRY 279

SAND VERBENA 256

SANDWORT 274-5

Sanguisorba 428

Sanicula 609

SANICLE 609

SANTALACEAF 817

Saponaria 284

Sarcobatus 251

SARSAPARILLA 633

Saussurea 1002

Savastana 40

Saxifraga 385 adscendens 386 aestivalis 389

Aizoon 387

arguta 389

arnoglossa 388

austrina 388

austromontana 391

Bongardi 389

brachypus 388

bronchialis 391

caespitosa 386

cernua 386

chrysantha 390

cognata 391

columbiana 388

crenatifolia 387

debilis 385

delicatula 386

denudata 389

exarata 386

ferruginea 390

flagellaris 391

heterantha 391

Hirculus 390

Jamesii 385

Lyallii 388

Mertensiana 391

micropetala 386

montancnsis 388

monticola 386

nivalis 388

nootkana 389

occidentalis 389

oppositifolia 391

oregana 388

oregonensis 386

punctata 389

ranunculifolia 384

rhomboidea 388

rivularis 385

Rydbergii 387

saximontana 389

subapetala 388

simulata 386

tricuspidata 391

Van-Bruntiae 391

SAXIFRAGACEAE 376

SAXIFRAGE 385-389

GOLDEN 377

MOUNTAIN 391

PURPLE 391 
SEDGE FAMI Y 103

Sedum 374, 473-4

SEED-VESSELED

PLANTS 20

SEgo LILY 171

SEGO, SWAMP 166

Selaginella 1056

SELAGINELLACE-

AE 1055

SELF-HEAL 745

Selinocarpus 258

Selinum 631

Senecio 982

accidens 987

acutidens 995

admirabilis 989

alpicola 998

altus 998

ambrosioides 990

amplectens 988

anacletus 991

andinus 999

aquariensis 996

arachnoideus 1000

atratus 991

atriapiculatus 1000

aurellus 995

aureus 994-9

Bigelovii 987

blitojdes 989

Burkei 995

canovirens 993

canus 992

cartamoides 988

cernuus 988

chloranthus 987

columbianus 1000 ,

cognatus 998

compactus 994

condensatus 1000 ,

$$
994
$$

conterminus 998

contristatus 988

crassulus 999

crocatus 996

cymbalarioides 995

debilis 997

densus 994

dimorphophyllus 996

discoideus 997

dispar 1000

Douglasii 990

ductoris 989

erimophilus 990

exaltatus 1000

fastigiatus 992

Farriae 997

fedifolius 997

Fendleri 993

filicifolius 990

flavovirens 996

foliosus 991

Flintii 1000

flavulus 995

Fremontii 989

fulgens 994

glaucescens 991

glauciphyllus 990

Hallii 992

Harbourii 992

heterodoxus 996

Holmii 988

Hookeri 999

Howellii 992

hydrophiloides 998

hydrophilus 998

idahoensis 997

integerrimus 999 invenustus $\mathbf{9 8 9}$

Jonesii 995

Kingii 990

Kuntzei 990

lactucinus 988, 999

laetiflorus 994

lanatifolius 993

lanceolatus 990

lapatifolium 999

larimiensis 992

lathyroides 990

latus $\mathbf{1 0 0 0}$

Leibergii 1000

Leonardi 993

leucocrinus 992

longilobus 991

longipetiolatus 994

lugens 991, 1000

Lyallii 998

megacephalus 1001

Metcalfei 994

milliflorus 991

multicapitatus 990

multilobus 994

multnomensis 996

mutabile 995

Nelsoni 993-4

neomexicanus 993

nephrophyllus 997

oblanceolatus 994

oodes 994

ovinus 998

pacificus 998

pagosanus 988

Pammelii 996

palustris 1001

pauciflorus 997

pentodontus 998

perennans 998

perezifolius 999

perplexus 1000

petraeus 997

petrocallis 997

petrophilus 997

plattensis 993

platylobus 995

Porteri 997

pseudaureus 995

pseudotomentosus 992

pudicus 988

Purshianus 992

pyrrochrous 996

rapifolius 999

renifolius 997

Riddellii 990

rosulatus 993

rubricaulis 995

Rydbergii 994

salicinus 993

saliens 989

scaposus 989

scopulinus 987

Seribneri 999

semiamplexicaulis 999

seridophyllus 988

Serra 989, 990

Soldanella 988

Solidago 989

solitarius 1001

spartioides 991

spatuliformis 992

sphaerocephalus 992

subcuneatus 995

subnudus 997

taraxacoides 988

toluccanus 991

Tracyi 996 triangularis 989

tridenticulatus 994

turbinatus 998

Tweedyi 996

uintahensis 993

varifolius 989

vulgaris 1001

Wardii 997

werneriaefolius 998

Willingii 996

Wootonii 991

SENNA FAMILY 453

SENSITIVE BRIER 452

SENSITIVE FERN 1041

SENSITIVE PEA 453

SENSITIVE PLANT,

WILD 453

Serapias 180-1

Sericotheca 405-6

SERVICE-BERRY 446

Sesuvium 261

Setaria 38-9

SHADBERRY 446

SHAD-SCALES 245,248

SHEEP-POD 503

SHEEP SORREL 231

Shepherdia 582

SHEPHERD'S PURSE 329

SHEPHERD'S WEATHERGLASS 651

SHIELD FERN 1044

SHINING WILLOW 191

SHOE-STRINGS 479

SHOOTING STAR 652

SHRUBBY BITTERSWEET 548

SHRUBBY CINQUEFOIL 425

SHRUBBY TREFOIL 540

Sibbaldia 424-5

Sida 561-2

Sidalcea 558-9

Sideranthus 810

Sieversia 432,433

Silene 280-2, 283

SILKWEED 671

Silphium 924

SILVER-BERRY 581

SILVER-BUSH 581

SILVER POPLAR 187

SILVER PLANT 219

SILVER-WEED 421

SILVER WILLOW 196

Sinapis 345

SINGLE BEAUTY 636

Sisyrinchium 174-5. 176

Sisymbrium 337,336 , $338-41,365$

Sitanion 97

SITKA WILLOW 196

Sium 617

SIX-WEEK GRAMA 65

SKELETON WEED 1023

SKULLCAP 743

SKULLCAP, BLADDER 744

SKUNK-BUSH 550

SKUNK CABBAGE 143. 147

SKUNK-GRASS 68

SKUNK-WEED 680,682

SKYROCKET 694

SLEEPY CATCHFLY 281

SLIPPER, LADIES' 177 VENU', 183

SLOUGH GRASS 64

SMARTWEED 235, 237

Smelowskia 329

SMILACACEAE 173

Smilacina 166-8

SMILAX 173

SMILAX FAMILY 173

SMEOTH-BARKED COTTONWEED 186

SNAKE-ROOT 609 BUTTON 844

WHITE 841

SNAKE'S HEAD 1022

SNAPDRAGON 762

SNEEZEWEED 954

SNEEZEWORT ASTER 878

SNOW-BALLS 811

SNOW-BERRY 812

CREEPING 644

SNOW BRUSH 554

SNOW-ON-THE-MOUNTAIN 545

SNOW WILLOW 199

SOAP-ROOT 169

SOAP-WEED 169

SOAPWORT 284

SOLANACEAE 753

Solanum 756-7

Solidago 867

altissima 870

canadensis 870

ciliosa 869

concinna 870

corymbosa 869

decumbens 869

diffusa 871

dilatata 869

dumetorum 870

elongata 870

Garrettii 871

glaberrima 870

glaucophyla 870

gilvocanescens 871

humilis 869-70

laevicaulis 869

missouriensis 870

mollis 871 
Sophora 456

Sorbus 448

Sorghastrum 34

Sorghum 3 '

SORREL 230

MoUntaIn 232

SHEEP 231

SOUR DOCK 231

SOUR GREENS 231

SOW-THISTLE 1037

SPANISH BAYONET 169

SPANISH LETTUCE 263

SPARGANIACEAE 20

Sparganium 21

Spartina 63-4

SPATTER-DOCK 285

Spatularia 389-90

SPEARMINT 752

SPEAR GRASS 42

SPECKLED ALDER 205

Specularia 824

SPEEDWELL 782

Spergula 279

Spergularia 279

Sphaeralcea 559-61, 562

Sphaeromeria 960

Sphaerostigma 600-2

Sphenopholis 70

Sphenosciadium 632

SPIDER MILKWEED 674

SPIDERWORT 144

SPIDERWORT FAMILY 144

SPIK F-GRASS 72

SPIKENARD 633 WILD 166

SPIKE-RUSH 105

SPINY ASTER 876

Spirzea 403-4, 402, $40+-6$

Spiranthes 181

Spirodela 144

Spirostachus 251

SPLEENWORT 1045

Sporobolus 51-2, 47 , 48,51

SPOTTED PRIMIROSE 599

SPOTTED SAXIFRAGE 390

SPRAGUEA 266

SPRAY MOUNTAIN 405

SPRAY, OCEAN 405

SPRING BEAUTY 262

SPRING-BEAUTY, WATER 264

SPRUCE 15-6

SPURGE 542, 545, 547

SPURGE FAMULY 541

SPURRED GENTIAN 666

SPURRY 279

CORN 279

SAND 279

SQUAW APPLE 448

SQUAW CABBAGE 263

SQUAW FEATHERS 785

SQUAW LETTUCE 263

SQUAW-ROOT 612

SQUAW-WEED 982

SQUASH 822

SQUIRREI-TAIL 96

Stachys 746-7

STAFF-TREE 548

STAFF-TREE FAMILY 548
STAG-BERRY 812

Stanleya 368-70

Stanleyella 368

STAR-FLOWFR 377 , 640

STAR-GRASS 173

WATER 146

STAR OF BETHLEHEM 163

STAR-STRIKERS 164

STAR THISTLE 1015

STARWORT 268

WATER 548

Steironema 651

Steiropteris 1043

Stellaria 268-70

Stenanthella 147

Stenanthium 147

Stenophragma 341

Stenophyllus 107

Stenosiphon 604

Stenotopsis 863

Stenotus 865, 867

Stephanomeria $1017-8$

STICK-LEAF 574

STICKSEED 714

STICK-TIGHTS 714

STINK FLOWER 371

STINK-GRASS 68-9

Stipa 42-44

STONE-CROP 374

STONE-CROP FAMILY 373

STORKBILL 533

STRAMONIUM 759

STRAW, FLOWERING 1017

STRAWBERRY 422 BARREN 429

STRAWBERRY BLITE 242

STRAWBERRY PIGWEED 242

STRAWBERRY TOMATO 753

Streptantella 364

Streptanthus 359,3647

Streptopus 168

Strobus 13

Strophostyles 529

Struthiopteris 1042

Stylocline 913

Stylopappus 103.3

SUBALPINE FIR 15

Subularia 333

Suckleya 250

SUGAR CORN 34

Juksdorfia 384

Sullivantia 384

SULPHUR PLANT 218

SUMACH 550

POISON 551

SUMACH FAMILY 550

SUNDEW 373

SUNDEW FAMILY 372

SUN-FIOWER 930

Svida 634

SWAMP BIRCH 204

CURRANTS 396

HONEYSUCKLE 814

I.AURFL 641

Potato 27

SEGO 166

SWAN Potato 27

SWEDISH CRANBERRY 645

SWEDISII TURNIPS 346

SWEFT ALYsSUM 347 WILD 328
SWeEt Cicely 609

SWEET CLOVER 477

SWEET COLTSFOOT 974

SWEET FLAG 143

SWEET GRASS 40

SWEET WILLLAM 687

Swertia 664

Symphoricarpos 8124

Symphytum 739

Syntherisma 35-6

Synthyris $783-4$

Syntrichopappus 948

SYRINGA 392

Syrmatium 479

Talinum 262

TALL GRAMA 65

TAMARACK 13-4

Tanacetum 960, 961

TANSY 960

GoOSE 421

TANSY ASTER 892

TANSY MUSTARD 338

Taraxia 600

Taraxacum 1034-5

TAXACEAE 18

Taxus 18

TEA, BRTgHAM 18 LABRADOR 640 NEW JERSEY $\mathbf{5 5 4}$

TEAR-THUMB 238

TEASEL 827

TEASEL FAMIIY 827

TEA-VINE 751

Telesonix 385

Tellima 378,380

Tessaranthium 666

Tessaria 913

Tetradymia 1001

TETRAGONIACEAE 261

Tetragonanthus 6667

Tetraneuris 949-51

Teucrium 742

TEXas TIMOTHY 49

Thalesia 803-4

Thalictrum 288-90

Thamnosma 540

Thaspium 623

Thelesperma 936

Thelypodiopsis 365-6

Thelypodium 366 , $325,366,368$

Thelypteris 1043

Thernopsis 456

Therophon 384

THIMBLEBERRY 435

THISTLE 1003

CANADA 1014

COTTON 1014

RUSSIAN 252

SCOTCH 1014

STAR 1014

THISTLE FAMILY 836

THISTLE POPPY 317

THISTLE SAGE 747

Thlaspi 328-9

THORN-APPLE 759

THOROUGHWORT 841

Thuja 17

THUMB, LADY's 235 , 237

Thymophylla 956

Thysanocarpus 346-7

Tiarella 383

TICKLE-GRASS 53

TICKS, BEGGAR's 525 . 714

TICKSEED 935

TICK-TREFOIL 525

Tidestromia 255

Tiedemannia 633

TIGER LILY 164

Tillaea 375

Tillaeastrum 375

TIMOTHY 49

TEXAS 49

Tiniaria 239

Tintinabulum 698

TINY TIM 956

Tissa 279

Tithonia 933

Tithymalus 545-7

Tium 497-9

TOAD-FLAX 762 BASTARD 818

TOBACCO 759

TOBACCO-ROOT 819

ToBosa Grass 34-5

Tofieldia 146-7

TOMATILLO 753

TOMATO 757

STRAWBERRY 753

Tonella 762-3

Tonestus 867

TOOTHWORT 347

Torresia 40

Touterea 570-2

TOUCH-ME-NOT 536

TOWER MUSTARD 337

Townsendia, 873

Toxicodendron 551

Toxicoseordion 149

Tsuga 15,16

Tracaulon 238

Tradesoantia 144-5

Tragia 542

Tragopogon 1019

Trautvetteria 290

TRAVELER'S JOY 290

TREe CACTUS 575-6

TREFOIL 469

BIRD'S-FOOT 477

MARSH 667

SHRUBBY 540

Tribulus 539 
Trifolium

longipes $473,472-3$

macilentum 472

macrocephalum 472

megacephalum 472 microcephalum 476 montanense 475

nanum 473

nemorale 474

oliganthum 476

orbiculatum 472

oxydon 475

Parryi 475

pauciflorum 476

pedunculatum 472

petraeum 474

plumosus 472

pratense 472

procumbens 476

repens 473

Rusbyi 472

Rydbergii 473

salictorum 475

scariosus 474

spinulosum 475

stenolobum 474

subacaulescens 474

subsalinum 475

tropicum 472

uintensis 475

variegatum 475

villiferum 472

Triglochin 26-7

TRILLIACEAE 172

Trillium 172

TRILLTUM FAMILY 172

Triodia 67

Triplasis 67

Triphysaria 796

Tripterocalyx 257-8

Triquiliopsis 711

Trisetum 60, 61

Triteleia 162

Triticum 95

Trollius 304

Troximon 1020, 10303

Tsuga 15

TUBEROSE, WILD 163

TUFTED LOOSESTRIFE 651

TULE 108, 110

TULIP, BLUE 288

TUMBLE MUSTARD 337

TUMBLEWEED 243, 253-4

TURKEY-BEARD 147

TURKEY PEAS 611

TURNIP 346

TURNIP, INDIAN 480

TURNIPS, SWEDISH 346

Turritis $337,359,361$

Tussilago 976

TWAY-BLADE 181, 183

TWIFOLE 181

TWINBERRY 814

TWIN-FLOWER 812

TWISTED-STALK 168

TWO-LEAVED SOLOMON'S SEAL 167

Typha 20

TYPHACEAE 20

ULMACEAE 206

Ulmus 206

UMBRElla Plant 211
UMBRELLA-WORT 259

Unamia 877

UNICORN-PLANT 804

UNICORN-PLANT FAMILY 804

Unifolium 167-8

Uropappus 1020

Urtica 208-9

URTICACEAE 208

UTAF OAK 200

Utricularia 802

Uva-ursi 643

Vaccaria 284

VACCINIACEAE 643

Vaccinium 644-5, 645-6

Vagnera 166-7

VALERIAN 819

Valeriana 819-21

VALERIANACEAE 818

Valerianella 819

VALERIAN FAMILY 818

Vallota 36

Vanclevea 849

VASE-VINE 291

VELVET LEAF 562

VELVET-ROSETTES 975

VENUS'-HATR FERN, 1047

VENUS' LOOKINGGLASS 824

VENUS' SLIPPER 183

Veratrum 147-8

Verbascum 761-2

Verbena 739

VERBENA, SAND 256

VERBENACEAE 739

Verbesina 933-5

Vernonia 840

Veronica 782-3

VERVAIN 739

VERVAIN FAMILY 739

VETCH 525

MILK 493

VETCHLING 526

Viburnum 811-2

Vicia 525-6

Vilfa 48

Villanova 941

Viola 565-8

VIOLACEAE 565

VIOLET 565

DAME'S 344

DOG-TOOTH 164

GREEN 569

VIOLET FAMILY 565

VIOLET WOOD-SORREL 533

Viorna 291-2

VIRGLANA CREEPER 556

VIRGIN'S BOWER 290 PURPLE 292

VISCID ASTER 894

VITACEAE 556

Vitis 556

Vitis-Idaea 645-6

Vleckia 744

Wahlbergella 283

WAHOO 548

WAKE-ROBIN 172

Waldsteinia 429

WALKING-STICK, DEVIL'S 634
WALL-FLOWER, WILD 342

WARRIOR, INDIAN 798

WATER BIRCH 204

WATER CARPET 377

WATER-CRESS 337

YELLOW 334

WATER CROWFOOT, WHITE 293

WATER HEMLOCK 617

WATER-HEMP 254

WATER HOREHOUND 751

WATER HYSSOP 781

WATER-LEAF 699

WATERLEAF FAMILY 699

WATER LILY 285

WATER LILY FAMILY 284

WATER MILFOIL 605

WATER MILFOIL FAMILY 605

WATER PARSNIP 612, 617

WATER Pepper 235 , 237

WATER PIMPERNEL 655

WATER-PLANTAIN 27

WATER-PLANTAIN FAMILY 27

WATER SPRING-

BEAUTY 264

WATER STAR-GRASS 146

WATER STARWORT 548

WATER STARWORT FAMILY 547

WATER-WEED 29

WATER-WEED FAMILY 28

WATER-WORT 564

WATER-WORT FAMILT 564

Washingtonia 609-10

WAXWORK 548

WEATHER-GLASS, POOR MAN's 651 SHFPHERD's 651

Wedelia 261

Wedeliella 261

Welwitschia 688

WESTERN BALSAM POPLAR 186

WESTERN COTTONWOOD 186

WESTERN HEMLOCK 15

WESTERN LARCH 14

WESTERN PENNYROYAL 750

WESTERN WHITE PINE 13

WESTERN WITCHGRASS 37

WHEAT 95

WHEAT-GRASS 92

WHISK-BROOM PARSLEY 624

WHISKERS, OLD MAN's 291, 432

WHISPERING BELLS 708

WHITE ASTER 891

WHITE BARK PINE 13

WHITE BIRCH 203

WHITE CAMAS 148

WHITE CEDAR 17

White Clematis 290

WHITE ELM 206

WHITE FIR 15

WHITE EVENING

PRTMROSE 594

WHITE HEATHER 642

WHITE HELLEBORE 147

White PINES 13

WHITE POPLAR 187

WHITE RHODODENDRON 640

WHITE SAGE 250

WHITE SNAKE-ROOT 841

WHITE SPRUCE 16

WHITE WATER CROWFOOT 293

WHITE WILLOW 192

WHITLOW GRASS 350

WHITLOW-WORT 267

WHITLOW-WORT FAMILY 267

WHORTLEBERRY 644

WILD ALMONDS 452

WILD Asparagus 1023

WILD BEAN 529

WILD BEGONIA 231

WILD BERGAMOT 748

WILD CABBAGE 364

WILD CANDYTUFT 356

WILD Cosmos 944

WILD CRAB 448

WILD CROCUS 288

WILD GERANIUM 530

WILD GINGER 821

WILD GINSENG 633

WILD HOLLYHOCK 558,561

WILD HOPS 208

WILD HYACINTH 162, 166

WILD HYDRANGEA 231

WILD LILY-OF-THE-

VALLEY 166

Wild Marigold 940

WILD OAT-GRASS 62

WILD OATS 62

WILD PARSNIP 628

WIID PEA 525 
WOLF-BERRY 812

WOLFSBANE 313

WOLF'S BEAN 457

WOODBINE 556

WOODLAND STAR 377

WOOD ORCHID 180

WOOD-RUSH 155

WOOD SAGE 742

WOODSIA 1041

WOOD-SORREL 533

WOOD-SORREL FAMILY 533

WOOLLY YELLOW

DAISY 947

WORM-SEED MUSTARD 343

WORMWOOD 961 ROMAN 829
Wulfenia 785

Wyethia 929

YELLOW FLAX 535

10 -

Xanthium 832

Ximenesia 934

Xerophyllum 147

Xylophacos 503-6

Xylorrhiza 876-7

Xylosteum 814

YAMP 612

YARROW 957

YERBA BUENA 751

YERBA SANTA 709

YELLOW BELL 164

YELLOW DAISY,
WoOLLY 947

YELLOW HEATHER 641

YeLLOW PEA 456

YELLOW PHLOX 342

YELLOW POND LILY 285

YeLLOW RATTLE 801

YELLOW ROSE 425

YELLOW SAXIFRAGE 390

YELLOW WATER-

CRESS 334

YELLOW WILLOW 193

YELLOW WOOD-SORREL 533

YEW 18
YeW FAMILY 18

Youngia 1021

YUCCA $169-70,170$

YUCCA FAMILY 169

Zanichellia 25

ZANNICHELLIACEAE 21

Zauchneria 590

Zinnia 925

Zizia 614-5

Zizyphus 816

Zosterella 146

$Z$ ygadenus 148-9

ZYGOPHYLLACEAE 538

Zygophyllidium 545 